Catalogue

of

Minor Planet Names

and

Discovery Circumstances 


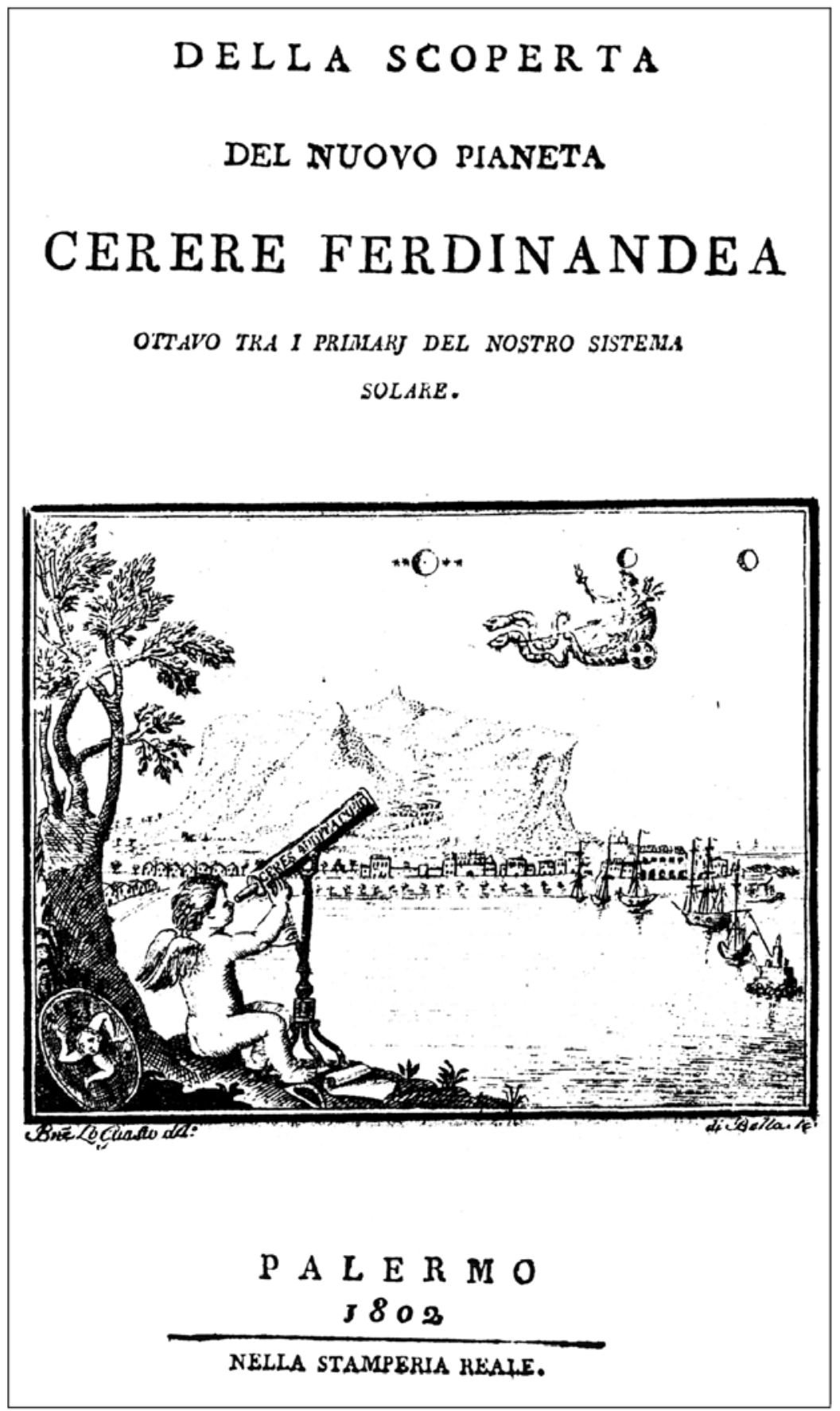

Title page of Giuseppe Piazzi's book "On the discovery of the new planet CERES FERDINANDEA, the eight of those known in our solar system". The vignette, against the background of Monte Pelegrini and the city of Palermo, shows an angel observing the goddess Ceres sitting in a carriage drawn by two snakes. The inscription on the telescope "CERES ADDITA COELI" (Ceres was added to the heavens) celebrates this epoch-making discovery of the first of the minor planets. (Courtesy of A. Baldi, Bologne) 


\section{(1) Ceres}

Discovered 1801 Jan. 1 by G. Piazzi at Palermo.

Named after the Roman goddess of corn and harvests, daughter of Rhea \{see planet (577)\} and Saturn, sister of Juno, Vesta \{see planets (3) and (4)\}, Jupiter, Neptune and Pluto, mother of Proserpina \{see planet (26)\} by Jupiter. (H 1)

The symbol used for Ceres in ancient was a reaper's hook.

The planet was originally named Ceres Ferdinandea, honoring King Ferdinand IV (1751-1825) of Sicily, who has also been King of Naples, and who was taking refuge in Palermo at the time of the discovery. In Germany J. E. Bode proposed the name Juno; others called it Hera \{this is now planet (103)\} for a short time. F. X. von Zach \{see planet (999)\} first discussed the original right of the discoverer to propose a name for a newly discovered object. In the naming controversy about this planet he stated: "Da Herr Prof. Piazzi nunmehr sein eigenes Kind getauft, und Ceres Ferdinandea benannt hat, wozu er als erster Entdecker das offenbar Recht hat, auch alle seine Correspondenten zu dieser Benennung von ihm aufgefordert sind: so unterschreiben wir auch unserer Seits diese recht schickliche Benennung mit wahrem und desto grösserem Vergnügen, weil dem Könige von Neapel unstreitig als eifrigem Beschützer und Beförderer der Sternkunde, und als grossmüthigem Stifter einer neuen stattlichen Sternwarte, unsere dankbarste Erkenntlichkeit um so mehr gebührt, da er eine Sternwarte zu bauen nicht nur angefangen, sondern auch vollendet hat; nicht bloss die prächtigsten und kostbarsten Englischen Werkzeuge angekauft hat, und in Kisten und Verschlägen auf Rumpelkammern aufbewahrt, sondern, wohin sie gehören, setzen lässt: diese vortrefflichen Instrumente nicht ungeschickten und unfleissigen Händen, sondern einem Gelehrten von anerkannten Verdiensten und Geschicklichkeit anvertraut, und diesen ein für allemahl in den Stand gesetzt, seine Arbeiten und Beobachtungen auf königl. Kosten zum Druck zu befördern. Daher denn auch in so kurzer Zeit die nützlichsten und glänzendsten Früchte aus der Palermer Sternwarte hervorgegangen, die gelehrte Welt mit mehreren Bänden der schätzbarsten Beobachtungen beschenkt, und dieser Tempel der Sicilianischen Urania durch die merkwürdigste Entdeckung, mit dem pünctlich eintretenden neuen Jahrhundert, auf Jahrtausende mit ihrem Stifter und Priester ist verewigt worden. Mit Recht sagt daher Piazzi in seiner Abhandlung, dass Ferdinand IV mit grösserem Rechte eine Stelle am Himmel, als manchem andern Protector der Sternkunde gebühre." (Mon. Corr., Band IV, p. 577-578 (1804)). The naming controversy is discussed in some detail by A. Manara (Mem. Soc. Astron. Ital., Vol. 68, No. 3, p. 679-686 (1997)).

\section{(2) Pallas}

Discovered 1802 Mar. 28 by H. W. Olbers at Bremen.

War-like appellation of Athene \{see planet (881)\} or Minerva \{see planet (93)\}, goddess of wisdom, war and the liberal arts, who sprang from Zeus' \{see planet (5731)\} head. (H 1)

The symbol used for Pallas in ancient times was a head of a spear.

$f$ or 4

The planet was discovered accidentally while looking for (1) Ceres. This is also the name of a lunar crater.

\section{(3) Juno}

Discovered 1804 Sept. 1 by K. Harding at Lilienthal.

Named after the queen of all the gods, daughter of Saturn and Rhea see planet (577)\}, wife of Jupiter, mother of Mars, Hebe \{see planet (6)\}, Lucina \{see planet (146)\} and Vulcan, sister of Ceres \{see planet (1)\}. (H 1)

The symbol used for Juno in ancient times was a scepter surmounted with a star.

$$
\text { or 米 }
$$

\section{(4) Vesta}

Discovered 1807 Mar. 29 by H. W. Olbers at Bremen.

Named for the patroness of the vestal virgins, goddess of fire and sister of Ceres \{see planet (1)\}. (H 1) Named by C. F. Gauss. The symbol used
for Vesta in ancient times was an altar with fire upon it.

\section{(5) Astraea}

Discovered 1845 Dec. 8 by K. L. Hencke at Driesen.

This is the Latin name for the Greek Astraia. This was the goddess of justice, daughter of Zeus and Themis \{see planets (5731) and (24)\}. Astraea lived on earth during the Golden Age, but the wickedness and impiety of mankind during the Brazen and Iron ages drove her to heaven, where she was placed among the constellations of the zodiac under the name Virgo. (H 2; Z 34)

Named by J. F. Encke (Am. J. Sci., Vol. 2, p. 435 (1846)). The symbol used for Astraea in ancient times was a pair of balances.

for कांड

The planet was accidentally discovered while looking for (4) Vesta.

\section{(6) Hebe}

Discovered 1847 July 1 by K. L. Hencke at Driesen.

Named after the Greek goddess of youth and cupbearer to all the gods, daughter of Zeus and Hera \{see planets (5731) and (103)\}, wife of Hercules. (H 2)

Named by C. F. Gauss (AN 26, 155 (1847)). The symbol used for Hebe in ancient times was a beaker.

\section{(7) Iris}

Discovered 1847 Aug. 13 by J. R. Hind at London.

Named after the messenger of the gods, especially Juno \{see planet (3)\}, daughter of Thaumas and Electra \{see planet (130)\}, sister of the Harpies. Synonym with the term rainbow. W. Bishop (Astronomical 
Observations, 1839-1851) stated: "The name of Iris, an attendant upon Juno, appeared peculiarly appropriate under the circumstances of the discovery. Juno was then in the 18th hour of right ascension and Iris closely followed in the 19th." The planet was discovered at Mr. Bishop's private observatory. The rainbow symbol is shown in AN 26, 207 (1847). (H 2)

\section{(8) Flora}

Discovered 1847 Oct. 18 by J. R. Hind at London.

Named for the goddess of flowers and gardens, wife of Zephyrus. (H 2)

Named by J. Herschel (AN 26, 254 (1847)): "Pallas, Juno, Ceres and Vesta, as sober and majestic Duennas will abundantly provide for the respectability of the group between Mars and Jupiter, while Astraea, Iris, Hebe, and Flora will attract all eyes and fill all imaginations with sweet and graceful images." The symbol used for Flora in ancient times was the rose of England.

\section{(9) Metis}

Discovered 1848 Apr. 25 by A. Graham at Markree.

Named after an Oceanid, daughter of Tethys and Oceanus, and first wife of Jupiter. He devoured her lest she bear a child more powerful than he. She personalizes prudence. ( $\mathrm{H} 2)$

The planet was discovered at the private observatory of Mr. Cooper who delegated to the discoverer the choice of a name from either Metis, put forward by Robinson, Armagh or Thetis suggested by J. Herschel. The name Thetis was later given to planet (17).

The name Metis has also been given to the satellite Jupiter XVI, discovered 1979 by S. P. Synnott. The symbol used for Metis in ancient times was an eye and a star.

\section{(10) Hygiea}

Discovered 1849 Apr. 12 by A. de Gasparis at Naples.

Named for the goddess of health, daughter of Aesculapius \{see planet (1027)\}. (H 2)

Named by M. Capocci, director of the Naples observatory. The symbol used for Hygiea in ancient times was a star and a serpent.

\section{(11) Parthenope}

Discovered 1850 May 11 by A. de Gasparis at Naples.

Named for a Siren, sometimes described as having a fish's body, who, cast upon the shore, founded the city of Parthenope, now Naples. (H 2)

The symbol used for Parthenope in ancient times was

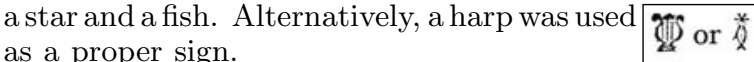

The discoverer "used his utmost endeavors to realize a Parthenope in the heavens, such being the name suggested by Sir John Herschel on the occasion of the discovery of (10) Hygiea." (Mon. Not. R. Astron. Soc., Vol. 10, p. 145 (1850)).

\section{(12) Victoria}

Discovered 1850 Sept. 13 by J. R. Hind at London.

Named after the Roman goddess of victory, daughter of the giant Pallas \{see planet (2)\}, or Titan and Styx; also the reigning queen of England. The corresponding Greek goddess Nike \{see planet (307)\} was added some 40 years later to the asteroid sky. The adopted sign for this planet is described in AN 31, 191 (1850): „ ए or (H 3)

A celebrated controversy arose over the naming, as some astronomers objected to the use of the name of a reigning sovereign. B. A. Gould, editor of the Astronomical Journal adopted Clio, an alternative name proposed by the discoverer. W. C. Bond s see planet (767)\}, Harvard College Observatory, held that the mythological condition was fulfilled, and the name justified, an opinion concurred in by the great majority of astronomers.

\section{(13) Egeria}

Discovered 1850 Nov. 2 by A. de Gasparis at Naples.

Named for the nymph of Aricia in Italy, wife of Numa Pompilius, second king of Rome. (H 3)

Named by U. J. J. Leverrier. The symbol used for Egeria in ancient times was a star and a plate.

\section{(14) Irene}

Discovered 1851 May 19 by J. R. Hind at London.

Named for one of the Hours, personification of peace, daughter of Jupiter and Themis \{see planet (24)\}. The others are Eunomia and Dike ssee planets (15) and $(99)\}$. They were represented as opening the gates of heaven and of Olympus. The discoverer states in AN 32, 277 (1851): "You will readily discover that this name, properly Eirene (peace), has some relation to this event (the Great Industrial Exhibition) which is now filling our Metropolis with the talent of art and science, in which all mankind must feel an interest." (H 3)

Named by J. Herschel. The symbol used for Irene in ancient times was a dove carrying an olive
branch and having a star on its head. Sometimes an alternative sign, representing an olive branch, a flag of truce and a star, was in use.

\section{(15) Eunomia}

Discovered 1851 July 29 by A. de Gasparis at Naples.

Named for one of the Hours, personification of order and the law. The others are Irene and Dike ssee planets (14) and (99)\}. (H 3)

The symbol used for Eunomia in ancient times $\pi$ was a heart, surmounted with a star.

\section{(16) Psyche}

Discovered 1852 Mar. 17 by A. de Gasparis at Naples. Named after the nymph whom Cupid married. Venus put her to death because she had robbed the world of her son; but Jupiter at the request of Cupid granted 
immortality to Psyche. The word signified "the soul" which she personifies. (H 3)

The symbol used for Psyche in ancient times was a butterfly's wing, a personification of the soul.

\section{(17) Thetis}

Discovered 1852 Apr. 17 by R. Luther at Düsseldorf. Named after the wife of Peleus \{see planet (11311)\}, king of Thessaly, daughter of Nereus and Doris \{see planet (48)\}, mother of Achilles \{see planet (588)\}. (H 3)

Named by F. W. A. Argelander. The symbol used $\mathbf{5}$ for Thetis in ancient times was a dolphin and a star.

\section{(18) Melpomene}

Discovered 1852 June 24 by J. R. Hind at London.

Named for the Muse of tragedy. All the Muses were offspring of Jupiter and Mnemosyne \{see planet (57)\}. The others are Klio, Euterpe, Thalia, Terpsichore, Erato, Polyhymnia, Kalliope and Urania \{see, respectively, planets (84), (27), (23), (81), (62), (33), (22), (30)\}. (H 4; AN 34, 391 (1852))

Named by the Astronomer Royal G. B. Airy who, in a letter to the Cape astronomer D. Gill, stated: "I look upon her as my planet for the following reason which you will not find in books. On 1839 June 24 I lost my noble boy Arthur. On 1852 June 24 (just 13 years later) I lost my dear daughter Elizabeth. And, while feeling that day of sorrow, I learnt that on that day a planet was discovered which I was requested to name. So I fixed on the name of the Muse of sadness." (cf. G. Forbes: David Gill, man and astronomer, p. 91 (London, 1916))

For the first time, no sign was adopted for this planet.

\section{(19) Fortuna}

Discovered 1852 Aug. 22 by J. R. Hind at London.

Named after a powerful deity among the ancients, goddess of fortune, dispenser of riches and poverty, pleasures and misfortunes. (H 4)

Named by the discoverer "at the deputation of Mr. Bishop". The planet was discovered at W. Bishop's private observatory.

\section{(20) Massalia}

Discovered 1852 Sept. 19 by A. de Gasparis at Naples. Independently discovered 1852 Sept. 20 by

J. Chacornac at Marseilles.

This is the Greek name of the city of Marseilles. The Latin spelling Massilia was also used sometimes. (H 4)

Named by B. Valz without knowledge of the Naples discovery. The planet was detected independently by J. Chacornac at Marseilles 1852 September 20. De Gasparis acquiesced in the matter. Valz was one of the first to suggest the encircled number of the planet as its symbol which is now modified to parentheses (AN 35, 194 (1852)). A. de Gasparis had chosen the name Themis for this planet \{see also planet (24)\} as proposed by Herschel (AN 35, 279 (1852)).

This is the first minor planet name which does not originate from ancient mythologies.

\section{(21) Lutetia}

Discovered 1852 Nov. 15 by H. Goldschmidt at Paris.

This planet is named for the city of Paris by its Latin name. The discoverer was a German painter living in Paris who discovered 14 minor planets, some from his window above the Cafe Procope. (H 4)

Named (AN 35, 343 (1852)) by F. J. D. Arago, director of the Paris Observatory.

This is the first minor planet discovered by an amateur astronomer.

\section{(22) Kalliope}

Discovered 1852 Nov. 16 by J. R. Hind at London.

Named for the Muse of heroic poetry s see also planet (18)\}. (H 4)

Named by J. C. Adams, president of the Royal Astronomical Society.

\section{(23) Thalia}

Discovered 1852 Dec. 15 by J. R. Hind at London.

Named for the Muse of comedy ssee also planet (18)\}. Thalia is also one of the three Graces, daughters of Venus by Jupiter or Bacchus \{see planet (2063)\}. The other Graces are Euphrosyne and Aglaja \{see planets (31) and (47)\}. (H 4)

Named by W. Bishop at whose private observatory the planet was discovered (AN 35, 380 (1852)).

\section{(24) Themis}

Discovered 1853 Apr. 5 by A. de Gasparis at Naples.

Named for one of the Titans, goddess of justice, daughter of Uranus and Gaea \{see planet (1184)\}, mother of the Hours \{see planets (14) Irene, (15) Eunomia, and (99) Dike\} and Fates \{see planets (97) Klotho, (120) Lachesis, and (273) Atropos\} by Zeus \{see planet (5731)\}. Themis is known as the goddess of law. (H 4)

Named by A. Secchi. This is the same name that A. de Gasparis had planned to call planet (20).

\section{(25) Phocaea}

Discovered 1853 Apr. 6 by J. Chacornac at Marseilles.

Named after a maritime town of Ionia in Asia Minor with colonies in Italy, Spain, and France. Beset by the tyrant Haspages a group of the inhabitants built Massalia (Marseilles, see planet (20)), sometimes designated Phocaica, about 600 B.C. (H 5; AN 36, 279 (1853))

Named by B. Valz.

\section{(26) Proserpina}

Discovered 1853 May 5 by R. Luther at Düsseldorf.

Named after the daughter of Ceres \{see planet (1)\} and Jupiter, carried away by Pluto to become queen of the infernal regions. Her mother after a lengthy search 
was unable even with the aid of Jupiter to secure her daughter's return to the upper regions since she had partaken of food in the Elysian fields - a pomegranate. A compromise was brought about whereby she spent half the year in the upper world. Proserpina presided over the death of mankind. See also the citation for planet (399) Persephone which is the Greek name for Proserpina. (H 5)

Named by "Sr. Excellenz dem wirklichen Geheimen Rath" Alexander von Humboldt (AN 36, 26 (1853)). The sign of the planet is "ein Granatapfel mit \& einem Stern im Innern."

\section{(27) Euterpe}

Discovered 1853 Nov. 8 by J. R. Hind at London.

Named for the Muse of music and lyric poetry s see also planet (18)\}. Her symbol was the flute. Some legends say she invented the flute and all the wind instruments. She loved wild melodies and associated more with Bacchus than with Apollo \{see planets (2063) and (1862)\}. (Z 105)

\section{(28) Bellona}

Discovered 1854 Mar. 1 by R. Luther at Düsseldorf.

Named for the war goddess, wife, sister, nurse or mother of Mars. (H 5)

Named by J. F. Encke.

The planet was named at the outset of the Crimean War (1854-1856). See also the remarks to planets (40) and (494). The sign of the planet is given in AN 38, 143 (1854): "die Geissel und der Spiess der kriegerischen Schwester des Mars."

\section{(29) Amphitrite}

Discovered 1854 Mar. 1 by A. Marth at London. Independently discovered 1854 Mar. 2 by N. R. Pogson at Oxford and Mar. 3 by J. Chacornac at Paris.

Named after an Oceanid, wife of Poseidon \{see planet (4341)\} and mother of Triton. (H 5)

Named by W. Bishop at whose private observatory the planet was discovered. The symbol used for Amphitrite in ancient times was a shell and a star.

\section{(30) Urania}

Discovered 1854 July 22 by J. R. Hind at London.

Named for the Muse of astronomy \{see also planet (18)\}. (H 5; AN 39, 92 (1854))

Named by A. de Morgan, secretary of the Royal Astronomical Society.

\section{(31) Euphrosyne}

Discovered 1854 Sept. 1 by J. Ferguson at Washington.

Named for one of the three Graces. The others are

Thalia and Aglaja \{see planets (23) and (47)\}. (H 5)

This is the first numbered minor planet discovered in North America.

\section{(32) Pomona}

Discovered 1854 Oct. 26 by H. Goldschmidt at Paris.

Named for a nymph at Rome, goddess of the fruit trees and gardens and wife of Vertumnus. (H 5)

Named by U. J. J. Leverrier. Wrongly, the symbol of an apple and a star was used sometimes. This sign, however, belongs to (26) Proserpina.

\section{(33) Polyhymnia}

Discovered 1854 Oct. 28 by J. Chacornac at Paris.

Named for the Muse of singing and rhetoric s see also planet (18)\}. (H 6)

Named by U. J. J. Leverrier.

\section{(34) Circe}

Discovered 1855 Apr. 6 by J. Chacornac at Paris.

Named for the enchantress, daughter of the Sun, celebrated for her knowledge of magic and venomous herbs. Circe changed the companions of Odysseus \{see planet (1143)\} into pigs. She had no influence on Odysseus because Hermes protected him. Odysseus lived a year with Circe, his friends were retransformed into men. (H 6)

The planet was named by the members of Paris observatory.

\section{(35) Leukothea}

Discovered 1855 Apr. 19 by R. Luther at Düsseldorf.

Named for the daughter of Cadmus and Hermione \{see planet (121)\} who was also called Ino \{see planet (173)\}. She married Athamas, king of Thebes, and was later changed to a sea deity. ( $\mathrm{H} 6$ )

Named by G. Rümker and C. A. F. Peters (AN 40, 373 (1855)) for the "Beschützerin der Seefahrer". The sign adopted for the planet consisted of an ancient $T$ lighthouse.

\section{(36) Atalante}

Discovered 1855 Oct. 5 by H. Goldschmidt at Paris.

Named for a girl of Arcadia \{see planet (1020)\} whose hand was won by Hippomenes who defeated her in a race by dropping three golden apples given him by Aphrodite \{see planet (1388)\}. (H 6)

Named by U. J. J. Leverrier.

\section{(37) Fides}

Discovered 1855 Oct. 5 by R. Luther at Düsseldorf.

Named after the Roman goddess of faith, oaths and honesty. (H 6)

Named by the Düsseldorf municipal council (AN 42 , 107 (1855)): "... dass der Düsseldorfer Gemeinderath in seiner gestrigen Sitzung, aus einer vom Curatorium der Sternwarte zu diesem Zweck entworfenen Liste, für meinen neuesten Planeten den Namen ... gewählt † hat." A cross was adopted as the sign for this planet.

\section{(38) Leda}

Discovered 1856 Jan. 12 by J. Chacornac at Paris.

Named for the wife of the king of Sparta. By Jupiter, who had taken the form of a swan, she produced 
two eggs from one of which came Pollux and Helena \{see planet (101)\} and from the other Castor and Klytemnaestra \{see planet (179)\}. (H 6)

Named by U. J. J. Leverrier.

This planet could not be observed in its second apparition. It was rediscovered in its third opposition by W. Foerster. The name Leda has also been given to the satellite Jupiter XIII, discovered 1974 by C. Kowal.

\section{(39) Laetitia}

Discovered 1856 Feb. 8 by J. Chacornac at Paris.

Named for the secondary Roman goddess of gaiety. (H 6)

Named by U. J. J. Leverrier.

\section{(40) Harmonia}

Discovered 1856 Mar. 31 by H. Goldschmidt at Paris.

Named after the daughter of Ares and Aphrodite \{see planet (1388)\}, wife of Cadmus \{see planet (7092)\}, the founder of Thebes. She introduced art and music into Greece. ( $\mathrm{H} 6$ )

Named by U. J. J. Leverrier.

The name was selected in order to "place a lasting monument to the happy re-establishment of peace". The Crimean War (1854-1856) came to a close with the signing of peace in Paris, February 1856. See also the citation for planet (28).

\section{(41) Daphne}

Discovered 1856 May 22 by H. Goldschmidt at Paris.

Named after the daughter of Terra. She entreated the gods to save her from the pursuit of Apollo \{see planet (1862)\} and she was changed into a laurel tree. (H 6)

Named by U. J. J. Leverrier.

\section{(42) Isis}

Discovered 1856 May 23 by N. R. Pogson at Oxford.

Named after the Egyptian goddess. Isis (the Moon) and her brother-husband Osiris the Sun, see planet (1923)\} comprehended all nature and were the most beneficial of the Egyptian gods. ( $\mathrm{H} \mathrm{7}$ )

Named by Prof. Manuel J. Johnson, director of the Radcliffe Observatory, Oxford.

The planet is probably also named for the discoverer's daughter, Elizabeth Isis Pogson, who was a member of the Royal Astronomical Society.

\section{(43) Ariadne}

Discovered 1857 Apr. 15 by N. R. Pogson at Oxford.

Named for the daughter of Minos \{see planet (6239)\}, second king of Crete, and Pasiphae. Ariadne fell in love with Theseus who was shut up in the labyrinth to be devoured by the Minotaur. She aided his escape with a thread and was later married and forsaken by him. (H 7)

\section{(44) Nysa}

Discovered 1857 May 27 by H. Goldschmidt at Paris.

It was to the nymphs of Nysa that the education of the young Bacchus \{see planet (2063)\} was entrusted.
No less than ten places had the name of Nysa including those in Ethiopia, Arabia, India \{see planets (1432) and (1157)\}, Thrace and Euboea \{see planet (1119)\}. (H 7)

Named by A. von Humboldt.

\section{(45) Eugenia}

Discovered 1857 June 27 by H. Goldschmidt at Paris.

Named by the discoverer in honor of the French empress and Spanish noblewoman Eugenia de Montijo de Guzmán (1826-1920), wife of Napoleon III. (H 7)

This is the first example of assigning the name of a human being to a minor planet. William J. Merline et al. reported the discovery of a satellite of (45) on 1998 Nov. 1. The moon with the preliminary designation S/1998 (45) 1 orbits the minor planet in a near-circular orbit every 4.7 days (IAU Circ. No. 7129).

\section{(46) Hestia}

Discovered 1857 Aug. 16 by N. R. Pogson at Oxford.

This is the Greek name for Vesta \{see planet (4)\}, here considered as one of the Hesperides, daughters of Hesperis and Atlas, guardians of the golden apples given to Juno \{see planet (3)\} by Jupiter on their wedding day. The other Hesperides are Aegle and Arethusa \{see planets (96) and (95)\}. (H 7)

Named by Admiral W. H. Smyth, "who oblingly complied with my request to stand God-father to this first offspring of his former telescope" (AN 47, 213 (1857)).

\section{(47) Aglaja}

Discovered 1857 Sept. 15 by R. Luther at Düsseldorf.

Named for one of the three Graces. The others are Thalia and Euphrosyne \{see planets (23) and (31)\}. (H 7)

This planet was named by the members of the Philosophical Faculty of the University of Bonn (AN 47, 47 (1858)).

\section{(48) Doris}

Discovered 1857 Sept. 19 by H. Goldschmidt at Paris.

Named for one of the sea nymphs, called Oceanides, daughter of Oceanus and Tethys. Doris married her brother Nereus \{see planet (4660)\} by whom she bore the sea nymphs called Nereids, about fifty in number. (H 7)

Named by E. de Beaumont.

The name was chosen by the French geologist from a list of suggestions by Babinet, Secretary of the Paris Academy of Sciences. Beaumont further suggested the appellation deux Jumelles (the Twins) for this planet and (49) Pales, both discovered by Goldschmidt on the same night - a unique occurrence at that time.

\section{(49) Pales}

Discovered 1857 Sept. 19 by H. Goldschmidt at Paris.

Named for the Roman goddess of sheepfolds and pastures. (H 8)

See also the remarks on planet (48). 


\section{(50) Virginia}

Discovered 1857 Oct. 4 by J. Ferguson at Washington. Independently discovered 1857 Oct. 19 by R. Luther at Düsseldorf.

Two possible interpretations for this name are published. Virginia is perhaps the famous Roman girl, stabbed by her father, the centurion Virginius, to save her from the decemvir Appius Claudius in 448 B.C. The name could be also an allusion to the contiguous state of Virginia. (H 8)

\section{(51) Nemausa}

Discovered 1858 Jan. 22 by A. Laurent at Nimes.

The planet was named "in memory and honor of the city and the fountain of the god Nemausus". Nemausus was the ancient name of Nimes. (H 8)

Named (AN 47, 349 (1858)) by B. Valz with permission of the discoverer.

\section{(52) Europa}

Discovered 1858 Feb. 4 by H. Goldschmidt at Paris.

Named for the daughter of Agenor \{see planet (1873)\}, king of Phoenicia, and sister of Cadmus \{see planet (7092)\}. She was carried off across the water to Crete on the back of a bull, which form had been assumed by Jupiter who was enamored of her. Europa became the mother of Minos, Sarpedon ssee planets (6239) and (2223), respectively $\}$ and Rhadamanthus. (H 8)

Named by Marshal Vaillant.

The name Europa has also been given to the second satellite of Jupiter, discovered 1610 by Galilei.

\section{(53) Kalypso}

Discovered 1858 Apr. 4 by R. Luther at Düsseldorf.

Named for one of the Oceanides, goddess of silence and daughter of Oceanus and Tethis. Kalypso received Odysseus \{see planet (1143)\} with hospitality when he was shipwrecked on her shores on the island of Ogygia and became enamored of him. (H 8)

Named by E. Schönfeld.

The name Calypso has also been given to the satellite Saturn XIV, discovered 1980 by B. Smith.

\section{(54) Alexandra}

Discovered 1858 Sept. 10 by H. Goldschmidt at Paris.

Named in honor of Baron Alexander von Humboldt (1769-1859), renowned naturalist and explorer of South America, Mexico and Siberia. His name is also associated with the Humboldt stream in the Pacific Ocean. (H 8)

Named by F. Moigno.

The departure in the naming usage from the broad mythological category was probably allowed because of Alexandra, daughter of Priamus \{see planet (884)\}, although the discoverer is clear in his intent (Comptes Rendus 47, p. 446).

\section{(55) Pandora}

Discovered 1858 Sept. 10 by G. Searle at Albany.

Named after the first mortal female. Pandora was made from clay by Vulcan at the request of Jupiter as a curse on Prometheus \{see planet (1809)\}. She was given all the necessary gifts by the gods - beauty by Venus, eloquence by Mercury, etc., hence the name. Then she was given a beautiful box to present to the man who married her. Prometheus saw through the deceit but his brother Epimetheus \{see planet (1810)\} married Pandora. He opened the box and there issued a multitude of evils which have not ceased to this day to afflict the human race. Only hope remained at the bottom of the box. In another version she was not to open the box but curiosity overruled. (H 8)

A famous controversy of the last century was that which raged between B. A. Gould and the trustees of the Dudley Observatory at Albany, from which place he issued the Astronomical Journal. The published charges and countercharges can be found today in astronomical libraries. He was eventually ejected by "hired ruffians". Mrs. Dudley has proposed the name Pandora, "the apt significance of which will be obvious to all" (Gould). The name Pandora has also been given to the satellite Saturn XVII, discovered 1980 by the Voyager 1 spacecraft.

\section{(56) Melete}

Discovered 1857 Sept. 9 by H. Goldschmidt at Paris.

Named for one of the three ancient Muses worshipped on Mount Helicon, daughter of Uranus. (H 9)

Named by E. Schubert, Ann Arbor, the orbit computer, at the request of the discoverer (AN 56, 349 (1861)).

The planet was also known as Pseudo-Daphne due to a confusion with planet (41).

\section{(57) Mnemosyne}

Discovered 1859 Sept. 22 by R. Luther at Düsseldorf.

Named after the daughter of Coleus and Terra, mother of the nine Muses \{see also planet (18)\} by Jupiter. The word signifies "memory" without which endowment progress in the spheres of the Muses would not take place. (H 9)

Named by M. Hoek, director of the Utrecht Observatory (AN 51, 255 (1859)).

\section{(58) Concordia}

Discovered 1860 Mar. 24 by R. Luther at Düsseldorf.

Named for the Roman goddess of peace and concord, daughter of Jupiter and Themis \{see planet (24)\}. (H 9)

Named (AN 53, 58 (1860)) by C. Bruhns, Leipzig at the request of the discoverer.

\section{(59) Elpis}

Discovered 1860 Sept. 12 by J. Chacornac at Paris.

Named after the Greek word for hope, also the personification of hope. (AN 56, 229 (1861)) 
Named by K. von Littrow on the request of E. Weiss. Weiss stated: "Da ich die Bearbeitung dieses Planeten übernommen und der Herr Entdecker keine Anstalten getroffen hat, ihn zu benennen, obwohl er schon vor mehr als einem Jahre aufgefunden wurde, habe ich Herrn Director v. Littrow ersucht, einen Namen für denselben auszusuchen. Er wählte 'Elpis' zur Erinnerung an die politische Stimmung der Epoche, in welche die Entdeckung fiel, oder, wenn man will, als Anspielung darauf, dass der Planet eben seinen Namen so lange zu erwarten hatte..."

Leverrier, director of the Paris Observatory did not want to have this planet named, attempting to introduce a new nomenclature - attaching the name of the discoverer to the number. Hind, Goldschmidt, Luther, Airy, Herschel, Argelander and others pronounced against the innovation. Dr. Weiss of the Vienna Observatory, who had taken particular charge of the observations of the planet, requested Prof. K. von Littrow, director of that observatory to name it. He chose Elpis in allusion to the political condition in Europe at the time of discovery and the name was adopted in Germany. In January 1862 Leverrier finally allowed the discoverer to select a name. The latter delegated the office to J. R. Hind who selected Olympia now the name of planet (582)\}, and the dual appellation was in use for a short time.

\section{(60) Echo}

Discovered 1860 Sept. 14 by J. Ferguson at Washington.

Named for an Oread, daughter of the Air and Tellus, condemned by Juno \{see planet (3)\} for her chattering to the loss of voice except for purposes of reply. She subsequently fell in love with Narcissus who was driven away by her manner of speech. Gradually she faded away till nothing was left but her voice. (H 9)

The planet was called Titania at first without knowledge of the previous appropriation of the name for a satellite of Uranus by J. Herschel.

\section{(61) Danaë}

Discovered 1860 Sept. 9 by H. Goldschmidt at Paris.

Named after the daughter of Acrisius, king of Argos, and Eurydike \{see planet (75)\}. Danaë was confined by her father to a brazen tower which was entered by Zeus \{see planet (5731)\} in the form of rain. By him she had Perseus. (H 9)

Named (AN 54, 93 (1860)) by R. Luther at the request of the discoverer.

The discoverer conceded the naming because of illness.

\section{(62) Erato}

Discovered 1860 Sept. 14 by O. Lesser and W. Foerster at Berlin.

Named after the muse of lyric poetry \{see also planet (18)\}. (H 9)

Named by J. F. Encke, director of the Berlin Observatory.

\section{(63) Ausonia}

Discovered 1861 Feb. 10 by A. de Gasparis at Naples. Named for a part or all of Italy after its king Auson, a son of Odysseus \{see planet (1143)\} and Kallisto \{see planet (204)\}. (H 10)

Named by M. Capocci (AN 55, 79 (1861)).

The planet was first called Italia, a name which nowadays is assigned to planet (477).

\section{(64) Angelina}

Discovered 1861 Mar. 4 by E. W. Tempel at Marseilles.

Named in remembrance of the astronomical station of Baron F. X. von Zach (1754-1832) \{see planet (999)\} at Notre-Dame-des-Anges on the mountain of Mimet near Marseilles, hermitage and convent of the Pères de l'Oratoire. The aim of von Zach's observations was to determine the plumb deviation caused by mountains. He published his results in his monumental work L'attraction des montagnes (Avignon, 1814). Zach travelled extensively in his early life, promoted international cooperation, was active as editor of an astronomical publication, and helped organize the search for the missing planet between Mars and Jupiter. (H 10)

Named by B. Valz.

A storm of protest raised by Herschel, Airy and Argelander arose over the naming of this planet. The discoverer stated in AN 71, 96 (1868): "Der Planet, welcher von Herrn Valz ... Angelina getauft wurde und Anfechtungen erhielt, wäre durch Weglassung des letzten 'n' classisch mythologisch geworden und hätte gewiss beide Theile befriedigt."

\section{(65) Cybele}

Discovered 1861 Mar. 8 by E. W. Tempel at Marseilles.

Named for the Phrygian goddess often identified with Rhea \{see planet (577)\}. (H 10)

The planet was originally named Maximiliana by the Bavarian Ministerialrat K. A. von Steinheil in allusion to Maximilian II, the king of Bavaria. The name was regarded as non-classical and was changed after protest by Herschel, Airy, Argelander and others by the Berliner Astronomisches Jahrbuch. The discoverer transferred the naming rights to Steinheil "aus Anerkennung für die ausgezeichneten Leistungen seines aus dessen Werkstätte bezogenen Fernrohrs." (AN 55, 93 (1861))

\section{(66) Maja}

Discovered 1861 Apr. 9 by H. P. Tuttle at Cambridge, Massachusetts.

Named for one of the Pleiades, daughters of Atlas and Pleione. Maja was the mother of Mercury by Jupiter. (H 10)

Named by J. Quincy, former president of Harvard University, friend of the Observatory and member of its Visiting Committee.

Further three minor planets are named for one of the Pleiades: Elektra, Asterope, and Merope \{see planets (130), (233), and (1051), respectively\}. G. P. Bond, 
director of the Harvard College Observatory, in AN 55, 299 (1861) pointed out: "It may perhaps be objected that the same name has been applied to one of the Plejades, but there can scarcely be any risk of confusions from the double application."

\section{(67) Asia}

Discovered 1861 Apr. 17 by N. R. Pogson at Madras.

Asia was the wife of Iapetus and the mother of Atlas and Prometheus \{see planet (1809)\}. The discoverer stated in AN 55, 285 (1861)): "The name "Asia" has been selected in consequence of this being the first discovery made in this quarter of the globe. As one of the Oceanides, Asia has just as much right to a celestial celebrity as her sisters Europa, Doris \{see planets (52) and (48)\} and many others of the same family long since adopted." (H 10)

This is the first numbered minor planet discovered in Asia.

\section{(68) Leto}

Discovered 1861 Apr. 29 by R. Luther at Düsseldorf.

Named for the daughter of Coeus and Phoebe and mother of Artemis \{see planet (105)\} and Apollo \{see planet (1862)\} by Zeus \{see planet (5731)\}. (H 10)

Named by F. W. A. Argelander, C. N. A. Krueger and Tiele at Bonn.

The Latin name for Leto is Latona - see planet (639).

\section{(69) Hesperia}

Discovered 1861 Apr. 26 by G. Schiaparelli at Milan.

Hesperia is the Greek name for Italy derived from Hespera or Vesper, the setting Sun, the evening or the evening star in which direction Italy lay. (H 10)

\section{(70) Panopaea}

Discovered 1861 May 5 by H. Goldschmidt at Paris.

Named for a sea nymph, one of the Nereids, whom sailors invoked during storms. (H 11)

Named (AN 55, 235 (1861)) by R. Main, Oxford Observatory, president of the Royal Astronomical Society, who had the occasion to present the Gold Medal of the RAS to the discoverer for his planetary discoveries.

\section{(71) Niobe}

Discovered 1861 Aug. 13 by R. Luther at Düsseldorf.

Named for the daughter of Tantalus ssee planet (2102)\} and sister of Pelops, the king of Phrygia. She presumed to be greater than Latona \{see planet (639)\}. Apollo \{see planet (1862)\} punished her by killing her seven sons and seven daughters and changing her into a rock. (H 11)

The name was chosen by a majority of astronomers who met in Dresden on August 20/21, 1861.

\section{(72) Feronia}

Discovered 1861 May 29 by C. H. F. Peters at Clinton.

Named for the Roman goddess of groves and freedmen. (H 11)
Named by T. H. Safford, assistant at Harvard, who discovered that this was a new planet and not (66) as originally identified.

\section{(73) Klytia}

Discovered 1862 Apr. 7 by H. P. Tuttle at Cambridge, Massachusetts.

Named for the nymph loved by and later despised by Apollo \{see planet (1862)\}. She was changed into a sunflower. (H 11)

Named by J. I. Bowditch of Boston, member of the Harvard Observatory Visiting Committee.

\section{(74) Galatea}

Discovered 1862 Aug. 29 by E. W. Tempel at Marseilles.

Two possible interpretations of the name are published. Galatea probably refers to the name given by the Cypriot sculptor Pygmalion to his marble statue of which he had become enamored. The other possibility is that the planet was named after the Nereid loved by Acis who was destroyed by the jealous Cyclops Polyphemus. (H 11)

Named by K. von Littrow (AN 58, 255 (1862)) at the request of the discoverer (AN 58, 207 (1862)).

The name Galatea has also been given to the satellite Neptune VI.

\section{(75) Eurydike}

Discovered 1862 Sept. 22 by C. H. F. Peters at Clinton.

Named for the wife of Orpheus \{see planet (3361)\} who descended into Hades to secure her return which he obtained on the condition that he would not look back at her until reaching the upper world. She was returned to Hades when he looked back at the last moment. (H 11)

\section{(76) Freia}

Discovered 1862 Oct. 21 by H. d'Arrest at Copenhagen.

Named after the Norse goddess of love and beauty. (AN 59, 16 (1862))

\section{(77) Frigga}

Discovered 1862 Nov. 12 by C. H. F. Peters at Clinton.

Named after the Norse goddess and queen of all the gods. Frigga is the wife of Odin \{see planet (3989)\}. (H 11)

The discoverer stated in AN 60, 107 (1863): ".. erlaube ich mir den Namen Frigga vorzuschlagen, da Frigga und Freia \{see planet (76)\} in der nordischen Mythologie so häufig in Gesellschaft sich finden..."

\section{(78) Diana}

Discovered 1863 Mar. 15 by R. Luther at Düsseldorf.

Named for the goddess of the hunt and daughter of Jupiter and Latona \{see planet (639)\}. The Greek name of Diana is Artemis \{see planet (105)\}. (H 11)

Named by Privy Councilor of Justice W. Luther of Naumburg, uncle of the discoverer.

\section{(79) Eurynome}

Discovered 1863 Sept. 14 by J. C. Watson at Ann Arbor. 
Named after a nymph, daughter of the Ocean and Thetis \{see planet (17)\} and mother of Leukothea \{see planet (35)\}. (H 12)

\section{(80) Sappho}

Discovered 1864 May 2 by N. R. Pogson at Madras.

Named in honor of the renowned Greek lyric poetess (610 B.C.) who threw herself into the ocean because of her unrequited love for the young Phaon. (H 12)

\section{(81) Terpsichore}

Discovered 1864 Sept. 30 by E. W. Tempel at Marseilles.

Named for the Muse of choral dance and song ssee also planet (18)\}. (H 12)

Named (AN 63, 127 (1874)) by C. A. F. Peters.

\section{(82) Alkmene}

Discovered 1864 Nov. 27 by R. Luther at Düsseldorf.

Named after the mother of Hercules by Jupiter who had assumed the shape of her husband Amphitryon. (H 12)

Named by C. von Littrow, E. Weiss and Th. von Oppolzer in Vienna at the request of the discoverer (AN 63, 269 (1864)).

\section{(83) Beatrix}

Discovered 1865 Apr. 26 by A. de Gasparis at Naples.

Named for a Florentine lady of the noble family of Portinari, immortalized by Dante \{see planet (2999)\} in his "Divine Comedy". Beatrix is also the name of the discoverer's daughter. (H 12)

The remark in Mon. Not. R. Astron. Soc., Vol. 25, p. 221 (1875) states "in honor to Dante". The discoverer in AN 64, 256 (1875) stated: "Sauf précédence dans la découverte, en hommage au Dante je propose pour cette planète le nom de Béatrix".

\section{(84) Klio}

Discovered 1865 Aug. 25 by R. Luther at Düsseldorf.

Named for the Muse of history \{see also planet (18)\}. (H 12)

Named by Leipzig astronomers at the meeting on August 31, 1865.

\section{(85) Io}

Discovered 1865 Sept. 19 by C. H. F. Peters at Clinton.

Named after the daughter of the river god Inachus, son of Oceanus. She was changed into a heifer by Jupiter at the approach of Juno \{see planet (3)\} who saw through the deception and had her guarded by Argus who had a hundred eyes and slept with them closed only two at a time. The latter was killed by Mercury at Jupiter's order and Io escaped through the Ionian Sea, named for her, to Egypt where some say she became Isis, the wife of Osiris \{see planets (42) and (1923)\}. (H 12)

The name Io has also been given to the first satellite of Jupiter, discovered 1610 by Galilei.

\section{(86) Semele}

Discovered 1866 Jan. 4 by F. Tietjen at Berlin.
Named for the daughter of Cadmus and mother of Bacchus \{see planet (2063)\} by Jupiter. (H 12)

\section{(87) Sylvia}

Discovered 1866 May 16 by N. R. Pogson at Madras.

Named possibly in honor of Sylvie Petiaux-Hugo Flammarion, first wife of Camille Flammarion \{see planet (1021)\}, French popularizer of astronomy. This interpretation seems very questionable. Paluzíe-Borrell quoted the book of Camille Flammarion, Astronomie Populaire, Lib. IV, Chap. V: "La 87e, la 107e, la 141e, la $154 \mathrm{e}$, la $169 \mathrm{e}$, ont été nommées en l'honneur d'un jeune astronome qui consacrait ses meilleures années au culte de l'astronomie et à l'apostolat de cette belle science." (H 12)

On February 18, 2001 the CalTec astronomers J.-L. Margot and M. Brown discovered a small satellite of (87) Sylvia using the adaptive optics system of the 10-m Keck II telescope in Hawaii. The satellite S/2001 (87) 1 orbits Sylvia at a distance of approx. $1200 \mathrm{~km}$ once every four days.

The discoverer stated: "The name Sylvia as in the case of Sappho \{see planet (80)\} was chosen out of a list supplied to me some years back by Sir John Herschel." Herschel undoubtedly was an advocate for using classical names. A very similar way of thinking must be assumed for Pogson who exclusively used classical names for former discoveries \{see planets (29), (42), (43), (46), (67), and (80), respectively\}.

\section{(88) Thisbe}

Discovered 1866 June 15 by C. H. F. Peters at Clinton.

Pyramus and Thisbe were two Babylonian lovers prominent in Shakespeare's A Midsummer Night's Dream. (H 13)

\section{(89) Julia}

Discovered 1866 Aug. 6 by E. Stephan at Marseilles.

Named probably after the patron saint Julia of Corsica who died as a martyr in the fifth century. At the time of the discovery, the island in the vicinity of Marseilles already was a part of France. (LDS)

\section{(90) Antiope}

Discovered 1866 Oct. 1 by R. Luther at Düsseldorf.

The name appears twice in the mythology. Antiope was the daughter of Nycteus, king of Thebes, and Polyxo $\{$ see planet (308)\} and mother of two children by Zeus \{see planet (5731)\}. Antiope is also mentioned as one of the queens of the Amazones and daughter of Ares. She was taken prisoner by Hercules and given in marriage to Theseus. (H 13)

Named by von Kühlwetter, district president of Düsseldorf.

Antiope seems to be the first double asteroid ever discovered. A survey team of astronomers led by W. Merline, Boulder (U.S.A.) detected the pair using the W. M. Keck telescope atop Mauna Kea, Hawaii by 
means of adaptive optics procedures. Each member of the pair has a diameter of about $80 \mathrm{~km}$ with a mutual separation of approximately $160 \mathrm{~km}$.

\section{(91) Aegina}

Discovered 1866 Nov. 4 by A. Borrelly at Marseilles.

Named after the daughter of Asopus, a son of Poseidon \{see planet (4341)\}. She was changed by Zeus \{see planet (5731)\}, father of one of her sons, into the island bearing her name. (H 13)

Named by C. Bruhns (AN 71, 37 (1868)).

\section{(92) Undina}

Discovered 1867 July 7 by C. H. F. Peters at Clinton.

Named for the heroine of the early 19 th century novel Undine by the German romantic writer F. H. K. de la Motte Fouqué (1777-1843) who wrote many chivalric romances, tales and plays based on Norse mythology. Undine is one of a group of female water spirits. When an Undine married a mortal and born a child she received a soul. If, however, her lover proved to be unfaithful, she would be forced to return to the sea. (LDS)

The discoverer explained the naming in AN 69, 349 (1867): "Der Planet ... hat den Namen Undina erhalten, welcher sich vielleicht nicht in den alten Classikern findet, aber jedenfalls klassisch richtig gebildet, und ausserdem durch die liebliche Dichtung von de la Motte Fouqué verherrlicht worden ist." Two romantic operas by A. Lortzing (1801-1851) and by E. T. A. Hoffmann (1776-1822) are based on the tale.

\section{(93) Minerva}

Discovered 1867 Aug. 24 by J. C. Watson at Ann Arbor.

Minerva is the Latin name of the goddess Athene or Pallas ssee planets (881) and (2)\}. (H 13)

Named by the Astronomische Gesellschaft.

\section{(94) Aurora}

Discovered 1867 Sept. 6 by J. C. Watson at Ann Arbor.

Aurora is the Latin name for Eos \{see planet (221)\}, the goddess of the dawn. (H 13)

Named by the Astronomische Gesellschaft.

\section{(95) Arethusa}

Discovered 1867 Nov. 23 by R. Luther at Düsseldorf.

Named after one of the Hesperides \{ see also planet (46)\}. (H 13)

Named by J. Galle, the discoverer of Neptune, and Günther in Breslau (AN 70, 237 (1867)).

\section{(96) Aegle}

Discovered 1868 Feb. 17 by J. Coggia at Marseilles.

Named after one of the Hesperides \{see also planet (46)\}. (H 13)

\section{(97) Klotho}

Discovered 1868 Feb. 17 by E. W. Tempel at Marseilles.
Named after one of the three Fates. The others are Lachesis and Atropos \{see planets (120) and (273)\}. Klotho presides over birth and spins destinies. (H 13)

Named Clotho by the Société Impériale des Sciences naturelles de Cherbourg.

Tempel proposed also names for the next two planets (AN 71, 97 (1868)): "Il me semble qu'il serait un peu poétique, de donner aux trois dernières planètes (97), (98) et (99) les noms de 3 Parques: Clotho, Lachésis et Atropos, non pas avec l'idée que le ciseau d'Atropos dût couper le fil de cette recherche, mais avec la pensée de diviser la première centaine des petites planètes, qui représentent assurément un grand et noble travail astronomique." His naming proposals, however, were not realized. The two other Fates received the numbers (120) and (273), respectively.

\section{(98) Ianthe}

Discovered 1868 Apr. 18 by C. H. F. Peters at Clinton.

Named for the young girl who became betrothed to Iphis, a Cretan girl who was changed by Isis \{ see planet (42)\} into a man. (H 14)

\section{(99) Dike}

Discovered 1868 May 28 by A. Borrelly at Marseilles.

Dike represents the human justice who with the divine justice Themis \{see planet (24)\} sat beside Zeus \{see planet (5731)\} on Olympus. (H 14) Named by E. Stephan.

\section{(100) Hekate}

Discovered 1868 July 11 by J. C. Watson at Ann Arbor. Independently discovered 1868 July 18 by C. Wolf at Paris.

Named after the goddess of the lower world and of darkness in the upper world. (H 14)

The naming was delegated to the National Academy of Sciences, Washington, D.C. The name was submitted by a committee of four including B. Peirce and B. A. Gould.

J. Meeus suggested the interesting interpretation that the choice of this name could have been influenced by the fact that the Greek word 'hekaton' means 100 .

\section{(101) Helena}

Discovered 1868 Aug. 15 by J. C. Watson at Ann Arbor.

Named after the daughter of Zeus and Leda \{see planets (5731) and (38)\}, and cause for the Trojan War. (H 14)

The naming was delegated to the U.S. National Academy of Sciences, of which the discoverer was a member. The naming was redelegated to B. A. Gould who selected the name (AN 72, 191 (1868)).

\section{(102) Miriam}

Discovered 1868 Aug. 22 by C. H. F. Peters at Clinton.

Named after the sister of Moses, the Hebrew prophet who led the Israelites out of Egyptian slavery and 
at Mt. Sinai delivered to them the Law establishing God's covenant with them. (H 14)

The naming of this planet produced a controversy. Edward S. Holden \{see planet (2974)\} stated: "The name of the asteroid Miriam was chosen in defiance of a rule, and of malice aforethought; so that the discoverer could tell a theological professor, whom he thought to be too pious, that Miriam also was a 'mythological personage'."

\section{(103) Hera}

Discovered 1868 Sept. 7 by J. C. Watson at Ann Arbor.

Named after the Greek goddess, daughter of Cronus and Rhea $\{$ see planet (577)\}, sister and at the same time wife of Zeus \{see planet (5731)\}, and mother of Ares, Hephaistos \{see planet (2212)\}, Hebe \{see planet (6)\}, and Eileithyia. Hera is the Greek name for the Latin Juno \{see planet (3)\}. (H 14)

\section{(104) Klymene}

Discovered 1868 Sept. 13 by J. C. Watson at Ann Arbor.

There are about ten mythological characters by this name. In the Iliad Clymene is a female servant of Helen \{see planet (101)\}, who accompanied her mistress when Paris \{see planet (3317)\} abducted her. Clymene is also known as the daughter of Oceanus and Tethys and mother of Epimetheus and Prometheus \{see planets (1810) and (1809)\}. (Z 65)

\section{(105) Artemis}

Discovered 1868 Sept. 16 by J. C. Watson at Ann Arbor.

Artemis (Roman name Diana, see planet (78)) was the daughter of Zeus by Leto \{see planets (5731) and (68) $\}$ and the twin sister of Apollo \{see planet (1862)\}. She was the Moon goddess and goddess of hunting. In Roman mythology she was also the goddess of childbirth as Lucina \{see planet (146)\} and the patroness of unmarried girls and of chastity. (Z 32)

\section{(106) Dione}

Discovered 1868 Oct. 10 by J. C. Watson at Ann Arbor.

Named for the mother of Aphrodite by Zeus \{see planets (1388) and (5731)\}. When Aphrodite was wounded by Diomedes \{see planet (1437)\}, Dione comforted her daughter. Dione foretold the death of Diomedes for daring to wage war against the immortals. Aphrodite is sometimes called Dione. ( $\mathrm{Z}$ 87)

The name Dione has also been given to the fourth satellite of Saturn, discovered 1684 by J. D. Cassini.

\section{(107) Camilla}

Discovered 1868 Nov. 17 by N. R. Pogson at Madras.

Named possibly for a daughter of Metabus. When she was young, her father dedicated her to the service of Artemis \{see planet (105)\}. She became a virgin warrior and queen of the Volscians. She assisted Turnus against Aeneas \{see planet (1172)\}. Camilla fought with one breast bared to give freedom to her bow arm. She was a swift runner, comparable to Atalanta \{see planet (36)\}. She was killed by the spear of Aruns. (LDS; Z 49)

Other sources - see the remarks to planet (87) - give the alternative interpretation that the name refers to the French astronomer Camille Flammarion (see planet (1021)). This seems unlikely, however, because Pogson frequently used mythological names for his discoveries.

\section{(108) Hecuba}

Discovered 1869 Apr. 2 by R. Luther at Düsseldorf.

Named for the wife of Priam \{see planet (884)\} at the time of the Trojan War. She was a most unfortunate mother of fifty sons and twelve daughters. Many of her sons were slain, Polyxena \{see planet (595)\} was sacrified, Polydorus \{see planet (4708)\} drowned, Cassandra \{see planet (114)\} was murdered, Hecuba herself changed into a bitch. (Z 118)

Named by Dr. Franz Heinen, director of the Realschule in Düsseldorf and trustee of the Bilk Observatory (AN 74, 31 (1869)).

\section{(109) Felicitas}

Discovered 1869 Oct. 9 by C. H. F. Peters at Clinton.

Named for the divinity personifying happiness. She is portrayed seated in a throne with a caduceus and a horn of plenty in her hands. (H 15)

\section{(110) Lydia}

Discovered 1870 Apr. 19 by A. Borrelly at Marseilles.

Named after the country in Asia Minor whose early inhabitants were called Phrygians. About the time of the Trojan War, the Heraclidae reigned there. ( $\mathrm{Z}$ 156)

\section{(111) Ate}

Discovered 1870 Aug. 14 by C. H. F. Peters at Clinton.

Named for the goddess of all evil, infatuation, and mischief. Ate (or Eris) was a daughter of Zeus \{see planet (5731)\}. Not invited to the marriage of Peleus and Thetis \{see planet (17)\}, she rolled the Golden Apple that led to the Judgement of Paris \{see planet (3317)\}, a main cause for the Trojan War. Hesiod says she was a daughter of Eris. (Z 35)

\section{(112) Iphigenia}

Discovered 1870 Sept. 19 by C. H. F. Peters at Clinton.

Named for the daughter of Agamemnon ssee planet (911)\} and Clytemnestra \{see planet (179)\} and sister of Orestes and Electra \{see planet (130)\}. The Greeks, detained at Aulis by contrary winds and unable to sail for Troy, were informed by a soothsayer that Iphigenia must be sacrificed to appease the gods, for Agamemnon had provoked Artemis \{see planet (105)\} by killing her favorite stag. As Agamemnon was about to strike the fatal blow, a large and beautiful stag appeared in Iphigenia's place. The winds became favorable and 
the Greeks sailed for Troy. In Iliad, Iphigenia is called Chrysothemis \{see planet (637)\}. (Z 138)

\section{(113) Amalthea}

Discovered 1871 Mar. 12 by R. Luther at Düsseldorf.

Named for the daughter of King Melissus of Crete, who nourished Zeus \{see planet (5731)\} with the milk of a goat. (H 15)

Named (AN 77, 217 (1871)) by the Berlin astronomers by a vote of 5 to 3 .

The name Amalthea has also been given to the fifth satellite of Jupiter, discovered 1892 by E. Barnard.

\section{(114) Kassandra}

Discovered 1871 July 23 by C. H. F. Peters at Clinton.

Named after one of the twelve daughters of Priam \{see planet (884)\} and Hecuba \{see planet (108)\} of Troy. The twin of Helenus \{see planet (1872)\}, she had fifty brothers. She was the most beautiful of Priam's daughters and was courted by many princes. Apollo \{see planet (1862)\} loved her and promised to give her what she desired if she would gratify his passion. She asked for the power of prophecy, but as soon as she obtained the gift, refused to fulfill the bargain. Apollo could not withdraw the gift of prophecy he had granted her, but he wet her lips with his tongue, thus effecting a curse that no reliance would ever be placed upon her predictions. She would indeed be able to foretell the future, but no credence would ever be given to her prophecy. Her name has become synonymous with prophets of doom whose warnings are heeded too late. (Z 51)

\section{(115) Thyra}

Discovered 1871 Aug. 6 by J. C. Watson at Ann Arbor.

Named after an early Danish queen. Queen Thyri was the wife of King Gorm the Old of Denmark (?-940) and the mother of the Dane Harald Bluetooth (935-986), who died as a Christian. In 935 King Harald wrote on a runic stone, that he had unified all Denmark and Norway under himself and made the Danes Christians. This unique monument Harald erected to himself and his parents at Jellings, Jutland. These two vast runestones are the largest and most impressing in the world. The smaller of the two is dedicated by Gorm to honor his wife Thyri, restorer of Denmark. (H 15; R. Bremer)

At the time that this planet was discovered, the discoverer had just returned from a visit to Europe, and probably this particular name was chosen as a memento of his stay in Denmark.

\section{(116) Sirona}

Discovered 1871 Sept. 8 by C. H. F. Peters at Clinton.

Named after the Celtic mother goddess of Belgian and Roman Gaul, whose worship was in connection with the thermal fountains. (H 15)

\section{(117) Lomia}

Discovered 1871 Sept. 12 by A. Borrelly at Marseilles.

Very probably, the name 'Lamia' originally was misspelled to 'Lomia'. Lamia, queen of Lybia, was beloved by Zeus $\{$ see planet (5731)\} and made insane by a jealous Hera \{see planet (103)\}. (I. van HoutenGroeneveld)

Lamia, or Greek Lameia, exists as planet (248).

\section{(118) Peitho}

Discovered 1872 Mar. 15 by R. Luther at Düsseldorf.

Named for a daughter of Hermes and Aphrodite \{see planet (1388)\}, goddess of persuasion among the Greeks and Romans. Peitho (also Pitho, Suada, Suadela) was an attendant of Eros \{see planet (433)\}. (Z 195)

Named by Becker, Leiden and G. Rümker, director of the Hamburg Observatory.

\section{(119) Althaea}

Discovered 1872 Apr. 3 by J. C. Watson at Ann Arbor.

Named after the mother of Meleager, who, having killed his mother's two brothers, was himself killed when she threw on the fire the log on whose existence his life depended. (H 16)

\section{(120) Lachesis}

Discovered 1872 Apr. 10 by A. Borrelly at Marseilles. Independently discovered 1872 Apr. 11 by C. H. F. Peters at Clinton.

Named for one the three Fates. The other two are Clotho \{see planet (97)\} and Atropos \{see planet (273)\}. They are daughters of Erebus and Nyx \{see planet (3908)\}. Lachesis carries the globe or scroll and determines the length of the thread of life. (H 16)

\section{(121) Hermione}

Discovered 1872 May 12 by J. C. Watson at Ann Arbor.

Named after the daughter of Menelaus and Helen \{see planets (1647) and (101)\}. She was promised in marriage to Orestes \{see planet (13475)\}, but Menelaus, ignorant of this, gave her to Pyrrhus \{see planet (5283)\} for the services he rendered in the Trojan War. (Z 125)

A satellite of (121) with an estimated diameter of $13 \mathrm{~km}$ was discovered on 2002 Sept. 18 with the $10-\mathrm{m}$ Keck II telescope. The preliminary designation of the satellite is S/2002 (121) 1.

\section{(122) Gerda}

Discovered 1872 July 31 by C. H. F. Peters at Clinton. Named for the wife of Freyr in Norse mythology. (H 16)

\section{(123) Brunhild}

Discovered 1872 July 31 by C. H. F. Peters at Clinton. Named for a character of the Nibelungenlied, the Volsung Cycle, and the Thidrek Saga. Brunhild was a queen in German legend, won by Siegfried for Gunther. Brunhild was the daughter of Odin \{or Wodan, see planets (3989) and (2155), respectively\} and Erda \{see 
planet (894)\}, tha eldest of the Valkyries. (H 16; I. van Houten-Groeneveld)

\section{(124) Alkeste}

Discovered 1872 Aug. 23 by C. H. F. Peters at Clinton. Named after the daughter of Pelias and Anaxibia and wife of Admetus. She volunteered to die for her husband on the promise of Apollo \{see planet (1862)\} that Admetus should never die if someone were found to die in his stead. Some legends say Heracles brought Alcestis back from Hades. (Z 15)

Named by Adelinde Weiss, wife of the Austrian astronomer E. Weiss, at the request of the discoverer.

\section{(125) Liberatrix}

Discovered 1872 Sept. 11 by P. M. Henry at Paris.

This name very probably is an allusion to the liberation of France at the time of the discovery. (Littrow, 7. ed., p. 445 (1886))

Another interpretation is $(\mathrm{H} 16)$ that this planet is possibly named for the first president of the French Republic, Adolphus Thiers, who arranged a loan of $5,000,000,000$ golden francs, by means of which the Prussian troops were evacuated from the French territory after the France-Prussian War, 1870/71.

\section{(126) Velleda}

Discovered 1872 Nov. 5 by P. P. Henry at Paris.

Named for a priestess of the Germans in the first century A.D. who was worshiped as a deity. She provoked the rebellion of the Bataves and other tribes against the Romans. (H 17)

\section{(127) Johanna}

Discovered 1872 Nov. 5 by P. M. Henry at Paris.

Named probably for Jeanne d'Arc (1412-1431), saint and French national heroine. (Littrow, 7. ed., p. 445 (1886))

\section{(128) Nemesis}

Discovered 1872 Nov. 25 by J. C. Watson at Ann Arbor. Independently discovered 1872 Dec. 5 by A. Borrelly at Marseilles.

Named for the goddess of vengeance. Nemesis was the daughter of Erebus and Nyx (the Night) \{see planet (3908)\}. (H 16)

\section{(129) Antigone}

Discovered 1873 Feb. 5 by C. H. F. Peters at Clinton. Named after the daughter of Oedipus, king of Thebes. She guided her father when he was blind and exiled by her uncle Creon. (H 17)

\section{(130) Elektra}

Discovered 1873 Feb. 17 by C. H. F. Peters at Clinton.

There are several meanings known in classical mythology. After Aeschylus, Sophocles and Euripides, Electra was the daughter of Agamemnon and Clytemnestra \{see, respectively, planets (911) and (179)\} and sister of Orestes, Iphigenia \{see planet (112)\}, and Chrysothemis \{see planet (637)\}. Electra incited her brother Orestes to avenge their father's murder by killing their mother and her lover Aegisthus. (Z 92)

\section{(131) Vala}

Discovered 1873 May 24 by C. H. F. Peters at Clinton.

Named for a prophetess in Scandinavian mythology. (AN 82, 130 (1873))

\section{(132) Aethra}

Discovered 1873 June 13 by J. C. Watson at Ann Arbor.

Named (in the Iliad) after the mother of Theseus, the Greek hero. After another legend Aethra was one of the seven Oceanids. They died of grief over the death of their brother Hyas and were changed into stars called the Hyades. (Z 10)

\section{(133) Cyrene}

Discovered 1873 Aug. 16 by J. C. Watson at Ann Arbor.

Named after a daughter of Hypseus, king of the Lapithae. She loved to hunt and wrestle with lions. Apollo \{see planet (1862)\} saw her wrestle with a lion and fell in love with her. He was the father of her two sons Aristaeus \{see planet (2135)\} and Idmon, the latter a famous seer. (Z 78)

\section{(134) Sophrosyne}

Discovered 1873 Sept. 27 by R. Luther at Düsseldorf.

Named for one of the virtues in Plato's (427?-347 B.C.) \{see planet (5451)\} system: equanimity, healthy mind and impartiality. (H 17)

Named (AN 82, 287 (1873)) by F. W. A. Argelander and Theodor Wolff, Bonn.

\section{(135) Hertha}

Discovered 1874 Feb. 18 by C. H. F. Peters at Clinton.

Named for the Teutonic and Scandinavian goddess of fertility (also Nerthus, see planet (601)). The discoverer was born in southern Schleswig, at that time a region of Denmark. A few years prior to the discovery he visited Scandinavia. (H 17)

E. Weiss stated in Littrow, Wunder des Himmels, 7. ed., p. 446 (1886): "Möge ihr Erscheinen Freude und Frieden wie in der deutschen Mythe, nur für längere Zeit als dort, bedeuten."

\section{(136) Austria}

Discovered 1874 Mar. 18 by J. Palisa at Pola.

Named by the discoverer in honor of his native country. This was the first (of a total of 121) numbered minor planet discovered by Palisa and also the first one discovered in Austria. (H 17)

\section{(137) Meliboea}

Discovered 1874 Apr. 21 by J. Palisa at Pola.

Named for a daughter of Oceanus. Meliboea married Pelasgus by whom she bore Lycaon \{see planet (4792)\}. (A. Schnell) 
Named (AN 85, 108 (1875)) by K. von Littrow.

There are two further figures in Greek mythology with this name. The explanation given above, however, was published by K. von Littrow in an appendix to the Wiener 'Kalender für alle Stände' for 1876, p. 21.

\section{(138) Tolosa}

Discovered 1874 May 19 by J. Perrotin at Toulouse.

Named for the city where this planet was discovered. Tolosa is the Latin name for Toulouse. It became a Roman colony under Augustus and was afterwards celebrated for the cultivation of the sciences. (H 17)

\section{(139) Juewa}

Discovered 1874 Oct. 10 by J. C. Watson at Beijing.

The name stands as Juewa, or more fully, Juewa-sing, which means literally the "Star of China's Fortune". (H 18)

This planet was discovered while preparing for the transit of Venus of December 9, 1874. The discoverer stated (Observation of the Transit of Venus, Part II, p. 108 (1881)): "On the night of the 10th October, while observing in the constellation Pisces, with the 5-inch equatorial, I came across a star of the 11th magnitude in a region of the heavens with which I was very familiar, and where I had not hitherto seen any such star. Subsequent observations the same night by means of a micrometer, extemporized for the purpose, showed that the star was slowly retrograding, and that it was a new member of the group of planets between Mars and Jupiter. The discovery was duly announced to astronomers in other lands, and it became also speedily known in Peking. Some mandarins of high rank came to our station to see the stranger with their own eyes, and upon observing the change of configuration with neighboring stars on two successive nights, they gave free expression to their astonishment and delight. This being the first planet discovered in China, I requested Prince Kung, regent of the Empire, to give it a suitable name. In due time, a mandarin of high rank brought to me the document containing the name by which the planet should be known, coupled with a request - communicated verbally - that I would not publish the name in China until the astronomical board had communicated to the Emperor an account of the discovery and the name which had been given to the planet. This request was of course promptly acceded to; and I afterwards learned upon inquiry that if the knowledge had come to the Emperor otherwise than through the astronomical board, organized specially for his guidance in celestial matters, some of the ministers would have been disgraced."

\section{(140) Siwa}

Discovered 1874 Oct. 13 by J. Palisa at Pola.

Named for the Slavic goddess of fertility. This naming refers to the numerous Illyric population of Istria. Pola is situated at the southern coast of this peninsula. (A. Schnell)
Named by Marine-Commandant Vice-Admiral Freiherr F. von Pöck. The planet is erroneously published as (139) in AN 85, 108 (1875). The meaning of the name is published in the Wiener 'Kalender für alle Stände' for 1876 , p. 20 .

\section{(141) Lumen}

Discovered 1875 Jan. 13 by P. P. Henry at Paris.

Named after a literary work of the French astronomer Camille Flammarion \{see planet (1021)\}, Lumen: Récits de l'infini. (H 18)

\section{(142) Polana}

Discovered 1875 Jan. 28 by J. Palisa at Pola.

Named for the city of discovery, located on the northern Adriatic sea. Since Palisa's days Pola has become first part of Italy and now Yugoslavia. Pola was the main naval port of Austria since 1850. The Pola Naval Observatory was a department of the Austrian Hydrographic Service. Palisa served as head of this department. (H 18; A. Schnell)

\section{(143) Adria}

Discovered 1875 Feb. 23 by J. Palisa at Pola.

Named for the Adriatic sea. The city of Pola \{see planet (142)\}, at the time of discovery the chief naval station of Austria-Hungary, is an Adriatic seaport. (H 19)

\section{(144) Vibilia}

Discovered 1875 June 3 by C. H. F. Peters at Clinton.

Named for the Roman goddess and patroness of journeyings. The planet was discovered immediately after the return of Peters from the transit of Venus expedition of 1874. (H 19)

\section{(145) Adeona}

Discovered 1875 June 3 by C. H. F. Peters at Clinton.

Named for the Roman divinity and patroness of homecomings. See also the remarks to planet (144) which was discovered at the same night. (H 19)

\section{(146) Lucina}

Discovered 1875 June 8 by A. Borrelly at Marseilles.

Named for the Roman goddess of the travails of women and of childbirth. For the Greek counterpart see the citation for planet (105) Artemis. See also the remarks to planet (494). (Z 153)

\section{(147) Protogeneia}

Discovered 1875 July 10 by L. Schulhof at Vienna.

The name, translated from Greek, means first-born. (A. Schnell)

Named by K. von Littrow (AN 86, 122 (1875)) on request of the discoverer in allusion to the first discovery of a minor planet by an astronomer which in other fields of astronomy was already well known. Schulhof at the time of the discovery was assistant at the Vienna Observatory. 
K. von Littrow (Wunder des Himmels, 6. ed., Berlin 1878) stated: "Erhielt ihren Namen auf Einladung des Entdeckers..., um die Erstlingsschaft des Fundes für diesen Entdecker anzudeuten."

\section{(148) Gallia}

Discovered 1875 Aug. 7 by P. M. Henry at Paris.

Named in honor of the discoverer's home country. Gallia is the Latin name for France. (H 19)

\section{(149) Medusa}

Discovered 1875 Sept. 21 by J. Perrotin at Toulouse.

Named for one of the three Gorgons. Medusa was mortal whereas the other two, Euryale and Stheno, were immortal. The eyes of the three Gorgons had the power of killing or turning onlookers into stone. Perseus killed Medusa, cut off her head, and placed it on the shield of Athena \{see planet (881)\}, where it had the same petrifying power as when Medusa was alive. From the blood of Medusa sprang the winged horse Pegasus. (Z 161)

\section{(150) Nuwa}

Discovered 1875 Oct. 18 by J. C. Watson at Ann Arbor.

Named for a character in Chinese mythology. This planet was possibly named in remembrance of the discoverer's trip to China. For more details see the remarks to planet (139). (H 19)

\section{(151) Abundantia}

Discovered 1875 Nov. 1 by J. Palisa at Pola.

This name is the personification of fulness, its main attribute is the horn of plenty. The naming refers to the large number of newly discovered bodies between Mars and Jupiter. Von Littrow (Wunder des Himmels, 6. ed., p. 434, Berlin 1878) complained: "Benannt ... nach einer Göttin, die mit den armen Astronomen auf diesem Felde seit Jahren erbarmungsloses Spiel treibt und namentlich in dieser Epoche ihr Füllhorn über uns ausschüttete." (A. Schnell)

Named by Prof. E. Weiss, director of the Vienna Observatory.

\section{(152) Atala}

Discovered 1875 Nov. 2 by P. P. Henry at Paris

Named for the character in the novel Atala (1801) by the French author François René de Chateaubriand (1768-1848). (H 19; LDS)

Another heroine of Chateaubriand's novel René was used for naming minor planet (186) Celuta, discovered by P. M. Henry.

\section{(153) Hilda}

Discovered 1875 Nov. 2 by J. Palisa at Pola.

Named in honor of (probably the eldest) daughter of the Austrian astronomer Theodor von Oppolzer (1841-1886) \{see planet (1492)\}. She died some years prior to her father. (Vierteljahrsschr. Astron. Ges., 22. Jahrg., p. 191 (1887))

Named by Th. von Oppolzer.

\section{(154) Bertha}

Discovered 1875 Nov. 4 by P. M. Henry at Paris.

Named probably in honor of Berthe Martin-Flammarion (1844-1936), sister of Camille Flammarion \{see planet (1021)\}. (H 20)

\section{(155) Scylla}

Discovered 1875 Nov. 8 by J. Palisa at Pola.

Named for the daughter of Phorcys and Ceto and sister of Gorgons, Sirens and Graeae. The sea nymph Scylla and Charybdis \{see planet (388)\} guarded the strait between Sicily and Italy, expanding her long necks and six heads to remove one sailor from each passing ship. (H 20)

The planet was lost for many decades - see the detective recovering story in Sky Telesc., Vol. 40, No. 6 , p. 361-362 (1970).

\section{(156) Xanthippe}

Discovered 1875 Nov. 22 by J. Palisa at Pola.

Named for the wife of the Greek philosopher Socrates (470?-399 B.C.) \{see planet (5450)\} whose peevish disposition and ill humor have become proverbial. (H 20)

Named by Amalia Palisa, (first) wife of the discoverer.

\section{(157) Dejanira}

Discovered 1875 Dec. 1 by A. Borrelly at Marseilles.

Named for the second wife Dejanira (Greek: Deianeira) of Heracles; Megara was the first. She unwittingly killed Heracles by sending him a garment steeped in the poisoned blood of the centaur Nessus \{ see planet (7066)\}. This garment, Nessus has said, had power to reclaim a husband from unlawful loves. ( $\mathrm{Z} 82$ )

\section{(158) Koronis}

Discovered 1876 Jan. 4 by V. Knorre at Berlin.

There exist several interpretations of this name among mythologists. After Pausanias, Coronis was the mother of Aesculapius by Apollo \{see, respectively, planets (1027) and (1862)\}. Coronis is also the name of a Hyades member, originally a nymph, daughter of Atlas and the Oceanid Aethra \{see planet (132)\}. (H 20; LDS)

Named by Dr. Maywald.

\section{(159) Aemilia}

Discovered 1876 Jan. 26 by P. P. Henry at Paris.

Named probably after the famous Roman road 'Via Aemilia' which went from Piacenza to Rimini. (I. van Houten-Groeneveld)

K. von Littrow (Wunder des Himmels, 6. ed., Berlin 1878) ironically stated: "Mit dem Namen begegnet man auf mythologischem Gebiete nur einer Dienerin der Vesta, die vom Paten wohl kaum gemeint war."

\section{(160) Una}

Discovered 1876 Feb. 20 by C. H. F. Peters at Clinton.

Named after the heroine of the poetic work Faerie Queene by the English writer Edmund Spenser (1552-1599). (H 20) 
(161) Athor

Discovered 1876 Apr. 19 by J. C. Watson at Ann Arbor.

Named for the Egyptian goddess, often identified with Isis $\{$ see planet (42)\}. She had the head of a cow and wore the Sun's disk and possessed the characteristics of Aphrodite \{see planet (1388)\}. (H 20)

Athor is the same goddess as Hathor see planet (2340)\}.

\section{(162) Laurentia}

Discovered 1876 Apr. 21 by P. M. Henry at Paris.

Named in honor of the amateur astronomer A. Laurent, Nimes, the discoverer of (51) Nemausa. (H 20)

\section{(163) Erigone}

Discovered 1876 Apr. 26 by J. Perrotin at Toulouse.

Apollodorus mentioned Erigone as daughter of Icarus see planet (1566)\}, who hanged herself when she learned that her father had been killed by drunken shepherds. She was changed into the constellation Virgo. According to Pausanias, Erigone was a daughter of Aegisthus and Clytemnestra \{see planet (179)\} and has a son by Orestes. She brought Orestes to trial for the murder of her mother and hanged herself when Orestes was acquitted before the Areopagus. (Z 98)

\section{(164) Eva}

Discovered 1876 July 12 by P. P. Henry at Paris.

Any reference of this name to a person or occurrence is unknown.

K. von Littrow (Wunder des Himmels, 6. ed., Berlin 1878) characterized the naming practice of the discoverer ironically: "Mit dem Namen könnten wir wie bei Miriam \{see planet (102)\} wieder den biblischen Boden zu betreten glauben, wenn wir bei diesem Entdecker nicht an Taufen weltlichen Ursprungs gewöhnt wären."

\section{(165) Loreley}

Discovered 1876 Aug. 9 by C. H. F. Peters at Clinton.

Named after a siren of Germanic legend who by her songs lures Rhine river boatmen to destruction on a reef. Sirenes appear in the Nibelungenlied and other tales. (H 21)

\section{(166) Rhodope}

Discovered 1876 Aug. 15 by C. H. F. Peters at Clinton.

Named after an attendant of Artemis see planet (105)\}. She thought herself more beautiful than Hera \{see planet (103)\}, and the goddess changed her into the high mountain in Thrace that bears her name. (Z 229)

\section{(167) Urda}

Discovered 1876 Aug. 28 by C. H. F. Peters at Clinton.

Named for one of the three Norns in Norse mythology. Urda stands for the Past. (H 21)

The other Norns are Werdandi (the Present) and Skuld (the Future) $\{$ see planets (621) and (1130)\}.
(168) Sibylla

Discovered 1876 Sept. 28 by J. C. Watson at Ann Arbor.

Named probably for the Sibyls collectively. The Sibyls were women, young and old, inspired by heaven and endowed with prophetic powers, who interceded with the gods on behalf of men. The most famous of the (presumably ten) Sibyls was that of Cumae in Italy, a woman of wisdom and vision. (Z 239)

\section{(169) Zelia}

Discovered 1876 Sept. 28 by P. M. Henry at Paris.

Named in honor of a niece of Camille Flammarion \{see planet (1021)\} and daughter of his sister Berthe \{see planet (154)\}. (H 21)

\section{(170) Maria}

Discovered 1877 Jan. 10 by J. Perrotin at Toulouse. Independently discovered 1877 Jan. 22 by C. H. F. Peters at Clinton.

Named in honor of the sister of Antonio Abetti who computed the orbit, and aunt of Giorgio Abetti see planet (2646)\}. She died in her youth. (H 21)

\section{(171) Ophelia}

Discovered 1877 Jan. 13 by A. Borrelly at Marseilles.

Named for the daughter of Polonius in Shakespeare's \{see planet (2985)\} play Hamlet. (H 21)

The name Ophelia has also been given to the satellite Uranus VI, discovered 1986 by the Voyager 2 spacecraft.

\section{(172) Baucis}

Discovered 1877 Feb. 5 by A. Borrelly at Marseilles.

Baucis and her husband Philemon entertained the gods Zeus $\{$ see planet (5731)\} and Hermes most hospitably in their humble cottage in Phrygia. As a reward for this kindness their cottage was changed into a beautiful golden-roofed marble temple. Baucis and Philemon desired to die at the same time, and their bodies were changed into trees, an oak and a linden. (Z 40)

\section{(173) Ino}

Discovered 1877 Aug. 1 by A. Borrelly at Marseilles.

Named after the daughter of Cadmus and Harmonia \{see planet (40)\}, sister of Agave, Autonoe, Polydorus \{see planet (4708)\}, and Semele \{see planet (86)\} and second wife of Athamas, king of Thebes. She was the wicked stepmother of Helle and Phrixus, the boy who was saved from death by the ram of the Golden Fleece. Ino later became a sea goddess who saved Odysseus \{see planet (1143)\} from drowning when his raft was shattered. Her name was even later changed to Leukothea $\{$ see planet (35)\}. (H 21)

\section{(174) Phaedra}

Discovered 1877 Sept. 2 by J. C. Watson at Ann Arbor.

Named for the daughter of Minos \{see planet (6239)\}, king of Crete, and Pasiphae, sister of Ariadne \{see 
planet (43)\} and wife of Theseus. Phaedra became infatuated with her stepson Hippolytus and made overtures to him, but was rejected. In anger and humiliation she hanged herself, but left a message accusing Hippolytus of having attacked her. The outraged Theseus, without hearing Hippolytus' side of the story, appealed to Poseidon \{see planet (4341)\}, god of sea, for appropriate revenge. Poseidon sent a sea monster which terrified Hippolytus' horses so that they bolted and dragged their master to his death under the wheels of his own chariot. (Z 202)

\section{(175) Andromache}

Discovered 1877 Oct. 1 by J. C. Watson at Ann Arbor.

Named for the devoted and faithful wife of Hector \{see planet (624)\}. Andromache warned Hector against engaging in battle during the Trojan War. After the war she became a concubine of Neoptolemus \{see planet (2260)\} and later married Helenus s see planet (1872)\}. Aeneas \{see planet (1172)\} found her at Epirus on his way to Italy. (Z 22)

\section{(176) Iduna}

Discovered 1877 Oct. 14 by C. H. F. Peters at Clinton. Named by the discoverer after a club in Stockholm, Sweden on the occasion of a meeting of the Astronomische Gesellschaft, 1877. In Norse mythology, Iduna was keeper of the apples which preserve the youth of the gods. ( $\mathrm{H} \mathrm{22}$ )

The planet originally received the name Idunna and the number 175 (AN 91, 63 (1877): "Ich lege diesem Planeten den Namen Idunna bei, womit wenigstens diejenigen Mitglieder der Astronomischen Gesellschaft, die in Stockholm an der Gastfreundschaft der "Ydun" Theil nahmen, einverstanden sein werden."

\section{(177) Irma}

Discovered 1877 Nov. 5 by P. P. Henry at Paris.

Any reference of this name to a person or occurrence is unknown.

\section{(178) Belisana}

Discovered 1877 Nov. 6 by J. Palisa at Pola.

Named for Belisana, the name of Athene or Minerva \{see planets (881) and (93)\} among the Gauls, signifying the "queen of heaven". Belisana is also the most warlike goddess among British Celts. (H 22; A. Schnell)

Named by M. Loewy at the request of the discoverer. The first interpretation seems more likely because the naming was performed after Loewy's naturalization in France.

\section{(179) Klytaemnestra}

Discovered 1877 Nov. 11 by J. C. Watson at Ann Arbor.

Named after the daughter of Tyndareus, king of Sparta, by Leda $\{$ see planet (38)\}. She became the wife of Agamemnon \{see planet (911)\} and the mother of Orestes, Electra, Iphigenia and Chrysothemis \{see, respectively, planets (130), (112), (637)\}. When Agamemnon went to Trojan War, Clytemnestra became the paramour of Aegisthus. When Agamemnon returned from Trojan War, Aegisthus and Clytemnestra murdered him. Orestes later killed the murderers of his father. (Z 65)

\section{(180) Garumna}

Discovered 1878 Jan. 29 by J. Perrotin at Toulouse.

Named for the Garonne river on which the city of discovery is situated. Garumna is the ancient name. (H 22)

\section{(181) Eucharis}

Discovered 1878 Feb. 2 by P. Cottenot at Marseilles.

Named for a nymph of the goddess Calypso \{see planet (53)\}. (H 22)

\section{(182) Elsa}

Discovered 1878 Feb. 7 by J. Palisa at Pola.

Named after the Austrian form 'Elsbeth' of the most common feminine Christian name 'Elisabeth'. It was also the name of the Austrian empress. This name was later changed in agreement with the discoverer into the more melodious 'Elsa'. (A. Schnell)

Named by Admiral Bourgignon at the request of the discoverer. Bourgignon was the military superior of Palisa in Pola.

\section{(183) Istria}

Discovered 1878 Feb. 8 by J. Palisa at Pola.

Named for the (now Croatian) peninsula at the northern end of the Adriatic sea, containing Trieste and the city of discovery. (H 183; A. Schnell)

Named by Vice-Admiral B. Freiherr von Wüllerstorf who was the commander of the first Austrian circumnavigatory adventure with the frigate 'Novara'.

\section{(184) Dejopeja}

Discovered 1878 Feb. 28 by J. Palisa at Pola.

Named for the fairest of the 14 nymphs who attended Juno \{see planet (3)\} who promised her in marriage of Aeolus, god of the winds, if he would destroy the fleet of Aeneas \{see planet (1172)\} which was sailing for Italy. Some sources call Dejopeja an attendant nymph of Cyrene \{see planet (133)\}. (H 23)

Named by R. Müller, director of the Hydrographic Service in Pola.

\section{(185) Eunike}

Discovered 1878 Mar. 1 by C. H. F. Peters at Clinton.

Named for one of the Nereids meaning "happy victory", commemorating the treaty of San Stefano, signed by Russia and Turkey, two days after the discovery of the asteroid, at the Turkish village of Yesilkoy (San Stefano), concluding the Russo-Turkish War (1877-1878). The treaty gave enormous gains to the Russians. (AN 92, 207 (1878); H 23)

\section{(186) Celuta}

Discovered 1878 Apr. 6 by P. M. Henry at Paris.

Named for the main character in the novel René (1805), the second episode of the larger book Les 
Natchez (1826), by the famous French author François René de Chateaubriand (1768-1848). (LDS)

The discoverer's brother P. P. Henry named minor planet (152) for another heroine of a novel by Chateaubriand.

\section{(187) Lamberta}

Discovered 1878 Apr. 11 by J. Coggia at Marseilles.

Named in honor of Johann Heinrich Lambert (17281777), who described the Milky Way as "the ecliptic of the fixed stars" and made other remarkably good cosmological guesses. His law of exponential absorption of light and his theorem regarding inferences from the curvature of the apparent paths of comets are still in use. He first proved the irrationality of $\pi$ (1768) and he introduced the present hyperbolic function symbols and elaborated the new subject. ( $\mathrm{H} 23)$

Lambert is also honored by craters on the Moon and on Mars. The cgs unit of brightness equal to the brightness of a perfectly diffusing surface that radiates or reflects one lumen per square centimeter bears his name.

\section{(188) Menippe}

Discovered 1878 June 18 by C. H. F. Peters at Clinton. Named after a daughter of the celebrated hunter Orion who offered to die with her sister Metioche when a pestilence was raging in the Greek province Boeotia and the oracle had demanded the sacrifice of two virgins. Their voluntary sacrifice was rewarded by a place in the heavens as comets. Menippe is also the name of one of the Nereids. (H 23)

\section{(189) Phthia}

Discovered 1878 Sept. 9 by C. H. F. Peters at Clinton. Many explanations are given in Greek mythology: (1) Phthia was a daughter of Niobe see planet (71) and was killed by Artemis \{see planet (105)\}. (2) Phthia was a mistress of Zeus, Apollo \{see planets (5731), (1862)\}, or Phoenix. It is also the name of a town in Thessaly where Achilles \{see planet (588)\} was born. (Z 209)

\section{(190) Ismene}

Discovered 1878 Sept. 22 by C. H. F. Peters at Clinton.

Named for the daughter of Oedipus and Jocaste \{see planet (899)\}, sister of Antigone \{see planet (129)\}, Eteocles, and Polynices. When her sister Antigone was condemned by Creon to be entombed alive for giving burial to their brother Polynices, Ismene declared herself as guilty as her sister and demanded to be punished equally, but Antigone did not want Ismene to be involved in her calamities. (Z 141)

\section{(191) Kolga}

Discovered 1878 Sept. 30 by C. H. F. Peters at Clinton.

Named for the daughter of Aeger in Norse mythology. All names of his daughters are personifications of waves. (H 24)

\section{(192) Nausikaa}

Discovered 1879 Feb. 17 by J. Palisa at Pola.

Named after the daughter of Alcinous, king of the Phaeacians. She befriended the shipwrecked Odysseus \{see planet (1143)\} and persuaded her father to be kind to the visitor. Some accounts say Nausicaa later married Telemachus, Odysseus' son. (Z 172)

Named by the Berlin astronomers on the occasion of the September 1879 assembly of the Astronomische Gesellschaft. These astronomers also proposed wellknown names from the Odyssey for planets (195), (197), and (201) (Astronomischer Kalender für 1882, p. 106).

\section{(193) Ambrosia}

Discovered 1879 Feb. 28 by J. Coggia at Marseilles.

Named for the food of the gods. Their drink was nectar. Ambrosia gives the gods immortality. This is also the name of one of the Hyades which have been originally nymphs, daughters of Atlas and Aethra \{see planet (132)\}. The second interpretation seems more likely because Coggia named another planet after one of these nymphs \{see planet (217)\}. (H 24; LDS)

\section{(194) Prokne}

Discovered 1879 Mar. 21 by C. H. F. Peters at Clinton.

Named for the daughter of Pandion, king of Athens, and wife of Tereus, king of Thrace. She sent her husband to Athens to bring her sister Philomela \{see planet (196)\}, to whom she was attached, to Thrace. Tereus became enamored of Philomela and she was carried of to a castle and her tongue removed; reporting back, Tereus claimed she had died. When the infamy became known Prokne served her son Itys to her husband at a feast. Upon this disclosure he drew his sword but was changed into a hoopoe; Philomela, also present, into a nightingale, and Prokne into a swallow. The discoverer stated: "Prokne, found on the day of the vernal equinox, was suggested by the swallow coming with spring; in May followed Philomela, the nightingale." (H 24; AN 96, 336 (1880))

\section{(195) Eurykleia}

Discovered 1879 Apr. 19 by J. Palisa at Pola.

Named for Odysseus' \{see planet (1143)\} aged nurse. When, after twenty years away, Odysseus returned home disguised as a beggar, she recognized him by the scar of a wound given him by a wild boar. (Z 103)

Named by the Berlin astronomers - see the remarks to planet (192).

\section{(196) Philomela}

Discovered 1879 May 14 by C. H. F. Peters at Clinton. Named for the sister of Prokne \{see planet (194)\}. Philomela was changed into a nightingale. See the remarks to (194). (H 24)

\section{(197) Arete}

Discovered 1879 May 21 by J. Palisa at Pola.

Named for the wife of Alcinous, king of the Phaeacians and mother of Nausicaa \{see planet (192)\}. 
Arete is also the name for the goddess of virtue. (H 24)

Named by the Berlin astronomers - see the remarks to planet (192).

\section{(198) Ampella}

Discovered 1879 June 13 by A. Borrelly at Marseilles. Named probably after Ampelos, a friend of Dionysus \{see planet (3671)\}, god of wine and revelry. (R. R. de Freitas Mourão)

\section{(199) Byblis}

Discovered 1879 July 9 by C. H. F. Peters at Clinton.

Named after the daughter of Miletus and Idothea, who was in love with her brother Caunus who she pursued through various lands, till at length, worn out with sorrow, she was changed into a fountain. (H 24)

\section{(200) Dynamene}

Discovered 1879 July 27 by C. H. F. Peters at Clinton.

The meaning is twofold: Dynamene is one of the Nereids and the Greek prefix "di" stands for number two. The discoverer wrotes (AN 96, 336 (1880)): "The name of Dynamene may aid the memory in writing its number, 200." (H 25)

\section{(201) Penelope}

Discovered 1879 Aug. 7 by J. Palisa at Pola.

Named after the celebrated princess of Greece, daughter of Icarius and Periboea. She was the wife of Odysseus \{see planet (1143)\} and mother of Telemachus. During the absence of her husband, she was beset with 108 suitors whom she treated with coldness and disdain. The three most persistent were Amphinomus, Antinous \{see planet (1863)\}, and Eurymachus, but she was relieved of their unwelcome attentions when Odysseus returned home after an absence of twenty years. Odysseus killed his rivals. Penelope is described as a model of feminine virtue and chastity by Homer. (Z 198)

Named by the Berlin astronomers - see the remarks to planet (192).

\section{(202) Chryseïs}

Discovered 1879 Sept. 11 by C. H. F. Peters at Clinton.

Named for the daughter of Chryses, a priest of Apollo \{see planet (1862)\}. She was captured by Achilles \{see planet (588)\} but awarded to Agamemnon \{see planet (911)\}. Apollo sent a plague to avenge her capture, and the Greeks were compelled to return Chryseïs to her father. Then Agamemnon took Briseïs \{see planet (655)\}, another captive of Achilles, and the famous quarrel resulted. Achilles, angry because he had lost both Briseïs and Chryseïs, withdrew from the Trojan War. (Z 61)

\section{(203) Pompeja}

Discovered 1879 Sept. 25 by C. H. F. Peters at Clinton.

The discoverer wrote: "For the planet, whose discovery very coincided with the day, when at
Pompeji was commemorated the destruction of that city by Mt. Vesuvius 18 centuries ago, I believed the name Pompeja eminently proper." (AN 96, 336 (1880))

\section{(204) Kallisto}

Discovered 1879 Oct. 8 by J. Palisa at Pola.

Named for the mother of Arcas, king of Arcadia, by Zeus \{see planets (1020) and (5731)\}. She was changed by Zeus into the constellation Ursa, and Arcas was translated into a bear keeper, located in the heavens behind his mother as her guardian. (Z 28)

Named by Th. von Oppolzer at the request of the discoverer.

This name was also given by Simon Marius to the fourth satellite of Jupiter, discovered 1610 by Galilei.

\section{(205) Martha}

Discovered 1879 Oct. 13 by J. Palisa at Pola.

Named for the biblical Martha (Book of Luke of the New Testament), sister of Mary and Lazarus of Bethany. Martha's hospitality to Jesus is documented. Palisa selected this name in remembrance to the hospitality of his Berlin colleagues on the occasion of the September 1879 assembly of the Astronomische Gesellschaft. (Astronomischer Kalender für 1883, p. 108)

\section{(206) Hersilia}

Discovered 1879 Oct. 13 by C. H. F. Peters at Clinton. Named after one of the Sabines carried away by the Romans. She was given and married to Romulus. After death she was deified by Juno \{see planet (3)\} and became Hora, a goddess of beauty. (H 25)

\section{(207) Hedda}

Discovered 1879 Oct. 17 by J. Palisa at Pola.

Named in honor of Hedwig Winnecke, wife of Friedrich A. T. Winnecke, director of the Strassburg Observatory. Hedwig Winnecke, née Dell, was a niece of Otto Struve \{see planet (2227)\}. (Vierteljahrsschr. Astron. Ges., 16. Jahrg., p. 281 (1881))

Named during the meeting of the Astronomische Gesellschaft at Strassburg, September 1881 (BAJ Circ., No. 174 (1882)). The nordic form 'Hedda' was proposed by J. Gyldén.

\section{(208) Lacrimosa}

Discovered 1879 Oct. 21 by J. Palisa at Pola.

The name means whining, deplorable. Very probably, this name should reflect the sorrow about the difficulties associated with a recovery of this planet. Lacrimosa could have been observed only four times by Palisa. (Astronomischer Kalender für 1883, p. 108)

Named by L. Schulhof, astronomer in Paris (BAJ Circ., No. 174 (1882)), at the request of the discoverer.

\section{(209) Dido}

Discovered 1879 Oct. 22 by C. H. F. Peters at Clinton. Dido (also named Elissa) was the daughter of Belus, king of Tyre. Her husband Sichaeus was secretly murdered for his money by her brother Pygmalion. 
She went to Africa, founded Carthage, and became its queen. When Aeneas \{see planet (1172)\} came to Carthage on his way to Italy after the Trojan War, Dido fell in love with him. When he left for Italy she uttered a curse against the Trojans and then stabbed herself with her sword. (Z 86)

\section{(210) Isabella}

Discovered 1879 Nov. 12 by J. Palisa at Pola.

Any reference of this name to a person or occurrence is unknown.

\section{(211) Isolda}

Discovered 1879 Dec. 10 by J. Palisa at Pola.

Named possibly for the character in the early mediaeval Arthurian legend perpetuated in the opera Tristan und Isolde (1865) by Richard Wagner see planet (3992)\}. (H 26; A. Schnell)

Named by the wife of K. Friesach, professor of mathematics in Graz.

\section{(212) Medea}

Discovered 1880 Feb. 6 by J. Palisa at Pola.

Named for the daughter of Aeetes, king of Colchis \{see planet (1135)\} and niece of Circe \{see planet (34)\}. Medea was a powerful enchantress, she aided Jason \{see planet (6063)\} in obtaining the Golden Fleece, she restored Aeson, Jason's aged father, to the vigor of youth, and she caused the death of Glauce \{see planet (288)\}. When Jason abandoned her, she killed their two children and fled to Athens. There she married Aegeus, king of Athens, became jealous of his son Theseus, and finally left him and returned to Colchis. (Z 161)

Named (BAC Circ., No. 176 (1882)) by the Vienna astronomers.

The naming history is handed down in the (Wiener) Astronomischer Kalender für 1883, p. 108: "Nun waren von den in Pola entdeckten Planeten noch die folgenden vier 212, 216, 218 und 219 zu benennen, deren Taufe der Entdecker den Wiener Astronomen überliess. Zu diesem Zwecke wurde eine kleine Conferenz veranstaltet, an welcher auch Dr. H. Kreutz \{editor of the Astronomische Nachrichten $\}$, der sich damals in Wien befand, und Frau Direktor Weiss theilnahmen. Jeder der Anwesenden nannte mehrere ihm passend erscheinende Namen, so dass im Ganzen etwa 30 vorgeschlagen wurden, aus denen nach mehreren Wahlgängen Medea, Kleopatra, Bianca und Thusnelda als gewählt hervorgingen. Den Schluss der Conferenz bildete ein fröhliches Mahl, bei dem auch auf die Wiederauffindung der neu benannten Himmelsbürger ein Glas geleert wurde."

\section{(213) Lilaea}

Discovered 1880 Feb. 16 by C. H. F. Peters at Clinton.

Named for one of the Naiads. The Naiads are water nymphs, female beings granted very long life but still mortal. The Naiads incarnate the divinity of the spring or stream which they inhabit. (E. Weiss in Littrow, Wunder des Himmels, 7. ed., p. 458 (1886); Z 301)

\section{(214) Aschera}

Discovered 1880 Feb. 29 by J. Palisa at Pola.

Named for a goddess of the Sidonians, identified by the Phoenicians with Astarte \{see planet (672)\} or Ashtoreth. (H 26; A. Schnell)

Named by R. Müller, director of the Hydrographic Service in Pola. The Astronomischer Kalender für 1883, p. 108 stated: "Bei der Taufe von Dejopeja \{planet (184)\} hatte sich Dir. Müller in Pola scherzweise auch die Taufe des 25. Fundes von Palisa vorbehalten."

\section{(215) Oenone}

Discovered 1880 Apr. 7 by V. Knorre at Berlin.

Named for a nymph of Mount Ida in Phrygia. Oenone was the wife of Paris \{see planet (3317)\}. She foretold that her husband would desert her, abduct Helen \{see planet (101)\}, and bring ruin to Troy. (Z 181)

\section{(216) Kleopatra}

Discovered 1880 Apr. 10 by J. Palisa at Pola.

Named for the Egyptian queen (69-30 B.C.), famed as mistress of Julius Caesar and of Mark Antony. (H 26)

Named (BAJ Circ., No. 176 (1882)) by the Vienna astronomers. See also the remarks to planets (212) and (494).

\section{(217) Eudora}

Discovered 1880 Aug. 30 by J. Coggia at Marseilles.

Eudora is the name for (1) one of the Nereides, (2) one of the Atlantides, and (3) one of the Hyades in Greek mythology. The last interpretation seems most likely because Coggia also named another planet \{see planet (193)\} after a Hyades member. (H 26; LDS)

\section{(218) Bianca}

Discovered 1880 Sept. 4 by J. Palisa at Pola.

Named by the Vienna astronomers in honor of the famous coloratura soprano Bianca Bianchi (stage name; Bertha Schwarz (1858-1947), born in Mannheim, Germany), prima donna at the Vienna opera. (A. Schnell; BAJ Circ., No. 176 (1882))

The naming circumstances were published in great detail by several Vienna newspapers in spring 1882. The Fremdenblatt, Abendblatt, 36. Jahrg., Nr. 74 (15 March 1882) stated: "Bianca Bianchi unter den Sternen. Vor Kurzem fand auf der Sternwarte eine recht interessante Sitzung der Mitglieder dieses Institutes statt. Auf der Tagesordnung derselben stand die Taufe jener Asteroiden, welche der fixige Herr Adjunkt Palisa in der letzten Zeit wieder entdeckt, ja sozusagen aus dem Aermel des Weltenraumes geschüttelt hat. Die Adjunkten und Assistenten der Sternwarte zerbrachen sich ihre gelehrten Köpfe... Da erhob sich Dr. Hepperger, ein junger Astronom, und stellte in Anbetracht der Verdienste, welche sich die Primadonna Bianca Bianchi um die schöne Kunst des Gesanges erworben, den Antrag, einen der neuentdeckten Asteroiden Bianca zu taufen. Der Antrag wurde unter stürmischer Akklamation zum Beschlusse erhoben, und so schwebt 
denn der erste Stern unserer Oper als kleiner Stern in unendlichen Sphären." See also the remarks to planet (212).

The name Bianca has also been given to the satellite Uranus VIII, discovered 1986 by the Voyager 2 spacecraft.

\section{(219) Thusnelda}

Discovered 1880 Sept. 30 by J. Palisa at Pola.

Named probably after the daughter of the German chief Segestes. She was taken to wife by force by the German hero Arminius (17 B.C.?-21) who maintained a bloody war against the Romans. He was finally defeated by general Germanicus (15 B.C.-19). Thusnelda was brought to Rome to be seen in the triumph procession of Germanicus. (H 26)

Named (BAJ Circ., No. 176 (1882)) by the Vienna astronomers - see the remarks to planet (212).

\section{(220) Stephania}

Discovered 1881 May 19 by J. Palisa at Vienna.

Named in honor of Princess Stephanie of Belgium who in the year of discovery married Archduke Rudolf (1858-1889), Crown Prince of Austria and only son of Emperor Franz Joseph I (1830-1916). Rudolf's later romance with a court beauty, Baroness Maria Vetsera, led to one of the most discussed tragedies of the day when they were found dead in his hunting lodge at Mayerling, near Vienna. (H 27)

Named (BAJ Circ., No. 220 (1884)) by His Majesty the Emperor of Austria.

This was Palisa's first discovery after transferring to Vienna from Pola.

\section{(221) Eos}

Discovered 1882 Jan. 18 by J. Palisa at Vienna.

Named for the Greek goddess of the dawn (also Aurora, see planet (94)). (H 27; A. Schnell)

Named (BAJ Circ., No. 220 (1884)) by Staatsrath A. von Braun in Vienna. The Vienna Astronomischer Kalender für 1885, p. 88 stated the reason for this choice: "... eine sehr sinnige Anspielung, um der Hoffnung Ausdruck zu geben, dass mit der Vollendung der neuen Sternwarte die Morgenröte einer besseren Zeit für die Astronomie in Österreich angebrochen sei."

\section{(222) Lucia}

Discovered 1882 Feb. 9 by J. Palisa at Vienna.

Named probably after the youngest daughter of Graf Wilczek. (A. Schnell)

Named (BAJ Circ., No. 220 (1884)) by Graf Johann N. Wilczek (1837-1922) who sponsored and participated in the preliminary voyages of the Austro-Hungarian Arctic expedition of 1872-1874 and the Austrian polar expedition to Jan Mayen as part of the First International Polar Year 1882-1883.

\section{(223) Rosa}

Discovered 1882 Mar. 9 by J. Palisa at Vienna.

Any reference of this name to a person or occurrence is unknown.

Named (BAJ Circ., No. 218 (1883)) by Prof. E. Vincent of Vienna.

\section{(224) Oceana}

Discovered 1882 Mar. 30 by J. Palisa at Vienna.

Named for the Pacific Ocean. (H 27)

The discoverer communicated from Honolulu on return from the solar eclipse expedition of May 6,1883 that Governor von Dessarts of Tahiti has named this planet (BAJ Circ., No. 210 (1883)).

\section{(225) Henrietta}

Discovered 1882 Apr. 19 by J. Palisa at Vienna.

Named in honor of the wife of the French astronomer Pierre J. C. Janssen (1824-1907), pioneer of solar spectroscopy and director of the Meudon Observatory. (H 27)

Named (BAJ Circ., No. 213 (1883)) by P. J. C. Janssen.

\section{(226) Weringia}

Discovered 1882 July 19 by J. Palisa at Vienna.

Named for Währing, a part of Vienna in which the University Observatory is situated. (H 27)

Named (BAJ Circ., No. 212 (1883)) by Ferdinand Oberwimmer, architect of the Vienna Observatory.

\section{(227) Philosophia}

Discovered 1882 Aug. 12 by P. P. Henry at Paris.

The name personifies philosophy. (H 27)

\section{(228) Agathe}

Discovered 1882 Aug. 19 by J. Palisa at Vienna.

Named in honor of the youngest daughter of Theodor von Oppolzer (1841-1886), professor of astronomy in Vienna. (Vierteljahrsschr. Astron. Ges., 22. Jahrg., p. 191 (1887))

Named (BAJ Circ., No. 218 (1883)) by Th. von Oppolzer.

\section{(229) Adelinda}

Discovered 1882 Aug. 22 by J. Palisa at Vienna.

Named in honor of the wife of E. Weiss, director of the Vienna Observatory. (Astronomischer Kalender für 1884, p. 112)

Named (BAJ Circ., No. 213 (1883)) at the September 1883 Vienna meeting of the Astronomische Gesellschaft by the participants.

\section{(230) Athamantis}

Discovered 1882 Sept. 3 by L. de Ball at Bothkamp.

Athamantis or Helle was the daughter of Athamas, king of Thebes, and Nephele \{see planet (431)\} and the sister of Phrixus. (A. Paluzie-Borrell)

This planet was accidentally discovered during the observation of the nearby planet (12) Victoria. The planet was very bright. The naming obviously was influenced by this fact because the German word 'Helle' means brightness. 


\section{(231) Vindobona}

Discovered 1882 Sept. 10 by J. Palisa at Vienna.

Named for Vienna, the place of discovery. Vindobona

is the Latin name of Vienna. ( $\mathrm{H} 28)$

Named (BAJ Circ., No. 213 (1883)) by the participants of the September 1883 Vienna meeting of the Astronomische Gesellschaft.

\section{(232) Russia}

Discovered 1883 Jan. 31 by J. Palisa at Vienna.

Named after the former empire in eastern Europe and northern Asia which is nearly coextensive with the present U.S.S.R. (H 28)

Named (BAJ Circ., No. 200 (1883)) by Baron Basil von Engelhardt of Dresden. The Engelhardt Observatory near Kasan, U.S.S.R. resulted from a gift of the instruments of Engelhardt's private observatory in Dresden. Engelhardt was born in Russia.

Times are changing - Russia -> U.S.S.R. -> "new" Russia!

\section{(233) Asterope}

Discovered 1883 May 11 by A. Borrelly at Marseilles.

Named for one the seven Pleiades (also Sterope), daughters of Atlas by Pleione, greatly beloved by the gods. Asterope is also commemorated by a Pleiades star. (H 28)

\section{(234) Barbara}

Discovered 1883 Aug. 12 by C. H. F. Peters at Clinton.

Named probably for the Saint Barbara and also for a relative of Prof. Ibbotson of Vienna. (R. R. de Freitas Mourão)

Named (BAJ Circ., No. 213 (1883)) at the Vienna meeting of the Astronomische Gesellschaft.

\section{(235) Carolina}

Discovered 1883 Nov. 28 by J. Palisa at Vienna.

Named for an atoll of the Line Islands, 450 miles northwest of Papeete, Tahiti, where the discoverer observed the solar eclipse of May 6, 1883. Palisa observed the solar neighborhood in order to find an intra-Mercurian planet. (H 28)

Named by the discoverer (BAJ Circ., No. 218 (1883)) in remembrance of his voyage to this island.

\section{(236) Honoria}

Discovered 1884 Apr. 26 by J. Palisa at Vienna.

Named possibly for the goddess personifying honor, worshiped at Rome. (H 28)

Named (BAJ Circ., No. 227 (1884)) by Edward Singleton Holden (1846-1914) \{see planet (2974)\}, director of the Washburn Observatory of the University of Wisconsin in Madison and later director of the Lick Observatory. Holden was head of the American expedition to Caroline Island ssee also the citation for planet (235)\} where he met the discoverer. Holden searched visually for an intra-Mercurian planet.

\section{(237) Coelestina}

Discovered 1884 June 27 by J. Palisa at Vienna.

Named in honor of Coelestine, née Mauthner von Markhof, wife of Theodor von Oppolzer, professor of astronomy in Vienna. Coelestine was the daughter of the well-known Viennese industrialist family Mauthner von Markhof. (Vierteljahrsschr. Astron. Ges., 22. Jahrg., p. 191 (1887))

Named by Th. von Oppolzer.

\section{(238) Hypatia}

Discovered 1884 July 1 by V. Knorre at Berlin.

Named probably after the daughter of the famous mathematician and philosopher Theon of Alexandria, whom she is said to have surpassed in erudition. She was celebrated for her beauty. Among Hypatia's (370?-415 B.C.) writings were commentaries on ancient astronomical works. She was murdered by a mob of Christian fanatics. (H 29)

Hypatia is also honored by a lunar crater.

\section{(239) Adrastea}

Discovered 1884 Aug. 18 by J. Palisa at Vienna.

Named for a nymph of Crete to whose care Rhea \{see planet (577)\} entrusted the infant Zeus \{see planet (5731)\}. (H 29)

Named (BAJ Circ., No. 242 (1884)) by Mrs. Bertha Schneider. In that source, planet (243) is named for another nurse of Zeus.

The name Adrastea has also been given to the satellite Jupiter XV.

\section{(240) Vanadis}

Discovered 1884 Aug. 27 by A. Borrelly at Marseilles.

Named for Freya \{see planet (76)\}, the Norse goddess of love and beauty. Vanadis is one of the names of Freya. She drives forth with a chariot drawn by cats. (H 29)

\section{(241) Germania}

Discovered 1884 Sept. 12 by R. Luther at Düsseldorf.

This is the Latin name for Germany, the native country of the discoverer. (H 29)

\section{(242) Kriemhild}

Discovered 1884 Sept. 22 by J. Palisa at Vienna.

Named probably after the sister of Gunther in the medieval German Nibelungenlied who married the hero Siegfried. (H 29)

Named (BAJ Circ., No. 241 (1884)) by Moritz von Kuffner, owner of an important private observatory in Ottakring.

\section{(243) Ida}

Discovered 1884 Sept. 29 by J. Palisa at Vienna.

Named for a nymph of Crete who nursed the young Zeus \{see planet (5731) \}. See also the remarks to planet (239). (H 29)

Named (BAJ Circ., No. 242 (1884)) by Moritz von Kuffner. 
The planet was imaged by the Galileo spacecraft in 1994. It measures $56 \times 24 \times 21 \mathrm{~km}$ and is heavily cratered. Ida has a satellite which was named Dactyl. The moon is remarkably spherical with a mean diameter of $1.4 \mathrm{~km}$. The Dactyls of Mount Ida were Daemons, Cretan or Phrygian in origin. Their name means 'the fingers'. The Dactyls were magicians, credited with the spread, and sometimes the invention, of the Mysteries. To amuse the infant Zeus, they organized the first Olympic Games. (Z 124; LDS)

\section{(244) Sita}

Discovered 1884 Oct. 14 by J. Palisa at Vienna.

Named possibly for the wife of Rama in the Sanskrit epic The Ramayana. It is a symbol of the ideal spouse and of everlasting faith. (H 29)

Named by Baron von Pfungen (BAJ Circ., No. 247 (1885)).

\section{(245) Vera}

Discovered 1885 Feb. 6 by N. R. Pogson at Madras.

Any reference of this name to a person or occurrence is unknown.

Name suggested by the wife of the discoverer (AN 111, 318 (1885)).

\section{(246) Asporina}

Discovered 1885 Mar. 6 by A. Borrelly at Marseilles.

Named for the mother of the gods worshiped at the

Asporenus mountain in Asia Minor. (H 30)

\section{(247) Eukrate}

Discovered 1885 Mar. 14 by R. Luther at Düsseldorf.

Named for one of the Nereids. (H 30)

Named by Geh. Rath. Schönfeld, Bonn (AN 111, 335 (1885)).

\section{(248) Lameia}

Discovered 1885 June 5 by J. Palisa at Vienna.

Named for the daughter of Belus loved by Zeus \{see planet (5731)\}. Hera \{see planet (103)\}, out of jealousy, deformed Lameia and killed all her children but one. Lameia had the face and breasts of a woman and the body of a serpent. Because she could not avenge herself on Hera, Lameia lured strangers so that she might devour them. (Z 146)

\section{(249) Ilse}

Discovered 1885 Aug. 16 by C. H. F. Peters at Clinton. Named probably after a legendary princess of the Harz mountains in Germany. It is also the name of a small river flowing from the Harz. (H 30)

\section{(250) Bettina}

Discovered 1885 Sept. 3 by J. Palisa at Vienna.

Named for Baroness Bettina von Rothschild of the Austrian plutocratic family. In Observatory, Vol. 8, p. 63 (1885) the following information is published: "Herr Palisa, being desirous to raise funds for his intended expedition to observe the total solar eclipse of Aug. 29, 1886 will sell the right of naming the minor planet No. 244 for 50 pounds." The bright idea seems to have struck Palisa, who had already discovered many planets and begun to find difficulties in assigning suitable names, that he might turn his difficulty into a source of profit in a good cause. The offer was not responded to immediately, nor until Palisa had discovered two more planets (Nos. (248) and (250)). He found names for two, leaving, however, the last discovered always open for a patron. A note in Observatory, Vol. 9, p. 142 (1886) informs: "Minor planet No. 250 has been named "Bettina" by Baron Albert von Rothschild." (H 30)

\section{(251) Sophia}

Discovered 1885 Oct. 4 by J. Palisa at Vienna.

Named in honor of Sophie von Seeliger, née Stoeltzel, wife of the German astronomer Hugo von Seeliger \{see planet (892)\}. Palisa was informed on the marriage which took place in 1885 , the year of the meeting of the Astronomische Gesellschaft in Geneva. (A. Schnell) Name proposed by H. von Seeliger.

\section{(252) Clementina}

Discovered 1885 Oct. 11 by J. Perrotin at Nice.

Any reference of this name to a person or occurrence is unknown.

Named (BAJ Circ., No. 265 (1885)) by the discoverer.

\section{(253) Mathilde}

Discovered 1885 Nov. 12 by J. Palisa at Vienna.

Named probably in honor of Mathilde, née Worms, wife of the astronomer Moritz Loewy (1833-1907). (A. Schnell)

Named by V. A. Lebeuf who computed the orbit. Lebeuf (1859-1929) was a staff member of the Paris Observatory. Loewy served as a vice-director of the observatory.

\section{(254) Augusta}

Discovered 1886 Mar. 31 by J. Palisa at Vienna.

Named in honor of the widow of Carl Ludwig von Littrow (1811-1877) who succeeded his father Johann Joseph von Littrow (1781-1840) as director of the Vienna Observatory in 1842. Auguste von Littrow (1819-1890) worked as an author with the pen name Otto August. Her home was one of the intellectual centers in Vienna. (H 30; A. Schnell)

\section{(255) Oppavia}

Discovered 1886 Mar. 31 by J. Palisa at Vienna.

Named for the city of Troppau in northern Silesia \{see planet 257)\}, Austria, where the discoverer was born. The city now belongs to Czechoslovakia. Oppavia is the Czech name of Troppau. (H 31)

\section{(256) Walpurga}

Discovered 1886 Apr. 3 by J. Palisa at Vienna.

Named after St. Walpurga $\{710 ?-777\}$, princess of Wessex, England who with her brothers went to 
Germany to convert the heathen. Her feast day is May 1 (hence Walpurgis Night) when the witches ride on broomsticks to the ancient places of sacrifice to revel with Satan. The best known of this places is the Brocken \{see planet (4724)\}, highest peak in the Harz mountains, immortalized by the scene of the witches' sabbath in Goethe's \{see planet (3047)\} Faust. (H 31, I. Heinrich)

Named by Baroness Bettina von Rothschild (BAJ Circ., No. 291 (1887)).

\section{(257) Silesia}

Discovered 1886 Apr. 5 by J. Palisa at Vienna.

Named for the native province of the discoverer. There was an Austrian and a German part of Silesia, bordering the Sudeten mountains and the valley of the upper Oder river. The region nowadays chiefly belongs to northern Czechoslovakia and southwestern Poland. (H 31)

\section{(258) Tyche}

Discovered 1886 May 4 by R. Luther at Düsseldorf.

Named for the Greek goddess of fortune. Tyche is also the name of one of the Oceanids. (H 31)

Name proposed (AN 114, 383 (1886)) by G. Rümker.

\section{(259) Aletheia}

Discovered 1886 June 28 by C. H. F. Peters at Clinton.

Named for a daughter of Zeus \{see planet (5731)\}, one of the nurses of Apollo \{see planet (1862)\}. Aletheia is the Greek goddess of truth. (Z 18)

\section{(260) Huberta}

Discovered 1886 Oct. 3 by J. Palisa at Vienna.

Named for St. Hubertus (656?-727) of Liège, patron of the hunters. (A. Schnell)

The 'Beilage zum (Wiener) Astronomischer Kalender für 1888 ', p. 87 ironically stated: "... Palisa ... Huberta nannte, offenbar nach dem heiligen Hubertus, der sich aber der Aufnahme unter die Gestirne durch eine Veränderung der Endsylbe us in a, und damit durch die Verwandlung aus einem Patrone in eine Patronin der Jäger erkaufen musste."

\section{(261) Prymno}

Discovered 1886 Oct. 31 by C. H. F. Peters at Clinton. Named after an Oceanid nymph. (H 31)

\section{(262) Valda}

Discovered 1886 Nov. 3 by J. Palisa at Vienna.

Any reference of this name to a person or occurrence is unknown.

Name proposed by the Baroness Bettina von Rothschild \{see the remarks to planet (250)\}.

\section{(263) Dresda}

Discovered 1886 Nov. 3 by J. Palisa at Vienna.

The planet is named to honor the German city of Dresden \{see also planet (3053)\}. (H 31; A. Schnell)

Named by Baron B. von Engelhardt, owner of a private observatory in the city of Dresden.

\section{(264) Libussa}

Discovered 1886 Dec. 22 by C. H. F. Peters at Clinton.

Named after the princess who founded the city of Prague \{see planet (2367) $\}$ in the 8th century. (H 31)

\section{(265) Anna}

Discovered 1887 Feb. 25 by J. Palisa at Vienna.

Named probably in honor of Anny Weiss, née Kretschmar, daughter-in-law of Prof. E. Weiss, director of the Vienna Observatory. (A. Schnell)

In the 'Beilage zum astronomischen Kalender 1888', p. 88, the contributor E. Weiss laconically noted: "... erhielten die Namen Anna und Aline, die eines weiteren Commentares nicht bedürfen."

\section{(266) Aline}

Discovered 1887 May 17 by J. Palisa at Vienna.

Named probably in honor of Linda von Schuster, daughter of Prof. E. Weiss, director of the Vienna Observatory. (A. Schnell)

See also the remark to planet (265).

\section{(267) Tirza}

Discovered 1887 May 27 by A. Charlois at Nice.

Named after the biblical Tirzah (Solomon's Song $6,4)$. (H 32)

\section{(268) Adorea}

Discovered 1887 June 8 by A. Borrelly at Marseilles.

Named after the flat cake produced from meal and salt which was offered by the Romans as a sacrifice to their gods. (Beilage zum astronomischen Kalender 1889, p. 86)

The naming was violently criticized in the 'Astronomischer Kalender': "Der Asteroid hat mittlerweile den Namen Adorea erhalten, womit die Römer die leichten flachen Kuchen aus Mehl und Salz bezeichneten, welche sie den Göttern opferten. Wir haben also jetzt neben einem Büchertitel \{planet (141) Lumen)\}, einem Romanhelden \{planet (152) Atala\} und der Götternahrung \{planet (193) Ambrosia\} auch noch eine Opferspeise durch die Asteroiden am Himmel verewigt erhalten: fürwahr wohl die beste denkbare Satire auf die Grundsätze, die in den letzten Jahren beim Benennen dieser Himmelskörper massgebend geworden sind."

\section{(269) Justitia}

Discovered 1887 Sept. 21 by J. Palisa at Vienna.

Named for the goddess of justice, daughter of Jupiter and Astraea \{see planet (5)\}. She and her mother went to heaven when the Golden Age was ended. She carries a balance and a sword. (H 32)

Named by Hofrath August Biela, "einem eifrigen Freunde der Astronomie und Besitzer einer sehr hübschen kleinen Privatsternwarte" (Beilage zum astronomischen Kalender für 1889, p. 83) 


\section{(270) Anahita}

Discovered 1887 Oct. 8 by C. H. F. Peters at Clinton.

Named for the Persian Great Mother, goddess of fertility. (H 32)

The discoverer proposed the name and, simultaneously, provided a quotation in AN 118, 44 (1887): "Ich schlage für diesen Planeten den Namen Anahita vor, von der altpersischen Göttin, bei den Occidentalen zuweilen auch Anaitis übersetzt. (Man mag darüber z.B. nachlesen: Ebers, Aegyptische Königstochter, Bd. 2, die Anmerkung 38)." Prof. E. Weiss, director of the Vienna Observatory, stated that this planet is also named in honor of Anita, daughter of the famous American astronomer S. Newcomb see planet (855)\}. (Beilage zum astronomischen Kalender 1889, p. 83)

\section{(271) Penthesilea}

Discovered 1887 Oct. 13 by V. Knorre at Berlin.

Named for the queen of the Amazones see planet (1042) $\}$ and ally of Troy in the Trojan War. She fought against Achilles $\{$ see planet (588)\} by whom she was slain. (H 32)

\section{(272) Antonia}

Discovered 1888 Feb. 4 by A. Charlois at Nice.

Any reference of this name to a person or occurrence is unknown.

\section{(273) Atropos}

Discovered 1888 Mar. 8 by J. Palisa at Vienna.

Named after one of the three Fates. The others are Clotho and Lachesis ssee planets (97) and (120), respectively\}. Atropos carries the shears and cuts the thread of life. (Z 37)

Named by the Berlin astronomers (BAJ Circ., No. 317 (1888)).

The Beilage zum astronomischen Kalender 1889, p. 86 gives a connection between the choice of this particular name with the death of the German emperor Wilhelm I.: "Der Planet wurde am 8. März, wenige Stunden vor dem Hinscheiden Kaiser Wilhelm I., aufgefunden und in Folge dessen von den Berliner Astronomen für ihn sehr sinnig der Name der Parze Atropos gewählt."

\section{(274) Philagoria}

Discovered 1888 Apr. 3 by J. Palisa at Vienna.

Named by the discoverer for a recreation club in Olmütz. (A. Schnell)

\section{(275) Sapientia}

Discovered 1888 Apr. 15 by J. Palisa at Vienna.

This is the Latin name for wisdom. (H 32)

\section{(276) Adelheid}

Discovered 1888 Apr. 17 by J. Palisa at Vienna.

Any reference of this name to a person or occurrence is unknown.

\section{(277) Elvira}

Discovered 1888 May 3 by A. Charlois at Nice.

Named possibly for the principal character in Méditations poétiques (1820) and Harmonies poétiques et religieuses (1830) of the French statesman and poet Alphonse de Lamartine (1790-1869). (H 32)

\section{(278) Paulina}

Discovered 1888 May 16 by J. Palisa at Vienna.

Any reference of this name to a person or occurrence is unknown.

\section{(279) Thule}

Discovered 1888 Oct. 25 by J. Palisa at Vienna.

Named for an island in the northernmost part of the North Sea to which the ancients gave the name Ultima Thule. Its location has never been accurately ascertained. Some writers have thought it to be Iceland, Greenland, or the Shetland Islands. To the ancients, it was the northern limit of the habitable world. (Z 271)

The name is exceptionally appropriate because the planet's orbit was the farthest from the Sun then known. Except for the special dynamical case of the Trojan asteroids and some other spectacular objects, which probably are cometary nuclei, Thule still occupies this position. It is very near the 3:4 commensurability of period with Jupiter.

\section{(280) Philia}

Discovered 1888 Oct. 29 by J. Palisa at Vienna.

This name belongs to the nymph who, with Koronis \{see planet (158)\} and Clyda educated the young Dionysos $\{$ see planet $(3671)\}$ on Naxos. See also the citation for planet (44). (H 33)

Named by A. Berberich.

The planet was accidentally discovered while searching for (255) Oppavia. The ephemeris position, computed by Berberich, however was in error by 1 degree in declination. A spelling mistake thus led to the discovery of a new planet. Palisa therefore transferred the naming right to the Berlin astronomer.

\section{(281) Lucretia}

Discovered 1888 Oct. 31 by J. Palisa at Vienna.

Named in honor of Lucretia Caroline Herschel (1750-1848), sister of the discoverer (1781) of Uranus Sir William Herschel (1738-1822) \{see planet (2000)\}, whom she assisted, beginning in 1772. She independently discovered seven or eight comets. After her brother's death she returned from England to Hannover, Germany and constructed a catalogue of the nebulae and clusters discovered by him. She received the Gold Medal of the Royal Astronomical Society in 1828. (AN 120, 335 (1889))

Named by Mrs. Šafařik, wife of the astronomer Adalbert Šafarik, professor of astronomy at the Prague University. 


\section{(282) Clorinde}

Discovered 1889 Jan. 28 by A. Charlois at Nice.

Named probably after the heroine of the epic poem

Jerusalem Delivered by the Italian writer Torquato Tasso (1544-1595). (H 33)

\section{(283) Emma}

Discovered 1889 Feb. 8 by A. Charlois at Nice.

Any reference of this name to a person or occurrence is unknown.

See also the comment to planet (295).

\section{(284) Amalia}

Discovered 1889 May 29 by A. Charlois at Nice.

Any reference of this name to a person or occurrence is unknown.

See also the comment to planet (295).

\section{(285) Regina}

Discovered 1889 Aug. 3 by A. Charlois at Nice.

Any reference of this name to a person or occurrence is unknown.

See also the comment to planet (295).

\section{(286) Iclea}

Discovered 1889 Aug. 3 by J. Palisa at Vienna.

Named "in honor of the heroine of the astronomical romance Uranie, published last year by Camille Flammarion" (l'Astronomie, Vol. 9, p. 392 (1890)). (H 33)

\section{(287) Nephthys}

Discovered 1889 Aug. 25 by C. H. F. Peters at Clinton.

Named for the Egyptian goddess of the dead, sister of Isis \{see planet (42)\} and wife of Seth. (H 34)

The discoverer wrote in AN 122, 393 (1889): "Ich schlage den Namen Nephthys vor - bei den Ägyptern repräsentirt Neb-ta vielleicht den Planeten Venus ..."

\section{(288) Glauke}

Discovered 1890 Feb. 20 by R. Luther at Düsseldorf.

Named for the daughter of Creon, king of Corinth, whom Jason \{see planet (6063)\} planned to marry. Glauke is also the name of one of the Danaides and of one of the Nereides. (Z 111)

Named by the son of the discoverer. Luther stated in AN 124, 288 (1890): "Nachdem ich mich von der Neuheit des Planeten hinlänglich überzeugt zu haben glaubte, schickte ich an meinen Sohn in Hamburg, welcher den Planeten seit dem 24. Februar $\{1890\}$ daselbst eifrigst beobachtet hat, eine Namen-Liste zur Auswahl eines Namens, worunter sich auch drei seiner Zeit von Argelander gewünschte Namen befanden. Nach einem Briefe meines Sohnes vom 9. März hat einer dieser drei Namen "Glauke" in Hamburg besonders gefallen, so dass ich denselben als gewählt betrachte."

\section{(289) Nenetta}

Discovered 1890 Mar. 10 by A. Charlois at Nice.

The name originates from a French argot which denotes a more or less frivolous woman. (M.-A. Combes)
Une "nénette" est un mot français argotique qui signifie tout simplement une fille, pas forcément frivole. C'est un mot plutôt sympathique. See also the comments to planets (295) and (494), respectively.

\section{(290) Bruna}

Discovered 1890 Mar. 20 by J. Palisa at Vienna.

Named by Hofrath August Biela for his home town Brünn, now Brno, Czechoslovakia ssee also planet (2889)\}. (A. Schnell; Beilage zum Astronomischen Kalender 1892, p. 92)

\section{(291) Alice}

Discovered 1890 Apr. 25 by J. Palisa at Vienna.

Any reference of this name to a person or occurrence is unknown.

Named by the Société Astronomique de France "at the gracious invitation of the discoverer" (l'Astronomie, Vol. 10, p. 112 (1891)). The planets (291) and (292) were independently discovered by $\mathrm{A}$. Charlois at Nice one night later.

\section{(292) Ludovica}

Discovered 1890 Apr. 25 by J. Palisa at Vienna.

Any reference of this name to a person or occurrence is unknown.

Named by the Société Astronomique de France. See the note to planet (291).

\section{(293) Brasilia}

Discovered 1890 May 20 by A. Charlois at Nice.

Named for the South American country. Dom Pedro II (1825-1891), former emperor of Brazil who had withdrawn to France after the revolution of 1889 may have occasioned the naming. He was known as an enthusiastic patron of astronomy. Dom Pedro was an admirer and friend of Camille Flammarion who invited him to Juvisy (see planets (1021), (605)). (H 34; M.-A. Combes)

\section{(294) Felicia}

Discovered 1890 July 15 by A. Charlois at Nice.

Any reference of this name to a person or occurrence is unknown.

See also the comment to planet (295).

\section{(295) Theresia}

Discovered 1890 Aug. 17 by J. Palisa at Vienna.

Any reference of this name to a person or occurrence is unknown.

The name was erroneously attributed to Maria Theresia (1717-1780), queen of Hungary and Bohemia, and wife of emperor Franz I. As was mentioned in the Beilage zum Astronomischen Kalender 1892, p. 91, this interpretation obviuosly is wrong: "Die Namen der neun Planeten 283, 284, 285, 289, 294, 295, 297 , 302 und 303, welche der Reihe nach lauten: Emma, Amelia, Regina, Nenetta, Felicia, Theresia, Cäcilia, Clarissa und Josefina und von den Entdeckern oder Freunden derselben gewählt wurden, gehören, wie 
man leicht erkennt, nicht antiken, sondern lebenden Göttinnen an: es gebietet daher schon die Courtoisie, sich weiterer Commentare über dieselben zu enthalten." (Communicated by A. Schnell)

\section{(296) Phaëtusa}

Discovered 1890 Aug. 19 by A. Charlois at Nice.

Named for one of the daughters of Apollo and Klymene \{see planets (1862) and (104)\}, changed by Zeus \{see planet (5731)\} into poplars after the death of their brother Phaethon \{see planet (3200)\}. (H 34)

\section{(297) Caecilia}

Discovered 1890 Sept. 9 by A. Charlois at Nice.

Any reference of this name to a person or occurrence is unknown.

See also the comment to planet (295).

\section{(298) Baptistina}

Discovered 1890 Sept. 9 by A. Charlois at Nice.

Any reference of this name to a person or occurrence is unknown.

\section{(299) Thora}

Discovered 1890 Oct. 6 by J. Palisa at Vienna.

Named for the Norse god of thunder, weather and crops. (A. Schnell)

Named by Geheimrat Prof. Scheibler in Berlin. In Norse mythology this name repeatedly exists as spouse of Helge, spouse of Ragnar Lodbrok, and as a girlfriend of Gudrun (Beilage zum Astronomischen Kalender 1892, p. 92).

\section{(300) Geraldina}

Discovered 1890 Oct. 3 by A. Charlois at Nice.

Any reference of this name to a person or occurrence is unknown.

\section{(301) Bavaria}

Discovered 1890 Nov. 16 by J. Palisa at Vienna.

Named to commemorate the August 1891 meeting of the Astronomische Gesellschaft in Munich, the capital city of Bavaria. (AN 128, 197 (1891))

Name proposed by B. A. Gould.

\section{(302) Clarissa}

Discovered 1890 Nov. 14 by A. Charlois at Nice.

Any reference of this name to a person or occurrence is unknown.

See also the comment on planet (295).

\section{(303) Josephina}

Discovered 1891 Feb. 12 by E. Millosevich at Rome.

The discoverer states in the Memoirs of the Collegio Romano College that the planet was named "... in homage to a person dear to me ...". (H 35)

See also the comment on planet (295).

\section{(304) Olga}

Discovered 1891 Feb. 14 by J. Palisa at Vienna.

Named by F. W. Argelander in honor of his niece. (H 35)

\section{(305) Gordonia}

Discovered 1891 Feb. 16 by A. Charlois at Nice.

Named probably in honor of James Gordon Bennett Jr. (1841-1918), editor of the New York Herald, founded by his father. He sent Stanley to Africa to find Livingstone (1869-1871). Bennett gave monetary aid to the Juvisy \{see planet (605)\} Observatory of Flammarion \{see planet (1021)\} by whom he is praised in l'Astronomie, p. 307 (1890). (H 35)

\section{(306) Unitas}

Discovered 1891 Mar. 1 by E. Millosevich at Rome.

Named in honor of the Italian astronomer Angelo Pietro Secchi (1818-1878) \{see planet (4705)\} and also for the unity of Italy. The citation reads: "Al pianeta, scoperto ... dal E. Millosevich, e da lui pregato di denominarlo, do il nome di Unitas, associando in questo nome due idee, la prima il ricordo d'un libro classico del mio illustre predecessore ed amico A. Secchi, la seconda l'unità della patria." (AN 127, 167 (1891))

Named by P. Tacchini (1838-1905), director of the Modena Observatory in 1859 . He went to Palermo in 1863 and succeeded Secchi in 1879 as director of the Osservatorio del Collegio Romano. He was a pioneer of solar spectroscopy, paying particular attention to solar prominences which he showed to obey the 11-year period (H 35).

\section{(307) Nike}

Discovered 1891 Mar. 5 by A. Charlois at Nice.

Named for the Greek goddess of victory corresponding to the Roman Victoria see planet (12)\}. The name also denotes the Greek name of the city of discovery. (H 35)

\section{(308) Polyxo}

Discovered 1891 Mar. 31 by A. Borrelly at Marseilles. Named for a priestress of Apollo's \{see planet (1862)\} temple in Lemnos and the nurse of Queen Hypsipyle \{see planet (587)\}. She advised the Lemnian women to murder their husbands, and suggested to Hypsipyle welcoming the Argonauts so that they would father sons by the Lemnian women, in order that the race would not become extinct. Polyxo is also the name of one of the Hyades which were said to have been originally nymphs, daughters of Atlas and the Oceanid Aethra \{see planet (132)\}. This second interpretation seems more likely because Borrelly named another planet after a Hyades member - see planet (322). (Z 218; LDS)

\section{(309) Fraternitas}

Discovered 1891 Apr. 6 by J. Palisa at Vienna.

This is the Latin word for fraternity. ( $\mathrm{H} \mathrm{35}$; A. Schnell)

The Beilage zum Astronomischen Kalender 1892, p. 92 reported the occasion of the naming: "... wurde bei einer geselligen Zusammenkunft der Studiengenossen Palisa's zur Feier des 25. Jahrestages der Ablegung der Maturitätsprüfung Fraternitas getauft." 
(310) Margarita

Discovered 1891 May 16 by A. Charlois at Nice.

Any reference of this name to a person or occurrence is unknown.

\section{(311) Claudia}

Discovered 1891 June 11 by A. Charlois at Nice.

Any reference of this name to a person or occurrence is unknown.

\section{(312) Pierretta}

Discovered 1891 Aug. 28 by A. Charlois at Nice.

Any reference of this name to a person or occurrence is unknown.

\section{(313) Chaldaea}

Discovered 1891 Aug. 30 by J. Palisa at Vienna.

Named for the country in Asia between the Tigris and Euphrates whose capital was Babylon. The Chaldaeans were famous for originating astrology as it is known today. (H 36)

Name assigned by Miss Catherine W. Bruce of New York at the invitation of Dr. Palisa, in token of the gratitude of astronomers (Astron. J., Vol. 11, No. 8, p. 64 (1891)).

\section{(314) Rosalia}

Discovered 1891 Sept. 1 by A. Charlois at Nice.

Any reference of this name to a person or occurrence is unknown.

\section{(315) Constantia}

Discovered 1891 Sept. 4 by J. Palisa at Vienna.

This name describes a special attribute: "Mot latin qui signifie constance et persévérance, qualité jugée essentielle pour faire un bon astronome par Camille Flammarion qui proposa le nom." (J. Meeus)

This interpretation originates from M.-A. Combes.

\section{(316) Goberta}

Discovered 1891 Sept. 8 by A. Charlois at Nice.

Any reference of this name to a person or occurrence is unknown.

\section{(317) Roxane}

Discovered 1891 Sept. 11 by A. Charlois at Nice.

Named for the daughter of the Persian king Oxyartes and wife of the Macedonian king Alexander the Great (356-323 B.C.). (A. Schnell; I. van HoutenGroeneveld)

Named by F. Bidschof, assistant at the Vienna Observatory, at the request of the discoverer. (Kalender für alle Stände, Vienna 1894). The planet originally (AN 132, 176 (1893)) was named 'Roxana'.

\section{(318) Magdalena}

Discovered 1891 Sept. 24 by A. Charlois at Nice.

Any reference of this name to a person or occurrence is unknown.

\section{(319) Leona}

Discovered 1891 Oct. 8 by A. Charlois at Nice.
Any reference of this name to a person or occurrence is unknown.

\section{(320) Katharina}

Discovered 1891 Oct. 11 by J. Palisa at Vienna.

Named in honor of the mother of the discoverer, Katharina. (H 36)

\section{(321) Florentina}

Discovered 1891 Oct. 15 by J. Palisa at Vienna.

Named in honor of the daughter of the discoverer, Florentine. (H 36)

\section{(322) Phaeo}

Discovered 1891 Nov. 27 by A. Borrelly at Marseilles.

Named for one of the Hyades which were said to have been originally nymphs, daughters of Atlas and an oceanid named Aethra ssee planet (132)\}. Their number varies from two to seven, and their names were no less variable. The most usual seem to have been Ambrosia \{see planet (193)\}, Eudora $\{(217)\}$, Aesyle, Coronis $\{(158)\}$, Dione $\{(106)\}$, Polyxo $\{(308)\}$ and Phaeo. (M.-A. Combes)

\section{(323) Brucia}

Discovered 1891 Dec. 22 by M. F. Wolf at Heidelberg.

Named in honor of Miss Catherine Wolfe Bruce (1816-1900), noted American patroness of astronomy "who presented Dr. Wolf with the means to secure the largest and best photographic telescope that could be made for his especial research in the domain of planet and nebula photography." (J. A. Brashear, Pop. Astron., Vol. 11, p. 548 (1903)). (H 36)

This is the first numbered minor planet discovered photographically. With the Bruce telescope of the Heidelberg Observatory more now numbered minor planets were discovered than with any other telescope in the world. Miss Bruce is also honored by a lunar crater.

\section{(324) Bamberga}

Discovered 1892 Feb. 25 by J. Palisa at Vienna.

"Der Planet ... hat bei Gelegenheit der Astronomenversammlung in Bamberg den Namen Bamberga erhalten." Bamberg is a leading city of Bavaria, Germany. (AN 141, 405 (1896))

Named by Dr. von Brandt, mayor of the city of Bamberg, at the occasion of the September 1896 AG meeting.

\section{(325) Heidelberga}

Discovered 1892 Mar. 4 by M. F. Wolf at Heidelberg.

Named for the famous German city on the Neckar \{see planet (1223)\} river. This planet was discovered at Wolf's private observatory in the Märzgasse in the old part of the city of Heidelberg. (H 36)

\section{(326) Tamara}

Discovered 1892 Mar. 19 by J. Palisa at Vienna.

Named for a queen of Georgia (1184-1212) who became a legendary figure in late medieval romance. 
She had her lovers killed and thrown into a river from her palace window when she was tired of them. (H 37)

Name proposed by the Russian Grand Duke Georg Alexandrovich.

\section{(327) Columbia}

Discovered 1892 Mar. 22 by A. Charlois at Nice.

Named in honor of Christopher Columbus (1446?1506) to commemorate the 400th anniversary of his first voyage to the New World. See also the citation for planet (334). (H 37)

Columbus is also honored by craters on the Moon and on Mars.

\section{(328) Gudrun}

Discovered 1892 Mar. 18 by M. F. Wolf at Heidelberg.

Named for the wife of Sigurd and later of Atli in the Gudrun Saga in Norse mythology. (I. van Houten-Groeneveld)

\section{(329) Svea}

Discovered 1892 Mar. 21 by M. F. Wolf at Heidelberg.

This name is an allusion to Sweden. The discoverer has made studies in Sweden in 1889. (H 37)

\section{(330) Adalberta}

A910 CB. Discovered 1910 Feb. 2 by M. F. Wolf at Heidelberg.

Named in honor of Adalbert Merx \{see planet (808)\}, father-in-law of the discoverer, or, possibly, for Adalbert Krüger, editor of the Astronomische Nachrichten. (H 37)

Another planet also discovered by Max Wolf had been called (330) Ilmatar (AN 130, 159 (1892)). This planet was identified with (298) Baptistina and the name was transferred (Veröff. Rechen-Inst. 16, p. 27 (1901)) to (385). The "original" Adalberta was discovered by Wolf 1892 March 18. There exist no other observations than those from the discovery apparition. A reexamination of the original plates by R. M. West, C. Madsen and L. D. Schmadel (Astron. Astrophys., Vol. 110, p. 198202 (1982)) indicates that Wolf measured two stellar images and that therefore this planet is non-existent. The number and name were therefore assigned to another minor planet (M 6939).

\section{(331) Etheridgea}

Discovered 1892 Apr. 1 by A. Charlois at Nice.

Any reference of this name to a person or occurrence is unknown.

\section{(332) Siri}

Discovered 1892 Mar. 19 by M. F. Wolf at Heidelberg.

Any reference of this name to a person or occurrence is unknown.

\section{(333) Badenia}

Discovered 1892 Aug. 22 by M. F. Wolf at Heidelberg.

Named for the region in southwestern Germany, former German grand-duchy, in which Heidelberg \{see planet (325)\} is situated. It is now part of the German state of Baden-Württemberg. (H 37)

\section{(334) Chicago}

Discovered 1892 Aug. 23 by M. F. Wolf at Heidelberg.

Named by the discoverer at an astronomical congress in Chicago to honor this great city. (AN 134, 167 (1893))

This congress was in connection with the World's Columbian Exposition (May to October 1893) to commemorate the 400th anniversary of Columbus' discovery of America. The name Columbia was to be chosen but it had been appropriated shortly before by A. Charlois for (327). The newly constructed mounting and tube of the Yerkes 40-inch refractor in operating position were exhibited at the Exposition by the builders Warner and Swasey (see also planets (990) and (992)) (H 37).

\section{(335) Roberta}

Discovered 1892 Sept. 1 by A. Staus at Heidelberg.

Named by the discoverer in honor of Robert von der Osten-Sacken who lived in Heidelberg as a private scientist. He was an entomologist and his research trips led him many times to the U.S.A. From one of these trips he brought back a 3-inch refractor which he gave to Staus as a present. The planet was named in recognition and gratitude for his friendship. (H 38)

Staus discovered this planet with the 6-inch telescope of Max Wolf's private observatory in the Märzgasse in Heidelberg.

\section{(336) Lacadiera}

Discovered 1892 Sept. 19 by A. Charlois at Nice.

Named for the village La Cadière-d'Azur in the departement Var in southern France where the discoverer held some property. (H 38)

\section{(337) Devosa}

Discovered 1892 Sept. 22 by A. Charlois at Nice.

Any reference of this name to a person or occurrence is unknown.

\section{(338) Budrosa}

Discovered 1892 Sept. 25 by A. Charlois at Nice.

Any reference of this name to a person or occurrence is unknown.

\section{(339) Dorothea}

Discovered 1892 Sept. 25 by M. F. Wolf at Heidelberg.

Named in honor of Dorothea Klumpke Roberts (1861-1943) \{see also planet (1040)\}. She was the first lady to gain the degree Doctor of Mathematical Sciences at the Sorbonne. She assisted her husband Isaac Roberts (1829-1904), a building contractor who took up astronomy as a hobby when about 50 , built two private observatories at Liverpool and Crowborough, and became a pioneer in the photography of clusters and nebulae. (H 38) 


\section{(340) Eduarda}

Discovered 1892 Sept. 25 by M. F. Wolf at Heidelberg.

Named in honor of Eduard von Lade, amateur astronomer at Geisenheim on the Rhine. (H 38)

\section{(341) California}

Discovered 1892 Sept. 25 by M. F. Wolf at Heidelberg.

Named by the discoverer for the state of California in order to commemorate his visit in 1893. (H 38)

\section{(342) Endymion}

Discovered 1892 Oct. 17 by M. F. Wolf at Heidelberg.

Named for the youthful shepherd who so enchanted Selene (the Moon) by his unsurpassed beauty as he lay sleeping on Mt. Latmos that she came down every night to visit him. (H 38)

Named by F. Bidschof (AN 141, 71 (1896)), who was an orbit computer and served as assistant at the Vienna Observatory. For the first time, the name of a male god was used for a minor planet. (A. Schnell)

Endymion is also commemorated by a lunar crater.

\section{(343) Ostara}

Discovered 1892 Nov. 15 by M. F. Wolf at Heidelberg.

Named after the early Norse goddess of Spring.

The Easter rabbit was the escort of Ostara who thus contributed the name Easter. The German word is "Ostern". (H 39)

\section{(344) Desiderata}

Discovered 1892 Nov. 15 by A. Charlois at Nice.

Named probably in honor of Désirée Clary of Marseilles who became the wife of General JeanBaptiste Jules Bernadotte (1763-1844). He later became King Charles XIV John of Sweden (1818-1844) and was the founder of the present Swedish dynasty. Désirée was a former fiancée of Napoleon. (H 39)

\section{(345) Tercidina}

Discovered 1892 Nov. 23 by A. Charlois at Nice.

Any reference of this name to a person or occurrence is unknown.

\section{(346) Hermentaria}

Discovered 1892 Nov. 25 by A. Charlois at Nice.

Named probably for the village of Herment in the département du Puy-de-Dôme (Auvergne region). (H 39; M.-A. Combes)

\section{(347) Pariana}

Discovered 1892 Nov. 28 by A. Charlois at Nice.

Any reference of this name to a person or occurrence is unknown.

\section{(348) May}

Discovered 1892 Nov. 28 by A. Charlois at Nice.

Named possibly in honor of the contemporal German writer Karl May (1842-1912), well-known for his many novels dealing with adventures among the Indians of the wild West (Winnetou). May also published a lot of exciting travelogues from the Ottoman Empire. (G. Zech; LDS)
Karl May was later also honored by planet (15728).

The books of Karl May were widely distributed in many languages - partly in large editions - in central Europe. French translations appeared in journals (starting 1881) as well as in books (by Mame et Fils, Tours, since 1885).

\section{(349) Dembowska}

Discovered 1892 Dec. 9 by A. Charlois at Nice.

Named in honor of Ercole Dembowski (1812-1881), native of Milan, Italy who established a private observatory at Naples which was later transferred to Milan. His careful measurements of double stars marked an important stage in this branch of astronomy. (H 39)

Dembowski is also honored by a lunar crater.

\section{(350) Ornamenta}

Discovered 1892 Dec. 14 by A. Charlois at Nice.

Named "in remembrance of the mariner Hornemann, of Holland, whose son is a very zealous member of the Société Astronomique de France". (l'Astronomie, Vol. 11, p. 332 (1897))

\section{(351) Yrsa}

Discovered 1892 Dec. 16 by M. F. Wolf at Heidelberg.

Any reference of this name to a person or occurrence is unknown.

\section{(352) Gisela}

Discovered 1893 Jan. 12 by M. F. Wolf at Heidelberg.

Named in honor of Gisela Wolf, neé Merx \{see planet (808)\}, wife of the discoverer. (H 39)

\section{(353) Ruperto-Carola}

Discovered 1893 Jan. 16 by M. F. Wolf at Heidelberg.

The discoverer stated in AN 154, 15 (1900): "Der Planet hat durch die Versammlung der A.G. in Heidelberg den Namen Ruperto-Carola erhalten." This is a reference to Heidelberg \{see planet (325)\} University, one of the oldest and most famous of German universities, which was founded by Elector Ruprecht I (1309-1390) in 1386. Grand Duke Karl Friedrich von Baden reestablished the university in 1803. (H 39)

\section{(354) Eleonora}

Discovered 1893 Jan. 17 by A. Charlois at Nice.

Any reference of this name to a person or occurrence is unknown.

\section{(355) Gabriella}

Discovered 1893 Jan. 20 by A. Charlois at Nice.

Named in honor of Gabrielle Renaudot (1877-1962), later Mme. Camille Flammarion \{see planet (1021)\}, in recognition of her zeal as a student of astronomy and an observer at the Observatory of Juvisy s see planet (605)\}. Later she was editor-in-chief of l'Astronomie, Laureate of the Académie des Sciences de France, and officier de la Légion d'Honneur. (H 39) 


\section{(356) Liguria}

Discovered 1893 Jan. 21 by A. Charlois at Nice.

Named after the region in northwest Italy and southern France between Genoa and Nice, bordering on the Ligurian sea north of the island of Corsica. (H 40)

In AN 156, 239 (1901), 34 names of planets between numbers (356) and (451) are published by J. Bauschinger. The text only states: "Nach Zustimmung des Herrn Charlois haben folgende Planeten ... Namen erhalten." It therefore seems obvious that the names were selected by the Astronomisches Rechen-Institut.

\section{(357) Ninina}

Discovered 1893 Feb. 11 by A. Charlois at Nice.

Any reference of this name to a person or occurrence is unknown.

\section{(358) Apollonia}

Discovered 1893 Mar. 8 by A. Charlois at Nice.

The planet was probably named for a "ville ancienne de l'Illyrie, à l'embouchure de l'Aoüs, réputée à l'époque gréco-romaine comme centre culturel et commercial." This interpretation was given by M.-A. Combes. (J. Meeus)

See also the remarks to planet (356).

\section{(359) Georgia}

Discovered 1893 Mar. 10 by A. Charlois at Nice.

This planet was named at the 1902 meeting of the Astronomische Gesellschaft in Göttingen. It honors Georg August, later King George II of England (1683-1760), who founded the University of Göttingen in 1737. (H 40; AN 159, 279 (1902))

Named by Miss Klein, daughter of the famous mathematician.

\section{(360) Carlova}

Discovered 1893 Mar. 11 by A. Charlois at Nice.

Any reference of this name to a person or occurrence is unknown.

\section{(361) Bononia}

Discovered 1893 Mar. 11 by A. Charlois at Nice.

This is the Latin name for the city of Bologna \{see planet (2601)\} in north central Italy and of Boulogne, the French seaport on the English Channel. (H 40) See also the remarks to planet (356).

\section{(362) Havnia}

Discovered 1893 Mar. 12 by A. Charlois at Nice.

This planet is probably named for the city of Copenhagen, capital of Denmark. The Latin name is Hafnia. (H 40)

See also the remarks to planet (356).

\section{(363) Padua}

Discovered 1893 Mar. 17 by A. Charlois at Nice.

Named after the city of Padova near Venice, Italy. (H 40)

See also the remarks to planet (356).

\section{(364) Isara}

Discovered 1893 Mar. 19 by A. Charlois at Nice.

Isara is an early name of the Isère river which joins the Rhone river in southern France. (H 40)

See also the remarks to planet (356).

\section{(365) Corduba}

Discovered 1893 Mar. 21 by A. Charlois at Nice.

This planet is possibly named for the city of Córdoba, Spain on the Guadalquivir river. Corduba is the ancient name. (H 40)

See also the remarks to planet (356).

\section{(366) Vincentina}

Discovered 1893 Mar. 21 by A. Charlois at Nice.

Named by the orbit computer Prof. G. Boccardi to honor the Italian astronomer Vincenzo Cerulli (1859-1927). Boccardi worked for many years in the private observatory of Cerulli in Teramo. See also the citation for planet (704). (H 40)

This planet was studied by E. Strömgren on its approach of only 4.5 million miles to (386) Siegena in January, 1921.

\section{(367) Amicitia}

Discovered 1893 May 19 by A. Charlois at Nice.

This planet is named with the Latin word for friendship. (H 40)

See also the remarks to planet (356).

\section{(368) Haidea}

Discovered 1893 May 19 by A. Charlois at Nice.

Any reference of this name to a person or occurrence is unknown.

\section{(369) Aëria}

Discovered 1893 July 4 by A. Borrelly at Marseilles.

Named presumably after one of the four elements of the ancients. E. Weiss stated in the Astronomischer Kalender für 1896, p. 155: "... während wir wohl kaum fehlgehen dürften, wenn wir annehmen, dass mit Aëria eines der vier Elemente (Feuer, Luft, Wasser und Erde) der Alten am Himmel verewigt werden sollte..." (A. Schnell)

The naming may be influenced by the two letters of the provisional designation 1893 AE. See also the remarks to planet (579).

\section{(370) Modestia}

Discovered 1893 July 14 by A. Charlois at Nice.

Named for the quality of modesty, the freedom from conceit or vanity. (H 41)

See also the remarks to planet (356).

\section{(371) Bohemia}

Discovered 1893 July 16 by A. Charlois at Nice.

Named for the region which today lies in western Czechoslovakia. With Moravia and Silesia \{see planets (1901) and (257)\}, Bohemia now forms one of the two constituent states of Czechoslovakia. At the time of 
the discovery, Bohemia was a part of Austria. (H 41)

Named by A. Abetti.

The planet's orbit was computed by H. Mader (AN 153, 447 (1900)) whose native country is Bohemia.

\section{(372) Palma}

Discovered 1893 Aug. 19 by A. Charlois at Nice.

Named probably for the capital of Mallorca, the largest of the Balearic islands in the Mediterranean south of France. (H 41)

See also the remarks to planet (356).

\section{(373) Melusina}

Discovered 1893 Sept. 15 by A. Charlois at Nice.

Named probably for the legendary ancestress of the noble family of Lusignan of the 10th century, a heroine of French romance. She married a knight on the condition that he was never to see her on Saturday. But his curiosity led to the discovery that she was half snake. Thereupon she took the form of a dragon and flew away to reappear as an omen before the death of her descendants. The town of Lusignan is supposed to be named for her. (H 41)

See also the remarks to planet (356).

\section{(374) Burgundia}

Discovered 1893 Sept. 18 by A. Charlois at Nice.

Named for the former kingdom, duchy and province in eastern France. (H 41)

See also the remarks to planet (356).

\section{(375) Ursula}

Discovered 1893 Sept. 18 by A. Charlois at Nice.

Any reference of this name to a person or occurrence is unknown.

See also the remarks to planet (356).

\section{(376) Geometria}

Discovered 1893 Sept. 18 by A. Charlois at Nice.

The Latin word originally means "to measure the Earth". It concerns a branch of mathematics that deals with the measurement, properties and relationships of points, lines, angles, surfaces, and solids. (H 41) See also the remarks to planet (356).

\section{(377) Campania}

Discovered 1893 Sept. 20 by A. Charlois at Nice.

Named after a region in southern Italy bordering on the Tyrrhenian sea and containing the city of Naples. (H 41)

See also the remarks to planet (356).

\section{(378) Holmia}

Discovered 1893 Dec. 6 by A. Charlois at Nice.

This is the ancient name of Stockholm, the capital of Sweden. (H 41)

See also the remarks to planet (356).

\section{(379) Huenna}

Discovered 1894 Jan. 8 by A. Charlois at Nice.
This is the Latin form for Hveen. Tycho Brahe \{see planet (1677)\} observed for more than 20 years on this small island in the Sound between Denmark and Sweden. See also the citations for planets (499) and (1678). This interpretation was given by P. Colombier who found "Huenne" under the entry Tycho-Brahé in the Grand Vocabulaire Français (1773). (J. Meeus) See also the remarks to planet (356).

\section{(380) Fiducia}

Discovered 1894 Jan. 8 by A. Charlois at Nice. This is the Latin name for confidence. (H 42) See also the remarks to planet (356).

\section{(381) Myrrha}

Discovered 1894 Jan. 10 by A. Charlois at Nice.

Named for a woman in Greek mythology who was changed into a myrrh tree. Her son Adonis s see planet (2101)\} was born out of this tree. (H 42) See also the remarks to planet (356).

\section{(382) Dodona}

Discovered 1894 Jan. 29 by A. Charlois at Nice.

Named for a famous ancient town with a celebrated oracle of Zeus \{see planet (5731)\} on a nearby hill. The town and temple were built by Deucalion after the universal flood. Dodona was destroyed in 219 B.C. ( $\mathrm{H} 42)$

See also the remarks to planet (356).

\section{(383) Janina}

Discovered 1894 Jan. 29 by A. Charlois at Nice.

Any reference of this name to a person or occurrence is unknown.

\section{(384) Burdigala}

Discovered 1894 Feb. 11 by F. Courty at Bordeaux.

Named in honor of the city of the discovery of this planet. Burdigala is the Latin name of Bordeaux. (H 42)

\section{(385) Ilmatar}

Discovered 1894 Mar. 1 by M. F. Wolf at Heidelberg.

Named for a figure in Finnish mythology which symbolizes the daughter of the Air, who brought forth the Earth, Sky, Sun, Moon and Stars. (AN 130, 159 (1892))

Named by A. Krüger, editor of the Astronomische Nachrichten.

Krüger stated: "In Bezug auf (330) wünscht der Entdecker, dass ich den Namen vorschlagen solle." This planet, however, was identified as (298) Baptistina. The planet, also discovered by M. F. Wolf, which eventually became (330) was named "Adalberta". The name "Ilmatar" was transferred to (385). Krüger (1832-1896) spent several years in Finland, having gone to Helsingfors in 1862, hence the choice of the name. Earlier he had been assistant to Argelander \{see planet (1551)\} in Bonn. In 1876 he went to Gotha \{see planet 
(1346)\}. He determined a number of stellar parallaxes and in 1893 published a catalogue of over 2,000 red stars. (H 42). See also the remarks to (330).

\section{(386) Siegena}

Discovered 1894 Mar. 1 by M. F. Wolf at Heidelberg.

Named for the city of Siegen in Westphalia, Germany, home town of Prof. Kreutz, by whom it was named. (H 42; AN 154, 15 (1900))

\section{(387) Aquitania}

Discovered 1894 Mar. 5 by F. Courty at Bordeaux.

Named for a Roman division of southwestern Gaul to which Bordeaux \{Burdigala, see planet (384)\} belonged. Under Caesar the region consisted of the country between the Pyrenees mountains and Garonne river, and under Augustus expanded to the Loire and Allier rivers. ( $\mathrm{H} 42)$

\section{(388) Charybdis}

Discovered 1894 Mar. 7 by A. Charlois at Nice.

Named for a daughter of Poseidon and Gaea who was thrown into the sea off Sicily by Zeus s see planet (5731)\} where by swallowing and spewing water she created a whirlpool. Odysseus \{see planet (1143)\}, concerned with avoiding Charybdis, lost six of his men to the monster Scylla \{see planet (155)\}. Charybdis is an island, close to Scylla, where a whirlpool was. A giant woman was spying water in and out three times per day. (H 42)

See also the remarks to planet (356).

\section{(389) Industria}

Discovered 1894 Mar. 8 by A. Charlois at Nice. This is the Latin name for diligence. (J. Reichert) See also the remarks to planet (356).

\section{(390) Alma}

Discovered 1894 Mar. 24 by G. Bigourdan at Paris.

This planet is probably named for the river in southwest Russia and Crimea which gives its name to a famous victory gained over the Russians (1854) by the French and English in the Crimean War. (H 43) See also the remarks to planet (356).

\section{(391) Ingeborg}

Discovered 1894 Nov. 1 by M. F. Wolf at Heidelberg.

Any reference of this name to a person or occurrence is unknown.

\section{(392) Wilhelmina}

Discovered 1894 Nov. 4 by M. F. Wolf at Heidelberg.

Concerning this name there exist different explanations. E. Weiss (Astronomischer Kalender für 1896 , p. 155) interpreted the name as "eine Ehrenbezeugung für Kaiser Wilhelm", the German emperor. T. Gehrels gives the more likely explanation that this planet was named in honor of Queen Wilhelmina of the Netherlands (1880-1962): "At the time of discovery, it must have drawn quite a bit of attention in western
Europe that Princess Wilhelmina was so young and, because of the death of her father became nominally Queen already at the age of 10 ! There must have been sympathetic publicity because the Dutch Royal Family was and is highly respected." Queen Wilhelmina abducated 1948 in favor of her daughter Juliana \{see also the citation for planet (816)\}. (LDS)

\section{(393) Lampetia}

Discovered 1894 Nov. 4 by M. F. Wolf at Heidelberg.

There are two characters in Greek mythology with this name: (1) Lampetia was a daughter of Apollo \{see planet (1862)\} and Neaera and the sister of Phaetusa \{see planet (296)\} with whom she guarded her father's sacred cattle on the island of Thrinacia, where Odysseus \{see planet (1143)\} and his men arrived. Although warned by Odysseus to keep their hands off the sacred cattle of Apollo, the men carried away and killed some of the sacred beasts. Lampetia informed her father of the sacrilege. Apollo requested that Zeus ssee planet (5731)\} punish the offenders. As the men sailed away from Thrinacia, a terrible storm rose and all of the Greeks perished - except Odysseus, who held on to a piece of broken mast and saved himself from the shipwreck. (2) Lampetia is the name of one of the Heliades, who, with her sisters was changed into a poplar tree at the death of her brother Phaethon \{see planet (3200)\}. (Z 146) Named by A. Berberich (AN 156, 127 (1901)).

\section{(394) Arduina}

Discovered 1894 Nov. 19 by A. Borrelly at Marseilles.

Named probably for Arduenna, goddess of hunting among the Gauls. Silva Arduenna was the vast Ardennes Forest in northeastern Gaul. (H 43)

The planet was erroneously called Darwina in Bull. Astron., Vol. 21, p. 267 (AN 166, 319 (1904)). Darwin is honored by planet (1991).

\section{(395) Delia}

Discovered 1894 Nov. 30 by A. Charlois at Nice.

Delia is another name for Artemis, Cynthia, Diana, Hecate, Luna, Phoebe, or Selene - the goddess of the Moon. Artemis \{see planet (105)\} was called Delia because she was born on the island of Delos. Delia was also the name of a festival, instituted by Theseus in honor of Apollo \{see planet (1862)\}, celebrated on the island of Delos. (Z 83)

Named by the discoverer (AN 162, 54 (1903)).

\section{(396) Aeolia}

Discovered 1894 Dec. 1 by A. Charlois at Nice.

Named for the ancient country of northwestern Asia Minor near the Aegean Sea. Aeolus was the god of storms and winds and supposedly a great astronomer. Another possible interpretation belongs to the Lipari (or Aeolian) islands in the Tyrrhenian sea northeast of Sicily. (H 43)

Named by the discoverer (AN 162, 54 (1903)). 


\section{(397) Vienna}

Discovered 1894 Dec. 19 by A. Charlois at Nice.

The most probable explanation was given by M.-A. Combes: "Nommée probablement en l'honneur de la ville de Vienna en Autriche où observa Johann Palisa de 1881 à sa mort et pour lequel Auguste Charlois, le découvreur, avait une grande admiration." (M.-A. Combes; A. Schnell)

Named by J. Bauschinger.

See also the remarks to planet (356).

\section{(398) Admete}

Discovered 1894 Dec. 28 by A. Charlois at Nice.

Named for a daughter of Eurystheus who appointed the Twelve Labors of Heracles \{see planet (5143)\}. Obtaining the golden girdle of Hippolyta, queen of the Amazons, was one of the labors because Admete coveted it. ( $\mathrm{Z}$ 43)

\section{(399) Persephone}

Discovered 1895 Feb. 23 by M. F. Wolf at Heidelberg.

The Greek word means maiden. Persephone was the daughter of Zeus and Demeter \{see planets (5731) and (1108)\}, the wife of Pluto, and the queen of Hades. Pluto abducted her while she was gathering flowers on the plain of Enna in Sicily. Demeter sought her everywhere and threatened destruction for all mankind by withdrawing fertility from the Earth if she could not find her. Zeus promised to restore Persephone to her mother provided Persephone had eaten nothing in Hades; but she had eaten some pomegranate seeds and was compelled to spend six months each year with Pluto but allowed six months with her mother. The Latin name for Persephone is Proserpina ssee planet (26)\}. (Z 200)

Named by A. Berberich (AN 156, 127 (1901)).

\section{(400) Ducrosa}

Discovered 1895 Mar. 15 by A. Charlois at Nice.

Named by the discoverer (AN 170, 375 (1906)) in honor of J. Ducros, mechanician at the Nice Observatory. (H 44)

\section{(401) Ottilia}

Discovered 1895 Mar. 16 by M. F. Wolf at Heidelberg.

"Für den Planeten wurde der in der Schwarzwaldund Vogesensage eine Rolle spielende Name Ottilia gewählt." The Black Forest runs north and south along the eastern side of the Rhine river in Germany, the Vosges along the western side of the river in France. (AN 138, 31 (1895))

Named by A. Berberich

Berberich was interested in the planet because of the commensurability with Jupiter.

\section{(402) Chloë}

Discovered 1895 Mar. 21 by A. Charlois at Nice.

Named for the pretty, sportive shepherdess in an old Greek pastoral romance of Daphnis and Chloë attributed to Longus. (H 44)

See also the remarks to planet (356).
(403) Cyane

Discovered 1895 May 18 by A. Charlois at Nice.

Named for a nymph of Sicily who tried to prevent Hades from taking Persephone (or Proserpina, see planet (26)) to the underworld. Hades changed her into a fountain. (H 44)

See also the remarks to planet (356).

\section{(404) Arsinoë}

Discovered 1895 June 20 by A. Charlois at Nice.

Named for the mother of Asclepius (or Aesculapius, see planet (1027)) by Apollo \{see planet (1862)\}, according to some mythologists, although Coronis \{see planet (158)\} is usually accepted as the mother of Asclepius. The name is also in use for a nurse of Orestes. Arsinoë put her own son in the bed of Orestes, where he was killed by Aegisthus, and Orestes was saved. (H 44)

See also the remarks to planet (356).

\section{(405) Thia}

Discovered 1895 July 23 by A. Charlois at Nice.

Named for one of the Titans, daughter of Uranus and Gaea \{see planet (1184)\}. Her attribute was light and she was the mother of Helios (the Sun), Selene (the Moon, see planet (580)), and Eos (the dawn, see planet (221)). She married her brother Hyperion. After another source, Thia (or Thea, Theia) was a daughter of Chiron \{see planet (2060)\} the centaur. She was ravished by Aeolus and feared that her father would know that she was pregnant. She was changed by Poseidon into a mare named Euippe and gave birth to a foal named Melanippe. Euippe became a constellation named the Horse. The foal was changed into a girl. (Z 262) See also the remarks to planet (356).

\section{(406) Erna}

Discovered 1895 Aug. 22 by A. Charlois at Nice.

Named probably in honor of the grand-daughter of Palisa, Erna Bidschof. Erna is the daughter of the astronomer Friedrich Bidschof (1864-1915) and his wife Helene, née Palisa. (A. Schnell) Named (AN 169, 363 (1905)) by J. Palisa.

\section{(407) Arachne}

Discovered 1895 Oct. 13 by M. F. Wolf at Heidelberg.

Named for a daughter of Idmon, a dyer. She was so skillful in weaving that she challenged Athena ssee planet (881)\} to a weaving contest. When Athena ripped the cloth, Arachne hanged herself and was changed into a spider. (Z 27)

Named by A. Berberich (AN 156, 127 (1901)).

\section{(408) Fama}

Discovered 1895 Oct. 13 by M. F. Wolf at Heidelberg. Named for a daughter of Titan and the Earth. Fama was a powerful goddess worshipped by the ancients, usually represented winged and blowing a trumpet. Fama, in Greek Pheme, is the goddess of fame. (H 44) Named by A. Berberich (AN 156, 127 (1901)). 


\section{(409) Aspasia}

Discovered 1895 Dec. 9 by A. Charlois at Nice.

Named for the Greek adventuress (470?-410 B.C.) and consort of Pericles. Aspasia of Miletus was a famous courtesan. Her house was a literary and philosophical center. (H 45)

See also the remarks to planet (356).

\section{(410) Chloris}

Discovered 1896 Jan. 7 by A. Charlois at Nice.

Named for the goddess of flowers who married Zephyrus. Chloris was daughter of Amphion and Niobe \{see planet (71)\}. Some legends say she married Neleus, king of Pylos, was the mother of Nestor \{see planet (659)\}, eleven other sons, and one daughter. All her sons except Nestor were killed by Heracles \{see planet (5143)\}. (Z 60)

\section{(411) Xanthe}

Discovered 1896 Jan. 7 by A. Charlois at Nice.

Xanthe is the name of an Oceanid, one of more than 40 daughters of Oceanus and Tethys. (H 45; R. Bremer)

\section{(412) Elisabetha}

Discovered 1896 Jan. 7 by M. F. Wolf at Heidelberg.

Named probably after Elise Wolf (1840-1924), née

Helwerth \{see planet (801)\}, the mother of the discoverer. (I. van Houten-Groeneveld)

\section{(413) Edburga}

Discovered 1896 Jan. 7 by M. F. Wolf at Heidelberg.

Any reference of this name to a person or occurrence is unknown.

\section{(414) Liriope}

Discovered 1896 Jan. 16 by A. Charlois at Nice.

Named for an Oceanid, wife of Cephissus and mother of Narcissus. (Z 152)

\section{(415) Palatia}

Discovered 1896 Feb. 7 by M. F. Wolf at Heidelberg.

Named for the Pfalz, a region in southwestern Germany in which Heidelberg \{see planet (325)\} is situated. (H 45)

Named by A. Berberich (AN 156, 127 (1901)).

\section{(416) Vaticana}

Discovered 1896 May 4 by A. Charlois at Nice.

Named for a hill near the city of Rome. It is now part of the Vatican City State. (H 45)

\section{(417) Suevia}

Discovered 1896 May 6 by M. F. Wolf at Heidelberg.

Named for a Heidelberg student fraternity. (H 45)

Named by A. Berberich (AN 156, 127 (1901)).

\section{(418) Alemannia}

Discovered 1896 Sept. 7 by M. F. Wolf at Heidelberg.

Named for a Heidelberg student fraternity. (H 45)

Named by A. Berberich (AN 156, 127 (1901)).
(419) Aurelia

Discovered 1896 Sept. 7 by M. F. Wolf at Heidelberg.

Any reference of this name to a person or occurrence is unknown.

Named by A. Berberich (AN 156, 127 (1901)).

\section{(420) Bertholda}

Discovered 1896 Sept. 7 by M. F. Wolf at Heidelberg.

Named in memory of Markgraf Berthold von Baden, ancestor of the Grand Dukes of Baden \{see also planet (333)\}. He built the Zähringen castle in the 11th century (see also planet (421)). (H 46)

\section{(421) Zähringia}

Discovered 1896 Sept. 7 by M. F. Wolf at Heidelberg.

Named for a family of Grand Dukes of Baden (see also planet (420)). (H 46)

\section{(422) Berolina}

Discovered 1896 Oct. 8 by G. Witt at Berlin.

This is the Latin name of the city of Berlin, Germany, where this planet was discovered. (H 46)

\section{(423) Diotima}

Discovered 1896 Dec. 7 by A. Charlois at Nice.

Named for a priestess and teacher of the Greek philosopher Socrates (470?-399 B.C.) \{see planet (5450)\}. (H 46)

See also the remarks to planet (356).

\section{(424) Gratia}

Discovered 1896 Dec. 31 by A. Charlois at Nice.

This is the Latin name of grace. The three Graces Aglaia, Euphrosyne, and Thalia \{see planets (47), (31), and (23), respectively $\}$ were called Gratiae or Charites. ( $\mathrm{H} 46)$

See also the remarks to planet (356).

\section{(425) Cornelia}

Discovered 1896 Dec. 28 by A. Charlois at Nice.

Named probably after Cornelia (ca. 180 B.C.), daughter of Scipio Africanus, mother of Tiberius Sempronius Gracchus and Gaius Sempronius Gracchus. Cornelia is also the name of the first wife of the Roman statesman Gaius Julius Caesar (100-44 B.C.). (H 46) See also the remarks to planet (356).

\section{(426) Hippo}

Discovered 1897 Aug. 25 by A. Charlois at Nice.

Named for the ancient city in northern Africa and chief town of Numidia (also Hippo Regius). (H 46)

\section{(427) Galene}

Discovered 1897 Aug. 27 by A. Charlois at Nice.

Named for a Nereid, one of the many daughters of Nereus and Doris (see planet (48)), and grand-daughter of Oceanus. (H 46)

\section{(428) Monachia}

Discovered 1897 Nov. 18 by W. Villiger at Munich. 
This is the Latin name of the discovery city of Munich, the capital of the German country of Bavaria \{see planet (301)\}. (H 46)

\section{(429) Lotis}

Discovered 1897 Nov. 23 by A. Charlois at Nice.

Named for a beautiful nymph and daughter of Poseidon \{see planet (4341)\}. Pursued by Priapus, she fled from his lust and prayed to the gods to help her. She was changed into a tree called the lotus. ( $\mathrm{Z}$ 153)

\section{(430) Hybris}

Discovered 1897 Dec. 18 by A. Charlois at Nice.

Named for the personification of insolent justice in Greek mythology. (H 46)

\section{(431) Nephele}

Discovered 1897 Dec. 18 by A. Charlois at Nice.

Named after the first wife of Athamas, king of Thebes. She was the mother of Phrixus and Helle. See also the notes to planet (173). (H 47)

\section{(432) Pythia}

Discovered 1897 Dec. 18 by A. Charlois at Nice.

Named after the famous priestess of Apollo ssee planet (1862)\} at Delphi (which is another name for Pythia). She was fifty years old before she assumed the office. She delivered the answers of Apollo to those who came to consult the famous oracle. The oracle could be consulted only one month in the year, and rich presents were required for Apollo, hence the opulence, splendor, and magnificence of the celebrated temple at Delphi. (Z 226)

See also the remarks to planet (356).

\section{(433) Eros}

Discovered 1898 Aug. 13 by G. Witt and F. Linke at Berlin. Independently discovered 1898 Aug. 13 by A. Charlois at Nice.

Named after the Greek god of love (in Latin called Cupido or Amor), son of Mercury and Venus. He protected the beautiful Psyche \{see planet (16)\} from the vengeance of his mother and when he later married her she became immortal. See also the citation for planet (763). (H 47)

This is the first minor planet with a male name. Named by G. Witt (AN 148, 175 (1899)).

\section{(434) Hungaria}

Discovered 1898 Sept. 11 by M. F. Wolf at Heidelberg.

This is the Latin name for Hungary. The planet was named in remembrance of an astronomical meeting at Budapest in 1898. (H 47; AN 147, 335 (1898))

\section{(435) Ella}

Discovered 1898 Sept. 11 by M. F. Wolf and A. Schwassmann at Heidelberg.

Any reference of this name to a person or occurrence is unknown.

Named by A. Schwassmann (AN 156, 239 (1901)).
(436) Patricia

Discovered 1898 Sept. 13 by M. F. Wolf and A.

Schwassmann at Heidelberg.

Any reference of this name to a person or occurrence is unknown.

Named by A. Schwassmann (AN 156, 239 (1901)).

\section{(437) Rhodia}

Discovered 1898 July 16 by A. Charlois at Nice.

Named for one of the Oceanid nymphs, daughter of Oceanus and Tethys. (H 48)

\section{(438) Zeuxo}

Discovered 1898 Nov. 8 by A. Charlois at Nice.

Named for one of the Oceanid nymphs, daughter of Oceanus and Tethys. (H 48)

\section{(439) Ohio}

Discovered 1898 Oct. 13 by E. F. Coddington at Mount Hamilton.

Named for the state in the eastern part of central U.S.A. and for the river flowing from the junction of Allegheny and Monongahela rivers into the Mississippi. (H 48)

\section{(440) Theodora}

Discovered 1898 Oct. 13 by E. F. Coddington at Mount Hamilton.

Named in honor of the daughter of Mr. Julius F. Stone who was a benefactor and long time trustee of The Ohio State University. She became the wife of Charles Sutton, professor of landscape architecture at that university. (H 48; AN 152, 175 (1900))

Named by J. F. Stone.

\section{(441) Bathilde}

Discovered 1898 Dec. 8 by A. Charlois at Nice.

Any reference of this name to a person or occurrence is unknown.

\section{(442) Eichsfeldia}

Discovered 1899 Feb. 15 by M. F. Wolf and A. Schwassmann at Heidelberg.

Named for the region of Eichsfeld in central Germany. (AN 154, 443 (1901); LDS)

Named by Rev. Anton K. Thraen \{1843-1902\} \{see planet (4098)\} who improved the elements of this planet. Thraen was born in Holungen und died in Dingelstädt, both villages in the Eichsfeld region.

\section{(443) Photographica}

Discovered 1899 Feb. 17 by M. F. Wolf and A. Schwassmann at Heidelberg.

The name refers to the method found by M. F. Wolf to discover asteroids. (H 48)

Named (AN 156, 239 (1901)) by A. Schwassmann.

\section{(444) Gyptis}

Discovered 1899 Mar. 31 by J. Coggia at Marseilles.

Named for the wife of Protis, chief of the expedition from Phocaea see planet (25)\} which founded Mar- 
seilles, the most ancient city in France, about 600 B.C. She was the daughter of the king of the Segobrigs who assigned the ground where Marseilles (or Massalia, see planet (20)) was built. (H 48)

\section{(445) Edna}

Discovered 1899 Oct. 2 by E. F. Coddington at Mount Hamilton.

Named in honor of the wife of Julius F. Stone who has made outstanding gifts to promote scientific work at The Ohio State University (see also the remarks to planet (440)). (H 48; AN 152, 175 (1900))

Named by J. F. Stone.

\section{(446) Aeternitas}

Discovered 1899 Oct. 27 by M. F. Wolf and A. Schwassmann at Heidelberg.

This name is a personification of eternity among the Romans, that is represented by a snake biting its tail and by the phoenix reborn from its ashes. (H 48)

Named by A. Schwassmann (AN 156, 239 (1901)).

\section{(447) Valentine}

Discovered 1899 Oct. 27 by M. F. Wolf and A. Schwassmann at Heidelberg.

Named probably for Valentine Noëmi von Rothschild (1886-1969), the only daughter of Baron Albert von Rothschild, a benefactor of the Vienna Observatory \{ see also planets (250), and (719), respectively \}. (A. Schnell)

Named by J. Palisa (AN 156, 143 (1901)) at the request of M. F. Wolf.

The name is given as 'Valentina' in 'Wiener Astronomischer Kalender für 1903'. This can also be interpreted as the feminine form of the German Christian name 'Valentin'.

\section{(448) Natalie}

Discovered 1899 Oct. 27 by M. F. Wolf and A. Schwassmann at Heidelberg.

Any reference of this name to a person or occurrence is unknown.

Named by J. Palisa (AN 156, 143 (1901)) at the request of M. F. Wolf.

\section{(449) Hamburga}

Discovered 1899 Oct. 31 by M. F. Wolf and A. Schwassmann at Heidelberg.

Named by A. Schwassmann, Seewarte Hamburg, to honor the city of Hamburg, Germany, during the annual festival of the Mathematical Society of Hamburg in 1901. (AN 156, 239 (1901))

The city of Hamburg is also honored by planet (723).

\section{(450) Brigitta}

Discovered 1899 Oct. 10 by M. F. Wolf and A. Schwassmann at Heidelberg.

Any reference of this name to a person or occurrence is unknown.

Named by A. Berberich (AN 156, 127 (1901)).
(451) Patientia

Discovered 1899 Dec. 4 by A. Charlois at Nice.

This is the Latin name for patience. (H 49)

See also the remarks to planet (356).

\section{(452) Hamiltonia}

Discovered 1899 Dec. 6 by J. E. Keeler at Mount Hamilton.

Named for Mt. Hamilton in California, the site of the Lick Observatory. (H 49)

\section{(453) Tea}

Discovered 1900 Feb. 22 by A. Charlois at Nice.

Any reference of this name to a person or occurrence is unknown.

\section{(454) Mathesis}

Discovered 1900 Mar. 28 by A. Schwassmann at Heidelberg.

This Greek word for science was given to this planet at the anniversary of the founding of the Mathematische Gesellschaft in Hamburg in 1901. (AN 156, 239 (1901))

\section{(455) Bruchsalia}

Discovered 1900 May 22 by M. F. Wolf and A. Schwassmann at Heidelberg.

Named for the city of Bruchsal in southwestern Germany, the native city of Secretary Nokk, who promoted the erection of Heidelberg Observatory. The discoverer stated in AN 156, 157 (1901): "Zur Erinnerung an unseren in den Ruhestand getretenen Staatsminister Dr. Nokk, der unserer Wissenschaft in Baden durch die Errichtung der Observatorien auf dem Königstuhl eine ausgezeichnete Arbeitsstätte geschaffen hat, \{habe ich\} dem Planeten den Namen "Bruchsalia" gegeben, so dass durch die Erinnerung an den Geburtsort eine dauernde Erinnerung an unseren Wohlthäter gegeben sein möge." (H 49)

\section{(456) Abnoba}

Discovered 1900 June 4 by M. F. Wolf and A. Schwassmann at Heidelberg.

This name was used by the Roman troops in southern Germany for the mountainous region of the Black Forest. 'Diana Abnoba' is the Celtic-Roman deity of the Black Forest as was found in old inscriptions. (LDS)

\section{(457) Alleghenia}

Discovered 1900 Sept. 15 by M. F. Wolf and A. Schwassmann at Heidelberg.

Named by the first discoverer in honor of the famous optician John A. Brashear \{see planet (5502)\}: "Dem ersten mit meinem neuen Fernrohr entdeckten kleinen Planeten habe ich in meiner Freude über die ausgezeichneten Linsen, die mir mein Freund Brashear in Allegheny dazu geschliffen hat, den Namen Alleghenia gegeben. (AN 154, 443 (1901))

See also the citation of planet (484). Brashear is also honored by craters on Mars and the Moon. 


\section{(458) Hercynia}

Discovered 1900 Sept. 21 by M. F. Wolf and A.

Schwassmann at Heidelberg.

This is the Latin name for the mountainous forests in Germany from the upper part of the Rhine to the Carpathian Mountains in southeastern Europe, which, according to Caesar, required nine days journey to cross it. The name (Hercynia silva) was later used only for parts of the entire region. (H 50; AN 162, 195 (1903))

Named by J. Riem of Astronomisches RechenInstitut, Berlin, who computed the orbit.

\section{(459) Signe}

Discovered 1900 Oct. 22 by M. F. Wolf at Heidelberg. Named probably after the character of the Volsunga Saga, daughter of Volsung and sister of Sigmund. (H 50)

Named at the meeting of the Astronomische Gesellschaft in Lund, Sweden (AN 166, 207 (1904)).

\section{(460) Scania}

Discovered 1900 Oct. 22 by M. F. Wolf at Heidelberg.

Named at the meeting of the Astronomische Gesellschaft in Lund, Sweden, in 1904. This is the Latin name of the province in southern Sweden in which Lund is situated. (H 50; AN 166, 207 (1904))

\section{(461) Saskia}

Discovered 1900 Oct. 22 by M. F. Wolf at Heidelberg.

Named probably in honor of Saskia van Uylenburgh, wife (in 1634) of the famous Dutch painter Rembrandt van Rijn (1606-1669) \{see planet (4511)\}. (H 50)

\section{(462) Eriphyla}

Discovered 1900 Oct. 22 by M. F. Wolf at Heidelberg. Named for the sister of Adrastus, king of Argos, and wife of Amphiaraus who foretold the disastrous end of the expedition of the Seven against Thebes. Eriphyle caused her husband to accompany the expedition and was killed by her son Alcmaeon on the news of his father's death. (H 50)

\section{(463) Lola}

Discovered 1900 Oct. 31 by M. F. Wolf at Heidelberg.

Named conceivably for a character in the opera Cavalleria Rusticana (1890) by the Italian composer Pietro Mascagni (1863-1945). (H 50)

\section{(464) Megaira}

Discovered 1901 Jan. 9 by M. F. Wolf at Heidelberg.

Named for one of the three Erinyes or Furiae, daughters of Nox and Acheron, avenging spirits who bring retribution on those guilty of a wide variety of sins including homicide, perjury, and lack of hospitality. The three are Alecto (Unresting), Megaera (Jealous), and Tisiphone (Avenger). (H 50)

This is the first numbered minor planet detected in the 20th century.
(465) Alekto

Discovered 1901 Jan. 13 by M. F. Wolf at Heidelberg.

Named for one of the three Furies. Alecto is represented with flaming torches, her head covered with serpents, and breathing vengeance, war and pestilence. See also planet (464). (H 50)

\section{(466) Tisiphone}

Discovered 1901 Jan. 17 by M. F. Wolf and L. Carnera at Heidelberg.

Named for one of the three Furies. Tisiphone was represented with a whip in her hand and with snakes for bracelets. See also planet (464). (H 50)

\section{(467) Laura}

Discovered 1901 Jan. 9 by M. F. Wolf at Heidelberg.

Named probably after a character in the opera $\mathrm{La}$ Gioconda by the Italian composer Amilcare Ponchielli (1834-1886). The opera is based on a play by the French poet Victor Hugo (1802-1885) \{see planet (2106)\}. This planet could also have been named after the character in Sonnets to Laura by the Italian poet Francesco Petrarca (1304-1374). (H 51)

\section{(468) Lina}

Discovered 1901 Jan. 18 by M. F. Wolf at Heidelberg. Named for a housemaid of the discoverer's family. (H 51)

\section{(469) Argentina}

Discovered 1901 Feb. 20 by L. Carnera at Heidelberg.

Named by the discoverer, who was at that time in Oncativo, Argentina, for the country in South America. (AN 173, 63 (1906))

\section{(470) Kilia}

Discovered 1901 Apr. 21 by L. Carnera at Heidelberg.

Named for the city of Kiel in northern Germany. Kilia is the Latin form. (H 51)

Named by Dr. J. Möller (AN 156, 127 (1901)) who was honorary director of the "Seefahrtsschule Elsfleth" in Kiel.

\section{(471) Papagena}

Discovered 1901 June 7 by M. F. Wolf at Heidelberg. Named for the girl friend of Papageno in the opera Die Zauberföte (1791) by Wolfgang Amadeus Mozart \{see planet (1034)\}. (H 51)

\section{(472) Roma}

Discovered 1901 July 11 by L. Carnera at Heidelberg.

Named for the capital city of Italy, the native country of the discoverer. (AN 158, 255 (1902))

Named by A. Abetti.

\section{(473) Nolli}

Discovered 1901 Feb. 13 by M. F. Wolf at Heidelberg.

This is the pet name of a small child in the Wolf family. (H 51) 


\section{(474) Prudentia}

Discovered 1901 Feb. 13 by M. F. Wolf at Heidelberg.

Named for the allegorical divinity personifying prudence, represented by a mirror surrounded by a snake. (H 51)

\section{(475) Ocllo}

Discovered 1901 Aug. 14 by D. Stewart at Arequipa.

Named by the discoverer for the first Inca queen, by tradition daughter of the Sun. (AN 159, 129 (1902))

This is the first minor planet discovered in South America and also the first discovered in the southern hemisphere.

\section{(476) Hedwig}

Discovered 1901 Aug. 17 by L. Carnera at Heidelberg.

Named in honor of the wife of the Danish astronomer Elis Strömgren (1870-1947) who computed the orbit of this planet $\{$ see also planet (1422)\}. (H 51)

Named by E. Strömgren (AN 158, 48 (1902)).

\section{(477) Italia}

Discovered 1901 Aug. 23 by L. Carnera at Heidelberg.

Named by the discoverer in honor of his native country. (P. Sicoli)

See also the remarks to planets (63) and (69), respectively. For the naming source see the citation for planet (478).

\section{(478) Tergeste}

Discovered 1901 Sept. 21 by L. Carnera at Heidelberg.

This is the ancient name of Trieste, the city at the northeast of the Adriatic sea. Luigi Carnera (1875-1962) was born in Trieste. (P. Sicoli)

Named by the discoverer (Mem. Soc. Spettrosc. Ital., Vol. 32, p. 164 (1903).

\section{(479) Caprera}

Discovered 1901 Nov. 12 by L. Carnera at Heidelberg.

Named by the discoverer (AN 173, 63 (1906)) for the island off the northeast coast of Sardinia. Caprera was the place where Garibaldi s see planet (4317)\} retired and died, after his brilliant military exploits that helped bring about the unification of Italy. (P. G. Comba)

\section{(480) Hansa}

Discovered 1901 May 21 by M. F. Wolf and L. Carnera at Heidelberg.

Named in memory of the medieval Hanse, a merchant trading association. The Hanseatic League was constituted of merchants of various free German cities and reached the height of its power in the 14th and 15 th centuries. (H 52)

Named by H. Kreutz (AN 172, 127 (1906)), editor of the Astronomische Nachrichten at Kiel, an old Hanse city.

\section{(481) Emita}

Discovered 1902 Feb. 12 by L. Carnera at Heidelberg.

Any reference of this name to a person or occurrence is unknown.
(482) Petrina

Discovered 1902 Mar. 3 by M. F. Wolf at Heidelberg. Named after the dog Peter of the discoverer. (H 52)

\section{(483) Seppina}

Discovered 1902 Mar. 4 by M. F. Wolf at Heidelberg. Named after the dog Sepp of the discoverer. (H 52)

\section{(484) Pittsburghia}

Discovered 1902 Apr. 29 by M. F. Wolf at Heidelberg.

Named for the city of Pittsburgh, Pennsylvania, home of John A. Brashear, who figured the lenses of the discoverer's 16-inch photographic doublet. (H 52)

Named by J. A. Brashear \{see planet (5502)\}, who stated in Pop. Astron., Vol. 11, No. 10, p. 549 (1903) that the discoverer presents him the honor of naming the planet. "Desiring to share this honor with the good people of this great city, he proposed the name, which has been accepted by Dr. Wolf, and henceforth planet No. 484 will be recorded in astronomical annals with the name of our city as it is engraved upon its great seal, except that the Greek suffix has been attached to the last syllable to make the name more euphonious, as has been the custom in all names permitting this ending. Some time in the far-distant future our great city may lie silent and dead, as Mycenae or Pompeii, but her name, now recorded in the skies, will be remembered as long as the beautiful science of astronomy has its votaries on Old Mother Earth."

The optics of this famous Bruce \{see planet (323)\} telescope were later removed and replaced by two four-lens Zeiss objectives. See also the citation for planet (457)

\section{(485) Genua}

Discovered 1902 May 7 by L. Carnera at Heidelberg.

Named for the city of Genova, Italy. Genua is the ancient name. (H 52; AN 168, 307 (1905))

Name suggested by Prof. F. Porro.

\section{(486) Cremona}

Discovered 1902 May 11 by L. Carnera at Heidelberg.

Named after the city in northern Italy in Lombardy on the Po. (H 52; AN 168, 307 (1905))

Name suggested by Prof. F. Porro.

\section{(487) Venetia}

Discovered 1902 July 9 by L. Carnera at Heidelberg.

Named for the area in northeast Italy and northwest Yugoslavia including the territory between lower Po river and the Alps. The city of Venice lies in this region. (H 52; P. Sicoli)

Name suggested by Prof. E. Millosevich (Mem. Oss. Astron. Coll. Romano, Ser. III, Vol. IV, part 1, p. 27 (1904)).

\section{(488) Kreusa}

Discovered 1902 June 26 by M. F. Wolf and L. Carnera at Heidelberg.

The name Kreusa exists in some variations in Greek mythology: (1) Kreusa (also Glauke, see planet (288)) 
was the daughter of Creon, king of Corinth. (2) Kreusa is one of the Nereides or, respectively, one of the Danaides. (3) She was the daughter of Priam by Hecuba and the wife of Aeneas \{see planets (884), (108), and (1172), respectively\}. (4) Kreusa was the daughter of Erechtheus, king of Athens, and mother of Janus by Apollo \{see planet (1862)\}. Some accounts say she was the mother of Ion by Apollo. She deserted her son Ion but when she later married Xuthus she was reunited with Ion. Apollodorus and Pausanias say Ion was the son of Xuthus by Kreusa. (Z 74)

\section{(489) Comacina}

Discovered 1902 Sept. 2 by L. Carnera at Heidelberg.

Named for a little island in Lake Como in northern Italy. The name is conceivably related to the Comacine masters, the Lombard master builders of the Middle Ages who influenced the architecture of that period. (H 53)

Named by the discoverer (AN 169, 95 (1905)) at the suggestion of L. Volta.

\section{(490) Veritas}

Discovered 1902 Sept. 3 by M. F. Wolf at Heidelberg.

The word means "truth". It was personified by the ancients as a deity and called the daughter of Cronos and the mother of Virtue. Democritus used to say that Veritas hides herself at the bottom of a well, she is so difficult to find. (H 53; Z 286)

\section{(491) Carina}

Discovered 1902 Sept. 3 by M. F. Wolf at Heidelberg.

Any reference of this name to a person or occurrence is unknown.

Named by Premierlieutenant Th. Lassen, Odense, Denmark, who computed an orbit for this planet (AN162, 63 (1903)).

\section{(492) Gismonda}

Discovered 1902 Sept. 3 by M. F. Wolf at Heidelberg.

Named after the daughter of Tancred, prince of Salerno, from the Decamerone of the Italian author Giovanni Boccacio (1313-1375). (R. Bremer)

\section{(493) Griseldis}

Discovered 1902 Sept. 7 by M. F. Wolf at Heidelberg.

Named for the lady proverbial for her virtue and patience. She appears in the Decamerone by the Italian author Giovanni Boccaccio (1313-1375) and in an opera by Paer (1771-1839). (H 53)

\section{(494) Virtus}

Discovered 1902 Sept. 7 by M. F. Wolf at Heidelberg.

Named for the personification of virtue. The ancient Romans made deities of all the major virtues and built temples to virtue and to honor. The statues of the most important virtues - temperance, honesty, modesty, and liberty - were characterized by their dress. Among the Romans, virtues came to include many of the manly virtues - manliness, courage, integrity, strength, and fortitude. (H 53; AN 168, 307 (1905))
Named at the request of the discoverer by C. Flammarion (l'Astronomie, Vol. 19, p. 309 (1905)) who states that by an oversight the astronomers had neglected to place Virtue in the skies and that if it disappeared from the Earth, it would be nice to find it in the heavens. He expressed his regret that the name Virtus was chosen long time after names such as (28) Bellona, (146) Lucina, (216) Kleopatra, and (289) Nenetta.

\section{(495) Eulalia}

Discovered 1902 Oct. 25 by M. F. Wolf at Heidelberg. Named in honor of the grandmother of Mrs. Wolf. (H 53)

\section{(496) Gryphia}

Discovered 1902 Oct. 25 by M. F. Wolf at Heidelberg.

Named in honor of the German baroque poet Andreas Gryphius (1616-1664). (H 53; AN 167, 223 (1905))

Named with permission of the discoverer by W. Ebert, Paris, who computed an early orbit for this planet.

\section{(497) Iva}

Discovered 1902 Nov. 4 by R. S. Dugan at Heidelberg.

Named after Iva Shores, a little daughter in the household where the discoverer lived while in Amherst College. (H 53)

The naming information was provided by Mrs. Edith Eveleth, sister of the discoverer.

\section{(498) Tokio}

Discovered 1902 Dec. 2 by A. Charlois at Nice.

Named for the capital of Japan. An earlier planet discovered 1900 March 6 by S. Hirayama in Tokio for which circular elements had been computed was shown to be identical with the newly discovered planet. (H 54)

The first photograph was taken by Hirayama, assisted by K. Toda. The circular elements were computed by K. Saotome. The planet, temporarily designated 1990 FF, was identified by P. V. Neugebauer with the Nice object. Tokio is the German transliteration form of Tokyo. Tokyo means eastern metropolis. (K. Tomita).

\section{(499) Venusia}

Discovered 1902 Dec. 24 by M. F. Wolf at Heidelberg.

Named for the insula Venusia, or Hveen, island in the Sound between Denmark and Sweden, provided by King Frederick II of Denmark in 1576 to Tycho Brahe \{see planet (1677)\} for his observatories Uraniborg and Stjerneborg. (H 54; AN 166, 319 (1904))

Named on the occasion of a visit of the participants of the 1904 meeting of the Astronomische Gesellschaft in Lund, Sweden, by Miss Bruhns, daughter of C. Bruhns, director of the Leipzig Observatory.

The island is also commemorated by planets (379) and (1678).

\section{(500) Selinur}

Discovered 1903 Jan. 16 by M. F. Wolf at Heidelberg.

Named after a character in the novel Auch Einer (1879) by the German writer Friedrich Theodor Vischer 
(1807-1887). Selinur represents a Celtic Moon goddess whose symbol is the half moon. She is opposed by the evil spirit "Grippo" who is responsible for having inflicted the "Grippe" (influenza) on the villager's male population. In order to ban evil Grippo and his helpers the villagers stage all kinds of coughing contests, coughing worships, coughing procedures, etc. ( $\mathrm{H} \mathrm{54;}$ R. Bremer)

\section{(501) Urhixidur}

Discovered 1903 Jan. 18 by M. F. Wolf at Heidelberg. Named after a character in the novel Auch Einer (1879) by the German writer Friedrich Theodor Vischer (1807-1887). Urhixidur is housekeeper, nurse and female companion of the priest Angus. He, a progressive, opposes her conservative views. She eventually dominates him since he cannot live without her. (H 54; R. Bremer)

\section{(502) Sigune}

Discovered 1903 Jan. 19 by M. F. Wolf at Heidelberg.

Named after a character in the novel Auch Einer (1879) by the German writer Friedrich Theodor Vischer (1807-1887). (I. van Houten-Groeneveld)

\section{(503) Evelyn}

Discovered 1903 Jan. 19 by R. S. Dugan at Heidelberg.

Named by the discoverer in honor of his mother,

Evelyn Smith Dugan. (H 54)

See the remark for planet (497).

\section{(504) Cora}

Discovered 1902 June 30 by S. I. Bailey at Arequipa.

Named for a figure from old Peruvian mythology. (AN 169, 95 (1905))

\section{(505) Cava}

Discovered 1902 Aug. 21 by R. H. Frost at Arequipa.

Named for a figure from old Peruvian mythology. (AN 169, 95 (1905))

\section{(506) Marion}

Discovered 1903 Feb. 17 by R. S. Dugan at Heidelberg. Named by the discoverer in honor of his cousin Marion Orcutt. (H 54)

See the remark for planet (497).

\section{(507) Laodica}

Discovered 1903 Feb. 19 by R. S. Dugan at Heidelberg.

Named for a daughter of Priam and Hecuba \{see planets (884) and (108)\}. She fell in love with Acamas \{see planet (2594)\}, son of Theseus and Phaedra ssee planet (174)\}, when he and Diomedes \{see planet (1437)\} came from the Greeks to demand the restoration of Hellen. (H 54)

The planet is not named by the discoverer. It had previously been observed by A. Charlois in Nice, but lost. The name appeared when an ephemeris was published.

\section{(508) Princetonia}

Discovered 1903 Apr. 20 by R. S. Dugan at Heidelberg. Named by the discoverer in honor of the Princeton University in Princeton, New Jersey. (H 55)

See also the remarks for planets (497), and (534). Princeton University is also honored by planets (534) and (6151).

\section{(509) Iolanda}

Discovered 1903 Apr. 28 by M. F. Wolf at Heidelberg.

Any reference of this name to a person or occurrence is unknown.

\section{(510) Mabella}

Discovered 1903 May 20 by R. S. Dugan at Heidelberg. Named by the discoverer in honor of Mabel Loomis Todd, daughter of the mathematician and astronomer Elias Loomis. She was the wife of David P. Todd \{ see planet (511)\}, the discoverer's professor of astronomy at Amherst College. (H 55)

See the remark for planet (497).

\section{(511) Davida}

Discovered 1903 May 30 by R. S. Dugan at Heidelberg.

Named by the discoverer in honor of David P. Todd (1855-1939), professor of astronomy and director of the Amherst College Observatory (1881-1920). (H 55)

See the remark for planet (497).

\section{(512) Taurinensis}

Discovered 1903 June 23 by M. F. Wolf at Heidelberg. This is the ancient name of the city of Turin, Italy. (H 55)

The planet was named (AN 167, 239 (1905)) with permission of the discoverer by the Turin astronomers.

\section{(513) Centesima}

Discovered 1903 Aug. 24 by M. F. Wolf at Heidelberg.

The naming commemorates the 100th planet discovery by Max Wolf. (H 55)

\section{(514) Armida}

Discovered 1903 Aug. 24 by M. F. Wolf at Heidelberg. Named for the beautiful legendary sorceress in Torquato Tasso's (1544-1595) Jerusalem Delivered. She is the leading character in the opera Armida (composed 1777) by Christoph Willibald Gluck (1714-1787). (H 55) See also the remarks to planet (579).

\section{(515) Athalia}

Discovered 1903 Sept. 20 by M. F. Wolf at Heidelberg.

Named for the impious and murderous queen of Judah, daughter of Ahab and Jezebel (II Kings 8, $26 ; 11,1-20)$. Athalia was the only woman who ever occupied the throne of either of the Hebrew kingdoms. (H 55)

\section{(516) Amherstia}

Discovered 1903 Sept. 20 by R. S. Dugan at Heidelberg.

Named in honor of the discoverer's Alma Mater, the Amherst College in Amherst, Massachusetts. (H 55) See the remark for planet (497). 


\section{(517) Edith}

Discovered 1903 Sept. 22 by R. S. Dugan at Heidelberg.

Named by the discoverer in honor of his sister Mrs.

Edith Dugan Eveleth. (H 55)

See the remark for planet (497).

\section{(518) Halawe}

Discovered 1903 Oct. 20 by R. S. Dugan at Heidelberg.

Named after an Arabic sweetmeat that was a favorite of the discoverer. The origin of this taste may have been during Dugan's sojourn as instructor in the American University, Beirut, Lebanon (1899-1902). (H 55)

See the remark for planet (497).

\section{(519) Sylvania}

Discovered 1903 Oct. 20 by R. S. Dugan at Heidelberg.

This planet is named for the large forests that the discoverer enjoyed tramping through even as a small boy. Mrs. Edith Eveleth, sister of the discoverer, stated: "In Heidelberg he climbed up and down from the city to the Königstuhl through deep woods; for holidays he tramped through the Black Forest, the Odenwald and all the forest within reach." (H 56) See the remark for planet (497).

\section{(520) Franziska}

Discovered 1903 Oct. 27 by M. F. Wolf and P. Götz at Heidelberg.

Any reference of this name to a person or occurrence is unknown.

Named by Götz (AN 169, 363 (1905)).

\section{(521) Brixia}

Discovered 1904 Jan. 10 by R. S. Dugan at Heidelberg.

This is the Latin name of Brescia, Italy, the native town of Prof. E. Bianchi, who computed the orbit. It was at his request his birthplace was honored. (H 56) See the remark for planet (497).

\section{(522) Helga}

Discovered 1904 Jan. 10 by M. F. Wolf at Heidelberg.

Any reference of this name to a person or occurrence is unknown.

Named (AN 169, 363 (1905)) by Lieutenant Th. Lassen who computed the orbit.

\section{(523) Ada}

Discovered 1904 Jan. 27 by R. S. Dugan at Heidelberg.

Named by the discoverer in honor of Ada Helme, a school friend and neighbor of the discoverer in Montague, Massachusetts \{see planet (535)\}. (H 56) See the remark for planet (497).

\section{(524) Fidelio}

Discovered 1904 Mar. 14 by M. F. Wolf at Heidelberg.

This is the name of Leonora when disguised as a man in the opera Fidelio (composed 1805) by the German composer Ludwig van Beethoven \{see planet (1815)\}. (H 56)

\section{(525) Adelaide}

Discovered 1908 Oct. 21 by J. H. Metcalf at Taunton.

Named by Max Wolf probably for the German-born Queen Adelaide, consort of the British king William IV (1765-1837). The capital of Southern Australia (founded 1836) was named for her. (LDS; B. G. Marsden)

The number and name were originally given to a minor planet discovered 1904 by Max Wolf at Heidelberg. A. Patry (MPC 1831) established the identity of (525) with (1171) Rusthawelia on the basis of well known elements of (1171). There are only a few references to (525) in the literature. The Minor Planet Center retained the number and name of (1171) and vacated the number (525). In MPC 1935 the vacated number and name were assigned to the 1908 Metcalf planet.

\section{(526) Jena}

Discovered 1904 Mar. 14 by M. F. Wolf at Heidelberg.

Named for the city of Jena in eastern Germany at the occasion of the September 1906 meeting of the Astronomische Gesellschaft in Jena. (AN 172, 287 (1906))

Name proposed by J. Palisa.

\section{(527) Euryanthe}

Discovered 1904 Mar. 20 by M. F. Wolf at Heidelberg.

Named after the character Euryanthe of Savoy in the opera Euryanthe by the German composer Carl Maria von Weber (1786-1826) \{see planet (4152)\}. (H 56)

\section{(528) Rezia}

Discovered 1904 Mar. 20 by M. F. Wolf at Heidelberg. Named for a character in the opera Oberon by the German composer Carl Maria von Weber (1786-1826) \{see planet (4152)\}. (H 56)

\section{(529) Preziosa}

Discovered 1904 Mar. 20 by M. F. Wolf at Heidelberg. This is the title of a play (1810) by Pius Alexander Wolff, set to music (1820) by Carl Maria von Weber ssee planet (4152)\}. It is also a character in the young gipsy novel La Gitanilla by the Spanish novelist, dramatist and poet Miguel de Cervantes Saavedra (1547-1616). (R. R. de Freitas Mourão; LDS; R. Bremer)

\section{(530) Turandot}

Discovered 1904 Apr. 11 by M. F. Wolf at Heidelberg.

Named for the daughter of the Emperor of China in the opera Turandot by the Italian composer Giacomo Puccini (1858-1924) \{see planet (4579)\}. (H 57)

\section{(531) Zerlina}

Discovered 1904 Apr. 12 by M. F. Wolf at Heidelberg.

Named for a character in the opera Don Giovanni (1787) by Wolfgang Amadeus Mozart \{see planet (1034)\}. (H 57)

\section{(532) Herculina}

Discovered 1904 Apr. 20 by M. F. Wolf at Heidelberg.

Any reference of this name to a person or occurrence is unknown. 
Named by E. Millosevich, Osservatorio al Collegio Romano (AN 167, 45 (1905)).

\section{(533) Sara}

Discovered 1904 Apr. 19 by R. S. Dugan at Heidelberg. Named in honor of a friend of the discoverer. (H 57)

\section{(534) Nassovia}

Discovered 1904 Apr. 19 by R. S. Dugan at Heidelberg.

Named in honor of Princeton University. Lyman Spitzer \{see planet (2160)\}, Director of Princeton University Observatory stated: "Nassovia is presumably a Latinized version of Nassau. When the first building in the town of Princeton was built for what was then the College of New Jersey, this building was named Nassau Hall "in memory of the glorious King William III, who was a branch of the illustrious House of Nassau". The quotation marks enclose a recommendation of the Governor of New Jersey who was a member of the Board of Trustees. Nassau Hall has been the center of the university ever since it was built, and the name Nassau has become associated with Princeton University." (H 57)

Princeton University is also honored by minor planets (508) and (6151), respectively.

\section{(535) Montague}

Discovered 1904 May 7 by R. S. Dugan at Heidelberg.

Named by the discoverer in honor of his native town in Massachusetts. (H 57)

See the remark for planet (497).

\section{(536) Merapi}

Discovered 1904 May 11 by G. H. Peters at Washington.

Named after a mountain in west central Sumatra, site of the U.S. Naval Observatory and other expeditions to the total solar eclipse of May 17, 1901. It gives off smoke more or less continuously and the name means "with fire". It should not to be confused with the nearby active volcano of the same name in central Java. The discoverer was a member of the eclipse expedition. (H 57)

\section{(537) Pauly}

Discovered 1904 July 7 by A. Charlois at Nice.

Named in memory of Max Pauly (1849-1917) of the Jena Carl Zeiss optical works. The genial Pauly was a good friend of Max Wolf. Pauly ground the 10-inch lens of the Bruce telescope, "das Juwel des Königstuhls". Under his supervision, many large telescopes were produced for European as well as American Observatories. (H 57)

Named by Max Wolf.

Obituary published in Astron. Nachr., Band 207, Nr. 4963, p. 219-224 (1918).

\section{(538) Friederike}

Discovered 1904 July 18 by P. Götz at Heidelberg.

Named in honor of a friend of the discoverer in Heidelberg. (H 57)

\section{(539) Pamina}

Discovered 1904 Aug. 2 by M. F. Wolf at Heidelberg.

Named for the daughter of the Queen of the Night in the opera Die Zauberflöte by Wolfgang Amadeus Mozart \{see planet (1034)\}. (H 57)

\section{(540) Rosamunde}

Discovered 1904 Aug. 3 by M. F. Wolf at Heidelberg.

Named for the character in the opera of the same name by the Austrian composer Franz Peter Schubert (1797-1828) (H 58)

\section{(541) Deborah}

Discovered 1904 Aug. 4 by M. F. Wolf at Heidelberg.

Named for the Biblic prophetess in Israel who helped to free the Israelites from the Canaanites, and celebrated the victory by famous verses (Judges 4, 4). (H 58)

\section{(542) Susanna}

Discovered 1904 Aug. 15 by P. Götz and A. Kopff at Heidelberg.

Named by the first discoverer in honor of a friend in Heidelberg. (H 58)

\section{(543) Charlotte}

Discovered 1904 Sept. 11 by P. Götz at Heidelberg.

Named in honor of a friend of the discoverer in Heidelberg. (H 58)

\section{(544) Jetta}

Discovered 1904 Sept. 11 by P. Götz at Heidelberg.

Named by the discoverer after a legendary figure of Heidelberg. The name of the site on which the Heidelberg castle was built in the 15th century is called Jettenbühl. (H 58; R. Bremer)

\section{(545) Messalina}

Discovered 1904 Oct. 3 by P. Götz at Heidelberg.

Named after Valeria Messalina (c. 25-48), the third wife of the Roman emperor Claudius (10 B.C.-54). Messalina was the great-granddaughter of Marcus Antonius. (H 58)

\section{(546) Herodias}

Discovered 1904 Oct. 10 by P. Götz at Heidelberg.

Named for the consort of Herod Antipas. She and her daughter Salome see planet (562)\} caused the death of John the Baptist. (H 58)

\section{(547) Praxedis}

Discovered 1904 Oct. 14 by P. Götz at Heidelberg.

Named after a character in the narration Ekkehard by the German author Victor von Scheffel (1826-1886). (H 58)

\section{(548) Kressida}

Discovered 1904 Oct. 14 by P. Götz at Heidelberg.

Named for a beautiful girl, proverbial for her infidelity in Shakespeare's \{see planet (2985)\} Troilus and Cressida (1601). The figure belongs to a medieval, not ancient, myth. The name is derived from Chryseis \{see also planet (202)\}. (H 58) 
The name Cressida has also been given to the satellite Uranus IX.

\section{(549) Jessonda}

Discovered 1904 Nov. 15 by M. F. Wolf at Heidelberg.

Named presumably after the character in the opera of the same name by the German composer, conductor and violinist Ludwig Spohr (1784-1859), one of the leading composers in the early romantic period. (H 58)

\section{(550) Senta}

Discovered 1904 Nov. 16 by M. F. Wolf at Heidelberg.

Named probably for the daughter of Daland, Norse sea captain in the opera Der fliegende Holländer (composed 1841) by Richard Wagner ssee planet (3992)\}, which is based on Heinrich Heine's (1797-1856) version of the legend. (H 58)

\section{(551) Ortrud}

Discovered 1904 Nov. 16 by M. F. Wolf at Heidelberg.

Named for the wife of Frederick of Telramund \{see planet (9506)\} in the opera Lohengrin (1878) by Richard Wagner \{see, respectively, planets (9505) and (3992)\}. (H 58)

\section{(552) Sigelinde}

Discovered 1904 Dec. 14 by M. F. Wolf at Heidelberg.

Named after a character in the opera Die Walküre \{see planet (877)\} by Richard Wagner ssee planet (3992)\}. (H 59)

\section{(553) Kundry}

Discovered 1904 Dec. 27 by M. F. Wolf at Heidelberg.

Named for a girl, part sorceress, part mortal woman, in the opera Parsifal \{see planet (2095)\} by Richard Wagner ssee planet (3992)\}. The opera is based on the epic by Wolfram von Eschenbach (who is a leading character in Wagner's opera Tannhäuser). (H 59)

\section{(554) Peraga}

Discovered 1905 Jan. 8 by P. Götz at Heidelberg.

Named for a village between Padua and Venice. (H 59)

Named (AN 168, 141 (1905)) with permission of the discoverer by G. Abetti, Padua, who computed the orbit, because his relatives had a country place there.

\section{(555) Norma}

Discovered 1905 Jan. 14 by M. F. Wolf at Heidelberg.

Named for the high priestess of the druids in the opera Norma by the Italian composer Vincenzo Bellini (1801-1835). (H 59)

\section{(556) Phyllis}

Discovered 1905 Jan. 8 by P. Götz at Heidelberg.

Named for the daughter of Lycurgus, king of Thrace. She fell in love with Demophon, son of Theseus, who stopped in Thrace on his return from the Trojan War. He married her and became king. Shortly thereafter, Demophon went to Athens, and when he failed to return after one month, Phyllis threw herself into the sea. (Z 210)

\section{(557) Violetta}

Discovered 1905 Jan. 26 by M. F. Wolf at Heidelberg.

Named for the frivolous woman and leading character in the opera La Traviata by Giuseppe Verdi \{see planet (3975) \}, which is based on La Dame aux Camelias by Alexandre Dumas the younger (1824-1895). (H 59)

\section{(558) Carmen}

Discovered 1905 Feb. 9 by M. F. Wolf at Heidelberg.

Named for the leading character in the opera Carmen by the French composer Alexandre César Léopold (named Georges) Bizet (1838-1875), which is based on the novel by the French writer Prosper Mérimée (1803-1870). (H 59)

\section{(559) Nanon}

Discovered 1905 Mar. 8 by M. F. Wolf at Heidelberg.

Named after the operetta Nanon, die Wirtin vom Goldenen Lamm (1877) by the German-Austrian composer Richard Genée (1823-1895) which is based on a French comedy, set in Paris of Louis XIV. (R. Bremer; LDS)

\section{(560) Delila}

Discovered 1905 Mar. 13 by M. F. Wolf at Heidelberg.

Named for the mistress and betrayer of Samson in the book of Judges, set to music by the French composer Camille Saint-Saëns (1835-1877) \{see planet (5210)\} in his opera Samson et Delila (1877). (H 59)

\section{(561) Ingwelde}

Discovered 1905 Mar. 26 by M. F. Wolf at Heidelberg.

Named probably after the opera by the German composer Max von Schillings (1868-1933) who became well-known by his opera Mona Lisa (1915). (R. Bremer; LDS)

\section{(562) Salome}

Discovered 1905 Apr. 3 by M. F. Wolf at Heidelberg.

Named for the daughter of Herod Antipas who was given the head of John the Baptist as a reward for her dancing. She is the leading figure in the opera Salome (1905) by the German composer Richard Strauss (1864-1949) \{see planet (5039)\}, which is based on the romance by the Irish-born writer Oscar Wilde (1854-1900). (H 59)

\section{(563) Suleika}

Discovered 1905 Apr. 6 by P. Götz at Heidelberg.

Named for a character in Also sprach Zarathustra (1885) by the German philospher Friedrich Wilhelm Nietzsche (1844-1900). Suleika and Dudu ssee planet (564)\} are mentioned in Part IV in the chapter Unter Töchtern der Wüste. These are the only feminine names in Zarathustra. (I. van Houten-Groeneveld)

\section{(564) Dudu}

Discovered 1905 May 9 by P. Götz at Heidelberg.

Named for a character in Also sprach Zarathustra (1885) by the German philosopher Friedrich Wilhelm Nietzsche (1844-1900). (I. van Houten-Groeneveld) See also the remarks to planet (563). 
(565) Marbachia

Discovered 1905 May 9 by M. F. Wolf at Heidelberg.

Named for the town Marbach in southwest Germany, the native city of the German poet Friedrich Schiller \{see planet (3079)\}. (H 60)

\section{(566) Stereoskopia}

Discovered 1905 May 28 by P. Götz at Heidelberg.

This name is an allusion to C. Pulfrich's stereocomparator (see also his paper in AN 159, 83 (1902)), by the aid of which he discovered a planet which had previously been overlooked on older photographic plates. It was the first planet discovered by the method and was later identified with Stereoskopia. (H 60)

Named (AN 169, 363 (1905)) by C. Pulfrich.

\section{(567) Eleutheria}

Discovered 1905 May 28 by P. Götz at Heidelberg.

Named after the Greek goddess of liberty. (H 60)

\section{(568) Cheruskia}

Discovered 1905 July 26 by P. Götz at Heidelberg. Named for a Heidelberg student fraternity. (H 60)

\section{(569) Misa}

Discovered 1905 July 27 by J. Palisa at Vienna.

Named after Misa, or Mise, a mytic divinity that appears in the Orphic mysteries. Misa is known as the mother of Bacchus \{see planet (2063)\}. (H 60; A. Schnell)

\section{(570) Kythera}

Discovered 1905 July 30 by M. F. Wolf at Heidelberg.

Named for the famous island in the Ionian Sea which contends with Cyprus for the honor of being the island to which Aphrodite \{see planet (1388)\} floated when she rose from the foam. Kythera is also a name for Aphrodite. (Z 78)

\section{(571) Dulcinea}

Discovered 1905 Sept. 4 by P. Götz at Heidelberg.

Named for the beautiful girl, object of the attention of Don Quixote in the famous novel El Ingenioso Hidalgo Don Quijote de La Mancha by the Spanish writer Miguel de Cervantes Saavedra (1547-1616). (H 60)

\section{(572) Rebekka}

Discovered 1905 Sept. 19 by P. Götz at Heidelberg.

Named by the discoverer for a "Heidelberger Bürgerstochter" as he stated to I. van Houten-Groeneveld. (I. van Houten-Groeneveld)

The naming might be influenced by the two letters of the provisional designation $1905 \mathrm{RB}$. See also the remarks to planet (579).

\section{(573) Recha}

Discovered 1905 Sept. 19 by M. F. Wolf at Heidelberg.

Named after the feminine character Recha in the drama Nathan der Weise by the German dramatist and critic Gotthold Ephraim Lessing (1729-1781), a strong advocate of religious tolerance. (H 60; R. Bremer)
The naming might be influenced by the two letters of the provisional designation $1905 \mathrm{RC}$. See also the remarks to planet (579).

\section{(574) Reginhild}

Discovered 1905 Sept. 19 by M. F. Wolf at Heidelberg.

Any reference of this name to a person or occurrence is unknown.

The naming might be influenced by the two letters of the provisional designation $1905 \mathrm{RD}$. See also the remarks to planet (579).

\section{(575) Renate}

Discovered 1905 Sept. 19 by M. F. Wolf at Heidelberg.

Any reference of this name to a person or occurrence is unknown.

The naming might be influenced by the two letters of the provisional designation $1905 \mathrm{RE}$. See also the remarks to planet (579).

\section{(576) Emanuela}

Discovered 1905 Sept. 22 by P. Götz at Heidelberg.

Named for a friend of the discoverer. (H 61; AN 180, 183 (1909))

\section{(577) Rhea}

Discovered 1905 Oct. 20 by M. F. Wolf at Heidelberg.

Named for the daughter of Uranus and Gaea \{see planet (1184)\}, sister and wife of Cronus, and mother of Zeus, Poseidon \{see planets (5731), (4341)\}, Hades, Demeter \{see planet (1108)\}, Hera \{see planet (103)\}, and Hestia \{see planet (46)\}. Rhea was called "the mother of the gods" or the "great mother goddess". Her Roman name was Tellus (or Terra) and her Phrygian name was Cybele \{see planet (65)\}. (Z 228)

The naming might be influenced by the two letters of the provisional designation $1905 \mathrm{RH}$. See also the remarks to planet (579). Rhea is also the name of the fifth satellite of Saturn, discovered 1672 by J. D. Cassini.

\section{(578) Happelia}

Discovered 1905 Nov. 1 by M. F. Wolf at Heidelberg.

Named in honor of Carl Happel (1820-1914), painter and great benefactor to the Heidelberg Observatory. From his financial support the Happel-Labor on the Königstuhl was erected. (H 61; LDS)

\section{(579) Sidonia}

Discovered 1905 Nov. 3 by A. Kopff at Heidelberg.

Named for a character in the opera Armida (composed 1777) by the German composer Christoph Willibald Gluck (1714-1787) which is based on Torquato Tasso's (1544-1595) poem Jerusalem Delivered. See also the citation for planet (514). (H 61)

In 1913, the Astronomisches Rechen-Institut insisted to name a number of planets in order to avoid possible errors. F. Cohn (AN 196, 137 (1913)) stated: "Seit längerer Zeit hat eine regelmässige Benennung der Kleinen Planeten nicht mehr stattgefunden. Die 
Unbequemlichkeit und Möglichkeit der Verwechselungen ... gab den Anlass zu einer an die Entdecker gerichteten Aufforderung, wenigstens die Planeten bis zur Nr. 700 benennen zu wollen. Eine ihnen zugesandte Vorschlagsliste enthielt in üblicher Art weibliche Vornamen, insbesondere aus Mythologie und Geschichte. Nach verschiedenen Abänderungsvorschlägen seitens der Herren Götz, Helffrich, Kopff und Lohnert sind die Namen vereinbart worden ...". A list of 108 names between (570) and (727) follows. An inspection reveals that, obviously, a lot of names were chosen according to the two letters of the provisional designation assigned to the planets. There is a strong correlation in this way for about 30 planets which demonstrates a statistical significance. The provisional designation for (579) Sidonia was 1905 SD.

\section{(580) Selene}

Discovered 1905 Dec. 17 by M. F. Wolf at Heidelberg.

This name personified the Moon among the Greeks. See also the remarks to planet (105). (H 61)

The naming might be influenced by the two letters of the provisional designation $1905 \mathrm{SE}$. See also the remarks to planet (579).

\section{(581) Tauntonia}

Discovered 1905 Dec. 24 by J. H. Metcalf at Taunton.

Named after the city in southeast Massachusetts and place of the discovery. ( $\mathrm{H} 61$ )

Named (AN 172, 391 (1906)) by the orbit computer Herbert R. Morgan. Morgan was sometime director of the observatory in Glasgow, Missouri and for many years director of the nine-inch transit circle division at the U.S. Naval Observatory.

\section{(582) Olympia}

Discovered 1906 Jan. 23 by A. Kopff at Heidelberg.

Named for the town in the northwestern part of the Peloponnese where Zeus \{see planet (5731)\} had a famous temple with a celebrated statue by Phidias \{see planet (4753)\}. The statue was reckoned one of the Seven Wonders of the Ancient World. At Olympia the Olympic games originated in 776 B.C. (Z 182)

\section{(583) Klotilde}

Discovered 1905 Dec. 31 by J. Palisa at Vienna.

Named in honor of the daughter of the Austrian astronomer Hofrat Edmund Weiss (1837-1917) who founded with Karl von Littrow the Vienna Imperial Observatory in 1875. Later, he was director of the observatory where this planet was discovered. (H 61)

Named (AN 173, 31 (1907)) by Adelinde Weiss, wife of E. Weiss.

\section{(584) Semiramis}

Discovered 1906 Jan. 15 by A. Kopff at Heidelberg.

Named for the mythical Assyrian queen, wife of Ninus, founder of Niniveh, whom she succeeded as ruler. She was famed for her beauty, wisdom, and voluptuousness. She is said to have built Babylon with its hanging gardens and many other cities. Semiramis conquered Egypt and much of Asia and Ethiopia and unsuccessfully attacked India. She was queen of Babylon during the days of Pyramus and Thisbe \{see planet (88)\}. (Z 237)

\section{(585) Bilkis}

Discovered 1906 Feb. 16 by A. Kopff at Heidelberg.

Bilkis, or Balkis, is the name in the Koran of the queen of Sheba \{see planet (1196)\} who visited Solomon. Ancient Abyssinian tradition says that all the rulers of that country are descendants of Menelik, son of Solomon and the queen of Sheba and legendary first king of Abyssinia. (H 62)

\section{(586) Thekla}

Discovered 1906 Feb. 21 by M. F. Wolf at Heidelberg.

Named probably after St. Thekla, who, according to Apocryphical sources, accompanied Paul on some of his missionary journeys. The name was selected from the list mentioned in the remarks to planet (579). (H 62)

\section{(587) Hypsipyle}

Discovered 1906 Feb. 22 by M. F. Wolf at Heidelberg.

Named after the queen of Lemnos. The women of Lemnos put to death all other males, but Hypsipyle saved the life of her father Thoas \{see planet (4834)\}, king of Lemnos. When the Argonauts landed at Lemnos, all the women of Lemnos became pregnant. By Jason \{see planet (6063)\}, Hypsipyle became the mother of twins. Jason forgot his vows of fidelity to Hypsipyle, abandoned her, and the women of Lemnos banished the queen of Nemea. (Z 132)

\section{(588) Achilles}

Discovered 1906 Feb. 22 by M. F. Wolf at Heidelberg.

Named for the bravest of the Greeks in the Trojan War. As an infant he was plunged in the River Styx by his mother Thetis \{see planet (17)\}, thus rendering his body invulnerable excepting the heel by which he was held. He slew Hector \{see planet (624)\}, the greatest Trojan warrior. He was eventually killed by an arrow in the heel by Paris \{see planet (3317)\}. Achilles is the central figure in Homer's Iliad \{see planets (5700), (6604)\}. (H 62)

Name suggested (AN 175, 191 (1907)) by J. Palisa.

This planet oscillates around the leading equilateral libration point formed with the Sun and Jupiter. It is the first known example of the stable solution of the three-body problem worked out by Lagrange \{see planet (1006)\} in 1772. Palisa also named planets (617) and (624) which have similar orbital characteristics to (588) after heroes from the Trojan War. Henceforth such planets have been known as Trojan asteroids. It might seem natural to place the Greeks in one equilateral point and the Trojans in the other. Crommelin s see planet (1899)\} remarked in Observatory, Vol. 30, 
p. 328 (1907) that "it seems strange that Achilles and Patroclus should be placed on opposite sides of Jupiter".

\section{(589) Croatia}

Discovered 1906 Mar. 3 by A. Kopff at Heidelberg.

Named for the region in southeast Europe which was a part of Yugoslavia and, since 1991, is an independent state. (H 62)

\section{(590) Tomyris}

Discovered 1906 Mar. 4 by M. F. Wolf at Heidelberg.

Named after the queen of the Massagets in Scythia who sold and killed the Persian king Cyrus the Great \{see planet (7209)\} 529 B.C. (H 62)

The naming might be influenced by the two letters of the provisional designation 1906 TO. See also the remarks to planet (579)

\section{(591) Irmgard}

Discovered 1906 Mar. 14 by A. Kopff at Heidelberg.

Any reference of this name to a person or occurrence is unknown.

\section{(592) Bathseba}

Discovered 1906 Mar. 18 by M. F. Wolf at Heidelberg.

Named for the Biblic character, wife of Urias and later king David, who was the mother of Solomon. (H 62)

\section{(593) Titania}

Discovered 1906 Mar. 20 by A. Kopff at Heidelberg.

Named after the wife of Oberon, queen of fairies and gnomes in Shakespeare's \{see planet (2985)\} A Midsummer Night's Dream. (H 63)

The naming might be influenced by the two letters of the provisional designation 1906 TT. See also the remarks to planet (579). Titania is also the name of the third satellite of Uranus, discovered 1787 by W. Herschel.

\section{(594) Mireille}

Discovered 1906 Mar. 27 by M. F. Wolf at Heidelberg.

Named after the poem of the Provencal poet Frédéric Mistral (1830-1914). (H 63)

Name proposed by C. Flammarion (l'Astronomie, p. 118 (1913)).

\section{(595) Polyxena}

Discovered 1906 Mar. 27 by A. Kopff at Heidelberg.

Named for the daughter of Priam and Hecuba \{see planets (884) and (108)\}. Beautiful and accomplished, she was courted by Achilles, but the marriage was opposed by Hector \{see planets (588) and (624)\}. She accompanied her father when he went to Achilles to claim the body of Hector. When Achilles was killed by Paris \{see planet (3317)\}, Polyxena sacrificed herself at his tomb. Some accounts say the sacrifice was not voluntary but that the spirit of Achilles appeared to the Greeks and demanded her sacrifice. (Z 218)

\section{(596) Scheila}

Discovered 1906 Feb. 21 by A. Kopff at Heidelberg.

Named in honor of an acquaintance of the discoverer, an English woman student in Heidelberg. (H 63)

\section{(597) Bandusia}

Discovered 1906 Apr. 16 by M. F. Wolf at Heidelberg. Named after a fountain near Polezzo, Apulia, Italy. The Roman poet and satirist Horace (65-8 B.C.) \{see planet (4294)\} had a cottage near this fountain. (H 63)

\section{(598) Octavia}

Discovered 1906 Apr. 13 by M. F. Wolf at Heidelberg. Named for Octavia (70?-11 B.C.), sister of the first Roman emperor Augustus (63 B.C.-14), and later the second wife of Marcus Antonius (83?-30 B.C.). (H 63)

\section{(599) Luisa}

Discovered 1906 Apr. 25 by J. H. Metcalf at Taunton. Any reference of this name to a person or occurrence is unknown.

\section{(600) Musa}

Discovered 1906 June 14 by J. H. Metcalf at Taunton.

Named for the nine goddesses in Greek mythology presiding over song and poetry and the arts and sciences. The muses are daughters of Zeus by Mnemosyne \{see planets (5731) and (57)\}. They were Erato (amatory verses and hymnes), Euterpe (music), Kalliope (heroic verses), Klio (history), Melpomene (tragedy), Polyhymnia (solemn songs), Thalia (comedy), Terpsichore (dance), and Urania (astronomy). All muses are existent at the minor planet sky ssee planets (62), (27), (22), (84), (18), (33), (23), (81), and (30), respectively\}. (H 63)

\section{(601) Nerthus}

Discovered 1906 June 21 by M. F. Wolf at Heidelberg.

Named for the Nordic goddess, wife of the Heaven's god. (H 63)

\section{(602) Marianna}

Discovered 1906 Feb. 16 by J. H. Metcalf at Taunton. Independently discovered 1906 Feb. 22 by A. Kopff at Heidelberg.

Any reference of this name to a person or occurrence is unknown.

\section{(603) Timandra}

Discovered 1906 Feb. 16 by J. H. Metcalf at Taunton. Named for the daughter of Tindareus and Leda in Greek mythology. Timandra was the wife of Equemus and the mother of Evandrus. (H 63)

\section{(604) Tekmessa}

Discovered 1906 Feb. 16 by J. H. Metcalf at Taunton. Named for the daughter of the Phrygian prince Teubrantes, captive of Ajax \{see planet (1404)\}, by whom she had a son Eurysaces \{see planet (8317)\}. (H 64) 
The naming might be influenced by the two letters of the provisional designation 1906 TK. See also the remarks to planet (579).

\section{(605) Juvisia}

Discovered 1906 Aug. 27 by M. F. Wolf at Heidelberg.

Named for the city of Juvisy-sur-Orge in the department of Essonne, near Paris, France, where the French astronomer Camille Flammarion ssee planet (1021) \} had his observatory. He lived there between 1882 and 1925. (H 64)

\section{(606) Brangäne}

Discovered 1906 Sept. 18 by A. Kopff at Heidelberg.

Named for a maid servant of Isolde in the opera Tristan und Isolde (composed 1859) \{see planets (1966) and (211)\} by the German composer Richard Wagner \{see planet (3992)\}. (H 64)

\section{(607) Jenny}

Discovered 1906 Sept. 18 by A. Kopff at Heidelberg.

Named in honor of the wife of a friend of the discoverer on the occasion of her engagement. Her full name was Jenny Adolfine Kessler (see also planet (608)). (H 64)

\section{(608) Adolfine}

Discovered 1906 Sept. 18 by A. Kopff at Heidelberg. See the name citation of planet (607). (H 64)

\section{(609) Fulvia}

Discovered 1906 Sept. 24 by M. F. Wolf at Heidelberg. Named for Fulvia, first wife of the orator, triumvir and general Marcus Aurelius Antonius (83?-30 B.C.). (H 64)

\section{(610) Valeska}

Discovered 1906 Sept. 26 by M. F. Wolf at Heidelberg.

Any reference of this name to a person or occurrence is unknown.

The naming might be influenced by the two letters of the provisional designation 1906 VK. See also the remarks to planet (579).

\section{(611) Valeria}

Discovered 1906 Sept. 24 by J. H. Metcalf at Taunton.

Any reference of this name to a person or occurrence is unknown.

The naming might be influenced by the two letters of the provisional designation 1906 VL. See also the remarks to planet (579).

\section{(612) Veronika}

Discovered 1906 Oct. 8 by A. Kopff at Heidelberg.

Any reference of this name to a person or occurrence is unknown.

The naming might be influenced by the two letters of the provisional designation 1906 VN. See also the remarks to planet (579).

\section{(613) Ginevra}

Discovered 1906 Oct. 11 by A. Kopff at Heidelberg.

Named very probably after Guinevere, wife of King Arthur \{see planet (2597)\}. In the novel Le morte d'Arthur \{orig.: Le Morte Darthur\} (1469) by Thomas Malory her adulterous love, which Arthur is reluctant to recognize, causes Lancelot's \{see planet (2041)\} estrangement from Arthur and leads indirectly to Arthur's death and the destruction of the fellowship of the Round Table. (G. Cibis; LDS)

\section{(614) Pia}

Discovered 1906 Oct. 11 by A. Kopff at Heidelberg.

Named probably after the Pia Observatory at Trieste, Italy, which was named by the astronomer Krieger after his wife. (R. Bremer)

\section{(615) Roswitha}

Discovered 1906 Oct. 11 by A. Kopff at Heidelberg.

Named in honor of the German poetess Roswitha von Gandersheim. (H 64)

\section{(616) Elly}

Discovered 1906 Oct. 17 by A. Kopff at Heidelberg.

Named in honor of Mrs. Elly Boehm, wife of Prof. K. Boehm, who was professor of mathematics at the Technical University at Karlsruhe, Germany. (H 64)

\section{(617) Patroclus}

Discovered 1906 Oct. 17 by A. Kopff at Heidelberg.

Named for the Greek hero and friend of Achilles slain by Hector (see also planets (588) and (624)) at the Trojan War. (H 65)

Name suggested (AN 175, 191 (1907)) by J. Palisa.

The L5-Trojan Patroclus is the first known binary among the Trojans. The discovery of S/2001 (617) 1 on 2001 September 22 was made by W. J. Merline, L. M. Close, N. Siegler and D. Potter with the 8.1-m Gemini North Telescope on Mauna Kea (IAUC 7741).

\section{(618) Elfriede}

Discovered 1906 Oct. 17 by K. Lohnert at Heidelberg. Any reference of this name to a person or occurrence is unknown.

\section{(619) Triberga}

Discovered 1906 Oct. 22 by A. Kopff at Heidelberg.

Named for the small town of Triberg, near the city of Villingen, in the Black Forest in Germany because of the discoverer's love for that region. (H 65)

\section{(620) Drakonia}

Discovered 1906 Oct. 26 by J. H. Metcalf at Taunton. Named probably in honor of the Drake University, Des Moines, Iowa. (LDS; AN 175, 305 (1907))

Named by D. W. Morehouse and E. B. Stouffer, who calculated the orbit, both of the Drake University.

\section{(621) Werdandi}

Discovered 1906 Nov. 11 by A. Kopff at Heidelberg.

Named for one of the three Norns in Norse mythology. Werdandi stands for the Present. (H 21) 
The other Norns are Urda (the Past) and Skuld (the Future) \{see planets (167) and (1130)\}.

\section{(622) Esther}

Discovered 1906 Nov. 13 by J. H. Metcalf at Taunton. Named probably for the Jewish heroine of the Old Testament book of Esther. (H 65)

\section{(623) Chimaera}

Discovered 1907 Jan. 22 by K. Lohnert at Heidelberg.

Named for the mount in Lycia whose summit emits flames and produces lions. Half way up there are pastures where goates graze. The foot is infested by snakes. Bellerophon \{see planet (1808)\} made this mount habitable. This is the basis of the fable in which Chimaera is a monster that emits flames, has the lion's head, the goat's body and the dragon's tail and that was killed by Bellerophon. Others say that the Chimaera had three heads, one of the lion, one of the goat and one of the snake. (H 65)

\section{(624) Hektor}

Discovered 1907 Feb. 10 by A. Kopff at Heidelberg.

Named for a son of Priam, husband of Andromache, and Trojan champion slain by Achilles \{see also planets (884), (175), and (588), respectively $\}$. (H 65)

Name suggested (AN 175, 191 (1907)) by J. Palisa. The original spelling was "Hector".

\section{(625) Xenia}

Discovered 1907 Feb. 11 by A. Kopff at Heidelberg.

Any reference of this name to a person or occurrence is unknown. (H 65)

The naming might be influenced by the two letters of the provisional designation $1907 \mathrm{XN}$. See also the remarks to planet (579).

\section{(626) Notburga}

Discovered 1907 Feb. 11 by A. Kopff at Heidelberg.

Named after the Catholic Saint Notburga von Hochhausen (ca. 1517), a small town in the Neckar Valley. (H 65)

\section{(627) Charis}

Discovered 1907 Mar. 4 by A. Kopff at Heidelberg.

Named for the Greek goddess and wife of Hephaistos \{see planet (2212)\}. The Charites were the three Greek goddesses of charm and grace. The three graces (47) Aglaja, (31) Euphrosyne, and (23) Thalia are all members of the asteroid sky. (H 65)

\section{(628) Christine}

Discovered 1907 Mar. 7 by A. Kopff at Heidelberg.

Any reference of this name to a person or occurrence is unknown.

\section{(629) Bernardina}

Discovered 1907 Mar. 7 by A. Kopff at Heidelberg.

Any reference of this name to a person or occurrence is unknown.

\section{(630) Euphemia}

Discovered 1907 Mar. 7 by A. Kopff at Heidelberg.

Named after a Christian holy figure whose festival is on the 16th of September. The name also means a good omen. (H 66)

\section{(631) Philippina}

Discovered 1907 Mar. 21 by A. Kopff at Heidelberg.

Named in honor of Philipp Kessler, a friend of the discoverer, on the occasion of his engagement. (H 66)

\section{(632) Pyrrha}

Discovered 1907 Apr. 5 by A. Kopff at Heidelberg.

Named after the daughter of Epimetheus and Pandora \{see planets (1810) and (55), respectively\}. She married Deucalion, a son of Prometheus \{see planet (1809)\}. Deucalion and Pyrrha were the only survivors of the deluge which Zeus \{see planet (5731)\} sent to destroy mankind. The couple replaced the loss of mankind by throwing stones behind their backs - those Deucalion threw became men, those Pyrrha threw became women. (Z 226)

\section{(633) Zelima}

Discovered 1907 May 12 by A. Kopff at Heidelberg.

Any reference of this name to a person or occurrence is unknown. (H 66)

The naming might be influenced by the two letters of the provisional designation 1907 ZM. See also the remarks to planet (579).

\section{(634) Ute}

Discovered 1907 May 12 by A. Kopff at Heidelberg.

Named by the discoverer in honor of a friend on the occasion of her engagement. (H 66)

\section{(635) Vundtia}

Discovered 1907 June 9 by K. Lohnert at Heidelberg.

Named in honor of the German physicist Vundt. (H 66)

\section{(636) Erika}

Discovered 1907 Feb. 8 by J. H. Metcalf at Taunton.

Any reference of this name to a person or occurrence is unknown.

\section{(637) Chrysothemis}

Discovered 1907 Mar. 11 by J. H. Metcalf at Taunton.

Named for the daughter of Agamemnon and Klytaemnestra in Greek mythology \{see planets (911) and (179)\}. (LDS)

\section{(638) Moira}

Discovered 1907 May 5 by J. H. Metcalf at Taunton.

Named for the Greek goddess of fate. Hesiod mentioned three goddesses of fate, daughters of Zeus, Klotho, Lachesis and Atropos \{see planets (5731), (97), (120) and (273), respectively\}. (H 66)

\section{(639) Latona}

Discovered 1907 July 19 by K. Lohnert at Heidelberg. 
This is the Latin name for Leto \{see planet (68)\}, the mother of Apollo \{see planet (1862)\} and Artemis \{see planet (105)\}. She was the daughter of the Titan Coeus and Phoebe. (H 66)

\section{(640) Brambilla}

Discovered 1907 Aug. 29 by A. Kopff at Heidelberg.

Named after the novel Prinzessin Brambilla (written 1821 ) by the German writer and composer E. T. A. Hoffmann (1776-1822), set to music by Walter Braunfels (1882-1954). (H 66)

\section{(641) Agnes}

Discovered 1907 Sept. 8 by M. F. Wolf at Heidelberg.

Any reference of this name to a person or occurrence is unknown.

\section{(642) Clara}

Discovered 1907 Sept. 8 by M. F. Wolf at Heidelberg.

Named by the discoverer for a housekeeper of the Wolf family. (H 67)

\section{(643) Scheherezade}

Discovered 1907 Sept. 8 by A. Kopff at Heidelberg.

Named for the fictional wife of an oriental king and the narrator of the tales in Arabian Nights. (H 67)

\section{(644) Cosima}

Discovered 1907 Sept. 7 by A. Kopff at Heidelberg.

Named in honor of Cosima Wagner (1837-1930). She was the daughter of the Hungarian composer Franz Liszt \{see planet (3910)\} and the Countess d'Agoult and the second wife of the German composer Richard Wagner \{see planet (3992)\}. (H 67)

\section{(645) Agrippina}

Discovered 1907 Sept. 13 by J. H. Metcalf at Taunton.

Named for two characters of the Roman history. Agrippina the elder (13? B.C.-33) was the daughter of the Roman statesman Marcus Vipsanius Agrippa, the wife of Germanicus and the mother of Caligula. Her daughter Agrippina the younger (15?-59) was the mother of Emperor Nero. (LDS)

The naming might be influenced by the two letters of the provisional designation 1907 AG. See also the remarks to planet (579).

\section{(646) Kastalia}

Discovered 1907 Sept. 11 by A. Kopff at Heidelberg.

Named for the fountain in the footing of the Parnassus mountain, near Delphi, consecrated to Apollo \{see planet (1862)\} and the Muses. In Greek mythology Kastalia is the symbol for poetry. ( $\mathrm{H} 67$ )

Another spelling of Kastalia is used with planet (4769) Castalia.

\section{(647) Adelgunde}

Discovered 1907 Sept. 11 by A. Kopff at Heidelberg.

Any reference of this name to a person or occurrence is unknown.
The naming might be influenced by the two letters of the provisional designation 1907 AD. See also the remarks to planet (579).

\section{(648) Pippa}

Discovered 1907 Sept. 11 by A. Kopff at Heidelberg.

Named for the main character in Und Pippa tanzt by the German writer Gerhart Hauptmann (1862-1946). (H 67)

\section{(649) Josefa}

Discovered 1907 Sept. 11 by A. Kopff at Heidelberg.

Any reference of this name to a person or occurrence is unknown.

\section{(650) Amalasuntha}

Discovered 1907 Oct. 4 by A. Kopff at Heidelberg.

Named after the daughter of the Ostrogoth king Theodoric the Great (474-526) and regent for his grandson Athalarich during his whole reign (526-534). Amalasuntha (also Amalaswintha) was killed 535 by her cousin Theodahat who succeeded as Ostrogoth king. The assassination gave rise to the intervention in Italy by the Byzantine emperor Justinian I. (483-565). (LDS)

The naming might be influenced by the two letters of the provisional designation 1907 AM. See also the remarks to planet (579).

\section{(651) Antikleia}

Discovered 1907 Oct. 4 by A. Kopff at Heidelberg.

Named for the wife of Laertes, king of Ithaca, who died of an affliction caused by the prolonged absence of her son, Odysseus \{see planet (1143)\}. (H 67)

The naming might be influenced by the two letters of the provisional designation 1907 AN. See also the remarks to planet (579).

\section{(652) Jubilatrix}

Discovered 1907 Nov. 4 by J. Palisa at Vienna.

This planet was named at the occasion of the 1908 meeting of the Astronomische Gesellschaft in Vienna (AN 179, 47 (1908)). It honors the 60th year reign jubilee of the Austrian Emperor Franz Joseph (1830-1916). (H 67)

Named by E. Weiss. A report on the meeting is published in Observatory, Vol. 31, p. 448 (1908): "The evening before the opening of the Congress a great number of foreign astronomers were present at the University Observatory at the formal unveiling of a bust of the Emperor Francis Joseph I. on the occasion of the sixtieth anniversary of his succession to the throne... Lastly, Prof. Palisa, of the Vienna Observatory, presented to the Assembly the new photographic celestial charts, publication of which had been undertaken by himself and Prof. Wolf... It seems that on these occasions it is customary to christen a small planet. This year, 1905 AU, discovered by Prof. Palisa, was named Jubilatrix, in honour of the Jubilee of the Emperor..." 


\section{(653) Berenike}

Discovered 1907 Nov. 27 by J. H. Metcalf at Taunton.

Named after the daughter of king Magas of Cyrene (273?-221 B.C.) and wife (247 B.C.) of Ptolemaeus III. Berenike sacrified her magnificent hair at the temple of Venus after the safely return of Ptolemaeus from a war against Syria. The hair was transferred to the skies and formed a constellation (Coma Berenices). (LDS)

The naming might be influenced by the two letters of the provisional designation 1907 BK. See also the remarks to planet (579).

\section{(654) Zelinda}

Discovered 1908 Jan. 4 by A. Kopff at Heidelberg.

Named by Elia Millosevich with the permission of the discoverer in honor of Zelinda, sister of the famous Italian mathematician Ulisse Dini (1845-1918). Dini was a good friend of Millosevich. (Mem. Soc. Spettrosc. Italiani, Vol. XXXVII, 1908 (E. Colombini))

\section{(655) Briseïs}

Discovered 1907 Nov. 4 by J. H. Metcalf at Taunton. Named after the Trojan girl captured by the Greeks and given to Achilles \{see planet (588)\}. When Agamemnon ssee planet (911)\} demanded her for himself, Achilles refused to take further part in the Trojan War. (Z 43)

\section{(656) Beagle}

Discovered 1908 Jan. 22 by A. Kopff at Heidelberg.

Named for the ship with which Charles Darwin see planet (1991)\} sailed around the world (1831-1836). (H 68)

\section{(657) Gunlöd}

Discovered 1908 Jan. 23 by A. Kopff at Heidelberg.

Named after the daughter of the giant Sutung who took care of the Scandinavian hydromel. Odin \{see planet (3989)\} seduced her and stole three sips of the liquor. Gunlöd, changed into an eagle, pursued Odin who let fall some drops. (A. Paluzie-Borrell)

\section{(658) Asteria}

Discovered 1908 Jan. 23 by A. Kopff at Heidelberg.

The name appears with different meanings in Greek mythology: (1) Asteria was the daughter of the Titans Coeus and Phoebe, the sister of Leto \{see planet (68)\}, and by Perseus the mother of Hecate \{see planet (100)\}. She was changed into a quail. (2) Asteria was one of the fifty daughters of Danaus. (3) Apollodorus says that Asteria was a daughter of Atlas. (4) Asteria is also a name of a town in Greece. ( $\mathrm{Z}$ 34)

\section{(659) Nestor}

Discovered 1908 Mar. 23 by M. F. Wolf at Heidelberg.

Named for the king of Pylos who served in his old age as a counselor to the Greeks at Troy. (LDS; AN 186, 223 (1910))

Named at the meeting of the Astronomische Gesellschaft in Breslau in 1910.

\section{(660) Crescentia}

Discovered 1908 Jan. 8 by J. H. Metcalf at Taunton.

Any reference of this name to a person or occurrence is unknown.

The naming might be influenced by the two letters of the provisional designation 1908 CC. See also the remarks to planet (579).

\section{(661) Cloelia}

Discovered 1908 Feb. 22 by J. H. Metcalf at Taunton.

Named probably for a Roman noble girl. With nine other girls she was an hostage given to Porsenna who had besieged Rome. But during the night she escaped and swimming crossed the Tiber river. (A. PaluzieBorrell)

The naming might be influenced by the two letters of the provisional designation 1908 CL. See also the remarks to planet (579).

\section{(662) Newtonia}

Discovered 1908 Mar. 30 by J. H. Metcalf at Taunton.

Named for the city of Newton, Massachusetts. (B. G. Marsden; AN 182, 332 (1909))

Named by Z. Daniel, Princeton University Observatory.

Previously, the name was interpreted as an honor for the great English physicist Isaac Newton. The correct interpretation was now given by Brian G. Marsden who met Zaccheus Daniel at the April 1960 meeting of the American Astronomical Society in Pittsburgh, PA. Marsden states: "As I interpreted it, the point was that Z. Daniel did not know whether to honor Isaac or H. A. Newton, so he got around the matter by choosing Newton, Massachusetts, instead." The Small Bodies Names Committee in 1998 corrected the situation by naming planet (8000) to the great physicist.

\section{(663) Gerlinde}

Discovered 1908 June 24 by A. Kopff at Heidelberg.

Any reference of this name to a person or occurrence is unknown.

\section{(664) Judith}

Discovered 1908 June 24 by A. Kopff at Heidelberg.

Named after the figure from the play (1839) of the German dramatist Friedrich Hebbel (1813-1863). Judith is a book of Scripture included in the Roman Catholic canon of the Old Testament and in the Protestant Apocrypha. (H 68)

\section{(665) Sabine}

Discovered 1908 July 22 by W. Lorenz at Heidelberg.

Any reference of this name to a person or occurrence is unknown.

\section{(666) Desdemona}

Discovered 1908 July 23 by A. Kopff at Heidelberg.

Named for the wife of Othello in William Shakespeare's \{see planet (2985)\} tragedy (written 1604). (H 68) 
The naming might be influenced by the two letters of the provisional designation $1908 \mathrm{DM}$. See also the remarks to planet (579). The name Desdemona has also been given to the satellite Uranus X, discovered 1986 by the Voyager 2 spacecraft.

\section{(667) Denise}

Discovered 1908 July 23 by A. Kopff at Heidelberg.

Any reference of this name to a person or occurrence is unknown.

The naming might be influenced by the two letters of the provisional designation 1908 DN. See also the remarks to planet (579).

\section{(668) Dora}

Discovered 1908 July 27 by A. Kopff at Heidelberg.

Named after a girl friend of the discoverer's wife. (H 68)

The naming might be influenced by the two letters of the provisional designation 1908 DO. See also the remarks to planet (579).

\section{(669) Kypria}

Discovered 1908 Aug. 20 by A. Kopff at Heidelberg.

Named after a poem, in early days ascribed to Homer \{see planet (5700)\} but denied to him by Herodotus \{see planet (3092)\}. It detailed the causes of the Trojan War and served as a sort of introduction to the Iliad. Kypria is also a surname of Aphrodite ssee planet (1388)\}, who was born from the foam of the sea and came to land near the island of Cyprus. (H 68; I. van Houten-Groeneveld)

\section{(670) Ottegebe}

Discovered 1908 Aug. 20 by A. Kopff at Heidelberg.

Named for a woman character in the drama Der arme

Heinrich by the German writer Gerhart Hauptmann (1862-1946). (H 69)

\section{(671) Carnegia}

Discovered 1908 Sept. 21 by J. Palisa at Vienna.

Named by the discoverer (AN 184, 159 (1910)) in honor of the American philanthropist Andrew Carnegie (1835-1919), founder of the Carnegie Institution in Washington. D.C. (H 69)

\section{(672) Astarte}

Discovered 1908 Sept. 21 by A. Kopff at Heidelberg.

Named for the Phoenician goddess of love and fertility. (H 69)

\section{(673) Edda}

Discovered 1908 Sept. 20 by J. H. Metcalf at Taunton. Independently discovered 1908 Sept. 21 by A. Kopff at Heidelberg.

Named for the Norse Edda which is a 13th century collection of mythological, heroic, and aphoristic poems in alliterative verse. (H 69)

The naming might be influenced by the two letters of the provisional designation 1908 EA. See also the remarks to planet (579).
(674) Rachele

Discovered 1908 Oct. 28 by W. Lorenz at Heidelberg.

Named in honor of the wife of the orbit computer E. Bianchi. (H 69; AN 181, 292 (1909))

Named by E. Bianchi.

\section{(675) Ludmilla}

Discovered 1908 Aug. 30 by J. H. Metcalf at Taunton. Named probably after the title figure of the opera Ruslan and Ludmilla by the Russian composer Mikhail Ivanovich Glinka (1804-1857) \{see planet (2205)\}. (I. van Houten-Groeneveld)

\section{(676) Melitta}

Discovered 1909 Jan. 16 by P. J. Melotte at Greenwich.

Melitta is the Attic form of the Greek Melissa, daughter of the Cretan king Melissus and sister of Amalthea \{see planet (113)\}. She was changed into a bee. At the same time the name is a play upon words for its resemblance to the discoverer's name. (H 69)

\section{(677) Aaltje}

Discovered 1909 Jan. 18 by A. Kopff at Heidelberg.

Named in honor of the Dutch singer Aaltje Noordewier Reddingius. (H 69)

\section{(678) Fredegundis}

Discovered 1909 Jan. 22 by W. Lorenz at Heidelberg.

Named after an unfinished opera by Ernest Guirand which was completed by the French composer Camille Saint-Saëns (1835-1921) \{see planet (5210)\}. (H 69)

The naming might be influenced by the two letters of the provisional designation 1909 FS. See also the remarks to planet (579).

\section{(679) Pax}

Discovered 1909 Jan. 28 by A. Kopff at Heidelberg.

Named for the Roman goddess of peace. (H 69)

Named (AN 186, 223 (1910)) by G. Zappa, who computed the orbit.

\section{(680) Genoveva}

Discovered 1909 Apr. 22 by A. Kopff at Heidelberg.

Named probably after the main figure in the drama Genoveva by the German dramatist Friedrich Hebbel (1813-1863). See also planet (664). (H 69)

\section{(681) Gorgo}

Discovered 1909 May 13 by A. Kopff at Heidelberg.

Gorgo is the German word for Gorgon. In the Greek mythology by Homer \{see planet (5700)\} only one Gorgon exists as a monster. Later there are three Gorgons, the three daughters of Ceto and Phorcys. Two of them, Euryale and Stheno, were immortal, the third, Medusa (see planet (149)), was mortal. (I. van Houten-Groeneveld)

\section{(682) Hagar}

Discovered 1909 June 17 by A. Kopff at Heidelberg.

Named for the concubine of Abraham driven into the desert with her son Ishmael because of Sarah's 
jealousy according to the account in the Old Testament (Genesis XXI, 14). (H 70)

The naming might be influenced by the two letters of the provisional designation 1909 HA. See also the remarks to planet (579).

\section{(683) Lanzia}

Discovered 1909 July 23 by M. F. Wolf at Heidelberg.

Named in honor of Karl Lanz, founder of the Heidelberg Academy of Sciences. (H 70)

\section{(684) Hildburg}

Discovered 1909 Aug. 8 by A. Kopff at Heidelberg.

Any reference of this name to a person or occurrence is unknown.

The naming might be influenced by the two letters of the provisional designation 1909 HD. See also the remarks to planet (579).

\section{(685) Hermia}

Discovered 1909 Aug. 12 by W. Lorenz at Heidelberg.

Any reference of this name to a person or occurrence is unknown.

The naming might be influenced by the two letters of the provisional designation $1909 \mathrm{HE}$. See also the remarks to planet (579).

\section{(686) Gersuind}

Discovered 1909 Aug. 15 by A. Kopff at Heidelberg.

Named for a woman character out of a drama of the German writer Gerhart Hauptmann (1862-1946). (H 70)

\section{(687) Tinette}

Discovered 1909 Aug. 16 by J. Palisa at Vienna.

Any reference of this name to a person or occurrence is unknown.

The name was first published (AN 184, 320 (1910)) by R. Coniel, Paris.

\section{(688) Melanie}

Discovered 1909 Aug. 25 by J. Palisa at Vienna.

Any reference of this name to a person or occurrence is unknown.

Named (AN 186, 15 (1910)) by Dr. O. Prelinger, co-worker at the Wolf-Palisa photographic star charts.

\section{(689) Zita}

Discovered 1909 Sept. 12 by J. Palisa at Vienna.

Named in honor of Empress Zita von Bourbon-Parma (1892-1989), wife of Emperor Karl I of Austria (and

King Karl IV of Hungary) (1887-1922). (H 70)

The name was assigned on the occasion of the marriage of Zita 1911. After planet (220) this is the second planet which was given as a wedding present.

\section{(690) Wratislavia}

Discovered 1909 Oct. 16 by J. H. Metcalf at Taunton.

Named for the (then German) city of Breslau in the province of Silesia \{see planet (257)\}. Wratislavia is the Latin form of the name. (H 70)
Named (AN 186, 223 (1910)) on the occasion of the meeting of the Astronomische Gesellschaft in Breslau in 1910 .

\section{(691) Lehigh}

Discovered 1909 Dec. 11 by J. H. Metcalf at Taunton. Named for the Lehigh University, Bethlehem, Pennsylvania. (H 70)

Named in accordance with the discoverer by the orbit computer J. B. Reynolds, Lehigh University.

\section{(692) Hippodamia}

Discovered 1901 Nov. 5 by M. F. Wolf at Heidelberg.

Named for a daughter of Oenomaus, king of Pisa, wife of Pelops and mother of Atreus and Thyestes. She bribed Myrtilus, her father's charioteer, to remove a spoke from the royal chariot wheels so that Pelops could win her. Oenomaus had already defeated and killed 13 other suitors whom he had challenged to chariot races. After killing Oenomaus, Pelops murdered Myrtilus. These murders were primal sins, all paid for later by the many troubles of the house of Atreus. (Z 128)

The naming might be influenced by the two letters of the provisional designation 1901 HD. See also the remarks to planet (579). The planet was rediscovered by A. Kopff at the 1910 apparition.

\section{(693) Zerbinetta}

Discovered 1909 Sept. 21 by A. Kopff at Heidelberg.

Named after a character from the opera Ariadne auf Naxos by the German composer Richard Strauss (1864-1949) \{see planet (5039)\}. (H 70)

\section{(694) Ekard}

Discovered 1909 Nov. 7 by J. H. Metcalf at Taunton. Independently discovered 1909 Nov. 9 by J. Helffrich at Heidelberg.

Named by the American astronomer Seth Barnes Nicholson \{see planet (1831)\} and his wife while they were at the Drake University, Des Moines, Iowa. They were the first to compute its orbit and the name is "Drake" spelled backwards. (H 70)

\section{(695) Bella}

Discovered 1909 Nov. 7 by J. H. Metcalf at Taunton.

Any reference of this name to a person or occurrence is unknown.

\section{(696) Leonora}

Discovered 1910 Jan. 10 by J. H. Metcalf at Taunton. Named by Arthur Snow of the Nautical Almanac Office, Washington, D.C., who computed the orbit for this planet, in honor of his wife, Mary Leonora Snow. (Astron. J., Vol. 27, p. 16 (1911))

\section{(697) Galilea}

Discovered 1910 Feb. 14 by J. Helffrich at Heidelberg.

Named for the discovery of the Jupiter satellites by Galileo Galilei: "Im besonderen soll der Name Galilea 
daran erinnern, dass der Planet am Tage der 300jährigen Wiederkehr der Entdeckung der Jupitersatelliten durch Galilei aufgefunden wurde." (AN 196, 139 (1913))

Galilei is also honored by a lunar crater.

\section{(698) Ernestina}

Discovered 1910 Mar. 5 by J. Helffrich at Heidelberg.

Named in honor of Ernst Wolf, son of Max Wolf. (H 71)

\section{(699) Hela}

Discovered 1910 June 5 by J. Helffrich at Heidelberg.

Named possibly after Hel \{see also planet (949)\}, the Norse goddess of the dead. Yggdrasil was a tree, one of whose roots grew in Asgard, the second in Nifflheim and the third in the realm of Hela or Death. The lower world was ruled by the goddess Hel and to it were consigned those who had not died in battle. (H 71; R. Bremer)

\section{(700) Auravictrix}

Discovered 1910 June 5 by J. Helffrich at Heidelberg.

This planet is named in memory of the trips of the Schutte-Lanz Zeppelin No. 1. It is a Latin word meaning "victory against the wind". The first flights were performed in the years 1911 and 1912. (H 71)

\section{(701) Oriola}

Discovered 1910 July 12 by J. Helffrich at Heidelberg.

Named after a family of usually bright colored Old World passerine birds related to the crows. The English name for the most known bird of this family is 'golden oriole'. (H 71)

\section{(702) Alauda}

Discovered 1910 July 16 by J. Helffrich at Heidelberg.

Named for the numerous singing birds of the Alaudidae family (the lark) mostly of Europe, Asia, and northern Africa. (H 71)

\section{(703) Noëmi}

Discovered 1910 Oct. 3 by J. Palisa at Vienna.

Probably named for Valentine Noëmi von Rothschild at the occasion of her marriage with Baron Sigismund von Springer in 1911. At that time Baron Rothschild donated a Zeiss Stereocomparator to the Vienna Observatory. \{See also the citations for planets (250), (447), and, respectively (719)\}. (A. Schnell)

\section{(704) Interamnia}

Discovered 1910 Oct. 2 by V. Cerulli at Teramo.

Ancient name of the city of Teramo where the discoverer was born and where this planet was discovered. (J. Meeus)

Vincenzo Cerulli (1859-1927) in 1890 built a private observatory with a 40-cm Cooke telescope which he left to the Italian nation. He extensively studied minor planet (433) Eros at its 1900 opposition. The name Interamnia was sometimes erroneously interpreted as the ancient name of Terni in Umbria, Italy. The ancient name of Terni \{see planet (5654)\}, however, is Interamna. This clarification was given by S. De Meis.

\section{(705) Erminia}

Discovered 1910 Oct. 6 by E. Ernst at Heidelberg.

Named after an opera (1885) by Jacobowsky termed the "most successful operetta of modern times" and based on an old melodrama Robert Macaire. (H 71)

\section{(706) Hirundo}

Discovered 1910 Oct. 9 by J. Helffrich at Heidelberg.

Named for the numerous small long-winged passerine birds of the Hirundinidae family (the swallow) that are noted for their graceful flight and regular migrations, have a short bill with a wide gape, small weak feet, and often a deeply forked tail, occur in all parts of the world except New Zealand and the polar regions, and feed on insects caught on the wing. (H 71)

\section{(707) Steina}

Discovered 1910 Dec. 22 by M. F. Wolf at Heidelberg.

Named after Mr. Stein, benefactor of the Breslau Observatory. (H 71; AN 214, 69 (1921))

Stein was honored twice: "Am 30. Juli 1921 fand ... die Einweihung des neuen Institutes (of the Breslau Observatory) statt; dem hervorragendsten Freund der Sternwarte, Herrn Fabrikdirektor Stein, wurde bei dieser Gelegenheit die Ehrenbürgerschaft der Universität verliehen. Dank der grossen Liebenswürdigkeit von Herrn Geheimrat Wolf in Heidelberg wurde Herr Stein in dankbarer Anerkennung seines Verdienstes um die Förderung der Astronomie an den Himmel versetzt, indem der Planet 707 auf den Namen Steina getauft wurde." (Vierteljahrsschr. Astron. Ges., 57. Jahrg., p. $78(1922)$

\section{(708) Raphaela}

Discovered 1911 Feb. 3 by J. Helffrich at Heidelberg.

Named in honor of Raphael von Bischoffsheim, founder of the Nice Observatory. The name was chosen because A. Charlois, Nice, discovered the planet $1892 \mathrm{~S}$ which was identical to (708). (AN 196, 139 (1913))

\section{(709) Fringilla}

Discovered 1911 Feb. 3 by J. Helffrich at Heidelberg.

Named after the numerous singbirds of the Fringillidae family (the finch) having a short stout conical bill adapted for crushing seeds. (H 72)

\section{(710) Gertrud}

Discovered 1911 Feb. 28 by J. Palisa at Vienna.

Named probably in honor of Gertrud Rheden, daughter of the astronomer J. Rheden and granddaughter of J. Palisa \{see planet (914)\}. (A. Schnell)

Named (AN 190, 223 (1912)) by E. Anding in Gotha.

\section{(711) Marmulla}

Discovered 1911 Mar. 1 by J. Palisa at Vienna.

Named possibly after the German word "Marmel" or "Murmel" ("Marmul" in the medieval form) which 
means a marble - surely a nice allusion to a minor planet. (P. Wild)

The name was spelled 'Marmula' in the naming announcement (AN 191, 216 (1912)).

\section{(712) Boliviana}

Discovered 1911 Mar. 19 by M. F. Wolf at Heidelberg.

Named in honor of Simon Bolivar (1783-1830), the liberator of South America. (H 72)

Name proposed by C. Flammarion.

\section{(713) Luscinia}

Discovered 1911 Apr. 18 by J. Helffrich at Heidelberg.

Named after several Old World thrushes of genus Luscinia (the nightingale) noted for the sweet and usually nocturnal song of the male. (H 72)

The naming might be influenced by the two letters of the provisional designation 1911 LS. See also the remarks to planet (579).

\section{(714) Ulula}

Discovered 1911 May 18 by J. Helffrich at Heidelberg.

Named for an order of birds (the owl) of prey with large head and eyes, short hooked bill, strong talons, and more or less nocturnal habits. Ulula comes from the Latin word ululare which is an imitation of the call of the owl. (H 72)

\section{(715) Transvaalia}

Discovered 1911 Apr. 22 by H. E. Wood at Johannesburg.

Named after the province in the northeastern part of the Republic of South Africa between the Vaal and the Limpopo \{see planet (1490)\} rivers. (H 72)

This is the first numbered minor planet discovered in Africa.

\section{(716) Berkeley}

Discovered 1911 July 30 by J. Palisa at Vienna.

This planet was named after the city of Berkeley, California, where Armin O. Leuschner (see planet (1361)) studied the orbits of minor planets. Leuschner especially worked on an orbit determination of the lost Palisa planet (719) Albert. (A. Schnell)

\section{(717) Wisibada}

Discovered 1911 Aug. 26 by F. Kaiser at Heidelberg.

This is the Latin name of the city of Wiesbaden, the home of the discoverer. (H 72)

The city of Wiesbaden, Germany is also honored by the discoverer by planet (765) Mattiaca.

\section{(718) Erida}

Discovered 1911 Sept. 29 by J. Palisa at Vienna.

Named in honor of the daughter of A. O. Leuschner \{see planet (1361)\}, Erida. (H 72; A. Schnell)

The friendship between Palisa and his colleague Leuschner is also documented by the naming of planet (716).

\section{(719) Albert}

Discovered 1911 Oct. 3 by J. Palisa at Vienna.

Named by the Vienna astronomers in honor of Albert Freiherr von Rothschild, a benefactor of the Vienna Observatory. (AN 193, 334 (1913))

The naming was commented on in Observatory, Vol.36, p. 153 (1913): "Masculine names are used only in the case of remarkable orbits like Eros, Albert, and the Trojan group." This minor planet was supposed to be lost for nearly 90 years. It was accidentally recovered on May 12000 by J. A. Larsen in the course of the Spacewatch program at Kitt Peak as 2000 JW8. G. V. Williams, associate director of the Minor Planet Center identified this object with (719) Albert, the last lost numbered planet. Further observations from the apparitions in 1971, 1988 and 1993, respectively, confirmed this identification. (IAUC 7420, MPC 40671)

\section{(720) Bohlinia}

Discovered 1911 Oct. 18 by F. Kaiser at Heidelberg.

Named in honor of the Swedish astronomer Karl Petrus Theodor Bohlin (1860-1939), author of a study of Jupiter's perturbations, on the occasion of his 65th birthday. B. Asplind stated in AN 225, 354 (1925): "Dieser zur Koronis-Gruppe gehörende Planet ... hat mit Zustimmung des Entdeckers als Ehrung für Prof. Karl Bohlin in Stockholm zu seinem 65. Geburtstage (30. Okt. 1925) für seine großen Verdienste auf dem Gebiet der Kleinen Planeten, insbesondere für seine Arbeiten zur gruppenweisen Berechnung der allgemeinen Störungen, den Namen Bohlinia erhalten." (H 72)

Named by M. F. Wolf at the meeting of the Astronomische Gesellschaft without the knowledge of the discoverer.

\section{(721) Tabora}

Discovered 1911 Oct. 18 by F. Kaiser at Heidelberg.

This planet was named by M. F. Wolf after the ocean liner Tabora which was inspected by the participants in a meeting of the Astronomische Gesellschaft in Hamburg in 1913. The discoverer adds that Tabora also was the name of a coastal town in former German East Africa. (H 73; AN 196, 139 (1913))

\section{(722) Frieda}

Discovered 1911 Oct. 18 by J. Palisa at Vienna.

Named probably in honor of Frieda Hillebrand, grand-daughter of Prof. Weiss, director of the Vienna Observatory. Frieda is the daughter of Prof. Karl Hillebrand (1861-1939), astronomer at the Graz University, and his wife Irene, née Weiss s see planet (794)\}. (A. Schnell)

\section{(723) Hammonia}

Discovered 1911 Oct. 21 by J. Palisa at Vienna.

The planet was named (AN 196, 139 (1913)) on the occasion of the 24th meeting of the Astronomische 
Gesellschaft in Hamburg in 1913. It is an allusion to the city. (H 73)

The city of Hamburg is also honored by planet (449).

\section{(724) Hapag}

Discovered 1911 Oct. 21 by J. Palisa at Vienna.

This planet honors by the initials the "HamburgAmerika Paketfahrt Aktien-Gesellschaft". The planet was named on the occasion of the meeting of the Astronomische Gesellschaft in Hamburg, 1913. (H 73; AN 196, 139 (1913))

At the Hamburg AG meeting the planets (721), (723), (724) and (725) were named. Turner (Observatory, Vol. 36, No. 466, p. 415-416 (1913)) published verses, written by Palisa, which elucidate the naming history.

\section{(725) Amanda}

Discovered 1911 Oct. 21 by J. Palisa at Vienna.

Named in honor of the wife of the Hamburg astronomer Richard Schorr \{see planet (1235)\}. (H 73)

The planet was named at the occasion of the 24th meeting of the Astronomische Gesellschaft in Hamburg in 1913 (AN 196, 139 (1913)). Turner noted in Observatory, Vol. 36, No. 466, p. 414 (1913): "Before the end of the meeting we had another christening of a planet: Prof. Palisa announced the name "Amanda". It is difficult for us who have not yet seen the planet to judge of the suitability of the celestial application: but Prof. Palisa was kind enough to give us a terrestrial parallel, the suitability of which was recognized with hearty applause."

\section{(726) Joëlla}

Discovered 1911 Nov. 22 by J. H. Metcalf at Winchester.

Named in honor of the discoverer, Joel H. Metcalf (1866-1925). (H 73)

The discoverer is also honored by planet (792). See also the remarks to planet (1052).

\section{(727) Nipponia}

Discovered 1912 Feb. 11 by A. Massinger at Heidelberg.

Named after the country of Japan where this planet was discovered accidently (by Hirayama, Tokyo) twice in 1900 and 1908, respectively. (AN 196, 140 (1913))

The planet was first photographed on March 3, 1900 by S. Hirayama under the assistance of K. Toda. K. Saotome computed first circular elements for $1900 \mathrm{FE}$. This is the first minor planet discovered in Japan. Nippon is the official transliteration of Japan. (K. Tomita).

\section{(728) Leonisis}

Discovered 1912 Feb. 16 by J. Palisa at Vienna.

Named in honor of Geheimrat Leo Gans (1843-1935), president of the Physical Society at Frankfurt a.M., Germany on the occasion of his 70th birthday. The emblem of the Society is an Isis, thus the combined name for this planet. (AN 197, 416 (1914))

Named by M. Brendel.

\section{(729) Watsonia}

Discovered 1912 Feb. 9 by J. H. Metcalf at Winchester.

Named in honor of the American astronomer James Craig Watson (1838-1880), director of the Ann Arbor Observatory, Michigan, who detected some comets and 22 minor planets. He left an endowment with the National Academy for the care of the "Watson" asteroids. (H 73)

Watson is also honored by a lunar crater. See also the remarks to planet (1052).

\section{(730) Athanasia}

Discovered 1912 Apr. 10 by J. Palisa at Vienna.

Athanasia is the Greek word for immortality. Any reference to a person or occurrence is unknown. (H 73)

Named by friends of the discoverer (Astronomischer Kalender für 1917).

\section{(731) Sorga}

Discovered 1912 Apr. 15 by A. Massinger at Heidelberg.

The name 'surga' means 'the heavens' in the Indonesian language. The paradise on earth was named 'surga dunia'. Both, 'surga' and 'sorga' are possible transliterations from Indonesian. (B. Hidayat)

\section{(732) Tjilaki}

Discovered 1912 Apr. 15 by A. Massinger at Heidelberg.

Named for a river in Indonesia. "Tji" means river. The river rises in the mountains where the city of Malabar \{see planet (754)\} is situated. (H 74; B. Hidayat)

\section{(733) Mocia}

Discovered 1912 Sept. 16 by M. F. Wolf at Heidelberg.

Named in honor of Max Wolf's youngest son, Werner Wolf, who in his childhood had the nickname "Mok". (I. van Houten-Groeneveld)

\section{(734) Benda}

Discovered 1912 Oct. 11 by J. Palisa at Vienna.

Named in honor of Anna Benda, second wife of the discoverer, which he married in 1902. (M. G. Firneis, Astron. Ges., Abstr. Ser., No. 13, p. 143 (1997))

This name erroneously was attributed to the Czech composer Karl Bendl (1838-1897) in previous editions of this Dictionary.

Named by friends of the discoverer (Astronomischer Kalender für 1917).

\section{(735) Marghanna}

Discovered 1912 Dec. 9 by H. Vogt at Heidelberg.

Named in honor of the discoverer's mother Margarete Vogt and after Hanna, who was a relative of $\mathrm{H}$. Vogt \{see planet (1439)\}. (H 74)

\section{(736) Harvard}

Discovered 1912 Nov. 16 by J. H. Metcalf at Winchester.

Named for the famous University at Cambridge, Massachusetts. (H 74)

See also the remarks to planet (1052). 


\section{(737) Arequipa}

Discovered 1912 Dec. 7 by J. H. Metcalf at Winchester.

Named for the city in Peru where the Harvard Observatory had a southern observing station. (H 74) See also the remarks to planet (1052).

\section{(738) Alagasta}

Discovered 1913 Jan. 7 by F. Kaiser at Heidelberg.

Named after the first German name of the city of Gaualgesheim on the Rhine river from which the family of the discoverer originated. The city originally was named Alagastesheim after Alagast, modified from Alberich, the trustee of the "Hort der Nibelungen". (H 74)

\section{(739) Mandeville}

Discovered 1913 Feb. 7 by J. H. Metcalf at Winchester.

Named for the city of Mandeville, Jamaica, where Edward C. Pickering \{see planet (784)\} observed. (H 74)

See also the remarks to planet (1052).

\section{(740) Cantabia}

Discovered 1913 Feb. 10 by J. H. Metcalf at Winchester.

This name is probably a contraction of Cantabridgia, the Latin form of Cambridge, Massachusetts, site of the Harvard Observatory. (H 74)

See also the remarks to planet (1052).

\section{(741) Botolphia}

Discovered 1913 Feb. 10 by J. H. Metcalf at Winchester.

Named for the city of Boston, Massachusetts. The city derives its name from Saint Botolph who founded a monastery in the year 654 . (H 74)

See also the remarks to planet (1052).

\section{(742) Edisona}

Discovered 1913 Feb. 23 by F. Kaiser at Heidelberg.

Named in honor of the great American scientist and inventor Thomas Alva Edison (1847-1931) immediately after his death. The "Astronomical Society Urania, Wiesbaden", which Franz Kaiser founded, sent an artistically arranged scroll of dedication to the heirs of Edison by the help of the American Consulate at Frankfurt a.M. (H 75)

Edison is also honored by a lunar crater.

\section{(743) Eugenisis}

Discovered 1913 Feb. 25 by F. Kaiser at Heidelberg.

This name is composed from the two Greek words "eu" (good, well) and "genesis" (creation). Obviously, there is a close connection with the birth of the daughter of the discoverer (see also the citation for planet (746)). (M. Kretlow; I. van Houten-Groeneveld)

The naming information was given by Dr. M.-L. Kaiser, daughter of the discoverer.

\section{(744) Aguntina}

Discovered 1913 Feb. 26 by J. Rheden at Vienna.
Named for Aguntinum, a Roman town in the province of Noricum close to Lienz, the birthplace of the discoverer. (H 75)

The naming information was given by Mrs. Rheden, widow of the discoverer and daughter of J. Palisa.

\section{(745) Mauritia}

Discovered 1913 Mar. 1 by F. Kaiser at Heidelberg.

Named by the discoverer after the patron St. Mauritius of a church of Wiesbaden \{see planet (717)\}, Germany. (H 75)

\section{(746) Marlu}

Discovered 1913 Mar. 1 by F. Kaiser at Heidelberg.

Named by the discoverer in honor of his daughter, the physician Dr. Marie-Louise Kaiser. See also the citation for planet (743). (H 75)

\section{(747) Winchester}

Discovered 1913 Mar. 7 by J. H. Metcalf at Winchester. Named by the discoverer for the city of Winchester, Massachusetts, where he made this discovery. (H 75)

\section{(748) Simeïsa}

Discovered 1913 Mar. 14 by G. N. Neujmin at Simeis.

Named for the Simeis Observatory and the town of Simeis, Crimea, where the planet was first discovered. (H 75)

This is the first minor planet discovered in Russia.

\section{(749) Malzovia}

Discovered 1913 Apr. 5 by S. I. Belyavskij at Simeis.

Named in honor of the Russian amateur astronomer S. I. Malzov. In 1911, he deeded his private observatory at Simeis as a gift to the Pulkovo Observatory. Malzov was a close friend of the discoverer and of J. O. Backlund \{see planet (856)\}. After 1918, Malzov resided at Menton, French Riviera. (H 75)

\section{(750) Oskar}

Discovered 1913 Apr. 28 by J. Palisa at Vienna.

Named very probably in remembrance of Oskar Ruben von Rothschild (1888-1909), the youngest son of Baron Albert von Rothschild \{see planet (719)\}. The reconstruction and improvement of the telescope drive of the so-called Rothschild Coudé Telescope of the Vienna Observatory was payed by the Oskar Freiherr von Rothschild-Stiftung in 1913. (A. Schnell)

Named by friends of the discoverer (Astronomischer Kalender für 1917).

\section{(751) Faïna}

Discovered 1913 Apr. 28 by G. N. Neujmin at Simeis. Named in honor of Mrs. F. M. Neujmin, the first wife of the discoverer. (N. S. Samojlova-Yakhontova)

\section{(752) Sulamitis}

Discovered 1913 Apr. 30 by G. N. Neujmin at Simeis.

Named for Sulamith, a woman in the book "Solomon's Song" 7, 1 of the Old Testament. The writer describes 
her great beauty. Sulamith probably was the queen of Sheba. (I. van Houten-Groeneveld)

\section{(753) Tiflis}

Discovered 1913 Apr. 30 by G. N. Neujmin at Simeis.

Named for the native city of the discoverer. Tiflis (or Tbilisi) is the capital city of Georgia on the Kura river. (H 75)

\section{(754) Malabar}

Discovered 1906 Aug. 22 by A. Kopff at Heidelberg.

Named in remembrance of the Dutch-German solar eclipse expedition to Christmas Island in 1922. Malabar is a city and mountain on Java. (I. van Houten-Groeneveld; B. Hidayat)

The naming is described in AN 218, 253 (1923): "Aus Anlass der holländisch-deutschen SonnenfinsternisExpedition nach Christmas Island wurde der Planet der Niederländisch-Indischen Sternkundigen-Vereinigung zur Benennung überlassen als Zeichen des Dankes für die der Expedition zuteil gewordene Förderung. Herr K. A. R. Bosscha auf Malabar (Java), der Vorsitzende der Vereinigung, erteilte ihm den Namen." Bosscha and his friend Kerkhoven determined that after their death a great part of their capital should be put into a fund to serve astronomy in the Netherlands and Indonesia. In 1954 the Kerkhoven-Bosscha-Fund was established in Leiden. In the course of the years this fund has grown and helps today the Dutch and Indonesian astronomy in many ways. Bosscha dedicated the name to the Malabar mountain, $40 \mathrm{~km}$ south of the city of Bandung, location of his beautifully cultivated tea plantations.

\section{(755) Quintilla}

Discovered 1908 Apr. 6 by J. H. Metcalf at Taunton.

This is the name of an Italian girl. The name was suggested by Miss Arville D. Walker, secretary to H. Shapley \{see planet (1123)\}, because at the time of the naming (in 1926) no other planet name began with the letter "Q". (H 76)

See also the remarks to planet (1052).

\section{(756) Lilliana}

Discovered 1908 Apr. 26 by J. H. Metcalf at Taunton. Named in honor of the sister of H. Shapley \{see planet (1123)\}. (H 76)

Name suggested by H. Shapley in 1926 .

See also the remarks to planet (1052).

\section{(757) Portlandia}

Discovered 1908 Sept. 30 by J. H. Metcalf at Taunton.

Named for the city of Portland, Maine, where the discoverer was minister of a church at the time of his death. (H 76)

\section{(758) Mancunia}

Discovered 1912 May 18 by H. E. Wood at Johannesburg.
Named after the city of Manchester, England, the native city of the discoverer. Mancunia is the Latin name of Manchester. (H 76)

\section{(759) Vinifera}

Discovered 1913 Aug. 26 by F. Kaiser at Heidelberg.

Named by the discoverer after the vine from which his ancestors made a living. (H 76)

\section{(760) Massinga}

Discovered 1913 Aug. 28 by F. Kaiser at Heidelberg. Independently discovered 1913 Aug. 28 by G. N. Neujmin at Simeis.

Named in honor of A. Massinger, assistant astronomer at the Heidelberg Königstuhl Observatory who died in the World War I as a soldier. (H 76)

\section{(761) Brendelia}

Discovered 1913 Sept. 8 by F. Kaiser at Heidelberg.

Named by the discoverer in honor of the late theoreticist of the minor planets, Otto Rudolph Martin Brendel (1862-1939), who at that time was director of the "Planeteninstitut" at the University of Frankfurt am Main. (H 76; AN 215, 471 (1922))

Brendel himself chose for the planet to be named the object with the smallest inclination from the planets discovered by Kaiser and not previously named.

Obituary published in Astron. Nachr., Band 270, p. 248 (1940).

\section{(762) Pulcova}

Discovered 1913 Sept. 3 by G. N. Neujmin at Simeis.

Named for Pulkovo, the locality near St. Petersburg (the former Leningrad), where the famous observatory was erected in 1839. (H 76)

\section{(763) Cupido}

Discovered 1913 Sept. 25 by F. Kaiser at Heidelberg.

Named after the Roman god of erotic love because of its relatively small distance from the Sun. See also the citation for planet (433). (H 76)

Named probably by B. Asplind.

\section{(764) Gedania}

Discovered 1913 Sept. 26 by F. Kaiser at Heidelberg.

Named by the discoverer after the Latin name of the free city of Danzig (now Gdansk, Poland) in which he was first assistant at the Observatory 1921-1925. (H 77)

The city of Danzig is also honored by planet (1419).

\section{(765) Mattiaca}

Discovered 1913 Sept. 26 by F. Kaiser at Heidelberg.

Named by the discoverer for his home town. Mattiacum was the Latin name for the city of Wiesbaden, Germany. (H 77)

The city of Wiesbaden was also honored by the discoverer with planet (717) Wisibada.

\section{(766) Moguntia}

Discovered 1913 Sept. 29 by F. Kaiser at Heidelberg. 
Named by the discoverer in honor of the city of Mainz (Latin name Moguntia), Germany. He was active for more than three years at the University as an instructor in astronomy and as the first who gave lectures within the natural sciences faculty. (H 77)

\section{(767) Bondia}

Discovered 1913 Sept. 23 by J. H. Metcalf at Winchester.

Named in honor of William Cranch Bond (1789-1859) and his son George Phillips Bond (1825-1865) who both were directors of the Harvard College Observatory in Cambridge, Massachusetts. W. C. Bond was codiscoverer of comet 1850 II and was one of the first astronomers who used the photographic technique in astronomy. G. P. Bond discovered in 1848 the Saturn satellite Hyperion and (1850) Saturn's faint crepe ring. (H 77)

Both astronomers are also honored by lunar craters, G. P. Bond also by a crater on Mars. See also the remarks to planet (1052).

\section{(768) Struveana}

Discovered 1913 Oct. 4 by G. N. Neujmin at Simeis.

Named in honor of Friedrich Georg Wilhelm Struve (1793-1864), Otto Wilhelm Struve (1819-1905), directors of the Pulkovo Observatory and famous for their double star studies, and Hermann Struve (1854-1920), director of the Königsberg and Berlin Observatories. (H 77) The Struves are also honored by a lunar crater.

\section{(769) Tatjana}

Discovered 1913 Oct. 6 by G. N. Neujmin at Simeis.

Named possibly in honor of a former scientific collaborator at the Pulkovo Observatory. Another interpretation says that this planet is named for the heroine of the celebrated poem Evgeni Onigin by the Russian poet Aleksander Sergeevich Pushkin (1799-1837, see planet (2208)). (H 77)

The naming might be influenced by the two letters of the provisional designation 1913 TA.

\section{(770) Bali}

Discovered 1913 Oct. 31 by A. Massinger at Heidelberg.

This planet was named after the Indonesian island east of Java. The discoverer repeatedly named planets after geographic items of Indonesia (cf. planets (732) and (772)). (LDS; B. Hidayat)

\section{(771) Libera}

Discovered 1913 Nov. 21 by J. Rheden at Vienna.

Named by Mrs. Hedwig Rheden in honor of a friend of the discoverer. (H 77)

\section{(772) Tanete}

Discovered 1913 Dec. 19 by A. Massinger at Heidelberg.

Named very probably after the city of Tanete on the southwest coast of Celebes, Indonesia. (R. Bremer) See also the citation for planet (770).

\section{(773) Irmintraud}

Discovered 1913 Dec. 22 by F. Kaiser at Heidelberg.

Named by the discoverer for an old German woman's name which frequently appears in old songs and sagas. (H 77)

\section{(774) Armor}

Discovered 1913 Dec. 19 by C. Le Morvan at Paris.

Armor or Armorica is the Celtic name of the Normandy and Brittany coastal regions in France. Brittany is the native region of the discoverer. (H 77)

\section{(775) Lumière}

Discovered 1914 Jan. 6 by J. Lagrula at Nice.

Named in honor of Auguste Lumière (1862-1954) and his brother Louis Lumière (1864-1948), noted French physicists and inventors of photography and cinematography. (H 78)

\section{(776) Berbericia}

Discovered 1914 Jan. 24 by A. Massinger at Heidelberg.

Named in honor of the German astronomer Adolf Berberich (1861-1920). (H 78)

Named by Max Wolf, who (AN 211, 44 (1920)) wrote: "Dem Planeten 776 möchte ich den Namen Berbericia, dem Planeten 914 den Namen Palisana beilegen, um so für die beiden Astronomen Adolf Berberich und Johann Palisa, denen die Erforschung der Planetoiden in den letzten Dezennien wohl am meisten verdankte, eine Erinnerung zu stiften."

\section{(777) Gutemberga}

Discovered 1914 Jan. 24 by F. Kaiser at Heidelberg.

Named by the discoverer in memory of Johann Gensfleisch (Gutenberg) (1400?-1468) who discovered the art of printing from movable types. He lived and died in Mainz and the neighboring Eltville. (H 78)

Gutenberg is also honored by a lunar crater.

\section{(778) Theobalda}

Discovered 1914 Jan. 25 by F. Kaiser at Heidelberg.

Named by the discoverer in honor of his father Theobald Kaiser. (H 78)

\section{(779) Nina}

Discovered 1914 Jan. 25 by G. N. Neujmin at Simeis.

Named in honor of the sister of the discoverer, the mathematician Nina Nikolaevna Neujmina (18771956). (N. S. Samojlova-Yakhontova; N. Solovaya; N. S. Chernykh)

\section{(780) Armenia}

Discovered 1914 Jan. 25 by G. N. Neujmin at Simeis.

Named for the region in western Asia southeast of the Black sea and southwest of the Caspian sea. The area is now divided between the USSR, Turkey and Iran. (H 78)

\section{(781) Kartvelia}

Discovered 1914 Jan. 25 by G. N. Neujmin at Simeis. 
This name honors the people of the Russian region of Georgia. Kartveli is the ancient name of the inhabitants. (H 78)

\section{(782) Montefiore}

Discovered 1914 Mar. 18 by J. Palisa at Vienna.

Probably named in honor of the wife of Alphonse Mayer Rothschild (1878-1942), the second son of Baron Albert von Rothschild \{see planet (719)\}, Clarice Sebag-Montefiore. The marriage took place in 1912. (A. Schnell)

Named by friends of the discoverer (Astronomischer Kalender für 1917).

\section{(783) Nora}

Discovered 1914 Mar. 18 by J. Palisa at Vienna.

Named probably for the drama of the Norwegian poet Henrik Ibsen (1828-1906) \{see planet (5696)\}. (H 78)

Named by friends of the discoverer (Astronomischer Kalender für 1917).

\section{(784) Pickeringia}

Discovered 1914 Mar. 20 by J. H. Metcalf at Winchester.

Named in honor of the brothers Edward Charles Pickering (1846-1919), director of Harvard Observatory, and William Henry Pickering (1858-1930), director of

Arequipa \{see planet (737)\} Observatory and discoverer (1898) of the ninth satellite of Saturn. (H 78)

The Pickerings are also honored by craters on the Moon and on Mars. See also the remarks to planet (1052).

\section{(785) Zwetana}

Discovered 1914 Mar. 30 by A. Massinger at Heidelberg. Named in honor of the daughter of Prof. K. Pophoff, Sofia. (H 78)

Named by A. Kopff.

\section{(786) Bredichina}

Discovered 1914 Apr. 20 by F. Kaiser at Heidelberg.

Named in honor of the Russian astronomer Feodor Alexandrovich Bredichin (1831-1904) who was director of the Pulkovo Observatory. He made important contributions to the study of comets. (H 78)

Bredichin is also honored by a lunar crater.

\section{(787) Moskva}

Discovered 1914 Apr. 20 by G. N. Neujmin at Simeis.

This planet was named for the city of Moscow, USSR. (H 79)

\section{(788) Hohensteina}

Discovered 1914 Apr. 28 by F. Kaiser at Heidelberg.

Named by the discoverer after the castle Hohenstein in the Taunus mountains near Bad Schwalbach, the original residence of the knights "Breder von Hohenstein" which is synonymous with the family name (Broeder or Breder) of his wife, who's ancestors came from that region. (H 79)

\section{(789) Lena}

Discovered 1914 June 24 by G. N. Neujmin at Simeis. Named in honor of Lena (Elena) Petrovna Neujmina (1860-1942), mother of the discoverer. (N. S. Chernykh)

\section{(790) Pretoria}

Discovered 1912 Jan. 16 by H. E. Wood at Johannesburg.

Named after the capital city of Transvaal \{see planet (715)\} in South Africa. (H 79)

\section{(791) Ani}

Discovered 1914 June 29 by G. N. Neujmin at Simeis. Named for the ruined city in the Erivan district which was destroyed by an earthquake in 1319 . Ani is situated 30 miles southeast of Kars, northeast Turkey, near the border to Armenia. Ani had so many churches that Sir John Mandeville (?-1372) called it 'the city of 1001 churches'. (H 79; R. Bremer)

\section{(792) Metcalfia}

Discovered 1907 Mar. 20 by J. H. Metcalf at Taunton.

Named in honor of Rev. Joel Hastings Metcalf (1866-1925). A member of the Committee of Harvard Observatory, he discovered six comets and 41 minor planets. He designed two objectives of 10 and 16 inch aperture. (H 79)

Metcalf is also honored by planet (726). See also the remarks to planet (1052).

\section{(793) Arizona}

Discovered 1907 Apr. 9 by P. Lowell at Flagstaff. Independently discovered 1907 Apr. 17 by J. H. Metcalf at Taunton.

Named for the state in which the Lowell Observatory is located at Flagstaff \{see planet (2118)\}. (H 79)

\section{(794) Irenaea}

Discovered 1914 Aug. 27 by J. Palisa at Vienna.

Named probably in honor of Irene Hillebrand, née Weiss, daughter of the director of the Vienna Observatory E. Weiss. The name had to be given a 'classical' form because of the existence of planet (14). (A. Schnell)

\section{(795) Fini}

Discovered 1914 Sept. 26 by J. Palisa at Vienna.

Any reference of this name to a person or occurrence is unknown.

In Austria, this nick name is a short form of Josefine.

\section{(796) Sarita}

Discovered 1914 Oct. 15 by K. Reinmuth at Heidelberg.

Any reference of this name to a person or occurrence is unknown.

\section{(797) Montana}

Discovered 1914 Nov. 17 by H. Thiele at Bergedorf.

This is the first asteroid discovered at the Bergedorf Observatory and is named by this Latin word in honor of Bergedorf ("mountain village"). (H 79) 


\section{(798) Ruth}

Discovered 1914 Nov. 21 by M. F. Wolf at Heidelberg.

This planet is possibly named for the biblical heroine in the Old Testament (Book of Ruth). (H 79)

\section{(799) Gudula}

Discovered 1915 Mar. 9 by K. Reinmuth at Heidelberg. See the remarks to planet (913).

\section{(800) Kressmannia}

Discovered 1915 Mar. 20 by M. F. Wolf at Heidelberg.

Named in honor of Major A. Kressmann who donated the Kressmann refractor for the Heidelberg Königstuhl Observatory. (H 80; AN 214, 69 (1921))

\section{(801) Helwerthia}

Discovered 1915 Mar. 20 by M. F. Wolf at Heidelberg. Named in honor of Mrs. Elise Helwerth-Wolf (18401924), the mother of the discoverer. See also planet (412). (H 80)

\section{(802) Epyaxa}

Discovered 1915 Mar. 20 by M. F. Wolf at Heidelberg. Named after Epyaxa (fl.401 B.C.) the queen of Cilicia (at the coast of Anatolia northeast of Cyprus). She was married to Syennis III. The couple supported the revolt of Cyrus the Younger against his brother Artaxerxes II Mnemon \{see planet (7212)\} as discussed by Xenophon \{see planet (5986)\} in Anabasis. Epyaxa had her own army and her own lavish budget to spend. After the defeat of Cyrus at Cunaxa, the position of Syennesis and Epyaxa was difficult and Cilicia became an ordinary strapy. (LDS)

\section{(803) Picka}

Discovered 1915 Mar. 21 by J. Palisa at Vienna.

Named in honor of the Czech physician Friedrich Pick (1867-1921). He was the first physician in Prague who introduced endoscopic methods in medicine. (H 80; A. Schnell)

Named by friends of the discoverer (Astronomischer Kalender für 1917).

\section{(804) Hispania}

Discovered 1915 Mar. 20 by J. Comas Solá at Barcelona.

This is the Latin name of Spain. Hispania is the first planet discovered in this country. (H 80)

\section{(805) Hormuthia}

Discovered 1915 Apr. 17 by M. F. Wolf at Heidelberg.

Named in honor of Mrs. Hormuth Kopff, the wife of A. Kopff \{see planet (1631)\}. (H 80)

\section{(806) Gyldénia}

Discovered 1915 Apr. 18 by M. F. Wolf at Heidelberg.

Named in honor of the Swedish astronomer Johan August Hugo Gyldén (1841-1896), director of the Stockholm Observatory and author of a new method for computing perturbations of planets and comets. (H 80)

Gyldén is also honored by a lunar crater.

\section{(807) Ceraskia}

Discovered 1915 Apr. 18 by M. F. Wolf at Heidelberg.

Named in honor of the Russian astronomer Vitold Karlovich Ceraski (1849-1925). Born in Slutsk (now in Byelorussia), he graduated from Moscow University and worked for 45 years at the Moscow Observatory. He was director of that observatory for 25 years. Ceraski worked extensively on stellar and solar photometry. (N. S. Chernykh)

Ceraski is also honored by a lunar crater. The citation (H 80) given in the first three editions of this 'Dictionary' is erroneous.

\section{(808) Merxia}

Discovered 1901 Oct. 11 by L. Carnera at Heidelberg.

Named in honor of Adalbert Merx, the father-in-law of Max Wolf. (H 80)

\section{(809) Lundia}

Discovered 1915 Aug. 11 by M. F. Wolf at Heidelberg.

Named for the city of Lund in southwestern Sweden and for the Lund Observatory. (H 80)

\section{(810) Atossa}

Discovered 1915 Sept. 8 by M. F. Wolf at Heidelberg. Named after the Persian queen, daughter of king Cyrus and wife of Darius I \{see, respectively, planets (7209) and (7210)\}. (H 80)

\section{(811) Nauheima}

Discovered 1915 Sept. 8 by M. F. Wolf at Heidelberg.

Named for the city of Bad Nauheim in Hessen, Germany. (H 80)

\section{(812) Adele}

Discovered 1915 Sept. 8 by S. I. Belyavskij at Simeis. Independently discovered 1915 Sept. 11 by M. F. Wolf at Heidelberg.

Named probably after a figure from the opera Die Fledermaus by Johann Strauss (1825-1899) \{see planet (4559)\}. (R. Bremer; I. van Houten-Groeneveld) Named by the independent discoverer M. F. Wolf.

\section{(813) Baumeia}

Discovered 1915 Nov. 28 by M. F. Wolf at Heidelberg. Named by the discoverer in honor of $\mathrm{H}$. Baum, student of astronomy at Heidelberg, who died in World War I. (H 81; AN 214, 69 (1921))

\section{(814) Tauris}

Discovered 1916 Jan. 2 by G. N. Neujmin at Simeis.

Named for the Tauric Mount on the southwest coast of Crimea. It is also the ancient name of Crimea. Gustav L. W. von Struve (1858-1920) taught astronomy at the Tauris University in Simferopol, Crimea. (H 81; R. Bremer)

\section{(815) Coppelia}

Discovered 1916 Feb. 2 by M. F. Wolf at Heidelberg. 
Named for the short ballet in two acts by Léo Delibes (1836-1891) which is based on a tale by E. T. A. Hoffmann (1776-1822). (H 81)

\section{(816) Juliana}

Discovered 1916 Feb. 8 by M. F. Wolf at Heidelberg. Named presumably in honor of Queen Juliana (1909-

) of the Netherlands. T. Gehrels, in connection with his interpretation of the meaning of the name Wilhelmina (see planet (392)) pointed out that it seems very consistent that Max Wolf named an asteroid after Queen Wilhelmina's daughter, too. (LDS)

\section{(817) Annika}

Discovered 1916 Feb. 6 by M. F. Wolf at Heidelberg.

Any reference of this name to a person or occurrence is unknown.

\section{(818) Kapteynia}

Discovered 1916 Feb. 21 by M. F. Wolf at Heidelberg.

Named in honor of the late Prof. Jacobus Cornelius Kapteyn \{1851-1922\}, who was director of the Groningen Astronomical Laboratory from 1878 till 1921. He made pioneering researches in the field of galactic structure, initiated the plan of Selected Areas and made a major contribution to the Cape Photographic Durchmusterung. (M 2822)

See also the remark to (1694) Kaiser. Kapteyn is also honored by a lunar crater.

\section{(819) Barnardiana}

Discovered 1916 Mar. 3 by M. F. Wolf at Heidelberg.

Named in honor of the American astronomer Edward Emerson Barnard (1857-1923), great observer and star photographer who discovered many double stars, 17 comets, the Jupiter satellite Amalthea (1892) and the high proper motion star which is named after him. (H 81; AN 215, 471 (1922))

Barnard is also honored by a lunar crater, a crater on the Mars surface and a region on the Jupiter satellite Ganymede.

\section{(820) Adriana}

Discovered 1916 Mar. 30 by M. F. Wolf at Heidelberg.

Any reference of this name to a person or occurrence is unknown.

\section{(821) Fanny}

Discovered 1916 Mar. 31 by M. F. Wolf at Heidelberg.

Any reference of this name to a person or occurrence is unknown.

\section{(822) Lalage}

Discovered 1916 Mar. 31 by M. F. Wolf at Heidelberg.

Any reference of this name to a person or occurrence is unknown.

\section{(823) Sisigambis}

Discovered 1916 Mar. 31 by M. F. Wolf at Heidelberg.

Named for Sisigambis, the mother of Darius III, the last Persian king. During the Issus Battle (333 B.C.) she was taken prisoner by Alexander the Great along with the wife Roxane see planet (317)\} and daughter of Darius. (H 81)

\section{(824) Anastasia}

Discovered 1916 Mar. 25 by G. N. Neujmin at Simeis. Independently discovered 1916 Apr. 1 by M. F. Wolf at Heidelberg.

Named in memory of Mrs. Anastasia Semenoff. (AN 223, 103 (1925))

\section{(825) Tanina}

Discovered 1916 Mar. 27 by G. N. Neujmin at Simeis. Independently discovered 1916 Apr. 3 by M. F. Wolf at Heidelberg.

Any reference of this name to a person or occurrence is unknown.

\section{(826) Henrika}

Discovered 1916 Apr. 28 by M. F. Wolf at Heidelberg.

Any reference of this name to a person or occurrence is unknown.

\section{(827) Wolfiana}

Discovered 1916 Aug. 29 by J. Palisa at Vienna.

Named in honor of Max \{Franz Josef Cornelius\} Wolf (1863-1932), professor of astronomy at the University of Heidelberg and founder and director of the Königstuhl Observatory. Wolf discovered several novae, comets and hundreds of minor planets. The original citation for this planet and (828) is published in AN 211, 441 (1920): "Den Planeten 827 widme ich meinem Freunde Wolf, dem Begründer der photographischen Entdeckungsmethode Kleiner Planeten; den Planeten 828 widme ich Herrn Lindemann, dem uneigennützigen und großherzigen Förderer astronomischer Forschung." (H 82)

Wolf is also honored by a lunar crater and by planet (1217).

\section{(828) Lindemannia}

Discovered 1916 Aug. 29 by J. Palisa at Vienna.

Named in honor of Prof. Adolf F. Lindemann (18461931) of Sidmouth, England, who invented, together with his son F. A. Lindemann, the Lindemann Electrometer. Wolf visited Lindemann's private observatory during a stay in England in 1896. See also the citation for planet (827). (H 82; A. Schnell)

\section{(829) Academia}

Discovered 1916 Aug. 25 by G. N. Neujmin at Simeis. Independently discovered 1916 Aug. 31 by M. F. Wolf at Heidelberg.

This planet honors the 200th anniversary of the founding of the Academy of Sciences in St. Petersburg (see also planet (830)). (H 82)

\section{(830) Petropolitana}

Discovered 1916 Aug. 25 by G. N. Neujmin at Simeis. Independently discovered 1916 Sept. 3 by M. F. Wolf at Heidelberg. 
This planet is named on the same occasion as planet (829) which was discovered at the same night. It honors the city of St. Petersburg (the former Leningrad). (H 82)

\section{(831) Stateira}

Discovered 1916 Sept. 20 by M. F. Wolf at Heidelberg.

Named after the wife of king Artaxerxes II of Persia who died following poisoning by her mother-in-law Parysatis $\{$ see planet (888)\}. (H 82)

\section{(832) Karin}

Discovered 1916 Sept. 20 by M. F. Wolf at Heidelberg.

Named after Karin Mansdotter from Swedish history. She was the mistress of Erik XIV of Sweden in the 16th century. Karin married Erik 1567, but he was pushed from his throne because of this marriage. (H 82)

\section{(833) Monica}

Discovered 1916 Sept. 20 by M. F. Wolf at Heidelberg.

Any reference of this name to a person or occurrence is unknown.

\section{(834) Burnhamia}

Discovered 1916 Sept. 20 by M. F. Wolf at Heidelberg.

Named in honor of the American astronomer Sherburne Wesley Burnham (1838-1921). From 1869 he observed as an amateur astronomer and discovered many visual binaries. Later he observed in Chicago (1877), Lick (1888) and Yerkes (1897) Observatories. Burnham is the author of the famous General Catalogue of Double Stars of 13,665 binaries. (H 82; AN 214, 69 (1921))

Burnham is also honored by a lunar crater.

\section{(835) Olivia}

Discovered 1916 Sept. 23 by M. F. Wolf at Heidelberg.

Any reference of this name to a person or occurrence is unknown.

\section{(836) Jole}

Discovered 1916 Sept. 23 by M. F. Wolf at Heidelberg.

Named for Jole or Iole, the daughter of Eurytos and by force wife of Hercules. (LDS)

\section{(837) Schwarzschilda}

Discovered 1916 Sept. 23 by M. F. Wolf at Heidelberg.

Named in honor of the German astronomer Karl Schwarzschild (1873-1916), director of the Göttingen (1901) and Potsdam (1909) Observatories. He worked in photometry, geometrical optics, stellar statistics and theoretical astrophysics. (H 82)

Schwarzschild is also honored by a lunar crater. The Schwarzschild black hole, the Schwarzschild radius and the Schwarzschild telescope bear his name.

\section{(838) Seraphina}

Discovered 1916 Sept. 24 by M. F. Wolf at Heidelberg.

Any reference of this name to a person or occurrence is unknown.

\section{(839) Valborg}

Discovered 1916 Sept. 24 by M. F. Wolf at Heidelberg.

Named for the heroine in the drama Axel e Valborg of the Danish writer Adam Gottlob Oehlenschläger (1779-1850). (H 82)

\section{(840) Zenobia}

Discovered 1916 Sept. 25 by M. F. Wolf at Heidelberg.

The planet is probably named for the Slavic goddess of hunting. It is also the name of a queen of Palmyra. Zenobia enlarged her country with Egypt and parts of Arabia and Asia Minor. She was defeated by Marcus Aurelius in 272 near Antiochia. (H 83; I. van Houten-Groeneveld)

\section{(841) Arabella}

Discovered 1916 Oct. 1 by M. F. Wolf at Heidelberg.

Named after the opera of the same name by the German composer Richard Strauss (1864-1949) \{see planet (5039)\}. (H 83)

\section{(842) Kerstin}

Discovered 1916 Oct. 1 by M. F. Wolf at Heidelberg.

Any reference of this name to a person or occurrence is unknown.

\section{(843) Nicolaia}

Discovered 1916 Sept. 30 by H. Thiele at Bergedorf.

Named in honor of Torvald Nicolai Thiele (1838-1910), the father of the discoverer. (H 83)

\section{(844) Leontina}

Discovered 1916 Oct. 1 by J. Rheden at Vienna.

Named by the discoverer for his home town Lienz in the province of Tirol, Austria. (AN 204, 63 (1917))

\section{(845) Naëma}

Discovered 1916 Nov. 16 by M. F. Wolf at Heidelberg. Any reference of this name to a person or occurrence is unknown.

\section{(846) Lipperta}

Discovered 1916 Nov. 26 by W. Gyllenberg at Bergedorf.

Named in honor of Eduard Lippert, donor of the Lippert Astrograph of the Bergedorf Observatory. (H 83)

\section{(847) Agnia}

Discovered 1915 Sept. 2 by G. N. Neujmin at Simeis.

Named in honor of a Simeis physician, Agnia Ivanovna Bad'ina (1877-1956). (N. S. Samojlova-Yakhontova; N. Solovaya; N. S. Chernykh)

\section{(848) Inna}

Discovered 1915 Sept. 5 by G. N. Neujmin at Simeis. Independently discovered 1915 Sept. 9 by M. F. Wolf at Heidelberg.

Named in honor of Inna Nikolaevna Leman-Balanovskaya (1881-1945), astronomer at the Pulkovo Observatory. (N. S. Chernykh) 


\section{(849) Ara}

Discovered 1912 Feb. 9 by S. I. Belyavskij at Simeis.

Named in appreciation of the help rendered by ARA (American Relief Administration) under Herbert Hoover during the famine of 1922-1923. (H 83)

\section{(850) Altona}

Discovered 1916 Mar. 27 by S. I. Belyavskij at Simeis.

Named for the German city on the Elbe river near Hamburg. Altona is the home-town of W. Struve, founder of the Pulkovo Observatory. (H 83)

\section{(851) Zeissia}

Discovered 1916 Apr. 2 by S. I. Belyavskij at Simeis.

Named in honor of the famous German optician and mechanician Carl Zeiss (1816-1888) who founded 1846 the Zeiss optical works in Jena. (H 83)

\section{(852) Wladilena}

Discovered 1916 Apr. 2 by S. I. Belyavskij at Simeis.

Named in honor of the Russian Communist leader Vladimir Ilyich Ulyanov (Lenin) (1870-1924). The name comprises the first syllables of Lenin's name. (H 84)

\section{(853) Nansenia}

Discovered 1916 Apr. 2 by S. I. Belyavskij at Simeis.

Named in honor of the Norwegian Arctic explorer Fridtjov Nansen (1861-1930). With his ship "Fram" he explored the vicinity of the North Pole (1893-1896). Nansen is also known as statesman who, in 1922, received the Nobel Peace Prize. (H 84)

Nansen is also honored by craters on the Moon and on Mars.

\section{(854) Frostia}

Discovered 1916 Apr. 3 by S. I. Belyavskij at Simeis.

Named in honor of the American astronomer Edwin Brant Frost (1866-1935) in gratitude for his generous help during the difficult years after World War I (see also planet (849)). Frost was professor of astrophysics at the University of Chicago and director of the Yerkes Observatory. He also edited the Astrophysical Journal. (H 84)

Frost is also honored by a lunar crater.

\section{(855) Newcombia}

Discovered 1916 Apr. 3 by S. I. Belyavskij at Simeis. Independently discovered 1916 Apr. 28 by M. F. Wolf at Heidelberg.

Named in honor of the American astronomer Simon Newcomb (1835-1909), professor of astronomy and director of the U.S. Nautical Almanac Office. Newcomb worked on cometary and planetary orbits and on the theory of the orbit of the Earth. He measured the velocity of light and determined the astronomical unit anew. (H 84)

Newcomb is also honored by craters on the Moon and on Mars, respectively.

\section{(856) Backlunda}

Discovered 1916 Apr. 3 by S. I. Belyavskij at Simeis.

Named in honor of the Russian astronomer Johann Oskar Backlund (1846-1916). Backlund, who was born in Sweden, worked on the orbits of comets and especially on comet Encke. (H 84)

Backlund is also honored by a lunar crater.

\section{(857) Glasenappia}

Discovered 1916 Apr. 6 by S. I. Belyavskij at Simeis.

Named in honor of Sergej Pavlov Glasenapp (18481937), director of the Observatories in Pulkovo (18701877) and St. Petersburg (1893). Glasenapp worked on visual binaries and on the satellites of Jupiter. He observed the transits of Venus and Mercury and several solar eclipses. Glasenapp was a founder of the Russian Astronomical Society. (H 84)

Glasenapp is also honored by a lunar crater.

\section{(858) El Djezaïr}

Discovered 1916 May 26 by F. Sy at Algiers.

This is the Arabian name for the city of Algiers which means "the islands". (H 84)

This is the first minor planet whose name is composed of two words.

\section{(859) Bouzaréah}

Discovered 1916 Oct. 2 by F. Sy at Algiers.

This planet was named after the locality where the Algiers Observatory was erected. (H 84)

\section{(860) Ursina}

Discovered 1917 Jan. 22 by M. F. Wolf at Heidelberg. Any reference of this name to a person or occurrence is unknown.

\section{(861) Aïda}

Discovered 1917 Jan. 22 by M. F. Wolf at Heidelberg.

Named for the opera of the same name by the Italian composer Giuseppe Verdi (1813-1901) \{see planet (3975)\}. (H 84)

\section{(862) Franzia}

Discovered 1917 Jan. 28 by M. F. Wolf at Heidelberg.

Named in honor of Franz Wolf, son of the discoverer. (H 84)

\section{(863) Benkoela}

Discovered 1917 Feb. 9 by M. F. Wolf at Heidelberg.

Named possibly for the city of Benkoelen on the island of Sumatra. (H 84)

(864) Aase

A921 SB. Discovered 1921 Sept. 30 by K. Reinmuth at Heidelberg.

Named for a character in the play Peer Gynt of the Norwegian poet and dramatist Henrik Ibsen (1828-1906) \{see planet (5696)\}. (LDS)

The French astronomer A. Patry, Nice, detected in 1958 the identity between the numbered planets (864) Aase and (1078) Mentha (MPC 1763). (864) has never 
been re-observed after the discovery opposition of 1917 until the identification with (1078). Therefore, the Minor Planet Center retained the number and name for (1078) Mentha and vacated the number (864). This number was later assigned to the Reinmuth discovery.

\section{(865) Zubaida}

Discovered 1917 Feb. 15 by M. F. Wolf at Heidelberg. Named after a character from $A b u$ Hassan by the German composer Carl Maria Friedrich Ernst von Weber (1786-1826) \{see planet (4152)\}. (H 85)

\section{(866) Fatme}

Discovered 1917 Feb. 25 by M. F. Wolf at Heidelberg.

Named after a character from Abu Hassan by the German composer Carl Maria Friedrich Ernst von Weber (1786-1826) \{see planet (4152)\}. (H 85)

\section{(867) Kovacia}

Discovered 1917 Feb. 25 by J. Palisa at Vienna.

Named in honor of Prof. Friedrich Kovacs (18611931), a Vienna physician who restored Mrs. Palisa's health. (H 85)

\section{(868) Lova}

Discovered 1917 Apr. 26 by M. F. Wolf at Heidelberg.

Any reference of this name to a person or occurrence is unknown.

\section{(869) Mellena}

Discovered 1917 May 9 by R. Schorr at Bergedorf. Independently discovered 1917 May 10 by M. F. Wolf at Heidelberg.

Named in honor of the Bürgermeister (mayor) of Hamburg, von Melle, founder of the Hamburg Observatory. (H 85)

\section{(870) Manto}

Discovered 1917 May 12 by M. F. Wolf at Heidelberg.

Named for the famous soothsayer and daughter of Teresias Thebanus. She erected Apollo's \{see planet (1862)\} oracle in Delphi. (H 85)

\section{(871) Amneris}

Discovered 1917 May 14 by M. F. Wolf at Heidelberg. Named for a character from the opera Aida ssee planet (861)\} by the Italian composer Giuseppe Verdi (1813-1901) \{see planet (3975)\}. (H 85)

\section{(872) Holda}

Discovered 1917 May 21 by M. F. Wolf at Heidelberg.

Named presumably in honor of Edward Singleton

Holden (1846-1914), American astronomer at Lick Observatory, which Wolf had visited before World

War I. (I. van Houten-Groeneveld)

Holden, definitively, is honored by planet (2974).

\section{(873) Mechthild}

Discovered 1917 May 21 by M. F. Wolf at Heidelberg.

Any reference of this name to a person or occurrence is unknown.

\section{(874) Rotraut}

Discovered 1917 May 25 by M. F. Wolf at Heidelberg.

Named probably after the poem Schön Rotraut by the German poet Eduard Mörike (1804-1875). (I. van Houten-Groeneveld)

\section{(875) Nymphe}

Discovered 1917 May 19 by M. F. Wolf at Heidelberg.

Named for the minor divinities of nature in ancient mythology represented as beautiful maidens dwelling in the mountains, forests, trees and waters. $(\mathrm{H} 85)$

\section{(876) Scott}

Discovered 1917 June 20 by J. Palisa at Vienna.

This name had been attributed erroneously to the British polar explorer Robert Fulcon Scott in earlier publications. The real motive is published in the (Vienna) Astronomischer Kalender für 1923: "Herr Palisa hat dem von ihm entdeckten Planeten den Namen Scott zur dankbaren Erinnerung an Miss E. Scott gegeben, welche lange Zeit hindurch in selbstlosester Weise die Hilfeleistung der Society of Friends in Wien geleitet und sich ganz besonders um die Verbesserung der Lage von Mitgliedern der Hochschulen Österreichs bemüht hat." The name therefore honors Miss E. Scott in recognition of her help and assistance to the members of the Austrian universities after World War I. (A. Schnell)

\section{(877) Walküre}

Discovered 1915 Sept. 13 by G. N. Neujmin at Simeis.

he heroes to be slain in battle and conduct them to Valhalla \{see planet (1260)\}. It is also the title of an opera by the German composer Richard Wagner (1813-1883) \{see planet (3992)\} in Ring der Nibelungen. (LDS)

Named (AN 219, 401 (1923)) by S. I. Belyavskij.

\section{(878) Mildred}

Discovered 1916 Sept. 6 by S. B. Nicholson at Mount Wilson.

Named in honor of Mildred Shapley Matthews \{1915- \}, the daughter of Harlow Shapley \{see planet (1123)\}. (H 85)

\section{(879) Ricarda}

Discovered 1917 July 22 by M. F. Wolf at Heidelberg. Named in honor of the German poetess Ricarda Huch (1864-1947). (H 85)

Ricarda Huch is also honored by planet (8847).

\section{(880) Herba}

Discovered 1917 July 22 by M. F. Wolf at Heidelberg.

Named for the Greek god of misery and poverty. (H 86)

\section{(881) Athene}

Discovered 1917 July 22 by M. F. Wolf at Heidelberg.

Named for the Greek goddess of wisdom, comparable to the Roman Minerva ssee planet (93)\}. Athene is often called Pallas Athene. (H 86) 


\section{(882) Swetlana}

Discovered 1917 Aug. 15 by G. N. Neujmin at Simeis. Independently discovered 1917 Aug. 18 by M. F. Wolf at Heidelberg.

Any reference of this name to a person or occurrence is unknown.

\section{(883) Matterania}

Discovered 1917 Sept. 14 by M. F. Wolf at Heidelberg. Independently discovered 1917 Sept. 14 by R. Schorr at Bergedorf.

Named for the producer of photographic plates who donated many photographic plates for the Heidelberg Observatory. Max Wolf in June 1921 wrote: "In Anerkennung der Verdienste, die sich Herr August Matter in Mannheim um unsere wissenschaftliche Arbeit erworben hat, dadurch dass er jahrelang seine Kraft und Geschicklichkeit an die Herstellung unserer Aufnahmeplatten setzte, sodass dadurch zahlreiche Entdeckungen und Grundlagen für die künftige Forschung ermöglicht worden sind, geben wir dem Planeten (883) 1917 CP, entdeckt am 14. Sept. 1917 mit Matterplatten, den Namen Matterania zur dauernden Erinnerung an unseren Wohltäter, dem wir dadurch unseren Dank ausdrücken wollen." Matter's factory was destroyed in World War II. (LDS; AN 214, 69 (1921))

\section{(884) Priamus}

Discovered 1917 Sept. 22 by M. F. Wolf at Heidelberg.

Named for the king of Troy during the Trojan War, father of Hector and Paris \{see planets (624) and (3317), respectively\}. (H 86)

\section{(885) Ulrike}

Discovered 1917 Sept. 23 by S. I. Belyavskij at Simeis. Independently discovered 1917 Sept. 26 by M. F. Wolf at Heidelberg.

Named presumably in honor of Ulrike von Levetzow (1804-1899). The eminent German poet Johann Wolfgang von Goethe \{see planet (3047)\} met Ulrike during summertime 1821-1823 in Marienbad, Bohemia. Goethe proposed to her but she denied his offer of marriage. His grief found an expression in the famous Marienbader Elegie (1823). (A. N. Deutsch; LDS)

This interpretation seems very likely in view of the fact that the discoverer studied in Göttingen, Germany, and was an expert in German literature.

\section{(886) Washingtonia}

Discovered 1917 Nov. 16 by G. H. Peters at Washington. Independently discovered 1917 Nov. 12 by M. Harwood at Nantucket.

Named in honor of George Washington (1732-1799), the first president (1789-1797) of the United States of America. (H 86)

For a more detailed description of the discovery circumstances see the the citations for planets (7040) and (7041), respectively.

\section{(887) Alinda}

Discovered 1918 Jan. 3 by M. F. Wolf at Heidelberg.

According to Australian aboriginal mythology, Alinda is the man in the moon. He drowned his two sons after they returned from fishing and lied that they had caught nothing. His two wives then burned him to death. Alinda proclaimed that although death would henceforth be the fate of everyone else, except for three days each month he would live forever. (From John Gunther's Inside Australia, Harper \& Row, New York, 1971 , p. 81). R. Bremer in an alternative explanation suggested that Alinda is a name of an ancient city and recent archaeological site in Asia Minor in the province of ancient Caria. (B. G. Marsden)

Name proposed by H. Kobold (AN 250, 145 (1933)).

\section{(888) Parysatis}

Discovered 1918 Feb. 2 by M. F. Wolf at Heidelberg.

Named after the wife of the Persian king Darius II, mother of Artaxerxes II \{see planet (831)\} and Cyrus the Younger. (H 86)

\section{(889) Erynia}

Discovered 1918 Mar. 5 by M. F. Wolf at Heidelberg.

Named after one of the avenging deities who according to Greek mythology tormented criminals and inflicted plagues. In Roman mythology they are called furies. (H 86)

\section{(890) Waltraut}

Discovered 1918 Mar. 11 by M. F. Wolf at Heidelberg.

Named after a character in the opera Götterdämmerung (the fourth and last part of Der Ring der Nibelungen) of the German composer Richard Wagner (1813-1883) \{see planet (3992)\}. (H 86)

\section{(891) Gunhild}

Discovered 1918 May 17 by M. F. Wolf at Heidelberg.

Any reference of this name to a person or occurrence is unknown.

\section{(892) Seeligeria}

Discovered 1918 May 31 by M. F. Wolf at Heidelberg.

Named in honor of the German astronomer Hugo Hans von Seeliger (1849-1924), director of the Munich Observatory. Von Seeliger investigated the movement of the perihelion of Mercury and was one of the founders of stellar astronomy. He published books on the motion of binaries and on the theory of the heliometer. (H 86)

Seeliger is also honored by a lunar crater.

\section{(893) Leopoldina}

Discovered 1918 May 31 by M. F. Wolf at Heidelberg.

Named in honor of the "Carolinisch-Leopoldinische Akademie der Naturforscher in Halle", Germany. (H 86)

(894) Erda

Discovered 1918 June 4 by M. F. Wolf at Heidelberg. 
Named for the Norse goddess, incarnation of the nature, a seer who knows the origin and the destination of all things. (H 87)

\section{(895) Helio}

Discovered 1918 July 11 by M. F. Wolf at Heidelberg.

Named by the German physicist Friedrich Paschen

(1865-1940) in remembrance of common investigations about the helium spectrum together with Runge. (H 87)

\section{(896) Sphinx}

Discovered 1918 Aug. 1 by M. F. Wolf at Heidelberg.

Named for a female monster having, according to Greek mythology, a winged lion's body and a human head and having the habit of asking a riddle and killing anyone who failed to answer it. ( $\mathrm{H} 87$ )

\section{(897) Lysistrata}

Discovered 1918 Aug. 3 by M. F. Wolf at Heidelberg.

Named after the comedy of the Athenian dramatist Aristophanes (448?-380? B.C.) \{see planet (2934)\}. Lysistrata organized a general strike of women in order to prevent a war. (H 87)

\section{(898) Hildegard}

Discovered 1918 Aug. 3 by M. F. Wolf at Heidelberg.

Named probably after the St. Hildegard von Bingen (1098-1179). (H 87)

\section{(899) Jokaste}

Discovered 1918 Aug. 3 by M. F. Wolf at Heidelberg.

Named for the mother of Oedipus. She married her son without recognizing him, and by him had sons Polynice and Eteocles. (H 87)

\section{(900) Rosalinde}

Discovered 1918 Aug. 10 by M. F. Wolf at Heidelberg.

Named probably for a figure in the opera Die Fledermaus by Johann Strauss (1825-1899) \{see planet (4559)\}. (I. van Houten-Groeneveld)

See also the citation for planet (812).

\section{(901) Brunsia}

Discovered 1918 Aug. 30 by M. F. Wolf at Heidelberg.

Named in honor of Ernst Heinrich Bruns (1848-1919), professor of astronomy and director of the Leipzig Observatory. (H 87; AN 214, 69 (1921))

\section{(902) Probitas}

Discovered 1918 Sept. 3 by J. Palisa at Vienna.

This name stands for the adherence to the highest principles and ideals. This has been assigned in honor of the discoverer after his death because uprightness was considered to be one of the essential traits of his character. (H 87)

Named by the Austrian astronomer J. Rheden in agreement with Anna Palisa, the second wife of the discoverer (AN 240, 303 (1930)).

The planets (975) and (996) have been named in a similar way after the death of Palisa.
(903) Nealley

Discovered 1918 Sept. 13 by J. Palisa at Vienna.

Named in honor of the New York amateur astronomer Nealley who supported the edition of the Wolf-Palisa photographic star charts. (Beobachtungszirk. AN 3, 61 (1921))

\section{(904) Rockefellia}

Discovered 1918 Oct. 29 by M. F. Wolf at Heidelberg. Named in honor of John David Rockefeller (18391937), founder of the Rockefeller Foundation. (H 87)

\section{(905) Universitas}

Discovered 1918 Oct. 30 by A. Schwassmann at Bergedorf.

Named by the discoverer in memory of the founding of the University of Hamburg, Germany. (H 88)

\section{(906) Repsolda}

Discovered 1918 Oct. 30 by A. Schwassmann at Bergedorf.

Named in honor of Johann Georg Repsold (17711830), famous manufacturer of optics and precision mechanics for astrometric instruments. (H 88) Repsold is also honored by a lunar crater.

\section{(907) Rhoda}

Discovered 1918 Nov. 12 by M. F. Wolf at Heidelberg. Named in honor of the wife of the American astronomer Edward Emerson Barnard \{see planet (819)\}. (H 88; AN 215, 471 (1922))

\section{(908) Buda}

Discovered 1918 Nov. 30 by M. F. Wolf at Heidelberg.

Named for a part of the Hungarian city of Budapest on the Danube. (H 88)

\section{(909) Ulla}

Discovered 1919 Feb. 7 by K. Reinmuth at Heidelberg.

Named in honor of Ulla Ahrens, a daughter of a friend of the discoverer. See also the citation for planet (950). (H 88)

\section{(910) Anneliese}

Discovered 1919 Mar. 1 by K. Reinmuth at Heidelberg. Named for an acqaintance of the German astronomer Julius Dick from the Babelsberg Observatory. (H 88) Named by J. Dick.

\section{(911) Agamemnon}

Discovered 1919 Mar. 19 by K. Reinmuth at Heidelberg.

Named for the king of Mycenae who was the leader of the Greeks in the Trojan War. (H 88)

\section{(912) Maritima}

Discovered 1919 Apr. 27 by A. Schwassmann at Bergedorf.

Probably named during the first marine travel of Hamburg University. Before World War II, once a year the University closed during the summer semester and went out on the North Sea for three to four days 
on one of the larger ocean liners which were put at the disposal of the University by the big Hamburg shipping companies. (H 88)

Named by R. Schorr.

See also the citation for planet (947).

\section{(913) Otila}

Discovered 1919 May 19 by K. Reinmuth at Heidelberg.

Karl Reinmuth discovered so many minor planets that he often had difficulties to find proper names for the numbered ones. He therefore frequently used girl's names from the calendar Der Lahrer hinkende Bote. These names need not to have any connections to his contemporaries. (I. van Houten-Groeneveld)

\section{(914) Palisana}

Discovered 1919 July 4 by M. F. Wolf at Heidelberg.

Named in honor of the famous Austrian astronomer Johann Palisa (1848-1925), observer at the Marine Observatory in Pola and vice-director of the Vienna Observatory. Palisa discovered more than 120 minor planets and the comet $1879 \mathrm{~V}$. In collaboration with M. F. Wolf he produced the famous Wolf-Palisa star charts and he initiated the Carte du Ciel endeavor. (H 88)

Palisa is also honored by a lunar crater and by the planets (902), (975), and (996). See also the remarks to planet (776).

\section{(915) Cosette}

Discovered 1918 Dec. 14 by F. Gonnessiat at Algiers.

Named in honor of the youngest daughter of the discoverer. (H 88)

\section{(916) America}

Discovered 1915 Aug. 7 by G. N. Neujmin at Simeis.

Named for the American continent possibly in appreciation of the help rendered by the American Relief Administration under President Hoover during the famine in Crimea. (H 89)

Named (AN 219, 59 (1923)) by the Pulkovo astronomers.

\section{(917) Lyka}

Discovered 1915 Sept. 5 by G. N. Neujmin at Simeis.

Named after a girl-friend of the sister of the discoverer. (N. S. Chernykh)

\section{(918) Itha}

Discovered 1919 Aug. 22 by K. Reinmuth at Heidelberg. See the remarks to planet (913).

\section{(919) Ilsebill}

Discovered 1918 Oct. 30 by M. F. Wolf at Heidelberg. Named for the famous character appearing in the German fairy tale Von den Fischer un sijne Fru (The Fisherman and His Wife) by J. and W. Grimm. (H 89) Name proposed by Mrs. G. Wolf (RI 1013).
(920) Rogeria

Discovered 1919 Sept. 1 by K. Reinmuth at Heidelberg. See the remarks to planet (913).

\section{(921) Jovita}

Discovered 1919 Sept. 4 by K. Reinmuth at Heidelberg. See the remarks to planet (913).

\section{(922) Schlutia}

Discovered 1919 Sept. 18 by K. Reinmuth at Heidelberg.

Named in honor of the important businessmen Edgar Schlubach (Hamburg) and Mr. Tiarks (London) who together supported the Dutch-German solar eclipse expedition to Christmas Island in 1922. (H 89)

Named (AN 218, 253 (1923)) by Schlubach and Tiarks.

\section{(923) Herluga}

Discovered 1919 Sept. 30 by K. Reinmuth at Heidelberg. See the remarks to planet (913).

\section{(924) Toni}

Discovered 1919 Oct. 20 by K. Reinmuth at Heidelberg. See the remarks to planet (913).

\section{(925) Alphonsina}

Discovered 1920 Jan. 13 by J. Comas Solá at Barcelona.

Named in honor of two kings of Spain: Alphonsus X (1223-1284), King of Castille, and Alphonsus XIII (1886-1941), King of Spain. The original citation reads: "La petite planète ... a reçu le nom de Alphonsina, comme double hommage au roi Alphonse X, dit le Savant, roi de Castille et de Léon (siècle XIII), et à qui on doit de si importantes inspirations sur l'astronomie pendant le moyen âge, et au roi Alphonse XIII, grand enthousiaste pour le développement des Sciences dans son pays. Le nom de Alphonsina a été accepté avec plaisir par S.M. le roi d'Espagne." (AN 211, 223 (1920))

\section{(926) Imhilde}

Discovered 1920 Feb. 15 by K. Reinmuth at Heidelberg. See the remarks to planet (913).

\section{(927) Ratisbona}

Discovered 1920 Feb. 16 by M. F. Wolf at Heidelberg.

Named for the German city of Regensburg (Ratisbona is the Latin name). The famous astronomer Johannes Kepler \{see planet (1134)\} died in Regensburg in 1630 . (AN 240, 135 (1930))

\section{(928) Hildrun}

Discovered 1920 Feb. 23 by K. Reinmuth at Heidelberg. See the remarks to planet (913).

\section{(929) Algunde}

Discovered 1920 Mar. 10 by K. Reinmuth at Heidelberg. See the remarks to planet (913).

\section{(930) Westphalia}

Discovered 1920 Mar. 10 by W. Baade at Bergedorf.

Named by the discoverer for the region Westfalen in western Germany bordering the Netherlands and the 
Rhine river. Baade was born in Schröttinghausen in Westfalen. (H 90)

\section{(931) Whittemora}

Discovered 1920 Mar. 19 by F. Gonnessiat at Algiers. Independently discovered 1920 Mar. 21 by K. Reinmuth at Heidelberg.

Named in honor of Thomas Whittemore who was professor at both Harvard and Columbia Universities. (H 90)

\section{(932) Hooveria}

Discovered 1920 Mar. 23 by J. Palisa at Vienna.

Named in honor of Herbert Clark Hoover (1874-1964) in recognition of his help and assistance to Austria after World War I. (AN 216, 192 (1922))

Named by the Academic Senate of the Vienna University.

Hoover, later president of the United States, was also honored by planet (1363).

\section{(933) Susi}

1927 CH. Discovered 1927 Feb. 10 by K. Reinmuth at Heidelberg.

Named in honor of Mrs. S. Graff, wife of the director of the Vienna Observatory. (H 90)

\section{(934) Thüringia}

Discovered 1920 Aug. 15 by W. Baade at Bergedorf.

Thüringia was one of the ships of the HamburgAmerica Line. The discoverer made two trips from Hamburg to New York on this ship during the 1920's. The captain of the ship was an amateur astronomer and was invited by the discoverer to name one of his minor planets. (H 90)

The planet and the ship are named for the German province of Thüringen.

\section{(935) Clivia}

Discovered 1920 Sept. 7 by K. Reinmuth at Heidelberg. Named after a flower of the Amaryllis family. (H 90)

\section{(936) Kunigunde}

Discovered 1920 Sept. 6 by K. Reinmuth at Heidelberg. See the remarks to planet (913).

\section{(937) Bethgea}

Discovered 1920 Sept. 12 by K. Reinmuth at Heidelberg.

Named in honor of the German lyrical poet Hans Bethge (1876-1946). (H 90)

\section{(938) Chlosinde}

Discovered 1920 Sept. 9 by K. Reinmuth at Heidelberg. See the remarks to planet (913).

\section{(939) Isberga}

Discovered 1920 Oct. 4 by K. Reinmuth at Heidelberg. See the remarks to planet (913).

\section{(940) Kordula}

Discovered 1920 Oct. 10 by K. Reinmuth at Heidelberg. See the remarks to planet (913).

\section{(941) Murray}

Discovered 1920 Oct. 10 by J. Palisa at Vienna.

Named in honor of the family of the American professor Gilbert Murray (1866-1957) who helped Austria after World War I in 1920. (H 91)

\section{(942) Romilda}

Discovered 1920 Oct. 11 by K. Reinmuth at Heidelberg. Independently discovered 1920 Oct. 11 by A. Schwassmann at Bergedorf.

See the remarks to planet (913).

\section{(943) Begonia}

Discovered 1920 Oct. 20 by K. Reinmuth at Heidelberg.

Named after a genus of tropical herbs having asymmetrical leaves and being widely cultivated as ornamentals. (H 91)

\section{(944) Hidalgo}

Discovered 1920 Oct. 31 by W. Baade at Bergedorf.

German astronomers observed the total solar eclipse 1923 September 10 in Mexico. After the eclipse they had an audience with the president of Mexico and asked permission to call this planet after Miguel Hidalgo y Costilla (1753-1811) who proclaimed the Mexican independence in 1810. R. Schorr wrote: "Zur Erinnerung an die Deutsche Sonnenfinster-Expedition nach Mexiko im Sommer 1923 und die ihr durch die mexikanische Regierung erwiesene gastliche Aufnahme ist unter der Zustimmung des Staatspräsidenten Don Alvaro Obregón der ... am Bergedorfer Spiegelteleskop entdeckte, durch seine Bahn besonders interessante Planet ... nach dem mexikanischen Nationalhelden Hidalgo benannt worden." (AN 221, 159 (1924))

\section{(945) Barcelona}

Discovered 1921 Feb. 3 by J. Comas Solá at Barcelona.

Named for the birthplace of the discoverer and the place were this minor planet was discovered. (H 91)

\section{(946) Poësia}

Discovered 1921 Feb. 11 by M. F. Wolf at Heidelberg. Named after the goddess of poetry. (H 91) Name proposed by N. Komendantov.

\section{(947) Monterosa}

Discovered 1921 Feb. 8 by A. Schwassmann at Bergedorf.

Probably named for the ship "Monterosa" on the occasion of a marine travel by the Hamburg University to the North Sea. (RI 929; H 91)

Named by R. Schorr.

See also the citation for planet (912).

\section{(948) Jucunda}

Discovered 1921 Mar. 3 by K. Reinmuth at Heidelberg. See the remarks to planet (913). 


\section{(949) Hel}

Discovered 1921 Mar. 11 by M. F. Wolf at Heidelberg.

Named for the Norse goddess of the dead and the queen of the underworld. (LDS)

Name proposed by Mrs. G. Wolf, the widow of the discoverer, two years after his death (RI 1013).

\section{(950) Ahrensa}

Discovered 1921 Apr. 1 by K. Reinmuth at Heidelberg.

Named in honor of the Ahrens family, friends of the

discoverer who helped financially at the Königstuhl

Observatory. See also the citation for planet (909). (H 91)

\section{(951) Gaspra}

Discovered 1916 July 30 by G. N. Neujmin at Simeis.

Named after the resort on the southern shore of Crimea in which the famous Russian writer Lev Nikolaevich Tolstoj (1828-1910) spent many years of his life. (H 91)

This planet was the first space mission asteroid target with the Galileo spacecraft. Galileo submitted the first detailed photograph of a minor planet from the flyby of 1991 October 29.

\section{(952) Caia}

Discovered 1916 Oct. 27 by G. N. Neujmin at Simeis.

Named after a heroine in the novel Quo Vadis of the Polish writer Henryk Sienkiewicz (1846-1916). (N. S. Samojlova-Yakhontova)

\section{(953) Painleva}

Discovered 1921 Apr. 29 by B. Jekhovsky at Algiers.

Named in honor of Paul Painlevé (1863-1933), French mathematician and several times French minister (1917-1933). His scientific works refer to analysis and aerodynamics. (H 92; M.-A. Combes)

\section{(954) Li}

Discovered 1921 Aug. 4 by K. Reinmuth at Heidelberg.

Named in honor of Mrs. Lina Alstede Reinmuth, wife of the discoverer. (H 92)

Mrs. Reinmuth is also honored by planet (955).

\section{(955) Alstede}

Discovered 1921 Aug. 5 by K. Reinmuth at Heidelberg.

Named in honor of Mrs. Lina Alstede Reinmuth, wife of the discoverer. (H 92)

Mrs. Reinmuth is also honored by planet (954).

\section{(956) Elisa}

Discovered 1921 Aug. 8 by K. Reinmuth at Heidelberg.

Named in honor of Elisa Reinmuth, mother of the discoverer. (H 92)

\section{(957) Camelia}

Discovered 1921 Sept. 7 by K. Reinmuth at Heidelberg.

Named for a genus of shrubs or trees of the tea family, especially a ornamental greenhouse shrub with glossy evergreen leaves and showy roselike flowers. (H 92)

\section{(958) Asplinda}

Discovered 1921 Sept. 28 by K. Reinmuth at Heidelberg.

Named in honor of Bror Ansgar Asplind \{1890-1954\}, the Swedish computer of planetary orbits. (H 92)

\section{(959) Arne}

Discovered 1921 Sept. 30 by K. Reinmuth at Heidelberg. Named in honor of a son of B. Asplind \{see planet (958)\}. (H 92)

\section{(960) Birgit}

Discovered 1921 Oct. 1 by K. Reinmuth at Heidelberg. Named in honor of a daughter of B. Asplind s see planet (958)\}. (H 92)

\section{(961) Gunnie}

Discovered 1921 Oct. 10 by K. Reinmuth at Heidelberg.

Named in honor of a daughter of B. Asplind ssee planet (958)\}. (H 92)

\section{(962) Aslög}

Discovered 1921 Oct. 25 by K. Reinmuth at Heidelberg.

This is a Christian name from Norse mythology. Aslög followed her foster-father hidden in his harp. Her fiancé Ragnar wanted to test Aslög's intelligence and asked her to come to him: naked but dressed. She used a fishnet as dress and so she was accepted as his wife. (H 92)

Name proposed by B. Asplind.

\section{(963) Iduberga}

Discovered 1921 Oct. 26 by K. Reinmuth at Heidelberg. See the remarks to planet (913).

\section{(964) Subamara}

Discovered 1921 Oct. 27 by J. Palisa at Vienna.

Amarus is the Latin word for bitter and the addition of the prefix sub yield the meaning 'very bitter'. This name very probably reflects the bad observing situation from the Vienna Observatory during the last years of Palisa's life. This interpretation is supported by his paper in AN 222, 172 (1924). (A. Schnell)

\section{(965) Angelica}

Discovered 1921 Nov. 4 by J. Hartmann at La Plata.

Named in honor of Angelica Hartmann, wife of the discoverer. (H 92)

\section{(966) Muschi}

Discovered 1921 Nov. 9 by W. Baade at Bergedorf.

Named in honor of the wife of the discoverer. Muschi is a nickname. (H 93)

\section{(967) Helionape}

Discovered 1921 Nov. 9 by W. Baade at Bergedorf.

Named in honor of the theatrical artist Sonnenthal. Helionape is the Greek translation (Sonne $=$ helio, Tal = nape). Adolf Ritter von Sonnenthal (1834-1909), famous actor at the Vienna Burgtheater and later director of this institution, was known world-wide by 
many guest performances in Europe and America. (AN 223, 247 (1925))

Named by C. Wirtz.

\section{(968) Petunia}

Discovered 1921 Nov. 24 by K. Reinmuth at Heidelberg.

Named for a genus of tropical American herbs of the nightshade family with funnel-shaped corollas. (H 93)

\section{(969) Leocadia}

Discovered 1921 Nov. 5 by S. I. Belyavskij at Simeis. Independently discovered 1921 Nov. 25 by K. Reinmuth at Heidelberg.

Any reference of this name to a person or occurrence is unknown.

\section{(970) Primula}

Discovered 1921 Nov. 29 by K. Reinmuth at Heidelberg.

Named for a genus of perennial herbs with large tufted basal leaves and showy variously colored flowers. The English name is primrose. (H 93)

\section{(971) Alsatia}

Discovered 1921 Nov. 23 by A. Schaumasse at Nice.

Named after the province Alsace in northeast France between the Rhine river and the Vosges mountains. (H 93)

The discoverer proposed the name Alsace (J. Obs., Tome V, p. 6, 100 (1922)). The Astronomisches Rechen-Institut changed the name in Alsatia.

\section{(972) Cohnia}

Discovered 1922 Jan. 18 by M. F. Wolf at Heidelberg.

Named in honor of the German astronomer F. Cohn (1866-1921) who was director of the Astronomisches Rechen-Institut in Berlin. (H 93)

Named by M. F. Wolf and G. Stracke (AN 219, 401 (1923)) who wrote: "Der Planet 972 hat zum Andenken an den verstorbenen Direktor des Astronomischen Rechen-Instituts zu Berlin-Dahlem, Professor F. Cohn, den Namen erhalten. Es ist dies nur ein schwacher Ausdruck für die großen Verdienste, die sich Cohn gerade auf dem Gebiete der Kleinen Planeten erworben hat."

\section{(973) Aralia}

Discovered 1922 Mar. 18 by K. Reinmuth at Heidelberg.

Named after a widely cultivated ornamental climbing or prostrate or sometimes shrubby Eurasian vine of the ginseng family with evergreen leaves, small yellowish flowers, and black berries. (H 93)

\section{(974) Lioba}

Discovered 1922 Mar. 18 by K. Reinmuth at Heidelberg.

Named after the Saint Lioba, abbess in Tauberbischofsheim, Germany. She was buried at the side of Bonifatius in 782 in Fulda, Germany. (I. van Houten-Groeneveld)
(975) Perseverantia

Discovered 1922 Mar. 27 by J. Palisa at Vienna.

Named in honor of the discoverer after his death (1925). Perseverance was an essential trait of Palisa's character. (H 93)

Named by the Austrian astronomer J. Rheden in agreement with Anna Palisa, the second wife of the discoverer (AN 240, 303 (1930)).

The planets (902) and (996) have been named in a similar way after the death of Palisa.

\section{(976) Benjamina}

Discovered 1922 Mar. 27 by B. Jekhovsky at Algiers.

Named in honor of the discoverer's son Benjamin. (H 93)

\section{(977) Philippa}

Discovered 1922 Apr. 6 by B. Jekhovsky at Algiers.

Named in honor of the financier Philipp von Rothschild. (H 94)

\section{(978) Aidamina}

Discovered 1922 May 18 by S. I. Belyavskij at Simeis. Independently discovered 1922 May 30 by M. F. Wolf at Heidelberg.

Named in honor of Aida Minaevna, friend of the discoverer's family. (N. S. Samojlova-Yakhontova; N. Solovaya; N. S. Chernykh)

\section{(979) Ilsewa}

Discovered 1922 June 29 by K. Reinmuth at Heidelberg.

Named in honor of Ilse Walldorf, an acquaintance of the discoverer. (H 94)

\section{(980) Anacostia}

Discovered 1921 Nov. 21 by G. H. Peters at Washington.

Named for an urban district in the city of Washington, D.C. and also for a river in the region. (H 94)

\section{(981) Martina}

Discovered 1917 Sept. 23 by S. I. Belyavskij at Simeis.

Named in honor of the French revolutionary Henri Martin. (H 94)

\section{(982) Franklina}

Discovered 1922 May 21 by H. E. Wood at Johannesburg.

Named by the discoverer in honor of the late John Franklin Adams (1843-1912), British amateur astronomer and author of stellar maps. (H 94)

Franklin Adams is also honored by planet (1925).

\section{(983) Gunila}

Discovered 1922 July 30 by K. Reinmuth at Heidelberg. See the remarks to planet (913).

\section{(984) Gretia}

Discovered 1922 Aug. 27 by K. Reinmuth at Heidelberg. Named for a sister-in-law of A. Kahrstedt \{see planet (1587)\}. (H 94)

See also the remarks to planet (1026). 


\section{(985) Rosina}

Discovered 1922 Oct. 14 by K. Reinmuth at Heidelberg. See the remarks to planet (913).

\section{(986) Amelia}

Discovered 1922 Oct. 19 by J. Comas Solá at Barcelona. Named in honor of the discoverer's wife. (H 94)

\section{(987) Wallia}

Discovered 1922 Oct. 23 by K. Reinmuth at Heidelberg. See the remarks to planet (913).

\section{(988) Appella}

Discovered 1922 Nov. 10 by B. Jekhovsky at Algiers.

Named in honor of Paul Émile Appell (1855-1930), president of the Academy of Sciences and of the Société Astronomique de France. Appell is the author of the magisterial Traité de Mécanique Rationnelle. (H 94)

Obituary published in l'Astronomie, Vol. 45, p. 42-43 (1931).

\section{(989) Schwassmannia}

Discovered 1922 Nov. 18 by A. Schwassmann at Bergedorf.

Named in honor of the German astronomer Arnold Schwassmann (1870-1964) who discovered four comets and 22 minor planets. Schwassmann worked at the Potsdam and Hamburg-Bergedorf Observatories. (H 94)

\section{(990) Yerkes}

Discovered 1922 Nov. 23 by G. Van Biesbroeck at Williams Bay. Independently discovered 1922 Dec. 14 by M. F. Wolf at Heidelberg.

Named by the discoverer for the observatory where this planet was discovered. It was the first planet, Van Biesbroeck discovered at the Yerkes Observatory. (H 95)

The name Yerkes also appear as a lunar crater.

\section{(991) McDonalda}

Discovered 1922 Oct. 24 by O. Struve at Williams Bay. Named for the observatory erected on Mount Locke, Fort Davis, Texas, whose 82 -inch reflector was made up with the legacy of Mr. W. J. McDonald who is also honored by this planet. (H 95)

\section{(992) Swasey}

Discovered 1922 Nov. 24 by O. Struve at Williams Bay.

Named in honor of the optician Dr. Swasey of the Warner and Swasey Works who built the 82-inch reflector of the McDonald Observatory. (H 95)

\section{(993) Moultona}

Discovered 1923 Jan. 12 by G. Van Biesbroeck at Williams Bay.

Named by the discoverer in honor of the American astronomer and mathematician Forest Ray Moulton (1872-1952) who is wellknown for his work on celestial mechanics. (H 95)

Moulton is also honored by a lunar crater.

\section{(994) Otthild}

Discovered 1923 Mar. 18 by K. Reinmuth at Heidelberg. See the remarks to planet (913).

\section{(995) Sternberga}

Discovered 1923 June 8 by S. I. Belyavskij at Simeis.

Named in honor of the Russian astronomer Pavel K. Sternberg (1865-1920) from the Moscow University. (H 95)

Sternberg is also honored by a lunar crater.

\section{(996) Hilaritas}

Discovered 1923 Mar. 21 by J. Palisa at Vienna.

The name stands for a happy or contented mind. This was an important quality of Palisa's character who is honored by this planet. (H 95)

Named by the Austrian astronomer J. Rheden in agreement with Anna Palisa, the second wife of the discoverer (AN 240, 303 (1930)).

The planets (902) and (975) have been named in a similar way after the death of Palisa.

\section{(997) Priska}

Discovered 1923 July 12 by K. Reinmuth at Heidelberg. See the remarks to planet (913).

\section{(998) Bodea}

Discovered 1923 Aug. 6 by K. Reinmuth at Heidelberg.

Named in honor of the German astronomer and mathematician Johann Elert Bode (1747-1826). He was the founder of the Berliner Astronomisches Jahrbuch (1774) and director of the Berlin Observatory in 1780 . He is also known for the empiric law of planetary distances (1766) which was originally found by J. D. Titius \{see planet (1998)\}. (H 95)

Name proposed by B. Asplind.

Bode is also honored by a lunar crater.

\section{(999) Zachia}

Discovered 1923 Aug. 9 by K. Reinmuth at Heidelberg.

Named in honor of the astronomer and mathematician Franz Xaver Freiherr von Zach (1754-1832). He was the director of the Seeberg Observatory near Gotha, Germany. Von Zach recovered planet (1) Ceres profiting the Gauss computings because the planet was lost in consequence of Piazzi's serious illness. He founded the journal Monatliche Correspondenz zur Beförderung der Erd- und Himmelskunde which was the main medium for exchange and improvements in observation and data treatment of the first asteroids. (H 95) Zach is also honored by a lunar crater.

\section{(1000) Piazzia}

Discovered 1923 Aug. 12 by K. Reinmuth at Heidelberg. Named in honor of Giuseppe Piazzi (1746-1826), Theatin monk and director of the observatories of Palermo and Naples. He discovered (1) Ceres and elaborated a catalog of 7,646 stars. (H 96)

Piazzi is also honored by a lunar crater. 


\section{(1001) Gaussia}

Discovered 1923 Aug. 8 by S. I. Belyavskij at Simeis.

Named in honor of Carl Friedrich Gauss (1777-1855), director of the Göttingen Observatory. With his new computing method F. X. von Zach \{see planet (999)\} rediscovered (1) Ceres. (H 96)

Named by B. Asplind.

Gauss is also honored by a lunar crater.

\section{(1002) Olbersia}

Discovered 1923 Aug. 15 by V. A. Albitskij at Simeis. Named in honor of Heinrich Wilhelm Matthias Olbers (1758-1840) who was a physician in Bremen and a keen amateur astronomer. Olbers discovered (2) Pallas, (4) Vesta and six comets and was the author of the first method for computing cometary orbits. (H 96)

Named by B. Asplind.

Olbers is also honored by a lunar crater.

\section{(1003) Lilofee}

Discovered 1923 Sept. 13 by K. Reinmuth at Heidelberg.

Named by the discoverer (RI 402) for a legendary character which is the title figure in an old German folk-song Die schöne junge Lilofee by August Schnezler. Lilofee was a mermaid of the Mummelsee in the Black Forest. (H 96; R. Bremer)

Name proposed by J. Riem, astronomer at the Astronomisches Rechen-Institut in Berlin.

\section{(1004) Belopolskya}

Discovered 1923 Sept. 5 by S. I. Belyavskij at Simeis. Independently discovered 1923 Sept. 13 by K. Reinmuth at Heidelberg.

Named in honor of A. A. Belopolsky (1854-1934), astrophysicist at the Pulkovo Observatory. (H 96)

Belopolsky is also honored by a lunar crater.

\section{(1005) Arago}

Discovered 1923 Sept. 5 by S. I. Belyavskij at Simeis.

Named in honor of François Arago (1786-1853), since 1843 director of the Paris Observatory, life-secretary of the Academy of Sciences, politician and author of the four volume Astronomie Populaire (1854-1857). (H 96)

Arago is also honored by craters on Mars and the Moon.

\section{(1006) Lagrangea}

Discovered 1923 Sept. 12 by S. I. Belyavskij at Simeis.

Named in honor of the astronomer and mathematician Joseph Louis Lagrange (1736-1813). He was professor of mathematics in Turin (1753), Berlin (1766) and Paris (1787) and author of the famous Mécanique analytique (1788) and Théories des fonctions analytiques (1797). (H 96)

Lagrange is also honored by a lunar crater.

\section{(1007) Pawlowia}

Discovered 1923 Oct. 5 by V. A. Albitskij at Simeis.
Named in honor of the Russian biologist Ivan Petrovich Pavlov (1849-1936), the 1904 Nobel Prize winner for physiology and medicine. (H 96)

Pavlov is also honored by a lunar crater.

\section{(1008) La Paz}

Discovered 1923 Oct. 31 by M. F. Wolf at Heidelberg. Named for the capital of Bolivia, South America. (H 96)

\section{(1009) Sirene}

Discovered 1923 Oct. 31 by K. Reinmuth at Heidelberg. Named for the sirens in Greek mythology. (H 96)

\section{(1010) Marlene}

Discovered 1923 Nov. 12 by K. Reinmuth at Heidelberg.

The name honors the Berlin born motion picture star Maria Magdalena von Losch alias Marlene Dietrich \{1901-1992\}. (H 97)

Name suggested by G. Stracke.

\section{(1011) Laodamia}

Discovered 1924 Jan. 5 by K. Reinmuth at Heidelberg.

This name has two meanings in the Greek mythology: (1) Laodamia, the daughter of Akastos, was the wife of Protesilaos \{see planet (3540)\}.who was killed in the Trojan War. Her fate is described in a tragedy of Euripides $\{$ see planet (2930)\}. (2) Laodamia was the daughter of Bellerophon \{see planet (1808)\} and the wife of Sarpedon \{see planet (2223)\}. She was killed by the arrows of Artemis \{see planet (105)\}. (LDS)

Name suggested by N. Komendantov (RI 740).

\section{(1012) Sarema}

Discovered 1924 Jan. 12 by K. Reinmuth at Heidelberg.

Named after a character in one of the poems of Aleksandr Pushkin \{see planet (2208)\}. (H 97) Name suggested by N. Komendantov (RI 740).

\section{(1013) Tombecka}

Discovered 1924 Jan. 17 by B. Jekhovsky at Algiers.

Named in honor of D. Tombeck, secretary of the Faculty of Sciences of Paris. (H 97)

\section{(1014) Semphyra}

Discovered 1924 Jan. 29 by K. Reinmuth at Heidelberg.

Named after a character in one of the poems of Aleksandr Pushkin \{see planet (2208)\}. (H 97) Name proposed by N. Komendantov (RI 740).

\section{(1015) Christa}

Discovered 1924 Jan. 31 by K. Reinmuth at Heidelberg. Any reference of this name to a person or occurrence is unknown.

Name possibly proposed by G. Stracke.

\section{(1016) Anitra}

Discovered 1924 Jan. 31 by K. Reinmuth at Heidelberg. Named probably after the Arabian dancer Anitra in Henrik Ibsen's (1828-1906) \{see planet (5696)\} drama Peer Gynt. The Norwegian Edvard Grieg (1843-1907) 
\{see planet (4872)\} composed the Peer Gynt Suite No. 1 of which one of the pieces is called Anitra's Dance. (R. Bremer; I. van Houten-Groeneveld)

\section{(1017) Jacqueline}

Discovered 1924 Feb. 4 by B. Jekhovsky at Algiers.

Named in honor of Jacqueline Zadoc-Kahn, an old disciple of the discoverer. (H 97)

\section{(1018) Arnolda}

Discovered 1924 Mar. 3 by K. Reinmuth at Heidelberg. Der Planet hat aus Anlass des 70. Geburtstags des Herausgebers der Naturwissenschaften, Dr.Ing. e.h. Dr.phil. Arnold Berliner den Namen "Arnolda" erhalten. (AN 247, 295 (1933))

\section{(1019) Strackea}

Discovered 1924 Mar. 3 by K. Reinmuth at Heidelberg.

Named in honor of the German astronomer Gustav Stracke (1887-1943). Stracke for decades until his death was in charge of the minor planet department at the Astronomisches Rechen-Institut in Berlin-Dahlem. (H 97)

The original citation (RI 2501) reads: "Der Planet ... ist vor Jahren von dem Entdecker ... "Strackea" getauft worden. Auf Wunsch von Prof. Stracke ist bisher die Benennung unterblieben. Zum Andenken an den langjährigen Leiter der Arbeiten an den Kleinen Planeten soll nun der Planet 1019 den Namen "Strackea" tragen." Stracke was also honored by a series of planets - see the citation of planet (1234).

\section{(1020) Arcadia}

Discovered 1924 Mar. 7 by K. Reinmuth at Heidelberg.

The planet was named for the Greek province on the Peloponnese peninsula. (H 97)

\section{(1021) Flammario}

Discovered 1924 Mar. 11 by M. F. Wolf at Heidelberg.

Named in honor of the French astronomer Camille

Flammarion (1842-1925), author of many astronomical books. Flammarion founded the journal l'Astronomie (1882) and the "Société Astronomique de France" (1887). (H 98)

Flammarion is also honored by craters on Mars and the Moon.

\section{(1022) Olympiada}

Discovered 1924 June 23 by V. A. Albitskij at Simeis.

Named in honor of Olimpiada Albitskaya, the mother of the discoverer. (N. S. Chernykh)

\section{(1023) Thomana}

Discovered 1924 June 25 by K. Reinmuth at Heidelberg.

Named in honor of the famous boys' choir (Thomaner) in the Thomas-Kirche in Leipzig, Germany. Reinmuth stated in a letter: "Auf der Leipziger Astronomentagung erhielt er zu Ehren des Thomanerchores dann den Namen..." (H 98; LDS)

\section{(1024) Hale}

Discovered 1923 Dec. 12 by G. Van Biesbroeck at Williams Bay.

Named in honor of George Ellery Hale (1868-1938), founder and first director of Yerkes and Mt. Wilson Observatories and inspirer of the observatory at Mt. Palomar. With J. E. Keeler \{see planet (2261)\} he founded the Astrophysical Journal, and he invented the spectroheliograph. (H 98)

Hale is also honored by craters on Mars and the Moon.

\section{(1025) Riema}

Discovered 1923 Aug. 12 by K. Reinmuth at Heidelberg.

Named in honor of Johannes Riem \{1868-1945\}, a German astronomer at the Astronomisches RechenInstitut in Berlin-Dahlem. (H 98)

Name proposed by the Astronomisches Rechen-Institut (RI 762).

\section{(1026) Ingrid}

Discovered 1923 Aug. 13 by K. Reinmuth at Heidelberg. Named after a niece of A. Kahrstedt ssee planet (1587)\} as a present on the day of baptism. (H 98; LDS)

The naming of this planet and that of (984) Gretia is well documented by a letter from Kahrstedt to the discoverer from Feb. 24, 1926: "...Ich möchte Sie bitten, mir zu gestatten, dass ich zwei der von Ihnen entdeckten Planetoiden "Gretia" und "Ingrid" taufe, Namen, die entschieden vernünftiger sind, als mancher Unsinn, der schon auf unserer Namensliste steht. Im Laufe des Sommers soll nämlich das Töchterchen meines Bruders "Ingrid" getauft werden, ich soll Pate stehen und würde mich sehr freuen, wenn ich Mutter und Kind je einen kleinen Planeten als Patengeschenk mitbringen könnte..."

\section{(1027) Aesculapia}

Discovered 1923 Nov. 11 by G. Van Biesbroeck at Williams Bay.

Named for Aesculapius, the Roman god of medicine, son of Apollo \{see planet (1862)\} and Koronis \{see planet (158)\}. (H 98)

\section{(1028) Lydina}

Discovered 1923 Nov. 6 by V. A. Albitskij at Simeis.

Named in honor of Lydia Il'inichna Albitskaya, the wife of the discoverer. (N. S. Chernykh)

\section{(1029) La Plata}

Discovered 1924 Apr. 28 by J. Hartmann at La Plata. Named after the city of La Plata, Argentina. (H 98)

\section{(1030) Vitja}

Discovered 1924 May 25 by V. A. Albitskij at Simeis.

Named in honor of Viktor (Vitja) Viktorovich Zaslavskij (1925-1944), a nephew of Spiridon Zaslavskij \{see planet (1330)\}, the brother-in-law of the discoverer. (LDS) 
(1031) Arctica

Discovered 1924 June 6 by S. I. Belyavskij at Simeis.

Named for the Arctic sea. (H 98)

(1032) Pafuri

Discovered 1924 May 30 by H. E. Wood at Johannesburg.

Named for a river in northern Transvaal, South Africa. (H 98)

\section{(1033) Simona}

Discovered 1924 Sept. 4 by G. Van Biesbroeck at Williams Bay. Independently discovered 1924 Sept. 5 by S. I. Belyavskij at Simeis.

Named in honor of the discoverer's daughter who is now Mrs. John Titus. (H 98)

\section{(1034) Mozartia}

Discovered 1924 Sept. 7 by V. A. Albitskij at Simeis.

Named in honor of the composer Wolfgang Amadeus Mozart \{1756-1791\}. (M 837)

\section{(1035) Amata}

Discovered 1924 Sept. 29 by K. Reinmuth at Heidelberg.

Named possibly after the wife of king Latinus and mother of Lavinia, the wife of Aeneas ssee planet (1172)\} in Latium. (Z 19; R. Bremer; LDS)

\section{(1036) Ganymed}

Discovered 1924 Oct. 23 by W. Baade at Bergedorf.

Named after the beautiful youth in classical mythology carried off to Olympus to be the cupbearer of the gods. (LDS)

The name Ganymede has also been given to the third satellite of Jupiter, discovered 1610 by Galilei.

\section{(1037) Davidweilla}

Discovered 1924 Oct. 29 by B. Jekhovsky at Algiers.

Named in honor of David Weill, a member of the Academy of Sciences and benefactor of the Sorbonne University, Paris. (H 99)

\section{(1038) Tuckia}

Discovered 1924 Nov. 24 by M. F. Wolf at Heidelberg.

Named in honor of Mr. and Mrs. Edward Tuck, philantropists. He is the son of the founder of the Republican Party in the United States. (H 99)

Name proposed by Mme. G. Camille Flammarion (l'Astronomie, Vol. 41, p. 229 (1927)).

\section{(1039) Sonneberga}

Discovered 1924 Nov. 24 by M. F. Wolf at Heidelberg.

Named for the city of Sonneberg in Thüringen, Germany, location of the Sonneberg Observatory. (H 99)

\section{(1040) Klumpkea}

1925 BD. Discovered 1925 Jan. 20 by B. Jekhovsky at Algiers.

Named in honor of the amateur astronomer Dorothea Klumpke \{1861-1943\} \{see also planet (339)\}, wife of the English astronomer Isaac Roberts. She was the first woman to receive the degree of Doctor of Mathematical Sciences at the Sorbonne University. (H 99)

(1041) Asta

1925 FA. Discovered 1925 Mar. 22 by K. Reinmuth at Heidelberg.

This planet is possibly named in honor of the Danish actress Asta Nielsen (1881-1972). (LDS)

Name proposed by G. Stracke.

\section{(1042) Amazone}

1925 HA. Discovered 1925 Apr. 22 by K. Reinmuth at Heidelberg.

Named for the women of Scythia near the rivers Tanais and Thermodon. They had no men and joined with their neighbours, killed the sons and educated the daughters of whom the teats were burnt so that they could discharge the arrows more rapidly. The name means "without teat". Heracles \{see planet (5143)\} and Theseus fought against the Amazones. The most famous queens are Penthesileia and Hippolyte \{see, respectively, planets (271) and (10295)\}. (I. van Houten-Groeneveld)

Name proposed by G. Stracke.

\section{(1043) Beate}

1925 HB. Discovered 1925 Apr. 22 by K. Reinmuth at Heidelberg.

Any reference of this name to a person or occurrence is unknown.

Name proposed by G. Stracke.

\section{(1044) Teutonia}

Discovered 1924 May 10 by K. Reinmuth at Heidelberg.

Named after the region, now in Denmark and Germany, that was once inhabited by the tribe of Teutons. (I. van Houten-Groeneveld)

Name proposed by G. Stracke.

\section{(1045) Michela}

Discovered 1924 Nov. 19 by G. Van Biesbroeck at Williams Bay.

Named in honor of the discoverer's daughter Micheline. (H 99)

\section{(1046) Edwin}

Discovered 1924 Dec. 1 by G. Van Biesbroeck at Williams Bay.

Named in honor of the discoverer's son. (H 99)

\section{(1047) Geisha}

Discovered 1924 Nov. 17 by K. Reinmuth at Heidelberg.

Named for the opera of the same name by Jones. The dictionary defines: a Japanese girl who is trained to provide entertaining and lighthearted company especially for a man or a group of men. (H 100)

\section{(1048) Feodosia}

Discovered 1924 Nov. 29 by K. Reinmuth at Heidelberg. 
Named for the city Feodosija in the Crimea. (A. Paluzíe-Borrell)

Named in accordance with a proposal by the computer I. Putilin (RI 628).

\section{(1049) Gotho}

1925 RB. Discovered 1925 Sept. 14 by K. Reinmuth at Heidelberg.

Any reference of this name to a person or occurrence is unknown.

(1050) Meta

1925 RC. Discovered 1925 Sept. 14 by K. Reinmuth at Heidelberg.

Any reference of this name to a person or occurrence is unknown.

\section{(1051) Merope}

1925 SA. Discovered 1925 Sept. 16 by K. Reinmuth at Heidelberg.

Named for one of the Pleiades, daughters of Atlas and Pleione.

\section{(1052) Belgica}

1925 VD. Discovered 1925 Nov. 15 by E. Delporte at Uccle.

Named in honor of the state of Belgium. This is the first minor planet to be discovered in Uccle \{see planet (1276)\}, Belgium. (H 100)

Brian G. Marsden (private communication) discovered a remarkable piece of history involving minor planet names and World War I. He detected a correspondence between Prof. W. W. Campbell, director of the Lick Observatory, and Rev. J. Metcalf which proves that Metcalf submitted the name "Belgica", evidently during 1915-1917 (after the Belgian relief effort but before the United States entered the war), and had it turned down by Prof. F. Cohn, director of the Astronomisches Rechen-Institut in Berlin.

In a letter from October 1, 1919 Prof. Campbell wrote to Metcalf: "Professor Russell of Princeton told a group of astronomers in Washington last June about a most remarkable incident of which he said you were the hero. The circumstances were reported to be as follows: Before the United States entered the great war you forwarded to the Rechen-Institut in Berlin a list of four asteroids discovered by you, with proposals for the names which they should bear. One of these names was Belgica. The head of the Recheninstitut responded refusing to utilize this name and expressing the hope that you were not casting political aspersions, or something of that kind. Would you be so good as to let me have the precise facts in the case? I think the incident is most remarkable..." The \{undated answer by Metcalf says the following: "...The facts of the would be Belgica are briefly these. At the Allied Bazaar Prof. \{Henry Norris\} Russell asked me for an unnamed asteroid that the naming of it might be sold to the highest bidder. I sent him four. The people paid the price (about $\$ 50$ ) and sent me through Prof.
Russell the names. One of them was Belgica. I saw the possibility of trouble but I sent it along as I had agreed to. Prof. Cohn of the Rechen-Institut sent backward that it was "impossible" at that moment anyway. I think myself it was poor taste. Of course he blamed me. I never took the trouble to tell him how it happened. The other names were very long queer ones that they objected also. In fact, the only successful part of it was that we obtained some money for the Allied Bazaar. I am afraid Belgium was a pretty sore spot with them about the time I wrote the letter..." Unfortunately, our search did not show any surviving ARI documents that shed more light on this incident. Marsden suspects that all minor planets discovered by Metcalf from (726) Joëlla onward, with the possible exception of (747) Winchester \{home town of Rev. Metcalf\}, were named by Harlow Shapley soon after Metcalf's death in 1925. Metcalf moved from Winchester, Mass. to Portland, Maine around 1920, two years before Shapley came from Mt. Wilson to direct the Harvard College Observatory.

\section{(1053) Vigdis}

1925 WA. Discovered 1925 Nov. 16 by M. F. Wolf at Heidelberg.

Any reference of this name to a person or occurrence is unknown.

\section{(1054) Forsytia}

1925 WD. Discovered 1925 Nov. 20 by K. Reinmuth at Heidelberg.

Named after a genus of ornamental shrubs of the olive family with opposite leaves and yellow bell-shaped flowers appearing before the leaves in early spring. (H 100)

Reinmuth published (RI 803) a large list of new names for 66 planets between (1009) and (1200). In this compilation there is a number of 28 consecutive names which belong to flowers and other plants.

\section{(1055) Tynka}

1925 WG. Discovered 1925 Nov. 17 by E. Buchar at Algiers.

Named in honor of the mother of the discoverer who worked at the Institute of Astronomy and Geophysics at the Technical University, Prague. (H 100)

\section{(1056) Azalea}

Discovered 1924 Jan. 31 by K. Reinmuth at Heidelberg.

Named after a genus of rhododendrons with funnelshaped corollas and usually deciduous leaves including many species and hybrid forms cultivated as ornamentals. (H 100)

See also the remark to planet (1054).

\section{(1057) Wanda}

1925 QB. Discovered 1925 Aug. 16 by G. Shajn at Simeis. Independently discovered 1925 Aug. 19 by K. Reinmuth at Heidelberg. 
Named in honor of the well-known Polish and Soviet writer Wanda Wasilewska (1905-1964). In the USSR her name is Wasilewskaya. Another interpretation says that Wanda was a mythic person in ancient Polish annals. Daughter of Krakus or Krak, she was the legendary founder of Cracow. (N. S. Chernykh; A. Paluźie-Borrell)

\section{(1058) Grubba}

1925 MA. Discovered 1925 June 22 by G. Shajn at Simeis.

Named in honor of Sir Howard Grubb of Grubb Parson and Co., Newcastle on Tyne, England, manufacturer of the 40-inch reflector of the Simeis Observatory \{see planet (748)\}. (H 100)

\section{(1059) Mussorgskia}

1925 OA. Discovered 1925 July 19 by V. A. Albitskij at Simeis.

Named in honor of the Russian composer Modest Mussorgsky \{1839-1881\}. (M 837)

\section{(1060) Magnolia}

1925 PA. Discovered 1925 Aug. 13 by K. Reinmuth at Heidelberg.

Named after a genus of North American and Asian shrubs and trees with entire evergreen or deciduous leaves and usually showy white, yellow, rose, or purple flowers appearing in early spring. (H 101)

See also the remark to planet (1054).

\section{(1061) Paeonia}

1925 TB. Discovered 1925 Oct. 10 by K. Reinmuth at Heidelberg.

Named after a flower. (H 101)

See also the remark to planet (1054).

\section{(1062) Ljuba}

1925 TD. Discovered 1925 Oct. 11 by S. I. Belyavskij at Simeis.

Named in honor of the perished lady-parachutist Ljuba Berlin (1915-1936). See also planets (1084) and (1086). (N. S. Samojlova-Yakhontova; N. Solovaya)

\section{(1063) Aquilegia}

1925 XA. Discovered 1925 Dec. 6 by K. Reinmuth at Heidelberg.

Named after a genus of plants of the buttercup family with irregular showy spurred flowers. The English name of the flower is columbine. (H 101) See also the remark to planet (1054).

\section{(1064) Aethusa}

1926 PA. Discovered 1926 Aug. 2 by K. Reinmuth at Heidelberg.

Named after a plant of the carrot family. The fool's parsley belongs to the Aethusa family. (H 101) See also the remark to planet (1054).

\section{(1065) Amundsenia}

1926 PD. Discovered 1926 Aug. 4 by S. I. Belyavskij at Simeis.

Named in honor of the Norwegian polar explorer Roald E. Amundsen (1872-1928). He explored the Arctic regions in 1901-1906, 1918-1920, and the Antarctic in 1897 and 1910, the north pole by aeroplane in 1925 and by dirigible in 1926. Amundsen perished in searching for the wreckage of the dirigible Italia. (H 101)

Amundsen is also honored by a lunar crater.

\section{(1066) Lobelia}

1926 RA. Discovered 1926 Sept. 1 by K. Reinmuth at Heidelberg.

Named for a genus of widely distributed herbaceous plants cultivated for their terminal clusters of showy lipped flowers. (H 101)

See also the remark to planet (1054).

\section{(1067) Lunaria}

1926 RG. Discovered 1926 Sept. 9 by K. Reinmuth at Heidelberg.

Named after any of a genus of European plants of the mustard family with cordate leaves and broad siliques (e.g. honesty). (H 101)

See also the remark to planet (1054).

\section{(1068) Nofretete}

1926 RK. Discovered 1926 Sept. 13 by E. Delporte at Uccle.

Named for the Egyptian queen and wife of Amenhotep IV ssee also planet (4847)\}. (H 101)

Named by G. Stracke.

Nofretete is honored twice because the name Nefertiti \{see planet (3199)\} is only a different spelling.

\section{(1069) Planckia}

1927 BC. Discovered 1927 Jan. 28 by M. F. Wolf at Heidelberg.

Named in honor of the famous German physicist Max Karl Ernst Ludwig Planck (1858-1947), Nobel prize winner in 1918, on the occasion of his 80th birthday anniversary. He was a professor of physics at Berlin University and the discoverer of the quantum nature of radiation. (H 101)

Planck is also honored by a lunar crater.

\section{(1070) Tunica}

1926 RB. Discovered 1926 Sept. 1 by K. Reinmuth at Heidelberg.

Named after one of numerous cultivated usually double-flowered pinks derived from the common gillyflower. (LDS)

See also the remark to planet (1054).

\section{(1071) Brita}

Discovered 1924 Mar. 3 by V. A. Albitskij at Simeis.

Named by the discoverer in honor of Great Britain as a mark of gratitude to the country where the 1-m 
telescope for the Simeis Observatory \{see planet (748)\} was made. (N. Solovaya; N. S. Chernykh)

\section{(1072) Malva}

1926 TA. Discovered 1926 Oct. 4 by K. Reinmuth at Heidelberg.

Named after any of a genus of herbs with palmately lobed or dissected leaves, usually showy flowers, and a disk-shaped fruit. The English name for the genus is mallow. (H 101)

See also the remark to planet (1054).

\section{(1073) Gellivara}

Discovered 1923 Sept. 14 by J. Palisa at Vienna.

Named for the small town Gällivare in Swedish Lapland where in the year 1927 astronomers from several countries observed the total solar eclipse of 1927 June 29. (H 101)

Named by the Austrian astronomer J. Rheden and endorsed by Anna Palisa.

\section{(1074) Beljawskya}

1925 BE. Discovered 1925 Jan. 26 by S. I. Belyavskij at Simeis.

This planet is named in honor of the discoverer S. I. Belyavskij (1883-1953), astronomer at the Simeis Observatory. He discovered 36 numbered minor planets between 1912 and 1927 and the brilliant comet 1911 IV. (H 102)

Name proposed by the Simeis Observatory staff.

\section{(1075) Helina}

1926 SC. Discovered 1926 Sept. 29 by G. N. Neujmin at Simeis.

Named in honor of Helij Grigor'evich Neujmin (1910-1982), a son of the discoverer. (N. S. Chernykh; I. I. Neyachenko)

\section{(1076) Viola}

1926 TE. Discovered 1926 Oct. 5 by K. Reinmuth at Heidelberg.

Named after the family of garden hybrids with solitary white, yellow, or purple often variegated flowers resembling but smaller than typical pansies. (H 102)

See also the remark to planet (1054).

\section{(1077) Campanula}

1926 TK. Discovered 1926 Oct. 6 by K. Reinmuth at Heidelberg.

Named after the bellflower. (H 102)

See also the remark to planet (1054).

\section{(1078) Mentha}

1926 XB. Discovered 1926 Dec. 7 by K. Reinmuth at Heidelberg.

Named after a planet of the mint family. (H 102)

See also the remark to planet (1054). A. Patry, Nice, in 1958 found an identity between this planet and (864) Aase (see the remarks for that planet, too).
(1079) Mimosa

1927 AD. Discovered 1927 Jan. 14 by G. Van Biesbroeck at Williams Bay.

Named after a genus of leguminous trees, shrubs, and herbs of tropical and warm regions with usually bipinnate often prickly leaves and globular heads of small white or pink flowers. (H 102)

\section{(1080) Orchis}

1927 QB. Discovered 1927 Aug. 30 by K. Reinmuth at Heidelberg.

Named after a flower of a genus with fleshy roots and a spurred lip. (H 102)

See also the remark to planet (1054).

\section{(1081) Reseda}

1927 QF. Discovered 1927 Aug. 31 by K. Reinmuth at Heidelberg.

Named after a genus of Old World herbs of the mignonette family having racemose flowers with cleft petals and numerous stamens. (H 102) See also the remark to planet (1054).

\section{(1082) Pirola}

1927 UC. Discovered 1927 Oct. 28 by K. Reinmuth at Heidelberg.

Named after a member of the plant family of flowering herbs, mostly evergreen. (H 102) See also the remark to planet (1054).

\section{(1083) Salvia}

1928 BC. Discovered 1928 Jan. 26 by K. Reinmuth at Heidelberg.

Named after a largely and widely distributed genus of herbs or shrubs of the mint family having a two-lipped open calyx and two anthers. The English name of the flower is sage. (H 102)

See also the remark to planet (1054).

\section{(1084) Tamariwa}

1926 CC. Discovered 1926 Feb. 12 by S. I. Belyavskij at Simeis.

This is a combination of the feminine name Tamara Ivanova (1912-1936), a perished lady-parachutist. See also planets (1062) and (1086). (N. S. SamojlovaYakhontova)

\section{(1085) Amaryllis}

1927 QH. Discovered 1927 Aug. 31 by K. Reinmuth at Heidelberg.

Named after a genus of bulbous African herbs with showy umbellate flowers. (H 102)

See also the remark to planet (1054).

\section{(1086) Nata}

1927 QL. Discovered 1927 Aug. 25 by S. I. Belyavskij and N. Ivanov at Simeis.

Named in honor of the perished lady-parachutist Nata (Nadezhda) Babushkina (1915-1936). See also planets (1062) and (1084). (N. S. Samojlova-Yakhontova; N. Solovaya; N. S. Chernykh) 
(1087) Arabis

1927 RD. Discovered 1927 Sept. 2 by K. Reinmuth at Heidelberg. Independently discovered 1927 Sept. 2 by S. I. Belyavskij and N. Ivanov at Simeis.

Named after a large genus of herbs from the mustard family. (H 102)

See also the remark to planet (1054).

\section{(1088) Mitaka}

1927 WA. Discovered 1927 Nov. 17 by O. Oikawa at Tokyo.

Named for a little village near Tokyo, the site of the Tokyo Astronomical Observatory. (H 103)

\section{(1089) Tama}

1927 WB. Discovered 1927 Nov. 17 by O. Oikawa at Tokyo.

Named for a river near the Tokyo Astronomical Observatory. (H 103)

\section{(1090) Sumida}

1928 DG. Discovered 1928 Feb. 20 by O. Oikawa at Tokyo. Independently discovered 1928 Feb. 24 by

K. Reinmuth at Heidelberg.

Named for a river near Tokyo, Japan. (H 103)

\section{(1091) Spiraea}

1928 DT. Discovered 1928 Feb. 26 by K. Reinmuth at Heidelberg.

Named after a genus of shrubs of the rose family with small perfect white or pink flowers in dense racemes, corymbs, cymes, or panicles. (H 103)

See also the remark to planet (1054).

\section{(1092) Lilium}

Discovered 1924 Jan. 12 by K. Reinmuth at Heidelberg.

Named after a genus of erect perennial leafystemmed bulbous herbs that are native to the northern hemisphere and are widely culticated for their showy flowers. The English name of the flower is lily. (H 103) See also the remark to planet (1054).

\section{(1093) Freda}

1925 LA. Discovered 1925 June 15 by B. Jekhovsky at Algiers.

Named in memory of Fred Prévost, a civil engineer of mines and benefactor of the Faculty of Sciences of Bordeaux, France. (H 103)

\section{(1094) Siberia}

1926 CB. Discovered 1926 Feb. 12 by S. I. Belyavskij at Simeis.

Named for a region of Russia located in northern Asia. (H 103)

\section{(1095) Tulipa}

1926 GS. Discovered 1926 Apr. 14 by K. Reinmuth at Heidelberg.

Named after a genus of Eurasian bulbous herbs of the lily family that have linear or broadely lanceolate leaves and are widely grown for their showy flowers. The English name of the flower is tulip. (H 103)

See also the remark to planet (1054). The name was first assigned to planet 1928 DC, discovered 1928 February 24 by K. Reinmuth at Heidelberg. This object, however, was proofed to be identical with planet (1449) Virtanen. Therefore, the name Tulipa has been reassigned to the above object.

\section{(1096) Reunerta}

1928 OB. Discovered 1928 July 21 by H. E. Wood at Johannesburg.

Named by the discoverer (RI 636) in honor of Dr. Reunert, Johannesburg, an engineer and friend. (H 103)

\section{(1097) Vicia}

1928 PC. Discovered 1928 Aug. 11 by K. Reinmuth at Heidelberg. Independently discovered 1928 Aug. 15 by P. F. Shajn at Simeis and Aug. 22 by H. E. Wood at Johannesburg.

Named after a flower of the Papilionaceae family. The English name of the flower is vetch. (H 103) See also the remark to planet (1054).

\section{(1098) Hakone}

1928 RJ. Discovered 1928 Sept. 5 by O. Oikawa at Tokyo. Independently discovered 1928 Sept. 9 by M. F. Wolf at Heidelberg and Sept. 11 by G. N. Neujmin at Simeis.

Named for a well-known composite volcanic mountain about $80 \mathrm{~km}$ from the observatory where this planet was discovered. It is a typical mountain resort of Japan with a lake and numerous hot springs. It provides a wonderful view of Mt. Fuji (see planet (1584)) and attracts a lot of tourists all over the year. (K. Tomita)

\section{(1099) Figneria}

1928 RQ. Discovered 1928 Sept. 13 by G. N. Neujmin at Simeis. Independently discovered 1928 Sept. 13 by M. F. Wolf at Heidelberg.

Named by the discoverer in honor of the well-known Russian writer and revolutionary Vera N. Figner (1852-1942). (RI 789)

\section{(1100) Arnica}

1928 SD. Discovered 1928 Sept. 22 by K. Reinmuth at Heidelberg. Independently discovered 1928 Oct. 14 by A. Schwassmann and A. A. Wachmann at Bergedorf.

Named after a genus of composite herbs including some with bright yellow ray flowers. (H 103) See also the remark to planet (1054).

\section{(1101) Clematis}

1928 SJ. Discovered 1928 Sept. 22 by K. Reinmuth at Heidelberg.

Named after a vine or herb of the buttercup family having three leaflets on each leaf and usually white or purple flowers. (H 103)

See also the remark to planet (1054). 


\section{(1102) Pepita}

1928 VA. Discovered 1928 Nov. 5 by J. Comas Solá at Barcelona.

Named in honor of the discoverer José Comas Solá (1868-1937), astronomer at Barcelona and founder of the "Sociedad Astronomica de España y America". Pepita is the feminine form of Pepito, the familiar name of the discoverer. The discoverer is also honored by planet (1655). (H 104)

Comas Solá is also honored by a crater on Mars.

\section{(1103) Sequoia}

1928 VB. Discovered 1928 Nov. 9 by W. Baade at Bergedorf.

Named by the discoverer for the Sequoia National Park where he spent vacations. The park is named after the huge coniferous California trees of the pine family that reach a height of over 100 meters. (H 104)

\section{(1104) Syringa}

1928 XA. Discovered 1928 Dec. 9 by K. Reinmuth at Heidelberg.

Named after a genus of ornamental shrubs of the saxifrage family of which several are widely known in temperate regions for their showy white flowers. The genus Syringa is also known as philadelphus. The English name of the plant is lilac. (H 104)

See also the remark to planet (1054).

\section{(1105) Fragaria}

1929 AB. Discovered 1929 Jan. 1 by K. Reinmuth at Heidelberg.

Named after a genus of the rose family that is technically an enlarged pulpy receptacle bearing numerous achenes (strawberry). (H 104)

See also the remark to planet (1054).

\section{(1106) Cydonia}

1929 CW. Discovered 1929 Feb. 5 by K. Reinmuth at Heidelberg.

Named after a tree (English name quince) belonging to the apple family. (H 104)

See also the remark to planet (1054).

\section{(1107) Lictoria}

1929 FB. Discovered 1929 Mar. 30 by L. Volta at Pino Torinese. Independently discovered 1929 Mar. 17 by K. Reinmuth at Heidelberg.

The name is strictly connected with the symbol of the fascist party, which in Italian was called "Fasci Littori", derived from the Latin "Fasces Lictores". During the fascist regime it became common-place to apply that name to events or objects ranging from festivals ("littoriali") to fast trains ("littorine"). When the Pontine Marshes were being reclaimed, the first two towns established there were Littoria and Sabaudia \{see planet (1115)\}. It is noteworthy that after the demise of the fascist regime the town of Littoria was renamed "Latina". (P. G. Comba)

\section{(1108) Demeter}

1929 KA. Discovered 1929 May 31 by K. Reinmuth at Heidelberg.

Named for the Greek goddess of the fruitful soil and of agriculture. The Romans identified Demeter with Ceres \{see planet (1)\}. (H 104)

\section{(1109) Tata}

1929 CU. Discovered 1929 Feb. 5 by K. Reinmuth at Heidelberg.

Any reference of this name to a person or occurrence is unknown.

\section{(1110) Jaroslawa}

1928 PD. Discovered 1928 Aug. 10 by G. N. Neujmin at Simeis. Independently discovered 1928 Aug. 18 by E. Delporte at Uccle.

Named in honor of Jaroslav Grigor'evich Neujmin (1928- ), a son of the discoverer. (N. S. Chernykh; I. I. Neyachenko)

\section{(1111) Reinmuthia}

1927 CO. Discovered 1927 Feb. 11 by K. Reinmuth at Heidelberg.

Named in honor of Karl Reinmuth \{1892-1979\}, a tireless observer on the staff of the Heidelberg Königstuhl Observatory. Reinmuth discovered more than 380 now numbered minor planets - a unique record for many years. (H 104)

Obituaries published in Sterne Weltraum, Jahrg. 18, p. 202 (1979); Minor Planet Bull., Vol. 7, p. 10 (1979); Mitt. Astron. Ges., Nr. 50, p. 7-8 (1980).

\section{(1112) Polonia}

1928 PE. Discovered 1928 Aug. 15 by P. F. Shajn at Simeis. Independently discovered 1928 Aug. 16 by G. N. Neujmin at Simeis.

Named for the country of Poland. Polonia is the Latin name. (H 104)

Named in accordance with the discoverer by L. Matkiewicz (RI 304), who computed the orbit of this planet.

This is the first minor planet that was discovered by a woman.

\section{(1113) Katja}

1928 QC. Discovered 1928 Aug. 15 by P. F. Shajn at Simeis. Independently discovered 1928 Aug. 24 by M. F. Wolf at Heidelberg.

Named in honor of the laboratory assistant and calculator Katja (Ekaterina) Ios'ko of the discovery observatory. She was the daughter of the Simeis mechanician Iosif Gavrilovich Ios'ko. (N. S. SamojlovaYakhontova; N. Solovaya; N. S. Chernykh; V. A. Shor)

\section{(1114) Lorraine}

1928 WA. Discovered 1928 Nov. 17 by A. Schaumasse at Nice. Independently discovered 1928 Nov. 18 by L. Volta at Pino Torinese. 
Named after the region and former duchy in northeastern France, remnant of the medieval kingdom of Lotharingia. (R. Bremer)

\section{(1115) Sabauda}

1928 XC. Discovered 1928 Dec. 13 by L. Volta at Pino Torinese. Independently discovered 1928 Dec. 18 by J. Comas Solá at Barcelona.

Sabauda, or Sapauda, is the Latin name of the House of Savoy, the former rulers of Italy. The planet probably could also have been named after the new established town Sabauda in the Pontine Marshes see the remarks to planet (1107). (H 104)

\section{(1116) Catriona}

1929 GD. Discovered 1929 Apr. 5 by C. Jackson at Johannesburg.

Named probably after the novel (1893) by the Scottish poet and novelist Robert Louis Balfour Stevenson (1850-1894). (R. Bremer)

\section{(1117) Reginita}

1927 KA. Discovered 1927 May 24 by J. Comas Solá at Barcelona.

Named in honor of the niece of the discoverer. (H 105)

\section{(1118) Hanskya}

1927 QD. Discovered 1927 Aug. 29 by S. I. Belyavskij and N. Ivanov at Simeis. Independently discovered 1927 Aug. 30 by K. Reinmuth at Heidelberg and Sept. 17 by E. Delporte at Uccle.

The planet was named "zum Andenken an den vor 25 Jahren verstorbenen ersten Astronomen der Sternwarte Simeis, Alexis Hansky \{1872-1908\}, dessen Initiative diese Sternwarte ihre Entstehung verdankt." (RI 858)

Hansky is also honored by a lunar crater.

\section{(1119) Euboea}

1927 UB. Discovered 1927 Oct. 27 by K. Reinmuth at Heidelberg. Independently discovered 1927 Oct. 29 by S. I. Belyavskij at Simeis.

Euboea (or Negropont) is the largest island of Greece in the Aegean. (H 105)

\section{(1120) Cannonia}

1928 RV. Discovered 1928 Sept. 11 by P. F. Shajn at Simeis. Independently discovered 1928 Sept. 13 by G. N. Neujmin at Simeis and Sept. 23 by E. Delporte at Uccle.

Named by the discoverer (RI 584) in honor of Miss Annie Jump Cannon (1863-1941). At Harvard University she classified the spectra of about 225,000 stars for the Henry Draper Catalogue in a system of spectral types which she had developed. (H 105) Cannon is also honored by a lunar crater.

\section{(1121) Natascha}

1928 RZ. Discovered 1928 Sept. 11 by P. F. Shajn at Simeis.

Named - as a birthday present - in honor of the hydrogeologist Natasha (Natalia) Tichomirova, daughter of the Simeis astronomer G. N. Neujmin. (N. S. SamojlovaYakhontova; N. Solovaya; N. S. Chernykh)

\section{(1122) Neith}

1928 SB. Discovered 1928 Sept. 17 by E. Delporte at Uccle.

Named for the Egyptian goddess of Libyan origin. She passed for the mother of the Sun, Râ. (H 105)

\section{(1123) Shapleya}

1928 ST. Discovered 1928 Sept. 21 by G. N. Neujmin at Simeis.

Named by the discoverer (RI 509) in honor of the American astronomer and director of Harvard Observatory Harlow Shapley (1885-1972). (H 105)

Obituaries published in Nature, Vol. 240, p. 429-430 (1972); Orion, 30. Jahrg., p. 186 (1972); Sky Telesc., Vol. 44, p. 354-357 (1972); Sterne Weltraum, Vol. 11, p. 296 (1972); Astrophys. Space Sci., Vol. 18, p. 258-266 (1972); Coelum, Vol. 41, p. 13-15 (1973); J.R. Astron. Soc. Can., Vol. 67, p. 31-33 (1973); Irish Astron. J., Vol. 10, p. 302-303 (1972); C.R. Acad. Sci., Vie Acad., Vol. 277, p. 119-120 (1973); Vesmír, Vol. 52, p. 254 (1973); Alm. Österr. Akad Wiss., 123. Jahrg., p. 315-321 (1973).

\section{(1124) Stroobantia}

1928 TB. Discovered 1928 Oct. 6 by E. Delporte at Uccle.

Named in honor of Paul Stroobant (1868-1936), director of the Royal Observatory at Uccle, Belgium. His work concerned the number, mass and distribution of the minor planets. (H 105)

\section{(1125) China}

$1957 \mathrm{UN}_{1}$. Discovered 1957 Oct. 30 by Y. C. Chang at Nanking.

Named for the country in which this planet was discovered. (M 13179)

See also the citation for minor planet (3789).

\section{(1126) Otero}

1929 AC. Discovered 1929 Jan. 11 by K. Reinmuth at Heidelberg.

Named probably after Caroline Otéro (1868-1965), known as "la belle Otéro". The whole world admired her for being charming and beautiful; for a long period she embodied "la femme de grand luxe" and "la Belle Epoque". At the turn of the century she was the most demanded of the Parisian courtesans and led an excessive life. Thanks to her numerous rich and famous lovers, who fought each other and ruined themselves in favor of her, she was able to amass immense riches. Unfortunately, she was bound to lose them, because 
she was passionately fond of gambling. She died in poverty at the age of 97 after a life of fulfillment. (M.-A. Combes)

Named by the discoverer (RI 803).

\section{(1127) Mimi}

1929 AJ. Discovered 1929 Jan. 13 by S. Arend at Uccle.

Named in honor of the wife of E. Delporte. (H 105)

The planets (1127) and (1145) have been discovered at the Uccle Observatory by S. Arend and E. Delporte, respectively. Arend proposed the name Robelmonte for his planet, while Delporte chose the name Mimi for his own. Through an error, planet (1127) received the name Mimi and the name Robelmonte was assigned to (1145).

\section{(1128) Astrid}

1929 EB. Discovered 1929 Mar. 10 by E. Delporte at Uccle.

Named in honor of H.M. Astrid (1905-1935), Queen of the Belgians. (H 106)

\section{(1129) Neujmina}

1929 PH. Discovered 1929 Aug. 8 by P. Parchomenko at Simeis.

Named by the discoverer (RI 369) in honor of Grigory N. Neujmin (1885-1946), astronomer at the Pulkovo and Simeis Observatories. Neujmin discovered seven comets and more than 70 minor planets. (H 106) Neujmin is also honored by a lunar crater.

\section{(1130) Skuld}

1929 RC. Discovered 1929 Sept. 2 by K. Reinmuth at Heidelberg. Independently discovered 1929 Sept. 12 by

A. Schwassmann and A. A. Wachmann at Bergedorf.

Named for one of the three Norns in Norse mythology. Skuld stands for the Future. (H 106)

The other Norns are Urda (the Past) and Werdandi (the Present) \{see planets (167) and (621)\}.

\section{(1131) Porzia}

1929 RO. Discovered 1929 Sept. 10 by K. Reinmuth at Heidelberg.

Named for a character in Shakespeare's play Julius Caesar (1599). (H 106)

\section{(1132) Hollandia}

$1929 \mathrm{RB}_{1}$. Discovered 1929 Sept. 13 by H. van Gent at Johannesburg.

This is the Latin name for Holland, a synonymous name for the Netherlands. (H 106)

Named by the discoverer and the orbit computer G. Pels.

\section{(1133) Lugduna}

$1929 \mathrm{RC}_{1}$. Discovered 1929 Sept. 13 by H. van Gent at Johannesburg.

Lugdunum Batavorum is the Latin name for the city of Leiden, The Netherlands. (I. van Houten-Groeneveld)
Named by the discoverer and the orbit computer G. Pels.

\section{(1134) Kepler}

1929 SA. Discovered 1929 Sept. 25 by M. F. Wolf at Heidelberg.

Named in honor of the famous German astronomer Johannes Kepler (1571-1630) on the occasion of the 300th anniversary of his death. After incredible labor, Kepler discovered the elliptical orbits of the planets, the law of equal areas, and the relation between the period and the size of an orbit. (AN 240, 135 (1930))

Kepler is also honored by craters on the Moon and Mars and by a mountain on Phobos.

\section{(1135) Colchis}

1929 TA. Discovered 1929 Oct. 3 by G. N. Neujmin at Simeis.

Named for the ancient country bordering on Black Sea south of the Caucasus mountains. The area now constitutes the western part of the Georgian Republic. (H 106)

\section{(1136) Mercedes}

1929 UA. Discovered 1929 Oct. 30 by J. Comas Solá at Barcelona.

Named in honor of the sister-in-law of the discoverer. (H 106)

\section{(1137) Raïssa}

1929 WB. Discovered 1929 Oct. 27 by G. N. Neujmin at Simeis. Independently discovered 1929 Nov. 21 by K. Reinmuth at Heidelberg.

Named in honor of Raïssa Izrailevna Maseeva (19001930), a former scientific collaborator at the Pulkovo Observatory. (H 106)

\section{(1138) Attica}

1929 WF. Discovered 1929 Nov. 22 by K. Reinmuth at Heidelberg.

Named after the region in eastern Greece with the capital Athens. (H 106)

\section{(1139) Atami}

1929 XE. Discovered 1929 Dec. 1 by O. Oikawa and K. Kubokawa at Tokyo.

Named after a harbor near Tokyo, Japan. (H 106)

\section{(1140) Crimea}

1929 YC. Discovered 1929 Dec. 30 by G. N. Neujmin at Simeis.

Named for the southern peninsula of Russia extending into the Black Sea where Simeis is located. (H 106)

\section{(1141) Bohmia}

1930 AA. Discovered 1930 Jan. 4 by M. F. Wolf at Heidelberg.

Named in honor of Mrs. Katharina Bohm-Waltz (? -1901) who donated the $72-\mathrm{cm}$ Waltz reflector to the Heidelberg Observatory. (H 107; LDS) 
Mrs. Bohm donated a sum of 25,000 M. The invoice of Zeiss Jena for this superb instrument from July 1906 amounts to $20,000 \mathrm{M}$.

\section{(1142) Aetolia}

1930 BC. Discovered 1930 Jan. 24 by K. Reinmuth at Heidelberg.

Named for the Greek province north of the Gulf of Patras. (H 107)

\section{(1143) Odysseus}

1930 BH. Discovered 1930 Jan. 28 by K. Reinmuth at Heidelberg.

Named after the king of Ithaca and Greek hero in the Trojan War who after the war wandered 10 years before reaching home. (H 107)

\section{(1144) Oda}

1930 BJ. Discovered 1930 Jan. 28 by K. Reinmuth at Heidelberg.

See the remarks to planet (913).

\section{(1145) Robelmonte}

1929 CC. Discovered 1929 Feb. 3 by E. Delporte at Uccle.

Named for the city of Robelmont, Belgium, the birthplace of S. Arend \{see planet (1502)\}. Robelmonte is the feminine form. (H 107)

See also the remarks to planet (1127).

\section{(1146) Biarmia}

1929 JF. Discovered 1929 May 7 by G. N. Neujmin at Simeis.

Named by the discoverer after a legendary country in northern Russia near to the Finnish border. (H 107)

\section{(1147) Stavropolis}

1929 LF. Discovered 1929 June 11 by G. N. Neujmin at Simeis.

Named by the discoverer for the city of Stavropol' in northern Caucasus region. Between 1936 and 1946 the city was named Woroschilowsk. (H 107)

\section{(1148) Rarahu}

1929 NA. Discovered 1929 July 5 by A. N. Deutsch at Simeis. Independently discovered 1929 July 28 by C. Jackson and H. E. Wood at Johannesburg.

This is a Tahitian name for a girl. The name is taken from the novel by Louis Marie Julien Viaud (pseudonym Pierre Loti, 1850-1923) Mariage de Loti. (H 107)

For many decades the wrong spelling "Raraju" was used. J. Meeus showed that an erroneous transliteration from French to Russian to German caused the name of this minor planet to be spelled incorrectly in the literature. The correct name Rarahu has officially been adopted in 1985 (M 10194).

\section{(1149) Volga}

1929 PF. Discovered 1929 Aug. 1 by E. F. Skvortsov at Simeis.

This planet is named for the large river in the European part of the USSR. (M 2740)

Name proposed by the Institute of Theoretical Astronomy, Leningrad.

\section{(1150) Achaia}

1929 RB. Discovered 1929 Sept. 2 by K. Reinmuth at Heidelberg. Independently discovered 1929 Sept. 12 by A. Schwassmann and A. A. Wachmann at Bergedorf.

Named after the Greek region in northern Peloponnese bordering on the gulfs of Corinth and Patras. The spelling Achaea for the province is also in use. (H 107)

\section{(1151) Ithaka}

1929 RK. Discovered 1929 Sept. 8 by K. Reinmuth at Heidelberg. Independently discovered 1929 Sept. 13 by G. N. Neujmin at Simeis.

Named after the Greek island, the island of Odysseus, in the Ionian Sea. (H 107)

\section{(1152) Pawona}

1930 AD. Discovered 1930 Jan. 8 by K. Reinmuth at Heidelberg. Independently discovered 1930 Jan. 19 by L. Volta at Pino Torinese and Jan. 21 by G. N. Neujmin at Simeis.

This name stands for a combination of the names of J. Palisa and M. Wolf in honor of the cooperation between these two important astronomers. (H 107)

Name proposed by B. Asplind who found the identity of (1152) with $1925 \mathrm{SF}$ which was the last minor planet discovered by Palisa (AN 240, 406 (1930)).

\section{(1153) Wallenbergia}

Discovered 1924 Sept. 5 by S. I. Belyavskij at Simeis.

Named in honor of the German mathematician Georg James Wallenberg (1864-1924). (H 107)

\section{(1154) Astronomia}

1927 CB. Discovered 1927 Feb. 8 by K. Reinmuth at Heidelberg.

Named for the science which explores the celestial bodies. (H 108)

\section{(1155) Aënna}

1928 BD. Discovered 1928 Jan. 26 by K. Reinmuth at Heidelberg.

This artificial name contains in the German pronunciation the initials "A" and "N" followed by the feminine ending. It honors the Astronomische Nachrichten. The naming was published together with that for planet (1164). (H 108)

Name proposed by the Astronomisches Rechen-Institut (RI 709).

\section{(1156) Kira}

1928 DA. Discovered 1928 Feb. 22 by K. Reinmuth at Heidelberg. 
Any reference of this name to a person or occurrence is unknown.

The naming of this planet was granted to the Heidelberg astronomer M. Mündler.

\section{(1157) Arabia}

1929 QC. Discovered 1929 Aug. 31 by K. Reinmuth at Heidelberg.

Named for the peninsula in southwest Asia. (H 108)

\section{(1158) Luda}

1929 QF. Discovered 1929 Aug. 31 by G. N. Neujmin at Simeis.

Named in honor of the sister of the discoverer. Luda is a diminutive of Ludmilla. (N. S. Samojlova-Yakhontova)

\section{(1159) Granada}

1929 RD. Discovered 1929 Sept. 2 by K. Reinmuth at Heidelberg.

Named after the Spanish city and province in Andalusia in southern Spain. (H 108)

\section{(1160) Illyria}

1929 RL. Discovered 1929 Sept. 9 by K. Reinmuth at Heidelberg.

Named for the ancient region in the Balkan peninsula bordering on the Adriatic Sea. (H 108)

\section{(1161) Thessalia}

1929 SF. Discovered 1929 Sept. 29 by K. Reinmuth at Heidelberg.

Named for the region in eastern Greece between Pindus mountains and the Aegean Sea. (H 108)

\section{(1162) Larissa}

1930 AC. Discovered 1930 Jan. 5 by K. Reinmuth at Heidelberg.

Named for the city in eastern Thessaly \{ see planet (1161)\}, Greece. (H 108)

The name Larissa has also been given to the satellite Neptune VII.

\section{(1163) Saga}

1930 BA. Discovered 1930 Jan. 20 by K. Reinmuth at Heidelberg.

The planet is named after a detailed recital of events, historical or legendary or both, of Icelandic heroes, most often set down in prose. (H 108)

\section{(1164) Kobolda}

1930 FB. Discovered 1930 Mar. 19 by K. Reinmuth at Heidelberg. Independently discovered 1930 Mar. 20 by W. Baade at Bergedorf.

Named in honor of Hermann Albert Kobold \{18581942\}, astronomer at Kiel and editor of the Astronomische Nachrichten \{see also planet (1155)\} from 1907 to 1938 . (H 108)

\section{(1165) Imprinetta}

1930 HM. Discovered 1930 Apr. 24 by H. van Gent at Johannesburg.

Named in honor of the wife of the discoverer. (H 108)

Named by the discoverer and the orbit computer G. Pels.

\section{(1166) Sakuntala}

1930 MA. Discovered 1930 June 27 by P. Parchomenko at Simeis. Independently discovered 1930 June 29 by K. Reinmuth at Heidelberg.

Named by the discoverer (RI 895) for the heroine of a famous sanskrit drama by the Indian poet Kalidasa. The Hindu poet and dramatist lived sometime between the fourth and sixth century, was a native of Ujjain and lived at the court of one King Vikramaditya. Sakuntala is a dramatization of part of the Mahabharata. (H 108; LDS)

\section{(1167) Dubiago}

1930 PB. Discovered 1930 Aug. 3 by E. F. Skvortsov at Simeis.

This planet is named in honor of the late Prof. Alexander D. Dubiago (1903-1959), an eminent astronomer of the USSR. (M 2740)

Name proposed by the Institute of Theoretical Astronomy, Leningrad.

Dubiago is also honored by a lunar crater.

\section{(1168) Brandia}

1930 QA. Discovered 1930 Aug. 25 by E. Delporte at Uccle. Independently discovered 1930 Aug. 31 by G. N. Neujmin at Simeis.

Named in honor of Eugène Brand, Professor of mathematics at the University of Brussels, Belgium. (H 109)

\section{(1169) Alwine}

1930 QH. Discovered 1930 Aug. 30 by M. F. Wolf and M. Ferrero at Heidelberg.

Any reference of this name to a person or occurrence is unknown.

\section{(1170) Siva}

1930 SQ. Discovered 1930 Sept. 29 by E. Delporte at Uccle.

Named for the god of destruction and regeneration in the Hindu sacred triad (with Brahma and Vishnu). A legendary, colorful personality and delight to the intellectuals of the Hindu priesthood, Siva was the divine dancer who could interpret the mathematical law of the universe in 108 different movements, and he was the lord of knowledge, the center about whom the universe revolved. (H 109)

\section{(1171) Rusthawelia}

1930 TA. Discovered 1930 Oct. 3 by S. Arend at Uccle. Independently discovered 1930 Sept. 29 by G. N. Neujmin at Simeis. 
Named in honor of the Georgian poet Schota Rusthaweli (c. 1300). See also the remarks to planet (525). (H 109)

Name proposed by Simeis astronomers.

\section{(1172) Äneas}

1930 UA. Discovered 1930 Oct. 17 by K. Reinmuth at Heidelberg.

Named for the defender of Troy and hero of Vergil's Aeneid, son of Anchises \{see planet (1173)\} and Aphrodite $\{$ see planet (1388)\}. (H 109)

\section{(1173) Anchises}

1930 UB. Discovered 1930 Oct. 17 by K. Reinmuth at Heidelberg.

Named for the father of Aeneas \{see planet (1172)\}, rescued by his son from the burning city of Troy. (H 109)

\section{(1174) Marmara}

1930 UC. Discovered 1930 Oct. 17 by K. Reinmuth at Heidelberg.

Named by the discoverer (RI 803) for the Marmara Sea which is connected with the Black Sea by the Bosporus and with the Aegean Sea by the Dardanelles. (H 109)

\section{(1175) Margo}

1930 UD. Discovered 1930 Oct. 17 by K. Reinmuth at Heidelberg.

Any reference of this name to a person or occurrence is unknown.

Named by the discoverer (RI 803).

\section{(1176) Lucidor}

1930 VE. Discovered 1930 Nov. 15 by E. Delporte at Uccle. Independently discovered 1930 Nov. 15 by M. F. Wolf at Heidelberg and Nov. 30 by G. N. Neujmin at Simeis.

Named in honor of an amateur astronomer and feminine friend of the discoverer. (H 109)

\section{(1177) Gonnessia}

1930 WA. Discovered 1930 Nov. 24 by L. Boyer at Algiers.

Named in honor of the late François Gonnessiat (1856-1934), director of the Algiers Bouzaréah and Quito Observatories. (H 109)

\section{(1178) Irmela}

1931 EC. Discovered 1931 Mar. 13 by M. F. Wolf at Heidelberg.

Named in honor of Mrs. Irmela Ruska, the wife of Ernest Ruska who invented the electron microscope and received the Nobel Prize in 1986. The prize had to be shared with B. Binnig and H. Rohrer. (H 109)

The naming was granted by the discoverer to A. Kopff.
(1179) Mally

1931 FD. Discovered 1931 Mar. 19 by M. F. Wolf at Heidelberg.

Named by the discoverer in honor of his daughterin-law, the wife of Franz Wolf. (H 110)

\section{(1180) Rita}

1931 GE. Discovered 1931 Apr. 9 by K. Reinmuth at Heidelberg.

Any reference of this name to a person or occurrence is unknown.

\section{(1181) Lilith}

1927 CQ. Discovered 1927 Feb. 11 by B. Jekhovsky at Algiers.

Named by the discoverer in honor of the French composer Mme. Marie Juliette Olga 'Lili' Boulanger (1893-1918) and sister of the better-known conductor and composer Nadia Boulanger. The nickname is derived from Lilith, the first wife of Adam. (H 110; LDS)

\section{(1182) Ilona}

1927 EA. Discovered 1927 Mar. 3 by K. Reinmuth at Heidelberg.

Any reference of this name to a person or occurrence is unknown.

Name proposed by G. Stracke.

\section{(1183) Jutta}

1930 DC. Discovered 1930 Feb. 22 by K. Reinmuth at Heidelberg.

Any reference of this name to a person or occurrence is unknown.

Name proposed by G. Stracke.

\section{(1184) Gaea}

1926 RE. Discovered 1926 Sept. 5 by K. Reinmuth at Heidelberg.

Named after the Greek Earth goddess. After Chaos, Gaea appeared and bore Uranus, the personification of Heaven that covered the Earth. Gaea united with her son Uranus to produce the first race, the twelve Titans, six males and six females. Uranus and Gaea were also the parents of the Cyclops, the Centimani, and the Giants. (LDS; Z 108)

Name proposed by G. Stracke.

\section{(1185) Nikko}

1927 WC. Discovered 1927 Nov. 17 by O. Oikawa at Tokyo.

Named for a popular city and tourist resort in Japan noted for its shrines. (H 110)

\section{(1186) Turnera}

1929 PL. Discovered 1929 Aug. 1 by C. Jackson at Johannesburg.

Named in honor of the British astronomer Herbert Hall Turner (1861-1930), director of the Oxford University Observatory. (H 110) 
(1187) Afra

1929 XC. Discovered 1929 Dec. 6 by K. Reinmuth at Heidelberg.

Any reference of this name to a person or occurrence is unknown.

Name proposed by G. Stracke.

\section{(1188) Gothlandia}

1930 SB. Discovered 1930 Sept. 30 by J. Comas Solá at Barcelona. Independently discovered 1930 Oct. 17 by G. N. Neujmin at Simeis and Oct. 18 by K. Nakamura at Kyoto.

This is the ancient name of Catalonia which has the city of Barcelona $\{$ see planet (945)\} as the capital. (H 110)

\section{(1189) Terentia}

1930 SG. Discovered 1930 Sept. 17 by G. N. Neujmin at Simeis.

Named in remembrance of the deceased collaborator at the Simeis Observatory, Mrs. Lidiya Ivanovna Terent'eva (1879-1933), an orbit computer. (RI 762)

Name proposed by the scientific collaborators of the Simeis Observatory.

\section{(1190) Pelagia}

1930 SL. Discovered 1930 Sept. 20 by G. N. Neujmin at Simeis.

Named in honor of the Simeis astronomer Pelageya Fedorovna Shajn (1894-1956), the first woman who discovered a minor planet (planet (1112)). (RI 895)

See also the citation for planet (1648).

\section{(1191) Alfaterna}

1931 CA. Discovered 1931 Feb. 11 by L. Volta at Pino Torinese.

The ancient city founded by the Oschi about 1000 B.C. between Pompeii and Salerno. It is entombed beneath the present Nocera Superiore, birthplace of A. Fresa, who proposed the name (in 1957). (M 2882)

\section{(1192) Prisma}

1931 FE. Discovered 1931 Mar. 17 by A. Schwassmann at Bergedorf.

This planet was named in honor of the Bergedorf Spectral Catalogue. (H 111)

\section{(1193) Africa}

1931 HB. Discovered 1931 Apr. 24 by C. Jackson at Johannesburg.

Named for the large continent in which Johannesburg is located. (H 111)

\section{(1194) Aletta}

1931 JG. Discovered 1931 May 13 by C. Jackson at Johannesburg.

Named in honor of the wife of the discoverer. (H 111)

\section{(1195) Orangia}

1931 KD. Discovered 1931 May 24 by C. Jackson at Johannesburg.
Named in honor of the South African province of Orange Free State. (H 111)

\section{(1196) Sheba}

1931 KE. Discovered 1931 May 21 by C. Jackson at Johannesburg.

This planet is named for the biblical queen of Sheba, who visited Solomon. (H 111)

\section{(1197) Rhodesia}

1931 LD. Discovered 1931 June 9 by C. Jackson at Johannesburg.

Named after the country in southern Africa which now has the name Zimbabwe. (H 111)

\section{(1198) Atlantis}

1931 RA. Discovered 1931 Sept. 7 by K. Reinmuth at Heidelberg.

This planet is named for the legendary island which sank.

Name proposed by G. Stracke.

\section{(1199) Geldonia}

1931 RF. Discovered 1931 Sept. 14 by E. Delporte at Uccle.

Geldonia is the Latin name of Geldenaken (Jodoigne), Belgium, the native town of the discoverer. (H 111)

\section{(1200) Imperatrix}

1931 RH. Discovered 1931 Sept. 14 by K. Reinmuth at Heidelberg.

Imperatrix is the Latin name for empress. Any reference to a person is unknown. (I. van HoutenGroeneveld)

The name was proposed by G. Stracke.

\section{(1201) Strenua}

1931 RK. Discovered 1931 Sept. 14 by K. Reinmuth at Heidelberg.

This name was assigned in honor of Prof. Gustav Stracke (1887-1943), famous German astronomer at the Berlin Rechen-Institut, without his knowledge of the meaning. The name is from the Latin word "strenuus" which means strong, careful, and exemplifies virtues of G. Stracke. The German substantive is "Stärke" which sounds quite similar as "Stracke". (H 111)

G. Stracke is also honored by minor planet (1019) and the eight planets (1227) to (1234).

\section{(1202) Marina}

1931 RL. Discovered 1931 Sept. 13 by G. N. Neujmin at Simeis. Independently discovered 1931 Sept. 15 by K. Reinmuth at Heidelberg.

Named in honor of Mrs. Marina Davidovna LavrovaBerg (1898-1943), scientific collaborator at the Pulkovo Observatory. (N. S. Samojlova-Yakhontova; N. Solovaya; N. S. Chernykh)

\section{(1203) Nanna}

1931 TA. Discovered 1931 Oct. 5 by M. F. Wolf at Heidelberg. 
This planet is named honoring the many paintings named "Nanna" by the German painter Anselm Feuerbach (1829-1880). One such painting was in the possession of the Wolf family. (H 111)

\section{(1204) Renzia}

1931 TE. Discovered 1931 Oct. 6 by K. Reinmuth at Heidelberg.

Named in honor of Franz Robert Renz (1860-1942), astronomer at Dorpat and Pulkowo. (H 112)

\section{(1205) Ebella}

1931 TB$_{1}$. Discovered 1931 Oct. 6 by K. Reinmuth at Heidelberg.

Named in honor of Carl Wilhelm Ludwig Martin Ebell (1871-1944) who was an astronomer in Kiel, Germany on the staff of the Astronomische Nachrichten. (H 112)

\section{(1206) Numerowia}

1931 UH. Discovered 1931 Oct. 18 by K. Reinmuth at Heidelberg.

Named in honor of the Russian astronomer Boris Vasil'evich Numerov (1891-1941), the founder and director of the Institute of Theoretical Astronomy in Leningrad. (H 112)

Numerov is also honored by a lunar crater.

\section{(1207) Ostenia}

1931 VT. Discovered 1931 Nov. 15 by K. Reinmuth at Heidelberg.

Named in honor of the amateur astronomer, orbital computer, and business man, Hans Osten. (H 112)

\section{(1208) Troilus}

1931 YA. Discovered 1931 Dec. 31 by K. Reinmuth at Heidelberg.

Named for a son of Priam \{see planet (884)\} who in a medieval legend loved Cressida \{see planet (548)\} and lost her to Diomedes \{see planet (1437)\}. Troilus was killed by Achilles $\{$ see planet (588)\}. (H 112)

\section{(1209) Pumma}

1927 HA. Discovered 1927 Apr. 22 by K. Reinmuth at Heidelberg.

This is the nickname of the niece of A. Kahrstedt \{see planet (1587)\}. (H 112)

Name proposed by A. Kahrstedt.

\section{(1210) Morosovia}

1931 LB. Discovered 1931 June 6 by G. N. Neujmin at Simeis.

Named in honor of the Russian revolutionist and scientist Nikolaj A. Morozov (1854-1946). (H 112) Morozov is also honored by a lunar crater.

\section{(1211) Bressole}

1931 XA. Discovered 1931 Dec. 2 by L. Boyer at Algiers.

Named in honor of a nephew of the discoverer. (H 112)
(1212) Francette

1931 XC. Discovered 1931 Dec. 3 by L. Boyer at Algiers.

Named in honor of the wife of the discoverer. (H 112)

\section{(1213) Algeria}

1931 XD. Discovered 1931 Dec. 5 by G. Reiss at Algiers. Independently discovered 1931 Dec. 8 by G. Van Biesbroeck at Williams Bay.

Named for the country in North Africa and its capital city Algiers in which this planet was discovered. (H 112)

\section{(1214) Richilde}

1932 AA. Discovered 1932 Jan. 1 by M. F. Wolf at Heidelberg. Independently discovered 1932 Jan. 6 by K. Nakamura at Kyoto.

Any reference of this name to a person or occurrence is unknown.

\section{(1215) Boyer}

1932 BA. Discovered 1932 Jan. 19 by A. Schmitt at Algiers. Independently discovered 1932 Jan. 27 by K. Reinmuth at Heidelberg.

Named in honor of Louis Boyer, astronomer at the Algiers Observatory and later at the Nice Observatory who has worked extensively on minor planets and comets. At Algiers he discovered 40 minor planets and at Nice has worked on identifications. (M 4418)

\section{(1216) Askania}

1932 BL. Discovered 1932 Jan. 29 by K. Reinmuth at Heidelberg.

Named after the Askania works in Berlin, manufacturers of optical and astronomical instruments. (H 112)

\section{(1217) Maximiliana}

1932 EC. Discovered 1932 Mar. 13 by E. Delporte at Uccle. Independently discovered 1932 Mar. 12 by M. F. Wolf at Heidelberg.

Named in honor of Max Wolf (1863-1932), founder and director of the Heidelberg Königstuhl Observatory. Wolf is also honored by planet (827). (H 112)

The citation (RI 695) reads: "E. Delporte hat den Wunsch geäussert, den von ihm entdeckten Planeten, der auch von Max Wolf entdeckt ist, zu Ehren des Verstorbenen zu benennen. Auf Vorschlag von Frau G. Wolf hat der Planet den Namen erhalten."

\section{(1218) Aster}

1932 BJ. Discovered 1932 Jan. 29 by K. Reinmuth at Heidelberg. Independently discovered 1932 Jan. 31 by M. Ferrero at Pino Torinese.

Named after various chiefly fall-blooming leafystemmed composite herbs with often showy heads containing tubular flowers or both tubular and ray flowers. (H 113) 


\section{(1219) Britta}

1932 CJ. Discovered 1932 Feb. 6 by M. F. Wolf at Heidelberg.

Any reference of this name to a person or occurrence is unknown.

\section{(1220) Crocus}

1932 CU. Discovered 1932 Feb. 11 by K. Reinmuth at Heidelberg.

Named for a genus of herbs of the iris family having solitary long-tubed flowers and slender linear leaves. (H 113)

\section{(1221) Amor}

1932 EA $_{1}$. Discovered 1932 Mar. 12 by E. Delporte at Uccle.

Amor is the Latin name for the Greek Eros, the god of love. Like (433) Eros this planet makes close approaches to the Earth. (H 113)

\section{(1222) Tina}

1932 LA. Discovered 1932 June 11 by E. Delporte at Uccle.

Tina is the Christian name of a woman, amateur astronomer, and friend of the discoverer. (H 113)

\section{(1223) Neckar}

1931 TG. Discovered 1931 Oct. 6 by K. Reinmuth at Heidelberg. Independently discovered 1931 Oct. 11 by F. Rigaux at Uccle.

Named for the Neckar river which has its origin in the Black Forest, crosses the city of Heidelberg, and flows into the Rhine. (H 113)

\section{(1224) Fantasia}

1927 SD. Discovered 1927 Aug. 29 by S. I. Belyavskij and N. Ivanov at Simeis. Independently discovered 1927 Sept. 17 by E. Delporte at Uccle.

Possibly named for a work as a poem or play in which the author's fancy roves unrestricted. Fantasia is the Latin word for fantasy. (LDS)

\section{(1225) Ariane}

1930 HK. Discovered 1930 Apr. 23 by H. van Gent at Johannesburg.

Named for the principal role, Ariane Leprieur in the play Le Chemin de Crête by the French dramatist Gabriel Marcel (1889-1973). (H 113)

\section{(1226) Golia}

1930 HL. Discovered 1930 Apr. 22 by H. van Gent at Johannesburg.

Named in honor of Golius, the first professor of astronomy and founder of the Leiden Observatory in 1633. He also bought the quadrant, used by Snellius for his trigonometry of the Netherlands, which is now in the Museum of History and Sciences in Leiden. (I. van Houten-Groeneveld)

\section{(1227) Geranium}

1931 TD. Discovered 1931 Oct. 5 by K. Reinmuth at Heidelberg.

Named after a genus of plants having regular flowers without spurs and with glands that alternate with the petals. (H 113)

See also the citation for planet (1234).

\section{(1228) Scabiosa}

1931 TU. Discovered 1931 Oct. 5 by K. Reinmuth at Heidelberg.

Named after a genus of herbs of the teasel family with terminal flower heads subtended by a leafy involucre. (H 113)

See also the citation for planet (1234).

\section{(1229) Tilia}

$1931 \mathrm{TP}_{1}$. Discovered 1931 Oct. 9 by K. Reinmuth at Heidelberg.

Named after a plant (limetree, basswood) from the Tiliaceae family. (H 113)

See also the citation for planet (1234).

\section{(1230) Riceia}

1931 TX $_{1}$. Discovered 1931 Oct. 9 by K. Reinmuth at Heidelberg.

Named in honor of Hugh Rice, amateur astronomer of New York and director of the Museum of Natural Sciences. See also the citation for planet (1234). (H 113; LDS)

Name proposed by I. L. Meyer and endorsed by G. Stracke. See also the remarks to planet (1249).

\section{(1231) Auricula}

$1931 \mathrm{TE}_{2}$. Discovered 1931 Oct. 10 by K. Reinmuth at Heidelberg. Independently discovered 1931 Oct. 11 by F. Rigaux at Uccle.

Named after the yellow flowered Alpine primrose. (H 113)

See also the citation for planet (1234).

\section{(1232) Cortusa}

$1931 \mathrm{TF}_{2}$. Discovered 1931 Oct. 10 by K. Reinmuth at Heidelberg.

Named after a plant of the primrose family. (H 114)

See also the citation for planet (1234).

\section{(1233) Kobresia}

$1931 \mathrm{TG}_{2}$. Discovered 1931 Oct. 10 by K. Reinmuth at Heidelberg.

Kobresia is the name of a grass. (I. van HoutenGroeneveld)

See also the citation for planet (1234).

\section{(1234) Elyna}

1931 UF. Discovered 1931 Oct. 18 by K. Reinmuth at Heidelberg.

This is a name of a plant. The first letters of planets (1227) through (1234) form the name G. Stracke. Due to the desire of Stracke that no planet be named after 
him it was in this manner that the discoverer was able to circumvent and to honor the noted German astronomer and diligent orbit computer. Stracke later was also honored by planet (1019). (H 114)

The same method to honor an astronomer by using consecutive initial letters was used again in 1995 - see the citation of planet (5699).

\section{(1235) Schorria}

1931 UJ. Discovered 1931 Oct. 18 by K. Reinmuth at Heidelberg.

Named in honor of the German astronomer Richard Schorr (1867-1951), staff member of the Hamburg Bergedorf Observatory. He discovered the periodic comet 1918 III and the planets (869) and (1240). (H 114)

Named by the Astronomisches Rechen-Institut in accordance with the discoverer (RI 862).

Schorr is also honored by a lunar crater.

\section{(1236) Thaïs}

1931 VX. Discovered 1931 Nov. 6 by G. N. Neujmin at Simeis.

Named for the famous Athenian hetaera who accompanied Alexander the Great (356-323 B.C.) in Asia. She later joined king Ptolemy I, from whom she had three children. Thaïs also is the title figure of a novel (1890) of the French novelist and satirist and 1921 Nobel laureate Anatole France (1844-1924, pseudonym of Jacques Anatole François Thibault). (N. Solovaya; A. Paluzíe-Borrell)

\section{(1237) Geneviève}

1931 XB. Discovered 1931 Dec. 2 by G. Reiss at Algiers. Independently discovered 1931 Dec. 3 by G. N. Neujmin at Simeis.

Named in honor of the eldest daughter of the discoverer. (H 114)

\section{(1238) Predappia}

1932 CA. Discovered 1932 Feb. 4 by L. Volta at Pino Torinese.

Named after the small village of Predappio near Forli, Italy. Predappio was the birthplace of "il Duce" Mussolini and, obviously, this is another clear instance of homage to him. (P. G. Comba)

\section{(1239) Queteleta}

1932 CB. Discovered 1932 Feb. 4 by E. Delporte at Uccle. Independently discovered 1932 Feb. 4 by L. Boyer at Algiers and Feb. 13 by G. Van Biesbroeck at Williams Bay.

Named in honor of Lambert Adolphe Jacques Quetelet (1796-1874), Belgian astronomer, mathematician, meteorologist, statistician and in 1828 first director of the Royal Observatory of Belgium which he helped to found. (H 114)

Quetelet is also honored by a lunar crater.

\section{(1240) Centenaria}

1932 CD. Discovered 1932 Feb. 5 by R. Schorr at Bergedorf.

Named on the occasion of the 100th anniversary of the Hamburg Observatory (1933 Oct. 31). (H 114)

\section{(1241) Dysona}

1932 EB $_{1}$. Discovered 1932 Mar. 4 by H. E. Wood at Johannesburg.

Named in honor of Sir Frank Watson Dyson (1868-1939), Astronomer Royal of England, director of the Greenwich Observatory and president of the International Astronomical Union 1928-1932. (RI 814; H 114)

Dyson is also honored by a lunar crater.

\section{(1242) Zambesia}

1932 HL. Discovered 1932 Apr. 28 by C. Jackson at Johannesburg.

The name applies to the former British territories in the Zambezi Basin, southern Africa. (H 114)

\section{(1243) Pamela}

1932 JE. Discovered 1932 May 7 by C. Jackson at Johannesburg.

Named in honor of the daughter of the discoverer. (H 114)

\section{(1244) Deira}

1932 KE. Discovered 1932 May 25 by C. Jackson at Johannesburg.

Named after the ancient name of the birthplace of the discoverer. (H 115)

Jackson (see planet (2193)) was born in the town of Ossett, Yorkshire.

\section{(1245) Calvinia}

1932 KF. Discovered 1932 May 26 by C. Jackson at Johannesburg.

Named for a village in the Cape Province, South Africa. (H 115)

\section{(1246) Chaka}

1932 OA. Discovered 1932 July 23 by C. Jackson at Johannesburg.

Named for Chaka (or Tchaka), king of the Zulu tribe and founder of the Zulu empire in 1812. (H 115)

\section{(1247) Memoria}

1932 QA. Discovered 1932 Aug. 30 by M. Laugier at Uccle. Independently discovered 1932 Aug. 30 by G. N. Neujmin at Simeis and Sept. 6 by K. Reinmuth at Heidelberg.

This is the Latin word for remembrance. The discoverer was often reminded of her pleasant relationship while in Uccle in 1932. (H 115)

\section{(1248) Jugurtha}

1932 RO. Discovered 1932 Sept. 1 by C. Jackson at Johannesburg. Independently discovered 1932 Sept. 29 by G. N. Neujmin at Simeis. 
Named after the Numidian king (160-104 B.C.) and enemy of Rome. Jugurtha was throttled to death in Rome. (H 115)

\section{(1249) Rutherfordia}

1932 VB. Discovered 1932 Nov. 4 by K. Reinmuth at Heidelberg. Independently discovered 1932 Nov. 29 by

E. Delporte at Uccle.

Named after the city of Rutherford, New York. (LDS)

Name proposed by Irving L. Meyer, Rutherford, N.Y. and endorsed by G. Stracke (RI 1534).

The name is erroneously interpreted in many sources as belonging to the 1908 Nobel Prize winner Lord Ernest Rutherford (1871-1937). The correct interpretation, however, has been found on a postcard, dated Feb. 2, 1937, from G. Stracke to the discoverer: "Ein amerikanischer Kollege, der selber keinen Planeten entdeckt hat, möchte gern zwei Planeten mit dem Namen "Riceia" \{see planet (1230)\} (Leiter Rice vom Amerik. Museum der Naturwissenschaften in New York) und "Rutherfordia" (Rutherford ist der Ort einer Privatsternwarte) taufen..."

\section{(1250) Galanthus}

1933 BD. Discovered 1933 Jan. 25 by K. Reinmuth at Heidelberg.

Named after a flower, the snowdrop. (H 115)

\section{(1251) Hedera}

1933 BE. Discovered 1933 Jan. 25 by K. Reinmuth at Heidelberg.

Named after a plant of the ivy family. (H 115)

\section{(1252) Celestia}

1933 DG. Discovered 1933 Feb. 19 by F. L. Whipple at Cambridge, Massachusetts.

Named by the discoverer in honor of his mother. For the naming of this planet the spelling needed no change. (H 115)

\section{(1253) Frisia}

$1931 \mathrm{TV}_{1}$. Discovered 1931 Oct. 9 by K. Reinmuth at Heidelberg. Independently discovered 1931 Nov. 6 by

P. F. Shajn at Simeis.

Named for the people that inhabit principally the Netherlands province of Friesland and the Friesian islands in the North sea. (H 115)

\section{(1254) Erfordia}

1932 JA. Discovered 1932 May 10 by J. Hartmann at La Plata.

Named (RI 835) by J. Hartmann for the city of Erfurt, Germany, which was the birthplace of the discoverer. (H 115)

\section{(1255) Schilowa}

1932 NC. Discovered 1932 July 8 by G. N. Neujmin at Simeis.

Named in honor of M. W. Schilowa (1870-1934), astronomer and orbit computer at the Pulkovo Observatory. (H 115)
The spelling of the name originally was "Shilowa" (RI 1160).

\section{(1256) Normannia}

1932 PD. Discovered 1932 Aug. 8 by K. Reinmuth at Heidelberg.

This planet is probably named for the inhabitants of Normandy. (H 115)

\section{(1257) Móra}

1932 PE. Discovered 1932 Aug. 8 by K. Reinmuth at Heidelberg.

Named in honor of the Hungarian astronomer Károly Móra (1899-1938). (H 116; I. van Houten-Groeneveld)

The number and name of this planet were later used for another object in a rather unusual manner - see the citation for planet (2517).

\section{(1258) Sicilia}

1932 PG. Discovered 1932 Aug. 8 by K. Reinmuth at Heidelberg.

Named for the island of Sicily in the Mediterranean sea. (H 116)

\section{(1259) Ógyalla}

1933 BT. Discovered 1933 Jan. 29 by K. Reinmuth at Heidelberg.

Named for the Hungarian seismological, meteorological and astronomical observatory. (H 116)

\section{(1260) Walhalla}

1933 BW. Discovered 1933 Jan. 29 by K. Reinmuth at Heidelberg.

Named for the memorial hall near Regensburg, Germany. In Norse mythology it was the hall of Odin \{see planet (3989)\} where warriors who have died in battle are received. (H 116)

\section{(1261) Legia}

1933 FB. Discovered 1933 Mar. 23 by E. Delporte at Uccle.

Legia is the Latin name for the city of Liège (Luik), Belgium. (H 116)

\section{(1262) Sniadeckia}

1933 FE. Discovered 1933 Mar. 23 by S. Arend at Uccle.

Named in honor of Jan Sniadecki (1756-1830), a Polish scholar, professor of mathematics and astronomy, and founder of the Cracow Observatory. (H 116)

Named by T. Banachiewicz (RI 843).

Sniadecki is also honored by a lunar crater.

\section{(1263) Varsavia}

1933 FF. Discovered 1933 Mar. 23 by S. Arend at Uccle.

Varsavia is the Latin name for Warsaw, Poland. The citation reads: "zum Dank der Stadt Warschau für ihre der Sternwarte Lubomir (Beskiden) geleistete Hilfe." (RI 843)

Named by T. Banachiewicz. 
(1264) Letaba

1933 HG. Discovered 1933 Apr. 21 by C. Jackson at Johannesburg.

Named for a river in Transvaal, South Africa. (H 116)

\section{(1265) Schweikarda}

Discovered 1911 Oct. 18 by F. Kaiser at Heidelberg.

Named by the discoverer for his mother's family name, Schweikard. (H 116)

\section{(1266) Tone}

1927 BD. Discovered 1927 Jan. 23 by O. Oikawa at Tokyo. Independently discovered 1927 Jan. 24 by G. N. Neujmin at Simeis.

Named for the largest river in Japan. (H 116)

\section{(1267) Geertruida}

1930 HD. Discovered 1930 Apr. 23 by H. van Gent at Johannesburg. Independently discovered 1930 Apr. 28 by K. Reinmuth at Heidelberg.

Named in honor of the daughter of the Mrs. Hamerslag, a sister of G. Pels. (I. van Houten-Groeneveld)

Named by G. Pels \{see planet (1667)\} who computed the orbit.

\section{(1268) Libya}

1930 HJ. Discovered 1930 Apr. 29 by C. Jackson at Johannesburg.

Named for the country in northern Africa bordering the Mediterranean sea. (H 116)

\section{(1269) Rollandia}

1930 SH. Discovered 1930 Sept. 20 by G. N. Neujmin at Simeis.

Named in honor of the French writer and 1915 Nobel laureate Romain Rolland (1866-1944). (H 116)

\section{(1270) Datura}

1930 YE. Discovered 1930 Dec. 17 by G. Van Biesbroeck at Williams Bay. Independently discovered 1930 Dec. 20 by M. F. Wolf at Heidelberg.

Named for a genus of widely distributed strongscented herbs, shrubs, or trees of the nightshade family (e.g. hawthorn). (H 116)

\section{(1271) Isergina}

1931 TN. Discovered 1931 Oct. 10 by G. N. Neujmin at Simeis.

Named in honor of the friend and physician of the discoverer, Pyotr Vasil'evich Isergin (1870-1936) who treated him. (H 117; G. R. Kastel'; I. I. Neyachenko)

\section{(1272) Gefion}

$1931 \mathrm{TZ}_{1}$. Discovered 1931 Oct. 10 by K. Reinmuth at Heidelberg.

Named for a figure in Norse mythology and for the Gefion spring in Copenhagen. (H 117)

\section{(1273) Helma}

1932 PF. Discovered 1932 Aug. 8 by K. Reinmuth at Heidelberg.
Named in honor of an acquaintance of the German astronomer W. Schaub. (H 117)

\section{(1274) Delportia}

1932 WC. Discovered 1932 Nov. 28 by E. Delporte at Uccle.

Named in honor of the discoverer, Eugène J. Delporte (1882-1955). He observed and discovered more than 60 minor planets at the Uccle Observatory where he was director from 1936 to 1947 . (H 117)

Name proposed by G. Stracke.

Delporte is also honored by a lunar crater.

\section{(1275) Cimbria}

1932 WG. Discovered 1932 Nov. 30 by K. Reinmuth at Heidelberg.

Named for the people encountered by the Romans in Noricum about 113 B.C. At first victorious, they were destroyed by Marius in 101 B.C. (H 117)

\section{(1276) Ucclia}

1933 BA. Discovered 1933 Jan. 24 by E. Delporte at Uccle. Independently discovered 1933 Jan. 26 by R. Schorr at Bergedorf.

Named in honor of Uccle, both the city and the observatory, where this planet was discovered. (H 117)

\section{(1277) Dolores}

1933 HA. Discovered 1933 Apr. 18 by G. N. Neujmin at Simeis.

Named in honor of Dolores Gómez Ibarruri "La Pasionária") (1895-1989), a leading figure of the Spanish communists. In 1920, she was co-founder of the communist party in Spain. She served as general secretary (1942-1960) and chairwoman (1960-1967) of the exile party. She returned to her home country in 1977 and was selected as member of the parliament. (H 117)

\section{(1278) Kenya}

1933 LA. Discovered 1933 June 15 by C. Jackson at Johannesburg.

Named for the country in eastern Africa. (H 117)

\section{(1279) Uganda}

1933 LB. Discovered 1933 June 15 by C. Jackson at Johannesburg.

Named for the country in central Africa, north of Lake Victoria. (H 117)

\section{(1280) Baillauda}

1933 QB. Discovered 1933 Aug. 18 by E. Delporte at Uccle. Independently discovered 1933 Aug. 19 by G. N. Neujmin at Simeis.

Named in honor of Jules Baillaud (1876-1960), astronomer at the Paris Observatory and director of the Pic-du-Midi Observatory from 1937 to 1947. (H 117)

Baillaud is also honored by a lunar crater. 
(1281) Jeanne

1933 QJ. Discovered 1933 Aug. 25 by S. Arend at Uccle.

Named in honor of the daughter of the discoverer. (H 117)

\section{(1282) Utopia}

$1933 \mathrm{QM}_{1}$. Discovered 1933 Aug. 17 by C. Jackson at Johannesburg.

Named for that imaginary country, a place of ideal perfection especially in laws, government, and social conditions. It was described 1516 by the English statesman and author Sir Thomas More (1478-1535). (H 117)

\section{(1283) Komsomolia}

1925 SC. Discovered 1925 Sept. 25 by V. A. Albitskij at Simeis. Independently discovered 1925 Oct. 10 by

K. Reinmuth at Heidelberg.

The name of the communistic youth organization of \{the former USSR. (M 838)

\section{(1284) Latvia}

1933 OP. Discovered 1933 July 27 by K. Reinmuth at Heidelberg. Independently discovered 1933 Aug. 19 by G. N. Neujmin at Simeis.

Named for the country of Latvia. Since 1991 Latvia again is an independent state. (H 118)

Name proposed by J. Stein.

\section{(1285) Julietta}

1933 QF. Discovered 1933 Aug. 21 by E. Delporte at Uccle.

Named in honor of the discoverer's mother. (J. Meeus)

\section{(1286) Banachiewicza}

1933 QH. Discovered 1933 Aug. 25 by S. Arend at Uccle.

Named in honor of the Polish astronomer Tadeusz Banachiewicz (1882-1954), director of the Cracow Observatory. (H 118)

Obituary published in l'Astronomie, Vol. 69, p. 290

(1955). Banachiewicz is also honored by a lunar crater.

\section{(1287) Lorcia}

1933 QL. Discovered 1933 Aug. 25 by S. Arend at Uccle.

Named in honor of the wife of T. Banachiewicz. (H 118)

Named by T. Banachiewicz.

\section{(1288) Santa}

1933 QM. Discovered 1933 Aug. 26 by E. Delporte at Uccle.

Any reference of this name to a person or occurrence is unknown.

Named by De Caro who computed the orbit.
(1289) Kutaïssi

1933 QR. Discovered 1933 Aug. 19 by G. N. Neujmin at Simeis. Independently discovered 1933 Aug. 25 by E. Delporte at Uccle and Sept. 11 by C. Jackson at Johannesburg.

Named for a city in the Georgian Republic. (H 118)

\section{(1290) Albertine}

$1933 \mathrm{QL}_{1}$. Discovered 1933 Aug. 21 by E. Delporte at Uccle.

Named in honor of Albert I (1875-1934), King of the Belgians. (H 118)

\section{(1291) Phryne}

1933 RA. Discovered 1933 Sept. 15 by E. Delporte at Uccle.

Named for a hetaera of the 4th century B.C. celebrated for her beauty. She was the model for several statues including the Cnidian Aphrodite of Praxiteles \{see planet (5983)\} and also, it is said, for the Aphrodite Anadyomene of Apelles. (H 118)

\section{(1292) Luce}

1933 SH. Discovered 1933 Sept. 17 by F. Rigaux at Uccle.

Named in honor of the wife of the discoverer. (H 118)

\section{(1293) Sonja}

1933 SO. Discovered 1933 Sept. 26 by E. Delporte at Uccle. Independently discovered 1933 Sept. 28 by G. N. Neujmin at Simeis.

Any reference of this name to a person or occurrence is unknown.

Name proposed by the Astronomisches Rechen-Institut (RI 1039).

The naming might be influenced by the two letters of the provisional designation 1933 SO. See also the remarks to planet (579).

\section{(1294) Antwerpia}

1933 UB $_{1}$. Discovered 1933 Oct. 24 by E. Delporte at Uccle.

Named for the city of Antwerp, Belgium. (H 118)

\section{(1295) Deflotte}

1933 WD. Discovered 1933 Nov. 25 by L. Boyer at Algiers.

Named by the discoverer in honor of his nephew. (H 118)

\section{(1296) Andrée}

1933 WE. Discovered 1933 Nov. 25 by L. Boyer at Algiers.

Named by the discoverer in honor of his niece. (H 118)

\section{(1297) Quadea}

1934 AD. Discovered 1934 Jan. 7 by K. Reinmuth at Heidelberg.

Named by the discoverer in honor of the parents-inlaw of his brother, Prof. E. Reinmuth. (H 119) 


\section{(1298) Nocturna}

1934 AE. Discovered 1934 Jan. 7 by K. Reinmuth at Heidelberg.

Nocturna is the feminine adjective of nocturnus and means nightly. (H 119)

Name proposed by G. Stracke.

\section{(1299) Mertona}

1934 BA. Discovered 1934 Jan. 18 by G. Reiss at Algiers.

Named for the English astronomer Gerald Merton \{1893-1983\}. (H 119)

Obituary published in J. Br. Astron. Assoc., Vol. 94, No. 1, p. 28-30 (1983)

\section{(1300) Marcelle}

1934 CL. Discovered 1934 Feb. 10 by G. Reiss at Algiers. Independently discovered 1934 Feb. 14 by S. Arend at Uccle.

Named in honor of the second daughter of the discoverer. (H 119)

\section{(1301) Yvonne}

1934 EA. Discovered 1934 Mar. 7 by L. Boyer at Algiers.

Named in honor of the sister of the discoverer. (H 119)

\section{(1302) Werra}

Discovered 1924 Sept. 28 by K. Reinmuth at Heidelberg.

Named for the German river which joins the Fulda at Münden to form the Weser. (H 119)

\section{(1303) Luthera}

1928 FP. Discovered 1928 Mar. 16 by A. Schwassmann at Bergedorf.

Named in honor of the German astronomer Karl Theodor Robert Luther (1822-1900) who, at the Bilk Observatory near Düsseldorf, discovered 24 minor planets between 1852 and 1890. (H 119)

Luther is also honored by a lunar crater.

\section{(1304) Arosa}

1928 KC. Discovered 1928 May 21 by K. Reinmuth at Heidelberg.

Named for the small city in Switzerland. (H 119)

\section{(1305) Pongola}

1928 OC. Discovered 1928 July 19 by H. E. Wood at Johannesburg.

Named by the discoverer for a river in South Africa. (H 119)

\section{(1306) Scythia}

1930 OB. Discovered 1930 July 22 by G. N. Neujmin at Simeis.

Named for the country of the ancient Scythians comprising parts of Europe and Asia now in the U.S.S.R. in regions north of the Black sea and east of the Aral sea. (H 119)

\section{(1307) Cimmeria}

1930 UF. Discovered 1930 Oct. 17 by G. N. Neujmin at Simeis.

Named after the ancient inhabitants of the Crimea peninsula. The Cimmerians were expelled by the Scythians $\{$ see planet (1306)\} in the 7th century B.C. (A. N. Deutsch)

\section{(1308) Halleria}

1931 EB. Discovered 1931 Mar. 12 by K. Reinmuth at Heidelberg.

Named in honor of Albrecht von Haller (1708-1777), physician, botanist, and poet at the 1935 meeting of the Astronomische Gesellschaft in Berne, Switzerland. (I. van Houten-Groeneveld)

\section{(1309) Hyperborea}

1931 TO. Discovered 1931 Oct. 11 by G. N. Neujmin at Simeis. Independently discovered 1931 Oct. 13 by E. Delporte at Uccle.

Named for the region in Greek mythology which is the home of a group of people placed by Herodotus \{see planet (3092)\} in the extreme north who were especially associated with the cult of Apollo \{see planet (1862)\}. The land was so far north that it was regarded as the region of perpetual sunshine as it was beyond the north wind. (N. S. Samojlova-Yakhontova)

\section{(1310) Villigera}

1932 DB. Discovered 1932 Feb. 28 by A. Schwassmann at Bergedorf.

Named in honor of the Swiss astronomer Walter Augustin Villiger (1872-1938) who was head of the department for astronomical instruments of Carl Zeiss, Jena. (H 120)

\section{(1311) Knopfia}

$1933 \mathrm{FF}_{1}$. Discovered 1933 Mar. 24 by K. Reinmuth at Heidelberg.

Named in honor of the German astronomer O. Knopf \{1856-1945\} who worked at Jena. (H 120) Name proposed by H. Vogt (RI 1445).

\section{(1312) Vassar}

1933 OT. Discovered 1933 July 27 by G. Van Biesbroeck at Williams Bay.

Named by Mrs. Maud W. Makemson who computed the orbit while teaching in the women's college of Vassar, Poughkeepsie, N.Y. (H 120)

\section{(1313) Berna}

1933 QG. Discovered 1933 Aug. 24 by S. Arend at Uccle.

Named for the capital of Switzerland. (H 120)

Name proposed by S. Mauderli of the University of Berne who computed the definitive orbit of this planet.

The planet was first announced (RI 1156) as "Bernia" but Mauderli (RI 1161) requested the actual name. 


\section{(1314) Paula}

1933 SC. Discovered 1933 Sept. 16 by S. Arend at Uccle.

Named by the discoverer in honor of his wife. (H 120)

\section{(1315) Bronislawa}

$1933 \mathrm{SF}_{1}$. Discovered 1933 Sept. 16 by S. Arend at Uccle.

Named for the Polish saint Bronislava $\{1203 ?-1259\}$, a cousin of St. Hyazinth of Poland. She was a professed Premonstratensian nun, but died a recluse. (H 120; R. Bremer, I. Heinrich)

Name proposed (RI 1254) by Miss L. Stankiewicz.

\section{(1316) Kasan}

1933 WC. Discovered 1933 Nov. 17 by G. N. Neujmin at Simeis.

Named for the city on the Volga river east of Moscow and for the Kasan Observatory. (H 120)

\section{(1317) Silvretta}

1935 RC. Discovered 1935 Sept. 1 by K. Reinmuth at Heidelberg. Independently discovered 1935 Sept. 19 by C. Jackson at Johannesburg and P. F. Shajn at Simeis.

Named for a peak (3282 m) and a lake in Graubünden, Swiss Alps. (H 120)

\section{(1318) Nerina}

1934 FG. Discovered 1934 Mar. 24 by C. Jackson at Johannesburg.

Named after a genus of south African bulbous herbs from the amaryllidaceae family. (H 120)

\section{(1319) Disa}

1934 FO. Discovered 1934 Mar. 19 by C. Jackson at Johannesburg.

Named for a large genus of tropical African terrestrial orchids, perhaps the most showy of all orchids. (H 120)

\section{(1320) Impala}

1934 JG. Discovered 1934 May 13 by C. Jackson at Johannesburg.

Named after the large brownish African antelope. The male has slender lyrate horns. (H 120)

\section{(1321) Majuba}

1934 JH. Discovered 1934 May 7 by C. Jackson at Johannesburg.

Named for a mountain in northwest Natal, South Africa. (H 120)

\section{(1322) Coppernicus}

1934 LA. Discovered 1934 June 15 by K. Reinmuth at Heidelberg. Independently discovered 1934 June 15 by E. Delporte at Uccle.

Named for the great Polish astronomer Nicolaus Copernicus (1473-1543), the founder of the heliocentric planetary system and of modern astronomy. (H 120)

Copernicus is also honored by a lunar and a Martian crater.
(1323) Tugela

1934 LD. Discovered 1934 May 19 by C. Jackson at Johannesburg.

Named after a river in Natal, South Africa. (H 121)

\section{(1324) Knysna}

1934 LL. Discovered 1934 June 15 by C. Jackson at Johannesburg.

Named by the discoverer for the village in the Cape Province, South Africa. (H 121)

\section{(1325) Inanda}

1934 NR. Discovered 1934 July 14 by C. Jackson at Johannesburg.

This is a name of a village community inhabited by the Zulus. (H 121)

\section{(1326) Losaka}

1934 NS. Discovered 1934 July 14 by C. Jackson at Johannesburg.

Named for the capital of northern Rhodesia. Lusaka today is the capital of Zambia. (H 121)

\section{(1327) Namaqua}

1934 RT. Discovered 1934 Sept. 7 by C. Jackson at Johannesburg.

Named after a coastal region in Namibia, southwest Africa. (H 121)

\section{(1328) Devota}

1925 UA. Discovered 1925 Oct. 21 by B. Jekhovsky at Algiers.

Named by the discoverer in honor of his friend Fortunato Devoto, director of the La Plata Observatory and president of the National Council of Observatories of Argentina. (H 121)

\section{(1329) Eliane}

1933 FL. Discovered 1933 Mar. 23 by E. Delporte at Uccle.

Named in honor of the daughter of Prof. Paul Bourgeois \{see planet (1543)\} of the Royal Observatory at Uccle, Belgium. (H 121)

\section{(1330) Spiridonia}

1925 DB. Discovered 1925 Feb. 17 by V. A. Albitskij at Simeis.

Named in honor of Spiridon Il'ich Zaslavskij (18831942), the brother of Mrs. Albitskij. Zaslavskij was the uncle of Vitja \{see planet (1030)\}. (M 2882; LDS)

\section{(1331) Solvejg}

1933 QS. Discovered 1933 Aug. 25 by G. N. Neujmin at Simeis. Independently discovered 1933 Sept. 11 by C. Jackson at Johannesburg.

Named for the heroine of Henrik Ibsen's (1828-1906) \{see planet (5696)\} drama Peer Gynt. (N. S. SamojlovaYakhontova)

\section{(1332) Marconia}

1934 AA. Discovered 1934 Jan. 9 by L. Volta at Pino Torinese. 
Named in honor of Marchese Guglielmo Marconi (1874-1937), Italian electrical engineer and inventor and winner of the physics Nobel prize in 1909 (together with K. F. Braun). (H 121)

Marconi is also honored by a lunar crater.

\section{(1333) Cevenola}

1934 DA. Discovered 1934 Feb. 20 by O. Bancilhon at Algiers.

Named for the Cévennes mountain range in southern France at the eastern edge of the Massif Central. (H 121)

\section{(1334) Lundmarka}

1934 OB. Discovered 1934 July 16 by K. Reinmuth at Heidelberg.

Named in honor of the Swedish astronomer Knut Emil Lundmark (1889-1958). Lundmark studied extensively globular clusters and galaxies and determined absolute stellar magnitudes as well as galactic distances. He also contributed to our knowledge in the field of history of astronomy. (H 121)

Lundmark is also honored by a lunar crater.

\section{(1335) Demoulina}

1934 RE. Discovered 1934 Sept. 7 by K. Reinmuth at Heidelberg. Independently discovered 1934 Sept. 13 by E. Delporte at Uccle.

Named in honor of Prof. Demoulin of the University of Ghent, Belgium. (H 121)

\section{(1336) Zeelandia}

1934 RW. Discovered 1934 Sept. 9 by H. van Gent at Johannesburg.

Named for a province in southwestern Netherlands. (H 121)

\section{(1337) Gerarda}

$1934 \mathrm{RA}_{1}$. Discovered 1934 Sept. 9 by H. van Gent at Johannesburg.

Named in honor of Mrs. G. Prins, wife of Mr. Prins who was a computer at the Leiden Observatory. (I. van Houten-Groeneveld)

Named by G. Pels who computed the orbit.

\section{(1338) Duponta}

1934 XA. Discovered 1934 Dec. 4 by L. Boyer at Algiers.

Named by the discoverer in honor of his nephew Marc Dupont. (H 122)

\section{(1339) Désagneauxa}

1934 XB. Discovered 1934 Dec. 4 by L. Boyer at Algiers. Independently discovered 1934 Dec. 8 by G. N. Neujmin at Simeis and Dec. 9 by E. Delporte at Uccle.

Named in honor of the brother-in-law of the discoverer. (H 122)
(1340) Yvette

1934 YA. Discovered 1934 Dec. 27 by L. Boyer at Algiers.

Named by the discoverer in honor of his niece. (H 122)

\section{(1341) Edmée}

1935 BA. Discovered 1935 Jan. 27 by E. Delporte at Uccle.

Named in honor of Mrs. Edmée Chandon who was an astronomer at the Paris Observatory. (H 122)

\section{(1342) Brabantia}

1935 CV. Discovered 1935 Feb. 13 by H. van Gent at Johannesburg.

Named for the northern part of Brabant which is a province of the Netherlands. (I. van Houten-Groeneveld)

\section{(1343) Nicole}

1935 FC. Discovered 1935 Mar. 29 by L. Boyer at Algiers. Independently discovered 1935 Apr. 3 by E. Delporte at Uccle.

Named by the discoverer in honor of his niece. (H 122)

\section{(1344) Caubeta}

1935 GA. Discovered 1935 Apr. 1 by L. Boyer at Algiers.

Named in honor of Paul Caubet (? -1942), astronomer at the Toulouse Observatory. (H 122)

\section{(1345) Potomac}

Discovered 1908 Feb. 4 by J. H. Metcalf at Taunton.

Named for the river on which Washington, D.C. is located. The river flows from West Virginia into the Chesapeake Bay and forms the southern boundary of Maryland. (H 122)

See also the remarks to planet (1052).

\section{(1346) Gotha}

1929 CY. Discovered 1929 Feb. 5 by K. Reinmuth at Heidelberg.

Named for the city of Gotha in the district of Erfurt in Thüringen \{see, respectively, planets (1254) and (934)\}, Germany. Gotha is wellknown in astronomy by his famous observatory and the work of F. X. von Zach \{see planet (999)\}. (H 122)

\section{(1347) Patria}

1931 VW. Discovered 1931 Nov. 6 by G. N. Neujmin at Simeis.

This is the Latin word for native country or fatherland. (H 122)

(1348) Michel

1933 FD. Discovered 1933 Mar. 23 by S. Arend at Uccle.

Named in honor of the elder son of the discoverer. (H 122) 


\section{(1349) Bechuana}

1934 LJ. Discovered 1934 June 13 by C. Jackson at Johannesburg.

Named for the region south of the Molopo river which became a province of the Union of South Africa in 1895. It is now the independent state of Botswana. (H 122)

\section{(1350) Rosselia}

1934 TA. Discovered 1934 Oct. 3 by E. Delporte at Uccle. Independently discovered 1934 Nov. 3 by

R. Schorr at Bergedorf.

Named in honor of Miss Rossel, editor of the Belgian newspaper Le Soir. (H 122)

\section{(1351) Uzbekistania}

1934 TF. Discovered 1934 Oct. 5 by G. N. Neujmin at Simeis.

Named in honor of the \{former\} Uzbek Soviet Socialist Republic, where the discoverer resided during World War II. (M 2882; M 2903; N. S. Chernykh)

This name was found in the discoverer's handwriting in his personal volume of "Kleine Planeten für 1941" by Dr. S. G. Makover

\section{(1352) Wawel}

1935 CE. Discovered 1935 Feb. 3 by S. Arend at Uccle.

Named for a castle of the ancient kings of Poland at Cracow. (H 123)

Name proposed by T. Banachiewicz.

\section{(1353) Maartje}

1935 CU. Discovered 1935 Feb. 13 by H. van Gent at Johannesburg.

Named in honor of the daughter of B. G. Mekking who was a computer at the Leiden Observatory. (H 123)

\section{(1354) Botha}

1935 GK. Discovered 1935 Apr. 3 by C. Jackson at Johannesburg.

Named after a distinguished South African patriot who was also one of the prime movers in the formation of the Union of South Africa. \{Louis Botha (1862-1919) was the first prime minister of Transvaal (1907) and of the Union of South Africa (1910-1919)\}. (M 908)

\section{(1355) Magoeba}

1935 HE. Discovered 1935 Apr. 30 by C. Jackson at Johannesburg.

The name of a native chief of the North Transvaal, South Africa, who has given his name also to one of the beauty spots of Transvaal, viz. MagoebasKloof. (M 908)

\section{(1356) Nyanza}

1935 JH. Discovered 1935 May 3 by C. Jackson at Johannesburg.

Named for a region in southwestern Kenya with the capital Kisumu. (H 123)

\section{(1357) Khama}

1935 ND. Discovered 1935 July 2 by C. Jackson at Johannesburg.

Name of the late Paramount Chief of the Bechuana tribe and a distinguished native leader. (M 908)

\section{(1358) Gaika}

1935 OB. Discovered 1935 July 21 by C. Jackson at Johannesburg.

Name of a native chief of the Transkei, Cape Province, who figures largely in South African history. (M 909)

\section{(1359) Prieska}

1935 OC. Discovered 1935 July 22 by C. Jackson at Johannesburg.

Named for a village in the Cape Province, South Africa. (H 123)

\section{(1360) Tarka}

1935 OD. Discovered 1935 July 22 by C. Jackson at Johannesburg.

Same as above $\{$ cf. citation for planet (1358)\}. His name is given to the South African town of Tarkastad. (M 909)

\section{(1361) Leuschneria}

1935 QA. Discovered 1935 Aug. 30 by E. Delporte at Uccle.

Named in honor of the American astronomer Armin Otto Leuschner (1868-1953), director of Students' Observatory (now Leuschner Observatory), Berkeley, University of California. Leuschner worked extensively on celestial mechanics and is wellknown for his books Celestial Mechanics and The Minor Planets of the Hecuba Group. (H 123)

Named at the suggestion of S. Arend during his visit to Berkeley.

Leuschner is also honored by a lunar crater.

\section{(1362) Griqua}

1935 QG $_{1}$. Discovered 1935 July 31 by C. Jackson at Johannesburg.

Named for the tribe of mixed people of Bushman and Hottentot descent in Griqualand which is the district around the city of Kimberley, north of the Orange river. (H 124)

\section{(1363) Herberta}

1935 RA. Discovered 1935 Aug. 30 by E. Delporte at Uccle.

Named in honor of Herbert Clark Hoover (1874-1964), 31st president of the United States from 1929 to 1933. He was also president of the Commission for Relief in Belgium. This planet was named for the president after his visit to Belgium in 1938. (H 124)

Hoover is also honored by planet (932). 


\section{(1364) Safara}

1935 VB. Discovered 1935 Nov. 18 by L. Boyer at Algiers.

Named in honor of André Safar, Algiers. (H 124)

\section{(1365) Henyey}

1928 RK. Discovered 1928 Sept. 9 by M. F. Wolf at Heidelberg.

Named in honor of Dr. Louis G. Henyey \{1910$1970\}$, late professor of astronomy at the University of California, Berkeley, a pioneer in the calculation of stellar interiors and stellar evolution, and a member of the U.S. National Academy of Sciences. (M 3143)

Name proposed by William Westbrooke.

Obituaries published in Publ. Astron. Soc. Pac., Vol. 82, p. 367-369 (1970); Sky Telesc., Vol. 39, p. 290 (1970). Henyey is also honored by a lunar crater.

\section{(1366) Piccolo}

1932 WA. Discovered 1932 Nov. 29 by E. Delporte at Uccle.

Named in honor of M. d'Arsac, editor-in-chief of the Brussels newspaper Le Soir who used this pseudonym. (H 124)

\section{(1367) Nongoma}

1934 NA. Discovered 1934 July 3 by C. Jackson at Johannesburg. Independently discovered 1934 July 6 by K. Reinmuth at Heidelberg.

Named for the capital city of the Kwa-Zulu homeland in South Africa. (M 5181)

\section{(1368) Numidia}

1935 HD. Discovered 1935 Apr. 30 by C. Jackson at Johannesburg.

Named for the ancient country in northern Africa, east of Mauretania, in modern Algeria. (H 124)

\section{(1369) Ostanina}

1935 QB. Discovered 1935 Aug. 27 by P. F. Shajn at Simeis. Independently discovered 1935 Aug. 31 by K. Reinmuth at Heidelberg.

Named for a small town in the Perm district, USSR, the birthplace of the astronomer P. F. Shajn \{see planet (1190)\}. (M 838; LDS)

\section{(1370) Hella}

1935 QG. Discovered 1935 Aug. 31 by K. Reinmuth at Heidelberg.

Named in honor of Helene Nowacki \{1904-1972\}, an astronomer at the Astronomisches Rechen-Institut, Heidelberg. (H 124)

Name proposed by G. Stracke (RI 1644).

Obituary published in Astron. Nachr., Band 294, p. 191 (1973).

\section{(1371) Resi}

1935 QJ. Discovered 1935 Aug. 31 by K. Reinmuth at Heidelberg.

Named for a cousin of Mrs. Schaub, an acquaintance of the discoverer. (H 124)

Name proposed by W. Schaub (RI 1644).
(1372) Haremari

1935 QK. Discovered 1935 Aug. 31 by K. Reinmuth at Heidelberg.

The name jointly honors all the women on the staff of the Astronomisches Rechen-Institut. It is combined from the word "harem" and the abbreviation "ARI". This often published version for the meaning of the name is not fully correct. Reinmuth has been asked by some collaborators of the ARI to 'donate' planets for their girl-friends, popular actresses etc. He compiled all these suggestions to this peculiar term. However, Reinmuth did not want to publish the original meaning and he, therefore, devised the interpretation of the first sentence in 1948. (I. van Houten-Groeneveld)

\section{(1373) Cincinnati}

1935 QN. Discovered 1935 Aug. 30 by E. Hubble at Mount Wilson.

Since most of the orbit computations for this planet have been provided by the staff of the Cincinnati Observatory, this name has been recommended by the Minor Planet Center. (M 2116)

\section{(1374) Isora}

1935 UA. Discovered 1935 Oct. 21 by E. Delporte at Uccle.

This name is a combination of the word "Isor" (which is the backward form of the feminine name "Rosi") and the traditional "a". (H 125)

Name proposed by G. Stracke.

\section{(1375) Alfreda}

1935 UB. Discovered 1935 Oct. 22 by E. Delporte at Uccle.

Named in honor of a friend of the discoverer. (H 125)

\section{(1376) Michelle}

1935 UH. Discovered 1935 Oct. 29 by G. Reiss at Algiers.

Named in honor of the third daughter of the discoverer. (H 125)

\section{(1377) Roberbauxa}

1936 CD. Discovered 1936 Feb. 14 by L. Boyer at Algiers. Independently discovered 1936 Feb. 20 by E. Delporte at Uccle.

Nommée en l'honneur de l'ingénieur français Robert Baux (1900-1987), ami d'enfance du découvreur Louis Boyer, qui proposa un nom soudé pour cet astéroïde. Robert Baux était spécialiste dans les études des productivité des grandes entreprises et devient directeur et administrateur des sociétés. C'était aussi un alpiniste au titre de capitaine de réserve des Chasseurs alpins et il participa à de nombreuses ascensions. (B. G. Marsden; J. Baux; M.-A. Combes)

The original naming citation bei Herget (H 125) read 'Named in honor of the engineer Mr. Roberbaux'. The correct name was first mentioned by Marsden. M.-A. Combes elucidates the full story through a contact with the widow of the honoree, Mrs. Jacqueline Baux. Citation by M.-A. Combes. 
(1378) Leonce

1936 DB. Discovered 1936 Feb. 21 by F. Rigaux at Uccle.

Named in honor of the father of the discoverer. (H 125)

\section{(1379) Lomonosowa}

1936 FC. Discovered 1936 Mar. 19 by G. N. Neujmin at Simeis. Independently discovered 1936 Mar. 19 by P. Djurkovic at Uccle.

Named in honor of the first famous Russian physicist and astronomer, Mikhail Vasilevich Lomonosov, 17111765. (M 1252)

Name submitted by N. Yakhontova, Institute of Theoretical Astronomy, Leningrad.

Lomonosov is also honored by craters on Mars and the Moon.

\section{(1380) Volodia}

1936 FM. Discovered 1936 Mar. 16 by L. Boyer at Algiers. Independently discovered 1936 Mar. 21 by

E. Delporte at Uccle.

Named in honor of Vladimir Vesselovskij (diminuted Volodia) who was born the same night the minor planet was discovered. (H 125)

\section{(1381) Danubia}

1930 QJ. Discovered 1930 Aug. 20 by E. F. Skvortsov at Simeis.

Named for the great European river Danube (or Donau) flowing from southern Germany into the Black sea. (H 125)

Name proposed by the orbit computer C. Popovici (RI 1534).

\section{(1382) Gerti}

1925 BB. Discovered 1925 Jan. 21 by K. Reinmuth at Heidelberg.

Named in honor of Miss Gertrud Höhne who was a secretary at the Astronomisches Rechen-Institut in Berlin. (H 125)

Name proposed by L. Ringelmann (RI 1642). In the RI copy of Reinmuth, this name is framed by two hearts with red pencil.

\section{(1383) Limburgia}

1934 RV. Discovered 1934 Sept. 9 by H. van Gent at Johannesburg.

Named for the province of Limburg in southern Netherlands. (H 125)

\section{(1384) Kniertje}

1934 RX. Discovered 1934 Sept. 9 by H. van Gent at Johannesburg.

Named after the principal character in the Dutch play $O p$ Hoop van Zegen by Herman Heyermans (1864-1924). (H 125)

\section{(1385) Gelria}

1935 MJ. Discovered 1935 May 24 by H. van Gent at Johannesburg.
Named for the province Gelderland in the eastern Netherlands bordering on the Ijsselmeer. Gelre is an old name of Gelderland. (H 125)

\section{(1386) Storeria}

1935 PA. Discovered 1935 July 28 by G. N. Neujmin at Simeis. Independently discovered 1935 Aug. 2 by E. Delporte at Uccle.

The orbit was computed from Van Biesbroeck's observations by a student (Miss Brenton) at the University of Kansas, and she named it after her professor, Dr. N. Wyman Storer. (RI 1602; H 125)

\section{(1387) Kama}

1935 QD. Discovered 1935 Aug. 27 by P. F. Shajn at Simeis. Independently discovered 1935 Aug. 31 by K. Reinmuth at Heidelberg.

The name of a large river in USSR east of Kasan, and a tributary to the Volga. (M 838)

\section{(1388) Aphrodite}

1935 SS. Discovered 1935 Sept. 24 by E. Delporte at Uccle.

Named for the Greek goddess of love and beauty, daughter of Zeus and Dione ssee planets (5731) and (106)\} in the Iliad but in later poems it is said that she sprung from the foam of the sea near Cyprus. According to later poems she was the mother of Eros \{see planet (433)\}. (H 126)

Name proposed by the Astronomisches Rechen-Institut (RI 1702).

\section{(1389) Onnie}

$1935 \mathrm{SS}_{1}$. Discovered 1935 Sept. 28 by H. van Gent at Johannesburg.

Named in honor of Mrs. A. Kruyt, a sister-in-law of G. Pels. (I. van Houten-Groeneveld)

Named by G. Pels \{see planet (1667)\}who computed the orbit.

\section{(1390) Abastumani}

1935 TA. Discovered 1935 Oct. 3 by P. F. Shajn at Simeis. Independently discovered 1935 Oct. 3 by C. Jackson at Johannesburg.

The name of a town in the Georgian Caucasus; more recently the site of a new astronomical observatory. (M 838)

\section{(1391) Carelia}

1936 DA. Discovered 1936 Feb. 16 by Y. Väisälä at Turku.

Named for the region in northeastern Europe between the Gulf of Finland and the White sea in the U.S.S.R. (H 126)

\section{(1392) Pierre}

1936 FO. Discovered 1936 Mar. 16 by L. Boyer at Algiers.

Named in honor of a nephew of the discoverer. (H 126) 


\section{(1393) Sofala}

1936 KD. Discovered 1936 May 25 by C. Jackson at Johannesburg.

Name of the largest province of the former Portuguese African Territory of Mozambique. (M 909)

\section{(1394) Algoa}

1936 LK. Discovered 1936 June 12 by C. Jackson at Johannesburg.

Name of a South African Bay which has historical associations. (M 909)

\section{(1395) Aribeda}

1936 OB. Discovered 1936 July 16 by K. Reinmuth at Heidelberg.

This name is an abbreviation formed by the first letters of "Astronomisches Rechen-Institut, BerlinDahlem". (H 126)

\section{(1396) Outeniqua}

1936 PF. Discovered 1936 Aug. 9 by C. Jackson at Johannesburg.

Name of a range of mountains in the south western Cape Province and also home of a now extinct race of Hottentots. (M 909)

\section{(1397) Umtata}

1936 PG. Discovered 1936 Aug. 9 by C. Jackson at Johannesburg.

Name of the capital town of the native province of the Transkei and seat of the native administration. (M 909)

\section{(1398) Donnera}

1936 QL. Discovered 1936 Aug. 26 by Y. Väisälä at Turku.

Named in honor of the Finnish astronomer Anders Severin Donner (1854-1939), director of the Helsinki Observatory. (H 127)

Donner is also honored by a lunar crater.

\section{(1399) Teneriffa}

1936 QY. Discovered 1936 Aug. 23 by K. Reinmuth at Heidelberg.

Named for the largest of the Spanish Canary islands. (H 127)

\section{(1400) Tirela}

1936 WA. Discovered 1936 Nov. 17 by L. Boyer at Algiers.

Named in honor of Charles Tirel, a friend of the discoverer. (H 127)

\section{(1401) Lavonne}

1935 UD. Discovered 1935 Oct. 22 by E. Delporte at Uccle.

Named in honor of the granddaughter of Mrs. Maud W. Makemson who computed the orbit of this planet and received permission by the discoverer to name it. (H 127)
(1402) Eri

1936 OC. Discovered 1936 July 16 by K. Reinmuth at Heidelberg.

Named in honor of Erika Kollnig-Schattschneider \{1913-1978\}, astronomer at the Heidelberg Königstuhl Observatory. (H 127)

\section{(1403) Idelsonia}

1936 QA. Discovered 1936 Aug. 13 by G. N. Neujmin at Simeis. Independently discovered 1936 Aug. 17 by K. Reinmuth at Heidelberg.

Named in honor of the late, well-known Soviet astronomer, Naum I. Idelson \{1885-1951\}. He was a member of the staff of the Pulkovo Observatory. (M 1252)

Name submitted by N. Yakhontova, Institute of Theoretical Astronomy, Leningrad.

Idelson is also honored by a lunar crater.

\section{(1404) Ajax}

1936 QW. Discovered 1936 Aug. 17 by K. Reinmuth at Heidelberg.

Named for the Greek hero in the Trojan War and son of Telamon \{see planet (1749)\} who kills himself because the armor of Achilles \{see planet (588)\} was awarded to Odysseus \{see planet (1143)\}. (H 127)

\section{(1405) Sibelius}

1936 RE. Discovered 1936 Sept. 12 by Y. Väisälä at Turku.

Named in honor of the great Finnish composer Jean Sibelius (1865-1957). (M 3928)

\section{(1406) Komppa}

1936 RF. Discovered 1936 Sept. 13 by Y. Väisälä at Turku.

Named in honor of G. Komppa, a chancellor of Turku University and one of the founders of the Turku Observatory. (H 127)

\section{(1407) Lindelöf}

1936 WC. Discovered 1936 Nov. 21 by Y. Väisälä at Turku.

Named in honor of the late Ernest L. Lindelöf, professor of mathematics at the Helsinki University. (H 127)

\section{(1408) Trusanda}

1936 WF. Discovered 1936 Nov. 23 by K. Reinmuth at Heidelberg.

Named in honor of Trude Hochgesand, an acquaintance of the Heidelberg astronomer H. Vogt \{see planet (1439)\}. (H 127)

\section{(1409) Isko}

1937 AK. Discovered 1937 Jan. 8 by K. Reinmuth at Heidelberg.

Named in honor of Ise Koch, wife of the astronomer Kubach. (H 127) 
(1410) Margret

1937 AL. Discovered 1937 Jan. 8 by K. Reinmuth at Heidelberg.

Named in honor of Margret Braun (?-1991), wife of the Heidelberg astronomer H. Vogt \{see planet (1439)\}. (H 127)

Mrs. Vogt is also honored by planet (1411).

\section{(1411) Brauna}

1937 AM. Discovered 1937 Jan. 8 by K. Reinmuth at Heidelberg.

Named in honor of Margret Braun, wife of H. Vogt (see also the citation for planet (1410)). (H 128)

\section{(1412) Lagrula}

1937 BA. Discovered 1937 Jan. 19 by L. Boyer at Algiers.

Named in honor of Joanny-Philippe Lagrula (18701941), director of the Quito and Algiers Observatories. (LDS)

\section{(1413) Roucarie}

1937 CD. Discovered 1937 Feb. 12 by L. Boyer at Algiers.

Named in honor of the mother of the discoverer. (H 128)

\section{(1414) Jérôme}

1937 CE. Discovered 1937 Feb. 12 by L. Boyer at Algiers.

Named in honor of the father of the discoverer. (H 128)

\section{(1415) Malautra}

1937 EA. Discovered 1937 Mar. 4 by L. Boyer at Algiers.

Named in honor of the wife of the discoverer. (H 128)

(1416) Renauxa

1937 EC. Discovered 1937 Mar. 4 by L. Boyer at Algiers.

Named in honor of P. Renaux, assistant astronomer at the Algiers Observatory. (H 128)

\section{(1417) Walinskia}

1937 GH. Discovered 1937 Apr. 1 by K. Reinmuth at Heidelberg. Independently discovered 1937 Apr. 9 by G. N. Neujmin at Simeis.

Named in honor of an acqaintance of an astronomer at the Astronomisches Rechen-Institut, Berlin.

Name proposed by W. Schaub.

\section{(1418) Fayeta}

Discovered 1903 Sept. 22 by P. Götz at Heidelberg.

Named in honor of Gaston-Jules Fayet (1874-1967), director of the Nice Observatory who computed extensive tables of minor planets and searched for mutual close encounters. (H 128)

Name proposed by the orbit computer Ch. Cailliatte.
Obituaries published in C.R. Acad. Sci., Vol. 266, p. 16, Vol. 267, p. 103-104 (1968).

\section{(1419) Danzig}

1929 RF. Discovered 1929 Sept. 5 by K. Reinmuth at Heidelberg.

Named for the city (now Gdansk) and port on the Baltic sea. (H 128)

The city of Danzig is also honored by planet (764).

\section{(1420) Radcliffe}

1931 RJ. Discovered 1931 Sept. 14 by K. Reinmuth at Heidelberg. Independently discovered 1931 Oct. 10 by F. Rigaux at Uccle.

Named by the orbit computer, Mrs. Maud W. Makemson, in honor of the class of 1912 of Radcliffe College, Cambridge, Mass. (H 128)

\section{(1421) Esperanto}

1936 FQ. Discovered 1936 Mar. 18 by Y. Väisälä at Turku.

Named to commemorate the international language which was proposed by L. L. Zamenhof \{see planet (1462)\} in 1887 for common scientific usage. The inventor used the pseudonym "doctoro Esperanto". (M 1350)

\section{(1422) Strömgrenia}

1936 QF. Discovered 1936 Aug. 23 by K. Reinmuth at Heidelberg.

Named in honor of the Danish astronomer Prof. Elis Strömgren (1870-1947) who was director of the Copenhagen University Observatory, and director of the Bureau Central des Télégrammes Astronomiques. (H 128)

Strömgren is also honored by a lunar crater.

\section{(1423) Jose}

1936 QM. Discovered 1936 Aug. 28 by J. Hunaerts at Uccle.

Named in honor of Giuseppina Bianchi, deceased young daughter of the Italian astronomer E. Bianchi. (H 128)

Name proposed by the orbit computer Cesare Lombardi.

\section{(1424) Sundmania}

1937 AJ. Discovered 1937 Jan. 9 by Y. Väisälä at Turku.

Named in honor of K. F. Sundman (1873-1949), director of the Helsingfors Observatory, who intensively worked on the n-body problem. (H 129)

Sundman is also honored by a lunar crater.

\section{(1425) Tuorla}

1937 GB. Discovered 1937 Apr. 3 by K. Inkeri at Turku.

Named in honor of the Research Institute for Astronomy and Optics near Turku, Finland. (M 2277) 


\section{(1426) Riviera}

1937 GF. Discovered 1937 Apr. 1 by M. Laugier at Nice. Independently discovered 1937 Apr. 3 by C. Jackson at Johannesburg.

Named for the southeast Mediterranean coast of France, noted for its mild weather, which favors the observatory at which this planet was discovered. (M 6831)

Name proposed by F. Pilcher.

\section{(1427) Ruvuma}

1937 KB. Discovered 1937 May 16 by C. Jackson at Johannesburg.

Name of the most important river in southern Tanganyika, now Tanzania. (M 909)

\section{(1428) Mombasa}

1937 ND. Discovered 1937 July 5 by C. Jackson at Johannesburg.

Name of the chief port in Kenya, East Africa, which has also ancient historical associations. (M 909)

\section{(1429) Pemba}

1937 NH. Discovered 1937 July 2 by C. Jackson at Johannesburg.

A large island off the East Coast of Africa which was under the rule of the Sultan of Zanzibar. (M 909)

\section{(1430) Somalia}

1937 NK. Discovered 1937 July 5 by C. Jackson at Johannesburg.

Named for the state in the northeast of Africa. (M 5181)

\section{(1431) Luanda}

1937 OB. Discovered 1937 July 29 by C. Jackson at Johannesburg.

Named for the capital city of Angola. (M 5182)

\section{(1432) Ethiopia}

1937 PG. Discovered 1937 Aug. 1 by C. Jackson at Johannesburg.

Ancient name of Abyssinia; still called the empire of Ethiopia. (M 909)

\section{(1433) Geramtina}

1937 UC. Discovered 1937 Oct. 30 by E. Delporte at Uccle.

This is a compound name which has been formed to recall and to honor Miss Asplind, sister of B. Asplind \{see planet (958)\}. (H 129)

Named by B. Asplind who computed several orbits of planets found at Uccle on the occasion of the 1938 Stockholm IAU meeting.

\section{(1434) Margot}

1936 FD $_{1}$. Discovered 1936 Mar. 19 by G. N. Neujmin at Simeis.
Named in honor of Miss Gertrud Margot Görsdorf (1915-1990), later Mrs. Zottmann. She was for some years in Berlin friend and schoolfellow of the German astronomer W. Gliese \{see planet (1823)\} who proposed this name. (LDS)

\section{(1435) Garlena}

1936 WE. Discovered 1936 Nov. 23 by K. Reinmuth at Heidelberg. Independently discovered 1936 Dec. 13 by G. N. Neujmin at Simeis.

Named in honor of an acquaintance of the German astronomer W. Schaub. (H 129)

\section{(1436) Salonta}

1936 YA. Discovered 1936 Dec. 11 by G. Kulin at Budapest. Independently discovered 1936 Dec. 14 by A. Patry at Nice.

Named for the birthplace of the discoverer. (M 5182)

\section{(1437) Diomedes}

1937 PB. Discovered 1937 Aug. 3 by K. Reinmuth at Heidelberg.

Named for Diomedes, king of Argos, one of the Greek heroes of the Trojan War. (H 129)

\section{(1438) Wendeline}

1937 TC. Discovered 1937 Oct. 11 by K. Reinmuth at Heidelberg.

Any reference of this name to a person or occurrence is unknown.

Name proposed by W. Schaub.

\section{(1439) Vogtia}

1937 TE. Discovered 1937 Oct. 11 by K. Reinmuth at Heidelberg.

Named in honor of the Heidelberg astronomer Heinrich Vogt (1890-1968). In 1929, Vogt became professor and director of the Jena University Observatory. From 1933 he was director of the Heidelberg Königstuhl Observatory. Vogt is especially well known for his fundamental work on the theory of stellar interiors. He detected the Vogt-Russell theorem which uniquely describes the structure of a star by using only the mass and the chemical composition. (G. Klare)

Obituaries published in Astron. Nachr., Vol. 292, p. 45-46 (1970); Jahrb. Heidelb. Akad. Wiss., p. 47-49 (1970).

\section{(1440) Rostia}

1937 TF. Discovered 1937 Oct. 11 by K. Reinmuth at Heidelberg.

Named probably in honor of the German amateur astronomer, poet, and popularizer Johann Leonhard Rost (1688-1727) whose Astronomisches Handbuch (1718) has found a wide distribution. (LDS)

Rost is also honored by a lunar crater.

\section{(1441) Bolyai}

1937 WA. Discovered 1937 Nov. 26 by G. Kulin at Budapest. 
Name proposed by the discoverer in honor of Farkas Wolfgang Bolyai (1775-1856), a Hungarian astronomer and computer. (H 130)

\section{(1442) Corvina}

1937 YF. Discovered 1937 Dec. 29 by G. Kulin at Budapest. Independently discovered 1937 Dec. 29 by K. Reinmuth at Heidelberg.

Named by the discoverer probably in memory of the Hungarian king Matthias I. Corvinus (1440-1490) who conquered Vienna in 1485 and who was the founder of the Pressburg University. Corvinus was the surname of the Hungarian kings. His library at Buda ssee planet (908)\}, the Corvina, was one of the finest in Europe. (LDS)

\section{(1443) Ruppina}

1937 YG. Discovered 1937 Dec. 29 by K. Reinmuth at Heidelberg.

Named for the German city of Ruppin, the birthplace of the astronomer M. Ebell \{see planet (1205)\}, who proposed this name (RI 2247). (H 130)

\section{(1444) Pannonia}

1938 AE. Discovered 1938 Jan. 6 by G. Kulin at Budapest.

Named for the province of the Roman empire that includes much of modern Hungary. (M 5182)

\section{(1445) Konkolya}

1938 AF. Discovered 1938 Jan. 6 by G. Kulin at Budapest.

Named in honor of the founder of the Ógyalla \{see planet (1259)\} Observatory, Miklós (Nicolaus) von Konkoly Thege \{1842-1916\}. He was chiefly interested in the new methods of celestial photography and astrophysics - especially spectroscopy. In 1898, Konkoly Thege presented his observatory to the Hungarian government, together with the funds necessary to ensure its continuation. The instruments became the basis for the new Budapest observatory. From 1890 Konkoly Thege directed the Hungarian Meteorological Service until his retirement in 1911. (LDS)

\section{(1446) Sillanpää}

1938 BA. Discovered 1938 Jan. 26 by Y. Väisälä at Turku.

The great Finnish writer, Frans Eemil Sillanpää (1888-1964), winner of the Nobel prize for literature in 1939. (M 3928)

\section{(1447) Utra}

1938 BB. Discovered 1938 Jan. 26 by Y. Väisälä at Turku.

Named in honor of the birthplace of the discoverer in northeastern Finland. (M 2277)

\section{(1448) Lindbladia}

1938 DF. Discovered 1938 Feb. 16 by Y. Väisälä at Turku.

Named in honor of the Swedish astronomer Bertil Lindblad (1895-1965), director of the Stockholm Observatory at Salsjöbaden, and president of the I.A.U. during the critical, post-war years 1948-52. (M 1350)

Lindblad is also honored by a lunar crater.

\section{(1449) Virtanen}

1938 DO. Discovered 1938 Feb. 20 by Y. Väisälä at Turku.

Named by the discoverer in honor of Artturi Ilmari Virtanen, famous Finnish biochemist, on the occasion of his 75 th birthday. He was awarded the Nobel prize in chemistry in 1945, and was for many years president of the Academy of Finland. (M 3023) See also the remark to planet (1095).

\section{(1450) Raimonda}

1938 DP. Discovered 1938 Feb. 20 by Y. Väisälä at Turku.

Named in honor of Dr. Jean Jacques Raimond (19031961), president of the Dutch Astronomical Society, Nederlandse Vereniging voor Weer- en Sterrenkunde and director of the Zeiss planetarium at The Hague. (M 2347)

Name suggested by Jean Meeus.

Raimond is also honored by a lunar crater.

\section{(1451) Granö}

1938 DT. Discovered 1938 Feb. 22 by Y. Väisälä at Turku.

Named in honor of J. G. Granö (1882-1956), first professor of geography, later chancellor of the Turku University. (M 2277)

\section{(1452) Hunnia}

$1938 \mathrm{DZ}_{1}$. Discovered 1938 Feb. 26 by G. Kulin at Budapest.

Named in honor of the Hungarian nation. (M 5182)

\section{(1453) Fennia}

1938 ED $_{1}$. Discovered 1938 Mar. 8 by Y. Väisälä at Turku. Independently discovered 1938 Mar. 23 by G. N. Neujmin at Simeis.

This is the Latin word for the country of Finland. (H 130)

\section{(1454) Kalevala}

1936 DO. Discovered 1936 Feb. 16 by Y. Väisälä at Turku.

Named for the Finnish national epic, a source of inspiration for the music of Sibelius \{see planet (1405)\}. (M 3928) 


\section{(1455) Mitchella}

1937 LF. Discovered 1937 June 5 by A. Bohrmann at Heidelberg.

Named in honor of the American woman astronomer Maria Mitchell (1818-1889) who was professor of astronomy and director of Vassar College Observatory. (H 131)

Mitchell is also honored by a lunar crater. The observatory in Nantucket, Massachusetts bears her name.

\section{(1456) Saldanha}

1937 NG. Discovered 1937 July 2 by C. Jackson at Johannesburg.

Named for the newly-discovered harbor on the southwest tip of South Africa. (M 5182)

\section{(1457) Ankara}

1937 PA. Discovered 1937 Aug. 3 by K. Reinmuth at Heidelberg.

Named for the Turkish capital. (H 131)

Name proposed by W. Gleissberg.

\section{(1458) Mineura}

1937 RC. Discovered 1937 Sept. 1 by F. Rigaux at Uccle.

Named in honor of Adolphe Mineur who was professor of mathematics at the University of Brussels, Belgium. (H 131)

\section{(1459) Magnya}

1937 VA. Discovered 1937 Nov. 4 by G. N. Neujmin at Simeis. Independently discovered 1937 Nov. 6 by

A. Patry at Nice.

The word, translated from Latin to Russian, means "clear, bright, wonderful". (N. Solovaya; N. S. Chernykh)

Name suggested by A. Patry who computed a first orbit.

\section{(1460) Haltia}

1937 WC. Discovered 1937 Nov. 24 by Y. Väisälä at Turku.

Named for the highest mountain in Finland. (M 3928)

\section{(1461) Jean-Jacques}

1937 YL. Discovered 1937 Dec. 30 by M. Laugier at Nice.

This planet is named by the discoverer in honor of her son. (M 2116)

\section{(1462) Zamenhof}

1938 CA. Discovered 1938 Feb. 6 by Y. Väisälä at Turku.

Named in honor of L. L. Zamenhof (1859-1917), a Polish physician and inventor of the international language, Esperanto \{see minor planet (1421)\}. (M 1350)

\section{(1463) Nordenmarkia}

1938 CB. Discovered 1938 Feb. 6 by Y. Väisälä at Turku. Independently discovered 1938 Feb. 19 by E. Delporte at Uccle.

Named in honor of the Swedish astronomer N. V. E. Nordenmark (1867-1962) whose writings created increased interest in astronomy. (M 1350)

\section{(1464) Armisticia}

1939 VO. Discovered 1939 Nov. 11 by G. Van Biesbroeck at Williams Bay.

Since this was the 21st anniversary of the signing of the armistice of World War I, the name was given in the hope for a continuation of world peace, in the presence of the then ominous conditions. (M 2196)

\section{(1465) Autonoma}

1938 FA. Discovered 1938 Mar. 20 by A. A. Wachmann at Bergedorf.

According to the wishes of the discoverer and of O. Heckmann \{see planet (1650)\}, director of the Hamburg-Bergedorf Observatory, the planet is named "Autonoma". This name has been chosen in honor of the "Universidad Autonoma de El Salvador", in recognition of the hospitality granted by this university to the Hamburg Observatory. (M 698)

\section{(1466) Mündleria}

1938 KA. Discovered 1938 May 31 by K. Reinmuth at Heidelberg.

Named in honor of the German astronomer Max Mündler (1876-1969) who worked at the Heidelberg Königstuhl Observatory. (H 131)

Name proposed by H. Vogt (RI 2284).

Obituaries published in Astron. Nachr., Vol. 291, p. 224 (1969); Mitt. Astron. Ges., Nr. 27, p. 236 (1969); Astron. Nachr., Vol. 292, p. 143-144 (1970).

\section{(1467) Mashona}

1938 OE. Discovered 1938 July 30 by C. Jackson at Johannesburg.

Name of a large race of native people who inhabit Rhodesia. (M 909)

\section{(1468) Zomba}

1938 PA. Discovered 1938 July 23 by C. Jackson at Johannesburg. Independently discovered 1938 Aug. 2 by L. Boyer at Algiers.

Name of an important town in Nyassaland. (M 909)

\section{(1469) Linzia}

1938 QD. Discovered 1938 Aug. 19 by K. Reinmuth at Heidelberg. Independently discovered 1938 Aug. 31 by G. N. Neujmin at Simeis.

Named after the city of Linz, Austria, on the Danube river. (H 132)

Name proposed by A. Wersig (RI 2319).

\section{(1470) Carla}

1938 SD. Discovered 1938 Sept. 17 by A. Bohrmann at Heidelberg. 
This planet is named in honor of Mrs. Carla Ziegler, Heidelberg, a friend of the Bohrmann family. (M 1129)

\section{(1471) Tornio}

1938 SL $_{1}$. Discovered 1938 Sept. 16 by Y. Väisälä at Turku.

Named for a Finnish river and town at the northern end of the Gulf of Bothnia. (M 3928)

\section{(1472) Muonio}

1938 UQ. Discovered 1938 Oct. 18 by Y. Väisälä at Turku.

One of the principal rivers of Finland. (M 3928)

\section{(1473) Ounas}

1938 UT. Discovered 1938 Oct. 22 by Y. Väisälä at Turku.

One of the principal rivers of Finland. (M 3928)

\section{(1474) Beira}

1935 QY. Discovered 1935 Aug. 20 by C. Jackson at Johannesburg.

Name of an important port in Mozambique. (M 909)

\section{(1475) Yalta}

1935 SM. Discovered 1935 Sept. 21 by P. F. Shajn at Simeis.

A resort city in Crimea; site of an important political conference during World War II. (M 838)

\section{(1476) Cox}

1936 RA. Discovered 1936 Sept. 10 by E. Delporte at Uccle.

Named in honor of Jacques Cox (1898-1972), professor of astronomy at the University of Brussels. He has been rector of the university, permanent secretary of the Royal Academy of Belgium, president of the Belgian National Committee of Astronomy, and president of the Belgian Society of Astronomy, Meteorology and Physics of the Globe. He is well known for his researches concerning minor planets and the origin of comets. (M 3824)

\section{(1477) Bonsdorffia}

1938 CC. Discovered 1938 Feb. 6 by Y. Väisälä at Turku.

Named in honor of Ilmari Bonsdorff \{1879-1950\}, Finnish astronomer and founder and director of the Geodetic Institute of Finland. (H 132)

\section{(1478) Vihuri}

1938 CF. Discovered 1938 Feb. 6 by Y. Väisälä at Turku.

Named in honor of A. Vihuri, a Finnish ship owner, and generous patron of science and the arts. (M 2882)

\section{(1479) Inkeri}

1938 DE. Discovered 1938 Feb. 16 by Y. Väisälä at Turku.

A popular feminine Christian name in Finland; name of the discoverer's granddaughter and niece. Also a province inhabited by Finns. (M 1350)

\section{(1480) Aunus}

1938 DK. Discovered 1938 Feb. 18 by Y. Väisälä at Turku.

A popular masculine Christian name in Finland; name of the discoverer's grandson. Also, a province inhabited by Finns. (M 1350)

\section{(1481) Tübingia}

1938 DR. Discovered 1938 Feb. 7 by K. Reinmuth at Heidelberg. Independently discovered 1938 Feb. 22 by Y. Väisälä at Turku.

Named for the German city of Tübingen on the Neckar river south of Stuttgart, where Kepler \{see planet (1134)\} has worked for many years, and renowned for its university. (H 133)

Name proposed by A. Wersig (RI 2319).

\section{(1482) Sebastiana}

1938 DA $_{1}$. Discovered 1938 Feb. 20 by K. Reinmuth at Heidelberg. Independently discovered 1938 Feb. 24 by Y. Väisälä at Turku.

Named in honor of the German scientist Sebastian Finsterwalder, Munich. (RI 2417)

Name proposed by O. Volk.

\section{(1483) Hakoila}

1938 DJ $_{1}$. Discovered 1938 Feb. 19 by Y. Väisälä at Turku. Independently discovered 1938 Mar. 6 by M. B. Protitch at Belgrade.

Named by the discoverer in honor of his former assistant in physics, K. J. Hakoila, Ph. D., D. Eng. (1898- ). His technical assistance has been of great value in the construction of the new Turku Observatory. (M 2278)

\section{(1484) Postrema}

1938 HC. Discovered 1938 Apr. 29 by G. N. Neujmin at Simeis.

The name signifies the last link of the last of a group. It is assigned to the last minor planet discovered by Neujmin which has been numbered. (M 1252)

Name submitted by N. Yakhontova, Institute of Theoretical Astronomy, Leningrad.

The citation statement holds for the time of publication of MPC 1252 (June 24, 1955). Until now, (4420) $1936 \mathrm{~PB}$ is the Neujmin discovery with the highest number. The latest numbered discovery of Neujmin is planet (2536), discovered 1939 August 15.

\section{(1485) Isa}

1938 OB. Discovered 1938 July 28 by K. Reinmuth at Heidelberg.

Isa is a diminutive of the Italian name Marisa. (H 133)

The naming was granted by the discoverer to Massimo Cimino, astronomer at the Monte Mario Observatory, Rome who calculated the first orbit.

\section{(1486) Marilyn}

1938 QA. Discovered 1938 Aug. 23 by E. Delporte at Uccle. 
Named in honor of the daughter of Paul Herget \{see planet (1751)\} who computed the orbit. (H 133)

\section{(1487) Boda}

1938 WC. Discovered 1938 Nov. 17 by K. Reinmuth at Heidelberg.

Named in honor of the German astronomer Karl Boda \{1889-1942\} who at the Frankfurt Planeten-Institut worked on minor planet dynamics. (H 133)

\section{(1488) Aura}

1938 XE. Discovered 1938 Dec. 15 by Y. Väisälä at Turku.

Named for the river on which Turku stands. (M 3928)

\section{(1489) Attila}

1939 GC. Discovered 1939 Apr. 12 by G. Kulin at Budapest.

Named for the fifth-century king of the Huns. (M 5182)

\section{(1490) Limpopo}

1936 LB. Discovered 1936 June 14 by C. Jackson at Johannesburg.

Name of the large river which flows round the northern edge of the Transvaal and through Portuguese East Africa, now Mozambique. (M 909)

\section{(1491) Balduinus}

1938 EJ. Discovered 1938 Feb. 23 by E. Delporte at Uccle.

This planet is named in honor of Baudouin \{19301993\}, King of the Belgians. It was the intention of the discoverer, long time observer at the Royal Observatory of Belgium, to honor his king and his patron in this way. (M 1860)

\section{(1492) Oppolzer}

1938 FL. Discovered 1938 Mar. 23 by Y. Väisälä at Turku.

Named in honor of Hofrath Professor Theodor Ritter von Oppolzer (1841-1886), professor of astronomy in Vienna and author of the monumental Canon der Finsternisse. (M 2278)

Name suggested by Jean Meeus.

Oppolzer is also honored by a lunar crater.

\section{(1493) Sigrid}

1938 QB. Discovered 1938 Aug. 26 by E. Delporte at Uccle.

Named in honor of Sigrid Strömgren, wife of the Danish astronomer Bengt Strömgren \{see planet (1846)\}. (H 134; RI 2297)

\section{(1494) Savo}

1938 SJ. Discovered 1938 Sept. 16 by Y. Väisälä at Turku. Independently discovered 1938 Sept. 18 by A. A. Wachmann at Bergedorf.

Named after a province in Finland. (M 1350)

\section{(1495) Helsinki}

1938 SW. Discovered 1938 Sept. 21 by Y. Väisälä at Turku.

Named for the capital city of Finland. (M 3928)

\section{(1496) Turku}

1938 SA $_{1}$. Discovered 1938 Sept. 22 by Y. Väisälä at Turku.

Named in honor of the city which in ancient times was the capital of Finland, is now the home of the discoverer, and was the home of Argelander \{see planet (1551)\} when he began his monumental Durchmusterung. (M 1350)

\section{(1497) Tampere}

1938 SB$_{1}$. Discovered 1938 Sept. 22 by Y. Väisälä at Turku.

Named for the second largest city in Finland. (M 3928)

\section{(1498) Lahti}

1938 SK$_{1}$. Discovered 1938 Sept. 16 by Y. Väisälä at Turku.

Named for a town in Finland. (M 3928)

\section{(1499) Pori}

1938 UF. Discovered 1938 Oct. 16 by Y. Väisälä at Turku.

Named for an important Finnish town and port on the Gulf of Bothnia. (M 3928)

\section{(1500) Jyväskylä}

1938 UH. Discovered 1938 Oct. 16 by Y. Väisälä at Turku.

Named for a town in central Finland. (M 3928)

\section{(1501) Baade}

1938 UJ. Discovered 1938 Oct. 20 by A. A. Wachmann at Bergedorf.

Named in memory of Wilhelm Heinrich Walter Baade (1893-1960), German-born astronomer who joined the staff of Mount Wilson Observatory in 1931 and whose observations of M31 and its companion led to the classification of stars in two discrete populations. While at Bergedorf in 1920 he discovered (944) Hidalgo, and at Palomar in 1949 he discovered (1566) Icarus. These are the minor planets of largest aphelion and smallest perihelion distance, respectively. (M 4236)

Presently, the record holding planets are (7066) Nessus and (3200) Phaeton, respectively. Baade is also honored by a lunar crater.

Obituaries published in Astron. Nachr., Band 285, p. 286 (1960); Nordisk Astron. Tidsskr., p. 115-116 (1960); Nature, Vol. 187, p. 1075 (1960); Observatory, Vol. 80, p. 166 (1960); Phys. Bl., Vol. 16, p. 428 (1960); Publ. Astron. Soc. Pac., Vol. 72, p. 434 (1960); Science, Vol. 132, p. 137 (1960); Sky Telesc., Vol. 20, p. 76 (1960); Sterne, Band 36, p. 204-207 (1960); J. R. Astron. Soc. Canada, Vol. 55, p. 113-116 (1961); Mitt. Astron. Ges., p. 5-9 (1960); Orion, Vol. 6, p. 135-138 (1961); Q.J.R. Astron. Soc., Vol. 2, p. 118-121 (1961). 


\section{(1502) Arenda}

1938 WB. Discovered 1938 Nov. 17 by K. Reinmuth at Heidelberg.

Named in honor of Sylvain Arend \{1902-1992\}, astronomer at the Uccle Observatory near Brussels, Belgium, who observed and discovered more than 50 numbered minor planets and a bright comet. (H 134)

Name proposed by T. Banachiewicz (RI 2333).

Obituaries published in Ciel Terre, Vol. 108, No. 4, p. 101-102 (1992); Astronomie, Vol. 106, p. 25 (1993); Inf. Circ. IAU Comm. 26, No. 122, p. 4 (1994).

\section{(1503) Kuopio}

1938 XD. Discovered 1938 Dec. 15 by Y. Väisälä at Turku.

Named for a town in central Finland. (M 3928)

\section{(1504) Lappeenranta}

1939 FM. Discovered 1939 Mar. 23 by L. Oterma at Turku.

Named for a town in south-eastern Finland. (M 3928)

\section{(1505) Koranna}

1939 HH. Discovered 1939 Apr. 21 by C. Jackson at Johannesburg.

Name of a tribe of wandering bushmen who inhabit the southern part of the Kalahari Desert in southern Africa. (M 909)

\section{(1506) Xosa}

1939 JC. Discovered 1939 May 15 by C. Jackson at Johannesburg.

Name of a tribe of native peoples of the Cape Province who early came into contact with the white people. Nowadays the name Xosa is spelled Xhosa. (M 909; I. van Houten-Groeneveld)

\section{(1507) Vaasa}

1939 RD. Discovered 1939 Sept. 12 by L. Oterma at Turku.

Named for an important Finnish town and port on the Gulf of Bothnia. (M 3928)

\section{(1508) Kemi}

1938 UP. Discovered 1938 Oct. 21 by H. Alikoski at Turku. Independently discovered 1938 Oct. 30 by G. Kulin at Budapest.

Named for a Finnish river and town at the northern end of the Gulf of Bothnia. The four-letter name is in keeping with the names of several other minor planets of large orbital eccentricity and inclination. (M 3928)

\section{(1509) Esclangona}

1938 YG. Discovered 1938 Dec. 21 by A. Patry at Nice.

Named in honor of Ernest Esclangon (1876-1954), director of the Paris Observatory. He served as president of the International Astronomical Union from 1935 to 1938. (H 134)

A satellite of (1509) was discovered on 2003 February 13 by W. J. Merline et al. with the ESO 8-m VLT(UT4) on Cerro Paranal (IAUC 8075).

\section{(1510) Charlois}

1939 DC. Discovered 1939 Feb. 22 by A. Patry at Nice.

Named in memory of Auguste Charlois (1864-1910), assistant at the Nice Observatory from 1881 and subsequently first observer until his early and tragic death. An indefatigable observer of comets and minor planets, he discovered 99 numbered minor planets. Although the first 27 of his discoveries were visual ones, he started making photographic searches in 1892, a few months after the pioneering work in that field at Heidelberg. (M 4190)

\section{(1511) Daléra}

1939 FB. Discovered 1939 Mar. 22 by L. Boyer at Algiers.

Named in honor of Paul Daléra, a friend of the discoverer. (H 135)

\section{(1512) Oulu}

1939 FE. Discovered 1939 Mar. 18 by H. Alikoski at Turku.

Named in honor of the birthplace of the discoverer, a town in northern Finland. (M 2278)

\section{(1513) Mátra}

1940 EB. Discovered 1940 Mar. 10 by G. Kulin at Budapest.

Named for the mountain in northern Hungary where an outstation of the Konkoly \{see planet (1445)\} Observatory is located. (M 5182)

\section{(1514) Ricouxa}

Discovered 1906 Aug. 22 by M. F. Wolf at Heidelberg.

Any reference of this name to a person or occurrence is unknown. (H 135)

Named by the French astronomer A. Patry.

\section{(1515) Perrotin}

1936 VG. Discovered 1936 Nov. 15 by A. Patry at Nice.

Named in memory of Henri Joseph Anastase Perrotin (1845-1904), the first director of the Nice Observatory and discoverer of (252) Clementina, the first minor planet found there. While working at Toulouse he had previously discovered five other minor planets and developed a precise theory of the motion of (4) Vesta. (M 4358)

\section{(1516) Henry}

1938 BG. Discovered 1938 Jan. 28 by A. Patry at Nice.

Named in memory of the brothers Paul Pierre Henry (1848-1905) and Prosper Matthieu Henry (1849-1903), who constructed several telescopes, including the 76$\mathrm{cm}$ refractor at Nice and most of the Carte du Ciel telescopes. In the course of their program of mapping the ecliptic they each visually discovered seven minor planets. (M 4358)

Both brothers are also honored by lunar craters. Paul is honored by a crater on Mars. 


\section{(1517) Beograd}

1938 FD. Discovered 1938 Mar. 20 by M. B. Protitch at Belgrade.

Named by the discoverer in honor of his native city and the capital of his country. (M 2277)

\section{(1518) Rovaniemi}

1938 UA. Discovered 1938 Oct. 15 by Y. Väisälä at Turku. Independently discovered 1938 Oct. 21 by

E. Delporte at Uccle.

Named for a town in Finland, located nearly on the arctic circle. (M 3929)

\section{(1519) Kajaani}

1938 UB. Discovered 1938 Oct. 15 by Y. Väisälä at

Turku.

Named for a town in central Finland. (M 3929)

\section{(1520) Imatra}

1938 UY. Discovered 1938 Oct. 22 by Y. Väisälä at Turku.

Named for a town in south-eastern Finland. (M 3929)

\section{(1521) Seinäjoki}

1938 UB $_{1}$. Discovered 1938 Oct. 22 by Y. Väisälä at Turku.

Named for a town in western Finland. (M 3929)

\section{(1522) Kokkola}

1938 WO. Discovered 1938 Nov. 18 by L. Oterma at Turku.

Named for a Finnish town and port on the Gulf of Bothnia. (M 3929)

\section{(1523) Pieksämäki}

1939 BC. Discovered 1939 Jan. 18 by Y. Väisälä at Turku.

Named for a town in central Finland. (M 3929)

\section{(1524) Joensuu}

1939 SB. Discovered 1939 Sept. 18 by Y. Väisälä at Turku.

Named for the town in eastern Finland where the discoverer received his early schooling. (M 3929)

\section{(1525) Savonlinna}

1939 SC. Discovered 1939 Sept. 18 by Y. Väisälä at Turku.

Named for a town in eastern Finland. (M 3929)

\section{(1526) Mikkeli}

1939 TF. Discovered 1939 Oct. 7 by L. Oterma at Turku.

Named for a town in eastern Finland. (M 3929)

\section{(1527) Malmquista}

1939 UG. Discovered 1939 Oct. 18 by Y. Väisälä at Turku.

Named in honor of the Swedish astronomer G. Malmquist (1893-1982), director of the Uppsala Observatory. (M 1350)

Obituary published in Astron. Tidsskr., Arg. 15, p. 176-177 (1982)

\section{(1528) Conrada}

1940 CA. Discovered 1940 Feb. 10 by K. Reinmuth at Heidelberg.

Named in honor of Fritz Conrad (1883-1944), rearadmiral of the German navy and well-known nautical expert and oceanographer. (LDS; RI 2485)

Name presumably proposed by A. Kohlschütter.

A lot of detailed informations concerning the life and work of Admiral Conrad were provided by Mrs. Ilse Palm, née Conrad. During World War I, Conrad commanded two cruisers. After the war he studied astronomy, geodesy, mathematics and physics at the Berlin University and got his Ph.D. in 1933 with Astronomische Ortsbestimmung und Kimmtiefenmessung auf See. Conrad was founder and head of the Naval Meteorology Service and of the Nautic and Hydrographic Department of the Deutsche Seewarte in Hamburg as well as of the Naval Observatory Wilhelmshaven. He is also honored by the "Conrad Mountains" in Neu-Schwabenland which were discovered by the German Antarctic Expedition $1938 / 39$

\section{(1529) Oterma}

1938 BC. Discovered 1938 Jan. 26 by Y. Väisälä at Turku.

This member of the Hilda Group is named in honor of Liisi Oterma (1915-2001), astronomer at, and since 1971 director of, the Astronomical-Optical Institute at Turku. She is well known for her discoveries and observations of comets and minor planets and also for her work on their orbits. (M 3929)

Name proposed by B. G. Marsden and E. Roemer.

\section{(1530) Rantaseppä}

1938 SG. Discovered 1938 Sept. 16 by Y. Väisälä at Turku. Independently discovered 1938 Sept. 18 by E. Delporte at Uccle.

Named in memory of Hilkka Rantaseppä-Helenius (1925-1975), astronomer at the Turku AstronomicalOptical Institute, observer of comets and minor planets. (M 3929)

\section{(1531) Hartmut}

1938 SH. Discovered 1938 Sept. 17 by A. Bohrmann at Heidelberg.

Named by the discoverer in honor of his grandson, Hartmut Neckel, whose father is an astronomer at the Hamburg-Bergedorf Observatory. (M 3929)

\section{(1532) Inari}

1938 SM. Discovered 1938 Sept. 16 by Y. Väisälä at Turku.

One of the principal lakes of Finland. (M 3929)

\section{(1533) Saimaa}

1939 BD. Discovered 1939 Jan. 19 by Y. Väisälä at Turku.

One of the principal lakes of Finland. (M 3929) 
(1534) Näsi

1939 BK. Discovered 1939 Jan. 20 by Y. Väisälä at Turku.

One of the principal lakes of Finland. (M 3929)

\section{(1535) Päijänne}

1939 RC. Discovered 1939 Sept. 9 by Y. Väisälä at Turku.

One of the principal lakes of Finland. (M 3929)

\section{(1536) Pielinen}

1939 SE. Discovered 1939 Sept. 18 by Y. Väisälä at Turku.

One of the principal lakes of Finland. (M 3930)

\section{(1537) Transylvania}

1940 QA. Discovered 1940 Aug. 27 by G. Strommer at Budapest.

Named for the section of the old Hungarian empire in which the discoverer was born. (M 5182)

\section{(1538) Detre}

1940 RF. Discovered 1940 Sept. 8 by G. Kulin at Budapest.

Named in memory of Laszlo Detre (1906-1974), Hungarian astronomer well known for his work on variable stars, director of the Konkoly \{see planet (1445)\} Observatory for many years. (M 5182)

Obituaries published in BAV Rundbrief, 24. Jahrg., p. 40 (1975); Coelum, Vol. 43, p. 113 (1975); Sterne Weltraum, Vol. 14, p. 83 (1975); Mitt. Astron. Ges., Nr. 38, p. 7-9 (1976).

\section{(1539) Borrelly}

1940 UB. Discovered 1940 Oct. 29 by A. Patry at Nice.

Named in honor of Alphonse Louis Nicolas Borrelly (1842-1926), astronomer at the Marseilles Observatory who discovered 19 minor planets between 1866 and 1894 and at least 16 comets between 1871 and 1919 . (M 4358)

\section{(1540) Kevola}

1938 WK. Discovered 1938 Nov. 16 by L. Oterma at Turku.

Named for one of the observing stations of the Turku Astronomical-Optical Institute. (M 3930)

\section{(1541) Estonia}

1939 CK. Discovered 1939 Feb. 12 by Y. Väisälä at Turku.

Named in honor of the country south of Finland, formerly populated by the Finno-Ugric tribe of Esthonians on the east shores of the Baltic. Since 1991 Estonia is again an independent state. (M 1350)

\section{(1542) Schalén}

1941 QE. Discovered 1941 Aug. 26 by Y. Väisälä at Turku.

Named in honor of Carl Adam Wilhelm Schalén $\{1902-1993\}$ of the Lund Institute of Astronomy.
Sometime director of the Lund Observatory, he is noted for his work on interstellar reddening. Some of his research was made using plates taken with the Schmidt-Väisälä telescope at Uppsala. (M 3930)

Obituary published in Astron. Tidsskr., Arg. 27, Nr. 2, p. 84-85 (1994).

\section{(1543) Bourgeois}

1941 SJ. Discovered 1941 Sept. 21 by E. Delporte at Uccle.

Named in honor of Paul E.-E. Bourgeois \{1898-1974\}, late director of the Royal Observatory of Belgium, professor at the Free University of Brussels, author of many publications in astrometry, meridian astronomy, astrophysics and stellar statistics. (M 3930)

Obituary published in Ciel Terre, Vol. 91, p. 1-4 (1975).

\section{(1544) Vinterhansenia}

1941 UK. Discovered 1941 Oct. 15 by L. Oterma at Turku.

Named in honor of Miss Julie M. Vinterhansen (18901960), astronomer at the Copenhagen Observatory. She was for a long time editor of the IAU circulars and telegrams. (M 1350)

\section{(1545) Thernöe}

1941 UW. Discovered 1941 Oct. 15 by L. Oterma at Turku.

Named in honor of Karl August Thernöe, formerly an astronomer at the Copenhagen Observatory who worked in celestial mechanics. He has for some time been well known as a popularizer of astronomy in Denmark and from 1950 to 1964 was director of the IAU Central Telegram Bureau. (M 3930)

\section{(1546) Izsák}

1941 SG $_{1}$. Discovered 1941 Sept. 28 by G. Kulin at Budapest.

Named in memory of Imre Izsák (1929-1965), Hungarian-born astronomer and celestial mechanician, who made important contributions to the study of artificial-satellite motion. In his later years he worked at the Cincinnati Observatory and the Smithsonian Astrophysical Observatory. (M 5182)

Izsák is also honored by a lunar crater.

\section{(1547) Nele}

1929 CZ. Discovered 1929 Feb. 12 by P. Bourgeois at Uccle.

Named for the wife of Till Eulenspiegel, the roguish fourteenth-century German folk-hero. The earliest extant edition of the stories about him was published in Antwerp in 1515 by Charles Théodore Henri de Coster in La Légende d'Ulenspiegel. (M 6831; I. van Houten-Groeneveld)

Name proposed by the wife of J. Meeus.

Nele is a Frisian name, an abbreviation of Cornelia. 
(1548) Palomaa

1935 FK. Discovered 1935 Mar. 26 by Y. Väisälä at Turku.

Named in honor of Prof. M. H. Palomaa (1871-1947), the first professor of chemistry in the University of Turku, and for many years the dean of the faculty of sciences. (M 1351)

\section{(1549) Mikko}

1937 GA. Discovered 1937 Apr. 2 by Y. Väisälä at Turku.

Named in honor of Mikko Arthur Levander, a Finnish pastor, amateur astronomer and the father-in-law of the discoverer. (H 136)

\section{(1550) Tito}

1937 WD. Discovered 1937 Nov. 29 by M. B. Protitch at Belgrade.

Named in honor of Josip Tito (1892-1980), president of Yugoslavia, the leader of Yugoslavian resistance against aggression during World War II, and an early enthusiast of the United Nations. (M 2277)

\section{(1551) Argelander}

1938 DC $_{1}$. Discovered 1938 Feb. 24 by Y. Väisälä at Turku.

Named in honor of F. W. A. Argelander (1799-1875), director of the ancient observatory of Turku (Abo), and later director of the Bonn Observatory, and author of the famous Bonner Durchmusterung. (M 2278)

Argelander is also honored by a lunar crater.

\section{(1552) Bessel}

$1938 \mathrm{DE}_{1}$. Discovered 1938 Feb. 24 by Y. Väisälä at Turku.

Named in honor of the eminent German astronomer F. W. Bessel (1789-1846), who measured the first stellar parallax (61 Cyg). (M 2278)

Bessel is also honored by a lunar crater.

\section{(1553) Bauersfelda}

1940 AD. Discovered 1940 Jan. 13 by K. Reinmuth at Heidelberg.

This planet is named in honor of Prof. Dr.Ing. W. Bauersfeld \{1879-1959\} on the occasion of his 75 th birthday anniversary, 1954 January 23. Prof. Bauersfeld, formerly with Zeiss-Opton at Oberkochen/Württemberg (Germany), is best known as the designer of the famous Zeiss planetaria \{see also planet (851)\}. (M 994)

\section{(1554) Yugoslavia}

1940 RE. Discovered 1940 Sept. 6 by M. B. Protitch at Belgrade.

Named by the discoverer in honor of his country, which has been defended by martyrs during two World Wars. (M 2277)

\section{(1555) Dejan}

1941 SA. Discovered 1941 Sept. 15 by F. Rigaux at Uccle.
Named in honor of the son of the Yugoslav astronomer P. M. Djurkovic (1908-1981) from the Belgrade Observatory. (H 137)

\section{(1556) Wingolfia}

1942 AA. Discovered 1942 Jan. 14 by K. Reinmuth at Heidelberg.

Named in honor of one of the Heidelberg student fraternities on the occasion of its 104th anniversary celebrated 1955 June 17. Reinmuth writes, "Dem Kleinen Planeten (1556) 1942 AA gebe ich den Namen "Wingolfia" zu Ehren der alten, christlichen, in der Hitlerzeit verbotenen und nach dem 2. Weltkriege wieder erstandenen Heidelberger Studentenverbindung "Wingolf", aus Anlass ihres 104. Stiftungsfestes am 17. Juni 1955." (M 1221)

\section{(1557) Roehla}

1942 AD. Discovered 1942 Jan. 14 by K. Reinmuth at Heidelberg.

This planet is named in honor of Dr. Lars Roehl of Lund, Sweden, presently the chief physician of the surgical clinic in Heidelberg, to whom the discoverer is grateful for the restoration of his health. (M 2277)

\section{(1558) Järnefelt}

1942 BD. Discovered 1942 Jan. 20 by L. Oterma at Turku.

Named in honor of Gustaf J. Järnefelt, director of the Helsinki Observatory from 1945 to 1969, who has worked on relativity theory and has published extensive catalogues of observations of artificial satellites. (M 3930)

\section{(1559) Kustaanheimo}

1942 BF. Discovered 1942 Jan. 20 by L. Oterma at Turku.

Named in honor of Paul H. Kustaanheimo \{1924-

\}, an astronomer at the Helsinki Observatory who has made important contributions to celestial mechanics and relativity theory. (M 3930)

\section{(1560) Strattonia}

1942 XB. Discovered 1942 Dec. 3 by E. Delporte at Uccle.

Named in honor of Professor Frederick J. M. Stratton \{1881-1960\}, Director of the Solar Physics Observatory, Cambridge, England, and long time member of the International Astronomical Union \{General Secretary 1925-1938\}, upon the occasion of the presentation of a commemorative volume at the R.A.S. meeting of 1955 August 23. (M 1255)

The dedication by the discoverer appears at the beginning of the volume "Vistas in Astronomy" (A. Beer, ed., Pergamon Press, 1955).

Stratton is also honored by a lunar crater.

\section{(1561) Fricke}

1941 CG. Discovered 1941 Feb. 15 by K. Reinmuth at Heidelberg.

Named in honor of Walter Ernst Fricke $\{1915-1988\}$, Director of the Astronomisches Rechen-Institut in 
Heidelberg since 1955. The principal author of the FK4, he has also worked extensively on the system of astronomical constants. He served as president of IAU Commissions 4 (1958-1964) and 8 (1970-1973) and vice president of the IAU (1964-1967). (M 3930)

Obituaries published in Mitt. Astron. Ges., Nr. 72, p. 4-14 (1989); Q.J.R. Astron. Soc., Vol. 31, No. 3, p. 515-517 (1990); Astron. Nachr., Vol. 309, No. 3, p. 226 (1988); Sterne Weltraum, 27. Jahrg., Nr. 5, p. 279 (1988); Alm. Österr. Akad. Wiss., 138. Jahrg., p. 377-383 (1988); Observatory, Vol. 108, No. 1087, p. 251 (1988); Heidelb. Akad. Wiss. 1989, p. 89-91 (1990).

\section{(1562) Gondolatsch}

1943 EE. Discovered 1943 Mar. 9 by K. Reinmuth at Heidelberg.

Named in honor of Friedrich Gondolatsch \{1904- $\quad$ \}, astronomer at the Heidelberg Rechen-Institut since 1928, who has worked on the orbits and ephemerides of minor planets, notably of Hermes. He was also in charge of the preparation of the Astronomisch-Geodätisches Jahrbuch. (M 3930)

\section{(1563) Noël}

1943 EG. Discovered 1943 Mar. 7 by S. Arend at Uccle.

Named in honor of Emanuel Arend, son of the discoverer. (H 138)

\section{(1564) Srbija}

1936 TB. Discovered 1936 Oct. 15 by M. B. Protitch at Belgrade. Independently discovered 1936 Oct. 15 by M. Laugier at Nice.

The name has been given at the request of Prof. V. V. Michkovitch \{see planet (2348)\} in honor of the land of Serbia in Yugoslavia. This is the first minor planet to be discovered in Belgrade. The spelling is Serbian. (M 844)

\section{(1565) Lemaître}

1948 WA. Discovered 1948 Nov. 25 by S. Arend at Uccle.

Named in honor of Canon Georges Lemaître (18941966), professor of astronomy and celestial mechanics at the University of Louvain. He was a recognized authority on relativity, the three-body problem and cosmology. He was president of the Pontifical Academy, and he received the first Franqui Prize in Belgium. (M 3824)

This is the first newly numbered planet after World War II. Since then, all newly assigned names have been appropriately described in the MPC's when they are announced. Lemaitre is also honored by a lunar crater.

\section{(1566) Icarus}

1949 MA. Discovered 1949 June 27 by W. Baade at Palomar.
The discoverer has assigned to this unusual planet the name of the mythological boy who escaped imprisonment on wings of wax, but he flew too near the Sun and they melted, so that he fell into the sea. (M 347)

Name suggested by R. C. Cameron and Dr. Folkman.

This is the first minor planet which was observed (in 1968) by radar. Icarus, like his father Daedalus \{see planet (1864)\}, is also honored by a lunar crater.

\section{(1567) Alikoski}

1941 HN. Discovered 1941 Apr. 22 by Y. Väisälä at Turku.

Named in honor of Heikki A. Alikoski, assistant to the discoverer from 1937 to 1956 and observer and discoverer of minor planets. He helped greatly in establishing the Turku Astronomical-Optical Institute. (M 3930)

\section{(1568) Aisleen}

1946 QB. Discovered 1946 Aug. 21 by E. L. Johnson at Johannesburg.

Named by the discoverer in honor of his wife. (M 941)

\section{(1569) Evita}

1948 PA. Discovered 1948 Aug. 3 by M. Itzigsohn at La Plata.

The discoverer has assigned the name in honor of the wife of President Peron \{1895-1974\} of Argentina. (M 519)

Eva Peron (1919-1952) is also honored by planets (1581), (1582), (1588), and (1589), respectively.

\section{(1570) Brunonia}

1948 TX. Discovered 1948 Oct. 9 by S. Arend at Uccle.

This planet is named in honor of Brown University, Providence, Rhode Island. Chartered in 1764, it is the seventh oldest university in the United States. Its astronomical history dates back to the transit of Venus in 1769, observed by Prof. Benjamin West. Two local streets are named Planet and Transit. (M 1040)

\section{(1571) Cesco}

1950 FJ. Discovered 1950 Mar. 20 by M. Itzigsohn at La Plata.

Named in memory of Ronaldo P. Cesco, a former director of the La Plata Observatory, an outstanding mathematician and celestial mechanician. The planet also honors his brother, Carlos U. Cesco, in charge of the program of astrometric observations of comets and minor planets at El Leoncito. (M 6954)

The Felix Aguilar (see planet (1800)) Observatory at El Leoncito (see planet (2311)) was renamed into Carlos U. Cesco Observatory.

\section{(1572) Posnania}

1949 SC. Discovered 1949 Sept. 22 by J. Dobrzycki and A. Kwiek at Poznan.

This planet is named in honor of the city and the observatory at which it was discovered. (M 877) 


\section{(1573) Väisälä}

1949 UA. Discovered 1949 Oct. 27 by S. Arend at Uccle.

This planet is named in honor of Prof. Yrjö Väisälä \{1891-1971\}, Director of the Turku Observatory. (M 2116)

Väisälä is also honored by planet (2804).

Obituaries published in Bull. Geod., Nouv. Ser., No. 102, p. 348 (1971); Sky Telesc., Vol. 42, p. 273 (1971); Bull. Geod., Nouv. Ser., No. 103, p. 4 (1972); Astron. Tidsskr., Arg. 5, p. 100 (1972); Sci. Rev. Beograd, Vol. 22, p. 133-140 (1971); Irish Astron. J., Vol. 11, p. 159 (1973).

\section{(1574) Meyer}

1949 FD. Discovered 1949 Mar. 22 by L. Boyer at Algiers.

Named in honor of M. Georges Meyer \{1894- \}, director of the Algiers Observatory. (M 837)

\section{(1575) Winifred}

1950 HH. Discovered 1950 Apr. 20 by R. C. Cameron at Brooklyn, Indiana.

This planet is named in honor of Miss Winifred Sawtelle, a staff member of the U.S. Naval Observatory, at the request of Mr. R. C. Cameron, whose discovery and observations of this planet in 1950 lead to its being numbered. (M 844)

\section{(1576) Fabiola}

1948 SA. Discovered 1948 Sept. 30 by S. Arend at Uccle.

This planet is named in honor of H. M. Fabiola \{1928- \}, Queen of the Belgians. (M 2116)

\section{(1577) Reiss}

1949 BA. Discovered 1949 Jan. 19 by L. Boyer at Algiers.

Named in honor of Guy Reiss (1904-1964), astronomer at the Algiers Observatory and later at Nice, discoverer of five minor planets. (M 4418)

\section{(1578) Kirkwood}

1951 AT. Discovered 1951 Jan. 10 at the Goethe Link Observatory at Brooklyn, Indiana.

This planet has been named in honor of Daniel Kirkwood \{1814-1895\}, professor of mathematics at Indiana University from 1856 to 1886 . In 1866 he discovered the gaps in the distribution of the mean distances of the minor planets which bear his names: Kirkwood's Gaps. This is the first numbered planet to result from the minor planet observing program at Indiana University. (M 738)

Kirkwood is also honored by a lunar crater.

\section{(1579) Herrick}

1948 SB. Discovered 1948 Sept. 30 by S. Arend at Uccle.

Named in honor of Samuel Herrick (1911-1974), well-known for his many contributions to celestial mechanics and astrodynamics, particularly for his perturbation method in vector elements and for his concept of universal variables. Dr. Herrick also worked extensively on the orbits of the Earth-approaching minor planets (1580) Betulia, (1685) Toro (each of which was named for Mrs. Herrick), (1566) Icarus and (1620) Geographos. (M 3824)

Obituaries published in Sky Telesc., Vol. 48, No. 1, p. 3 (1974); Celest. Mech., Vol. 10, p. 2-3 (1974); J. Navig., Vol. 27, p. 402-403 (1974); Science, Vol. 186, p. 461 (1974); Spaceflight, Vol. 16, p. 472 (1974); Q.J.R. Astron. Soc., Vol. 16, p. 321-322 (1975).

\section{(1580) Betulia}

1950 KA. Discovered 1950 May 22 by E. L. Johnson at Johannesburg.

This planet has been named at the request of Dr. S. J. Herrick in honor of his wife. (M 768)

\section{(1581) Abanderada}

$1950 \mathrm{LA}_{1}$. Discovered 1950 June 15 by M. Itzigsohn at La Plata.

This name signifies a leader who carries a banner, and it is bestowed to honor the late Eva Peron \{1919-1952\} \{see planet (1569)\} for her labors in behalf of social development. (M 877)

\section{(1582) Martir}

1950 LY. Discovered 1950 June 15 by M. Itzigsohn at La Plata.

The Spanish spelling of martyr, this name is also assigned as an homage to Eva Peron ssee planet (1569)\}. (M 877)

\section{(1583) Antilochus}

1950 SA. Discovered 1950 Sept. 19 by S. Arend at Uccle.

The discoverer has assigned to this Trojan the name Antilochus, who was the youngest son of Nestor, intimate friend of Achilles \{see planets (659) and (588)\}, and commander of the Pylians in the Trojan war. (M 770)

\section{(1584) Fuji}

1927 CR. Discovered 1927 Feb. 7 by O. Oikawa at Tokyo.

Named in honor of Mt. Fuji, the highest mountain in Japan and a place of sacred worship. (M 2882)

The proposal of the discoverer was transmitted by S. Kanda.

\section{(1585) Union}

1947 RG. Discovered 1947 Sept. 7 by E. L. Johnson at Johannesburg.

Named in honor of the Union Observatory at Johannesburg. (M 941)

\section{(1586) Thiele}

1939 CJ. Discovered 1939 Feb. 13 by A. A. Wachmann at Bergedorf.

Named in memory of Thorvald Nicolai Thiele (1838-1910), sometime director of the Copenhagen 
Observatory, who worked on theoretical celestial mechanics. His son Holger Thiele, the discoverer of comet 1906 VII, later observed minor planets at Bergedorf and subsequently moved to Leuschner Observatory in California. (M 4236)

\section{(1587) Kahrstedt}

1933 FS $_{1}$. Discovered 1933 Mar. 25 by K. Reinmuth at Heidelberg.

Named in memory of Albrecht Kahrstedt (1897-1971), on the staff of the Astronomisches Rechen-Institut since 1922 and later in charge of the section at Potsdam. When that section combined with the Babelsberg Observatory, he became director. He was an indefatigable computer of minor planet orbits, notably of (1221) Amor, and he also prepared the right-ascension system of the FK3. (M 3930)

Obituaries published in Mitt. Astron. Ges., Nr. 30, p. 166 (1971); Astron. Nachr., Vol. 292, p. 282 (1971), Vol. 294, p. 147-148 (1973).

\section{(1588) Descamisada}

$1951 \mathrm{MH}$. Discovered 1951 June 27 by M. Itzigsohn at La Plata.

Literally a naked woman. As a symbol of the Argentine trade unions, it means a shirtless worker. Eva Peron \{see planet (1569)\} adopted this symbol of the very poor people and she was called The First Descamisada. (M 1069)

\section{(1589) Fanatica}

1950 RK. Discovered 1950 Sept. 13 by M. Itzigsohn at La Plata.

Literally a fanatical woman or a feminine zealot. Named as a tribute to Eva Peron \{see planet (1569)\} whose devotion and enthusiasm for the welfare of the Argentine people led her to champion the cause of the workers. (M 1069)

\section{(1590) Tsiolkovskaja}

1933 NA. Discovered 1933 July 1 by G. N. Neujmin at Simeis.

This planet is named in honor of the well-known Russian physicist and teacher Konstantin Tsiolkovsky (1857-1935), designer of liquid fuel rockets and space vehicles. (M 2116)

Tsiolkovsky is also honored by a lunar crater.

\section{(1591) Baize}

1951 KA. Discovered 1951 May 31 by S. Arend at Uccle.

This planet is named in honor of Dr. Paul Baize \{1901-1995\} of Paris who \{was\} a practicing physician and at the same time an assiduous amateur double star observer and computer at the Paris Observatory. This planet was recovered by Van Biesbroeck in 1952 . Both he and the discoverer are ardent double star observers and they join in signifying their high esteem for their colleague. (M 943)
Obituaries published in Int. Astron. Union Comm. 26, Inf. Circ., No. 127, p. 2 (1995); Ciel Terre, Vol. 112, No. 3, p. 119-120 (1996); Astronomie, Vol. 110, p. 32 (1996).

\section{(1592) Mathieu}

1951 LA. Discovered 1951 June 1 by S. Arend at Uccle.

Named after one of the grand-children of the discoverer. (M 3825)

\section{(1593) Fagnes}

1951 LB. Discovered 1951 June 1 by S. Arend at Uccle.

Named after the "Plateau des Hautes Fagnes", largest national park of Belgium. (M 3825)

Name proposed by Jean Meeus.

\section{(1594) Danjon}

1949 WA. Discovered 1949 Nov. 23 by L. Boyer at Algiers.

Named in honor of Prof. André Danjon \{1890-1967\}, Director of the Paris Observatory, and former president of the International Astronomical Union \{1955-1958\}. (M 2196)

Danjon is also honored by a lunar crater.

\section{(1595) Tanga}

1930 ME. Discovered 1930 June 19 by C. Jackson and H. E. Wood at Johannesburg.

Named for a port on the eastern seabord of Tanzania. (M 5182)

\section{(1596) Itzigsohn}

1951 EV. Discovered 1951 Mar. 8 by M. Itzigsohn at La Plata.

Named by the La Plata Observatory in memory of Miguel Itzigsohn, some time professor of spherical and practical astronomy and head of the department of extrameridian astronomy at the La Plata Observatory. He was in charge of the work on minor planets at La Plata and contributed extensively to the development of astrometry in Argentina. (M 5449)

\section{(1597) Laugier}

1949 EB. Discovered 1949 Mar. 7 by L. Boyer at Algiers.

Named in memory of Margueritte Laugier (18961976), astronomer at the Nice Observatory and discoverer of $\{19\}$ minor planets. (M 4418)

\section{(1598) Paloque}

1950 CA. Discovered 1950 Feb. 11 by L. Boyer at Algiers.

Named in honor of E. Paloque, Director of the Observatory of Toulouse. (M 1221)

Name assigned by the discoverer, following a suggestion made by P. Pretre, Toulouse, who computed the orbit of this planet. 


\section{(1599) Giomus}

1950 WA. Discovered 1950 Nov. 17 by L. Boyer at Algiers.

Named in honor of the birthplace of P. Pretre. This is the sixth-century name of the present town of Gien (Loiret), which has a rich history and suffered terribly during the occupation of 1940. (M 1221)

Name assigned by the discoverer, following a suggestion made by P. Pretre, Toulouse, who computed the orbit of this planet.

\section{(1600) Vyssotsky}

1947 UC. Discovered 1947 Oct. 22 by C. A. Wirtanen at Mount Hamilton.

Named in honor of Prof. Alexander Vyssotsky (1888-1973) who joined the faculty of the University of Virginia in 1923 and was active in astrometry, photometry and spectral classification at the Leander McCormick Observatory. (M 3931)

Obituary published in Sky Telesc., Vol. 47, p. 166 (1974).

\section{(1601) Patry}

1942 KA. Discovered 1942 May 18 by L. Boyer at Algiers.

Named in honor of André Patry \{1902-1960\}, astronomer at the Nice Observatory, especially distinguished for his research in establishing identities of minor planets from observations in widely separated years, of which this planet is one example. (M 2196)

\section{(1602) Indiana}

1950 GF. Discovered 1950 Mar. 14 at the Goethe Link Observatory at Brooklyn, Indiana.

Named in honor of the state of Indiana and Indiana University, the parent institution of the astronomy department and the observatory in which the planet was discovered. (M 1171)

The discovery was credited (MPC 1171) to Beryl H. Potter \{see planet (1729)\}. Frank K. Edmondson \{see planet (1761)\}, however, stated that 'during the first years there were 10 or 12 persons involved in blinking the plates'. The discovery is therefore credited to Indiana University.

\section{(1603) Neva}

1926 VH. Discovered 1926 Nov. 4 by G. N. Neujmin at Simeis.

This planet is named after the large river in Russia upon whose banks the city of Leningrad is situated. Leningrad was renamed in St. Petersburg in 1991. (M 2117)

\section{(1604) Tombaugh}

1931 FH. Discovered 1931 Mar. 24 by C. W. Tombaugh at Flagstaff.

Named by the Lowell Observatory for Clyde W. Tombaugh $\{1906-1997\}$, the discoverer of Pluto, on the occasion of a symposium on Pluto, held on the fiftieth anniversary of its discovery, 1980 Feb. 18. Tombaugh marked, during the course of his blink examination, over 4000 minor planets on plates obtained with the $0.33-\mathrm{m}$ photographic telescope during the transSaturnian search program at the Lowell Observatory. (M 5280)

Obituaries published in Zenit, Jaarg. 24, Nr. 7/8, p. 310-311 (1997); Nature, Vol. 385, No. 6619, p. 778 (1997); Icarus, Vol. 127, No. 1, p. V (1997); Astronomy, Vol. 25, No. 4, p. 28, 30 (1997); Sidereal Times, Vol. 47, No. 4, p. 12 (1997); Mon. Notes Astron. S. Afr., Vol. 56, No. 3-4, p. 20 (1997); Planet. Rep., Vol. 17, No. 4, p. 14 (1997); Phys. Today, Vol. 50, No. 7, p. 77 (1997); Orion, Jahrg. 55, Nr. 282, p. 7 (1997); G. Astron., Vol. 23, N. 1, p. 55-56 (1997); Astron. Geophys., Vol. 38, Issue 2, p. 38 (1997); J. R. Astron. Soc. Canada, Vol. 91, No. 2, p. 91-92 (1997); Sky Telesc., Vol. 93, No. 4, p. 102-103 (1997).

\section{(1605) Milankovitch}

1936 GA. Discovered 1936 Apr. 13 by P. Djurkovic at Uccle. Independently discovered 1936 Apr. 15 by J. Piegza at Cracow and T. Banachiewicz at Warsaw.

Named in memory of M. Milankovitch (1879-1958), famous Yugoslav astronomer, celestial mechanician and mathematician, known for his astronomical theory of long-term changes in the Earth's climate and for numerous papers on the history of astronomy. (M 5449)

Milankovitch is also honored by craters on Mars and the Moon.

\section{(1606) Jekhovsky}

1950 RH. Discovered 1950 Sept. 14 by L. Boyer at Algiers.

Named in memory of Benjamin Jekhovsky, astronomer at the Algiers and later the Bordeaux and Toulouse observatories, discoverer of $\{12\}$ minor planets between 1921 and 1927. (M 4418)

\section{(1607) Mavis}

1950 RA. Discovered 1950 Sept. 3 by E. L. Johnson at Johannesburg.

Named in honor of the wife of J. A. Bruwer \{see planet (1811)\}, astronomer at the observatory in Johannesburg. (M 3931)

\section{(1608) Muñoz}

1951 RZ. Discovered 1951 Sept. 1 by M. Itzigsohn at La Plata.

Named in memory of F. A. Muñoz, an assistant in the department of extra-meridian astronomy at the La Plata Observatory and involved for many years in computational and observational work on minor planets at La Plata; he also took an active part in site testing for the 2.15-m Argentine telescope. (M 5449) 


\section{(1609) Brenda}

1951 NL. Discovered 1951 July 10 by E. L. Johnson at Johannesburg.

Named by the discoverer in honor of his granddaughter. (M 3931)

\section{(1610) Mirnaya}

1928 RT. Discovered 1928 Sept. 11 by P. F. Shajn at Simeis.

The name means peaceful. (M 2740)

Name proposed by the Institute of Theoretical Astronomy, Leningrad.

\section{(1611) Beyer}

1950 DJ. Discovered 1950 Feb. 17 by K. Reinmuth at Heidelberg.

This planet is named by the discoverer in honor of Dr. h.c. Max Beyer \{1894-1982\}, astronomer at the Hamburg-Bergedorf Observatory. (M 1948)

Obituaries published in BAV Rundbrief, 32. Jahrg., Nr. 2, p. 51 (1983); Mitt. Astron. Ges., Nr. 59, p. 5-6 (1983).

\section{(1612) Hirose}

1950 BJ. Discovered 1950 Jan. 23 by K. Reinmuth at Heidelberg.

Named in honor of the Japanese astronomer, Prof. H. Hirose, under whose leadership the observations of minor planets and the computation of their orbits at the Tokyo-Mitaka astronomical observatory have been so successfully conducted. (M 1342)

\section{(1613) Smiley}

1950 SD. Discovered 1950 Sept. 16 by S. Arend at Uccle.

Named in honor of Charles Hugh Smiley \{1903$1977\}$, interested mainly in orbit computations by Leuschner's method, director of the Ladd Observatory and professor at Brown University, Providence, R.I. (M 3931)

Smiley not only worked on the field of minor planet dynamics. He led 14 solar eclipse expeditions, in Peru, Canada, Brazil, Thailand, Pakistan, and the U.S.A., and did much work on the study of the Mayan calendar. Obituaries are published in J.R. Astron. Soc. Canada, Vol. 72, p. 46-47 (1978); Q.J.R. Astron. Soc., Vol. 19, p. 510-511 (1978).

\section{(1614) Goldschmidt}

1952 HA. Discovered 1952 Apr. 18 by A. Schmitt at Uccle.

Named in memory of Hermann Goldschmidt (18021866), German-born astronomer who observed in Paris and discovered there 14 of the first 70 minor planets. (M 4418)

Goldschmidt is also honored by a lunar crater.

(1615) Bardwell

1950 BW. Discovered 1950 Jan. 28 at the Goethe Link Observatory at Brooklyn, Indiana.
Named in honor of Conrad M. Bardwell \{1926- \}, research associate in the Minor Planet Center at the Cincinnati Observatory, in recognition of his close cooperation with the observing program of the Goethe Link Observatory. He has provided observers with numerous reliable ephemerides and has had repeated successes in establishing identifications of observations in widely separated oppositions. (M 3643)

Name proposed by Dr. F. K. Edmondson and Mrs. Deloris J. Owings.

\section{(1616) Filipoff}

1950 EA. Discovered 1950 Mar. 15 by L. Boyer at Algiers.

Named in memory of Lionel Filipoff (1893-1940), astronomer at the Algiers Observatory and later at Paris, assiduous observer of minor planets and comets. (M 4418)

\section{(1617) Alschmitt}

1952 FB. Discovered 1952 Mar. 20 by L. Boyer at Algiers.

Named in memory of Alfred Schmitt (1907-1973), astronomer at the Algiers and Strasbourg observatories and some time director of the Quito Observatory. He made numerous observations of minor planets at Algiers and Uccle and at Strasbourg was concerned with astrometric problems involving artificial Earth satellites. (M 4418)

\section{(1618) Dawn}

1948 NF. Discovered 1948 July 5 by E. L. Johnson at Johannesburg.

Named by the discoverer in honor of his granddaughter. (M 3931)

\section{(1619) Ueta}

1953 TA. Discovered 1953 Oct. 11 by T. Mitani at Kwasan.

Named by the discoverer after the former Director of Kwasan Observatory who encouraged him to keep on with his observations of asteroids and comets. (M 2347)

\section{(1620) Geographos}

1951 RA. Discovered 1951 Sept. 14 by A. G. Wilson and R. Minkowski at Palomar.

The name, meaning Geographer, has been assigned by the discoverers to honor the National Geographic Society for its contribution to astronomy by the support of the National Geographic Society - Palomar Mountain Sky Survey. (M 1468)

\section{(1621) Druzhba}

1926 TM. Discovered 1926 Oct. 1 by S. I. Belyavskij at Simeis.

Druzhba means friendship. (M 2740)

Name proposed by the Institute of Theoretical Astronomy, Leningrad. 


\section{(1622) Chacornac}

1952 EA. Discovered 1952 Mar. 15 by A. Schmitt at Uccle.

Named in memory of Jean Chacornac (1823-1873), astronomer at Marseilles and later Paris, co-discoverer of (20) Massalia and discoverer of (25) Phocaea and five other minor planets. (M 4418)

Chacornac is also honored by a lunar crater.

\section{(1623) Vivian}

1948 PL. Discovered 1948 Aug. 9 by E. L. Johnson at Johannesburg.

Named in honor of the daughter of W. P. Hirst \{see planet (3172)\}, who calculated the preliminary orbit for this and several other planets discovered by Johnson. (M 3569)

This name had previously been assigned to (1605) $1952 \mathrm{OH}$, until that planet was found to be identical with (735) Marghanna \{see MPC 1116, 1119\}.

\section{(1624) Rabe}

$1931 \mathrm{TT}_{1}$. Discovered 1931 Oct. 9 by K. Reinmuth at Heidelberg.

Named in memory of Eugene Rabe (1911-1974), on the staff of the Astronomisches Rechen-Institut from 1937 to 1948 and then at the Cincinnati Observatory. He worked extensively on the theory of the motions of the Trojan minor planets and especially the orbit of (433) Eros. (M 3931)

Obituaries published in Science, Vol. 186, p. 719 (1974); Sky Telesc., Vol. 48, p. 157 (1974).

\section{(1625) The NORC}

1953 RB. Discovered 1953 Sept. 1 by S. Arend at Uccle.

This planet is named in honor of the Naval Ordnance Research Calculator at Dahlgren, Virginia. This was the most powerful electronic calculator ever built up to the time the planet was named. It was conceived by Mr. Byron Havens and developed at the Watson Scientific Computation Laboratory under the direction of Dr. W. J. Eckert \{see planet (1750)\}. The NORC has already served to provide a vast amount of computations of minor planet orbits, and it is to be expected that more will follow. This has been made possible through the assistance of the Naval Proving Grounds, the Office of Naval Research and the National Science Foundation. (M 1591)

The assignment of the name was granted by the discoverer to Paul Herget.

\section{(1626) Sadeya}

1927 AA. Discovered 1927 Jan. 10 by J. Comas Solá at Barcelona.

Named in honor of the Sociedad Astronomica de España y America. (M 2277)

Name communicated by J. F. Carbo, president of the Society.

\section{(1627) Ivar}

1929 SH. Discovered 1929 Sept. 25 by E. Hertzsprung at Johannesburg.

This planet is named by the discoverer in honor of his late brother Ivar. (M 1860)

\section{(1628) Strobel}

Discovered 1923 Sept. 11 by K. Reinmuth at Heidelberg.

Named in honor of Willi Strobel $\{1909-1988\}$, at the Astronomisches Rechen-Institut since 1938 and author of the 1963 edition of the Identifizierungsnachweis der Kleinen Planeten. (M 3931)

\section{(1629) Pecker}

1952 DB. Discovered 1952 Feb. 28 by L. Boyer at Algiers.

Named by the discoverer in honor of Prof. Jean-Claude Pecker \{1923- \}, director of the Nice Observatory. (M 2740)

Pecker served as general secretary of the International Astronomical Union from 1964 to 1967.

\section{(1630) Milet}

1952 DA. Discovered 1952 Feb. 28 by L. Boyer at Algiers.

Named in honor of Bernard Milet, astronomer at the Nice Observatory who conducts a large program of observations of minor planets and comets. (M 4418)

\section{(1631) Kopff}

1936 UC. Discovered 1936 Oct. 11 by Y. Väisälä at Turku.

Named in memory of August Kopff (1882-1960), who as Wolf's assistant in Heidelberg discovered and observed many minor planets. In 1924 he became Director of the Astronomisches Rechen-Institut in Berlin, and after the western section moved to Heidelberg he also became director of Heidelberg-Königstuhl Observatory. He was responsible for constructing the FK3 and initiated work on the FK4. (M 3931)

Karl Reinmuth discovered the planet as $1926 \mathrm{TH}$ on 1926 October 5 . The planet could only have been observed on two nights which was not sufficient to derive a reliable orbit. The discovery is therefore credited to Y. Väisälä. Elliptical elements were derived by $\mathrm{H}$. Walter (MPC 1897) from five positions of 1936 UC. The identity between both apparitions was found by A. Patry (MPC 1451). Kopff is also honored by a lunar crater.

\section{(1632) Sieböhme}

1941 DF. Discovered 1941 Feb. 26 by K. Reinmuth at Heidelberg.

Named in honor of Siegfried Böhme \{1909-1996\}, an astronomer at the Heidelberg Rechen-Institut since 1949, who has improved the orbits of many minor planets, notably (919) Ilsebill. (M 3931) 


\section{(1633) Chimay}

1929 EC. Discovered 1929 Mar. 3 by S. Arend at Uccle. Independently discovered 1929 Mar. 8 by M. F. Wolf at Heidelberg.

The name of the native town of Georges Roland, co-discoverer of the comet Arend-Roland. (M 3931)

\section{(1634) Ndola}

1935 QP. Discovered 1935 Aug. 19 by C. Jackson at Johannesburg.

Named for the most important mining town in Zambia. (M 5182)

\section{(1635) Bohrmann}

Discovered 1924 Mar. 7 by K. Reinmuth at Heidelberg.

Named in honor of Alfred Bohrmann (1904-2000), at the Königstuhl Observatory from 1924 to 1969. Well known as an observer of minor planets, he was responsible for the publication of 700 accurate observations of these bodies. (M 3931)

\section{(1636) Porter}

1950 BH. Discovered 1950 Jan. 23 by K. Reinmuth at Heidelberg.

Named for the U.S. astronomer Jermain Gildersleeve Porter (1852-1933), Director of the Cincinnati Observatory from 1884 to 1930 and well known for his work on star positions. Also named for John Guy Porter (1900-1981), for many years principal scientific officer at H.M. Nautical Almanac Office, Director of the Computing Section of the British Astronomical Association, and well-known popularizer of astronomy. Both J. G. Porters have contributed extensively to the astronomy of comets and minor planets, the first one as an observer, the second as a computer and a compiler of a catalogue of cometary orbits. (M 3932)

Obituaries published in Int. Comet Q., Vol. 4, p. 55 (1982); Q.J.R. Astron. Soc., Vol. 24, No. 3, p. 364-367 (1983); Q.J.R. Astron. Soc., Vol. 24, No. 3, p. 364-367 (1983).

\section{(1637) Swings}

1936 QO. Discovered 1936 Aug. 28 by J. Hunaerts at Uccle. Independently discovered 1936 Sept. 15 by C. Jackson at Johannesburg.

Named in honor of Pol Swings \{1906-1983\}, president of the I.A.U. during 1964-1967. He has contributed immensely to our knowledge of the physics of comets, especially the analysis and understanding of their spectra. (M 3932)

Obituaries published in Ciel, Vol. 45, p. 252-253 (1983); C.R. Séances Acad. Sci., Suppl., Tome 297, No. 13, p. 91 (1983); Sky Telesc., Vol. 67, No. 4, p. 325 (1984); Astrophys. Space Sci., Vol. 102, No. 1, p. 1-2 (1984); Ciel Terre, Vol. 100, No. 4, p. 135-138 (1984); C.R. Acad Sci., Sér. Gén., Vie Sci., Tome 2, No. 6, p. 657-662 (1986); Q.J.R. Astron. Soc., Vol. 27, No. 2, p. 305-308 (1986); Postepy Astron., Tom 32, Zesz. 1, p. 87-98 (1984).

\section{(1638) Ruanda}

1935 JF. Discovered 1935 May 3 by C. Jackson at Johannesburg.

Named for the state of Ruanda-Urundi. (M 5182)

\section{(1639) Bower}

1951 RB. Discovered 1951 Sept. 12 by S. Arend at Uccle.

Named in honor of Ernest Clare Bower who worked intensively on the Laplacian method of orbit computation and the preliminary orbit of Pluto at the Students Observatory, Berkeley. He proposed the system of provisional designations which has been in use since 1925. (M 3932)

\section{(1640) Nemo}

1951 QA. Discovered 1951 Aug. 31 by S. Arend at Uccle.

Named for the fictional builder of advanced technology in the novel by Jules Verne \{see planet (5231)\}, Twenty Thousand Leagues under the Sea $\{1870\}$. (M 6831) Name proposed by J. Meeus.

\section{(1641) Tana}

1935 OJ. Discovered 1935 July 25 by C. Jackson at Johannesburg.

Named for a river in Kenya. (M 5183)

\section{(1642) Hill}

1951 RU. Discovered 1951 Sept. 4 by K. Reinmuth at Heidelberg.

Named in memory of George William Hill (1838-1914), American celestial mechanician whose works include the development of precepts for the Hill-Brown lunar theory and the derivation of second-order theories for the motions of Jupiter and Saturn. (M 3932)

\section{(1643) Brown}

1951 RQ. Discovered 1951 Sept. 4 by K. Reinmuth at Heidelberg.

Named in memory of Ernest William Brown (18661938), the Cambridge-Yale mathematical astronomer who spent much of the last fifty years of his life working on the theory of the motion of the Moon, developing the method of G. W. Hill \{see planet (1642)\} with spectacular success. He also concerned himself with the problem of the Earth's variable rotation, studied the motions of minor planets on resonant orbits (particularly the Trojans) and wrote treatises on lunar theory and planetary theory. (M 3932)

\section{(1644) Rafita}

1935 YA. Discovered 1935 Dec. 16 by R. Carrasco at Madrid.

Named by the discoverer in honor of his late son. (M 2277)

\section{(1645) Waterfield}

1933 OJ. Discovered 1933 July 24 by K. Reinmuth at Heidelberg.

Named in honor of Reginald Lawson Waterfield \{1900-1986\}, for many years a hemotologist at Guy's 
Hospital in London and one of England's best known amateur astronomers. He has been photographing comets since 1927 and still maintains an extensive program of astrometric observations. The minor planet also honors his cousin, William Francis Herschel Waterfield (1886-1933), a grandson of Sir John Herschel, a prolific observer of variable stars, a staff member of the Harvard Observatory during 1926-1928 and subsequently chief assistant at the Boyden Station. (M 3932)

Obituaries published in Q.J.R. Astron. Soc., Vol. 28 , No. 4, p. 544-546, p. 546-551 (1987); J. Br. Astron. Assoc., Vol. 97, No. 4, p. 211-214 (1987).

\section{(1646) Rosseland}

1939 BG. Discovered 1939 Jan. 19 by Y. Väisälä at Turku.

Named in honor of Svein Rosseland \{1894-1985\}, the renowned Norwegian Astrophysicist who founded the Institute of Theoretical Astrophysics at Oslo and served as its first director. His work on the theory of stellar interiors included studies of stellar rotation and stability and the derivation of the "Rosseland Mean". (M 3932)

Obituaries published in Astron. Tidsskr., Årg. 18, Nr. 2, p. 71-72 (1985); Inst. Teor. Astrofys., BlindernOslo, Småtrykk, Nr. 106 (1985); Q.J.R. Astron. Soc., Vol. 27, No. 3, p. 512-514 (1986).

\section{(1647) Menelaus}

1957 MK. Discovered 1957 June 23 by S. B. Nicholson at Mount Wilson.

The name was selected by the discoverer to enable another of the famous Greek heroes to join the majority of his compatriots in the camp to the east of Jupiter. (M 2019)

Menelaus is also commemorated by a lunar crater.

\section{(1648) Shajna}

1935 RF. Discovered 1935 Sept. 5 by P. F. Shajn at Simeis. Independently discovered 1935 Sept. 19 by C. Jackson at Johannesburg.

The planet is named in honor of the two late Russian astronomers Mr. G. A. Shajn $\{1892-1956\}$ and Mrs. P. F. Shajn \{1894-1956\} \{see planet (1190)\}. (M 2117)

G. A. Shajn is also honored by a lunar crater.

\section{(1649) Fabre}

1951 DE. Discovered 1951 Feb. 27 by L. Boyer at Algiers.

Named in honor of Hervé Fabre \{1905-1995\}, astronomer at the Nice Observatory and author of numerous works in celestial mechanics. (M 4418)

Obituary published in J. Astron. Fr., No. 50, p. 4-6 (1996).

\section{(1650) Heckmann}

1937 TG. Discovered 1937 Oct. 11 by K. Reinmuth at Heidelberg.

Named in honor of Otto Heckmann \{1901-1983\}, Director of the Hamburg-Bergedorf Observatory from
1941 to 1962 and subsequently the first Director of the European Southern Observatory, the foundation of which had been initiated by him. His research activities cover cosmology and several aspects of fundamental astronomy. He was president of the IAU from 1967 to 1970. (M 3932)

Obituaries published in Messenger, No. 33, p. 1 (1983); Mitt. Astron. Ges., Nr. 60, p. 9-12 (1983); C.R. Séances Acad. Sci., Suppl., Tome 297, No. 13, p. 91-92 (1983); Q.J.R. Astron. Soc., Vol. 25, No. 3, p. 374-376 (1984); C.R. Acad. Sci., Sér. Gén., Vie Sci., Tome 1, No. 6, p. 591-593 (1984).

\section{(1651) Behrens}

1936 HD. Discovered 1936 Apr. 23 by M. Laugier at Nice. Independently discovered 1936 May 18 by K. Reinmuth at Heidelberg.

Named in memory of Johann Gerhard Behrens (1889-1978), pastor at Detern, well known for his orbit computations on comets and minor planets. (M 5523)

Name proposed by O. Kippes, who found some of the identifications involving this planet.

\section{(1652) Hergé}

1953 PA. Discovered 1953 Aug. 9 by S. Arend at Uccle.

Named in honor of Georges Remi, better known under his pseudonym Hergé, on the occasion of his seventy-fifth birthday. Considered by many as the father of the comic strip, he created his hero Tintin in 1929. (M 6831)

Name proposed by J. Meeus.

\section{(1653) Yakhontovia}

1937 RA. Discovered 1937 Aug. 30 by G. N. Neujmin at Simeis. Independently discovered 1937 Aug. 31 by H. Alikoski at Turku.

Named in honor of Prof. N. S. Yakhontova. Mrs. Yakhontova was in charge of the Minor Planet Department of the Institute of Theoretical Astronomy for about 30 years. (M 2740)

Name proposed by the Institute of Theoretical Astronomy, Leningrad.

\section{(1654) Bojeva}

1931 TL. Discovered 1931 Oct. 8 by P. F. Shajn at Simeis.

This planet is named in honor of Dr. Nina Fedorovna Bojeva (1890-1956) who was a valuable member of the staff of the Institute of Theoretical Astronomy for many years. Miss Bojeva served as computer of minor planet orbits and perturbations. (M 2740)

Name proposed by the Institute of Theoretical Astronomy, Leningrad.

\section{(1655) Comas Solá}

1929 WG. Discovered 1929 Nov. 28 by J. Comas Solá at Barcelona.

Named by the Fabra Observatory in memory of José Comas Solá (1868-1937), first director of the Fabra Observatory, Barcelona, and a well-known observer of 
minor planets and comets for many years. Among his discoveries were the short-period comet Comas Solá and 11 numbered minor planets. The discoverer is also honored by planet (1102). (M 5357)

Comas Solá is also honored by a crater on Mars.

\section{(1656) Suomi}

1942 EC. Discovered 1942 Mar. 11 by Y. Väisälä at Turku.

The name of this Hungaria-type minor planet, like that of (1453) Fennia, honors the country in which it was discovered. (M 3932)

\section{(1657) Roemera}

1961 EA. Discovered 1961 Mar. 6 by P. Wild at Zimmerwald.

Named by the discoverer in honor of Dr. Elizabeth Roemer \{1929- $\quad$ \}, U.S. Naval Observatory, in appreciation of her untiring and successful efforts to advance the knowledge of the motions and physical properties of comets and minor planets. (M 2347)

\section{(1658) Innes}

1953 NA. Discovered 1953 July 13 by J. A. Bruwer at Johannesburg.

Named in honor of R. T. A. nnes (1861-1933), first Director of the Republic Observatory (originally Transvaal Observatory, later Union Observatory), from 1903 to 1927 . He was not only a first-class observer, well-known for his observations of double stars and his deliberate search for Proxima Centauri, but he also made important theoretical and computational contributions to celestial mechanics, including the first convincing demonstration of the irregular rotation of the Earth. (M 3297)

Innes is also honored by a lunar crater.

\section{(1659) Punkaharju}

1940 YL. Discovered 1940 Dec. 28 by Y. Väisälä at Turku.

Named for a well-known and beautiful isthmus in southeastern Finland. (M 3933)

\section{(1660) Wood}

1953 GA. Discovered 1953 Apr. 7 by J. A. Bruwer at Johannesburg.

Named in honor of H. E. Wood (1881-1946), second Director of the Republic (then Union) Observatory (1928-1941). He had the prime responsibility for the Franklin-Adams camera since its acquisition in 1909 and inaugurated the Observatory's program for observing minor planets. (M 3297)

\section{(1661) Granule}

A916 FA. Discovered 1916 Mar. 31 by M. F. Wolf at Heidelberg.

Named in honor of Edward A. Gall, M.D., internationally renowned pathologist, to commemorate his discovery of Gall's granule in lymphocytes, and his career as an inspiring teacher, on the occasion of his retirement as Director of the Medical Center of the University of Cincinnati. (M 3757)

The name was suggested by Mrs. Anne L. Herget of the Cincinnati Observatory.

\section{(1662) Hoffmann}

A923 RB. Discovered 1923 Sept. 11 by K. Reinmuth at Heidelberg.

Named for Irmtraud Hoffmann who is the daughterin-law of the discoverer. (M 2901)

\section{(1663) van den Bos}

1926 PE. Discovered 1926 Aug. 4 by H. E. Wood at Johannesburg.

Named in honor of W. H. van den Bos \{1896-1974\}, Director of the Republic (then Union) Observatory from 1941 to 1956. He has made an outstanding series of visual micrometric observations of double stars and is responsible for the preeminence of the Republic Observatory in this work. (M 3297)

Obituaries published in Circ. Inf., No. 63 (1974);

Mon. Not. Astron. Soc. S. Afr., Vol. 33, p. 60-61 (1974); l'Astronomie, 88. année, p. 305, 309-311 (1974).

\section{(1664) Felix}

1929 CD. Discovered 1929 Feb. 4 by E. Delporte at Uccle.

Named in memory of Felix Timmermans (1886-1947), popular Belgian writer. (M 6831)

Name proposed by J. Meeus.

\section{(1665) Gaby}

1930 DQ. Discovered 1930 Feb. 27 by K. Reinmuth at Heidelberg.

Named by the discoverer for his daughter-in-law, Gaby Reinmuth. (M 2901)

\section{(1666) van Gent}

1930 OG. Discovered 1930 July 22 by H. van Gent at Johannesburg.

This planet is named in honor of the late Dr. H. van Gent $\{1900-1947\}$, who was a Leiden observer in South Africa from 1928 to 1946, during which time he discovered many new minor planets. (M 2740) Van Gent is also honored by a lunar crater.

\section{(1667) Pels}

1930 SY. Discovered 1930 Sept. 16 by H. van Gent at Johannesburg.

This planet is named in honor of the late Mr. G. Pels \{1893-1966\}, a life long member of the scientific staff of the Leiden Observatory. He observed minor planets at the Leiden Observatory and in addition he computed orbital elements for many of the minor planets found by van Gent. (M 2740)

\section{(1668) Hanna}

1933 OK. Discovered 1933 July 24 by K. Reinmuth at Heidelberg. 
Named by the discoverer for his daughter-in-law, Hanna Reinmuth. (M 2901)

\section{(1669) Dagmar}

1934 RS. Discovered 1934 Sept. 7 by K. Reinmuth at Heidelberg.

Named by the discoverer, a German feminine name. No special meaning is assigned to this name. (M 2901)

\section{(1670) Minnaert}

1934 RZ. Discovered 1934 Sept. 9 by H. van Gent at Johannesburg.

Named in honor of the late Prof. Marcel G. J. Minnaert $\{1893-1970\}$, who was Director of the Utrecht Observatory from 1937 until 1963. He made major contributions to solar research and prepared (with Mulders and Houtgast) the Photometric Atlas of the Solar Spectrum. He was an extraordinarily effective lecturer and writer in the popularization of astronomy. (M 3185)

Minnaert is also honored by a lunar crater. Obituaries published in Astron. Nachr., Vol. 292, p. 192 (1970); Orion, 28. Jahrg., p. 195 (1970); Hemel en Dampkring, Vol. 68, p. 289-292 (1970); l'Astronomie, Vol. 84, p. 525 (1970); Observatory, Vol. 90, p. 272 (1970); Sky Telesc., Vol. 40, p. 344 (1970); Nature, Vol. 229, p. 214 (1971); Astrophys. Space Sci., Vol. 10, p. 183-185 (1971); Solar Phys., Vol. 17, p. 3-5 (1971); Astron. Tidsskr., Vol. 3, p. 199-200 (1970); Icarus, Vol. 15, p. 147-148 (1971); Q.J.R. Astron. Soc., Vol. 12, p. 338-341 (1971); Irish Astron. J., Vol. 11, p. 161 (1973).

\section{(1671) Chaika}

1934 TD. Discovered 1934 Oct. 3 by G. N. Neujmin at Simeis.

The name means sea gull. This planet honors V. V. Nikolajeva-Tereshkova who was given the name the "sea gull" as she was the first woman to fly in space. (M 2740)

Name proposed by the Institute of Theoretical Astronomy, Leningrad.

\section{(1672) Gezelle}

1935 BD. Discovered 1935 Jan. 29 by E. Delporte at Uccle.

Named in memory of Guido Gezelle (1830-1899), famous Flemish poet, who wrote extensively on religion and nature. (M 6832)

Name proposed by J. Meeus.

\section{(1673) van Houten}

1937 TH. Discovered 1937 Oct. 11 by K. Reinmuth at Heidelberg.

Named by the discoverer in honor of Cornelis Johannes van Houten (1920-2002), who is an astronomer at the Leiden Observatory. (M 2901)
(1674) Groeneveld

1938 DS. Discovered 1938 Feb. 7 by K. Reinmuth at Heidelberg. Independently discovered 1938 Feb. 22 by Y. Väisälä at Turku and G. Kulin at Budapest.

Named by the discoverer in honor of I. van HoutenGroeneveld, who is an astronomer at the Leiden Observatory. (M 2901)

\section{(1675) Simonida}

1938 FB. Discovered 1938 Mar. 20 by M. B. Protitch at Belgrade. Independently discovered 1938 Mar. 20 by F. Rigaux at Uccle.

In Yugoslavia this name is a symbol of beauty and is related to the personality of a gracious Serbian princess from the middle ages. (M 3359)

\section{(1676) Kariba}

1939 LC. Discovered 1939 June 15 by C. Jackson at Johannesburg.

Named for a large manmade lake between Zambia and Zimbabwe-Rhodesia. (M 5183)

\section{(1677) Tycho Brahe}

1940 RO. Discovered 1940 Sept. 6 by Y. Väisälä at Turku.

Named for the great Danish-born astronomer Tycho Brahe (1546-1601). (M 4236)

Brahe is also honored by craters on Mars and the Moon.

\section{(1678) Hveen}

1940 YH. Discovered 1940 Dec. 28 by Y. Väisälä at Turku.

Named for the island of Hveen, where Tycho Brahe's \{see planet (1677)\} most productive observations were made between 1576 and 1597. (M 4236)

The island is also commemorated by planets (379) and (499).

\section{(1679) Nevanlinna}

1941 FR. Discovered 1941 Mar. 18 by L. Oterma at Turku.

Named in honor of Rolf H. Nevanlinna \{1895-1980\}, great Finnish mathematician, on the occasion of his 80th birthday, 1975 Oct. 22 . He was a member of the Academy of Finland from 1948 to 1965 and chancellor of Turku University from 1965 to 1970 . (M 3933)

\section{(1680) Per Brahe}

1942 CH. Discovered 1942 Feb. 12 by L. Oterma at Turku.

Named in memory of the Swedish count Per Brahe (1602-1680), who was governor general of Finland. The "count's epoch" was a happy era, with the establishment of Academia Aboensis, the first university in Finland, the construction of various new towns and many schools, and the publication of the first Finnish Bible. (M 5280) 


\section{(1681) Steinmetz}

1948 WE. Discovered 1948 Nov. 23 by M. Laugier at Nice.

Named in memory of Julius Steinmetz (1893-1965), pastor at Gerolfingen; orbit computer. (M 5523)

Name proposed by O. Kippes, who found one of the identifications involving this planet.

\section{(1682) Karel}

1949 PH. Discovered 1949 Aug. 2 by K. Reinmuth at Heidelberg.

Named by the discoverer for the son of Dr. and Mrs. van Houten of the Leiden Observatory. (M 2901)

See also the citations for (1673) and (1674).

\section{(1683) Castafiore}

1950 SL. Discovered 1950 Sept. 19 by S. Arend at Uccle.

Named for Bianca Castafiore, a comic-strip character created by Hergé \{see planet (1652)\}. (M 6832)

Name proposed by J. Meeus.

\section{(1684) Iguassú}

1951 QE. Discovered 1951 Aug. 23 by M. Itzigsohn at La Plata.

Named for the large waterfall 60 meters high and more than $1 \mathrm{~km}$ wide on a river of the same name. The Iguassú river forms part of the boundary between Argentina and Brazil. (M 6832)

Name proposed by F. Pilcher.

\section{(1685) Toro}

1948 OA. Discovered 1948 July 17 by C. A. Wirtanen at Mount Hamilton.

Named, as companion to (1580) Betulia, to honor the maiden name of Mrs. Herrick, and because of its phonetic, masculine, and legendary appropriateness to the group of close minor planets. (M 2504)

Naming delegated to Samuel Herrick and his associates, especially Kenneth C. Ford, whose predictions led to its recovery in 1956 and 1964.

\section{(1686) De Sitter}

$1935 \mathrm{SR}_{1}$. Discovered 1935 Sept. 28 by $\mathrm{H}$. van Gent at Johannesburg.

Named in honor of the late Prof. Willem de Sitter $\{1872-1934\}$, who was director of the Leiden Observatory from 1918 till 1934. He made major contributions in the theory of the Jupiter satellites, astronomical constants and cosmology. (M 2822)

Name proposed by the Leiden Observatory.

De Sitter is also honored by a lunar crater.

\section{(1687) Glarona}

1965 SC. Discovered 1965 Sept. 19 by P. Wild at Zimmerwald.

Named by the discoverer in honor of his home valley, the Swiss canton and town of Glarus. (M 2971)

\section{(1688) Wilkens}

$1951 \mathrm{EQ}_{1}$. Discovered 1951 Mar. 3 by M. Itzigsohn at La Plata.

Named in memory of the German astronomer Alexander Wilkens $\{1881-1968\}$, researcher in many branches of astronomy, most notably celestial mechanics. He worked for many years in Germany, then at the La Plata Observatory, where he produced two generations of celestial mechanicians before returning to his native country. (M 5449)

Obituary published in Astron. Nachr., Vol. 291, p. 87-88 (1969).

\section{(1689) Floris-Jan}

1930 SO. Discovered 1930 Sept. 16 by H. van Gent at Johannesburg. Independently discovered 1930 Sept. 21 by E. F. Skvortsov at Simeis.

This planet is named after Floris-Jan van der Meulen, the 5000th visitor to a 14-day astronomical exhibition at the Leiden Observatory. (M 3470)

\section{(1690) Mayrhofer}

1948 VB. Discovered 1948 Nov. 8 by M. Laugier at Nice.

Named in honor of Karl Mayrhofer, Austrian astronomer, currently living at Ried im Innkreis, well known for his orbit computations on minor planets. (M 5523)

Name proposed by O. Kippes, who found some of the identifications involving this planet. Mayrhofer died 1982 at the age of 79 .

\section{(1691) Oort}

1956 RB. Discovered 1956 Sept. 9 by K. Reinmuth and I. Groeneveld at Heidelberg.

Named in honor of Jan Hendrik Oort \{1900-1992\}, director of the Leiden Observatory 1945-1970, former president of the International Astronomical Union \{1958-1961\}, and a well-known authority on stellar statistics and galactic structure. (M 3023)

Obituaries published in Mercury, Vol. 21, No. 6, p. 196 (1992); Messenger, No. 70, p. 1-2 (1992); Mon. Notes Astron. Soc. S. Afr., Vol. 51, Nos. 11-12, p. 107-108 (1992); Phys. Today, Vol. 46, No. 11, p. 104-105 (1993); C.R. Acad. Sci., Sér. Gén, Vie Sci., Tome 10, No. 5, p. 535-540 (1993); Bull. Am. Astron. Soc., Vol. 25, No. 4, p. 1499 (1993); Q.J.R. Astron. Soc., Vol. 35, No. 2, p. 237-242 (1994); J. R. Astron. Soc. Can., Vol. 87, No. 2, p. 73-76 (1993); IAU Inf. Bull., No. 69, p. VII (1993); Astronomie, Vol. 107, p. 60-64 (1993); Zenit, Jaarg. 20, Nr. 5, p. 196-210 (1993); Zemlya Vselennaya, No. 2, p. 53-56 (1993);Sky Telesc., Vol. 85, No. 4, p. 44-45 (1993); Int. Astrom. Union Symp., No. 169, p. XV-XVI (1996).

\section{(1692) Subbotina}

1936 QD. Discovered 1936 Aug. 16 by G. N. Neujmin at Simeis. Independently discovered 1936 Aug. 17 by K. Reinmuth at Heidelberg. 
This planet is named in honor of the late Prof. Mikhail F. Subbotin (1893-1966) who was Director of the Institute of Theoretical Astronomy for about 20 years. (M 2740)

Name proposed by the Institute of Theoretical Astronomy, Leningrad.

Subbotin is also honored by a lunar crater.

\section{(1693) Hertzsprung}

1935 LA. Discovered 1935 May 5 by H. van Gent at Johannesburg.

Named in honor of the late Prof. E. Hertzsprung \{1873-1967\}, who was Director of the Leiden Observatory from 1934 till 1945. A well-known authority in the field of astronomical photometry, he initiated the Leiden Variable Star Survey of the southern Milky Way, during which survey many asteroids and some comets were found. (M 2822)

Name proposed by the Leiden Observatory.

Hertzsprung is also honored by a lunar crater. Obituary published in Astron. Nachr., Vol. 291, p. 85-87 (1969).

\section{(1694) Kaiser}

1934 SB. Discovered 1934 Sept. 29 by H. van Gent at Johannesburg.

Named in honor of the late Prof. Frederick Kaiser \{1808-1872\}, who was Director of the Leiden Observatory from 1837-1872. He is the founder of the new Leiden Observatory and stimulated Dutch astronomical research. (M 2883)

Due to an oversight, the name of Kapteyn was assigned to this planet in MPC 2822, when it had already been assigned to (818). Kaiser is also honored by craters on Mars and the Moon.

\section{(1695) Walbeck}

1941 UO. Discovered 1941 Oct. 15 by L. Oterma at Turku.

Named in memory of H. J. Walbeck (1793-1822), astronomer at the old Academia Aboensis who used the method of least squares to derive a good value for the Earth's flattening. (M 5281)

\section{(1696) Nurmela}

1939 FF. Discovered 1939 Mar. 18 by Y. Väisälä at Turku.

Named in honor of Finnish academician Tauno Kalervo Nurmela, some time professor of Romanic philology and later chancellor of Turku University. (M 5281)

\section{(1697) Koskenniemi}

1940 RM. Discovered 1940 Sept. 8 by H. Alikoski at Turku.

Named in memory of Veikko Antero Koskenniemi (1885-1962), the famous Finnish poet, a member of the Academy of Finland, professor of literature at Turku University. In various poems he wrote about the stars, and he was a founder member of the society Turun Ursa for amateur astronomers. (M 5281)

\section{(1698) Christophe}

1934 CS. Discovered 1934 Feb. 10 by E. Delporte at Uccle.

Named in honor of a grand-nephew of G. Roland, administrator of the Royal Observatory, Uccle, codiscoverer of comet Arend-Roland (1957 III). (M 6832)

\section{(1699) Honkasalo}

1941 QD. Discovered 1941 Aug. 26 by Y. Väisälä at Turku.

Named in memory of Tauno Bruno Honkasalo (1912-1975), a disciple of Y. Väisälä who measured geodesic standard base lines in various countries with the Väisälä interference comparator. (M 5281; M 5392)

\section{(1700) Zvezdara}

1940 QC. Discovered 1940 Aug. 26 by P. Djurkovic at Belgrade.

The Serbian word for observatory, this is the name of the section of the city of Belgrade in which the Observatory, founded in 1934, is located. (M 5449)

\section{(1701) Okavango}

1953 NJ. Discovered 1953 July 6 by J. Churms at Johannesburg.

Named for a large river in southern Africa. It flows into a swamp of the same name in Botswana. The swamp is an important wildlife preserve and has no outlet to the ocean. (M 7156)

Name proposed by F. Pilcher.

\section{(1702) Kalahari}

A924 NC. Discovered 1924 July 7 by E. Hertzsprung at Johannesburg.

Named for the great desert of Namibia \{see planet (1718)\} and adjoining region of the Republic of South Africa. It is continuous with the steppe country that extends to the vicinity of the discovery site. (M 7156) Name proposed by F. Pilcher.

\section{(1703) Barry}

1930 RB. Discovered 1930 Sept. 2 by M. F. Wolf at Heidelberg. Independently discovered 1930 Sept. 16 by H. van Gent at Johannesburg and Sept. 21 by E. F. Skvortsov at Simeis.

Named for Roger Barry (1752-1813), who became an astronomer at the Mannheim Observatory in 1788. The observatory at Heidelberg-Königstuhl is a direct successor to the old Mannheim Observatory. (M 3933)

\section{(1704) Wachmann}

A924 EE. Discovered 1924 Mar. 7 by K. Reinmuth at Heidelberg.

Named in honor of Arno Arthur Wachmann \{19021990\}, an astronomer at Hamburg-Bergedorf since 1927. He discovered and observed several minor planets, and together with Schwassmann, found four comets. He is 
well-known for his work on stellar spectroscopy and especially on variable and binary stars. (M 3933)

Obituary published in Mitt. Astron. Ges., Nr. 74, p. 5-6 (1991).

\section{(1705) Tapio}

$1941 \mathrm{SL}_{1}$. Discovered 1941 Sept. 26 by L. Oterma at Turku.

Named for the guardian spirit of the forest in Kalevala \{see planet (1454)\}, the Finnish national epic. Tapio is also a common boy's name in Finland. (M 5281)

\section{(1706) Dieckvoss}

1931 TS. Discovered 1931 Oct. 5 by K. Reinmuth at Heidelberg.

Named in honor of Wilhelm Dieckvoss \{1908-1982\}, Hamburg-Bergedorf astronomer since 1935 who has worked extensively on stellar positions and proper motions, especially on the catalogues AGK2 and AGK3. (M 3933)

Obituary published in Mitt. Astron. Ges., Nr. 59, p. 7-8 (1983)

\section{(1707) Chantal}

1932 RL. Discovered 1932 Sept. 8 by E. Delporte at Uccle.

Named in honor of a niece of Uccle astronomer G. Roland. (M 6832)

\section{(1708) Pólit}

1929 XA. Discovered 1929 Dec. 1 by J. Comas Solá at Barcelona.

Named in memory of Isidre Pólit (1880-1958), second director of the astronomical section of the Fabra Observatory and an assiduous observer of minor planets and comets. (M 5357)

\section{(1709) Ukraina}

1925 QA. Discovered 1925 Aug. 16 by G. Shajn at Simeis.

The planet is named for the \{former Ukrainian Soviet Socialist Republic. (M 2740)

Name proposed by the Institute of Theoretical Astronomy, Leningrad.

\section{(1710) Gothard}

1941 UF. Discovered 1941 Oct. 20 by G. Kulin at Budapest.

Named in memory of Jeno Gothard (1857-1909), a Hungarian astronomer who discovered the central star in M57. (M 5183)

\section{(1711) Sandrine}

1935 BB. Discovered 1935 Jan. 29 by E. Delporte at Uccle.

Named in honor of a grand-niece of Uccle astronomer G. Roland. (M 6832)
(1712) Angola

1935 KC. Discovered 1935 May 28 by C. Jackson at Johannesburg.

Named for the state on the southwestern coast of Africa. (M 5183)

\section{(1713) Bancilhon}

1951 SC. Discovered 1951 Sept. 27 by L. Boyer at Algiers.

Named in honor of Madame Alfred Schmitt, née Odette Bancilhon, astronomer at the Algiers and later the Strasbourg observatories, discoverer of (1333) Cevenola. (M 4419)

\section{(1714) Sy}

1951 OA. Discovered 1951 July 25 by L. Boyer at Algiers.

Named in memory of Frederic Sy, a computer at the Paris Observatory during 1879-1887 and an assistant astronomer at the Algiers Observatory during 1887-1918. An avid observer of minor planets and comets, he made the first discovery of a numbered minor planet at Algiers, (858) El Djezair, in 1916. (M 4419)

\section{(1715) Salli}

1938 GK. Discovered 1938 Apr. 9 by H. Alikoski at Turku.

Named in honor of the wife of the discoverer. (M 5281)

\section{(1716) Peter}

1934 GF. Discovered 1934 Apr. 4 by K. Reinmuth at Heidelberg.

Named by the discoverer in honor of his grandson. (M 3933)

\section{(1717) Arlon}

1954 AC. Discovered 1954 Jan. 8 by S. Arend at Uccle.

Named for the principal town of the province of Belgian Luxembourg, situated on a hill above the headwaters of the Semoise. The Orolaunum of the Romans was a station on the Antoninian way connecting Reims and Trier. (M 8150)

\section{(1718) Namibia}

1942 RX. Discovered 1942 Sept. 14 by M. Väisälä at Turku.

Named for the \{now independent African country, where the discoverer worked for many years, teaching the children of Finnish missionaries. (M 5281)

\section{(1719) Jens}

1950 DP. Discovered 1950 Feb. 17 by K. Reinmuth at Heidelberg.

Named by the discoverer in honor of his grandson. (M 3933)

\section{(1720) Niels}

1935 CQ. Discovered 1935 Feb. 7 by K. Reinmuth at Heidelberg. 
Named by the discoverer in honor of his grandson. (M 3933)

\section{(1721) Wells}

1953 TD $_{3}$. Discovered 1953 Oct. 3 at the Goethe Link Observatory at Brooklyn, Indiana.

Named for Herman B. Wells, president of Indiana University for 25 years from 1937 to 1962 . Following his retirement as president, he was given the new title of university chancellor, and has continued to be active in university affairs. Almost single handed, he changed Indiana University from a good university to a great university. Over the years he also served the cause of higher education on the national and international level with great distinction and statesmanship. (M 3508)

\section{(1722) Goffin}

1938 EG. Discovered 1938 Feb. 23 by E. Delporte at Uccle.

Named in honor of the Belgian amateur astronomer Edwin Goffin, who has made extensive computations involving minor-planet orbits, and whose initials are indicated by this object's provisional designation. (M 6832)

Name proposed by J. Meeus.

\section{(1723) Klemola}

1936 FX. Discovered 1936 Mar. 18 by Y. Väisälä at Turku.

Named in honor of Irja Klemola, formerly rector of a school in Turku, one of the founders and for many years secretary of the society Turun Ursa for amateur astronomers; she also frequently participated in the minor planet program at the Turku Observatory. This planet also honors Arnold R. Klemola, currently in charge of the proper-motion program at the Lick Observatory, also well known for his astrometric observations of comets and minor planets. (M 5281)

\section{(1724) Vladimir}

1932 DC. Discovered 1932 Feb. 28 by E. Delporte at Uccle.

Named by M. B. Protitch, whose rediscovery of this object in 1952 made the permanent numbering possible, in honor of his grandson. (M 5281)

\section{(1725) $\mathrm{CrAO}$}

1930 SK. Discovered 1930 Sept. 20 by G. N. Neujmin at Simeis.

The name is an abbreviation for the Crimean Astrophysical Observatory, which succeeded the Simeis Observatory. (M 2740)

Name proposed by the Institute of Theoretical Astronomy, Leningrad.

\section{(1726) Hoffmeister}

1933 OE. Discovered 1933 July 24 by K. Reinmuth at Heidelberg.
Named in memory of Cuno Hoffmeister (1892-1968), founder and later director of the Sonneberg \{see planet (1039)\} Observatory. Best known as a prolific discoverer and observer of variable stars, he also did extensive work on meteors and discovered a comet and several minor planets. (M 3933)

Hoffmeister is also honored by minor planet (4183) and by a lunar crater. Obituaries published in Irish Astron J., Vol. 9, p. 169 (1969); IAU Colloq. No. 15, p. 315-316 (1972).

\section{(1727) Mette}

1965 BA. Discovered 1965 Jan. 25 by A. D. Andrews at Bloemfontein.

Named by the discoverer in honor of his wife "for her tolerance of my nocturnal working hours and for the many months spent away from home". (M 5183)

\section{(1728) Goethe Link}

1964 TO. Discovered 1964 Oct. 12 at the Goethe Link Observatory at Brooklyn, Indiana.

Named in honor of Dr. Goethe Link, eminent surgeon of Indianapolis, Indiana, enthusiastic amateur astronomer, generous patron of astronomy at Indiana University, and donor of the Goethe Link Observatory. (M 2882)

\section{(1729) Beryl}

1963 SL. Discovered 1963 Sept. 19 at the Goethe Link Observatory at Brooklyn, Indiana.

Named in honor of Mrs. Beryl H. Potter \{1901-1985\}, whose devoted work from 1949 to 1966 contributed immensely to the program of minor planet observations at Indiana University. (M 2883)

An editorial notice concerning the retirement of Mrs. Potter is published in MPC 2561. Obituary published in Phys. Today, Vol. 39, No. 2, p. 92 (1986).

\section{(1730) Marceline}

1936 UA. Discovered 1936 Oct. 17 by M. Laugier at Nice. Independently discovered 1936 Oct. 24 by G. N. Neujmin at Simeis.

Named for the heroine of André Gide's novel L'Immoraliste. As a beautiful and devoted young wife Marceline nursed her husband from all the brink of death to robust health. When soon afterward Marceline became ill her husband benignly neglected her. Marceline suffered much physical and mental anguish and finally died needlessly. (M 6832) Name proposed by F. Pilcher.

\section{(1731) Smuts}

1948 PH. Discovered 1948 Aug. 9 by E. L. Johnson at Johannesburg.

Field-marshal Jan Christiaan Smuts \{1870-1950\}, a distinguished South African under whom the discoverer fought in both World Wars. He was prime minister of South Africa from 1919 to 1924 and again from 1938 to 1948. (M 3933) 
(1732) Heike

1943 EY. Discovered 1943 Mar. 9 by K. Reinmuth at Heidelberg.

Named in honor of Heike Neckel, a granddaughter of A. Bohrmann. (M 3933)

\section{(1733) Silke}

$1938 \mathrm{DL}_{1}$. Discovered 1938 Feb. 19 by A. Bohrmann at Heidelberg.

Named by the discoverer for his granddaughter, Silke Neckel. (M 3933)

\section{(1734) Zhongolovich}

1928 TJ. Discovered 1928 Oct. 11 by G. N. Neujmin at Simeis.

Named in honor of Prof. Ivan Danilovich Zhongolovich, a distinguished astronomer and geodesist, on the staff of the ITA \{Institute of Theoretical Astronomy, Leningrad $\}$ since 1920, the head of the Special Ephemeris Department, world renowned for his fundamental ideas in satellite geodesy. (M 3933)

\section{(1735) ITA}

$1948 \mathrm{RJ}_{1}$. Discovered 1948 Sept. 10 by P. F. Shajn at Simeis.

Named in 1979 on the occasion of the 60th anniversary of the founding of the Institute for Theoretical Astronomy, U.S.S.R. Academy of Sciences. (M 5357)

\section{(1736) Floirac}

1967 RA. Discovered 1967 Sept. 6 by G. Soulie at Bordeaux.

Named by the discoverer for the suburb in Bordeaux in which the observatory is located. (M 2883)

\section{(1737) Severny}

1966 TJ. Discovered 1966 Oct. 13 by L. I. Chernykh at Nauchnyj.

Named by the discoverer in honor of Prof. A. B. Severny $\{1913-1987\}$, who was the Director of the Crimean Astrophysical Observatory. (M 2971)

Obituaries published in Astron. Zh., Tom 64, Vyp. 4 , p. 891-892 (1987); Pis'ma Astron. Zh., Tom 13, No. 7, p. 638-640 (1987); Zemlya Vselennaya, No. 4, p. 33-34 (1987); Sov. Astron., Vol. 31, No. 4, p. 469-470 (1987); Sov. Astron. Lett., Vol. 13, No. 4, p. 268-269 (1987); Vestn. Akad. Nauk SSSR, No. 7, p. 131-132 (1987); Q.J.R. Astron. Soc., Vol. 29, No. 4, p. 581-584 (1988); Sol. Phys., Vol. 115, No. 1, p. 1-3 (1988); Izv. Krym. Astrofiz. Obs., Tom 78, p. 160-227 (1988).

\section{(1738) Oosterhoff}

1930 SP. Discovered 1930 Sept. 16 by H. van Gent at Johannesburg.

Named in memory of P. Th. Oosterhoff (1904-1978), professor of astronomy at Leiden University from 1948 until his retirement in 1972, Assistant General Secretary of the IAU during 1951-1952 and General Secretary during 1952-1958. He was well known for his contributions to photographic photometry and for his investigations of Cepheids with double periods. (M 4785)

\section{(1739) Meyermann}

1939 PF. Discovered 1939 Aug. 15 by K. Reinmuth at Heidelberg.

Named in memory of Bruno Meyermann (1876-1963), who spent most of his life as a classical astronomer and academic teacher at Göttingen Observatory. His fields of interest included polar motion and relativistic effects. (M 4155)

\section{(1740) Paavo Nurmi}

1939 UA. Discovered 1939 Oct. 18 by Y. Väisälä at Turku.

Named in memory of Turku-born Paavo Nurmi, the famous Finnish long-distance runner who won seven gold and three silver medals in the Olympic Games and broke 15 world records. (M 5281)

\section{(1741) Giclas}

1960 BC. Discovered 1960 Jan. 29 at the Goethe Link Observatory at Brooklyn, Indiana.

Named for Henry L. Giclas \{1910- \}, longtime staff member of the Lowell Observatory, who has had the major responsibility for the programs of minor planet positions and stellar proper motions carried out with the 13-inch Lawrence Lowell Telescope. (M 3934)

Name proposed by Frank K. Edmondson and Paul Herget.

\section{(1742) Schaifers}

1934 RO. Discovered 1934 Sept. 7 by K. Reinmuth at Heidelberg.

Named in honor of Karl Schaifers \{1921- \}, astronomer on the Heidelberg-Königstuhl staff, editor of Sterne und Weltraum and well-known popularizer of astronomy in Germany. (M 4358)

\section{(1743) Schmidt}

4109 P-L. Discovered 1960 Sept. 24 by C. J. van Houten and I. van Houten-Groeneveld at Palomar.

Named in honor of Bernhard Schmidt (1879-1935), the inventor of the Schmidt telescope. (M 3086)

This name has been proposed by Dr. Paul Herget.

A description of his life and work appeared in Sky Telesc., November 1955. Schmidt is also honored by a lunar crater.

\section{(1744) Harriet}

6557 P-L. Discovered 1960 Sept. 24 by C. J. van Houten and I. van Houten-Groeneveld at Palomar.

Named in honor of the wife of Paul Herget \{ see planet (1751)\}, Director of the Cincinnati Observatory. (M 3023)

\section{(1745) Ferguson}

$1941 \mathrm{SY}_{1}$. Discovered 1941 Sept. 17 by J. E. Willis at Washington.

Named in honor of James Ferguson (1797-1867), a civil engineer, member of the Northwest Boundary 
Survey, assistant in the U.S. Coast Survey, and from 1848-1867 an astronomer at the U.S. Naval Observatory on the 9.6 inch refractor. He made the first discovery of a minor planet in America in Sept. 1854, namely (31) Euphrosyne, and later discovered (50) Virginia and (60) Echo. He was a skilled computer, widely read, and an admirable conversationalist. (M 4155)

\section{(1746) Brouwer}

1963 RF. Discovered 1963 Sept. 14 at the Goethe Link Observatory at Brooklyn, Indiana.

Named in honor of the late Prof. Dirk Brouwer (19021966), Director of the Yale University Observatory since 1941, dean of celestial mechanicians in the U.S.A., president of Commission 20, I.A.U. (1948-1955), and an enthusiastic, inspiring leader in astrometry and dynamical astronomy. (M 2883)

The name was suggested by B. G. Marsden (who independently established the identity $1963 \mathrm{RF}=$ 1947 QA) to memorialize Prof. Brouwer's studies of the minor planet families. Following (1578) Kirkwood, this is the twenty-first permanently numbered member of the Hilda group.

Brouwer is also honored by a lunar crater.

\section{(1747) Wright}

1947 NH. Discovered 1947 July 14 by C. A. Wirtanen at Mount Hamilton.

Named in memory of William H. Wright (18711959), a pioneer in astrophysics who was on the Lick Observatory staff from 1897 to 1944 and the Director from 1935 to 1942. His last project was the design and construction of the 20-inch Carnegie double astrograph with which the recent discoveries of asteroids and comets are by-products of the proper motion program which he had conceived. (M 3934)

Wright is also honored by craters on Mars and the Moon.

\section{(1748) Mauderli}

1966 RA. Discovered 1966 Sept. 7 by P. Wild at Zimmerwald.

Named by the discoverer in honor of Prof. Sigmund Mauderli (1876-1962) who was Director of the Astronomical Institute of the University of Berne from 1921-1946. He devoted much of his time to orbit determination and perturbation computing of minor planets for the Astronomisches Rechen-Institut. (M 2971)

\section{(1749) Telamon}

1949 SB. Discovered 1949 Sept. 23 by K. Reinmuth at Heidelberg.

The name for this Trojan planet was selected by the discoverer. (M 3023)

Telamon was a son of Aecus and Endeis and the father of Ajax and Teucer ssee planets (1404) and (2797)\}. Ajax committed suicide, Teucer buried him in the sands of Troy, and when he returned home with this news and without the bones of Ajax, Telamon banished him as he had been banished by his own father. Telamon participated in the Calydonian boar hunt and also sailed the Argo to Colchis s see planet (1135)\} in search of the Golden Fleece. (Z 256).

\section{(1750) Eckert}

$1950 \mathrm{NA}_{1}$. Discovered 1950 July 15 by K. Reinmuth at Heidelberg.

Named in memory of Wallace J. Eckert (1902-1971), Director of the U.S. Nautical Almanac Office from 1940 to 1945 and a pioneer in the use of automatic computing machines. On two occasions he dedicated the most powerful computing machine ever built (SSEC in 1948 and the NORC \{see planet (1625)\} in 1954). With Brouwer and Clemence \{see planets (1746) and (1919)\} he produced the integration of the orbits of the five outer planets. By use of sophisticated computing techniques he was able to check and extend Brown's \{see planet (1643)\} lunar theory. He was president of the IAU Commission 7 from 1967 to 1970. (M 3934)

Obituaries published in Phys. Today, Vol. 24, No. 11, p. 73 (1971); Science, Vol. 173, p. 1115 (1971); Sky Telesc., Vol. 42, p. 207 (1971); Celest. Mech., Vol. 6, p. 3 (1972).

\section{(1751) Herget}

1955 OC. Discovered 1955 July 27 at the Goethe Link Observatory at Brooklyn, Indiana.

Named in honor of Paul Herget \{1908-1981\}, Director of the Cincinnati Observatory and distinguished service professor in the University of Cincinnati. He was founder of the Minor Planet Center in 1947, and a pioneer in the application of high speed computers to astronomical problems and one of the most skilled practitioners of this art at the present time. He was a member of the U.S. National Academy of Sciences, and past president of Commission 20 of the International Astronomical Union. (M 3143)

Proposed by F. K. Edmondson and approved by acclamation at the meeting of Comm. 20, University of Sussex, England, 1970 August 26.

Obituaries published in MPC 6221 (1981); Sky Telesc., Vol. 62, p. 531 (1981); Phys. Today, Vol. 35, No. 1, p. 86-87 (1982).

\section{(1752) van Herk}

1930 OK. Discovered 1930 July 22 by H. van Gent at Johannesburg.

Named in honor of G. van Herk \{1907- $\quad$ \}, former staff member of the Leiden Observatory and a wellknown authority on astrometry. (M 5357) Name proposed by the Leiden Observatory.

\section{(1753) Mieke}

1934 JM. Discovered 1934 May 10 by H. van Gent at Johannesburg.

Named in honor of the wife MMieke Oort-Graadt van Roggen, 1906-1993\} of former director of the Leiden 
Observatory, Jan Hendrik Oort \{see planet (1691)\}. (M 5357)

Name proposed by the Leiden Observatory.

\section{(1754) Cunningham}

1935 FE. Discovered 1935 Mar. 29 by E. Delporte at Uccle.

Named in honor of Leland E. Cunningham \{19041989\}, a prolific computer of comet orbits with F. L. Whipple \{see planet (1940)\} at Harvard during the 1930s, observer of faint comets, including the discovery of $1941 \mathrm{I}$ and the recovery of comet Gale in 1938, and since 1946 on the staff of the Leuschner Observatory, University of California. (M 3934)

\section{(1755) Lorbach}

1936 VD. Discovered 1936 Nov. 8 by M. Laugier at Nice.

Named in honor of Anne Lorbach Herget, assistant at the Cincinnati Observatory since 1962 and wife of Paul Herget \{see planet (1751)\}. She has been responsible for the assignment of provisional designations of minor planets and for key-punching almost all the material in the MPC's, work that was accomplished to a high standard of accuracy. (M 4419)

Name suggested by C. M. Bardwell and B. G. Marsden.

\section{(1756) Giacobini}

1937 YA. Discovered 1937 Dec. 24 by A. Patry at Nice.

Named in memory of Michel Giacobini (1873-1938), astronomer at the Nice Observatory who discovered 13 comets. (M 4358)

\section{(1757) Porvoo}

1939 FC. Discovered 1939 Mar. 17 by Y. Väisälä at Turku.

Named for the second oldest (after Turku) town in Finland. At the Porvoo Diet in 1809 the Russian czar confirmed that Finland was annexed to the Russian empire as an autonomous nation. (M 5449)

\section{(1758) Naantali}

1942 DK. Discovered 1942 Feb. 18 by L. Oterma at Turku.

Named for an idyllic small town near Turku, founded in the early fifteenth century around a convent and monastery. The summer residence of the Finnish president is located there. (M 5449)

\section{(1759) Kienle}

1942 RF. Discovered 1942 Sept. 11 by K. Reinmuth at Heidelberg.

Named in memory of Hans Kienle (1895-1975), an astrophysicist, who served as Director of several German observatories. He was director of the HeidelbergKönigstuhl Observatory from 1950-1962. His work on spectrophotometry is well-known. He was president of IAU Commission 36 from 1955 to 1958. (M 4155)
Obituaries published in Phys. Bl., 31. Jahrg., p. 222223 (1975); Sky Telesc., Vol. 49, p. 368 (1975); Sterne Weltraum, Vol. 14, p. 83, p. 184-186 (1975); Orion, 33. Jahrg., p. 111 (1975); Ruperto Carola, Univ. Heidelb., 27. Jahrg., p. 114-115 (1975); Astron. Nachr., Vol. 297, p. 99-105 (1976); Mitt. Astron. Ges., Nr. 38, p. 9-11 (1976).

\section{(1760) Sandra}

1950 GB. Discovered 1950 Apr. 10 by E. L. Johnson at Johannesburg.

Named by the discoverer in honor of his granddaughter. (M 3934; M 3988; M 5391)

\section{(1761) Edmondson}

1952 FN. Discovered 1952 Mar. 30 at the Goethe Link Observatory at Brooklyn, Indiana.

Named in honor of Prof. Frank K. Edmondson \{1912- \}, chairman of the Astronomy Department of Indiana University since 1944, treasurer of the American Astronomical Society (AAS) since 1954, program Director for astronomy of the National Science Foundation (NSF), 1956-57, and chairman of Section D (Astronomy) of the American Assoc. for the Advancement of Science (AAAS), 1962. He was chairman, U.S. National Committee of the International Astronomical Union (IAU), 1962-64. He was vice president, 1957-61, president, 1962-65 of the Association of Universities for Research in Astronomy, Inc. (AURA), and president of Comm. 20 of the International Astronomical Union (IAU), 1970. In 1964 he was decorated with the "Order of Merit" by the government of Chile. (M 3143)

The proposal of this name was presented by the entire departmental staff.

\section{(1762) Russell}

1953 TZ. Discovered 1953 Oct. 8 at the Goethe Link Observatory at Brooklyn, Indiana.

Named in honor of Henry Norris Russell \{1877-1957\}, one of the world's most distinguished astronomers, noted for the H-R diagram and his brilliant research on a variety of topics in fundamental astronomy, astrophysics, and the analysis of atomic spectra (RSor Russell-Saunders coupling). His advice and counsel were sought by many astronomers who valued his scientific judgement and respected his wide range of interests and encyclopedic knowledge of many subjects. His Ph.D. thesis at Princeton was on the general perturbations of the major axis of the orbit of $\{433\}$ Eros by the action of Mars. (M 3143)

Proposed by F. K. Edmondson.

Russell is also honored by craters on Mars and the Moon.

\section{(1763) Williams}

$1953 \mathrm{TN}_{2}$. Discovered 1953 Oct. 13 at the Goethe Link Observatory at Brooklyn, Indiana. 
Named in honor of K. P. Williams, professor of mathematics at Indiana University (1909-58). He was known for his textbook The calculation of the orbits of asteroids and comets and his detailed analysis of the transits of Mercury from 1723 to 1927 . He also wrote Lincoln finds a general, a definitive military history of the U.S. Civil War. (M 3143)

Proposed by F. K. Edmondson.

\section{(1764) Cogshall}

$1953 \mathrm{VM}_{1}$. Discovered 1953 Nov. 7 at the Goethe Link Observatory at Brooklyn, Indiana.

Named in honor of W. A. Cogshall, professor of astronomy at Indiana University (1900-44). He was known for his work on visual binary stars, photography of solar eclipses, and as a teacher of many who followed professional careers in astronomy. (M 3143)

Proposed by F. K. Edmondson.

\section{(1765) Wrubel}

1957 XB. Discovered 1957 Dec. 15 at the Goethe Link Observatory at Brooklyn, Indiana.

Named in honor of Marshal H. Wrubel, faculty member at Indiana University (1950-68) and university professor of astronomy (1966-68). He was co-founder of the Indiana University Research Computing Center and a pioneer in the use of high speed computers for astrophysical computations, and a brilliant teacher whose profound influence continues to show in the work of his 14 Ph.D. students. (M 3143)

Proposed by F. K. Edmondson.

\section{(1766) Slipher}

1962 RF. Discovered 1962 Sept. 7 at the Goethe Link Observatory at Brooklyn, Indiana.

Named in honor of Vesto Melvin Slipher \{1876-1969\} and E. C. Slipher $\{1883-1964\}$, graduates of Indiana University in 1901 and 1906. V. M. Slipher was a pioneer investigator of the spectra of the planets, and was the first to measure the redshifts of galaxies. E. C. Slipher developed the art of direct photography of the planets to the highest level, and his photographs are the only continuous and systematic record of the appearance of the planets for a period of more than half a century. (M 3144)

Proposed by F. K. Edmondson.

E. C. Slipher is also honored by a crater on Mars. Both brothers are honored by a lunar crater. Obituaries (V.M.S.) published in Publ. Astron. Soc. Pac., Vol. 81, p. 922-923 (1969); Science, Vol. 166, p. 1608 (1969); Phys. Today, Vol. 23, No. 2, p. 101 (1970); Year Book Am. Phil. Soc. 1970, p. 161-166.

\section{(1767) Lampland}

1962 RJ. Discovered 1962 Sept. 7 at the Goethe Link Observatory at Brooklyn, Indiana.

Named in honor of C. O. Lampland \{1873-1951\}, a graduate of Indiana University in 1902. His best known work was the radiometric measurement of planetary temperatures in collaboration with W. W. Coblentz, and the long photographic history of the changes in NGC 2261 (Hubble's variable nebula). (M 3144)

Proposed by F. K. Edmondson.

Lampland is also honored by craters on Mars and the Moon.

\section{(1768) Appenzella}

1965 SA. Discovered 1965 Sept. 23 by P. Wild at Zimmerwald.

Appenzella, named by the discoverer in honor of the Swiss Canton of Appenzell, on the occasion of the 150th anniversary of the Kantonsschule Trogen (Appenzell-Ausserrhoden). (M 3297)

\section{(1769) Carlostorres}

1966 QP. Discovered 1966 Aug. 25 by Z. M. Pereyra at Córdoba.

Named in memory of Carlos Guillermo Torres (1910-1965), astronomer at the Córdoba Observatory, an active observer with the meridian circle and of comets and minor planets. The planet also honors Carlos Torres R., who is in charge of the program for observing comets and minor planets at Santiago. (M 6954)

\section{(1770) Schlesinger}

1967 JR. Discovered 1967 May 10 by C. U. Cesco and A. R. Klemola at El Leoncito.

Named in memory of Frank Schlesinger (18711943), Director of the Allegheny Observatory from 1905 to 1920 and then Director of the Yale University Observatory until his retirement in 1941. His pioneering work in photographic astrometry revolutionized the determination of stellar parallaxes and the preparation of zone catalogues. His invention of the method of dependences for parallax reductions has also found extensive application in obtaining minor planet positions. He was prominent in the establishment of the IAU and served as its president from 1932 to 1935. (M 3934)

Schlesinger is also honored by a lunar crater.

\section{(1771) Makover}

1968 BD. Discovered 1968 Jan. 24 by L. I. Chernykh at Nauchnyj.

Named in honor of the late Samuel Gdalevich Makover \{1908-1970\}, scientist in the I.T.A. since 1946. He studied extensively the orbit of comet EnckeBacklund, and he was a pioneer in the use of electronic calculators for computing planetary perturbations and orbit improvements. In 1963 he became head of the Department of Minor Planets and Comets, and editor of the annual volume of Minor Planet Ephemerides. He was vice president of Comm. 20, I.A.U. (1964-67). (M 3185)

Obituaries published in Astron. Tsirk., No. 579, p. 7-8 (1970); Byull. Inst. Teor. Astron. Leningrad, Vol. 12, p. 437-438 (1970). 
(1772) Gagarin

1968 CB. Discovered 1968 Feb. 6 by L. I. Chernykh at Nauchnyj.

Named in honor of the late Yuri Gagarin \{1934-1968\}, the illustrious Soviet cosmonaut, and the first man to circumnavigate the Earth in outer space. (M 3185)

Gagarin is also honored by a lunar crater.

\section{(1773) Rumpelstilz}

1968 HE. Discovered 1968 Apr. 17 by P. Wild at Zimmerwald.

The leading character in one of Grimm's fairy tales. (M 4155)

\section{(1774) Kulikov}

1968 UG $_{1}$. Discovered 1968 Oct. 22 by T. M. Smirnova at Nauchnyj.

Named in honor of the late Dmitri Kuzmich Kulikov \{1912-1964\}, specialist in geodesy and fundamental astronomy. During 1934-1941 he led five geodetic expeditions. He was decorated for his service in World War II with two Orders of the Red Star. During 1949-1956 he served as scientific secretary of I.T.A. and since then as head of the Department of the Astronomical Yearbook. He worked on the orbits of comets and Jupiter VIII. In 1952 he was awarded a prize for his treatment of Zinger star pairs. (M 3185)

\section{(1775) Zimmerwald}

1969 JA. Discovered 1969 May 13 by P. Wild at Zimmerwald.

The charming village that harbours the new observing station, seven miles south of Berne \{see planet (1313)\}. (M 4155)

\section{(1776) Kuiper}

2520 P-L. Discovered 1960 Sept. 24 by C. J. van Houten and I. van Houten-Groeneveld at Palomar.

Named in honor of G. P. Kuiper \{1905-1973\}, former Director of the Lunar and Planetary Laboratory at Tucson, and former Director of the Yerkes Observatory. Dr. Kuiper was a well known authority on the solar system and initiated both the McDonald Survey and the Palomar-Leiden Survey of minor planets. (M 3185)

Kuiper is also honored by a crater on Mars. Obituaries published in Icarus, Vol. 22, p. 117-118 (1974); Nature, Vol. 248, p. 539-540 (1974); Observatory, Vol. 94, p. 94 (1974); Phys. Today, Vol. 27, No. 3, p. 85, 87 (1974); Science, Vol. 183, p. 1323 (1974); Sky Telesc., Vol. 47, p. 83 (1974); Zenit, Vol. 1, No. 1, p. 13 (1974); Irish Astron. J., Vol. 11, p. 158 (1973); Zemlya Vselennaya, No. 5, p. 56-58 (1974); l'Astronomie, 89. année, p. 84-85 (1975).

\section{(1777) Gehrels}

4007 P-L. Discovered 1960 Sept. 24 by C. J. van Houten and I. van Houten-Groeneveld at Palomar.

Named in honor of Tom Gehrels \{1925- \}, staff member of the Lunar and Planetary Laboratory at Tucson. Dr. Gehrels is well known for his photometric and polarimetric observations of minor planets and the Moon. (M 3185)

\section{(1778) Alfvén}

4506 P-L. Discovered 1960 Sept. 26 by C. J. van Houten and I. van Houten-Groeneveld at Palomar.

Named in honor of Nobel prize winner Hannes Alfvén \{1908-1995\} \{1970, together with L. E. N. Néel\}, who has stimulated physical studies of asteroids to be made with telescopes on the Earth and on future spacecraft. (M 3643)

This name has been proposed by Dr. T. Gehrels.

Obituaries published in Ciel Terre, Vol. 111, No. 3, p. 67-74 (1995); Phys. Today, Vol. 48, No. 9, p. 118-119 (1995); COSPAR Inf. Bull., No. 133, p. 57-58 (1995); Astrophys. Space Sci., Vol. 234, No. 2, p. 173-175 (1995); IEEE Trans. Plasma Sci., Vol. 25, No. 3, p. 409-414 (1997); Nature, Vol. 375, No. 6528, p. 187 (1995); Postepy Astron., Tom 44, No. 2, p. 91-92 (1996); Q.J.R. Astron. Soc., Vol. 37, No. 2, p. 259-260 (1996); Vasiona, Vol. 44, No. 1-2, p. 24-25 (1996).

\section{(1779) Paraná}

1950 LZ. Discovered 1950 June 15 by M. Itzigsohn at La Plata.

Named for a large river in northern Argentina, a major tributary to the La Plata \{see planet (1029)\} river, near which this minor planet was discovered. (M 6832)

Name proposed by F. Pilcher.

\section{(1780) Kippes}

A906 RA. Discovered 1906 Sept. 12 by A. Kopff at Heidelberg.

This name is bestowed by the Minor Planet Center in honor of Pastor Otto Kippes \{1905-1994\}, an instructor in religion in the Parochial School of Reckendorf, Germany. He is a diligent and meticulous worker, and an amateur astronomer in the finest sense, who established hundreds of identifications of minor planets in widely separated oppositions. (M 3508)

See also the Scylla story in Sky Telesc., Vol. 40, No. 6, p. 361-362 (1970).

\section{(1781) Van Biesbroeck}

A906 UB. Discovered 1906 Oct. 17 by A. Kopff at Heidelberg.

Named for Georges Van Biesbroeck $\{1880-1974\}$ in recognition of, and appreciation for, many years of devoted service to astronomy through observations and discoveries of minor planets, comets, satellites, and double stars. (M 3569)

Obituaries published in Circ. Inf., No. 62 (1974); Phys. Today, Vol. 27, No. 7, p. 59 (1974); Sky Telesc., Vol. 47, p. 215 (1974); Ciel Terre, Vol. 90, p. 321-325 (1974); Icarus, Vol. 23, p. 134-135 (1974); J.R. Astron. Soc. Can., Vol. 68, p. 202-204, p. L23-L24 (1974); l'Astronomie, 88. année, p. 305-308 (1974); Q.J.R. Astron. Soc., Vol. 16, p. 104-105 (1975). 


\section{(1782) Schneller}

$1931 \mathrm{TL}_{1}$. Discovered 1931 Oct. 6 by K. Reinmuth at Heidelberg.

Named in memory of Heribert Schneller (1901-1967), a prolific observer of variable stars, who worked at Berlin-Babelsberg Observatory, and later at the Astrophysical Observatory in Potsdam. He published many catalogues and collections of references on variable stars. (M 4156)

Schneller is also honored by a lunar crater.

\section{(1783) Albitskij}

1935 FJ. Discovered 1935 Mar. 24 by G. N. Neujmin at Simeis.

Named in memory of Vladimir Aleksandrovich Albitskij (1891-1952), head of the Simeis department of the Pulkovo Observatory from 1934 onward. He discovered ten numbered minor planets and is well known for his research on radial velocities and variable stars. (M 5357)

\section{(1784) Benguella}

1935 MG. Discovered 1935 June 30 by C. Jackson at Johannesburg.

Named for the chief port of Angola. (M 5183)

\section{(1785) Wurm}

1941 CD. Discovered 1941 Feb. 15 by K. Reinmuth at Heidelberg.

Named in memory of Karl Wurm (1899-1975), who is well-known for his work on interstellar matter and cometary physics. He worked at Potsdam, the Yerkes Observatory, and later at the Hamburg-Bergedorf Observatory. He was president of IAU Commission 15 from 1958 to 1964. (M 4156)

Obituaries published in Coelum, Vol. 43, p. 114-115 (1975); Orion, 33. Jahrg., p. 82 (1975); Sterne Weltraum, Vol. 14, p. 113 (1975); Astrophys. Space Sci., Vol. 35, p. 221-222 (1975); Mitt. Astron. Ges., Nr. 38, p. 14-16 (1976).

\section{(1786) Raahe}

1948 TL. Discovered 1948 Oct. 9 by H. Alikoski at Turku.

Named for a Finnish town, founded by Per Brahe \{see planet (1680)\} in 1649 on an ancient market place near Oulu \{see planet (1512)\}. (M 5449)

\section{(1787) Chiny}

1950 SK. Discovered 1950 Sept. 19 by S. Arend at Uccle.

Named for the principal town in the ancient county of the same name, situated on the beautiful river Semoise. (M 8402)

\section{(1788) Kiess}

1952 OZ. Discovered 1952 July 25 at the Goethe Link Observatory at Brooklyn, Indiana.

Named for Carl C. Kiess, a graduate of Indiana University (AB 1910, Honorary D.Sc. 1963). Dr. Kiess made distinguished contributions both in astronomy and spectroscopy. His spectroscopic research at the U.S. National Bureau of Standards began in 1917 and spanned a period of 40 years. He was a member of several eclipse expeditions, and conducted two expeditions to Hawaii to observe planetary spectra with high dispersion under good seeing conditions. He was serving on the Astronomy Faculty of Georgetown University at the time of his death in 1967. (M 3508)

\section{(1789) Dobrovolsky}

1966 QC. Discovered 1966 Aug. 19 by L. I. Chernykh at Nauchnyj.

Named in honor of Lt. Col. Georgi Timofeyevich Dobrovolsky, the commander. (M 3296)

This name and the following two names are a memorial to the cosmonauts of the spacecraft Soyuz 11, who perished on 30 June 1971 during the return of the vehicle to the Earth after completing the flight program of the first manned orbital station, Salyut.

\section{(1790) Volkov}

1967 ER. Discovered 1967 Mar. 9 by L. I. Chernykh at Nauchnyj.

Named in honor of Vladislav Nikolayevich Volkov, the flight engineer. (M 3296)

See the remark to (1789).

\section{(1791) Patsayev}

1967 RE. Discovered 1967 Sept. 4 by T. M. Smirnova at Nauchnyj.

Named in honor of Victor Ivanovich Patsayev, the test engineer. (M 3296)

See the remark to (1789).

\section{(1792) Reni}

1968 BG. Discovered 1968 Jan. 24 by L. I. Chernykh at Nauchnyj.

Named in honor of the town Reni (Ukrainian Soviet Socialist Republic), the birthplace of A. N. Deutsch, the well-known investigator of minor planets and authority in the field of astrophotometry and stellar astronomy. (M 3297)

\section{(1793) Zoya}

1968 DW. Discovered 1968 Feb. 28 by T. M. Smirnova at Nauchnyj.

Named in honor of Zoya Kosmodemyanskaya \{see planet (2072)\}, the young heroine of the Soviet people, who perished during the Great Patriotic War. (M 3297)

See also the citations for minor planets (1977) and (2072).

\section{(1794) Finsen}

1970 GA. Discovered 1970 Apr. 7 by J. A. Bruwer at Hartbeespoort.

Named in honor of W. S. Finsen \{1905-1979\}, Director of the Republic Observatory from 1957 to 1965. He has contributed immensely to the discovery and observation of double stars both micrometrically 
and by means of the eyepiece interferometer he invented. (M 3297)

Obituaries published in Circ. Inf., No. 79 (1979); Sky Telesc., Vol. 58, p. 137 (1979).

\section{(1795) Woltjer}

4010 P-L. Discovered 1960 Sept. 24 by C. J. van Houten and I. van Houten-Groeneveld at Palomar.

Named in honor of Dr. Jan J. Woltjer Jr. \{1891-1946\}, who was assistant professor at the Leiden Observatory from 1941-1946. He was an authority in the field of celestial mechanics and Cepheid pulsations. (M 3569) This name has been proposed by Dr. G. P. Kuiper. Woltjer is also honored by a lunar crater.

\section{(1796) Riga}

1966 KB. Discovered 1966 May 16 by N. S. Chernykh at Nauchnyj.

Named in honor of the capital of Latvia, site of the Astronomical Observatory of the Latvian State University. (M 3185)

Named at the request of Prof. M. Dirikis.

\section{(1797) Schaumasse}

1936 VH. Discovered 1936 Nov. 15 by A. Patry at Nice.

Named in memory of Alexandre Schaumasse (18821958), astronomer at the Nice Observatory who discovered (971) Alsatia and three comets. (M 4358)

Schaumasse also discovered minor planet (1114) Lorraine.

\section{(1798) Watts}

1949 GC. Discovered 1949 Apr. 4 at the Goethe Link Observatory at Brooklyn, Indiana.

Named for Chester B. Watts $\{1889-1971\}$, a graduate of Indiana University (AB 1915, Honorary D.Sc. 1953). Dr. Watts made distinguished contributions in the field of positional astronomy during his 44 years at the U.S. Naval Observatory. He pioneered in the field of automation of transit circle observations, leading to results of the highest systematic accuracy. Culminating his career was the monumental task of mapping every feature on the marginal zone of the Moon, which he commenced in the late 1940's and completed in 1963, four years after his normal retirement. (M 3508)

Obituaries published in Sky Telesc., Vol. 42, p. 131 (1971); Q.J.R. Astron. Soc., Vol. 13, p. 110-112 (1972); Moon, Vol. 6, p. 233-234 (1973).

\section{(1799) Koussevitzky}

1950 OE. Discovered 1950 July 25 at the Goethe Link Observatory at Brooklyn, Indiana.

Named in honor of Serge Koussevitzky, distinguished conductor of the Boston Symphony Orchestra during its golden years. His 25 year tenure was noteworthy for his efforts to encourage young American composers as well as for his masterly interpretations of the classic repertoire. (M 3569)
Proposed by Frank K. Edmondson to celebrate the centenary of the birth of Dr. Koussevitzky on July 26 , 1974 .

\section{(1800) Aguilar}

1950 RJ. Discovered 1950 Sept. 12 by M. Itzigsohn at La Plata.

Named in memory of Eng. Felix Aguilar \{1884$1943\}$, former director of the La Plata Observatory, founder of the University School of Astronomy and Geophysics, the most outstanding scientific worker for the development of Argentine astronomy in the first half of this century. (M 3934)

\section{(1801) Titicaca}

$1952 \mathrm{SP}_{1}$. Discovered 1952 Sept. 23 by M. Itzigsohn at La Plata.

Named for the large lake, at 3800 meters the highest in the world, that forms part of the border between Peru and Bolivia. (M 6832)

Name proposed by F. Pilcher.

\section{(1802) Zhang Heng}

$1964 \mathrm{TW}_{1}$. Discovered 1964 Oct. 9 at the Purple Mountain Observatory at Nanking.

Named for Zhang Heng (78-139), a prominent scientist of the eastern Han dynasty who devised and constructed armillary spheres and seismographs. He also invented a celestial sphere driven by water power that is in many respects the forerunner of the modern planetarium. (M 4419)

Zhang Heng (or Chang Heng) is also honored by a lunar crater.

\section{(1803) Zwicky}

1967 CA. Discovered 1967 Feb. 6 by P. Wild at Zimmerwald.

Named in memory of Fritz Zwicky (1898-1974), a Swiss citizen, who as a professor at Caltech, Pasadena, did pioneer work in many fields, notably in the study of supernovae and of clusters of galaxies, in high-energy astrophysics, and also in developing jet propulsion for airplanes and spacecraft. (M 4156)

Obituaries published in l'Astronomie, 88. année, p. 221-224 (1974); Observatory, Vol. 94, p. 94 (1974); Orion, 32. Jahrg., p. 63, p. 113-114 (1974); Phys. Today, Vol. 27, No. 6, p. 70-71 (1974); Sky Telesc., Vol. 47, p. 215 (1974); Sterne Weltraum, Vol. 13, p. 77-78 (1974); Acta Astronaut., Vol. 1, No. 7-8, p. IX (1974); Science, Vol. 186, p. 284 (1974); Q.J.R. Astron. Soc., Vol. 16, p. 106-108 (1975).

\section{(1804) Chebotarev}

1967 GG. Discovered 1967 Apr. 6 by T. M. Smirnova at Nauchnyj.

Named in honor of Prof. G. A. Chebotarev \{1913-1975\}, Director of the Institute of Theoretical Astronomy since 1964 and past president of Commission 20 of the International Astronomical Union. Prof. 
Chebotarev is well known for his intensive work on different problems of celestial mechanics concerned with the asteroids, comets and satellites. (M 3569)

Obituaries published in Zvaigžnotā Debess, p. 52-53

(1976); Byull. Inst. Teor. Astron., Vol. 14, p. 133-135 (1975); Celest. Mech., Vol. 12, p. 395-396 (1975); Zemlya Vselennaya, No. 6, p. 40-41 (1975).

\section{(1805) Dirikis}

1970 GD. Discovered 1970 Apr. 1 by L. I. Chernykh at Nauchnyj.

Named in honor of Dr. M\{atiss\} A. Dirikis \{1923$1993\}$, staff member of the Astronomical Observatory of the Latvian State University, chairman of the Latvian branch of the Astronomical-Geodetical Society of the U.S.S.R. His work on the motion of small bodies of the solar system contributes much to this field of theoretical astronomy. (M 3569)

Obituary published in Zvaigžnotā Debess, No. 143, p. 60-61 (1994).

\section{(1806) Derice}

1971 LC. Discovered 1971 June 13 at the Perth Observatory at Bickley.

Named in honor of the wife of Dennis Harwood, member of the astrometric team at the Perth Observatory. (M 6530)

This is the first numbered minor planet discovered in Oceania.

\section{(1807) Slovakia}

1971 QA. Discovered 1971 Aug. 20 by M. Antal at Skalnaté Pleso.

Named in honor of one of the two socialistic republics of Czechoslovakia \{see planet (2315)\}, the country in which the discoverer's observatory is situated. (M 3508)

The Slovak Republic now is an independent state.

\section{(1808) Bellerophon}

2517 P-L. Discovered 1960 Sept. 24 by C. J. van Houten and I. van Houten-Groeneveld at Palomar.

Named after the hero of a Greek saga, who vanquished the Chimaera \{see planet (623)\}, a monster which was partly lion, partly goat, partly serpent. (M 3934)

\section{(1809) Prometheus}

2522 P-L. Discovered 1960 Sept. 24 by C. J. van Houten and I. van Houten-Groeneveld at Palomar.

Named after the hero of a Greek saga, who stole the fire from the gods. (M 3934)

The name Prometheus has also been given to the satellite Saturn XVI, discovered 1980 by the Voyager 1 spacecraft.

\section{(1810) Epimetheus}

4196 P-L. Discovered 1960 Sept. 24 by C. J. van Houten and I. van Houten-Groeneveld at Palomar.

Epimetheus, the brother of Prometheus \{see planet (1809)\}, opened the Pandora \{see planet (55)\} box, which contained all the illnesses and ailments of mankind. (M 3935)

The name Epimetheus has also been given to the satellite Saturn XI, discovered 1980 by the Voyager 1 spacecraft.

\section{(1811) Bruwer}

4576 P-L. Discovered 1960 Sept. 24 by C. J. van Houten and I. van Houten-Groeneveld at Palomar.

Named in honor of Jacobus Albertus Bruwer \{1915-

\}, former staff member of the South African Astronomical Observatory in Johannesburg. He is well-known for his observational work on positions of minor planets with the Franklin-Adams camera at Hartbeespoort. (M 4547)

\section{(1812) Gilgamesh}

4645 P-L. Discovered 1960 Sept. 24 by C. J. van Houten and I. van Houten-Groeneveld at Palomar.

Named after the hero of an old-Babylonian saga. (M 4547)

\section{(1813) Imhotep}

7589 P-L. Discovered 1960 Oct. 17 by C. J. van Houten and I. van Houten-Groeneveld at Palomar.

Named for a famous physician and architect in the third dynasty of the ancient Egyptian Kingdom, builder of the step-pyramid near Sakkara. (M 4547)

\section{(1814) Bach}

$1931 \mathrm{TW}_{1}$. Discovered 1931 Oct. 9 by K. Reinmuth at Heidelberg.

The German composer, Johann Sebastian Bach (1685-1750). (M 3935)

\section{(1815) Beethoven}

$1932 \mathrm{CE}_{1}$. Discovered 1932 Jan. 27 by K. Reinmuth at Heidelberg.

The German composer, Ludwig van Beethoven (1770-1827). (M 3935)

\section{(1816) Liberia}

1936 BD. Discovered 1936 Jan. 29 by C. Jackson at Johannesburg.

Named for the state on the western coast of Africa. (M 5183)

\section{(1817) Katanga}

1939 MB. Discovered 1939 June 20 by C. Jackson at Johannesburg.

Named for the chief mining area of the Congo, today named Zaïre. (M 5183)

\section{(1818) Brahms}

1939 PE. Discovered 1939 Aug. 15 by K. Reinmuth at Heidelberg.

The German composer, Johannes Brahms (18331897). (M 3935) 
(1819) Laputa

1948 PC. Discovered 1948 Aug. 9 by E. L. Johnson at Johannesburg.

Named for the floating island in Gulliver's Travels, a novel by the English satirist, poet, political writer and clergyman Jonathan Swift (1667-1745). (M 3935)

\section{(1820) Lohmann}

1949 PO. Discovered 1949 Aug. 2 by K. Reinmuth at Heidelberg.

Named in honor of Werner Lohmann \{1911-1983\}, astronomer at Heidelberg, who worked at the Königstuhl Observatory, and later, since 1949, at the RechenInstitut. He was editor or co-editor of the Astronomischer Jahresbericht, indexing the astronomical literature of the period 1943-1968. (M 4156)

\section{(1821) Aconcagua}

1950 MB. Discovered 1950 June 24 by M. Itzigsohn at La Plata.

Named for one of the highest mountains in South America. It has an elevation of 6960 meters and is situated on the Argentina-Chile border. The western slope of the mountain is the headwaters of a river of the same name whose outlet to the Pacific Ocean is at Valparaiso. (M 7156)

Name proposed by F. Pilcher.

\section{(1822) Waterman}

1950 OO. Discovered 1950 July 25 at the Goethe Link Observatory at Brooklyn, Indiana.

Named to honor the memory of Alan T. Waterman \{1892-1967\}, first director of the U.S. National Science Foundation, in the year which marks the 25th anniversary of the foundation. After 25 years as an academic physicist, he went to Washington to serve with OSRD (1941-45), ONR (1946-51), and NSF (1951-63). Among the many honors he received was the Karl Taylor Compton Gold Medal for distinguished statesmanship in science, awarded by the American Institute of Physics two months before his death. (M 3825)

The name is proposed by Frank K. Edmondson.

Waterman is also honored by a lunar crater.

\section{(1823) Gliese}

1951 RD. Discovered 1951 Sept. 4 by K. Reinmuth at Heidelberg.

Named in honor of Wilhelm Gliese $\{1915-1993\}$, an astronomer at the Rechen-Institut since 1943, who is well-known for his work on the nearby stars and the FK4. (M 4156)

Obituary published in Mitt. Astron. Ges., Nr. 77, p. 5-7 (1994).

\section{(1824) Haworth}

1952 FM. Discovered 1952 Mar. 30 at the Goethe Link Observatory at Brooklyn, Indiana.

Named in honor of Leland J. Haworth, a graduate of Indiana University and second director of the National Science Foundation. His long and varied career included high school teaching, academic appointments at Wisconsin, MIT, and Illinois, director of the Brookhaven National Laboratory, vice-president and president of Associated Universities, Inc. (AUI), member of the Atomic Energy Commission, and director of the National Science Foundation from 1963 to 1969. He conducted the negotiations which led to the joint funding by NSF and the Ford Foundation of a 4 meter telescope at the Cerro Tololo Interamerican Observatory. (M 4156)

Proposed by Frank K. Edmondson.

\section{(1825) Klare}

1954 QH. Discovered 1954 Aug. 31 by K. Reinmuth at Heidelberg.

Named in honor of Gerhard Klare \{1932- $\}$, an observing astronomer at Heidelberg-Königstuhl Observatory since 1960, whose fields of interest include minor planets. (M 4156)

\section{(1826) Miller}

$1955 \mathrm{RC}_{1}$. Discovered 1955 Sept. 14 at the Goethe Link Observatory at Brooklyn, Indiana.

Named in honor of John A. Miller, founder of the Astronomy Department at Indiana University and first director of the Kirkwood \{see planet (1578)\} Observatory which he built and named for his former teacher. Later he built the Sproul Observatory at Swarthmore College to continue and expand the double star program he had started in Indiana. (M 4236) Proposed by Frank K. Edmondson.

\section{(1827) Atkinson}

1962 RK. Discovered 1962 Sept. 7 at the Goethe Link Observatory at Brooklyn, Indiana.

Named in honor of Robert d'Escourt Atkinson \{1898$1982\}$, noted for his contributions to fundamental astronomy. He also pioneered in studying nuclear energy-generation in the Sun and stars, in collaboration with Houtermans in the late 1920's. During his time as chief assistant at the Royal Observatory, Greenwich, he handled the many details of the move to Herstmonceux, Sussex. He was awarded the Eddington Medal by the Royal Astronomical Society in 1960. Following his retirement from the Royal Greenwich Observatory he served on the Faculty of Indiana University for several years. (M 4236)

Proposed by Frank K. Edmondson

Obituaries published in J. Br. Astron. Assoc., Vol. 93, No. 4, p. 172-173 (1983); Phys. Today, Vol. 36, No. 5 p. 81-82 (1983); Sky Telesc., Vol. 65, No. 5, p. 417 (1983); Astronomie, Vol. 97, p. 442 (1983); Q.J.R. Astron. Soc., Vol. 25, No. 1, p. 100-104 (1984).

\section{(1828) Kashirina}

1966 PH. Discovered 1966 Aug. 14 by L. I. Chernykh at Nauchnyj.

Named in honor of Valentin Semenovich Kashirin, physician from Simferopol (Crimea). (M 3825)

Name proposed by L. Chernykh. 
(1829) Dawson

1967 JJ. Discovered 1967 May 6 by C. U. Cesco and

A. R. Klemola at El Leoncito.

Named in memory of Bernhard H. Dawson (18901960), a U.S.-born astronomer who worked at the La Plata Observatory in Argentina from 1913 onward. From 1948 to 1955 he was a professor at the Faculdad de Ingeniera de San Juan. He was well known for his visual discoveries and observations of double stars and was also an active observer of minor planets and comets and computer of their orbits. (M 3935)

Dawson is also honored by a lunar crater.

\section{(1830) Pogson}

1968 HA. Discovered 1968 Apr. 17 by P. Wild at Zimmerwald.

Named in memory of Norman Robert Pogson (18291891), astronomer at Oxford and later at Madras, discoverer of eight minor planets, including (42) Isis and (67) Asia, and inventor of the astronomical magnitude scale. (M 4236)

Pogson is also honored by a lunar crater.

\section{(1831) Nicholson}

1968 HC. Discovered 1968 Apr. 17 by P. Wild at Zimmerwald.

Named in memory of Seth Barnes Nicholson (18911963), discoverer of four of Jupiter's satellites and pioneer in several branches of observational research on members of the solar system. (M 4236)

Nicholson is also honored by craters on the Moon and Mars and by a region on the Jupiter satellite Ganymed.

\section{(1832) Mrkos}

1969 PC. Discovered 1969 Aug. 11 by L. I. Chernykh at Nauchnyj.

Named in honor of Antonin Mrkos \{1918-1996\}, Director of the Kleť Observatory in Czechoslovakia, well known for his contributions to cometary astronomy. \{He was the founder and for many years head of Klet Observatory who initiated the Klet minor planet survey, the first one in Czechoslovakia.\} (M 3825; N. S. Chernykh)

Name proposed by L. Chernykh.

Obituaries published in Heavens, Vol. 77, p. 272-273

(1996); Int. Comet Q., Vol. 18, No. 4, p. 182-183 (1996).

\section{(1833) Shmakova}

1969 PN. Discovered 1969 Aug. 11 by L. I. Chernykh at Nauchnyj.

Named in honor of Mrs. M. Ya. hmakova (1910-1971), staff member of the I.T.A. \{Institute for Theoretical Astronomy, Leningrad\} who contributed much to planetary and cometary orbit computations. (M 3825)

\section{(1834) Palach}

1969 QP. Discovered 1969 Aug. 22 by L. Kohoutek at Bergedorf.

Named in memory of the Czech student of philosophy Jan Palach, who burned himself to death on 1969
Jan. 16 in Wenceslas Square, Prague, as a protest against the occupation of Czechoslovakia the previous August, resulting in the violent end of the reform movement known as Prague Spring. (M 18643)

\section{(1835) Gajdariya}

1970 OE. Discovered 1970 July 30 by T. M. Smirnova at Nauchnyj.

Named in honor of Arkadij Gajdar (1904-1941), Russian writer. (M 3825)

\section{(1836) Komarov}

1971 OT. Discovered 1971 July 26 by N. S. Chernykh at Nauchnyj.

Named in honor of the Soviet cosmonaut Vladimir Mikhajlovich Komarov (1927-1967). In 1964 he headed the manned flight on the Voskhod spacecraft. He perished on 24 April 1967 when completing the Soyuz-1 spacecraft test-flight. (M 3825)

Komarov is also honored by a lunar crater.

\section{(1837) Osita}

1971 QZ $_{1}$. Discovered 1971 Aug. 16 by J. Gibson at El Leoncito.

Named by the discoverer in honor of his wife Ursula, of which Osita is the Spanish equivalent. While the discoverer was located at the Yale-Columbia Southern Station she measured and/or reduced more than 150 positions of comets and minor planets. Her volunteer services as assistant, visitor's guide and secretary were performed in addition to the daily work of making a pleasant home at an isolated location. (M 3935)

\section{(1838) Ursa}

1971 UC. Discovered 1971 Oct. 20 by P. Wild at Zimmerwald.

Named for the discoverer's wife, Ursula, their son, Urs, and for the bears of Berne. (M 4156)

\section{(1839) Ragazza}

1971 UF. Discovered 1971 Oct. 20 by P. Wild at Zimmerwald.

The Italian word for girl. Also the name alludes to Bad Ragaz, a resort town with hot springs, in Switzerland. (M 4156)

\section{(1840) Hus}

1971 UY. Discovered 1971 Oct. 26 by L. Kohoutek at Bergedorf.

Named in honor of Jan Hus (1372-1415), Czech religious and linguistic reformer, rector of Charles University in Prague. He was condemned to death by the Council of Constance and burned at the stake for his reformation ideas. (M 3757)

\section{(1841) Masaryk}

$1971 \mathrm{UO}_{1}$. Discovered 1971 Oct. 26 by L. Kohoutek at Bergedorf.

Named in honor of Thomas G. Masaryk (1850-1937), Czechoslovak statesman and philosopher, known for his humanistic ideas. The first president of the independent Czechoslovak Republic. (M 3757) 


\section{(1842) Hynek}

1972 AA. Discovered 1972 Jan. 14 by L. Kohoutek at Bergedorf.

Named by the discoverer in honor of his father, Hynek Kohoutek, on the occasion of his 70th birthday. (M 3757)

\section{(1843) Jarmila}

1972 AB. Discovered 1972 Jan. 14 by L. Kohoutek at Bergedorf.

Named by the discoverer in honor of his mother, Jarmila Kohoutkova, on the occasion of her 70th birthday. (M 3757)

\section{(1844) Susilva}

1972 UB. Discovered 1972 Oct. 30 by P. Wild at Zimmerwald.

See the citation for (1845) which follows. (M 4156)

\section{(1845) Helewalda}

1972 UC. Discovered 1972 Oct. 30 by P. Wild at Zimmerwald.

Named for two charming former schoolmates of the discoverer, Susi and Helen, both from the town of Wald (Canton Zurich) Switzerland. (M 4156)

\section{(1846) Bengt}

6553 P-L. Discovered 1960 Sept. 24 by C. J. van Houten and I. van Houten-Groeneveld at Palomar.

Named in honor of Bengt Strömgren \{1908-1987\} on the occasion of his 70th birthday. This renowned Danish astronomer was an authority in the field of stellar structure and stellar evolution. He served as director of the Yerkes Observatory during 1951-1957 and as president of the IAU during 1970-1973. (M 4547)

Obituaries published in Astron. Tidsskr., Årg. 20, Nr. 4, p. 175-177 (1987); Messenger, No. 49, p. 1, 43-44 (1987); Sterne Weltraum, 26. Jahrg., Nr. 12, p. 677 (1987); Phys. Today, Vol. 41, No. 3, p. 112-114 (1988); Q.J.R. Astron. Soc., Vol. 29, No. 2, p. 282-284 (1988); Mitt. Astron. Ges., Nr. 73, p. 5-7 (1990); C.R. Acad. Sci., Sér. Gén., Vie Sci., Tome 6, p. 609-610 (1989); IAU Today (20th General Assembly, Baltimore, 1988), No. 3, p. 2, 8 (1988).

\section{(1847) Stobbe}

A916 CA. Discovered 1916 Feb. 1 by H. Thiele at Bergedorf.

Named in honor of Joachim Otto Stobbe (1900-1943), astronomer at the Hamburg-Bergedorf Observatory during 1925-1927 who observed comets and minor planets. As chief assistant at the Berlin-Babelsberg Observatory he later did an extensive study of the light curve of (433) Eros. From 1941 until his death he was director of the Poznan Observatory. (M 4236)

\section{(1848) Delvaux}

1933 QD. Discovered 1933 Aug. 18 by E. Delporte at Uccle.

Named in honor of the sister-in-law of Uccle astronomer G. Roland. (M 6832)

\section{(1849) Kresák}

1942 AB. Discovered 1942 Jan. 14 by K. Reinmuth at Heidelberg.

Named in honor of Luboš Kresák \{1927-1994\}, astronomer at the Slovak Academy of Sciences in Bratislava. Well-known for his theoretical work on meteors and the question of their relationship with comets and minor planets, he has also been an observer at the Skalnaté Pleso \{see planet (2619)\} Observatory, where in 1951 he rediscovered the shortperiod comet now known as Tuttle-Giacobini-Kresák \{see planets (5036) and (1756) for the codiscoverers\}. He was president of IAU Commission 20 for the period 1973-1976. (M 3935)

Obituaries published in Icarus, Vol. 109, No. 1, p. 1 (1994); WGN, Vol. 22, No. 1, p. 1-2 (1994); IAU Symp. No. 160 , p. $75-76$ (1994); Planet. Space Sci.. Vol. 42, No. 2, p. 99 (1994); Q.J.R. Astron. Soc., Vol. 35, No. 4, p. 579 (1994).

\section{(1850) Kohoutek}

1942 EN. Discovered 1942 Mar. 23 by K. Reinmuth at Heidelberg.

Named in honor of the Czech astronomer, Lubos Kohoutek \{1935- $\}$, on the staff of the observatory at Hamburg-Bergedorf since 1969. He has contributed much to our knowledge of planetary nebulae and emission-line stars and is also widely known as a discoverer and observer of comets and minor planets. (M 3935)

\section{(1851) Lacroute}

1950 VA. Discovered 1950 Nov. 9 by L. Boyer at Algiers.

Named in honor of Pierre Lacroute \{1906-1993\}, wellknown French astrometrist who made an independent reduction of the AGK3 using a plate-overlapping technique. As director of the Strasbourg Observatory he was instrumental in the establishment of the Stellar Data Center there, and he served as president of IAU Commission 24 during 1973-1976. (M 4419)

Obituaries published in Bull. Am. Astron. Soc. Vol. 25, No. 4, p. 1498 (1993); Astronomie, Vol. 107, p. $128-129$ (1993).

\section{(1852) Carpenter}

1955 GA. Discovered 1955 Apr. 1 at the Goethe Link Observatory at Brooklyn, Indiana.

Named in memory of Edwin F. Carpenter (18981963), second director of the Steward Observatory and a director-at-large on the AURA board. His primary research interests were spectroscopic binaries, photometry and interacting galaxies. Despite extremely limited financial resources he succeeded in keeping Steward Observatory an active research center during the nearly three decades of his directorship, and he played a major role in persuading the Papago Tribal Council to lease the top of Kitt Peak to the AURA Board, thereby enabling the construction of the National Observatory on Kitt Peak. (M 5282) 
Name proposed by F. K. Edmondson and E. Roemer. Citation written by W. S. Fitch.

\section{(1853) McElroy}

1957 XE. Discovered 1957 Dec. 15 at the Goethe Link Observatory at Brooklyn, Indiana.

Named in honor of William David McElroy, distinguished biologist and biochemist, chairman of the biology department at Johns Hopkins University during 1956-1969, later director of the National Science Foundation (1969-1972) and chancellor of the University of California at San Diego (1972-1980). During his tenure as director of N.S.F. the U.S. government decided to fund the Very Large Array, which will be the pre-eminent instrument for radio astronomy for many years to come. (M 5450)

\section{(1854) Skvortsov}

1968 UE $_{1}$. Discovered 1968 Oct. 22 by T. M. Smirnova at Nauchnyj.

Named in honor of Prof. E. F. Skvortsov (18821952), an instructor of astronomy in the Simferopol Pedagogical Institute, an active observer of minor planets at Simeis, and the discoverer of several new planets. (M 3825)

\section{(1855) Korolev}

$1969 \mathrm{TU}_{1}$. Discovered 1969 Oct. 8 by L. I. Chernykh at Nauchnyj.

Named in honor of academician Sergej Pavlovich Korolev (1907-1966), an outstanding designer of Soviet space rockets and spacecraft. (M 3825)

Korolev is also honored by craters on Mars and the Moon.

\section{(1856) Ružena}

1969 TW $_{1}$. Discovered 1969 Oct. 8 by L. I. Chernykh at Nauchnyj.

Named in honor of Miss Ružena Petrovicova, a staff member of the Klet Observatory, and an observer of comets and minor planets. (M 3825)

Name proposed by L. Chernykh.

\section{(1857) Parchomenko}

1971 QS $_{1}$. Discovered 1971 Aug. 30 by T. M. Smirnova at Nauchnyj.

Named in honor of Praskoviya Georgievna Parchomenko (1886-1970), astronomer. In 1930-1940 she observed minor planets at Simeis and discovered several new ones. (M 3826)

\section{(1858) Lobachevskij}

1972 QL. Discovered 1972 Aug. 18 by L. V. Zhuravleva at Nauchnyj.

Named in honor of Nikolaj Ivanovich Lobachevskij (1792-1856), Russian mathematician, the creator of the first comprehensive system of non-Euclidian geometry. (M 3826)

Lobachevskij is also honored by a lunar crater.

\section{(1859) Kovalevskaya}

$1972 \mathrm{RS}_{2}$. Discovered 1972 Sept. 4 by L. V. Zhuravleva at Nauchnyj.

Named in honor of Sophie Kovalevskaya (1850-1891), the first Russian woman mathematician, associate member of the St. Petersburg Academy of Sciences, widely known for her researches on differential equations, Abelian integrals and the rotational motion of solid bodies. (M 3826)

Kovalevskaya is also honored by a lunar crater.

\section{(1860) Barbarossa}

1973 SK. Discovered 1973 Sept. 28 by P. Wild at Zimmerwald.

The name of the famous German emperor was the nickname (Barba) of the discoverer's favorite mathematics teacher, Dr. Jakob Stauber, (1880-1952) in Trogen, Switzerland. (M 4157)

\section{(1861) Komenský}

1970 WB. Discovered 1970 Nov. 24 by L. Kohoutek at Bergedorf.

Named in honor of Jan Amos Komenský (Comenius, 1592-1670), Czech educational reformer and theologian, sometimes called the grandfather of modern education. He had to spend most of his life in exile. (M 3757)

\section{(1862) Apollo}

1932 HA. Discovered 1932 Apr. 24 by K. Reinmuth at Heidelberg.

This object is named for the god of the Sun, child of Zeus and Leto \{see planets (5731) and (68)\}. (M 3758) See also the naming citation of planet (4544).

\section{(1863) Antinous}

1948 EA. Discovered 1948 Mar. 7 by C. A. Wirtanen at Mount Hamilton.

Antinous was one of the many unwelcome suitors for Penelope's \{see planet (201)\} hand while her husband, Odysseus \{see planet (1143)\}, was away on his travels. Antinous, being the most insolent of all, was the first to be killed by Odysseus on his return. (M 3935)

\section{(1864) Daedalus}

1971 FA. Discovered 1971 Mar. 24 by T. Gehrels at Palomar.

Named for the builder of King Minos' \{see planet (6239)\} labyrinth, who was subsequently imprisoned there with his son Icarus. Both escaped, on wings of feathers and wax, but whereas Icarus was drowned when the wax in his wings melted ssee planet (1566)\}, Daedalus went on to Sicily and built there a temple to Apollo \{see planet (1862)\}. (M 3758)

This mythological figure also exists as a lunar crater.

\section{(1865) Cerberus}

1971 UA. Discovered 1971 Oct. 26 by L. Kohoutek at Bergedorf.

Named for the three-headed dog that guarded the entrance to Hades. His capture (and subsequent return) 
marked the last of the twelve labors of Hercules. Cerberus is also the name of an extinct constellation now contained in the eastern part of Hercules. (M 3758)

\section{(1866) Sisyphus}

1972 XA. Discovered 1972 Dec. 5 by P. Wild at Zimmerwald.

Named for the cruel king of Corinth, punished by being given the task of rolling a large stone up to a hill in Hades, only to have it roll down again each time he neared the top. (M 3758)

\section{(1867) Deiphobus}

1971 EA. Discovered 1971 Mar. 3 by C. U. Cesco at El Leoncito.

Named after the Trojan warrior, son of Priamus \{see planet (884)\} and Hecuba \{see planet (108)\}. (M 3935)

\section{(1868) Thersites}

2008 P-L. Discovered 1960 Sept. 24 by C. J. van Houten and I. van Houten-Groeneveld at Palomar.

Named after a Greek warrior who wanted to stop the siege of Troy and go home. This is a fitting name for this asteroid which was found farthest from the Trojan libration point. (M 3826)

\section{(1869) Philoctetes}

4596 P-L. Discovered 1960 Sept. 24 by C. J. van Houten and I. van Houten-Groeneveld at Palomar.

Named after a Greek archer and armor-bearer of Hercules, wounded and left to die on the way to the Trojan War. Since it had been prophesied that Troy could not be taken without the arrows of Hercules, Philoctetes was later taken to Troy, where he killed Paris $\{$ see planet (3317)\}. (M 3826)

\section{(1870) Glaukos}

1971 FE. Discovered 1971 Mar. 24 by C. J. van Houten and I. van Houten-Groeneveld at Palomar.

Glaukos, king of the Lycians, was an ally of Troy during the Trojan War. (M 3826)

\section{(1871) Astyanax}

1971 FF. Discovered 1971 Mar. 24 by C. J. van Houten and I. van Houten-Groeneveld at Palomar.

Named after a son of Hector and Andromache s see planets (624) and (175)\}, killed after the capture of Troy. (M 3826)

\section{(1872) Helenos}

1971 FG. Discovered 1971 Mar. 24 by C. J. van Houten and I. van Houten-Groeneveld at Palomar.

Named after a son of Priamus and Hecuba ssee planets (884) and (108)\}, who was taken prisoner by the Greeks during the Trojan War. (M 3826)

\section{(1873) Agenor}

1971 FH. Discovered 1971 Mar. 25 by C. J. van Houten and I. van Houten-Groeneveld at Palomar.
Named after a Trojan warrior, who fought with and wounded Achilles \{see planet (588)\}. Apollo \{see planet (1862)\} assumed his form in order to lead Achilles away from the retreating Trojans. (M 3826)

Name proposed by Brian G. Marsden.

\section{(1874) Kacivelia}

A924 RC. Discovered 1924 Sept. 5 by S. I. Belyavskij at Simeis.

Named in honor of the Black Sea Hydrographical Station (now the Marine Hydrographical Institute). Kaciveli is a village near Simeis see planet (748)\}, the site of the institute. (M 3936)

The name had been proposed in the 1930's by the late Prof. E. Skvortsov.

\section{(1875) Neruda}

1969 QQ. Discovered 1969 Aug. 22 by L. Kohoutek at Bergedorf.

Named in memory of Jan Neruda (1834-1891), Czech lyric poet, novelist and journalist. He published several volumes of poems, notably Cosmic Songs, as well as collections of essays, plays and stories, of which the best known is Stories from Malá Strana. (M 18446)

\section{(1876) Napolitania}

1970 BA. Discovered 1970 Jan. 31 by C. T. Kowal at Palomar.

Named in honor of the city of Naples, the birthplace of Mrs. Kowal. (M 3826)

\section{(1877) Marsden}

1971 FC. Discovered 1971 Mar. 24 by C. J. van Houten and I. van Houten-Groeneveld at Palomar.

Named in honor of Brian G. Marsden \{1937- \}, Smithsonian Astrophysical Observatory, in recognition of his numerous contributions in the field of orbit calculations for comets and minor planets, his improved versions of the Catalogue of Cometary Orbits, and his activities in the Central Bureau and in Commission 20 of the I.A.U. (M 3826)

Proposed by his colleagues, Elizabeth Roemer, Frank Edmondson, Tom Gehrels and Paul Herget.

Marsden was also honored by a series of minor planets - see the citation for planet (5699).

\section{(1878) Hughes}

1933 QC. Discovered 1933 Aug. 18 by E. Delporte at Uccle.

Named in honor of the son of Mireille (née Delporte) Demiddelaer \{see planet (1926)\}, granddaughter of the discoverer. (M 8402)

\section{(1879) Broederstroom}

1935 UN. Discovered 1935 Oct. 16 by H. van Gent at Johannesburg.

Named for the village in South Africa near which the Leiden Southern Observatory was located from 1957 to 1982 . (M 6833) 


\section{(1880) McCrosky}

1940 AN. Discovered 1940 Jan. 13 by K. Reinmuth at Heidelberg.

Named in honor of Richard E. McCrosky \{1924- \}, in appreciation of his role in the recovery of (1862) Apollo. On the staff of the Harvard-Smithsonian Center for Astrophysics, he has been in charge of the Prairie Network for the observations of fireballs, which led to the recovery of the Lost City meteorite in 1970. From 1970 to 1973 he was president of IAU Commission 22. (M 3936)

\section{(1881) Shao}

1940 PC. Discovered 1940 Aug. 3 by K. Reinmuth at Heidelberg.

Named in honor of Cheng-yuan Shao \{1927- $\quad$ \}, an assistant to McCrosky \{see planet (1880)\} in several observing projects at the Harvard-Smithsonian Center for Astrophysics, including the recovery of (1862) Apollo. (M 3936)

\section{(1882) Rauma}

1941 UJ. Discovered 1941 Oct. 15 by L. Oterma at Turku.

Named for a Finnish town, famous for its seafaring and lace-making, that developed around a monastery in the first part of the fifteenth century. The area was already populated in the bronze age. (M 5450)

\section{(1883) Rimito}

1942 XA. Discovered 1942 Dec. 4 by Y. Väisälä at Turku.

Named for Rymattyla, a Finnish country commune near Turku, already inhabited in the bronze age. Comprising about 400 islands with numerous summer cottages, it is also the center for winter seine-fishing in Finland. (M 5450)

\section{(1884) Skip}

1943 EB $_{1}$. Discovered 1943 Mar. 2 by M. Laugier at Nice.

Named in honor of Gunther (Skip) Schwartz, manager of and observer at Harvard Observatory Agassiz \{see planet (2267)\} Station and previously field manager of various other Harvard and Smithsonian optical and radio observing stations. He is best known for his role in the recovery of the Lost City meteorite in 1970. (M 4645) den.

Name proposed by R. E. McCrosky and B. G. Mars-

\section{(1885) Herero}

1948 PJ. Discovered 1948 Aug. 9 by E. L. Johnson at Johannesburg.

Named for a tribe in the northern highlands of South-West Africa who fought a disastrous war with the Nama Hottentots in 1930. They came under German rule in 1884 but were ruthless suppressed after a revolt in 1904. (M 3936)

\section{(1886) Lowell}

1949 MP. Discovered 1949 June 21 by H. L. Giclas and R. D. Schaldach at Flagstaff.

Named in honor of Percival Lowell \{1855-1916\}, the founder, director and endower of Lowell Observatory at Flagstaff, Arizona. Lowell, during his lifetime and beginning in 1905 directed three searches of the ecliptic for a trans-Neptunian planet. In all these surveys positions for all the minor planets found were measured and he was the discoverer of (793) Arizona. (M 4157)

The planet was found with the 13-inch astrograph with which Pluto, the PlanetX predicted by Lowell, was discovered. Lowell is also honored by craters on Mars and the Moon.

\section{(1887) Virton}

1950 TD. Discovered 1950 Oct. 5 by S. Arend at Uccle.

Named for the capital of the Gaume (or Belgian Lorraine), very close to Robelmont \{see planet (1145)\}, the discoverer's birthplace. (M 8151; M 8183)

\section{(1888) Zu Chong-Zhi}

$1964 \mathrm{VO}_{1}$. Discovered 1964 Nov. 9 at the Purple Mountain Observatory at Nanking.

Named for Zu Chong-Zhi (492-500), a distinguished astronomer-mathematician during the period of the Liu-Sung dynasty. He improved the calendrical system of his time. He constructed a bronze compass that can rotate freely while pointing in the same direction. He also ascertained that the ratio of the circumference to the diameter of a circle is between 3.1415926 and 3.1415927. (M 4419)

\section{(1889) Pakhmutova}

1968 BE. Discovered 1968 Jan. 24 by L. I. Chernykh at Nauchnyj.

Named in honor of Aleksandra Nikolaevna Pakhmutova, Soviet composer. (M 3936)

\section{(1890) Konoshenkova}

1968 CD. Discovered 1968 Feb. 6 by L. I. Chernykh at Nauchnyj.

Named in honor of Olga Petrovna Konoshenkova (1919-1975), the schoolmistress at the Crimean Observatory school. (M 3936)

\section{(1891) Gondola}

1969 RA. Discovered 1969 Sept. 11 by P. Wild at Zimmerwald.

Selected as a beautiful sounding word, well suited to an object moving smoothly and silently across the sky. (M 4157)

\section{(1892) Lucienne}

1971 SD. Discovered 1971 Sept. 16 by P. Wild at Zimmerwald.

Named in honor of Mlle. Lucienne Divan of the Institut d'Astrophysique in Paris, who is a spectroscopist working mainly on the spectral and 
luminosity classification of stars and on interstellar absorption. (M 4157)

\section{(1893) Jakoba}

1971 UD. Discovered 1971 Oct. 20 by P. Wild at Zimmerwald.

Named in honor of the discoverer's grandfather, Dr. Jakob Oberholzer (1862-1939) in Glarus, Switzerland, who was one of the outstanding alpine geologists of his time. (M 4157)

\section{(1894) Haffner}

1971 UH. Discovered 1971 Oct. 26 by L. Kohoutek at Bergedorf.

Named in honor of the German astronomer Hans Haffner (1912-1977), who worked in Göttingen from 1941 to 1953 prior to the Hamburg Observatory in Bergedorf. Since 1967 he has been Director at the Astronomical Institute of the University in Würzburg. His activity in astronomical photography and photometry is mainly directed towards the study of open clusters. Best known is his photographic photometry of Praesepe (together with Heckmann, see planet (1650)). In addition he discovered 26 open clusters. (M 3827)

Obituaries published in Mitt. Astron. Ges., Nr. 42, p. 5-8 (1977); Sterne Weltraum, 16. Jahrg., p. 121 (1977).

\section{(1895) Larink}

1971 UZ. Discovered 1971 Oct. 26 by L. Kohoutek at Bergedorf.

Named in honor of the German astronomer Johannes Larink (1893-1988), who worked at the Hamburg Observatory in Bergedorf as senior observer from 1922 until 1958. He determined the periods of Cepheids in M3, but his main field was classical astronomy. He carried out astrometric programs using the Bergedorf meridian circle, for instance making measurements of reference stars for the AGK2 and AGK3 and a catalogue of faint stars. (M 3827)

\section{(1896) Beer}

$1971 \mathrm{UC}_{1}$. Discovered 1971 Oct. 26 by L. Kohoutek at Bergedorf.

Named in honor of the astronomer Arthur Beer \{1900-1980\}, born in Bohemia in 1900, who worked at the Naval Observatory in Hamburg during 1929-1934, prior to moving to England. He was senior observer at the Cambridge Observatories from 1947 until his retirement in 1967. Although perhaps best known for his on-going series Vistas in Astronomy, he has worked extensively on spectroscopic binaries, on the nova DQ Herculis and on the spectrophotometry of $\mathrm{O}$ and $\mathrm{B}$ stars and galactic structure. (M 3827)

Name suggested by B. G. Marsden.

Obituaries published in Vistas Astron., Vol. 24, p. I-II (1980); Observatory, Vol. 101, p. 24 (1981).

\section{(1897) Hind}

$1971 \mathrm{UE}_{1}$. Discovered 1971 Oct. 26 by L. Kohoutek at Bergedorf.

Named in honor of John Russell Hind (1823-1895), discoverer of (7) Iris, (8) Flora and eight other minor planets. Hind worked for many years at George Bishop's Observatory near London and served also as superintendent of the British Nautical Almanac Office from 1853 to 1891. (M 3827)

Name suggested by B. G. Marsden. Hind is also honored by a lunar crater.

\section{(1898) Cowell}

$1971 \mathrm{UF}_{1}$. Discovered 1971 Oct. 26 by L. Kohoutek at Bergedorf.

Named in honor of Philip Herbert Cowell (1870-1949), superintendent of the British Nautical Almanac Office from 1910-1930 and inventor of the well-known method used for numerical integration of the orbits of comets and minor planets. (M 3827)

Name suggested by B. G. Marsden.

\section{(1899) Crommelin}

$1971 \mathrm{UR}_{1}$. Discovered 1971 Oct. 26 by L. Kohoutek at Bergedorf.

Named in honor of Andrew Claude de la Cherois Crommelin (1865-1939), who worked and wrote extensively on the orbits of comets and minor planets. Together with P. H. Cowell \{see minor planet (1898)\}, Crommelin computed the orbit of Jupiter VIII and identified appearances of Halley's comet back to the year -239. (M 3827)

Name suggested by B. G. Marsden.

Crommelin is also honored by craters on Mars and the Moon.

\section{(1900) Katyusha}

1971 YB. Discovered 1971 Dec. 16 by T. M. Smirnova at Nauchnyj.

Named in honor of Ekaterina Ivanovna Zelenko, airwoman who valorously perished at the front in Sept. 1941. Katyusha is a petname for Ekaterina. (M 3936)

\section{(1901) Moravia}

1972 AD. Discovered 1972 Jan. 14 by L. Kohoutek at Bergedorf.

Central region of Czechoslovakia, formerly a province. Other regions are Bohemia (371), Silesia (257) and Slovakia (1807), each with a distinct history and own folk culture. Native province of the discoverer. (M 3827)

\section{(1902) Shaposhnikov}

1972 HU. Discovered 1972 Apr. 18 by T. M. Smirnova at Nauchnyj.

Named in honor of Vladimir Grigorevich Shaposhnikov (1905-1942), an expert in astrometry. Before the Great Patriotic War he worked at the Simeis Observatory. He perished at the front. (M 3936) 


\section{(1903) Adzhimushkaj}

1972 JL. Discovered 1972 May 9 by T. M. Smirnova at Nauchnyj.

Named in honor of the heroic warriors of the Soviet Army and the Crimean guerillas who fought in the Adzhimushkaj quarries during the Great Patriotic War. The discoverer's mother was among the courageous defenders of the underground fortress. (M 3936)

\section{(1904) Massevitch}

1972 JM. Discovered 1972 May 9 by T. M. Smirnova at Nauchnyj.

Honoring Dr. Alla Genrichovna Massevitch \{1918-

\}, a well-known woman astronomer-astrophysicist, vice-president of the Astronomical Council of the USSR Academy of Sciences, the organizer of optical tracking of artificial Earth satellites in the USSR. (M 3936)

\section{(1905) Ambartsumian}

1972 JZ. Discovered 1972 May 14 by T. M. Smirnova at Nauchnyj.

Named in honor of Viktor Amazaspovich Ambartsumian $\{1908-1996\}$, a world renowned scientist, the founder of the Soviet School for Astrophysics, president of the Academy of Sciences of the Armenian SSR, served as president of the IAU in 1961-1964, Director of the Byurakan Astrophysical Observatory. (M 3937)

Obituaries published in Izv. Nats. Akad. Nauk Arm., Fiz., Tom 32, No. 1, p. 54-59 (1997); J. Astrophys. Astron., Vol. 18, No. 1, p. 1-2 (1997); Ir. Astron. J., Vol. 24, No. 1, p. 4-6 (1997); Astron. Geophys., Vol. 38, Issue 2, p. 37 (1997); South. Stars, Vol. 37, No. 3, p. 94-96 (1997); Postepy Astron., Tom 45, No. 2, p. 34-35 (1997); Zvaigznota Debess, No. 155, p. 18-27 (1997); IAU Inf. Bull., No. 79, p. V-VI (1997); Astron. Rep., Vol. 41, No. 2, p. 278-279 (1997); Astrophysics, Vol. 39, No. 4, p. 307-309 (1996); Sonderdr. Almanach Österreich. Akad. Wiss., 147. Jahrg., p. 497-504 (1996/97).

\section{(1906) Naef}

1972 RC. Discovered 1972 Sept. 5 by P. Wild at Zimmerwald.

Named in memory of Robert A. Naef (1907-1975) of Zurich, an ardent amateur astronomer, who since 1940 spent practically all his spare time (from the banking business) to produce the yearly observers almanac, Der Sternenhimmel. (M 4157)

Obituaries published in G. Ass. Astrofili Bologn., No. 38, p. 8 (1975); Orion, 33. Jahrg., p. 84-85 (1975); Sterne Weltraum, Vol. 14, p. 113, p. 209 (1975).

\section{(1907) Rudneva}

$1972 \mathrm{RC}_{2}$. Discovered 1972 Sept. 11 by N. S. Chernykh at Nauchnyj.

Named in honor of Evgeniya Maksimovna Rudneva, hero of the Soviet Union, member of Moscow branch of the Astronomical-Geodetical Society of the USSR, head of the solar department. During the Great Patriotic War she voluntarily joined the army. Being assigned to the Woman's Night Bombers Regiment, she fought at the front and perished valiantly in April 1944 while flying a mission. (M 3937)

\section{(1908) Pobeda}

$1972 \mathrm{RL}_{2}$. Discovered 1972 Sept. 11 by N. S. Chernykh at Nauchnyj.

The name pobeda (victory) is given on the occasion of the thirtieth anniversary of the victory of the Soviet people in the Great Patriotic War (1941-1945). (M 3937)

\section{(1909) Alekhin}

1972 RW $_{2}$. Discovered 1972 Sept. 4 by L. V. Zhuravleva at Nauchnyj.

Named in honor of Aleksandr Aleksandrovich Alekhin (1892-1946), an outstanding Russian chess-player, the world chess champion (1927-1935, 1937-1946). (M 3937)

\section{(1910) Mikhailov}

1972 TZ$_{1}$. Discovered 1972 Oct. 8 by L. V. Zhuravleva at Nauchnyj.

Named in honor of Aleksandr Aleksandrovich Mikhailov $\{1888-1983\}$, a prominent Soviet astronomer and gravimetrist, academician, president of the Astronomical Council of the USSR Academy of Sciences (1939-1962), vice-president of the International Astronomical Union (1946-1948), director of the Pulkovo Observatory (1947-1964). (M 3937)

Obituaries published in Astron. Zh., Tom 61, Vyp. 2, p. 412-413 (1984); Geod. i kartogr., No. 12, p. 55-56 (1983); Vesmír, Vol. 63, No. 4, p. 126 (1984); Zemlya Vselennaya, No. 2, p. 59-62 (1984); Sov. Astron., Vol. 28, No. 2, p. 243-244 (1984); Tsirk. Vses. astron.-geod. o-vo Akad. Nauk SSSR, No. 37, p. 78-88 (1984); Vestn. AN SSSR, No. 2, p. 99 (1984); Q.J.R. Astron. Soc., Vol. 26, No. 3, p. 209 (1985).

\section{(1911) Schubart}

1973 UD. Discovered 1973 Oct. 25 by P. Wild at Zimmerwald.

Named in honor of Joachim Schubart \{1928- $\}$ Astronomisches Rechen-Institut, who has developed averaging techniques for studying the long-term motions of minor planets and used them to investigate in detail the theory of the Hilda \{see planet (153)\} group of minor planets, of which this is a member. With P. Stumpff he has produced a widely-used computer program for the numerical integration of $n$ bodies and has utilized it in determinations of the masses of (1) Ceres and (2) Pallas. (M 3937)

\section{(1912) Anubis}

6534 P-L. Discovered 1960 Sept. 24 by C. J. van Houten and I. van Houten-Groeneveld at Palomar.

Named for the Egyptian god who had the shape of a jackal and was the protector of the dead. (M 5013)

\section{(1913) Sekanina}

1928 SF. Discovered 1928 Sept. 22 by K. Reinmuth at Heidelberg. 
Named in honor of Zdenek Sekanina $\{1936-\quad\}$, an astronomer at the Harvard-Smithsonian Center for Astrophysics, who has made many contributions to cometary astronomy, notably the calculation of orbits, the development of models for icy nuclei, and a detailed investigation of dust trails. (M 3937)

\section{(1914) Hartbeespoortdam}

$1930 \mathrm{SB}_{1}$. Discovered 1930 Sept. 28 by H. van Gent at Johannesburg.

Named for the lake in South Africa near which the Leiden Southern Observatory was located from 1957 to 1982. (M 6954)

\section{(1915) Quetzálcoatl}

1953 EA. Discovered 1953 Mar. 9 by A. G. Wilson at Palomar.

Named for the god of wisdom and culture who brought learning to the Toltec people and has been familiarized in D. H. Lawrence's novel The plumed serpent. (M 3827)

\section{(1916) Boreas}

1953 RA. Discovered 1953 Sept. 1 by S. Arend at Uccle.

Named for the god of the north wind, this Amor-type \{see planet (1221)\} object was discovered as it moved rapidly northward after passing the ascending node of its orbit. (M 6833)

Name proposed by J. Meeus.

\section{(1917) Cuyo}

1968 AA. Discovered 1968 Jan. 1 by C. U. Cesco and

A. G. Samuel at El Leoncito.

Named in honor of the Universidad Nacional de Cuyo, which operated the observatory at El Leoncito \{see planet (2311)\} in association with Yale and Columbia Universities. The name is also that of the region formed by three provinces in western Argentina, namely, Mendoza, San Juan and San Luis. (M 3828)

\section{(1918) Aiguillon}

1968 UA. Discovered 1968 Oct. 19 by G. Soulie at Bordeaux.

Named for the discoverer's birthplace, a small town on the Garonne river. (M 5038)

\section{(1919) Clemence}

1971 SA. Discovered 1971 Sept. 16 by J. Gibson and

C. U. Cesco at El Leoncito.

Named in memory of Gerald M. Clemence (19081974), Director of the U.S. Nautical Almanac Office from 1945 to 1958 and then the first scientific director of the U.S. Naval Observatory. Later he became professor of astronomy at the Yale Observatory. Although best known for his work on the theory of the motion of Mars, he made numerous other contributions in celestial mechanics, notably on the motion of Mercury and on the system of astronomical constants. He served as president of the American Astronomical Society and of IAU Commissions 4 and 7. Among his many honors were the awards of the Gold Medal of the R.A.S. and honorary doctorates from Case Institute of Technology and from Cuyo University in Western Argentina, where the Yale-Columbia Station was located. (M 3937)

Obituaries published in Phys. Today, Vol. 28, No. 3, p. 59, 61 (1975); Q.J.R. Astron. Soc., Vol. 16, p. 210-214 (1975); Sky Telesc., Vol. 49, p. 93, p. 215-216 (1975); J.R. Astron. Soc. Can., Vol. 69, p. 136-138 (1975).

\section{(1920) Sarmiento}

1971 VO. Discovered 1971 Nov. 11 by J. Gibson and C. U. Cesco at El Leoncito.

Named for Domingo F. Sarmiento, president of Argentina between 1868 and 1874 who promoted education, particularly in scientific fields, in his country. Born in San Juan, he grew to maturity in the province and knew the region where the $\mathrm{El}$ Leoncito Observatory now stands. With the aid of B. A. Gould he was responsible for founding the Córdoba Observatory, dedicating it with the words 'it is said that an observatory is premature or superfluous for a rising country whose public treasury is exhausted or overburdened. But I say that we must renounce the rank of nation, or the title of civilized people, if we do not take our part in the progress and movement of the natural sciences'. (M 3938)

\section{(1921) Pala}

1973 SE. Discovered 1973 Sept. 20 by T. Gehrels at Palomar.

Named for the Indian reservation at the base of Palomar Mountain. The name is believed to apply to an Indian tribe whose members have lived in the area for many centuries. (M 3938)

\section{(1922) Zulu}

1949 HC. Discovered 1949 Apr. 25 by E. L. Johnson at Johannesburg.

Named for the well-known South African tribe, to recognize some of the tribesmen who were faithful workmen at the Johannesburg Observatory. Coupled with two other planets having tribal names, (1362) Griqua and (1921) Pala, these planets presently librate in the 2/1 ratio of Jupiter's mean motion. (M 3938)

\section{(1923) Osiris}

4011 P-L. Discovered 1960 Sept. 24 by C. J. van Houten and I. van Houten-Groeneveld at Palomar.

Named for the Egyptian god of vegetation, of the waxing and waning Moon and of the annual flooding of the Nile. (M 5013)

\section{(1924) Horus}

4023 P-L. Discovered 1960 Sept. 24 by C. J. van Houten and I. van Houten-Groeneveld at Palomar.

Named for the son of Osiris ssee minor planet (1923)\}, an Egyptian god in the shape of a falcon, king of the sky and the stars. (M 5013) 


\section{(1925) Franklin-Adams}

1934 RY. Discovered 1934 Sept. 9 by H. van Gent at Johannesburg.

Named in memory of John Franklin-Adams (18431912), the British amateur astronomer who acquired and originally owned the $0.25-\mathrm{m}$ photographic refractor he later donated to the Union Observatory in Johannesburg. Initially utilized for the pioneering photographic survey of the Milky Way, the FranklinAdams Star Camera was employed for observations of minor planets in Johannesburg and Hartbeespoort for almost 70 years. Among the many discoveries with this celebrated instrument was Proxima Centauri. (M 8402)

Franklin-Adams is also honored by planet (982).

\section{(1926) Demiddelaer}

1935 JA. Discovered 1935 May 2 by E. Delporte at Uccle.

Named in honor of the family of Mireille Demiddelaer, granddaughter of the discoverer. (M 8402)

\section{(1927) Suvanto}

1936 FP. Discovered 1936 Mar. 18 by R. Suvanto at Turku.

Named in memory of Rafael Suvanto, an assistant of Y. Väisälä \{see planets (1573) and (2804)\}. Later, as rector of a school in Naantali \{see planet (1758)\}, he continued to participate in orbit calculations. He fell near Summa \{see planet (1928)\} in the last days of the Finnish winter war of 1939-40. (M 5450)

\section{(1928) Summa}

1938 SO. Discovered 1938 Sept. 21 by Y. Väisälä at Turku.

Named for a village on the Karelian isthmus, scene of violent battles during the Finnish winter war \{1939/40\}. (M 5450)

\section{(1929) Kollaa}

1939 BS. Discovered 1939 Jan. 20 by Y. Väisälä at Turku.

Named for a river in Karelia, scene of violent battles during the Finnish winter war $\{1939 / 40\}$. (M 5450)

\section{(1930) Lucifer}

1964 UA. Discovered 1964 Oct. 29 by E. Roemer at Flagstaff.

Named for the proud, rebellious archangel, identified with Satan, who was expelled from heaven. (M 4419)

\section{(1931) Čapek}

1969 QB. Discovered 1969 Aug. 22 by L. Kohoutek at Bergedorf.

Named in memory of Karel Čapek (1890-1938), Czech dramatist and novelist, best known for his allegorical plays "R.U.R." (Rossum's Universal Robots) and The Insect Comedy and for his novel Krakatit. He anticipated both the destructive possibilities of nuclear physics and the moral problems these possibilities would raise. (M 18447)

\section{(1932) Jansky}

1971 UB $_{1}$. Discovered 1971 Oct. 26 by L. Kohoutek at Bergedorf.

Named for Karl Guthe Jansky (1905-1950), the father of radio astronomy, the research engineer at Bell Telephone Laboratories who in 1932 made the first detection of extraterrestrial radio emission. (M 4785) Jansky is also honored by a lunar crater.

\section{(1933) Tinchen}

1972 AC. Discovered 1972 Jan. 14 by L. Kohoutek at Bergedorf.

Named in honor of Christine Kohoutek, wife of the discoverer. (M 3938)

\section{(1934) Jeffers}

1972 XB. Discovered 1972 Dec. 2 by A. R. Klemola at Mount Hamilton.

Named in honor of Hamilton M. Jeffers \{1893-1976\}, an astronomer on the staff of the Lick Observatory from 1924 until his retirement in 1961. He has conducted an extensive program of astrometric observations of comets and faint minor planets and has made important contributions to double-star astronomy, notably his collaboration on the Index Catalogue of Double-star Observations. (M 3938)

Obituaries published in Q.J.R. Astron. Soc., Vol. 21, p. 69-70 (1980); Phys. Today, Vol. 29, No. 10, p. 69 (1976), Sky Telesc., Vol. 52, p. 91 (1976).

\section{(1935) Lucerna}

1973 RB. Discovered 1973 Sept. 2 by P. Wild at Zimmerwald.

This and the following three minor planets are named for a Swiss lake and a city on its shores. (M 4358)

\section{(1936) Lugano}

1973 WD. Discovered 1973 Nov. 24 by P. Wild at Zimmerwald.

See the citation for minor planet (1935). (M 4358)

\section{(1937) Locarno}

1973 YA. Discovered 1973 Dec. 19 by P. Wild at Zimmerwald.

See the citation for minor planet (1935). (M 4358)

\section{(1938) Lausanna}

1974 HC. Discovered 1974 Apr. 19 by P. Wild at Zimmerwald.

See the citation for minor planet (1935). (M 4358)

\section{(1939) Loretta}

1974 UC. Discovered 1974 Oct. 17 by C. T. Kowal at Palomar.

Named by the discoverer in honor of his daughter. (M 3828) 


\section{(1940) Whipple}

1975 CA. Discovered 1975 Feb. 2 at the Harvard College Observatory at Harvard.

Named in honor of Fred L.Whipple \{1906- \}, Harvard astronomer since 1931, professor since 1950 and director of the Smithsonian Astrophysical Observatory from 1955 to 1973 . His countless contributions to our knowledge of the smaller bodies of the solar system include his icy-conglomerate model for cometary nuclei, and the development of modern techniques for the photographic observations of meteors. He has served as president of IAU Commissions 6, 15, and 22, and is now active on the NASA panel of space missions to comets and minor planets. (M 3828)

\section{(1941) Wild}

$1931 \mathrm{TN}_{1}$. Discovered 1931 Oct. 6 by K. Reinmuth at Heidelberg.

Named in honor of Paul Wild, of the Astronomical Institute, Berne University, whose principal work involves the discovery and observation of supernovae in other galaxies. His program has also produced discoveries of comets and minor planets, several of which he subsequently recovered as a result of his own unpublished orbit computations. (M 3938)

\section{(1942) Jablunka}

1972 SA. Discovered 1972 Sept. 30 by L. Kohoutek at Bergedorf.

Named after a village in eastern Moravia \{see planet (1901)\}, Czechoslovakia, which is alive in the discoverer's memory as the site of summer camps where he made his first astronomical observations. Dedicated to all friends of Jablunka. (M 4157)

\section{(1943) Anteros}

1973 EC. Discovered 1973 Mar. 13 by J. Gibson at El Leoncito.

Anteros was in attendance upon Eros and was sometimes said to be the avenger of slighted love, sometimes the one who opposes love, and was said by other authorities to be the twin brother of Eros. Although briefly used for the minor planet $\{(2101)\}$ Adonis shortly after its discovery, the name is particularly suitable for (1943) because of the similarity of its orbit to that of (433) Eros. (M 4237)

Name proposed by M.-A. Combes.

\section{(1944) Günter}

1925 RA. Discovered 1925 Sept. 14 by K. Reinmuth at Heidelberg.

Named by the discoverer in honor of his son, Günter Reinmuth. (M 4157; M 26599)

\section{(1945) Wesselink}

1930 OL. Discovered 1930 July 22 by H. van Gent at Johannesburg.

Named in honor of A. J. Wesselink \{1909-1995\}, astronomer at the Leiden, Radcliffe and Yale Obser- vatories. From 1946 to 1950 he was Leiden observer at the Union Observatory, Johannesburg. (M 10311)

Name proposed by the Leiden Observatory.

Obituaries published in Zenith, No. 11, p. 483 (1995); Astron. Soc. Pac. Conf. Ser., Vol. 83, p. XXII (1995); Q. J. R. Astron. Soc., Vol. 37, p. 95-97 (1996); Bull. Am. Astron. Soc., Vol. 27, No. 4, p. 1486-1488 (1995); Mon. Notes Astron. Soc. S. Afr., Vol. 54, No. 9/10, p. 84-85 (1995).

\section{(1946) Walraven}

1931 PH. Discovered 1931 Aug. 8 by H. van Gent at Johannesburg.

Named in honor of Th. Walraven $\{1916-\quad$ \}, retired professor of astronomy at the University of Leiden and for many years resident astronomer at the former Leiden Southern Station near Hartbeespoortdam, South Africa. He constructed special photometers for the telescopes at the station, including the 5-color photometer for which he developed the Walraven photometric system. (M 12968)

Name proposed by the Leiden Observatory, following a suggestion by C. J. van Houten.

\section{(1947) Iso-Heikkilä}

1935 EA. Discovered 1935 Mar. 4 by Y. Väisälä at Turku.

Named for the farm, owned by Turku University, that became the site of the Turku Observatory. This minor planet was the first one to be discovered there. (M 5450)

\section{(1948) Kampala}

1935 GL. Discovered 1935 Apr. 3 by C. Jackson at Johannesburg.

Named for the capital of Uganda. (M 5183)

\section{(1949) Messina}

1936 NE. Discovered 1936 July 8 by C. Jackson at Johannesburg.

Named for a copper-mining town on the border between South Africa and Zimbabwe-Rhodesia. (M 5183)

\section{(1950) Wempe}

1942 EO. Discovered 1942 Mar. 23 by K. Reinmuth at Heidelberg.

Named in honor of Johann Wempe \{1906-1980\}, astronomer at the Astrophysical Observatory in Potsdam since 1944, and editor of Astronomische Nachrichten from 1951 to 1973. In 1936 and 1937 he observed and discovered minor planets at HeidelbergKönigstuhl. (M 4157)

Obituaries published in Astron. Nachr., Band 302, p. 59-60 (1981); Sterne, 57. Band, p. 109-112 (1981); Mitt. Astron. Ges., Nr. 53, p. I-II (1981).

\section{(1951) Lick}

1949 OA. Discovered 1949 July 26 by C. A. Wirtanen at Mount Hamilton. 
Named in honor of James Lick (1796-1876) the founder of the Lick Observatory of the University of California. (M 3938)

Lick is also honored by a lunar crater.

\section{(1952) Hesburgh}

1951 JC. Discovered 1951 May 3 at the Goethe Link Observatory at Brooklyn, Indiana.

Named in honor of the Very Reverend Theodore M. Hesburgh, C.S.C., president of the University of Notre Dame since 1952. Father Hesburgh has an extraordinary record of public service in areas ranging from the humanitarian to the technical and scientific. During his 12 years as a member of the National Science Board he played a very important role in the founding of both the Kitt Peak National Observatory and the Cerro Tololo Interamerican Observatory. His support for CTIO during the 1964 period of inflation in Chile was decisive. (M 5688)

Name proposed by F. K. Edmondson.

\section{(1953) Rupertwildt}

1951 UK. Discovered 1951 Oct. 29 at the Goethe Link Observatory at Brooklyn, Indiana.

Named in memory of Rupert Wildt (1905-1976), who was awarded the Eddington Medal by the Royal Astronomical Society in 1966 for his discovery in 1939 that the negative hydrogen ion is an important contributor to the opacity of the solar atmosphere. He identified the absorption bands in the red part of the spectra of the outer planets as due to methane and ammonia, and he made pioneer calculations of models for the interiors of the giant planets. A professor in Yale University's Department of Astronomy for many years, he was Yale's first scientific representative on the Board of Directors of the Association of Universities for Research in Astronomy and served two terms as AURA president and chairman of the board (1965-1968, 1971-1974). (M 6954)

Obituaries published in Q.J.R. Astron. Soc., Vol. 17, p. 522 (1976); Strolling Astron., Vol. 26, p. 46 (1976); Phys. Today, Vol. 29, No. 4, p. 89 (1976); Sky Telesc., Vol. 51, p. 156 (1976); Icarus, Vol. 30, p. 441-445 (1977).

\section{(1954) Kukarkin}

1952 PH. Discovered 1952 Aug. 15 by P. F. Shajn at Simeis.

Named in memory of Boris Vasil'evich Kukarkin (1909-1977), professor of stellar astronomy and astrometry at Moscow State University for many years and a prominent specialist in the fields of variable stars and the structure of stellar systems. He was the initiator and one of the compilers of the General Catalogue of Variable Stars, served as Vice President of the Astronomical Council of the U.S.S.R. Academy of Sciences from 1947 to 1960, as Vice President of the IAU from 1955 to 1961 and as President of IAU Commission 27 from 1951 to 1958. (M 5358)
Obituaries published in Perem. Zvezdy, Tom 20, p. 493-498, 499-500 (1978); Priroda, No. 10, p. 155 (1977), Astron. Tsirk., No. 969, p. 1-3 (1977), Astron. Zh., Vol. 55, p. 202-204 (1978), Coelum, Vol. 46 , p. 72-75 (1978), Q.J.R. Astron. Soc., Vol. 19, p. 247-248 (1978), Zemlya i Vselennaya, No. 1, p. 59-60 (1978).

\section{(1955) McMath}

1963 SR. Discovered 1963 Sept. 22 at the Goethe Link Observatory at Brooklyn, Indiana.

Named in memory of Robert R. McMath (1891-1962), astronomer, engineer and businessman. Co-donor of the McMath-Hulbert Observatory to the University of Michigan in 1931, he served as its director during 1931-1961. He was an adviser to the National Science Foundation in its early years and chaired the panel that advised NSF on the need for a national observatory and conducted the site survey leading to the selection of Kitt Peak. He played a leading role in the incorporation of AURA, served as its first president (1957-1958) and then as chairman of the AURA board. (M 5848)

Name proposed by F. K. Edmondson.

McMath is also honored by a lunar crater.

\section{(1956) Artek}

1969 TX $_{1}$. Discovered 1969 Oct. 8 by L. I. Chernykh at Nauchnyj.

Named for an all-Union young pioneer's camp in Crimea. (M 4190)

\section{(1957) Angara}

1970 GF. Discovered 1970 Apr. 1 by L. I. Chernykh at Nauchnyj.

Named for a river in Siberia. (M 4190)

\section{(1958) Chandra}

1970 SB. Discovered 1970 Sept. 24 by C. U. Cesco at El Leoncito.

Named for Subrahmanyan Chandrasekhar \{1910$1995\}$, the Indian-born distinguished service professor at the University of Chicago, generally regarded as the world's leading theoretical astrophysicist. (M 5013)

Chandrasekhar, with W. A. Fowler, received the 1983 Nobel prize for physics.

Obituaries published in Khagol, No. 24, p. 2 (1995); Orion, Jahrg. 53, Nr. 271, p. 323 (1995); Phys. Today, Vol. 48, No. 11, p. 106-108 (1995); Astrophys. J., Vol. 454, No. 2, p. 551 (1995); Bull. Am. Astron. Soc., Vol. 28, No. 4, p. 1448 (1996); Nature, Vol. 377, No. 6549, p. 484 (1995); Phys. Bl., Jahrg. 51, Heft 12, p. 1193 (1995); Zenit, Jaarg. 22, Nr. 12, p. 518-519 (1995); Zemlya Vselennaya, No. 1, p. 57-60 (1996); J. Astrophys. Astron., Vol. 17, No. 3-4, p. I-VII (1996); Zvaigznota Debess, No. 157, p. 30-34 (1997); Observatory, Vol. 116, No. 1131, p. 121-124 (1996); Q.J.R. Astron. Soc., Vol. 37, No. 2, p. 261-263 (1996); Ciel Terre, Vol. 112, No. 3, p. 117-119 (1996). 


\section{(1959) Karbyshev}

1972 NB. Discovered 1972 July 14 by L. V. Zhuravleva at Nauchnyj.

Named in honor of Dmitrij Michajlovich Karbyshev (1880-1945), Soviet military leader, hero of the Soviet Union, who had been taken prisoner at the beginning of the Great Patriotic War and was atrociously tortured to death by fascists at the extermination camp at Mauthausen. (M 4190)

\section{(1960) Guisan}

1973 UA. Discovered 1973 Oct. 25 by P. Wild at Zimmerwald.

Named in memory of Henri Guisan (1874-1960), the general of the Swiss army from 1939 to 1945. His integrity and courage were essential to the strength of Switzerland during the Second World War. (M 4157)

\section{(1961) Dufour}

1973 WA. Discovered 1973 Nov. 19 by P. Wild at Zimmerwald.

Named in memory of Henri Dufour (1787-1875), citizen of Geneva, who as a general in 1847 swiftly and with almost no bloodshed, subdued the catholic Sonderbund, and who later as an engineer, initiated and directed the first complete geodetic survey of Switzerland. (M 4157)

\section{(1962) Dunant}

1973 WE. Discovered 1973 Nov. 24 by P. Wild at Zimmerwald.

Named in memory of Henri Dunant (1828-1910), citizen of Geneva, and founder of the Red Cross. (M 4158)

Dunant, together with F. Passey, received the first Peace Nobel Prize in 1901.

\section{(1963) Bezovec}

1975 CB. Discovered 1975 Feb. 9 by L. Kohoutek at Bergedorf.

Named after a mountain in western Slovakia, Czechoslovakia, in remembrance of the numerous meteor expeditions that have been organized in that area since 1958. Dedicated to all participants, mostly amateur astronomers. (M 4158)

\section{(1964) Luyten}

2007 P-L. Discovered 1960 Sept. 24 by C. J. van Houten and I. van Houten-Groeneveld at Palomar.

Named in honor of Willem Jacob Luyten \{1899-1994\}, emeritus professor of astronomy at the University of Minnesota, well known for his investigations on stars with large proper motion. (M 5038)

Obituaries published in I.A.P.P.P. Commun., No. 58, p. 60-61 (1994); Bull. Am. Astron. Soc., Vol. 27, No. 4, p. 1480-1481 (1995); Q.J.R. Astron. Soc., Vol. 37, No. 3, p. 453-456 (1996); Phys. Today, Vol. 68, No. 4, p. 107 (1995).

\section{(1965) van de Kamp}

2521 P-L. Discovered 1960 Sept. 24 by C. J. van Houten and I. van Houten-Groeneveld at Palomar.

Named in honor of Peter van de Kamp \{1901-1995\}, director of Sproul Observatory from 1937 until 1972, well known for his investigations on astrometric binary stars. (M 5038)

Obituaries published in Phys. Today, Vol. 48, No. 8, p. 70-71 (1995); Bull. Am. Astron. Soc., Vol. 27, No. 4, p. 1483-1484 (1995); Publ. Astron. Soc. Pac., Vol. 108, No. 725, p. 556-559 (1996).

\section{(1966) Tristan}

2552 P-L. Discovered 1960 Sept. 24 by C. J. van Houten and I. van Houten-Groeneveld at Palomar.

Named for one of the knights of the round table. (M 6421)

\section{(1967) Menzel}

A905 VC. Discovered 1905 Nov. 1 by M. F. Wolf at Heidelberg.

Named in honor of Donald Howard Menzel (19011976), Harvard astronomer since 1932 and director of the Harvard College Observatory from 1954 to 1966. Both a theoretical and observational pioneering solar and stellar astrophysicist, he calculated atomic transition probabilities, chemically analysed stars and nebulae, and made fundamental contributions to our understanding of physical processes in gaseous nebulae, the solar chromosphere, and interpretation of stellar spectra. He observed 15 solar eclipses, determined spectroscopically the rotation rates of Uranus and Neptune and helped educate a number of prominent astronomers. On the lighter side he is well known for his doodling and for debunking of UFO's. (M 4158)

Obituaries published in Astronomie, Vol. 91, p. 50 (1977); Nature, Vol. 267, p. 189 (1977); Phys. Today, Vol. 30, No. 5, p. 96, 98 (1977); Sky Telesc., Vol. 53, p. 244-251 (1977).

\section{(1968) Mehltretter}

1932 BK. Discovered 1932 Jan. 29 by K. Reinmuth at Heidelberg.

Named in honor of Johannes Peter Mehltretter \{1934-1982\}, who became a solar astronomer at the Fraunhofer-Institut in Freiburg in 1962, after he started with work at Königstuhl Observatory. (M 4158)

Obituary published in Mitt. Astron. Ges., Nr. 59, p. 9-10 (1983).

\section{(1969) Alain}

1935 CG. Discovered 1935 Feb. 3 by S. Arend at Uccle.

Named in honor of Alain Vanheste, husband of Isabelle Dubois, granddaughter of the discoverer. (M 8151) 


\section{(1970) Sumeria}

1954 ER. Discovered 1954 Mar. 12 by M. Itzigsohn at La Plata.

Named in honor of one of the oldest known civilizations, located in the southernmost part of Mesopotamia between the Tigris and Euphrates rivers. It was first settled between 4500 to 4000 B.C., probably shortly after JD 0 , by Ubaidans. The Sumerians themselves arrived around 3300 B.C. and lost their separate identity around 1900 B.C. when conquered by the Amorites. The Sumerians contributed many technological and cultural innovations, among them the first wheeled vehicles and potter's wheels, the first system of writing, the first written codes of law, and the first city-state. (M 21128)

Named by the Minor Planet Names Committee following a suggestion by F. Pilcher.

\section{(1971) Hagihara}

$1955 \mathrm{RD}_{1}$. Discovered 1955 Sept. 14 at the Goethe Link Observatory at Brooklyn, Indiana.

Named in honor of Yusuke Hagihara \{1897-1979\}, professor of astronomy at the University of Tokyo from 1935 to 1957, Director of the Tokyo Observatory from 1946 to 1957, and long an inspiring leader and teacher, principally in celestial mechanics and also in several other branches of astronomy and astrophysics. Best known for his theory of libratory motions and general discussion of stability problems in celestial mechanics, he has also made important contributions to the study of the velocity distribution of free electrons in planetary nebulae. In recent years he has produced a monumental five-volume treatise on celestial mechanics. He served as a vice-president of the IAU during 1961-1967 and as president of Commission 7 during 1964-1967. (M 4419)

This minor planet was named at the IAU Symposium No. 81, The Dynamics of the Solar System, held in Tokyo in May 1978 on the occasion of his 81st birthday.

Obituaries published in Phys. Today, Vol. 32, No. 6, p. 71 (1979); Q.J.R. Astron. Soc., Vol. 20, p. 325-328 (1979).

\section{(1972) Yi Xing}

$1964 \mathrm{VQ}_{1}$. Discovered 1964 Nov. 9 at the Purple Mountain Observatory at Nanking.

Named for Yi Xing or I Hsing (683-727), also known as Zhang Sui. This famous Chinese astronomer of the Tang dynasty constructed a bronze armillary sphere for measuring stellar altitudes, and he conducted a large-scale latitude-measurement project in many places across China. He also reformed the Chinese calendrical system. (M 4420)

\section{(1973) Colocolo}

1968 OA. Discovered 1968 July 18 by C. Torres at Cerro El Roble.

Named for the old and wise Araucanian chief who succeeded in unifying the Araucanian Indian tribes against the Spanish conquerors. (M 5358)

\section{(1974) Caupolican}

1968 OE. Discovered 1968 July 18 by C. Torres at Cerro El Roble.

Named for the Great Chief of the unified Araucanian tribes. He was selected after winning a competition in which a trunk had to be carried on the shoulders for as long as possible; he carried it for three days and nights. (M 5358)

\section{(1975) Pikelner}

1969 PH. Discovered 1969 Aug. 11 by L. I. Chernykh at Nauchnyj.

Named in honor of Solomon Borisovich Pikelner (1921-1975), renowned astronomer, professor at the University of Moscow, founder of the Soviet school of cosmic electrodynamics. He was among the first to understand the significance of plasma physics and magnetohydrodynamics for astrophysics. His research activities cover physics of the Sun, interstellar matter, gaseous nebulae, remnants of supernova explosions, galactic structure, formation of stars, cosmology. He was chairman of the Commission 34 (Interstellar matter) of IAU (1964-1967). (M 4190)

Obituaries published in Q.J.R. Astron. Soc., Vol. 17, p. 352-355 (1976); Astron. Tsirk., No. 896, p. 7-9 (1975); Astron. Zh., Vol. 53, p. 233-235 (1976); Astrophys. Space Sci., Vol. 40, p. 241-242 (1976); Phys. Today, Vol. 29, No. 2, p. 65 (1976); Sky Telesc., Vol. 51, p. 98 (1976); Zemlya Vselennaya, p. 71-72 (1976).

\section{(1976) Kaverin}

1970 GC. Discovered 1970 Apr. 1 by L. I. Chernykh at Nauchnyj.

Named in memory of Aleksej Aleksandrovich Kaverin (1904-1976), an instructor in astronomy at Irkutsk Pedagogical Institute, expert in the field of the theory of eclipses. (M 4190)

\section{(1977) Shura}

1970 QY. Discovered 1970 Aug. 30 by T. M. Smirnova at Nauchnyj.

Named in honor of Aleksandr Anatolevich Kosmodemyanskij (1925-1945), hero of the Soviet Union, died valiantly at the front during the Great Patriotic War. Shura is a pet name for Aleksandr. (M 4190)

See also the citations for minor planets (1793) and (2072). 
(1978) Patrice

1971 LD. Discovered 1971 June 13 at the Perth Observatory at Bickley.

Named in honor of the daughter of Dennis Harwood, member of the astrometric team at the Perth Observatory. (M 6530)

\section{(1979) Sakharov}

2006 P-L. Discovered 1960 Sept. 24 by C. J. van

Houten and I. van Houten-Groeneveld at Palomar.

Named in honor of Academician Andrej Dmitrievich Sakharov, distinguished physicist and mathematician. (M 6207)

Sakharov received the 1975 Nobel peace prize.

\section{(1980) Tezcatlipoca}

1950 LA. Discovered 1950 June 19 by A. G. Wilson and A. A. E. Wallenquist at Palomar.

Named for the Toltec god of matter, "the smoking mirror", the counterpart to (1915) Quetzálcoatl, "the plumed serpent". The two gods are the twin serpents that entwine to produce time, the opposites that display constancy and change. (M 4237)

\section{(1981) Midas}

1973 EA. Discovered 1973 Mar. 6 by C. T. Kowal at Palomar

Named for the Phrygian king supposed to have the gift of transforming all that he touched to gold. Although he had chosen this power as a reward for kind treatment of his captive, Silenus, he soon realized his folly and was relieved of his power by bathing in the Pactolus River. (M 4237)

\section{(1982) Cline}

1975 VA. Discovered 1975 Nov. 4 by E. F. Helin at Palomar.

Named to honor the memory of a friend, Edwin Lee Cline. Cline was a distinguished inventor in the automotive field who looked to space as the new frontier. (M 4158)

\section{(1983) Bok}

1975 LB. Discovered 1975 June 9 by E. Roemer at Kitt Peak.

Named for Bart J. \{1906-1983\} and Priscilla F. Bok $\{1896-1975\}$. This is the first minor planet discovered with the 229-cm telescope of the Steward Observatory to be numbered. It is named for the Boks in recognition of their role in bringing the large reflector of the Steward Observatory into operation and for their support of the astrometric work on comets, minor planets, and satellites. This minor planet was at far southern declination at discovery (and observations at Wellington were important in obtaining a reliable orbit). This is also in fitting association with the Boks, who have devoted much effort to study of the structure of the southern Milky Way and to encouragement of astronomy in the southern hemisphere. (M 4158)
Name proposed by E. Roemer and A. C. Gilmore.

Priscilla F. Bok is also honored by minor planet (2137). Obituaries (B.J.B) published in Sky Telesc., Vol. 66, No. 4, p. 303-306 (1983); Phys. Today, Vol. 36, No. 12, p. 73 (1983); Mercury, Vol. 12, No. 5, p. 155 (1983); ESA Spec. Publ., ESA SP-201, p. 14-15 (1983); J.R. Astron. Soc. Can., Vol. 78, No. 1, p. 8-9 (1984); South. Stars, Vol. 30, No. 6, p. 424-426 (1984); Zenit, 11. Jaarg., No. 2, p. 38-42 (1984); Proc. Astron. Soc. Aust., Vol. 5, No. 4, p. 608-610 (1984); Q.J.R. Astron. Soc., Vol. 28, No. 4, p. 539-542 (1987). Obituary (P.F.B.) published in Sky Telesc., Vol. 51, p. 25 (1976).

\section{(1984) Fedynskij}

1926 TN. Discovered 1926 Oct. 10 by S. I. Belyavskij at Simeis.

Named in memory of Vsevolod Vladimirovich Fedynskij (1908-1978), an outstanding expert in reconnaissance geophysics, physics of the Earth and meteor astronomy, a capable organizer of scientific research, Vice President of IAU Commission 22 (1958-1964), and an honorary member and Vice President of the All-Union Astronomy and Geodesy Association. (M 5358)

Obituary published in Meteoritika, Vyp. 38, p. 157158 (1979).

\section{(1985) Hopmann}

1929 AE. Discovered 1929 Jan. 13 by K. Reinmuth at Heidelberg.

Named in memory of Josef Hopmann (1890-1975), the former director of the Universitäts-Sternwarte in Vienna, who was active as an observer of binary and variable stars. During $1930 / 31$ he took part in an international program to observe $\{433\}$ Eros. (M 4237)

Obituaries published in Mitt. Astron. Ges., Nr. 40, p. 7-9 (1976), Sternenbote, 18. Jahrg., p. 189 (1975), 19. Jahrg., p. 22-30 (1976), Sterne Weltraum, 15. Jahrg., p. 21 (1976)

\section{(1986) Plaut}

$1935 \mathrm{SV}_{1}$. Discovered 1935 Sept. 28 by H. van Gent at Johannesburg.

Named in honor of Lukas Plaut (1910-1984), Dutch astronomer, who worked at the Leiden Observatory from 1933 to 1940 and at the Kapteyn Laboratory in Groningen from 1940 to 1975. He is well known for his investigations of RR Lyrae variables near the Galactic Center. Born in Germany, he emigrated to Holland in 1933. During part of World War II he was interned in a working camp near the German town of Fürstenau under an assumed name, because of his Jewish descent; he escaped from there and returned to Holland. (M 17026)

Name proposed by the Leiden Observatory.

Obituary published in Zenit, 12. Jaarg., No. 4, p. 152-153 (1985). 


\section{(1987) Kaplan}

1952 RH. Discovered 1952 Sept. 11 by P. F. Shajn at Simeis.

Named in memory of Samuil Aronovich Kaplan (1921-1978), head of the astrophysics department of the Lvov Observatory from 1948 to 1961 and subsequently a staff member of the Scientific Research Radiophysics Institute in Gorkij. He contributed extensively to a wide range of astrophysical topics, including white dwarfs, interstellar matter, radiative transfer, solar radiation, pulsars and galactic nuclei. (M 5358)

Obituaries published in Astrofizika, Vol. 14, p. 695696 (1978); Zemlya Vselennaya, No. 1, p. 46-47 (1979).

\section{(1988) Delores}

1952 SV. Discovered 1952 Sept. 28 at the Goethe Link Observatory at Brooklyn, Indiana.

Named in honor of Mrs. Delores Owings, who has worked diligently in the minor planet program of Indiana University, first as a co-worker with Dr. T. Gehrels \{see planet (1777)\} in the absolute magnitude determinations and then as the supervisor of all plate measurements for accurate positions. (M 4190)

Name proposed by Paul Herget, Director of the Minor Planet Center.

\section{(1989) Tatry}

1955 FG. Discovered 1955 Mar. 20 by A. Paroubek and R. Podstanicka at Skalnaté Pleso.

Named for Vysoke Tatry, the High Tatras, the highest mountain range in Czechoslovakia. The Skalnaté Pleso Observatory $\{$ see planet $(2619)\}$ is located in this range. (M 5183)

\section{(1990) Pilcher}

1956 EE. Discovered 1956 Mar. 9 by K. Reinmuth at Heidelberg.

Named in honor of Frederick Pilcher, associate professor of physics at Illinois College, Jacksonville, who has done much to promote interest in minor planets among amateur astronomers. He has himself made visual observations of almost 1100 different minor planets, an all-time record. (M 6833)

Name proposed by J. U. Gunter and J. Meeus, endorsed by C. M. Bardwell and B. G. Marsden.

\section{(1991) Darwin}

1967 JL. Discovered 1967 May 6 by C. U. Cesco and A. R. Klemola at El Leoncito.

Named in memory of Charles Robert Darwin (18091882), the English naturalist who first established the theory of organic evolution; much of his research was done in Argentina, and he crossed the Andes at a pass located some $100 \mathrm{~km}$ south of El Leoncito. This planet also honors his second son, George Howard Darwin (1845-1912), the astronomer noted for his pioneering application of detailed dynamical analyses to problems of cosmogony and geology. (M 5282)

The Darwins are also honored by craters on the Moon and on Mars (G.H.D.)

\section{(1992) Galvarino}

1968 OD. Discovered 1968 July 18 by C. Torres at Cerro El Roble.

Named for the heroic Araucanian chief condemned by the Spanish soldiers to have his hands cut off and then to be freed as a living lesson to other Indians. Since his request for death was not granted, he promised revenge. He continued to fight the conquerors until recaptured and condemned to the gallows. (M 5358)

\section{(1993) Guacolda}

$1968 \mathrm{OH}_{1}$. Discovered 1968 July 25 by H. Wroblewski at Cerro El Roble.

Named for the beautiful and heroic wife of the Araucanian chief Lautaro \{see planet (2976)\}, formerly a servant in a Spanish home. She accompanied her husband in battle, fighting side by side with him. (M 5358)

\section{(1994) Shane}

1961 TE. Discovered 1961 Oct. 4 at the Goethe Link Observatory at Brooklyn, Indiana.

Named in honor of Charles D. Shane \{1895-1983\}, the second president of AURA (1958-1962). He played a major role in the planning and construction of the first telescopes and buildings on Kitt Peak and also the Tucson headquarters building. Even more important was his initiative in arranging for AURA to take on the responsibility for the construction of a major observatory in the southern hemisphere; this led to the establishment of the Cerro Tololo Interamerican Observatory. His long and distinguished career at the University of California spanned a period of more than 50 years; he was director of the Lick Observatory during 1945-1958 and was responsible for modernizing and expanding its facilities. (M 5848)

Name proposed by F. K. Edmondson.

Obituaries published in Phys. Today, Vol. 37, No. 2, p. 80 (1984); South. Stars, Vol. 30, No. 6, p. 427-428 (1984); Q.J.R. Astron. Soc., Vol. 25, No. 4, p. 532-533 (1984).

\section{(1995) Hajek}

1971 UP $_{1}$. Discovered 1971 Oct. 26 by L. Kohoutek at Bergedorf.

Named in honor of Tadeas Hajek (Hagecius, 15251600), Czech humanist astronomer regarded today as one of the founders of modern stellar and cometary astronomy. Known especially for his studies on the great comet of 1577 and on the supernova of 1572 . He also worked in other scientific fields, notably medicine and botany. (M 4358) 
(1996) Adams

1961 UA. Discovered 1961 Oct. 16 at the Goethe Link Observatory at Brooklyn, Indiana.

Named in memory of John Couch Adams (1819-1892), the British mathematical astronomer who predicted the existence of the planet Neptune. (M 4237)

Adams is also honored by a lunar crater.

\section{(1997) Leverrier}

1963 RC. Discovered 1963 Sept. 14 at the Goethe Link Observatory at Brooklyn, Indiana.

Named in memory of Urbain Joseph Le Verrier (1811-1877), the French mathematical astronomer who predicted the existence of the planet Neptune. (M 4237)

Leverrier is also honored by craters on Mars and the Moon

\section{(1998) Titius}

1938 DX $_{1}$. Discovered 1938 Feb. 24 by A. Bohrmann at Heidelberg.

Named in memory of Johann Daniel Titius (17291796), who made the initial formulation of the Titius-Bode Law of planetary distances. (M 4237)

Titius is also honored by a lunar crater.

\section{(1999) Hirayama}

1973 DR. Discovered 1973 Feb. 27 by L. Kohoutek at Bergedorf.

Named in memory of Kiyotsugu Hirayama (18741943), discoverer of the so-called Hirayama families of minor planets. (M 4237)

Hirayama is also honored by a lunar crater.

\section{(2000) Herschel}

1960 OA. Discovered 1960 July 29 by J. Schubart at Sonneberg.

Just as (1000) honors Giuseppe Piazzi, the discoverer of the first minor planet, so (2000) honors William Herschel, (1738-1822), the discoverer of the first telescopic major planet. (M 4237)

Herschel is also honored by craters on Mars and the Moon.

\section{(2001) Einstein}

1973 EB. Discovered 1973 Mar. 5 by P. Wild at Zimmerwald.

Named in memory of Albert Einstein (1879-1955), the greatest scientist of the twentieth century. Although Einstein was born in Germany and died in the U.S., it is particularly fitting that his name be given to a Bernese minor planet, for he laid the foundations of his revolutionary scientific thoughts while working as an examiner in the Swiss Patent Office in Berne. (M 4237)

Einstein received the Nobel prize for physics in 1921. He is also honored by a lunar crater.

\section{(2002) Euler}

1973 QQ $_{1}$. Discovered 1973 Aug. 29 by T. M. Smirnova at Nauchnyj.
Named for the great Swiss-born mathematician and astronomer Leonhard Euler (1707-1783), who spent much of his time in St. Petersburg and was associated with the Russian Academy of Sciences from the age of 20 until his death. Among the many contributions to astronomy were two theories for the motion of the Moon. (M 4238)

Euler is also honored by a lunar crater.

\section{(2003) Harding}

6559 P-L. Discovered 1960 Sept. 24 by C. J. van Houten and I. van Houten-Groeneveld at Palomar.

Named in memory of Karl Ludwig Harding (17651834), the discoverer of (3) Juno. (M 4238)

Harding is also honored by a lunar crater.

\section{(2004) Lexell}

$1973 \mathrm{SV}_{2}$. Discovered 1973 Sept. 22 by N. S. Chernykh at Nauchnyj.

St. Petersburg and for a short period Euler's \{see planet (2002)\} successor as professor of mathematics. He was the first to realize that the object discovered by Herschel \{see planet (2000)\} was a new planet. His name is also associated with comet $1770 \mathrm{I}$, for which he established the revolution period as less than six years. (M 4238)

Lexell is also honored by a lunar crater.

\section{(2005) Hencke}

1973 RA. Discovered 1973 Sept. 2 by P. Wild at Zimmerwald.

Named in honor of Karl Ludwig Hencke (1793-1866), postmaster at Driesen, the discoverer of (5) Astraea and (6) Hebe. (M 4238)

\section{(2006) Polonskaya}

1973 SB $_{3}$. Discovered 1973 Sept. 22 by N. S. Chernykh at Nauchnyj.

Named in honor of Elena Ivanovna KazimirchakPolonskaya \{1902-1992\}, a prominent researcher on cometary motion and the evolution of cometary orbits. She has demonstrated with numerous examples the possibility of the formation of typical short-period cometary orbits from the capture of comets by major planets. In 1968 she was awarded the F. A. Bredikhin \{see planet (786)\} prize by the U.S.S.R. Academy of Sciences for her considerable contributions to cometary astronomy. She is a member of the organizing committee of IAU Commission 20. (M 4481)

\section{(2007) McCuskey}

1963 SQ. Discovered 1963 Sept. 22 at the Goethe Link Observatory at Brooklyn, Indiana.

Named in memory of Sidney W. McCuskey (19071979), director of the Warner and Swasey Observatory during 1959-1970. His papers on the stellar luminosity function and its variations form a major contribution to the understanding of these problems of galactic structure. He served as president of IAU Commission 
33 (Structure and Dynamics of the Galactic System). (M 6954)

Citation prepared by F. D. Miller.

Obituaries published in Sky Telesc., Vol. 58, p. 117 (1979); Q.J.R. Astron. Soc., Vol. 21, p. 214-215 (1980).

\section{(2008) Konstitutsiya}

1973 SV $_{4}$. Discovered 1973 Sept. 27 by L. I. Chernykh at Nauchnyj.

Named on the occasion of the adoption of the new constitution of the U.S.S.R. in 1977. (M 4481)

\section{(2009) Voloshina}

1968 UL. Discovered 1968 Oct. 22 by T. M. Smirnova at Nauchnyj.

Named in honor of Vera Danilovna Voloshina (19191941), a partisan who perished valiantly during the Great Patriotic War (1941-1945). (M 4481)

\section{(2010) Chebyshev}

1969 TL $_{4}$. Discovered 1969 Oct. 13 by B. A. Burnasheva at Nauchnyj.

Named in honor of Academician Pafnutij Lvovich Chebyshev (1821-1894), the great Russian mathematician and mechanician. (M 4481)

Chebyshev is also honored by a lunar crater.

\section{(2011) Veteraniya}

1970 QB 1 . Discovered 1970 Aug. 30 by T. M. Smirnova at Nauchnyj.

Named in honor of the Soviet veterans of the Great Patriotic War. (M 4481)

\section{(2012) Guo Shou-Jing}

$1964 \mathrm{TE}_{2}$. Discovered 1964 Oct. 9 at the Purple Mountain Observatory at Nanking.

Named for Guo Shou-Jing (1231-1316), a prominent Chinese astronomer of the Yuan dynasty. Believing that observations are fundamental to calendrical work and that high-quality instruments are indispensable for making satisfactory observations, he devised and constructed numerous ingenious astronomical instruments. He also conducted an expedition to measure latitudes and derived an accurate value for the obliquity of the ecliptic. (M 4420)

\section{(2013) Tucapel}

$1971 \mathrm{UH}_{4}$. Discovered 1971 Oct. 22 by C. Torres at Cerro El Roble.

Named for one of the brave Araucanian chiefs who, with his wife Gualeva, victoriously entered the city of Imperial. He died in 1560, fighting against the Spanish soldiers. (M 5359)

\section{(2014) Vasilevskis}

1973 JA. Discovered 1973 May 2 by A. R. Klemola at Mount Hamilton.

Named in honor of Stanislavs Vasilevskis \{ 1988\}, an astronomer on the staff of the Lick Observatory from 1949 until his retirement in 1974. He has conducted extensive programs of astrometric observations for stellar proper motions and parallaxes and has made important contributions to astrometric instrumentation, notably his success in establishing a system of automatic plate measurement coupled with the use of electronic computers. (M 4190)

\section{(2015) Kachuevskaya}

1972 RA $_{3}$. Discovered 1972 Sept. 4 by L. V. Zhuravleva at Nauchnyj.

Named in honor of Natasha Kachuevskaya, a heroine of the Great Patriotic War, killed in the battle of Stalingrad. (M 4481)

\section{(2016) Heinemann}

1938 SE. Discovered 1938 Sept. 18 by A. Bohrmann at Heidelberg.

Named in memory of Karl Heinemann (1898-1970), astronomer at the Astronomisches Rechen-Institut from 1927 to 1963. His activities included fundamental astronomy and the editing of the Astronomischer Jahresbericht for the period 1934-1958. (M 4238)

Obituary published in Astron. Nachr., Vol. 292, p. 190 (1970).

\section{(2017) Wesson}

A903 SC. Discovered 1903 Sept. 20 by M. F. Wolf at Heidelberg.

Named in honor of Mary Joan Wesson Bardwell, wife of Conrad M. Bardwell \{see planet (1615)\}. The latter established the identifications for this minor planet. (M 4358)

\section{(2018) Schuster}

1931 UC. Discovered 1931 Oct. 17 by K. Reinmuth at Heidelberg.

Named in honor of Hans-Emil Schuster \{1934- \}, astronomer at the European Southern Observatory, who is active as observer and discoverer of minor planets and comets. (M 4358)

\section{(2019) van Albada}

1935 SX $_{1}$. Discovered 1935 Sept. 28 by H. van Gent at Johannesburg.

Named in memory of G. B. van Albada (1911-1972), Dutch astronomer, director of the Bosscha Observatory in Lembang from 1948 to 1958 and of the Astronomical Institute of the Municipal University in Amsterdam from 1959 until his death. (M 18135)

\section{(2020) Ukko}

1936 FR. Discovered 1936 Mar. 18 by Y. Väisälä at Turku.

Named for the supreme god in Finnish folklore. Ukko means "old man"; ukkonen means "thunder". (M 5450)

\section{(2021) Poincaré}

1936 MA. Discovered 1936 June 26 by L. Boyer at Algiers.

Named in honor of Henri Poincaré (1854-1912), distinguished French mathematician and celestial 
mechanician, contributor to the theory of functions, modern algebra, algebraic topology, number theory, and Les méthodes nouvelles de la mécanique céleste. (M 4420)

Poincaré is also honored by a lunar crater.

\section{(2022) West}

1938 CK. Discovered 1938 Feb. 7 by K. Reinmuth at Heidelberg.

Named in honor of Richard M. West, astronomer at the European Southern Observatory, well known as the discoverer of a bright comet, and active as an observer and discoverer of minor planets. (M 4359)

West served as general secretary of the International Astronomical Union from 1982 to 1985, and as president of IAU Commission 20 from 1988 to 1991.

\section{(2023) Asaph}

1952 SA. Discovered 1952 Sept. 16 at the Goethe Link Observatory at Brooklyn, Indiana.

Named in memory of Asaph Hall (1829-1907), discoverer of Phobos and Deimos, the satellites of Mars. (M 4238)

This minor planet was named at a special meeting held at the U.S. Naval Observatory in Washington on 1977 Aug. 11, the one-hundredth anniversary of the discovery of Deimos.

\section{(2024) McLaughlin}

1952 UR. Discovered 1952 Oct. 23 at the Goethe Link Observatory at Brooklyn, Indiana.

Named in memory of Dean Benjamin McLaughlin (1901-1965), astronomical spectroscopist and geologist at Swarthmore College and the University of Michigan. He made the first rigorous spectroscopic measurement of stellar rotation - the rotation of Algol. He also applied his skill as a structural geologist to an interpretation of the telescopically observable markings on Mars, and this was later confirmed by direct observation from space vehicles. (M 6955)

Citation prepared by O. C. Mohler.

McLaughlin is also honored by craters on Mars and the Moon.

\section{(2025) Nortia}

1953 LG. Discovered 1953 June 6 by J. Churms at Johannesburg.

Nortia was the Etruscan goddess of fortune who was worshipped at Volsinii. Each year a nail was driven into the wall of her temple, for the purpose of counting the years. (M 21128)

Named by the Minor Planet Names Committee following a suggestion by F. Pilcher.

\section{(2026) Cottrell}

1955 FF. Discovered 1955 Mar. 30 at the Goethe Link Observatory at Brooklyn, Indiana.

Named in memory of Frederick Gardner Cottrell in the centennial year of his birth. Cottrell organized the
Research Corporation in 1912 and provided an initial endowment consisting of his valuable electrostatic precipitation rights for the United States east of the Rocky Mountains. Grants from the Research Corporation have been of great assistance in many fields of science, and they have made possible the purchase of the measuring engine used in the minor planet program at the Goethe Link Observatory. (M 4547)

\section{(2027) Shen Guo}

$1964 \mathrm{VR}_{1}$. Discovered 1964 Nov. 9 at the Purple Mountain Observatory at Nanking.

Named for the versatile Chinese scholar Shen Guo (1031-1095), who lived during the Sung dynasty and had many achievements in astronomy. He determined the distance of Polaris from the north celestial pole to be $3^{\circ}$ and devised an experiment to demonstrate that the Moon is a dark, spherical body illuminated by sunlight. He also proposed that the traditional lunar calendar be abandoned in favor of one based on solar reckoning. (M 4785)

\section{(2028) Janequeo}

1968 OB $_{1}$. Discovered 1968 July 18 by C. Torres at Cerro El Roble.

Named for the wife of the Araucanian chief Guepotan. After her husband's death in battle, she took command and won. Later, she brought together Indians from various tribes and commanded them successfully in several further battles. (M 5359)

\section{(2029) Binomi}

1969 RB. Discovered 1969 Sept. 11 by P. Wild at Zimmerwald.

This minor planet, five ahead of (2034) Bernoulli, is named for the mythical inventor of mathematical formulae. It seems that a student, on being asked when Binomi lived, credited him with having been a contemporary of Newton \{see planet (8000)\}, a response that became notorious around the university. A few years later another student, on being asked when Bernoulli lived, immediately answered: "I'm not going to fall into the trap; it is well known that the man never existed!" (M 6208)

\section{(2030) Belyaev}

$1969 \mathrm{TA}_{2}$. Discovered 1969 Oct. 8 by L. I. Chernykh at Nauchnyj.

Named in honor of Colonel Pavel Ivanovich Belyaev (1925-1970), hero of the Soviet Union, Soviet cosmonaut, commander of the spaceship Voskhod 2. (M 4482) Belyaev is also honored by a lunar crater.

\section{(2031) BAM}

$1969 \mathrm{TG}_{2}$. Discovered 1969 Oct. 8 by L. I. Chernykh at Nauchnyj.

Named in honor of the heroic builders of the Baikal-Amur-Main railroad line. (M 4482) 


\section{(2032) Ethel}

1970 OH. Discovered 1970 July 30 by T. M. Smirnova at Nauchnyj.

Named in honor of the English writer Ethel Lilian Voynich (1864-1960). (M 4482)

\section{(2033) Basilea}

1973 CA. Discovered 1973 Feb. 6 by P. Wild at Zimmerwald.

Named for the old city of Basel and the 50th anniversary of the Astronomical Institute at Basel University. (M 5359)

\section{(2034) Bernoulli}

1973 EE. Discovered 1973 Mar. 5 by P. Wild at Zimmerwald.

Named for the great dynasty of mathematicians of Basel, notably Jakob (1654-1705), founder of the calculus of variations; Johann (1667-1748), contributor to integral calculus and the teacher of Euler ssee planet (2002)\}; and Daniel (1700-1782), cofounder of hydrodynamics. (M 5359)

The name Bernoulli is also commemorated by a lunar crater.

\section{(2035) Stearns}

1973 SC. Discovered 1973 Sept. 21 by J. Gibson at El Leoncito.

Named in memory of Carl Leo Stearns (1892-1972), Fisk professor of astronomy at Wesleyan University and second director of the Van Vleck Observatory. His primary research consisted of the determination of more than 200 trigonometric parallaxes. He also participated in the world-wide $\{433\}$ Eros campaign in 1931 but is perhaps best known as the discoverer of comet $1927 \mathrm{IV}$, which holds the record for the maximum heliocentric distance at which a comet has ever been observed. (M 4548)

Obituary published in Science, Vol. 179, p. 1212 (1973).

\section{(2036) Sheragul}

$1973 \mathrm{SY}_{2}$. Discovered 1973 Sept. 22 by N. S. Chernykh at Nauchnyj.

Named in honor of the Siberian village where the discoverer spent his school years. The name also honors his school-mates and relatives. (M 4482)

\section{(2037) Tripaxeptalis}

1973 UB. Discovered 1973 Oct. 25 by P. Wild at Zimmerwald.

A whimsical name, suggested by the fact that (2037) $=3 \times$ (679) Pax $=7 \times$ (291) Alice. (M 5359)

\section{(2038) Bistro}

1973 WF. Discovered 1973 Nov. 24 by P. Wild at Zimmerwald.

The French name for a small, cozy restaurant. The name is also suggested by the fact that $(2038)=2 \mathrm{x}$ (1019) Strackea. (M 5359)

\section{(2039) Payne-Gaposchkin}

1974 CA. Discovered 1974 Feb. 14 at the Harvard College Observatory at Harvard.

Named in honor of Cecilia Payne-Gaposchkin \{19001979\}, Harvard astronomer since 1923, professor of astronomy since 1956, and a staff member of the Smithsonian Astrophysical Observatory since 1962. One of the pioneers of modern astrophysics, she was engaged in research on the physical states and chemical composition of stars and nebulae in the 1920s. She is a leading authority on variable stars, supergiants, novae and supernovae, and the author of seven important and influential books whose topics include stars of high luminosity, stars in the making, novae, and variable stars. (M 4238)

Obituaries published in Phys. Today, Vol. 33, No. 6, p. 64-65 (1980); Irish Astron. J., Vol. 14, p. 69 (1979); Q.J.R. Astron. Soc., Vol. 23, p. 450-451 (1982).

\section{(2040) Chalonge}

1974 HA. Discovered 1974 Apr. 19 by P. Wild at Zimmerwald.

Named in honor of Daniel Chalonge (1895-1977), astronome titulaire at the Paris Observatory, a cofounder of the Institut d'Astrophysique, well known for his fundamental spectrophotometric work, especially on the Sun and on early-type stars. He was the author of the first three-dimensional stellar classification. A native of Grenoble, he was a passionate mountaineer and had some first ascents to his credit. (M 4785)

Obituary published in Q.J.R. Astron. Soc., Vol. 21, p. 481-483 (1980).

\section{(2041) Lancelot}

2523 P-L. Discovered 1960 Sept. 24 by C. J. van Houten and I. van Houten-Groeneveld at Palomar.

Named for one of the knights of the round table. (M 6421)

\section{(2042) Sitarski}

4633 P-L. Discovered 1960 Sept. 24 by C. J. van Houten and I. van Houten-Groeneveld at Palomar.

Named in honor of Grzegorz Sitarski \{1932- \}, astronomer at the Polish Academy of Sciences, well known for his studies of the motions of comets, including consideration of nongravitational effects. He has recently succeeded in dynamically linking the observations made of (1862) Apollo and (2101) Adonis in the 1930s and the 1970s. Currently involved in an extensive program of new orbit determinations of one-apparition comets, he was (1979-1982) President of IAU Commission 20. (M 5523)

\section{(2043) Ortutay}

1936 TH. Discovered 1936 Nov. 12 by G. Kulin at Budapest.

Named in memory of Gyula Ortutay, a professor of ethnography and a Hungarian cultural leader who patronized the popularization of astronomy in his country. (M 5183) 


\section{(2044) Wirt}

1950 VE. Discovered 1950 Nov. 8 by C. A. Wirtanen at Mount Hamilton.

Named in honor of Carl A. Wirtanen \{1910-1990\}, known for his discovery of several comets and minor planets and for his contribution to the Shane-Wirtanen survey of galaxies. He contributed to astrometric and other programs of the Lick Observatory for 33 years, including the proper-motion program with respect to galaxies. (M 5688)

Name proposed by A. R. Klemola.

Obituary published in Bull. Am. Astron. Soc., Vol. 23, No. 4, p. 1495-1496 (1991).

\section{(2045) Peking}

1964 TB $_{1}$. Discovered 1964 Oct. 8 at the Purple Mountain Observatory at Nanking.

Named for the largest city in northern China and the capital of the People's Republic of China today. Peking has served as the Chinese capital for most of the time since the early 13 th century. (M 4786)

\section{(2046) Leningrad}

1968 UD $_{1}$. Discovered 1968 Oct. 22 by T. M. Smirnova at Nauchnyj.

Named for one of the largest industrial, cultural and scientific centers of the U.S.S.R. (M 5282)

The city was renamed into St. Petersburg in 1991.

\section{(2047) Smetana}

1971 UA $_{1}$. Discovered 1971 Oct. 26 by L. Kohoutek at Bergedorf.

Named for the great Czech national composer Bedřich Smetana (1824-1884) who wrote songs, piano pieces, chamber music, operas and instrumental works. Best known are the opera The Bartered Bride, the cycle of six symphonic poems My country and the string quartet From my life. (M 4786)

\section{(2048) Dwornik}

1973 QA. Discovered 1973 Aug. 27 by E. F. Helin at Palomar.

Named by the discoverer for Stephen E. Dwornik, a geologist, noted for his role in the exploration of the Moon and planets by unmanned spacecraft. As chief of the planetology programs of NASA, he was instrumental in the application of systematic geologic mapping to Mars and to Mercury. (M 4359)

\section{(2049) Grietje}

1973 SH. Discovered 1973 Sept. 29 by T. Gehrels at Palomar.

Named in honor of Mrs. G. A. M. Haring-Gehrels, an exceptional person. (M 5282)

\section{(2050) Francis}

1974 KA. Discovered 1974 May 28 by E. F. Helin at Palomar.

Named by the discoverer in honor of her parents, Fred and Kay Francis. (M 4359)

\section{(2051) Chang}

1976 UC. Discovered 1976 Oct. 23 at the Harvard College Observatory at Harvard.

Named in honor of Yu-che Chang \{1902-1986\}, one of the leading astronomers in the Peoples Republic of China, Director of the Purple Mountain Observatory, Nanking, since 1950, and long an active observer of minor planets and comets and computer of their orbits. $\mathrm{He}$ has also determined rotation periods of minor planets and has worked on spectroscopic binaries. From 1927 to 1929 he was on the staff of the Yerkes Observatory. (M 4420)

\section{(2052) Tamriko}

1976 UN. Discovered 1976 Oct. 24 by R. M. West at La Silla.

Named in honor of Tamara West, wife of the discoverer. (M 4786)

\section{(2053) Nuki}

1976 UO. Discovered 1976 Oct. 24 by R. M. West at La Silla.

Named in honor of Nodari West, son of the discoverer. (M 4786)

\section{(2054) Gawain}

4097 P-L. Discovered 1960 Sept. 24 by C. J. van Houten and I. van Houten-Groeneveld at Palomar.

Named for one of the knights of the round table. (M 6421)

\section{(2055) Dvořák}

1974 DB. Discovered 1974 Feb. 19 by L. Kohoutek at Bergedorf.

Named for Antonin Dvořák (1841-1904), the great Czech composer who wrote in virtually all the musical genres and received worldwide recognition. Symphony No. 8 From the New World, Slavonic Dances and the opera Rusalka are his best known works. (M 4786)

\section{(2056) Nancy}

A909 TB. Discovered 1909 Oct. 15 by J. Helffrich at Heidelberg.

Named in honor of Nancy Lou Zissell Marsden, wife of Brian G. Marsden \{see planet (1877)\}. The latter established the identifications for this minor planet. (M 4359)

\section{(2057) Rosemary}

1934 RQ. Discovered 1934 Sept. 7 by K. Reinmuth at Heidelberg.

Named in honor of Rosemary Birky Hoffmann Scholl, \{first\} wife of Hans Scholl \{see planet (2959)\}. The latter was an astronomer at the Astronomisches Rechen-Institut in Heidelberg \{who now works at the Observatoire de Nice\}. (M 4359)

\section{(2058) Róka}

1938 BH. Discovered 1938 Jan. 22 by G. Kulin at Budapest. 
Named in memory of Gedeon Róka, a well-known popularizer of astronomy in Hungary for three decades. (M 5183)

\section{(2059) Baboquivari}

1963 UA. Discovered 1963 Oct. 16 at the Goethe Link Observatory at Brooklyn, Indiana.

This Amor-type object, recovered with the Steward Observatory's 2.3-m reflector on Kitt Peak in 1976, is named in honor of the Papago Indian Tribe, which made available the land on which the AURA observatories are based. Baboquivari, located a few kilometers south of Kitt Peak, is the highest and most sacred peak in Papago country. It figures prominently in Papago mythology as the home of the culture hero I'itoi. (M 5038)

Name proposed by F. K. Edmondson.

\section{(2060) Chiron}

1977 UB. Discovered 1977 Oct. 18 by C. T. Kowal at Palomar.

The name is that of the wisest and most just of the Centaurs, son of Kronos and the ocean nymph Philyra. Beloved by Apollo and Diana ssee planets (1862) and (78), respectively\}, he learned from them botany, music, astronomy, divination and medicine and served in turn as instructor of the Greek heroes. (M 4359)

\section{(2061) Anza}

1960 UA. Discovered 1960 Oct. 22 by H. L. Giclas at Flagstaff.

Named for Captain Juan Bautista de Anza, born at the Presidio of Fronteras, $250 \mathrm{~km}$ southeast of Tucson, Arizona, in 1736. He became the commander at the Presidio of Tubac and in 1774-1776 explored the first overland route from southern Arizona to Monterey, California. (M 4420)

\section{(2062) Aten}

1976 AA. Discovered 1976 Jan. 7 by E. F. Helin at Palomar.

Named for the Egyptian sun god. This object is distinguished among the Apollo asteroids as the first discovered to have a semimajor axis less than $1 \mathrm{AU}$ and a period less than one year. (M 4420)

\section{(2063) Bacchus}

1977 HB. Discovered 1977 Apr. 24 by C. T. Kowal at Palomar.

This Apollo-type object is named for the god of wine and merriment, son of Jupiter and Semele \{see planet (86)\}. Bacchus was honored in various festivals, such as the Bacchanalia, characterized by drink and debauchery. (M 4421)

\section{(2064) Thomsen}

1942 RQ. Discovered 1942 Sept. 8 by L. Oterma at Turku.
Named in memory of Ivan Leslie Thomsen (1910-1969), director of the Carter Observatory, Wellington, from 1945 until his appointment as astronomer-in-charge of the Mount John Observatory only two months before his death. He was an enthusiastic coordinator of astronomy in New Zealand, and his efforts eventually led to the minor-planet observing program with the Carter Observatory 41-cm reflector. It was the 1977 rediscovery at the Carter Observatory that allowed this minor planet to be numbered. (M 4421)

\section{(2065) Spicer}

1959 RN. Discovered 1959 Sept. 9 at the Goethe Link Observatory at Brooklyn, Indiana.

Named in memory of Edward H. Spicer (1906-1983), professor of anthropology at the University of Arizona, and a former president of the American Anthropological Association. His assistance was a major factor in the success of the negotiations with the Schuk Toak District Council and the Papago Tribal Council in 1955 to obtain permission for the site testing of Kitt Peak as a possible location for an astronomical observatory. (M 7944)

Name proposed by F. K. Edmondson.

\section{(2066) Palala}

1934 LB. Discovered 1934 June 4 by C. Jackson at Johannesburg.

Named for a river, a tributary of the Limpopo \{see planet (1490)\}, in the northwestern Transvaal, South Africa. (M 5184)

\section{(2067) Aksnes}

1936 DD. Discovered 1936 Feb. 23 by Y. Väisälä at Turku.

Named in honor of Kaare Aksnes \{1938- \}, celestial mechanician at the Smithsonian Astrophysical Observatory from 1971 to 1978, well-known for his work on both artificial and natural satellites, especially for his detailed analyses of observations of the mutual phenomena of the Galilean satellites. He is currently on the staff of the Norwegian Defense Research Establishment. (M 4482)

\section{(2068) Dangreen}

1948 AD. Discovered 1948 Jan. 8 by M. Laugier at Nice.

Named in honor of Daniel W. E. Green \{1958-

\}, student aide at the Smithsonian Astrophysical Observatory during 1978 June-August, in appreciation of his invaluable assistance during the transition of the Minor Planet Center from Cincinnati to Cambridge. (M 4482)

Name proposed by B. G. Marsden and C. M. Bardwell.

\section{(2069) Hubble}

1955 FT. Discovered 1955 Mar. 29 at the Goethe Link Observatory at Brooklyn, Indiana.

Named in memory of Edwin P. Hubble (1889-1953), who provided the first comprehensive exploration of 
the universe beyond our own galaxy. He established a self-consistent distance scale as far as the 2.5-m Mount Wilson reflector could reach, and his classification scheme for galaxies is still the standard. He discovered the unique minor planet (1373) Cincinnati. His greatest achievement, however, known as Hubble's law of redshifts, can be interpreted as observational basis for the expanding universe. (M 8403)

Name proposed by F. K. Edmondson. Citation written by N. U. Mayall.

Hubble is also honored by a lunar crater.

\section{(2070) Humason}

1964 TQ. Discovered 1964 Oct. 14 at the Goethe Link Observatory at Brooklyn, Indiana.

Named in memory of Milton L. Humason (18911972), who provided all the larger redshifts in the Hubble-Humason epoch-making program. Unrivaled in obtaining spectrograms of very faint galaxies, he correctly identified the few available features. Originally a mule skinner who brought up material for the construction of the Mount Wilson Observatory, he rose through the ranks as a janitor, night assistant and telescope user for colleagues. Appointed a regular staff member with only grammar-school education, he was eventually awarded an honorary degree by the University of Lund. (M 8403)

Name proposed by F. K. Edmondson. Citation written by N. U. Mayall.

Obituaries published in Mercury, Vol. 1, No. 5, p. 12 (1972); Phys. Today, Vol. 25, No. 10, p. 59 (1972); Sky Telesc., Vol. 44, p. 87 (1972); Orion, 31. Jahrg., p. 15 (1973); Q.J.R. Astron. Soc., Vol. 14, p. 235-236 (1973).

\section{(2071) Nadezhda}

1971 QS. Discovered 1971 Aug. 18 by T. M. Smirnova at Nauchnyj.

Named in memory of Nadezhda Konstantinova Krupskaya (1869-1939), one of the creators of the Soviet public education system, wife of V. I. Lenin \{see planet (852)\}. (M 5282)

\section{(2072) Kosmodemyanskaya}

1973 QE $_{2}$. Discovered 1973 Aug. 31 by T. M. Smirnova at Nauchnyj.

Named in memory of Lubov' Timofeevna Kosmodemyanskaya (1900-1978), social worker, mother of Soviet heroes Zoya and Aleksandr Kosmodemyanskij. (M 5282)

See also the citations for minor planets (1793) and (1977).

\section{(2073) Janáček}

1974 DK. Discovered 1974 Feb. 19 by L. Kohoutek at Bergedorf.

Named for the Moravian musician Leos Janáček (1854-1928), the leading Czech composer of the early twentieth century. His chief works are Sinfonietta and the opera Jenufa. (M 4786)

\section{(2074) Shoemaker}

1974 UA. Discovered 1974 Oct. 17 by E. F. Helin at Palomar.

Named by the discoverer to honor her colleague and friend Eugene M. Shoemaker \{1928-1997\}. An outstanding scientist, he has played a principal role in the Lunar Ranger, Surveyor and Apollo missions. His definitive work on meteor craters is a classic. His more recent areas of interest and contributions range from paleomagnetism to a planet-crossing asteroid survey. (M 4548)

This name has also been proposed by B. G. Marsden.

Obituaries published in Publ. Astron. Soc. Pac., Vol. 110, p. 490-492 (1998); Meteorit. Planet. Sci., Vol. 32, No. 6, p. 985-986 (1997); Planet. Space Sci., Vol. 45, No. 8, p. 1049-1050 (1997); Ir. Astron. J., Vol. 25, No. 1, p. 3 (1998); J. R. Astron. Soc. Can., Vol. 91, No. 5, p. 238-239 (1997); Heavens, Vol. 78, No. 9, p. 26-28 (1997); Nature, Vol. 389, No. 6647, p. 132 (1997); Int. Comet Q., Vol. 19, No. 3, p. 153-154 (1997); Astron. Raumfahrt Unterr., Jahrg. 34, Heft 6, p. 41 (1997); WGN, Vol. 25, No. 4, p. 145-146 (1997); Sterne Weltraum, Jahrg. 36, Nr. 10, p. 898 (1997).

\section{(2075) Martinez}

1974 VA. Discovered 1974 Nov. 9 at the Felix Aguilar Observatory at El Leoncito.

Named in memory of Hugo Arturo Martinez (18901976), astronomer at the La Plata Observatory for many years. (M 5013)

\section{(2076) Levin}

1974 WA. Discovered 1974 Nov. 16 at the Harvard College Observatory at Harvard.

Named in honor of Boris Julevich Levin \{19121989\}, Moscow astronomer and geophysicist who has contributed much to our knowledge of the evolution of the solar system. He has made many important specific studies in the areas of meteors and meteorites, and his desorption model played a crucial role in understanding the physical processes in comets. (M 4421)

Obituaries published in Pis'ma Astron., Tom 15, No. 8, p. 767 (1989); Astron. Vestn., Tom 23, No. 4, p. 345-346 (1989); Zemlya Vselennaya, No. 5, p. 4546 (1989); Komety Meteory, No. 39, p. 58 (1989); Meteoritics, Vol. 24, No. 4, p. 353 (1989); Icarus, Vol. 84, No. 2, p. 277-279 (1990).

\section{(2077) Kiangsu}

1974 YA. Discovered 1974 Dec. 18 at the Purple Mountain Observatory at Nanking.

Named for a maritime province in eastern China. In Kiangsu are located two major cities, Shanghai, the largest in China and a major seaport, and Nanking, the provincial capital. (M 4786)

\section{(2078) Nanking}

1975 AD. Discovered 1975 Jan. 12 at the Purple Mountain Observatory at Nanking. 
Named for the city on whose outskirts the Purple Mountain \{see planet (3444)\} Observatory is located. On the southern bank of the Yangtze River in central eastern China, Nanking served as China's capital during several imperial periods prior to the 15th century. It is the capital of Kiangsu \{see planet (2077)\} province of the People's Republic today. (M 4786)

\section{(2079) Jacchia}

1976 DB. Discovered 1976 Feb. 23 at the Harvard College Observatory at Harvard.

Named in honor of Luigi Giuseppe Jacchia \{19111996\}, research associate at the Harvard College Observatory since 1939 and a physicist at the Smithsonian Astrophysical Observatory. In his work on meteors and subsequently on the motions of artificial satellites he has made pioneering investigations of the Earth's upper atmosphere. His interest in variable stars dates from his student days in Bologna, and he is well known as an extraordinary linguist. (M 4421)

Obituaries published in Bull. Am. Astron. Soc., Vol. 28, No. 4, p. 1453-1454 (1996); G. Astron., Vol. 23, N. 1, p. 54 (1997).

\section{(2080) Jihlava}

1976 DG. Discovered 1976 Feb. 27 by P. Wild at Zimmerwald.

Named for a Moravian town, by the river of the same name. Founded in the 11th century, the community prospered from rich silver deposits. The municipal and mining laws of Jihlava were to become a model for analogous regulations all over the world. (M 4786)

This minor planet was named by I. Bauersima, a geodesist at Berne University, in honor of his native town.

\section{(2081) Sázava}

1976 DH. Discovered 1976 Feb. 27 by P. Wild at Zimmerwald.

Named for a river in Bohemia, running from the Zdar Mountains into the Vltava \{see also (2123)\} south of Prague. (M 4787)

Name proposed by I. Bauersima.

\section{(2082) Galahad}

7588 P-L. Discovered 1960 Oct. 17 by C. J. van Houten and I. van Houten-Groeneveld at Palomar.

Named for one of the knights of the round table. (M 6421)

\section{(2083) Smither}

1973 WB. Discovered 1973 Nov. 29 by E. F. Helin at Palomar.

Named by the discoverer and E. M. Shoemaker for John C. Smith in appreciation and recognition of his dedicated assistance in the Palomar planet-crossing minor planet program. As an undergraduate student at Caltech he was known as Smither. (M 4548)

\section{(2084) Okayama}

1935 CK. Discovered 1935 Feb. 7 by S. Arend at Uccle.
Named for the station of the Tokyo Astronomical Observatory at which the Japanese $1.9-\mathrm{m}$ reflector is located. (M 8151)

Name proposed by the discoverer, following a suggestion by K. Tomita, who made an accidental discovery of this object as $1965 \mathrm{HA}$.

\section{(2085) Henan}

1965 YA. Discovered 1965 Dec. 20 at the Purple Mountain Observatory at Nanking.

Named for the province situated in the lower stretch of the Yellow River, the cradle of civilization in ancient China. (M 5184)

\section{(2086) Newell}

1966 BC. Discovered 1966 Jan. 20 at the Goethe Link Observatory at Brooklyn, Indiana.

Named in memory of Homer E. Newell (1915-1983), one of the most important organizers of the U.S. space program. He was a member of the advisory committee that helped to establish the National Aeronautics and Space Administration, and he became one of the original staff members when NASA came into being in 1958. Newell served in a number of leading positions and was Associate Administrator of NASA at the time of his retirement in 1973. (M 8151)

Name proposed by F. K. Edmondson.

\section{(2087) Kochera}

1975 YC. Discovered 1975 Dec. 28 by P. Wild at Zimmerwald.

Named in memory of Theodor Kocher (1841-1917), surgeon of world fame, Nobel laureate in 1909, benefactor of Berne University. (M 4787)

\section{(2088) Sahlia}

1976 DJ. Discovered 1976 Feb. 27 by P. Wild at Zimmerwald.

Named in memory of Hermann Sahli (1856-1933), professor of internal medicine at Berne University, philosophically minded teacher, inventor of many new methods and improved instruments of diagnosis. (M 4787)

\section{(2089) Cetacea}

1977 VF. Discovered 1977 Nov. 9 by N. G. Thomas at Flagstaff.

Named for the order of mammals commonly called whales, many species of which are currently endangered. (M 4787)

\section{(2090) Mizuho}

1978 EA. Discovered 1978 Mar. 12 by T. Urata at Yakiimo.

Named by the discoverer in honor of his daughter. (M 4482)

\section{(2091) Sampo}

1941 HO. Discovered 1941 Apr. 26 by Y. Väisälä at Turku. 
Named for the wonder-object in Kalevala \{see planet (1454)\}, the Finnish national epic. Sampo was to produce every kind of fortune. When Kalevala and Pohjola \{the North, see planet (3606)\}) were fighting for its possession, out at sea, it broke into pieces, and only tiny fragments could be found. (M 5450)

\section{(2092) Sumiana}

1969 UP. Discovered 1969 Oct. 16 by L. I. Chernykh at Nauchnyj.

Named for the town of Sumy, in the Ukrainian S.S.R. (M 5282)

\section{(2093) Genichesk}

1971 HX. Discovered 1971 Apr. 28 by T. M. Smirnova at Nauchnyj.

Named for the discoverer's birthplace, a town in the Ukrainian S.S.R. (M 5282)

\section{(2094) Magnitka}

$1971 \mathrm{TC}_{2}$. Discovered 1971 Oct. 12 at the Crimean Astrophysical Observatory at Nauchnyj.

Named for the town of Magnitogorsk, one of the largest centers of metallurgy in the U.S.S.R. (M 5282)

\section{(2095) Parsifal}

6036 P-L. Discovered 1960 Sept. 24 by C. J. van Houten and I. van Houten-Groeneveld at Palomar.

Named for one of the knights of the round table. (M 6421)

\section{(2096) Väinö}

1939 UC. Discovered 1939 Oct. 18 by Y. Väisälä at Turku.

Named for Väinämöinen, an old and wise magician, a central figure in Finnish folklore and Kalevala \{see planet (1454)\}. This minor planet also honors Väinö Väisälä, brother of the discoverer. (M 5451)

\section{(2097) Galle}

1953 PV. Discovered 1953 Aug. 11 by K. Reinmuth at Heidelberg.

Named in memory of Johann Gottfried Galle (1812-1910), famous German astronomer who in 1846 discovered the planet Neptune, the existence of which had been theoretically demonstrated by J. C. Adams and U. J. Leverrier \{see planets (1996) and (1997), respectively\}. Galle studied mathematics and natural sciences in Berlin and was appointed staff astronomer at the Berlin Observatory by its director J. F. Encke. He then went to the University of Breslau and in 1851 became professor of astronomy and director of the Breslau Observatory. The discoverer of three comets within only three months in 1839-40, Galle was also known for his catalogues of cometary orbits that culminated with the definitive edition of 1894 . In 1872 , more than three decades before its realization, Galle proposed the use of minor planet observations for the determination of the solar parallax. He was also engaged in meteorological problems. (M 18304)
Name suggested and citation prepared by L. D. Schmadel, endorsed by the Heidelberg-Königstuhl Observatory.

Galle is also honored by craters on Mars and the Moon.

\section{(2098) Zyskin}

1972 QE. Discovered 1972 Aug. 18 by L. V. Zhuravleva at Nauchnyj.

Named in honor of Lev Yur'evich Zyskin, professor at the Crimean Medical Institute, head of the Pulmonary Surgery Center. (M 5283)

\section{(2099) Öpik}

1977 VB. Discovered 1977 Nov. 8 by E. F. Helin and E. M. Shoemaker at Palomar.

Named in honor of Ernst J. Opik \{1893-1985\} on the occasion of his 85th birthday. Over a career spanning more than 60 years he has influenced almost every branch of astronomy. In particular he has developed the discipline of statistical celestial mechanics and of methods for estimating the lifetimes of small bodies on planet-crossing orbits. In 1951 he computed the probability of collision with Mars of the Mars-crossing minor planets recognized at that time, and 14 years before their discovery by the Mariner 4 spacecraft he inferred that it would be worthwhile to search for impact craters on Mars. It is therefore fitting that (2099) Öpik should be a Mars-crosser. (M 4548)

Obituaries published in Icarus, Vol. 66, No. 2, p. 193-194 (1986); Sky Telesc., Vol. 71, No. 2, p. 149 (1986); Astrophys. Space Sci., Vol. 124, No. 1, p. 1-3 (1986); Q.J.R. Astron. Soc., Vol. 27, No. 3, p. 508-512 (1986).

\section{(2100) Ra-Shalom}

1978 RA. Discovered 1978 Sept. 10 by E. F. Helin at Palomar.

Named by the discoverer for the Egyptian sun-god Ra, who symbolizes enlightenment and life, and for Shalom, the traditional Hebrew greeting meaning peace. This name is chosen to commemorate the Camp David mid-east peace conference, at which time this unusual body was found. May it stand as a symbol for the universal hope for peace. (M 4548)

\section{(2101) Adonis}

1936 CA. Discovered 1936 Feb. 12 by E. Delporte at Uccle.

This Apollo-type minor planet was named previously for the lover of Aphrodite \{see planet (1388)\}. Adonis was ordered by Zeus \{see planet (5731)\} to spend part of each year with Aphrodite and part with Persephone \{see planet (399)\}. He is regarded as a god of vegetation and of swine and was killed by a boar sent by Artemis \{see planet (105)\}. (M 4548) 


\section{(2102) Tantalus}

1975 YA. Discovered 1975 Dec. 27 by C. T. Kowal at Palomar.

Named for the king of Sipylus, who was punished by being immersed to his neck in water and prevented from drinking the water or gathering fruit hung above his head. (M 4645)

\section{(2103) Laverna}

1960 FL. Discovered 1960 Mar. 20 at the La Plata Observatory at La Plata.

Laverna was the protecting divinity of thieves and imposters. Her name was probably connected with the Latin word levator, meaning thief. (M 21128)

Named by the Minor Planet Names Committee following a suggestion by F. Pilcher.

\section{(2104) Toronto}

1963 PD. Discovered 1963 Aug. 15 by K. W. Kamper at Tautenburg.

This minor planet, the first to be found at a Canadian Observatory, is named in honor of the University of Toronto, during whose sesquicentennial celebration it was discovered, to acknowledge the central role played by the university in the development of astronomy in Canada. (M 4645)

This planet was detected at the David Dunlap Observatory on plates taken by S. van den Bergh at the Tautenburg Observatory, East Germany.

\section{(2105) Gudy}

1976 DA. Discovered 1976 Feb. 29 by H.-E. Schuster at La Silla.

Named by the discoverer for Mrs. Gudrun Werner of Hamburg in sentimental reminiscence of college days. This Phocaea-type $\{$ see planet (25)\} minor planet was found on the same blue survey plates as the large-perihelion comet $1976 \mathrm{c}=1975$ II. (M 4645)

\section{(2106) Hugo}

1936 UF. Discovered 1936 Oct. 21 by M. Laugier at Nice.

Named for the celebrated French writer Victor Hugo (1802-1885). (M 6833)

Name proposed by J. Meeus.

\section{(2107) Ilmari}

1941 VA. Discovered 1941 Nov. 12 by L. Oterma at Turku.

Named for the master-smith Ilmarinen, who forged Sampo \{see planet (2091)\}, the wonder-object in Kalevala \{see planet (1454)\}. Ilmari is a common boy's name in Finland. (M 5451)

\section{(2108) Otto Schmidt}

1948 TR $_{1}$. Discovered 1948 Oct. 4 by P. F. Shajn at Simeis.

Named in memory of Otto Yul'evich Schmidt (1891-1956), a prominent Soviet scientist famous for his investigations in mathematics, astronomy and geophysics. He was also an outstanding Arctic researcher, academician and statesman. His cosmogonic theories contributed extensively to the evolution of concepts on the formation of the Earth and other planets. (M 5359)

\section{(2109) Dhotel}

$1950 \mathrm{TH}_{2}$. Discovered 1950 Oct. 13 by S. Arend at Uccle.

Named in honor of André d'Hotel, recipient of the 1974 "Grand Prix de Littérature de l'Académie Française" and a friend of the Arend family. (M 8323)

The originally adopted name d'Hotel (MPC 8151) was later changed.

\section{(2110) Moore-Sitterly}

1962 RD. Discovered 1962 Sept. 7 at the Goethe Link Observatory at Brooklyn, Indiana.

Named to honor Charlotte E. Moore (Mrs. Bancroft W. Sitterly) \{1898-1990\}, whose long-time collaboration with Henry Norris Russell \{see planet (1762)\} included analyses of many atomic spectra and the important work on dynamical parallaxes that led to their landmark treatise, The masses of the stars, in 1940. She joined the staff of the U.S. National Bureau of Standards in 1945 and continued her work on atomic spectra of astrophysical interest. She served as president of IAU Commission 14 during 1961-1967. Her formal retirement in 1968 did not stop her activities, and she continues to be an international resource in this field. (M 8797)

Name proposed by F. K. Edmondson.

Obituaries published in Q.J.R. Astron. Soc., Vol. 32, No. 2, p. 209-210 (1991); Bull. Am. Astron. Soc., Vol. 23, No. 4, p. 1492-1494 (1991); Phys. Today, Vol. 44, No. 4, p. 128, 130 (1991).

\section{(2111) Tselina}

1969 LG. Discovered 1969 June 13 by T. M. Smirnova at Nauchnyj.

Named on the 25th anniversary of the development of tselina (virgin soil) and long fallow lands in the U.S.S.R. (M 5283)

\section{(2112) Ulyanov}

1972 NP. Discovered 1972 July 13 by T. M. Smirnova at Nauchnyj.

Named in memory of Aleksandr Ulyanov (1866-1887), eldest brother of V. I. Lenin \{see planet (852). (M 5283)

\section{(2113) Ehrdni}

$1972 \mathrm{RJ}_{2}$. Discovered 1972 Sept. 11 by N. S. Chernykh at Nauchnyj.

Named in memory of Ehrdni Tel'dzhievich Delikov (1922-1942), a hero from the Kalmyk S.S.R. who was killed in the Great Patriotic War (1941-1945). (M 5283)

\section{(2114) Wallenquist}

1976 HA. Discovered 1976 Apr. 19 by C.-I. Lagerkvist at Mount Stromlo. 
Named in honor of Åke A. E. Wallenquist \{1904-1994\}, retired director of the Kvistaberg \{see planet (3331) Station but still active at the Uppsala Observatory, where he studies dark matter in open clusters. While observing at Palomar in 1950 he was a codiscoverer of (1980) Tezcatlipoca. (M 4645)

Obituary published in Astron. Tidsskr., Arg. 27, Nr. 3, p. 123-124 (1994).

\section{(2115) Irakli}

1976 UD. Discovered 1976 Oct. 24 by R. M. West at La Silla.

Named in honor of Irakli West, son of the discoverer. (M 4787)

\section{(2116) Mtskheta}

1976 UM. Discovered 1976 Oct. 24 by R. M. West at La Silla.

Named after the ancient capital of the Kingdom of Georgia, at the confluence of the rivers Mtkvari and Aragvi, rich in architectural treasures and the scene of many decisive events in the history of Georgia. The name is proposed by the discoverer in admiration of a beautiful country and its valiant people. (M 4787)

\section{(2117) Danmark}

1978 AC. Discovered 1978 Jan. 9 by R. M. West at La Silla.

Named in honor of the native country of the discoverer. (M 4787)

\section{(2118) Flagstaff}

1978 PB. Discovered 1978 Aug. 5 by H. L. Giclas at Anderson Mesa.

Named of the city of Flagstaff, Arizona, where Percival Lowell \{see planet (1886)\} founded the Lowell Observatory in 1894. In more recent times several other astronomical facilities have been set up in Flagstaff. (M 5184)

\section{(2119) Schwall}

1930 QG. Discovered 1930 Aug. 30 by M. F. Wolf and

M. Ferrero at Heidelberg.

Named in memory of August Schwall (1877-1947), mechanician at the Heidelberg-Königstuhl Observatory for almost half a century, night assistant to Wolf during 1914-1932, guiding exposures with the 0.72-m reflector. (M 5524)

Name proposed by A. Bohrmann.

\section{(2120) Tyumenia}

1967 RM. Discovered 1967 Sept. 9 by T. M. Smirnova at Nauchnyj.

Named for the Tyumen' district of the \{former\} R.S.F.S.R., the center of the west Siberian oil-gas basin that has become in recent years the main source of power in the U.S.S.R. (M 5283)

\section{(2121) Sevastopol}

1971 ME. Discovered 1971 June 27 by T. M. Smirnova at Nauchnyj.
Named for this Crimean city on the 200th anniversary of its foundation. (M 7616)

\section{(2122) Pyatiletka}

1971 XB. Discovered 1971 Dec. 14 by T. M. Smirnova at Nauchnyj.

Named on the 50th anniversary of the adoption of the first five-year plan for the development of the national economy of the U.S.S.R. (M 5283)

\section{(2123) Vltava}

$1973 \mathrm{SL}_{2}$. Discovered 1973 Sept. 22 by N. S. Chernykh at Nauchnyj.

Named for the river on which the city of Prague is situated. (M 5283)

\section{(2124) Nissen}

1974 MK. Discovered 1974 June 20 at the Felix Aguilar Observatory at El Leoncito.

Named in memory of Juan Jose Nissen (19011978), first director of the Felix Aguilar Observatory, previously director of the Córdoba Observatory and a department head at the La Plata Observatory. (M 5013)

\section{(2125) Karl-Ontjes}

2005 P-L. Discovered 1960 Sept. 24 by C. J. van Houten and I. van Houten-Groeneveld at Palomar.

Named in honor of Karl-Ontjes Groeneveld \{1935-

\}, a well-known physicist at the Institut für Kernphysik, Frankfurt-am-Main, and a brother of one of the discoverers. (M 7471)

\section{(2126) Gerasimovich}

1970 QZ. Discovered 1970 Aug. 30 by T. M. Smirnova at Nauchnyj.

Named in memory of Boris Petrovich Gerasimovich (1889-1937), professor at Kharkov University (19221931), then chief of the astrophysics section and from 1933 director of the Pulkovo Observatory. His scientific papers cover a large range of astrophysical problems, and he was a member of many scientific societies. (M 5359)

Gerasimovich is also honored by a lunar crater.

\section{(2127) Tanya}

$1971 \mathrm{~KB}_{1}$. Discovered 1971 May 29 by L. I. Chernykh at Nauchnyj.

Named in memory of Tanya Savicheva, a 12-year-old schoolgirl who perished during the 1941-1944 blockade of Leningrad. In her diary she made a record as her parents and other relatives died, one by one. Her last note was "... all the Savichev's have died, Tanya is left alone". (M 5283)

\section{(2128) Wetherill}

1973 SB. Discovered 1973 Sept. 26 by E. F. Helin at Palomar.

Named in honor of George W. Wetherill \{1925- $\quad$, director of the Department of Terrestrial Magnetism, Carnegie Institution of Washington. Noted for his work on isotopic age determination, meteorites, and 
the origin of the terrestrial planets, he has been a leading student of the dynamical evolution of orbits of meteorites and planet-crossing asteroids. (2128) is a Mars crosser that lies close to a secular resonance shown by Wetherill to be of importance in the delivery of meteorites and asteroids into Earth-crossing orbits. (M 4787)

\section{(2129) Cosicosi}

1973 SJ. Discovered 1973 Sept. 27 by P. Wild at Zimmerwald.

The Italian characterization of indifference. (M 5359)

\section{(2130) Evdokiya}

$1974 \mathrm{QH}_{1}$. Discovered 1974 Aug. 22 by L. V. Zhuravleva at Nauchnyj.

Named by the discoverer in honor of her mother, Evdokiya Efimovna Shchelokova. (M 5283)

\section{(2131) Mayall}

1975 RA. Discovered 1975 Sept. 3 by A. R. Klemola at Mount Hamilton.

Named in honor of Nicholas U. Mayall \{19061993\}, director of the Kitt Peak National Observatory during 1960-1971. It was under his direction that the planning and construction of a major portion of the astronomical facilities at the Kitt Peak and Cerro Tololo observatories were accomplished. He was on the Lick Observatory staff from 1945 to 1960. His major research contribution spans the domains of nebular spectroscopy, radial velocities of globular clusters and planetary nebulae, and the redshifts and internal motions of galaxies. (M 5848)

Obituary published in Bull. Am. Astron. Soc., Vol. 25, No. 4, p. 1499 (1993).

\section{(2132) Zhukov}

1975 TW $_{3}$. Discovered 1975 Oct. 3 by L. I. Chernykh at Nauchnyj.

Named in memory of Georgij Konstantinovich Zhukov (1896-1974), Marshal of the Soviet Union and leader during the Great Patriotic War. (M 5283)

\section{(2133) Franceswright}

1976 WB. Discovered 1976 Nov. 20 at the Harvard College Observatory at Harvard.

Named in honor of Frances Woodworth Wright \{18981990\}, long time staff member of the Harvard College Observatory, known for her research on photographic meteors, extraterrestrial dust and variable stars, and revered for teaching generations of navigators to fare forth and return safely to port. (M 5039)

\section{(2134) Dennispalm}

1976 YB. Discovered 1976 Dec. 24 by C. T. Kowal at Palomar.

Named in memory of C. Dennis Palm (1945-1974), a night assistant at Palomar Observatory, an active amateur astronomer, and a dear friend to those who were privileged to work with him. (M 4788)

\section{(2135) Aristaeus}

1977 HA. Discovered 1977 Apr. 17 by E. F. Helin and S. J. Bus at Palomar.

This Apollo object is named for the son of Apollo and the nymph Cyrene ssee planets (1862) and (133), respectively\}. (M 5014)

\section{(2136) Jugta}

1933 OC. Discovered 1933 July 24 by K. Reinmuth at Heidelberg.

Named in honor of J. U. Gunter \{1911-1994\} and his publication Tonight's Asteroids. This publication has been extraordinary successful at interesting the general public in minor planets and has inspired countless amateur and several professional astronomers to study these objects. (M 5284)

Name proposed by E. Fogelin; endorsed by C. M. Bardwell, D. W. E. Green and B. G. Marsden.

Obituary published in Minor Planet Bull., Vol. 22, No. 1, p. 1 (1995).

\section{(2137) Priscilla}

1936 QZ. Discovered 1936 Aug. 24 by K. Reinmuth at Heidelberg.

Named in memory of Priscilla Fairfield Bok (18961975). With her husband, Bart J. Bok, she participated in four decades of fruitful galactic research, first at the Harvard College Observatory, then at the Mt. Stromlo Observatory, Steward Observatory, with briefer tours elsewhere. She also enjoyed teaching astronomy courses successively at Smith College, Wellesley College and Connecticut College for Women. Together with her husband she prepared several editions of The Milky Way, a popular title in the Harvard Books on Astronomy. (M 7616)

Name proposed by F. Pilcher.

Priscilla F. and Bart J. Bok are also honored by minor planet (1983).

\section{(2138) Swissair}

1968 HB. Discovered 1968 Apr. 17 by P. Wild at Zimmerwald.

Named for the Swiss national airline, for which HB is the international designation. (M 5360)

\section{(2139) Makharadze}

1970 MC. Discovered 1970 June 30 by T. M. Smirnova at Nauchnyj.

Named in memory of the friendship between the Georgian and Ukrainian peoples. Makharadze is the Georgian twin city of Genichesk \{see planet (2093)\} in the Ukraine. (M 6647)

\section{(2140) Kemerovo}

1970 PE. Discovered 1970 Aug. 3 by T. M. Smirnova at Nauchnyj.

Named for the regional center of the Kemerovo district of Russia, an important industrial center of Siberia. (M 6647) 


\section{(2141) Simferopol}

1970 QC $_{1}$. Discovered 1970 Aug. 30 by T. M. Smirnova at Nauchnyj.

Named for the central city of the Crimean district of the Ukrainian SSR on the occasion of its two-hundredth anniversary. (M 8911)

\section{(2142) Landau}

1972 GA. Discovered 1972 Apr. 3 by L. I. Chernykh at Nauchnyj.

Named in memory of Lev Davydovich Landau (1908-1968), founder of the study of modern theoretical physics in the U.S.S.R. Among his accomplishments was fundamental research in quantum electrodynamics, superconductivity and neutrino theory. (M 5284) Landau is also honored by a lunar crater.

\section{(2143) Jimarnold}

1973 SA. Discovered 1973 Sept. 26 by E. F. Helin at Palomar.

Named in honor of James R. Arnold, professor of chemistry at the University of California at San Diego, distinguished for his applications of nuclear chemistry to the interpretation of meteorites, the history of cosmic radiation, the lunar regolith and compositional mapping of the Moon. In order to elucidate the origin of meteorites he developed a Monte Carlo method for studying the effects of close planetary encounters on the orbital evolution of small planet-crossing bodies. The method has become the primary technique for investigating the dynamical history of planet-crossing asteroids, of which (2143) is an example. (M 4788)

Name proposed by E. F. Helin and E. M. Shoemaker.

\section{(2144) Marietta}

$1975 \mathrm{BC}_{1}$. Discovered 1975 Jan. 18 by L. I. Chernykh at Nauchnyj.

Named in honor of Marietta Sergeevna Shaginyan, Soviet writer, doctor of philology, a member of the Armenian Academy of Sciences. (M 5284)

\section{(2145) Blaauw}

1976 UF. Discovered 1976 Oct. 24 by R. M. West at La Silla.

Named by the discoverer in honor of Adriaan Blaauw \{1914- $\}$, director of ESO (1970-74), president of the IAU (1976-79) and professor at the Leiden Observatory (1975-1981). He has made many important contributions to stellar kinematics, the structure of the Galaxy and the study of stellar associations. He has been closely associated with ESO since its beginning and has been very active in the furthering of collaboration in European astronomy. He is one of the founders of the European journal Astronomy and Astrophysics and has been Chairman of the Board of Directors since 1969. (M 4788)

\section{(2146) Stentor}

1976 UQ. Discovered 1976 Oct. 24 by R. M. West at La Silla.

This Trojan planet is named for the Greek warrior with the famous voice as loud as fifty men together. (M 4788)

\section{(2147) Kharadze}

1976 US. Discovered 1976 Oct. 25 by R. M. West at La Silla.

Named by the discoverer in honor of Academician Evgenij Kirillovich Kharadze \{1907- \}, founder and director since 1932 of the Abastumani \{see planet (1390)\} Astrophysical Observatory, Vice-President (1972-1978) and now President of the Academy of Sciences of the Georgian S.S.R., and Vice-President of the IAU (1976-1982). He has made numerous contributions to the study of interstellar matter and the structure of the Galaxy. He is the author of several astronomical textbooks in the Georgian language and has developed a modern Georgian astronomical terminology. (M 4788)

\section{(2148) Epeios}

1976 UW. Discovered 1976 Oct. 24 by R. M. West at La Silla.

This Trojan planet is named for the leader of the troops from Phocis, who also constructed the Wooden Horse that became the fate of Troy. (M 4788)

\section{(2149) Schwambraniya}

1977 FX. Discovered 1977 Mar. 22 by N. S. Chernykh at Nauchnyj.

Named for the wonderland created by the characters in L. A. Kassil's children's novel Conduite and Schwambraniya. (M 5284)

\section{(2150) Nyctimene}

1977 TA. Discovered 1977 Oct. 13 by W. Sebok at Palomar.

Nyctimene was a daughter of Epopeus, King of Lesbos. Pursued and raped by her father, she concealed herself in the shade of forests. Athena ssee planet (881) $\}$ rescued her there by metamorphosing her into an owl. (M 21128)

Named by the Minor Planet Names Committee following a suggestion by F. Pilcher.

\section{(2151) Hadwiger}

1977 VX. Discovered 1977 Nov. 3 by P. Wild at Zimmerwald.

Named in memory of Hugo Hadwiger (1908-1981), for more than 40 years professor of mathematics at the University of Berne, very popular for the human and historical touch of his lectures, and admired by students and colleagues alike for his refined art of presentation. Known as a "master of beautiful formulae", his course on special functions deservedly drew crowds of students of all ages. (M 8151) 


\section{(2152) Hannibal}

1978 WK. Discovered 1978 Nov. 19 by P. Wild at Zimmerwald.

Named for the great Carthaginian general who, on his way to Rome in 217 B.C., crossed the Alps with his army, including some elephants to frighten the enemy. For the Swiss, WK is the abbreviation for "Wiederholungskurs", the yearly repetition of military exercises, and the 1978 WK for a colleague of the discoverer consisted of a large Alpine maneuver called Hannibal. (M 8151)

\section{(2153) Akiyama}

1978 XD. Discovered 1978 Dec. 1 at the Harvard College Observatory at Harvard.

Named in memory of Kaoru Akiyama (1901-1970), professor at Hosei University, Tokyo, during 1930-1940 and 1949-1970, well known for his work on minor planets. Initially in collaboration with K. Hirayama \{see minor planet (1999)\}, he made the first detailed study of the orbit of the $3 / 2$ commensurability object (153) Hilda. (M 5014)

Name proposed by K. Tomita.

\section{(2154) Underhill}

2015 P-L. Discovered 1960 Sept. 24 by C. J. van Houten and I. van Houten-Groeneveld at Palomar.

Named in honor of Anne B. Underhill, a well-known astrophysicist and an expert in the field of the structure of early-type stars. (M 7471)

\section{(2155) Wodan}

6542 P-L. Discovered 1960 Sept. 24 by C. J. van

Houten and I. van Houten-Groeneveld at Palomar.

Named for the chief god of Teutonic mythology, also honored in some languages by the fourth day of the week. (M 7782)

\section{(2156) Kate}

A917 SH. Discovered 1917 Sept. 23 by S. I. Belyavskij at Simeis.

Named by L. K. Kristensen, who found several of the identifications involving this planet, in honor of his wife. (M 5284)

\section{(2157) Ashbrook}

A924 EF. Discovered 1924 Mar. 7 by K. Reinmuth at Heidelberg.

Named in honor of Joseph Ashbrook \{1918-1980\}, Editor of "Sky and Telescope", co-discoverer of periodic comet Ashbrook-Jackson. His extensive professional background in astronomy, together with his encyclopedic knowledge of intriguing and obscure astronomical facts and fancies, have secured for "Sky and Telescope" a unique position as a vital source of information, not only for professional astronomers and historians of science, but also for amateur astronomers of all levels of expertise. (M 5284)

Name proposed by N. Sperling; endorsed by C. M. Bardwell and B. G. Marsden.
Obituaries published in J. Hist. Astron., Vol. 11, p. 201 (1980); Sky Telesc., Vol. 60, p. 281-284 (1980); J. Am. Assoc. Variable Star Obs., Vol. 9, p. 43-44 (1980); Strolling Astron., Vol. 28, p. 203 (1980).

\section{(2158) Tietjen}

1933 OS. Discovered 1933 July 24 by K. Reinmuth at Heidelberg.

Named in memory of Friedrich Tietjen (1832-1895), professor of astronomy at Berlin University and director of the Astronomisches Rechen-Institut since 1874. For many years, he served as an editor of the respected Berliner Astronomisches Jahrbuch and Nautisches Jahrbuch. After a 13-year period of observations of minor planets and comets, Tietjen became the most prolific orbit computer of the ARI. (M 18447)

Name proposed and citation prepared by L.D.Schmadel.

\section{(2159) Kukkamäki}

1941 UX. Discovered 1941 Oct. 16 by L. Oterma at Turku.

Named in honor of T. J. Kukkamäki \{1909- \} on the occasion of his 70th birthday, 1979 Oct. 11. A distinguished disciple of Y. Väisälä \{see planet (1573)\}, this leading geodesist was for many years director of the Finnish Geodetic Institute. He is an active member of several international scientific organizations and has served as president of the International Association of Geodesy since 1975. (M 5014)

\section{(2160) Spitzer}

1956 RL. Discovered 1956 Sept. 7 at the Goethe Link Observatory at Brooklyn, Indiana.

Named in honor of Lyman Spitzer Jr. \{1914-1997\}, director of the Princeton University Observatory from 1947 to 1979 and one of the most influential pioneers in recognizing and promoting the importance of making astronomical observations from space vehicles. In addition to performing outstanding astronomical research, he was involved in the Princeton project for the controlled release of thermonuclear energy as director of Project Matterhorn (1953-1961) and chairman of the executive committee of the Plasma Physics Laboratory (1961-1966). A member of the AURA board of directors during 1959-1969, he became chairman of the new AURA Space Telescope Institute Council in 1981. (M 8798)

Name proposed by F. K. Edmondson.

Obituaries published in Nature, Vol. 387, No. 6630, p. 244 (1997); Astron. Geophys., Vol. 38, Issue 6, p. 36 (1997); Vasiona, Vol. 46, No. 3, p. 79-80 (1998); Phys. Today, Vol. 50, No. 10, p. 123-124 (1997); Bull. Astron. Soc. India, Vol. 25, No. 2, p. 281-283 (1997); Pub. Astron. Soc. Pac., Vol. 110, No. 745, p. 215-222 (1998); Space Telesc. Sci. Inst., Newsl., Vol. 14, No. 2, p. 2 (1997); Zvaigňotā Debess, No. 163, p. 36-40 (1999). 


\section{(2161) Grissom}

1963 UD. Discovered 1963 Oct. 17 at the Goethe Link Observatory at Brooklyn, Indiana.

Named in memory of Virgil I. "Gus" Grissom (1926-1967), one of the seven Mercury astronauts. On 1961 July 21, as pilot of the Mercury-Redstone 4 suborbital mission, he became the second American in space. In 1965 he commanded a three-orbit mission, the first manned Gemini flight. As command pilot of Apollo 1, he lost his life in the tragic fire in that spacecraft. (M 5848)

Name proposed by D. Owings and F. K. Edmondson. Citation prepared by Muriel M. Thorne, NASA. Grissom is also honored by a lunar crater.

\section{(2162) Anhui}

1966 BE. Discovered 1966 Jan. 30 at the Purple Mountain Observatory at Nanking.

Named for a province in the northeastern part of East China that straddles the Yangtze and Huai Rivers. (M 5184)

\section{(2163) Korczak}

$1971 \mathrm{SP}_{1}$. Discovered 1971 Sept. 16 at the Crimean Astrophysical Observatory at Nauchnyj.

Named in memory of Janusz Korczak (1878-1942), Polish writer, teacher and doctor who perished with his 200 pupils at Treblinka. (M 5284)

\section{(2164) Lyalya}

$1972 \mathrm{RM}_{2}$. Discovered 1972 Sept. 11 by N. S. Chernykh at Nauchnyj.

Named in memory of Elena (Lyalya) Konstantinova Ubijvovk (1918-1942), a student in astronomy at Kharkov University who perished with other members of the Resistance during the Great Patriotic War. (M 5285)

\section{(2165) Young}

1956 RJ. Discovered 1956 Sept. 7 at the Goethe Link Observatory at Brooklyn, Indiana.

Named in memory of Charles Augustus Young (18341908), known affectionately as "Twinkle" Young by the Princeton students. He accepted the professorship of astronomy at Princeton in 1877, the year that his most famous student, Henry Norris Russell \{see planet (1762)\}, was born. Earlier he was a professor at Dartmouth, as his father and grandfather had been. He discovered the green line $(\lambda 5304)$ in the solar corona in 1869, and the following year he was the first both to observe the "flash spectrum" and to photograph a prominence. In 1876 he made the first use of the grating spectroscope in astronomy for the determination of the Sun's rotation period. The last of his three successful textbooks, Manual of astronomy, was updated by Russell, Dugan \{see planet (2772)\} and Stewart in 1926. (M 8798)

Name proposed by F. K. Edmondson.

\section{(2166) Handahl}

1936 QB. Discovered 1936 Aug. 13 by G. N. Neujmin at Simeis. Independently discovered 1936 August 17 by K. Reinmuth at Heidelberg.

Named by D. W. E. Green, who found identifications for this planet, in honor of his mother, Violet Handahl Green. (M 5285)

\section{(2167) Erin}

1971 LA. Discovered 1971 June 1 at the Perth Observatory at Bickley.

Named in honor of the daughter of George Punko, member of the astrometric team at the Perth Observatory. (M 6530)

\section{(2168) Swope}

$1955 \mathrm{RF}_{1}$. Discovered 1955 Sept. 14 at the Goethe Link Observatory at Brooklyn, Indiana.

Named in memory of Henrietta Hill Swope (19021980), best known for her work in establishing distance ratios for nearby galaxies. One of her most significant contributions was the calibration of the distance of the Andromeda galaxy. She worked as an assistant at the Harvard College Observatory during 1928-1942 and was on the staff of the Mount Wilson and Palomar Observatories during 1952-1968. She received the Annie J. Cannon \{see planet (1120)\} prize of the American Astronomical Society in 1968 and an honorary Ph.D. from the University of Basel in 1975. The 1-m Swope telescope at the Las Campañas Observatory was named in her honor by the Carnegie Institution of Washington. (M 8798)

Name proposed by F. K. Edmondson.

Obituary published in Phys. Today, Vol. 34, No. 3, p. 88 (1981).

\section{(2169) Taiwan}

$1964 \mathrm{VP}_{1}$. Discovered 1964 Nov. 9 at the Purple Mountain Observatory at Nanking.

Named for an insular province of China. (M 5184)

\section{(2170) Byelorussia}

1971 SZ. Discovered 1971 Sept. 16 at the Crimean Astrophysical Observatory at Nauchnyj.

Named for one of the Soviet Socialist Republics. (M 5285)

Since 1991 Byelorussia is an independent state.

\section{(2171) Kiev}

1973 QD 1 . Discovered 1973 Aug. 28 by T. M. Smirnova at Nauchnyj.

Named on the occasion of the 1500th anniversary of this city, the capital of the Ukraine and one of the largest industrial, cultural and scientific centers of the \{former\} U.S.S.R. (M 6647)

\section{(2172) Plavsk}

1973 QA $_{2}$. Discovered 1973 Aug. 31 by T. M. Smirnova at Nauchnyj.

Named for the district center of the Tula region of the \{former R.S.F.S.R. Plavsk is the twin town of 
the Ukrainian town Genichesk \{see the citation for minor planet (2093)\}, the birthplace of the discoverer. (M 7616)

\section{(2173) Maresjev}

$1974 \mathrm{QG}_{1}$. Discovered 1974 Aug. 22 by L. V. Zhuravleva at Nauchnyj.

Named in honor of Alexej Petrovich Maresjev, a war veteran whose heroic deed is described in B. Polevoj's novel Story about a True Man. (M 5285)

\section{(2174) Asmodeus}

1975 TA. Discovered 1975 Oct. 8 by S. J. Bus and J. P. Huchra at Palomar.

Named for the Babylonian god of lust. (M 5039)

\section{(2175) Andrea Doria}

1977 TY. Discovered 1977 Oct. 12 by P. Wild at Zimmerwald.

Named for the head of the Genoan family prominent in Schiller's \{see planet (3079)\} tragedy Die Verschwörung des Fiesco zu Genua. In combination with (2176) Donar, the name suggests the repeated curse of Giannettino Doria (nephew of Andrea) against the Republican conspirators; "Donner und Doria" is now used as an exclamation of dismay. (M 8151)

Name proposed by the discoverer, following a suggestion by W. Gurtner.

This name became known worldwide through the Italian ship which sunk in the Atlantic ocean on 25 July 1956.

\section{(2176) Donar}

2529 P-L. Discovered 1960 Sept. 24 by C. J. van Houten and I. van Houten-Groeneveld at Palomar.

Named for the god of thunderstorms in Teutonic mythology, also honored in some languages by the fifth day of the week. (M 7782)

\section{(2177) Oliver}

6551 P-L. Discovered 1960 Sept. 24 by C. J. van Houten and I. van Houten-Groeneveld at Palomar.

Named in honor of Bernard M. Oliver \{1916-1995\}, retired Vice President for Research and Development of the Hewlett-Packard Company, where he was an innovator in the field of electronic instrumentation. He has made major contributions toward the search for extraterrestrial intelligence, the Monterey Institute for Research in Astronomy, and sky surveying with charge-coupled devices. (M 8541)

Obituary published in Bull. Am. Astron. Soc., Vol. 28, No. 4, p. 1459-1461 (1996).

\section{(2178) Kazakhstania}

1972 RA $_{2}$. Discovered 1972 Sept. 11 by N. S. Chernykh at Nauchnyj.

Named for one of the Soviet Socialist Republics. (M 5285)

Since 1991 the Kazakh Republic is an independent state.

\section{(2179) Platzeck}

1965 MA. Discovered 1965 June 28 by C. U. Cesco and A. R. Klemola at El Leoncito.

Named in honor of Ricardo Pablo Platzeck, director of the Córdoba Observatory; the Córdoba Institute of Mathematics, Physics and Astronomy; and the Balseiro Institute of Atomic Physics at Cuyo University. An authority on the construction, testing and treatment of telescope mirrors, he played an important role in the completion of the $1.5-\mathrm{m}$ reflector at Bosque Alegre in 1941. (M 8798)

\section{(2180) Marjaleena}

1940 RJ. Discovered 1940 Sept. 8 by H. Alikoski at Turku.

Named by the discoverer in honor of his daughter, Marjaleena Johnsson. (M 7944)

\section{(2181) Fogelin}

1942 YA. Discovered 1942 Dec. 28 by K. Reinmuth at Heidelberg.

Named in honor of Eric S. Fogelin \{1961- $\}$, an assistant at the Minor Planet Center during 1979-1980 who has helped extensively in the production of the Minor Planet Circulars and in the preparation of computerized data relevant to the Minor Planet Center. (M 5451)

Name proposed by C. M. Bardwell and B. G. Marsden.

\section{(2182) Semirot}

$1953 \mathrm{FH}_{1}$. Discovered 1953 Mar. 21 at the Goethe Link Observatory at Brooklyn, Indiana.

Named in memory of Pierre Sémirot (1907-1972), who joined the staff of the Bordeaux Observatory in 1931, spent the war years at the Paris Observatory, and served as director of the Bordeaux Observatory from 1947 to 1970 . His work in positional astronomy included collaboration with Paul Herget \{see planet (1751)\} to improve the plate constants of the Bordeaux zone of the Carte du Ciel. He was president of IAU Commission 23 during 1961-1967. (M 8798)

Name proposed by F. K. Edmondson.

Obituary published on l'Astronomie, 87. année, p. 295-297 (1973).

\section{(2183) Neufang}

1959 OB. Discovered 1959 July 26 by C. Hoffmeister at Bloemfontein.

Named for a village in Thuringia where the discoverer lived and worked for many decades. The village is in the vicinity of the Sonneberg \{see planet (1039)\} Observatory, which was established by the discoverer, and it is the current staff members of that Observatory who have proposed the name for this minor planet. (M 18135)

\section{(2184) Fujian}

$1964 \mathrm{TV}_{2}$. Discovered 1964 Oct. 9 at the Purple Mountain Observatory at Nanking.

Named for a coastal province in southeastern China. (M 5184) 


\section{(2185) Guangdong}

1965 WO. Discovered 1965 Nov. 20 at the Purple

Mountain Observatory at Nanking.

Named for a coastal province in southern China. (M 5184)

\section{(2186) Keldysh}

1973 SQ4. Discovered 1973 Sept. 27 by L. I. Chernykh at Nauchnyj.

Named in memory of Academician Mstislav Vsevolodovich Keldysh (1911-1978), famous Soviet scientist and mathematician who made a valuable contribution to space science and engineering. He was president of the U.S.S.R. Academy of Sciences from 1961 to 1975. (M 5849)

Obituary published in Icarus, Vol. 41, p. 320-322 (1980).

\section{(2187) La Silla}

1976 UH. Discovered 1976 Oct. 24 by R. M. West at La Silla.

Named for the mountain in the Chilean Atacama desert on the top of which the European Southern Observatory is situated. (M 5039)

\section{(2188) Orlenok}

1976 UL $_{4}$. Discovered 1976 Oct. 28 by L. V. Zhuravleva at Nauchnyj.

Named on the occasion of the 20th anniversary of the all-Union pioneer camp in the Tuapse region. An orlenok, or an eaglet, is the symbol of the young revolutionary. (M 5849)

\section{(2189) Zaragoza}

1975 QK. Discovered 1975 Aug. 30 at the Felix Aguilar Observatory at El Leoncito.

Named in memory of Aldo Zaragoza (1924-1979), a member of the staff of the Felix Aguilar Observatory for over 20 years. As head of the Calculations Office he was responsible for the analysis and reduction of the plates taken at El Leoncito, and he calculated orbits for the comets and minor planets observed. (M 5524)

\section{(2190) Coubertin}

1976 GV $_{3}$. Discovered 1976 Apr. 2 by N. S. Chernykh at Nauchnyj.

Named in memory of Pierre de Coubertin (18631937), a prominent French public figure, teacher, historian and man of letters. He was responsible for the renaissance of the Olympic Games, and the name is suggested by the discoverer in connection with the 22nd Olympic Games in Moscow. (M 5360)

\section{(2191) Uppsala}

$1977 \mathrm{PA}_{1}$. Discovered 1977 Aug. 6 by C.-I. Lagerkvist at Mount Stromlo.

Named for the ancient Swedish city and university. (M 5285)

\section{(2192) Pyatigoriya}

1972 HP. Discovered 1972 Apr. 18 by T. M. Smirnova at Nauchnyj.

Named on the occasion of the 200th anniversary of the town Pyatigorsk, in the Caucasus. (M 5849)

\section{(2193) Jackson}

1926 KB. Discovered 1926 May 18 by H. E. Wood at Johannesburg.

Named in honor of Cyril V. Jackson \{1903-1988\}, whose $\{70\}$ discoveries of numbered minor planets constitute a record for the southern hemisphere. After working at the former Union Observatory in Johannesburg he was subsequently associated with the Yale-Columbia Southern Station at its successive locations. (M 5451)

Name proposed by C. M. Bardwell and B. G. Marsden

Obituaries published in Mon. Notes Astron. Soc. S. Afr., Vol. 48, No. 7/8, p. 66 (1989); Q.J.R. Astron. Soc., Vol. 32, No. 2, p. 211 (1991).

\section{(2194) Arpola}

1940 GE. Discovered 1940 Apr. 3 by Y. Väisälä at Turku.

Named for the discoverer's summer cottage, located in the archipelago off Turku. A keen sailor, the discoverer yachted from Turku to Arpola about a hundred times each year. (M 7944)

\section{(2195) Tengström}

$1941 \mathrm{SP}_{1}$. Discovered 1941 Sept. 27 by L. Oterma at Turku.

Named in honor of Erik Tengström, emeritus professor at the University of Uppsala, on the occasion of his 70th birthday, 1983 Apr. 3. Initiator of the study of modern geodesy at Uppsala, he directed research in a wide number of subjects, including astronomy. One of his ancestors, Jacob Tengström, lived in Turku, was vice chancellor of the old Academia Aboensis (18031817) and the first archbishop of Finland (1817-1832). (M 7782)

\section{(2196) Ellicott}

1965 BC. Discovered 1965 Jan. 29 at the Goethe Link Observatory at Brooklyn, Indiana.

Named in memory of Andrew Ellicott Douglass (1867-1962), American astronomer and founder in 1901 of the science of dendrochronology. As Percival Lowell's \{see planet (1886)\} principal assistant from 1894 to 1901, Douglass had investigated observing sites in Arizona and Mexico, and upon joining the faculty of the University of Arizona in Tucson in 1906 he mounted a campaign to bring a major observatory to southern Arizona. Through a gift from Lavinia Steward this effort met success with the completion in 1921 of a $0.9-\mathrm{m}$ telescope, and Douglass served as director of the Steward Observatory until 1937. Having already made a mark in the use of dendrochronology for the dating of archaeological ruins, he then founded and 
directed until his 91st year the University's Laboratory for Tree Ring Research. (M 8799)

Name proposed by F. K. Edmondson. Citation prepared by E. Roemer.

\section{(2197) Shanghai}

1965 YN. Discovered 1965 Dec. 30 at the Purple Mountain Observatory at Nanking.

Named for the largest city in China, one of the best known ports in the world, located at the mouth of the Yangtze River. (M 6059)

\section{(2198) Ceplecha}

1975 VF. Discovered 1975 Nov. 7 at the Harvard College Observatory at Harvard.

Named in honor of the Czechoslovak astronomer Zdeněk Ceplecha, well known for his work on meteors. His investigation of the Pribram meteorite represents the first time that an accurate orbit could be derived for such an object. (M 5285)

\section{(2199) Kleð̃}

1978 LA. Discovered 1978 June 6 by A. Mrkos at Kleť.

Named for the observatory at which this minor planet was discovered and for the mountain in southern Bohemia on which the observatory is located. (M 5524)

\section{(2200) Pasadena}

6090 P-L. Discovered 1960 Sept. 24 by C. J. van Houten and I. van Houten-Groeneveld at Palomar.

Named for a suburb of Los Angeles, California. Prominent astronomical institutions in Pasadena are the California Institute of Technology (which operates Palomar Observatory), the Mount Wilson Observatory of the Carnegie Institution of Washington, and the Jet Propulsion Laboratory. (M 5524)

Name proposed by E. Bowell.

\section{(2201) Oljato}

1947 XC. Discovered 1947 Dec. 12 by H. L. Giclas at Flagstaff.

Named for the place of Moonlight Water near Monument Valley, Utah, on the Navajo Indian Reservation. During the day the hot Sun evaporates the small amount of spring water that seeps up through the sand. During the night, with less evaporation, the sand becomes moist enough to reflect the light of the Moon. (M 7782; M 8025)

This Apollo object was rediscovered as $1979 \mathrm{XA}$ on 1979 Dec. 13 by Q. Passey and S. J. Bus at Palomar.

\section{(2202) Pele}

1972 RA. Discovered 1972 Sept. 7 by A. R. Klemola at Mount Hamilton.

Named for the goddess of fire in Hawaiian legend. She made her home in the volcanoes Kilauea, after being driven out of the western sea by her angry sister, the sea goddess. (M 5360)

\section{(2203) van Rhijn}

1935 SQ1. Discovered 1935 Sept. 28 by H. van Gent at Johannesburg.

Named in memory of Pieter J. van Rhijn (1886-1960), Dutch astronomer, former director of the Kapteyn Astronomical Laboratory at Groningen. His main activity was the investigation of the Galactic structure. (M 18135)

Van Rhijn is also honored by a lunar crater.

\section{(2204) Lyyli}

1943 EQ. Discovered 1943 Mar. 3 by Y. Väisälä at Turku.

Named in honor of Lyyli Heinanen (née Hartonen), a disciple of the discoverer. In 1927, as a student, she assisted in the first attempt to measure a length of $192 \mathrm{~m}$ by the Väisälä interference method. It was winter, the weather was very cold, and it seemed that the experiment would fail. She urged that they try once more, and the interferences were found. Later she taught mathematics in secondary school and was for many years chairman of the society Mikkelin Ursa for amateur astronomers. (M 7944)

\section{(2205) Glinka}

1973 SU $_{4}$. Discovered 1973 Sept. 27 by L. I. Chernykh at Nauchnyj.

Named for Mikhail Ivanovich Glinka (1804-1857), celebrated composer and the acknowledged founder of Russian classical music. (M 5849)

\section{(2206) Gabrova}

1976 GR $_{3}$. Discovered 1976 Apr. 1 by N. S. Chernykh at Nauchnyj.

Discovered on All Fools' Day, this minor planet is named for the Bulgarian town known for its humor and high-spirited merriment. (M 5849)

\section{(2207) Antenor}

1977 QH$_{1}$. Discovered 1977 Aug. 19 by N. S. Chernykh at Nauchnyj.

This Trojan planet is named for the Trojan hero and sage who called for peace with the Greeks. He advised the citizens of Troy to put an end to the war by returning the kidnapped Helena to her husband Menelaus \{see planets (101) and (1647)\}. (M 5849)

\section{(2208) Pushkin}

1977 QL $_{3}$. Discovered 1977 Aug. 22 by N. S. Chernykh at Nauchnyj.

Named for the great Russian poet Aleksandr Sergeevich Pushkin (1799-1837). (M 5849)

\section{(2209) Tianjin}

1978 US $_{1}$. Discovered 1978 Oct. 28 at the Purple Mountain Observatory at Nanking.

Named for the largest port city in northern China, site of the latitude station of the Peking Observatory. (M 6059) 
(2210) Lois

9597 P-L. Discovered 1960 Sept. 24 by C. J. van Houten and I. van Houten-Groeneveld at Palomar.

Named in honor of Lois J. Baldwin, spouse of Ralph B. Baldwin, author of several books, including the pioneering studies The face of the Moon and The measure of the Moon. (M 11155)

\section{(2211) Hanuman}

$1951 \mathrm{WO}_{2}$. Discovered 1951 Nov. 26 by L. E. Cunningham at Mount Wilson.

Named for the monkey-god in the mythology of India. Son of Vayu, Hanuman was gifted with almost unlimited physical strength, powerful virility and total chastity, a combination that made him the perfect worshipper of Rama. After a great victory, Rama gave a necklace of fine pearls to Hanuman, who proceeded to break them apart one after another with his teeth. After inspection Hanuman threw away the pieces. "They do not contain the name of Rama", he declared, "and have no value". Then he tore open his own chest, and on his heart in letters of flame stood out the name of Rama. (M 21605)

Named by the Minor Planet Names Committee following a suggestion by F. Pilcher.

\section{(2212) Hephaistos}

1978 SB. Discovered 1978 Sept. 27 by L. I. Chernykh at Nauchnyj.

This Apollo-type object is named for the god of fire and blacksmiths. (M 5849)

\section{(2213) Meeus}

$1935 \mathrm{SO}_{1}$. Discovered 1935 Sept. 24 by E. Delporte at Uccle.

Named in honor of the Belgian amateur astronomer and professional meteorologist Jean Meeus, among whose numerous contributions to astronomy are the original 1963 edition of Tables des Petites Planètes and improved and updated versions of Oppolzer's canon of eclipses. His other writings range from dynamical studies of long-term motions of Apollo objects, through examinations of geometrical configurations of the planets, to the debunking of the idea that there exist observations of faint natural satellites of the Earth. (M 6208)

Name proposed by E. Bowell, who made the key identification for this planet, and also by J. U. Gunter, following a suggestion by E. Fogelin.

\section{(2214) Carol}

1953 GF. Discovered 1953 Apr. 7 by K. Reinmuth at Heidelberg.

Named by the Minor Planet Center for Carol D. Valenti, in honor of her service as secretarial assistant to the Central Bureau for Astronomical Telegrams since 1974 and to the Minor Planet Center since 1978. (M 6833)

\section{(2215) Sichuan}

1964 VX $_{2}$. Discovered 1964 Nov. 12 at the Purple Mountain Observatory at Nanking.

Named for the most populous province of China, noted for its agricultural products. (M 6059)

\section{(2216) Kerch}

1971 LF. Discovered 1971 June 12 by T. M. Smirnova at Nauchnyj.

Named for the hero city in the Crimea. (M 5850)

\section{(2217) Eltigen}

$1971 \mathrm{SK}_{2}$. Discovered 1971 Sept. 26 by T. M. Smirnova at Nauchnyj.

Named for the site of the heroic landing of Soviet troops in the Crimea in November 1943. (M 5850)

\section{(2218) Wotho}

1975 AK. Discovered 1975 Jan. 10 by P. Wild at Zimmerwald.

Named for an atoll in the Ralik Chain in the Pacific, perhaps an appropriate variation of (1282) Utopia. (M 8152)

Name proposed by the discoverer following a suggestion by R. Fiedler, formerly director of the public relations office at the California Institute of Technology.

\section{(2219) Mannucci}

1975 LU. Discovered 1975 June 13 at the Felix Aguilar Observatory at El Leoncito.

Named in memory of Edgardo Mannucci, outstanding precision mechanic, whose work at the Felix Aguilar Observatory benefited astronomy in Argentina for many years. He played an important part in setting up the meridian circle and Danjon \{see planet (1594)\} astrolabe and the adaption of the K-50 geodesic camera for observations of artificial satellites. Chief of precision work in the department of geodesy, topography and cartography of San Juan, and a valued member of the faculty of engineering at the Cuyo National University, he had previously served as assistant chief for the light and buoy workshop in the Argentine Naval Hydrographic Service. (M 8152)

\section{(2220) Hicks}

1975 VB. Discovered 1975 Nov. 4 by E. F. Helin at Palomar.

Named in honor of William B. Hicks, alumnus of the California Institute of Technology, distinguished engineer, businessman and supporter of the sciences. (M 5285)

Name proposed by E. F. Helin and E. M. Shoemaker.

\section{(2221) Chilton}

1976 QC. Discovered 1976 Aug. 25 at the Harvard College Observatory at Harvard.

Named in honor of Jean Chilton McCrosky, wife of Harvard-Smithsonian astronomer Richard E. McCrosky \{see planet (1880)\}. (M 5285) 


\section{(2222) Lermontov}

$1977 \mathrm{ST}_{1}$. Discovered 1977 Sept. 19 by N. S. Chernykh at Nauchnyj.

Named for the great Russian poet Mikhail Yur'evich Lermontov (1814-1841). (M 5850)

\section{(2223) Sarpedon}

1977 TL $_{3}$. Discovered 1977 Oct. 4 at the Purple Mountain Observatory at Nanking.

One of the leaders of the Lycians, Sarpedon was killed by Patroclus $\{$ see planet (617) $\}$ in the Trojan War. At the command of Zeus \{see planet (5731)\}, his body was seized by Apollo \{see planet (1862)\} and returned to Lycia. (M 6208)

\section{(2224) Tucson}

2528 P-L. Discovered 1960 Sept. 24 by C. J. van Houten and I. van Houten-Groeneveld at Palomar.

Named for the city in Arizona. Prominent astronomical institutions in Tucson are the Lunar and Planetary Laboratory of the University of Arizona, Kitt Peak National Observatory, and Steward Observatory. (M 5524)

Name proposed by E. Bowell.

\section{(2225) Serkowski}

6546 P-L. Discovered 1960 Sept. 24 by C. J. van Houten and I. van Houten-Groeneveld at Palomar.

Named in memory of Krzysztof M. Serkowski (19301981), an astronomer distinguished particularly in the fields of interstellar polarization and the development of astronomical instrumentation. Despite a debilitating illness during the last eight years of his life, he remained actively working and maintained a serene and courageous attitude. (M 8541)

Obituary published in Astron. Q., Vol. 4, p. 76-81 (1982).

\section{(2226) Cunitza}

1936 QC $_{1}$. Discovered 1936 Aug. 26 by A. Bohrmann at Heidelberg.

Named by the discoverer for the family of his sister-in-law, Lydia Cunitz. (M 5451)

\section{(2227) Otto Struve}

1955 RX. Discovered 1955 Sept. 13 at the Goethe Link Observatory at Brooklyn, Indiana.

Named in memory of Otto Struve (1897-1963), last of a remarkable astronomical lineage. His greatgrandfather, Wilhelm Struve \{see planet (768)\}, founded the Pulkovo Observatory in 1839; his grandfather (Otto), uncle (Hermann) and father (Ludwig) were also distinguished astronomers. Following a period of great privation and misery after World War I, he was invited by Edwin B. Frost \{see planet (854)\} to come to Yerkes Observatory in 1921. He started working in spectroscopy and remained a spectroscopist to the end of his days. He succeeded Frost as Yerkes director in 1932 and was the major force responsible for the establishment of the McDonald Observatory in 1933. Managing editor of the Astrophysical Journal from 1932 to 1947 , he raised it to the preeminent position it now occupies. He became head of the astronomy department of the University of California in Berkeley in 1950, and he served as director of the National Radio Astronomy Observatory from 1960 to 1962 . He served as president of the IAU during 1952-1955. (768) Struveana is named for three of his ancestors; following in their footsteps, Otto Struve received the Royal Astronomical Society's gold medal in 1944. (M 8912)

Name proposed by F. K. Edmondson.

Struve is also honored by a lunar crater.

\section{(2228) Soyuz-Apollo}

1977 OH. Discovered 1977 July 19 by N. S. Chernykh at Nauchnyj.

Named in honor of the joint Soviet-American space flight in 1975. (M 5850)

\section{(2229) Mezzarco}

1977 RO. Discovered 1977 Sept. 7 by P. Wild at Zimmerwald.

Italian for "half arch, half vault", the name is that of the house and studio, on Lake Maggiore, of a friend of the discoverer. A painting of hers, The Separation of the Elements, is from a cycle Creation. The name is therefore suggested for this planet because (2229) = $3 \times$ (743) Eugenisis. (M 8152)

\section{(2230) Yunnan}

$1978 \mathrm{UT}_{1}$. Discovered 1978 Oct. 29 at the Purple Mountain Observatory at Nanking.

Named for a province along the southwestern border of China. The Yunnan Observatory is situated in its capital city of Kunming. (M 6059)

\section{(2231) Durrell}

1941 SG. Discovered 1941 Sept. 21 by S. Arend at Uccle.

Named in honor of the British writer Lawrence Durrell, author of the Alexandria Quartet (Justine, Balthazar, Mountolive and Clea) and a friend of the Arend family. (M 8152)

\section{(2232) Altaj}

$1969 \mathrm{RD}_{2}$. Discovered 1969 Sept. 15 by B. A. Burnasheva at Nauchnyj.

Named by the discoverer for the place of residence of her mother, Elena Andreevna Vasil'eva. (M 5850)

\section{(2233) Kuznetsov}

$1972 \mathrm{XE}_{1}$. Discovered 1972 Dec. 3 by L. V. Zhuravleva at Nauchnyj.

Named in memory of Nikolaj Ivanovich Kuznetsov (1911-1944), hero of the Soviet Union, renowned participant in the partisan movement during the Second World War. (M 5850) 


\section{(2234) Schmadel}

1977 HD. Discovered 1977 Apr. 27 by H.-E. Schuster at La Silla.

Named in honor of Lutz D. Schmadel \{1942- \}, Astronomisches Rechen-Institut, computer of orbits and ephemerides of minor planets, and Editor of Astronomy and Astrophysics Abstracts. The lost objects (1206) Numerowia and (1370) Hella were recovered as the result of his calculations. (M 5285)

\section{(2235) Vittore}

A924 GA. Discovered 1924 Apr. 5 by K. Reinmuth at Heidelberg.

Named in honor of the Osservatorio S. Vittore, Bologna, where this object was rediscovered in 1979. It was a result of the extensive and careful series of observations there by a dedicated group of amateur astronomers that the earlier observations could be identified and the object permanently numbered. (M 5524)

\section{(2236) Austrasia}

1933 FX. Discovered 1933 Mar. 23 by K. Reinmuth at Heidelberg.

Named for the eastern kingdom of the Merovingian Franks from the sixth to the eighth centuries. Austrasia embodied an extensive region on both sides of the Rhine, with Metz as its capital. (M 5524)

Name proposed by E. Bowell, who found one of the identifications involving this planet.

\section{(2237) Melnikov}

1938 TB. Discovered 1938 Oct. 2 by G. N. Neujmin at Simeis.

Named in memory of Oleg Aleksandrovich Melnikov (1912-1982), on the staff of the Pulkovo Observatory since 1933 and a professor at Leningrad University since 1947. His scientific research was centered on the study of the Sun, stellar astronomy and interstellar matter by spectroscopic methods. He was also concerned with astronomical instruments and served as president of IAU Commission 9. (M 8912)

Obituaries published in Astron. Zh., Tom 59, p. 10361037 (1982); Astrofizika, Tom 18, Vyp. 3, p. 498-500 (1982); Zemlya Vselennaya, No. 1, p. 46-47 (1983).

\section{(2238) Steshenko}

1972 RQ1. Discovered 1972 Sept. 11 by N. S. Chernykh at Nauchnyj.

Named in honor of Nikolaj Vladimirovich Steshenko \{1927- \}, deputy director of the Crimean Astrophysical Observatory, whose comprehensive support has contributed to the success of the program for the discovery and observation of minor planets. Well-known for his work in solar physics, he is in charge of the program of solar observations from space, and he is the author of the design for the Soviet 25-m-diameter mosaic optical telescope. (M 5850)

\section{(2239) Paracelsus}

1978 RC. Discovered 1978 Sept. 13 by P. Wild at Zimmerwald.

Named for the great physician and natural philosopher whose real name was Theophrastus Bombastus von Hohenheim (1493?-1541). Because of his vehement fight against traditions, he was hounded throughout Europe during his lifetime, but with his concept of dosages of medicaments, he clearly set the foundations for modern medicine and pharmacology. (M 8152)

Paracelsus is also honored by a lunar crater.

\section{(2240) Tsai}

1978 YA. Discovered 1978 Dec. 30 at the Harvard College Observatory at Harvard.

Named in honor of Tsai Chang-hsien, director of the Taipei Observatory since World War II, an active observer of planets and variable stars, and a long-time popularizer of astronomy. He has enlightened the public and directed amateur activity in astronomy for more than three decades with great patience and dedication. (M 5360)

\section{(2241) Alcathous}

1979 WM. Discovered 1979 Nov. 22 by C. T. Kowal at Palomar.

Alcathous proved himself the noblest suitor in all of Troy by marrying Hippodamia \{see planet (692)\}, eldest and dearest daughter of Anchises ssee planet (1173)\}, who excelled all other girls of her age in beauty, skill and wit. As the Trojans achieved their greatest advance toward the Greek ships, Alcathous, previously uninjured in the Trojan War, was struck by Poseidon \{see planet (4341)\} with blindness and paralysis. In this hapless state he was killed easily by a spear thrown by Idomeneus \{see planet (2759)\}. (M 21128)

Named by the Minor Planet Names Committee following a suggestion by F. Pilcher.

\section{(2242) Balaton}

1936 TG. Discovered 1936 Oct. 13 by G. Kulin at Budapest.

Named for the largest lake in Hungary, located in the western part of the country. (M 21605)

Named by the Minor Planet Names Committee following a suggestion of F. Pilcher.

\section{(2243) Lönnrot}

1941 SA $_{1}$. Discovered 1941 Sept. 25 by Y. Väisälä at Turku.

Named for Elias Lönnrot (1802-1884), a physician in Kajaani and later professor of the Finnish language in Helsinki. While on extensive walking tours he wrote down a great number of runes and other traditional poems. He published the Finnish national epic Kalevala \{see planet (1454)\} and numerous medical, philosophical and other works. (M 7944) 


\section{(2244) Tesla}

1952 UW $_{1}$. Discovered 1952 Oct. 22 by M. B. Protitch at Belgrade.

Named in memory of Nikola Tesla (1856-1943), the famous Yugoslav-born physicist well known for his numerous scientific researches and discoveries in the field of multi-phase and high frequency currents and radio electro-communications. (M 9477)

Tesla is also honored by a lunar crater.

\section{(2245) Hekatostos}

1968 BC. Discovered 1968 Jan. 24 by L. I. Chernykh at Nauchnyj.

The Greek ordinal number acknowledges this as the 100th minor planet to be numbered as a result of the joint observational program of the Institute for Theoretical Astronomy in Leningrad and the Crimean Astrophysical Observatory at Nauchnyj. (M 5850)

\section{(2246) Bowell}

1979 XH. Discovered 1979 Dec. 14 by E. Bowell at Anderson Mesa.

Named in honor of Edward L. G. Bowell, Lowell Observatory astronomer who has made and who continues to make impressive contributions in many areas of minor planet astronomy. Following his comprehensive UBV photoelectric photometry of minor planets, he has revived and augmented the Lowell photographic astrometric program and has discovered several new objects. He also does extensive orbital work on minor planets, including the establishment of identifications and the prediction of occultations. (M 5688)

Name proposed by B. G. Marsden.

\section{(2247) Hiroshima}

6512 P-L. Discovered 1960 Sept. 24 by C. J. van Houten and I. van Houten-Groeneveld at Palomar.

Named for the Japanese city Hiroshima in the hope that this planet may be a symbol for world peace. (M 14207)

\section{(2248) Kanda}

1933 DE. Discovered 1933 Feb. 27 by K. Reinmuth at Heidelberg.

Named in memory of Shigeru Kanda (1894-1974), a staff member of the Tokyo Astronomical Observatory from 1920 to 1943 and a leading source of inspiration and encouragement to amateur astronomers in Japan. He published papers on observations of minor planets, comets and variable stars, identifications of minor planets, orbits of comets, and the history of Japanese and Chinese astronomy. He wrote several popular books on astronomy and in 1926 began publication of the Kanda Circular for amateur astronomers. After leaving Tokyo Observatory he founded the Kanda Astronomical Society, which later became the Japan Astronomy Study Group. (M 6647)

Name proposed by T. Urata, who found the identifications for this planet.

\section{(2249) Yamamoto}

1942 GA. Discovered 1942 Apr. 6 by K. Reinmuth at Heidelberg.

Named in memory of Issei Yamamoto (1889-1959), professor of astronomy at Kyoto University, director of the Kwasan Observatory, and first president of the IAU commission on the zodiacal light. The most well-known popularizer of astronomy in Japan, he founded the Oriental Astronomical Association in 1920 and was a source of encouragement for many amateur astronomers in Japan. (M 6648)

Name proposed by S. Nakano, who determined the orbit for this planet.

Yamamoto is also honored by a lunar crater.

\section{(2250) Stalingrad}

1972 HN. Discovered 1972 Apr. 18 by T. M. Smirnova at Nauchnyj.

Named in commemoration of the fierce battle for the city. The victory by the defenders was an important turning point in World War II. The city is now called Volgograd. (M 6648)

\section{(2251) Tikhov}

1977 SU $_{1}$. Discovered 1977 Sept. 19 by N. S. Chernykh at Nauchnyj.

Named in memory of Gavriil Adrianovich Tikhov (1875-1960), active on the staff of the Pulkovo Observatory during 1906-1941 and from 1947 head of the astrobotanical department of the Kazakh Academy of Sciences. His principal scientific work was concerned with stellar and planetary photometry and colorimetry and with atmospheric optics. He was also known for his research on the physical nature of Mars. (M 5451)

Tikhov is also honored by craters on Mars and the Moon.

\section{(2252) CERGA}

1978 VT. Discovered 1978 Nov. 1 by K. Tomita at Caussols.

Named for the Centre d'Etudes et de Recherches Géodynamiques et Astronomiques, which operates the 0.9-m Schmidt telescope at Caussols-Cipieres with which this minor planet was discovered. (M 5451)

\section{(2253) Espinette}

1932 PB. Discovered 1932 July 30 by G. Van Biesbroeck at Williams Bay. Independently discovered 1932 July 31 by C. Jackson at Johannesburg and August 4 by G. N. Neujmin at Simeis.

Named for the discoverer's residence in Williams Bay, Wisconsin. For many of the 45 years the discoverer worked at the Yerkes Observatory. The Van Biesbroecks fed and housed students and visiting astronomers from all over the world. The name originally comes from a small cafe in one of the parks in Brussels. (M 6059)

Name proposed by the discoverer's children, Edwin Van Biesbroeck, Simone Van Biesbroeck Titus and Micheline Van Biesbroeck Wilson. 
(2254) Requiem

1977 QJ $_{1}$. Discovered 1977 Aug. 19 by N. S. Chernykh at Nauchnyj.

The name is dedicated to the memory of the discoverer's mother, Melaniya Petrovna Chernykh, who died on 1977 Aug. 19, the day that this minor planet was discovered. (M 5524)

\section{(2255) Qinghai}

1977 VK $_{1}$. Discovered 1977 Nov. 3 at the Purple Mountain Observatory at Nanking.

Named for a large province in the western part of China. The sources of the two largest rivers in China, the Yellow River and the Yangtze, are in this province. (M 6059)

\section{(2256) Wisniewski}

4519 P-L. Discovered 1960 Sept. 24 by C. J. van Houten and I. van Houten-Groeneveld at Palomar.

Named in honor of Wieslaw Z. Wisniewski \{19311994\}, astronomer at the University of Arizona. Wisniewski worked on the lightcurves of comets and minor planets, especially Earth-approaching objects. He was a leading authority on photometric standards and on photometry with CCDs as well as with photomultipliers. (M 16040)

Obituaries published in Minor Planet. Bull., Vol. 21, No. 2, p. 20 (1994); Icarus, Vol. 112, No. 2, p. 300-301 (1994); Q.J.R. Astron. Soc., Vol. 37, No. 4, p. 845 (1996); Bull. Am. Astron. Soc., Vol. 26, No. 4, p. 1611-1612 (1994); Postepy Astron., Tom 43, No. 1, p. 41-43 (1995).

\section{(2257) Kaarina}

1939 QB. Discovered 1939 Aug. 18 by H. Alikoski at Turku.

Named by the discoverer in honor of his daughter, Kaarina Soini. (M 7944)

\section{(2258) Viipuri}

1939 TA. Discovered 1939 Oct. 7 by Y. Väisälä at Turku.

Named for an old Finnish town on the Gulf of Finland. Runic inscriptions mention Viipuri as a market place in the eleventh century. The Scandinavian name is Viborg. At present the town belongs to Russia. (M 7945)

\section{(2259) Sofievka}

1971 OG. Discovered 1971 July 19 by B. A. Burnasheva at Nauchnyj.

Named for a dendrological park in Uman', in the Cherkasskaya district of the \{former\} Ukrainian SSR. The park is a monument to the landscaping and architecture of the 18th and 19th centuries. (M 8912)

\section{(2260) Neoptolemus}

$1975 \mathrm{WM}_{1}$. Discovered 1975 Nov. 26 at the Purple

Mountain Observatory at Nanking.

The son of Achilles and Deidameia, Neoptolemus was brought to Troy by Odysseus in the last year of the Trojan War. He was one of the warriors in the wooden horse and was responsible for the death of Priam. (M 6208)

See also the citations for (588) Achilles, (3912) Troja, (1143) Odysseus, and (884) Priamus, respectively.

\section{(2261) Keeler}

1977 HC. Discovered 1977 Apr. 20 by A. R. Klemola at Mount Hamilton.

Named in memory of James Edward Keeler (18571900), pioneer American astrophysicist and second director of the Lick Observatory. He measured accurately the wavelengths of the chief nebular lines, confirmed spectroscopically the particle nature of Saturn's rings and recognized the spiral "nebulae" as numerous, important constituents of the universe. In 1899 he also discovered photographically with the Crossley reflector the faint minor planet (452) Hamiltonia. (M 13172)

Citation prepared by D. E. Osterbrock.

Keeler is also honored by craters on Mars and the Moon.

\section{(2262) Mitidika}

1978 RB. Discovered 1978 Sept. 10 by P. Wild at Zimmerwald.

Named for the gypsy girl of great charm and courage, one of the central figures in Clemens Brentano's novel Die mehreren Wehmüller und ungarischen Nationalgesichter. (M 8152)

\section{(2263) Shaanxi}

$1978 \mathrm{UW}_{1}$. Discovered 1978 Oct. 30 at the Purple Mountain Observatory at Nanking.

Named for a province in central China, near the upper reaches of the Yellow River. Its capital, Xi'an \{see planet (2387)\}, is one of the best known ancient cities in the country. (M 6059)

\section{(2264) Sabrina}

1979 YK. Discovered 1979 Dec. 16 by E. Bowell at Anderson Mesa.

Named for a legendary English princess, daughter of King Locrine. Along with her mother, Sabrina was drowned in the River Severn by Locrine's angry widow. Sabrina became the Roman name for the River Severn. (M 5451)

\section{(2265) Verbaandert}

1950 DB. Discovered 1950 Feb. 17 by S. Arend at Uccle.

Named in memory of Jean Verbaandert (1901-1974), a Belgian astronomer who was a colleague of the discoverer for many years. (M 8403)

\section{(2266) Tchaikovsky}

1974 VK. Discovered 1974 Nov. 12 by L. I. Chernykh at Nauchnyj.

Named in memory of the celebrated Russian composer Petr Il'ich Chajkovskij (1840-1893). (M 7782) 


\section{(2267) Agassiz}

1977 RF. Discovered 1977 Sept. 9 at the Harvard College Observatory at Harvard.

Named in memory of Jean Louis Rodolphe Agassiz (1807-1873), Swiss-born naturalist, later a professor at Harvard, where he was the leading U.S. opponent of Darwin; his son Alexander Agassiz (1835-1910), marine zoologist and oceanographer; and his grandson George Russell Agassiz (1862-1951), for many years a friend and benefactor of the Harvard Observatory and for whom the Agassiz Station is named. (M 5451)

Agassiz is also honored by a crater on Mars.

\section{(2268) Szmytowna}

1942 VW. Discovered 1942 Nov. 6 by L. Oterma at Turku.

Named in honor of the distinguished Polish scientist Maria Szmytowna on the occasion of her eightieth birthday, 1983 March 26. A professor of inorganic and analytical chemistry at the Akademia Medyczna w Poznaniu, she has done extensive research work for half a century on waters and mineral springs and is an active member of many societies in the areas of balneology and hydrobiology. (M 7945)

\section{(2269) Efremiana}

$1976 \mathrm{JA}_{2}$. Discovered 1976 May 2 by N. S. Chernykh at Nauchnyj.

Named in memory of Ivan Antonovich Efremov (1907-1972), renowned paleontologist and the author of historical, science-fiction and adventure novels. (M 7782)

\section{(2270) Yazhi}

1980 ED. Discovered 1980 Mar. 14 by E. Bowell at Anderson Mesa.

The name comes from the Navajo Indian language and means 'little one'. (M 5525)

The name was suggested by Debbie Geoffrion.

\section{(2271) Kiso}

$1976 \mathrm{UV}_{5}$. Discovered 1976 Oct. 22 by H. Kosai and K. Hurukawa at Kiso.

Named for the station of the Tokyo Observatory at which this minor planet was discovered. (M 5525)

\section{(2272) Montezuma}

1972 FA. Discovered 1972 Mar. 16 by T. Gehrels at Palomar.

Named in honor of the ninth emperor of the Aztec empire, who reigned 1502-1520. He believed that his land rightly belonged to the serpent god Quetzálcoatl \{see planet (1915)\}, who one day would return from the East. When the first Spanish invaders landed in Central America, Montezuma interpreted them as the followers of Quetzálcoatl returning. After only feeble negotiation, he allowed Cortez to occupy his capital city peacefully and rule through him. During Cortez' temporary absence hostilities developed between Spaniards and Aztecs in which Montezuma was among the first killed. (M 21605)
Named by the Minor Planet Names Committee following a suggestion by F. Pilcher.

\section{(2273) Yarilo}

$1975 \mathrm{EV}_{1}$. Discovered 1975 Mar. 6 by L. I. Chernykh at Nauchnyj.

Named for the ancient Slavic god of the Sun, spring, fertility and love. (M 7783)

\section{(2274) Ehrsson}

1976 EA. Discovered 1976 Mar. 2 by C.-I. Lagerkvist at Kvistaberg.

Named in honor of a friend of the discoverer. (M 5525)

\section{(2275) Cuitlahuac}

1979 MH. Discovered 1979 June 16 by H.-E. Schuster at La Silla.

Named in honor of the tenth emperor of the Aztec empire, who reigned briefly in 1520 . Brother of Montezuma \{see planet (2272)\}, he was released from captivity by Cortez to negotiate a dispute. Immediately he rallied the Aztecs to battle the Spaniards. After many days of fierce fighting in which thousands of Aztec warriors were killed, Cuitlahuac drove Cortez from the city with the loss of over half his men and all his treasure. Within a few months Cuitlahuac and uncounted thousands of his fellow Aztecs died from smallpox brought by an occupying Spanish soldier. (M 21605)

Named by the Minor Planet Names Committee following a suggestion by F. Pilcher.

\section{(2276) Warck}

1933 QA. Discovered 1933 Aug. 18 by E. Delporte at Uccle. Independently discovered 1933 August 19 by G. N. Neujmin at Simeis.

Named in honor of the family of Evelyne (née Delporte) Warck, granddaughter of the discoverer. (M 8403)

\section{(2277) Moreau}

1950 DS. Discovered 1950 Feb. 18 by S. Arend at Uccle.

Named in memory of Fernand Moreau (1888-1979), a long-time colleague of the discoverer at the Uccle Observatory. (M 8403)

Obituary published in Ciel Terre, Vol. 96, p. 123-124 (1980).

\section{(2278) Götz}

1953 GE. Discovered 1953 Apr. 7 by K. Reinmuth at Heidelberg.

Named in memory of Paul Götz, first assistant of Max Wolf \{see planets (827) and (1217)\} at the Heidelberg-Königstuhl Observatory during 1903-1905. Götz was a skillful and diligent observer with the Bruce telescope and the 0.15-m astrograph. He discovered 20 minor planets. (M 18447)

Name proposed and citation prepared by G. Klare and L. D. Schmadel. 


\section{(2279) Barto}

1968 DL. Discovered 1968 Feb. 25 by L. I. Chernykh at Nauchnyj.

Named in memory of Agniya Lvovna Barto (19061982), a famous Soviet poetess, who dedicated all her works to children. (M 7783)

\section{(2280) Kunikov}

$1971 \mathrm{SL}_{2}$. Discovered 1971 Sept. 26 by T. M. Smirnova at Nauchnyj.

Named in memory of Tzezar' L'vovich Kunikov (1909-1943), commander of the landing party that seized Malaya Zemlya in the Novorossijsk region in February 1943. (M 6059)

\section{(2281) Biela}

1971 UQ 1 . Discovered 1971 Oct. 26 by L. Kohoutek at Bergedorf.

Named in memory of Wilhelm von Biela (17821850), Austrian military officer and astronomer, who discovered comet $1826 \mathrm{I}$ in Josefov, Bohemia. The comet is famous for having split and disappeared and for helping establish the connection between comets and meteors. In 1971 the discoverer of this minor planet tried unsuccessfully to recover the comet. (M 22244) Biela is also honored by a lunar crater.

\section{(2282) Andrés Bello}

1974 FE. Discovered 1974 Mar. 22 by C. Torres at Cerro El Roble.

Named for Andrés Bello, Venezuelan intellectual, first rector of the University of Chile, who helped establish the Observatorio Astronomico Nacional in Santiago in 1852. Bello persuaded the Chilean government to purchase the equipment brought to Chile by a U.S. Naval Observatory team headed by J. M. Gillis. This homage is made in 1981 to commemorate the bicentennial of Bello's birth. (M 6531)

\section{(2283) Bunke}

$1974 \mathrm{SV}_{4}$. Discovered 1974 Sept. 26 by L. V. Zhuravleva at Nauchnyj.

Named in memory of the German patriot Tamara Bunke (1937-1967). (M 7616)

\section{(2284) San Juan}

1974 TG$_{1}$. Discovered 1974 Oct. 10 at the Felix Aguilar Observatory at El Leoncito.

Named for the university of which the Felix Aguilar \{see planet (1800)\} Observatory is a part and for the Argentine state in which it is located. (M 8152)

\section{(2285) Ron Helin}

1976 QB. Discovered 1976 Aug. 27 by S. J. Bus at Palomar.

Named in honor of Ronald P. Helin, husband of Eleanor F. Helin. His never-ending friendship and encouragement have been invaluable to the success of the Palomar planet-crossing asteroid survey. (M 6531)

\section{(2286) Fesenkov}

1977 NH. Discovered 1977 July 14 by N. S. Chernykh at Nauchnyj.

Named in memory of Vasilej Grigor'evich Fesenkov (1889-1972), one of the founders of the study of astrophysics in the U.S.S.R. His scientific activities covered a wide range of topics, including solar and stellar physics, the Moon and planets, atmospheric optics, meteoritics and cosmogony. From 1924 to 1964 he was editor of the Astronomicheskij Zhurnal and from 1945 Chairman of the Committee on Meteorites of the U.S.S.R. Academy of Sciences. (M 5525)

Fesenkov is also honored by a crater on Mars. Obituaries published in Astron. Zhurn., Vol. 49, p. 678-682 (1972); Sky Telesc., Vol. 43, p. 284 (1972); Zemlya Vselennaya, No. 3, p. 46-47 (1972); Astron. Tsirk., No. 713, p. 4-7 (1972); Meteoritika, No. 3, p. 162-163 (1972); Trudy Astrofiz. Inst. Alma Ata, Vol. 19, p. 129 (1972); Vestn. AN KazSSR, No. 4, p. 67 (1972); Irish Astron. J., Vol. 11, p. 162 (1973).

\section{(2287) Kalmykia}

1977 QK $_{3}$. Discovered 1977 Aug. 22 by N. S. Chernykh at Nauchnyj.

Named for one of the autonomous republics of the \{former\} R.S.F.S.R. (M 5688)

\section{(2288) Karolinum}

1979 UZ. Discovered 1979 Oct. 19 by L. Brožek at Klět.

Named for the original main building, still in use, of the Charles University, founded in Prague in 1348. (M 5525)

Charles University is also honored by planet (4339).

\section{(2289) McMillan}

6567 P-L. Discovered 1960 Sept. 24 by C. J. van Houten and I. van Houten-Groeneveld at Palomar.

Named in honor of Robert S. McMillan, astronomer at the University of Arizona. McMillan heads the radial velocity program that searches for planets of other stars. He also works for Spacewatch, being instrumental in that project's development for the discovery of asteroids and comets. (M 16040)

\section{(2290) Helffrich}

1932 CD $_{1}$. Discovered 1932 Feb. 14 by K. Reinmuth at Heidelberg.

Named in memory of $\mathrm{J}$ \{oseph\} Helffrich \{1890-1971\}, on the staff of the Heidelberg-Königstuhl Observatory between 1909 and 1911. As an assistant of Max Wolf \{see planets (827) and (1217)\}, he discovered 13 numbered minor planets. (M 18447)

Name proposed and citation prepared by G. Klare and L. D. Schmadel.

\section{(2291) Kevo}

1941 FS. Discovered 1941 Mar. 19 by L. Oterma at Turku.

Named for the field station of the University of Turku's Kevo Subarctic Research Institute. Situated in 
the valley of the river Kevo in far Lappland at latitude $69^{\circ} 45^{\prime}$, the station cooperates with other research centers above the Arctic circle in the study of biology and Earth sciences. (M 7945)

\section{(2292) Seili}

1942 RM. Discovered 1942 Sept. 7 by Y. Väisälä at Turku.

Named for an island, some $30 \mathrm{~km}$ from Turku, originally a leper colony, and in 1619 the site of the first hospital in Finland. In 1965 a station of the University of Turku's Archipelago Institute was established there. (M 7945)

\section{(2293) Guernica}

$1977 \mathrm{EH}_{1}$. Discovered 1977 Mar. 13 by N. S. Chernykh at Nauchnyj.

Named for the town Guernica y Luno, Spain, historical center of Basque culture. (M 9767)

\section{(2294) Andronikov}

1977 PL $_{1}$. Discovered 1977 Aug. 14 by N. S. Chernykh at Nauchnyj.

Named in memory of Iraklij Luarsabovich Andronikov (Andronikashvili, 1908-1990), Soviet writer and literary scholar. He was a brilliant teller of his own stories and reminiscences about writers, artists and other men of art. His main research was devoted to the life and creative work of the celebrated Russian poet M. Yu. Lermontov \{see planet (2222)\}. (M 17465)

\section{(2295) Matusovskij}

1977 QD . Discovered 1977 Aug. 19 by N. S. Chernykh at Nauchnyj.

Named in memory of Mikhail L'vovich Matusovskij (1915-1990), well known Soviet poet. (M 17465)

\section{(2296) Kugultinov}

1975 BA $_{1}$. Discovered 1975 Jan. 18 by L. I. Chernykh at Nauchnyj.

Named in honor of David Nikitich Kugul'tinov, renowned Soviet poet and national poet of Kalmykia \{see planet (2287)\}. (M 17465)

\section{(2297) Daghestan}

1978 RE. Discovered 1978 Sept. 1 by N. S. Chernykh at Nauchnyj.

Named for one of the autonomous republics of the \{former\} R.S.F.S.R. (M 5688)

\section{(2298) Cindijon}

A915 TA. Discovered 1915 Oct. 2 by M. F. Wolf at Heidelberg.

Named by B. G. Marsden \{see planet (1877)\}, who found the identification for this planet, in honor of his children, Cynthia Louise and Jonathan Brian. (M 6833)

\section{(2299) Hanko}

1941 SZ. Discovered 1941 Sept. 25 by Y. Väisälä at Turku.
Named for a Finnish town on the Gulf of Finland, famous for its beaches and regattas. Its harbor was already known in the thirteenth century. (M 7945)

\section{(2300) Stebbins}

$1953 \mathrm{TG}_{2}$. Discovered 1953 Oct. 10 at the Goethe Link Observatory at Brooklyn, Indiana.

Named in memory of Joel Stebbins (1878-1966), who pioneered the development of photoelectric methods for measuring astronomical radiation, first at the University of Illinois, then at the University of Wisconsin. He applied the method in work on eclipsing binaries, interstellar reddening and the integrated magnitudes of galaxies. Others have used the technique to study the shapes, rotation periods and surface properties of asteroids. (M 8403)

Name proposed by F. K. Edmondson. Citation written by A. E. Whitford.

Stebbins ia also honored by a lunar crater.

\section{(2301) Whitford}

1965 WJ. Discovered 1965 Nov. 20 at the Goethe Link Observatory at Brooklyn, Indiana.

Named in honor of Albert E. Whitford \{1905-2002\}, director of the Washburn Observatory (1945-1958), director of the Lick Observatory (1958-1968), and a past president of the American Astronomical Society. As a pioneer in photoelectric photometry he developed, in collaboration with Stebbins \{see planet (2300)\}, the first precise multicolor photometric system. He made major contributions in both galactic and extragalactic research. His studies of the wavelength dependence of interstellar extinction are fundamental to the understanding of interstellar particles, and the standard galactic extinction curve is referred to as the Whitford curve. (M 8403)

Name proposed by F. K. Edmondson. Citation written by A. D. Code.

Obituary published in Bull. Am. Astron. Soc., Vol. 34, No. 4, p. 1387 (2002)

\section{(2302) Florya}

1972 TL. Discovered 1972 Oct. 2 by N. E. Kurochkin at Nauchnyj.

Named in memory of Nikolaj Fyodorovich Florya (1912-1941), astronomer at the Sternberg State Astronomical Institute, skilled observer and prominent researcher on variable stars. (M 12208)

\section{(2303) Retsina}

1979 FK. Discovered 1979 Mar. 24 by P. Wild at Zimmerwald.

Named on the occasion of the Patras IAU General Assembly in honor of the resined wine of Greece. $(2303)=(47)$ Aglaja $\mathrm{x}$ (49) Pales, the product of one of the three Graces and the goddess of pastures, and a reminder of the discoverer's tour of the Peloponnese with three charming companions. (M 8152) 
(2304) Slavia

1979 KB. Discovered 1979 May 18 by A. Mrkos at Kleť.

This is an ancient Slavonic name, now also that of a famous sports club in Prague. (M 6060)

\section{(2305) King}

$1980 \mathrm{RJ}_{1}$. Discovered 1980 Sept. 12 at the Harvard College Observatory at Harvard.

Named in memory of Martin Luther King (19291968), the American civil rights leader who worked to bring about social, political and economic equality for blacks by peaceful means. A Baptist minister who received the 1964 Nobel peace prize, he preached 'non-violent resistance' to achieve full civil rights for all. (M 6208)

\section{(2306) Bauschinger}

1939 PM. Discovered 1939 Aug. 15 by K. Reinmuth at Heidelberg.

Named in memory of Julius Bauschinger (1860-1934), eminent German astronomer, professor of astronomy and director of the Astronomisches Rechen-Institut, Berlin, and the Leipzig University Observatory. For almost 15 years, Bauschinger worked on classical astrometric problems at the Munich Observatory. His extensive meridian observations resulted in two large catalogues, Münchener Sternverzeichnisse, including mean places of almost 50,000 stars. He also discussed the orbit of periodic comet Brooks $2(1889 \mathrm{~V})$ in great detail. Successor of F. Tietjen \{see planet (2158)\}, Bauschinger in 1897 managed the separation of the ARI from the Berlin Observatory. For many years, he was editor of the famous Berliner Astronomisches Jahrbuch. With P. V. Neugebauer, Bauschinger elaborated tables of the history and statistics of minor planets (1901) and his well-known textbook on orbit determination Die Bahnbestimmung der Himmelskörper (1906). The decade 1909-1919 was a period of practical work at the Strasbourg Observatory 49-cm refractor, with which he photometrically observed NGC nebulae and measured double stars. As director of the Leipzig Observatory (1920-1930), Bauschinger heavily supported a repetition of the AG zones project. (M 18447)

Name proposed and citation prepared by L.D.Schmadel.

\section{(2307) Garuda}

1957 HJ. Discovered 1957 Apr. 18 at the La Plata Observatory at La Plata.

Named for a son of the sage Kasyapa and Vinata \{see planet (2347)\} in the mythology of India. Vinata laid two eggs, and after a thousand years one hatched into Garuda. He symbolizes aspiration to spiritual truth on the higher planes, and feels hatred toward the serpents who are guardians of spiritual truth on the material and terrestrial planes. He was the mount chosen by Vishnu, protector and conservator of the universe. (M 21605)
Named by the Minor Planet Names Committee following a suggestion by F. Pilcher.

\section{(2308) Schilt}

1967 JM. Discovered 1967 May 6 by C. U. Cesco and A. R. Klemola at El Leoncito.

Named in honor of Jan Schilt \{1894-1982\}, Columbia University astronomer who has made significant contributions to the study of galactic structure and dynamics and the problems of stellar luminosity calibrations. The cooperative venture by Schilt at Columbia and Brouwer \{see planet (1746)\} at Yale, together with the Argentine astronomers at San Juan, led to the establishment of the Yale-Columbia Southern Station in the early 1960s. (M 6531)

Obituary published in Phys. Today, Vol. 35, No. 6 , p. 67-68 (1982); Zenit, 9. Jaarg., p. 375 (1982).

\section{(2309) Mr. Spock}

1971 QX $_{1}$. Discovered 1971 Aug. 16 by J. Gibson at El Leoncito.

Named for the ginger short-haired tabby cat (1967-

) who selected the discoverer and his soon-to-be wife at a cat show in California and accompanied them to Connecticut, South Africa and Argentina. At El Leoncito he provided endless hours of amusement, brought home his trophies, dead or alive, and was a figure of interest to everyone who knew him. He was named after the character in the television program Star Trek who was also imperturbable, logical, intelligent and had pointed ears. (M 10042)

\section{(2310) Olshaniya}

1974 SU $_{4}$. Discovered 1974 Sept. 26 by L. V. Zhuravleva at Nauchnyj.

Named in honor of Konstantin Olshanskij and the other daring fighters who entered the occupied city of Nikolaev in March 1944. (M 6648)

\section{(2311) El Leoncito}

1974 TA$_{1}$. Discovered 1974 Oct. 10 at the Felix Aguilar Observatory at El Leoncito.

Named for the observing station at which this minor planet was discovered. (M 8153)

\section{(2312) Duboshin}

1976 GU $_{2}$. Discovered 1976 Apr. 1 by N. S. Chernykh at Nauchnyj.

Named in honor of Georgij Nikolaevich Duboshin \{1904-1986\}, distinguished authority on celestial mechanics, author of several textbooks, president of IAU Commission 7 during 1970-1973. (M 7471)

Obituary published in Celest. Mech., Vol. 39, No. 2, p. 115 (1986).

\section{(2313) Aruna}

1976 TA. Discovered 1976 Oct. 15 by H. L. Giclas at Anderson Mesa.

Named for a son of the sage Kasyapa and Vinata \{see planet (2347)\} in the mythology of India. Vinata 
laid two eggs. When after five hundred years neither had hatched, she broke one open to find Aruna with only his upper half developed. He went into the sky to become the red glow of dawn, where ever since he has driven the suns's chariot each morning. (M 21605)

Named by the Minor Planet Names Committee following a suggestion by F. Pilcher.

\section{(2314) Field}

1977 VD. Discovered 1977 Nov. 12 at the Harvard College Observatory at Harvard.

Named in honor of George B. Field \{1929- \}, director of the Harvard College Observatory and Smithsonian Astrophysical Observatory since 1973. A well-known theoretician who has made significant contributions in many areas of astrophysics, most notably concerning processes in the interstellar medium and intergalactic medium, he was also serving as chairman of the U.S. Astronomy Survey committee on the needs of astronomy in the 1980s. (M 6648)

\section{(2315) Czechoslovakia}

1980 DZ. Discovered 1980 Feb. 19 by Z. Vávrová at Klě̌.

Named in honor of the discoverer's country, renowned for its research activity on minor planets, comets, meteorites and meteor streams. (M 6060)

\section{(2316) Jo-Ann}

1980 RH. Discovered 1980 Sept. 2 by E. Bowell at Anderson Mesa.

Named in honor of Jo-Ann Bowell, wife of the discoverer \{see planet (2246)\}, on the occasion of her nth birthday, 1982 May 13. (M 6833)

\section{(2317) Galya}

2524 P-L. Discovered 1960 Sept. 24 by C. J. van Houten and I. van Houten-Groeneveld at Palomar.

Named in honor of Galya Lubarsky, a friend of T. Gehrels. \{See also the citation for planet (2318)\}. (M 9214)

\section{(2318) Lubarsky}

6521 P-L. Discovered 1960 Sept. 24 by C. J. van Houten and I. van Houten-Groeneveld at Palomar.

Named in honor of Cronid Lubarsky, a friend of T. Gehrels. \{See also the citation for planet (2317)\}. (M 9214)

\section{(2319) Aristides}

7631 P-L. Discovered 1960 Oct. 17 by C. J. van Houten and I. van Houten-Groeneveld at Palomar.

Named for the Athenian politician Aristides (fl. c. 500 B.C.), famous for his just determination of the contribution from Athens' allies. (M 16590)

\section{(2320) Blarney}

1979 QJ. Discovered 1979 Aug. 29 by P. Wild at Zimmerwald.
Named for the famous Irish castle near Cork. What will happen to the first astronaut to kiss this stone remains to be seen. (M 17465)

\section{(2321) Lužnice}

$1980 \mathrm{DB}_{1}$. Discovered 1980 Feb. 19 by Z. Vávrová at Klet.

Named for the small river running through the idyllic southern Bohemian countryside very close to the fifteenth meridian. (M 6060; M 30493)

\section{(2322) Kitt Peak}

$1954 \mathrm{UQ}_{2}$. Discovered 1954 Oct. 28 at the Goethe Link Observatory at Brooklyn, Indiana.

Named to commemorate two important events in the history of the Kitt Peak National Observatory. Members of the Papago Tribal Council and the Schuk Toak District Council visited the Steward Observatory on the evening of 1955 Oct. 28, just one year after the discovery of this minor planet. This was the first step in arranging for the establishment of an astronomical observatory on Kitt Peak. The Association of Universities for Research in Astronomy (AURA) was incorporated on 1957 Oct. 28. (M 9079) Name proposed by F. K. Edmondson.

\section{(2323) Zverev}

$1976 \mathrm{SF}_{2}$. Discovered 1976 Sept. 24 by N. S. Chernykh at Nauchnyj.

Named in honor of Mitrofan Stepanovich Zverev \{1903-1991\}, specialist in fundamental astrometry, initiator of the international program to compile the Catalogue of Faint Stars (KSZ). This Pulkovo astrometrist organized expeditions in the 1960s for the observation of stars in the southern hemisphere. He is also popular as a fine pianist. (M 7783)

Obituary published in Zemlya Vselennaya, No. 4, p. 44-45 (1992).

\section{(2324) Janice}

1978 VS $_{4}$. Discovered 1978 Nov. 7 by E. F. Helin and S. J. Bus at Palomar.

Named in honor of Janice Cline, who for many years has encouraged astrometric studies of minor planets at Caltech. Her kindness and support are greatly appreciated. (M 5850)

\section{(2325) Chernykh}

1979 SP. Discovered 1979 Sept. 25 by A. Mrkos at Kleť.

Named in honor of Ludmilla I. Chernykh \{1935- $\quad\}$ and Nikolaj S. Chernykh \{1931- $\}$, astronomers at the Crimean Astrophysical Observatory who lead the impressive program of observations and discoveries of minor planets there. (M 6060)

\section{(2326) Tololo}

1965 QC. Discovered 1965 Aug. 29 at the Goethe Link Observatory at Brooklyn, Indiana. 
Named to commemorate the founding of the Cerro Tololo Inter-American Observatory in northern Chile on 1962 Nov. 23. CTIO is funded by the National Science Foundation and operated by AURA. (M 9079) Name proposed by F. K. Edmondson.

\section{(2327) Gershberg}

1969 TQ4. Discovered 1969 Oct. 13 by B. A. Burnasheva at Nauchnyj.

Named in honor of the Soviet astronomer Roald Evgenevich Gershberg \{1933- $\}$, who has made significant contributions to the study of processes occurring in gaseous nebulae and of the nature of stellar outbursts. (M 8912)

\section{(2328) Robeson}

1972 HW. Discovered 1972 Apr. 19 by T. M. Smirnova at Nauchnyj.

Named in memory of the American singer and actor Paul Robeson (1898-1976). (M 6648)

\section{(2329) Orthos}

1976 WA. Discovered 1976 Nov. 19 by H.-E. Schuster at La Silla.

Named for Orthos, the two-headed dog from Greek mythology. Together with his master Eurytion, this dog looked after the cattle of Geryones. One of the twelve labors of Heracles \{see planet (5143)\} was to steal these cattle. (M 5688)

\section{(2330) Ontake}

$1977 \mathrm{DS}_{3}$. Discovered 1977 Feb. 18 by H. Kosai and K. Hurukawa at Kiso.

Named for the conical volcano near the Kiso station. In October 1979, for the first time in its recorded history, the volcano, which is $3063 \mathrm{~m}$ high, exhibited small eruptions. (M 5851)

\section{(2331) Parvulesco}

1936 EA. Discovered 1936 Mar. 12 by E. Delporte at Uccle.

Named in memory of the Roumanian professor Constantin Parvulesco (1890-1945), who worked with the discoverer at the Uccle Observatory in the early 1930s. The planet also honors his daughter, Carina Parvulesco, who was born at Uccle, and who, as a professor of astronomy at San Mateo College, California, has made contributions in stellar and galactic dynamics; she has more recently served as vice-president of two corporations and as president of the U.N. Association of San Mateo County. The planet also honors her brother, Antares Parvulesco, mathematical physicist and acoustician, formerly at Columbia University, now at the University of Hawaii. (M 8799)

\section{(2332) Kalm}

1940 GH. Discovered 1940 Apr. 4 by L. Oterma at Turku.
Named for Pehr Kalm (1716-1779), a Finnish naturalist, and from 1747 the first professor of economics at the old Academia Aboensis. His numerous explorations took him as far as North America. He also founded a botanical garden for the Academia and wrote the pioneering work Flora Fennica. (M 7945)

\section{(2333) Porthan}

1943 EP. Discovered 1943 Mar. 3 by Y. Väisälä at Turku.

Named for Henrik Gabriel Porthan (1739-1804), historian and professor of oratory at the Academia Aboensis. This 'Father of Finnish History' pioneered the study of history based on facts, rather than on fantasy. (M 7945)

\section{(2334) Cuffey}

1962 HD. Discovered 1962 Apr. 27 at the Goethe Link Observatory at Brooklyn, Indiana.

Named in honor of James Cuffey, a member of the Indiana University faculty from 1946 to 1966 and then of the New Mexico State University faculty until 1976. He played a major role in arranging for the transfer of the 10-inch Cooke triplet from the Cincinnati Observatory to the Goethe Link Observatory in 1948 and thus the start of the Indiana minor-planet program. (M 9079)

Name proposed by F. K. Edmondson.

\section{(2335) James}

1974 UB. Discovered 1974 Oct. 17 by E. F. Helin at Palomar.

Named in honor of James G. Williams, celestial mechanician who extended the theory of secular perturbations to orbits of high inclination. This minor planet lies very near one of the secular resonances discovered by Williams, and its argument of perihelion librates around the value of 90 degrees. (M 5688)

\section{(2336) Xinjiang}

$1975 \mathrm{WL}_{1}$. Discovered 1975 Nov. 26 at the Purple Mountain Observatory at Nanking.

Named for the Xinjiang Uygur Autonomous Region, the largest Chinese region by area, situated at the northwestern border of the country. (M 6060)

\section{(2337) Boubín}

$1976 \mathrm{UH}_{1}$. Discovered 1976 Oct. 22 by P. Wild at Zimmerwald.

Named for a mountain in Bohemia that offers a wonderful panorama and still has a virgin forest on its slopes. (M 17465; M 30493)

Name suggested by I. Bauersima.

\section{(2338) Bokhan}

1977 QA $_{3}$. Discovered 1977 Aug. 22 by N. S. Chernykh at Nauchnyj.

Named in honor of Nadezhda Antonovna Bokhan \{1916- \}, a staff member of the Institute for 
Theoretical Astronomy in Leningrad during 1944-1957 and 1965-1974, known for her valuable contributions to the study of minor planets and for her investigation on the motion of periodic comet Encke. (M 6060)

\section{(2339) Anacreon}

2509 P-L. Discovered 1960 Sept. 24 by C. J. van Houten and I. van Houten-Groeneveld at Palomar.

Named for the Greek poet Anacreon (fl. c. 550 B.C.), whose poems celebrate wine, love and friendship. (M 16590)

\section{(2340) Hathor}

1976 UA. Discovered 1976 Oct. 22 by C. T. Kowal at Palomar.

Like the other objects of Aten type, (2340) is named for an Egyptian deity. Known as a sky-goddess and the daughter of Ra, Hathor was also identified with Aphrodite \{see planet (1388)\}. (M 6060)

Name proposed by E. Helin, who made an independent discovery of the object and who also made crucial recovery observations in 1981.

Hathor is the same goddess as Athor ssee planet (161)\}.

\section{(2341) Aoluta}

1976 YU $_{1}$. Discovered 1976 Dec. 16 by L. I. Chernykh at Nauchnyj.

Named on the occasion of the centennial, in 1981, of the founding of the Astronomical Observatory of Leningrad University. The first part of the name is an acronym for that institution. (M 6648)

\section{(2342) Lebedev}

1968 UQ. Discovered 1968 Oct. 22 by T. M. Smirnova at Nauchnyj.

Named in memory of Nikolaj Aleksandrovich Lebedev (1914-1942), a valiant tank officer who fell in the battle of Stalingrad. (M 6060)

\section{(2343) Siding Spring}

$1979 \mathrm{MD}_{4}$. Discovered 1979 June 25 by E. F. Helin and S. J. Bus at Siding Spring.

Named for the New South Wales community in which the Australian National Observatory, Anglo-Australian Observatory and U.K. Schmidt telescope are located. This is the first minor planet discovered with the U.K. Schmidt telescope to be numbered. (M 5851)

\section{(2344) Xizang}

$1979 \mathrm{SC}_{1}$. Discovered 1979 Sept. 27 at the Purple Mountain Observatory at Nanking.

Named for the autonomous region, also known as Tibet, on the southwestern border of China. (M 6060)

\section{(2345) Fučik}

1974 OS. Discovered 1974 July 25 by T. M. Smirnova at Nauchnyj.

Named in memory of Julius Fučik (1903-1943), a Czechoslovak national hero and writer. (M 6648)

\section{(2346) Lilio}

1934 CB. Discovered 1934 Feb. 5 by K. Reinmuth at Heidelberg.

Named on the occasion of the 400th anniversary of the establishment of the Gregorian Calendar in memory of its inventor, Luigi Lilio (ca. 1510-1576), an obscure physician from southern Italy. (M 7471)

Name proposed by B. G. Marsden, who found the identifications involving this planet.

\section{(2347) Vinata}

1936 TK. Discovered 1936 Oct. 7 by H. L. Giclas at Flagstaff.

Named for a daughter of Prajapati and wife of the sage Kasyapa in the mythology of India. She laid only two eggs, while her sister and Kasyapa's other wife laid a thousand. After five hundred years her sister's eggs hatched into serpents. Jealous and impatient, she broke the shell of one of her two eggs to find Aruna \{see planet (2313)\} inside with only his upper half developed. The second egg hatched into Garuda \{see planet (2307)\}, who had such spiritual purity as to exceed that of all his thousand half-brothers. (M 21606)

Named by the Minor Planet Names Committee following a suggestion by F. Pilcher.

\section{(2348) Michkovitch}

1939 AA. Discovered 1939 Jan. 10 by M. B. Protitch at Belgrade.

Named by the discoverer as a sign of much appreciation and in memory of his professor, Vojislav V. Michkovitch (1892-1976), the first director of the new Belgrade Astronomical Observatory, which, by his efforts, was built in 1932. He was also founder of the Astronomical Institute of the Serbian Academy of Sciences and was well known for his works on minor planets, especially their identifications. (M 9477)

Obituary published in Bull. Obs. Astron. Belgrade, No. 129, p. III-VI (1978).

\section{(2349) Kurchenko}

1970 OG. Discovered 1970 July 30 by T. M. Smirnova at Nauchnyj.

Named in memory of Nadezhda Kurchenko (19501970), an airline stewardess killed in a clash with two armed bandits. (M 6648)

\section{(2350) von Lüde}

1938 CG. Discovered 1938 Feb. 6 by A. Bohrmann at Heidelberg.

Named in memory of Heinz von Lüde (1914-1974), astronomer at the Astronomisches Rechen-Institut who calculated many preliminary orbits of minor planets. He also studied a fictitious example of $3 / 1$ libration in the restricted three-body problem and was involved with the meridian-circle program at the Heidelberg Observatory. (M 6060) 


\section{(2351) O'Higgins}

1964 VD. Discovered 1964 Nov. 3 at the Goethe Link Observatory at Brooklyn, Indiana.

Named in memory of Bernardo O'Higgins (1778-1842) and to honor the people of Chile, who regard him as the "Father of the Country". Chile declared independence from Spanish rule on 1810 Sept. 18. This became a reality on 1817 Feb. 22, when the Spaniards were defeated by General O'Higgins and his forces in a decisive battle at Chacabuco. (M 9079)

Name proposed by F. K. Edmondson.

\section{(2352) Kurchatov}

1969 RY. Discovered 1969 Sept. 10 by L. I. Chernykh at Nauchnyj.

Named in memory of Igor' Vasil'evich Kurchatov (1902-1960), great atomic physicist and organizer of science, founder and first director of the Institute of Atomic Energy of the U.S.S.R. Academy of Sciences. (M 7617)

Kurchatov is also honored by a lunar crater.

\section{(2353) Alva}

1975 UD. Discovered 1975 Oct. 27 by P. Wild at Zimmerwald.

Named for an American former girlfriend of the discoverer. (M 17465)

\section{(2354) Lavrov}

1978 PZ $_{3}$. Discovered 1978 Aug. 9 by L. I. Chernykh and N. S. Chernykh at Nauchnyj.

Named in honor of Svyatoslav Sergeevich Lavrov \{1923- \}, director of the Institute for Theoretical Astronomy, Leningrad, a corresponding member of the U.S.S.R. Academy of Sciences, and a well-known authority on computer mathematics and computer languages. (M 7617)

\section{(2355) Nei Monggol}

$1978 \mathrm{UV}_{1}$. Discovered 1978 Oct. 30 at the Purple Mountain Observatory at Nanking.

Named for an autonomous region, also known as Inner Mongolia, on the northern border of China, noted for its extensive prairie lands. (M 6061)

\section{(2356) Hirons}

1979 UJ. Discovered 1979 Oct. 17 by E. Bowell at Anderson Mesa.

Named in honor of the discoverer's parents-in-law, Charles and Ann Hirons. (M 6208)

\section{(2357) Phereclos}

1981 AC. Discovered 1981 Jan. 1 by E. Bowell at Anderson Mesa.

This Trojan planet is named for the skilled craftsman and builder of the ships that took Paris to Sparta. Phereclos was killed in battle by Meriones \{see planet (3596)\}. (M 6208)

\section{(2358) Bahner}

1929 RE. Discovered 1929 Sept. 2 by K. Reinmuth at Heidelberg.

Named in honor of Klaus Bahner \{1921- $\quad$ \}, staff member of the Heidelberg-Königstuhl Observatory who has made outstanding contributions to the design of large telescopes. The design of the $1.2-\mathrm{m}, 2.2-\mathrm{m}$ and 3.5-m large telescopes of the Max-Planck-Institut für Astronomie is mainly due to his efforts. (M 6649)

Name proposed by L. D. Schmadel; endorsed by O. Kippes, who found the identifications for this planet.

\section{(2359) Debehogne}

1931 TV. Discovered 1931 Oct. 5 by K. Reinmuth at Heidelberg.

Named in honor of Henri Debehogne \{1928- \}, astronomer at the Royal Observatory, Uccle, noted for his astrometric work on comets and minor planets. In recent years he has trained and collaborated with several astronomers in South America, and it was during one of these collaborations that he rediscovered this minor planet in 1979. (M 6209)

Name proposed by E. Bowell, who made the identification.

\section{(2360) Volgo-Don}

1975 VD $_{3}$. Discovered 1975 Nov. 2 by T. M. Smirnova at Nauchnyj.

Named on the occasion of the 30th anniversary of the construction of the Volgo-Don Navigation Canal, which connects the Volga and Don rivers at their closest approach. (M 7617)

\section{(2361) Gogol}

1976 GQ1. Discovered 1976 Apr. 1 by N. S. Chernykh at Nauchnyj.

Named for the celebrated writer Nikolaj Vasil'evich Gogol' (1809-1852). (M 7783)

\section{(2362) Mark Twain}

$1976 \mathrm{SH}_{2}$. Discovered 1976 Sept. 24 by N. S. Chernykh at Nauchnyj.

Named for Mark Twain, pen name of Samuel Langhorne Clemens (1835-1910), world-famous American writer. (M 9214)

\section{(2363) Cebriones}

1977 TJ $_{3}$. Discovered 1977 Oct. 4 at the Purple Mountain Observatory at Nanking.

This Trojan planet is named for the charioteer of Hektor see planet (624)\}, wounded in the conflict between Hektor and Patroclus \{see planet (617)\} that led to the latter's death. (M 6209)

\section{(2364) Seillier}

1978 GD. Discovered 1978 Apr. 14 by H. Debehogne at La Silla.

Named by the discoverer in honor of his mother and her family. (M 9079) 


\section{(2365) Interkosmos}

1980 YQ. Discovered 1980 Dec. 30 by Z. Vávrová at Klě̌.

Named for the eastern European organization for space exploration. (M 6649)

\section{(2366) Aaryn}

1981 AC $_{1}$. Discovered 1981 Jan. 10 by N. G. Thomas at Anderson Mesa.

Named in honor of Aaryn G. Baltutis, grandson of the discoverer. (M 7617)

\section{(2367) Praha}

1981 AK $_{1}$. Discovered 1981 Jan. 8 by A. Mrkos at Klě̀.

Named for the capital of \{the former Czechoslovakia, which has a longstanding astronomical tradition going back to the time of Tycho Brahe and Johannes Kepler. (M 6649)

\section{(2368) Beltrovata}

1977 RA. Discovered 1977 Sept. 4 by P. Wild at Zimmerwald.

This Amor object shares the name given by the Zürich-born writer Gottfried Keller to his friend Betty Tendering. Keller's novel Der grüne Heinrich contains a comparable character in Dortchen Schönfund. (M 6209)

\section{(2369) Chekhov}

1976 GC $_{8}$. Discovered 1976 Apr. 4 by N. S. Chernykh at Nauchnyj.

Named for the celebrated writer Anton Pavlovich Chekhov (1860-1904). (M 7783)

\section{(2370) van Altena}

1965 LA. Discovered 1965 June 10 by A. R. Klemola at El Leoncito.

Named in honor of William F. van Altena, well-known astrometrist at the Yale University Observatory. His contributions include works on stellar proper motions and parallaxes, including a revised edition of the Yale Catalogue of Stellar Trigonometric Parallaxes. The southern proper motion program with respect to galaxies is conducted under his direction with the 0.5-m astrograph at El Leoncito. (M 9477)

\section{(2371) Dimitrov}

$1975 \mathrm{VR}_{3}$. Discovered 1975 Nov. 2 by T. M. Smirnova at Nauchnyj.

Named in memory of Georgij Mikhailovich Dimitrov (1882-1949), founder and leader of the Bulgarian Patriotic Front and chairman of the council of ministers of Bulgaria. (M 6649)

\section{(2372) Proskurin}

1977 RA 8 . Discovered 1977 Sept. 13 by N. S. Chernykh at Nauchnyj.

Named in memory of Vitalij Fedorovich Proskurin (1919-1964), celestial mechanician at the Institute for Theoretical Astronomy, known for his work on the motions of Ceres, Jupiter VI and VIII and artificial satellites. (M 7783)

\section{(2373) Immo}

1929 PC. Discovered 1929 Aug. 4 by M. F. Wolf at Heidelberg.

Named in honor of Immo Appenzeller (1940- ) professor of astronomy at Heidelberg University and since 1975 director of the observatory at Königstuhl. He has made important contributions to the fields of star formation, stellar evolution, interstellar magnetic fields and active galaxies. Appenzeller is also deeply involved in the development of astronomical instrumention. (M 18447)

Name proposed and citation prepared by G. Klare and L. D. Schmadel.

\section{(2374) Vladvysotskij}

$1974 \mathrm{QE}_{1}$. Discovered 1974 Aug. 22 by L. V. Zhuravleva at Nauchnyj.

Named in memory of Vladimir Semenovich Vysotskij (1938-1980), a notable dramatic actor, composer and poet, particularly popular as a music-hall singer who performed songs of his own composition. (M 7617)

\section{(2375) Radek}

1975 AA. Discovered 1975 Jan. 8 by L. Kohoutek at Bergedorf.

Named by the discoverer in honor of his brother, Ctirad Kohoutek (1929- ), Czech composer, who has been professor for music at the academies in Brno and Prague as well as director of the Czech Philharmonic Orchestra. (M 22244)

\section{(2376) Martynov}

1977 QG $_{3}$. Discovered 1977 Aug. 22 by N. S. Chernykh at Nauchnyj.

Named in honor of Dmitrij Yakovlevich Martynov \{1904-1989\}, outstanding astrophysicist, for many years the director of the Sternberg Astronomical Institute in Moscow, author of widely used texts on astrophysics. (M 7783)

Obituaries published in Astron. Calendar Bulg., p. 124-126 (1991); Astron. Vestn., Tom 24, No. 2, p. 173-175 (1990); Astron. Zh., Tom 67, Vyp. 2, p. 440-442 (1990); Zemlya Vselennaya, No. 1, p. 45-48 (1990); Astron. Tsirk., No. 1541, p. 39-40 (1989).

\section{(2377) Shcheglov}

$1978 \mathrm{QT}_{1}$. Discovered 1978 Aug. 31 by N. S. Chernykh at Nauchnyj.

Named in honor of Vladimir Petrovich Shcheglov \{1904-1985\}, since 1941 the director of the Astronomical Institute of the \{former\} Uzbek SSR in Tashkent, investigator in astrometry and the history of astronomy, renowned popularizer of astronomy. (M 7783)

\section{(2378) Pannekoek}

1935 CY. Discovered 1935 Feb. 13 by H. van Gent at Johannesburg. 
Named in memory of A. Pannekoek (1873-1960), Dutch astronomer, director of the Astronomical Institute of the Municipal University in Amsterdam from 1921 to 1941. His main activity was stellar astrophysics. (M 18135)

Pannekoek is also honored by a lunar crater.

\section{(2379) Heiskanen}

1941 ST. Discovered 1941 Sept. 21 by Y. Väisälä at Turku.

Named in memory of V. A. Heiskanen (1895-1971), professor of geodesy at the Helsinki Technological University and director of the Finnish Geodetic Institute. After 1950 he worked mainly at the Ohio State University in Columbus, where he began the program in geodesic sciences. He also wrote several Finnish textbooks on astronomy. (M 7945)

\section{(2380) Heilongjiang}

1965 SN. Discovered 1965 Sept. 18 at the Purple Mountain Observatory at Nanking.

Named for a forested province in northeastern China, rich in petroleum, coal and gold. (M 7617)

\section{(2381) Landi}

1976 AF. Discovered 1976 Jan. 3 at the Felix Aguilar Observatory at El Leoncito.

Named in honor of Jorge Landi Dessy, formerly director of the Córdoba Observatory and professor at the Córdoba Institute of Mathematics, Physics and Astronomy; also vice-president of the Argentine Association of Astronomy. His principal fields of study involved astronomical optics and photometry, and the structure of the Magellanic Clouds. (M 8799)

\section{(2382) Nonie}

1977 GA. Discovered 1977 Apr. 13 at the Perth Observatory at Bickley.

Named in honor of the daughter of Peter Jekabsons \{see planet (3188)\}, member of the astrometric team at the Perth Observatory. (M 6531)

\section{(2383) Bradley}

1981 GN. Discovered 1981 Apr. 5 by E. Bowell at Anderson Mesa.

Named in honor of Martin and Maud Bradley, friends of the discoverer. (M 6209)

\section{(2384) Schulhof}

$1943 \mathrm{EC}_{1}$. Discovered 1943 Mar. 2 by M. Laugier at Nice.

Named in memory of Leopold Schulhof (1847-1921), Hungarian-born astronomer who spent most of his working life in Paris, although he discovered (147) Protogeneia while a student in Vienna. His extensive computations on the orbits of comets and minor planets frequently involved the interplay of perturbations and determinacy, and he contributed much toward the recovery of lost objects. His very detailed study of the comet now known as $\mathrm{P} /$ Crommelin is acknowledged as that object comes now again to perihelion. (M 8541)

Name proposed by B. G. Marsden, who found the identifications involving this planet.

\section{(2385) Mustel}

1969 VW. Discovered 1969 Nov. 11 by L. I. Chernykh at Nauchnyj.

Named in honor of Evald Rudolfovich Mustel' \{1911-1988\}, chairman of the Astronomical Council of the U.S.S.R. Academy of Sciences, editor of the Astronomicheskij Zhurnal, and a vice-president of the IAU during 1970-1976. His research activities involve several aspects of solar and stellar physics and the correlation of geophysical phenomena and solar activity. (M 7617)

Obituaries published in Astron. Zh., Tom 65, Vyp. 4, p. 891-892 (1988); Pis'ma Astron. Zh., Tom 14, No. 8, p. 764 (1988); Zemlya Vselennaya, No. 5, p. 42-45 (1988); Astrophys. Space Sci., Vol. 155, No. 1, p. 1 (1989); Sov. Astron. Lett., Vol. 14, No. 4, p. 326 (1988); Sov. Astron., Vol. 32, No. 4, p. 466-467 (1988).

\section{(2386) Nikonov}

$1974 \mathrm{SN}_{1}$. Discovered 1974 Sept. 19 by N. S. Chernykh at Nauchnyj.

Named in honor of Vladimir Borisovich Nikonov \{1905- $\}$, chief of the stellar department of the Crimean Astrophysical Observatory, a pioneer in stellar photoelectric photometry. (M 7471)

\section{(2387) Xi'an}

1975 FX. Discovered 1975 Mar. 17 at the Purple Mountain Observatory at Nanking.

Named for the famous historical city, origin of Chinese splendid culture and home of a rich treasure of human civilization. Known in ancient times as Chang'an, it takes first place among the six ancient capitals of China, serving in this capacity for twelve dynasties since the eleventh century B.C. With Athens, Cairo and Rome it ranks among the four leading ancient capitals of the world. The terra cotta warriors and horses at the Museum of Qin Shihuang are praised as an "eighth wonder of the world". Today, Xi'an is the political and economic center of Shaanxi ssee planet (2263)\} province and the largest central city in the western part of China. It is an important center for national higher education and scientific research, as well as for the aerospace, aviation, electronic, textile and power industries. (M 17655)

\section{(2388) Gase}

$1977 \mathrm{EA}_{2}$. Discovered 1977 Mar. 13 by N. S. Chernykh at Nauchnyj.

Named in memory of Vera Fedorovna Gaze (18991954), who worked at the Pulkovo and Simeis observatories on stellar spectroscopy and the study of diffuse nebulae. As a young assistant at the Astronom- 
ical Institute (predecessor of ITA) in Leningrad she determined the orbits of minor planets. (M 7783)

\section{(2389) Dibaj}

1977 QC 1 . Discovered 1977 Aug. 19 by N. S. Chernykh at Nauchnyj.

Named in memory of Ernest Apushevich Dibaj (19311983), an astrophysicist known for his research on the interstellar medium, variable stars and extragalactic systems. A professor at Moscow University, he was head of the Crimean Station of the Sternberg Astronomical Institute from 1962 to 1977. (M 8542)

Obituary published in Pis'ma Astron. Zh., Tom 9, No. 12, p. 755 (1983); Astron. Zh., Tom 61, Vyp. 1, p. 204-205 (1984); Sov. Astron. Lett., Vol. 9, No. 6, p. 390-391 (1983); Sov. Astron., Vol. 28, No. 1, p. 121-122 (1984).

\section{(2390) Nežárka}

$1980 \mathrm{PA}_{1}$. Discovered 1980 Aug. 14 by Z. Vávrová at Klět.

Named for a small river running through the town of Veseli \{see planet (2599)\} in southern Bohemia where the discoverer lives. (M 6649)

\section{(2391) Tomita}

1957 AA. Discovered 1957 Jan. 9 by K. Reinmuth at Heidelberg.

Named in honor of Koichiro Tomita, astronomer at the Tokyo Astronomical Observatory during 19471985, prominent observer of comets and minor planets, discoverer of comet $1964 \mathrm{VI}$ and recoverer of almost all the comets that returned in 1967. Also a leading popularizer of astronomy in Japan, Tomita has been a source of inspiration for H. Oishi \{see planet (3379)\}, who made the key identification for this planet and proposed the name. (M 2391)

\section{(2392) Jonathan Murray}

$1979 \mathrm{MN}_{1}$. Discovered 1979 June 25 by E. F. Helin and S. J. Bus at Siding Spring.

Named for Jonathan Murray, the young son of Bruce and Suzanne Murray, longtime friends of the discoverers. The planet was discovered a few weeks before his birth on 1979 July 19. (M 6209)

\section{(2393) Suzuki}

1955 WB. Discovered 1955 Nov. 17 by M. Laugier at Nice.

Named in honor of Keishin Suzuki (1905- ), professor of astronomy at Tokyo Gakugei University, an expert on practical astronomy and teaching of astronomy. He played the principal part in first publishing the Japanese Nautical Almanac, when astronomical almanacs could not be imported during the second World War. He has made a great contribution to the teaching and popularization of astronomy in Japan, mainly by writing or translating a great many books and articles over a period of more than fifty years. (M 11441)
Name proposed by T. Urata, who found the identifications involving this planet.

\section{(2394) Nadeev}

1973 SZ $_{2}$. Discovered 1973 Sept. 22 by N. S. Chernykh at Nauchnyj.

Named in memory of Lev Nikolaevich Nadeev (1902-1974), an astrometrist and geodesist who made extensive geodetic surveys in the northern USSR. He founded the Laboratory of Time and Frequency in Irkutsk \{see planet (3224)\}, where the discoverer began his own career under Nadeev's guidance. (M 7784)

\section{(2395) Aho}

1977 FA. Discovered 1977 Mar. 17 at the Harvard College Observatory at Harvard.

Named in honor of Arne J. Aho by his coworkers in appreciation of his hard work that made their work easier. (M 6833)

\section{(2396) Kochi}

1981 CB. Discovered 1981 Feb. 9 by T. Seki at Geisei.

Named by the discoverer in honor of his native city. (M 6421)

See also the citation for planet (3150).

\section{(2397) Lappajärvi}

1938 DV. Discovered 1938 Feb. 22 by Y. Väisälä at Turku.

Named for a lake, which proved to be a meteorite crater, in the western part of central Finland. (M 7945)

\section{(2398) Jilin}

$1965 \mathrm{UD}_{2}$. Discovered 1965 Oct. 24 at the Purple Mountain Observatory at Nanking.

Named for the province in northeastern China, famous for its "ginseng". (M 7617)

\section{(2399) Terradas}

1971 MA. Discovered 1971 June 17 by C. U. Cesco at El Leoncito.

Named in memory of Esteban Terradas e Illa (18831950), outstanding Spanish mathematician, professor at the universities of Zaragoza, Barcelona and Madrid, and later at the Astronomical School of La Plata University. He made important contributions to geodesy and was involved with the fundamental precision marigraph in Puerto Madryn. (M 8799)

\section{(2400) Derevskaya}

1972 KJ. Discovered 1972 May 17 by T. M. Smirnova at Nauchnyj.

Named in memory of Alexandra Avramovna Derevskaya (1902-1959), mother heroine, who brought up 48 orphans of different nationalities. (M 7617)

\section{(2401) Aehlita}

$1975 \mathrm{VM}_{2}$. Discovered 1975 Nov. 2 by T. M. Smirnova at Nauchnyj.

Named for the heroine in one of the novels of Aleksej Nikolaevich Tolstoj (1883-1945, see planet (3771)). In 
the book of the same name Aehlita was a Martian girl who fell in love with an Earth man who went to Mars in a space ship. (M 6649)

\section{(2402) Satpaev}

1979 OR $_{13}$. Discovered 1979 July 31 by N. S. Chernykh at Nauchnyj.

Named in memory of Kanysh Imantaevich Satpaev (1899-1964), outstanding geologist. As president of the Academy of Sciences of the Kazakh SSR he contributed much to the development of astronomy in Kazakhstan. (M 8542)

\section{(2403) Šumava}

1979 SQ. Discovered 1979 Sept. 25 by A. Mrkos at Klet.

Named for the mountains on the southern border of Bohemia in the vicinity of the Klet Observatory. (M 6649)

\section{(2404) Antarctica}

1980 TE. Discovered 1980 Oct. 1 by A. Mrkos at Klet.

Named for the southernmost continent, in honor of the third Soviet Antarctic Expedition, in which the discoverer participated. (M 6649)

\section{(2405) Welch}

1963 UF. Discovered 1963 Oct. 18 at the Goethe Link Observatory at Brooklyn, Indiana.

Named in honor of David F. ("Kelly") Welch, AURA Corporate Staff Executive from 1978 to 1983. He upgraded AURA administrative and operational procedures and brought modern technology into the corporate office. He also played a major role in the preparation of the successful proposal to NASA for AURA to establish and operate the Space Telescope Science Institute. Following (2404) Antarctica, this planet also acknowledges Welch's earlier career in the U.S. Navy, which culminated in his service as commander of the Naval Support Force for the scientific bases in Antarctica during 1969-1971. (M 9079)

Name proposed by F. K. Edmondson.

\section{(2406) Orelskaya}

1966 QG. Discovered 1966 Aug. 20 at the Crimean Astrophysical Observatory at Nauchnyj.

Named in honor of Varvara Ivanovna Orel'skaya, a member of the staff of the Institute for Theoretical Astronomy from 1937 to 1982, well-known for her work on determining the equator-equinox correction using observations of minor planets. Her plan, supported by IAU Commission 20, of observations of 20 selected planets during 1974-1990 is continuing. (M 7618)

\section{(2407) Haug}

1973 DH. Discovered 1973 Feb. 27 by L. Kohoutek at Bergedorf.

Named in memory of Ulrich Haug (1929-1992), German astronomer, who investigated interplanetary dust particles in his early years in Tübingen and who is known from later work at the Hamburg Observatory, mainly for his contributions on interstellar extinction and for observations with the Schmidt telescope, moved from Hamburg-Bergedorf to the GermanSpanish Astronomical Center at Calar Alto, where he made tests for quasars being the basis for the Hamburg Quasar Survey. (M 22244)

Obituary published in Mitt. Astron. Ges., Nr. 76, p. 5-7 (1993).

\section{(2408) Astapovich}

1978 QK $_{1}$. Discovered 1978 Aug. 31 by N. S. Chernykh at Nauchnyj.

Named in memory of Igor' Stanislavovich Astapovich (1908-1976), a professor at Kiev University known for his research in meteor astronomy. (M 7784)

Obituary published in Komety Meteory, No. 26, p. 43-48 (1977). A biographic notice is published in WGN, Vol. 27, No. 2, p. 103-110 (1999).

\section{(2409) Chapman}

1979 UG. Discovered 1979 Oct. 17 by E. Bowell at Anderson Mesa.

Named in honor of Clark R. Chapman, planetary astronomer at the Planetary Science Institute in Tucson. He has made outstanding contributions to our understanding of asteroid compositions and physical processes, particularly surface mineralogical identification, taxonomy and collisional evolution. (M 6209)

\section{(2410) Morrison}

1981 AF. Discovered 1981 Jan. 3 by E. Bowell at Anderson Mesa.

Named in honor of David Morrison, astronomer at the University of Hawaii, Honolulu. His research into the infrared radiometric properties of asteroids has been fundamental in revealing the diversity of asteroid surface albedos and compositions. He has also worked on the definition of a taxonomic system for asteroids and on the distribution of the various taxonomic types in the main belt. (M 6209)

\section{(2411) Zellner}

1981 JK. Discovered 1981 May 3 by E. Bowell at Anderson Mesa.

Named in honor of Benjamin H. Zellner, astronomer at the University of Arizona, Tucson. He brought to fruition the polarimetric-photometric method of albedo and diameter determination for asteroids. He has also helped define a taxonomic system for asteroids and has investigated in detail the distribution of the various taxonomic types in the main belt. (M 6209)

\section{(2412) Wil}

3537 P-L. Discovered 1960 Oct. 17 by C. J. van Houten and I. van Houten-Groeneveld at Palomar.

Named in honor of Wil van de Hulst, psychotherapist, married to the astronomer Henk C. van de Hulst \{see planet (2413)\}. (M 9767) 
(2413) van de Hulst

6816 P-L. Discovered 1960 Sept. 24 by C. J. van Houten and I. van Houten-Groeneveld at Palomar.

Named in honor of Henk C. van de Hulst \{19182000\}, husband of Wil van de Hulst (see 2412) and astrophysicist at the Leiden Observatory. A leader in the development of radioastronomy in the Netherlands, van de Hulst predicted the interstellar hydrogen 21$\mathrm{cm}$ line. He has made contributions to the theory of light scattering by small particles, about which topic he wrote two books. He is active in promoting international cooperation in space research. (M 11640)

\section{(2414) Vibeke}

1931 UG. Discovered 1931 Oct. 18 by K. Reinmuth at Heidelberg.

Named by L. K. Kristensen \{see planet (3455)\}, who made the identifications involving this planet, in honor of his daughter. (M 6210)

\section{(2415) Ganesa}

1978 UJ. Discovered 1978 Oct. 28 by H. L. Giclas at Anderson Mesa.

In the mythology of India, Ganesa is the son of Siva and Parvati s see planets (1170) and (2847), respectively\}, who represents the call to spiritual power. Soon after birth he glanced at the god Sani, who symbolizes obstacles, and the baby's head was reduced to ashes. His head was then replaced with the head of Indra's elephant, Airavata. He procures wealth and encourages the success of all enterprises, and is much revered by the merchant class. (M 21606)

Named by the Minor Planet Names Committee following a suggestion by F. Pilcher.

\section{(2416) Sharonov}

$1979 \mathrm{OF}_{13}$. Discovered 1979 July 31 by N. S. Chernykh at Nauchnyj.

Named in memory of Vsevolod Vasil'evich Sharonov (1901-1964), professor at Leningrad University and director of the Leningrad University Observatory, who contributed greatly to physical studies of the Moon and planets. (M 7784)

Sharonov is also honored by craters on Mars and the Moon.

\section{(2417) McVittie}

1964 CD. Discovered 1964 Feb. 15 at the Goethe Link Observatory at Brooklyn, Indiana.

Named in honor of George C. McVittie \{1904-1988\} on the occasion of his 80th birthday, 1984 June 5. Born in Turkey, he was educated and spent his early career in the U.K. Moving to the U.S., he served as head of the astronomy department at the University of Illinois from 1952 to 1972 , during which time he converted a one-man undergraduate teaching department into a major graduate and research center. His own research was theoretical, involving relativity and cosmology, but he built up observational optical astronomy and added radio astronomy to the department to produce a well-rounded program. From 1961 to 1970 he served as secretary of the American Astronomical Society. Following his formal retirement he returned to the U.K. to a position at the University of Kent. (M 9080) Name proposed by F. K. Edmondson.

Obituaries published in Phys. Today, Vol. 42, No. 3, p. 128-132 (1989); Q.J.R. Astron. Soc., Vol. 30, No. 1, p. 119-122 (1989).

\section{(2418) Voskovec-Werich}

1971 UV. Discovered 1971 Oct. 26 by L. Kohoutek at Bergedorf.

Named in memory of Jiří Voskovec (1905-1981) and Jan Werich (1905-1980), Czech actors and dramatists who became famous in the 1930s for several theater plays and reviews, mainly in the avant-garde Liberal Theater and the "V+W" Theater in Prague. After World War II they acted in many theater, film and TV productions, Voskovec in the U.S. and Werich in Czechoslovakia. They were highly respected for their humanistic ideas. (M 27124)

\section{(2419) Moldavia}

1974 SJ. Discovered 1974 Sept. 19 by N. S. Chernykh at Nauchnyj.

Named for the \{former Moldavian Soviet Socialist Republic. (M 7471)

\section{(2420) Čiurlionis}

1975 TN. Discovered 1975 Oct. 3 by N. S. Chernykh at Nauchnyj.

Named in memory of M. K. Ciurlionis (1875-1911), a well-known Lithuanian painter and composer. (M 8542)

\section{(2421) Nininger}

1979 UD. Discovered 1979 Oct. 17 by E. Bowell at Anderson Mesa.

Named on the occasion of the 95th birthday, 1982 Jan. 17, of Harvey Harlow Nininger $\{1887-1986\}$, celebrated U.S. meteoriticist. Through field investigations and publicity he was responsible for the recovery of some 200 separate meteorite falls and finds, and his resulting 3000 samples are more than those of any other individual prior to the exploration of the Antarctic blue-ice fields. The author of many popular and technical works, he conducted much of his research at the Arizona meteorite crater, not far from Flagstaff. (M 6531)

Name proposed by N. Sperling.

Obituaries published in Meteoritics, Vol. 21, No. 2, p. 239, No. 4, p. 551-552 (1986).

\section{(2422) Perovskaya}

1968 HK $_{1}$. Discovered 1968 Apr. 28 by T. M. Smirnova at Nauchnyj.

Named in memory of Sofya Lvovna Perovskaya (1853-1881), executed for organizing the attempt of the life of Tsar Alexander II on 1881 Mar. 1. (M 6649) 


\section{(2423) Ibarruri}

1972 NC. Discovered 1972 July 14 by L. V. Zhuravleva at Nauchnyj.

Named in memory of Ruben Ibarruri (1920-1942), who died valiantly in the battle of Stalingrad. (M 6649)

\section{(2424) Tautenburg}

$1973 \mathrm{UT}_{5}$. Discovered 1973 Oct. 27 by F. Börngen at Tautenburg.

Named for the village near which the Karl Schwarzschild Observatory is located, some $15 \mathrm{~km}$ to the northeast of the city of Jena \{see planet (526)\}. (M 7784)

\section{(2425) Shenzhen}

1975 FW. Discovered 1975 Mar. 17 at the Purple Mountain Observatory at Nanking.

Named for China's first special economic zone, well known at home and abroad. It has often been referred to as an 'overnight' modernized, export-oriented and multifunctional city with industry as its mainstay but combining industry with trade. Located on the east bank of the Pearl river estuary in Guangdong \{see planet (2185)\} province and neighboring Hong Kong, Shenzhen enjoys geographical advantages and is an ideal tourist attraction. Rich in natural resources and technological expertise, it has a well-developed commodity economy and an efficient transportation and telecommunications system. Shenzhen serves as the nation's major gateway to international trade and exchange. (M 17655)

\section{(2426) Simonov}

1976 KV. Discovered 1976 May 26 by N. S. Chernykh at Nauchnyj.

Named in memory of Konstantin Mikhailovich Simonov (1915-1979), Soviet writer and public figure. (M 8064)

\section{(2427) Kobzar}

1976 YQ7. Discovered 1976 Dec. 20 by N. S. Chernykh at Nauchnyj.

Named in memory of the great Ukrainian poet and painter Taras Grigor'evich Shevchenko (1814-1861), who exerted a profound influence on Ukrainian literature. He was popularly known as Kobzar, which in old Ukraine means one who sings to the accompaniment of a kobza, a stringed instrument. (M 7471)

\section{(2428) Kamenyar}

1977 RZ $_{6}$. Discovered 1977 Sept. 11 by N. S. Chernykh at Nauchnyj.

Named in memory of Ivan Yakovlevich Franko (1856-1916), a Ukrainian writer and scientist whose remarkably rich creative legacy is now being published in 50 volumes. He was sometimes called Kamenyar, or 'stonecrusher', the title of one of his poems. (M 7471)

\section{(2429) Schürer}

1977 TZ. Discovered 1977 Oct. 12 by P. Wild at Zimmerwald.
Named in honor of Max Schürer (1910-1997), who from 1947 to 1980 was director of the Astronomical Institute of the University of Berne. The existence of the observatory at Zimmerwald \{see planet (1775)\} is due to his initiative, endurance and great technical competence. As a pupil of S. Mauderli \{see planet (1748)\} he did much numerical work on the orbits of minor planets. Then he dealt with stellar dynamics and finally got deeply involved as a pioneer in satellite geodesy. His courses had broad scope and great clarity, and they inspired many young physicists to have a lasting interest in astronomical problems. (M 21129)

Obituary published in Orion, Jahrg. 56, Nr. 287, p. 1-2 (1998).

\section{(2430) Bruce Helin}

1977 VC. Discovered 1977 Nov. 8 by E. F. Helin and E. M. Shoemaker at Palomar.

Named in honor of the first discoverer's son, who has for many years tolerated his mother's preoccupation with extraterrestrial objects. (M 6421)

\section{(2431) Skovoroda}

$1978 \mathrm{PF}_{3}$. Discovered 1978 Aug. 8 by N. S. Chernykh at Nauchnyj.

Named in memory of Grigorij Savvich Skovoroda (1722-1794), an outstanding Ukrainian philosopher and poet. He wandered over the Ukraine preaching his learning to the people. (M 7472)

\section{(2432) Soomana}

1981 FA. Discovered 1981 Mar. 30 by E. Bowell at Anderson Mesa.

In the Hopi Indian language of northern Arizona, Soomana means "star girl". A Hopi child is traditionally named by its father's mother or sister clan, in this case the Sun clan. (M 6650)

Name proposed by Michael Lomatewama and Ekkehart Malotki.

\section{(2433) Sootiyo}

1981 GJ. Discovered 1981 Apr. 5 by E. Bowell at Anderson Mesa.

In the Hopi Indian language, Sootiya means "star boy". The tradition and proposers are as for (2432) Soomana. (M 6650)

\section{(2434) Bateson}

1981 KA. Discovered 1981 May 27 by A. C. Gilmore and P. M. Kilmartin at Lake Tekapo.

Named in honor of Frank Maine Bateson \{1909- \}, director of the Variable Star Section of the Royal Astronomical Society of New Zealand since 1928. He led the site survey of New Zealand that resulted in the establishment of the Mount John University Observatory and was astronomer-in-charge there until 1968. Dr. Bateson and his wife Doris continue to support and encourage astronomy in New Zealand. (M 6210) 


\section{(2435) Horemheb}

4578 P-L. Discovered 1960 Sept. 24 by C. J. van Houten and I. van Houten-Groeneveld at Palomar.

Named for the last pharaoh of the eighteenth dynasty in ancient Egypt. His tomb was recently excavated by a joint British-Dutch expedition. (M 8153)

\section{(2436) Hatshepsut}

6066 P-L. Discovered 1960 Sept. 24 by C. J. van Houten and I. van Houten-Groeneveld at Palomar.

Named for the only female pharaoh to reign over ancient Egypt. (M 8153)

\section{(2437) Amnestia}

1942 RZ. Discovered 1942 Sept. 14 by M. Väisälä at Turku.

Named to honor the work of Amnesty International. (M 7946)

\section{(2438) Oleshko}

$1975 \mathrm{VO}_{2}$. Discovered 1975 Nov. 2 by T. M. Smirnova at Nauchnyj.

Named in memory of Valentina Iosifovna Oleshko (1924-1943), who organized an underground resistance group at Lampovo, near Leningrad. (M 6650)

\section{(2439) Ulugbek}

1977 QX $_{2}$. Discovered 1977 Aug. 21 by N. S. Chernykh at Nauchnyj.

Named for the celebrated Uzbek astronomer and mathematician Ulugbek (Ulugh Beg) Mukhammed Taragaj (1394-1449). (M 7784)

Ulugh Beg is also honored by a lunar crater.

\section{(2440) Educatio}

1978 VQ$_{4}$. Discovered 1978 Nov. 7 by E. F. Helin and S. J. Bus at Palomar.

The Latin name of one of the most important human endeavors. The education of people on Earth is foremost to the industrialization of space. (M 7618)

Name proposed by M. Bush, of the World Space Foundation, which supports the Asteroid Project at Palomar.

\section{(2441) Hibbs}

$1979 \mathrm{MN}_{2}$. Discovered 1979 June 25 by E. F. Helin and S. J. Bus at Siding Spring.

Named in honor of $\mathrm{Al}$ and Marka Hibbs, long time friends of the first discoverer, who wishes to acknowledge the role Al Hibbs played in introducing her to Space Science at Caltech shortly after Sputnik. (M 6422)

\section{(2442) Corbett}

1980 TO. Discovered 1980 Oct. 3 by Z. Vávrová at Klě̌t.

Named for Jim Corbett, hunter, writer and a great friend of animals, born in Nainital, India. (M 6650)

\section{(2443) Tomeileen}

A906 BJ. Discovered 1906 Jan. 24 by M. F. Wolf at Heidelberg.

Named by B. G. Marsden, who found the identifications for this planet, in memory of his parents, Thomas Marsden (1905-1980) and Eileen (née West) Marsden (1905-1981). (M 6833)

\section{(2444) Lederle}

1934 CD. Discovered 1934 Feb. 5 by K. Reinmuth at Heidelberg.

Named in honor of Trudpert Lederle \{1922-2002\}, astronomer at the Astronomisches Rechen-Institut since 1942. Mainly involved with the program of fundamental star catalogues, he has also worked on the motion of (1036) Ganymed. (M 6833)

Name proposed by B. G. Marsden and J. Schubart.

\section{(2445) Blazhko}

1935 TC. Discovered 1935 Oct. 3 by P. F. Shajn at Simeis.

Named in memory of Sergej Nikolaevich Blazhko (1870-1956), director of the Moscow Observatory during 1920-1931, a professor at Moscow University during 1931-1953 and a corresponding member of the U.S.S.R. Academy of Sciences. The founder of the Moscow school of variable-star research, he constructed the first general theory of eclipsing variables of the Algol type. He also proposed a new method of photographing minor planets and constructed a number of original instruments, including the blink microscope and slitless stellar spectrograph. (M 6834)

Name proposed by the Institute for Theoretical Astronomy.

Blazhko is also honored by a lunar crater.

\section{(2446) Lunacharsky}

1971 TS $_{2}$. Discovered 1971 Oct. 14 by L. I. Chernykh at Nauchnyj.

Named in memory of Anatolij Vasil'evich Lunacharskij (1875-1933), Soviet statesman, writer and literary and art critic. (M 7784)

\section{(2447) Kronstadt}

1973 QY $_{1}$. Discovered 1973 Aug. 31 by T. M. Smirnova at Nauchnyj.

Named for the town, situated on Kotlin Island in the Gulf of Finland, that played an integral part in the defense of Leningrad in World War II. (M 6650)

\section{(2448) Sholokhov}

1975 BU. Discovered 1975 Jan. 18 by L. I. Chernykh at Nauchnyj.

Named in memory of Mikhail Aleksandrovich Sholokhov (1905-1984), famous Soviet writer, 1965 Nobel prize-winner. (M 13172)

\section{(2449) Kenos}

1978 GC. Discovered 1978 Apr. 8 by W. Liller at Cerro Tololo. 
Named for the first man in the mythology of the native Americans of Tierra del Fuego, sent by the Supreme Being to bring order into the world. He created the human race by using peat to make male and female organs, taught them language and instructed them in rules to fashion a harmonious society. (M 21606)

Named by the Minor Planet Names Committee following a suggestion by F. Pilcher.

\section{(2450) Ioannisiani}

1978 RP. Discovered 1978 Sept. 1 by N. S. Chernykh at Nauchnyj.

Named in honor of Bagrat Konstantinovich Ioannisiani \{1911-1985\}, designer of astronomical instruments, including the largest Soviet telescopes. (M 7784)

Obituary published in Astrofizika, Tom 24, Vyp. 1, p. 208 (1986).

\section{(2451) Dollfus}

1980 RQ. Discovered 1980 Sept. 2 by E. Bowell at Anderson Mesa.

Named in honor of Audouin Dollfus, astronomer at the Observatoire de Paris, Meudon. Dollfus is renowned for his fundamental work on planetary polarimetry and ground-based imaging, including studies of Saturn's rings, the Martian and lunar surfaces, and the Venus atmosphere. Recently he has worked on the polarimetric properties of minor planets. (M 6531)

\section{(2452) Lyot}

1981 FE. Discovered 1981 Mar. 30 by E. Bowell at Anderson Mesa.

Named in memory of the French astronomer Bernard Lyot (1897-1952). One of the outstanding experimental astronomers of the twentieth century, Lyot invented the solar coronagraph and the birefringent filter. He developed the study of the polarization of light from planets to a perfection that has hardly been surpassed. (M 6531)

Lyot is also honored by craters on Mars and the Moon.

\section{(2453) Wabash}

A921 SA. Discovered 1921 Sept. 30 by K. Reinmuth at Heidelberg.

Named in honor of Bob (Wabash) Warshow, occasional operator in the central computing facility at the Harvard-Smithsonian Center for Astrophysics. In his spare time he is a spelunker, and among his exploits was an expedition directly underneath the radio telescope at Arecibo. (M 18448)

Name proposed by B. G. Marsden, who found the key identification involving this planet.

\section{(2454) Olaus Magnus}

1941 SS. Discovered 1941 Sept. 21 by Y. Väisälä at Turku.

Named for Olaus Magnus (1490-1557), the last Catholic archbishop of Sweden, who spent most of his life in exile in Rome. His 'Carta Marina' was the first map to represent Finland approximately correctly. (M 7946)

\section{(2455) Somville}

$1950 \mathrm{TO}_{4}$. Discovered 1950 Oct. 5 by S. Arend at Uccle.

Named in memory of Oscar Somville (1880-1980), some time head of the seismological section of the Uccle Observatory. (M 8404)

\section{(2456) Palamedes}

$1966 \mathrm{BA}_{1}$. Discovered 1966 Jan. 30 at the Purple Mountain Observatory at Nanking.

Named for the most intelligent of all the Greek commanders who fought in the Trojan War. (M 7618)

(2457) Rublyov

$1975 \mathrm{TU}_{2}$. Discovered 1975 Oct. 3 by L. I. Chernykh at Nauchnyj.

Named for Andrej Rublyov (ca. 1360-ca. 1430), a world-renowned Russian painter who worked on the paintings of some of the cathedrals in Moscow and elsewhere. (M 13172)

\section{(2458) Veniakaverin}

$1977 \mathrm{RC}_{7}$. Discovered 1977 Sept. 11 by N. S. Chernykh at Nauchnyj.

Named in memory of the famous Soviet writer Veniamin Aleksandrovich Kaverin (1902-1989). (M 18304)

\section{(2459) Spellmann}

1980 LB $_{1}$. Discovered 1980 June 11 by C. S. Shoemaker at Palomar.

Named in honor of the discoverer's father Leonard Spellmann, who has been a never-failing source of encouragement and support. (M 6532)

\section{(2460) Mitlincoln}

$1980 \mathrm{TX}_{4}$. Discovered 1980 Oct. 1 by L. G. Taff and D. Beatty at Socorro.

The name honors the Lincoln Laboratory and its association with the Massachusetts Institute of Technology. (M 9080)

\section{(2461) Clavel}

$1981 \mathrm{EC}_{1}$. Discovered 1981 Mar. 5 by H. Debehogne and G. DeSanctis at La Silla.

Named in honor of Gustavine Clavel and her family on the occasion of her hundredth birthday, 1991 Apr. 13, in recognition of a life of work and humility. (M 19332)

\section{(2462) Nehalennia}

6578 P-L. Discovered 1960 Sept. 24 by C. J. van Houten and I. van Houten-Groeneveld at Palomar.

Named for a Roman goddess of fortune, worshiped mainly in the region that is now the Netherlands. (M 8153) 


\section{(2463) Sterpin}

1934 FF. Discovered 1934 Mar. 10 by G. Van Biesbroeck at Williams Bay.

Name proposed by the discoverer's daughter, Micheline Van Biesbroeck Wilson, in memory of her mother, Julia Sterpin Van Biesbroeck (1882-1968). (M 14480)

\section{(2464) Nordenskiöld}

1939 BF. Discovered 1939 Jan. 19 by Y. Väisälä at Turku.

Named for the Finnish explorer Nils Adolf Erik Nordenskiöld (1832-1901). He conducted many Arctic expeditions and first navigated the northeast passage from the Atlantic to the Pacific Ocean in 1878-1879. (M 7946)

\section{(2465) Wilson}

1949 PK. Discovered 1949 Aug. 2 by K. Reinmuth at Heidelberg.

Named in honor of Sir Robert Wilson F.R.S., Perren Professor of Astronomy at University College London, and head of the Department of Physics and Astronomy. Wilson played a leading role in the development of the International Ultraviolet Explorer, one of the most successful astronomical satellites ever launched. He is one of the U.K.'s foremost astronomers and a past vice president of the IAU. (M 18448)

Name proposed by C. M. Bardwell, who made the identifications involving this minor planet, and G. V. Williams, following a suggestion by M. M. Dworetsky, who prepared the citation.

\section{(2466) Golson}

1959 RJ. Discovered 1959 Sept. 7 at the Goethe Link Observatory at Brooklyn, Indiana.

Named in memory of John C. Golson (1927-1984), the first employee of the Kitt Peak National Observatory. "J. C." had been a night assistant at the McDonald Observatory before he was hired by Aden B. Meinel \{see planet (4065)\} to work as an observer on the site survey for a national optical astronomy observatory. The first person hired after Kitt Peak was selected, he received a special service award during the celebration of KPNO's 25th anniversary in February 1983. (M 10043)

Name proposed by F. K. Edmondson.

\section{(2467) Kollontai}

1966 PJ. Discovered 1966 Aug. 14 by L. I. Chernykh at Nauchnyj.

Named in memory of Aleksandra Mikhailovna Kollontai (1872-1952), who served as Soviet ambassador to Norway, Mexico and Sweden, the first woman of any nation ever to become an accredited minister to a foreign country. (M 8064)

\section{(2468) Repin}

1969 TO$_{1}$. Discovered 1969 Oct. 8 by L. I. Chernykh at Nauchnyj.
Named in honor of Il'ya Efimovich Repin (1844-1930), famous Russian painter. (M 13172)

\section{(2469) Tadjikistan}

1970 HA. Discovered 1970 Apr. 27 by T. M. Smirnova at Nauchnyj.

Named for the \{former\} Tadjik Soviet Socialist Republic. (M 6650)

\section{(2470) Agematsu}

1976 UW $_{15}$. Discovered 1976 Oct. 22 by H. Kosai and K. Hurukawa at Kiso.

Named for one of three towns to which the Kiso Station administratively belongs. (M 8912)

For the two other cities mentioned, see the citations of planets (2924) Mitake-mura and (2960) Ohtaki.

\section{(2471) Ultrajectum}

6545 P-L. Discovered 1960 Sept. 24 by C. J. van Houten and I. van Houten-Groeneveld at Palomar.

Named in honor of the University Observatory at Utrecht, best known for its work on solar physics. Ultrajectum was the Roman name for Utrecht. (M 8799)

\section{(2472) Bradman}

1973 DG. Discovered 1973 Feb. 27 by L. Kohoutek at Bergedorf.

Named in honor of the legendary Australian cricketer Donald George Bradman (1908-2001), whose test-match batting average of 99.94 in 80 innings far exeeds that of his closest meaningful competitor, and whose 42 half-centuries give him the best consistency ratio. Bradman's score of 334 runs in a test match against England in 1930 was then a record, as was his 452 (not out) for New South Wales against Queensland, a record in first-class cricket that was unbroken for 29 years. (M 27329)

Name suggested by B. G. Marsden, D. I. Steel and G. V. Williams.

\section{(2473) Heyerdahl}

1977 RX $_{7}$. Discovered 1977 Sept. 12 by N. S. Chernykh at Nauchnyj.

Named in honor of Thor Heyerdahl \{1914-2002\}, outstanding Norwegian ethnographer and archaeologist, brave traveller and prominent writer, famous for his expeditions along ancient sea routes. (M 11156)

\section{(2474) Ruby}

1979 PB. Discovered 1979 Aug. 14 by Z. Vávrová at Klě́.

Named for the discoverer's dog, which lives at the Kleť Observatory. (M 6650)

\section{(2475) Semenov}

$1972 \mathrm{TF}_{2}$. Discovered 1972 Oct. 8 by L. V. Zhuravleva at Nauchnyj.

Named in memory of Pavel Afanes'evich Semenov (1912-1942), a fighter in the International Brigade 
in Spain during 1937-1938 and one of the valiant defenders who perished in the battle of Stalingrad. (M 6650)

\section{(2476) Andersen}

$1976 \mathrm{JF}_{2}$. Discovered 1976 May 2 by N. S. Chernykh at Nauchnyj.

Named for Hans Christian Andersen (1805-1875), great Danish writer of fairy tales. (M 9767)

\section{(2477) Biryukov}

1977 PY $_{1}$. Discovered 1977 Aug. 14 by N. S. Chernykh at Nauchnyj.

Named in memory of Nikolaj Zotovich Biryukov (1912-1966), famous Soviet writer. In a rescue attempt at the age of 18 he rushed into icy water, and as a result was bedridden for the rest of his life, an example of courage and fortitude. (M 7472)

\section{(2478) Tokai}

1981 JC. Discovered 1981 May 4 by T. Furuta at Tokai.

Named by the discoverer for the city in which he lives. (M 6650)

\section{(2479) Sodankylä}

1942 CB. Discovered 1942 Feb. 6 by Y. Väisälä at Turku.

Named for a large country commune, more than 12,000 square kilometers in area, in southern Lapland. A temporary observatory was erected there during the first Polar Year (1882-1883), and since 1913 the Finnish Academy of Sciences and Letters has maintained its Geophysical Observatory there. (M 7946)

\section{(2480) Papanov}

1976 YS $_{1}$. Discovered 1976 Dec. 16 by L. I. Chernykh at Nauchnyj.

Named in memory of Anatolij Dmitrievich Papanov (1922-1987), talented Soviet actor. (M 13172)

\section{(2481) Bürgi}

1977 UQ. Discovered 1977 Oct. 18 by P. Wild at Zimmerwald.

Named for Jost Bürgi (1552-1632) of Lichtensteig in the Toggenburg valley, who won European fame as a highly skilled maker of precious instruments for astronomy and geometry. As a practical mathematician, he also devised and used refined new methods. Initially in the service of the landgraves Wilhelm and Moritz of Kassel, he later served the emperors Rudolf and Mathias in Prague, where he became a good friend and helper to Kepler \{see planet (1134)\}. Bürgi on his own invented logarithms, but being slow (or even loath) to publish his system, he lost the priority to John Napier. (M 21129)

\section{(2482) Perkin}

1980 CO. Discovered 1980 Feb. 13 at the Harvard College Observatory at Harvard.
Named in honor of Richard S\{cott $\}$ and Gladys $\mathrm{T}$ \{almage Perkin, long-time friends and supporters of astronomical research, particularly at the Harvard College Observatory. Richard Perkin (1906-1969) was a founder of the Perkin-Elmer Corporation, the company that has been responsible for the construction of a number of advanced astronomical instruments, including the Space Telescope. Gladys Perkin \{1907$2000\}$ served for over a decade as a member of the Committee to Visit the Harvard University Department of Astronomy. (M 6955)

Richard Perkin is also honored by a lunar crater.

Obituary for GTP published in Bull. Am. Astron. Soc., Vol. 34, No. 4, p. 1371 (2002).

\section{(2483) Guinevere}

1928 QB. Discovered 1928 Aug. 17 by M. F. Wolf at Heidelberg.

Named for the heroine of the Arthurian legends, the wife of King Arthur \{see planet (2597)\}, but the lover of Lancelot \{see planet (2041)\}. When this affair was made public, civil war developed between King Arthur and Lancelot. Lancelot rescued Guinevere from burning at the stake, but these events initiated the downfall of Arthur's idyllic kingdom. (M 8064)

Following a suggestion by F. Pilcher, the name was proposed by E. Bowell, who found the key identification for this planet.

\section{(2484) Parenago}

1928 TK. Discovered 1928 Oct. 7 by G. N. Neujmin at Simeis.

Named in memory of Pavel Petrovich Parenago (1906-1960), a professor at Moscow University, a corresponding member of the U.S.S.R. Academy of Sciences and the founder of the Moscow school of stellar astronomy. In the early 1940s he developed a method for the determination of the interstellar absorption of light. He established the existence of the subdwarf sequence and its location on the Hertzsprung-Russell diagram. He also determined the galactic orbit of the Sun and the first more-or-less reliable determination of the velocity of the Galaxy relative to its neighbors. (M 6955)

Name proposed by the Institute for Theoretical Astronomy.

Parenago is also honored by a lunar crater.

\section{(2485) Scheffler}

1932 BH. Discovered 1932 Jan. 29 by K. Reinmuth at Heidelberg.

Named in honor of Helmut Scheffler (1928- ), staff member of the Heidelberg Königstuhl Observatory and professor of astronomy at Heidelberg University (1963-1991), on the occasion of his retirement. He has made important contributions to the fields of radiation transfer in the outer solar atmosphere, atmospheric seeing and the structure of the interstellar medium. 
In collaboration with H. Elsässer \{see planet (4385)\}, Scheffler has written the well-known textbooks Physik der Sterne und der Sonne and Physics of the Galaxy and Interstellar Matter. (M 18643)

Name proposed and citation prepared by G. Klare and L. D. Schmadel. Endorsed by E. Bowell, who found the key identification involving this planet.

\section{(2486) Metsähovi}

1939 FY. Discovered 1939 Mar. 22 by Y. Väisälä at Turku.

Named for a donated farm near Helsinki, where various institutes have established their observing stations: the Finnish Geodetic Institute for space geodesy, the University of Helsinki for astrophysics, and the Helsinki Technological University for radio astronomy. (M 7946)

\section{(2487) Juhani}

1940 RL. Discovered 1940 Sept. 8 by H. Alikoski at Turku.

Named by the discoverer in honor of his son. (M 7946)

\section{(2488) Bryan}

1952 UT. Discovered 1952 Oct. 23 at the Goethe Link Observatory at Brooklyn, Indiana.

Named in memory of William Lowe Bryan (18601955), president of Indiana University from 1902 to 1937, whose pioneering work in experimental psychology was recognized by his election as president of the American Psychological Association in 1903. Appointed to the faculty soon after his graduation from Indiana University in 1884 (two years before the retirement of Daniel Kirkwood \{see planet (1578)\}), Bryan also served for more than a quarter of a century as vice president and president emeritus, and he was the architect of the present-day structure of the university: the present academic organization, including the department of astronomy, is truly his creation. (M 10043)

Name proposed by F. K. Edmondson.

\section{(2489) Suvorov}

1975 NY. Discovered 1975 July 11 by L. I. Chernykh at Nauchnyj.

Named in memory of Alexandr Vasil'evich Suvorov (1729-1800), military theoretician, famous for his progressive ideas, renowned among the common people of Russia. (M 7946)

\section{(2490) Bussolini}

1976 AG. Discovered 1976 Jan. 3 at the Felix Aguilar Observatory at El Leoncito.

Named in memory of Juan A. Bussolini, S.J. (19051966), solar physicist, director of the Observatorio de Fisica Cosmica de San Miguel and a member of the commission of the International Year of the Quiet Sun. He was also an important benefactor to the Felix Aguilar Observatory. (M 8800)

\section{(2491) Tvashtri}

1977 CB. Discovered 1977 Feb. 15 by W. Sebok at Palomar.

Named for the carpenter in the mythology of India, the divine power for construction in the world. $\mathrm{He}$ molds all forms and assembles the pieces, and has given to earth and sky the marvelous variety of their forms. (M 21606)

Named by the Minor Planet Names Committee following a suggestion by F. Pilcher.

\section{(2492) Kutuzov}

1977 NT. Discovered 1977 July 14 by N. S. Chernykh at Nauchnyj.

Named for Mikhail Illarionovich Kutuzov (17451813), military leader, commander-in-chief during the 1812 war against the troops of Napoleon. (M 9767)

\section{(2493) Elmer}

1978 XC. Discovered 1978 Dec. 1 at the Harvard College Observatory at Harvard.

Named in memory of Charles Wesley Elmer (18721954), whose meeting with Richard S. Perkin ssee planet (2482)\} at the Harvard Tercentenary celebration in 1936 led to the establishment of the PerkinElmer Corporation two years later. Director of the astronomy department at the Brooklyn Academy of Arts and Sciences, he founded the Amateur Astronomers Association in New York City and the Custer Institute in Southold, Long Island. His summer abode in Southold long served as a lending repository of telescopes for amateur astronomers. (M 8404)

\section{(2494) Inge}

1981 LF. Discovered 1981 June 4 by E. Bowell at Anderson Mesa.

Named in honor of Jay L. Inge, friend of the discoverer and cartographer at the U.S. Geological Survey's Branch of Astrogeologic Studies, Flagstaff. Inge has been responsible for producing many topographic and geologic maps of planets and satellites. (M 6834)

\section{(2495) Noviomagum}

7071 P-L. Discovered 1960 Oct. 17 by C. J. van Houten and I. van Houten-Groeneveld at Palomar.

Named in honor of the Astronomical Institute of the Nijmegen University, where many of the positions for the Palomar-Leiden Trojan survey are being measured. Noviomagus was the Roman name for Nijmegen. (M 8800)

\section{(2496) Fernandus}

$1953 \mathrm{TC}_{1}$. Discovered 1953 Oct. 8 at the Goethe Link Observatory at Brooklyn, Indiana.

Named in memory of Fernandus Payne (1881-1977), dean of the graduate school and head of the department of zoology at Indiana University from 1927 to 1947 and dean of the college of arts and sciences from 1942 to 1947. His support played an important role in expanding the department of astronomy and the establishment of a graduate program leading to the Ph.D. degree. 
President of the American Society of Zoologists in 1931, Payne was chairman of the Association of American Universities' Committee on Classification for 18 years. Following his formal retirement in 1951, he served for a year as assistant director for biological and medical sciences of the newly-established National Science Foundation and actively continued his research for two more decades. (M 10043)

Name proposed by F. K. Edmondson.

\section{(2497) Kulikovskij}

$1977 \mathrm{PZ}_{1}$. Discovered 1977 Aug. 14 by N. S. Chernykh at Nauchnyj.

Named in honor of Petr Grigor'evich Kulikovskij \{1910- \}, stellar astronomer and distinguished authority on the history of astronomy. An assistant professor at Moscow University, Kulikovskij is widely known as the author of a reference book for amateur astronomers and also as a musician and composer. (M 7784)

\section{(2498) Tsesevich}

1977 QM$_{3}$. Discovered 1977 Aug. 23 by N. S. Chernykh at Nauchnyj.

Named in honor of Vladimir Platonovich Tsesevich \{1907-1983\}, former director of the Odessa University Observatory, renowned for his research on variable stars. He also studied the brightness variations of $\{433\}$ Eros and is the author of a handbook for amateur astronomers. (M 7784)

Obituaries published in Astron. Tsirk., No. 1319, p. 6-8 (1984); Tsirk Vses astron.-geod. o-vo Akad. Nauk SSSR, No. 37, p. 89-92 (1984); Zemlya Vselennaya, No. 4 , p. 58-60 (1984); Rocznik Astron. Obs. Krakowskiego 1986, p. VII (1985); Perem. Zvezdy, Tom 22, No. 6, p. 816-817 (1988).

\section{(2499) Brunk}

$1978 \mathrm{VJ}_{7}$. Discovered 1978 Nov. 7 by E. M. Shoemaker and E. F. Helin and S. J. Bus at Palomar.

Named in honor of William E. Brunk, astronomer with the National Aeronautics and Space Administration. As chief of NASA's Planetary Astronomy Program, he played an important role in the construction of the 2.6-m reflector at the McDonald Observatory and the Infrared Telescope Facility at Mauna Kea. He is also known for his work on the rings of Saturn, the atmosphere of Jupiter, and the feasibility of detecting planets about other stars. (M 6955)

\section{(2500) Alascattalo}

1926 GC. Discovered 1926 Apr. 2 by K. Reinmuth at Heidelberg.

Named for Alaska's mythical beast, supposedly a cross between a moose and a walrus and genetically bred by miners during the Alaska Gold Rush around 1900. The alascattalo is also the epitome of Alaska's unique sense of humor, "absurding", which is the Alaskan way of dealing with tourists who ask stupid questions. A parade, lasting just four minutes and extending just one block down an alley, is held each year at three minutes past noon on Alascattalo Day, the first Sunday after the third Saturday in November. (M 19332)

Named by the Minor Planets Names Committee following a suggestion by S. C. Levi.

\section{(2501) Lohja}

1942 GD. Discovered 1942 Apr. 14 by L. Oterma at Turku.

Named for a town, ridge and lake in southern Finland. An important market in the Middle Ages, Lohja is famous for its limestone quarries. In the old mine shafts, $150 \mathrm{~m}$ under the Earth's surface, the Finnish Geodetic Institute has established a station for studying Earth tides. (M 7946)

\section{(2502) Nummela}

1943 EO. Discovered 1943 Mar. 3 by Y. Väisälä at Turku.

Named for a village in southern Finland. On a plateau atop the Lohja \{see planet (2501)\} Ridge lies the Finnish Geodetic Institute's standard base line, $864 \mathrm{~m}$ long. (M 7946)

\section{(2503) Liaoning}

$1965 \mathrm{UB}_{1}$. Discovered 1965 Oct. 16 at the Purple Mountain Observatory at Nanking.

Named for a province in northeastern China, noted for its coal and iron mines. (M 7618)

\section{(2504) Gaviola}

1967 JO. Discovered 1967 May 6 by C. U. Cesco and

A. R. Klemola at El Leoncito.

Named in honor of Enrique Gaviola \{1900-1990\}, some time director of the Córdoba Observatory, founder of the Córdoba Institute of Mathematics, Physics and Astronomy. An authority on the construction, testing and treatment of astronomical mirrors, it was he who brought to completion, in 1941, the $1.5-\mathrm{m}$ reflector at Bosque Alegre. (M 7618)

Obituary published in Bol. Asoc. Argent. Astron., No. 35, p. 7-12 (1989).

\section{(2505) Hebei}

1975 UJ. Discovered 1975 Oct. 31 at the Purple Mountain Observatory at Nanking.

Named for a province in northern China. The Yellow River and the Great Wall run through the province. (M 7946)

\section{(2506) Pirogov}

1976 QG $_{1}$. Discovered 1976 Aug. 26 by N. S. Chernykh at Nauchnyj.

Named in memory of Nikolaj Ivanovich Pirogov (18101881), distinguished Russian surgeon and anatomist who developed new methods of anatomical research and the basic principles of field surgery. He has been credited with placing surgery on a scientific basis. (M 9214) 


\section{(2507) Bobone}

$1976 \mathrm{WB}_{1}$. Discovered 1976 Nov. 18 at the Felix Aguilar Observatory at El Leoncito.

Named in memory of Jorge Bobone (1901-1958), some time director of the Córdoba Observatory, well known for his work on the orbits of comets, minor planets and the satellites of Jupiter. His investigation on the orbit of $\mathrm{P} /$ Halley for the 1986 return was unfinished at his death. He also participated in astrometric programs and recovered $\mathrm{P} /$ Encke and $\mathrm{P} /$ Kopff at their returns in 1931 and 1932, respectively. (M 11156) Bobone is also honored by a lunar crater.

\section{(2508) Alupka}

1977 ET $_{1}$. Discovered 1977 Mar. 13 by N. S. Chernykh at Nauchnyj.

Named for a small town on the south coast of the Crimea, famous for its health resorts, also the Vorontsov palace and nearby park. (M 9214)

\section{(2509) Chukotka}

1977 NG. Discovered 1977 July 14 by N. S. Chernykh at Nauchnyj.

Named for a National Area of the \{former\} R.S.F.S.R., situated in the northeastern part of the U.S.S.R. The discoverer participated in an expedition there to observe the 1972 total solar eclipse. (M 7472)

\section{(2510) Shandong}

1979 TH. Discovered 1979 Oct. 10 at the Purple Mountain Observatory at Nanking.

Named for a province in eastern China. The Shandong peninsula stretches between the Bohai Sea and the Yellow Sea. (M 7618)

\section{(2511) Patterson}

1980 LM. Discovered 1980 June 11 by C. S. Shoemaker at Palomar.

Named in honor of Clair C. Patterson \{1922-1995\}, geochemist at the California Institute of Technology. Patterson is world-renowned for his determination, through exquisite techniques of isotopic analysis, of the age of the Earth and of meteorites at $4.55 \times 10^{9}$ years; with the aid of additional lines of evidence, this can be shown to be the age of the solar system as a whole. He also played a leading role in revising the estimates of elemental abundances in various solar system materials. (M 6955)

Name proposed by C. S. Shoemaker and E. F. Helin.

Obituary published in Nature, Vol. 379, No. 6565, p. 487 (1996).

\section{(2512) Tavastia}

1940 GG. Discovered 1940 Apr. 3 by Y. Väisälä at Turku.

The Latin name for the province of Hame, in the lake district of south-central Finland. Archeological studies show evidence for the presence of man 9,000 years ago. The Finns began to settle there in the fifth century. (M 7947)

\section{(2513) Baetslé}

1950 SH. Discovered 1950 Sept. 19 by S. Arend at Uccle.

Named in memory of Paul-Louis Baetslé (1909-1983), professor of astronomy and geodesy at the Brussels Royal Military School and a friend of the discoverer. (M 8404)

Obituary published in Ciel Terre, Vol. 100, No. 1, p. 11-12 (1984).

\section{(2514) Taiyuan}

$1964 \mathrm{TA}_{1}$. Discovered 1964 Oct. 8 at the Purple Mountain Observatory at Nanking.

Named for the capital city of the province of Shaanxi \{see planet (2263)\}, located in northern China, near the central portion of the Yellow River. (M 7618)

\section{(2515) Gansu}

1964 TX $_{1}$. Discovered 1964 Oct. 9 at the Purple Mountain Observatory at Nanking.

Named for a province in northwestern China, at the boundary of the Qinghai-Xizang and loess plateaux. (M 7618)

\section{(2516) Roman}

1964 VY. Discovered 1964 Nov. 6 at the Goethe Link Observatory at Brooklyn, Indiana.

Named in honor of Nancy Grace Roman, a space-age astronomer who joined the staff of the National Aeronautics and Space Administration during its first year and who served with distinction at NASA headquarters in positions of increasing responsibility for two decades. Her earlier professional experience included positions at the Yerkes Observatory and the U.S. Naval Research Laboratory. Her many honors include the NASA Exceptional Scientific Achievement award in 1969, the NASA Outstanding Leadership award in 1978 and four honorary degrees. (M 10311)

Name proposed by F. K. Edmondson.

\section{(2517) Orma}

1968 SB. Discovered 1968 Sept. 28 by P. Wild at Zimmerwald.

The name, the Italian word for a trace or track, seems very appropriate for a minor planet. That it should apply to this particular object follows from the fact that the number and name are an alphanumerical variation of (1257) Móra. (M 17465)

\section{(2518) Rutllant}

1974 FG. Discovered 1974 Mar. 22 by C. Torres at Cerro El Roble.

Named in memory of Federico Rutllant Alcina (1904-1971), director of the Observatório Astronómico Nacional of the Universidad de Chile in Santiago from 1950 to 1963, later professor of mathematics at the Universidad Tecnica Federico Santa Maria in Valparaiso. Among his principal contributions to Chilean astronomy were his arrangement for moving the observatory from Lo Espejo to its present location 
at Cerro Calán, an agreement with the University of Florida that created the Radio Observatório de Maipu, an agreement with the Universities of Chicago and Texas - and later AURA - that produced the Cerro Tololo Interamerican Observatory, and an agreement with the U.S.S.R. Academy of Sciences that produced the Estacion Astronómica de Cerro El Roble - where this minor planet was discovered. (M 10545)

\section{(2519) Annagerman}

$1975 \mathrm{VD}_{2}$. Discovered 1975 Nov. 2 by T. M. Smirnova at Nauchnyj.

Named in memory of Anna German (1936-1982), a popular Polish variety singer. (M 11156)

\section{(2520) Novorossijsk}

1976 QF $_{1}$. Discovered 1976 Aug. 26 by N. S. Chernykh at Nauchnyj.

Named for a town on the Black Sea coast. (M 7618)

\section{(2521) Heidi}

1979 DK. Discovered 1979 Feb. 28 by P. Wild at Zimmerwald.

Named for the heroine of a still highly popular, deeply moving children's tale from the Swiss Alps, by Johanna Spyri (1829-1901). (M 17465)

\section{(2522) Triglav}

1980 PP. Discovered 1980 Aug. 6 by Z. Vávrová at Klě́.

Named for a Slavonic deity. (M 21954)

\section{(2523) Ryba}

1980 PV. Discovered 1980 Aug. 6 by Z. Vávrová at Klě́.

Named for Jakub Jan Ryba (1765-1815), Czech baroque composer, author of the famous Czech Christmas Mass. (M 21954)

\section{(2524) Budovicium}

1981 QB $_{1}$. Discovered 1981 Aug. 28 by Z. Vávrová at Klě́.

The ancient Roman name for the town of České Budějovice \{see planet (11134)\}, the center of South Bohemia near which the Klet Observatory is located. (M 7618)

\section{(2525) O'Steen}

1981 VG. Discovered 1981 Nov. 2 by B. A. Skiff at Anderson Mesa.

Named in honor of the discoverer's mother, Mary Elizabeth O'Steen Skiff. (M 6834)

\section{(2526) Alisary}

1979 KX. Discovered 1979 May 19 by R. M. West at La Silla.

Named by the discoverer in honor of his parents, Alice Benedicta (née Loethman) West and Harry Richard West, as an expression of sincere filial gratitude and in thankful recognition of their many sacrifices and unremitting efforts to give their children a good start in life. (M 6834)

\section{(2527) Gregory}

1981 RE. Discovered 1981 Sept. 3 by N. G. Thomas at Anderson Mesa.

Named in honor of Bruce Gregory Thomas, youngest son of the discoverer, whose name was taken from that of James Gregory, the Scottish astronomer. (M 6834)

\section{(2528) Mohler}

$1953 \mathrm{TF}_{1}$. Discovered 1953 Oct. 8 at the Goethe Link Observatory at Brooklyn, Indiana.

Named in memory of Orren C. Mohler (1908-1985), solar astronomer, director of the McMath-Hulbert Observatory (1962-1979), chairman of the department of astronomy at the University of Michigan (1962-1970), member of the board of directors of the Association of Universities for Research in Astronomy (1962-1974). Mohler pioneered the exploration of the infrared solar spectrum with the lead sulphide infrared detector. His development of the vacuum spectrograph at the McMath-Hulbert Observatory led to the discovery of the "wiggly" solar spectral lines and to an understanding of the role of turbulence in the solar structure of the solar photosphere. (M 10546)

Name proposed by F. K. Edmondson. Citation written by W. A. Hiltner.

Obituary published in Phys. Today, Vol. 39, No. 4, p. 74 (1986).

\section{(2529) Rockwell Kent}

$1977 \mathrm{QL}_{2}$. Discovered 1977 Aug. 21 by N. S. Chernykh at Nauchnyj.

Named for Rockwell Kent (1882-1971), American artist and writer of travel books, whose works draw upon the experiences of his varied career as an architectural draftsman, a lobsterman and a carpenter on the coast of Maine. He also illustrated the works of Melville, Shakespeare and Chaucer \{see, respectively, planets (2985), (2984)\}. (M 9767)

\section{(2530) Shipka}

$1978 \mathrm{NC}_{3}$. Discovered 1978 July 9 by L. I. Chernykh at Nauchnyj.

Named for the mountainous site of the victory of the Russian and Bulgarian troops during the Russo-Turkish war of 1877-1878. (M 7947)

\section{(2531) Cambridge}

1980 LD. Discovered 1980 June 11 by E. Bowell at Anderson Mesa.

Named for the centers of learning in England and in Massachusetts, U.S.A. The Minor Planet Center is located at the Smithsonian Astrophysical Observatory in the latter city. (M 6834) 


\section{(2532) Sutton}

1980 TU $_{5}$. Discovered 1980 Oct. 9 by C. S. Shoemaker at Palomar.

Named in honor of Robert L. Sutton, geologist of the U.S. Geological Survey. As a member of the field geology investigation team for the Apollo lunar landing missions, Sutton had the unique responsibility of identifying the exact location, orientation and geologic field relationships of each sample returned from the Moon. This information is the necessary link that ties the detailed analyses of the returned samples to the heavenly body from which the samples were obtained and is crucial to the correct interpretation of many of the laboratory observations. (M 6956)

\section{(2533) Fechtig}

A905 VA. Discovered 1905 Nov. 3 by M. F. Wolf at Heidelberg.

Named in honor of Hugo Fechtig (1929- ) , director at the Max-Planck Institute for Nuclear Physics in Heidelberg and professor of physics at Heidelberg University. Early in his career Fechtig became interested in cosmophysics. He is a well-known specialist in studies of micrometeoroids and interplanetary dust by rockets and spacecraft and has shared in the organization and development of laboratory and space experiments on meteoritic, lunar, interplanetary and cometary material. This especially refers to the projects on the Helios, Giotto, Vega, Ulysses and Galileo space missions. (M 18643)

Name proposed and citation prepared by L. D. Schmadel and J. Schubart. Endorsed by E. Bowell, who found the key identifications involving this planet.

\section{(2534) Houzeau}

1931 VD. Discovered 1931 Nov. 2 by E. Delporte at Uccle.

Named in memory of Jean-Charles Houzeau (18201888), second director of the Observatoire Royal de Bruxelles and one of the greatest Belgian astronomers. $\mathrm{He}$ is best known internationally as co-author with A.-B. Lancaster, of the Bibliographie générale de l'astronomie jusqu'à 1880; he also wrote the Vademecum de l'astronomie. (M 8800)

Houzeau is also honored by a lunar crater.

\section{(2535) Hämeenlinna}

1939 DH. Discovered 1939 Feb. 17 by Y. Väisälä at Turku.

Named for an old town in the province of Häme. The town grew around a thirteenth-century castle (linna) in an ancient populated area. With its ridges, hills and lakes, Hämeenlinna presents the most fascinating views. It has been an important educational center since 1639, and the renowned Finnish composer Jean Sibelius \{see planet (1405)\} received his schooling there. (M 7947)

\section{(2536) Kozyrev}

1939 PJ. Discovered 1939 Aug. 15 by G. N. Neujmin at Simeis.

Named in honor of Nikolaj Aleksandrovich Kozyrev (1908-1983), a staff member of the Pulkovo Observatory, distinguished expert on the physics of stars, the Moon and the planets, skillful experimenter and observer. He developed a theory on extended atmospheres and found properties of the radiation emitted from them, and he discovered volcanic activity on the Moon and the presence of hydrogen in the atmosphere of Mercury. (M 10546)

Obituary published in Zemlya Vselennaya, No. 1, p. $50-51$ (1984).

\section{(2537) Gilmore}

1951 RL. Discovered 1951 Sept. 4 by K. Reinmuth at Heidelberg.

Named in honor of Alan C. and Pamela M. (Kilmartin) Gilmore, whose program of astrometric observations of comets and minor planets has for more than a decade been one of the most productive and rapidly responsive such efforts ever to be undertaken in the southern hemisphere. At the Mount John University Observatory since 1980, they were formerly on the staff of the Carter Observatory. They also serve as co-directors of the Comet and Minor Planet Section of the Royal Astronomical Society of New Zealand. (M 8064)

Name proposed by C. M. Bardwell and B. G. Marsden, identifiers for this planet.

Pamela M. Gilmore is also honored by minor planet (3907) Kilmartin.

\section{(2538) Vanderlinden}

1954 UD. Discovered 1954 Oct. 30 by S. Arend at Uccle.

Named in memory of Henri Vanderlinden (1892-1983), a Belgian astronomer and professor at the Ghent State University. (M 8404)

\section{(2539) Ningxia}

$1964 \mathrm{TS}_{2}$. Discovered 1964 Oct. 8 at the Purple Mountain Observatory at Nanking.

Named for a province in northwestern China, along the middle section of the Yellow River. (M 7619)

\section{(2540) Blok}

$1971 \mathrm{TH}_{2}$. Discovered 1971 Oct. 13 by L. I. Chernykh at Nauchnyj.

Named in honor of Aleksandr Aleksandrovich Blok (1880-1921), outstanding Russian poet. (M 13172)

\section{(2541) Edebono}

1973 DE. Discovered 1973 Feb. 27 by L. Kohoutek at Bergedorf.

Named in honor of Edward de Bono (1933- ) who is regarded as the leading international authority in conceptual and creative thinking and in the teaching 
of thinking as a skill. He originated the term 'lateral thinking' and is well known for the deliberate creative techniques associated with it and the powerful Six Hats method. He has written over 50 books, published in 28 languages, and has made two TV series. (M 27124)

Name proposed by P. Colemont.

\section{(2542) Calpurnia}

1980 CF. Discovered 1980 Feb. 11 by E. Bowell at Anderson Mesa.

Named for the last wife of Julius Caesar. She bade him stay home from the Senate on the Ides of March, but he ignored her advice and was assassinated there. (M 6834)

Name suggested by F. Pilcher.

\section{(2543) Machado}

1980 LJ. Discovered 1980 June 1 by H. Debehogne at La Silla.

Named in honor of Luiz Eduardo da Silva Machado $\{-1992\}$, director of the Valongo Observatory and professor at the Universidade Federal do Rio de Janeiro, codeveloper with the discoverer of the program of astrometry of minor planets and comets at the European Southern Observatory. He has also promoted the installation of a Zeiss astrograph at Campinas. (M 10844)

\section{(2544) Gubarev}

1980 PS. Discovered 1980 Aug. 6 by Z. Vávrová at Kleť.

Named in honor of Soviet cosmonaut Aleksei A. Gubarev, commander of the spacecraft Soyuz 28. (M 7619)

\section{(2545) Verbiest}

1933 BB. Discovered 1933 Jan. 26 by E. Delporte at Uccle.

Named in memory of Father Ferdinand Verbiest, Belgian missionary in China and astronomer at the court of Emperor Kang-Hi. (M 8800)

\section{(2546) Libitina}

1950 FC. Discovered 1950 Mar. 23 by E. L. Johnson at Johannesburg.

Named for an ancient Roman divinity who presided over the burial of the dead. Roman poets frequently employed her name to mean death itself. (M 21606)

Named by the Minor Planet Names Committee following a suggestion by F. Pilcher.

\section{(2547) Hubei}

$1964 \mathrm{TC}_{2}$. Discovered 1964 Oct. 9 at the Purple Mountain Observatory at Nanking.

Named for a province in the central part of China, located in the middle stretch of the Yangtze River. (M 7947)

\section{(2548) Leloir}

1975 DA. Discovered 1975 Feb. 16 at the Felix Aguilar Observatory at El Leoncito.

Named in honor of the outstanding Argentinian biochemist Luis Federico Leloir \{1906-1987\}, recipient of the Nobel prize in chemistry in 1970 and many other international honors. Born in France, he worked for several years in the United States. He has served as Extraordinary Research Professor at the Universidad Nacional de Buenos Aires and as director of the Instituto de Investigaciones Bioquimicas. As a member of the board of directors of the Consejo Nacional de Investigaciones Cientificas y Tecnicas during 1958-1964 he had an important influence on scientific research in Argentina. (M 11156)

\section{(2549) Baker}

1976 UB. Discovered 1976 Oct. 23 at the Harvard College Observatory at Harvard.

Named in honor of James G. Baker \{1914- \}, astrophysicist, innovator, advisor. To many he is best known for his legendary designs of very demanding optical cameras and spectrographs. By some he is appreciated for his unselfish contributions to the success of difficult endeavors, both on behalf of his fellow scientists and his country. (M 8800)

\section{(2550) Houssay}

$1976 \mathrm{UP}_{20}$. Discovered 1976 Oct. 21 at the Felix Aguilar Observatory at El Leoncito.

Named in memory of the remarkable Argentinian scientist and teacher Bernardo A. Houssay (1887-1971), one of the most influential researchers and teachers in medicine in Latin America, recipient of the Nobel prize for medicine in 1947 and many other international honors. Known in particular for his work in physiology and pharmacology, he wrote extensively on nutrition, internal secreting glands, experimental pathology and toxicology. (M 11156)

The 1947 Nobel prize in medicine was shared between Houssay and C. F. Cori, and G. T. Cori, respectively \{see planet $(6173)\}$.

\section{(2551) Decabrina}

1976 YX $_{1}$. Discovered 1976 Dec. 16 by L. I. Chernykh at Nauchnyj.

Named in memory of the revolutionary group of noblemen that led the uprising against tsarist autocracy and servitude in 1825. (M 7947)

\section{(2552) Remek}

1978 SP. Discovered 1978 Sept. 24 by A. Mrkos at Kleť.

Named for the first Czechoslovak astronaut Vladimir Remek, born in South Bohemia, a member of the crew of Soyuz 28. (M 7619) 
(2553) Viljev

$1979 \mathrm{FS}_{2}$. Discovered 1979 Mar. 29 by N. S. Chernykh at Nauchnyj.

Named in honor of Mikhail Anatol'evich Vil'ev (1893-1919), who, because of his exceptional abilities and tireless efforts, and in spite of his short life, made a prodigious number of investigations in the areas of celestial mechanics, theoretical astronomy and the history of astronomy. (M 7785)

Viljev is also honored by a lunar crater.

\section{(2554) Skiff}

1980 OB. Discovered 1980 July 17 by E. Bowell at Anderson Mesa.

Named in honor of Brian A. Skiff, who has recently made valuable contributions to the asteroid astrometry program at Lowell Observatory. (M 6834)

\section{(2555) Thomas}

1980 OC. Discovered 1980 July 17 by E. Bowell at Anderson Mesa.

Named in honor of Norman G. Thomas, for many years an observer on the Lowell proper motion and asteroid astrometry programs. (M 6835)

\section{(2556) Louise}

1981 CS. Discovered 1981 Feb. 8 by N. G. Thomas at Anderson Mesa.

Named in honor of Carol Louise Thomas-Baltutis, youngest daughter of the discoverer. (M 6835)

\section{(2557) Putnam}

$1981 \mathrm{SL}_{1}$. Discovered 1981 Sept. 26 by B. A. Skiff and

N. G. Thomas at Anderson Mesa.

Named in appreciation of the long and continuing support of the Lowell Observatory by members of the Putnam family, in particular Roger Lowell Putnam (1893-1972) and Michael C. J. Putnam, father and son, successive trustees of the Lowell Observatory. (M 6835)

\section{(2558) Viv}

$1981 \mathrm{SP}_{1}$. Discovered 1981 Sept. 26 by N. G. Thomas at Anderson Mesa.

Named in memory of the discoverer's mother, Vivian Russell Thomas. (M 6835)

\section{(2559) Svoboda}

1981 UH. Discovered 1981 Oct. 23 by A. Mrkos at Klě́.

Named in memory of Jindřich Svoboda (18841941), professor of astronomy and geodesy at Prague Polytechnic. (M 22828)

\section{(2560) Siegma}

1932 CW. Discovered 1932 Feb. 14 by K. Reinmuth at Heidelberg.

Named in honor of Siegfried A. Marx (1934-1995), director of the Karl Schwarzschild Observatory at Tautenburg and professor of astronomy at Jena University. Marx is working on problems of interstellar and intergalactic matter, and he has made important contributions to questions of techniques and proper interpretations of astrophotographic observations. He is well-known for the publication of many textbooks and is one of the great popularizers of astronomy in Germany. His interests include the astrometric work on minor planets and he always supported observational campaigns with the largest Schmidt telescope in the world. (M 18643)

Name proposed and citation prepared by L. D. Schmadel. Endorsed by E. Bowell, who found the key identifications involving this planet.

Obituaries published in Sterne Weltraum, Jahrg. 34, Nr. 11, p. 783 (1995); Astron. Raumfahrt, Jahrg. 32, Heft 29, p. 6 (1995); Mitt. Astron. Ges., Nr. 79, p. 5-7 (1996); Mitt. Astronomiegesch., Nr. 7, p. 5 (1995); Ahnerts Kalender Sternfreunde 1996, p. 6 (1995).

\section{(2561) Margolin}

1969 TK$_{2}$. Discovered 1969 Oct. 8 by L. I. Chernykh at Nauchnyj.

Named in memory of Mikhail Vladimirovich Margolin (1906-1975), blind designer and inventor, a man of heroic fate. (M 7785)

\section{(2562) Chaliapin}

$1973 \mathrm{FF}_{1}$. Discovered 1973 Mar. 27 by L. V. Zhuravleva at Nauchnyj.

Named in memory of Feodor Ivanovich Chaliapin (1873-1938), outstanding Russian singer and actor. (M 17026)

\section{(2563) Boyarchuk}

1977 FZ. Discovered 1977 Mar. 22 by N. S. Chernykh at Nauchnyj.

Named in honor of Aleksandr Alekseevich Boyarchuk \{1931- \}, deputy director of the Crimean Astrophysical Observatory, well known for his research on stellar physics, president of IAU Commission 29 (Stellar spectra) during 1973-76. (M 7785)

Boyarchuk was elected IAU president for the period 1991-1994.

\section{(2564) Kayala}

1977 QX. Discovered 1977 Aug. 19 by N. S. Chernykh at Nauchnyj.

Named for the river in The Song of Igor's Campaign on the occasion of the 800th anniversary of the old Russian literary monument. (M 12012)

\section{(2565) Grögler}

1977 TB $_{1}$. Discovered 1977 Oct. 12 by P. Wild at Zimmerwald.

Named in memory of Norbert Grögler (1928-1983), mineralogist and planetologist who made significant contributions in meteorite research and in the analysis of lunar samples. After graduating from the University of Vienna he followed the invitation of F. G. Houtermans to join an interdisciplinary team of space physicists and planetologists at the University of Berne. He 
developed sophisticated methods for the quantitative separation of minerals from meteorites and lunar samples and made several significant discoveries on the mineralogy and petrography of meteorites and lunar rocks. He also had strong interests in archaeology and made relevant scientific contributions investigating thermoluminescence of ancient pottery. (M 21129)

\section{(2566) Kirghizia}

$1979 \mathrm{FR}_{2}$. Discovered 1979 Mar. 29 by N. S. Chernykh at Nauchnyj.

Named for the \{former\} Kirghiz Soviet Socialist Republic. (M 7472)

\section{(2567) Elba}

1979 KA. Discovered 1979 May 19 by O. Pizarro and G. Pizarro at La Silla.

Named by the discoverers in memory of their mother, Elba Aguilera de Pizarro (1926-1965). (M 6835)

\section{(2568) Maksutov}

1980 GH. Discovered 1980 Apr. 13 by Z. Vávrová at Klě̌t.

Named in memory of Dmitrij Dmitrievich Maksutov (1896-1964), inventor of catadioptric meniscus optical systems. The observations of minor planets at the Klet Observatory are made with a telescope of Maksutov design. (M 7619)

Maksutov is also honored by a lunar crater.

\section{(2569) Madeline}

1980 MA. Discovered 1980 June 18 by E. Bowell at Anderson Mesa.

Named for the heroine in John Keats' poem 'The Eve of St. Agnes'. According to the legend, virtuous young girls who perform the proper ceremonies on the evening before St. Agnes' Day (January 21) were supposed to dream that night of their future husbands. (M 7156)

Name proposed by F. Pilcher.

\section{(2570) Porphyro}

1980 PG. Discovered 1980 Aug. 6 by E. Bowell at Anderson Mesa.

Named for the hero in John Keats' poem The Eve of St. Agnes. Porphyro was deeply in love with Madeline (planet 2569) but was thoroughly despised by all of Madeline's family. A friend helped Porphyro hide in Madeline's bedchamber before her bedtime on the Eve of St. Agnes. Porphyro stood over Madeline as she wakened from her dream of him. With Madeline's family in drunken stupor following revelry the evening before, Porphyro was able to carry her away. (M 7157) Name proposed by F. Pilcher.

\section{(2571) Geisei}

1981 UC. Discovered 1981 Oct. 23 by T. Seki at Geisei.

Named for the location of the discoverer's observatory, some $35 \mathrm{~km}$ to the east of the city of Kochi \{see planet (2396)\}. (M 6956)

\section{(2572) Annschnell}

1950 DL. Discovered 1950 Feb. 17 by K. Reinmuth at Heidelberg.

Named in honor of Anneliese Schnell (1941- ), Austrian astronomer at the Vienna Observatory Although she mainly studies variable stars, she also works on problems in the history of astronomy, especially on the meaning of the names and on the discovery circumstances of the minor planets discovered by J. Palisa \{see planet (914)\}. Schnell was the first woman on the board of the Astronomische Gesellschaft - more than one century after its founding. (M 19333)

Name suggested and citation provided by L. D. Schmadel and endorsed by E. Bowell and B. G. Marsden

\section{(2573) Hannu Olavi}

1953 EN. Discovered 1953 Mar. 10 by H. Alikoski at Turku.

Named by the discoverer in honor of his son. (M 7947)

\section{(2574) Ladoga}

1968 UP. Discovered 1968 Oct. 22 by T. M. Smirnova at Nauchnyj.

Named for the largest lake in Europe, situated near St. Petersburg. (M 8912)

\section{(2575) Bulgaria}

1970 PL. Discovered 1970 Aug. 4 by T. M. Smirnova at Nauchnyj.

Named for the People's Republic of Bulgaria. (M 8912)

\section{(2576) Yesenin}

1974 QL. Discovered 1974 Aug. 17 by L. V. Zhuravleva at Nauchnyj.

Named in memory of the lyric poet Sergej Alexandrovich Yesenin (1895-1925). (M 7619)

\section{(2577) Litva}

$1975 \mathrm{EE}_{3}$. Discovered 1975 Mar. 12 by N. S. Chernykh at Nauchnyj.

Named for the Lithuanian Soviet Socialist Republic, since 1991 the independent state of Lithuania. (M 7472)

\section{(2578) Saint-Exupéry}

1975 VW $_{3}$. Discovered 1975 Nov. 2 by T. M. Smirnova at Nauchnyj.

Named in memory of the French writer Antoine de Saint-Exupéry (1900-1944), some time pilot, author of several novels and the world-famous tale The Little Prince. (M 12012)

\section{(2579) Spartacus}

$1977 \mathrm{PA}_{2}$. Discovered 1977 Aug. 14 by N. S. Chernykh at Nauchnyj.

Named for the leader of a large-scale rebellion of the slaves in Rome in 73-71 B.C. (M 9767)

\section{(2580) Smilevskia}

1977 QP 4 . Discovered 1977 Aug. 18 by N. S. Chernykh at Nauchnyj. 
Named in memory of Moisej Vasil'evich Smilevskij (1913-1944), a journalist from the city of Cherson \{see planet (2701)\} in the Ukraine. (M 12968)

\section{(2581) Radegast}

1980 VX. Discovered 1980 Nov. 11 by Z. Vávrová at Kleť.

Named for a Slavonic deity. (M 21954)

\section{(2582) Harimaya-Bashi}

1981 SA. Discovered 1981 Sept. 26 by T. Seki at Geisei.

Named for the well-known red bridge in the center of the city of Kochi. (M 6956)

\section{(2583) Fatyanov}

$1975 \mathrm{XA}_{3}$. Discovered 1975 Dec. 3 by T. M. Smirnova at Nauchnyj.

Named in memory of Aleksej Ivanovich Fat'yanov (1919-1959), well-known Soviet poet and writer of popular songs. (M 13172)

\section{(2584) Turkmenia}

1979 FG $_{2}$. Discovered 1979 Mar. 23 by N. S. Chernykh at Nauchnyj.

Named for the \{former\} Turkmen Soviet Socialist Republic. (M 7472)

\section{(2585) Irpedina}

1979 OJ $_{15}$. Discovered 1979 July 21 by N. S. Chernykh at Nauchnyj.

Named in honor of the Irkutsk ssee planet (3224)\} Pedagogical Institute. The name is dedicated to fellow students of the discoverer there. (M 8542)

\section{(2586) Matson}

1980 LO. Discovered 1980 June 11 by C. S. Shoemaker at Palomar.

Named in honor of Dennis L. Matson, planetary scientist at the Jet Propulsion Laboratory, who has played a leading role in developing the method for determination of the sizes and albedos of minor planets by means of infrared radiometry. He has also shown that the heat flow from the interior of Jupiter's satellite Io can be measured and monitored from ground-based telescopes. (M 6956)

\section{(2587) Gardner}

1980 OH. Discovered 1980 July 17 by E. Bowell at Anderson Mesa.

Named in honor of the American mathematician Martin Gardner, well known for his column on mathematical games in Scientific American. His wide interests range from recreational mathematics to philosophy to the debunking of pseudoscience. (M 7157)

Name proposed by J. Meeus.

\section{(2588) Flavia}

1981 VQ. Discovered 1981 Nov. 2 by B. A. Skiff at Anderson Mesa.
The name is the feminine form of Flavius, a Roman gens, or patrilineal clan, which included the Emperors Vespasian, Titus and Domitian. The name also appeared in the science-fiction novel A Torrent of Faces (J. Blish and N. Knight, 1967), wherein Flavia is an asteroid on a collision course with the Earth. (M 6956)

\section{(2589) Daniel}

1979 QU $_{2}$. Discovered 1979 Aug. 22 by C.-I. Lagerkvist at La Silla.

Named by the discoverer in honor of his son. (M 7472)

\section{(2590) Mourão}

1980 KJ. Discovered 1980 May 22 by H. Debehogne at La Silla.

Named in honor of R. R. de Freitas Mourão \{1935-

\}, astronomer at the National Observatory in Rio de Janeiro, known for his work on double stars, minor planets and comets. He has participated extensively in the discoverer's program of observations of minor planets at the European Southern Observatory, is the author of several astronomical books and is the leader of the Foundation of the Brazilian Museum for Astronomy. (M 9767)

\section{(2591) Dworetsky}

1949 PS. Discovered 1949 Aug. 2 by K. Reinmuth at Heidelberg.

Named in honor of Michael M. Dworetsky, senior lecturer at University College, London. His research interests mainly involve the stellar abundances of the mercury group of elements. He has also taken a large part in the development of the undergraduate astronomy degree program, particularly the practical work associated with it. $\mathrm{He}$ is currently tutor to astronomy studies and has maintained a wide interest in all matters astronomical. (M 18448)

Name proposed by C. M. Bardwell, who made the identifications involving this minor planet, following a suggestion by G. V. Williams. Citation written by D. McNally.

\section{(2592) Hunan}

1966 BW. Discovered 1966 Jan. 30 at the Purple Mountain Observatory at Nanking.

Named for a province in southern China, rich in the production of rice and world-famous for its embroidery. (M 7619)

\section{(2593) Buryatia}

1976 GB $_{8}$. Discovered 1976 Apr. 2 by N. S. Chernykh at Nauchnyj.

Named for the \{former Buryat Autonomous Soviet Socialist Republic. (M 7472)

\section{(2594) Acamas}

1978 TB. Discovered 1978 Oct. 4 by C. T. Kowal at Palomar. 
Named for a commander of the Thracians who allied themselves with the Trojans in order to fight the Greeks. (M 21606)

Named by the Minor Planet Names Committee following a suggestion by F. Pilcher.

\section{(2595) Gudiachvili}

1979 KL. Discovered 1979 May 19 by R. M. West at La Silla.

Named in memory of Lado Gudiachvili (1896-1980), a great painter and a dear friend of the discoverer. Born in Ducheti, Georgia, he studied in Tbilisi, and after a period in Paris (1919-1927), he returned to his native country, where he remained the rest of his life. He early developed a very personal style, to some extent influenced by early church frescoes. His persistent affection for beauty in all its aspects and his uncompromising pursuit of poetic and sometimes fantastic expressions was only fully recognized at a later time. His drawings and paintings are frequently of a philosophical or allegorical nature, and many are connected with the turbulent history of Georgia. He is one of the founders of twentieth-century Georgian art and became a national legend during his lifetime. (M 6835)

\section{(2596) Vainu Bappu}

1979 KN. Discovered 1979 May 19 by R. M. West at La Silla.

Named in memory of Manali Kallat Vainu Bappu (1927-1982), famous Indian astrophysicist and a dear friend of the discoverer. Educated at Harvard and Caltech, he established, under difficult circumstances, the first modern Indian observatory at Naini Tal during the 1950s. Appointed director of the Kodaikanal Observatory in 1960, he subsequently founded and directed the Indian Institute of Astrophysics in Bangalore. He was the initiator and driving force of many projects, among them the $2.3-\mathrm{m}$ Kavalur telescope, entirely designed and built in India. In the multiple roles of brilliant scientist, teacher and administrator, he contributed decisively to the high level of astronomy and astrophysics in India today. He served as vice-president (1967-1973) and president (1979-1982) of the IAU and as chairman of the editorial board of the Indian Journal of Astronomy and Astrophysics. (M 10043)

Obituaries published in Messenger, No. 29, p. 1, No. 30, p. 1-2 (1982); Astrophys. Space Sci., Vol. 89, No. 1, p. 3-4 (1983); J. Astrophys. Astron., Vol. 3, No. 3, p. 217-218 (1983); Patrika, No. 5, p. 13 (1983); Sky Telesc., Vol. 65, No. 2, p. 137 (1983); Trans. IAU, Vol. XVIII B, p. 1-6 (1983); Bull. Astron. Soc. India, Vol. 10, No. 4, p. 275-279 (1982); Q.J.R. Astron. Soc., Vol. 24, No. 3, p. 360-361 (1983).

\section{(2597) Arthur}

1980 PN. Discovered 1980 Aug. 8 by E. Bowell at Anderson Mesa.

Named for the central figure of the Arthurian legends of medieval England. In his youth, Arthur pulled the sword Excalibur \{see planet (9499)\} out of a rock where all others had failed. This feat entitled him to become king. He established a castle at Camelot s see planet (9500)\} wherein he placed a Round Table, around which all knights who were worthy sat as equals with Arthur, and for many years the kingdom flourished in this spirit of democracy. (M 7157)

Name proposed by F. Pilcher.

\section{(2598) Merlin}

1980 RY. Discovered 1980 Sept. 7 by E. Bowell at Anderson Mesa.

Named for the sage and sorcerer of the Arthurian legends. Merlin's magic enabled Arthur \{see planet (2597)\} to pull the sword Excalibur from the rock and thereby become king. Afterward, Arthur continued to rely heavily on Merlin for advice in running his kingdom. When Merlin withdrew from the scene, Arthur could not guide the kingdom successfully on his wisdom alone. (M 7157)

Name proposed by F. Pilcher.

\section{(2599) Veselí}

1980 SO. Discovered 1980 Sept. 29 by Z. Vávrová at Klě́.

Named for the town in South Bohemia where the dicoverer resides. (M 7619)

\section{(2600) Lumme}

1980 VP. Discovered 1980 Nov. 9 by E. Bowell at Anderson Mesa.

Named in honor of Kari Lumme, of the University of Helsinki. This Finnish astronomer has done much theoretical work on the scattering of light from particles in Saturn's rings. He has recently considered the lightscattering properties of the surfaces of atmosphereless bodies, especially asteroids, and has devised a theory to explain the observed phase curves of these bodies. (M 6956)

\section{(2601) Bologna}

1980 XA. Discovered 1980 Dec. 8 at the Osservatorio San Vittore at Bologna.

Named for the famous Italian city, home of one of the oldest universities in the world, in which the Osservatorio San Vittore is located. (M 6835)

\section{(2602) Moore}

1982 BR. Discovered 1982 Jan. 24 by E. Bowell at Anderson Mesa.

Named in honor of Patrick Moore \{1924- \}, astronomer, broadcaster, and writer. For some years director of the Lunar Section of the British Astronomical Association, Moore has been most energetic and 
successful in popularizing astronomy. He is author of many books and has regularly presented 'The Sky at Night' on BBC television since April 1957. In 1967 he was awarded the Order of the British Empire. (M 7157)

\section{(2603) Taylor}

1982 BW $_{1}$. Discovered 1982 Jan. 30 by E. Bowell at Anderson Mesa.

Named in honor of Gordon E. Taylor, astronomer at the Nautical Almanac Office, Royal Greenwich Observatory. Taylor has been director of the Computing Section of the British Astronomical Association since 1974. His research has centered on the prediction of occultations of stars by solar system objects, and in recent years he has been instrumental in the successful determination of several asteroid sizes by the occultation method. (M 7157)

\section{(2604) Marshak}

1972 LD $_{1}$. Discovered 1972 June 13 by T. M. Smirnova at Nauchnyj.

Named in memory of Samuil Yakovlevich Marshak (1887-1964), famous Soviet poet, writer of classic children's literature. His translations of poems by Robert Burns and of sonnets by Shakespeare \{see planet (2985)\} won him wide recognition. (M 13172)

\section{(2605) Sahade}

1974 QA. Discovered 1974 Aug. 16 at the Felix Aguilar Observatory at El Leoncito.

Named in honor of Jorge Sahade, former \{1985-1988\} president of the International Astronomical Union, well-known Argentinian astrophysicist who has served as director of the Córdoba and La Plata Observatories and was the first director of the Instituto de Astronomia y Fisica del Espacio. During the 1960s he initiated the process that led to the acquisition of the $2.15-\mathrm{m}$ reflector in the Complejo Astronomica El Leoncito. (M 11156)

\section{(2606) Odessa}

1976 GX $_{2}$. Discovered 1976 Apr. 1 by N. S. Chernykh at Nauchnyj.

Named for the large port and industrial and cultural city on the coast of the Black Sea. (M 7472)

\section{(2607) Yakutia}

1977 NR. Discovered 1977 July 14 by N. S. Chernykh at Nauchnyj.

Named for the \{former\} Yakut Autonomous Soviet Socialist Republic. (M 7473)

\section{(2608) Seneca}

1978 DA. Discovered 1978 Feb. 17 by H.-E. Schuster at La Silla.

Named for the great Roman philosopher and statesman Lucius Annaeus Seneca \{4 B.C.-65\}. (M 6835)

Seneca is also honored by a lunar crater.

\section{(2609) Kiril-Metodi}

1978 PB $_{4}$. Discovered 1978 Aug. 9 by L. I. Chernykh and N. S. Chernykh at Nauchnyj.

Named for the brothers Kiril (827-869) and Metodi (815-885), also known as Cyril and Methodius, 'the apostles of the Slavs', great Slavic enlighteners, generally credited with the creation of the Slavic alphabet. (M 7785)

\section{(2610) Tuva}

1978 RO$_{1}$. Discovered 1978 Sept. 5 by N. S. Chernykh at Nauchnyj.

Named for the \{former\} Tuvinian Autonomous Soviet Socialist Republic. (M 7473)

\section{(2611) Boyce}

1978 VQ$_{5}$. Discovered 1978 Nov. 7 by E. M. Shoemaker and E. F. Helin and S. J. Bus at Palomar.

Named in honor of Joseph M. Boyce, planetary scientist at the National Aeronautics and Space Administration. A leading investigator of the cratering record of the surfaces of planets and satellites, his detailed studies of the small craters on the lunar plains are the foundation for our present knowledge of the ages and sequence of volcanic eruptions on the Moon. (M 6956)

\section{(2612) Kathryn}

1979 DE. Discovered 1979 Feb. 28 by N. G. Thomas at Anderson Mesa.

Named in honor of Kathryn Gail Thomas-Hazelton, daughter of the discoverer. Her birthdate, Dec. 26, is apparent in both the object's number and provisional designation. (M 6957)

\section{(2613) Plzeň}

1979 QE. Discovered 1979 Aug. 30 by L. Brožek at Kleť.

Named for the industrial and cultural center of West Bohemia, birthplace of the discoverer. (M 7619)

\section{(2614) Torrence}

1980 LP. Discovered 1980 June 11 by C. S. Shoemaker at Palomar.

Named in honor of Torrence V. Johnson, planetary scientist at the Jet Propulsion Laboratory, who is best known for his systematic investigations of the satellites of Jupiter and Saturn, both by means of ground-based telescopes and the data returned from the Voyager missions. He is also well known for his photometric observations of minor planets. (M 6957)

\section{(2615) Saito}

1951 RJ. Discovered 1951 Sept. 4 by K. Reinmuth at Heidelberg.

Named in honor of Keiji Saito, astrophysicist at the Tokyo Astronomical Observatory during 1961-1985 who has studied the physics of comets and meteors. While still a college student, he was an independent 
discoverer of the nova $\mathrm{T} \mathrm{CrB}$ at its 1946 recurrence and has inspired many amateur astronomers in Japan. (M 11748)

Name proposed by H. Oishi, who made the key identification involving this planet.

\section{(2616) Lesya}

1970 QV. Discovered 1970 Aug. 28 by T. M. Smirnova at Nauchnyj.

Named for Lesya Ukrainka, the pen name of Larisa Petrovna Kosach (1871-1913), an outstanding Ukrainian poetess, playwright and literary critic. (M 8912)

\section{(2617) Jiangxi}

$1975 \mathrm{WO}_{1}$. Discovered 1975 Nov. 26 at the Purple Mountain Observatory at Nanking.

Named for a province in southern China, located along the eastern stretch of the Yangtze River. (M 7619)

\section{(2618) Coonabarabran}

$1979 \mathrm{MX}_{2}$. Discovered 1979 June 25 by E. F. Helin and S. J. Bus at Siding Spring.

Named for this typical country town situated at the base of the beautiful Warrumbungle mountain range in New South Wales. The town is home for many of the astronomers and staff who work at the Siding Spring \{see planet (2343)\} Observatory. (M 7473)

\section{(2619) Skalnaté Pleso}

$1979 \mathrm{MZ}_{3}$. Discovered 1979 June 25 by E. F. Helin and S. J. Bus at Siding Spring.

Named for the observatory in the Tatra mountains of Slovakia $\{$ see planet (1807)\}. A remarkably successful program of visual comet hunting was conducted there, beginning in 1946, and the observatory is also noted for an excellent series of star charts. (M 7473)

\section{(2620) Santana}

1980 TN. Discovered 1980 Oct. 3 by Z. Vávrová at Klě̌.

Named in honor of the contemporary composer and singer Carlos Santana, author of magic music. (M 22245)

\section{(2621) Goto}

1981 CA. Discovered 1981 Feb. 9 by T. Seki at Geisei.

Named in honor of Seizo Goto, well-known manufacturer of telescopes and planetaria, founder of Goto Optics. In 1981 he greatly aided astronomical education by presenting to his native prefecture of Kochi a $60-\mathrm{cm}$ reflector, the largest made by Goto Optics. (M 6957)

\section{(2622) Bolzano}

1981 CM. Discovered 1981 Feb. 9 by L. Brožek at Kleť.

Named on the 200th anniversary of the birth of Bernardo Bolzano (1781-1848), distinguished Czech mathematician and philosopher, professor at the Charles University during 1805-1819. (M 7619)

\section{(2623) Zech}

A919 SA. Discovered 1919 Sept. 22 by K. Reinmuth at Heidelberg.

Named in honor of Gert Zech (1941- ), astronomer at the Astronomisches Rechen-Institut and editor of Astronomy and Astrophysics Abstracts who has also worked on the determination of the mass of the earth and the astronomical unit from observations of (433) Eros. (M 19692)

Name proposed and citation prepared by L. D. Schmadel; endorsed by O. Kippes, who found the key identification involving this planet.

\section{(2624) Samitchell}

1962 RE. Discovered 1962 Sept. 7 at the Goethe Link Observatory at Brooklyn, Indiana.

Named in memory of Samuel Alfred Mitchell (18741960), a faculty member of Columbia University from 1899 to 1913 and then director of the Leander McCormick Observatory until 1945, known for his work on solar eclipses and stellar parallaxes. His measurements of the flash spectrum at the eclipses in 1900, 1901 and 1905 referred to nearly 3,000 lines. His book Eclipses of the Sun went through five editions. His photographic parallax work with the McCormick refractor resulted in the publication of 2,001 parallaxes by 1950 . Subsequent work by van de Kamp \{see planet (1965)\} and Vyssotsky \{see planet (1600)\}, encouraged and supported by Mitchell, yielded absolute proper motions of 29,000 stars between magnitudes 8 and 12 . (M 10844)

Name proposed by F. K. Edmondson.

\section{(2625) Jack London}

$1976 \mathrm{JQ}_{2}$. Discovered 1976 May 2 by N. S. Chernykh at Nauchnyj.

Named for the celebrated American writer Jack London (1876-1916). (M 8542)

\section{(2626) Belnika}

$1978 \mathrm{PP}_{2}$. Discovered 1978 Aug. 8 by N. S. Chernykh at Nauchnyj.

Named in honor of Nikolaj Alekseevich Belyaev, a celestial mechanician at the Institute for Theoretical Astronomy, known for his research on the dynamics of comets and the evolution of cometary orbits. (M 8542)

\section{(2627) Churyumov}

$1978 \mathrm{PP}_{3}$. Discovered 1978 Aug. 8 by N. S. Chernykh at Nauchnyj.

Named in honor of Klim Ivanovich Churyumov \{1937- \}, an astronomer on the Astronomical Faculty of Kiev University known for his work on comets. He was a codiscoverer of periodic comet Churyumov-Gerasimenko in 1969. (M 8542) 


\section{(2628) Kopal}

$1979 \mathrm{MS}_{8}$. Discovered 1979 June 25 by E. F. Helin and S. J. Bus at Siding Spring.

Named in honor of Zdeněk Kopal \{1914-1993\}, astronomer, Czech-born chairman of the astronomy department of Victoria University, Manchester, during 1951-1981. A world authority on eclipsing variables, the Moon and the terrestrial planets, Kopal played a leading role in the exploration of the Moon in a NASA-sponsored program. (M 7158)

Name proposed by E. Helin, endorsed by E. M. Shoemaker.

Obituaries published in Bull. Am. Astron. Soc., Vol. 25, No. 4, p. 1498 (1993); Q.J.R. Astron. Soc., Vol. 35, No. 2, p. 229-230 (1994); Phys. Today, Vol. 47, No. 3, p. 80 (1994); Astrophys. Space Sci., Vol. 213, No. 2, p. 171-173 (1994).

\section{(2629) Rudra}

$1980 \mathrm{RB}_{1}$. Discovered 1980 Sept. 13 by C. T. Kowal at Palomar.

Named for the destroyer aspect of Siva ssee planet (1170)\}, who in the mythology of India was both destroyer and regenerator of all things in the universe. His strength was especially unleashed on all sin and evil, and even the gods feared him. (M 27329)

Name suggested by F. Pilcher.

\section{(2630) Hermod}

$1980 \mathrm{TF}_{3}$. Discovered 1980 Oct. 14 at the Haute Provence Observatory at St. Michel.

Named for a son of Odin and Frigga ssee planets (3989) and (77)\} in Scandinavian mythology. He entered the land of the dead, guarded by Hel ssee planet (949)\}, in an attempt to rescue his brother Balder \{see planet (4059)\}. Hel agreed on condition that everyone and everything in the world, even the plants, stones, and metals, should mourn for Balder. All did, except for a single giant witch in a cave, Thokk. (M 22495)

Named by the Minor Planet Names Committee following a suggestion by F. Pilcher.

\section{(2631) Zhejiang}

$1980 \mathrm{TY}_{5}$. Discovered 1980 Oct. 7 at the Purple Mountain Observatory at Nanking.

Named for a province in eastern China. The West Lake in its capital city of Hangzhou attracts visitors from all over the world. (M 7619)

\section{(2632) Guizhou}

$1980 \mathrm{VJ}_{1}$. Discovered 1980 Nov. 6 at the Purple Mountain Observatory at Nanking.

Named for a province in southwestern China. Many minority people live in this province. (M 7620)

\section{(2633) Bishop}

$1981 \mathrm{WR}_{1}$. Discovered 1981 Nov. 24 by E. Bowell at Anderson Mesa.
Named for George Bishop (1785-1861), from whose observatory in Regents Park, London, eleven minor planets were discovered. The proprietor of a winemaking business, Bishop served as president of the Royal Astronomical Society in 1857 and 1858. (M 9768) Citation prepared by B. Hetherington

\section{(2634) James Bradley}

1982 DL. Discovered 1982 Feb. 21 by E. Bowell at Anderson Mesa.

Named for James Bradley (1693-1762), one of the greatest observers of his time and third Astronomer Royal, from 1742 until his death. Discoverer of aberration (1729) and nutation (1748), Bradley pioneered modern methods of determining instrumental effects on position measurements and published positions of some 3,000 stars with an accuracy never before attained. (M 9768)

Name suggested and citation prepared by B. Hetherington.

\section{(2635) Huggins}

1982 DS. Discovered 1982 Feb. 21 by E. Bowell at Anderson Mesa.

Named for William Huggins (1824-1910), pioneer in astronomical spectroscopy. Huggins stated that the chemical elements on the Earth also existed in the stars, discovered the gaseous nature of bright nebulae, was the first to study the spectrum of a nova and measured the radial velocity of Sirius. As early as 1875 he had devised methods of photographing spectra, and this resulted in the publication of his Atlas of Representative Stellar Spectra in 1899. (M 9768)

Name suggested and citation prepared by B. Hetherington.

Huggins is also honored by craters on Mars and the Moon.

\section{(2636) Lassell}

1982 DZ. Discovered 1982 Feb. 20 by E. Bowell at Anderson Mesa.

Named for William Lassell (1799-1880), discoverer of Neptune's satellite Triton and Uranus' satellites Ariel and Umbriel and an independent discoverer of Saturn's satellite Hyperion. A brewer by trade, he also found some 600 nebulae. (M 9768)

Name suggested and citation prepared by B. Hetherington.

Lassell is also honored by craters on Mars and the Moon.

\section{(2637) Bobrovnikoff}

A919 SB. Discovered 1919 Sept. 22 by K. Reinmuth at Heidelberg.

Named in honor of Nicholas T. Bobrovnikoff, director of the Perkins Observatory from 1934 to 1951, who prepared an authoritative history of astronomy. Perhaps best known for his pioneering investigations on the effect of aperture size on the observed total magnitude 
of comets, he made an exhaustive investigation of the 1909-11 apparition of Halley's Comet and prepared in manuscript form a comprehensive catalogue of physical observations of comets. His spectroscopic study showing differences in the surfaces of minor planets, published in 1929, has been cited as 'so far ahead of its time that it was overlooked'. (M 8064)

Following suggestions by D. D. Meisel and N. Sperling, the name was proposed by B. G. Marsden, who found the identifications involving this planet.

\section{(2638) Gadolin}

1939 SG. Discovered 1939 Sept. 19 by Y. Väisälä at Turku.

Named for Jacob Gadolin (1719-1802), the first astronomer at the Academia Aboensis, and Johan Gadolin (1760-1852), the 'Father of Finnish Chemistry'. (M 7947)

\section{(2639) Planman}

1940 GN. Discovered 1940 Apr. 9 by Y. Väisälä at Turku.

Named for Anders Planman (1724-1803), an astronomer and from 1763 professor of physics at the Academia Aboensis. A participant in the international program to determine the astronomical unit, he made careful observations in Kajaani \{see planet (1519)\} of the 1761 and 1769 transits of Venus. (M 7947)

\section{(2640) Hällström}

1941 FN. Discovered 1941 Mar. 18 by L. Oterma at Turku.

Named for Gustav Gabriel Hällström (1775-1844), professor of physics and several times rector at the Academia Aboensis. His efforts led to the acquisition by Turku of an astronomical observatory and the regular appointment of an observer. (M 7947)

\section{(2641) Lipschutz}

1949 GJ. Discovered 1949 Apr. 4 at the Goethe Link Observatory at Brooklyn, Indiana.

Named in honor of Michael E. Lipschutz, professor of chemistry at Purdue University and author or coauthor of more than 100 scientific papers on meteorites, radiochemistry, cosmochemistry, the Antarctic and extraterrestrial materials processing. Recipient of the first annual Nininger \{see planet (2421)\} Award for meteorite research in 1962 , he has also received three NASA achievement awards and in 1986 was given a certificate of appreciation by the National Commission on Space. He has served as treasurer and council member of the Meteoritical Society (1979-1984), was associate editor of the proceedings of the eleventh Lunar and Planetary Science Conference (1980) and co-convenor of a workshop on Antarctic Glaciology and Meteorites (1982). (M 12012)

Name proposed by F. K. Edmondson.

\section{(2642) Vésale}

1961 RA. Discovered 1961 Sept. 14 by S. Arend at Uccle.

Named in memory of André Vésale (1514-1564), physician to Charles V, promoter of the value of the dissection of cadavers to medicine and author of De humani corporis fabrica, which brought about a revolution in the study of human anatomy. (M 12209)

\section{(2643) Bernhard}

1973 SD. Discovered 1973 Sept. 19 by T. Gehrels at Palomar.

Named in honor of H.R.H. Prince Bernhard of the Netherlands, in recognition of his interest in comets and minor planets. (M 22828)

\section{(2644) Victor Jara}

$1973 \mathrm{SO}_{2}$. Discovered 1973 Sept. 22 by N. S. Chernykh at Nauchnyj.

Named in memory of the internationally-known Chilean singer and composer Victor Jara (1938-1973). (M 8800)

\section{(2645) Daphne Plane}

1976 QD. Discovered 1976 Aug. 30 by E. F. Helin at Palomar.

Named in honor of Daphne Plane, librarian in Caltech's geology department for more than a quarter of a century and a long-time friend of the discoverer. (M 7620)

\section{(2646) Abetti}

1977 EC $_{1}$. Discovered 1977 Mar. 13 by N. S. Chernykh at Nauchnyj.

Named in memory of Antonio Abetti (1846-1928) and of his son Giorgio Abetti (1882-1982), who each served as director of the Asiago Astrophysical Observatory. Collectively they made important contributions to the study of minor planets, solar physics, and the history of astronomy. (M 8542)

Name proposed by the discoverer, following a suggestion from E. Colombini at the Osservatorio San Vittore, where the object was rediscovered as 1982 FB.

Obituaries (G.A.) published in Coelum, Vol. 50, p. 289-291 (1982); Observatory, Vol. 103, No. 1054, p. 184 (1983); Sky Telesc., Vol. 65, No. 1, p. 27 (1983); Vesmír, Vol. 62, p. 94 (1983); Q.J.R. Astron. Soc., Vol. 25, No. 1, p. 98-100 (1984); Zenit, 10. Jaarg., No. 3, p. 128 (1983)

\section{(2647) Sova}

1980 SP. Discovered 1980 Sept. 29 by Z. Vávrová at Klě́.

Named in memory of Antonín Sova (1864-1928), Czech poet, who sang of southern Bohemia. (M 22245)

\section{(2648) Owa}

1980 VJ. Discovered 1980 Nov. 8 by E. Bowell at Anderson Mesa. 
In the Hopi Indian language of northern Arizona owa means 'rock', the almost certain constituent of this minor planet. (M 7473)

Name suggested by E. Malotki.

\section{(2649) Oongaq}

1980 WA. Discovered 1980 Nov. 29 by E. Bowell at Anderson Mesa.

In the Hopi Indian language oongaq means 'from up there', being the ablative case form of the locative stem oo- ('up' or 'high'). The word can be used to donate things that come from the sky, although it is to be hoped that this particular minor planet will remain in orbit. (M 7473)

Name suggested by E. Malotki.

\section{(2650) Elinor}

1931 EG. Discovered 1931 Mar. 14 by M. F. Wolf at Heidelberg.

Named by the Minor Planet Center in honor of Elinor Gates in appreciation of her assistance in preparing and checking observations as a summer student, 1989 May-August. (M 14971)

\section{(2651) Karen}

1949 QD. Discovered 1949 Aug. 28 by E. L. Johnson at Johannesburg.

Named by F. N. Bowman, who found the key identification involving this planet, in honor of Karen S. Mayer, his sister-in-law, and also Karen S. Franz, a fellow physics major at the University of Cincinnati. (M 7158)

\section{(2652) Yabuuti}

1953 GM. Discovered 1953 Apr. 7 by K. Reinmuth at Heidelberg.

Named in honor of Kiyosi Yabuuti, a member of the Japan Academy, former professor of the Astronomical Institute and former director of the Research Institute for Humanistic Studies, Kyoto University. A pioneer in the study of sinology, he has published various books on Chinese ancient astronomy and technology. The minor planet is named on the occasion of the international conference on the history of science in China (Kyoto, 1987), which was held in his honor. (M 12803)

Name proposed by K. Hurukawa, who was a student of Yabuuti and who found the identifications involving this planet.

\section{(2653) Principia}

1964 VP. Discovered 1964 Nov. 4 at the Goethe Link Observatory at Brooklyn, Indiana.

Named in honor of Isaac Newton's \{1642-1727, see planet (8000)\} Philosophiae Naturalis Principia Mathematica on the three-hundredth anniversary of its publication. The culminating work of the seventeenthcentury scientific revolution, weaving together many diverse strands into one consistent fabric and establishing the enduring paradigm of modern science,
Newton's book was also of major importance for astronomy, including programs for the discovery and observation of minor planets. (M 12012)

Name proposed by F. K. Edmondson. Citation prepared by R. S. Westfall.

\section{(2654) Ristenpart}

1968 OG. Discovered 1968 July 18 by C. Torres at Cerro El Roble.

Named in memory of the German astronomer Friedrich Wilhelm Ristenpart (1868-1913), appointed in 1906 as director of the Observatorio Astronomico Nacional in Santiago with the mission to modernize it. He accomplished the move from the downtown site of Quinta Normal to Lo Espejo, about $13 \mathrm{~km}$ south of the city. Of the 1260 plates assigned to the Santiago zone of the Astrographic Catalogue, 745 were taken before his untimely death. A series of fifty charts showing southern-hemisphere stars down to tenth magnitude is known as the Carta de Ristenpart. (M 10546)

\section{(2655) Guangxi}

1974 XX. Discovered 1974 Dec. 14 at the Purple Mountain Observatory at Nanking.

Guangxi Zhuangzu Zizhiqu is located in southwestern China. Its Guilin district is famous for its beauty. (M 7620)

\section{(2656) Evenkia}

1979 HD $_{5}$. Discovered 1979 Apr. 25 by N. S. Chernykh at Nauchnyj.

Named for the Evenkian National Area of the \{former\} R.S.F.S.R. (M 7473)

\section{(2657) Bashkiria}

1979 SB $_{7}$. Discovered 1979 Sept. 23 by N. S. Chernykh at Nauchnyj.

Named for the fformer Bashkir Autonomous Soviet Socialist Republic. (M 7473)

\section{(2658) Gingerich}

1980 CK. Discovered 1980 Feb. 13 at the Harvard College Observatory at Harvard.

Named in honor of Owen Jay Gingerich $\{1930-\quad\}$, Harvard professor of astronomy and of the history of science, and an astrophysicist at the Smithsonian Astrophysical Observatory. Although he has made important contributions to the modeling of stellar atmospheres, he is best known for effectively setting the standards of scholarship for modern studies of the history of astronomy and astrophysics. His historical interests are broad, but much of his work centers on Copernicus and Kepler, as is appropriately acknowledged by this planet's provisional designation. $\mathrm{He}$ is also celebrated for his basic course on science to non-scientist Harvard students, and he served as director of the IAU Central Bureau for Astronomical Telegrams for the three years following the transfer from Copenhagen at the end of 1964. (M 9477) 
(2659) Millis

1981 JX. Discovered 1981 May 5 by E. Bowell at Anderson Mesa.

Named in honor of Robert L. Millis, planetary astronomer at Lowell Observatory, whose work on occultations of stars by solar-system objects has led to the discovery of the rings of Uranus and accurate determination of the sizes of a number of minor planets. He has also used the occultation technique to probe the atmospheres of Mars and Uranus, to refine the ephemerides of the Galilean satellites and to search for possible rings around Neptune. (M 7620)

\section{(2660) Wasserman}

1982 FG. Discovered 1982 Mar. 21 by E. Bowell at Anderson Mesa.

Named in honor of Lawrence H. Wasserman, planetary astronomer at Lowell Observatory. Like his colleague Millis \{see planet (2659)\}, Wasserman has specialized in the study of solar-system objects by the occultation technique. He has analyzed lightcurves of stars occulted by planetary atmospheres and has worked on the prediction, observation and reduction of occultations of stars by minor planets. (M 7620)

\section{(2661) Bydžovský}

$1982 \mathrm{FC}_{1}$. Discovered 1982 Mar. 23 by Z. Vávrová at Klět.

Named in honor of Academician Bohumil Bydžovský (1880-1969), professor of mathematics and chancellor of the Charles University in Prague. He was born in the small town of Veselí nad Lužnicí \{see planets (2599) and (2321)\} in southern Bohemia and became its most eminent citizen. (M 21607)

\section{(2662) Kandinsky}

4021 P-L. Discovered 1960 Sept. 24 by C. J. van Houten and I. van Houten-Groeneveld at Palomar.

Named in memory of the Russian-born painter Vassily Kandinsky (1866-1944), one of the first and best of the abstract painters. (M 9080)

\section{(2663) Miltiades}

6561 P-L. Discovered 1960 Sept. 24 by C. J. van Houten and I. van Houten-Groeneveld at Palomar.

Named for the commander of the Athenian troops who conquered the Persian army in the battle near Marathon in 490 B.C. (M 16590)

\section{(2664) Everhart}

1934 RR. Discovered 1934 Sept. 7 by K. Reinmuth at Heidelberg.

Named in honor of Edgar Everhart \{1920-1990\}, since 1969 in the physics-astronomy department at the University of Denver and director of the Chamberlain Observatory. After an impressive career working on atomic cross-sections, he has made equally fundamental contributions to our knowledge of the distribution of comets and the evolution of cometary orbits, including the development of an efficient integration technique for the purpose. Visual discoverer of comets 1964 IX and $1966 \mathrm{IV}$, he has more recently designed and constructed a measuring engine and used it in a highly successful program of photographic astrometry of comets. (M 8065)

Name proposed by B. G. Marsden, who found the identifications involving this planet.

\section{(2665) Schrutka}

1938 DW $_{1}$. Discovered 1938 Feb. 24 by A. Bohrmann at Heidelberg.

Named in honor of the Austrian astronomer Guntram Schrutka von Rechtenstamm (1910-1995), who worked as professor of astronomy at Vienna University. In 1936 he became the first astronomer to derive the shape of minor planet (433) Eros, assuming it to be a triaxial ellipsoid. Furthermore, Schrutka is an eminent computer of cometary orbits, and he worked extensively on the difficult cases of $\mathrm{P} /$ Tempel $1, \mathrm{P} /$ Tempel-Swift and $\mathrm{P} /$ Westphal. His work on positions and heights of lunar formations is also well known. (M 20519; M 20542)

Name proposed and citation prepared by H. Haupt and L. D. Schmadel.

Obituary published in Mitt. Astron. Ges., Nr. 79, p. 9-10 (1996).

\section{(2666) Gramme}

1951 TA. Discovered 1951 Oct. 8 by S. Arend at Uccle.

Named in memory of Zénobe Gramme (1826-1901), a joiner by profession, who constructed the first directcurrent dynamo and invented the collector that derives direct current from a revolving armature. (M 12209)

\section{(2667) Oikawa}

1967 UO. Discovered 1967 Oct. 30 by L. Kohoutek at Bergedorf.

Named in memory of Okuro Oikawa (1896-1980), who joined the staff of the Tokyo Astronomical Observatory while the new observatory at Mitaka \{see planet (1088)\} was under construction. The Brashear \{see planet (5502)\} astrograph used at the original Azabu \{see planet (3290)\} site by S. Hirayama when he made the 1900 prediscovery observations of the objects later named (498) Tokio and (727) Nipponia was also moved to Mitaka, and Oikawa used it to discover eight numbered and seven unnumbered minor planets during 1926-1930. (M 27329)

Name suggested by Y. Kozai.

\section{(2668) Tataria}

1976 QV. Discovered 1976 Aug. 26 by N. S. Chernykh at Nauchnyj.

Named for the \{former Tatar Autonomous Soviet Socialist Republic. (M 7473)

\section{(2669) Shostakovich}

1976 YQ $_{2}$. Discovered 1976 Dec. 16 by L. I. Chernykh at Nauchnyj. 
Named in memory of Dmitrij Dmitrievich Shostakovich (1906-1975), outstanding twentieth-century Soviet composer. (M 7785)

\section{(2670) Chuvashia}

1977 PW . Discovered 1977 Aug. 14 by N. S. Chernykh at Nauchnyj.

Named for the fformer Chuvash Autonomous Soviet Socialist Republic. (M 7473)

\section{(2671) Abkhazia}

1977 QR $_{2}$. Discovered 1977 Aug. 21 by N. S. Chernykh at Nauchnyj.

Named for the \{former\} Abkhazian Autonomous Soviet Socialist Republic. (M 7474)

\section{(2672) Písek}

1979 KC. Discovered 1979 May 31 by J. Květoň at Klě̆.

Named for a town in western South Bohemia where many outstanding Czech writers and artists were born and lived. (M 7620)

\section{(2673) Lossignol}

1980 KN. Discovered 1980 May 22 by H. Debehogne at La Silla.

The family name of friends of the discoverer. (M 15572)

\section{(2674) Pandarus}

$1982 \mathrm{BC}_{3}$. Discovered 1982 Jan. 27 at the Oak Ridge Observatory at Harvard.

Named for the Lycian warrior whose treacherous wounding of Menelaus \{see planet (1647)\} broke the truce in the Trojan War. (M 6957)

\section{(2675) Tolkien}

1982 GB. Discovered 1982 Apr. 14 by M. Watt at Anderson Mesa.

Named in memory of J. R. R. Tolkien (1892-1973), author and philologist, Merton professor of English language at the University of Oxford. Best known for his imaginative writings, in particular The Lord of the Rings and The Hobbit, he also had a lifelong interest in astronomy. (M 7474)

\section{(2676) Aarhus}

1933 QV. Discovered 1933 Aug. 25 by K. Reinmuth at Heidelberg.

Named by L. K. Kristensen, who found the identifications involving this object, in honor of the Danish city and its university. (M 7158)

\section{(2677) Joan}

1935 FF. Discovered 1935 Mar. 25 by M. Laugier at Nice.

Named in honor of Joan Jordan, secretary in the

Solar and Stellar Physics division at the HarvardSmithsonian Center for Astrophysics. (M 22495)
Name proposed by members of the Planetary Sciences division, the identifications for this object having been made by B. G. Marsden.

\section{(2678) Aavasaksa}

$1938 \mathrm{DF}_{1}$. Discovered 1938 Feb. 24 by Y. Väisälä at Turku.

Named for a hill in the Tornio \{see planet (1471)\} river valley. Just south of the Arctic circle, it offers a fine view of the midnight Sun each June. (M 7947)

\section{(2679) Kittisvaara}

1939 TG. Discovered 1939 Oct. 7 by Y. Väisälä at Turku.

Named for the mountain that is the northern terminus of the 'degree measurement' conducted in the Tornio \{see planet (1471)\} valley in 1736-1737 by Maupertuis \{see planet (3281)\}. (M 7948)

\section{(2680) Mateo}

1975 NF. Discovered 1975 July 1 at the Felix Aguilar Observatory at El Leoncito.

Named in memory of José Mateo (1914-1978), a geophysicist who was for many years in charge of the Gravimetry and Tide Department of the La Plata Observatory. Later, as director of the observatory, he started the final phase of construction of the astronomical complex at El Leoncito. (M 13608)

\section{(2681) Ostrovskij}

$1975 \mathrm{VF}_{2}$. Discovered 1975 Nov. 2 by T. M. Smirnova at Nauchnyj.

Named in memory of Nikolaj Alekseevich Ostrovskij (1904-1936), Soviet writer, known for his book How the steel was tempered. (M 10546; I. I. Neyachenko)

\section{(2682) Soromundi}

$1979 \mathrm{MF}_{4}$. Discovered 1979 June 25 by E. F. Helin and S. J. Bus at Siding Spring.

Named by E. Helin in honor of the Los Angeles chapter of the Young Women's Christian Association, 'sisters of the world'. (M 7620)

\section{(2683) Brian}

$1981 \mathrm{AD}_{1}$. Discovered 1981 Jan. 10 by N. G. Thomas at Anderson Mesa.

Named by the discoverer in honor of his eldest son. (M 7474)

\section{(2684) Douglas}

$1981 \mathrm{AH}_{1}$. Discovered 1981 Jan. 3 by N. G. Thomas at Anderson Mesa.

Named by the discoverer in honor of his brother, Douglas B. Thomas, a physicist at the National Bureau of Standards. (M 7474)

\section{(2685) Masursky}

1981 JN. Discovered 1981 May 3 by E. Bowell at Anderson Mesa.

Named in honor of Harold Masursky \{1923-1990\}, planetary geologist at the Branch of Astrogeologic 
Studies of the U.S. Geological Survey, Flagstaff. He has been active in nearly every U.S. program of lunar and planetary exploration including Ranger, Surveyor, Lunar Orbiter, Apollo, Mariner 9, Viking, Pioneer Venus, and Voyager. He was involved in planning future space missions, including the Galileo mission (Jupiter orbiter probe) and the Venus Radar Mapper. (M 7158)

Obituaries published in Sky Telesc., Vol. 81, No. 2, p. 130-131 (1991); Bull. Am. Astron. Soc., Vol. 25, No. 4, p. 1499 (1993).

\section{(2686) Linda Susan}

$1981 \mathrm{JW}_{1}$. Discovered 1981 May 5 by C. S. Shoemaker at Palomar.

Named in honor of Linda Susan Salazar, youngest daughter of the discoverer. (M 8404)

\section{(2687) Tortali}

1982 HG. Discovered 1982 Apr. 18 by M. Watt at Anderson Mesa.

Named for the spirit of daytime and the Sun in the mythology of the Melanesians of the New Hebrides Islands, which recognizes no gods. He was the rival of Ul \{see planet (3271)\}, spirit of nighttime and the Moon. (M 22496)

Named by the Minor Planet Names Committee following a suggestion by F. Pilcher.

\section{(2688) Halley}

$1982 \mathrm{HG}_{1}$. Discovered 1982 Apr. 25 by E. Bowell at Anderson Mesa.

Named in memory of the great English astronomer Edmond Halley (1656-1742) on the occasion of the recovery, in October 1982, of the comet that bears his name. (M 7474)

Halley is also honored by craters on Mars and the Moon

\section{(2689) Bruxelles}

1935 CF. Discovered 1935 Feb. 3 by S. Arend at Uccle. Named for the capital of Belgium. (M 12209)

\section{(2690) Ristiina}

1938 DG $_{1}$. Discovered 1938 Feb. 24 by Y. Väisälä at Turku.

Named for a country commune in the lake district of southern Finland. In 1968 over sixty prehistoric rock-paintings were found there in the largest discovery of this type in Fennoscandia. (M 7948)

\section{(2691) Sersic}

1974 KB. Discovered 1974 May 18 at the Felix Aguilar Observatory at El Leoncito.

Named in honor of José Luis Sersic \{1933-1993\}, well known for his work in extragalactic astronomy and on supernovae. He has served as director of the Córdoba Observatory and is currently head of the section for extragalactic studies. With Jorge Sahade \{see planet 2605)\} he was responsible for establishing
IAFE, the Argentinian Institute for Astronomy and Physics of Space, and he played an important role in the establishment of the El Leoncito \{see planet (2311)\} Station. (M 14207)

Obituary published in Q.J.R. Astron. Soc., Vol. 36, No. 1, p. 79 (1995).

\section{(2692) Chkalov}

$1976 \mathrm{YT}_{3}$. Discovered 1976 Dec. 16 by L. I. Chernykh at Nauchnyj.

Named in memory of Valerij Pavlovich Chkalov (1904-1938), who participated in the historic flight from Moscow over the North Pole to the U.S.A. in 1937. (M 7785)

\section{(2693) Yan'an}

1977 VM $_{1}$. Discovered 1977 Nov. 3 at the Purple Mountain Observatory at Nanking.

Named for a town in the northern part of Shaanxi \{see planet (2263)\} province, along the Yan River. (M 9478)

\section{(2694) Pino Torinese}

1979 QL $_{1}$. Discovered 1979 Aug. 22 by C.-I. Lagerkvist at La Silla.

Named for the small village in which the Turin Observatory is situated. (M 7474)

\section{(2695) Christabel}

1979 UE. Discovered 1979 Oct. 17 by E. Bowell at Anderson Mesa.

Named for a lovely lady in a poem of the same name by the English poet Samuel Taylor Coleridge (1772-1834). While riding at night, Christabel rescued another lovely lady, who turned out to be the daughter of her father's estranged boyhood friend. Christabel sought to reconcile the two fathers. (M 7158)

\section{(2696) Magion}

1980 HB. Discovered 1980 Apr. 16 by L. Brožek at Klet.

Named for the first Czechoslovak artificial satellite, launched together with Interkosmos 18 in 1978. Designed for studying the relationship of the magnetosphere and the ionosphere, Magion examined the special structure of ELF- and E-wave phenomena. (M 7620)

\section{(2697) Albina}

1969 TC $_{3}$. Discovered 1969 Oct. 9 by B. A. Burnasheva at Nauchnyj.

Named in honor of Albina Alekseevna Serova, Moscow astronomer, friend of the discoverer. (M 11156)

\section{(2698) Azerbajdzhan}

1971 TZ. Discovered 1971 Oct. 11 at the Crimean Astrophysical Observatory at Nauchnyj.

Named for the \{former\} Azerbajdzhan Soviet Socialist Republic. (M 7474) 


\section{(2699) Kalinin}

1976 YX. Discovered 1976 Dec. 16 by L. I. Chernykh at Nauchnyj.

Named in memory of Mikhail Ivanovich Kalinin (1875-1946), Soviet statesman. (M 8065)

\section{(2700) Baikonur}

$1976 \mathrm{YP}_{7}$. Discovered 1976 Dec. 20 by N. S. Chernykh at Nauchnyj.

Named for the Soviet cosmodrome, where the world's first artificial satellite was launched just 25 years ago \{1957\}. (M 7474)

\section{(2701) Cherson}

1978 RT. Discovered 1978 Sept. 1 by N. S. Chernykh at Nauchnyj.

Named for a town in the Ukraine, center of the Chersonian region, which borders with the Crimea. (M 7474)

\section{(2702) Batrakov}

1978 SZ$_{2}$. Discovered 1978 Sept. 26 by L. V. Zhuravleva at Nauchnyj.

Named in honor of Yurij Vasil'evich Batrakov \{1926-

\}, deputy director of the Institute for Theoretical Astronomy, Leningrad, head of the Small Bodies of the Solar System Department and editor-in-chief of the annual Ehfemeridy Malykh Planet \{see planet (5001)\}. Soon after joining ITA in 1955 he studied new classes of periodic solutions in celestial mechanics and application of the results to minor planets and the rings of Saturn. Beginning in 1958 he worked extensively on the orbits of artificial satellites, including the development, with V. F. Proskurin \{see planet (2372)\}, of a widely-used analytical theory of their motions, the use of radio measurements and of synchronous observations, and he was the pioneer in the determination of the earth's gravitational field from resonant satellites. He served as vice president of IAU Commission 20 during 1985-1988. (M 18304)

\section{(2703) Rodari}

$1979 \mathrm{FT}_{2}$. Discovered 1979 Mar. 29 by N. S. Chernykh at Nauchnyj.

Named in memory of Gianni Rodari (1920-1980), Italian writer of children's books. (M 9768)

\section{(2704) Julian Loewe}

$1979 \mathrm{MR}_{4}$. Discovered 1979 June 25 by E. F. Helin and S. J. Bus at Siding Spring.

Named in honor of Julian Loewe, a science and staff writer for the Pasadena Star News who has for a number of years written on activities at the California Institute of Technology and Jet Propulsion Laboratory. (M 7620)

\section{(2705) $\mathrm{Wu}$}

1980 TD 4 . Discovered 1980 Oct. 9 by C. S. Shoemaker at Palomar.
Named in honor of Sherman S. C. Wu, chief photogrammetrist of the Astrogeology Branch of the U.S. Geological Survey. $\mathrm{Wu}$ and his group have published highly detailed topographic maps of selected regions of the Moon and of Mars, including Olympus Mons and parts of the Valles Marineris. These maps, obtained by means of analytical photogrammetry, represent the most accurate solutions extant of the morphology of surfaces on extraterrestrial bodies. (M 8153)

\section{(2706) Borovský}

1980 VW. Discovered 1980 Nov. 11 by Z. Vávrová at Klě́.

Named in memory of Karel Havlíček Borovský (18211856), Czech writer, poet and journalist. (M 16441)

\section{(2707) Ueferji}

$1981 \mathrm{QS}_{3}$. Discovered 1981 Aug. 28 by H. Debehogne at La Silla.

Named in honor of the Universidade Federal do Rio de Janeiro, which, through the Valongo Observatory, supports research in astrometry of minor planets in South America. Staff members have participated in the discoverer's observing program at La Silla. (M 9768)

\section{(2708) Burns}

1981 WT. Discovered 1981 Nov. 24 by E. Bowell at Anderson Mesa.

Named in honor of Joseph A. Burns, planetary astronomer at Cornell University. Burns' wide-ranging research on solar-system dynamics includes the study of planetary rings, satellites, orbital evolution and tides, origin of the solar system, dust motions, and planetary and asteroid rotation. He is currently editor of the journal Icarus. (M 7158)

\section{(2709) Sagan}

1982 FH. Discovered 1982 Mar. 21 by E. Bowell at Anderson Mesa.

Named in honor of Carl Sagan \{1934-1996\}, planetary scientist at Cornell University. He has been active on a number of planetary space missions, including the Mariner 9 and Viking missions to Mars and the Voyager mission to the outer planets. Sagan's research has included studies of the greenhouse effect on Venus, windblown dust on Mars, the atmosphere and surface of Titan, and the possibility of extraterrestrial intelligent life. He has been editor of the journal Icarus and won the 1978 Pulitzer prize for literature. A leading popularizer of astronomy, Sagan is founder of the Planetary Society. (M 7158)

Obituaries published in Astron. Raumfahrt Unterr., Jahrg. 34, Heft 2, p. 7 (1997); Astron. Now, Vol. 11, No. 2, p. 4 (1997); Sidereal Times, Vol. 47, No. 4, p. 12 (1997); Postepy Astron., Tom 45, No. 1, p. 40-41 (1997); Phys. Today, Vol. 50, No. 9, p. 94-95 (1997); Mon. 
Notes Astron. Soc. S. Afr., Vol. 56, No. 1-2, p. 3-4 (1997); Astronomy, Vol. 25, No. 3, p. 28 (1997); Origins Life Evol. Biosphere, Vol. 27, No. 4, p. 309-310 (1997); Nature, Vol. 385, No. 6615, p. 400 (1997); Vasiona, Vol. 45, No. 1-2, p. 30-31 (1997); Planet. Rep., Vol. 17, No. 2, p. 4-22 (1997); Astronomy, Vol. 25, No. 4, p. 38-39 (1997); Sky Telesc., Vol. 93, No. 3, p. 6-7 (1997).

\section{(2710) Veverka}

1982 FQ. Discovered 1982 Mar. 23 by E. Bowell at Anderson Mesa.

Named in honor of Joseph Veverka, planetary astronomer at Cornell University. One of the first to study the polarimetric and photometric properties of asteroids, Veverka has made substantial contributions to our knowledge of other small objects in the solar system, notably in his detailed work on Phobos and Deimos. He has also studied the morphology and motions of wind streaks on the Martian surface and has been a strong advocate of space missions to comets. (M 7159)

\section{(2711) Aleksandrov}

1978 QB $_{2}$. Discovered 1978 Aug. 31 by N. S. Chernykh at Nauchnyj.

Named in honor of Anatolij Petrovich Aleksandrov, outstanding physicist, president of the USSR Academy of Sciences. (M 8542)

\section{(2712) Keaton}

1937 YD. Discovered 1937 Dec. 29 by G. Kulin at Budapest. Independently discovered 1937 December 29 by K. Reinmuth at Heidelberg.

Named for Joseph Francis ("Buster") Keaton (18951966), American comedian, film actor and director. He joined his family's acrobatic act in vaudeville when still a child, and he perfected his art both as a comic actor and director producing three classic stony-faced performances in Sherlock Junior, The Navigator and The General, all masterpieces of the silent screen. Thereafter his career declined, but the film The Buster Keaton Story, a 1957 screen biography, restored Keaton to his rightful place as one of the world's greatest comedians. (M 22496)

Name proposed by G. V. and R. Williams, the identifications for this object having been made by C. M. Bardwell.

\section{(2713) Luxembourg}

1938 EA. Discovered 1938 Feb. 19 by E. Delporte at Uccle.

Named for the country in western Europe. (M 12209)

\section{(2714) Matti}

1938 GC. Discovered 1938 Apr. 5 by H. Alikoski at Turku.

Named by the discoverer in honor of his son. (M 7948)

\section{(2715) Mielikki}

1938 US. Discovered 1938 Oct. 22 by Y. Väisälä at Turku.

Named for the mistress of the forest in Kalevala \{see planet (1454)\}. Her favor was needed for successful hunting. Mielikki is a common girl's name in Finland. (M 7948)

\section{(2716) Tuulikki}

1939 TM. Discovered 1939 Oct. 7 by Y. Väisälä at Turku.

Also a common girl's name in Finland, Tuulikki was a fairy of the forest in Kalevala \{see planet (1454)\}. (M 7948)

\section{(2717) Tellervo}

1940 WJ. Discovered 1940 Nov. 29 by L. Oterma at Turku.

Named for the fairy of the forest in Kalevala \{see planet (1454)\}, whose duty was to protect domestic animals from beasts of prey. Tellervo is another common Finnish girl's name. (M 7948)

\section{(2718) Handley}

1951 OM. Discovered 1951 July 30 by E. L. Johnson at Johannesburg.

Named for Tommy Handley (1894-1949), one of Britain's greatest entertainers of the Second World War. He began his career in variety and concert parties, but from about 1926 he found that his very fast, zany style of spoken humor suited the new medium of radio. Tommy Handley's biggest success was the radio show ITMA ("It's That Man Again"), which was first broadcast in 1939. He introduced many colorful characters and catch-phrases, including Mrs. Mopp, the charlady, with her eternal question - "Can I do you now, sir?" (M 22496)

Name proposed by B. G. Marsden and G. V. and R. Williams, the identifications for this object having been made by C. M. Bardwell.

\section{(2719) Suzhou}

1965 SU. Discovered 1965 Sept. 22 at the Purple Mountain Observatory at Nanking.

Named for a city in southeastern Jiangsu province, famous at home and abroad for its beautiful scenery and elegant ancient gardens. Long described as "the land of fish and rice", "home of silk" and "Venice of the Orient", Suzhou is a shining pearl inlaid on the Yangtse River delta and is also a center of industry and commerce. (M 18448)

\section{(2720) Pyotr Pervyj}

1972 RV $_{3}$. Discovered 1972 Sept. 6 by L. V. Zhuravleva at Nauchnyj.

Named in memory of Peter I (1672-1725), the Russian tsar known as Peter the Great for his progressive reforms and military talent. (M 7621) 


\section{(2721) Vsekhsvyatskij}

$1973 \mathrm{SP}_{2}$. Discovered 1973 Sept. 22 by N. S. Chernykh at Nauchnyj.

Named in honor of Sergej Konstantinovich Vsekhsvyatskij \{1905-1984\}, professor at Kiev University, a prominent researcher on comets, the Sun and solar activity. (M 7785)

Obituaries published in Říše hvězd, Vol. 66, No. 5, p. 88 (1985); Zemlya Vselennaya, No. 2, p. 60-63 (1985); Vesmír, Vol. 64, No. 9, p. 538 (1985). - This planet and the following ones are named on the occasion of the fiftieth anniversary of the All-Union Astronomical Geodetical Organization. The initial letters of the four names spell out the Russian abbreviation VAGO (Vsesoyuznoe Astronomo-Geodezicheskoe Obshchestvo) for this body.

\section{(2722) Abalakin}

$1976 \mathrm{GM}_{2}$. Discovered 1976 Apr. 1 by N. S. Chernykh at Nauchnyj.

Named in honor of Viktor Kuz'mich Abalakin \{1930-

\}, leader of the ephemeris group at the Institute for Theoretical Astronomy, editor of the Astronomicheskij Ezhegodnik, president of IAU Commission 4 (Ephemerides) during 1976-79, outstanding linguist and friend of astronomers around the world. (M 7785)

See also the citation for minor planet (2721).

\section{(2723) Gorshkov}

1978 QL $_{2}$. Discovered 1978 Aug. 31 by N. S. Chernykh at Nauchnyj.

Named in memory of Petr Mikhailovich Gorshkov (1883-1975), professor at Leningrad University, prominent geodesist and astronomer, researcher in geodesy, gravimetry, celestial mechanics and the history of astronomy. (M 7786)

See also the citation for minor planet (2721).

\section{(2724) Orlov}

1978 RZ $_{5}$. Discovered 1978 Sept. 13 by N. S. Chernykh at Nauchnyj.

Named in memory of Sergej Vladimirovich Orlov (1880-1958), professor at Moscow University who contributed much to research on comets. This planet also honors Aleksandr Yakovlevich Orlov (18801954), founder and first director of the Golosseevo Astronomical Observatory, known for his research on the Earth's polar motion and on tidal variations in gravity. (M 7786)

See also the citation for minor planet (2721). Aleksandr and Sergej Orlov are also honored by lunar craters.

\section{(2725) David Bender}

1978 VG $_{3}$. Discovered 1978 Nov. 7 by E. F. Helin and S. J. Bus at Palomar.

Named in honor of David F. Bender, whose analytical techniques and innovations are widely used to evaluate potential space missions to minor planets. A pioneer in the generation of trajectories for both flyby and rendezvous missions, and now a septuagenarian, he is still actively involved in related work at the Jet Propulsion Laboratory, where he has long been a member of the Advance Project Group in the Mission Design Section. (M 8065)

\section{(2726) Kotelnikov}

1979 SEg. Discovered 1979 Sept. 22 by N. S. Chernykh at Nauchnyj.

Named in honor of academician Vladimir Aleksandrovich Kotel'nikov \{1908- $\}$, Soviet scientist, radio engineer and vice-president of the U.S.S.R. Academy of Sciences. Radar observations of Mercury, Venus, Mars and Jupiter conducted under his supervision were of help in correcting the value of the astronomical unit, in determining the period and the direction of the rotation of Venus, and in understanding the physics and dynamics of these planets. (M 9214)

\section{(2727) Paton}

$1979 \mathrm{SO}_{9}$. Discovered 1979 Sept. 22 by N. S. Chernykh at Nauchnyj.

Named in memory of Evgenij Oskarovich Paton (18701953), Soviet scientist known for bridge building and electric welding. The planet also honors academician Boris Evgen'evich Paton, prominent Soviet metallurgist and president of the Academy of Sciences of the Ukrainian S.S.R. (M 9214)

\section{(2728) Yatskiv}

1979 ST $_{9}$. Discovered 1979 Sept. 22 by N. S. Chernykh at Nauchnyj.

Named in honor of Yaroslav Stepanovich Yatskiv \{1940- \}, Soviet astrometrist and geodynamicist, director of the Main Astronomical Observatory of the Ukrainian Academy of Sciences, a vice-president of the IAU, president of IAU Commission 19, and a member of the International Halley Watch Steering Group. (M 9215)

\section{(2729) Urumqi}

$1979 \mathrm{UA}_{2}$. Discovered 1979 Oct. 18 at the Purple Mountain Observatory at Nanking.

Named for an open city in the western part of China, capital of the Xinjiang Uygur ssee planet (2336)\} autonomous region. The political, economic, cultural, scientific and technological center of Xinjiang, Urumqi is located at the northern foot of the Tianshan Mountains, with the Junggar Basin in the north. It is farther from a sea than any other city in the world. It is a "treasure bowl" rich in natural resources and with a wide cultural diversity. Strategically located on the ancient "Silk Road", Urumqi now occupies an important place on the second Eurasian Land Bridge. (M 18448) 
(2730) Barks

1981 QH. Discovered 1981 Aug. 30 by E. Bowell at

Anderson Mesa.

Named for Carl Barks, writer and illustrator. His comic-book stories have emphasized exploration and invention, often featuring space adventure, satellites and minor planets. He touched on the idea of 'rubble pile asteroids' more than 20 years ago. (M 7621)

Name proposed by P. Thomas.

\section{(2731) Cucula}

1982 KJ. Discovered 1982 May 21 by P. Wild at Zimmerwald.

After (1775) Zimmerwald, this is the second minor planet to be discovered at Zimmerwald in the month of May, when the call of the cuckoo is continually heard from the large woods nearby. (M 8153)

\section{(2732) Witt}

1926 FG. Discovered 1926 Mar. 19 by M. F. Wolf at Heidelberg.

Named in memory of Gustav Witt (1866-1946), astronomer at the Berlin Observatory, discoverer of (433) Eros. (M 8153)

Following a suggestion by M. Gressmann, of Falkensee, the city to which Witt moved in 1943 and in which he died, this planet was named by B. G. Marsden, who found the identifications involving it.

\section{(2733) Hamina}

1938 DQ. Discovered 1938 Feb. 22 by Y. Väisälä at Turku.

Named for an old Finnish town on the eastern Gulf of Finland. It was known as market place and harbor as early as the fourteenth century. (M 7948)

\section{(2734) Hašek}

1976 GJ $_{3}$. Discovered 1976 Apr. 1 by N. S. Chernykh at Nauchnyj.

Named for Jaroslav Hašek (1883-1923), prominent Czech writer. (M 9768)

\section{(2735) Ellen}

1977 RB. Discovered 1977 Sept. 13 by S. J. Bus and

T. Lauer at Palomar.

Named by the discoverer of comet $1981 \mathrm{~b}$ (P/Bus) in honor of the discoverer of comet 1981k (P/Howell), then his fiancée, now his wife. (M 7474)

\section{(2736) Ops}

1979 OC. Discovered 1979 July 23 by E. Bowell at Anderson Mesa.

Named for the Roman goddess of abundance. (M 7621)

\section{(2737) Kotka}

1938 DU. Discovered 1938 Feb. 22 by Y. Väisälä at Turku.
Named for an important Finnish industrial center and harbor, a town constructed mainly on islands in the eastern Gulf of Finland. (M 7948)

\section{(2738) Viracocha}

1940 EC. Discovered 1940 Mar. 12 by G. Kulin at Budapest.

Named for the supreme being in Inca mythology. He created the human race and gave them laws for which he required obedience. In his later travels in the Andes Mountains he was accompanied by the Deceiver, Taguacipa \{see planet (2739)\}, who turns to evil the good men he created. Later, the creation completed, he departed in the direction of the setting Sun. (M 22496)

Named by the Minor Planet Names Committee following a suggestion by F. Pilcher.

\section{(2739) Taguacipa}

1952 UZ $_{1}$. Discovered 1952 Oct. 17 by J. L. Brady at Mount Wilson.

Named for the great Deceiver in Inca mythology. $\mathrm{He}$ is the evil dual of the creator of the human race Viracocha \{see planet (2738)\}, who turns to evil the good men Viracocha created. The two always traveled in company, and their companionship continues by their being adjacent in the minor planet tables. (M 22496)

Named by the Minor Planet Names Committee following a suggestion by F. Pilcher.

\section{(2740) Tsoj}

1974 SY $_{4}$. Discovered 1974 Sept. 26 by L. V. Zhuravleva at Nauchnyj.

Named in memory of Victor Robertovich Tsoj (19621990), poet, composer and soloist of the rock-group Kino. (M 20834)

\section{(2741) Valdivia}

1975 XG. Discovered 1975 Dec. 1 by C. Torres at Cerro El Roble.

Named in memory of the Spanish Captain Pedro de Valdivia (1502-1553), conqueror of Chile, who left Peru accompanied by seven soldiers, one Spanish woman and many Indians, to realize his dreams of being discoverer of new territories and governor of a country, of laying the foundations of new cities, and of mixing the Spanish and native races as the first step for a new identity. (M 10546)

\section{(2742) Gibson}

$1981 \mathrm{JG}_{3}$. Discovered 1981 May 6 by C. S. Shoemaker at Palomar.

Named in honor of James B. Gibson, discoverer of the Amor object (1943) Anteros, one of the most accessible known neighbors of the Earth. His painstaking follow-up observations of periodic comets and newly-discovered minor planets and his search for lost objects have been conducted in California and Argentina during much of the past quarter of a century. (M 7621) 


\section{(2743) Chengdu}

1965 WR. Discovered 1965 Nov. 21 at the Purple Mountain Observatory at Nanking.

Named for the capital of Sichuan \{see planet (2215)\} province in southwestern China. Located in the heart of the Sichuan basin, Chengdu was the capital of the Shu-Han dynasty during the Three Kingdoms period of Chinese history. Today, Chengdu is a major agricultural and industrial center, and it is also the homeland of the Giant Panda. (M 20834)

\section{(2744) Birgitta}

1975 RB. Discovered 1975 Sept. 4 by C.-I. Lagerkvist at Kvistaberg.

Named in honor of Anna Birgitta Angelica Lagerkvist, daughter of the discoverer. (M 8800)

\section{(2745) San Martin}

1976 SR $_{10}$. Discovered 1976 Sept. 25 at the Carlos U. Cesco Observatory at El Leoncito.

Named in memory of General José de San Martin (1778-1850), considered the father of Argentina and liberator of Chile and Peru. After fighting for Spain in Bailen against the Napoleonic army he returned to his native Argentina and created the Granaderos a Caballo regiment, which won the battle of San Lorenzo in 1812. As governor intendent of Cuyo ssee planet (1917)\}, he created the Andes army, crossed those mountains, and by conquering the Spanish army at the battles of Chacabuco and Maipu (1817-1818) assured Chile's independence. His defeat of the Royal army in Peru in 1820 led to the independence of that nation also. He refused to take part in the subsequent civil war in Argentina and moved to Europe. (M 17026)

\section{(2746) Hissao}

1979 SJ $_{9}$. Discovered 1979 Sept. 22 by N. S. Chernykh at Nauchnyj.

Named for the Hissar (Gissar) Astronomical Observatory, part of the Institute of Astrophysics of the Tadjik Academy of Sciences in Dushanbe, famous for its research activities on meteors, comets and minor planets. (M 7786)

\section{(2747) Český Krumlov}

1980 DW. Discovered 1980 Feb. 19 by A. Mrkos at Klě́.

Named for the historical town on the Vltava \{see planet (2123)\} river. Klet Observatory is situated $700 \mathrm{~m}$ above the town. (M 22828)

\section{(2748) Patrick Gene}

$1981 \mathrm{JF}_{2}$. Discovered 1981 May 5 by C. S. Shoemaker at Palomar.

Named in honor of Patrick Gene Shoemaker, son of the discoverer. (M 8404)

\section{(2749) Walterhorn}

1937 TD. Discovered 1937 Oct. 11 by K. Reinmuth at Heidelberg.
Named in memory of Walter Horn (1881-1967), promoter of astronomical knowledge in NordrheinWestfalen, Germany's most industrialized area. Horn founded the public observatory in Solingen and, as early as 1924, a society for amateur astronomers. He was considered, not only as an amateur with remarkable didactic skills, but also as a philanthropist who helped many people in the economically unstable mid 1920s. (M 20158)

Name proposed and citation prepared by L. D. Schmadel and W. Schlosser.

\section{(2750) Loviisa}

1940 YK. Discovered 1940 Dec. 30 by Y. Väisälä at Turku.

Named for a small Finnish town, an important export harbor, on the eastern Gulf of Finland. About two-thirds of its area is water. (M 7948)

\section{(2751) Campbell}

1962 RP. Discovered 1962 Sept. 7 at the Goethe Link Observatory at Brooklyn, Indiana.

Named in memory of W. W. Campbell (18621938), observational spectroscopist, director of the Lick Observatory (1901-1930), president of the University of California (1923-1930), president of the International Astronomical Union (1922-1925) and president of the U.S. National Academy of Sciences (1931-1935). He pioneered in conceiving, organizing and carrying out the first large-scale systematic program for the accurate measurement of stellar radial velocities. (M 12457)

Name proposed by F. K. Edmondson. Citation prepared by D. E. Osterbrock.

Campbell is also honored by craters on Mars and the Moon.

\section{(2752) Wu Chien-Shiung}

1965 SP. Discovered 1965 Sept. 20 at the Purple Mountain Observatory at Nanking.

Named in honor of Wu Chien-Shiung, born in China and currently Pupin Professor Emerita at Columbia University. She is renowned for her work in nuclear physics, particularly in the experimental study of the beta decay of radioactive atomic nuclei. The precision and elegance of her experiments have earned her the title of greatest living woman physicist. With coworkers she made her most famous contribution in 1956 with a critical experiment on polarized cobalt- 60 beta decay. The result of this work, which substantiated the theory of Lee and Yang, shocked the world of physics and overthrew the concept of parity conservation in weak interactions. (M 16040)

\section{(2753) Duncan}

1966 DH. Discovered 1966 Feb. 18 at the Goethe Link Observatory at Brooklyn, Indiana.

Named in memory of John Charles Duncan (18821967), a graduate of Indiana University, who taught astronomy at Harvard and Radcliffe until 1916 and at Wellesley until his retirement in 1950 - after which 
he taught for another 14 years at the University of Arizona. The first edition of his widely-used textbook appeared in 1916; the fifth edition appeared in 1955. His Lick Ph.D. thesis on the orbits of two cepheid variables was the first step toward the abandonment of the widely-held binary star theory of cepheid variation. During a 28-year association with the Mount Wilson Observatory he measured the expansion of the Crab Nebula (1921), discovered three variable stars in external galaxies (1922) and took a superb series of pictorial photographs of galaxies, nebulae and Milky Way fields. (M 12457)

Name proposed by F. K. Edmondson.

\section{(2754) Efimov}

1966 PD. Discovered 1966 Aug. 13 by T. M. Smirnova at Nauchnyj.

Named in memory of the aviator Mikhail Nikiforovich Efimov (1881-1919), who was the first to realize steep turns and dives. (M 13173)

\section{(2755) Avicenna}

1973 SJ $_{4}$. Discovered 1973 Sept. 26 by L. I. Chernykh at Nauchnyj.

Named for the medieval scientist, philosopher, physician and poet Ibn Sina, or Abu Ali al Hussein ibn Abdallah (980-1037), known in Europe under the name Avicenna. (M 7786)

Avicenna is also honored by a lunar crater.

\section{(2756) Dzhangar}

1974 SG $_{1}$. Discovered 1974 Sept. 19 by L. I. Chernykh at Nauchnyj.

Named for the Kalmyk epics, which reflect the hopes, dreams, and struggles of the Kalmyk people. (M 8912)

\section{(2757) Crisser}

1977 VN. Discovered 1977 Nov. 11 by S. Barros at Cerro El Roble.

The name is formed from the first halves of the first names of the discoverer's wife, Cristina, and himself, Sergio. (M 11157)

\section{(2758) Cordelia}

1978 RF. Discovered 1978 Sept. 1 by N. S. Chernykh at Nauchnyj.

Named for the younger daughter of King Lear in Shakespeare's tragedy. (M 9769)

The name Cordelia has also been given to the satellite Uranus VI, discovered 1986 by the Voyager 2 spacecraft.

\section{(2759) Idomeneus}

1980 GC. Discovered 1980 Apr. 14 by E. Bowell at Anderson Mesa.

Named for a king of Crete, renowned for his valor in the Trojan War, during which he slew many Trojans. (M 8404)

\section{(2760) Kacha}

1980 TU $_{6}$. Discovered 1980 Oct. 8 by L. V. Zhuravleva at Nauchnyj.

Named for the flying school in Kacha, a settlement in the Crimea, where some Soviet cosmonauts receive training. In 1980 the school celebrated its 70th anniversary. (M 8913)

\section{(2761) Eddington}

1981 AE. Discovered 1981 Jan. 1 by E. Bowell at Anderson Mesa.

Named in memory of the great English astronomer and physicist Arthur Stanley Eddington (1882-1944) on the occasion of the centennial of his birth. Eddington made fundamental contributions to studies of stellar structure and relativity, and he was also a lucid and undefatigable popularizer of astronomy. (M 7621)

Eddington served as president of the International Astronomical Union from 1938 to 1943 . He is also honored by a lunar crater.

\section{(2762) Fowler}

1981 AT. Discovered 1981 Jan. 14 by E. Bowell at Anderson Mesa.

Named in memory of Ralph Howard Fowler (18891944), well-known English astrophysicist. Among his many discoveries was the recognition of the state of matter in white-dwarf stars. (M 7621)

Fowler is also honored by a lunar crater.

\section{(2763) Jeans}

1982 OG. Discovered 1982 July 24 by E. Bowell at Anderson Mesa.

Named in memory of the celebrated English astronomer James Hopwood Jeans (1877-1946), whose wide-ranging research embraced cosmogony, stellar evolution and stellar dynamics. Jeans was also a brilliant writer and popularizer of astronomy. (M 7621)

Jeans is also honored by craters on Mars and the Moon.

\section{(2764) Moeller}

1981 CN. Discovered 1981 Feb. 8 by N. G. Thomas at Anderson Mesa.

Named by the discoverer in honor of his mother, Sonia Louise Moeller-Thomas. (M 7621)

\section{(2765) Dinant}

1981 EY. Discovered 1981 Mar. 4 by H. Debehogne and G. DeSanctis at La Silla.

Named for a city in southern Belgium, birthplace of Adolphe Sax \{see planet (3534)\}, inventor of the saxophone, and of the painter Wiertz. (M 19333)

\section{(2766) Leeuwenhoek}

$1982 \mathrm{FE}_{1}$. Discovered 1982 Mar. 23 by Z. Vávrová at Klě́.

Named in memory of Antonius van Leeuwenhoek (1632-1723), inventor of the microscope. (M 16441) Leeuwenhoek is also honored by a lunar crater. 


\section{(2767) Takenouchi}

1967 UM. Discovered 1967 Oct. 30 by L. Kohoutek at Bergedorf.

Named in honor of Tadao Takenouchi (1922- ), who worked variously in the Department of Astronomy of Tokyo University, the Tokyo Astronomical Observatory, the space agency NASDA and the Institute of Space and Astronautical Sciences. During the 1950s he worked with H. Hirose \{see planet (1612)\} computing ephemerides of minor planets by hand for the Minor Planet Center. Also by hand, he made a numerical study of the orbit of (279) Thule and examined the behavior of its 4:3 libration with Jupiter over a complete cycle. (M 27329)

Name suggested by Y. Kozai.

\section{(2768) Gorky}

1972 RX $_{3}$. Discovered 1972 Sept. 6 by L. V. Zhuravleva at Nauchnyj.

Named for Maxim Gorky, pen name of Aleksei Makhsimovich Peshkov (1868-1936), outstanding Russian writer and the founder of Soviet literature. (M 8913)

\section{(2769) Mendeleev}

$1976 \mathrm{GZ}_{2}$. Discovered 1976 Apr. 1 by N. S. Chernykh at Nauchnyj.

Named in memory of Dmitrij Ivanovich Mendeleev (1834-1907), world-famous Russian chemist, discoverer of the periodic law of the elements. (M 9215) Mendeleev is also honored by a lunar crater.

\section{(2770) Tsvet}

$1977 \mathrm{SM}_{1}$. Discovered 1977 Sept. 19 by N. S. Chernykh at Nauchnyj.

Named in memory of Mikhail Semenovich Tsvet (1872-1919), physiologist and plant biochemist, the founder of chromatography. (M 12012)

\section{(2771) Polzunov}

$1978 \mathrm{SP}_{7}$. Discovered 1978 Sept. 26 by L. V. Zhuravleva at Nauchnyj.

Named for Ivan Ivanovich Polzunov (1728-1766), inventor of the first universal steam-engine in Russia. (M 13173)

Polzunov is also honored by a lunar crater.

\section{(2772) Dugan}

1979 XE. Discovered 1979 Dec. 14 by E. Bowell at Anderson Mesa.

Named in memory of the American astronomer Raymond Smith Dugan (1878-1940), perhaps best known as a co-author with Russell and Stewart of an important astronomical textbook. His principal field of research concerned variable stars, but during 19021904 he participated in the Heidelberg minor-planet program, discovering 18 planets. (M 7622)

Dugan is also honored by a lunar crater.

\section{(2773) Brooks}

$1981 \mathrm{JZ}_{2}$. Discovered 1981 May 6 by C. S. Shoemaker at Palomar.

Named in honor of William R. Brooks (1844-1921), American astronomer. As the village photographer at Phelps, New York, he independently discovered comet 1881 V with a 5-inch reflector. Although credited to Denning, this find encouraged Brooks to build a 9 1/4-inch telescope with which he found comet Brooks-Swift 1883 I. During the next 28 years, Brooks discovered 20 more comets to which his name has been attached. Three of those were found during a particularly successful 4-week period in 1886. In 1900 he became professor of astronomy at Hobart College in Geneva, New York. (M 17655)

Citation provided by D. H. Levy at the request of the discoverer.

\section{(2774) Tenojoki}

1942 TJ. Discovered 1942 Oct. 3 by L. Oterma at Turku.

Named for the border stream between Norway and Finland. (M 7948)

\section{(2775) Odishaw}

$1953 \mathrm{TX}_{2}$. Discovered 1953 Oct. 14 at the Goethe Link Observatory at Brooklyn, Indiana.

Named in memory of Hugh Odishaw (1916-1984), an organizer in international geophysical research during a time of revolution in Earth and space sciences. He served as executive director of the U.S. committee for the International Geophysical Year, director of the IGY World Data Center, executive director of the Space Science Board, executive secretary of the U.S. National Academy of Sciences' division of physical sciences and dean of the University of Arizona's college of Earth and space sciences. His excitement and enthusiasm about the recent flood of discoveries in geophysics led to a television film series, Planet Earth, premiered not long after his death. (M 12968)

Name proposed by F. K. Edmondson. Citation prepared by E. Roemer.

\section{(2776) Baikal}

1976 SZ 7 . Discovered 1976 Sept. 25 by N. S. Chernykh at Nauchnyj.

Named for the large Siberian lake. (M 8543)

\section{(2777) Shukshin}

1979 SY $_{11}$. Discovered 1979 Sept. 24 by N. S. Chernykh at Nauchnyj.

Named in memory of Vasilij Makarovich Shukshin (1929-1974), distinguished Soviet writer, film director and actor. (M 8543)

\section{(2778) Tangshan}

1979 XP. Discovered 1979 Dec. 14 at the Purple Mountain Observatory at Nanking.

Named for a city in Hebei \{see planet (2505)\} province in northern China with a long history and 
flourishing industry. Tangshan city overlooks Bohai Bay, which is rich in natural resources. The coal, iron and steel and power industries are its economic pillars, and the city is well known as the "granary of eastern Hebei province", the "northern city of coal" and the "northern center of porcelain". (M 20834)

\section{(2779) Mary}

1981 CX. Discovered 1981 Feb. 6 by N. G. Thomas at Anderson Mesa.

Named by the discoverer in honor of his wife, Maryanna Ruth Thomas. During the 1960s she measured positions of comets and minor planets in the program then conducted by Elizabeth Roemer \{see planet (1657)\} at the U.S. Naval Observatory's station in Flagstaff. (M 7622)

\section{(2780) Monnig}

$1981 \mathrm{DO}_{2}$. Discovered 1981 Feb. 28 by S. J. Bus at Siding Spring.

Named in honor of Oscar Monnig, of Fort Worth, Texas, who has devoted a lifetime to the study and popularization of meteoritics. He has made outstanding contributions as the result of countless field investigations of meteorite falls. His tireless efforts have led to the accumulation of one of the world's largest private collections of meteorites. (M 7786)

Name proposed by E. Helin.

\section{(2781) Kleczek}

1982 QH. Discovered 1982 Aug. 19 by Z. Vávrová at Klě̆.

Named in honor of Josip Kleczek (1923- ), distinguished astronomer and solar physicist, known in particular for his outstanding organization of the IAU/UNESCO International School for Young Astronomers. $\mathrm{He}$ is the author of many books, including The Six Languages Astronomical Dictionary. (M 22245)

\section{(2782) Leonidas}

2605 P-L. Discovered 1960 Sept. 24 by C. J. van

Houten and I. van Houten-Groeneveld at Palomar.

Named for the king of Sparta who defended the Thermophylae pass against the Persians in 480 B.C. (M 16590)

\section{(2783) Chernyshevskij}

$1974 \mathrm{RA}_{2}$. Discovered 1974 Sept. 14 by N. S. Chernykh at Nauchnyj.

Named in memory of Nikolaj Gavrilovich Chernyshevskij (1828-1889), Russian writer and philosopher. (M 9215)

\section{(2784) Domeyko}

1975 GA. Discovered 1975 Apr. 15 by C. Torres at Cerro El Roble.

Named in memory of Ignacio Domeyko (1802-1889), a Polish scientist who moved to Chile in 1830 as a teacher of chemistry and mineralogy in La Serena. In 1846 he became professor of mineralogy and later rector at the University of Chile in Santiago. In recognition of his extensive geological investigations throughout the country, the government offered him Chilean nationality. (M 11157)

\section{(2785) Sedov}

1978 QN $_{2}$. Discovered 1978 Aug. 31 by N. S. Chernykh at Nauchnyj.

Named in memory of Georgij Yakovlevich Sedov (1877-1914), celebrated Russian Arctic explorer who perished on an expedition to the North Pole. (M 8543)

\section{(2786) Grinevia}

1978 RR $_{5}$. Discovered 1978 Sept. 6 by N. S. Chernykh at Nauchnyj.

Named in memory of the Soviet writer-romanticist Aleksandr Stepanovich Grinevskij (1880-1932). (M 8543)

\section{(2787) Tovarishch}

1978 RC $_{6}$. Discovered 1978 Sept. 13 by N. S. Chernykh at Nauchnyj.

Named for the Soviet training ship that has participated in many international sailing regattas and has twice been awarded first prize. (M 8800)

\section{(2788) Andenne}

1981 EL. Discovered 1981 Mar. 1 by H. Debehogne and G. DeSanctis at La Silla.

Named for an industrial city in southern Belgium, known for its foundries and metallurgic factories. (M 19333)

\section{(2789) Foshan}

1956 XA. Discovered 1956 Dec. 6 at the Purple Mountain Observatory at Nanking.

Named for a famous city in the Guangdong ssee planet (2185)\} province in southern China with a long history and flourishing industry. With its favorable geographical conditions, fertile land and developed commodity economy, and well known for its industry of textiles, electronics, pottery and porcelain, casting, etc., Foshan is a bright pearl of the Pearl River delta. (M 15088)

\section{(2790) Needham}

1965 UU $_{1}$. Discovered 1965 Oct. 19 at the Purple Mountain Observatory at Nanking.

Named in honor of Joseph Needham, a famous natural scientist and academician of the British Royal Academy of Sciences. For nearly half a century, he was diligent and unremitting in writing Science and Civilization in China, a monumental series that vividly elaborates the historical contributions of China to science and technology. (M 16041)

\section{(2791) Paradise}

1977 CA. Discovered 1977 Feb. 13 by S. J. Bus at Palomar.

Named for the town of Paradise, California. Situated on the lower slopes of the Sierras, this old mining town 
is now a thriving community and the home of Schelte und Alice Bus, parents of the discoverer. (M 7948)

\section{(2792) Ponomarev}

$1977 \mathrm{EY}_{1}$. Discovered 1977 Mar. 13 by N. S. Chernykh at Nauchnyj.

Named in memory of Nikolaj Georgievich Ponomarev (1900-1942), designer of astronomical instruments. (M 11157)

\section{(2793) Valdaj}

1977 QV. Discovered 1977 Aug. 19 by N. S. Chernykh at Nauchnyj.

Named for the Valdaj Hills, near Moscow, well known in Russian history. The discoverer als dedicates this name to the memory of his father, Stepan Semenovich Chernykh, who perished there on 1942 Mar. 3 in World War II. (M 9769)

\section{(2794) Kulik}

$1978 \mathrm{PS}_{3}$. Discovered 1978 Aug. 8 by N. S. Chernykh at Nauchnyj.

Named in memory of Leonid Alekseevich Kulik (18831942), Soviet mineralogist, researcher of meteorites, and a founder of meteoric research in the U.S.S.R. He is particularly known for his investigation of the place and circumstances of the Tunguska event s see planet (5471)\}. (M 9215)

Kulik is also honored by a lunar crater.

\section{(2795) Lepage}

1979 YM. Discovered 1979 Dec. 16 by H. Debehogne and E. R. Netto at La Silla.

Named in honor of Theophile Lepage, professor of mathematics at the Université de Liège during 1928-1930 and at the Université de Bruxelles during 1931-1971. Known for his work in analysis, modern algebra, group theory and the theory of geodesic fields, he directed the doctoral studies of the first discoverer. (M 9769)

\section{(2796) Kron}

1980 EC. Discovered 1980 Mar. 13 by E. Bowell at Anderson Mesa.

Named in honor of Gerald E. Kron, member of the staff of the Lick Observatory during 19381965 and director of the U.S. Naval Observatory's Flagstaff station during 1965-1973. A pioneer in the application of the photomultiplier tube to astronomical photometry, he has published a large quantity of highprecision photometric measurements of stars, clusters and galaxies. In addition, he developed an improved data-retrieval system for the Lallemand electronic camera, which he then applied to a study of globular clusters. (M 8800)

\section{(2797) Teucer}

1981 LK. Discovered 1981 June 4 by E. Bowell at Anderson Mesa.

Named for the son of Telamon \{see planet (1749)\} and half-brother of Ajax \{see planet (1404)\}. This most renowned of the Greek archers disposed of many Trojan soldiers by springing out from his great shield to loose an arrow, then darting back behind its cover. (M 8543)

\section{(2798) Vergilius}

2009 P-L. Discovered 1960 Sept. 24 by C. J. van Houten and I. van Houten-Groeneveld at Palomar.

Named for the Roman poet Virgil (70-18 B.C.), author of the poems Bucolica, Georgica and Aeneis. (M 16590)

\section{(2799) Justus}

3071 P-L. Discovered 1960 Sept. 25 by C. J. van Houten at Palomar.

Named in honor of Justus Cramer, a descendant of H. G. van de Sande Bakhuyzen, a former director of the Leiden Observatory. (M 8404)

\section{(2800) Ovidius}

4585 P-L. Discovered 1960 Sept. 24 by C. J. van Houten and I. van Houten-Groeneveld at Palomar.

Named for the Roman poet Ovid (43 B.C.-A.D. 18), whose collections of poems include Ars Amatoria, Metamorphoses, Tristia and Fasti. (M 16590)

\section{(2801) Huygens}

$1935 \mathrm{SU}_{1}$. Discovered 1935 Sept. 28 by H. van Gent at Johannesburg.

Named in memory of Christian Huygens (1629-1695), celebrated Dutch physicist and astronomer, well known for his wave theory of light and as the discoverer of Saturn's satellite Titan. (M 18135)

Huygens is also honored by a crater on Mars.

\section{(2802) Weisell}

1939 BU. Discovered 1939 Jan. 19 by Y. Väisälä at Turku.

Named in memory of the discoverer's father, whose many technical and scientific interests included astronomy. (M 7948)

\section{(2803) Vilho}

1940 WG. Discovered 1940 Nov. 29 by L. Oterma at Turku.

Named in memory of Vilho Väisälä (1889-1969), a meteorologist and geophysicist, elder brother of Y. Väisälä \{see planet (2804)\}. Director of the Finnish Meteorological Institute (1919-1948) and professor of meteorology at the University of Helsinki (1948-1958), he was well known for devising scientific apparatus, including a radiosonde used in many countries. (M 7949)

\section{(2804) Yrjö}

1941 HF. Discovered 1941 Apr. 19 by L. Oterma at Turku.

Named in memory of Yrjö Väisälä (1891-1971), originator and leader of the minor-planet program at Turku, and a teacher of the discoverer. He became the first professor of physics at the University of Turku in 1923 and soon afterward he inaugurated instruction in 
astronomy. He was also well known as a geodesist and an esperantist. An important contributor to astronomical fields as diverse as optics and orbit determination, he planned and constructed the observatory and the telescopes at Iso-Heikkilä \{see planet (1947)\}. In 1951 he was appointed a member of the Academy of Finland. On his initiative the University of Turku then established the Astronomical-Optical Institute at Tuorla \{see planet (1425)\}, and he served as its director until his death. (M 7949)

Väisälä is also honored by planet (1573).

\section{(2805) Kalle}

1941 UM. Discovered 1941 Oct. 15 by L. Oterma at Turku.

Named in memory of Kalle Väisälä (1893-1968), an algebraist and number theorist, younger brother of Y. Väisälä \{see planet (2804)\}. Author of various textbooks for secondary school and university, he was professor of mathematics at Tartu University during 1919-1922, at the University of Turku during 1922-1938, and at the Helsinki Technological University during 1939-1960. (M 7949)

\section{(2806) Graz}

1953 GG. Discovered 1953 Apr. 7 by K. Reinmuth at Heidelberg.

Named for the capital city of the Austrian province of Styria \{see planet (6482)\}. With its three universities and a population of 240,000, Graz is a center of culture, music and the arts. The city also hosts and supports the Institute for Space Research of the Austrian Academy of Sciences. Among its distinguished past residents is Johannes Kepler \{see planet (1134)\}, who lived there from 1594 to 1600. (M 20519)

Name proposed and citation prepared by H. Haupt and L. D. Schmadel.

\section{(2807) Karl Marx}

$1969 \mathrm{TH}_{6}$. Discovered 1969 Oct. 15 by L. I. Chernykh at Nauchnyj.

Named in memory of Heinrich Karl Marx (1818-1883), author of Das Kapital, philosopher of history and a student of the theory of socio-economic systems. (M 8065)

\section{(2808) Belgrano}

1976 HS. Discovered 1976 Apr. 23 at the Carlos U. Cesco Observatory at El Leoncito.

Named in memory of General Manuel Belgrano (1770-1820), creator of the Argentinian national flag. After studying law in Spain he returned to his native land and served as secretary for the commerce consulate of the viceroyship El Rio de la Plata. A deep believer in freedom and education, he hailed the establishment of the schools of agriculture, commerce and navigation in La Plata and was restless in his fight to improve the social and economic conditions of his people. Pioneer of the May revolution and a member of the first La Plata governmental meeting (1810), he participated in the first military campaign to Paraguay (1811) and defeated the Spanish army in Tucumán and Salta (1812-1813). He traveled to Europe on a diplomatic mission in the hope of gaining independence for these lands. On his return he was put in charge of the army fighting in Peru, and after his death in Buenos Aires he was considered the spiritual martyr of anarchy in his motherland. (M 17027)

\section{(2809) Vernadskij}

1978 QW $_{2}$. Discovered 1978 Aug. 31 by N. S. Chernykh at Nauchnyj.

Named in memory of Academician Vladimir Ivanovich Vernadskij (1863-1945), distinguished naturalist, mineralogist and crystallographer, founder of the geochemical and radiogeological investigation of the terrestrial biosphere. (M 11157)

Vernadskij is also honored by a lunar crater.

\section{(2810) Lev Tolstoj}

1978 RU $_{5}$. Discovered 1978 Sept. 13 by N. S. Chernykh at Nauchnyj.

Named for the great Russian writer Lev Nikolaevich Tolstoj (1828-1910). (M 8801)

\section{(2811) Střemchoví}

1980 JA. Discovered 1980 May 10 by A. Mrkos at Klet.

Named for the small village in Moravia \{see planet (1901)\} where the discoverer was born. (M 22828; M 25457)

\section{(2812) Scaltriti}

1981 FN. Discovered 1981 Mar. 30 by E. Bowell at Anderson Mesa.

Named in honor of Franco Scaltriti, astronomer at the Pino Torinese Observatory. With his colleague Zappalà \{see planet (2813)\}, Scaltriti has undertaken an extensive program of minor-planet rotational studies. He has also worked on lightcurves of variable stars. (M 8404)

\section{(2813) Zappalà}

1981 WZ. Discovered 1981 Nov. 24 by E. Bowell at Anderson Mesa.

Named in honor of Vincenzo Zappalà, astronomer at the Pino Torinese Observatory. Zappalà's work on minor-planet brightness variation has provided a wealth of data on rotation and shape for the brighter main-belt objects. He has also studied collisional evolution and has been active in a program of minor-planet astrometry. (M 8405)

\section{(2814) Vieira}

$1982 \mathrm{FA}_{3}$. Discovered 1982 Mar. 18 by H. Debehogne at La Silla.

Named in honor of Gilson Vieira, astronomer at the Valongo Observatory and professor at the Universidade Federal do Rio de Janeiro, collaborator in the program that produced the discovery of this object, in particular by adapting computer programs for orbit computations and astrometric reductions. (M 10845) 


\section{(2815) Soma}

1982 RL. Discovered 1982 Sept. 15 by E. Bowell at Anderson Mesa.

Named for the Soma cube, a three-dimensional mathematical game invented by the Danish writer Piet Hein and popularized in articles by Martin Gardner \{see planet (2587)\}. (M 9080)

Name proposed by the discoverer, following a suggestion by J. Meeus.

\section{(2816) Pien}

1982 SO. Discovered 1982 Sept. 22 by E. Bowell at

Anderson Mesa.

Named in honor of Armand Pien, of the Royal Meteorological Institute, Uccle. Well known for his popularization of meteorology and astronomy, he has presented televised weather forecasts in Belgium for more than 30 years. (M 9080)

Name proposed by the discoverer, following a suggestion by J. Meeus.

\section{(2817) Perec}

1982 UJ. Discovered 1982 Oct. 17 by E. Bowell at Anderson Mesa.

Named for Georges Perec, who wrote a 300-page novel La Disparition (Paris, 1969) without using the letter "e". This "eccentricity" would seem to suit him to studies of minor planets. (M 9080)

Name proposed by the discoverer, following a suggestion by J. Meeus.

\section{(2818) Juvenalis}

2580 P-L. Discovered 1960 Sept. 24 by C. J. van

Houten and I. van Houten-Groeneveld at Palomar.

Named for the Roman satirical poet Juvenal (fl. c. A.D. 100). (M 16591)

\section{(2819) Ensor}

1933 UR. Discovered 1933 Oct. 20 by E. Delporte at Uccle.

Named in memory of Baron James Ensor (18601949), renowned painter and sculptor from Ostende, whose works were principally about death or the sea. (M 12209)

\section{(2820) Iisalmi}

1942 RU. Discovered 1942 Sept. 8 by Y. Väisälä at Turku.

Named for a town, parts of which date back to the stone age, in the lake district of central Finland. Known for the spa Runni, monuments there memorialize important events in Finnish history. Iisalmi was also the home of famous writers, including Eero Salmelainen, who compiled the celebrated collection of Finnish Folk-Tales, published during 1852-1866. (M 7949)

\section{(2821) Slávka}

1978 SQ. Discovered 1978 Sept. 24 by Z. Vávrová at Klę̌t.

Named in memory of Sláva Vávrová (1910-1985), the discoverer's mother. (M 22245)
(2822) Sacajawea

1980 EG. Discovered 1980 Mar. 14 by E. Bowell at Anderson Mesa.

Named for the young Shoshone Indian woman who guided Lewis and Clark on their expedition of discovery across North America to the Pacific Ocean during 1804-1806. She displayed limitless courage and loyalty to both the expedition, in which she faced danger as bravely as any other member, and to her infant son, whom she carried for the entire trip. (M 8065)

\section{(2823) van der Laan}

2010 P-L. Discovered 1960 Sept. 24 by C. J. van Houten and I. van Houten-Groeneveld at Palomar.

Named in honor of Harry van der Laan, former professor of astronomy at Leiden Observatory and well-known for his work on radio radiation of gaseous nebulae. He is especially honored for his activity in securing the Dutch participation in the Observatorio de Roque de los Muchachos at La Palma, Canary Islands. Van der Laan is since 1987 director of the European Southern Observatory. (M 10043)

\section{(2824) Franke}

1934 CZ. Discovered 1934 Feb. 4 by K. Reinmuth at Heidelberg.

Named in honor of Ernst H. Franke, professor of biophysics at the University of Cincinnati. He gained the respect of his students by being a doer first and a teacher second, facts enhanced by his experience and desire to teach the latest technologies. (M 8065)

Name proposed by F. N. Bowman, who found the key identification involving this planet.

\section{(2825) Crosby}

1938 SD $_{1}$. Discovered 1938 Sept. 19 by C. Jackson at Johannesburg.

Named for Harry Lillis ("Bing") Crosby (1903-1977), American singer and film actor. Crosby began to sing while studying law at college and, after a spell with the Paul Whiteman Orchestra in a trio called "The Rhythm Boys", appeared in the early talkie King of Jazz (1930). Later, turning solo, he began to make films in earnest, notably the 'Road' series of films with Bob Hope \{see planet (2829)\} and Dorothy Lamour, and won an Academic Award for Going My Way (1944). Crosby's 'White Christmas' and 'Silent Night' are two of the biggest selling recordings of all time. (M 22496)

Name proposed by G. V. and R. Williams, the identifications for this object having been made by C. M. Bardwell.

\section{(2826) Ahti}

1939 UJ. Discovered 1939 Oct. 18 by Y. Väisälä at Turku.

Named for the male water sprite in Kalevala ssee planet (1454)\}. Ahti is a common boy's name in Finland. (M 7949)

\section{(2827) Vellamo}

1942 CC. Discovered 1942 Feb. 11 by L. Oterma at Turku. 
Named for the female water sprite in Kalevala \{see planet (1454)\}. Vellamo is yet another common girl's name in Finland. (M 7949)

\section{(2828) Iku-Turso}

1942 DL. Discovered 1942 Feb. 18 by L. Oterma at Turku.

Named for the deep-sea monster in Kalevala \{see planet (1454)\}. (M 7949)

\section{(2829) Bobhope}

1948 PK. Discovered 1948 Aug. 9 by E. L. Johnson at Johannesburg.

Named in honor of Bob Hope (real name Leslie Townes Hope), American comedian, born Eltham, England, in 1903. Star of numerous radio and television productions, Hope made his mark playing bumbling fools and cowards in such films as Cat and the Canary (1939), Caught in the Draft (1941) and Princess and the Pirate (1944). Hope has been the recipient of four special Academy Awards and more than forty honorary doctorates. (M 22496)

Name proposed by G. V. and R. Williams, the identifications for this object having been made by C. M. Bardwell.

\section{(2830) Greenwich}

1980 GA. Discovered 1980 Apr. 14 by E. Bowell at Anderson Mesa.

Named for the Royal Greenwich Observatory on the occasion of the centennial of its adoption as the prime meridian for longitude and time. Founded by King Charles II in 1675 for the determination of longitude at sea, the Royal Observatory was soon established as one of the world's leading astronomical research institutions. The prime meridian was agreed upon, after some dispute, at an international conference in Washington, D.C., on 1884 October 13. (M 8801) Citation material provided by S. R. Malin.

\section{(2831) Stevin}

1930 SZ. Discovered 1930 Sept. 17 by H. van Gent at Johannesburg.

Named in memory of Simon Stevin (1548-1620), Dutch mathematician, inventor of the decimal point. (M 18135)

\section{(2832) Lada}

1975 EC $_{1}$. Discovered 1975 Mar. 6 by N. S. Chernykh at Nauchnyj.

Named for the ancient Slavic goddess of marriage and family happiness. (M 12013)

\section{(2833) Radishchev}

$1978 \mathrm{PC}_{4}$. Discovered 1978 Aug. 9 by L. I. Chernykh and N. S. Chernykh at Nauchnyj.

Named in memory of Aleksandr Nikolaevich Radishchev (1749-1802), Russian writer, philosopher and revolutionary. (M 8913)

\section{(2834) Christy Carol}

1980 TB $_{4}$. Discovered 1980 Oct. 9 by C. S. Shoemaker at Palomar.

Named in honor of Christine Carol Woodard, eldest daughter of the discoverer. (M 8405)

\section{(2835) Ryoma}

1982 WF. Discovered 1982 Nov. 20 by T. Seki at Geisei.

Named in memory of the Japanese revolutionary, Ryoma Sakamoto (1835-1867), born in the discoverer's hometown of Kochi \{see planet (2396)\}, assassinated for his efforts, eventually successful, to democratize his country. (M 7786)

\section{(2836) Sobolev}

1978 YQ. Discovered 1978 Dec. 22 by N. S. Chernykh at Nauchnyj.

Named in honor of Academician Viktor Viktorovich Sobolev \{1915-1998\}, professor at Leningrad University, distinguished theoretical astrophysicist, one of the founders of the modern theory of radiative transfer in stellar atmospheres, author of fundamental works on the theory of stellar spectra. (M 8543)

Obituary published in Astrofizika, Tom 42, Vyp. 1, p. 161-162 (1999).

\section{(2837) Griboedov}

1971 TJ $_{2}$. Discovered 1971 Oct. 13 by L. I. Chernykh at Nauchnyj.

Named in memory of Aleksandr Sergeevich Griboedov (1795-1829), Russian dramatic author and diplomat. His Gore ot Uma, or The mischief of being clever, is one of the great comedies of European literature. (M 8913)

\section{(2838) Takase}

1971 UM $_{1}$. Discovered 1971 Oct. 26 by L. Kohoutek at Bergedorf.

Named in honor of Bunshiro Takase (1924- ), who worked at the Tokyo Astronomical Observatory and the Department of Astronomy of Tokyo University, where he taught a course on Galactic structure. With the start of the project of building the 105-cm Schmidt telescope at Kiso \{see planet (2271)\} he returned to the Tokyo Astronomical Observatory and during 1974-84 served as its first director. Early in the 1950s Takase worked with H. Hirose \{see planet (1612)\} on the computation of ephemerides of minor planets for the Minor Planet Center. (M 27329)

Name suggested by Y. Kozai.

\section{(2839) Annette}

1929 TP. Discovered 1929 Oct. 5 by C. W. Tombaugh at Flagstaff.

Named by the discoverer in honor of his daughter. (M 10845) 


\section{(2840) Kallavesi}

1941 UP. Discovered 1941 Oct. 15 by L. Oterma at Turku.

Named for a large lake, dotted with numerous islands, in south-central Finland. After the ice age the lake was a gulf, and it still contains relics from the Arctic Ocean. (M 7949)

\section{(2841) Puijo}

1943 DM. Discovered 1943 Feb. 26 by L. Oterma at Turku.

Named for a hill on Lake Kallavesi ssee planet (2840)\}. An important tourist and skiing center, it is well known for its beautiful view. (M 7950)

\section{(2842) Unsöld}

1950 OD. Discovered 1950 July 25 at the Goethe Link Observatory at Brooklyn, Indiana.

Named in honor of Albrecht Unsöld \{1905-1995\}, author of Physik der Sternatmosphären, long-term professor and director of the Institute for Theoretical Physics at the Christian Albrecht University at Kiel. A student of Sommerfeld's, he pioneered the use of physics in understanding the structure of stellar atmospheres through the analysis of the strengths and profiles of spectral lines, and he sowed the seeds for the new science of laboratory astrophysics as a source of information about the properties of atoms and for the simulation of physical conditions in astronomical objects. Unsöld is respected as much for his vision for the future of astronomy as for his deep sense of appreciation for its history. (M 12969)

Name proposed by F. K. Edmondson. Citation written by G. K. Oertel.

Obituaries published in Publ. Astron. Soc. Pac., Vol. 108, No. 725, p. 553-555 (1996); Phys. Bl., Jahrg. 52, Heft 9, p. 890-891 (1996); Sterne Weltraum, Jahrg. 35, Nr. 3, p. 182-183 (1996); Mitt. Astron. Ges., Nr. 79, p. 11-15 (1996); Astron. Geophys., Vol. 38, Issue 1, p. 37-38 (1997).

\section{(2843) Yeti}

1975 XQ. Discovered 1975 Dec. 7 by P. Wild at Zimmerwald.

Named to ensure reality for the mysterious "abominable snowman" that supposedly roams the Himalayan glaciers. (M 17465)

\section{(2844) Hess}

1981 JP. Discovered 1981 May 3 by E. Bowell at Anderson Mesa.

Named in honor of Frederick Hess, professor of natural sciences at the State University of New York at Fort Schuyler and long-time lecturer at the Hayden Planetarium-American Museum in New York City. Hess has directed a number of solar eclipse expeditions and has accumulated more than 30 minutes in the shadow of the Moon. (M 9215)
Name proposed by the discoverer following a suggestion from the Custer Institute. Citation prepared by T. Carey.

\section{(2845) Franklinken}

1981 OF. Discovered 1981 July 26 by E. Bowell at Anderson Mesa.

Named in honor of Kenneth Linn Franklin, astronomer at the Hayden Planetarium-American Museum in New York City. At the Carnegie Institution of Washington he was co-discoverer of high-frequency radio emission from Jupiter, and while at the American Museum he directed the Kalbfleisch Research Station on Long Island and designed a watch that displays lunar time. (M 9215)

Name proposed by the discoverer following a suggestion by the Custer Institute. Citation prepared by T. Carey.

\section{(2846) Ylppö}

1942 CJ. Discovered 1942 Feb. 12 by L. Oterma at Turku.

Named in honor of the distinguished Finnish physician and scientist Arva Ylppö on the occasion of his hundredth birthday, 1987 October 12. He has been a pioneer in saving premature babies and in the development of pediatrics and mother-and-child welfare in Finland. (M 12803)

\section{(2847) Parvati}

$1959 \mathrm{CC}_{1}$. Discovered 1959 Feb. 1 at the Lowell Observatory at Flagstaff.

Named for the daughter of the Himalayas and wife of Siva $\{$ see planet (1170)\} in the mythology of India. She was often portrayed as a beautiful young woman at Siva's side and was instructed by him in the arts of asceticism and dancing. (M 22828)

Named by the Minor Planet Names Committee following a suggestion by F. Pilcher.

\section{(2848) ASP}

1959 VF. Discovered 1959 Nov. 8 at the Goethe Link Observatory at Brooklyn, Indiana.

Named in honor of the Astronomical Society of the Pacific on the 100th anniversary of its founding, 1889 Feb. 7. The A.S.P., composed of both professional and amateur astronomers from around the world, has worked throughout its existence to promote the field of astronomy and to improve public understanding of it, through the Publications of the A.S.P., Mercury magazine and its newsletter for teachers (The Universe in the Classroom). (M 14029)

Name proposed by F. K. Edmondson. Citation prepared by K. Bracher.

\section{(2849) Shklovskij}

$1976 \mathrm{GN}_{3}$. Discovered 1976 Apr. 1 by N. S. Chernykh at Nauchnyj. 
Named in honor of Iosif Samuilovich Shklovskij \{19161985\}, corresponding member of the USSR Academy of Sciences, professor at Moscow University and member of the staff at the Space Research Institute. A brilliant popularizer of astronomy, he has also made substantial contributions to research on the solar corona, galactic radio emission and various cosmic objects. (M 8543)

Obituaries published in Astron. Zh., Tom 62, Vyp. 3, p. 618-619 (1985); Kosm. Issled., Tom 23, Vyp. 3, p. 495 (1985); Pis'ma Astron. Zh., Tom 11, No. 4, p. 319-320 (1985); Říše hvězd, Vol. 66, No. 6, p. 113 (1985); Astron. Vestn., Tom 19, No. 4, p. 359-361 (1985); Sky Telesc., Vol. 70, No. 2, p. 109 (1985); Sov. Astron., Vol. 29, No. 3, p. 364-365 (1985); Sov. Astron. Lett., Vol. 11, No. 2, p. 131-132 (1985); Sterne, 61. Band, Heft 4, p. 232-234 (1985); Sterne Weltraum, 24. Jahrg., Nr. 8-9, p. 427 (1985); Zemlya Vselennaya, No. 4, p. 44-46 (1985); Astron. Zh., Tom 63, Vyp. 5, p. 835-838 (1986); Q.J.R. Astron. Soc., Vol. 27, No. 4, p. 700-702 (1986); Sov. Astron., Vol. 30, No. 5, p. 495-497 (1986).

\section{(2850) Mozhaiskij}

1978 TM$_{7}$. Discovered 1978 Oct. 2 by L. V. Zhuravleva at Nauchnyj.

Named in memory of Aleksandr Fedorovich Mozhaiskij (1825-1890), Russian inventor and pioneer of flight. (M 20834)

\section{(2851) Harbin}

1978 UQ $_{2}$. Discovered 1978 Oct. 30 at the Purple Mountain Observatory at Nanking.

Named for the city in the north of China, famed as "the jewel of the Eurasia Continent Bridge". Harbin is the capital of Heilongjiang \{see planet (2380)\} province and is a popular summer resort, on account of its cool and pleasant climate. (M 20834)

\section{(2852) Declercq}

$1981 \mathrm{QU}_{2}$. Discovered 1981 Aug. 23 by H. Debehogne at La Silla.

The family name of the wife of the discoverer. (M 15573)

\section{(2853) Harvill}

1963 RG. Discovered 1963 Sept. 14 at the Goethe Link Observatory at Brooklyn, Indiana.

Named in memory of Richard A. Harvill (1905-1988), president of the University of Arizona from 1951 to 1971, the longest term in the history of the university and a period of major growth. During these 20 years the enrollment grew from 5,700 to 26,500 , and 45 new buildings were constructed. Harvill provided significant help in many ways to those who were involved in the establishment of the Kitt Peak National Observatory. He was also successful in using the presence of AURA and KPNO to push for increased appropriations from the legislature, following Board of Regents approval, for expansion of the department of astronomy and increased support for the other physical sciences. (M 14207)

Name proposed by F. K. Edmondson.

\section{(2854) Rawson}

1964 JE. Discovered 1964 May 6 by D. McLeish at Córdoba.

Named in memory of Guillermo Colesbery Rawson (1825-1890), Argentine physician who worked very hard during the 19th century epidemic in Buenos Aires. He was also a member of the National Parliament on numerous occasions. (M 22496)

\section{(2855) Bastian}

$1931 \mathrm{~TB}_{2}$. Discovered 1931 Oct. 10 by K. Reinmuth at Heidelberg.

Named in honor of Ulrich Bastian (1951- ), astronomer at the Astronomisches Rechen-Institut, Heidelberg. Together with S. Röser \{see planet (2856)\}, Bastian produced the PPM Star Catalogue, which is a valuable practical tool for minor planet and comet work and constitutes an important aid for the transition from the FK4/B1950 to the FK5/J2000 reference system. He has also worked on other astrometric topics, such as Giotto targeting and the voluminous Hipparcos data-reduction task. (M 20520)

Name proposed and citation prepared by L. D. Schmadel, endorsed by G. Klare and B. G. Marsden.

\section{(2856) Röser}

1933 GB. Discovered 1933 Apr. 14 by K. Reinmuth at Heidelberg.

Named in honor of Siegfried Röser (1948- ), astronomer at the Astronomisches Rechen-Institut, Heidelberg. Together with U. Bastian ssee planet (2855)\}, Röser produced the PPM Star Catalogue. Röser has also contributed to astrometry by re-reducing all the positional data of Halley's Comet at its 1835/36 and 1909/11 apparitions. (M 20520)

Name proposed and citation prepared by L. D. Schmadel, endorsed by G. Klare and B. G. Marsden.

\section{(2857) NOT}

1942 DA. Discovered 1942 Feb. 17 by L. Oterma at Turku.

Named for the 2.56-m Nordic Optical Telescope, erected on La Palma. The optics were made in Y. Väisälä's tunnel laboratory at Tuorla, University of Turku, in a project led by Tapio Korhonen, a student of Väisälä \{see planets (2988) and (1573)\}. (M 18449)

\section{(2858) Carlosporter}

1975 XB. Discovered 1975 Dec. 1 by H. Wroblewski at Cerro El Roble.

Named in memory of Carlos Porter (1867-1942), Chilean zoologist, director of the Valparaiso museum and a professor at Chilean and foreign universities, 
honored by the Chilean Academy of Natural Sciences and in several other countries. From 1911 to 1928 he was in charge of the invertebrate section of the Museum of Natural History in Santiago. (M 11641)

\section{(2859) Paganini}

1978 RW $_{1}$. Discovered 1978 Sept. 5 by N. S. Chernykh at Nauchnyj.

Named for the great Italian violinist and composer Niccolo Paganini (1782-1840). (M 11157)

\section{(2860) Pasacentennium}

1978 TA. Discovered 1978 Oct. 8 by E. F. Helin at Palomar.

Named as a celestial tribute to the city of Pasadena \{see also the citation for planet (2200)\}, home of Caltech, and a world center for astronomical research, in honor of the Pasadena Centennial, 1886-1986. (M 10546)

The name was suggested by the city of Pasadena.

\section{(2861) Lambrecht}

$1981 \mathrm{VL}_{2}$. Discovered 1981 Nov. 3 by F. Börngen at Tautenburg.

Named in memory of Hermann Lambrecht (19081983), professor at the University of Jena and director of the University Observatory from 1948 to 1968. An authority on the physics and chemistry of interstellar gas and dust particles, he worked on a wide number of astronomical topics and was also well known as a popularizer of astronomy. (M 9080)

Obituaries published in Sterne, 59. Band, Heft 4, p. 195-197 (1983); Mitt. Astron. Ges., Nr. 60, p. 13-14 (1983).

\section{(2862) Vavilov}

1977 JP. Discovered 1977 May 15 by N. S. Chernykh at Nauchnyj.

Named in memory of Academician Nikolaj Ivanovich Vavilov (1887-1943), prominent botanist and geneticist, who organized and participated in many botanical expeditions to the various parts of the globe. He established the Soviet collection of plant cultures that includes more than 300,000 samples. The planet also honors his brother, Academician Sergej Ivanovich Vavilov (1891-1951), president of the U.S.S.R. Academy of Sciences from 1945 until his death, renowned for his work in the field of physical optics. (M 11157)

Vavilov is also honored by a lunar crater.

\section{(2863) Ben Mayer}

$1981 \mathrm{QG}_{2}$. Discovered 1981 Aug. 30 by E. Bowell at Anderson Mesa.

Named in honor of the Californian amateur astronomer Ben Mayer, who has conceived, developed and coordinated the PROBLICOM Sky Survey for novae. This project was inspired following his accidental observations of the rise of Nova Cygni 1975. (M 8065)

Name proposed by the discoverer, following a suggestion by P. L. Dombrowski.

\section{(2864) Soderblom}

1983 AZ. Discovered 1983 Jan. 12 by B. A. Skiff at Anderson Mesa.

Named in honor of Lawrence A. Soderblom, planetary geologist with the U.S. Geological Survey. His contributions to planetary science have included research in the geologic histories of both rocky and icy planets and satellites, image processing of spacecraft imagery, and a vigorous program of lunchtime volleyball. A former chief of the U.S.G.S. Branch of Astrogeologic Sciences, he was a member of the Viking and Voyager imaging teams, the Galileo Near Infrared Mapping Spectrometer Team, and the Space Science Advisory Committee. (M 7950)

\section{(2865) Laurel}

1935 OK. Discovered 1935 July 31 by C. Jackson at Johannesburg.

Named for Stan Laurel (1890-1965), American comedian (born Arthur Stanley Jefferson in Ulverston, England), the thin half and gag deviser of Hollywood's first great comedy duo. Stan performed in circuses and vaudeville before acting in silent films. He teamed with Oliver Hardy \{see planet (2866)\} in 1926, and the pair (Stan as the bumbling innocent and pompous Ollie with his long-suffering glances into the camera) made more than 200 timeless slapstick films and shorts. (M 22496)

Name proposed by G. V. and R. Williams, the identifications for this object having been made by C. M. Bardwell.

\section{(2866) Hardy}

1961 TA. Discovered 1961 Oct. 7 by S. Arend at Uccle.

Named for Oliver Norville Hardy (1892-1957), American comedian, the fat half of Hollywood's first great comedy duo. Ollie was a former vaudeville actor and singer, who began doing silent-film comedy in 1913. Laurel \{see planet (2865)\} and Hardy successfully made the transition from silent to sound movies. Among their outstanding films is Way Out West, which incorporates Ollie's and Stan's rendition of 'Trail of the Lonesome Pine'. (M 22496)

Name proposed by G. V. and R. Williams, the identifications for this object having been made by C. M. Bardwell.

\section{(2867) Šteins}

1969 VC. Discovered 1969 Nov. 4 by N. S. Chernykh at Nauchnyj.

Named in memory of Karlis Augustovich Šteins (19111983), director of the Latvian University's Astronomical Observatory from 1959, well known for his work on cometary cosmogony. He also studied the rotation of the Earth and designed astronomical instruments. (M 11157)

Obituary published in Zvaigžnotā Debess, gada ziema, p. 39-40 (1983/84). 


\section{(2868) Upupa}

1972 UA. Discovered 1972 Oct. 30 by P. Wild at Zimmerwald.

Named for a European nonpasserine bird of the family upupidae, or hoopie, this is a cousin of (2731) Cucula, a rare bird of somewhat peculiar habit and habits. (M 21129)

\section{(2869) Nepryadva}

$1980 \mathrm{RM}_{2}$. Discovered 1980 Sept. 7 by N. S. Chernykh at Nauchnyj.

Named to commemorate the Russian victory over the Tatar-Mongolians in the battle at Kulikovo near the Nepryadva River on 1380 Sept. 8. (M 12013)

\section{(2870) Haupt}

1981 LD. Discovered 1981 June 4 by E. Bowell at Anderson Mesa.

Named in honor of Hermann F. Haupt \{1926- \}, director of the Institute for Astronomy, University of Graz. One of the pioneers of photometry of minor planets, he made photoelectric observations while working at the Lick Observatory in 1951 and 1952. He found the peculiar brightness distribution in the near infrared and the reddening with phase of Vesta. (M 9769)

\section{(2871) Schober}

$1981 \mathrm{QC}_{2}$. Discovered 1981 Aug. 30 by E. Bowell at Anderson Mesa.

Named in honor of Hans Josef Schober \{1944- \}, astronomer at the Institute for Astronomy, University of Graz \{see planet (2806)\}. Most of his research has been devoted to photoelectric photometry of minor planets, where he made a major contribution to the study of lightcurves and rotation periods. He is known especially for discoveries of very slow-spinning minor planets and for studies of minor planets with complex lightcurve features. (M 9769)

\section{(2872) Gentelec}

1981 RU. Discovered 1981 Sept. 5 at the Oak Ridge Observatory at Harvard.

Named for the GTE Research Laboratories, Waltham, Massachusetts, in recognition of their support of astronomy during the current apparition of Halley's Comet. (M 9478)

\section{(2873) Binzel}

1982 FR. Discovered 1982 Mar. 28 by E. Bowell at Anderson Mesa.

Named in honor of Richard P. Binzel \{1958- $\quad$ \} of the University of Texas at Austin. During his thesis research, Binzel has been one of the most prolific observers of minor-planet lightcurves, especially in determining rotation periods of small, main-belt objects. (M 9215)

Citation prepared by A. W. Harris.

\section{(2874) Jim Young}

1982 TH. Discovered 1982 Oct. 13 by E. Bowell at Anderson Mesa.

Named in honor of James W. Young, resident astronomer at the Table Mountain Observatory of the Jet Propulsion Laboratory. In recent years he has obtained photoelectric lightcurves for more than 100 minor planets, thus contributing about a third of the currently known rotation rates. (M 9081)

Name proposed by the discoverer, following a suggestion by A. W. Harris.

\section{(2875) Lagerkvist}

1983 CL. Discovered 1983 Feb. 11 by E. Bowell at Anderson Mesa.

Named in honor of Claes-Ingvar Lagerkvist, planetary astronomer at the Uppsala Astronomical Observatory, well known for his observational work on shapes and spin properties of minor planets, particularly small ones. His research has also provided extensive astrometric data and has led to the numbering of six of his discoveries as of July 1984. An inspiring teacher with a great ability to stimulate the interest and research activity of young students, Lagerkvist has made important contributions to the popularization of astronomy in Sweden in recent years. (M 9081) Citation prepared by H. Rickman.

Lagerkvist is discoverer of 29 numbered planets as of 1996 .

\section{(2876) Aeschylus}

6558 P-L. Discovered 1960 Sept. 24 by C. J. van Houten and I. van Houten-Groeneveld at Palomar.

Named for the author of tragedies in ancient Athens (525-456 B. C.). Of his more than 90 tragedies only seven survived. (M 10044)

\section{(2877) Likhachev}

$1969 \mathrm{TR}_{2}$. Discovered 1969 Oct. 8 by L. I. Chernykh at Nauchnyj.

Named in honor of Dmitrij Sergeevich Likhachev, prominent Soviet literary scholar and outstanding expert on the history of Slavic culture. (M 8913)

\section{(2878) Panacea}

1980 RX. Discovered 1980 Sept. 7 by E. Bowell at Anderson Mesa.

Named for the Roman goddess of health, daughter of Aesculapius \{see planet (1027)\} and sister of Machaon, Podalirius and Hygiea \{see planets (3063), (4086), and (10), respectively\}. (M 8405)

Name proposed by the discoverer, following a suggestion by J. Meeus.

\section{(2879) Shimizu}

1932 CB $_{1}$. Discovered 1932 Feb. 14 by K. Reinmuth at Heidelberg.

Named in honor of Shin-ichi Shimizu (1889- ), a pioneer in astrophotography among amateur astronomers in Japan, who in 1937, with only an 80-mm 
astrocamera, recovered periodic comet Daniel, which had been lost since its discovery apparition of 19091910. He also observed many comets and minor planets in response to requests from the Tokyo Observatory. (M 8801)

Name proposed by T. Urata, who found the identifications involving this planet, and who lives in the city of Shimizu, Shizuoka prefecture.

\section{(2880) Nihondaira}

1983 CA. Discovered 1983 Feb. 8 by T. Seki at Geisei.

Named for a hill and prominent beauty spot in central Japan. Overlooking the city and harbor of Shimizu, it offers a fine view of Mt. Fuji. The minor planet also honors the Nihondaira Observatory, where T. Urata conducts his observational and orbital work on comets and minor planets. (M 8066)

\section{(2881) Meiden}

1983 AA $_{1}$. Discovered 1983 Jan. 12 by B. A. Skiff at Anderson Mesa.

Named for the hare-god of ancient Lithuanian mythology, Meiden was also deity of animals and forests. (M 22828)

Named by the Minor Planet Names Committee following a suggestion by F. Pilcher.

\section{(2882) Tedesco}

1981 OG. Discovered 1981 July 26 by E. Bowell at Anderson Mesa.

Named in honor of Edward F. Tedesco, planetary scientist at the Jet Propulsion Laboratory, who has made wide-ranging contributions to minor-planet science, including studies of rotational brightness variation, pole and shape determination, and the compositional structure of the belt. He is currently engaged in analyzing observations of minor planets by the Infrared Astronomical Satellite. (M 8543)

\section{(2883) Barabashov}

1978 RG $_{6}$. Discovered 1978 Sept. 13 by N. S. Chernykh at Nauchnyj.

Named in memory of Nikolaj Pavlovich Barabashov (1894-1971), director of the Kharkov Observatory for 40 years, known for his research on the Moon and planets. (M 9216)

Barabashov is also honored by a crater on Mars.

\section{(2884) Reddish}

$1981 \mathrm{ES}_{22}$. Discovered 1981 Mar. 2 by S. J. Bus at Siding Spring.

Named in honor of Vincent C. Reddish, former Astronomer Royal for Scotland and director of the Royal Observatory, Edinburgh. Project scientist for the U.K. Schmidt Telescope, he played a leading role in organizing the survey of the southern sky being undertaken at Siding Spring. (M 8405)

Name proposed by J. A. Dawe, current director of the U.K. Schmidt.

\section{(2885) Palva}

1939 TC. Discovered 1939 Oct. 7 by Y. Väisälä at Turku.

Named in honor of Tauno Palva, son-in-law of the discoverer, internationally known ear surgeon and professor of otorhinolaryngology at the University of Helsinki. (M 18449)

\section{(2886) Tinkaping}

1965 YG. Discovered 1965 Dec. 20 at the Purple Mountain Observatory at Nanking.

Named in honor of Tinkaping, well-known Hong Kong industrialist, who has made important contributions to health and education. (M 22828)

\section{(2887) Krinov}

1977 QD 5 . Discovered 1977 Aug. 22 by N. S. Chernykh at Nauchnyj.

Named in memory of Evgenij Leonidovich Krinov (1906-1984), celebrated Soviet meteoriticist, recipient of the Leonard medal of the American Meteoritical Society. (M 11157)

Obituaries published in Meteoritics, Vol. 19, No. 1, p. 67 (1984); Meteoritika, Vyp. 43, p. 186-187 (1984); Zemlya Vselennaya, No. 5, p. 73-75 (1984).

\section{(2888) Hodgson}

1982 TO. Discovered 1982 Oct. 13 by E. Bowell at Anderson Mesa.

Named in honor of Richard G. Hodgson, professor at Dordt College, Sioux Center, Iowa. Founder in 1973 of the Minor Planets Section of the Association of Lunar and Planetary Observers, and Section Recorder for more than nine years, Hodgson has inspired many amateur astronomers around the world to make scientifically-valuable observations of minor planets. He continues, as a full-time teacher, to direct students toward minor-planet studies and other astronomical fields. (M 8801)

Citation written by R. P. Binzel.

\section{(2889) Brno}

$1981 \mathrm{WT}_{1}$. Discovered 1981 Nov. 17 by A. Mrkos at Kleť.

Named for the capital of Moravia \{see planet (1901)\}. (M 22828)

The town of Brno is also honored by minor planet (290).

\section{(2890) Vilyujsk}

$1978 \mathrm{SY}_{7}$. Discovered 1978 Sept. 26 by L. V. Zhuravleva at Nauchnyj.

Named for the central town of the Vilyujsk district of the \{former\} Yakut Autonomous SSR on the occasion of its 350th anniversary. (M 8913)

\section{(2891) McGetchin}

1980 MD. Discovered 1980 June 18 by C. S. Shoemaker at Palomar. 
Named in memory of Thomas R. McGetchin (19361979), geologist and planetary scientist, from 1977 director of the Lunar and Planetary Institute in Houston. A leading investigator of volcanism and tectonics on the Earth and other solid bodies in the solar system, he was particularly noted for his work on kimberlite pipes and on the dynamics of volcanoes. (M 8153)

Obituaries published in Icarus, Vol. 41, p. 177 (1980); Proc. Tenth Lunar Planet Sci. Conf., p. VII-VIII (1979).

\section{(2892) Filipenko}

$1983 \mathrm{AX}_{2}$. Discovered 1983 Jan. 13 by L. G. Karachkina at Nauchnyj.

Named in honor of Aleksandr Grigorevich Filipenko, chief of surgery at the Crimean regional hospital in Bakhchisaraj. The discoverer owes him for saving the life of a person dear to her. (M 8913)

\section{(2893) Peiroos}

1975 QD. Discovered 1975 Aug. 30 at the Felix Aguilar Observatory at El Leoncito.

Named for the Thracian chief who fought courageously to defend Troy. (M 13608)

\section{(2894) Kakhovka}

$1978 \mathrm{SH}_{5}$. Discovered 1978 Sept. 27 by L. I. Chernykh at Nauchnyj.

Named for a town of the \{former\} Chersonian district of the Ukrainian SSR. (M 8913)

\section{(2895) Memnon}

$1981 \mathrm{AE}_{1}$. Discovered 1981 Jan. 10 by N. G. Thomas at Anderson Mesa.

Named for a king of Ethiopia, who took 10,000 men to Troy to assist his uncle Priam in the Trojan War. Slayer of Antilochos, Nestor's son, Memnon was killed in combat by Achilles. (M 8405)

Name proposed by the discoverer, following a suggestion by E. Bowell.

See also the citations for planets (1432) Ethiopia, (3912) Troja, (884) Priamus, (1583) Antilochus, (659) Nestor, and (588) Achilles, respectively.

\section{(2896) Preiss}

1931 RN. Discovered 1931 Sept. 15 by K. Reinmuth at Heidelberg.

Named in honor of Günter Preiss (1929- _ ) on the occasion of his retirement in 1992 from the position of lawyer and administrator of the Max-Planck-Society. He earned great merit through his involvement in the construction and development of the Max-PlanckInstitut in Heidelberg and also at its observatory at Calar Alto in southern Spain. The same holds for his involvement in the Institut für Radioastronomie in Bonn. (M 21607)

Name proposed and citation prepared by H. Elsässer, endorsed by G. Klare and L. D. Schmadel.

\section{(2897) Ole Römer}

1932 CK. Discovered 1932 Feb. 5 by K. Reinmuth at Heidelberg.

Named for Ole Römer (1644-1710), discoverer of the finite velocity of light and inventor of the transit circle. Born in Aarhus \{see planet (2676)\}, he did his best astronomical work in Paris. Later professor of mathematics at the University of Copenhagen, he became extensively involved with terrestrial weights and measures, including the establishment of a temperature scale tied to the freezing and boiling points of water, the definition of the pound, and the measurement of spirit strength. He was also an authority on hydraulics and ballistics, and he served in various civil capacities, including mayor of Copenhagen, master of the mint, and head of the Danish state council. (M 8544)

Name proposed by L. K. Kristensen, who found some of the identifications involving this planet.

\section{(2898) Neuvo}

1938 DN. Discovered 1938 Feb. 20 by Y. Väisälä at Turku.

Named in honor of Yrjö Neuvo, grandson of the discoverer, professor of digital sound processing at Tampere University of Technology and research professor of the Academy of Finland. (M 18449)

\section{(2899) Runrun Shaw}

$1964 \mathrm{TR}_{2}$. Discovered 1964 Oct. 8 at the Purple Mountain Observatory at Nanking.

Named in honor of Run Run Shaw, a famous entrepreneur of movie and television in Hong Kong. Public-spirited and wishing to perform social and welfare services, he has made important contributions to the development of Chinese education. (M 16041)

\section{(2900) Luboš Perek}

1972 AR. Discovered 1972 Jan. 14 by L. Kohoutek at Bergedorf.

Named in honor of Luboš Perek, well known for his work on galactic dynamics and planetary nebulae. He worked at the Purkyne University in Brno and later at the Astronomical Institute of the Czechoslovak Institute of Sciences in Prague, serving as director from 1968 to 1975 . Subsequently he has been chief of the space department in the secretariat of the United Nations. He was general secretary of the IAU from 1967 to 1970 and has also served as president of the International Astronautical Federation. (M 9478)

\section{(2901) Bagehot}

1973 DP. Discovered 1973 Feb. 27 by L. Kohoutek at Bergedorf.

Named in memory of Walter Bagehot (18261877), English economist, political analyst and highly influential editor of The Economist from 1860 until his death. He has been described as Victorian England's "most versatile genius". (M 27329; M 27347)

Name suggested by O. Morton. 


\section{(2902) Westerlund}

$1980 \mathrm{FN}_{3}$. Discovered 1980 Mar. 16 by C.-I. Lagerkvist at La Silla.

Named in honor of Bengt E. Westerlund, director of the Uppsala Astronomical Observatory, on the occasion of his retirement. Well known for his study of the structure of the Milky Way and for his work on the Magellanic Clouds, he has for many years given strong moral support to the Uppsala program on minor planets and comets, and he has even participated in the observations of minor planets with the Schmidt telescope at the Uppsala Southern Station. (M 12013)

\section{(2903) Zhuhai}

$1981 \mathrm{UV}_{9}$. Discovered 1981 Oct. 23 at the Purple Mountain Observatory at Nanking.

Named for an important open city in southern China, located at the west coast of Zhujiang port in Guangdong \{see planet (2185)\} province. With its fertile land and scenic beauty, Zhuhai is sometimes called a bright pearl of the South China Sea. It is a new city, developing especially in industry, but also in agriculture, fishing, animal husbandry, commerce and tourism. (M 16041)

\section{(2904) Millman}

1981 YB. Discovered 1981 Dec. 20 by E. Bowell at Anderson Mesa.

Named in honor of Peter MacKenzie Millman \{19061990\}, former head of Upper Atmosphere Research and, since his formal retirement, a guest scientist at the Herzberg Institute of Astrophysics of the National Research Council of Canada. Well known for his research on meteors and for his interest in meteorites, comets and planets, he has served as president of the Royal Astronomical Society of Canada and of the Meteoritical Society, as well as president of Commission 22 and chairman of the Working Group on Planetary System Nomenclature of the IAU. (M 9081)

Name proposed by the discoverer, following a suggestion by C. E. Spratt.

Obituaries published in Icarus, Vol. 93, No. 2, p. 181-182 (1990); WGN, Vol. 19, Nr. 1, p. 1 (1991); IAU Colloquium No. 126, p. xxvii (1991); J. R. Astron. Soc. Can., Vol. 85, No. 2, p. 67-78 (1991); Radiant, Jaarg. 13, Nr. 2, p. 27 (1991); Meteoritics, Vol. 26, No. 2, p. 173 (1991).

\section{(2905) Plaskett}

$1982 \mathrm{BZ}_{2}$. Discovered 1982 Jan. 24 by E. Bowell at Anderson Mesa.

Named in memory of John Stanley Plaskett (18651941), director of the Dominion Astrophysical Observatory in Victoria from its founding in 1917 to 1935; and of his son, Harry Hemley Plaskett (1893-1980), Savilian professor of astronomy at the University of Oxford and director of the Oxford Observatory from 1932 to 1960. Known for his work on the radial velocities of O- and B-type stars that provided observational confirmation of the theory of galactic rotation,
J. S. Plaskett was also particularly associated with the massive Plaskett's star. The younger Plaskett made far-reaching contributions to stellar spectroscopy and spectrophotometry and to solar physics; as president of the Royal Astronomical Society just after World War II he was instrumental in bringing into being the $2.5-\mathrm{m}$ telescope, completed in 1967 and initially installed at the Royal Greenwich Observatory at Herstmonceux. Both father and son were awarded the gold medal of the Royal Astronomical Society. (M 9081)

Name proposed by the discoverer, following a suggestion by C. E. Spratt.

John S. Plaskett is also honored by a lunar crater. Obituaries (H.H.P.) published in Nature, Vol. 285, p. 58 (1980); J.R. Astron. Soc. Canada, Vol. 74, p. 234-236 (1980); Q.J.R. Astron. Soc., Vol. 21, p. 486-488 (1980).

\section{(2906) Caltech}

$1983 \mathrm{AE}_{2}$. Discovered 1983 Jan. 13 by C. S. Shoemaker at Palomar.

Named for the California Institute of Technology, of which the Palomar Observatory is a part. The 0.46-m Schmidt telescope, with which this minor planet was discovered, was the first telescope placed into operation by Caltech on Palomar Mountain. Five Caltech students assisted Caltech staff members C. S. and E. M. Shoemaker in the observations that established the unusual nature of the orbit of this object. (M 8154)

\section{(2907) Nekrasov}

$1975 \mathrm{TT}_{2}$. Discovered 1975 Oct. 3 by L. I. Chernykh at Nauchnyj.

Named in memory of Nikolaj Alekseevich Nekrasov (1821-1878), a poet and revolutionary who expressed in his works the sorrows and sufferings of the common people. (M 8913)

\section{(2908) Shimoyama}

1981 WA. Discovered 1981 Nov. 18 by T. Furuta at Tokai.

Named for the village where the Tokai ssee planet (2478)\} station is located. (M 8801)

\section{(2909) Hoshi-no-ie}

1983 JA. Discovered 1983 May 9 by S. Sei at Chirorin.

Named for the discoverer's observatory. The English translation is "a star house". (M 8544)

\section{(2910) Yoshkar-Ola}

1980 TK$_{13}$. Discovered 1980 Oct. 11 by N. S. Chernykh at Nauchnyj.

Named for a city on the Volga basin, capital of the \{former\} Mari Autonomous Soviet Socialist Republic, on the occasion of the city's 400th anniversary. (M 9216)

\section{(2911) Miahelena}

1938 GJ. Discovered 1938 Apr. 8 by H. Alikoski at Turku.

Named by the discoverer in honor of his wife. (M 18449) 


\section{(2912) Lapalma}

1942 DM. Discovered 1942 Feb. 18 by L. Oterma at Turku.

Named for one of the Canary Islands, site of the Nordic Optical Telescope \{see planet (2857)\} and telescopes from several other European countries. (M 18449)

\section{(2913) Horta}

1931 TK. Discovered 1931 Oct. 12 by E. Delporte at Uccle.

Named in memory of Baron Victor Horta (18611947), Belgian architect, who broke with tradition and was one of the first to glimpse the ornamental and calligraphic value of iron. (M 12209)

\section{(2914) Glärnisch}

1965 SB. Discovered 1965 Sept. 19 by P. Wild at Zimmerwald.

Named for the most prominent mountain chain near the discoverer's home town of Glarus \{see planet (1687)\}. Its highest summit is 2914 meters above sea level. In 1926 the famous astronomer Fritz Zwicky \{see planet (1803)\} and one of his friends (the later Nobel laureate in chemistry, Thadeus Reichstein) became the first to climb the upper half of its north wall. (M 21129)

\section{(2915) Moskvina}

1977 QY $_{2}$. Discovered 1977 Aug. 22 by N. S. Chernykh at Nauchnyj.

Named in honor of Valentina Nikolaevna Moskvina, a doctor at the Bakchisaraj regional hospital in the Crimea. (M 9216)

\section{(2916) Voronveliya}

$1978 \mathrm{PW}_{2}$. Discovered 1978 Aug. 8 by N. S. Chernykh at Nauchnyj.

Named in honor of Boris Aleksandrovich VorontsovVel'yaminov \{1904-1994\}, famous Soviet astrophysicist at the Sternberg Astronomical Institute for many decades. His scientific works cover a wide range of topics, including comets, variable stars, galaxies, nebulae and the history of astronomy. He is also well-known as an author of textbooks and popular books on astronomy. (M 9216)

Obituary published in Zemlya Vselennaya, No. 3, p. 36-40 (1994).

\section{(2917) Sawyer Hogg}

1980 RR. Discovered 1980 Sept. 2 by E. Bowell at Anderson Mesa.

Named in honor of Helen Sawyer Hogg \{1905-1993\}, professor emeritus of astronomy at the University of Toronto, known for her research on globular clusters and for her inspiring course in introductory astronomy, which she taught for more than 35 years. She has served as president of the Royal Astronomical Society of Canada, the Canadian Astronomical Society, and the American Association of Variable Star Observers. For nearly 30 years she wrote a weekly astronomical column for the Toronto Star, and she conducted a series of television programs for the Ontario Educational Television Authority. She is a Companion of the Order of Canada, a recent recipient of the Klumpke-Roberts award from the Astronomical Society of the Pacific, and the first Canadian and second woman to receive the Rittenhouse silver medal. (M 8801)

Name proposed by C. E. Spratt.

Obituaries published in J.R. Astron. Soc. Canada, Vol. 87, No. 6, p. 351-356 (1993); Bull. Am. Astron. Soc., Vol. 25, No. 4, p. 1497 (1993); J. Am. Assoc. Variable Star Obs., Vol. 22, No. 1, p. 83-86 (1993).

\section{(2918) Salazar}

1980 TU$_{4}$. Discovered 1980 Oct. 9 by C. S. Shoemaker at Palomar.

Named in honor of Frederick Salazar, son-in-law of the discoverer. (M 9216)

\section{(2919) Dali}

1981 EX $_{18}$. Discovered 1981 Mar. 2 by S. J. Bus at Siding Spring.

Named in honor of the great Spanish painter Salvador Dali (1904-1989), who in a career spanning over six decades has produced countless works dealing in imageries of the subconscious mind. His art has been influenced by surrealist contemporaries, as well as by his love for his wife Gala, but his own hallucinatory style and mastery of multiple illusions have made him a genius of our time. (M 8802)

\section{(2920) Automedon}

1981 JR. Discovered 1981 May 3 by E. Bowell at Anderson Mesa.

Named for the son of Diores and the charioteer of Achilles \{see planet (588)\}. Automedon killed the Trojan Aretus to avenge the death of Patroclus \{see planet (617)\}. (M 8544)

\section{(2921) Sophocles}

6525 P-L. Discovered 1960 Sept. 24 by C. J. van Houten and I. van Houten-Groeneveld at Palomar.

Named for the author of tragedies in ancient Athens (496-406 B.C.). Of his 123 tragedies only seven survived. (M 10044)

\section{(2922) Dikan'ka}

$1976 \mathrm{GY}_{1}$. Discovered 1976 Apr. 1 by N. S. Chernykh at Nauchnyj.

Named for the Ukrainian village mentioned in Gogol's \{see planet (2361)\} novel Evenings at the farmstead near Dikan'ka. (M 11158)

\section{(2923) Schuyler}

1977 DA. Discovered 1977 Feb. 22 at the Harvard College Observatory at Harvard.

Named in honor of Catherine Schuyler on the occasion of the completion of her studies at Harvard University and in appreciation of her assistance with the administration of the Minor Planet Center and 
Central Bureau for Astronomical Telegrams during two years. (M 9769)

\section{(2924) Mitake-mura}

$1977 \mathrm{DJ}_{2}$. Discovered 1977 Feb. 18 by H. Kosai and K. Hurukawa at Kiso.

Named for another of the three towns to which the Kiso Station administratively belongs. Although in Roman characters the name is very similar to that of Mitaka, the town in which the Tokyo Observatory's headquarters are located, the names are very different when written in Japanese characters. The endings "take" and "taka" mean mountain and hawk, respectively. (M 8914)

For the other two cities mentioned, see the citations for planets (2470) Agematsu and (2960) Ohtaki.

\section{(2925) Beatty}

1978 VC $_{5}$. Discovered 1978 Nov. 7 by E. F. Helin and S. J. Bus at Palomar.

Named in honor of J. Kelly Beatty, associate editor of Sky and Telescope, on the occasion of his marriage, 1983 Oct. 1. A long-time friend of the first discoverer, and a geologist and planetary scientist in his own right, he has given encouragement to the Palomar planet-crossing asteroid survey for many years. (M 8405)

\section{(2926) Caldeira}

1980 KG. Discovered 1980 May 22 by H. Debehogne at La Silla.

Named in honor of Felipe Caldeira, astronomer at the Valongo Observatory and professor at the Universidade Federal do Rio de Janeiro, participant in the minor-planet program at the European Southern Observatory. (M 10845)

\section{(2927) Alamosa}

1981 TM. Discovered 1981 Oct. 5 by N. G. Thomas at Anderson Mesa.

Named for the discoverer's birthplace, the central town of the San Luis Valley of southern Colorado, located on the upper Rio Grande River. (M 8405)

\section{(2928) Epstein}

1976 GN $_{8}$. Discovered 1976 Apr. 5 at the Felix Aguilar Observatory at El Leoncito.

Named in honor of Isadore Epstein, professor emeritus of astronomy at Columbia University and formerly director of Harriman Observatory. He conducted extensive site testing for a southern observatory in Australia, Chile and Argentina during 1957-1962. This resulted in the inauguration of the Yale-Columbia Southern Observatory at El Leoncito on 1965 Mar. 30. (M 12969)

\section{(2929) Harris}

$1982 \mathrm{BK}_{1}$. Discovered 1982 Jan. 24 by E. Bowell at Anderson Mesa.

Named in honor of Alan W. Harris, planetary scientist at the Jet Propulsion Laboratory, whose research has included studies of the origin of the solar system and the dynamics of planetary satellites and ring systems. In recent years he has become the most prolific observer of minor-planet rotational lightcurves. (M 8406)

\section{(2930) Euripides}

6554 P-L. Discovered 1960 Sept. 24 by C. J. van Houten and I. van Houten-Groeneveld at Palomar.

Named for the author of tragedies in ancient Athens (480-406 B.C.). Of his 92 plays 19 survived. (M 10044)

\section{(2931) Mayakovsky}

1969 UC. Discovered 1969 Oct. 16 by L. I. Chernykh at Nauchnyj.

Named in memory of the Soviet poet Vladimir Vladimirovich Mayakovskij (1893-1930). (M 8914)

\section{(2932) Kempchinsky}

$1980 \mathrm{TK}_{4}$. Discovered 1980 Oct. 9 by C. S. Shoemaker at Palomar.

Named in honor of Paula M. Kempchinsky, daughterin-law of the discoverer. (M 9216)

\section{(2933) Amber}

1983 HN. Discovered 1983 Apr. 18 by N. G. Thomas at Anderson Mesa.

Named in honor of the discoverer's granddaughter, Amber Marie Baltutis. (M 8406)

\section{(2934) Aristophanes}

4006 P-L. Discovered 1960 Sept. 25 by C. J. van Houten and I. van Houten-Groeneveld at Palomar.

Named for the author of comedies in ancient Athens (445-385 B.C.). Of his 44 plays 11 survived. (M 10044)

\section{(2935) Naerum}

1976 UU. Discovered 1976 Oct. 24 by R. M. West at La Silla.

Named after the small town of Naerum, some $15 \mathrm{~km}$ north of Copenhagen, where the discoverer spent his early years in the parental home. Archaeological finds from the stone age and bronze age tumuli bear witness to habitation during several millenia, as does the present name, which is derived from "Njarthar-heim", i.e. the home of Njord, god of the sea and its riches in Norse mythology. (M 12969)

\section{(2936) Nechvíle}

1979 SF. Discovered 1979 Sept. 17 by A. Mrkos at Kleť.

Named in memory of V. Nechvíle (1890-1964), professor of astronomy at Charles University. During a stay in France he collaborated with J. W. Ritchey and the Henry brothers. (M 22828)

\section{(2937) Gibbs}

1980 LA. Discovered 1980 June 14 by E. Bowell at Anderson Mesa.

Named in memory of Josiah Willard Gibbs (18391903), mathematician and physicist, who worked at 
Yale and Princeton Universities. Although his principal work concerned thermodynamics, theories of optics and vector analysis, he made significant contributions to minor-planet studies through his work on orbits. (M 8544)

Gibbs is also honored by a lunar crater.

\section{(2938) Hopi}

1980 LB. Discovered 1980 June 14 by E. Bowell at Anderson Mesa.

Named for the Pueblo Indian people, who have maintained a continuous presence in northeastern Arizona for almost a thousand years. The Hopis' vital cultural heritage is reflected in their elaborate ceremonies, in particular the kachina and snake dances, and in their distinctive arts and crafts. (M 8544)

\section{(2939) Coconino}

1982 DP. Discovered 1982 Feb. 21 by E. Bowell at Anderson Mesa.

Named for the county of Arizona of which Flagstaff is the county seat. The word Coconino derives from the Hopi koonina and refers primarily to the Supai and Hualapai Indian peoples living to the west of the Hopi. A secondary meaning applies to Hopi children not yet initiated into the religious practices of the Hopi kachina society. (M 8544)

\section{(2940) Bacon}

3042 P-L. Discovered 1960 Sept. 24 by C. J. van

Houten and I. van Houten-Groeneveld at Palomar.

Named for the English scholar Francis Bacon (15611626), thought by some to have been the author of Shakespeare's plays. (M 10044)

\section{(2941) Alden}

1930 YV. Discovered 1930 Dec. 24 by C. W. Tombaugh at Flagstaff.

Named by the discoverer in honor of his son. (M 10845)

\section{(2942) Cordie}

1932 BG. Discovered 1932 Jan. 29 by K. Reinmuth at Heidelberg.

Named in honor of Cordula (Cordie) Astrid Robinson, planetary geologist at the Harvard-Smithsonian Center for Astrophysics. Cordula gained her Ph.D. from University College, London, studying the crustal dichotomy of Mars, and she is currently using Magellan data to investigate the surface electrical properties on Venus with respect to geochemical and weathering processes. (M 21607)

Name proposed by C. M. Bardwell, who found the identifications for this planet, following a suggestion by G. V. Williams.

\section{(2943) Heinrich}

1933 QU. Discovered 1933 Aug. 25 by K. Reinmuth at Heidelberg

Named in honor of Inge Heinrich (1941- ), astronomer at the Astronomisches Rechen-Institut Heidelberg and editor of Astronomy and Astrophysics Abstracts. Her ever-lasting dedication and profound knowledge of the astronomical literature significantly contribute to the worldwide reputation of this bibliography. (M 21607)

Name proposed and citation prepared by L.D.Schmadel.

(2944) Peyo

1935 QF. Discovered 1935 Aug. 31 by K. Reinmuth at Heidelberg.

Named in memory of Pierre Culliford (1928-1992), better known under his pseudonym Peyo. He was known worldwide for his comic strips, where he created the blue dwarfs known as the Smurfs. Together with Georges Remi (Hergé) \{see planet (1652)\}, the father of Tintin, Peyo raised the drawing of comic strips to a 'Belgian' work of art. (M 21954)

Name proposed and citation prepared by J. Meeus, endorsed by G. Klare and L. D. Schmadel.

\section{(2945) Zanstra}

$1935 \mathrm{ST}_{1}$. Discovered 1935 Sept. 28 by H. van Gent at Johannesburg.

Named in memory of H. Zanstra (1894-1972), Dutch astronomer, director of the Astronomical Institute of the Municipal University in Amsterdam from 1946 to 1959. He is well known for his method for obtaining the surface temperatures of the central stars of planetary nebulae. (M 18135)

Obituary published in 18th Coll. Int. Astrophys. Liège 1972, P. 11-15 (1973).

\section{(2946) Muchachos}

1941 UV. Discovered 1941 Oct. 15 by L. Oterma at Turku.

Named for the Roque de los Muchachos, the mountain on La Palma where the Nordic Optical Telescope \{see planet (2857)\} and other European telescopes are situated. (M 18449)

\section{(2947) Kippenhahn}

$1955 \mathrm{QP}_{1}$. Discovered 1955 Aug. 22 by I. Groeneveld at Heidelberg.

Named in honor of Rudolf Kippenhahn (1926- ), German astronomer, director of the Max-PlanckInstitut für Physik und Astrophysik at Garching and currently a vice president of the IAU. (M 18136)

\section{(2948) Amosov}

$1969 \mathrm{TD}_{2}$. Discovered 1969 Oct. 8 by L. I. Chernykh at Nauchnyj.

Named in honor of Nikolaj Mikhailovich Amosov, distinguished cardiologist, specialist in medical cybernetics, and member of the Academy of Sciences of the Ukrainian S.S.R. He has performed more than four thousand heart operations. (M 9216)

\section{(2949) Kaverznev}

1970 PR. Discovered 1970 Aug. 9 at the Crimean Astrophysical Observatory at Nauchnyj. 
Named in memory of Aleksandr Aleksandrovich Kaverznev (1932-1983), Soviet journalist, documentary-film maker and political commentator. (M 8914)

\section{(2950) Rousseau}

$1974 \mathrm{VQ}_{2}$. Discovered 1974 Nov. 9 by P. Wild at Zimmerwald.

Named in honor of Jean-Jacques Rousseau (17121778), citizen of Geneva, moralist and writer. The guiding idea of his discourses and novels was that human nature is principally good but gets corrupted by society under the influence of science and art, which he believed to enhance social inequality and discontentment. Hence his emotional exhortations for a return to nature and simple life. Real and also imagined persecution made him seek refuge in many remote places in western Europe. Rousseau's ideas later proved highly influential in inspiring the French Revolution, Storm and Stress, romanticism and socialism. (M 22496)

\section{(2951) Perepadin}

1977 RB 8 . Discovered 1977 Sept. 13 by N. S. Chernykh at Nauchnyj.

Named in honor of Aleksandr Ivanovich Perepadin, friend of the discoverer, learned agronomist, good manager, reader at the Crimean Agricultural Institute and chairman of the Bakhchisaraj District Council. (M 18136)

\section{(2952) Lilliputia}

$1979 \mathrm{SF}_{2}$. Discovered 1979 Sept. 22 by N. S. Chernykh at Nauchnyj.

Named for the land of tiny people in Gulliver's Travels, a novel by the English satirist and poet Jonathan Swift (1667-1745), this minor planet is one of the smallest discovered at this observatory. (M 9216)

\section{(2953) Vysheslavia}

1979 SV $_{11}$. Discovered 1979 Sept. 24 by N. S. Chernykh at Nauchnyj.

Named in honor of Leonid Nikolaevich Vysheslavskij, Soviet writer, author of Stellar sonnets and numerous other poetical works. (M 11158)

\section{(2954) Delsemme}

$1982 \mathrm{BT}_{1}$. Discovered 1982 Jan. 30 by E. Bowell at Anderson Mesa.

Named in honor of Armand H. Delsemme, professor of astrophysics at the University of Toledo, Ohio, recognized for his extensive investigations of the chemical, physical, dynamical and evolutionary processes of comets. In 1952 he proposed, with P. Swings s see planet (1637)\}, that cometary nuclei contain clathrate hydrates of gases, a theory that has been popular ever since. In 1976 he organized and edited the proceedings of the Lyons IAU colloquium "Comets, Asteroids and Meteorites". (M 11158)

Citation prepared by Z. Sekanina.

\section{(2955) Newburn}

1982 BX $_{1}$. Discovered 1982 Jan. 30 by E. Bowell at Anderson Mesa.

Named in honor of Ray L. Newburn, astronomer at the Jet Propulsion Laboratory, recognized for his development of physical models of comets based on spectrophotometric observations and for his adroit leadership of the International Halley Watch during the apparition of that comet that began in 1982 . (M 11158)

Citation prepared by S. J. Edberg.

\section{(2956) Yeomans}

$1982 \mathrm{HN}_{1}$. Discovered 1982 Apr. 28 by E. Bowell at Anderson Mesa.

Named in honor of Donald K. Yeomans, celestial mechanician at the Jet Propulsion Laboratory and discipline specialist for the astrometric team of the International Halley Watch. Well known for his orbit determinations that take account of the nongravitational forces acting on comets, he has made a detailed study of the motion of Halley's Comet back to the year -1404 and has analyzed the orbits of meteor showers and their relation to the orbits of parent comets. (M 11158)

Citation prepared by S. J. Edberg and Z. Sekanina.

\section{(2957) Tatsuo}

1934 CB $_{1}$. Discovered 1934 Feb. 5 by K. Reinmuth at Heidelberg.

Named in honor of Tatsuo Yamada (1923- ), who is a Japanese observer and researcher of variable stars. Yamada was the director of the variable star section of the Oriental Astronomical Association (O.A.A.), and he is devoted to the diffusion of astronomical knowledge. Yamada has continued to hold monthly meetings of the Nagoya branch of the O.A.A. since 1954. (M 20158)

Name proposed by T. Furuta, who found the identifications involving this planet, and who was inspired by T. Yamada.

\section{(2958) Arpetito}

1981 DG. Discovered 1981 Feb. 28 by H. Debehogne and G. DeSanctis at La Silla.

Named in honor of E. Araya, J. Perez, R. Tighe and A. Torrecon, who prepare the plates used in the observing program on minor planets with the Grand Prism Objectif at La Silla. (M 19333)

\section{(2959) Scholl}

$1983 \mathrm{RE}_{2}$. Discovered 1983 Sept. 4 by E. Bowell at Anderson Mesa.

Named in honor of Hans Scholl \{1942- $\quad$ \}, former astronomer at the Astronomisches Rechen-Institut, Heidelberg, now at Nice Observatory. Well known for his theoretical work on the orbits of minor planets, Scholl 
has investigated resonant motion in the outer belt and has studied a variety of particularly interesting orbits, including those of Aten and Chiron. His broad range of minor-planet research has also embraced problems from mass determination to asteroid missions and from libration to depletion. (M 8802)

Citation written by J. Schubart.

\section{(2960) Ohtaki}

$1977 \mathrm{DK}_{3}$. Discovered 1977 Feb. 18 by H. Kosai and K. Hurukawa at Kiso.

Named for the third of the towns to which the Kiso Station administratively belongs. In fact, the Observatory is located at the top of the mountain where the boundaries of the three towns converge. (M 8914)

For the other two cities mentioned, see the citations for planets (2470) Agematsu and (2924) Mitake-mura.

\section{(2961) Katsurahama}

1982 XA. Discovered 1982 Dec. 7 by T. Seki at Geisei.

Named for the beautiful seashore in the discoverer's home city of Koc0hi \{see planet (2396)\} and one of the most famous tourist resorts in Japan. (M 8802)

\section{(2962) Otto}

1940 YF. Discovered 1940 Dec. 28 by Y. Väisälä at Turku.

Named in honor of Otto Oskari Väisälä, great-grandson of the discoverer. (M 18449)

\section{(2963) Chen Jiageng}

$1964 \mathrm{VM}_{1}$. Discovered 1964 Nov. 9 at the Purple Mountain Observatory at Nanking.

Named in memory of Chen Jiageng (1874-1961), a famous Chinese educator who devoted his life and finances to running schools, and who made brilliant contributions to the development of Chinese education. (M 16041)

\section{(2964) Jaschek}

$1974 \mathrm{OA}_{1}$. Discovered 1974 July 16 at the Carlos U. Cesco Observatory at El Leoncito.

Named in honor of Carlos Jaschek \{1926-1999\}, professor of astronomy at the University of Strasbourg and director of the Stellar Data Center. Born in Germany, he was educated in Argentina and served as head of the astrophysics department at La Plata from 1957 to 1973 . His earliest work, around 1950, was with the La Plata program for astrometric observations of minor planets. As head of the astrophysics group he inaugurated programs in stellar spectroscopy and arranged for the development of instrumentation, especially for photoelectric photometry. He was also involved with the start of radioastronomy and space activities in Argentina and in 1972 organized the first Latin American conference on astrophysics. After a year in Geneva, he began work in Strasbourg in 1974, strengthening the research there in astrophysics and attempting to make the stellar data center the largest such center in the world. He has also contributed to the creation of data centers in China, Japan, India, the U.S.S.R. and Argentina. A member of the Argentine National Academy of Sciences, he has also served in the CNRS and as president of IAU Commission 45. (M 17221)

Obituary published in Bull. Am. Astron. Soc., Vol. 31, No. 5, p. 1602 (1999).

\section{(2965) Surikov}

1975 BX. Discovered 1975 Jan. 18 by L. I. Chernykh at Nauchnyj.

Named in memory of Vasilij Ivanovich Surikov (1848-1916), famous Russian painter. (M 13173)

\section{(2966) Korsunia}

1977 EB 2 . Discovered 1977 Mar. 13 by N. S. Chernykh at Nauchnyj.

Named for the ancient Crimean town of Chersonesus, known in medieval Russia as Korsun'. (M 12969)

\section{(2967) Vladisvyat}

1977 SS 1 . Discovered 1977 Sept. 19 by N. S. Chernykh at Nauchnyj.

Named for Vladimir Svyatoslavich (ca. 950-1015), Kiev Grand Prince who worked for the consolidation of Kiev and introduced Christianity into Russia in 988-989. (M 12969)

\section{(2968) Iliya}

1978 QJ. Discovered 1978 Aug. 31 by N. S. Chernykh at Nauchnyj.

Named for the Russian epic hero Il'ya Muromets, defender of the Russian land. (M 12969)

\section{(2969) Mikula}

$1978 \mathrm{RU}_{1}$. Discovered 1978 Sept. 5 by N. S. Chernykh at Nauchnyj.

Named for the Russian epic hero Mikula Selyaninovich, the grain grower. (M 12970)

\section{(2970) Pestalozzi}

1978 UC. Discovered 1978 Oct. 27 by P. Wild at Zimmerwald.

Named for Johann Heinrich Pestalozzi (1746-1827), Swiss educator of worldwide influence. Inspired by the ideas of J.-J. Rousseau \{see planet (2950)\}, he worked unremittingly for better education and schooling of the children of the poor. Some of his highly unselfish actions failed at the time, but in the long term his way of thinking succeeded. Even today people use his name as a hallmark for true altruism. (M 21129)

\section{(2971) Mohr}

1980 YL. Discovered 1980 Dec. 30 by A. Mrkos at Kleť.

Named in memory of Josef M. Mohr (1901-1979), professor of astronomy at Charles University, founder of modern stellar astronomy in the former Czechoslovakia. (M 22828) 


\section{(2972) Niilo}

1939 TB. Discovered 1939 Oct. 7 by Y. Väisälä at Turku.

Named in honor of Niilo Anselmi Väisälä, greatgrandson of the discoverer. (M 18449)

\section{(2973) Paola}

1951 AJ. Discovered 1951 Jan. 10 by S. Arend at Uccle.

Named in honor of Princess Paola, sister-in-law of King Baudouin of Belgium \{see planet (1491)\}. (M 12209)

\section{(2974) Holden}

1955 QK. Discovered 1955 Aug. 23 at the Goethe Link Observatory at Brooklyn, Indiana.

Named in memory of Edward Singleton Holden (1846-1914), first director of the Lick Observatory and founder of the Astronomical Society of the Pacific \{see planet (2848)\}. (M 14480)

Name proposed by F. K. Edmondson in the ASP's centennial year and one year after the centennial of the Lick Observatory.

Holden was also director of the Washburn Observatory of the University of Wisconsin in Madison. He is also honored by craters on the Moon and on Mars.

\section{(2975) Spahr}

$1970 \mathrm{AF}_{1}$. Discovered 1970 Jan. 8 by H. Potter and A. Lokalov at Cerro El Roble.

Named in honor of Timothy Bruce Spahr (1970- ) of the Bigelow Sky Survey. This photographic survey utilizes the 0.41-m Catalina Schmidt in a search for high-latitude minor planets. (M 27124)

Name proposed by B. G. Marsden, G. V. Williams and S. M. Larson.

\section{(2976) Lautaro}

1974 HR. Discovered 1974 Apr. 22 by C. Torres at Cerro El Roble.

Named in honor of the Chilean Indian Levtraru (1534-1557), modified to Lautaro (Swift Hawk) by the Spanish soldiers during the conquest of Chile. Son of an Indian chief, he was made prisoner by Pedro de Valdivia \{see planet (2741)\}, who named him his horseboy. In this activity, Lautaro learned a great deal about Spanish soldiers, their horses and military science, knowledge he used together with his own strategies when, at the age of 18 , he became by acclamation big chief of all tribes to defend their land against the Spanish soldiers. After Lautaro's death his head was brought to Santiago and exhibited for fifteen days at the center of Plaza de Armas. (M 10547)

\section{(2977) Chivilikhin}

1974 SP. Discovered 1974 Sept. 19 by L. I. Chernykh at Nauchnyj.

Named in memory of Vladimir Alekseevich Chivilikhin (1928-1984), prominent Soviet writer. (M 9216)

\section{(2978) Roudebush}

1978 SR. Discovered 1978 Sept. 26 at the Harvard College Observatory at Harvard.

Named in honor of Susan Horner Roudebush, in appreciation of her outstanding work as administrator for the Planetary Sciences division of the HarvardSmithsonian Center for Astrophysics, through which both the Minor Planet Center and the Oak Ridge Observatory (formerly the Agassiz Station) are also administered. She has in the past also served with distinction as head of the Smithsonian Astrophysical Observatory's travel office. (M 16244)

\section{(2979) Murmansk}

1978 TB $_{7}$. Discovered 1978 Oct. 2 by L. V. Zhuravleva at Nauchnyj.

Named for the famous Arctic seaport. (M 8914)

\section{(2980) Cameron}

$1981 \mathrm{EU}_{17}$. Discovered 1981 Mar. 2 by S. J. Bus at Siding Spring.

Named in honor of Alastair G. W. Cameron \{1925-

\}, astrophysicist and cosmogonist and currently associate director for theoretical astrophysics at the Harvard-Smithsonian Center for Astrophysics. Known to his colleagues as "Big Al", Cameron has, in his long and distinguished career, been a prolific producer of cosmogonical theories, never hesitating to revise or replace them when confronted with new data. He has consistently emphasized that the origin of planetary systems must be understood in the context of star formation. He was among the first to advocate such concepts as a turbulent accretion disk solar nebula, and the origin of the moon by a giant impact on the proto-earth. Cameron has also contributed greatly to studies of nucleosynthesis in stars and supernovae, and to understanding the significance of the cosmic abundances of nuclides. This work has been valuable for interpreting the meteoritic record of the early history of the solar system. (M 18449)

Citation provided by S. J. Weidenschilling.

\section{(2981) Chagall}

$1981 \mathrm{EE}_{20}$. Discovered 1981 Mar. 2 by S. J. Bus at Siding Spring.

Named in honor of the Russian-born painter Marc Chagall (1887-1985), whose dreamlike, often whimsical, representations of people and animals have made him one of the most popular and innovative artists of the twentieth century. Chagall's paintings reflect his strong religious background and an inner, almost childish, joy and love for life and the world. His major works include hundreds of paintings and book illustrations, as well as stage and costume design for theater and ballet. (M 8802)

\section{(2982) Muriel}

$1981 \mathrm{JA}_{3}$. Discovered 1981 May 6 by C. S. Shoemaker at Palomar.

Named in honor of Muriel May Scott Shoemaker, mother-in-law of the discoverer. (M 9217) 


\section{(2983) Poltava}

$1981 \mathrm{RW}_{2}$. Discovered 1981 Sept. 2 by N. S. Chernykh at Nauchnyj.

Named for the city in the \{former $\}$ Ukrainian S.S.R. (M 11158)

\section{(2984) Chaucer}

1981 YD. Discovered 1981 Dec. 30 by E. Bowell at Anderson Mesa.

Named for the English poet Geoffrey Chaucer (1340?-1400). (M 10044)

Chaucer is also honored by a lunar crater.

\section{(2985) Shakespeare}

$1983 \mathrm{TV}_{1}$. Discovered 1983 Oct. 12 by E. Bowell at Anderson Mesa.

Named for the English poet and playwright William Shakespeare (1564-1616). (M 10044)

\section{(2986) Mrinalini}

2525 P-L. Discovered 1960 Sept. 24 by C. J. van Houten and I. van Houten-Groeneveld at Palomar.

Named in honor of Mrinalini Sarabhai, a distinguished author, choreographer and performer of classical South Indian dances, and deeply involved with the problems of the people of India. SSee also the citation for planet (2987)\}. (M 9478)

\section{(2987) Sarabhai}

4583 P-L. Discovered 1960 Sept. 24 by C. J. van Houten and I. van Houten-Groeneveld at Palomar.

Named in honor of Vikram Ambalal Sarabhai (1919-1971), a cosmic-ray physicist who created several institutions, including the Physical Research Laboratory in Ahmedabad, and directed the Indian programs of space research and atomic energy. He was married to Mrinalini Sarabhai \{see planet (2986)\}. (M 9478)

\section{(2988) Korhonen}

1943 EM. Discovered 1943 Mar. 1 by L. Oterma at Turku.

Named in honor of Tapio Korhonen, well-known telescope maker, especially of telescope optics. Among his successes is the optical system of the Nordic Optical Telescope ssee planet (2857)\}, for which an image quality of $0 " .2$ is obtainable in principle. (M 18450)

\section{(2989) Imago}

$1976 \mathrm{UF}_{1}$. Discovered 1976 Oct. 22 by P. Wild at Zimmerwald.

The Latin word for image, in various degrees of reality, from full appearance (as e.g. the mature stage of an insect) to a mental picture (e.g. of oneself or another person), to visions and dreams. (M 22496)

\section{(2990) Trimberger}

$1981 \mathrm{EN}_{27}$. Discovered 1981 Mar. 2 by S. J. Bus at Siding Spring.

Named in honor of Stephen M. Trimberger, who as a Caltech undergraduate participated in the Palomar Planet-Crossing Asteroid Survey. He works in computer software development and has authored two books on computer-aided design for integrated circuits. (M 13173)

\section{(2991) Bilbo}

1982 HV. Discovered 1982 Apr. 21 by M. Watt at Anderson Mesa.

Named for the central character in J. R. R. Tolkien's \{see planet (2675)\} classic tale of Middle Earth, The Hobbit. (M 27124)

The name is proposed by G. V. Williams and is in keeping with the discoverer's first numbered object, (2675) Tolkien.

\section{(2992) Vondel}

2540 P-L. Discovered 1960 Sept. 24 by C. J. van Houten and I. van Houten-Groeneveld at Palomar.

Named for the Dutch poet and playwright (15871679). (M 10044)

\section{(2993) Wendy}

1970 PA. Discovered 1970 Aug. 4 at the Perth Observatory at Bickley.

Named by Peter Birch \{see planet (3924)\} in honor of his wife. This was the first minor planet discovered at the Bickley site. (M 18644)

\section{(2994) Flynn}

1975 PA. Discovered 1975 Aug. 14 at the Perth Observatory at Bickley.

Named by Mike Candy \{see planet (3015)\} in honor of his wife Vicki Marie Flynn, at one time a staff observer and still an observer on her own time. (M 18644)

\section{(2995) Taratuta}

1978 QK. Discovered 1978 Aug. 31 by N. S. Chernykh at Nauchnyj.

Named in honor of Evgeniya Aleksandrovna Taratuta, Soviet writer and literary scholar. (M 11158)

\section{(2996) Bowman}

1954 RJ. Discovered 1954 Sept. 5 at the Goethe Link Observatory at Brooklyn, Indiana.

Named in honor of Fred N. Bowman, a volunteer astronomer at the Cincinnati Observatory, born on the day this object was discovered, and who has found several minor-planet identifications. (M 9478)

Name proposed by F. K. Edmondson, following a suggestion by Viola R. Bowman.

\section{(2997) Cabrera}

1974 MJ. Discovered 1974 June 17 at the Carlos U. Cesco Observatory at El Leoncito.

Named in honor of Laurentino Ascencion Cabrera (1917- ), an outstanding Argentine astronomer, long on the staff of the La Plata Observatory. His early research involved gravimetry, and from 1949 to 1952 he also worked for the International Latitude Service. From 1958 to 1969 he was in charge of the sitesurvey commission for the $2.15-\mathrm{m}$ reflector of the Argentine National Observatory and since 1986 has been collaborating with that observatory. (M 18305) 


\section{(2998) Berendeya}

1975 TR $_{3}$. Discovered 1975 Oct. 3 by L. I. Chernykh at Nauchnyj.

Named for the wonderland in A. N. Ostrovskij's (1823-1886) fairy tale The Snow-Maiden. (M 11159; I. I. Neyachenko)

\section{(2999) Dante}

1981 CY. Discovered 1981 Feb. 6 by N. G. Thomas at Anderson Mesa.

Named for Dante Alighieri (1265-1321), greatest of the Italian poets. (M 10044)

Dante is also honored by a lunar crater.

\section{(3000) Leonardo}

$1981 \mathrm{EG}_{19}$. Discovered 1981 Mar. 2 by S. J. Bus at Siding Spring.

Named for Leonardo da Vinci (1452-1519), Italian painter, sculptor, architect, musician, enigineer and natural philosopher. (M 10044)

Da Vinci is also honored by a crater on Mars.

\section{(3001) Michelangelo}

1982 BC $_{1}$. Discovered 1982 Jan. 24 by E. Bowell at Anderson Mesa.

Named for Michelangelo Buonarroti (1475-1564), Italian artist. (M 10045)

\section{(3002) Delasalle}

$1982 \mathrm{FB}_{3}$. Discovered 1982 Mar. 20 by H. Debehogne at La Silla.

Named for St. Jean-Baptiste de la Salle, founder of the Frères des Ecoles Chrétiennes in France during the eighteenth century. The Frères are teachers who prepare pupils for the higher education. The discoverer has both studied and taught in their schools, and he wishes to honor all his fellow teachers and pupils. (M 15573)

\section{(3003) Konček}

1983 YH. Discovered 1983 Dec. 28 by A. Mrkos at Klě̆.

Named in memory of academician Mikuláš Konček (1900-1982), founder of the Meteorological Institute in Bratislava. (M 22828)

\section{(3004) Knud}

1976 DD. Discovered 1976 Feb. 27 by R. M. West at La Silla.

Named in memory of the Danish-Eskimo explorer and ethnologist Knud (Johan Victor) Rasmussen (1879-1933). He first visited the Polar Eskimos in northwestern Greenland in 1902-04. Later he founded the Thule station, which became the starting point of his legendary "Thule expeditions", during which he eventually visited virtually every Eskimo tribe between Greenland and the Bering Strait. The vast scope and depth of his many-sided scientific studies brought new insights into the ancient Eskimo culture. His many writings opened this fascinating world to the wide public. Knud Rasmussen was a close friend of the discoverer's paternal grandfather and namesake, a captain in the Royal Danish Navy who frequently sailed in Greenland waters in the 1920s. (M 27124)

\section{(3005) Pervictoralex}

1979 QK $_{2}$. Discovered 1979 Aug. 22 by C.-I. Lagerkvist at La Silla.

Named by the discoverer in honor of his son, Per Victor Alexander Lagerkvist, born on 1987 Apr. 9. (M 12970)

\section{(3006) Livadia}

1979 SF $_{11}$. Discovered 1979 Sept. 24 by N. S. Chernykh at Nauchnyj.

Named for a suburb of the Crimean city of Yalta \{see planet (1475)\}. (M 9769)

\section{(3007) Reaves}

1979 UC. Discovered 1979 Oct. 17 by E. Bowell at Anderson Mesa.

Named in honor of Gibson Reaves, astronomer, historian and educator at the University of Southern California. Himself an expert on dwarf galaxies in clusters, his students have made signal contributions to the study of minor planets. (M 9769) Citation prepared by D. T. Thompson.

\section{(3008) Nojiri}

1938 WA. Discovered 1938 Nov. 17 by K. Reinmuth at Heidelberg.

Named in memory of Hoei Nojiri (1885-1977), the most famous popularizer of astronomy in Japan. Having begun his career as a teacher of English, he wrote many books based on his study of the mythology and ethnology of stars in Japan and abroad. His books have inspired many professional astronomers currently active in Japan. (M 9478)

Name proposed by T. Urata, who found the identifications involving this planet, and endorsed by Y. Kozai.

\section{(3009) Coventry}

$1973 \mathrm{SM}_{2}$. Discovered 1973 Sept. 22 by N. S. Chernykh at Nauchnyj.

Named for the city in England, twin city of Volgograd. (M 9770)

\section{(3010) Ushakov}

1978 SB$_{5}$. Discovered 1978 Sept. 27 by L. I. Chernykh at Nauchnyj.

Named in memory of the Russian admiral and sea captain Fedor Fedorovich Ushakov (1744-1817). (M 11159)

\section{(3011) Chongqing}

1978 WM $_{14}$. Discovered 1978 Nov. 26 at the Purple Mountain Observatory at Nanking.

Named for a city in southwestern China on the upper reach of the Yangtse River. Founded more than 3,000 years ago, Chongqing was the capital of Ba state in ancient times as well as the provisional capital of China from 1937 to 1946. (M 20834) 


\section{(3012) Minsk}

1979 QU9. Discovered 1979 Aug. 27 by N. S. Chernykh at Nauchnyj.

Named for the capital city of the \{former Byelorussian S.S.R. \{see the citation for planet (2170)\}. (M 9770)

\section{(3013) Dobrovoleva}

1979 SD $_{7}$. Discovered 1979 Sept. 23 by N. S. Chernykh at Nauchnyj.

Named in honor of Oleg Vail'evich Dobrovol'skij \{1914-1989\}, head of the Cometary Astronomy Department of the Institute of Astrophysics of the Tadjik S.S.R. Academy of Sciences in Dushanbe, well known for his research on the physics of comets. (M 11159)

Obituaries published in Icarus, Vol. 94, No. 2, p. 259

(1991); Astron. Vestn., Tom 24, No. 3, p. 271-272 (1990); Komet. Tsirk., No. 409, p. 2 (1990).

\section{(3014) Huangsushu}

1979 TM. Discovered 1979 Oct. 11 at the Purple Mountain Observatory at Nanking.

Named in memory of Su-Shu Huang (1915-1977), professor of physics and astronomy at Northwestern University and well-known theoretical astrophysicist. He made many pioneering studies and important contributions, especially on close binary systems. Huang died on a visit to his native China. (M 22828)

\section{(3015) Candy}

1980 VN. Discovered 1980 Nov. 9 by E. Bowell at Anderson Mesa.

Named in honor of Michael P. Candy \{1928-1994\}, acting director of Perth Observatory and an active astrometrist and orbit computer for more than thirty years. While on the staff of the Royal Greenwich Observatory he discovered comet 1961 II, and he now fulfills a major role in southern-hemisphere astronomy by obtaining positions, particularly of comets and minor planets, that would be difficult for northern observers. A former director of the comet section of the British Astronomical Association and editor of the B.A.A. Circulars, he served as president of IAU Commission 6 during 1982-1985. (M 10845)

Citation prepared by P. V. Birch and B. G. Marsden.

Obituaries published in Aust. J. Astron., Vol. 5, No. 5, p. 191-192 (1994); Q. J. R. Astron. Soc., Vol. 36, No. 3, p. 285-286 (1995); J. Br. Astron. Assoc., Vol. 105, No. 2, p. 56 (1995)

\section{(3016) Meuse}

1981 EK. Discovered 1981 Mar. 1 by H. Debehogne and G. DeSanctis at La Silla.

Named for the river, more than $900 \mathrm{~km}$ long, with its sources at Langres that flows through the cities of Verdun, Domremy and Sedan in France, Dinant, Namur \{see planets (2765) and (3374)\}, Huy and Liège in Belgium, and Maastricht, Nijmegen and Rotterdam in the Netherlands. (M 19333)

\section{(3017) Petrovič}

1981 UL. Discovered 1981 Oct. 25 by A. Mrkos at Kleť.

Named in honor of Štefan Petrovič (1906-2000), organizer of modern climatology in Slovakia. (M 22828)

\section{(3018) Godiva}

1982 KM. Discovered 1982 May 21 by E. Bowell at Anderson Mesa.

Named for the wife of Leofric, Earl of Mercia, who, it is said, rode naked, but for her long hair, through the streets of Coventry \{see planet (3009)\} so that her husband would reduce the oppressive taxes he levied on the people of the city. In a later, embellished version of the legend, the populace was entreated to stay behind shuttered windows; but a tailor named Peeping Tom, who disobeyed, was instantly struck blind. (M 9770)

\section{(3019) Kulin}

1940 AC. Discovered 1940 Jan. 7 by G. Kulin at Budapest.

Named in memory of György Kulin (1905-1989), staff astronomer at the Konkoly Observatory from 1935 to 1947. Internationally renowned for his discoveries of minor planets (19 of which have been numbered) with the Konkoly 0.60-m reflector, he also made accurate computations of their orbits. In Hungary he was known for encouraging the development of amateur astronomy: he made almost 7000 telescope mirrors, wrote dozens of books and hundreds of articles to popularize astronomy. The Hungarian "Flammarion" \{see planet (1021)\}, he directed the Urania Observatory in Budapest from 1947 to 1975 and facilitated in many ways the publication of the Hungarian Astronomical Association's magazine Meteor. (M 17465)

Name suggested by Attila Mizser and endorsed by E. Bowell and B. G. Marsden, who found the identifications involving this planet. The actual number of numbered planets amounts to 21 .

\section{(3020) Naudts}

1949 PR. Discovered 1949 Aug. 2 by K. Reinmuth at Heidelberg.

Named in memory of Ignace Naudts (1949-1992), active Belgian amateur astronomer, editor of the monthly magazine Heelal of the Flemish association 'Vereniging voor Sterrenkunde'. His particular fields of interest were planetary satellites and rings, chaos in the solar system, and theoretical and practical study of sundials. He was a talented mathematician, a dynamic and enthusiastic popularizer of astronomy and science. (M 21955)

Name proposed and citation prepared by C. Steyaert, endorsed by G. Klare and L. D. Schmadel.

\section{(3021) Lucubratio}

1967 CB. Discovered 1967 Feb. 6 by P. Wild at Zimmerwald. 
The original meaning of this Latin word is "night work" (from lucubrum, meaning candle). Then it seems to have been extended to any laboriously earned study to overlabored work - and even to idle talk. In spite of this pejorative development the discoverer hopes that this naming will be welcomed by astronomical observers and theorists alike. (M 21130)

\section{(3022) Dobermann}

1980 SH. Discovered 1980 Sept. 16 by Z. Vávrová at Klě́.

Named in honor of Karl Friedrich Louis Dobermann (1834-1894), German zoologist and amateur astronomer. (M 16441)

\section{(3023) Heard}

1981 JS. Discovered 1981 May 5 by E. Bowell at Anderson Mesa.

Named in memory of John Frederick Heard (19071976), professor of astronomy at the University of Toronto and fourth director of the David Dunlap Observatory. An outstanding and meticulous spectroscopist, he specialized in spectroscopic binaries and stellar radial-velocity standards. In addition, he was a dedicated teacher who helped train many Canadian astronomers. (M 9770)

Citation prepared by H. Guetter.

Obituary published in J.R. Astron. Soc. Canada, Vol. 71, p. 1-8 (1977).

\section{(3024) Hainan}

$1981 \mathrm{UW}_{9}$. Discovered 1981 Oct. 23 at the Purple Mountain Observatory at Nanking.

Named for a newly established province in southern China. Hainan Island, under its jurisdiction, has rich developing resources of tropical plants and animals, sea aquatic products, petrochemical and metallurgical industry, rare-earth metals, etc. With its bright and colorful scene, Hainan Island, acclaimed as "Eastern Hawaii", is a tourist resort and a bright pearl in the vast South China Sea. (M 15088)

\section{(3025) Higson}

1982 QR. Discovered 1982 Aug. 20 by C. S. Shoemaker and E. M. Shoemaker at Palomar.

Named in honor of Roger Higson, night assistant for the $1.2-\mathrm{m}$ Schmidt telescope at Palomar Observatory since 1979. An outstanding and thoroughly dedicated member of the observatory's supporting staff, he has skillfully assisted astronomers in a broad range of research conducted with the 1.2-m Schmidt. His efforts have been especially appreciated by observers of comets and minor planets. (M 9217)

Name proposed by the discoverers, endorsed by J. Gibson and C. Kowal.

\section{(3026) Sarastro}

$1977 \mathrm{TA}_{1}$. Discovered 1977 Oct. 12 by P. Wild at Zimmerwald.
Named for the lord or high priest in the Temple of Wisdom, a leading figure in Mozart's s see planet (1034)\} opera "Die Zauberföte". (M 21130)

\section{(3027) Shavarsh}

1978 PQ $_{2}$. Discovered 1978 Aug. 8 by N. S. Chernykh at Nauchnyj.

Named in honor of Shavarsh Vladimirovich Karapetyan, Armenian sportsman, eleven times the world champion in underwater sports. Also known for heroic deeds, he saved twenty persons in a trolley bus submerged in water from a dam in Erevan. (M 11159)

\section{(3028) Zhangguoxi}

1978 TA $_{2}$. Discovered 1978 Oct. 9 at the Purple Mountain Observatory at Nanking.

Named in honor of Zhang Guoxi, Chinese industrialist, for his contributions to social welfare and public education. (M 21607)

\section{(3029) Sanders}

$1981 \mathrm{EA}_{8}$. Discovered 1981 Mar. 1 by S. J. Bus at Siding Spring.

Named in honor of Jeffrey D. Sanders, who participated in the Palomar Planet-Crossing Asteroid Survey as a Caltech undergraduate student. (M 13173)

\section{(3030) Vehrenberg}

$1981 \mathrm{EH}_{16}$. Discovered 1981 Mar. 1 by S. J. Bus at Siding Spring.

Named in honor of Hans Vehrenberg (1910-1991) of Düsseldorf: publisher, amateur astronomer, and creator of atlases of the sky. His Falkauer Atlas and Atlas Stellarum are widely used by amateur and professional astronomers interested in or conducting research on minor planets and comets. His other publications include the popular Atlas of Deep-Sky Splendors. (M 9081)

Name proposed by the discoverer following a suggestion by T. P. Kohman and J. U. Gunter.

Obituaries published in Sterne Weltraum, Jahrg. 30, Nr. 12, p. 766-768 (1991); Mitt. Astron. Ges., Nr. 75, p. 11-12 (1992).

\section{(3031) Houston}

1984 CX. Discovered 1984 Feb. 8 by E. Bowell at Anderson Mesa.

Named in honor of Walter Scott Houston, American amateur astronomer well known for his column "Deep Sky Wonders" in the magazine Sky and Telescope. Houston has specialized in the visual study of deep-sky objects and has guided countless amateurs to view and marvel at the varied objects within the grasp of small telescopes. (M 10845)

Name proposed by the discoverer following a suggestion by P. L. Dombrowski.

\section{(3032) Evans}

$1984 \mathrm{CA}_{1}$. Discovered 1984 Feb. 8 by E. Bowell at Anderson Mesa. 
Named in honor of the Reverend Robert O. Evans, Australian amateur astronomer and discoverer of several extragalactic supernovae. Evans has successfully used a systematic visual search program to examine selected galaxies for supernova activity. (M 10845)

Name proposed by the discoverer following a suggestion by P. L. Dombrowski.

\section{(3033) Holbaek}

1984 EJ. Discovered 1984 Mar. 5 by K. Augustesen and P. Jensen and H. J. Fogh Olsen at Brorfelde.

Named in honor of the town nearest to the Brorfelde \{see planet (3309)\} Observatory on the occasion of the town's 700th anniversary in 1986. (M 10045)

Holbaek is situated on the Danish island of Sjaelland in the Baltic Sea.

\section{(3034) Climenhaga}

A917 SE. Discovered 1917 Sept. 24 by M. F. Wolf at Heidelberg.

Named in honor of John L. Climenhaga, first head of physics at the University of Victoria, on the occasion of his seventieth birthday. Known for his work on the $\mathrm{C} 12 / \mathrm{C} 13$ abundance ratio in carbon stars and for studies of line blanketing and microturbulence in late-type stars, he has also long had an interest in cometary spectra. On his retirement in 1982 the University's Observatory was named in his honor, and among the Observatory's activities is the only Canadian program of astrometric observations of comets and minor planets. (M 11441)

Following a suggestion from C. E. Spratt, the name was proposed by B. G. Marsden, who found the identifications involving this minor planet.

\section{(3035) Chambers}

A924 EJ. Discovered 1924 Mar. 7 by K. Reinmuth at Heidelberg.

Named in honor of John Eric Chambers (1969- ), graduate student at Manchester University, currently a predoctoral fellow at the Harvard-Smithsonian Center for Astrophysics. John's research concentrates on the effect of mean-motion resonances on the orbital evolution of solar system objects, and he has recently completed a study of $\mathrm{P} /$ Swift-Tuttle, showing that the motion of this object is dominated by the 1:11 resonance with Jupiter. (M 22497)

Name proposed by members of the Planetary Sciences division, the identifications for this object having been made by B. G. Marsden.

\section{(3036) Krat}

1937 TO. Discovered 1937 Oct. 11 by G. N. Neujmin at Simeis.

Named in memory of Vladimir Alekseevich Krat (1911-1983), corresponding member of the U.S.S.R. Academy of Sciences, a staff member of the Pulkovo Observatory and from 1964 to 1979 its director. His main contributions to astronomy involved solar physics and chromospheric structure, figures of equilibrium of close binaries, classification of eclipsing variables and cosmogony. He initiated and actively participated in the development of the first Soviet stratospheric balloon observatory. (M 10547)

Obituaries published in Zemlya Vselennaya, No. 6, p. 33-34 (1983); Sol. Phys., Vol. 89, No. 1, p. 1-2 (1983); Izv. Glav. Astron. Obs. Pulkovo, Astrometr. Astrofiz., No. 202, p. 3-5 (1984).

\section{(3037) Alku}

1944 BA. Discovered 1944 Jan. 17 by Y. Väisälä at Turku.

Named for the boat the discoverer enjoyed in his boyhood. It was built by the father of the discoverer and instilled in him a lifelong love of sailing. The name means "the beginning". (M 18450)

\section{(3038) Bernes}

1978 QB $_{3}$. Discovered 1978 Aug. 31 by N. S. Chernykh at Nauchnyj.

Named in memory of Mark Naumovich Bernes (1911-1969), popular Soviet film actor and singer. (M 12970)

\section{(3039) Yangel}

$1978 \mathrm{SP}_{2}$. Discovered 1978 Sept. 26 by L. V. Zhuravleva at Nauchnyj.

Named in memory of Mikhail Kuz'mich Yangel' (1911-1971), Soviet designer of space-rocket systems. (M 10547)

\section{(3040) Kozai}

1979 BA. Discovered 1979 Jan. 23 by W. Liller at Cerro Tololo.

Named in honor of Yoshihide Kozai, astronomer and celestial mechanician at the Tokyo Observatory, whose interests include natural and artificial satellites, the motions of comets and minor planets, families of minor planets, and the use of satellite and lunar positions for astronomy and geodesy. His investigation of the theory of secular perturbations of minor planets of large orbital inclination or eccentricity led to the recognition of the first object known to exhibit argument-of-perihelion libration. (M 9770)

Name proposed by J. G. Williams, who has found that this object also to be an argument-of-perihelion librator.

Kozai served as IAU president 1988-1991.

\section{(3041) Webb}

1980 GD. Discovered 1980 Apr. 15 by E. Bowell at Anderson Mesa.

Named for Thomas William Webb, discoverer of S Ori. Like many other English clergymen of his days, he was a keen amateur astronomer. His observations on many years formed the basis of his Celestial Objects for Common Telescopes (1859), a work covering many aspects of astronomical observation and destined to 
become a classic handbook for the amateur astronomer. (M 9770)

Name suggested and citation prepared by B. Hetherington.

\section{(3042) Zelinsky}

$1981 \mathrm{EF}_{10}$. Discovered 1981 Mar. 1 by S. J. Bus at Siding Spring.

Named in honor of David S. Zelinsky, now a mathematician at Brown University, Providence, formerly an active participant in the Palomar Planet-Crossing Asteroid Survey while an undergraduate student at Caltech. (M 13173)

\section{(3043) San Diego}

1982 SA. Discovered 1982 Sept. 20 by E. F. Helin at Palomar.

Named as a celestial tribute to the city of San Diego in appreciation of the city's responsiveness and cooperation in the campaign to restore dark skies for astronomers probing the universe. (M 8914)

\section{(3044) Saltykov}

$1983 \mathrm{RE}_{3}$. Discovered 1983 Sept. 2 by N. V. Metlova and N. E. Kurochkin at Nauchnyj.

Named by the first discoverer in memory of her grandfather, Nikita Saltykov (1893-1946), well known as a grower of vegetables in the region of Yaroslavl and the Urals. (M 22245)

\section{(3045) Alois}

1984 AW. Discovered 1984 Jan. 8 by J. F. Wagner at Anderson Mesa.

Named by the discoverer in memory of his grandfather, Alois T. Stuczynski. (M 9479)

\section{(3046) Molière}

4120 P-L. Discovered 1960 Sept. 24 by C. J. van Houten and I. van Houten-Groeneveld at Palomar.

Named for the French playwright (1622-1673). (M 10045)

\section{(3047) Goethe}

6091 P-L. Discovered 1960 Sept. 24 by C. J. van Houten and I. van Houten-Groeneveld at Palomar.

Named for the German poet and playwright \{Johann Wolfgang von Goethe\} (1749-1832). (M 10045)

\section{(3048) Guangzhou}

$1964 \mathrm{TH}_{1}$. Discovered 1964 Oct. 8 at the Purple Mountain Observatory at Nanking.

Named for the largest open city in southern China and the capital of Guangdong province. The provincial center of culture, finance and technology, and located in the inner part of the Pearl River delta, Guangzhou is celebrated as the city of Flowers, Rams and the Ear of Grain, and it has a sound foundation in industry and commerce and a long history of trade relations with foreign countries. (M 15089)

\section{(3049) Kuzbass}

1968 FH. Discovered 1968 Mar. 28 by T. M. Smirnova at Nauchnyj.

Named for the Kuznetskij coal basin, one of the richest coal deposits in the U.S.S.R. and the world. (M 13173)

\section{(3050) Carrera}

1972 NW. Discovered 1972 July 13 by C. Torres at Cerro El Roble.

Named in memory of the brothers Carrera, Javiera (1781-1862), Juan José (1782-1818), José Miguel (17851821) and Luis (1791-1818), active participants in gaining Chile's independence from Spain, in spite of continuous disagreements with Bernardo O'Higgins \{see planet (2351)\}, the "Father of the Country", and José de San Martin \{see planet (2745)\}, an Argentine general and political liberator of Argentina, Chile and Peru. José Miguel Carrera was the first president of Chile. During his government Chile acquired its first political constitution, a law against slavery, a law prohibiting obedience to foreign authorities, a law of civil rights, and the establishment of diplomatic relations with the United States. (M 10547)

\section{(3051) Nantong}

1974 YP. Discovered 1974 Dec. 19 at the Purple Mountain Observatory at Nanking.

Named for the industrial port city at the mouth of the Yangtse, on the Yellow Sea. The city has a long history of education and culture, and the first school and the first museum in China were here. (M 20835)

\section{(3052) Herzen}

$1976 \mathrm{YJ}_{3}$. Discovered 1976 Dec. 16 by L. I. Chernykh at Nauchnyj.

Named in memory of Aleksandr Ivanovich Herzen (1812-1870), revolutionary, writer and philosopher, founder of the free Russian press abroad. (M 11159)

\section{(3053) Dresden}

1977 QS. Discovered 1977 Aug. 18 by N. S. Chernykh at Nauchnyj.

Named for the city in the \{former\} German Democratic Republic \{see also planet (263)\}. (M 9770)

Dresden now is an important town in the Federal Republic of Germany.

\section{(3054) Strugatskia}

$1977 \mathrm{RE}_{7}$. Discovered 1977 Sept. 11 by N. S. Chernykh at Nauchnyj.

Named in honor of the brothers Arkadij Natanovich and Boris Natanovich Strugatskij, well-known Soviet writers of science fiction. (M 9771)

\section{(3055) Annapavlova}

1978 TR $_{3}$. Discovered 1978 Oct. 4 by T. M. Smirnova at Nauchnyj.

Named in honor of the renowned ballet-dancer Anna Pavlovna Pavlova (1881-1931). (M 13173) 
(3056) INAG

$1978 \mathrm{VD}_{1}$. Discovered 1978 Nov. 1 by K. Tomita at Caussols.

Named in honor of the French Institut National d'Astronomie et de Géophysique, at which the 0.9-m Schmidt telescope used for the discovery of this object was constructed. The 3.6-m Canada-France-Hawaii telescope and the 2-m Pic-du-Midi telescope were also built at INAG. (M 9082)

\section{(3057) Mälaren}

1981 EG. Discovered 1981 Mar. 9 by E. Bowell at Anderson Mesa.

Named for the large Swedish lake between Stockholm and Uppsala. A souvenir of a relaxing shipboard evening spent at the conclusion of a most successful conference on minor planets, comets and meteors held in Uppsala in June 1985. (M 10311)

Name suggested by B. G. Marsden following a request by the discoverer.

\section{(3058) Delmary}

$1981 \mathrm{EO}_{17}$. Discovered 1981 Mar. 1 by S. J. Bus at Siding Spring.

Named in honor of the American artist Delmary Rose Schanz (1938- ), whose seascapes, rendered in the glazed oil technique of the Flemish masters, have inspired art enthusiasts internationally. Highly respected for her sensitive use of light and color, the artist has produced an extensive body of work widely acclaimed by collectors and peers for its spiritual power and technical mastery. (M 9082)

\section{(3059) Pryor}

$1981 \mathrm{EF}_{23}$. Discovered 1981 Mar. 3 by S. J. Bus at Siding Spring.

Named in honor of Carlton P. Pryor, who participated in the Palomar Planet-Crossing Asteroid Survey while an undergraduate student at Caltech. Until recently an astronomer at Vanderbilt University, he is now a research fellow at Rutgers University. (M 13173)

\section{(3060) Delcano}

$1982 \mathrm{RD}_{1}$. Discovered 1982 Sept. 12 by P. Wild at Zimmerwald.

Named in memory of Juan Sebastián del Cano, the first to circumnavigate the globe. While Magellan \{see planet (4055)\} is usually credited as being the first, this is true only by virtue of splicing his first voyage eastward from Europe to the Philippines with his second one westward to those islands where he was killed. The first true continuous circumnavigation was the heroic voyage of Juan del Cano, a young lieutenant of Magellan, who in command of the only remaining ship of the five that had begun the westward voyage navigated it safely for about 30,000 additional kilometers, returning home with his fellow 30 or so survivors more than three years after leaving home. Of astronomical interest is the fact that his log failed to tally by one day with the calendar of those who had not made the voyage - demonstrating the need for an international data line or its equivalent. (M 21130)

Name proposed and citation written by the late Harlan J. Smith.

\section{(3061) Cook}

1982 UB $_{1}$. Discovered 1982 Oct. 21 by E. Bowell at Anderson Mesa.

Named for James Cook (1728-1779), British circumnavigator and one of the first scientific navigators. He observed the solar eclipse of 1766 Aug. 5 from Newfoundland and in 1769 measured the transit of Venus from Tahiti. In 1761 he assisted the Astronomer Royal, Nevil Maskelyne, in tests of John Harrison's fourth marine chronometer as a means of determining longitude at sea. (M 10846)

Name proposed by the discoverer following a suggestion by $\mathrm{B}$. Hetherington.

Cook is also honored by a lunar crater.

\section{(3062) Wren}

1982 XC. Discovered 1982 Dec. 14 by E. Bowell at Anderson Mesa.

Named for Christopher Wren (1632-1723), British architect and astronomer who was professor of astronomy at Gresham College, London, and later professor of astronomy at Oxford. Wren prepared a scheme for rebuilding London after the Great Fire of 1666, his most noted building being St. Paul's Cathedral. He also designed and built the Royal Observatory at Greenwich in 1675. (M 10846)

Name proposed by the discoverer following a suggestion by B. Hetherington.

\section{(3063) Makhaon}

1983 PV. Discovered 1983 Aug. 4 by L. G. Karachkina at Nauchnyj.

Named for the physician to the Greek troops during the Trojan War. (M 10547)

\section{(3064) Zimmer}

1984 BB $_{1}$. Discovered 1984 Jan. 28 by E. Bowell at Anderson Mesa.

Named in memory of Louis Zimmer (1888-1970), world-famous Belgian maker of astronomical clocks. Many of his clocks were made for crowned heads and political leaders all over the world. Today he is best remembered for his "wonderclock", exhibited at the 1939 New York World Fair; his "Jubilee clock", donated to his native town of Lier in 1930; and his Astronomical Studio. All three masterpieces were housed in or near the "Zimmer Tower", which has subsequently become one of the main attractions of Lier. (M 11748)

Name proposed by the discoverer, following a suggestion by E. Goffin, who prepared the citation. 


\section{(3065) Sarahill}

1984 CV. Discovered 1984 Feb. 8 by E. Bowell at Anderson Mesa.

Named in honor of Sarah J. Hill, professor of astronomy at Wellesley College (1952-1974) and chairman of its astronomy department (1952-1971). Her enthusiasm for teaching and for observational astronomy influenced the graduates to earn doctorates and become professional astronomers. Many others among her students earned advanced degrees in astronomy or related fields. (M 12013)

Name proposed by the discoverer following a suggestion by F. Vilas, who provided the citation.

\section{(3066) McFadden}

1984 EO. Discovered 1984 Mar. 1 by E. Bowell at Anderson Mesa.

Named in honor of Lucy-Ann A. McFadden, planetary scientist at the University of Maryland, for her studies of the nature of Earth-approaching minor planets and for the comparison of their spectra with those of meteorites. Recently, she has been working on the relationship between cometary nuclei and Earth approachers, and on ultraviolet spectrophotometry of comets. (M 11748)

Name endorsed by M. F. A'Hearn.

\section{(3067) Akhmatova}

$1982 \mathrm{TE}_{2}$. Discovered 1982 Oct. 14 by L. G. Karachkina and L. V. Zhuravleva at Nauchnyj.

Named in honor of Anna Andreevna Akhmatova (1889-1966), outstanding poetess, awarded an honorary doctorate by the University of Oxford. (M 13174)

\section{(3068) Khanina}

1982 YJ $_{1}$. Discovered 1982 Dec. 23 by L. G. Karachkina at Nauchnyj.

Named in honor of Frida Borisovna Khanina, specialist on orbit computations, a staff member of the Institute for Theoretical Astronomy from 1946 to 1983. She contributed extensively to nearly forty volumes of Ehfemeridy Malykh Planet and improved the orbits of many hundreds of minor planets. (M 10547)

\section{(3069) Heyrovský}

1982 UG $_{2}$. Discovered 1982 Oct. 16 by Z. Vávrová at Klet.

Named in honor of Jaroslav Heyrovský (1890-1967), Czech physicist and inventor of polarography, recipient of the 1959 Nobel Prize for Chemistry. (M 16441)

\section{(3070) Aitken}

1949 GK. Discovered 1949 Apr. 4 at the Goethe Link Observatory at Brooklyn, Indiana.

he Lick Observatory (1930-1935), and as associate director under W. W. Campbell \{see planet (2751)\} he ran the Observatory when the latter was also president of the University of California (1923-1930). During his 40 years at Lick Aitken became the leading authority on double stars, his work culminating in the publication of his New General Catalogue of Double Stars within 120 degrees of the North Pole, published in two large volumes in 1932. His book The Binary Stars was published in 1918, and an updated second edition appeared in 1935. (M 14481)

Name proposed by F. K. Edmondson.

Aitken is also honored by a lunar crater.

\section{(3071) Nesterov}

$1973 \mathrm{FT}_{1}$. Discovered 1973 Mar. 28 by T. M. Smirnova at Nauchnyj.

Named in honor of Petr Nikolaevich Nesterov (18871914), the Russian airman who was the first to carry out a number of piloting maneuvers, among them the loop. (M 11159)

\section{(3072) Vilnius}

1978 RS $_{1}$. Discovered 1978 Sept. 5 by N. S. Chernykh at Nauchnyj.

o planet (2577)\}. (M 9771)

Vilnius is since 1991 the capital of the independent state of Lithuania.

(3073) Kursk

1979 SW $_{11}$. Discovered 1979 Sept. 24 by N. S. Chernykh at Nauchnyj.

Named for an old Russian city. (M 9771)

\section{(3074) Popov}

$1979 \mathrm{YE}_{9}$. Discovered 1979 Dec. 24 by L. V. Zhuravleva at Nauchnyj.

Named in memory of Aleksandr Stepanovich Popov (1859-1906), the inventor of radio in Russia. (M 13174) Popov is also honored by a lunar crater.

\section{(3075) Bornmann}

$1981 \mathrm{EY}_{15}$. Discovered 1981 Mar. 1 by S. J. Bus at Siding Spring.

Named in honor of Patricia L. Bornmann, who participated in the Palomar Planet-Crossing Asteroid Survey while an undergraduate student at Caltech and now performs solar research at the National Oceanic and Atmospheric Administration in Boulder. (M 13174)

\section{(3076) Garber}

1982 RB $_{1}$. Discovered 1982 Sept. 13 at the Oak Ridge Observatory at Harvard.

Named in honor of Paul E. Garber, historian emeritus and Ramsey fellow of the Smithsonian Institution's National Air and Space Museum, on the occasion of his ninetieth birthday and in recognition of his lifelong commitment to aviation and the exploration of both air and space. (M 14971)

Citation prepared by J. C. Cornell.

\section{(3077) Henderson}

1982 SK. Discovered 1982 Sept. 22 by E. Bowell at Anderson Mesa. 
Named for Thomas Henderson (1798-1844), Scottish astronomer and noted computer. He was appointed Royal Astronomer at the Cape of Good Hope and later Astronomer Royal for Scotland. Henderson computed an improved value for the solar parallax and was the first to measure the distance to a star, Alpha Centauri, in 1839. (M 10846)

Name proposed by the discoverer following a suggestion by B. Hetherington.

Henderson is also honored by a lunar crater.

\section{(3078) Horrocks}

1984 FG. Discovered 1984 Mar. 31 by E. Bowell at Anderson Mesa.

Named for Jeremiah Horrocks (1619-1641), the English astronomer who predicted the transit of Venus across the face of the Sun in 1639 Nov. and became the first to see such an event. From his observations he improved the orbital elements and the diameter of Venus. He believed the Moon to have an elliptical orbit with the Earth at one focus - a fact that Newton \{see planet (8000)\} was later to acknowledge. (M 10846)

Name proposed by the discoverer following a suggestion by B. Hetherington.

\section{(3079) Schiller}

2578 P-L. Discovered 1960 Sept. 24 by C. J. van Houten and I. van Houten-Groeneveld at Palomar.

Named for the German poet and playwright (17591805). (M 10045)

\section{(3080) Moisseiev}

1935 TE. Discovered 1935 Oct. 3 by P. F. Shajn at Simeis.

Named in memory of Nikolaj Dmitrevich Moisseiev (Moiseev) (1902-1955), professor at Moscow University and founder of the Moscow school of celestial mechanics. He studied the secular and long-period perturbations in the motion of natural celestial bodies, especially minor planets. (M 10548)

Moisseiev is also honored by a lunar crater.

\section{(3081) Martinůboh}

1971 UP. Discovered 1971 Oct. 26 by L. Kohoutek at Bergedorf.

Named in memory of the Czech composer Bohuslav Martinů (1890-1959), known in the musical world as the author of remarkable orchestral and scenic works (six symphonies and twelve operas), as well as chamber and vocal music. (M 31609)

\section{(3082) Dzhalil}

1972 KE. Discovered 1972 May 17 by T. M. Smirnova at Nauchnyj.

Named in memory of Musa Mustafovich Dzhalil' (1906-1944), outstanding Tatar Soviet poet, author of lyric poetry, poems and opera libretti. (M 10548)

\section{(3083) OAFA}

1974 MH. Discovered 1974 June 17 at the Felix Aguilar Observatory at El Leoncito.

Named in honor of the Observatorio Astronomico Felix Aguilar \{see also planet (1800)\}, established on 1953 Sept. 28 under the auspices of the National San Juan University in San Juan province, Argentina. OAFA has made important contributions to astronomy in the areas of meridian and extrameridian astrometry. Since 1974 the observing station at El Leoncito \{see planet (2311)\}, operated in collaboration with Yale University and now known as the Dr. Carlos U. Cesco Observatory, has been a branch of OAFA. (M 19333)

\section{(3084) Kondratyuk}

1977 QB 1 . Discovered 1977 Aug. 19 by N. S. Chernykh at Nauchnyj.

Named in memory of Yurij Vasil'evich Kondratyuk (1897-1942), one of the Soviet pioneers in rocket technology and cosmonautics, known for his work in electrical engineering. (M 12970)

Kondratyuk is also honored by a lunar crater.

\section{(3085) Donna}

1980 DA. Discovered 1980 Feb. 18 at the Harvard College Observatory at Harvard.

Named in honor of Donna Marie Thompson, who as administrative assistant for the Minor Planet Center and the Central Bureau for Astronomical Telegrams is in charge of handling subscriptions. Her official position as secretary for the Planetary Sciences division of the Harvard-Smithsonian Center for Astrophysics scarecely describes her talents, which include serving as timekeeper and deputy administrator, setting up audio-visual aids at meetings and maintaining laser printers. (M 16244)

\section{(3086) Kalbaugh}

1980 XE. Discovered 1980 Dec. 4 by E. Bowell at Anderson Mesa.

Named in honor of Carroll Kalbaugh Liller, father of astronomer William Liller \{see planet (3222)\}, lover of life and nature, friend of all who come in peace. (M 10548)

Named by the discoverer following a suggestion by W. Liller.

\section{(3087) Beatrice Tinsley}

$1981 \mathrm{QJ}_{1}$. Discovered 1981 Aug. 30 by A. C. Gilmore and P. M. Kilmartin at Lake Tekapo.

Named in memory of Beatrice Muriel Tinsley (19411981), a graduate of the University of Canterbury, New Zealand, and a professor at Yale University, well known for her work on the evolution of galaxies. (M 9479)

Obituary published in Phys. Today, Vol. 34, No. 9, p. 110, 112 (1981); Q.J.R. Astron. Soc., Vol. 23, p. $162-165$ (1982). 


\section{(3088) Jinxiuzhonghua}

1981 UX $_{9}$. Discovered 1981 Oct. 24 at the Purple Mountain Observatory at Nanking.

The name reflects the natural beauty and ancient civilization of China. Jinxiuzhonghua, or "Splendid China", is the largest miniature scenic spot in the world. Situated in Shenzhen, in the southern part of China, and constructed by China Travel Service, it is an attractive place for tourists and well-known for its outstanding scenery, including the Great Wall, the Imperial Palace, the Terra-Cotta Warriors and Horses of Qin Shihuang Mausoleum, and scenic and historical sites such as Guilin, Suzhou \{see planet (2719)\} and Hangzhou. (M 17221)

\section{(3089) Oujianquan}

$1981 \mathrm{XK}_{2}$. Discovered 1981 Dec. 3 at the Purple Mountain Observatory at Nanking.

Named in honor of Oujianquan, Chinese entrepreneur, for his notable contributions in developing township enterprises. (M 22497)

\section{(3090) Tjossem}

1982 AN. Discovered 1982 Jan. 4 by J. Gibson at Palomar.

Named in honor of a pioneer family in central Washington, four generations of whose members have been friends of the discoverer and his family. It honors in particular the memory of Peter Tjossem (1878-1957), millwright, farmer, amateur entomologist, lapidarist, amateur paleobotanist working at a professional level on identification of Miocene fossil woods of central Washington, elder in the Presbyterian Church - and friend to any young person who came to him, in the best traditions of the amateur scientist. (M 10045)

\section{(3091) van den Heuvel}

6081 P-L. Discovered 1960 Sept. 24 by C. J. van Houten and I. van Houten-Groeneveld at Palomar.

Named in honor of E. P. J. van den Heuvel, professor of astronomy at the Municipal University of Amsterdam, well known for his studies on the structure and evolution of neutron stars. The name also honors Julia Edith van den Heuvel, niece of the astronomer, for her lively interest in astronomy. (M 11159)

\section{(3092) Herodotus}

6550 P-L. Discovered 1960 Sept. 24 by C. J. van Houten and I. van Houten-Groeneveld at Palomar.

Named for the Greek historian who lived in the fifth century B.C. and is known as the "Father of Historiography". (M 11159)

Herodotus is also commemorated by a lunar crater.

\section{(3093) Bergholz}

1971 MG. Discovered 1971 June 28 by T. M. Smirnova at Nauchnyj.

Named in memory of Ol'ga Fedorovna Bergholz (1910-1975), talented poetess and writer. (M 13174)

\section{(3094) Chukokkala}

$1979 \mathrm{FE}_{2}$. Discovered 1979 Mar. 23 by N. S. Chernykh at Nauchnyj.

Named in memory of Kornej Ivanovich Chukovskij, pen name of Nikolaj Vasil'evich Kornejchukov (18821969), outstanding writer and literary scholar, known especially for his poetry for children. The name comes from Chukovskij's album "Chukokkala". Many prominent writers, artists and other men of culture included their notes, poetry, and paintings in this work. (M 12013)

\section{(3095) Omarkhayyam}

$1980 \mathrm{RT}_{2}$. Discovered 1980 Sept. 8 by L. V. Zhuravleva at Nauchnyj.

Named for the great Tadjik and Persian poet, mathematician and philosopher Omar Khayyam Giyasaddinabu-L'Fatkh ibn Ibragim (ca. 1048-after 1122).

(M 13174)

\section{(3096) Bezruč}

1981 QC $_{1}$. Discovered 1981 Aug. 28 by Z. Vávrová at Klě́.

Named in honor of Petr Bezruč (1867-1958), popular Silesian poet. (M 21607)

\section{(3097) Tacitus}

2011 P-L. Discovered 1960 Sept. 24 by C. J. van Houten and I. van Houten-Groeneveld at Palomar.

Named for the Roman historian who lived in the first century A.D. (M 11159)

Tacitus is also honored by a lunar crater.

\section{(3098) van Sprang}

4579 P-L. Discovered 1960 Sept. 24 by C. J. van Houten and I. van Houten-Groeneveld at Palomar.

Named in honor of Bert van Sprang, a Dutch amateur who is very active in popularizing astronomy. An organization of young amateur astronomers, founded by him, has at present 1,400 members. He initiated the International Astronomical Youth Camps, which are held in various European countries each year. $\mathrm{He}$ also gives many popular lectures and stimulates the construction of small telescopes by young people. (M 12013)

\section{(3099) Hergenrother}

1940 GF. Discovered 1940 Apr. 3 by Y. Väisälä at Turku.

Named in honor of Carl William Hergenrother (1973-

) of the Bigelow Sky Survey. This photographic survey has been very successful in discovering new high-inclination minor planets. (M 27124)

Name proposed by B. G. Marsden, G. V. Williams and S. M. Larson.

\section{(3100) Zimmerman}

1977 EQ$_{1}$. Discovered 1977 Mar. 13 by N. S. Chernykh at Nauchnyj. 
Named in memory of Nikolaj Vladimirovich Zimmerman (1890-1942), head of the astrometric department of Pulkovo Observatory from 1938, and professor at Leningrad University from 1937, known for his work on astrometry and star catalogues. (M 12970)

\section{(3101) Goldberger}

1978 GB. Discovered 1978 Apr. 11 by E. F. Helin at Palomar.

Named in honor of Marvin L. Goldberger, gifted physicist, teacher and humanitarian, to commemorate his birthday, Oct. 22. Since his inauguration in 1978 as president of the California Institute of Technology, he has dedicated himself to sustaining the Institute's excellence and to opening new opportunities for women in science. His steadfast support for research on minor planets has enhanced the importance and vitality of the subject as a scientific endeavor. (M 9217)

\section{(3102) Krok}

1981 QA. Discovered 1981 Aug. 21 by L. Brožek at Klě̆.

Krok was a mythical prince of the Slavonic tribes in ancient Bohemia. He had three daughters. The youngest of them was the sibyl Libuše, who married the young Prremysl; together they are considered the mythical founders of the Czech royal dynasty of the Přemyslids. (M 24410)

\section{(3103) Eger}

1982 BB. Discovered 1982 Jan. 20 by M. Lovas at Piszkéstetö.

Named for a famous Hungarian city. In 1762 its bishop, Count Karoly Esterhazy, established a university there at his own expense. The university included an observatory, which he furnished on consultation with Maximilian Hell \{see planet (3727)\} in Vienna, instruments being made in both Vienna and London. The Eger observations began in 1778, and the results were published in Hell's annual astronomical ephemerides. The city is also known for the successful stand of its populace against the besieging Turks in 1552. It is situated in an excellent wine-growing area and is known internationally for its hearty red Egri Bikaver ("bull's blood"). (M 23135)

\section{(3104) Dürer}

1982 BB $_{1}$. Discovered 1982 Jan. 24 by E. Bowell at Anderson Mesa.

Named for Albrecht Dürer of Nuremberg (14711528), master painter, woodcutter, engraver, scholar of the Renaissance. Dürer is noted for his meticulous applications of perspective geometry to art, not only for his rendering of the unusual themes of his times, but also for his beautiful and accurate depictions of scientific instruments and of constellations. (M 10846)

Name proposed by the discoverer following a suggestion by G. Reaves.

\section{(3105) Stumpff}

A907 PB. Discovered 1907 Aug. 8 by A. Kopff at Heidelberg.

Named in memory of Karl Stumpff (1895-1970), eminent celestial mechanist and professor of astronomy at Berlin, Graz and Göttingen. His method of treatment of periodic processes was a forerunner of the Fast Fourier Analysis. The collected experience of decades of research went into his main scientific heritage, the three-volume Himmelsmechanik. (M 22497)

Name proposed by G. Klare and L. D. Schmadel. Citation prepared by P. Brosche.

\section{(3106) Morabito}

1981 EE. Discovered 1981 Mar. 9 by E. Bowell at Anderson Mesa.

Named in honor of Linda A. Morabito, member of the Optical Navigation Team for the Voyager 1 spacecraft, who because of her alertness, knowledge of astronomy and skill in image processing discovered an active volcano on the Galilean Satellite Io. (M 10846)

Name proposed by the discoverer following a suggestion by G. Reaves.

\section{(3107) Weaver}

$1981 \mathrm{JG}_{2}$. Discovered 1981 May 5 by C. S. Shoemaker at Palomar.

Named in honor of Kenneth F. Weaver, senior assistant editor for science of the National Geographic magazine. For more than two decades Weaver has followed closely the exploration of the solar system by spacecraft. He has been responsible for the accurate and skillful presentation of new discoveries in space to a large segment of the public. (M 10311)

\section{(3108) Lyubov}

1972 QM. Discovered 1972 Aug. 18 by L. V. Zhuravleva at Nauchnyj.

Named in memory of Lyubov Petrovna Orlova (1902-1975), outstanding Soviet actress. (M 13174)

\section{(3109) Machin}

1974 DC. Discovered 1974 Feb. 19 by L. Kohoutek at Bergedorf.

Named in memory of renowned sculptor Arnold Machin (1911-1999). His sculpture of the effigy of queen Elizabeth II was used on British coinage from 1968 until 1984. Machin also sculpted the monarch's profile, and this formed the basis for the Machin definitive series of British definitive stamps, first issued in June 1967 and still in use today. (M 34618)

Name suggested by B. G. Marsden, who made identifications for this object, following a prompting by G. V. Williams.

\section{(3110) Wagman}

1975 SC. Discovered 1975 Sept. 28 by H. L. Giclas at Anderson Mesa.

Named in memory of Nicholas E. Wagman (19051980), American astronomer and leading astrometrist. 
Associated with the Allegheny Observatory beginning in 1930, he was its director and the chairman of the University of Pittsburgh's Astronomy Department from 1941 until 1970. Under his direction the 0.76-m Thaw refractor was renovated and used to set the standard for parallax determinations, of which were over 1200 made; and a number of astrometric binaries were discovered and characterized. In his honor the Amateur Astronomers Association of Pittsburgh named its Nicholas E. Wagman Observatory in 1976. (M 27733)

Name proposed and citation prepared by T. P. Kohman on behalf of the association.

\section{(3111) Misuzu}

1977 DX $_{8}$. Discovered 1977 Feb. 19 by H. Kosai and K. Hurukawa at Kiso.

This planet is being given the former name of Nagano prefecture, where the Kiso Station fof the Tokyo Observatory $\}$ is located. (M 11441)

\section{(3112) Velimir}

1977 QC 5 . Discovered 1977 Aug. 22 by N. S. Chernykh at Nauchnyj.

Named for Velimir (Viktor Vladimirovich) Khlebnikov (1885-1922), Russian poet known for his experiments in poesy, who also applied mathematical analysis to history and discovered some cycles among historical events. (M 12970)

\section{(3113) Chizhevskij}

1978 RO. Discovered 1978 Sept. 1 by N. S. Chernykh at Nauchnyj.

Named in honor of Aleksandr Leonidovich Chizhevskij (1897-1964), Soviet biologist and one of the founders of heliobiology, who discovered the dependence of many phenomena of the biosphere and atmosphere upon the solar cycle. (M 12970)

\section{(3114) Ercilla}

$1980 \mathrm{FB}_{12}$. Discovered 1980 Mar. 19 by C. Torres at Cerro El Roble.

Named in memory of Don Alonso de Ercilla y Zuniga (1533-1594), Spanish poet and soldier who distinguished himself in the campaign in Chile against the Araucanians. He returned to Spain in 1562, taking with him the first fifteen cantos of La Araucana, his epic poem about the early part of the 300-year-long war between Spanish soldiers and Chilean Indians. He can be considered the first chronicler of the history of Chile. (M 11160)

\section{(3115) Baily}

1981 PL. Discovered 1981 Aug. 3 by E. Bowell at Anderson Mesa.

Named for Francis Baily (1774-1844), English astronomer and one of the founders of the Royal Astronomical Society. During his observation of the total solar eclipse of 1836 he noticed intrusions of sunlight around the Moon's limb, which have become known as Baily's beads. (M 10847)
Name proposed by the discoverer following a suggestion by B. Hetherington.

Baily is also honored by a lunar crater.

\section{(3116) Goodricke}

1983 CF. Discovered 1983 Feb. 11 by E. Bowell at Anderson Mesa.

Named for John Goodricke (1764-1786), the deaf and dumb Dutch-English astronomer who studied the light variations of the star Algol and correctly suggested that it is what we now call an eclipsing variable. He also discovered and studied the variable star Delta Cephei. (M 10847)

Name proposed by the discoverer following a suggestion by B. Hetherington.

\section{(3117) Niepce}

$1983 \mathrm{CM}_{1}$. Discovered 1983 Feb. 11 by N. G. Thomas at Anderson Mesa.

Named for the Frenchman Joseph Nicéphore Niepce (1765-1833), who made the first photograph in 1827 using the bitumen heliographic process. (M 10548)

Name suggested by Douglas B. Thomas, brother of the discoverer.

Niepce is also honored by a lunar crater.

\section{(3118) Claytonsmith}

1974 OD. Discovered 1974 July 19 at the Felix Aguilar Observatory at El Leoncito.

Named in memory of Clayton Albert Smith (19341993), a leading expert on astrometry. Smith was known for his work on stellar catalogues and for improving the celestial coordinate system. He was director of the Yale-Columbia Southern Observatory (now the Dr. Carlos U. Cesco Station) in El Leoncito from 1968 to 1970 and director of the U.S. Naval Observatory's Astrometry Department from 1992. (M 22497)

\section{(3119) Dobronravin}

1972 YX. Discovered 1972 Dec. 30 by T. M. Smirnova at Nauchnyj.

Named in honor of Petr Pavlovich Dobronravin \{1908- \}, well-known Soviet astrophysicist and spectroscopist, who served successively on the staffs of the Leningrad Astronomical Institute, the Leningrad State Optical Institute and the Pulkovo Observatory. As deputy director of the Crimean Astrophysical Observatory during 1952-1969 he made an impressive contribution to the development of that organization, equipping it with powerful optical and radio telescopes. (M 10548)

\section{(3120) Dangrania}

1979 RZ. Discovered 1979 Sept. 14 by N. S. Chernykh at Nauchnyj.

Named in honor of Daniil Aleksandrovich Granin, Soviet writer whose work is mainly about scientists and researchers. (M 12970) 
(3121) Tamines

1981 EV. Discovered 1981 Mar. 2 by H. Debehogne and G. DeSanctis at La Silla.

Named for an industrial city on the river Sambre \{see planet (4016)\} in southern Belgium, known for foundries and glass works. (M 19333)

\section{(3122) Florence}

$1981 \mathrm{ET}_{3}$. Discovered 1981 Mar. 2 by S. J. Bus at Siding Spring.

Named in memory of Florence Nightingale (18201910), English nurse and hospital reformer, who almost singlehandedly established trained nursing as an honorable profession for women. She transformed the English field hospitals during the Crimean War and was known there for her quiet dignity, her rigorous discipline and her determination. Florence Nigthingale is most remembered as The Lady of the Lamp for her courage, compassion and devotion to the injured troops as she visited the hospital wards after a full day's work. (M 21955)

Citation prepared by C. S. Shoemaker at the request of the discoverer.

\section{(3123) Dunham}

$1981 \mathrm{QF}_{2}$. Discovered 1981 Aug. 30 by E. Bowell at Anderson Mesa.

Named in honor of David W. Dunham, American astronomer and organizer of the International Occultation Timing Association. Dunham has played a cardinal role in collecting and analyzing occultation observations, particularly those involving asteroids and grazing occultations by the Moon. In addition, he has stimulated many observers to make accurate and useful timings of occultation phenomena. (M 10847)

Name proposed by the discoverer following suggestions by E. Goffin and P. L. Dombrowski.

\section{(3124) Kansas}

1981 VB. Discovered 1981 Nov. 3 by D. J. Tholen at Kitt Peak.

Named for the discoverer's home state, which derives its name from that of the Kansa Indians who migrated into the northeastern region of the state during the latter portion of the 18th century. The state's motto is "Ad astra per aspera", which means "To the stars through difficulties". The planet is also named for the University of Kansas, the discoverer's alma mater, to commemorate the centennial of observational astronomy there, which began with the purchase of an Alvan Clark 6-inch refractor in 1885, an instrument still in use today. (M 10045)

\section{(3125) Hay}

1982 BJ $_{1}$. Discovered 1982 Jan. 24 by E. Bowell at Anderson Mesa.

Named for William Thompson Hay (1888-1949), British music-hall comedian and film star of the 1930s and early 1940s. Will Hay was an accomplished planetary observer who in 1933 discovered a famous white spot on Saturn. (M 10847)

Name proposed by the discoverer following a suggestion by B. Hetherington.

\section{(3126) Davydov}

1969 TP $_{1}$. Discovered 1969 Oct. 8 by L. I. Chernykh at Nauchnyj.

Named in memory of Denis Vasil'evich Davydov (1784-1839), officer, writer and poet, hero of the war of 1812 in Russia. (M 11160)

\section{(3127) Bagration}

$1973 \mathrm{ST}_{4}$. Discovered 1973 Sept. 27 by L. I. Chernykh at Nauchnyj.

Named in memory of Petr Ivanovich Bagration (1765-1812), Russian general, hero of the war of 1812 . (M 11160)

\section{(3128) Obruchev}

$1979 \mathrm{FJ}_{2}$. Discovered 1979 Mar. 23 by N. S. Chernykh at Nauchnyj.

Named in honor of Vladimir Afanasjevich Obruchev (1863-1956), outstanding geologist and geographer who made a valuable contribution to the geologic exploration of Siberia and central Asia. He also wrote popular books on science and science-fiction novels. (M 12013)

Obruchev is also honored by a lunar crater.

\section{(3129) Bonestell}

$1979 \mathrm{MK}_{2}$. Discovered 1979 June 25 by E. F. Helin and S. J. Bus at Siding Spring.

Named in honor of Chesley Bonestell \{1888-1986\}, whose art has inspired generations of astronomers, space enthusiasts and artists. (M 10548)

Name proposed by the first discoverer, following a suggestion from Ronald Paludan.

Obituaries published in Icarus, Vol. 67, No. 3, p. 343-344 (1986); Spaceflight, Vol. 28, Nos. 9/10, p. 355 (1986).

\section{(3130) Hillary}

1981 YO. Discovered 1981 Dec. 20 by A. Mrkos at Klě́t.

Named in honor of the New Zealand mountaineer Sir Edmund Percival Hillary (1919- ), who, with Sherpa Tenzing Norgay \{see planet (6481)\}, was the first to conquer Mt. Everest. The discoverer worked with Hillary in Antarctica during the International Geophysical Year, 1957-1958. (M 23135)

\section{(3131) Mason-Dixon}

$1982 \mathrm{BM}_{1}$. Discovered 1982 Jan. 24 by E. Bowell at Anderson Mesa.

Named for Charles Mason (1730-1787) and Jeremiah Dixon (1773-1779), British astronomers who observed the 1761 transit of Venus from the Cape of Good Hope. Between 1763 and 1767 they surveyed the 
boundary between Pennsylvania and Maryland - the Mason-Dixon Line. (M 10847)

Name proposed by the discoverer following a suggestion by B. Hetherington.

\section{(3132) Landgraf}

1940 WL. Discovered 1940 Nov. 29 by L. Oterma at Turku.

Named in honor of Werner Landgraf \{1959- \}, who found the identifications and computed the orbit for this minor planet, and whose initials appear in the object's principal provisional designation. (M 12457)

\section{(3133) Sendai}

A907 TC. Discovered 1907 Oct. 4 by A. Kopff at Heidelberg.

Named for the biggest city in northeastern Japan, home of Tôhuku University and several other institutes of higher learning, sometimes called the "Heidelberg of the East". The Sendai Municipal Astronomical Observatory, established in 1955 at the urging of the Sendai Amateur Astronomical Association, has an active program for astrometric observations of comets. (M 10045)

Name proposed by S. Nakano, who found the identifications involving this planet.

\section{(3134) Kostinsky}

A921 VA. Discovered 1921 Nov. 5 by S. I. Belyavskij at Simeis.

Named in honor of Sergej Konstantinovich Kostinsky (1867-1936), one of the founders of astrophotography and photographical astrometry in Russia, a corresponding member of the U.S.S.R. Academy of Sciences and a staff member of the Pulkovo Observatory. He made numerous determinations of stellar parallaxes and proper motions, studied star clusters and nebulae, as well as planets and their satellites. (M 10548)

Kostinsky is also honored by a lunar crater.

\section{(3135) Lauer}

$1981 \mathrm{EC}_{9}$. Discovered 1981 Mar. 1 by S. J. Bus at Siding Spring.

Named in honor of Tod R. Lauer, who participated in the Palomar Planet-Crossing Asteroid Survey while an undergraduate student at Caltech. Now an astronomer at the Princeton University, he is engaged in extragalactic studies and is a member of the Space Telescope Wide-Field Camera Team. (M 13174)

\section{(3136) Anshan}

$1981 \mathrm{WD}_{4}$. Discovered 1981 Nov. 18 at the Purple Mountain Observatory at Nanking.

Named for the city, known as the "Steel Metropolis", in the Liaodong peninsula. The largest iron and steel producer in China, Anshan is rich in natural resources and is an industrial center. (M 21607)

\section{(3137) Horky}

$1982 \mathrm{SM}_{1}$. Discovered 1982 Sept. 16 by A. Mrkos at Kleť.

Named for the hill where the discoverer installed his first telescope in 1939. (M 22828)

\section{(3138) Ciney}

1980 KL. Discovered 1980 May 22 by H. Debehogne at La Silla.

Named for the chief town of the Condroz, in the province of Namur \{see planet (3374)\}, where the discoverer studied and maintains a residence. Ciney is renowned for its schools, its horse and cattle fairs and its casting houses. (M 15573)

\section{(3139) Shantou}

$1980 \mathrm{VL}_{1}$. Discovered 1980 Nov. 11 at the Purple Mountain Observatory at Nanking.

Named for an open city on the coast of southeast China. A fine seaport, it is also a flourishing industrial and agricultural center. (M 16244)

\section{(3140) Stellafane}

1983 AO. Discovered 1983 Jan. 9 by B. A. Skiff at Anderson Mesa.

Named for the regional telescope maker's annual meeting in Vermont that has become recognized worldwide as a preeminent gathering for telescopic design and innovation. The "Shrine to the Stars" has provided a forum to exchange astronomical ideas, to enhance the performance of astronomical instruments and to further good contact between amateurs and professionals. (M 13174)

Name suggested and citation provided by P. L. Dombrowski.

\section{(3141) Buchar}

1984 RH. Discovered 1984 Sept. 2 by A. Mrkos at Kleť.

Named in memory of Emil Buchar (1901-1979), professor of astronomy and geodesy at Prague Polytechnic. He was one of the pioneers of satellite geodesy. (M 22828)

\section{(3142) Kilopi}

1937 AC. Discovered 1937 Jan. 9 by A. Patry at Nice.

The name acknowledges the fact that the number of this planet is the approximate circumference of a circle of diameter 1,000 units. (M 9771)

Following a suggestion by J. G. Williams, this planet was named by B. G. Marsden, who made the identifications involving it.

\section{(3143) Genecampbell}

1980 UA. Discovered 1980 Oct. 31 at the Harvard College Observatory at Harvard.

Named in honor of I. Gene Campbell, systems programmer in the central computing facility at the Harvard-Smithsonian Center for Astrophysics. Ever 
helpful and always patient, he has quickly and quietly resolved many problems over the years, both for the observing program at Oak Ridge and for the Minor Planet Center and Central Bureau for Astronomical Telegrams. It is a rare magnetic tape that he cannot salvage and decipher, and fixing recalcitrant modems is second nature to him. When it became necessary to dispense with the teletype machines for the MPC/CBAT TWX number, he did the necessary programming for operating EASYLINK from the CFAPS2 MicroVAX and arranged for the automatic receipt there of TWX/telex messages. (M 16244)

\section{(3144) Brosche}

$1931 \mathrm{TY}_{1}$. Discovered 1931 Oct. 10 by K. Reinmuth at Heidelberg.

Named in honor of Peter Brosche (1936- ), astronomer at Heidelberg and Bonn. He has developed the determination of systematic differences into orthogonal functions, participated in the foundation of absolute radio interferometry and investigated the history of the Seeberg Observatory and its scientific founder F. X. von Zach \{see planet (999)\}. (M 22497)

Name proposed by L. D. Schmadel, endorsed by G. Klare.

\section{(3145) Walter Adams}

1955 RY. Discovered 1955 Sept. 14 at the Goethe Link Observatory at Brooklyn, Indiana.

Named in memory of Walter S. Adams (1876-1956), whose spectroscopic studies of sunspots and stars led to the discovery, with A. Kohlschütter, of a spectroscopic method for determining stellar distances, the relative intensities of spectral lines being used to determine absolute magnitudes of both giant and main-sequence stars. Adams identified Sirius B as the first white-dwarf star known, and his measurement of its gravitational redshift was taken as confirming evidence for the general theory of relativity. He served as director of the Mount Wilson Observatory from 1923 to 1946. (M 15089)

Name proposed by F. K. Edmondson. Citation prepared by J. Tenn.

\section{(3146) Dato}

1972 KG. Discovered 1972 May 17 by T. M. Smirnova at Nauchnyj.

Named in memory of Dato Kratsashvili (1963-1980), gifted Georgian painter. (M 13174)

\section{(3147) Samantha}

1976 YU $_{3}$. Discovered 1976 Dec. 16 by L. I. Chernykh at Nauchnyj.

Named in memory of Samantha Smith (1971-1985), the American girl who dreamed about the friendship of people all over the world. (M 11160)

\section{(3148) Grechko}

1979 SA $_{12}$. Discovered 1979 Sept. 24 by N. S. Chernykh at Nauchnyj.

Named in honor of Georgij Mikhajlovich Grechko, Soviet cosmonaut and scientist who made three space flights involving astronomical and geophysical observations and research. (M 12971)

\section{(3149) Okudzhava}

1981 SH. Discovered 1981 Sept. 22 by Z. Vávrová at Kleť.

Named in honor of the contemporary Soviet writer, poet and singer Bulat Okudzhava. (M 12209; M 12851)

\section{(3150) Tosa}

1983 CB. Discovered 1983 Feb. 11 by T. Seki at Geisei.

This planet is being given the old name of Kochi \{see planet (2396)\} prefecture, where the discoverer resides. (M 10847)

\section{(3151) Talbot}

1983 HF. Discovered 1983 Apr. 18 by N. G. Thomas at Anderson Mesa.

Named for the Englishman William Henry Fox Talbot (1800-1877), who made the first silver nitrate photographic negatives in 1834. With Rawlinson and Hincks he was one of the earliest to decipher the cuneiform inscriptions of Nineveh. (M 10548)

\section{(3152) Jones}

1983 LF. Discovered 1983 June 7 by A. C. Gilmore and P. M. Kilmartin at Lake Tekapo.

Named in honor of Albert Francis Arthur Lofley Jones, New Zealand amateur astronomer renowned for the quantity and precision of his visual magnitude estimates of variable stars. His record of some 300,000 variable star observations over nearly 50 years is unrivaled worldwide. He is also a noted observer of comets and the discoverer of comet 1946 VI. He was an independent discoverer of supernova 1987A in the Large Magellanic Cloud. (M 13175)

\section{(3153) Lincoln}

$1984 \mathrm{SH}_{3}$. Discovered 1984 Sept. 28 by B. A. Skiff at Anderson Mesa.

Named in memory of Abraham Lincoln (1809-1865), sixteenth president of the United States. Lincoln served tirelessly during the great drama of the American Civil War as commander-in-chief of the Union armies in a struggle to preserve the country. A self-taught prairie lawyer, Lincoln rose to greatness through sheer determination and hard work. His election as president in 1860 sparked the southern secession movement, which had smoldered for decades. Lincoln's brilliance as a politician and army strategist is well documented. His efforts to preserve the Union and emancipate American slaves ended in Union victory just days before he was assassinated at Ford's Theatre in Washington, D.C., on Good Friday, 1865 Apr. 14. (M 16442)

Name proposed and citation prepared by D. J. Eicher. 
(3154) Grant

$1984 \mathrm{SO}_{3}$. Discovered 1984 Sept. 28 by B. A. Skiff at Anderson Mesa.

Named in memory of Ulysses Simpson Grant (18221885), eighteenth president of the United States and lieutenant general commanding the armies of the Union during the American Civil War. Grant served with distinction as a young lieutenant during the Mexican War and afterward resigned his commission to enter civilian life. Having failed at several dozen occupations, a poor, distraught Grant entered the volunteer service as a colonel at the outbreak of the Civil War. Grant captured Fort Donelson on the Tennessee River and Vicksburg on the Mississippi, and this transformed him from an obscure army commander to the best-known general in Blue. In the spring of 1864 Lincoln \{see planet (3153)\} promoted him to general-in-chief; his crunching "May Campaign" through Virginia ended in Lee's \{see planet (3155)\} surrender at Appomattox Court House on 1865 Apr. 9. (M 16442)

Name proposed and citation prepared by D. J. Eicher.

\section{(3155) Lee}

$1984 \mathrm{SP}_{3}$. Discovered 1984 Sept. 28 by B. A. Skiff at Anderson Mesa.

Named in memory of Robert Edward Lee (18071870), general-in-chief of the Confederate States of America during the American Civil War. The son of Revolutionary War patriot Henry "Lighthorse Harry" Lee and great-grandnephew of George Washington \{see planet (886)\}, Robert E. Lee attended the U.S. Military Academy of West Point and distinguished himself in the Mexican War. He was a career soldier whose expertise as an engineer served the U.S. Army well until his native state, Virginia, seceded from the Union. Lee's actions throughout the Civil War demonstrated a cunning ability to out-command many of his opponents, despite having a smaller, poorly-fed army. With his grandfatherly bearing and grey-white beard, Lee came to epitomize the southern gentleman, and, after the war was over, he stirred dream-like memories of an Old South that would never return. (M 16442)

Name proposed and citation prepared by D. J. Eicher.

\section{(3156) Ellington}

1953 EE. Discovered 1953 Mar. 15 by A. Schmitt at Uccle.

Named in honor of Edward Kennedy ("Duke") Ellington (1899-1974), renowned jazz pianist, composer and bandleader. Ellington crafted more than 1,000 orchestrations for big bands, film scores, operas, ballets, musicals and church services. (M 22497)

Name proposed by B. G. Marsden, who made the identifications for this object.

\section{(3157) Novikov}

1973 SX $_{3}$. Discovered 1973 Sept. 25 by L. V. Zhuravleva at Nauchnyj.
Named in memory of Aleksej Ivanovich Novikov (1916-1986), Soviet aviator and poet. (M 13175)

\section{(3158) Anga}

$1976 \mathrm{SU}_{2}$. Discovered 1976 Sept. 24 by N. S. Chernykh at Nauchnyj.

Named for a Siberian village, birthplace of the Russian ethnographers Ivan Evseevich Venyaminov (1797-1879) and Afanasij Prokopevich Shchapov (18311876). The former was the first explorer of the Aleutians and the latter a historian and popularizer of culture. (M 12014)

\section{(3159) Prokof'ev}

1976 US $_{2}$. Discovered 1976 Oct. 26 by T. M. Smirnova at Nauchnyj.

Named in honor of Vladimir Konstantinovich Prokof'ev \{1898-1993\}, well-known expert on atomic spectroscopy and emission spectral analysis, a professor at the Leningrad and Gorkij universities and since 1961 on the staff of the Crimean Astrophysical Observatory. He contributed much to solar ultraviolet spectroscopic research and discovered the presence of oxygen in the atmosphere of Venus. He served as president of IAU Commission 44 during 1970-1973. (M 10847)

Obituary published in Izv. Krym. Astrofiz. Obs., Tom 88, p. $156-157$ (1993).

\section{(3160) Angerhofer}

1980 LE. Discovered 1980 June 14 by E. Bowell at Anderson Mesa.

Named in memory of Philip E. Angerhofer (19501986), astronomer at the U.S. Naval Observatory, Washington. He was involved in using the National Radio Astronomy Observatory connected-element interferometer at Green Bank for the determination of Earth-oriented parameters. His other research interests included supernova remnants such as CTB 80 and Cas A. Angerhofer's caring attitude toward his colleagues and family are greatly missed. (M 10848)

Name proposed by the discoverer, following a suggestion by P. K. Seidelmann, who also prepared the citation.

\section{(3161) Beadell}

1980 TB 5 . Discovered 1980 Oct. 9 by C. S. Shoemaker at Palomar.

Named in honor of Len Beadell, surveyor at Salisbury, South Australia. The last of the geographical explorers of the Australian outback, Beadell laid out more than $6,000 \mathrm{~km}$ of graded track, including the well-known "Gun Barrel Highway", through the most remote regions of Australia. (M 11748)

\section{(3162) Nostalgia}

1980 YH. Discovered 1980 Dec. 16 by E. Bowell at Anderson Mesa.

Named in remembrance of good things that are no more. (M 11641) 
Name proposed by the discoverer, following a suggestion by J. Meeus.

\section{(3163) Randi}

1981 QM. Discovered 1981 Aug. 28 by C. T. Kowal at Palomar.

Named in honor of the American magician James Randi (1928- ); (real name Randall James Hamilton Zwinge) for his continuing efforts in debunking the claims of the paranormal community and exposing the tricks that charlatans use. His use of scientific techniques in many disciplines has contributed to the refutation of suspicious and fraudulent claims of paranormal results. (M 27124)

Name proposed by A. Dill and J. Meeus.

\section{(3164) Prast}

6562 P-L. Discovered 1960 Sept. 24 by C. J. van Houten and I. van Houten-Groeneveld at Palomar.

Named in honor of Martin Prast, friend of one of the discoverers. Severely wounded in Vietnam in 1970, he became paraplegic and confined to a wheelchair. Together with his father he founded "Prast Research Association: Mobility Aids for Handicapped Persons". In 1977 he received the Outstanding Citizen award in the 36th Congressional District of New York State, and in 1982 he parachuted successfully into the Niagara River near Grand Island, N.Y. (M 12457)

\section{(3165) Mikawa}

1984 QE. Discovered 1984 Aug. 31 by K. Suzuki and T. Urata at Toyota.

Named for the district in which the Toyota Station is located. Mikawa, the old name of the district, also appears in the title of the Western Mikawa Astronomical Club, of which the first discoverer is a member. (M 10046)

\section{(3166) Klondike}

1940 FG. Discovered 1940 Mar. 30 by Y. Väisälä at Turku.

Named in memory of the brothers Karl F. Joutsen and Anton F. Johnson, who during 1901-1905 made a fortune in their mine, Dominion Creek 21, in the Klondike gold rush. Among their benefactions to the University of Turku were the means to construct its library in 1954. (M 18450)

\section{(3167) Babcock}

1955 RS. Discovered 1955 Sept. 13 at the Goethe Link Observatory at Brooklyn, Indiana.

Named in memory of Harold D. Babcock (1882-1968) and in honor of his son Horace W. Babcock, astronomers at Mount Wilson Observatory, the latter also serving as director of Palomar Observatory. The elder Babcock's precise laboratory studies of atomic spectra allowed others to identify the first "forbidden" lines in the laboratory and to discover the rare isotopes of oxygen. With C. E. St. John and others, he extended Rowland's tables of the solar spectrum into the ultraviolet and infrared. The Babcocks ruled excellent large gratings, including those used in the coudé spectrographs of the 2.5-m and 5-m telescopes, and they measured the distribution of magnetic fields over the solar surface to unprecedented precision. The younger Babcock invented and built many astronomical instruments, including the solar magnetograph, microphotometers and automatic guiders. By combining his polarization analyzer with the spectrograph he discovered magnetic fields in other stars, and he developed important models of sunspots and their magnetism. (M 15089)

Name proposed by F. K. Edmondson. Citation prepared by J. Tenn.

Obituary published in Q.J.R. Astron. Soc., Vol. 10, p. 68-72 (1969). Harold Babcock is also honored by a lunar crater.

\section{(3168) Lomnický Štít}

1980 XM. Discovered 1980 Dec. 1 by A. Mrkos at Kleť.

Named for the meteorological and solar observatory in the High Tatras, where the discoverer worked for some 20 years. (M 23136; M 30819)

\section{(3169) Ostro}

1981 LA. Discovered 1981 June 4 by E. Bowell at Anderson Mesa.

Named in honor of Steven J. Ostro, planetary scientist at the Jet Propulsion Laboratory of the California Institute of Technology. Ostro has specialized in radar studies of solar system objects, including the Galilean satellites. He is the leader in radar research on minor planets and has used his observations to deduce their surface roughness and radar reflectivity. He has also combined his radar data with optical rotational lightcurves to study the shapes and axial orientations of minor planets. (M 11749)

Citation prepared by the discoverer and A. W. Harris.

\section{(3170) Dzhanibekov}

1979 SS $_{11}$. Discovered 1979 Sept. 24 by N. S. Chernykh at Nauchnyj.

Named in honor of Vladimir Aleksandrovich Dzhanibekov, famous Soviet cosmonaut who flew into outer space five times and made a valuable contribution to outer space research. (M 12971)

\section{(3171) Wangshouguan}

1979 WO. Discovered 1979 Nov. 19 at the Purple Mountain Observatory at Nanking.

Named in honor of Wang Shouguan, member of the Chinese Academy of Sciences and an unfailing friend of the discoverers. Wang has contributed to the development of modern Chinese astronomy and has served as chief editor of Acta Astrophysica Sinica since its inception. He is also an honorary president of the Chinese Astronomical Society and honorary director of Beijing Observatory. (M 21607) 
(3172) Hirst

1981 WW. Discovered 1981 Nov. 24 by E. Bowell at Anderson Mesa.

Named in honor of William P. Hirst, computer of the orbits of several of the minor planets discovered in Johannesburg. A Yorkshireman by birth, he worked for many years as Shell Oil's chief chemist in South Africa. He led the Cape Town Moonwatch Team from its inception in 1957, and following his retirement from Shell he served for several years at the Smithsonian Astrophysical Observatory as Moonwatch world coordinator. After returning to South Africa he continued to lecture on celestial mechanics at the University of Cape Town until the age of 83 . (M 12014)

Name proposed by the discoverer, following a suggestion by R. Hurly and B. G. Marsden.

\section{(3173) McNaught}

1981 WY. Discovered 1981 Nov. 24 by E. Bowell at Anderson Mesa.

Named in honor of Rob McNaught, who has been in charge of the University of Aston's satellite-tracking camera at Herstmonceux and more recently at Siding Spring. In his spare time he successfully conducts patrols for novae, identifies images of prenovae and unusual variable stars on survey plates, measures their positions, makes astrometric observations of comets and minor planets and photometric observations of comets and novae, carries out extensive observational and computational work on meteors, as well as on occultations by minor planets. (M 12457)

Named by the discoverer, following a suggestion by D. A. J. Seargent.

\section{(3174) Alcock}

1984 UV. Discovered 1984 Oct. 26 by E. Bowell at Anderson Mesa.

Named in honor of the outstanding British amateur astronomer George E. D. Alcock $\{1912-2000\}$, visual discoverer of five comets and four novae. (M 12458)

Obituary published in Int. Comet Q., Vol. 23, No. 1, p. 3 (2001)

\section{(3175) Netto}

1979 YP. Discovered 1979 Dec. 16 by H. Debehogne and E. R. Netto at La Silla.

Named by the first discoverer in honor of the second, Edgar Rangel Netto, astronomer at the Valongo Observatory (Universidade do Rio de Janeiro), measurer of many of the plates obtained in the program that produced this discovery. (M 10848)

\section{(3176) Paolicchi}

$1980 \mathrm{VR}_{1}$. Discovered 1980 Nov. 13 by Z. Knežević at Piszkéstetö.

Named in honor of Paolo Paolicchi, planetary scientist, associate professor of astrophysics at the University of Pisa. His research activity has included studies on the origin of stellar and planetary systems and the dynamical and collisional history of small solar-system bodies. His work on minor planets has focused on the evolution of rotational properties and on the modeling of catastrophic breakup events. (M 12209)

Name proposed by the discoverer following a suggestion by V. Zappalà and P. Farinella, the latter of whom prepared the citation.

\section{(3177) Chillicothe}

1934 AK. Discovered 1934 Jan. 8 by H. L. Giclas at Flagstaff.

Named for the southern Ohio city of Chillicothe, located at the confluence of the Scioto River and Paint Creek, on the occasion of the bicentennial of its founding by Nathanial Massie. The name is derived from the Shawnee Indian word meaning "principal town". This area was occupied by the Adena Mound Builders over 2000 years ago and at the time of its founding by the Shawnee Indians. Chillicothe served as the capital of the eastern section of the Northwest Territory and was the first capital of Ohio from 1803 to 1816. (M 27733)

Name proposed by F. N. Bowman, who independently made the principal identification involving this planet and who lives 20 miles southwest of Chillicothe.

\section{(3178) Yoshitsune}

1984 WA. Discovered 1984 Nov. 21 by K. Suzuki and T. Urata at Toyota.

Named for one of the most famous and tragic Japanese military commanders, Minamoto Yoshitsune (1159-1189). In 1185, he defeated the Heike in the great sea battle of Dannoura, and afterwards the jealousy of his elder brother Yoritomo \{see planet (3902)\} forced him to commit suicide by the sword. (M 19692)

\section{(3179) Beruti}

1962 FA. Discovered 1962 Mar. 31 at the La Plata Observatory at La Plata.

Named in memory of Arturo Beruti (1862-1938), Argentine composer, author of the operas Pampa, Kryse, Evangelina and Taras Bulba, among others. (M 22497)

\section{(3180) Morgan}

1962 RO. Discovered 1962 Sept. 7 at the Goethe Link Observatory at Brooklyn, Indiana.

Named in honor of William W. Morgan \{1906-1994\}, whose career at the Yerkes Observatory since 1926 has been devoted to morphology, the classification of objects by their form and structure. He and P. Keenan \{see planet (10030)\} introduced stellar luminosity classes and the two-dimensional classification of stellar spectra strictly on the basis of the spectra themselves. With D. Osterbrock \{see planet (6107)\} and S. Sharpless he discovered spiral arms in the Galaxy from spectral studies of $\mathrm{O}$ and $\mathrm{B}$ stars. Morgan invented the UBV system of magnitudes and colors, and with N. Mayall \{see planet (2131)\} he developed a spectral classification system for giant galaxies. (M 15089) 
Name proposed by F. K. Edmondson. Citation prepared by J. Tenn.

Obituaries published in Phys. Today, Vol. 67, No. 12, p. 82-83 (1994); Bull. Am. Astron. Soc., Vol. 26, No. 4, p. 1606 (1994); Q.J.R. Astron. Soc., Vol. 36, No. 2, p. 175-177 (1995); Publ. Astron. Soc. Pac., Vol. 107, No. 712 , p. 507-512 (1995).

\section{(3181) Ahnert}

1964 EC. Discovered 1964 Mar. 8 by F. Börngen at Tautenburg.

Named in honor of Paul Ahnert \{1897-1989\}, author since 1949 of the annual Kalender für Sternfreunde and well known by professional and amateur astronomers alike in many countries. Although his principal aim is the popularization of astronomy, and he has published several books on the art of making observations, he has carried out research since 1938 at the Sonneberg \{see planet (1039)\} Observatory on variable stars and on the physics of the solar system. (M 9771)

Obituaries published in Ahnerts Kalender Sternfreunde 1990, p. 7 (1989); Sterne Weltraum, Jahrg. 28, Nr. 7/8, p. 480 (1989); Astron. Tidsskr., Årg. 22, Nr. 4, p. 155-156 (1989); Bull. Assoc. Fr. Obs. Etoiles Variables, No. 51, p. 8 (1990).

\section{(3182) Shimanto}

1984 WC. Discovered 1984 Nov. 27 by T. Seki at Geisei.

Named for the longest river in the discoverer's home prefecture of Kochi \{see planet (2396)\}. (M 10848)

\section{(3183) Franzkaiser}

1949 PP. Discovered 1949 Aug. 2 by K. Reinmuth at Heidelberg.

Named in memory of Franz Kaiser (1891-1962), astronomer at the Heidelberg-Königstuhl Observatory from 1911 to 1914. In 1914 Kaiser modified and improved the formulae for deriving photographic positions of minor planets by the interpolation method. He discovered 21 numbered minor planets. (M 22497)

Name proposed and citation prepared by G. Klare.

\section{(3184) Raab}

1949 QC. Discovered 1949 Aug. 22 by E. L. Johnson at Johannesburg.

Named in honor of Herbert Raab (1969- ), author of the widely-used and acclaimed Astrometrica software package. Astrometrica has enabled many amateur astronomers to participate in their own astrometric programs on comets and minor planets. Raab is a software developer and is also president of the Linzer Astronomische Gemeinschaft \{see planet (7491)\}, the oldest amateur association in Austria. (M 27124)

Name proposed by B. G. Marsden and G. V. Williams.

\section{(3185) Clintford}

$1953 \mathrm{VY}_{1}$. Discovered 1953 Nov. 11 at the Goethe Link Observatory at Brooklyn, Indiana.
Named in honor of Clinton B. Ford \{1913-1992\}, secretary of the American Association of Variable Star Observers since 1948 and president in 1961, the year of his retirement from a career in industry. In 1965 he helped found what is now called the Ford Observatory in southern California, an amateur facility with a $0.46-\mathrm{m}$ telescope dedicated to observing variable stars. Since joining the AAVSO at the age of 16 Ford has made more than 60,000 observations, drawn up over 800 new finding charts, and encouraged and assisted many hundreds of amateur observers in monitoring variables. He has also taught classes in astronomy at Brown University and Smith College. In 1987 he received the Amateur Achievement Award of the Astronomical Society of the Pacific for his contributions to science and to the fostering of interest in amateur astronomy. (M 15260)

Name proposed by F. K. Edmondson, following a suggestion by A. G. Fraknoi, who also prepared the citation.

Obituaries published in Bull. Assoc. Fr. Obs. Etoiles Variables, No. 62, p. 18-19 (1992); J. Am. Assoc. Variable Star Obs., Vol. 21, No. 2, p. 144-146 (1992); Sky Telesc., Vol. 85, No. 4, p. 102-103 (1993); Bull. Am. Astron. Soc., Vol. 26, No. 4, p. 1602-1603 (1994).

\section{(3186) Manuilova}

1973 SD $_{3}$. Discovered 1973 Sept. 22 by N. S. Chernykh at Nauchnyj.

Named in memory of the prominent sculptor Ol'ga Maksimilianovna Manuilova (1893-1984). (M 12014)

\section{(3187) Dalian}

$1977 \mathrm{TO}_{3}$. Discovered 1977 Oct. 10 at the Purple Mountain Observatory at Nanking.

Named for the city in northeastern China, located on the southern tip of the Liao Dong peninsula. A center for industry, technology and education, Dalian is a port city and a tourist center. (M 22497)

\section{(3188) Jekabsons}

1978 OM. Discovered 1978 July 28 at the Perth Observatory at Bickley.

Named in memory of Peter Jekabsons (1943-1990), a gifted observer on the Perth staff for sixteen years. His astronomical paintings adorn the walls of the Observatory. His talents as an artist carried over into his scientific work, and he produced some of the Observatory's best plates. (M 18644)

\section{(3189) Penza}

$1978 \mathrm{RF}_{6}$. Discovered 1978 Sept. 13 by N. S. Chernykh at Nauchnyj.

Named for a Russian city, the center of the region where Lermontov, Belinskij, Davydov, Kuprin \{see planets (2222), (3747), (3126), and (3618), respectively\} and some other Russian writers lived. (M 12971) 


\section{(3190) Aposhanskij}

1978 SR $_{6}$. Discovered 1978 Sept. 26 by L. V. Zhuravleva at Nauchnyj.

Named in memory of Vladimir Mikhailovich Aposhanskij (1910-1943), Soviet poet and journalist. (M 11160)

\section{(3191) Svanetia}

1979 SX. Discovered 1979 Sept. 22 by N. S. Chernykh at Nauchnyj.

Named for Svanetia, a historical region in Georgia near the Caucasus Mountains. (M 12971)

\section{(3192) A'Hearn}

1982 BY $_{1}$. Discovered 1982 Jan. 30 by E. Bowell at Anderson Mesa.

Named in honor of Michael F. A'Hearn, professor of astronomy at the University of Maryland. A prominent student of cometary physics, A'Hearn has pursued coordinated spectroscopic and spectrophotometric observations of comets spanning the spectral interval from the vacuum ultraviolet to the radio region. He participated in the 1983 discovery with the IUE spacecraft of diatomic sulphur in the spectrum of Comet IRAS-Araki-Alcock (1983d) and has made many other important contributions to our current understanding of comets. (M 10848)

Citation prepared by R. L. Millis.

\section{(3193) Elliot}

1982 DJ. Discovered 1982 Feb. 20 by E. Bowell at Anderson Mesa.

Named in honor of James L. Elliot, professor of physics and astronomy at the Massachusetts Institute of Technology and codiscoverer of the Uranian rings. A pioneer in the study of solar-system bodies through photometric observations of stellar occultations, he has made major contributions to understanding the structure of planetary atmospheres and ring systems. Elliot is currently involved in planning solar-system studies using the Hubble Space Telescope and other Earth-orbiting platforms. (M 10848)

Citation prepared by R. L. Millis.

\section{(3194) Dorsey}

$1982 \mathrm{KD}_{1}$. Discovered 1982 May 27 by C. S. Shoemaker and E. M. Shoemaker at Palomar.

Named in honor of Dorsey Taylor Shoemaker Jr., businessman in Gabbs, Nevada, and uncle of the second discoverer. (M 10311)

\section{(3195) Fedchenko}

$1978 \mathrm{PT}_{2}$. Discovered 1978 Aug. 8 by N. S. Chernykh at Nauchnyj.

Named for the family of scientists, including Aleksej Pavlovich Fedchenko (1844-1873), outstanding Russian naturalist and geographer known for his exploration of central Asia; his wife Ol'ga Aleksandrovna Fedchenko (1845-1921), prominent Russian botanist and plant collector, pioneer in the study of Turkestan flora; and their son Boris Alekseevich Fedchenko (1872-1947), distinguished botanist and geographer, prolific writer, and one of the initiators and most active contributors to the multi-volume "Flora of the U.S.S.R." (M 12971)

Name proposed by the discoverer, following a suggestion by C. E. Spratt.

\section{(3196) Maklaj}

1978 RY. Discovered 1978 Sept. 1 by N. S. Chernykh at Nauchnyj.

Named in honor of Nikolaj Nikolaevich MiklukhoMaklaj (1846-1888), a prominent Russian anthropologist and ethnographer who studied the native populations of southeast Asia, Australia and Oceania and who lived for about three years among the Papuans in New Guinea. (M 12971)

\section{(3197) Weissman}

1981 AD. Discovered 1981 Jan. 1 by E. Bowell at Anderson Mesa.

Named in honor of Paul R. Weissman \{1947- \}, cometary physicist at the Jet Propulsion Laboratory who has made studies of the dynamics of the Oort cloud and of the thermal properties of cometary nuclei. (M 11160)

\section{(3198) Wallonia}

$1981 \mathrm{YH}_{1}$. Discovered 1981 Dec. 30 by F. Dossin at St. Michel.

Named in honor of Wallonia, the French speaking part of Belgium, where the discoverer was born and where the Institut d'Astrophysique is located. (M 10848)

\section{(3199) Nefertiti}

1982 RA. Discovered 1982 Sept. 13 by C. S. Shoemaker and E. M. Shoemaker at Palomar.

Named for the beautiful consort of the revolutionary pharaoh Akhenaten of the seventeenth dynasty in Egypt. She is generally believed to have had a major influence on radical changes that occurred in the court and religion of Egypt during the reign of Akhenaten. (M 10311)

The name Nefertiti is only a different spelling of Nofretete \{see planet (1068)\}.

\section{(3200) Phaethon}

1983 TB. Discovered 1983 Oct. 11 with the Infrared Astronomical Satellite.

This object associated with the Geminid meteor stream has the smallest known perihelion distance for a body in a short-period orbit and is named for the son of Helios, who operated the solar chariot for a day, lost control of it and almost set fire to the Earth. (M 9771)

\section{(3201) Sijthoff}

6560 P-L. Discovered 1960 Sept. 24 by C. J. van Houten and I. van Houten-Groeneveld at Palomar.

Named in honor of Albert Georg Sijthoff, publisher, owner of the former Zeiss planetarium in The Hague 
and first president of the board of the Omniversum space theater there. Through his lifelong efforts he greatly contributed to the popularization of astronomy in the Netherlands. He played a key role in founding Omniversum, the main center in the Netherlands for the popularization of science in general and astronomy in particular. (M 12458)

\section{(3202) Graff}

A908 AA. Discovered 1908 Jan. 3 by M. F. Wolf at Heidelberg.

Named in honor of Gareth (Graff) Vaughan Williams \{1965- \}, of Leighton Buzzard, England, where he has during the past three years identified several low-numbered minor planets among objects that had been given provisional designations. During 1990 January-April he has been at the Minor Planet Center, where he continued this work with ingenuity and success, has made excellent progress on the daunting task of correcting the MPC files of old observations of low-numbered minor planets, and has generally been improving the efficiency of the whole MPC operation. (M 16245)

Name proposed by B. G. Marsden and C. M. Bardwell, the identification of this Hilda-type object having been made by the latter.

\section{(3203) Huth}

1938 SL. Discovered 1938 Sept. 18 by C. Hoffmeister at Sonneberg.

Named in memory of Hans Huth (1925-1988), an assiduous observer who obtained more than 100,000 patrol plates at the Sonneberg Observatory. Huth was also known for his bibliographic catalogue of variable stars. (M 15260)

\section{(3204) Lindgren}

1978 RH. Discovered 1978 Sept. 1 by N. S. Chernykh at Nauchnyj.

Named in honor of Astrid Anna Emilia Lindgren \{1907-2002\}, renowned Swedish writer, author of many fascinating stories for children and recipient of the international H. C. Andersen \{see planet (2476)\} gold medal. (M 12971)

\section{(3205) Boksenberg}

$1979 \mathrm{MO}_{6}$. Discovered 1979 June 25 by E. F. Helin and S. J. Bus at Siding Spring.

Named in honor of Alexander Boksenberg, director of the Royal Greenwich Observatory, in recognition of his invention of the image-photon counting system and its application to a wide variety of astronomical problems. The first discoverer acknowledges the role he played in introducing her to the U.K. 1.2-m Schmidt facility in New South Wales, where she conducted the program in which (3205) was discovered. (M 13480) Name endorsed by W. L. W. Sargent.

\section{(3206) Wuhan}

$1980 \mathrm{VN}_{1}$. Discovered 1980 Nov. 13 at the Purple Mountain Observatory at Nanking.

Named for the largest city in central China. Located at the confluence of the Han and Yangtze rivers, Wuhan has served as an inland commercial center since the third century AD. (M 16245)

\section{(3207) Spinrad}

$1981 \mathrm{EY}_{25}$. Discovered 1981 Mar. 2 by S. J. Bus at Siding Spring.

Named in honor of Hyron Spinrad \{1934- \}, a professor of astronomy at the University of California at Berkeley and a specialist in the study of both comets and galaxies. Spinrad has been a pioneer in the use of the metastable oxygen line at $630 \mathrm{~nm}$ to determine water production in comets and in the study of faint periodic comets at large heliocentric distances. His image-dissector scanner observations of 25 comets constitute one of the larger, uniform cometary data sets. He is currently adding to cometary knowledge with interpretation of very high dispersion CCD échelle spectroscopy and two-dimensional (interference filter) CCD photometry of brighter comets. In more than a quarter-century of teaching Spinrad has guided many outstanding students in their doctorate research. (M 18450)

Citation provided by Ray L. Newburn at the request of the discoverer.

\section{(3208) Lunn}

1981 JM. Discovered 1981 May 3 by E. Bowell at Anderson Mesa.

Named in memory of Borge Lunn (1912-1986), Danish civil engineer and metallurgist who did much to encourage the study of metal and iron meteorites. He invented a particular unmagnetized bronze for deepwater experiments on the marine Galathea expedition in 1950, and for his work on the metallurgy of sleeve bearing metals he was awarded the Hunt Medal of the American Society of Lubrication Engineers. Twice chairman of the Danish Metallurgical Society, he served as head of the department of metallurgy at the Technical University of Denmark and was permanent censor in metallurgy in that department for 27 years. (M 12014)

Name proposed by the discoverer, following a suggestion of J. Gradie.

\section{(3209) Buchwald}

$1982 \mathrm{BL}_{1}$. Discovered 1982 Jan. 24 by E. Bowell at Anderson Mesa.

Named in honor of Vagn Fabritius Buchwald, associate professor in the department of metallurgy at the Technical University of Denmark. Participant in numerous expeditions, most recently to Antarctica, to search for iron meteorites, he discovered the 20-tonne iron meteorite Agpalilik in Greenland in 1963. Among his international publications is the three-volume Handbook of Iron Meteorites (1975) and a catalogue of meteorites (1965, 1976). (M 12014) 
Name proposed by the discoverer, following a suggestion by J. Gradie.

\section{(3210) Lupishko}

$1983 \mathrm{WH}_{1}$. Discovered 1983 Nov. 29 by E. Bowell at Anderson Mesa.

Named in honor of Dmitrij Fedorovich Lupishko \{1942- \}, deputy director of the Kharkow Astronomical Observatory. An assiduous observer of minor-planet lightcurves, Lupishko has made fundamental contributions to the understanding of how photometric data may be used to derive the shapes and spin rates of these bodies. He has also undertaken photometry of Mars and since its inception in 1984 has been chairman of the Working Group on Asteroids of the U.S.S.R. Academy of Sciences. (M 12014)

Citation prepared by V. A. Shor at the request of the discoverer.

\section{(3211) Louispharailda}

1931 CE. Discovered 1931 Feb. 10 by G. Van Biesbroeck at Williams Bay.

Named in memory of the discoverer's parents, Louis Pierre Van Biesbroeck (1839-1919) and Pharailda de Colpaert Van Biesbroeck (1840-1920). (M 14481)

Name proposed by Micheline Van Biesbroeck Wilson.

\section{(3212) Agricola}

$1938 \mathrm{DH}_{2}$. Discovered 1938 Feb. 19 by Y. Väisälä at Turku.

Named for Mikael Agricola (c. 1510-1557), bishop, the reformer of Finland, 'father of Finnish literature'. Around 1538 he issued his ABC-kiria, the first book printed in the Finnish language, and in 1548 he translated the New Testament into Finnish. (M 18450)

\section{(3213) Smolensk}

1977 NQ. Discovered 1977 July 14 by N. S. Chernykh at Nauchnyj.

Named for the one of the oldest towns in Russia. (M 12971)

\section{(3214) Makarenko}

1978 TZ $_{6}$. Discovered 1978 Oct. 2 by L. V. Zhuravleva at Nauchnyj.

Named in memory of Anton Semenovich Makarenko (1888-1939), outstanding Soviet teacher and writer. (M 13175)

\section{(3215) Lapko}

1980 BQ. Discovered 1980 Jan. 23 by L. G. Karachkina at Nauchnyj.

Named in honor of Konstantin Kuz'mich Lapko, assistant professor at the Crimean medical institute, a surgeon to whom the discoverer owes her recovery. (M 10549)

\section{(3216) Harrington}

1980 RB. Discovered 1980 Sept. 4 by E. Bowell at Anderson Mesa.
Named in honor of Robert S. Harrington \{19421993 , astronomer at the U.S. Naval Observatory in Washington and director of the program to determine parallaxes and proper motions of faint nearby stars. A leading investigator on the orbital characteristics of Pluto's satellite and the mass of Pluto, he has made observational and theoretical studies of the motions of the planets and satellites and likely evolutions leading to the current distribution of the planets. He has also investigated the possible existence of another principal planet in the solar system. (M 11160)

Obituary published in Bull. Am. Astron. Soc., Vol. 25, No. 4, p. 1496-1497 (1993).

\section{(3217) Seidelmann}

1980 RK. Discovered 1980 Sept. 2 by E. Bowell at Anderson Mesa.

Named in honor of P. Kenneth Seidelmann \{1937-

\}, director of the Nautical Almanac Office of the U.S. Naval Observatory, currently vice president of IAU Commission 4, and a past chairman and secretary of the Division on Dynamical Astronomy of the American Astronomical Society. Seidelmann has played an important role in the introduction of new constants, theories, timescales and reference frames into the astronomical ephemerides, particularly a new theory of nutation. He has also explored the use of new techniques for obtaining astrometric data on minor planets and satellites. (M 11161)

\section{(3218) Delphine}

6611 P-L. Discovered 1960 Sept. 24 by C. J. van Houten and I. van Houten-Groeneveld at Palomar.

Named in honor of Delphine Jehoulet Delsemme, wife of astronomer Armand Delsemme \{see planet (2954)\} of the University of Toledo, Ohio. Before her marriage she contributed to astronomical research by investigating the behavior of the population II Cepheid RU Camelopardalis and as a co-recoverer of periodic comet Honda-Mrkos-Pajdušaková at its first predicted return. (M 13175)

\section{(3219) Komaki}

1934 CX. Discovered 1934 Feb. 4 by K. Reinmuth at Heidelberg.

Named in memory of Kojiro Komaki (1903-1969), director of the meteor section of the Oriental Astronomical Association from 1928 until 1969 and well known as a meteor observer and a leader of amateur astronomy in Japan. He established the Kii Astronomical Society (1943), the Japan Meteor Committee (1956) and the Japan Meteor Society (1968), and he was the director of these until his death. Together with his wife Sigeyo, he observed more than 30,000 meteors. He was a strong influence on many astronomers now active in Japan, including S. Nakano s see planet (3431)\}, who found the identifications involving this planet and proposed the name. (M 10046) 


\section{(3220) Murayama}

1951 WF. Discovered 1951 Nov. 22 by M. Laugier at Nice.

Named in honor of Sadao Murayama, observer of Mars, authority on meteorites, and director of the Earth-science section of the National Science Museum, at Ueno Park, Tokyo. (M 11441)

Named by one of his former students, S. Nakano, who found the identifications involving this planet.

\section{(3221) Changshi}

$1981 \mathrm{XF}_{2}$. Discovered 1981 Dec. 2 at the Purple Mountain Observatory at Nanking.

Named for a bright pearl city in the lower reaches of the Yangtze river in China, with charming natural scenery and a cultural history dating back for more than 3000 years. It is famed for its abundant products and enjoys another name - the 'land rich in rice and fish'. (M 25229)

\section{(3222) Liller}

1983 NJ. Discovered 1983 July 10 by E. Bowell at Anderson Mesa.

Named in honor of William Liller, formerly Robert Wheeler Wilson Professor of Applied Astronomy at Harvard University, on the occasion of his sixtieth birthday. A premier observer, he has made substantial contributions through observations of a broad range of astronomical objects and phenomena: planetary nebulae, minor planets, comets, novae, variable stars, globular clusters, X-ray sources, quasars, solar eclipses and stellar occultations. Now living in Chile, he has in recent years participated in the PROBLICOM survey and has discovered several novae. During the recent passage of Halley's Comet he was a crucial member of the IHW Island Network. He has been a leader in astronomical education and an important supporter of amateur astronomy. His enthusiastic encouragement has been greatly appreciated by his colleagues and students. (M 12015)

\section{(3223) Forsius}

1942 RN. Discovered 1942 Sept. 7 by Y. Väisälä at Turku.

Named for Sigfrid Aronus Forsius (c. 1550-1624), pastor, naturalist and astronomer. Among his various life-works he was rector of several parishes, mapped the Tornio river valley (1601-1602), was professor of astronomy at Uppsala University (1608-1610), and prepared almanacs for the horizons of Stockholm and Turku, from 1613 as a monopoly. (M 18450)

\section{(3224) Irkutsk}

1977 RL $_{6}$. Discovered 1977 Sept. 11 by N. S. Chernykh at Nauchnyj.

Named for the Siberian city on the occasion of its 300th anniversary. (M 11161)

\section{(3225) Hoag}

1982 QQ. Discovered 1982 Aug. 20 by C. S. Shoemaker and E. M. Shoemaker at Palomar.

Named in honor of Arthur Allen Hoag \{1921-1999\}, American astronomer and, since 1977, director of the Lowell Observatory at Flagstaff, Arizona. He is specially recognized for his work on both photoelectric and photographic photometry, development of astronomical sites and instruments, and investigations of quasistellar sources. (M 10311)

Name endorsed by E. Bowell and W. A. Baum.

Obituary published in Bull. Am. Astron. Soc., Vol. 31, No. 5, p. 1601-1602 (1999).

\section{(3226) Plinius}

6565 P-L. Discovered 1960 Sept. 24 by C. J. van Houten and I. van Houten-Groeneveld at Palomar.

Named for Pliny (62-114), the Roman author who described the A.D. 79 eruption of Vesuvius. (M 16591) Plinius is also honored by a lunar crater.

\section{(3227) Hasegawa}

1928 DF. Discovered 1928 Feb. 24 by K. Reinmuth at Heidelberg.

Named in honor of Ichiro Hasegawa \{1928- \}, editor of the Yamamoto Circulars, well known for his research on the origin of comets and for the computation of their orbits. Author of several books, including some on orbit determination, he is also the mentor of S. Nakano \{see planet (3431)\}, who found the identifications involving this planet. (M 11441)

\section{(3228) Pire}

1935 CL. Discovered 1935 Feb. 8 by S. Arend at Uccle.

Named in memory of Dominique Pire (1910-1969), who worked for the underprivileged and won the Nobel peace prize in 1958. (M 12209)

\section{(3229) Solnhofen}

A916 PC. Discovered 1916 Aug. 9 by H. Thiele at Bergedorf.

The rocks around the limestone quarry at Solnhofen, Bavaria, consist of fossilized reefs. It seems that during the Upper Jurassic this region was covered by lagoons, in which limy sediments slowly accumulated to form very fine-grained limestones. This slow accumulation permitted the remarkable preservation of fossils - even internal organs and soft-bodied creatures are preserved in exquisite detail. The most famous specimen to come from Solnhofen was one of the few complete examples of Archaeopteryx, the earliest known flying vertebrate. (M 23351)

Name proposed by G. V. Williams, the identifications for this object having been made by C. M. Bardwell.

\section{(3230) Vampilov}

1972 LE. Discovered 1972 June 8 by N. S. Chernykh at Nauchnyj.

Named in memory of Aleksandr Valentinovich Vampilov (1937-1972), talented Soviet dramatist. (M 12972) 
(3231) Mila

$1972 \mathrm{RU}_{2}$. Discovered 1972 Sept. 4 by L. V. Zhuravleva at Nauchnyj.

Named in memory of the Soviet ice dancer Ludmila Alekseevna Pakhomova (1946-1986). (M 13175)

\section{(3232) Brest}

1974 SL. Discovered 1974 Sept. 19 by L. I. Chernykh at Nauchnyj.

Named for the well-known city in Byelorussia \{see planet (2170)\}. (M 12015)

\section{(3233) Krišbarons}

1977 RA $_{6}$. Discovered 1977 Sept. 9 by N. S. Chernykh at Nauchnyj.

Named for Krišjanis Barons (1835-1923), prominent Latvian folklorist, writer and public figure. He collected and published the most complete collection of 'dainas', Latvian folksongs. (M 12015)

\section{(3234) Hergiani}

$1978 \mathrm{QO}_{2}$. Discovered 1978 Aug. 31 by N. S. Chernykh at Nauchnyj.

Named in memory of Mikhail Vissarionovich Hergiani (1932-1969), outstanding Soviet mountaineer. (M 12015)

\section{(3235) Melchior}

$1981 \mathrm{EL}_{1}$. Discovered 1981 Mar. 6 by H. Debehogne and G. DeSanctis at La Silla.

Named in honor of Paul Melchior, well-known geophysicist, general secretary of the IUGG since 1971 and director of the Royal Observatory of Belgium. His demonstration of the relationship of astronomical phenomena (precession-nutation) and geophysical phenomena (earth tides) was the basis of the IAU nutation series adopted in 1979. His development of a world tidal gravitational network permitted the evaluation of the indirect effects of the oceanic tides and revealed a correlation between the amplitudes of the earth tides and tectonic features. (M 16442)

\section{(3236) Strand}

$1982 \mathrm{BH}_{1}$. Discovered 1982 Jan. 24 by E. Bowell at Anderson Mesa.

Named in honor of Kaj Aa. Strand \{1907-2000\}, former Scientific Director of the U.S. Naval Observatory. Strand is known for his advances in the photographic astrometry of double stars. He was responsible for the construction and initial programs of the Naval Observatory's 1.55-meter astrometric reflector and its associated semi-automatic measuring machine. These led to the determination of stellar trigonometric parallaxes having an order-of-magnitude greater accuracy than heretofore possible, thus expanding the realm of the nearest stars. (M 11641)

Name suggested by and citation prepared by R. S. Harrington.

Obituary published in Bull. Am. Astron. Soc., Vol. 33, No. 4, p. 1584 (2001).

\section{(3237) Victorplatt}

$1984 \mathrm{SA}_{5}$. Discovered 1984 Sept. 25 by J. Platt at Palomar.

Named in honor of Victor D. Platt, M.D., father of the discoverer. (M 10549)

\section{(3238) Timresovia}

1975 VB. Discovered 1975 Nov. 8 by N. S. Chernykh at Nauchnyj.

Named in honor of Nikolaj Vladimirovich TimofeevResovskij (1900-1981), famous Soviet biologist, one of the founders of radiation genetics and molecular biology. (M 12972)

\section{(3239) Meizhou}

1978 UJ $_{2}$. Discovered 1978 Oct. 29 at the Purple Mountain Observatory at Nanking.

Named for the historical cultural city in China, situated in northeastern Guangdong province \{see planet (2185)\}. (M 23792)

\section{(3240) Laocoon}

1978 VG$_{6}$. Discovered 1978 Nov. 7 by S. J. Bus at Palomar.

Named for the priest of Apollo at Troy who warned the Trojans against the Trojan Horse. He and his two sons were killed by serpents sent by Athena \{see planet (881)\} or Apollo \{see planet (1862)\}. (M 12210)

\section{(3241) Yeshuhua}

$1978 \mathrm{WH}_{14}$. Discovered 1978 Nov. 28 at the Purple Mountain Observatory at Nanking.

Named in honor of Ye Shuhua, well-known Chinese astronomer, member of the Chinese Academy of Sciences and an unfailing friend of the discoverers. She has contributed to the development of modern Chinese astronomy, is an honorary president of the Chinese Astronomical Society and a vice-president of the IAU (1988-1994). (M 23792)

\section{(3242) Bakhchisaraj}

1979 SGg. Discovered 1979 Sept. 22 by N. S. Chernykh at Nauchnyj.

Named for a town in Crimea, the center of the district in which the Crimean Astrophysical Observatory is located. The name is widely known, thanks to Pushkin's \{see planet (2208)\} poem The Bakhchisaraj Fountain. (M 12015)

\section{(3243) Skytel}

1980 DC. Discovered 1980 Feb. 19 at the Harvard College Observatory at Harvard.

Named in honor of the golden anniversary of Sky and Telescope magazine, which for 50 years has chronicled the development of astronomy and space exploration, while serving as a vital link between the amateur and professional astronomical communities. (M 17655)

\section{(3244) Petronius}

4008 P-L. Discovered 1960 Sept. 24 by C. J. van Houten and I. van Houten-Groeneveld at Palomar. 
Named for Petronius (fl. c. A.D. 60), Roman author whose main work is the novel Satyricon. (M 16591)

\section{(3245) Jensch}

1973 UL $_{5}$. Discovered 1973 Oct. 27 by F. Börngen at Tautenburg.

Named in honor of Alfred Jensch, internationally renowned for his creative genius in the advancement of the design of astronomical instruments at the Jena Zeiss Works for almost 40 years. The $300-\mathrm{mm}$ and 600-mm Jensch Coelostats are particularly innovative, and he was essentially responsible for the design of the $2 \mathrm{~m}$ reflectors at Tautenburg, Shemakha, Ondřejov and Rozhen. The new 'support' mounting, perhaps his most important innovation, proved to be of enormous value. Jensch has also represented Zeiss Jena on several national and international panels and holds a number of awards. (M 10046)

\section{(3246) Bidstrup}

1976 GQ $_{3}$. Discovered 1976 Apr. 1 by N. S. Chernykh at Nauchnyj.

Named in memory of Herluf Bidstrup (1912-1988), well known Danish caricaturist. (M 18136)

\section{(3247) Di Martino}

1981 YE. Discovered 1981 Dec. 30 by E. Bowell at Anderson Mesa.

Named in honor of Mario Di Martino, astronomer at the Osservatorio di Torino, who in recent years has been a prolific observer of minor planet lightcurves. Di Martino has specialized in observations for the purpose of shape and pole determinations. (M 11749)

Name proposed by the discoverer, following a suggestion by A. W. Harris, who also prepared the citation.

\section{(3248) Farinella}

1982 FK. Discovered 1982 Mar. 21 by E. Bowell at Anderson Mesa.

Named in honor of Paolo Farinella (1953-2000), planetary scientist at the University of Pisa, whose research has included studies of the origin of the solar system and the dynamics of planetary satellites and ring systems. Farinella's work on minor planets has concerned the collisional evolution of the belt and the formation of families, both from a theoretical and an experimental point of view. (M 11749)

Named by the discoverer, following a suggestion by A. W. Harris. Citation prepared by A. Coradini and V. Zappalà.

\section{(3249) Musashino}

$1977 \mathrm{DT}_{4}$. Discovered 1977 Feb. 18 by H. Kosai and K. Hurukawa at Kiso.

Named for the area surrounding Tokyo that includes Mitaka \{see planet (1088)\}, site of the headquarters of the Tokyo Astronomical Observatory. (M 11442)
(3250) Martebo

1979 EB. Discovered 1979 Mar. 6 by C.-I. Lagerkvist at Mount Stromlo.

Named for a small village on the island of Gotland, where the discoverer spends his summer vacations. (M 12972)

\section{(3251) Eratosthenes}

6536 P-L. Discovered 1960 Sept. 24 by C. J. van Houten and I. van Houten-Groeneveld at Palomar.

Named for the Greek scholar Eratosthenes, who lived in Alexandria around 250 B.C. and was the first person to determine the size of the Earth correctly. (M 16591)

Eratosthenes is also honored by a lunar crater.

\section{(3252) Johnny}

$1981 \mathrm{EM}_{4}$. Discovered 1981 Mar. 2 by S. J. Bus at Siding Spring.

Named in honor of Johnny Carson (1925- ), entertainer and host of television's "The Tonight Show" from 1962 to 1992. Carson's witty monologue and unique, relaxed style of interviewing guests helped make this show a popular, late-night tradition in millions of American households. Away from the public spotlight, Johnny Carson is a devoted amateur astronomer. This interest in astronomy was shared with his TV audience through numerous light-hearted chats with guest Carl Sagan \{see planet (2709)\}. (M 27124)

\section{(3253) Gradie}

$1982 \mathrm{HQ}_{1}$. Discovered 1982 Apr. 28 by E. Bowell at Anderson Mesa.

Named in honor of Jonathan C. Gradie, planetary scientist at the Hawaiian Institute of Geophysics, University of Hawaii. Gradie's research has centered on the physics of minor planets, satellites and comets, particularly on their light-scattering properties. His wide-ranging contributions to minor-planet science include a detailed physical study of the Eos and Koronis \{see planets (221) and (158)\} families and development of a number of aspects of minor-planet taxonomy. (M 11749)

\section{(3254) Bus}

1982 UM. Discovered 1982 Oct. 17 by E. Bowell at Anderson Mesa.

Named in honor of S. J. ("Bobby") Bus \{1956- \}, currently a research assistant at Lowell Observatory. Bus has been largely responsible for the successful planning and carrying out of the U.K. Schmidt Telescope/California Institute of Technology Asteroid Survey (UCAS). Observations at Siding Spring and subsequent analysis at Caltech, the Jet Propulsion Laboratory and Lowell Observatory have led to the establishment of more than a thousand orbits of faint minor planets, almost all of which are potentially recoverable. (M 9771) 


\section{(3255) Tholen}

1980 RA. Discovered 1980 Sept. 2 by E. Bowell at Anderson Mesa.

Named in honor of David J. Tholen \{1955- \}, planetary scientist at the Institute for Astronomy of the University of Hawaii. Tholen's work on the eight-color survey of minor planets led him to devise an improved taxonomy of minor planets. He has considered the physical properties of minor planets, satellites and comets in terms of composition and evolution, and he was among the first to observe events in the series of occultations and transits now occurring between Pluto and its satellite Charon. (M 11749)

\section{(3256) Daguerre}

1981 SJ $_{1}$. Discovered 1981 Sept. 26 by B. A. Skiff and

N. G. Thomas at Anderson Mesa.

Named for the Frenchman Louis Jacques Mande Daguerre (1787-1851), who invented the daguerrotype photographic process in 1835. (M 10549)

Daguerre is also honored by a lunar crater.

\section{(3257) Hanzlík}

1982 GG. Discovered 1982 Apr. 15 by A. Mrkos at Klet.

Named in memory of Stanislav Hanzlík (1878-1956), professor of meteorology and climatology at Charles University, Prague. He founded modern dynamical meteorology in Czechoslovakia. (M 23136)

\section{(3258) Somnium}

1983 RJ. Discovered 1983 Sept. 8 by P. Wild at Zimmerwald.

The Latin word for dream or vision. Title of Johannes Kepler's \{see planet (1134)\} famous posthumously (1643) published science-fiction work expounding astronomy for an observer on the Moon. (M 22497)

\section{(3259) Brownlee}

1984 SZ $_{4}$. Discovered 1984 Sept. 25 by J. Platt at Palomar.

Named in honor of Donald E. Brownlee, professor of astronomy at the University of Washington. Brownlee is renowned for his successful recovery, identification and chemical and minerological investigation of extraterrestrial particles from the atmosphere - the "Brownlee" particles. He showed that many of these particles very probably are cometary dust. Brownlee also extracted and studied extraterrestrial particles from deep sea sediments and polar ice. His results from the interplanetary dust captured by the earth provide especially important clues about the material from which comets accreted. (M 18450)

Citation provided by E. M. and C. S. Shoemaker.

\section{(3260) Vizbor}

$1974 \mathrm{SO}_{2}$. Discovered 1974 Sept. 20 by L. V. Zhuravleva at Nauchnyj.

Named in memory of Yurij Iosifovich Vizbor (19341984), well-known journalist, poet, actor, producer and bard. (M 13175)
(3261) Tvardovskij

$1979 \mathrm{SF}_{9}$. Discovered 1979 Sept. 22 by N. S. Chernykh at Nauchnyj.

Named in memory of Aleksandr Trifonovich Tvardovskij (1910-1971), famous Soviet poet. (M 12972)

\section{(3262) Miune}

1983 WB. Discovered 1983 Nov. 28 by T. Seki at Geisei.

Named for a mountain in the eastern part of Kochi \{see planet (2396)\} prefecture. (M 10849)

\section{(3263) Bligh}

1932 CN. Discovered 1932 Feb. 5 by K. Reinmuth at Heidelberg.

Named for Lt. William Bligh (1754-1817), renowned navigator, who had sailed with Captain Cook ssee planet (3061)\} on the latter's second voyage to the south Pacific. Despatched to Tahiti in H.M.S. Bounty \{see planet (3264)\}, Bligh was cast adrift in an open boat by mutineers off the Friendly Islands with 18 of his crew. Without charts, Bligh managed to navigate the tiny vessel over some 4000 miles of ocean to safety in Timor. Commended for his command of the Bounty's launch by the court-martial set up to investigate the loss of his ship, Bligh was cleared of all blame for the mutiny. However, he remains unique in British naval history as the only naval commander to suffer two mutinies - the second being in 1808, while he was Governor of New South Wales. (M 19692)

Name proposed by G. V. Williams, who wrote the citation, and endorsed by E. Bowell, who made the principal identification involving this planet.

\section{(3264) Bounty}

1934 AF. Discovered 1934 Jan. 7 by K. Reinmuth at Heidelberg.

Named for His Majesty's Ship Bounty. In 1787 the Admiralty dispatched the ship, under the command of Lt. Bligh \{see planet (3263)\}, to Tahiti, to collect breadfruit plants for the slave plantations in the West Indies. The Bounty was taken by mutineers to Pitcairn Island, where the ship was destroyed, in a bay now known as Bounty Bay. The mutineers' refuge was accidentally discovered in 1808 by an American whaling vessel, which found only one survivor from the mutineers who went to Pitcairn. (M 19692)

Name proposed by G. V. Williams, who wrote the citation, and endorsed by E. Bowell, who made the principal identification involving this planet.

\section{(3265) Fletcher}

$1953 \mathrm{VN}_{2}$. Discovered 1953 Nov. 9 by K. Reinmuth at Heidelberg.

Named for Fletcher Christian \{1764-1792\}, leader of the mutiny aboard H.M.S. Bounty \{see planet (3264)\}. A long-standing friend of Bligh's \{see planet (3263)\}, Fletcher was invited by Bligh to accompany him on the voyage to Tahiti as Master's Mate. After the mutiny, the ship returned to Tahiti, where 16 of the mutineers 
decided to stay. Fletcher took the other mutineers to Pitcairn Island, where they hoped to avoid capture by the Royal Navy. Although the descendants of Fletcher Christian still live on Pitcairn, the fate of Christian himself remains unclear - one account has him being killed on Pitcairn, another has him returning secretly to England. (M 19692)

Name proposed by G. V. Williams, who wrote the citation, and endorsed by E. Bowell, who made the principal identification involving this planet.

\section{(3266) Bernardus}

1978 PA. Discovered 1978 Aug. 11 by H.-E. Schuster at La Silla.

Named in honor of Andres Bernardus Muller, astronomer at the Leiden Observatory and leader of the site-testing campaigns for the European Southern Observatory in South Africa and Chile. From 1964 to 1969 he was superintendent at La Silla ssee planet (2187)\} while ESO was under construction. He was involved with instrumental improvements at ESO, especially for the 1-m Schmidt telescope, with which this minor planet was discovered. (M 27124)

\section{(3267) Glo}

1981 AA. Discovered 1981 Jan. 3 by E. Bowell at Anderson Mesa.

Named in honor of Eleanor F. ("Glo") Helin, planetary scientist at the Jet Propulsion Laboratory, in appreciation of her extraordinary contributions to the discovery of near-Earth minor planets. Her finding of 1976 AA (=2062 Aten) heralded the recognition of a new class of planet-crossers, and her initiation of the Palomar planet-crossing asteroid survey has resulted in increased worldwide interest in the observation of minor planets. Helin's education and experience as a geologist and in the analysis of meteorites has provided a unique background for her interest in asteroids and comets. (M 11641)

Citation prepared by R. Helin.

\section{(3268) DeSanctis}

1981 DD. Discovered 1981 Feb. 26 by H. Debehogne and G. DeSanctis at La Silla.

Named by the first discoverer in honor of the second, Giovanni DeSanctis, astronomer at the Osservatorio Astronomico di Torino who has also participated in minor-planet programs at the European Southern Observatory, Catania and elsewhere. (M 10849)

\section{(3269) Vibert-Douglas}

1981 EX $_{16}$. Discovered 1981 Mar. 6 by S. J. Bus at Siding Spring.

Named in memory of Alice Vibert Douglas (18941988), the pioneer in the teaching of astronomy at McGill University and later dean of women at Queen's University \{see planet (5457)\}. Her research interests included spectroscopic absolute magnitudes of stars and the Stark effect in stellar atmospheres. An authority on historical astronomy, she was the biographer of Eddington \{see planet (2761)\}, as well as an early advocate of an increased role for women in science. She was made an Officer of the Order of Canada. (M 13481)

Name suggested and citation prepared by C. J. Cunningham, endorsed by P. M. Millman.

Obituaries published in Phys. Today, Vol. 42, No. 7, p. 88-89 (1989); J. R. Astron. Soc. Can., Vol. 82, No. 6, p. 309-311 (1988).

\section{(3270) Dudley}

1982 DA. Discovered 1982 Feb. 18 by C. S. Shoemaker and S. J. Bus at Palomar.

Named in honor of H. Dudley Wright, engineer, inventor, entrepreneur and benefactor of science, education and the arts in California and in Geneva, Switzerland. (M 10312)

Name endorsed by E. M. Shoemaker.

\section{(3271) Ul}

1982 RB. Discovered 1982 Sept. 14 by H.-E. Schuster at La Silla.

Named for the spirit of night-time and the moon in the mythology of the Melanesians of the New Hebrides Islands. Ul was the rival of Tortali \{see planet (2687)\}, spirit of daytime and the sun. The Melanesians recognize no gods. The name is shared by a god character in a best-selling fantasy series by David Eddings. (M 27329)

Name suggested by F. Pilcher.

\section{(3272) Tillandz}

1938 DB $_{1}$. Discovered 1938 Feb. 24 by Y. Väisälä at Turku.

Named for Elias Tillandz (1640-1693), from 1670 professor of medicine at the old Academia Aboensis. He was a botanist and the only physician in Finland at the time, cultivating his own medicinal plants. (M 18451)

\section{(3273) Drukar}

$1975 \mathrm{TS}_{2}$. Discovered 1975 Oct. 3 by L. I. Chernykh at Nauchnyj.

Named for Ivan Fedorov (ca. 1510-1583), the first printer of books in Russia and the Ukraine. In old Russian (and in modern Ukrainian) the word means 'bookprinter'. (M 12015)

\section{(3274) Maillen}

$1981 \mathrm{QO}_{2}$. Discovered 1981 Aug. 23 by H. Debehogne at La Silla.

Named for the discoverer's birthplace, a village of 1,000 inhabitants in Wallony, $15 \mathrm{~km}$ south of Namur. (M 15573)

\section{(3275) Oberndorfer}

$1982 \mathrm{HE}_{1}$. Discovered 1982 Apr. 25 by E. Bowell at Anderson Mesa.

Named in honor of Hans Oberndorfer, director of the Bavarian Public Observatory, which he founded 
in Munich in 1947. He has contributed greatly to the development of German amateur astronomy and is well known for his publications on telescope construction and for his articles in the periodical Sterne und Weltraum. (M 12016)

Name proposed by the discoverer, following a suggestion of L. D. Schmadel, H. Schwaiger and J. Stromeyer, the last of whom prepared the citation.

\section{(3276) Porta Coeli}

$1982 \mathrm{RZ}_{1}$. Discovered 1982 Sept. 15 by A. Mrkos at Klě̆.

Named for the twelfth-century convent and church in Tišnov, Moravia. (M 23136)

\section{(3277) Aaronson}

$1984 \mathrm{AF}_{1}$. Discovered 1984 Jan. 8 by E. Bowell at Anderson Mesa.

Named in memory of Marc Aaronson (1950-1987), associate professor of astronomy at the University of Arizona, killed in a tragic accident at the 4-m telescope at Kitt Peak. After completing his dissertation on the infrared properties of spiral galaxies, Aaronson demonstrated the determination of relative distances of galaxies independently of redshifts and detected the decelerative effect of the Virgo cluster on the Hubble flow. Observations of globular clusters in the Magellanic clouds showed carbon stars to be a characteristic of stellar populations of intermediate age, and his measurement of the large velocity dispersion of carbon stars in dwarf spheroidal galaxies suggested that even the smallest galaxies possess halos of cold dark matter. (M 12016)

Obituary published in Nature, Vol. 327, No. 6118, p. 92 (1987); Sterne Weltraum, 26. Jahrg., Nr. 9, p. 465 (1987); IAU Coll. No. 95, p. XVIII-IXX (1987); Phys. Today, Vol. 41, No. 7, p. 91-92 (1988).

\section{(3278) Běhounek}

1984 BT. Discovered 1984 Jan. 27 by A. Mrkos at Klě́.

Named in memory of František Běhounek (18981973), the first professor of cosmic-ray physics at Charles University, Prague. He was also a member of Nobile's airship expedition to the north pole. (M 23136)

\section{(3279) Solon}

9103 P-L. Discovered 1960 Oct. 17 by C. J. van Houten and I. van Houten-Groeneveld at Palomar.

Named for the Athenian legislator who lived around 600 B.C. (M 16591)

\section{(3280) Grétry}

1933 SJ. Discovered 1933 Sept. 17 by F. Rigaux at Uccle.

Named in memory of André Grétry (1741-1813), composer from Liège, particularly known for his comic operas, although his compositions included symphonies and a requiem. (M 12210)

\section{(3281) Maupertuis}

1938 DZ. Discovered 1938 Feb. 24 by Y. Väisälä at Turku.

Named for Pierre-Louis Moreau de Maupertuis (16981759), French mathematician and geodesist, from 1731 a member of the French Academy. During 1736-1737 he conducted the degree measurement in the Tornio \{see planet (1471)\} river valley in Finland. (M 18451) Maupertuis is also honored by a lunar crater.

\section{(3282) Spencer Jones}

1949 DA. Discovered 1949 Feb. 19 at the Goethe Link Observatory at Brooklyn, Indiana.

Named in memory of Harold Spencer Jones (18901960), successively astronomical assistant at the Royal Greenwich Observatory, H.M. astronomer at the Cape of Good Hope, and Astronomer Royal (1933-1955). He also served as president of the IAU (1945-1948). His work was devoted to fundamental positional astronomy, and he conclusively demonstrated that the small residuals in the apparent motions of the planets were due to the irregular rotation of the Earth. He led the worldwide effort to determine the length of the astronomical unit by triangulating the distance to (433) Eros when it passed near the Earth in 1930-31. (M 16041)

Name proposed by F. K. Edmondson. Citation prepared by J. S. Tenn.

Spencer Jones is also honored by a lunar crater.

\section{(3283) Skorina}

1979 QA $_{10}$. Discovered 1979 Aug. 27 by N. S. Chernykh at Nauchnyj.

Named in honor of Francis Skorina, who lived from before 1490 to not later than 1551, and who pioneered printing in Belorus. (M 20835)

\section{(3284) Niebuhr}

1953 NB. Discovered 1953 July 13 by J. A. Bruwer at Johannesburg.

Named in memory of Carsten Niebuhr (1733-1815), astronomer-surveyor, the sole survivor of the ill-fated Danish expedition to Arabia Felix (Yemen) in 1760-67. During an adventurous return voyage via India, and at great personal sacrifice, he carefully copied the inscriptions at the ruins of Persepolis. This served as the basis for the subsequent decoding of the cuneiform script and thus our access to source documents of early astronomical observations in that geographical area. (M 27329)

Name suggested by R. M. West.

\section{(3285) Ruth Wolfe}

1983 VW $_{1}$. Discovered 1983 Nov. 5 by C. S. Shoemaker and E. M. Shoemaker at Palomar.

Named in honor of Ruth Fanton Wolfe \{1937-

\}, mathematician with the U.S. Geological Survey, recognized for her dynamical investigations of the orbital evolution and collision of small bodies in the solar system. (M 10312)

Name endorsed by B. G. Marsden. 


\section{(3286) Anatoliya}

1980 BV. Discovered 1980 Jan. 23 by L. G. Karachkina at Nauchnyj.

Named in memory of Anatolij Vasilevich Karachkin (1947-1984), brother of the discoverer's husband, a skilled specialist in the construction of industrial establishments. (M 12016)

\section{(3287) Olmstead}

$1981 \mathrm{DK}_{1}$. Discovered 1981 Feb. 28 by S. J. Bus at Siding Spring.

Named in honor of C. Michelle Olmstead for her enthusiastic assistance in the asteroid astrometry programs at Lowell Observatory and the U.S. Geological Survey. As a student at Northern Arizona University, Olmstead is a NASA undergraduate fellow, and she has participated in the observational, discovery, identification and astrometric stages of the asteroid survey work. (M 18451)

Name and citation endorsed by E. Bowell, E. M. and C. S. Shoemaker and H. E. Holt.

\section{(3288) Seleucus}

1982 DV. Discovered 1982 Feb. 28 by H.-E. Schuster at La Silla.

Named for one of the generals of Alexander the Great and heir to the largest part of his empire. Seleucus maintained the best of relations with the great Babylonian teachers and priests, and the Chaldean astronomers are said to have predicted his becoming king. (M 10046)

Seleucus is also a name of a lunar crater.

\section{(3289) Mitani}

1934 RP. Discovered 1934 Sept. 7 by K. Reinmuth at Heidelberg.

Named in honor of Tesuyasu Mitani, discoverer of (1619) Ueta and independent recoverer of periodic comet Honda-Mrkos-Pajdušaková in 1954. He worked at Ikoma-san Solar Observatory of Kyoto Imperial University during 1944-1945 and under the difficult conditions following World War II he enthusiastically made astrometric observations of Pluto, comets and minor planets at Kyoto University's Kwasan Observatory. From 1957 to 1960 he was engaged in occultation observations for the geodetic survey (U.S. Army Map Service, Far East). (M 15426)

Name proposed by H. Oishi, who found the identifications involving this minor planet, endorsed by I. Hasegawa and K. Hurukawa.

\section{(3290) Azabu}

1973 SZ 1 . Discovered 1973 Sept. 19 by C. J. van

Houten and I. van Houten-Groeneveld at Palomar.

Named for the former site of the Tokyo Astronomical Observatory. (M 11442)

See also the comment for minor planet (3291).

\section{(3291) Dunlap}

1982 VX $_{3}$. Discovered 1982 Nov. 14 by H. Kosai and

K. Hurukawa at Kiso.
Named in honor of Larry Dunlap, research assistant at the Lunar and Planetary Laboratory who has published lightcurves of asteroids and is now teaching high-school and other students the beauty of astronomy at the Flandrau planetarium. (M 11161)

Named in accordance with a proposal by T. Gehrels that naming rights for (3291) and the Palomar discovery (3290) be interchanged, so that this and the following three names can be in sequence.

\section{(3292) Sather}

2631 P-L. Discovered 1960 Sept. 24 by C. J. van Houten and I. van Houten-Groeneveld at Palomar.

Named in honor of Lunar and Planetary Laboratory research assistant and high-school teacher Bob Sather, who has published lightcurves of asteroids and discovered a new method of determining the orientation of asteroidal rotational axes in space. (M 11161)

\section{(3293) Rontaylor}

4650 P-L. Discovered 1960 Sept. 24 by C. J. van Houten and I. van Houten-Groeneveld at Palomar.

Named in honor of Ron Taylor, internationally known expert in the determination of asteroid shapes, sense of rotation, and orientation of rotational axes in space. A research specialist at the Lunar and Planetary Laboratory, he is also a dedicated high-school teacher. (M 11161)

\section{(3294) Carlvesely}

6563 P-L. Discovered 1960 Sept. 24 by C. J. van Houten and I. van Houten-Groeneveld at Palomar.

Named in honor of Carl Vesely, high-school teacher and research assistant at the Lunar and Planetary Laboratory who published lightcurves of asteroids. He also assisted G. Van Biesbroeck \{see planet (1781)\} in his comet observations and participated extensively in the completion of Van Biesbroeck's work for publication after the latter's death in 1974. (M 11161)

\section{(3295) Murakami}

1950 DH. Discovered 1950 Feb. 17 by K. Reinmuth at Heidelberg.

Named in memory of Tadayoshi Murakami (19071985), professor of astronomy at the Hiroshima University, president of the Hiroshima Jogakuin College. He studied meteors extensively and encouraged many meteor observers in Japan. He contributed much to the teaching and popularization of astronomy in Japan, not only by lecturing at universities, but also by writing many books and articles over a period of fifty years. His father, Harutaro Murakami, studied lunar theory and is known for his work Theory of the perturbation of the Moon. (M 11442)

Name proposed by $T$. Urata, who found the identifications involving this planet.

\section{(3296) Bosque Alegre}

1975 SF. Discovered 1975 Sept. 30 at the Felix Aguilar Observatory at El Leoncito. 
Named in honor of the Astrophysical Station of the Córdoba Astronomical Observatory, founded in 1942 some $40 \mathrm{~km}$ southwest of Córdoba. (M 22828)

\section{(3297) Hong Kong}

1978 WN $_{14}$. Discovered 1978 Nov. 26 at the Purple Mountain Observatory at Nanking.

Named for the island and city in southeast Asia, a key center of international finance and trade. (M 32787)

\section{(3298) Massandra}

1979 OB $_{15}$. Discovered 1979 July 21 by N. S. Chernykh at Nauchnyj.

Named for a suburb of Yalta \{see planet (1475)\}, a beautiful site noted for its production of the finest Crimean wines. (M 21608)

\section{(3299) Hall}

1980 TX $_{5}$. Discovered 1980 Oct. 10 by C. S. Shoemaker at Palomar.

Named in honor of John Scoville Hall \{19081991\}, American astronomer and director of the Lowell Observatory from 1958 to 1977 . He was a pioneer in the photoelectric photometry of stars in the infrared region of the spectrum and codiscoverer with W. A. Hiltner of the polarization of starlight. (M 10312)

Obituary published in Bull. Am. Astron. Soc., Vol. 24, No. 4, p. 1323-1325 (1992).

\section{(3300) McGlasson}

1928 NA. Discovered 1928 July 10 by H. E. Wood at Johannesburg.

Named in honor of Van McGlasson, head of the Computation Facility at the Harvard-Smithsonian Center for Astrophysics. (M 22497)

Name proposed by B. G. Marsden, who made the identifications for this object.

\section{(3301) Jansje}

1978 CT. Discovered 1978 Feb. 6 at the Perth Observatory at Bickley.

Named by Arie Verveer \{see planet (3974)\} in honor of his mother. (M 18644)

\section{(3302) Schliemann}

$1977 \mathrm{RS}_{6}$. Discovered 1977 Sept. 11 by N. S. Chernykh at Nauchnyj.

Named in memory of Heinrich Schliemann (18221890), famous German archaeologist, who undertook, at his own expense, a 12-year excavation at Hissarlik and discovered the ancient site of Troy. (M 18136)

Name proposed following a suggestion by C. E. Spratt. Schliemann is also honored by a lunar crater.

\section{(3303) Merta}

1967 UN. Discovered 1967 Oct. 30 by L. Kohoutek at Bergedorf.

Named by the discoverer in memory of his grandfather, František Merta (1872-1953), elementary-school teacher and pedagogic journalist, a writer and translator who propagated humanistic ideas. (M 29142)
(3304) Pearce

1981 EQ $_{21}$. Discovered 1981 Mar. 2 by S. J. Bus at Siding Spring.

Named in honor of Joseph A. Pearce \{1893-1988\}, who joined the staff of the Dominion Astrophysical Observatory in 1924 and served as its director from 1940 to 1951. Together with J. S. Plaskett \{see planet (2905)\}, he conducted studies of the motions of distant early-type stars that established the reality of galactic rotation. An active promoter of both science and culture, he served as president of the Royal Society of Canada in 1949-50. (M 13481)

Name suggested and citation prepared by J. C. Cunningham, endorsed by P. M. Millman.

Obituary published in J.R. Astron. Soc. Canada, Vol. 83, No. 1, p. 3-7 (1989).

\section{(3305) Ceadams}

1985 KB. Discovered 1985 May 21 by A. C. Gilmore and P. M. Kilmartin at Lake Tekapo.

Named in memory of Charles Edward Adams (18701945), New Zealand Government Astronomer and Seismologist 1912-36. Among his many innovations was the introduction of the $\mathrm{P}$ and $\mathrm{Q}$ coefficients for ephemeris computation. He began the transmission of radio time signals in New Zealand, pioneered the use of the cine-camera for astronomical timing and devised one of the first moon cameras for direct measurement of the moon's position against background stars. He was also noted for his contributions to seismology. (M 18305)

\section{(3306) Byron}

1979 SM $_{11}$. Discovered 1979 Sept. 24 by N. S. Chernykh at Nauchnyj.

Named for the great English poet Lord George Noel Gordon Byron (1788-1824). (M 12972)

\section{(3307) Athabasca}

$1981 \mathrm{DE}_{1}$. Discovered 1981 Feb. 28 by S. J. Bus at Siding Spring.

Named for the native North Americans who originally settled in the subarctic region that is now Northwestern Canada and central Alaska. The Athabascan huntergatherers comprise a diverse group whose influence spread, about a thousand years ago, as far as the southwestern United States. They are the ancestors of the Navajo \{see planet (3688)\} and Apache peoples. (M 18644)

Name suggested and citation prepared by J. J. Klavetter.

\section{(3308) Ferreri}

1981 EP. Discovered 1981 Mar. 1 by H. Debehogne and G. DeSanctis at La Silla.

Named in honor of Walter Ferreri, who works in the photographic minor-planet program at the Osservatorio Astronomico di Torino and has discovered several minor planets at the European Southern Observatory. (M 11750) 
(3309) Brorfelde

1982 BH. Discovered 1982 Jan. 28 by K. S. Jensen and K. Augustesen at Brorfelde.

On the observatory's fortieth anniversary, this first minor planet discovered at the Copenhagen University Observatory in Brorfelde is named for the village in the middle of Zealand where the observatory is situated. (M 12210)

\section{(3310) Patsy}

$1931 \mathrm{TS}_{2}$. Discovered 1931 Oct. 9 by C. W. Tombaugh at Flagstaff.

Named by the discoverer in honor of his wife. (M 10849)

\section{(3311) Podobed}

$1976 \mathrm{QM}_{1}$. Discovered 1976 Aug. 26 by N. S. Chernykh at Nauchnyj.

Named in honor of Vladimir Vladimirovich Podobed \{1918-1992\}, professor at the Sternberg Astronomical Institute, prominent specialist on meridian and photographic astrometry and author of two textbooks on astrometry. (M 18136)

Obituary published in Zemlya Vselennaya, No. 3, p. 54 (1992)

\section{(3312) Pedersen}

1984 SN. Discovered 1984 Sept. 24 by K. Augustesen and P. Jensen and H. J. Fogh Olsen at Brorfelde.

Named in honor of Bodil and Helge Pedersen, who have made a great contribution to the popularization of astronomy in Denmark by donating a planetarium (to be erected in Copenhagen) to the Danish people. (M 10849)

\section{(3313) Mendel}

1980 DG. Discovered 1980 Feb. 19 by A. Mrkos at Klět.

Named in memory of Gregor Johann Mendel (18221884), Austrian monk and botanist, discoverer of the law of genetics. (M 23136)

Mendel is also honored by a craters on Mars and on the Moon.

\section{(3314) Beals}

1981 FH. Discovered 1981 Mar. 30 by E. Bowell at Anderson Mesa.

Named in memory of Canadian astronomer Carlyle Smith Beals (1899-1979), fourth Dominion Astronomer and the only man who has been both President of the American Astronomical Society and the National President of the Royal Astronomical Society of Canada. Beals made important contributions to the observation and interpretation of emission lines in the spectra of hot stars, to the understanding of the nature of interstellar gas clouds, and to the development of instrumentation for astronomy. He also initiated a program to identify and study meteorite craters in Canada. (M 12210)
Name proposed by the discoverer following a suggestion by P. M. Millman.

Obituaries published in J.R. Astron. Soc. Canada, Vol. 73, p. 325-332 (1979); Q.J.R. Astron. Soc., Vol. 21, p. 212-213 (1980)

\section{(3315) Chant}

1984 CZ. Discovered 1984 Feb. 8 by E. Bowell at Anderson Mesa.

Named in memory of Clarence Augustus Chant (18651956), generally referred to as the "father of Canadian astronomy". A renowned teacher, Chant organized the Astronomy Department of the University of Toronto and built up the Royal Astronomical Society of Canada. He participated in five solar eclipse expeditions, the most important being the one he led to Australia in 1922 to test Einstein's \{see planet (2001)\} prediction of the deflection of starlight by a massive body. (M 12210)

Name proposed by the discoverer following a suggestion by P. M. Millman.

Chant is also honored by a lunar crater.

\section{(3316) Herzberg}

$1984 \mathrm{CN}_{1}$. Discovered 1984 Feb. 6 by E. Bowell at Anderson Mesa.

Named in honor of Gerhard Herzberg \{1904-1999\}, Canadian Nobel Laureate in Chemistry in 1971 and acknowledged world leader in the study of molecular spectra. Herzberg's specialty has been free radicals, both in the laboratory and in interstellar space. He has identified numerous features in the spectra of comets, planets and interstellar material. In 1975 the National Research Council of Canada's astronomy and spectroscopy units were reorganized as the Herzberg Institute of Astrophysics. (M 12210)

Name proposed by the discoverer following a suggestion by P. M. Millman.

Obituary published in Nature, Vol. 398, No. 6729, p. 670 (1999).

\section{(3317) Paris}

1984 KF. Discovered 1984 May 26 by C. S. Shoemaker and E. M. Shoemaker at Palomar.

Named for one of the numerous sons of Priam \{ see planet (884)\}, the king of Troy. Paris, considered by the gods to be the most handsome man on Earth, abducted Helen see planet (101)\}, the most beautiful woman and the wife of Menelaus \{see planet (1647)\}, thereby precipitating the Trojan War. (M 10312)

\section{(3318) Blixen}

1985 HB. Discovered 1985 Apr. 23 by P. Jensen at Brorfelde.

Named in memory of the celebrated Danish writer Karen Blixen (1885-1962) on the hundredth anniversary of her birth. Among her best known writings are Seven Gothic Tales (1934) and the memory-novel Out 
of Africa (1937). An American screen version of the latter was produced in 1985. (M 11161)

\section{(3319) Kibi}

1977 EJ $_{5}$. Discovered 1977 Mar. 12 by H. Kosai and K. Hurukawa at Kiso.

This planet was given the former name of the area in Okayama \{see planet (2084)\} where co-discoverer Kosai grew up. (M 11442)

\section{(3320) Namba}

$1982 \mathrm{VZ}_{4}$. Discovered 1982 Nov. 14 by H. Kosai and K. Hurukawa at Kiso.

This planet was given the former name of Osaka, where co-discoverer Hurukawa grew up. (M 11442)

For another former name of the city of Osaka see the citation for minor planet (3607).

\section{(3321) Dasha}

$1975 \mathrm{TZ}_{2}$. Discovered 1975 Oct. 3 by L. I. Chernykh at Nauchnyj.

Named in honor of Dar'ya Lavrent'evna Mikhailova, the first Russian army sister of charity during the Crimean War, known as Dasha Sevastopol'skaya.

(M 13175)

\section{(3322) Lidiya}

$1975 \mathrm{XY}_{1}$. Discovered 1975 Dec. 1 by T. M. Smirnova at Nauchnyj.

Named in honor of Lidiya Vissarionovna Zvereva (1890-1916), the first Russian female pilot. She began flying in 1911, instructed other pilots and was also involved in constructing airplanes. (M 17027)

\section{(3323) Turgenev}

$1979 \mathrm{SY}_{9}$. Discovered 1979 Sept. 22 by N. S. Chernykh at Nauchnyj.

Named in memory of the famous Russian writer Ivan Sergeevich Turgenev (1818-1883). (M 18136)

\section{(3324) Avsyuk}

$1983 \mathrm{CW}_{1}$. Discovered 1983 Feb. 4 by A. Mrkos at Klě́t.

Named in honor of Yurij N. Avsyuk, geodesist and gravimetrist, who worked with the discoverer on the Antarctic plateau during the International Geophysical Year $\{1957-1958\}$. (M 23136; M 33817)

\section{(3325) TARDIS}

1984 JZ. Discovered 1984 May 3 by B. A. Skiff at Anderson Mesa.

The acronym TARDIS stands for Time And Relative Dimensions In Space and derives from the long-running science-fiction television program 'Dr. Who'. It is the name of the vehicle The Doctor uses for travel through space-time. Whimsically, it has the outward appearance of a British police telephone box but is quite spacious inside. (M 16041)

Name suggested and citation provided by C. J. Cunningham.

\section{(3326) Agafonikov}

1985 FL. Discovered 1985 Mar. 20 by A. Mrkos at Klě̌t.

Named in honor of Askol'd M. Agafonikov, geophysicist and navigator of the third Russian Antarctic expedition, in recognition of his work with the discoverer in the region of the south magnetic pole. (M 23136)

\section{(3327) Campins}

1985 PW. Discovered 1985 Aug. 14 by E. Bowell at Anderson Mesa.

Named in honor of Humberto Campins, research scientist at the Planetary Science Institute in Tucson. Well known for his work on the properties of cometary comae, Campins has helped establish pioneering techniques to measure the physical properties of cometary nuclei using simultaneous infrared and visual observations. He has also undertaken infrared searches for intramercurial bodies. (M 12458)

Citation written by R. P. Binzel at the request of the discoverer.

\section{(3328) Interposita}

1985 QD $_{1}$. Discovered 1985 Aug. 21 by T. Schildknecht at Zimmerwald.

The discovery film was exposed hastily between two satellite laser ranging sessions in the adjacent dome. (M 27125)

\section{(3329) Golay}

$1985 \mathrm{RT}_{1}$. Discovered 1985 Sept. 12 by P. Wild at Zimmerwald.

Named in honor of Marcel Golay (1927- ), who from 1956 to 1992 was director of the Observatoire de Genève. He developed a seven-color system of stellar photometry that allows precise and relatively rapid determination of temperature, gravity, rotation, and chemistry. Under his inspiring leadership the observatory staff made these measurements on myriads of stars and cultivated practically all the branches of astrophysics profiting from them. It is due mainly to Golay that Switzerland is adhering firmly to ESO and ESA, giving access to the most modern observing methods and instruments. Golay has been president of IAU commissions 25, 37 and 45. (M 22497)

\section{(3330) Gantrisch}

$1985 \mathrm{RU}_{1}$. Discovered 1985 Sept. 12 by T. Schildknecht at Zimmerwald.

Named for a prominent mountain about $20 \mathrm{~km}$ due south of the Zimmerwald \{see planet (1775)\} Observatory. (M 27125)

\section{(3331) Kvistaberg}

1979 QS. Discovered 1979 Aug. 22 by C.-I. Lagerkvist at La Silla.

Named for the location of the Uppsala Observatory's observing station. Several minor planets have been discovered with the Schmidt telescope there. (M 12972) 
(3332) Raksha

$1978 \mathrm{NT}_{1}$. Discovered 1978 July 4 by L. I. Chernykh at Nauchnyj.

Named in memory of Yurij Mikhajlovich Raksha (1937-1980), gifted artist well known for his paintings and for his work in film-making. (M 13175)

\section{(3333) Schaber}

1980 TG $_{5}$. Discovered 1980 Oct. 9 by C. S. Shoemaker at Palomar.

Named in honor of Gerald G. Schaber, geologist with the U.S. Geological Survey and chief of the branch of astrogeology since 1983. Schaber is specially recognized for his research on the geology of the Moon, Mercury, Venus, Mars and the satellite Io and for the application of radar to the investigation of the terrestrial planets. He was a codiscoverer, with J. F. McCauley and C. S. Breed, of the ancient buried river channels of the western desert of Egypt. (M 10549)

\section{(3334) Somov}

1981 YR. Discovered 1981 Dec. 20 by A. Mrkos at Kleť.

Named in memory of Mikhail M. Somov, leader of the first Russian Antarctic expedition during the International Geophysical Year $\{1957-1958\}$. (M 23136)

\section{(3335) Quanzhou}

1966 AA. Discovered 1966 Jan. 1 at the Purple Mountain Observatory at Nanking.

Named for a well-known historical and cultural city. In ancient times, Quanzhou was a starting point of "the Silk Road at Sea", and its port of Citong was famed as "First Port in the East" from 960 to 1368. As a result of its economic development in recent times Quanzhou has become a star city on the southeastern coast of China. (M 26424)

\section{(3336) Grygar}

1971 UX. Discovered 1971 Oct. 26 by L. Kohoutek at Bergedorf.

Named in honor of Jiří Grygar on the occasion of his 60th birthday. A Czech astronomer working in Prague, he has contributed to our knowledge of meteors, comets and variable stars. He is also known in both the Czech and the Slovak republics as a very successful scientific popularizer and as the author of several astronomical books for the public. (M 26424)

\section{(3337) Miloš}

$1971 \mathrm{UG}_{1}$. Discovered 1971 Oct. 26 by L. Kohoutek at Bergedorf.

Named in honor of Miloš Tichý (1966- ), Czech astronomer at the Kleť Observatory. He is known for his work on minor planets and comets, discoveries of minor planets and mainly for confirmations and follow-up of NEOs (near-earth objects). In 1994, his technical expertise allowed the upgrade of Klet observations with CCD cameras. (M 35481)
Name proposed following a suggestion by his wife, Jana Tichá, on the occasion of the 15th anniversary of his first student assignment at Klet in 1984.

\section{(3338) Richter}

1973 UX $_{5}$. Discovered 1973 Oct. 28 by F. Börngen at Tautenburg.

Named in memory of Nikolaus B. Richter (1910-1980), first director of the Tautenburg Observatory (19601975), renowned for his experiments with meteorites and his comparative study of terrestrial particles and interplanetary matter. Author of the monograph Statistik und Physik der Kometen (1954; English edition published in 1963 under the title The nature of comets), he served as president of IAU Commission 15 during 1973-1976. He was also interested in the study of blue objects and compact galaxies. (M 10549)

Obituaries published in Astron. Nachr., Band 302, p. 203 (1981); Mitt. Astron. Ges., Nr. 53, p. III-V (1981); Sterne, 57. Band, p. 182-183 (1981).

\section{(3339) Treshnikov}

1978 LB. Discovered 1978 June 6 by A. Mrkos at Kleť.

Named in honor of Aleksej F. Treshnikov, leader of the second Russian Antarctic expedition, in recognition of his first meeting with the discoverer on the Antarctic plateau in 1957. (M 23136)

\section{(3340) Yinhai}

1979 TK. Discovered 1979 Oct. 12 at the Purple Mountain Observatory at Nanking.

Named for a beautiful city located on Hailing Island in the South China Sea, famous for its scenery. It is a tourist attraction with a pretty beach and known as the 'eastern Hawaii'. (M 25229)

\section{(3341) Hartmann}

1980 OD. Discovered 1980 July 17 by E. Bowell at Anderson Mesa.

Named in honor of William K. Hartmann, senior scientist at the Planetary Science Institute in Tucson. Hartmann's contributions to solar system research have ranged from work on planetary cratering rates and the origin of the Moon to studies of comets and Trojan minor planets. $\mathrm{He}$ is the author of several textbooks on astronomy and planetary science, as well as popular books on space exploration. Hartmann is also a renowned space artist whose paintings depict scenes predicted by modern research. (M 12458)

Citation written by R. P. Binzel at the request of the discoverer.

\section{(3342) Fivesparks}

$1982 \mathrm{BD}_{3}$. Discovered 1982 Jan. 27 at the Oak Ridge Observatory at Harvard.

Named in honor of Newton and Margaret Mayall, who have enriched the literature for amateur astronomers with their delightful and informative books entitled Sundials and Skyshooting; who have preserved the papers and memorabilia of Annie Jump Cannon; and 
who carried the AAVSO through the difficult period of moving its headquarters from the Harvard College Observatory. (M 15573)

The name, which refers to the Mayall's residence in Cambridge, Massachusetts, was suggested by B. L. Welther, who also wrote the citation.

\section{(3343) Nedzel}

1982 HS. Discovered 1982 Apr. 28 by L. G. Taff at Socorro.

Named in memory of V. Alexander Nedzel, scholar, gentleman, patron of the sciences and friend. The foremost supporter of the Lincoln Laboratory EarthApproaching Asteroid Search, he was head of the Laboratory's Aerospace Division, and the Search was carried out under his auspices until his untimely death on 1984 Sept. 6. (M 10849)

\section{(3344) Modena}

1982 JA. Discovered 1982 May 15 at the Osservatorio San Vittore at Bologna.

Named for the city near Bologna, famous for its beautiful bell-tower Ghirlandia, the Romanesque cathedral Duomo, and the military academy that was formerly the royal palace of the Estensi, the dynasty that governed the city until 1859. Modena was the home of the astronomers Montanari (1633-1687), Amici (1786-1863) \{see planet (3809)\} and Bianchi (1791-1866). It is also the birthplace and residence of Ermes Colombini, an amateur astronomer of the group at the Osservatorio San Vittore \{see planet (2235)\} in Bologna. (M 10549)

\section{(3345) Tarkovskij}

1982 YC $_{1}$. Discovered 1982 Dec. 23 by L. G. Karachkina at Nauchnyj.

Named in memory of Andrej Arsen'evich Tarkovskij (1932-1986), Soviet theater and film producer. (M 13176)

\section{(3346) Gerla}

1951 SD. Discovered 1951 Sept. 27 by S. Arend at Uccle.

Named in honor of Gertrude Lawrence (1898-1952), real name Gertrud Alexandra Dagmar Lawrence Klasen, English actress, best remembered for her performances in musicals and Noël Coward plays. (M 22497)

Citation written by G. V. Williams following a suggestion by J. Bardwell, the identifications for this object having been made by C. M. Bardwell.

\section{(3347) Konstantin}

1975 VN $_{1}$. Discovered 1975 Nov. 2 by T. M. Smirnova at Nauchnyj.

Named in memory of Konstantin Alekseevich Kalinin (1889-1938), a remarkable flier and talented aircraft designer who constructed many aircraft of various types, one of which was awarded a gold medal at the International Aviation Exhibition in Berlin in 1928. (M 17027)

\section{(3348) Pokryshkin}

$1978 \mathrm{EA}_{3}$. Discovered 1978 Mar. 6 by N. S. Chernykh at Nauchnyj.

Named in memory of Aleksandr Ivanovich Pokryshkin (1913-1985), a Soviet pilot known as a writer, the author of four popular books on Soviet aviation. His contribution to the theory and practice of flying and maneuvering small, high-speed aircraft allowed Soviet pilots to win some world aviation records. He was also involved in the selection of the first cosmonauts and the realization of the first Soviet space flights. (M 12972)

\section{(3349) Manas}

$1979 \mathrm{FH}_{2}$. Discovered 1979 Mar. 23 by N. S. Chernykh at Nauchnyj.

Named for an epic poem of the Kirghiz people. (M 18136)

\section{(3350) Scobee}

1980 PJ. Discovered 1980 Aug. 8 by E. Bowell at Anderson Mesa.

Named in memory of Francis R. Scobee (1939-1986), commander. (M 10549)

This planet and the following six are named in memory of the astronauts who perished in the flight of the space shuttle Challenger on 1986 Jan. 28.

\section{(3351) Smith}

$1980 \mathrm{RN}_{1}$. Discovered 1980 Sept. 7 by E. Bowell at Anderson Mesa.

Named in memory of Michael J. Smith (1945-1986), pilot. (M 10550)

See the comment to planet (3350).

\section{(3352) McAuliffe}

1981 CW. Discovered 1981 Feb. 6 by N. G. Thomas at Anderson Mesa.

Named in memory of S. Christa C. McAuliffe (1948-1986), teacher, observer. (M 10550) See the comment to planet (3350).

\section{(3353) Jarvis}

1981 YC. Discovered 1981 Dec. 20 by E. Bowell at Anderson Mesa.

Named in memory of Gregory B. Jarvis (1944-1986), payload specialist. (M 10550)

See the comment to planet (3350).

\section{(3354) McNair}

1984 CW. Discovered 1984 Feb. 8 by E. Bowell at Anderson Mesa.

Named in memory of Ronald E. McNair (1950-1986), mission specialist. (M 10550)

See the comment to planet (3350).

\section{(3355) Onizuka}

1984 CC $_{1}$. Discovered 1984 Feb. 8 by E. Bowell at Anderson Mesa.

Named in memory of Ellison S. Onizuka (1946-1986), mission specialist. (M 10550)

See the comment to planet (3350). 


\section{(3356) Resnik}

1984 EU. Discovered 1984 Mar. 6 by E. Bowell at Anderson Mesa.

Named in memory of Judith A. Resnik (1949-1986), mission specialist. (M 10550)

See the comment to planet (3350).

\section{(3357) Tolstikov}

1984 FT. Discovered 1984 Mar. 21 by A. Mrkos at Klět.

Named in memory of Evgenij I. Tolstikov, Russian meteorologist and leader of the third Antarctic expedition during International Geophysical Year \{1957-1958\}. Tolstikov and the discoverer worked for three years at the Antarctic station Mirny. (M 23136)

\section{(3358) Anikushin}

1978 RX. Discovered 1978 Sept. 1 by N. S. Chernykh at Nauchnyj.

Named in honor of Mikhail Konstantinovich Anikushin, member of the U.S.S.R. Academy of Arts, well known Soviet sculptor, creator of the Pushkin \{see planet (2208)\} momument in Leningrad and other works. (M 18136)

\section{(3359) Purcari}

1978 RA $_{6}$. Discovered 1978 Sept. 13 by N. S. Chernykh at Nauchnyj.

Named for the producer of the best Moldavian wines. (M 18136)

\section{(3361) Orpheus}

1982 HR. Discovered 1982 Apr. 24 by C. Torres at Cerro El Roble.

Named for the poet and musician of Greek mythology who almost rescued his wife Eurydice from Hades by charming Pluto and Persephone with his lyre. (M 11442)

Name proposed by the discoverer following a suggestion by S. J. Ostro.

See also the citations for minor planets (75) Eurydike and (399) Persephone.

\section{(3362) Khufu}

1984 QA. Discovered 1984 Aug. 30 by R. S. Dunbar and M. A. Barucci at Palomar.

Named for the Egyptian god-king Khufu, better known by his Greek name of Cheops, a pharaoh of the 29th century B.C. and builder of the largest of the great pyramids at Giza \{see planet $(5249)\}$, one of the seven wonders of the ancient world. (M 10550)

\section{(3363) Bowen}

1960 EE. Discovered 1960 Mar. 6 at the Goethe Link Observatory at Brooklyn, Indiana.

Named in memory of Ira S. Bowen (1898-1973), whose investigation of the ultraviolet spectra of highly ionized atoms led to his identification of the mysterious 'nebulium' spectral lines of gaseous nebulae as forbidden lines of ionized oxygen and nitrogen; he soon explained most of the spectral lines of gaseous nebulae. As director of the Mount Wilson and Palomar Observatories from 1948 to 1964 he oversaw the completion of the 5-m reflector and 1.2-m Schmidt and designed many of their instruments, including a novel spectrograph. He also initiated the baking of photographic plates to improve their sensitivity. (M 16245)

Name proposed by F. K. Edmondson. Citation prepared by J. S. Tenn.

Obituaries published in Publ. Astron. Soc. Pac., Vol. 85, p. 174 (1973); Science, Vol. 180, p. 1158 (1973); Sky Telesc., Vol. 45, p. 212-214 (1973); Mercury, Vol. 2, No. 3, p. 3-5 (1973); Q.J.R. Astron. Soc., Vol. 15, p. 193-196 (1974).

\section{(3364) Zdenka}

1984 GF. Discovered 1984 Apr. 5 by A. Mrkos at Kleť.

Named in honor of Zdenka Vávrová for her 20 devoted years in the astrometric program at Klet. (M 23136)

\section{(3365) Recogne}

$1985 \mathrm{CG}_{2}$. Discovered 1985 Feb. 13 by H. Debehogne at La Silla.

Named for a high point in the Ardennes, in the Province de Luxembourg. (M 15573)

\section{(3366) Gödel}

1985 SD $_{1}$. Discovered 1985 Sept. 22 by T. Schildknecht at Zimmerwald.

Named for Kurt Gödel (1906-1978), American logician of Austrian origin. He is the author of the famous article Über formal unentscheidbare Sätze der Principia Mathematica und verwandter Systeme (1931). His ideas accompany the discoverer through many observing nights. (M 27125)

\section{(3367) Alex}

$1983 \mathrm{CA}_{3}$. Discovered 1983 Feb. 15 by N. G. Thomas at Anderson Mesa.

Named by the discoverer in honor of his grandson, Alex R. Baltutis. (M 10550)

\section{(3368) Duncombe}

1985 QT. Discovered 1985 Aug. 22 by E. Bowell at Anderson Mesa.

Named in honor of Raynor L. Duncombe $\{1917-\quad\}$, astronomer at the University of Texas, on the occasion of his seventieth birthday. A leader in positional and dynamical astronomy, he has pursued wide-ranging research that has included the study of the motions of major planets, minor planets and satellites; he was a pioneer in artificial-satellite orbit determination and in the use of digital computers in astronomy; and he has recently been involved with the astrometric uses of the Hubble Space Telescope as a member of the Astrometry Team. He served as director of the U.S. Nautical Almanac Office from 1963 to 1975, was the 
first chairman of the American Astronomical Society's Division on Dynamical Astronomy and for a number of years the executive editor of Celestial Mechanics. (M 11750)

Name proposed by the discoverer following a suggestion by P. K. Seidelmann, who provided the citation.

\section{(3369) Freuchen}

1985 UZ. Discovered 1985 Oct. 18 by K. Augustesen and P. Jensen at Brorfelde.

Named in memory of the well-known Danish polar explorer and writer Peter Freuchen (1886-1957) on the hundredth anniversary of his birth. He participated in several arctic expeditions to Greenland, and in 1910 he was co-founder of the Thule trading station, which he led until 1919. (M 11161)

Name proposed by the second discoverer.

\section{(3370) Kohsai}

1934 CU. Discovered 1934 Feb. 4 by K. Reinmuth at Heidelberg.

Named in honor of Hiroki Kosai \{1933- \}, astronomer at the Tokyo Astronomical Observatory, outstanding observer of comets and minor planets, codiscoverer of comet $1976 \mathrm{XVI}$ and popularizer of astronomy in Japan. (M 11750)

Name proposed by H. Oishi and K. Hurukawa, who found the identifications for this planet.

\section{(3371) Giacconi}

1955 RZ. Discovered 1955 Sept. 14 at the Goethe Link Observatory at Brooklyn, Indiana.

Named in honor of Riccardo Giacconi \{1931- \}, since 1981 the first director of the Space Telescope Science Institute. After serving as a research associate in the cosmic-ray physics group at Indiana University, and then briefly at Princeton, in 1959 he joined American Science and Engineering, where he began work on X-ray astronomy. His team there developed grazing-incidence X-ray telescopes, and in 1962 they discovered Sco X-1, the first known X-ray source outside the solar system. This was followed by the orbiting Xray observatory UHURU, which made the first surveys of the X-ray sky. Joining the Harvard-Smithsonian Center for Astrophysics in 1973 as associate director for high-energy physics, Giacconi led the construction and successful operation of the powerful X-ray observatory HEAO-2, also known as Einstein, which made detailed images of X-ray sources. (M 16884)

Name proposed by F. K. Edmondson. Citation prepared with the help of J. Tenn.

Giacconi received the Nobel prize for physics 2002 .

\section{(3372) Bratijchuk}

$1976 \mathrm{SP}_{4}$. Discovered 1976 Sept. 24 by N. S. Chernykh at Nauchnyj.

Named in honor of Matrena Vasil'evna Bratijchuk, professor of astronomy and founder and head of the
Laboratory for Space Research at Uzhgorod University. (M 18137)

\section{(3373) Koktebelia}

1978 QQ$_{2}$. Discovered 1978 Aug. 31 by N. S. Chernykh at Nauchnyj.

Named for the Crimean settlement of Koktebel', home and workplace of the brilliant Russian poet, painter and water-colorist Maksimilian Aleksandrovich Kirienko-Voloshin (1877-1932), almost all of whose work was devoted to the Crimea. (M 18137)

\section{(3374) Namur}

1980 KO. Discovered 1980 May 22 by H. Debehogne at La Silla.

Named for the principal town in the Belgian province of the same name, a place where the discoverer studied. Namur is at the confluence of the Meuse and the Sambre \{see planets (3016) and (4016)\} rivers, and it was there that Julius Caesar battled Belgian tribes in 59 and 57 B.C. (M 15573)

\section{(3375) Amy}

$1981 \mathrm{JY}_{1}$. Discovered 1981 May 5 by C. S. Shoemaker at Palomar.

Named in honor of Amy Shoemaker Prescott, aunt of E. M. Shoemaker. (M 11750)

\section{(3376) Armandhammer}

1982 UJ $_{8}$. Discovered 1982 Oct. 21 by L. V. Zhuravleva at Nauchnyj.

Named in honor of the American businessman Armand Hammer, a champion of good trade relations between the U.S.A. and the U.S.S.R. (M 13176)

\section{(3377) Lodewijk}

4122 P-L. Discovered 1960 Sept. 24 by C. J. van Houten and I. van Houten-Groeneveld at Palomar.

Named in honor of Lodewijk Woltjer, former editor of the Astronomical Journal and former director of the European Southern Observatory, well known for his studies on the Crab nebula. (M 16591)

Name proposed by J. H. Oort.

\section{(3378) Susanvictoria}

A922 WB. Discovered 1922 Nov. 25 by G. Van Biesbroeck at Williams Bay.

Named in honor of the discoverer's granddaughters, Susan Titus and Victoria Van Biesbroeck Streeter. (M 14481)

Name proposed by Micheline Van Biesbroeck Wilson.

\section{(3379) Oishi}

1931 TJ $_{1}$. Discovered 1931 Oct. 6 by K. Reinmuth at Heidelberg.

Named in honor of Hideo Oishi, orbit computer and identifier of minor planets, editor of the Japan Astronomical Association's Minor Planet Circulars. (M 11442)

Name proposed by S. Nakano, who found the identifications involving this planet. 


\section{(3380) Awaji}

1940 EF. Discovered 1940 Mar. 15 by G. Kulin at Budapest.

Named for the largest island in the Seto inland sea in Japan. In Japanese mythology, this was the first island created. (M 22497)

Name proposed by H. Oishi and S. Nakano, who found the identifications involving this object.

\section{(3381) Mikkola}

1941 UG. Discovered 1941 Oct. 15 by L. Oterma at Turku.

Named in honor of Seppo Mikkola, well-known specialist in celestial mechanics and stellar dynamics, a student of Väisälä \{see planet (1573)\} who has continued the Turku tradition of computing orbits of minor planets and comets. (M 18451)

\section{(3382) Cassidy}

1948 RD. Discovered 1948 Sept. 7 by H. L. Giclas at Flagstaff.

Named in honor of William A. Cassidy (1928- ), geologist at the University of Pittsburgh. He was a pioneer investigator of tektite strewn fields and meteorite-impact craters. At the Vampo del Cielo in Argentina he documented one of the first known occurrences of multiple impact craters intimately associated with meteorite masses. For 15 years he led meteorite recovery teams on glacial stranding surfaces in Antarctica and was responsible for the acquisition of several thousand meteorites there, including lunar and martian specimens. He has investigated crystallization in plasmas simulating dust condensation in stellar atmospheres and vapor-deposition processes on surfaces simulating the moon and planets. (M 29142)

Named by the discoverer following a suggestion by T. P. Kohman and B. W. Hapke, who wrote the citation.

\section{(3383) Koyama}

1951 AB. Discovered 1951 Jan. 9 by K. Reinmuth at Heidelberg.

Named in honor of Hisako Koyama \{1916-1997\}, staff member of the National Science Museum in Tokyo for more than 40 years, internationally known for her solar observations. (M 11442)

Name proposed by S. Nakano, who found the identifications involving this planet.

Obituary published in Yamamoto Circ., No. 2279, p. 2 (1997).

\section{(3384) Daliya}

1974 SB $_{1}$. Discovered 1974 Sept. 19 by L. I. Chernykh at Nauchnyj.

Named for Vladimir Ivanovich Dal' (1801-1872), outstanding lexicologist, ethnographer and writer, compiler of the famous Explanatory Dictionary of the Living Russian Language. (M 13176)

\section{(3385) Bronnina}

1979 SK $_{11}$. Discovered 1979 Sept. 24 by N. S. Chernykh at Nauchnyj.

Named in honor of Nina Mikhailovna Bronnikova, astronomer at the Pulkovo Observatory. One of the main observers with the Pulkovo normal astrograph for many years, she is known for her work on star catalogues and for her observations of minor planets and comets. (M 18137)

\section{(3386) Klementinum}

1980 FA. Discovered 1980 Mar. 16 by L. Brožek at Kleť.

Named for the Jesuit college of St. Clemens in the Old Town of Prague. At the beginning of the eighteenth century a mathematical museum and astronomical observatory were established there, the observation tower being completed in 1722. Klementinum was long an important center for astronomical, meteorological and geophysical research and measurements. Now it contains the national and university libraries. (M 21130)

\section{(3387) Greenberg}

1981 WE. Discovered 1981 Nov. 20 by E. Bowell at Anderson Mesa.

Named in honor of Richard J. Greenberg \{1947-

\}, planetary scientist at the University of Arizona. Greenberg has carried out careful and innovative studies of the evolution of dynamical resonances in outer-planet satellite and ring systems. He has also contributed important new insights into collisional processes between minor planets and into the formation of resulting dust bands. (M 12803)

Citation prepared by W. B. Hubbard following a suggestion by L. A. Lebofsky.

\section{(3388) Tsanghinchi}

$1981 \mathrm{YR}_{1}$. Discovered 1981 Dec. 21 at the Purple Mountain Observatory at Nanking.

Named in honor of Tsanghinchi, well-known Chinese industrialist, honorary principal of the Life Science College of Zhongshan University. He has made important contributions to education and culture. (M 22829)

\section{(3389) Sinzot}

1984 DU. Discovered 1984 Feb. 25 by H. Debehogne at La Silla.

The family name of the discoverer's maternal grandmother. (M 15573)

\section{(3390) Demanet}

$1984 \mathrm{ES}_{1}$. Discovered 1984 Mar. 2 by H. Debehogne at La Silla.

The family name of the discoverer's paternal grandmother. (M 15573)

\section{(3391) Sinon}

$1977 \mathrm{DD}_{3}$. Discovered 1977 Feb. 18 by H. Kosai and K. Hurukawa at Kiso. 
Named for an ancient Greek warrior, a hero of the Trojan War. (M 11443)

\section{(3392) Setouchi}

1979 YB. Discovered 1979 Dec. 17 by H. Kosai and G. Sasaki at Kiso.

Named for a beautiful place around the Seto Inland Sea. (M 11443)

\section{(3393) Štúr}

$1984 \mathrm{WY}_{1}$. Discovered 1984 Nov. 28 by M. Antal at Piszkéstetö.

Named in memory of Ľudovít Velislav Štúr (18151856), ideologist and organizer of the Slovak nationalliberation movement, codifier of the Slovak literary language, linguist, philosopher, historian, writer, poet, journalist, educationalist and editor. Štúr was also an enthusiastic promoter of Czecho-Slovak contacts, Slavonic solidarity and human coexistence with high respect for democracy. An active authority during the 1848-1849 revolution, he led the revival from the oppression of a millenium that almost caused the Slovaks to lose their identity. (M 13608)

\section{(3394) Banno}

1986 DB. Discovered 1986 Feb. 16 by S. Inoda and T. Urata at Karasuyama.

Named in memory of Yoshiaki Banno (1952-1991), a coworker of the discoverers and a computer engineer at the National Laboratory for High-Energy Physics in Tsukuba city. A discoverer of (4200) Shizukagozen, he was one of the pioneers among Japanese amateur astronomers in the use of electronic computers for orbital calculations. He was tragically killed in a traffic accident on his way home from the laboratory. (M 21130)

\section{(3395) Jitka}

1985 UN. Discovered 1985 Oct. 20 by A. Mrkos at Klet.

Named in honor of Jitka Beneš in recognition of her assistance at Klet during the International Halley Watch. (M 23136)

\section{(3396) Muazzez}

A915 TE. Discovered 1915 Oct. 15 by M. F. Wolf at Heidelberg.

Named in honor of Muazzez K. Lohmiller, weekend operator in the Smithsonian Astrophysical Observatory's Computer Center, who has for several years assisted the work of the Minor Planet Center by loading and unloading the magnetic tapes for archiving the Minor Planet Circulars and attending to massive piles of computer printout. (M 11443)

Name proposed by B. G. Marsden, who found the identifications involving this minor planet.
(3397) Leyla

1964 XA. Discovered 1964 Dec. 8 by R. Burnham and N. G. Thomas at Flagstaff.

Nancy Leyla Lohmiller (1985- ), daughter of Muazzez Kumrucu Lohmiller, administrative assistant at the Minor Planet Center, is an accomplished flutist and poet. Her poem about comet C/1996 B2 (Hyakutake) appeared in the Boston Globe. She is an occasional volunteer at the Minor Planet Center. (M 40700)

\section{(3398) Stättmayer}

1978 PC. Discovered 1978 Aug. 10 by H.-E. Schuster at La Silla.

Named in honor of Peter Stättmayer \{1945- \}, director of the Munich Public Observatory, on the occasion of his 50th birthday, 1995 Nov. 3. He has been a very active amateur astronomer all his lifetime and is well known for his great ability to communicate with the public. His excellent astrophotographic observations, mostly made from his well-equipped private observatory in Herrsching at the Ammersee, are unsurpassed among amateurs in Germany and beyond. (M 25976)

Proposed by the discoverer and R. M. West, as well as his amateur friends in Munich.

\section{(3399) Kobzon}

1979 SZg. Discovered 1979 Sept. 22 by N. S. Chernykh at Nauchnyj.

Named in honor of Iosif Davidovich Kobzon, wellknown singer in the former Soviet Union. (M 22829)

\section{(3400) Aotearoa}

1981 GX. Discovered 1981 Apr. 2 by A. C. Gilmore and P. M. Kilmartin at Lake Tekapo.

Usually taken to be the Maori name for New Zealand, although originally it referred only to the North Island. Commonly accepted to mean 'Land of the Long White Cloud', it is attributed to Hine-te-aparangi, wife of the legendary Maori navigator, Kupe. She is said to have called out 'He, ao' ('A Cloud!') on sighting land when first arriving in the vicinity of the country, and Kupe used this declaration in naming the new land. The name is therefore particularly appropriate for this minor planet, the first to be discovered from New Zealand. (M 18305)

\section{(3401) Vanphilos}

1981 PA. Discovered 1981 Aug. 1 at the Harvard College Observatory at Harvard.

Named by G. V. Williams in honor of his friends Vanessa Hall and Philip Osborne, on the occasion of their marriage, 1991 August 3. Both planned a two-year tour of duty with the Voluntary Service Overseas organization. (M 18644)

\section{(3402) Wisdom}

1981 PB. Discovered 1981 Aug. 5 by E. Bowell at Anderson Mesa.

Named in honor of Jack Wisdom, a dynamicist at the Massachusetts Institute of Technology. Wisdom is 
well known for his discovery of a dynamical mechanism for the removal of minor-planet type objects from the $3: 1$ and other Kirkwood \{see planet (1578)\} gaps via chaotic behavior, which can also deliver meteorites to the Earth. He and his colleagues have also explored the long-term stability of the solar system, the tidal evolution of planetary satellite systems and the chaotic rotation states of irregularly shaped natural satellites. (M 12803)

Citation prepared by W. C. Tittemore and L. M. French at the request of the discoverer.

\section{(3403) Tammy}

1981 SW. Discovered 1981 Sept. 25 by L. G. Taff at Socorro.

Named in honor of the wife of R. L. Irelan, principal night assistant at Lincoln Laboratory's Observatory, as a token of thanks for her patience and support during the years of strange and trying schedules of his effort. (M 12016)

\section{(3404) Hinderer}

1934 CY. Discovered 1934 Feb. 4 by K. Reinmuth at Heidelberg.

Named in memory of Fritz Hinderer (1912-1991), German astronomer at the Potsdam and Babelsberg Observatories and professor at the Berlin Free University. For many years, Hinderer was engaged in the study of irregular variables, as well as W UMa stars. By means of more than 850 plates taken at the Babelsberg Observatory, he thoroughly investigated the spectrophotometric behavior of SS Cyg. After World War II, Hinderer served solely as an academic teacher of astronomy in West Berlin. (M 22497)

Name suggested and citation prepared by L. D. Schmadel, who was a student of Hinderer.

Obituary published in Mitt. Astron. Ges., Nr. 75, p. 5-7 (1992)

\section{(3405) Daiwensai}

1964 UQ. Discovered 1964 Oct. 30 at the Purple Mountain Observatory at Nanking.

Named in memory of Dai Wensai (1911-1979), one of the founders of modern astronomy in China, and director of the astronomy department at Nanjing University from 1955 to 1979 . He worked on stellar spectroscopy, stellar astronomy and the origin of the solar system. (M 21608)

\section{(3406) Omsk}

1969 DA. Discovered 1969 Feb. 21 by B. A. Burnasheva at Nauchnyj.

Named for the city of Omsk, the discoverer's birthplace, one of the great industrial, cultural and scientific centers in Siberia \{see planet (1094)\}. (M 19693)

\section{(3407) Jimmysimms}

1973 DT. Discovered 1973 Feb. 28 by L. Kohoutek at Bergedorf.
Named in honor of James A. C. Simms III (1957- ), a system administrator in the AXAF Science Center at the Smithsonian Astrophysical Observatory. Beginning in 1980, as an operator in the observatory's central computing facility, he was always particularly helpful in expediting the Minor Planet Center's computing jobs. (M 34618)

Name proposed by B. G. Marsden and C. M. Bardwell, who made the identifications involving this object.

(3408) Shalamov

1977 QG $_{4}$. Discovered 1977 Aug. 18 by N. S. Chernykh at Nauchnyj.

Named in memory of the Soviet writer Varlam Tikhonovich Shalamov (1907-1982). (M 18137)

\section{(3409) Abramov}

$1977 \mathrm{RE}_{6}$. Discovered 1977 Sept. 9 by N. S. Chernykh at Nauchnyj.

Named in memory of Fyodor Aleksandrovich Abramov (1920-1983), well-known writer who depicted in his works the life and fates of the ordinary people of northern Russia. (M 22498)

\section{(3410) Vereshchagin}

1978 SZ7. Discovered 1978 Sept. 26 by L. V. Zhuravleva at Nauchnyj.

Named for Vasilij Vasil'evich Vereshchagin (18421904), Russian publicist and war artist. (M 20835)

\section{(3411) Debetencourt}

1980 LK. Discovered 1980 June 2 by H. Debehogne at La Silla.

The family name of the mother of Georges Roland, codiscoverer of the naked-eye comet Arend-Roland 1957 III. (M 15574)

\section{(3412) Kafka}

$1983 \mathrm{AU}_{2}$. Discovered 1983 Jan. 10 by R. Kirk and D. Rudy at Palomar.

Named in memory of the Bohemian writer Franz Kafka (1883-1924). In his novels and short stories (of which The Castle, The Trial and Metamorphosis are best known), Kafka depicted the fatalistic struggles of ordinary individuals to cope with a world turned surreal and incomprehensibly hostile. (M 11641)

\section{(3413) Andriana}

1983 CB $_{3}$. Discovered 1983 Feb. 15 by N. G. Thomas at Anderson Mesa.

Named in honor of Andriana Marie Hazelton, granddaughter of the discoverer. (M 12016)

\section{(3414) Champollion}

1983 DJ. Discovered 1983 Feb. 19 by E. Bowell at Anderson Mesa.

Named for Jean-François Champollion (1790-1832), French Egyptologist who in 1822 found the key to the decipherment of the Egyptian hieroglyphics on the Rosetta stone. (M 12458) 
Named by the discoverer following a suggestion by C. E. Spratt.

Champollion is also honored by a lunar crater.

\section{(3415) Danby}

1928 SL. Discovered 1928 Sept. 22 by K. Reinmuth at Heidelberg.

Named in honor of John Michael Anthony Danby \{1929- \}, celestial mechanician and sometime oboeist in the London Symphony Orchestra. An inspiring teacher, at the Yale University Observatory during the Brouwer \{see planet (1746)\} era and more recently at the North Carolina State University, he is the author of modern texts on celestial mechanics and differential equations. The name also honors his daughter, Dinah, who while a student at Harvard provided occasional volunteer assistance with address labels for the MPCs and IAU Circulars. (M 11443)

Name proposed by B. G. Marsden, who found the identifications involving this Hilda-type planet.

\section{(3416) Dorrit}

1931 VP. Discovered 1931 Nov. 8 by K. Reinmuth at Heidelberg.

Named in honor of Dorrit Hoffleit \{1907- \}, renowned authority on variable stars, director of the Maria Mitchell Observatory from 1957 to 1978, research astronomer at Harvard and later Yale. The summer research internship program she conducted at the M.M.O. provided training for more than 100 female students, many of whom subsequently became well-known astronomers. Her research at Harvard also included stellar spectra and meteors. Author of the third and fourth editions $(1964,1982)$ of the Yale Bright Star Catalogue, she was also in charge of the Yale astrometric zone work for several years. (M 11641)

Name proposed by B. G. Marsden, who found the identifications involving this planet. Citation prepared in collaboration with J. A. Mattei.

\section{(3417) Tamblyn}

1937 GG. Discovered 1937 Apr. 1 by K. Reinmuth at Heidelberg.

Named in honor of Peter Tamblyn, enthusiastic volunteer at the Minor Planet Center during the summer of 1987. (M 12210)

Name proposed by B. G. Marsden, who found the identifications involving this planet.

\section{(3418) Izvekov}

1973 QZ $_{1}$. Discovered 1973 Aug. 31 by T. M. Smirnova at Nauchnyj.

Named in honor of Vladimir Andreevich Izvekov, an expert on solar-system dynamics and a staff member of the Institute for Theoretical Astronomy from 1951 to 1988. One of the first in the U.S.S.R. to employ electronic computers for improving orbits of minor planets and computing ephemerides, he contributed extensively to automation and quality control in the preparation of the Ephemerides of Minor Planets \{see planet (5001)\}. (M 17027)

\section{(3419) Guth}

1981 JZ. Discovered 1981 May 8 by L. Brožek at Kleť.

Named in memory of Vladimír Guth (1905-1980), outstanding Czech astronomer, founder of contemporary Czechoslovak meteoric astronomy. He started his astronomical work at Ondřejov Observatory and during the 1950s went to Slovakia (to Skalnaté Pleso, then later as first director of the Astronomical Institute of the Slovak Academy of Sciences). After his return to Ondřejov, Guth led the department of interplanetary matter. Guth was president of IAU Commission 22 from 1952 to 1958. (M 22498)

Name proposed by L. Kresák.

\section{(3420) Standish}

1984 EB. Discovered 1984 Mar. 1 by E. Bowell at Anderson Mesa.

Named in honor of E. Myles Standish Jr., celestial mechanician at the Jet Propulsion Laboratory, who has continually improved the accuracy of planetary ephemerides by making use of diverse types of data, including optical astrometry, planetary ring occultations, radio interferometry, planetary radar and spacecraft tracking data. His efforts have been important in making the JPL planetary ephemeris an international standard. (M 12016)

Name proposed by the discoverer following a suggestion by D. K. Yeomans, who provided the citation.

\section{(3421) Yangchenning}

$1975 \mathrm{WK}_{1}$. Discovered 1975 Nov. 26 at the Purple Mountain Observatory at Nanking.

Named in honor of the theoretical physicist, Chen Ning Yang (1922- ), Albert Einstein Professor of Physics at the State University of New York. The Yang-Mills theory, parity nonconservation in weak interactions and the Yang-Baxter equation are epoch making contributions to physics and mathematics. Yang has received the Nobel Prize (1957), the Benjamin Franklin Medal (1993) and the Bower Award (1994). (M 27125)

Yang received the Nobel prize together with TsungDao Lee, see planet (3443).

\section{(3422) Reid}

1978 OJ. Discovered 1978 July 28 by B. Stewart and C. Pratt at Bickley.

Named in honor of Gordon Reid (1923-1989) and his wife Ruth. Gordon Reid was foundation professor of politics at the University of Western Australia and became deputy vice-chancellor of the university in 1978. A Companion of the Order of Australia, he served as governor of Western Australia from 1984 until his death. Ruth Reid is well known in Western 
Australia for her warmth and compassion for the disadvantaged in the community. (M 20520)

Citation prepared by M. P. Candy.

\section{(3423) Slouka}

1981 CK. Discovered 1981 Feb. 9 by L. Brožek at Kleť.

Named in memory of Hubert Slouka (1903-1973), Czech astronomer, well known as a popularizer of astronomy and as the author of a great number of books, articles and lectures. Slouka was the long-time editor-in-chief of Říše hvězd, a Czech journal for amateur astronomers. His wonderful book Views into the Sky inspired an interest in astronomy in many Czech and Slovak astronomers. (M 22498)

\section{(3424) Nušl}

1982 CD. Discovered 1982 Feb. 14 by L. Brožek at Klě́.

Named in memory of František Nušl (1867-1951), Czech astronomer and mathematician, director of the National Observatory in Prague and for many years the chairman of the Czech Astronomical Society. His main interest consisted in the construction of astronomical instruments for the determination of geographical coordinates (circumzenithal, diazenithal, radiozenithal, etc.) in collaboration with J. J. Frič. (M 22498)

Nušl is also honored by a lunar crater.

\section{(3425) Hurukawa}

1929 BD. Discovered 1929 Jan. 29 by K. Reinmuth at Heidelberg.

Named in honor of Kiichiro Hurukawa, astronomer at the Tokyo Astronomical Observatory, known for his identifications and orbit computations and for his participation in the observational program of minor planets with the Kiso \{see planet (2271)\} Schmidt. (M 11443)

Name proposed by S. Nakano, who found the identifications involving this planet.

\section{(3426) Seki}

1932 CQ. Discovered 1932 Feb. 5 by K. Reinmuth at Heidelberg.

Named in honor of Tsutomu Seki, visual discoverer of six comets between 1961 and 1970. He later undertook an extensive program of photographic astrometric observations and has recovered several returning periodic comets. Editor of the Oriental Astronomical Association's Comet Bulletin, he is also an accomplished performer and teacher of classical guitar. (M 11443)

Name proposed by S. Nakano, who found the identifications involving this planet.

\section{(3427) Szentmártoni}

1938 AD. Discovered 1938 Jan. 6 by G. Kulin at Budapest.
Named in memory of Belá Szentmártoni (19311988), outstanding Hungarian amateur astronomer. He founded the Albireo Amateur Astronomical Society and its magazine 'Albireo' in 1971 and through his articles and translations helped promote amateur astronomy in Hungary. Belá was an all-rounder, although he specialized in deep-sky and double star observing, as well as variable stars. He was also a mirror maker. (M 23792)

\section{(3428) Roberts}

1952 JH. Discovered 1952 May 1 at the Goethe Link Observatory at Brooklyn, Indiana.

Named in memory of Walter Orr Roberts (1915-1990), from 1960 to 1970 the founding director of the National Center for Atmospheric Research. In the early 1940s he established the Harvard College Observatory's Fremont Pass Station (which later became the University of Colorado's High Altitude Observatory), where he made solar observations with the first coronagraph in the western hemisphere. His interests soon broadened from solar physics to climatic research in general, and he served as president (and later president emeritus) of the University Corporation for Atmospheric Research. His final major activity was the Greenhouse Glasnost project between scientists in the U.S. and the U.S.S.R. (M 16885)

Name proposed by F. K. Edmondson.

Obituaries published in Bull. Am. Astron. Soc., Vol. 24, No. 4, p. 1331-1332 (1992); Q.J.R. Astron. Soc., Vol. 33, No. 1, p. 35-37 (1992).

\section{(3429) Chuvaev}

1974 SU$_{1}$. Discovered 1974 Sept. 19 by L. I. Chernykh at Nauchnyj.

Named in memory of Konstantin Konstantinovich Chuvaev (1917-1994), astrophysicist and staff member of the Crimean Astrophysical Observatory from 1947. He investigated nocturnal airglow, variable stars and active galaxies. One of the first observers at the $2.6-\mathrm{m}$ Shajn telescope, Chuvaev was a pioneer in the use of electronic imaging with this telescope. (M 27125)

Obituary published in Bull. Crimean Astrophys. Obs., Vol. 93, p. 184-186 (1996).

\section{(3430) Bradfield}

$1980 \mathrm{TF}_{4}$. Discovered 1980 Oct. 9 by C. S. Shoemaker at Palomar.

Named in honor of William A. Bradfield, rocket engineer of Dernancourt, South Australia. Discoverer of twelve comets, Bradfield has been chiefly responsible for the greatly increased rate of discovery of bright comets from the southern hemisphere during the 1970 s and 1980s. (M 11750)

\section{(3431) Nakano}

1984 QC. Discovered 1984 Aug. 24 by T. Seki at Geisei. 
Named in honor of Syuichi Nakano \{1947- \}, energetic computer of orbits and identifier of minor planets, prolific author of computer software and related astronomical books, catalogues and circulars. (M 10849)

\section{(3432) Kobuchizawa}

1986 EE. Discovered 1986 Mar. 7 by M. Inoue and O. Muramatsu and T. Urata at Kobuchizawa.

Named for the observing station, $150 \mathrm{~km}$ west of Tokyo, at which this minor planet was the first discovery. (M 10849)

\section{(3433) Fehrenbach}

1963 TJ $_{1}$. Discovered 1963 Oct. 15 at the Goethe Link Observatory at Brooklyn, Indiana.

Named in honor of Charles Fehrenbach \{1914- $\}$, who pioneered the successful use of the objective prism to measure stellar radial velocities. One of his instruments was used to identify members of the Magellanic Clouds from their radial velocities, starting in 1961 during the ESO site survey in southern Africa and continuing in 1968 on La Silla in Chile. He served as vice president of the IAU from 1973 to 1979 , as a member of ESO and president of its Commission on Instruments, and as a member and president of the council of the Canada-France-Hawaii Observatory. His many honors include membership in the French Academy of Sciences, the gold medal of the CNRS and the grand scientific prize of the city of Paris. (M 17027)

Name proposed by F. K. Edmondson.

\section{(3434) Hurless}

1981 VO. Discovered 1981 Nov. 2 by B. A. Skiff at Anderson Mesa.

Named in memory of Carolyn J. Hurless \{1934-1987\}, of Lima, Ohio. From 1959 until her death in 1987 she made over 79,000 observations of variable stars for the American Association of Variable Star Observers, which places her among the ten most prolific observers in the AAVSO's history. Besides these observations, Hurless was also active in promoting variable-star observing among hundreds of amateur astronomers by means of a newsletter and other correspondence with observers worldwide. The amateur variable star observing community benefited greatly from her interest and enthusiasm. (M 16041)

Name suggested and citation provided by P. L. Sventek.

Obituary published in J. Am. Assoc. Variable Star Obs., Vol. 16, No. 1, p. 35-36 (1987).

\section{(3435) Boury}

$1981 \mathrm{XC}_{2}$. Discovered 1981 Dec. 2 by F. Dossin at St. Michel.

Named in memory of Arsène Boury (1934-1982), fellow-student, colleague and friend of the discoverer.
He was a theoretical astrophysicist known for his work on stellar evolution and stability, mainly concerning massive and population III stars. The discovery of this minor planet was announced around the date of his untimely death. (M 11750)

Obituary published in Proc. 24th Liège Int. Astrophys. Colloq., p. I (1983).

\section{(3436) Ibadinov}

$1976 \mathrm{SS}_{3}$. Discovered 1976 Sept. 24 by N. S. Chernykh at Nauchnyj.

Named in honor of Hursandkul Ibadinov, researcher on comets, founder and head of the laboratory for modeling cometary processes at the Tadjik Academy of Sciences' Institute of Astrophysics in Dushanbe. (M 18137)

\section{(3437) Kapitsa}

1982 UZ $_{5}$. Discovered 1982 Oct. 20 by L. G. Karachkina at Nauchnyj.

Named in memory of the celebrated physicist Pyotr Leonidovich Kapitsa (1894-1984), recipient of the Nobel prize for physics in 1978 sshared with A. A. Penzias and R. W. Wilson\}. (M 12016)

\section{(3438) Inarradas}

$1974 \mathrm{SD}_{5}$. Discovered 1974 Sept. 21 at the Felix Aguilar Observatory at El Leoncito.

Named for the Instituto Argentino de Radioastronomia, founded in 1962, for its outstanding contributions to astronomy. (M 23351)

\section{(3439) Lebofsky}

$1983 \mathrm{RL}_{2}$. Discovered 1983 Sept. 4 by E. Bowell at Anderson Mesa.

Named in honor of Larry A. Lebofsky, planetary scientist at the Lunar and Planetary Laboratory of the University of Arizona, Tucson. Lebofsky was the first to find chemically-bound water and the presence of ice in the regoliths of minor planets and has been a major contributor to the development of minor-planet thermal models. He has also played an important role in the extraction of minor-planet data from IRAS \{see planet (3728)\} infrared observations. He has undertaken related laboratory spectral studies on icy condensates and the comparison of minor planets with cometary dust, planetary satellites and Pluto. (M 12458)

Citation prepared by J. S. Lewis.

\section{(3440) Stampfer}

1950 DD. Discovered 1950 Feb. 17 by K. Reinmuth at Heidelberg.

Named in memory of Simon Stampfer (17901864), who despite his humble beginnings became an astronomer and a founding member of the Imperial Academy of Sciences in Vienna. He was the first, in 1851, to compute photometric diameters of minor planets on the basis of the mean albedo derived from observations of the satellites of the giant planets, and 
in 1862 he was the first to show that the revolution period of $\mathrm{P} /$ Swift-Tuttle \{see also planets (5035), (5036), respectively\} was somewhat in excess of a century. (M 22498)

Named by the Minor Planet Names Committee following a suggestion by $\mathrm{H}$. Haupt.

\section{(3441) Pochaina}

1969 TS $_{1}$. Discovered 1969 Oct. 8 by L. I. Chernykh at Nauchnyj.

Named for the small river in the old town of Kiev. According to some historians, the inhabitants of Kiev were baptized here in 988 when Christianity was accepted by Russia. (M 13481)

\section{(3442) Yashin}

1978 TO$_{7}$. Discovered 1978 Oct. 2 by L. V. Zhuravleva at Nauchnyj.

Named in memory of Lev Ivanpvich Yashin (19291990), football goalkeeper and trainer. (M 20835)

\section{(3443) Leetsungdao}

1979 SB $_{1}$. Discovered 1979 Sept. 26 at the Purple Mountain Observatory at Nanking.

Named in honor of the theoretical physicist TsungDao Lee (1926- ), professor at Columbia University, winner of the Nobel prize in physics in 1957 together with C. N. Yang, see planet (3421)\}. Among his outstanding works is the discovery of parity and other symmetry violations in weak interactions. From the late 1940 s onward, he made many other landmark contributions to weak interactions. In the 1970s and 1980s Lee established the field of nontopological solitons and discovered a large class of new astronomical solutions of general relativity, called soliton stars. (M 27733)

\section{(3444) Stepanian}

$1980 \mathrm{RJ}_{2}$. Discovered 1980 Sept. 7 by N. S. Chernykh at Nauchnyj.

Named in honor of husband-and-wife staff members at the Crimean Astrophysical Observatory for more than 30 years. Natalia Nikolaevna Stepanian, prominent astrophysicist, is head of the observatory's solar physics department. Arnol'd Artashesovich Stepanian, head of the gamma-ray laboratory, initiated the construction of the unique 48-element telescope for the observatory's research on gamma-ray sources. (M 18137)

\section{(3445) Pinson}

1983 FC. Discovered 1983 Mar. 16 by E. Barr at Anderson Mesa.

William Hamet Pinson, Jr. (1919- ), emeritus professor of geology at the Massachusetts Institute of Technology, is known in particular for his extensive studies of the rubidium-strontium ratio in lunar rocks and soil, tektites, meteorites and meteorite craters. (M 40700)

The name was suggested by P. Topalian.

\section{(3446) Combes}

1942 EB. Discovered 1942 Mar. 12 by K. Reinmuth at Heidelberg.

Named in honor of the French amateur astronomer Michel-Alain Combes (1942- ), who for many years has been interested in minor planets, especially the near-earth asteroids and their discovery circumstances. He writes a regular column about minor planets in the French periodical L'Astronomie, and he contributed to the Dictionary of Minor Planet Names by L. D. Schmadel \{see planet (2234)\}, who found the identification involving this planet and who proposed the name. (M 21130)

Citation prepared by J. Meeus.

\section{(3447) Burckhalter}

1956 SC. Discovered 1956 Sept. 29 at the Goethe Link Observatory at Brooklyn, Indiana.

Named in memory of Charles Burckhalter (18491923), well known for his research in solar-eclipse photography, a founder of the Astronomical Society of the Pacific and its first vice president. He became the first full-time director of the two-year-old Chabot Observatory in downtown Oakland, California, in 1885 and built it into an important popular-science institution. Under his direction it was moved to a new building at a darker hill site in 1913 and featured a 50-cm refractor. (M 17028)

Name proposed by N. Sperling with the concurrence of F. K. Edmondson.

\section{(3448) Narbut}

1977 QA 5 . Discovered 1977 Aug. 22 by N. S. Chernykh at Nauchnyj.

Named in memory of Georgij Ivanovich Narbut (1886-1920), outstanding Ukrainian artist, master of graphic arts, and rector of the Ukrainian Academy of Arts. One of his pictures shows Halley's Comet in 1910. (M 18137)

\section{(3449) Abell}

1978 VR$_{9}$. Discovered 1978 Nov. 7 by E. F. Helin and S. J. Bus at Palomar.

Named in memory of George O. Abell (1927-1983), astronomer at the University of California at Los Angeles, noted author, lecturer, educator, popularizer of astronomy and long-time director of the Summer Science Program of Thacher School in Ojai, California. As a graduate student, he took a large fraction of the plates for the Palomar-National Geographic Sky Survey, and his analysis of them produced the Abell catalogue of rich clusters of galaxies. In addition, he discovered a new class of planetary nebulae and showed that planetary nebulae represent a normal phase in the evolution of solar-mass stars in the disks of galaxies. (M 11162)

Name proposed by the first discoverer following a suggestion from D. A. Pierce. 
Obituaries published in Mercury, Vol. 12, No. 6, p. 186 (1983); Phys. Today, Vol. 37, No. 2, p. 76-77 (1984); Sky Telesc., Vol. 67, No. 1, p. 22 (1984); Mercury, Vol. 13, No. 4, p. 108-112 (1984); Q.J.R. Astron. Soc., Vol. 30, No. 2, p. 283-285 (1989).

\section{(3450) Dommanget}

1983 QJ. Discovered 1983 Aug. 31 by H. Debehogne at La Silla.

Named in honor of Jean Dommanget, head of the department of astrometry and celestial mechanics at the Royal Observatory of Belgium (1967-89), for his more than 40 years of continuous research activity in doublestar astronomy and on related problems concerning astrometry and image quality. He participated in the ESO site survey in South Africa (1955-57) and was acting director of the Boyden Observatory (1964-65). He served as president of IAU Commission 26 during 1970-73 and since 1980 has been coordinator on double stars for the Hipparcos Input Catalogue Consortium. (M 15574)

\section{(3451) Mentor}

1984 HA $_{1}$. Discovered 1984 Apr. 19 by A. Mrkos at Klět.

Named for the father of Imbrius and son of Imbrus at Pedaseus, who allied with the Trojans. (M 22829)

Name proposed by A. Mrkos following a suggestion by F. Pilcher.

\section{(3452) Hawke}

1980 OA. Discovered 1980 July 17 by E. Bowell at Anderson Mesa.

Named in honor of B. R. Hawke, planetary geologist at the University of Hawaii, Honolulu. Hawke's research has concentrated on the geologic evolution of the Moon as revealed by sample studies, spacecraft photography and infrared spectroscopy. He has also undertaken spectroscopic evaluation of minor planet mineralogy. (M 12804)

Name suggested and citation prepared by J. F. Bell.

\section{(3453) Dostoevsky}

$1981 \mathrm{SS}_{5}$. Discovered 1981 Sept. 27 by L. G. Karachkina at Nauchnyj.

Named for the great Russian writer Fyodor Mikhailovich Dostoevsky (1821-1881). (M 12017)

\section{(3454) Lieske}

$1981 \mathrm{WB}_{1}$. Discovered 1981 Nov. 24 by E. Bowell at Anderson Mesa.

Named in honor of Jay Henry Lieske \{1941- $\quad$ \}, astronomer at the Jet Propulsion Laboratory, well known for his work on the Galilean satellites, ephemerides and astronomical constants, the precessional formulation in the J2000 system and for an accurate determination of the solar parallax from the motion of (433) Eros. (M 11162)
Name proposed by the discoverer following a suggestion from L. D. Schmadel, who also prepared the citation.

\section{(3455) Kristensen}

1985 QC. Discovered 1985 Aug. 20 by E. Bowell at Anderson Mesa.

Named in honor of Leif Kahl Kristensen, teacher in theoretical physics at the University of Aarhus, who has extensively discussed the orbit of (51) Nemausa and has thereby derived equinox and equator corrections to the FK4 system. In addition, he has worked on the recovery of long-lost minor planets, on orbit determinations and identifications. (M 11162)

Name proposed by the discoverer following a suggestion by L. D. Schmadel, who also prepared the citation.

\section{(3456) Etiennemarey}

$1985 \mathrm{RS}_{2}$. Discovered 1985 Sept. 5 by H. Debehogne at La Silla.

In 1890 the French physiologist Etienne-Jules Marey (1830-1904) made the first use of celluloid roll film in movie photography. (M 40700)

The name is derived from a suggestion by T. Wullin, who, as part of a minor-planet naming competition on the BBC Radio 4 program Word of Mouth, noted that $3456=$ FILM on the keys of a telephone.

\section{(3457) Arnenordheim}

$1985 \mathrm{RA}_{3}$. Discovered 1985 Sept. 5 by H. Debehogne at La Silla.

The Norwegian composer Arne Nordheim (1931is one of the most influential musical voices of his country, and he has achieved wide international acclaim. He has on several occasions found inspiration in the heavens, as in his Celestial Mechanics, written for the opening ceremony of the 1994 Olympic Winter Games in Lillehammer. (M 43041)

\section{(3458) Boduognat}

$1985 \mathrm{RT}_{3}$. Discovered 1985 Sept. 7 by H. Debehogne at La Silla.

Named for Boduognat, chief of the Nerviens, a Belgian tribe in the provinces of Hainaut and Brabant. Boduognat fought against the Roman invaders led by Julius Caesar and was defeated and killed at the battle of Sambre $\{$ see planet (4016)\} in 59 B.C. (M 23792)

\section{(3459) Bodil}

1986 GB. Discovered 1986 Apr. 2 by P. Jensen at Brorfelde.

Named in honor of Bodil Jensen, wife of the discoverer. (M 12211)

\section{(3460) Ashkova}

1973 QB $_{2}$. Discovered 1973 Aug. 31 by T. M. Smirnova at Nauchnyj.

Named in honor of Nataliya Vladimirovna Ashkova \{1932- $\quad\}$, an expert on the dynamics of minor planets 
on the staff of the Institute for Theoretical Astronomy from 1954 to 1987. She was heavily involved in the automation of computations and to the improvement of orbits of minor planets for the Ephemerides of Minor Planets \{see planet (5001)\}. (M 17028)

\section{(3461) Mandelshtam}

1977 SA $_{1}$. Discovered 1977 Sept. 18 by N. S. Chernykh at Nauchnyj.

Named in memory of the Soviet poet Osip Emilievich Mandel'shtam (1891-1938). (M 18137)

\section{(3462) Zhouguangzhao}

$1981 \mathrm{UA}_{10}$. Discovered 1981 Oct. 25 at the Purple Mountain Observatory at Nanking.

Named in honor of Zhou Guangzhao, president of the Chinese Academy of Sciences and known for his creative work in several major fields of theoretical physics, notably particle physics, quantum-field physics, condensed-matter physics and statistical physics. He is recognized internationally as one of the founding fathers of research on the partially conserved axial vector current, and he introduced the concept of helicity amplitude and its corresponding mathematical description. He has also developed a unified formalism for the study of equilibrium and non-equilibrium states. (M 26424)

\section{(3463) Kaokuen}

$1981 \mathrm{XJ}_{2}$. Discovered 1981 Dec. 3 at the Purple Mountain Observatory at Nanking.

Named in honor of Charles Kuen Kao (1933- ), an internationally renowned telecommunications scientist and electronic engineer. In 1966 he was the principal author of the seminal paper on the theory and practice of the use of optical fibers for communication applications, heralding a new era in telecommunications. For his numerous contributions to the field he is referred to as the "Father of Fiber Optics". (M 27125)

\section{(3464) Owensby}

1983 BA. Discovered 1983 Jan. 16 by E. Bowell at Anderson Mesa.

Named in honor of Pamela D. Owensby, planetary astronomer at the University of Hawaii, Honolulu. Her hard work and dedication to accurate data analysis have made possible the success of several large observational programs at Mauna Kea Observatory, including the 24-color visual and 52-color infrared spectral surveys of minor planets. (M 12804)

Name suggested and citation prepared by J. F. Bell.

\section{(3465) Trevires}

1984 SQ5. Discovered 1984 Sept. 20 by H. Debehogne at La Silla.

Named for the Trevires, an ancient Belgian tribe, mentioned in Julius Caesar's Gallic Wars. (M 23792)

\section{(3466) Ritina}

1975 EA $_{6}$. Discovered 1975 Mar. 6 by N. S. Chernykh at Nauchnyj.

Named in honor of discoverer's daughter Margarita, an astronomer at the Crimean Astrophysical Observatory. (M 20835)

\section{(3467) Bernheim}

$1981 \mathrm{SF}_{2}$. Discovered 1981 Sept. 26 by N. G. Thomas at Anderson Mesa.

Named in honor of Robert Burnham Jr. \{1931$1993\}$, past staff member of the Lowell Observatory during the Lowell Proper Motion Survey, discoverer or co-discoverer of six comets, and author of the Celestial Handbook, a 2,000-page 'wunderwerk' of the universe beyond the solar system. Bernheim is the ancestral Bohemian name of the Burnham family. (M 12017)

Obituaries published in Heavens, Vol. 79, No. 3, p. 12-13 (1998); J. R. Astron. Soc. Can., Vol. 92, No. 1, p. 18-19 (1998); Int. Comet Q., Vol. 19, No. 4, p. 221 (1997).

\section{(3468) Urgenta}

1975 AM. Discovered 1975 Jan. 7 by P. Wild at Zimmerwald.

This minor planet is named for a popular, wholesome type of potato, perhaps alluding to the likely form of the object. The name also indicates that the time is near when the discoverer might lose the privilege of naming the object. (M 27125)

\section{(3469) Bulgakov}

1982 UL $_{7}$. Discovered 1982 Oct. 21 by L. G. Karachkina at Nauchnyj.

Named in memory of Mikhail Afanasevich Bulgakov (1891-1940), Soviet writer and dramatist. (M 12017)

\section{(3470) Yaronika}

1975 ES. Discovered 1975 Mar. 6 by N. S. Chernykh at Nauchnyj.

Named in honor of the discoverer's son Yaroslav, who works in electronics at the Crimean Astrophysical Observatory. (M 20835)

\section{(3471) Amelin}

1977 QK$_{2}$. Discovered 1977 Aug. 21 by N. S. Chernykh at Nauchnyj.

Named in memory of Valentin Mikhajlovich Amelin (1930-1989), an authority on geodesy who lectured on the subject at Leningrad University. A staff member of the Institute for Theoretical Astronomy since 1956, he took part in the preparation of the Naval Astronomical Almanac from 1962 and became supervisor of this work in 1977. (M 17028)

\section{(3472) Upgren}

1981 EJ $_{10}$. Discovered 1981 Mar. 1 by S. J. Bus at Siding Spring.

Named in honor of Arthur R. Upgren Jr., director of Van Vleck Observatory and president of IAU 
Commission 24. He has contributed to our knowledge of galactic structure by the determination of parallaxes and proper motions of both nearby stars and the halo population. (M 11642)

Name suggested by J. Caruso and K. Gloria.

\section{(3473) Sapporo}

A924 EG. Discovered 1924 Mar. 7 by K. Reinmuth at Heidelberg.

Named for the capital of Hokkaido ssee planet (3720)\}, location of the Winter Olympic games in 1972. One of the many cultural institutions in Sapporo, the Sapporo Science Center, has an active program for astrometric observations of comets and minor planets. (M 12972)

Name suggested by K. Watanabe and proposed by S. Nakano, who found the identifications involving this planet.

\section{(3474) Linsley}

1962 HE. Discovered 1962 Apr. 27 at the Goethe Link Observatory at Brooklyn, Indiana.

Named in memory of Earle Garfield Linsley (18821969), professor of geography at Mills College, Oakland, California. He was the second director of the Chalbot Observatory, serving from 1923 until his retirement in 1947. He nurtured several young astronomers who went on to distinguished research careers, including John W. Evans, Gibson Reaves \{see planet (3007)\}, Elizabeth Roemer \{see planet (1657)\}, Dorothy Locanthi and Elizabeth Scott. (M 18305)

Name proposed by Norman Sperling with the concurrence of F. K. Edmondson.

\section{(3475) Fichte}

1972 TD. Discovered 1972 Oct. 4 by L. Kohoutek at Bergedorf.

Named in memory of Hubert Fichte (1935-1986), German writer and an important presence in the post-World War II literature scene. (M 34618)

\section{(3476) Dongguan}

$1978 \mathrm{UF}_{2}$. Discovered 1978 Oct. 28 at the Purple Mountain Observatory at Nanking.

Named for the "Town of Fish and Rice and Fruit", a developing industrial city with modernized construction and natural rural scenery. (M 29142)

\section{(3477) Kazbegi}

1979 KH. Discovered 1979 May 19 by R. M. West at La Silla.

Named for one of the highest mountains in Georgia, Kazbegi (also known as Mkinvartsveri), in the Caucasian range. At its foot, on the banks of the wild river Tergi, is situated the village of Kazbegi (formerly Stepantsminda), whence the ancient church of Sameba is seen against the backdrop of eternal snows. The high mountains, the clear skies and the turbulent streams of this beautiful region have been a rich source of inspiration to many poets. It is the home of the Mokheve people, whose ways of life were described by the famous Georgian writer Alexandre Kazbegi (1848-1893), who was born in the village of Stepantsminda into the Chopikachvili family, of which the discoverer's wife is also a member. (M 14632)

\section{(3478) Fanale}

1979 XG. Discovered 1979 Dec. 14 by E. Bowell at Anderson Mesa.

Named in honor of Fraser P. Fanale, planetary scientist at the University of Hawaii, Honolulu. Fanale has specialized in the study of volatile compounds in the planets and carried out some of the earliest work in relating $\mathrm{C}$-type minor planets to the carbonaceous chondrites. (M 12804)

Name suggested and citation prepared by J. F. Bell.

\section{(3479) Malaparte}

1980 TQ. Discovered 1980 Oct. 3 by Z. Vávrová at Klet.

Named in memory of the discoverer's favorite writer and poet, Curzio Malaparte \{1898-1957\}, born Kurt Erich Suckert. (M 12017)

\section{(3480) Abante}

1981 GB. Discovered 1981 Apr. 1 by E. Bowell at Anderson Mesa.

Named in honor of Robert Hamilton Brown, planetary astronomer at the Jet Propulsion Laboratory. A pioneer in the study of the compositions of the satellites of Uranus, Brown has also contributed greatly to the development of the radiometric method of diameter determination for minor planets and satellites. He has been involved in several calibrations of the radiometric method using occultation diameters, and he has investigated the geometric assumptions by developing a generalized ellipsoidal radiometric model. "Abante" derives from the name of Brown's Italian grandfather; in English it loosely corresponds to "Bob", a nickname for Robert. (M 12804)

Citation prepared by D. L. Matson and L. A. Lebofsky following a suggestion by the discoverer.

\section{(3482) Lesnaya}

$1975 \mathrm{VY}_{4}$. Discovered 1975 Nov. 2 by T. M. Smirnova at Nauchnyj.

Named in honor of the village in the Mogilev district (Belorussia) near which the Russian army under the command of Peter the Great defeated the Swedes on 1708 Sept. 28. (M 22498)

\section{(3483) Svetlov}

$1976 \mathrm{YP}_{2}$. Discovered 1976 Dec. 16 by L. I. Chernykh at Nauchnyj.

Named in memory of the Soviet poet and dramatist Mikhail Arkad'evich Svetlov (1903-1964). (M 13481)

\section{(3484) Neugebauer}

1978 NE. Discovered 1978 July 10 by E. F. Helin and E. M. Shoemaker at Palomar. 
Named in honor of the Neugebauers, prominent family of physicists and mathematicians who have made significant contributions in their chosen fields. Gerry Neugebauer is chairman of the division of physics, mathematics and astronomy, California Institute of Technology, and director of Palomar Observatory; Marcia Neugebauer is project scientist for the Comet Asteroid Flyby mission at the Jet Propulsion Laboratory; and Otto E. Neugebauer, now on the faculty of the Institute for Advanced Study, Princeton, is professor emeritus, Brown University, and celebrated his ninetieth birthday on 1989 May 26. (M 14632)

Obituaries for Otto Neugebauer (1899-1990) are published in Isis, Vol. 82, No. 311, p. 87-88 (1991); J. Hist. Astron., Vol. 24, Part 4, p. 289-299 (1993).

\section{(3485) Barucci}

1983 NU. Discovered 1983 July 11 by E. Bowell at Anderson Mesa.

Named in honor of M. Antonella Barucci, planetary scientist at the Istituto di Astrofisica Spaziale in Rome. A prolific contributor to the study of the physical properties of minor planets, Barucci has carried out both photometric and astrometric observations at the telescope and has studied minor planet body shapes and surface light-scattering properties in the laboratory. (M 11750)

Citation prepared by the discoverer, with assistance from A. Coradini, A. W. Harris and V. Zappalà.

\section{(3486) Fulchignoni}

1984 CR. Discovered 1984 Feb. 5 by E. Bowell at Anderson Mesa.

Named in honor of Marcello Fulchignoni, associate professor of physics at the University of Rome and director of the Istituto di Astrofisica Spaziale. Fulchignoni has played a crucial role in promoting planetary science in Italy, particularly in stimulating Italian participation in space exploration. His research has included studies of the geological and geochemical evolution of the Moon and planetary surfaces. His interest in minor planets has centered on the problem of lightcurve inversion by means of laboratory simulation and numerical modeling. (M 11751)

Citation prepared in part by A. Coradini and V. Zappalà.

\section{(3487) Edgeworth}

1978 UF. Discovered 1978 Oct. 28 by H. L. Giclas at Anderson Mesa.

Named in memory of Kenneth Essex Edgeworth (1880-1972), Irish engineer, economist, military man and independent theoretical astronomer, who reasoned that the solar system did not end with Neptune. As early as 1943 he pointed out the likely existence of a reservoir of potential comets near the invariable plane. This preceded the discovery of $1992 \mathrm{QB}_{1}$ by almost half a century. (M 34618)

\section{(3488) Brahic}

1980 PM. Discovered 1980 Aug. 8 by E. Bowell at Anderson Mesa.

Named in honor of André Brahic, astronomer at the Observatoire de Paris, Meudon, and at the Université de Paris. His studies of the dynamics of planetary rings have provided insight into how collisional interactions among particles can control the large-scale behavior of a swarm. He was leader of the team that discovered the apparent "ring arcs" of Neptune and has performed several other ring occultation experiments. Brahic is also a member of the imaging team for the Voyager spacecraft. Through popular articles, public talks and books, he has helped convey the excitement of planetary science to the public in both his native France and abroad. (M 12804)

Citation prepared by R. J. Greenberg at the request of the discoverer.

\section{(3489) Lottie}

$1983 \mathrm{AT}_{2}$. Discovered 1983 Jan. 10 by K. Herkenhoff and G. Ojakangas at Palomar.

Named in honor of Lottie Soll-Herkenhoff, wife of one of the co-discoverers. (M 11751)

\section{(3490) Šolc}

1984 SV. Discovered 1984 Sept. 20 by A. Mrkos at Klě́.

Named in honor of Ivan Šolc, well-known Czech inventor of birefringent polarizing filters for research on solar prominences and surface activity. (M 25976)

\section{(3491) Fridolin}

$1984 \mathrm{SM}_{4}$. Discovered 1984 Sept. 30 by P. Wild at Zimmerwald.

Named for the patron saint of the Swiss valley of Glarus, where it is still a popular Christian name, usually abbreviated to Fritz. The number of this object exceeds by one the sum of (1687) Glarona and (1803) Zwicky. (M 17466)

\section{(3492) Petra-Pepi}

1985 DQ. Discovered 1985 Feb. 16 by M. Mahrová at Kleť.

Named in honor of the discoverer's daughter on the occasion of her eighteenth birthday. (M 21955)

\section{(3493) Stepanov}

1976 GR $_{6}$. Discovered 1976 Apr. 3 by N. S. Chernykh at Nauchnyj.

Named in memory of Vladimir Evgen'evich Stepanov (1913-1986), a corresponding member of the former Soviet Academy of Sciences, well-known for his work in solar physics and solar-terrestrial relations. For many years he led the solar researches at the Siberian Institute of Terrestrial Magnetism, Ionosphere and Radio Wave Propagation, and he did much for the development of astronomy in Siberia. (M 20835) 


\section{(3494) Purple Mountain}

1980 XW. Discovered 1980 Dec. 7 at the Purple Mountain Observatory at Nanking.

Named in honor of the Purple Mountain Observatory (PMO), established in 1934 in the eastern part of Nanjing \{see planet (2078)\}, near the Yangtse River. Research undertaken at PMO includes celestial mechanics, astrophysics, and radio and space astronomy. Four comets and over one hundred minor planets have been discovered at PMO. The observatory has also played an important role in developing modern Chinese astronomy. (M 22829)

\section{(3495) Colchagua}

1981 NU. Discovered 1981 July 2 by L. E. Gonzalez at Cerro El Roble.

Named for the Provincia de Colchagua, situated in the central part of Chile. It is the land of the "huasos", cheerful cattleman and agriculturists. The province includes the city of San Fernando, birthplace of the discoverer. (M 11642)

\section{(3496) Arieso}

1977 RC. Discovered 1977 Sept. 5 by H.-E. Schuster at La Silla.

This Pallas-type object was the first to be discovered during the 1977 survey of High-Inclination Minor Planets jointly conducted by the Astronomisches Rechen-Institut and the European Southern Observatory. The name, consisting of the acronyms of the two institutions involved, was suggested by the astronomers involved, L. D. Schmadel, J. Schubart, H.-E. Schuster and R. M. West s see planets (2234), (1911), (2018), and (2022), respectively\}. (M 11642)

\section{(3497) Innanen}

1941 HJ. Discovered 1941 Apr. 19 by L. Oterma at Turku.

Named in honor of the Finnish-Canadian astronomer Kimmo Innanen, wellknown specialist in celestial mechanics and galactic dynamics. With Seppo Mikkola \{see planet (3381)\} he predicted the existence of "Mars Trojans", the first of which was recently discovered. (M 18451)

\section{(3498) Belton}

$1981 \mathrm{EG}_{14}$. Discovered 1981 Mar. 1 by S. J. Bus at Siding Spring.

Named in honor of Michael J. S. Belton \{1934- $\}$ of the National Optical Astronomy Observatories for his fundamental contributions to our understanding of solar system astrophysics, his contagious enthusiasm for astronomy, and his many outstanding achievements as an internationally highly respected scientist and a motivating teacher who has the ability to convey the excitement of astronomy to specialist and public alike. Belton has tirelessly and selflessly worked to further the causes of space science and space exploration and has repeatedly demonstrated that the U.S. has a future in space that is exciting to the individual and important to the nation and the human race. Among many other things, he has made significant discoveries about the properties of comets and asteroids, as well as the outer solar system. He has worked on a number of planetary and astrophysics missions, most recently as team leader of the Galileo imaging investigation of the Jovian system. (M 18451)

Citation provided by J. H. Rahe at the request of the discoverer.

\section{(3499) Hoppe}

1981 VW $_{1}$. Discovered 1981 Nov. 3 by F. Börngen at Tautenburg.

Named in honor of Johannes Hoppe (1907-1987), appointed professor of astronomy at the University of Jena in 1959. He studied the physical processes involved with the passage of meteors through the Earth's atmosphere, in particular the differentiation relative to height, the real deceleration and mass loss, vaporization and fragmentation, with conclusions concerning the size and consistency of meteoroidal bodies. He is also the author of the monograph PlanetenSterne-Nebel and of the chapter "Planetensystem" in the Grundriss der Astrophysik of Graff-Lambrecht. (M 11642)

Obituaries published in Astron. Raumfahrt, 25. Jahrg., Heft 5, p. 155 (1987); Publ. Astron. Inst. Czech. Acad. Sci., No. 67, p. 139 (1987).

\section{(3500) Kobayashi}

A919 SD. Discovered 1919 Sept. 18 by K. Reinmuth at Heidelberg.

Named in honor of Takao Kobayashi, an active computer of cometary orbits and identifier of minor planets. He is also a vice-director of the Computing Section of Oriental Astronomical Association and is currently collecting and verifying almost all the observations of minor planets made by Japanese amateur astronomers. (M 12972)

Name proposed by S. Nakano, who found the identifications involving this planet.

\section{(3501) Olegiya}

1971 QU. Discovered 1971 Aug. 18 by T. M. Smirnova at Nauchnyj.

Named in honor of Oleg Nikolaevich Korottsev (1922- ), a member of the Astronomical-Geodetical Society since 1946 and a well-known St. Petersburg popularizer of astronomical knowledge, especially on minor planets and comets. He is the author of a number of astronomical books. (M 22498)

\section{(3502) Huangpu}

$1964 \mathrm{TR}_{1}$. Discovered 1964 Oct. 9 at the Purple Mountain Observatory at Nanking.

Named for Huangpu district, located in the center of Shanghai \{see planet (2197)\}. It is a center for commercial and financial business, as well as foreign trade and culture. (M 21608) 
(3503) Brandt

$1981 \mathrm{EF}_{17}$. Discovered 1981 Mar. 1 by S. J. Bus at Siding Spring.

Named in honor of John C. Brandt of the Laboratory for Atmospheric and Space Physics, University of Colorado, for his fundamental contributions to our understanding of solar system astrophysics. Founder of a "Comet Observatory", Brandt has worked on many aspects of cometary science, particularly the interaction of the solar wind with comets. He was Comet Scientist on the International Cometary Explorer mission, which ushered in a new era of in situ exploration by flying through the tail of Comet Giacobini-Zinner in 1985, and thus represented the only tail interception by any of the Giacobini-Zinner or Halley spacecraft. (M 18452)

Citation provided by J. H. Rahe at the request of the discoverer.

\section{(3504) Kholshevnikov}

$1981 \mathrm{RV}_{3}$. Discovered 1981 Sept. 3 by N. S. Chernykh at Nauchnyj.

Named in honor of the celestial mechanician Konstantin Vladislavovich Kholshevnikov \{1939- \}, professor at Leningrad University. (M 18138)

\section{(3505) Byrd}

1983 AM. Discovered 1983 Jan. 9 by B. A. Skiff at Anderson Mesa.

Named in honor of Deborah Byrd, writer and producer of "Star Date", a radio program that since 1978 has broadcast astronomical news and information over several hundred stations in the United States. Byrd began her career providing public information via telephone messages and brochures for the University of Texas McDonald Observatory. This has progressed to include the popular radio program, a series of brief spots for television and more extensive writing for magazines such as Physics Today, "Highlights for Children", Astronomy and Sky and Telescope. In 1979 she founded the "Texas Star Party" \{see planet (4932)\}, now one of the largest meetings for amateur astronomers in North America, which takes place each year near the McDonald Observatory in west Texas. (M 16443)

Citation provided by D. H. Levy at the request of the discoverer.

\section{(3506) French}

$1984 \mathrm{CO}_{1}$. Discovered 1984 Feb. 6 by E. Bowell at Anderson Mesa.

Named in honor of Linda M. French, planetary scientist at the Department of Earth, Atmospheric and Planetary Sciences of the Massachusetts Institute of Technology. An active teacher, French has encouraged undergraduate research in planetary astronomy by using a hands-on approach to observing and data analysis and by arranging for students to observe at major facilities. Involved in research on the shapes, spin states and surface compositions of small solar-system bodies, she has emphasized the properties of Trojan asteroids in an effort to understand their origins. (M 12805)

Citation prepared by F. Vilas.

\section{(3507) Vilas}

1982 UX. Discovered 1982 Oct. 21 by E. Bowell at Anderson Mesa.

Named in honor of Faith Vilas, planetary scientist at the Johnson Manned Space Center in Houston. Vilas has used high-resolution visual and near-infrared spectral measurements to search for compositional trends among outer-belt minor planets and to investigate the mineralogy of Mercury. She designed and built the coronagraph/spectrograph that was used to image the planetary disk around Beta Pictoris and is currently evaluating the hazard presented by Earth-orbiting debris for future manned missions, including NASA's Space Station. (M 12805)

Citation prepared by M. V. Sykes, with assistance from N. Lebofsky and E. Roemer.

\section{(3508) Pasternak}

$1980 \mathrm{DO}_{5}$. Discovered 1980 Feb. 21 by L. G. Karachkina at Nauchnyj.

Named in memory of Boris Leonidovich Pasternak (1890-1960), famous poet and writer. (M 12017)

Pasternak received the 1958 literature Nobel prize.

\section{(3509) Sanshui}

$1978 \mathrm{UH}_{2}$. Discovered 1978 Oct. 28 at the Purple Mountain Observatory at Nanking.

Named for the Chinese city situated on the delta of the Pearl River. (M 23792)

\section{(3510) Veeder}

1982 TP. Discovered 1982 Oct. 13 by E. Bowell at Anderson Mesa.

Named in honor of Glenn J. Veeder, planetary astronomer at the Jet Propulsion Laboratory. Veeder was chiefly responsible for the initiation of minor planet observations through the $\mathrm{J}, \mathrm{H}$ and $\mathrm{K}$ bandpasses. This work resulted in the identification of new minor planet types and led to a new classification scheme. Veeder is also noted for his work on minor planet radiometry for the determination of diameters and albedos, particularly among the Earth-crossers, and he was in charge of the scientific analysis of the characteristics of the IRAS \{see planet (3728)\} Asteroid and Comet Survey. (M 12805)

Citation prepared by D. L. Matson and L. A. Lebofsky following a suggestion by the discoverer.

\section{(3511) Tsvetaeva}

1982 TC $_{2}$. Discovered 1982 Oct. 14 by L. G. Karachkina and L. V. Zhuravleva at Nauchnyj.

Named in honor of Marina Ivanovna Tsvetaeva (1892-1941), talented Soviet poetess. (M 13176) 


\section{(3512) Eriepa}

1984 AC $_{1}$. Discovered 1984 Jan. 8 by J. F. Wagner at Anderson Mesa.

Named for the discoverer's home town of Erie, Pennsylvania. (M 14481)

\section{(3513) Quqinyue}

1965 UZ. Discovered 1965 Oct. 16 at the Purple Mountain Observatory at Nanking.

Named in honor of Qu Qinyue, professor of astronomy at Nanjing University, known for his research on X-ray and $\gamma$-ray sources and neutron stars, as well as for his contributions to the development of high-energy astrophysics in China. During his twelve years of service as president, he raised the academic standard and reputation of Nanjing University considerably. (M 34619)

\section{(3514) Hooke}

1971 UJ. Discovered 1971 Oct. 26 by L. Kohoutek at Bergedorf.

English experimental scientist Robert Hooke (16351703) is known for his law of elasticity, the spring balance, an escapement for clocks and a Universal Joint commonly used at the end of a propeller shaft. (M 40700)

The name was suggested for this specific minor planet by D. Bowater in the BBC Word of Mouth competition.

\section{(3515) Jindra}

$1982 \mathrm{UH}_{2}$. Discovered 1982 Oct. 16 by Z. Vávrová at Klě̆.

Named in honor of Lumír Jindra (1936- ), an old friend of the discoverer, for his contribution to Czech pharmacology. (M 27125)

\section{(3516) Rusheva}

1982 UH $_{7}$. Discovered 1982 Oct. 21 by L. G. Karachkina at Nauchnyj.

Named in memory of Nadya Rusheva (1952-1969), a talented painter who died in her youth. (M 12017)

\section{(3517) Tatianicheva}

$1976 \mathrm{SE}_{1}$. Discovered 1976 Sept. 24 by N. S. Chernykh at Nauchnyj.

Named in memory of the lyric poetess Lyudmila Konstantinovna Tatianicheva (1915-1980). (M 20835)

\section{(3518) Florena}

1977 QC $_{4}$. Discovered 1977 Aug. 18 by N. S. Chernykh at Nauchnyj.

Named in memory of Pavel Aleksandrovich Florenskij (1882-1943), well-known Russian religious philosopher, physicist and mathematician. The name also honors his son, Kirill Pavlovich Florenskij (1915-1982), geochemist and mineralogist. (M 22498)

Obituary (K.P.F.) published in Icarus, Vol. 61, No. 3, p. 351-354 (1985).
(3519) Ambiorix

1984 DO. Discovered 1984 Feb. 23 by H. Debehogne at La Silla.

Named for Ambiorix, chief of the Eburons, an ancient Belgian tribe. Ambiorix revolted against the occupying forces under Julius Caesar and was pursued and killed in the forest. There is a statue of Ambiorix in the town of Tongres. (M 23792)

\section{(3520) Klopsteg}

1952 SG. Discovered 1952 Sept. 16 at the Goethe Link Observatory at Brooklyn, Indiana.

Named in memory of Paul E. Klopsteg (1889-1991), who died on 1991 Apr. 28, a month before his 102nd birthday. He left Northwestern University in 1951 to become the National Science Foundation's first assistant director for mathematical, physical and engineering sciences. He was appointed to the new position of associate director in 1952 and retired in 1958. His many honors include election as president of the American Association for the Advancement of Science in 1959, two medals and an award from three different archery organizations and membership in the Archery Hall of Fame. During his time at the National Science Foundation he played an important role in the planning for the National Radio Astronomy Observatory and the Kitt Peak National Observatory. (M 18305)

Name proposed by F. K. Edmondson.

\section{(3521) Comrie}

1982 MH. Discovered 1982 June 26 by A. C. Gilmore and P. M. Kilmartin at Lake Tekapo.

Named in memory of Leslie John Comrie (1893-1950), New Zealand-born innovator in computational science and authority on the production of mathematical tables. Superintendent of the British Nautical Almanay Office for six years from 1930, he applied calculating machines to astronomical computing. As president of IAU Commission 4 (Ephemerides) he initiated the annual Apparent Places of Fundamental Stars and saw adopted his earlier proposal for the use of standard equinoxes, the first being 1950. Though resident in Britain for most of his working life he actively fostered and assisted astronomy in New Zealand. (M 18306) Comrie is also honored by a lunar crater.

\section{(3522) Becker}

1941 SW. Discovered 1941 Sept. 21 by Y. Väisälä at Turku.

Named for Reinhold von Becker (1788-1858), a member of the old Academia Aboensis from 1813 onward. The weekly Turun Viikkosanomat, which he began publishing in 1820 , had an essential influence on the evolution of the Finnish literary language. (M 18452)

\section{(3523) Arina}

1975 TV $_{2}$. Discovered 1975 Oct. 3 by L. I. Chernykh at Nauchnyj. 
Named for Arina Rodionova Yakovleva (1758-1828), the nurse of A. S. Pushkin \{see planet (2208)\}. (M 13481)

\section{(3524) Schulz}

$1981 \mathrm{EE}_{27}$. Discovered 1981 Mar. 2 by S. J. Bus at Siding Spring.

Named in honor of Charles M. Schulz (1922- ), cartoonist and creator of the syndicated comic strip "Peanuts". Since 1950, Charlie Brown, Snoopy and the rest of the Peanuts gang have reminded us of the innocent, though sometimes frustrating, experiences of childhood. Through tireless devotion to his work, Schulz has managed to capture the hearts of both young and old, making Peanuts one of the most celebrated and enduring comic strips of all time. (M 27125)

\section{(3525) Paul}

$1983 \mathrm{CX}_{2}$. Discovered 1983 Feb. 15 by N. G. Thomas at Anderson Mesa.

Named in honor of Paul J. Baltutis, son-in-law of the discoverer. (M 12017)

\section{(3526) Jeffbell}

1984 CN. Discovered 1984 Feb. 5 by E. Bowell at Anderson Mesa.

Named in honor of Jeffrey F. Bell, planetary astronomer at the University of Hawaii, Honolulu. Bell has contributed greatly to our understanding of the composition of minor planets and to their relationship with meteorites. He was responsible for the 0.3 to 2.5 micrometer 52-color minor planet survey, which has led to the spectral characterization of more than 100 minor planets. Recently, he has proposed that the CV and $\mathrm{C} 0$ chondrite meteorites may be derived from Eos \{see planet (221)\} family members. (M 12805)

Citation prepared by L. A. Lebofsky following a suggestion by the discoverer.

\section{(3527) McCord}

$1985 \mathrm{GE}_{1}$. Discovered 1985 Apr. 15 by E. Bowell at Anderson Mesa.

Named in honor of Thomas B. McCord, planetary scientist at the University of Hawaii, Honolulu. McCord developed reflection spectroscopy as a means of probing the mineralogical composition of planetary surfaces and played a major role in early applications of this technique to minor planets and the Moon. (M 12805)

Citation prepared by J. F. Bell at the request of the discoverer.

\section{(3528) Counselman}

$1981 \mathrm{EW}_{3}$. Discovered 1981 Mar. 2 by S. J. Bus at Siding Spring.

Named in honor of Charles C. Counselman III (1943-

), professor of planetary science at the Massachusetts Institute of Technology. As a scientist involved with the Pioneer Venus mission, he used interferometric measurements of the spacecraft multiprobes to deduce the vertical distribution of Venusian wind velocities. More recently, he has pioneered the use of Global
Positioning System satellites to achieve very high precision geodetic measurements of the surface of the earth. Counselman is also a dedicated teacher and is particularly devoted to student advising and the instruction of planetary astronomy laboratory courses. (M 27125)

Citation prepared by R. P. Binzel.

\section{(3529) Dowling}

1981 EQ $_{19}$. Discovered 1981 Mar. 2 by S. J. Bus at Siding Spring.

Named in honor of Timothy E. Dowling, professor of planetary science at the Massachusetts Institute of Technology. An expert in the dynamics of the atmospheres of the giant planets, Dowling determined a relationship between potential vorticity and the zonal wind on Jupiter and developed explicit planetary isentropic-coordinate models for Jupiter, Saturn, Uranus and Neptune. He is also a dedicated teacher of planetary science at the undergraduate and graduate levels. (M 27125) Citation prepared by R. P. Binzel.

\section{(3530) Hammel}

$1981 \mathrm{EC}_{20}$. Discovered 1981 Mar. 2 by S. J. Bus at Siding Spring.

Named in honor of Heidi Beth Hammel, planetary scientist at the Massachusetts Institute of Technology. An indefatigable observer of the atmospheres of the outer planets, she is best known for her long-term monitoring of Neptune. As an expert in planetary imaging, she was selected as the team leader for the Hubble Space Telescope project to observe the consequences of the July 1994 Jupiter impact by comet D/1993 F2 (Shoemaker-Levy 9). Hammel also devotes substantial effort to public education and is a great communicator of the excitement of planetary science. (M 27125)

Citation prepared by J. l. Elliot and R. P. Binzel.

\section{(3531) Cruikshank}

1981 FB. Discovered 1981 Mar. 30 by E. Bowell at Anderson Mesa.

Named in honor of Dale P. Cruikshank, planetary scientist at the University of Hawaii, Honolulu. Cruikshank is well known for his observational work on solar system small bodies, including Trojan asteroids, comets and Pluto. He is especially known for studies of outer-planet satellites, including Triton, Iapetus and Io, through both telescopic and Voyager spacecraft observations. He has been active in developing instrumentation and facilities at Mauna Kea Observatory and has promoted historical studies of planetary science. Through several extended working visits to the Soviet Union and other projects, Cruikshank has also been a leader in furthering international scientific relations. (M 12806)

Citation prepared by W. K. Hartmann and D. J. Tholen at the request of the discoverer. 


\section{(3532) Tracie}

$1983 \mathrm{AS}_{2}$. Discovered 1983 Jan. 10 by G. Ojakangas and K. Herkenhoff at Palomar.

Named in honor of Tracie Lynn Ojakangas, wife of one of the co-discoverers. (M 11751)

\section{(3533) Toyota}

1986 UE. Discovered 1986 Oct. 30 by K. Suzuki and T. Urata at Toyota.

Named for the city in central Japan, home of the first discoverer and known throughout the world for its car industry. (M 12211)

\section{(3534) Sax}

1936 XA. Discovered 1936 Dec. 15 by E. Delporte at Uccle.

Named in memory of Adolphe Sax (1814-1894), inventor of the saxophone. (M 12211)

\section{(3535) Ditte}

$1979 \mathrm{SN}_{11}$. Discovered 1979 Sept. 24 by N. S. Chernykh at Nauchnyj.

Named for the principal heroine of Ditte, a human child, a novel by the Danish writer Martin Andersen Nex\{ø\} (1869-1954). (M 18138)

\section{(3536) Schleicher}

$1981 \mathrm{EV}_{20}$. Discovered 1981 Mar. 2 by S. J. Bus at Siding Spring.

Named in honor of David G. Schleicher of the Lowell Observatory for his many contributions to the physical study of comets. An enthusiastic observer, Schleicher has pursued spectroscopic and spectrophotometric investigations of cometary comae using a variety of ground-based telescopes and the International Ultraviolet Explorer satellite. Theseies of comets and the identification of a number of peculiar objects with clearly anomalous relative abundances. Schleicher played a key role in the discovery of Comet Halley's periodic variability and in the subsequent interpretation of this behavior in terms of nuclear rotation. In addition to his observational research, Schleicher's detailed calculation of the fluorescence efficiency of $\mathrm{OH}$ has been extremely important to the analysis of cometary spectra. (M 18452)

Citation provided by R. L. Millis at the request of the discoverer.

\section{(3537) Jürgen}

1982 VT. Discovered 1982 Nov. 15 by E. Bowell at Anderson Mesa.

Named in honor of Jürgen Rahe \{1939-1997\}, planetary scientist. Rahe was director of the Dr. Remeis Sternwarte and the Astronomisches Institut der Universität Erlangen-Nürnberg, and is discipline scientist in the planetary science branch of NASA's Solar System Exploration Division. He is co-leader of the International Halley Watch and has been for a long time associated with the work of IAU Commission 15. While he has worked in a number of fields of astrophysics, Rahe is especially noted for his work on comets, both from the ground and with the International Ultraviolet Explorer, as well as for his two atlases of cometary morphology. His diplomatic leadership in the IAU and the IHW has been particularly important in projects requiring international cooperation. (M 12973)

Citation prepared by R. L. Newburn and S. J. Edberg at the request of the discoverer.

Obituaries published in Icarus, Vol. 131, No. 1, p. 1-3 (1998); Phys. Today, Vol. 50, No. 12, p. 92 (1997); Int. Comet Q., Vol. 19, No. 3, p. 154-155 (1987).

\section{(3538) Nelsonia}

6548 P-L. Discovered 1960 Sept. 24 by C. J. van Houten and I. van Houten-Groeneveld at Palomar.

Named in honor of Elisabeth Nelson, former secretary of the Landessternwarte and the Max-Planck-Institut für Astronomie, both at Heidelberg. She took care of the investigators of the Palomar-Leiden Survey during the blinking of the survey plates in Heidelberg. (M 16591)

\section{(3539) Weimar}

$1967 \mathrm{GF}_{1}$. Discovered 1967 Apr. 11 by F. Börngen at Tautenburg.

Named for the venerable town, $30 \mathrm{~km}$ from Tautenburg \{see planet (2424)\}, renowned for its contributors (Goethe, Schiller \{see planets (3047) and (3079)\} and others) to 'classical' German literature around the end of the eighteenth century and the home of several famous musicians and painters. The town is also known for the Weimar Republic (1919) and the Weimar Constitution. (M 12017)

\section{(3540) Protesilaos}

1973 UF $_{5}$. Discovered 1973 Oct. 27 by F. Börngen at Tautenburg.

Named for the first Greek warrior to jump to the shore in the landing at Asia Minor in the Trojan war. He died at the hand of Aeneas \{see planet (1172)\}. (M 11751)

\section{(3541) Graham}

1984 ML. Discovered 1984 June 18 by V. M. Candy and M. P. Candy at Bickley.

Named in honor of Lloyd Wilson Graham (1940-

), executive director of the department of state services, for his sympathetic support of the Perth Observatory in 1987, a difficult time in its history. He was also instrumental in the formation of the Perth Astronomy Research Group, which includes staff from the observatory and three local tertiary institutions. (M 20520)

\section{(3542) Tanjiazhen}

$1964 \mathrm{TN}_{2}$. Discovered 1964 Oct. 9 at the Purple Mountain Observatory at Nanking.

Named in honor of Tan Jiazhen (1909- ), professor at Fudan University and considered the founder of 
genetics in China. His creative work leading to the discovery of the mosaic-dominance phenomenon in the color-pattern inheritances of the ladybug and of the role of chromosomal rearrangements and gene changes in Drosophila speciation were recognized as outstanding contributions to the development of classical gene theory and the modern synthetic theory of evolution. (M 34619)

\section{(3543) Ningbo}

$1964 \mathrm{VA}_{3}$. Discovered 1964 Nov. 11 at the Purple Mountain Observatory at Nanking.

Named for the historic Chinese port city, birthplace of the Neolithic Hemudu culture, dating back 7000 years and symbolized by oars and rice. It is also a birthplace of modern Chinese industry. (M 32787)

\section{(3544) Borodino}

$1977 \mathrm{RD}_{4}$. Discovered 1977 Sept. 7 by N. S. Chernykh at Nauchnyj.

Named for a village not far from Moscow where there was a fierce battle between the Russians and Napoleon's troops in 1812. (M 21130)

\section{(3545) Gaffey}

$1981 \mathrm{WK}_{2}$. Discovered 1981 Nov. 20 by E. Bowell at Anderson Mesa.

Named in honor of Michael J. Gaffey, planetary scientist at the Rensselaer Polytechnic Institute. His pioneering and comprehensive study of the spectra of meteorites has become the principal resource in interpreting minor planet spectra. More recently, he has demonstated that careful spectrophotometry can resolve geological units on minor planet surfaces. (M 12806)

Citation prepared by J. F. Bell at the request of the discoverer.

\section{(3546) Atanasoff}

1983 SC. Discovered 1983 Sept. 28 by E. F. Helin and V. G. Shkodrov and V. G. Ivanova and A. Georgieva at Rozhen.

Named in honor of the mathematician John Atanasoff (1903-1995), a pioneer in the development of computers who between 1936 and 1942 created an operating model with regenerative memory that utilized a magnetic drum and some relay logical schemes. At the same time he lectured on mathematics and physics at Iowa State University. Atanasoff, whose father was a Bulgarian, has been a member of the Bulgarian Academy of Sciences since 1983. (M 12806)

\section{(3547) Serov}

$1978 \mathrm{TM}_{6}$. Discovered 1978 Oct. 2 by L. V. Zhuravleva at Nauchnyj.

Named in memory of Valentin Alexandrovich Serov (1865-1911), a famous Russian painter. (M 24120)

\section{(3548) Eurybates}

1973 SO. Discovered 1973 Sept. 19 by C. J. van Houten and I. van Houten-Groeneveld at Palomar.

Eurybates was a herald in the Greek army during the siege of Troy. (M 18138)

\section{(3549) Hapke}

1981 YH. Discovered 1981 Dec. 30 by E. Bowell at Anderson Mesa.

Named in honor of Bruce W. Hapke, planetary scientist at the University of Pittsburgh. A pioneer investigator of the physical and chemical nature of the surfaces of minor planets, he was one of the first to recognize the division of minor planets into two principal color classes (later known as $\mathrm{C}$ and $\mathrm{S}$ types) on the basis of UBV photometry. More recently, he has developed a comprehensive theoretical treatment of the scattering of sunlight in planetary regoliths. (M 12806)

Citation prepared by J. F. Bell at the request of the discoverer.

\section{(3550) Link}

1981 YS. Discovered 1981 Dec. 20 by A. Mrkos at Kleť.

Named in memory of František Link (1906-1984), founder and for ten years director of the modern astrophysical observatory at Ondřejov and a specialist in solar astronomy, high-atmosphere physics and the study of interplanetary matter. (M 26424)

Obituaries published in Rise hvezd, Vol. 65, No. 11, p. 238 (1984); Earth, Moon, Planets, Vol. 35, No. 3, p. 201-202 (1986).

\section{(3551) Verenia}

1983 RD. Discovered 1983 Sept. 12 by R. S. Dunbar at Palomar.

Named for the first vestal virgin consecrated by the legendary Roman king Numa Pompilius, builder of the temple of Vesta \{see planet (4)\}, in the eighth to seventh centuries B.C. This Amor object is the first V-Type (Vesta) asteroid known after (4) Vesta itself. It was under consideration for a flyby mission by the Clementine spacecraft in October 1995. (M 23540; M 23697)

\section{(3552) Don Quixote}

1983 SA. Discovered 1983 Sept. 26 by P. Wild at Zimmerwald.

Named for the hero of Cervantes' \{1547-1616\} great romance, the Knight of the Sorrowful Countenance, the noble-minded eccentric who tries, in strange ways and in vain, to bring back the Age of Chivalry. The naming of this object is rather obvious, given the long-term erratic nature of the extended orbit, comparable to that of (944) Hidalgo. (M 17466)

\section{(3553) Mera}

1985 JA. Discovered 1985 May 14 by C. S. Shoemaker and E. M. Shoemaker at Palomar. 
Named for a daughter of Praetus. She was a follower of Artemis \{see planet (105)\} and was killed by the goddess for having given herself to Zeus ssee planet (5731)\}. Before dying, she gave birth to Locri, ancestor of the Locrians. (M 11751)

\section{(3554) Amun}

1986 EB. Discovered 1986 Mar. 4 by C. S. Shoemaker and E. M. Shoemaker at Palomar.

Named for the invisible or hidden god of Hermopolis, who later became the local god of Thebes and then the king of the gods of the Egyptian empire. Great temples at Karnak and Luxor were dedicated to Amun. (M 11751)

\section{(3555) Miyasaka}

$1931 \mathrm{TC}_{1}$. Discovered 1931 Oct. 6 by K. Reinmuth at Heidelberg.

Named in honor of Seidai Miyasaka (1955- ), an active observer of minor planets and one of the few observers in Japan who devote themselves to follow-up observations. He has observed many minor planets so that they could be numbered. (M 18644)

Name proposed by T. Kobayashi, who found the identifications involving this minor planet, and with whom Miyasaka has been collaborating for many years.

\section{(3556) Lixiaohua}

1964 UO. Discovered 1964 Oct. 30 at the Purple Mountain Observatory at Nanking.

Named in honor of Li Xiaohua, a young industrialist in Beijing whose concern for education led him to establish middle and primary schools in remote villages and mountain districts of China. (M 26424)

\section{(3557) Sokolsky}

1977 QE $_{1}$. Discovered 1977 Aug. 19 by N. S. Chernykh at Nauchnyj.

Named in honor of Andrej Georgievich Sokolskij, director of the Institute of Theoretical Astronomy in St. Petersburg, known for his work on the theory of periodic and quasiperiodic solutions of Hamiltonian systems. As founder and executive director of the International Institute for Problems of the Asteroid Hazard he is much involved in the current international interest in Near-Earth asteroids. (M 20835)

\section{(3558) Shishkin}

1978 SQ $_{2}$. Discovered 1978 Sept. 26 by L. V. Zhuravleva at Nauchnyj.

Named in memory of Ivan Ivanovich Shishkin (1832-1898), a well-known Russian painter. (M 24120)

\section{(3559) Violaumayer}

1980 PH. Discovered 1980 Aug. 8 by E. Bowell at Anderson Mesa.

Named for the village Violau in Bavaria and in honor of Martin Mayer, who there directs the "Bruder-KlausHeim", a Catholic educational center. Known for his enthusiastic and didactic style of teaching astronomy,
Mayer has erected a well-equipped observatory to show the beauty of the universe to his guests and to the public. International Astronomical Youth Camps and conventions of the German Planetary Observers, a group of amateur astronomers, have been held in Violau. (M 12806)

Name suggested and citation prepared by C. M. Schambeck and G. Marxer.

\section{(3560) Chenqian}

$1980 \mathrm{RZ}_{2}$. Discovered 1980 Sept. 3 at the Purple Mountain Observatory at Nanking.

Named in honor of Chen Qian, director of the History Museum of Chinese Astronomy for some years and a great contributor to the popularization of astronomy in China. (M 26424)

\section{(3561) Devine}

1983 HO. Discovered 1983 Apr. 18 by N. G. Thomas at Anderson Mesa.

Named in honor of John Devine Hazelton, son-in-law of the discoverer and grandson of Colonel John Devine, who was with the forces under General Gordon at Khartoum. (M 12017)

\section{(3562) Ignatius}

1984 AZ. Discovered 1984 Jan. 8 by J. F. Wagner at Anderson Mesa.

Named in honor of the 500th anniversary of the birth of Ignatius Loyola (1491-1556) \{see also planet (3589)\}, founder of the Jesuits. (M 17028)

\section{(3563) Canterbury}

1985 FE. Discovered 1985 Mar. 23 by A. C. Gilmore and P. M. Kilmartin at Lake Tekapo.

Named for the province of New Zealand on the eastern side of the South Island. The name also honors Canterbury University, based in the city of Christchurch, of which Mount John University Observatory is a field station. The region was named after the Canterbury Association formed in England in 1848 with the purpose of organizing an idealized Anglican settlement in New Zealand. (M 18306)

\section{(3564) Talthybius}

$1985 \mathrm{TC}_{1}$. Discovered 1985 Oct. 15 by E. Bowell at Anderson Mesa.

Named for the chief herald of the Greek forces in the Trojan war. (M 12459)

\section{(3565) Ojima}

1986 YD. Discovered 1986 Dec. 22 by T. Niijima and T. Urata at Ojima.

Named for the small town in the central Japan where the observing station is located. Known for the manufacture of Japanes dolls, Ojima is the home of the first discoverer. It is close to the 1828-m volcano Agaki and the river Tone see planet (1266)\}. (M 12211) 


\section{(3566) Levitan}

1979 YA. Discovered 1979 Dec. 24 by L. V. Zhuravleva at Nauchnyj.

Named in memory of Isaac Il'ich Levitan (1860-1900), a famous Russian landscape painter. (M 24120)

\section{(3567) Alvema}

1930 VD. Discovered 1930 Nov. 15 by E. Delporte at Uccle.

Named for the three great-granddaughters of the discoverer, Aline De Middelaer, and Véronique and Martine Warck. (M 25652)

Name proposed by M. De Middelaer-Delporte and endorsed by J. Denoyelle, who prepared the citation.

\section{(3568) ASCII}

1936 UB. Discovered 1936 Oct. 17 by M. Laugier at Nice.

Named for the computer character code, which is also the name of the principal magazine on microcomputers in Japan. (M 12973)

Name proposed by S. Nakano, who found the identifications involving this planet and whose stay at the Smithsonian Astrophysical Observatory has partly been supported by articles written for this magazine.

ASCII is the acronym for American Standard Code for Information Interchange.

\section{(3569) Kumon}

$1938 \mathrm{DN}_{1}$. Discovered 1938 Feb. 20 by K. Reinmuth at Heidelberg.

Named in honor of Toru Kumon, a pioneer in the education of children in Japan and founder of the Kumon Education Research Center in Osaka. (M 12973)

Name proposed by S. Nakano, who found the identification involving this planet, and whose stay at the Smithsonian Astrophysical Observatory has been partly supported by the Kumon Center.

\section{(3570) Wuyeesun}

1979 XO. Discovered 1979 Dec. 14 at the Purple Mountain Observatory at Nanking.

Named in honor of $\mathrm{Wu}$ Yeesun, a famous bonsai artist, who has been engaged in research on the art of bonsai for many years and who is regarded as a representative of the Lingnan School. His book Potted Landscape of Wennong, published in 1969, is the most highly regarded Chinese-English bilingual volume on the subject, and it has exerted a great influence in the bonsai art circles of the world. (M 32787)

\section{(3571) Milanštefánik}

1982 EJ. Discovered 1982 Mar. 15 by A. Mrkos at Klě̌t.

Named in memory of Milan Rastislav Štefánik (18801919), astronomer and meteorologist. He worked at Meudon Observatory during 1905-1907 and proposed to build a new observatory on the island of Tahiti.
He received the Janssen award in 1907 and the Wilde award in 1911. (M 25976)

\section{(3572) Leogoldberg}

$1954 \mathrm{UJ}_{2}$. Discovered 1954 Oct. 28 at the Goethe Link Observatory at Brooklyn, Indiana.

Named in memory of Leo Goldberg (1913-1987), one of the three incorporators of the Association of Universities for Research in Astronomy on 1957 Oct. 28, exactly three years after the discovery of this minor planet. Having begun work in solar physics as a student of Donald H. Menzel \{see planet (1967)\}, he served as director of the University of Michigan's observatory from 1946 to 1960, after which he moved to Harvard University and succeeded Menzel as director of the Harvard College Observatory in 1966. He became the third director of the Kitt Peak National Observatory in 1971 and retired in 1977. He was president of the American Astronomical Society during 1964-1966 and of the International Astronomical Union during 1973-1976. (M 19333)

Name proposed by B. G. Marsden with the concurrence of F. K. Edmondson, who prepared the citation.

Obituaries published in Phys. Today, Vol. 43, No. 2, p. 146-148 (1990); IAU Today (20th General Assembly, Baltimore, 1988), No. 1, p. 4 (1988).

\section{(3573) Holmberg}

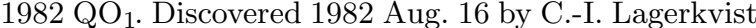
at La Silla.

Named in honor of the Swedish astronomer Erik Holmberg \{1909-2000\} on the occasion of his eightieth birthday. Internationally renowned for his pioneering work on galaxies, paricularly multiple galaxies, Holmberg served as an assistant and associate professors at Lund during 1937-1951 and as professor at Uppsala and director of the Uppsala Observatory during 1959-1975. Holmberg was an inspiring teacher, and the discoverer is very grateful to him for allowing a young student to start work on minor planets, until then an almost unknown topic for research in Uppsala. (M 12973)

Obituary published in Astron. Tidskr., Jrgg. 1, Nr. 2, p. 37 (2000).

\section{(3574) Rudaux}

1982 TQ. Discovered 1982 Oct. 13 by E. Bowell at Anderson Mesa.

Named for Lucien Rudaux (1874-1947), French astronomical painter, writer and amateur astronomer. Rudaux is considered the grandfather of astronomical art. He maintained his own observatory at Donville and used his observations of mountain profiles on the lunar limb to argue that lunar mountains are rounded. His lunar paintings and articles, from about 1910 onward, correctly described lunar topography, whereas the popular misconception was of spiky crags. His paintings also showed various aspects of other planets, satellites, the zodiacal light and comets, using the best 
available data. His writings include many illustrated articles about astronomy and space travel and the book Sur les Autres Mondes (1937). (M 12807)

Name suggested and citation prepared by W. K. Hartmann.

\section{(3575) Anyuta}

$1984 \mathrm{DU}_{2}$. Discovered 1984 Feb. 26 by N. S. Chernykh at Nauchnyj.

Named in honor of the outstanding sportswoman and pioneer Soviet parachutist Anna Aleksandrovna Shishmareva. See also the citation for planet (3576). (M 18138)

\section{(3576) Galina}

1984 DB $_{3}$. Discovered 1984 Feb. 26 by N. S. Chernykh at Nauchnyj.

Named in honor of Galina Bogdanova Pyasetskaya, who with Anna Shishmareva ssee planet (3575)\} accomplished in 1935 a twin parachute jump from an altitude of 7923 meters without oxygen equipment. (M 18138)

\section{(3577) Putilin}

1969 TK. Discovered 1969 Oct. 7 by L. I. Chernykh at Nauchnyj.

Named in memory of Ivan Ivanovich Putilin (18931954), assistant professor at the Kiev State University, known mainly for his works on minor planets. He observed minor planets and computed their orbits. His book Malye planety was for many years a reference source for observers and other researchers on minor planets. (M 18452)

\section{(3578) Carestia}

1977 CC. Discovered 1977 Feb. 11 at the Felix Aguilar Observatory at El Leoncito.

Named in memory of Reinaldo Augusto Carestia (1932-1993) outstanding researcher who was, for more than 26 years, in charge of the Repsold Meridian Circle at the Felix Aguilar Observatory in San Juan, Argentina. He published five fundamental catalogues listing about 10,000 stars. He was also a professor of spherical astronomy and geographic determinations at the School of Topography of the National University of San Juan, as well as a member of the National Committee of Scientific and Technological Research of Chile. (M 24120)

\section{(3579) Rockholt}

1977 YA. Discovered 1977 Dec. 18 by M. Lovas at Piszkéstetö.

The lifelong affection of Ronald Rockholt Sr. (1928-

) for the stars led him to pursuits in aviation, rocketry, telescope making and astronomy. Most importantly, he is recognized for inspiring two generations of rural California students to love science through his innovative, hands-on teaching. (M 41381)

The name was suggested by K. Beatty.

\section{(3580) Avery}

$1983 \mathrm{CS}_{2}$. Discovered 1983 Feb. 15 by N. G. Thomas at Anderson Mesa.

Named for the discoverer's grandson Avery Jordan Thomas, who was born 1994 March 4. (M 23540)

\section{(3581) Alvarez}

1985 HC. Discovered 1985 Apr. 23 by C. S. Shoemaker and E. M. Shoemaker at Palomar.

Named in honor of Luis W. Alvarez \{1911-1988\}, physicist and Nobel laureate, and his son Walter Alvarez, geologist, both on the faculty of the University of California at Berkeley. The Alvarezes headed a team that discovered a global geochemical anomaly of noble metals at the Cretaceous-Tertiary boundary. They propounded the theory that a mass extinction of living species at the end of the Cretaceous period was triggered by impact of an asteroid or a comet about $10 \mathrm{~km}$ in diameter. Their work has stimulated intensive international research on the possible relationships between large body impacts and the evolution of life. (M 12807)

Obituary (L.W.A.) published in Phys. Bl., Jahrg. 45, Heft 1, p. 29 (1989).

\section{(3582) Cyrano}

$1986 \mathrm{TT}_{5}$. Discovered 1986 Oct. 2 by P. Wild at Zimmerwald.

Named for the whimsical French poet and soldier Cyrano de Bergerac (1619-1655), who in some of his comedies made brisk use of fanciful ways of spaceflight. (M 22498)

\section{(3583) Burdett}

1929 TQ. Discovered 1929 Oct. 5 by C. W. Tombaugh at Flagstaff.

Named for the discoverer's home town in Kansas \{see planet (3124)\}. (M 12018)

\section{(3584) Aisha}

1981 TW. Discovered 1981 Oct. 5 by N. G. Thomas at Anderson Mesa.

Named for the discoverer's granddaughter Aisha Renee Thomas, who was born 1991 June 13. (M 23540)

\section{(3585) Goshirakawa}

1987 BE. Discovered 1987 Jan. 28 by T. Niijima and T. Urata at Ojima.

Named for the 77th emperor of Japan, Goshirakawa (1127-1192), who reigned from 1155 to 1158 . He influenced five later emperors and managed to keep the authority of the imperial household during a period of increasing military power of the Genji and the Heike. (M 30798)

Name proposed by the second discoverer.

\section{(3586) Vasnetsov}

$1978 \mathrm{SW}_{6}$. Discovered 1978 Sept. 26 by L. V. Zhuravleva at Nauchnyj.

Named in memory of Viktor Mikhailovich Vasnetsov (1848-1926) and Apollinarij Mikhailovich Vasnetsov 
(1856-1933), famous Russian painters. (M 22245; M 26439)

\section{(3587) Descartes}

$1981 \mathrm{RK}_{5}$. Discovered 1981 Sept. 8 by L. V. Zhuravleva at Nauchnyj.

Named in honor of René Descartes (1596-1650), outstanding French mathematician and philosopher. (M 22245)

Descartes is also honored by a lunar crater.

\section{(3588) Kirik}

$1981 \mathrm{TH}_{4}$. Discovered 1981 Oct. 8 by L. I. Chernykh at Nauchnyj.

Named for Kirik Novgorodets, a twelfth-century chronicler from the town of Novgorod, author of the first Russian treatise on the luni-solar calendar. "The First Novgorod Chronicle" contains many of his remarks about the various astronomical events he observed. (M 13481)

\section{(3589) Loyola}

$1984 \mathrm{AB}_{1}$. Discovered 1984 Jan. 8 by J. F. Wagner at Anderson Mesa.

Named for the town in Spain, birthplace of Ignatius \{see planet (3562)\}, founder of the Jesuits. (M 17028)

\section{(3590) Holst}

1984 CQ. Discovered 1984 Feb. 5 by E. Bowell at Anderson Mesa.

Named for English composer Gustav Holst (18741934). One of Holst's best-known and most popular compositions is the symphonic suite The Planets, written between 1914 and 1916. The titles of the seven movements are taken from the name of the seven major planets (excluding the Earth) known at the time the piece was written. Although the ideas for the scores are based on the astrological character of each planet, the work is nevertheless enjoyed by astronomers throughout the world. (M 12807)

Name suggested and citation provided by D. J. Tholen.

\section{(3591) Vladimirskij}

1978 QJ $_{2}$. Discovered 1978 Aug. 31 by N. S. Chernykh at Nauchnyj.

Named in honor of Boris Mikhajlovich Vladimirskij, astronomer at the Crimean Astrophysical Observatory since 1958, well known for his researches in various fields of astronomy, especially high-energy astrophysics and solar-terrestrial relations. (M 20836)

\section{(3592) Nedbal}

1980 CT. Discovered 1980 Feb. 15 by Z. Vávrová at Klèt.

Named in memory of the Czech composer and conductor Oskar Nedbal (1874-1930). (M 16443)

\section{(3593) Osip}

$1981 \mathrm{~EB}_{20}$. Discovered 1981 Mar. 2 by S. J. Bus at Siding Spring.
Named in honor of David J. Osip. As an undergraduate at the Massachusetts Institute of Technology, Osip was involved in a number of projects concerning solar system occultation research, including both lunar occultations and the prediction of occultations of stars by Saturn's rings. In his current role as a research assistant at Lowell Observatory, he has taken part in asteroid occultation chases and has participated in an extensive program of cometary research. This research has involved the observation of comets using both photoelectric photometry and CCD imaging. (M 18452)

Citation provided by D. G. Schleicher at the request of the discoverer.

\section{(3594) Scotti}

1983 CN. Discovered 1983 Feb. 11 by E. Bowell at Anderson Mesa.

Named in honor of James V. Scotti \{1960- $\}$ of the University of Arizona, Tucson. Scotti works with the SPACEWATCH see planet (4255)\} Telescope, which is the $0.9-\mathrm{m}$ reflector of the Steward Observatory on Kitt Peak. He has developed most of the system's software and has carried out final checks and data reduction for the CCD scanning observations of comets and minor planets. (M 12211)

\section{(3595) Gallagher}

$1985 \mathrm{TF}_{1}$. Discovered 1985 Oct. 15 by E. Bowell at Anderson Mesa.

Named in honor of John S. Gallagher III, director of Lowell Observatory. Gallagher's particular devotion to astronomy has been manifest in his service to the community, energetic and productive research, and teaching. He is a council member of the American Astronomical Society, is an editor of the Astrophysical Journal and has served on numerous committees and boards. His research has included work on luminous stars, novae, a broad variety of extragalactic problems, and cosmology. With a colleague, he discovered the ultraviolet output of novae and developed a method to evaluate star-formation rates at different stages in the evolution of galaxies. (M 12807)

Citation prepared by D. A. Hunter at the request of the discoverer.

\section{(3596) Meriones}

1985 VO. Discovered 1985 Nov. 14 by P. Jensen and K. Augustesen at Brorfelde.

Named for the Greek warrior, who with Idomeneus \{see planet (2759)\} was leader of the Cretans, and who achieved distinction in the Trojan War, especially in the Battle of the Ships. (M 12211)

\section{(3597) Kakkuri}

1941 UL. Discovered 1941 Oct. 15 by L. Oterma at Turku.

Named in honor of Juhani Kakkuri, since 1977 director of the Finnish Geodetic Institute, interested also in astronomy. He developed for practical use the 
stellar triangulation method first presented by Väisälä \{see planet (1573)\}. The Institute measured and still measures standard baselines in various continents using the Väisälä interference method. (M 18453)

\section{(3598) Saucier}

$1977 \mathrm{KK}_{1}$. Discovered 1977 May 18 by E. S. Bus at Palomar.

Named in honor of Agnes Elizabeth Saucier, grandmother of the discoverer. (M 12018)

\section{(3599) Basov}

1978 PB $_{3}$. Discovered 1978 Aug. 8 by N. S. Chernykh at Nauchnyj.

Named in honor of the contemporary physicist Nikolaj Gennadievich Basov \{1922- $\}$, Nobel Prize Laureate \{in 1964, with A. M. Prochorow ssee planet (7269) $\}$ and C. H. Townes and one of the founders of quantum electronics. (M 22498)

\section{(3600) Archimedes}

1978 SL7. Discovered 1978 Sept. 26 by L. V. Zhuravleva at Nauchnyj.

Named for Archimedes (c. 287-212 B.C.), great ancient Greek scientist. (M 22245)

Archimedes is also honored by a lunar crater.

\section{(3601) Velikhov}

1979 SP $_{9}$. Discovered 1979 Sept. 22 by N. S. Chernykh at Nauchnyj.

Named in honor of Evgenij Pavlovich Velikhov, member of the Russian Academy of Sciences, renowned for his research in plasma physics, magnetohydrodynamics and controllable thermonuclear synthesis. He is the president of the International Center for Scientific Culture-World Laboratory. (M 20836)

\section{(3602) Lazzaro}

$1981 \mathrm{DQ}_{2}$. Discovered 1981 Feb. 28 by S. J. Bus at Siding Spring.

Named in honor of Daniela Lazzaro (1956- ), an expert on the dynamics of planetary satellites at the Observatório Nacional, Rio de Janeiro. She has worked on the dynamics of the $\beta$ Pictoris system, and in 1993 she began working on the physical properties of minor planets and comets. Lazzaro is playing an important role in developing a researh group of planetary scientists in Brazil. (M 27458)

Name suggested and citation provided by M. A. Barucci.

\section{(3603) Gajdušek}

1981 RM. Discovered 1981 Sept. 5 by L. Brožek at Klět.

Named in memory of Vilém Gajdušek (1895-1977), Czech optician and maker of many outstanding telescopes at Czech and Slovak observatories. A 0.57-m $\mathrm{f} / 5.2$ reflector with Gajdušek's main mirror is used at Klet ssee planet (2199)\} Observatory for CCD observations of minor planets and comets. (M 23792)

\section{(3604) Berkhuijsen}

5550 P-L. Discovered 1960 Oct. 17 by C. J. van Houten and I. van Houten-Groeneveld at Palomar.

Named in honor of E. M. Berkhuijsen \{1937- $\quad$ \} of the Max-Planck-Institut für Radioastronomie, Bonn. Her fields of interest include continuum radio radiation of our Galaxy and other galaxies and the study of supernova remnants. (M 16885)

\section{(3605) Davy}

1932 WB. Discovered 1932 Nov. 28 by E. Delporte at Uccle.

Named for Davy DeWinter, son of the current administrator of the Royal Observatory of Belgium, Mrs. Asselberghs. (M 14029)

Name proposed by G. Roland.

\section{(3606) Pohjola}

1939 SF. Discovered 1939 Sept. 19 by Y. Väisälä at Turku.

Named for a place in the Finnish national epic Kalevala \{see planet (1454)\}. Pohjola, ruled by the mistress Louhi \{see planet (3897)\}, was the home of darkness, coldness and all kinds of badness, an exact opposite of Kalevala. (M 18453)

\section{(3607) Naniwa}

$1977 \mathrm{DO}_{4}$. Discovered 1977 Feb. 18 by H. Kosai and K. Hurukawa at Kiso.

This planet is being given the former name of Osaka, where co-discoverer Hurukawa grew up. (M 12018)

For another former name of the city of Osaka see the citation for minor planet (3320).

\section{(3608) Kataev}

1978 SD $_{1}$. Discovered 1978 Sept. 27 by L. I. Chernykh at Nauchnyj.

Named in memory of the writer Valentin Petrovich Kataev (1897-1986). (M 13608)

\section{(3609) Liloketai}

$1980 \mathrm{VM}_{1}$. Discovered 1980 Nov. 13 at the Purple Mountain Observatory at Nanking.

Named in honor of Li Loketai, founder of the Zishan College. He has won a high reputation for his efforts to develop education in poor districts of China. (M 26424)

\section{(3610) Decampos}

1981 EA $_{1}$. Discovered 1981 Mar. 5 by H. Debehogne and G. DeSanctis at La Silla.

Named in honor of Jose Adolfo Snajdauf de Campos, of the Valongo Observatory, Federal University of Rio de Janeiro. A teacher of astronomy and a researcher on the photometry of minor planets, he participates in the first discoverer's group for photometric observations at the European Southern Observatory. (M 19334)

\section{(3611) Dabu}

$1981 \mathrm{YY}_{1}$. Discovered 1981 Dec. 20 at the Purple Mountain Observatory at Nanking. 
Named for a county in the northeastern part of Guangdong \{see planet (2185)\} province. Often called "the land of ceramics and tea", it enjoys a high reputation for its beautiful scenery and unique Hakka culture. It is the birthplace of observer J.-x. Yang. (M 34619)

\section{(3612) Peale}

1982 TW. Discovered 1982 Oct. 13 by E. Bowell at Anderson Mesa.

Named in honor of Stanton J. Peale, planetary astronomer at the University of California at Santa Barbara. Peale has made important contributions to the theory of tidal interactions between orbiting bodies and resulting capture into spin-orbit and orbit-orbit resonances, and to chaotic orbital and rotational motion. He is perhaps best known for predicting, almost literally on the eve of the Voyager 1 encounter with Jupiter, that its satellite Io would show extensive evidence of volcanism as a result of tidal heating by Jupiter. (M 12808)

Citation prepared by A. W. Harris at the request of the discoverer.

\section{(3613) Kunlun}

$1982 \mathrm{VJ}_{11}$. Discovered 1982 Nov. 10 at the Purple Mountain Observatory at Nanking.

Named for a mountain range in the western part of China. (M 34619)

\section{(3614) Tumilty}

$1983 \mathrm{AE}_{1}$. Discovered 1983 Jan. 12 by N. G. Thomas at Anderson Mesa.

Named in honor of Jodi Anne Tumilty Thomas, daughter-in-law of the discoverer. The name is derived from the Irish 'Tomaltach'. (M 25443)

\section{(3615) Safronov}

1983 WZ. Discovered 1983 Nov. 29 by E. Bowell at Anderson Mesa.

Named in honor of Victor S. Safronov \{1917- $\}$ of the O. Yu. Shmidt Institute of Earth Physics in Moscow. Starting with Shmidt's pioneering work from 1944 to 1960, Safronov developed a comprehensive theory of the origin of planetary bodies from the protoplanetary swarm. This work has well stood the tests of time and scrutiny by other scientists and it is the basis of most modern research on the origin of terrestrial and minor planets. (M 12808)

Citation prepared by A. W. Harris at the request of the discoverer

\section{(3616) Glazunov}

$1984 \mathrm{JJ}_{2}$. Discovered 1984 May 3 by L. V. Zhuravleva at Nauchnyj.

Named in honor of Il'ya Sergeevich Glazunov (1930- ), well-known Russian painter. (M 22245)

\section{(3617) Eicher}

1984 LJ. Discovered 1984 June 2 by B. A. Skiff at Anderson Mesa.
Named in honor of David J. Eicher, founder and editor-in-chief of Deep Sky magazine. In June 1977, as a high-school student, Eicher began Deep Sky Monthly, designed to promote amateur deep-sky observing. After more than fifty issues, the monthly became a quarterly in 1982, and Eicher became an assistant editor of Astronomy magazine. Through his magazine and two books on viewing, Eicher has worked tirelessly to encourage amateur astronomers to make high-quality observations of galaxies, clusters and nebulae. (M 16245)

Name proposed and citation provided by D. H. Levy.

\section{(3618) Kuprin}

1979 QP. Discovered 1979 Aug. 20 by N. S. Chernykh at Nauchnyj.

Named in honor of Aleksandr Ivanovich Kuprin (1870-1938), famous Russian writer. (M 20836)

\section{(3619) Nash}

$1981 \mathrm{EU}_{35}$. Discovered 1981 Mar. 2 by S. J. Bus at Siding Spring.

Named in honor of Douglas B. Nash of the San Juan Capistrano Research Institute, California, in recognition of his many contributions to the understanding of the compositions and processes affecting solar system bodies. Nash has achieved these advances by innovation and persistence in designing, executing and applying the results of laboratory investigations. His work on the spectral reflectances of lunar samples, meteorites, rock and mineral samples, and frozen gases has allowed comparison with and interpretation of telescopic data. His investigations of luminescence, ultraviolet irradiation, sputtering by a variety of ion species, and evaporation have led to the identification of new "space weathering" processes and a better understanding of the surfaces of the moon and the Galilean satellites of Jupiter. (M 18453)

Citation provided by Dennis L. Matson at the request of the discoverer.

\section{(3620) Platonov}

$1981 \mathrm{RU}_{2}$. Discovered 1981 Sept. 7 by L. G. Karachkina at Nauchnyj.

Named in memory of the writer Andrej Platonovich Platonov (1899-1951). (M 13176)

\section{(3621) Curtis}

1981 SQ . Discovered 1981 Sept. 26 by N. G. Thomas at Anderson Mesa.

Named in memory of the discoverer's high-school science teacher Curtis R. Carbutt (1911-1976), who was known for his personal attention to his students. For nearly 40 years, Curtis was a school administrator, teacher and junior-college instructor in Colorado and California. (M 24916)

Assistance with the citation was provided by B. Carbutt. 


\section{(3622) Ilinsky}

1981 SX $_{7}$. Discovered 1981 Sept. 29 by L. V. Zhuravleva at Nauchnyj.

Named in memory of the actor Igor' Vladimirovich Il'insky (1901-1987). (M 13176)

\section{(3623) Chaplin}

$1981 \mathrm{TG}_{2}$. Discovered 1981 Oct. 4 by L. G. Karachkina at Nauchnyj.

Named in memory of the great film actor and producer Charles Spencer Chaplin (1889-1977). (M 13176)

\section{(3624) Mironov}

$1982 \mathrm{TH}_{2}$. Discovered 1982 Oct. 14 by L. G. Karachkina and L. V. Zhuravleva at Nauchnyj.

Named in memory of Soviet actor and producer Andrej Aleksandrovich Mironov (1941-1987). (M 13176)

\section{(3625) Fracastoro}

$1984 \mathrm{HZ}_{1}$. Discovered 1984 Apr. 27 by W. Ferreri at La Silla.

Named in honor of Mario Girolamo Fracastoro, former director of the Catania and the Pino Torinese \{see planet (2694)\} observatories. His early research (in Florence) included solar physics, astronomical technology and the physics of photometric binaries. In 1963 he began a systematic study of the star RS CVn. More recently, he has been involved in astrometric work on binary systems, serving as president of IAU Commission 26 during 1982-1985 and as a member of the Hipparcos mission definition group. (M 13608)

\section{(3626) Ohsaki}

1929 PA. Discovered 1929 Aug. 4 by M. F. Wolf at Heidelberg.

Named in honor of Shoji Ohsaki (1912- ) on the occasion of the publication of his life work of historical research on the Chinese constellations. An amateur astronomer and historian, Ohsaki is well known for his work on the astronomical histories of the far-eastern countries and as a collaborator in S. Kanda's \{ see planet (2248)\} 1935 publication of astronomical phenomena in Japanese historical records before the year 1600 . (M 12973)

Name proposed by $\mathrm{H}$. Oishi, who found the identifications involving this minor planet.

\section{(3627) Sayers}

1973 DS. Discovered 1973 Feb. 28 by L. Kohoutek at Bergedorf.

Named in memory of Dorothy Leigh Sayers (18931957), British author of the Peter Wimsey detective stories, which she wrote during the 1920s and 1930s. In later life she tried hard to play down this notoriety, turning her considerable talents instead to the writing of theological plays and translating the works of Dante \{see planet (2999)\}. (M 34619)

Name suggested by B. G. Marsden, with whom she consulted extensively during the last year of her life in an attempt to rehabilitate the Roman poet Lucan, whose astronomy and geography had been condemned by other twentieth-century critics.

\section{(3628) Božněmcová}

1979 WD. Discovered 1979 Nov. 25 by Z. Vávrová at Kleť.

Named in memory of Božena Němcová (1820-1862), outstanding Czech writer, author of the well-known book Granny. (M 22245)

\section{(3629) Lebedinskij}

1982 WK. Discovered 1982 Nov. 21 by A. Mrkos at Kleť.

Named in memory of Aleksandr Ignat'evich Lebedinskij (1913-1967), astrophysicist at Moscow State University known for his research on the cosmogony of stars and planets, novae, aurorae and the magnetohydrodynamics of the solar atmosphere, as well as for his design of astronomical and geophysical instruments. He and the discoverer collaborated on spectroscopic research on aurorae in Antarctica during the International Geophysical Year. (M 26424)

\section{(3630) Lubomír}

1984 QN. Discovered 1984 Aug. 28 by A. Mrkos at Kleť.

A well-known old Slavic name, widespread in southern Bohemia \{see planet (371)\}. (M 25976)

\section{(3631) Sigyn}

1987 BV $_{1}$. Discovered 1987 Jan. 25 by E. W. Elst at La Silla.

Named by the discoverer in honor of his daughter, who has a lively interest in astronomy and who accompanied him on his mission from Belgium to the Bulgarian National Observatory last year. (M 12459)

\section{(3632) Grachevka}

1976 SJ $_{4}$. Discovered 1976 Sept. 24 by N. S. Chernykh at Nauchnyj.

Named for a village in the Tambov (now Lipetsk) region in Russia, the birthplace of the discoverer's parents, Stepan Semenovich Chernykh (1904-1942) and Melaniya Petrovna Chernykh (1910-1977). (M 20836)

\section{(3633) Mira}

$1980 \mathrm{EE}_{2}$. Discovered 1980 Mar. 13 at the Felix Aguilar Observatory at El Leoncito.

Named in memory of Hugo Mira (1937-1994), outstanding researcher who worked for more than twenty-five years at the discovery site of this minor planet. Mira was an observer at the transit circle of the U.S. Naval Observatory's Yale-Columbia Southern Observatory for four years. He also worked for twenty years on minor planets and proper motions with the double astrograph. (M 24120)

\section{(3634) Iwan}

1980 FV. Discovered 1980 Mar. 16 by C.-I. Lagerkvist at La Silla. 
Named in honor of Iwan P. Williams, of Queen Mary College, London, in recognition of his well-known work on meteor streams and interest in comets and minor planets. The discoverer appreciates their long and fruitful collaboration. (M 15427)

\section{(3636) Pajdušáková}

1982 UJ $_{2}$. Discovered 1982 Oct. 17 by A. Mrkos at Kleť.

Named in memory of Ludmila Pajdušáková (19161979), the first Slovak woman astronomer, a specialist in solar astronomy and recognized as the discoverer of five comets. Some time wife of the discoverer, she was the third director of the Skalnaté Pleso Observatory \{see planet (2619)\} and Astronomical Institute in Tatranská Lomnica. (M 26424)

\section{(3637) O'Meara}

1984 UQ. Discovered 1984 Oct. 23 by B. A. Skiff at Anderson Mesa.

Named in honor of Stephen James O'Meara. Well known for his fine drawings of solar system objects, O'Meara joined Sky and Telescope \{see planet (3243)\} in 1979 and in 1989 was promoted to associate editor. His unique visual observations have included pre-Voyager sightings of spokes in Saturn's B ring and a determination of Uranus' rotation period. In January 1985 he made an apparent visual observation of $\mathrm{P} /$ Halley at magnitude 19.6 using a $0.6-\mathrm{m}$ telescope on Mauna Kea. O'Meara's writing and remarkable visual skill inspires other observers to improve the quality of their observations. An energetic speaker, he has taught introductory classes in astronomy in Massachusetts and Hawaii and is regularly sought for astronomy talks in the U.S. and abroad. (M 16245) Name suggested and citation provided by D. H. Levy.

\section{(3638) Davis}

1984 WX. Discovered 1984 Nov. 20 by E. Bowell at Anderson Mesa.

Named in honor of Donald R. Davis, senior scientist at the Planetary Science Institute in Tucson. Davis has made fundamental theoretical and experimental contributions to research on the collisional evolution of minor planets. With colleagues, he was the first to propose the "gravitationally bound rubble pile" model for large minor planets. Another of his research interests is infrared searching for intramercurial bodies. (M 12459)

Citation written by R. P. Binzel at the request of the discoverer

\section{(3639) Weidenschilling}

1985 TX. Discovered 1985 Oct. 15 by E. Bowell at Anderson Mesa.

Named in honor of Stuart J. Weidenschilling, research scientist at the Planetary Science Institute in Tucson. Weidenschilling is a noted expert in the study of the origin of the solar system, and his research has also included collisional evolution of minor planets. He and colleagues are conducting a program of "photometric geodesy" to model the shapes of large, rapidly rotating minor planets from extensive lightcurve observations. (M 12459)

Citation written by R. P. Binzel at the request of the discoverer.

\section{(3640) Gostin}

1985 TR $_{3}$. Discovered 1985 Oct. 11 by C. S. Shoemaker and E. M. Shoemaker at Palomar.

Named in honor of Victor A. Gostin, geologist on the faculty of the University of Adelaide, South Australia. A specialist in sedimentology and stratigraphy, Gostin discovered in the Flinders Ranges of South Australia a deposit of shocked debris ejected from the Lake Acraman impact structure about $300 \mathrm{~km}$ to the west. His careful studies of this ancient deposit have provided the first detailed picture of the distant ejecta from a known large terrestrial impact crater. (M 12808)

\section{(3641) Williams Bay}

A922 WC. Discovered 1922 Nov. 24 by G. Van Biesbroeck at Williams Bay.

Named for the village where the Yerkes Observatory is situated and where this minor planet was discovered. (M 14632)

Name proposed by Micheline Wilson, daughter of the discoverer.

\section{(3642) Frieden}

$1953 \mathrm{XL}_{1}$. Discovered 1953 Dec. 4 by H. Gessner at Sonneberg.

This planet is given the German form of the goddess Pax see planet (679)\} in the hope for peace around the world. (M 12808)

\section{(3643) Tienchanglin}

$1978 \mathrm{UN}_{2}$. Discovered 1978 Oct. 29 at the Purple Mountain Observatory at Nanking.

Chang-lin Tien (1935- ) was the seventh chancellor of the University of California at Berkeley, serving from 1990 to 1997, and is now the Nippon Electric Company distinguished professor of engineering there. His professional work is mainly in energy, environment and high-tech areas. (M 36126)

\section{(3644) Kojitaku}

1931 TW. Discovered 1931 Oct. 5 by K. Reinmuth at Heidelberg.

Named for Takuo Kojima, who has made more than 1,000 accurate observations of comets and discovered more than 10 numbered minor planets. He has also written the Comet Observers Guide column in GekkanTenmon since 1990. (M 22498)

Name proposed by T. Kobayashi, who found the identifications involving this minor planet. Until 1996 , Kojima has discovered 23 numbered minor planets. 


\section{(3645) Fabini}

1981 QZ. Discovered 1981 Aug. 28 by A. Mrkos at Kleť.

Named in memory of Tatiana Fabini (1943-1989), editor-in-chief of the Slovak popular-astronomy magazine Kozmos and a source of inspiration for many amateur astronomers. (M 26424)

Obituary published in Kozmos, Vol. 20, No. 2, p. 39 (1989).

\section{(3646) Aduatiques}

$1985 \mathrm{RK}_{4}$. Discovered 1985 Sept. 11 by H. Debehogne at La Silla.

Named for the Aduatiques, an ancient Belgian tribe from Namur \{see planet (3374)\}. The tribe is mentioned in Julius Caesar's Gallic Wars. (M 23792)

\section{(3647) Dermott}

$1986 \mathrm{AD}_{1}$. Discovered 1986 Jan. 11 by E. Bowell at Anderson Mesa.

Named in honor of Stanley F. Dermott, planetary scientist at Cornell University, Ithaca, New York. Dermott's unusually broad range of contributions includes work on planetary origin, resonance effects on planetary satellites, rings, zodiacal dust bands, tidal interactions, and minor planets, for the last of which he is known for his study of the statistics of spin rates. (M 12808)

Citation prepared by A. W. Harris at the request of the discoverer.

\section{(3648) Raffinetti}

1957 HK. Discovered 1957 Apr. 24 at the La Plata Observatory at La Plata.

Named in memory of Virgilio Raffinetti (1869-1946), Argentine astronomer, who was director of La Plata Observatory between 1889 and 1905. Under his personal supervision the Gautier meridian circle was installed at this Observatory in 1903. (M 22498)

\section{(3649) Guillermina}

1976 HQ. Discovered 1976 Apr. 26 at the Felix Aguilar Observatory at El Leoncito.

Named in honor of Maria Guillermina Martin de Cesco (1915- ), widow of Carlos U. Cesco ssee planet (1571)\} and mother of M. R. Cesco. She was the first student registered at the Astronomy School of La Plata State University and was a generous collaborator of Ing. Felix Aguilar \{see planet (1800)\}. (M 24120)

\section{(3650) Kunming}

$1978 \mathrm{UO}_{2}$. Discovered 1978 Oct. 30 at the Purple Mountain Observatory at Nanking.

Kunming, the capital of Yunnan \{see planet (2230)\} province, is one of the hub cities in southwestern China. It enjoys a reputation as "The City of Eternal Spring". (M 36126)

\section{(3651) Friedman}

1978 VB $_{5}$. Discovered 1978 Nov. 7 by E. F. Helin and S. J. Bus at Palomar.
Named in honor of Louis and Connie Friedman on the occasion of their 25th wedding anniversary. As executive director of the Planetary Society, Louis D. Friedman is a leader in promoting the exploration of the solar system. At the Jet Propulsion Laboratory, he originated the International Halley Watch. Connie Friedman has shared her husband's excitement for planetary exploration. (M 13481)

Name proposed by the first discoverer, endorsed by R. L. Staehle.

\section{(3652) Soros}

$1981 \mathrm{TC}_{3}$. Discovered 1981 Oct. 6 by T. M. Smirnova at Nauchnyj.

Named in honor of George Soros, the founder of the International Science Foundation. This charitable organization provides financial support to scientifically meritorious scientists of the former Soviet Union in the field of fundamental civilian research. (M 23136)

Name proposed by the Institute of Theoretical Astronomy.

\section{(3653) Klimishin}

$1979 \mathrm{HF}_{5}$. Discovered 1979 Apr. 25 by N. S. Chernykh at Nauchnyj.

Named in honor of Ivan Antonovich Klimishin, professor of astronomy at the Ivano-Frankovsk Pedagogical Institute. Prominent in the field of cosmic hydrodynamics, Klimishin is also an expert on the history of astronomy and is the author of some popular astronomical books. (M 22498)

\section{(3654) AAS}

$1949 \mathrm{QH}_{1}$. Discovered 1949 Aug. 21 at the Goethe Link Observatory at Brooklyn, Indiana.

Named in honor of the American Astronomical Society, the professional society of American astronomers and astrophysicists from its founding in 1899 until today. Through its journals, its meetings, and especially its members now numbering over five thousand, it has promoted research and education in every branch of astronomy, including the study of minor planets. (M 19334)

Name proposed by D. E. Osterbrock and F. K. Edmondson. Citation by D. E. Osterbrock.

\section{(3655) Eupraksia}

1978 SA $_{3}$. Discovered 1978 Sept. 26 by L. V. Zhuravleva at Nauchnyj.

Named for the wife of the thirteenth-century prince Fyodor Ryazansky. She preferred death to being taken prisoner by the Tatar-Mongolians. (M 13176)

\section{(3656) Hemingway}

1978 QX. Discovered 1978 Aug. 31 by N. S. Chernykh at Nauchnyj.

Named in honor of Ernest Hemingway (1899-1961), great American writer. (M 22498)

Hemingway received the 1954 Literature Nobel Prize. 
(3657) Ermolova

$1978 \mathrm{ST}_{6}$. Discovered 1978 Sept. 26 by L. V. Zhuravleva at Nauchnyj.

Named in memory of Maria Nikolaevna Ermolova (1853-1928), outstanding Russian actress. (M 22246)

\section{(3658) Feldman}

1982 TR. Discovered 1982 Oct. 13 by E. Bowell at Anderson Mesa.

Named in honor of Paul D. Feldman, professor of physics and astronomy at the Johns Hopkins University, Baltimore, for his numerous contributions in ultraviolet spectroscopy, particularly of the Earth's atmosphere, Venus, the outer planets and comets. His design and supervision of a number of spacecraft instruments have led to many advances in our understanding of physical processes in the solar system. The minor planet also honors Paul A. Feldman, a radioastronomer at the Herzberg Institute of Astrophysics, Ottawa, who is currently involved in making submillimeter observations of minor planets. (M 12974)

Name suggested and citation provided by M. F. A'Hearn and B. G. Marsden.

\section{(3659) Bellingshausen}

$1969 \mathrm{TE}_{2}$. Discovered 1969 Oct. 8 by L. I. Chernykh at Nauchnyj.

Named in memory of the Russian admiral Faddej Faddeevich Bellingshausen (1778-1852), head of the first Russian Antarctic expedition in 1819-1821. (M 13608)

Bellingshausen is also honored by a lunar crater.

\section{(3660) Lazarev}

1978 QX $_{2}$. Discovered 1978 Aug. 31 by N. S. Chernykh at Nauchnyj.

Named in honor of the Russian admiral Mikhail Petrovich Lazarev (1797-1851), a participant in the first Russian Antarctic expedition and commander of the ship Mirnyj. (M 13608)

\section{(3661) Dolmatovskij}

1979 UY $_{3}$. Discovered 1979 Oct. 16 by N. S. Chernykh at Nauchnyj.

Named in honor of Evgenij Aronovich Dolmatovskij, poet and publicist. (M 20836)

\section{(3662) Dezhnev}

$1980 \mathrm{RU}_{2}$. Discovered 1980 Sept. 8 by L. V. Zhuravleva at Nauchnyj.

Named in honor of Semen Ivanovich Dezhnev (c. 1605-1673), Russian seafarer. (M 22246)

\section{(3663) Tisserand}

1985 GK $_{1}$. Discovered 1985 Apr. 15 by E. Bowell at Anderson Mesa.

Named for François Tisserand (1845-1896), contributor to the theory of general perturbations (Tisserand's criterion) and lunar theory, and author of the fourvolume compendium Traité de Mécanique Céleste. (M 12974)
Name suggested and citation provided by G. Reaves.

Tisserand is also honored by a lunar crater.

\section{(3664) Anneres}

4260 P-L. Discovered 1960 Sept. 24 by C. J. van Houten and I. van Houten-Groeneveld at Palomar.

Named in honor of Anna Theresia ("Anneres") Schmadel. She is the wife of Lutz D. Schmadel \{see planet (2234)\}, a senior staff astronomer at the Astronomisches Rechen-Institut in Heidelberg. (M 16591)

\section{(3665) Fitzgerald}

1979 FE. Discovered 1979 Mar. 19 by A. Mrkos at Klě́.

Named in memory of Ella Fitzgerald (1917-1996), renowned jazz singer known internationally as the "First Lady of Song". A phenomenal improvisationalist who used her voice as if it were a musical instrument, she was also known for her albums of definitive performances of the works of many of the leading songwriters of the first half of the twentieth century. (M 27733)

Name proposed by M. Tichý and B. G. Marsden.

\section{(3666) Holman}

1979 HP. Discovered 1979 Apr. 19 by J. C. Muzzio at Cerro Tololo.

Named in honor of Matthew J. Holman (1967- ), astronomer in the planetary sciences division at the Harvard-Smithsonian Center for Astrophysics. He is particularly known for his long-term investigations on the stability of the outer solar system by means of the sympletic integrator he codeveloped, and he has studied the stability of planets around other stars. Recently, he has also become an active observer of centaurs and transneptunian objects. (M 34619)

\section{(3667) Anne-Marie}

1981 EF. Discovered 1981 Mar. 9 by E. Bowell at Anderson Mesa.

Named for Anne-Marie Malotki, a friend of the discoverer. (M 12974)

\section{(3668) Ilfpetrov}

1982 UM7. Discovered 1982 Oct. 21 by L. G. Karachkina at Nauchnyj.

Named for Il'ya Arnol'dovich Feinsilberg (1897-1937) and Eugeny Petrovich Kataev (1903-1942), the authors of the books Twelve Chairs and Golden Calf. (M 13176)

\section{(3669) Vertinskij}

1982 UO $_{7}$. Discovered 1982 Oct. 21 by L. G. Karachkina at Nauchnyj.

Named in memory of Aleksandr Nikolaevich Vertinskij (1889-1957), variety actor, composer and poet, famous for his sincere rendition of songs with words by Blok, Akhmatova and Tsvetaeva \{see, respectively, planets (2540), (3067) and (3511)\}. (M 20836) 
(3670) Northcott

1983 BN. Discovered 1983 Jan. 22 by E. Bowell at Anderson Mesa.

Named for the Canadian astronomer Ruth Josephine Northcott (1913-1969), an associate professor at the University of Toronto and a staff member of the David Dunlap Observatory from its inception in 1935. A specialist in stellar radial velocities, Northcott served on IAU Commissions 26 (double stars), 30 (radial velocities) and 41 (history of astronomy). In 1956 she succeeded C. A. Chant $\{$ see planet (3315)\} as editor of the Observer's Handbook of the Royal Astronomical Society of Canada, a position she held until her untimely death. (M 12974)

Name suggested and citation provided by C. E. Spratt.

Obituaries published in J.R. Astron. Soc. Canada, Vo. 63, p. 225-226 (1969); Sky Telesc., Vol. 38, p. 211 (1969).

\section{(3671) Dionysus}

1984 KD. Discovered 1984 May 27 by C. S. Shoemaker and E. M. Shoemaker at Palomar.

Originating in Thrace, where he was revered as a god of wine, the cult of Dionysus spread gradually through Greece. Dionysus became, in turn, the god of vegetation and warm moisture, the god of pleasure, the god of civilization, and ultimately a kind of supreme god and a symbol of rebirth or everlasting life. In some instances he appeared as a Sun deity. (M 12808; M 19347)

The original name 'Dionysius' (M 12808) was corrected by the Minor Planet Names Committee.

\section{(3672) Stevedberg}

1985 QQ. Discovered 1985 Aug. 22 by E. Bowell at Anderson Mesa.

Named in honor of Stephen J. Edberg, planetary scientist at the Jet Propulsion Laboratory, for his long commitment to bringing amateur and professional astronomers together. Although his most noted activity has been his work with the Amateur Observations Net of the International Halley Watch, he has also been a leader in the program for amateur use of the Hubble Space Telescope, in the Mars project of the Planetary Society, and as president of the Western Amateur Astronomers. (M 12974)

Citation prepared by D. H. Levy at the request of the discoverer.

\section{(3673) Levy}

1985 QS. Discovered 1985 Aug. 22 by E. Bowell at Anderson Mesa.

Named in honor of David H. Levy \{1948- \}, comet discoverer and observer, recognized for his perseverance in observing comets using the oldest visual and the newest electronic techniques. Author of several books and articles, he is known for his biographies of astronomers. As an educator Levy has concentrated on bringing observational astronomy to both amateur astronomers and to children, and he has initiated school and camp programs for this purpose. (M 12974)

Citation prepared by S. J. Edberg at the request of the discoverer.

\section{(3674) Erbisbühl}

1963 RH. Discovered 1963 Sept. 13 by C. Hoffmeister at Sonneberg.

Named for the mountain on which the Sonneberg see planet (1039)\} Observatory is situated. The discoverer, who founded the observatory, lived and worked there for many decades. (M 12809)

\section{(3675) Kemstach}

$1982 \mathrm{YP}_{1}$. Discovered 1982 Dec. 23 by L. G. Karachkina at Nauchnyj.

Named in memory of Marfa Vladimirovna Kemstach (1888-1971) and Semen Stepanovich Kemstach (18801938), grandparents of the discoverer. (M 13177)

\section{(3676) Hahn}

1984 GA. Discovered 1984 Apr. 3 by E. Bowell at Anderson Mesa.

Named in honor of Gerhard Hahn, a planetary astronomer at Uppsala Observatory and a member of the research group studying minor planets and comets. Hahn has undertaken extensive photometry and astrometry of minor planets and has been studying the long-term orbital evolution and physical properties of these objects. (M 12975)

Citation prepared by C.-I. Lagerkvist at the request of the discoverer.

\section{(3677) Magnusson}

1984 QJ $_{1}$. Discovered 1984 Aug. 31 by E. Bowell at Anderson Mesa.

Named in honor of Per Magnusson, a planetary astronomer at Uppsala Observatory and a member of the research group studying minor planets and comets. Well known for his method of determining the spin characteristics of minor planets, Magnusson has estimated pole directions for more than thirty objects. (M 12975)

Citation prepared by C.-I. Lagerkvist at the request of the discoverer.

\section{(3678) Mongmanwai}

1966 BO. Discovered 1966 Jan. 20 at the Purple Mountain Observatory at Nanking.

Named in honor of Man Wai Mong, prominent in the Chinese electrical engineering community. Mong takes an active interest in the development of education and sciences at several universities in China. (M 27125)

\section{(3679) Condruses}

1984 DT. Discovered 1984 Feb. 24 by H. Debehogne at La Silla.

Named for the Condruses, an ancient Belgian tribe from southeast Namur \{see planet (3374)\} and southern Liège. The tribe is mentioned in Julius Caesar's Gallic Wars. (M 23792) 
(3680) Sasha

1987 MY. Discovered 1987 June 28 by E. F. Helin at Palomar.

Named in honor of Alexandra Rachel Druyan Sagan, young daughter of Carl Sagan \{see planet (2709)\} and Ann Druyan $\{$ see planet (4970)\}. Sasha's charismatic parents are passionately committed to preserving a peaceful, intact world to their children to inherit. This is well expressed in the dedication of his book Cosmos: "for Alexandra, who comes of age with the millenium. May we leave your generation a world better than the one we were given." In the hope that they will continue and expand the quests of their parents, this minor planet is dedicated to Sasha and her contemporaries throughout the world. (M 12459)

\section{(3681) Boyan}

$1974 \mathrm{QO}_{2}$. Discovered 1974 Aug. 27 by L. I. Chernykh at Nauchnyj.

Named for Wise Boyan, the legendary old Russian story-teller and bard. (M 18453)

\section{(3682) Welther}

A923 NB. Discovered 1923 July 12 by K. Reinmuth at Heidelberg.

Named in honor of Barbara Welther (1938- ), historian of science at the Harvard-Smithsonian Center for Astrophysics. Barbara has recently completed an educational video examining the life and work of Annie Jump Cannon \{see planet (1120)\}. (M 22499)

Name proposed by members of the Planetary Sciences division, the identifications for this object having been made by B. G. Marsden.

\section{(3683) Baumann}

1987 MA. Discovered 1987 June 23 by W. Landgraf at La Silla.

Named in honor of Paul Baumann (1901-1976) and his wife Helene (1899-1986). An amateur astronomer since 1959, Baumann founded the astronomical association (1961) and public observatory (1962) in Mainz, was involved in the establishment of several other associations in this area and was well known throughout Germany and in many other countries. Baumann was also a member of the first parliament of Rheinland-Pfalz (1947-1951) and for a long time a member of the Mainz city council. The Baumann family were good friends of the father of the discoverer for several decades. (M 12459)

\section{(3684) Berry}

1983 AK. Discovered 1983 Jan. 9 by B. A. Skiff at Anderson Mesa.

Named in honor of Richard Berry, since 1979 editor-in-chief of Astronomy. He has actively promoted amateur astronomy by means of books on beginning astronomy and telescope making as well as editorship of the technical journal Telescope Making. He was also a pioneer in increasing awareness of light pollution by mapping its extent in southern Ontario in the 1970s. (M 16246)

Citation prepared by D. H. Levy and S. J. Edberg at the request of the discoverer.

\section{(3685) Derdenye}

$1981 \mathrm{EH}_{14}$. Discovered 1981 Mar. 1 by S. J. Bus at Siding Spring.

Named in honor of Derald and Denise Nye, dedicated amateur astronomers and observatory builders in Tucson. For the past thirteen years, Derald, with the assistance of Denise, has served as distributor for the Minor Planet Bulletin, the publication of the Minor Planets Section of the Association for Lunar and Planetary Observers. Through this work they have served as a contact point for hundreds of amateur astronomers around the world seeking to contribute to minor planet research. (M 27125)

Name suggested and citation prepared by R. P. Binzel.

\section{(3686) Antoku}

1987 EB. Discovered 1987 Mar. 3 by T. Niijima and T. Urata at Ojima.

Named for the 81st emperor of Japan, Antoku (1178-1185), son of Kenreimonin \{see planet (5242)\}. He reigned from 1180 to 1185, and when the Heike was destroyed at Dannoura, he was drowned in Niinoama's \{see planet (4959)\} arms. (M 30798)

Name proposed by second discoverer.

\section{(3687) Dzus}

A908 TC. Discovered 1908 Oct. 7 by A. Kopff at Heidelberg.

Named in honor of Paul K. Dzus \{1969- $\}$ in appreciation of his helpful assistance at the Minor Planet Center since October 1987, much of the time as a volunteer. (M 14029)

Named by B. G. Marsden, who found the identifications involving this minor planet, on Dzus' departure for the University of Arizona.

\section{(3688) Navajo}

1981 FD. Discovered 1981 Mar. 30 by E. Bowell at Anderson Mesa.

This 2:1 Jupiter librator is named for the indigenous North American people, inhabitants of a 60,000-square kilometer area of Arizona, New Mexico and Utah. The Navajo people probably migrated to the southwest United States in the fifteenth century. Today their flourishing culture is particularly renowned for its artistic achievement, including weaving and silver work. (M 12975)

P. E. Roques contributed to the citation.

\section{(3689) Yeates}

$1981 \mathrm{JJ}_{2}$. Discovered 1981 May 5 by C. S. Shoemaker at Palomar.

Named in honor of Anthony N. Yeates, geologist with the Bureau of Mineral Resources of the Commonwealth 
of Australia. In the course of regional geologic mapping at the southern edge of the Great Sandy desert of Western Australia, Yeates led a team of geologists that discovered the Veevers meteorite crater. This site, discovered in 1975, is the fifteenth and latest recognized locality where meteorites have been found associated with an impact crater. (M 12809)

\section{(3690) Larson}

1981 PM. Discovered 1981 Aug. 3 by E. Bowell at Anderson Mesa.

Named in honor of Stephen M. Larson, planetary scientist at the Lunar and Planetary Laboratory. Well known for his work on comets, Larson has recently digitized many 1910 images of Comet Halley to bring out fresh details of jet structure and has been active in organizing the Near Nucleus Studies Net of the International Halley Watch. His program of monitoring comets by means of spectroscopy and imaging continues to reveal interesting aspects of cometary phenomena. With J. Fountain, he correctly demonstrated the existence of and specified the revolution period of Saturn's eleventh satellite before the extensive 1980 data completely clarified the confusing situation presented at the 1966 ring-plane passage. (M 12975) Name suggested and citation prepared by D. H. Levy.

\section{(3691) Bede}

1982 FT. Discovered 1982 Mar. 29 by L. E. Gonzalez at Cerro El Roble.

The Venerable Bede (c. 672-735), the "Father of English History" who popularized the A.D. reckoning of years, compiled a history of England since the time of Caesar. (M 40700)

The name follows a suggestion by B. Hafferty in the BBC Word of Mouth competition in this centenary year of St. Bede's School, Bradford, West Yorkshire.

\section{(3692) Rickman}

$1982 \mathrm{HF}_{1}$. Discovered 1982 Apr. 25 by E. Bowell at Anderson Mesa.

Named in honor of Hans Rickman, a planetary astronomer at Uppsala Observatory and a member of the research group studying minor planets and comets. Rickman is widely known for his theoretical modelling of cometary nuclei, and he is also interested in the relationships between comets and planetcrossing asteroids. He has for a long time favored the popularization of astronomy, and to this end he has written a large number of articles in popular magazines and has lectured to general audiences. Rickman is a co-organizer of the "Asteroids, Comets, Meteors" meetings that are held regularly in Uppsala. (M 12975)

Citation prepared by C.-I. Lagerkvist at the request of the discoverer.
(3693) Barringer

1982 RU. Discovered 1982 Sept. 15 by E. Bowell at Anderson Mesa.

Named for Daniel Moreau Barringer (1860-1929), pioneer investigator of terrestrial meteorite craters. From intensive field studies, including much subsurface exploration, Barringer demonstrated the impact origin of Meteor Crater, Arizona, now widely known as the Barringer Crater, the first recognized impact crater on the Earth. On the basis of his studies, Barringer strongly supported the hypothesis of impact origin for the craters on the Moon. (M 12976)

Name proposed jointly by E. M. and C. S. Shoemaker. Barringer is also honored by a lunar crater.

\section{(3694) Sharon}

$1984 \mathrm{SH}_{5}$. Discovered 1984 Sept. 27 by A. Grossman at Palomar.

Named in honor of Sharon Rachel Vinick, a great source of joy and inspiration to the discoverer. (M 15260)

\section{(3695) Fiala}

1973 UU $_{4}$. Discovered 1973 Oct. 21 by H. L. Giclas at Anderson Mesa.

Alan D. Fiala (1942- ) is an expert on predicting and observing eclipses, with special application to precise measurement of the solar radius. A staff astronomer at the U.S. Naval Observatory since 1962, he has been Chief of the U.S. Nautical Almanac Office since 1996. This naming is on the occasion of his retirement. (M 40700)

\section{(3696) Herald}

1980 OF. Discovered 1980 July 17 by E. Bowell at Anderson Mesa.

Named in honor of the Australian amateur astronomer David Herald for his astrometric observations of comets and his work on occultations by minor planets. The number of his cometary positions is the second highest in the world for an amateur astronomer in modern times, and his prompt and reliable attention to new comets discovered in the southern hemisphere has been invaluable. (M 12809)

Name suggested by B. G. Marsden, who wrote the citation.

\section{(3697) Guyhurst}

1984 EV. Discovered 1984 Mar. 6 by E. Bowell at Anderson Mesa.

Named in honor of Guy M. Hurst, editor of the British amateur astronomical journal The Astronomer \{see planet (6411)\} since 1975. An enthusiastic visual observer of comets and variable stars himself, he is in contact with an enormous network of other observers all over western Europe, and his frequent assistance in thereby securing verifications of reports for the IAU Central Telegram Bureau is greatly appreciated. (M 12809)

Name suggested by R. H. McNaught and B. G. Marsden, the citation being prepared by the latter. 


\section{(3698) Manning}

$1984 \mathrm{UA}_{2}$. Discovered 1984 Oct. 29 by E. Bowell at Anderson Mesa.

Named in honor of Brian Manning, British amateur cometary astrometrist, whose numerous contributions to the IAU Circulars and Minor Planet Circulars, as well as to the astrometric campaigns of International Halley Watch, have been consistently timely and of the highest accuracy. (M 12809)

Name suggested by D. K. Yeomans and B. G. Marsden, the citation being prepared by the latter.

\section{(3699) Milbourn}

$1984 \mathrm{UC}_{2}$. Discovered 1984 Oct. 29 by E. Bowell at Anderson Mesa

Named in honor of Stanley William Milbourn \{1925-1997\}, editor of the circulars of the British Astronomical Association during 1969-1986, director of the comet section during 1968-1977 and currently assistant director of the computing section. Long interested in astronomical computations, particularly those involving returning periodic comets, he has produced a steady stream of accurate predictions over the years, as he has adapted procedures from mechanical calculating machine to pocket calculator to personal computer. (M 12810)

Name suggested by B. G. Marsden, who wrote the citation.

Obituaries published in Int. Comet Q., Vol. 20, No. 1, p. 3 (1998); J. Br. Astron. Assoc., Vol. 108, No. 3, p. 181-182 (1998)

\section{(3700) Geowilliams}

1984 UL $_{2}$. Discovered 1984 Oct. 23 by C. S. Shoemaker and E. M. Shoemaker at Palomar.

Named in honor of George E. Williams, exploration geologist with Broken Hill Propriety Co., Ltd. at Adelaide, South Australia. Williams discovered the Lake Acraman impact structure of South Australia, the largest such feature found so far on the Australian continent. He also discovered rhythmically layered sedimentary deposits of Precambrian age that exhibit periods closely matching those of the modern solar cycle. (M 12810)

\section{(3701) Purkyně}

1985 DW. Discovered 1985 Feb. 20 by A. Mrkos at Kleť.

Named in memory of J. E. Purkyně (1787-1869), professor of physiology in Wroclaw and Prague. He discovered the physiological effect, well known to observers of variable stars, that causes comparable variations in brightness to appear more extreme for red light than for blue light. (M 26424)

\section{(3702) Trubetskaya}

1970 NB. Discovered 1970 July 3 by L. I. Chernykh at Nauchnyj.

Named for Ekaterina Ivanovna Trubetskaya (18001854), a princess who voluntarily followed her husband, the Decembrist S. P. Trubetskoj, to exile in Siberia. (M 13609)

\section{(3703) Volkonskaya}

1978 PU $_{3}$. Discovered 1978 Aug. 9 by L. I. Chernykh at Nauchnyj.

Named for Mariya Nikolaevna Volkonskaya (18051865), a princess who voluntarily followed her husband, the Decembrist S. G. Volkonskij, to exile in Siberia. (M 13609)

\section{(3704) Gaoshiqi}

$1981 \mathrm{YX}_{1}$. Discovered 1981 Dec. 20 at the Purple Mountain Observatory at Nanking.

Gao Shi-Qi (1905-1988) is considered the founder of science popularization in China. His contraction of encephalitis during a scientific experiment at the University of Chicago in 1928 caused paralysis of his whole body. (M 36126)

\section{(3705) Hotellasilla}

$1984 \mathrm{ET}_{1}$. Discovered 1984 Mar. 4 by H. Debehogne at La Silla.

Named in honor Erich Schumann and his Chilean team, who, for almost three decades and with great dedication, have secured the accomodation and catering of thousands of staff members and visitors to the European Southern Observatory at the "Hotel La Silla" in Chile. (M 33786)

\section{(3706) Sinnott}

$1984 \mathrm{SE}_{3}$. Discovered 1984 Sept. 28 by B. A. Skiff at Anderson Mesa.

Named in honor of Roger W. Sinnott, associate editor of Sky and Telescope. His extensive telescope-making experience began with a first mirror ground when he was aged 13 and has culminated in his conducting the 'Gleanings for ATMs' department of the magazine for many years. He also created (with Alan Hirshfeld) the two-volume Sky Catalogue 2000.0 and edited NGC 2000.0 using computer databases. This led to the farranging magazine column 'Astronomical Computing'. (M 16246)

Citation provided by D. H. Levy, S. J. Edberg and J. K. Beatty at the request of the discoverer.

\section{(3707) Schröter}

1934 CC. Discovered 1934 Feb. 5 by K. Reinmuth at Heidelberg.

Named in honor of Egon Horst Schröter (1928- ), German solar astronomer and director of the Freiburg Kiepenheuer-Institut, on the occasion of his retirement. In 1976 he succeeded K.-O. Kiepenheuer at the Freiburg Institute for Solar Physics. An important achievement during his directorship consisted in negotiations about the erection of two new tower telescopes at Teide Observatory on Tenerife, Canary Islands. Schröter served as president of the Astronomische Gesellschaft from 1987 to 1990 . In 1978 he became a member of the German Committee in COSPAR. (M 22499) 
Name proposed and citation prepared by J. Schubart, endorsed by G. Klare and L. D. Schmadel.

\section{(3709) Polypoites}

1985 TL $_{3}$. Discovered 1985 Oct. 14 by C. S. Shoemaker and E. M. Shoemaker at Palomar.

Named after the victor in a contest among the Greeks to see who would win an iron meteorite by throwing it the farthest. Polypoites flung the meteorite "as far as a herdsman throws a cattle staff, rifling it clear across the herd". When it landed it probably made a small impact crater. (M 12976)

Name proposed by Dorothy and Jerome Preston, who suggested that, had the discoverers been present at the Trojan War, they might have studied with some interest the result of Polypoites' throw.

\section{(3710) Bogoslovskij}

1978 RD $_{6}$. Discovered 1978 Sept. 13 by N. S. Chernykh at Nauchnyj.

Named in honor of Nikita Bogoslovskij, well-known contemporary composer and writer, on the occasion of his eightieth birthday. (M 22499)

\section{(3711) Ellensburg}

1983 QD. Discovered 1983 Aug. 31 by J. Gibson at Palomar.

Named by the discoverer to honor the city of his birth, established in the 1880 s by the tracks of the Northern Pacific Railroad. Originally a small trading post in what was then Washington Territory, the city is named for Ellen Shoudy, wife of its founder and first mayor. The city is home to Central Washington University, originally Washington State Normal School, which this year celebrates the centennial of its founding. (M 18453)

\section{(3712) Kraft}

1984 YC. Discovered 1984 Dec. 22 by E. A. Harlan and A. R. Klemola at Mount Hamilton.

Named in honor of Robert P. Kraft (1927- ), professor of astronomy and astrophysics at the University of California at Santa Cruz and Lick Observatory (1967-1993) and director of Lick Observatory (19811991). His research spans stellar spectroscopy, galactic structure, and chemical composition and evolution of stars in the galactic field and star clusters and the Magellanic Clouds. Kraft served as president (19741976) and vice president (1982-1988) of the American Astronomical Society and is currently president-elect of the International Astronomical Union. (M 26761)

\section{(3713) Pieters}

$1985 \mathrm{FA}_{2}$. Discovered 1985 Mar. 22 by E. Bowell at Anderson Mesa.

Named in honor of Carle M. Pieters, geologist on the faculty of Brown University, Providence. Pieters obtained the first compositionally diagnostic observations of an Earth-approaching minor planet when she observed (433) Eros during its 1974-75 apparition.
She has extensively studied the surface composition of geological units on the near side of the Moon using groundbased reflectance spectroscopy combined with laboratory measurements of returned lunar samples. Pieters has also developed and applied remote sensing techniques for the study of the Earth, Mars and Venus using airborne and spacecraft data. (M 13177)

Name suggested and citation provided by L. A. McFadden.

\section{(3714) Kenrussell}

$1983 \mathrm{TT}_{1}$. Discovered 1983 Oct. 12 by E. Bowell at Anderson Mesa.

Named for Ken S. Russell, an astronomer at the U.K. Schmidt Telescope Unit, Siding Spring Observatory. For more than a decade, Russell has been concerned with most aspects of the operation of the 1.2-m U.K. Schmidt, including observation, data analysis and computer programming. He has been involved with the so-called ESO/SERC Southern Sky Survey and was instrumental in securing a very fine series of photographic images of $\mathrm{P} / \mathrm{Halley}$ during its recent apparition. Russell has discovered five comets - four of them periodic - since 1979, and he worked on the observational phase of the U.K. Schmidt-Caltech Asteroid Survey in 1981. Recently, he began a collaboration with the discoverer on a deep astrometric survey of minor planets, bringing to bear his expertise in image recognition to the problem of semiautomatic identification and measurement of minor-planet images. (M 13177)

Name endorsed by S. J. Bus and B. G. Marsden.

\section{(3715) Štohl}

1980 DS. Discovered 1980 Feb. 19 by A. Mrkos at Klet.

Named in memory of Ján Śtohl (1932-1993), well known for his work on the dynamics of meteors, director of the Astronomical Institute at Tatranská Lomnica and president of IAU Commission 22 (Meteors and Interplanetary Dust) during 1991-1993. (M 25976)

Name proposed by the discoverer, following a suggestion by astronomers at Tatranská Lomnica.

Obituaries published in WGN, Vol. 21, No. 3, p. 77-78 (1993); Kozmos, Vol. 24, No. 3, p. 2-3 (1993); International astronomical symposium: Meteoroids and their parent bodies, p. 8 (1993).

\section{(3716) Petzval}

1980 TG. Discovered 1980 Oct. 2 by A. Mrkos at Kleť.

Named in memory of József Miska Petzval (18071891), mathematician, professor and inventor at the University of Vienna. He proposed the Petzval lens, and many minor planets were discovered by means of this portrait design at the end of the nineteenth century. (M 25976)

Name proposed by the discoverer, following a suggestion by astronomers of the Astronomical Institute at Tatranská Lomnica.

Petzval is also honored by a lunar crater. 


\section{(3717) Thorenia}

1964 CG. Discovered 1964 Feb. 15 at the Goethe Link Observatory at Brooklyn, Indiana.

Named in memory of Victor Eugene Thoren (19351991), one of the foremost contemporary historians of astronomy and a faculty member in Indiana University's department of history and philosophy of science for his entire academic career. Although Thoren's research contributions were wide-ranging, they nonetheless focused on Tycho Brahe \{see planet (1677) $\}$ and his emphasis on accuracy in a manner never before thought possible. A copy of his monumental study, The Lord of Uraniborg: A Biography of Tycho Brahe, reached Thoren a few days before his tragic death, thus affording him an opportunity to enjoy, all too briefly, the fruits of his intellectual labors. (M 19334)

Name proposed by F. K. Edmondson and endorsed by IAU Commission 41. Citation prepared by E. Grant.

Obituaries published in Isis, Vol. 82, No. 314, p. 693-694 (1991); J. Hist. Astron., Vol. 22, Part 3, p. 253-254 (1991); Bull. Am. Astron. Soc., Vol. 24, No. 4, p. 1334 (1992).

\section{(3718) Dunbar}

1978 VS $_{10}$. Discovered 1978 Nov. 7 by E. F. Helin and S. J. Bus at Palomar.

Named in honor of Roy Scott Dunbar, physicist and planetary scientist at the Jet Propulsion Laboratory. The discoverers wish to acknowledge his dedicated commitment and participation in the Palomar planetcrossing asteroid search, which included his own discovery of the Aten-type asteroid (3362) Khufu. His dissertation on the stability of Trojan-type librations in the Earth-Sun system led to an Earth-Trojan search program at Palomar. (M 12976)

\section{(3719) Karamzin}

1976 YO $_{1}$. Discovered 1976 Dec. 16 by L. I. Chernykh at Nauchnyj.

Named in memory of Nikolaj Mikhailovich Karamzin (1766-1826), author of the celebrated twelve-volume History of the Russian State. (M 13609)

\section{(3720) Hokkaido}

1987 UR $_{1}$. Discovered 1987 Oct. 28 by S. Ueda and

\section{H. Kaneda at Kushiro.}

Named for the northern island of Japan, which has a population of 5.5 million. This planet was the first to be discovered in Hokkaido. In addition to Kushiro \{see planet (4096)\}, there are active programs in Sapporo \{see planet (3473)\} and Kitami \{see planet (3785)\} concerned with the astrometric observations of minor planets and comets. (M 12976)

\section{(3721) Widorn}

1982 TU. Discovered 1982 Oct. 13 by E. Bowell at Anderson Mesa.

Named in memory of Thomas R. Widorn, for several decades an astronomer at the Vienna University
Observatory. Widorn is best known for his discovery of an inverse relationship between the geometric albedo and the rate of change of the optical polarization with solar phase angle, which led to improved estimates of the diameters of minor planets. (M 13177)

Name suggested and citation provided by H. F. Haupt.

\section{(3722) Urata}

1927 UE. Discovered 1927 Oct. 29 by K. Reinmuth at Heidelberg.

Named in honor of Takeshi Urata (1947- ), one of the most active amateur astronomers in Japan and the director of the minor planet section of the Oriental Astronomical Association. Well known for both his astrometric observations and his orbital computations for both comets and minor planets, he pioneered the contributions by Japanese amateur astronomers in both the discovery and the identification of minor planets. His discovery of (2090) Mizuho in 1978 was the first to be made of a minor planet by an amateur astronomer anywhere in more than half a century. $\mathrm{He}$ also discovered periodic comet Urata-Niijima in 1986 . Details of his work are included in the Nihondaira Observatory Circular, of which some 1700 issues have appeared since he established this publication in 1967. $\mathrm{He}$ is also an editor of the Japanese Ephemerides of Minor Planets. (M 16591)

Name proposed and citation prepared by S. Nakano, who found the identifications involving this planet, and who has been his best friend for many years.

\section{(3723) Voznesenskij}

$1976 \mathrm{GK}_{2}$. Discovered 1976 Apr. 1 by N. S. Chernykh at Nauchnyj.

Named in honor of Andrej Andreevich Voznesenskij, distinguished contemporary poet, known also as the author of unique word-and-figure combinations ("vidioms"), and a friend of some of the astronomers of the Crimean Astrophysical Observatory. (M 22499)

\section{(3724) Annenskij}

1979 YN $_{8}$. Discovered 1979 Dec. 23 by L. V. Zhuravleva at Nauchnyj.

Named for Innokentij Fedorovich Annenskij (18551909), well-known Russian poet and writer. (M 22246; M 26439)

\section{(3725) Valsecchi}

1981 EA $_{11}$. Discovered 1981 Mar. 1 by S. J. Bus at Siding Spring.

Named in honor of Giovanni B. Valsecchi, of the Istituto di Astrofisica Spaziale, Rome. Valsecchi's work on the dynamical effects of the outer planets, principally Jupiter, on cometary orbits gave new insight to the existence of temporary captures and the evolution of cometary orbits. This work is summarized in the first Atlas of Orbital Patterns at Close Encounters, of which he is a co-author. He was one of the first, together with Andrea Carusi \{see planet (4700)\}, to recognize the difficulties in reliably identifying asteroid 
families, and he pointed out many inconsistencies in the existing families claimed by various workers. He also contributed to the theory of the dynamical evolution of a swarm of gravitationally interacting small bodies and the understanding of three-body interactions in terms of a two-body model. His keen insight into the physical nature of problems makes it always fruitful to seek his counsel. (M 18453)

Citation provided by Donald R. Davis at the request of the discoverer.

\section{(3726) Johnadams}

1981 LJ. Discovered 1981 June 4 by E. Bowell at Anderson Mesa.

Named in honor of John B. Adams, geologist at the University of Washington, Seattle. Adams experimentally calibrated the relationship between pyroxene chemistry and the wavelength of the pyroxene band present in the absorption spectra of many minor planets, this band being the most important diagnostic feature for interpreting surface composition. He has continued to develop remote sensing techniques that have contributed to our understanding of the composition and evolution of the asteroids and planets, including the Earth. (M 13177)

Name suggested and citation provided by L. A. McFadden.

\section{(3727) Maxhell}

1981 PQ. Discovered 1981 Aug. 7 by A. Mrkos at Kleť.

Named in memory of Maximilian Hell (1720-1792), famous for his determination of the solar parallax from his observations of the transit of Venus in 1769 . Appointed director of the Imperial Observatory in Vienna in 1755 , he prepared and published an important series of astronomical ephemerides. (M 26424)

Name suggested by astronomers at the Astronomical Institute at Tatranská Lomnica.

\section{(3728) IRAS}

1983 QF. Discovered 1983 Aug. 23 with the Infrared Astronomical Satellite.

Named for the Infrared Astronomical Satellite (IRAS), a joint U.S.-Netherlands-U.K. spaceborne allsky infrared survey satellite launched on 1983 Jan. 26. Over its ten-month lifespan, IRAS made observations of more than 250,000 solar-system and extra-solar-system bodies at wavelengths of $12,25,60$ and $100 \mu \mathrm{m}$. IRAS discovered (3200) Phaethon, parent body of the Geminid meteor stream, as well as four long-period and two short-period comets. (M 34619)

\section{(3729) Yangzhou}

$1983 \mathrm{VP}_{7}$. Discovered 1983 Nov. 1 at the Purple Mountain Observatory at Nanking.

Situated between the Yangtze and Huai rivers, Yangzhou is the location of China's earliest canal, dating back to 486 B.C. During the Tang dynasty it was China's busiest metropolis and an important port on the Oriental Sea Silk Road. (M 36126)

\section{(3730) Hurban}

$1983 \mathrm{XM}_{1}$. Discovered 1983 Dec. 4 by M. Antal at Piszkéstetö.

Named in memory of Jozef Miloslav Hurban (18171888), poet, writer, journalist, editor, critic, historian and a leading ideologist of the Slovak national revival. A close colleague (and biographer) of Ľudovít Štúr \{see planet (3393)\}, he promoted the Slovak literary language and organized cultural and educational activities. During the revolution of 1848-1849 he asserted Slovak national and social claims. (M 13609)

\section{(3731) Hancock}

$1984 \mathrm{DH}_{1}$. Discovered 1984 Feb. 20 by V. M. Candy and M. P. Candy at Bickley.

Named in memory of Langley George ("Lang") Hancock (1909-1992), who started life as manager of the family sheep station and became a leading Australian mining prospector, entrepreneur and visionary. He prospected for and developed many minerals, but he will be forever famous for his discovery of the massive iron ore deposits in the Pilbara region of Western Australia. Hancock had a profound influence on the development of Western Australia, establishing several newspapers and writing many books and other publications on mining and free enterprise. The family corporation is now chaired by daughter Georgina Rinehart, who prepared the citation. (M 22246)

\section{(3732) Vávra}

1984 SR $_{1}$. Discovered 1984 Sept. 27 by Z. Vávrová at Klět.

Named in honor of Anton Alfred Vávra (1896- ), the discoverer's father. (M 22246)

\section{(3733) Yoshitomo}

1985 AF. Discovered 1985 Jan. 15 by K. Suzuki and T. Urata at Toyota.

Named for a Japanese military commander, Minamoto Yoshitomo (1123-1160), father of Yoritomo and Yoshitsune \{see planets (3902) and (3178)\}. Though he won the battle of Hogen (1156) and had a chance to enter the militarist government of Japan, he lost the battle of Heiji (1159) and was put to death. (M 19693)

\section{(3734) Waland}

9527 P-L. Discovered 1960 Oct. 17 by C. J. van Houten and I. van Houten-Groeneveld at Palomar.

Named in honor of Scottish optician Robert L. Waland, who developed new techniques for making the optics of Schmidt telescopes. In the 1960s, when he was at the University of Arizona's Lunar and Planetary Laboratory, he made the superb mirrors for the 1.54-meter reflector at the Catalina Station. Waland authored the book Optics of the Cassegrain Telescope in 1990. (M 20158; I. van Houten-Groeneveld) Name proposed by Tom Gehrels. 
(3735) Třebon̆

1983 XS. Discovered 1983 Dec. 4 by Z. Vávrová at Klět.

Named in honor of the discoverer's home town in South Bohemia. (M 16443)

\section{(3736) Rokoske}

$1987 \mathrm{SY}_{3}$. Discovered 1987 Sept. 26 by E. Bowell at Anderson Mesa.

Named for Thomas Leo Rokoske, professor of physics and astronomy at Appalachian State University in Boone, North Carolina. A specialist in solid-state physics, he is known for his exceptional teaching skills and has been active in developing and expanding ASU's astronomical instrumentation and teaching staff. He has played an instrumental role in the publication of the International Comet Quarterly (and its predecessors) since its inception in 1973, and his unselfish work has helped to create this very useful archive of cometary photometric data. (M 12976)

Name suggested by D. W. E. Green, ICQ editor and one of his former students, who found the identifications involving this minor planet.

\section{(3737) Beckman}

1983 PA. Discovered 1983 Aug. 8 by E. F. Helin at Palomar.

Named in honor of Arnold O. Beckman, the inventor of the first practical electrical $\mathrm{pH}$ meter. Through his personal efforts and accomplishments, he has created scientific instrumentation of extraordinary consequence to the world in the areas of chemistry and medicine. $\mathrm{He}$ is an alumnus, former professor and past chairman of the Board of Trustees of Caltech. Beckman and his wife, Mabel, throughout their 63 years of marriage developed a partnership that has made a lasting impact on scientific research and education. This minor planet is named in part to commemorate their immeasurable philanthropic gestures. (M 14971)

\section{(3738) Ots}

1977 QA 1 . Discovered 1977 Aug. 19 by N. S. Chernykh at Nauchnyj.

Named in memory of the opera singer Georg Karlovich Ots (1920-1975). (M 22499)

\section{(3739) Rem}

$1977 \mathrm{RE}_{2}$. Discovered 1977 Sept. 8 by N. S. Chernykh at Nauchnyj.

Named in memory of Rem Viktorovich Khokhlov (1926-1977), Soviet physicist and one of the founders of nonlinear optics. An academician, professor and then rector of the Moscow University, Rem was an outstanding alpinist who perished ascending the Pamirs. (M 22499)

\section{(3740) Menge}

1981 EM. Discovered 1981 Mar. 1 by H. Debehogne and G. DeSanctis at La Silla.

Named in honor of Sergio Menge de Freitas, vicedirector of the Valongo Observatory, Federal University of Rio de Janeiro, during 1983-1990. Known for his research on stellar motions, he has also been a collaborator of the first discoverer. (M 19334)

\section{(3741) Rogerburns}

$1981 \mathrm{EL}_{19}$. Discovered 1981 Mar. 2 by S. J. Bus at Siding Spring.

Named in memory of Roger George Burns (19371994), professor of mineralogy and geochemistry at the Massachusetts Institute of Technology. Author of the book Mineralogical Applications of Crystal Field Theory, first published in 1970, Burns was a pioneer in the field of mineral spectroscopy and in establishing the fundamental basis for interpreting modern remote sensing observations of planetary surfaces. Burns also applied his expertise in geochemistry to understanding chemical weathering processes on Mars. (M 27126)

Name suggested and citation prepared by R. P. Binzel.

\section{(3742) Sunshine}

1981 EQ27. Discovered 1981 Mar. 2 by S. J. Bus at Siding Spring.

Named in honor of Jessica M. Sunshine, visiting scientist at the Massachusetts Institute of Technology. She is best known for developing a technique called the "Modified Gaussian Model" that allows reflectance spectroscopy measurements to be deconvolved and interpreted in terms of constituent absorptions from a suite of mineral species. Sunshine has applied this technique to the study of minor planets, satellites, meteorites and the surfaces of Mars and the earth. (M 27126)

Citation prepared by R. P. Binzel.

\section{(3743) Pauljaniczek}

1983 EW. Discovered 1983 Mar. 10 by E. Barr at Anderson Mesa.

Paul M. Janiczek (1937- ), at the U.S.Ñaval Observatory during 1967-1997 and head of the Astronomical Applications department since 1990, is a specialist in celestial mechanics, ephemerides and navigation. He supervised the U.S. contributions to and production of the Astronomical, Nautical and Air Almanacs. (M 40700)

\section{(3744) Horn-d'Arturo}

1983 VE. Discovered 1983 Nov. 5 at the Osservatorio San Vittore at Bologna.

Named in memory of Guido Horn-d'Arturo (18791967), director of the Bologna Observatory for almost half a century and a talented astronomer far ahead of his time. A pioneer in the design and construction of multiple-mirror telescopes, he designed and utilized the world's first such instrument, a 1.80-m zenith telescope at Bologna. In the 1920s he correctly interpreted the shadow-band phenomenon and attributed an important component of stellar scintillation to currents in the Earth's stratosphere. Following a suggestion by Luigi Jacchia see planet (2079)\}, he founded the magazine Coelum in 1931. (M 13178) 


\section{(3745) Petaev}

1949 SF. Discovered 1949 Sept. 23 by K. Reinmuth at Heidelberg.

Named in honor of Michail Ivanovich Petaev, visiting planetary geologist in the Harvard-Smithsonian Center for Astrophysics Planetary Sciences division. Petaev's investigations include the study of the origins of enstatite chondrite and achondrite meteorites, and he has made detailed studies of numerous meteorites. (M 22499)

Name proposed by members of the Planetary Sciences division, the identifications for this object having been made by C. M. Bardwell.

\section{(3746) Heyuan}

$1964 \mathrm{TC}_{1}$. Discovered 1964 Oct. 8 at the Purple Mountain Observatory at Nanking.

The city of Heyuan is located in the Chinese northeastern province of Guangdong ssee planet (2185)\}. Its Evergreen Lake is very famous, and the wealth of fossil dinosaur eggs discovered in Heyuan in 1996 has important scientific value. (M 40700)

\section{(3747) Belinskij}

$1975 \mathrm{VY}_{5}$. Discovered 1975 Nov. 5 by L. I. Chernykh at Nauchnyj.

Named in honor of Vissarion Grigor'evich Belinskij (1811-1848), Russian literary critic and publicist, revolutionary democrat. (M 13609)

\section{(3748) Tatum}

1981 JQ. Discovered 1981 May 3 by E. Bowell at Anderson Mesa.

Named in honor of Jeremy B. Tatum, professor of astronomy at the University of Victoria, British Columbia. An enthusiastic teacher and expert in molecular spectroscopy, especially of comets and interstellar gas clouds, Tatum was the chief founder and is the driving force behind the Climenhaga s see planet (3034)\} Observatory's program of astrometry of minor planets and comets, the only one of its kind in Canada. (M 13178)

Name suggested and citation provided by C. Spratt.

\section{(3749) Balam}

$1982 \mathrm{BG}_{1}$. Discovered 1982 Jan. 24 by E. Bowell at Anderson Mesa.

Named in honor of David D. Balam, research assistant at the University of Victoria's Climenhaga Observatory. In addition to being the observatory's principal observer, Balam has developed most of the software for the astrometric program on minor planets and comets. (M 13178)

Name suggested and citation provided by C. Spratt.

On 2002 Feb. 8.4 the discovery of S/2002 (3749) 1 - a satellite of minor planet (3749) Balam with an estimated diameter of $1.5 \mathrm{~km}$ - was reported (IAUC 7827).

\section{(3750) Ilizarov}

1982 TD $_{1}$. Discovered 1982 Oct. 14 by L. G. Karachkina at Nauchnyj.

Named in honor of Gavriil Abramovich Ilizarov, a remarkable orthopedic surgeon whose new methods have cured more than half a million patients. (M 17028)

\section{(3751) Kiang}

1983 NK. Discovered 1983 July 10 by E. Bowell at Anderson Mesa.

Named in honor of Tao Kiang, an astronomer at the Dunsink Observatory, near Dublin. A teacher of the discoverer, Kiang has carried out a wide range of astronomical research, including contributions to the study of minor planets, comets, quasars and cosmology. In particular, he has worked on the structure of the asteroidal belt and the stability of Kirkwood gaps. He has served as editor of Chinese Astronomy and Astrophysics since its inception in 1977 and has published several papers on astronomical research in China, both ancient and modern. (M 12976)

\section{(3752) Camillo}

1985 PA. Discovered 1985 Aug. 15 by E. F. Helin and M. A. Barucci at Caussols.

Named for the young son of Turno, king of the earliest Romans. The name also honors the son of the second discoverer. (M 14633)

\section{(3753) Cruithne}

1986 TO. Discovered 1986 Oct. 10 by J. D. Waldron at Siding Spring.

Named for the most common term used by the Irish for the Picts - one of the ancient peoples of Scotland. 'Cruithne' was the eponymous ancestor of the Picts, and it was his seven sons who gave their names to the seven divisions of the Pictish Kingdom. (M 31609)

\section{(3754) Kathleen}

1931 FM. Discovered 1931 Mar. 16 by C. W. Tombaugh at Flagstaff.

Named in honor of Kathleen Willoughby Clifford, granddaughter of the discoverer. (M 18306)

\section{(3755) Lecointe}

1950 SJ. Discovered 1950 Sept. 19 by S. Arend at Uccle.

Named in honor of Georges Lecointe (1869-1929), director of the Royal Observatory of Belgium from 1900 to 1925 . Under his leadership, the observatory obtained several instruments and deployed great scientific activity. (M 25976)

Proposed by P. Páquet and N. Arend.

\section{(3756) Ruscannon}

$1979 \mathrm{MV}_{6}$. Discovered 1979 June 25 by E. F. Helin and S. J. Bus at Siding Spring.

Named in honor of Russell Cannon, astrophysicist, director of the Anglo-Australian Observatory, coordinating the activities of the joint observatories. His special interests are the study of stars in globular 
clusters and in dwarf galaxies of the Local Group. Cannon was officer-in-charge of the U.K. 1.2-m Schmidt from its first operation in 1974 and is responsible for setting the high standards for which it is renowned. The first discoverer wishes to acknowledge his support in helping her initiate special asteroid surveys at the U.K. Schmidt telescope in Siding Spring \{see planets (4128) and (2343), respectively\}. (M 19334)

\section{(3758) Karttunen}

1983 WP. Discovered 1983 Nov. 28 by E. Bowell at Anderson Mesa.

Named for Hannu Karttunen, Finnish astronomer and mathematician. Karttunen has developed a rather general method to model the lightcurves of minor planets and, in collaboration with the discoverer and other colleagues, has sought to understand lightcurves and phase curves in terms of body morphology and large-scale albedo features. He has recently served as an editor of a comprehensive college-level text on fundamental astronomy, which has been published in Finnish and English. (M 12977)

Name endorsed by B. A. Skiff, who took the discovery plates.

\section{(3759) Piironen}

1984 AP. Discovered 1984 Jan. 8 by E. Bowell at Anderson Mesa.

Named in honor of Jukka Piironen, astronomer at the Finnish Meteorological Institute, Helsinki. Working with the discoverer, Piironen made accurate lightcurve observations of a number of brighter minor planets. Subsequently, he was involved in the physical interpretation of such lightcurves by studying the behavior of rotating models in the laboratory. In Turku he participated in the grinding and figuring of the 2.5-m mirror for the Nordic Optical Telescope \{see planet (2857) , and he worked on aspects of the Soviet Phobos mission. (M 12977)

Name endorsed by B. A. Skiff, who took the discovery plates.

\section{(3760) Poutanen}

1984 AQ. Discovered 1984 Jan. 8 by E. Bowell at Anderson Mesa.

Named in honor of Markku Poutanen, Finnish astronomer. Poutanen has been active in the observation of asteroid lightcurves and, with the discoverer, obtained the most extensive phase curve of a minor planet then observed, especially at small phase angles. Like his colleague Karttunen \{see planet (3758)\}, Poutanen recently served as coeditor of a textbook on astronomy. In addition, he has enthusiastically sought to bring amateur and professional astronomers together, by means of both teaching and writing. (M 12977)

Name endorsed by B. A. Skiff, who took the discovery plates.
(3761) Romanskaya

1936 OH. Discovered 1936 July 25 by G. N. Neujmin at Simeis.

Named in memory of Sof'ya Vasil'evna Romanskaya (1886-1969). The first Russian woman concerned with astronomical observations, she made over 20,000 highly precise latitude determinations with a ZTF-135 zenithtelescope. Her major scientific interests were in the fields of the variation of latitude and the earth's polar motion. From 1908 to 1959 she worked at the Pulkovo Observatory. (M 24916)

Name proposed by L. D. Kostina.

\section{(3762) Amaravella}

1976 QN $_{1}$. Discovered 1976 Aug. 26 by N. S. Chernykh at Nauchnyj.

Named for a group of Russian painters, known for the cosmic themes of their work. (M 20836)

\section{(3763) Qianxuesen}

$1980 \mathrm{TA}_{6}$. Discovered 1980 Oct. 14 at the Purple Mountain Observatory at Nanking.

Qian Xuesen (1911- ), known for his pioneering contributions to aerodynamics, the physics of solids and engineering cybernetics, laid the theoretical foundation for overcoming the sound barrier and is recognized in the Karman-Tsien rule. He is honorary president of the Chinese Association for Sciences and Technology. (M 43188)

\section{(3764) Holmesacourt}

$1980 \mathrm{TL}_{15}$. Discovered 1980 Oct. 10 by A. McNay at Bickley.

Named in honor of Robert Holmes a Court (19371990), a leading Australian lawyer, businessman and collector. Holmes a Court was born in South Africa and studied in New Zealand and Australia. He practised law for a number of years before embarking on a business career and developed a world-ranking reputation for original and lateral thinking in every pursuit, from art and bloodstock to corporate management and philantropy. He was described by his peers as a renaissance man and a citizen of the world. (M 22829)

\section{(3765) Texereau}

$1982 \mathrm{SU}_{1}$. Discovered 1982 Sept. 16 by K. Tomita at Caussols.

Named in honor of Jean Texereau, leading figure in the world of astronomical optics. Among the fine telescopes he has constructed is the Caussols 0.9-m Schmidt with which this minor planet was discovered. Wide diffusion of his books and advice has greatly helped others, notably thousands of amateur astronomers, to build their own instruments. (M 14481)

\section{(3766) Junepatterson}

1983 BF. Discovered 1983 Jan. 16 by E. Bowell at Anderson Mesa.

Named in memory of June C. Patterson (19231988) of Sierra Vista, Arizona. She and her husband David were well-known amateur astronomers. Through 
their volunteer work with astronomy clubs and the Flandrau Planetarium in Tucson, the Patterson's inspired many young people to pursue interests in astronomy. (M 13178)

Name proposed by J. V. Scotti and D. H. Levy.

\section{(3767) DiMaggio}

1986 LC. Discovered 1986 June 3 by E. F. Helin at Palomar.

Named in memory of the Yankee Clipper, Joe DiMaggio (1914-1999), U.S. baseball legend. DiMaggio's most enduring record was set during the 1941 season, when he had hits in 56 consecutive games. (M 34619)

DiMaggio was married with the movie star Marilyn Monroe $\{$ see planet (3768)\}.

\section{(3768) Monroe}

1937 RB. Discovered 1937 Sept. 5 by C. Jackson at Johannesburg.

Named for Marilyn Monroe (1926-1962), née Norma Jean Mortensen (also known as Baker), renowned glamorous star of the movie screen. (M 34619)

Monroe was married with the baseball player Joe DiMaggio \{see planet (3767)\}.

\section{(3770) Nizami}

$1974 \mathrm{QT}_{1}$. Discovered 1974 Aug. 24 by L. I. Chernykh at Nauchnyj.

Named in memory of the distinguished Azerbaijani poet and thinker Nizami Ghiandjevi Abu Mukhammed Il'yas ibn Yusub (1141-1209), whose poetry had an major influence on the development of literature in the Middle East. (M 18454)

\section{(3771) Alexejtolstoj}

1974 SB $_{3}$. Discovered 1974 Sept. 20 by L. V. Zhuravleva at Nauchnyj.

Named in memory of Alexej Nikolaevich Tolstoj (1883-1945), a well-known Russian writer and public figure. (M 24121)

\section{(3772) Piaf}

1982 UR $_{7}$. Discovered 1982 Oct. 21 by L. G. Karachkina at Nauchnyj.

Named in memory of the great French singer Edith Piaf (1915-1963). (M 17028)

\section{(3773) Smithsonian}

1984 YY. Discovered 1984 Dec. 23 at the Oak Ridge Observatory at Harvard.

Named in honor of the Smithsonian Institution on the occasion of the centennial celebration of its Astrophysical Observatory, 1990 Nov. 2-4. (M 17221)

\section{(3774) Megumi}

1987 YC. Discovered 1987 Dec. 20 by T. Kojima at Chiyoda.

Named in honor of the discoverer's wife and observing partner. (M 12977)

\section{(3775) Ellenbeth}

$1931 \mathrm{TC}_{4}$. Discovered 1931 Oct. 6 by C. W. Tombaugh at Flagstaff.

Named in honor of Ellen Elizabeth Willoughby, granddaughter of the discoverer. (M 18306)

\section{(3776) Vartiovuori}

1938 GG. Discovered 1938 Apr. 5 by H. Alikoski at Turku.

Named for the hill in Turku on which Argelander's \{see planet (1551)\} old observatory was situated. The building now includes astronomical collections in memory of Väisälä \{see planet (1573)\}. (M 18454)

\section{(3777) McCauley}

$1981 \mathrm{JD}_{2}$. Discovered 1981 May 5 by C. S. Shoemaker at Palomar.

Named in honor of John Francis McCauley, geologist with the U.S. Geological Survey and chief of the Branch of Astrogeologic Studies from 1970 to 1974. McCauley is specially recognized for his pioneering research on the geology of the Moon, Mars, and Mercury and for his leading role in using Space Shuttle imaging radar data to describe an ancient trans-African river system that crossed the now hyperarid Sahara Desert. (M 13482)

Citation provided by G. G. Schaber at the request of the discoverer.

\section{(3778) Regge}

$1984 \mathrm{HK}_{1}$. Discovered 1984 Apr. 26 by W. Ferreri at La Silla.

Named in honor of Tullio Regge, professor of the theory of relativity at Turin University. His research has included particle scattering at high energy and the development of the concept of complex angular momentum. Regge is a recipient of the American Physical Society's Heineman award and of the Lewis Strauss Foundation's Einstein medal. (M 13609)

\section{(3779) Kieffer}

$1985 \mathrm{JV}_{1}$. Discovered 1985 May 13 by C. S. Shoemaker and E. M. Shoemaker at Palomar.

Named in honor of Hugh Hartman Kieffer, geophysicist with the U.S. Geological Survey and chief of the Branch of Astrogeology since 1986. Kieffer is specially recognized for his work on the geology of Mars and his participation in spacecraft missions. His laboratory studies of the spectra of water and carbon-dioxide ices, his leadership in the design of the Viking Infrared Thermal Mapper, and his analysis of its data with colleagues, many of whom are his former students, defined the thermal properties of Mars and the seasonal behavior of water and carbon dioxide in the polar caps. (M 13482)

\section{(3780) Maury}

1985 RL. Discovered 1985 Sept. 14 by E. Bowell at Anderson Mesa.

Named in honor of Alain Maury, photographic scientist working on the Palomar Sky Survey II 
at Mount Palomar Observatory. Well known as a discoverer of comets and Earth-approaching minor planets, Maury began his professional career in his native France at the CERGA \{see planet (2252)\} Schmidt telescope. He joined the Palomar team in 1984. (M 13178)

Citation provided by D. H. Levy at the request of the discoverer.

\section{(3781) Dufek}

$1986 \mathrm{RG}_{1}$. Discovered 1986 Sept. 2 by A. Mrkos at Klet.

Named in honor of George Dufek, an associate of Richard E. Byrd and for a long time the leader of American expeditions in Antarctica. (M 26424)

\section{(3782) Celle}

1986 TE. Discovered 1986 Oct. 3 by K. Augustesen and H. J. Fogh Olsen and P. Jensen at Brorfelde.

Named for the beautiful German city of Celle on the occasion of its seven-hundredth anniversary in 1992. Celle, which is situated in the province of Niedersachsen, is the twin town to Holbaek ssee planet (3033)\}, the Danish town nearby the Brorfelde \{see planet (3309)\} Observatory. The Danish queen Caroline Mathilde (1751-1775), banished from the court in 1772, went to Celle, where she died of copper poisoning. She was buried in the old Celle castle. (M 19693)

Name proposed by the discoverers following a suggestion from the town of Holbaek.

\section{(3783) Morris}

$1986 \mathrm{TW}_{1}$. Discovered 1986 Oct. 7 by E. Bowell at Anderson Mesa.

Named for Charles S. Morris, one of the foremost visual observers of comets. In addition to making more than 1,200 photometric observations of more than 90 comets, he made a rare visual recovery of $\mathrm{P} /$ Faye in 1983, and he has been most helpful in confirming newly discovered comets at the request of the Central Bureau for Astronomical Telegrams. He has done much analytical work with visual magnitude data and has contributed extensively to the development of the International Comet Quarterly, of which he is associate editor, and its photometric archive. (M 13178)

Name suggested and citation prepared by D. W. E. Green and D. H. Levy.

\section{(3784) Chopin}

1986 UL $_{1}$. Discovered 1986 Oct. 31 by E. W. Elst at St. Michel.

Named in memory of the great composer and pianist Frédéric Chopin (1810-1849). (M 13179)

\section{(3785) Kitami}

1986 WM. Discovered 1986 Nov. 30 by T. Seki at Geisei.

Named for a city in Hokkaido \{see planet (3720)\} that has been since 1983 a "friendship city" of the discoverer's own city of Kochi \{see planet (2396)\}. Several amateur astronomers there have been conducting an active program of astrometric observations of minor planets and comets. (M 13482)

\section{(3786) Yamada}

1988 AE. Discovered 1988 Jan. 10 by T. Kojima at Chiyoda.

Named in memory of Sakao Yamada (1918-1986), an outstanding Japanese engineer who devoted his life to the research and development of aspherical optics. Founder of Japan Special Optics, he made much optical equipment for Japanese amateur astronomers in cooperation with Nobuhisa Kojima \{see planet (4351)\}, discoverer of two comets and $1973 \mathrm{MA}$, the first minor planet discovered by a Japanese amateur and one of the identifications for 1988 AE. Yamada, a teacher of both $\mathrm{N}$. Kojima and the discoverer (no relation), pioneered the mass production of Schmidt-type cameras in Japan. With their high performance and capability, ease of handling and precise star images, these Schmidt cameras, which include the $0.25-\mathrm{m}$ Wright Schmidt with which this discovery was made, have produced many splendid astro-photographs and discoveries of new heavenly bodies. (M 17028)

\section{(3787) Aivazovskij}

1977 RG$_{7}$. Discovered 1977 Sept. 11 by N. S. Chernykh at Nauchnyj.

Named in honor of Ivan Konstantinovich Aivazovskij (1817-1900), great Russian painter of seascapes who lived and worked in Feodosia \{see planet (1048)\}, in the Crimea. (M 22499)

\section{(3789) Zhongguo}

1928 UF. Discovered 1928 Oct. 25 by Y. C. Chang at Williams Bay.

This minor planet, originally intended to be (1125) China, was accidentally usurped from that number and name by 1957 UN1, discovered by Y. C. Chang s see planet (2051)\} at the Purple Mountain Observatory. It seems therefore particularly appropriate that $1928 \mathrm{UF}$ should receive the Chinese form of the name of China. The minor planet is a 2:1 Jupiter librator. (M 13179)

\section{(3790) Raywilson}

1937 UE. Discovered 1937 Oct. 26 by K. Reinmuth at Heidelberg.

Named in honor of Raymond N. Wilson (1928- ), astronomical optician and pioneer of new-technology telescopes, on the occasion of his retirement. After serving as a department head and chief optician with Carl Zeiss, in 1972 he joined the European Southern Observatory, where he began work on ESO's telescopes and auxiliary instrumentation. His great experience in the optical design of large telescopes, as well as his profound knowledge of test methods led him to develop the concept of deformable, adjustable active optical elements. Wilson was responsible for the optical design and the evaluation of suitable tests for the large MPIA and ESO telescopes. (M 22499) 
Name suggested and citation prepared by L. D. Schmadel, endorsed by the Heidelberg Königstuhl Observatory.

\section{(3791) Marci}

$1981 \mathrm{WV}_{1}$. Discovered 1981 Nov. 17 by A. Mrkos at Klě́.

Named in memory of Jan Marcus Marci of Kronland (1595-1667), Czech physicist, mathematician, astronomer and physician at the Charles University in Prague during the Thirty Years War. Twenty years before Newton, Marci thoroughly described the spectral dispersion and diffraction of light, color effects on thin layers and rainbow colors. He also studied elastic and inelastic collisions of spheres, the motion of a pendulum and tried to solve the problem of squaring the circle. (M 27733)

Name suggested by J. Tichá and M. Šolc.

\section{(3792) Preston}

1985 FA. Discovered 1985 Mar. 22 by C. S. Shoemaker and E. M. Shoemaker at Palomar.

Named for Richard Preston, American author and teacher of English literature. Preston's prize-winning book, First Light, describes the history of Palomar Observatory, including the personalities and the research of many astronomers who have observed at Palomar. (M 13482)

\section{(3793) Leonteus}

$1985 \mathrm{TE}_{3}$. Discovered 1985 Oct. 11 by C. S. Shoemaker and E. M. Shoemaker at Palomar.

Named for a good fighter who strove in a contest among his fellow Greeks to win a valuable piece of loot - an iron meteorite - by throwing it the farthest, Leonteus threw mightily, but lost. (M 13482)

Name proposed by Dorothy and Jerome Preston.

\section{(3794) Sthenelos}

$1985 \mathrm{TF}_{3}$. Discovered 1985 Oct. 12 by C. S. Shoemaker and E. M. Shoemaker at Palomar.

Named for the fighting companion who accompanied Diomedes \{see planet (1437)\} during his great rush against the Trojans. Sthenelos pulled an arrow from Diomedes' shoulder and then stole Aeneas' \{see planet (1172)\} chariot horses and drove them back among the Greeks. (M 13482)

Name proposed by Anna McCann Taggart and Robert Taggart.

\section{(3796) Lene}

1986 XJ. Discovered 1986 Dec. 6 by K. Augustesen and P. Jensen at Brorfelde.

Named in honor of Lene Augustesen, daughter of the first discoverer. (M 15089)

\section{(3797) Ching-Sung Yu}

1987 YL. Discovered 1987 Dec. 22 at the Oak Ridge Observatory at Harvard.
Named in memory of Ching-Sung Yu (1897-1978), a Chinese-American astrophysicist, whose spectrophotometric measurements of 91 stars at the Lick Observatory in the early 1920s represented a milestone in research on stellar energy distribution. After returning to China he established the Purple Mountain Observatory and served as its first director. He also developed the site of what is now the Yunnan Observatory, was director of the Academia Sinica's Institute of Astronomy and president of the Chinese Astronomical Society. After World War II $\mathrm{Yu}$ worked at the Harvard College Observatory and later became professor of astronomy and director of the Williams Observatory at Hood College in Frederick, Maryland. (M 14481)

\section{(3798) de Jager}

2402 T-3. Discovered 1977 Oct. 16 by I. van HoutenGroeneveld at Palomar.

Named in honor of Cornelis de Jager, Dutch astronomer, former director of the observatory at Utrecht and General Secretary of the IAU from 1967 to 1973 . His research concentrated on solar physics. He promoted international scientific collaboration, in particular with the Soviet Union. (M 18138)

\section{(3799) Novgorod}

1979 SLg. Discovered 1979 Sept. 22 by N. S. Chernykh at Nauchnyj.

Named for one of the oldest towns in Russia. (M 22499)

\section{(3800) Karayusuf}

1984 AB. Discovered 1984 Jan. 4 by E. F. Helin at Palomar.

Named in honor of Alford S. Karayusuf, M.D., in recognition of his enthusiasm and dedication for the extension of space exploration. With a vitality uncommon since the first days of space exploration, he has encouraged the dreams of man's discovery and adventure in the solar system. He has generously supported near-earth asteroid research projects at the Jet Propulsion Laboratory and has spearheaded a World Space Foundation program to investigate the distant regions of the solar system. (M 17221)

\section{(3801) Thrasymedes}

1985 VS. Discovered 1985 Nov. 6 by the Spacewatch at Kitt Peak.

Named for the son of Nestor \{see planet (659)\} and brother of Antilochus. Thrasymedes commanded a fleet of 15 ships to Troy and was involved in the fight against Memnon \{see planet (2895)\} during which Antilochus was killed. He later was among the warriors hidden inside the wooden horse. It has been noted that the orbits of (1583) Antilochus and (3801) Thrasymedes are quite similar, suggesting a common origin for these two minor planets. (M 13179)

\section{(3802) Dornburg}

$1986 \mathrm{PJ}_{4}$. Discovered 1986 Aug. 7 by F. Börngen at Tautenburg. 
Named for a small town, more than 1050 years old, a few kilometers distant from the Tautenburg Observatory. Situated on a limestock rock above the mean Saale \{see planet (5409)\} river valley, it is known for its ceramics and for the ensemble of three "Dornburg castles" from three architectural epochs. Goethe \{see planet (3047)\} spent some time in this attractive place. (M 13482)

\section{(3803) Tuchkova}

$1981 \mathrm{TP}_{1}$. Discovered 1981 Oct. 2 by L. V. Zhuravleva at Nauchnyj.

Named in memory of Margarita Mikhailovna Tuchkova (1781-1852), who built the Temple Spas Nerukotvorny in 1820 . She founded the SpasoBorodinskij nunnery in 1839 in honor of the battle at Borodino (1812) \{see planet (3544)\} where her husband and brother-in-law were killed. Her monastic name was Mother Maria. (M 24121)

\section{(3804) Drunina}

$1969 \mathrm{~TB}_{2}$. Discovered 1969 Oct. 8 by L. I. Chernykh at Nauchnyj.

Named in honor of the Soviet poetess Yuliya Vladimirovna Drunina. (M 18454)

\section{(3805) Goldreich}

$1981 \mathrm{DK}_{3}$. Discovered 1981 Feb. 28 by S. J. Bus at Siding Spring.

Named in honor of Peter Goldreich (1939- ), of the California Institute of Technology. Goldreich and his students have contributed to a remarkably broad range of topics in planetary science and astrophysics. Goldreich has written influential and much-quoted papers on polar wandering, the origin of the moon, solar oscillations, the cause of radio bursts from Jupiter, tidal evolution of satellite orbits and planetary spins, planetary rings, the formation of the solar system, instabilities in rotating stars, the origin of planetary nebulae, pulsar magnetospheres, accretion disks, astrophysical masers, spiral structure in galaxies and galaxy formation. (M 27458)

Citation provided by S. D. Tremaine.

\section{(3806) Tremaine}

$1981 \mathrm{EW}_{32}$. Discovered 1981 Mar. 1 by S. J. Bus at Siding Spring.

Named in honor of Scott D. Tremaine (1950- ). Tremaine has made seminal contributions to solarsystem and galactic dynamics. He is co-author with James Binney of the leading monograph on galactic dynamics. Since 1985 Tremaine has been director of the Canadian Institute for Theoretic Astrophysics in Toronto, and the success of that organization owes much to his vision and leadership. (M 27458)

Citation provided by P. M. Goldreich following a suggestion by the discoverer and A. W. Harris.

\section{(3807) Pagels}

$1981 \mathrm{SE}_{1}$. Discovered 1981 Sept. 26 by B. A. Skiff and N. G. Thomas at Anderson Mesa.
Named in memory of Heinz R. Pagels (1939-1988), physicist, activist, educator, administrator, editor and author. His books include The Dreams of Reason: The Computer and the Rise of Sciences of Complexity (1988), Perfect Symmetry: The Search for the Beginning of Time (1985), and The Cosmic Code: Quantum Physics as the Language of Nature (1985). Among his numerous offices were the executive directorship of the New York Academy of Sciences and the presidency of the International League for Human Rights. He was an avid mountaineer. (M 26761)

\section{(3808) Tempel}

$1982 \mathrm{FQ}_{2}$. Discovered 1982 Mar. 24 by F. Börngen at Tautenburg.

Named in memory of Wilhelm Ernst Tempel (18211889), discoverer of sixteen comets, five minor planets and several diffuse nebulae. Born in the German district of Upper Lusatia, Tempel was an uncommonly successful and enthusiastic observer. His minor planets were discovered while he was in Marseilles. (M 13483)

Name suggested by M. Gressmann on the 100th anniversary of Tempel's death in Florence.

Tempel is also honored by a lunar crater.

\section{(3809) Amici}

1984 FA. Discovered 1984 Mar. 26 at the Osservatorio San Vittore at Bologna.

Named in memory of Giovanni Battista Amici (1786-1863), professor of mathematics at the University of Modena \{see planet (3344)\} and astronomer at the Museum of Physics and Natural History in Florence. Well known for his construction of optical instruments, his famous $0.28-\mathrm{m}$ achromatic objective, one of the largest in the world when it was made, is still in use at the Arcetri Astrophysical Observatory. In Italian the name of this minor planet also means "friends". (M 13483)

Amici is also honored by a lunar crater.

\section{(3810) Aoraki}

1985 DX. Discovered 1985 Feb. 20 by A. C. Gilmore and P. M. Kilmartin at Lake Tekapo.

Aoraki, or Aorangi in northern dialects, is the Maori name for New Zealand's highest mountain, 3764 meters high, also known as Mount Cook. The name is also given to the region in which Mount John lies, east of the mountain. (M 18306)

\section{(3811) Karma}

1953 TH. Discovered 1953 Oct. 13 by L. Oterma at Turku.

Named in memory of Birger Karma (1899-1943), mathematician, a teacher of the discoverer at school and university and one of the founders of the society Turun Ursa for amateur astronomers. (M 18454)

\section{(3812) Lidaksum}

$1965 \mathrm{AK}_{1}$. Discovered 1965 Jan. 11 at the Purple Mountain Observatory at Nanking. 
Named in honor of Li Dak Sum, noted public figure and enthusiastic promoter of Chinese educational and cultural activities. (M 27126)

\section{(3813) Fortov}

1970 QA 1 . Discovered 1970 Aug. 30 by T. M. Smirnova at Nauchnyj.

Named in honor of Russian academician Vladimir Evgen'evich Fortov (1946- ), well-known for his work on the theory of high-velocity processes of burning and impact. He has made valuable contributions to the theory of the interaction of cosmic bodies with the earth's atmosphere and surface. (M 23136)

Name proposed by the International Institute of Problems of the Asteroid Hazard (St. Petersburg).

\section{(3814) Hoshi-no-mura}

1981 JA. Discovered 1981 May 4 by T. Furuta at Tokai.

Named for a small vocational training institute not far from the discoverer's home. The main purpose of the institute is to help mentally handicapped people obtain job opportunities and participate positively in various social activities. The name, which means "star village", was suggested by Youichi Hanaki, an amateur astronomer and one of the institute's leaders. (M 16042)

\section{(3815) König}

1959 GG. Discovered 1959 Apr. 15 by A. König and G. Jackisch and W. Wenzel at Heidelberg.

Named by the second and third discoverers in memory of the first, Arthur König (1895-1969), who succeeded Reinmuth \{see planet (1111)\} in 1957 as the leader of the long-standing Heidelberg observing program on minor planets. An astrometrist known also for his work on stellar positions and proper motions, König also held a leading position in the astronomical department of the Zeiss company and was an authority on coordinate measuring engines. (M 13483)

\section{(3816) Chugainov}

1975 VG9. Discovered 1975 Nov. 8 by N. S. Chernykh at Nauchnyj.

Named in memory of Pavel Fedorovich Chugainov (1933-1992), astronomer at the Crimean Astrophysical Observatory for more than 30 years, and a prominent specialist in stellar photometry and physics. Known for his research of red dwarfs, Chugainov was the head of the Working Group on Flare Stars of IAU Commission 27 and he had been a member of the Organizing Committee of IAU Commission 25 for some years. (M 22499)

Obituary published in Izv. Krym. Astrofiz. Obs., Tom 87, p. 169-170 (1993).

\section{(3817) Lencarter}

$1979 \mathrm{MK}_{1}$. Discovered 1979 June 25 by E. F. Helin and S. J. Bus at Siding Spring.
Named in honor of Leonard J. Carter \{1922-1998\}, executive secretary of the British Interplanetary Society. For more than 50 years, his efforts have been the basis for the constructive role of the BIS in space advocacy, education and international communications. (M 13483)

Name proposed by the first discoverer following a suggestion by W. I. McLaughlin and endorsed by R. L. Staehle.

Obituary published in Spaceflight, Vol. 41, No. 1, p. 40-41 (1999).

\section{(3818) Gorlitsa}

1979 QL. Discovered 1979 Aug. 20 by N. S. Chernykh at Nauchnyj.

Named in honor of Mariya Avksent'evna Rudenko, village schoolmistress in the Ukrainian region of Mogilev-Podol'skij, collector of Ukrainian folklore, and founder and leader of Gorlitsa. Meaning turtledove, this women's amateur chorus is very popular throughout Ukraine. (M 20836)

\section{(3819) Robinson}

1983 AR. Discovered 1983 Jan. 12 by B. A. Skiff at Anderson Mesa.

Named in honor of Leif J. Robinson, editor of 'Sky and Telescope'. Robinson's career as an observer began with a series of planetary drawings and observations of the rapidly changing variable stars in the Orion Nebula. He worked at the Griffith Planetarium in Los Angeles before joining the staff of the magazine in 1962 as an editorial assistant, and he succeeded the late Joseph Ashbrook \{see planet (2157)\} as editor in 1980. Robinson has been an active promoter of professional-amateur cooperation in astronomy, and retains interests in solar-eclipse viewing and birdwatching. (M 16246)

Citation provided by D. H. Levy, S. J. Edberg and J. K. Beatty at the request of the discoverer.

\section{(3820) Sauval}

1984 DV. Discovered 1984 Feb. 25 by H. Debehogne at La Silla.

Henri Sauval (1623-1676) was a French legal expert at the High judicial Court of Paris in the age of the Sun King, Louis XIV, and also a scrupulous historian and author of Histoire et recherches des antiquités de la ville de Paris (1724). (M 42668)

The name was suggested by A. J. Sauval.

\section{(3821) Sonet}

$1985 \mathrm{RC}_{3}$. Discovered 1985 Sept. 6 by H. Debehogne at La Silla.

Jean Sonet (1908-1987), a Belgian Jesuit, was a specialist in Romance languages, professor and later rector (1953-1958) of the University of Namur. From 1958 to his death he was Vice-Rector of the Catholic 
University of Cordoba (Argentina), where the discoverer met him. (M 42668)

The name was suggested by A. Sonet.

\section{(3822) Segovia}

1988 DP $_{1}$. Discovered 1988 Feb. 21 by T. Seki at Geisei.

Named in memory of Andreas Segovia (1893-1987), considered by many to be the most celebrated guitarist of all time. The discoverer heard Segovia perform in Japan in 1959, and this greatly inspired his own interest in playing the guitar. (M 14481)

\section{(3823) Yorii}

$1988 \mathrm{EC}_{1}$. Discovered 1988 Mar. 10 by M. Arai and H. Mori at Yorii.

Named for the small town in central Japan where this minor planet was discovered. Known for the attractions of Hachigata Castle and Five Hundred Rakans (small stone statues), Yorii is situated close to the Tokyo Astronomical Observatory's Dodaira Station. (M 13483)

\section{(3824) Brendalee}

1929 TK. Discovered 1929 Oct. 5 by C. W. Tombaugh at Flagstaff.

Named in honor of Brenda Willoughby Anderson, granddaughter of the discoverer. (M 18306)

\section{(3826) Handel}

$1973 \mathrm{UV}_{5}$. Discovered 1973 Oct. 27 by F. Börngen at Tautenburg.

Named for the illustrious composer Georg Friedrich Handel (1685-1759). Although his greatest works were composed after he moved to England, Handel was born in Halle, only some $60 \mathrm{~km}$ from Tautenburg. (M 13483)

Handel is the anglicized form of the original German spelling Händel.

\section{(3827) Zdeněkhorský}

1986 VU. Discovered 1986 Nov. 3 by A. Mrkos at Kleť.

Named in memory of Zdeněk Horský (1929-1988), outstanding Czech historian of medieval and renaissance astronomy and authority on Kepler \{see planet (1134)\}. Horský also studied megalithic localities in Bohemia, explained the cosmological architectural symbolism of the gothic Charles Bridge and the New Town of Prague and dated the origin of the famous astronomical clock on the Old Town Hall in Prague. (M 27733; M 30819)

Name suggested by J. Tichá, M. Tichý and Z. Moravec.

Obituary published in J. Hist. Astron., Vol. 19, Part 3, p. 215 (1988).

\section{(3828) Hoshino}

1986 WC. Discovered 1986 Nov. 22 by K. Suzuki and T. Urata at Toyota.
Named in honor of Jiro Hoshino, an amateur astronomer who has ground more than seven hundred telescope mirrors, one of which is in the telescope with which this minor planet was found. Formerly a public officer in Fukuoka prefecture, he is author of How to make a reflecting telescope and Album of astrophotography. (M 14971)

\section{(3829) Gunma}

1988 EM. Discovered 1988 Mar. 10 by T. Kojima at Chiyoda.

Named for the prefecture in central Japan that is home to the discoverer. A public astronomical observatory under construction in Gunma will include a 1.5-m telescope, the largest in Japan for public use. This telescope will also be used for astronomical research and discovery. (M 28089)

\section{(3830) Trelleborg}

1986 RL. Discovered 1986 Sept. 11 by P. Jensen and K. Augustesen and H. J. Fogh Olsen at Brorfelde.

Named in honor of an old town in southern Sweden, twinned with Holbaek \{see planet (3033)\}, the nearest town to the Brorfelde \{see planet (3309)\} Observatory. (M 22499)

Name proposed by the third discoverer.

\section{(3831) Pettengill}

$1986 \mathrm{TP}_{2}$. Discovered 1986 Oct. 7 by E. Bowell at Anderson Mesa.

Named in honor of Gordon H. Pettengill, planetary physicist at the Massachusetts Institute of Technology and currently director of the MIT Center for Space Research. Pettengill pioneered the development of planetary radar astronomy, beginning in the late 1950s with the first application of coherent Earth-based radar to lunar studies. In 1965 he led delay-Doppler observations that revealed the $3 / 2$ spin-orbit resonance of Mercury. Since then his observations have helped characterize the physical and dynamical properties of the inner planets, the Galilean satellites, Saturn's rings, and several asteroids and comets. Pettengill was principal investigator for the Pioneer Venus radar mapper experiment, which during 1978-1981 provided the first global maps of Venus topography, radar reflectivity and surface slope. He is also PI for the radar experiments on the Magellan Mission to Venus. (M 13610)

Name suggested and citation written by S. J. Ostro, who was a student of Pettengill.

\section{(3832) Shapiro}

1981 QJ. Discovered 1981 Aug. 30 by E. Bowell at Anderson Mesa.

Named in honor of Irwin I. Shapiro \{1929- \}, physicist associated with the Massachusetts Institute of Technology and with Harvard University during the past three decades, and since 1983 the director of the Harvard-Smithsonian Center for Astrophysics. 
Shapiro has been responsible for major advances in radio and radar science, and he has made fundamental theoretical and observational contributions to celestial mechanics, astrometry, astrophysics, gravitation physics, geophysics and planetary physics. His planetary ephemerides, considered among the best available, have been used for virtually every Arecibo Observatory radar observation of asteroids, comets, planets, and the satellites of Mars and Jupiter. The underlying ephemeris software also constitutes a primary tool for analysis of VLBI measurements, whose diverse applications include high-precision terrestrial geodesy. During the early 1960s Shapiro played a central role in the radar determination of the astronomical unit, and his research since then has led to refined values for planetary orbital elements, masses, dimensions and spin vectors. (M 13610)

Name suggested and citation written by S. J. Ostro, who was a student of Shapiro.

\section{(3833) Calingasta}

1971 SC. Discovered 1971 Sept. 27 by J. Gibson and C. U. Cesco at El Leoncito.

Named for the region of Argentina where the discovery site is located. The region has good astronomical seeing, and a large area has been declared as both an astronomical and an ecological reserve in order to preserve the observing conditions. (M 29142)

Name proposed by the first discoverer following a suggestion by J. G. Sanguin.

\section{(3834) Zappafrank}

1980 JE. Discovered 1980 May 11 by L. Brožek at Kleť.

Named in memory of Frank Zappa (1940-1993), rock musician and composer of innovative contemporary symphonic, chamber and electronic music. Zappa was an eclectic, self-trained artist and composer with incredible energy and a biting wit, and his music transcends the usual music barriers. Before 1989 he was regarded as a symbol for democracy and freedom by many people in Czechoslovakia. (M 23792)

\section{(3835) Korolenko}

1977 SD $_{3}$. Discovered 1977 Sept. 23 by N. S. Chernykh at Nauchnyj.

Named in honor of Vladimir Galaktionovich Korolenko (1853-1921), Russian writer and publicist whose works are filled with democratic and humanistic ideas. (M 22499)

\section{(3836) Lem}

1979 SR $_{9}$. Discovered 1979 Sept. 22 by N. S. Chernykh at Nauchnyj.

Named in honor of Stanislaw Lem (1921- ), famous Polish writer and founder of the Polish Astronautical Society. (M 20837)

\section{(3837) Carr}

$1981 \mathrm{JU}_{2}$. Discovered 1981 May 6 by C. S. Shoemaker at Palomar.

Named for Michael Harold Carr, geologist with the U.S. Geological Survey and chief of the Branch of Astrogeologic Studies from 1974 to 1978. As leader of the Viking Orbiter Imaging Team, Carr is widely recognized for his role in planetary exploration. He is best known for his comprehensive investigations of the geology and climatic history of Mars. (M 13483)

\section{(3838) Epona}

1986 WA. Discovered 1986 Nov. 27 by A. Maury at Palomar.

Named for the Gaulish goddess of horses and horseriders, specifically with respect to those on Palomar Mountain, where this object was discovered. The name derives from the ancient Indo-European word "Ekwos", which gave among others the words Epos (in Gaulish), Hippos (in Greek) and Equus (in Latin). Horses have been long used by mankind in their conquest of new worlds, and there is hope that rockets with large "horsepower" will let us soon explore earth-crossing asteroids such as this one. (M 16443)

Citation written by the discoverer with the very knowledgeable help of J. P. Rivet and at the suggestion of many other French amateur astronomers.

\section{(3839) Bogaevskij}

1971 OU. Discovered 1971 July 26 by N. S. Chernykh at Nauchnyj.

Named in honor of Konstantin Fedorovich Bogaevskij (1872-1943), Russian painter who lived and worked in the Crimea for many years and who devoted many of his paintings to the eastern part of that peninsula. (M 20837)

\section{(3840) Mimistrobell}

$1980 \mathrm{TN}_{4}$. Discovered 1980 Oct. 9 by C. S. Shoemaker at Palomar.

Named in honor of Mary E. (Mimi) Strobell, geologist with the U.S. Geological Survey. Early in her career she was a member of a team that conducted some of the earliest airborne surveys in the United States. In recent years she has coordinated much of the detailed information used to establish the extensive nomenclature of features on the terrestrial planets and on the satellites of the giant planets. (M 15574)

\section{(3841) Dicicco}

$1983 \mathrm{VG}_{7}$. Discovered 1983 Nov. 4 by B. A. Skiff at Anderson Mesa.

Named in honor of Dennis di Cicco, since 1974 a staff member and since 1983 an associate editor of Sky and Telescope. An imaginative and outstanding astrophotographer, he has participated in many expeditions, specifically to observe eclipses and comets, although his best-known work is probably the analemma showing the Sun from the same spot at the same 
mean time every few days throughout the year. Particularly meticulous and appropriately cautions in all his writings, he regularly conducts the 'Observers Page' column in the magazine. (M 16246)

Citation prepared by B. G. Marsden at the request of the discoverer.

\section{(3842) Harlansmith}

$1985 \mathrm{FC}_{1}$. Discovered 1985 Mar. 21 by E. Bowell at Anderson Mesa.

Named in honor of Harlan J. Smith \{1924-1991\}, the Edward Randall Jr., M.D. Centennial Professor in Astronomy at the University of Texas and director of McDonald Observatory since 1963. Under his leadership, McDonald has become one of the most productive observatories in the world. While serving as chairman of the astronomy department from 1963 to 1978, Smith oversaw its development into the largest and one of the best academic astronomy programs in the United States. (M 13610)

Name suggested and citation prepared by R. P. Binzel in celebration of Harlan Smith's 25th year as observatory director.

Obituaries published in Phys. Today, Vol. 45, No. 8, p. 83 (1992); Bull. Am. Astron. Soc., Vol. 24, No. 4, p. 1332-1334 (1992); Postepy Astron., Tom 42, No. 4, p. 179-183 (1994); J. Astrophys. Astron., Vol. 13, No. 1, p. 145-150 (1992); Q.J.R. Astron. Soc., Vol. 34, No. 1, p. 109-111 (1993).

\section{(3843) OISCA}

1987 DM. Discovered 1987 Feb. 28 by Y. Oshima at Gekko.

Named for the Organization for Industrial, Spiritual and Cultural Advancement, founded by Yonosuke Nakano in 1961 as a sister organization of the International Foundation fur Cultural Harmony, to which Gekko \{see planet (4261)\} Observatory belongs. OISCA-International is now active in supporting the efforts of people in developing countries to be free from poverty and hunger through promoting education. (M 13610)

\section{(3844) Lujiaxi}

1966 BZ. Discovered 1966 Jan. 30 at the Purple Mountain Observatory at Nanking.

Lu Jia-xi (1915-2001), known for his creative work in physical chemistry, structural chemistry and crystal material sciences, made outstanding contributions to the structural chemistry of cluster compounds. (M 31188)

\section{(3845) Neyachenko}

1979 SA $_{10}$. Discovered 1979 Sept. 22 by N. S. Chernykh at Nauchnyj.

Named in memory of Il'ya Isakovich Neyachenko, journalist and amateur astronomer from Yalta, known for his research on the history of the Simeis Astronomical Observatory and the names of minor planets discovered there. (M 20837)

\section{(3846) Hazel}

$1980 \mathrm{TK}_{5}$. Discovered 1980 Oct. 9 by C. S. Shoemaker at Palomar.

Named in honor of Hazel Arthur Spellmann (18961968), mother of the discoverer. (M 15574)

\section{(3847) Šindel}

$1982 \mathrm{DY}_{1}$. Discovered 1982 Feb. 16 by A. Mrkos at Klet.

Named in memory of Jan Ondřejův, known as Šindel (c.1375-c.1456), Czech medieval astronomer, mathematician, physician, professor at the universities in Nuremberg, Vienna and Prague, rector of the Charles University in Prague. He designed the famous Prague astronomical clock, which was built by the clockmaster Nicolas of Kadaň in 1410 and is still working today. (M 27733)

Name suggested by J.Tichá and M. Šolc.

\section{(3848) Analucia}

$1982 \mathrm{FH}_{3}$. Discovered 1982 Mar. 21 by H. Debehogne at La Silla.

Named in honor of Ana Lucia Martins, a good friend of the discoverer and who helps him very much when he is working in connection with his observing program at the Universidade Federal do Rio de Janeiro. (M 21955)

Name proposed by the discoverer and by U.F.R.J. professor L. E. Machado, who died on 1992 July 13.

\section{(3849) Incidentia}

1984 FC. Discovered 1984 Mar. 31 by E. Bowell at Anderson Mesa.

Named in honor of Roger W. Martin, a graduate of the Electrical and Computer Engineering Department at the University of California, San Diego. He has creatively contributed to asteroid science by his analysis of the spectra of (2201) Oljato and objects near the 3:1 Kirkwood gap, exhibiting both a wide range of technical expertise and an infectiously high-spirited nature. Incidentia is named after the school of music developed by Martin, who is also a talented musician. The name is quite the antithesis of the effects of Martin's efforts in whatever he undertakes. (M 14029)

Name proposed and citation provided by L. A. McFadden.

\section{(3850) Peltier}

$1986 \mathrm{TK}_{2}$. Discovered 1986 Oct. 7 by E. Bowell at Anderson Mesa.

Named in memory of Leslie C. Peltier (1900-1980), one of this century's most highly respected American amateur astronomers. Between 1925 and 1954 he independently discovered 12 comets (of which 10 bear his name), Nova Herculis 1963, and several other novae. Over a span of 62 years he made 132,123 observations of variable stars. In 1965 he published his autobiography, Starlight Nights, a moving account of a man who loved the sky. (M 14633) 
Name suggested by D. Levy and J. Mattei. Citation provided by Levy.

Obituary published in J. Am. Assoc. Variable Star Obs., Vol. 9, p. 32-34 (1980).

\section{(3851) Alhambra}

1986 UZ. Discovered 1986 Oct. 30 by T. Seki at Geisei.

Named for the famous palace of the Moorish kings in Granada. The great guitarist Segovia ssee planet (3822)\} frequently included "Memory of Alhambra" in his performances. (M 14482)

\section{(3853) Haas}

$1981 \mathrm{WG}_{1}$. Discovered 1981 Nov. 24 by E. Bowell at Anderson Mesa.

Named in honor of Walter H. Haas of Las Cruces, New Mexico, founder and director, from 1947 until 1985, of the Association of Lunar and Planetary Observers. His leadership resulted in the evolution of A.L.P.O. into a respected organization dedicated to observing solar-system objects. Through the example set by his meticulous observations and his correspondence with members around the world he is responsible for launching the careers of many solar-system students. (M 14633)

Name suggested and citation provided by D. Levy.

\section{(3854) George}

1983 EA. Discovered 1983 Mar. 13 by C. S. Shoemaker and E. M. Shoemaker at Palomar.

Named in honor of George Estel Shoemaker (19041960), father of the second discoverer. (M 15574)

\section{(3855) Pasasymphonia}

$1986 \mathrm{NF}_{1}$. Discovered 1986 July 4 by E. F. Helin at Palomar.

Named in honor of the Pasadena Symphony, now celebrating its 60th anniversary. The orchestra has brought artistic recognition to honor the community. Under the brilliant musical direction of Maestro Jorge Mester, the symphony has won nationwide acclaim as an ensemble of outstanding musicians dedicated to the performance of a richly diverse repertoire. (M 13484)

Name suggested by Edith Roberts and endorsed by the discoverer.

\section{(3856) Lutskij}

1976 QX. Discovered 1976 Aug. 26 by N. S. Chernykh at Nauchnyj.

Named in honor of Valerij Konstantinovich Lutskij, Moscow astronomer and scientific commentator on astronomy and space exploration. An authority on the history of astronomy, he has been a scientific consultant at the Moscow Planetarium for many years. (M 20837)

\section{(3857) Cellino}

$1984 \mathrm{CD}_{1}$. Discovered 1984 Feb. 8 by E. Bowell at Anderson Mesa.

Named in honor of Alberto Cellino, an astronomer at the Osservatorio Astronomico di Torino. Cellino has been involved in several minor planet photometric campaigns. He has also studied in detail the processes connected with catastrophic collisional break-up and how they can affect minor planet evolution. (M 14030)

Name suggested and citation provided by V. Zappalà.

\section{(3858) Dorchester}

1986 TG. Discovered 1986 Oct. 3 by K. Augustesen and P. Jensen and H. J. Fogh Olsen at Brorfelde.

Named for the county town of Dorset, England. Founded by the Romans in A.D. 70, Dorchester was made the twin town of Holbaek \{see planet (3033)\}, Denmark, the nearest town to the observatory at Brorfelde \{see planet (3309)\}. (M 21608)

Name proposed by the third discoverer.

\section{(3859) Börngen}

1987 EW. Discovered 1987 Mar. 4 by E. Bowell at Anderson Mesa.

Named in honor of Freimut Börngen, senior staff astronomer at the Karl Schwarzschild Observatory, Tautenburg. For 27 years Börngen has worked as an observer at the 1.3-m Schmidt telescope. He has been particularly interested in problems of photographic photometry and has published numerous papers on galaxies of a wide variety of types. Eighteen of his many minor planet discoveries have so far been numbered. (M 14207)

Name suggested and citation provided by L. D. Schmadel.

The actual number of minor planets detected by Börngen amounts to 165 in 1999.

\section{(3860) Plovdiv}

$1986 \mathrm{PM}_{4}$. Discovered 1986 Aug. 8 by E. W. Elst and V. G. Ivanova at Rozhen.

Named for an ancient town in Bulgaria. (M 14030)

\section{(3861) Lorenz}

A910 FA. Discovered 1910 Mar. 30 by J. Helffrich at Heidelberg.

Named in memory of Konrad Zacharias Lorenz (1903-1989), Austrian ethologist, who established the field of ethology, the basic concept of which is that animal behavior is genetically programmed. He shared the 1973 Nobel Prize for Physiology and Medicine with Nikolaas Tinbergen and Karl von Frisch for their work on animal behavior and its impact on the understanding of human nature. (M 20520)

Name proposed by T. Urata and S. Nakano, who found the identifications involving this planet. Citation prepared by T. Hidaka.

\section{(3862) Agekian}

1972 KM. Discovered 1972 May 18 by T. M. Smirnova at Nauchnyj.

Named in honor of Tateos Artemjevich Agekian, professor at the St. Petersburg University. Agekian is a world famous scientist in stellar statistics, kinematics and dynamics. He has found two evolutionary sequences 
of stellar systems: nearly spherical and strongly flattened. He initiated a numerical study of the dynamics of triple systems, developed a new approach to study the motion in the field of axially symmetric potential, and he suggested an essentially new method to investigate the structure and kinematics of the Milky Way Galaxy using radio observations of neutral hydrogen. His attractive book Stars, Galaxies, the Metagalaxy, translated into many languages, is the lodestar for many young astronomers. His manuals on probability theory and the treatment of observations are reference books for astronomers and physicists. (M 24121)

\section{(3863) Gilyarovskij}

1978 SJ $_{3}$. Discovered 1978 Sept. 26 by L. V. Zhuravleva at Nauchnyj.

Named after the Russian writer Vladimir Alexeevich Gilyarovskij (1853-1935). (M 24121)

\section{(3864) Søren}

1986 XF. Discovered 1986 Dec. 6 by K. Augustesen and P. Jensen at Brorfelde.

Named in honor of Søren Augustesen, son of the first discoverer. (M 15090)

\section{(3867) Shiretoko}

1988 HG. Discovered 1988 Apr. 16 by M. Yanai and K. Watanabe at Kitami.

Shiretoko is the name of the peninsula in northeastern Hokkaido \{see planet (3720)\}, not far from the city of Kitami \{see planet (3785)\}. Established in 1964, Shiretoko is a land of mystery, still in a pristine state. (M 14030)

\section{(3868) Mendoza}

4575 P-L. Discovered 1960 Sept. 24 by C. J. van Houten and I. van Houten-Groeneveld at Palomar.

Named in honor of Eugenio E. Mendoza V. (1928- ) on the occasion of his 65th birthday. After obtaining his Ph.D. at the University of Chicago, he undertook a postdoctoral position at the University of Cambridge. Mendoza taught astronomy at several universities in Mexico, and he is an expert on photometry and spectroscopy. (M 22499)

\section{(3869) Norton}

1981 JE. Discovered 1981 May 3 by E. Bowell at Anderson Mesa.

Named in memory of Arthur P. Norton (1876-1955), author of Norton's Star Atlas, the most widely used publication of its type. Born in Cardiff, Wales, Norton was a geography teacher with a lifelong interest in astronomy. The first edition of his atlas, published in 1910, achieved immediate success, largely due to the use of a low-distortion projection of Norton's devising. For the 1933 edition, Norton redrew the maps to incorporate new IAU constellation boundaries, and he extended the magnitude limit to 6.2. Many of today's astronomers, amateur and professional, use the version first published in 1943, which has maps of epoch 1950.0 and limiting magnitude 6.35. The naming of this planet also celebrates the publication of the epoch 2000.0 edition of the atlas, the first edition not drawn by Norton. (M 15090)

Name suggested and citation provided by I. Ridpath, editor of the new atlas.

\section{(3870) Mayré}

1988 CG $_{3}$. Discovered 1988 Feb. 13 by E. W. Elst at La Silla.

Named in honor of the discoverer's youngest daughter. (M 14030)

\section{(3871) Reiz}

$1982 \mathrm{DR}_{2}$. Discovered 1982 Feb. 18 by R. M. West at La Silla.

Named in honor of Anders Reiz (1915- ), professor emeritus at the Copenhagen University Observatory and highly esteemed teacher and friend of the discoverer. He obtained a doctorate in astronomy from the Lund University Observatory in 1941 and worked there until 1958, when he became a full professor in Copenhagen and director of the university observatories in Copenhagen and Brorfelde. With remarkable skills as teacher and administrator, he contributed substantially to the rapid progress in theoretical and observational astrophysics in Denmark that commenced in the early 1960s. In particular, his persistent efforts soon provided the young generation of astronomers with better tools and research opportunities, from the first digital GIER computer at the observatory in 1961 and several medium-size instruments at the Brorfelde observatory, to the large telescopes at La Silla when Denmark became a member of ESO in 1967. He took the initiatives for the construction of the national Danish 1.5-m telescope on La Silla and the 2.5-m Nordic Optical Telescope \{see planet (2857)\} on La Palma, two first-class instruments which serve astronomers from Scandinavia and beyond. His research interests have ranged from galaxies to stellar evolution, including the first models of red giants in 1947 and of metal-deficient subdwarfs in 1953, as well as the perfection of associated numerical methods. He made more than 30,000 visual observations with the meridian circle in Lund during the war and recently returned to high-precision astrometry with the Danish 1.5-m telescope at ESO. He early conceived the idea of a joint European professional astronomy journal and was instrumental to the mergers that led to the launch of Astronomy and Astrophysics in 1968. (M 16592)

\section{(3872) Akirafujii}

1983 AV. Discovered 1983 Jan. 12 by B. A. Skiff at Anderson Mesa.

Named for Japan's highly talented and renowned astrophotographer, Akira Fujii of Koriyama. He edited the quarterly magazine Hoshi No Techou (star handbook) and is the author of a beautifully illustrated series of popular astronomy books for 
young people. Fujii has fostered public awareness of astronomy through television broadcasts from his Chiro Observatory in Shirakawa, Fukushima prefecture, and he toured Japan in 1986, offering the public views of Halley's Comet with a trailer-mounted $60-\mathrm{cm}$ reflector. Fujii is best known outside of Japan for his stunning celestial photographs, a hallmark of which is technical perfection. (M 22829)

Name proposed by D. di Cicco and R. W. Sinnott and endorsed by the discoverer.

\section{(3873) Roddy}

1984 WB. Discovered 1984 Nov. 21 by C. S. Shoemaker and E. M. Shoemaker at Palomar.

Named in honor of David J. Roddy, geologist with the U.S. Geological Survey. A leading investigator of impact and explosion craters, Roddy is best known for his work on the impact crater of Devonian age at Flynn Creek, Tennessee, the structure of craters produced by large field experiments with high explosives, and numerical modeling of large impacts. (M 15574)

\section{(3874) Stuart}

1986 TJ $_{1}$. Discovered 1986 Oct. 4 by E. Bowell at Anderson Mesa.

Named in honor of Stuart E. Jones on the occasion of his retirement as Lowell Observatory's photographic specialist. A member of the Lowell staff since 1962, Jones has been responsible for a wide variety of photographic tasks, including, in particular, the processing of high-quality photographic images for the International Planetary Patrol, a decade-long program that led to the production of about 1 million planetary images. He helped develop a method of photographically extracting fine planetary surface features by means of compositing and a method of reproducing images of planets in true color. Jones will be warmly remembered for his multifaceted talents, which range from practical chemistry to the construction of sophisticated electronics, and for his cheerful disposition and dedication. (M 14207)

\section{(3875) Staehle}

1988 KE. Discovered 1988 May 17 by E. F. Helin at Palomar.

Named in honor of Robert L. Staehle, astronautical engineer, member of the technical staff of the Jet Propulsion Laboratory, and president and founder of the World Space Foundation. The Foundation, a non-profit corporation, promotes research and the exploration of space and provides funding from private sources. The discoverer wishes to acknowledge Rob Staehle for the role he and the Foundation have played in recognizing the importance of near-earth asteroids and sponsoring some of the research carried out by the Palomar Planet-Crossing Asteroid Survey. The NASA/JPL Asteroid Project has received valuable assistance and encouragement from Staehle and the Foundation since 1981. (M 14482)

\section{(3876) Quaide}

1988 KJ. Discovered 1988 May 19 by E. F. Helin at Palomar.

Named in honor of William L. Quaide for his extraordinary record of scientific achievement in furthering the understanding of our solar system; his many years of service to NASA and the scientific community in support of solar system exploration; his dedication to his work, his personal and professional integrity, which have earned him the trust and respect of his colleagues and friends. (M 14482)

Name proposed by the discoverer, following a suggestion by J. Rahe.

\section{(3877) Braes}

3108 P-L. Discovered 1960 Sept. 24 by C. J. van Houten and I. van Houten-Groeneveld at Palomar.

Named in honor of Luc L. Braes (1936- ), born in Belgium and since 1958 living and working in the Netherlands, first in Groningen and then at Leiden Observatory. His main interests are the OB-stars and the determination of stellar proper motions. (M 22500)

\section{(3878) Jyoumon}

1982 VR $_{4}$. Discovered 1982 Nov. 14 by H. Kosai and K. Hurukawa at Kiso.

Named for the Jyoumon Era, from the eighth to the third centuries B.C., when the early Japanese people used a special type of pottery with rope-print decoration. (M 21608)

\section{(3879) Machar}

1983 QA. Discovered 1983 Aug. 16 by Z. Vávrová at Klět.

Named in honor of the Czech writer and poet, Josef Svatopluk Machar (1864-1942), whose work is close to the discoverer's heart. (M 16443)

\section{(3880) Kaiserman}

1984 WK. Discovered 1984 Nov. 21 by C. S. Shoemaker and E. M. Shoemaker at Palomar.

Named in honor of Michael Kaiserman, American aeronautical engineer and enthusiastic supporter of research in astronomy. (M 15574)

\section{(3881) Doumergua}

1925 VF. Discovered 1925 Nov. 15 by B. Jekhovsky at Algiers.

Named in memory of Gaston Doumergue (1863-1937), president of France during 1924-1931, and his wife. (M 22500)

This name was proposed for $1925 \mathrm{VF}$ by the discoverer in 1933 in J. Obs., Vol. 17, p. 102, long before the enactment of the rule excluding contemporary politicians from being honored with minor planets.

\section{(3882) Johncox}

1962 RN. Discovered 1962 Sept. 7 at the Goethe Link Observatory at Brooklyn, Indiana.

Named in memory of John Paul Cox (1926-1984), whose professional life was devoted to an investigation 
of the pulsational mechanisms in variable stars. First at Cornell University and later at the University of Colorado, from where he collaborated with workers at the Los Alamos National Laboratories, he made several outstanding contributions in his field. He produced the first exact, linear, non-adiabatic treatment of pulsation. Along with Zhevakin, Cox realized the importance of the second helium ionization zone as the source of the driving power for Cepheids. He also made significant contributions to our understanding of the Beta Cephei and RR Lyrae stars and authored several review papers and two books that are models of clarity in a very complex subject and will be cited for years to come. (M 19335)

Name proposed by H. R. Johnson and F. K. Edmondson.

Obituaries published in Phys. Today, Vol. 38, No. 1, p. 112 (1985); Q.J.R. Astron. Soc., Vol. 27, No. 2, p. 302-305 (1986).

\section{(3883) Verbano}

1972 RQ. Discovered 1972 Sept. 7 by N. S. Chernykh at Nauchnyj.

Named after the lake, also known as Lake Maggiore, in Italy and Switzerland between the south spurs of the Alps. IAU Symposium No. 160, 'Asteroids, Comets, Meteors', was held on the western shore of the lake in the resort village of Belgirate \{see planet (5110)\}, 1993 June 14-18. (M 23136)

Name proposed by the Symposium participants from Russia, Ukraine and Tadjikistan.

\section{(3884) Alferov}

$1977 \mathrm{EM}_{1}$. Discovered 1977 Mar. 13 by N. S. Chernykh at Nauchnyj.

Named in honor of the outstanding physicist and academician Zhores Ivanovich Alferov (1930-

), director of the Ioffe Physical and Technical Institute in St. Petersburg. Alferov made fundamental contributions to the physics of solid bodies and semiconductors, semiconductor heterostructures and semiconductor and quantum electronics. (M 29143)

Named by the discoverer following a suggestion by the Institute of Theoretical Astronomy.

\section{(3885) Bogorodskij}

$1979 \mathrm{HG}_{5}$. Discovered 1979 Apr. 25 by N. S. Chernykh at Nauchnyj.

Named in memory of Aleksandr Fyodorovich Bogorodskij (1907-1984), Soviet astrophysicist, director of the Astronomical Observatory of Kiev University, well known for his works on Einsteinian gravitation, solar physics and planetary nebulae. (M 19693)

\section{(3886) Shcherbakovia}

$1981 \mathrm{RU}_{3}$. Discovered 1981 Sept. 3 by N. S. Chernykh at Nauchnyj.

Named in memory of Sergej Vasil'evich Shcherbakov (1856-1931), founder of the Nizhegorodskij circle of amateur physicists and astronomers, author of the first Manual of Cosmography in Russia and involved in establishing the Russian Astronomical Calendar. The name is also in memory of his granddaughter Marianna Valentinovna Shcherbakova (1910-1991), docent of geography of Kiev University and an active lecturer in the Kiev Planetarium. (M 19693)

\section{(3887) Gerstner}

1985 QX. Discovered 1985 Aug. 22 by A. Mrkos at Klě́.

Named in memory of the physicist František Josef Gerstner (1756-1832) and his son František Antonín Gerstner (1795-1840). F. J. Gerstner worked at the observatories in Vienna and Prague but then turned from astronomy to applied mathematics, physics, mechanics and metallurgy. He founded the Prague Polytechnic School, later Technical University, in 1806. He also designed the horse railroad from České Budějovice to Linz. F. A. Gerstner continued building this horse railroad, which was completed in 1832 and is considered the first railroad in continental Europe. (M 27733)

Name suggested by J. Tichá and M. Šolc.

\section{(3888) Hoyt}

1984 FO. Discovered 1984 Mar. 28 by C. S. Shoemaker and E. M. Shoemaker at Palomar.

Named in memory of William Graves Hoyt (19211985), American journalist and historian. His books Planet ' $X$ ' and Pluto, Lowell and Mars, and Coon Mountain Controversies (about Meteor Crater, Arizona), written while he was resident historian at Lowell Observatory, are widely recognized as major contributions to the history of planetary science. (M 15575)

\section{(3889) Menshikov}

1972 RT $_{3}$. Discovered 1972 Sept. 6 by L. V. Zhuravleva at Nauchnyj.

Named in honor of Aleksandr Danilovich Menshikov (1673-1729), Russian statesman and military leader during the reign of Peter the Great. (M 22246)

\section{(3890) Bunin}

1976 YU $_{5}$. Discovered 1976 Dec. 18 by L. I. Chernykh at Nauchnyj.

Named in memory of an outstanding Russian writer and 1933 Nobel laureate Ivan Alekseevich Bunin (1870-1953). (M 18454)

\section{(3891) Werner}

1981 EY $_{31}$. Discovered 1981 Mar. 3 by S. J. Bus at Siding Spring.

Named in honor of Robert A. Werner, graduate student in aerospace engineering at the University of Texas at Austin. Werner's dissertation work on Polyhedron Gravitation has direct application to the problem of calculating orbits around small irregularly shaped objects such as minor planets. For the past eleven years Werner has also served as the typesetter and producer of the Minor Planet Bulletin, an activity which has fostered scientific interactions on minor 
planet research between professional and amateur astronomers. (M 27126)

Name suggested and citation prepared by R. P. Binzel.

\section{(3892) Dezsö}

1941 HD. Discovered 1941 Apr. 19 by L. Oterma at Turku.

Named in honor of the Hungarian astronomer Dezsö Loránt, an old friend of the discoverer, founder of the Observatory for Solar Physics in Debrecen and its director for many years. (M 18454)

\section{(3893) DeLaeter}

$1980 \mathrm{FG}_{12}$. Discovered 1980 Mar. 20 by M. P. Candy at Bickley.

Named in honor of John DeLaeter, retired professor at Curtin University, Western Australia, in recognition of his pioneering application of mass spectrometry to a range of astrophysical, chemical, geological and nuclear problems over many decades. His outstanding scientific achievements and communication skills have been recognized in awards from ANZAAS, the Royal Society and the Australian Geological Society. He is an officer of the Order of Australia. His support of the Perth Observatory during funding crises was instrumental in maintaining the operation of this isolated institution. (M 27733)

Name suggested and citation provided by J. Biggs and P. Birch.

\section{(3894) Williamcooke}

$1980 \mathrm{PQ}_{2}$. Discovered 1980 Aug. 14 by P. Jekabsons and M. P. Candy at Bickley.

Named in memory of William Ernest Cooke (18631947), government astronomer for Western Australia during 1896-1912 and first director of the Perth Observatory. His astronomical expertise and willingness to engage in international collaboration paved the way for the establishment of the Observatory and led to its involvement with the 'Carte du Ciel' project and the acquisition of all the plates for the declination zone $-31^{\circ}$ and $-41^{\circ}$. During 1912-1926 Cooke was government astronomer for New South Wales, and he remains the only Sydney Observatory director to hold the post of professor of astronomy at Sydney University at the same time. (M 27733)

Name suggested and citation provided by J. Biggs and P. Birch.

\section{(3895) Earhart}

1987 DE. Discovered 1987 Feb. 23 by C. S. Shoemaker and E. M. Shoemaker at Palomar.

Named for Amelia Mary Earhart (1897-1937), a distinguished pioneer in the field of aviation. She was the first woman to fly across the Atlantic, the first person to fly across the Pacific Ocean from Honolulu to California, the first to solo from Mexico City to New York and the first woman to receive the Distinguished Flying Cross. She was an organizer of the National
Glider Association, first president of the Ninety-Nines and a charter member of Zonta International, a women's professional organization. Earhart perished in a second attempt to fly around the world, when her plane was lost at sea near Howland Island in the Pacific. (M 24916)

\section{(3896) Pordenone}

1987 WM. Discovered 1987 Nov. 18 by J. M. Baur at Chions.

Named in memory of Giovanni Antonio Licinio (1483-1539), also known as Il Pordenone, from the birthplace, not far from the Chaonis \{see planet (4630)\} Observatory. One of the masters of painting of the sixteenth century, Il Pordenone was declared a prince of the Friuli region, and the Pictor Modernus, for his exploits in drawing, chiaroscuro and relief. He invented an original language that was violently dynamic and expressive. A disciple of Bellini and Giorgione, he studied the works of Raffael and Michelangelo ssee planet (3001)\}, influenced Tintoretto and was a rival of Titian. (M 14208)

\section{(3897) Louhi}

1942 RT. Discovered 1942 Sept. 8 by Y. Väisälä at Turku.

Named for the powerful mistress of the dark and cold Pohjola \{see planet (3606)\}, a place in the national epic Kalevala \{see planet (1454)\}. (M 18454)

\section{(3898) Curlewis}

$1981 \mathrm{SF}_{9}$. Discovered 1981 Sept. 26 by M. P. Candy at Bickley.

Named in honor of Harold Burnham Curlewis (18741960), government astronomer for Western Australia during 1912-1940 and second director of the Perth Observatory. Because of severe funding cuts, he was sometimes the observatory's only employee, but he managed to keep the observatory operational during the severe years of the depression. His 38 years of continuous service remain the longest of any employee of the Perth Observatory. (M 27734)

Name suggested and citation provided by J. Biggs and P. Birch.

\section{(3899) Wichterle}

$1982 \mathrm{SN}_{1}$. Discovered 1982 Sept. 17 by M. Mahrová at Klět.

Named in honor of Otto Wichterle (1913-1998), Czech chemist with a special interest in macromolecular substances. He is well known as the inventor of hydrophilic gels used for the production of contact lenses. (M 22500)

\section{(3900) Knežević}

1985 RK. Discovered 1985 Sept. 14 by E. Bowell at Anderson Mesa.

Named in honor of Zoran Knežević, an astronomer at the Astronomical Observatory of Belgrade. Knežević has studied the physical properties of minor planets 
using both observational and theoretical approaches. He has analyzed the evolution of minor planet families and has investigated high-order perturbation theories with a view to improving the determination of proper elements. (M 14030)

Citation prepared by $\mathrm{V}$. Zappalà at the request of the discoverer.

\section{(3901) Nanjingdaxue}

1958 GQ. Discovered 1958 Apr. 7 at the Purple Mountain Observatory at Nanking.

One of the oldest universities in China, Nanjing Daxue (Nanjing University) will be celebrating its centennial in 2002. In 1952 the School of Liberal Arts and the School of Sciences from an earlier establishment also merged with the Nanjing University. (M 43189)

\section{(3902) Yoritomo}

1986 AL. Discovered 1986 Jan. 14 by S. Inoda and T. Urata at Karasuyama.

Named for Minamoto Yoritomo (1147-1199), the first shogun and founder of the Japanese feudal system. In his boyhood, Yoritomo was confined under the Heike's surveillance for 20 years in a place of exile near the residence of the second discoverer of this asteroid. Yoritomo destroyed the Heike with his brother's \{Yoshitsune, see planet (3178)\} help and became the first supreme commander of Japan in 1192, marking the beginning of the Kamakura era. (M 19693)

\section{(3903) Kliment Ohridski}

$1987 \mathrm{SV}_{2}$. Discovered 1987 Sept. 20 by E. W. Elst and

V. G. Shkodrov and V. G. Ivanova at Rozhen.

Named in memory of Kliment Ohridski (840-916), one of the first Bulgarian philosophers \{of Macedonian origin\}. A disciple of Konstantin, he took holy orders in Rome in 868. A pupil and collaborator of Kyril and Methodius, he established a school where he taught some 3,500 students the Bulgarian alphabet and contributed to development of the Bulgarian language. This minor planet, named on the occasion of the 100th anniversary of the founding of the University of Sofia, of which he is considered the patron, is testament to Ohridski's influence on Bulgarian science and culture. (M 14208)

\section{(3904) Honda}

1988 DQ. Discovered 1988 Feb. 22 by R. H. McNaught at Siding Spring.

Named in honor of Minoru Honda \{1917-1990\} for his outstanding achievement in the discovery of 12 comets and 12 novae. The comet discoveries were made visually over the period 1940 to 1968 , the latter year adding three discoveries. Honda's emphasis then turned to photographic nova searching, with his first two discoveries coming in 1970. The first, FH Ser, displayed a pronounced minimum during its fade, and multifrequency observations made of this object make it a benchmark in nova studies. Although he was chronologically not the first discoverer of the bright nova V1500 Cyg in 1975, it was his observation that was first disseminated to the astronomical community. These discoveries acted as a major influence in the development of the discoverer's astronomical interests. (M 14633)

Citation prepared by the discoverer, with assistance from Charles Morgan.

Obituaries published in Yamamoto Circ., No. 2154 (1990); Komet Tsirk., No. 420, p. 16 (1990).

\section{(3905) Doppler}

1984 QO. Discovered 1984 Aug. 28 by A. Mrkos at Klě̀.

Named in memory of the Austrian physicist Christian Doppler (1803-1853), professor of mathematics and geometry at the Technical University in Prague and later the first director of the Physical Institute in Vienna. The well-known effect relating a shift in observed wavelength to the relative motion of source and observer was formulated by Doppler in Prague in his book Ueber das farbige Licht der Doppelsterne (1842). (M 27734)

Name suggested by J. Tichá and M. Šolc.

\section{(3906) Chao}

$1987 \mathrm{KE}_{1}$. Discovered 1987 May 31 by C. S. Shoemaker and E. M. Shoemaker at Palomar.

Named in honor of Edward C. T. Chao, geologist with the U.S. Geological Survey. A discoverer of the high-pressure silica polymorphs coesite and stishovite at Meteor Crater, Arizona, Chao was the pioneer investigator of the shock metamorphism of rocks. He studied numerous terrestrial impact structures, including especially the Ries \{see planet (4327)\} crater in Germany, and played a prominent role in demonstrating impact effects in the rocks brought back from the moon. Chao also carried out intensive studies of tektites and advanced key evidence that they are also the product of impacts. (M 18454)

\section{(3907) Kilmartin}

A904 PC. Discovered 1904 Aug. 14 by M. F. Wolf at Heidelberg.

Named in honor of Pamela Margaret Kilmartin, co-director with her husband, Alan C. Gilmore \{see planet (2537)\}, of the Comets and Minor Planets section of the Royal Astronomical Society of New Zealand. Originally employed as the librarian of the Carter Observatory in Wellington, she quickly became an astronomer in her own right and has been solely responsible for the measurement and reduction of the plates taken in the course of the astrometric programs in Wellington and more recently at the Mount John University Observatory. (M 14482)

Name proposed by B. G. Marsden, who found the identifications involving this minor planet, and endorsed by A. C. Gilmore and F. M. Bateson. 
(3908) Nyx

1980 PA. Discovered 1980 Aug. 6 by H.-E. Schuster at La Silla.

Named for the goddess and personification of the night. She was a daughter of Chaos and had many children by her brother Erebus, who personifies the subterranean darkness. The realm of Nyx was in the far West, beyond the land of Atlas. (M 34339)

\section{(3909) Gladys}

1988 JD $_{1}$. Discovered 1988 May 15 by K. W. Zeigler at Anderson Mesa.

Named in memory of the discoverer's mother, Gladys Marie Zeigler (1921-1988), who encouraged him as a youth to pursue his interest in astronomy despite all obstacles. Her continued encouragement was directly responsible for the discovery of this minor planet. (M 15260)

\section{(3910) Liszt}

1988 SF. Discovered 1988 Sept. 16 by E. W. Elst at St. Michel.

Named in memory of Franz Liszt (1811-1886), legendary master of the piano and a courageous fighter for progress in the musical art. A grand and many-sided composer, his works ranged from Hungarian rhapsodies to symphonic poems. While a student at the University of Bonn, the discoverer became acqainted with Lady Elisabeth von Loe-Schultz, who was privileged to have known the composer. At her home the discoverer regularly played before a small audience of students several of Liszt's famous piano etudes. (M 15575)

Name endorsed by F. Börngen, Tautenburg, who independently proposed the name for another minor planet, and who notes that from 1848 to 1861 Liszt was the conductor of the court orchestra in Weimar, not far from Tautenburg.

\section{(3911) Otomo}

1940 QB. Discovered 1940 Aug. 31 by K. Reinmuth at Heidelberg.

Named in honor of Satoshi Otomo, a dentist living in Kiyosato \{see planet (5488)\}. Discoverer of numerous minor planets since 1991, he is also an active confirmer of new objects in collaboration with S. Nakano \{see planet (3431)\}, who proposed the name and made the identifications involving this object. (M 22500)

\section{(3912) Troja}

1988 SG. Discovered 1988 Sept. 16 by E. W. Elst at St. Michel.

Named for the ancient legendary city featured in the works of Homer \{see planet (5700)\}. The historical site of Troy was found in 1872 at Hissarlik, Turkey, by Schliemann \{see planet (3302)\}. (M 14208)

\section{(3913) Chemin}

$1986 \mathrm{XO}_{2}$. Discovered 1986 Dec. 2 by the CERGA at Caussols.

Named in honor of Henriette and Robert Chemin, who, after many years at the Paris Observatory as librarian and engineer, respectively, observed, discovered and measured many asteroids on plates taken at the Caussols Schmidt Telescope. After Henriette's death in 1991, Robert retired and started popularizing and teaching astronomy. (M 22829) Name suggested by J.-L. Heudier and C. Pollas.

\section{(3914) Kotogahama}

1987 SE. Discovered 1987 Sept. 16 by T. Seki at Geisei.

Named for the beautiful coast situated $2 \mathrm{~km}$ south of the Geisei station on the Pacific shore of Shikoku \{see planet (4223)\} island. There are many pine trees on this coast, and there is a famous place where their leaves play the sound on the Japanese harp Koto in the breeze. (M 15090)

\section{(3915) Fukushima}

$1988 \mathrm{PA}_{1}$. Discovered 1988 Aug. 15 by M. Yanai and K. Watanabe at Kitami.

Named in honor of Hisao Fukushima (1910-1997), professor emeritus at Hokkaido University, famous for his research in hydrodynamics. An active amateur astronomer, he is a representative of the Hokkaido Astronomical Liaison Group. He works particularly on astronomical history and is a great source of inspiration to younger amateur astronomers. (M 14030)

Obituaries published in Heavens, Vol. 79, No. 2, p. 8-18 (1998); Heavens, Vol. 79, No. 3, p. 20-21 (1998).

\section{(3916) Maeva}

$1981 \mathrm{QA}_{3}$. Discovered 1981 Aug. 24 by H. Debehogne at La Silla.

Named in memory of Maeva d'Alloy d'Hocquincourt Vitry, who died tragically on 1992 June 7 at the age of seven. Niece of ESO staff astronomer Patrice Bouchet Vitry \{see planet (4313)\}, this extraordinary open-hearted little girl was fond of nature, flowers and beauties of the universe, and she showed every promise of becoming an astronomer herself. (M 21131)

\section{(3917) Franz Schubert}

1961 CX. Discovered 1961 Feb. 15 by F. Börngen at Tautenburg.

Named for the great composer Franz Schubert (1797-1828). (M 14208)

\section{(3918) Brel}

$1988 \mathrm{PE}_{1}$. Discovered 1988 Aug. 13 by E. W. Elst and G. Sause at St. Michel.

Named in memory of the well-known Belgian artist Jacques Brel (1929-1978), famous also for his songs and poems. The songs Marieke and Le plat pays are a tribute to Flanders. (M 14030)

\section{(3919) Maryanning}

1984 DS. Discovered 1984 Feb. 23 by H. Debehogne at La Silla.

Named in memory of Mary Anning (1799-1847), whose discoveries from the age of 12 of marine fossils were catalytic to the recognition of dinosaurs as the giant extinct monsters of antiquity. From early 
childhood, she and her brother Joseph followed their father in searches for ammonite fossils in the cliffs around Lyme Regis, England. After the death of her father in 1810, fossil hunting became the means of support for the two surviving children and their mother. She discovered the first complete skeleton of the fish-lizard Ichthyosaurus, which aroused great interest as it passed into the hands of fossil collectors and then to the British Museum a few years later. Her other major discoveries include the Plesiosaurus, Pterodactylus and Squaloraja. (M 34619)

\section{(3920) Aubignan}

1948 WF. Discovered 1948 Nov. 28 by S. Arend at Uccle.

Named for the small village in the French Provence, at the foot of the Mont Ventoux, where the discoverer regularly spent his holidays in the home of his youngest son Noel \{see planet (1563)\}, who proposed this name. (M 25976)

Name endorsed by P. Páquet.

\section{(3921) Klement'ev}

1971 OH. Discovered 1971 July 19 by B. A. Burnasheva at Nauchnyj.

Named in memory of Zakhar Ivanovich Klement'ev (1903-1994), professor of mathematics at Tomsk University. For more than 60 years he delivered lectures on mathematical analysis, functional analysis and other topics, imbuing in young minds by the beauty and accessibility of his presentation the most complex problems of mathematics. He authored more than 60 scientific papers and the six-part series Lectures on Mathematical Analysis. The fascination of his personality and creative individuality is preserved in the memory of his numerous disciples, scattered now throughout Russia and abroad. (M 24916)

\section{(3922) Heather}

$1971 \mathrm{SP}_{3}$. Discovered 1971 Sept. 26 by C. Torres at Cerro El Roble.

Named in honor of Heather Couper (1949- ), British popularizer and promoter of astronomy, on the occasion of her 50th birthday, 1999 June 2. Former Gresham professor of astronomy and a past president of the British Astronomical Association, she regularly appears on radio and television and is the author of more than 25 books. As one of the nine Millennium Commissioners, she is responsible for allocating some 500 million GBP to public science projects in the U.K., including the National Space Centre in Leicester. (M 35481)

\section{(3923) Radzievskij}

$1976 \mathrm{SN}_{3}$. Discovered 1976 Sept. 24 by N. S. Chernykh at Nauchnyj.

Named in honor of Vladimir Vyacheslavovich Radzievskij, professor at the Nizhegorodskij Pedagogical Institute, known for his work in celestial mechanics, the cosmogony of the solar system and the origin of comets. (M 19695)

\section{(3924) Birch}

1977 CU. Discovered 1977 Feb. 11 by E. Bowell at Palomar.

Named in honor of Peter V. Birch. An astronomer at the Perth Observatory since 1970, Birch made many planetary photographic observations as part of Lowell Observatory's International Planetary Patrol Program. In 1977 he was involved in the discovery of the rings of Uranus. He has also carried out a variety of photometric observations, including photoelectric lightcurves of minor planets and comets and CCD work on Comet Halley. (M 14208)

Citation provided by M. P. Candy at the request of the discoverer.

\section{(3925) Tret'yakov}

$1977 \mathrm{SS}_{2}$. Discovered 1977 Sept. 19 by L. V. Zhuravleva at Nauchnyj.

Named in memory of Pavel Mikhailovich Tret'yakov (1832-1898) and his brother Sergej Mikhailovich (18341892). Pavel founded the Art Gallery; Sergej presented his Western-European art collection to the city of Moscow. (M 24121)

\section{(3926) Ramirez}

1978 VQ $_{3}$. Discovered 1978 Nov. 7 by E. F. Helin and S. J. Bus at Palomar.

Named in honor of Abel R. Ramirez, manager and impeccable host of the California Institute of Technology's Athenaeum, on the occasion of his 50th birthday, 1992 May 18. Fondly regarded by faculty, students and guests from all over the world, he has graciously presided over this elegant establishment since 1978, the year that this minor planet was discovered. (M 20520)

\section{(3927) Feliciaplatt}

$1981 \mathrm{JA}_{2}$. Discovered 1981 May 5 by C. S. Shoemaker and E. M. Shoemaker at Palomar.

Named in honor of the mother of John Platt, who discovered (3237) Victorplatt and (3259) Brownlee while a student at Caltech. (M 25443)

\section{(3928) Randa}

1981 PG. Discovered 1981 Aug. 4 by P. Wild at Zimmerwald.

Named for a picturesque old village near Zermatt. This minor planet's number is the same as the village's code in the Swiss postal system. (M 17466)

The discoverer informed us that the Italian word 'randa' (which means 'brink') obviously explains the name of the village near the Italian border.

\section{(3929) Carmelmaria}

$1981 \mathrm{WG}_{9}$. Discovered 1981 Nov. 16 by P. Jekabsons at Bickley.

Named in honor of Carmel Maria Borg (nee Materazzo), secretary at the Perth Observatory and administrative assistant to three directors over 17 years. 
Her devotion to observatory projects, attention to detail and public-relations skills have seen the Perth Observatory through some turbulent times and played a large part in the successful interaction the observatory enjoys with the local community. She has also played a major role in preserving many of the observatory's historical documents and artifacts. (M 27734)

Name suggested and citation provided by J. Biggs and P. Birch.

\section{(3930) Vasilev}

1982 UV $_{10}$. Discovered 1982 Oct. 25 by L. V. Zhuravleva at Nauchnyj.

Named in memory of Konstantin Alekseevich Vasil'ev (1942-1976), a well known Russian painter. (M 17029)

\section{(3931) Batten}

1984 EN. Discovered 1984 Mar. 1 by E. Bowell at Anderson Mesa.

Named in honor of Alan H. Batten, an astronomer at the Dominion Astrophysical Observatory in Victoria, British Columbia. Batten's research has centered on close binary stars and radial velocities. He has served as a vice president of the IAU, as president of two of its commissions and as editor of the Journal of the Royal Astronomical Society of Canada. (M 14208)

Name suggested and citation provided by C. E. Spratt.

\section{(3932) Edshay}

1984 SC $_{5}$. Discovered 1984 Sept. 27 by M. C. Nolan and C. S. Shoemaker at Palomar.

Edwin L. Shay (1938-1998) was an educator in Worthington, Ohio, and Syracuse, New York, for 34 years and father of the Worthington Soccer League. His enthusiasm for learning and exploration, as well as his personal involvement in the education of students as individuals, inspired many to achieve their dreams. (M 43189)

\section{(3933) Portugal}

$1986 \mathrm{EN}_{4}$. Discovered 1986 Mar. 12 by R. M. West at La Silla.

Named in honor of the European country whose famous navigators studied the skies with great skill and discovered many new routes to distant shores under southern stars. Its recent association with ESO now opens new, exciting celestial paths for its modern astronomers. (M 17029)

\section{(3934) Tove}

$1987 \mathrm{DF}_{1}$. Discovered 1987 Feb. 23 by P. Jensen and

K. Augustesen and H. J. Fogh Olsen at Brorfelde.

Named in honor of Tove Augustesen, wife of the second discoverer. (M 29143)

\section{(3935) Toatenmongakkai}

1987 PB. Discovered 1987 Aug. 14 by T. Seki at Geisei.

Named in honor of the Oriental Astronomical Association, founded in 1920 by Issei Yamamoto \{see planet (2249)\}, then professor at the Astronomical Institute at Kyoto Imperial University. The O.A.A. is mainly composed of amateur astronomers in Japan.
The discoverer joined the O.A.A. in 1947 and has served as director of the Comet Section since 1970. (M 14633)

\section{(3936) Elst}

2321 T-3. Discovered 1977 Oct. 16 by C. J. van Houten and I. van Houten-Groeneveld at Palomar.

Named in honor of Eric W. Elst (1936- ), Belgian astronomer at the Observatory at Uccle. For many years he has been enthusiastically searching for minor planets, especially Trojans, and several of his discoveries have now been permanently numbered. (M 18138)

\section{(3937) Bretagnon}

1932 EO. Discovered 1932 Mar. 14 by K. Reinmuth at Heidelberg.

Named in honor of Pierre Bretagnon, astronomer at the Bureau des Longitudes. He is the author of a modern, high-precision analytical theory for the motion of the planets from Mercury to Neptune, called 'VSOP'. (M 22500)

Name proposed by J. Meeus, endorsed by G. Klare and L. D. Schmadel.

\section{(3938) Chapront}

1949 PL. Discovered 1949 Aug. 2 by K. Reinmuth at Heidelberg.

Named in honor of Jean Chapront and Michelle Chapront-Touzé, astronomers at the Bureau des Longitudes. They have constructed a high-precision analytical theory for the orbital motion of the moon, called 'ELP 2000-82'. (M 22500)

Name proposed and citation prepared by J. Meeus, endorsed by G. Klare and L. D. Schmadel.

\section{(3939) Huruhata}

1953 GO. Discovered 1953 Apr. 7 by K. Reinmuth at Heidelberg.

Named in memory of Masaaki Huruhata (1912-1988), director of the Tokyo Astronomical Observatory from 1968 to 1973, known for his work on meteors and variable stars and the photoelectric photometry of the zodiacal light and airglow. One of his early research projects involved the light variation of (433) Eros in 1930-1931. He served as president of IAU Commission 21 (1967-1970), vice president of the Astronomical Society of Japan (1961-1963) and a member of the Science Council of Japan (1969-1972). Following his retirement he carried out photographic observations of variable stars at his home and served as an advisor to amateur astronomers in the Variable Star Observers League in Japan. (M 15261)

Name proposed by S. Nakano, who found the identifications involving this minor planet, following a suggestion by Y. Kushida, M. Inoue and O. Muramatsu. Citation prepared by S. Sakuma.

Obituaries published in Variable Star Bull., No. 9, p. 36 (1989); IAU Colloquium No. 126, p. xxv-xxvi (1991). 
(3940) Larion

$1973 \mathrm{FE}_{1}$. Discovered 1973 Mar. 27 by L. V. Zhuravleva at Nauchnyj.

Named for Larisa Ivanovna Golubkina, dramatic actress, brilliant performer of romances. (M 22500)

\section{(3941) Haydn}

$1973 \mathrm{UU}_{5}$. Discovered 1973 Oct. 27 by F. Börngen at Tautenburg.

Named for the great composer Franz Joseph Haydn (1732-1809). (M 14208)

\section{(3942) Churivannia}

$1977 \mathrm{RH}_{7}$. Discovered 1977 Sept. 11 by N. S. Chernykh at Nauchnyj.

Named in memory of the father and the older brother of the astronomer K. I. Churyumov ssee planet (2627)\}, friend of the discoverer. Ivan Ivanovich Churyumov (1907-1942) perished in World War II near Kharkov, and Ivan Ivanovich Churyumov (1929-1988) was a philosopher and poet. (M 19694)

\section{(3943) Silbermann}

1981 RG $_{1}$. Discovered 1981 Sept. 3 by F. Börngen at Tautenburg.

Named for the famous Saxon organ builder Gottfried Silbermann (1683-1753), several of whose instruments have been carefully preserved. The specific Silbermann timbre is the prototype for numerous twentieth-century organs. (M 14209)

\section{(3944) Halliday}

$1981 \mathrm{WP}_{1}$. Discovered 1981 Nov. 24 by E. Bowell at Anderson Mesa.

Named in honor of Ian Halliday, an astronomer at the Herzberg Institute of Astrophysics, National Research Council of Canada. Halliday has achieved international recognition in three major areas of research in meteoritics: spectroscopy, dynamics and meteorite recovery. He was the first to identify the auroral green line in the spectra of meteors; he planned and directed a large Canadian camera network called the Meteorite Observation and Recovery Project (MORP) and together with his staff determined the definitive photographic orbits of 360 fireballs; and while leading a search party Halliday found the first and largest piece of the Innisfree meteorite, one of only three meteorites recovered entirely on the basis of network photography. Halliday was able to identify six photographic trails with the corresponding six largest Innisfree fragments discovered in the fall area - a unique achievement. He also used MORP data on Geminids to study the minor planet (3200) Phaethon. (M 14634)

Name suggested by C. J. Cunningham; citation prepared by Cunningham and P. M. Millman.

\section{(3945) Gerasimenko}

1982 PL. Discovered 1982 Aug. 14 by N. S. Chernykh at Nauchnyj.
Named in honor of Svetlana Ivanovna Gerasimenko, staff member of the Institute of Astrophysics in Dushanbe, researcher on comets and codiscoverer of periodic comet Churyumov-Gerasimenko. (M 19694)

\section{(3946) Shor}

1983 EL$_{2}$. Discovered 1983 Mar. 5 by L. G. Karachkina at Nauchnyj.

Named in honor of Viktor Abramovich Shor $\{1929$

\}. member of the staff of the Institute for Theoretical Astronomy in Leningrad, on the occasion of his sixtieth birthday, 1989 Sept. 29. Best known for his extensive work in connection with editing and compiling the annual volume of Ephemerides of Minor Planets \{see planet (5001)\}, he has also carried out significant research on a theory of the motion of the satellites of Mars. (M 15090)

\section{(3947) Swedenborg}

1983 XD. Discovered 1983 Dec. 1 by E. Bowell at Anderson Mesa.

Named for Emanuel Swedenborg (1688-1772), Swedish scientist, philosopher, poet and theologian. Swedenborg began publication of Sweden's first scientific journal in 1715. His work on the philosophy of nature included a cosmological theory that was a precursor to the now widely accepted Kant-Laplace nebular theory. Soon after his death, Swedenborg societies were formed to study his thoughts, which he had published in numerous Latin volumes. His ideas have been a source of inspiration for many prominent writers, including Honoré de Balzac, Charles Baudelaire, Ralph Waldo Emerson and William Butler Yeats. (M 14972)

Name suggested and citation provided by C. J. Cunningham.

\section{(3948) Bohr}

1985 RF. Discovered 1985 Sept. 15 by P. Jensen and K. Augustesen at Brorfelde.

Named in memory of the world-famous Danish physicist Niels Bohr (1885-1962), who received the Nobel prize for his atomic theory in 1922. (M 15427) Bohr is also honored by a lunar crater.

(3949) Mach

1985 UL. Discovered 1985 Oct. 20 by A. Mrkos at Kleť.

Named in memory of Ernst Mach (1838-1916), professor of physics at the universities of Graz and Prague and later professor of philosophy in Vienna. He made investigations on supersonic motion, explosions, electric sparks and philosophical positivism, and the Mach number and Mach's principle are forever associated with his name. (M 27734)

Name suggested by J. Tichá and M. Šolc.

\section{(3951) Zichichi}

$1986 \mathrm{CK}_{1}$. Discovered 1986 Feb. 13 at the Osservatorio San Vittore at Bologna.

Named in honor of Antonio Zichichi, former president of the European Society of Physics and one of the 
protagonists of CERN. In 1963 he established and since then has directed the Centro Interdisciplinare Ettore Maiorana at Erice, Sicily. (M 14634)

\section{(3952) Russellmark}

$1986 \mathrm{EM}_{2}$. Discovered 1986 Mar. 14 at the Bulgarian National Observatory at Rozhen.

Named for the Russell Mark Group, of Albany, California, "Specialists in Written Communication", in grateful appreciation of their enormous assistance in editing the citations for the name proposals submitted to the Minor Planet Center. Over the past two years, the Group's president, Susan Russell, has taken a personal interest in this effort, thereby saving the Minor Planet Center about a day's work each month. (M 34619)

\section{(3953) Perth}

1986 VB $_{6}$. Discovered 1986 Nov. 6 by E. Bowell at Anderson Mesa.

Named for the Perth Observatory in recognition of its many notable contributions to astronomy. These have included the Perth 70 catalogue, co-discovery of the rings of Uranus, and extensive work on Comet Halley during both its 1910 and 1986 apparition. Founded in 1896 on Mount Eliza, overlooking the city of Perth, Western Australia, the observatory initially undertook timekeeping, weather reporting and seismographic monitoring, as well as telescopic observations for such programs as the Carte du Ciel and the Astrographic Catalogue. City expansion and a need for darker skies led to a move to the Darling Range, east of Perth, in 1965. Current work includes astrometry and photometry of solar system objects, particularly minor planets and comets. (M 14972)

Citation prepared by P. V. Birch at the request of the discoverer.

\section{(3954) Mendelssohn}

1987 HU. Discovered 1987 Apr. 24 by F. Börngen at Tautenburg.

Named for the celebrated composer Felix Mendelssohn-Bartholdy (1809-1847). (M 14209)

\section{(3955) Bruckner}

$1988 \mathrm{RF}_{3}$. Discovered 1988 Sept. 9 by F. Börngen at Tautenburg.

Named for the Austrian composer Anton Bruckner (1824-1896), chiefly known for his nine monumental symphonies. (M 14209)

\section{(3956) Caspar}

$1988 \mathrm{VL}_{1}$. Discovered 1988 Nov. 3 by P. Jensen at Brorfelde.

Named in honor of Caspar Karstensen, grandson of the discoverer. (M 22500)

\section{(3957) Sugie}

1933 OD. Discovered 1933 July 24 by K. Reinmuth at Heidelberg.
Named in honor of Atsushi Sugie, who works at the Dynic Astronomical Observatory and who has discovered numerous minor planets there since 1988 . He is an active confirmer of new objects in collaboration with S. Nakano \{see planet (3431)\}, who proposed the name and made the identifications involving this object. (M 22500)

\section{(3958) Komendantov}

1953 TC. Discovered 1953 Oct. 10 by P. F. Shajn at Simeis.

Named in memory of Nikolaj Vasil'evich Komendantov (1895-1937), who was an active researcher of minor-planet motion. A staff member of the Astronomical Institute in Leningrad, he was arrested 1936 on spurious charges, and the date of his death in prison is uncertain. (M 34340)

Name suggested and citation prepared by Yu. V. Batrakov.

\section{(3959) Irwin}

$1954 \mathrm{UN}_{2}$. Discovered 1954 Oct. 28 at the Goethe Link Observatory at Brooklyn, Indiana.

Named in honor of John B. Irwin, professor of astronomy at Indiana University from 1948 to 1964. His paper published in Science on 1952 Feb. 29 was the first step in the series of events that led to the establishment of a national observatory in the U.S., Kitt Peak \{see planet (2322)\} being chosen as the site on 1958 Mar. 1. (M 25652)

Name proposed by F. K. Edmondson.

\section{(3960) Chaliubieju}

1955 BG. Discovered 1955 Jan. 20 at the Purple Mountain Observatory at Nanking.

Named in honor of Cha Liubieju, a friend of the discoverer. She devotes her every effort to caring for and educating sick and destitute mothers and children in China. (M 32787)

\section{(3961) Arthurcox}

1962 OB. Discovered 1962 July 31 at the Goethe Link Observatory at Brooklyn, Indiana.

Named in honor of Arthur N. Cox, one of the graduate student observers in the early years of the Indiana minor planet program and the first recipient of a $\mathrm{Ph} . \mathrm{D}$. in the graduate program established after the gift of the Goethe Link Observatory \{see planet (1728)\} to Indiana University in 1948. His four years at Indiana University included a six-month expedition, initiated by John B. Irwin \{see planet (3959)\}, to the South African observatories to introduce photometry by photoelectric methods to the southern hemisphere. Cox then moved to Los Alamos National Laboratory, becoming the leader of a scientific research group studying both nuclear test results and stellar astrophysics. His calculations of stellar opacities in the early 1960s enabled considerable progress to be made by 
many stellar astrophysicists, and they are used even now some 30 years later. (M 19335)

Name proposed by H. R. Johnson and F. K. Edmondson.

\section{(3962) Valyaev}

1967 CC. Discovered 1967 Feb. 8 by T. M. Smirnova at Nauchnyj.

Named in honor of Valerij Ivanovich Valyaev (1944-

), noted scientist in the field of ephemeris astronomy, head of the Ephemeris Astronomy Department of the ITA \{see planet (1735)\} and editor-in-chief of Morskoj Astronomicheskij Ezhegodnik and Aviatsionnyj Astronomicheskij Ezhegodnik. (M 24410)

Name proposed by the Institute of Theoretical Astronomy.

\section{(3963) Paradzhanov}

$1969 \mathrm{TP}_{2}$. Discovered 1969 Oct. 8 by L. I. Chernykh at Nauchnyj.

Named in memory of Sergej Iosifovich Paradzhanov (1924-1990), outstanding Soviet film producer. He directed several popular films, including Ghosts of Forgotten Ancestors, winner of several international film festivals. (M 27126)

\section{(3964) Danilevskij}

$1974 \mathrm{RG}_{1}$. Discovered 1974 Sept. 12 by L. V. Zhuravleva at Nauchnyj.

Named in memory of Grigorij Petrovich Danilevskij (1829-1890), Russian and Ukrainian writer. (M 24121)

\section{(3965) Konopleva}

$1975 \mathrm{VA}_{9}$. Discovered 1975 Nov. 8 by N. S. Chernykh at Nauchnyj.

Named in honor of Valentina Petrovna Konopleva, astronomer at the Main Astronomical Observatory at Golosseevo, near Kiev, known for her works on the physics and statistics of comets. (M 19694)

\section{(3966) Cherednichenko}

1976 SD $_{3}$. Discovered 1976 Sept. 24 by N. S. Chernykh at Nauchnyj.

Named in honor of Vladimir Ivanovich Cherednichenko, docent of Kiev Polytechnical Institute, known for his research on physical and chemical processes in comets. (M 19694)

\section{(3967) Shekhtelia}

1976 YW $_{2}$. Discovered 1976 Dec. 16 by L. I. Chernykh at Nauchnyj.

Named in memory of Fyodor Osipovich Shekhtel' (1859-1926), a famous Russian architect and a bright representative of the "Russian modern style". He designed many important buildings in Moscow and elsewhere. (M 18455)

\section{(3968) Koptelov}

1978 TU$_{5}$. Discovered 1978 Oct. 8 by L. I. Chernykh at Nauchnyj.
Named in honor of the Soviet writer Afanasij Lazarevich Koptelov, whose works depicted life of the people of the Altaj and Siberia. (M 18645)

\section{(3969) Rossi}

1978 TQ8. Discovered 1978 Oct. 9 by L. V. Zhuravleva at Nauchnyj.

Named in memory of the outstanding architect Karl Ivanovich Rossi (1775-1849), designer of splendid architectural ensembles in St. Petersburg. (M 24121)

\section{(3971) Voronikhin}

1979 YM $_{8}$. Discovered 1979 Dec. 23 by L. V. Zhuravleva at Nauchnyj.

Named in memory of Andrej Nikiforovich Voronikhin (1759-1814), a Russian architect, representative of classicism. (M 24121)

\section{(3972) Richard}

$1981 \mathrm{JD}_{3}$. Discovered 1981 May 6 by C. S. Shoemaker at Palomar.

Named in honor of Richard Arthur Spellmann, brother of the discoverer. Spellmann, a chemical engineer, was a pioneer in the application of computers to the control of petroleum refinery processes. He has also dedicated much of his time to the needs of his community and served as the mayor of El Cerrito, California. (M 15575)

\section{(3973) Ogilvie}

$1981 \mathrm{UC}_{1}$. Discovered 1981 Oct. 30 by L. G. Taff at Socorro.

Professor of metallurgy at MIT and a researcher at the Boston Museum of Fine Arts, Robert E. Ogilvie (1923- ) is known for his work in crystallography. Using homegrown woodruff, he also produces the essential ingredient for the annual May Wine Festival of the Harvard-Smithsonian Meteorite Discussion Group. (M 40700)

\section{(3974) Verveer}

1982 FS. Discovered 1982 Mar. 28 by E. Bowell at Anderson Mesa.

Named in honor of Arie J. B. Verveer, technical manager of the Perth Observatory, in recognition of his many contributions to research. Since 1974 , he has provided wide-ranging support for staff and visiting astronomers. His electronic, mechanical, and computer expertise, together with his broad astronomical knowledge and experience, have made him a great asset to the Observatory. (M 14972)

Name proposed by the discoverer, following a suggestion by M. P. Candy, who also prepared the citation.

\section{(3975) Verdi}

$1982 \mathrm{UR}_{3}$. Discovered 1982 Oct. 19 by F. Börngen at Tautenburg. 
Named for the Italian composer Giuseppe Verdi (18131901), renowned the world over for his brilliant operas. (M 14634)

\section{(3976) Lise}

1983 JM. Discovered 1983 May 6 by N. G. Thomas at Anderson Mesa.

Named for the discoverer's daughter-in-law, Lise Melinda Breakey Thomas. Lise is the author of Furry Outlaws, a fantasy role-playing game. (M 26929)

\section{(3977) Maxine}

1983 LM. Discovered 1983 June 14 by C. S. Shoemaker and E. M. Shoemaker at Palomar.

Named in honor of Maxine Shoemaker Heath, sister of the second discoverer. An entomologist at the University of Illinois, Heath is a leading authority on the cicadas of North America and Argentina. Her research on thermoregulation in cicadas, in collaboration with James E. Heath, led to their discovery of several species of warm-blooded cicadas in the forests and thorn scrub of Argentina. (M 15575)

\section{(3978) Klepešta}

$1983 \mathrm{VP}_{1}$. Discovered 1983 Nov. 7 by Z. Vávrová at Klě̆.

Named in memory of Josef Klepešta (1895-1976), outstanding Czech expert in astronomical photography and one of the founders of the Czech Astronomical Association. (M 22246)

\section{(3979) Brorsen}

$1983 \mathrm{VV}_{1}$. Discovered 1983 Nov. 8 by A. Mrkos at Klě̌t.

Named in memory of Theodor Brorsen (1819-1895), Danish astronomer, known for his discoveries of five comets and his studies of the gegenschein. After studying and working in Kiel, Heidelberg and Altona he worked at the private observatory of baron John Parish in Senftenberg (Žamberk) in eastern Bohemia from 1847 to 1870 . (M 27734)

Name suggested by J. Tichá.

\section{(3980) Hviezdoslav}

1983 XU. Discovered 1983 Dec. 4 by A. Mrkos at Kleť.

Named in memory of P. O. Hviezdoslav (1849-1921), the best known Slovak poet. (M 25976)

Name proposed by the discoverer following a suggestion by astronomers of the Astronomical Institute at Tatranská Lomnica.

\section{(3981) Stodola}

1984 BL. Discovered 1984 Jan. 26 by A. Mrkos at Klě̌.

Named in memory of A. Stodola (1859-1942), professor at ETH Zürich who taught on the construction and design of various devices, such as the artificial hand he designed in 1915. (M 25976)

Name proposed by the discoverer following a suggestion by astronomers of the Astronomical Institute at Tatranská Lomnica.

\section{(3982) Kastel}

$1984 \mathrm{JP}_{1}$. Discovered 1984 May 2 by L. G. Karachkina at Nauchnyj.

Named in honor of Galina Richardovna Kastel', well-known expert on the study of the motions of minor planets and comets, and a staff member of the Institute for Theoretical Astronomy since 1962. She contributed much to the study of the 1886 close approach of periodic comet Brooks 2 to Jupiter. For more than a quarter of a century she has headed the ITA service on comets and fast-moving minor planets, maintaining contacts with the IAU Central Bureau for Astronomical Telegrams and supplying observers in the U.S.S.R. with the necessary information on orbits and ephemerides. She also put much effort into the identification and orbit determination of minor planets observed in the course of the program at the Crimean Astrophysical Observatory, and the success of this program is in no small measure due to her help. (M 18306)

\section{(3983) Sakiko}

1984 SX. Discovered 1984 Sept. 20 by A. Mrkos at Klě́.

Named in honor of Sakiko Nakano, sister of orbit computer Syuichi Nakano \{see planet (3431)\}, in remembrance of the discoverer's meeting her during the IAU General Assembly in New Delhi in 1985. (M 25976)

\section{(3985) Raybatson}

1985 CX. Discovered 1985 Feb. 12 by C. S. Shoemaker and E. M. Shoemaker at Palomar.

Named in honor of Raymond M. Batson, planetary cartographer with the U.S. Geological Survey. Batson was responsible for detailed maps and mosaics of the lunar surface derived from the television images returned from five Surveyor spacecraft landed on the Moon in the 1960s. Later he organized and led a group to carry out systematic cartography of Mercury, Venus, Mars and the satellites of the outer planets. About 500 published maps and photomosaics have been prepared by Batson's group. (M 15575)

\section{(3986) Rozhkovskij}

$1985 \mathrm{SF}_{2}$. Discovered 1985 Sept. 19 by N. S. Chernykh and L. I. Chernykh at Nauchnyj.

Named in memory of Dmitrij Aleksandrovich Rozhkovskij (1915-1991), a leading astronomer at the Astrophysical Institute of the Kazakh Academy of Sciences for many decades. He was an outstanding observer and researcher on several types of celestial objects, especially reflection nebulae and new comets. (M 19694)

Obituary published in Zemlya Vselennaya, No. 1, p. 41 (1992).

\section{(3987) Wujek}

$1986 \mathrm{EL}_{1}$. Discovered 1986 Mar. 5 by E. Bowell at Anderson Mesa. 
Named in honor of Joseph H. Wujek, staff engineer in the Advanced Technology Group of Apple Computer, Inc. An electrical engineer by training, Wujek has worked on NASA's Orbiting Geophysical Observatory, the U.S.A.-U.S.S.R. Apollo-Soyuz mission and as a guest engineer at the Very Large Array of the National Radio Astronomy Observatory. His professional interests include ethics in engineering, space technology, engineering reliability, computing and the social implications of technology. In 1989 he was honored as "Volunteer of the Year" by the Astronomical Society of the Pacific. A member of the Board of Advisors of Lowell Observatory, he has given freely of his time and expertise, particularly by coordinating the donation of much-needed computer hardware and software from Apple Computer. (M 15261)

\section{(3989) Odin}

1986 RM. Discovered 1986 Sept. 8 by P. Jensen and K. Augustesen at Brorfelde.

Named after the first and mightiest god in Norse mythology, who is the god of battle and victory, but also of wisdom and poetry. He rules the world from his home in Asgaard, where he gathers all the heroes who fell in battle to the great hall of Valhal ssee planet (1260)\}, where they enjoy feasting and fighting until Ragnarok, the end of the world. (M 22500)

The Germanic form of Odin is Wodan ssee planet (2155)\} .

\section{(3990) Heimdal}

$1987 \mathrm{SO}_{3}$. Discovered 1987 Sept. 25 by P. Jensen and K. Augustesen at Brorfelde.

Named after the god of dawn and light in Norse mythology, son of Odin \{see planet (3989)\}, born of nine virgins (all sisters). He is the watchman of the Aesir and guards Bifrost, the bridge between heaven and earth, against the giants. He is famous for his eyesight and can hear the grass grow. When be blows his lure Gjallarhorn it is heard throughout the world. (M 22500)

\section{(3991) Basilevsky}

1987 SW $_{3}$. Discovered 1987 Sept. 26 by E. Bowell at Anderson Mesa.

Named in honor of Alexandr T. Basilevsky \{1937-

\}, a planetary geologist at the Vernadsky Institute, Moscow. Basilevsky has worked for the U.S.S.R. Geological Survey on mapping the central part of the Russian platform, and for the Space Research Institute of the U.S.S.R. Academy of Sciences on potential landing sites for the Lunakhod 1 and 2 probes and the Luna 16, 20 and 24 probes, which returned lunar rock samples to the Earth. He was involved in the photogeological analysis of television images from the Mars 4 and 5 and the Venera 9, 10, 13 and 14 missions. An expert on impact cratering, Basilevsky is a coauthor of the book "Impact Craters on the
Moon and Planets". He has recently worked on the interpretation of Venera 15 and 16 images of Venus. (M 16042)

\section{(3992) Wagner}

$1987 \mathrm{SA}_{7}$. Discovered 1987 Sept. 29 by F. Börngen at Tautenburg.

Named for the composer Richard Wagner (18131883), the founder of modern music-drama, known for both the music and the texts of his operas. (M 14634)

\section{(3993) Šorm}

$1988 \mathrm{VV}_{5}$. Discovered 1988 Nov. 4 by A. Mrkos at Klet.

Named in memory of František Šorm (1913-1980), president of the Czechoslovak Academy of Sciences during the International Geophysical Year, founder and longtime director of the Institute for Macromolecular Chemistry in Prague. (M 25976)

\section{(3994) Ayashi}

1988 XF. Discovered 1988 Dec. 2 by M. Koishikawa at Sendai.

Named for the western part of the city of Sendai. The observing station at which this discovery was made was set up there in 1975 in the graveyard of the Buddhist temple An-yo-ji. (M 15090)

\section{(3995) Sakaino}

1988 XM. Discovered 1988 Dec. 5 by T. Kojima at Chiyoda.

Named in honor of Teruo Sakaino (1917- ), a glass and ceramics chemist, professor emeritus of the Tokyo Institute of Technology and of the Wuhan (China) University of Engineering, known for his research on amorphous materials. In particular, he developed quantitative methods for estimating the quality of optical glass. He is also an amateur astronomer and a former teacher of the discoverer at the T.I.T. (M 28089)

\section{(3996) Fugaku}

$1988 \mathrm{XG}_{1}$. Discovered 1988 Dec. 5 by M. Arai and H. Mori at Yorii.

One of the ancient names of Mt. Fuji ssee planet (1584)\}, the highest mountain in Japan. (M 34619)

\section{(3997) Taga}

$1988 \mathrm{XP}_{1}$. Discovered 1988 Dec. 6 by A. Sugie at Taga.

Named for the town in which the Dynic Observatory is located. Known for its ancient shrine, Taga is located $10 \mathrm{~km}$ east of Lake Biwa, the largest lake in Japan, and is surrounded by the Suzuka mountain range. (M 14634)

\section{(3998) Tezuka}

1989 AB. Discovered 1989 Jan. 1 by T. Kojima at Chiyoda.

Named in memory of Osamu Tezuka (1928-1989), celebrated Japanese master of animation. A doctor of medicine, yet already a writer of comic books at the 
age of 18 , he made particular use of movie techniques in his works. His writings therefore differed from the usual comics or caricatures, and the style that he initiated is known in Japanese as "Manga". His works, amounting to more than 100 million copies of over 400 books, included Tetsuwan Atom (Astro Boy), Jungle Taitei (Emperor of the Jungle) and Hi no Tori (Fire Bird). They present both children and adults with dreams and hopes and cover a very wide range of subjects, from science fiction to human nature, philosophy, pacifism and faith. (M 19694)

\section{(3999) Aristarchus}

1989 AL. Discovered 1989 Jan. 5 by T. Kojima at Chiyoda.

Named by the Minor Planet Names Committee for one of the earliest (3rd century B.C.) astronomers of the Alexandrine school, known for his belief that the earth revolved around the sun. (M 19335)

Aristarchus is also honored by a lunar crater.

\section{(4000) Hipparchus}

1989 AV. Discovered 1989 Jan. 4 by S. Ueda and H. Kaneda at Kushiro.

Named by the Minor Planet Names Committee for the greatest astronomer of ancient times, renowned for his introduction of systematic and critical procedures with regard both to observations and to theoretical concepts. (M 19335)

Hipparchus is also honored by craters on Mars and on the Moon.

\section{(4001) Ptolemaeus}

1949 PV. Discovered 1949 Aug. 2 by K. Reinmuth at Heidelberg.

Named by the Minor Planet Names Committee for the celebrated author of the Almagest, whose ideas dominated astronomical thought in Europe and the Middle East from the second to the sixteenth centuries. (M 19335)

Ptolemaeus is also honored by craters on Mars and on the Moon.

\section{(4002) Shinagawa}

1950 JB. Discovered 1950 May 14 by K. Reinmuth at Heidelberg.

Named in honor of Seishi Shinagawa (1944- ), who was the first to use electronic computers for orbit computation in Japan, having written a computer program for this in 1965. This program was used by Yoshiaki Banno (1952-1991) \{see planet (3394)\}. (M 22500)

Name proposed by S. Nakano, who found the identifications involving this object and learnt orbit computation and programming from Shinagawa and Banno.

\section{(4003) Schumann}

1964 ED. Discovered 1964 Mar. 8 by F. Börngen at Tautenburg.
Named for the famous romanticist Robert Schumann (1810-1856), born in Zwickau, not far from Tautenburg, and known for his song creations, piano compositions, chamber music and cello concerti. (M 14634)

\section{(4004) List'ev}

$1971 \mathrm{SN}_{1}$. Discovered 1971 Sept. 16 at the Crimean Astrophysical Observatory at Nauchnyj.

Named in memory of Vladislav Nikolaevich List'ev (1957-1995), a talented Russian television journalist who fell victim to hired assasins. His clever, benevolent, analytical series of telecasts 'Vzglyad' (View), 'Tema' (Subject) and 'Chas pik' (Peak hour) were popular among millions of people. They had a great influence on the public consciousness of Russians in the posttotalitarian era. (M 25229)

Name proposed by the Institute of Theoretical Astronomy.

\section{(4005) Dyagilev}

$1972 \mathrm{TC}_{2}$. Discovered 1972 Oct. 8 by L. V. Zhuravleva at Nauchnyj.

Named in memory of the Russian impressario Sergej Pavlovich Dyagilev (1872-1929). He is mainly known as the patron of art and literature and the founder of the travelling Russian ballet company. (M 24121)

\section{(4006) Sandler}

1972 YR. Discovered 1972 Dec. 29 by T. M. Smirnova at Nauchnyj.

Named in memory of Grigorij Moiseevich Sandler (1912-1994), an outstanding Russian musician who made an enormous contribution to the development of choral performance. He was the main conductor of the Leningrad (now St. Petersburg) University chorus for more than 40 years. (M 24410)

Name proposed by the Institute of Theoretical Astronomy.

\section{(4007) Euryalos}

1973 SR. Discovered 1973 Sept. 19 by C. J. van Houten at Palomar.

Named for the commander of the troops from Argos during the siege of Troy. (M 16042)

\section{(4008) Corbin}

1977 BY. Discovered 1977 Jan. 22 at the Felix Aguilar Observatory at El Leoncito.

Named in honor of Thomas E. Corbin, head of the Meridian Circle Division at the U.S. Naval Observatory, and his wife, Brenda Groves Corbin, since 1973 the Observatory's librarian. Serving early in his career as astronomer-in-charge of the Observatory's southern station in Argentina, Tom Corbin has since been responsible for several important astrometric programs, including the Astrographic Catalogue Reference Stars catalogue. Brenda Corbin is one of the most renowned astronomical librarians in the world, known for her work in the Special Libraries Association, the IAU 
Commission 5 Working Group on Nomenclature and for her enthusiasm in tracking down copies of rare works. (M 31295)

\section{(4009) Drobyshevskij}

$1977 \mathrm{EN}_{1}$. Discovered 1977 Mar. 13 by N. S. Chernykh at Nauchnyj.

Named in honor of Ehduard Mikhajlovich Drobyshevskij, physicist and astrophysicist at the Ioffe Physical and Technical Institute in St. Petersburg, author of some original cosmological ideas and theories of the origin of the planets and the minor bodies of the solar system, also known for his research on the magnetic fields of the sun and other stars. (M 19694)

\section{(4010) Nikol'skij}

1977 QJ $_{2}$. Discovered 1977 Aug. 21 by N. S. Chernykh at Nauchnyj.

Named in memory of Gennadij Mikhajlovich Nikol'skij (1929-1982), Soviet astronomer, known for his research on the sun and the solar corona and as a codiscoverer of the solar wind. (M 19695)

Obituaries published in Zemlya Vselennaya, No. 3, p. 33-34 (1983); Properties and interactions of interplanetary dust, p. XXIII-XXIV (1985).

\section{(4011) Bakharev}

1978 SC $_{6}$. Discovered 1978 Sept. 28 by N. S. Chernykh at Nauchnyj.

Named in memory of Anatolij Mikhailovich Bakharev (1918-1979), observer and researcher on comets and meteors, one of the discoverers of comet BakharevMacfarlane-Krienke (1955 IV). (M 19695)

Obituary published in Byull. Inst. Astrofiz., No. 71, p. 40-41 (1982).

\section{(4013) Ogiria}

$1979 \mathrm{OM}_{15}$. Discovered 1979 July 21 by N. S. Chernykh at Nauchnyj.

Named in memory of Maiya Borisovna Ogir' (19331991), solar physicist and staff member of the Crimean Astrophysical Observatory for more than 30 years, known for her research on the active processes on the Sun. (M 22500)

Obituary published in Izv. Krym. Astrofiz. Obs., Tom 86, p. 211 (1992)

\section{(4014) Heizman}

1979 SG $_{10}$. Discovered 1979 Sept. 28 by N. S. Chernykh at Nauchnyj.

Named in honor of Leonie A. Heizman, docent of the historical museum at the San Juan Capistrano mission, and Charles L. Heizman, master of technical sciences working in the computer business. They served as hostess and host to the discoverer and K. I. Churyumov \{see planet (2627)\} during the conference on Near Earth Asteroids in San Juan Capistrano during 1991 June 30-July 3. (M 20159)

\section{(4015) Wilson-Harrington}

1979 VA. Discovered 1979 Nov. 15 by E. F. Helin at Palomar.

This Apollo object, which is identical with the singleapparition periodic comet 1949 III $=1949 \mathrm{~g}$ (which appeared cometary on its discovery night of 1949 Nov. 19), is being given the name of that comet, which was discovered by A. G. Wilson and R. G. Harrington early in the first Palomar Sky Survey. (M 22246)

Named by the Minor Planet Names Committee, in the knowledge that the name violates the normal 16-character maximum.

This Apollo object was identified by E. Bowell on Palomar Sky Survey plates of 1949 Nov. 19.1 while looking for prediscovery images of minor planets. B. A. Skiff found a very slightly fanned tail on the trailed images. Subsequently, B. G. Marsden (IAUC 5585) established the identity of (4015) with the periodic comet 1949 III Wilson-Harrington.

\section{(4016) Sambre}

1979 XK. Discovered 1979 Dec. 15 by H. Debehogne and E. R. Netto at La Silla.

Named for a tributary of the river Meuse \{see planet (3016)\} in Namur \{see planet (3374)\}, site of Caesar's victory over Boduognat \{see planet (3458)\}, leader of the Belgian tribes, in 59 B.C. (M 19336)

\section{(4017) Disneya}

1980 DL $_{5}$. Discovered 1980 Feb. 21 by L. G. Karachkina at Nauchnyj.

Named in memory of Walt Disney (1901-1966), the outstanding American movie producer and master of animation. (M 17029)

\section{(4018) Bratislava}

1980 YM. Discovered 1980 Dec. 30 by A. Mrkos at Kleť.

Named for the capital of Slovakia. (M 25976)

\section{(4019) Klavetter}

$1981 \mathrm{EK}_{14}$. Discovered 1981 Mar. 1 by S. J. Bus at Siding Spring.

Named in memory of James Jay Klavetter (19601997), professor of physics at California State University at Sacramento. His enthusiasm for teaching undergraduate astronomy will serve as a model for communicating the value and excitement of science. Klavetter studied the sources and behavior of cometary dust and gas tails through telescoping imaging, and he also established the chaotic rotation state of Hyperion. Klavetter's positive outlook and thirst for new experiences remained undimmed even in the final days of his battle with leukemia. (M 30475)

Name suggested and citation prepared by J. Harrington.

\section{(4020) Dominique}

$1981 \mathrm{ET}_{38}$. Discovered 1981 Mar. 1 by S. J. Bus at Siding Spring. 
Named in honor of Dominique Bockelée-Morvan (1957- ), researcher at the Observatoire de Paris. Bockelée-Morvan has developed excitation models for cometary parent molecules with a view to preparing and interpreting radio and infrared observations, both from space and the ground. She has been involved in the identification of new cometary species and has contributed to a better understanding of the origin of the 3.4- $\mu$ mband observed in comets. (M 27458)

Citation provided by M. A. Barucci following a suggestion by E. Bowell.

\section{(4021) Dancey}

1981 QD $_{2}$. Discovered 1981 Aug. 30 by E. Bowell at Anderson Mesa.

Named in honor of Roy Dancey and Bruce D. Dancey, father and son, who successively headed the optical shop at the Dominion Astrophysical Observatory in Victoria from 1965 until 1986. Under their hands and direction, the primary and secondary mirrors for the 3.6-m Canada-France-Hawaii Telescope were figured and polished. They also produced new primary mirrors for the $1.8-\mathrm{m}$ and $1.2-\mathrm{m}$ telescopes at Victoria, as well as a host of smaller telescope optics, spectrograph optics and associated test optics. Bruce Dancey's career was tragically terminated by blindness in 1986 . However, the Dancey's work has given the astronomers of Canada, France and Hawaii a superb eye with which to explore the mysteries of space. (M 16042)

Name proposed by the discoverer, following a suggestion by the staff of the Dominion Astrophysical Observatory. Citation prepared by C. Aikman.

\section{(4022) Nonna}

$1981 \mathrm{TL}_{4}$. Discovered 1981 Oct. 8 by L. I. Chernykh at Nauchnyj.

Named in honor of Nonna (Noyabrina) Viktorovna Mordyukova, a popular Soviet cinema actress. (M 18645)

\section{(4023) Jarník}

1981 UN. Discovered 1981 Oct. 25 by L. Brožek at Klě́.

Named in memory of Vojtěch Jarník (1897-1970), Czech mathematician and professor at the Charles University in Prague. He studied number theory and was also well known for his work on the theory of real variable functions. His excellent textbooks on the differential and integral calculus have been used by several generations of mathematicians and physicists. (M 24121)

\section{(4024) Ronan}

1981 WQ. Discovered 1981 Nov. 24 by E. Bowell at Anderson Mesa.

Named in honor of Colin A. Ronan \{1920-1995\}, author and specialist in the history and philosophy of science. Particularly interested in the moon and planets, he has written more than 20 books on astronomy. He has played key roles in the administration of the
British Astronomical Association and is its current president. In addition he has been director of the Association's Historical Section (1953-1965) and editor of its Journal (1965-1985). (M 17222)

Name suggested and citation material provided by S. A. Mitton.

Obituaries published in J. Br. Astron. Assoc., Vol. 105, No. 5, p. 262 (1995); Astron. Now, Vol. 9, No. 9, p. 7 (1995); Q.J.R. Astron. Soc., Vol. 37, No. 1, p. 93-94 (1996).

\section{(4025) Ridley}

1981 WU. Discovered 1981 Nov. 24 by E. Bowell at Anderson Mesa.

Named in honor of Harold B. Ridley \{1919-1995\}, distinguished British astrophotographer specializing in comet and asteroid astrometry and photography. For many years, Ridley has been a very active and dedicated member of the British Astronomical Association, having served as its president (1976-1978), vice president (19781981, 1982-1985, 1986-1987), director of the Meteor Section (1954-1968), assistant to the director of Comet Section (1975) and currently as a Council member. (M 17222)

Name independently suggested by S. A. Mitton and B. G. Marsden, with citation material provided by the former.

Obituaries published in J. Br. Astron. Assoc., Vol. 105, No. 4, p. 189-191 (1995).

\section{(4026) Beet}

$1982 \mathrm{BU}_{1}$. Discovered 1982 Jan. 30 by E. Bowell at Anderson Mesa.

Named in honor of Ernest A. Beet \{1904-1997\}, a member of the British Astronomical Association for half of its existence. Having served in various capacities on the B.A.A.'s council between 1946 and 1987, notably as president during 1962-1964 and for twelve years as secretary, he still attends the London meetings. A schoolteacher by profession, Beet has made outstanding contributions to the advancement of astronomy education in England and has been heavily involved in the B.A.A. education committee. He has written several popular books, including The Teaching of Astronomy in Schools (1948). (M 17222)

Name suggested by B. G. Marsden and citation material provided by S. A. Mitton.

Obituary published in J. Br. Astron. Assoc., Vol. 108, No. 2, p. 121-122 (1998).

\section{(4027) Mitton}

1982 DN. Discovered 1982 Feb. 21 by E. Bowell at Anderson Mesa.

Named in honor of Simon and Jacqueline Mitton, astronomers in Cambridge, England. Originally at the Mullard Radio Astronomy Observatory, Simon made comprehensive high-resolution observations of Cygnus A with the Cambridge One-Mile Telescope. Interested in the correlation of radio and optical 
observations, he moved to the Institute of Astronomy in 1972 and collaborated with Jacqueline on a study of the optical spectrum of Cygnus A. She also worked on equivalent widths and curves of growth. Both subsequently turned their interests to the dissemination of astronomy, he as editor of the Cambridge Encyclopedia of Astronomy and astronomy publisher for Cambridge University Press, she as editor of the Journal of the British Astronomical Association. (M 17222)

Citation provided by B. G. Marsden at the request of the discoverer.

\section{(4029) Bridges}

$1982 \mathrm{KC}_{1}$. Discovered 1982 May 24 by C. S. Shoemaker and S. J. Bus at Palomar.

Named in honor of Patricia M. Bridges, planetary cartographer with the U.S. Geological Survey. Based on intimate familiarity with the Moon's surface, gained from long hours at the eyepiece of the $0.6-\mathrm{m}$ Clark refractor at Lowell Observatory, and later on minutely detailed knowledge gleaned from spacecraft images, Bridges' shaded relief maps of the Moon, other satellites and the terrestrial planets, rendered with extraordinary skill by means of the airbrush, are generally regarded as unsurpassed. (M 15576)

\section{(4030) Archenhold}

$1984 \mathrm{EO}_{1}$. Discovered 1984 Mar. 2 by H. Debehogne at La Silla.

Named in memory of the German astronomer Friedrich Simon Archenhold (1861-1939). In 1896 he made it possible to build the world's longest refractor (focal length 21 meters), which is still in use at the Archenhold Observatory in Berlin - Europe's first public observatory. As its first director Archenhold had the aim of introducing astronomy to everyone. (M 34340)

Name suggested by A. Gnädig and A. Doppler and endorsed by L. D. Schmadel.

\section{(4031) Mueller}

1985 CL. Discovered 1985 Feb. 12 by C. S. Shoemaker and E. M. Shoemaker at Palomar.

Named in honor of Jean Mueller, observer for the Second Palomar Sky Survey with the 1.2-m Oschin Telescope at Palomar Observatory. She has made numerous discoveries of supernovae and earthapproaching asteroids in the course of this survey. (M 15576)

\section{(4032) Chaplygin}

$1985 \mathrm{UT}_{4}$. Discovered 1985 Oct. 22 by L. V. Zhuravleva at Nauchnyj.

Named in memory of Sergej Alexeevich Chaplygin (1869-1942), a notable expert in theoretical mechanics. He was one of the founders of the aerodynamics. (M 24121)

Chaplygin is also honored by a lunar crater.

\section{(4033) Yatsugatake}

1986 FA. Discovered 1986 Mar. 16 by M. Inoue and O. Muramatsu at Kobuchizawa.

Named for a mountain in central Japan, famous for its scenic beauty. The Kobuchizawa \{see planet (3432)\} observing station stands at the foot of this mountain. (M 14634)

\section{(4037) Ikeya}

1987 EC. Discovered 1987 Mar. 2 by K. Suzuki and T. Urata at Toyota.

Named in honor of Kaoru Ikeya, one of the most eminent Japanese amateur astronomers. Since 1963 he has discovered five comets, including the sungrazer Comet Ikeya-Seki (1965 VIII), and two extragalactic supernovae. He has ground many large telescopic mirrors, which are in good use at observatories in Japan. (M 16443)

Name proposed by T. Urata. Citation prepared by Y. Murai and I. Hasegawa.

\section{(4038) Kristina}

$1987 \mathrm{QH}_{2}$. Discovered 1987 Aug. 21 by E. W. Elst at La Silla.

Named in honor of Kristina Leterme, professor of French and Russian literature, life partner to the discoverer, for her encouragement and love. (M 15090)

\section{(4039) Souseki}

1987 SH. Discovered 1987 Sept. 17 by T. Seki at Geisei.

Named in memory of Souseki Natsume (1867-1916), a distinguished Japanese scholar in English literature who has left an indelible mark on the history of Japanese modern literature with Ougai Mori in the Meiji era, and whose brain is still kept in the medical department of Tokyo University. Many of his articles are still widely read and have been made into movies. One of the best known articles, Botchan, which means a greenhorn in English, is set in Shikoku, the island on which the Geisei \{see planet (2571)\} station is located. (M 16246)

\section{(4040) Purcell}

$1987 \mathrm{SN}_{1}$. Discovered 1987 Sept. 21 by E. Bowell at Anderson Mesa.

Named for Henry Purcell (1659-1695), English composer, a prolific and immensely gifted writer of many forms of music. Purcell's astonishing fantasias for viols, written when he was barely out of his teens, have had a great influence on the discoverer. (M 16592)

\section{(4041) Miyamotoyohko}

$1988 \mathrm{DN}_{1}$. Discovered 1988 Feb. 19 by T. Kojima at Chiyoda.

Named in honor of Yohko Miyamoto (1922- ), wife of the amateur astronomer Yukio Miyamoto \{see planet (6020)\}. Mrs. Miyamoto has assisted her husband in his work, directly and indirectly, for half a century. Her sage advice to young members of the Kumamoto 
Astronomical Society was beneficial to the discoverer in his youth. (M 28621)

\section{(4042) Okhotsk}

$1989 \mathrm{AT}_{1}$. Discovered 1989 Jan. 15 by K. Endate and K. Watanabe at Kitami.

Named for the sea that extends between the northeast coast of Hokkaido and the Kamchatka Peninsula. The sea of Okhotsk, which is completely covered by ice floes from January to March, holds rich gifts of salmon, scallops and crabs for the people of the north. (M 15427)

\section{(4043) Perolof}

1175 T-3. Discovered 1977 Oct. 17 by C. J. van Houten and I. van Houten-Groeneveld at Palomar.

Named in honor of Per Olof Lindblad, Swedish astronomer, director of the Stockholm Observatory at Saltsjöbaden. He has served as president of the council of the European Southern Observatory and is currently a vice president of the IAU. He is the son of the astronomer Bertil Lindblad (1895-1965) \{see planet (1448)\}. (M 18455)

\section{(4044) Erikhøg}

5142 T-3. Discovered 1977 Oct. 16 by C. J. van Houten and I. van Houten-Groeneveld at Palomar.

Named in honor of Erik Høg (1932- ), Danish astronomer at the Copenhagen Observatory. $\mathrm{He}$ is meridian circle astrometrist and designer of several instruments, including a micrometer for the Carlsberg Transit Circle. He has been involved with Hipparcos since the mission evaluation study in 1975 as a member of the science team, of the scientific advisory group for MATRA (leader of MESH-Consortium for construction of HIPPARCOS) and as team leader of the data reduction consortium of the Tycho part of the Hipparcos mission. (M 18455)

\section{(4045) Lowengrub}

1953 RG. Discovered 1953 Sept. 9 at the Goethe Link Observatory at Brooklyn, Indiana.

Named in honor of Morton Lowengrub in celebration of the completion of the WIYN Observatory. As dean for Research and Graduate Development at Indiana University, and later as dean of the College of Arts and Sciences, he played a major role in the planning and construction of the WIYN 3.5-meter telescope as a charter member of the WIYN Board of Governors. He has served as a professor and administrator at Indiana University since 1967. An applied mathematician, he has authored five books on mathematics and through his research has contributed critically to problems of the propagation of cracks in solids. (M 25229)

Name proposed by R. K. Honeycutt.

\section{(4046) Swain}

1953 TV. Discovered 1953 Oct. 7 at the Goethe Link Observatory at Brooklyn, Indiana.

Named in memory of Joseph Swain (1857-1927), successor of Daniel Kirkwood \{see planet (1578)\} as professor of mathematics at Indiana University in 1886 . In 1891 he became professor of mathematics on the original Stanford University faculty. He returned to Indiana University as president in 1893. Kirkwood Hall, a classroom building, and the Kirkwood Observatory were built during Swain's nine years as president, and the department of mechanics and astronomy was created in 1895 with John A. Miller \{see planet (1826)\} as head. Swain became president of Swarthmore College in 1902. He persuaded Miller to join him in 1906 after he raised money for a telescope twice the size of the Kirkwood Observatory 0.30-m refractor. (M 25653)

Name proposed by F. K. Edmondson.

\section{(4048) Samwestfall}

1964 UC. Discovered 1964 Oct. 30 at the Goethe Link Observatory at Brooklyn, Indiana.

Named in memory of Richard Samuel Westfall (1924-1996), distinguished professor of history and philosophy of science at Indiana University from 1976 to 1989 . Westfall is regarded as the foremost scholar of the Scientific Revolution, primarily because of his extraordinary scholarship on Newton \{see planet (8000)\}, exemplified in his 1971 treatise on the development of dynamics in the seventeenth century and his 1980 biography of Newton, Never at Rest, both of which won the coveted Pfizer Award of the History of Science Society. (M 34619)

Name proposed by F. K. Edmondson. Citation prepared by E. Grant.

\section{(4049) Noragal'}

1973 QD $_{2}$. Discovered 1973 Aug. 31 by T. M. Smirnova at Nauchnyj.

Named in memory of Eleonora Yakovlevna Gal'perina (1912-1992), literary critic and translator, well-known under her pseudonym Nora Gal' for her Russian translations of foreign works, namely those by the authors Theodor Dreiser, Ethel Lilian Voynich, Jack London \{see planet (2625)\}, Antoine de Saint-Exupéry \{see planet (2578)\} and others. (M 24916; M 26439) Name proposed by E. A. Taratuta.

\section{(4050) Mebailey}

1976 SF. Discovered 1976 Sept. 20 by C.-I. Lagerkvist and H. Rickman at Kvistaberg.

Named in honor of Mark E. Bailey, a British astronomer at the University of Manchester well known for his work on the origin of comets, the dynamics of the Oort cloud and the capture of comets into short-period orbits. (M 16042)

\section{(4051) Hatanaka}

1978 VP. Discovered 1978 Nov. 1 by K. Tomita at Caussols.

Named in memory of Takeo Hatanaka (1914-1963), professor of astrophysics at the University of Tokyo and on the staff of the Tokyo Astronomical Observatory. Hatanaka's theoretical work covered a wide variety of astrophysical problems, involving planetary nebulae, 
the solar atmosphere and stellar evolution. He also pioneered research on radio astronomy in Japan and wrote enlightening books. As a member of the Japanese Science Council he was very closely involved in the early development of the national space program. (M 16043)

Name proposed by the discoverer, whose wife, Tomoko, worked for Hatanaka as a secretary before her marriage. Citation prepared by F. Moriyama.

Hatanaka is also honored by a lunar crater.

\section{(4052) Crovisier}

$1981 \mathrm{DP}_{2}$. Discovered 1981 Feb. 28 by S. J. Bus at Siding Spring.

Named in honor of Jacques Crovisier (1948- ), an astronomer at Paris-Meudon Observatory. Crovisier has observed the $\mathrm{OH}$ lines of more than 40 comets using the Nançay radio telescope, as well as millimetric molecular lines of a number of comets using the IRAM telescope. $\mathrm{He}$ was co-investigator for the infrared spectrometer on the VEGA mission to comet $1 \mathrm{P} /$ Halley and is currently involved in several cometary observation programs with ISO. Crovisier is an expert in modeling molecular processes in comets and especially in molecular spectra at radio and infrared wavelengths. (M 27458)

Citation provided by M. A. Barucci following a suggestion by E. Bowell.

\section{(4053) Cherkasov}

1981 TQ . Discovered 1981 Oct. 2 by L. V. Zhuravleva at Nauchnyj.

Named in memory of Nikolaj Konstantinovich Cherkasov (1903-1966), a well-known Russian actor. (M 24121)

\section{(4054) Turnov}

1983 TL. Discovered 1983 Oct. 5 by A. Mrkos at Klě̌.

Named for a small city in a region of eastern Bohemia known as "Czech Paradise". The city is famous for the production of excellent optics and precious stones. (M 26424)

\section{(4055) Magellan}

$1985 \mathrm{DO}_{2}$. Discovered 1985 Feb. 24 by E. F. Helin at Palomar.

Named for the leader of the first expedition to circumnavigate the Earth and the present highly successful automated expedition to Venus. Ferdinand Magellan \{1480?-1521\} did not survive the epic voyage of 1519-1522, but the expedition was a triumph of navigation and yielded discoveries (including the closest galaxies to our own) that sustained generations of explorers. The Magellan spacecraft, unlike its namesake, completed its voyage in timely fashion and only then met its real goal, the mapping of the surface of our planetary twin, a task being carried out with stunning success. (M 17466)

Magellan is also honored by craters on Mars and the Moon.

\section{(4056) Timwarner}

$1985 \mathrm{FZ}_{1}$. Discovered 1985 Mar. 22 by E. Bowell at Anderson Mesa.

Named in memory of Timothy Warner (1961-1990), chief mission planner for the Cosmic Background Explorer's Diffuse Infrared Background Experiment (DIRBE). Tim skillfully integrated the science and engineering of DIRBE, translating the principal investigator's observing programs into common loads for the instrument that will perform an all-sky infrared survey and reveal the glow of the first stars and galaxies formed after the Big Bang. Prior to his work on COBE, he was an operations engineer for the Solar Maximum Mission's Coronagraph/Polarimeter experiment, scheduling the instrument and performing preliminary data analysis. He co-authored a paper on the instrument's observations of space debris, research that was consulted by Hubble Space Telescope engineers. Tim's artistic talents found expression in cartoons, paintings and contributions to Paramount Pictures' films, including special-effects work. He was also involved in rationalist causes, particularly in the exposure of flimflammery and fraudulent claims made in the name of science. Tim was found murdered on the night of 1990 Apr. 24, a day he had started with bright enthusiasm over the launch of the Space Telescope. (M 16885)

Name suggested and citation provided by S. T. Snell.

\section{(4057) Demophon}

1985 TQ. Discovered 1985 Oct. 15 by E. Bowell at Anderson Mesa.

Named for a Greek warrior, the second son of Theseus and Phaedra \{see planet (174)\}. After fighting in the Trojan War, Demophon visited Thrace, where he caused the queen, Phyllis \{see planet (556)\}, to fall in love with him. On his return to Athens, Demophon's neglect of Phyllis' kindness and love led to her suicide. (M 29669)

\section{(4058) Cecilgreen}

1986 JV. Discovered 1986 May 4 by E. Bowell at Anderson Mesa.

Named in honor of Cecil H. Green, co-founder of Texas Instruments and philanthropist extraordinary, to acknowledge a lifelong commitment to improve the quality of education and scientific research. Green and his late wife Ida funded educational and scientific projects throughout the world, such as academic buildings, health care centers, hospitals, libraries, scholarships and professorships. The Greens assisted in founding new colleges at the University of Texas at Dallas, at Oxford University in England and, in March 1990, Green College at the University of British Columbia. A graduate in electrical engineering, Green spent many years in geophysical field work before becoming a partner of Geophysical Service, Inc., in 1941. He and his partners created a division of that company that ultimately became Texas Instruments. 
In 1954 Texas Instruments pioneered the first successful commercialization of the silicon transistor. Green is a noted salmon fisherman. (M 17029)

Name suggested by and citation prepared at the University of British Columbia.

\section{(4059) Balder}

1987 SB $_{5}$. Discovered 1987 Sept. 29 by P. Jensen and K. Augustesen at Brorfelde.

Named after the kindest Norse god, handsome and wise, son of Odin \{see planet (3989)\}, peacemaker among the Aesir. Through the treachery of Loke see planet (4862)\}, Balder was killed with a mistletoe shaft by his blind brother Høder \{see planet (4669)\}. (M 22500)

\section{(4060) Deipylos}

$1987 \mathrm{YT}_{1}$. Discovered 1987 Dec. 17 by E. W. Elst at La Silla.

Named for the Greek hero ordered by Sthenelos \{see planet (3794)\} to bring the horses captured from Aeneas \{see planet (1172)\} to the Greek vessels. (M 15090)

\section{(4061) Martelli}

$1988 \mathrm{FF}_{3}$. Discovered 1988 Mar. 19 by W. Ferreri at La Silla.

Named in honor of Giuseppe Martelli \{19231994\}, head of the Space and Plasma Physics Group at the University of Sussex from 1964 to 1986. Martelli pioneered the development and use of explosive accelerating techniques for the study of macroscopic hypervelocity impacts. His experimental and theoretical work constitutes a major contribution to the understanding of impact magnetization of ferromagnetic rocks, a problem particularly relevant to the origin of lunar magnetism. Over the years he has organized numerous series of experiments to study catastrophic fragmentation of free falling bodies, thereby providing experimental input to theories of asteroidal evolution and other impact phenomena of astrophysical interest. (M 14972)

Obituaries published in Planet. Space Sci., Vol. 42, No. 12, p. 1011-1012 (1994); Icarus, Vol. 112, No. 2, p. 302 (1994); Q. J. R. Astron. Soc., Vol. 36, No. 4, p. $459-460$ (1995).

\section{(4062) Schiaparelli}

1989 BF. Discovered 1989 Jan. 28 at the Osservatorio San Vittore at Bologna.

Named in memory of Giovanni Virgilio Schiaparelli (1835-1910), discoverer of the connection between comets and meteor streams. A great observer of Mars, he discovered the famous "canali" and drew some fine maps. He made measurements of double stars and of the rotational periods of Mercury and Venus, and he discovered (69) Hesperia. From 1862 to 1900 he was director of the Brera Observatory in Milan. (M 15090)

Schiaparelli is also honored by craters on Mars and the Moon.

\section{(4063) Euforbo}

$1989 \mathrm{CG}_{2}$. Discovered 1989 Feb. 1 at the Osservatorio San Vittore at Bologna.

Named for the Trojan hero who wounded the Greek Patroclus in the breast before being killed by the Greek Hektor \{see also the citations for planets (617) and (624)\}. (M 19347)

The original citation (M 15091) was corrected by the Minor Planet Names Committee. According to the orbital elements, Euphorbos worked as a 'spy' in the foreign camp.

\section{(4064) Marjorie}

2126 P-L. Discovered 1960 Sept. 24 by C. J. van Houten and I. van Houten-Groeneveld at Palomar.

Named in honor of Marjorie Meinel, who with her husband Aden \{see planet (4065)\} has formed a lifelong team, working closely together with great success. (M 19695)

\section{(4065) Meinel}

2820 P-L. Discovered 1960 Sept. 24 by C. J. van Houten and I. van Houten-Groeneveld at Palomar.

Named in honor of U.S. astronomer Aden Meinel, originator of new techniques and facilities, including the Kitt Peak National Observatory, the Optical Sciences Center of the University of Arizona, and future space missions at the Jet Propulsion Laboratory. (M 19695)

\section{(4066) Haapavesi}

1940 RG. Discovered 1940 Sept. 7 by H. Alikoski at Turku.

Named for the birthplace of the discoverer's father. Haapavesi has been known for centuries for the manufacture of skis. (M 18455)

\section{(4067) Mikhel'son}

1966 TP. Discovered 1966 Oct. 11 by N. S. Chernykh at Nauchnyj.

Named in honor of Nikolaj Nikolaevich Mikhel'son (1918- ), outstanding Soviet scientist known for his astronomical optics and telescopes. (M 27126)

\section{(4068) Menestheus}

1973 SW. Discovered 1973 Sept. 19 by C. J. van Houten at Palomar.

Named for the commander of the troops from Athens during the siege of Troy. (M 16043)

\section{(4069) Blakee}

1978 VL $_{7}$. Discovered 1978 Nov. 7 by E. F. Helin and S. J. Bus at Palomar.

Named in honor of Lawrence E. Blakee, who for 37 years has worked diligently in many capacities at the Palomar Observatory and at the Mount Wilson Observatory to support the researchers using those facilities. The many astronomers who have worked at Mount Wilson and Palomar have benefited from his conscientiousness and dedication. (M 16247) 


\section{(4070) Rozov}

$1980 \mathrm{RS}_{2}$. Discovered 1980 Sept. 8 by L. V. Zhuravleva at Nauchnyj.

Named in honor of the Russian playwright Victor Sergeevich Rozov (1913- ). (M 24121)

\section{(4071) Rostovdon}

$1981 \mathrm{RD}_{2}$. Discovered 1981 Sept. 7 by L. G. Karachkina at Nauchnyj.

Named for the city of Rostov, the discoverer's birthplace, a large industrial and railroad center located on the picturesque banks of the Don. (M 17029)

\section{(4072) Yayoi}

$1981 \mathrm{UJ}_{4}$. Discovered 1981 Oct. 30 by H. Kosai and

K. Hurukawa at Kiso.

Named for the Yayoi Era, from the third century B.C. to the fourth century A.D., when the Japanese began to be influential beyond Asia. (M 21608)

\section{(4074) Sharkov}

1981 UN $_{11}$. Discovered 1981 Oct. 22 by N. S. Chernykh at Nauchnyj.

Named in honor of Viktor Ivanovich Sharkov (1935-

), an experimental astrophysicist known for his laboratory simulation of the physical phenomena in icy cometary nuclei. A staff member of the Ioffe Physical and Technical Institute in St. Petersburg for many years, he has been director of the St.-Petersburg Planetarium since 1993. (M 26762)

\section{(4075) Sviridov}

1982 TL $_{1}$. Discovered 1982 Oct. 14 by L. G. Karachkina at Nauchnyj.

Named in honor of Georgij Vasil'evich Sviridov \{1915-1998\}, a well-known Soviet composer. (M 17029)

\section{(4076) Dörffel}

$1982 \mathrm{UF}_{4}$. Discovered 1982 Oct. 19 by F. Börngen at Tautenburg.

Named in memory of Georg Samuel Dörffel (16431688), whose computations on the orbit of the great comet of $1680 / 1681$ were the first to be made on the assumption of parabolic motion with the Sun at the focus. (M 14972)

\section{(4077) Asuka}

$1982 \mathrm{XV}_{1}$. Discovered 1982 Dec. 13 by H. Kosai and K. Hurukawa at Kiso.

Named of the Asuka Era, from the fifth and sixth centuries, when the capital was in the Asuka area in the central part of Japan. (M 21608)

\section{(4078) Polakis}

1983 AC. Discovered 1983 Jan. 9 by B. A. Skiff at Anderson Mesa.

Named in honor of Thomas A. Polakis (1961- ), mechanical engineer and friend of the discoverer. As an observer of the sky, he exemplifies all that is best in an amateur astronomer. (M 27126)

\section{(4079) Britten}

1983 CS. Discovered 1983 Feb. 15 by E. Bowell at Anderson Mesa.

Named for Benjamin Britten (1913-1976), English composer. Best known for his operas and other vocal music, Lord Britten was also an accomplished pianist and conductor. His music is imbued with a rare beauty of line and limpidity of texture. (M 16592)

\section{(4080) Galinskij}

1983 PW. Discovered 1983 Aug. 4 by L. G. Karachkina at Nauchnyj.

Named in honor of Nikolaj Dmitrievich Galinskij, Soviet radio engineer, creator of high-sensitivity image tubes for astronomical observations. The high quantum efficiency and excellent quality of these tubes were significant to the successful development of modern observational astronomy, and as long ago as 1964 stars of twentieth magnitude were being recorded with the $0.5-\mathrm{m}$ telescope at the Crimean Astrophysical Observatory with an exposure of only 4 seconds. Galinskij is a coauthor of Television Astronomy, published in 1984. (M 17030)

Citation provided by V. V. Prokof'eva at the request of the discoverer.

(4081) Tippett

$1983 \mathrm{RC}_{2}$. Discovered 1983 Sept. 14 by E. Bowell at Anderson Mesa.

Named for Sir Michael Tippett (1905-1998), English composer. Tippett's music, particularly that for voice, is marked by a compassionate humanity. (M 16592)

\section{(4082) Swann}

1984 SW $_{3}$. Discovered 1984 Sept. 27 by C. S. Shoemaker and E. M. Shoemaker at Palomar.

Named in honor of Gordon A. Swann, geologist at Northern Arizona University. As principal investigator for the geological field investigations conducted at the Apollo 14 and 15 lunar landing sites, Swann forged a close knit and effective exploration effort that linked geologists, mission control engineers and the astronaut crew. The result was a rich return of geologic data from the first manned lunar missions planned explicitly for scientific exploration. (M 15576)

\section{(4083) Jody}

1985 CV. Discovered 1985 Feb. 12 by C. S. Shoemaker and E. M. Shoemaker at Palomar.

Named in honor of Joan D. (Jody) Swann, planetary data librarian at the U.S. Geological Survey. Her 25 years of experience in nearly every phase of lunar and planetary exploration have enabled her to establish the world's most complete and functional archive of photographs, maps, spacecraft images and supporting data on the solid bodies of the solar system. Recently, she has utilized this archive to prepare outstanding color mosaics of Mars. (M 15576) 
(4084) Hollis

1985 GM. Discovered 1985 Apr. 14 by E. Bowell at Anderson Mesa.

Named in honor of Andrew J. Hollis, a member of the British Astronomical Association since 1961. As director of the Asteroids and Remote Planets section, he has encouraged amateur astronomers to make photoelectric photometric observations of minor planets and has published several light curves and phase curves. (M 17223)

\section{(4085) Weir}

1985 JR. Discovered 1985 May 13 by C. S. Shoemaker and E. M. Shoemaker at Palomar.

Named in honor of Doris Blackman Weir, geologist with the U.S. Geological Survey. As technical editor for the branch of astrogeology, she has made significant contributions to the quality of hundreds of maps and scientific papers published on the planets and satellites. (M 15576)

\section{(4086) Podalirius}

$1985 \mathrm{VK}_{2}$. Discovered 1985 Nov. 9 by L. V. Zhuravleva at Nauchnyj.

Named for the Greek physician, son of Aesculapius \{see planet (1027)\} and Epione and brother of Hygiea, Machaon and Panacea see planets (10), (3063), (2878), respectively\}, who stopped a pestilence during the Trojan War. (M 22246)

\section{(4087) Pärt}

$1986 \mathrm{EM}_{1}$. Discovered 1986 Mar. 5 by E. Bowell at Anderson Mesa.

Named for Arvo Pärt (1935- ), Estonian-born composer. Until 1968, Pärt composed mainly serially. Since that year his music has evolved into what he terms a "tintinnabular" style, which is much influenced by medieval plainsong and organum. The calmness and linear clarity of the composer's recent music, which is often compared to that of Benjamin Britten \{see planet (4079)\}, have much affected the discoverer. (M 16593)

\section{(4088) Baggesen}

1986 GG. Discovered 1986 Apr. 3 by P. Jensen at Brorfelde.

Jens Baggesen (1764-1826) was a famous Danish poet and writer, born in Korsør. (M 39640)

\section{(4090) Říšehvězd}

$1986 \mathrm{RH}_{1}$. Discovered 1986 Sept. 2 by A. Mrkos at Klět.

Named for Říše hvězd (the Realm of Stars ), Czech popular journal for astronomy. Originally published by the Czech Astronomical Society in Prague, the journal has described new findings from astronomy, astrophysics and space exploration and provided information about Czech and Slovak amateur and professional astronomy for more than three-quarters of a century. (M 27734)
Name suggested by J. Tichá, M. Tichý and Z. Moravec

\section{(4091) Lowe}

$1986 \mathrm{TL}_{2}$. Discovered 1986 Oct. 7 by E. Bowell at Anderson Mesa.

Named in honor of Andrew Lowe, a Canadian professional geophysicist and amateur astronomer in Calgary who has particular interests in computational astronomy involving minor planets and occultations. In recent years, he has opened up a new area of identification research by establishing several cases of linkages of orbits where the observations of the minor planets involved were made on only two nights at individual oppositions. (M 16247)

\section{(4092) Tyr}

1986 TJ $_{4}$. Discovered 1986 Oct. 8 by P. Jensen and K. Augustesen at Brorfelde.

Named after one of the bravest gods in Norse mythology and a great warrior. It is unclear whether he is a son of Odin \{see planet (3989)\} or of the giant Ymer. Tyr lost his right hand when Fenrir was chained by the Aesir. (M 22500)

\section{(4093) Bennett}

1986 VD. Discovered 1986 Nov. 4 by R. H. McNaught at Siding Spring.

Named in honor of Jack Caister Bennett \{1914-1990\}, prominent South African amateur astronomer. Jack Bennett's interest in comets developed from stories told by his mother about seeing Halley's comet in 1910. His dedication to comet searching resulted in an excellent catalogue of southern comet-like objects, discovery of the bright comet 1970 II and also 1974 XV. During routine comet searches he discovered the bright supernova 19681 in M83. His interests covered a wide range from involvement in Moonwatch to holding many posts within the South African Astronomical Society, including its presidency. The sight of 1970 II was one of the first and most spectacular astronomical observations made by the discoverer of this minor planet. (M 14972)

Obituaries published in Mon. Notes Astron. Soc. S. Afr., Vol. 49, No. 9-10, p. 113-115, p. 115 (1990); Komet. Tsirk., No. 420, p. 15-16 (1990); Q.J.R. Astron. Soc., Vol. 35, No. 3, p. 353 (1994).

\section{(4094) Aoshima}

1987 QC. Discovered 1987 Aug. 26 by W. Kakei and M. Kizawa at Shizuoka.

Named in memory of Masaki Aoshima (1947-1987), founder of the Shizuoka City Amateur Astronomers' Society and an active advisor to beginning amateur astronomers. He died of a heart attack on his way home from an observing session just one month after this minor planet was discovered. (M 15427)

Name also suggested by many amateur astronomers in Shizuoka. 


\section{(4095) Ishizuchisan}

1987 SG. Discovered 1987 Sept. 16 by T. Seki at Geisei.

Named for the highest mountain on Shikoku, the island on which the Geisei Station is located ssee planets (4223) and (2571)\}. The mountain has an altitude of $1982 \mathrm{~m}$ and is sacred to many Japanese. (M 15427)

\section{(4096) Kushiro}

1987 VC. Discovered 1987 Nov. 15 by S. Ueda and H. Kaneda at Kushiro.

Named for a city of population of 220,000 on the Pacific coast of Hokkaido \{see planet (3720)\}. Its main industries are paper making, coal mining and fishing, and the citizens are especially proud of the fact that they have the largest fish catch in Japan. Behind the city area there are huge, wild fields that form Kushiro's Marsh National Park. In spite of the prevalence of fog during the summer months the first discoverer maintains his observing station there. (M 15427)

\section{(4097) Tsurugisan}

1987 WW. Discovered 1987 Nov. 18 by T. Seki at Geisei.

Named for the second highest mountain on Shikoku \{see planet (4223)\} island. There is a meteorological observatory on the 1955-m summit. (M 15427)

\section{(4098) Thraen}

$1987 \mathrm{WQ}_{1}$. Discovered 1987 Nov. 26 by F. Börngen at Tautenburg.

Named in memory of Anton Karl Thraen (18431902), an astronomer and catholic priest in the German district of Eichsfeld \{see planet (442)\}. In his time Thraen was one of the most versatile and successful computers of orbits and ephemerides, for both comets and minor planets. Many of his articles are published in the A.N., and he also participated in the publication of the B.A.J. He was the first to show that the hyperbolic orbits of some comets are due to planetary perturbations. (M 15091)

Name proposed by the discoverer, following a suggestion by J. Dorschner.

\section{(4100) Sumiko}

1988 BF. Discovered 1988 Jan. 16 by T. Hioki and N. Kawasato at Okutama.

Named in honor of Sumiko Hioki (1965- ), wife of the first discoverer. (M 34619)

\section{(4101) Ruikou}

1988 CE. Discovered 1988 Feb. 8 by T. Seki at Geisei.

Named in memory of Ruikou Kuroiwa (1862-1920), a great scholar, translator and commentator of the Meiji and Taisho eras. Among the best of his translations of western works are "Mask of red-hot iron", "Ghost tower" and "King of Cavern". He was born in Aki city, on the western side of which the Geisei Station is situated. The name Geisei \{see planet (2571)\} actually means "West side of Aki city". (M 16247)

\section{(4103) Chahine}

1989 EB. Discovered 1989 Mar. 4 by E. F. Helin at Palomar.

Named in honor of Moustafa Chahine, chief scientist of the Jet Propulsion Laboratory, where he coordinates the research of scientists on the world's foremost unmanned space probes. His own scientific research is in the field of atmospheric science and of remote sensing, both of which have advanced by his innovations and insight. His most recent involvement is in the project Mission to Planet Earth. Chahine possesses that rare quality that combines exceptional scientific and administrative skills. His friends and colleagues have the greatest respect and admiration for his remarkable sensitivity, vision and outstanding leadership. (M 15427)

\section{(4104) Alu}

1989 ED. Discovered 1989 Mar. 5 by E. F. Helin at Palomar.

Named for Jeff Alu, a talented musician and composer, as well as a participant in the Palomar Planet Crossing Asteroid Survey. He has shared the long cold winter nights at Palomar and the pleasure of discovery. Jeff himself found several near-earth asteroids, as well as main-belt objects. (M 15261)

This name is endorsed by Brian P. Roman, a fellow PCAS member and good friend.

\section{(4105) Tsia}

1989 EK. Discovered 1989 Mar. 5 by E. F. Helin at Palomar.

Named in honor of the ancient sun symbol used by Indians of the Zia Pueblo in central New Mexico (one of the Seven Golden Cities of Cibola sought by Coronado). Although the symbol's name is normally written "Zia", "Tsia" is the spelling in Keresan, the native language of the Zia Pueblo Indians. The symbol now adorns the New Mexico state flag and is often taken as an emblem of the state. It represents first and foremost the sun, the giver of life. From this symbolic sun there radiate four rays consisting of four tongues each; these represent the four cardinal directions (north, south, east and west), the four seasons (spring, summer, fall and winter) and the four stages of life (childhood, youth, adulthood and old age). Also, as ascribed in the official salute to the New Mexico state flag, the Zia is the "symbol of perfect friendship among united cultures". (M 16443)

Name proposed by the discoverer, following a suggestion of Louie V. Burke as part of a project during an undergraduate astronomy class at New Mexico State University. Citation prepared by Alan Hale, instructor of the class. 
(4106) Nada

1989 EW. Discovered 1989 Mar. 6 by T. Nomura and

K. Kawanishi at Minami-Oda.

Named in honor of the Nada Junior and Senior High School in Kobe, which is known as one of the most excellent high schools in Japan. The first discoverer teaches science, especially astronomy and geology, there. Established in 1927, the school has the mottoes "make good use of your energies" and "live and let live prosperously". These are the same as the mottoes of Kodokan Judo Institute. "Nada" means "the sea that is difficult to cross". (M 15091)

\section{(4107) Rufino}

1989 GT. Discovered 1989 Apr. 7 by E. F. Helin at Palomar.

Named in honor of Rufus J. Walker, an ardent supporter of the U.S. space program and a man of exceptional kindness and gentleness. As both friend and doctor he has often made the difference in enabling the discoverer to accomplish her goals by his sincere interest and restorative qualities. As manager of medical services at the Jet Propulsion Laboratory for the past decade, he has maintained a high level of comprehensive and compassionate medical services for employees. He has introduced, staffed and enriched a broad spectrum of counseling services that have aided countless employees and their families in coping with the inherent problems of emotional stress, substance abuse and alcoholism. (M 15428)

Name endorsed by his longtime JPL associate and personal friend, Richard House.

\section{(4108) Rakos}

3439 T-3. Discovered 1977 Oct. 16 by C. J. van Houten and I. van Houten-Groeneveld at Palomar.

Named in honor of Karl D. Rakos (1925- ）, Croatianborn Austrian astronomer, since 1973 professor of astronomy at the University of Vienna and former director of the Vienna Observatory. His main field is double stars, and he served as president of IAU Commission 26 from 1985 to 1988. (M 18138)

\section{(4109) Anokhin}

1969 OW. Discovered 1969 July 17 by B. A. Burnasheva at Nauchnyj.

Named in memory of Sergej Nikolaevich Anokhin (1910-1986), test pilot and sportsman. During one of his flights he lost an eye, but he later reverted to test work. During the last years of his life he was a trainer of the Soviet cosmonauts. (M 28089)

\section{(4110) Keats}

1977 CZ. Discovered 1977 Feb. 13 by E. Bowell at Palomar.

Named after the English poet John Keats (17951821), who wrote of the thrill he experienced when he opened a folio edition of Chapman's translation of Homer \{see planet (5700)\}. His poem On First Looking Into Chapman's Homer, written in 1816, includes the words: "Then felt I like some watcher of the skies/ When a new planet swims into his ken". (M 16247)

Name suggested and citation provided by J. B. Tatum.

\section{(4111) Lamy}

$1981 \mathrm{EN}_{12}$. Discovered 1981 Mar. 1 by S. J. Bus at Siding Spring.

Named in honor of Philippe Lamy, since 1973 a staff scientist at the Laboratoire d'Astronomie Spatiale, Marseilles. Lamy has been involved in studies of solar-system dust for more than 20 years. He has specialized in circumsolar, interplanetary and cometary dust, particularly in their optical and light-scattering properties. He is currently studying cometary nuclei using HST and ISO and is involved in a number of space missions (SOHO, Cassini and Rosetta). (M 27458)

Citation provided by M. A. Barucci following a suggestion by E. Bowell.

\section{(4112) Hrabal}

1981 ST. Discovered 1981 Sept. 25 by M. Mahrová at Kleť.

Named in honor of Bohumil Hrabal (1914-1997), one of the most reputable contemporary Czech writers, the author of many stories and non-traditional prose (I Attend The English King, Too Loud A Solitude, Harlequin's Millions). Some of his works have been adapted for film screenplays, e.g., A Close Watch On The Trains. (M 22500)

\section{(4113) Rascana}

1982 BQ. Discovered 1982 Jan. 18 by E. Bowell at Anderson Mesa.

Named to commemorate the centenary of the Royal Astronomical Society of Canada. Incorporated in 1890 under the name The Astronomical and Physical Society of Toronto, the RASC received the Royal Charter in March 1903. Its Journal has been published continuously since Volume 1 in 1907 . The members of the Society have always included both professional and amateur astronomers. The masthead of the Journal reads "devoted to the advancement of astronomy and allied sciences". (M 16247)

Citation prepared by the Council of the RASC at the request of the discoverer.

\section{(4114) Jasnorzewska}

1982 QB $_{1}$. Discovered 1982 Aug. 19 by Z. Vávrová at Kleť.

Named in memory of Maria Jasnorzewska-Pawlikowska (1910-1945), important Polish poet. (M 22247)

\section{(4115) Peternorton}

1982 QS $_{3}$. Discovered 1982 Aug. 29 by N. S. Chernykh at Nauchnyj.

Named in honor of Peter Norton, internationally known programer and expert on personal computers, creator of many service programs for the PC and author of several books on the subject. He is also 
known as a lover of the arts, a collector of modern art and a sponsor for many young artists. (M 21608)

\section{(4116) Elachi}

1982 SU. Discovered 1982 Sept. 20 by E. F. Helin at Palomar.

Named in honor of Charles Elachi, assistant laboratory director for Space Science and Instruments, Jet Propulsion Observatory. His expertise is in radar sensing from space, including the successful Shuttle imaging radar experiments. He has particular interest in the assessment of the surfaces of the Earth and other planets, from the standpoints of both measurement (his Ph.D. is in electrical sciences) and interpretation (he also holds an advanced degree in geology). His accomplishments include almost 200 papers, two textbooks, numerous honors and participation in almost every radar survey from space since the early 1970s. (M 15428)

\section{(4117) Wilke}

$1982 \mathrm{SU}_{3}$. Discovered 1982 Sept. 24 by F. Börngen at Tautenburg.

Named in memory of Alfred Wilke (1893-1972), an optician of the highest rank, who constructed a workshop and observatory at Falkensee, near Berlin. Right up to his death he made optics by the thousands for astronomical institutes and popular and school observatories, as well as for numerous amateurs. Among his works are the $0.50-\mathrm{m}$ Schmidt cameras for both Sonneberg and Babelsberg, the 0.70-m Cassegrain reflector for Potsdam and the $0.70-\mathrm{m}$ and $0.54-\mathrm{m}$ Cassegrains for Babelsberg. (M 15261)

Name proposed by the discoverer following a suggestion by M. Gressmann, who also prepared the citation.

Obituary published in Sterne, 49. Jahrg., p. 52-53 (1973).

\section{(4118) Sveta}

$1982 \mathrm{TH}_{3}$. Discovered 1982 Oct. 15 by L. V. Zhuravleva at Nauchnyj.

Named for Svetlana Evgen'evna Savitskaya (1948-

), 1970 world aerobatics champion, the second woman to fly in space (1982) and the first woman to fly in space twice (1984). On her second flight she became the first woman to walk in space. (M 22500)

\section{(4119) Miles}

1983 BE. Discovered 1983 Jan. 16 by E. Bowell at Anderson Mesa.

Named in honor of Howard G. Miles, founder director of the Artificial Satellite Section of the British Astronomical Association, in which capacity he has served continuously since 1960. Miles has given sterling service to the advancement of amateur astronomy in Britain. A lecturer at Lanchester Polytechnic, Coventry, he was awarded the Member of the Order of the British Empire for his civic service in education. Miles is a former business secretary of the B.A.A. and for many years has acted as coordinator for observations of fireballs and other transient phenomena. (M 17223)

Name suggested and citation material provided by S. A. Mitton.

\section{(4120) Denoyelle}

$1985 \mathrm{RS}_{4}$. Discovered 1985 Sept. 14 by H. Debehogne at La Silla.

Named in honor of Jozef Denoyelle (1937- ) on the occasion of his retirement from the Uccle ssee planet (1276)\} Observatory. His principal research concerned early-type stars and their relation to galactic structure. Early in his career he observed minor planets and comets, and his continuing interest in such work stimulated the discoverer to start observations at La Silla. Denoyelle is very active in the popularization of astronomy and has served as treasurer of the Flemish Association of Astronomy for some 20 years. (M 30095)

Name proposed by the discoverer, endorsed by E. W. Elst.

\section{(4121) Carlin}

1986 JH. Discovered 1986 May 2 at the Palomar Observatory at Palomar.

Named by Steve Singer-Brewster in honor of his daughter, Carlin Singer-Brewster, on the occasion of her seventh birthday. (M 17030)

\section{(4122) Ferrari}

1986 OA. Discovered 1986 July 28 at the Osservatorio San Vittore at Bologna.

Named in memory of Enzo Ferrari (1898-1988), world-famous Italian builder of racing cars and sports cars. After working some 20 years for Alfa Romeo, Ferrari built his factory at Maranello, near Modena, in 1940. A mechanical engineer 'honoris causa' at Bologna University, he produced racing cars that have won practically all the sporting competitions in the world. A benefactor, he gave medical apparatus to the university and to the hospital in Modena for research on muscular dystrophy. (M 16043)

\section{(4124) Herriot}

1986 SE. Discovered 1986 Sept. 29 by Z. Vávrová at Kleť.

Named in honor of James Herriot (1916-1995) \{pen name James Alfred Wright\}, veterinarian and writer. (M 21608)

\section{(4125) Lew Allen}

1987 MO. Discovered 1987 June 28 by E. F. Helin at Palomar.

Named in honor of Lew Allen, who has been vice president of the California Institute of Technology and director of the Jet Propulsion Laboratory since 1982. He has provided exceptional leadership and vision to extend the U.S. exploration of the solar system. Under his guidance, 1989 saw the successful 
launch of the Magellan spacecraft to the planet Venus and the Galileo spacecraft to Jupiter. Allen is highly regarded by JPL people as an excellent leader as well as a caring, accessible friend. The discoverer acknowledges his genuine interest and support over the years. (M 17223)

\section{(4126) Mashu}

1988 BU. Discovered 1988 Jan. 19 by K. Endate and K. Watanabe at Kitami.

Named for one of the lakes in Akan National Park, which is located in eastern Hokkaido, a one-hour drive from Kitami and Kushiro \{see planets (3720), (3785), and (4096), respectively . The caldera lake is $20 \mathrm{~km}$ in circumference, covers an area of 19.6 square $\mathrm{km}$ and has a maximum depth of $212 \mathrm{~m}$. No rivers flow into or out of the lake, which is one of the most transparent in the world, although its surface is almost always shrouded in fog. (M 15428)

\section{(4127) Kyogoku}

$1988 \mathrm{BA}_{2}$. Discovered 1988 Jan. 25 by S. Ueda and H. Kaneda at Kushiro.

Named for the second discoverer's birthplace, a town of population 4,000 located approximately 70 $\mathrm{km}$ southwest of Sapporo \{see planet (3473)\} at the foot of the most beautiful mountains in Hokkaido \{see planet (3720)\}. The town is known for its production of potatoes, asparagus and wheat, and nearby Fukidashi park provides high-quality mineral water, which has gained in popularity among the tourists. (M 15428)

\section{(4128) UKSTU}

1988 BM $_{5}$. Discovered 1988 Jan. 28 by R. H. McNaught at Siding Spring.

Named after the U.K. Schmidt Telescope Unit at the Royal Observatory Edinburgh and the 1.2-m U.K. Schmidt Telescope at Siding Spring. In association with ESO, UKSTU has been undertaking a multicolor survey and atlas of the southern sky since operations commenced in 1973. The high quality and faint limits of the survey material resulted in major discoveries in the morphology of galaxies. A significant proportion of quasars with redshifts greater than 4 were discovered in UKSTU material. Other programs utilizing the telescope include the UCAS survey for faint minor planets and the LUKAS survey extending to even fainter limits. The discovery images of this minor planet and those subsequently identified at earlier oppositions were all on 1.2-m U.K. Schmidt plates archived at Siding Spring and Edinburgh. In June 1988 control of the telescope passed from ROE to the Anglo-Australian Observatory. (M 15261)

\section{(4129) Richelen}

1988 DM. Discovered 1988 Feb. 22 by R. H. McNaught at Siding Spring.

Named in honor of Richard A. Keen and Helen C. Duran, friends of the discoverer, on the occasion of their wedding. Richard has been a research meteorologist, more recently turning to writing and popularization of meteorology. His interests in amateur astronomy include visual photometry of comets and studies of the brightness of lunar eclipses. Helen is a nurse specializing in hospice care. (M 15262)

\section{(4130) Ramanujan}

1988 DQ $_{1}$. Discovered 1988 Feb. 17 by R. Rajamohan at Kavalur.

Named in memory of Srinivasa Ramanujan (18871920), the Indian mathematical genius who has been classed with Euler \{see planet (2002)\} and Jacobi and is regarded as one of the truly great algorists in the history of mathematics. His work on the theory of partitions, done in Cambridge in collaboration with Hardy, won him worldwide recognition, and he became the first Indian mathematician to be elected a fellow of the Royal Society. The Hardy-Ramanujan theory led to the circle method, which is today one of the most powerful tools in analytic number theory. Ramanujan gave an analytic expression for pi that has been used on powerful digital computers to generate accurate values to seventeen million decimal places. Terminally ill, he returned to India in 1919 and spent his last year in Madras on further mathematical investigations, which he recorded in a notebook. This notebook was subsequently lost, eventually to be retrieved as it was about to be incinerated in Cambridge following the death of the mathematician Watson. G. E. Andrews resurrected the notebook in 1976 and by making it available for wide study caused a revival of interest in Ramanujan's work. (M 15262)

Citation prepared by D. C. V. Mallik.

\section{(4131) Stasik}

1988 DR $_{4}$. Discovered 1988 Feb. 23 by A. J. Noymer at Siding Spring.

Named in honor of John S. Stasik, science teacher at Weston Middle School, Massachusetts, responsible for introducing the discoverer to astronomy. (M 15091)

\section{(4132) Bartók}

1988 EH. Discovered 1988 Mar. 12 by J. Alu at Palomar.

Named for the great composer Bela Bartók (18811945). Bartók was influenced by the melodic lines and rhythms found in the folk songs of his native Hungary. He transformed these songs into great works of music without altering the basic musical elements of the folk songs. (M 15091)

\section{(4133) Heureka}

1942 DB. Discovered 1942 Feb. 17 by L. Oterma at Turku.

Named for the new science center in Vantaa, near Helsinki. (M 18455) 


\section{(4134) Schütz}

1961 CR. Discovered 1961 Feb. 15 by F. Börngen at Tautenburg.

Named in memory of Heinrich Schütz (1585-1672), the greatest German composer of the seventeenth century, born in Kostritz, $22 \mathrm{~km}$ from Tautenburg, and a very important precursor to J. S. Bach \{see planet (1814)\}. The epoch-making work of Schütz is principally documented in numerous pieces of sacred music. (M 16043)

\section{(4135) Svetlanov}

1966 PG. Discovered 1966 Aug. 14 by L. I. Chernykh and T. M. Smirnova at Nauchnyj.

Named in honor of the famous Soviet composer and conductor Evgenij Fyodorovich Svetlanov. (M 18455)

\section{(4136) Artmane}

1968 FJ. Discovered 1968 Mar. 28 by T. M. Smirnova at Nauchnyj.

Named in honor of Vija Artmane, famous Latvian actress who appeared in more than 60 movies. Rodnaya krov' (The Family Blood), in which she took the leading role, was honored with the Eric Johnston prize at the fourth international movie festival, held in Argentine in 1964. (M 28089)

\section{(4138) Kalchas}

1973 SM. Discovered 1973 Sept. 19 by C. J. van Houten at Palomar.

Named for a prophet on the side of the Greeks during the Trojan war. (M 16043)

\section{(4139) Ul'yanin}

$1975 \mathrm{VE}_{2}$. Discovered 1975 Nov. 2 by T. M. Smirnova at Nauchnyj.

Named in memory of Sergej Alekseevich Ul'yanin (1871-1921), Russian pilot and talented inventor, who graduated from the Framan pilot school in France in 1910. Two of his projects involved the design of new airplanes, one of which was realized. He also designed a radio navigation system for airplanes in flight, as well as apparatus for air photography. (M 28089)

\section{(4140) Branham}

1976 VA. Discovered 1976 Nov. 11 at the Felix Aguilar Observatory at El Leoncito.

Named in honor of Richard L. Branham Jr. (1943- ), a U.S. astronomer who works in meridian astronomy and celestial mechanics. Branham worked in the 7 -inch Transit Circle Division of the U.S. Naval Observatory from 1968 to 1982, toward the end of which time he was resident director of the Yale-Columbia Southern Station at El Leoncito and also in charge of the Naval Observatory's Austral Expedition. Since 1982 he has continued his astronomical research and teaching in Argentine. (M 29143)

\section{(4141) Nintanlena}

1978 PG $_{3}$. Discovered 1978 Aug. 8 by N. S. Chernykh at Nauchnyj.

Named in honor of Nina, Tanya and Elena, wife and daughters of Kiev astronomer K. I. Churyumov \{see planet (2627)\}. (M 19695)

\section{(4142) Dersu-Uzala}

1981 KE. Discovered 1981 May 28 by Z. Vávrová at Klět.

Named after an inhabitant of Siberian Taiga and the character from the novel of the same name by the Russian writer Vladimir K. Arsenev. Dersu-Uzala was a member of the Goldy tribe and he became a friend of Arsenev's during 1902-1910. (M 21609)

\section{(4144) Vladvasil'ev}

$1981 \mathrm{SW}_{6}$. Discovered 1981 Sept. 28 by L. V. Zhuravleva at Nauchnyj.

Named after the brilliant Russian ballet-dancer Vladimir Victorovich Vasil'ev (1940- ）. (M 24121)

\section{(4145) Maximova}

$1981 \mathrm{SJ}_{7}$. Discovered 1981 Sept. 29 by L. V. Zhuravleva at Nauchnyj.

Named in honor of the wonderful Russian balletdancer Ekaterina Sergeevna Maximova (1939- ). (M 24121)

\section{(4146) Rudolfinum}

$1982 \mathrm{DD}_{2}$. Discovered 1982 Feb. 16 by L. Brožek at Kleť.

Named for one of the most beautiful and important neo-Renaissance buildings in Prague. Constructed between 1876 and 1884, Rudolfinum originally served as a concert hall and art gallery, and from 1918 to 1938 it was the seat of the Czech National Assembly. Now it is again a center of musical life as home to the Czech Philharmonic Orchestra and the international music festival 'Prague Spring'. (M 24410)

\section{(4147) Lennon}

1983 AY. Discovered 1983 Jan. 12 by B. A. Skiff at Anderson Mesa.

Named in memory of John Lennon (1940-1980), musician and ex-Beatle. With Paul McCartney \{see planet (4148)\}, he wrote the early songs that helped make The Beatles \{see planet (8749)\} the most popular group of their generation. Perhaps the most famous Beatles album is Sergeant Pepper's Lonely Hearts Club Band, which represents the Lennon-McCartney partnership at its most fertile and innovative. From his solo recording career, the song that will probably best be remembered is 'Imagine'. Passionately anti-war, John, and his wife Yoko, also made many public demonstrations of their desire for a peaceful world. (M 16247; G. V. Williams) 


\section{(4148) McCartney}

1983 NT. Discovered 1983 July 11 by E. Bowell at Anderson Mesa.

Named in honor of Paul McCartney (1942- ), musician and ex-Beatle. A talented composer, he was responsible for some of The Beatles' \{see planet (8749)\} best loved songs - both 'Yesterday' and 'Michelle' have become classics of the popular repertoire, and have each been covered by several hundred artists. Paul was instrumental in the setting up of the Apple Corps, a philantropic organization that helped to launch the careers of several young musicians. Paul was the only member of The Beatles to continue regular live performances after the group split in 1970. He is still a popular performer, and many of his solo recordings have topped the charts around the world. (M 16248)

\section{(4149) Harrison}

1984 EZ. Discovered 1984 Mar. 9 by B. A. Skiff at Anderson Mesa.

Named in honor of George Harrison (1943-2001), the quiet Beatle. Although overshaded by John and Paul as composers while in The Beatles \{see planet (8749)\}, George wrote several songs for the group, including 'While My Guitar Gently Weeps' and 'Something'. Since The Beatles disbanded, George has undertaken many projects in addition to his solo recording career; notably his film company, HandMade Films. In 1971 he organized a star-studded charity concert for the relief of famine in Bangladesh, and many of his songs have reflected his concern for the environment. (M 16248)

\section{(4150) Starr}

1984 QC $_{1}$. Discovered 1984 Aug. 31 by B. A. Skiff at Anderson Mesa.

Named in honor of Ringo Starr (Richard Starkey: 1940- ), a Liverpudlian of lively personality and deadpan humor who occasionally sat in as drummer with The Beatles \{see planet (8749)\} during their early days in Hamburg. Ringo actually joined the group in 1962, after the original drummer, Pete Best, left. Ringo's solo career has encompassed several albums and a variety of film roles. (M 16248)

\section{(4151) Alanhale}

1985 HV $_{1}$. Discovered 1985 Apr. 24 by C. S. Shoemaker and E. M. Shoemaker at Palomar.

Named in honor of Alan Hale for his many observations of comets. In the past several years he has published careful visual observations of more than 130 comets, several at more than one apparition. His observations include both magnitude estimates and confirmations of discoveries. He has also applied his magnitude estimating skill to asteroids, particularly the fast moving objects $1989 \mathrm{AC}$ and $1989 \mathrm{VA}$, and has participated in asteroid occultation teams. He has done much to promote asteroid-comet education through articles on comets and emphasis on asteroids in his introductory astronomy classes. (M 18139) Citation provided by David Levy.

\section{(4152) Weber}

1985 JF. Discovered 1985 May 15 by E. Bowell at Anderson Mesa.

Named for Carl Maria von Weber (1786-1826), German composer. Although Weber did not invent German Romantic opera, he was strongly influential in setting its course, both as a composer and conductor. Similarly, he was a primary builder of the nineteenthcentury Romantic movement in music. His operas and overtures are often performed, but his symphonies, most of his concerti and his piano works have fallen into unjust neglect. (M 16593)

\section{(4153) Roburnham}

$1985 \mathrm{JT}_{1}$. Discovered 1985 May 14 by C. S. Shoemaker and E. M. Shoemaker at Palomar.

Named in honor of Robert Burnham, senior editor of the magazine Astronomy. Over many years he has been partly responsible for its evolution into the astronomical publication with the world's largest readership. In 1983, Burnham's The Star Book appeared with a series of clearly designed star charts to guide beginners on their way to an understanding of the night sky. (M 18139)

Citation provided by David Levy.

\section{(4154) Rumsey}

1985 NE. Discovered 1985 July 10 by A. C. Gilmore and P. M. Kilmartin at Lake Tekapo.

Norman J. Rumsey (1924- ) is New Zealand's foremost optical designer. With Garry Nankivell \{see planet (4243)\} he has developed numerous optical systems for professional and amateur astronomers throughout the country. Rumsey's three-mirror designs were of particular interest. (M 40700)

\section{(4155) Watanabe}

$1987 \mathrm{UB}_{1}$. Discovered 1987 Oct. 25 by S. Ueda and H. Kaneda at Kushiro.

Named in honor of Kazuro Watanabe (1955- ), known for his positional measurements of comets, minor planets and meteors. An astronomical specialist in the Sapporo Youth Science Museum, he is responsible for passing astronomical information to the public and is known throughout Hokkaido \{see planet (3720)\} as a popular leader of astronomical activities. He is also involved in the preparations of maps. (M 16593)

Name suggested by S. Nakano.

\section{(4157) Izu}

$1988 \mathrm{XD}_{2}$. Discovered 1988 Dec. 11 by Y. Oshima at Gekko.

Named for the southeastern part of Shizuoka prefecture that consists mainly of the Izu Peninsula. With its many hot springs and resorts it is well known as part of the Fuji-Hakone-Izu National Park. 
Gekko \{see planet (4261)\} Astronomical Observatory is located just at the base of the peninsula. (M 16043)

\section{(4158) Santini}

1989 BE. Discovered 1989 Jan. 28 at the Osservatorio San Vittore at Bologna

Named in memory of Giovanni Santini (1786-1877), director of the Padua Observatory from 1817 to 1867, a great observer of minor planets and comets and an indefatigable computer of their orbits and perturbations. His two-volume textbook Elementi di Astronomia was used by virtually all the Italian astronomers of the nineteenth century. (M 16043)

\section{(4159) Freeman}

1989 GK. Discovered 1989 Apr. 5 by E. F. Helin at Palomar.

Named in honor of Ann Freeman, executive secretary of the Seismological Laboratory of the California Institute of Technology and long-time friend of discoverer, on the occasion of her birthday, 1993 Feb. 10. She has enthusiastically supported the planetcrossing asteroid survey during its first decade at Caltech and continues to celebrate its successes. (M 21955)

\section{(4160) Sabrina-John}

1989 LE. Discovered 1989 June 3 by E. F. Helin at Palomar.

Named in memory of Sabrina M. Gonsalves (19621980) and John H. Riggins (1962-1980), young lovers tragically lost. In their brief lives they left a legacy of love and dedication to dreams and family. Hurling through space on its eternal journey, this minor planet symbolizes the endurance of their love. (M 21955)

Citation prepared by Carl and Teresa Atallah and endorsed by the families and friends of the young couple.

\section{(4161) Amasis}

6627 P-L. Discovered 1960 Sept. 24 by C. J. van Houten and I. van Houten-Groeneveld at Palomar.

Named after the Egyptian pharaoh Amasis (570526 B.C.). The Greek and Roman historians praised him greatly because he gave the Greek merchants their own town in the Nile delta. Amasis introduced the so-called demotic characters for the hieroglyphs. He died just before the Persians conquered Egypt. (M 22501)

\section{(4162) SAF}

1940 WA. Discovered 1940 Nov. 24 by A. Patry at Nice.

Named in honor of the Société Astronomique de France, founded in 1887 by Camille Flammarion \{see planet (1021)\} and acknowledged as being of public utility by the French government in 1897. The SAF has both professional and amateur astronomers as members, and its presidents have included Tisserand \{see planet (3663)\}, Janssen, Poincaré, Danjon and
Lyot \{see planets (2021), (1594), and (2452) for the last three astronomers\}. The society publishes the magazine L'Astronomie and the quarterly Observations et Travaux. The centenary of the SAF was celebrated by holding IAU Colloquium No. 98: Contributions of Amateur Astronomers to Astronomy. (M 22501)

Name suggested and citation prepared by M.-A. Combes.

\section{(4163) Saaremaa}

1941 HC. Discovered 1941 Apr. 19 by L. Oterma at Turku.

Named for an island in the Baltic. Some 2500 years ago a large iron meteorite impacted there, causing a lake $16 \mathrm{~m}$ deep and some smaller craters. (M 18455)

\section{(4164) Shilov}

1969 UR. Discovered 1969 Oct. 16 by L. I. Chernykh at Nauchnyj.

Named in honor of the outstanding Soviet painter Aleksandr Maksovich Shilov, who has created a gallery of portraits of his contemporaries. (M 18645)

\section{(4165) Didkovskij}

1976 GS $_{3}$. Discovered 1976 Apr. 1 by N. S. Chernykh at Nauchnyj.

Named in honor of Leonid Vladimirovich Didkovskij (1948- ), astrophysicist and deputy director of the Crimean Astrophysical Observatory ssee planet (1725)\}. He is known for his research on the brightness oscillations of the sun, for his development of scientific instrumentation for the Soviet space telescope "Astron" and for his work with the active main mirror on the 1.7-m Space Telescope "Spectrum UV", an international project. (M 34340)

\section{(4166) Pontryagin}

$1978 \mathrm{SZ}_{6}$. Discovered 1978 Sept. 26 by L. V. Zhuravleva at Nauchnyj.

Named after the outstanding Russian mathematician Lev Semenovich Pontryagin (1908-1988). (M 24121)

\section{(4167) Riemann}

1978 TQ7. Discovered 1978 Oct. 2 by L. V. Zhuravleva at Nauchnyj.

Named in memory of Georg Friedrich Bernhard Riemann (1826-1866), German mathematical genius. (M 24121)

Riemann is also honored by a lunar crater.

\section{(4168) Millan}

1979 EE. Discovered 1979 Mar. 6 at the Felix Aguilar Observatory at El Leoncito.

Named in memory of Julio Rodolfo Millan (19231995), first rector of the San Juan National University at the time that the old Yale-Columbia Southern Station was transferred there. Trained as a mining engineer and known for his research on the promotion and development of mining in Argentina, Millan was a professor of metallurgy and later a dean at Cuyo 
National University \{see planet (1917)\}, prior to his being appointed organizing delegate of the San Juan National University on its creation in 1973. (M 32787)

\section{(4169) Celsius}

$1980 \mathrm{FO}_{3}$. Discovered 1980 Mar. 16 by C.-I. Lagerkvist at La Silla.

Named in memory of the Swedish astronomer Anders Celsius (1701-1744), renowned for devising the thermometric scale. A participant in the French expedition to Lapland to measure the curvature of the Earth, he was also the first astronomer to try to determine stellar magnitudes by photometric methods. The year 1990 marks the 250th anniversary of his establishment of the Uppsala Observatory, the original building of which is still preserved in the center of Uppsala. The event has been celebrated at the Nordic-Baltic Astronomy Meeting held in Uppsala during 1990 June 17-21. (M 16044)

Celsius is also honored by a lunar crater.

\section{(4170) Semmelweis}

1980 PT. Discovered 1980 Aug. 6 by Z. Vávrová at Klě́.

Named in memory of Ignaz Fülöp Semmelweis (1818-1865), Hungarian physician. (M 22501)

\section{(4171) Carrasco}

$1982 \mathrm{FZ}_{1}$. Discovered 1982 Mar. 23 by C. S. Shoemaker and Q. R. Passey at Palomar.

Named in honor of Juan Carrasco, senior night assistant at the Palomar Observatory. The safe operation of the famous 5-m Hale telescope is entrusted chiefly to Carrasco's capable hands. (M 15576)

\section{(4172) Rochefort}

$1982 \mathrm{FC}_{3}$. Discovered 1982 Mar. 20 by H. Debehogne at La Silla.

Named for a small town in the province of Namur \{see also planet (3374)\} in southern Belgium. (M 21131)

\section{(4173) Thicksten}

$1982 \mathrm{KG}_{1}$. Discovered 1982 May 27 by C. S. Shoemaker and S. J. Bus at Palomar.

Named in honor of Robert P. Thicksten, superintendent of the Palomar Observatory, California Institute of Technology since 1981. By his technical skill and his leadership of the Observatory staff, he has maintained and improved the Palomar telescopes (the 200-inch Hale Telescope, the 48-inch Oschin Schmidt, the 60 -inch reflector and the 18-inch Schmidt) and their auxiliary instruments to keep them at the peak of their operational potential and, in doing so, provides invaluable support of the progress of astronomical research. (M 18139)

Citation provided by Robert J. Brucato at the request of the discoverers.

\section{(4174) Pikulia}

1982 SB $_{6}$. Discovered 1982 Sept. 16 by L. I. Chernykh at Nauchnyj.

Named in memory of the famous Soviet writer Valentin Savvich Pikul' (1928-1990), author of many novels on Russian history. (M 18455)

\section{(4175) Billbaum}

1985 GX. Discovered 1985 Apr. 15 by E. Bowell at Anderson Mesa.

Named in honor of William A. Baum on the occasion of his retirement from the directorship of the Planetary Research Center at Lowell Observatory, a post he has held since 1965. Baum's astronomical research is extraordinarily diverse, covering many of the major fields of optical astronomy. He has contributed importantly to studies of atmospheric and surface phenomena on Mars, Saturn's rings, the properties of grains in cometary comae, metallicity gradients in elliptical galaxies, and testing the constancy of fundamental atomic constants over cosmological timescales. Additionally, he has been active in the development of instrumentation, including early pulsecounting equipment, the Carnegie image tube, image stabilization devices and astronomical optics in general. Baum directed the International Planetary Patrol Program, was a member of the imaging team in the Viking missions to Mars and is currently a member of the Hubble Space Telescope Wide Field/Planetary Camera team. He has served on many national panels and committees and, in 1976-1977, as president of the Division for Planetary Sciences of the American Astronomical Society. (M 18139)

Citation material provided by R. L. Millis at the request of the discoverer.

\section{(4176) Sudek}

1987 DS. Discovered 1987 Feb. 24 by A. Mrkos at Klě́.

Named in memory of Josef Sudek (1896-1976), outstanding Czech photographer, well-known for his black-and-white series of still lifes and views of Prague. (M 31295)

Name suggested by M. Tichý.

\section{(4177) Kohman}

1987 SS $_{1}$. Discovered 1987 Sept. 21 by E. Bowell at Anderson Mesa.

Truman Paul Kohman (1916- ) , emeritus professor of nuclear chemistry at Carnegie-Mellon University, is codiscoverer of ${ }^{26} \mathrm{Al}$, an isotope that has given important information about meteorites and the early history of the solar system. He is also an ardent amateur astronomer and teacher. (M 40700)

\section{(4179) Toutatis}

1989 AC. Discovered 1989 Jan. 4 by C. Pollas at Caussols.

Named after the Gaulish god, protector of the tribe. This totemic deity is well known because of the cartoon 
series Les aventures d'Asterix by Uderzo and Goscinny. This tells the stories of two almost fearless heroes living in the late village under siege in Roman-occupied Gaul in 50 B.C., and whose only fear is that the sky may fall onto their heads one day. Since this object is the Apollo object with the smallest inclination known, it is a good candidate to fall on our heads one of these days... But as the chief of the village says: "C'est pas demain la veille..." (M 16444)

Citation written by the discoverer and A. Maury and endorsed by J. D. Mulholland, who with Maury obtained the discovery plates.

\section{(4180) Anaxagoras}

6092 P-L. Discovered 1960 Sept. 24 by C. J. van Houten and I. van Houten-Groeneveld at Palomar.

Named after the Greek philosopher Anaxagoras (c. 500-428 B.C.). He lived in Asia minor and in Athens, where he became friend of Pericles. He taught that solar and lunar eclipses originated in a scientific way and not as an act of the gods. This was an asebie (outrage against the gods) and Anaxagoras had to flee; he died in exile. (M 22501)

Anaxagoras is also honored by a lunar crater.

\section{(4181) Kivi}

$1938 \mathrm{DK}_{1}$. Discovered 1938 Feb. 24 by Y. Väisälä at Turku.

Named in memory of Aleksis Kivi (1834-1872), the first Finnish-language dramatist and novelist. His principal work, Seitsemän veljestä ('Seven brothers'), completed in 1870 , was translated into many languages and also made into a movie. (M 18456)

\section{(4182) Mount Locke}

1951 JQ. Discovered 1951 May 2 at the McDonald Observatory at Fort Davis.

Named for the mountain on which the McDonald Observatory is situated. The Cook instrument was placed on Mount Locke to take all the plates for the McDonald Survey. (M 20159)

Name proposed by I. van Houten-Groeneveld, one of the people who worked on the Survey.

\section{(4183) Cuno}

1959 LM. Discovered 1959 June 5 by C. Hoffmeister at Bloemfontein.

Following the theme that several earth-approaching minor planets have four-letter masculine names, this object bears the first name of the discoverer. (M 18307)

The discoverer is also honored by minor planet (1726)

\section{(4184) Berdyayev}

$1969 \mathrm{TJ}_{1}$. Discovered 1969 Oct. 8 by L. I. Chernykh at Nauchnyj.

Named in honor of the famous Russian philosopher Nikolaj Aleksandrovich Berdyayev (1874-1948). (M 18456)
(4185) Phystech

1975 ED. Discovered 1975 Mar. 4 by T. M. Smirnova at Nauchnyj.

Named in honor of the Moscow Physical and Technical Institute, the key institute in Russia for training experts and investigators in the domains of modern physics, mathematics and engineering. (M 29143)

Name proposed by the Institute of Theoretical Astronomy on the occasion of the 50th anniversary of the Institute in 1996.

\section{(4186) Tamashima}

$1977 \mathrm{DT}_{1}$. Discovered 1977 Feb. 18 by H. Kosai and K. Hurukawa at Kiso.

Named in honor of the city where the first discoverer was born and grew up. It is located near the Okayama \{see planet (2084)\} Astrophysical Observatory. For many years before the Meiji period Tamashima was one of the most important ports on the Inland Sea. (M 17979)

\section{(4187) Shulnazaria}

1978 GR $_{3}$. Discovered 1978 Apr. 11 by N. S. Chernykh at Nauchnyj.

Named in honor of Leonid Markovich Shul'man and Galina Kirillovna Nazarchuk, husband-and-wife team of researchers on comets, staff members of the Main Ukrainian Astronomical Observatory at Golosseevo, near Kiev. (M 19695)

\section{(4188) Kitezh}

1979 HX $_{4}$. Discovered 1979 Apr. 25 by N. S. Chernykh at Nauchnyj.

Named for the Old Russian epic town of Kitezh. As legend tells, Kitezh was a beautiful and prosperous town located near Lake Svetloyar. When troops of the Tartar khan Batyj assaulted the town, the citizens fought bravely and all fell in battle. But the town was not seized by the invaders, for it disappeared under the lake waters. Since that time, if one listens attentively, it is possible to hear the sound of the town bells under the lake waters. (M 23351)

\section{(4189) Sayany}

1979 SV $_{9}$. Discovered 1979 Sept. 22 by N. S. Chernykh at Nauchnyj.

Named for the mountain chain in the southern part of Siberia \{see planet (1094)\}. (M 23351)

\section{(4190) Kvasnica}

1980 JH. Discovered 1980 May 11 by L. Brožek at Klě́.

Named in memory of Jozef Kvasnica (1930-1992), Czechoslovak theoretical physicist, professor at Charles University in Prague and head of the department of mathematical physics. Kvasnica studied nonlinear electrodynamics, quantum field theory, statistical physics and plasma theory. He was also known as 
the author of several textbooks, and many students remember his excellent lectures. (M 26929)

\section{(4191) Assesse}

1980 KH. Discovered 1980 May 22 by H. Debehogne at La Silla.

Named for the birthplace of the discoverer's father, a charming village in southern Belgium, site of the victory of the Austrians over the Etats Belgiques Unis in 1790. (M 19336)

\section{(4192) Breysacher}

1981 DH. Discovered 1981 Feb. 28 by H. Debehogne and G. DeSanctis at La Silla.

Named in honor of Jacques Breysacher, astronomer in charge of the Section for Visiting Astronomers at the European Southern Observatory. His scientific work is mainly concerned with stellar spectroscopy and the classification in external galaxies, and he has carried out an extensive study of the Wolf-Rayet populations of the Magellanic Clouds. (M 19336)

\section{(4193) Salanave}

$1981 \mathrm{SM}_{1}$. Discovered 1981 Sept. 26 by B. A. Skiff and N. G. Thomas at Anderson Mesa.

Originally a meteorologist, as first executive officer of the Astronomical Society of the Pacific and first editor of Mercury, Leon E. Salanave took steps to ensure that amateur astronomers felt a sense of "belonging" to an organization dominated by professionals. (M 40700)

The name was suggested by W. J. Westbrooke.

\section{(4194) Sweitzer}

1982 RE. Discovered 1982 Sept. 15 by E. Bowell at Anderson Mesa.

Named in honor of Paul A. Sweitzer (1936- ) on the occasion of his 60th birthday. Sweitzer served as a reporter on the Arizona Daily Sun during 1958-1994, covering news, sports, the performing arts, religion, education, law enforcement and the courts. During that time he made a special effort to report on events and astronomical discoveries at the Lowell Observatory, and in the course of his work he developed warm relationships with many of Lowell's staff. His love of music, especially opera, has led him to become an unfailing supporter, through reviews and informative articles, of the Flagstaff Symphony Orchestra. (M 28089)

Name suggested by A.-M. Malotki, endorsed by W. L. Putnam.

\section{(4195) Esambaev}

$1982 \mathrm{SK}_{8}$. Discovered 1982 Sept. 19 by L. I. Chernykh at Nauchnyj.

Named in honor of Makhmud Alisultanovich Esambaev (1924- ), well-known Soviet ballet dancer, an outstanding performer of the national dances of the peoples of the world. (M 26762)

\section{(4196) Shuya}

1982 SA $_{13}$. Discovered 1982 Sept. 16 by L. I. Chernykh at Nauchnyj.

Named for the discoverer's birthplace, a town in Central Russia. The discoverer dedicates this name to her parents, Ekaterina Il'inichna Trushechkina (19071950) and Ivan Mokeevich Trushechkin (1907- ). (M 18456)

\section{(4198) Panthera}

1983 CK $_{1}$. Discovered 1983 Feb. 11 by N. G. Thomas at Anderson Mesa.

Name derived from the Latin for 'panther', referring to a large, intimidating cat. Also, Panthere tigris tigris, the Bengal tiger. Many of the large cats are on the endangered species list. (M 25443)

Name suggested in a communication from the World Wildlife Fund.

\section{(4199) Andreev}

$1983 \mathrm{RX}_{2}$. Discovered 1983 Sept. 1 by H. Debehogne at La Silla.

Named in memory of Gennadij Andreev and his family. A professor of celestial mechanics at the University of Tomsk, Andreev is one of the leaders of the expeditions that regularly go to unravel the mysteries of the Tunguska event of 1908. (M 21609)

\section{(4200) Shizukagozen}

1983 WA. Discovered 1983 Nov. 28 by Y. Banno and T. Urata at Karasuyama.

Named for a dancing girl, the mistress of Minamoto Yoshitsune. The orbit of this asteroid is very similar to that of (3178) Yoshitsune. (M 19695)

\section{(4201) Orosz}

$1984 \mathrm{JA}_{1}$. Discovered 1984 May 3 by B. A. Skiff at Anderson Mesa.

Named in honor of Elizabeth M. Orosz (1970- ), staff member at Melton Memorial Observatory at the University of South Carolina and friend of the discoverer. (M 27126)

\section{(4203) Brucato}

$1985 \mathrm{FD}_{3}$. Discovered 1985 Mar. 26 by C. S. Shoemaker and E. M. Shoemaker at Palomar.

Named for Robert J. Brucato, assistant director of the Palomar Observatory. Working with more than a dozen government agencies of the surrounding communities, he has vigorously and effectively led the effort to preserve the dark sky of Palomar. This effort has been crucial for the preservation of Palomar as a front-line astronomical observatory and has been especially important for projects such as the photographic searches for comets and minor planets. Brucato is also in charge of the new ten-year long survey of the northern sky, using the Oschin Schmidt telescope, and has directed the complete refurbishment of this telescope. He has been a strong advocate of all branches of astronomy carried out at Palomar 
and has helped to maintain it as one of the premier astronomical observatories in the world. (M 18456)

Citation provided by Gerry Neugebauer at the request of the discoverers.

\section{(4204) Barsig}

$1985 \mathrm{JG}_{1}$. Discovered 1985 May 11 by C. S. Shoemaker and E. M. Shoemaker at Palomar.

Named in honor of Walter Barsig, a teacher of science and director of a major Bavarian state school board; also a director of the Annual Cultural Festival of the Ries \{see planet (4327)\} of Nördlingen, Germany, the location of one of the best known impact craters on Earth. Barsig has successfully promoted popular knowledge about the local impact craters, Ries and Steinheim \{see planet (6563)\}, and the public recognition of their scientific significance. He has been remarkable in his efforts to make the local population of the Ries area aware of the intimate relationship between the geological, cultural, and economic evolution of a natural landmark, which was created by an asteroid impact 15 million years ago. (M 18139)

Citation provided by Dieter Stöffler at the request of the discoverers.

\section{(4205) David Hughes}

1985 YP. Discovered 1985 Dec. 18 by E. Bowell at Anderson Mesa.

Named in honor of David W. Hughes, reader in physics at Sheffield University, where he teaches courses on all aspects of astronomy. His research area concerns small solar-system bodies, particularly the relationship between comets and meteors. He has served astronomy in Britain as a vice president of both the Royal Astronomical Society and the British Astronomical Association. Hughes is a prolific reviewer of astronomy books and writes regularly on current issues in astronomy for Nature. (M 17223)

Name suggested and citation material provided by S. A. Mitton.

\section{(4207) Chernova}

$1986 \mathrm{RO}_{2}$. Discovered 1986 Sept. 5 by E. Bowell at Anderson Mesa.

Named in honor of Galina Pavlovna Chernova, a senior researcher at the Astrophysical Institute of the Tadjik Academy of Sciences, Dushanbe. An indefatigable observer of stars, comets and minor planets, Chernova has codiscovered a number of light-scattering effects in cometary atmospheres. She undertook an extensive program of photometric, polarimetric and astrometric observations of Comet Halley and is an active member of the Comets and Asteroids Working Groups of the U.S.S.R. Academy of Sciences. (M 16044)

Citation prepared by D. F. Lupishko at the request of the discoverer.

\section{(4208) Kiselev}

$1986 \mathrm{RQ}_{2}$. Discovered 1986 Sept. 6 by E. Bowell at Anderson Mesa.
Named in honor of Nikolaj Nikolaevich Kiselev, department head at the Astrophysical Institute of the Tadjik Academy of Sciences, Dushanbe. A preeminent observer of stars, comets and minor planets, Kiselev has carried out work that resulted in the discovery of a number of light-scattering effects in cometary atmospheres. He was leader of the Soviet program of polarimetric and photometric observations of Comet Halley and is one of the initiators of modern investigations of minor planets in the Soviet Union. Under his leadership the Sanglok Observatory, darksky site of the Astrophysical Institute, was built. (M 16044)

Citation prepared by D. F. Lupishko at the request of the discoverer.

\section{(4209) Briggs}

$1986 \mathrm{TG}_{4}$. Discovered 1986 Oct. 4 by E. F. Helin at Palomar.

Named in honor of Geoffrey A. Briggs, space physicist, former Director of the Solar System Exploration program at NASA headquarters, where he played a leading role in establishing the U.S.-Soviet Joint Working Group for Solar System Exploration and served as co-chairman. In the 1970s he was at JPL as an active member of the Viking Orbiter Imaging Team. Currently with the Air and Space Museum, Briggs continues to energize the presentation of Space related accomplishments to the public. The discoverer wishes to acknowledge his longterm support and enthusiasm for solar system research. (M 18456)

The naming is heartily endorsed by Jürgen Rahe and the scientific community who have known him as a serious, hardworking scientist trying to accomplish the most with limited resources.

\section{(4213) Njord}

$1987 \mathrm{ST}_{4}$. Discovered 1987 Sept. 25 by P. Jensen and K. Augustesen at Brorfelde.

Named after the god of winds, navigation and prosperity in Norse mythology. He belongs to the race of gods called the Vanir, who are often in conflict with the Aesir, and he was originally brought to Asgaard as a hostage. He is the father of Frej and Freja \{see planet (76)\}. (M 22501)

\section{(4214) Veralynn}

1987 UX $_{4}$. Discovered 1987 Oct. 22 by L. V. Zhuravleva at Nauchnyj.

Named in honor of Vera Lynn (1917- ) \{real name: Vera Margaret Welch\}, famous English singer. (M 24122)

\section{(4215) Kamo}

$1987 \mathrm{VE}_{1}$. Discovered 1987 Nov. 14 by S. Ueda and H. Kaneda at Kushiro.

Named in honor of Akira Kamo (1943- ), who established the Comet Observers Network in Japan, "Hoshi no Hiroba" \{see planet (4971)\} in 1968. He played a leading role for many observers and discoverers 
of comets for more than 20 years when he was the first president of the network. His words "let's come together at Hoshi no Hiroba" are well known among amateur and professional astronomers in Japan. (M 22501)

Name proposed by K. Watanabe. Citation prepared by T. Nomura.

\section{(4216) Neunkirchen}

$1988 \mathrm{AF}_{5}$. Discovered 1988 Jan. 14 by H. Debehogne at La Silla.

Named to honor the birthplace of Hermann Haupt \{see planet (2870)\} and Gerhard Hahn ssee planet (3676)\}, two Austrian astronomers and colleagues of the discoverer, active in minor planet research during the past decades. Neunkirchen, situated $60 \mathrm{~km}$ south of Vienna, is a district capital and a major center for education and commerce. (M 16248)

\section{(4217) Engelhardt}

$1988 \mathrm{BO}_{2}$. Discovered 1988 Jan. 24 by C. S. Shoemaker and E. M. Shoemaker at Palomar.

Named in honor of Wolf von Engelhardt, professor of mineralogy, and director of the Institute of Mineralogy and Petrography, University of Tübingen, Germany, from 1957 to 1977. In Europe, von Engelhardt was a pioneer in research on impact craters and shock metamorphism of minerals and rocks. In 1962 he initiated and successfully conducted one of the most comprehensive research programs devoted to the study of the Ries \{see planet (4327)\} crater, Germany. Since the first return of lunar samples in 1969, he was and continues to be a Principal Investigator in NASA's lunar sample analysis program. (M 18456)

Citation provided by Dieter Stöffler at the request of the discoverers.

\section{(4218) Demottoni}

$1988 \mathrm{BK}_{3}$. Discovered 1988 Jan. 16 by H. Debehogne at La Silla.

Named in memory of Glauco de Mottoni y Palacios (1901-1988), Italian astronomer, engineer and collaborator at the Milan and Paris Observatories. A specialist in the visual observation of the planet Mars, he distinguished himself with a large cartographic work on the aspect of the Martian surface between 1907 and 1971. He designed telescopes, often in an unconventional manner. A keen popularizer of astronomy, he founded the "Urania" association in Genoa in 1951 and directed it until his death. (M 16444)

\section{(4219) Nakamura}

1988 DB. Discovered 1988 Feb. 19 by M. Inoue and O. Muramatsu at Kobuchizawa.

Named in honor of Giichi Nakamura, the owner of Mitaka Koki, the leading maker of optical equipment in Japan. Mitaka Koki develops and produces observational and measuring equipment used at the National Astronomical Observatory and the Institute of Space and Astronomical Science. The company also puts an emphasis on producing equipment for Japanese amateur astronomers. (M 17223)

Name proposed by M. Inoue, who discovered this minor planet on films taken with a Mitaka Koki telescope. Citation prepared by O. Muramatsu and H. Kosai.

\section{(4220) Flood}

1988 DN. Discovered 1988 Feb. 22 by R. H. McNaught at Siding Spring.

Named in memory of Thomas Flood (1919-1988), one of Scotland's bestknown and respected amateur astronomers. Despite little more than a basic education, poverty during the Depression and frequent ill-health, he was a well-read and cultured man of great integrity. He joined the British Astronomical Association in 1954 and was for a time involved in the Lunar Section. A founder member of the Dundee Astronomical Society in 1955, he served in every position of responsibility, including secretary, treasurer and chairman, with distinction. After enforced early retiral from clerking work due to ill health he was assistant curator of the Mills Observatory in Dundee from 1974 to 1982, then wrote a history of the observatory. (M 16044)

Citation prepared by D. Gavine at the request of the discoverer.

\section{(4221) Picasso}

1988 EJ. Discovered 1988 Mar. 13 by J. Alu at Palomar.

Named for Pablo Picasso (1881-1973), the most prolific artist of all time. His career spanned the entire course of modern art. Picasso's creativity in painting, drawing, sculpture, graphics and ceramic is filled with inventive powers, uncontrolled impulses, limitless ambition and a continuous drive for never ending discovery. (M 16044)

Name endorsed by Eleanor F. Helin.

\section{(4222) Nancita}

1988 EK $_{1}$. Discovered 1988 Mar. 13 by E. F. Helin at Palomar.

Named in honor of Nancy Coker Helin, wife of Bruce Helin \{see planet (2430)\}, the discoverer's son. A talented singer, composer and teacher, Nancita has brought music and joy to the Helin family. (M 17466)

\section{(4223) Shikoku}

1988 JM. Discovered 1988 May 7 by T. Seki at Geisei.

Named for Japan's fourth largest island, the one on which the Geisei see planet (2571)\} Station is located. "Shikoku" means "the island that has four local counties". Three long bridges straddle the Seto Inland Sea and connect Shikoku to Honshu, the largest island. (M 16593)

\section{(4224) Susa}

1988 KG. Discovered 1988 May 19 by E. F. Helin at Palomar. 
Named in honor of Susan and Sarah Hicks, daughters of Bill and Nancy Hicks \{see also planet 2220)\}. They have shared in their parent's interest and generosity regarding space-related research over the years, particularly the pursuit of the small bodies in the solar system - minor planets and comets. (M 17466)

\section{(4226) Damiaan}

1989 RE. Discovered 1989 Sept. 1 by E. W. Elst at St. Michel.

Named for the Flemish priest Jozef De Veuster (1840-1889) on the occasion of the 100th anniversary of his death. At the age of 19 he entered the Congregation of the Fathers of the Sacred Hearts (Picpus Fathers) and chose for himself the new name of Damiaan. In 1863 Pater Damiaan (Father Damiaan) was sent as a missionary to Hawaii, where he was ordained a priest one year later. After eight years on Kohala he asked to be transferred to the leper colony at Kalawao on the island of Molokai. There he devoted all his energy to the improvement of the conditions at the settlement until he finally contracted leprosy himself. (M 15576)

Name endorsed by E. Goffin, who found the identifications involving this planet, and endorsed by the discoverer.

\section{(4227) Kaali}

1942 DC. Discovered 1942 Feb. 17 by L. Oterma at Turku.

Named for the place on the island of Saaremaa s see planet (4163)\} where a meteorite impacted 2500 years ago. In the smaller craters one can still use magnets to collect iron fragments. (M 18457)

\section{(4228) Nemiro}

1968 OC $_{1}$. Discovered 1968 July 25 by G. A. Plyugin and $\mathrm{Yu}$. A. Belyaev at Cerro El Roble.

Andrej Antonovich Nemiro (1909-1995) worked at the Pulkovo Observatory for more than 50 years and was one of the distinguished successors to the scientific traditions of the Pulkovo Astrometry School. (M 38194)

The name was suggested by the Pulkovo Observatory.

\section{(4229) Plevitskaya}

1971 BK. Discovered 1971 Jan. 22 by L. I. Chernykh at Nauchnyj.

Named in memory of Nadezhda Vasil'evna Plevitskaya (1884-1940), a splendid Russian singer who sparkled on the stages of Russia, Europe and America. Many great connoisseurs of Russian art called her "Russian skylark" and "nightingale". Leonid Sobinov \{see planet (4449)\} sang with her, and Sergej Rakhmaninov \{see planet (4345)\} accompanied for her. (M 26762)

\section{(4230) van den Bergh}

$1973 \mathrm{ST}_{1}$. Discovered 1973 Sept. 19 by C. J. van Houten and I. van Houten-Groeneveld at Palomar.

Named in honor of Sidney van den Bergh (1929- ) Dutch-born Canadian astronomer, former director of the Dominion Astrophysical Observatory in Victoria, B.C. He was president of IAU commission 50 from 1985 to 1988 and a vice president of the IAU during 1976-1982. (M 18307)

\section{(4231) Fireman}

1976 WD. Discovered 1976 Nov. 20 at the Harvard College Observatory at Harvard.

Named in memory of Edward Leonhard Fireman (1922-1990), on the staff of the Brookhaven National Laboratory during 1950-1956 and subsequently a physicist at the Harvard-Smithsonian Center for Astrophysics. Best known for his pioneering measurements of radioactive isotopes to determine the cosmic-ray exposure ages of freshly fallen meteorites, Fireman applied the technique to lunar samples and debris from artificial satellites as well. He also developed a method for measuring the relationship of age and depth in cores of ice bored into Antarctica and Greenland and examined the implications for the earth's climatic record over the last 200,000 years. Long interested in the experimental search for neutrinos, he was in recent years particularly involved in measuring the argon 37 produced in the chlorine and potassium detectors to a depth of $1.5 \mathrm{~km}$ in the Homestake Mine, South Dakota. (M 18457)

Obituaries published in Bull. Am. Astron. Soc., Vol. 24, No. 4, p. 1322-1323 (1992); Meteorictics, Vol. 26, No. 2, p. 171 (1991)

\section{(4232) Aparicio}

1977 CD. Discovered 1977 Feb. 13 at the Felix Aguilar Observatory at El Leoncito.

Named in memory of Emiliano Pedro Aparicio (1921-1988), mineralogist and geologist at the National University of Cuyo and the National University of San Juan, also rector of the latter university. (M 31023)

\section{(4233) Pal'chikov}

$1977 \mathrm{RO}_{7}$. Discovered 1977 Sept. 11 by N. S. Chernykh at Nauchnyj.

Named in memory of Nikolaj Borisovich Pal'chikov (1913-1937), a student in the astronomy department at Leningrad University. He wanted to specialize in celestial mechanics and was invited by M. Subbotin \{see planet (1692)\} to pursue post-graduate studies. Along with other Leningrad astronomers, Nikolaj was killed during one of Stalin's purges. (M 23351)

\section{(4234) Evtushenko}

$1978 \mathrm{JT}_{1}$. Discovered 1978 May 6 by N. S. Chernykh at Nauchnyj.

Named in honor of Evgenij Aleksandrovich Evtushenko (1933- ), well known Russian poet. (M 23351)

\section{(4235) Tatishchev}

1978 SL $_{5}$. Discovered 1978 Sept. 27 by L. I. Chernykh at Nauchnyj.

Named in memory of Vasilij Nikitick Tatishchev (1686-1750), an outstanding Russian scientist and statesman, fellow companion of Peter I ssee planet 
(2720)\}. The first Russian historiographer, he is known also for his works in geography, cartography, philosophy and economics. (M 18457)

\section{(4236) Lidov}

$1979 \mathrm{FV}_{1}$. Discovered 1979 Mar. 23 by N. S. Chernykh at Nauchnyj.

Named in honor of Mikhail L'vovich Lidov \{1926$1993\}$, celestial mechanician at the Keldysh Institute of Applied Mathematics of the Russian Academy of Sciences, known for his works in astrodynamics and astronautics. (M 22501)

Obituaries published in Astron. Lett., Vol. 20, No. 3 , p. 337-338 (1994); Cosmic Res., Vol. 32, No. 2 (1994).

\section{(4237) Raushenbakh}

1979 SD 4 . Discovered 1979 Sept. 24 by N. S. Chernykh at Nauchnyj.

Named in honor of Boris Viktorovich Raushenbakh (1915-2001), member of the Russian Academy of Sciences and the International Academy of Astronautics, and a professor at Moscow Physical and Technical Institute from 1947. He has made valuable contributions in the field of mechanics and in the theory and practice of rocket-building and space exploration. (M 27126)

\section{(4238) Audrey}

1980 GF. Discovered 1980 Apr. 13 by A. Mrkos at Klě́t.

Brought up in wartime Holland, Audrey Hepburn (1929-1993) became a highly acclaimed film actress. After her 1951 debut on Broadway in Gigi, her film successes included Roman Holiday, Funny Face, Breakfast at Tiffany's, Charade, My Fair Lady and Wait Until Dark. She later worked to improve the lot of children in Africa. (M 36944)

\section{(4239) Goodman}

1980 OE. Discovered 1980 July 17 by E. Bowell at Anderson Mesa.

Named in honor of Neville J. Goodman, a member of the British Astronomical Association since 1944. Professionally, he was commissioning editor for the British scientific publisher Adam Hilger for many years. Goodman's service to astronomy dates from 1952, when he became editor of the B.A.A. Journal, a post he filled with distinction for eight years. From 1962 to 1972 he devoted himself tirelessly to the position of business secretary of the Association. President from 1972 to 1974 , he again served as secretary from 1976 to 1984. Goodman has contributed many ephemerides to the B.A.A. Handbook and currently serves as Handbook editor. (M 17223)

Name suggested independently by the discoverer and B. G. Marsden. Citation material provided by S. A. Mitton.

\section{(4240) Grün}

$1981 \mathrm{EY}_{20}$. Discovered 1981 Mar. 2 by S. J. Bus at Siding Spring.
Named in honor of Eberhard Grün (1942- ), a physicist at the Max-Planck-Institut für Kernphysik, Heidelberg. Starting with the Helios missions, Grün has been responsible for dust collectors on a number of interplanetary spacecraft, including Giotto, Ulysses, Galileo and Cassini. He has also interpreted the data collected and determined the dynamical properties of dust particles. In addition to his research activities, Grün is a professor at the University of Heidelberg, where he passes on to students his knowledge and long experience in space missions. (M 27458)

Citation provided by $\mathrm{H}$. Scholl following a suggestion by E. Bowell.

\section{(4241) Pappalardo}

$1981 \mathrm{EX}_{46}$. Discovered 1981 Mar. 2 by S. J. Bus at Siding Spring.

A. Neil Pappalardo is a pioneer in medical information technology. Together with his wife Jane, he has been an energetic supporter of the Magellan Telescope Project in Chile and of promoting excellence in engineering, physics and astronomy at the Massachusetts Institute of Technology. (M 40700)

\section{(4242) Brecher}

1981 FQ. Discovered 1981 Mar. 28 at the Harvard College Observatory at Harvard.

Named in honor of Aviva and Kenneth Brecher, each of whose research interests cover an enormous range. Both on the staff of the Massachusetts Institute of Technology in the 1970s, Kenneth has since then been a professor of physics at Boston University, working in theoretical high- energy astrophysics, X-ray and gamma-ray astronomy, observational tests and consequences of gravitational theories and cosmology, as well as in archaeoastronomy and the history of astronomy, these last with the particular view of attempting to use ancient records to establish results of astrophysical interest. Aviva's astronomical interests have been more in the area of planetary evolution, with particular attention to the effects of magnetic fields and electric conductivity in meteorites and lunar samples. Subsequently she moved to the Arthur D. Little company, where her activities included the safety of nuclear and geotechnical systems and of the environment generally, and since 1985 she has joined her husband at Boston University as director of Academic and Corporate Relations. (M 18457)

\section{(4243) Nankivell}

$1981 \mathrm{GF}_{1}$. Discovered 1981 Apr. 4 by A. C. Gilmore and P. M. Kilmartin at Lake Tekapo.

Garry R. Nankivell (1929- ) is New Zealand's pre-eminent optical craftsman. Among his many productions are the optics for Mt. John Observatory's 1-m $f / 8-f / 13$ McLellan Telescope. He has collaborated with Norman Rumsey \{see planet (4154)\} on many innovative optical designs. (M 40701) 


\section{(4244) Zakharchenko}

1981 TO$_{3}$. Discovered 1981 Oct. 7 by L. I. Chernykh at Nauchnyj.

Named in honor of Vasilij Dmitrievich Zakharchenko (1915- ), remarkable Russian journalist and writer, as well as a great romantic. An expert in engineering, he is particularly known as the editor of the popular magazine Tekhnika molodezhi ("Engineering for Youth") for 40 years. He also edits a new magazine about adventures, travels, scientific hypotheses and science fiction called Chudesa i priklyucheniya ("Miracles and Adventures") and is the producer of telecasts about the achievements of amateur designers and inventors. (M 26762)

\section{(4246) Telemann}

$1982 \mathrm{SY}_{2}$. Discovered 1982 Sept. 24 by F. Börngen at Tautenburg.

Named in memory of Georg Philipp Telemann (16811767), whose authority as a musician and composer of numerous and varied compositions was in his time comparable with the glory of Händel \{see planet (3826)\} and surpassed the authority of Johann Sebastian Bach \{see planet (1814)\}. (M 16045)

\section{(4247) Grahamsmith}

1983 WC. Discovered 1983 Nov. 28 by E. Bowell at Anderson Mesa.

Named in honor of Sir Francis Graham-Smith, the thirteenth Astronomer Royal, and physics secretary of the Royal Society, London, on the occasion of his retirement. Sir Francis has been professor of Radio Astronomy at Manchester since 1964 and director of the Radio Astronomy Laboratories since 1981. In addition, he was director of the Royal Greenwich Observatory between 1975 and 1981 and served both as secretary of the Royal Astronomical Society from 1964 to 1971 and president from 1975 to 1977. (M 17030)

Name suggested and citation material provided by S. A. Mitton.

\section{(4248) Ranald}

1984 HX. Discovered 1984 Apr. 23 by A. C. Gilmore and P. M. Kilmartin at Lake Tekapo.

The orbit programs constructed by Ranald McIntosh (1933- ) enabled the discoverers to follow many of the new minor planets they found in the 1980s. He maintains the database for the Variable Star Section of the Royal Astronomical Society of New Zealand. (M 40701)

\section{(4249) Křemže}

$1984 \mathrm{SC}_{2}$. Discovered 1984 Sept. 29 by A. Mrkos at Kleť.

Named for a small town in southern Bohemia north of Klet Mountain. It was first mentioned as a village with the church of St. Michael Archangel in 1263, and as a town from the year 1365, but the site was first settled in ancient times. (M 29669)

Name proposed by J. Tichá, M. Tichý and Z. Moravec.
(4250) Perun

1984 UG. Discovered 1984 Oct. 20 by Z. Vávrová at Klět.

Named in honor of the Slavic god of thunder. (M 16444)

\section{(4251) Kavasch}

$1985 \mathrm{JK}_{1}$. Discovered 1985 May 11 by C. S. Shoemaker and E. M. Shoemaker at Palomar.

Named in honor of Julius Kavasch (1920-1978) and his son Wulf-Dietrich Kavasch, both amateur geologists and popular science writers about the Ries \{see planet (4327)\} impact crater, Germany. Julius Kavasch, principal of the elementary school of Mönchsdeggingen, Ries, spent all his life popularizing the geology of the Ries crater to the benefit of students and the local public. He played an outstanding role in providing local support for the national and international professional research on the Ries impact crater. His son, a veterinarian at Hohenaltheim, Ries, has taken over and enlarged upon his father's activities. As a director of the Annual Cultural Festival of the Ries, he initiated the foundation of the "RieskraterMuseum", which is not only devoted to the Ries crater but is one of the best examples of a museum that comprehensively presents impact cratering phenomena in the solar system. (M 18140)

Citation provided by Dieter Stöffler at the request of the discoverers.

\section{(4253) Märker}

1985 TN $_{3}$. Discovered 1985 Oct. 11 by C. S. Shoemaker and E. M. Shoemaker at Palomar.

Named after Wolfgang Märker, owner and director of the Märker cement factory at Harburg, located on the edge of the Ries \{see planet (4327)\} impact crater, Germany. Märker and his forebears have maintained a long tradition of support for geological research in one of the world's best studied impact craters. Märker's responsible interest in the Ries geology and his involvement in the production of special cement from local impact breccias has kept quarries in operation that have yielded invaluable information about the Ries crater. This has been of fundamental importance for research opportunities in the field of impact cratering. (M 18140)

Citation provided by Dieter Stöffler at the request of the discoverers.

\section{(4254) Kamél}

$1985 \mathrm{UT}_{3}$. Discovered 1985 Oct. 24 by C.-I. Lagerkvist at Kvistaberg.

Named in honor of Lars Kamél, planetary astronomer and meticulous compiler and analyzer of cometary brightness data, on the occasion of the defense of his doctoral dissertation on May 24, 1991. Kamél's analyses have been mainly directed toward interpretation of the nongravitational effects in cometary motions and 
elucidation of physical evolutionary effects in comets. (M 18307)

Citation prepared by H. Rickman.

\section{(4255) Spacewatch}

1986 GW. Discovered 1986 Apr. 4 by the Spacewatch at Kitt Peak.

Named for the Spacewatch program and its many supporters. The program uses a 2048 x 2048 CCD in the scanning mode on the Spacewatch Telescope, which is the 0.91-m Newtonian reflector of the Steward Observatory of the University of Arizona on Kitt Peak, to discover and provide astrometric observations for minor planets and comets. (M 16045)

\section{(4256) Kagamigawa}

1986 TX. Discovered 1986 Oct. 3 by T. Seki at Geisei.

Named for the river that flows through Kochi \{see planet (2396)\}, home town of the discoverer. (M 19336)

\section{(4257) Ubasti}

1987 QA. Discovered 1987 Aug. 23 by J. Mueller at Palomar.

Ubasti, also called Bastet or Bast, was an ancient Egyptian goddess worshipped in the form of a cat. Originally a goddess of the home, in the New Kingdom Ubasti was equated with the lioness war goddess. This name is being dedicated to observatory cats throughout the world. (M 19336)

Name suggested and citation prepared by G. V. Williams at the request of the discoverer.

This name is particularly dedicated to the discoverer's beloved companion for the past ten years, Pepper Cat (1974-1991).

\section{(4258) Ryazanov}

$1987 \mathrm{RZ}_{2}$. Discovered 1987 Sept. 1 by L. G. Karachkina at Nauchnyj.

Named in honor of Ehldar Aleksandrovich Ryazanov, a well-known Soviet movie producer, writer and poet. (M 17030)

\section{(4259) McCoy}

1988 SB $_{3}$. Discovered 1988 Sept. 16 by S. J. Bus at Cerro Tololo.

Timothy J. McCoy (1964- ) is a curator of the national meteorite collection at the National Museum of Natural History in Washington. His research has been crucial for understanding the complex heating and melting events on the parent body of the acapulcoite and lodranite meteorites. (M 40701)

\section{(4260) Yanai}

1989 AX. Discovered 1989 Jan. 4 by S. Ueda and H. Kaneda at Kushiro.

Named in honor of Masayuki Yanai (1959- ), who has since 1987 been an active observer and discoverer of minor planets. He lives in Kitami \{see planet (3785)\} and works for the Nippon Telephone and Telegram Company. (M 16593)

\section{(4261) Gekko}

1989 BJ. Discovered 1989 Jan. 28 by Y. Oshima at Gekko.

Named for the observatory at which this minor planet was discovered. The name means "moonlight". Founded in 1957, the observatory belongs to the International Foundation for Cultural Harmony and is active in the education and popularization of astronomy. (M 18307)

\section{(4263) Abashiri}

$1989 \mathrm{RL}_{2}$. Discovered 1989 Sept. 7 by M. Yanai and K. Watanabe at Kitami.

Named for a small city of population 43,000 in the eastern part of Hokkaido \{see planet (3720)\}. Located at the Sea of Okhotsk, it has prospered for many years on account of its fishing industry, and it serves as a center for transportation, culture and commerce. (M 19336)

\section{(4264) Karljosephine}

1989 TB. Discovered 1989 Oct. 2 by K. F. J. Cwach at Siding Spring.

Named by the discoverer in honor of his parents, Karl Wilhelm Cwach and Josephine Anna-Maria Cwach for their encouragement of his interest in science and amateur astronomy. (M 17979)

\section{(4265) Kani}

1989 TX. Discovered 1989 Oct. 8 by Y. Mizuno and T. Furuta at Kani.

Named for the quiet, rural town where the first discoverer lives. It is situated about $30 \mathrm{~km}$ north of Nagoya, the third largest city in Japan. Kani is located on the banks of the beautiful river Kiso, which is said to resemble the Rhine in Germany. (M 16045)

\section{(4266) Waltari}

1940 YE. Discovered 1940 Dec. 28 by Y. Väisälä at Turku.

Named in memory of Mika Waltari (1908-1979), Finnish writer, from 1957 a member of the Academy of Finland. He was best known internationally for his extensive historical novel Sinuhe, egyptiläinen ('Sinuhe, Egyptian'), which was translated into several languages and also filmed \{see also planet (4512)\}. (M 18457)

\section{(4267) Basner}

1971 QP. Discovered 1971 Aug. 18 by T. M. Smirnova at Nauchnyj.

Named in memory of Veniamin Efimovich Basner (1925-1996), outstanding Russian composer, author of operas, ballets, operettas, excellent songs, symphonic and chamber compositions and music for many movies. (M 29143)

Name proposed by the Russian St. Petersburg Composers' Union. 
(4268) Grebenikov

1972 TW $_{3}$. Discovered 1972 Oct. 5 by T. M. Smirnova at Nauchnyj.

Named in honor of Evgenij Alexandrovich Grebenikov, head of the department in the Institute of Problems of Cybernetics in Moscow, well-known expert on analytical and celestial mechanics and on the qualitative theory of differential equations. In co-authorship with E. P. Aksenov and V. G. Demin \{see planets (4777) and (5086), respectively\}, he has investigated the problem of two fixed centers and found its general solution. He has proved a number of theorems substantiating the averaging method by Delaunay-Hill. In a series of studies he and his numerous pupils applied these results to the construction of precise theories of the motions of artificial earth satellites, natural satellites and minor planets. (M 19695)

Name proposed by the Institute of Theoretical Astronomy, St. Petersburg.

\section{(4270) Juanvictoria}

1975 TJ $_{6}$. Discovered 1975 Oct. 1 at the Felix Aguilar Observatory at El Leoncito.

Named in memory of Juan Victoria (1906-1986), legal representative of the Yale-Columbia Southern Station when it was under construction in the early 1960s; he also supervised the construction of the dome and facilities for the U.S. Naval Observatory's station nearby. A mining engineer by training, Victoria was known for his teaching and research in the engineering department of the Cuyo ssee planet (1917)\} National University, and he also advised the government on the development and establishment of the Minerals Laboratory and the Mining Research Institute. One of Victoria's greatest accomplishments was the construction of the San Juan ssee planet (2284)\} Auditorium, considered to be one of best such buildings in Latin America. (M 31295)

\section{(4271) Novosibirsk}

1976 GQ6. Discovered 1976 Apr. 3 by N. S. Chernykh at Nauchnyj.

Named for the great Siberian industrial, cultural and scientific center, on the occasion of its 100th anniversary in 1993. (M 22501)

\section{(4272) Entsuji}

1977 EG $_{5}$. Discovered 1977 Mar. 12 by H. Kosai and K. Hurukawa at Kiso.

Named for a temple near where the first discoverer lived in his youth. The famous priest Ryokan (17581831) \{see planet (6031)\} was trained in this temple. (M 17979)

\section{(4273) Dunhuang}

1978 UU $_{1}$. Discovered 1978 Oct. 29 at the Purple Mountain Observatory at Nanking.

Dunhuang city, located in the northwest of China, was of strategic importance on the ancient Silk Road and as a metropolis for the exchange of culture between east and west in the Han and Tang dynasties. The Mogoa Grotto in Dunhuang is one of the largest well-preserved treasure houses of the world's Buddhist art. (M 43189)

\section{(4274) Karamanov}

1980 RZ $_{3}$. Discovered 1980 Sept. 6 by N. S. Chernykh at Nauchnyj.

Named in honor of Alemdar Sobitovich Karamanov, composer, who lives and works in the Crimea, known for his symphonies, ballets, music for performances and cinema films, piano concerti and other musical works, many of which are dedicated to the Crimea and its history. (M 22501)

\section{(4275) Bogustafson}

$1981 \mathrm{EW}_{14}$. Discovered 1981 Mar. 1 by S. J. Bus at Siding Spring.

Named in honor of Bo A. S. Gustafson (1953- ) of the University of Florida, Gainesville. Gustafson has specialized in studying the formation, evolution and fate of small particles in the solar system. Along with J. M. Greenberg, his name is associated with the "bird's nest" model of cometary grains as very porous aggregates. His work concerns both dynamics and physics, including optical properties in particular. Since 1994 he has led the Laboratory for Astrophysics in Gainesville, pursuing microwave simulation of light scattering. (M 27458)

Citation provided by H. Rickman following a suggestion by E. Bowell.

\section{(4276) Clifford}

1981 XA. Discovered 1981 Dec. 2 by E. Bowell at Anderson Mesa.

Named in honor of Clifford J. Cunningham \{1955-

\}, Canadian amateur astronomer and writer, whose interest in minor planets has encompassed positional measurements and photometry. Cunningham's book Introduction to Asteroids, published in 1988, has justifiably earned praise from both readers and reviewers. He has recently been working on a bibliographic database on minor planets that currently comprises more than 10,000 references dating back to the year 1789. (M 16248)

\section{(4277) Holubov}

1982 AF. Discovered 1982 Jan. 15 by A. Mrkos at Klět.

Named for a picturesque village in southern Bohemia northeast of Kleť Mountain. Near Holubov there are ruins of a Gothic castle, Dívčí Kámen, founded in 1349 by Rožmberks on the site of a Bronze Age settlement. (M 29669)

Name proposed by J. Tichá, M. Tichý and Z. Moravec, endorsed by M. J. Plavec. 
(4278) Harvey

1982 SF. Discovered 1982 Sept. 22 by E. Bowell at Anderson Mesa.

Named in honor of G. Roger Harvey, instructor in astronomy at the University of North Carolina in Charlotte. Using handcrafted Newtonian reflectors of up to $74-\mathrm{cm}$ aperture, Harvey has visually observed more than 2,600 different minor planets, far surpassing previous efforts. His observations have at times proved scientifically valuable for determining rotation periods and identifying wayward objects. (M 16593)

Name suggested and citation provided by J. U. Gunter, who sparked Harvey's interest in minor planets; name endorsed by B. G. Marsden.

\section{(4279) De Gasparis}

1982 WB. Discovered 1982 Nov. 19 at the Osservatorio San Vittore at Bologna.

Named in memory of Annibale De Gasparis (18191892), Italian astronomer, director of the Observatory of Naples from 1864 to 1889. A great observer of minor planets, he discovered visually those numbered 10,11 , 13, 15, 16, 20, 24, 63 and 83 and made an independent discovery of (14). He was also the author of several memoirs on orbit determination and other problems in theoretical astronomy. (M 17030)

De Gasparis is also honored by a lunar crater.

\section{(4280) Simonenko}

$1985 \mathrm{PF}_{2}$. Discovered 1985 Aug. 13 by N. S. Chernykh at Nauchnyj.

Named in memory of Alla Nikolaevna Simonenko (1935-1984), specialist on small bodies of the solar system. She made substantial contributions to the study of the physical process of meteoroid fragmentation, the distribution of meteor radiants, the influx of meteoric matter to the earth, and the dynamics of asteroid orbits. She published two books on the study of asteroids, and actively favored the development of physical investigations of asteroids in the former U.S.S.R. (M 22501)

Citation prepared by D. F. Lupishko at the request of the discoverer.

\section{(4281) Pounds}

$1985 \mathrm{TE}_{1}$. Discovered 1985 Oct. 15 by E. Bowell at Anderson Mesa.

Named in honor of Kenneth A. Pounds, professor of physics at Leicester University, where he has directed X-ray astronomy, in which he is a pioneer, for 25 years. Pounds leads the British participation on ROSAT, which has produced the first X-ray and XUV photographs of the Moon. An active supporter of amateur initiatives through many talks to societies, he is strongly in favour of publicising astronomy in the most general way. Pounds is currently president of the Royal Astronomical Society and was awarded the Commander of the British Empire for services to astronomy. (M 17030)
Name suggested and citation material provided by S. A. Mitton.

\section{(4282) Endate}

1987 UQ $_{1}$. Discovered 1987 Oct. 28 by S. Ueda and H. Kaneda at Kushiro.

Named in honor of Kin Endate (1960- ), a very active amateur astronomer who has been observing and discovering minor planets during the past few years. He lives in Bihoro \{see planet (4460)\} and works for the Endate Craft Company, where he makes wooden crafts, trays, cylinders, sugar pots, vessels, etc., along with the help of his family. (M 16593)

\section{(4283) Stöffler}

1988 BZ. Discovered 1988 Jan. 23 by C. S. Shoemaker and E. M. Shoemaker at Palomar.

Named in honor of Dieter Stöffler, professor and director of the Institute for Planetology, University of Münster, Germany. He is especially well known for his careful and elegant calibration of the temperatures and peak shock pressures associated with different grades of shock metamorphism. At the Ries \{see planet (4327)\} impact crater in Germany, he solved these relationships chiefly from quantitative study of shock-formed phases of silica. He has worked extensively on the origin of the regolith, impact breccias, and magnetic history of the Moon, and on the petrology of meteorites. (M 18140)

\section{(4284) Kaho}

$1988 \mathrm{FL}_{3}$. Discovered 1988 Mar. 16 by S. Ueda and H. Kaneda at Kushiro.

Named in memory of Sigeru Kaho (1909-1981), an earnest researcher of variable stars at the Tokyo Observatory. His discovery of comet 1936 III (KahoKozik-Lis) was the first cometary discovery in Japan in modern times. The Kaho prize, established after his death, has been awarded annually to an active amateur astronomer in Japan. (M 19336)

Name suggested by H. Fukushima.

\section{(4285) Hulkower}

1988 NH. Discovered 1988 July 11 by E. F. Helin at Palomar.

Named in honor of Neal D. Hulkower, mathematician, scientist and good friend of the discoverer with a special interest in celestial mechanics. While at the Jet Propulsion Laboratory he developed a method of analyzing accessibility for spacecraft missions to near-Earth asteroids and ranked them by energy requirements for rendezvous. His enthusiasm and expertise have helped in stimulating greater interest in these objects. (M 16045)

Named by the discoverer. Name endorsed by R. Staehle and D. Bender.

\section{(4286) Rubtsov}

1988 PU $_{4}$. Discovered 1988 Aug. 8 by L. I. Chernykh at Nauchnyj. 
Named in memory of the remarkable Soviet lyric poet Nikolaj Mikhajlovich Rubtsov (1936-1971). (M 18458)

\section{(4287) Třísov}

$1989 \mathrm{RU}_{2}$. Discovered 1989 Sept. 7 by A. Mrkos at Klě̌t.

Named for a village in southern Bohemia northeast of Klet Mountain. Near the village there are remnants of the ancient Celtic town of Abilunon, founded in the first century B.C. on a strategic peninsula in the Vltava \{see planet (2123)\} river. (M 29669)

Name proposed by J. Tichá, M. Tichý and Z. Moravec.

\section{(4289) Biwako}

$1989 \mathrm{UA}_{2}$. Discovered 1989 Oct. 29 by A. Sugie at Taga.

Named for the largest lake in Japan, $235 \mathrm{~km}$ in circumference and up to $104 \mathrm{~m}$ in depth. Like the Dynic Astronomical Observatory, the lake is located in Shiga prefecture. Lake Biwa, whose shape resembles the old Japanese instrument "Biwa", is one of the oldest lakes in the world and has played an important role in politics, economy, culture, transportation, and so on. It is a quasi-national park, surrounded by a spacious resort zone. (M 16249)

\section{(4290) Heisei}

$1989 \mathrm{UK}_{3}$. Discovered 1989 Oct. 30 by T. Seki at Geisei.

Named for the Japanese new era, or "Gengo", which began on 1989 Jan. 8. Heisei was taken from an old Chinese book Shihchi by Ssu-ma Chien and from Shu Ching, one of the Chinese Five Classics. The name embodies the hope that peace will be achieved inside and outside the country, on the earth and in the heavens. This minor planet was discoverered in the first year of Heisei. The Christian era 1990 corresponds to Japanese era 2650. (M 16444)

\section{(4291) Kodaihasu}

1989 VH. Discovered 1989 Nov. 2 by M. Arai and H. Mori at Yorii.

Kodaihasu, Japanese for "ancient lotus", refers to preserved lotus seeds, perhaps 2500-3000 years old, found in 1971 in the ground at Kemigawa, Chiba prefecture, where they started to grow. (M 36126)

\section{(4292) Aoba}

1989 VO. Discovered 1989 Nov. 4 by M. Koishikawa at Sendai.

Named for the castle Aoba-jo in Sendai. The castle was built in the early seventeenth century by Date Masamune, the feudal lord of the district. The name means "fresh leaves" and frequently represents the city of Sendai. In April 1989, Sendai became a "designated city". One of the five wards of the city is named Aoba-ku, and it is there that both the Sendai Astronomical Observatory and the Ayashi Station are located \{see also planets (3133) and (3994)\}. (M 16045)
(4293) Masumi

1989 VT. Discovered 1989 Nov. 1 by Y. Oshima at Gekko.

Named in honor of Masumi Furukawa (1917- ), a board member of the International Foundation for Cultural Harmony and long an eminent popularizer of astronomy, mainly in Kyushu. (M 18307)

\section{(4294) Horatius}

4016 P-L. Discovered 1960 Sept. 24 by C. J. van Houten and I. van Houten-Groeneveld at Palomar.

Named for the Roman poet Horatio (65-8 B.C.) whose main poems are collected in Sermones, Carmina and Epistolae. (M 16594)

\section{(4295) Wisse}

6032 P-L. Discovered 1960 Sept. 24 by C. J. van Houten and I. van Houten-Groeneveld at Palomar.

Named in honor of Marijke Wisse-Schouten, who as a staff member of the Leiden Observatory performed the photometry for the three Palomar-Leiden Trojan surveys. (M 16594)

\section{(4296) van Woerkom}

$1935 \mathrm{SA}_{2}$. Discovered 1935 Sept. 28 by H. van Gent at Johannesburg.

Named in honor of Adrianus Jan J. van Woerkom \{1915-1991\}, Dutch-born astronomer, who worked in Leiden on the distribution of comet orbits and at Yale Observatory on problems of celestial mechanics before moving to the Electric Boat Company in Connecticut around 1960. (M 18140)

Obituaries published in Bull. Am. Astron. Soc., Vol. 23, No. 4, p. 1495 (1991); Phys. Today, Vol. 45, No. 8, p. 84 (1992); Celest. Mech. Dyn. Astron., Vol. 53, No. 1, p. 1 (1992).

\section{(4297) Eichhorn}

1938 HE. Discovered 1938 Apr. 19 by W. Dieckvoss at Bergedorf.

Named in honor of Heinrich Karl Eichhorn (19271999), Austrian-American astronomer, educator and scholar, innovator in the astronomy of stellar positions and motions. He developed the central-overlap and other astrometric reduction methods that greatly improve their rigor, increasing the precision of stellar parallaxes and proper motions and thus also the distance scale of the universe. (M 28621)

Name proposed by A. R. Upgren.

Obituary published in Alm.Österr. Akad. Wiss., 149. Jahrg., p. 431-445 (1999).

\section{(4299) WIYN}

1952 QX. Discovered 1952 Aug. 28 at the Goethe Link Observatory at Brooklyn, Indiana.

Named for the WIYN telescope, located at the Kitt Peak National Observatory. This 3.5-m telescope is jointly operated by the University of Wisconsin, 
Indiana University, Yale University and the National Optical Astronomy Observatories. (M 34619)

Name proposed by F. K. Edmondson.

\section{(4300) Marg Edmondson}

$1955 \mathrm{SG}_{1}$. Discovered 1955 Sept. 18 at the Goethe Link Observatory at Brooklyn, Indiana.

Named in memory of Margaret Russell Edmondson (1914-1999), the youngest child of Henry Norris Russell \{see planet (1762)\} and Lucy May (Cole) Russell. The breadth of her intellectual interests and the depth of her knowledge were the result of her genetic heritage and her close intellectual rapport with her father. (M 24620)

Name proposed by F. K. Edmondson, her husband for 64 wonderful years.

Obituary published in Bull. Am. Astron. Soc., Vol. 31, No. 5, p. 1596-1597 (1999).

\section{(4302) Markeev}

1968 HP. Discovered 1968 Apr. 22 by T. M. Smirnova at Nauchnyj.

Named in honor of Anatolij Pavlovich Markeev, professor at the Moscow Aviation Institute, wellknown expert on theoretical and celestial mechanics. He investigated the stability of Hamiltonian systems in the case of resonances of the third and the fourth orders, constructed theories of motion in the vicinity of the libration points of the three body problem and developed a theory of the motion of large constructions at the near-earth orbits. In addition, he studied various cases of motion of rigid bodies on smooth and rough surfaces. He contributed much to the methods of teaching and published a number of text-books and monographs. (M 19696)

Name proposed by the ITA.

\section{(4303) Savitskij}

1973 SZ$_{3}$. Discovered 1973 Sept. 25 by L. V. Zhuravleva at Nauchnyj.

Named in honor of Evgenij Yakovlevich Savitskij (1910-1990), Russian aviator, father of cosmonaut Svetlana Savitskaya \{see planet (4118)\}. (M 22501)

\section{(4304) Geichenko}

1973 SW $_{4}$. Discovered 1973 Sept. 27 by L. I. Chernykh at Nauchnyj.

Named in honor of Semyon Stepanovich Geichenko, writer and literary scholar, researcher of the life and the creative work of A. S. Pushkin \{see planet (2208)\}. Geichenko is especially known as director and curator of Mikhailovskoe, the Pushkin country-house museum in the Pskov region. He made a great effort to rebuild this memorial to Pushkin following its destruction in World War II. (M 22501)

\section{(4305) Clapton}

1976 EC. Discovered 1976 Mar. 7 at the Harvard College Observatory at Harvard.

Named in honor of Eric Clapton (1945- ), singer, composer and guitarist extraordinaire. He is the most remarkable bluesman ever to come out of England and his rock career has spanned more than 25 years. In the mid-60s, a graffito on a brick wall in London proclaimed: 'Eric is God'. He remains a musical megastar today, and is probably best known for the rock classics 'Layla' and the ballad 'Wonderful Tonight'. (M 16249)

\section{(4306) Dunaevskij}

1976 SZ . Discovered 1976 Sept. 24 by N. S. Chernykh at Nauchnyj.

Named in memory of Isaak Osipovich Dunaevskij (1900-1955), prominent Soviet composer well known for his many operettas, songs and film scores. (M 23351)

\section{(4307) Cherepashchuk}

1976 UK $_{2}$. Discovered 1976 Oct. 26 by T. M. Smirnova at Nauchnyj.

Named in honor of Anatolij Mikhajlovich Cherepashchuk (1941- ), professor at Moscow State University and director of the Sternberg Astronomical Institute, respected worldwide for his work in theoretical and observational astrophysics. From an analysis of eclipses in close-binary systems he obtained correct estimates of the radii and temperatures of Wolf-Rayet stars, predicted x-ray emission in such systems, discovered optical eclipses in the unique system V1343 Aql and developed a commonly-adopted model of this object as a massive x-ray binary. He also discovered fast emission-line variability in the nuclei of Seyfert galaxies. (M 29143)

Name proposed by the Institute of Theoretical Astronomy.

\section{(4308) Magarach}

$1978 \mathrm{PL}_{4}$. Discovered 1978 Aug. 9 by N. S. Chernykh at Nauchnyj.

Named for the Research Institute of wine-making and viticulture at Magarach, near Yalta see planet (1475)\}. Founded in 1828 as a specialized school for gardening and wine-making, Magarach was one of the first such schools in what was then Russia. (M 22501)

\section{(4309) Marvin}

1978 QC. Discovered 1978 Aug. 30 at the Harvard College Observatory at Harvard.

Named in honor of Ursula B. Marvin \{1922-

\}, geologist at the Harvard-Smithsonian Center for Astrophysics, well-known for her outstanding mineralogical and petrologic research on meteorites and lunar samples. Her meteorite studies have focused in recent years on the rich wealth of samples from Antarctica, and she was also involved in collecting 
them. This work also led to her analysis of dust grains, some of them of volcanic origin, in Antarctic ice samples. Her discovery of cordierite in an Apollo 15 lunar sample strongly suggested that this particular rock must have originated more than $40 \mathrm{~km}$ below the lunar surface. Marvin has also been responsible for mapping sections of Ganymede, maintains a strong interest in the history of meteorites and currently serves as secretary general of the International Commission on the History of Geological Sciences. (M 18458)

\section{(4310) Strömholm}

$1978 \mathrm{RJ}_{7}$. Discovered 1978 Sept. 2 by C.-I. Lagerkvist at La Silla.

Named in honor of Stig Strömholm, scholar, author, professor and vice chancellor of Uppsala University, to commemorate his active and enduring effort to support and strengthen international collaboration in fundamental sciences and culture. Although a respector of tradition, he is ever open to significant new developments in science and society. (M 19336) Citation prepared by B. Gustafson.

\section{(4311) Zguridi}

1978 SY $_{6}$. Discovered 1978 Sept. 26 by L. V. Zhuravleva at Nauchnyj.

Named in memory of Aleksandr Mikhajlovich Zguridi (1904-1998), producer of popular scientific films and an actor who won public recognition, as well as official honor from the Soviet state. (M 34620)

\section{(4313) Bouchet}

$1979 \mathrm{HK}_{1}$. Discovered 1979 Apr. 21 by H. Debehogne at La Silla.

Named in honor of Patrice Bouchet, a staff astronomer at the European Southern Observatory at La Silla, where he leads the infrared section. His work has ranged from the discoveries of a ring around Neptune and of ice in Halley's Comet, to the determination of the extinction law in the Small Magellanic Cloud and monitoring to study dust formation in supernova 1987A. (M 19337)

\section{(4315) Pronik}

1979 SL $_{11}$. Discovered 1979 Sept. 24 by N. S. Chernykh at Nauchnyj.

Named in honor of Vladimir Ivanovich Pronik (1932-

) and Iraida Ivanovna Pronik, husband and wife, astronomers at the Crimean Astrophysical Observatory for more than 40 years. The Proniks, members of IAU Commission 28 (Galaxies), are known for their research on the gaseous and stellar components of galaxies and the nature of active galactic nuclei. V. I. Pronik is a prominent expert on astronomical instruments. (M 23351)

\section{(4316) Babinkova}

1979 TZ 1 . Discovered 1979 Oct. 14 by N. S. Chernykh at Nauchnyj.

Named in honor of Artur Nikolaevich Babin (1936-

) and Aleksandra Nikolaevna Koval', husband and wife, solar astrophysicists at the Crimean Astrophysical Observatory for more than 35 years, known for their research on the fine structure of active solar features. (M 23351)

\section{(4317) Garibaldi}

$1980 \mathrm{DA}_{1}$. Discovered 1980 Feb. 19 by Z. Vávrová at Klě́.

Named in memory of Giuseppe Garibaldi (1807-1882), fighter for human rights and hero of many battles. (M 21609)

\section{(4318) Bă̌a}

$1980 \mathrm{DE}_{1}$. Discovered 1980 Feb. 21 by Z. Vávrová at Kleť.

Named in honor of Tomáš Baťa (1876-1932), worldrenowned Czech businessman. (M 16444)

\section{(4319) Jackierobinson}

1981 ER $_{14}$. Discovered 1981 Mar. 1 by S. J. Bus at Siding Spring.

Jackie Robinson (1919-1972) was the first black major league baseball player in modern times. He joined the Brooklyn Dodgers in 1947 and was named league Most Valuable Player in 1949. After retiring from baseball he campaigned for civil rights and established a fund for minority scholarships. (M 40701)

\section{(4320) Jarosewich}

$1981 \mathrm{EJ}_{17}$. Discovered 1981 Mar. 1 by S. J. Bus at Siding Spring.

Eugene Jarosewich (1926- ), research chemist emeritus at the Smithsonian Institution, has analyzed meteorites for more than 30 years and compiled one of the largest and most important sets of bulk chemical analyses of meteorites. These data are invaluable for deciphering geochemical processing of meteorites. (M 41381)

\section{(4321) Zero}

$1981 \mathrm{EH}_{26}$. Discovered 1981 Mar. 2 by S. J. Bus at Siding Spring.

Samuel Joel "Zero" Mostel (1915-1977) was an American actor, singer and artist. A Tony Award winner for his theatrical performances, Mostel is probably best known for his comedic roles in movies such as A Funny Thing Happened on the Way to the Forum and The Producers. (M 40701)

\section{(4322) Billjackson}

$1981 \mathrm{EE}_{37}$. Discovered 1981 Mar. 11 by S. J. Bus at Siding Spring.

Named in honor of William M. Jackson (1936-

) of the Department of Chemistry, University of California at Davis, for his contributions to the study 
of the chemistry of comets. His laboratory studies of photodissociation processes have been important in understanding the processes in cometary comae and in understanding possible parent molecules. (M 27459)

Citation provided by M. F. A'Hearn following a suggestion by E. Bowell.

\section{(4323) Hortulus}

1981 QN. Discovered 1981 Aug. 27 by P. Wild at Zimmerwald.

The name is Latin for a small, cozy garden, sheltering those flowers that gave their names to minor planets. For (4323) there are at least eight different such flower arrangements, among them (4323) $=(1056)$ Azalea + (1080) Orchis + (1092) Lilium + (1095) Tulipa. (M 34620)

\section{(4325) Guest}

1982 HL. Discovered 1982 Apr. 18 by E. Bowell at Anderson Mesa.

Named in honor of John E. Guest, reader in Planetary Studies at University College, London, and a colleague of the discoverer at the University of London Observatory during the latter's postgraduate days. A leading British planetary geologist and a specialist in vulcanology, Guest has worked on the geological mapping of the moon, Mars and many of the atmosphereless satellites of the major planets. He was a principal investigator on the Soviet Phobos missions and is currently a team member on the Magellan radar-mapping mission to Venus. Guest has not neglected research on terrestrial vulcanology, however, as witness his book on Etna. (M 16594)

Citation provided by D. McNally at the request of the discoverer.

\section{(4326) McNally}

$1982 \mathrm{HS}_{1}$. Discovered 1982 Apr. 28 by E. Bowell at Anderson Mesa.

Named in honor of Derek McNally, Director of the University of London Observatory (University College London). A teacher of the discoverer while he was an undergraduate student, McNally's main astronomical research areas are theoretical modeling of star formation and interstellar spectroscopy using both groundbased observations and data from the International Ultraviolet Explorer satellite. He also takes a keen interest in astronomical education. Currently $\{1988-1991\}$, he is general secretary of the International Astronomical Union. (M 16594)

Citation provided by J. E. Guest at the request of the discoverer.

\section{(4327) Ries}

$1982 \mathrm{~KB}_{1}$. Discovered 1982 May 24 by C. S. Shoemaker and S. J. Bus at Palomar.

Named for a large topographic basin in southern Germany formed by the impact of an extraterrestrial body in Miocene time. Within this crater, which lies between the Swabian and Franconian plateaus, is the medieval city of Nördlingen with a church made from the impact breccia. The Ries is host to an annual cultural festival in celebration of its geology, history, art, music, folklore, handicrafts, industry and agriculture. (M 17655)

\section{(4328) Valina}

1982 SQ 2 . Discovered 1982 Sept. 18 by H. Debehogne at La Silla.

Named in honor of Valentina Arkadievna Andreichenko (and her daughter Alina Eduardovna) for her collaboration with the discoverer in the TomskObservatory-Brussels-Program, which was created in order to realize observations, in particular at the European Southern Observatory at La Silla, as well as orbital improvements and theoretical works in astrometry and celestial mechanics. Valentina has participated in expeditions to the site of the 1908 Tunguska \{see planet (5471)\} event. (M 22829)

\section{(4330) Vivaldi}

1982 UJ $_{3}$. Discovered 1982 Oct. 19 by F. Börngen at Tautenburg.

Named for the great Italian violin virtuoso and baroque composer Antonio Vivaldi (1680-1743). (M 16045)

\section{(4331) Hubbard}

1983 HC. Discovered 1983 Apr. 18 by N. G. Thomas at Anderson Mesa.

Named in memory of Ralph "Doc" Hubbard (18851980), of Medora, North Dakota. The son of Elbert Hubbard, Ralph was a nationally-recognized authority on American Indian culture, an expert at crafting Indian ceremonial clothing and an author and educator regarding the preservation of Indian culture and history. He worked for many years with the Boy Scouts of America; he had rich experiences in frontier life from ranching in Montana and Colorado around 1900, and the discoverer was one of hundreds of young people who later were enriched through Doc's biology teaching. (M 24916)

Assistance with the citation was provided by J. Stewart and J. Paulson.

\section{(4332) Milton}

1983 RC. Discovered 1983 Sept. 5 by C. S. Shoemaker and E. M. Shoemaker at Palomar.

Named for Daniel J. Milton, geologist with the U.S. Geological Survey. Milton, who has carried out geological studies of the moon and Mars, is best known for his investigations of meteorite craters and ancient impact features in Australia. His work on structural deformation at the largest Henbury meteorite craters and in the central uplift of the Gosses Bluff structure, Northern Territory, are tours de force in detailed geologic mapping. (M 17656) 


\section{(4333) Sinton}

$1983 \mathrm{RO}_{2}$. Discovered 1983 Sept. 4 by E. Bowell at Anderson Mesa.

Named in honor of William M. Sinton, planetary astronomer at the Institute for Astronomy, University of Hawaii, on the occasion of his retirement. Sinton came to Hawaii in 1966 from the Lowell Observatory, where he had already established himself in the field of infrared astronomy and was codiscoverer of $\mathrm{CO}$ in Alpha Orionis. Instrumental in the development of Mauna Kea as a premier astronomical observatory, Sinton was responsible for the specification and design of the computer operating environment for the University's 2.24-m telescope, one of the first telescopes to be computer controlled. He has been a pioneer in bringing new technology and ideas to the subject of thermal infrared studies of the planets, particularly Venus and Mars. He has habitually selected technically difficult problems to work on, including some of the very earliest spectroscopy with interferometers, thermal emission spectroscopy of the stars and planets, time-resolved radiometry of the satellites of Jupiter, the first astronomical far-infrared work with a helium-3 bolometer, near-infrared studies of the dark hemisphere of Venus, and the thermal properties of the satellites of Jupiter during their mutual eclipses and occultations. (M 16444)

Citation prepared at the discoverer's request by D. P. Cruikshank and D. J. Tholen.

\section{(4335) Verona}

$1983 \mathrm{VC}_{7}$. Discovered 1983 Nov. 1 at the Giordano Bruno Observatory at Cavriana.

Named for the Italian city, founded in the fourth century B.C., and situated at the foot of the Alps. Verona knew moments of splendor during the ancient Roman Epoca and still conserves the Arena, as well as thirteenth-century masterpieces from the reign of the Scaligeri family. Shakespeare's \{see planet (2985)\} Romeo and Juliet was sited in Verona, which is also the city in which the Cavriana observers, Luciano Lai, Ivano Rocchetti and Giordano Vesentini, were born and raised. (M 16249)

\section{(4336) Jasniewicz}

$1984 \mathrm{QE}_{1}$. Discovered 1984 Aug. 31 by B. A. Skiff at Anderson Mesa.

Named in honor of Gerard Jasniewicz, astronomer at Strasbourg Observatory. As a long-time member of this observatory's Centre de Données Astronomiques, he is responsible for maintaining the SIMBAD \{see planet (4692)\} bibliographic database. (M 27126)

\section{(4337) Arecibo}

1985 GB. Discovered 1985 Apr. 14 by E. Bowell at Anderson Mesa.

Named for the Arecibo Observatory in Puerto Rico, site of the largest filled-aperture telescope in the world. Arecibo is the principal research facility of the
National Astronomy and Ionosphere Center and is used for radio astronomy, planetary radar astronomy and ionospheric investigations. Radar echoes obtained at Arecibo have provided valuable information about the physical and dynamical properties of about fifty minor planets, five comets, the terrestrial planets, the Galilean satellites and Saturn's rings. (M 16445) Name suggested and citation provided by S. J. Ostro.

\section{(4338) Velez}

$1985 \mathrm{~PB}_{1}$. Discovered 1985 Aug. 14 by E. Bowell at Anderson Mesa.

Named in honor of Reinaldo Velez, senior telescope operator at the Arecibo Observatory for the past fifteen years and currently head of AO's Department of Telescope and Computer Operations. Rey's expertise, dedication and extensive experience with the telescope have contributed critically to hundreds of radar/radio astronomy experiments. In particular, his direct assistance with radar observations of main-belt and earth-approaching minor planets has been a key element in the success of that research. (M 16445) Name suggested and citation provided by S. J. Ostro.

\section{(4339) Almamater}

1985 UK. Discovered 1985 Oct. 20 by A. Mrkos at Klě́.

Named in anticipation of the 650th anniversary of Charles University (Univerzita Karlova) in Prague. This oldest university in central Europe was founded in 1348 by Charles IV of Luxembourg. (M 30475)

Name suggested by J. Tichá, M. Šolc, M. Tichý and Z. Morovec.

Charles University in Prague is also honored by planet (2288).

\section{(4340) Dence}

1986 JZ. Discovered 1986 May 4 by C. S. Shoemaker and E. M. Shoemaker at Palomar.

Named for Michael R. Dence, executive director of the Royal Society of Canada and formerly a geologist with the Dominion Observatory. Dence was a pioneer in the geologic investigation of ancient impact craters on the Canadian shield. He made one of the first good estimates of the cratering rate on the earth in Phanerozoic time from studies of impact structures in Canada and Europe. (M 17656)

\section{(4341) Poseidon}

1987 KF. Discovered 1987 May 29 by C. S. Shoemaker and E. M. Shoemaker at Palomar.

In Greek mythology, Poseidon, a brother of Zeus \{see planet (5731)\}, was lord of the sea and of earthquakes (since the earth is shaken by waves beating on the shore). He ruled all that lived in the sea and gathered clouds and raised storms. Poseidon was the constant enemy of Troy during the Trojan War. (M 17656) 


\section{(4342) Freud}

1987 QO $_{9}$. Discovered 1987 Aug. 21 by E. W. Elst at La Silla.

Named in memory of Sigmund Freud (1865-1939), father of psychoanalysis. In 1885 he went to Paris and studied under the neurologist Jean Charcot, who stimulated him to investigate hysteria from a psychological point of view. This view was strengthened by Josef Breuer, who cured hysterical symptoms by putting the patient under hypnosis. Soon afterward Freud replaced hypnotism by the method of free association. Among his writings are The Interpretations of Dreams (1900) and Moses and Monotheism (1939), the latter an elucidation of a historical-cultural problem that had always fascinated him. (M 16045)

\section{(4343) Tetsuya}

1988 AC. Discovered 1988 Jan. 10 by S. Ueda and H. Kaneda at Kushiro.

Named in honor of Tetsuya Fujii (1960- ), active observer and discoverer of minor planets and director of the astronomical club in Kitami \{see planet (3785)\}, where he also works for the NHK broadcasting office. (M 20159)

\section{(4344) Buxtehude}

1988 CR $_{1}$. Discovered 1988 Feb. 11 by E. W. Elst at La Silla.

Named in memory of the great organist and composer Dietrich Buxtehude (1637-1707), undoubtedly the most eminent master of the organ before Johann Sebastian Bach \{see planet (1814)\}. His inspired creative power is particularly evident in chorales such as "Wie schön leuchtet der Morgenstern". In 1668 he became the successor of Franz Tunder \{see planet (7871)\} as organist at the Marienkirche in Lübeck, a position he held until his death. (M 16046)

\section{(4345) Rachmaninoff}

$1988 \mathrm{CM}_{2}$. Discovered 1988 Feb. 11 by E. W. Elst at La Silla.

Named in memory of the composer and pianist Sergei Rachmaninoff (1873-1943), considered to be the last great figure in the tradition of Russian romanticism, and whose compositions embrace symphonies and piano concerti and preludes. Although his greatest productivity occurred in St. Petersburg and Moscow around the turn of the century, he composed the beautiful "Rhapsody on a Theme by Paganini" in the United States in 1934, during the exile in which he was principally a concert performer. (M 16046)

\section{(4346) Whitney}

$1988 \mathrm{DS}_{4}$. Discovered 1988 Feb. 23 by A. J. Noymer at Siding Spring.

Named in honor of Charles A. Whitney, professor at Harvard University. Whitney has done seminal work on Cepheid modeling, and he is the editor of the JAAVSO. He has brought astronomy to art history, using computer sky simulations to recreate, and hence date, the sky scenes of van Gogh \{see planet (4457)\}. Recently he has worked on physics and astronomy textbooks for high schools and has served as a science consultant to the Children's Television Workshop. Whitney is also the author of several astronomy books for the public, including The Discovery of our Galaxy and Whitney's Star Finder. (M 16046)

\section{(4347) Reger}

$1988 \mathrm{PK}_{2}$. Discovered 1988 Aug. 13 by F. Börngen at Tautenburg.

Named in memory of Max Reger (1873-1916), chief conductor and general music director of the renowned court orchestra in Meiningen during 1911-1914 and professor of composition and counterpoint in Leipzig until his death. Reger is well known for his monumental organ compositions and for his chamber and orchestra music. (M 16594)

\section{(4348) Poulydamas}

1988 RU. Discovered 1988 Sept. 11 by C. S. Shoemaker and E. M. Shoemaker at Palomar.

Named for Hektor's \{see planet (624)\} most trusted advisor and strategist, Poulydamas, who was born on the same night as Hektor. The gods gave Hektor skill with arms and gave Poulydamas better judgment. He sensibly advised Hektor to lock the gates of Troy against Achilles \{see planet (588)\}, but Hektor disregarded his friend's advice and went out of the city to his doom and to the eventual doom of Troy. (M 18141)

Name and citation provided by R. Preston at the request of the discoverers.

\section{(4349) Tibúrcio}

1989 LX. Discovered 1989 June 5 by W. Landgraf at La Silla.

Named in honor of Julio Cesar dos Santos Tibúrcio, a Brazilian amateur astronomer and student of information science. (M 16445)

\section{(4350) Shibecha}

$1989 \mathrm{UG}_{1}$. Discovered 1989 Oct. 26 by S. Ueda and H. Kaneda at Kushiro.

Named for a small town, located $47 \mathrm{~km}$ to the north of Kushiro \{see planet (4096)\}. Its cattle population, 45,500 , is four times that of its human population. (M 19337)

\section{(4351) Nobuhisa}

1989 UR $_{1}$. Discovered 1989 Oct. 28 by Y. Mizuno and T. Furuta at Kani.

Named in honor of Nobuhisa Kojima (1933- ), who has been interested in astronomy since childhood. Kojima was the first Japanese amateur to make a Schmidt camera, and he discovered two comets (1970r and 1972j) photographically with a 0.30-m reflector of his own making. Kojima was also the first Japanese amateur to discover a minor planet that was 
given a provisional designation (1973 MA). Kojima is an inspiration for other astronomical discoverers. (M 20159)

\section{(4352) Kyoto}

1989 UW $_{1}$. Discovered 1989 Oct. 29 by A. Sugie at Taga.

Named for the 1200th anniversary, in 1994, of the establishment by Emperor Kammu of Kyoto as the former capital of Japan. Home for many old national treasures and historical spots, Kyoto has been prosperous as a center of Japanese politics, economy and culture and nowadays attracts more than forty million visitors each year from all over the world. The Dynic Corporation, which built Dynic Astronomical Observatory, has its headquarter in Kyoto. (M 16249)

\section{(4353) Onizaki}

$1989 \mathrm{WK}_{1}$. Discovered 1989 Nov. 25 by Y. Mizuno and T. Furuta at Kani.

Named for the town where the second discoverer spent his boyhood. Since the name vanished when neighboring towns were united, it is particularly appropriate to revive it so that it can be the name of some location in the universe for ever. The town was situated on the Chita Peninsula in the central part of Japan and is famous for its beautiful yacht harbor. (M 16249)

\section{(4354) Euclides}

2142 P-L. Discovered 1960 Sept. 24 by C. J. van Houten and I. van Houten-Groeneveld at Palomar.

Named for the Greek mathematician Euclid, who lived in Alexandria about 300 B.C. (M 16594)

Euclid is also honored by a lunar crater.

\section{(4355) Memphis}

3524 P-L. Discovered 1960 Oct. 17 by C. J. van Houten and I. van Houten-Groeneveld at Palomar.

Named after the former capital of the old Egyptian kingdom. (M 18141)

\section{(4356) Marathon}

9522 P-L. Discovered 1960 Oct. 17 by C. J. van Houten and I. van Houten-Groeneveld at Palomar.

Named after a village near Athens, near which the Athenian troops defeated the invading Persian army in the year 490 B.C. (M 18141)

\section{(4357) Korinthos}

2069 T-2. Discovered 1973 Sept. 29 by C. J. van Houten at Palomar.

Named after the important seaport town in classical Greece. (M 18141)

\section{(4358) Lynn}

A909 TF. Discovered 1909 Oct. 5 by P. H. Cowell at Greenwich.

Named in memory of William Thynne Lynn (18351911), assistant at Greenwich Observatory from 1854 to 1880 and author of several popular books. He is best known, however, for the numerous short notes on astronomical matters he wrote in The Observatory for many years. Among those notes is an enigmatic one in 1902 in which he hinted that the Perseid comet $\mathrm{P} /$ Swift-Tuttle \{see also planets (5035), (5036)\} might be identical with Kegler's \{see planet (5005)\} comet of 1737. (M 22501)

Name proposed by B. G. Marsden, who made the identifications for this object.

\section{(4359) Berlage}

1935 TG. Discovered 1935 Sept. 28 by H. van Gent at Johannesburg.

Named in honor of H. P. Berlage (1896-1968), Dutch meteorologist and astronomer. His main astronomical activities were investigations about the origin of the solar system. (M 18141)

Berlage is also honored by a lunar crater.

\section{(4361) Nezhdanova}

1977 TG $_{7}$. Discovered 1977 Oct. 9 by L. I. Chernykh at Nauchnyj.

Named in memory of Antonina Vasil'evna Nezhdanova (1873-1950), an outstanding Soviet singer, actress at the Bolshoj Theater and professor at the Moscow Conservatory. (M 18458)

\section{(4362) Carlisle}

1978 PR $_{4}$. Discovered 1978 Aug. 1 by P. Jekabsons at Bickley.

Named in honor of Albert John Carlisle (1917-1993), who spent his life working in the Australian Bush. As a consequence, John Carlisle found more than 9000 meteorites on the Nullarbor Plain of Western Australia during the past 52 years. In 1982 he was awarded an Order of Australia Medal for his contribution to science. (M 22829)

\section{(4363) Sergej}

$1978 \mathrm{TU}_{7}$. Discovered 1978 Oct. 2 by L. V. Zhuravleva at Nauchnyj.

Named in honor of Sergej Vasil'evich Ezhov (1953-

), since 1978 a talented surgeon in the district hospital at Bakhchisaraj \{see planet (3242)\}, Crimea. (M 30798)

\section{(4364) Shkodrov}

1978 VV $_{5}$. Discovered 1978 Nov. 7 by E. F. Helin and S. J. Bus at Palomar.

Named for Vladimir Shkodrov, professor at the Bulgarian Academy of Sciences and an astronomer at the Bulgarian National Observatory. Dynamicist, science writer and translator of many astronomical classics, he has been a guiding light for many of his colleagues in Bulgaria and Europe. Shkodrov has collaborated with the discoverer on the International Near-Earth Asteroid Survey from Bulgaria and even through difficult times has persisted in carrying out asteroid and comet research. (M 18645) 


\section{(4365) Ivanova}

$1978 \mathrm{VH}_{8}$. Discovered 1978 Nov. 7 by E. F. Helin and S. J. Bus at Palomar.

Named in honor of Violetta Ivanova, astronomer at the Bulgarian Academy of Sciences, Bulgarian National Observatory and a friend and colleague of the discoverer. Violetta and her associates have been active members of Helin's JPL International Near-Earth Asteroid Survey for the last ten years, contributing to its global sky coverage in search for NEAs. Violetta is a diligent and enthusiastic observer. Helin has spent two observing sessions in Bulgaria working with Ivanova and Shkodrov \{see planet (4364)\}. (M 18645)

\section{(4366) Venikagan}

1979 YV $_{8}$. Discovered 1979 Dec. 24 by L. V. Zhuravleva at Nauchnyj.

Named in memory of the outstanding Soviet mathematician Veniamin Fyodorovich Kagan (18691953). (M 24122)

\section{(4367) Meech}

$1981 \mathrm{EE}_{43}$. Discovered 1981 Mar. 2 by S. J. Bus at Siding Spring.

Named in honor of Karen J. Meech (1959- ) of the Institute for Astronomy of the University of Hawaii for her pioneering studies of comets very far from the sun. Her work following new and long-period comets to great distance has been a major factor in changing our ideas about water as the predominant driver of cometary activity in most comets. Meech's studies of $(2060)=95 \mathrm{P} /$ Chiron have likewise been critical in changing our understanding of the nature of the cometary coma. (M 27459)

Citation provided by M. F. A'Hearn following a suggestion by E. Bowell.

\section{(4368) Pillmore}

$1981 \mathrm{JC}_{2}$. Discovered 1981 May 5 by C. S. Shoemaker at Palomar.

Named for Charles L. Pillmore, geologist with the U.S. Geological Survey. A specialist in the use of aerial photographs in geologic mapping, Pillmore is also an expert on the geology of the Raton Basin of Colorado and New Mexico, where he discovered the Cretaceous-Tertiary boundary claystone at about 20 different sites. Investigation of these sites has produced critical evidence that a large impact occurred at the end of the Cretaceous, coincident with a mass extinction of species. (M 17656)

\section{(4369) Seifert}

1982 OR. Discovered 1982 July 30 by L. Brožek at Kleť.

Named in memory of Jaroslav Seifert \{1901-1986\}, Czech poet and $\{1984\}$ Nobel laureate. One of his volumes of poems had the name "Halleys's comet". (M 25443)

\section{(4370) Dickens}

1982 SL. Discovered 1982 Sept. 22 by E. Bowell at Anderson Mesa.

Named for the great English novelist Charles Dickens (1812-1870). Dickens' works include The Pickwick Papers, Little Dorrit, A Christmas Carol, Oliver Twist, Great Expectations and David Copperfield, the last of which was based on his personal experiences. He created several comic characters, but he was most concerned with the social consequences of crime, corruption and moral evil. Most of his novels were first published in monthly installments, for popular consumption. Dickens later made successful reading tours of England and the United States, and several of his novels have been dramatized on the stage and on film. (M 16445)

Name suggested and citation provided by S. J. Ostro.

\section{(4371) Fyodorov}

$1983 \mathrm{GC}_{2}$. Discovered 1983 Apr. 10 by L. I. Chernykh at Nauchnyj.

Named in honor of Svyatoslav Nikolaevich Fyodorov, famous Moscow ophthalmologist, outstanding surgeon and brilliant manager who organized several clinics in Moscow and other cities for the treatment of eye diseases. (M 22502)

\section{(4372) Quincy}

1984 TB. Discovered 1984 Oct. 3 at the Oak Ridge Observatory at Harvard.

Named in memory of John Quincy Adams (17671848), sixth president of the United States and a lifelong patron of astronomy. Instrumental in founding the Harvard College Observatory, he also first proposed - albeit unsuccessfully at the time - the establishment of an observatory under the aegis of the Smithsonian Institution. The minor planet is named on the occasion of the joint Harvard-Smithsonian Center for Astrophysics celebration of the sesquicentennial of the Harvard College Observatory and the centennial of the Smithsonian Astrophysical Observatory \{see planet (3773)\}, 1990 Nov. 2-4. (M 17224)

\section{(4373) Crespo}

1985 PB. Discovered 1985 Aug. 14 by E. Bowell at Anderson Mesa.

Named in honor of Antonio Crespo, electrical engineer at the Arecibo \{see planet (4337)\} Observatory. For more than a decade, Crespo has been singularly responsible for maintaining the operational capability of the high-power transmitter used for all Arecibo planetary radar astronomy observations. The transmitter system is extremely complex; its outstanding performance throughout the 1980s is a credit to Crespo's expertise and hard work. (M 16446)

Name suggested and citation provided by S. J. Ostro.

\section{(4374) Tadamori}

1987 BJ. Discovered 1987 Jan. 31 by K. Suzuki and T. Urata at Toyota. 
Named for a Japanese commander of the Heike, Tairano Tadamori (1096-1153), father of Taira-no Kiyomori \{see planet (4375)\}. Tadamori was a man well-educated in classics, and he laid the foundation for his son's assumption of control over the country. (M 19696)

\section{(4375) Kiyomori}

1987 DQ. Discovered 1987 Feb. 28 by T. Niijima and T. Urata at Ojima.

Named for one of the most brilliant Japanese autocrats in the late Heian era, Taira-no Kiyomori (1118-1181). A hero of Tales of the Heike, Kiyomori succeeded his father, Taira-no Tadamori ssee planet (4374)\}, as chief of the Taira clan and rose to the Dajodaijin, which was the highest position in the Japanese court. In the year before his death, he crowned his two-year-old grandson as emperor and moved the capital to Kobe, where Japanese modern foreign trade has been developed. (M 19696)

\section{(4376) Shigemori}

1987 FA. Discovered 1987 Mar. 20 by T. Niijima and T. Urata at Ojima.

Named for a Japanese military commander, Taira-no Shigemori (1138-1179), the eldest son of Taira-no Kiyomori \{see planet (4375)\}. Shigemori was a gentle and popular Naidaijin, Minister of Interior; after his death, the Taira clan quickly went to ruin. (M 19696)

\section{(4377) Koremori}

1987 GD. Discovered 1987 Apr. 4 by T. Niijima and T. Urata at Ojima.

Named for Taira-no Koremori (1160-?), a Japanese military commander who was the eldest son of Taira-no Shigemori \{see planet (4376)\}. In 1183 he was beaten by the Genji (Minamoto) forces. It is believed that he drowned himself in the Pacific Ocean. (M 19696)

\section{(4378) Voigt}

1988 JF. Discovered 1988 May 14 by W. Landgraf at La Silla.

Named in honor of Hans-Heinrich Voigt \{1921- $\}$, known for his work on radiative transfer and stellar atmospheres, as well as for his studies of $\mathrm{Cp}, \mathrm{Ap}$ and magnetic stars. An outstanding teacher, he has been a great inspiration to the discoverer. Voigt served as director of the Göttingen Observatory from 1975 to 1983 and as presidents of the Göttingen Academy of Sciences and IAU Commissions 38 and 46. (M 16446)

\section{(4379) Snelling}

$1988 \mathrm{PT}_{1}$. Discovered 1988 Aug. 13 by C. S. Shoemaker and E. M. Shoemaker at Palomar.

Named in honor of Reginald and Heather Snelling. Former owners of Carranya Station in Western Australia and now owners of Leigh Creek Station in South Australia, the Snellings have been staunch friends and supporters of the discoverers in their studies of Australian impact structures. It was "Reggie" Snelling who first called attention to another very small crater
(Snelling Crater) on Carranya Station near Wolfe Creek Crater. These two Asutralians typify the independence, warmth and generosity the discoverers have come to think of as a national trait. (M 29669)

(4380) Geyer

$1988 \mathrm{~PB}_{2}$. Discovered 1988 Aug. 14 by E. W. Elst at St. Michel.

Named in honor of Edward H. Geyer \{1930- \}, since 1965 the head of the Hoher List Observatory, on the occasion of his 60th birthday. Geyer has left his mark in many fields of astronomy, spanning from instrumental development via stellar systems to variable stars and solar-like activity. His work in solar system astronomy has included, for example, the detection of the splitting of the nucleus of Comet West (1976 VI). He is also an enthusiastic teacher, especially in the field of observational astronomy. Like many other visiting astronomers at Hoher List, the discoverer has often been supported by Geyer, long a friend of minor planets. (M 16249)

Citation prepared by M. Geffert at the request of the discoverer.

\section{(4381) Uenohara}

1989 WD $_{1}$. Discovered 1989 Nov. 22 by N. Kawasato at Uenohara.

Named for the small town on the edge of which is the observing station where this minor planet was discovered. The town, in Yamanashi prefecture, is located in central Japan, about $100 \mathrm{~km}$ from Tokyo. (M 16446)

\section{(4382) Stravinsky}

$1989 \mathrm{WQ}_{3}$. Discovered 1989 Nov. 29 by F. Börngen at Tautenburg.

Named in memory of the famous composer Igor Stravinsky (1882-1971), known for his very versatile musical creations, including ballet music and operas. The discoverer finds his psalm symphony (1930) particularly impressive. Born in Russia, Stravinsky lived in Switzerland and France before moving to the United States in 1939. (M 16446)

\section{(4383) Suruga}

1989 XP. Discovered 1989 Dec. 1 by Y. Oshima at Gekko.

Named for the district where the Gekko ssee planet (4261)\} Observatory is located. Suruga is the old name of the central part of Shizuoka prefecture. The district is well known for its mild climate, and the view from the observatory covers the whole of beautiful Suruga Bay and its seashore. (M 18307)

\section{(4385) Elsässer}

2534 P-L. Discovered 1960 Sept. 24 by C. J. van Houten and I. van Houten-Groeneveld at Palomar.

Named in honor of Hans F. Elsässer (1929- ), professor of astronomy at Heidelberg University and since 1968 first director of the Max-Planck-Institut für 
Astronomie. During 1962-1975 he was also director of the Heidelberg Observatory at Königstuhl. A scientific member of the Max-Planck-Gesellschaft, Elsässer was a founder of MPIA in Heidelberg and its associated observatory at Calar Alto. He has made important contributions to the study of interplanetary matter and the zodiacal light, the optics of the earth's atmosphere, the structure of the Galaxy and the Magellanic Clouds and star formation. He was deeply concerned with the design and establishment of large telescopes and their auxiliary instrumentation at Calar Alto. Elsässer served as president of the IAU Commission 21 during $1970-1973$. His many honors include membership in the scientific academies of Austria, Halle (Leopoldina) and Heidelberg. (M 18141)

Name proposed and citation prepared by L. D. Schmadel.

\section{(4386) Lüst}

6829 P-L. Discovered 1960 Sept. 26 by C. J. van Houten and I. van Houten-Groeneveld at Palomar.

Named in honor of Reimar Lüst (1923- ), German astronomer, former director general of the Max-PlanckGesellschaft and of the European Space Agency. (M 18141)

\section{(4387) Tanaka}

4829 T-2. Discovered 1973 Sept. 19 by C. J. van Houten and I. van Houten-Groeneveld at Palomar.

Named in honor of Yasuo Tanaka (1931- ), Japanese astrophysicist, who organized the first group of space scientists in the Netherlands. Tanaka is head of the space research group in Japan. He contributed to the launching of the Japanese satellites Hakucho (1979), Tenma (1983) and Ginga (1987). Ginga observed the first X-ray signals from supernova 1987A. (M 18142)

\section{(4388) Jürgenstock}

1964 VE. Discovered 1964 Nov. 3 at the Goethe Link Observatory at Brooklyn, Indiana.

The German-Venezuelan astronomer Jürgen Stock (1923- ), renowned as a developer of observatories and their sites, has served as director of the Cerro Tololo Interamerican Observatory and the Venezuelan National Observatory. (M 36126)

\section{(4389) Durbin}

1976 GL $_{3}$. Discovered 1976 Apr. 1 by N. S. Chernykh at Nauchnyj.

Named in honor of Deanna Durbin (1921- ), talented Canadian-born American cinema actress, who played in many films in the 1930s and 40s. She was sensationally popular in America and Europe and later on in Russia. (M 23351)

\section{(4390) Madreteresa}

1976 GO $_{8}$. Discovered 1976 Apr. 5 at the Felix Aguilar Observatory at El Leoncito.

Named in memory of Albanian-born Ines Gonxha Bojaxhiu (1910-1997), better known as Mother Teresa of Calcutta, who devoted her life to helping sick, destitute and homeless people, first in India and then in the rest of the world. Among her many awards, in 1979 she received the Nobel Peace Prize. (M 31609)

\section{(4391) Balodis}

1977 QW $_{2}$. Discovered 1977 Aug. 21 by N. S. Chernykh at Nauchnyj.

Named in honor of Janis Balodis, chief of the cosmic geodesy department at the Astronomical Observatory of the Latvian University, known for his work on astrometric and laser observations of artificial satellites and on methods of mathematical reductions in photographic astrometry. A set of his computer programs has been used in the Crimean minor planet service for many years. (M 20837)

\section{(4392) Agita}

$1978 \mathrm{RX}_{5}$. Discovered 1978 Sept. 13 by N. S. Chernykh at Nauchnyj.

Named in honor of Agita Tarasova, a scientific worker at the Astronomical Observatory of the Latvian University, engaged in the mathematical reduction of observations and in the preparation of computer programs. She has rendered valuable assistance to the Crimean minor planet service by installing the Balodis \{see planet (4391)\} reduction programs on the $\mathrm{CrAO}$ computer. (M 20837)

\section{(4393) Dawe}

1978 VP $_{8}$. Discovered 1978 Nov. 7 by E. F. Helin and S. J. Bus at Palomar.

Named in honor of John A. Dawe, who was astronomer-in-charge at the U.K. Schmidt in 1979 when the first discoverer proposed that plates be taken for a limited asteroid survey. Dawe and his staff of astronomers were hospitable and helpful during that first short survey, and they later collaborated in the more comprehensive and highly successful United Kingdom-Caltech Faint Asteroid Survey (UCAS) that was carried out in 1981. (M 17031)

\section{(4394) Fritzheide}

1981 EB $_{19}$. Discovered 1981 Mar. 2 by S. J. Bus at Siding Spring.

German mineralogist Fritz von der Heide (1891-1973) studied meteorites at a time when little work was being done on these interesting extraterrestrial samples. His 1934 book Kleine Meteoritenkunde influenced a generation of meteorite researchers and has been reprinted several times and translated into English. (M 41381)

\section{(4395) Danbritt}

$1981 \mathrm{EH}_{41}$. Discovered 1981 Mar. 2 by S. J. Bus at Siding Spring.

As a research professor at the University of Tennessee, Daniel Britt (1950- ) studies the relationships between minor planets and meteorites using reflectance spectroscopy. He has been instrumental in unraveling 
the role of shock processes in modifying the reflectance properties of asteroidal surfaces. (M 41381)

\section{(4396) Gressmann}

1981 JH. Discovered 1981 May 3 by E. Bowell at Anderson Mesa.

Named in honor of Michael Gressmann, renowned astronomical optician of Falkensee, near Berlin. Scholar and successor to the famous Alfred Wilke ssee planet (4117)\}, Gressmann has for the past 20 years manufactured numerous telescope optics both for amateur astronomers and for observatories and institutes. These high-quality products also contain special laser and infrared optics of Gressmann's own design. Founder and leader of an East German working group on asteroids, he is also a distinguished popularizer of astronomy in his country. (M 16446)

Name proposed by the discoverer following a suggestion from L. D. Schmadel, who also prepared the citation.

\section{(4397) Jalopez}

1981 JS$_{1}$. Discovered 1981 May 9 at the Felix Aguilar Observatory at El Leoncito.

Named in honor of Jose Augusto Lopez (1922- ), known for his work in meridian astrometry and as director of the Felix Aguilar Observatory during 19661993. He also served on the Science and Technology Committee of the government of San Juan province, as well as an advisor to the Argentine government. (M 31023)

\section{(4398) Chiara}

$1984 \mathrm{HC}_{2}$. Discovered 1984 Apr. 23 by W. Ferreri at La Silla.

Named in honor of Chiara Maria Faletti (1955- ), wife of the discoverer. (M 23540)

\section{(4399) Ashizuri}

1984 UA. Discovered 1984 Oct. 21 by T. Seki at Geisei.

Named for a famous promontory in the southwestern part of Shikoku \{see planet (4223)\} island. Many tourists visit the promontory for its beautiful ocean view, but it is often subjected to summer typhoons. (M 16595)

\section{(4400) Bagryana}

$1985 \mathrm{QH}_{4}$. Discovered 1985 Aug. 24 by V. G. Ivanova and V. G. Shkodrov at Rozhen.

Named in honor of Elisveta Bagryana \{1893-1991\}, the greatest Bulgarian poetess. Her lyric poetry seems to have developed outside literary schools, and she was the first in Bulgarian literature to give a bold portrait of women and their nature; her poems have been translated into more than 25 languages. Bagryana was a great admirer of astronomy; in 1984, she wrote: "Now, after outliving my 90th birthday, my only will is to see for a second time Halley's comet, whose appearance when I was 17 years old aroused my incessant thirst to reveal the mysteries of the vast Universe." Her wish was fulfilled. (M 19696)

\section{(4401) Aditi}

1985 TB. Discovered 1985 Oct. 14 by C. S. Shoemaker and E. M. Shoemaker at Palomar.

Aditi was an Indian goddess of the sky and the air. She was the mother of 33 gods and of the sun, and also the mother of the 12 Adityas, described in Vedic literature as the gods of the heavenly light. (M 17656)

\section{(4402) Tsunemori}

1987 DP. Discovered 1987 Feb. 25 by T. Niijima and T. Urata at Ojima.

Named for the Japanese military commander in the late Heian era, Taira-no Tsunemori (1125-1185), a son of Tadamori \{see planet (4374)\}. As the elder of the Heike after the dead of Kiyomori \{see planet (4375)\}, he made an effort to restore his family. However, he was beaten at the battle of Dannoura, and he drowned in the sea. (M 31023)

Name proposed by the second discoverer.

\section{(4403) Kuniharu}

1987 EA. Discovered 1987 Mar. 2 by Y. Oshima at Gekko.

Named for a sister observatory that also belongs to the International Foundation for Cultural Harmony. The Kuniharu Observatory was founded in 1958 in Okazaki, Aichi prefecture, and is also active in the local popularization of astronomy. (M 18307)

\section{(4404) Enirac}

1987 GG. Discovered 1987 Apr. 2 by A. Maury at Palomar.

Named in honor of the discoverer's spouse Carine, herself an amateur astronomer. Always wanting to share her interest in astronomy with others, she founded an astronomy club in Nice in 1978 and has presided over summer astronomy camps for teenagers during several subsequent summers. Married since 1982 and now the mother of two, she has long been and continues to be a support to her husband's activities. (M 16595)

The name is Carine spelled backwards. Otherwise there would exist the danger of confusion with planet (491) Carina.

\section{(4405) Otava}

1987 QD . Discovered 1987 Aug. 21 by Z. Vávrová at Kleť.

Named for a Czech river that has its confluence with the Vltava \{see planet (2123)\} river near the Zvíkov castle. The Otava was considered to bear both gold and pearls in ancient and medieval times. (M 34620)

\section{(4406) Mahler}

1987 YD $_{1}$. Discovered 1987 Dec. 22 by F. Börngen at Tautenburg.

Named in honor of the great Austrian composer, conductor and opera-director Gustav Mahler (1860- 
1911). Mahler's creative endeavor was concentrated mainly to ten daring and unusual symphonies, supplemented by some lieder-groups, e.g. the four-part cycle "Lieder eines fahrenden Gesellen" and the cycle "Kindertotenlieder". (M 16446)

\section{(4407) Taihaku}

$1988 \mathrm{TF}_{1}$. Discovered 1988 Oct. 13 by M. Koishikawa at Sendai.

Named for the southwest part of the city of Sendai \{see planet (3133)\}, a scenic recreation area known as Taihaku-ku in which interesting Old Stone Age relics have been discovered. In ancient times, Venus was called "Taihaku" in Japan, and folklore says that this area's Mt. Taihaku was built up by the fall of Venus. (M 19697)

\section{(4408) Zlatá Koruna}

$1988 \mathrm{TH}_{2}$. Discovered 1988 Oct. 4 by A. Mrkos at Klě́t.

Named for a Gothic monastery and a village in southern Bohemia east of Klet Mountain. The Cistercian monastery of the Holy Crown of Thorns was founded there by the Czech king Přemysl Otakar II in 1263. The name of Klet for the mountain was first mentioned in the monastery's thirteenth-century documents. There is now a literature museum at the monastery. (M 29670)

Name proposed by J. Tichá, M. Tichý and Z. Moravec.

\section{(4409) Kissling}

1989 MD. Discovered 1989 June 30 by A. C. Gilmore and P. M. Kilmartin at Lake Tekapo.

Warwick M. Kissling (1957- ) is an innovative applied mathematician. His computations have allowed the follow-up and recovery of several new minor planets. Like many New Zealanders, he is fond of clambering around mountains in his spare time. (M 40701)

\section{(4410) Kamuimintara}

1989 YA. Discovered 1989 Dec. 17 by S. Ueda and H. Kaneda at Kushiro.

Kamuimintara is the name given by the Ainu, Hokkaido's indigenous people, to Hokkaido's highest peak, Mt. Taisetsu. In the Ainu language the name means 'Playground of the Gods'. (M 22829)

Name proposed by J. Ueda.

\section{(4411) Kochibunkyo}

1990 AF. Discovered 1990 Jan. 3 by T. Seki at Geisei.

Named for the association of volunteers active in education, inaugurated in the city of Kochi in April 1948 , and which puts a great deal of effort into the popularization of astronomy. (M 25443)

\section{(4412) Chephren}

2535 P-L. Discovered 1960 Sept. 26 by C. J. van Houten and I. van Houten-Groeneveld at Palomar.

Chephren was a pharaoh of the old Egyptian kingdom. He reigned about 2500 B.C. and built the second largest pyramid near Giza \{see planet (5249)\}.
He is also known because of his monumental sphinx \{see also planet (896)\}. (M 18142)

\section{(4413) Mycerinos}

4020 P-L. Discovered 1960 Sept. 24 by C. J. van Houten and I. van Houten-Groeneveld at Palomar.

Mycerinos was pharaoh of the old Egyptian kingdom of the fourth dynasty. He reigned about 2500 B.C. and built the third largest pyramid near Giza s see planet (5249)\}. (M 18142)

Mycerinos is the Greek name of the Egyptian pharao Menkaure \{see also planet (4568)\}.

\section{(4414) Sesostris}

4153 P-L. Discovered 1960 Sept. 24 by C. J. van Houten and I. van Houten-Groeneveld at Palomar.

Sesostris was the name of three pharaohs of the old Egyptian kingdom (twelfth dynasty). They reigned about 1900 B.C. During Sesostris I (1971-1926 B.C.) Egyptian architecture had one of its high points, with buildings in Karnak and Heliopolis. (M 18142)

\section{(4415) Echnaton}

4237 P-L. Discovered 1960 Sept. 24 by C. J. van Houten and I. van Houten-Groeneveld at Palomar.

Echnaton was a pharaoh of the old Egyptian kingdom who reigned from 1375 to 1358 B.C. He started a religious reformation by replacing the worship of the traditional Egyptian gods by that of the single god Aten \{see planet (2062)\}. In his time Egyptian art was more colorful and more relaxed. (M 18142)

\section{(4416) Ramses}

4530 P-L. Discovered 1960 Sept. 24 by C. J. van Houten and I. van Houten-Groeneveld at Palomar.

Ramses II, also called Ramesses, was a pharaoh of the old Egyptian kingdom who reigned from 1332 to 1298 B.C. He made war with the Hittites in Asia Minor and built large temple complexes at Abu Simbel. Ramses was one of the first names that Champollion \{see planet (3414)\} could read by translation of the Egyptian hieroglyphs. (M 18142)

\section{(4417) Lecar}

1931 GC. Discovered 1931 Apr. 8 by K. Reinmuth at Heidelberg.

Named in honor of Myron Lecar (1930- ), astrophysicist in the Planetary Sciences division of the Harvard-Smithsonian Center for Astrophysics. Lecar's research covers the dynamics of both solar system and stellar bodies, and the large-scale structure of the universe. (M 22502)

Named by the Minor Planet Names Committee following a suggestion by members of the Planetary Sciences division.

\section{(4418) Fredfranklin}

1931 TR $_{1}$. Discovered 1931 Oct. 9 by K. Reinmuth at Heidelberg.

Named in honor of Fred Franklin (1932- ), astronomer in the Planetary Sciences division of 
the Harvard-Smithsonian Center for Astrophysics. Franklin's researches have covered chaos in the solar system, the rings of Saturn, and mutual phenomena of planetary satellites. (M 22502)

Name proposed by members of the Planetary Sciences division, the identifications for this object having been made by B. G. Marsden.

\section{(4419) Allancook}

1932 HD. Discovered 1932 Apr. 24 by K. Reinmuth at Heidelberg.

Named in honor of Allan F. Cook II (1922-1998), astrophysicist in the Planetary Sciences division of the Harvard-Smithsonian Center for Astrophysics, whose astronomical interests range from meteors and the earth's upper atmosphere, to Saturn's rings, to spectroscopy and photometry. (M 22502)

Named by the Minor Planet Names Committee following a suggestion by members of the Planetary Sciences division.

\section{(4420) Alandreev}

1936 PB. Discovered 1936 Aug. 15 by G. N. Neujmin at Simeis.

Aleksandr Fedorovich Andreev (1939- ), vicepresident of the Russian Academy of Sciences and director of the P. Kapitsa \{see planet (3437)\} Institute of Physical Problems in Moscow, is a specialist in the physics of low temperature and condensed matter. He predicted the so-called Andreev reflection effect. (M 41027)

\section{(4421) Kayor}

1942 AC. Discovered 1942 Jan. 14 by K. Reinmuth at Heidelberg.

Named by G. V. Williams in honor of his parents, Kay and Roy, for their support over the years. This minor planet was discovered on the same day that the former Miss Merriman was born. (M 21131)

\section{(4422) Jarre}

1942 UA. Discovered 1942 Oct. 17 by L. Boyer at Algiers.

Named in honor of the French composers Maurice (1924- ) and Jean-Michel Jarre (1949- ). Maurice studied composition at the Paris conservatoire, and wrote several music for concert works and boldly dramatic theatre music, before turning to film music, winning Oscars for his score to Lawrence of Arabia (1963) and for 'Lara's Theme' from Doctor Zhivago (1965). Jean-Michel abandoned his musical studies at the Conservatoire de Paris in 1967 to experiment with electronic music. His first commercial success was Oxygene (1977). Further successful recordings followed, and in 1981 he became the first Western rock artist to play concerts in China. Jean-Michel is best known for his spectacular live shows. (M 17031)

Name proposed by G. V. Williams, who made the principal identification involving this object.

\section{(4423) Golden}

1949 GH. Discovered 1949 Apr. 4 at the Goethe Link Observatory at Brooklyn, Indiana.

William T. Golden (1909- ), author-editor of books on science policy, has served as treasurer of the American Association for the Advancement of Science for more than 30 years. Original architect of the office of science advisor to the U.S. president, he also played a key role in establishing the National Science Foundation. (M 36944)

\section{(4424) Arkhipova}

1967 DB. Discovered 1967 Feb. 16 by T. M. Smirnova at Nauchnyj.

Named in honor of Irina Konstantinovna Arkhipova (1925- ), an outstanding representative of the Russian vocal school. For more than 30 years she was a soloist at the Bol'shoj Theatre and sang in many well-known opera houses around the world. In 1995 there will be a celebration of her career. A professor at the Moscow Conservatoire, she educated a constellation of outstanding singers. Arkhipova is an eminent public figure who established a special charitable fund. Since 1967 she has been chief judge of the M. I. Glinka \{see planet (2205)\} competition, and on several occasions she chaired the international jury for the P. I. Chajkovskij (Tchaikovsky) \{see planet (2266)\} vocal competition. (M 24916)

Name proposed by the Institute of Theoretical Astronomy.

\section{(4426) Roerich}

$1969 \mathrm{~TB}_{6}$. Discovered 1969 Oct. 15 by L. I. Chernykh at Nauchnyj.

Named in honor of the family of outstanding Russian figures of culture whose lives were closely connected with India: Nikolaj Konstantinovich Roerich (18741947), painter, writer, philosopher, archaeologist, public figure and enlightener; his wife Elena Ivanovna Roerich (1879-1955), participant in all his expeditions, writer, philosopher; their elder son Yurij Nikolaevich Roerich (1902-1960), scientist in oriental studies and philology; and their younger son, Svyatoslav Nikolaevich Roerich (1904-1993), painter and public figure. (M 22502)

\section{(4427) Burnashev}

1971 QP $_{1}$. Discovered 1971 Aug. 30 by T. M. Smirnova at Nauchnyj.

Named in honor of Vladislav Ivanovich Burnashev (1943- ), staff scientist at the Crimean Astrophysical Observatory and an expert in stellar photometry and spectrophotometry. The name also honors his wife, Bella Alekseevna Burnasheva (1944- ), former minor-planet observer on the staff of the Institute of Theoretical Astronomy. She is now a systems programer at the Crimean Astrophysical Observatory. (M 30475)

\section{(4428) Khotinok}

1977 SN. Discovered 1977 Sept. 18 by N. S. Chernykh at Nauchnyj. 
Named in honor of Roman L'vovich Khotinok, meteorite researcher in the Meteorite Committee of the Russian Academy of Sciences, who has investigated many sites of possible meteorite falls and has discovered more than 20 different meteorites that are now stored in the Moscow collection. (M 22502)

\section{(4429) Chinmoy}

1978 RJ $_{2}$. Discovered 1978 Sept. 12 by N. S. Chernykh at Nauchnyj.

Named in honor of Sri Chinmoy, Bengali poet, artist and philosopher, preacher of peace, who travels the world, inspiring peace-loving peoples with his music, poetry and works of art. (M 23352)

Name proposed by some Russian admirers of Sri Chinmoy.

\section{(4430) Govorukhin}

1978 SX $_{6}$. Discovered 1978 Sept. 26 by L. V. Zhuravleva at Nauchnyj.

Named in honor of the well-known Russian cinematic producer and playwright Stanislav Sergeevich Govorukhin (1936- ). (M 24122)

\section{(4431) Holeungholee}

1978 WU $_{14}$. Discovered 1978 Nov. 28 at the Purple Mountain Observatory at Nanking.

S. H. Ho, K.-K. Leung, T. Ho and Q.-W. Lee jointly established the Holeungholee Foundation in 1994 to reward high-level Chinese achievements in science and technology and to promote the further development of those achievements. (M 41027)

\section{(4432) McGraw-Hill}

$1981 \mathrm{ER}_{22}$. Discovered 1981 Mar. 2 by S. J. Bus at Siding Spring.

Named after the 1.3-m McGraw-Hill telescope located on the southwest ridge of Kitt Peak, Arizona, which was the site for the first physical observations for this minor planet. The telescope is operated by a consortium comprising the University of Michigan, Dartmouth College and the Massachusetts Institute of Technology. Originally erected at Stinchfield Woods near Dexter, Michigan, in July 1969, the telescope was moved to its current location in 1975 through the generous financial support of McGraw-Hill Incorporated and the Sloan Foundation. (M 19697)

Name proposed and citation provided by R. P. Binzel.

\section{(4433) Goldstone}

1981 QP. Discovered 1981 Aug. 30 by E. Bowell at Anderson Mesa.

Named for the Goldstone Deep Space Communications Complex in Southern California's Mojave Desert. Goldstone is part of the National Aeronautics and Space Administration's Deep Space Network, which is managed, technically directed and operated by the Jet Propulsion Laboratory of the California Institute of Technology. Since 1962, the DSN has played a critical role in NASA's exploration of the solar system using unmanned spacecraft. The radio antennas at Goldstone and at similar facilities near Canberra, Australia, and
Madrid, Spain, are used to receive spacecraft telemetry and to transmit commands to the spacecraft. The largest antenna at Goldstone, Deep Space Station 14, is also used for planetary radar astronomy. It was in 1968 that Goldstone observations of (1566) Icarus, carried out by R. M. Goldstein \{see planet (5393)\}, yielded the first detection of radar echoes from a minor planet. (M 16447)

Name suggested and citation provided by S. J. Ostro.

\section{(4434) Nikulin}

1981 RD $_{5}$. Discovered 1981 Sept. 8 by L. V. Zhuravleva at Nauchnyj.

Named in honor of Yurij Vladimirovich Nikulin (1921- ), a Russian circus artist, clown, film star. (M 24122)

\section{(4435) Holt}

$1983 \mathrm{AG}_{2}$. Discovered 1983 Jan. 13 by C. S. Shoemaker at Palomar.

Named for Henry E. Holt, planetary geologist with the U.S. Geological Survey and Northern Arizona University. As a member of the Surveyor and Apollo scientific teams, he investigated the detailed geology and photometric properties of the lunar surface. Since retiring from the Geological Survey, he has been a principal participant in the Palomar Asteroid and Comet Survey and is the discoverer or codiscoverer of six comets and numerous asteroids, including (4581) Asclepius, the numbered asteroid that has made the closest approach to the earth. (M 17656)

\section{(4437) Yaroshenko}

$1983 \mathrm{GA}_{2}$. Discovered 1983 Apr. 10 by L. I. Chernykh at Nauchnyj.

Named in memory of Nikolaj Aleksandrovich Yaroshenko (1846-1898), wellknown Russian painter, a member and one of the leaders of the nineteenthcentury Russian Society of Traveling Art Exhibitions. (M 18458)

\section{(4438) Sykes}

1983 WR. Discovered 1983 Nov. 29 by E. Bowell at Anderson Mesa.

Named in honor of Mark V. Sykes, planetary scientist at the Steward Observatory of the University of Arizona, Tucson. Sykes was the first to suggest that the dust bands discovered in data from the Infrared Astronomical Satellite (IRAS) \{see planet (3728)\} were due to the catastrophic disruptions of small asteroids and comets. He has also discovered several additional dust bands, a second type of dust trail, and identified parent comets responsible for some of the IRAS dust trails. (M 18458)

Citation provided by E. F. Tedesco at the request of the discoverer.

\section{(4439) Muroto}

1984 VA. Discovered 1984 Nov. 2 by T. Seki at Geisei.

Named for a small seaside city in the southeastern part of the Japanese island of Shikoku s see planet 
(4223)\}, famous as a sightseeing spot for the beautiful headland. (M 25443)

\section{(4440) Tchantchès}

1984 YV. Discovered 1984 Dec. 23 by F. Dossin at St. Michel.

Named in honor of the folklore character Tchantchès (Walloon dialect for François), the typical Walloon hero of the region of the discoverer. Tchantchès is obstinate but has a great heart. (M 33385)

\section{(4441) Toshie}

1985 BB. Discovered 1985 Jan. 26 by T. Seki at Geisei.

Named in memory of Toshie Seki, the discoverer's mother, who encouraged her son to hunt for comets. She died on the day this minor planet was discovered. (M 17657)

\section{(4442) Garcia}

$1985 \mathrm{RB}_{1}$. Discovered 1985 Sept. 14 by the Spacewatch at Kitt Peak.

Named in memory of Jerry Garcia (1942-1995), lead guitarist for the "Grateful Dead". He was also a superb banjo player and steel pedal guitar player. His recorded work embrace many styles, among them rock-and-roll, bluegrass and country, and experimental electronic music. Garcia and the Grateful Dead have also sought to preserve endangered and underappreciated music. Garcia was best known for his consummate musicianship and for live performance and improvisations. Those embracing Garcia's music have now spanned several generations, attesting to the quality and timelessness of his music. (M 25976)

Name proposed by T. Gehrels, following a suggestion by S. Radford. Citation prepared by E. Olszewski and S. Radford.

\section{(4446) Carolyn}

1985 TT. Discovered 1985 Oct. 15 by E. Bowell at Anderson Mesa.

Named in honor of Carolyn Spellmann Shoemaker, comet and asteroid discoverer. Shoemaker began searching for asteroids in 1980, using plates taken at the U.K. Schmidt Telescope at Siding Spring. She helped develop a new photographic survey program using the 0.46-m Schmidt camera at Palomar Mountain and a newly designed stereomicroscope, which greatly increased the efficiency of film scanning. In 1983 Shoemaker found her first near-earth asteroid, the Amor object (3199) Nefertiti, and later that year she found her first comet, 1983p. By February 1991 she had discovered 22 comets, at a rate of about one per 100 hours of scanning, and for discoveries recognized in the names of the comets she thus surpassed the tally of W. R. Brooks \{see planet (2773)\} and moved into the all-time second place behind J.-L. Pons. Shoemaker already holds the record for finding new periodic comets: 9 by early 1991. (M 18458)

Citation prepared by D. H. Levy and J. Mueller at the request of the discoverer.

\section{(4447) Kirov}

$1985 \mathrm{VE}_{1}$. Discovered 1985 Nov. 7 by E. Bowell at Anderson Mesa.

Named in honor of the Kirov Ballet and State Theater of St. Petersburg (formerly Leningrad). Directly descended from the Russian Imperial Ballet of St. Petersburg, the Kirov has always preserved the highest values of classical dance. In the early nineteenth century, an extraordinary synthesis of French grace, Italian virtuosity and Russian temperament produced within this school a standard of artistry admired by the world and imitated by generations of dancers. In the late nineteenth century, the spectacular choreography of Marius Petipa, particularly in his Sleeping Beauty and Swan Lake, made St. Petersburg the capital of the ballet world. The Kirov has produced some of the greatest dancers, including Tamara Karsavina, Anna Pavlova \{see planet (3055)\} and Vaslav Nijinsky. Ever a company of supreme elegance and impeccable taste, the Kirov performs with grace, technical ease, sensitivity and refined dramatic intensity. (M 17979)

Name suggested and citation provided by J. M. Ostro and S. J. Ostro.

\section{(4448) Phildavis}

1986 EO. Discovered 1986 Mar. 5 by C. S. Shoemaker and E. M. Shoemaker at Palomar.

Named for Philip A. Davis, planetary geologist with the U.S. Geological Survey and chief of the Branch of Astrogeology since 1989. Davis has worked on the global geochemistry and petrology of the moon and the geology of Mars, Venus and Arabia. He is known especially for the techniques he has developed for the extraction of quantitative topographic information from spacecraft images and for analysing global patterns of geological and geophysical data. (M 17657)

\section{(4449) Sobinov}

$1987 \mathrm{RX}_{3}$. Discovered 1987 Sept. 3 by L. I. Chernykh at Nauchnyj.

Named in memory of Leonid Vital'evich Sobinov (1872-1934), a remarkable Russian singer, leading tenor soloist of the Bolshoj Theatre in Moscow. (M 18459)

\section{(4450) Pan}

1987 SY. Discovered 1987 Sept. 25 by C. S. Shoemaker and E. M. Shoemaker at Palomar.

Originally a shepherd god of Arcady, Pan developed into a hunter, fisherman and warrior. He was worshipped at Athens after the Battle of Marathon \{see planet (4356)\}, where he aided the Athenians by spreading panic through the Persian armies. He has been represented in art as a horned half-man, half goat. (M 17657)

The name Pan has also been given to the satellite Saturn XVIII.

(4451) Grieve

1988 JJ. Discovered 1988 May 9 by C. S. Shoemaker and E. M. Shoemaker at Palomar. 
Named for Richard A. F. Grieve, geologist with the Geological Survey of Canada and chief of their geophysical surveys. Grieve is a leading investigator of impact craters on the earth and moon. He maintains the global census of recognized terrestrial impact structures and has spearheaded the effort to obtain reliable ages for these structures. He also has been a leader in classifying the impacting bodies on the basis of siderophile element abundance patterns in impact melt rocks. (M 4451)

\section{(4452) Ullacharles}

1988 RN. Discovered 1988 Sept. 7 by P. Jensen at Brorfelde.

Ulla Augustesen (1914-1990) and Charles Augustesen (1909-1987) were the parents of Brorfelde \{see planet (3309)\} observer Karl Augustesen. (M 39640)

\section{(4453) Bornholm}

1988 VC. Discovered 1988 Nov. 3 by P. Jensen at Brorfelde.

The beautiful and famous Danish rocky island of Bornholm is situated in the southern part of the Baltic Sea. (M 39640)

\section{(4454) Kumiko}

1988 VW. Discovered 1988 Nov. 2 by S. Ueda and H. Kaneda at Kushiro.

Named in honor of Kumiko Kaneda (1951- ) , wife of the second discoverer. (M 19337)

\section{(4455) Ruriko}

1988 XA. Discovered 1988 Dec. 2 by S. Ueda and H. Kaneda at Kushiro.

Named in honor of Ruriko Ueda (1957- ), wife of the first discoverer. (M 19337)

\section{(4456) Mawson}

1989 OG. Discovered 1989 July 27 by R. H. McNaught at Siding Spring.

Named in memory of Sir Douglas Mawson (18821958), Australian geologist and Antarctic explorer. After graduating in engineering from the University of Sydney in 1902, Mawson gained valuable geological field experience on an expedition to the New Hebrides, returning to Sydney to take a geology degree in 1905 . From that year onward he was associated with the University of Adelaide, being professor of geology from 1921 to 1952, making pioneering studies of uranium ores and, later, the Precambrian rocks of the Flinders Ranges. During 1907-1909 he took part in the British Antarctic Expedition led by Shackleton, and from 1911 to 1914 he led the Australasian Antarctic Expedition; on the latter was found the "Adelie Land" meteorite, the first to be discovered on the Antarctic continent. The Home of the Blizzard, his account of that expedition and his near-death, has become a classic. Throughout his career he promoted active fieldwork and continued his involvement in Antarctic exploration; after his retirement he was involved in planning for the IGY. (M 17979)
Named by the discoverer and endorsed by D. I. Steel, who, along with R. G. Ferguson, provided additional citation material.

\section{(4457) van Gogh}

1989 RU. Discovered 1989 Sept. 3 by E. W. Elst at St. Michel.

Named in memory of the famous Dutch painter Vincent van Gogh (1853-1890) on the 100th anniversary of his death in Auvers sur Oise by his own hand. Deeply concerned with human suffering, van Gogh went in 1879 to the Borinage, a poor mining district in southern Belgium, to do some missionary work. It was there that he discovered his true vocation, not as a preacher but as a painter. This first great spiritual crisis in his life is testified by his early dark realistic pictures, which bear a social-critical message. In 1886 he went to Paris, where he met the "pointillists". In his later works color acquired a special function, providing a vision that influenced the upcoming expressionistic generation in the twentieth century. During his period in the Provence his landscapes expressed more and more his inner emotions. The colors become extremely vivid, although he was always in search of rest and harmony. (M 15595)

Citation prepared by Kristina Leterme, at the request of the discoverer.

\section{(4458) Oizumi}

1990 BY. Discovered 1990 Jan. 21 by Y. Kushida and O. Muramatsu at Yatsugatake.

Named for the beautiful village in which Yatsugatake \{see planet (4033)\} South Base Observatory is located. The name means "great spring". The village, surrounded by forest and located at the southern end of the Yatsugatake-renpo mountain range in central Japan, has many springs, the greatest of which produces 7 million liters of pure water per day. (M 17657)

\section{(4459) Nusamaibashi}

$1990 \mathrm{BP}_{2}$. Discovered 1990 Jan. 30 by M. Matsuyama and K. Watanabe at Kushiro.

Named for the bridge spanning the Kushiro \{see planet (4096)\} river and connecting the northern and southern parts of Kushiro city. When it was first built in 1889 the bridge was named Aihoku Bashi and was the longest in Hokkaido \{see planet (3720)\}. The bridge has been rebuilt five times, most recently in 1976, and it now has a length of $124 \mathrm{~m}$ and a width of $34 \mathrm{~m}$. The elegant Nusamai Bashi is known for its statues, by four well-known Japanese sculptors, of female representations of the seasons. (M 16885) Name suggested by the first discoverer.

\section{(4460) Bihoro}

1990 DS. Discovered 1990 Feb. 28 by K. Endate and K. Watanabe at Kitami.

Named for the city, home of the first discoverer, at the junction of the Bihoro and Abashiri ssee planet (4263)\} rivers, the latter running near the Kitami \{see planet (3785)\} station. Some $30 \mathrm{~km}$ from the sea of 
Okhotsk \{see planet (4042)\}, the city has a population of approximately 26,000, and its main industries are beets and potatoes. The Bihoro pass, $525 \mathrm{~m}$ above sea level, is in the Akan \{see planet (4584)\} national park $20 \mathrm{~km}$ from the nearest town and is renowned for its grand panorama that includes the Kussharo lake. (M 16595)

\section{(4461) Sayama}

1990 EL. Discovered 1990 Mar. 5 by A. Sugie at Taga.

Named in honor of a city located in the Musashino hills in the center of the Kantou \{see planet (3249)\} plain. In the southeastern part of Saitama prefecture, Sayama is on the Iruma river and famous for producing good Japanese green tea. Since 1954 Sayama has developed with Irumagawa city and some villages into a new industrial area and as a residential area for the commuters of Tokyo. Sayama observes and promotes various traditional cultures and is noted in particular for its Star Festival ("Tanabata"), when the main streets are beautifully decorated with bamboo trees. (M 17031)

\section{(4462) Vaughan}

$1952 \mathrm{HJ}_{2}$. Discovered 1952 Apr. 24 at the McDonald Observatory at Fort Davis.

Named in honor of Curtis T. Vaughan, Jr., a lifelong resident, prominent businessman, and community leader of San Antonio, Texas. His early interests in science led to a physics degree at Harvard, but the need to direct a family enterprise precluded science as a career. Nevertheless, his interests and activities have remained strongly scientific, especially astronomical, as he built an outstanding collection of early astronomical instruments and constructed one of the finest private observatories in the United States, with now a fully computer-controlled $0.40-\mathrm{m}$ reflector. For more than 20 years his uniquely strong encouragement and support, including financial, of astronomy at the University of Texas have played a major role in helping the astronomy program there grow into one of the preeminent such programs in the country. (M 20521)

Name proposed by the late Harlan J. Smith.

\section{(4463) Marschwarzschild}

$1954 \mathrm{UO}_{2}$. Discovered 1954 Oct. 28 at the Goethe Link Observatory at Brooklyn, Indiana.

The son of Karl Schwarzschild \{see planet (837)\}, Martin was a leader in research on the structure and evolution of stars. He was the first to use a hot-air balloon (Project Stratoscope, 1957) to carry a telescope into the stratosphere to take cleaner pictures of the sun. (M 41934)

The name was suggested by F. K. Edmondson.

\section{(4464) Vulcano}

1966 TE. Discovered 1966 Oct. 11 by N. S. Chernykh at Nauchnyj.

Named for one of the Aeolian Islands, site of the "original" volcano, a splendid place where the workshop
"Beginning the Spaceguard Survey" was held by the IAU Working Group on Near-Earth Objects during 1995 Sept. 18-22. (M 26762)

\section{(4465) Rodita}

1969 TD $_{5}$. Discovered 1969 Oct. 14 by B. A. Burnasheva at Nauchnyj.

Named in memory of the Soviet art critic Tat'yana Mikhajlovna Rodina (1914-1989). She was the author of Russian Theatre Art at the Beginning of the 19th Century and Blok and Russian Theatre of the Beginning of the 20th Century, as well as of numerous papers in the Great Soviet Encyclopedia and the Theatre Encyclopedia. (M 28089)

\section{(4466) Abai}

1971 SX $_{1}$. Discovered 1971 Sept. 23 at the Crimean Astrophysical Observatory at Nauchnyj.

Named in honor of Abai Kunanbaev (1845-1904), Kazakh poet, philosopher and enlightener, founder of Kazakh literature, and translator of the works of I. A. Krylov, A. S. Pushkin \{see planet (2208)\} and M. Yu. Lermontov \{see planet (2222)\}. (M 23352)

\section{(4467) Kaidanovskij}

$1975 \mathrm{VN}_{2}$. Discovered 1975 Nov. 2 by T. M. Smirnova at Nauchnyj.

Named in honor of Naum L'vovich Kaidanovskij (1907- ), a pioneer of radio astronomy, who began research in solar and galactic radio astronomy as early as 1948. In 1955 he co-founded the radio astronomy department at Pulkovo Observatory, the first in Russia. Kaidanovskij is well known for his designs of radio-telescopes and he was principal designer of the largest radio telescope, RATAN-600, at Zelenchukskaya. (M 30475)

Name suggested by the Institute of Applied Astronomy.

\section{(4468) Pogrebetskij}

1976 SZ $_{3}$. Discovered 1976 Sept. 24 by N. S. Chernykh at Nauchnyj.

Named in memory of Mikhail Timofeevich Pogrebetskij (1892-1956), well-known Ukrainian traveller and alpinist. He was the first to climb Khan Tengri, one of the highest mountains of Tien Shan. (M 23352)

The name was suggested by the Alpinist Club of the Crimea.

\section{(4469) Utting}

$1978 \mathrm{PS}_{4}$. Discovered 1978 Aug. 1 by P. Jekabsons at Bickley.

Named in honor of Muriel Janet Utting (1914- ), the Perth Observatory's honorary historian since 1985. Her researches include a history of the observatory since its foundation to the present day, and these will form theses for higher degrees at Murdoch University in 1994 and 1996, the observatory's centenary year. (M 22829) 


\section{(4470) Sergeev-Censkij}

1978 QP $_{1}$. Discovered 1978 Aug. 31 by N. S. Chernykh at Nauchnyj.

Named in memory of Sergej Nikolaevich SergeevCenskij (real name Sergeev) (1875-1958), famous Russian writer. He lived and worked in the Crimea and was the author of a multi-volume work on Russian history. (M 23352)

\section{(4471) Graculus}

1978 VB. Discovered 1978 Nov. 8 by P. Wild at Zimmerwald.

Pyrrhocorax graculus is the Alpine species of choughs. In great flocks they are sometimes a bit of a nuisance, but to watch their masterly elegant flight, especially in turbulent air, is a great delight. (M 34340)

\section{(4472) Navashin}

1980 TY 14 . Discovered 1980 Oct. 15 by N. S. Chernykh at Nauchnyj.

Named in honor of Mikhail Sergeevich Navashin (1896-1973), prominent Soviet cytologist, who was one of the first to undertake detailed research of human chromosomes. An outstanding amateur astronomer, Navashin was the father of amateur telescope making in the Soviet Union. He made several telescopes and wrote several books to aid amateur observers and telescope makers. (M 23352)

\section{(4473) Sears}

$1981 \mathrm{DE}_{2}$. Discovered 1981 Feb. 28 by S. J. Bus at Siding Spring.

A professor at the University of Arkansas, Derek Sears (1948- ) has championed thermoluminescence as a tool to unravel the geologic and thermal histories of meteorites. His stewardship of the journal Meteoritics and Planetary Science has placed it at the forefront in its field. (M 41381)

\section{(4474) Proust}

$1981 \mathrm{QZ}_{2}$. Discovered 1981 Aug. 24 by H. Debehogne at La Silla.

Named in honor of Dominique Proust, astrophysicist at the Meudon Observatory who works on observational cosmology. By means of extensive spectroscopic observations he has carried out dynamical studies of clusters of galaxies, large-scale structures and highredshift objects. He is also a church and concert organist, whose public and broadcast performances include the compositions of astronomer-musicians such as Galileo and Herschel \{see planets (697) and (2000), respectively\}. The name of this minor planet also honors the French writer Marcel Proust \{1871-1922\}. (M 21131)

\section{(4475) Voitkevich}

1982 UQ5. Discovered 1982 Oct. 20 by L. G. Karachkina at Nauchnyj.

Named in honor of George Vitol'dovich Voitkevich (1920- ), the 1967 Karpiński prizewinner for his outstanding geological research. He is the author of more than 190 publications on geochemistry, geophysics and cosmochemistry, including 32 books on different problems in geology. (M 22247)

\section{(4476) Bernstein}

1983 DE. Discovered 1983 Feb. 19 by E. Bowell at Anderson Mesa.

Named in memory of Leonard Bernstein (1918-1990), American composer, conductor, pianist, educator, and author. A colorful, multifaceted musician, Bernstein wrote music in many forms: symphonies, ballet music, operas, sacred music, chamber music and musicals, the last including West Side Story, an innovative recasting of Romeo and Juliet in terms of New York street gang rivalries. From 1958 to 1969, Bernstein was chief conductor of the New York Philharmonic Orchestra; during this tenure he devised a series of brilliant televised lecture demonstrations. More recently, he conducted orchestras worldwide and became particularly celebrated for his interpretation of the music of Haydn, Brahms and Mahler \{these composers are not only immortalized by their music but also by minor planets (3941), (1818), and (4406)\}. (M 17466)

\section{(4478) Blanco}

$1984 \mathrm{HG}_{1}$. Discovered 1984 Apr. 23 by W. Ferreri at La Silla.

Named in honor of Carlo Blanco, professor of astronomy at Catania University. Known for his intense activity in the observation and analysis of the mutual eclipses of the major satellites of Jupiter and Saturn, he is also involved in international campaigns devoted to observations of minor planets and the Pluto-Charon system. Furthermore, he has contributed to the study of solar-type stellar activity, in particular to analyses of stellar chromospheres and coronas. (M 17224)

\section{(4480) Nikitibotania}

1985 QM $_{4}$. Discovered 1985 Aug. 24 by N. S. Chernykh at Nauchnyj.

Named for the Nikitian State Botanical Gardens, located in southern Crimea and founded in 1812 by the well-known Russian botanist C. C. Steven. (M 23352)

\section{(4481) Herbelin}

1985 RR. Discovered 1985 Sept. 14 by E. Bowell at Anderson Mesa.

Named in honor of Claude Herbelin (1931- ), of Neuchâtel, on the occasion of his 65th birthday (1996 Dec. 13). A friend of the discoverer and brother of the discoverer's companion Anne-Marie Malotki \{see planet (3667)\}, Herbelin is an electrotechnical engineer by profession. He is also an enthusiastic telecommunications specialist (frequency standards, chronometry) and mountain skier and hiker. (M 28089)

Citation provided by S. Herbelin and C. GassmannHerbelin. 
(4482) Frèrebasile

1986 RB. Discovered 1986 Sept. 1 by A. Maury at Palomar.

Named in honor of Nicolas Dupont, in religious life Frère Basile \{1905-1999\} of the Frères des Ecoles Chrétiennes, professor of mathematics and amateur astronomer. Soon after World War II he was assigned to teach cosmography at the Institution Saint Joseph in Nancy. Many students considered the subject too dry and it was subsequently removed from French curricula. To interest his puplis further by giving them "hand-on" experience with the sky, Frère Basile designed and built with a small group a 26-cm telescope and observatory, founded the Cercle Orion and in 1965 co-founded the Société Lorraine d'Astronomie. Since then he has organized many trips to several European observatories and at the age of 84 continues to teach astronomy, observe, arrange astronomy camps in the summer and publish the Echo d'Orion. Several professional astronomers owe him their vocations. Frère Basile is a laureate of the Société Astronomique de France, a recipient of the gold medal of the city of Nancy, and he received the Academic Palms in 1989. (M 17224)

Citation written by $\mathrm{J}$. Blondelet at the request of the discoverer.

\section{(4483) Petöfi}

$1986 \mathrm{RC}_{2}$. Discovered 1986 Sept. 9 by L. G. Karachkina at Nauchnyj.

Named in memory of Shandor Petöfi (1823-1849), outstanding Hungarian poet and public figure. (M 22247)

The name for this Hungaria-type planet is proposed by V. A. Shor.

\section{(4484) Sif}

1987 DD. Discovered 1987 Feb. 25 by P. Jensen and

K. Augustesen at Brorfelde.

Named after Tor's wife, who after Odin's \{see planet (3989)\} wife, is the highest ranked of the Asynjur, the goddesses of the Aesir. She is much pursued by the other gods, though they fear the anger of her strong husband. (M 22502)

\section{(4485) Radonezhskij}

1987 QQ $_{11}$. Discovered 1987 Aug. 27 by L. I. Chernykh at Nauchnyj.

Named in honor of Reverend Sergij Radonezhskij (c. 1321-1391), prominent figure in the Russian Church, highly respected and honored person who was considered in Russia a protector of learners and learning. He actively supported Moscow Prince Dmitrij Donskoj in the policy of the consolidation of Russian principalities and in the national struggle for liberation against the Tartar-Mongolian yoke. (M 22502)

\section{(4486) Mithra}

1987 SB. Discovered 1987 Sept. 22 by E. W. Elst and V. G. Shkodrov at Rozhen.
Named for the Indo-Iranian god of the heavenly light that led to mithraism, one of the last oriental mystery cults to reach the west, where it became the chief rival to and opponent of christianity. In Babylonia, Chaldaean astrology was incorporated, while Greek art, religion and philosophy provided the models for mithraic iconography and the mithraic mysteries. The two religions have much in common: a divine lord by whom man was assured of elevation, a sacramental meal and a ritual of baptism. Many ruins of mithraic sanctuaries are still to be found in Europe, near Frankfurt and Heidelberg, for example. This minor planet is of Apollo type, and in Asia Minor around 330 B.C. the god Mithra was identified with the god Apollo \{see planet (1862)\}. (M 16885)

Citation prepared by E. W. Elst.

\section{(4487) Pocahontas}

1987 UA. Discovered 1987 Oct. 17 by C. S. Shoemaker and E. M. Shoemaker at Palomar.

An Indian princess and daughter of Powhatan, celebrated sachem and chief of the Chickahominy tribe of Virginia, Pocahontas (c. 1595-1617) developed a warm friendship for the English colonists and rendered them many services, including the rescue of their leader, Captain John Smith, from her father. Her marriage to John Rolfe pioneered the peace between the colonists and the native Americans. (M 17657)

\section{(4488) Tokitada}

1987 UK. Discovered 1987 Oct. 21 by K. Suzuki and T. Urata at Toyota.

Named for Taira-no Tokitada (1130-1189), a Japanese military commander in the late Heian era who was the uncle of Taira-no Kiyomori \{see planet (4375)\}. After the battle of Dannoura, Tokitada was sent into exile to the Noto peninsula, where Percival Lowell \{see planet (1886)\} visited in 1889 and wrote "Noto, an unexplored corner of Japan". (M 19697)

\section{(4490) Bambery}

1988 ND. Discovered 1988 July 14 by E. F. Helin and B. Roman at Palomar.

Named in honor of Raymond J. Bambery, chemist and image-processing scientist at the Jet Propulsion Laboratory with a great interest in all aspects of astronomy. He has spent several sessions at Palomar helping search for near-earth minor planets and has been instrumental in upgrading measuring and data reduction techniques. (M 17224)

\section{(4491) Otaru}

1988 RP. Discovered 1988 Sept. 7 by K. Endate and K. Watanabe at Kitami.

Named for a city of population 165,000, located in Hokkaido \{see planet (3720)\} some $30 \mathrm{~km}$ west of Sapporo \{see planet (3473)\} and overlooking the sea of Japan. Once a prosperous port, its trade has declined in recent years, but beautiful streets and houses, an 
old canal, warehouses and other stone buildings still remain. This combination makes Otaru a romantic city, and nowadays its main industry is artistic glassware. (M 16886)

Name proposed by the second discoverer, following a suggestion by T. Hurukawa, president of the Otaru-Hoshiono-Kai group of amateur astronomers.

\section{(4492) Debussy}

1988 SH. Discovered 1988 Sept. 17 by E. W. Elst at St. Michel.

Named in memory of Claude Debussy (18621918), famous French impressionistic composer, known particularly for his Clair de Lune, Jardins sous la Pluie and Feux d'Artifice, and more generally for his brilliant suites for the piano, such as Estampes, Bergamasque and Images. While his music is the spontaneous expression, the reflection and the image of sensation, it reaches the innermost part of one's subconscious. This effect is obtained by using free harmonies, different scales (from other cultures, e.g., in "Jardins sous la Pluie") and daring mixtures of tones. Debussy was a fervent admirer of Chopin ssee planet (3784)\}, even to the extent of also composing two books of twelve Préludes and an album of Etudes. (M 17031)

\section{(4494) Marimo}

$1988 \mathrm{TK}_{1}$. Discovered 1988 Oct. 13 by S. Ueda and H. Kaneda at Kushiro.

Named for spherically-shaped green algae that inhabit Lake Akan \{see planet (4584)\} in Hokkaido, Japan. A protected species since 1894, Marimo can grow as big as a baby's head: a Marimo with a diameter of $6 \mathrm{~cm}$ is estimated to be between 150 and 200 years old. (M 20521)

\section{(4496) Kamimachi}

$1988 \mathrm{XM}_{1}$. Discovered 1988 Dec. 9 by T. Seki at Geisei.

Named for the street on which the discoverer lives and from where he discovered six comets, including the sungrazer 1965 VIII (Ikeya-Seki). (M 19337)

\section{(4497) Taguchi}

$1989 \mathrm{AE}_{1}$. Discovered 1989 Jan. 4 by K. Endate and K. Watanabe at Kitami.

Named in honor of Takeo Taguchi (1950- ), famous polisher of telescope mirrors and supporter of the development of amateur astronomy in Japan. He is chief of the optics polishing room at Takahashi Seisakujo, Ltd., which makes excellent mirrors, including the one in the astrocamera Ipusiron with which this discovery was made. (M 16886)

\section{(4498) Shinkoyama}

1989 AG $_{1}$. Discovered 1989 Jan. 5 by T. Seki at Geisei.

Named in honor of the solar physicist Shin Koyama, who has served as a professor at Kagawa University for 30 years. Born in Kyoto in 1927, Koyama has retired from public life in March 1991. (M 18001)

This planet was first (MPC 17980) accidentally named Koyama. This name, however, was already assigned to planet (3383).

\section{(4499) Davidallen}

$1989 \mathrm{AO}_{3}$. Discovered 1989 Jan. 4 by R. H. McNaught at Siding Spring.

Named in honor of David \{Anthony Allen \{19461994\}, staff astronomer at the Anglo-Australian Observatory (AAO). Following his Ph.D. from Cambridge University, Allen held research fellowships at the Hale Observatories and the Royal Greenwich Observatory. In 1975 he became one of the "founding members" of the scientific staff of the AAO, initially as a research fellow. He has remained as one of the pillars of that establishment ever since, having become the only permanently-appointed research astronomer. Notable for his extraordinarily wide interests across all astronomy, from the solar system to observational cosmology, his main contributions have been in the field of infrared instrumentation and its applications. He developed the radiometric method for determining asteroid diameters and recently discovered several new infrared "windows" in the atmosphere of Venus. Allen is also a leading figure in public education in astronomy, contributing to many radio and TV programs and the author of many popular articles and several books. (M 17980)

Citation prepared by R. D. Cannon at the request of the discoverer.

Obituaries published in Publ. Astron. Soc. Aust., Vol. 12, No. 1, p. 139-141 (1995); Observatory, Vol. 114 , No. 1122, p. 250-252 (1994); J. Br. Astron. Assoc., Vol. 104, No. 5, p. 259 (1994); Q.J.R. Astron. Soc., Vol. 36, No. 2, p. 173-174 (1995).

\section{(4500) Pascal}

1989 CL. Discovered 1989 Feb. 3 by S. Ueda and H. Kaneda at Kushiro.

Named by the Minor Planet Names Committee for the French mathematician and philosopher Blaise Pascal (1623-1662). (M 19337)

Pascal is also honored by a lunar crater.

\section{(4501) Eurypylos}

1989 CJ $_{3}$. Discovered 1989 Feb. 4 by E. W. Elst at La Silla.

Named for the legendary king of Thessalon, who directed forty vessels at the siege of Troy. He was hit by an arrow from Paris \{see planet (3317)\} but was rescued by Patroclus $\{$ see planet (617)\}. (M 17031)

\section{(4502) Elizabethann}

1989 KG. Discovered 1989 May 29 by H. E. Holt at Palomar.

Named in honor of Elizabeth Ann Holt, daughter of the discoverer. (M 18459) 


\section{(4503) Cleobulus}

1989 WM. Discovered 1989 Nov. 28 by C. S. Shoemaker at Palomar.

Named for Cleobulus (fl. c. 560 B.C.), one of the Seven Sages of Greece. A native and tyrant of Lindus in Rhodes, Cleobulus was renowned for the wisdom of his sayings, the beauty of his lyric poetry and his skill with riddles. (M 17467)

Name proposed by the discoverer, following a suggestion by K. Williams, who provided material for the citation, and G. V. Williams, who solved the riddle of the identification involving this object.

\section{(4504) Jenkinson}

1989 YO. Discovered 1989 Dec. 21 by R. H. McNaught at Siding Spring.

Named for Nora Jenkinson, Scottish astronomy educator. In the town of Haddington, near Edinburgh, she conducted weekly classes in astronomy for youngsters for the past 22 years (missing only six weeks because of severe weather). In her retirement, she has expanded the classes, and her boundless cheerfulness and enthusiasm are communicated to all those whom she teaches, many of them having gone on to study astronomy at a university. (M 29143)

\section{(4505) Okamura}

$1990 \mathrm{DV}_{1}$. Discovered 1990 Feb. 20 by T. Seki at Geisei.

Named in honor of Keiichiro Okamura (1926- ), a retired junior high school teacher who now gives guidance in astronomy to visitors to the Geisei Observatory. (M 27126)

\section{(4506) Hendrie}

1990 FJ. Discovered 1990 Mar. 24 by B. G. W. Manning at Stakenbridge.

Named in honor of Michael J. Hendrie, an English amateur with a longstanding interest in astronomy and skilled in the construction of his own instruments. Hendrie has constructed several observatories, most recently one housing a $0.25 \mathrm{~m}$ folded reflector for astrometric comet photography. A co-discoverer of periodic comet Crommelin in 1956, he began systematic comet photography in 1952, an interest that stimulated him to take an important role in promoting professional-amateur collaboration in Britain during the International Halley Watch. He served as director of the Comet Section of the British Astronomical Association for ten years. (M 17225)

Name proposed by the discoverer and endorsed by B. G. Marsden. Citation material provided by S. A. Mitton.

\section{(4508) Takatsuki}

$1990 \mathrm{FG}_{1}$. Discovered 1990 Mar. 27 by K. Endate and

K. Watanabe at Kitami.

Named in honor of Yukihiro Takatsuki (1952- ), a member of the editorial staff of the astronomical periodical Tenmon Guide. He continues to make excellent astronomical tools and materials and is an advocate of the use of the Schmidt telescope as an astrocamera. The discoverers have introduced such instruments to observing stations at Tsubetsu and Sapporo \{see planets (4845) and (3473), respectively\}, and both were used to observe this minor planet. (M 16886)

\section{(4509) Gorbatskij}

A917 SG. Discovered 1917 Sept. 23 by S. I. Belyavskij at Simeis.

Vitaly Gerasimovich Gorbatskij (1920- ) ), professor at St. Petersburg University, is well known for his works in the field of cosmic gas dynamics. He put forward the mechanism of disk accretion, interpreted the emission spectra of variable stars and proposed an explanation for "hot spots" in systems of binary stars. (M 40701)

\section{(4510) Shawna}

1930 XK. Discovered 1930 Dec. 13 by C. W. Tombaugh at Flagstaff.

Named in honor of Shawna Willoughby, granddaughter of the discoverer. (M 18308)

\section{(4511) Rembrandt}

$1935 \mathrm{SP}_{1}$. Discovered 1935 Sept. 28 by H. van Gent at Johannesburg.

Named after Rembrandt Harmensz van Rijn, the greatest Dutch painter of the 17th century, born in 1606 in Leiden. He died in Amsterdam in 1669. (M 20159)

\section{(4512) Sinuhe}

1939 BM. Discovered 1939 Jan. 20 by Y. Väisälä at Turku.

Named for Mika Waltari's \{see planet (4266) world-renowned historical novel Sinuhe, egyptiläinen. (M 18459)

\section{(4513) Louvre}

$1971 \mathrm{QW}_{1}$. Discovered 1971 Aug. 30 by T. M. Smirnova at Nauchnyj.

Named in honor of the stately architectural ensemble in Paris, the former residence of French kings, now one of the most famous museums and largest collections of works of art in the world. (M 29143)

Name suggested by M. B. Piotrovsky.

\section{(4514) Vilen}

1972 HX. Discovered 1972 Apr. 19 by T. M. Smirnova at Nauchnyj.

Named in honor of Vilen Valentinovich Nesterov (1935- ), head of the Astrometry Department of the Sternberg Astronomical Institute in Moscow, respected for his work in astrometry, on the rotation of the earth and the analysis of observations of artificial and natural satellites. He is one of scientific leaders of the space-borne astrometric project 'Lomonosov'. 
His monograph, Common Astrometry, written with V. V. Podobed \{see planet (3311)\}, is used extensively by professional astronomers, students and amateurs. (M 30475)

Name suggested by the Institute of Theoretical Astronomy.

\section{(4515) Khrennikov}

1973 SD $_{6}$. Discovered 1973 Sept. 28 by N. S. Chernykh at Nauchnyj.

Named in honor of well-known Soviet composer Tikhon Nikolaevich Khrennikov (1913- ), who wrote many operas, operettas, ballets, symphony scores, and music for theater and films. He is a professor at the Moscow Conservatory and led the Union of Soviet Composers for many years. (M 34340)

\section{(4516) Pugovkin}

$1973 \mathrm{SN}_{6}$. Discovered 1973 Sept. 28 by N. S. Chernykh at Nauchnyj.

Named in honor of Mikhail Ivanovich Pugovkin (1923- ), outstanding and popular cinema actor who has appeared in almost 200 films since 1941. He is an honorary citizen of the Crimean city of Yalta \{see planet (1475)\} and also has the title honorary artist of Russia. (M 30095)

\section{(4517) Ralpharvey}

1975 SV. Discovered 1975 Sept. 30 by S. J. Bus at Palomar.

An assistant professor at Case Western University, Ralph Harvey (1960- ) leads the Antarctic Search for Meteorites, a program that has provided invaluable clues to the physical and chemical history of the solar system. His research interests focus on igneous processes that formed the martian meteorites. (M 41381)

\section{(4518) Raikin}

$1976 \mathrm{GP}_{3}$. Discovered 1976 Apr. 1 by N. S. Chernykh at Nauchnyj.

Named in memory of Arkadij Isaakovich Raikin (1911-1987), outstanding actor and performer of satirical sketches and monologues, master of quick transformations, founder and leader of the State Theater of Miniature. (M 23352)

\section{(4519) Voronezh}

$1976 \mathrm{YO}_{4}$. Discovered 1976 Dec. 18 by N. S. Chernykh at Nauchnyj.

Named for the Russian city, founded before 1177. A large industrial and cultural center, Voronezh was the site where Peter the First built the Azov Fleet in 16951696, and the birthplace of the well-known Russian poets A. V. Kol'tsov (1809-1842) and I. S. Nikitin (1824-1861). (M 23352)

\section{(4520) Dovzhenko}

1977 QJ J $_{3}$. Discovered 1977 Aug. 22 by N. S. Chernykh at Nauchnyj.

Named in honor of Aleksandr Petrovich Dovzhenko (1894-1956), well-known Ukrainian cinema producer and writer, one of the founders of Soviet cinematography. (M 23352)

\section{(4521) Akimov}

$1979 \mathrm{FU}_{2}$. Discovered 1979 Mar. 29 by N. S. Chernykh at Nauchnyj.

Named in honor of Nikolaj Pavlovich Akimov (19011968), prominent Soviet theater producer and painter, an art advisor at the Leningrad Theatre of Comedy for many years. (M 23352)

\section{(4522) Britastra}

1980 BM. Discovered 1980 Jan. 22 by E. Bowell at Anderson Mesa.

Named to commemorate the centenary of the founding of the British Astronomical Association. Intended to be a less technical counterpart of the Royal Astronomical Society, the BAA was established with the objectives: "The association of Observers, especially the possessors of small telescopes, for mutual help, and their organization in the work of Astronomical observation. The circulation of current Astronomical information. The encouragement of a popular interest in Astronomy." (M 17225)

\section{(4523) MIT}

$1981 \mathrm{DM}_{1}$. Discovered 1981 Feb. 28 by S. J. Bus at Siding Spring.

Since its founding in 1861, the Massachusetts Institute of Technology has become one of the world's preeminent universities. Emphasizing both education and research, MIT provides a stimulating environment in which real-world problems are addressed through advancements in science and technology. (M 40701)

\section{(4524) Barklajdetolli}

$1981 \mathrm{RV}_{4}$. Discovered 1981 Sept. 8 by L. V. Zhuravleva at Nauchnyj.

Named in memory of Mikhail Bogdanovich Barklaj de Tolli (Barclay de Tolly; 1761-1818), general field marshal, hero of Russian patriotic war of 1812. His family tree had roots in Scotland. During 1810-1812 he was military minister of Russia, and for two months during Napoleon's invasion he was commander-in-chief of the Russian armies. (M 34620)

\section{(4526) Konko}

$1982 \mathrm{KN}_{1}$. Discovered 1982 May 22 by H. Kosai and K. Hurukawa at Kiso.

Named for a city in the area where the first discoverer grew up. Before the Okayama s see planet (2084)\} Astrophysical Observatory was established, the Tokyo Astronomical Observatory operated a small station in Konko for the observation of variable stars. (M 17980)

\section{(4527) Schoenberg}

1982 OK. Discovered 1982 July 24 by E. Bowell at Anderson Mesa.

Named for Arnold Schönberg (1874-1951), Austrian composer. One of the twentieth century's seminal 
composers, Schönberg developed the dodecaphonic system of composition. He was founder of the so-called Second Viennese School, whose followers included Alban Berg and Anton Webern \{see, respectively, planets (4528) and (4529)\}. (M 16886)

\section{(4528) Berg}

1983 PP. Discovered 1983 Aug. 13 by E. Bowell at Anderson Mesa.

Named for Alban Berg (1885-1935), Austrian composer. A pupil of Arnold Schönberg \{see planet (4527)\}, Berg did not produce a great quantity of music, but his two operas are pinnacles of twentieth-century music. (M 16886)

\section{(4529) Webern}

1984 ED. Discovered 1984 Mar. 1 by E. Bowell at Anderson Mesa.

Named for Anton Webern (1883-1945), Austrian composer. Associated with Schönberg and Berg \{see planets (4527) and (4528)\}, Webern refined the use of serialism in music. His mature compositions are terse and concentrated miniatures. (M 16886)

\section{(4530) Smoluchowski}

1984 EP. Discovered 1984 Mar. 1 by E. Bowell at Anderson Mesa.

Named in honor of Roman Smoluchowski, solid state physicist and planetary astronomer. A native of Austria, Smoluchowski became head of the physics and metals sections of the Warsaw Institute of Technology. In 1940 he was able to reach the U.S., where he did research with the General Electric Company, the Carnegie Institute of Technology and as professor of solid state physics and director of the solid-state laboratory at Princeton University. Retiring in 1978 from Princeton, he moved to the University of Texas at Austin and continued his work on solids in astrophysics. During his long career Smoluchowski has served on or headed a large number of commissions, particularly those of the National Research Council and the Space Science Board concerning physical sciences, solids and magnetism. For the past several decades he has been one of the founders and primary developers of the field of the solid state behavior of matter in astrophysical situations. He has made important contributions to the fields of planetary interiors, dynamics of rings, asteroids and comets and the structure and thermal properties of cometary nuclei. (M 17980)

Name suggested by W. D. Cochran, and citation provided by Cochran and H. J. Smith.

\section{(4531) Asaro}

1985 FC. Discovered 1985 Mar. 20 by C. S. Shoemaker and E. M. Shoemaker at Palomar.

Named for Frank Asaro, nuclear chemist at the Lawrence Berkeley Laboratory of the University of California. With his colleagues Luis and Walter Alvarez \{see planet (3581)\} and Helen Michel, he discovered the global noble metal anomaly at the Cretaceous-Tertiary boundary, which is now accepted as evidence for impact of a large comet or asteroid. He also discovered noble metal anomalies in late Eocene and Miocene strata that are thought to indicate other major impacts related to the mass extinction of species. (M 17657)

\section{(4532) Copland}

1985 GM $_{1}$. Discovered 1985 Apr. 15 by E. Bowell at Anderson Mesa.

Named in memory of American composer Aaron Copland (1900-1990). Although his earliest works show the influence of European composers, most of his later compositions make inimitable use of American folk tunes and Jazz melodies. Copland's quintessential ballet scores "Billy the Kid", "Rodeo" and "Apalachian Spring" have long been concert-hall staples, and his "Fanfare for the Common Man", which is also part of the Third Symphony, represents one of the world's most recognizable melodies. (M 18142)

Name suggested and citation provided, in part, by D. J. Tholen.

\section{(4533) Orth}

1986 EL. Discovered 1986 Mar. 7 by C. S. Shoemaker and E. M. Shoemaker at Palomar.

Named for Charles J. Orth, nuclear chemist at the Los Alamos National Laboratory, New Mexico. Renowned for his precise analyses for elements by neutron activation methods, Orth has engaged in a world-wide search for evidence of impact of extraterrestrial bodies with the earth at the times of mass extinction of species. He discovered noble metal anomalies at the Cretaceous-Tertiary boundary in continental sedimentary deposits of North America and also near the Frasnian-Fammenian boundary in the Upper Devonian and the Cenomanian-Turonian boundary in the Upper Cretaceous. (M 17658)

\section{(4534) Rimskij-Korsakov}

$1986 \mathrm{PV}_{4}$. Discovered 1986 Aug. 6 by N. S. Chernykh at Nauchnyj.

Named in honor of Nikolaj Andreevich RimskijKorsakov (1844-1908), famous Russian composer. (M 23352)

\section{(4537) Valgrirasp}

$1987 \mathrm{RR}_{3}$. Discovered 1987 Sept. 2 by L. I. Chernykh at Nauchnyj.

Named in honor of the Soviet writer Valentin Grigorjevich Rasputin. (M 22502)

\section{(4539) Miyagino}

$1988 \mathrm{VU}_{1}$. Discovered 1988 Nov. 8 by M. Koishikawa at Sendai.

Named for the eastern part of the city of Sendai \{see planet (3133)\}, known as "Miyagino" since the seventh century. This area, where the Sendai International Port is located, sustains industry and agriculture. (M 19697) 


\section{(4540) Oriani}

$1988 \mathrm{VY}_{1}$. Discovered 1988 Nov. 6 at the Osservatorio San Vittore at Bologna.

Named in memory of Barnaba Oriani (1752-1832), famous Italian astronomer and director of the Brera Observatory, Milan, from 1802 to 1832 . Oriani studied the orbits of the planets, particularly Uranus, for which he published orbital elements and tables. A friend of Piazzi \{see planet (1000)\}, he was involved with the early work on Ceres and published analytical formulae for the calculation of perturbations by Jupiter on objects with highly-inclined orbits. Oriani also inspired Plana and Carlini to carry out their research on the motion of the moon. (M 17981)

\section{(4541) Mizuno}

1989 AF. Discovered 1989 Jan. 1 by K. Suzuki and T. Furuta at Toyota.

Named in honor of Yoshikane Mizuno (1954- ), who has discovered many minor planets at the Kani \{see planet (4265)\} Observatory. (M 26762)

\section{(4542) Mossotti}

1989 BO. Discovered 1989 Jan. 30 at the Osservatorio San Vittore at Bologna.

Named in memory of Ottaviano Fabrizio Mossotti (1791-1863), who studied at the Brera Observatory and then went as an exile to Geneva and London. In 1827 he was named engineer astronomer and professor of calculus and physics at the University of Buenos Aires. He then went to the University of Corfu (1838-1841) and in 1848 became professor of celestial mechanics and geodesy at the University of Pisa, where he remained until his death. He is celebrated for his memoir Nuova analisi del problema di determinazione delle orbite and for his books Nuova teoria degli strumenti ottici, Lezioni di Fisica Matematica and Meccanica Razionale. (M 17981)

\section{(4543) Phoinix}

1989 CQ$_{1}$. Discovered 1989 Feb. 2 by C. S. Shoemaker at Palomar.

Named for a wise old commander of the Greeks in the Trojan war. Phoinix, who had no sons, raised Achilles $\{$ see planet (588)\} as if he were his own son. When Achilles refused to fight for the Greeks, Phoinix pleaded with Achilles, "Many a time you wet my shirt, hiccuping wine-bubbles in distress, when you were small". (M 18143)

Name and citation provided by $\mathrm{R}$. Preston at the request of the discoverer.

\section{(4544) Xanthus}

1989 FB. Discovered 1989 Mar. 31 by H. E. Holt and N. G. Thomas at Palomar.

This is another Greek name for Apollo \{see planet (1862)\} meaning the 'Fair'; as such, Xanthus delighted in high places, such as the peaks of high mountains and wavelapped promontaries in the seas. (M 18459)
(4546) Franck

$1990 \mathrm{EW}_{2}$. Discovered 1990 Mar. 2 by E. W. Elst at La Silla.

Named in memory of the great Belgian composer César Franck (1822-1890), well known for his piano and organ works and beautiful symphony in D minor. His ancestry included members of the famous school of Wallonian painters, and his admiration for them influenced his way of composing - as a "musician painter". After only a year's study in Paris he received "grand prix d'honneur" for piano, and a few years later the first prize for fugue, the art of which in France he restored following a lengthy period of discredit. For organ he achieved only the second prize, because the jury was not inclined to accept his genial and daring way of combining the theme of the fugue with the free theme cyclic principle. Appointed organist at St. Clothilde in 1859, he became a master in the art of improvisation. (M 17467)

Name endorsed by J. Vanvinckenroye.

\section{(4547) Massachusetts}

1990 KP. Discovered 1990 May 16 by K. Watanabe and K. Endate at Sapporo.

Named for the U.S. state in which the Minor Planet Center is located. In 1876, the Sapporo School of Agriculture (now Hokkaido University), located in what was then a very undeveloped region, invited William S. Clark, head of the Massachusetts University of Agriculture, to teach them about American agriculture and technology, which at that time was far more advanced. Before leaving to return to the United States, Clark uttered the pioneer spirit of Hokkaido's people. On 1990 Feb. 7 Hokkaido \{see planet (3720)\} and Massachusetts established a sister-state relationship. (M 19337)

\section{(4548) Wielen}

2538 P-L. Discovered 1960 Sept. 24 by C. J. van Houten and I. van Houten-Groeneveld at Palomar.

Named in honor of Roland Wielen (1938- ), German astronomer, director of the Astronomisches Rechen-Institut in Heidelberg, professor of theoretical astronomy at Heidelberg University since 1985, and from 1978 to 1985 professor of astronomy and astrophysics at the Berlin Technical University. His main work covers the fields of the stellar dynamics (the luminosity function of nearby stars, kinematics and dynamics of galaxies, dynamical evolution of star clusters and of clusters of galaxies) and astrometry. $\mathrm{He}$ has also worked on problems of galactic structure and served as president of IAU Commission 33 from 1982 to 1985 . (M 18143)

Name proposed and citation prepared by L.D.Schmadel.

\section{(4549) Burkhardt}

1276 T-2. Discovered 1973 Sept. 29 by C. J. van Houten and I. van Houten-Groeneveld at Palomar.

Named in honor of Gernot Burkhardt (1951- ), astronomer at the Astronomisches Rechen-Institut 
in Heidelberg. Burkhardt is an expert in computer hardware and a skilled programmer whose work is close to indispensable to almost all of his colleagues. He also serves as an editor of Astronomy and Astrophysics Abstracts and is responsible for the rather complex data handling procedures. (M 18143)

Name proposed and citation prepared by L.D.Schmadel.

\section{(4550) Royclarke}

$1977 \mathrm{HH}_{1}$. Discovered 1977 Apr. 24 by S. J. Bus at Palomar.

Roy Clarke, Jr. (1925- ) served as curator of the U.S. National Meteorite Collection at the Smithsonian Institution for nearly 30 years. Clarke's research interests have focused on the structures of iron meteorites and have included the classification and study of Antarctic iron meteorites. (M 41381)

\section{(4551) Cochran}

1979 MC. Discovered 1979 June 28 by E. Bowell at Anderson Mesa.

Named in honor of William D. Cochran and Anita L. Cochran, husband and wife astronomers at the University of Texas at Austin. William's broad range of research has concerned planetary (including cometary) atmospheres, Raman scattering, stellar radial velocity variations and motions in stellar chromospheres and photospheres. Using a spectroscopic radial velocity meter, he is currently surveying several dozen stars to search for reflex motions (as small as about $2 \mathrm{~m} / \mathrm{s}$ ) that would indicate the presence of planetary companions. Anita is a specialist in the chemistry of cometary comae and in particular how the chemistry changes with changing heliocentric distance. An assiduous observer, she has used spatially resolved spectra to help transform the photometry of comets into a quantitative discipline. She has also developed sophisticated cometary models to understand how the observed atoms, molecules, and radicals are related to the larger parent molecules present in cometary nuclei. Anita is currently a team member of the Imaging Science Subsystem of the Comet Rendezvous-Asteroid Flyby mission. (M 18459)

\section{(4552) Nabelek}

1980 JC. Discovered 1980 May 11 by A. Mrkos at Klě̌.

Named in honor of Jan Nabelek (1908- ), now the most senior member of a group of teachers in Nove Mesto, Moravia, at the beginning of World War II. (M 26424)

\section{(4553) Doncampbell}

1982 RH. Discovered 1982 Sept. 15 by E. Bowell at Anderson Mesa.

Named in honor of Donald B. Campbell, planetary scientist at Cornell University, on the occasion of his 50th birthday. Campbell is responsible for the development of the Arecibo Observatory's high-power radar system and the considerable success of the Arecibo radar astronomy program during the past quarter century. He has carried out radar observations of every class of solar system target during this period. $\mathrm{He}$ is the discoverer of a large number of Venus surface features whose geologic character is now being clarified by the Magellan radar. Campbell's contributions to small-body astronomy include the first radar ranging to an asteroid ((433) Eros in 1975) and observations that revealed the existence of large-particle clouds around comets. (M 20159)

Name suggested and citation written by S. J. Ostro.

\section{(4554) Fanynka}

1986 UT. Discovered 1986 Oct. 28 by A. Mrkos at Kleť.

Named in memory of Frantiska ("Fanynka") Burian (1911-1980), associated with the discoverer during the difficult times at the beginning of World War II. (M 26424)

Name endorsed by J. Nabelek.

\section{(4556) Gumilyov}

1987 QW 10 . Discovered 1987 Aug. 27 by L. G. Karachkina at Nauchnyj.

Named in memory of Nikolaj Stepanovich Gumilyov (1886-1921), famous poet and dramatist. He was one of the founders of acmeism, a poetic tendency that was popular among the Russian intelligentsia at the beginning of the current century. (M 20837)

\section{(4557) Mika}

1987 XD. Discovered 1987 Dec. 14 by M. Yanai and K. Watanabe at Kitami.

Named in honor of Mika Watanabe (1963- ), wife of the second discoverer. (M 20160)

\section{(4558) Janesick}

1988 NF. Discovered 1988 July 12 by A. Maury and J. Mueller at Palomar.

Named in honor of James R. Janesick of the Jet Propulsion Laboratory. Janesick has been instrumental in the development of CCDs for astronomy and, of equal importance, in the education of astronomers in the use of these devices and of industry in establishing requirements for good scientific imagers. His contributions have ranged from making the detectors useful in the blue and ultraviolet to the development of techniques for excellent charge transfer at very low signal levels, of amplification methods with sub-electron noise and of procedures to avoid damaging effects in high-energy radiation. (M 19337)

Citation written by J. E. Gunn at the request of the first discoverer. Name endorsed by E. F. Helin.

\section{(4559) Strauss}

$1989 \mathrm{AP}_{6}$. Discovered 1989 Jan. 11 by F. Börngen at Tautenburg.

Named in memory of the Austrian composer Johann Strauss (1825-1899), who represented Viennese dance music at its zenith. The leading master of Viennese operettas (Die Fledermaus, Zigeunerbaron, etc.), he was also the creator of immortal waltzes, such as the $A n$ 
der schönen blauen Donau (Blue Danube), Geschichten aus dem Wiener Wald (Tales of the Vienna Woods) and Kaiserwalzer (Kaiser Waltz). (M 17031)

\section{(4560) Klyuchevskij}

1976 YD $_{2}$. Discovered 1976 Dec. 16 by L. I. Chernykh at Nauchnyj.

Named in memory of Vasilij Osipovich Klyuchevskij (1841-1911), a famous Russian historian. (M 18459)

\section{(4561) Lemeshev}

1978 RY $_{5}$. Discovered 1978 Sept. 13 by N. S. Chernykh at Nauchnyj.

Named in honor of Sergej Yakovlevich Lemeshev (1902-1977), outstanding Russian opera-singer, artist of the Bolshoi Theatre in Moscow for many years. (M 23352)

\section{(4563) Kahnia}

1980 OG. Discovered 1980 July 17 by E. Bowell at Anderson Mesa.

Named in honor of Franz D. Kahn, professor of astronomy and head of the department of astronomy at the University of Manchester. Kahn has made important contributions to many areas of astrophysics, including studies of $\mathrm{H}$ II regions, supernovae and cosmical gas dynamics, and he has shown great interest in and support for research on comets and minor planets at Manchester. (M 19338)

Name proposed and citation prepared by G. J. Hahn.

\section{(4564) Clayton}

$1981 \mathrm{ET}_{16}$. Discovered 1981 Mar. 6 by S. J. Bus at Siding Spring.

As a professor at the University of Chicago, Robert Clayton (1930- ) has pioneered the use of oxygen isotope compositions in understanding nebular and asteroidal processes. His discovery of isotopic anomalies in some chondritic meteorites established that presolar materials survived solar system formation. (M 41381)

\section{(4565) Grossman}

$1981 \mathrm{EZ}_{17}$. Discovered 1981 Mar. 2 by S. J. Bus at Siding Spring.

Chairman of the Department of Geophysical Sciences at the University of Chicago, Lawrence Grossman (1946-

) has spent his career studying calcium-aluminum inclusions (CAIs) in carbonaceous chondrites. He was among the first to propose that these minerals condensed from gases in the early solar system. (M 41381)

\section{(4566) Chaokuangpiu}

$1981 \mathrm{WM}_{4}$. Discovered 1981 Nov. 27 at the Purple Mountain Observatory at Nanking.

Named in honor of Kuang-piu Chao, consulting professor at Tsinghua University and Zhejiang University. For many years, he made remarkable contributions to the development of Chinese educational and cultural programs. (M 32788)

\section{(4567) Bečvár̆}

$1982 \mathrm{SO}_{1}$. Discovered 1982 Sept. 17 by M. Mahrová at Klět.

Named in memory of the Czech astronomer Antonín Bečvár (1901-1965), founder and first director of the Skalnaté Pleso \{see planet (2619)\} Observatory in Slovakia. Bečváŕ made observations of comets, meteors and the solar photosphere, but he is best known as the author of Atlas Coeli and the more detailed Atlases Eclipticalis, Borealis and Australis. (M 21956)

Bečvář is also honored by a lunar crater.

\section{(4568) Menkaure}

$1983 \mathrm{RY}_{3}$. Discovered 1983 Sept. 2 by N. G. Thomas at Anderson Mesa.

Menkaure (c. 2530 B.C.), the son of Chephren \{see planet (4412)\}, reigned for 18 years and built the third and smallest of the three pyramids at Giza s see planet (5249)\}. His mortuary temple was finished by his successor Shepseskaf and contained some of the finest sculptures of the pyramid age. (M 26929)

Pharao Menkaure is named in Greek Mycerinos \{see planet (4413)\}.

\section{(4569) Baerbel}

1985 GV $_{1}$. Discovered 1985 Apr. 15 by C. S. Shoemaker and E. M. Shoemaker at Palomar.

Named for Baerbel K. Lucchitta, planetary geologist with the U.S. Geological Survey. She is a leading investigator of the geology of Mars and the satellites Europa and Ganymede. She is especially well known for her work on the effects of landslides and ice movement on Mars and on mapping the ice cap and the flow of ice in Antarctica. (M 17658)

\section{(4570) Runcorn}

1985 PR. Discovered 1985 Aug. 14 by E. Bowell at Anderson Mesa.

Named in memory of Stanley Keith Runcorn (1922-1995), British geophysicist. Runcorn's research centered on the magnetic properties of rocks. He used their paleomagnetic signatures to make an important contribution to the emerging theory of plate tectonics, and he also studied the magnetism of the moon, convection in planetary interiors, and geomagnetic polarity reversals. For many years head of the department of physics at the University of Newcastle-upon-Tyne, Runcorn was celebrated for his organization of his NATO-sponsored international scientific discussion meetings. (M 28089)

Obituaries published in Nature, Vol. 379, No. 6561, p. 119 (1996); Q.J.R. Astron. Soc., Vol. 37, No. 3, p. $463-465$ (1996).

\section{(4571) Grumiaux}

$1985 \mathrm{RY}_{3}$. Discovered 1985 Sept. 8 by H. Debehogne at La Silla.

Named in memory of Arthur Grumiaux (1921-1986), Belgian violinist who studied at the conservatories of Charleroi and Brussels. After winning the Vieuxtemps 
Prize in 1939 he went to Paris to study with Georges Enesco. Of particular brilliance are his recordings of the Mozart and Beethoven sonatas with Clara Haskil at the piano and of Bach's sonatas and partitas for unaccompanied violin. \{The great composers mentioned are all on the minor planet sky - see planets (1034), (1815), and (1814), respectively.\} (M 19338; E. Goffin)

Name proposed in consultation with E. Goffin, who found the identifications involving this minor planet.

\section{(4572) Brage}

1986 RF. Discovered 1986 Sept. 8 by P. Jensen and K. Augustesen at Brorfelde.

Named after the god of poetry and music in Norse mythology, husband of Idun \{see planet (176)\} and son and principal counsellor of Odin \{see planet (3989)\}. (M 22502)

\section{(4573) Piešťany}

$1986 \mathrm{TP}_{6}$. Discovered 1986 Oct. 5 by M. Antal at Piwnice.

Named for the city located on the river Váh in the middle Považie region of western Slovakia, $70 \mathrm{~km}$ northwest of Bratislava \{see planet (4018)\}. Piešťany is the home of the discoverer and many generations of his ancestors, as well as the site of a famous spa. Evidence of settlement at Pieštany dates back to the Paleolithic era. (M 27126)

\section{(4574) Yoshinaka}

1986 YB. Discovered 1986 Dec. 20 by T. Niijima and T. Urata at Ojima.

Named for Kiso Yoshinaka (1154-1184), the Japanese military commander in the late Heian era. He was a first cousin of Minamoto Yoritomo \{see planet (3902)\}. Once Yoshinaka broke the Taira forces and invaded Kyoto, then capital of Japan, and he was called "General Asahi, the rising sun". (M 19697)

\section{(4575) Broman}

$1987 \mathrm{ME}_{1}$. Discovered 1987 June 26 by E. F. Helin at Palomar.

Named for Brian P. Roman, astronomer, chef extraordinaire and humorist, in recognition for his diligence and dedication in the pursuit of nearearth minor planets. His participation in the planetcrossing asteroid survey at Palomar has been a major contribution to its continuing success. This particular object was discovered on his birthday. (M 17225) Name endorsed by K. Lawrence and J. Alu.

\section{(4577) Chikako}

1988 WG. Discovered 1988 Nov. 30 by Y. Kushida and M. Inoue at Yatsugatake.

Named in honor of Chikako Mihashi (1950- ), who has for many years worked for the advancement of astronomical education in Japan. Her support greatly contributed to the "Astro Village" at Yatsugatake \{see planet (4033)\} South Base Observatory. The
"Astro Village" was established for the purpose of astronomical education for children. (M 17658)

\section{(4578) Kurashiki}

1988 XL $_{1}$. Discovered 1988 Dec. 7 by T. Seki at Geisei

Named for a beautiful city on the shore of the Seto inland sea in western Japan. Minoru Honda (1917-1990) \{see planet (3904)\}, discoverer of 12 comets and 12 novae, carried out work at the Kurashiki Observatory from 1950 until his death. The city is also the home of the Ohara art museum, one of the most famous of such museums in Japan. (M 17658)

\section{(4579) Puccini}

$1989 \mathrm{AT}_{6}$. Discovered 1989 Jan. 11 by F. Börngen at Tautenburg.

Named in memory of the Italian composer Giacomo Puccini (1858-1924), whose magnificent operas La Bohème, Tosca, Madame Butterfly and Turandot have received the highest appreciation in the music world \{see also planet (530)\}. (M 17981)

\section{(4580) Child}

1989 EF. Discovered 1989 Mar. 4 by E. F. Helin at Palomar.

Named in honor of Jack B. Child, software engineer at the Jet Propulsion Laboratory, Asteroid Project director of the World Space Foundation, and past president of the Orange County Astronomers. His generous helpfulness over the years has been greatly appreciated. He has played a very important role in introducing team members to the Palomar planetcrossing asteroid survey project. (M 17225)

Name endorsed by R. L. Staehle.

\section{(4581) Asclepius}

1989 FC. Discovered 1989 Mar. 31 by H. E. Holt and N. G. Thomas at Palomar.

Named for the Greek god of healing and medicine, son of Apollo by Coronis \{see planets (1862) and (158)\}. Physician to the Argonauts, many of whom he restored to life, he was killed by Zeus \{see planet (5731)\} with a thunderbolt for attempting to resuscitate Orion, who had been murdered by Artemis \{see planet (105)\}, Apollo's twin sister. For avenging Asclepius' murder by killing the Cyclops who had made the thunderbolt, Apollo was banished by Zeus. (M 18459)

\section{(4582) Hank}

1989 FW. Discovered 1989 Mar. 31 by H. E. Holt and N. G. Thomas at Palomar.

Named in honor of Henry Reid Holt, son of the first discoverer. (M 18460)

\section{(4584) Akan}

1990 FA. Discovered 1990 Mar. 16 by M. Matsuyama and K. Watanabe at Kushiro.

Named for an extensive national park in eastern Hokkaido \{see planet (3720)\}. Designated a national park in 1934, Akan has an area of 905 square km, 
within which are located the three large lakes Akan, Mashu \{see planet (4126)\} and Kussyaro, as well as the volcanic mountains Meakandake, Oakandake and Masyudake. (M 19338)

\section{(4585) Ainonai}

1990 KQ. Discovered 1990 May 16 by K. Endate and K. Watanabe at Kitami.

Named for a small town (population less than 3,000), situated $10 \mathrm{~km}$ west of Kitami in eastern Hokkaido \{see planets (3785) and (3720)\}. (M 19338)

\section{(4586) Gunvor}

6047 P-L. Discovered 1960 Sept. 24 by C. J. van Houten and I. van Houten-Groeneveld at Palomar.

Named in honor of Mrs. Gunvor Ulla Marie OllongrenLundgren (1942- ), Swedish-born wife of Dutch astronomer and mathematician Alexander Ollongren. She has recently helped provide explanations for several Scandinavian names of minor planets. (M 18143)

\section{(4587) Rees}

3239 T-2. Discovered 1973 Sept. 30 by C. J. van Houten and I. van Houten-Groeneveld at Palomar.

Named in honor of Martin J. Rees (1942- ）, English astronomer, professor of astronomy at the University of Cambridge and director of the Institute of Astronomy. His main research covers galactic evolution and related problems. (M 18143)

Name proposed by J. H. Oort.

\section{(4589) McDowell}

1933 OB. Discovered 1933 July 24 by K. Reinmuth at Heidelberg.

Named in honor of Jonathan Christopher McDowell (1960- ), astrophysicist, space enthusiast and feminist activist. His astrophysical interests include theoretical studies of background light and quasars. He shares his encyclopedic knowledge of spaceflight with the world by regularly releasing an electronic space newsletter. (M 22502)

Citation written by A. Prestwich at the request of B. G. Marsden and G. V. Williams, who appreciate Jonathan's assistance in trying to identify $1991 \mathrm{VG}$ with manmade space debris. Identifications for this object were made by C. M. Bardwell.

\section{(4590) Dimashchegolev}

1968 OG $_{1}$. Discovered 1968 July 25 by G. A. Plyugin and $\mathrm{Yu}$. A. Belyaev at Cerro El Roble.

Dimitrij Evgen'evich Shchegolev (1928-1988) was an astronomer at the Pulkovo Observatory known for his work on satellite geodesy and stellar spectrophotometry. He was chief of the Experimental Astronomy Department and worked at Pulkovo for 35 years. (M 43042)

The name was suggested by the Pulkovo Observatory.

\section{(4591) Bryantsev}

1975 VZ. Discovered 1975 Nov. 1 by T. M. Smirnova at Nauchnyj.

Named in memory of Aleksandr Aleksandrovich Bryantsev (1883-1961), producer, People's artist of the USSR and the founder of the Theater for Young Audiences in Petrograd. He staged 48 plays, laying down the techniques of children's theater production. (M 30475)

Named at the request of the staff of the St. Petersburg Theater of Young Audiences.

\section{(4592) Alkissia}

1979 SQ 11 . Discovered 1979 Sept. 24 by N. S. Chernykh at Nauchnyj.

Named in honor of Aleksej Alekseevich Kisselev (1927- ), astronomer at the Pulkovo Astronomical Observatory, skilled observer of double stars and leader in the field of photographic astrometry of planets and satellites. He has devised new methods of astrometric plate reduction and of orbit determination. His comprehensive treatise on photographic astrometry is a standard reference for all observers at the observatories of the former Soviet Union. After World War II, Kisselev spent seven years in prison as a victim of political repression. (M 30095)

\section{(4593) Reipurth}

$1980 \mathrm{FV}_{1}$. Discovered 1980 Mar. 16 by C.-I. Lagerkvist at La Silla.

Named in honor of Bo Reipurth, staff astronomer at the European Southern Observatory in charge of the Schmidt telescope. He is mainly working on stellar formation and related problems, but he also shows a very keen interest in meteorites and has a fine collection of them. (M 20521)

\section{(4594) Dashkova}

$1980 \mathrm{KR}_{1}$. Discovered 1980 May 17 by L. I. Chernykh at Nauchnyj.

Named in honor of princess Ekaterina Romanovna Dashkova (1744-1810), one of the most educated women in Russia of her time, well-known figure in Russian culture, director of the St. Petersburg Academy of Sciences and president of the Russian Academy during 1783-1796. (M 22502)

\section{(4595) Prinz}

$1981 \mathrm{EZ}_{2}$. Discovered 1981 Mar. 2 by S. J. Bus at Siding Spring.

Martin (Marty) Prinz (1931- ） is a long-time curator of the meteorite collection at the American Museum of Natural History in New York. Prinz has worked on a wide range of meteorite types and associated geologic processes and is perhaps best known for his work on silicate inclusions in iron meteorites. (M 41381)

\section{(4597) Consolmagno}

$1983 \mathrm{UA}_{1}$. Discovered 1983 Oct. 30 by S. J. Bus at Palomar. 
Through experimental petrology, Guy Consolmagno (1952- ) studied the origins of eucritic meteorites. As the curator of the Vatican meteorite collection, Guy's more recent efforts have focused on determining the densities and porosities of meteorites and making comparisons with the densities of minor planets. (M 41381)

\section{(4598) Coradini}

$1985 \mathrm{PG}_{1}$. Discovered 1985 Aug. 15 by E. Bowell at Anderson Mesa.

Named in honor of sister and brother Angioletta and Marcello Coradini, who have very actively promoted the development of planetary sciences in Europe, particularly in Italy, during the past twenty years. At the beginning of her scientific career, Angioletta carried out theoretical work on impact processes on planetary surfaces. Later, she studied the formation of planetesimals and the origin of satellite systems. Currently at the Istituto di Astrofisica Spaziale, she is involved in a number of proposed space missions. Marcello, also an IAS member but currently at the European Space Agency, has worked on Mars, participating in the Viking Lander Imaging Team, and he has carried out laboratory experiments on hypervelocity impacts. He was involved in the exploration of Halley's Comet as a co-investigator of the Giotto Multicolor Camera Team. As a member of the ESA scientific directorate, he is contributing to both the development of the European community of planetary scientists and to planetary exploration in general. (M 18460)

Citation provided by M. Fulchignoni at the request of the discoverer. Name endorsed by A. W. Harris.

\section{(4601) Ludkewycz}

1986 LB. Discovered 1986 June 3 by M. Rudnyk at Palomar.

Named in honor of Romana Ludkewycz, mother of the discoverer. Her unending support of her son's interest in astronomy has been a constant source of inspiration since his childhood. Associated with the Palomar planet-crossing asteroid program during 1985-1987, he is currently involved in JPL's Planetary Image Facility. (M 17467)

\section{(4602) Heudier}

1986 UD $_{3}$. Discovered 1986 Oct. 28 by the CERGA at Caussols.

Named in honor of Jean-Louis Heudier, astronomer in charge of the operations of the Schmidt telescope at Calern with which this object was discovered. Having initially gained experience in wide-field photography with the Antares satellite-tracking camera at the Observatoire de Nice, he played a crucial role in the development of the Schmidt at Calern and in convincing the French authorities to invest in modern photographic techniques. Under his leadership there were several discoveries of minor planets and supernovae. He has served as secretary and president of the IAU working group on photographic techniques. An authority on the history of astronomy, which he teaches at the University of Nice, he has always been active in the popularization of astronomy, serving in particular as the leading force behind the "Astrorama" center for public observations in the heights of Nice. (M 17981) Citation provided by C. Pollas and A. Maury.

\section{(4603) Bertaud}

$1986 \mathrm{WM}_{3}$. Discovered 1986 Nov. 25 by C. Pollas at Caussols.

Named in honor of Charles Bertaud, under whose leadership at Meudon the discoverer began his astronomical work. Well known as an observer of comets, supernovae and particular stars, he was one of the initiators of the project that led to the construction of the Schmidt telescope at Caussols. (M 17467)

\section{(4605) Nikitin}

1987 SV 17 . Discovered 1987 Sept. 18 by L. I. Chernykh at Nauchnyj.

Named for Afanasij Nikitin (?-1472), a merchant from the town of Tver'. Nikitin, who was the first Russian to journey to India, described the trip in his diary, later published as Walking Beyond Three Seas. (M 23136)

\section{(4606) Saheki}

$1987 \mathrm{UM}_{1}$. Discovered 1987 Oct. 27 by T. Seki at Geisei.

Named in honor of Tsuneo Saheki \{1916-1996\}, president of the Toa Astronomical Society. An observer of Mars, Saheki has extensive records of his results covering half a century. (M 18308)

Obituary published in Yamamoto Circ., No. 1607, p. 2 (1996).

\section{(4607) Seilandfarm}

1987 WR. Discovered 1987 Nov. 25 by K. Endate and K. Watanabe at Kitami.

Named for a farm, established by Akio Seino in 1942, located about $10 \mathrm{~km}$ from Kitami ssee planet (3785)\}. Covering an area of about 50 hectares of hilly terrain, this modern, large-scale dairy farm, with 150 cattle, is operated by four members of the Seino family. (M 20521)

\section{(4609) Pizarro}

$1988 \mathrm{CT}_{3}$. Discovered 1988 Feb. 13 by E. W. Elst at La Silla.

Named in honor of Guido and Oscar Pizarro, who operate the 1-m Schmidt telescope and who exposed the plates on which this minor planet was discovered. For almost 20 years the two brothers have been renowned for their patient and effective work with the telescope. They took the plates for the ESO sky surveys and have taken several thousand plates for general programs, including many specifically for the 
detection and follow-up of comets and minor planets. (M 17658)

Citation prepared by H.-E. Schuster at the request of the discoverer.

\section{(4610) Kájov}

1989 FO. Discovered 1989 Mar. 26 by A. Mrkos at Kleť.

Named for a village in southern Bohemia south of Klet Mountain that is the pilgrimage site of a Gothic church of the Assumption, founded in the fourteenth century. (M 29670)

Name proposed by J. Tichá, M. Tichý and Z. Moravec.

\section{(4611) Vulkaneifel}

1989 GR $_{6}$. Discovered 1989 Apr. 5 by M. Geffert at La Silla.

Named in honor of the landscape and people of a region to the southwest of Bonn. The landscape of that region is full of volcanic relics such as craters and lava streams, as well as "Maare", which are small lakes. The observatory of the University of Bonn, Hoher List, where the discoverer works, is located in the Vulkaneifel near one of these lakes. (M 17467)

\section{(4612) Greenstein}

1989 JG. Discovered 1989 May 2 by E. F. Helin at Palomar.

Named in honor of Jesse Greenstein (1909-2002), an expert in stellar spectroscopy with many discoveries concerning low-luminosity stars, white dwarfs, stellar chemical compositions and stellar evolution. In addition, Greenstein established and guided, during its first two decades, the astronomy department at the California Institute of Technology. As a statesman of science policy he was influential in the early history of radioastronomy in the United States, as well as in the early history of AURA. (M 27734)

His friends and colleagues heartily endorse this naming. Citation prepared by J. Cohen.

\section{(4613) Mamoru}

1990 OM. Discovered 1990 July 22 by K. Watanabe at Sapporo.

Named in honor of Mamoru Mohri (1948- ), a professor in the department of technology at Hokkaido University and the first payload specialist of the Japanese National Space Development Agency to travel into space. After lifting off in the space shuttle Endeavor on 1992 Sept. 12 he successfully performed 34 experiments ("Fuwatto '92") and lectured from space to Japanese school children. (M 21131)

\section{(4614) Masamura}

1990 QN. Discovered 1990 Aug. 21 by Y. Mizuno and T. Furuta at Kani.

Named in honor of Kazutada Masamura (1920-1998), the secretary of the Oriental Astronomical Association (O.A.A.). Masamura has been observing sunspots since 1935 and has made a great effort to diffuse astronomical knowledge. In addition to establishing the Gifu Astronomical Observatory in 1971, Masamura provides financial assistance for awards given by the O.A.A. to Japanese amateur discoverers of comets, novae and minor planets. (M 19697)

Obituaries published in Heavens, Vol. 79, No. 12, p. 1-3 (1998), Vol. 80, No. 2, p. 93-98 (1999).

\section{(4615) Zinner}

A923 RH. Discovered 1923 Sept. 13 by K. Reinmuth at Heidelberg.

Named in memory of Ernst Zinner (1886-1970), assistant astronomer (1910-1914) and director (19261953) of the Remeis-Sternwarte, Bamberg. In addition to his observational work on variable stars, Zinner was the first professor of astronomy to investigate the history of astronomy in the Middle Ages quantitatively. Giacobini's \{see planet (1756)\} comet 1900 I was rediscovered by Zinner in October 1913 and is now known as $\mathrm{P} /$ Giacobini-Zinner, parent of the Draconid meteors. (M 22502)

Name proposed by G. Klare and L. D. Schmadel, citation prepared by R. Knigge.

\section{(4616) Batalov}

1975 BF. Discovered 1975 Jan. 17 by L. I. Chernykh at Nauchnyj.

Named in honor of Aleksej Vladimirovich Batalov, well-known contemporary cinema actor and producer. (M 22503; M 22519)

\section{(4617) Zadunaisky}

1976 DK. Discovered 1976 Feb. 22 at the Felix Aguilar Observatory at El Leoncito.

Pedro E. Zadunaisky (1918- ), one of the most active celestial mechanicians in Argentina, worked in particular on the orbits of comet $1 \mathrm{P} /$ Halley and Saturn IX (Phoebe). His monograph A Guide to Celestial Mechanics was published in 1961. (M 41027)

(4618) Shakhovskoj

1977 RJ $_{3}$. Discovered 1977 Sept. 12 by N. S. Chernykh at Nauchnyj.

Named in honor of Nikolaj Mikhailovich Shakhovskoj (1930- ), astrophysicist at the Crimean Astrophysical Observatory, an authority in stellar polarimetry and photometry, known for his research of variable cosmic objects of diverse types, including eruptive stars, active galaxies, x-ray binaries and flare stars, as well as comets and minor planets. (M 27126)

\section{(4619) Polyakhova}

1977 RB $_{7}$. Discovered 1977 Sept. 11 by N. S. Chernykh at Nauchnyj.

Named in honor of Elena Nikolaevna Polyakhova, assistant professor of astronomy at St. Petersburg University, well-known specialist on celestial mechanics who obtained, in particular, new insights into the problems of using solar sails in interplanetary space flight. (M 23352; M 26439) 


\section{(4620) Bickley}

1978 OK. Discovered 1978 July 28 at the Perth Observatory at Bickley.

Named for the present site (since 1966) of the Perth Observatory. In 1915 the locality, in the Darling Range $23 \mathrm{~km}$ east-southeast of the center of the city, was officially named for Samuel Wallace Alexander Walsh Bickley (1810-1876), a pioneer in the area who was also a successful merchant and a nominated member of the Legislative Council of the colony (as it was at that time) of Western Australia. (M 31609)

\section{(4621) Tambov}

1979 QE $_{10}$. Discovered 1979 Aug. 27 by N. S. Chernykh at Nauchnyj.

Named for the city of Tambov, one of the industrial and cultural centers in Russia, center of the Tambov region. (M 23352)

\section{(4622) Solovjova}

$1979 \mathrm{WE}_{2}$. Discovered 1979 Nov. 16 by L. I. Chernykh at Nauchnyj.

Named in memory of Sergej Mikhailovich Solovjov (1820-1879), famous Russian historian and the author of many works on the history of Russia. The name also honors his son, Vladimir Sergeevich Solovjov (1853-1900), religious philosopher, poet and publicist. (M 23136)

\section{(4623) Obraztsova}

$1981 \mathrm{UT}_{15}$. Discovered 1981 Oct. 24 by L. I. Chernykh at Nauchnyj.

Named in honor of Elena Vasil'evna Obraztsova, outstanding singer of the Bolshoi Theatre in Moscow. (M 22503)

\section{(4624) Stefani}

$1982 \mathrm{FV}_{2}$. Discovered 1982 Mar. 23 by C. S. Shoemaker and Q. R. Passey at Palomar.

Named for J. Stefani Salazar, granddaughter of the first discoverer. (M 17658)

\section{(4625) Shchedrin}

1982 UG $_{6}$. Discovered 1982 Oct. 20 by L. G. Karachkina at Nauchnyj.

Named for the outstanding Russian composer Rodion Konstantinovich Shchedrin. (M 22247)

\section{(4626) Plisetskaya}

$1984 \mathrm{YU}_{1}$. Discovered 1984 Dec. 23 by L. G. Karachkina at Nauchnyj.

Named for the brilliant ballet-dancer Majya Mikhailovna Plisetskaya. (M 22247)

\section{(4628) Laplace}

$1986 \mathrm{RU}_{4}$. Discovered 1986 Sept. 7 by E. W. Elst at Rozhen.

Named in memory of the great French mathematician, astronomer and physicist, Pierre-Simon Marquis de Laplace (1749-1827). Although Newton ssee planet (8000)\} had concluded that divine intervention was periodically required to preserve the solar system in equilibrium, Laplace managed to prove in 1773, by applying Newtonian gravitation, the invariability of planetary mean motions to the cubes of the eccentricities and inclinations. In 1786 he showed that the effects of planetary perturbations were conservative and periodic, not cumulative and disruptive; the eccentricities and inclinations of planetary orbits to each other will remain small, constant and self-correcting. In 1796 he published his famous Exposition du système du monde, which treats also his "nebular hypothesis", which ascribes the origin of the solar system to the contraction of a gaseous nebula. His monumental Traité de mécanique céleste, published between 1798 and 1827 , offered a complete mechanical interpretation of the solar system. Laplace is also well known for his investigations on probability. (M 18460)

\section{(4629) Walford}

$1986 \mathrm{TD}_{7}$. Discovered 1986 Oct. 7 by E. F. Helin at Palomar.

Named in honor of Roy L. Walford, professor of pathology at the UCLA School of Medicine, noted for his work in gerontology. His numerous publications include not only scientific papers, but also popular books on the subject of aging in humans. A scientist, writer, actor and explorer, he has given inspiration and encouragement to many, including the discoverer and her family. (M 18460)

\section{(4630) Chaonis}

1987 WA. Discovered 1987 Nov. 18 by J. M. Baur at Chions.

Named in honor of the Chions, originally Chaonis, where the observatory of that name is located. The origins of this town in the province of Pordenone \{see also planet (3896)\} date back to the Roman empire and to the division of the Julia Concordia land, where important archaeological remains can still be found. The first settlement dates back to the time of the Longobardic king Autari, when it was founded by some of the survivors of the disastrous flood that swept over lower Friuli. Around the year 100 the town came under the jurisdiction of the Aquileia patriarchy. In 1420 it was passed to the republic of Venice and later to the 'free dominion' under the counts of Panigai. (M 17658)

\section{(4631) Yabu}

$1987 \mathrm{WE}_{1}$. Discovered 1987 Nov. 22 by S. Ueda and H. Kaneda at Kushiro.

Named in honor of Yasuo Yabu (1932- ), longstanding meteor observer, vice-president of the Nippon Meteor Society and editor of its Astronomical Circular since 1969. (M 21131)

Name suggested by K. Watanabe. Citation prepared by I. Hasegawa. 


\section{(4634) Shibuya}

1988 BA. Discovered 1988 Jan. 16 by M. Inoue and O. Muramatsu at Kobuchizawa.

Named for a cultural district of Tokyo that contains a concert hall, two theaters, two art museums and nine other educational facilities. Among them is the Gotoh planetarium and Astronomical Museum, which has been visited by 14 million people since its establishment in 1957. (M 17659)

Name proposed by the discoverers following a suggestion by six lecturers in the museum.

\section{(4635) Rimbaud}

1988 BJ $_{1}$. Discovered 1988 Jan. 21 by E. W. Elst at St. Michel.

Named in memory of the French poet Arthur Rimbaud (1854-1891) on the occasion of the hundredth anniversary of his death. At the age of 17 he was already known for his Dormeur du Val and Le Bateau ivre, the latter, together with Voyelles, probably being his most famous work. In 1872 he traveled with Paul Verlaine \{see planet (6871)\} to England and Belgium, their friendship ending with two gunshots fired by Verlaine at Rimbaud. In 1873 Rimbaud published Une Saison en Enfer, an autobiographical and psychological work. After Les Illuminations, written at the age of 19 and issued by Verlaine only in 1886, nothing remains of the work of this great poet. As a precursor of symbolism Rimbaud enormously influenced Verlaine and the following generation. (M 18645)

Name proposed and citation prepared by Kristina Leterme at the request of the discoverer.

\section{(4636) Chile}

1988 CJ $_{5}$. Discovered 1988 Feb. 13 by E. W. Elst at La Silla.

Named for the beautiful South American country in which the European Southern Observatory is located. Noted for its great wines, Chile is chiefly mountainous, with the Andes dominating the landscape. The extension of Chile across some 38 degrees of latitude embraces nearly all climates. The fascinating Chilean people are racially a mixture of Europeans (the conquistadores from Spain, Basque families) and indigenous tribes (Atacamenos, Diaguitas, Picunches, Araucanians, Huilliches, Pehuenches and Cuncos). Today the proud Araucanian Indians form the only significant ethnic minority. (M 19697)

\section{(4637) Odorico}

1989 CT. Discovered 1989 Feb. 8 by J. M. Baur at Chions.

Named for the renowned solitary traveler and missionary, the Franciscan monk Odorico (1265-1331). Born Odorico Mattiussi in Pordenone \{see planet (3896) $\}$ and pronounced blessed in 1775, between 1314 and 1330 he traveled in southern Asia, stopping in Ceylon, Sumatra, Java and Borneo as a messenger of the Christian faith and of the light of civilization. He went to Tibet, starting from Peking to Lhasa.
He visited the 'canati' di Boccara and Afghanistan and crossed Mesopotamia. On his return to Italy he dictated the famous 'Relatio' (report) of his travels to his brother-monk, Guglielmo di Solagna, in St. Anthony's monastery in Padua. Studies on the Relatio, which continue even today, can be found in major European libraries and archives. Odorico was a contemporary of Dante Alighieri \{see planet (2999)\} and has been linked to Marco Polo. (M 17659)

\section{(4638) Estens}

1989 EG. Discovered 1989 Mar. 2 by R. H. McNaught at Siding Spring.

Named for John (Jack) Locke Estens (1919- ), Australian astronomy educator. Following a life of farming, he devoted his retirement to bring astronomy to the public with his handsomely constructed observatory and lecture room in Gilgandra, N.S.W. Opened in 1975 , the observatory saw a steady stream of visitors until his second retirement in 1996. Always friendly and enthusiastic, he provided a service missing at the professional observatories, with his personal tours of the night sky. (M 29143)

\section{(4639) Minox}

$1989 \mathrm{EK}_{2}$. Discovered 1989 Mar. 5 by T. Seki at Geisei.

Named in honor of the Minox Club, a group of Japanese miniature-camera enthusiasts established in 1968. The discoverer is a member of the club, which holds an exhibition of still works and 9-mm movies each year in Tokyo. (M 18308)

\section{(4640) Hara}

1989 GA. Discovered 1989 Apr. 1 by Y. Kushida and O. Muramatsu at Yatsugatake.

Named in honor of Megumi Hara, professor at Aoyama-Gakuin University, and an authority on star names, myths and history of the constellations. An observer of variable stars for many years, and long very active in the popularization of astronomy through lectures and articles, he is a leading member of the advisory committee of the Gotoh planetarium and Astronomical Museum. (M 17659)

Named by the discoverers following a suggestion by S. Murayama.

\section{(4642) Murchie}

$1990 \mathrm{QG}_{4}$. Discovered 1990 Aug. 23 by H. E. Holt at Palomar.

Named in honor of Scott Murchie (1959- ), who has a diverse interest in planetary problems ranging from icy satellites, martian rocks and moons, to age dating of terrestrial rocks. On the staff of the Applied Physics Laboratory at Johns Hopkins University, he is currently the Near Earth Asteroid Rendezvous (NEAR) Instrument Scientist for the Multispectral Imager and the Near-Infrared Spectrograph. His hard work and dedication to the NEAR project, starting long before launch, has been key to maximizing mission scientific return. When NEAR enters orbit around (433) 
Eros, Murchie's groundwork in calibration, sequence planning and spectroscopy will contribute greatly to mission success. (M 35481)

Name proposed by J. Veverka and citation written by M. Robinson.

\section{(4643) Cisneros}

1990 QD $_{6}$. Discovered 1990 Aug. 23 by H. E. Holt at Palomar.

Named in honor of Ernest Cisneros (1964- ), one of the unsung heroes of planetary science. Cisneros began his career as a field geologist but has turned his energies to computer system management, software development, networking and data processing. Throughout the flight portion of the NEAR mission, Ernest insured that key hardware and software elements were developed and implemented. During the flybys of (253) Mathilde and (433) Eros (as well as the earth), Ernest worked with the science team delivering calibrated data within minutes of telemetry arrival for both optical navigation and science analysis. (M 35481)

Name proposed by J. Veverka and citation written by M. Robinson.

\section{(4644) Oumu}

$1990 \mathrm{SR}_{3}$. Discovered 1990 Sept. 16 by A. Takahashi and K. Watanabe at Kitami.

Named for a town, noted for its fishing industry, situated on the Sea of Okhotsk some $50 \mathrm{~km}$ of Kitami \{see planets (4042), (3785)\}. (M 19338)

\section{(4645) Tentaikojo}

$1990 \mathrm{SP}_{4}$. Discovered 1990 Sept. 16 by T. Fujii and K. Watanabe at Kitami.

Named for a museum of stars and their images, scheduled to be opened in Sapporo in 1993. Originally built in 1892 as a brewery, the historic and beautiful building is becoming a "star factory", where visitors can experience displays and stories about constellations and the birth of stars. (M 20837)

\section{(4646) Kwee}

4009 P-L. Discovered 1960 Sept. 24 by C. J. van Houten and I. van Houten-Groeneveld at Palomar.

Named in honor of the Leiden astronomer Kiem Keng Kwee (1927- ), who works intensively on eclipsing variable stars, using their lightcurves to determine the characteristics of those systems by means of the Wilson-Devinney program. While observing at Palomar in 1963 he codiscovered a well-known short-period comet. (M 20160)

\section{(4647) Syuji}

$1931 \mathrm{TU}_{1}$. Discovered 1931 Oct. 9 by K. Reinmuth at Heidelberg.

Named in honor of Syuji Hayakawa (1958- ), an active observer of minor planets and comets. (M 23540)

Name proposed by T. Kobayashi, who found the identifications involving this minor planet.

\section{(4648) Tirion}

1931 UE. Discovered 1931 Oct. 18 by K. Reinmuth at Heidelberg.

Named in honor of the Dutch cartographer Wil Tirion, author of the Sky Atlas 2000.0 and of many other modern celestial maps. (M 22503)

Name proposed and citation prepared by J. Meeus, endorsed by G. Klare and L. D. Schmadel.

\section{(4649) Sumoto}

1936 YD. Discovered 1936 Dec. 20 by M. Laugier at Nice.

Named for the chief city of Awaji island on the Seto inland sea of Japan. The Oriental Astronomical Association's Computing Service is based in this city. Many observations of comets and minor planets by Japanese amateurs, as well as identifications and orbits, are collected there before being reported to the Minor Planet Center. (M 22503)

Name proposed by S. Nakano, who found the identifications involving this object and who lives in Sumoto.

\section{(4650) Mori}

1950 TF. Discovered 1950 Oct. 5 by K. Reinmuth at Heidelberg.

Named in memory of Kiyoshi Mori (1906-1976) who calculated more than 400 circular, elliptical and parabolic orbits of minor planets and comets using an abacus and logarithm tables. After carrying out a statistical study of orbits of minor planets at Tokyo Imperial University in 1929 under the guidance of Hirayama \{see planet (1999)\}, he was a professor of physics, mathematics and statistics at many high schools and colleges. (M 18308)

Name proposed by $H$. Oishi, who found the identifications involving this minor planet.

\section{(4651) Wongkwancheng}

$1957 \mathrm{UK}_{1}$. Discovered 1957 Oct. 31 at the Purple Mountain Observatory at Nanking.

Named in memory of Kwan-cheng Wong (1907-1986), a leader in Chinese industrial and commercial circles. Wong was devoted to educational and social welfare projects all his life. The K. C. Wong Education Foundation he established has supported thousands of Chinese scholars studying abroad. (M 32788)

\section{(4652) Iannini}

1975 QO. Discovered 1975 Aug. 30 at the Felix Aguilar Observatory at El Leoncito.

Named in honor of Gualberto Mario Iannini (1917-

), Argentinean astronomer who has worked in the field of astrometry for almost 40 years. As a student, Iannini studied the orbit of C/1942 C1 (WhippleBernasconi-Kulin). In 1962 he joined the faculty of the School of Mathematics, Astronomy and Physics of the National University of Córdoba and became head of the Department of Astrometry of the Córdoba Observatory, where he finished the reduction of the 
meridian circle catalogue of the Southern Polar Cap, known as the Córdoba E catalogue. (M 33786)

\section{(4653) Tommaso}

1976 GJ J $_{2}$. Discovered 1976 Apr. 1 by N. S. Chernykh at Nauchnyj.

Named for Tommaso Campanella (1568-1639), Italian monk who was a philosopher, poet and political figure. $\mathrm{He}$ is known primarily as the author of Civitās Soleil and as a founder of Utopian Communism. Campanella was imprisoned for 27 years by the Spanish Inquisition. (M 23352)

\section{(4654) Gor'kavyj}

1977 RJ $_{6}$. Discovered 1977 Sept. 11 by N. S. Chernykh at Nauchnyj.

Named in honor of Nikolaj Nikolaevich Gor'kavyj (1959- ), staff member of the Crimean Astrophysical Observatory, celestial mechanician and cosmogonist. He has constructed a single model for the formation of the satellite systems of Jupiter, Saturn and Neptune and has offered an explanation for the origin of the retrograde satellites of the giant planets and the features of Neptune's rings. (M 27127)

\section{(4655) Marjoriika}

1978 RS. Discovered 1978 Sept. 1 by N. S. Chernykh at Nauchnyj.

Named in honor of Marjo Riika Kuusela (1964-

), specialist in Russian literature, whose perfect knowledge of the Russian language, lively wit and amiable disposition won the respect and friendship of all Russian-speaking participants at the Asteroids, Comets, Meteors 1991 conference in Flagstaff, Arizona. (M 20160)

\section{(4657) Lopez}

1979 SUg. Discovered 1979 Sept. 22 by N. S. Chernykh at Nauchnyj.

Named in honor of Alvaro Lopez Garcia (1941- ), professor of astronomy at Valencia University, director of the Valencia University Observatory and a specialist in astrometry and the dynamics of minor planets. In recent years he has initiated and organized several astronomical conferences in Spain that have attracted growing international participation. (M 26762)

\section{(4658) Gavrilov}

1979 SO $_{11}$. Discovered 1979 Sept. 24 by N. S. Chernykh at Nauchnyj.

Named in honor of Aleksej Evgenievich Gavrilov, friend of the discoverer, famous Ukrainian architect of bridges, director of the "Kievinterproekt" Institute of the International Academy of Architecture. He designed the south bridge over the Dnieper river at Kiev and the bridge over the Daugava river at Riga. He is the great-grandson of the astronomer and physicist S. V. Shcherbakov \{see planet (3886)\} and the son of the geographer M. V. Shcherbakova. (M 27127; M 27147)

\section{(4659) Roddenberry}

$1981 \mathrm{EP}_{20}$. Discovered 1981 Mar. 2 by S. J. Bus at Siding Spring.

Named in memory of Eugene "Gene" W. Roddenberry (1921-1991), creator and producer of the television series "Star Trek", "Star Trek: The Next Generation", and six Star Trek motion pictures. Roddenberry explored the human condition through the medium of science fiction, often circumventing television network censors to expound on controversial social and political topics. His unique vision of a positive future for a united humanity inspired a variety of devoted fans. Today Roddenberry, the starship Enterprise, and its crews are known worldwide, and fans number in the millions. (M 19698)

Citation provided by I. Heyer at the request of the discoverer.

\section{(4660) Nereus}

1982 DB. Discovered 1982 Feb. 28 by E. F. Helin at Palomar.

Named for the ancient Greek god Nereus, a son of Pontus and Gaia \{see planet (1184)\}. A benevolent sea-god associated with ancient origins (mythology, if not science), he had the power of prophecy. (M 19338)

Name proposed by Robert M. Cutler, a Planetary Society member interested in near-earth asteroids. To English-language speakers the name seems particularly appropriate for such an object.

\section{(4661) Yebes}

1982 WM. Discovered 1982 Nov. 17 by M. de Pascual at Yebes.

The village of Yebes, in the Alcarria region, is beautifully described by the Spanish Nobel laureate Camilo José Cela in one of his early books. This was the first minor planet discovered at the Centro Astronómico de Yebes, an optical and radio observatory located $70 \mathrm{~km}$ from Madrid. (M 36944)

\section{(4664) Hanner}

1985 PJ. Discovered 1985 Aug. 14 by E. Bowell at Anderson Mesa.

Named in honor of Martha S. Hanner, planetary scientist at the Jet Propulsion Laboratory who specializes in groundbased and space studies of particulate matter in the solar system, especially cometary dust. Her publications attest to her work as an enthusiastic observer of comets at infrared wavelengths, as an organizer of the $\mathrm{P} /$ Halley infrared monitoring program at the Infrared Telescope Facility on Mauna Kea, as a champion of improvements in infrared photometric standards, and on the nature of zodiacal light. She has investigated the formation of infrared spectral features in dust and the scattering properties of dust. Hanner is an energetic supporter of better science education for young people, to which end she has been a teacher and organizer of space science seminars for science teachers. (M 18461) 
Citation provided by Ray L. Newburn at the request of the discoverer.

\section{(4665) Muinonen}

$1985 \mathrm{TZ}_{1}$. Discovered 1985 Oct. 15 by E. Bowell at Anderson Mesa.

Named in honor of Karri O. Muinonen, planetary scientist at the Lowell Observatory. Formerly at the observatory and astrophysics laboratory of the University of Helsinki, Muinonen worked on the lightscattering properties of inhomogeneous media and independently originated the suggestion that coherent backscattering is responsible for both the opposition spike and the negative polarization of light from the surfaces of many atmosphereless bodies. He has since turned to the study of the spatial distribution of minor planets, particularly the population of planet crossers that might pose a hazard to the earth, and he has devised a new way of assessing the uncertainty of minor planet orbits, and hence ephemerides. (M 18461)

\section{(4666) Dietz}

$1986 \mathrm{JA}_{1}$. Discovered 1986 May 4 by C. S. Shoemaker and E. M. Shoemaker at Palomar.

Named in honor of Robert S. Dietz, geologist and professor emeritus at Arizona State University. Dietz is a pioneer in the study and recognition of terrestrial impact structures, and he was one of the early proponents of the impact origin of the craters of the moon. He championed the concept of shatter cones as diagnostic features of terrestrial impact structures and discovered shatter cones at many of the impact sites now known. On the basis of evidence from shatter cones, Dietz revived the hypothesis of impact origin of the great Vredefort Ring of South Africa and proposed an impact origin for the Sudbury Basin, Ontario. (M 18461)

\section{(4667) Robbiesh}

1986 VC. Discovered 1986 Nov. 4 by R. H. McNaught at Siding Spring.

Named for Hans-Christian Robert (Robbie) Wade Schmidt-Harms (1986- ), son of Soo Tan and stepson of the discoverer. This minor planet was discovered three weeks after Robbie's birth. (M 29670)

\section{(4669) Høder}

$1987 \mathrm{UF}_{1}$. Discovered 1987 Oct. 27 by P. Jensen and K. Augustesen at Brorfelde.

Named after the blind god in Norse mythology, son of Odin \{see planet (3989)\} and brother of Balder \{see planet (4059)\}, whom he killed with a mistletoe shaft with the treacherous help of Loke \{see planet (4862)\}. (M 22503)

\section{(4670) Yoshinogawa}

1987 YJ. Discovered 1987 Dec. 19 by T. Seki at Geisei.

Named for the longest river on Shikoku ssee planet (4223)\} island, flowing east-west for a distance of 194 km. (M 19338)

\section{(4671) Drtikol}

$1988 \mathrm{AK}_{1}$. Discovered 1988 Jan. 10 by A. Mrkos at Klě́.

Named in memory of František Drtikol (1883-1961), outstanding Czech photographer well-known for his black-and-white portraits in the Art Nouveau style and fine-art nude studies using geometric patterns of shadows and light. (M 34340)

Name suggested by M. Tichý.

\section{(4672) Takuboku}

1988 HB. Discovered 1988 Apr. 17 by S. Ueda and H. Kaneda at Kushiro.

Named in honor of the poet Takuboku Ishikawa (1886-1912), who lived in the late Meiji period in Japan. He published his first collection of poems, Akogale, when he was 20. His most famous work is Ichiakunosuna, containing 551 poems, published in 1910. (M 21131)

\section{(4673) Bortle}

1988 LF. Discovered 1988 June 8 by C. S. Shoemaker at Palomar.

Named for John E. Bortle, an American astronomer specializing in comets and variable stars. One of the great visual observers, he has made more than 2,000 observations of approximately 150 cometary apparitions over the course of three decades. He has often been first to report unusual cometary activity and is well-known for his analyses of visual magnitude estimates of comets. He has also reported tens of thousands of variable star observations. Bortle has written the Comet Digest column in Sky and Telescope for more than a decade and has edited the American Association of Variable Star Observers Circular since its founding in 1970. (M 17659)

Name suggested and citation prepared by C. S. Morris.

\section{(4674) Pauling}

1989 JC. Discovered 1989 May 2 by E. F. Helin at Palomar.

Named in honor of Professor Linus Pauling on the occasion of his ninetieth birthday, 1991 Feb. 28. Pauling has had a long and distinguished career, spending 37 years as a Caltech faculty member, including 22 years as chairman of Caltech's Division of Chemistry and Chemical Engineering. He is the recipient of Nobel prizes for both Chemistry $\{1954\}$ and Peace $\{1962\}$. The discoverer, and her husband Ronald, a Caltech graduate, are long time admirers of Pauling. (M 17981)

Asteroid tribute endorsed by the Caltech community.

\section{(4675) Ohboke}

1990 SD. Discovered 1990 Sept. 19 by T. Seki at Geisei.

Named for one of the valleys of the Yoshino river, famous for its tinted autumn leaves. (M 19338) 


\section{(4676) Uedaseiji}

$1990 \mathrm{SD}_{4}$. Discovered 1990 Sept. 16 by T. Fujii and K. Watanabe at Kitami.

Named in honor of Seiji Ueda (1952- ), well known for his observations of comets and minor planets. He lives in Kushiro \{see planet (4096)\} and has been an enthusiastic astronomer since his junior high school days. He played an active part in ice hockey as a Japanese-league player for six years. After retirement, he renewed his interest in astronomy. Since 1987 he has used a Wright-Schmidt Camera of $16 \mathrm{~cm}$ aperture and has discovered many minor planets. (M 22503)

\section{(4677) Hiroshi}

1990 SQ4. Discovered 1990 Sept. 26 by A. Takahashi and K. Watanabe at Kitami.

Named in honor of Hiroshi Kaneda (1953- ), well known for his orbit calculations of comets and minor planets. He lives in Sapporo \{see planet (3473)\} and is a computer programmer who has written much astronomical software. Recently, he has been finding many identifications of minor planets. He has also put much energy into the astrometric measurement of films he has obtained at the Kushiro ssee planet (4096)\} Observatory. (M 22503)

\section{(4678) Ninian}

1990 SS $_{4}$. Discovered 1990 Sept. 24 by R. H. McNaught at Siding Spring.

Named in honor of Ninian T. McNaught, father of the discoverer. (M 17982)

\section{(4679) Sybil}

1990 TR$_{4}$. Discovered 1990 Oct. 9 by R. H. McNaught at Siding Spring.

Named in honor of Sybil McNaught, mother of the discoverer. (M 17982)

\section{(4680) Lohrmann}

1937 QC. Discovered 1937 Aug. 31 by H.-U. Sandig at Bergedorf.

Named for Wilhelm Gotthelf Lohrmann, an amateur astronomer and author of the famous lunar topographic atlas Topographie der sichtbaren Mondoberfläche (1824). Lohrmann was director of the Dresden "Mathematisch-Physikalischer Salon". When H.-U. Sandig founded the Institute of Geodetical Astronomy at the Dresden University of Technology in 1961, he chose the name of Lohrmann for his new institute, now known as the Lohrmann Observatory. (M 18461)

Lohrmann is honored for his monumental selenographic work by a lunar crater.

\section{(4681) Ermak}

$1969 \mathrm{TC}_{2}$. Discovered 1969 Oct. 8 by L. I. Chernykh at Nauchnyj.

Named for Ermak Timofeevich (?-1585), hero of Russian folklore and the Cossack chieftain who led the campaign to join Siberia to Russia. (M 23136)

\section{(4682) Bykov}

$1973 \mathrm{SO}_{4}$. Discovered 1973 Sept. 27 by L. I. Chernykh at Nauchnyj.

Named in memory of Leonid Fyodorovich Bykov (1928-1979), talented Ukrainian cinematic actor and producer. (M 23137)

\section{(4683) Veratar}

1976 GJ J $_{1}$. Discovered 1976 Apr. 1 by N. S. Chernykh at Nauchnyj.

Named in honor of Vera Petrovna Tarashchuk, an astrophysicist at the Astronomical Observatory of Kiev University. An active observer of major planets, minor planets and comets, she is known for her contribution to photometric and spectroscopic research on minor bodies. She also studied the association of cometary processes with solar activity, as well as the structure and rotation of minor planets. (M 30095)

\section{(4684) Bendjoya}

1978 GJ. Discovered 1978 Apr. 10 by H. Debehogne at La Silla.

Named in honor of Philippe Bendjoya, astronomer at the Nice Observatory, who has carried out fruitful research on the identification and physical analysis of asteroid families, as well as the dynamics of planetary rings. Bendjoya was the first to apply to these fields the so-called wavelet analysis technique. (M 23137)

\section{(4685) Karetnikov}

$1978 \mathrm{SP}_{6}$. Discovered 1978 Sept. 27 by N. S. Chernykh at Nauchnyj.

Named in honor of Valentin Grigorievich Karetnikov (1938- ), professor at Odessa University and director of the astronomical observatory there. His fields of research include light variations of artificial earth satellites, the structure and evolution of eclipsing double stars and the motion of gas in close-binary systems. (M 27127)

\section{(4686) Maisica}

$1979 \mathrm{SX}_{2}$. Discovered 1979 Sept. 22 by N. S. Chernykh at Nauchnyj.

Named in honor of Maria Luisa Grima Garcia, a charming Spanish woman who is the soul of her family, a hospitable hostess, and founder and curator of a small home museum. Maisica is a pet name for Maria Luisa. (M 22503)

\section{(4687) Brunsandrej}

1979 SJ J1 $_{11}$. Discovered 1979 Sept. 24 by N. S. Chernykh at Nauchnyj.

Named in honor of Andrej Vladimirovich Bruns (1931- ), staff member of the Crimean Astrophysical Observatory, an authority on space astrophysics who has originated several unique instruments for ultraviolet observations of the sun, stars and galaxies from satellites and spacecraft. He designed the large Orbiting Solar Telescope controlled by cosmonauts on Salyut 4 in 1975. A relative of Ernst Heinrich Bruns 
\{see planet (901)\}, director of the Leipzig Observatory at the beginning of this century, he is related on his mother's side to Euler \{see planet (2002)\}. (M 26762; M 27749)

\section{(4689) Donn}

1980 YB. Discovered 1980 Dec. 30 by E. Bowell at Anderson Mesa.

Named in honor of Bertram D. Donn for his fundamental contributions to our understanding of solar system astrophysics. In addition to proposing an innovative theory of cometary composition, formation and evolution, Donn succeeded in deriving generally accepted fundamental properties of cometary nuclei that form the basis of current theories. He also carried out very original research on cometary structures using fractals and on the condensation of pre-cometary and interstellar materials. (M 18461)

Citation provided by J. H. Rahe at the request of the discoverer.

\section{(4690) Strasbourg}

1983 AJ. Discovered 1983 Jan. 9 by B. A. Skiff at Anderson Mesa.

Named for the French city of Strasbourg, capital of Alsace $\{$ see planet (971)\}. This city near the Rhine is known for its long history, majestic cathedral, and as a center of international cooperation. It is also home of the Centre de Données Astronomiques, which maintains the SIMBAD \{see planet (4692)\} stellar database. (M 27127)

\section{(4691) Toyen}

1983 TU. Discovered 1983 Oct. 7 by A. Mrkos at Klet.

Named in memory of Toyen (1902-1980), Czech painter and graphic artist, born Marie Čermínová. She is known for her imaginative abstraction, called artificialism, resulting in a surrealistic style. (M 34340) Name suggested by J. Tichá.

\section{(4692) SIMBAD}

$1983 \mathrm{VM}_{7}$. Discovered 1983 Nov. 4 by B. A. Skiff at Anderson Mesa.

Named in recognition of all the staff members of the Centre de Données Astronomiques, situated at the Observatoire de Strasbourg, for their efforts to create and maintain the SIMBAD (Set of Identifications, Measurements, and Bibliography for Astronomical Data) stellar bibliographic database and its associated on-line catalogue retrieval services. (M 27127)

\section{(4693) Drummond}

1983 WH. Discovered 1983 Nov. 28 by E. Bowell at Anderson Mesa.

Named in honor of Jack D. Drummond of the Steward Observatory, University of Arizona. Drummond's analysis of orbital similarities led to the identification of a cometary parent for the Epsilon Geminids and to the identification of streams among near-earth asteroids. He has done extensive analysis of asteroid lightcurves to find pole directions and shapes for more than 25 objects, as well as studies of phase curves which suggest the existence of both rough and smooth surfaces among the asteroids. As one of the first to apply speckle interferometry to these bodies, he developed many theoretical contributions to the analysis of speckle data and produced the first speckle images showing features on the surface of an asteroid, namely, that of (4) Vesta. His enthusiasm for studies of asteroids, comets and meteors has made him a pleasurable colleague for collaborative efforts. (M 18462)

Citation provided by Donald R. Davis at the request of the discoverer.

\section{(4694) Festou}

1985 PM. Discovered 1985 Aug. 14 by E. Bowell at Anderson Mesa.

Named in honor of Michel C. Festou of the Observatoire Midi-Pyrénées, Toulouse, for his extensive and wide-ranging studies of comets, both theoretical and observational. Festou was the first to calculate a vectorial model for the dissociation of water in cometary comae, and he has made major contributions to the theoretical understanding of emission by various species, including, for example, [O I] and $\mathrm{CN}$. He has been a preeminent practitioner of ultraviolet spectroscopy of comets, identifying features due to $\mathrm{OH}^{+}, \mathrm{CO}_{2}+$ and $[\mathrm{O} \mathrm{I}]$, and he has also contributed numerous ground-based observations of comets. (M 18462)

Citation provided by Michael F. A'Hearn at the request of the discoverer.

\section{(4696) Arpigny}

1985 TP. Discovered 1985 Oct. 15 by E. Bowell at Anderson Mesa.

Named in honor of Claude Arpigny of the Université de Liège, to recognize his preeminence in high-resolution cometary spectroscopy. Arpigny's fundamental studies of the excitation of molecular spectra in comets are unparalleled for care and detailed understanding. He has made significant contributions to our understanding of the emission by $\mathrm{NH}_{2},[\mathrm{O} \mathrm{I}], \mathrm{CN}$ and $\mathrm{CH}$. He has also shown care and diligence by encouraging the work of others both in spectroscopy and other types of cometary studies, in his service to the community in preparing the forthcoming "Atlas of Cometary Spectra" and in various activities of IAU Commission 15. (M 18462)

Citation provided by Michael F. A'Hearn at the request of the discoverer.

\section{(4698) Jizera}

$1986 \mathrm{RO}_{1}$. Discovered 1986 Sept. 4 by A. Mrkos at Klě́t.

Named for a Czech river rising in the Jizerské hory mountains and continuing through the towns of Turnov \{see planet (4054)\} and Mladá Boleslav to its confluence with the Labe river. (M 34340)

Name proposed by Z. Moravec. 


\section{(4699) Sootan}

1986 VE. Discovered 1986 Nov. 4 by R. H. McNaught at Siding Spring.

Named for Soo Hoay Tan (1956- ), partner of the discoverer and high-school science teacher. This asteroid was discovered two days before Soo's thirtieth birthday. (M 29670)

\section{(4700) Carusi}

$1986 \mathrm{VV}_{6}$. Discovered 1986 Nov. 6 by E. Bowell at Anderson Mesa.

Named in honor of Andrea Carusi, Istituto di Astrofisica Spaziale, in recognition of his work on the dynamics of cometary orbits and studies of the identification of asteroid families. Carusi was one of the first to use numerical techniques to study the effects of close planetary encounters in changing cometary orbits and was a principal contributor to the atlas of orbital patterns at close encounters. He identified many cases of temporary satellite capture about Jupiter and was the first, together with Giovanni Valsecchi \{see planet (3725)\}, to recognize the importance of near-tangent orbits in the case of close planetary encounters. He was also one of the first to apply the technique of numerical cluster analysis to the problem of the identification of asteroid families, and his early result on the number of families has withstood the test of time. His enthusiasm for solar system studies has led him to deliver many popular talks on a variety of topics in planetary science for the general public. (M 18462)

Citation provided by Donald R. Davis at the request of the discoverer.

\section{(4701) Milani}

$1986 \mathrm{VW}_{6}$. Discovered 1986 Nov. 6 by E. Bowell at Anderson Mesa.

Named in honor of Andrea Milani of the University of Pisa for his contributions to understanding the dynamics of asteroid orbits and the use of sophisticated numerical techniques to investigate the long-term evolution of orbits in the solar system. Milani was a pioneer in applying massively parallel computers to a variety of problems in solar system dynamics, ranging from integration of outer planet orbits over timescales of hundreds of millions of years to the evolution of hundreds of asteroids moving on orbits crossing that of the earth and other planets. He contributed to the development of refined proper elements for more than 4000 mainbelt asteroids and to the identification of secular resonances throughout the solar system. His very intense and energetic style of doing research has resulted in an impressive number of contributions so far in his career. (M 18463)

Citation provided by Donald R. Davis at the request of the discoverer.
(4702) Berounka

1987 HW. Discovered 1987 Apr. 23 by A. Mrkos at Kleť.

Named for a Czech river originating in Plzeň \{see planet (2613)\} as a confluence of four rivers: Mže, Radbúza, Úhlava and Úslava. It continues through the town of Beroun to its confluence with the Vltava river near Prague \{see planets (2123) and (2367), respectively\}. (M 34340)

Name proposed by Z. Moravec.

\section{(4703) Kagoshima}

1988 BL. Discovered 1988 Jan. 16 by M. Mukai and M. Takeishi at Kagoshima.

Named for the prefecture and its capital city, home of the discoverers, located at the southern tip of Kyushu Island in southwestern Japan. The rocket launching centers of the Institute of Space and Astronautical Science and the National Space Development Agency are located in Kagoshima prefecture. The city, often referred to as the "Naples of the East", is dominated by the presence of Sakurajima, one of the most active volcanoes in Japan, in the adjoining Kinko Bay. (M 18143)

\section{(4704) Sheena}

$1988 \mathrm{BE}_{5}$. Discovered 1988 Jan. 28 by R. H. McNaught at Siding Spring.

Named for Sheena Fleming Phillips (1952- ）, sister of the discoverer and a landscape artist in Haddington, Scotland. (M 29143)

\section{(4705) Secchi}

1988 CK. Discovered 1988 Feb. 13 at the Osservatorio San Vittore at Bologna.

Named in memory of Angelo Secchi (1818-1878), Italian astronomer, director of the observatory of the Collegio Romano in Rome from 1848 to 1878. Famous for his work on stellar spectroscopy, he made the first spectroscopic survey of the heavens, and his classification scheme divided the spectra of the stars into four groups. Secchi also made an extensive study of solar phenomena and was a co-founder of the Società degli Spettroscopisti Italiani, now the Società Astronomica Italiana. (M 20160)

Secchi is also honored by craters on Mars and on the Moon.

\section{(4707) Khryses}

1988 PY. Discovered 1988 Aug. 13 by C. S. Shoemaker and E. M. Shoemaker at Palomar.

Named for the priest of Apollo whose daughter, Khryseïs, was abducted by Agamemnon \{see planets (1862), (202), and (911)\}. Apollo, angered, sent a plague among the Greeks, until Agamemnon then took Achilles' girl, Briseïs \{see planet (655)\}, thus sparking the quarrel between Agamemnon and Achilles that led to the events described in the Iliad. (M 18144)

Name and citation provided by R. Preston at the request of the discoverers. 


\section{(4708) Polydoros}

1988 RT. Discovered 1988 Sept. 11 by C. S. Shoemaker and E. M. Shoemaker at Palomar.

Named for the brother of Lykaon \{see planet (4792)\} and the youngest son of Priam \{see planet (884)\}; born of the queen Laothoe. Although Polydoros was the swiftest of the sons of Priam, Priam refused to let the boy fight; but Polydoros rushed Achilles \{see planet (588)\} anyway, and Achilles killed him beside the River Skamander, near his brother Lykaon. (M 18144; M 18323)

Name and citation provided by $R$. Preston at the request of the discoverers.

\section{(4709) Ennomos}

$1988 \mathrm{TU}_{2}$. Discovered 1988 Oct. 12 by C. S. Shoemaker and E. M. Shoemaker at Palomar.

Named for a warrior of Mysia who was a prophet and a seer of birdflight. Ennomos was one of many Trojans butchered by Achilles $\{$ see planet (588)\} in the waters of the River Skamander. (M 18144)

Name and citation provided by R. Preston at the request of the discoverers.

\section{(4710) Wade}

1989 AX $_{2}$. Discovered 1989 Jan. 4 by R. H. McNaught at Siding Spring.

Named for Wade Richard Butler (1949- ), a friend of the discoverer. Son of the famous "bare-foot" bushwalker Dot Butler, he had a long-time interest in the bush and remote places. After graduating in engineering, he overwintered in Antarctica working in cosmic-ray physics. His romantic passion for astronomy brought him to the Warrumbungle Mountains, in the shadow of Siding Spring, where he and his wife Margaret, with many friends, built a home and an observatory. In December 1995 he disappeared during a solo bushwalk in a very rugged part of southeastern Tasmania. This minor planet places Wade Butler in the sky with his children Lyra, Rigel, Leo and Eric Antares Butler, as he would have wished. (M 29143)

\section{(4711) Kathy}

1989 KD. Discovered 1989 May 31 by H. E. Holt at Palomar.

Named in honor of Kathleen Garnette Moeller, daughter of the discoverer. (M 18463)

\section{(4712) Iwaizumi}

1989 QE. Discovered 1989 Aug. 25 by K. Endate and K. Watanabe at Kitami.

Named for a forestry town of population 15,000 in the eastern part of Iwate Prefecture. Birthplace of the first discoverer, Iwaizumi is famous for Ryusen-Do Cave, one of the Big Three Limestone Caves in Japan. (M 20838)

\section{(4713) Steel}

1989 QL. Discovered 1989 Aug. 26 by R. H. McNaught at Siding Spring.

Named in honor of Duncan Steel, Anglo-Australian astronomer who has conducted research on the origin and evolution of asteroids, comets and meteoroids. In particular, he has shown that several Apollo asteroids are the parents of meteor showers, indicating that these Apollos are likely to be extinct or moribund cometary nuclei. He has also worked extensively on radar observations of the meteoric influx to the atmosphere, planetary impact rates, and the dynamics of small solar system bodies. (M 17982)

\section{(4714) Toyohiro}

1989 SH. Discovered 1989 Sept. 29 by T. Fujii and K. Watanabe at Kitami.

Named in honor of the journalist Toyohiro Akiyama (1942- ), the first Japanese citizen to travel into space. He lifted off on 1990 Dec. 1 in Soyuz to travel to the space station Mir, and he described the effect of weightlessness and space sickness. (M 21131)

\section{(4716) Urey}

1989 UL $_{5}$. Discovered 1989 Oct. 30 by S. J. Bus at Cerro Tololo.

Winner of the 1934 Nobel Prize in chemistry for his discovery of deuterium, Harold Urey (1893-1981) was also one of the founders of planetary science as we know it today. His classic book The Planets (1952) discussed planetary objects and meteorites in the context of chemical and physical relationships. (M 41381)

\section{(4717) Kaneko}

1989 WX. Discovered 1989 Nov. 20 by Y. Mizuno and T. Furuta at Kani.

Named in honor of Isao Kaneko (1918- ), who worked toward social education during reconstruction in postwar Japan. He promoted cultural activities in mountain villages, established a private observatory and is now director of the Misono Space Education Service. Awarded the Chunichi Social Meritorious Prize by the Chubu-Nippon Press in 1976, he was also commended for his meritorious cultural service by the Board Education of Aichi Prefecture in 1979. (M 26762)

\section{(4718) Araki}

$1990 \mathrm{VP}_{3}$. Discovered 1990 Nov. 13 by T. Fujii and K. Watanabe at Kitami.

Named in honor of Chikara Araki (1946- ), an astronomical photographer in Hokkaido. He has formed a group called "Konpeito", and has been taking a lot of impressive astronomical photographs. (M 22503)

\section{(4719) Burnaby}

$1990 \mathrm{WT}_{2}$. Discovered 1990 Nov. 21 by S. Ueda and H. Kaneda at Kushiro. 
Named for the city in British Columbia, Canada, with a population of 150,000 . Burnaby and Kushiro \{see planet (4096)\}, which are at almost the same latitude, have been sister cities since 1965 and exchange students and share cultural experiences with each other. (M 21132)

\section{(4720) Tottori}

1990 YG. Discovered 1990 Dec. 19 by S. Ueda and H. Kaneda at Kushiro.

Named for a central city of the Sanin area, located on the Japan Sea, sister city of Kushiro \{see planet (4096)\} since 1963. (M 22503)

\section{(4721) Atahualpa}

4239 T-2. Discovered 1973 Sept. 29 by C. J. van Houten and I. van Houten-Groeneveld at Palomar.

On the 500th anniversary of the discovery of the Americas by Columbus \{see planet (327) \}, we want to remember the last king of the Incas in Peru: Atahualpa. He was born c. 1502 and was killed - even after he paid a room full of jewels and gold as a ransom - by the conquistador Pizarro in 1533. (M 20160)

\section{(4722) Agelaos}

4271 T-3. Discovered 1977 Oct. 16 by C. J. van Houten and I. van Houten-Groeneveld at Palomar.

Agelaos was a shepherd, who got the order to expose the baby Paris \{see planet (3317)\}, son of Priamus \{see planet (884)\}, king of Troy. He did not fulfill this order but raised and educated the boy. When Paris was still working for Agelaos as a shepherd, he had to give the 'judgement of Paris'. (M 18308)

\section{(4723) Wolfgangmattig}

1937 TB. Discovered 1937 Oct. 11 by K. Reinmuth at Heidelberg.

Named in honor of Wolfgang Mattig (1927- ), German solar physicist and cosmologist at the Freiburg Kiepenheuer-Institut, on the occasion of his retirement. In his thesis, Mattig worked on relativistic cosmology and, in 1957, he discovered an analytical relation between the redshift and the apparent magnitude of galaxies. He took an active part in the development of the Teide Observatory, Canary Islands. Since 1980, Mattig has been the German representative in the Solar Physics Commission of COSPAR. (M 22503)

Name proposed and citation prepared by J. Schubart, endorsed by G. Klare and L. D. Schmadel.

\section{(4724) Brocken}

1961 BC. Discovered 1961 Jan. 18 by C. Hoffmeister and J. Schubart at Tautenburg.

Named for the highest summit in the Harz Mountains that offers a wide view on a large part of northern Germany. (M 18144)

Name proposed by the second discoverer, following a suggestion of F. Börngen.

\section{(4725) Milone}

1975 YE. Discovered 1975 Dec. 31 at the Felix Aguilar Observatory at El Leoncito.

Named in honor of Luis Ambrosio Milone (1933- ), Argentinean astronomer who has been working in the field of stellar astrophysics for more than 30 years. Since 1964 he has been on the faculty of the School of Mathematics, Astronomy and Physics of the National University of Córdoba, where he teaches graduate and post-graduate courses in astronomy and astrophysics. Milone was responsible for building a photoelectric photometer for the Bosque Alegre Observatory $1.5-\mathrm{m}$ telescope. He was the initiator of photoelectric photometry in Córdoba and one of the first astronomers to apply these techniques. (M 33786)

\section{(4726) Federer}

1976 SV $_{10}$. Discovered 1976 Sept. 25 at the Harvard College Observatory at Harvard.

Named in honor of Charles A. Federer, Jr., founding editor of "Sky and Telescope" \{see planet (3243)\}. In January 1940, Federer became editor of "The Sky", a monthly popular astronomy magazine published since 1936 by the Hayden Planetarium in New York City. Then in November 1941, "The Sky" was combined with a similar publication, "The Telescope", which was founded at Perkins Observatory in 1931 but since 1934 had been published by Harvard College Observatory. Federer became editor-in-chief of "Sky and Telescope" in 1964 , a post he held until his retirement a decade later. (M 19339)

\section{(4727) Ravel}

1979 UD $_{1}$. Discovered 1979 Oct. 24 by F. Börngen at Tautenburg.

Named for the French composer Maurice Ravel (18751937), a significant representative of impressionism in music. His preference for Spanish music is manifested in his works Rhapsodie espagnole and Bolero. (M 18144)

\section{(4728) Lyapidevskij}

1979 VG. Discovered 1979 Nov. 11 by N. S. Chernykh at Nauchnyj.

Named in memory of Anatolij Vasil'evich Lyapidevskij (1908-1983), Soviet airman who participated in the search and rescue of the crew members of the "Chelyuskin", a ship crushed by ice in the Arctic Ocean on 1934 Feb. 13. (M 27127)

\section{(4729) Mikhailmil'}

$1980 \mathrm{RO}_{2}$. Discovered 1980 Sept. 8 by L. V. Zhuravleva at Nauchnyj.

Named in memory of Mikhail Leont'evich Mil' (1909-1970), scientist and designer of helicopters with which 60 official world records were set. (M 34620)

\section{(4731) Monicagrady}

$1981 \mathrm{EE}_{9}$. Discovered 1981 Mar. 1 by S. J. Bus at Siding Spring.

Monica Grady (1958- ), curator of the meteorite collection at the Natural History Museum in London, 
studies carbon isotopes in a wide range of meteorites with a focus on understanding the geologic processes leading to their formation. She is also actively involved in meteorite recovery efforts around the world. (M 41381)

\section{(4732) Froeschlé}

1981 JG. Discovered 1981 May 3 by E. Bowell at Anderson Mesa.

Named in honor of Claude and Christiane Froeschlé, Observatoire de la Côte d'Azur, Nice. Husband and wife, the Froeschlés have both contributed to our understanding of the dynamics of minor bodies (minor planets, comets, meteorites and dust particles) by numerical analysis of their orbital evolution. Claude was one of the first to investigate ergodic and chaotic regions in mean-motion resonances with Jupiter. He tested the so-called gravitational hypothesis for the formation of the Kirkwood gaps and showed that meteor streams situated in mean motion resonances may break into seperate parts. He also modeled the dynamical evolution of short-period comets using a Monte Carlo method. Christiane was one of the first to explore orbital evolution at secular resonances. She has shown that the principal secular resonances are good candidate sources for meteorites. (M 18463)

Citation provided by $\mathrm{H}$. Scholl at the request of the discoverer.

\section{(4733) ORO}

$1982 \mathrm{HB}_{2}$. Discovered 1982 Apr. 19 at the Oak Ridge Observatory at Harvard.

Named in honor of the Oak Ridge Observatory, established in Harvard, Massachusetts, by the Harvard College Observatory in 1932 and since 1982 operated by the Smithsonian Astrophysical Observatory. This minor planet is one of the 39 discovered in the course of the Oak Ridge (also known for many years as the Agassiz Station) astrometric program, which has been conducted with the 1.5-m Wyeth reflector, the largest telescope in the eastern United States, for almost 20 years. (M 19339)

\section{(4734) Rameau}

1982 UQ $_{3}$. Discovered 1982 Oct. 19 by F. Börngen at Tautenburg.

Named for Jean Philippe Rameau (1683-1764), the greatest French composer of the eighteenth century. $\mathrm{He}$ is well known for some operas, very charming piano pieces like Le Rappel des Oiseaux and for his fundamental writings on the theory of music. (M 18144)

\section{(4735) Gary}

1983 AN. Discovered 1983 Jan. 9 by E. Bowell at Anderson Mesa.

Named in honor of George Gary Shoemaker, manager of Meteor Crater Enterprises, Inc., on the occasion of the Asteroids, Comets, Meteors 1991 Conference in Flagstaff, Arizona, with which his company is associated. As manager of the visitor facilities and museum at Meteor Crater, Arizona, Shoemaker has played a leading role in the preservation of this National Natural Landmark and its associated meteorites and in developing the presentation of the scientific story of the crater to the public. He has consistently encouraged and supported research at the crater and the use of the crater for educational purposes. (M 18463)

Citation provided by E. M. Shoemaker at the request of the discoverer.

\section{(4736) Johnwood}

$1983 \mathrm{AF}_{2}$. Discovered 1983 Jan. 13 by C. S. Shoemaker and E. M. Shoemaker at Palomar.

Named for John A. Wood \{1932- \}, geologist at the Harvard-Smithsonian Center for Astrophysics, associate director of the planetary sciences division from 1981 to 1986. For more than 30 years, Wood has been a leading investigator of the petrography and petrology of chondritic meteorites as samples of primordial planetary materials. He also studied lunar rocks, beginning with those returned from the Apollo 11 mission. Wood is renowned for his theory that lunar anorthosites accumulated from a global magma ocean that developed very early in the history of the moon. (M 18464)

\section{(4737) Kiladze}

1985 QO $_{6}$. Discovered 1985 Aug. 24 by N. S. Chernykh at Nauchnyj.

Named in honor of Rolan Il'ich Kiladze (1931-

), astronomer at the Abastumani Observatory. His research has covered solar-system cosmogony and the dynamics and astrometry of Pluto, minor planets and artificial satellites. (M 27127; M 27147)

\section{(4739) Tomahrens}

$1985 \mathrm{TH}_{1}$. Discovered 1985 Oct. 15 by E. Bowell at Anderson Mesa.

Named in honor of Thomas J. Ahrens, professor of geophysics at the California Institute of Technology. Ahrens has built and directed the premier laboratory for experimental impact and shock physics, using lightgas guns. He has used this laboratory to investigate a broad array of problems, including the equations of state of minerals at very hight pressure, shock metamorphism and cratering mechanics. He has also addressed problems of impact cratering by computer code calculations and investigated the accumulation and early bombardment of the earth and the evolution of the atmosphere. (M 18645)

Citation provided by E. M. Shoemaker at the request of the discoverer.

\section{(4740) Veniamina}

1985 UV $_{4}$. Discovered 1985 Oct. 22 by L. V. Zhuravleva at Nauchnyj.

Named in memory of Veniamin Vasil'evich Somov (1945-1991), the discoverer's brother. (M 22503) 


\section{(4741) Leskov}

$1985 \mathrm{VP}_{3}$. Discovered 1985 Nov. 10 by L. G. Karachkina at Nauchnyj.

Named in memory of Nikolaj Semenovich Leskov (1831-1895), well-known Russian writer. (M 22247)

\section{(4742) Caliumi}

1986 WG. Discovered 1986 Nov. 26 at the Osservatorio San Vittore at Bologna.

Named in memory of Ferdinando Caliumi (19151993), well-known Italian amateur astronomer, generous constructor and restorer of astronomical telescopes. He was a great friend to the amateur astronomers at the discovery site, and he was also a member of both the Italian Astronomical Society and of the Unione Astrofili Italiani. (M 22829)

\section{(4743) Kikuchi}

1988 DA. Discovered 1988 Feb. 16 by T. Fujii and K. Watanabe at Kitami.

Named in honor of Ryoko Kikuchi (1964- ), who was backup to the first Japanese astronaut, Toyohiro Akiyama \{see planet (4714)\}, and helped to report details of environmental disruption. (M 21132)

\section{(4745) Nancymarie}

$1989 \mathrm{NG}_{1}$. Discovered 1989 July 9 by H. E. Holt at Palomar.

Named in honor of Nancy Marie Martinez, daughter of the discoverer. (M 18464)

\section{(4746) Doi}

$1989 \mathrm{TP}_{1}$. Discovered 1989 Oct. 9 by A. Takahashi and K. Watanabe at Kitami.

Named in honor of Takao Doi (1954- ), a backup payload specialist to Mamoru Mohri \{see planet (4613)\}. He has worked in the department of technology of the University of Tokyo and at the NASA Lewis Research Center. (M 21132)

\section{(4747) Jujo}

1989 WB. Discovered 1989 Nov. 19 by S. Ueda and H.

Kaneda at Kushiro.

Named for the place where the first discoverer works. (M 22829)

\section{(4748) Tokiwagozen}

1989 WV. Discovered 1989 Nov. 20 by K. Suzuki and T. Urata at Toyota.

Named for Tokiwagozen (1138-?), beautiful mother of Yoshitsune \{see planet (3178)\}. She was captured by the Heike at the battle of Heiji in 1159 and was later in favor with Kiyomori \{see planet (4375)\}. (M 21132)

\section{(4750) Mukai}

$1990 \mathrm{XC}_{1}$. Discovered 1990 Dec. 15 by T. Fujii and K. Watanabe at Kitami.

Named in honor of Chiaki Mukai (1952- _ ), a backup payload specialist to Mamoru Mohri \{see planet (4613)\}. She has worked in the medical department of Keio University. (M 21132)
(4751) Alicemanning

1991 BG. Discovered 1991 Jan. 17 by B. G. W. Manning at Stakenbridge.

Named in honor of Alice K. Manning, wife of the discoverer, for her support and encouragement of the discoverer's hobby over many years. The attention given to practical details such as warm clothing on cold nights, and the push needed to persuade him to finish the construction and fitting of measuringmachine encoders has contributed greatly to cometary astrometry and success in discovering minor planets. (M 18144)

\section{(4752) Myron}

1309 T-2. Discovered 1973 Sept. 29 by C. J. van Houten and I. van Houten-Groeneveld at Palomar.

Myron of Eleutherae (fl. 470 B.C.) in Attica, one of the most celebrated Greek artists, was a pupil of Ageladus and an older contemporary of Phidias \{see planet (4753)\} and Polyclitus. His works, mostly in bronze, include his statue of the 'Argive runner Ladas' and the Discobolus (discus-thrower), several marble copies of which are known. (M 20160)

\section{(4753) Phidias}

4059 T-3. Discovered 1977 Oct. 16 by C. J. van Houten and I. van Houten-Groeneveld at Palomar.

Named for the famous Greek artist, born c. 500 B.C. in Athens, a pupil of Ageladus. Eminent as an architect, a sculptor in bronze and a painter, Phidias was a friend of Pericles and his work is said to have included sculptures for the Acropolis. Phidias died in prison in 432 B.C. (M 20160)

\section{(4754) Panthoos}

5010 T-3. Discovered 1977 Oct. 16 by C. J. van Houten and I. van Houten-Groeneveld at Palomar.

A member of the Trojan senate, Panthoos warned against a marriage of a Trojan prince and a Greek princess and felt that disaster for Troy was inevitable. (M 18308)

\section{(4755) Nicky}

$1931 \mathrm{TE}_{4}$. Discovered 1931 Oct. 6 by C. W. Tombaugh at Flagstaff.

Named in honor of Nichole Tombaugh, granddaughter of the discoverer. (M 18308)

\section{(4756) Asaramas}

1950 HJ. Discovered 1950 Apr. 21 at the La Plata Observatory at La Plata.

Named in honor of the Asociación Argentina Amigos de la Astronomia, an amateur astronomical association in Argentina, founded 1929 January 4. The A.A.A.A. was the first contact with astronomy for a large number of professional astronomers at the La Plata Observatory. (M 22503)

\section{(4757) Liselotte}

1973 ST. Discovered 1973 Sept. 19 by C. J. van Houten and I. van Houten-Groeneveld at Palomar. 
Named after Elisabeth Charlotte von der Pfalz (1652-1722), known under her penname of Liselotte. A daughter of Kurfürst (Count Palatine) Karl Ludwig von der Pfalz, Liselotte married the brother of Louis XIV, Count Philipp I of Orleans. Her correspondence with her aunt, Kurfürstin Sophie von der Pfalz (wife of Herzog Ernst August von Hannover) and other famous contemporaries is preserved and gives a vivid insight into life at the time. (M 20161)

\section{(4758) Hermitage}

1978 SN $_{4}$. Discovered 1978 Sept. 27 by L. I. Chernykh at Nauchnyj.

Named for one of the largest museums in the world, the unique depository in St. Petersburg of works of the world's art and culture. (M 29143)

Name proposed by the discoverer following a suggestion by the Institute of Theoretical Astronomy.

\section{(4760) Jia-xiang}

$1981 \mathrm{GN}_{1}$. Discovered 1981 Apr. 1 at the Harvard College Observatory at Harvard.

Named in honor of Zhang Jia-xiang, an astronomer at the Purple Mountain Observatory and the director of its Planetary Laboratory. A student of the late Y. C. Chang \{see planet (2051)\}, Zhang has devoted himself to observations and orbital studies of comets and minor planets for more than three decades. He and his colleagues have discovered 115 numbered minor planets and four comets. (M 19339)

\section{(4761) Urrutia}

1981 QC. Discovered 1981 Aug. 27 by H.-E. Schuster at La Silla.

Named in honor of Antonio Urrutia A., Chilean lawyer in Santiago and for three decades legal advisor to the European Southern Observatory. The discoverer appreciates Urrutia's friendship and recalls his fruitful work. (M 34340)

\section{(4762) Dobrynya}

1982 SC $_{6}$. Discovered 1982 Sept. 16 by L. I. Chernykh at Nauchnyj

Named for the Russian epic hero Dobrynya Nikitich. (M 23137)

\section{(4763) Ride}

1983 BM. Discovered 1983 Jan. 22 by E. Bowell at Anderson Mesa.

Named in honor of Sally K. Ride, the first American woman to fly in space. From 1978 to 1987 Ride was a Space Shuttle astronaut, flying on two missions that launched scientific satellites. She has served the NASA administration, the National Research Council, and the U.S. Congress in both an advisory and administrative capacity. She has conducted studies of the Soviet Space Program and matters related to International Security and Arms Control. Ride is currently professor of physics and director of the California Space Institute at the University of California, San Diego, where she is actively involved in physics education and attracting and encouraging students to enter physics-related fields of study. Her research centers on free-electron lasers. (M 19698)

Citation provided by L. A. McFadden at the request of the discoverer.

\section{(4764) Joneberhart}

1983 CC. Discovered 1983 Feb. 11 by E. Bowell at Anderson Mesa.

Named in honor of Jonathan Eberhart, space science writer for the weekly publication Science News. For more than two decades Eberhart has reported advances and discoveries in planetary science through his coverage of planetary spacecraft encounters, the annual Lunar and Planetary Science Conference, and the annual meetings of the Division for Planetary Sciences (DPS) of the American Astronomical Society. $\mathrm{He}$ is known and respected for his attention to detail and accuracy in science reporting. Eberhart is also a talented composer and performer of folk music. As such, he is a founder of and performer in the "Titan Equatorial Band", an impromptu musical group that originated during the Voyager spacecraft encounters of Saturn. (M 18646)

Citation prepared by the Committee of the DPS at the request of the discoverer.

\section{(4765) Wasserburg}

$1986 \mathrm{JN}_{1}$. Discovered 1986 May 5 by C. S. Shoemaker and E. M. Shoemaker at Palomar.

Named for Gerald J. Wasserburg, professor of geology and geophysics at the California Institute of Technology. One of the pioneers in the development of techniques of isotopic age determination, Wasserburg is famous for the very high precision ages obtained in his laboratory for lunar rocks. These ages have provided much of the primary chronological control for deciphering the history of evolution of the moon. He has also carried out extensive investigations of the ages of meteorites and developed key evidence bearing on the earliest history of the solar system and of nucleosynthesis events that predate the solar system. (M 18464)

\section{(4766) Malin}

$1987 \mathrm{FF}_{1}$. Discovered 1987 Mar. 28 by E. F. Helin at Palomar.

Named in honor of David F. Malin, chemist and astrophotographer at the Anglo-Australian Observatory. He has developed new methods of extracting information from astronomical plates, an enhancement technique that has led to the discovery of extremely faint but large-scale features associated with otherwise normal galaxies. His special photographic and developing procedures have brought him worldwide recognition and acclaim. The discoverer has long been an admirer of his innovative photographic methods, which produce extraordinary photographs of celestial subjects in glorious color and detail. Malin is a 
well-known lecturer on his photographic techniques and has written many scientific papers and books on the subject. (M 18646)

\section{(4767) Sutoku}

1987 GC. Discovered 1987 Apr. 4 by T. Niijima and T. Urata at Ojima.

Sutoku (1119-1164), the 75th emperor of Japan, succeeded to the throne in 1123 . After his abdication, he was defeated in the war of Hogen against his brother, emperor Goshirakawa \{see planet (3585)\}, and exiled for life. (M 36944)

\section{(4768) Hartley}

$1988 \mathrm{PH}_{1}$. Discovered 1988 Aug. 11 by A. J. Noymer at Siding Spring.

Named in honor of Malcolm Hartley, deputy astronomer in charge of the U.K. Schmidt telescope at Siding Spring, with which this minor planet was discovered. Among his own discoveries are the Amor object $1988 \mathrm{SM}$ and ten comets, eight of which are of short period. (M 18464)

\section{(4769) Castalia}

1989 PB. Discovered 1989 Aug. 9 by E. F. Helin at Palomar.

Named for Castalia, a nymph pursued by Apollo \{see planet (1862)\}. Fleeing his attention, she dived into the earth, whence a spring burst forth and was given her name. The mythical spring, on Mount Parnassus at Delphi, was the site of the most important oracle to ancient Greece. Castalia was sacred to the muses and was considered a divine source of poetic inspiration. The name also refers to a genus of aquatic plants of the water-lily family, distinguished by rounded, floating leaves and large, fragrant flowers of various colors. (M 18464)

Name suggested by S. Ostro, who captured the stunning radar images of 1989 PB soon after its discovery.

The name Castalia is another spelling of Kastalia see planet (646)

\section{(4770) Lane}

1989 PC. Discovered 1989 Aug. 9 by E. F. Helin at Palomar.

Named in honor of Arthur Lonne Lane, manager of the geology and planetary section at the Jet Propulsion Laboratory, a physical chemist and planetary scientist with special interests in ultraviolet physics and photochemistry. He has been active in the field of ultraviolet planetary astronomy of atmospheres and solid surfaces, planetary rings, spectroscopic instrumentation, remote sensing pollution problems and science interactions with space-mission design. His most recent activity is as principal investigator of the delta star ultraviolet imaging experiment. "Lonne" is a diligent, innovative and enthusiastic scientist. He is a longtime friend and colleague of the discoverer who has appreciated his perception and guidance. (M 18646)
(4771) Hayashi

$1989 \mathrm{RM}_{2}$. Discovered 1989 Sept. 7 by M. Yanai and K. Watanabe at Kitami.

Named in honor of Kousuke Hayashi (1934- ), currently serving in the Exhibit Planning and Astronomy Section of the Sapporo Youth Science Museum, and Chairman of the Japan Planetarium Research Association since 1990. He served at the Sapporo City Astronomical Observatory for 20 years and has been a central figure in providing astronomical information to the public. One of his greatest achievements was the invention of a mobile observatory. (M 20521)

\section{(4773) Hayakawa}

1989 WF. Discovered 1989 Nov. 17 by K. Endate and K. Watanabe at Kitami.

Named in honor of Kazuo Hayakawa (1919- ) , an expert on mineralogy and petrology and professor of engineering at Hokkaigakuen University in Sapporo, Japan. His fields of interest include meteorites, craters and astroblemes. He has written a biography of William S. Clark (1826-1886) and many astrogeological essays. (M 20521)

Name proposed by K. Watanabe. Citation prepared by I. Hasegawa.

\section{(4774) Hobetsu}

$1991 \mathrm{CV}_{1}$. Discovered 1991 Feb. 14 by S. Ueda and H. Kaneda at Kushiro.

Named for a city, located $100 \mathrm{~km}$ southeast of Sapporo \{see planet (3473)\}, famous for the fossil of a sea dinosaur that was excavated there. Hobetsu is also well known as a production center for rice and melons. (M 22503)

\section{(4775) Hansen}

1927 TC. Discovered 1927 Oct. 3 by M. F. Wolf at Heidelberg.

Named in memory of Peter Andreas Hansen (17951874), leading theoretical astronomer of the nineteenth century, at the occasion of the 200th anniversary of his birth. Born in Tondern, Schleswig, he became director of the Seeberg Observatory near Gotha ssee planet (1346)\} in 1825. His most important work was the improvement of the theories and tables of the orbits of the principal bodies in the solar system. Hansen's lunar theory - yielding a very accurate new value of the astronomical unit - was used for the Nautical Almanac until 1922. He invented the method of perturbations in coordinates. Simon Newcomb \{see planet (855)\}, who continued his work, considered Hansen the greatest master of celestial mechanics since Laplace ssee planet (4628)\}. (M 25229)

Name proposed by L. K. Kristensen and endorsed by L. D. Schmadel.

Hansen is also honored by a lunar crater.

\section{(4776) Luyi}

1975 VD. Discovered 1975 Nov. 3 at the Harvard College Observatory at Harvard. 
Named for a town in the eastern Henan ssee planet (2085)\} province of China. Luyi is the birthplace of the legendary philosopher Laotze (born circa 640 B.C.) of the western Zhou dynasty and founder of Taoism. Luyi is the original hometown of C.-Y. Shao s see planet (1881)\}, who has been involved with the minor planet program at Harvard since its inception, and it is also the name of his son. (M 19339)

\section{(4777) Aksenov}

$1976 \mathrm{SM}_{2}$. Discovered 1976 Sept. 24 by N. S. Chernykh at Nauchnyj.

Named in memory of a well-known authority on celestial mechanics, Evgenij Petrovich Aksenov (19331995), director of the Sternberg Astronomical Institute in Moscow for many years. With Grebenikov and Demin \{see planets (4268) and (5086), respectively\}, he investigated and found a general solution for the generalized problem of two fixed centers, carrying out a qualitative investigation of all possible types of motion within the problem and considering their stability. He also developed an analytical theory for the motions of artificial satellites based on a non-Keplerian intermediate orbit, and he proved the existence of several new classes of periodic solutions within the circular restricted three-body problem. (M 29143)

Name suggested by the Institute of Theoretical Astronomy.

Obituary published in Astron. Rep., Vol. 39, No. 3, p. 382 (1995).

\section{(4778) Fuss}

1978 TV 8 . Discovered 1978 Oct. 9 by L. V. Zhuravleva at Nauchnyj.

Named in honor of the mathematicians Nikolaj Ivanovich Fuss (1755-1825) and his son Pavel Nikolaevich Fuss (1798-1855). Nikolaj Fuss contributed greatly to the development of mathematical education in Russia. Pavel Fuss published a bibliography of the more than 800 scientific papers of Euler \{see planet (2002)\}. (M 34620)

\section{(4779) Whitley}

1978 XQ. Discovered 1978 Dec. 6 by E. Bowell and A. Warnock at Palomar.

Named in memory of Keith Whitley (1958-1989), American country music singer who died tragically at the zenith of his profession. A powerful and emotional performer, Whitley began his professional career as a teenager, playing bluegrass music with Ralph Stanley and the Clinch Mountain Boys. His later success as a solo artist was a source of joy and inspiration for the many friends he made over the years. He helped rekindle an interest in traditional country music, reviving an entire industry. (M 18646; M 34673)

\section{(4780) Polina}

$1979 \mathrm{HE}_{5}$. Discovered 1979 Apr. 25 by N. S. Chernykh at Nauchnyj.
Named in honor of Polina Evgen'evna Zakharova, stellar astronomer and director of the Kourovka Astronomical Observatory of the Ural University. (M 27127)

\section{(4781) Sládkovič}

1980 TP. Discovered 1980 Oct. 3 by Z. Vávrová at Kleť.

Named in honor of Andrej Sládkovič (1820-1872), Slovak poet and author of the poem "Marina". (M 21609)

\section{(4782) Gembloux}

$1980 \mathrm{TH}_{3}$. Discovered 1980 Oct. 14 by H. Debehogne and L. Houziaux at St. Michel.

Named for an industrial city on the river Orneau in southern Belgium. (M 19339)

\section{(4783) Wasson}

$1983 \mathrm{AH}_{1}$. Discovered 1983 Jan. 12 by C. S. Shoemaker and E. M. Shoemaker at Palomar.

Named for John T. Wasson, cosmochemist and professor at the University of California at Los Angeles. Wasson is the leading investigator of the chemistry of iron meteorites and developed the chemical classification scheme for irons now in general use. He has written extensively on the origin and evolution of meteorites, their asteroid parent bodies and the solar nebula. With his student and colleague Frank T. Kyte, Wasson has also contributed important observations and insights on the geochemical signature left in the stratigraphic record by the impact of large extraterrestrial bodies on the earth. (M 18464)

\section{(4785) Petrov}

$1984 \mathrm{YH}_{1}$. Discovered 1984 Dec. 17 by L. G. Karachkina at Nauchnyj.

Named for the contemporary Russian composer Andrej Pavlovich Petrov (1930- ）. (M 22247)

\section{(4786) Tatianina}

$1985 \mathrm{PE}_{2}$. Discovered 1985 Aug. 13 by N. S. Chernykh at Nauchnyj.

Named in honor of Tatiana Aleksandrovna Somova, friend of the discoverer, nursery-school teacher in St. Petersburg, an unusual and interesting person. (M 26762)

\section{(4787) Shul'zhenko}

1986 RC $_{7}$. Discovered 1986 Sept. 6 by L. V. Zhuravleva at Nauchnyj.

Named in memory of Klavdiya Ivanovna Shul'zhenko (1906-1984), a famous Russian variety singer. (M 24122)

\section{(4788) Simpson}

$1986 \mathrm{TL}_{1}$. Discovered 1986 Oct. 4 by E. Bowell at Anderson Mesa.

Named in honor of Robert W. L. Simpson, English composer, who has celebrated his 70th birthday in 1991. Simpson's musical character has been mainly 
expressed in his symphonies and string quartets, which are influenced by Beethoven, Bruckner and Sibelius \{which are also present at the minor planet sky with numbers (1815), (3955), and (1405)\}. The discoverer has long regarded Simpson as one of the greatest musical structuralists. An astronomer by avocation, Simpson is a fellow of the Royal Astronomical Society. (M 18465)

\section{(4789) Sprattia}

$1987 \mathrm{UU}_{2}$. Discovered 1987 Oct. 20 by D. D. Balam at Victoria.

Named in honor of Christopher E. Spratt, an active amateur member of the Royal Astronomical Society of Canada for 20 years, with special interests in comets, minor planets, meteors and variable stars. He has written numerous articles on these subjects, including some on Canadian meteorites, in the Journal of the Royal Astronomical Society of Canada, and he has been of much practical help to the astrometric program carried out at the University of Victoria. Spratt maintains a carefully-chosen representative collection of meteorites and was coordinator for the northwest North American section of the Amateur Observation Network of the International Halley Watch. He has contributed more than 32,000 observations of longperiod and semiregular variable stars and dwarf novae to the American Association of Variable Star Observers and in 1976 was the most prolific observer of that year. The Chant Medal of the Royal Astronomical Society of Canada was bestowed upon him in 1988. Spratt holds an honors diploma in horticulture and, as a professional member of the gardening staff at the University of Victoria, does much to make the university a pleasant place in which to work. (M 18465)

Citation provided by J. B. Tatum at the request of the discoverer.

\section{(4790) Petrpravec}

1988 PP. Discovered 1988 Aug. 9 by E. F. Helin at Palomar.

Named in honor of Petr Pravec (1967- ), an astronomer at the Ondřejov Observatory well known for both astrometric and photometric work on minor planets and comets. He specializes in near-earth objects and has often been the first person to observe objects found in the course of the discoverer's NEAT program following their tentative announcement in the Minor Planet Center "NEO Confirmation Page". In his Ph.D. dissertation Pravec pointed out that the lightcurve of 1994 AW1, an NEO found by the discoverer, strongly suggests that the object is binary. (M 30095)

This minor planet is being named on the occasion of the marriage of Petr Pravec and Kateřina Macháčová, 1997 June 21 ssee also planet (7492)\}.

\section{(4791) Iphidamas}

1988 PB $_{1}$. Discovered 1988 Aug. 14 by C. S. Shoemaker and E. M. Shoemaker at Palomar.
Named for the huge, stalwart son of the Trojan counselor Antenor \{see planet (2207)\} and brother of Agenor \{see planet (1873)\}. During the battle near the Greek encampment, Iphidamas thrust his spear into Agamemnon \{see planet (911)\}, who was saved by his war belt. Pulling the spear toward himself, Agamemnon then killed Iphidamas with a sword stroke to the neck. (M 18465)

\section{(4792) Lykaon}

1988 RK $_{1}$. Discovered 1988 Sept. 10 by C. S. Shoemaker and E. M. Shoemaker at Palomar.

Named for the brother of Polydoros and a son of Priam \{see planets (4708) and (844)\}; born of the queen Laothoe. Some years before the Trojan war, Achilles \{see planet (588)\} captured Lykaon and sold him into slavery, but Lykaon made his way back to Troy, only to be killed by Achilles beside the River Skamander. (M 18465)

Name and citation provided by Richard Preston at the request of the discoverers.

\section{(4794) Bogard}

$1988 \mathrm{SO}_{2}$. Discovered 1988 Sept. 16 by S. J. Bus at Cerro Tololo.

Donald Bogard (1940- ) of NASA's Johnson Space Center has been at the forefront of understanding the chronology of formation and impact alterations of solar system bodies using argon isotope measurements. He played a key role in recognizing the martian origin of some meteorites using analyses of trapped gases. (M 41381)

\section{(4795) Kihara}

$1989 \mathrm{CB}_{1}$. Discovered 1989 Feb. 7 by A. Takahashi and K. Watanabe at Kitami.

Named in honor of Hideo Kihara (1911-1993), a founder of the Nayoro Astronomical Club, who established the Kihara Observatory, where he made observations of sunspots for 20 years. The observatory was presented to the city of Nayoro before his death and is now known as the Nayoro-Kihara Observatory. (M 22503)

Name suggested and citation prepared by H. Fukushima.

\section{(4796) Lewis}

1989 LU. Discovered 1989 June 3 by E. F. Helin at Palomar.

Named in honor of Joseph Walter Lewis, Jr. and his wife Anne Beech Lewis, good friends of the discoverer, on the occasion of their fiftieth wedding anniversary. Joe and Anne, an alumnus and alumna of Caltech and Stanford, respectively, have pursued distinguished civic as well as professional careers. Joe is president of DB Products, an electronic manufacturing company, and formerly vice president of Beckman Instruments. $\mathrm{He}$ is also a member of the Caltech Associates and has served as alumni president. Anne has been active in various civic and philanthropic organizations. Their 
three children, Jeff, Jack and Taffy, along with their many friends, warmly endorse this tribute. (M 21956)

\section{(4797) Ako}

1989 SJ. Discovered 1989 Sept. 30 by T. Nomura and K. Kawanishi at Minami-Oda.

Named for a city in Hyogo Prefecture and its ancient castle on the Seto inland sea. Ako is famous for its salt production and the story of "Chushin-Gura", which shows the loyalty of samurais to their local lord. Three centuries ago 47 loyal samurais committed harakari after avenging their master. The second discoverer, by profession a dentist, lives in Ako and observes comets and minor planets at his private observatory there. (M 18465)

\section{(4798) Mercator}

$1989 \mathrm{SU}_{1}$. Discovered 1989 Sept. 26 by E. W. Elst at La Silla.

Named in memory of the Flemish cartographer Gerard De Kremer (1512-1594), known under the Latinised form of his name Gerardus Mercator. After receiving a master's degree from the University of Leuven in 1532, he studied mathematics, geography and astronomy and became a skillful engraver. He established himself in that city as an independent scientific-instrument maker and cartographer in 1537 and began to build his reputation as the most important geographer of his time. Appointed court cosmographer to the Duke of Cleve in 1564, he perfected his cylindrical map projection now known as "Mercator projection" in 1569. To him we owe the term "atlas" for a collection of geographical maps. (M 19339)

Name proposed by the discoverer following a suggestion by E. Goffin, who also prepared the citation.

Mercator is also honored by a lunar crater.

\section{(4799) Hirasawa}

$1989 \mathrm{TC}_{1}$. Discovered 1989 Oct. 8 by Y. Mizuno and T. Furuta at Kani.

Named in honor of Yasuo Hirasawa (1927- ), a great source of inspiration for the discoverers. An eager observer of variable stars, he has also done much to impart a knowledge of astronomy in the planetarium at the Nagoya City Science Museum. (M 26762)

\section{(4801) Ohře}

1989 UR $_{4}$. Discovered 1989 Oct. 22 by A. Mrkos at Klě́.

Named for a Czech river rising in Germany near the Czech border and continuing through the towns of Karlovy Vary, Žatec and Louny to its confluence with the Labe river. (M 34340)

Name proposed by Z. Moravec.

\section{(4802) Khatchaturian}

1989 UA $_{7}$. Discovered 1989 Oct. 23 by F. Börngen at Tautenburg.
Named in memory of the Armenian composer Aram Khatchaturian (1903-1978), well known for his ballets Gajaneh and Spartakus, as well as for instrumental pieces such as the Sabre Dance. His compositions combine in melody, rhythm and orchestration the national folk music of the Transcaucasus with the traditions of classical symphonic music. (M 18466)

\section{(4803) Birkle}

1989 XA. Discovered 1989 Dec. 1 by J. M. Baur at Chions.

Named in honor of Kurt Birkle \{1939- \}, since 1974 the local director of the Calar Alto Observatory, which is managed in close cooperation with the Max-Planck-Institut für Astronomie in Heidelberg. As an MPI collaborator Birkle performed pioneering work on site testing in mediterranean and other countries for a new large observatory. He is also an expert in astrophotography, well known for his observations of comets. (M 18466)

\section{(4804) Pasteur}

$1989 \mathrm{XC}_{1}$. Discovered 1989 Dec. 2 by E. W. Elst at La Silla.

Named in memory of the great French chemist and microbiologist Louis Pasteur (1822-1895), who proved that fermentation and disease are caused by micro-organisms. His invention of the principle of immunization was successfully applied for the first time against rabies in 1885 . In 1888 the celebrated Pasteur Institute was established in Paris, and the process of pasteurization is well known throughout the whole world. (M 19340)

Pasteur is also honored by craters on Mars and on the Moon.

\section{(4805) Asteropaios}

$1990 \mathrm{VH}_{7}$. Discovered 1990 Nov. 13 by C. S. Shoemaker and E. M. Shoemaker at Palomar.

Named for the leader of the Paionians, among the greatest of the Trojan allies. Spear-throwing Asteropaios, considered by Sarpedon ssee planet (2223)\} to be one of the bravest warriors, challenged and wounded Achilles \{see planet (588)\} but was slain in the encounter. (M 18466)

\section{(4806) Miho}

1990 YJ. Discovered 1990 Dec. 22 by A. Natori and T. Urata at Yakiimo.

Named for a resort located in suburban Shimizu and about $3 \mathrm{~km}$ east of Yakiimo Station. Miho is known for its beautiful seashore and white sands, pine trees and its proximity to Mt. Fuji. It has interesting topography due to its sand-split, and it is most famous for the legend of angels bathing and dancing in the sky. (M 19698)

\section{(4807) Noboru}

1991 AO. Discovered 1991 Jan. 10 by T. Kobayashi at Oizumi. 
Named in memory of Noboru Yamada (1950-1989), one of the greatest Japanese alpinists. Yamada had intended to climb all the peaks in the $8000-\mathrm{m}$ class on the earth and climbed nine of them in twelve expeditions. (M 23540)

\section{(4810) Ruslanova}

1972 GL. Discovered 1972 Apr. 14 by L. I. Chernykh at Nauchnyj.

Named in memory of Lidiya Andreevna Ruslanova (1900-1973), Russian variety singer, popular for her renditions of ethnic folk songs. (M 23137)

\section{(4811) Semashko}

$1973 \mathrm{SO}_{3}$. Discovered 1973 Sept. 25 by L. V. Zhuravleva at Nauchnyj.

Named in memory of Nikolaj Alekseevich Semashko (1874-1949), organizer of the health-service system in the U.S.S.R. in the 1920s. He took the lead in the organization of mother-and-child health institutions, developed the network of medical research establishments and initiated the formation of the Central Medical Library and the House of Scientists in Moscow. During 1927-1936 he was editor-in-chief of the Large Medical Encyclopedia. (M 34620)

\section{(4812) Hakuhou}

1977 DL $_{3}$. Discovered 1977 Feb. 18 by H. Kosai and K. Hurukawa at Kiso.

Named for the Hakuhou Era, from the seventh and eighth centuries, when the influence of Buddhism in Japan was very high. (M 21609)

\section{(4813) Terebizh}

$1977 R_{7}$. Discovered 1977 Sept. 11 by N. S. Chernykh at Nauchnyj.

Named in honor of Valerij Yuzefovich Terebizh (1941- ), theoretical astrophysicist and observer at the Crimean station of the Sternberg Astronomical Institute. He found formal solutions to some important nonstationary and nonlinear problems of radiative transfer and time-series analysis. He developed the Occam approach to inversion problems of mathematical physics, in particular, to the problem of image restoration. (M 27127)

\section{(4814) Casacci}

1978 RW. Discovered 1978 Sept. 1 by N. S. Chernykh at Nauchnyj.

Named in honor of Claudio Casacci (1958- ), an Italian amateur astronomer who has been deeply involved in the popularization of astronomy and in the organization of meetings concerned, in particular, with minor bodies of the solar system. He was a member of the local organizing committee of the Asteroids, Comets, Meteors 1993 conference (IAU Symposium No. 160) and recently favored contacts between specialists of Italy and those of the Former Soviet Union, being particularly efficient in organizing the 1994 Belgirate Workshop on Near-Earth Asteroids. (M 25229)

Name proposed by the discoverer jointly with A. Sokolsky and V. Shor.

\section{(4815) Anders}

1981 EA $_{28}$. Discovered 1981 Mar. 2 by S. J. Bus at Siding Spring.

Edward Anders (1926- ), professor emeritus at the University of Chicago, has made many seminal contributions to the field of meteoritics. His work provided early evidence that meteorites are derived from minor planets rather than a larger fragmented planet and that meteoritic organics are of abiotic origin. (M 41382)

\section{(4816) Connelly}

1981 PK. Discovered 1981 Aug. 3 by E. Bowell at Anderson Mesa.

Named in honor of Robert Connelly, mathematician at Cornell University. A specialist in geometry, Connelly has made significant contributions to the theoretical interpretation of optical lightcurves and radar echo power spectra. His work has provided an important foundation for asteroid radar imaging and astrometry, and it has established a valuable framework for using radar data to derive joint constraints on an asteroid's shape, rotation and delay-Doppler trajectory. (M 19698)

Name suggested and citation written by S. J. Ostro.

\section{(4818) Elgar}

1984 EM. Discovered 1984 Mar. 1 by E. Bowell at Anderson Mesa.

Named for Sir Edward Elgar (1857-1934), English composer. Arguably the progenitor of the English musical renaissance of the 20th century, Elgar is best known for his orchestral and choral works. (M 19340)

\section{(4819) Gifford}

1985 KC. Discovered 1985 May 24 by A. C. Gilmore and P. M. Kilmartin at Lake Tekapo.

Algernon Charles Gifford (1861-1948) published important papers on the impact origin of lunar craters. He established an observatory at Wellington College, which is now reopening as Gifford Observatory. Mt. Gifford and the Gifford Crack, in Fiordland, are named for his legendary exploits in tramping and photography. (M 45231)

\section{(4820) Fay}

1985 RZ. Discovered 1985 Sept. 15 by C. S. Shoemaker and E. M. Shoemaker at Palomar.

Named for Fay Gillis Wells, charter member, historian and guiding spirit of the Ninety-Nines, an international organization now numbering nearly 7000 women pilots from 35 countries. She was the first woman member of the Caterpillar Club, having jumped from a disabled aircraft to save her life in 1929 , and being the first American woman pilot to fly in the Soviet Union. Still 
active at the age of 86 , she continues to spearhead the recognition of the contribution of women to aviation. (M 24916)

\section{(4821) Bianucci}

$1986 \mathrm{EE}_{5}$. Discovered 1986 Mar. 5 by W. Ferreri at La Silla.

Named in honor of Piero Bianucci, scientific journalist and member of the editorial staff of "La Stampa" of Turin, one of the most important newspapers in Italy. One of the best known popular writers on astronomy in Italy, Bianucci has written more than ten popular astronomical books and thousands of scientific articles. He has inspired a growing interest in astronomy in Italy, especially among young people. (M 19340)

\section{(4822) Karge}

1986 TC $_{1}$. Discovered 1986 Oct. 4 by E. Bowell at Anderson Mesa.

Named in honor of Orville B. Karge (1919-1990), instructor of physics at San Dieguito and Torrey Pines High Schools, near San Diego, California. Karge was known to be selflessly devoted to teaching and the development of opportunities for students to independently explore their interests beyond the classroom. His encouragement to enter science fairs, sponsorship of a long-lived rocketry and astronomy club, and an open-lab policy provided educational challenges and adventures for his physics students and many others. (M 19340)

Citation prepared by J. Bytof at the request of the discoverer.

\section{(4823) Libenice}

$1986 \mathrm{TO}_{3}$. Discovered 1986 Oct. 4 by A. Mrkos at Klě̌.

Named for the site of remnants of an ancient Celtic sanctuary in central Bohemia that has astronomical significance and dates back to the fourth century B.C. (M 34620)

Name suggested by M. Tichý.

\section{(4824) Stradonice}

$1986 \mathrm{WL}_{1}$. Discovered 1986 Nov. 25 by A. Mrkos at Klet.

Named for the site of an ancient Celtic town in central Bohemia above the Berounka ssee planet (4702)\} river. It was settled in the first century B.C. and is known for its treasures of gold and silver Celtic coins. (M 34620)

Name suggested by M. Tichý.

\section{(4825) Ventura}

$1988 \mathrm{CS}_{2}$. Discovered 1988 Feb. 11 by E. W. Elst at La Silla.

Named for the city near the coast of the Pacific, north of Los Angeles. After the conference "Near-Earth Asteroids" at San Juan Capistrano in July 1991 the discoverer and his family spent a most enjoyable time there at the home of friends. (M 19340)

\section{(4826) Wilhelms}

1988 JO. Discovered 1988 May 11 by C. S. Shoemaker and E. M. Shoemaker at Palomar.

Named for Don E. Wilhelms, a leading student of the moon. Wilhelms coordinated a 20-year-long U.S. Geological Survey program to map the geology of the moon. His masterpiece, The Geologic History of the Moon, was published as USGS Professional paper 1348. In his book, To a Rocky Moon, he recounts the human story of lunar geology from early research to the detailed exploration by the Apollo astronauts. (M 24916)

\section{(4827) Dares}

1988 QE. Discovered 1988 Aug. 17 by C. S. Shoemaker and E. M. Shoemaker at Palomar.

Named for one of Aeneas' \{see planet (1172)\} wandering companions at arms after the fall of Troy and the only Trojan who had dared to box with Paris \{see planet (3317)\}, according to Virgil's Aeneid. When Aeneas' men stopped in Sicily and had games with the Sicilians, Dares boxed with a Sicilian named Entellus, using rawhide gloves. Entellus nearly beat Dares, but Aeneas called off the fight. (M 18647)

Name and citation provided by R. Preston at the request of the discoverers.

\section{(4828) Misenus}

1988 RV. Discovered 1988 Sept. 11 by C. S. Shoemaker and E. M. Shoemaker at Palomar.

Named for Aeneas' \{see planet (1172)\} herald and trumpeter. As Virgil tells it, Misenus unluckily blew on a conch shell just as the Trojan wanderers were making landfall in Italy, near Cumae, and the clear note of the shell so enraged the god Triton that he killed Misenus and threw his body on the beach. In later years a Roman fleet was stationed near the legendary place, at Misenum, named after Misenus. (M 18647)

Name and citation prepared by $R$. Preston at the request of the discoverers.

\section{(4829) Sergestus}

$1988 \mathrm{RM}_{1}$. Discovered 1988 Sept. 10 by C. S. Shoemaker and E. M. Shoemaker at Palomar.

Named for one of Aeneas' \{see planet (1172)\} Trojan companions after the fall of Troy, commander of the galley named "Centaur". During the Sicilian games, as described in the Aeneid, Sergestus took the Centaur in a race against three other galleys. He drove his ship upon the rocks, lost the race and was mocked by the crowds, but to console him Aeneas gave him a reward of a slave woman named Pholoe. (M 18647)

Name and citation provided by R. Preston at the request of the discoverers.

\section{(4831) Baldwin}

1988 RX $_{11}$. Discovered 1988 Sept. 14 by S. J. Bus at Cerro Tololo. 
Through his pioneering work on the impact origins of lunar craters, Ralph Baldwin (1912- ) recognized the importance of impacts in the moon's geologic history. Baldwin's contributions to lunar science were published in his books The Face of the Moon (1949) and The Measure of the Moon (1963). (M 41382)

\section{(4832) Palinurus}

1988 TU$_{1}$. Discovered 1988 Oct. 12 by C. S. Shoemaker and E. M. Shoemaker at Palomar.

Named for Aeneas' \{see planet (1172)\} great helmsman and navigator, who led the remnant of the Trojan fleet across unknown seas from Troy to Carthage and Sicily, and finally to Italy, as told by Virgil in the Aeneid. As the fleet was making its final passage to Italy, the god Neptune put Palinurus to sleep while he held the tiller in his hands; he fell overboard and was drowned, and his naked body washed up on the shores of Italy. (M 18647)

Name and citation provided by $R$. Preston at the request of the discoverers.

\section{(4833) Meges}

$1989 \mathrm{AL}_{2}$. Discovered 1989 Jan. 8 by C. S. Shoemaker and E. M. Shoemaker at Palomar.

Named for the commander of the Greek islanders who dwelt off Elis, on the west coast of Peloponnese; he sailed for Troy with forty ships, and killed Amphiklos. Later Meges, with Thoas \{see planet (4834)\}, was part of the Greek delegation that persuaded Achilles \{see planet (588)\} to return to battle. (M 18647)

Name and citation provided by $\mathrm{R}$. Preston at the request of the discoverers.

\section{(4834) Thoas}

$1989 \mathrm{AM}_{2}$. Discovered 1989 Jan. 11 by C. S. Shoemaker and E. M. Shoemaker at Palomar.

Named for Thoas, the commander of the Aitolians, a tough man at spear-throwing, and eloquent in argument. The god Poseidon \{see planet (4341)\} (who favored the Greeks) must have respected Thoas for both his warlike skills and for his eloquence, because Poseidon chose to take the shape of Thoas, and, in Thoas's voice, rallied the Greeks when the Trojans were close to the Greek ships, and fought beside the Greeks in the shape of Thoas. (M 18647)

Name and citation provided by R. Preston at the request of the discoverers.

\section{(4836) Medon}

1989 CK $_{1}$. Discovered 1989 Feb. 2 by C. S. Shoemaker and E. M. Shoemaker at Palomar.

Named for an illegitimate son of Oileus, and halfbrother of Ajax Oiliades (also known as Little Ajax). Medon lived in exile for having killed a relative of his stepmother. He fought bravely at Troy, but was killed before the Greek ships by Aeneas \{see planet (1172)\}. (M 18648)
Name and citation provided by R. Preston at the request of the discoverers.

\section{(4837) Bickerton}

1989 ME. Discovered 1989 June 30 by A. C. Gilmore and P. M. Kilmartin at Lake Tekapo.

Alexander W. Bickerton (1842-1929), professor of chemistry at Canterbury College, was an inspiring teacher and popularizer of science. Ernest Rutherford was one of his distinguished pupils. Bickerton was known for his "partial impact" theory of novae, which he extended to variable stars and other phenomena. (M 45231)

\section{(4838) Billmclaughlin}

1989 NJ. Discovered 1989 July 2 by E. F. Helin at Palomar.

Named in honor of William I. McLaughlin (1935- ） on the occasion of his retirement from the Jet Propulsion Laboratory, where he made innovative contributions to many projects, including Viking, Seasat, the Infrared Astronomical Satellite and Voyager (Uranus), and to the management of two technical sections. He also served as deputy manager of the astrophysics and fundamental physics program office. For 14 years McLuaghlin wrote a column in Spaceflight called "Space at JPL". He takes a special interest in philosophy, mathematics, astronomy and epistemology, as well as space exploration and has written numerous papers. (M 34340)

\section{(4839) Daisetsuzan}

1989 QG. Discovered 1989 Aug. 25 by K. Endate and K. Watanabe at Kitami.

Named for the Daisetsuzan Mountains, which rise to the height of about 2,000 meters in central Hokkaido \{see planet $(3720)\}$. The mountains are a treasury of the beauty of nature. A quasi-national park, it contains many marshy districts and great stocks of alpine plants. (M 20838)

\section{(4840) Otaynang}

1989 UY. Discovered 1989 Oct. 23 by Y. Oshima at Gekko.

Named in honor of Hanne Otaynang (1935- ), who appealed for the environmental preservation of the Earth at the 1992 Earth Summit in Brazil. (M 24122)

Name proposed by the Gekko Astronomical Observatory.

\section{(4841) Manjiro}

$1989 \mathrm{UO}_{3}$. Discovered 1989 Oct. 28 by T. Seki at Geisei.

Named in memory of Manjiro Nakahama, a fisherman from Kochi prefecture who was rescued by an American whaling ship at the age of 16 when, in 1843 , he was drifting in the Pacific. Beginning a new life in the U. S. under the name John Manjiro, he served as first 
officer on several voyages and played a very important part in the early stages of cultural exchange between Japan and the United States. (M 19340)

\section{(4842) Atsushi}

1989 WK. Discovered 1989 Nov. 21 by S. Ueda and H. Kaneda at Kushiro.

Named in honor of Atsushi Takahashi (1965- ). A resident of Kitami \{see planet (3785)\}, he makes observations of minor planets and comets as a member of a group named "Hokkaido Showakusei Suisei Kaigi". (M 22503)

Name proposed by K. Watanabe.

\section{(4843) Mégantic}

$1990 \mathrm{DR}_{4}$. Discovered 1990 Feb. 28 by H. Debehogne at La Silla.

Named for Mont Mégantic, the largest observatory in Québec. Founded in 1978, its mission is to promote research in astrophysics, to train students and to promote astronomy in the local culture. The observatory is jointly operated by the Université de Montréal and the Université Laval. (M 32344)

Name proposed by the discoverer, following a suggestion by P. Bastien and Y. Dutil.

\section{(4844) Matsuyama}

$1991 \mathrm{BA}_{2}$. Discovered 1991 Jan. 23 by S. Ueda and H. Kaneda at Kushiro.

Named in honor of Masanori Matsuyama (1950- ), who started observing minor planets in 1987 and has discovered many new minor planets since then. He lives in Kushiro \{see planet (4096)\} and makes observations of minor planets and comets as a member of "Hokkaido Showakusei Suisei Kaigi". (M 22503)

Name proposed by K. Watanabe.

\section{(4845) Tsubetsu}

$1991 \mathrm{EC}_{1}$. Discovered 1991 Mar. 5 by K. Endate and K. Watanabe at Kitami.

Named for a timber town, with a population of less than 9,000, in eastern Hokkaido \{see planet (3720)\}. The first discoverer spent his boyhood in Tsubetsu between 1966 and 1972. (M 20838)

\section{(4846) Tuthmosis}

6575 P-L. Discovered 1960 Sept. 24 by C. J. van Houten and I. van Houten-Groeneveld at Palomar.

Tuthmosis (also written Thothmose) was the name of four Egyptian pharaohs of the 18th dynasty. The name means 'child of the god Thot'. Tuthmosis I was the first king to be buried in the Valley of the Tombs of the Kings near Thebes. Tuthmosis III was the successor of his stepmother and regent, Hatshepsut \{see planet 2436)\}. (M 20161)

\section{(4847) Amenhotep}

6787 P-L. Discovered 1960 Sept. 24 by C. J. van Houten and I. van Houten-Groeneveld at Palomar.
Named after pharaohs of the 18th dynasty. Amenhotep (Greek name Amenophis) means 'Amun is merciful'. Amenhotep II was buried in the Valley of the Kings and his tomb records his military successes. Amenhotep III built one of the most famous temples at Luxor, and his mummy is now in the Cairo Museum. (M 20161)

\section{(4848) Tutenchamun}

3233 T-2. Discovered 1973 Sept. 30 by C. J. van Houten and I. van Houten-Groeneveld at Palomar.

Named after the 18th dynasty pharaoh Tut-enchAmun or Tutanchamun, 1355-1337 B.C., son-in-law and probably also son of Echnaton \{see planet (4415)\} and Nofretete (also named Nefertiti, see planets (1068) and (3199), respectively). He died unexpectedly, probably violently, at about 18 years of age. His fabulously decorated tomb was undisturbed when discovered in 1922 by Howard Carter. (M 20161)

\section{(4849) Ardenne}

1936 QV. Discovered 1936 Aug. 17 by K. Reinmuth at Heidelberg.

Named in memory of Manfred von Ardenne (19071997), German inventor and researcher in various fields, especially known as a pioneer in television and radio engineering. His early interests in astronomy stimulated his enthusiasm for science and technology, and he emphasized the educational value of astronomy for young people. Ardenne established three private observatories, which were all open to the public. (M 30798)

Name proposed and citation prepared by D. B. Herrmann, endorsed by L. D. Schmadel.

\section{(4850) Palestrina}

1973 UJ $_{5}$. Discovered 1973 Oct. 27 by F. Börngen at Tautenburg.

Named for the famous Italian Renaissance composer Giovanni Pierluigi da Palestrina (1525?-1594). His works fill 34 volumes and are marked by quiet elevation, dignity, clearness and melodious sound. (M 19341)

\section{(4851) Vodop'yanova}

1976 US $_{1}$. Discovered 1976 Oct. 26 by T. M. Smirnova at Nauchnyj.

Named in honor of Galina Petrovna Vodop'yanova (1939- ), a talented surgeon of the Russian Academy of Sciences Hospital, St. Petersburg, since 1978. (M 30475)

Name suggested by N. A. Bokhan.

\section{(4852) Pamjones}

1977 JD. Discovered 1977 May 15 by N. S. Chernykh at Nauchnyj.

Named in honor of Pamela Ann Jones, of the Lunar and Planetary Institute, Houston, in appreciation of her organization of many conferences in planetary sciences, particularly two international conferences held in June-July 1991, "Asteroids, Comets, Meteors 
91" in Flagstaff and "Near-Earth Asteroids" in San Juan Capistrano. (M 18648)

\section{(4853) Marielukac}

1979 ML. Discovered 1979 June 28 by C. Torres at Cerro El Roble.

A staff member of the U.S. Nautical Office since 1971, Marie R. Lukac (1947- ) has played a major role in the continuing integrity of the data in The Astronomical Almanac (notably the list of observatories), The Air Almanac and The Nautical Almanac. This minor planet is named on the occasion of her retirement. (M 46005)

\section{(4854) Edscott}

$1981 \mathrm{ED}_{27}$. Discovered 1981 Mar. 2 by S. J. Bus at Siding Spring.

Edward Scott (1947- ), professor at the University of Hawaii, began his career by deciphering how minor planet cores fractionally crystallized to produce the observed range of iron meteorite compositions. His current work focuses on the chemical and physical processes that operated in the solar nebula. (M 41382)

\section{(4855) Tenpyou}

$1982 \mathrm{VM}_{5}$. Discovered 1982 Nov. 14 by H. Kosai and K. Hurukawa at Kiso.

Named for the Tenpyou Era, from the eighth century, when the Japanese capital was at Nara and many grand Buddhist temples were built. (M 21609)

\section{(4856) Seaborg}

1983 LJ. Discovered 1983 June 11 by C. S. Shoemaker and E. M. Shoemaker at Palomar.

Named in honor of Glenn T. Seaborg (1912-1999), American nuclear chemist, academic administrator and public servant. Seaborg participated in the discovery of most of the known transuranian elements, including plutonium, and led the chemical effort to isolate and characterize that element and produce it in large quantities from nuclear reactors. He served as professor and chancellor of the University of California at Berkeley and as a member and chairman of the U.S. Atomic Energy Commission. He shared with Edwin McMillan the 1951 Nobel prize for chemistry. (M 24916)

Name proposed and citation prepared by T. P. Kohman.

\section{(4857) Altgamia}

1984 FM. Discovered 1984 Mar. 29 by C. S. Shoemaker at Palomar.

Named for Andrew L. T. and Angela Maria Chiarappa Green, son and wife of D. W. E. Green ssee planet (2068)\}, who was involved in taking the discovery films and who found the identifications for this minor planet. Angela, known as 'Lina' to family and friends, did some volunteer work with the monthly subscription book-keeping of the Minor Planet Center in 1984-85, and occasionally helps the Center and the Central
Telegram Bureau with her expert linguistic knowledge of Italian and Spanish. (M 18648)

\section{(4859) Fraknoi}

$1986 \mathrm{TJ}_{2}$. Discovered 1986 Oct. 7 by E. Bowell at Anderson Mesa.

Named for Andrew Fraknoi on the occasion of his resignation as executive director of the Astronomical Society of the Pacific. Under his leadership, from 1978 to 1992 , the ASP \{see planet (2848)\} has grown into a nationally and internationally recognized science education organization, serving teachers, amateurs and the public. In addition to editing Mercury, Fraknoi founded and edited The Universe in the Classroom, a newsletter for teachers. He also organized workshops and wrote a nationally syndicated newspaper column. He hosted a radio talk show on science for two years and regularly explains astronomical developments on radio and television. An outspoken critic of astrology, he has given more than 300 public lectures on astronomical and skeptical topics. (M 20522; M 20542)

Citation provided by J. Wujek.

\section{(4860) Gubbio}

1987 EP. Discovered 1987 Mar. 3 by E. Bowell at Anderson Mesa.

Named for the city of Gubbio, Umbria, Italy. Dating from the Umbrian civilization in the 7th century B.C., Gubbio flourished in the Middle Ages and is one of the best-preserved Italian medieval cities. It was on a hill above the city that geologist Walter Alvarez \{see planet (3581)\} found an iridium-rich layer originating at the transition between the Cretaceous and Tertiary periods. His father, Luis Alvarez, physicist and Nobel laureate, interpreted the layer's presence as the result of a catastrophic impact of an asteroid with the earth. Gubbio is also famous for the story of St. Francis and the wolf, and for St. Francis' "Ceri Marathon". (M 22247)

Name suggested and citation prepared by M. A. Barucci.

\section{(4861) Nemirovskij}

1987 QU $_{10}$. Discovered 1987 Aug. 27 by L. G. Karachkina at Nauchnyj.

Named in honor of Lev Ruful'evich Nemirovskij (1937- ), engineer, chief-constructor and artistic director of the St. Petersburg House of Satire and Humor, and one of the authors of the miscellany Gold Ostap. (M 23137)

\section{(4862) Loke}

$1987 \mathrm{SJ}_{5}$. Discovered 1987 Sept. 30 by P. Jensen and K. Augustesen at Brorfelde.

Named after the strangest character in Norse mythology. Loke is one of the giants, but he lives among the Aesir in Asgaard. He is the symbol of falseness and intrigue - at the same time the enemy and the cunning helper of the gods. He caused the death of Balder \{see planet (4059)\}, and he is the father of 
Fenrir, Hel \{see planet (949)\} and the Midgard serpent. (M 22504)

\section{(4863) Yasutani}

$1987 \mathrm{VH}_{1}$. Discovered 1987 Nov. 13 by S. Ueda and

H. Kaneda at Kushiro.

Named in honor of Keiki Yasutani (1958- ), an astronomical photographer renowned for his photographs of the moon and Mars. He is a member of the Sapporo Observatory. (M 22504)

Name proposed by K. Watanabe.

\section{(4865) Sor}

1988 UJ. Discovered 1988 Oct. 18 by T. Seki at Geisei. Named for the great Spanish guitarist Fernando Sor. (M 19341)

\section{(4867) Polites}

1989 SZ. Discovered 1989 Sept. 27 by C. S. Shoemaker and E. M. Shoemaker at Palomar.

Polites was a son of Priam, as was Deiphobus \{see, respectively, planets (884) and (1867)\}. They were both killed during the last moments of Troy: Deiphobus was butchered and mutilated by Menelaus \{see planet (1647)\}, and Polites was transfixed with a spear handled by Pyrrhus \{see planet (5283)\}. Pyrrhus, the most ruthless of the Greeks, broke open and invaded Priam's great house of fifty chambers, and he chased Polites along empty colonnades until he cornered and slaughtered him in front of his father and mother, Priam and Hecuba \{see planet (108)\}. (M 22248)

Name and citation provided by Richard Preston at the request of the discoverers.

\section{(4868) Knushevia}

$1989 \mathrm{UN}_{2}$. Discovered 1989 Oct. 27 by E. F. Helin at Palomar.

Kyiv (Kiev) National Taras Shevchenko University is the Ukrainian national center of higher education, science and progressive thinking. Since its founding in 1834 the university has played a great role for the development of education, science and culture in the Ukraine. (M 45336)

\section{(4869) Piotrovsky}

1989 UE $_{8}$. Discovered 1989 Oct. 26 by L. I. Chernykh at Nauchnyj.

Named in memory of the outstanding archaeologist Boris Borisovich Piotrovsky (1908-1990), director of the Hermitage \{see planet (4758)\} museum in St. Petersburg for many years. The name also honors his son Mikhail Borisovich Piotrovsky (1944- ), a well-known orientalist who succeeded his father as Hermitage director. (M 29144)

Name proposed by the discoverer following a suggestion by the Institute of Theoretical Astronomy.

\section{(4870) Shcherban'}

1989 UK$_{8}$. Discovered 1989 Oct. 25 by L. V. Zhuravleva at Nauchnyj.
Named in honor of Vladimir Onufrievich Shcherban' (1938- ), who was director of an oil-extraction plant in Prikolotnoe for 30 years. He created an exceptional museum at the birthplace of Konstantin Ol'shanskij \{see planet (2310)\}. The plant organized a computer class and contained a beautiful garden for children and an indoor pool. (M 27329)

\section{(4871) Riverside}

$1989 \mathrm{WH}_{1}$. Discovered 1989 Nov. 24 by M. Koishikawa at Sendai.

Named to celebrate the 35th anniversary of the "sister city" affiliation of Sendai \{see planet (3133)\}, Japan, and Riverside, California, which began on 1957 Mar. 9. Riverside, which is the county seat of Riverside County and is located some $80 \mathrm{~km}$ east of Los Angeles, has many parks and is known as a health resort. (M 19699)

\section{(4872) Grieg}

$1989 \mathrm{YH}_{7}$. Discovered 1989 Dec. 25 by F. Börngen at Tautenburg.

Named for the Norwegian composer Edvard Grieg (1843-1907). In Grieg's work, the precipitous, harsh beauty of the Scandinavian landscape is reflected. Particularly popular is the orchestral suite Peer Gynt, a piano and violin concerto to accompany Ibsen's \{see planet (5696)\} play. Also well known are many short charming lyric compositions, for example the wedding march of Troldhaugen. (M 18648)

\section{(4873) Fukaya}

1990 EC. Discovered 1990 Mar. 4 by A. Sugie at Taga.

Named for a city $70 \mathrm{~km}$ northwest of Tokyo, not far from the National Astronomical Observatory's Dodaira Station. Originally a stop on one of the main routes between Tokyo and Kyoto \{see planets (498) and (4352)\}, the city received its present name in 1955, since when it has shown remarkable growth. Fukaya, home to one of the factories of the Dynic Corporation, is now one of the leading industrial centers in Saitama prefecture. (M 19341)

Name proposed by the discoverer following a suggestion by S. Sakabe.

\section{(4874) Burke}

1991 AW. Discovered 1991 Jan. 12 by E. F. Helin at Palomar.

Named in honor of James D. Burke on the occasion of his retirement from the Jet Propulsion Laboratory. Jim served as manager of the Ranger project, the first American mission to the moon, and as manager of advanced technical studies. He invented the SNAKE guide-rope for the Soviet Mars '96 mission. In 1991 Jim served as managing director of the International Space University. He made impressive contributions to humanity's efforts to reach the planets. (M 19699)

Name endorsed by the Planetary Society and the Jet Propulsion Laboratory. 


\section{(4875) Ingalls}

1991 DJ. Discovered 1991 Feb. 19 by Y. Kushida and R. Kushida at Yatsugatake.

Named in honor of Laura Ingalls Wilder (1867-1957) and the Ingalls family. Her books in the "Little House" series illustrate the love and strong mind of the family through the American pioneer life of her girlhood and still make a deep impression on all the people of the world. (M 18648)

\section{(4876) Strabo}

1133 T-2. Discovered 1973 Sept. 29 by C. J. van Houten and I. van Houten-Groeneveld at Palomar.

Named after the Greek geographer Strabo (Greek Strabon: 63 B.C.-c. A.D. 23), who devoted himself to historical and geographical studies and who took long journeys through Asia Minor, Egypt, Greece and Italy. His 47-volume Historical Sketches exists today only as fragments, but his 17-volume Geographica survives almost intact. (M 20161)

\section{(4877) Humboldt}

5066 T-2. Discovered 1973 Sept. 25 by C. J. van Houten and I. van Houten-Groeneveld at Palomar.

Named after the scientist Friedrich Heinrich Alexander Freiherr von Humboldt (1769-1859), who made extended expeditions to Siberia and South America to study the flora and geology of each region. His main publication was Cosmos, Entwurf einer physikalischen Weltbeschreibung. (M 20161)

\section{(4879) Zykina}

1974 VG. Discovered 1974 Nov. 12 by L. I. Chernykh at Nauchnyj.

Named in honor of Lyudmila Georgievna Zykina, a Russian singer who enjoys widespread popularity. She is a distinguished performer of Russian folk songs and of songs by Russian composers. (M 26762)

\section{(4880) Tovstonogov}

1975 TR $_{4}$. Discovered 1975 Oct. 14 by L. I. Chernykh at Nauchnyj.

Named in memory of Georgij Aleksandrovich Tovstonogov (1913-1989), outstanding Russian theatre producer, writer and art critic. As the chief producer at the Bolshoj Dramatic Theater in Leningrad (now St. Petersburg) for 40 years, he was the creator of numerous unique theatrical performances. (M 26762)

\section{(4882) Divari}

1977 QU $_{2}$. Discovered 1977 Aug. 21 by N. S. Chernykh at Nauchnyj.

Named in memory of Nikolaj Borisovich Divari (1921-1993), professor at the Odessa Polytechnical Institute and prominent in the study of the nature of the zodiacal light and interplanetary dust. (M 27127; M 27147)

\section{(4883) Korolirina}

1978 RJ $_{1}$. Discovered 1978 Sept. 5 by N. S. Chernykh at Nauchnyj.

Named in honor of Irina Leonidovna Korol', a friend of the discoverer and teacher of philology in St. Petersburg who displays a keen interest in astronomy. (M 26763)

\section{(4884) Bragaria}

1979 OK $_{15}$. Discovered 1979 July 21 by N. S. Chernykh at Nauchnyj.

Named in honor of Luka Fedorovich Bragar' (1938-

), a senior lecturer on the staff of Tiraspol Pedagogical Institute (Moldova), known for his contribution to the rotational dynamics of minor planets and as a splendid educator and popularizer of astronomical knowledge. (M 32345)

\section{(4885) Grange}

1980 LU. Discovered 1980 June 10 by C. S. Shoemaker at Palomar.

Named in honor of Alice Shoemaker Grange (1908-

), aunt of E. M. Shoemaker. (M 24917)

\section{(4886) Kojima}

$1981 \mathrm{EZ}_{14}$. Discovered 1981 Mar. 1 by S. J. Bus at Siding Spring.

Hideyasu Kojima (1951- ) is the curator of the Japanese Antarctic meteorite collection at the National Institute of Polar Research in Tokyo. He has also conducted research on a broad range of meteorite types aimed at understanding processes ranging from hydrothermal alteration to melting. (M 41382)

\section{(4887) Takihiroi}

$1981 \mathrm{EV}_{26}$. Discovered 1981 Mar. 2 by S. J. Bus at Siding Spring.

A researcher in the department of geological sciences at Brown University, Takahiro (Taki) Hiroi (1960- ) has worked extensively on linking minor planets and meteorites using reflectance spectroscopy. His extensive database of meteorite spectra is widely used by the scientific community to pursue this endeavor. (M 41567)

\section{(4888) Doreen}

1981 JX$_{1}$. Discovered 1981 May 5 by C. S. Shoemaker at Palomar.

Named in honor of Doreen Vingness Spellmann, sister-in-law of the discoverer. Spellmann led a sustained effort to beautify the city of El Cerrito, California, with flowers and shrubs. (M 24917)

\section{(4889) Praetorius}

1982 UW $_{3}$. Discovered 1982 Oct. 19 by F. Börngen at Tautenburg.

Named for Michael Praetorius (1571-1621), outstanding German composer and musical writer of the early baroque. He published a fundamental three-volume composition theory (Syntagma musicum) and about 
25 volumes with sacred and secular compositions and collections of church songs. Particularly well known is his beautiful melody for the Christmas carol "Es ist ein Ros entsprungen". (M 19341)

\section{(4890) Shikanosima}

$1982 \mathrm{VE}_{4}$. Discovered 1982 Nov. 14 by H. Kosai and K. Hurukawa at Kiso.

Named for the small island located off the northern coast of Kyushu. In 1784, a farmer found the golden seal that was the present from the emperor of ancient China to the king of $\mathrm{Na}$, one of the local states of ancient Japan, when the King sent the first delegation to China under Han Dynasty in AD 57. This association of China and Japan is the first one appearing in the Chinese historical records. (M 22504)

\section{(4891) Blaga}

1984 GR. Discovered 1984 Apr. 4 by V. G. Shkodrov and V. G. Ivanova at Rozhen.

Named in honor of Blaga Dimitrova, talented Bulgarian poetess, novelist and translator. Her intellectual works are profoundly philosophical, revealing the intrinsic psychology of modern mankind and the struggle for morality. The poetess herself maintains an open and courageous civic stand. Some of her works are translated into many languages. (M 19699)

\section{(4892) Chrispollas}

$1985 \mathrm{TV}_{2}$. Discovered 1985 Oct. 11 by the CERGA at Caussols.

Named in honor of Christian Pollas, currently head of the Schmidt telescope unit at the Observatoire de la Côte d'Azur. Christian is a dedicated observer who has discovered several asteroids and more than 60 supernovae in the last seven years. (M 23137)

Citation written by A. Maury and endorsed by J.-L. Heudier.

\section{(4893) Seitter}

$1986 \mathrm{PT}_{4}$. Discovered 1986 Aug. 9 by E. W. Elst and V. G. Ivanova at Rozhen.

Named in honor of Waltraud C. Seitter $\{1930-\quad\}$, director of the Münster (Westfalen) Astronomical Institute, famous for her spectroscopic researches on novae and a good friend of the discoverer. (M 19341)

\section{(4894) Ask}

1986 RJ. Discovered 1986 Sept. 8 by P. Jensen and K. Augustesen at Brorfelde.

Named after the first man, who, according to Norse mythology, was made from an ash tree by Odin \{see planet (3989)\} and his two brothers, Vile and Ve. (M 22504)

\section{(4895) Embla}

1986 TK $_{4}$. Discovered 1986 Oct. 13 by P. Jensen and K. Augustesen at Brorfelde.
Named after the first woman, who, according to Norse mythology, was made from an ash tree by Odin \{see planet (3989)\}, Vile and Ve. (M 22504)

\section{(4896) Tomoegozen}

1986 YA. Discovered 1986 Dec. 20 by T. Niijima and T. Urata at Ojima.

Named for Tomoegozen, mistress of Yoshinaka, known as a brave strategist on Yoshinaka's staff. After his death, Tomoegozen became a Buddhist nun. This planet was discovered on the same films as (4574) Yoshinaka. (M 21132)

\section{(4898) Nishiizumi}

1988 FJ. Discovered 1988 Mar. 19 by C. S. Shoemaker and E. M. Shoemaker at Palomar.

Named for Kunihiko Nishiizumi, nuclear chemist at the University of California at Berkeley. Nishiizumi is renowned for his work on cosmogenic nuclides in meteorites, particularly meteorites from the moon, and the determination of the terrestrial ages of meteorites. $\mathrm{He}$ also led the determination of surface exposure ages and erosion rates of terrestrial rocks, from ${ }^{10} \mathrm{Be}$ and ${ }^{26} \mathrm{Al}$ produced by cosmic rays in quartz, and used this technique to determine ages of ancient surfaces in Antarctica and Australia and of meteorite craters. (M 24917)

\section{(4899) Candace}

1988 JU. Discovered 1988 May 9 by C. S. Shoemaker and E. M. Shoemaker at Palomar.

Named for Candace P. Kohl, American chemist and a leading investigator of ancient solar activity through analysis of solar cosmic-ray-produced nuclides in lunar samples. She has also contributed importantly in the development of techniques for dating surface exposure of materials on the earth from cosmic-ray-produced nuclides. Through her popular lectures on meteorites, the moon and the solar system, Kohl has reached a wide audience ranging from primary-school children to high-school students and the lay community. (M 25443)

Citation provided by K. Nishiizumi at the request of the discoverers.

\section{(4900) Maymelou}

1988 ME. Discovered 1988 June 16 by E. F. Helin at Palomar.

Named in honor of Mayme Lou "Stevey" Stevens Bruce, a graduate of Pomona College, California. Mother of three daughters, she and her husband, Stuart Bruce, have had a long fascination with travel to remote corners of the world. The recently published book Beyond the Ranges, authored by her husband, documents their research and travels. "Stevey" is an enthusiastic supporter and spokesperson for solar system research and discovery, contributing to the expansion of basic research in Helin's \{see planet (3267)\} PCAS and DSSS programs. (M 20161) 


\section{(4902) Thessandrus}

$1989 \mathrm{AN}_{2}$. Discovered 1989 Jan. 9 by C. S. Shoemaker and E. M. Shoemaker at Palomar.

Thessandrus was one of the Greek captains who hid inside the Trojan horse, which was devised by Epeios, who himself hid inside the horse. This minor planet is paired dynamically with (2148) Epeios. Virgil \{see planet (2798)\}, in the Aeneid, seems to imply that Thessandrus was the first warrior to slide down the lowered rope from the belly of the horse, thus beginning the sack of Troy. (M 22248)

Name and citation provided by Richard Preston at the request of the discoverers.

\section{(4903) Ichikawa}

1989 UD. Discovered 1989 Oct. 20 by Y. Mizuno and T. Furuta at Kani.

Named in honor of the amateur astronomer Kiyotaka Ichikawa (1955- ). This particular minor planet is among the many for which he established identifications and computed orbits. (M 26763)

\section{(4904) Makio}

1989 WZ. Discovered 1989 Nov. 21 by Y. Mizuno and T. Furuta at Kani.

Named in honor of Makio Akiyama (1950- ), who has discovered several minor planets at the Susono \{see planet (6419)\} Observatory. (M 26763)

\section{(4905) Hiromi}

$1991 \mathrm{JM}_{1}$. Discovered 1991 May 15 by A. Takahashi and K. Watanabe at Kitami.

Named in honor of Hiromi Takahashi (1964- ), wife of the first discoverer. (M 22504)

\section{(4906) Seneferu}

2533 P-L. Discovered 1960 Sept. 24 by C. J. van Houten and I. van Houten-Groeneveld at Palomar.

Seneferu (also written Snefru) was the first king of the 4th dynasty and built two pyramids near Daschur. (M 20162; M 20191)

\section{(4907) Zoser}

7618 P-L. Discovered 1960 Oct. 17 by C. J. van Houten and I. van Houten-Groeneveld at Palomar.

Named after the Egyptian pharaoh of the third dynasty. Zoser, also written Djoser, erected the first stone pyramid - the step-pyramid at Sakkara, near Memphis. (M 20162)

\section{(4908) Ward}

1933 SD. Discovered 1933 Sept. 17 by F. Rigaux at Uccle.

Named in honor of Steven Ward, electronics technician in the Computation Facility at the HarvardSmithsonian Center for Astrophysics. Steve's assistance to the Minor Planet Center mainly involves system programming. (M 22504)

Name proposed by B. G. Marsden, who made the identifications for this object.

\section{(4909) Couteau}

$1949 \mathrm{SA}_{1}$. Discovered 1949 Sept. 28 by M. Laugier at Nice.

Named in honor of Paul Couteau, double-star observer at the Observatoire de Nice since 1959, on the occasion of his retirement. Using the large refractors at Lick, Yerkes and Nice, and the telescopes of Almeria and Pic du Midi, he has discovered more than 2700 new binaries, achieving 135,000 individual measurements. Couteau, having measured star separations down to the 60-milliarcsecond resolution limit of the 2-m telescope at Pic du Midi, is one of the sharpest 'eyes' on Earth. (M 23137)

\section{(4910) Kawasato}

1953 PR. Discovered 1953 Aug. 11 by K. Reinmuth at Heidelberg.

Named in honor of Nobuhiro Kawasato, who codiscovered $1988 \mathrm{VG}_{2}$ which was identified with the lost minor planet (724) Hapag. (M 22504)

Name proposed by S. Nakano, who found the identifications involving this object.

\section{(4911) Rosenzweig}

1953 UD. Discovered 1953 Oct. 16 at the Goethe Link Observatory at Brooklyn, Indiana.

'Pioneers of the Zone', Jack (1919-1994) and Marcelle (1929- ) Rosenzweig worked to help the Puerto Ordaz region of Venezuela. They built and operated a plant to make ice blocks for delivery to the mines. They manufactured baseball bats and furniture accessories from Belgian wood and opened a real estate company. (M 41027)

\section{(4914) Pardina}

1969 GD. Discovered 1969 Apr. 9 at the Felix Aguilar Observatory at El Leoncito.

Named in honor of Elsa Gutierrez Rodriguez-Pardina (1921- ), Argentinian astronomer who has worked in the field of celestial mechanics for more than 30 years. Form 1952 to 1956, she worked at the La Plata Observatory in the Department of Astrometry and Celestial Mechanics. In 1954 she obtained a scholarship from the French government to further her studies in celestial mechanics at the Sorbonne Henri Poincaré Institute. From 1978 to 1986, Pardina led the Celestial Mechanics Department of the Astronomical Observatory of Córdoba. For many years, she was responsible for the celestial mechanics courses taught to undergraduate students. (M 33786)

\section{(4915) Solzhenitsyn}

$1969 \mathrm{TJ}_{2}$. Discovered 1969 Oct. 8 by L. I. Chernykh at Nauchnyj.

Named in honor of Aleksandr Isaevich Solzhenitsyn (1918- ), world-renowned Russian writer and Nobel prize-winner $\{1970\}$. (M 23137) 


\section{(4916) Brumberg}

1970 PS. Discovered 1970 Aug. 10 at the Crimean Astrophysical Observatory at Nauchnyj.

Named in honor of Victor Aleksandrovich Brumberg (1933- ), staff member at the Institute of Theoretical Astronomy from 1958 to 1987 and the Institute of Applied Astronomy since 1988. His main scientific results are related to analytical and relativistic celestial mechanics (the three-body problem, general planetary theory, lunar theory, relativistic reduction of observations, reference systems and time scales, and the relativistic definitions of astronomical concepts and constants). (M 30475)

Name proposed by the Institute of Theoretical Astronomy and the Institute of Applied Astronomy.

\section{(4917) Yurilvovia}

1973 SC $_{6}$. Discovered 1973 Sept. 28 at the Crimean Astrophysical Observatory at Nauchnyj.

Named in memory of Yurij Alekseevich L'vov (19321994), deputy director of the Institute of Biology and Biophysics at the Tomsk State University. A prominent geobotanist and ecologist, L'vov was for 30 years an organizer of the regular expeditions to Tunguska \{see planet (5471)\}, and he made important contributions to the study of the 1908 impact. (M 27127)

\section{(4918) Rostropovich}

1974 QU $_{1}$. Discovered 1974 Aug. 24 by L. I. Chernykh at Nauchnyj.

Named in honor of Mstislav Leopol'dovich Rostropovich (1927- ), outstanding Russian musician and pedagogue, world-famous cellist and conductor. (M 23137)

\section{(4919) Vishnevskaya}

1974 SR $_{1}$. Discovered 1974 Sept. 19 by L. I. Chernykh at Nauchnyj.

Named in honor of Galina Pavlovna Vishnevskaya, outstanding Russian opera singer, actress of the Bolshoi Theatre in Moscow for many years and performer in many theaters around the world. (M 23137)

\section{(4920) Gromov}

1978 PY $_{2}$. Discovered 1978 Aug. 8 by N. S. Chernykh at Nauchnyj.

Named in memory of Mikhail Mikhajlovich Gromov (1899-1985), well-known Russian pilot who set the world record for long-distance flight in 1934 when his aircraft flew more than 12000 kilometers. In 1937, together with A. Yumashev and S. Danilin, he completed a nonstop flight from Moscow, over the North Pole, to the United States. He was the first Russian pilot to win the de Lawo medal of the Federation Aeronautique Internationale. Gromov also tested a great number of new aircraft. He was the founder of the State Research Center of Russia "Flying Research Institute", now named for him. (M 34340)

\section{(4921) Volonté}

1980 SJ. Discovered 1980 Sept. 29 by Z. Vávrová at Kleť.

Named for the popular Italian actor Gian Maria Volonté, who portrayed the title role in a film about Giordano Bruno. (M 21956)

\section{(4922) Leshin}

$1981 \mathrm{EH}_{4}$. Discovered 1981 Mar. 2 by S. J. Bus at Siding Spring.

Laurie Leshin (1965- ), assistant professor at Arizona State University, has used isotopic analyses to investigate geologic processes recorded in martian meteorites. Her work on oxygen and hydrogen isotopes has been fundamental to understanding the interaction between the hydrosphere and crust of Mars. (M 41382)

\section{(4923) Clarke}

$1981 \mathrm{EO}_{27}$. Discovered 1981 Mar. 2 by S. J. Bus at Siding Spring.

Named in honor of Arthur C. Clarke (1917- ), renowned author and visionary. His optimistic portrayal of the future and confidence in the human spirit are themes that pervade his writing. Clarke is best known for his novel 2001: A Space Odyssey, which was simultaneously developed into a landmark film. In his 1973 science fiction novel Rendezvous with Rama, Clarke describes the development of Project Spaceguard, a means for detecting and mitigating potentially hazardous objects in near-earth space. In recognition of Clarke's foresight, the name Spaceguard was adopted in a 1992 NASA proposal to the U.S. Congress for a dedicated program to survey the NEO population, as well as in the international foundation established in Rome on 1996 Mar. 26. (M 27127; M 27147)

Citation prepared with assistance from R. P. Binzel. Name independently suggested by D. I. Steel.

\section{(4924) Hiltner}

1981 EQ40. Discovered 1981 Mar. 2 by S. J. Bus at Siding Spring.

Named in memory of William Albert Hiltner (19141991), discoverer of the interstellar polarization of starlight, an early practitioner of precision stellar photometry, and pioneering observer of the optical counterparts of celestial x-ray sources. Director of the Yerkes Observatory for many years, while there he designed and built a rotatable telescope for polarization studies and developed photometric instrumentation. As director of the University of Michigan's observatory, he established the Michigan-Dartmouth-M.I.T. Observatory, led the construction of the 2.4-m telescope that is now named for him, and designed and constructed astronomical instrumentation. He also served as acting director of the Cerro Tololo Interamerican Observatory and as president of AURA. (M 20162) 
Name suggested by R. P. Binzel and citation prepared by R. G. Teske.

Obituary published in Bull. Am. Astron. Soc., Vol. 24, No. 4, p. 1326-1327 (1992).

\section{(4926) Smoktunovskij}

$1982 \mathrm{ST}_{6}$. Discovered 1982 Sept. 16 by L. I. Chernykh at Nauchnyj.

Named in honor of Innokentij Mikhailovich Smoktunovskij (1925- ), outstanding Russian theater and cinema actor. (M 23137)

\section{(4927) O'Connell}

$1982 \mathrm{UP}_{2}$. Discovered 1982 Oct. 21 by Z. Vávrová at Kleť.

Named for the Irish freedom fighter Daniel O'Connell (1775-1847). (M 21609)

\section{(4928) Vermeer}

1982 UG $_{7}$. Discovered 1982 Oct. 21 by L. G. Karachkina at Nauchnyj.

Named in memory of the famous Dutch painter Vermeer van Delft (1632-1675). (M 22504)

\section{(4929) Yamatai}

1982 XV. Discovered 1982 Dec. 13 by H. Kosai and K. Hurukawa at Kiso.

Named for a region of ancient Japan. According to a Wei-dynasty Chinese historical book, there were more than 70,000 houses in Yamatai. Himiko, the queen of Yamatai, dispatched an envoy to the ancient China in 238. There is no record of Yamatai (or Himiko) in any Japanese historical document, and the site of the city has not yet been located. (M 22504)

\section{(4930) Rephiltim}

$1983 \mathrm{AO}_{2}$. Discovered 1983 Jan. 10 by S. L. Salyards at Palomar.

A composite name to honor the children of the discoverer: Rebecca Anne Salyards (1988- ), Philip Stephen Salyards (1991- ) and Timothy Theodore Salyards (1995- ), all of whom enjoy studying the night sky. (M 29144)

\section{(4931) Tomsk}

$1983 \mathrm{CN}_{3}$. Discovered 1983 Feb. 11 by H. Debehogne and G. DeSanctis at La Silla.

Named by the first discoverer in honor of the Siberian city and its 500,000 inhabitants. (M 21609)

\section{(4932) Texstapa}

1984 EA $_{1}$. Discovered 1984 Mar. 9 by B. A. Skiff at Anderson Mesa.

Named for the Texas Star Party on the occasion of its 18th anniversary in May 1996. The TSP is held annually on the Prude Ranch, Fort Davis, near McDonald Observatory \{see planet (991)\}. Founded in 1979 by Deborah Byrd \{see planet (3505)\}, the event has since become one of the largest meetings of amateur astronomers in North America. It provides amateur astronomers from around the world with the opportunity for visual observing, astrophotography and fellowship under clear, dark skies. (M 27127)

\section{(4934) Rhôneranger}

1985 JJ. Discovered 1985 May 15 by E. Bowell at Anderson Mesa.

Named in honor of Randall Grahm, eclectic and irrepressible owner and winemaker of Bonny Doon Vineyard, near Santa Cruz, California. Often referred to as the Rhône Ranger, Grahm is best known as the creator of Le Cigare Volant, a Rhône-style wine that in some vintages has reached celestial heights. $\mathrm{He}$ is also renowned for Clos de Gilroy, a grenache wine containing not a hint of garlic; Big House Red, whose untrammeled grapes leap from the glass; and a number of fruit infusions, including Prunus, which plumbs the depths of intense flavor. (M 20522)

\section{(4935) Maslachkova}

$1985 \mathrm{PD}_{2}$. Discovered 1985 Aug. 13 by N. S. Chernykh at Nauchnyj.

Named in memory of Iya Mikhailovna Maslachkova (1937-1996), a poet and teacher of Russian literature from St. Petersburg who worked for some years at the Crimean Astrophysical Observatory and had many friends there. Her poems are mainly dedicated to the Crimea and St. Petersburg. (M 30096)

\section{(4936) Butakov}

1985 UY $_{4}$. Discovered 1985 Oct. 22 by L. V. Zhuravleva at Nauchnyj.

Named in memory of Grigorij Ivanovich Butakov (1820-1882), Russian admiral who drew up the first systematic directions for sailing in the Black Sea. In 1856 he became commander-in-chief of the Black Sea fleet and the military governor of Nikolaev and Sevastopol \{see planet (2121)\}. (M 34620)

\section{(4940) Polenov}

1986 QY $_{4}$. Discovered 1986 Aug. 18 by L. G. Karachkina at Nauchnyj.

Named in memory of the well-known Russian painter Vasilij Dmitrievich Polenov (1844-1927). (M 22504)

\section{(4943) Lac d'Orient}

1987 OQ. Discovered 1987 July 27 by E. W. Elst at St. Michel.

Named for the lake Lac de la Forêt d'Orient, situated about $20 \mathrm{~km}$ east of the city of Troyes (in the département de l'Aube, France). The region has great historical interest for its "commanderies" of the so-called Knights of the Temple. The discoverer favors this place very much for vacations, especially in the summer. (M 20838)

\section{(4944) Kozlovskij}

$1987 \mathrm{RP}_{3}$. Discovered 1987 Sept. 2 by L. I. Chernykh at Nauchnyj. 
Named in honor of Ivan Semyonovich Kozlovskij, distinguished opera-singer who has rare lyric tenor and is popular for his many opera parties and for his rendering of Russian folk-songs. (M 22504)

\section{(4945) Ikenozenni}

1987 SJ. Discovered 1987 Sept. 18 by K. Suzuki and T. Urata at Toyota.

Named for Ikenozenni, the second wife of (4374) Tadamori. She asked (4375) Kiyomori to spare the life of (3902) Yoritomo, who had come to destroy the Heike, family of Kiyomori. (M 21132)

\section{(4946) Askalaphus}

1988 BW $_{1}$. Discovered 1988 Jan. 21 by C. S. Shoemaker and E. M. Shoemaker at Palomar.

Askalaphus, a son of the god Ares, became one of the Argonauts, and also participated in the Trojan War. With his brother, Ialmenos, he drew up thirty ships in line of battle. Askalaphus was killed when Deiphobus \{see planet (1867)\} ran him through the shoulder with his heavy spear. (M 25443)

\section{(4947) Ninkasi}

1988 TJ J $_{1}$. Discovered 1988 Oct. 12 by C. S. Shoemaker and E. M. Shoemaker at Palomar.

Named for the Sumerian goddess of wine and beer. She aided the god Lugalbanda in rescuing the tablets of fate from the demon $\mathrm{Zu}$. In Semitic mythology, Ninkasi was also considered god of the Vine, corresponding to the Greek Dionysus \{see planet (3671)\}. An ode to Ninkasi, inscribed in cuneiform on 4000-year old clay tablets, provides a recipe that was used successfully by Fritz Maytag and Solomon H. Katz to recreate Sumerian beer. (M 20522)

\section{(4950) House}

$1988 \mathrm{XO}_{1}$. Discovered 1988 Dec. 7 by E. F. Helin at Palomar.

Named in honor of R. C. House, western novelist and journalist who has served, for the last 23 years, as editor of the Jet Propulsion Laboratory's internal publication 'Universe'. He has been responsible for this highly regarded chronicle of life at "the Lab" until his recent retirement. He captured for his readers the true spirit of the world's leading space exploration center. His natural warmth endeared him to all he had contact. (M 20162)

Name endorsed by Phil Neuhauser, a good friend for many years.

\section{(4951) Iwamoto}

1990 BM. Discovered 1990 Jan. 21 by Y. Mizuno and T. Furuta at Kani.

Named in honor of Masayuki Iwamoto (1954- ), who has discovered several minor planets at the Tokushima Observatory. (M 26763)

\section{(4952) Kibeshigemaro}

$1990 \mathrm{FC}_{1}$. Discovered 1990 Mar. 26 by A. Sugie at Taga.

Named in memory of Shigemaro Kibe (1912-1990), foremost amateur telescope maker in Japan and well known observer of the sun, planets and variable stars. The telescope mirrors made by him are used all over Japan and include the mirror for the $0.60-\mathrm{m}$ reflector at Kyoto University's Hida Observatory. (M 20838)

\section{(4954) Eric}

1990 SQ. Discovered 1990 Sept. 23 by B. Roman at Palomar.

The name dates back to ancient Norse times, and was also prominent among Scandinavian monarchs. Eric the Red was the first Norse explorer of Greenland and father of Leif Ericson, Eric IX was king of Sweden and is revered as Sweden's patron saint (although he was never formally canonized), and Eric of Pomerania was king of Denmark, Norway and Sweden. This Amor \{see planet (1221)\} object also honors Eric Dale Roman, the discoverer's first child, in his first year of life. (M 19341)

Name endorsed by E. F. Helin.

\section{(4955) Gold}

$1990 \mathrm{SF}_{2}$. Discovered 1990 Sept. 17 by H. E. Holt at Palomar.

Named in honor of Rob Gold (1943- ), who has made many contributions to space science through numerous spacecraft missions including Ulysses, Geotail, Delta Star and ACE. Rob is currently the payload manager for the NEAR mission, the first spacecraft bound to orbit a minor planet. Rob played a key role in insuring that the six science instruments on NEAR were delivered and integrated on time and under cost for NASA's first Discovery class mission. (M 35481)

Name proposed by J. Veverka and citation written by M. Robinson.

\section{(4956) Noymer}

1990 VG $_{1}$. Discovered 1990 Nov. 12 by R. H. McNaught at Siding Spring.

Named in honor of Andrew J. Noymer on the occasion of his twentieth birthday, 1991 Nov. 4. A student at Harvard University, he has since the age of 14 been an enthusiastic assistant in a number of astronomical activities. In addition to those at the Harvard-Smithsonian Center for Astrophysics, where he is currently working at the Minor Planet Center and Central Bureau for Astronomical Telegrams, he spent several weeks at Siding Spring in 1988 (where he discovered several minor planets) and at the U.K. Infrared Telescope in 1989. (M 19341)

Name proposed by the discoverer, following a suggestion by C. M. Bardwell, D. W. E. Green, B. G. Marsden and G. V. Williams. 


\section{(4957) Brucemurray}

1990 XJ. Discovered 1990 Dec. 15 by E. F. Helin at Palomar.

Named in honor of Bruce C. Murray, professor of planetary science at the California Institute of Technology and former director of the NASA/Caltech Jet Propulsion Laboratory. As a co-founder of The Planetary Society, he has been instrumental in making science accessible and understandable to the general public. This minor planet is a deep Mars-crosser, coming within $0.2 \mathrm{AU}$ of the earth at perihelion, and it is a particularly appropriate object for Murray, who has so diligently championed a mission to Mars. Future spacecraft missions could flyby or rendezvous with (4957) on the way to Mars. This tribute to 'BC' is hailed by his family, friends and colleagues. (M 22829)

\section{(4958) Wellnitz}

$1991 \mathrm{NT}_{1}$. Discovered 1991 July 13 by H. E. Holt at Palomar.

Named in honor of Dennis D. Wellnitz (1951- ), University of Maryland instrument builder, observer, data analyst and all-around physicist. Wellnitz has designed and developed a wide variety of astronomical instrumentation, and he has participated in many major observational programs, including occultations by minor planets and comets and the 1994 cometary collision with Jupiter. His work with the NEAR mission has resulted in improved signal-to-noise spectra from the near-infrared spectrometer, contributing to the mineralogical analysis of the surface of (433) Eros. Wellnitz' thorough, detailed studies and his great patience are particularly appreciated by his colleagues. (M 35482)

Name proposed by J. Veverka, based on a suggestion by L. A. McFadden. Citation by McFadden and M. F. A'Hearn.

\section{(4959) Niinoama}

$1991 \mathrm{PA}_{1}$. Discovered 1991 Aug. 15 by A. Natori and T. Urata at Yakiimo.

Named for Tokiko (?-1185), wife of (4375) Kiyomori. She is called Niinoama because she took the rank of secondary-nii after Kiyomori's death. After the battle of Dannoura, she drowned herself holding the 7-year-old Emperor Antoku \{see planet (3686)\} in her arms. (M 21132)

\section{(4960) Mayo}

4657 P-L. Discovered 1960 Sept. 24 by C. J. van Houten and I. van Houten-Groeneveld at Palomar.

Named in honor of Mayo Greenberg \{1922-2001\} on the occasion of his 70th birthday. Well known for his model of cometary and interstellar grains, he worked at the State University at Albany and later as head of the Astrophysical Laboratory in Leiden. (M 20162)

Obituaries published in Bull. Am. Astron. Soc., Vol. 34, No. 4, p. 1362 (2002), Int. Comet Q., Vol. 23, No. 4, p. 153 (2001).

\section{(4962) Vecherka}

1973 TP. Discovered 1973 Oct. 1 by T. M. Smirnova at Nauchnyj.

Named for the popular St. Petersburg evening newspaper Vechernij Petersburg. The newspaper regularly publishes astronomical information and articles popularizing astronomical knowledge. (M 31023)

Name proposed by the Institute of Theoretical Astronomy (ITA).

\section{(4963) Kanroku}

1977 DR $_{1}$. Discovered 1977 Feb. 18 by H. Kosai and K. Hurukawa at Kiso.

Named for a Pekche priest who presented, by way of tribute, books on calendar-making, astronomy, geography, divination, etc., to the Japanese Government in 602. He taught the Japanese the algorithm of the luni-solar calendar used in China. (M 22504)

\section{(4964) Kourovka}

1979 OD $_{15}$. Discovered 1979 July 21 by N. S. Chernykh at Nauchnyj.

Named for the astronomical observatory of the Ural State University, situated near the village of Kourovka, in the Ekaterinburg region of Russia. Founded in 1965, the Kourovka Observatory is known for research in stellar astronomy and the astrometry of comets, minor planets and artificial satellites. Since 1972 it has held an annual Student Winter Astronomical School and is now a mecca for Russian students in astronomy. (M 26763)

\section{(4965) Takeda}

$1981 \mathrm{EP}_{28}$. Discovered 1981 Mar. 6 by S. J. Bus at Siding Spring.

Hiroshi Takeda (1934- ), professor at the Chiba Institute of Technology in Narashino, has conducted seminal research on both lunar meteorites and primitive achondrites. These studies have contributed to our understanding of the melting and differentiation of small bodies in the solar system. (M 41382)

\section{(4966) Edolsen}

$1981 \mathrm{EO}_{34}$. Discovered 1981 Mar. 2 by S. J. Bus at Siding Spring.

Edward Olsen (1927- ) is a long-time curator of the meteorite collection at the Field Museum of Natural History in Chicago. His studies of stony-iron meteorites and phosphate minerals have focused on unraveling the processes that led to core formation in minor planets. (M 41382)

\section{(4967) Glia}

$1983 \mathrm{CF}_{1}$. Discovered 1983 Feb. 11 by N. G. Thomas at Anderson Mesa.

Name derived from the Latin word for 'glue'. Glia are the cells providing support for the components of nervous tissue in the brain. According to one theory, the intricate structure of the glia may be involved 
in quantum processes that generate 'new' ideas, i.e. invention. (M 25443)

\section{(4968) Suzamur}

1986 PQ. Discovered 1986 Aug. 1 by E. F. Helin at Palomar.

Named in honor of Suzanne Moss Murray, a charming and compassionate person, on the occasion of her birthday, 1993 Apr. 2. Suzanne, a special friend of the discoverer, has always shown enthusiasm and given encouragement to Helin's pursuit of minor planets. (M 22504)

\section{(4969) Lawrence}

1986 TU. Discovered 1986 Oct. 4 by E. F. Helin at Palomar.

Named in honor of Kenneth J. Lawrence (1964- ), astronomer and valuable member of the Palomar Planet-Crossing Asteroid Survey team, on the occasion of his 28th birthday, 1992 May 30. Discoverer of nearearth-asteroids and comets, his congenial personality and wry wit contribute to the smooth operation of the highly-focused NEA discovery program. (M 20522)

This recognition is heartily endorsed by his friends and coworkers, Jeff Alu, Perry Rose and Brian Roman.

\section{(4970) Druyan}

$1988 \mathrm{VO}_{2}$. Discovered 1988 Nov. 12 by E. F. Helin at Palomar.

Named as a tribute to Ann Druyan for her many contributions to the public understanding of the humane applications of planetary exploration and her creative directorship of the Voyager interstellar record, humanity's gift to the universe. (M 24122)

Presented on the occasion of astronomer Carl Sagan's \{see planet (2709)\} 60th birthday in recognition of his love and admiration for his wife and colleague.

\section{(4971) Hoshinohiroba}

1989 BY. Discovered 1989 Jan. 30 by T. Fujii and K. Watanabe at Kitami.

Named after the Comet Observers Network in Japan, "Hoshi no Hiroba", established by Akira Kamo \{see planet (4215)\} in 1968. About 350 earnest observers made 8805 visual magnitude estimates of 89 comets in the first 20 years. "Hoshi no Hiroba" means an open space where everybody can come and enjoy watching stars. (M 22504)

Citation prepared by T. Nomura.

\section{(4972) Pachelbel}

1989 UE $_{7}$. Discovered 1989 Oct. 23 by F. Börngen at Tautenburg.

Named for the composer Johann Pachelbel (16531706) of Nürnberg, an important representative of the art of organ music whose free-form choral preludes and fuges had a considerable influence on J. S. Bach \{see planet (1814)\}. (M 19699)

\section{(4973) Showa}

1990 FT. Discovered 1990 Mar. 18 by K. Endate and K. Watanabe at Kitami.

Named for an industrial-pump company that started the production of astronomical telescopes in 1988. The first discoverer uses a Showa equatorial telescope for his observations of minor planets. (M 21132)

\section{(4974) Elford}

1990 LA. Discovered 1990 June 14 by R. H. McNaught at Siding Spring.

Named in honor of W. Graham Elford (1926- ), past president of IAU Commission 22. Since entering radar meteor research soon after taking his bachelor's degree in 1949, he has spent his entire career at the University of Adelaide working in that area, apart from periods spent as a visiting scientist at Cambridge, Lund and with the Harvard Radio Meteor Project in the 1960s. Elford has made a number of major contributions to our understanding of meteor astronomy, meteor physics and atmospheric physics. (M 29144)

Name proposed by the discoverer following a suggestion by D. I. Steel, who prepared the citation.

\section{(4975) Dohmoto}

1990 SZ $_{1}$. Discovered 1990 Sept. 16 by T. Fujii and K. Watanabe at Kitami.

Named in honor of Yoshio Dohmoto (1914- ), the former head of the Asahikawa Observatory in Hokkaido. Over a period of about 30 years, he carried out many observations of comets, occultations, artificial satellites, sunspots, etc. He is now an active leader of the Asahikawa Astronomical Club. (M 22504)

Name suggested and citation prepared by H. Fukushima.

\section{(4976) Choukyongchol}

1991 PM. Discovered 1991 Aug. 9 by K. Watanabe at Sapporo.

Kyong Chol Chou (1929- ) is one of the leading astronomers in Korea. After working at NASA and the U.S. Naval Observatory, he now teaches at Kyunghee University and is active in astronomical research and popularization. (M 44110)

The name was suggested by K. Hurukawa.

\section{(4977) Rauthgundis}

2018 P-L. Discovered 1960 Sept. 24 by C. J. van Houten and I. van Houten-Groeneveld at Palomar.

Named in honor of Rauthgundis Seitz, a friend of the discoverers, on the occasion of her 70th birthday. (M 21956)

\section{(4978) Seitz}

4069 T-2. Discovered 1973 Sept. 29 by C. J. van Houten and I. van Houten-Groeneveld at Palomar.

Named in honor of Horstmar Seitz (1920-1943), a close friend of one of the discoverers. (M 22505) 


\section{(4979) Otawara}

1949 PQ. Discovered 1949 Aug. 2 by K. Reinmuth at Heidelberg.

Named in honor of Akira Otawara (1950- ), photo artist and writer. In 1983 he published two books, Field Star Map 2000 and Star \& Planet Catalogue 2000, in collaboration with S. Nakano \{see planet (3431)\}, who proposed the name and found the identifications involving this object. (M 22505)

\section{(4980) Magomaev}

$1974 \mathrm{SP}_{1}$. Discovered 1974 Sept. 19 by L. I. Chernykh at Nauchnyj.

Named in honor of Muslim Magometovich Magomaev (1942- ), famous Soviet singer, a soloist at the Azerbaijan Theatre of opera and ballet and later at the Bolshoj Theatre in Moscow. A remarkable performer of the songs of Russian and Azerbaijani composers and of arias in classical operas, he is also known as a songwriter and composer of movie scores. (M 26763)

\section{(4981) Sinyavskaya}

1974 VS. Discovered 1974 Nov. 12 by L. I. Chernykh at Nauchnyj.

Named in honor of Tamara Il'inichna Sinyavskaya, distinguished Russian singer, soloist at the Bolshoj Theatre in Moscow and performer of many roles in classical and modern operas. (M 26763)

\section{(4982) Bartini}

1977 PE$_{1}$. Discovered 1977 Aug. 14 by N. S. Chernykh at Nauchnyj.

Named in memory of Robert Lyudvigovich Bartini (1897-1974), Italian baron by birth who lived and worked in the Soviet Union. The designer of several original aircraft, Bartini was also known for his research in aerodynamics, theoretical physics and cosmology. (M 30096)

\section{(4983) Schroeteria}

1977 RD7. Discovered 1977 Sept. 11 by N. S. Chernykh at Nauchnyj.

Named in memory of Johann Hieronymus Schroeter (1745-1816), outstanding German amateur astronomer and telescope maker. At his private observatory in Lilienthal, Schroeter made numerous observations of the sun, the moon, and major and minor planets, comets and stars, with a special emphasis on the physical constitution and surface characteristics of celestial bodies. In particular, Schroeter correctly identified the strip-shaped details on Mars as sand storms. His drawings were important for an understanding of the physical nature of the comets of 1799, 1807 and 1811. Schroeter was one of the founders of the Astronomische Gesellschaft and host for the meeting of the famous "celestial police" in 1800. (M 26763)

Name suggested and citation provided by V. K. Abalakin.

Schroeter is also honored by a lunar crater.
(4985) Fitzsimmons

1979 QK$_{4}$. Discovered 1979 Aug. 23 by C.-I. Lagerkvist at La Silla.

Named after Alan Fitzsimmons, who works on the relationships between minor planets and comets and has collaborated with the discoverer for several years. His enthusiasm and good spirit when observing on La Palma has always been very much appreciated by the discoverer. (M 21609)

\section{(4986) Osipovia}

1979 SL7. Discovered 1979 Sept. 23 by N. S. Chernykh at Nauchnyj.

Named in memory of Valerij Ivanovich Osipov (1945-1993), distinguished Russian historian, archivist, archaeologist and linguist in the St. Petersburg Department of Archives of the Russian Academy of Sciences. He made a valuable contribution to the study of the Russo-German scientific relations in the eighteenth century, discovered some new documents on the founding and work of the Pulkovo Astronomical Observatory, studied the peculiarities of the language of eighteenth-century Russian writers and carried out archaeological investigations in the countries of Middle Asia. (M 26763)

Name suggested and citation material provided by V. K. Abalakin.

\section{(4987) Flamsteed}

$1980 \mathrm{FH}_{12}$. Discovered 1980 Mar. 20 at the Perth Observatory at Bickley.

John Flamsteed (1646-1719), the first Astronomer Royal, is renowned for his systematic telescopic positional observations of the sun, moon, planets and stars, culminating in Historia Coelestis Britannica (1725), containing his catalogue of 3000 stars, and Atlas Coelestis (1729), celestial charts completed by his widow. (M 43380)

\section{(4989) Joegoldstein}

$1981 \mathrm{DX}_{1}$. Discovered 1981 Feb. 28 by S. J. Bus at Siding Spring.

As dean of the College of Engineering at the University of Massachusetts at Amherst, Joseph Goldstein (1939- ) leads a research group focused on metallographic techniques and experimentally determined phase relationships. This work is vital to understanding the formation and structure of iron meteorites. (M 41382)

\section{(4990) Trombka}

$1981 \mathrm{ET}_{26}$. Discovered 1981 Mar. 2 by S. J. Bus at Siding Spring.

A researcher at NASA's Goddard Space Flight Center, Jacob (Jack) Trombka (1930- ) was instrumental in analyzing $\gamma$-ray and x-ray measurements of the moon obtained during the Apollo missions. He is the principal investigator for the -ray and x-ray instruments on the NEAR mission to (433) Eros. (M 41382) 
(4991) Hansuess

$1981 \mathrm{EU}_{29}$. Discovered 1981 Mar. 1 by S. J. Bus at Siding Spring.

Hans Suess (1909-1993) was one of the pioneers of cosmochemistry. He proposed that the relative abundance of each element depends on its mass and that patterns in elemental abundances were caused by a combination of nuclear properties and the mechanisms by which heavy elements are created in stars. (M 41382)

\section{(4992) Kálmán}

1982 UX $_{10}$. Discovered 1982 Oct. 25 by L. V. Zhuravleva at Nauchnyj.

Named in memory of the Hungarian composer Imre Kálmán (1882-1953). (M 24765)

\section{(4996) Veisberg}

1986 PX $_{5}$. Discovered 1986 Aug. 11 by L. G. Karachkina at Nauchnyj.

Named for the Russian painter Vladimir Grigor'evich Veisberg (1924-1985). (M 22505)

\section{(4997) Ksana}

1986 TM. Discovered 1986 Oct. 6 by L. G. Karachkina at Nauchnyj.

Named in honor of Kseniya Andreevna Nessler, chemist by profession and fighter against environmental pollution by avocation, friend of the discoverer. Ksana is a familiar variant of Kseniya, the Russian form of Xenia. (M 22505; M 22609)

\section{(4999) MPC}

1987 CJ. Discovered 1987 Feb. 2 by E. W. Elst at La Silla.

Named by the Minor Planet Names Committee for the Minor Planet Circulars, the series established in 1947 for the publication of astrometric observations, orbital elements and limited ephemerides of minor planets - as well as for the announcement of new names. The abbreviation also honors the Minor Planet Center, which operates through IAU Commission 20 to issue the Circulars. Originally located at the Cincinnati Observatory, the Minor Planet Center moved to the Smithsonian Astrophysical Observatory in 1978. Data on comets also now appear in the publication, which has the alternate title Minor Planets and Comets. (M 19342)

\section{(5000) IAU}

1987 QN $_{7}$. Discovered 1987 Aug. 23 by E. F. Helin at Palomar.

Named in honor of the International Astronomical Union, established in 1919 as the international association of professional astronomers. Most of its activity is concentrated in some 40 commissions, each devoted to some particular area of astronomical or astrophysical research. At a competition held in July 1991 among members of Commission 20, "Positions and Motions of Minor Planets, Comets and Satellites", for the selection of a name for the five-thousandth minor planet to be given a permanent number the name "IAU" received the largest number of votes, including that of the discoverer. (M 19342)

\section{(5001) EMP}

1987 SB $_{1}$. Discovered 1987 Sept. 19 by E. Bowell at Anderson Mesa.

Named by the Minor Planet Names Committee for the Ehfemeridy Malykh Planet or Ephemerides of Minor Planets, the annual publication of ephemerides of the numbered minor planets and updates of the orbital elements of these bodies to a current epoch. Many new orbit improvements are also included in the EMP each year. Under the auspices of the IAU Commission 20, the EMP, successor to the old Kleine Planeten volumes, has been published since 1948 by the Minor Planets and Comets department of the Institute of Theoretical Astronomy in St. Petersburg (formerly Leningrad). The EMP is also now available in a computer-diskette edition. (M 19342)

\section{(5002) Marnix}

$1987 \mathrm{SS}_{3}$. Discovered 1987 Sept. 20 by E. W. Elst at Rozhen.

Named for Philips Marnix van Sint Aldegonde (1538-1598), mayor of Antwerp during 1583-1585 and player of a major role in defending the city against the Spanish troops. He was concerned with the religious struggle between catholics and protestants and is considered to be the composer of the beautiful Dutch national hymn 'Wilhelmus'. (M 20162)

Citation based on information supplied by R. Grignard.

\section{(5004) Bruch}

$1988 \mathrm{RR}_{3}$. Discovered 1988 Sept. 8 by F. Börngen at Tautenburg.

Named for the German composer Max Bruch (18381920), particularly well known for his grandiose first violin concerto. (M 19699)

\section{(5005) Kegler}

1988 UB. Discovered 1988 Oct. 16 by S. Ueda and H. Kaneda at Kushiro.

Named for Ignatius Kegler (1680-1746), a German Jesuit, who worked for 29 years as Astronomer Royal in Beijing. The identity of a comet he observed in 1737 with $\mathrm{P} /$ Swift-Tuttle, briefly suggested by W. T. Lynn \{see planet (4358)\} and discussed in considerable detail by B. G. Marsden \{see planet (1877)\}, was proven by the comet's recovery in 1992. (M 22505)

Name suggested by I. Hasegawa.

\section{(5006) Teller}

1989 GL $_{5}$. Discovered 1989 Apr. 5 by E. F. Helin at Palomar.

Named in honor of the distinguished Hungarian-born, U.S. physicist Edward Teller \{1908- \}. Known for his seminal work in physics and astrophysics, notably on the Gamow-Teller relationship, he has also made 
significant contributions in chemical physics, molecular physics and quantum theory. He has been a professor of physics at George Washington University, the University of Chicago and the University of California. $\mathrm{He}$ inspired the creation of the Lawrence Livermore National Laboratory and has served as its director. Senior research associate at the Hoover Institute, Stanford University, since 1975, he has been highly effective in promoting open international science free of secrecy. Having entered the world a few months before the Tunguska \{see planet (5471)\} event, Teller was honored by the naming of this minor planet by his colleagues on his eighty-fourth birthday, 1992 Jan. 15, during his participation in a NASA Workshop on procedures for the interception of threatening near-earth asteroids and comets. (M 19699)

\section{(5007) Keay}

$1990 \mathrm{UH}_{2}$. Discovered 1990 Oct. 20 by R. H. McNaught at Siding Spring.

Named in honor of Colin Stewart Lindsay Keay (1930- ), past president of IAU Commission 22 and chairman of the IAU Working Group on the Prevention of Interplanetary Pollution, who has made several major contributions to our understanding of the meteoroidal flux to the earth. His well-controlled radar patrol from the University of Canterbury during 1960-65 in collaboration with Clifton Ellyett \{see planet (5378)\} remains our best knowledge of the southern-hemisphere influx. Since 1965 Keay has worked at the University of Newcastle (N.S.W.), one of his most noteworthy achievements being the development of a physical theory for the production of electrophonic sounds by bright fireballs. (M 29144)

Name proposed by the discoverer following a suggestion by D. I. Steel, who prepared the citation, and an endorsement by B. G. Marsden.

\section{(5008) Miyazawakenji}

1991 DV. Discovered 1991 Feb. 20 by A. Sugie at Taga.

Named in memory of Kenji Miyazawa (1896-1933), a poet and fairy-tale writer with few parallels in the history of literature in Japan. His great works show a love for nature and a unique sense and expression cultivated through his life as a farmer, while he discharged his duties devotedly as an agricultural leader in Iwate Prefecture. (M 26763; M 27477)

\section{(5009) Sethos}

2562 P-L. Discovered 1960 Sept. 24 by C. J. van Houten and I. van Houten-Groeneveld at Palomar.

Named after the Egyptian pharaoh Sethos I (reigned 1304-1290 B.C.) of the 19th dynasty. His father was Ramses I, who reigned for only two years. Sethos I built the Great Hall of Columns of the Amun \{see planet (3554)\} temple in Karnak and the Osiris \{see planet (1923)\} temple in Abydos. Sethos I was the father of Ramses II \{see planet (4416)\}. (M 22505)

\section{(5010) Amenemhêt}

4594 P-L. Discovered 1960 Sept. 24 by C. J. van Houten and I. van Houten-Groeneveld at Palomar.

Named after the Egyptian pharaoh Amenemhêt III (1844-1797 B.C.), son of Sesostris III ssee planet (4414)\}. He regulated the oasis Fajum which became rich agricultural land. There he built an immense temple which Herodotus \{see planet (3092)\} later visited and called a 'labyrinth'. (M 22505)

\section{(5011) Ptah}

6743 P-L. Discovered 1960 Sept. 24 by C. J. van Houten and I. van Houten-Groeneveld at Palomar.

In Egyptian religion Ptah was the creator of the universe and a patron of craftsmen, especially sculptors. Ptah was originally the local deity of Memphis, capital of Egypt from the 1st dynasty; the political importance of Memphis led to the expansion of Ptah's cult throughout Egypt. Ptah was always represented in purely human form, often swathed in a winding sheet. (M 20163)

\section{(5012) Eurymedon}

9507 P-L. Discovered 1960 Oct. 17 by C. J. van Houten and I. van Houten-Groeneveld at Palomar.

Eurymedon was servant to the Greek king Nestor \{see planet (659)\} during the siege of Troy. (M 20163)

\section{(5014) Gorchakov}

1974 ST. Discovered 1974 Sept. 19 by L. I. Chernykh at Nauchnyj.

Named in memory of Aleksandr Mikhailovich Gorchakov (1798-1883), an outstanding statesman and one of the eminent diplomats of the nineteenth century. He was Minister of Foreign Affairs of Russia from 1856 to 1882. (M 32345)

Named on the occasion of the 200th anniversary of his birth.

\section{(5015) Litke}

1975 VP. Discovered 1975 Nov. 1 by T. M. Smirnova at Nauchnyj.

Named for Fedor Petrovich Litke (1797-1882), Russian navigator and geographer, investigator of the Arctic regions, admiral and scientist, president of the Imperial Academy of Sciences in St. Petersburg during 18641882. His name is often found on world maps. (M 31295)

\section{(5016) Migirenko}

1976 GX $_{3}$. Discovered 1976 Apr. 2 by N. S. Chernykh at Nauchnyj.

Named in honor of Georgij Sergeevich Migirenko (1916- ), academician and professor at the Siberian Department of Russian Academy of Sciences in Novosibirsk, known for his work in applied and theoretical mechanics, hydrodynamics, mathematics and ship-building. In recent years he has worked on design problems of ecology-safe machines and transport for northern regions. Migirenko also takes an active 
part in research on the possibility of asteroids colliding with the earth. He is also a talented singer who graduated from the Odessa Conservatory. (M 30096)

\section{(5017) Tenchi}

$1977 \mathrm{DS}_{2}$. Discovered 1977 Feb. 18 by H. Kosai and K. Hurukawa at Kiso.

Named for the emperor (626-671) who made the first clepsydra in Japan in 660. On 671 June 10 (Gregorian style) he placed a new clepsydra on a new pavilion, and it sounded out the hours with bells and drums. In commemoration of this, June 10 is designated as the "Time Day" in Japan. (M 22505)

\section{(5018) Tenmu}

$1977 \mathrm{DY}_{8}$. Discovered 1977 Feb. 19 by H. Kosai and K. Hurukawa at Kiso.

Named for a Japanese Emperor (?-686), younger brother of the emperor Tenchi \{see planet (5017)\}, skilled in astronomy and in divination. He erected the first Japanese astronomical observatory in 675 . (M 22505; M 22519)

\section{(5020) Asimov}

1981 EX $_{19}$. Discovered 1981 Mar. 2 by S. J. Bus at Siding Spring.

Named in memory of Isaac Asimov (1920-1992), author and scientist. A prolific writer, Asimov produced nearly 500 works of science fiction and nonfiction, covering topics ranging from mathematics and physics to Shakespeare and history. His Robot stories revolutionized modern ideas about intelligent machines by introducing his "Three Laws of Robotics", an ethical code of robot behavior. While a professor of biochemistry at Boston University, Asimov also devoted himself to making science accessible to the general public through writing and lecturing. (M 27128; M 27147)

Name independently proposed by B. A. Skiff.

Obituary published in Nature, Vol. 357, No. 6374, p. 113 (1992).

\section{(5021) Krylania}

1982 VK $_{12}$. Discovered 1982 Nov. 13 by L. G. Karachkina at Nauchnyj.

Named in honor of Anna Alexeevna Kapitsa (1903-

), the daughter of Alexei Nikolaevich Krylov. She was an outstanding Russian mathematician and the wife of famous physicist Pyotr Leonidovich Kapitsa \{see planet (3437)\}. (M 22505)

Name proposed by the discoverer following a suggestion by Maria Sergeevna Kapitsa.

\section{(5023) Agapenor}

1985 TG$_{3}$. Discovered 1985 Oct. 11 by C. S. Shoemaker and E. M. Shoemaker at Palomar.

King and leader of the Arcadians \{see planet (1020)\} who went with the Greeks to the Trojan War, Agapenor commanded sixty ships loaned to him by Agamemnon \{see planet (911)\}. The Arcadians, who were able in war, thronged to go aboard as they had no ships or knowledge of seafaring themselves. (M 25443)

\section{(5024) Bechmann}

1985 VP. Discovered 1985 Nov. 14 by P. Jensen at Brorfelde.

Poul Bechmann is the former head of the mechanical workshop at the Brorfelde Observatory. (M 38194)

\section{(5026) Martes}

1987 QL $_{1}$. Discovered 1987 Aug. 22 by A. Mrkos at Klě́.

Named for Martes martes and Martes foina, or pine marten and beech marten, delightful small animals of the Mustelidae family that live in the forests on Klet Mountain. (M 34920)

Name suggested by J. Tichá and M. Tichý.

\section{(5027) Androgeos}

1988 BX $_{1}$. Discovered 1988 Jan. 21 by C. S. Shoemaker and E. M. Shoemaker at Palomar.

Androgeos was a Greek warrior who led a detachment of Greeks into the burning city of Troy. There he encountered Aeneas \{see planet (1172)\} in the company of other Trojan defenders. Androgeos and his detachment were set upon and killed, after which they were stripped of their armor by the Trojans, who then disguised themselves with it. It can be said that Androgeos supplied Aeneas and his men with tickets to safety. (M 22248)

Name and citation provided by Richard Preston at the request of the discoverers.

\section{(5028) Halaesus}

1988 BY . Discovered 1988 Jan. 23 by C. S. Shoemaker and E. M. Shoemaker at Palomar.

Halaesus was a son of Agamemnon \{see planet (911)\}. This minor planet is dynamically paired with (2759) Idomeneus, and like the Greek warrior Idomeneus, Halaesus found a home in Italy, settling on Mount Massiscus in Campania. Unlike Idomeneus, Halaesus missed joining the Trojan War and the sack of Troy. He made up for this later, for he fought against Aeneas \{see planet (1172)\} in the war for Italy, where he killed a large number of Trojans on Italian soil. (M 22248)

Name and citation provided by Richard Preston at the request of the discoverers.

\section{(5029) Ireland}

$1988 \mathrm{BL}_{2}$. Discovered 1988 Jan. 24 by C. S. Shoemaker and E. M. Shoemaker at Palomar.

Named in honor of Ireland, known poetically as Erin or Hibernia, to celebrate a year of anniversaries in 1995: the 150th anniversary of the Geological Survey of Ireland, the 150th anniversary of the Queen's Colleges (now University Colleges, Cork and Galway, and Queen's University, Belfast), and the 750th anniversary of the town of Sligo. (M 25653) 
Citation prepared by P. M. Bruck at the request of the discoverers.

\section{(5030) Gyldenkerne}

1988 VK $_{4}$. Discovered 1988 Nov. 3 by P. Jensen at Brorfelde.

Danish astronomer Kjeld Gyldenkerne (1919-1999) worked in the areas of galactic dynamics and binary stars and was the principal founder and former head of the Brorfelde Observatory. (M 38194)

\section{(5031) Švejcar}

$1990 \mathrm{FW}_{1}$. Discovered 1990 Mar. 16 by Z. Vávrová at Klet.

Named in honor of Josef Švejcar $\{1897-1997\}$, Czech physician. (M 22505)

\section{(5032) Conradhirsh}

1990 OO. Discovered 1990 July 18 by E. F. Helin at Palomar.

Conrad W. Hirsh (1941-1999) was an inspiring teacher and explorer of the bush, rivers and mountains. He began a long-term relationship with Africa as a Peace Corps teacher at Haile Selassie University in Addis Ababa in 1964 and later explored terra incognita in East Africa and Madagascar. (M 42668)

The name was suggested by Bruce Helin.

\section{(5033) Mistral}

1990 PF. Discovered 1990 Aug. 15 by E. W. Elst at St. Michel.

Named in memory of the great poet from the Provence, Frederic Mistral (1830-1914), whose entire life was dedicated to the restoration of the original dialect of the Langue d'Oc, the language of the 'troubadours'. In 1859 he published the poem Mir entire Provence. In 1886 he finished his Lou tresor dou felibrige, a Provencal-French dictionary. He was honored with the Nobel prize for literature \{in 1904 together with J. Echegaray\}. The Northern wind that blows through the Rhone valley and sweeps all the clouds from the sky bears the same name. (M 20163)

Citation prepared by Kristina Leterme at the request of the discoverer.

\section{(5034) Joeharrington}

1991 PW $_{10}$. Discovered 1991 Aug. 7 by H. E. Holt at Palomar.

Named in honor of Joseph Harrington (1967- ), planetary scientist at Cornell University. Harrington has worked extensively with atmospheric modeling, and his work on modeling the 1994 cometary impacts on Jupiter was featured on the cover of Nature. His work on waves in the atmospheres of the giant planets utilized computer "pipeline" programs to analyze data sets too large to manage by hand. Living by his belief in the way things should be, Harrington has actively promoted the sharing of data and data processing software/tools for the benefit of all. (M 35482)
Name proposed by B. E. Clark. Citation written by A. Simon and S. Sullivan.

\section{(5035) Swift}

1991 UX. Discovered 1991 Oct. 18 by S. Ueda and H. Kaneda at Kushiro.

Named in memory of Lewis Swift (1820-1913), famous U.S. comet hunter. The first of his 13 discoveries, $\mathrm{P} /$ Swift-Tuttle (1862 III) \{see planet (5036) for the co-discoverer\}, parent of the Perseid meteors, is also the most famous. He discovered his last comet at the age of 79. (M 22505)

Name suggested by I. Hasegawa.

\section{(5036) Tuttle}

$1991 \mathrm{US}_{2}$. Discovered 1991 Oct. 31 by S. Ueda and H. Kaneda at Kushiro.

Named for Horace P. Tuttle (1837-1923), astronomer at Harvard and - after serving in the U.S. Navy during the Civil War - at the Naval Observatory in Washington. Co-discoverer of both the Perseid comet $\mathrm{P}$ /Swift-Tuttle and the Leonid comet $\mathrm{P} /$ Tempel-Tuttle \{see planets (5035) and (3808) for the co-discoverers\}, he also found four other comets and the minor planets (66) Maja and (73) Klytia. (M 22505)

Name suggested and citation prepared by I. Hasegawa.

\section{(5037) Habing}

6552 P-L. Discovered 1960 Sept. 24 by C. J. van Houten and I. van Houten-Groeneveld at Palomar.

Named in honor of Harm Habing (1937- ), professor of astronomy at the University of Leiden and president of IAU Commission 34 (Interstellar Matter). Habing was the Dutch co-chairman of the Joint Science Team of the Infrared Astronomical Satellite (IRAS) \{see planet (3728)\}. Since 1983 he has supervised many publications based on IRAS observations of galaxies. Habing is a stimulating supervisor for his students and young scientists. (M 22505)

\section{(5038) Overbeek}

1948 KF. Discovered 1948 May 31 by E. L. Johnson at Johannesburg

Michiel Daniel Overbeek (1920_ _ ) is a prolific South African observer of variable stars and occultations. A past president of the Astronomical Society of Southern Africa and director of its occultation section, he is actively involved in fostering amateur astronomers in Southern Africa. (M 41567)

\section{(5039) Rosenkavalier}

$1967 \mathrm{GM}_{1}$. Discovered 1967 Apr. 11 by F. Börngen at Tautenburg.

Named in memory of Richard Strauss (1864-1949), one of the most important twentieth-century composers of opera, notably Der Rosenkavalier. He also wrote numerous song compositions and symphonic poems. (M 20163)

Name endorsed by Werner Tscharnuter. 


\section{(5040) Rabinowitz}

1972 RF. Discovered 1972 Sept. 15 by T. Gehrels at Palomar.

Named in honor of the U.S. astronomer David Rabinowitz and his work in the Spacewatch program. (M 22505)

\section{(5041) Theotes}

1973 SW $_{1}$. Discovered 1973 Sept. 19 by C. J. van

Houten and I. van Houten-Groeneveld at Palomar.

Theotes was a Greek herald during the siege of Troy. (M 20163)

\section{(5042) Colpa}

1974 ME. Discovered 1974 June 20 at the Felix Aguilar Observatory at El Leoncito.

Colpa is the word used by the Huarpe aborigines of Argentina to refer to those stones that, in their judgment, were composed of pure minerals. Agriculture and mining were the two most important activities of the Huarpes, who flourished in what is now San Juan province, where this minor planet was discovered. (M 41027)

\section{(5043) Zadornov}

1974 SB $_{5}$. Discovered 1974 Sept. 19 by L. I. Chernykh at Nauchnyj.

Named in honor of Mikhail Nikolaevich Zadornov (1948- ), Russian satirist widely known for his masterful readings of his own short stories. (M 34340)

\section{(5044) Shestaka}

$1977 \mathrm{QH}_{4}$. Discovered 1977 Aug. 18 by N. S. Chernykh at Nauchnyj.

Named in memory of Ivan Sofronovich Shestaka (1937-1994), senior scientist and head of the Comet and Meteor Department at the Odessa University Astronomical Observatory. He was known for his research on the physics and dynamics of meteoritic and cometary matter and its interaction with other minor bodies in the solar system. (M 27128)

\section{(5046) Carletonmoore}

1981 DQ. Discovered 1981 Feb. 28 by S. J. Bus at Siding Spring.

A professor of chemistry and geology at Arizona State University, Carleton Moore (1932- ) performed carbon, nitrogen, and sulphur analyses on Apollo lunar samples. Carleton is the founding director of the Center for Meteorite Studies at Arizona State University and was editor of the journal Meteoritics for 20 years. (M 41382)

\section{(5047) Zanda}

$1981 \mathrm{EO}_{42}$. Discovered 1981 Mar. 2 by S. J. Bus at Siding Spring.

Brigitte Zanda (1958- ) is a meteorite curator at the Museum National d'Histoire Naturelle in Paris and an adjunct faculty member at Rutgers University. Her research on the formation of chondrules has placed important constraints on chemical and physical processes operating in the solar nebula. (M 41382)

\section{(5048) Moriarty}

1981 GC. Discovered 1981 Apr. 1 by E. Bowell at Anderson Mesa.

Named for Professor James Moriarty, whom some would describe as a fictional character in the Sherlock Holmes \{see planet (5049)\} stories of Sir Arthur Conan Doyle. Described by Holmes as "the Napoleon of crime", and also as "the celebrated author of The Dynamics of an Asteroid - a book that ascends to such rarefied heights of pure mathematics that it is said that there was no man in the scientific press capable of criticizing it", the "most dangerous and capable criminal in Europe" died in a struggle with Holmes at the Reichenbach Falls in Switzerland. (M 22505)

Name suggested by J. F. Bowers, citation prepared by J. B. Tatum.

\section{(5049) Sherlock}

$1981 \mathrm{VC}_{1}$. Discovered 1981 Nov. 2 by E. Bowell at Anderson Mesa.

Named for Sherlock Holmes, the famous detective in the stories by Sir Arthur Conan Doyle. Holmes's knowledge of astronomy was nil; he was ignorant of the Copernican Theory and of the composition of the solar system. "You say that we go round the sun. If we went round the moon it would not make a pennyworth of difference to me or my work." (M 22506)

Name suggested by J. F. Bowers, citation prepared by J. B. Tatum.

\section{(5050) Doctorwatson}

$1983 \mathrm{RD}_{2}$. Discovered 1983 Sept. 14 by E. Bowell at Anderson Mesa.

Named for Dr. John H. Watson, M.D., friend, confidant and chronicler of the detective Sherlock Holmes \{see planet (5049)\} in the stories by Sir Arthur Conan Doyle. (M 22506)

Name suggested by J. F. Bowers, citation prepared by J. B. Tatum.

\section{(5051) Ralph}

1984 SM. Discovered 1984 Sept. 24 by P. Jensen at Brorfelde.

Ralph Florentin Nielsen (1942-1995) was head of the electronics laboratory at the Brorfelde Observatory. (M 38194)

\section{(5052) Nancyruth}

$1984 \mathrm{UT}_{3}$. Discovered 1984 Oct. 23 by C. S. Shoemaker and E. M. Shoemaker at Palomar.

Named in honor of Nancy R. Lebofsky of the University of Arizona's ARTIST and ACCESS! astronomy education programs, for her contributions to education. Through teacher workshops and presentations at national meetings, Lebofsky has brought the excitement of astronomy to thousands of teachers and 
their students. She has developed hands-on activities and produced a video that have been distributed to educators throughout the United States and other countries. (M 25443; M 25457)

Name proposed by the discoverers, following a suggestion by L. Lebofsky and D. H. Levy. Citation prepared by L. Lebofsky.

\section{(5053) Chladni}

$1985 \mathrm{FB}_{2}$. Discovered 1985 Mar. 22 by E. Bowell at Anderson Mesa.

Named in honor of Ernst Florens Friedrich Chladni (1756-1827), German meteoriticist. Generally regarded as the 'Father of Meteoritics', Chladni was initially trained as a lawyer. He never held a permanent position, but he travelled among the great cities of Europe giving lectures. It was on these travels that Chladni's interest turned to meteorites, and in 1794 he published a pioneering book in which he presented convincing evidence that meteorites originate in space. Never before or since has the birth of a scientific discipline been so closely associated with the publication of a single book. (M 22829)

Name suggested and citation prepared by T. J. McCoy, who also recently recognized Chladni by the naming of a mineral - chladniite.

Chladni is also honored by a lunar crater.

\section{(5054) Keil}

$1986 \mathrm{AO}_{2}$. Discovered 1986 Jan. 12 by E. Bowell at Anderson Mesa.

Named in honor of Klaus Keil (1934- ), American meteoriticist. An authority on the petrology of enstatite meteorites, Keil has also studied almost every other group of meteorites. He has headed active meteorite research groups at the University of New Mexico and the University of Hawaii. He was awarded the Leonard Medal of the Meteoritical Society, the highest award bestowed by that body, in 1988. Recently, Keil has been actively involved in spectral studies of meteorites as asteroid analogues. His work on shockdarkened meteorites and gas-rich regolith breccias has increased our understanding of the spectral properties of asteroidal surfaces. (M 22830)

Name suggested and citation prepared by T. J. McCoy.

\section{(5055) Opekushin}

1986 PB $_{5}$. Discovered 1986 Aug. 13 by L. I. Chernykh at Nauchnyj.

Named in memory of Aleksandr Mikhailovich Opekushin (1838-1923), outstanding Russian sculptor. He has produced memorials and sculptures of many historical persons and is especially famous for the Pushkin monument in Moscow and the Lermontov monument in Pyatigorsk \{see planet (2192)\}. (M 30096)

\section{(5058) Tarrega}

1987 OM. Discovered 1987 July 28 by T. Seki at Geisei.
Named in honor of Francisco Tarrega, modern Spanish guitarist. (M 22830)

\section{(5059) Saroma}

1988 AF. Discovered 1988 Jan. 11 by K. Endate and K. Watanabe at Kitami.

Named for a lake in Abashiri \{see planet (4263)\} National Park in eastern Hokkaido \{see planet (3720)\}. With an area of 151.2 square kilometers Saroma is the third largest lake in Japan, and it is famous for its harvest of scallops and oysters. Each autumn many visitors come to see its large stock of "sango-so" plants. (M 20838)

\section{(5060) Yoneta}

$1988 \mathrm{BO}_{5}$. Discovered 1988 Jan. 24 by S. Ueda and H. Kaneda at Kushiro.

Named in honor of Katsuhiko Yoneta (1904-1957), doctor of engineering and a graduate of Hokkaido Imperial University. A pioneer of astronomical observation by amateur astronomers in Hokkaido, he established the Hokkaido branch of the Oriental Astronomical Association in 1924 and inspired many young students. (M 22506)

Name suggested and citation prepared by H. Fukushima.

\section{(5061) McIntosh}

1988 DJ. Discovered 1988 Feb. 22 by R. H. McNaught at Siding Spring.

Bruce A. McIntosh (1929- ） worked at the National Research Council Canada. The radar meteor survey work he carried out with Peter Millman s see planet (2904)\} remains a benchmark. The Czech Academy of Science awarded him a special gold medal for fostering cooperative research on meteors. (M 43189)

The name was suggested by C. Keay.

\section{(5063) Monteverdi}

1989 CJ $_{5}$. Discovered 1989 Feb. 2 by F. Börngen at Tautenburg.

Named in memory of Claudio Monteverdi (15671643), with Schütz \{see planet (4134)\} the greatest musician of the seventeenth century and reputed to be one of the first composers of opera. (M 20163)

Name endorsed by Ingeborg Stein, director of the Heinrich-Schütz-Haus, Bad Köstritz, Thuringia.

\section{(5064) Tanchozuru}

1990 FS. Discovered 1990 Mar. 16 by M. Matsuyama and K. Watanabe at Kushiro.

Named for the crane that mainly inhabits Kushiro Marsh Nationalpark in eastern Hokkaido. This bird is designated as a Special Natural Species. The white-bodied bird is about 1 meter in height and characterized by partial black plumage and a red spotted head. It is widely regarded in Japan as a lucky bird. Although the bird was once nearly exterminated, conservation means that there are now more than 400 individuals. (M 22506) 
(5065) Johnstone

$1990 \mathrm{FP}_{1}$. Discovered 1990 Mar. 24 by E. F. Helin at Palomar.

Named in memory of Paul Johnstone (?-1976), the first director and producer of the well-known British TV program "The Sky at Night", now celebrating its 40th anniversary. (M 30475)

\section{(5066) Garradd}

1990 MA. Discovered 1990 June 22 by R. H. McNaught at Siding Spring.

Named for Gordon John Garradd (1959- ), amateur astronomer and photographer who has wide-ranging interests in astronomy and natural history, amply demonstrated by his discovery of four novae in the Large Magellanic Cloud, a photographic fireball patrol and outstanding photographs of wildlife and storms. He has made extensive astrometric observations of minor planets and comets that have otherwise often gone unobserved in the southern hemisphere. He has produced some spectacular astronomical photographs and CCD images, been an observer with Spaceguard Australia and served as coordinator of a storm-spotter network. (M 29144)

Named by the discoverer, endorsed by D. I. Steel, B. G. Marsden and G. V. Williams.

\section{(5067) Occidental}

1990 OX. Discovered 1990 July 19 by E. F. Helin at Palomar.

Named for Occidental College, a prestigious institution established in Los Angeles in 1887. Occidental is widely known for its outstanding liberal arts curricula of music, art, and political and physical science. The discoverer wishes to honor her alma mater on the occasion of Founders Day (1995 Apr. 19) and to pay special tribute to president John Brooks Slaughter, the faculty and students. May Oxy continue to provide its students with an exemplary educational experience, always inspiring excellence, equity, community and service for and from its student body with its celestial namesake elevated to heavenly rank. (M 24917)

\section{(5068) Cragg}

1990 TC. Discovered 1990 Oct. 9 by R. H. McNaught at Siding Spring.

Named in honor of Thomas A. Cragg, a quintessential amateur astronomer. In 1945 at age 17 he joined the American Association of Variable Star Observers; by 1992 he had contributed 120,702 brightness estimates, many being of variables at their faintest, as well as sunspot counts made every clear day with a 0.15-m Newtonian reflector. After the Association of Lunar and Planetary Observers was formed in 1947, Cragg served for many years as its Saturn recorder. In 1949 he was one of the founders of the Western Amateur Astronomers. After 24 years at Mount Wilson Observatory, he resigned his position as solar observer in 1976 and joined the Anglo-Australian Observatory as chief night assistant, retiring in 1992. (M 20163) Citation provided by Leif J. Robinson.

\section{(5069) Tokeidai}

1991 QB. Discovered 1991 Aug. 16 by K. Watanabe at Sapporo.

Named for a wooden clock tower, built in 1878 as a drill house for Sapporo Agricultural College. The clock is still ticking more than a century later, and the pleasant chimes still mark the hours. The building is one of Sapporo's most famous landmarks. (M 26929)

\section{(5070) Arai}

1991 XT. Discovered 1991 Dec. 9 by S. Ueda and H. Kaneda at Kushiro.

Named in honor of Ikunosuke Arai (1836-1909), the first director of the Central Meteorological Observatory. In his early days, he contributed to the triangulation of Hokkaido. In 1887 he observed the total eclipse of the sun at Sanjo, Niigata, and successfully photographed the event. (M 22506)

Name suggested and citation prepared by H. Fukushima.

\section{(5071) Schoenmaker}

3099 T-2. Discovered 1973 Sept. 30 by C. J. van Houten and I. van Houten-Groeneveld at Palomar.

Named in honor of Ton A. Schoenmaker (1945- ), for many years technical officer at Leiden Observatory. He wrote computer programs for the van Houtens \{see planets (1673) and (1674)\}, so that they were able to make the first identifications for their three Trojan Surveys. The help of Ton is very much appreciated. Ton is also a visual comet observer. (M 22506)

\section{(5072) Hioki}

1931 TS $_{1}$. Discovered 1931 Oct. 9 by K. Reinmuth at Heidelberg.

Named in honor of Tsutomu Hioki, who co-discovered $1988 \mathrm{VG}_{2}$, which was identified with the lost minor planet (724) Hapag. (M 22506)

Name proposed by S. Nakano, who found the identifications involving this object.

\section{(5073) Junttura}

1943 EN. Discovered 1943 Mar. 3 by Y. Väisälä at Turku.

Junttura embodies the Finnish mentality to get things done, stubbornly and at all costs. As Väinö Linna's novel, Täälä pohjantähden alla ("Here under the north star"), put it, "In the beginning, there was the swamp, the hoe and Jussi". Yet Jussi persisted and built a house. (M 42355)

The name was suggested by K. Nousiainen.

\section{(5075) Goryachev}

1969 TN $_{4}$. Discovered 1969 Oct. 13 by B. A. Burnasheva at Nauchnyj.

Named in memory of Nikolaj Nikanorovich Goryachev (1883-1940), professor of astronomy at Tomsk 
University, who in 1920 founded and until 1940 headed the department of astronomy. He is the author of numerous papers on celestial mechanics, comets, meteors and astrometry. In particular, he was known for his work on Halphen's method for computing secular perturbations and his application of this to (1) Ceres. For more than 20 years Goryachev delivered lectures on astronomy and geodesy at Tomsk University and Tomsk Polytechnic Institute. (M 28089)

\section{(5076) Lebedev-Kumach}

1973 SG $_{4}$. Discovered 1973 Sept. 26 by L. I. Chernykh at Nauchnyj.

Named in memory of Vasilij Ivanovich LebedevKumach (1898-1949), prominent poet and song-writer, known for his lyrical and patriotic verses for songs for many Soviet films. (M 30096)

\section{(5078) Solovjev-Sedoj}

1974 SW. Discovered 1974 Sept. 19 by L. I. Chernykh at Nauchnyj.

Named in memory of Vasilij Pavlovich Solovjev-Sedoj (1907-1979), distinguished composer, author of about 400 songs that are still popular, seven operettas and musical comedies, two ballets and music for several dozen films. (M 30096)

\section{(5080) Oja}

1976 EB. Discovered 1976 Mar. 2 by C.-I. Lagerkvist at Kvistaberg.

Named in honor of Tarmo Oja, professor in astronomy at Uppsala University working on galactic structure and variable stars. During the last few years he has also enthusiastically participated in photometric observations of (4) Vesta and (10) Hygiea at both Kvistaberg and La Palma. (M 20522)

\section{(5082) Nihonsyoki}

$1977 \mathrm{DN}_{4}$. Discovered 1977 Feb. 18 by H. Kosai and K. Hurukawa at Kiso.

Named for the chronicles of Japan from the earliest times to 697, written in Chinese and completed in 720. It was the first historical record compiled by the Japanese government and contained records of various astronomical phenomena, such as appearances of seven comets (including the 684 return of $\mathrm{P} /$ Halley), 13 solar eclipses (e.g. in 628), occultations of stars and planetary phenomena. It was translated into English by W. G. Aston and published under the title of Nihongi. \{See also the citation for planet (5454)\}. (M 22506)

\section{(5083) Irinara}

1977 EV. Discovered 1977 Mar. 13 by N. S. Chernykh at Nauchnyj.

Named in honor of Irina Evgen'evna Raksha, wellknown writer in Moscow and a friend of the discoverer's family. (M 22506)

\section{(5084) Gnedin}

$1977 \mathrm{FN}_{1}$. Discovered 1977 Mar. 26 by N. S. Chernykh at Nauchnyj.

Named in honor of Yurij Nikolaevich Gnedin (1935- ), well-known Russian astrophysicist, deputy director of the Pulkovo Astronomical Observatory and professor at St. Petersburg Technical University. Gnedin has studied the transfer of polarized radiation in cosmic media, the physics of neutron stars, black holes and comets, cosmomicrophysics and the physics of x-ray sources. (M 30475)

Name suggested by the Institute of Theoretical Astronomy.

\section{(5085) Hippocrene}

1977 NN. Discovered 1977 July 14 by N. S. Chernykh at Nauchnyj.

Named for the ancient Greek mythological spring of inspiration. The name is given in connection with the discovery of many new minor planets at the Crimean Astrophysical Observatory during the second half of 1977. (M 34620)

\section{(5086) Demin}

$1978 \mathrm{RH}_{1}$. Discovered 1978 Sept. 5 by N. S. Chernykh at Nauchnyj.

Named in memory of Vladimir Grigor'evich Demin (1929-1996), well-known expert on celestial mechanics and dynamics of rigid bodies, professor at Moscow University for many years and member of the editorial board of Kosmicheskie Issledovaniya (Cosmic Researches). With Aksenov and Grebenikov \{see planets (4777) and (4268), respectively\} he investigated the generalized problem of two fixed centers, and he was among the first, to develop theories of the motions of artificial satellites. He was also known for numerous monographs and textbooks on celestial mechanics, and he blazed the way to science for many students. (M 29144)

Name proposed by the discoverer following a suggestion by the Institute of Theoretical Astronomy.

\section{(5087) Emel'yanov}

$1978 \mathrm{RM}_{2}$. Discovered 1978 Sept. 12 by N. S. Chernykh at Nauchnyj.

Named in honor of Nikolaj Vladimirovich Emel'yanov (1946- ), head of the Celestial Mechanics Department of the Sternberg Astronomical Institute in Moscow. He constructed a practical analytical theory for artificialsatellite motion based on non-keplerian intermediate orbits. He has derived precise values for the orbital parameters of Phobos and Deimos and the dynamical parameters of Mars. He also developed ephemeris software for the majority of natural satellites. (M 30475)

Name suggested by the Institute of Theoretical Astronomy.

\section{(5088) Tancredi}

1979 QZ $_{1}$. Discovered 1979 Aug. 22 by C.-I. Lagerkvist at La Silla. 
Named in honor of Gonzalo Tancredi, Uruguayan astronomer who spent several years in Uppsala, working with the planetary group there. He has specialized in a broad range of problems related to the dynamical and physical evolution of comets and their interrelations with minor planets, using both observations and theoretical modeling. (M 22506)

\section{(5089) Nádherná}

1979 SN. Discovered 1979 Sept. 25 by A. Mrkos at Klět.

Named in memory of Sidonie Nádherná (1885-1950), baroness of Borutín and author of The Chronicle of Vrchotovy Janovice. She created a splendid park around her château of Vrchotovy Janovice in central Bohemia and became widely known as a friend of German poet Rainer Maria Rilke and Austrian writer Karl Kraus. She died a resident of Great Britain. (M 34340)

Name suggested by J. Tichá.

\section{(5090) Wyeth}

1980 CG. Discovered 1980 Feb. 9 at the Harvard College Observatory at Harvard.

Named in memory of Stuart Wyeth, who provided the means for the construction, sixty years ago, of the Wyeth $1.5-\mathrm{m}$ reflector, with which this minor planet was discovered. (M 20164)

\section{(5091) Isakovskij}

1981 SD $_{4}$. Discovered 1981 Sept. 25 by L. I. Chernykh at Nauchnyj.

Named in memory of Mikhail Vasil'evich Isakovskij (1900-1973), a poet whose verses are remarkable for their tunefullness. Many of them were set to music and became popular songs. (M 30096)

\section{(5092) Manara}

1982 FJ. Discovered 1982 Mar. 21 by E. Bowell at Anderson Mesa.

Named in honor of Alessandro Manara, since 1963 an astronomer at the Brera Astronomical Observatory in Milan. His fields of interest include astrometry, and the physics and dynamics of minor solar system bodies. In particular, he has studied the dynamics of comets and has carried out polarimetric analyses on several minor planets. He has recently written a study of Schiaparelli \{see planet (4062)\}. (M 21956)

Named suggested and citation prepared by V. Zappalà.

\section{(5093) Svirelia}

1982 TG $_{1}$. Discovered 1982 Oct. 14 by L. G. Karachkina at Nauchnyj.

Named for Elsa Gustavovna Sviridova, the wife of Georgij Vasil'evich Sviridov \{see planet (4075)\}. (M 22506)

\section{(5094) Seryozha}

1982 UT $_{6}$. Discovered 1982 Oct. 20 by L. G. Karachkina at Nauchnyj.

Named in honor of Serguei Pyotrovich Kapitsa (1928- ), professor of nuclear physics, active in public matters of science, the history of science and moderator of the principal Russian television program on science and society since 1973. He has been vice-president of the European Physical Society (1977-1980) and president of the Physical Society of the U.S.S.R. (1989-1992). He received the UNESCO Kalinga prize in 1979. (M 22506)

\section{(5095) Escalante}

1983 NL. Discovered 1983 July 10 by E. Bowell at Anderson Mesa.

Named in honor of Jaime Escalante, a mathematics teacher who has inspired thousands of underprivileged high school students to use academic accomplishment to rise above the harsh realities of the inner city. In 1982, his work at Garfield High School in Los Angeles attracted national attention when fourteen of his students passed the mathematics Advanced Placement exam, were accused of cheating, were retested, and passed again. Escalante, an immigrant from Bolivia, had been acclaimed as a teacher in his native country, but in the U.S. he was required to repeat college to obtain teaching credentials. (M 22830)

Citation by S. Ostro, who assisted the making of the movie Stand and Deliver, which dramatized the story of Escalante's calculus students at Garfield.

\section{(5096) Luzin}

$1983 \mathrm{RC}_{5}$. Discovered 1983 Sept. 5 by L. V. Zhuravleva at Nauchnyj.

Named in memory of the mathematician Nikolaj Nikolaevich Luzin (1883-1950), professor at Moscow University, who made fundamental contributions to the theory of real functions. (M 34620)

\section{(5097) Axford}

1983 TW $_{1}$. Discovered 1983 Oct. 12 by E. Bowell at Anderson Mesa.

Named in honor of William Ian Axford, director of the Max-Planck-Institut fur Aeronomie, Lindau, and current president of the Committee on Space Research, on the occasion of his sixtieth birthday. Axford's seminal contributions in the areas of magnetospheric, heliospheric, cometary and cosmic ray physics and interstellar gas dynamics have greatly enhanced our understanding and stimulated further investigation. While providing strong leadership in promoting space missions, including the highly successful Giotto mission to comet Halley in 1986, he has also been a leading advocate for international cooperation in space. (M 21956)

Name suggested and citation prepared by D. A. Mendis. 


\section{(5100) Pasachoff}

1985 GW. Discovered 1985 Apr. 15 by E. Bowell at Anderson Mesa.

Named in honor of Jay M. Pasachoff, Field Memorial professor of astronomy, director of the Hopkins Observatory and chair of the astronomy department of Williams College, Williamstown, Massachusetts. Pasachoff's broad range of astronomical research has centered on the sun, and especially on studies of solar eclipses. He is also well known for an extensive series of college-level textbooks and popular-astronomy textbooks and articles. Besides being an indefatigable public lecturer, Pasachoff has served as chairperson of the astronomy section of the American Association for the Advancement of Science, as a committee member of the American Association of Physics Teachers and on the Astrophysics Council of the National Aeronautics and Space Administration. (M 21956)

\section{(5101) Akhmerov}

1985 UB $_{5}$. Discovered 1985 Oct. 22 by L. V. Zhuravleva at Nauchnyj.

Named in honor of Vadim Zinov'evich Akhmerov (1929- ), who has returned health to many people during his 45-year medical service. Since 1980 he has worked in the Alushta (Crimea) maternity hospital. (M 34620)

\section{(5102) Benfranklin}

$1986 \mathrm{RD}_{1}$. Discovered 1986 Sept. 2 by A. Mrkos at Klě́t.

Named in memory of the American scientist, philosopher and statesman Benjamin Franklin (17061790), who was one of the brightest and most creative scholars of his time. He contributed in many areas of natural science: electricity, aurorae, earthquakes and atmospheric storms. Franklin proposed the two kinds of electric charge, positive and negative, and his famous experiments in 1752 with kites flown into storm clouds led to the invention of the lightning rod. (M 34621)

Name suggested by J. Tichá and M. Šolc.

\section{(5103) Diviš}

$1986 \mathrm{RP}_{1}$. Discovered 1986 Sept. 4 by A. Mrkos at Kleť.

Named in memory of the Czech scientist, Praemonstrat monk and priest Prokop Václav Diviš (1698-1765), who was known for his experiments with electricity. On 1754 June 15 he erected his "meteorological machine" on the grounds of his vicarage near Znojma in South Moravia. This was a kind of lightning rod consisting of some 400 iron peaks on plates on a high bar. Its aim was to exhaust the electricity from storm clouds and lead it groundward along chains, thus preventing lightning strikes. Diviš also used electricity in medical treatment. (M 34621)

Name suggested by J. Tichá and M. Šolc on the tricentennial of his $\{$ Diviš' $\}$ birth.

\section{(5104) Skripnichenko}

1986 RU $_{5}$. Discovered 1986 Sept. 7 by L. I. Chernykh at Nauchnyj.

Named in honor of Vladimir Il'ich Skripnichenko (1942- ）, staff member of the Institute of Theoretical Astronomy since 1968 and its deputy director since 1994, well known expert on computational methods of celestial mechanics. He has studied the application of Hansen's \{see planet (4775)\} method of partial anomalies to the investigation of cometary motions, the development of the Universal Poissonian processor and the development of the programing system ERA. (M 30475)

Name proposed by the Institute of Theoretical Astronomy.

\section{(5105) Westerhout}

$1986 \mathrm{TM}_{1}$. Discovered 1986 Oct. 4 by E. Bowell at Anderson Mesa.

Named in honor of Gart Westerhout, radio astronomer, on the occasion of his retirement as scientific director of the U.S. Naval Observatory. Westerhout developed the astronomy program at the University of Maryland into one of the best in the U.S. At the Naval Observatory, his incisive leadership and pioneering work in interferometric astrometry, including development of the first radio interferometer dedicated to astrometry, led to substantial advances in precise position, motion and time determination. (M 22830)

Name suggested and citation prepared by R. H. McCracken.

\section{(5106) Mortensen}

1987 DJ. Discovered 1987 Feb. 19 by P. Jensen at Brorfelde.

Inger Mortensen (1910- ) is an aunt of Brorfelde \{see planet (3309)\} observer Karl Augustesen. (M 39640)

\section{(5108) Lübeck}

$1987 \mathrm{QG}_{2}$. Discovered 1987 Aug. 21 by E. W. Elst at La Silla.

Named in memory of the famous organist and composer Vincent Lübeck (1654-1740), born in Paddingbüttel, near Dorum (Bremen area). In 1675 he became organist at St. Casmae et Damiani in Stade, retaining this post for more than 27 years. There he had one of the most beautiful north German organs made by Arp Schnitger at his disposal. In 1702 he went to Hamburg and became organist at St. Nicolai, which housed Schnitger's largest organ (four manuals, pedal and 66 voices). In 1721 the composer and organist Johann Mattheson wrote: "This unusual organ has an unusual organist. I need only say the name Vincent Lübeck and the whole panegyric is complete." (M 20164)

\section{(5110) Belgirate}

1987 SV. Discovered 1987 Sept. 19 by E. Bowell at Anderson Mesa. 
Named for the pleasant village on the western shore of Lake Maggiore, close to the town of Novara, on the occasion of the first IAU Symposium dedicated to the small bodies of the solar system (June 1993). (M 22248)

Name suggested and citation written by V. Zappalà and M. Di Martino.

\section{(5111) Jacliff}

$1987 \mathrm{SE}_{4}$. Discovered 1987 Sept. 29 by E. Bowell at Anderson Mesa.

Named in honor of Clifford (1929-1993) and Jackie (1935- ) Holmes. With his wife Jackie's backing and support, Cliff was for decades an astronomical observer, organizer and educator. Cliff and Jackie founded the Riverside Telescope Makers' Conference in 1969; from small beginnings it has become a leading event for amateur astronomers and is known worldwide. After retirement, Cliff began a second career as an educator, teaching astronomy courses at Riverside City College. (M 22830)

Name suggested by D. H. Levy, J. Young and S. J. Edberg, citation prepared by Edberg.

\section{(5112) Kusaji}

1987 SM $_{13}$. Discovered 1987 Sept. 23 by S. Ueda and H. Kaneda at Kushiro.

Named in honor of Shigeji Kusaji (1879-1956), agricultural worker in Asahikawa. He was the first head of the Asahikawa Astronomical Club and was an earnest observer of sunspots. His observations were made from 1928 to 1955 , and observations are still being made by amateur astronomers at his club. (M 22506)

Name suggested by H. Kohsai. Citation prepared by H. Fukushima.

\section{(5113) Kohno}

1988 BN. Discovered 1988 Jan. 19 by T. Seki at Geisei.

Named in honor of Masaru Kohno (1926- ), Japanese guitarist. The discoverer delights in playing a handmade guitar made by Kohno. (M 23137)

\section{(5114) Yezo}

1988 CO. Discovered 1988 Feb. 15 by S. Ueda and H. Kaneda at Kushiro.

Named for Japan's northern island of Hokkaido \{see planet (3720)\}, which was known as Yezo until 1869 . (M 27734)

\section{(5115) Frimout}

1988 CD $_{4}$. Discovered 1988 Feb. 13 by E. W. Elst at La Silla.

Named in honor of Dirk Frimout, the first Belgian astronaut. On 1992 Mar. 24 he went into orbit with his American colleagues on board of the space shuttle Atlantis. He is a member of BIRA, the Belgian Institute of Space Aeronomy at Uccle. The main purpose of this flight was the study of the ozone layer. (M 20164)

\section{(5116) Korsør}

1988 EU. Discovered 1988 Mar. 13 by P. Jensen at Brorfelde.

Korsør, a town on the southwestern coast of Sjælland almost exactly $100 \mathrm{~km}$ from Copenhagen, is the birthplace of Brorfelde observer Karl Augustesen. (M 38194)

\section{(5117) Mokotoyama}

1988 GH. Discovered 1988 Apr. 8 by K. Endate and K. Watanabe at Kitami.

Named for a mountain in eastern Hokkaido \{see planet (3720)\}. Rising to 1,000 feet, the mountain gives a view from Lake Kussharo to the southwest to the Sea of Okhotsk \{see planet (4042)\} to the north. A hut at its eighth station has "Ginryosui", the only spring in the area. (M 20838)

\section{(5118) Elnapoul}

1988 RB. Discovered 1988 Sept. 7 by P. Jensen at Brorfelde.

Elna (1917-1992) and Poul Hyttel (1909-_ ) are the parents-in-law of Brorfelde \{see planet (3309)\} observer Karl Augustesen. (M 39640)

\section{(5120) Bitias}

1988 TZ 1 . Discovered 1988 Oct. 13 by C. S. Shoemaker and E. M. Shoemaker at Palomar.

Bitias was a great Trojan warrior and a companion of Aeneas \{see planet (1172)\}. He was the first Trojan to drink a toast to the ill-fated Queen Dido ssee planet (209)\}, at the feast when Aeneas narrated his adventures to Dido, and she began to fall in love with him. Later, in Italy, during the Latin war, Bitias made a mistake that cost him and many other Trojans their lives, when he opened the gates of the Trojan's fortress in an effort to coax Latin warriors inside, where they could be trapped. Instead, the Latin warrior Turnus rushed inside the Trojan fortress and made slaughter, killing Bitias with a whirling pike. (M 22249)

Name and citation provided by Richard Preston at the request of the discoverers.

\section{(5121) Numazawa}

1989 AX $_{1}$. Discovered 1989 Jan. 15 by M. Yanai and K. Watanabe at Kitami.

Named in honor of Shigemi Numazawa (1958- ), a Japanese space artist with an international reputation. Relying on his rich experience as an amateur astronomer and space photographer, he has produced a large body of work, including a collection of astrophotographs taken with a Schmidt camera. (M 25653)

\section{(5122) Mucha}

1989 AZ $_{1}$. Discovered 1989 Jan. 3 by A. Mrkos at Kleť.

Named in memory of Alfons Mucha (1860-1939), Czech painter, graphic artist and decorative artist, who also lived in Paris and the U.S. His work symbolizes the full flowering of the Art Nouveau style, as is evidenced 
by his posters of Sarah Bernhardt, illustrations and jewelry. (M 34621)

Name suggested by J. Tichá

\section{(5124) Muraoka}

1989 CW. Discovered 1989 Feb. 4 by T. Seki at Geisei.

Named in honor of Kenji Muraoka (1955- ), a Japanese amateur astronomer who plays an active role in calculating comet orbits. (M 24765)

\section{(5125) Okushiri}

$1989 \mathrm{CN}_{1}$. Discovered 1989 Feb. 10 by S. Ueda and H. Kaneda at Kushiro.

Named for an island, some $30 \mathrm{~km}$ to the southwest of Hokkaido \{see planet (3720)\}, noted for its rich fishing grounds for squid and scallops. (M 28621)

Name suggested by H. Ueda.

\section{(5126) Achaemenides}

$1989 \mathrm{CH}_{2}$. Discovered 1989 Feb. 1 by C. S. Shoemaker and E. M. Shoemaker at Palomar.

Born in Ithaca, Achaemenides was a Greek warrior who eventually became an ally of Aeneas' \{see planet (1172)\} Trojans. Originally he was a companion of Odysseus \{see planet (1143)\} and fought on the Greek side at Troy. Later, he was left behind in the land of the Cyclops when Odysseus blinded the Cyclops and escaped. There Aeneas found him - squalid, dressed in rags held together with thorns - and rescued him. (M 22249)

Name and citation provided by Richard Preston at the request of the discoverers.

\section{(5127) Bruhns}

$1989 \mathrm{CO}_{3}$. Discovered 1989 Feb. 4 by E. W. Elst at La Silla.

Named in memory of the famous organist and composer Nicolaus Bruhns (1665-1697), born at Schwabstedt, near Husum (Schleswig in the north of Germany), as a descendant of an old family of musicians. He got his first lessons at the organ from his father Paul Bruhns, a pupil of Franz Tunder \{see planet (7871)\}. In 1681 he went to the city of Lübeck, to study the organ and composition with Dietrich Buxtehude \{see planet (4344)\} and the violin and viola da gamba with his uncle Peter Bruhns. He was noted for his virtuosity, sometimes playing the upper parts on the violin - with accompaniment from an appropriate pedal bass part with his feet. (M 20522)

\section{(5128) Wakabayashi}

1989 FJ. Discovered 1989 Mar. 30 by M. Koishikawa at Sendai.

Wakabayashi is named for Wakabayashi-ku, a ward in the southeastern part of the city of Sendai \{see planet (3133)\}. About 400 years ago the warlord who founded Sendai city, Date Masamune \{see planet (6859)\}, spent his last days in this area. (M 25230)

\section{(5129) Groom}

1989 GN. Discovered 1989 Apr. 7 by E. F. Helin at Palomar.

Named in honor of Steven L. Groom, a computer specialist at the Jet Propulsion Laboratory, who designed and assembled the Near-Earth Asteroid Tracking (NEAT) autonomous observing system, the first of its kind to search for near-earth objects. He used his expertise in systems-level software (including device drivers), parallel processing architectures, network programming and device integration to make NEAT a success. The NEAT team wishes to salute his ingenuity and dedication to the project. (M 26929)

\section{(5130) Ilioneus}

$1989 \mathrm{SC}_{7}$. Discovered 1989 Sept. 30 by C. S. Shoemaker and E. M. Shoemaker at Palomar.

Ilioneus, a ship commander of Aeneas ssee planet (1172)\}, was the official spokesman for Aeneas' band of wandering Trojans. He was the first to speak to strangers on behalf of Aeneas, and his soft words often preceded conflict. First he advised Dido ssee planet (209)\}, the queen of Carthage, that the Trojans and Aeneas posed no threat to her realm /when, in fact, Aeneas would break her heart and drive her to suicide). Later he spoke to King Latinus, seeking permission for the Trojans to stay in Italy, and that request ultimately led to devastating war, when the Latins tried to drive Aeneas away. (M 22249)

Name and citation provided by Richard Preston at the request of the discoverers.

\section{(5132) Maynard}

1990 ME. Discovered 1990 June 22 by H. E. Holt at Palomar.

Named in honor of Owen E. Maynard, who played a major role in the achievement of the first manned landing on the moon. An engineer in the Apollo program from the beginning, he helped design the Apollo spacecraft and oversaw the design of the command-service and lunar modules. He led the team that developed the complex lunar mission flight plans. As chief of the Systems Engineering Division, he was responsible for all aspects of the construction and testing of the Apollo hardware. He planned the early Apollo test flights, including that of the first lunar landing, Apollo 11. (M 27734)

Name suggested and citation prepared by R. Attwood.

\section{(5133) Phillipadams}

1990 PA. Discovered 1990 Aug. 12 by R. H. McNaught at Siding Spring.

Named in honor of Phillip Adams (1939- ), Australian broadcaster, writer, journalist, wit and philosopher. Amongst his multifarious good works, he helped promote the Australian search and follow-up program on near-earth asteroids from 1990 until its cessation in 1996. (M 29144) 
Name proposed by the discoverer following a suggestion by D. I. Steel, who prepared the citation.

\section{(5134) Ebilson}

$1990 \mathrm{SM}_{2}$. Discovered 1990 Sept. 17 by H. E. Holt at Palomar.

Named in honor of Elizabeth M. Bilson (1937- ), administrative director of the Center for Radiophysics and Space Research (CRSR), Cornell University. Raised in Hungary, Bilson studied at the Sorbonne and obtained her Ph.D. in chemistry from the University of Illinois at Champaign-Urbana. She was a research associate under Thomas Gold at the CRSR from 1969 to 1983, directing the Lunar Laboratory, and she has coauthored numerous articles related to the physical properties of lunar material, in particular explaining the reason for the low albedo of the moon. She is also a very a good cook. (M 35482)

Name proposed by B. E. Clark, and citation written by M. Bilson.

\section{(5135) Nibutani}

1990 UE. Discovered 1990 Oct. 16 by S. Ueda and H. Kaneda at Kushiro.

Named for a valley sacred to the indigenous Ainu people of Hokkaido \{see planet (3720)\}. (M 28621) Name suggested by H. Ueda.

\section{(5136) Baggaley}

1990 UG $_{2}$. Discovered 1990 Oct. 20 by R. H. McNaught at Siding Spring.

Named in honor of W. Jack Baggaley (1938- ), radar meteor researcher at the University of Canterbury. Born and educated in Sheffield (England), where he took his Ph.D. in the mid-1960s under Tom Kaiser, he then moved to Christchurch, where he currently has the rank of professor of physics. Baggaley's research has encompassed many distinct areas of radio studies of meteors, and during the 1990s he has measured more meteoroid orbits than in all previous experiments combined. (M 29144)

Name proposed by the discoverer following a suggestion by D. I. Steel, who prepared the citation.

\section{(5137) Frevert}

1990 VC. Discovered 1990 Nov. 8 by J. M. Baur at Chions.

Named in honor of Friedrich Frevert $\{-2001\}$, an amateur astronomer from Wetzlar, well-known for his work on astrometric observations and on mathematical methods of reduction in photographic astrometry. For many years he was the chief of the Vereinigung der Sternfreunde in Germany. In 1965 he established the Astronomical Group in Wetzlar and later organized a very successful Minor Planet Working Group of amateur astronomers. (M 21610)

\section{(5138) Gyoda}

$1990 \mathrm{VD}_{2}$. Discovered 1990 Nov. 13 by T. Hioki and S. Hayakawa at Okutama.
Named for an industrial city, home of the second discoverer, located some $60 \mathrm{~km}$ north of Tokyo, between the Ara and the Tone see planet (1266)\} rivers. The city contains one of the three most celebrated ancient burial grounds in Japan, and an old sword with golden Kanji characters was found there. Gyoda is sister city of Kuwana \{see planet (5629)\}. (M 20523)

\section{(5139) Rumoi}

$1990 \mathrm{VH}_{4}$. Discovered 1990 Nov. 13 by M. Mukai and M. Takeishi at Kagoshima.

Named for the city of Rumoi, situated in the northwest part of Hokkaido \{see planet (3720)\}, where one of the discoverers was born. (M 20523)

\section{(5140) Kida}

1990 XH. Discovered 1990 Dec. 8 by S. Ueda and H. Kaneda at Kushiro.

Named in memory of Kinjiro Kida (1893-1962), Hokkaido-born painter, known for his landscapes, and whose work has been compared to that of Cézanne \{see planet (6674)\} and other impressionists. (M 28621; M 28637)

Name suggested by H. Ueda.

\section{(5141) Tachibana}

1990 YB. Discovered 1990 Dec. 16 by T. Seki at Geisei.

Tachibana is a Kendo club formed in 1950 in Kochi prefecture. Kendo is a sport similar to fencing in the same category as judo in Japan. The discoverer is a member of this club, the name of which means 'mandarin orange'. (M 22830)

\section{(5142) Okutama}

1990 YD. Discovered 1990 Dec. 18 by T. Hioki and S. Hayakawa at Okutama.

Named for the observatory at which this minor planet was discovered. Okutama is located to the west of Tokyo and is famous for its beautiful lake and its cherry blossom. (M 20523)

\section{(5143) Heracles}

1991 VL. Discovered 1991 Nov. 7 by C. S. Shoemaker and E. M. Shoemaker and D. H. Levy at Palomar.

Heracles, son of Zeus and the Theban princess Alcmena see planets (5731) and (82)\}, united the finest qualities of mind and heart, according to the traditions of the heroic age. His perseverance, crowned with victories, showed the triumph of the divine part of man's nature over the earthly. Through his fabled twelve labors, he achieved immortality and took his seat among the gods. (M 20523)

\section{(5144) Achates}

1991 XX. Discovered 1991 Dec. 2 by C. S. Shoemaker and E. M. Shoemaker at Palomar.

Achates was the best friend and companion-at-arms of Aeneas \{see planet (1172)\} in Virgil's ssee planet (2798)\} "Aeneid". Known as "fidus Achates" - faithful Achatus - he commanded his own ship in the wandering 
fleet of Trojans as they sought to establish a new city after the fall of Troy. Achates wandered far from known paths with Aeneas, traveling at Aeneas' side during their passage through the underworld, as the two friends threaded their way through "broad, silent tracts of night" in a journey to meet Aeneas' father, as described in the great Book VI of Virgil's poem. (M 22249)

Name and citation provided by Richard Preston at the request of the discoverers.

\section{(5145) Pholus}

1992 AD. Discovered 1992 Jan. 9 by the Spacewatch at Kitt Peak.

This Chiron-type object is being named by the Minor Planet Names Committee for a centaur who, like Chiron \{see planet (2060)\}, was hospitable, charitable and shunned violence. Pholus entertained Heracles \{see planet (5143)\} and gave him wine, the smell of which attracted and maddened the other centaurs, who were known for their brutal behavior and who began to fight with Heracles. Heracles used his poisoned arrows and killed many of them. As Pholus buried them, he wounded himself in extracting one of the arrows. Heracles tried to save him, but the poison was too deadly. Heracles buried Pholus on a mountain that he named Pholoe. (M 20523)

\section{(5146) Moiwa}

1992 BP. Discovered 1992 Jan. 28 by S. Ueda and H. Kaneda at Kushiro.

Named for the mountain that offers an outstanding panorama of the city of Sapporo \{see planet (3473)\} and is popular both to skiers and to hikers in its virgin forest. (M 28621)

Name suggested by H. Ueda.

\section{(5147) Maruyama}

1992 BQ. Discovered 1992 Jan. 28 by S. Ueda and H. Kaneda at Kushiro.

Named for a small hill, situated near Mt. Moiwa \{see planet (5146)\} in the southwestern part of Sapporo \{see planet (3473)\} and known for a beautiful park and zoo, as well as the Hokkaido Shrine. (M 28621) Name suggested by H. Ueda.

\section{(5148) Giordano}

5557 P-L. Discovered 1960 Oct. 17 by C. J. van Houten and I. van Houten-Groeneveld at Palomar.

Named in honor of Giordano Bruno (1548-1600), Dominican priest, who spent 16 years travelling through Europe, but who was mostly in London, where many of his papers were published. Bruno assumed the existence of other worlds on which people could live, and he was convinced of the correctness of the heliocentric system. This brought him in conflict with the church and he was condemned and burned on the Campo dei Fiori in Rome. (M 22507)

Giordano Bruno is also honored by a lunar crater.

\section{(5149) Leibniz}

6582 P-L. Discovered 1960 Sept. 24 by C. J. van Houten and I. van Houten-Groeneveld at Palomar.

Named after Gottfried Wilhelm Leibniz (1646-1716), German philosopher and mathematician, co-inventor of the calculus. (M 22507; M 25993)

Leibniz is also honored by a lunar crater.

\section{(5150) Fellini}

7571 P-L. Discovered 1960 Oct. 17 by C. J. van Houten and I. van Houten-Groeneveld at Palomar.

Named in memory of Frederico Fellini (1920-1993), one of the world's greatest film directors. He was called 'the maestro of the Italian cinema' and was an inspiration to a whole generation of film makers. Fellini's first film was Lo Sceicco Bianco, released in 1951. His first success came with I vitelloni, and in 1954 he won an Oscar for La strada. Further Oscars followed in 1957 for Le notti di Cabiria, in 1964 for Otto e mezzo and in 1974 for Amarcord. In April 1993 Fellini was honored with an Oscar for his lifetime achievements in film. (M 23137)

Name proposed by M.-R. Visscher.

\section{(5151) Weerstra}

2160 T-2. Discovered 1973 Sept. 29 by C. J. van Houten and I. van Houten-Groeneveld at Palomar.

Named in honor of Klaas Weerstra, administrative officer and longtime programmer at the Leiden Observatory. $\mathrm{He}$ is an enthusiastic visual comet observer and is always very helpful when the van Houtens \{see planets (1673), (1674)\} need help with new programs for their minor planet surveys. (M 22507; M 24421)

\section{(5154) Leonov}

1969 TL $_{1}$. Discovered 1969 Oct. 8 by L. I. Chernykh at Nauchnyj.

Named in memory of Evgenij Pavlovich Leonov (1926-1994), prominent Soviet artist, an actor of the Moscow Lenin Komsomol Theatre. Well known for his many brilliant and impressive roles on stage and screen, he was a favorite actor of children and the public generally. (M 34621)

\section{(5155) Denisyuk}

1972 HR. Discovered 1972 Apr. 18 by T. M. Smirnova at Nauchnyj.

Named in honor of academician Yurij Nikolaevich Denisyuk (1927- ), head of a laboratory at the Ioffe Physical and Technical Institute in St. Petersburg and a member of the Royal Photographic Society, known worldwide for his discoveries in holography. (M 32788)

Name suggested by the Institute of Applied Astronomy.

\section{(5156) Golant}

1972 KL. Discovered 1972 May 18 by T. M. Smirnova at Nauchnyj. 
Named in honor of academician Victor Evgen'evich Golant (1928- ）, director of the department of plasma physics, atomic physics and astrophysics at the Ioffe Physical and Technical Institute in St. Petersburg. Golant is widely known for his work in the fields of controlled thermonuclear fusion, interaction of electromagnetic waves with plasma, transfer processes, plasma diagnostics and heating of plasma in tokamaks. (M 32788)

Name suggested by the Institute of Applied Astronomy.

\section{(5157) Hindemith}

1973 UB $_{5}$. Discovered 1973 Oct. 27 by F. Börngen at Tautenburg.

Named in memory of the German composer Paul Hindemith (1895-1963), whose extensive creations encompassed almost all areas of music. Composer of the symphonies Mathis der Maler and Harmonie der Welt, he wrote concerning the latter that "it deals with the life and work of Johannes Kepler s see planet (1134)\} and with the search for harmony, ruling the universe undubiously". He defined a system of free tonality, on the other side of major and minor, in contrast to twelve-tone music. (M 20523)

\section{(5158) Ogarev}

1976 YY. Discovered 1976 Dec. 16 by L. I. Chernykh at Nauchnyj.

Named in memory of Nikolaj Platonovich Ogarev (1813-1877), poet and publicist, friend and associate of A. I. Herzen \{see planet (3052)\}, and a firm upholder of democratic ideas. He initiated and co-edited the Russian democratic newspaper Kolokol (The Bell), and on emigrating in 1856 became one of the leaders of The Free Russian Printing House in London. (M 30096)

\section{(5159) Burbine}

1977 RG. Discovered 1977 Sept. 9 at the Harvard College Observatory at Harvard

Named in honor of Thomas Burbine in appreciation of his assistance at the Minor Planet Center during January to May 1992. He has recently drawn attention to the similarity of (387) Aquitania and (980) Anacostia, S-type minor planets that share unusual features in their near-infrared spectra and have similar mean distances and proper inclinations - but different proper eccentricities. (M 20523)

\section{(5160) Camoes}

1979 YO. Discovered 1979 Dec. 23 by H. Debehogne and E. R. Netto at La Silla.

Named in memory of Luiz de Camoes (Camoens, 1524-1580), the greatest of the Portuguese poets, whose epic Os Lusiadas displays an extraordinary knowledge of astronomy. (M 21610)

\section{(5161) Wightman}

1980 TX $_{3}$. Discovered 1980 Oct. 9 by C. S. Shoemaker at Palomar.
Named in honor of Kingsley W. Wightman, loved and respected teacher of astronomy, who inspired generations of students, teachers and the lay public at the Chabot Science Center in Oakland, California. He served as director of the Center from 1976 to 1986 and played a major role in securing its future. (M 21133)

Name and citation provided by the Eastbay Astronomical Society at the request of the discoverer.

\section{(5162) Piemonte}

1982 BW. Discovered 1982 Jan. 18 by E. Bowell at Anderson Mesa.

Named for the northwestern region of Italy. Its capital, Torino, houses a historic university famous worldwide for its scientific research. Piemonte is also well known for its natural beauty, for its manufacturing industries, and for the production of a number of wines prized by connoisseurs. (M 22249)

Name suggested and citation written by V. Zappalà and M. Di Martino.

\section{(5164) Mullo}

$1984 \mathrm{WE}_{1}$. Discovered 1984 Nov. 20 by C. Pollas at Caussols.

Named for a Celtic divinity venerated in western France, especially in Mayenne, where the discoverer's family originates. The Romans associated Mullo with Mars. Several local sanctuaries with circular towers have been found, particularly in the goldmine area of Athee. (M 27128)

Citation material prepared from the work of J. Naveau.

\section{(5166) Olson}

$1985 \mathrm{FU}_{1}$. Discovered 1985 Mar. 22 by E. Bowell at Anderson Mesa.

Named in memory of Irvin Edward ('Ole') Olson (1910-1993), telescope-dome manufacturer. After an unsuccessful request to a silo maker to construct telescope domes suitable for amateur astronomers, Olson quit his job to found the Ash Manufacturing Company of Plainfield, Illinois. The company's first 'Ash Dome', erected at a junior-high school in 1961, was one of more than a thousand so far made for customers in 36 countries. (M 23137)

Name suggested by J. W. Young and citation prepared by Young and R. Olson.

\section{(5167) Joeharms}

$1985 \mathrm{GU}_{1}$. Discovered 1985 Apr. 11 by C. S. Shoemaker and E. M. Shoemaker at Palomar.

Named in honor of John (Joe) Eric Harms, former chief geologist of Broken Hill Pty., a large Australian mineral and petroleum-producing company. During his pioneering geological exploration in Western Australia, Harms discovered and recognized the Spider, Goat Paddock and Teague Ring impact structures. In the course of a 30-year career with BHP, he led in the discovery of major iron-ore, nickel and zinc-lead 
deposits, which have contributed importantly to the economy of Australia. (M 27329)

\section{(5168) Jenner}

1986 EJ. Discovered 1986 Mar. 6 by C. S. Shoemaker and E. M. Shoemaker at Palomar.

Named in memory of English country doctor Edward Jenner (1749-1823), who on 1796 May 14 vaccinated a boy against and later inoculated him with smallpox, the first successful step in a nearly 200-year journey that eventually resulted in the worldwide elimination of this disease. (M 27329)

Name suggested by B. G. Marsden.

\section{(5169) Duffell}

$1986 \mathrm{RU}_{2}$. Discovered 1986 Sept. 6 by E. Bowell at Anderson Mesa.

Named in honor of Stephen Duffell (1943- ), a long-time friend of the discoverer, on the occasion of his 50th birthday in November 1993. (M 22830)

\section{(5170) Sissons}

1987 EH. Discovered 1987 Mar. 3 by E. Bowell at Anderson Mesa.

Named in honor of Anthony Sissons (1943- ), a long-time friend of the discoverer, on the occasion of his 50th birthday in November 1993. (M 22830)

\section{(5172) Yoshiyuki}

$1987 \mathrm{UX}_{1}$. Discovered 1987 Oct. 28 by S. Ueda and H. Kaneda at Kushiro.

Yoshiyuki Endo (1953- ) is the landowner of the Kushiro Observatory. (M 41934)

\section{(5174) Okugi}

1988 HF. Discovered 1988 Apr. 16 by M. Yanai and

K. Watanabe at Kitami.

Named in honor of Susumu Okugi (1952- ), director of the software division of Goto Optical Laboratory \{see planet (2621)\}. Under his direction numerous automated planetarium programs have been developed. In this way, he has contributed much to the popularization of astronomy and space science. (M 25653)

\section{(5175) Ables}

$1988 \mathrm{VS}_{4}$. Discovered 1988 Nov. 4 by C. S. Shoemaker and E. M. Shoemaker at Palomar.

Named in honor of Harold D. Ables (1938- ), an astronomer and former director at the U.S. Naval Observatory's Flagstaff Station. Ables led the Flagstaff Station in its development of CCD capabilities for astrometry and spearheaded the transition from photographic to CCD techniques in parallax determinations. (M 27459)

Name proposed by the discoverers following a suggestion by the JPL ephemeris group.

\section{(5176) Yoichi}

1989 AU. Discovered 1989 Jan. 4 by S. Ueda and H. Kaneda at Kushiro.

Yoichi is a city of population of 24000 located in southwestern Hokkaido \{see planet (3720)\} and noted for its fruit and marine products. (M 43189)

\section{(5177) Hugowolf}

$1989 \mathrm{AY}_{6}$. Discovered 1989 Jan. 10 by F. Börngen at Tautenburg.

Named in memory of the Austrian composer Hugo Wolf (1860-1903), the creator of more than 200 songs from the late-romantic era. Many of these glorious songs had texts by Goethe \{see planet (3047)\}, Mörike and Eichendorff. (M 50524)

\section{(5179) Takeshima}

$1989 \mathrm{EO}_{1}$. Discovered 1989 Mar. 1 by T. Seki at Geisei.

Named in honor of Toshio Takeshima (1930- ), friend of the discoverer. He is a grand master of the Japanese martial art of Iai. Takeshima is also a nature photographer, producing many excellent pictures of birds. (M 23352)

\section{(5180) Ohno}

1989 GF. Discovered 1989 Apr. 6 by T. Fujii and K. Watanabe at Kitami.

Named in honor of Keiko Ohno (1959- ) for her activities in promoting the public awareness of the study of astronomy and space science. As a software developer at Goto Optical Laboratory \{see planet (2621)\} she has produced many computerized planetarium programs. (M 25653)

\section{(5181) SURF}

1989 GO. Discovered 1989 Apr. 7 by E. F. Helin at Palomar.

Named to honor Caltech's Summer Undergraduate Research Fellowship (SURF) program, which was begun in 1979 by professor of chemical engineering, Frederick H. Shair. The purpose of SURF is to encourage collegial interaction between a research sponsor - Caltech faculty and JPL technical staff - and undergraduate students around a research problem of mutual interest. This tribute pays special note to those SURF students who have participated in asteroid discovery and physical observation programs at JPL. The SURF program offers a hands-on learning experience for the students and a mentor-challenging role for the research sponsors. (M 21133)

\section{(5182) Bray}

1989 NE. Discovered 1989 July 1 by E. F. Helin at Palomar.

Named in honor of Olin D. Bray on the occasion of his 85th birthday, 1992 August 28. A medical doctor formerly in the U.S. Army and a lifetime caregiver to innumerable patients, Dr. Bray has been the healer and longtime friend of four generations of the families of the discoverer and her husband. He has always 
found time to live life to its fullest while doctoring and rendering comfort to others wherever needed. (M 20838)

\section{(5183) Robyn}

$1990 \mathrm{OA}_{1}$. Discovered 1990 July 22 by E. F. Helin at Palomar.

Named in honor of Laurie Robyn Ernst Yeomans, wife of current IAU Commission 20 president Donald K. Yeomans \{see planet (2956)\}. Her kindness and good nature have given Robyn a wide circle of friends and the love of her family. (M 24410)

\section{(5184) Cavaillé-Coll}

$1990 \mathrm{QY}_{7}$. Discovered 1990 Aug. 16 by E. W. Elst at La Silla.

Named in memory of Aristide Cavaillé-Coll (18111899), the most famous member of a family of organ builders and considered the initiator of the orchestral style of French organ building and composing. His first large organ, that at the basilica of Saint-Denis (completed in 1841), became a model for many later French organs. Napoleon III put him in charge of rebuilding a number of important cathedral organs; more than 600 instruments bore his name, a number of them in England. He made important improvements in mechanism and pipework, aiming at making the organ as expressive as symphony orchestra, and the typical romantic sound influenced a new school of composers, such as César Franck and Charles-Marie Widor \{see, respectively planets (4546) and (6829)\}. One of the most beautiful organs by Cavaillé-Coll is at Saint-Sulpice in Paris. (M 20524)

\section{(5185) Alerossi}

$1990 \mathrm{RV}_{2}$. Discovered 1990 Sept. 15 by H. E. Holt at Palomar.

Named in honor of Alessandro Rossi (1964- ), member of the Group of Satellite Flight Dynamics at the Istituto CNECE in Pisa. Rossi is an expert in space geodesy and participated in the Laser Geodynamics Satellite (LAGEOS) mission. He also studies the manmade space debris that pollutes the near-earth environment. Rossi has used his expertise to study natural "debris" around space mission targets to optimize encounter/rendezvous operations. He has also studied the hazard of earth-crossing objects. (M 5185)

Name suggested and citation prepared by M. A. Barucci and M. Fulchignoni.

\section{(5186) Donalu}

$1990 \mathrm{SB}_{4}$. Discovered 1990 Sept. 22 by B. Roman at Palomar.

Named for Dona(lu) Wheeler Roman, wife of the discoverer. Dona is an actress, teacher, administrator and mother. Her love and support have touched everyone around her. (M 20839)

\section{(5187) Domon}

$1990 \mathrm{TK}_{1}$. Discovered 1990 Oct. 15 by K. Endate and K. Watanabe at Kitami.

Named in memory of Ken Domon (1911-1991), renowned in the field of art and news photography. Born in Sakata City, he developed what came to be known as "Domon realism". Among his works, collections of photographs including "Hiroshima" and "Children in Chikuno" are especially famous. (M 20839)

\section{(5188) Paine}

$1990 \mathrm{TZ}_{2}$. Discovered 1990 Oct. 15 by E. F. Helin at Palomar.

Named in memory of Thomas O. Paine, administrator of NASA from 1968 to 1970 . He led the American space agency to its greatest achievement - the Apollo 11 mission, in which humans first walked on the moon. During his tenure at NASA, Paine laid the groundwork for the Apollo-Soyuz \{see planet (2228)\} test project, which marked the first joint flight of American and Soviet space travelers. In 1985 he was called again to serve the space program as chairman of the National Commission of Space, where he laid out his vision of humanity's future as a spacefaring species. Tom Paine's most enduring contribution may be the inspiration he has provided that will take humans beyond the moon to the frontier of Mars. (M 21133)

Citation prepared by Charlene Anderson of The Planetary Society.

\section{(5192) Yabuki}

1991 CC. Discovered 1991 Feb. 4 by T. Fujii and K. Watanabe at Kitami.

Named in honor of Hiroshi Yabuki (1960- ), one of the leaders in developing automated planetarium programs at Goto Optical Laboratory see planet (2621)\}. (M 25653)

\section{(5194) Böttger}

4641 P-L. Discovered 1960 Sept. 24 by C. J. van Houten and I. van Houten-Groeneveld at Palomar.

Named after Johann Friedrich Böttger (1682-1719). He was supposed to have made gold as alchemist to King August II the Strong of Saxonia. But instead he developed, together with mathematician and physician Ehrenfried Walter von Tschirnhaus, the first European porcelain in 1707-08. In 1710, Böttger became the head of the Dresden (later Meissen) Porcelain Manufacture. Böttger tried to sell the secret for the production of porcelain to the king of Prussia, so August II put Böttger into prison, where he died a short time later. (M 22507)

\section{(5195) Kaendler}

3289 T-1. Discovered 1971 Mar. 26 by C. J. van Houten and I. van Houten-Groeneveld at Palomar.

Named after Johann Joachim Kaendler (17061775), sculptor and porcelain-modeller at the Meissen Porcelain Manufacture. Kaendler was the first to 
develop the fine baroque porcelain figures, which are still imitated today. (M 22507)

\section{(5196) Bustelli}

3102 T-2. Discovered 1973 Sept. 30 by C. J. van Houten and I. van Houten-Groeneveld at Palomar.

Named after Franz Anton Bustelli (1723-1763), Italian-Swiss artist. Bustelli worked first in Vienna and then became famous as modeller for the Bavarian Porcelain Manufacture in Nymphenburg. His figures from the Commedia dell'arte are especially fine. (M 22507)

\section{(5197) Rottmann}

4265 T-2. Discovered 1973 Sept. 29 by C. J. van Houten and I. van Houten-Groeneveld at Palomar.

Named after Friedrich Rottmann (1797-1850), German Romantic landscape painter. He travelled on the order of King Ludwig I of Bavaria to Salzburg, Tirol, Rome and especially to Greece. His main work is kept in museums in Heidelberg and Munich. (M 22507)

\section{(5198) Fongyunwah}

$1975 \mathrm{BP}_{1}$. Discovered 1975 Jan. 16 at the Purple Mountain Observatory at Nanking.

Named in honor of Fong Yunwah, friend and fellow villager of the discoverer Yang Jiexing. Yang was introduced to astronomy as a child by Fong, who is a folk educationalist and has won the respect of all who know him. (M 23792)

Traditionally, the Purple Mountain Observatory did not announce the discoverers of minor planets. The citation therefore is exceptional.

\section{(5199) Dortmund}

$1981 \mathrm{RP}_{2}$. Discovered 1981 Sept. 7 by L. G. Karachkina at Nauchnyj.

Named for the capital of Nordrhein-Westfalen and the sister city of Rostov-on-Don \{see planet (4071)\}. Founded more than 1100 years ago, Dortmund is now one of the largest industrial, financial and cultural centers in Germany. (M 22507)

\section{(5200) Pamal}

1983 CM. Discovered 1983 Feb. 11 by E. Bowell at Anderson Mesa.

Named for Patrick Michael Malotki (1974- ～), friend of the discoverer, on the occasion of his 21st birthday. For many Francophones, the phrase "pas mal" is the highest form of compliment. (M 24765)

\section{(5201) Ferraz-Mello}

1983 XF. Discovered 1983 Dec. 1 by E. Bowell at Anderson Mesa.

Named in honor of Sylvio Ferraz-Mello (1936- ), dynamicist at the University of São Paulo, well known for a number of contributions to solar-system dynamics. These include a perturbation model valid for very high eccentricities, the discovery of chaotic eccentricity jumps to values larger than 0.9 in the $3: 1$ resonance with Jupiter, and the explanation of the lack of large long-lived objects in the 2:1 resonance, in contrast to the existence of many objects in the 3:2 resonance (Hildas). In other areas, he has worked on a Fourier transform able to deal with unevenly spaced observations, Hamiltonian perturbation theories for nonlinear resonances, and the study of variable dMe stars. Ferraz-Mello served as president of IAU Commission 7 (Celestial Mechanics) from 1994 to 1997. (M 35482)

\section{(5203) Pavarotti}

$1984 \mathrm{SF}_{1}$. Discovered 1984 Sept. 27 by Z. Vávrová at Kleť.

Named in honor of Luciano Pavarotti (1935- ), world-famous Italian opera singer. (M 22830)

\section{(5204) Herakleitos}

$1988 \mathrm{CN}_{2}$. Discovered 1988 Feb. 11 by E. W. Elst at La Silla.

Named for the Greek philosopher Herakleitos (540480 B.C.) of Ephesus. By means of his metaphoric clash ("life and death are the same so opponents that become metaphorical are identified with each other") he constructed and visualized relations of a higher conceptual order. He was thereby able to give a unique and decisive contribution to the history of thought. He is well known for his sayings such as "no one can step twice into the same river" and his famous "panta rhei" (everything changes). (M 21133)

Herakleitos is also honored by a lunar crater.

\section{(5206) Kodomonomori}

1988 ED. Discovered 1988 Mar. 7 by Y. Oshima at Gekko.

Named for the Children's Forest Program, operated by OISCA International \{see planet (3843)\}, the Organization for Industrial, Spiritual and Cultural Development, which is affiliated with the Gekko Observatory \{see planet (4261)\}. The aim of the program is to encourage children all over the world to plant more trees. (M 25653)

\section{(5208) Royer}

$1989 \mathrm{CH}_{1}$. Discovered 1989 Feb. 6 by E. F. Helin at Palomar.

Named in honor of Monsignor Ronald Royer, whose work in astronomical photography and variable-star observation has been a life-long passion. For over twenty years he has contributed to astronomical research and has exemplified the ideals of amateur astronomy by sharing his telescopes and enthusiasm with hundreds of students, children of his parish and the general public. Royer is one of the true pioneers of tricolor astrophotography, having first applied this technology to illustrate the different colors of the gas and dust tails of Comet West (1976 VI) \{see also planet (2022)\}. (M 21957)

This naming is enthusiastically endorsed by Jack Child, Steve Padilla and all his many friends. 


\section{(5210) Saint-Saëns}

1989 EL $_{6}$. Discovered 1989 Mar. 7 by F. Börngen at Tautenburg.

Named in memory of the French composer Charles Camille Saint-Saëns (1835-1921), whose extensive musical creations ranged from church music to neoclassicism. Among his best known works are the symphonic poem La danse macabre, the opera Samson and Delilah and his third organ symphony. (M 20524)

\section{(5211) Stevenson}

1989 NX. Discovered 1989 July 8 by C. S. Shoemaker and E. M. Shoemaker at Palomar.

Named in honor of David J. Stevenson (1948- ) of the California Institute of Technology. A citizen of New Zealand, Stevenson displays scientific breadth and depth to an unusual degree; his research interests span much of theoretical geophysics and planetary science. Stevenson's contributions include novel insights into our understanding of planetary interiors and the origin of planetary magnetic fields. (M 27459)

Citation provided by P. M. Goldreich following a suggestion by the discoverers and A. W. Harris.

\section{(5213) Takahashi}

1990 FU. Discovered 1990 Mar. 18 by K. Endate and K. Watanabe at Kitami.

Named in memory of Kiichiro Takahashi (1922-

), whose father founded the company Takahashi Seisakujo in 1932, and who started the production of astronomical telescopes in 1967. Many Japanese amateur astronomers have discovered minor planets using telescopes made by the company. (M 21133)

\section{(5214) Oozora}

$1990 \mathrm{VN}_{3}$. Discovered 1990 Nov. 13 by A. Takahashi and K. Watanabe at Kitami.

Oozora, or 'Big Sky', is the name of the express train that connects Hakodate, the rail gateway to Hokkaido, with Kushiro \{see planets (3720) and (4096), respectively\}, the largest city on the eastern side of the island. The $580-\mathrm{km}$ journey takes less than eight hours. (M 26930)

\section{(5215) Tsurui}

1991 AE. Discovered 1991 Jan. 9 by M. Matsuyama and K. Watanabe at Kushiro.

Named for a small town situated $20 \mathrm{~km}$ north of Kushiro in eastern Hokkaido \{see planets (4096) and (3720), respectively\}. (M 22507)

\section{(5218) Kutsak}

1969 TB $_{3}$. Discovered 1969 Oct. 9 by B. A. Burnasheva at Nauchnyj.

Mariya Romanovna Kutsak (1928-1997) was a schoolteacher of physics and astronomy in the city of Omsk for about 40 years. (M 45336)

\section{(5219) Zemka}

$1976 \mathrm{GU}_{3}$. Discovered 1976 Apr. 2 by N. S. Chernykh at Nauchnyj.
Named in honor of Aleksandr Grigorjevich Zemka (1947- ), friend of the discoverer, electrotechnics engineer in Zaporozhje, both a prominent specialist and a good organizer who wins the respect of his colleagues and acquaintances. He provided valuable help to the discoverer in improving the 0.64-m telescope used for the Crimean NEA Survey. (M 32345)

\section{(5220) Vika}

$1979 \mathrm{SA}_{8}$. Discovered 1979 Sept. 23 by N. S. Chernykh at Nauchnyj.

Named in honor of Victoriya Semenovna Vinogradova (1928- ), doctor at the Crimean Astrophysical Observatory in Nauchnyj who has attended to the staff members of the observatory for 40 years. (M 30096)

\section{(5221) Fabribudweis}

1980 FB. Discovered 1980 Mar. 16 by L. Brožek at Klet.

Named for the medieval Czech astronomer, physician and theologian Wenceslaus (Václav) Fabri de Budweis (c.1460-1518), mainly known as the author of almanacs. After a university career in Leipzig he returned to his native town, now České Budějovice, where he is considered one of the most distinguished medieval intellectual personages. (M 27734)

\section{(5222) Ioffe}

1980 TL $_{13}$. Discovered 1980 Oct. 11 by N. S. Chernykh at Nauchnyj.

Named in memory of Abram Fedorovich Ioffe (18801960), one of the originators of the Soviet physics school, a pioneer in the investigation of semiconductors and an academician of the U.S.S.R. Academy of Sciences. Ioffe was the organizer and the first director of the Physical and Technical Institute, of the Institute of Semiconductors and of the Physical and Agricultural Institute in Leningrad. He also initiated the creation of physical and technical institutes in Kharkov, Dnepropetrovsk, Sverdlovsk and Tomsk. (M 26763)

Name proposed by the Institute of Theoretical Astronomy.

\section{(5223) McSween}

$1981 \mathrm{EX}_{6}$. Discovered 1981 Mar. 6 by S. J. Bus at Siding Spring.

A professor at the University of Tennessee, Harry (Hap) McSween Jr. (1945- ) has specialized in studies of martian meteorites, and he has led the way in integrating petrologic data with results from missions to Mars. He also makes planetary science understandable to the public with his numerous books. (M 41382)

\section{(5224) Abbe}

1982 DX $_{3}$. Discovered 1982 Feb. 21 by F. Börngen at Tautenburg.

Named in memory of Ernst Karl Abbe (1840-1905), director of the Jena Observatory from 1877 to 1900, known for his fundamental contributions to optics. These includes work on microscopes, the Abbe number 
and comparators - the last being very useful for the detection of minor planets. Abbe, a long-time collaborator and friend of Carl Zeiss ssee planet (851)\}, secured considerable financial support for the University of Jena from the Zeiss foundation. The minor planet is being named on the occasion of the first meeting of the Astronomische Gesellschaft in the \{eastern part of the reunited Germany. (M 20839) Abbe is also honored by a lunar crater.

\section{(5225) Loral}

$1983 \mathrm{TS}_{1}$. Discovered 1983 Oct. 12 by E. Bowell at Anderson Mesa.

Named for Loral, Inc., an American manufacturer of charge-coupled device chips. Several of Loral's large-format chips are to be used in a search for near-earth minor planets and comets to be conducted by the discoverer. (M 23137)

\section{(5226) Pollack}

1983 WL. Discovered 1983 Nov. 28 by E. Bowell at Anderson Mesa.

Named in memory of James B. Pollack (1938-1994), a planetary scientist who spent much of his career at the NASA Ames Research Center. He was a world leader in the study of planetary atmospheres and particles using radiative transfer techniques. His work was highly creative and interdisciplinary, and it led to numerous advances in our understanding of the solar system. He played major roles in many NASA flight missions from Mariner 9 to Cassini and guided numerous young planetary scientists into productive careers. Work on the effects on the earth's atmosphere and surface biology of the Cretaceous-Tertiary impactor led Pollack and others to the concept of "nuclear winter". (M 25653)

Citation prepared by J. Cuzzi.

Obituaries published in Bull. Am. Astron. Soc., Vol. 26, No. 4, p. 1606-1608 (1994); Icarus, Vol. 113, No. 2, p. 227-231 (1995).

\section{(5228) Máca}

1986 VT. Discovered 1986 Nov. 3 by Z. Vávrová at Klet.

Named in honor of Jan Máca, one-time schoolmate and old friend of the discoverer, for his contribution to the protection of nature. (M 27128)

\section{(5230) Asahina}

1988 EF. Discovered 1988 Mar. 10 by J. Alu at Palomar.

Takashi Asahina (1908- ) is music director of the Osaka Philharmonic. As one of the oldest living conductors, Maestro Asahina is highly praised for his expertise in interpreting the German and Austrian repertories of Beethoven, Bruckner and Brahms \{see planets (1814), (3955) and (1818), respectively\}. (M 43042)

\section{(5231) Verne}

1988 JV. Discovered 1988 May 9 by C. S. Shoemaker and E. M. Shoemaker and H. E. Holt at Palomar.

Named for Jules Verne (1828-1905), French novelist and playwright. One of the founding fathers of modern science fiction, he was also the author of numerous works of mainstream adventure fiction. His best-known tales include From the Earth to the Moon (1865), Twenty Thousand Leagues under the Sea (1870) and Around the World in Eighty Days (1873). (M 24765)

The discoverers are great fans of Verne's work, as is M. M. Dworetsky, who suggested the name and prepared the citation.

Jules Verne is also honored by a lunar crater.

\section{(5232) Jordaens}

$1988 \mathrm{PR}_{1}$. Discovered 1988 Aug. 14 by E. W. Elst at St. Michel.

Named for Jacob Jordaens (1593-1678) on the 400th anniversary of his birth. This famous Flemish painter of Antwerp was a pupil of Adam van Noort and a contemporary of P. P. Rubens. His paintings were inspired by family life and popular situations, like the joy of daily life in the villages. His well-known painting "So als de ouden songhen so pijpen de jonghen" is typically nationalistic and representative of the revival of Flemish art, putting it on an equal level with more internationalistic tendencies. (M 21610)

Citation prepared by Kristina Leterme at the request of the discoverer.

\section{(5234) Sechenov}

1989 VP. Discovered 1989 Nov. 4 by L. G. Karachkina at Nauchnyj.

Named in honor of the outstanding Russian naturalist Ivan Mikhailovich Sechenov (1829-1905). (M 22507) Sechenov is also honored by a lunar crater.

\section{(5235) Jean-Loup}

$1990 \mathrm{SA}_{1}$. Discovered 1990 Sept. 16 by H. E. Holt at Palomar.

Named in honor of Jean-Loup Bertaux (1942- ), French planetary scientist and head of the Department of Solar System Studies at the Service d'Aéronomie of the Centre National de Recherche Spatiale. Since 1964 Bertaux has played a crucial role in space-mission exploration of the solar system, acting in collaboration with his American and Russian colleagues. He was the first to map a hydrogen cloud around a comet, and in 1975 he discovered the interstellar wind in the solar system. Bertaux has been involved in several experiments on the Vega mission to comet $1 \mathrm{P} /$ Halley and in other missions to study Venus, Mars, the earth and the sun. (M 27459)

Name suggested and citation prepared by M. A. Barucci.

\section{(5236) Yoko}

$1990 \mathrm{TG}_{3}$. Discovered 1990 Oct. 10 by Y. Mizuno and T. Furuta at Kani. 
Named in honor of Yoko Furuta (1946- ), wife of the second discoverer. (M 27128)

\section{(5237) Yoshikawa}

$1990 \mathrm{UF}_{3}$. Discovered 1990 Oct. 26 by T. Urata at Oohira.

Named in honor of Katsunori Yoshikawa (1942- ), owner of the land on which the Nihondaira ssee planet (2880)\} Observatory stands. He and his family appreciate the discoverer's surveys for minor planets and protect the observatory, which is located in one of the green-tea producing areas in Japan. (M 21134)

\section{(5238) Naozane}

$1990 \mathrm{VE}_{2}$. Discovered 1990 Nov. 13 by T. Hioki and S. Hayakawa at Okutama.

Named for Naozane Jiro Kumagaya (1141-1208), respected for his courage as a soldier during the turbulent Heian-Kamakura era. (M 22507)

\section{(5239) Reiki}

$1990 \mathrm{VC}_{4}$. Discovered 1990 Nov. 14 by S. Izumikawa and O. Muramatsu at Yatsugatake.

Named in honor of Reiki Kushida, amateur astronomer and discoverer of supernova $1991 \mathrm{bg}$, the first visual discovery of a supernova by a woman. (M 21610)

\section{(5240) Kwasan}

1990 XE. Discovered 1990 Dec. 7 by K. Suzuki and T. Urata at Toyota.

Named for the Kyoto University's Kwasan Observatory, which is located at the top of Kwasan hill on the eastern side of Kyoto city \{see planet (4352)\}. Kwasan Observatory was established in 1929 and is known for its observational studies of the solar system, especially of Mars, Pluto, minor planets, comets and natural satellites. (M 21610)

Name proposed by T. Mitani, who observed this planet at Kyoto on 1953 Nov. 3.

\section{(5242) Kenreimonin}

1991 BO. Discovered 1991 Jan. 18 by S. Inoda and T. Urata at Karasuyama.

Named for Tokuko Kenreimon-in (1155-1213), daughter of Kiyorami and mother of Emperor Antoku \{see planet (3686)\}. She was rescued from drowning after the battle of Dannoura in 1185. (M 21134; M 21155)

\section{(5243) Clasien}

1246 T-2. Discovered 1973 Sept. 29 by C. J. van Houten and I. van Houten-Groeneveld at Palomar.

Named in honor of Clasien Shane, wife of astronomy professor W. W. Shane (1928- ), of Nijmegen and the Leiden Observatory. From 1982 to 1987 the second discoverer lodged with the Shanes during the measuring for the T-1, T-2 and T-3 Trojan Surveys, and she is very grateful for their charming hospitality. (M 22507)

\section{(5244) Amphilochos}

1973 SQ . Discovered 1973 Sept. 29 by C. J. van Houten and I. van Houten-Groeneveld at Palomar.

Like his father Amphiaraos, Amphilochos could foretell the future. As the Greek fleet departed from Troy he was warned by a vision, and in the final moment before the ship departed he jumped to the shore. In this way he saved his life and lived together with Kalchas \{see planet (4138)\} in Asia Minor. (M 23137)

\section{(5245) Maslyakov}

1976 GR $_{2}$. Discovered 1976 Apr. 1 by N. S. Chernykh at Nauchnyj.

Named in honor of Aleksandr Vasil'evich Maslyakov, Moscow television journalist, one of the founders and for many years presenter of the program $K V N$ (Club of Merry and Resourceful Persons), which is very popular not only in the countries of the former Soviet Union but in others too. (M 30096)

\section{(5246) Migliorini}

1979 OB. Discovered 1979 July 26 by E. Bowell at Anderson Mesa.

Named in memory of Fabio Migliorini (1971-1997), a young researcher tragically killed in a mountain accident. Migliorini obtained important results relating to both dynamical and physical studies of minor planets. In particular, he investigated the various processes in the main belt responsible for replenishing the NEA population and was the first to point out the importance of Mars-crossing objects. He also made essential contributions to the physical study of minor planet families (among which are reconstruction of ejection velocity fields and assessment of the number of family interlopers). (M 32345)

Name suggested by A. Cellino, D. Davis, M. Di Martino, P. Farinella, V. Zappalà and endorsed by many colleagues and friends in the research community on minor planets.

Obituary published in Ir. Astron. J., Vol. 25, No. 1, p. 5 (1998).

\section{(5247) Krylov}

1982 UP $_{6}$. Discovered 1982 Oct. 20 by L. G. Karachkina at Nauchnyj.

Named in the memory of famous Russian mathematician and naval architect Alexei Nikolaevich Krylov (1863-1945). (M 22507)

Krylov is also honored by a lunar crater.

\section{(5248) Scardia}

1983 GQ. Discovered 1983 Apr. 6 by H. Debehogne and G. DeSanctis at La Silla.

Named in honor of Marco Scardia (1948- ), astrometrist at the Merate branch of the Brera Astronomical Observatory. His principal fields of interest are visual double stars and minor solar-system bodies. As a specialist on visual binaries, in the past fifteen years he has carried out more than four thousand 
measurements and calculated approximately 80 orbits of binary stars. He is also active in the astrometric observation of minor planets and comets and in the calculation of their orbits. (M 23138)

Name proposed and citation prepared by H. Debehogne.

\section{(5249) Giza}

1983 HJ. Discovered 1983 Apr. 18 by N. G. Thomas at Anderson Mesa.

Named for the Egyptian town and regional capital on the west bank of the Nile. This strip of land contains some of Egypt's greatest antiquities: the step pyramid; the sphinx \{see planet (896)\}; Abu Sir pyramids; the great pyramids; and Memphis, the ancient capital of Egypt. (M 26930)

\section{(5250) Jas}

1984 QF. Discovered 1984 Aug. 21 by A. Mrkos at Klět.

The Czech word for brightness, Jas symbolizes the South Bohemian Astronomical Society, known in Czech as Jihočeská Astronomická Společnost. Inaugurated in 1928, the society has been concerned mainly with the education and popularization of astronomy, and for this purpose it founded the Ceské Budějovice Observatory in 1937. The establishment of an observatory on the top of the Klet mountain was inspired by JAS members. State-aided since the 1950s, the Ceské Budějovice Observatory oversees the directorship of the Klet Obserservatory and is the home of the Klet archives. (M 27734)

Name suggested by M. Tichý.

\section{(5252) Vikrymov}

$1985 \mathrm{PZ}_{1}$. Discovered 1985 Aug. 13 by N. S. Chernykh at Nauchnyj.

Named in honor of Viktor Aleksandrovich Krymov (1929- ) deputy director of the Institute of Theoretical Astronomy for many years. His skillful and energetic work contributes much to the proper functioning of the Institute. (M 29144)

Name proposed by the discoverer following a suggestion by the Institute of Theoretical Astronomy.

\section{(5254) Ulysses}

$1986 \mathrm{VG}_{1}$. Discovered 1986 Nov. 7 by E. W. Elst at St. Michel.

Named for the Latin form of Odysseus \{see planet (1143)\}, hero of Homer's \{see planet (5700)\} Iliad and Odyssey. In the Iliad Ulysses is characterised by intelligence, experience (as a builder of machines) and endurance. He caused the chief commander Agamemnon \{see planet (911)\} to be restored and rallied the disaffected Greeks. The killing of the Trojan Dolon by Ulysses (which means "giver of pain") and Diomedes \{see planet (1437)\} was a tragic episode. Ulysses invented the strategem of the wooden horse, and it was first mentioned in the Odyssey, his journey of more than nine years after the battle of Troy. The pleasant episode of Ulysses and Nausikaa \{see planet (192)\} at Scheria has inspired many writers and composers. In James Joyce's \{see planet (5418)\} famous novel "Ulysses" the man of hostility becomes a man of peace. (M 21134)

\section{(5255) Johnsophie}

1988 KF. Discovered 1988 May 19 by E. F. Helin at Palomar.

Named in honor of John and Sophie Karayusuf, parents of Alford S. Karayusuf \{see planet (3800)\}, a friend of the discoverer. Under the starry skies of the Syrian Desert, they inspired their children to study the stars and planets and to wonder in amazement at the ability of mankind to explore the heavens. (M 32093)

\section{(5256) Farquhar}

1988 NN. Discovered 1988 July 11 by E. F. Helin and C. Mikolajczak and R. Coker at Palomar.

Named in honor of Robert Farquhar, who has been active in the design of spacecraft and missions for lowcost solar system exploration. His work has been carried out at the Goddard Space Flight Center and NASA Headquarters (1970-1990) and more recently at Johns Hopkins University Applied Physics Laboratory. Of particular interest are his efforts to utilize international cooperation and innovative trajectory design to plan missions to comets and minor planets. He was instrumental in designing and bringing to fruition the retargeting of the third International Sun Earth Explorer spacecraft to fly through the tail of periodic comet Giacobini-Zinner \{see planets (1756) and (4615) \} in September 1985 thus allowing the first in situ measurements of cometary phenomena. (M 21134)

Name endorsed heartily by D. K. Yeomans, who also contributed to the preparation of the citation.

\section{(5259) Epeigeus}

1989 BB $_{1}$. Discovered 1989 Jan. 30 by C. S. Shoemaker and E. M. Shoemaker at Palomar.

A noble Myrmidon fighter, Epeigeus was a son of Agakles. Before the Trojan War, he had ruled in the flourishing town of Boudeion, but there he slew a kinsman. As a suppliant to Peleus and Thetis \{see planet (17)\}, he was enlisted along with Achilles \{see planet (588)\} to make war against the Trojans. At Troy he was killed when Hector \{see planet (624)\} hit him upon the crest of his helmet with a great stone. (M 25443)

\section{(5260) Philvéron}

1989 RH. Discovered 1989 Sept. 2 by E. W. Elst at St. Michel.

Named in honor of Philippe Véron, director of the Observatoire de Haute Provence. In addition to conducting research on quasars and active galaxies, Véron is a student of early cometary books and broadsides. (M 21957) 
(5261) Eureka

1990 MB. Discovered 1990 June 20 by H. E. Holt and D. H. Levy at Palomar.

Named for Eureka, an expression of joy after making a discovery. According to a story that is probably apocryphal, Hiero II asked the Greek physicist Archimedes (287-212 B.C.) \{see planet (3600)\} to judge whether a crown contained pure gold or gold mixed with silver. After some consternation he found the answer while taking a bath: the weight of the crown in and out of water would allow the density to be determined, and hence the proportions of silver and gold. Thus Archimedes' principle was born, that a solid body surrounded by liquid is supported by a force equal to the weight of the liquid displaced. Archimedes was so thrilled by the revelation that he leaped out of the bath and dashed down the street, presumably still nude and shouting "Eureka! Eureka!" (I have found it!) (M 21134)

This planet is the first detected Martian Trojan. It moves near the Lagrangean libration point L5.

\section{(5262) Brucegoldberg}

$1990 \mathrm{XB}_{1}$. Discovered 1990 Dec. 14 by E. F. Helin at Palomar.

Named in honor of Bruce A. Goldberg, scientist and astronomer at Caltech's Jet Propulsion Laboratory and the USAF Phillips Laboratory, as well as friend and colleague of the discoverer. He received his $\mathrm{Ph}$.D. from the University of British Columbia and has conducted research in modeling and spectroscopy of Io and comet 21P/Giacobini-Zinner \{see also planets (1756), (4615)\}, on adaptive optics and as guest observer at a variety of telescopes throughout the world for over twenty years. (M 25653)

Name endorsed by R. Bambery, K. J. Lawrence and his many friends at JPL.

\section{(5263) Arrius}

$1991 \mathrm{GY}_{9}$. Discovered 1991 Apr. 13 by D. I. Steel at Siding Spring.

Named for Harrison Callum Bertram Steel, firstborn child of the discoverer. Harrison, born on 1992 December 16, shares his birth-date with several luminaries, including Christopher P. McKay (space scientist at NASA-Ames Research Center and friend of the discoverer), Arthur C. Clarke and Ludwig van Beethoven \{see planets (4923) and (1815), respectively\}. Their first initials provide the beginning of Harrison's second name. The 'Arrius' name is inspired by the Latin form of 'Harry', and in particular the poem 'Harrius' by the Roman poet Catullus, concerning a man of that appellation who dropped his h's. (M 23138)

\section{(5264) Telephus}

1991 KC. Discovered 1991 May 17 by C. S. Shoemaker and E. M. Shoemaker at Palomar.

Telephus, a son of Heracles \{see planet (5143)\} and Auge, was exposed on Mount Parthenius, nursed by a goat, and nurtured by kindly shepherds. Telephus had married a daughter of Priam \{see planet (884)\}, but was so grateful to the Greeks for healing a severe wound that he fought with the Greeks against his father-in-law. An oracle had declared that Troy could not be taken against the aid of a son of Heracles. (M 25444)

\section{(5265) Schadow}

2570 P-L. Discovered 1960 Sept. 24 by C. J. van Houten and I. van Houten-Groeneveld at Palomar.

Named after Johann Gottfried Schadow (1764-1850), German sculptor in the classicistic style. His bestknown sculpture is the Quadriga at the Brandenburg Gate in Berlin. (M 22507; M 25993)

\section{(5266) Rauch}

4047 T-2. Discovered 1973 Sept. 29 by C. J. van Houten and I. van Houten-Groeneveld at Palomar.

Named after Christian Daniel Rauch (1777-1857), German sculptor, first servant of King Friedrich Wilhelm III of Prussia. He received a grant from the king to become a pupil of Schadow \{see planet (5265) \}. Rauch worked in the classic style in Rome from 1804 to 1811, and his main work is the sarcophagus of Queen Luise of Prussia. (M 22507)

\section{(5269) Paustovskij}

1978 SL $_{6}$. Discovered 1978 Sept. 28 by N. S. Chernykh at Nauchnyj.

Konstantin Georgievich Paustovskij (1892-1968) was a well-known Russian writer, a master of lyric prose. (M 38194)

\section{(5270) Kakabadze}

1979 KR. Discovered 1979 May 19 by R. M. West at La Silla.

David Kakabadze (1889-1952) was a world-famous Georgian painter and avantgardist. During 1918-1927 he lived in Paris, where he held exhibitions together with Picasso \{see planet (4221)\}, Braque and others. A multi-talent, he was also professor of physics and mathematics and an innovator in the field of cinematography. (M 45336)

\section{(5272) Dickinson}

$1981 \mathrm{QH}_{2}$. Discovered 1981 Aug. 30 by E. Bowell at Anderson Mesa.

Named in honor of Terence Dickinson (1943- ), Canada's foremost popularizer of astronomy. Dickinson is the author of several books, notably Night Watch, The Universe and Beyond, Exploring the Sky by Day and Exploring the Night Sky, the last of which received the New York Academy of Sciences Children's Science Book Award in 1988. He reaches a wide Canadian audience every week with his astronomy column in The Toronto Star newspaper and on Canadian Broadcasting Corporation programs. From 1973 to 1975 he was editor of Astronomy magazine, and he has held scientific positions with the Ontario Science Centre in 
Toronto, the Strasenburgh Planetarium in Rochester and the McLaughlin Planetarium in Toronto. Dickinson teaches astronomy at St. Lawrence College in Kingston, Ontario. (M 23138)

Name suggested and citation prepared by C. J. Cunningham.

\section{(5274) Degewij}

1985 RS. Discovered 1985 Sept. 14 by E. Bowell at Anderson Mesa.

Named in honor of Johan Degewij (1944- ), of Utrecht Polytechnic Institute, for his contributions to small-bodies research. Degewij was among the first to use spectroscopy to search for cometary activity on near-earth asteroids and to detect color and polarization variations with rotation. His discovery of rotational albedo variegation on Vesta \{see planet (4)\} was the crucial observation that led to the recognition of its true rotation period as 5.34 hours, rather than 10.68 hours, the value accepted at the time. Degewij has also made significant contributions to the photometric study of comets, distant asteroids and the small satellites of Jupiter and Saturn. (M 24917)

Name suggested and citation provided by E. F. Tedesco.

\section{(5275) Zdislava}

1986 UU. Discovered 1986 Oct. 28 by Z. Vávrová at Kleť.

Named for Saint Zdislava (c. 1220-1252), a noblewoman who devoted her life to performing charity for the poor. She is the beloved saint of Marie Mácová, wife of an old schoolmate of the discoverer. (M 27128)

\section{(5276) Gulkis}

1987 GK. Discovered 1987 Apr. 1 by E. F. Helin at Palomar.

Named in honor of Samuel Gulkis of the Jet Propulsion Laboratory. He has over twenty-five years of research experience in radio and submillimeter astronomy, specializing in studies of Jovian magnetospheric physics, planetary atmospheres and experimental cosmology. Since 1978 he has been the project scientist in the JPL program for the search for Extra-Terrestrial Intelligence. Currently, he heads the Office of Science and Information Systems within the Space and Earth Science Programs Directorate. The discoverer and members of the Near-Earth Asteroid Tracking program wish to recognize his interest and support in the establishment of the JPL NEAT program in collaboration with the Air Force GEODSS site in Maui. (M 26930)

\section{(5278) Polly}

1988 EJ $_{1}$. Discovered 1988 Mar. 12 by E. F. Helin at Palomar.

Named in honor of "Polly" Blanton Brooks (1917-

), a fascinating, charming Texan, whose childhood was spent on the family's Yates Ranch, where oil was discovered in 1926. She married and raised three children on the Circle C Ranch, now known as Circle C City, Texas. Polly has been a member of the The Planetary Society's New Millennium Committee, providing support and inspiration for many projects. An enthusiastic proponent of space exploration, she has fostered international communication and cooperation over the years. (M 30096)

Name proposed on the occasion of her eightieth birthday, 1997 March 11

\section{(5279) Arthuradel}

1988 LA. Discovered 1988 June 8 by T. Rodriquez at Palomar.

Named in honor of Arthur Adel \{1908-1994\}, a pioneer in the field of infrared spectroscopy and upper atmospheric research. Much of his work was pursued at the Atmospheric Research Observatory, built for his use in 1952 on the campus of Northern Arizona University at Flagstaff. In the 1950s and 1960s he discovered atmospheric nitrous oxide, atmospheric heavy water and the 20-micron window, and he prepared the first maps of the solar-telluric spectrum from 7 to 14 microns. (M 22830)

Name endorsed by E. M. and C. S. Shoemaker.

Obituary published in Bull. Am. Astron. Soc., Vol. 26, No. 4, p. 1600-1601 (1994).

\section{(5281) Lindstrom}

1988 SO $_{1}$. Discovered 1988 Sept. 6 by S. J. Bus at Cerro Tololo.

Marilyn Lindstrom (1946- ) is curator of the U.S. Antarctic meteorite collection at NASA's Johnson Space Center. In addition to serving the scientific community in this important role, she has also been active in geochemical research, education and public outreach efforts related to meteorites. (M 41382)

\section{(5282) Yamatotakeru}

1988 VT. Discovered 1988 Nov. 2 by Y. Oshima at Gekko.

Named after the tragic hero, Yamatotakeru, who is well known by many Japanese people. He appears in Japanese ancient literature such as Kojiki and Nihon Shoki. (M 24122; M 24251)

Name proposed by the Gekko Astronomical Observatory.

\section{(5283) Pyrrhus}

1989 BW. Discovered 1989 Jan. 31 by C. S. Shoemaker and E. M. Shoemaker at Palomar.

Pyrrhus received his name from the yellow color of his hair. Also known as Neoptolemus s see planet (2260)\}, he was the king of Epirus and a son of Achilles \{see planet (588)\}. After Achilles was killed, a Greek delegation led by Odysseus \{see planet (1143)\} went to Epirus and brought Pyrrhus to the Trojan War. Enraged at the death of his father, he became the most ruthless of all the Greeks. Using a battle-axe, he broke the doors leading into King Priam's s see planet 
(884)\} house, which he sacked and burned, showing no mercy to women and children. After killing Priam's son Polites \{see planet (4867)\}, he also slew Priam on an altar - a sacrilege. He took away Hector's \{see planet (624)\} wife, Andromache \{see planet (175)\} as his prize. (M 22250)

Name and citation provided by Richard Preston at the request of the discoverers.

\section{(5284) Orsilocus}

1989 CK $_{2}$. Discovered 1989 Feb. 1 by C. S. Shoemaker and E. M. Shoemaker at Palomar.

Orsilocus, one of twin sons of Diokles, was a great man among the Danaans. As he grew up, he and his brother followed along with the Argives to Troy. He helped to win honor for Agamemnon and Menelaus \{see planets (911) and (1647), respectively\}, before being killed by Aeneas \{see planet (1172)\}. (M 25444)

\section{(5285) Krethon}

1989 EO $_{11}$. Discovered 1989 Mar. 9 by C. S. Shoemaker and E. M. Shoemaker at Palomar.

Krethon, one of two great Danaans, was one of the twin sons of Diokles. As a very young man he went with his brother Orsilocus \{see planet (5284)\} in the service of Agamemnon and Menelaus \{see planets (911) and (1647), respectively\}. Fighting with the Argives at Troy, he was killed by Aeneas \{see planet (1172)\}. (M 25444)

\section{(5286) Haruomukai}

$1989 \mathrm{VT}_{1}$. Discovered 1989 Nov. 4 by M. Mukai and M. Takeishi at Kagoshima.

Named in memory of Haruo Mukai (1949-1986), younger brother of one of the discoverers. (M 21957)

\section{(5287) Heishu}

1989 WE. Discovered 1989 Nov. 20 by Y. Mizuno and T. Furuta at Kani.

Named in memory of Heishu Hosoi (1728-1801), beloved scholar during the Edo era, born in the present-day city of Tokai, home of the second discoverer. \{Tokai already is a member of the minor planet sky - see planet (2478)\}. (M 22507)

\section{(5288) Nankichi}

1989 XD. Discovered 1989 Dec. 3 by Y. Mizuno and T. Furuta at Kani.

Named in memory of Nankichi Ni-imi (1913-1943), teacher and writer of fairy tales. (M 22508; M 22519)

\section{(5290) Langevin}

$1990 \mathrm{OD}_{4}$. Discovered 1990 July 30 by H. E. Holt at Palomar.

Named in honor of Yves Langevin (1951- ), French planetary scientist at the Institut d'Astrophysique Spatiale, Orsay University. Langevin is an expert on the evolution of the surfaces of small solar system bodies, and has worked on characterizing planetary surface materials using IR spectrometry. As a member of the Space Science Advisory Committee of the European Space Agency, he has helped define international programs for planetary exploration. As director of the National Planetology Program he has played a crucial role in promoting and developing planetary science in France. (M 35482)

Name suggested and citation prepared by M. A. Barucci and M. Fulchignoni.

\section{(5291) Yuuko}

1990 YT. Discovered 1990 Dec. 20 by M. Matsuyama and K. Watanabe at Kushiro.

Named in honor of Yuuko Matsuyama (1950- ), wife of the first discoverer. (M 22508)

\section{(5293) Bentengahama}

1991 BQ2. Discovered 1991 Jan. 23 by M. Matsuyama and K. Watanabe at Kushiro.

Named for a beautiful sandy beach between Kushirozaki lighthouse and Chiyonoura, in the southern part of Kushiro \{see planet (4096)\} City. The second discoverer spent his childhood there. The beach is being eroded and is gradually disappearing. (M 22508)

\section{(5294) Onnetoh}

1991 CB. Discovered 1991 Feb. 3 by K. Endate and K. Watanabe at Kitami.

Named for the small lake in Akan Nationalpark \{see planet (4584)\} in eastern Hokkaido. The lake, surrounded by volcanic mountains, is 620 meters above sea level and $4 \mathrm{~km}$ in circumference. (M 22508)

\section{(5295) Masayo}

1991 CE. Discovered 1991 Feb. 5 by Y. Mizuno and T. Furuta at Kani.

Named in honor of Masayo Mizuno (1955- ), wife of the first discoverer. (M 27128)

\section{(5296) Friedrich}

9546 P-L. Discovered 1960 Oct. 17 by C. J. van Houten and I. van Houten-Groeneveld at Palomar.

Named after Caspar David Friedrich (1774-1840), German painter of the Romantic school. Most of his work has a melancholic but peaceful expression. (M 22508)

\section{(5297) Schinkel}

4170 T-2. Discovered 1973 Sept. 29 by C. J. van Houten and I. van Houten-Groeneveld at Palomar.

Named after Karl Friedrich Schinkel (1781-1841), German architect and painter. He lived in Italy for two years. His style was mostly classicistic, but he also admired the Gothic style. His best known buildings are Schloss Charlottenhof in the park of Sanssouci and the mausoleum for Queen Luise of Prussia. (M 22508; M 24781)

\section{(5299) Bittesini}

1969 LB. Discovered 1969 June 8 by C. U. Cesco at El Leoncito. 
Named in honor of Luciano Bittesini (1950- ), Italian amateur astronomer and astrometrist. (M 30096)

Name suggested by B. G. Marsden, who made the identifications involving this object, and by G. V. Williams, who was hosted by Luciano and family during a 1995 visit to speak at a convention of Italian astrometrists.

\section{(5300) Sats}

1974 SX $_{1}$. Discovered 1974 Sept. 19 by L. I. Chernykh at Nauchnyj.

Named in memory of Nataliya Il'inichna Sats (19031993). An outstanding figure in Soviet theatre culture for children, she was the founder and art advisor of the Moscow Musical Children's Theatre, the first institution of its type in the world. She was also the author of many plays, librettos, operas and ballets for children. (M 34621)

\section{(5301) Novobranets}

$1974 \mathrm{SD}_{3}$. Discovered 1974 Sept. 20 by L. V. Zhuravleva at Nauchnyj.

Named in honor of Vasilij Andreevich Novobranets (1904-1984), Russian and Ukrainian writer. (M 28089)

\section{(5302) Romanoserra}

1976 YF $_{5}$. Discovered 1976 Dec. 18 by N. S. Chernykh at Nauchnyj.

Named in honor of Romano Serra (1954- ), enthusiastic president of the amateur observatory of San Giovanni in Persiceto near Bologna. A great specialist in meteorites, he has gathered the largest collection of meteorite specimens in Italy. He participated in two Tunguska \{see planet (5471)\} expeditions, in 1991 and 1998, and built a planetarium, the third largest in Italy. (M 34341)

Name suggested by M. di Martino and supported by the discoverer

\section{(5303) Parijskij}

$1978 \mathrm{TT}_{2}$. Discovered 1978 Oct. 3 by N. S. Chernykh at Nauchnyj.

Named in honor of Yurij Nikolaevich Parijskij (1932- ), radio astronomer and cosmologist. He was principal scientific investigator during the design and construction of the largest radio telescope, RATAN600 , at Zelenchukskaya, and he is now head of the radio astronomy department of the Special Astrophysical Observatory. (M 30476)

Name proposed by the Institute of Theoretical Astronomy and the Institute of Applied Astronomy.

\section{(5304) Bazhenov}

1978 TA $_{7}$. Discovered 1978 Oct. 2 by L. V. Zhuravleva at Nauchnyj.

Named in memory of Vasilij Ivanovich Bazhenov (1738-1799), Russian architect, teacher and architectural theorist. (M 34621)

\section{(5306) Fangfen}

1980 BB. Discovered 1980 Jan. 25 at the Harvard College Observatory at Harvard.

Named in honor of Fang Fen, a native of Zhangzhou in southern Fujian and wife of astronomer C.-Y. Shao \{see planet (1881)\}, one of the Agassiz see planet (2267)\} observers. (M 22508)

\section{(5307) Paul-André}

1980 YC. Discovered 1980 Dec. 30 by E. Bowell at Anderson Mesa.

Named in memory of Paul-André Herbelin (19331994) of Ayent, near Sion, Switzerland, friend of the discoverer and brother of the discoverer's companion Anne-Marie Malotki \{see planet (3667)\}. By profession a surveyor, Herbelin was by avocation a winemaker and raclette chef extraordinaire. (M 23540)

\section{(5308) Hutchison}

$1981 \mathrm{DC}_{2}$. Discovered 1981 Feb. 28 by S. J. Bus at Siding Spring.

Robert Hutchison (1938- ) recently retired as curator of meteorites at the Natural History Museum in London. His chemical, mineralogical and petrological studies of chondritic meteorites have advanced our understanding of the early solar system processes leading to the formation of chondrites. (M 46005)

\section{(5309) MacPherson}

$1981 \mathrm{ED}_{25}$. Discovered 1981 Mar. 2 by S. J. Bus at Siding Spring.

Glenn MacPherson (1950- ) , curator at the Smithsonian's National Museum of Natural History, has studied chondrules and Ca-Al-rich inclusions to investigate the nebular processes that formed chondritic meteorites. His work on short-lived isotopes has helped constrain the timing of these processes. (M 46006)

\section{(5310) Papike}

$1981 \mathrm{EP}_{26}$. Discovered 1981 Mar. 2 by S. J. Bus at Siding Spring.

James Papike (1937- ), director emeritus of the Institute of Meteoritics at the University of New Mexico, is one of the world's foremost experts on the mineralogy and petrology of planetary materials. His studies of lunar rocks have helped reveal the complexity of the earth's nearest neighbor. (M 46006)

\section{(5312) Schott}

$1981 \mathrm{VP}_{2}$. Discovered 1981 Nov. 3 by F. Börngen at Tautenburg.

Named in memory of Friedrich Otto Schott (18511935), analytical chemist and glass engineer. In 1882 he founded a glass-technical laboratory and, together with E. Abbe \{see planet (5224)\} two years later, also the Jenaer Glaswerk Schott und Genossen. Among the glass products Schott devised are filters, thermometers and the famous "Jenaer Glas". (M 21610) 
(5313) Nunes

$1982 \mathrm{SC}_{2}$. Discovered 1982 Sept. 18 by H. Debehogne at La Silla.

Named in memory of Pedro Nunes, Portuguese mathematician and geographer, called "the peak figure in Portuguese nautical science". He invented the instrument later known as the vernier, and he translated Sacrobosco into Portuguese. (M 21610)

\section{(5314) Wilkickia}

$1982 \mathrm{SG}_{4}$. Discovered 1982 Sept. 20 by N. S. Chernykh at Nauchnyj.

Named in memory of Andrej Ippolitovich Wilkitzky (Wilkicki; 1858-1913) and his son Boris Andreevich Wilkitzky (1885-1961), outstanding Russian hydrographers and Arctic explorers, who made an invaluable contribution to mastering the navigation of the Northern Maritime Way. In 1913 Boris Wilkitzky discovered a new archipelago, named by him "The Land of Emperor Nicholas II" (now Severnaya Zemlya), as well as a strait named for him. (M 30096)

This minor planet is named by the discoverer following a suggestion by V. K. Abalakin.

\section{(5315) Bal'mont}

1982 SV $_{5}$. Discovered 1982 Sept. 16 by L. I. Chernykh at Nauchnyj.

Named in memory of Konstantin Dmitrievich Bal'mont (1867-1942), a Russian poet who lived in exile after 1920, one of the most famous of the symbolists. Known for his Russian translations of the works of many European writers, he also collected and published examples of the creative works of Egypt, Mexico, Peru, India and other countries. (M 30097)

\section{(5316) Filatov}

1982 UB $_{7}$. Discovered 1982 Oct. 21 by L. G. Karachkina at Nauchnyj.

Named for the well-known ophthalmologist and surgeon Vladimir Petrovich Filatov (1875-1956). (M 22508)

\section{(5317) Verolacqua}

1983 CE. Discovered 1983 Feb. 11 by C. S. Shoemaker at Palomar.

Named in honor of Veronica Lynn Passalacqua, on the occasion of her twenty-fifth birthday, by her long-time friend D. W. E. Green, who made the identifications of this object. She has done tremendous volunteer work over several years, while a student at Harvard University, toward compiling the International Comet Quarterly archive of photometric data on comets. (M 21957)

\section{(5318) Dientzenhofer}

$1985 \mathrm{HG}_{1}$. Discovered 1985 Apr. 21 by A. Mrkos at Klě́.

Kryštof Dientzenhofer (1655-1722) and his son Kilián Ignác (1689-1751) were among the leading architects and builders in the Bohemian Baroque style. Their churches and monasteries in Prague as well as in the country are still a part of Czech scenery. (M 41934) The name was suggested by J. Tichá.

\section{(5319) Petrovskaya}

$1985 \mathrm{RK}_{6}$. Discovered 1985 Sept. 15 by N. S. Chernykh at Nauchnyj.

Named in honor of Margarita Sergeevna Petrovskaya, staff member of the Institute of Theoretical Astronomy since 1960. She determined the domains of convergence of series representing periodic solutions in planetary and satellite problems and obtained a new expansion for the perturbing function that converges even in the case of overlapping orbits. She was the first to construct convergent global expansions for the earth's potential. (M 30476)

Name proposed by the Institute of Theoretical Astronomy.

\section{(5320) Lisbeth}

1985 VD. Discovered 1985 Nov. 14 by P. Jensen and K. Augustesen and H. J. Fogh Olsen at Brorfelde.

Named in honor of Lisbeth Fogh Olsen, daughter of the third discoverer, currently graduating in astronomy at the Copenhagen Observatory. (M 29144)

\section{(5321) Jagras}

1985 VN. Discovered 1985 Nov. 14 by P. Jensen and K. Augustesen and H. J. Fogh Olsen at Brorfelde.

Named in honor of Jakob Grove Rasmussen, fiancé of the daughter of the third discoverer, currently graduating in astronomy at the Copenhagen Observatory. (M 29144)

\section{(5324) Lyapunov}

1987 SL. Discovered 1987 Sept. 22 by L. G. Karachkina at Nauchnyj.

This unusual object is named in honor of the outstanding Russian mathematician Alexandr Mikhailovich Lyapunov (1857-1918), famous for his theory of the stability of motion and the 'Lyapunov characteristic exponents'. (M 22508)

\section{(5325) Silver}

1988 JQ. Discovered 1988 May 12 by C. S. Shoemaker and E. M. Shoemaker at Palomar.

Named for Leon T. Silver, professor of geology at the California Institute of Technology. Famed for his studies of the regional geology and precise determinations of ages of precambrian and mesozoic crystalline rocks of the southwestern United States, Silver also made important contributions to the study of the moon. He played a major role in the geologic training of astronauts for the Apollo 15, 16 and 17 missions to the moon and in the planning and conduct of these missions. (M 24917) 


\section{(5330) Senrikyu}

1990 BQ 1 . Discovered 1990 Jan. 21 by A. Sugie at Taga.

Named in memory of Sen-no Rikyu (1522-1591), a celebrated Japanese tea master who perfected the tea ceremony and was the founder of Senke style during the Azuchi-Momoyama period. He was given an important position by both Oda-Nobunaga and Toyotomi-Hideyoshi, who were two of the greatest warriors in history. Rikyu was known as "the supreme tea master" and left his mark on the culture of the tea ceremony. (M 25653)

\section{(5331) Erimomisaki}

$1990 \mathrm{BT}_{1}$. Discovered 1990 Jan. 27 by K. Endate and K. Watanabe at Kitami.

Named for the promontory at the southern end of Hokkaido. Warm and cold currents, crossing each other near the promontory, bring strong winds and thick fog. (M 22508)

\section{(5333) Kanaya}

1990 UH. Discovered 1990 Oct. 18 by M. Akiyama and T. Furuta at Mishima.

Named for the first discoverer's native town, an old station on the ancient national road "Tokai-do", some $200 \mathrm{~km}$ west of Tokyo. The Malinohara tablelands to the south of this town on the west bank of the Oi river are famous as one of the largest tea fields in Japan. (M 21610)

\section{(5334) Mishima}

1991 CF. Discovered 1991 Feb. 8 by M. Akiyama and T. Furuta at Mishima.

Named for the first discoverer's second home, a city some $100 \mathrm{~km}$ west of Tokyo and famous for the great amount of clear water from Mt. Fuji \{see planet (1584)\}, $30 \mathrm{~km}$ to the northwest. The city's old shrine, Mishima Taisya, is famous as the point where Yoritomo Minamoto \{see planet (3902)\}, founder of the Kamakura shogunate, began his battle to unify the nation. (M 21611)

\section{(5335) Damocles}

1991 DA. Discovered 1991 Feb. 18 by R. H. McNaught at Siding Spring.

Legend has it that Damocles, a courtier of the tyrant Dionysius the Elder of Syracuse, was invited to a feast, where he was seated below a sword suspended by a thread. Intended to demonstrate the impermanence of power, the 'sword of Damocles' has become a symbol of impending disaster. This minor planet, in an unusual orbit of very high eccentricity and inclination and crossing the orbits of Mars to Uranus, could itself be seen as such a sword during periods of its orbital evolution when it becomes an Earth crosser. (M 22508)

\section{(5337) Aoki}

1991 LD. Discovered 1991 June 6 by S. Otomo and O. Muramatsu at Kiyosato.

Named in memory of Masahiro Aoki (1920-1984), amateur astronomer and director of the variablestar section of the Oriental Astronomical Association during 1969-1984. He contributed to the popularization of astronomy and to the protection of the natural environment and was active in fighting light pollution. (M 21135)

\section{(5338) Michelblanc}

$1991 \mathrm{RJ}_{5}$. Discovered 1991 Sept. 13 by H. E. Holt at Palomar.

Named in honor of Michel Blanc (1949- ), French planetary scientist and director of the Observatoire Midi Pyrenées. Blanc is a expert in dynamics and electrodynamics in the space environments of the earth and planets. He is Cassini Mission Interdisciplinary Scientist for studies of Saturn's magnetosphere. As president of the National Planetology Program of the Institut National de Science de l'Univers of the French National Scientific Research Council, Blanc has played a pivotal role in promoting and developing planetary science in France. (M 35482)

Name suggested and citation prepared by $\mathrm{M}$. Fulchignoni.

\section{(5340) Burton}

4027 P-L. Discovered 1960 Sept. 24 by C. J. van Houten and I. van Houten-Groeneveld at Palomar.

Named in honor of William Butler Burton (1940- ), American born and since 1981 professor of astronomy at the University of Leiden. He was a student of Peter van de Kamp \{see planet (1965)\} at Sproul Observatory. His main interest is the structure of the Galactic system at different wavelengths. He served as president of IAU Commission 33 (Structure and Dynamics of the Galactic System) from 1985 to 1987 and is chairman of the Science Team of the DENIS (Deep Near Infrared Survey of the Southern Sky) collaboration. (M 22508)

\section{(5341) Purgathofer}

6040 P-L. Discovered 1960 Sept. 24 by C. J. van Houten and I. van Houten-Groeneveld at Palomar.

Named in memory of Alois Purgathofer (1925-1984), Austrian astronomer. Purgathofer mainly worked on photometry of galactic clusters, and he also observed special minor planets, e.g., (51) Nemausa. He put much effort into establishing an observatory with two telescopes at a remote site outside Vienna. Purgathofer was a member of the Committee on Image Tubes for Telescopes of the Carnegie Institution. He investigated planetary nebulae after building an image-tube spectrograph of his own design. (M 22508)

Name proposed and citation prepared by A. Schnell, endorsed by L. D. Schmadel. 
Obituaries published in Sternenbote, 27. Jahrg., Nr. 4, p. 63-66 (1984); Mitt. Astron. Ges., Nr. 61, p. 7-8 (1984).

\section{(5342) Le Poole}

3129 T-2. Discovered 1973 Sept. 30 by C. J. van Houten and I. van Houten-Groeneveld at Palomar.

Named in honor of Rudolf Le Poole (1942- ), who spent several years in Tucson, working with G. P. Kuiper \{see planet (1776)\}, before moving to the Leiden Observatory. Le Poole is a member of the HIPPARCOS Science Team. He is also developing the Astroscan II, a very accurate measuring instrument for photographic plates, for the Leiden Observatory. (M 22508)

\section{(5343) Ryzhov}

1977 SG 3 . Discovered 1977 Sept. 23 by N. S. Chernykh at Nauchnyj.

Named in honor of Yurij Alekseevich Ryzhov (1930-

), a member of the Russian Academy of Sciences, outstanding specialist on aero- and hydrodynamics, former long-time rector of the Moscow Aviation Institute. (M 30476; M 32561)

Name proposed by A. G. Sokolsky.

\section{(5344) Ryabov}

1978 RN. Discovered 1978 Sept. 1 by N. S. Chernykh at Nauchnyj.

Named in honor of Yurij Aleksandrovich Ryabov (1923- ), professor at the Moscow Road-Transport Institute. He developed the Poincaré-Lyapunov method of small parameters for the investigation of fineresonance effects. He is also the author of monographs on the modern problems of celestial mechanics, as well as of popular books on astronomy. (M 30476)

Name proposed by the Institute of Theoretical Astronomy.

\section{(5345) Boynton}

$1981 \mathrm{EY}_{8}$. Discovered 1981 Mar. 1 by S. J. Bus at Siding Spring.

William Boynton (1944- ）, professor of cosmochemistry and geochemistry at the University of Arizona, has measured elemental abundances in meteorites as a means of probing the early history of the solar system. $\mathrm{He}$ is the team leader for the $\gamma$-ray spectrometer on the Mars Odyssey spacecraft. (M 46006)

\section{(5349) Paulharris}

1988 RA. Discovered 1988 Sept. 7 by E. F. Helin at Palomar.

Named in honor of Paul Harris (1868-1947) who, in 1905, founded Rotary International as a forum for business leaders to meet and provide services to benefit their local communities and contribute to international understanding. Now, with 1.2 million members worldwide, Rotarians support a variety of worthy causes, including the Polio Plus program that has immunized millions of children around the globe. In addition, as the world's largest privately sponsored scholarship organization, Rotary provides 1350 scholarships each year to deserving students. (M 24917)

Name proposed by Theodore Combes and endorsed by Joseph Lewis and the international members of the Rotary.

\section{(5350) Epetersen}

1989 GL $_{1}$. Discovered 1989 Apr. 3 by E. W. Elst at La Silla.

Named in honor of Erik V. Petersen (1911- ), Danish amateur astronomer, who has contributed to astronomy through his study of minor planets, especially of (51) Nemausa. During 1955-1965 Petersen used the refractor at the Copenhagen University Observatory to take 712 plates, on which he measured 2,562 positions of minor planets. This is the largest single project ever carried out with that telescope. The data were used in an international collaboration, and Petersen's work received a special commendation at the IAU General Assembly in Prague in 1967. (M 21611)

Name proposed by B. Reipurth, who prepared the citation at the request of the discoverer.

\section{(5351) Diderot}

1989 SG $_{5}$. Discovered 1989 Sept. 26 by E. W. Elst at La Silla.

Named in memory of Denis Diderot (1713-1784), French author of dramas, novels and philosophical essays. Together with d'Alembert \{see planet (5956)\}, he will be remembered for his Encyclopedia, a huge task that took almost 20 years of his life and resulted in more than one thousand articles on philosophy, literature, religion, politics, economics and applied sciences. (M 23540)

Citation by $K$. Leterme at the request of the discoverer.

\section{(5352) Fujita}

1989 YN. Discovered 1989 Dec. 27 by Y. Kushida and O. Muramatsu at Yatsugatake.

Named in honor of Yoshio Fujita, professor emeritus of the University of Tokyo, known for his pioneering work on the spectra of late-type stars, in particular of cool, carbon stars, with his determination of the carbon isotope ratio. He served as president of the Astronomical Society of Japan during 1961-1963 and as president of IAU Commission 29 during 1970-1973. He has been a member of the Japan Academy since 1965 and of the Société Royale des Sciences de Liège since 1969. (M 21611)

Name proposed by the discoverers following a suggestion by T. Tsuji and Y. Yamashita. 


\section{(5354) Hisayo}

$1990 \mathrm{BJ}_{2}$. Discovered 1990 Jan. 30 by S. Ueda and H. Kaneda at Kushiro.

Named in honor of Hisayo Kaneda (1977- ), daughter of the second discoverer. (M 27734)

\section{(5355) Akihiro}

1991 CA. Discovered 1991 Feb. 3 by S. Ueda and H. Kaneda at Kushiro.

Named in honor of Akihiro Ueda (1983- ), son of the first discoverer. (M 27734)

\section{(5359) Markzakharov}

1974 QX $_{1}$. Discovered 1974 Aug. 24 by L. I. Chernykh at Nauchnyj.

Named in honor of Mark Anatolievich Zakharov (1933- ), chief producer of the Moscow Lenin Komsomol Theatre, People's Artist of the U.S.S.R. and Russian Federation State Prize laureate. He has produced many musical plays, performances in the genre of political drama and films for television. (M 34621)

\section{(5360) Rozhdestvenskij}

1975 VD $_{9}$. Discovered 1975 Nov. 8 by N. S. Chernykh at Nauchnyj.

Named in memory of Robert Ivanovich Rozhdestvenskij (1932-1994), outstanding poet and journalist, one of the most popular Russian poet-songwriters. For 15 years he wrote and presented the television program The Documentary Screen. His books were translated into many languages, and he won many awards for literature. In his last poems he appeared, not only as a lyric poet, but also as a philosopher who showed the grandeur and tragedy of his time. He arranged for the publication of Osip Mandelshtam's \{see planet (3461)\} works, edited the first collection of Vladimir Vysotskij's poems and organized Marina Tsvetaeva's \{see planet (3511)\} Memorial Museum. (M 30097)

\section{(5361) Goncharov}

1976 YC $_{2}$. Discovered 1976 Dec. 16 by L. I. Chernykh at Nauchnyj.

Ivan Aleksandrovich Goncharov (1812-1891) is known for his four novels Oblomov, Obryv ("Precipice"), Obyknovennaya istoriya ("Usual event") and Fregat "Pallada" ("Frigate Pallada"). The first of these, referring to the name of a main character, is still a subject for obligatory study in schools in Russia. (M 38194)

\section{(5363) Kupka}

1979 UQ. Discovered 1979 Oct. 19 by A. Mrkos at Klě̆.

Named in memory of František Kupka (1871-1957), Czech painter and graphic artist, resident in France after 1906. He is considered one of the initiators of abstract art, as his Stories of Black and White, Amorpha or Cosmic prime show. (M 34621)

Name suggested by J. Tichá.

\section{(5365) Fievez}

$1981 \mathrm{EN}_{1}$. Discovered 1981 Mar. 7 by H. Debehogne and G. DeSanctis at La Silla.

Named in memory of Charles Fievez (1844-1890), the pioneer of astrophysics in Belgium. His scientific career at the Observatoire Royal de Bruxelles was short (1877-1890) but very fruitful. In 1880 he started the first spectroscopic laboratory in Belgium. He published two dozen papers on spectroscopy, including an atlas of the solar spectrum, and in 1885 he observed the broadening effect of spectral lines due to the presence of a magnetic field (but without finding the correct interpretation) eleven years before Zeeman. (M 23138)

\section{(5366) Rhianjones}

$1981 \mathrm{EY}_{30}$. Discovered 1981 Mar. 2 by S. J. Bus at Siding Spring.

Rhian Jones (1960- ) is an experimental and sample petrologist at the Institute of Meteoritics at the University of New Mexico. Her work has enhanced our understanding of processes by which chondrules were formed in the solar nebula and later modified by heat and fluids on minor planets. (M 46006; M 46469)

\section{(5367) Sollenberger}

1982 TT. Discovered 1982 Oct. 13 by E. Bowell at Anderson Mesa.

Named in memory of Paul Sollenberger (1891-1995), the U.S. Naval Observatory's first civilian director of Time Service (from 1928 until his retirement in 1953). Sollenberger's contributions to the design of quartz-crystal clocks, chronographs and the photographic zenith tube greatly increased the precision of timekeeping during his tenure. By 1934 he had not only introduced quartz-crystal clocks, but also arranged for the automatic transmission of time by them, accurate to a millisecond. In 1949 he established the USNO's Time Service station using a PZT in Richmond, Florida. Sollenberger served as president of IAU Commission 19 during 1948-1955. (M 25653)

Citation prepared by D. D. McCarthy. Name endorsed by P. K. Seidelmann.

Obituary published in Bull. Am. Astron. Soc., Vol. 27, No. 4, p. 1482-1483 (1995).

\section{(5369) Virgiugum}

$1985 \mathrm{SE}_{1}$. Discovered 1985 Sept. 22 by P. Wild at Zimmerwald.

Latinization of Jungfraujoch, at $3572 \mathrm{~m}$, the site of the highest astronomical observatory in the Swiss Alps. $(5369)=(2040)+(3329)$, the numbers of the minor planets named for the astronomers Chalonge and Golay, who, with their teams did extensive observing there, contributing much to the fame of the High-Alpine Research Station, run by a foundation of the academies of eight European countries. In his student years, the discoverer was several times an assistant in Chalonge's group, thus getting the most impressive introduction to practical astronomy. (M 22508) 


\section{(5370) Taranis}

1986 RA. Discovered 1986 Sept. 2 by A. Maury at Palomar.

Named after the Gaulish god of thunder (Irish "torann" and Gallic "Taran"). His symbols are the wheel and the lightning. His cult was very common in ancient Gaul. Taranis is also the name of the first computer network in France for amateur astronomers, established by J. C. Merlin in 1988. (M 22509)

Citation by the discoverer and J. C. Merlin.

\section{(5372) Bikki}

1987 WS. Discovered 1987 Nov. 29 by K. Endate and K. Watanabe at Kitami.

Named in honor of Bikki Sunazawa (1931-1989), self-taught Japanese sculptor. In 1954 his sculpture was honored at the Japanese Modern Art Exhibition. His major works are Four Winds and Nitsunekamui. (M 22509)

\section{(5374) Hokutosei}

$1989 \mathrm{AM}_{1}$. Discovered 1989 Jan. 4 by M. Yanai and K. Watanabe at Kitami.

Hokutosei, or 'Big Dipper', is the luxury all-sleeper train that connects Sapporo and Tokyo ssee planets (3473) and (498)\}, a 1000-km distance in 16 hours. The train passes through Seikan, the longest tunnel in the world. (M 26930)

\section{(5375) Siedentopf}

$1989 \mathrm{AN}_{6}$. Discovered 1989 Jan. 11 by F. Börngen at Tautenburg.

Named in memory of Heinrich Siedentopf (19061963), professor of astronomy and director of the observatories in Jena (1933-1945) and in Tübingen (1949-1963). His research activities covered stellar atmospheres, in particular the theory of convection and solar granulation, interplanetary matter, optics of the earth's atmosphere, and astronomical instruments. He introduced the iris-diaphragm method for photographic stellar photometry. Together with O. Heckmann and W. Fricke \{see planets (1650) and (1561), respectively\} he was one of the German promoters of the European Southern Observatory. (M 21611)

Citation prepared by $\mathrm{H}$. Elsässer at the request of the discoverer.

Siedentopf is also honored by a lunar crater.

\section{(5377) Komori}

1991 FM. Discovered 1991 Mar. 17 by S. Otomo and O. Muramatsu at Kiyosato.

Named in honor of Yukimasa Komori, owner of the Astro-Dome Company and a committee member of the Gotoh Planetarium and Astronomical Museum. Born in 1900, he is the oldest known amateur astronomer in Japan, and he had the pleasure of watching Halley's Comet in both 1910 and 1986. His main interests are in observing lunar occultations and solar eclipses. Long active in the popularization of astronomy, particularly over Japanese national radio, he planned and carried out a minute-by-minute broadcast of the total solar eclipse in 1936, linking observers at various stations. (M 21957)

Name proposed by the discoverers following suggestions by S. Kimura and E. Kobayashi.

\section{(5378) Ellyett}

1991 GD. Discovered 1991 Apr. 9 by R. H. McNaught at Siding Spring.

Named in honor of Clifton Darfield Ellyett (1915- ）, pioneer of radar meteor research in New Zealand. After taking his Ph.D. at Jodrell Bank in the late 1940s, Ellyett returned to his native country and began a research program in radar meteors at what is now the University of Canterbury. In the early 1960s he carried out with Colin Keay \{see planet (5007)\} the important southern-hemisphere radar patrol of meteors from near Christchurch. In 1965 Ellyett left to become professor of physics in the University of Newcastle (N.S.W.), starting there a new research group in atmospheric science. (M 29144)

Name proposed by the discoverer following a suggestion by D. I. Steel, who prepared the citation.

\section{(5379) Abehiroshi}

1991 HG. Discovered 1991 Apr. 16 by S. Otomo and O. Muramatsu at Kiyosato.

Named in honor of Hiroshi Abe (1958- ), a resident of Shimane. Discoverer of numerous minor planets at Yatsuka \{see planet (7097)\} Observatory since 1993, he is also an active confirmer of new objects in collaboration with S. Nakano \{see planet (3431)\}. (M 35482)

\section{(5380) Sprigg}

1991 JT. Discovered 1991 May 7 by R. H. McNaught at Siding Spring.

Named for Reginald C. Sprigg (1919-1994), Australian exploration geologist, oceanographer, biologist, author and conservationist who in 1946 discovered the diverse pre-Cambrian Ediacaran soft-body fauna fossils representing the earliest known multicellular life on the earth. Sprigg's recognition of hydrocarbons in central Australia led to the discovery of the vast Cooper Basin gas and oil fields. His work on the formation of Australian deserts and dunes has resulted in greater understanding of present-day climate patterns. In 1968 he founded the Arkaroola Wilderness Sanctuary in the northern Flinders Ranges, and this includes an astronomical observatory. (M 31609)

Name suggested by D. I. Steel and citation prepared by the Sprigg family.

\section{(5381) Sekhmet}

1991 JY. Discovered 1991 May 14 by C. S. Shoemaker at Palomar. 
The daughter of the Egyptian god Ra and wife of Ptah \{see planets (2100) and (5011), respectively\}, Sekhmet was a lion-headed sun goddess. Her role was that as defender of the divine order, not as creator of it. Her title was the "Mighty One", and she was a fierce goddess of war and strife and bringer of destruction to the enemies of Ra. She was considered the Eye of Ra, representing the scorching, destructive power of the sun. (M 24917)

\section{(5382) McKay}

$1991 \mathrm{JR}_{2}$. Discovered 1991 May 8 by R. H. McNaught at Siding Spring.

Named for Christopher P. McKay (1954- ), space scientist and exobiologist at NASA-Ames Research Center. McKay has made numerous seminal contributions to planetary science and the search for zones of life in the solar system, with a special interest in Mars, Titan, comets and microbial life in hostile environments on the earth. (M 31610)

Name suggested and citation prepared by D. I. Steel.

\section{(5383) Leavitt}

4293 T-2. Discovered 1973 Sept. 29 by C. J. van Houten and I. van Houten-Groeneveld at Palomar.

Named in memory of Henriette Swan Leavitt (18681921) of the Harvard College Observatory, discoverer of the period-luminosity law for the classical Cepheids. (M 22509)

Leavitt is also honored by a lunar crater.

\section{(5385) Kamenka}

1975 TS $_{3}$. Discovered 1975 Oct. 3 by L. I. Chernykh at Nauchnyj.

Kamenka, a small town in the Cherkassian region of Ukraine, is connected with many great persons of Russian culture and history, including Pushkin, Tchaikovsky \{see planets (2208) and (2266), respectively\} and the Decembrists. (M 38194)

\section{(5388) Mottola}

1981 ED $_{1}$. Discovered 1981 Mar. 5 by H. Debehogne and G. DeSanctis at La Silla.

Named in honor of Stefano Mottola, of the Planetary Remote Sensing Section at the Deutsche Forschungsanstalt für Luft- und Raumfahrt, Wesseling. He has investigated the photometric properties of surfaces of minor planets by applying numerical computer modeling to modern CCD observations, particularly of Trojans and other objects in the outer belt. He is also an active participant in the campaigns on (951) Gaspra and (243) Ida in connection with the Galileo flybys of these objects. (M 21958)

\section{(5389) Choikaiyau}

1981 UB $_{10}$. Discovered 1981 Oct. 29 at the Purple Mountain Observatory at Nanking.

Named in honor of Choi Kaiyau, honorary director of the Zhongshan Scientific Center and chairman of the Choi Educational Foundation. He made a great effort to wipe out illiteracy in China and won a high reputation for popularizing children's education. (M 25230)

\section{(5390) Huichiming}

$1981 \mathrm{YO}_{1}$. Discovered 1981 Dec. 19 at the Purple Mountain Observatory at Nanking.

For his help in alleviating poverty, Hui Chi Ming (1964- ) received the China Glory Facilitative Poverty Aid Award and the United Nations Humanity and Peace Promotion Award. (M 45746)

\section{(5391) Emmons}

$1985 \mathrm{RE}_{2}$. Discovered 1985 Sept. 13 by E. F. Helin at Palomar.

Richard Emmons (1919- ), emeritus professor of physics at Ohio's Kent State University, had his interest in astronomy sparked by an article published soon after the discovery of $1932 \mathrm{HA}$, now (1862) Apollo. He was an early observer of artificial satellites. (M 40701)

\section{(5392) Parker}

1986 AK. Discovered 1986 Jan. 12 by C. S. Shoemaker and E. M. Shoemaker at Palomar.

This Mars-crossing Phocaea \{see planet (25) for the prototype $\}$ is named in honor of the American amateur astronomer Don Parker, who specializes in high-resolution photography and CCD imaging of Mars and Jupiter. Through his precise imaging, new features have been recognized on Mars. His investigations of planetary atmospheres have improved the understanding of weather phenomena there. (M 23138)

Name proposed and citation written by P. L. Dombrowski, endorsed by D. H. Levy.

\section{(5393) Goldstein}

1986 ET. Discovered 1986 Mar. 5 by E. Bowell at Anderson Mesa.

Named in honor of Richard M. Goldstein (1927- ) radar astronomer at the Jet Propulsion Laboratory, on the occasion of the twenty-fifth anniversary of his detection of the first radar echoes from a minor planet ((1566) Icarus in June 1968). Goldstein also led observations that resulted in the first radar detections of Mars and of Saturn's rings and in the discovery of the anomalous rotation of Venus. (M 22830)

Name suggested and citation prepared by S. J. Ostro.

\section{(5394) Jurgens}

$1986 \mathrm{EZ}_{1}$. Discovered 1986 Mar. 6 by E. Bowell at Anderson Mesa.

Named in honor of Raymond F. Jurgens (1937- ), a radar astronomer at the Jet Propulsion Laboratory, who developed the data-acquisition system used for high-resolution delay-Doppler imaging of (4179) Toutatis in 1992. Jurgens led the dual-polarization, dual-wavelength radar investigations of (433) Eros in 1975 (the first of a minor planet). He also pioneered 
techniques for using radar spectra to constrain smallbody shapes and led the first three-station radar interferometric observations of Venus. (M 23138)

Name suggested and citation material provided by S. J. Ostro.

\section{(5395) Shosasaki}

1988 RK $_{11}$. Discovered 1988 Sept. 14 by S. J. Bus at Cerro Tololo.

Sho Sasaki (1960- ), a professor at the University of Tokyo, has carried out laser irradiation experiments to simulate the processes of lunar-like space weathering. $\mathrm{He}$ is also a lead researcher in interplanetary dust particle experiments that are part of many Japanese planetary missions. (M 46006)

\section{(5399) Awa}

1989 BT. Discovered 1989 Jan. 29 by M. Iwamoto and T. Furuta at Tokushima.

Named by the first discoverer for the town in which he lives in the northern part of Shikoku island \{see planet (4223)\}. The "Awa-odori" dancing festival, held every August, is as famous as it is unique. (M 22250)

\section{(5401) Minamioda}

1989 EV. Discovered 1989 Mar. 6 by T. Nomura and K. Kawanishi and M. Sugano at Minami-Oda.

Named for the Minami-Oda district, inhabitants of which cooperated in establishing the observatory in 1971. Minami-Oda is located in the middle of Hyogo \{see planet (6879)\} prefecture and has the biggest hydroelectric power plant in Japan. The district has made efforts to limit light pollution. (M 22509)

\section{(5402) Kejosmith}

$1989 \mathrm{UK}_{2}$. Discovered 1989 Oct. 27 by E. F. Helin at Palomar.

Named in honor of Keith C. Smith and Joan Furlong of University College, London, on the occasion of their wedding. Keith is a stellar spectroscopist whose work on abundance analyses of ultraviolet and optical spectra of $\mathrm{HgMn}$ stars and on non-LTE effects in OB stars is well-known to his colleagues worldwide. Joan is a laboratory spectroscopist and has recently moved from UCL to the metrology division of the U.K. National Physical Laboratory. (M 29670)

Name suggested and citation prepared by M. M. Dworetsky.

\section{(5403) Takachiho}

1990 DM. Discovered 1990 Feb. 20 by Y. Kushida and M. Inoue at Yatsugatake.

Named for the home town of the wife of the second discoverer, Takachiho is located at the center of Miyazaki \{see planet (6905)\} prefecture in Kyusyu, some $900 \mathrm{~km}$ southwest of Tokyo, and surrounded by mountains. Takachiho is famous for its legends and myths on the root of gods. The most famous is the legend of Amano-Iwato of Amaterasu-Ohmikami \{see planet (10385)\} (the god of the sun). This story has been handed down by Yokagura (sacred music and dance) as performed by farmers. (M 22250)

\section{(5404) Uemura}

$1991 \mathrm{EE}_{1}$. Discovered 1991 Mar. 15 by K. Endate and K. Watanabe at Kitami.

Named in honor of Naomi Uemura (1941-1984), a famous explorer, born in Hidaka, Hyogo \{see planet (6879)\} Prefecture. He was the first to climb the highest mountains in five continents and the first Japanese to reach the summit of Mount Everest. From 1976 to 1978 he devoted himself to exploration of the north polar regions and Greenland by dogsled. He disappeared in an attempt to reach the summit of Mount McKinley in 1984. (M 22509)

\section{(5405) Neverland}

1991 GY. Discovered 1991 Apr. 11 by Y. Kushida and O. Muramatsu at Yatsugatake.

Named after the world famous play Peter Pan, written by Sir James M. Barrie (1860-1937) and later adapted into an animated film by Walt Disney see planet (4017)\}. "Never Land" is a fantastic island floating among stars, where Peter Pan, Tinker Bell, and many others dwell. "Peter Pan" has enthralled generations of children and the young at heart throughout the world. (M 22509)

\section{(5406) Jonjoseph}

$1991 \mathrm{PH}_{11}$. Discovered 1991 Aug. 9 by H. E. Holt at Palomar.

Named in honor of Jonathan Joseph (1966- ), computer programmer analyst at Cornell University. Joseph has worked on the NASA NEAR, Comet Nucleus Tour and Cassini missions, lending his creativity and technical expertise in support of imaging science goals. He has been instrumental in creating motion picture renderings of minor planets and comets to enhance our understanding of their shapes, sizes and other physical properties. Known for his sense of humor, Joseph is also a fine limerick poet and finger-paint artist. (M 35482)

Citation written by B. E. Clark.

\section{(5408) Thé}

1232 T-1. Discovered 1971 Mar. 25 by C. J. van Houten and I. van Houten-Groeneveld at Palomar.

Named in honor of Pik Sin Thé (1927- ) on the occasion of his 65th birthday. Pik Sin Thé studied in the US, became director of Lembang Observatory, Indonesia, and later professor at the University of Amsterdam. His main field of interest is young variable stars, on which he has done much important research. (M 22509; M 22519)

\section{(5409) Saale}

1962 SR. Discovered 1962 Sept. 30 by F. Börngen at Tautenburg.

Named for the river that originates in the Fichtelgebirge of Bavaria, runs not far from Tautenburg \{see 
planet (2424)\}, crosses the cities of Jena \{see planet (526)\} and Halle (the latter the birthplace of the discoverer) and flows into the Elbe. (M 22250)

\section{(5410) Spivakov}

1967 DA. Discovered 1967 Feb. 16 by T. M. Smirnova at Nauchnyj.

Named in honor of the outstanding Russian musician, violinist Vladimir Theodorovich Spivakov (1944- ), leader of the State Chamber Orchestra "Virtuosos of Moscow" since 1979, laureate of many international competitions, artistic director of the International Musical Festival in Colmar, France, and president of the International Charitable Fund. (M 24410)

Name proposed by the Institute of Theoretical Astronomy.

\section{(5411) Liia}

$1973 \mathrm{AT}_{3}$. Discovered 1973 Jan. 2 by N. S. Chernykh at Nauchnyj.

Named in honor of Liia Forrer-Tsiganovskaja, wife of a friend of the discoverer, on the occasion of her 25th birthday. A student of art at Saratov and of philosophy at St. Gallen, she also takes an interest in literature and architecture. (M 30097)

\section{(5412) Rou}

1973 SR $_{3}$. Discovered 1973 Sept. 25 by L. V. Zhuravleva at Nauchnyj.

Named in memory of Aleksandr Arturovich Rou (1906-1973), an actor and film producer specializing in Russian fairy tales. (M 34621)

\section{(5413) Smyslov}

$1977 \mathrm{EC}_{2}$. Discovered 1977 Mar. 13 by N. S. Chernykh at Nauchnyj.

Named in honor of Vasilij Vasil'evich Smyslov (1921- ), Soviet chess grandmaster and world chess champion during 1957-1958. He is known also as a gifted amateur singer, performing operatic arias and Russian folk songs. (M 30097)

\section{(5414) Sokolov}

1977 RW $_{6}$. Discovered 1977 Sept. 11 by N. S. Chernykh at Nauchnyj.

Named in honor of Viktor Georgievich Sokolov (1946- ), specialist in analytical methods of celestial mechanics and scientific secretary of the Institute of Theoretical Astronomy. His scientific and organizational work is an essential constituent of the Institute's activity and contributes significantly to its successful operation. (M 29145)

Name proposed by the discoverer following a suggestion by the Institute of Theoretical Astronomy.

\section{(5415) Lyanzuridi}

$1978 \mathrm{~TB}_{2}$. Discovered 1978 Oct. 3 by N. S. Chernykh at Nauchnyj.
Named in honor of Konstantin Petrovich Lyanzuridi (1934- ), engineer in vacuum technology and optics who has worked at the Crimean Astrophysical Observatory \{see planet (1725)\} for more than 30 years. A talented experimenter, he created a new method of ion etching of optical surfaces for making precision astronomical optics for ground-based and space telescopes. (M 34341)

\section{(5417) Solovaya}

1981 QT. Discovered 1981 Aug. 24 by L. Brožek at Kleť.

Named in honor of Nina A. Solovaya (1940- ), an astronomer in the celestial mechanics department of the Sternberg State Astronomical Institute in Moscow. Her general field of work involves analytical and qualitative methods of celestial mechanics, especially the three-body problem. She has applied the results to triple-star systems, to planetary satellites and to minor planets in the outer part of the main belt. (M 29145)

Name proposed by the Klet Observatory following a suggestion by E. M. Pittich.

\section{(5418) Joyce}

$1981 \mathrm{QG}_{1}$. Discovered 1981 Aug. 29 by A. Mrkos at Kleť.

Named in memory of James Joyce (1882-1941), Irish novelist noted for his experimental use of language and exploration of new literary methods in large works, such as Ulysses. Gell-Mann adopted the fanciful term 'quark' from a passage in his novel Finnegans Wake. (M 34621)

Name suggested by J. Tichá.

\section{(5419) Benua}

$1981 \mathrm{SW}_{7}$. Discovered 1981 Sept. 29 by L. V. Zhuravleva at Nauchnyj.

Named in memory of the Russian architect Nikolaj Leont'evich Benua (Benois; 1813-1898), as well as of his sons, the architect Leontij Nikolaevich Benua (1856-1928) and the painter Aleksandr Nikolaevich Benua (1870-1960). (M 34621)

\section{(5421) Ulanova}

1982 TD $_{2}$. Discovered 1982 Oct. 14 by L. G. Karachkina and L. V. Zhuravleva at Nauchnyj.

Named in honor of the brilliant Russian balletdancer Galina Sergeevna Ulanova (1910- ), whose picturesque dancing in the ballets Giselle, Swan Lake and others are unmatched. (M 24122)

\section{(5422) Hodgkin}

1982 YL $_{1}$. Discovered 1982 Dec. 23 by L. G. Karachkina at Nauchnyj.

Named for the famous English chemist and biochemist Dorothy Crowfoot-Hodgkin, 1964 Nobel prize-winner. (M 22509) 


\section{(5424) Covington}

$1983 \mathrm{TN}_{1}$. Discovered 1983 Oct. 12 by E. Bowell at Anderson Mesa.

Named in honor of Arthur Covington \{1913-2001\}, Canada's first radio astronomer. His discovery, during the partial solar eclipse of 1946 Nov. 23, that microwave emission was far more intense from the vicinity of sunspots than elsewhere on the sun, was the first indicator that magnetic fields were important in the generation of nonthermal cosmic radio emission. In 1947 Covington inaugurated at the National Research Council of Canada daily measurements of the solar microwave flux at $10.7 \mathrm{~cm}$. (M 23541)

Name suggested and citation prepared by C. J. Cunningham.

Obituary published in Bull. Am. Astron. Soc., Vol. 34, No. 4, p. 1357 (2002).

\section{(5425) Vojtěch}

1984 SA $_{1}$. Discovered 1984 Sept. 20 by A. Mrkos at Klet.

Named in memory of Václav Vojtěch (1901-1932), Czech traveler and Antarctic explorer. In 1929 he became the first Czechoslovak to step on the Antarctic continent. This minor planet commemorates the seventieth anniversary of his participation with the Byrd expedition. (M 34621)

Name suggested by J. Tichá and M. Tichý.

\section{(5426) Sharp}

1985 DD. Discovered 1985 Feb. 16 by C. S. Shoemaker and E. M. Shoemaker at Palomar.

Named for Robert P. Sharp, emeritus professor of geology at the California Institute of Technology. A leading American geomorphologist, Sharp is best known for his work on glaciers and the movement of desert sand. He played a prominent role in the interpretation of the surface features of Mars from images returned by early spacecraft missions. As chairman for 15 years he built the Division of Geological Sciences at Caltech into one of the finest research groups of its kind. (M 24917)

\section{(5430) Luu}

$1988 \mathrm{JA}_{1}$. Discovered 1988 May 12 by C. S. Shoemaker and E. M. Shoemaker at Palomar.

Named in honor of Jane X. Luu (1963- ) for her research on the small bodies of the solar system. Luu is best known for her work with David Jewitt in discovering the first and subsequent members of the Kuiper belt, as well as in following up with physical studies of those bodies. She has also contributed the most stringent upper limits on the existence of dusty comae around minor planets that might be dormant or extinct comets. (M 27459)

Citation provided by M. F. A'Hearn following a suggestion by E. Bowell and endorsed by the discoverers.

\section{(5431) Maxinehelin}

1988 MB. Discovered 1988 June 19 by E. F. Helin at Palomar.

Named in honor of Maxine Anne Helin, mother-inlaw of the discoverer, on the occasion of the 90th anniversary of her birth. A resident of Colorado until 1928, she moved to California in search of a more hospitable climate. During her early years an occupational/psychiatric therapist, she has relied on that experience to provide the wisdom to help guide her family and friends along the trail of life. (M 26425)

\section{(5432) Imakiire}

1988 VN. Discovered 1988 Nov. 3 by T. Kojima at Chiyoda.

Named in honor of Kyoko Imakiire (1965- ), a Kagoshima yachtswoman who made a solo round-trip voyage between Kagoshima \{see planet (4703)\} and San Francisco in 1988 and a solo non-stop voyage round the world in 1991-1992. (M 26763)

Name proposed by the discoverer following a suggestion by T. Sato.

\section{(5433) Kairen}

$1988 \mathrm{VZ}_{2}$. Discovered 1988 Nov. 10 by T. Kojima at Chiyoda.

Named for the yacht in which Kyoko Imakiire see planet (5432)\} made her solo non-stop voyage round the world in 1991-1992. 'Kai' means 'Sea' or 'Ocean' and 'Ren' means 'Connection', Kairen being a yacht that therefore connects the seas and oceans of the world. Kairen also symbolizes Imakiire's parents, the name of her mother Umiko meaning 'a child of the ocean' and the Chinese character for the name of her father Muraji also being pronounced as 'Ren'. (M 26763)

Name proposed by the discoverer following a suggestion by T. Sato.

\section{(5435) Kameoka}

1990 BS $_{1}$. Discovered 1990 Jan. 21 by A. Sugie at Taga.

Named for a city with a castle and a good deal of natural beauty, situated just west of Kyoto \{see planet (4352)\}. (M 24917)

Name proposed by S. Sakabe.

\section{(5436) Eumelos}

1990 DK. Discovered 1990 Feb. 20 by C. S. Shoemaker and E. M. Shoemaker at Palomar.

Eumelos was a charioteer who had the swiftest horses in the Greek army. When the riders gathered for the funeral games for Patroclus \{see planet (617)\}, Eumelos was the first to rise up. He competed against Diomedes, Menelaus, Antilochus and Meriones \{see planets (1437), (1647), (1583), and (3596), respectively\}. He was in the lead until the goddess Athena see planet (881)\} smashed the yoke of his chariot, spinning 
him out. Though he came in last, Achilles \{see planet (588)\} awarded Eumelos the bronze corselet stripped from Asteropaios \{see planet (4805)\}, and he accepted it joyfully. (M 25444)

\section{(5438) Lorre}

1990 QJ. Discovered 1990 Aug. 18 by E. F. Helin at Palomar.

Named in honor of Jean Lorre, one of the original members of the Image Processing Laboratory at the Jet Propulsion Laboratory. He has been working on JPL flight projects since 1971 and was the first to apply image processing techniques to astronomical images outside of the NASA flight projects. His expertise encompasses map projections, correlation, photometric functions, color reproduction, camera calibration, SAR, stereo, morphing and filtering. His latest astronomical project has been to optimize the NEAT processing algorithms. The NEAT team whiches to acknowledge his important contributions in software development. (M 29670)

\section{(5439) Couturier}

1990 RW. Discovered 1990 Sept. 14 by H. E. Holt at Palomar.

Named in honor of Pierre Couturier (1942- ), president of the Observatoire de Paris. An expert in coronal heating and solar wind expansion, Couturier was initially a plasma physicist working on the solar wind. He became co-investigator of the radio experiment on the International Comet Explorer, which flew by comet 21P/Giacobini-Zinner in 1985 . For five years, Couturier was associate director of the Institut National des Sciences de l'Univers, and he then became director of the Canada-France-Hawaii Telescope Corporation. (M 35482)

Name suggested by M. A. Barucci and M. Fulchignoni, and citation prepared by C. de Bergh.

\section{(5440) Terao}

1991 HD. Discovered 1991 Apr. 16 by A. Sugie at Taga.

Named in memory of Hisashi Terao (1855-1923), who was the first Japanese professor of astronomy (18841919) at Tokyo Imperial University, the first director (1888-1919) of the Tokyo Astronomical Observatory and the first president of the Astronomical Society of Japan. Soon after he finished the course of physics at the newly-established Tokyo University he was sent to Paris to study celestial mechanics under Tisserand \{see planet (3663)\}, his main interest being in transits of Venus. He was also one of the founders of Tokyo Science University and later served as its president. (M 25653)

\section{(5442) Drossart}

$1991 \mathrm{NH}_{1}$. Discovered 1991 July 12 by H. E. Holt at Palomar.

Named in honor of Pierre Drossart (1956- ), researcher of the CNRS at Paris-Meudon Observatory. Drossart is a specialist on the atmospheres of the giant planets and has worked on the interpretation of the infrared spectra of Jupiter from Voyager and groundbased observations (Jupiter $\mathrm{H}_{2} \mathrm{O}$ measurements, first detection of $\mathrm{H}_{3}^{+}$on Jupiter, observations of aurorae, etc.). He has been involved as a co-investigator in several space-mission imaging spectrometers used to study Mars and the giant planets. (M 27459) Name suggested and citation provided by M. A. Barucci.

\section{(5443) Encrenaz}

$1991 \mathrm{NX}_{1}$. Discovered 1991 July 14 by H. E. Holt at Palomar.

Named in honor of Thérèse Encrenaz (1946- ), director of the Department of Space Research at the Paris Observatory. Encrenaz is an expert on planetary atmospheres, in particular the study of the chemical composition of planetary and cometary atmospheres, mostly by means of infrared and millimeter spectroscopy. Her main achievements include determining abundance ratios in the giant planets, the detection of several planetary minor species and the detection of parent molecules in comet $1 \mathrm{P} /$ Halley. She has been a co-investigator on several space missions, and she is Mission Scientist on the ISO mission. (M 27459)

Citation provided by M. A. Barucci following a suggestion by E. Bowell.

\section{(5444) Gautier}

$1991 \mathrm{PM}_{8}$. Discovered 1991 Aug. 5 by H. E. Holt at Palomar.

Named in honor of Daniel Gautier (1936- ), senior scientist in the Department of Space Research at the Paris Observatory. Gautier has played an important role in the development of European planetary space research. His work concerns the origin of the solar system through the study of planetary atmospheres. He has played a particular crucial role in promoting planetary science in France, and his enthusiasm has contributed much to the French planetary community's present-day level of excellence. (M 27459)

Citation provided by M. A. Barucci following a suggestion by E. Bowell.

\section{(5445) Williwaw}

$1991 \mathrm{PA}_{12}$. Discovered 1991 Aug. 7 by H. E. Holt at Palomar.

Named after a dramatic mountain on the skyline of Anchorage. A williwaw is a sudden seaward gust of cold air common along mountainous coasts at high latitudes. Mt. Williwaw was named by the Mountaineering Club of Alaska in 1963 and stands 5445 feet above sea level. 
It is the highest point in the Campbell Creek drainage. (M 34341)

Name suggested by D. Hamilton.

\section{(5446) Heyler}

$1991 \mathrm{~PB}_{13}$. Discovered 1991 Aug. 5 by H. E. Holt at Palomar.

Named in honor of Gene A. Heyler (1956- ), spacecraft attitude control expert at the Applied Physics Laboratory of Johns Hopkins University. Heyler has been responsible for developing innovative techniques for tracking minor planets during fast flybys. These techniques played a major role in the success of the NEAR flyby of (253) Mathilde in June 1997. (M 35483)

Name suggested and citation provided by J. Veverka.

\section{(5447) Lallement}

$1991 \mathrm{PO}_{14}$. Discovered 1991 Aug. 6 by H. E. Holt at Palomar.

Named in honor of Rosine Lallement (1951-

), French astrophysicist working at the Service d'Aéronomie in Verrières-le-Buisson. Lallement was the first to identify the local interstellar cloud, a few parsecs in diameter, which the sun is currently traversing. At a larger scale (100 parsecs), using new stellar distances from Hipparcos, she has studied the boundary of the interstellar local bubble, a region of very low interstellar density and high temperature, and she has discovered a hole in the local bubble, called the local tube, connecting it to the galactic halo. (M 35483)

Name suggested and citation prepared by M. A. Barucci and M. Fulchignoni.

\section{(5448) Siebold}

1992 SP. Discovered 1992 Sept. 26 by A. Sugie at Taga.

Named in memory of Philipp Franz Balthasar von Siebold (1796-1866), who went to Japan as a ship's doctor in the Dutch East India Company in 1823 and remained there for six years, studying in particular the natural history and ethnography of the country in an unprecedented manner. On returning to Europe he published this research. (M 27329)

\section{(5450) Sokrates}

2780 P-L. Discovered 1960 Sept. 24 by C. J. van Houten and I. van Houten-Groeneveld at Palomar.

Named after the Greek philosopher Sokrates (c. 470399 B.C.), who taught that one should always say the truth. He was forced to drink hemlock, because the state was afraid that Sokrates influenced the youth and denied the official religion. As a good citizen he took the cup in the presence of all his pupils, without protesting against the government. As he never wrote anything down, all we know about Sokrates is from his pupil Plato \{see planet (5451)\}. (M 22509)

\section{(5451) Plato}

4598 P-L. Discovered 1960 Sept. 24 by C. J. van Houten and I. van Houten-Groeneveld at Palomar.

Named after Plato (c. 428-348 B.C.), the most famous pupil of Sokrates \{see planet (5450)\}. He was the founder of the philosophical Academy near Athens, which existed for over 900 years. His preserved papers were written in dialogue form as the 'lessons' of Sokrates. His philosophy has strongly influenced the western world to the present day. (M 22509)

Plato is also honored by a lunar crater.

\section{(5453) Zakharchenya}

1975 VS $_{5}$. Discovered 1975 Nov. 3 by T. M. Smirnova at Nauchnyj.

Named in honor of academician Boris Petrovich Zakharchenya (1928- ), outstanding Russian scientist, director of a department in the Ioffe Physical and Technical Institute in St. Petersburg. Zakharchenya is well known for his investigations in the fields of solid state physics, magneto-optics and optical orientation of electrons and nuclei in semiconductors. (M 32788)

Name suggested by the Institute of Applied Astronomy.

\section{(5454) Kojiki}

$1977 \mathrm{EW}_{5}$. Discovered 1977 Mar. 12 by H. Kosai and K. Hurukawa at Kiso.

Named for the first book of historical stories written in Japanese. Completed in 712, it contains myths, legends and historical accounts of the Imperial court from the earliest days of the creation up to 628 . Kojiki is based on the oral shaman tradition and was written in the Chinese characters used to represent Japanese phonetics. Together with Nihonsyoki \{see planet (5082)\}, it is an important source book for the mythology, history and ethnology of ancient Japan. (M 22509)

\section{(5455) Surkov}

1978 RV $_{5}$. Discovered 1978 Sept. 13 by N. S. Chernykh at Nauchnyj.

Named in honor of Vladimir Vasil'evich Surkov (1945- ), well-known Russian specialist on databases and staff member of the Moscow Aviation Institute. (M 30476)

Name proposed by the discoverer following a suggestion by the Institute of Theoretical Astronomy.

\section{(5456) Merman}

$1979 \mathrm{HH}_{3}$. Discovered 1979 Apr. 25 by N. S. Chernykh at Nauchnyj.

Named in honor of Grigorij (Hirsh) Aronovich Merman (1921- ), staff member of the Institute of 
Theoretical Astronomy from 1951 to 1985. Merman has obtained important results in different areas of celestial mechanics. His work on the three-body problem involved the construction of a rigorous theory of capture, establishment of criteria for the feasibility of various types of end motions and derivation of a general solution in the form of a convergent series of polynomials. He also investigated the stability of canonical equations and estimated the remainders of the infinite series used in celestial mechanics. (M 29145)

Name proposed by the discoverer following a suggestion by the Institute of Theoretical Astronomy.

\section{(5457) Queen's}

1980 TW 5 . Discovered 1980 Oct. 9 by C. S. Shoemaker at Palomar.

Named in honor of Queen's University at Kingston, Ontario. Founded by Royal Charter in 1841, its first classes were held the following spring. In more than 150 years Queen's has evolved to become one of Canada's strongest universities in many fields. The home of A. Vibert Douglas \{see planet (3269)\}, one of Canada's pioneering astronomers, Queen's has had a long tradition of support to professional and amateur astronomical groups. (M 24917)

Name proposed and citation prepared by D. H. Levy.

\section{(5458) Aizman}

1980 TB $_{12}$. Discovered 1980 Oct. 10 by N. S. Chernykh at Nauchnyj.

Named in honor of Mikhael Iosifovich Aizman (1947-

), telecommunications specialist and president of MTU-INFORM. One of the largest systems for telephone communication and data transfer in Russia, this company was developed under his supervision in Moscow. Support from MTU-INFORM enabled ITA to create a communication channel allowing the integration of the ITA computer system in the World Wide Web. (M 31023)

Name proposed by the discoverer following a suggestion by ITA.

\section{(5459) Saraburger}

$1981 \mathrm{QP}_{3}$. Discovered 1981 Aug. 26 by H. Debehogne at La Silla.

Named in honor of Sara Schöffer-Burger \{1894- \}, who celebrated her 100th birthday on 1994 March 1 . She provided in her house in Amsterdam a hide-out for Jewish compatriots who had to go underground during the German occupation of The Netherlands during World War II. She and her husband were awarded the Jad. Vashem distinction. (M 24410)

Name proposed by the discoverer following a suggestion by Uccle astronomer Marijke Burger, niece of the honoree.
(5460) Tsénaat'a'í

1983 AW. Discovered 1983 Jan. 12 by B. A. Skiff at Anderson Mesa.

This name, 'Flying Rock' or 'Rock Which Flies' in the Navajo language, signifies the motion of the minor planet through space and gives recognition to the contribution of the Navajo culture and language to northern Arizona. (M 28621)

Name suggested by Derekson Bert, eighth-grade student at Rocky Ridge School in Dinnebito, Arizona, winner of a contest to name this object in conjunction with the 1996 Flagstaff Festival of Science.

\section{(5463) Danwelcher}

1985 TO. Discovered 1985 Oct. 15 by E. Bowell at Anderson Mesa.

Named in honor of Dan Welcher (1948- ), American composer and conductor, on the occasion of the first performance of his Symphony No. 2 for large orchestra by the Flagstaff Symphony Orchestra on 1994 Nov. 9. Subtitled Night Watchers, the fourmovement work marks the centennial of the founding of Lowell Observatory and of the city of Flagstaff. Welcher was trained as a pianist and bassoonist and became principal bassoonist of the Louisville Orchestra. From 1990 to 1992, he was composer in residence of the Honolulu Symphony. Welcher's wideranging compositions encompass orchestral, chamber, instrumental and vocal works, and he specializes in conducting the music of living American composers. He is professor of composition at the University of Texas at Austin. (M 24122)

\section{(5464) Weller}

$1985 \mathrm{VC}_{1}$. Discovered 1985 Nov. 7 by E. Bowell at Anderson Mesa.

Named in honor of Harold Weller (1941- ). Conductor of the Flagstaff Symphony Orchestra since 1981, Weller received his musical training at the Oberlin and Cincinnati Conservatories of Music, Miami University and Ohio State University. He has held positions as musical director of the Hamilton (Ohio) and Ashland (Ohio) Symphony Orchestras and has been a faculty member at Ashland College in Ohio and Old Dominion University in Norfolk, Virginia. (M 24122)

\section{(5465) Chumakov}

1986 RF $_{13}$. Discovered 1986 Sept. 9 by L. G. Karachkina at Nauchnyj.

Named in honor of the well-known Russian microbiologist Mikhail Petrovich Chumakov (1909- ), who founded an institute for the study of poliomyelitis and tick encephalitis. (M 22509)

\section{(5466) Makibi}

$1986 \mathrm{WP}_{8}$. Discovered 1986 Nov. 30 by H. Kosai and K. Hurukawa at Kiso. 
Named for Kibi-no Makibi (695-775), a Japanese scholar and statesman, who travelled to T'ang-dynasty China to study in 717 . Upon his return to Japan 17 years later, he presented many books on various fields (including astronomy and surveying) to the Japanese government and introduced Chinese technology into Japan. He subsequently served as an ambassador to China and also achieved the high post of minister. (M 22509)

\section{(5468) Hamatonbetsu}

1988 BK. Discovered 1988 Jan. 16 by M. Mukai and M. Takeishi at Kagoshima.

Located near the northern extremity of Japan, Hamatonbetsu is the town where the second discoverer lives. The lake and swamp around the town are very important for waterfowl, and this site has been registered with the Convention on Wetlands of International Importance Especially as Waterfowl Habitat (Ramusar Convention). The name also honors the inhabitants of the town, who have supported the astronomical activities of the discoverers. (M 22509; M 22519)

\section{(5471) Tunguska}

1988 PK $_{1}$. Discovered 1988 Aug. 13 by E. W. Elst at St. Michel.

Named for the site, in Siberia, of the presumed impact of a 60-meter minor planet on the 85th anniversary of the great explosion that occurred there on 1908 June 30. (M 22250)

\section{(5473) Yamanashi}

1988 VR. Discovered 1988 Nov. 5 by Y. Kushida and O. Muramatsu at Yatsugatake.

Named for the prefecture in which Yatsugatake South Base Observatory and many other amateur astronomical observatories are located. This prefecture is in central Japan about $150 \mathrm{~km}$ west of Tokyo and is famous for Mt. Fuji \{see planet (1584)\} and the mountain's five lakes. This prefecture promotes environmental protection. (M 22510)

\section{(5474) Gingasen}

$1988 \mathrm{XE}_{1}$. Discovered 1988 Dec. 3 by T. Fujii and K. Watanabe at Kitami.

Gingasen, or 'Milky Way', is a railroad track in Hokkaido \{see planet (3720)\}. This $150-\mathrm{km}$ public railroad connects the island's eastern cities. Each station along the line is named for a constellation. (M 26930)

\section{(5478) Wartburg}

$1989 \mathrm{UE}_{4}$. Discovered 1989 Oct. 23 by F. Börngen at Tautenburg.

Named for a castle on a hill near the town of Eisenach, a jewel of the German territories, earlier the dwelling-place of the Thuringian landgraves and of
Saint Elisabeth (1211-1227). In a special way, Wartburg was the scene of historical events in the past. In 1521-1522 Martin Luther there translated the New Testament into German, defended from his pursuers. In 1817 German students came together to express their striving for unity and liberty. In 1845 Wagner \{see planet (3992)\} digested in the opera Tannhäuser the contest of the minnesingers in the late Romanic palace of Wartburg. (M 22250)

\section{(5479) Grahamryder}

$1989 \mathrm{UT}_{5}$. Discovered 1989 Oct. 30 by S. J. Bus at Cerro Tololo.

Graham Ryder (1949-2002) was a U.S. lunar scientist who pioneered several important concepts about the moon and its evolution. He was among the first to recognize evidence in the lunar sample collection that mare volcanism began very early in lunar history, before the period of late heavy bombardment had ended. (M 46006)

\section{(5481) Kiuchi}

1990 CH. Discovered 1990 Feb. 15 by K. Endate and K. Watanabe at Kitami.

Named in honor of Tsuruhiko Kiuchi (1954- ), Japanese amateur astronomer, who recovered the Perseid comet P/Swift-Tuttle \{see planets (5035) and (5036)\} with binoculars on 1992 Sept. 26 in accordance with a prediction by B. G. Marsden. Kiuchi also co-discovered two new comets in 1990. He is employed in the manufacture of motor parts and is on the staff of a community school for star lovers. (M 22510) Name suggested by I. Hasegawa.

\section{(5483) Cherkashin}

1990 UQ $_{11}$. Discovered 1990 Oct. 17 by L. I. Chernykh at Nauchnyj.

Andrej Andreevich Cherkashin (1920-1993) was a literary scholar and historian, researcher of A. S. Pushkin's \{see planet (2208)\} genealogy and author of The Millennial Family Tree of Pushkin. (M 38195)

\section{(5484) Inoda}

$1990 \mathrm{VH}_{1}$. Discovered 1990 Nov. 7 by T. Urata at Oohira.

Named in honor of Shigeru Inoda (1955- ), ophthalmic vitreo-retinal surgeon and associate professor in the ophthalmology department of the Jichi Medical School. He is one of the most active amateur astronomers in the minor planet survey at Karasuyama Astronomical Observatory and is the discoverer of several minor planets. He has been an technical adviser at the Nihondaira \{see planet (2880)\} Observatory. (M 22510)

\section{(5485) Kaula}

$1991 \mathrm{RQ}_{21}$. Discovered 1991 Sept. 11 by H. E. Holt at Palomar.

Named in honor of William M. Kaula (1926- ), professor of earth and space science at the University 
of California at Los Angeles. Kaula pioneered the use of artificial satellites in geodesy, producing global gravity maps of the earth, the moon, Venus and Mars. He has used the gravity, cratering record and surface topography of Venus to infer current and historical tectonics and properties of the interior. He also played an active role in establishing the Apollo Lunar Laser Ranging Experiment and has had a longstanding and wide-ranging interest in the origin and evolution of the solar system. (M 27359)

Name suggested and citation prepared by A. W. Harris, with help from S. J. Peale.

\section{(5488) Kiyosato}

$1991 \mathrm{VK}_{5}$. Discovered 1991 Nov. 13 by S. Otomo at Kiyosato

Named for the town where the discoverer lives and his observatory is located. Kiyosato is famous for its natural beauty and is located on the southern slope of the Yatsugatake mountains, about $150 \mathrm{~km}$ west of Tokyo. Millions of visitors enjoy their vacations in Kiyosato, play sports and go picnicking and camping. (M 22250)

\section{(5489) Oberkochen}

$1993 \mathrm{BF}_{2}$. Discovered 1993 Jan. 17 by Y. Kushida and O. Muramatsu at Yatsugatake.

Named for the town in Germany in which the Zeiss \{see also planet (851)\} Optical works are located. This minor planet was discovered on the night that two Zeiss engineers visited the \{Yatsugatake South Base\} observatory. (M 22510)

\section{(5490) Burbidge}

2019 P-L. Discovered 1960 Sept. 24 by C. J. van Houten and I. van Houten-Groeneveld at Palomar.

Named in honor of E. Margaret Burbidge, astronomer at the University of California at San Diego. She is well-known for her investigations of galaxies and quasars. From 1972-73 she served as head of the Royal Greenwich Observatory, the only woman director in its 300-year history. (M 22510)

\section{(5491) Kaulbach}

3128 T-1. Discovered 1971 Mar. 26 by C. J. van Houten and I. van Houten-Groeneveld at Palomar.

Named after Wilhelm von Kaulbach (1805-1874), German painter of portraits, historical scenes and natural scenes of country life. From 1849 he was for many years director of the Art Academy of Munich. (M 22510)

\section{(5492) Thoma}

3227 T-1. Discovered 1971 Mar. 26 by C. J. van Houten and I. van Houten-Groeneveld at Palomar.

Named after Hans Thoma (1839-1924), German painter of mostly peaceful scenes depicting people in harmony with nature. He also painted many portraits. After a visit to Paris he was influenced by Courbet. Thoma worked in Munich, Frankfurt and Karlsruhe, where he was director of the art academy and the art museum. (M 22510)

\section{(5493) Spitzweg}

1617 T-2. Discovered 1973 Sept. 24 by C. J. van Houten and I. van Houten-Groeneveld at Palomar.

Named after Carl Spitzweg (1808-1885), German painter of the Biedermeier art period. His anecdotal and humoristic paintings mostly criticise his time through fine irony. Spitzweg travelled a lot through Europe, and his later work shows the influence of the coming impressionists. (M 22510)

\section{(5495) Rumyantsev}

1972 RY $_{3}$. Discovered 1972 Sept. 6 by L. V. Zhuravleva at Nauchnyj.

Named in memory of the Russian count Nikolaj Petrovich Rumyantsev (1754-1826), the Minister for Foreign Affairs and President of the State Council in Russia from 1807 to 1814 . He amassed great collections of books, manuscripts, ethnographic and numismatic materials that became basis for Moscow's Rumyantsev museum, inaugurated in 1862. The book collection later became the foundation of the Russian State Library. (M 30476)

\section{(5497) Sararussell}

1975 SS. Discovered 1975 Sept. 30 by S. J. Bus at Palomar.

As a researcher at the Natural History Museum in London, Sara Russell (1966- ） studies the chemistry and mineralogy of meteorites to investigate the early solar system and origin of interstellar grains. She has collected meteorites in both hot and cold deserts and is principal editor of the Meteoritical Bulletin. (M 46006)

\section{(5498) Gustafsson}

$1980 \mathrm{FT}_{3}$. Discovered 1980 Mar. 16 by C.-I. Lagerkvist at La Silla.

Named in honor of Bengt Gustafsson, professor of theoretical astrophysics at and director of the Uppsala Astronomical Observatory, on the completion of his first half centennial. (M 22830)

\section{(5500) Twilley}

1981 WR. Discovered 1981 Nov. 24 by E. Bowell at Anderson Mesa.

Named in honor of Royston C. Twilley (1914- ), primary school teacher of the discoverer in Tooting, London, during 1954-1955. Twilley was the most inspiring of teachers, leading his pupils not only through the required curriculum, but also into areas of academic discipline not usually encountered by pre-teenagers. Especially noteworthy was a thorough exploration of the past and contemporaneous River Wandle, a short river nowadays flowing mostly underground through south London that in the eighteenth century sported a wide variety of industrial mills, a few of which were still in operation in the 1950s. During 1959 to 1977 , Twilley was headmaster of two London schools, and 
after retiring he served as a School Governor of a Dorset primary school (1993-1994). (M 25976)

Citation material provided by B. Twilley. Name endorsed by M. C. Bradley, S. J. Duffell and A. J. Sissons.

\section{(5502) Brashear}

1984 EC. Discovered 1984 Mar. 1 by E. Bowell at Anderson Mesa.

Named in memory of John A. Brashear (18401920), maker of astronomical telescopes and scientific instruments, popularizer of astronomy and university administrator. Brashear contributed much to the siting, design and fundraising for the Allegheny Observatory \{see also planet (457)\}, and his firm constructed its $0.76-\mathrm{m}$ refractor and $0.79-\mathrm{m}$ Keeler reflector. He figured the $0.4-\mathrm{m}$ photographic doublet with which Max Wolf \{see planets (827) and (1217), respectively\} discovered many minor planets. He also had connections with the Lowell Observatory, notably in the design and construction of a fast spectrograph that was ultimately used to record the first recessional velocities of galaxies, and through the provision of a $0.13-\mathrm{m}$ objective used in Lowell's \{see planet (1886)\} first search for a transneptunian planet. (M 25977; M 26439)

Citation provided by T. P. Kohman and H. L. Giclas following a suggestion by Kohman on behalf of the Amateur Astronomer Association of Pittsburgh.

See also the citations for planets (457) and (484). Brashear is also honored by craters on Mars and the Moon.

\section{(5504) Lanzerotti}

$1985 \mathrm{FC}_{2}$. Discovered 1985 Mar. 22 by E. Bowell at Anderson Mesa.

Named in honor of Louis J. Lanzerotti, American space physicist, on the occasion of his completion of six years as chair of the U.S. National Academy of Sciences Space Studies Board. Lanzerotti helped lay the experimental foundation of our understanding of energetic particles and waves in the Van Allen Belts and in the earth's magnetosphere, and his measurements of solar energetic particles elucidated their propagation in the interplanetary medium and solar corona. His experiments on proton bombardment of ices were applied to spectroscopic characteristics of interstellar grains, comet nuclei, asteroids and icy satellites in planetary magnetospheres, and he showed that the dark color of some of these objects resulted from interactions with particulate radiation. (M 23792) Name suggested and citation prepared by M. S. Allen.

\section{(5507) Niijima}

1987 UJ. Discovered 1987 Oct. 21 by K. Suzuki and T. Urata at Toyota.

Named in honor of Tsuneo Niijima (1955- ), codiscoverer of periodic comet Urata-Niijima ssee minor planet (3722) for the co-discoverer $\}$ and discoverer of several minor planets. (M 22510)

Name proposed by T. Urata.

\section{(5509) Rennsteig}

1988 RD $_{3}$. Discovered 1988 Sept. 8 by F. Börngen at Tautenburg.

Named for a narrow forest road, $168 \mathrm{~km}$ in length, that crosses the ridge-like hill of the chain of mountains of the Thuringian Forest. It is a favorite place for wanderers. (M 22510)

\section{(5511) Cloanthus}

1988 TH$_{1}$. Discovered 1988 Oct. 8 by C. S. Shoemaker and E. M. Shoemaker at Palomar.

Racing the sea-blue Scylla \{see planet (155)\}, Cloanthus was the winner of the boat race at the funeral games for Anchises \{see planet (1173)\}. Although the weight of the ship made it slower, Cloanthus called upon the gods of the sea to help him and came in first. (M 25444)

\section{(5513) Yukio}

1988 WB. Discovered 1988 Nov. 27 by W. Kakei and M. Kizawa and T. Urata at Oohira.

Named in honor of Yukio Hasegawa (1950- ), amateur astronomer and an excellent telescope maker. Periodic comet Urata-Niijima see planets (3722) and (5507)\}, (2090) Mizuho, (3394) Banno and this minor planet were discovered using a telescope made by him. (M 22510)

Name proposed by T. Urata.

\section{(5516) Jawilliamson}

1989 JK. Discovered 1989 May 2 by E. F. Helin at Palomar.

Named in honor of Jack Williamson, science-fiction writer, who has helped define the development of contemporary science fiction. For 65 years, Jack has written science fiction of every conceivable sort, from space opera to the most modern technologically oriented variety. He has influenced many people in their pursuit of careers in science and science writing. (M 23138)

Name endorsed by D. Brin and Williamson's many friends and colleagues.

\section{(5517) Johnerogers}

1989 LJ. Discovered 1989 June 4 by E. F. Helin at Palomar.

Named in honor of John E. Rogers, Range Safety Officer at Point Mugu, California, and an amateur astronomer long known for his computer software and for his computation of orbits. More recently he has developed an astrometric system using a CCD camera and related software that he expertly uses at his home in Camarillo. The discoverer acknowledges his unstinting assistance in using this equipment to obtain crucial observations of newly-discovered near-earth objects, and from time to time he has also joined the discoverer's team at Palomar to search for them. (M 23138; M 26947)

Name proposed by the discoverer, endorsed by K. Lawrence, B. G. Marsden and G. V. Williams. 


\section{(5518) Mariobotta}

1989 YF. Discovered 1989 Dec. 30 by J. M. Baur at Chions.

Named in honor of Mario Botta, Swiss architect. His buildings are influenced by his early meetings with Le Corbusier and Louis Kahn and are inspired by the belief that 'every building has its own individual surroundings'. Botta also lectures and is an honorary fellow of the American Institute of Architects. (M 22831)

\section{(5519) Lellouch}

$1990 \mathrm{QB}_{4}$. Discovered 1990 Aug. 23 by H. E. Holt at Palomar.

Named in honor of Emmanuel Lellouch (1963- ), planetary scientist at Observatoire de Paris. Lellouch works mainly on planetary and satellite atmospheres using infrared and millimeter spectroscopy. He made important contributions to the first observations of Io's global atmosphere, wind measurements in Venus and Mars, and detection of water in outer planets. He also studies planetary surfaces and comets, and has been or is coinvestigator or associate on many spacecraft experiments (Phobos, Galileo, ISO, Cassini, Mars Express, Rosetta, FIRST). (M 35483)

Name suggested and citation prepared by M. A. Barucci and M. Fulchignoni.

\section{(5520) Natori}

1990 RB. Discovered 1990 Sept. 12 by T. Urata at Oohira.

Named in honor of Akira Natori (1956- ), discoverer of several minor planets. He has collaborated with the Nihondaira \{see planet (2880)\} Observatory for follow-up observations, and this minor planet was numbered as a result of this cooperation. (M 22510)

\section{(5521) Morpurgo}

$1991 \mathrm{PM}_{1}$. Discovered 1991 Aug. 15 by E. F. Helin at Palomar.

Named in honor of Pieter Morpurgo, who has been the producer for the last 18 years of "The Sky at Night", a British TV program celebrating its 40th anniversary featuring Patrick Moore \{see planet (2602)\} as host. Morpurgo and Moore have worked closely and successfully creating this upbeat informative program about astronomy for public education in an imaginative, entertaining forum. (M 30476)

\section{(5522) De Rop}

$1991 \mathrm{PJ}_{5}$. Discovered 1991 Aug. 3 by E. W. Elst at La Silla.

Named in honor of Willy De Rop (1933- ), astronomer at the Royal Observatory, Uccle, on the occasion of his retirement. Besides his professional work in positional astronomy, timekeeping and rotation of the earth, De Rop has been involved in the popularization of astronomy and several other cultural societies in Belgium. For several years he was most helpful in taking care of the communication of telexes between the discoverer and observation sites, and also the Minor Planet Center. (M 22251)

Citation prepared by J. Denoyelle at the request of the discoverer.

\section{(5523) Luminet}

$1991 \mathrm{PH}_{8}$. Discovered 1991 Aug. 5 by H. E. Holt at Palomar.

Named in honor of Jean-Pierre Luminet (1951- ), French researcher at the Paris Observatory. Luminet specializes in general relativity and its applications to cosmology and astrophysics. He was the first to "visualize" numerically accretion disks around black holes, and he discovered the phenomenon of "crèpe stellaire", which causes the crushing of stars by the tidal forces of giant black holes. In cosmology, Luminet proposed a series of models of "univers chiffonnés", in which complex topologies create ghost images. He is deeply involved in science outreach, both by publishing popular books and as a TV broadcaster. (M 35483) Name suggested and citation prepared by M. A. Barucci.

\section{(5524) Lecacheux}

1991 RA $_{30}$. Discovered 1991 Sept. 15 by H. E. Holt at Palomar.

Named in honor of Jean Lecacheux, a planetary scientist at Paris Observatory. Lecacheux is one of the most assiduous observers of solar system objects. He discovered the Saturnian satellite Helène. At Pic du Midi Observatory he developed a planetary observational station with which he fruitfully imaged Venus, Jupiter, Saturn, the jovian impacts of comet D/1993 F2, as well as other comets and minor planets. (M 27459)

Citation provided by M. A. Barucci following a suggestion by E. Bowell.

\section{(5526) Kenzo}

1991 UP $_{1}$. Discovered 1991 Oct. 18 by T. Urata at Oohira.

Named in honor of Kenzo Suzuki (1950- ), a leading amateur observer of minor planets and comets in Japan, who has been performing astrometry since 1972 and has discovered several minor planets. (M 22510)

\section{(5529) Perry}

2557 P-L. Discovered 1960 Sept. 24 by C. J. van Houten and I. van Houten-Groeneveld at Palomar.

Named in honor of Marcus Perry and his work in the Spacewatch program. (M 22510)

\section{(5530) Eisinga}

2835 P-L. Discovered 1960 Sept. 24 by C. J. van Houten and I. van Houten-Groeneveld at Palomar.

Named in honor of Eise Eisinga (1744-1821), Dutch amateur astronomer, on the 250th anniversary of his birth. Eisinga lived in the northern town of Franeker, where he constructed a large (and still functioning) mechanical planetarium. (M 23541) 


\section{(5531) Carolientje}

1051 T-2. Discovered 1973 Sept. 29 by C. J. van

Houten and I. van Houten-Groeneveld at Palomar.

Named for Caroline van Houten, daughter of Karel and Thea van Houten, and granddaughter of the discoverers. (M 22510)

\section{(5532) Ichinohe}

1932 CY. Discovered 1932 Feb. 14 by K. Reinmuth at Heidelberg.

Named in memory of Naozo Ichinohe (1872-1920), instructor at the University of Tokyo and astronomer at Tokyo Observatory. He was a pioneer of astrophysics in Japan. He studied under E. B. Frost, E. E. Barnard and S. W. Burnham \{see respectively planets (854), (819), and (834)\} during 1905-07 at the Yerkes Observatory, where he measured the radial velocities of some spectroscopic binaries. He left about 12,000 visual observations of variable stars (including three stars discovered by himself ) that were carried out in the U.S.A. and Japan. He insisted on the necessity of a large telescope in Japan. He was also a pioneer of science journalism in Japan. After he retired from the University of Tokyo, he was the editor of the monthly magazine Gendai no Kagaku, which he founded on the model of Nature. (M 25230)

Name proposed by S. Nakano, one of the identifiers involving this minor planet, following a suggestion by M. Hara and S. Sakuma.

\section{(5533) Bagrov}

1935 SC. Discovered 1935 Sept. 21 by P. F. Shajn at Simeïs.

Named in honor of Nikolaj Vasil'evich Bagrov (1937-

), geographer, professor at the Simferopol State University and author of research on geographical peculiarities of the Crimea. (M 34621; M 34673)

Name proposed by the Crimean Astrophysical Observatory.

\section{(5535) Annefrank}

1942 EM. Discovered 1942 Mar. 23 by K. Reinmuth at Heidelberg.

Named in memory of Anne Frank (1929-1945), whose life and diary form a poignant record of the ravages of war and racism, as seen through the eyes of a young person. Notebooks and papers in Anne's handwriting were found in the family's hiding place on the Prinsengracht in Amsterdam by Miep Gies, a friend who had protected and sustained the group during their isolation. They appeared in published form in 1947 and have since been widely read in more than thirty languages. Despite the incredible adversity it records, the message is inherently one of hope. Proposed on the fiftieth anniversary of the cessation of hostilities in Europe. (M 25230)

Name proposed and citation prepared by G. C. L. Aikman.

\section{(5538) Luichewoo}

$1964 \mathrm{TU}_{2}$. Discovered 1964 Oct. 9 at the Purple Mountain Observatory at Nanking.

Named in honor of Lui Chewoo, an expert in mineralogy. Lui served as a director of the Mineralogical Institute of South China for many years. He was also recently engaged as an honorary consultant at the Purple Mountain Observatory and has made a great contribution to the cause of astronomy in China. (M 25230)

\section{(5540) Smirnova}

1971 QR $_{1}$. Discovered 1971 Aug. 30 by T. M. Smirnova at Nauchnyj.

Named in honor of Tamara Mikhajlovna Smirnova (1935-2001), devoted observer of minor planets and a staff member of the Institute of Theoretical Astronomy from 1966 to 1988. During her long-lasting activity she made about 9,000 observations and measured numerous positions of minor planets at the Crimean Astrophysical Observatory. She discovered over one hundred minor planets and a comet, this object being her hundredth discovery. (M 24917)

Name proposed by the Institute of Theoretical Astronomy.

\section{(5541) Seimei}

$1976 \mathrm{UH}_{16}$. Discovered 1976 Oct. 22 by H. Kosai and K. Hurukawa at Kiso.

Named for Abe-no Seimei (921-1005), an authority of astronomy, astrology and divination. At the request of the Emperor and nobles he told their fortune. There are many mysterious legends regarding his abilities. His descendants played important roles in compiling the Japanese annotated calendar for about 800 years. (M 22511)

\section{(5542) Moffatt}

$1978 \mathrm{PT}_{4}$. Discovered 1978 Aug. 6 at the Perth Observatory at Bickley.

Ethelwin Frances Flamsteed Moffatt (née Winzar, b. 1926) is a direct descendant of John Flamsteed, the first Astronomer Royal. Born in Fremantle, Western Australia, she now resides in Adelaide, where she and her husband, Mervyn Moffatt, are kind benefactors of the Perth Observatory. (M 43380)

\section{(5543) Sharaf}

$1978 \mathrm{TW}_{2}$. Discovered 1978 Oct. 3 by N. S. Chernykh at Nauchnyj.

Named in honor of Shafika Gil'mievna Sharaf (1915-

), well known expert on celestial mechanics and staff member of the Institute of Theoretical Astronomy from 1939 to 1986. She co-developed an analytical theory of Pluto using the Laplace-Newcomb method and determined new orbital elements for the planet. Later she investigated the secular variations of solar radiation incident upon given area of the earth's 
surface caused by perturbations of the earth's orbit. (M 30476)

Name suggested by the Institute of Theoretical Astronomy.

\section{(5544) Kazakov}

$1978 \mathrm{TH}_{6}$. Discovered 1978 Oct. 2 by L. V. Zhuravleva at Nauchnyj.

Named in memory of Matvej Fedorovich Kazakov (1738-1812), Russian architect, one of the founders of classicism in Russian architecture in the eighteenth century. (M 34621)

\section{(5545) Makarov}

1978 VY $_{14}$. Discovered 1978 Nov. 1 by L. V. Zhuravleva at Nauchnyj.

Named in honor of Askol'd Anatol'evich Makarov (1925- ), an outstanding Russian choreographer and professor of the St. Petersburg Conservatoire. From 1942 to 1970 he was the leading soloist at the Mariinskij Theatre, and since 1976 he has been artistic director at the St. Petersburg State Academic Ballet Theatre. (M 24918)

Name proposed by the Institute of Theoretical Astronomy.

\section{(5546) Salavat}

1979 YS. Discovered 1979 Dec. 18 by H. Debehogne at La Silla.

Named in honor of the industrial city of Salavat, located in Bashkiria \{see planet (2657)\}, just west of the Ural mountains. (M 23138)

\section{(5547) Acadiau}

$1980 \mathrm{LE}_{1}$. Discovered 1980 June 11 by C. S. Shoemaker at Palomar.

Named in honor of Acadia University, Wolfville, Nova Scotia. Founded in 1838, Acadia U. has become one of Canada's finest liberal arts institutions. It is located near the Minas Basin, which boasts some of the most dramatic tides on the earth, and it is also located under some of Canada's darkest night skies. Acadia's academic excellence and small student population provide a fertile environment for a good undergraduate education. (M 24918)

Name proposed and citation prepared by D. H.Levy.

\section{(5549) Bobstefanik}

$1981 \mathrm{GM}_{1}$. Discovered 1981 Apr. 1 at the Harvard College Observatory at Harvard.

Named in honor of Robert Stefanik (1938- ), director of the Oak Ridge Observatory, where this minor planet was discovered. Stefanik's stellar research includes the determination of a new set of radialvelocity standards, the search for low-mass stellar companions and the determination of binary-star orbits. (M 22511)

Name proposed by members of the HarvardSmithsonian Center for Astrophysics Planetary Sciences division.

\section{(5551) Glikson}

1982 BJ. Discovered 1982 Jan. 24 by C. S. Shoemaker and E. M. Shoemaker at Palomar.

Named in honor of Andrew Y. Glikson, retired senior research scientist with the Australian Geological Survey Organization. Glikson, a geologist of vision and creativity, is one of the leading investigators of the early Precambrian. He is especially noted for his work on the Archean of Western Australia and on the complex rocks of the Musgrave Block. He is also well known for his work on impact craters and on the possible role of impacts in the geology of the Archean. (M 29670)

\section{(5552) Studnička}

1982 SJ $_{1}$. Discovered 1982 Sept. 16 by A. Mrkos at Kleť.

Named in memory of František Josef Studnička (18361903), professor of mathematics at Charles University in Prague, also active in astronomy and meteorology. He was known as the author of several textbooks and popular articles. He started his work as a lecturer in Ceské Budějovice (1862-1864). (M 31295)

Name suggested by J. Tichá and M. Šolc.

\section{(5553) Chodas}

$1984 \mathrm{CM}_{1}$. Discovered 1984 Feb. 6 by E. Bowell at Anderson Mesa.

Paul W. Chodas (1952- ) is a member of the Solar System Dynamics Group at the Jet Propulsion Laboratory. His work has contributed to the understanding of cometary nongravitational forces, the use of radar data in asteroidal and cometary orbits, orbital error analyses, earth close approaches and impact probabilities. He developed the system that allowed the use of radar landmark data on the surface of Venus for improved orbital solutions of the Magellan spacecraft. (M 22831)

Citation prepared by D. K. Yeomans, a colleague of the honoree.

\section{(5554) Keesey}

$1985 \mathrm{TW}_{1}$. Discovered 1985 Oct. 15 by E. Bowell at Anderson Mesa.

Michael S. W. Keesey (1937- ) is a member of the Solar System Dynamics Group at the Jet Propulsion Laboratory. He began his career at JPL in 1970, and his knowledge of fundamental astronomy and celestial mechanics has been put to good use in the ephemeris development efforts for those planets, comets and minor planets that have been mission candidates or targets of ground-based observations. (M 22831)

Citation prepared by D. K. Yeomans, a colleague of the honoree.

\section{(5555) Wimberly}

$1986 \mathrm{VF}_{5}$. Discovered 1986 Nov. 5 by E. Bowell at Anderson Mesa.

Ravenel N. Wimberly (1946- ) is a member of the Solar System Dynamics Group at the Jet Propulsion 
Laboratory. His intimate knowledge of various computer systems has proven invaluable in helping organize and carry out the ephemeris development efforts for the comet and asteroid targets of several flyby missions. (M 22831)

Citation prepared by D. K. Yeomans, a colleague of the honoree.

\section{(5557) Chimikeppuko}

$1989 \mathrm{CM}_{1}$. Discovered 1989 Feb. 7 by K. Endate and K. Watanabe at Kitami.

Named for the small lake in Tsubetsu ssee planet (4845)\}, a town in the eastern part of Hokkaido \{see planet (3720)\}. Some $12 \mathrm{~km}$ in circumference, the lake is surrounded by a deep green virgin forest. The lake is the nesting place for many wild birds and famous as bird-watching spot. (M 25977)

\section{(5560) Amytis}

1990 MX. Discovered 1990 June 27 by E. F. Helin at Palomar.

Named in honor of Amytis Barrett (1909- ), in celebration of her 85th birthday, in recognition of her many contributions to the Caltech community, including all aspects of undergraduates' activities and her significant influence on the Associates' program. (M 23352)

Name proposed by Dr. and Mrs. J. Bonner and endorsed by her many Caltech friends.

\section{(5561) Iguchi}

1991 QD. Discovered 1991 Aug. 17 by S. Otomo at Kiyosato.

Named in honor of Masatoshi Iguchi (1928- ), president of the Photovoltaic Popularization Association in Japan and publisher of The Photovoltaic News. (M 25654)

\section{(5565) Ukyounodaibu}

$1991 \mathrm{VN}_{2}$. Discovered 1991 Nov. 10 by A. Natori and T. Urata at Yakiimo.

Named for the Japanese poetess, Kenreimon-in Ukyounodaibu (1157-?). She wrote a diary with 359 poems that describe her life at court and reminiscences of her young lover Taira-no Sukemori, who died at the battle of Dannoura. She worked for Kenreimonin \{see planet (5242)\}. (M 30476)

Name suggested and citation provided by A. Sato.

\section{(5570) Kirsan}

1976 GM $_{7}$. Discovered 1976 Apr. 4 by N. S. Chernykh at Nauchnyj.

Named in honor of Kirsan Nikolaevich Ilyumzhinov (1962- ), chess grandmaster and president of the International Chess Federation, elected in 1996 for a second term. (M 30097)

\section{(5572) Bliskunov}

$1978 \mathrm{SS}_{2}$. Discovered 1978 Sept. 26 by L. V. Zhuravleva at Nauchnyj.
Named in memory of Aleksandr Ivanovich Bliskunov (1938-1996), well-known Crimean orthopedic surgeon and professor. (M 34621)

\section{(5576) Albanese}

$1986 \mathrm{UM}_{1}$. Discovered 1986 Oct. 26 by the CERGA at Caussols.

Named in honor of Dominique Albanese, photographer and observer at the Schmidt telescope of the Observatoire de la Côte d'Azur. Dominique has also installed a 30-cm Schmidt telescope with which he regularly photographs the skies. (M 23138)

Citation written by A. Maury and endorsed by J.-L. Heudier.

\section{(5577) Priestley}

$1986 \mathrm{WQ}_{2}$. Discovered 1986 Nov. 21 by J. D. Waldron at Siding Spring.

Named for Joseph Priestley (1733-1804), an English clergyman who was the first to publish an account of his discovery in 1774 of the element oxygen. The number 5577, corresponding to the number of this minor planet, is also the wavelength in Ångstroms of the main emission line of green auroral light, due to triply-ionized oxygen. (M 22207; M 33786)

\section{(5578) Takakura}

1987 BC. Discovered 1987 Jan. 28 by T. Niijima and T. Urata at Ojima.

Takakura (1161-1181), the 80th emperor of Japan, succeeded to the throne in 1168 . He was the seventh son of emperor Goshirakawa \{see planet (3585)\} and an expert at playing the Japanese flute. (M 36944)

\section{(5579) Uhlherr}

1988 JL. Discovered 1988 May 11 by C. S. Shoemaker and E. M. Shoemaker at Palomar.

Named in honor of engineer H. Ralph Uhlherr, a founder of the Siemens plant in Melbourne. An indefatigable collector of tektites, Uhlherr has meticulously recorded and mapped over a thousand australites from the Port Campbell Embayment of Victoria, thereby helping to resolve the conflict between the apparent young stratigraphic age of the tektites and the middle Pleistocene ages obtained by various chronometric methods. (M 29670; M 29691)

\section{(5580) Sharidake}

$1988 \mathrm{RP}_{1}$. Discovered 1988 Sept. 10 by K. Endate and K. Watanabe at Kitami.

Named for a mountain in eastern Hokkaido \{see planet (3720)\}, 1545 meters high and known as "Japan's Matterhorn". It is in the Shiretoko \{see planet (3867)\} range, part of the Chishima volcanic belt. (M 25977)

\section{(5581) Mitsuko}

$1989 \mathrm{CY}_{1}$. Discovered 1989 Feb. 10 by M. Iwamoto and T. Furuta at Tokushima.

Named in honor of Mitsuko Iwamoto (1956- ), wife of the first discoverer. (M 27128) 


\section{(5583) Braunerová}

$1989 \mathrm{EY}_{1}$. Discovered 1989 Mar. 5 by A. Mrkos at Klět.

Zdenka Braunerová (1858-1934), painter and graphic artist, is known for her landscapes, historical Prague views and book design. She is considered the first Czech professional woman painter. (M 41934) The name was suggested by J. Tichá.

\section{(5584) Izenberg}

1989 KK. Discovered 1989 May 31 by H. E. Holt at Palomar.

Named in honor of Noam Izenberg (1967- ), planetary scientist at the Applied Physics Laboratory of Johns Hopkins University and an expert in the geologic interpretation of reflectance spectra. Izenberg played a major role during the NEAR mission to (433) Eros through accurate calibration of the Near-Infrared Spectrometer and through a careful analysis of the data returned. (M 35483)

Name suggested and citation provided by J. Veverka.

\section{(5585) Parks}

1990 MJ. Discovered 1990 June 28 by E. F. Helin at Palomar.

Named in honor of Robert J. Parks, a leader in the exploration of the solar system. Early in his career at the Caltech Jet Propulsion Laboratory, he developed radio control and telemetry for the first guided missiles. As these techniques matured to become the basis for the control of and communication with interplanetary spacecraft, Parks was assigned overall responsibility for the first missions to Mercury, Venus and Mars, as well as for the first U.S. lunar lander, "Surveyor" and the "Voyager" missions to Jupiter, Saturn, Uranus and Neptune. His final position at the Jet Propulsion Laboratory was deputy director, but throughout all his assignments his task was the same: to make sure the flight missions worked. Because of his expertise and dedication, they did. (M 25977)

\section{(5591) Koyo}

$1990 \mathrm{VF}_{2}$. Discovered 1990 Nov. 10 by T. Urata at Oohira.

Named in honor of Koyo Kawanishi (1959- ), a dentist living in Ako-city, Hyogo. He has been observing comets and minor planets using his homemade $0.20-\mathrm{m}$ reflector at his private observatory with his wife Kumi and daughter Saki. Familiar with electronics and mechanics, he has developed his own CCD instrumentation. (M 22511)

\section{(5592) Oshima}

$1990 \mathrm{VB}_{4}$. Discovered 1990 Nov. 14 by K. Suzuki and T. Urata at Toyota.

Named in honor of Yoshiaki Oshima (1952- ), discoverer of the Apollo-type minor planet 1988 XB and several other minor planets. He contributed to the development of the instrumentation at the Nihondaira \{see planet (2880)\} Observatory. (M 22511) Name proposed by T. Urata.

\section{(5593) Jonsujatha}

$1991 \mathrm{JN}_{1}$. Discovered 1991 May 9 by E. F. Helin at Palomar.

Named in honor of Jonathan Brian Marsden and Sujatha Nagarajan on the occasion of their wedding on 1993 Nov. 14 in Lexington, Massachusetts. Jon and Sujatha are talented young professionals who are friends and neighbors of the discoverer in California. Hearty good wishes are extended to them for a long, healthy and happy life together. (M 22831)

\section{(5594) Jimmiller}

$1991 \mathrm{NK}_{1}$. Discovered 1991 July 12 by H. E. Holt at Palomar

Named in honor of James K. Miller (1939- ), celestial mechanics and orbital dynamics expert at the Jet Propulsion Laboratory. Miller played a key role in navigating the NEAR spacecraft and in determining the mass of (433) Eros from perturbations of the NEAR spacecraft's trajectory. (M 35483)

Name and citation provided by J. Veverka and D. K. Yeomans.

\section{(5595) Roth}

1991 PJ. Discovered 1991 Aug. 5 by H. E. Holt at Palomar.

Named in honor of Mary L. Roth (1935- ), executive assistant to the organizing committee of the "Asteroids, Comets, Meteors" meeting held at Cornell University in July 1999. Roth has been a diligent contributor to the Cornell space effort for the past 25 years, encompassing missions such as Viking, Voyager, Galileo, NEAR and CONTOUR. (M 35483)

Name suggested by B. E. Clark and citation provided by J. Veverka.

\section{(5596) Morbidelli}

$1991 \mathrm{PQ}_{10}$. Discovered 1991 Aug. 7 by H. E. Holt at Palomar.

Named in honor of Alessandro Morbidelli (1966- ). From Cuneo, in extreme western Italy, he joined the solar system dynamics group in Nice $(50 \mathrm{~km}$ to the south) as an H. Poincaré \{see planet (2021)\} postdoctoral fellow and became a permanent staff member in 1993. Morbidelli's main interests are the theory of dynamical systems and resonances in the solar system. For his pioneering work on the overlapping of mean-motion and secular resonances, Morbidelli was awarded the bronze medal of the CNRS in 1995. (M 27460)

Name proposed and citation provided by H. Scholl.

\section{(5597) Warren}

$1991 \mathrm{PC}_{13}$. Discovered 1991 Aug. 5 by H. E. Holt at Palomar. 
Named in honor of Jeffery Warren (1960- ), optical engineer at the Applied Physics Laboratory of Johns Hopkins University. Warren was responsible for the design, fabrication and operation of a major instrument on the NEAR spacecraft, the Near-Infrared Spectrometer (NIS). The NIS investigation represents the first-ever mapping of the surface of a minor planet from orbit. (M 35483)

Name suggested and citation provided by J. Veverka.

\section{(5598) Carlmurray}

$1991 \mathrm{PN}_{18}$. Discovered 1991 Aug. 8 by H. E. Holt at Palomar.

Named in honor of Carl Desmond Murray (1955-

), of Queen Mary and Westfield College, London, in recognition of his immense contribution to our understanding of the dynamics of the minor bodies of the solar system. In particular, he has investigated the effects of various resonances on a number of sub-systems within the solar system; for example, the Kirkwood \{see planet (1578)\} gaps and the interrelationships between ring structures and small satellites around the giant planets. (M 27460)

Citation prepared by I. P. Williams.

\section{(5603) Rausudake}

1992 CE. Discovered 1992 Feb. 5 by K. Endate and K. Watanabe at Kitami.

Named for the mountain in the Shiretoko range in Hokkaido \{see planets (3867) and (3720), respectively\}. Known as the "Shiretoko Fuji", this 1661-meter mountain is in the Shiretoko peninsula that juts into the Sea of Okhotsk \{see planets (3867), (4042)\}. (M 25977)

\section{(5605) Kushida}

1993 DB. Discovered 1993 Feb. 17 by S. Otomo at Kiyosato.

Named in honor of Yoshio Kushida (1957- ), Japanese seismologist. Discoverer of numerous minor planets and comets since 1989, he is also an active confirmer of new objects in collaboration with S. Nakano \{see planet (3431)\}. He established Yatsugatake South Base Observatory to the benefit of many amateur astronomers. (M 35483)

\section{(5606) Muramatsu}

1993 EH. Discovered 1993 Mar. 1 by S. Otomo at Kiyosato.

Named in honor of Osamu Muramatsu (1949- ), who works at the planetarium in Sibuya and who has discovered numerous minor planets and comets since 1986. (M 35483)

\section{(5609) Stroncone}

1993 FU. Discovered 1993 Mar. 22 by A. Vagnozzi at Stroncone.

Named for the suburb where the Santa Lucia observatory is based. The name Stroncone is thought to come from the Greek 'astronicos', from 'astron' (star) and 'icons' (image), so it is a very appropriate name for the site of an astronomical observatory. (M 23353)

\section{(5610) Balster}

2041 T-3. Discovered 1977 Oct. 16 by C. J. van Houten and I. van Houten-Groeneveld at Palomar.

Named in honor of Harry A. M. Balster (1946- ) and his younger sister Yvonne. Harry is a very active amateur astronomer in Nijmegen, The Netherlands. His main fields of interest are sunspot research and making the general public enthusiastic for astronomy. By profession he is an electronic engineer. When I. van Houten was measuring her plates at Nijmegen, Harry always helped when there was something wrong with the measuring engine. His sister was a programmer and general assistant in the Nijmegen astronomy department, and she was just as great a help for I. van Houten as her brother. (M 23541; M 25351)

\section{(5612) Nevskij}

$1975 \mathrm{TX}_{2}$. Discovered 1975 Oct. 3 by L. I. Chernykh at Nauchnyj.

Named for Novgorod prince Aleksandr Yaroslavich (1220-1263), astute politician and skilled military leader of Russian troops who defended northwestern Russia from annexation by Swedish and German feudal lords. He was named Nevskij for his victory over Swedish troops at the Neva River in 1240, and he is also famous for his defeat of Teutonic knights at Chudskoe Lake in 1242. (M 30097)

\section{(5613) Donskoj}

1976 YP $_{1}$. Discovered 1976 Dec. 16 by L. I. Chernykh at Nauchnyj.

Named for Dmitrij Donskoj (1350-1389), Alexandr Nevskij's \{see planet (5612)\} great-grandson, grand prince of Moscow and Vladimir principalities. He led the Russian struggle against the Tatar-Mongolian yoke and was named Donskoj for his victory over the Tatar-Mongolians in the 1380 battle at Kulikovo field between the Don and the Nepryadva \{see planet (2869)\} rivers. This historic victory of joint Russian troops under Dmitrij's leadership began the liberation of Russian lands from the Tatars. (M 30097)

\section{(5614) Yakovlev}

1979 VN. Discovered 1979 Nov. 11 by N. S. Chernykh at Nauchnyj.

Named in honor of Konstantin Karol'evich Yakovlev (1954- ), director of the St. Petersburg scientificproduction firm "Blok". Yakovlev takes an interest in astronomy and is rendering technical support in the restoration of the Crimean $64-\mathrm{cm}$ telescope and equipping it for the observation of near-earth objects. (M 27330; M 27749)

\section{(5615) Iskander}

1983 PZ. Discovered 1983 Aug. 4 by L. G. Karachkina at Nauchnyj. 
Named in honor of Fazil' Abdulovich Iskander (1929), well-known writer, poet, essayist, author of the humorous Sandro from Chegem and the winner of such literature prizes as the Pushkin \{see also planet (2208)\}. He is a vice-president of the Russian Pen Club. (M 23139)

Name suggested by L. R. Nemirovskij.

\section{(5616) Vogtland}

1987 ST $_{10}$. Discovered 1987 Sept. 29 by F. Börngen at Tautenburg.

Named after the mountainous district of Germany that lies partly in Saxony, Thuringia, Bavaria and Bohemia. (M 22831)

\section{(5617) Emelyanenko}

1989 EL. Discovered 1989 Mar. 5 by E. F. Helin at Palomar.

Vyacheslav Emelyanenko (1952- ), head of the department of theoretical mechanics at South Ural University, has made a lifetime study of celestial mechanics, with major contributions to understanding the dynamical evolution of comets, minor planets and meteoroid streams. (M 41934)

The name was suggested by M. Bailey.

\section{(5618) Saitama}

1990 EA. Discovered 1990 Mar. 4 by A. Sugie at Taga. Named for the Japanese prefecture. (M 27734)

\section{(5619) Shair}

$1990 \mathrm{HC}_{1}$. Discovered 1990 Apr. 26 by E. F. Helin at Palomar.

Named in honor of Fredrick H. Shair, manager of the Educational Affairs Office at the Jet Propulsion Laboratory and former dean of the College of Natural Sciences and Mathematics at California State University, Long Beach, and professor at the California Institute of Technology. While at CALTECH, he established the Summer Undergraduate Research Fellowship (SURF) \{see planet (5181)\} Program, which integrates students' classroom experience with a research environment. Shair has been honored with numerous awards for his teaching excellence. The discoverer has been a SURF sponsor since the early years of the program. (M 23541)

Name heartily endorsed by Shair's many friends and colleagues.

\section{(5621) Erb}

1990 SG$_{4}$. Discovered 1990 Sept. 23 by K. J. Lawrence at Palomar.

Named in honor of Bryan and Dona Erb, friends of the discoverer. Brian is assistant director of the Canadian Space Agency, Canadian liaison officer to NASA's Johnson Space Center and assistant program manager for the space station. Dona is a software engineer working on ground control facilities. Both are currently working on the space station. The Erbs played an important role in generating the discoverer's interest in space physics. (M 25654; M 26599)

\section{(5623) Iwamori}

1990 UY. Discovered 1990 Oct. 20 by A. Sugie at Taga.

Named in memory of Yasuke Iwamori, late principal of Kyoto \{see planet (4352)\} city Rakuyou \{see planet (5825)\} technical high school who taught physics and astronomy there. (M 27735)

Name proposed by the discoverer following a suggestion by S. Sakabe.

\section{(5624) Shirley}

1991 AY $_{1}$. Discovered 1991 Jan. 11 by E. F. Helin at Palomar.

Named in honor of Mr. and Mrs. William J. Shirley in recognition of their generous, enthusiastic support of Caltech and Mt. Wilson Observatory. They have preserved and restored the Hale Solar Observatory in San Marino, a landmark of scientific and historical significance that they share generously with the community and educational groups for visits and study. (M 22831)

Name endorsed by their many friends.

\section{(5628) Preußen}

$1991 \mathrm{RP}_{7}$. Discovered 1991 Sept. 13 by L. D. Schmadel and F. Börngen at Tautenburg.

Named for the former kingdom and German state of Prussia and for the so-called Prussian virtues of sense of duty, austerity, punctuality, order and unselfishness. Prussia, originally the name of the region at the southern end of the Baltic Sea, became a duchy in 1525. In 1701, Frederick I became king of Prussia and established his capital at Berlin. The defeat of Napoleon yielded a great territorial enlargement of Prussia. The victory over France in 1870 resulted in the creation of the German Empire, which declined in 1918. The name Prussia was abolished in World War II; the Prussian virtues, however, continue to be desirable. (M 27330)

Name proposed by the first discoverer, whose birthplace is Berlin.

\section{(5629) Kuwana}

$1993 \mathrm{DA}_{1}$. Discovered 1993 Feb. 20 by T. Hioki and S. Hayakawa at Okutama.

Kuwana is a city located in the delta of the Nagara and Ibe rivers, near the city of Nagoya and the Yoro and Suzuka mountains. Kuwana is the sister city of Gyoda \{see planet (5138)\}, where the second discoverer lives. (M 25230)

\section{(5630) Billschaefer}

1993 FZ. Discovered 1993 Mar. 21 by J. B. Child at Palomar.

Named in honor of William Schaefer, telescope maker and amateur astronomer. For over forty years Bill 
Schaefer has been producing precision telescopes for amateur astronomers throughout the United States. His enthusiasm, skill and creativity have sparked the interest and involvement of hundreds of people, young and old, and have raised the quality of amateur astronomy in the Southern California community. He has patiently shared his knowledge with other telescope makers, and his award-winning telescopes will serve serious observers throughout the world for many years to come. (M 22831)

\section{(5631) Sekihokutouge}

$1993 \mathrm{FE}_{1}$. Discovered 1993 Mar. 20 by K. Endate and K. Watanabe at Kitami.

Named for a pass in central Hokkaido s see planet (3720)\}. At an altitude of 1050 meters, the pass connects the Taisetsu mountain range, Hokkaido's highest peak, with the city of Kitami \{see planet (3785)\}. (M 25977)

\section{(5632) Ingelehmann}

1993 GG. Discovered 1993 Apr. 15 by C. S. Shoemaker and E. M. Shoemaker at Palomar.

Named in honor of Inge Lehmann (1888-1993), Danish seismologist and a pioneer in the field when the science of seismology was still young and unexplored. She made fundamental contributions to the study of geophysics and was the first chief of the seismology department of the newly established Royal Danish Geodetic Institute. Her most important contribution suggested a new discontinuity in the seismic structure of the earth, now known as the Lehmann discontinuity, a region that divides the core into inner and outer parts. In later years, Lehmann became an authority on the structure of the upper mantle. (M 29670; M 29691)

Obituary published in Q.J.R. Astron. Soc., Vol. 35, No. 2, p. 231-234 (1994)

\section{(5635) Cole}

$1981 \mathrm{ER}_{5}$. Discovered 1981 Mar. 2 by S. J. Bus at Siding Spring.

Named for the fictional character Joshua Cole, amateur astronomer and star of Arthur Preston Hankin's 1923 novel Cole of Spyglass Mountain. A character reminiscent of Oliver Twist, Cole studied variable stars while incarcerated in a reformatory in which the boys do not use names but numbers; Cole's is 5635. He survived one crisis after another, inlcuding a near-fatal shooting in his observatory at the moment he discovered evidence of life on Mars. (M 31024)

Name proposed by the discoverer following a suggestion by D. H. Levy, who prepared the citation.

\section{(5636) Jacobson}

1985 QN. Discovered 1985 Aug. 22 by E. Bowell at Anderson Mesa.

Robert A. Jacobson (1944- ) is a noted authority on spacecraft navigation techniques, and he is currently developing ephemerides for natural satellites at the
Jet Propulsion Laboratory. He was instrumental in generating the accurate satellite ephemerides used by the Voyager 2 spacecraft project during its encounters with Uranus and Neptune. These ephemerides were developed using both ground-based astrometry and spacecraft optical navigation data. (M 22831)

Citation prepared by D. K. Yeomans, a colleague of the honoree.

\section{(5637) Gyas}

1988 RF $_{1}$. Discovered 1988 Sept. 10 by C. S. Shoemaker and E. M. Shoemaker at Palomar.

A companion of Aeneas \{see planet (1172)\}, Gyas took part in the boat race at the funeral games for Anchises \{see planet (1173)\}. He captained the Chimaera \{see also the citation for planet (623)\}, a boat huge in length and weight. He came in third when he was slowed by the loss of his helmsman, whom he threw overboard in anger because he sailed too wide of a dangerous rock. (M 25444)

\section{(5638) Deikoon}

1988 TA $_{3}$. Discovered 1988 Oct. 10 by C. S. Shoemaker and E. M. Shoemaker at Palomar.

Deikoon was a son of Pergasos and a friend of Aeneas \{see planet (1172)\}. He was a spear fighter and a man much honored by the Trojans, because he was quick to join the battle line. He was killed by the thrust of Agamemnon's \{see planet (911)\} spear through his shield. (M 25444)

\section{(5640) Yoshino}

1989 UR $_{3}$. Discovered 1989 Oct. 21 by M. Mukai and M. Takeishi at Kagoshima.

Named for the hometown of the first discoverer. Part of Kagoshima \{see planet (4703)\} City, it lies at the southern tip of Kyushu island. (M 33786)

\section{(5641) McCleese}

1990 DJ. Discovered 1990 Feb. 27 by E. F. Helin at Palomar.

Named in honor of Daniel J. McCleese, whose research is primarily in atmospheric physics and infrared instrumentation for remote sensing of planetary atmospheres. As manager of the Jet Propulsion Laboratory's Earth and Space Science Division, he includes in his purview all science aspects of the NearEarth Asteroid Tracking program. The discoverer and other NEAT team members wish to recognize the important role he played in the establishment of the program. (M 26930)

\section{(5642) Bobbywilliams}

1990 OK $_{1}$. Discovered 1990 July 27 by H. E. Holt at Palomar.

Named in honor of Bobby G. Williams (1951- ), celestial mechanics and spacecraft navigation expert at the Jet Propulsion Laboratory. Williams has been a leader of the navigation effort for the NEAR mission to (253) Mathilde and (433) Eros. (M 35483) 
Name suggested and citation provided by J. Veverka and D. K. Yeomans.

\section{(5643) Roques}

$1990 \mathrm{QC}_{2}$. Discovered 1990 Aug. 22 by H. E. Holt at Palomar.

Named in honor of Françoise Roques (1956- ) for her work on the dynamics of planetary and circumstellar disks. Roques has numerically explored the interaction of circumstellar dust disks with embedded planets and has applied her work both to the $\beta$ Pictoris system and to binary stars. She has also observed stellar occultations by the giant planets with the principal goal of analyzing the dynamics of the planetary atmospheres. (M 27460)

Citation provided by M. A. Barucci following a suggestion by E. Bowell.

\section{(5644) Maureenbell}

$1990 \mathrm{QG}_{2}$. Discovered 1990 Aug. 22 by H. E. Holt at Palomar.

Maureen E. Ockert-Bell (1961- ), an imageprocessing specialist at Cornell University, has published results on the physical and optical properties of the Saturnian, Uranian and Jovian ring systems, on the physical and radiative properties of dust in Mars' atmosphere, and on clouds in Earth's atmosphere. (M 36126)

\section{(5649) Donnashirley}

$1990 \mathrm{WZ}_{2}$. Discovered 1990 Nov. 18 by E. F. Helin at Palomar.

Named in honor of Donna Shirley, manager of the highly successful Mars Exploration program at NASA's Jet Propulsion Laboratory. She managed the robotics development program that produced Sojourner, the automated rover that explored the surface of Mars in mid-1997. She was also project engineer for the Cassini mission, the spacecraft now on its way to explore Saturn, as well as the project engineer for Mariner 10, which flew by Mercury in the 1970s. In her thirty years at JPL she has had many other successful assignments in space exploration and in the development of non-space systems using space technology. She has balanced a demanding career with parenthood, writing, acting and music. (M 31024)

\section{(5650) Mochihito-o}

1990 XK. Discovered 1990 Dec. 10 by A. Natori and T. Urata at Yakiimo.

Prince Mochihito-o (1151-1180) was the third son of emperor Goshirakawa \{see planet (3585)\}. He was a fount of knowledge, known for his poetry and for playing the Japanese flute. With Minamoto Yorimasa \{see planet (5744)\}, he fought against the Heike without success. (M 36944)

\section{(5651) Traversa}

$1991 \mathrm{CA}_{2}$. Discovered 1991 Feb. 14 by E. W. Elst at St. Michel.
In honor of Gilles Traversa, technical night-assistant at the Observatory of Haute Provence. He has been involved mainly in the Fehrenbach \{see planet (3433)\} Program of Radial Velocities and has made observations at Zeekoegat (South Africa), La Silla (Chile) and Haute Provence, where he has observed with the Grand Prisme Objectif (GPO), the PPO (Petit Prisme Objectif) and the Schmidt telescope. From 1986 to 1993 he has been of irreplaceable help to, and has become a very good friend of, the discoverer during the observations at Haute Provence. (M 23353)

\section{(5652) Amphimachus}

1992 HS $_{3}$. Discovered 1992 Apr. 24 by C. S. Shoemaker and E. M. Shoemaker at Palomar.

Amphimachus was the great-hearted son of Aktorian Kteatos. He had been a suitor of Helen ssee planet (101)\}. He was a leader of the Epeians and was accidentally killed by Hector's \{see planet (624)\} spear, which had been thrown at Teucer see planet (2797)\} and had missed. (M 25444)

\section{(5653) Camarillo}

1992 WD $_{5}$. Discovered 1992 Nov. 21 by E. F. Helin and K. J. Lawrence at Palomar.

At his private observatory in Camarillo, John Rogers secured follow-up observations of this minor planet. On California's El Camino Real, the town was named by the Southern Pacific Railroad in 1901 in tribute to Adolfo Camarillo (1864-1958), a prominent local rancher. The first discoverer is a former town resident. (M 43189)

\section{(5654) Terni}

1993 KG. Discovered 1993 May 20 by A. Vagnozzi at Stroncone.

Named for the city located in a natural amphitheater, at the confluence of the Serra and Nera rivers. Founded in A.D. 672, the city (ancient name Interamna), \{see also the citation for planet (704)\} has long been famous for the nearby Marmore falls and is now an important industrial center. (M 23353)

\section{(5655) Barney}

1159 T-2. Discovered 1973 Sept. 29 by C. J. van Houten and I. van Houten-Groeneveld at Palomar.

Named in memory of Ida Barney (1886-1982), astronomer at the Yale Observatory from 1924 to 1959 and supervisor of the Yale Zone Catalogue program of positions and proper motions of stars. (M 23541)

\section{(5656) Oldfield}

A920 TA. Discovered 1920 Oct. 8 by W. Baade at Bergedorf.

Named in honor of Mike Oldfield (1953- ), English composer and multi-instrumentalist, best known for Tubular Bells, his 1973 album that has influenced a generation of contemporary musicians. In addition to numerous studio recordings, Oldfield wrote the moving soundtrack to the 1984 film The Killing Fields. (M 23353) 
Name proposed by G. V. Williams, who made the identifications involving this object.

\section{(5658) Clausbaader}

1950 DO. Discovered 1950 Feb. 17 by K. Reinmuth at Heidelberg.

Named in memory of Claus Baader (1824-1995), German manufacturer of planetaria, domes and telescopes, and well-known mentor of amateur astronomers in the German-speaking countries. A design engineer by profession and self-taught in astronomy, Baader constructed a new type of a small desktop planetarium that is in use in schools in many countries throughout the world. In his later years Baader, together with his son and successor Thomas, was deeply concerned with the construction and development of observatory domes, astronomical telescopes and their auxiliary instrumentation for amateur and professional astronomers alike. (M 25977)

Name proposed and citation prepared by L.D.Schmadel.

Obituaries published in Sterne Weltraum, Jahrg. 35, Nr. 2, p. 152-153 (1996); Mitt Astron. Ges., Nr. 80, p. 5-7 (1997).

\section{(5661) Hildebrand}

$1977 \mathrm{PO}_{1}$. Discovered 1977 Aug. 14 by N. S. Chernykh at Nauchnyj.

This Hilda group member is named in honor of the well-known Canadian geologist Alan R. Hildebrand (1955- ), who discovered that the Chicxulub Crater in the Yucatan region resulted from an asteroid impact that coincided with the terminal Cretaceous extinctions. His linking of a "smoking gun" to a major extinction event in geologic history provided evidence of fundamental importance to the resolution of a centuries-old debate on the demise of the dinosaurs and the occurrence of catastrophes in the earth's history. Hildebrand also has been highly supportive of the asteroid research program at the University of Victoria. (M 24410)

Named by the discoverer at the suggestion of J. B. Tatum. Citation provided by D. Russell.

\section{(5662) Wendycalvin}

$1981 \mathrm{EL}_{4}$. Discovered 1981 Mar. 2 by S. J. Bus at Siding Spring.

Wendy Calvin (1961- ) has made many important contributions to the field of planetary spectroscopy. Her work has included spectral studies of the martian surface and polar caps, Charon, Callisto and Ganymede. She has also helped pioneer the concept of using aircraft in the exploration of Mars. (M 46006)

\section{(5663) McKeegan}

1981 EQ 12 . Discovered 1981 Mar. 1 by S. J. Bus at Siding Spring.

Kevin McKeegan (1958- ), professor of geochemistry at the University of California in Los Angeles, has pioneered isotopic measurements with the ion microprobe and used the data to decipher the origins and histories of interplanetary dust particles, as well as refractory inclusions in chondrites. (M 46006)

\section{(5664) Eugster}

$1981 \mathrm{EX}_{43}$. Discovered 1981 Mar. 6 by S. J. Bus at Siding Spring.

Otto Eugster (1938- ), professor at the University of Bern, investigates the chronologies and exposure histories of meteorites in space based on cosmic-ray effects. His work on the cosmic-ray exposure of lunar regolith has been fundamental to understanding the complex history of lunar materials. (M 46006)

\section{(5665) Begemann}

1982 BD $_{13}$. Discovered 1982 Jan. 30 by S. J. Bus at Palomar.

Friedrich Begemann (1927- ), director emeritus of the Max-Planck-Institut für Chemie at Mainz, is a pioneering cosmochemist who determined the first cosmic-ray-exposure age of a meteorite. $\mathrm{He}$ later investigated isotopic anomalies in meteorites and established the physical conditions that produced these anomalies. (M 46006)

\section{(5666) Rabelais}

1982 TP $_{1}$. Discovered 1982 Oct. 14 by L. G. Karachkina at Nauchnyj.

Named in memory of François Rabelais (c.14941553), great French writer, outstanding representative of European humanism and the author of the immortal literary works La vie inestimable du grand Gargantua, Père de Pantagruel and Pantagruel. (M 23139)

The name is given on the occasion of the fivehundredth anniversary of his birth, following a suggestion by the St. Petersburg House of Satire and Humor.

\section{(5667) Nakhimovskaya}

$1983 \mathrm{QH}_{1}$. Discovered 1983 Aug. 16 by T. M. Smirnova at Nauchnyj.

Named on the occasion of the 50th anniversary of the Nakhimov Nautical College (St. Petersburg) named after an outstanding Russian naval commander, Pavel Stepanovich Nakhimov (1802-1855). Founded to train young navigators, many of the colleges former students have become experienced captains and prominent scientists, who have made considerable contributions to the development of Russian science and the Russian navy. (M 23793)

The name is given by the Institute of Theoretical Astronomy, following a suggestion by the college.

\section{(5668) Foucault}

1984 FU. Discovered 1984 Mar. 22 by A. Mrkos at Kleť.

Named in memory of Jean Bernard Léon Foucault (1819-1868), French physicist and astronomer, well known for his pendulum demonstration of the earth's rotation, first in Paris in 1851. (M 30476)

Name suggested by J. Tichá, M. Tichý and Z. Moravec. 


\section{(5670) Rosstaylor}

$1985 \mathrm{VF}_{2}$. Discovered 1985 Nov. 7 by C. S. Shoemaker and E. M. Shoemaker at Palomar.

Named in honor of Stuart Ross Taylor, one of the world's leading geochemists, who has worked extensively on the abundances of the elements in the earth, moon and meteorites. His high-precision analyses have taught us much about the origin and evolution of the earth's continental crust, the sources of magmas, and the origin and evolution of the moon. As an author, he has presented comprehensive overviews of lunar and planetary science. (M 29670)

\section{(5671) Chanal}

1985 XR. Discovered 1985 Dec. 13 by the CERGA at Caussols.

Named in honor of Roger Chanal, French amateur astronomer and friend of the discoverer. Roger has over the years built a well-equipped observatory and is a contributor to the MPCs. Apart from his interest in asteroid astrometry, he is also the discoverer of V1118 Orionis, temporarily named "Chanal's object". (M 23793)

Name suggested by the discoverer, Robert Chemin, and endorsed by the entire OCA Schmidt telescope team.

Officially, the institution CERGA serves as corporate discoverer.

\section{(5672) Libby}

$1986 \mathrm{EE}_{2}$. Discovered 1986 Mar. 6 by E. Bowell at Anderson Mesa.

Named in honor of Eleanor W. Libby, founder and president of the Donald Ware Waddell Foundation, which has provided funds to arts organizations, museums, and to cancer research. Libby's generosity has done much to enhance the visitors' program at Lowell Observatory. (M 23541)

Name suggested by W. L. Putnam, citation provided by Putnam and M. L. Evans.

\section{(5673) McAllister}

$1986 \mathrm{RT}_{2}$. Discovered 1986 Sept. 6 by E. Bowell at Anderson Mesa.

Named in honor of Frances McAllister, humanitarian and leading philanthropist of Flagstaff, Arizona. Founder of The Arboretum at Flagstaff, a center of horticulture and plant research, McAllister sponsored a program that allowed high-school students to observe $\mathrm{P} /$ Halley in 1985-86 and has helped considerably to improve Lowell Observatory's library and scientific facilities. (M 23541)

Names suggested by W. L. Putnam, citation provided by Putnam, O. G. Franz and M. L. Evans.

\section{(5674) Wolff}

$1986 \mathrm{RW}_{2}$. Discovered 1986 Sept. 6 by E. Bowell at Anderson Mesa.

Named in honor of John M. Wolff, a long-time trustee of the Wolff Foundation. Endowed by Wolff's father, the foundation has provided support for children's hospitals, for children with special needs, and for arts and music organizations in Phoenix, Arizona, and St. Louis, Missouri. Generous donations to Lowell Observatory have enabled the construction of automated offset guiders and other instrumentation. (M 23541)

Name suggested by W. L. Putnam, citation provided by Putnam and M. L. Evans.

\section{(5675) Evgenilebedev}

1986 RY $_{5}$. Discovered 1986 Sept. 7 by L. I. Chernykh at Nauchnyj.

Named in honor of Evgenij Alekseevich Lebedev (1917-1997), an actor at the Tovstonogov Bolshoi Dramatic Theater in St. Petersburg and a People's Artist of the U.S.S.R. The summit of his art was the unusual role of the horse in the performance History of a horse, after a story by Tolstoj \{see planet (3771)\}. (M 34622)

\section{(5676) Voltaire}

$1986 \mathrm{RH}_{12}$. Discovered 1986 Sept. 9 by L. G. Karachkina at Nauchnyj.

Named in memory of Marie François Arouet (Voltaire) (1694-1778), the great French writer, philosopher, historian, inspirer of French enlightenment during the eighteenth century, and the acknowledged leader of the age. (M 23139)

The name is given on the occasion of the threehundredth anniversary of his birth, following a suggestion by the St. Petersburg House of Satire and Humor.

Voltaire is also honored by a crater on the Mars satellite Deimos.

\section{(5677) Aberdonia}

1987 SQ . Discovered 1987 Sept. 21 by E. Bowell at Anderson Mesa.

Named in honor of the University of Aberdeen on the occasion of the quincentenary of its founding, 1995 Feb. 10. The University is noted as having been home to the first chair of medicine in the Englishspeaking world. The teaching of natural philosophy was established more than 400 years ago, and the earliest record of the teaching of astronomy dates back to 1593. Occupants of chairs of natural philosophy include James Clerk Maxwell and more recently the Nobel laureate George Paget Thomson. (M 24765)

\section{(5678) DuBridge}

1989 TS. Discovered 1989 Oct. 1 by E. F. Helin at Palomar.

Named in memory of Lee Alvin DuBridge (19011994), noted nuclear physicist and former president of the California Institute of Technology. DuBridge set an extraordinary example of excellence in scientific research and the administration of science. Included among his many accomplishments was the establishment and direction of the Massachusetts Institute of Technology's radiation laboratory for the development of radar. In the field of science he was a key advisor to several U.S. presidents. (M 23139) 
This tribute, initiated before DuBridge's death, is endorsed by his many friends and colleagues and the discoverer's husband, Ron Helin, who was a student during DuBridge's presidency at Caltech.

\section{(5679) Atsukadou}

1989 VR. Discovered 1989 Nov. 2 by K. Endate and K. Watanabe at Kitami.

Named for one of Japan's largest stalactite caves, located in Iwate Prefecture. (M 25977)

\section{(5681) Bakulev}

$1990 \mathrm{RS}_{17}$. Discovered 1990 Sept. 15 by L. V. Zhuravleva at Nauchnyj.

Named in memory of Aleksandr Nikolaevich Bakulev (1890-1967), one of the pioneers of neurosurgery in the U.S.S.R. He made advances in kidney surgery, bone surgery and a surgical treatment for stomach ulcers. (M 34622)

\section{(5682) Beresford}

1990 TB. Discovered 1990 Oct. 9 by R. H. McNaught at Siding Spring.

Named in honor of Anthony Charles Beresford (1942- ), prominent Australian amateur astronomer. Amongst his wide ranging astronomical interests he is an active artificial satellite observer, having been part of Operation Moonwatch from 1960 to 1975. He plays an important role in the dissemination of astronomical information and discoveries in South Australia. Always knowledgable about current events, Tony Beresford has been of considerable help to the discoverer on many occasions. (M 34341)

Name suggested and citation endorsed by D. I. Steel.

\section{(5683) Bifukumonin}

1990 UD. Discovered 1990 Oct. 19 by T. Urata at Oohira.

Bifukumon-in Tokushi (1117-1160) was the empress of emperor Toba. Her interference in the succession of emperor Goshirakawa \{see planet (3585)\} became a cause of the war of Hogen. (M 36944)

\section{(5684) Kogo}

$1990 \mathrm{UB}_{2}$. Discovered 1990 Oct. 21 by T. Urata at Oohira.

Kogo-no-Tsubone was the lover of emperor Takakura \{see planet (5578)\}. She is the most well-known heroine in the story of Heike. She excelled at playing Koto, the Japanese lyre, but she was ostracized from the palace and went to live in seclusion. (M 36944)

\section{(5685) Sanenobufukui}

1990 XA. Discovered 1990 Dec. 8 by T. Nomura and K. Kawanishi at Minami-Oda.

Named in honor of Sanenobu Fukui (1916- ), a well-known observer of Mars for more than 60 years. He was a director of the Oriental Astronomical Association and one of the leaders of its Kobe branch. (M 35483)

\section{(5686) Chiyonoura}

1990 YQ. Discovered 1990 Dec. 20 by M. Matsuyama and K. Watanabe at Kushiro.

Named for a beautiful sandy beach between Bentengahama $\{$ see planet (5293)\} and Shiundai, in the southern part of the city of Kushiro \{see planet (4096)\}. A new port is under construction, and the beach is gradually disappearing as a result of erosion. (M 26930)

\section{(5687) Yamamotoshinobu}

$1991 \mathrm{AB}_{1}$. Discovered 1991 Jan. 13 by Y. Kushida and O. Muramatsu at Yatsugatake.

Named in honor of Shinobu Yamamoto (1911- ), who served as director of the Gotoh Planetarium in Tokyo from 1987 to 1990. In the 1950s, he had made a great effort to establish that planetarium, following the destruction of its predecessor during World War II. Completed in 1957, the Gotoh Planetarium immediately attracted many people, as the first artificial satellites were launched at that time. (M 29145)

\section{(5688) Kleewyck}

$1991 \mathrm{AD}_{2}$. Discovered 1991 Jan. 12 by E. F. Helin at Palomar.

The name Klee Wyck was given by Vancouver Island's coastal people to the famous Victoria artist Emily Carr on one of her many painting expeditions into the coastal wilderness in the early 1900s. The name in the Nuu-Chah-Nulth people's language translates to "the smiling one". The name was also used for the friendly orca that served as the official mascot to the fifteenth Commonwealth Games held in Victoria, British Columbia, 1994 Aug. 18-28. By way of compensation for a small and temporary amount of light interference during the games, the Victoria Commonwealth Games Society has been strongly supportive of the asteroid research program at the University of Victoria, and the name chosen for this asteroid reflects the gratitude of the university's astronomers to the society. (M 24410)

Name proposed by the discoverer at the suggestion of J. B. Tatum. Citation prepared by A. Tanner.

\section{(5689) Rhön}

1991 RZ $_{2}$. Discovered 1991 Sept. 9 by F. Börngen and L. D. Schmadel at Tautenburg.

Named for the range of young volcanic mountains that lie across Bavaria, Hesse and Thuringia. Name proposed by the first discoverer, who considers this region to be one of the most beautiful in Germany. (M 22831)

\section{(5692) Shirao}

1992 FR. Discovered 1992 Mar. 23 by K. Endate and K. Watanabe at Kitami.

Named in honor of Motomaro Shirao (1953- ), a geologist and photographer whose specialties are volcanoes, geological features and the moon. (M 26930) 


\section{(5694) Berényi}

3051 P-L. Discovered 1960 Sept. 24 by C. J. van Houten and I. van Houten-Groeneveld at Palomar.

Named in honor of Dénes Berényi (1928- ), professor of the Institute of Nuclear Research of the Hungarian Academy of Sciences in Debrecen and for many years its director. His research activities include nuclear physics, atomic collision processes and electron spectrometry. In 1990 Berényi became vice-president of the Hungarian Academy of Sciences. (M 24918)

Name proposed by K.-O. Groeneveld, who works in the same fields.

See also the citation for planet (5699).

\section{(5695) Remillieux}

4577 P-L. Discovered 1960 Sept. 24 by C. J. van Houten and I. van Houten-Groeneveld at Palomar.

Named in honor of Joseph Remillieux (1940- ), professor at the Institut de Physique Nucléaire de l'Université de Lyon and vice-president of that university. His research interest is atomic collision processes in solids. (M 24918)

Name proposed by K.-O. Groeneveld.

See also the citation for planet (5699).

\section{(5696) Ibsen}

4582 P-L. Discovered 1960 Sept. 24 by C. J. van Houten and I. van Houten-Groeneveld at Palomar.

Named in memory of the famous Norwegian writer Henrik Ibsen (1828-1906), whose most important tragedies are Peer Gynt, Nora, Ghosts, and Hedda Gabler. Ibsen lived in Germany for 20 years, before returning to Norway in 1891. His influence on the modern theater was very great. (M 25977)

See also the citation for planet (5699).

\section{(5697) Arrhenius}

6766 P-L. Discovered 1960 Sept. 24 by C. J. van Houten and I. van Houten-Groeneveld at Palomar.

Named in memory of the Swedish physicochemist Svante August Arrhenius (1859-1927). A professor in Stockholm, he received the Nobel Prize for chemistry in 1903. He was the first to explain, in 1900, the formation of the tails of comets as a result of radiation pressure. (M 25977)

Arrhenius is also honored by craters on Mars and on the Moon. See also the citation for planet (5699).

\section{(5698) Nolde}

4121 T-1. Discovered 1971 Mar. 26 by C. J. van Houten and I. van Houten-Groeneveld at Palomar.

Named in memory of the German expressionist painter Emil Nolde (1867-1957, real name Emil Hansen). He was a member of a group of artists called 'Die Brücke' and after 1926 lived in Seebüll together with his Danish wife. In 1937 his work was declared to be 'Entartete Kunst', and many of his paintings were therefore confiscated. In 1941 the government even forbade him to paint, although he secretly created his so-called 'unpainted paintings'. (M 25977)

See also the citation for planet (5699).

\section{(5699) Munch}

2141 T-3. Discovered 1977 Oct. 16 by C. J. van Houten and I. van Houten-Groeneveld at Palomar.

Named in memory of Edvard Munch (1863-1944), a Norwegian expressionist painter. In his paintings the artist expresses his loneliness and anxiety. Some of his most famous paintings are 'The Cry', 'Jealousy', and 'The Girls on the Bridge'. (M 25977)

The discoverers of planets (5694) - (5699) stated in an e-mail from November 11, 1995 to Brian G. Marsden:

"In honor of Brian Marsden the first letters of the names of minor planets (5694), (5695), (5696), (5697), (5698), (5699) form the name BRIAN M. Because we never, till now, had enough minor planets numbered after each other, to give your full name, we had to make it in this way." See also the addition to planet (1234).

\section{(5700) Homerus}

5166 T-3. Discovered 1977 Oct. 16 by C. J. van Houten and I. van Houten-Groeneveld at Palomar.

Named for the legendary Greek poet Homerus, who depicted in his epic poem Ilias an episode of the battle around Troy. Without Homerus, we would know nothing of the heroes of Troy and Greece, including those whose names are given to minor planets. (M 23139)

\section{(5702) Morando}

1931 FC. Discovered 1931 Mar. 16 by M. F. Wolf at Heidelberg.

Named in honor of Bruno Morando (1931-1995), astronomer at the Bureau des Longitudes, Paris, where he has been director for 13 years. A former president of the Société Astronomique de France, he is now responsible for the reduction of the minor planet data from the Hipparcos satellite. (M 24122)

Name proposed and citation prepared by D. Savoie and J. Meeus, endorsed by L. D. Schmadel.

Obituaries published in Astronomie, Vol. 109, p. 324 (1995); Int. Astron. Union Symp., No. 172, p. 1-2 (1996); J. Astron. Fr., No. 50, p. 2-4 (1996).

\section{(5703) Hevelius}

1931 VS. Discovered 1931 Nov. 15 by K. Reinmuth at Heidelberg.

Named in memory of the eminent astronomer Johannes Hevelius (1611-1687), brewer and city councillor of Danzig, now Gdansk. After studies at Leiden, London, Paris and Avignon he erected a private observatory and was an ardent observer. His Selenographia (1647), which contains detailed lunar maps obtained with long refractors, made him well-known. Further important works include Cometographia, Machina coelestis 
(astrometric observations of stars and planets), Annus climactericus, the Star Atlas and the Star Catalogue based on measurements with Tychonic-type quadrants and sextants. Hevelius' second wife, Catharina Elisabeth, was one of the first female astronomers. (M 24122)

Name proposed by J. Wünsch and L. D. Schmadel.

\section{(5704) Schumacher}

1950 DE. Discovered 1950 Feb. 17 by K. Reinmuth at Heidelberg.

Named for the astronomer and geodesist Heinrich Christian Schumacher (1780-1850), who in 1821 founded the Astronomische Nachrichten. Living in Altona, he was professor in Copenhagen and leader of the Danish geodetic survey. Schumacher was the center of a lively correspondence with the leading astronomers of his day, and this ensured a collaboration across frontiers of the European geodetic surveys. His greatest service to astronomers was the institution of the $A N$ \{see also planet (1155)\}. Its purpose was to disseminate, as quickly as possible, information about discoveries, ephemerides, short articles, reviews, and so forth. This was achieved by mailing single sheets of eight pages as soon as they could be completed. The spirit of this journal was truly international and astronomers of all nations could contribute in their own language. (M 24122)

Name proposed and citation prepared by L. K. Kristensen and endorsed by L. D. Schmadel.

Originally, this name was proposed for minor planet (6000) but received not enough votes by IAU Commission 20.

\section{(5705) Ericsterken}

1965 UA. Discovered 1965 Oct. 21 by H. Debehogne at Uccle.

Named in memory of Eric Sterken (1948-1998), professional gardener and landscaper who took care of the gardens of the Brussels Planetarium. He is remembered by hundreds of people for his friendliness and modesty, and at the same time he was respected for his great efforts to preserve plantlife and wildlife. He was proud to have been the brother of a professional astronomer, Chris Sterken. (M 31610)

\section{(5706) Finkelstein}

1971 SS $_{1}$. Discovered 1971 Sept. 23 at the Crimean Astrophysical Observatory at Nauchnyj.

Named in honor of Andrej Mikhajlovich Finkelstein (1942- ), expert in relativistic celestial mechanics and radioastrometry, founder and director of the Russian Academy of Sciences' Institute of Applied Astronomy in St. Petersburg. (M 29145)

Name proposed by the Institute of Theoretical Astronomy.

\section{(5707) Shevchenko}

$1976 \mathrm{GY}_{3}$. Discovered 1976 Apr. 2 by N. S. Chernykh at Nauchnyj.

Named in honor of Vladislav Vladimirovich Shevchenko (1940- ), head of the Lunar and Planetary Research Department of the Sternberg Astronomical Institute in Moscow and the Chairman of the Lunar Task Group of the IAU Working Group for Planetary System Nomenclature. He was a participant of the 'Zond' and 'Lunokhod' space missions and was coauthor and scientific leader of the Global Mapping of the Moon and Mars projects. (M 30476)

Name suggested by the Institute of Theoretical Astronomy.

\section{(5708) Melancholia}

$1977 \mathrm{TC}_{1}$. Discovered 1977 Oct. 12 by P. Wild at Zimmerwald.

One of the four humors or human temperaments. The gloom besetting astronomers when the sky remains overcast for weeks on end. (M 30097)

\section{(5710) Silentium}

1977 UP. Discovered 1977 Oct. 18 by P. Wild at Zimmerwald.

Silence. (M 30097)

This is - by far - the shortest official naming citation ever published.

\section{(5711) Eneev}

$1978 \mathrm{SO}_{4}$. Discovered 1978 Sept. 27 by L. I. Chernykh at Nauchnyj.

Timur Magometovich Eneev (1924- ), applied mathematician and celestial mechanician at the Keldysh Institute of Applied Mathematics, made valuable contributions to Soviet cosmonautics and is also known for his works in the areas of cosmogony and ecology. (M 43380)

\section{(5712) Funke}

1979 SR. Discovered 1979 Sept. 25 by A. Mrkos at Klět.

Jaromír Funke (1896-1945) was a Czech photographer, known for his images of architecture and landscape issuing from functionalism. (M 42355)

The name was suggested by M. Tichý.

\section{(5714) Krasinsky}

1982 PR. Discovered 1982 Aug. 14 by N. S. Chernykh at Nauchnyj.

Named in honor of Georgij Al'bertovich Krasinskij [Krasinsky] (1939- ), staff member of the Institute of Theoretical Astronomy from 1964 to 1987, now chief of the Ephemeris Astronomy Laboratory of the Institute of Applied Astronomy in St. Petersburg. He has investigated planetary motions by analytical and numerical methods, and he was one of the creators of the global relativistic theory of the inner planets and the moon in the 1970s. (M 30798) 
Name suggested by Institute of Theoretical Astronomy and the Institute of Applied Astronomy.

\section{(5715) Kramer}

$1982 \mathrm{SE}_{1}$. Discovered 1982 Sept. 22 by E. Bowell at Anderson Mesa.

Named in honor of Kathryn Xymena Kramer, Development Director at Lowell Observatory. Kramer has been central in securing funding for the Observatory's Steel Visitor Center and for research purposes. Additionally she has been instrumental in greatly expanding the membership of the Friends of Lowell Observatory (currently to more than 1000 members) and was named Lowell Observatory employee of the year for 1994. (M 24411)

Citation prepared with the help of E. D. Pickard.

\section{(5716) Pickard}

1982 UH. Discovered 1982 Oct. 17 by E. Bowell at Anderson Mesa.

Named in honor of Elizabeth D. Pickard, philanthropist and community volunteer in Flagstaff, Arizona, for her long-time support of Lowell Observatory, and in particular for spearheading local fundraising efforts that resulted in the construction of a major new visitors' center. (M 24411)

Citation prepared with the help of K. X. Kramer.

\section{(5717) Damir}

1982 UM $_{6}$. Discovered 1982 Oct. 20 by L. G. Karachkina at Nauchnyj.

Named in memory of Alim Matveevich Damir (18941982), well-known physician, professor at the First and Second Medical Institutes in Moscow. (M 23139)

Name suggested by his son-in-law, S. P. Kapitsa.

\section{(5719) Křižík}

1983 RX. Discovered 1983 Sept. 7 by A. Mrkos at Klet.

Czech electrical engineer and inventor František Křižík (1847-1941), constructed an arc lamp with a regulating gear in 1881 and the first electric street car in Prague in 1891. He contributed significantly in the electrification of Bohemia. (M 36945)

The name was suggested by Z. Moravec and M. Tichý.

\section{(5720) Halweaver}

1984 FN. Discovered 1984 Mar. 29 by C. S. Shoemaker and E. M. Shoemaker at Palomar.

Named in honor of Harold A. Weaver (1953- ） for his work on the chemical composition of comets and for pioneering the use of the Hubble Space Telescope for cometary studies. His combination of infrared and ultraviolet spectroscopy has demonstrated the way in which different wavelength regimes must be combined to obtain a proper picture of the composition of comets. (M 27460)

Citation provided by M. F. A'Hearn following a suggestion by E. Bowell and endorsed by the discoverers.

\section{(5723) Hudson}

$1986 \mathrm{RR}_{2}$. Discovered 1986 Sept. 6 by E. Bowell at Anderson Mesa.

Named in honor of R. Scott Hudson (1959- ) of the School of Electrical Engineering and Computer Science at Washington State University. Hudson has pioneered techniques for using delay-doppler radar images of an asteroid to estimate its shape, rotation and radar scattering properties, as well as the delay-doppler trajectory of the target's center of mass, a result that can improve orbit accuracy by several orders of magnitude. His reconstruction of (4769) Castalia is the first reasonably detailed model of the shape of an earth-crossing asteroid. For (4179) Toutatis, Hudson's inversion defined the non-principal-axis spin state and the ratios of the principal moments of inertia. Hudson's techniques are a cornerstone of radar investigation of small bodies and open the door to a variety of theoretical studies of these objects. (M 25654)

Name suggested and citation prepared by S. J. Ostro.

\section{(5725) Nördlingen}

1988 BK $_{2}$. Discovered 1988 Jan. 23 by C. S. Shoemaker and E. M. Shoemaker at Palomar.

Named for the attractive, medieval, walled city located in the heart of the Ries \{see planet (4327)\} Basin, site of an impact crater formed by a comet or a minor planet 15 million years ago. Nördlingen is the central town of the Danube-Ries district of the Bavarian region of Swabia \{see planet (6209)\}. The first records of this city date back to A.D. 750-800, and its position on important trade routes allowed it to develop into a market town and cultural center. Its St. Georges Cathedral is the largest building ever constructed from suevite, the local stone created by the impact. (M 29670)

\section{(5726) Rubin}

$1988 \mathrm{BN}_{2}$. Discovered 1988 Jan. 24 by C. S. Shoemaker and E. M. Shoemaker at Palomar.

Named in honor of American astronomer Vera Cooper Rubin (1928- ) , who has studied the motions of gas and stars in galaxies and the motions of galaxies in clusters. Her observations have been fundamental to our understanding of the distribution of mass in the universe. A member of the National Academy of Sciences, she received the National Medal of Science in 1993 and in 1996 became only the second woman to receive the Gold Medal of the Royal Astronomical Society. (M 29670)

\section{(5731) Zeus}

1988 VP $_{4}$. Discovered 1988 Nov. 4 by C. S. Shoemaker and E. M. Shoemaker at Palomar.

Originally Zeus was the god of the sky and of atmospheric phenomena, of winds, clouds, rain and thunder. Later Zeus, father of gods (Athene ssee planet (881)\}, Artemis \{see planet (105)\}, Apollo \{see planet (1862)\}, Ares and Dionysus \{see planet (3671)\}) and 
men, became the supreme god of the Greeks, the protector of laws and morals and the dispenser of good and evil. (M 25230)

\section{(5734) Noguchi}

$1989 \mathrm{AL}_{1}$. Discovered 1989 Jan. 15 by K. Endate and K. Watanabe at Kitami.

Named in honor of Souichi Noguchi (1965- ), an astronaut working for the Japanese Aerospace Development Agency NASDA, chosen among 572 applicants for the position in 1996. He obtained a master's degree in aeronautics at the University of Tokyo and has been training as a mission specialist for NASA. (M 29145)

Name proposed by the second discoverer following a suggestion by K. Tomita.

\section{(5735) Loripaul}

1989 LM. Discovered 1989 June 4 by E. F. Helin at Palomar.

Named in honor of Lori L. Paul, Friend of All Animals, assistant director of Telescopes in Education (TIE) at the Mount Wilson Institute and Jet Propulsion Laboratory, environmentalist, veterinary technician, part time educator and artist, former zookeeper and laser operator. Her role in acquiring important sponsorship and recognition for TIE is particularly acknowledged. Like her many eclectic pursuits, her accomplishments have resulted from her curiosity, an aesthetic sense of excellence and attention to detail. This minor planet is being named to celebrate her wedding engagement to Rob Staehle ssee planet (3875)\}. (M 31024)

\section{(5736) Sanford}

1989 LW. Discovered 1989 June 6 by E. F. Helin at Palomar.

Named in honor of John Sanford, teacher, author, former president of the Orange County Astronomers, and a source of inspiration for hundreds of amateur astronomers. Recipient of the Western Amateur Astronomers' Bruce Blair Award, he has served amateur astronomers worldwide with the unselfish sharing of his photographic and observational skills for nearly twenty years. (M 24411)

Name proposed by the discoverer following a suggestion by J. B. Child.

\section{(5737) Itoh}

1989 SK. Discovered 1989 Sept. 30 by T. Nomura and K. Kawanishi at Minami-Oda.

Japanese amateur astronomer Kazuyuki Itoh (1951-

) has made more than 1000 astrometric observations of comets and minor planets. He discovered minor planet (6879) Hyogo. (M 38195)

The name was suggested by M. Sugano.

\section{(5738) Billpickering}

1989 UY $_{3}$. Discovered 1989 Oct. 27 by E. F. Helin at Palomar.
Named in honor of William H. Pickering (1910- ), former director of the Jet Propulsion Laboratory. Under his guidance instrumented probes were first sent to the inner planets, and work was begun on the "Grand Tour" of the outer planets. He was a pioneer in the development of telemetry, which was to become the essential tool of the space exploration program. In his years as an administrator he encouraged major advances in space science and technology. Many of these led to new inventions, and some spawned new industries. His inspiration and leadership established the U.S. program for the exploration of the solar system. (M 27128)

\section{(5740) Toutoumi}

$1989 \mathrm{WM}_{3}$. Discovered 1989 Nov. 29 by Y. Oshima at Gekko.

Named for the area in the western part of Shizuoka prefecture that is the location of the Nakano-Gakuen Astro-Geological College. Several of its graduates have worked at the observatories belonging to the International Foundation for Cultural Harmony. (M 33786)

\section{(5743) Kato}

1990 UW. Discovered 1990 Oct. 19 by M. Akiyama and T. Furuta at Mishima.

Named in honor of Yasuo Kato (1949-1982), a famous climber, born in Omiya, Saitama Prefecture. After reaching the summit of Mt. Everest in 1973, he lost from frostbite all of his toes and three finger tips of his right hand. In spite of that, he continued climbing. In 1982 he made the first winter ascent of Everest but was reported missing on the way down. (M 25230; M 25993; M 32127)

\section{(5744) Yorimasa}

1990 XP. Discovered 1990 Dec. 14 by A. Natori and T. Urata at Yakiimo.

Named for a Japanese military commander and well-known poet in the late Heian era, Minomoto-no Yorimasa (1104-1180). He advised Prince Mochihitoou to fight the Heike. However, word of the plan leaked out, and Yorimasa took his own life. (M 31024)

Name proposed by the second discoverer.

\section{(5748) Davebrin}

1991 DX. Discovered 1991 Feb. 19 by E. F. Helin at Palomar.

Named in honor of David Brin, astrophysicist and popular science-fiction writer. His scientific training has given credibility and authority to his exploration of new ideas and story themes. He is the recipient of many prestigious awards, among them the Hugo, Nebula and LOCUS. (M 23139)

\section{(5750) Kandatai}

1991 GG $_{1}$. Discovered 1991 Apr. 11 by A. Takahashi and K. Watanabe at Kitami. 
Named in honor of Tai Kanda (1938- ), a staff member of the Japanese National Astronomical Observatory who works for the Public Service Division and as the editor of Rika Nenpyo (Chronological Science Tables), published by the Observatory. He grew up in a family of astronomers as a son of Kiyoshi Kanda and a nephew of Shigera Kanda \{see planet (2248)\}. (M 29145)

Name proposed by the second discoverer following a suggestion by K. Tomita.

\section{(5751) Zao}

1992 AC. Discovered 1992 Jan. 5 by M. Koishikawa at Sendai.

Mt. Zao is the general name of the volcanic mountains that lie in the northern part of mainland Japan. The Zao range forms the border between Yamagata and Miyagi Prefectures and was designated as a National Park in 1963. With its abundance of nature and clear skies, Mt. Zao is one of the most attractive mountains for mountaineers, skiers and starwatchers. (M 25230)

\section{(5753) Yoshidatadahiko}

1992 EM. Discovered 1992 Mar. 4 by K. Endate and K. Watanabe at Kitami.

Named in honor of Tadahiko Yoshida (1941- ) , the director of the Tsukuba regional office of the company Advanced Engineering Service, which supports space development for NASDA. (M 29145)

\section{(5756) Wassenbergh}

6034 P-L. Discovered 1960 Sept. 24 by C. J. van Houten and I. van Houten-Groeneveld at Palomar.

Named in honor of Or Wassenbergh (1924- ), from 1977 to 1994 professor of air and space law, on the occasion of the valedictory address at Leiden University. During World War II Or joined the Dutch underground forces. Later he obtained his doctorate, working first at KLM (Royal Dutch Air Line) and becoming more and more involved, not only with aviation policy and air law, but also with space law. He was vice-president of foreign relations and cooperation at KLM until 1990. He has published several books and articles about this subject. (M 24123)

The name was proposed by his secretary and his colleagues in Leiden.

\section{(5757) Tichá}

1967 JN. Discovered 1967 May 6 by C. U. Cesco and A. R. Klemola at El Leoncito.

Named in honor of Jana Tichá, Czech astronomer, director of the Kleť Observatory since 1992. Under her leadership, the Klet program for astrometric observations of minor planets and comets was modernized with the introduction of a CCD camera, computers and catalogues. (M 27128; M 27147)

Name proposed following a suggestion by her husband, Miloš Tichý.

\section{(5759) Zoshchenko}

1980 BJ $_{4}$. Discovered 1980 Jan. 22 by L. G. Karachkina at Nauchnyj.

Named in honor of the outstanding Russian writersatirist Mikhail Mikhailovich Zoshchenko (1894-1958). (M 23541)

The name is given on the occasion of the onehundredth anniversary of his birth, following a suggestion by L. R. Nemirovskij.

\section{(5760) Mittlefehldt}

1981 EX $_{13}$. Discovered 1981 Mar. 1 by S. J. Bus at Siding Spring.

David (Duck) Mittlefehldt (1951- ) of NASA's Johnson Space Center has applied petrologic and geochemical techniques to understanding the origin and evolution of differentiated planets, major and minor. He is a leading expert on both asteroidal basalts and martian meteorites. (M 46006)

\section{(5761) Andreivanov}

$1981 \mathrm{ED}_{21}$. Discovered 1981 Mar. 2 by S. J. Bus at Siding Spring.

Andrei V. Ivanov (1937- ), a cosmochemist at the Vernadsky Institute of Geochemistry, was one of the principal investigators to study lunar samples returned by the Luna missions. He is currently working to unravel the origin of primitive materials in the Kaidun meteorite. (M 46006)

\section{(5762) Wänke}

$1981 \mathrm{EG}_{28}$. Discovered 1981 Mar. 2 by S. J. Bus at Siding Spring.

Heinrich Wänke (1928- ), director emeritus of the Max-Planck-Institut für Chemie at Mainz, is a premier cosmochemist who first developed the ${ }^{40}$ Argon- ${ }^{39}$ Argon method of dating meteoritic and lunar materials. He also has investigated the chemical composition and accretion history of the terrestrial planets. (M 46006)

\section{(5765) Izett}

1986 GU. Discovered 1986 Apr. 4 by C. S. Shoemaker and E. M. Shoemaker at Palomar.

Named in honor of Glen A. Izett, an American geologist of many talents. Izett has carried out the most detailed studies of the Cretaceous-Tertiary boundary clay layers in the western United States and their implications for the great impact event that terminated the Cretaceous. He has also contributed the most precise determinations of ages of tektites from the extensive Australasian strewn field. His work with John Obradovich on the ages of volcanic ashes and tektites has led to the most highly refined time scale for the reversals of the geomagnetic field in the late Quaternary. (M 29671)

\section{(5767) Moldun}

$1986 \mathrm{RV}_{2}$. Discovered 1986 Sept. 6 by E. Bowell at Anderson Mesa. 
Named for the town of Meudon, Hauts-de-Seine, location of the Astrophysics Section of the Paris Observatory, where the discoverer had the pleasure of working for about five years. Moldun is the old Gaelic form of the names and means "sand hill". Meudon has in the past been home to Auguste Rodin \{see planet (6258)\}, Jean Arp, Richard Wagner \{see planet (3992)\}, Marcel Dupré and Georges Enescu. (M 27460)

Proposed by the discoverer following suggestions by M. A. Barucci and M. Fulchignoni.

\section{(5768) Pittich}

$1986 \mathrm{TN}_{1}$. Discovered 1986 Oct. 4 by E. Bowell at Anderson Mesa.

Named in honor of Eduard M. Pittich (1940- ) of the Astronomical Institute of the Slovak Academy of Sciences, Bratislava. Pittich has worked on the dynamics and evolution of comets, and also on the motions of dust particles in heliocentric orbits, as influenced by sunlight. He participated in setting up the Astronomical and Geophysical Observatory of the Comenius University in Modra-Piesky and has been active in the popularization of astronomy as a successful book author. (M 27460)

Citation provided by H. Rickman.

\section{(5769) Michard}

1987 PL. Discovered 1987 Aug. 6 by the CERGA at Caussols.

Named in honor of Raymond Michard (1925- ), administrator of the Observatoire de la Côte d'Azur since 1987 and ardent supporter of the CERGA s see planet (2252)\} Schmidt. He had earlier studied the sun at Sacramento Peak and led the Service Solaire at Meudon during 1971-76. He later studied the morphology of elliptical galaxies in Texas and at Nice, where he was director in 1981. (M 23541)

\section{(5771) Somerville}

$1987 \mathrm{ST}_{1}$. Discovered 1987 Sept. 21 by E. Bowell at Anderson Mesa.

Named for Mary Somerville (née Fairfax, 1780-1872), one of Europe's most distinguished women scientists of her time. Her treatise on Laplace's s see planet (4628)\} Mécanique Céleste brought her widespread recognition, including an Honorary Fellowship of the Royal Astronomical Society. The Royal Society, unable to elect a woman as a Fellow, commissioned a sculpted bust to be displayed in their premises. J. C. Adams \{see planet (1996)\} is said to have told her that it was the statement, in the sixth edition of her On the connexion of the physical sciences, that the departure of Uranus from its predicted path might reveal the existence of an undiscovered planet that minded him to carry out his calculations that successfully predicted the position of Neptune. She campaigned for education rights and voting rights for women. Somerville College in the University of Oxford was named in her honor when founded in 1878 for the education of women undergraduates. (M 25444)

Name suggested and citation prepared by S. A. and J. Mitton.

\section{(5772) Johnlambert}

1988 LB. Discovered 1988 June 15 by E. F. Helin at Palomar.

John V. Lambert (1945- ） has developed techniques for determining the sizes and shapes of minor planets from occultation and lightcurve observations. He is now involved in the U.S. Air Force Space Command and the Phillips Laboratory programs for the study of near-earth objects. (M 38195)

\section{(5775) Inuyama}

1989 SP. Discovered 1989 Sept. 29 by Y. Mizuno and T. Furuta at Kani.

Named for a city in the northern part of Aichi Prefecture. Rich in natural beauty and featuring the Hida-Kiso River National Park, Inuyama is also known for its traditional events, such as the Nihon-Rhine Rapid Ride and Inuyama cormorant fishing. It also boasts some historically valuable architecture, including Japan's oldest donjon (in the Inuyama Castle) and the Tea Arbor JO-AN. Both are national treasures. (M 33385)

Name proposed by the discoverers following a suggestion by their teacher, T. Yamada.

\section{(5777) Hanaki}

1989 XF. Discovered 1989 Dec. 3 by Y. Mizuno and T. Furuta at Kani.

Many years ago, Yoichi Hanaki (1937- ) used to make astronomical observations, notably of Jupiter, with the second discoverer. Later he established the vocational training facility Hoshi-no-mura \{see planet (3814)\} that endeavors to help mentally handicapped people. (M 42668)

\section{(5778) Jurafrance}

$1989 \mathrm{YF}_{5}$. Discovered 1989 Dec. 28 by E. W. Elst at St. Michel.

The French Jura, a department in eastern France, was created in 1674 from the southern part of Franche-Comté. Extensively forested, the country is characterized by long and severe winters. The Ain river, Gruyère cheese from the valleys and excellent wine (Arbois) makes a stay there very agreeable. (M 47163)

\section{(5780) Lafontaine}

$1990 \mathrm{EJ}_{2}$. Discovered 1990 Mar. 2 by E. W. Elst at La Silla.

Named in memory of the French lyric poet Jean de la Fontaine (1621-1695), on the occasion of the 300th anniversary of his death. He is well known from the "fables" (first published in six books in 1668, with a total of 12 books by 1694) and his "contes". The fables were inspired by Greek and Latin writers such as Aesop 
and Phaedrus, and the contes, mainly by the French writers Rabelais \{see planet (5666)\} and Marguerite de Navarre. Although la Fontaine continued the classical tradition, he created his own style and language that exhibits versatility and fecundity. He is considered one of the greatest classical French writers. (M 23541)

Citation material provided by $\mathrm{K}$. Leterme at the request of the discoverer.

\section{(5781) Barkhatova}

1990 SM $_{28}$. Discovered 1990 Sept. 24 by G. R. Kastel' and L. V. Zhuravleva at Nauchnyj.

Named in memory of Claudia Alexandrovna Barkhatova (1917-1990), founder of the Kourovka ssee planet (4964)\} Observatory, Ural State University, Ekaterinburg. Under her guidance Kourovka became one of the best university observatories in Russia. Barkhatova made valuable contributions to stellar astronomy and to our understanding of Galactic structure. In particular, she investigated the dependence of angular diameters of open clusters on interstellar extinction, and this led to a revision of the distance scale. She also established that the orbital eccentricities of the clusters depend on their age. Her disciples work in practically all the astronomical institutions of Russia. (M 24123) Name proposed by the first of the discoverers.

\section{(5783) Kumagaya}

1991 CO. Discovered 1991 Feb. 5 by T. Hioki and S. Hayakawa at Okutama.

Kumagaya, also known as the 'City of Cherry Blossoms' and 'Rugby Town', is an industrial city located northwest of Tokyo. Kumagaya is famous for the Yukoku Temple, built for the warrior Naozane \{see planet (5238)\}, and for the Uchiwa Festival. (M 25230)

\section{(5785) Fulton}

1991 FU. Discovered 1991 Mar. 17 by E. F. Helin at Palomar.

Named in honor of Joseph A. Fulton, hardware engineer specializing in electro-mechanical devices. Over the years he assisted in the digitization of the Planet Crossing Asteroid Survey films and Oschin Schmidt plates for the discoverer's research on minor planets. This naming is made on the occasion of Fulton's retirement after 37 years of dedicated work at the Jet Propulsion Laboratory. (M 30097)

\section{(5786) Talos}

1991 RC. Discovered 1991 Sept. 3 by R. H. McNaught at Siding Spring.

A cousin of Icarus \{see planet (1566)\}, Talos was murdered by his uncle, Daedalus \{see planet (1864)\}, through jealousy of his inventiveness. There is another Talos in legend, a living bronze work of art created by the god Hephaistos \{see planet (2212)\}. Talos would run around the island of Crete and ward off strangers from its shores by throwing stones. Unwanted visitors unlucky enough to be caught would be held to his bosom, which he made red hot. It is believed that Talos is the winged figure, running with large strides and holding a stone in each hand, depicted in coins from the town of Phaestos. (M 23542)

Named by the discoverer following a suggestion by D. J. Asher.

The semimajor axis, eccentricity and inclination of this asteroid show a remarkable similarity to (1566) Icarus.

\section{(5789) Sellin}

4018 P-L. Discovered 1960 Sept. 24 by C. J. van Houten and I. van Houten-Groeneveld at Palomar.

Named in honor of Ivan A. Sellin (1939- ), professor at Oak Ridge National Laboratory and at the University of Tennessee in Knoxville. In 1976 he received the Humboldt Award. His research interests include photon and atomic collision processes, and the results of his research are given in more than 200 publications. (M 24918)

Name proposed by K.-O. Groeneveld.

\section{(5790) Nagasaki}

9540 P-L. Discovered 1960 Oct. 17 by C. J. van Houten and I. van Houten-Groeneveld at Palomar.

Named for the Japanese city of Nagasaki in the hope that this minor planet may be a symbol for world peace. (M 25230)

Name proposed by T. Gehrels.

\section{(5791) Comello}

4053 T-2. Discovered 1973 Sept. 29 by C. J. van Houten and I. van Houten-Groeneveld at Palomar.

Named in honor of Georg Comello (1942- ), Dutch amateur astronomer. His interests in astronomy include variable stars, comets and traveling around the world to observe solar eclipses. Since 1960 he has been employed at the Kapteyn Institute of the University of Groningen, currently as a librarian. He assisted L. Plaut \{see planet (1986)\} in measuring and analyzing his plates of variable stars and is still on the board of the Working Group for Variable Star Observers. For several years he has been the draftsman of the Sterrengids (the Dutch yearbook on astronomical events), for which he prepares in particular finding charts for minor planets. He has written articles for Hemel en Dampkring and Zenit and contributes to newspapers, radio and television. (M 24918)

Name proposed and citation prepared by T. Jurriens.

\section{(5792) Unstrut}

1964 BF. Discovered 1964 Jan. 18 by F. Börngen at Tautenburg.

Named for the Thuringian river that flows for $189 \mathrm{~km}$ from Eichsfeld \{see planet (442)\}, past the cathedral town of Naumburg, into the Saale \{see planet (5409)\}. (M 23353) 


\section{(5794) Irmina}

$1976 \mathrm{SW}_{3}$. Discovered 1976 Sept. 24 by N. S. Chernykh at Nauchnyj.

Named in memory of Irma Mikhailovna Golodyaevskaya (1931-1956), a student of the Moscow Conservatory and talented singer who tragically perished at the very beginning of her development as an artist. (M 30097)

\section{(5795) Roshchina}

$1978 \mathrm{SH}_{1}$. Discovered 1978 Sept. 27 by L. I. Chernykh at Nauchnyj.

Named in memory of Elena Olegovna Roshchina (1966-1994), a journalist and cinema critic from the Ivanovo region of Russia and a young poet tragically killed. She took an interest in astronomy, and some of her poems were dedicated to cosmic themes. (M 30097)

\section{(5797) Bivoj}

1980 AA. Discovered 1980 Jan. 13 by A. Mrkos at Klet.

This Amor-type object is named for the honorable hero of ancient Bohemian myths, known for his great courage and other good qualities. Bivoj conquered a colossal wild boar barehanded to save the crops and lives of his people. He later became acquainted with and married Kazi, the oldest daughter of prince Krok \{see planet (3102)\}. (M 27735)

Name suggested by J. Tichá, M. Tichý and Z. Moravec.

\section{(5798) Burnett}

$1980 \mathrm{RL}_{7}$. Discovered 1980 Sept. 13 by S. J. Bus at Palomar.

As a professor at the California Institute of Technology, Donald Burnett (1937- ） investigates the chemical evolution of the solar system through studies of nucleosynthesis and elemental abundances. He is lead investigator for the Genesis mission that will collect particles from the solar wind. (M 46007)

\section{(5799) Brewington}

1980 TG$_{4}$. Discovered 1980 Oct. 9 by C. S. Shoemaker at Palomar.

Named in honor of Howard Brewington, discoverer of four comets beginning in 1989. To improve his chances of making a find, he moved with his wife Trudy from South Carolina to the mountaintop town of Cloudcroft, New Mexico, and built an observatory to house his homebuilt telescopes. (M 24918)

\section{(5800) Pollock}

$1982 \mathrm{UV}_{1}$. Discovered 1982 Oct. 16 by A. Mrkos at Klě̆.

Jackson Pollock (1912-1956), American painter, was a leader of the Abstract Expressionist movement. (M 41567)

The name was suggested by J. Tichá.
(5801) Vasarely

1984 BK. Discovered 1984 Jan. 26 by A. Mrkos at Kleť.

Victor Vasarely (1908-1997), painter, sculptor, and graphic artist of Hungarian birth, is considered the founder of the Op Art movement. (M 41567)

The name was suggested by J. Tichá.

\section{(5803) Ötzi}

1984 OA. Discovered 1984 July 21 by A. Mrkos at Kleť.

Ötzi, or Iceman, is a popular name for a prehistoric man of the late Stone Age. His mummified body was found on the Similaun Glacier in the Tirolean Ötztal Alps, on the Italian-Austrian border in 1991. (M 40701)

The name was proposed by M. Tichý.

\section{(5804) Bambinidipraga}

$1985 \mathrm{RL}_{1}$. Discovered 1985 Sept. 9 by A. Mrkos at Klě́.

Bambini di Praga is a Czech children's chorus. Choirmasters Blanka and Bohumil Kulínský developed a repertoire ranging from classical music to the folk songs of the many countries they have visited. (M 40701)

\section{(5805) Glasgow}

1985 YH. Discovered 1985 Dec. 18 by E. Bowell at Anderson Mesa.

Named for the city of Glasgow, Scotland, and for the Astronomical Society of Glasgow, whose 100th anniversary in this year being marked by a civic dinner hosted by the Glasgow City Council. (M 24123) Citation provided by M. Kennedy.

\section{(5806) Archieroy}

$1986 \mathrm{AG}_{1}$. Discovered 1986 Jan. 11 by E. Bowell at Anderson Mesa.

Named in honor of Archibald Edmiston Roy (1924- ), Scottish astrophysicist, teacher and writer. Although Roy has studied stellar interiors, neural networks, the history of astronomy, as well as psychical phenomena, he is best known as a celestial mechanician. He has worked on mean-motion commensurabilities, the restricted and general three-body problems, highorder Taylor series and the long-term stability of the solar system. While teaching in the Department of Astronomy, Glasgow University (a department he headed for five years), Roy had occasion to write four textbooks. In addition, he has published six works of fiction. (M 24123)

\section{(5807) Mshatka}

1986 QA $_{4}$. Discovered 1986 Aug. 30 by L. I. Chernykh at Nauchnyj.

Named for the country estate of Nikolaj Yakovlevich Danilevskij (1822-1885), thinker, philosopher, sociologist, publicist and natural scientist, whose book Russia and Europe contains ideas that are still vital today. 
Many well-known Russian writers stayed at Mshatka, and Danilevskij is buried there. (M 34622)

\section{(5808) Babel'}

$1987 \mathrm{QV}_{10}$. Discovered 1987 Aug. 27 by L. G. Karachkina at Nauchnyj.

Named in honor of the outstanding Russian writer and dramatist Isaac Emmanuilovich Babel' (1894-1940). (M 23542)

The name is given on the occasion of the onehundredth anniversary of his birth, following a suggestion by L. R. Nemirovskij.

\section{(5809) Kulibin}

1987 RG $_{6}$. Discovered 1987 Sept. 4 by L. V. Zhuravleva at Nauchnyj.

Named in memory of Ivan Petrovich Kulibin (1735-1818), brilliant Russian self-educated mechanical engineer. He designed original clockwork pieces, planned a bridge over the Neva \{see planet (1603)\} river and constructed various labor-saving devices. (M 34622)

\section{(5811) Keck}

1988 KC. Discovered 1988 May 19 by E. F. Helin at Palomar.

Named in honor of Howard B. Keck, chairman and president emeritus of the W. M. Keck Foundation. The foundation was established in 1954 by his father, William M. Keck, Sr., to support higher education, medical research and science. Under Howard Keck's leadership, the Foundation provided the grants to build the giant twin telescopes of the W. M. Keck Observatory on the summit of Mauna Kea. (M 27128)

At the suggestion of E. C. Stone, this minor planet is being named on the occasion of the dedication of the second Keck Telescope on 1996 May 8.

\section{(5812) Jayewinkler}

1988 PJ J $_{1}$. Discovered 1988 Aug. 11 by A. J. Noymer at Siding Spring.

Named in honor of Jaye Scott Winkler, a friend of the discoverer. A resident of Cambridge, Massachusetts, she is an alumna of the Harvard School of Public Health, and also an accomplished equestrienne. (M 24411)

\section{(5815) Shinsengumi}

1989 AH. Discovered 1989 Jan. 3 by T. Seki at Geisei.

Shinsengumi was the name of a 300-member group of samurai that organized the defense of the Tokugawa shogunate and kept order in Kyoto \{see planet (4352)\} during 1863-1869. (M 24765; M 24781)

\section{(5816) Potsdam}

$1989 \mathrm{AO}_{6}$. Discovered 1989 Jan. 11 by F. Börngen at Tautenburg.

Named for the capital of the German state of Brandenburg. Besides Berlin, Potsdam was the residence of Brandenburgian Electors and Prussian kings (Friedrich the Great, Friedrich Wilhelm I). Several famous castles, e.g. Sanssouci and the New Palace are located there. After World War II the Potsdam Conference took place at the Cecilienhof Palace. The Astrophysikalisches Observatorium Potsdam, devoted to the introduction and development of new research methods in astrophysics, was founded in 1874 at the Telegrafenberg. The well-known Einstein Tower for solar studies was erected by the architect Erich Mendelsohn in 1922. (M 23542)

This planet is named on the occasion of the 1994 meeting of the Astronomische Gesellschaft in Potsdam.

\section{(5817) Robertfrazer}

1989 RZ. Discovered 1989 Sept. 5 by E. F. Helin at Palomar.

Robert E. Frazer (1918- ), longtime friend and colleague of the discoverer, studied optics at the University of Rochester. He has participated in and supported many space-related programs at the Jet Propulsion Laboratory, ranging from the construction of early deep space antennas to devising a means of replicating optical mirrors. (M 41027)

\section{(5819) Lauretta}

$1989 \mathrm{UZ}_{4}$. Discovered 1989 Oct. 29 by S. J. Bus at Cerro Tololo.

Dante Lauretta (1970- ), a professor at the University of Arizona, is known for his groundbreaking experimental work on the formation of iron-bearing sulfides in the solar nebula. He has also investigated the cosmochemical behavior of many elements such as mercury, boron and beryllium in meteorites. (M 46007)

\section{(5820) Babelsberg}

$1989 \mathrm{UF}_{7}$. Discovered 1989 Oct. 23 by F. Börngen at Tautenburg.

Named for a residential district of the city of Potsdam \{see planet (5816)\}, known as the summer residence of Emperor Wilhelm I and for its famous film studios. The Berlin Observatory, founded in 1700, was transferred because of bad seeing conditions to Babelsberg before World War I. Therefore, the Babelsberg Observatory is the oldest still-existing astronomical institute in the German-speaking world. Former directors have included J. E. Bode \{see planet (998)\}, J. F. Encke, W. Foerster and K. H. Struve. The assistant astronomer J. G. Galle \{see planet (2097)\} discovered Neptune at this observatory in 1846. (M 23542)

This planet is named on the occasion of the 1994 meeting of the Astronomische Gesellschaft in Potsdam.

\section{(5823) Oryo}

1989 YH. Discovered 1989 Dec. 20 by T. Seki at Geisei.

Named for Oryo Narasaki (1842-1913), wife of the Japanese revolutionary Ryoma Sakamoto \{see planet (2835)\}. (M 24765) 


\section{(5824) Inagaki}

1989 YM. Discovered 1989 Dec. 24 by T. Seki at Geisei.

Named in honor of Minoru Inagaki (1958- ) well-known guitarist from Akashi city. (M 24765)

\section{(5825) Rakuyou}

$1990 \mathrm{BR}_{1}$. Discovered 1990 Jan. 21 by A. Sugie at Taga.

Named for the Kyoto \{see planet (4352)\} city Rakuyou technical high school, originally established in 1894 as Kyoto city dyeing and weaving school. Since its foundation the school has consistently been concerned with industrial technology and has graduated many young technicians. (M 27735)

Name proposed by the discoverer following a suggestion by S. Sakabe.

\section{(5827) Letunov}

1990 VB $_{15}$. Discovered 1990 Nov. 15 by L. I. Chernykh at Nauchnyj.

Yurij Aleksandrovich Letunov (1926-1984), a Russian journalist and radio commentator, held a doctorate in the history of science. Author of several books, he was one of the founders of Mayak ("Beacon"), a popular and informative radio program on music. (M 38195)

\section{(5829) Ishidagoro}

$1991 \mathrm{CT}_{1}$. Discovered 1991 Feb. 11 by S. Otomo and O. Muramatsu at Kiyosato.

Named in memory of Goro Ishida (1924-1992), who was associate director of the Okayama Astrophysical Observatory \{see planet (2084)\} (a branch of the Tokyo Astronomical Observatory) for over a quarter of a century and contributed much to astronomical research. After retirement he was actively engaged in literary work, notably as president of the Herschel Society of Japan. He also led several study tours sponsored by that society to Europe and South Africa. He was a man of wide tastes and well known as a researcher of Kabuki (traditional drama). (M 25230)

Named by the discoverers following a suggestion by S. Kimura and T. Ohtani.

Obituary published in Bull. Am. Astron. Soc., Vol. 25, No. 4, p. 1497 (1993).

\section{(5832) Martaprincipe}

$1991 \mathrm{LE}_{1}$. Discovered 1991 June 15 by E. F. Helin at Palomar.

Marta Carusi \{see also planet (4700)\} and Raffaele "Principe" Ranucci were married in Nov. 2000. (M 41934)

The name was suggested by A. Carusi.

\section{(5833) Peterson}

1991 PQ. Discovered 1991 Aug. 5 by H. E. Holt at Palomar.

Colin A. Peterson (1977- ), a research support specialist at Cornell University, and responsible for designing sequences for the NEAR spacecraft MultiSpectral Imager and Near-Infrared Spectrometer team, has developed innovative methods for obtaining spectral maps of (433) Eros. (M 36126)

The name was suggested by J. Veverka.

\section{(5835) Mainfranken}

1992 SP $_{24}$. Discovered 1992 Sept. 21 by F. Börngen at Tautenburg.

Named for the German district of Franken in the northern part of Bavaria, marked by the Main river that originates both in the Fichtelgebirge and in the Fränkische Schweiz. The discoverer's mother and her ancestors are from this district. (M 23353)

\section{(5837) Hedin}

2548 P-L. Discovered 1960 Sept. 24 by C. J. van Houten and I. van Houten-Groeneveld at Palomar.

Named in memory of Sven Hedin (1865-1952), famous Swedish explorer of Central Asia. In his days there were still many unexplored spots on the map of our planet. Hedin made many expeditions and discovered, inter alia, the old Silk route through Asia, the Takla Makan and Gobi deserts, Lake Lop Nor and the Tarim river, as well as the sources of the Brahmaputra and Indus rivers. He was renowned, not only for his scientific papers, but also for writing articles that were interesting for laymen to read. (M 25978)

Hedin is also honored by a lunar crater.

\section{(5838) Hamsun}

2170 T-2. Discovered 1973 Sept. 29 by C. J. van Houten and I. van Houten-Groeneveld at Palomar.

Named in memory of Knut Hamsun, pseudonym of Knut Pedersen (1859-1952), the Norwegian novelist, dramatist, poet and winner of the Nobel Prize for literature in 1920. He achieved his greatest success with the book Sult (Hunger) in 1890. Among his other best known works are Growth of the Soil, Pan, Mysteries and Victoria. (M 25978)

Name suggested by N. Arend.

\section{(5839) GOI}

$1974 \mathrm{SJ}_{3}$. Discovered 1974 Sept. 21 by N. S. Chernykh at Nauchnyj.

Named for Gosudarstvennyj Opticheskij Institut, the State Optical Institute, and its first director, academician Dmitrij Sergeevich Rozhdestvenskij (18761940), an outstanding physicist-optician. The institute has undertaken important investigations in the field of physical and applied optics. (M 32345)

The name is given on the occasion of the 80th anniversary of its founding (1918 Dec. 15).

\section{(5841) Stone}

1982 ST. Discovered 1982 Sept. 19 by E. F. Helin at Palomar.

Named in honor of Edward C. Stone for his distinguished achievements in expanding the frontiers of 
robotic space flight, planetary exploration, interplanetary science and the remote sensing of the earth. While highly respected for his scientific contributions, he has also achieved outstanding success as director of the Jet Propulsion Laboratory, primarily through his perspicacity and an approach to management that blends diverse individuals and ideas into a productive organization. He is also Morrison professor of physics and a vice president at the California Institute of Technology. Among his many awards and honors he received the National Medal of Science. (M 26425)

Citation prepared by M. S. Reid with the enthusiastic endorsement of the JPL staff.

\section{(5846) Hessen}

$1989 \mathrm{AW}_{6}$. Discovered 1989 Jan. 11 by F. Börngen at Tautenburg.

Named for the mountainous German state. The most important towns in the region are Frankfurt/Main, Wiesbaden (the capital, see also planets (717) and (765)), Kassel and Darmstadt. (M 23793)

\section{(5847) Wakiya}

1989 YB. Discovered 1989 Dec. 18 by K. Endate and K. Watanabe at Kitami.

Named in honor of Nanayo Wakiya (1953- ), who joined the Japan Planetarium Laboratory in 1985 with the space artist Numazawa \{see planet (5121)\}, after working for the Mito and Niigata planetaria. Among her many activities she writes articles for astronomical magazines and directs programs about space on television. (M 29145)

\section{(5848) Harutoriko}

1990 BZ 1 . Discovered 1990 Jan. 30 by M. Matsuyama and $\mathrm{K}$. Watanabe at Kushiro.

Named for a small lake in Kushiro ssee planet (4096)\}. The peaceful and popular park area around the lake is designated as a National Natural Monument and contains historical spots, science museums and cultural facilities. The lake is renowned for the mutated Crucian carp, Hibuna. (M 26930)

\section{(5850) Masaharu}

1990 XM. Discovered 1990 Dec. 8 by K. Endate and K. Watanabe at Kitami.

Named in honor of Masaharu Suzuki (1949- ), who is in charge of the Planetarium Programs Production Division of the Gotoh Optical Laboratory. He is also known for his production of 70-mm large-format films. (M 29145)

\section{(5852) Nanette}

1991 HO. Discovered 1991 Apr. 19 by C. S. Shoemaker and D. H. Levy at Palomar.

Named in honor of Nanette and Mark Vigil, daughter and son-in-law of Wendee and David Levy \{see, respectively, planets (6485) and (3673)\}, at their suggestion. (M 30476)

\section{(5855) Yukitsuna}

$1992 \mathrm{UO}_{2}$. Discovered 1992 Oct. 26 by A. Natori and T. Urata at Yakiimo.

Named for a Japanese military commander in the late Heian era, Minamoto-no Yukitsuna. When Yoshinaka \{see planet (4574)\} invaded Kyoto in 1183, Yukitsuna also fought against the Heike, and in 1185 he obstructed Yoshitsune's \{see planet (3178)\} departure from the city. (M 31024)

Name proposed by the second discoverer.

\section{(5857) Neglinka}

$1975 \mathrm{TM}_{2}$. Discovered 1975 Oct. 3 by L. I. Chernykh at Nauchnyj.

Named for a small river that flows into the Moskva river. On Borovitskij \{see planet (5858)\} hill, near the mouth of the Neglinka, a settlement appeared in the eleventh century. (M 30097)

This name and the three next are given on the occasion of the celebration of the 850th anniversary of the city of Moscow in 1997. See also planets (5858), (5859) and (5887), respectively.

\section{(5858) Borovitskia}

1978 SU$_{5}$. Discovered 1978 Sept. 28 by L. I. Chernykh at Nauchnyj.

Named for Borovitskij hill (from the Russian word bor or pine forest), the location of the first buildings in the ancient settlement of Moscow. In the fourteenth century a stone fortress, known as the Kremlin, was erected on the hill. (M 30097)

\section{(5859) Ostozhenka}

$1979 \mathrm{FD}_{2}$. Discovered 1979 Mar. 23 by N. S. Chernykh at Nauchnyj.

Named for one of the oldest streets in the center of Moscow. Ostozhenka, derived from the Russian word stog, or haystack, shows that the street was built on a former hayfield. (M 30098)

\section{(5861) Glynjones}

1982 RW. Discovered 1982 Sept. 15 by E. Bowell at Anderson Mesa.

Named in memory of Kenneth Glyn Jones (19151995), a British historian of astronomy. Glyn Jones is the author of the Messier's Nebulae and Star Clusters (1968). He was one of the founders of the Webb Society, a British-based deep-sky society formed in 1967, and served as its president until 1991. Membership of the Webb Society is now 440 in more than twenty countries worldwide. (M 25654)

Name suggested and citation prepared by R. W. Argyle, endorsed by the executive committee of the Webb Society.

Obituary published in Q.J.R. Astron. Soc., Vol. 37, No. 2, p. 265-266 (1996).

\section{(5862) Sakanoue}

1983 AB. Discovered 1983 Jan. 13 by T. Seki at Geisei. 
Named in honor of Tsutomu Sakanoue (1921- ), professor emeritus of Kyushu University whose specialties included agricultural meteorology, countermeasures against meteorological disasters, medical meteorology and rainmaking. An amateur astronomer with particular interests in atmospheric seeing, the green flash and shadow bands, he contributed to the popularization of astronomy as an advisor at several science museums. $\mathrm{He}$ also served as vice president and president of the Oriental Astronomical Association. (M 32788)

Name proposed by the discoverer following a suggestion by S. Murayama, T. Sato and A. Fujii.

\section{(5863) Tara}

1983 RB. Discovered 1983 Sept. 7 by C. S. Shoemaker and E. M. Shoemaker at Palomar.

In Indian Hinduism, the star-goddess Tara is a manifestation of the queen of time. She is the absolute, unquenchable hunger that propels all life. Among the Buddhists and Jains, as well as in Tibetan Lamaism, she became the symbol of spiritual hunger for release from the purely physical world. As such, Tara is the goddess of self-mastery and mysticism. She is a compassionate goddess, who sees life for the game it is. (M 25230)

\section{(5864) Montgolfier}

$1983 \mathrm{RC}_{4}$. Discovered 1983 Sept. 2 by N. G. Thomas at Anderson Mesa.

Named in memory of the Montgolfier brothers, Jacques Etienne (1745-1799) and Joseph Michal (17401810), who engineered the first manned free flight in a hot-air balloon, sailing nine $\mathrm{km}$ over Paris in 25 minutes on 1783 Nov. 25. Their father owned and they helped manage a paper-manufacturing business. While burning some waste paper they noticed how a paper bag was sent aloft by the hot air. (M 26930)

\section{(5865) Qualytemocrina}

1984 QQ. Discovered 1984 Aug. 31 by A. Mrkos at Klět.

Named for the International Comet Quarterly, which serves as an international archive of photometric data on comets, striving to maintain a useful bridge between amateur and professional astronomers; the naming occurs with the journal's century issue. Qualytemocrina is a play on the journal's title, each letter of the title being used and with a combination of word-order and letter-order reversal. The discoverer of this object was one of the most prolific comet discoverers and astrometrists of recent decades. (M 28089)

Name suggested by D. W. E. Green, who made the key identification for this minor planet.

\section{(5866) Sachsen}

$1988 \mathrm{PM}_{2}$. Discovered 1988 Aug. 13 by F. Börngen at Tautenburg.

Named for the state of Sachsen, the richest German region in the 15 th and 16th centuries. The zenith of the Saxon electors (Dresden baroque) was during the reign of Friedrich August I (August the Strong, 1694-1733). The most important towns in the territory are Dresden (the capital, see planets (263) and (3053)), Leipzig, Chemnitz and Zwickau. (M 23793)

\section{(5868) Ohta}

1988 TQ. Discovered 1988 Oct. 13 by K. Endate and K. Watanabe at Kitami.

Named in honor of Kentaro Ohta (1942- ), who was in charge of designing optical telescopes at the Gotoh Optical Laboratory for many years and who now leads the large-format film section. He has also written many articles in astronomical magazines for amateur astronomers. (M 29145)

\section{(5869) Tanith}

1988 VN $_{4}$. Discovered 1988 Nov. 4 by C. S. Shoemaker and E. M. Shoemaker at Palomar.

Seen as a heavenly goddess by the conquering Romans who called her Caelestis, Tanith was worshipped by the Carthaginians. This winged sky-goddess of the Punic people wore a zodiac around her head and held the sun and moon in either hand. (M 24918)

\section{(5870) Baltimore}

$1989 \mathrm{CC}_{1}$. Discovered 1989 Feb. 11 by E. F. Helin at Palomar.

Named for the city located on the Chesapeake Bay in Maryland. Celebrating the bicentennial of its 1797 incorporation, Baltimore is home to the Maryland Academy of Sciences, founding organization of the Maryland Science Center, also celebrating its 200th year. Baltimore is also home to the Space Telescope Science Institute and Johns Hopkins University. (M 29671)

Named by the discoverer following a suggestion by J. O'Leary.

\section{(5871) Bobbell}

$1989 \mathrm{CE}_{2}$. Discovered 1989 Feb. 11 by E. F. Helin at Palomar.

Named in honor of Robert L. Bell, friend and associate of the discoverer's husband. Bob Bell graduated from the California Institute of Technology with a B.S. in physics and an M.S. in applied mechanics, which he promptly utilized to invent pressure-sensing devices to monitor automobile-engine functions, enabling us to drive efficiently down our highways. More recently he has joined the astronomical community with his own private dome and CCD-equipped telescope. Bob is the quintessential entrepreneur, applying and promoting new ideas to solve problems. (M 28090)

\section{(5872) Sugano}

1989 SL. Discovered 1989 Sept. 30 by T. Nomura and K. Kawanishi at Minami-Oda.

Named in honor of Matsuo Sugano (1939- ), the first discoverer of comet C/1983 J1. He also discovered three novae (V827 Her, V838 Her and V4327 Sgr) and 
the peculiar variable V1143 Ori. He worked at Akashi Municipal Planetarium for 36 years to encourage the development of amateur astronomy. (M 35483)

\section{(5873) Archilochos}

1989 SB $_{3}$. Discovered 1989 Sept. 26 by E. W. Elst at La Silla.

Named for the Greek poet Archilochos (fl. 700 B.C.) who, through his provocative attitude against the established moral values of his time, confronted his subjective comprehension of reality, his personal experience and his own notion of morality to the heroic myths of his epoch. (M 23793)

Name proposed and citation prepared by Antonia Svarna on the request of the discoverer.

\section{(5875) Kuga}

1989 XO. Discovered 1989 Dec. 5 by K. Endate and K. Watanabe at Kitami.

Named in honor of Naoto Kuga (1964- ), who produces planetarium programs at the Gotoh Optical Laboratory. (M 29145)

\section{(5878) Charlene}

1991 CC $_{1}$. Discovered 1991 Feb. 14 by E. F. Helin at Palomar.

Named in honor of Charlene Marie Anderson, director of publications for the Planetary Report, who has brought the planetary sciences to hundreds of thousands of people worldwide. As an editor she has made invaluable contributions to the public understanding of space science and planetary exploration. Her inviting, natural style of writing makes science come to life. (M 24123)

\section{(5879) Almeria}

$1992 \mathrm{CH}_{1}$. Discovered 1992 Feb. 8 by K. Birkle and U. Hopp at Calar Alto.

Named for the Spanish city and province where the Calar Alto Observatory of the German-Spanish Astronomical Center is located. The observatory is operated jointly by the Max-Planck-Institut für Astronomie in Heidelberg and the Spanish National Commission for Astronomy. The naming acknowledges the great Spanish hospitality experienced by German astronomers at the observatory. (M 34341)

\section{(5881) Akashi}

1992 SR $_{12}$. Discovered 1992 Sept. 27 by M. Sugano and T. Nomura at Minami-Oda.

Named for a city facing the Setouchi Inland Sea. Akashi Municipal Planetarium was established in 1960 precisely on the meridian for Japan Standard Time ( $135^{\circ}$ east of Greenwich), and about 6.6 million people have visited it. (M 35484)

\section{(5884) Dolezal}

6045 P-L. Discovered 1960 Sept. 24 by C. J. van

Houten and I. van Houten-Groeneveld at Palomar.

Named in memory of Erich Dolezal (1902-1990). He was a talented writer and popularizer of astronomy and space science. He wrote many books and later became Science Advisor of Radio Austria in Vienna, where he gave numerous lectures to schoolchildren and adults. In 1949, he was a co-founder of the Austrian Society for Space Research that was eventually merged into the International Astronautical Federation. (M 24765)

Name proposed by the discoverers following a suggestion by H. Haupt.

\section{(5885) Apeldoorn}

3137 T-2. Discovered 1973 Sept. 30 by C. J. van Houten and I. van Houten-Groeneveld at Palomar.

Named in honor of Berend Caspar Jan Apeldoorn (1944- ), Dutch amateur astronomer, on the occasion of his 50th birthday. Since 1961, Ben has specialized in meteors and meteorites, observing meteors both visually and photographically. He has written many articles on astronomy for astronomical periodicals and yearbooks, as well as for general magazines and newspapers. Apeldoorn still makes important contributions to the popularization of astronomy and is a member of the Meteor Section of the Dutch Society for Meteorology and Astronomy. (M 24765)

Name proposed by the discoverers following a suggestion by F. Bettonvil, chairman of the Meteor Section.

\section{(5887) Yauza}

$1976 \mathrm{SG}_{2}$. Discovered 1976 Sept. 24 by N. S. Chernykh at Nauchnyj.

Named for one of Moscow's little rivers. Between the place where it flows into Moscow river and the mouth of the Neglinka \{see planet (5858)\} was the site of the first buildings of the ancient settlement of Moscow. (M 30098)

\section{(5889) Mickiewicz}

$1979 \mathrm{FA}_{3}$. Discovered 1979 Mar. 31 by N. S. Chernykh at Nauchnyj.

Named in memory of Adam Mickiewicz (1798-1855), great Polish poet. (M 27128)

\section{(5890) Carlsberg}

1979 KG. Discovered 1979 May 19 by R. M. West at La Silla.

Named in honor of Carlsbergfondet, established in 1876 by Jacob Christian Jacobsen (1811-1887), philantropic founder of the first Carlsberg Brewery in 1847 , in order to ensure the continuation of scientific work at the Carlsberg Laboratories and to provide support for the natural sciences, mathematics, philosophy, history and linguistics. The impact of Carlsbergfondet on Danish scientific and cultural life has been immense, and thousands of research projects, including many in astronomy and astrophysics, have become possible. This minor planet was numbered in 1994 when the discoverer was living in Munich, just 150 years after Jacobsen's visit to the breweries of that city, when he obtained a famous sample of yeast that contributed much to his subsequent success. (M 27330) 


\section{(5891) Gehrig}

1981 SM. Discovered 1981 Sept. 22 by A. Mrkos at Kleť.

Named in memory of Henry Louis (Lou) Gehrig (1903-1941), professional U.S. baseball player. From 1925 to 1939 Gehrig appeared in 2130 consecutive games for the New York Yankees, a reliability record that remained unbroken until 1995. Gehrig was a consistent left-handed batsman, with a career average of 0.340 , but his career was ended prematurely as a result of amyothrophic lateral sclerosis ("Lou Gehrig's Disease"). (M 27735)

Name suggested by G. V. Williams, who made the identifications involving this object, and T. B. Spahr.

(5894) Telč

$1982 \mathrm{RM}_{1}$. Discovered 1982 Sept. 14 by A. Mrkos at Kleťt.

Telč, a small town on the border of southern Bohemia and Moravia, was founded in the twelfth century. The historic center of Telč has been listed on the UNESCO World Heritage roster of cultural and natural sites since 1992. (M 36945)

The name was suggested by M. Tichý.

\section{(5896) Narrenschiff}

$1982 \mathrm{VV}_{10}$. Discovered 1982 Nov. 12 by L. G. Karachkina at Nauchnyj.

Named in honor of Sebastian Brant (c.1458-1521), an outstanding German writer and humanist, and the author of the immortal satiric poem Narrenschiff, published in 26 editions in several European languages in the sixteenth century alone. (M 23793)

The name is given on the occasion of the quincentenary of the publication in Basel in 1494 of the first edition of Narrenschiff. Name proposed by L. R. Nemirovskij.

\section{(5897) Novotná}

1984 SZ $_{1}$. Discovered 1984 Sept. 29 by A. Mrkos at Klě́t.

Named in memory of Jarmila Novotná-Daubková (1907-1994), Czech opera singer, who lived in the U.S. from 1948, where she was engaged at the Metropolitan Opera in New York for 16 seasons. She is also known for The Songs of Lidice, a selection of Czech and Moravian folk songs, which she recorded with Jan Masaryk in 1942. (M 29671)

Name suggested by J. Tichá on the occasion of ninetieth anniversary of Novotná's birth.

\section{(5899) Jedicke}

1986 AH. Discovered 1986 Jan. 9 by C. S. Shoemaker and E. M. Shoemaker at Palomar.

Named in honor of the Jedicke family, notably Peter, Robert and June. One of Canada's best known amateur astronomers, Peter Jedicke is a superb teacher of astronomy and physics, especially to young people. His brother Robert, a physicist, observes with the Spacewatch survey for near-earth objects. Although sister June Zehr has not followed in her siblings' astronomical footsteps, she often shares observing sessions with her brothers. (M 25444)

Name suggested and citation prepared by D. H. Levy.

\section{(5900) Jensen}

1986 TL. Discovered 1986 Oct. 3 by P. Jensen and K. Augustesen and H. J. Fogh Olsen at Brorfelde.

Named in honor of Poul B. Jensen, who served in the Meridian Circle Department at the Brorfelde Observatory for 35 years, and his wife, Bodil Jensen. During the past ten years Poul also took part in the minor planet program carried out with the Schmidt telescope. (M 23793)

Name proposed by K. Augustesen and H. J. Fogh Olsen.

\section{(5902) Talima}

1987 QY 10 . Discovered 1987 Aug. 27 by L. G. Karachkina at Nauchnyj.

Named for Tatiana Alimovna Damir (1923- ), friend of the discoverer, daughter of Alim Matveevich Damir and wife of Sergej Petrovich Kapitsa \{see, respectively, planets (5717) and (5094)\}. (M 24765)

\section{(5904) Württemberg}

$1989 \mathrm{AE}_{7}$. Discovered 1989 Jan. 10 by F. Börngen at Tautenburg.

Named for a region in southwestern Germany that includes both parts of the Schwarzwald, the Schwäbische Alb and the Alpenvorland. Both Johannes Kepler and Albert Einstein \{see, respectively, planets (1134) and (2001)\} were born in this region of Baden-Württemberg, as were the poets Martin Wieland, Friedrich Schiller, Friedrich Hölderlin and Eduard Mörike \{see, respectively, planets (8108), (3079), (9189) and (9204)\}. The major towns in Württemberg include Stuttgart, Tübingen, Ulm and Heilbronn. (M 24123; M 25351)

\section{(5905) Johnson}

1989 CJ $_{1}$. Discovered 1989 Feb. 11 by E. F. Helin at Palomar.

Named for Lindley N. Johnson, who is responsible for planning the potential use of space-surveillance assets to detect and track near-earth objects. With degrees in astronomy and engineering management, he has been a space enthusiast since the age of 12 . The discoverer and the Near-Earth Asteroid Tracking team wish to express their appreciation for his contributions to the development of the NASA-JPL NEAT program, which became operational on the Maui GEODSS telescope in Dec. 1995. (M 27128)

\section{(5908) Aichi}

1989 UF. Discovered 1989 Oct. 20 by Y. Mizuno and T. Furuta at Kani.

Named for the prefecture, Japan's fourth largest by population, in which both discoverers were born and raised. It is the main industrial prefecture. In olden times it nurtured the Karakuri (intricate puppet). Nowadays the making of clocks and cars, as well as the robotic and aerospace industries, thrive there. (M 33385) 


\section{(5909) Nagoya}

1989 UT. Discovered 1989 Oct. 23 by Y. Mizuno and T. Furuta at Kani.

Named for Japan's fourth largest city, where the first discoverer was born and raised. From the time of the Tokugawa period, when the first shogun Tokugawa Ieyasu built a castle in this region, Nagoya has been an important area for land and sea travel, connecting Tokyo with Kyoto and Osaka. It is blessed with a rich cultural history and many cultural attractions, such as Nagoya Castle and the Tokugawa Art Museum, which displays artifacts of the Samurai warrior. (M 33385)

\section{(5910) Zátopek}

$1989 \mathrm{WH}_{4}$. Discovered 1989 Nov. 29 by A. Mrkos at Klět.

Named in honor of the great Czechoslovak longdistance runner, Emil Zátopek (1922- ). In a twelve-year career he set eighteen world records and won five Olympic medals: silver in 1948 and gold in 1952 at $5000 \mathrm{~m}$, gold in 1948 and 1952 at $10000 \mathrm{~m}$ and gold in the 1952 marathon. The name also honors his wife Dana (1922- ), who won Olympic gold for the javelin in 1952. (M 27735)

Name suggested by G. V. Williams, who made the identifications involving this object.

\section{(5915) Yoshihiro}

1991 EU. Discovered 1991 Mar. 9 by T. Seki at Geisei.

Named for Yoshihiro Yamada (1946- ), astronomical scholar and keen popularizer of astronomy in Japan. (M 25231)

\section{(5916) van der Woude}

$1991 \mathrm{JD}_{1}$. Discovered 1991 May 8 by E. F. Helin at Palomar.

Named in honor of Jurrie van der Woude, Jet Propulsion Laboratory Public Information Representative and the co-author of the "25 Years of Space Photography" Exhibit. He joined JPL in 1976 and became an active member of the photo lab and Public Information Office. He develops special products for the Director's Office and the Laboratory's Community Relations Program. (M 30477)

\section{(5919) Patrickmartin}

1991 PW $_{12}$. Discovered 1991 Aug. 5 by H. E. Holt at Palomar.

Patrick Martin (1967- ), a research associate at Cornell University, works on the analysis and interpretation of data acquired by the Near Infrared Spectrometer instrument on the NEAR mission to (433) Eros. (M 36126)

The name was suggested by B. E. Clark.

\section{(5922) Shouichi}

1992 UV. Discovered 1992 Oct. 21 by S. Otomo at Kiyosato

Named in honor of Shouichi Sato (1950- ), an electric engineer who developed an inexpensive and efficient photovoltaic inverter that can be connected to commercial power supply lines. (M 25654)
(5923) Liedeke

1992 WC $_{8}$. Discovered 1992 Nov. 26 by the Spacewatch at Kitt Peak.

Named in honor of Liedeke Gehrels-de Stoppelaar on the occasion of her completion of 21 years teaching Art History and French at University High School, a magnet school in Tucson that gives students the opportunity to pass advanced-placement examinations for credit at universities. She guided these programs through their formative years when this type of school was new in the United States, after her own preparation with a Ph.D. on the theme of justice in the writings of Albert Camus and with 13 years of teaching elsewhere. (M 29145)

Named following a suggestion by C. J. van Houten and I. van Houten-Groeneveld.

\section{(5924) Teruo}

$1994 \mathrm{CH}_{1}$. Discovered 1994 Feb. 7 by T. Kobayashi at Oizumi.

Named in memory of Teruo Saegusa (1957-1989), one of the greatest Japanese alpinists, who climbed Mount Everest twice. (M 23542)

\section{(5926) Schönfeld}

1929 PB. Discovered 1929 Aug. 4 by M. F. Wolf at Heidelberg.

Named in memory of Eduard Schönfeld (18281891), famous German astronomer and director of the Mannheim and Bonn observatories. Pupil and, from 1853, assistant of F. W. A. Argelander \{see planet (1551)\}, Schönfeld took part in the huge Bonner Durchmusterung project. His time as director of the Mannheim observatory mainly was devoted to the detection of variable stars. The results were published in two parts in 1866 and 1874. After Argelander's death in 1875, Schönfeld started the task to enlarge the $\mathrm{BD}$ with the zone between $-2^{\circ}$ and $-23^{\circ}$. In 1886 his momumental Südliche Durchmusterung, containing 24 charts with 133,659 stars, was published, completing the greatest task of the Bonn observatory. Schönfeld also served as an important promoter of the foundation and development of the Astronomische Gesellschaft. (M 23793)

Name proposed and citation prepared by L.D.Schmadel. Schönfeld is also honored by a lunar crater.

\section{(5928) Pindarus}

1973 SK $_{1}$. Discovered 1973 Sept. 19 by C. J. van Houten and I. van Houten-Groeneveld at Palomar.

Named for the Greek lyric poet Pindarus (c. 520-446 B.C.), long the mainstay of Greek poetry. He lived in Greece and Sicily and united the Greek people with his poems and tragic and victory songs during festivals. He had great influence on the work of the German poet Friedrich Hölderlin \{see planet (9189)\}. (M 26764) 


\section{(5930) Zhiganov}

1975 VW $_{2}$. Discovered 1975 Nov. 2 by T. M. Smirnova at Nauchnyj.

Named in memory of Nazib Gayazovich Zhiganov (1911-1988), outstanding Soviet Tatar composer and public figure, founder of the Tatarian professional musical school. Zhiganov was the organizer and chairman of the Composers Union of Tatarstan during 1939-1976, as well as of the Kazan State Conservatory from 1945 until his death. His most significant musical compositions are the opera Dzhalil, the ballet Two legends, and his Second, Seventh and Ninth symphonies, in which he combined classical musical traditions with Tatar folk melodies. (M 25978)

Name suggested by the Institute of Theoretical Astronomy.

\section{(5931) Zhvanetskij}

1976 GK$_{3}$. Discovered 1976 Apr. 1 by N. S. Chernykh at Nauchnyj.

Named in honor of the Russian writer Mikhail Zhvanetskij (1934- ), whose satirical talent has won nation-wide recognition. He won the international festival "Gold Ostap" in 1993 and the independent prize "Triumph" in 1995. He is also an honorary citizen of Odessa, president of the World-Wide Club of Odessa Citizens and holder of the order "Friendship of peoples". (M 30098)

\section{(5932) Prutkov}

$1976 \mathrm{GO}_{3}$. Discovered 1976 Apr. 1 by N. S. Chernykh at Nauchnyj.

Named for Koz'ma Prutkov, a parody character, fictitious poet and author of many fables, humorous poems and aphorisms. Prutkov is the collective pen-name invented by the nineteenth-century poets A. K. Tolstoj and the brothers A. M. and V. M. Zhemchuzhnikov. Many of Prutkov's utterances have become by-words in Russian. (M 30098)

\section{(5933) Kemurdzhian}

1976 QN. Discovered 1976 Aug. 26 by N. S. Chernykh at Nauchnyj.

Named in honor of Aleksandr Leonovich Kemurdzhian (1921- ), an expert on the design of cosmic transportation and specialized robots for the investigation of the surfaces of planets and their satellites. He was responsible for designing the self-propulsion system of Lunokhod 1 and Lunokhod 2 as these vehicles explored the moon's surface in the early 1970s. Subsequently he headed the design of mobile apparatus for the investigation of Venus, Mars and Phobos. (M 31024)

Name proposed by the discoverer following a suggestion by ITA.

\section{(5934) Mats}

1976 SJ. Discovered 1976 Sept. 20 by C.-I. Lagerkvist and H. Rickman at Kvistaberg.
Named for Mats Lindgren of Uppsala Astronomical Observatory, whose research into Jupiter's role in shaping the fate of comets led to spectacular results, in particular relating to the evolution and demise of comet D/1993 F2 (Shoemaker-Levy 9). He obtained some of the best ground-based images of the impact plumes and scars in July 1994. His contributions were condensed into his doctoral thesis at Uppsala University in June 1995. (M 25444)

\section{(5935) Ostankino}

$1977 \mathrm{EF}_{1}$. Discovered 1977 Mar. 13 by N. S. Chernykh at Nauchnyj.

Named for a district of Moscow that included the village Ostankino, the eighteenth-century county seat of the counts Sheremetev. Among places of interest there are a county-house museum, television tower and center, and the Memorial Museum of Cosmonautics. (M 30098)

\section{(5936) Khadzhinov}

1979 FQ $_{2}$. Discovered 1979 Mar. 29 by N. S. Chernykh at Nauchnyj.

Named in honor of Leonid Petrovich Khadzhinov (1927- ), prominent Ukrainian electrical engineer involved with the construction of electrotechnical machines. (M 30098)

\section{(5937) Lodén}

1979 XQ. Discovered 1979 Dec. 11 by C.-I. Lagerkvist at Kvistaberg.

Named for Kerstin and Lars Olof Lodén. Kerstin, an astronomer at Stockholm Observatory, is a coauthor (with the discoverer) of two books in introductory astronomy. Lars Olof is professor of astronomy at Uppsala Observatory. Both have devoted most of their research to studies of the Milky Way, in particular by making a large survey of the Southern Milky Way. (M 25444)

\section{(5938) Keller}

$1980 \mathrm{FH}_{2}$. Discovered 1980 Mar. 16 by C.-I. Lagerkvist at La Silla.

Named for Horst Uwe Keller, well-known scientist at the Max Planck Institute in Lindau. Uwe was the driving force of the science team for the ESA study on 'The Orbiting Planetary Telescope', in which the discoverer also participated. (M 25444)

\section{(5939) Toshimayeda}

1981 EU $_{8}$. Discovered 1981 Mar. 1 by S. J. Bus at Siding Spring.

Toshiko Mayeda (1923- ), senior research associate at the University of Chicago Enrico Fermi Institute, has produced a comprehensive body of data on oxygen isotopes in meteorites. These data have provided an essential tool for the classification of meteorites, and for relating meteorites to their parent bodies. (M 46007) 


\section{(5940) Feliksobolev}

$1981 \mathrm{TJ}_{4}$. Discovered 1981 Oct. 8 by L. I. Chernykh at Nauchnyj.

Named in memory of the Ukraine film producer Feliks Mikhailovich Sobolev (1931-1984), great master of scientific films, Honored Artist of the Ukraine and U.S.S.R. State Prize Winner. His films, made at the Kiev studio for scientific films, provided a fresh outlook at popular science, obtained the appreciation of audience and critics alike and won awards at prestigious festivals in many countries. (M 34622)

\section{(5941) Valencia}

1982 UQ6. Discovered 1982 Oct. 20 by L. G. Karachkina at Nauchnyj.

Named for the large Mediterranean seaport city in Spain, administrative center of the province of the same name and an important industrial, cultural and scientific center. (M 24765)

Name proposed by the Institute of Theoretical Astronomy, which collaborates with the Astronomical Observatory of the University of Valencia.

\section{(5942) Denzilrobert}

$1983 \mathrm{AN}_{2}$. Discovered 1983 Jan. 10 by B. E. Behymer and M. S. Marley at Palomar.

Denzil Marley (1918- ) and Robert Behymer (1926-

), fathers of the discoverers, encouraged, along with Louise Marley and Mary Behymer, their sons' interests in the natural world, inspired them to strive for high goals and provided for the education that made possible their participation in the discovery of this minor planet. (M 38195)

\section{(5943) Lovi}

1984 EG. Discovered 1984 Mar. 1 by E. Bowell at Anderson Mesa.

Named in memory of George Lovi (1939-1993), astronomical cartographer, planetarium lecturer and popularizer of sky lore. Lovi was staff astronomer at Vanderbilt Planetarium and lecturer at the American Museum-Hayden Planetarium and at the Jones Planetarium Theater, all in the New York area. Author of two books (Men, Monsters, and the Modern Universe and Uranometria 2000.0), Lovi created (in 1968) and maintained (until 1992) a monthly series of star charts for Sky and Telescope \{see planet (3243)\} magazine. In addition, he was author of the column "Rambling Through the Skies" for 260 consecutive issues of that magazine (1971-1993). A noted bibliophile and independent scholar, Lovi's diverse work ranged from planetarium installation to presentation, and from tours of the night sky to tours of major subways and railways around the world. (M 25654)

Name suggested and citation prepared by J. Rao and S. Storch.

Obituaries published in Sky Telesc., Vol. 86, No. 2, p. 59, 74 (1993); J. Br. Astron. Assoc., Vol. 103, No. 4, p. 201 (1993).

\section{(5944) Utesov}

$1984 \mathrm{JA}_{2}$. Discovered 1984 May 2 by L. G. Karachkina at Nauchnyj.

Named in memory of Leonid Osipovich Utesov (18951982), famous Russian singer, musician, actor, founder and artistic leader of the first Russian theatricalized jazz band (1929). (M 24765)

The name is given by the discoverer on the occasion of onehundredth anniversary of Utesov's birth, following a suggestion by L. R. Nemirovskij.

\section{(5945) Roachapproach}

1984 SQ $_{3}$. Discovered 1984 Sept. 28 by B. A. Skiff at Anderson Mesa.

Named in honor of Steve Roach, musician and composer of 'space music'. Among the most progressive performers in the genre, his prolific output includes seminal works such as "Structures from Silence" (1984), "Dreamtime Return" (1988) and "The Magnificent Void" (1996). His mixture of heavily-processed electronic sounds with primitive woodwinds and percussion conveys powerful impressions of spatial immensity. These have inspired the discoverer through endless nights at the telescope. (M 31296)

Name suggested by L. Kohanov.

\section{(5946) Hrozný}

$1984 \mathrm{UC}_{1}$. Discovered 1984 Oct. 28 by A. Mrkos at Kleť.

Named in memory of Bedřich Hrozný (1879-1952), Czech archeologist, orientalist and language scholar. He deciphered the Hittite language and proved that it is a member of the Indo-European language group. (M 38195)

The name was suggested by M. Tichý.

\section{(5947) Bonnie}

1985 FD. Discovered 1985 Mar. 21 by C. S. Shoemaker and E. M. Shoemaker at Palomar.

Named in memory of Bonnie Gail Farquhar (19361993), late wife of the mission director for the Near-Earth Asteroid Rendezvous (NEAR) mission, Robert Farquhar \{see planet (5256)\}. Rendezvous operations at (433) Eros will begin on Bonnie's birthday, 1998 Dec. 20. (M 30477)

Name proposed by the discoverers following a suggestion by R. Farquhar.

\section{(5948) Longo}

1985 JL. Discovered 1985 May 15 by E. Bowell at Anderson Mesa.

Named in honor of Giuseppe Longo (1920- ), a physicist at the University of Bologna. For most of his professional life a nuclear physicist, in the late 1980s Longo became interested in the Tunguska ssee planet (5471)\} event. He organized an expedition to the site of the explosion in 1991, at which time microscopic particles, trapped in the resin of surviving trees, were collected. Later detailed analysis showed that the 
annual distribution of the particles peaked in 1908, and elements were identified that probably originated in meteoritic material. Longo recently organized in Bologna the first workshop where Russian and other modelers of the Tunguska event met and compared their views and results. (M 28621)

Name suggested and citation prepared by M. Di Martino and P. Farinella.

\section{(5950) Leukippos}

$1986 \mathrm{PS}_{4}$. Discovered 1986 Aug. 9 by E. W. Elst and

V. G. Ivanova at Rozhen.

Named for the great Greek philosopher Leukippos, born around 450 B.C., probably at Miletus, on the west coast of Asia Minor. His main concern was to harmonize Ionic cosmology with Greek ontology. Although it was Demokritos \{see planet (6129)\} who brilliantly elaborated many of his ideas, the atomistic theory of matter originated with Leukippos. Only a few fragments of his work remain, and these show that he made a clear distinction between empty space and matter. (M 24918)

\section{(5951) Alicemonet}

$1986 \mathrm{TZ}_{1}$. Discovered 1986 Oct. 7 by E. Bowell at Anderson Mesa.

Named in honor of Alice K. B. Monet (1954- ), an astronomer at the U.S. Naval Observatory's Flagstaff Station and former chair of the Division on Dynamical Astronomy of the American Astronomical Society. Monet has made valuable astrometric observations of solar-system bodies in support of NASA's Galileo and Near Earth Asteroid Rendezvous (NEAR) missions. Using the $0.20-\mathrm{m}$ transit telescope in an autonomous operating mode, she has generated, in part in collaboration with the discoverer, accurate astrometric data for many asteroids and comets. (M 27460; M 27477)

Name proposed by the discoverer following a suggestion by the JPL ephemeris group.

\section{(5952) Davemonet}

1987 EV. Discovered 1987 Mar. 4 by E. Bowell at Anderson Mesa.

Named in honor of David G. Monet (1951- ), an astronomer at the U.S. Naval Observatory's Flagstaff Station. Monet received the USNO's Newcomb Award for his development of a program of high-precision differential CCD astrometry, which was implemented on the $1.55-\mathrm{m}$ astrometric reflector. Monet is also the principal investigator for the Precision Measuring Microdensitometer (PMM) project. Over the years, he has been extremely generous with technical advice to the discoverer. (M 27460)

Name proposed by the discoverer following a suggestion by the JPL ephemeris group.

\section{(5953) Shelton}

1987 HS. Discovered 1987 Apr. 25 by C. S. Shoemaker and E. M. Shoemaker at Palomar.
Named in honor of Ian Shelton, Canadian astronomer, best known for his discovery of the supernova in the Large Magellanic Cloud on 1987 Feb. 24. During his four years as resident observer at the University of Toronto Southern Observatory, he participated in programs with astronomers worldwide, and more recently he has generously contributed to the astronomical education of school children, parents and teachers. (M 31296)

Name suggested and citation prepared by D. MacCormack and R. Garrison.

\section{(5954) Epikouros}

1987 QS $_{1}$. Discovered 1987 Aug. 19 by E. W. Elst at La Silla.

Named for the great philosopher Epikouros (341270 B.C.), well known for his exposition of the atomistic theory of physics, inspired by the teachings of Demokritos \{see planet (6129)\}. He was also celebrated for his ethical teaching, to which we owe "epicurism". Living in an age when the Greeks had lost their political freedom in Macedonia, Epikouros wanted to restore mental freedom by means of his physics to ensure "quietude of the mind". (M 24765)

\section{(5955) Khromchenko}

$1987 \mathrm{RT}_{3}$. Discovered 1987 Sept. 2 by L. I. Chernykh at Nauchnyj.

Vladimir Anatolievich Khromchenko is a music teacher at Yalta and a talented designer who constructed the first home-built organ in Ukraine. He founded the Centre of Organ Music in the former power station of the Imperial Livadia Palace at Yalta. (M 38195)

\section{(5956) d'Alembert}

$1988 \mathrm{CF}_{5}$. Discovered 1988 Feb. 13 by E. W. Elst at La Silla.

Named in memory of Jean Le Rond d'Alembert (17171783), French philosopher and mathematician, famous for his mechanical principle (1742). He introduced the calculus of partial differences and solved the problem of the precession of the equinoxes. He is perhaps best remembered for his association with Diderot \{see planet (5351)\} in the preparation of the Encyclopedia. D'Alembert was much interested in music, both as a science and as an art. (M 23793)

D'Alembert is also honored by a lunar crater.

\section{(5957) Irina}

1988 JN. Discovered 1988 May 11 by C. S. Shoemaker and E. M. Shoemaker at Palomar.

Named in honor of Irina Victorovna Farquhar, wife of the NEAR mission director, Robert Farquhar \{see planet (5256)\}. NEAR's initial close pass by Eros will occur on 1999 January 10, their fifth wedding anniversary. Since earning a doctoral degree in economics from Leningrad State University in 1983, Irina has made several important contributions in the fields of labor, regional and health economics. (M 30477) 
Name proposed by the discoverers following a suggestion by R. Farquhar, who prepared the citation.

\section{(5958) Barrande}

1989 BS $_{1}$. Discovered 1989 Jan. 29 by A. Mrkos at Klet.

The French geologist and paleontologist Joachim Barrande (1799-1883) made studies of the fossil strata of Bohemia that revealed the abundance and rich variety of life in the Early Paleozoic era. (M 38195) The name was suggested by M. Tichý.

\section{(5959) Shaklan}

$1989 \mathrm{NB}_{1}$. Discovered 1989 July 2 by E. F. Helin at Palomar.

Named in honor of Stuart B. Shaklan, an optical engineer, who performed the imaging design and analysis required for the Near-Earth Asteroid Tracking program. He developed the models needed to understand the performance of the NEAT optical system and analyzed the imaging results to determine the optimal instrument configuration. His expertise in CCD characterization and telescope design for high-precision astrometry was an important element of the NEAT success. (M 26930)

\section{(5960) Wakkanai}

1989 US. Discovered 1989 Oct. 21 by M. Mukai and M. Takeishi at Kagoshima.

Wakkanai, situated at the northern tip of Japan, is a city known for its marine industry, dairy farming and tourist industry. The second discoverer lived in Wakkanai for four years, and this name is proposed as a token of his gratitude to the people of the town. (M 24411)

\section{(5962) Shikokutenkyo}

1990 HK. Discovered 1990 Apr. 18 by T. Seki at Geisei.

Named for an amateur astronomical society with 50 members on Shikoku Island \{see planet (4223)\}. (M 25231)

\section{(5966) Tomeko}

$1990 \mathrm{VS}_{6}$. Discovered 1990 Nov. 15 by T. Seki at Geisei.

Named for Tomeko Goto (1899- ), who supported her husband, Seizo Goto \{see planet (2621)\}, president of the Goto Optical Laboratory. (M 27330)

\section{(5967) Edithlevy}

$1991 \mathrm{CM}_{5}$. Discovered 1991 Feb. 9 by C. S. Shoemaker and D. H. Levy at Palomar.

Named in honor of Edith Pailet Levy (1918- ), mother of the second discoverer. Born in New Orleans, she married Nathaniel Lewis Levy in 1939 and headed to Montreal to become one of McGill University's first women medical students. Levy excelled in hematology, but once her children were grown she went back to McGill to launch a career in genetics. She spent several years studying Alzheimer's patients at Montreal's Jewish Hospital of Hope. (M 24918)
(5968) Trauger

1991 FC. Discovered 1991 Mar. 17 by E. F. Helin at Palomar.

Named in honor of John T. Trauger, widely known for his remarkable achievements as principal investigator for the Wide Field/Planetary Camera II on the Hubble Space Telescope. For defining, guiding and leading both scientific and technical aspects of the entire project, he was awarded the NASA Outstanding Leadership Medal in 1994. He is an outstanding instrumentalist, noted for his development and use of Fabry-Perot technology. He has also provided critical assistance to the Air Force Maui Optical Site (AMOS) program that has acquired follow-up astrometry for new discoveries, particularly for JPL's PCAS and NEAT programs. (M 27128)

\section{(5969) Ryuichiro}

1991 FT. Discovered 1991 Mar. 17 by T. Seki at Geisei.

Named in honor of Ryuichiro Goto (1938- ), grandson of Seizo Goto \{see planet (2621)\}. He directs the Goto Optical Laboratory and is very active in the development of new planetaria and the popularization of astronomy. (M 27330)

\section{(5970) Ohdohrikouen}

$1991 \mathrm{JS}_{1}$. Discovered 1991 May 13 by K. Watanabe at Sapporo.

Named for a belt-shaped park, $105 \mathrm{~m}$ wide and $1.6 \mathrm{~km}$ long, that runs east-west through the center of Sapporo \{see planet (3473)\}. Statues and fountains are situated among the walkways and grassy areas. Citizens and tourists gather here throughout the year, and it is the site of the world-famous Sapporo Snow Festival in the winter. (M 26930)

\section{(5973) Takimoto}

1991 QC. Discovered 1991 Aug. 17 by S. Otomo at Kiyosato.

Named in memory of Daisuke Takimoto (1950-1997), an activist and computer programmer who lived in Tokyo. He represented the shareholders of the Tokyo Electric Power Company in the nuclear-power phaseout movement, joining thousands of other shareholders who wished to phase out nuclear power. (M 35484)

\section{(5975) Otakemayumi}

1992 SG. Discovered 1992 Sept. 21 by K. Endate and K. Watanabe at Kitami.

Named in honor of Mayumi Otake (1967- ), well known for her work as sound producer of planetarium programs. (M 29146)

\section{(5976) Kalatajean}

$1992 \mathrm{SR}_{2}$. Discovered 1992 Sept. 25 at the Oak Ridge Observatory at Harvard.

Named in honor of Jean Marie Kalata, a social science analyst in the Institutional Studies Office of the Smithsonian Institution. Raised in New Jersey, she lives in Alexandria, Virginia, and among other 
interests sings with the Congressional Chorus. She served as a volunteer with the Christian Appalachian Project in Kentucky for 18 months. (M 27460)

Named as part of the Great Smithsonian Giveaway on the occasion of the sesquicentennial of the Smithsonian Institution.

\section{(5978) Kaminokuni}

1992 WT. Discovered 1992 Nov. 16 by K. Endate and K. Watanabe at Kitami.

Named for one of the oldest towns in Hokkaido \{see planet (3720)\}, with a population of 8000 . The history of the town can be traced for 800 years, which is unusually long in Hokkaido. (M 29146)

\section{(5981) Kresilas}

2140 P-L. Discovered 1960 Sept. 24 by C. J. van Houten and I. van Houten-Groeneveld at Palomar.

Named for the Greek sculptor Kresilas, who lived in the 5th century B.C. He is mostly known for his sculpture of Pericles, of which several copies still exist. (M 26764)

\section{(5982) Polykletus}

4862 T-1. Discovered 1971 May 13 by C. J. van Houten and I. van Houten-Groeneveld at Palomar.

Named for the Greek sculptor Polykletus of Argos (c. 480-423 B.C.). Together with Phidias ssee planet (4753)\}, he was the most important sculptor of his time. Nothing of his original work remains, but many old copies and images on coins are handed down to us, as well as detailed written descriptions. (M 26764)

\section{(5983) Praxiteles}

2285 T-2. Discovered 1973 Sept. 29 by C. J. van Houten and I. van Houten-Groeneveld at Palomar.

Named for the great Athenian sculptor Praxiteles (c. 370-325 B.C.). Antique sources indicate that Praxiteles worked in Athens and created at least 50 statues, although only Roman copies now exist. His figures no longer had the classical character of Phidias and Polykletus \{see planets (4753) and (5982)\} but had become ideal beings of smooth beauty. (M 26764)

\section{(5984) Lysippus}

4045 T-3. Discovered 1977 Oct. 16 by C. J. van Houten and I. van Houten-Groeneveld at Palomar.

Named for Lysippus of Sikyon (c. 370-300 B.C.), a great Greek sculptor in the time of Alexander the Great. He worked in the late-classical style and had an influence on the later hellenistic style. Most of his work survives in Roman copies and descriptions. His statues have smaller heads and simulate more movement than those sculpted in the time of Polykletus s see planet (5982)\}. (M 26764)

\section{(5986) Xenophon}

1969 TA. Discovered 1969 Oct. 2 by P. Wild at Zimmerwald.

Named for the Athenian nobleman, pupil and interpreter of Socrates \{see planet (5450)\}, historian, agriculturist, and military officer who lived from about 440 to 354 B.C. Because of his support of Spartan culture and politics he was exiled from Athens. He participated in a military expedition against the Persian king Artaxerxes \{see planet (7212)\} and, after his defeat near Babylon in 401 B.C., he prevailed to lead the army of 10000 Greek mercenaries safely home through the mountains of Asia Minor, a great feat described in his famous book Anabasis. (M 34341)

\section{(5988) Gorodnitskij}

$1976 \mathrm{GN}_{2}$. Discovered 1976 Apr. 1 by N. S. Chernykh at Nauchnyj.

Named in honor of Aleksandr Moiseevich Gorodnitskij (1933- ), Russian scientist and bard. A prominent geologist and oceanologist, who works at the Russian Academy of Science's Institute of Oceanology, he has participated in many nautical research expeditions. $\mathrm{He}$ is also well known as an author and performer of lyric songs, filled with the romance of voyages and the exploration of novel lands. (M 34622)

\section{(5989) Sorin}

1976 QC $_{1}$. Discovered 1976 Aug. 26 by N. S. Chernykh at Nauchnyj.

Named in memory of Sergej Ivanovich Sorin (19161995), astronomer and teacher who participated in the choice of a site for the astronomical observatory of the Azerbaijan Academy of Sciences and in equipping it with telescopes and other instruments. Head of the astronomical circle at the Baku Young Pioneers' Palace for some forty years, he was an outstanding educator of young amateur astronomers. Many of his pupils became prominent astronomers and are working now at various observatories in the former Soviet Union. (M 34622)

Name proposed by the discoverer, following a suggestion by some of Sorin's former pupils.

\section{(5990) Panticapaeon}

1977 EO. Discovered 1977 Mar. 9 by N. S. Chernykh at Nauchnyj.

Named for an ancient town, the capital of a Bospor realm dating back to the sixth century B.C., located at the site of the present town of Kerch \{see also planet (2216)\} in the eastern Crimea. This minor planet is dedicated to the Kerch HistoricalArchaeological Museum, the main repository of the Panticapaeon archaeological materials. Founded in 1826, the Kerch Museum makes a valuable contribution to the investigation of the ancient history of the region and acquaints the general public with the remote past of the region. (M 34622)

\section{(5991) Ivavladis}

$1979 \mathrm{HE}_{3}$. Discovered 1979 Apr. 25 by N. S. Chernykh at Nauchnyj.

Named in honor of Vladislav Aleksandrovich Ivanov (1936- ), professor at the St. Petersburg Institute of Fine Mechanics and Optics. An electromechanical 
engineer and metrologist, he discovered a new imaging technique on the basis of magnetic resonance and invented a number of instruments for space, air, marine and subterranean investigations. (M 34622)

\section{(5992) Nittler}

1981 DZ. Discovered 1981 Feb. 28 by S. J. Bus at Siding Spring.

Larry Nittler (1969- ), a scientist at the Carnegie Institute of Washington, is well known for his innovative work on identifying presolar grains in meteorites and using them as probes of stellar processes. His work on the NEAR mission to (433) Eros helped provide the first chemical analyses of a minor planet. (M 46007)

\section{(5993) Tammydickinson}

$1981 \mathrm{EU}_{22}$. Discovered 1981 Mar. 2 by S. J. Bus at Siding Spring.

Tamara Dickinson (1959- ) has been actively involved in research on lunar rocks and aubritic meteorites. She has been a staunch supporter of planetary science in a number of project management roles at NASA, the National Science Foundation and the National Research Council. (M 46007)

\section{(5994) Yakubovich}

$1981 \mathrm{SZ}_{7}$. Discovered 1981 Sept. 29 by L. V. Zhuravleva at Nauchnyj.

Named in honor of Leonid Arkad'evich Yakubovich (1945- ), writer, dramatist and television journalist. His high professional skill and fine sense of humor led to his becoming director of the most popular all-Russian television programs, such as Field of miracles and Wheel of history. (M 34622)

\section{(5995) Saint-Aignan}

1982 DK. Discovered 1982 Feb. 20 by E. Bowell at Anderson Mesa.

Named in honor of Charles P. de Saint-Aignan (1977- ) on the occasion of his 20th birthday, 1997 February 16. During two seasons as a summer student of the discoverer, de Saint-Aignan worked on measuring minor planet positions for orbit improvement. He has also worked at the Minor Planet Center and is currently a student at Brown University. (M 29146)

Name proposed by the discoverer, following a suggestion by B. G. Marsden, endorsed by G. V. Williams.

\section{(5996) Julioangel}

1983 NR. Discovered 1983 July 11 by E. Bowell at Anderson Mesa.

Named in honor of Julio Angel Fernández (1946- ) of the Universidad de la República, Montevideo. Fernández is a noted dynamicist who has worked on the evolution of comet orbits and planetesimal scattering in the outer solar system, including the formation of the Oort \{see planet (1691)\} Cloud. His work has led to some of the first clear indications for the existence of the transneptunian belt. Since 1985 he has contributed to the reestablishment of Uruguayan astronomy by educating a vigorous group of young planetary scientists and dynamicists. (M 27460) Citation procided by H. Rickman.

\section{(5997) Dirac}

1983 TH. Discovered 1983 Oct. 1 by A. Mrkos at Kleť.

Paul Adrien Maurice Dirac (1902-1984), English theoretical physicist and Nobel laureate, is known for his work in quantum mechanics, for his theory of the spinning electron and his prediction of the existence of the positron. (M 41028; M 41061)

The name was suggested by M. Tichý and Z. Moravec and, independently, by F. Börngen.

\section{(5998) Sitenský}

$1986 \mathrm{RK}_{1}$. Discovered 1986 Sept. 2 by A. Mrkos at Kleť.

Ladislav Sitenský (1919- ) is a Czech landscape photographer, well-known also for his photography from World War II, when he was a technician for the Czech wing of the Royal Air Force. (M 41567)

The name was suggested by M. Tichý.

\section{(5999) Plescia}

1987 HA. Discovered 1987 Apr. 23 by C. S. Shoemaker and E. M. Shoemaker at Palomar.

Named in honor of Jeffrey B. Plescia, a versatile scientist at the Jet Propulsion Laboratory who works with equal ease in geology, geophysics and planetary science. He has been a leading investigator of the cratering history of the satellites of Jupiter, Saturn and Uranus. More recently, Plescia has pursued gravity studies of terrestrial impact craters, including Upheaval Dome in Utah, the Manson structure of Iowa, and the Mt. Toondina, Kelly West and Teague Ring structures in Australia. (M 29671)

\section{(6000) United Nations}

1987 UN. Discovered 1987 Oct. 27 by P. Jensen at Brorfelde.

Named by vote of IAU Commission 20 at its 1994 meeting in The Hague on the recommendation of the Minor Planet Names Committee. (M 24123)

The name was proposed by L. D. Schmadel (according to the letters UN of the provisional designation).

\section{(6001) Thales}

$1988 \mathrm{CP}_{2}$. Discovered 1988 Feb. 11 by E. W. Elst at La Silla.

Named for the famous Greek philosopher Thales of Miletus (c.625-547 B.C.). None of Thales' writings has come down to us, but from Aristoteles \{see planet (6123)\} we know that he was the first to suggest a single substratum (water) for the Universe. The correct prediction of the solar eclipse of -584 May 28 contributed considerably to his reputation as an astronomer. Thales' significance, however, lies in the fact that he attempted to explain natural phenomena by causes within nature itself, rather than by caprices of anthropomorphic gods. He must be credited with at 
least five important geometrical theorems. (M 24766)

Thales is also honored by a lunar crater.

\section{(6006) Anaximandros}

$1989 \mathrm{~GB}_{4}$. Discovered 1989 Apr. 3 by E. W. Elst at La Silla.

Named for the great Greek philosopher Anaximander of Miletus (610-546 B.C.). A pupil of Thales \{see planet (6001) , he wrote treatises on geography, astronomy and cosmology. From all this only the so-called B 1 fragment remains. Although it barely embraces nine sentences, it may be considered as the oldest philosophical citation. Anaximander derived the world from the apeiron (unlimited), which is the arche (beginning) and principal element, from which all existing things owe their birth and to which they will eventually return. Although a rationalist, he described the emergence of particular substances in metaphors, drawn from human society, in which physical injustices (hot or cold may not prevail forever) are penalized. (M 24918)

Anaximandros is also honored by a lunar crater.

\section{(6010) Lyzenga}

1990 OE. Discovered 1990 July 19 by E. F. Helin at Palomar.

Named in honor of Gregory Lyzenga, professor of physics at Harvey Mudd College. His keen interest in minor planets and expertise in observational astronomy are combined with an aptitude for relating scientific topics to diverse audiences. His generous gifts of time and talent in support of asteroid research are greatly appreciated. (M 25231)

Citation prepared by J. B. Child.

\section{(6011) Tozzi}

$1990 \mathrm{QU}_{5}$. Discovered 1990 Aug. 29 by H. E. Holt at Palomar.

Named in honor of Gian Paolo Tozzi (1949- ) of the Arcetri Astrophysical Observatory. Tozzi's research, primarily in cometary physics, is focused on the study of dust in comae and on the problem of atomic carbon production. Part of his activity has concerned infrared observations of asteroids. (M 27461)

Citation prepared by M. DiMartino.

\section{(6020) Miyamoto}

$1991 \mathrm{SL}_{1}$. Discovered 1991 Sept. 30 by K. Endate and K. Watanabe at Kitami.

Named in honor of Yukio Miyamoto (1921- ), who has contributed much to the popularization of astronomy and took part in establishing the Kumamoto Astronomical Society in 1968. He studied mirror-making under Jiro Hoshino \{see planet (3828)\} and in 1971 became the first amateur to make a Wright-Schmidt telescope. He was central to the establishment in 1982 of the society's observatory, the Kumamoto Civil Astronomical Observatory. (M 26930)

\section{(6022) Jyuro}

1992 UB $_{4}$. Discovered 1992 Oct. 26 by K. Endate and K. Watanabe at Kitami.

Named in honor of Jyuro Kobayashi (1949- ), Japanese amateur astronomer and comet observer. He is a member of the Kumamoto Astronomical Society and participated in the establishment of the Kumamoto Civil Astronomical Observatory in 1982. (M 27128)

\section{(6023) Tsuyashima}

1992 UQ $_{4}$. Discovered 1992 Oct. 26 by K. Endate and K. Watanabe at Kitami.

Named in honor of Takaaki Tsuyashima (1949- ), popularizer of astronomy who planned the Kumamoto Civil Astronomical Observatory, which is unique in that it is open to the public every night, thanks to the volunteer activity of amateur astronomers. (M 26930)

\section{(6024) Ochanomizu}

$1992 \mathrm{UT}_{4}$. Discovered 1992 Oct. 27 by A. Sugie at Taga.

Named for the area in Tokyo that includes KandaSurugadai and Yushima. The name means 'water of tea', because during the Edo period high-quality water sprang out from the cliff there and was used for the tea ceremony by Tokugawa Shogunate. (M 29146)

\section{(6025) Naotosato}

$1992 \mathrm{YA}_{3}$. Discovered 1992 Dec. 30 by T. Urata at Oohira.

Named in honor of Naoto Sato (1953- ), active amateur astronomer and junior high school science teacher. His outstanding educational achievement has been creating life-long interest in space and the universe among his students and followers. At his own Chichibu Astronomical Observatory, he uses a CCD camera to observe minor planets. He made a prediscovery observation of comet C/1989 Y2 (McKenzie-Russell). (M 33786)

\section{(6026) Xenophanes}

1993 BA $_{8}$. Discovered 1993 Jan. 23 by E. W. Elst at La Silla.

Named for the Greek philosopher Xenophanes of Colophon (570-475 B.C.). He was in the first place a poet, using poetry to express his reflections about philosophical problems. Although he continued the tradition of Ionic philosophy (e.g., on nature), he spent much of his time attacking the idea of anthropomorphic gods, such as we know them from the work of Homer \{see planet (5700)\} and Hesiod. From this the idea of a more abstract god, in combination with ethic principles, has been evolved. Much later, Plato \{see planet (5451)\} took up this picture. However, the great achievement of Xenophanes remains his introduction of reflection on knowledge into philosophy. (M 24918) Xenophanes is also honored by a lunar crater. 


\section{(6029) Edithrand}

1948 AG. Discovered 1948 Jan. 14 by E. Wirtanen at Mount Hamilton.

Named for Edith (Rand) Wirtanen, who found this minor planet on an astrographic plate taken by her husband, the Lick astronomer Carl A. Wirtanen ssee planet (2044)\}. As a long-term resident at Mt. Hamilton, she performed numerous jobs, from library assistant to observing assistant under F. J. Neubauer and G. \{see planet (2796)\} and K. Kron. (M 26764)

Name endorsed by A. R. Klemola.

\section{(6030) Zolensky}

1981 EG $_{36}$. Discovered 1981 Mar. 7 by S. J. Bus at Siding Spring.

As curator of interplanetary dust at NASA's Johnson Space Center, Michael Zolensky (1955- ) has been at the forefront of understanding the origin of interplanetary dust particles, their relationship to carbonaceous chondrites and the processes that formed them on comets and minor planets. (M 46007)

\section{(6031) Ryokan}

1982 BQ $_{4}$. Discovered 1982 Jan. 26 by H. Kosai and K. Hurukawa at Kiso.

Named for Ryokan (1758-1831), a famous Buddhist monk of the Zen sect and a poet during the Edo era. He was born in Echigo (present-day Niigata Prefecture). When young, he was trained at the temple of Entsuji \{see planet (4272)\}, near the birthplace of the first discoverer. (M 26764)

\section{(6032) Nobel}

1983 PY. Discovered 1983 Aug. 4 by L. G. Karachkina at Nauchnyj.

Named in memory of Alfred Bernhard Nobel (18331896), Swedish inventor of dynamite. He was founder of the famous Nobel International Fund, organized after his death according to his stipulation. Originally, the annual profit from this fund was divided into five parts and awarded annually for outstanding studies in physics, chemistry, physiology (including medicine), literature and peace. The centenary of the honored Nobel procedure, which includes participation by Swedish royalty, will be in 2000. (M 25231)

The name was suggested by S. P. Kapitsa, the son of P. L. Kapitsa, who won the Nobel prize in physics in 1978.

Nobel is also honored by a lunar crater.

\section{(6036) Weinberg}

1988 CV $_{3}$. Discovered 1988 Feb. 13 by E. W. Elst at La Silla.

Named in honor of Steven Weinberg, elementaryparticle physicist and recipient of the 1979 Nobel Prize for Physics. Weinberg is considered one of the world's most creative scientists. He is also well known for his writings about science. In his latest book, Dreams of a Final Theory, he discusses quantum mechanics, beautiful theories, the weakness of philosophy and the honor of accepting a world without God. (M 24766)

\section{(6039) Parmenides}

1989 RS. Discovered 1989 Sept. 3 by E. W. Elst at St. Michel.

Named for Parmenides of Elea, born around 515 B.C. and the founder of "Eleaticism". From his lengthy poem On Nature, a hexametric work of which only a small part has been preserved, one learns that he considered the plurality of things as the appearance of only one eternal reality. Greek philosophers before him, such as Thales and Anaximenes ssee planets (6001) and (6051), respectively\}, tried to explain the physical world by means of sometimes very remarkable hypotheses. Parmenides, probably influenced by the skeptical Xenophanes \{see planet (6026)\}, wanted to be absolutely certain about the theory he put forward. He therefore investigated the validity of theories, not by experiments, but by means of the logical soundness of laws and concepts that had been incorporated. (M 24919)

\section{(6041) Juterkilian}

1990 KL. Discovered 1990 May 21 by E. F. Helin at Palomar

Klas Juter (1962- ) is a Swedish architect and international architectural photographer, and his wife, Danuta Kilian (1963- ), is a Polish designer and artist. Just as this minor planet is a celestial traveler, they are travelers between continents. (M 39649)

\section{(6042) Cheshirecat}

$1990 \mathrm{WW}_{2}$. Discovered 1990 Nov. 23 by A. Natori and T. Urata at Yakiimo.

Named for a cat appearing in Lewis Carroll's \{see planet (6984)\} famous fairy tale Alice in Wonderland. Its unique characteristics is its laughing voice that lingers after the cat fades away. (M 33786) Name and citation proposed by T. Urata.

\section{(6043) Aurochs}

$1991 \mathrm{RK}_{2}$. Discovered 1991 Sept. 9 by S. Otomo at Kiyosato.

Modern cattle are believed to have descended from the Aurochs, Bos primigenius, the wild ox of Europe, often depicted in cave paintings. Hunted to extinction, the last known member was recorded in Poland in 1627. The name is sometimes wrongly applied to the European bison. (M 36126)

\section{(6044) Hammer-Purgstall}

1991 RW $_{4}$. Discovered 1991 Sept. 13 by L. D. Schmadel and F. Börngen at Tautenburg.

Named in memory of Joseph Freiherr von HammerPurgstall (1774-1856) on the occasion of the 150th anniversary of the Austrian Academy of Sciences. As a profound orientalist, poet and historian, he was the founder and first president (1847-1849) of the (then 
Imperial) Academy of Sciences in Vienna. His most famous work is the ten-volume History of the Osman Empire. (M 30798)

Name proposed by the first discoverer following a suggestion from the presidency of the Austrian Academy of Sciences, citation prepared by H. Haupt.

\section{(6049) Toda}

1991 VP. Discovered 1991 Nov. 2 by A. Takahashi and K. Watanabe at Kitami

Named in memory of Kojun Toda (1879-1951), an observer of the Tokyo Astronomical Observatory during 1902-1940 who assisted Shin Hirayama in making a photographic survey of the Milky May. He discovered the minor planet (804) Hispania at its 1903 prediscovery opposition. (M 29146)

\section{(6051) Anaximenes}

1992 BX $_{1}$. Discovered 1992 Jan. 30 by E. W. Elst at La Silla.

Named for the great Greek philosopher Anaximenes of Miletus. He was born in 545 B.C. and is to be considered, with Thales and Anaximander \{see, respectively, planets (6001) and (6006)\}, one of the three first philosophers in the western world. His principal element was "aer" (vapor, air), from which the various types of matter can be derived by condensation. His thought is typical of the transition from mythology to science. However, he was not completely liberated from mystical tendencies (orphism), since he believed that there is a kind of overarching principle between microcosmos and macrocosmos. (M 24919)

Anaximenes is also honored by a lunar crater.

\section{(6052) Junichi}

$1992 \mathrm{CE}_{1}$. Discovered 1992 Feb. 9 by K. Endate and K. Watanabe at Kitami.

Named in honor of Junichi Watanabe (1960- ), division chief of the Public Information Office of the National Astronomical Observatory and, from 1994, president of the Japanese comet conference. Actively involved in research on minor planets, comets and meteors, he has organized an effective observational team and has contributed to the development of the planetary sciences infrastructure in Japan. He also plays an important role in the popularization of astronomy and planetary sciences. (M 26930)

\section{(6054) Ghiberti}

4019 P-L. Discovered 1960 Sept. 24 by C. J. van Houten and I. van Houten-Groeneveld at Palomar.

Named for Lorenzo Ghiberti (1378-1455), one of the most famous Italian sculptors. In the pestilence year of 1400 he vowed to create new porches for the Baptisterium, the oldest church in Florence. Donatello, Brunelleschi \{see planets (6056) and (6055)\} and Ghiberti together created the bronze door - the so-called Paradise door - in 41 years. In 1414 Ghiberti created the first large renaissance bronze statue of St. John the Baptist. He also worked in Siena. (M 26764)
(6055) Brunelleschi

2158 T-3. Discovered 1977 Oct. 16 by C. J. van Houten and I. van Houten-Groeneveld at Palomar.

Named for Filippo Brunelleschi (Brunellesco, 13771446), a famous Italian sculptor and architect of the Early Renaissance. He built the 45-m dome of the cathedral of Florence. He also worked in Milan, Rimini and Mantua. (M 26764)

\section{(6056) Donatello}

2318 T-3. Discovered 1977 Oct. 16 by C. J. van Houten and I. van Houten-Groeneveld at Palomar.

Named for Donato di Nivolo di Betto Bardi, generally known as Donatello (c. 1386-1466), a great Italian sculptor. His work in the Early Renaissance style had much influence on following generations of Italian artists. His statues and reliefs are done in marble, terracotta and wood. His statue of Gattamelata was the first equestrian statue since the antique statue of Hadrian \{see planet (7446)\}. Most of his work is found in Florence and Siena. (M 26764)

\section{(6057) Robbia}

5182 T-3. Discovered 1977 Oct. 16 by C. J. van Houten and I. van Houten-Groeneveld at Palomar.

Named for Luca della Robbia (1400-1482) and his family of most important Italian sculptors. Apart from Donatello and Ghiberti \{see planets (6056) and (6054)\}, he was the greatest sculptor in the Early Renaissance. His first sculpture was the marble pulpit in the cathedral of Florence, and he also made reliefs for its campanile. He is mostly recognized by his clay reliefs with colored enamel. (M 26764)

\section{(6060) Doudleby}

1980 DX. Discovered 1980 Feb. 19 by A. Mrkos at Klět.

Named for a village in southern Bohemia, south of České Budějovice. It was first mentioned as a site of a Slavonic fortified settlement above the Malše \{see planet (7669)\} river in 981. The Gothic church of St. Vincent was built on this site. The region of Doudleby is known for its lively traditional folk customs, including carnivals. (M 34341)

Name suggested by J. Tichá and M. Tichý.

\section{(6062) Vespa}

1983 JQ. Discovered 1983 May 6 by N. G. Thomas at Anderson Mesa.

Named for the popular motor scooter used throughout the world. June 1996 marks the occasion of the 50th anniversary of its introduction. (M 26931)

\section{(6063) Jason}

1984 KB. Discovered 1984 May 27 by C. S. Shoemaker and E. M. Shoemaker at Palomar.

Jason, the son of Aeson of Thessaly, was educated by Chiron \{see planet (2060)\}, the wisest of the centaurs. He became leader of the Argonauts in the quest for the Golden Fleece, an expedition celebrated in the annals of all Greece. Many of the famous heroes of Greece 
accompanied Jason. The voyage of the Argo was full of struggle against the elements as well as against men. Jason succeeded in seizing the Golden Fleece, and the Argonauts made their return after a long and perilous voyage across the Danube, the Ocean, the Libyan deserts, the Red Sea and the Mediterranean. (M 25445)

\section{(6064) Holašovice}

$1987 \mathrm{HE}_{1}$. Discovered 1987 Apr. 23 by A. Mrkos at Klě́.

Named for a village in southern Bohemia north of Klet Mountain. Holašovice is an exceptionally intact and well-preserved example of traditional Central European village architecture, containing a number of vernacular buildings from the eighteenth and nineteenth centuries in a style known as the South Bohemian Folk Baroque. Since 1998 Holašovice has been listed on the UNESCO World Heritage roster of cultural and natural sites. (M 34341)

Name proposed by J. Tichá.

\section{(6066) Hendricks}

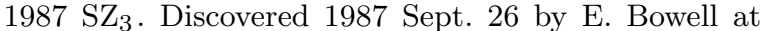
Anderson Mesa.

Named in honor of John Hendricks (1952- ), founder of Discovery Communications, Inc., which owns and operates the Discovery Channel and the Learning Channel. Hendricks is a strong supporter of astronomy through his service on the Lowell Observatory Advisory Board, his sponsorship of astronomical documentaries broadcast on the Discovery Channel and his direct support of various astronomical projects. Hendricks founded the Discovery Channel to fill a void. He believes that to be human is to be curious about the world around us, and he tries to fill that need with informative and educational television programming. (M 26931)

Name suggested and citation prepared by K. X. Kramer.

\section{(6068) Brandenburg}

$1990 \mathrm{TJ}_{2}$. Discovered 1990 Oct. 10 by F. Börngen and L. D. Schmadel at Tautenburg.

Named for the district in Germany around Berlin \{see planet (422)\}. The medieval capital of this region was the town of Brandenburg, and the current capital is Potsdam \{see planet (5816)\}. Brandenburg is a region with many lakes, waterways and pine forests. The poets Th. Fontane \{see planet (8667)\} and H. von Kleist, the scientist W. von Humboldt and the architect K. Fr. Schinkel \{see planet (5297)\} were all born in the region. Six well-known compositions by J. S. Bach \{see planet (1814)\} have the title Brandenburgische Konzerte. (M 24919)

Name proposed by the first discoverer.

\section{(6069) Cevolani}

1991 PW $_{17}$. Discovered 1991 Aug. 8 by H. E. Holt at Palomar.
Named in honor of Giordano Cevolani (1945- ), researcher of the Italian National Research Council (CNR) in Bologna. His main fields of interest are the physics of the earth's atmosphere, astronomy of minor bodies and space science. His scientific activity mainly concerns radar observation of meteors, the phenomena connected with their interaction with the atmosphere, and study of the wind structure (prevailing components: gravity, tidal and planetary waves) in the mesosphere and in the lower troposphere of the polar regions (katabatic winds). (M 27461)

Name suggested and citation prepared by M. DiMartino.

\section{(6070) Rheinland}

$1991 \mathrm{XO}_{1}$. Discovered 1991 Dec. 10 by F. Börngen at Tautenburg.

The name "Rheinland" strictly speaking denotes the territory on both sides of the river Rhine from the town of Bingen to the border with the Netherlands. The Rheinland people (the Rheinländer) enjoy merry celebrations at carnival time and during the grape harvesting. Rheinländer is also the name of a Polka-like dance. The composer L. van Beethoven ssee planet (1815)\}, the physicist W. C. Röntgen and the surgeon F. Sauerbruch had their roots in the Rheinland. (M 24919)

\section{(6071) Sakitama}

1992 AS $_{1}$. Discovered 1992 Jan. 4 by T. Hioki and S. Hayakawa at Okutama.

Sakitama, a region of Gyoda city and from which Saitama prefecture takes its name, is known for its burial mounds, constructed from clay and rocks between the fourth and seventh centuries. (M 36126)

\section{(6072) Hooghoudt}

1280 T-1. Discovered 1971 Mar. 25 by C. J. van Houten and I. van Houten-Groeneveld at Palomar.

Named in memory of Bernard G. Hooghoudt (19241995), key engineer for Dutch radio telescopes, having designed the Dwingeloo telescope (1956) and the Synthesis Radio Telescope at Westerbork (1970). As a private consulting engineer he designed and led the construction of some of the world's larger telescopes, not only for radio wavelengths, but also for millimeter and optical wavelengths. (M 25978)

Name suggested and citation prepared by R. LePoole.

\section{(6074) Bechtereva}

1968 QE. Discovered 1968 Aug. 24 by T. M. Smirnova at Nauchnyj.

Named in honor of Natalia Petrovna Bechtereva (1924- ), outstanding neuro-physiologist, director of the Institute of Experimental Medicine in St. Petersburg for many years and founder of the Institute of the Human Brain of the Russian Academy of Sciences. Bechtereva laid the foundation for basic research into the physiology of healthy and diseased human brains. She discovered the cerebral mechanisms that optimize 
cognitive processes - the error detector. The theory of the brain's stable pathological state as the adaptation background for many chronic diseases was developed by Bechtereva, opening up new opportunities for their treatment. (M 33786)

Name suggested by the Institute of the Human Brain and the Institute of Applied Astronomy.

\section{(6075) Zajtsev}

$1976 \mathrm{GH}_{2}$. Discovered 1976 Apr. 1 by N. S. Chernykh at Nauchnyj.

Named in honor of Aleksandr Leonidovich Zajtsev (1945- ), staff member of the Moscow Institute of Radio Electronics, noted expert on radar observations of the planets. Under his leadership, observations of (4179) Toutatis were successfully carried out in December 1992 using the Evpatorian planetary radar, Crimea, as the signal transmitter and the radio telescope in Effelsberg, Germany, as the receiver of the radar echo from the minor planet's surface. Zajtsev is also responsible for initiating the world's first intercontinental radar astronomy experiment, Goldstone to Evpatoria observations of (6489) 1991 JX \{now (6489) Golevka\} in June 1995. (M 25445)

Name proposed by the discoverer following a suggestion by the Institute of Theoretical Astronomy.

\section{(6076) Plavec}

1980 CR. Discovered 1980 Feb. 14 by L. Brožek at Klě́t.

Named in honor of Mirek J. Plavec (1925- ）, Czech astronomer living in the U.S. since 1969, professor of astronomy at the University of California at Los Angeles. His early works dealt with meteor showers, but he is also widely known for his studies of close binaries, especially of mass transfer in binary systems. (M 25654)

Name suggested by J. Tichá, M. Tichý and Z. Moravec, who observed this minor planet at Klét at the 1994 opposition, just prior to its numbering.

\section{(6077) Messner}

1980 TM. Discovered 1980 Oct. 3 by Z. Vávrová at Kleť.

Named in honor of Reinhold Messner (1944- ), Italian mountaineer, adventurer and writer. (M 33385)

\section{(6078) Burt}

1980 TC $_{5}$. Discovered 1980 Oct. 10 by C. S. Shoemaker at Palomar.

Named in honor of Burton G. Shoemaker (1912- ), uncle of E. M. Shoemaker \{see planet (2074)\}. (M 24919)

\section{(6079) Gerokurat}

$1981 \mathrm{DG}_{3}$. Discovered 1981 Feb. 28 by S. J. Bus at Siding Spring.

Gero Kurat (1938- ), of the Natural History Museum in Vienna, is curator of the Vienna meteorite collection and president of the Meteoritical Society. His provocative ideas on the origin of meteorites have caused scientists to question basic paradigms about the origin of our solar system. (M 46007)

\section{(6080) Lugmair}

$1981 \mathrm{EY}_{26}$. Discovered 1981 Mar. 2 by S. J. Bus at Siding Spring.

Günter Lugmair (1940- ), director of the MaxPlanck-Institut für Chemie at Mainz, has made many contributions to the fields of meteoritic, lunar and terrestrial isotope geochemistry and solar system chronology. Among his achievements is the development of a dating method using samarium and neodymium isotopes. (M 46007)

\section{(6081) Cloutis}

$1981 \mathrm{EE}_{35}$. Discovered 1981 Mar. 2 by S. J. Bus at Siding Spring.

Edward Cloutis (1958- ）, professor at the University of Winnipeg, studies the spectra of mineral assemblages similar to those found on planetary surfaces. He was the first to derive a relationship between the olivineorthopyroxene fraction and the ratio of silicate absorption bands in reflectance spectra. (M 46007)

\section{(6082) Timiryazev}

$1982 \mathrm{UH}_{8}$. Discovered 1982 Oct. 21 by L. V. Zhuravleva at Nauchnyj.

Named in memory of Russian physiologist Kliment Arkad'evich Timiryazev (1843-1920), a corresponding member of the Imperial St. Petersburg Academy of Sciences and one of the founders of the Russian school of plant physiology. (M 34622)

\section{(6083) Janeirabloom}

$1984 \mathrm{SQ}_{2}$. Discovered 1984 Sept. 25 by B. A. Skiff at Anderson Mesa.

Named in honor of soprano saxophonist and jazz composer Jane Ira Bloom. Bloom is known for her chromatic, lyrical playing and compositions for orchestra, unusual ensembles and dance troupes. Her performances with traditional jazz groups appear on several acclaimed recordings. As the first musician in the NASA Art Program, she wrote "Most Distant Galaxy" and "Einstein's Red/Blue Universe", the latter on commission for the American Composers' Orchestra. (M 31296)

\section{(6084) Bascom}

1985 CT. Discovered 1985 Feb. 12 by C. S. Shoemaker and E. M. Shoemaker at Palomar.

Named in memory of Florence Bascom (1862-1945), the first woman geologist in the United States. She was an expert in crystallography, mineralogy and petrography and worked in the fields of metamorphism and crystallography in their infancy. Bascom was also an educator who trained a generation of young women as professionals at Bryn Mawr, where she founded the geology department. She was the first woman hired by the U.S. Geological Survey and the first woman elected to the Council of the Geological Society of 
America. Her pioneering work earned her a position among the country's hundred leading geologists in the early twentieth century. (M 31610)

\section{(6087) Lupo}

1988 FK. Discovered 1988 Mar. 19 by C. S. Shoemaker and E. M. Shoemaker at Palomar.

Named in honor of Bob Lupo. Wearing a black hat and a genial smile, Lupo typifies the Western cowboy of today's imagination. Born in Boston, he sought his fortune in the West, becoming a registered farrier and at one time taking part in team roping in Colorado. Today he ownes and manages a fine Western-style eatery, Horsemen Lodge and Restaurant, in Flagstaff, Arizona, where he has served outstanding seafood (a heritage from Boston), steaks and barbecue to the many renowned visiting scientists and others who have entered his doors. (M 32345; M 32377)

\section{(6088) Hoshigakubo}

1988 UH. Discovered 1988 Oct. 18 by T. Seki at Geisei.

The name refers to a section of low ground at Choja, a mountainous place in the western part of Kochi prefecture. Legend has it sthat a meteorite fell there in olden times. Now there is a pond 20 meters across. (M 28621)

\section{(6089) Izumi}

$1989 \mathrm{AF}_{1}$. Discovered 1989 Jan. 5 by M. Koishikawa at Sendai.

Named for Izumi-ku, a ward in the northern part of the city of Sendai \{see planet (3133)\}. The symbol of the city, Mt. Izumigatake, is a popular recreational area. (M 25654)

\section{(6091) Mitsuru}

$1990 \mathrm{DA}_{1}$. Discovered 1990 Feb. 28 by K. Endate and K. Watanabe at Kitami.

Named in honor of Mitsuru Soma (1954- ), of the National Astronomical Observatory of Japan, a specialist in meridian astrometry who also analyses eclipses and occultations involving various celestial objects. (M 26931)

\section{(6092) Johnmason}

1990 MN. Discovered 1990 June 27 by E. F. Helin at Palomar.

John W. Mason (1954- ） has contributed to research on comets and meteors and to the popularization of astronomy. He was president of the British Astronomical Association during 1993-1995. (M 41567)

\section{(6093) Makoto}

1990 QP $_{5}$. Discovered 1990 Aug. 30 by K. Endate and K. Watanabe at Kitami.

Named in honor of Makoto Yoshikawa (1962- ), senior researcher in the Communications Research Laboratory in Japan. Known for his active research in celestial mechanics, he works on the orbital analysis of minor planets, comets, meteors, artificial satellites and space debris. He is perhaps best known for his long-term orbital analyses of minor planets in mean-motion and secular resonances. (M 26931)

\section{(6097) Koishikawa}

1991 UK $_{2}$. Discovered 1991 Oct. 29 by K. Endate and K. Watanabe at Kitami.

Named in honor of Masahiro Koishikawa (1952- ), a staff member of the Sendai Astronomical Observatory since 1972 . He has made great efforts to observe major planets, minor planets and comets at the observatory's Ayashi station. He has also attempted to develop public awareness of astronomy as a social educational project. (M 26931)

\section{(6099) Saarland}

$1991 \mathrm{UH}_{4}$. Discovered 1991 Oct. 30 by F. Börngen at Tautenburg.

Named for the German state of Saarland, a district of beautiful landscapes situated in the middle course of the river Saar. The modern capital Saarbrücken, a center for the coal and iron industry, is named for the first stone bridge across the river and arose from a Celtic settlement, a Roman castle and the Franconian court Villa Sarabrucca. (M 25445)

\section{(6100) Kunitomoikkansai}

$1991 \mathrm{VK}_{4}$. Discovered 1991 Nov. 9 by A. Sugie at Taga.

Named in memory of Ikkansai Kunimoto (1778-1840). Born into a family of famous gun makers in the Edo period in Japan, he made several Gregorian reflecting telescopes entirely of his own design and observed the sun, moon and planets. For 14 months during 1835-1836 he made a continuous series of observations of sunspots. (M 33385)

Name proposed by the discoverer, endorsed by S. Murayama, K. Sato and A. Fujii.

\section{(6102) Visby}

$1993 \mathrm{FQ}_{25}$. Discovered 1993 Mar. 21 by the UppsalaESO Survey at La Silla.

Visby is a city, still surrounded by a medieval wall, on the Swedish island of Gotland. (M 36126)

\section{(6104) Takao}

1993 HZ. Discovered 1993 Apr. 16 by K. Endate and K. Watanabe at Kitami.

Named in honor of Takao Saito (1930- ), retired professor of astrogeophysics at Tohoku University known for his study of solar-terrestrial physics. He has investigated the various effects of the solar wind on cometary ion tails. He has also cooperated with Japanese amateur astronomers on cometary observations. (M 26931)

\section{(6105) Verrocchio}

4580 P-L. Discovered 1960 Sept. 24 by C. J. van Houten and I. van Houten-Groeneveld at Palomar.

Named for the Italian sculptor and painter Andrea del Verrocchio (1435-1488). Originally named Andrea di Cione, he adopted the name of his teacher, Giuliano 
Verrocchio, as his own. With Donatello \{see planet (6056)\}, he was the leading sculptor in bronze of the Florentine Renaissance. His best-known work is the statue of Bartolomeo Colleoni in Venice. (M 26764)

\section{(6106) Stoss}

6564 P-L. Discovered 1960 Sept. 24 by C. J. van Houten and I. van Houten-Groeneveld at Palomar.

Named for the German sculptor and wood-carver Veit Stoss (c. 1445-1553), who worked in Nürnberg and Cracow. In Cracow he worked for 13 years on the 11-m by 13-m Mary altar in late-gothic/baroque style. After 1496 he lived again in Nürnberg and made many wonderful altars for the church and city. (M 26764)

\section{(6107) Osterbrock}

1948 AF. Discovered 1948 Jan. 14 by C. A. Wirtanen at Mount Hamilton.

Named in honor of Donald E. Osterbrock (1924), professor of astronomy and astrophysics at the University of Wisconsin-Madison (1958-1973) and at the University of California at Santa Cruz and UCO/Lick Observatory (1972-1992) and director of the Lick Observatory (1973-1981). His research spans gaseous nebulae, interstellar matter, galactic structure, and quasars and active nuclei of galaxies, and he has authored a historical series on the life and work of several astronomers who played vital roles in the progress of American astronomy. Osterbrock served as president of the American Astronomical Society during 1987-1989. He is a member of the National Academy of Sciences and the National Academy of Arts and Sciences. (M 27735)

Citation prepared by A. R. Klemola.

\section{(6108) Glebov}

1971 QN. Discovered 1971 Aug. 18 by T. M. Smirnova at Nauchnyj.

Named in honor of academician Igor' Alekseevich Glebov (1914- ), outstanding scientist in the field of electrical engineering and power engineering, since 1975 director of the Science Research Institute of Electric Machine Engineering in St. Petersburg. Glebov is renowned for his work in control systems for power turbo-generators and his application of superconductivity in electric machine engineering. (M 34341)

Name suggested by the Institute of Applied Astronomy and the Institute of Problems of Electrophysics of RAS \{Russian Academy of Sciences\}.

\section{(6110) Kazak}

1978 NQ$_{1}$. Discovered 1978 July 4 by L. I. Chernykh at Nauchnyj.

Yurij Ivanovich Kazak (1949- ), surgeon at Bakhchisaraj district hospital, treated many staff members of the Crimean Astrophysical Observatory. A skilled and kind doctor, he is always ready to help people. (M 38195)
(6111) Davemckay

$1979 \mathrm{SP}_{13}$. Discovered 1979 Sept. 20 by S. J. Bus at Palomar.

David McKay (1936- ) of NASA's Johnson Space Center has helped highlight the complexity and wealth of information contained in lunar regolith. His study of the martian meteorite Allan Hills 84001 caused scientists to reexamine the issue of life beyond the earth and prompted NASA to renew efforts in exploring Mars. (M 46007)

\section{(6112) Ludolfschultz}

$1981 \mathrm{DB}_{1}$. Discovered 1981 Feb. 28 by S. J. Bus at Siding Spring.

Ludolf Schultz (1937- ) , professor at the JohannesGutenberg-Universität in Mainz, has dedicated much of his career to the study of noble gases in meteorites. He also has passionately taught planetology and put considerable effort into introducing the enigmatic field of meteoritics to the public. (M 46007)

\section{(6115) Martinduncan}

$1984 \mathrm{SR}_{2}$. Discovered 1984 Sept. 25 by B. A. Skiff at Anderson Mesa.

Named in honor of Martin J. Duncan (1950of Queen's University, Kingston, Ontario. Duncan has made several important contributions to the understanding of the origin and dynamical evolution of small bodies in the solar system, particularly comets and the likelihood that they originated in the Kuiper \{see planet (1776)\} Belt. He has been involved in the development of two important numerical algorithms that have led to orbital integrations of unprecedented duration. (M 27461)

Citation provided by H. Levison.

\section{(6116) Still}

$1984 \mathrm{UB}_{3}$. Discovered 1984 Oct. 26 by E. Bowell at Anderson Mesa.

Named in memory of William Grant Still (18951978), American composer, also known as the "Dean of American Negro Composers". Although he was very much at home in the musical world of blues and spirituals, Still's major contribution to music is as an outstanding and prolific composer of symphonies, operas, ballets, chamber music, piano music and other works in the tradition of classical musical forms. His style is basically neo-romantic, even when featuring structural complexities. Still always considered himself an American composer first and a colored composer last. (M 25654)

Name proposed and citation provided by M. J. Shott, endorsed by the composer's daughter J. A. Still and her family.

\section{0) Anhalt}

1987 QR. Discovered 1987 Aug. 21 by F. Börngen at Tautenburg.

Named for the former principality of Anhalt, at the northern border of the Harz mountains. About 1770, 
Prince Leopold Franz of Anhalt built the Wörlitz castle in a great park that was much praised by Goethe \{see planet (3047)\}. Anhalt was united with the Prussian province of Sachsen \{see planet (5866)\} to form the state of Sachsen-Anhalt. (M 24919)

\section{(6122) Henrard}

1987 SW $_{1}$. Discovered 1987 Sept. 21 by E. Bowell at Anderson Mesa.

Named in honor of Jacques Henrard (1940- ), professor of mathematics at the University of Namur. Henrard has applied algorithms based on Hamiltonian and Lie formalisms, particularly to the motions of the moon, the Galilean satellites of Jupiter and artificial satellites. With his celestial mechanics research group, which he formed in 1971, Henrard extended the adiabatic-invariant and action-angle theory and introduced it as a practical tool. He has also worked on the theory of slow chaotic motion and has been intensively involved in modeling mean-motion resonances in the asteroid belt. Since 1989 he has been editor-in-chief of the journal Celestial Mechanics. (M 27461)

Citation provided by A. Lemaître.

\section{(6123) Aristoteles}

$1987 \mathrm{SH}_{2}$. Discovered 1987 Sept. 19 by E. W. Elst at Rozhen.

Named for Aristoteles (384-322 B.C.), one of the most significant Greek philosophers, charging the demerits of his philosophy on the level of the knowledge at his era and ascribing the misuse of his ideas to human weakness. He was the first, and possibly the greatest, theoretician of the mechanism of thought and deduction, being at the same time well aware of the importance of what happens in the real world and in nature. (M 24766)

Citation prepared by A. Svarna and D. Sinachopoulos at the request of the discoverer. Proposal endorsed by V. Shkodrov.

Aristoteles is also honored by a lunar crater.

\section{(6124) Mecklenburg}

$1987 \mathrm{SL}_{10}$. Discovered 1987 Sept. 29 by F. Börngen at Tautenburg.

Named for a district in northern Germany, characterized by deposits of glacial moraines and hundreds of lakes rich in fishes and birds of many kinds. The towns of Wismar and Rostock are important Baltic Sea ports. The poet F. Reuter \{see planet (8666)\}, the archaeologist H. Schliemann \{see planet (3302)\} and the sculptor and poet E. Barlach \{see planet (6428)\} were born in Mecklenburg. Today Mecklenburg is part of the state of Mecklenburg-Vorpommern. (M 24919)

Named on the occasion of the thousandth anniversary of Mecklenburg in 1995.

\section{(6127) Hetherington}

1989 HD. Discovered 1989 Apr. 25 by E. F. Helin at Palomar.
Named in honor of Ernest Hetherington, a highly respected authority on Orchids (Orchidaceae). He was a good friend and mentor to Kay Francis \{see planet (2050)\}, the discoverer's mother, who grew and hybridized many exceptional "new" orchids. "Ernie" is an orchid judge, gifted writer on orchidaceae and recipient of many honors, awards and special recognition for his role as a grower, educator and popularizer of orchid culture. (M 30477)

\section{(6128) Lasorda}

1989 LA. Discovered 1989 June 3 by E. F. Helin at Palomar.

The achievements of baseball Hall of Famer Tommy Lasorda (1927- ) include leading the Los Angeles Dodgers to two World Series championships, four National League pennants and eight division titles. He also coached the U.S. Olympic Baseball team to the coveted Gold Medal in the 2000 Olympiad in Sydney. (M 45746)

\section{(6129) Demokritos}

$1989 \mathrm{RB}_{2}$. Discovered 1989 Sept. 4 by E. W. Elst at St. Michel.

Named for the Greek philosopher Demokritos of Abdera (460-380 B.C.), well-known for his atomistic theory of matter. He was a pupil of Leukippos \{see planet (5950)\}, to whom he owed many ideas. His great concern was to harmonize Ionic cosmology with Greek ontology, and he is credited with at least 57 works on ethics, physics, nature, mathematics and art. He considered an observation to be the result of an interaction between observer and observed. (M 24919) Demokritos is also honored by a lunar crater.

\section{(6131) Towen}

$1990 \mathrm{OO}_{3}$. Discovered 1990 July 27 by H. E. Holt at Palomar.

Named in honor of Tobias C. (Toby) Owen (1936- ) of the Institute for Astronomy of the University of Hawaii. Known for his broad work in planetary science, Owen has productively used chemical ratios and isotopic ratios from planetary atmospheres, from meteorites and from comets to understand the early solar system and the processes of formation of comets and planetary atmospheres. He has also played an important role in searching for and identifying new species in reflection spectra of ices on planetary surfaces. (M 27461)

Citation provided by M. F. A'Hearn following a suggestion by D. Morrison.

\section{(6132) Danielson}

$1990 \mathrm{QY}_{3}$. Discovered 1990 Aug. 22 by H. E. Holt at Palomar.

Named in honor of G. Edward Danielson (1939- ) of the Division of Geological and Planetary Sciences at California Institute of Technology. After working in industry in high-energy laser research, Danielson came to the Jet Propulsion Laboratory and Caltech, where he 
has been involved since 1967 in the design, calibration, testing and data analysis of remote-sensing imagers. He has worked on numerous space missions, including Voyager, Pioneer Venus, Mariner Venus Mercury, the Hubble Space Telescope and Mars Observer. In 1982 Danielson was co-recoverer of comet 1P/Halley. (M 27461)

Name suggested by A. W. Harris and citation provided by W. A. Baum.

\section{(6135) Billowen}

1990 RD. Discovered 1990 Sept. 14 by H. E. Holt at Palomar.

Named in honor of William Mann Owen, Jr. (1954-

), an astronomer at the Jet Propulsion Laboratory. Owen developed the initial orbits for the small satellites of Uranus and Neptune discovered during the Voyager space mission. He also participated in the first determination of the mass ratio of Pluto and Charon using the Hubble Space Telescope. Using his extensive knowledge of astrometry, Owen played a significant role in reducing the ephemeris uncertainties for some flight project target bodies, including (951) Gaspra and (243) Ida. (M 27461; M 27477)

Name proposed by the discoverer following a suggestion by the JPL ephemeris group.

\section{(6136) Gryphon}

1990 YH. Discovered 1990 Dec. 22 by A. Natori and

T. Urata at Yakiimo.

In Lewis Carroll's \{see planet (6984)\} Alice's adventures in Wonderland, the Gryphon had an eagle's head, a front half with wings and talons, and at the back a lion's legs and tail. Unfortunately, Alice did not quite like the look of the creature. The Gryphon appears to have been a friend of the Mock Turtle \{see planet (8889)\}. (M 42355)

\section{(6139) Naomi}

1992 AD $_{1}$. Discovered 1992 Jan. 10 by A. Sugie at Taga.

Naomi Sugie (1966- ) is the wife of the discoverer. (M 36945)

\section{(6140) Kubokawa}

$1992 \mathrm{AT}_{1}$. Discovered 1992 Jan. 6 by K. Endate and K. Watanabe at Kitami.

Named in memory of Kazuo Kubokawa (1903-1943), a staff member of Tokyo Astronomical Observatory who made photographic observations of minor planets and comets with the Brashear \{see planet (5502)\} astrograph at Mitaka \{see planet (1088)\}. He and O. Oikawa \{see planet (2667)\} discovered (1139) Atami in 1929. (M 29146)

\section{(6141) Durda}

1992 YC $_{3}$. Discovered 1992 Dec. 26 by the Spacewatch at Kitt Peak.

Named in honor of Daniel D. Durda, who has studied the generation and evolution of dust from and the size distribution of minor planets. As a member of the Galileo imaging team, he has carried out fragmentation studies of minor planets and a detailed analysis of the formation of their satellites - in particular, of (243) Ida's moon Dactyl. An avid pilot, he is also a noted astronomical artist whose paintings are inspired by his scientific work. (M 32345)

\section{(6143) Pythagoras}

1993 JV. Discovered 1993 May 14 by E. W. Elst at La Silla.

Named for the great Greek philosopher and mathematician Pythagoras of Samos (580-500 B.C.). He contributed to the development of mathematics and is generally credited with the first mathematical foundation of theories about harmony in physics and the arts. Although it is difficult to distinguish his teaching from those of his disciples, Pythagorean principles strongly influenced the thought of Plato and to a somewhat lesser extent that of Aristoteles \{see, respectively, planets (5451) and (6123)\}. (M 24919; M 25351)

Citation written by D. Sinachopoulos at the request of the discoverer.

Pythagoras is also honored by a lunar crater.

\section{(6145) Riemenschneider}

2630 P-L. Discovered 1960 Sept. 26 by C. J. van Houten and I. van Houten-Groeneveld at Palomar.

Named for Tilman Riemenschneider (c. 1460-1531), German sculptor in stone and in wood. He lived in Würzburg and served as the city's mayor. During the 'Bauernkrieg' of 1525 he was on the side of the peasants, who lost the war. This probably resulted in his being tortured, and there is no record that he continued to sculpt after that time. In southern Germany and Austria there exist many wonderful altars from his hands, notably in Rothenburg, Creglingen, Heidelberg and Würzburg. (M 26764)

\section{(6146) Adamkrafft}

3262 T-2. Discovered 1973 Sept. 30 by C. J. van Houten and I. van Houten-Groeneveld at Palomar.

Named for the German sculptor Adam Krafft (also written Kraft, 1460-c.1508), who lived in Nürnberg and its vicinity. His most important works are to be seen in the Sebaldus and Lorenz churches and the museum of Nürnberg. (M 26765)

\section{(6147) Straub}

1081 T-3. Discovered 1977 Oct. 17 by C. J. van Houten and I. van Houten-Groeneveld at Palomar.

Named for the German sculptor Johann Baptist Straub (1704-1784). His most famous work is in the south-German rococo style, with transition to the classicistic style. His white and golden altars can be seen in the churches of Schäftlarn and Ettal. He worked together with his pupil Ignaz Günther \{see planet (6148)\}. (M 26765) 


\section{(6148) Ignazgünther}

5119 T-3. Discovered 1977 Oct. 16 by C. J. van Houten and I. van Houten-Groeneveld at Palomar.

Named for Ignaz Günther (also written Ginter and Ginther, 1725-1775). In 1743 he became a pupil of Straub \{see planet (6147)\} and in 1754 opened his own workshop. He is regarded as one of the most important rococo sculptors. His works can be seen in many churches and also in the Bürgersaal in München. (M 26765)

\section{(6149) Pelčák}

1979 SS. Discovered 1979 Sept. 25 by A. Mrkos at Klě́t.

Oldřich Pelčák (1943- ) has been a Czechoslovak astronaut-candidate, a member of a team of Czechoslovak astronauts with Vladimír Remek \{see planet (2552)\}. (M 41567)

The name was suggested by M. Tichý.

\section{(6150) Neukum}

$1980 \mathrm{FR}_{1}$. Discovered 1980 Mar. 16 by C.-I. Lagerkvist at La Silla.

Named in honor of Gerhard Neukum, director of the DLR Institute of Planetary Exploration in BerlinAdlershof, which he has led with great dedication and enthusiasm through the challenging years following German reunification. His research on the impact record of the moon, the terrestrial planets and the minor planets has led to a method of age determination that is applicable to all planetary surfaces in the solar system. (M 26931)

Name proposed by the discoverer and G. Hahn, who prepared the citation.

\section{(6151) Viget}

1987 WF. Discovered 1987 Nov. 19 by E. Bowell at Anderson Mesa.

Named in honor of Princeton University on the occasion of its 250th birthday 1996 Oct. 22. The name derives from Princeton's official motto: "Dei Sub Numine Viget", or "Under the Power of God She Flourishes". Princeton first became involved with astronomy when its sixth president, John Witherspoon, purchased the Rittenhouse Orrery in 1771. This miniature planetarium was one of the finest scientific instruments of the eighteenth century, and it still survives in working order. Viget joins (508) Princetonia and (534) Nassovia, both discovered by R. S. Dugan \{see planet (2772)\}, as the third minor planet named for Princeton. (M 27461)

Name suggested and citation prepared by J. T. Miller.

\section{(6152) Empedocles}

$1989 \mathrm{~GB}_{3}$. Discovered 1989 Apr. 3 by E. W. Elst at La Silla.

Named for the Greek philosopher Empedocles (490430 B.C.). Only some 400 lines remain of his poem On Nature, which considered that matter is composed of the four basic elements of fire, air, water and earth. Nothing comes into being or is destroyed, but things are merely transformed. Like Herakleitos \{see planet (5204)\} he believed that two forces, love and hate, interact to bring together and to separate the four ingredients. Fewer than 100 verses are left of Purifications, another poem of Empedocles. (M 24919)

\section{(6153) Hershey}

1990 OB. Discovered 1990 July 19 by E. F. Helin at Palomar.

Named in memory of Wesley Lamar Hershey (19131989), director of the Caltech "Y" at the California Institute of Technology for 30 years. Always ready to help students with sympathy and understanding, he developed the $\mathrm{Y}$ into a major factor of campus life. He provided an environment where exploration of ideas and concerns, controversial or not, was not only acceptable but encouraged. He encouraged students to face the issues of values in their own lives and for society as a whole. (M 25978)

\section{(6154) Stevesynnott}

$1990 \mathrm{QP}_{1}$. Discovered 1990 Aug. 22 by H. E. Holt at Palomar.

Named in honor of Stephen P. Synnott (1946- ), a space scientist at the Jet Propulsion Laboratory. Synnott is a noted authority on spacecraft optical navigation techniques. He discovered the Jovian satellites Thebe and Metis and was a member of the Voyager 2 imaging team, which discovered the small Uranian and Neptunian satellites. (M 27461)

Name proposed by the discoverer following a suggestion by the JPL ephemeris group.

\section{(6155) Yokosugano}

$1990 \mathrm{VY}_{2}$. Discovered 1990 Nov. 11 by T. Nomura and K. Kawanishi at Minami-Oda.

Named in honor of Yoko Sugano (1943- ), wife of Matsuo Sugano \{see planet (5872)\} and a warm-hearted friend of the observers at Minami-Oda. (M 35484)

\section{(6156) Dall}

$1991 \mathrm{AF}_{1}$. Discovered 1991 Jan. 12 by B. G. W. Manning at Stakenbridge.

Named in memory of Horace E. Dall (1901-1986), a talented craftsman known internationally for his skill in instrument making, optics and optical design. Inventor of the Dall 'null' test for parabolic telescope mirrors and coinventor of the Dall-Kirkham Cassegrain-type telescope, Dall was well known for his Maksutov telescopes, in particular a six-inch-aperture folding model that he used to take on his world travels. Dall refigured many telescope objective lenses to give optimum resolution, and he was also well known for making high-power microscope objectives. Dall joined the British Astronomical Association in 1925 and was awarded its Walter Goodacre Medal in 1967. (M 25231)

Obituary published in J. Br. Astron. Assoc., Vol. 97, No. 2, p. 76-80 (1987). 
(6157) Prey

$1991 \mathrm{RX}_{2}$. Discovered 1991 Sept. 9 by L. D. Schmadel and F. Börngen at Tautenburg.

Named in memory of Adalbert Prey (1873-1949), professor of astronomy in Innsbruck, Prague and, eventually, Vienna, where he was elected to membership in the Austrian Academy of Sciences. After World War II until his death he served as one of the two secretaries of the Academy. He worked on the motion of 70 Oph (sometimes called "Prey's star"), as well as on the dynamics of minor planets and the moon. He thoroughly investigated the field of isostasy and gravitation, to which he devoted a series of papers. (M 31296)

Named by the first discoverer following a suggestion by H. Haupt, who also prepared the citation.

\section{(6160) Minakata}

1993 JF. Discovered 1993 May 15 by Y. Shimizu and T. Urata at Nachi-Katsuura.

Named in memory of Kumagusu Minakata (18671941), a renowned Japanese naturalist who, as a child, studied mycology. Employed from 1895 as a temporary specialist by the British Museum, he returned to Japan in 1900 to continue his studies of biology and other fields. He promoted the movement to protect the forest of Kumano in the Wakayama prefecture from destruction by the government. (M 30477)

\section{(6161) Vojno-Yasenetsky}

$1971 \mathrm{TY}_{2}$. Discovered 1971 Oct. 14 by L. I. Chernykh at Nauchnyj.

Named in memory of Valentin Feliksovich VojnoYasenetsky (1877-1961), surgeon and bishop. As a physician, he practised in a number of district hospitals in central Russia, serving as head physician in the Tashkent urban hospital and as a professor at Central Asia University. In the early 1920s he took vows and was ordained as a bishop. During his life he published 55 scientific works on surgery and anatomy, winning the state prize in 1946. Although he was arrested many times and sent into exile for his views, when he died he had dignity as the archbishop of the Crimea and Simferopol. (M 32345)

\section{(6162) Prokhorov}

$1973 \mathrm{SR}_{6}$. Discovered 1973 Sept. 25 by L. V. Zhuravleva at Nauchnyj.

Named in honor of Yurij Vasil'evich Prokhorov (1929- ), Russian mathematician noted for his work on probability theory and a member of the editorial board of the Soviet Encyclopedia. (M 34622)

\section{(6163) Reimers}

1977 FT. Discovered 1977 Mar. 16 by H.-E. Schuster at La Silla.

Dieter Reimers (1943- ), director of the Hamburg Observatory, is well known for his work on white dwarfs and on mass loss from cool giant stars. He was instrumental in using Schmidt telescopes for wide-field quasar surveys. (M 36126)

\section{(6164) Gerhardmüller}

$1977 \mathrm{RF}_{2}$. Discovered 1977 Sept. 9 by N. S. Chernykh at Nauchnyj.

Named in memory of academician Gerhard Friedrich Müller (miller, according to traditional spelling in Russian; 1705-1783), first rector of St. Petersburg University and editor of the first Russian academic journal. He is considered the father of St. Petersburg's historical school, and his works were the foundation for research on the history, ethnography, archeology and geography of Russia and Siberia. (M 34341)

\section{(6165) Frolova}

1978 PD $_{3}$. Discovered 1978 Aug. 8 by N. S. Chernykh at Nauchnyj.

Named in honor of Natalia Borisovna Frolova, assistant professor of astronomy at Ural State University in Ekaterinburg. She worked on a detailed catalogue of stars along the path of comet $1 \mathrm{P} /$ Halley, and this contributed to the success of the space missions Vega and Giotto. As a leader in educating local schoolchildren about astronomy, she takes an active part in organizing the annual Winter Astronomical Students' School at Kourovskaya Observatory. (M 34341)

\section{(6166) Univsima}

$1978 \mathrm{SP}_{4}$. Discovered 1978 Sept. 27 by L. I. Chernykh at Nauchnyj.

Named for the Simferopol State University on the eightieth anniversary of the establishment of this first institution of higher education in the Crimea. Academicians A. P. Pavlov, I. P. Pavlov, V. I. Vernadskij \{see planet (2809)\} and N. I. Andrusov were founding faculty members. Academicians V. I. Obruchev, A. F. Ioffe \{see, respectively, planets (3128) and (5222)\}, N. M. Krylov and V. I. Smirnov worked there. Among its 65,000 graduates are academicians I. V. Kurchatov \{see planet (2352)\} and K. I. Shchelkin. (M 34622)

\section{(6167) Narmanskij}

1979 QB 10 . Discovered 1979 Aug. 27 by N. S. Chernykh at Nauchnyj.

Named in honor of Vladimir Yakovlevich Narmanskij (1948- ), Crimean amateur astronomer and founder of the amateur laboratory "Heliorythm", where research is conducted on the resonance structure of the solar system and on solar-terrestrial relations. He is also a poet, known for writing the text for Mass for Chersones by Crimean composer A. Karamanov \{see planet (4274)\}. (M 34341)

\section{(6169) Sashakrot}

$1981 \mathrm{EX}_{4}$. Discovered 1981 Mar. 2 by S. J. Bus at Siding Spring.

Alexander (Sasha) Krot (1959- ) is a world-class cosmochemist who has made many contributions to 
the field of meteoritics. His achievements include the discovery of an energetic astrophysical setting for chondrule formation and identifying the existence of an ${ }^{16}$ Oxygen-rich gaseous reservoir in the solar nebula. (M 46007)

\section{(6170) Levasseur}

1981 GP. Discovered 1981 Apr. 5 by E. Bowell at Anderson Mesa.

Named in honor of Anny-Chantal Levasseur-Regourd (1945- ), professor at Paris VI University. An incisive planetary scientist, Levasseur-Regourd works at the Service d'Aéronomie of the CNRS. She was selected as an astronaut, though her main scientific interest concerns the interplanetary medium, the physics of comets and the light-scattering properties of dust. Levasseur-Regourd has been principal investigator for several space experiments, inlcuding the Halley Optical Probe of the Giotto mission. Through her research and teaching, she actively encourages future generations of scientists. (M 27461)

Citation provided by M. A. Barucci.

\section{(6172) Prokofeana}

1982 TX. Discovered 1982 Oct. 14 by L. G. Karachkina at Nauchnyj.

Named in honor of Valentina Vladimirovna Prokof'eva (1929- ), prominent astrophysicist at the Crimean Astrophysical Observatory, a pioneer in the use of television photometry in astronomy and one of the authors of the monograph Televisionnaya Astronomiya, published in Russian in 1974 and 1984. She devised methods for receiving and calibrating television photometric data from such objects as galaxies, binaries, major and minor planets, comets and artificial satellites. Prokof'eva has obtained significant results in the interpretation of the blue clearings on Mars, nonradial pulsations of red giants, the components of symbiotic stars, and periodic light variations of the x-ray source V1055 Ori. She discovered multiple periodicities in light curves of a number of minor planets and interpreted them as a consequence of their duplicity and rotation of their components. (M 25231)

Name proposed by the discoverer following a suggestion of Yu. V. Batrakov.

\section{(6173) Jimwestphal}

1983 AD. Discovered 1983 Jan. 9 by B. A. Skiff at Anderson Mesa.

Named in honor of James A. Westphal (1930), professor of planetary science at the California Institute of Technology and director of the Palomar Observatory. After leading a geological research group in the petroleum industry, Westphal went to Caltech in 1961, where he developed modern infrared detectors for use in astronomy, and (with Bruce Murray, see planet (4957)) made important early observations of stars and planets. In later work (with Kristian and
Sandage) he pioneered SIT spectroscopy and twodimensional photometry of faint galaxy clusters. As principal investigator (from 1977) for the Hubble Space Telescope WFPC camera system, Westphal has played a key role in the development of CCD detctors suitable for astronomical and space research. (M 27462)

Citation provided by W. A. Baum following a suggestion by A. W. Harris.

\section{(6174) Polybius}

$1983 \mathrm{TR}_{2}$. Discovered 1983 Oct. 4 by N. G. Thomas at Anderson Mesa.

Named for Polybius (c. 200-118 B.C.), Greek historian and father of pragmatic history, one of 1000 eminent Archeans deported to Rome after Perseus' defeat at Pydna in 168 B.C. Making favorable friends in Rome, he traveled with them to Spain, North Africa and through the Alps back to Rome. He mediated Roman troubles in Greece and collected works of Greek historians. His own narratives cover the Punic Wars and contemporary events but with such conciseness that various problems of chronology and strategy remain. (M 26931)

\section{(6175) Cori}

1983 XW. Discovered 1983 Dec. 4 by A. Mrkos at Kleť.

Carl Ferdinand Cori (1896-1984) and Gerty Theresa Cori (1896-1957) were American biochemists born in Prague, a husband-and-wife team who studied the hormonal influence on the interconversion of sugars in an animal organism. They won the 1947 Nobel Prize in medicine. (M 40701; M 40877)

The name was suggested by J. Tichá.

\section{(6179) Brett}

1986 EN. Discovered 1986 Mar. 3 by C. S. Shoemaker and E. M. Shoemaker at Palomar.

Named in honor of Robin Brett (1935- ), an Australian-born, Harvard-educated American citizen active in the planetary-science program from its early days. His research has included geochemical studies of meteoritic and lunar samples, modeling the cores of the terrestrial planets and geologic mapping of impact craters. He was responsible for much of the planning for the massive study of the Apollo lunar samples. A born organizer, Brett has directed his activities toward advancing international cooperation in research; the fact that he is known as a "nice guy" with a great sense of humor may have helped. (M 34623)

\section{(6180) Bystritskaya}

1986 PX $_{4}$. Discovered 1986 Aug. 8 by L. I. Chernykh at Nauchnyj.

Named in honor of Ehlina Avraamovna Bystritskaya, distinguished Soviet actress. An actress with Moscow Malyj Theatre since 1958, she is especially popular for her brilliant roles in several films. (M 34342) 


\section{(6182) Katygord}

1987 SC $_{4}$. Discovered 1987 Sept. 21 by E. Bowell at Anderson Mesa.

Named in honor of Katherine Carson Gordon Kron (1917- ) on the occasion of her 80th birthday, 1997 May 24. Kron devoted much of her professional life to observational astronomy at the Lick Observatory. During the second world war she served as a physicist for the U.S. Navy and for much of the 1960s was editor of the Publications of the Astronomical Society of the Pacific. (M 30098)

Name suggested, with love and affection, by her husband G. E. Kron \{see planet (2796)\}, and warmly endorsed by the discoverer.

\section{(6183) Viscome}

$1987 \mathrm{SF}_{7}$. Discovered 1987 Sept. 26 by C. S. Shoemaker and E. M. Shoemaker at Palomar.

Named in honor of George R. Viscome (1956- ), of Lake Placid, New York. A broadcast technician responsible for master control and videotape operations at a television station in Albany, Viscome is an accomplished astrometrist. His observations of this minor planet at the 1994 opposition were sufficient for numbering it. (M 24766)

Name proposed by the discoverers, following a suggestion by G. V. Williams (who made the idenfication involving this object).

\section{(6186) Zenon}

$1988 \mathrm{CC}_{2}$. Discovered 1988 Feb. 11 by E. W. Elst at La Silla.

Named for the great Greek philosopher and mathematician Zenon of Elea (494-430 B.C.). As a friend and pupil of Parmenides \{see planet (6039)\}, he continued his teacher's abstract and analytic thought, taking the theses of his opponents and refuting them by reductio ad absurdum. He tried to show that the assumption of the existence of a plurality of things in time and space carried with it more serious inconsistencies. He is especially known for the paradoxes he used for this purpose. (M 24919)

Citation by D. Sinachopoulos at the request of the discoverer.

\section{(6188) Robertpepin}

$1988 \mathrm{SW}_{2}$. Discovered 1988 Sept. 16 by S. J. Bus at Cerro Tololo.

Robert Pepin (1933- ), professor at the University of Minnesota, studies the origin and early history of volatile elements in the solar system. He helped solidify the link between SNC meteorites and Mars through his measurements of noble gases and nitrogen in glasses that are found in these meteorites. (M 46007)

\section{(6189) Völk}

$1989 \mathrm{EY}_{2}$. Discovered 1989 Mar. 2 by E. W. Elst at La Silla.

Named in honor of Elisabeth Völk (1946- ), secretary at the European Southern Observatory's headquarters in Garching, where she is chiefly responsible for the administration of the ESO Schmidt plates. During the July 1994 observing campaign on comet D/1993 F2 (Shoemaker-Levy 9) she did an excellent job solving so many problems that occurred at that hectic time. During all the years (1987-1994) of the Uccle-ESO observing program on minor planets she has become a very good friend to the discoverer. (M 24766)

Proposal endorsed by L. D. Schmadel, who independently suggested naming a minor planet for Mrs. Völk.

\section{(6190) Rennes}

1989 TJ $_{1}$. Discovered 1989 Oct. 8 by M. Koishikawa at Sendai.

Named for the city in France, Rennes is the international sister city of Sendai \{see planet (3133)\}, Japan, affiliated since 1997. It is the center of administration and culture in Brittany. (M 33786)

\section{(6191) Eades}

$1989 \mathrm{WN}_{1}$. Discovered 1989 Nov. 22 by B. G. W. Manning at Stakenbridge.

Named in honor of George Eades, currently celebrating his fiftieth year of membership in the British Astronomical Association. A structural engineer by profession, Eades constructed two 15-cm reflecting telescopes, including the mirrors and eyepiece lenses. An expert microscopist, he also constructed a high-power binocular microscope, including all the optics except for the objective lenses. Eades was of great help to the discoverer many years ago by introducing him to the BAA and scientific literature that led eventually to an interest in astrometry and the discovery of (6191) and other minor planets. (M 25445)

Name suggested by A. Manning.

\section{(6193) Manabe}

1990 QC $_{1}$. Discovered 1990 Aug. 18 by K. Endate and K. Watanabe at Kitami.

Named in memory of Ryonosuke Manabe (19261983), who worked for many years as a computer assistant for H. Hirose \{see planet (1612)\} at the Tokyo Astronomical Observatory. In 1974 he went to work for NASDA, where he was involved with the Japanese geodesy satellite. (M 29146)

Name proposed by the second discoverer following a suggestion by K. Tomita.

\section{(6194) Denali}

1990 TN. Discovered 1990 Oct. 12 by R. H. McNaught at Siding Spring.

Mt. Denali, rising 6194 meters above the sea level, is the tallest peak in North America. The name Denali originates from the Tanana Indian language and translates into English as "The Great One". The Tanana Indians are a subgroup of the Athabaskans; the Athabaskans were the original inhabitants of central and south central Alaska. (M 34342)

Name proposed by D. Hamilton. 


\section{(6195) Nukariya}

$1990 \mathrm{VL}_{2}$. Discovered 1990 Nov. 13 by K. Endate and K. Watanabe at Kitami.

Named in honor of Motoi Nukariya (1943- ), who was active in software development at the Tokyo Astronomical Observatory before moving to NASDA in 1971 to develop their orbit-determination system for satellites. (M 29146)

Name proposed by the second discoverer following a suggestion by K. Tomita.

\section{(6198) Shirakawa}

$1992 \mathrm{AF}_{1}$. Discovered 1992 Jan. 10 by T. Hioki and S. Hayakawa at Okutama.

Shirakawa is a city in Fukushima prefecture, $180 \mathrm{~km}$ north of Tokyo. (M 36126)

\section{(6199) Yoshiokayayoi}

$1992 \mathrm{BK}_{1}$. Discovered 1992 Jan. 26 by A. Sugie at Taga.

Yayoi Yoshioka (1871-1959) was the 27th licenced female physician in Japan and entered the medical profession in 1892, when it was difficult for women to be doctors. In 1900, she and her husband Arata founded the Tokyo Women's Medical School, the first in Japan to accept female students. (M 36945)

\section{(6200) Hachinohe}

1993 HL. Discovered 1993 Apr. 16 by K. Endate and K. Watanabe at Kitami.

Named for the amateur astronomer Akio Hachinohe (1958- ), who has contributed much to amateur astronomy in Hokkaido \{see planet (3720)\}. He is also active in sky sports such as hot-air ballooning and hang-gliding. (M 25978)

\section{(6201) Ichiroshimizu}

1993 HY. Discovered 1993 Apr. 16 by K. Endate and K. Watanabe at Kitami.

Named in honor of Ichiro Shimizu (1923-1996), who began work for the Tokyo Astronomical Observatory in 1945 and was heavily involved in the construction of the Corona Observing Station on Mt. Norikura. He was later a key astronomer in the solar physics division of the Observatory until he retired in 1984 . (M 29146)

Name proposed by the second discoverer following a suggestion by K. Tomita.

\section{(6202) Georgemiley}

3332 T-1. Discovered 1971 Mar. 26 by C. J. van Houten and I. van Houten-Groeneveld at Palomar.

Named for George Kildare Miley (1942- ） to honor his 25-year association with the Leiden Observatory. A senior scientist at the Space Telescope Science Institute during 1984-1988, he became a professor in Leiden in 1988. His research has included investigations of radio, optical, infrared and x-ray properties of active galaxies. He instigated an extensive new radio survey of the northern sky and in 1989 discovered the galaxy 4C 41.17 with the largest known redshift. (M 26765)

\section{(6203) Lyubamoroz}

$1981 \mathrm{EC}_{23}$. Discovered 1981 Mar. 3 by S. J. Bus at Siding Spring.

Lyubov Moroz (1966- ), a laboratory spectroscopist at the German Aerospace Center in Berlin, has investigated the effects of temperature and opaques on the spectra of minor planets. She was the first researcher to try to simulate the optical effects due to impact melting of minerals using a pulse laser. (M 46007)

\section{(6204) MacKenzie}

$1981 \mathrm{JB}_{3}$. Discovered 1981 May 6 by C. S. Shoemaker at Palomar.

Named in honor of Norman MacKenzie, a leading scholar of the poetry of Gerard Manley Hopkins. Professor of English at the University of Rhodesia from 1954 to 1964, he has subsequently been at Queen's University \{see planet (5457)\} in Canada. His works include co-editing the fourth edition of Hopkins' Poems (1967) and most recently the Oxford English Texts Poetical Works of Gerard Manley Hopkins (1990). MacKenzie has followed Hopkins' close observation of nature, especially astronomy, and has maintained an active interest in the sky throughout his life. (M 24919)

Name proposed and citation prepared by D. H. Levy.

\section{(6205) Menottigalli}

1983 OD. Discovered 1983 July 17 by E. Bowell at Anderson Mesa.

Named in honor of Menotti Galli (1922- ), a physicist at the University of Bologna. Galli's research activity began with the study of cosmic rays and meteorites and was subsequently extended to the physics of the sun and the heliosphere. He has studied sun-earth relationships, cosmogenic isotopes and radiocarbon in tree rings. He suggested searching for microparticles embedded in the resin of trees surviving the Tunguska \{see planet (5471)\} explosion, and he participated in the 1991 expedition to collect the necessary wood samples, with the result that a group of elements was identified as possible constituents of the Tunguska body. (M 33786)

Name suggested and citation provided by M. di Martino.

\section{(6206) Corradolamberti}

1985 TB $_{1}$. Discovered 1985 Oct. 15 by E. Bowell at Anderson Mesa.

Named in honor of Corrado Lamberti, an excellent writer and popularizer of astronomy and one of the founders and now director of the Italian popular astronomy review l'Astronomia. With his accurate work over the last 20 years, he has made a fundamental contribution to the dissemination of knowledge of astronomy in Italy. (M 33787)

Name suggested and citation provided by M. di Martino. 


\section{(6208) Wakata}

1988 XT. Discovered 1988 Dec. 3 by K. Endate and K. Watanabe at Kitami.

Named in honor of Kouichi Wakata, chosen by NASDA as the astronaut in 1992 among 372 applicants, after receiving a master's degree in applied dynamics at the University of Kyushu and working for Japan Air Lines. In January 1996 he was on board the space shuttle Endeavor and succeeded in recovering a Japanese satellite. (M 29146)

\section{(6209) Schwaben}

$1990 \mathrm{TF}_{4}$. Discovered 1990 Oct. 12 by F. Börngen and L. D. Schmadel at Tautenburg.

Schwaben was a German dukedom, in 1079 passing over to the Swabian race of the Staufer. From 1138 to 1254 , this race supplied the German kings and emperors. In the middle ages Schwaben was a rich trading place. Today, it is a Bavarian governmental district with its capital in Augsburg. It extends from the Allgäuer Alps and Lake Constance (Swabian Sea) to the Swabian-Franconian Alb. (M 25654)

Name proposed by the first discoverer

\section{(6211) Tsubame}

1991 DO. Discovered 1991 Feb. 19 by S. Inoda and T. Urata at Karasuyama.

Tsubame, Japanese for a swallow, is the nickname of an express train that was a star of Japan's rail transportation system during the 1950s. In 1954 Tsubame achieved the Japanese record of $129 \mathrm{~km}$ per hour for steam locomotion. In the 1930s an earlier Tsubame did the Tokyo-Kobe run in $8 \frac{1}{2}$ hours. (M 36945)

\section{(6213) Zwiers}

2196 P-L. Discovered 1960 Sept. 24 by C. J. van Houten and I. van Houten-Groeneveld at Palomar.

Named in memory of Hendrikus Johannes Zwiers (1865-1923), astronomer at the Leiden Observatory who worked in positional astronomy. He is best known for his method for calculating the orbit of visual binaries and for his computation of the orbit of comet 17P/Holmes. (M 26765)

Obituary published in Hemel en Dampkring, Vol. 22, p. 37 (1924).

\section{(6214) Mikhailgrinev}

$1971 \mathrm{SN}_{2}$. Discovered 1971 Sept. 26 by T. M. Smirnova at Nauchnyj.

Named in honor of Mikhail Vasil'evich Grinev (1929- ), outstanding Russian surgeon, director of St. Petersburg Djanelidze Research Institute of Emergency Medicine from 1984 to 1998, member of the board of directors of the European Association of Trauma and Emergency Surgery, professor of St. Petersburg Medical University and medical academy for postgraduate training. Grinev is internationally renowned for his classis research in the field of emergency surgery, polytrauma and shock. (M 34342)
Name suggested by the Institute of Applied Astronomy and Djanelidze Research Institute of Emergency Medicine.

\section{(6216) San Jose}

1975 SJ. Discovered 1975 Sept. 30 by S. J. Bus at Palomar.

Named for the city in northern California, to acknowledge it as the Capital of Silicon Valley and to honor it as the world's leader in innovation and advanced technology research. The San Jose area, home of the Ohlone Indians, was settled by the Spanish in 1777. In 1849 San Jose became the first capital of the state of California. Since then it has grown into a major metropolitan area and is now the eleventh largest city in the United States. San Jose has made a major contribution to astronomy through its cooperative and friendly relationship with the Lick Observatory, which lies 20 miles to the east at the summit of Mount Hamilton. (M 31024)

Named by the discoverer following a suggestion by S. M. Faber. Citation prepared by B. F. Jones.

\section{(6218) Mizushima}

$1977 \mathrm{EG}_{7}$. Discovered 1977 Mar. 12 by H. Kosai and K. Hurukawa at Kiso.

Named for a site in the city of Kurashiki \{see planet (4578)\} near the birthplace of the first discoverer. Mizushima is a scenic spot in the Inland Sea and includes an old battlefield from the conflict between the Genji and Heike samurai families. This battle occurred during an annular eclipse of the sun in 1183, and Heike gained a great victory. (M 26765)

\section{(6219) Demalia}

1978 PX $_{2}$. Discovered 1978 Aug. 8 by N. S. Chernykh at Nauchnyj.

Named in memory of Aleksandra Alekseevna Demenko (1930-1983), Ukrainian astronomer, staff member of the Astronomical Observatory of Kiev University, known for her research on comets. (M 30098)

Obituary published in Komet. Tsirk., No. 316 (1983).

\section{(6220) Stepanmakarov}

$1978 \mathrm{SN}_{7}$. Discovered 1978 Sept. 26 by L. V. Zhuravleva at Nauchnyj.

Named in memory of Stepan Osipovich Makarov (1848-1904), Russian vice-admiral and naval commander, oceanographer, polar researcher and ship builder. (M 34623)

\section{(6221) Ducentesima}

1980 GO. Discovered 1980 Apr. 13 by A. Mrkos at Klě́.

The naming commemorates the 200th Klet numbered minor planet. Its Latin name was inspired by classical female names from the pioneer days of the searching for minor planets in the nineteenth century. (M 27735) Name suggested by J. Tichá. 


\section{(6223) Dahl}

$1980 \mathrm{RD}_{1}$. Discovered 1980 Sept. 3 by A. Mrkos at Klě́t.

Named in honor of the Welsh-born author Roald Dahl (1916- ). His Willy Wonka and the Chocolate Factory and James and the Giant Peach are classics of children's literature. (M 27735)

Name suggested by G. V. Williams, who made the identifications involving this object.

\section{(6224) El Goresy}

$1981 \mathrm{EK}_{8}$. Discovered 1981 Mar. 1 by S. J. Bus at Siding Spring.

Ahmed El Goresy (1933- ), a scientist at the MaxPlanck-Institut für Chemie at Mainz, has conducted pioneering research on shock processes in meteorites and terrestrial impact craters. He is an acknowledged expert in the field of sulfide mineralogy and reflected light optical microscopy of opaque minerals. (M 46008)

\section{(6225) Hiroko}

1981 EK $_{12}$. Discovered 1981 Mar. 1 by S. J. Bus at Siding Spring.

Hiroko Nagahara (1952- ), professor at the University of Tokyo, has studied a wide array of meteoritic materials and made fundamental contributions to our understanding of chondrule formation, condensation and evaporation in the solar nebula, and partial melting of minor planets. (M 46008)

\section{(6226) Paulwarren}

$1981 \mathrm{EY}_{18}$. Discovered 1981 Mar. 2 by S. J. Bus at Siding Spring.

Paul Warren (1953- ), a research geochemist at the University of California in Los Angeles, has applied a wide range of petrologic and geochemical studies toward understanding differentiated planets. His work on lunar rocks helped identify those samples least altered by impact. (M 46008)

\section{(6227) Alanrubin}

1981 EQ $_{42}$. Discovered 1981 Mar. 2 by S. J. Bus at Siding Spring.

Alan Rubin (1953- ), a research geochemist at the University of California in Los Angeles, works on a wide variety of topics such as the origin of chondrules and shock processes in meteorites. He is best known for studying the geologic processes that altered the parent bodies of chondritic meteorites. (M 46008)

\section{(6228) Yonezawa}

1982 BA. Discovered 1982 Jan. 17 by T. Furuta at Tokai.

Yonezawa city, located in the southern part of Yamagata prefecture, has an area of 549 square kilometers. The city is in a basin surrounded by the well-known Azuma and Iide mountain ranges. (M 42668)

\section{(6229) Tursachan}

1983 VN $_{7}$. Discovered 1983 Nov. 4 by B. A. Skiff at Anderson Mesa.

The name is "Standing Stones" in Gaelic, a term used to refer to the stones placed during neolithic times into groups - often circles - throughout the British Isles. Many of these arrangements exhibit astronomical alignments and may have been used to track the progression of seasons and mark the occurrence of other significant astronomical events. (M 31296)

The name was suggested by Alice Cathryne Dennis, a seventh-grade student at the Mountain School in Flagstaff, Arizona, as winner of a contest to name this minor planet in conjunction with the 1997 Flagstaff Festival of Science. Citation prepared by C. B. Luginbuhl.

\section{(6231) Hundertwasser}

1985 FH. Discovered 1985 Mar. 20 by A. Mrkos at Kleť.

Friedensreich Hundertwasser (Friedrich Stowasser, 1928-2000) was an Austrian graphic artist and painter whose decorative abstract style follows in the Secessionist (Art Nouveau) tradition of Gustav Klimt and Egon Schiele. (M 40701)

The name was suggested by J. Tichá.

\section{(6232) Zubitskia}

$1985 \mathrm{SJ}_{3}$. Discovered 1985 Sept. 19 by N. S. Chernykh and L. I. Chernykh at Nauchnyj.

Named in honor of Danila Nikiforovich Zubitskij and Natalia Petrovna Zubitska, doctors and psychotherapists in Kiev, who have developed original methods of treatment using herbal medicines. The authors of several books, they are well known in the Ukraine, and their methods and preparations are also being used in other countries. Natalia Petrovna, who has a broadcast program in Kiev about herbs and "people's medicine", has also published several books of poetry. (M 32345)

\section{(6233) Kimura}

1986 CG. Discovered 1986 Feb. 8 by S. Inoda and T. Urata at Karasuyama.

Named in memory of Hisashi Kimura (1870-1943), the first director of the International Latitude Observatory of Mizusawa ssee planet (7530)\}. Serving in this capacity from 1899 to 1941, he was also director of the International Latitude Service from 1922 to 1934. In 1902 Kimura discovered the $Z$ term of polar motion, the first astronomical clue for inferring physical states and processes in the earth's deep interior, in particular at the core-mantle boundary. (M 34623)

Name proposed by the second discoverer, following a suggestion by K. Hurukawa and K. Yokoyama, and in commemoration of the Mizusawa Observatory's centennial. Citation prepared by K. Yokoyama. 


\section{(6236) Mallard}

1988 WF. Discovered 1988 Nov. 29 at the Nihondaira Observatory at Oohira.

In 1938 the British steam locomotive "Mallard" set the world's speed record of $203 \mathrm{~km}$ per hour for steam locomotion. (M 36945)

The name was suggested by B. G. Marsden.

\section{(6237) Chikushi}

1989 CV. Discovered 1989 Feb. 4 by T. Seki at Geisei.

This is the old name of the Fukuoka region in northern Kyushu. During 1944-1947 the Chikushi Astronomical Association was active. Several of its members, including Isao Ebihara, Takeo Mori, Mineo Nishiyama, Kiichiro Hurukawa \{see planet (3425)\} and Ichiro Hasegawa \{see planet (3227)\}, made their first studies of the orbits of comets and minor planets. (M 28621)

\section{(6239) Minos}

1989 QF. Discovered 1989 Aug. 31 by C. S. Shoemaker and E. M. Shoemaker at Palomar.

Minos was the son of Zeus and Europa \{see planets (5731) and (52)\}. As king of Crete, he distinguished himself by the wisdom of his laws, which remained in force for nearly 1000 years, and by his sense of justice and moderation approved by all the Greeks and gods. These earned Minos, after his death, promotion to the dignity of judge of the Underworld. (M 25445)

\section{(6240) Lucretius Carus}

$1989 \mathrm{SL}_{1}$. Discovered 1989 Sept. 26 by E. W. Elst at La Silla.

Named for the Latin philosopher and poet Titus Lucretius Carus. He was born around 90 B.C., probably in Rome, and he is known from his De rerum natura, a long poem written in Latin hexameters. In this he expounds on the physical theory of the Greek philosopher Epicurus \{see planet (5954)\}, of whom he speaks with great admiration. The third part of the poem deals with atomic structure and the mortality of the soul, the latter with the famous words 'Death means nothing to us'. (M 25445)

Lucretius is also honored by a lunar crater.

\section{(6241) Galante}

1989 TG. Discovered 1989 Oct. 4 at the Osservatorio San Vittore at Bologna.

Named in honor of Maria Pia Galante (1916- ) wife of Ciro Vacchi, proprietor and director of Osservatorio San Vittore. (M 25978)

\section{(6243) Yoder}

$1990 \mathrm{OT}_{3}$. Discovered 1990 July 27 by H. E. Holt at Palomar.

Named in honor of Charles F. Yoder (1943- ), of Los Angeles, California. Yoder developed the first analysis of capture into orbit-orbit mean-motion resonances among the satellites of the giant planets, as well as the explanation of the origin and evolution of the three-body Laplacian orbital resonance among the Galilean satellites of Jupiter. He has connected the variations of the rotation of the earth with properties of the core and of the core-mantle interface, found evidence for the dissipative effects of a possible fluid core-solid mantle interaction for the moon and put constraints on the core of Venus and Venus' rotational history required by Venus' obliquity. (M 27462)

Name suggested by A. W. Harris, citation provided by S. J. Peale.

\section{(6244) Okamoto}

1990 QF. Discovered 1990 Aug. 20 by T. Seki at Geisei.

Named in honor of Hiroshi Okamoto (1915- ), an entomologist and elementary-school teacher who inspired the discoverer with a love of the stars. (M 32093)

\section{(6245) Ikufumi}

$1990 \mathrm{SO}_{4}$. Discovered 1990 Sept. 27 by T. Urata at Oohira.

Named in honor of Ikufumi Makino (1944- ), a telecommunications systems engineer and active amateur astronomer. His extensive knowledge of computer technologies has enabled him to contribute to astronomical magazines many articles about systems for making observations. He has played an important role in introducing and spreading the data-reduction tool Astrometrica in Japan. He is a collaborating member of the Nihondaira Observatory. (M 32094)

\section{(6246) Komurotoru}

$1990 \mathrm{VX}_{2}$. Discovered 1990 Nov. 13 by T. Fujii and K. Watanabe at Kitami.

Named in memory of the sculptor Toru Komuro (1899-1953), on the hundredth anniversary of his birth. Komuro's work was first accepted for the Teiten (Imperial Art Exhibition, now known as Nitten) in 1924. His most important work is the equestrian statue of Datemasamune \{see planet (6859)\}, placed in the ruins of the castle of Sendai \{see planet (3133)\} as a symbol of the city. (M 34623)

\section{(6247) Amanogawa}

$1990 \mathrm{WY}_{3}$. Discovered 1990 Nov. 21 by K. Endate and K. Watanabe at Kitami.

Named for a river that runs through the Hokkaido town of Kaminokuni \{see planet (5978)\}. It is also the Japanese word for the Milky Way. (M 29146)

\section{(6249) Jennifer}

$1991 \mathrm{JF}_{1}$. Discovered 1991 May 7 by E. F. Helin at Palomar.

Named in honor of Jennifer Jones Simon, an actress whose creativity captivated hearts in memorable performances. She has shared with the world her passionate delight in the arts in guiding the destiny of the Norton Simon Museum of Art in Pasadena. Her Pasadena friends and admirers worldwide heartfully endorse this naming, a celebratory tribute to her talents and beautiful persona. (M 26425) 
(6251) Setsuko

1992 DB. Discovered 1992 Feb. 25 by M. Akiyama and T. Furuta at Mishima.

Named in honor of Setsuko Akiyama (1953- ), wife of the first discoverer. (M 27129)

\section{(6252) Montevideo}

1992 EV $_{11}$. Discovered 1992 Mar. 6 by the Uppsala-ESO Survey at La Silla.

Named for the capital of Uruguay and city of the birth of G. Tancredi \{see planet (5088)\}, one of the discoverers of this minor planet. The meaning of the name comes from the fact that the city is "watched over" by a bowl-shaped hill. Founded in 1726 by the Spanish crown in order to stop Portuguese expansion, Montevideo has a long tradition in astronomy, starting in 1789 when the first observatory was built to study the transit of Mercury, the observations of which were later used by Leverrier \{see planet (1997)\} to discover the secular advance of Mercury's perihelion. In 1955 the first planetarium in the Spanish-speaking world was built there. (M 26425)

Named on the occasion of the eighth Latino-american regional meeting of the IAU, held in Montevideo in November 1995

\section{(6255) Kuma}

1994 XT. Discovered 1994 Dec. 5 by A. Nakamura at Kuma.

Named for the small Japanese town on Shikoku \{see planet (4223)\} where this planet was discovered. Kuma town, known for forestry, agriculture and as an important destination for pilgrims, also encourages local cultural activities. Kuma Kogen Astronomical Observatory was built in 1992 for astronomical education and tourism. (M 25231)

\section{(6256) Canova}

4063 P-L. Discovered 1960 Sept. 24 by C. J. van Houten and I. van Houten-Groeneveld at Palomar.

Named for Antonio Canova (1757-1822), an Italian sculptor in the classicistic style. An opponent of the wild form of the baroque style, he worked in a realistic style with a quiet and smooth form. He made idealized portraits of Napoleon and his family. One of his most famous sculptures is 'Amor and Psyche'. (M 26765)

\section{(6257) Thorvaldsen}

4098 T-1. Discovered 1971 Mar. 26 by C. J. van Houten and I. van Houten-Groeneveld at Palomar.

Named for the Danish sculptor Bertel Thorvaldsen (1768-1844). With Canova \{see planet (6256)\} he was the greatest representative of the classicistic style. His work is found in Copenhagen, in St. Peter's in Rome, in Munich, Lucerne and Warsaw. (M 26765)

\section{(6258) Rodin}

3070 T-2. Discovered 1973 Sept. 30 by C. J. van Houten and I. van Houten-Groeneveld at Palomar.

Named for the French sculptor Auguste Rodin (1840-1917). In his sculptures Rodin tried to express personal inner feelings with bearing and gestures. He was one of the first sculptors to abandon the classicistic style of Thorvaldsen and Canova see planets (6257) and (6256)\}. Among his most famous works are 'The Citizens of Calais', 'The Kiss' and 'The Thinker'. (M 26765)

\section{(6259) Maillol}

3236 T-2. Discovered 1973 Sept. 30 by C. J. van Houten and I. van Houten-Groeneveld at Palomar.

Named for the French sculptor and graphic artist Aristide Maillol (1861-1944). He first studied painting with Paul Gauguin but because of a disease of his eyes became a sculptor. After Rodin \{see planet (6258)\} he is generally regarded as the greatest French sculptor. (M 26765)

\section{(6260) Kelsey}

1949 PN. Discovered 1949 Aug. 2 by K. Reinmuth at Heidelberg.

Named in honor of Frances Oldham Kelsey (1914- ), research pharmacologist at the U.S. Food and Drug Administration in Washington, D.C. Kelsey's prescient research led to the recognition that fetal malformation can result from drugs that appear harmless to adults. Her integrity as a scientist and as a citizen prevented the marketing of the sedative drug thalidomide in the United States, thereby preventing an occurrence of an alarming number of limbless infants being born, as happened in countries where the drug was marketed between the late 1950s and 1962. For this action, she received in 1962 the U.S. president's award for distinguished civilian service for (in the words of president J. F. Kennedy) "sparing the nation a human tragedy". (M 25654)

Name proposed and citation prepared by G. C. L. Aikman.

\section{(6261) Chione}

1976 WC. Discovered 1976 Nov. 30 by H.-E. Schuster at La Silla.

Named for the Greek princess Chione, who had the misfortune of having both Apollo \{see planet (1862)\} and Hermes fall in love with her. She was the mother of Autolykos by Hermes and of Philammon by Apollo. She was arrogant enough to compare herself with Artemis \{see planet (105)\}, who killed her in revenge. (M 27129)

\section{(6262) Javid}

1978 RZ. Discovered 1978 Sept. 1 by N. S. Chernykh at Nauchnyj.

Named in memory of Hussein Javid (1882-1941), Azerbaijani poet, playwright and historian, author of several historical plays, such as Sheikh Sanan, Teimur, the lame and Khayyam. In his works he preached the ideas of progressive romanticism. In 1937 he was branded as a dissident and exiled to Siberia. (M 30098) 
(6266) Letzel

$1986 \mathrm{~TB}_{3}$. Discovered 1986 Oct. 4 by A. Mrkos at Klět.

Named in memory of Jan Letzel (1880-1925), Czech architect inspired by the Art Nouveau style and who worked in Japan from 1907 to 1923. He designed the Hiroshima Prefectural Commercial Exhibition Hall in 1915. This building, the most elegant in the city, became world famous as the Genbaku Dome or A-bomb Dome, which was left in ruins as an eternal symbol of the tragedy of Hiroshima on 1945 Aug. 6. (M 34342) Name suggested by J. Tichá.

\section{(6267) Rozhen}

$1987 \mathrm{SO}_{9}$. Discovered 1987 Sept. 20 by E. W. Elst at Rozhen.

The National Observatory of Bulgaria has been established at Rozhen, not far from the city of Smoljan, close to the Greek border. The observatory, located at a height of $1700 \mathrm{~m}$, profits from excellent instrumental and observational possibilities. In 1986 intensive searches for new minor planets were initiated there. (M 47163)

\section{(6268) Versailles}

$1990 \mathrm{SS}_{5}$. Discovered 1990 Sept. 22 by E. W. Elst at La Silla.

Named for the city, site of the grandiose palace and start of the French revolution in 1789. In 1624 Louis XIII had a small castle built there, some $17 \mathrm{~km}$ from Paris, to serve as a lodge after his hunts in the surrounding woods. The present palace was built by Louis XIV, who moved his entire staff there in 1682 , while carefully maintaining the old hunting lodge. The palace was substantially altered by Louis XV, and it is known for its magnificent gardens and 'Salle du jeu de paume'. (M 25445)

\section{(6269) Kawasaki}

1990 UJ. Discovered 1990 Oct. 20 by T. Urata at Oohira.

Named in memory of Shun'ichi Kawasaki (18961943), the second director of the International Latitude Observatory of Mizusawa see planet (7530)\} and brother-in-law of the astronomer Issei Yamamoto \{see planet (2249)\}. He introduced the floating zenith telescope to supplement the visual zenith telescope for routine observations. (M 34623)

Name proposed by the discoverer following a suggestion by K. Hurukawa and K. Yokoyama. Citation prepared by K. Yokoyama.

\section{(6271) Farmer}

1991 NF. Discovered 1991 July 9 by E. F. Helin at Palomar.

Named in honor of Crofton Bernard Farmer, distinguished visiting scientist at the Jet Propulsion Laboratory whose research has been primarily in earth and planetary atmospheres. He has been awarded the NASA Exceptional Scientific Achievement Medal on three occasions. The discoverer and members of the Near-Earth Asteroid Tracking program wish to recognize his efforts in providing crucial assistance to the NEAT task as motivator, organizer and representative to the sponsor. (M 26931)

\section{(6273) Kiruna}

1992 ER $_{31}$. Discovered 1992 Mar. 1 by the Uppsala-ESO Survey at La Silla.

North of the Arctic Circle in the province of Norrbotten, Kiruna is the northernmost city in Sweden, known for its iron-ore mining since the late-nineteenth century. (M 36126)

\section{(6274) Taizaburo}

1992 FV. Discovered 1992 Mar. 23 by K. Endate and K. Watanabe at Kitami.

Named in honor of Taizaburo Koyama (1927- ), a pioneer amateur astrophotographer who in 1973 invented the portable automatic equatorial telescope Sky Memo. (M 29146)

\section{(6275) Kiryu}

1993 VQ. Discovered 1993 Nov. 14 by T. Kobayashi at Oizumi.

The city of Kiryu, in the eastern part of Gunma \{see planet (3829)\} prefecture, is famous for its textile industry and baseball. The Kiryu-Daiichi junior high school won the eighty-first National High School baseball tournament. (M 36945)

\section{(6276) Kurohone}

1994 AB. Discovered 1994 Jan. 1 by T. Kobayashi at Oizumi.

Kurohone is a small village, with population less than 3000 , in the eastern part of Gunma s see planet (3829)\} prefecture. It is known for its beautiful parks, clear streams and dark skies. (M 36945)

\section{(6278) Ametkhan}

1971 TF. Discovered 1971 Oct. 10 by B. A. Burnasheva at Nauchnyj.

The Crimea's famous inhabitant Sultan Amet-khan (1920-1971) was an honored test pilot of the former U.S.S.R. He perished in an air disaster while testing a new airplane. (M 44593)

\section{(6280) Sicardy}

1980 RJ. Discovered 1980 Sept. 2 by E. Bowell at Anderson Mesa.

Named in honor of Bruno Sicardy (1958- ), professor of astronomy at Paris VI University. Sicardy's research concerns solar-system dynamics. Using both theoretical and numerical approaches, he has studied the confining mechanism of shepherd satellites on planetary rings and arcs. He has also taken part in the observation of the giant planets using various techniques to search for new satellites, analyze the ring systems and determine atmopsheric temperature profiles. (M 27462) Citation provided by M. A. Barucci. 


\section{(6281) Strnad}

1980 SD. Discovered 1980 Sept. 16 by A. Mrkos at Kleť.

Antonín Strnad (1747-1799) was the third director of the Klementinum observatory in Prague. The daily meteorological measurements he began in 1775 still continue today. He rescued the Gothic Astronomical Clock on the Prague Town Hall. (M 42355)

The name was suggested by J. Tichá and M. Šolc.

\section{(6282) Edwelda}

1980 TS $_{4}$. Discovered 1980 Oct. 9 by C. S. Shoemaker at Palomar.

Named in honor of Edwin L. Aguirre and Imelda B. Joson, who have popularized astronomy in the Philippines for more than 15 years. Their 1985 book about Comet Halley, The Second Coming, is the first and only astronomical book ever written by Filipino authors. They designed two astronomical stamps issued by the Philippine Postal Service, and in 1990 the Philippine Department of Science and Technology commissioned them to construct a $0.44-\mathrm{m}$ reflector, the largest operational telescope in the country, for a public observatory in Manila. That same year, the couple obtained the approval of then-president Corazon Aquino for an executive proclamation declaring an annual National Astronomy Week. (M 25978) Citation prepared by S. J. O'Meara and D. H. Levy.

\section{(6284) Borisivanov}

$1981 \mathrm{EM}_{19}$. Discovered 1981 Mar. 2 by S. J. Bus at Siding Spring.

Boris Ivanov (1948- ) of the Institute for Dynamics of Geospheres in Moscow has made many contributions to the geological and geophysical study of terrestrial impact craters through explosion simulations and computer modeling. He has also clarified the physical processes that determine planetary crater populations. (M 46008)

\section{(6285) Ingram}

$1981 \mathrm{EA}_{26}$. Discovered 1981 Mar. 2 by S. J. Bus at Siding Spring.

During their sixteen-year tenure as housemasters of Ashdown House, a graduate dorm at the Massachusetts Institute of Technology, Vernon (1924- ) and Elizabeth (1940- ) Ingram interacted with thousands of students. Vernon, who discovered the genetic defect for sickle cell anemia, is a professor of biology at MIT. (M 46008)

\section{(6287) Lenham}

1984 AR. Discovered 1984 Jan. 8 by E. Bowell at Anderson Mesa.

Named in memory of Alan P. Lenham (1930-1996), British research scientist at the Royal College of Science in Shrivenham and an amateur astronomer whose careful observations of the moon and planets caught the attention of Gerard Kuiper ssee planet (1776)\}, who invited him to spend some time at Yerkes Observatory. In 1958, using the 2.1-m telescope at the McDonald Observatory, Lenham made a superb drawing of a region on Mars now called Vallis Marineris. (M 30098)

Citation written and name endorsed by S. F. Dermott following a suggestion by the discoverer.

\section{(6291) Renzetti}

$1985 \mathrm{TM}_{1}$. Discovered 1985 Oct. 15 by E. Bowell at Anderson Mesa.

Named in honor of Nicholas A. Renzetti (1914- ） on the occasion of his retirement from the Jet Propulsion Laboratory after 37 years of contributions to NASA's Deep Space Network. As manager of the DSN's Science Office, Renzetti revitalized the Goldstone \{see planet (4433)\} Solar System Radar, which has been used for investigations of 34 minor planets. He also successfully advanced the use of DSN antennas for geodynamics research, radio interferometry, microwave spectroscopy and SETI. (M 30477)

Name suggested and citation prepared by S. J. Ostro.

\section{(6293) Oberpfalz}

$1987 \mathrm{WV}_{1}$. Discovered 1987 Nov. 26 by F. Börngen at Tautenburg.

Oberpfalz is a governmental district in Bavaria on the river Danube. In the Middle Ages its capital, Regensburg \{see planet (927)\}, was an arena of German history. Now the Oberpfalz extends from the Fir Mountains to the Franconian Alb, and from the Upper Palatinate forest to the northern part of the Bavarian forest. (M 25655)

\section{(6294) Czerny}

1988 CX $_{1}$. Discovered 1988 Feb. 11 by E. W. Elst at La Silla.

Named in memory of the well-known German piano teacher and composer Karl Czerny (1791-1857). His first piano lessons were from his father, his later lessons from Beethoven \{see planet (1815)\}. He became a piano teacher at 14 and was soon world famous, counting Liszt \{see planet (3910)\} and Thalberg among his pupils. Occupied with composing in the evening, he earned a living by giving piano lessons during the day. Among his enormous number of compositions the 848 etudes are in the arsenal of every pianist. (M 25655)

\section{(6295) Schmoll}

$1988 \mathrm{CF}_{3}$. Discovered 1988 Feb. 11 by E. W. Elst at La Silla.

Named for the German piano teacher Antoine Schmoll, who at the age of seven received his first piano lessons and tuition in the art of composing. He left his native country to become a piano teacher, first in Toulouse (1864), later in Brussels (1873) and Paris (1875). In 1881 he published his famous Nouvelle méthode de piano, théorique, pratique et récréative (with 16 editions in less than 14 years), in which the difficulty of the lessons increases gradually. (M 25445) 


\section{(6296) Cleveland}

1988 NC. Discovered 1988 July 12 by E. F. Helin at Palomar.

Named in honor of the city in Ohio as a tribute to its bicentennial celebration. NASA's Lewis Research Center has been in Cleveland since 1941 performing aeronautical research and contributing to the exploration of space. In the early nineteenth century, Warner and Swasey \{see planet (992)\} made numerous telescopes in Cleveland that are still in use today throughout the U.S. In addition, it was at the Case Institute in Cleveland that Michelson and Morley performed the famous experiment that disproved the existence of ether. (M 25655)

Name proposed by R. L. Bondurant, Jr.

\section{(6302) Tengukogen}

1989 CF. Discovered 1989 Feb. 2 by T. Seki at Geisei.

Tengukogen is a highland region on the western side of the Shikoku \{see planet (4223)\} mountain range. The highland is karstic and contains rocks that look like a flock of sheep. (M 43189)

\section{(6304) Josephus Flavius}

$1989 \mathrm{GT}_{3}$. Discovered 1989 Apr. 2 by E. W. Elst at La Silla.

Named for the Jewish historian Josephus Bar Mattheus, born around A.D. 37 in Jerusalem. He was a member of the Pharisees, an ancient Jewish sect noted for the strict observance of rites and ceremonies of the traditional law. In 66 he organised a revolt against the Roman occupation, but he was defeated and led before Vespasianus. Because of a correct prophesy he acquired his liberty and added the last part of his name. He left several Greek writings, such as The Jewish War and Jewish Antiquities. (M 25445)

\section{(6305) Helgoland}

$1989 \mathrm{GE}_{8}$. Discovered 1989 Apr. 6 by F. Börngen at Tautenburg.

Named for a small island in the North Sea, $45 \mathrm{~km}$ distant from the German coast, commanding the mouths of the rivers Elbe, Weser and Eider. It consists of a red-brown sandstone rock, about $60 \mathrm{~m}$ high, towering up nearly vertically from the ocean. There is a green plain upland, and the rock Long Anna is at the northern point. Helgoland has been owned successively by the dukedom of Schleswig, Denmark, Great Britain and - since 1890 - Germany. (M 25445)

\section{(6306) Nishimura}

$1989 \mathrm{UL}_{3}$. Discovered 1989 Oct. 30 by A. Sugie at Taga.

Yuji Nishimura (1946- ) is manager of one of the leading manufacturers of optical telescopes in Japan. (M 41934)

\section{(6308) Ebisuzaki}

1990 BK. Discovered 1990 Jan. 17 by Y. Kushida and O. Muramatsu at Yatsugatake.
Japanese astronomer Toshikazu Ebisuzaki (1958- ) has greatly contributed to the development of the super-highspeed specialized computer GRAPE (Gravity Pipe). Since 1999 he has been director of the advanced computing center of RIKEN, the Institute of Physical and Chemical Research. (M 43380)

\section{(6309) Elsschot}

$1990 \mathrm{EM}_{3}$. Discovered 1990 Mar. 2 by E. W. Elst at La Silla.

Named in memory of the famous Flemish writer Willem Elsschot, pseudonym of Alfons de Ridder (1882-1960). His work is very personal and deeply human. He never belonged to any literary school. In his poems and stories he shows great sincerity, sometimes evolving into bitter cynism about human mediocrity. His style is sober and shows a remarkable pureness. The cosmopolitical character of his first novel Villa des Roses was a complete change from the Flemish literature of that time, still trapped in a regional mentality. Because of his obvious atheism, he was for a long time despised by the catholic critics. (M 25445)

Citation by $K$. Leterme at the request of the discoverer.

\section{(6310) Jankonke}

1990 KK. Discovered 1990 May 21 by E. F. Helin at Palomar.

Named in honor of Janis L. Konke, space advocate and good friend of the discoverer. Born in Wisconsin and educated in Minnesota and Illinois, she has pursued a career in psychology, studying human capabilities and desires. Inspired by a friend and the starry skies of Palomar Mountain, she developed an interest in space travel and exploration, believing that humankind's greatest adventure is in the heavens. Thus began her enthusiastic support for the discoverer's Deep Solar System Survey. (M 25978)

\section{(6311) Porubčan}

$1990 \mathrm{RQ}_{2}$. Discovered 1990 Sept. 15 by H. E. Holt at Palomar.

Named in honor of Vladimír Porubčan (1940- ） of the Astronomical Institute of the Slovak Academy of Sciences, Bratislava. Porubčan has worked on obtaining and analyzing observations of meteor showers. His work on the Taurid complex, together with Ján Štohl \{see planet (3715)\}, is widely recognized. Porubčan took an active part in the organization of the international conferences Meteoroids and their Parent Bodies in Smolenice in 1992, and in particular Meteoroids in Bratislava in 1994. (M 27462)

Name suggested and citation provided by H. Rickman.

\section{(6317) Dreyfus}

$1990 \mathrm{UP}_{3}$. Discovered 1990 Oct. 16 by E. W. Elst at La Silla.

Named for the infamous Dreyfus case, which dominated French politics, reinforced religious feelings, disrupted the old party system and divided the nation 
for more than 10 years. In 1894 a French Jewish army officer, Alfred Dreyfus \{1859-1935\}, was wrongfully convicted of high treason. The famous French writer Emile Zola $\{$ see planet (8096)\} came to his defense by writing the emotional article "J'accuse" in the journal l'Aurore. In 1906 Dreyfus was rehabilitated and decorated with the légion d'honneur. (M 25446)

\section{(6318) Cronkite}

1990 WA. Discovered 1990 Nov. 18 by E. F. Helin at Palomar.

Named in honor of Walter Cronkite (1916- ), whose integrity and unflappable character during his 60 -year career in radio and television journalism have won him the acclaim and trust of his colleagues and the American people alike. Cronkite worked for the United Press during World War II, taking part in the Normandy beachhead assults and flying in B-17 raids. In 1950, he joined CBS News, becoming anchor of the then-15-minute-long 'CBS Evening News' in 1962. The following year this became U.S. network television's first half-hour weeknight news broadcast, marking the debut of the new format with Cronkite's interview of President Kennedy. Since retiring as news anchor in the early 1980s, Cronkite has produced and narrated dozens of award-winning programs. (M 28090)

\section{(6319) Beregovoj}

$1990 \mathrm{WJ}_{3}$. Discovered 1990 Nov. 19 by E. W. Elst at La Silla.

Named in memory of the Russian cosmonaut Georgij Beregovoj (1921-1995). In October 1968 he orbited the earth 64 times in a Soyuz 3 spacecraft and was safely recovered on land at Karaganda. He also performed space maneuvers near an unmanned Soyuz 2 spacecraft. Author of more than 300 scientific articles, he always put an emphasis on the importance of the role of the human factor in cosmic flights. Beregovoj was a member of the organizing committee for the 1995 international meeting "ecological consequences of the collision of the earth with small bodies of the solar system". His efforts led to the acquisition from the Russian government of a military airplane for use in the 37th expedition to Vanavara-Tunguska, and he hoped to participate in this exploration of the site of the 1908 impact. Sadly, he died unexepectedly during medical treatment shortly beforehand. (M 25655)

\section{(6320) Bremen}

$1991 \mathrm{AL}_{3}$. Discovered 1991 Jan. 15 by F. Börngen at Tautenburg.

Named for the important commercial seaport on the Lower Weser, seat of the shipping company Norddeutscher Lloyd and of a navigation school. In 787, Bremen became an episcopate. At the end of the Middle Ages, it was one of the most important Hanse cities. Olbers \{see planet (1002)\} discovered the minor planets (2) Pallas and (4) Vesta from Bremen, and Harding \{see planet (2003)\} discovered (3) Juno from nearby Lilienthal. In 1920 the Olbers Gesellschaft was founded in Bremen to encourage enthusiastic amateur astronomers. (M 25446)

\section{(6321) Namuratakao}

1991 BV. Discovered 1991 Jan. 19 by A. Sugie at Taga.

Takao Namura (1937- ) is a well-known telescopemirror maker who has ground more than a thousand telescope mirrors. He has made mirrors for the National Astronomical Observatory and many public observatories. (M 41934)

\section{(6323) Karoji}

$1991 \mathrm{CY}_{1}$. Discovered 1991 Feb. 14 by K. Endate and K. Watanabe at Kitami.

Named in honor of Hiroshi Karoji (1946- ), a professor at the Japanese National Astronomical Observatory and one of the leading astronomers in the team to construct the 8-meter Subaru telescope at Mauna Kea. He spent more than ten years at the Institut d'Astrophysique in Paris before joining the Subaru team. His main interests are the redshift distribution of galaxies and activity in infrared galaxies. (M 29146)

\section{(6326) Idamiyoshi}

$1991 \mathrm{FJ}_{1}$. Discovered 1991 Mar. 18 by A. Sugie at Taga.

Miyoshi Ida (1953- ) is a schoolteacher and active observer of occultations. He made the first observation from Japan of an occultation by a minor planet, that of a star by (106) Dione on 1983 Feb. 26. (M 41935)

\section{(6329) Hikonejyo}

$1992 \mathrm{EU}_{1}$. Discovered 1992 Mar. 12 by A. Sugie at Taga.

The castle in Hikone city, Shiga prefecture, was built by the Ii family, which exercised feudal control over the Hikone area. Hikone Castle is widely praised as one of the finest castles in Japan. (M 42668)

\section{(6330) Koen}

1992 FN. Discovered 1992 Mar. 23 by K. Endate and K. Watanabe at Kitami.

Named in honor of Koen Yanagiya (1954- ), a professional comic story teller, 'rakugoka' in Japanese. His style is different from that of other 'rakugokas', as he is very interested in astronomy, and his topics include astronomical events. He often appears at star parties to entertain the participants. (M 29146)

\section{(6332) Vorarlberg}

$1992 \mathrm{FP}_{3}$. Discovered 1992 Mar. 30 by F. Börngen at Tautenburg.

Named for the westernmost Austrian province, until 1918 part of the state of Tirol \{see planet (6439)\}. Its capital is Bregenz (Brigantium), on Lake Constance. Vorarlberg is a mountainous region and an important center for cattle-breeding and dairy-farming. (M 25978) 


\section{(6333) Helenejacq}

1992 LG. Discovered 1992 June 3 by G. J. Leonard at Palomar.

Named in honor of the discoverer's mother Helene Jacquelin, whose love and inspiration have enabled her son to discover new worlds both without and within. (M 25978)

\section{(6334) Robleonard}

1992 MM. Discovered 1992 June 27 by G. J. Leonard at Palomar.

Named in honor of the discoverer's father Robert David Leonard Sr., who has been a ceaseless source of support, inspiration and laughter. (M 25978)

\section{(6336) Dodo}

1992 UU. Discovered 1992 Oct. 21 by S. Otomo at Kiyosato.

Named for a large, flightless bird first discovered in 1507 on the island of Mauritius and extinct since the seventeenth century. (M 35484)

\section{(6337) Shiota}

$1992 \mathrm{UC}_{4}$. Discovered 1992 Oct. 26 by K. Endate and K. Watanabe at Kitami.

Named in honor of Kazuo Shiota (1949- ), a Japanese amateur astronomer who developed imageprocessing technology for astronomical photographs. $\mathrm{He}$ is also interested in total solar eclipses and developed a special filter for use in observing these eclipses. (M 29146)

\section{(6338) Isaosato}

$1992 \mathrm{UO}_{4}$. Discovered 1992 Oct. 26 by K. Endate and K. Watanabe at Kitami.

Named in honor of Isao Sato (1963- ), Japanese expert on occultations. He succeeded in making the first photographic observation in Japan of an occultation by a minor planet, that of $\gamma$ Geminorum by (381) Myrrha on 1991 Jan. 13. He promotes observations of occultations by minor planets in Japan generally and made the first use of a color video to obtain flash spectra at the northern and southern limits of total solar eclipses. (M 27462; M 27477)

\section{(6339) Giliberti}

1993 SG. Discovered 1993 Sept. 20 by V. S. Casulli at Colleverde di Guidonia.

Named in honor of Giuseppina Giliberti (1947- ), wife of the discoverer. (M 25655)

\section{(6340) Kathmandu}

$1993 \mathrm{TF}_{2}$. Discovered 1993 Oct. 15 by K. Endate and K. Watanabe at Kitami.

Named for the capital city of Nepal, a favorite destination for trekkers and climbers in the Himalayas. (M 27462)

Name proposed by I. Sato.

\section{(6345) Hideo}

1994 AX $_{1}$. Discovered 1994 Jan. 5 by K. Endate and K. Watanabe at Kitami.

Named in honor of Hideo Fukushima (1953- ), a staff member in the public information office of the Japanese National Astronomical Observatory. Long active as an amateur astronomer, he has experimented extensively with CCD techniques and has published a book on the subject. (M 29146)

\section{(6346) Syukumeguri}

1995 AY. Discovered 1995 Jan. 6 by T. Kobayashi at Oizumi.

Syukumeguri is a district in the southern part of the village of Kurohone, Gunma \{see planet (3829)\} prefecture. The discoverer is constructing there a new search system for comets and minor planets. (M 36945)

\section{(6349) Acapulco}

$1995 \mathrm{CN}_{1}$. Discovered 1995 Feb. 8 by M. Koishikawa at Sendai.

Named for the city in Mexico, Acapulco is the international sister city of Sendai \{see planet (3133)\}, Japan, affiliated since 1973. Acapulco is a famous resort and well known as one of the three most beautiful ports in the world. Hasekura Tsunenaga, the retainer of the famous Japanese feudal lord Date Masamune, made a stop there after he crossed the Pacific Ocean on his way to Rome. (M 33787)

\section{(6350) Schlüter}

3526 P-L. Discovered 1960 Oct. 17 by C. J. van Houten and I. van Houten-Groeneveld at Palomar.

Named for Andreas Schlüter (c. 1660-1714), German sculptor and architect. Most of his work is found in Berlin, and his style was north-German baroque. His masterpieces include the sarcophagus of Queen Sophie Charlotte and King Friedrich I, as well as the equestrian statue of Friedrich Wilhelm, the Great Elector. He also designed the Berlin Castle, which was damaged during World War II and subsequently demolished. (M 26765)

\section{(6351) Neumann}

4277 T-1. Discovered 1971 Mar. 26 by C. J. van Houten and I. van Houten-Groeneveld at Palomar.

Named for Johann Balthasar Neumann (1687-1753), one of the famous German baroque architects. He worked for the princes of Schönborn, who were the bishops of Würzburg, Bamberg \{see planet (324)\}, Mainz, Speyer and also of Trier. He developed the Würzburg Castle, in which he combined elements of Italian and French style with south-German late baroque. He also designed the Bruchsal \{see planet (455)\} Castle, destroyed during World War II but later reconstructed in its original glory. He also built churches in Vierzehnheiligen, Neresheim and Gössweinstein. (M 26765) 


\section{(6352) Schlaun}

2400 T-3. Discovered 1977 Oct. 16 by C. J. van Houten and I. van Houten-Groeneveld at Palomar.

Named for Johann Conrad Schlaun (1694-1773), baroque architect who worked mostly for the princebishop Klemens August of Köln. Schlaun travelled through Europe to see for himself the main buildings of his time. So he saw Neumann \{see planet (6351)\} in Würzburg. Schlaun constructed the Augustusburg Castle in Brühl and several other churches and castles in the style of Westphalian baroque. (M 26765)

\section{(6353) Semper}

3107 T-3. Discovered 1977 Oct. 16 by C. J. van Houten and I. van Houten-Groeneveld at Palomar.

Named for the German architect Gottfried Semper (1803-1873). On the recommendation of Schinkel \{see planet (5297)\} he became a professor at Dresden Academy. He built the Dresden \{see planet (3053)\} museum and synagogue, as well as the most famous "Semper Operahouse", destroyed during World War II but rebuilt. Semper also worked in Zürich and Wien, where many buildings designed by him - including the Zürich Observatory - are still in use. (M 26766)

\section{(6354) Vangelis}

1934 GA. Discovered 1934 Apr. 3 by E. Delporte at Uccle.

Named in honor of the Greek composer and multiinstrumentalist Vangelis Papathanassiou (1943- ). Vangelis began to compose and play the piano at age four. At six, without any formal training, he gave the first public performance of this own compositions, and soon developed the unique, spontaneous sound for which he has become world renowned. In addition to numerous studio albums and scores for theater and ballet, Vangelis has also composed numerous film soundtracks, including 1492-Conquest of Paradise (1993), The Bounty (1984), Bladerunner (1983) and Chariots of Fire (1981), the last of which won him an Oscar for Best Original Score. (M 25978; M 34089; M 42649)

Name proposed by G. V. Williams, who made the identification involving this object.

\section{(6356) Tairov}

1976 QR. Discovered 1976 Aug. 26 by N. S. Chernykh at Nauchnyj.

Named in honor of Vasilij Egorovich Tairov (18591938), Russian viticulturist and oenologist, author of a famous catalogue of wines (including counterfeits). He was founder and head of the first Russian research institute on viticulture, near Odessa (now the Ukrainian Tairov Research Institute of Viticulture). (M 34623)

\section{(6357) Glushko}

1976 SK$_{3}$. Discovered 1976 Sept. 24 by N. S. Chernykh at Nauchnyj.

Named in memory of Valentin Petrovich Glushko (1908-1989), Soviet pioneer in liquid-fuel rocket-engine construction. The engines of many Soviet space rockets were designed under his leadership. (M 34623)

\section{(6358) Chertok}

1977 AL $_{1}$. Discovered 1977 Jan. 13 by N. S. Chernykh at Nauchnyj.

Named in honor of Boris Evseevich Chertok (1912-

), an authority on automation and control systems for space vehicles who has written several books on the history of Soviet rocketry and cosmonautics. (M 34623)

\section{(6359) Dubinin}

1977 AZ $_{1}$. Discovered 1977 Jan. 13 by N. S. Chernykh at Nauchnyj.

Named in honor of Yurij Vladimirovich Dubinin (1930- ), Russian diplomat, scientist, author and translator of several books from the French. (M 34342)

\section{(6362) Tunis}

1979 KO. Discovered 1979 May 19 by R. M. West at La Silla.

Located on the southern Mediterranean coast, Tunis (Tunisia) has always been a meeting place between peoples, cultures and religions. Thanks to its position between Orient and Occident, Europe and Africa, the heir of Carthage has been the cradle of civilisations during millennia. (M 42668)

\section{(6363) Doggett}

$1981 \mathrm{CB}_{1}$. Discovered 1981 Feb. 6 by E. Bowell at Anderson Mesa.

Named in memory of LeRoy E. Doggett (1941-1996), a staff astronomer at the U.S. Naval Observatory known for his application of Chebyshev polynomials to celestial mechanics and positional astronomy. An expert in calendars, astronomical phenomena, the history of astronomy, and planetary theory, he was chief of the U.S. Nautical Almanac Office, associate editor of Archaeoastronomy, organizer of the nationwide "Moon Watch" program to determine earliest visibility of the lunar crescent, and secretary-treasurer of the Historical Astronomy Division of the American Astronomical Society. (M 27330)

Name proposed by the discoverer upon a suggestion by A. K. B. Monet. Citation by G. Kaplan, endorsed by D. DeVorkin and B. G. Marsden.

Obituaries published in Bull. Am. Astron. Soc., Vol. 28, No. 4, p. 1450-1451 (1996); Phys. Today, Vol. 49, No. 9, p. 110-111 (1996).

\section{(6365) Nickschneider}

$1981 \mathrm{ES}_{29}$. Discovered 1981 Mar. 1 by S. J. Bus at Siding Spring.

Nick Schneider (1956- ） is an expert on Io's extended atmosphere and plasma torus. He has pioneered the use of mutual occultation events to study Io's corona, discovered evidence for sodium-bearing molecules in the jovian magnetosphere, and was co-discoverer of Ionian chlorine. (M 46008) 


\section{(6366) Rainerwieler}

$1981 \mathrm{UM}_{22}$. Discovered 1981 Oct. 24 by S. J. Bus at Palomar.

Rainer Wieler (1949- ), professor at the Institute of Isotope Geology and Mineral Resources at ETH Zürich, has used analyses of cosmogenic nuclides and noble gases in meteorites to understand the conditions of their early formation, as well as their subsequent exposure and ejection histories. (M 46008)

\section{(6370) Malpais}

1984 EY. Discovered 1984 Mar. 9 by B. A. Skiff at Anderson Mesa.

Spanish for "bad country," early explorers of the American Southwest described as Malpais a countryside strewn with rough lava flows or rocks that was difficult to traverse. (M 41935)

The name was suggested by Van Francis Campbell, winner of a contest to name this minor planet in conjunction with the 1999 Flagstaff Festival of Science.

\section{(6371) Heinlein}

1985 GS. Discovered 1985 Apr. 15 by E. Bowell at Anderson Mesa.

Named in honor of Dieter Heinlein (1956- ). A resident of Augsburg, Germany, Heinlein in 1989 took over direction of the western part of the European All Sky Meteor Camera Network, in collaboration with the Czech network. Since then, he has increased the network's scope to include observing stations all over Germany, Austria and the Benelux countries. Heinlein is an enthusiastic meteorite and tektite collector, and he and his wife Gabriele are friends of the discoverer. (M 27462; M 32127)

Name suggested by H. Fechtig, citation provided by K. Hopf.

\section{(6372) Walker}

$1985 \mathrm{JW}_{1}$. Discovered 1985 May 13 by C. S. Shoemaker and E. M. Shoemaker at Palomar.

Named in honor of Robert M. Walker (1929- ), a leading figure in the study of radiation damage in solids and in the investigation of interstellar grains recovered from meteorites. His work on fission tracks with others opened a new approach to the dating of rocks on the earth and the moon and led to new information on the energy spectrum, composition and flux of solar and galactic cosmic rays. He founded whole new methods of scientific study and created a premier center for research in these new fields at Washington University, where he has provided inspiring leadership to a host of students and post-doctoral fellows. (M 34623)

\section{(6373) Stern}

1986 EZ. Discovered 1986 Mar. 5 by E. Bowell at Anderson Mesa.

Named in honor of S. Alan Stern (1957- ) of the Boulder, Colorado, office of Southwest Research Institute. Stern's research has focused on both observational and theoretical studies of the satellites of the outer planets, Pluto, comets, the Oort Cloud and the Kuiper Belt \{see, respectively, planets (1691) and (1776)\}. He is also active in instrument development, with a strong concentration in ultraviolet and imaging technologies. He has participated in ten planetary sounding-rocket missions, two Space Shuttle mid-deck experiments and a Shuttle-deployable satellite. He was chair of NASA's Outer Planets Science Working Group during 1991-1994. (M 27462)

Citation provided by H. Levison and J. Parker.

\section{(6375) Fredharris}

1986 TB $_{5}$. Discovered 1986 Oct. 1 by the CERGA at Caussols

Named in honor of Frederick Harlan Harris, CCD guru. Harris worked at Caltech for the Palomar Observatory for many years before moving to the U.S. Naval Observatory, where he is involved in the Sloan Digital Sky Survey. Harris is a good friend of Caussols astronomer Alain Maury \{see planet (3780)\}, and his patient help has been essential in the development of the CCD cameras for the Schmidt telescope with which this minor planet was discovered. (M 25979) Citation endorsed by M. Carr.

\section{(6376) Schamp}

$1987 \mathrm{KD}_{1}$. Discovered 1987 May 29 by C. S. Shoemaker and E. M. Shoemaker at Palomar.

Named in honor of Americans Larry and Becky Schamp of Alice Springs. Larry, an electrical engineer by training, is currently the manager of a TRW high-tech aerospace group located in this remote outpost of Northern Territory. Becky is renowned for her outback hospitality. This couple took in members of the Shoemaker family on their arrival from the United States after the car collision in which Eugene \{see planet (2074)\} died, and then they hosted Carolyn \{see planet (4446)\} when she left the hospital. Larry's 6 feet, 8 inches of gentleness and know-how and Becky's warmth, understanding and enthusiasm for life helped to sustain this family in a time of great need. (M 31610)

\section{(6377) Cagney}

$1987 \mathrm{ML}_{1}$. Discovered 1987 June 25 by A. Mrkos at Klě́.

Named in memory of the movie actor James Cagney (1899-1986). Although he played tough-guy roles in numerous gangster movies, Cagney was also a talented singer and dancer, and in 1942 he won an Academy Award for his portrayal of showman George M. Cohan in Yankee Doodle Dandy. (M 30098)

Name suggested by G. V. Williams, who made the identifications for this minor planet.

\section{(6379) Vrba}

1987 VA $_{1}$. Discovered 1987 Nov. 15 by A. Mrkos at Klě́.

Karel Vrba (1845-1922) was professor of mineralogy at Charles University in Prague and founder of the 
mineralogical collections in the National Museum of Prague, including meteorites. (M 41028)

The name was suggested by J. Tichá and M. Šolc.

\section{(6383) Tokushima}

$1988 \mathrm{XU}_{1}$. Discovered 1988 Dec. 12 by M. Iwamoto and T. Furuta at Tokushima.

Named for the first discoverer's observatory and the prefecture in which he lives. (M 33385)

\section{(6384) Kervin}

1989 AM. Discovered 1989 Jan. 3 by E. F. Helin at Palomar.

Named in honor of Paul W. Kervin, chief scientist for the Phillips Laboratory's Air Force Maui Optical Station (AMOS). He has played a leading role in establishing and conducting the JPL/AMOS program, which is primarily focused on obtaining crucial followup observations of near-earth and other interesting minor planets. Before coming to AMOS, he was the chief scientist for the Relay Mirror Experiment, which received the SPIE Technology Achievement Award in 1991. (M 26931)

\section{(6385) Martindavid}

$1989 \mathrm{EC}_{2}$. Discovered 1989 Mar. 5 by A. Mrkos at Klě́.

Martin Alois David (1757-1836), the fourth director of the Klementinum observatory in Prague, organized extensive longitude and latitude measurements in Bohemia. (M 42355)

The name was suggested by J. Tichá and M. Šolc.

\section{(6389) Ogawa}

1990 BX. Discovered 1990 Jan. 21 by K. Endate and K. Watanabe at Kitami.

Named in honor of Shigeo Ogawa (1932- ), president of Seibundo Shinkosha Company, which publishes the monthly astronomical magazine Tenmon Guide, and many astronomical books. (M 29146)

\section{(6390) Hirabayashi}

1990 BG $_{1}$. Discovered 1990 Jan. 26 by K. Endate and K. Watanabe at Kitami.

Named in honor of Shigeto Hirabayashi (1953-

), amateur astronomer known for his expertise in astronomical photography. His method for increasing the sensitivity of photographic films has been used by many amateurs. (M 29147)

\section{(6391) Africano}

$1990 \mathrm{BN}_{2}$. Discovered 1990 Jan. 21 by E. F. Helin at Palomar.

Named in honor of John L. Africano, astronomer with the Air Force Maui Optical Station (AMOS), who has played a central role in the JPL/AMOS program on minor planets. Previously he was involved with numerous photometric projects, ranging from analyses of cool stars to the timing of occultations, as a staff observer at Kitt Peak National Observatory, and before that at the Cloudcroft Observatory. (M 26931)

\section{(6392) Takashimizuno}

1990 HR. Discovered 1990 Apr. 29 by Y. Mizuno and T. Furuta at Kani.

Takashi Mizuno (1955- ) is an architect and amateur astronomer who observes from Tajimi city, Gifu prefecture, and discovered some minor planets. (M 42668)

\section{(6395) Hilliard}

$1990 \mathrm{UE}_{1}$. Discovered 1990 Oct. 21 by Y. Kushida and O. Muramatsu at Yatsugatake.

Named in honor of Elizabeth (1904- ) and Leslie Hilliard (1905- ), who acquired the house in Bath, England, from the garden of which Herschel \{see planet (2000)\} discovered Uranus. The Hilliards restored the historic building and gave it to the William Herschel Society. For many years they worked tirelessly for the society following the opening of the Herschel Museum in the house on 1981 Mar. 13, the 200th anniversary of the discovery of the planet. The eighteenth-century house was thus saved from the threat of "development" and continues to please visitors from all over the world. The Hilliards also purchased the Lansdown Tower, which had been built in Bath in 1827 by William Beckford, a famous writer and art connoisseur. (M 25655)

Named by the discoverers following a suggestion by S. Kimura.

\section{(6396) Schleswig}

$1991 \mathrm{AO}_{3}$. Discovered 1991 Jan. 15 by F. Börngen at Tautenburg.

Schleswig, formerly an independent dukedom, is the most northern territory of Germany, situated between the North Sea and the Baltic Sea. Since 1386 it has been united with Holstein \{see planet (6402)\}, a duchy that borders it to the south. Prominent towns are Flensburg, the "Gate to the North", and Schleswig, site of Gottorp castle and Petri cathedral. The poet Theodor Storm was born in North Frisia, a part of Schleswig. (M 25655)

\section{(6398) Timhunter}

1991 CD $_{1}$. Discovered 1991 Feb. 10 by C. S. Shoemaker and E. M. Shoemaker and D. H. Levy at Palomar.

Named in honor of Tim Hunter, president of the International Dark Sky Association. A radiologist by profession, Hunter has followed the increasing effects of light pollution over the earth's night sky. By founding with David Crawford an association that is devoted to raising public awareness about the need for safe and sensible lighting, Hunter has performed an invaluable service to astronomy. (M 27330)

\section{(6399) Harada}

1991 GA. Discovered 1991 Apr. 3 by T. Seki at Geisei. 
Named in honor of Shoji Harada (1953- ), amateur photographer and student of the orbits of comets and minor planets. (M 30798)

\section{(6400) Georgealexander}

1991 GQ1. Discovered 1991 Apr. 10 by E. F. Helin at Palomar.

Named in honor of George Alexander, soon to retire from the Jet Propulsion Laboratory as public-affairs manager. He has spent almost 40 years communicating science and space exploration to the public. After seven years as a reporter for Aviation Week magazine, he went to Newsweek in 1967, writing all the cover stories about the Apollo moon program. Alexander left Newsweek to become science writer for The Los Angeles Times, and he won several major awards for excellence in science writing. He became very well acquainted with JPL through his coverage of the Viking, Voyager and other missions, and he joined the staff in 1988. He was president of both the National Association of Science Writers and the Council for the Advancement of Science Writing in the 1970s and 1980s. (M 35484)

\section{(6401) Roentgen}

1991 GB$_{2}$. Discovered 1991 Apr. 15 by C. S. Shoemaker and E. M. Shoemaker and D. H. Levy at Palomar.

Named to commemorate the centennial of the discovery of x-rays by the German physicist Wilhelm Conrad Roentgen \{1845-1923\} in November 1895. His first x-ray of a human being was of his wife's hand. Roentgen's research revolutionized medicine by providing a diagnostic tool still unrivaled in accuracy and simplicity. X-rays quickly became an indispensable part of patient care. Early in 1896 x-ray therapy came into being and has remained a standard treatment for cancer. This research has spread into many fields, especially astronomy, where x-rays provide a unique window on the universe. (M 27330)

Citation prepared by D. Patton, T. Hunter and D. Levy.

Roentgen was the first physicist who received the Nobel Prize in physics in 1901.

\section{(6402) Holstein}

1991 GQ10. Discovered 1991 Apr. 9 by F. Börngen at Tautenburg.

Holstein, the southern part of the German state Schleswig-Holstein \{see also planet (6396)\}, developed from a county to a dukedom. Well known towns are Kiel, the capital, and Lübeck, one of the leading and most prosperous Hansa cities, with its old city hall, Marien church, Holsten gate and ancient salt lofts. In the church of Mölln is the sepulchre of the famous buffoon and jeerer, Till Eulenspiegel \{see also planet (1547)\}. Holstein is the birthplace of the composer Carl Maria von Weber \{see planet (4152)\}, the dramatist Friedrich Hebbel, the writers Heinrich and Thomas
Mann \{see planet (4152)\} and the physicist Max Planck \{see planet (1069)\}. (M 25655)

\section{(6403) Steverin}

1991 NU. Discovered 1991 July 8 by E. F. Helin at Palomar.

Named for Steven Newburn and Erin Fischer on the occasion of their marriage. Steven is the son of Ray Newburn \{see planet (2955)\}, science coordinator for near-earth objects at the Jet Propulsion Laboratory and former co-leader of the International Halley Watch. Both young people greatly enjoyed their college astronomy courses, although neither plans a career in science. (M 27330)

\section{(6404) Vanavara}

$1991 \mathrm{PS}_{6}$. Discovered 1991 Aug. 6 by E. W. Elst at La Silla.

Named for the town near the Podkammenaya (stony) Tunguska river in Siberia \{see planet (5471)\}. On 1908 June 30 a large bolide, probably an asteroid fragment, exploded in the atmosphere, almost $70 \mathrm{~km}$ north of Vanavara. Almost 2000 square kilometers of the taiga forest were suddenly flattened. Tungus reindeer herders, living in the forests, were thrown to the ground, and many of them lost their herds and tepees. Several houses in Vanavara were damaged. On the occasion of the 37th expedition to Tunguska, the discoverer was very warmly received by the people of Vanavara. (M 25979)

\section{(6405) Komiyama}

1992 HJ. Discovered 1992 Apr. 30 by Y. Kushida and O. Muramatsu at Yatsugatake.

Fukuji Komiyama (1924- ） is a Japanese agriculture and forestry technician. His long-time support has contributed greatly to the Yatsugatake South Base Observatory and its work. (M 45746)

\section{(6408) Saijo}

1992 UT $_{5}$. Discovered 1992 Oct. 28 by K. Endate and K. Watanabe at Kitami.

Named in honor of Yoshihiro Saijo (1959- ), amateur astronomer and editor of a monthly magazine, known for his work in astrophotography. (M 29147)

\section{(6410) Fujiwara}

$1992 \mathrm{WO}_{4}$. Discovered 1992 Nov. 29 by S. Otomo at Kiyosato.

Named in memory of Masahito Fujiwara (1960-1997), Japanese amateur astronomer who contributed to the popularization of astronomy. (M 35484)

Name proposed by the discoverers following a suggestion by A. Hagino.

\section{(6411) Tamaga}

1993 TA. Discovered 1993 Oct. 8 by R. H. McNaught at Siding Spring.

Named for The Astronomer, a British magazine in which active amateur astronomers publish and discuss 
their observations. Founded in 1964 by James Muirden as The Casual Astronomer, the magazine has developed over the years to include rapid discovery announcements and many other initiatives by the current editor, Guy Hurst \{see planet (3697)\}. The search programs for novae and supernovae and the observational programs for cataclysmic variables initiated through the magazine have been most successful. The subscribers include many of the most active and talented amateurs in the U.K. and overseas. The discoverer's own interest in observational astronomy was spurred by TA. (M 29671)

\section{(6412) Kaifu}

$1993 \mathrm{TL}_{2}$. Discovered 1993 Oct. 15 by K. Endate and K. Watanabe at Kitami.

Named in honor of Norio Kaifu (1943- ), recently appointed the first director of the 8.2-m Subaru Telescope in Hawaii, following his direction of the construction of that telescope during the past six years. $\mathrm{He}$ also played an important role in the construction of the 45-m millimeter-wave radio telescope at the Nobeyama Radio Observatory, in particular, by his development of the acousto-optical radio spectrometer, a powerful instrument for very high resolution able to identify many interstellar molecular lines. Kaifu served as chairman of the Radio Astronomy Division of the National Astronomical Observatory at Mitaka during 1988-1990 and as associate director during 1992-1996. (M 30098)

\section{(6413) Iye}

$1993 \mathrm{TJ}_{3}$. Discovered 1993 Oct. 15 by K. Endate and K. Watanabe at Kitami.

Named in honor of Masanori Iye (1949- ), a professor at the National Astronomical Observatory who works mainly on structure and evolution of galaxies and executive secretary of the Japanese National Committee of Astronomy since 1994. As project scientist for Subaru, he led the engineering core team to design and manufacture the 8.2-m telescope, and he also led teams to develop a CCD camera, active and adaptive optics, as well as a faint-object spectrograph. (M 30098)

\section{(6414) Mizunuma}

1993 UX. Discovered 1993 Oct. 24 by T. Kobayashi at Oizumi.

Mizunuma, a district in the village of Kurohone \{see planet (6276)\}, in Gunma ssee planet (3829)\} prefecture, is famous for the hot spring in its railroad station. (M 36945; M 37373)

\section{(6416) Nyukasayama}

$1993 \mathrm{VY}_{3}$. Discovered 1993 Nov. 14 by M. Hirasawa and S. Suzuki at Nyukasa.

Named for a mountain in central Japan, famous for many beautiful flowers and a wonderful view. Mt. Nyukasa station, where this minor planet was discovered, is located near the top of this mountain. (M 32094)

\section{(6417) Liberati}

1993 XA. Discovered 1993 Dec. 4 by A. Vagnozzi at Stroncone.

Named in memory of Libero Liberati (1926-1962), motorcyclist who won the Absolute Italian Championship in 1955 and 1956 riding a four-cylinder Gilera. In 1957 he won the Absolute World Championship and was given the Athlete of the Year Award by the Italian Sport Press. (M 28621)

\section{(6418) Hanamigahara}

1993 XJ. Discovered 1993 Dec. 8 by T. Kobayashi at Oizumi.

Hanamigahara is beautiful forest park in the northern part of Kurohone village, Gunma prefecture \{see, respectively, planets (6276) and (3829)\}. (M 36945)

\section{(6419) Susono}

1993 XX. Discovered 1993 Dec. 7 by M. Akiyama and T. Furuta at Mishima.

Named by the first discoverer for the town in which he lives, some $100 \mathrm{~km}$ west of Tokyo. The name of this town means "foot" in English. Mt. Fuji \{see planet (1584)\} can be seen $25 \mathrm{~km}$ to the northwest and Mt. Hakone \{see planet (1098)\} $10 \mathrm{~km}$ to the east of the town. The Kise river, which reflects the beauty of the changing seasons, runs through the center. (M 27330)

\section{(6420) Riheijyaya}

$1993 \mathrm{XG}_{1}$. Discovered 1993 Dec. 14 by T. Kobayashi at Oizumi.

Riheijyaya is a beautiful forest park in the western part of Kurohone village, Gunma prefecture \{see, respectively, planets (6276) and (3829)\}. (M 36945)

\section{(6424) Ando}

$1994 \mathrm{EN}_{3}$. Discovered 1994 Mar. 14 by K. Endate and K. Watanabe at Kitami.

Named in honor of Hiroyasu Ando (1946- ), chairman of the Optical and Infrared Astronomy Division of the National Astronomical Observatory since 1994 and an authority on stellar oscillations and high-resolution spectroscopy. His theoretical work with Yoji Osaki on five-minute solar oscillations played an important role in the development of the exciting field of helioseismology. A core member of the Subaru project from its beginning, Ando now leads the group constructing the high-dispersion spectrograph. (M 30099)

\section{(6426) Vanýsek}

1995 ED. Discovered 1995 Mar. 2 by M. Tichý at Klě́.

Named in honor of Vladimír Vanýsek (1926-1997), Czech astronomer, professor emeritus of astrophysics at Charles University in Prague. His works deal with physics and chemistry of comets, interstellar matter, and also with cosmology. From 1972 to 1986 he headed the Department of Astronomy and Astrophysics of Charles University, after which he moved to Bamberg for a three-year visiting professorship at the University 
of Erlangen-Nürnberg. He was president of IAU Commission 15 during 1970-1973. During the latest passage of Halley's Comet he was a member of the International Halley Watch Steering Group and a discipline specialist for the Photometry and Polarimetry Network. (M 25979)

Name proposed by the discoverer, endorsed by J. Tichá and Z. Moravec.

Obituaries published in Earth, Moon, Planets, Vol. 76, No. 1-2, p. 1-3 (1997/98); Mitt. Astron. Ges., Nr. 81 , p. 9-12 (1998)

\section{(6428) Barlach}

3513 P-L. Discovered 1960 Oct. 17 by C. J. van Houten and I. van Houten-Groeneveld at Palomar.

Named for Ernst Barlach (1870-1938), German sculptor, graphic artist and poet. In his work he expressed human sorrow - but also the element of hope. Sometimes he could even express humor and gladness. His sculptures have mostly the form of a pyramid. During the Nazi era his work was regarded as 'entartete Kunst' and removed from museums and other public places. (M 26766)

\section{(6429) Brancusi}

4050 T-1. Discovered 1971 Mar. 26 by C. J. van Houten and I. van Houten-Groeneveld at Palomar.

Named for the Roumanian sculptor Constantin Brancusi (1876-1957). He initially worked in the style of Rodin \{see planet (6258)\} but later became increasingly abstract. Much of his work is found in Paris, where he lived after 1904. (M 26766)

\section{(6432) Temirkanov}

1975 TR $_{2}$. Discovered 1975 Oct. 3 by L. I. Chernykh at Nauchnyj.

Named in honor of Yurij Khatuevich Temirkanov (1938- ), an outstanding conductor. From 1976 to 1988 he was the conductor of the Kirov theater \{see planet (4447)\} in Leningrad, where a number of splendid operas and ballets were produced under his leadership. Since 1988 Temirkanov has been the artistic director and orchestra conductor of the St. Petersburg Philharmonic Society. He is also a conductor of the Royal Philharmonic Orchestra and a main invited conductor for the Dresden Philharmonic. (M 32345; M 32377)

Name suggested by the Union of Concert Workers of Russia and supported by the discoverer.

\section{(6433) Enya}

1978 WC. Discovered 1978 Nov. 18 by A. Mrkos at Klě́t.

Named in honor of the Irish singer and songwriter Eithne Ní Bhraonáin (1961- ), professional name Enya). (M 30099)

Name suggested by G. V. Williams, who made the identifications involving this object.
(6434) Jewitt

1981 OH. Discovered 1981 July 26 by E. Bowell at Anderson Mesa.

Named in honor of David Jewitt (1958- ) of the Institute for Astronomy, University of Hawaii. The consummate astronomer, Jewitt has been devoted to astronomy from a very early age. He has made several important contributions to planetary astronomy, starting with his discovery of the Jovian satellite Adrastea from Voyager data in 1979. He was corecoverer of comet $1 \mathrm{P} /$ Halley in 1982 . Jewitt is perhaps best known for co-discovering the first body in the Kuiper \{see planet (1776)\} Belt in 1992, thus providing that accretion occurs beyond the planetary region. Jewitt's main area of research is comets, but his wide-ranging interests have also produced work on planetary rings, minor planets, Pluto and circumstellar disks. (M 27462)

Citation provided by J. Luu.

\section{(6435) Daveross}

1984 DA. Discovered 1984 Feb. 24 by E. F. Helin and R. S. Dunbar at Palomar.

David Justin Ross (1949- ) is co-developer of the Prime Rib curve, a graphical display of energy requirements for rendezvous trajectories. A leading developer of context-based optical character recognition, he co-founded three successful companies that apply his technology. (M 38195)

The name was suggested by N. D. Hulkower.

\section{(6436) Coco}

1985 JX $_{1}$. Discovered 1985 May 13 by C. S. Shoemaker and E. M. Shoemaker at Palomar.

Named in honor of Mark and Colleen Coco and their children Kymberly, Jennifer, Lisa and Travis. An author of astronomical articles and an active observer, Mark has written about his many interests, including astrophotography, the Green Flash, and the relation between astronomy and religion. During his five years as manager of customer relations for Celestron International that began in 1988, Mark helped thousands of new telescope users find their way to enjoy the sky. The discoverers wish to honor the Coco family for their courage and love in dealing with Mark's long illness. (M 25979)

Name proposed and citation prepared by D. H. Levy.

\section{(6439) Tirol}

1988 CV. Discovered 1988 Feb. 13 by F. Börngen at Tautenburg.

Named for the Austrian province, the capital of which is Innsbruck. The North Tirolian Limestone Alps, Ötztaler, Stubaier and Zillertaler Alps are popular tourist attractions. The beauty of the region is immortalized in the song "The dear God must be a Tiroler!" (M 25979) 


\section{(6440) Ransome}

$1988 \mathrm{RA}_{2}$. Discovered 1988 Sept. 8 by A. Mrkos at Klět.

Named in memory of Arthur Ransome (1884-1967), one of the best loved of all children's writers. His novels depict the adventures of boys and girls, Swallows and Amazons, who explore the lakes and mountains of England. (M 34342)

Name suggested by J. Tichá.

\section{(6441) Milenajesenská}

$1988 \mathrm{RR}_{2}$. Discovered 1988 Sept. 9 by A. Mrkos at Klě̌t.

Named in memory of Milena Jesenská (1896-1944), outstanding Czech journalist and mediator between the Czech and German cultures in Bohemia. She was detained for her political involvement and resistance in the concentration camp at Ravensbrück, where she died. She is widely known for her correspondence with Prague writer Franz Kafka \{see planet (3412)\} (Briefe an Milena). (M 34342)

Name suggested by J. Tichá.

\section{(6442) Salzburg}

$1988 \mathrm{RU}_{3}$. Discovered 1988 Sept. 8 by F. Börngen at Tautenburg.

Named for the Austrian province and its capital on the river Salzach. Visitors flock to the province's high mountains and the celebrated festivals in the capital, well-known as the birthplace of Mozart and Doppler \{see planets (1034) and (3905)\}. On 1818 December 24, the curate Joseph Mohr and his organist Franz Gruber created the well-known Christmas carol Stille Nacht, Heilige Nacht near the town of Hallein. (M 25979)

\section{(6445) Bellmore}

$1990 \mathrm{FS}_{1}$. Discovered 1990 Mar. 23 by E. F. Helin at Palomar.

Named in honor of Tamara Bell and Michael More on the occasion of their wedding. They are recent graduates of the University of Arizona with degrees in political science and geology. The discoverer and her husband wish the newlyweds a harmonious marriage and rewarding careers. (M 28090)

\section{(6446) Lomberg}

1990 QL. Discovered 1990 Aug. 18 by E. F. Helin at Palomar.

Named in honor of Jon Lomberg (1948- ), graphic arts virtuoso, who has excelled in his renditions of space and astronomical subjects. One of the world's leading astronomical artists, he worked with Carl Sagan see planet (2709)\} and on many television documentaries about space science, including the Cosmos series. He was also the design director for the Voyager Interstellar Record. His works can be found in museums and science centers all over the world. His technical research, artistic interpretation and precision in the planning of each painting is characteristic of this dedicated, accomplished artist in portraying space as it is, to the extent we know it. (M 33385)
(6447) Terrycole

$1990 \mathrm{TO}_{1}$. Discovered 1990 Oct. 14 by E. F. Helin at Palomar.

Named in honor of Terry Cole, chief technologist at the Jet Propulsion Laboratory and senior faculty associate in the Caltech Division of Chemistry and Chemical Engineering. In addition to his numerous technical contributions to JPL and Caltech, Cole played a central role in the development of the Caltech/JPL Summer Undergraduate Research Fellowship (SURF) \{see planet (5181)\} program through his vision while chairing the SURF Fellowship Executive Committee. (M 32788)

\section{(6449) Kudara}

$1991 \mathrm{CL}_{1}$. Discovered 1991 Feb. 7 by T. Seki at Geisei.

Named in memory of Kyoyu Kudara (1894-1964), Japanese astronomer and Buddhist priest. A staff member of the Tokyo Astronomical Observatory from 1917 to 1925, he recovered comet 10P/Tempel 2 in 1920 according to his own prediction, and he observed this comet again in 1925. Later he taught positional astronomy and the science of the calendar at Kyoto University. One of the cofounders of the Oriental Astronomical Association, he served as its president from 1959 to 1964. (M 32788)

Name proposed by the discoverer following a suggestion by I. Hasegawa and T. Sato. Citation by I. Hasegawa.

\section{(6451) Kärnten}

1991 GP $_{10}$. Discovered 1991 Apr. 9 by F. Börngen at Tautenburg.

Named for the southernmost Austrian province. The capital Klagenfurt is situated on a plain beside the Wörther Lake. The name is derived from the Celtish people of the Karner. The region was part of the Roman province of Noricum. (M 25979)

\section{(6452) Johneuller}

1991 HA. Discovered 1991 Apr. 17 by T. J. Balonek at Hamilton.

Named in honor of John E. Euller, a dedicated and highly respected teacher of high-school physics. Educated at Pennsylvania State University and the University of Buffalo, he taught physics and chemistry over a 33-year career. From 1959 to 1984 he taught physics at Eastridge High School in Irondequoit, NY, where his animated demonstrations inspired generations of students. He has had life-long interests in science and travel. (M 27129; M 27147)

\section{(6456) Golombek}

1992 OM. Discovered 1992 July 27 by E. F. Helin and K. J. Lawrence at Palomar.

Named in honor of Matthew P. Golombek, research scientist in geology and planetary geology at the Jet Propulsion Laboratory. He has devoted the past five of his 14 years there to the Pathfinder project, distinguishing himself by his highly effective performance as the Mars Pathfinder project scientist, 
responsible for all aspects of the mission's science. The discoverers wish to salute this popular spokesman for his understandable science and Pathfinder mission status reports. His descriptions and explanations captured the attention of a public excited by the Mars landing and the rocky excursions of the small rover, Sojourner. (M 31024)

\section{(6457) Kremsmünster}

1992 RT. Discovered 1992 Sept. 2 by L. D. Schmadel and F. Börngen at Tautenburg.

Named as a celestial tribute to the famous Benedictine monastery, educational center and observatory in Austria. A place of scientific effort in many disciplines, the Kremsmünster Observatory remains one of the most outstanding cultural institutions in Austria even a quarter of a millenium after its founding. This planet is also named in memory of Abbot Augustin Reslhuber (1808-1875), an ardent observer to whom it was not granted to discover a minor planet himself. (M 31610)

Named by the first discoverer and citation prepared with the support of Father Amand Kraml.

\section{(6458) Nouda}

1992 TD $_{1}$. Discovered 1992 Oct. 2 by T. Seki at Geisei.

Named in memory of Tadasuke Nouda (1901-1989),

Japanese astronomer. A pioneer in the field of ancient Chinese astronomy, he made important contributions to the study of early luni-solar calendars. He was a professor at the Osaka University of Education and Kyoto Sangyo University. He served as president of the Japan Calendar Association (1959-1989) and of the Oriental Astronomical Association (1965-1989). (M 32788)

Name proposed by the discoverer following a suggestion by I. Hasegawa and T. Sato. Citation by I. Hasegawa.

\section{(6459) Hidesan}

1992 UY $_{5}$. Discovered 1992 Oct. 28 by K. Endate and K. Watanabe at Kitami.

Named in honor of Hideo Sato (1940- ), staff member of the National Astronomical Observatory (formerly Tokyo Astronomical Observatory) who first worked on the solar corona, later moving to the Sky Patrol Section as a night observer. His life's work is the photometry of close binaries. He is also one of the leading members of the observatory's baseball team. (M 30099)

Name proposed by the second discoverer following a suggestion by K. Tomita.

\section{(6460) Bassano}

$1992 \mathrm{UK}_{6}$. Discovered 1992 Oct. 26 by U. Quadri and

L. Strabla at Bassano Bresciano.

Named for Bassano Bresciano, an ancient village in the Italian province of Brescia. Situated on the Padana plain, in the early Middle Ages it was under Longobard and Frank dominion. Later it was ruled by Sforza and the Venice republic. In the sixteenth century the Brescian agronomists Camillo Tarello and Agostino Gallo reclaimed this marshland. The most important monuments are Luzzago's sixteenth-century palace and Brunelli's seventeenth-century villa. In the church there is a Via Crucis attributed to Tiepolo's school. (M 25655)

\section{(6463) Isoda}

1994 AG $_{3}$. Discovered 1994 Jan. 13 by K. Endate and K. Watanabe at Kitami.

Named in memory of Sachiko Isoda (1912-1993), who joined the Tokyo Astronomical Observatory in 1943 as a computing assistant. After the war she moved to the Department of Astronomy at University of Tokyo and was for many years secretary to Y. Hagihara \{see planet (1971)\}. After her formal retirement she stayed on as a part-time employee, and her fine work impressed many astronomers who graduated from the Univerity of Tokyo. (M 30099)

Name proposed by the second discoverer following a suggestion by K. Tomita.

\section{(6464) Kaburaki}

1994 CK. Discovered 1994 Feb. 1 by Y. Kushida and O. Muramatsu at Yatsugatake.

Named in memory of Masaki Kaburaki (1902-1987), a professor of astronomy at the University of Tokyo before he retired in 1963. He taught spherical and practical astronomy there, and his main interest was in kinematics of our Galaxy. He served as the president of the Japanese Astronomical Society around 1955 and was the director of Gotoh Astronomical Museum during 1974-1987. (M 29147)

\section{(6465) Zvezdotchet}

1995 EP. Discovered 1995 Mar. 3 by T. V. Kryachko at Zelenchukskaya.

Named for the Russian amateur astronomers' magazine Zvezdotchet (Stargazer) and its readers. (M 29147)

\section{(6467) Prilepina}

1979 TS $_{2}$. Discovered 1979 Oct. 14 by N. S. Chernykh at Nauchnyj.

Named in honor of Svetlana Semenovna Prilepina, a graduate of the Astronomical Department at the Ural State University in Ekaterinburg and one of the organizers of the annual Winter Astronomical School at the Kourovka \{see planet (4964)\} Observatory. She is also a gifted amateur singer. (M 30099)

\section{(6469) Armstrong}

1982 PC. Discovered 1982 Aug. 14 by A. Mrkos at Kleť.

Named in honor of Neil Alden Armstrong (1930- ), U.S. astronaut, the first man to set foot on the moon. In 1966 he and David Scott aboard Gemini 8 conducted the first docking in space. In 1969, along with Aldrin and Collins \{see planets (6470) and (6471)\}, 
he blasted off in Apollo 11 toward the moon, and on July 20 the Eagle module landed on a plain near the southwestern edge of Mare Tranquillitatis. This minor planet commemorates the 30th anniversary of the first manned lunar-landing mission. (M 34623)

Name suggested by J. Tichá, M. Tichý and Z. Moravec, who observed this minor planet at its 1995 opposition, just prior to numbering.

\section{(6470) Aldrin}

$1982 \mathrm{RO}_{1}$. Discovered 1982 Sept. 14 by A. Mrkos at Klět.

Named in honor of Edwin Eugene (Buzz) Aldrin Jr. (1930- ), U.S. astronaut, the second man to set foot on the moon. In 1966 he made a record 5.5-hour spacewalk in the course of the Gemini 12 mission. In 1969 he joined Armstrong \{see planet (6469)\} on the surface of the moon. This minor planet commemorates the thirtieth anniversary of the first manned lunar-landing mission. (M 34623)

Name suggested by J. Tichá, M. Tichý and Z. Moravec, who observed this minor planet at its 1995 opposition, just prior to numbering.

\section{(6471) Collins}

1983 EB $_{1}$. Discovered 1983 Mar. 4 by A. Mrkos at Klě́t.

Named in honor of Michael Collins (1930- ), U.S. astronaut. In 1966 he served as pilot of the Gemini 10 mission. In 1969 he was assigned to Apollo 11 as the command-module pilot. While Armstrong and Aldrin \{see planets (6469) and (6470)\} took their first walk on the lunar surface, Collins flew a lonely lifeguard assignment for more than 24 hours, waiting for them to launch their lunar craft and rejoin him in lunar orbit. This minor planet commemorates the thirtieth anniversary of the first manned lunar-landing mission. (M 34623)

Name suggested by J. Tichá, M. Tochý and Z. Moravec, who observed this minor planet at its 1995 opposition, just prior to its numbering.

\section{(6472) Rosema}

1985 TL. Discovered 1985 Oct. 15 by E. Bowell at Anderson Mesa.

Named in honor of Keith D. Rosema (1967- ), computer scientist at the Jet Propulsion Laboratory. In 1989, Rosema completed the first California Institute of Technology senior thesis in asteroid radar astronomy. Since then he has used his formidable computerprogramming expertise and analytic talents to make crucial contributions to observations of near-earth and main-belt asteroids. His library of software has proved to be an essential tool for reduction and analysis of echoes from most of the radar-detected asteroids, including (4769) Castalia, (4179) Toutatis, (1620) Geographos and (6489) Golevka. Rosema is also one of a handful of people who have devoted extensive time to asteroid radar astronomy at both Arecibo and Goldstone \{see, respectively, planets (4337) and (4433)\}. (M 25655)

Name suggested and citation prepared by S. J. Ostro.

\section{(6473) Winkler}

1986 GM. Discovered 1986 Apr. 9 by E. Bowell at Anderson Mesa.

Named in honor of Ron Winkler (1954- ), digital engineer in the radio astronomy and radar group at NASA's Goldstone \{see planet (4433)\} deep space communications complex. Since the mid-1980s, Winkler has been singularly important in Goldstone radar astronomy and especially in observations of near-earth asteroids. His understanding of the interface between data-acquisition, antenna-pointing and transmitting systems is unique. His energy, endurance and mastery of procedures for observing close asteroids, demanding frequent switching between transmit and receive configurations, was critical to the success of the radar imaging of (4179) Toutatis, (1620) Geographos and (6489) Golevka. (M 25655)

Name suggested and citation prepared by S. J. Ostro.

\section{(6474) Choate}

1987 SG $_{1}$. Discovered 1987 Sept. 21 by E. Bowell at Anderson Mesa.

Named in honor of Dennis Choate (1952- ), senior engineer at NASA's Goldstone \{see planet (4433)\} deep space communications complex. His profound understanding of the high-power planetary radar transmitter system and his awesome trouble-shooting capabilities have been a mainstay of Goldstone \{see planet (4433)\} radar astronomy during the past decade. In 1995, Choate's dedication and expertise were manifest in the flawless transmission of many continuous hours of radio signals toward (6489) Golevka during the Goldstone-Evpatoria and Goldstone-Kashima \{see planet (6489)\} intercontinental radar astronomy experiments. (M 25656)

Name suggested and citation prepared by S. J. Ostro.

\section{(6475) Refugium}

1987 SZ $_{6}$. Discovered 1987 Sept. 29 by P. Wild at Zimmerwald.

The name is Latin for a refuge, such as might come from examining the prime factors of (6475): (5) Astraea, goddess of justice; (7) Iris, the rainbow; and (37) Fides, goddess of faith and honesty. (M 34623)

\section{(6478) Gault}

$1988 \mathrm{JC}_{1}$. Discovered 1988 May 12 by C. S. Shoemaker and E. M. Shoemaker at Palomar.

Named in memory of Donald Gault (1923-1999), a giant in the field of impact cratering processes. Gault applied his understanding and insight as an experimentalist to interpreting impact data and its application to the moon, the earth, Mars and Mercury. His work is at the heart of the most basic of all processes concerned with solid bodies in the solar system. It is the "rock" upon which others tried to build. (M 35484) 


\section{(6479) Leoconnolly}

1988 LC. Discovered 1988 June 15 by E. F. Helin at Palomar.

Named in honor of Leo P. Connolly, astronomer and teacher at California State University, San Bernardino, and director (1985-1995) of the Summer Science Program, held for six weeks each summer at the Thacher School in Ojai. In this tranquil setting, and with a rigorous curriculum requiring high-school students to take photographic plates of minor planets and learn how to determine their orbits, Leo and his wife Jackie have nurtured the minds and spirits of nearly 400 bright and motivated young men and women. (M 25979)

Name proposed by the staff and students of SSP '95. Citation prepared at the request of the discoverer, who has lectured over the years to the summer science students at Thacher.

\section{(6480) Scarlatti}

$1988 \mathrm{PM}_{1}$. Discovered 1988 Aug. 12 by E. W. Elst at St. Michel.

Named in memory of the great Italian composer Domenico Scarlatti (1685-1757). He spent the first half of his life under the shadow of his father, Alessandro Scarlatti. After leaving Italy for Portugal in 1719, and particularly after his father's death in 1725 , he developed a style that made him one of the greatest keyboard composers of all time. At the Portuguese court he served as music master for the young Princess Maria Barbara. In 1729 she moved with him to Spain, where he spent the rest of his life. Most of his known 550 harpsichord sonatas were dedicated to this princess, who herself was unusually gifted musically. (M 26766)

\section{(6481) Tenzing}

$1988 \mathrm{RH}_{2}$. Discovered 1988 Sept. 9 by A. Mrkos at Klět.

Tenzing Norgay (1914-1986) was a Nepalese mountain climber of the Sherpa tribe. On 1953 May 29, as members of a British party, Tenzing Norgay and the New Zealand mountaineer Edmund Hillary \{see planet (3130)\} became the first to scale the summit of Mount Everest - and return. (M 36945)

The name was suggested by M. Tichý.

\section{(6482) Steiermark}

$1989 \mathrm{AF}_{7}$. Discovered 1989 Jan. 10 by F. Börngen at Tautenburg.

Named for the Austrian province, also known as Styria, and the capital of which is Graz ssee planet (2806)\}. The territory was colonized by the Illyrians and then by the Celts. Later it was part of the Roman provinces of Noricum and Pannonia. The writer Peter Rosegger (1843-1918) and the conductor Karl Böhm (1894-1981) were born in Styria. The white Lippizaner horses of the Spanish Court riding school in Vienna are bred in this region. (M 25979)
(6483) Nikolajvasil'ev

$1990 \mathrm{EO}_{4}$. Discovered 1990 Mar. 2 by E. W. Elst at La Silla.

Named in honor of Nikolaj Vasil'ev, scientific director of the Interdisciplinary Independent Tunguska Expeditions. A professor of medicine and a well-known oncologist at the Institute for Microbiology in Kharkov, he has for many years been interested in the history and scientific investigation of the Tunguska event \{see planet (5471)\}. In his capacity as IITE director he and other members of the group succeeded in having 4000 square kilometers of the Tunguska region set aside as a national reserve for the next 20 years. (M 26425)

\section{(6484) Barthibbs}

$1990 \mathrm{FT}_{1}$. Discovered 1990 Mar. 23 by E. F. Helin at Palomar.

Named in honor of Bart Hibbs, whom the discoverer has known since his earliest days, through his years of education and into his maturity as an expert and inventive aeronautical engineer. Bart was responsible for the aerodynamic design for the "Sunracer", which won the first race across central Australia for solar-powered cars. More recently, he designed a large, remote-controlled airplane, also solar powered, designed to stay at extremely high altitudes, night and day, for an extended period. (M 30099)

\section{(6485) Wendeesther}

1990 UR $_{1}$. Discovered 1990 Oct. 25 by C. S. Shoemaker and E. M. Shoemaker and D. H. Levy at Palomar.

Named in honor of Wendee Esther Wallach on the occasion of her engagement to David Levy \{see planet (3673)\}. For 26 years beginning in September 1970, Wendee taught physical education in three public schools of Las Cruces, New Mexico. As an instructortrainer in swimming with the American Red Cross for almost three decades, Wendee has taught water safety to students and to swimming instructors. Through her inspired teaching, leadership and example, she has touched the lives of thousands of young people. (M 27330)

\section{(6487) Tonyspear}

1991 GA $_{1}$. Discovered 1991 Apr. 8 by E. F. Helin at Palomar.

Named in honor of Anthony Spear, manager of the successful Pathfinder Project. In his 37 years at the Jet Propulsion Laboratory he has been associated with several successful space projects, usually in a management position. These include the Magellan and VOIR projects to orbit Venus, and Seasat, the first earth satellite to make images of the surface of the oceans using radar. His association with Mars exploration goes back to the beginning of the program, when he was Cognizant Engineer for the command system of Mariner 4, which in 1964 became the first spacecraft to reach Mars successfully. (M 31024) Citation prepared by A. Hibbs. 


\section{(6488) Drebach}

1991 GU $_{9}$. Discovered 1991 Apr. 10 by F. Börngen at Tautenburg.

Named for the German village in the Erzgebirge mountains, $20 \mathrm{~km}$ south of the Saxon town of Chemnitz. It is noted for its crocuses, blooming over an area of seven hectares. The Volkssternwarte Drebach, originally established as the school observatory in 1969, is widely known, especially after the completion of a planetarium and, in 1986, of a new main building. This minor planet was numbered as a result of observations made at Drebach in April-May 1995. (M 25979)

\section{(6489) Golevka}

1991 JX. Discovered 1991 May 10 by E. F. Helin at Palomar.

Named to honor the success of the multinational radar observations of this minor planet in June 1995. The 70-m Goldstone \{see planet (4433)\} antenna in California provided the transmitted signal, and echoes from the object were detected by the Russian 70-m antenna near the Crimean city of Evpatoria, and also by the Japanese 34-m antenna at Kashima. This experiment, which produced the first international radar astronomy observations and also initiated planetary radar astronomy in Japan, was done during the closest approach of this minor planet for at least the next several centuries. The discoverer has encouraged radar and remote sensing observations for many years and is pleased with the results. (M 26425; M 26439)

Name proposed by the discoverer following a suggestion by A. L. Zajtsev. Citation prepared by S. J. Ostro.

The name is composed by the leading letters of the names of the observing places: GOLdstone - EVpatoria - KAshima.

\section{(6493) Cathybennett}

1992 CA. Discovered 1992 Feb. 2 by E. F. Helin at Palomar.

Named in honor of Catherine A. Bennett, who with her vision, wisdom and actions has played a key role in the establishment of a successful NEO detection system. The discoverer and her JPL colleagues wish to pay tribute to Bennett with asteroid $1992 \mathrm{CA}$, discovered in the year of their first interaction, which led to new NEO discoveries by NEAT/GEODSS in early 1996. (M 27331)

\section{(6496) Kazuko}

$1992 \mathrm{UG}_{2}$. Discovered 1992 Oct. 19 by K. Endate and

K. Watanabe at Kitami.

Named in honor of Kazuko Otsuka (1934- ), who joined the staff of the Tokyo Astronomical Observatory in 1957 on the occasion of the International Geophysical Year. She did secretarial work relating to observations with the Markowitz Moon Camera, by the Baker-Nunn Satellite-Tracking Camera and the Moonwatch project. Later she worked for the Sky Patrol Section and the Dodaira Station, and she retired in 1995. (M 30099)
Name proposed by the second discoverer following a suggestion by K. Tomita.

\section{(6497) Yamasaki}

$1992 \mathrm{UR}_{3}$. Discovered 1992 Oct. 27 by T. Seki at Geisei.

Named in memory of Masamitsu Yamasaki (18861959), who worked at the International Latitude Observatory in Mizusawa \{see planet (7530)\}. As a codiscoverer of comet $27 \mathrm{P} /$ Crommelin (then named Pons-Coggia-Winnecke-Forbes) in 1928, he was the first Japanese to receive the Astronomical Society of the Pacific's Donohoe medal. (M 30798)

\section{(6498) Ko}

1992 UJ $_{4}$. Discovered 1992 Oct. 26 by K. Endate and K. Watanabe at Kitami.

Named in honor of Ko Nagasawa (1932- ), who retired from the University of Tokyo's Earthquake Research Institute in 1994 and now works for the Public Information Office at the National Astronomical Observatory of Japan. He has long been interested in the study of meteors, and he obtained many high-quality photographic spectra of the 1965 Leonids at the Dodaira Station. (M 30099)

Name proposed by the second discoverer following a suggestion by K. Tomita.

\section{(6499) Michiko}

$1992 \mathrm{UV}_{6}$. Discovered 1992 Oct. 27 by M. Hirasawa and S. Suzuki at Nyukasa.

Named in honor of Michiko Hirasawa (1955- ), wife of the first discoverer. She is manager of Mt. Nyukasa station, where this minor planet was discovered. (M 32094)

\section{(6500) Kodaira}

1993 ET. Discovered 1993 Mar. 15 by K. Endate and K. Watanabe at Kitami.

Named in honor of Keiichi Kodaira (1937- ), who works mainly in stellar and galactic physics and served as president of IAU Commission 36 during 1982-1985. Scientific director of the Japanese National Large Telescope (SUBARU) project from its beginning, he played an essential role on its completion. He has been director of the National Astronomical Observatory of Japan since 1994. (M 27331)

\section{(6501) Isonzo}

1993 XD. Discovered 1993 Dec. 5 at the Farra d'Isonzo Observatory at Farra d'Isonzo.

Named for the river near which the town of Farra d'Isonzo and its observatory are located. Long known as a landmark in northeastern Italy, the river has been a crossing point to eastern Europe since Roman times. (M 30099)

\section{(6504) Lehmbruck}

4630 P-L. Discovered 1960 Sept. 24 by C. J. van Houten and I. van Houten-Groeneveld at Palomar.

Named for the German sculptor Wilhelm Lehmbruck (1881-1919). After his education at the Düsseldorf 
Academy he went to Paris to study with Rodin and Maillol \{see planets (6258) and (6259)\}. All his sculptures are elongated and have thin limbs. Most of his work can be seen in the museum in Duisburg, his birthplace. (M 26766)

\section{(6508) Rolčík}

1982 QM. Discovered 1982 Aug. 22 by A. Mrkos at Klě́.

Viktor Rolčík (1884-1954) was a Czech optician and telescope maker. The $0.31-\mathrm{m}$ reflector, the main telescope of the České Budějovice \{see planet (11134)\} Observatory, was made by Rolčík in 1937. (M 41028)

The name was suggested by J. Tichá and M. Tichý.

\section{(6510) Tarry}

1987 DF. Discovered 1987 Feb. 23 by C. S. Shoemaker and E. M. Shoemaker at Palomar.

Named in honor of Americans William and Nancy Tarry, whose kindness, thoughtfulness and friendship have left a lasting impression on Carolyn Shoemaker \{see planet (4446)\} and her family and good friends. When Eugene Shoemaker \{see planet (2074)\} was killed in an outback car collision far from Alice Springs, the Tarrys unhesitatingly provided their hospitality and assistance to them for several weeks. Bill is general manager for Boeing Constructors with the Boeing Defence and Space Group in Alice Springs. (M 31610)

\section{(6511) Furmanov}

1987 QR $_{11}$. Discovered 1987 Aug. 27 by L. I. Chernykh at Nauchnyj.

Named in honor of Rudol'f Davidovich Furmanov (1938- ), artist, producer and impresario, founder and art manager of the Andrej Mironov ssee planet (3624)\} Theater "Russian enterprise" in St. Petersburg, where many of the stars of the Russian theater perform. Furmanov is originator and author of the theater programs Russian seasons, which are widely popular even outside the country. (M 34624)

\section{(6512) de Bergh}

1987 SR $_{1}$. Discovered 1987 Sept. 21 by E. Bowell at Anderson Mesa.

Named in honor of Catherine de Bergh (1945- ), planetary scientist at the Paris Observatory who has studied the composition of the giant and terrestrial planets. She found CO on Titan and HDO in the Martian atmosphere. She has described the chemistry of Venus' lower atmosphere and has also been interested in the icy surfaces of Io, Triton and Pluto. She enthusiastically works for international cooperation in studying the solar system. (M 27462) Citation provided by M. A. Barucci.

\section{(6514) Torahiko}

1987 WY. Discovered 1987 Nov. 25 by T. Seki at Geisei.

Named in memory of Torahiko Terada (1878-1935), experimental physicist, geophysicist and author. His literary works are still popular today. (M 27129)

\section{(6516) Gruss}

1988 TC $_{2}$. Discovered 1988 Oct. 3 by A. Mrkos at Klět.

Czech astronomer Gustav Gruss (1854-1922) was head of the Astronomical Institute of the Czech division of Charles University in Prague from 1891 to 1914. He studied the spectroscopy of variable stars. (M 40701)

The name was suggested by J. Tichá and M. Šolc.

\section{(6518) Vernon}

1990 FR. Discovered 1990 Mar. 23 by E. F. Helin at Palomar.

Named in honor of Robert and Esther Vernon, longtime friends and, for more than 35 years, neighbors of the discoverer and her parents, Fred and Kay Francis \{see planet (2050)\}. Their wise counsel, advice and solace over the years have been a source of comfort and renewed strength. Bob, now "retired", travels the world from Slovakia to Mongolia, sharing his wealth of experience and expertise with emerging democracies. (M 31296)

\section{(6519) Giono}

$1991 \mathrm{CX}_{2}$. Discovered 1991 Feb. 12 by E. W. Elst at St. Michel.

Named in memory of the Provençal writer Jean Giono (1895-1970). Born in Manosque, he left this small town only to make short trips around Provence and to Italy. His natural writing style makes his work easy to read, showing remarkable strength and a sense of humor. The wealth of poetic images, inspired by the splendid and at the same time rough nature of the Provence, evokes his personal ideas on the irreplacable things of life. In Refus d'obeissance (1937) rural anarchism and courageous pacifism is proclaimed, an attitude that led to difficulties with the authorities, who imprisoned him. Giono's well-known writings include the Trilogy of Pan and Que ma joie demeure. (M 25979)

Citation prepared by C. Leterme at the request of the discoverer.

\section{(6520) Sugawa}

1991 HH. Discovered 1991 Apr. 16 by S. Otomo and O. Muramatsu at Kiyosato.

Named in honor of Chikara Sugawa (1916- ), who worked for the International Latitude Observatory in Mizusawa \{see planet (7530)\} during 1943-1981. In 1984 he was nominated as the first president of the Herschel Society of Japan, and the following year he realized a Herschel concert in Tokyo and led a study tour to Europe. Since then he has done much to promote knowledge of the Herschels \{see planet (2000)\} and their contemporaries. (M 26766)

Name proposed by the discoverers following a suggestion by S. Kimura.

\section{(6521) Pina}

1991 LC $_{1}$. Discovered 1991 June 15 by E. F. Helin at Palomar. 
Named in honor of Pina Toscano Blanco, regular "accompanying person" at astronomical meetings during the last 25 years. Her continuous presence has made her a supporting member of the "wives' committees" that do so much to improve such meetings. (M 28090)

Name suggested by Pina's husband Carlo Blanco \{see planet (4478)\}, with the blessing of the discoverer.

\section{(6522) Aci}

1991 NQ. Discovered 1991 July 9 by E. F. Helin at Palomar.

Named for a river southeast of Mount Etna, and also honoring the many towns and villages along it that contain the name: Acicastello, Acitrezza, Acireale, Acibonaccorsi, Acicatena, Aci Sant'Antonio and Aci Santo Filippo. The modern-day river evokes the myth of Aci (or Acis), the young Sicilian shepherd who was in love with Galatea, a Nereid \{see planet (74)\}. The jealous cyclops Polyphemus hurled a large rock and killed Aci, whose blood was transformed into an underground river that plunged into the Ionian Sea to hug his beloved Galatea. (M 28090)

Name proposed by the discoverer, following a suggestion by Carlo Blanco.

\section{(6523) Clube}

1991 TC. Discovered 1991 Oct. 1 by R. H. McNaught at Siding Spring.

Named for the English astronomer S. Victor M. Clube (1934- ), renowned for his heterodox views on various areas of astrophysics and planetary science. Clube was a student at Oxford, where he was a cricketer of note, his bowling bamboozling various famous West Indian batsmen before the young Gary Sobers \{see planet (6581)\} hit him for six. After working for many years at the Royal Observatory, Edinburgh, Clube returned to Oxford, where he continues research on the small bodies in the solar system, their putative giant comet origin, and their influence upon the terrestrial climate and human civilizations. He also has interests in various other areas of astrophysics and general relativity. (M 29147)

Name proposed by the discoverer following a suggestion by D. I. Steel, who prepared the citation.

\section{(6524) Baalke}

1992 AO. Discovered 1992 Jan. 9 by E. F. Helin at Palomar.

Named in honor of Ron Baalke, software engineer at the Jet Propulsion Laboratory who works on telemetry systems for the Deep Space Network. Since 1989 he has been performing public outreach services on the Internet on the behalf of NASA. His numerous homepages on the World Wide Web have reached millions of people around the world and have been among the most popular home pages from NASA. These pages have been instrumental in promoting the World Wide Web as a vehicle for distributing information and images. (M 29147)
Name proposed by the discoverer following a suggestion by A. Beresford.

\section{(6525) Ocastron}

1992 SQ . Discovered 1992 Sept. 20 by J. B. Child and G. Fisch at Wrightwood.

Named in recognition and appreciation of the Orange County Astronomers, a non-profit, publicservice organization that has served the southern California area for more than 20 years. The group has conducted public star parties, telescope making classes, observing classes and public lectures. It has been, and continues to be, a valuable resource to the community and to fledgling astronomers through the efforts of its dedicated members. (M 27331)

\section{(6526) Matogawa}

1992 TY. Discovered 1992 Oct. 1 by K. Endate and K. Watanabe at Kitami.

Named in honor of Yasunori Matogawa (1942- ), a specialist in rocket trajectory engineering, and now the chief of the External Cooperation Office at the Institute of Space and Astronautical Science in Tokyo, working to inform the public about space technology. (M 30099)

Name proposed by the second discoverer following a suggestion by K. Tomita.

\section{(6528) Boden}

$1993 \mathrm{FL}_{24}$. Discovered 1993 Mar. 21 by the Uppsala-ESO Survey at La Silla.

Boden, a city in the province of Norrbotten in northern Sweden, is the birthplace of Mats Lindgren, one of the discoverers of this object. The Boden fortress, located inside the gently sloping wooded hills surrounding the city, was in the early 1900s a part of Sweden's northern line of defense. (M 36945)

\section{(6529) Rhoads}

$1993 \mathrm{XR}_{2}$. Discovered 1993 Dec. 14 at the Palomar Observatory at Palomar.

Named in honor of R. Rhoads Stephenson for his significant contributions to the advancement of technology needed and used for the exploration of outer space by robotic spacecraft. A mechanical engineer by training, he was a deputy director at the California Institute of Technology Jet Propulsion Laboratory, where he was responsible for the development and application of technology which broadly supports the United States space exploration mission. He has published in the areas of earth-based tracking and orbit determination, orbit evaluation techniques, spacecraft attitude and articulation control, flight computers, telerobotics, space power and electric propulsion. (M 32788)

\section{(6530) Adry}

1994 GW. Discovered 1994 Apr. 12 by V. S. Casulli at Colleverde di Guidonia.

Named in honor of Adriano Casulli (1974- ), son of the discoverer. (M 31610) 


\section{(6532) Scarfe}

1995 AC. Discovered 1995 Jan. 4 by D. D. Balam at Victoria.

Named in honor of Colin D. Scarfe (1940- ), professor of astronomy at the University of Victoria since 1965. President of Commission 30 (Radial Velocities) and of Division IX (Optical Techniques) of the IAU since 1994, Scarfe is an authority on spectroscopic and eclipsing binary stars and has made fundamental contributions to the very difficult problem of interpreting the radial-velocity curves of triple systems, as well as the determination of the orbits of systems that are simultaneously spectroscopic and eclipsing binary stars or spectroscopic and visual binary stars. This has led to the determination of stellar masses with unprecedented precision. (M 25980)

Citation prepared by J. B. Tatum at the request of the discoverer.

\section{(6533) Giuseppina}

$1995 \mathrm{DM}_{1}$. Discovered 1995 Feb. 24 by C. W. Hergenrother at Tucson.

Josephine Hergenrother (1949- ), maiden name Giuseppina Fratarcangeli, is the mother of the discoverer. (M 45231; M 45821)

\section{(6535) Archipenko}

3535 P-L. Discovered 1960 Oct. 17 by C. J. van Houten and I. van Houten-Groeneveld at Palomar.

Named for Alexander Archipenko (1887-1964), Ukrainian-American sculptor. He was the first to transform the cubism and abstract style of paintings into figurative sculptures (plastic art). He studied first in Kiev, then in Paris and Berlin, emigrating to the U.S. in 1923. Among his works are Queen of Saba and King Salomon. (M 26766)

\section{(6536) Vysochinska}

1977 NK. Discovered 1977 July 14 by N. S. Chernykh at Nauchnyj.

Named in honor of Lyudmilla Iosifovna Vysochinska, composer, pianist and music critic in Kiev and a public figure throughout Ukraine. She has written many songs based on the poetry of Ukrainian, Russian and Bulgarian poets. The founding director of the Ukraine's first Theater of Songs, she has research interests that include the connections between Ukrainian classical composers and writers. (M 32345)

\section{(6537) Adamovich}

1979 QK$_{6}$. Discovered 1979 Aug. 19 by N. S. Chernykh at Nauchnyj.

Named in memory of Aleksandr Mikhajlovich Adamovich (Ales' Adamovich; 1927-1994), ByelorussianRussian writer, literary scholar and publicist. He exhibited a harmonious combination of talent and civic responsibility. (M 34624)

\section{(6539) Nohavica}

1982 QG. Discovered 1982 Aug. 19 by Z. Vávrová at Kleť.
Named in honor of Jaromír Nohavica (1953- ), Czech singer, poet and composer. (M 33385; M 35765)

\section{(6540) Stepling}

1982 SL $_{1}$. Discovered 1982 Sept. 16 by A. Mrkos at Klet.

Named in memory of Joseph Stepling (1716-1778), founder and the first director of the astronomical observatory at the Jesuit college in Prague called Klementinum \{see planet (3386)\} (1751). He was also known for introducing Newtonian physics to Prague. (M 31296)

Name suggested by J. Tichá and M. Šolc.

\section{(6542) Jacquescousteau}

$1985 \mathrm{CH}_{1}$. Discovered 1985 Feb. 15 by A. Mrkos at Kleť.

Jacques Yves Cousteau (1910-1997) was a French marine explorer, author and documentary filmmaker. (M 36945)

The name was suggested by M. Tichý and Z. Moravec.

\section{(6543) Senna}

$1985 \mathrm{TP}_{3}$. Discovered 1985 Oct. 11 by C. S. Shoemaker and E. M. Shoemaker at Palomar.

Named in memory of Ayrton Senna Da Silva (19601994), Brazilian race-car driver. One of the greatest race-car drivers of all time, he competed in the top category of motor sport, Formula One. His career highlights in this top echelon include 65 pole positions, 19 fastest laps, 41 victories and three championships. He was tragically killed while competing in his 161st race. (M 25980)

Name suggested by the Astronomical Society of South Australia and the Ayrton Senna Fan Club of Australia, the 1993 Australian Grand Prix having been his last victory.

\section{(6546) Kaye}

$1987 \mathrm{DY}_{4}$. Discovered 1987 Feb. 24 by A. Mrkos at Klet.

Named in memory of Danny Kaye (1913-1987, born David Daniel Kominski), actor and comedian on stage and screen. Kaye's trademark screen role was the mild mannered bumbler who triumphs in the end, as in The Court Jester (1956). (M 30099)

Name suggested by G. V. Williams, who made the identifications involving this object.

\section{(6549) Skryabin}

1988 PX $_{1}$. Discovered 1988 Aug. 13 by E. W. Elst at St. Michel.

Named in memory of the Russian composer Alexandr Nikolaevich Skryabin (1872-1915). Though one of the most fascinating phenomena at the beginning of the twentieth century, his music was largely unappreciated because of his contradictory philosophical ideas. His most important symphonies, sonatas and other pieces for the piano were composed to an ever-increasing degree following his bold aim to create a mystery that should unite all the arts in a grand liturgic-artistical 
action to uplift and redeem humanity above itself into a condition of supreme ecstasy. (M 26766)

\section{(6550) Parlér}

$1988 \mathrm{VO}_{5}$. Discovered 1988 Nov. 4 by A. Mrkos at Klě́t.

Beginning in 1356, the German-born master builder Petr Parlér (c. 1333-1399) led the construction of the Gothic St. Vitus cathedral in Prague. The works created by members of the Parlér family are known in both Czech and German medieval architecture. (M 36945)

The name was suggested by J. Tichá and M. Tichý.

\section{(6553) Seehaus}

$1989 \mathrm{GP}_{6}$. Discovered 1989 Apr. 5 by M. Geffert at La Silla.

Named in memory of the painter Paul A. Seehaus (1891-1919) and the other painters of the "Rheinische Expressionisten". Born in Bonn, Seehaus was from 1910 to 1914 a student of August Macke. In 1913 Macke, Seehaus and other members of the group had an exhibition in Bonn, and this established them as expressionist painters in Germany in their own right - in addition to the existing group of "Die Brücke" and "Der blaue Reiter". In his work Seehaus was always interested in a balance between traditional and modern painting. (M 26425)

\section{(6554) Takatsuguyoshida}

1989 UO $_{1}$. Discovered 1989 Oct. 28 by Y. Mizuno and T. Furuta at Kani.

Takatsugu Yoshida (1951- ) is a Japanese amateur astronomer and optical engineer who specializes in making observations by television. He is a member of the professional-amateur working group of IAU Commission 22 and serves as general secretary of the Nippon Meteor Society. (M 44185)

\section{(6556) Arcimboldo}

$1989 \mathrm{YS}_{6}$. Discovered 1989 Dec. 29 by A. Mrkos at Kleť.

Giuseppe Arcimboldo (1527?-1593) was an Italian Mannerist painter whose grotesque, almost surrealist compositions of fruits, vegetables and other objects were arranged to resemble human portraits. He became a favorite court painter of the Hapsburg emperor Rudolph II in Prague. (M 24668)

The name was suggested by J. Tichá.

\section{(6557) Yokonomura}

$1990 \mathrm{VR}_{3}$. Discovered 1990 Nov. 11 by T. Nomura and K. Kawanishi at Minami-Oda.

Named in honor of Yoko Nomura (1950- ), wife of the first discoverer and an independent discoverer of comet C/1975 N1. "Yoko" means "a child of the sun". (M 35484)

\section{(6558) Norizuki}

1991 GZ. Discovered 1991 Apr. 14 by K. Endate and K. Watanabe at Kitami.
Named in memory of Sojiro Norizuki (1912-1995), founder of Norizuki Technical Works. Under the guidance of $\mathrm{H}$. Tanaka, he constructed the first parabolic antenna for solar observations in Japan in 1949. He was later engaged in the construction of the interferometer at the Nobeyama Solar Radio Observatory and for other radio telescopes. After 1972 he extended his work to infrared and optical telescopes. (M 30099)

Name proposed by the second discoverer following a suggestion by K. Tomita.

\section{(6559) Nomura}

1991 JP. Discovered 1991 May 3 by M. Sugano and K. Kawanishi at Minami-Oda.

Named in honor of Toshiro Nomura (1954- ), science teacher at Nada High School in Kobe. As head of the Kobe branch of the Oriental Astronomical Association, he is making every effort to popularize astronomy. He has visited Tunguska several times with his colleagues to search for meteorites since 1992 . (M 35484)

\section{(6560) Pravdo}

1991 NP. Discovered 1991 July 9 by E. F. Helin at Palomar.

Named in honor of Steven H. Pravdo, who works in the fields of X-ray astrophysics and extrasolar planet detection, as well as in mission and instrument development for space programs at the Jet Propulsion Laboratory. As the task manager for the Near-Earth Asteroid Tracking system, he has contributed to the design, fabrication, installation and operations of NEAT. His expertise in systems engineering, analysis and management contributed significantly to the success of the project. (M 26931)

\section{(6561) Gruppetta}

$1991 \mathrm{TC}_{4}$. Discovered 1991 Oct. 10 by K. J. Lawrence at Palomar.

John M. Gruppetta (1957- ), a long-time friend of the discoverer, is a design engineer with an interest in astronomy. (M 39640)

\section{(6562) Takoyaki}

1991 VR $_{3}$. Discovered 1991 Nov. 9 by M. Yanai and K. Watanabe at Kitami.

Takoyaki is a well-known local food in the Osaka area. It is a baked flower ball cake containing small pieces of boiled octopus. The name was selected among other candidates proposed by children who attended the Fureai Space Festival 2001, held in Osaka on the Space Day in Japan. (M 45336)

\section{(6563) Steinheim}

1991 XZ $_{5}$. Discovered 1991 Dec. 11 by F. Börngen at Tautenburg.

Named for the impact crater in southwestern Germany, $10 \mathrm{~km}$ west of the town of Heidenheim on the river Brenz. The rim of the crater has a diameter of $4 \mathrm{~km}$, and its central hillock is named Steinhirt- 
Klosterberg. The larger and more famous Ries crater \{see planet (4327)\} is located some $40 \mathrm{~km}$ away. Both impacts have an age of 14.5 million years, and it is very probable that they were formed simultaneously by an impactor that fragmented. (M 26425)

\section{(6564) Asher}

1992 BB. Discovered 1992 Jan. 25 by R. H. McNaught at Siding Spring.

Named in honor of David John Asher (1966- ), researcher on the dynamics of the small bodies in the solar system. Born in Scotland, Asher took degrees at the universities of Cambridge, Oxford and Edinburgh. Following this, he took the words of Douglas Adams in The Hitchhiker's Guide to the Galaxy to heart - "With a degree in maths, and another in astrophysics, it was either that or back to the dole queue on Monday" - and moved to Australia, where he spent two years at the Anglo-Australian Observatory. He is currently working at the National Astronomical Observatory in Japan. (M 29147)

Name proposed by the discoverer following a suggestion by D. I. Steel, who prepared the citation.

\section{(6565) Reiji}

1992 FT. Discovered 1992 Mar. 23 by K. Endate and K. Watanabe at Kitami.

Named in honor of Reiji Shin Matumoto (1938- ), whose many scientific cartoons are held in high regard among young people in Japan. As chief director of the Young Astronauts Club of Japan, he endeavors to educate future generations to participate in the development of space. (M 30099)

Name proposed by the second discoverer following a suggestion by K. Tomita.

\section{(6567) Shigemasa}

1992 WS. Discovered 1992 Nov. 16 by K. Endate and K. Watanabe at Kitami.

Named in honor of Shigemasa Suzuki (1920- ), an instrumentalist whose career began at the Tokyo Astronomical Observatory in Mitaka ssee planet (1088)\}, where he assisted in the development of a multiphase radio interferometer. In 1960 he took up a fellowship offered by the Commonwealth Scientific and Industrial Organization and joined its division of radiophysics. In 1966 he became the first person of Japanese birth naturalized as an Australian citizen. (M 30100)

Name proposed by the second discoverer, following a suggestion by K. Tomita, who was Suzuki's neighbor in Mitaka.

\section{(6570) Tomohiro}

1994 JO. Discovered 1994 May 6 by K. Endate and K. Watanabe at Kitami.

Named in honor of Tomohiro Hirayama (1938- ), who joined the Tokyo Astronomical Observatory in 1960 as an observer with the Baker-Nunn Satellite-Tracking Camera. He later joined the observatory's computer center and developed many programs for satellite laser ranging and other astronomical purposes. Between 1967 and 1987 all but one of the telex messages from the observatory to the Central Bureau for Astronomical Telegrams were typed by his hands. (M 30100)

Name proposed by the second discoverer K. Watanabe following a suggestion by K. Tomita.

\section{(6571) Sigmund}

3027 P-L. Discovered 1960 Sept. 24 by C. J. van Houten and I. van Houten-Groeneveld at Palomar.

Named in honor of Peter Sigmund (1936- ), professor at the Institute of Physics at Odense University and since 1970 one of the leading Danish physicists. His research as a theoretical physicist ranges from particle penetration and collision cascade phenomena to charge exchange and electron emission. He has inspired Danish and foreign colleagues immensely in these areas. (M 26932)

Name proposed by K.-O. Groeneveld. Citation prepared by J. Schou.

\section{(6572) Carson}

1938 SX. Discovered 1938 Sept. 22 by Y. Väisälä at Turku.

Named in memory of Rachel Louise Carson (19071964). While a biologist with the U.S. Fish and Wildlife Service, she autored Under the Sea Wind, The Sea Around Us and The Edge of the Sea. But she is best remembered for Silent Spring, a landmark book that created a wide awareness of the dangers of environmental pollution and fundamentally altered humankind's perception of our global environment. (M 27129)

Name proposed and citation prepared by G. C. L. Aikman.

\section{(6573) Magnitskij}

1974 SK$_{1}$. Discovered 1974 Sept. 19 by L. I. Chernykh at Nauchnyj.

Leontij Filippovich Magnitskij (1669-1739), a teacher of mathematics at the School of Mathematical and Navigation Sciences in Moscow from 1701, was author of the first printed book in Russia on "arithmetics", an encyclopedia of mathematical and astronomical knowledge at that time. (M 42355)

\section{(6574) Gvishiani}

$1976 \mathrm{QE}_{1}$. Discovered 1976 Aug. 26 by N. S. Chernykh at Nauchnyj.

Named in honor of Jermen Mikhailovich Gvishiani (1928- ), known for his many works in philosophy, sociology and theory of management. He serves as president of the Foundation for Prospective Research and the Moscow Institute of Economics, Politics and Law. He is a member of the Russian Academy of Sciences, the Rome Club and many foreign academies, foundations and associations. His work promotes the use of foreign achievements in science, technology and culture in present-day Russia. (M 32346) 


\section{(6575) Slavov}

$1978 \mathrm{PJ}_{2}$. Discovered 1978 Aug. 8 by N. S. Chernykh at Nauchnyj.

Named in honor of Nikolaj Antonovich Slavov (1926-

), Ukrainian river fleet engineer and sportsman. He helped lead the clean-up effort after the 1986 disaster at Chernobyl, where he had been working for several months. A national boxing champion, he is president of the Professional Boxing League of Ukraine. His interests extend to the arts, and he is president of the All-Ukrainian Foundation for the artist Leonid Bykov \{see planet (4682)\}. He actively contributes to the development of culture and sport in Ukraine. (M 32346)

\section{(6576) Kievtech}

$1978 \mathrm{RK}_{1}$. Discovered 1978 Sept. 5 by N. S. Chernykh at Nauchnyj.

Named for the Kiev Polytechnical Institute-National Technical University of Ukraine, on the hundredth anniversary of its founding in 1898 as the model for other institutions of higher education in Ukraine. Many famous people have taught there, including S. P. Korolov and B. E. Paton \{see planets (1855) and (2727), respectively\}. The famous aircraft and helicopter designer I. I. Sikorskij was one of the 120,000 students who have graduated from the Institute. (M 34624)

Name proposed by the discoverer following a suggestion by the Simferopol State University.

\section{(6578) Zapesotskij}

1980 TQ $_{14}$. Discovered 1980 Oct. 13 by T. M. Smirnova at Nauchnyj.

Named in honor of Alexander Sergeevich Zapesotskij (1954- ), president of St. Petersburg University of Humanities and Social Sciences, Russian culturologist, known for his public activity as one of the leaders of the Congress of the Russian Intelligentsia. (M 34624)

Name suggested by the Institute of Applied Astronomy

\section{(6581) Sobers}

1981 SO. Discovered 1981 Sept. 22 by A. Mrkos at Klě́t.

Named in honor of Garfield St. Aubrun (Gary) Sobers (1936- ), West Indian cricketer, considered by many as the best all-rounder of all time. As a batsman, Sobers scored 8032 runs in 160 Test innings, including 26 centuries and 365 (not out) against Pakistan in 1957-1958. As a bowler, he took 235 Test wickets, averaging one wicket for each 34 runs given up, and was also an excellent close-fielder. (M 27735)

Name suggested by G. V. Williams, who made the identifications involving this object.

\section{(6582) Flagsymphony}

1981 VS. Discovered 1981 Nov. 5 by E. Bowell at Anderson Mesa.

The Flagstaff Symphony Orchestra is celebrating its 50th season in 1999-2000. It is considered by many to be the best symphony orchestra in a small community in the U.S.A. (M 38195)

\section{(6583) Destinn}

1984 DE. Discovered 1984 Feb. 21 by A. Mrkos at Klet.

Named in memory of Ema Destinn (1878-1930), Czech opera singer, considered one of the finest sopranos of the early twentieth century, particularly together with the excellent tenor of Enrico Caruso. (M 29671)

Name suggested by J. Tichá.

\section{(6584) Ludekpesek}

1984 FK. Discovered 1984 Mar. 31 by E. Bowell at Anderson Mesa.

Ludek Pesek (1919-1999) was a Swiss astronomical artist and writer known for scientifically realistic illustrations published in National Geographic (ca. 1969-1973). He wrote several novels and illustrated books such as Planets of the Solar System (1963). (M 39650)

The name was suggested by W. K. Hartmann.

\section{(6585) O'Keefe}

1984 SR. Discovered 1984 Sept. 26 by C. S. Shoemaker and E. M. Shoemaker at Palomar.

Named in honor of John Aloysius O'Keefe (19162000), American astronomer and a leading figure in establishing the Theoretical Division of NASA's Goddard Space Flight Center. He is renowned for his discovery of the "pear shape" of the gravitational field of the earth from observations of the first artificial satellites. He is one of the leading students of tektites and has stimulated much interest and research on these natural glasses and played a key role in helping to found the astrogeology program of the U.S. Geological Survey. (M 29671)

\section{(6586) Seydler}

1984 UK $_{1}$. Discovered 1984 Oct. 28 by A. Mrkos at Klet.

Named in memory of August Seydler (1849-1891), professor of astronomy and theoretical physics at Charles University in Prague. He founded the Astronomical Institute of the Czech part of Charles University in 1886. Several of his works deal with celestial mechanics and orbit computations for minor planets and comets. (M 30477)

Name suggested by J. Tichá and M. Šolc.

\section{(6587) Brassens}

$1984 \mathrm{WA}_{4}$. Discovered 1984 Nov. 27 by the CERGA at Caussols.

Named in memory of George Brassens (1921-1981), a French poet born on the Mediterranean coast. This gruff artist with a soft heart sang of human nature through texts that were often nonconformist. Henceforth, accompanied by his faithful guitar, he will belong to the heritage of French culture. (M 28621) 
Citation provided by members of the Groupement d'Astronomie Populaire de la Région d'Antibes, translated by C. Hayter.

\section{(6589) Jankovich}

$1985 \mathrm{SL}_{3}$. Discovered 1985 Sept. 19 by N. S. Chernykh and L. I. Chernykh at Nauchnyj.

Milan Jankovich, economist and ecologist in Monaco, is head of the Zepter company. He is devoted to helping young people, improving the environment and encouraging cultural advances. He has won many prestigious international prizes. (M 38195)

The name was suggested by the Ukrainian Ecological Academy of Sciences.

\section{(6590) Barolo}

$1985 \mathrm{TA}_{2}$. Discovered 1985 Oct. 15 by E. Bowell at Anderson Mesa.

Barolo, in the Langhe district of the Italian region of Piedmont, is known for some of the world's finest wines. (M 36126)

The name was suggested by V. Zappalà.

\section{(6592) Goya}

1986 TB $_{12}$. Discovered 1986 Oct. 3 by L. G. Karachkina at Nauchnyj.

Named for Francisco José de Goya y Lucientes (1746-1828) on the 250th anniversary of the birth of this great Spanish painter, etcher and graphic artist. (M 26766)

Name proposed by the discoverer following a suggestion by L. R. Nemirovskij.

\section{(6594) Tasman}

$1987 \mathrm{MM}_{1}$. Discovered 1987 June 25 by A. Mrkos at Klě́.

Named for the Dutch navigator and explorer Abel Janszoon Tasman (c.1603-c.1659), who explored the south Pacific and discovered Tasmania, New Zealand, Tonga and the Fiji Islands. (M 30100)

Name suggested by G. V. Williams, who made the identifications involving this object.

\section{(6595) Munizbarreto}

1987 QZ 1 . Discovered 1987 Aug. 21 by E. W. Elst at La Silla.

Named in honor of former director Luiz Muniz Barreto of the National Observatory in Rio de Janeiro, who stimulated the development of astrophysics in Brazil and was responsible for the creation in Itajubá of the Laboratorio Nacional de Astrofisica. He also established research groups in astronomy and geophysics, such as the Observatory of Piedade in Minas Gerais. In 1994 he went to the Universidade Nacional Autonoma de Mexico, where he is currently involved in geophysical research. In the 1970s the discoverer was regularly invited by Muniz Barreto to carry out research at the National Observatory and to teach astrophysics at the Universidade Federal of Belo Horizonte. (M 26766)

Citation material supplied by R. Tarsia.

\section{(6596) Bittner}

$1987 \mathrm{VC}_{1}$. Discovered 1987 Nov. 15 by A. Mrkos at Klě́.

Adam Bittner (1777-1844), the fifth director of the Klementinum observatory in Prague, introduced a timeball in Prague that fell daily at noon. (M 42355)

The name was suggested by J. Tichá and M. Šolc.

\section{(6597) Kreil}

$1988 \mathrm{AF}_{1}$. Discovered 1988 Jan. 9 by A. Mrkos at Klet.

Karl Kreil (1798-1862), the sixth director of the Klementinum observatory in Prague, carried out geomagnetic measurements in the Austro-Hungarian empire. He was later director of the Central Institute for Meteorology and Geomagnetism in Vienna. (M 42355) The name was suggested by J. Tichá and M. Šolc.

\section{(6598) Modugno}

1988 CL. Discovered 1988 Feb. 13 at the Osservatorio San Vittore at Bologna.

Named in memory of Domenico Modugno (19281994), famous Italian singer, composer and actor. Modugno won the famous festival of Italian song at San Remo three times; in 1958 with "Nel blu dipinto di blu" (also known as "Volare"), in 1959 with "Piove" and in 1966 with "Dio, come ti amo!". (M 27129)

\section{(6599) Tsuko}

1988 PV. Discovered 1988 Aug. 8 by K. Endate and K. Watanabe at Kitami.

Named in honor of Tsuko Nakamura (1943- ), who studied celestial mechanics in the University of Tokyo's Department of Astronomy and whose research at the National Astronomical Observatory includes observations of the mutual phenomena of Jupiter's Galilean satellites and statistical investigations of the long-term orbital behavior of minor planets and comets. His interests also include the study of old Japanese archives for observations of astronomical phenomena. (M 30100)

Name proposed by the second discoverer following a suggestion by K. Tomita.

\section{(6602) Gilclark}

1989 EC. Discovered 1989 Mar. 4 by E. F. Helin at Palomar

Named in honor of Gilbert A. Clark, creator of Telescopes in Education, the first opportunity for students in classrooms to operate a research-grade telescope in real time. Since TIE saw first light in 1994, several thousand students and their teachers have observed using the $0.6-\mathrm{m}$ reflector on Mount Wilson, thereby providing inspiration in astronomy, science and critical thinking. With untiring leadership, Clark reassembled and automated a telescope others thought unusable, and he created a team of volunteers, sponsors and staff to keep it operating for students everywhere. Now ready to expand to other telescopes around the world, the educational inspiration of TIE 
has reached and connected students in inner cities, rural communities and eight different countries. (M 31024)

\section{(6603) Marycragg}

1990 KG. Discovered 1990 May 19 by E. F. Helin at Palomar.

Mary A. Cragg (1938- ) developed the Telescopes in Education (TIE) office infrastructure. It is used as a model for other remote educational telescope operations. (M 47163)

\section{(6604) Ilias}

$1990 \mathrm{QEE}_{8}$. Discovered 1990 Aug. 16 by E. W. Elst at La Silla.

Named for the greatest of the Greek epics, the Iliad of Homer \{see planet (5700)\}. This work was later divided, more or less arbitrarily, by Alexandrian scientists into 24 books of some 500-800 verses each. Although the Trojan War raged for ten years, Homer reviewed but a small episode of it. King Agamemnon \{see planet (911)\} was to render the captured Chryseis \{see planet (202)\} to her father, and he demanded Briseis \{see planet (655)\}, then mistress of Achilles \{see planet (588)\}, for himself. Thereupon Achilles withdrew himself and all his men from the battle. However, after his friend Patroclus \{see planet (617)\} was killed by Hektor \{see planet (624)\}, Achilles resumed fighting and killed Hektor. The epic ends with the funeral of Patroclus. The name also honors Ilias, born 1995 Oct. 28, the first grandson of the discoverer and son of Sigyn and Philip de Jager-Elst. (M 26425)

\section{(6606) Makino}

1990 UF. Discovered 1990 Oct. 16 by T. Seki at Geisei.

Named in memory of Tomitaro Makino (1862-1957), Kochi-born botanist of international repute. He became interested in plants in his childhood and is credited with the discovery of 500 new species. (M 28621)

\section{(6607) Matsushima}

$1991 \mathrm{UL}_{2}$. Discovered 1991 Oct. 29 by K. Endate and K. Watanabe at Kitami.

Named in honor of Koichi Matsushima (1938- ), head of the Instrumentation Laboratory, Control Systems Division, National Aerospace Laboratory. He has played a leading role in the design of Japan's minorplanet exploration program. He has also promoted research into minor planets, comets and meteors. (M 30477)

\section{(6612) Hachioji}

$1994 \mathrm{EM}_{1}$. Discovered 1994 Mar. 10 by Y. Kushida and O. Muramatsu at Yatsugatake.

Located $50 \mathrm{~km}$ to the west of Tokyo, Hachioji is the city where the first discoverer was born and grew up. It was formerly "the silk and textile city", but now that several colleges have been estabished or moved there it is called "the college city". (M 45336)

\section{(6613) Williamcarl}

1994 LK. Discovered 1994 June 2 by C. W. Hergenrother at Tucson.

William Carl Hergenrother (1946- ) is the father of the discoverer. (M 45231)

\section{(6614) Antisthenes}

6530 P-L. Discovered 1960 Sept. 24 by C. J. van Houten and I. van Houten-Groeneveld at Palomar.

Named for the Greek philosopher Antisthenes (c.455c.360 B.C.). In ethics he said that everyone could learn "Arete" (virtue, see also planet (197)), and he founded the cynic school of philosophy. (M 26932)

\section{(6615) Plutarchos}

9512 P-L. Discovered 1960 Oct. 17 by C. J. van Houten and I. van Houten-Groeneveld at Palomar.

Named for the great Greek philosopher and writer Plutarchos (c.45-125), who studied at the Academia of Plato \{see planet (5451)\} in Athens. About half of his philosophical work is preserved. His parallel biographies of 46 prominent Greeks and Romans is one of his best known works. In his Moralia he speaks about the correct faith and style of living in a form as Plato did. (M 26932)

\section{(6616) Plotinos}

1175 T-1. Discovered 1971 Mar. 25 by C. J. van Houten and I. van Houten-Groeneveld at Palomar.

Named for the Greek philosopher Plotinos (205-270). In Alexandria Plotin studied under the philosopher Ammonios Sakkas and participated in the war of Gordianus III against the Persians. During 246-268 he operated a school in neo-Platonic philosophy. He combined the school of Plato \{see planet (5451)\} with gnostic elements and oriental mysticism, and he strongly influenced Augustine - and therefore also christianity. (M 26932)

\section{(6617) Boethius}

2218 T-1. Discovered 1971 Mar. 25 by C. J. van Houten and I. van Houten-Groeneveld at Palomar.

Named for the western Roman politician, poet and philosopher Anicius Manilius Severinus Boethius (c. 480-524). An Advisor to the Ostrogoth king Theoderich the Great, he is called "the last Roman and the first scholastic". He translated the works of the Greek philosophers, especially Aristotle \{see planet (6123)\}, into Latin. He was accused of high treason, put into prison and executed without due process. In prison he wrote his most famous book, Consolation of Philosophy. (M 26932; M 26947)

\section{(6620) Peregrina}

1973 UC. Discovered 1973 Oct. 25 by P. Wild at Zimmerwald.

Peregrina is a foreign lady, especially one on pilgrimage. The minor planets might be compared to an immense, multifarious crowd of perpetual pilgrims, 
and this one fancied to be an especially earnest, devout member. (M 41383)

\section{(6621) Timchuk}

1975 VN $_{5}$. Discovered 1975 Nov. 2 by T. M. Smirnova at Nauchnyj.

Named in honor of neuropathologist Evdokiya Ivanovna Timchuk (1937- ), a physician at a hospital near Simferopol and a good friend of the discoverer. (M 35484)

\section{(6622) Matvienko}

1978 RG $_{1}$. Discovered 1978 Sept. 5 by N. S. Chernykh at Nauchnyj.

Named in honor of Vladimir Pavlovich Matvienko (1938- ), Ukrainian economist, author of many works on economics and banking and a member of the Ukrainian Academy of Ecological Studies. He is also a poet, and some of his poetic works have been set to music. (M 32346)

\section{(6628) Dondelia}

$1981 \mathrm{WA}_{1}$. Discovered 1981 Nov. 24 by E. Bowell at Anderson Mesa.

Named in honor of Donald S. C. and Delia West of Wareham, Dorset. Friends of the discoverer, Don and Delia have had the perspicacity to make their home in one of the loveliest parts of England. (M 27463)

\section{(6629) Kurtz}

1982 UP. Discovered 1982 Oct. 17 by E. Bowell at Anderson Mesa.

Named in honor of Paul Kurtz (1925- ) of the State University of New York at Buffalo. Kurtz is professor emeritus of philosophy, chairman and founder of the Committee for the Scientific Investigation of Claims of the Paranormal (CSICOP), chairman of the Council for Secular Humanism, and founder and chairman of Prometheus Books. A noted author and philosopher, he has written more than 30 books and 650 articles on philosophy, humanism and skepticism. He has been influential in bringing philosophy back from a pure analytical study to a more activist stance. Kurtz actively promotes science and the refutation of pseudoscience. (M 27735)

Name suggested and citation provided by J. McGaha.

\section{(6630) Skepticus}

$1982 \mathrm{VA}_{1}$. Discovered 1982 Nov. 15 by E. Bowell at Anderson Mesa.

Named for the Committee for the Scientific Investigation of Claims of the Paranormal and its journal The Skeptical Enquirer. CSICOP is nonprofit educational organization, founded in 1976 to investigate paranormal, occult and fringe claims using rigorous scientific methodology. CSICOP has spawned a grassroots movement of some 70 autonomous groups worldwide. Throught public education and outreach, CSICOP has become a voice of reason to counter pseudoscience and superstition. (M 27735)

Named and citation provided by J. McGaha.
(6631) Pyatnitskij

1983 RQ4. Discovered 1983 Sept. 4 by L. V. Zhuravleva at Nauchnyj.

Named in memory of Mitrofan Efimovich Pyatnitskij (1864-1927), founder of the Russian National Chorus, performer and collector of Russian folk-songs, and Honored Artist of Russia (1925). (M 34624)

\section{(6632) Scoon}

1984 UX $_{1}$. Discovered 1984 Oct. 29 by E. Bowell at Anderson Mesa.

Named in honor of George E. N. Scoon (1936-

). Born in Grenada, West Indies, Scoon studied in The Netherlands and the U.K. in the fields of telecommunications engineering, general management, and business administration. He now works at the Future Scientific Project Division of the European Space Agency in Noordwijk. With his intelligence and energy, he has promoted and continues to promote solar-system exploration in Europe and cooperation among the major space agencies. Missions such as Vesta, Cassini-Huyghens, Moro, Marsnet and the Mercury Orbiter ESA cornerstone found an enthusiastic and competent supporter in Scoon, to whom the space-science community owes a debt of gratitude. (M 27463)

Name suggested and citation prepared by $\mathrm{M}$. Fulchignoni.

\section{(6635) Zuber}

$1987 \mathrm{SH}_{3}$. Discovered 1987 Sept. 26 by C. S. Shoemaker and E. M. Shoemaker at Palomar.

Named in honor of Maria T. Zuber, American geophysicist whose research interests have taken her into theoretical modeling of geophysical processes and the relationships between gravity, topography and tectonic features in planetary lithospheres. She has contributed to various space missions, including Mars Observer, the Clementine mission, Mars Global Surveyor and the Near Earth Asteroid Rendezvous mission. (M 32346)

\section{(6637) Inoue}

1988 XZ. Discovered 1988 Dec. 3 by K. Endate and K. Watanabe at Kitami.

Named in honor of Keisuke Inoue (1928- ), who worked for Tentai Ichiyou, nautical almanacs, at Japan's Hydrographic Department for 38 years. He was an expert in calculating the orbits of artificial satellites. After retirement, he worked for a software company and is now on the editorial staff of the astronomical almanac Tenmon Nenkan. (M 30477)

\section{(6640) Falorni}

1990 DL. Discovered 1990 Feb. 24 at the Osservatorio San Vittore at Bologna.

Named in memory of Marco Falorni (1944-1995), Italian amateur astronomer, president of Unione Astrofili Italiani, the leading Italian association of amateur astronomers. A great visual observer of planets, principally Mars, he used in this work 
the refractor Amici at the Arcetri Astrophysical Observatory in Florence and the $0.83-\mathrm{m}$ refractor at Meudon. Falorni also collaborated with the group of amateurs at the Osservatorio San Vittore ssee planet (2235)\} in Bologna, examining and measuring hundreds of photographs of planetary surfaces taken around 1970 by C. Vacchi, G. Sassi and G. Sette. (M 27331)

\section{(6641) Bobross}

$1990 \mathrm{OK}_{2}$. Discovered 1990 July 29 by H. E. Holt at Palomar.

Robert Ross (1920- ) has devoted his life to the Muscular Dystrophy Association for almost 50 years. Now senior vice president and executive director, Ross has built the MDA into a world-famous organization funding research and opening new avenues for the care of patients and their families. (M 43042)

\section{(6643) Morikubo}

1990 VZ. Discovered 1990 Nov. 7 by Y. Kushida and O. Muramatsu at Yatsugatake.

Named in honor of Shigeru Morikubo (1913- ), since 1930 an amateur astronomer, observer of variable stars, sunspots, meteors and occultations, and a pioneer in observing meteoric dust. Since 1955 he has been continuing to study meteoric dust through his medical microscope. In 1967 he became the first chairman of the Japan Amateur Astronomers' Convention, and he continues to edit a history of amateur astronomy in Japan. (M 29147)

Name proposed by the discoverers following a suggestion by S. Sakuma.

\section{(6644) Jugaku}

1991 AA. Discovered 1991 Jan. 5 by A. Takahashi and K. Watanabe at Kitami.

Named in honor of Jun Jugaku (1927- ), a professor at Tokai University, formerly a professor at the Tokyo Astronomical Observatory. He is known for his work on early-type stars, particularly chemically-peculiar stars and B stars. As an associate editor of the Publications of the Astronomical Society of Japan from 1965 to 1989, he made every effort to upgrade the scientific level of that journal. He served as president of IAU Commission 29 during 1982-1985. (M 30798; M 30819)

Name proposed by the second discoverer, following a suggestion by W. Liller.

\section{(6645) Arcetri}

1991 AR$_{1}$. Discovered 1991 Jan. 11 by E. F. Helin at Palomar.

Named for the Florence Observatory, moved in 1872 from the center of the city to Arcetri, near the house in which Galileo died. The original observatory, La Specola, was also associated with Galileo, and nineteenth-century directors included the comet hunters Pons, Donati and Tempel \{see planet (3808)\}. It was Donati who moved the observatory to its present location. (M 28090)

\section{(6646) Churanta}

$1991 \mathrm{CA}_{3}$. Discovered 1991 Feb. 14 by E. F. Helin at Palomar.

Antonina Mikhailovna Churyumova (1907- ) is the mother of astronomer Klim Churyumov \{see planet (2627)\}. A poet who has participated actively in public issues in the Ukraine, she has seven other children. (M 42668)

\section{(6647) Josse}

1991 GG $_{5}$. Discovered 1991 Apr. 8 by E. W. Elst at La Silla.

Named in honor of Raymond Josse (1914- ), a graduate of the Ecole Militaire de l'Air and the Ecole Nationale Supérieure de l'Aéronautique who has occupied important positions in the French aeronautical administration. He is also a member of the Société des Amis de Jean de La Fontaine, one of his ancestors, as well as of the Société Astronomique de France. He has authored about 100 articles on historical and on technical subjects. During the festivities in 1995 on the occasion of the 300th anniversary of the death of de La Fontaine \{see planet (5780)\} at Château Thierry he became a very good friend of the Elst family. (M 26766; E. W. Elst)

\section{(6649) Yokotatakao}

1991 RN. Discovered 1991 Sept. 5 by A. Natori and T. Urata at Yakiimo.

Takao Yokota (1956- ) is a systems engineer who works on space and astronomical technologies and also an active amateur astronomer. He contributed to the International Space Station project and is a staff member of the Japan Spaceguard Association. (M 45746)

\section{(6650) Morimoto}

$1991 \mathrm{RS}_{1}$. Discovered 1991 Sept. 7 by K. Endate and K. Watanabe at Kitami.

Named in honor of Masaki Morimoto (1932- ), Japanese radio astronomer who started his career at Mitaka ssee planet (1088)\} and participated in the construction of the Culgoora radioheliograph in Australia. He successfully completed and used the Mitaka 6-m millimeter-wavelength telescope, then the 45-m telescope and 10-m interferometer at Nobeyama. His ideas led to the launch of the HALCA (VSOP) satellite with an 8-m telescope for space VLBI. He is now professor at Kagoshima University and established the astronomy program there. He has also served as president of IAU Commission 40. (M 30798; M 30819)

Name proposed by the second discoverer following a suggestion by J. Watanabe.

\section{(6653) Feininger}

1991 XR $_{1}$. Discovered 1991 Dec. 10 by F. Börngen at Tautenburg.

Named for the American painter and graphic artist Lyonel Feininger (1871-1956). Descended from a family of German musician, he lived in Germany (Hamburg, Berlin, Weimar and Dessau) from 1887 to 1937, 
almost without interruption. Initially working as a caricaturist, he began in 1907 to create architectural and landscape paintings in a very personal style similar to cubism. Feininger was a master of the Bauhaus and particularly fond of Weimar and numerous Thüringian villages. Some 120 of his works alone are of the church of Gelmeroda. Outlawed by the Nazis, he returned to the U.S. and, beginning in 1939, painted his series Skyscrapers of Manhattan. In 1947 he became the president of the Federation of American Painters and Sculptors. (M 26766)

\section{(6654) Luleå}

$1992 \mathrm{DT}_{6}$. Discovered 1992 Feb. 29 by the Uppsala-ESO Survey at La Silla.

Luleå, a center of the steel industry on the northwestern coast of the Gulf of Bothnia and capital of the Swedish province of Norrbotten, dates back to the fourteenth century as a center for trade between the inland Samis and the population of southern Sweden. (M 36126)

\section{(6655) Nagahama}

1992 EL $_{1}$. Discovered 1992 Mar. 8 by A. Sugie at Taga.

Birthplace of the discoverer, the city of Nagahama is in the northeastern part of Shiga prefecture, in the vicinity of Lake Biwa \{see planet (4289)\}. The city occupies an area of approximately 45 square kilometers and is home to about 59000 people. (M 42668)

\section{(6656) Yokota}

1992 FF. Discovered 1992 Mar. 23 by K. Endate and K. Watanabe at Kitami.

Named in honor of Hiroshi Yokota (1927- ), Japanese amateur astronomer. For almost half a century he has delivered lectures on astronomy and has guided many able amateur astronomers. He organized several national astronomical gatherings in Yamaguchi, and he also played an important role in the investigation of a previously-unknown type of meteorite. (M 30799)

Name proposed by the discoverers following a suggestion by M. Koishikawa and T. Sato.

\section{(6657) Otukyo}

1992 WY. Discovered 1992 Nov. 17 by A. Sugie at Taga.

The palace of emperor Tenchi \{see planet (5017)\} was moved to Otukyo (modern Otsu city, Shiga prefecture) in the seventh century. (M 42669)

\section{(6658) Akiraabe}

$1992 \mathrm{WT}_{2}$. Discovered 1992 Nov. 18 by K. Endate and K. Watanabe at Kitami.

Named in honor of Akira Abe (1934- ), managing editor of Hoshino Techo ("Star Handbook"), a quarterly journal that existed from 1978 to 1993 and popularized astronomy with the help of high-quality articles by professional astronomers. He has played a pivotal role in introducing many amateurs and professionals to astronomy. (M 31610)
Name proposed by the discoverers following a suggestion by A. Fujii and A. Tanno.

\section{(6660) Matsumoto}

1993 BC. Discovered 1993 Jan. 16 by T. Seki at Geisei.

Named in honor of Tatsujiro Matsumoto (1930- ), popular Japanese telescope maker, known also for his observations of Mars and Jupiter. (M 30799)

\section{(6661) Ikemura}

1993 BO. Discovered 1993 Jan. 17 by Y. Mizuno and T. Furuta at Kani.

Toshihiro Ikemura (1952- $\quad$ ) is a Japanese communications technician and amateur astronomer. He was a codiscoverer of comet $76 \mathrm{P} /$ West-Kohoutek-Ikemura on 1975 Mar. 1. He has also endeavored to observe the planets photographically and independently made a map of Mars that is used by many observers. (M 43762)

\section{(6663) Tatebayashi}

1993 CC. Discovered 1993 Feb. 12 by T. Kobayashi at Oizumi.

Named for a city in Kanto Plain in the eastern part of Gunma \{see planet (3829)\} prefecture. Famous for the Tsutsujigaoka Park, where some of the trees are 1000 years old and 10000 azalea blossoms bloom every year, the city is blessed by its beautiful natural surroundings. There are several lakes, such as Jonuma and Tataranuma, where swans and other birds come regularly. Tatebayashi is also the birthplace of nature writer Katai Tayama and Japan's first female astronaut, Chiaki Mukai \{see planet (4750)\}. The Tatebayashi Children's Science Exploratorium held a "star" naming competition to commemorate her second space shuttle flight, and this was a winning entry. (M 33787)

\section{(6664) Tennyo}

1993 CK. Discovered 1993 Feb. 14 by T. Kobayashi at Oizumi.

A maiden who dances in the heavens scattering flowers, playing music and perfuming the atmosphere, this angelic figure can be seen in Buddhist sculptures and paintings traditionally found all over Japan. During astronaut Chiaki Mukai's \{see planet (4750)\} first space shuttle flight, she cummunicated by radio with junior high school students in Tatebayashi \{see planet (6663)\}. In the radio exchange, one of the students asked how it felt to be in space. She answered, "It feels like I have become a 'tennyo' and am flying." The word became famous all over Japan as another name for Mukai. This naming was also a winning entry in the Exploratorium "star" naming competition. (M 33787)

\section{(6666) Frö}

$1993 \mathrm{FG}_{20}$. Discovered 1993 Mar. 19 by the UppsalaESO Survey at La Silla.

Frö, son of Njord \{see planet (4213)\}, was the fertility god in the old Nordic religion. He was also the god of peace, good crops and marriage. According to the old tales he had the largest ship in the world, Skidbladner, 
able to sail both on land and sea. His holy animal was the pig, playing a central role in this religion. In the Nordic countries we still can see some remains of the worship to Frö. The Midsummer pole may have originated as a tribute to Frö. His sister Fröja \{see planet (76)\}, tremendously beautiful, who drove a carriage pulled by cats. (M 30100)

\section{(6667) Sannaimura}

$1994 \mathrm{EK}_{2}$. Discovered 1994 Mar. 14 by Y. Kushida and O. Muramatsu at Yatsugatake.

Sannaimura is a village in southern Akita prefecture in Japan. Sannai means 'in the mountains' and mura means 'village'. This beautiful village has many hot springs, and the Yatsugatake \{see planet (4033)\} South Base Observatory is located there. (M 44593)

\section{(6669) Obi}

$1994 \mathrm{JA}_{1}$. Discovered 1994 May 5 by K. Endate and K. Watanabe at Kitami.

Named in honor of Shinya Obi (1925- ), professor emeritus of the University of Tokyo. In addition to his numerous research papers, he has published many popular astronomy books. He has just retired of the University of the Air, which educates via communication satellites. (M 31610)

Name proposed by the discoverers following a suggestion by A. Fujii and A. Abe.

\section{(6670) Wallach}

$1994 \mathrm{LL}_{1}$. Discovered 1994 June 4 by C. S. Shoemaker and D. H. Levy at Palomar.

Named for Annette and Leonard Wallach, in honor of their monumental effort in building Treasure Island, a unique day camp and school on Long Island, N.Y. More than a day camp, the facilities were donated to the American Red Cross each year for a small craft and safety school. (M 30477)

Citation and name suggested by Wendee and David Levy.

\section{(6672) Corot}

1213 T-1. Discovered 1971 Mar. 24 by C. J. van Houten and I. van Houten-Groeneveld at Palomar.

Named for the French painter and etcher Camille Corot (1796-1875). In his early years his style was classicistic, and he painted especially fine landscapes in the style of Claude Lorrain and Nicolas Poussin. Later, through his treatment of the light in his paintings, Corot became a forerunner of impressionism. (M 27331)

\section{(6673) Degas}

2246 T-1. Discovered 1971 Mar. 25 by C. J. van Houten and I. van Houten-Groeneveld at Palomar.

Named for the French painter and sculptor Edgar Degas (1834-1917). His early paintings and sculptures were influenced by Ingres and Japanese woodcuts. Following his acquaintance with Edouard Manet, he changed to the impressionistic style. Beginning around 1900 he modeled about 70 statuettes of women, dancers and horses, and these were cast in bronze after his death. (M 26932)

\section{(6674) Cézanne}

4272 T-1. Discovered 1971 Mar. 26 by C. J. van Houten and I. van Houten-Groeneveld at Palomar.

Named for the French impressionist Paul Cézanne (1839-1906). Cézanne was self-taught and influenced by the baroque and romantic styles. Later he came in contact with Pissarro and became an impressionist. At the end of his life he was the forerunner of expressionism, cubism and fauvism. (M 26932)

\section{(6675) Sisley}

1493 T-2. Discovered 1973 Sept. 29 by C. J. van Houten and I. van Houten-Groeneveld at Palomar.

Named for the French impressionist painter Alfred Sisley (1839-1899). He was influenced by Monet and Renoir \{see planets (6676) and (6677)\}. Most of his paintings are landscapes in wonderful gleaming colors. (M 26932)

\section{(6676) Monet}

2083 T-2. Discovered 1973 Sept. 29 by C. J. van Houten and I. van Houten-Groeneveld at Palomar.

Named for the French impressionist painter Claude Monet (1840-1926). He became acquainted with the navy painter Eugéne Boudin, who encouraged him to paint directly in natural surroundings, rather than to make a sketch in the open air and to paint it later in the studio. Monet, Manet and the other impressionist painters influenced each other strongly. (M 26932)

\section{(6677) Renoir}

3045 T-3. Discovered 1977 Oct. 16 by C. J. van Houten and I. van Houten-Groeneveld at Palomar.

Named for the French impressionist painter Pierre Auguste Renoir (1841-1919). He had a great influence on the other impressionist painters. Renoir's great paintings show people in natural surroundings and in wonderful colors. (M 26932)

\section{(6678) Seurat}

3422 T-3. Discovered 1977 Oct. 16 by C. J. van Houten and I. van Houten-Groeneveld at Palomar.

Named for the French impressionist painter Georges Seurat (1859-1891). Together with his friend, the painter Signac \{see planet (8239)\}, Seurat invented the pointillistic style. (M 26932)

\section{(6681) Prokopovich}

1972 RU $_{3}$. Discovered 1972 Sept. 6 by L. V. Zhuravleva at Nauchnyj.

Named in memory of Feofan Prokopovich (16811736), Ukrainian and Russian writer, archbishop and associate of Peter the Great. (M 34624)

\section{(6682) Makarij}

$1973 \mathrm{ST}_{3}$. Discovered 1973 Sept. 25 by L. V. Zhuravleva at Nauchnyj.

Named in memory of Metropolitan Makarij (14821563), who had great influence on education, the church 
and politics in Russia. He promoted the creation of the first Russian printing-house and led a circle of educated booklovers. (M 34624)

\section{(6683) Karachentsov}

1976 GQ $_{2}$. Discovered 1976 Apr. 1 by N. S. Chernykh at Nauchnyj.

Nikolaj Petrovich Karachentsov is an actor and singer at the Moscow Lenkom Theatre. As one review said, "He has a remarkable sense of rhythm and an exceptional voice, captivating audiences with his songs". (M 38195)

\section{(6684) Volodshevchenko}

1977 QU. Discovered 1977 Aug. 19 by N. S. Chernykh at Nauchnyj.

Vladimir Nikitovich Shevchenko (1929-1987) was a Ukrainian film producer best known for his film about the Chernobyl' disaster. A special prize in his memory was founded in Italy, awarded for films on the challenges of peace and the protection of the environment. (M 38195)

\section{(6685) Boitsov}

1978 QG $_{2}$. Discovered 1978 Aug. 31 by N. S. Chernykh at Nauchnyj.

Named in memory of Vasilij Vasil'evich Boitsov (Bojtsov, 1908-1997), specialist on the technology of mechanical engineering and standardization. From 1963 to 1984 he headed the U.S.S.R. State Committee for standards and represented his country in the International Organization for Standardization, of which he served as president (1977-1979). Boitsov was an initiator and active participant in fundamental research on the creation of standard measurement systems. (M 31296)

Name suggsted by the Institute of Theoretical Astronomy and supported by the discoverer.

\section{(6686) Hernius}

1979 QC $_{2}$. Discovered 1979 Aug. 22 by C.-I. Lagerkvist at La Silla.

Named in honor of Olof Hernius, who participated in the Uppsala-ESO Survey of Asteroids and Comets (UESAC) as an undergraduate student. (M 26932)

\section{(6687) Lahulla}

$1980 \mathrm{FN}_{1}$. Discovered 1980 Mar. 16 by C.-I. Lagerkvist at La Silla.

Named in honor of José Felix Lahulla, astronomer at the Observatorio Astronómico de Madrid. Lahulla has participated in photometric surveys of Hilda asteroids from Calar Alto, La Palma and ESO. (M 27129)

\section{(6690) Messick}

$1981 \mathrm{SY}_{1}$. Discovered 1981 Sept. 25 by B. A. Skiff at Anderson Mesa.

Hank H. Messick (1955- ) first taught the discoverer the constellations. (M 36126)

\section{(6695) Barrettduff}

1986 PD $_{1}$. Discovered 1986 Aug. 1 by E. F. Helin at Palomar.

Barrett Duff (1923- ) coordinated the formation of the nonprofit, educational outreach organization Telescopes in Education (TIE) Foundation. His efforts were critical to the successful development of the TIE Foundation. (M 47163)

\section{(6696) Eubanks}

$1986 \mathrm{RC}_{1}$. Discovered 1986 Sept. 1 at the Oak Ridge Observatory at Harvard.

Named in honor of Marshall Eubanks of the U.S. Naval Observatory. His contributions to astrometry and geodesy, through his development and imaginative use of the navy radio interferometry network and through his astute analyses of data relating to the earth's rotation and polar motion, have resulted in new insights on the causes of those complex phenomena. (M 26767)

Name proposed by I. I. Shapiro.

\section{(6697) Celentano}

$1987 \mathrm{HM}_{1}$. Discovered 1987 Apr. 24 by Z. Vávrová at Klě́.

Named in honor of Adriano Celentano (1938- ), Italian singer and film actor. (M 33787)

\section{(6698) Malhotra}

1987 SL $_{1}$. Discovered 1987 Sept. 21 by E. Bowell at Anderson Mesa.

Named in honor of Renu Malhotra (1961- ), accomplished dynamicist and celestial mechanician at the Lunar and Planetary Institute in Houston. Born and raised in India, she has made major contributions to our understanding of how resonances affect satellite systems, the asteroid belt, and particularly Pluto. Malhotra was awarded the Harold C. Urey Prize by the Division for Planetary Sciences of the American Astronomical Society in 1997. Her talents and good spirits are much enjoyed by her colleagues. (M 31025)

Name proposed by the discoverer following a suggestion by S. A. Stern, who also wrote the citation.

\section{(6699) Igaueno}

1987 YK. Discovered 1987 Dec. 19 by T. Seki at Geisei.

Named for a small town in Mie prefecture. A branch of the Oriental Astronomical Association was inaugurated there around the time this minor planet was discovered. (M 32094)

\section{(6700) Kubišová}

1988 AO $_{1}$. Discovered 1988 Jan. 12 by Z. Vávrová at Klě́.

Named in honor of Marta Kubišová (1942- ), Czech singer. (M 33787; M 34089)

\section{(6701) Warhol}

1988 AW $_{1}$. Discovered 1988 Jan. 14 by A. Mrkos at Kleť. 
The American painter and film-maker Andy Warhol (Andrew Warhola, 1928-1987) was a leader of the Pop Art movement. In the 1960s he attracted attention with exhibition of prints of startlingly ordinary images. Warhol worked also on experimental underground films. (M 36945)

\section{(6707) Shigeru}

$1988 \mathrm{VZ}_{3}$. Discovered 1988 Nov. 13 by M. Yanai and K. Watanabe at Kitami.

Named in honor of Shigeru Nakano (1918- ), doctor of medicine specializing in obstetrics and gynecology and in medical jurisprudence. An amateur astronomer, he has published many observational guidebooks and star atlases, including the most detailed one in Japan. (M 31610)

Name proposed by the discoverers following a suggestion by A. Fujii and T. Sato.

\section{(6708) Bobbievaile}

1989 AA $_{5}$. Discovered 1989 Jan. 4 by R. H. McNaught at Siding Spring.

Named in memory of Roberta (Bobbie) Vaile (19591996), lecturer in physics at the University of Western Sydney. Bobbie Vaile excelled in communicating the beauty and complexity of science to students and to the wider community. The SETI Australia Centre was founded at the UWS as a result of Bobbie's participation in the Search for Extraterrestrial Intelligence and her innovative use of SETI for teaching science. A profound faith sustained her during the achievements of her last seven years, while a brain tumor took its toll. To many colleagues and students Bobbie was a uniquely understanding and close friend, and she remains an inspiration. (M 29671)

Name proposed by P. Cass and the discoverer, citation prepared by J. Caswell.

\section{(6710) Apostel}

$1989 \mathrm{GF}_{4}$. Discovered 1989 Apr. 3 by E. W. Elst at La Silla.

Named in memory of the well-known Flemish philosopher Leo Apostel (1925-1995). He was a pupil of Chaim Perelman (Brussels), Jean Piaget (Geneva) and Rudolf Carnap (Chicago). In 1956-57 he joined the universities of Brussels and Ghent, teaching logic and epistemology there for many years. In 1990 he established the independent interdisciplinary investigation center, Worldviews, in which the discoverer has been asked to guide the group "cosmology". (M 27129)

\section{(6711) Holliman}

1989 HG. Discovered 1989 Apr. 30 by E. F. Helin at Palomar.

Named in memory of John Holliman (1948-1998), a national correspondent for CNN, the U.S. Cable News Network. Holliman reported extensively on the role of the Jet Propulsion Laboratory in space exploration. Specifically, he served as the network's lead reporter for the Pathfinder mission to Mars, anchoring CNN's continous coverage of the landing and mission as the spacecraft beamed live video of the planet's surface. Holliman possessed a special ability to make the complex and complicated process of space exploration understandable and accessible to his viewers. (M 32788)

\section{(6712) Hornstein}

$1990 \mathrm{DS}_{1}$. Discovered 1990 Feb. 23 by A. Mrkos at Klě́t.

Karl Hornstein (1824-1882), the eighth director of the Klementinum observatory in Prague, studied the orbits of minor planets, including the irregularities in their distribution that were later called the Kirkwood \{see planet (1578)\} gaps. (M 42356)

The name was suggested by J. Tichá and M. Šolc.

\section{(6714) Montréal}

$1990 \mathrm{OE}_{2}$. Discovered 1990 July 29 by H. E. Holt at Palomar.

Host city for the IAU General Assembly in 1979, Montreal has combined the best of English and French cultures since its founding in 1642. The city has a rich astronomical tradition, as can be seen in several outdoor works of art that emphasize the city's connection to the stars. (M 42356)

\section{(6715) Sheldonmarks}

$1990 \mathrm{QS}_{1}$. Discovered 1990 Aug. 22 by H. E. Holt and D. H. Levy at Palomar.

Sheldon Marks (1956- ) is a world-renowned urologist and surgeon whose book Prostate and Cancer has helped thousands of men with serious prostategland problems. His surgery has saved and extended many lives. His eclectic interest in science includes assisting in the search for comets and asteroids. (M 43042)

\section{(6717) Antal}

1990 TU $_{10}$. Discovered 1990 Oct. 10 by F. Börngen and L. D. Schmadel at Tautenburg.

Named in honor of the Slovak astronomer Milan Antal \{1935-1999\}, on the staff of the observatories at Skalnaté Pleso \{see planet (2619)\} and Hurbanovo for over 38 years. Known as an excellent observer of comets and minor planets, Antal determined accurate photographic astrometric positions by the thousand. In 1973 he observed two outbursts of comet 41P/TuttleGiacobini-Kresák. Six of his minor planet discoveries have been numbered so far. He is a founder member and vice president of the General Štefánik Society, founded in 1989 in honor of Milan Rastislav Štefánik (18801919), some time assistant at the Meudon Observatory. (M 26767)

Name proposed by the first discoverer.

Obituary published in Int. Comet Q., Vol. 23, No. 2, p. 41 (2001)

\section{(6718) Beiglböck}

1990 TT $_{12}$. Discovered 1990 Oct. 14 by L. D. Schmadel and F. Börngen at Tautenburg.

Named in honor of Wolf D. Beiglböck (1939- ), German mathematician and professor at the University 
of Heidelberg. His main research as a mathematical physicist ranges from the theory of Lie groups and harmonic analysis to a discussion of the equations of motion of extended bodies in the framework of Einstein's gravitation theory. For 30 years, Beiglböck has served as scientific advisor to Springer-Verlag in Heidelberg. He is the founder and co-editor of the well-known series "Lecture Notes in Physics" and "Texts and Monographs in Physics". His persistent support made it possible to realize the publication of the Dictionary of Minor Planet Names. (M 33386)

Name proposed and citation prepared by the first discoverer.

\section{(6719) Gallaj}

1990 UL $_{11}$. Discovered 1990 Oct. 16 by L. V. Zhuravleva and G. R. Kastel' at Nauchnyj.

Named in honor of Mark Lazarevich Gallaj (1914-

), a distinguished Soviet test pilot who tested 125 types of aircraft and helicopter. He pioneered in testing rocket technology and was one of the first to succeed in gaining insight into the flutter phenomenon that emerges when aircraft travel near Mach 1. Gallaj participated in training the first generation of Soviet cosmonauts and is the author of excellent books on aviation and the conquest of space. (M 26767)

Name proposed by G. R. Kastel'.

\section{(6720) Gifu}

$1990 \mathrm{VP}_{2}$. Discovered 1990 Nov. 11 by T. Seki at Geisei.

Named for the city of 400,000 , capital of the prefecture of the same name, site of ancient battlefields and a modern public observatory. (M 32094)

\section{(6722) Bunichi}

$1991 \mathrm{BG}_{2}$. Discovered 1991 Jan. 23 by K. Endate and K. Watanabe at Kitami.

Named in honor of Bunichi Saito (1925- ), professor emeritus at Niigata University and an expert on the earth's upper atmosphere, particularly the airglow. He is also an authority on the poet and novelist Kenji Miyazawa see planet (5008) and currently directs the museum at the Kenji Miyazawa Iihatobu Center. (M 31610)

Name proposed by the discoverers following a suggestion by A. Fujii and Y. Yoneda.

\section{(6723) Chrisclark}

$1991 \mathrm{CL}_{3}$. Discovered 1991 Feb. 14 by E. F. Helin at Palomar.

Named in honor of Christopher C. Clark, an electrooptical engineer at the Jet Propulsion Laboratory who designed and assembled the Near-Earth Asteroid Tracking camera system. This NEAT camera contains a large-format CCD sensor that provides digital image data, allowing for computer-automated data analysis and Near-Earth Object discoveries. He used his expertise in the development, integration and testing of focal plane arrays to make NEAT a success. (M 26932)

\section{(6729) Emiko}

$1991 \mathrm{VV}_{2}$. Discovered 1991 Nov. 4 by S. Otomo at Kiyosato.

Named in honor of Emiko Otomo (1963- ), wife of the discoverer. (M 35484)

\section{(6730) Ikeda}

1992 BH. Discovered 1992 Jan. 24 by T. Urata at Oohira.

Named in honor of Tetsuro Ikeda (1894-1981), the third director of the International Latitude Observatory of Mizusawa \{see planet (7530)\}. During his tenure (1943-1963) he established a measurement system for understanding meteorological effects on observations of the variation of latitude. (M 34624)

Name proposed by the discoverer following a suggestion by K. Hurukawa. Citation prepared by K. Yokoyama.

\section{(6731) Hiei}

1992 BK. Discovered 1992 Jan. 24 by Y. Kushida and O. Muramatsu at Yatsugatake.

Named in honor of Eijiro Hiei (1931- ), professor at Meisei University and professor emeritus of the National Astronomical Observatory of Japan. A solar physicist best known for his research on white-light flares, Hiei was the fourth director (1982-1992) of the Norikura Solar Observatory, where he conducted coronagraphic studies. (M 28090)

Name proposed by the discoverers following a suggestion by T. Sakurai.

\section{(6735) Madhatter}

$1992 \mathrm{WM}_{3}$. Discovered 1992 Nov. 23 by T. Urata at Oohira.

The Mad Hatter was a character who appears in various places in Lewis Carroll's \{see planet (6984)\} classic story Alice's adventures in Wonderland. (M 41935)

The citation was prepared by D. J. Asher.

\section{(6736) Marchare}

1993 EF. Discovered 1993 Mar. 1 by T. Urata at Oohira.

A minor planet discovered in March can appropriately be named for the March Hare, a character in Lewis Carroll's \{see planet (6984)\} Alice's adventures in Wonderland. Alice sees him and the Mad Hatter \{see planet (6735)\} at 'A Mad Tea-Party', where they are talking to each other while leaning on a dormouse sleeping between them. (M 41935)

\section{(6737) Okabayashi}

1993 ER. Discovered 1993 Mar. 15 by K. Endate and K. Watanabe at Kitami.

Named in memory of Shigeki Okabayashi (19131944), a self-taught Japanese astronomer. The first 
in Japan to discover more than one kind of new celestial object, he discovered Nova V630 Sgr in 1936 and comet C/1940 S1 (Okabayashi-Honda), and also independently discovered C/1939 H1 and C/1939 V1. He was employed by Kurashiki Observatory from 1939 to 1941. Tragically, he was killed on his way home from a geological survey in Sumatra when his hospital ship was torpedoed. (M 31610)

Name proposed by the discoverers following a suggestion by T. Sato and A. Fujii.

\section{(6738) Tanabe}

$1993 \mathrm{FD}_{1}$. Discovered 1993 Mar. 20 by K. Endate and K. Watanabe at Kitami.

Named in honor of Hiroyoshi Tanabe (1928- ), astronomer at the National Astronomical Observatory (formerly known as the Tokyo Astronomical Observatory) during 1953-1989. Tanabe's research fields is the light of the night sky. He made extensive ground-based observations of the gegenschein, the first rocket observation of the inner zodiacal light and outer corona, and he estimated the background light by making star counts in various regions of the sky. He made regular airglow observations for 33 years, Tanabe served as president of IAU Commission 21 during 1979-1982 and was an officer of the Astronomical Society of Japan for many years. (M 32094)

\section{(6739) Tärendö}

$1993 \mathrm{FU}_{38}$. Discovered 1993 Mar. 19 by the UppsalaESO Survey at La Silla.

Archaeological remains show that Tärendö, a small community just north of the Arctic Circle in the Swedish province of Norrbotten, has been populated since the Stone Age. In its wooded surroundings, annual midsummer festivities draw thousands of visitors, who celebrate joie de vivre. (M 36127)

\section{(6740) Goff}

1993 GY. Discovered 1993 Apr. 14 by C. S. Shoemaker and E. M. Shoemaker at Palomar.

Named in honor of Robert and Valerie Goff, of Tucson, Arizona. One of the finest masters of optics in the world, Bob Goff makes mirrors that are used in research and educational institutions worldwide. The Goffs are active in trying to increase a public interest in the sky, both through observing sessions and through the manufacture of good optics. (M 30100)

Name proposed by the discoverers following a suggestion by D. H. Levy, who prepared the citation.

\section{(6741) Liyuan}

1994 FX. Discovered 1994 Mar. 31 by K. Endate and K. Watanabe at Kitami.

Named in honor of Li Yuan (1925- ), popularizer of astronomy in the People's Republic of China. He played an important role in the opening of Beijing Planetarium in 1957 and served as a leader of planetarium activities in China. He has published more than 50 books on science, including astronomy, and has frequently contributed to domestic and foreign publications. (M 31611)

Name proposed by the discoverers following a suggestion by A. Fujii, H. Tomioka and Y. Shiono.

\section{(6742) Biandepei}

1994 GR. Discovered 1994 Apr. 8 by K. Endate and K. Watanabe at Kitami.

Named in honor of Bian Depei (1926- ), popularizer of science and astronomy in the People's Republic of China. He has published more than 60 books, many winning national prizes, and nearly 800 articles. He played an important role in establishing the Beijing Planetarium in 1954 and launching Amateur Astronomer magazine in 1958, both the first of their kind in China. (M 31611)

Name proposed by the discoverers following a suggestion by A. Fujii and T. Sato.

\section{(6743) Liu}

1994 GS. Discovered 1994 Apr. 8 by K. Endate and K. Watanabe at Kitami.

Named in honor of Joseph H. C. Liu (1931- ) , who played a leading role in establishing the Hong Kong Space Museum and who became its first chief curator. In 1982 he received the Chiro Astronomical Award in Japan, and in 1984 he became a member of the Most Excellent Order of the British Empire, both for his promotion of popular astronomy in Hong Kong. Well known as an astrophotographer, he now lives in California. (M 31611)

Name proposed by the discoverers following a suggestion by A. Fujii and T. Sato

\section{(6744) Komoda}

1994 JL. Discovered 1994 May 6 by K. Endate and K. Watanabe at Kitami.

Named in memory of Kazuyoshi Komoda (1915-1967), amateur astronomer in Japan. Though handicapped by poliomyelitis, he enthusiastically observed Jupiter from 1944 to 1961. (M 31611)

Name proposed by the discoverers following a suggestion by T. Sato, I. Hirabayashi and A. Fujii.

\section{(6745) Nishiyama}

$1994 \mathrm{JD}_{1}$. Discovered 1994 May 7 by K. Endate and K. Watanabe at Kitami.

Named in honor of Minewo Nishiyama (1925- ), amateur astronomer and president of the Chikushi Astronomical Association \{see also planet (6237)\} from 1944 to 1947 . Beginning in 1944 and under the direction of H. Hirose \{see planet (1612)\}, Nishiyama was the first amateur in Japan to make orbital calculations on minor planets. More recently he has studied the astronomical histories of Asian countries, particularly the old Burmese constellations. (M 32094)

Name proposed by the discoverers following a suggestion from $\mathrm{H}$. Oishi. 
(6746) Zagar

1994 NP. Discovered 1994 July 9 at the Osservatorio San Vittore at Bologna.

Named in memory of Francesco Zagar (1900-1976), professor of astronomy at the University of Milan and director of the Brera Astronomical Observatory, president of IAU Commission 31 (1967-1970) and of the Italian Astronomical Society. A lover of theoretical astronomy, Zagar studied the problem of three bodies, the orbit of Pluto, stellar statistics, stellar dynamics and cosmogony. His book Astronomia Sferica e Teorica is still widely studied and was recently reprinted. (M 27331)

\section{(6748) Bratton}

$1995 \mathrm{UV}_{30}$. Discovered 1995 Oct. 20 by the Spacewatch at Kitt Peak.

Named in honor of Durley H. Bratton (1923- ), who has been a mentor and inspiration for amateur astronomers and telescope makers in the Memphis, Tennessee, area since the late 1960s. An electronics technician by profession, he became a highly skilled optical craftsman, constructing or advising in the construction of many telescopes. His designs often involved remarkable resourcefulness and ingenuity, such as using borosilicate glass cut from old color television picture-tube faceplates as $\mathrm{f} / 2$ Schmidt camera primary mirror blanks. (M 33787)

Name suggested and citation by R. Tucker.

\section{(6749) Ireentje}

7068 P-L. Discovered 1960 Oct. 17 by C. J. van Houten and I. van Houten-Groeneveld at Palomar.

Named in honor of the discoverers' second granddaughter, Irene Cornelia Francisca van Houten, daughter of Karel and Thea van Houten. (M 26933)

\section{(6750) Katgert}

1078 T-1. Discovered 1971 Mar. 24 by C. J. van Houten and I. van Houten-Groeneveld at Palomar.

Named in honor of Peter Katgert (1944- ), astronomer at the Leiden Observatory, and his wife, Leiden astronomer Jet Katgert-Merkelijn (1943- ). Peter's main research interests are the statistics of radio sources and also the formation and dynamics of clusters of galaxies. Jet is now working on the archive of J. H. Oort \{see planet (1691)\}. (M 26933)

\section{(6751) van Genderen}

1114 T-1. Discovered 1971 Mar. 25 by C. J. van Houten and I. van Houten-Groeneveld at Palomar.

Named in honor of Arnout van Genderen (1936- ), astronomer at the Leiden Observatory, whose main interest is photometry of $\eta$ Carinae, eclipsing variable stars, VBLUW photometry of OB stars and the photometric variability of hypergiants. (M 26933)

\section{(6752) Ashley}

4150 T-1. Discovered 1971 Mar. 26 by C. J. van Houten and I. van Houten-Groeneveld at Palomar.
Named in honor of Ashley Thomas McDermott, professor of astronomy at the College of the Desert, Palm Desert, California, for the past 34 years. During this time he has taught astronomy to well over 10,000 students with his own special wisdom, love, enthusiasm and humor for the subject. He has also contributed many years of valuable service to the Riverside Telescope Makers' Conference, the Astronomical Society of the Pacific, the Western Amateur Astronomers and the History of Astronomy Society. He founded the Astronomical Society of the Desert and the Andromeda Astronomical Society. (M 27331)

Name proposed by T. Gehrels, following a suggestion by J. R. Crisman, who wrote the citation.

\section{(6753) Fursenko}

1974 RV $_{1}$. Discovered 1974 Sept. 14 by N. S. Chernykh at Nauchnyj.

Named in honor of Margarita Aleksandrovna Fursenko (1931- ), staff member of the Institute of Theoretical Astronomy during 1955-1997 and a well-known expert on ephemeris astronomy. She made major contribution to the calculation and publication of 40 volumes of the annual Astronomicheskij Ezhegodnik, as well as to the development of special ephemerides for space missions, lunar laser ranging and radioastronomical observations with RATAN-600. (M 31296)

Name suggested by ITA and supported by the discoverer.

\section{(6754) Burdenko}

1976 UD $_{4}$. Discovered 1976 Oct. 28 by L. V. Zhuravleva at Nauchnyj.

Named in memory of Nikolaj Nilovich Burdenko (1876-1946), one of the founders of neurosurgery in the U.S.S.R. and from 1944 the first president of the Academy of Medical Sciences. (M 34624)

\section{(6755) Solov'yanenko}

$1976 \mathrm{YE}_{1}$. Discovered 1976 Dec. 16 by L. I. Chernykh at Nauchnyj.

Anatolij Borisovich Solov'yanenko (1932-1999) was a Ukrainian singer and People's Artist of the former U.S.S.R. (M 38195)

\section{(6758) Jesseowens}

1980 GL. Discovered 1980 Apr. 13 by A. Mrkos at Kleť.

Named in memory of the American athlete James Cleveland (Jesse) Owens (1913-1980), one of the finest track-and-field competitors in history. In the space of 45 minutes on 1935 May 26, Owens equalled the world record for the 100-yard dash and set new world records for the 220-yard dash, the 220-yard low hurdles and the long jump. At the 1936 Olympics he won four gold medals, equalling or setting new records in every event. (M 27735) 
Name suggested by G. V. Williams, who made the identifications involving this object.

\section{(6763) Kochiny}

$1981 \mathrm{RA}_{2}$. Discovered 1981 Sept. 7 by L. G. Karachkina at Nauchnyj.

Named for Nikolaj Evgrafovich Kochin (1901-1944) and his wife Pelageya Yakovlevna Kochina (1899- ), both academicians and professors of mathematics. One of the founders of modern dynamical meteorology, N. E. Kochin made great contributions to various branches of aerodynamics, hydrodynamics and theoretical meteorology. The scientific interests of P. Y. Kochina have been in subterranean hydrodynamics; she is also the author of biographies of Kochin, Kovalevskaya \{see planet (1859)\}, Weierstrass and Mittag-Leffler. (M 27331; M 30309)

Name proposed by A. A. Kapitsa.

\section{(6764) Kirillavrov}

$1981 \mathrm{TM}_{3}$. Discovered 1981 Oct. 7 by L. I. Chernykh at Nauchnyj.

Kirill Yur'evich Lavrov (1925- ) is a prominent Russian actor and public figure, People's Artist of the former U.S.S.R. and laureate of the Lenin and State Prizes. He was an actor at the Bolshoi Dramatic Theatre in St. Petersburg from 1955 and artistic adviser since 1989. (M 38195)

\section{(6765) Fibonacci}

1982 BQ . Discovered 1982 Jan. 20 by L. Brožek at Klě̆.

Named in memory of Leonardo Fibonacci of Pisa (c. 1170-1240), the first "western" mathematician, whose Liber abaci (1202) contains the earliest mention of the famous sequence of numbers that bears his name. The number of this minor planet is the twentieth in that sequence, the first five members of which are $1,1,2,3$ and 5 , and every fifth member of which is divisible by five. (M 26767)

Name proposed following a suggestion by B. G. Marsden.

\section{(6766) Kharms}

1982 UC $_{6}$. Discovered 1982 Oct. 20 by L. G. Karachkina at Nauchnyj.

Named in honor of the outstanding Russian poet, writer and dramatist Daniil Ivanovich Yuvachev (19051942), whose pen-name is Kharms. He was one of the founders of the literary school known in twentiethcentury European literature as "absurd". (M 27129)

Name suggested by L. R. Nemirovskij.

\section{(6767) Shirvindt}

$1983 \mathrm{AA}_{3}$. Discovered 1983 Jan. 6 by L. G. Karachkina at Nauchnyj.

Named in honor of the remarkable actor, People's Artist of Russia and professor at the Shchukin Theatre Institute in Moscow, Aleksandr Anatol'evich Shirvindt (1934- ). He is one of the founders of the International
Festival of Satire and Humor "Golden Ostap" and the first president of the "Academy of Authorities" (Academy of Humor). (M 27129)

Name suggested and citation prepared by L. R. Nemirovskij.

\section{(6768) Mathiasbraun}

1983 RY. Discovered 1983 Sept. 7 by A. Mrkos at Klet.

Mathias (Matyáš) Bernard Braun (1684-1738) was the most prominent sculptor of the Baroque period in Bohemia. His well-known works are allegories of virtues and vices at the Kuks Castle. (M 40701)

The name was suggested by J. Tichá and M. Tichý.

\section{(6769) Brokoff}

1985 CJ $_{1}$. Discovered 1985 Feb. 15 by A. Mrkos at Kleť.

Father and son, Jan (1652-1718) and Ferdinand Maxmilian (1688-1731) Brokoff were prominent sculptors of the Baroque period in Bohemia. Their well known works include some of the statues on the Charles Bridge in Prague. (M 40702)

The name was suggested by J. Tichá and M. Tichý.

\section{(6770) Fugate}

1985 QR. Discovered 1985 Aug. 22 by E. Bowell at Anderson Mesa.

Named in honor of Robert Q. Fugate (1943- ), of the U.S. Air Force's Starfire Optical Range (SOR), near Albuquerque. Under Fugate's leadership, the SOR has developed and operates the most advanced adaptive optics system worldwide. Fugate performed the first experiment to demonstrate the feasibility of using laser beacons for adaptive optics. He has chaired many committees and received numerous awards, including the 1997 Distinguished Civilian Award, the highest given to a civilian by the U.S. Department of Defense. (M 31025)

Named by the discoverer following a suggestion by J. D. Drummong, who prepared the citation.

\section{(6771) Foerster}

$1986 \mathrm{EZ}_{4}$. Discovered 1986 Mar. 9 by C.-I. Lagerkvist at Siding Spring.

Named in honor of Wilhelm Julius Foerster (18321921), director of the Berlin Observatory for nearly 40 years. He made measurements of star positions and in 1860 was a codiscoverer of (62) Erato. He was a strong campaigner for the organized rapid and reliable telegraphic dissemination of urgent astronomical news and arranged for the establishment of the Astronomische Zentralstelle in Kiel. In 1889 he founded the Berlin "Urania", the first large public observatory, equipped with a $0.30-\mathrm{m}$ refractor. This minor planet is being named on the occasion of the 50th anniversary of the "Wilhelm-Foerster-Sternwarte e.V.". (M 28090) Citation prepared in part by $\mathrm{W}$. Tost. 


\section{(6774) Vladheinrich}

$1988 \mathrm{VH}_{5}$. Discovered 1988 Nov. 4 by A. Mrkos at Klě̌.

Vladimír Václav Heinrich (1884-1965) was a Czech astronomer, professor and head of the Astronomical Institute of Charles University in Prague from 1919 to 1934. He studied celestial mechanics, and some of his works dealt with Hecuba and Trojan motion. (M 40702)

The name was suggested by J. Tichá.

\section{(6775) Giorgini}

1989 GJ. Discovered 1989 Apr. 5 by E. F. Helin at Palomar.

Named in honor of Jon D. Giorgini, who has contributed significantly to radar astronomy of minor planets through his development of an On-Site Orbit Determination software system. This allows radar astrometric measurements to be used immediately to improve a target's orbit, and hence yields ephemerides for pointing, time delay and doppler frequency. Since the system became operational at Goldstone s see planet (4433)\} in 1993, there has been an order-of-magnitude improvement in the efficiency with which radar observations can progress. In particular, Giorgini's software was key to the success of the radar imaging of (1620) Geographos in Aug. 1994 and (6489) Golevka in June 1995. (M 26933)

Citation prepared by D. K. Yeomans and S. J. Ostro.

\section{(6776) Dix}

$1989 \mathrm{GF}_{8}$. Discovered 1989 Apr. 6 by F. Börngen at Tautenburg.

Named for the painter and graphic artist Otto Dix (1891-1969), born in the Thuringian town of Gera-Untermhaus. He was a representative of the new functionalism and is ranked with the great critical realists of the twentieth century. His pictures of the horrors of war are shocking and deeply moving. Dix was a member of the Prussian academy of arts and a master of the academy of arts in Dresden until he was dismissed by the Nazis in 1933. He was then outlawed as a "degenerate" artist, and 260 of his works were confiscated. (M 27129)

\section{(6777) Balakirev}

1989 SV $_{1}$. Discovered 1989 Sept. 26 by E. W. Elst at La Silla.

Named in memory of the famous Russian composer and pianist Milij Alekseevich Balakirev (1837-1910). With Borodin \{see planet (6780)\}, Kyui, Musorgskij and Rimskij-Korsakov \{see planets (1059) and (4534)\}, he formed a group known as "The Innovators". Although Balakirev started to study mathematics, he changed his field to music under the influence of the diplomat A. D. Ulybyshev. He was the ruling spirit of the group and its - sometimes dictatorial - teacher of composition. Balakirev composed two symphonies and many other pieces for orchestra and piano. His fantasy for piano
Islamei has become world-famous, and although he was himself a brilliant pianist, he admitted - with complete modesty - that there were certain passages in it that he couldn't manage. (M 26767)

\section{(6778) Tosamakoto}

1989 TX $_{10}$. Discovered 1989 Oct. 4 by A. Takahashi and K. Watanabe at Kitami.

Named in honor of Makoto Tosa (1944- ), a professor at Tohoku University, known for his research on galaxies. He has served as vice president of Astronomical Society of Japan and as a member of the advisory councils of both the National Astronomical Observatory and the Sendai Astronomical Observatory. He encourages and assists the activities of amateur astronomers in the Sendai Astronomical Society and the volunteer group "Utyu-sen" (Space Ship), which popularizes astronomy for children and laymen. (M 34624)

\section{(6779) Perrine}

$1990 \mathrm{DM}_{1}$. Discovered 1990 Feb. 20 by A. Mrkos at Klět.

Named in memory of Charles Dillon Perrine (18671951), American astronomer working at Lick Observatory from 1893, an enthusiastic observer, who discovered the satellites Jupiter VI (Himalia) and VII (Elara) and nine comets during 1895-1902. He was appointed director of the Córdoba Observatory in Argentina in 1909 and retired in 1936. The discoverer of this minor planet rediscovered Perrine's periodic comet, lost for six returns, visually at Lomnický Štít \{see planet (3168)\} in 1955. After 1968 the comet was again lost. (M 34624; M 34673; M 40877)

Name suggested by J. Tichá, who searched unsuccessfully for this comet, now known as 18D/Perrine-Mrkos, at Klet in 1995.

\section{(6780) Borodin}

$1990 \mathrm{ES}_{3}$. Discovered 1990 Mar. 2 by E. W. Elst at La Silla.

Named in memory of the famous Russian composer Alexandr Porfirevich Borodin (1833-1887). After studies in medicine and chemistry and a brief stay in the army as a doctor, he became a professor at the Medical Academy in St. Petersburg. But he was a musician at heart. He became acquainted with Balakirev ssee planet (6777)\}, to whom he owed his further musical education. Among his principal works are two symphonies, his well-known In the Steppes of Central Asia and several pieces for piano. His unfinished opera Prince Igor was completed by Glazunov and Rimskij-Korsakov \{see planet (4534)\}. (M 26767)

\section{(6783) Gulyaev}

$1990 \mathrm{SO}_{28}$. Discovered 1990 Sept. 24 by L. I. Chernykh at Nauchnyj.

Yurij Aleksandrovich Gulyaev (1930-1986) was a brilliant Russian singer, People's artist of the U.S.S.R., 
soloist of the Kiev Theatre of Opera and Ballet during 1960-1974 and soloist of the Bolshoj Theatre in Moscow from 1975. (M 42356)

\section{(6784) Bogatikov}

$1990 \mathrm{UN}_{13}$. Discovered 1990 Oct. 28 by L. I. Chernykh at Nauchnyj.

Yurij Iosifovich Bogatikov (1932- ) is a RussianUkrainian singer, People's artist of the U.S.S.R., soloist of the Crimean Philharmonic Society from 1975 and a performer of folk songs and vocal works by Soviet composers. (M 42356)

\section{(6786) Doudantsutsuji}

1991 DT. Discovered 1991 Feb. 21 by S. Inoda and T. Urata at Karasuyama.

Doudantsutsuji is the Japanese name for Enkianthus perulatus, an ericaceous deciduous shrub. Expressed in Kanji characters, the name also means "the stars of the whole sky". (M 36127)

\section{(6790) Pingouin}

$1991 \mathrm{SF}_{1}$. Discovered 1991 Sept. 28 by S. Otomo at Kiyosato

Named for an Arctic bird, similar to the penguin of Antarctica. The pingouin become extinct in Newfoundland in 1844. (M 35484)

\section{(6792) Akiyamatakashi}

1991 WC. Discovered 1991 Nov. 30 by M. Akiyama and T. Furuta at Mishima.

Named in honor of Takashi Akiyama (1923- ), a leader in youth education for many years in Kanaya, Shizuoka. Long interested in science, he taught the young people of this small town to appreciate the wonders of animals, plants, and especially the cosmos. He introduced the first discoverer to astronomy and taught him a great deal. (M 31611)

\section{(6793) Palazzolo}

1991 YE. Discovered 1991 Dec. 30 by U. Quadri and L. Strabla at Bassano Bresciano.

Named for the village of Palazzolo sull'Oglio, situated between Brescia and Bergamo and crossed by the river Oglio. The village is noted for its industries, including the first Italian factories for making cement and buttons. With a current population of 16,000 , Palazzolo is famous all over the world for its production of spinning machines and zippers. Discoveries of Roman relics attest to its very ancient origin. (M 26933)

\section{(6794) Masuisakura}

1992 DK. Discovered 1992 Feb. 26 by A. Sugie at Taga.

Sakura Masui (1968- ) is a Japanese novelist and essayist known for her books about business. She is also a lover of astronomy. (M 47163)
(6795) Örnsköldsvik

$1993 \mathrm{FZ}_{12}$. Discovered 1993 Mar. 17 by the Uppsala-ESO Survey at La Silla.

On the western coast of the Gulf of Bothnia in the Swedish province of Ångermanland, Örnsköldsvik is an important center dominated by forestry-related industry. It is the hometown of one of Sweden's most skillful ice-hockey teams, MoDo, where many world-famous players have their roots. (M 36127)

\section{(6796) Sundsvall}

$1993 \mathrm{FH}_{24}$. Discovered 1993 Mar. 21 by the UppsalaESO Survey at La Silla.

On the western coast of the Gulf of Bothnia, Sundsvall has developed from a center for trade to a center for the Swedish forestry industry. City privileges were granted in 1621 by king Gustav II Adolf, and the city was destroyed by Russian troops in 1721 . (M 36127)

\section{(6797) Östersund}

$1993 \mathrm{FG}_{25}$. Discovered 1993 Mar. 21 by the UppsalaESO Survey at La Silla.

The provincial capital of Jämtland in northern Sweden, Östersund is on the shores of lake Storsjön in which, legend says, there resides a large monster. Although sightings are claimed quite regularly, the monster of lake Storsjön, like that of Loch Ness, remains a mystery. (M 36127)

\section{(6798) Couperin}

$1993 \mathrm{JK}_{1}$. Discovered 1993 May 14 by E. W. Elst at La Silla.

Named for the French family that produced a succession of musicians from the early seventeenth to the mid-nineteenth century. Louis Couperin (16261661) was born in Chaumes and was the first of the many Couperins to become organist at the church of St. Gervais in Paris. His style was characterized by an almost aggressive use of dissonance and of baroque ornamentation. His nephew, François Couperin (16681733), often known as "Le Grand", is especially remembered for his keyboard pieces and for his somewhat ambiguous and obscure, theoretical work L'art de toucher le clavecin. François Couperin's chamber and church music is also very important, well-known examples being his two organ masses and the four volumes for the harpsichord. He was held in great esteem by J. S. Bach \{see planet (1814)\}. (M 26767)

\section{(6800) Saragamine}

1994 UC. Discovered 1994 Oct. 29 by A. Nakamura at Kuma.

Named for a mountain (height $1271 \mathrm{~m}$ ) located in the north of Kuma \{see planet (6255)\}, the town where this minor planet was discovered. Situated in a park, Mt. Saragamine is popular with campers and hikers. (M 26933) 


\section{(6801) Střekov}

$1995 \mathrm{UM}_{1}$. Discovered 1995 Oct. 22 by Z. Moravec at Klě̌.

Named for a castle situated near the town Ústí nad Labem in northern Bohemia. The castle, founded in 1318, towers above the river Labe on a steep rock $100-\mathrm{m}$ high and dominates the town. Thanks to its advantageous position, the castle was never conquered. Strekov is also the name of a district in the town, the discoverer's birthplace. (M 26933; M 34089)

\section{(6802) Černovice}

1995 UQ $_{2}$. Discovered 1995 Oct. 24 by M. Tichý at Klě́.

Named for the small town where the discoverer lived in his youth. Founded in the fourteenth century, Cernovice is situated amid the pleasant landscape of the Czech-Moravian Highlands in southern Bohemia. (M 27736)

Name dedicated to the parents of the discoverer.

\section{(6804) Maruseppu}

1995 WV. Discovered 1995 Nov. 16 by A. Nakamura at Kuma.

Named for a small town (population 2400) in eastern Hokkaido. Since 1994, Maruseppu has been promoting inter-town friendship with Kuma \{see planet (6255)\}, where this minor planet was discovered. (M 26933)

\section{(6805) Abstracta}

4600 P-L. Discovered 1960 Sept. 24 by C. J. van Houten and I. van Houten-Groeneveld at Palomar.

Named for the astronomical bibliography Astronomy and Astrophysics Abstracts. Founded in 1969, the AAA present a comprehensive documentation of all aspects of astronomy, astrophysics and related fields. The AAA are prepared under the auspices of the IAU by a special department of the Astronomisches Rechen-Institut, Heidelberg. The department, headed by Lutz D. Schmadel \{see planet (2234)\} for the last 20 years, has recorded, abstracted and indexed more than 500,000 documents. AAA is the direct successor of the Astronomischer Jahresbericht, which was founded in 1900. The AAA already amount to more than 60 volumes, occupying more than 3 meters of shelf space. (M 27331)

\section{(6806) Kaufmann}

6048 P-L. Discovered 1960 Sept. 24 by C. J. van Houten and I. van Houten-Groeneveld at Palomar.

Named in honor of Horst W. Kaufmann (1929-

), well-known German astronomical optician. After spending several years of optical apprenticeship with famous firms such as Fecker and Zeiss ssee planet (851)\}, Kaufmann founded his own company. He manufactured numerous telescope optics for observatories and institutes as well as for amateur astronomers. He produced several medium-sized systems for the Bonn and Heidelberg observatories and tackled very difficult light-weight infrared secondary mirrors for the $2.2-\mathrm{m}$ telescope of the Max-Planck-Institut for Astronomy and for UKIRT. (M 27331)

Name suggested and citation prepared by L.D.Schmadel.

\section{(6807) Brünnow}

6568 P-L. Discovered 1960 Sept. 24 by C. J. van Houten and I. van Houten-Groeneveld at Palomar.

Named in memory of Franz Friedrich Ernst Brünnow (1821-1891), who started his scientific career in Berlin. He continued as the director of the observatory at Bilk, near Düsseldorf, but in 1851 returned to Berlin to become the first assistant at the observatory. He worked on comets and minor planets and published a textbook on spherical astronomy. He later moved to the United States to take up the post of director of the new observatory at Ann Arbor. In 1865 he was appointed Royal Astronomer for Ireland. In that capacity he published in two parts his astronomical observations and researches made at Dunsink. (M 27736)

Name suggested by L. D. Schmadel and J. Schubart, citation prepared by J. Schubart.

\section{(6808) Plantin}

1932 CP. Discovered 1932 Feb. 5 by K. Reinmuth at Heidelberg.

Named in memory of Christophe Plantin (c.15201589), printer and founder of an important printing house in Antwerp. As a youth he learned the profession of bookbinder. In 1549 he settled in Antwerp and printed his first book there in 1555 . Throughout the ensuing years he established himself as a printer of great fame. His "Officina Plantiniana" published the works of contemporary scientists (among others Dodoens, Mercator \{see planet (4798)\}, Stevin and Vesalius \{see planets (2831) and (2642), respectively\}) and also many religious works. At the height of his career he had sixteen presses running, producing publications of exceptional quality. His greatest venture was the Biblia Regia. The "Officina" was sold in 1876 to the city of Antwerp and is now one of its most important museum pieces. (M 27736)

Name proposed and citation written by E. Goffin.

\section{(6809) Sakuma}

$1938 \mathrm{DM}_{1}$. Discovered 1938 Feb. 20 by K. Reinmuth at Heidelberg.

Named in honor of Seiichi Sakuma (1929- ), a Japanese amateur astronomer and an eminent observer of variable stars since 1942. Sakuma played the principal role in founding the Variable Star Observers League in Japan, publishing its Variable Star Bulletin and constructing its database of more than one million Japanese observations of some 4000 variable stars. This database contains observations back to 1906 and includes more than 30,000 magnitude estimates by Sakuma. (M 28090)

Name proposed by H. Oishi, who made the principal identifications involving this minor planet. 
(6811) Kashcheev

1976 QP. Discovered 1976 Aug. 26 by N. S. Chernykh at Nauchnyj.

Named in honor of Boris Leonidovich Kashcheev (1920- ), professor of radioelectronics at Kharkov Technical University, researcher in the physics and dynamics of meteors. In 1956 he founded the laboratory for the exploration of meteors by radio techniques. He was the chief designer of MARS, the first automatic meteor radio system in Ukraine. More than 20 million meteors were detected with this system during 1972-1978, and many thousands of meteor orbits were determined and studied. He was also chair of the Meteor Commission of the Soviet Geophysical Committee. (M 32346)

\section{(6817) Pest}

$1982 \mathrm{BP}_{2}$. Discovered 1982 Jan. 20 by A. Mrkos at Kleť.

Named for the largest of the three towns, Buda \{see planet (908)\}, Pest and Óbuda, that form the modern capital of Hungary. The 125th anniversary of the establishment of Budapest as Hungary's political, cultural and scientific center is being celebrated this year. The University Observatory played a major part in the life of both Pest and Buda, with its buildings dominating the panorama for three-quarters of a century after it was founded in 1780. Since 1921 the headquarters of the Konkoly \{see also planet (1445)\} Observatory has also been located in the city, which provided support for the construction of its large dome. (M 33386)

\section{(6818) Sessyu}

$1983 \mathrm{EM}_{1}$. Discovered 1983 Mar. 11 by H. Kosai and K. Hurukawa at Kiso.

Born at Soja-Akahama in Okayama prefecture, Sessyu (1420-1508) is called the "saint of painting". According to tradition, he drew a mouse with his own tears on a corridor when he was a novitiate at Houhukuji-Temple in Soja City. Afterwards he went to Ming (now People's Republic of China) and was initiated into the mysteries of ink painting-monochrome painting characterized by the use of sumi (black ink). In Japan he then laid the foundation for Japanese ink painting. (M 33787; M 34673)

\section{(6819) McGarvey}

1983 LL. Discovered 1983 June 14 by S. Smrekar at Palomar.

Flora McGarvey Smrekar (1924-1977) had many ambitions and dreamed of pursuing her interests in a satisfying career. She instilled this same goal in her daughter, who became a planetary scientist. Flora faced many obstacles but has finally found a place among the stars. (M 40702)

\section{(6820) Buil}

1985 XS. Discovered 1985 Dec. 13 by the CERGA at Caussols.
Named in honor of Christian Buil, French amateur astronomer and long-term CCD enthusiast. Buil has been one of the first amateur astronomers to build a CCD camera - and use it. An avid observer, as well as electronician and computer programer, he has co-discovered supernovae and with his colleagues has imaged more than 5000 celestial objects incorporated in the Buil-Thouvenot Atlas, the first digital atlas available to the amateur community. He has also spent much time helping others and has for many years been the president of the T60 association that allows amateurs to use a $0.60-\mathrm{m}$ telescope at Pic du Midi. (M 27463)

Name endorsed by his many friends, among them Eric and Guylaine Thouvenot and Alain Klotz.

\section{(6821) Ranevskaya}

$1986 \mathrm{SZ}_{1}$. Discovered 1986 Sept. 29 by L. G. Karachkina at Nauchnyj.

Named in honor of the outstanding Russian actress Faïna Grigor'evna Ranevskaya (1896-1984). With her uncommon sense of humor, Ranevskaya payed dozens of splendid comedy and dramatic parts for the theater and cinema. (M 27331; M 30309)

Name proposed by L. R. Nemirovskij on the occasion of the centennial of her birth.

\section{(6824) Mallory}

$1988 \mathrm{RE}_{2}$. Discovered 1988 Sept. 8 by A. Mrkos at Kleť.

George Herbert Leigh Mallory (1886-1924) was a British mountain climber whose 1924 expedition to conquer Everest culminated in a bold and possibly successful drive with Irvine toward the summit. Just 75 years later Mallory's body was recovered 600 meters below the summit after what had been a precipitous fall. (M 36945)

\section{(6825) Irvine}

1988 TJ $_{2}$. Discovered 1988 Oct. 4 by A. Mrkos at Klet.

The British mountaineer Andrew Irvine (1901-1924) was George Mallory's partner for a final bid for the summit of Everest. The two disappeared from the view of their colleagues less than 200 meters from their goal. (M 36946)

\section{(6826) Lavoisier}

$1989 \mathrm{SD}_{1}$. Discovered 1989 Sept. 26 by E. W. Elst at La Silla.

Named for Antoine-Laurent Lavoisier (1743-1794), father of modern chemistry. In a memoir presented to the Paris Academy in 1777 he explained combustion as the result of the combination of a burning substance with oxygen (that name being due to Lavoisier). In his 1789 Traité élémentaire de Chimie he gave a list of simple substances that could not be further decomposed by any known process, thus providing the concept of a chemical element. He was also associated with committees on hygiene, coinage and public education. 
His membership in the Ferme Générale caused the authorities to be suspicious of him during the French Revolution, and he was condemned to the guillotine. The day after the execution, Lagrange ssee planet (1006) \} lamented: "It required only a moment to sever that head, and perhaps a century will not be sufficient to produce another like it". (M 26933)

\section{(6827) Wombat}

$1990 \mathrm{SN}_{4}$. Discovered 1990 Sept. 27 by T. Urata at Oohira.

Three species of this marsupial inhabit Australia and Tasmania. The common wombat is the most widespread. The southern hairy-nosed wombat is restricted to arid regions. The northern hairy-nosed wombat is apparently on the brink of extinction. (M 36127)

\section{(6828) Elbsteel}

$1990 \mathrm{VC}_{1}$. Discovered 1990 Nov. 12 by D. I. Steel at Siding Spring.

Named in honor of Elliot Lewis Barnaby Steel, second child of the discoverer and Helen M. Steel. Elliot was born in Adelaide on 1995 Feb. 28, and his first home was within sight of the Siding Spring Observatory. Building on this auspicious start in life, at the age of 15 months he is already taking an interest in the night sky and other aspects of the universe around him. (M 27332)

\section{(6829) Charmawidor}

$1991 \mathrm{BM}_{1}$. Discovered 1991 Jan. 18 by E. W. Elst at St. Michel.

Named in memory of the famous French composer and organist Charles-Marie Widor (1845-1937). At the age of 19, by recommendation of Aristide Cavaillé-Coll \{see planet (5184)\}, Widor went to Brussels to study organ and composition with N. J. Lemmens and F. J. Fétis. After returning from Belgium, and after having inaugurated many organs built by CavailléColl, he was finally appointed to St. Sulpice in Paris in 1869. There he had at his disposal the most magnificient organ ever built by Cavaillé-Coll. Widor, who remained there for more than sixty years, is especially remembered for his ten Symphonies for organ, a genre he created. (M 34624)

\section{(6832) Kawabata}

1992 FP. Discovered 1992 Mar. 23 by K. Endate and K. Watanabe at Kitami.

Named in memory of Yasunari Kawabata (1899-1972), Japanese novelist and author of "Izu no Odoriko". He was awarded the 1968 Nobel Prize in literature. (M 32346)

\section{(6835) Molfino}

$1994 \mathrm{HT}_{1}$. Discovered 1994 Apr. 30 at the Santa Lucia Observatory at Stroncone.

Named in memory of Alberto Molfino (1906-1977), Italian wrestler. He took part in the 1936 Berlin
Olympics and won the Italian title in the $62-\mathrm{kg}$ category six times, the last time being at the age of 43. (M 30799)

\section{(6836) Paranal}

$1994 \mathrm{PW}_{5}$. Discovered 1994 Aug. 10 by E. W. Elst at La Silla.

Named for the 2600-m high mountain in northern Chile, approximately $130 \mathrm{~km}$ south of the city of Antofagasta, upon which the Very Large Telescope of the European Southern Observatory is being erected. Although La Silla \{see planet (2187)\} ranks among the best astronomical sites in the world, subsequent studies have shown that Paranal has a substantially lower frequency of clouds and very much lower humidity. The mean value of the seeing is less than 1 arcsecond. (M 27332)

\section{(6837) Bressi}

$1994 \mathrm{XN}_{4}$. Discovered 1994 Dec. 8 by the Spacewatch at Kitt Peak.

Named in honor of Terrence H. Bressi, a dedicated and multi-talented engineer at the University of Arizona's Lunar and Planetary Laboratory. He has applied his expertise and ingenuity to the construction and improvement of telescopes and equipment used by the Spacewatch search for minor planets and comets. (M 33787)

\section{(6838) Okuda}

1995 UD. Discovered 1995 Oct. 30 by Y. Shimizu and T. Urata at Nachi-Katsuura.

Named in honor of Toyozo Okuda (1908-1983), the fourth director of International Latitude Observatory at Mizusawa \{see planet 7530)\} and a former director of the Geographical Survey Institute of Japan. During his 1963-1976 tenure at Mizusawa he established a modern system of geophysical measurements of gravity and earth tides for research on the earth's rotation. (M 34624)

Name proposed by the second discoverer following a suggestion by K. Hurukawa. Citation prepared by K. Yokoyama.

\section{(6841) Gottfriedkirch}

2034 P-L. Discovered 1960 Sept. 24 by C. J. van Houten and I. van Houten-Groeneveld at Palomar.

Named in memory of Gottfried Kirch (1639-1710), who was called to Berlin in 1700 to become the first astronomer at the Berlin Academy. He was recognized as the first discoverer of the great comet of 1680, and he made the sole observation of comet 55P/Tempel-Tuttle in 1699. His wife Maria Margaretha and son Christfried were also known as astronomers. (M 30799)

Name suggested and citation prepared by J. Schubart.

\section{(6842) Krosigk}

3016 P-L. Discovered 1960 Sept. 24 by C. J. van Houten and I. van Houten-Groeneveld at Palomar.

Named in memory of Bernhard Friedrich Baron von Krosigk (1656-1714), an enthusiastic German amateur 
astronomer who financed astronomical expeditions to Cape Town and to Archangelsk. He owned private observatories at Poplitz and in Berlin. The latter was well equipped and used for observations by members of the Kirch \{see also planet (6841)\} family. (M 30799)

Name suggested by A. von Alvensleben and J. Schubart, the citation being prepared by the latter.

\section{(6843) Heremon}

1975 TC $_{6}$. Discovered 1975 Oct. 9 by J. D. Mulholland at Fort Davis.

Named for the seventh son of Milesius, Celtic ruler of Iberia. Heremon was the first of the discoverer's Gaelic ancestors to set foot on Ireland some 25 centuries ago. (M 27129)

\section{(6844) Shpak}

$1975 \mathrm{VR}_{5}$. Discovered 1975 Nov. 3 by T. M. Smirnova at Nauchnyj.

Named in honor of Vladimir Stepanovich Shpak (1909- ), distinguished technical organic chemist and director of the State Institute of Applied Chemistry in Leningrad (now St. Petersburg) from 1953 to 1977. He was the initiator and organizer of fundamental, scientific and technical investigations of the main organic synthesis processes of new classes of chemical compounds. He has introduced new technologies into the chemical and petrochemical industries. At present he is the chairman of the Northwestern Scientific Board of the Russian Academy of Sciences on burning and the editor-in-chief of the journal Applied Chemistry. (M 35484)

\section{(6845) Mansurova}

$1976 \mathrm{JG}_{2}$. Discovered 1976 May 2 by N. S. Chernykh at Nauchnyj.

Named in memory of Kira Sergeevna Mansurova (1931-1990), an astronomer in Irkutsk known for her observations with the zenith telescope. She was director of the Astronomical Observatory of Irkutsk University for many years and lecturer of astronomy at the University and Pedagogical Institute in Irkutsk. An active popularizer of astronomy, she published a number of works on astrometry and methods of teaching astronomy. (M 32346)

\section{(6846) Kansazan}

$1976 \mathrm{UG}_{15}$. Discovered 1976 Oct. 22 by H. Kosai and K. Hurukawa at Kiso.

Named for the writer Kansazan (1748-1827), who published many books in Chinese verse during the latter part of the Edo era. To him are attributed many popular sayings on "astronomical phenomena". (M 33787)

\section{(6847) Kunz-Hallstein}

1977 RL. Discovered 1977 Sept. 5 by H.-E. Schuster at La Silla.

The German lawyer Hans Peter Kunz-Hallstein (1939-

) has been legal advisor for the European Southern Observatory for more than 20 years. A highlight of his work was the negotiations with the Chilean government over the interpretation, modification and amendment of the ESO-Chile agreement of 1963. (M 36127)

(6855) Armellini

1989 BG. Discovered 1989 Jan. 29 at the Osservatorio San Vittore at Bologna.

Named in memory of Giuseppe Armellini (18871958), professor of astronomy at the University of Rome and director of the astronomical observatory there. Principally interested in celestial mechanics and classical astronomy and astrophysics, he observed and measured positions of double stars and minor planets. He is also known for his textbooks Trattato di Astronomia Siderale, I Fondamenti Scientifici dell'Astronomia and I Fondamenti Scientifici dell'Astrofisica. (M 27332)

\section{(6856) Bethemmons}

1989 EM. Discovered 1989 Mar. 5 by E. F. Helin at Palomar.

Elizabeth Emmons (1955- ) has been key to the success of the Earth and Space Sciences Division of the Jet Propulsion Laboratory and its members. As its administrator from 1978 to 2000, her brilliant interpersonal skills are complemented by a rare ability to combine authoritative answers with good humor. (M 41935)

\section{(6859) Datemasamune}

1991 CZ. Discovered 1991 Feb. 13 by M. Koishikawa at Sendai.

Named in honor of Date Masamune (1567-1636), the Japanese feudal lord who built the Sendai castle in 1601 and established the foundation of Date Clan. He made efforts to increase international relationships and trade with foreign countries, sending a mission led by his retainer Hasekuro Tsunega to Mexico, Spain and Rome. Sendai \{see planet (3133)\} will celebrate the 400th anniversary of its founding in 2001. (M 33787)

\section{(6860) Sims}

$1991 \mathrm{CS}_{1}$. Discovered 1991 Feb. 11 by S. Otomo and O. Muramatsu at Kiyosato.

Named in honor of Alan Sims (1920-1995), a naval officer who moved to Dublin in 1953 and became chairman of the Dublin Centre of the Irish Astronomical Society. On his retirement in 1983 he moved to Bath, where he took an active part in the William Herschel \{see planet (2000)\} Society, serving first as secretary and later as vice chairman. He was also editor of the society's bulletin. Historians and librarians around the world corresponded with him, as he answered queries about the Herschels. (M 27736; J. O'Neill)

Named by the discoverers following suggestions by F. Ring and S. Kimura.

\section{(6862) Virgiliomarcon}

1991 GL. Discovered 1991 Apr. 11 at the Osservatorio San Vittore at Bologna. 
Named in memory of Virgilio Marcon (1903-1976), painter and teacher of art at San Donà del Piave in Venice. Also famous for building optics for amateur and professional astronomers, during the last 30 years of his life he constructed hundreds of astronomical mirrors that are still in use and famous for their quality. In 1968 he improved the technique for making aluminum mirrors and successfully worked the 1.2-meter telescope at the Merate Observatory. This technique has been carried on by his son Gianfranco, who built mirrors up to 3 meters in diameter for infrared astronomy. (M 28621; M 28637)

\section{(6864) Starkenburg}

$1991 \mathrm{RC}_{4}$. Discovered 1991 Sept. 12 by F. Börngen and L. D. Schmadel at Tautenburg.

Named for a castle erected around 1064 near the town of Heppenheim. The name also applies to a region in the southern part of the German state of Hessen $\{$ see planet (5846) . As a private initiative, the Starkenburg Sternwarte was founded in 1970 on the Schlossberg just below the castle. This observatory is heavily involved in educating the public and providing astronomical knowledge to people far beyond the region. This minor planet was numbered as a result of astrometric CCD observations made at Starkenburg in Dec. 1995. (M 27332)

Name proposed by the first discoverer, endorsed by the second.

\section{(6865) Dunkerley}

$1991 \mathrm{TE}_{2}$. Discovered 1991 Oct. 2 by Y. Kushida and O. Muramatsu at Yatsugatake.

Named in honor of Charlotte Herschel Dunkerley, a descendant of William Herschel \{see planet (2000)\} who recently completed the Herschel family genealogy as a result of the family reunion that took place in Bath in 1988 to celebrate the 250th anniversary of William Herschel's birth. More than 80 descendants attended the occasion and amended the family records upon which the revised genealogy is based. The record of the Herschel family began around the year 1600 and is a valuable resource for researchers and historians in the field of astronomy. (M 29147)

Name proposed by the discoverers following a suggestion by S. Kimura.

\section{(6866) Kukai}

1992 CO. Discovered 1992 Feb. 12 by S. Otomo at Kiyosato.

Named for Kouboudaishi Kukai (774-835), Buddhist priest who was born in Zentsugi on Shikoku ssee planet (4223)\} Island. He went to China to study Buddhism. After returning to Japan he established 88 temples on Shikoku Island and the temple on Kouya Mountain. (M 35484)

\section{(6867) Kuwano}

$1992 \mathrm{FP}_{1}$. Discovered 1992 Mar. 28 by K. Endate and K. Watanabe at Kitami.
Named in memory of Yoshiyuki Kuwano (1931-1998), librarian and later director of Hita Municipal Tanso Memorial Library, Oita Prefecture. As an amateur astronomer, he discovered five novae ( IV Cep, V3888 Sgr, V3889 Sgr, V2104 Oph, V4021 Sgr) and the peculiar variable PU Vul. An organizer and leader of local amateur astronomers, he actively popularized astronomy to the public through his frequent lectures and star parties. (M 32346)

Name proposed by the discoverers following a suggestion by T. Funada, T. Sato and A. Fujii.

Obituaries published in Yamamoto Circ., No. 2291, p. 2 (1998); Heavens, Vol. 79, No. 3, p. 16-20 (1998).

\section{(6869) Funada}

1992 JP. Discovered 1992 May 2 by K. Endate and K. Watanabe at Kitami.

Named in honor of Takumi Funada (1932- ), retired schoolmaster and science teacher who is currently director of Sekizaki Kaisei Kan (Sea and Star Museum) and honorary president of the Oita Astronomical Society. He has greatly contributed to amateur astronomy and has helped popularize astronomy to the public. Also well known as an astrophotographer, he has published several books on astronomy. (M 32346)

Name proposed by the discoverers following a suggestion by T. Sato and A. Fujii.

\section{(6870) Pauldavies}

1992 OG. Discovered 1992 July 28 by R. H. McNaught at Siding Spring.

Named for Paul C. W. Davies (1946- ) , a British mathematical physicist resident in Australia, with research interests in cosmology, quantum gravity, astrophysics and the origin of life, who also has an international reputation as an author and broadcaster. His books range from the scholarly Quantum Fields in Curved Space (with N. D. Birrell) to the popular About Time. He has a long-standing interest in the relationship between science and theology, summarized in his well-known book The Mind of God. His contributions to this field were recognized in 1995 with the award of the Templeton Prize for Progress in Religion. Davies has been a vociferous supporter of the need for search programs for near-earth objects. (M 33787)

Name proposed and citation prepared by D. I. Steel and the discoverer.

\section{(6871) Verlaine}

$1993 \mathrm{BE}_{8}$. Discovered 1993 Jan. 23 by E. W. Elst at La Silla.

Named in memory of the well-known French poetsymbolist Paul Verlaine (1844-1896). He was born in the grey and rainy Ardennes, a landscape that would never be far from his sad life. In his early work he declared himself as doomed, a "poète maudit", torn between a mystic search for pureness and demonic 
sensuality. Alcohol ruined his health and mind, during a libertine and bohemian existence with his friend, the poet Arthur Rimbaud \{see planet (4635)\}. Verlaine will be remembered for his splendid verse: "Il pleure dans mon coeur/ comme il pleut sur la ville./ Quelle est cette langueur/ qui pénétre mon coeur?". (M 27129; M 27147)

Citation written by C. Leterme at the request of the discoverer.

\section{(6873) Tasaka}

$1993 \mathrm{HT}_{1}$. Discovered 1993 Apr. 21 by K. Endate and K. Watanabe at Kitami.

Named in honor of Ichiro Tasaka (1929- ), Japanese farmer, Mars observer and astronomical optician. He has made hundreds of precision telescope mirrors currently being used by observatories and amateur astronomers. He operates a tourist house that has an observatory. Its main telescope is a $0.73-\mathrm{m}$ equatorial reflector, both the optical and mechanical parts of which were made by Tasaka himself. (M 32346)

Name proposed by the discoverers following a suggestion by T. Sato and A. Fujii.

\section{(6876) Beppeforti}

$1994 \mathrm{RK}_{1}$. Discovered 1994 Sept. 5 by A. Boattini and M. Tombelli at Cima Ekar.

Named in honor of Giuseppe (Beppe) Forti, astronomer at the Arcetri Observatory in Florence. His encouragement and advice continuously help the discoverers to refine their observational work. Forti was trained as a solar physicist and worked for six years with the Harvard-Smithsonian Radio Meteor Project from 1965. He has done some work on nongravitational forces acting on comets and now has interests in the dynamics of minor planets. (M 27129)

\section{(6877) Giada}

1994 TB $_{2}$. Discovered 1994 Oct. 10 by V. S. Casulli at Colleverde di Guidonia.

Named in honor of Giada Casulli (1978- ～), daughter of the discoverer. (M 29671)

\section{(6878) Isamu}

$1994 \mathrm{TN}_{2}$. Discovered 1994 Oct. 2 by K. Endate and K. Watanabe at Kitami.

Named in honor of Isamu Hirabayashi (1941- ), amateur astronomer who founded the Japan Lunar and Planetary Observers Network when he was a highschool student in 1959 and who has been its president ever since. This organization soon became one of the most active groups of lunar and planetary observers and theorists in Japan. He also served as director of the Jupiter-Saturn Section of the Oriental Astronomical Association from 1971 to 1989. (M 32346)

Name proposed by the discoverers following a suggestion by T. Sato and A. Fujii.

\section{(6879) Hyogo}

$1994 \mathrm{TC}_{15}$. Discovered 1994 Oct. 14 by K. Itoh at Sengamine.

Named for the prefecture where this planet was discovered. Hyogo prefecture, which includes Kobe City and the island of Awaji \{see planet (3380)\}, was severely damaged by the Great Hanshin Earthquake on 1995 Jan. 17, when more than 6000 people were killed and numerous houses were destroyed. (M 27130)

\section{(6880) Hayamiyu}

$1994 \mathrm{TG}_{15}$. Discovered 1994 Oct. 13 by S. Otomo at Kiyosato.

Named in honor of Yu Hayami (1966- ), famous Japanese actress and singer. She is very interested in astronomy and popular at star parties. (M 35484)

\section{(6882) Sormano}

1995 CC $_{1}$. Discovered 1995 Feb. 5 by P. Sicoli and V. Giuliani at Sormano.

Named in honor of the mountain village of Sormano and its nearby observatory where this object was discovered. The facility, built in 1986 by amateur astronomers of the Gruppo Astrofili Brianza, is located in the pre-Alps of Lombardy, between the southern arms of Lake Como. Since its foundation, the observatory has been involved in astrometric work on minor planets and comets, in particular the follow-up of near-earth objects. (M 27130)

\section{(6884) Takeshisato}

9521 P-L. Discovered 1960 Oct. 17 by C. J. van Houten and I. van Houten-Groeneveld at Palomar.

Named in honor of Takeshi (Ken) Sato, a devoted educator who is currently director of the planetarium at Hiroshima's Children's Museum. He is an amateur planetary observer who served as director of the JupiterSaturn Section of the Oriental Astronomical Association during 1960-1971. He initiated the ordinance to minimize light pollution in the town of Bisei, Okayama Prefecture. Enacted in 1989, this ordinance was the first of its kind in Japan. (M 29147)

\section{(6885) Nitardy}

9570 P-L. Discovered 1960 Oct. 17 by C. J. van Houten and I. van Houten-Groeneveld at Palomar.

Named in honor of John H. Nitardy, who has worked in communications engineering for the Boeing Company since 1965 and is currently a consultant to them. Together with his wife Ilene, he saved the Spacewatch \{see planet (4255)\} program in an intricate financial situation in early 1996. They are also known for their hospitality for and endorsement of foreign exchange students. (M 29147)

\section{(6886) Grote}

1942 CG. Discovered 1942 Feb. 11 by L. Oterma at Turku.

Named in honor of Grote Reber (1911-2002), pioneer radioastronomer. A radio engineer by profession, he 
became intrigued by Jansky's \{see planet (1932)\} 1932 detection of radio waves of extraterrestrial origin. From a series of homemade radio receivers and a 9.4-m parabolic dish antenna in his backyard in Wheaton, Illinois, Reber obtained the first detailed quantitative maps of the radio sky and published these in a series of papers during the 1940s. His stunning results gradually opened the consciousness of others to this very powerful method of observing the universe. (M 68622)

Name suggested and citation prepared by G. C. L. Aikman.

\section{(6891) Triconia}

1976 SA. Discovered 1976 Sept. 23 at the Harvard College Observatory at Harvard.

Named in honor of the Tri-Con Barber Shop in Lexington, Massachusetts, and for Paul, Joe, Charlie and Art who work there. (M 30100)

Name obviously propoposed by Brian G. Marsden, who, in a note to the Small Bodies Names Committee stated: "No, I am not getting free haircuts..."

\section{(6894) Macreid}

$1986 \mathrm{RE}_{2}$. Discovered 1986 Sept. 5 by E. F. Helin at Palomar.

Named in honor of Macgregor S. Reid, a highly regarded manager at the Jet Propulsion Laboratory. For the past ten years he has been technical executice assistant to the director, responsible for planning and identifying issues of significance to the national space program and the laboratory's future. Reid is internationally recognized for his activities concerning international standard-setting. This object is being named to honor him on his retirement after a 30-year career at JPL. (M 32094)

Citation prepared by E. C. Stone.

\section{(6897) Tabei}

1987 VQ. Discovered 1987 Nov. 15 by A. Mrkos at Klet.

In 1975, Junko Tabei (1939- ) became the first woman to scale the summit of Mount Everest. (M 40702)

The name was suggested by M. Tichý.

\section{(6898) Saint-Marys}

1988 LE. Discovered 1988 June 8 by C. S. Shoemaker at Palomar.

Saint Mary's University, Halifax, N.S., is Atlantic Canada's primary center for instruction, public relations and research in astronomy and astrophysics. The university, founded in 1802 , is the site of the Burke-Gaffney Observatory, used for the detection of supernova $1995 \mathrm{~F}$, the first such discovery of an all-Canadian nature. (M 46101)

\section{(6901) Roybishop}

1989 PA. Discovered 1989 Aug. 2 by C. S. Shoemaker and E. M. Shoemaker at Palomar.

Named in honor of Roy L. Bishop, retired professor of physics at Acadia University, Nova Scotia. Since
1982 Bishop has edited the Observer's Handbook of the Royal Astronomical Society of Canada, a vital reference for professional and amateur astronomers. Bishop is also known for his unique photographs, especially one of a double rainbow over Isaac Newton's \{see planet (8000)\} birthplace. (M 30477)

Citation provided by Carolyn and Eugene Shoemaker and Wendee and David Levy.

\section{(6902) Hideoasada}

1989 US $_{3}$. Discovered 1989 Oct. 26 by Y. Mizuno and T. Furuta at Kani.

Hideo Asada (1953- ) worked in the shop of a Japanese telescope maker and is now popularizing astronomy in Japan by writing books and articles in astronomical magazines. (M 45336)

\section{(6904) McGill}

1990 QW $_{1}$. Discovered 1990 Aug. 22 by H. E. Holt at Palomar

One of Canada's oldest and most highly regarded universities, McGill (founded 1838) has enjoyed a first-rate reputation. Once home to Stephen Leacock and physicist Ernest Rutherford, the university has done pioneering research both on the earth in medicine and in space through its department of earth and planetary sciences. (M 42356)

\section{(6905) Miyazaki}

1990 TW. Discovered 1990 Oct. 15 by K. Endate and K. Watanabe at Kitami.

Named in honor of Isao Miyazaki (1961- ), amateur astronomer well known for his high-quality visual, photographic and CCD observations of the planets. He has been director of the Jupiter-Saturn Section of the Oriental Astronomical Association (OAA) anice 1989. He is a winner of the I. Yamamoto s see planet (2249)\} Award (OAA), the W. H. Steavenson Award (British Astronomical Association) and the W. H. Haas \{see planet (3853)\} Award (Association of Lunar and Planetary Observers). (M 32346)

Name proposed by the discoverers following a suggestion by T. Sato and A. Fujii.

\section{(6908) Kunimoto}

$1990 \mathrm{WB}_{3}$. Discovered 1990 Nov. 24 by K. Endate and K. Watanabe at Kitami.

Named in honor of Yoshihiro Kunimoto (1958- ), Japanese composer and synthesizer musician. He has written and played theme and background music for more than 60 planetarium shows at the Hiroshima Children's Museum. (M 32347)

Name proposed by the discoverers following a suggestion by T. Sato and K. Kato.

\section{(6909) Levison}

$1991 \mathrm{BY}_{2}$. Discovered 1991 Jan. 19 by C. S. Shoemaker and E. M. Shoemaker at Palomar.

Named in honor of Harold Levison (1959- ) of the Boulder, Colorado, office of the Southwest Research Institute. Since 1988 Levison has, in collaboration 
with Martin Duncan \{see planet (6115)\}, virtually revolutionized our view of the dynamics of shortperiod comets. The work uses sophisticated numerical models of test particles perturbed by the planets, and it has revealed important details about the Kuiper \{see planet (1776)\} Belt, Centaurs, Pluto-Charon and short-period comets. Levison has also contributed revealing insights into the dynamics of perturbers in the $\beta$ Pictoris system and was a leading member of the team that used Hubble Space Telescope to discover possible observational evidence for small comets in the transneptunian region. (M 27463)

Citation prepared by S. A. Stern.

\section{(6910) Ikeguchi}

1991 FJ. Discovered 1991 Mar. 17 by S. Otomo and O. Muramatsu at Kiyosato.

Kunio Ikeguchi (1953- ) is a member of the Yonago Astronomy Club who popularizes astronomy in Tottori \{see planet (4720)\}. (M 36127)

The name was suggested by $H$. Abe.

\section{(6911) Nancygreen}

1991 GN. Discovered 1991 Apr. 10 by E. F. Helin at Palomar.

Named in honor of Nancy Green Hicks, enthusiastic horsewoman and talented artist. A graduate of Scripps College, she is with her family a principal benefactor and longterm volunteer at the Scripps Home for the elderly. Her personal contributions have made the difference for the continuation of many of the discoverer's astronomical pursuits. Her loyalty and encouragement have given support during times of diminishing governmental funds, allowing the work on observing NEOs to survive. She was most generous in her leadership role of fundraising for the planetcrossing asteroid program carried out photographically at Palomar for many years and has most recently enabled a successful transition to the CCD NEAT program. (M 27332)

\section{(6912) Grimm}

$1991 \mathrm{GQ}_{2}$. Discovered 1991 Apr. 8 by E. W. Elst at La Silla.

Named in memory of Friedrich Melchior Baron von Grimm (1723-1807). After studying at the University of Leipzig he went to France, as delegate of the young Prince of Saxe-Gotha. There he became associated with writers of the Encyclopédie such as Rousseau, Voltaire and d'Alembert \{see, respectively, planets (2950), (5676) and (5956)\}, but especially with Diderot \{see planet (5351)\}, for whom he felt great affection. The 17 volumes of his Correspondance littéraire, philosophique et critique, published a few years after his death, show that no eighteenth-century foreigner in France has known the country, its people and its language better than him. This correspondence, characterized by a dry and skeptical philosophy, remains an inexhaustible mine of anecdotes and judgements on men and their works. (M 27332)

\section{(6913) Yukawa}

$1991 \mathrm{UT}_{3}$. Discovered 1991 Oct. 31 by K. Endate and K. Watanabe at Kitami.

Named in memory of Hideki Yukawa (1907-1981), Japanese theoretical physicist who was awarded the 1949 Nobel Prize in physics. He predicted the existence of the $\pi$ meson, which causes the nuclear force. (M 32347)

\section{(6914) Becquerel}

1992 GZ. Discovered 1992 Apr. 3 by C. S. Shoemaker and D. H. Levy and H. E. Holt at Palomar.

Named for the French physicist Henri Becquerel \{1852-1908\} on the centennial of his discovery of radioactivity in March 1896. Becquerel's work led to the discovery of radium, nuclear transmutation and nuclear fission, and it has had a myriad applications in medicine, the sciences and industry. Radionuclides are used in diagnosis (nuclear medicine), therapy and research. Radiodating has revolutionized geology, archaeology, anthropology and history. Radioactivity explains how the earth has stayed warm; nuclear reactions explain how the sun and other stars maintain their immense energy output. (M 27332; M 27347)

Citation provided by D. Patton, T. Hunter and D. Levy.

Becquerel, together with Marie and Pierre Curie \{see planet (7000)\}, received the 1903 physics Nobel prize.

\section{(6916) Lewispearce}

1992 OJ. Discovered 1992 July 27 by R. H. McNaught at Siding Spring.

Named in memory of Lewis Percival Pearce, infant son of amateur astronomer and comet observer Andrew Pearce. Born in Nedlands, Western Australia, on 1999 Jan. 23, Lewis suffered oxygen deprivation during delivery and never gained consciousness. Before his death twelve days later, he shared some experiences with his parents, including "observing the stars" with his dad. (M 34342)

\section{(6918) Manaslu}

$1993 \mathrm{FV}_{3}$. Discovered 1993 Mar. 20 by M. Hirasawa and S. Suzuki at Nyukasa.

Named for an 8156-m mountain in the Himalayas. The summit was first reached by the Japanese party led by Aritsune Maki in 1956. (M 34342)

\section{(6919) Tomonaga}

1993 HP. Discovered 1993 Apr. 16 by K. Endate and K. Watanabe at Kitami.

Named in memory of Shinichiro Tomonaga (19061979), Japanese theoretical physicist who was awarded the 1965 Nobel Prize in physics. He made great contributions to the field of quantum electrodynamics, especially in the renormalization theory to remove singularities. (M 32347) 
(6920) Esaki

1993 JE. Discovered 1993 May 14 by K. Endate and K. Watanabe at Kitami.

Named in honor of Leo Esaki (1925- ), Japanese experimental physicist who was awarded the 1973 Nobel Proze in physics. He devised the Esaki diode using the tunnel effect. (M 32347)

\section{(6922) Yasushi}

$1993 \mathrm{KY}_{1}$. Discovered 1993 May 27 by S. Otomo at Kiyosato.

Yasushi Sato (1957- ) is a member of the Matsue Astronomy Club who popularizes astronomy in Shimane. (M 36127)

The name was suggested by $\mathrm{H}$. Abe.

\section{(6923) Borzacchini}

1993 SD. Discovered 1993 Sept. 16 at the Santa Lucia Observatory at Stroncone.

Named in memory of Baconin Borzacchini (18981933), Italian automobile racing champion. (M 30799)

\section{(6924) Fukui}

1993 TP. Discovered 1993 Oct. 8 by K. Endate and K. Watanabe at Kitami.

Named in memory of Ken'ichi Fukui (1918-1997), Japanese chemist who was awarded the 1981 Nobel Prize in chemistry. He proposed the frontier orbital theory. (M 32347; M 32561)

\section{(6925) Susumu}

$1993 \mathrm{UW}_{2}$. Discovered 1993 Oct. 24 by T. Seki at Geisei.

Named in honor of Augustin Susumu Yamamoto (1915- ), agronomist and director of the Yamamoto Observatory and, from 1988 to 1994, chairman of the board of directors of the Oreintal Astronomical Association, which maintains its headquarters there. He published a Catalogue of Cometary Orbits in 1936. His father was the astronomer Issei Yamamoto \{see planet (2249)\}. (M 32788)

Name proposed by the discoverer following a suggestion by I. Hasegawa and T. Sato.

\section{(6927) Tonegawa}

$1994 \mathrm{TE}_{1}$. Discovered 1994 Oct. 2 by K. Endate and K. Watanabe at Kitami.

Named in honor of Susumu Tonegawa (1939- ), Japanese biologist who was awarded the 1987 Nobel Prize for medicine and physiology. He revealed the mechanism of genes that produce various antibodies. (M 32347)

\section{(6928) Lanna}

$1994 \mathrm{TM}_{3}$. Discovered 1994 Oct. 11 by M. Tichý at Klě́.

Named in memory of Vojtěch Lanna (1805-1866), well-known Czech entrepreneur. He contributed to the development of trade and business in southern and central Bohemia. Most of his activities - shipbuilding, sailing and bridge building - were closely connected with the Vltava \{see planet (2123)\} river. (M 30477)

\section{(6929) Misto}

1994 UE. Discovered 1994 Oct. 31 by V. S. Casulli at Colleverde di Guidonia.

Named in memory of Angela Misto (1902-1993), mother of the discoverer. (M 31611)

\section{(6931) Kenzaburo}

$1994 \mathrm{VP}_{6}$. Discovered 1994 Nov. 4 by K. Endate and K. Watanabe at Kitami.

Named in honor of Kenzaburo Ohe (1935- ), Japanese writer who was awarded the 1994 Nobel Prize in literature. His important works include "Sexual Human" and "Football on the first year of Man-en era". (M 32347)

\section{(6935) Morisot}

4524 P-L. Discovered 1960 Sept. 24 by C. J. van Houten and I. van Houten-Groeneveld at Palomar.

Named in memory of Berthe Morisot (1841-1895), important French impressionistic painter. Her teachers were Guichart and Camille Corot \{see planet (6672)\} and later Edouard Manet. In turn, she influenced Manet to paint landscapes outside, rather than to make sketches first and paint the landscapes in the studio. Morisot was a specialist in oil and water colors of natural family life. (M 27463)

\section{(6936) Cassatt}

6573 P-L. Discovered 1960 Sept. 24 by C. J. van Houten and I. van Houten-Groeneveld at Palomar.

Named in memory of Mary Cassatt (1845-1927), American impressionistic painter, who studied in Italy, Spain, Holland and especially France. She and Degas \{see planet (6673)\} became great friends and influenced each other. The Japanese print makers, whose work became known during her lifetime, also made an impression on her. (M 27463)

\section{(6937) Valadon}

1010 T-2. Discovered 1973 Sept. 29 by C. J. van Houten and I. van Houten-Groeneveld at Palomar.

Named in memory of the French painter Suzanne Valadon (1865-1938), the first model for Chavannes and the impressionists Degas and Renoir \{see, respectively, planets (6673) and (6677)\}. Valadon learned drawing and painting from observing these painters. Until 1909 she mainly made drawings. Later she painted nudes, still life and landscapes. Her son was the well-known painter Maurice Utrillo (1883-1955). (M 27463)

\section{(6938) Soniaterk}

5140 T-2. Discovered 1973 Sept. 25 by C. J. van Houten and I. van Houten-Groeneveld at Palomar.

Named in memory of Sonia Delaunay-Terk (18851979), Russian-born French painter and wife of the painter Robert Delaunay (1885-1941). In addition to her abstract painting she set the trend for modern design in her own fashion house. (M 27463) 


\section{(6939) Lestone}

$1952 \mathrm{SW}_{1}$. Discovered 1952 Sept. 22 by L. E. Cunningham at Mount Wilson.

Named for Leighton Buzzard, a small market town in south Bedfordshire, England. The town is recorded in the Domesday Book (1086) as Lestone, and later variations of the name include Leyton and Leighton. The suffix Buzzard is believed to have been added in the twelfth century and to be a corruption of the family name of the first town prebendary, Thoebald de Busar. (M 29147)

Name suggested by G. V. Williams, who made the identifications for this object and who grew up in the town.

\section{(6941) Dalgarno}

1976 YA. Discovered 1976 Dec. 16 at the Harvard College Observatory at Harvard.

Named in honor of Alexander Dalgarno (1928- ), on the occasion of his 70th birthday. Renowned for his seminal research on collisions and radiative processes involving atoms, molecules, ions and electrons, Dalgarno has led the exploration of atmomic and molecular phenomena occurring in the interstellar medium, planetary and cometary atmospheres, supernova ejecta, the early universe and the terrestrial thermosphere. Due to his intellectual leadership, the Institute for Theoretical Atomic and Molecular Physics was established at the Harvard-Smithsonian Center for Astrophysics. He served as director of the Institute for five years and as acting director of the Harvard College Observatory for three years. (M 32347)

\section{(6945) Dahlgren}

$1980 \mathrm{FZ}_{3}$. Discovered 1980 Mar. 16 by C.-I. Lagerkvist at La Silla.

Named in honor of Mats Dahlgren (1966- ) in celebration of the completion of his Ph.D. thesis on Hilda-type minor planets. He has made a spectroscopic and photometric survey of a substantial fraction of the numbered Hildas and has studied the collisional evolution and population of the Hildas. (M 30799)

\section{(6950) Simonek}

1982 YQ. Discovered 1982 Dec. 22 by F. Dossin at St. Michel.

Named in honor of Simone Ek, wife of the discoverer, in acknowledgment of the patience and understanding of a dedicated astronomer's wife. (M 33386)

Name proposed by the late discoverer in 1996 . Citation prepared by J. Denoyelle.

\section{(6952) Niccolò}

1986 JT. Discovered 1986 May 4 by E. Bowell at Anderson Mesa.

Named for Niccolò Fulchignoni (1991- ), second son of Marcello Fulchignoni and M. Antonietta Barucci \{see, respectively, planets (3486) and (3485)\}, planetary scientists at the Observatoire de Paris. Niccolò is the "Renaissance" Italian form of the name Nikolaus (northern Europe's Santa Claus) and has been given to distinguished personalities of the arts, literature and philosphy - Paganini \{see planet (2859), Tommaseo and Machiavelli, for example. (M 31296)

Name suggested and citation provided by $\mathrm{M}$. Fulchignoni.

\section{(6953) Davepierce}

$1986 \mathrm{PC}_{1}$. Discovered 1986 Aug. 1 by E. F. Helin at Palomar.

David A. Pierce (1936- ) has developed and taught college-level astronomy and physics courses for classroom, television and online distribution. He also directed gifted high-school students in observing and computing orbits for minor planets in the Summer Science Program at the Thacher School in Ojai. (M 44593)

\section{(6954) Potemkin}

1987 RB $_{6}$. Discovered 1987 Sept. 4 by L. V. Zhuravleva at Nauchnyj.

Russian grand duke Grigorij Aleksandrovich Potemkin (1739-1791) was a statesman, field marshal, diplomat and long the principal confidant of Catherine the Great. (M 41028)

\section{(6955) Ekaterina}

$1987 \mathrm{SP}_{15}$. Discovered 1987 Sept. 25 by L. V. Zhuravleva at Nauchnyj.

Named in honor of the empress Ekaterina Vtoraya (Catherine II; Catherine the Great; 1729-1796), whose reign was noted for the strengthening of autocracy and the position of Russia in the world. Born the princess of Anhalt-Zerbst, she was an educated person who wrote historical and dramatic compositions, comic operas and fairy tales for children. (M 34625)

\section{(6956) Holbach}

1988 CX $_{3}$. Discovered 1988 Feb. 13 by E. W. Elst at La Silla.

Named in memory of the famous German philosopher Paul Heinrich Dietrich von Holbach (1723-1780), with Diderot, d'Alembert, Grimm, de Jaucourt and Helvetius \{see, respectively, planets (5351), (5956), (6912), (6977), and (6972)\} one of the Encyclopedists. He spent almost his entire life in Paris, where his residence became the assembly of the greatest free-thinkers of his time. One of his numerous works, Système de la Nature (1770), often called "The bible of materialism", became well known and had a great impact on the philosophy that there is nothing but material and motion. According to Holbach, the greatest enemy of natural morality is religion, a product of fantasy. (M 27463)

\section{(6961) Ashitaka}

1989 KA. Discovered 1989 May 26 by M. Akiyama and T. Furuta at Mishima.

Named for a dormant volcano in Numazu-city, close to Mt. Fuji \{see planet (1584)\}. (M 34625) 
Name proposed by the first discoverer following a suggestion by the Numazu Astronomical Association.

\section{(6962) Summerscience}

1990 OT. Discovered 1990 July 22 by E. F. Helin at Palomar.

Every summer since 1959 a group of gifted highschool students has gathered for six weeks to study college-level science, observe selected minor planets and calculate their orbits in the Summer Science Program in Ojai, California. (M 46101)

\section{(6964) Kunihiko}

1990 TL $_{1}$. Discovered 1990 Oct. 15 by K. Endate and K. Watanabe at Kitami.

Named in memory of Kunihiko Kodaira (1915-1997), Japanese mathematician who was awarded the Fields Medal in 1954. He contributed to the harmonic integral theory. (M 32347)

\section{(6965) Niyodogawa}

$1990 \mathrm{VS}_{2}$. Discovered 1990 Nov. 11 by T. Seki at Geisei.

Named for a river, $100 \mathrm{~km}$ in length, that has its source at the center of Shikoku Island s see planet (4223)\}. (M 32094)

\section{(6966) Vietoris}

1991 RD $_{5}$. Discovered 1991 Sept. 13 by L. D. Schmadel and F. Börngen at Tautenburg.

Named in honor of Leopold Vietoris (1891- ), professor emeritus of mathematics of the LeopoldFranzens-University in Innsbruck, on the occasion of his forthcoming 107th birthday. Vietoris is the oldest full member of the Austrian Academy of Sciences and a highly decorated scientist. He made fundamental contributions to algebraic and set-theory topology, and he also wrote outstanding papers on the theory of real functions and on applied mathematics. (M 32094)

Named by the first discoverer following a suggestion by $\mathrm{H}$. Haupt, who prepared the citation.

\section{(6969) Santaro}

$1991 \mathrm{VF}_{5}$. Discovered 1991 Nov. 4 by S. Otomo at Kiyosato.

Santaro Harada (1913- ～) is a Japanese astronomer and optical engineer living in Nagano prefecture. (M 40702)

The name was suggested by Y. Saigusa.

\section{(6970) Saigusa}

$1992 \mathrm{AL}_{1}$. Discovered 1992 Jan. 10 by S. Otomo at Kiyosato.

Yosikazu Saigusa (1928- ), a retired broadcast engineer is a Japanese amateur astronomer. He discovered comets C/1975 T2 and C/1983 J1 visually from Kofu city. (M 40702)

(6971) Omogokei

1992 CT. Discovered 1992 Feb. 8 by T. Seki at Geisei.
Named for a ravine, $18 \mathrm{hm}$ long, at the foot of Mt. Ishizuti $\{$ see planet (4095)\}, the highest mountain in western Japan. (M 32094)

\section{(6972) Helvetius}

1992 GY $_{3}$. Discovered 1992 Apr. 4 by E. W. Elst at La Silla.

Named in memory of the famous French philosopher and Encyclopedist Claude Adrien Helvetius (17151771). While still very young he read Locke's Essay concerning human understanding, which influenced his life. In 1758 Helvetius' De l'Esprit was published. The book was immediately banned by parliament on the grounds that it was dangerous to the state and to religion. Another famous work, Les progrès de la raison dans la recherche (1775), espoused the idea that all knowledge comes from our sentences and that morality has to be based on a rational, moderate hedonism. He proposed a workday of only seven to eight hours and supported education and culture for all. (M 27463)

\section{(6975) Hiroaki}

1992 QM. Discovered 1992 Aug. 25 by S. Otomo at Kiyosato.

Hiroaki Hayashi (1954- ) is a factory manager in the city of Yashio. Each year he teaches hundreds of children how to make telescopes. (M 39650)

\section{(6976) Kanatsu}

$1993 \mathrm{KD}_{2}$. Discovered 1993 May 23 by S. Otomo at Kiyosato.

Named in honor of Kazuyoshi Kanatsu (1953- ), discoverer of the 1993 nova V705 Cas. (M 35484)

Name proposed by the discoverer following a suggestion by H. Abe.

\section{(6977) Jaucourt}

$1993 \mathrm{OZ}_{4}$. Discovered 1993 July 20 by E. W. Elst at La Silla.

Named in memory of the French writer Chevalier Louis de Jaucourt (1704-1779), who studied theology at Geneva and medicine at Cambridge and Leiden. He came into contact with the Encyclopedists and wrote for the Encyclopédie articles on physiology, chemistry, botany, pathology, history and politics. Diderot \{ see planet (5351)\} expressed his great esteem for de Jaucourt in a letter to Sophie Volland, remarking on his prodigious labors, often reading, dictating to six or seven secretaries for thirteen or fourteen hours each day, and on his great unhappiness when the work neared completion. (M 27463)

\section{(6978) Hironaka}

1993 RD. Discovered 1993 Sept. 12 by K. Endate and K. Watanabe at Kitami.

Named in honor of Heisuke Hironaka (1931- ), Japanese mathematician who was awarded the Fields Medal in 1970. He proved the theorem of resolution of singularity. (M 32347) 


\section{(6979) Shigefumi}

1993 RH. Discovered 1993 Sept. 12 by K. Endate and

K. Watanabe at Kitami.

Named in honor of Shigefumi Mori (1951- ), Japanese mathematician who was awarded the Fields Medal in 1990. He resolved Hartshorne's expectation. (M 32347)

\section{(6980) Kyusakamoto}

$1993 \mathrm{SV}_{1}$. Discovered 1993 Sept. 16 by K. Endate and K. Watanabe at Kitami.

Named in memory of Kyu Sakamoto (1941-1985), a popular singer in Japan who was beloved as Kyu-chan. His songs "Let's walk turning our faces upward", "Look up at the stars at night" and others were big hits. The first song (English title "Sukiyaki") became one of the world's bestsellers. This planet also symbolizes the famous trio of which Kyu Sakamoto was a member, with songwriter Rokusuke Ei and pianist Hachidai Nakamura - in Japanese, Roku is 6, Kyu 9 and Hachi 8. (M 32789)

Name proposed by the discoverers following a suggestion by T. Sato, A. Fujii and Y. Katagiri.

\section{(6981) Chirman}

$1993 \mathrm{TK}_{2}$. Discovered 1993 Oct. 15 at the Bassano Observatory at Bassano Bresciano.

Named for the Surgical Department of the hospital in the Italian village of Manerbio, located a few kilometers from the Bassano \{see planet (6460)\} Observatory. The name, a contraction of Chirurgia (Surgery) and the name of the village, is presented in honor of the doctors, nurses and all the personnel of the hospital for the competence, absorption and passion they devote to the care of patients. (M 27736)

\section{(6983) Komatsusakyo}

1993 YC. Discovered 1993 Dec. 17 by T. Kobayashi at Oizumi.

Sakyo Komatsu (1931- ) is a novelist, essayist, reporter and playwright. One of the most famous science fiction writers in Japan, his best-known tales include Bye-bye Jupiter (1980) and Japan Sinks (1973). (M 46680)

\section{(6984) Lewiscarroll}

1994 AO. Discovered 1994 Jan. 4 by H. Shiozawa and T. Urata at Fujieda.

Named after the English fairy-tale author and mathematician Lewis Carroll (Charles Lutwidge Dodgson, 1832-1898). His great works Alice in Wonderland and Through the Looking Glass were loved not only by children, but by all generations throughout the world for over a century. (M 33788)

Name and citation proposed by $\mathrm{T}$. Urata.

\section{(6996) Alvensleben}

2222 T-2. Discovered 1973 Sept. 29 by C. J. van Houten and I. van Houten-Groeneveld at Palomar.
Named in memory of Bertha von Alvensleben (18591912), wife of Friedrich Winfried Schubart. Her ancestor Joachim von Alvensleben (1514-1588) amassed a library and was known as a scientist in his own time. His son Gebhard Johann was interested in astronomical observations. (M 27464)

Name suggested and citation prepared by her grandson, Joachim Schubart \{see planet (1911)\}.

\section{(6997) Laomedon}

3104 T-3. Discovered 1977 Oct. 16 by C. J. van Houten and I. van Houten-Groeneveld at Palomar.

Named for Laomedon, king of Troy and father of Priam and Tithonus ssee planets (884) and (6998)\}. (M 27736)

\section{(6998) Tithonus}

3108 T-3. Discovered 1977 Oct. 16 by C. J. van Houten and I. van Houten-Groeneveld at Palomar.

Named for Tithonus, son of Laomedon and brother of Priam \{see, respectively, planets (6997) and (884)\}, kings of Troy. (M 27736)

\section{(6999) Meitner}

4379 T-3. Discovered 1977 Oct. 16 by C. J. van Houten and I. van Houten-Groeneveld at Palomar.

Named in memory of Lise Meitner (1878-1968), Austrian nuclear physicist. Meitner was only the second woman to receive a doctorate from the University of Vienna, where she had been much inspired by Boltzmann. In 1912 she joined the KaiserWilhelm-Institut in Berlin. Her collaboration with the director, Otto Hahn \{see planet (19126)\}, resulted in the discovery of protactinium, thereby demonstrating the existence of uranium-235. In 1938 Meitner moved to Stockholm, where, with her nephew, Otto Frisch, she explained the presence of barium in the neutronbombardment experiments of Hahn and Strassmann \{see planet (19136)\} as due to fission, a term they coined. (M 27464)

Named by the Small Bodies Names Committee.

\section{(7000) Curie}

1939 VD. Discovered 1939 Nov. 6 by F. Rigaux at Uccle.

Named in memory of Marie Curie (1867-1934), the only person to receive Nobel prizes for both physics (1903) and chemistry (1911), famous for her work on radioactivity, a word she invented. The name also honors Pierre Curie (1859-1906), who shared the Nobel prize for physics with his wife and Becquerel \{see planet (6914)\}. Best known for the discovery of radium, the Curies also discovered polonium, an element named in honor of Marie's native land, where she was born Maria Skłodowska in Warsaw. After Pierre's death his widow was appointed to his professorship and thereby became the first woman to teach at the Sorbonne. She was also involved with the development of radiology for the medical profession. (M 27464)

Named by the Small Bodies Names Committee. 
(7001) Noether

1955 EH. Discovered 1955 Mar. 14 at the Goethe Link Observatory at Brooklyn, Indiana.

Named in memory of Emmy Noether (1882-1935), extraordinarily talented mathematician who exerted a great influence on the development of mathematics and laid the foundations of modern algebra. Educated in Erlangen, she moved to Göttingen in 1915 and was for many years the central figure in mathematical studies there, before leaving for positions at Princeton and Bryn Mawr in 1933. From axiomatic principles she developed a theory of ideals, relating them to groups and rings. She also contributed extensively to the study of noncommutative algebras. (M 27464) Named by the Small Bodies Names Committee.

\section{(7002) Bronshten}

1971 OV. Discovered 1971 July 26 by N. S. Chernykh at Nauchnyj.

Vitalij Aleksandrovich Bronshten (1918- ) is a Moscow astronomer and specialist in physics and cosmogony of the minor bodies of the solar system. In addition, he contributed extensively to the development of amateur astronomy in the former U.S.S.R. (M 38196)

\section{(7003) Zoyamironova}

1976 SZg. Discovered 1976 Sept. 25 by N. S. Chernykh at Nauchnyj.

Named in honor of Zoya Sergeevna Mironova (1913-

), well-known surgeon and traumatologist. During World War II, she saved the lives and health of hundreds of wounded soldiers. Since 1952 she has worked at the Central Research Institute for Orthopedics and Traumatology in Moscow. During her long career, she has performed more than 10,000 surgical operations, many of them unique. Many world-famous sports figures and ballet dancers have benefited from her skill. She has received many honors, including recognition from the International Olympic Committee. (M 32347)

Name suggested by a group of scientists and the Olympic Committee of Russia and supported by the discoverer.

\section{(7008) Pavlov}

$1985 \mathrm{QH}_{5}$. Discovered 1985 Aug. 23 by N. S. Chernykh at Nauchnyj.

Named in memory of Nikolaj Nikiforovich Pavlov (1902-1985), professor at Leningrad University and head of the Pulkovo Observatory Time Service. He made a great contribution to the study of the earth's rotation and was the first to apply photoelectric, rather than visual, registration to meridian observations. (M 32347)

\section{(7009) Hume}

$1987 \mathrm{QU}_{1}$. Discovered 1987 Aug. 21 by E. W. Elst at La Silla.

Named in memory of the famous British philosopher David Hume (1711-1776). He started to study law but found it distasteful. In 1744 he became a candidate for the chair of moral philosophy at Edinburgh, but he was not successful, since his opponents found evidence for heresy and even atheism in his Treatise of Human Nature. In 1761 the Vatican put his writings on the Index. Hume regarded himself chiefly as a moralist: "It is our nature to find certain human qualities intrinsically good. However, we can not explain this, since any attempt would take us into the vacuum of metaphysics." (M 27736)

\section{(7010) Locke}

$1987 \mathrm{QH}_{3}$. Discovered 1987 Aug. 28 by E. W. Elst at La Silla.

Named in memory of the famous British philosopher John Locke (1632-1704), initiator of the Age of Enlightenment and Reason in England and France. Although he worked extensively on political ideas, his main concern was with epistemology, noting that human knowledge rests on experience of the external world and on reflection. Mathematical reasoning is deductive and is to be understood in terms of an intellectual intuition of relations between ideas. In his famous Essay concerning Human Understanding (1690), he set down the foundations of an epistemology of modern science. (M 28622)

Citation prepared by S. Elst at the request of the discoverer.

\section{(7011) Worley}

1987 SK $_{1}$. Discovered 1987 Sept. 21 by E. Bowell at Anderson Mesa.

Named in memory of Charles Edmund Worley (1935-1997), indefatigable observer and cataloguer of double-star positions. Following two years at the Lick Observatory, he was on the staff of the U.S. Naval Observatory from 1961. His work has significantly enhanced our knowledge of the motion of doublestar and multiple-star systems and of stellar masses. (M 31296)

Name suggsted by H. Eichhorn.

Obituaries published in Inf. Circ. IAU Comm. 26, No. 134 (1998); Bull. Am. Astron. Soc., Vol. 30, No. 4, p. $1470-1471$ (1998).

\section{(7012) Hobbes}

$1988 \mathrm{CH}_{2}$. Discovered 1988 Feb. 11 by E. W. Elst at La Silla.

Named in memory of the great British political philosopher Thomas Hobbes (1588-1679). In 1651 he published his masterpiece Leviathan, wherein he insisted that the first requirement of political and moral institutions is that they should provide citizens with security. He analyzed the conditions for peace and security and gave a recipe for constructing an ideal state: men can only live together in peace if they agree to subject themselves to an absolute and individual sovereign. He made a severe attack on the attempt of papists and presbyterians to challenge the rights of this sovereign. (M 28622)

Citation prepared by S. Elst at the request of the discoverer. 


\section{(7014) Nietzsche}

$1989 \mathrm{GT}_{4}$. Discovered 1989 Apr. 3 by E. W. Elst at La Silla.

Named in memory of the great German philosopher Friedrich Nietzsche (1844-1900), renowned for his criticisms on religion, philosphy and morality. One of his early writings, The Birth of Tragedy from the Spirit of Music (1872), remains a classic in the history of esthetics. His best-known work is Thus spoke Zarathustra (1883-1885), in which he noted that most men can not accept the intrinsic meaninglessness of existence: they therefore seek supplanting absolutes to invest life with meaning (philosphy and religion). But now "God is dead". The slaughter of rivals and the conquest of the earth will proceed, under the banners of universal brotherhood, democracy and socialism. (M 29148)

\section{(7015) Schopenhauer}

1990 QC $_{8}$. Discovered 1990 Aug. 16 by E. W. Elst at La Silla.

Named for the celebrated German philosopher of pessimism, Arthur Schopenhauer (1788-1860). In 1813 he went to Weimar and came in intimate association with Goethe \{see planet (3047)\}. Later he considered that Hindu scriptures, together with Plato and Kant \{see, respectively, planets (5451) and (7083)\}, should constitute the foundations on which to erect his own philosophical system. In On Vision and Colours (1816), he supported Goethe against Newton ssee planet (8000)\}. His main work was The World as Will and Idea (1819), wherein he develops the fundamental idea that "the world is my representation". The world is only comprehensible with the aid of the constructs of man's intellect - space, time and causality. (M 29148)

\section{(7016) Conandoyle}

1991 YG. Discovered 1991 Dec. 30 by T. Urata at Oohira.

Educated as a physician, Scots-born Arthur Conan Doyle (1859-1930) became famous for his Adventures of Sherlock Holmes and the detective-story genre. His other best-known works include A Study in Scarlet (1886), The Lost World (1912) and The Poison Belt (1913). (M 36946)

\section{(7017) Uradowan}

$1992 \mathrm{CE}_{2}$. Discovered 1992 Feb. 1 by T. Seki at Geisei.

Named for the bay that is the principal entrance by sea to Kochi prefecture \{see also planet (2396)\}. (M 32094)

\section{(7020) Yourcenar}

$1992 \mathrm{GR}_{2}$. Discovered 1992 Apr. 4 by E. W. Elst at La Silla.

Named in memory of the French-Belgian-American writer Marguerite Yourcenar (Marguerite de Crayencour, 1903-1987). Well known for her novels, essays and short stories, she also did translational work. In the historical novel Mémoires d'Hadrien (1951), she explored the world and thoughts of the fascinating second-century Roman emperor and meditated on human destiny, morality and power. Her 1968 L'oeuvre au noir (The Abyss) is an erudite evocation of the medieval spirit in Flanders and Italy by means of the life of a fictitious sixteenth-century alchemist and philosopher. In 1980 she became the first woman writer to be elected to the pretigious French Academy. (M 28622)

Citation prepared by K. Leterme at the request of the discoverer.

\section{(7027) Toshihanda}

1993 XT. Discovered 1993 Dec. 11 by T. Kobayashi at Oizumi.

Toshihiro Handa (1959- ) is a research associate at the Institute of Astronomy, University of Tokyo. He works in the area of radio astronomy, studying interstellar matter in our Galaxy and nearby galaxies. $\mathrm{He}$ is also active in public outreach in astronomy and astrophysics. (M 46008)

\section{(7028) Tachikawa}

$1993 \mathrm{XC}_{1}$. Discovered 1993 Dec. 5 by M. Hirasawa and S. Suzuki at Nyukasa.

Tachikawa is a suburban city west of Tokyo. After World War II Tachikawa was reborn as a commercial center. It declared itself a peaceful city and continues to grow to this day. (M 43189)

\section{(7030) Colombini}

1993 YU. Discovered 1993 Dec. 18 at the Santa Lucia Observatory at Stroncone.

Named in honor of Ermes Colombini (1956- ), since 1974 a member of the staff at the Osservatorio San Vittore, near Bologna. He was the first Italian amateur to obtain precise positions of comets and minor planets. He was also involved in the computation of orbits and in 1981 was awarded the Cerulli prize of the Italian Astronomical Society for his work on (2235) Vittore. (M 30799)

\section{(7032) Hitchcock}

$1994 \mathrm{VC}_{2}$. Discovered 1994 Nov. 3 by Y. Shimizu and T. Urata at Nachi-Katsuura.

The British-born American movie director and producer Alfred Joseph Hitchcock (1899-1980) was known as "a master of suspense" and "god of the thriller". His work includes North by Northwest (1959), Psycho (1960) and The Birds (1963). (M 36946)

\section{(7035) Gomi}

$1995 \mathrm{BD}_{3}$. Discovered 1995 Jan. 28 by K. Endate and K. Watanabe at Kitami.

Named in honor of Kazuaki Gomi (1911- ), amateur astronomer and long-time observer of variable stars. In 1936 he discovered the nova CP Lac. Although there were several earlier novae independently discovered by Japanese observers, this was the first nova of which a Japanese observer was the first discoverer. (M 33386) 
Name proposed by the discoverers following a suggestion by T. Sato and A. Fujii.

\section{(7037) Davidlean}

$1995 \mathrm{BK}_{3}$. Discovered 1995 Jan. 29 by Y. Shimizu and

T. Urata at Nachi-Katsuura.

British film director David Lean (1908-1991) was considered a master of both epics and small literary classics. He won Oscars for The Bridge over the River Kwai (1957) and Lawrence of Arabia (1962). (M 36946)

\section{(7039) Yamagata}

$1996 \mathrm{GO}_{2}$. Discovered 1996 Apr. 14 by T. Okuni at Nanyou.

Named for one of the six prefectures in the Tohoku (northeast) district in Japan, its capital being Yamagata city with a population of 1.25 million. The prefecture is famous for fruit production, notably cherries, apples and grapes. The Zaou and Tukigata areas of Yamagata are popular for skiing. (M 29148)

\section{(7040) Harwood}

2642 P-L. Discovered 1960 Sept. 24 by C. J. van

Houten and I. van Houten-Groeneveld at Palomar.

Named in memory of the American astronomer Margaret Harwood (1885-1979). Appointed the first director of the Maria Mitchell \{see planet (1455)\} Observatory in 1916, she maintained that post for 41 years. She had previously been an assistant at the Harvard College Observatory, where she worked again for 20 more years after her formal retirement. Known for her research on variable stars and the lightcurves of minor planets, she has been accorded only limited credit for her discovery of (886) Washingtonia four days before its official discovery at the U.S. Naval Observatory in November 1917. At that time, her mentors at Harward did not consider it appropriate for a woman to discover a minor planet. (M 30799)

\section{(7041) Nantucket}

4081 P-L. Discovered 1960 Sept. 24 by C. J. van Houten and I. van Houten-Groeneveld at Palomar.

Named for the Massachusetts island and the Maria Mitchell \{see planet (1455)\} Observatory located there. The observatory was founded by the Maria Mitchell Association, which in 1912 created an astronomical fellowship for women to work at the observatory during the summer months. Margaret Harwood \{see planet (7040)\} was the first fellow and director and had wished to give the name of the island to minor planet (886), when she independently discovered it just 80 years ago. This belated new assignment of that name also comes on the sesquicentennial of the appearance of Nantucket on the astronomical map, when Maria Mitchell discovered a comet on 1847 Oct. 1 from the roof of her father's house. (M 30799)

\section{(7042) Carver}

$1933 \mathrm{FE}_{1}$. Discovered 1933 Mar. 24 by K. Reinmuth at Heidelberg.
Named in memory of George Washington Carver (1860-1943), credited by many as the first black American scientist. Born into slavery, he was largely self-educated, but he earned a master's degree in science in 1896 and devoted the remainder of his life to agricultural research, especially the development of food and household products from peanuts, soybeans and sweet potatoes. His scientific stature earned him election to the Royal Society in 1916, but Carver was also an outstanding teacher, artist and humanitarian. $\mathrm{He}$ is perhaps best remembered for his most enduring and beloved invention, peanut butter. (M 28622)

Name suggested and citation prepared by G. C. L. Aikman.

\section{(7043) Godart}

1934 RB. Discovered 1934 Sept. 2 by E. Delporte at Uccle.

Named in honor of Odon Godart (1913-1996), Belgian mathematician who published distinguished papers on cosmic rays, theoretical and applied meteorology and cosmology. He was a professor at the Catholic University of Louvain and worked in the team of Georges Lemaitre \{see planet (1565)\}. His main contribution was the introduction of isobaric coordinates in meteorology (1942), and this generated new developments in applied meteorology. He served as president of the Belgian Society for Astronomy, Meteorology and Physics of the Earth. (M 27736)

Proposal made and citation provided by P. Pâquet.

\section{(7046) Reshetnev}

1977 QG $_{2}$. Discovered 1977 Aug. 20 by N. S. Chernykh at Nauchnyj.

An authority on theoretical and applied mechanics, Mikhail Fedorovich Reshetnev (1924-1996) constructed space devices and systems. He was head of the Research and Industrial Joint Institution of Applied Mechanics at Krasnoyarsk, and satellites for scientific research and communications were made under his leadership. (M 38196)

\section{(7047) Lundström}

1978 RZ9. Discovered 1978 Sept. 2 by C.-I. Lagerkvist at La Silla.

Named in honor of Magnus Lundström (1967- ), a former student of astronomy at Uppsala and at the German Aerospace Research Establishment (DLR), Berlin, who was involved with a numerical study of the 4:1 Jupiter resonance and with several asteroid surveys, including the Uppsala-DLR Trojan Survey and the European Near-Earth Asteroids Search Observatories (EUNEASCO). (M 30799)

\section{(7051) Sean}

1985 JY. Discovered 1985 May 13 by C. S. Shoemaker and E. M. Shoemaker at Palomar.

Named for Sean Colin Woodard, oldest grandson of the discoverers. (M 32347) 


\section{(7054) Brehm}

1989 GL $_{8}$. Discovered 1989 Apr. 6 by F. Börngen at Tautenburg.

Named in memory of the Thuringian naturalists Christian Ludwig Brehm (1787-1864) and Alfred Edmund Brehm (1829-1884), father and son. Ludwig Brehm was a renowned ornithologist who gathered a unique scientific collection of 15000 bird skins and was the author of several ornithological books. Alfred Brehm,a zoologist, went on several expeditions across Europe and to Siberia and North Africa, as a result of which he published the famous Brehms Tierleben (1863-1870), which has been translated into many languages. Both father and son were buried in the village of Renthendorf, near Jena \{see planet (526)\}, where Ludwig was parson for more than 50 years and Alfred was born and died. (M 27736)

\section{(7056) Kierkegaard}

$1989 \mathrm{SE}_{2}$. Discovered 1989 Sept. 26 by E. W. Elst at La Silla.

Named in memory of the great Danish religious philosopher Søren Kierkegaard (1813-1855), known as the "father of existentialism". All his life he suffered from the influence of the overpowering personality of his father, who educated him in strict adherence to orthodox Lutheranism. His unfortunate relationship with Regine Olsen also severely influenced his life and writings. Kierkegaard believed in the necessity for each individual to make a fully conscious, responsible choice among the alternatives that life offers. His well-known Fear and Trembling and Repetition dealt with faith and the idea of sacrifice. In The Sickness unto Death he anticipated aspects of Freudian \{see planet (4342)\} psychoanalysis. He made also severe attacks on Hegel's attempt to systematize the whole of existence. (M 28622)

\section{(7061) Pieri}

$1991 \mathrm{PE}_{1}$. Discovered 1991 Aug. 15 by E. F. Helin at Palomar.

David C. Pieri (1949- ), a staff scientist in the Earth and Space Sciences Division at the Jet Propulsion Laboratory since 1979, has research interests in volcanology, fluvial geomorphology, and planetary geology. (M 39650)

\section{(7062) Meslier}

$1991 \mathrm{PY}_{5}$. Discovered 1991 Aug. 6 by E. W. Elst at La Silla.

Named for the French priest and philosopher Jean Meslier (1664-1729). After his death, a 1200-page manuscript Lettres aux Curés du Voisinage was discovered. This showed him as a fervent atheist, materialist and revolutionist: "The real original sin of men is to be born in poverty, in misery, in dependence and tyranny of the mighty one. We must do everything to free them from this disgusting and damned sin." Although some copies of the manuscript circulated throughout the eighteenth century (eliciting comments from Voltaire and Holbach \{see planets (5676) and (6956)\}), the work was finally published only in 1864 . (M 29148)

\section{(7064) Montesquieu}

1992 OC $_{5}$. Discovered 1992 July 26 by E. W. Elst at La Silla.

Named for the French philosopher and writer CharlesLouis de Secondat (1689-1755). Better known by the name of his birthplace, Montesquieu is remembered especially for his De l'Esprit des lois (1748), an immense work on the laws and customs of mankind. (M 30799)

\section{(7066) Nessus}

$1993 \mathrm{HA}_{2}$. Discovered 1993 Apr. 26 by the Spacewatch at Kitt Peak.

Named for the centaur responsible for the death of Heracles \{see planet (5143)\}. Driven from his home in Arcadia \{see planet (1020)\} by Heracles, Nessus established himself as a ferryman who later encountered Heracles on travels with his new bride Dejanira \{see planet (157)\}. Entrusted with ferrying Dejanira across the river Evenus, Nessus attempted to violate her and was as a result killed by Heracles. Before dying, Nessus gave Dejanira a poisonous love charm that she later unwittingly administered to Heracles. (M 29671)

\section{(7067) Kiyose}

1993 XE. Discovered 1993 Dec. 4 by M. Hirasawa and S. Suzuki at Nyukasa.

Named for Kiyose City, a western suburb of Tokyo. The city was once home to many sanitaria because of its clean air and good environment. This minor planet was observed at Kiyose station under heavy light pollution. (M 34342)

\section{(7068) Minowa}

1994 WD $_{1}$. Discovered 1994 Nov. 26 by Y. Kushida and O. Muramatsu at Yatsugatake.

Named in honor of Toshiyuki Minowa (1918- ), a Japanese amateur astronomer. During ten years beginning in 1949, a meteor camera of the Tokyo Astronomical Observatory was installed in his garden as the end of a baseline. He was one of the founders, in 1953, of Kawasaki Astronomy Club. As a schoolmaster, he was eager to popularize astronomy among children, and he contributed a telescope that can be operated by a wheelchair user. He was the second chairman of the Japan Amateur Astronomers' Convention (1980-1983). (M 29148)

Name proposed by the discoverers following a suggestion by S. Sakuma.

\section{(7072) Beijingdaxue}

$1996 \mathrm{CB}_{8}$. Discovered 1996 Feb. 3 at the Beijing Observatory at Xinglong.

Named for the 100th anniversary of the Peking University (Beijing Daxue), the oldest national university in China. Founded in 1898, Peking University distinguishes itself by its rigorous style of study, 
prominent academic standing and fruitful education achievements. (M 30477)

\section{(7073) Rudbelia}

$1972 \mathrm{RU}_{1}$. Discovered 1972 Sept. 11 by N. S. Chernykh at Nauchnyj.

Ol'ga Ivanovna Belyaeva (née Rudneva) is a teacher of English at the Moscow College and Institute of Economics, Politics and Law. (M 38196)

\section{(7074) Muckea}

$1977 \mathrm{RD}_{3}$. Discovered 1977 Sept. 10 by N. S. Chernykh at Nauchnyj.

Hermann Mucke (1935- ), director of the Urania Sternwarte and planetarium in Vienna, is well known for his work in ephemeris astronomy and the theory of astronomical phenomena. He has contributed much to the astronomical education of schoolchildren and adults. (M 38196)

The name was suggested by V. K. Abalakin.

\section{(7075) Sadovnichij}

$1979 \mathrm{SN}_{4}$. Discovered 1979 Sept. 24 by N. S. Chernykh at Nauchnyj.

Named in honor of Viktor Antonovich Sadovnichij (1939- ), prominent mathematician, head of Moscow State University. An authority on differential equations, he has made valuable contributions to the study of mechanics and to mathematical methods for deciphering images. (M 34625)

\section{(7077) Shermanschultz}

1982 VZ. Discovered 1982 Nov. 15 by E. Bowell at Anderson Mesa.

Named in honor of Sherman W. Schultz (1922- ), retired lecturer of astronomy and telescope making who taught for more than 40 years at Macalester College, St. Paul, Minnesota. An optometrist by profession, Schultz figured the mirrors and built an array of telescopes for the college observatory, and these enabled undergraduates to perform photometric observations of minor planets and variable stars that are published in the professional literature. He guided more than 250 students and college faculty to make their own telescopes. The naming of this minor planet commemorates the May 1998 dedication of the Sherman W. Schultz Observatory at Macalester College. (M 32094)

Name proposed by the discoverer following a suggestion by R. P. Binzel, who prepared the citation.

\section{(7078) Unojönsson}

$1985 \mathrm{UH}_{3}$. Discovered 1985 Oct. 17 by C.-I. Lagerkvist at Kvistaberg.

Named in honor of Uno Jönsson (1937- ), a friend of the discoverer, to celebrate his 60th birthday. Long interested in astronomy, Jönsson has written several books for a general audience. He has also edited textbooks on astronomy, in one case with the discoverer as a contributing author. (M 31297)

\section{(7081) Ludibunda}

$1987 \mathrm{QF}_{7}$. Discovered 1987 Aug. 30 by P. Wild at Zimmerwald.

From the Latin ludibundus, meaning merry or joyful, Ludibunda is a frolicsome, playful woman, on the same pilgrimage as (6620) Peregrina, but of strongly contrasting temper. (M 41383)

\section{(7082) La Serena}

$1987 \mathrm{YL}_{1}$. Discovered 1987 Dec. 17 by E. W. Elst and G. Pizarro at La Silla.

La Serena is a beautiful small city near the Pacific, about $600 \mathrm{~km}$ north of Santiago de Chile. For many years it was a stopping point for astronomers on their way to the Chilean observatories. With the construction of a landing facility at Camp Pelicano, the ESO office at La Serena was abandoned. (M 47163)

\section{(7083) Kant}

1989 CL $_{3}$. Discovered 1989 Feb. 4 by E. W. Elst at La Silla.

Named for the great German philosopher Immanuel Kant (1724-1804), foremost thinker of the Enlightenment. His comprehensive and systematic works in the theory of knowledge, ethics and esthetics have greatly influenced all subsequent philosophy. Although he started his study with theology, he was principally attracted to mathematics and physics. In 1781 his most famous work, Kritik der reinen Vernunft, was published. This deals with the roots of knowledge and the conditions of possible experience. The human mind cannot arrive, by pure thought, at truths about entities that, by their very nature, can never be objects of experience. (M 29148)

\section{(7086) Bopp}

1991 TA$_{1}$. Discovered 1991 Oct. 5 by C. S. Shoemaker and E. M. Shoemaker at Palomar.

Named in honor of Tom Bopp, codiscoverer of comet C/1995 O1 (Hale-Bopp), and his father, Frank Bopp. During the last year the two Bopps have enjoyed observing the comet and in lecturing about it as a team. Tom Bopp is an accomplished observer and Frank a superb machinist who has fashioned materials for the Shoemaker-Levy observing program. (M 30100)

Name proposed by the discoverers following a suggestion by D. H. Levy, who prepared the citation.

\section{(7087) Lewotsky}

1991 TG$_{4}$. Discovered 1991 Oct. 13 by E. F. Helin at Palomar.

Named in honor of the Lewotsky family, especially Kristin and Gretchen, friends of the discoverer. Kristin, a classmate at the California State University at Fullerton, is currently a writing editor for an optics industry trade magazine; with a degree in optical science and engineering from the University of Central Florida, she worked on mirror fabrication for NASA's Advanced X-Ray Astrophysics Facility program. Gretchen is executive director of environmental operations with a 
major film studio and is currently a board member of a non-profit environmental group. (M 30100)

\section{(7088) Ishtar}

1992 AA. Discovered 1992 Jan. 1 by C. S. Shoemaker and E. M. Shoemaker at Palomar.

Named for the chief goddess of the Mesopotamian pantheon and a principal goddess of the Assyrians and Babylonians. She was a goddess of love, fertility, sex and war. Not only did she rule the moon, but Ishtar owned the morning and evening stars. As the morning star, the goddess arrayed herself in armor and hitched her chariot to seven lions before setting off in the dawn to hunt animals or humans. As the evening star, she was seen as the goddess "whose song is sweeter than honey and wine, sweeter than sprouts and herbs, superior even to pure cream". (M 29671; M 29691)

\section{(7092) Cadmus}

1992 LC. Discovered 1992 June 4 by C. S. Shoemaker and E. M. Shoemaker at Palomar.

Named for the son of the Phoenician king Agenor \{see planet (1873)\}, and the brother of Europa \{see planet (52)\}, Cilix and Phoenix. He was famous for the search for his sister Europa, whom Zeus \{see planet (5731)\} carried away. Cadmus overcame a dragon at Thebes with the assistance of Athena \{see planet (881)\} and sowed the dragon's teeth on the plain. Immediately, a company of armed men sprang up, ready for attack. Cadmus cast a stone into their midst and, in the resulting confusion, all but five of the warriors slew each other. The survivors became allies of Cadmus and helped him build Thebes. Cadmus married Harmonia \{see planet (40)\}, daughter of Aphrodite \{see planet (1388)\}. It was he who introduced the use of letters into Greece. (M 29671; M 29691)

\section{(7094) Godaisan}

1992 RJ. Discovered 1992 Sept. 4 by T. Seki at Geisei.

Named for a small mountain on the eastern side of Kochi City \{see planet (2396)\}. (M 32094)

\section{(7095) Lamettrie}

$1992 \mathrm{SB}_{22}$. Discovered 1992 Sept. 22 by E. W. Elst at La Silla.

Named in memory of the French medical doctor and philosopher Julien Offray de La Mettrie (1709-1751). After publishing Traité de l'Ame in 1745, he had to flee to Holland, where he published L'Homme-Machine (1748). "Soul' is just an empty word. Matter by its own has the faculty of perception." In his last work Discours préliminaire (1751), he wrote: "How can one possibly think that reasoning is dangerous? It has never led to fanatics, sects or even theologians." (M 29672)

\section{(7096) Napier}

1992 VM. Discovered 1992 Nov. 3 by R. H. McNaught at Siding Spring.

Named for the Scottish astronomer William (Bill) M. Napier (1940- ), who has made seminal contribu- tions in several areas of astrophysics. In collaboration with Victor Clube \{see planet (6523)\}, Napier was one of the first to suggest that impacts by comets and minor planets have had a significant influence upon life on the earth, and that those impacts are temporally linked to cyclic disturbances of the Oort Cloud \{see planet (1691)\} as the sun moves about the galactic plane, as well as to the sporadic arrival of giant comets in the inner solar system. Napier is currently investigating the effect upon the terrestrial climate of the varying influx of cometary dust in such a picture, although he also actively works on the apparent quantization of galactic redshifts. (M 29148)

Name proposed by the discoverer following a suggestion by D. I. Steel, who prepared the citation.

\section{(7097) Yatsuka}

1993 TF. Discovered 1993 Oct. 8 by H. Abe and S. Miyasaka at Yatsuka.

Named for the first discoverer's home town, in the eastern part of Shimane prefecture, known for its production of ginseng and peonies. (M 28090)

\section{(7098) Réaumur}

1993 TK$_{39}$. Discovered 1993 Oct. 9 by E. W. Elst at La Silla.

René-Antoine Ferchault de Réaumur (1683-1757) was a French scientist and important entomologist who developed the thermometer scale bearing his name. Well known for his Cupola furnace used for melting gray iron, he published his masterpiece Mémoires pour servir à l'histoire des insectes during 1734-1742. (M 47163)

\section{(7099) Feuerbach}

$1996 \mathrm{HX}_{25}$. Discovered 1996 Apr. 20 by E. W. Elst at La Silla.

Named in memory of the famous German philosopher and moralist Ludwig Andreas Feuerbach (1804-1872). In his Über Philosophie und Christentum (1839), he claimed that "Christianity has in fact long vanished not only from the reason but from the life of mankind and is nothing more than an obsession". But it is in his Das Wesen des Christentums (1841) that he put forward his ideas on religion: "God is merely the outward projection of man's inward nature". His views were later endorsed in Germany by extremists in the struggle between church and state. (M 29672)

\section{(7100) Martin Luther}

1360 T-2. Discovered 1973 Sept. 29 by C. J. van Houten and I. van Houten-Groeneveld at Palomar.

Named in memory of Martin Luther (1483-1546), German theologian and religious reformer. After studying law, he became an Augustinian monk and priest in 1507 and a professor of biblical exegesis in Wittenberg in 1508. On 1517 Oct. 31 he posted his famous 95 theses at the door of the university church. These theses were against the misuse of indulgences by the Catholic Church, and here the Reformation 
started. Luther also influenced the German language through his translations of the Old and the New Testaments into German. (M 33386)

\section{(7104) Manyousyu}

1977 DU. Discovered 1977 Feb. 18 by H. Kosai and K. Hurukawa at Kiso.

Named for the earliest collection of Japanese poetry, by many poets spanning about 400 years. Celestial phenomena are mentioned in several of the poems. (M 34625)

\section{(7105) Yousyozan}

1977 DB $_{1}$. Discovered 1977 Feb. 18 by H. Kosai and K. Hurukawa at Kiso.

Named for a 400-m mountain to the south of the Okayama \{see planet (2084)\} station of the National Astronomical Observatory of Japan. Site testing for the observatory was conducted for about a year on this mountain, resulting in the observatory's construction. It was opened in 1960. (M 33788)

\section{(7106) Kondakov}

$1978 \mathrm{PM}_{3}$. Discovered 1978 Aug. 8 by N. S. Chernykh at Nauchnyj.

Named in honor of Aleksandr Konstantinovich Kondakov (1928- ), researcher on agricultural chemistry and fertilizers for fruit plants, and head of the laboratory of agrochemistry at the Michurin All-Russian Research Institute of Gardening in Michurinsk. He is well known for his new concepts involving the fertilization of garden soil and for diagnostics concerning the nourishment of garden plants. (M 30799)

\section{(7107) Peiser}

$1980 \mathrm{~PB}_{1}$. Discovered 1980 Aug. 15 by A. Mrkos at Klě́t.

Named in honor of Benny Josef Peiser (1957- ), social anthropologist with a particular research interest in neocatastrophism and its implications for human, societal and cultural evolution. A senior lecturer at John Moores University in Liverpool, he launched and now moderates the Cambridge-Conference Network, a scholarly network of some 300 researchers from around the world. (M 34342)

Name suggested by J. Tichá, M. Tichý and Z. Moravec, who observed this minor planet at Klet at the 1994 and 1996 oppositions, prior to its numbering.

\section{(7108) Nefedov}

$1981 \mathrm{RM}_{3}$. Discovered 1981 Sept. 2 by N. S. Chernykh at Nauchnyj.

Named in honor of Oleg Matveevich Nefedov (1931-

), vice president of the Russian Academy of Sciences and chairman of the National Committee of Russian chemists. An outstanding scientist in the field of physical, synthetic and technical organic chemistry, he is best known for his fundamental research on highly reactive intermediates and small cycles. (M 32789)

Name proposed by the discoverer following a suggestion by the Institute of Applied Astronomy.

\section{(7109) Heine}

$1983 \mathrm{RT}_{4}$. Discovered 1983 Sept. 1 by L. G. Karachkina at Nauchnyj.

Named in memory of Heinrich Heine (1797-1856), the great German poet and writer, an outstanding master of lyric poems and political satire. The name is proposed on the occasion of the two-hundredth anniversary of his birth. (M 29148)

\section{(7112) Ghislaine}

1986 GV. Discovered 1986 Apr. 3 by C. S. Shoemaker and E. M. Shoemaker at Palomar.

Named in honor of the cosmochemist Ghislaine Crozaz (1939- ), who began her immensely productive career three decades ago, with studies of fission tracks in lunar samples and meteorites. Since then she has contributed significantly to our understanding of the early history of the solar system and to the formation histories of various meteorite types through innovative studies of trace element microdistributions and extinct radionuclides in these objects. As a professor in the Department of Earth and Planetary Sciences and McDonnell Center for the Space Sciences at Washington University, she actively participates in the training of the next generation of planetary scientists with her characteristic nurturing and enthusiastic spirit. (M 34625)

Citation prepared by M. Wadhwa at the request of the first discoverer.

\section{(7113) Ostapbender}

$1986 \mathrm{SD}_{2}$. Discovered 1986 Sept. 29 by L. G. Karachkina at Nauchnyj.

Named for the character Ostap Bender, celebrated hero of the satirical novels Twelve Chairs (1928) and Golden Calf (1931) by the Soviet writers Il'ya Il'f (penname of I. Feinsilberg) and Eugeny Petrov (penname of E. Kataev). The International Festival of Satire and Humor in St. Petersburg 'Gold Ostap' (founded in 1992) bears the name of this witty and resourceful character. (M 29148)

Name proposed by L. R. Nemirovskij on the occasion of the one-hundredth anniversary of the birth of Il'ya Il'f.

\section{(7114) Weinek}

$1986 \mathrm{WN}_{7}$. Discovered 1986 Nov. 29 by A. Mrkos at Klě́.

Ladislaus Weinek (1848-1913), the ninth director of the Klementinum observatory in Prague, collaborated with Küstner in the discovery of polar motion. He published a lunar atlas based on photographs from the Lick Observatory. (M 42356) The name was suggested by J. Tichá and M. Šolc.

\section{(7115) Franciscuszeno}

$1986 \mathrm{WO}_{7}$. Discovered 1986 Nov. 29 by A. Mrkos at Kleť.

Franciscus Zeno (1734-1781), the second director of the Klementinum observatory in Prague, was a 
paleontologist and professor of mathematics at Prague University. (M 42356)

The name was suggested by J. Tichá and M. Šolc.

\section{(7116) Mentall}

1986 XX. Discovered 1986 Dec. 2 by E. Bowell at Anderson Mesa.

Named in honor of E. Talmadge Mentall (1927-

), who retired from a drafting career to join Sky Publishing Corporation in 1994. With his artistic skill and life-long enthusiasm for astronomy, "Tal" soon played a pivotal role in the Millennium Star Atlas (1997), a joint undertaking with the European Space Agency's Hipparcos project. He meticulously drafted all the outlines of nebulae and measured the orientations of 2000 galaxies not available from the literature. (M 31297)

Name proposed by R. W. Sinnott, endorsed by B. G. Marsden and the discoverer.

\section{(7117) Claudius}

$1988 \mathrm{CA}_{1}$. Discovered 1988 Feb. 14 by F. Börngen at Tautenburg.

Named for the popular German poet and writer Matthias Claudius (1740-1815). He was the editor of the elitist journal Messenger of Wandsbeck and wrote lyric poetry and prose that is distinguished by simplicity, naturalness and heartful piety. Among this work is his evening song Der Mond ist aufgegangen. (M 29148)

\section{(7118) Kuklov}

1988 VD $_{5}$. Discovered 1988 Nov. 4 by A. Mrkos at Klě̆.

Kuklov is a small village in southern Bohemia northwest of Klět Mountain. There are impressive remnants of a Gothic church and monastery from the first half of the sixteenth century and the remnants of the castle from the fourteenth century. (M 42356) The name was suggested by J. Tichá.

\section{(7119) Hiera}

$1989 \mathrm{AV}_{2}$. Discovered 1989 Jan. 11 by C. S. Shoemaker and E. M. Shoemaker at Palomar.

A famous woman warrior and general of the Mysians, Hiera fought in the Trojan War but was edited from Homer's \{see planet (5700)\} account because, Philostratus says, "this greatest and finest women would have outshone his heroine Helen \{see planet (101)\}". (M 34625)

\section{(7121) Busch}

$1989 \mathrm{AL}_{7}$. Discovered 1989 Jan. 10 by F. Börngen at Tautenburg.

Named for the German poet and draughtsman Wilhelm Busch (1832-1908), who became worldrenowned for his popular humorous and satiric picture stories. His drawing style is full of verve and movement and is of the highest originality. As creator of immortal comic types such as Max and Moritz, as well as Pious Helen, he spread much laughter. Einstein s see planet
(2001)\} wrote of him that "He is one of the greatest masters of the stylistic accuracy of aim". (M 29149)

\section{(7122) Iwasaki}

$1989 \mathrm{EN}_{2}$. Discovered 1989 Mar. 12 by K. Endate and K. Watanabe at Kitami.

Named in honor of Kazuaki Iwasaki (1935- ), amateur astronomer and world-renowned space artist. His work has been frequently exhibited and he has published many books on the subject of space art. In July 1998 he opened his own space art gallery in Ito City, Shizuoka Prefecture. (M 32789)

Name proposed by the discoverers following a suggestion by T. Sato and A. Fujii.

\section{(7124) Glinos}

$1990 \mathrm{OJ}_{4}$. Discovered 1990 July 24 by H. E. Holt at Palomar.

Canadian amateur astronomer Tom Glinos (1960-

) has contributed observations in several fields for almost a quarter of a century. He recently donated a high-quality equatorial telescope mount to the London Centre of the Royal Astronomical Society of Canada, a group with which he has been long active. (M 42356)

\section{(7125) Eitarodate}

$1991 \mathrm{CN}_{1}$. Discovered 1991 Feb. 7 by T. Seki at Geisei.

Named in memory of Eitaro Date (1912-1953), Japanese amateur astronomer who observed the planets, particularly Mars, and who taught other planetary observers. (M 32789)

Name proposed by the discoverer following a suggestion by T. Sato and A. Fujii.

\section{(7126) Cureau}

1991 GJ $_{4}$. Discovered 1991 Apr. 8 by E. W. Elst at La Silla.

Named in memory of Marin Cureau de la Chambre (1594-1669), a doctor of medicine and author of several scientific works. In 1635 he became one of the first members of the prestigious Académie Française and will be remembered for his Traité de la Connaisance des Animaux (1647), a work that made clear that animals, like humans, have feelings, knowledge and thoughts. (M 30478)

\section{(7127) Stifter}

1991 RD $_{3}$. Discovered 1991 Sept. 9 by F. Börngen and L. D. Schmadel at Tautenburg.

Named for the most famous Austrian narrator Adalbert Stifter (1805-1868). After formative years spent in the Bohemian Forest, he studied near the Benedictine Abbey in Kremsmünster, later living in Vienna and Linz \{see planets (397) and (1469)\}. In his brillant novels and epics (The Timber Forest, Rock Crystal, Indian Summer and Witiko) landscapes were described in a superb manner. Stifter described the correlation of man and nature in a subtle manner, full of feeling. He dealt with questions of education, love and piety, and he was also engaged in painting and 
science. He gave full details of the total solar eclipse of 1842 July 8 as observed in Vienna. (M 29149)

\section{(7128) Misawa}

$1991 \mathrm{SM}_{1}$. Discovered 1991 Sept. 30 by K. Endate and

K. Watanabe at Kitami.

Named in memory of Katsue Misawa (1885-1937). Although he received only a limited education, through his own efforts he became a junior-high-school geography teacher. His unique teaching practices are highly appreciated in the history of Japanese education. In astronomy, he was the real pioneer of sunspot observation in Japan, systematically observing sunspots from 1921 until 1934, when failing eyesight prevented it. His data were invaluable because in those days foreign data arrived in Japan only after a long delay. (M 34342)

Name proposed by the discoverers following a suggestion by K. Gomi, T. Sato, K. Fujimori and A. Fujii.

\section{(7130) Klepper}

1992 HR $_{4}$. Discovered 1992 Apr. 30 by F. Börngen at Tautenburg.

Named for the German novelist and lyric poet Jochen Klepper (1903-1942), with The Father an important representative of the Christian historical novel. He was dismissed from his post at the Berlin Radio already in 1933 because his wife was Jewish. By courageously raising his voice against Hitler's terror he consoled people who suffered from the system. His letters and diary Under the Shadows of your Wings are moving. Pressed by the circumstances, he decided to die voluntarily with his wife and her daughter in order to protect them from the concentration camp. (M 29149)

\section{(7131) Longtom}

1992 YL. Discovered 1992 Dec. 23 by A. Natori and T. Urata at Yakiimo.

Longtom, the nine-pound cannon in Treasure Island, is the nickname of the Nikon $10-\mathrm{cm}$ refractor used regularly by Hoei Nojiri (1885-1977) \{see planet (3008)\}, who ordered the telescope and translated Stevenson's novel into Japanese in 1928. The telescope was at one time also used by Tokyo astronomer Koichiro Tomita \{see planet (2391)\}. (M 36946)

\section{(7132) Casulli}

1993 SE. Discovered 1993 Sept. 17 at the Santa Lucia Observatory at Stroncone.

Named in honor of Silvano Casulli (1944- ), who was the first amateur astronomer in the world to obtain precise astrometric positions of minor planets using a CCD camera. He lives and works near Rome, and his great enthusiasm played a significant role in organizing the amateur astrometrists in Italy. (M 30800)

\section{(7133) Kasahara}

1993 TX $_{1}$. Discovered 1993 Oct. 15 by K. Endate and K. Watanabe at Kitami.

Named in honor of Shin Kasahara (1953- ), doctor of dentistry and senior lecturer at Tohoku University. An amateur astronomer, he has been enthusiastically engaged in positional observation and orbit calculation of minor planets and comets since 1973. He also played an important role in designing and constructing the biggest portable telescope in Japan, the $84-\mathrm{cm}$ Chiro Memorial Telescope, which went on a national tour to allow the observation of comet 1P/Halley. (M 32789)

Name proposed by the discoverers following a suggestion by M. Koishikawa and A. Fujii.

\section{(7134) Ikeuchisatoru}

1993 UY. Discovered 1993 Oct. 24 by T. Kobayashi at Oizumi.

Satoru Ikeuchi (1944- ) works mainly on the evolution of the interstellar medium and the formation of large-scale structure of the universe. He is a member of the Science Council of Japan and served as the Japanese national representative to the IAU since 1997. (M 46008)

\section{(7137) Ageo}

$1994 \mathrm{AQ}_{1}$. Discovered 1994 Jan. 4 by S. Otomo at Kiyosato.

Ageo is a city north of Tokyo in Saitama s see planet (5618)\} Prefecture. (M 39650)

The name was suggested by M. Sekine.

\section{(7139) Tsubokawa}

$1994 \mathrm{CV}_{2}$. Discovered 1994 Feb. 14 by T. Niijima and T. Urata at Ojima.

Named in memory of Ietsune Tsubokawa (19181994), the fifth director of the International Latitude Observatory of Mizusawa ssee planet (7530)\} (19761986) and a former director of the Earthquake Research Institute of the University of Tokyo. He strove to automate the instruments used for the geodetic survey and astronomical observations. (M 34625)

Name proposed by the second discoverer following a suggestion by K. Hurukawa and K. Yokoyama. Citation prepared by K. Yokoyama.

\section{(7140) Osaki}

$1994 \mathrm{EE}_{1}$. Discovered 1994 Mar. 4 by T. Kobayashi at Oizumi.

Yoji Osaki (1938- ) works mainly in stellar physics and served as president of the Japan Astronomical Society during 1999-2000. In 1974 he proposed the disk-instability model for outbursts of dwarf novae, a model that is now widely accepted. (M 46008)

\section{(7141) Bettarini}

$1994 \mathrm{EZ}_{1}$. Discovered 1994 Mar. 12 by A. Boattini and M. Tombelli at Cima Ekar.

Named in memory of Otello Bettarini (1905-1982), a pioneer who left great footprints in our way of life. 
The astronomical observatory, built by him, allowed the discoverers to "cut their teeth" in astronomy. (M 30478)

\section{(7142) Spinoza}

$1994 \mathrm{PC}_{19}$. Discovered 1994 Aug. 12 by E. W. Elst at La Silla.

Named for the Dutch-Jewish philosopher Benedict de Spinoza (1632-1677). He incurred the disapproval of the synagogue authorities, and in 1656 he was excommunicated. Although acknowledging Descartes \{see planet (3587)\} to be the father of modern philosophy, he did not agree with his metaphysics. In his masterpiece, Ethica (1663-1675), he constructed a metaphysical system entirely deductively in terms of Euclidean geometry. Spinoza was also an expert in grinding and polishing lenses, but the inhalation of glass dust contributed to his death. (M 30800)

\section{(7143) Haramura}

$1995 \mathrm{WU}_{41}$. Discovered 1995 Nov. 17 by S. Otomo at Kiyosato.

Haramura is a village in Nagano prefecture, $200 \mathrm{~km}$ east of Tokyo. A large star party is held there each summer. (M 40702)

\section{(7144) Dossobuono}

1996 KQ. Discovered 1996 May 20 by L. Lai at Madonna di Dossobuono.

Named for the village of Madonna di Dossobuono, known for its sanctuary for "700 dedicated to the virgin Mary". Located $7 \mathrm{~km}$ from Verona, it is the site of the observatory at which this minor planet was discovered. (M 31025)

\section{(7145) Linzexu}

1996 LO. Discovered 1996 June 7 at the Beijing Observatory at Xinglong.

Named in honor of Lin Zexu (1785-1850) for his pioneering campaign against drug abuse and drugrelated crimes. Born in Minhou, Fujian Province, China, his illustrious work was crowned by the burning of 1200 tons of opium in June 1839 on the beach of Humen in southern China. As an official of Qing dynasty, he is also remembered for his achievements in water conservancy, from which his native province and other districts in China greatly benefited. (M 33788)

\section{(7146) Konradin}

3034 P-L. Discovered 1960 Sept. 24 by C. J. van Houten and I. van Houten-Groeneveld at Palomar.

Named in honor of Konradin Ferrari d'Occhieppo (1907- ), professor emeritus of astronomy of Vienna University and full member of the Austrian Academy of Sciences, on his forthcoming ninetieth birthday. Well known in Austria as a profound teacher and scientist, he is also a nobleman of extraordinary personal modesty and generosity. He has worked on variable stars, as well as on astrometric and calendrical problems and the history of astronomy. His main interest has been in the astronomical aspects of the Star of Bethlehem, a subject to which he devoted a book and many articles. (M 28622)

Name suggested by H. F. Haupt (who prepared the citation) and L. D. Schmadel.

\section{(7147) Feijth}

4015 P-L. Discovered 1960 Sept. 24 by C. J. van Houten and I. van Houten-Groeneveld at Palomar.

Named in honor of Hendrik (Henk) Feijth (19441997), a devoted and true amateur astronomer: making variable star observations is his passion. Since the early 1960s he has been an observer in the variable star observing group Nederlandse Vereniging voor Weer en Sterrenkunde, Werkgroep Veranderlijke Sterren. Since 1981 he has been this group's representative to the American Association of Variable Star Observers. Feijth has made nearly 100,000 observations of variable stars and has lectured and written articles for journals and books. (M 29672)

Name proposed and citation prepared by T. Jurriens.

Obituaries published in Radiant, Jaarg. 19, Nr. 3, p. 49-50 (1997); Zenit, Jaarg. 24, Nr. 7/8 (1997); Int. Comet Q., Vol. 20, No. 2, p. 53 (1993).

\section{(7148) Reinholdbien}

1047 T-1. Discovered 1971 Mar. 25 by C. J. van Houten and I. van Houten-Groeneveld at Palomar.

Named in honor of Reinhold Bien (1947- ), astronomer at the Astronomisches Rechen-Institut in Heidelberg. Bien's fields of interest include numerical studies on celestial mechanics, stellar dynamics and involving interacting galaxies. He is known in particular for his work on the long-period evolution of Trojan orbits. (M 30800)

Name proposed and citation prepared by J. Schubart.

\section{(7149) Bernie}

3220 T-3. Discovered 1977 Oct. 16 by C. J. van Houten and I. van Houten-Groeneveld at Palomar.

Named in honor of Hans-Heinrich "Bernie" Bernstein (1953- ), senior astronomer at the Astronomisches Rechen-Institut in Heidelberg. He analyzed pulsetiming data on pulsars and was instrumental in developing an algorithm for the detection of astrometric binaries with ESA's satellite HIPPARCOS. He detected 110 new double-star systems, together with a few brown-dwarf candidates. Bernstein is an expert in numerical mathematics, with many special applications in astrometry. (M 30800)

Name proposed and citation prepared by L.D.Schmadel.

\section{(7152) Euneus}

$1973 \mathrm{SH}_{1}$. Discovered 1973 Sept. 19 by C. J. van Houten and I. van Houten-Groeneveld at Palomar.

Named for the king of Lemnos and a son of Jason \{see planet (6063)\}. Euneus supplied the Greek forces with wine during the Trojan war. (M 30478) 


\section{(7153) Vladzakharov}

$1975 \mathrm{XP}_{3}$. Discovered 1975 Dec. 2 by T. M. Smirnova at Nauchnyj.

Named in honor of Vladimir Evgen'evich Zakharov (1939- ), outstanding mathematical and theoretical physicist, director of L. D. Landau Institute for Theoretical Physics of the Russian Academy of Sciences, and department head at the Moscow Institute for Physics and Technology. He is widely known for his investigations of nonlinear plasma physics and theoretical and computational hydrodynamics. His pioneering work in the field of nonlinear interaction of electromagnetic waves with plasma opened important new directions in space and stellar physics. (M 35485)

Name suggested by the Institute of Applied Astronomy.

\section{(7161) Golitsyn}

1982 UY $_{10}$. Discovered 1982 Oct. 25 by L. V. Zhuravleva at Nauchnyj.

Russian field marshal Mikhail Mikhailovich Golitsyn (1675-1730) was a participant in the Azov campaign of 1695-1696 and the Northern war of 1700-1721. From 1728 he was president of the Military Board and a member of the Supreme Secret Council. (M 42669)

\section{(7162) Sidwell}

1982 VB $_{1}$. Discovered 1982 Nov. 15 by E. Bowell at Anderson Mesa.

Named in honor of Daniel R. Sidwell (1932- ), the facility operations manager of the Table Mountain Facility, upon his retirement after 42 years of dedicated service to the Jet Propulsion Laboratory. Sidwell worked with the "wind tunnel" group at JPL's Pasadena facility before moving to Table Mountain in 1976, where he has been a source of dedicated and sustained help beyond the call of duty. (M 35485) Name suggested and citation prepared by J. W. Young.

\section{(7164) Babadzhanov}

1984 ET. Discovered 1984 Mar. 6 by E. Bowell at Anderson Mesa.

Named in honor of Pulat Babadzhanov (1930- ), director of the Institute of Astrophysics, Tajik Academy of Sciences, Dushanbe. Babadzhanov's research includes the photographic investigation of meteors, the physics and dynamics of meteors, the evolution of meteoroid streams and the association of comets and minor planets with meteor showers. He has served as rector of the Tajik State University, vice president of the Tajik Academy of Sciences and as president of IAU Commission 22. (M 32347)

\section{(7165) Pendleton}

1985 RH. Discovered 1985 Sept. 14 by E. Bowell at Anderson Mesa.

Named for astronomer Yvonne Jean Pendleton (1957- ) of the NASA Ames Research Center. She specializes in the spectroscopic study of the organic components of interstellar dust and the incorporation of that dust into bodies in the solar system and extrasolar planetary systems. She has pursued the identification of interstellar organics through comparative studies using materials produced in the laboratory and those derived from meteorites. Her research is focused on the connection of interstellar organic matter to the origin of life on the earth and other planets. Pendleton is a codiscoverer of the organic matter in interstellar dust in external galaxies by infrared spectroscopy. (M 29149)

Name proposed by the discoverer following a suggestion by D. P. Cruikshank, who prepared the citation.

\section{(7166) Kennedy}

1985 TR. Discovered 1985 Oct. 15 by E. Bowell at Anderson Mesa.

Named in memory of Malcolm Kennedy (1944-1997), tireless and popular secretary of the Astronomical Society of Glasgow. Born and raised in New Zealand, Kennedy became a civil engineer in Scotland. He was an energetic member of the Free Church in Cumbernauld, near Glasgow. As secretary of the ASG, he ensured that meetings ran smoothly, enlivening them with wordplay and puns. (M 32348)

\section{(7167) Laupheim}

1985 TD $_{3}$. Discovered 1985 Oct. 12 by C. S. Shoemaker and E. M. Shoemaker at Palomar.

Named in honor of Robert Clausen (1951- ) and his team at the public observatory in Laupheim, a town in southern Germany. In 1975 Clausen founded an association of amateur astronomers Volkssternwarte Laupheim e.V. and became its president. By organizing traveling astronomical exhibitions and numerous international astrofests, he expanded Laupheim's reputation far beyond Germany. Since 1990 Clausen, assisted by his coworkers, has excelled in running, with great professionalism, a Zeiss planetarium and observatory that were mostly built through the members' own initiative. (M 34625)

Citation provided by G. and D. Heinlein at the request of C. Shoemaker, who visited the Laupheim facilities in 1998 .

\section{(7169) Linda}

1986 TK $_{1}$. Discovered 1986 Oct. 4 by E. Bowell at Anderson Mesa.

Named in memory of Linda McCartney (1941-1998), wife of Beatle Paul McCartney \{see planet (4148)\}, member of the musical group Wings, photographer, and author of vegetarian cookbooks. McCartney's strength of purpose as a friend of the environment, of animals, and of all humanity, together with her devotion to her family, provided a shining example to others. (M 32789)

Name proposed by the discoverer following a suggestion by J. Dunne, who prepared the citation. 


\section{(7171) Arthurkraus}

$1988 \mathrm{AT}_{1}$. Discovered 1988 Jan. 13 by A. Mrkos at Klě̌t.

Baron Arthur Kraus (1854-1930) was a man of wide interests, including new technology, sports and aviation. He privately funded the Public Observatory at Pardubice in 1912, made observations of sunspots and mainly served as a sedulous popularizer of astronomy. (M 42356)

The name was suggested by J. Tichá.

\section{(7172) Multatuli}

$1988 \mathrm{DE}_{2}$. Discovered 1988 Feb. 17 by E. W. Elst at La Silla.

Named in memory of the great Dutch writer Multatuli ("I have suffered much", pseudonym of Eduard Douwes Dekker, 1820-1887). In 1838 he went to the Durch East Indies, where he held a number of governmental posts. In 1856 he resigned as assistant commissioner of Lebak, Java, because he was not supported by the government in his struggle to protect the Javanese from exploitation by their own chiefs. Back in Europe, he soon became internationally known with his novel Max Havelaar (1860), which enabled him to plead for justice in Java and to satirize the Dutch middle-class mentality. (M 28622)

Name proposed by the discoverer, endorsed by C.-F. Merks and J. Meeus.

\section{(7173) Sepkoski}

1988 PL $_{1}$. Discovered 1988 Aug. 15 by C. S. Shoemaker and E. M. Shoemaker at Palomar.

Named in memory of paleontologist J. John Sepkoski Jr. (1948-1999). His far-reaching work made a major contribution to quantifying the nature of life's diversity through time. The compilation of a huge database, begun while he was at the University of Rochester and continued at the University of Chicago, enabled researchers to combine mathematical modeling and paleoecology with massive data arrays. Together with his colleague David Raup, Sepkoski developed the theory that catastrophic extinction events have a 26-million-year periodicity. (M 35485)

\section{(7176) Kuniji}

1989 XH. Discovered 1989 Dec. 1 by A. Takahashi and K. Watanabe at Kitami.

Named in honor of Kuniji Saito (1913- ), who joined the Tokyo Astronomical Observatory in 1936 and was engaged mainly in research on the solar corona. Following his retirement in 1974, he has collected historical materials from Japan, China and other countries to analyze them from the viewpoint of modern astronomy, using computers. He named this field of research "paleoastronomy" and hopes that many other reearchers will enter into this kind of research. He also served as president of the Astronomical Society of Japan. (M 32789; M 33151)

Name proposed by the discoverers following a suggestion by A. Fujii and A. Tanno.

\section{(7178) Ikuookamoto}

$1990 \mathrm{VA}_{3}$. Discovered 1990 Nov. 11 by T. Nomura and K. Kawanishi at Minami-Oda.

Named in honor of Ikuo Okamoto (1946- ), optician and amateur astronomer. He owns the Schmidt camera with which this minor planet was discovered. (M 35485)

\section{(7179) Gassendi}

1991 GQ $_{6}$. Discovered 1991 Apr. 8 by E. W. Elst at La Silla.

Named for the French philosopher and scientist Pierre Gassendi (1592-1655). Originally trained in theology, he came under the influence of the mathematiciantheologian Mersenne. On 1631 Nov. 7 he made the first known observation of a transit of Mercury, thereby confirming the work of Kepler \{see planet (1134)\}. As a philosopher, he revived Epicureanism as a substitute for Aristotelianism. At Mersenne's request, he refuted Descartes' \{see planet (3587)\} Meditations in his Disquisitio Metaphysica (1644). In his great Syntagma Philosophicum, finally published as part of his opera omnia in 1658 , he rejected the innate ideas of Descartes and favored the senses as the primary sources of knowledge. (M 31025)

\section{(7186) Tomioka}

1991 YF. Discovered 1991 Dec. 26 by K. Endate and K. Watanabe at Kitami.

Named in honor of Hiroyuki Tomioka (1942- ), director of weather information in Hitachi City. An amateur astronomer, he is a charter member of the Nippon Meteor Society and has observed meteors for more than 40 years, both visually and photographically. In addition to his observations from Japan, he often visits the Chiro Observatory Southern Station in Australia to observe southern meteor showers. (M 32789; M 33151)

Name proposed by the discoverers following a suggestion by A. Fujii and T. Sato.

\section{(7187) Isobe}

1992 BW. Discovered 1992 Jan. 30 by E. F. Helin at Palomar.

Syuzo Isobe (1942- ), of the National Astronomical Observatory, has been instrumental in establishing the Bisei Spaceguard Center, an observatory designed for the observation of near-earth objects and earthorbiting space debris. He is also president of the Japan Spaceguard Association. (M 43762)

\section{(7188) Yoshii}

$1992 \mathrm{SF}_{1}$. Discovered 1992 Sept. 23 by K. Endate and K. Watanabe at Kitami.

Named in honor of Koichi Yoshii (1914- ), retired postmaster and amateur astronomer. He was a pioneer in meteor photography in Japan. In the 1930s, when the sensitivity of photographic emulsion was still very low, he succeeded in photographing 86 meteors with his homemade camera. (M 32789)

Name proposed by the discoverers following a suggestion by A. Fujii, Y. Yabu and T. Sato. 


\section{(7189) Kuniko}

1992 SX $_{12}$. Discovered 1992 Sept. 28 by K. Endate and K. Watanabe at Kitami.

Named in honor of Kuniko Fujita (1923-1992), née Sofue, amateur astronomer and poet. She became interested in astronomy at an early age and made an important discovery - a nova, later named CP Pup when she was a 19-year-old schoolgirl; she was awarded a prize from the Japan Astronomical Society as the first discoverer. She became a member of the Kawasaki Astronomical Club in 1972, and she visited Australia and New Zealand in 1986 to observe comet 1P/Halley. She joined expeditions to the Okinawa annular eclipse in 1986 and to the total eclipse in Mexico in 1991. A talented poet and calligrapher, she published a book of petry, Hoshinagisa. (M 32789; M 32819; M 32819)

Named by the discoverers following suggestions from S. Morikubo and T. Minowa.

\section{(7192) Cieletespace}

1993 RY $_{1}$. Discovered 1993 Sept. 12 by K. Endate and

K. Watanabe at Kitami.

Named for the monthly astronomical magazine edited in Paris by Alain Cirou and published by the Association Française d'Astronomie. Created in 1947 by a small group of amateurs under the name $L e$ ciel normand, Ciel et Espace is one of the leading magazines of astronomy and space science in Europe. Scientists, journalists and amateurs all write for the magazine, and important celestial phenomena, such as eclipses and comets, provide an opportunity for the editorial staff to invite their readers to observe the sky. (M 33386)

Name proposed by the discoverers following a suggestion by A. Fujii.

\section{(7193) Yamaoka}

$1993 \mathrm{SE}_{2}$. Discovered 1993 Sept. 19 by K. Endate and K. Watanabe at Kitami.

Named in honor of Hitoshi Yamaoka (1965- ), astrophysicist at Kyushu University who spezializes in the study of supernovae and novae. He promotes a supernova search project at public observatories in Japan. (M 33386)

\section{(7195) Danboice}

1994 AJ. Discovered 1994 Jan. 2 by T. Kobayashi at Oizumi.

Astronomer Daniel Craig Boice (1953- ) is an expert in cometary science and a dedicated educator. He was a member of NASA's Deep Space 1 Mission to comet $19 \mathrm{P} /$ Borrelly, codiscoverer of a radio flare on Menkar and recipient of the P. Gott Award. $\mathrm{He}$ is strongly committed to international scientific collaboration. (M 46008)

\section{(7196) Baroni}

1994 BF. Discovered 1994 Jan. 16 by A. Boattini and M. Tombelli at Cima Ekar.

Named in honor of the amateur astronomer Sandro Baroni (1939- ). Since 1953 he has pursued many different kinds of astronomical observation, especially of variable stars, comets, lunar occultations and asteroidal occultations. He gives lectures on a regular basis at the Civic Planetarium in Milan, where he lives. Baroni has been an inspiration for generations of amateur astronomers and has shared his knowledge by publishing many informative articles, especially on the history of astronomy. (M 29149)

\section{(7197) Pieroangela}

1994 BH. Discovered 1994 Jan. 16 by A. Boattini and M. Tombelli at Cima Ekar.

Named in honor of Piero Angela (1928- ). A journalist and science writer, he has created hundreds of science programs for Italian television, including the weekly science magazine "Quark". He has produced and hosted many popular series, such as "The Marvellous Machine" (a journey inside the human body) and "The Planet of the Dinosaurs", both of which have been shown in more than 40 countries. He has written numerous books on a variety of subjects, including astronomy, biology, psychology and economics, and he has received two honorary doctorates from Italian universities in natural and biological sciences. (M 29672)

\section{(7198) Montelupo}

1994 BJ. Discovered 1994 Jan. 16 by A. Boattini and M. Tombelli at Cima Ekar.

Named for a small but busy town very near Florence with a tradition in ceramics that goes back to the Middle Ages. During the Renaissance, Montelupo was the center of the majolica production under the Medici family. Today, the town is well known for its artistic production and for its industrial and handicraft activities, so that it is also called the "City of the ceramics". (M 29149)

Name proposed by the second discoverer, who was born in Montelupo, where most of the follow-up observations of this minor planet were made, and where she and the first discoverer both started their astrometric work on minor planets and comets.

\section{(7199) Brianza}

1994 FR. Discovered 1994 Mar. 28 by M. Cavagna and V. Giuliani at Sormano.

Named for the area located among the cities of Milan, Como and Lecco. The name is thought to be derived from the Celtic word "brig", i.e., height. In fact, Brianza is a verdant land, with lakes, hills and prealpine mountains. It is also one of the most industrial and productive parts of Italy. The name also honors the "Gruppo Astrofili Brianza", a group of amateur astronomers to which the discoverers belong, as it celebrates 15 years of activity. (M 29149)

\section{(7201) Kuritariku}

$1994 \mathrm{UF}_{1}$. Discovered 1994 Oct. 25 by S. Otomo at Kiyosato.

A broadcaster with KOFU-FM, Hiroe Kurimoto (1961- ), whose radio name is Kuritariku, is an active 
participant in the Star Week program sponsored each August by the National Astronomical Observatory. She is also the toastmaster of star parties. (M 41028)

\section{(7203) Sigeki}

$1995 \mathrm{DG}_{2}$. Discovered 1995 Feb. 27 by S. Otomo at Kiyosato.

Sigeki Horiuchi (1949- ) is a factory manager in the town of Shimosuwa, Nagano prefecture. He is involved with the organization of the annual Haramura star party. (M 40702)

\section{(7204) Ondřejov}

1995 GH. Discovered 1995 Apr. 3 by P. Pravec at Ondřejov.

Named for the village, $35 \mathrm{~km}$ to the southeast of Prague, where the oldest active astronomical observatory in the Czech Republic is located. The Ondřejov Observatory was founded in 1898, and it merged into the Astronomical Institute in 1953. The observatory also belongs to the Academy of Sciences of the Czech Republic. This is the first numbered minor planet to be discovered from the Ondřejov Observatory. (M 29149)

\section{(7206) Shiki}

1996 QT. Discovered 1996 Aug. 18 by A. Nakamura at Kuma.

Named in memory of Shiki Masaoka (1867-1902), one of the most famous Haiku poets of the Meiji period, born in Matsuyama City. He proposed a revolutionary movement to adopt a new style of Haiku in terms of sketches from life, instead of using the fictitious and imaginary expressions that were common before him. His style attracted many followers and has since become common. In Japan Standard Time this minor planet was discovered on Aug. 19, which is the day of Haiku. (M 29149)

\section{(7207) Hammurabi}

2133 P-L. Discovered 1960 Sept. 24 by C. J. van Houten and I. van Houten-Groeneveld at Palomar.

Named for the Babylonian king Hammurabi, who reigned from 1792 to 1750 B.C. and united the different small states of Ur into a single state covering much of Mesopotamia, with Babylon as its capital. Many cuneiform tablets praise his justice. Famous is the stela from Susa containing the Code of Hammurabi. (M 30800)

\section{(7208) Ashurbanipal}

2645 P-L. Discovered 1960 Sept. 24 by C. J. van Houten and I. van Houten-Groeneveld at Palomar.

Named for the Assyrian king Ashurbanipal (c.693626 B.C.), who became king in 669 B.C. and is historically important because of his collection of Babylonian and Assyrian documents and literature on clay tablets in cuneiform characters. The great epic poem of Gilgamesh \{see planet (1812)\} is found in his library. Also impressive are the large stone reliefs at his palace, where Ashurbanipal's deeds are detailed. (M 30800)

\section{(7209) Cyrus}

3523 P-L. Discovered 1960 Oct. 17 by C. J. van Houten and I. van Houten-Groeneveld at Palomar.

Named for the Persian king Cyrus II, the Great, who reigned from 559 to 529 B.C. He conquered the Medean capital of Ecbatana and subjugated the Lydian king Croesus and the Greek colonies of Asia Minor. In 539 B.C. he conquered Babylon, then the greatest city of the ancient world. He gave the Jews permission to return to Canaan and to rebuild their temple. (M 30800)

\section{(7210) Darius}

6555 P-L. Discovered 1960 Sept. 24 by C. J. van Houten and I. van Houten-Groeneveld at Palomar.

Named for the Persian king Darius I, the Great (550-486 B.C.), who became king after the death of Cambyses II and married two daughters of Cyrus II \{see planet (7209)\}. His splendid palace in Persepolio was destroyed by Alexander the Great. Darius was defeated by the Greeks at the battle of Marathon in 490 B.C., and he died as he was preparing a new campaign against them. (M 30800)

\section{(7211) Xerxes}

1240 T-1. Discovered 1971 Mar. 25 by C. J. van Houten and I. van Houten-Groeneveld at Palomar.

Named for the Persian king Xerxes I (519-465 B.C.), son of Darius and Atossa \{see, respectively, planets (7210) and (810)\}. He continued the war against the Greeks but was defeated by them in naval battles at Salamis (480 B.C.) and Mycale (479 B.C.) and on land at Plateaa (479 B.C.). He was killed during a palace revolution. Aeschylus \{see planet (2876)\} made him the main character in his tragedy Persai. (M 30800)

\section{(7212) Artaxerxes}

2155 T-2. Discovered 1973 Sept. 29 by C. J. van Houten and I. van Houten-Groeneveld at Palomar.

Named for the Persian kings Artaxerxes. Artaxerxes I, Macrocheir (484-424 B.C.) was the younger son of Xerxes I \{see planet (7211)\} and the father of Xerxes II. A peace treaty with Athens in 449 B.C. marked the end of Persian expansion, with Persia recognizing the independence of the Greek cities in Asia Minor. Artaxerxes II, Mnemon, reacquired those Greek cities and also received Cyprus in a peace treaty in 386 B.C. (M 30800)

\section{(7214) Antielus}

$1973 \mathrm{SM}_{1}$. Discovered 1973 Sept. 19 by C. J. van Houten and I. van Houten-Groeneveld at Palomar.

Named for one of the Greek heroes during the Trojan war. Antielus was one of the heroes hidden in the wooden horse. (M 30478) 


\section{(7215) Gerhard}

1977 FS. Discovered 1977 Mar. 16 by H.-E. Schuster at La Silla.

Named in memory of Gerhard Bachmann (1931-1996), who came to the European Southern Observatory in 1970 and was head of administration at the organization from 1972 to 1996. Throughout this time he greatly contributed to ESO's success. His unusual diplomatic abilities and thorough knowledge of the interaction of science and politics ensured the smooth running of the observatory and efficient interaction with the member countries and the European Union. The naming marks his retirement from ESO and subsequent untimely death. (M 28622)

Name proposed by the discoverer. Citation prepared by R. M. West.

\section{(7216) Ishkov}

1977 QQ2. Discovered 1977 Aug. 21 by N. S. Chernykh at Nauchnyj.

Vitalij Nikitich Ishkov, astrophysicist at the Institute of Terrestrial Magnetism, Ionosphere and Radiowave Propagation in Moscow, works in the fields of solar physics, solar activity and solar-terrestrial relations. (M 38196)

\section{(7217) Dacke}

1979 QX $_{3}$. Discovered 1979 Aug. 22 by C.-I. Lagerkvist at La Silla.

Named for Nils Dacke (?-1543), born in Torsås in the Swedish province Småland. Dacke was the leader of the peasants who rebelled against king Gustav Wasa in 1542. This uprising, mainly against clerical policy, tax policy and prohibition of trade across the Danish border, was the last of the large rebellions in Sweden against the king and centralized power. Initially, Dacke and his army had great success and forced the king to sign a peace treaty after he lost most of the southern provinces to the rebels. The next year the king hired foreign mercenaries, and Dacke's army was beaten. Dacke was shot, and the uprising was at an end. (M 31297)

\section{(7220) Philnicholson}

1981 QE. Discovered 1981 Aug. 30 by E. Bowell at Anderson Mesa.

Named in honor of Philip D. Nicholson (1951-

), professor of astronomy at Cornell University, an Australian by birth. Nicholson's research centers on the orbital dynamics of planetary ring systems and natural satellites, and infrared observational studies of planets, their satellites and rings. He has also investigated the dynamics of a planetary system around the pulsar PSR $1257+12$ and has studied the zodiacal dust bands. Nicholson is codiscoverer of two irregular satellites of Uranus and is currently editor of the journal Icarus, which is devoted to planetary science. (M 32790)
(7222) Alekperov

1981 TJ $_{3}$. Discovered 1981 Oct. 7 by T. M. Smirnova at Nauchnyj.

Vagit Yusuphovich Alekperov (1950- ) is known for his development of economical foundations and organizational principles for oil companies. His ideas were used by LUKOIL, one of the largest international oil companies. He is also an active sponsor of science and culture in Russia. (M 36127; M 38241)

\section{(7223) Dolgorukij}

$1982 \mathrm{TF}_{2}$. Discovered 1982 Oct. 14 by L. V. Zhuravleva and L. G. Karachkina at Nauchnyj.

Named in memory of Yurij Dolgorukij (c.1095-1157), prince of Suzdal and Kiev's grand prince, son of Vladimir Monomakh. The first reference to Moscow, made in connection with Dolgorukij's visit there, is in a monastic chronicle dated 1147. Later on, in 1156 Moscow was fortified by him. This is the reason to consider 1147 as the year of the foundation of the city and Dolgorukij as its founder, although archaeological evidence indicates that the site had been settled as early as the ninth century. (M 30100)

The name is given on the occasion of the 850th anniversary of the founding of Moscow.

\section{(7224) Vesnina}

1982 TK$_{3}$. Discovered 1982 Oct. 15 by L. V. Zhuravleva at Nauchnyj.

Named in memory of the brothers Leonid Aleksandrovich Vesnin (1880-1933), Viktor Aleksandrovich Vesnin (1882-1950) and Aleksandr Aleksandrovich Vesnin (1883-1959), Russian architects who worked in creative cooperation. (M 34625)

\section{(7225) Huntress}

1983 BH. Discovered 1983 Jan. 22 by E. Bowell at Anderson Mesa.

Named in honor of Wesley T. Huntress, Jr. (1942- ), planetary cosmochemist and highly regarded director of NASA space science programs during the 1990s. Gaining international recognition for pioneering studies of chemical evolution in interstellar clouds, comets and planetary atmospheres, Huntress was instrumental in developing the astrochemical research group at the Jet Propulsion Laboratory. During his six years as NASA Associate Administrator for Space Science, the rate at which science missions were launched increased dramatically, along with the public awareness of space science. The naming honors Huntress on his departure from NASA after an illustrious 29-year career with the agency. (M 32348)

Name proposed by the discoverer following a suggestion by M. S. Allen, who prepared the citation.

\section{(7226) Kryl}

1984 QJ. Discovered 1984 Aug. 21 by A. Mrkos at Klě́.

Named in memory of Karel Kryl (1944-1994), Czech singer and songwriter, from 1969 a resident of 
Germany working at Radio Free Europe. His songs were appreciated as a symbol of freedom by many people in the former Czechoslovakia. (M 31297)

Name suggsted by J. Tichá and M. Tichý.

\section{(7228) MacGillivray}

1985 GO. Discovered 1985 Apr. 15 by E. Bowell at Anderson Mesa.

Named in honor of Sally M. MacGillivray of Sky Publishing Corporation. With an early bent for music and philosophy, followed by 20 years' experience in book publishing, she brought to the Millennium Star Atlas (1997) an elegance that is rare in a scientific work and evokes bibliophilic traditions. As publication manager of this collaborative venture with the European Space Agency's Hipparcos project, she masterfully orchestrated the many iterations by two teams of illustrators needed to complete the 1548 charts in the atlas. (M 31297)

Name suggested by R. W. Sinnott and endorsed by the discoverer.

\section{(7229) Tonimoore}

1985 RV. Discovered 1985 Sept. 12 by the Spacewatch at Kitt Peak.

Named in honor of Toni L. Moore, who has worked at the University of Arizona's Lunar and Planetary Laboratory since 1986 as an observer, programer and data analyst on radial velocity observations of stars. She has devoted thousands of hours of observations to a search for planets orbiting other stars, a study of the stability of the solar spectrum and a unique investigation of $p$-mode oscillations in a star other than the sun. (M 33788)

\section{(7230) Lutz}

$1985 \mathrm{RZ}_{1}$. Discovered 1985 Sept. 12 by E. Bowell at Anderson Mesa.

Named in honor of Barry L. Lutz (1944- ), professor of physics and astronomy and currently department chair at Northern Arizona University. Raised in H. L. Mencken's "Red Lion, PA", Lutz entered a career in astrophysical sciences in which he applied his training in molecular spectroscopy to astronomical objects ranging from comets to planets to stars. He was responsible for the discovery of diatomic carbon in the interstellar medium, providing important confirmation of ion-molecule chemistry in interstellar clouds. He was also codiscoverer of the pressured-induced LutzDressler band of molecular nitrogen and of deuterated methane and carbon monoxide in the atmosphere of Titan. (M 33788)

\section{(7231) Porco}

1985 TQ 1 . Discovered 1985 Oct. 15 by E. Bowell at Anderson Mesa.

Named in honor of Carolyn C. Porco (1953- ), planetary scientist at the University of Arizona. A pioneer in the study of planetary ring systems, Porco has made important contributions to our knowledge of spokes in Saturn's rings, eccentric ring features in the systems of Saturn and Uranus and the azimuthal structure in the rings of Neptune. Through her contributions to the Voyager project and as the team leader for the Cassini imaging system, Porco has been a leader in spacecraft exploration of the outer solar system. In 1997, she originated the idea of sending a capsule containing ashes of E. M. Shoemaker \{see planet (2074)\} to the moon aboard the Lunar Prospector spacecraft. (M 32348; M 32377) Name andorsed by the Shoemaker family.

\section{(7232) Nabokov}

1985 UQ. Discovered 1985 Oct. 20 by A. Mrkos at Klet.

Vladimir Vladimirovich Nabokov (1899-1977) was a Russian-American novelist, poet and critic. His best works, including Lolita (1955), feature stylish, intricate literary effects. (M 42356)

The name was suggested by J. Tichá.

\section{(7235) Hitsuzan}

1986 UY. Discovered 1986 Oct. 30 by T. Seki at Geisei.

Hitsuzan is a mountain that is reflected in the Kagami River \{see planet (4256)\} as it flows through the center of Kochi \{see planet (2396)\} city. (M 43189)

\section{(7239) Mobberley}

1989 TE. Discovered 1989 Oct. 4 by B. G. W. Manning at Stakenbridge.

Named in honor of Martin P. Mobberley, photographer and astrometrist of comets, minor planets, variable stars, novae and supernovae. His fine photographs and CCD images have appeared in the Journal of the British Astronomical Association for many years. Since 1990 he has occupied the position of Papers Secretary to the association, and as such he is responsible for arranging, refereeing and recommending articles for publication. For the past six years he has prepared and given an entertaining short talk on currently visible sky phenomena at every monthly meeting of the association. Mobberley is also assistant editor of The Astronomer magazine. (M 30100; M 30117)

Name proposed by the discoverer following a suggestion by $\mathrm{H}$. McGee, who also wrote the citation.

\section{(7241) Kuroda}

$1990 \mathrm{VF}_{3}$. Discovered 1990 Nov. 11 by K. Endate and K. Watanabe at Kitami.

Named in honor of Takehiko Kuroda (1946- ), since 1990 the first director of the Nishi-Harima Astronomical Observatory (NHAO) and one of the leading astronomers in Japanese public observatories. He played an important role in determining activities for public education, along with astronomical research, at public observatories. His main interests include interstellar dust distribution and surveys of our galaxy in infrared light. Kuroda is currently heavily engaged in the implementation of Japan's soon-to-be largest telescope, a 2.0-m at NHAO. (M 33788) 
Name proposed by the discoverers following a suggestion by Y. Yamada.

\section{(7242) Okyudo}

$1990 \mathrm{VG}_{3}$. Discovered 1990 Nov. 11 by K. Endate and K. Watanabe at Kitami.

Named in honor of Masami Okyudo (1961- ), Japanese astronomer and currently director of the Misato Observatory, Wakayama Prefecture. Since 1995, he has been a pioneer in astronomical education over the Internet, using remotely controlled telescopes to broadcast live images of celestial objects through cyberspace. (M 33788)

Name proposed by the discoverers following a suggestion by Y. Yamada.

\section{(7244) Villa-Lobos}

$1991 \mathrm{PQ}_{1}$. Discovered 1991 Aug. 5 by E. W. Elst at La Silla.

Named in memory of the well-known Brazilian musician Heitor Villa-Lobos (1887-1959), one of the foremost Latin-American composers of the twentieth century. After traveling throughout his country he returned to Rio de Janeiro with a large collection of manuscripts and an intimate knowledge of AfroBrazilian music. In 1930 he was appointed director of musical education in São Paulo, and in 1945 he founded the Brazilian Academy of Music. His 2000 compositions include operas, ballets, symphonies and pieces for solo instrument. Bachianas brasileiras, one of his most characteristic works, shows the influence of Bach \{see planet (1814)\} and some of the French composers by his use of contrapunctal techniques applied to themes of Brazilian origin. (M 28623)

\section{(7248) Älvsjö}

$1992 \mathrm{EV}_{21}$. Discovered 1992 Mar. 1 by the Uppsala-ESO Survey at La Silla.

Älvsjö, now a residential suburb of Stockholm, is the location of the battle of Brännkyrka (1518), in which the young king-to-be Gustaf Vasa participated. More than a thousand lives were lost, and many streets of Älvsjö bear the names of men killed in the battle. (M 36127)

\section{(7250) Kinoshita}

$1992 \mathrm{SG}_{1}$. Discovered 1992 Sept. 23 by K. Endate and K. Watanabe at Kitami.

Named in honor of Hiroshi Kinoshita (1941- ), a celestial mechanician at the National Astronomical Observatory (formerly known as the Tokyo Astronomical Observatory) who works mainly on the dynamics of the solar system bodies. The present IAU Nutation Series is based on his nutation theory of the rigid earth. He served as president of Commission 4 during 1994-1997. (M 32790)

Name proposed by the discoverers following a suggestion by K. Hurukawa.

\section{(7251) Kuwabara}

$1992 \mathrm{SF}_{13}$. Discovered 1992 Sept. 30 by K. Endate and K. Watanabe at Kitami.

Named in honor of Syoji Kuwabara (1927- ). A retired school teacher in Japan, he was superintendent of the board of education in Himeji City (1981-1993) and director of the city's Science Museum (1993-1996). An amateur astronomer, he was once an enthusiastic observer of occultations; now he studies local names and legends of stars and asterisms. (M 33386)

Name proposed by the discoverers following a suggestion by T. Sato, A. Fujii and K. Kitao.

\section{(7252) Kakegawa}

1992 UZ. Discovered 1992 Oct. 21 by T. Urata at Oohira.

Named for an ancient city in central Japan famous for the wooden castle that was reconstructed there in 1993 following old carpentry methods. Also, a well-known Japanese green tea is produced in this area. (M 33788)

Name suggested and citation prepared by S. Kasahara.

\section{(7253) Nara}

1993 CL. Discovered 1993 Feb. 13 by F. Uto at Kashihara.

Named for the prefecture and city where the oldest capital in Japan was located, and where the first Japanese astronomical observatory was established in 675 . Nara held a central position in politics, economics and culture from the latter half of the sixth to the end of the eighth century. (M 30800)

\section{(7254) Kuratani}

$1993 \mathrm{TN}_{1}$. Discovered 1993 Oct. 15 by K. Endate and K. Watanabe at Kitami.

Named in honor of Hiroshi Kuratani (1934- ), astronomer and educator at Toyama Observatory since 1956. He played an important role in establishing Toyama Science Museum, which opened in 1979 and from which he retired in 1998. In the 1960s he was a pioneer in improving observational techniques, such as the application of TV and development of cooled emulsion cameras. Currently he is developing a new generation space simulator. (M 33386)

Name proposed by the discoverers following a suggestion by T. Sato and A. Fujii.

\section{(7256) Bonhoeffer}

1993 VJ J $_{5}$. Discovered 1993 Nov. 11 by F. Börngen at Tautenburg.

Named in memory of the German theologian Dietrich Bonhoeffer (1906-1945). Already the author of numerous papers and well-traveled, he was shocked by the offenses of the Nazi Regime and therefore grew to a revolutionary. He was pressed by two questions: "What is the Will of God?" and "What is the Task of the Church in this time?". Bonhoeffer was expelled from Berlin in 1938 and not allowed to discourse, print 
or publish. In 1943 he was arrested and on 1945 Apr. 9 was executed at Flossenbürg. (M 29149)

\section{(7257) Yoshiya}

$1994 \mathrm{AH}_{1}$. Discovered 1994 Jan. 7 by T. Kobayashi at Oizumi.

Yoshiya Watanabe (1968- ) is a science educator and planetarian of the Osaka Science Museum. Although his main work is teaching astronomy, he also operates several nation wide networks for astronomical education and has organized monthly star-gazing campaigns since 1996. (M 46680)

\section{(7258) Pettarin}

1994 EF. Discovered 1994 Mar. 5 at the Santa Lucia Observatory at Stroncone.

Enrico Pettarin (1970- ), Italian amateur astronomer, has been for many years the "factotum" at the CCAF (Circolo Culturale Astronomico di Farra d'Isonzo) observatory in Farra d'Isonzo s see planet (7501)\}. He likes software, maintains the telescopes and has participated in almost all of the more than 200 new discoveries at this site. (M 36946)

\section{(7259) Gaithersburg}

1994 EG $_{1}$. Discovered 1994 Mar. 6 by Y. Shimizu and

T. Urata at Nachi-Katsuura.

Gaithersburg, Maryland, is a city to the north of Washington, D.C. Located at the agreed latitude of $+39^{\circ} 08^{\prime}$, one of the six stations of the International Latitude Service was established there in 1899, and it is now the home of the National Institute of Standards and Technology. (M 44594)

\section{(7260) Metelli}

1994 FN. Discovered 1994 Mar. 18 at the Santa Lucia Observatory at Stroncone.

Named in memory of Orneore Metelli (1872-1938). $\mathrm{He}$ is internationally acknowledged as the founder of the school for naïve painting. He started painting well past the age of 50 in the back of his shoemaker's shop. In his more than 200 works, he represented a town that is a mirror of the world, a reflection of thousands of aspects of daily life. (M 33386)

\section{(7261) Yokootakeo}

1994 GZ. Discovered 1994 Apr. 14 by T. Kobayashi at Oizumi.

Takeo Yokoo (1939- ), of Osaka Kyoiku University, mainly studies galactic astronomy. He also served as president of the Society for Teaching and Popularization of Astronomy in Japan from 1998 to 2002. (M 46680)

\section{(7265) Edithmüller}

2908 T-2. Discovered 1973 Sept. 30 by C. J. van Houten and I. van Houten-Groeneveld at Palomar.

Named in memory of the Spanish-born Swiss astronomer Edith A. Müller (1918-1995). She was well known for her publications on theoretical astrophysics, including supernovae. She worked at many different observatories in Europe and the United States. Müller served as IAU General Secretary during 1976-1979 and was the first woman to hold this post. (M 30800)

Obituaries published in Q.J.R. Astron. Soc., Vol. 37, No. 2, p. 267-268 (1996); JOSO Annu. Rep., 1995, p. VI (1996); IAU Inf. Bull., No. 76, p. V (1996); Bull. Am. Astron. Soc., Vol. 28, No. 4, p. 1457-1458 (1996).

\section{(7266) Trefftz}

4270 T-2. Discovered 1973 Sept. 29 by C. J. van Houten and I. van Houten-Groeneveld at Palomar.

Named in honor of the German astronomer Eleonore Trefftz (1920- ). Known for her work on physical processes of astronomical interest, she worked from 1948 until her retirement at the Max-Planck-Institute for Physics and Astrophysics in Munich. (M 30800)

\section{(7268) Chigorin}

1972 TF. Discovered 1972 Oct. 3 by L. V. Zhuravleva at Nauchnyj.

Mikhail Ivanovich Chigorin (1850-1908), founder of the Russian chess school, was Russian chess champion from 1899 to 1906 . He gained victories in international chess tournaments in New York (1889), Budapest (1896) and Vienna (1903). (M 42356)

\section{(7269) Alprokhorov}

1975 VK$_{2}$. Discovered 1975 Nov. 2 by T. M. Smirnova at Nauchnyj.

Aleksandr Mikhajlovich Prokhorov (1916- ), renowned for fundamental research in quantum electronics that led to the creation of masers and lasers, was the 1964 recipient (with N. G. Basov s see planet (3599)\} and C. H. Townes) of the Nobel prize for physics and is honorary director of the Russian Academy of Sciences' General Physics Institute. (M 36127)

\section{(7270) Punkin}

$1978 \mathrm{NY}_{7}$. Discovered 1978 July 7 by E. Bowell at Palomar.

Named in honor of Erica Ann Broman (1956- ) on the occasion of her 41st birthday 1997 August 25. Punkin is an affectionate family name for Broman, who originated the logo used for the Lowell Observatory during its centennial in 1994 and thereafter. She has been a significant donor to the observatory, as well as a patron of the deaf, the aged and God's lesser creatures. An educator and supporter of public education, she is a most gracious lady. (M 30100)

Name proposed by the discoverer following a suggestion by W. L. Putnam, who provided the citation.

\section{(7271) Doroguntsov}

1979 SR $_{2}$. Discovered 1979 Sept. 22 by N. S. Chernykh at Nauchnyj.

Sergej Ivanovich Doroguntsov (1929- ), corresponding member of the National Academy of Sciences of Ukraine, is prominent in the study of economics and ecology, head of a faculty at Kiev National Economic 
University and president of the Ukrainian Ecological Academy of Sciences. (M 38196)

\section{(7274) Washioyama}

1982 FC. Discovered 1982 Mar. 21 by T. Seki at Geisei.

Named for a small mountain in the southern part of Kochi City \{see planet (2396)\}. (M 32094)

\section{(7276) Maymie}

1983 RE. Discovered 1983 Sept. 4 at the Oak Ridge Observatory at Harvard.

Named in honor of Marion R. Aymie, manager of the Human Resources Department at the Smithsonian Astrophysical Observatory from 1990 to 1997. A shrewd negotiator and trusted counselor, she is noted for her creativity, humanity and wisdom, as well as for having the courage and integrity to give her best advice, even when what she has to say may be difficult for the listener to hear. (M 29672)

\section{(7277) Klass}

$1983 \mathrm{RM}_{2}$. Discovered 1983 Sept. 4 by E. Bowell at Anderson Mesa.

Named in honor of Philip J. Klass (1919- ), for more than 30 years the senior avionics editor of Aviation Week and Space Technology magazine. Klass is best known to the public for his work in skeptically evaluating sensationalist claims about UFOs, making numerous TV appearances and writing five books on the subject. He has also written extensively on surveillance satellites. (M 33788)

Name and citation provided by R. Sheaffer.

\section{(7278) Shtokolov}

$1985 \mathrm{UW}_{4}$. Discovered 1985 Oct. 22 by L. V. Zhuravleva at Nauchnyj.

Boris Timofeevich Shtokolov (1930- ), is a Russian singer, actor and bass soloist for the Mariinskij Theatre in St. Petersburg. (M 41028)

\section{(7279) Hagfors}

$1985 \mathrm{VD}_{1}$. Discovered 1985 Nov. 7 by E. Bowell at Anderson Mesa.

Named in honor of Tor Hagfors (1930- ), in celebration of his 68th birthday and his retirement as director of the Max-Planck-Institut für Aeronomie. In the 1960s, at the Massachusetts Institute of Technology's Lincoln Laboratory, Hagfors conducted extensive radar investigations of the moon. The radar backscattering function now called the Hagfors Law, which he derived to support his analysis of lunar echoes, remains the most widely applied model for interpreting quasispecular echoes from the moon, Mercury, Mars and Venus. Hagfors served as director of operations of the National Astronomy and Ionosphere Center's Arecibo \{see planet (4337)\} Observatory from 1971 to 1973 and as director of NAIC during the time, 1982-1992, when Arecibo conducted 68 successful radar experiments on minor planets. (M 34342)

\section{(7280) Bergengruen}

1988 RA $_{3}$. Discovered 1988 Sept. 8 by F. Börngen at Tautenburg.

Named in memory of the German writer Werner Bergengruen (1892-1964) a representative of Christian humanism in his numerous reports, novels, short stories and about 400 poems. He refused the despotism through his novels The Great Tyrant and On Earth as in Heaven. He gave many people strength by his distinct conviction against the Nazi terror. (M 29149)

\section{(7285) Seggewiss}

$1990 \mathrm{EX}_{2}$. Discovered 1990 Mar. 2 by E. W. Elst at La Silla.

Named in honor of Wilhelm Seggewiss (1937- ), since 1995 head of the Hoher List Observatory, on the occasion of his 60 th birthday. He works mainly on Wolf-Rayet stars and related topics. In 1981 he became a professor of astronomy at the University of Bonn. Seggewiss regularly gives lectures about subjects such as the history of the calendar and astrology, in order to put them in a proper perspective. (M 30801)

Name endorsed and citation written by M. Geffert at the request of the discoverer.

\section{(7287) Yokokurayama}

$1990 \mathrm{VN}_{2}$. Discovered 1990 Nov. 10 by T. Seki at Geisei.

Named for a mountain in Kochi prefecture that is a treasure house of rare plants. A museum was built on its summit in 1997. (M 32348)

\section{(7289) Kamegamori}

1991 JU. Discovered 1991 May 5 by T. Seki at Geisei.

Named for a grassy mountain in the center of the mountainous region of Shikoku Island ssee planet (4223)\}. (M 32348)

\section{(7290) Johnrather}

$1991 \mathrm{JY}_{1}$. Discovered 1991 May 11 by E. F. Helin at Palomar.

Named in honor of John D. Rather (1938- ), astrophysicist, on the completion of his 60th revolution around the sun on 1998 Jan. 25. Long associated with special projects at NASA and in industry, he served in the early 1990s as chair of the Near-Earth Object Interception Committee, which examined possible mitigation processes against the threat of minor planets and comets on collision courses with the earth. As a direct consequence of his urging the use of an aggressive treatment that allowed his wife to triumph over cancer, he has in recent years transferred his interest in mitigation to a new career in leading-edge research to fight this scourge. (M 31297)

\section{(7291) Hyakutake}

$1991 \mathrm{XC}_{1}$. Discovered 1991 Dec. 13 by S. Otomo at Kiyosato.

Yuji Hyakutake \{1950-2002\} discovered comets $\mathrm{C} / 1995 \mathrm{Y} 1$ and $\mathrm{C} / 1996 \mathrm{~B} 2$ visually from the town 
of Aira, in Kagoshima prefecture. He later became a curator at the astronomical museum in Aira. (M 40702) The name was suggested by H. Hayasi.

\section{(7292) Prosperin}

$1992 \mathrm{EM}_{7}$. Discovered 1992 Mar. 1 by the Uppsala-ESO Survey at La Silla.

Erik Prosperin (1739-1803), professor in astronomy at Uppsala Observatory during 1773-1798, calculated the orbits of many comets and was also interested in the orbit of the then recently discovered first minor planet, (1) Ceres. (M 45231)

\section{(7293) Kazuyuki}

1992 FH. Discovered 1992 Mar. 23 by K. Endate and K. Watanabe at Kitami.

Named in honor of Kazuyuki Saitoh (1957- ), associate director of the Nichihara Observatory since 1985 and president of the Shimane Society of Astronomy, Shimane Prefecture. He is a widely respected astronomy scholar and a keen popularizer of astronomy, well known throughout his home province. (M 33788)

Name proposed by the discoverers following a suggestion by Y. Yamada.

\section{(7296) Lamarck}

1992 PW $_{1}$. Discovered 1992 Aug. 8 by E. W. Elst and C. Pollas at Caussols.

Named for Jean-Baptiste Lamarck (1744-1829), French biologist, renowned for his idea that acquired traits are inheritable. In 1778, after nine years of botanical field study, he published his three volume Flore française. As a result of his urging, the Muséum National d'Histoire Naturelle was founded in 1793. (M 30801)

\section{(7299) Indiawadkins}

$1992 \mathrm{WZ}_{5}$. Discovered 1992 Nov. 21 by E. F. Helin at Palomar.

India Wadkins (1947-1999) helped initiate and administer many programs of The Planetary Society, including NEO projects. As the society's voice and heart, she became known to thousands of people around the world for her unfailing kindness and enthusiasm. (M 38196)

The name was suggested by The Planetary Society.

\section{(7300) Yoshisada}

$1992 \mathrm{YV}_{2}$. Discovered 1992 Dec. 26 by T. Urata at Oohira.

Named for Yoshisada Shimizu (1943- ), a Japanese orthopaedist and an active amateur astronomer. In addition to publishing many outstanding astrophotographies, he has been searching for minor planets since 1993. (M 30478)

\section{(7304) Namiki}

$1994 \mathrm{AE}_{2}$. Discovered 1994 Jan. 9 by T. Kobayashi at Oizumi.

Namiki Mitsuo (1957- ) is a Japanese amateur astronomer on the staff of the public-information office of the National Astronomical Observatory. He acts as a bridge between Japanese professionals and amateurs and helps create friendly relationships. (M 42356)

\section{(7305) Ossakajusto}

1994 CX $_{1}$. Discovered 1994 Feb. 8 by K. Endate and K. Watanabe at Kitami.

Named in memory of Justo Ossaka (1922-1998), emeritus director of the Sendai \{see planet (3133)\} Astronomical Observatory. Graduating from the Geophysical Institute, Tohoku University, in 1950, he worked at the Sendai Observatory from 1956 to 1994. He contributed greatly to attracting amateur astronomers and planetarium visitors. (M 33788)

Name proposed by A. Watanabe and M. Koishikawa of the Sendai Astronomical Observatory.

\section{(7306) Panizon}

1994 EH. Discovered 1994 Mar. 6 at the Santa Lucia Observatory at Stroncone.

Named in honor of Franco Panizon (1925- ). Head of the pediatric department of the University of Trieste, he is one of the key figures in Italian pediatrics, endowed with a deep knowledge of all scientific disciplines focusing on human beings, a true master of science and life. From Trieste he has influenced pediatricians all over the country and has founded a pediatric school that teaches care for children through mind and heart. (M 33386)

\section{(7308) Hattori}

1995 BQ4. Discovered 1995 Jan. 31 by Y. Shimizu and T. Urata at Nachi-Katsuura.

Named in honor of Tadahiko Hattori (1908-1962), who worked at the Tokyo Astronomical Observatory and International Latitude Observatory and was appointed the first director of the central bureau of the International Polar Motion Service two months before his death. (M 34625)

Name proposed by the second discoverer following a suggestion by K. Hurukawa. Citation prepared by K. Yokoyama

\section{(7313) Pisano}

6207 P-L. Discovered 1960 Sept. 24 by C. J. van Houten and I. van Houten-Groeneveld at Palomar.

Named for the family of Italian sculptors. Nicoló Pisano (1225-c.1280) combined in his sculptures the Italian Romanesque and French Gothic styles. His work is found in the pulpits of the baptistery in Pisa and the dome in Siena, in the fountain of Perugia and tombs in Bologna. Giovanni Pisano (c.1250-c.1314), the son of Nicoló, produced work found in Siena, Pisa and Padua. Andrea Pisano (c.1290-c.1348) created the bronze south door of the baptistery in Florence. (M 30801)

\section{(7314) Pevsner}

2146 T-1. Discovered 1971 Mar. 25 by C. J. van Houten and I. van Houten-Groeneveld at Palomar. 
Named in memory of Antoine Pevsner (1886-1962), Russian-born French sculptor and painter. He and his brother, who used the name Naum Gabo (18901977) and later moved to the United States, used mathematical figures as a basis for their many modern sculptures. They worked with bronze, copper and various plastics. They were inspired by the Russian icons and later by Braque and Picasso ssee planet (4221)\}. In turn, they had a marked influence on younger generations of sculptors. (M 30801)

\section{(7315) Kolbe}

1136 T-2. Discovered 1973 Sept. 29 by C. J. van

Houten and I. van Houten-Groeneveld at Palomar.

Named in memory of the German sculptor Georg Kolbe (1877-1947). Kolbe was educated as a painter, but in 1911 he became famous for his bronze figure of the dancer. In 1947 he created the monumental statue of Beethoven \{see planet (1815)\} in Frankfurt. (M 30801)

\section{(7316) Hajdu}

3145 T-2. Discovered 1973 Sept. 30 by C. J. van Houten and I. van Houten-Groeneveld at Palomar.

Named in memory of Etienne Hajdu (1907-1996), Roumanian-born sculptor who studied in Budapest and Vienna and who lived and worked in Paris from 1927. His abstract sculptures are carved directly in marble of various colors, schist and onyx, and the free-standing works in stone, bronze, aluminum and wood combine a refined effect of light and shadow on the surfaces of volumes with a controlled tension of outlines both of inner open spaces and other contours. Reliefs stamped into thick paper, designs for coins, tapestries, stage-settings and customs, as well as decorations for Sèvres porcelain, show Hajdu's many-sided talent. (M 30801)

Name proposed by the discoverers following a suggestion by $\mathrm{C}$. Portheine, who also prepared the citation.

\section{(7317) Cabot}

1940 ED. Discovered 1940 Mar. 12 by G. Kulin at Budapest.

Named for Giovanni Caboto or John Cabot (1449/501498/99), who made the first recorded landfall in North America since the Norse voyages. Genoese by birth and Venetian by citizenship, Cabot moved to England in 1484, apparently motivated by his idea of reaching Asia by sailing westward across the Atlantic. In 1497 he and his crew of 18 sailed from Bristol in a tiny vessel, the 'Matthew', arriving off Newfoundland on June 24, after which he explored the coast southward to Nova Scotia. His account of the sea swarming with fish led to great interest in the rich fishery around the 'New found land'. Named to commemorate 500 years of continued contact between Europe and Canada. (M 30101)

Name suggested and citation prepared by G. C. L. Aikman.
(7318) Dyukov

1969 OX. Discovered 1969 July 17 by B. A. Burnasheva at Nauchnyj.

Vitalij Petrovich Dyukov (1945- ), a professor at the Siberian State Geodesy Academy in Novosibirsk, is a specialist on the earth's gravitational field and author of more than ten textbooks for students. (M 45231)

\section{(7319) Katterfeld}

1976 SA $_{6}$. Discovered 1979 Sept. 24 by N. S. Chernykh at Nauchnyj.

Named in honor of Gennadij Nikolaevich Katterfeld (1927- ), geologist and planetologist in St. Petersburg, author of investigations on the earth, the moon, Mercury and Mars, as well as a specialist in the history of science and culture. (M 34625)

\section{(7320) Potter}

1978 TP $_{6}$. Discovered 1978 Oct. 2 by L. V. Zhuravleva at Nauchnyj.

Pulkovo astronomer Kheino Potter (1929- ) is known for his work on the determination of astronomical constants and the problems of selenodesy. He was initiator of and an active contributor to FOCAT, the reference catalogue for the southern sky, and he organized the observational station at Ordubad. (M 42356)

\section{(7322) Lavrentina}

$1979 \mathrm{SW}_{2}$. Discovered 1979 Sept. 22 by N. S. Chernykh at Nauchnyj.

Soviet mathematician Mikhail Alekseevich Lavrent'ev (1900-1980) was the first head of the Siberian Department of the U.S.S.R. Academy of Sciences. His son Mikhail Mikhailovich Lavrent'ev (1932- ) also works in mathematical physics. (M 38196)

\section{(7323) Robersomma}

1979 SD. Discovered 1979 Sept. 22 by N. S. Chernykh at Nauchnyj.

Roberto Somma (1944- ）, an Italian space engineer at Alenia Spazio, has promoted ideas and organized international meetings in Italy on the exploration of the solar system, in particular of near-earth objects. (M 38196)

\section{(7324) Carret}

1981 BC. Discovered 1981 Jan. 31 at the Harvard College Observatory at Harvard.

Named in honor of Philip L. Carret (1896- ), on the occasion of his 101st birthday and the 80th anniversary of his graduation from Harvard University. Passionately interested in solar eclipses, Carret has travelled the globe for most of the century in search of them - from Borneo to Siberia, from Baja to Kenya and from Prince Edward Island to Indonesia. Dean of American investment management firms and legendary stock picker, he created one of the first mutual funds in the U.S., Pioneer Fund, in 1928 and helped to found the mutual fund industry. He has been 
generously concerned about education, and about the environment and wildlife. (M 31025)

\section{(7327) Crawford}

$1983 \mathrm{RZ}_{1}$. Discovered 1983 Sept. 6 by E. Bowell at Anderson Mesa.

Named in honor of David L. Crawford (1931- ), astronomer at the Kitt Peak National Observatory recognized for his fundamental contributions to protecting dark skies around observatories from light pollution through good outdoor lighting practices. In 1972 he was instrumental in establishing the first comprehensive lighting code, which regulated outdoor lighting in southern Arizona, and the code has become a model for such regulation throughout the world. Crawford was cofounder and executive director of the International Dark-Sky Association, a worldwide organization dedicated to the preservation of dark skies. He was also responsible for establishing the fundamental standards of the Strömgren photometric system. (M 34343)

Name suggested and citation provided by D. R. Davis.

\section{(7328) Casanova}

1984 SC $_{1}$. Discovered 1984 Sept. 20 by A. Mrkos at Klět.

Giovanni Giacomo Casanova (1725-1798) was a writer, spy and diplomat, the prince of Italian adventurers. His autobiography Histoire de ma vie established his reputation as an archetypal seducer of women. He spent his final years in Bohemia as librarian in the château of Dux, now Duchcov. (M 38196)

The name was suggested by M. Tichý.

\section{(7329) Bettadotto}

1985 GK. Discovered 1985 Apr. 14 by E. Bowell at Anderson Mesa.

Named in honor of Elisabetta Dotto (1965- ), Italian planetary scientist. Dotto studied the rotational properties of a large number of minor planets by carrying out accurate photometric observations. She assisted the Galileo mission fly-by of (243) Ida by determining the spin vector and a reference shape using ground-based observations, and she contributed to the ISO mission by interpreting infrared observations. (M 35485)

Name suggested and citation prepared by M. A. Barucci and M. Fulchignoni.

\section{(7330) Annelemaître}

1985 TD. Discovered 1985 Oct. 15 by E. Bowell at Anderson Mesa.

Named in honor of Belgian mathematician Anne Lemaître (1957- ) for her pioneering analytic studies of the dynamics of minor planets in mean-motion resonances. She has also investigated the process of adiabatic capture into resonance, and has computed accurate proper elements for objects with large orbital eccentricities and inclinations. (M 35485)
Name suggested and citation provided by A. Morbidelli.

\section{(7331) Balindblad}

1985 TV. Discovered 1985 Oct. 15 by E. Bowell at Anderson Mesa.

Named in honor of Bertil A. Lindblad (1921-

) of the Lund Observatory, in recognition of his lifetime work on meteor orbits; his long-term effort in establishing a database for all meteor orbits, now generally used by all meteor workers; his stewardship of IAU Commission 22, which he served as president in the early 1970s; and, in particular, his contribution to starting the very successful "Asteroids, Comets, Meteors" series of conferences. (M 35485)

Name suggested and citation written by I. P. Williams.

\section{(7332) Ponrepo}

1986 XJ J $_{5}$. Discovered 1986 Dec. 4 by A. Mrkos at Klet.

Viktor Ponrepo, born Dismas Šlambor (1858-1926), was founder of the first permanent cinema in Prague in 1907. (M 42356)

The name was suggested by M. Tichý.

\section{(7333) Bec-Borsenberger}

$1987 \mathrm{SM}_{4}$. Discovered 1987 Sept. 29 by E. Bowell at Anderson Mesa.

Named in honor of Annick Bec-Borsenberger (1940-

), astronomer at the Bureau des Longitudes, Institut de Mécanique Céleste de l'Observatoire de Paris. BecBorsenberger is well known for her analytical theory of the motion of the moon. She is an expert in the dynamics of small bodies, particularly in the convergence of algorithms used to determine perturbed orbits. She helped analyze Hipparcos data on minor planets and satellites and has been involved in the ISO mission. (M 35485)

Citation provided by M. A. Barucci.

\section{(7334) Sciurus}

1988 QV. Discovered 1988 Aug. 17 by A. Mrkos at Klě̃.

Sciurus vulgaris and Sciurus carolinensis are squirrels, animals that live mainly in the tops of trees in parks and forests around many observatories, including Klet and the České Budějovice Observatory. (M 42356) The name was suggested by J. Tichá.

\section{(7336) Saunders}

$1989 \mathrm{RS}_{1}$. Discovered 1989 Sept. 6 by E. F. Helin at Palomar.

R. Stephen Saunders (1940- ), chief scientist for the Solar System Exploration Office at the Jet Propulsion Laboratory, is the project scientist for the Mars Surveyor Program 2001/2003 mission, director of JPL's Regional Planetary Image Facility and former project scientist of the Magellan mission to Venus. (M 41028) 


\section{(7342) Uchinoura}

1992 FB $_{1}$. Discovered 1992 Mar. 23 by K. Endate and

K. Watanabe at Kitami.

Named for the town in southern Kyushu where the Kagoshima \{see planet (4703)\} Space Center of the Institute of Space and Astronautical Science (ISAS) is located. A small fishing village, the town entered the limelight in 1962 , when it was selected as the launching site for ISAS (now ISAS Ministry of Education, Science, Sports and Culture). ISAS satellites are launched toward the Pacific Ocean from a plateau in the southeastern part of the town. The facilities are getting larger as the rockets also grow in size. The usual population of the town is about 10 000 , but at the time of a launch staff and reporters typically cause a 20-percent increase. (M 34343)

\section{(7343) Ockeghem}

$1992 \mathrm{GE}_{2}$. Discovered 1992 Apr. 4 by E. W. Elst at La Silla.

Named for the Flemish composer Johannes Ockeghem (1420-1497), the most renowned polyphonist of the second half of the fifteenth century. He started career at the Antwerp cathedral and later served at the court of several French kings. Among his compositions were motets, chansons, canons and a Deo gratias for 36 voices. He had a great influence on his fellow musicians and still fascinates contemporary composers. (M 30801)

Citation written by $\mathrm{K}$. Leterme at the request of the discoverer.

\section{(7344) Summerfield}

1992 LU. Discovered 1992 June 4 by C. S. Shoemaker and D. H. Levy at Palomar.

Named in honor of Robert and Lisa Summerfield, for their exhaustive effort to spread astronomy to the public. The couple brings their collection of telescopes, one a $0.9-\mathrm{m}$ reflector, to public star parties across the United States, and they complete several cross-country marathon drives in this effort. Their organization, "Astronomy To Go", sets up education sessions in dozens of schools each year. (M 30478)

Citation prepared by David and Wendee Levy.

\section{(7345) Happer}

1992 OF. Discovered 1992 July 28 by R. H. McNaught at Siding Spring.

Named for Felix Happer, a character in Bill Forsyth's wonderful motion picture Local Hero. Happer desperately wanted a comet to be named for him; this minor planet will have to do. (M 29672)

Name suggested by D. I. Steel, who prepared the citation.

\section{(7346) Boulanger}

1993 DQ. Discovered 1993 Feb. 20 by E. W. Elst at Caussols.

Nicolas Boulanger (1722-1759), a geologist and one of the Encyclopedists, believed that the irrational behavior of the human species, together with all the heritage of religious rites and much of the political of his own and other ages, were engendered in cataclysmic experiences. (M 46008)

\section{(7349) Ernestmaes}

$1993 \mathrm{QK}_{4}$. Discovered 1993 Aug. 18 by E. W. Elst at Caussols

Ernest Maes (1915- ), a doctor of medicine (dermatology), has long had a great interest in anthropology, history of religion and psychiatry, resulting in several books on the critical evaluation of religious tradition. (M 46008)

\section{(7351) Yoshidamichi}

1993 XB $_{1}$. Discovered 1993 Dec. 12 by T. Kobayashi at Oizumi.

Michitoshi Yoshida (1963- ) is the director of Okayama Astrophysical Observatory, a branch of the National Astronomical Observatory of Japan. His main interests are extragalactic astronomy, especially observational study of active galaxies, and astronomical instrumentation. (M 46680)

\section{(7353) Kazuya}

$1995 \mathrm{AC}_{1}$. Discovered 1995 Jan. 6 by M. Hirasawa and S. Suzuki at Nyukasa.

Named in honor of Kazuya Yoshida (1960- ). An authority in robot engineering at Tohoku University, Yoshida is now developing a robotic system to explore the minor planets. He is an excellent astrophotographer and a member of Mt. Nyukasa Station, where this minor planet was discovered. (M 34343)

\section{(7355) Bottke}

$1995 \mathrm{HN}_{2}$. Discovered 1995 Apr. 25 by the Spacewatch at Kitt Peak.

Named in honor of William F. Bottke, Jr., known for his research on the collisional and dynamical evolution of minor planets. He has also contributed to the study of the origin and evolution of NEAs, in particular by analyzing the formation of doublet craters found on the terrestrial planets. (M 32348)

\section{(7356) Casagrande}

$1995 \mathrm{SK}_{5}$. Discovered 1995 Sept. 27 at the Santa Lucia Observatory at Stroncone.

Named in memory of Alessandro Casagrande (19221964). Composer and orchestra conductor, he skillfully headed the music school in Terni and served as artistic manager of the city's symphonic bureau "S. Falchi". He was also a painter. In 1965 an international piano competition was named for him. (M 33386)

\section{(7359) Messier}

1996 BH. Discovered 1996 Jan. 16 by M. Tichý at Klě́.

Named in memory of Charles Messier (1730-1817), French astronomer and first "comet hunter". He found more than a dozen comets and independently recovered 
Halley's Comet at its 1759 return. Nowadays, Messier is best known for his catalogue of 103 nebulae, star clusters and galaxies - a compilation he made in order to reduce confusion to comet hunters. (M 28672)

\section{(7360) Moberg}

1996 BQ 17 . Discovered 1996 Jan. 30 by C.-I. Lagerkvist at La Silla.

Named in memory of Vilhelm Moberg (1898-1973), Swedish novelist and writer. Moberg mainly wrote about society's lower classes and always fought for the individual against the authorities. He also strove unsuccessfully to make Sweden a republic. Among his best-known novels are Utvandrarna ("The Emigrants") and Invandrarna ("The Immigrants"), about a familiy moving from Småland to Minnesota during the nineteenth century. (M 31297)

\section{(7361) Endres}

$1996 \mathrm{DN}_{1}$. Discovered 1996 Feb. 16 by the JPL NEAT Program at Haleakala.

Named for Michael Hart Endres, who as former site manager of the GEODSS project played a seminal role in the early discussions, meetings and concepts that ultimately resulted in the establishment of the Near-Earth Asteroid Tracking (NEAT) program in collaboration with the U.S. Air Force using the Ground-Based Electro Optical Deep Space Surveillance (GEODSS) 1-m telescope. "Mike" for forty years thrived in a wide-ranging career from design, installation, operation of technical equipment and management of personnel associated with technical services at various companies. (M 29672)

The NEAT team and GEODSS personnel heartily endorse the naming of the first NEAT numbered minor planet in his honor.

\section{(7362) Rogerbyrd}

1996 EY. Discovered 1996 Mar. 15 by the JPL NEAT Program at Haleakala.

Named in honor of Roger Byrd, who has 16 years experience in project management, systems research and development, computer systems, and electronics maintenance and repair. He has extensive management experience with the GEODSS Project. He is currently the site manager at the GEODSS site in Maui and he has obtained research and development experiences working on radar projects and various space-related projects, as well as hands-on technical experience of hardware and software. (M 29672)

The NEAT and GEODSS personnel salute his dedication by honoring him with one of the first numbered NEAT minor planets.

\section{(7363) Esquibel}

$1996 \mathrm{FA}_{1}$. Discovered 1996 Mar. 18 by the JPL NEAT Program at Haleakala.

Named in honor of Albert Esquibel, who has for 19 years been active in project management and electronic maintenance. For the last 13 years he has been with the GEODSS project at the four U.S. Air Force sites. He has worked closely with the Jet Propulsion Laboratory as they first tested the NEAT instrument with the GEODSS telescope system in Maui. Through his diligence on site, the NEAT/GEODSS program has enjoyed unparalleled success with its autonomous NEO discovery program. (M 29672)

The NEAT and GEODSS personnel salute his dedication by honoring him with one of the first numbered NEAT minor planets.

\section{(7364) Otonkučera}

1996 KS. Discovered 1996 May 22 by K. Korlević at Višnjan.

Founder of the Zagreb Observatory, Oton Kučera (1857-1931) was a teacher, field biologist, astronomer and early ham-radio enthusiast. His introductory book on astronomy, Naše nebo ("Our sky", 1895) has made a strong impact on young readers in Croatia for more than a century. (M 42669)

\section{(7365) Sejong}

$1996 \mathrm{QV}_{1}$. Discovered 1996 Aug. 18 by K. Watanabe at Sapporo.

Named on the occasion of the 600th anniversary of the birth of the Korean king Sejong (1397-1450), renowned for his many achievements in astronomy. He built the Royal Observatory of Choson in Seoul in 1437, equipping it with a whole series of astronomical instruments and installing an automatic striking clepsydra. He revised the Chinese calendar for Korean use and invented the rain gauge. He established the Hangul alphabet, which is still used throughout Korea. (M 30801)

Name suggested by K. Hurukawa, citation material provided by I.-S. Nha.

\section{(7366) Agata}

1996 UY. Discovered 1996 Oct. 20 by T. Kobayashi at Oizumi.

Hidehiko Agata (1961- ) is a staff member in the public information office of the National Astronomical Observatory of Japan. His main interests are education and populiarization of astronomy, and he has published many books on elementary astronomy. He has also studied cometary plasma tails. (M 45336)

\section{(7367) Giotto}

3077 T-1. Discovered 1971 Mar. 26 by C. J. van Houten and I. van Houten-Groeneveld at Palomar.

Named for Giotto di Bondone (c.1266-1337), great Italian painter and architect. Giotto liberated art in general from Byzantine art and painted mainly religious themes. His most famous works are in Assisi and Florence, and he constructed the campanile of the Florence cathedral. Giotto saw comet $1 \mathrm{P} /$ Halley in 1301 and is supposed to have incorporated it into his fresco, the Adoration of the Magi, in Padua. For this reason, the European spacecraft that intercepted that same comet at its return in 1986 bore his name. (M 30801) 


\section{(7369) Gavrilin}

1975 AN. Discovered 1975 Jan. 13 by T. M. Smirnova at Nauchnyj.

Valerij Aleksandrovich Gavrilin (1939-1999) was an outstanding Russian composer whose compositions have became a national property of Russia and occupy a well-deserved place in the culture of the twentieth century. (M 38196)

The name was suggested by the Union of Concert Workers of Russia.

\section{(7373) Stashis}

1979 QX . Discovered 1979 Aug. 27 by N. S. Chernykh at Nauchnyj.

Vladimir Vladimirovich Stashis (1925- ) is a Ukrainian scholar of jurisprudence, vice-rector of the Ukrainian National Academy of Law and a member of the International Court of the United Nations. He also likes poetry and art and has a large collection of pictures of classical Russian painters. (M 38196)

\section{(7381) Mamontov}

1981 RG $_{5}$. Discovered 1981 Sept. 8 by L. V. Zhuravleva at Nauchnyj.

Named in memory of Savva Ivanovich Mamontov (1841-1918), manufacturer and patron of the arts, a prominent figure in Russian art, theater and music. (M 34625)

\section{(7382) Bozhenkova}

$1981 \mathrm{RJ}_{5}$. Discovered 1981 Sept. 8 by L. V. Zhuravleva at Nauchnyj.

The Russian writer Margarita Ivanovna Bozhenkova (1941- ) is a member of the Writers' Union of Russia, vice-president of the Writers' Naval Association in St. Petersburg and laureate of the "Gold Pen" prize. (M 38196)

\section{(7383) Lassovszky}

1981 SE. Discovered 1981 Sept. 30 at the Oak Ridge Observatory at Harvard.

Named in memory of Károly Lassovszky (1897-1961), a staff member of the Konkoly \{see planet (1445)\} Observatory in Budapest from 1921 and director from 1938 to 1943 . His main research was on variable stars, but he initiated the Konkoly observational program on minor planets that was largely carried out by G. Kulin \{see planet (3019)\}. In 1958 Lassovszky was invited to join the staff of the Smithsonian Astrophysical Observatory (which operates the Oak Ridge Observatory), where he became chief of the Satellite Tracking Program's Photoreduction Division. (M 30801)

Named following a proposal made at the 1997 General Assembly of the Hungarian Astronomical Association.

\section{(7385) Aktsynovia}

1981 UQ $_{11}$. Discovered 1981 Oct. 22 by N. S. Chernykh at Nauchnyj.

Lyudmila Mikhailovna Aktsynova (1910-1997) and her husband Arkadij Vsevolodovich Aktsynov (19101997) were masters of portraiture and landscape painting. They depicted the beauties of nature in various parts of Russia, including Siberia, Baikal, Sayany, Altaj and Volga. (M 38196)

\section{(7386) Paulpellas}

1981 WM. Discovered 1981 Nov. 25 at the Oak Ridge Observatory at Harvard.

Named in memory of Paul Pellas (1924-1997), physicist, meteoriticist, and curator at the Muséum d'Histoire Naturelle in Paris. He timed the early cooling histories of minor planets by studying the pattern of thermal annealing of fission tracks, created by the decay of the short-lived isotope plutonium 244, in the minerals of meteorites that once resided in these larger bodies. He also measured cosmic-ray track densities in lunar rocks to determine their residence times on the surface of the moon. (M 30101)

Name proposed by J. A. Wood.

Obituary published in Meteorit. Planet. Sci., Vol. 32, No. 6, p. 983-984 (1997).

\section{(7387) Malbil}

1982 BS $_{1}$. Discovered 1982 Jan. 30 by E. Bowell at Anderson Mesa.

Named in honor of Malcolm Bilson (1935- ), Frederick J. Whiton Professor of Music at Cornell University. Best known as a pianist, Bilson has recorded scintillating performances of music by Mozart, Beethoven and others. His research interests center on music of the late eigteenth and nineteenth centuries, performance practice, problems of notation and execution, instruments and musical aesthetics. He has won several awards. Bilson gave a recital at the "Asteroids, Comets, Meteors" meeting at Cornell University in July 1999. (M 35485)

\section{(7389) Michelcombes}

1982 UE. Discovered 1982 Oct. 17 by E. Bowell at Anderson Mesa.

Named in honor of Michel André Combes (1939- ), French planetary scientist and president of the Paris Observatory from 1992 to 1998. Combes studied planetary atmospheres using infrared observations carried out both from the ground and from space. He has been particularly active in designing and building newtechnology instruments for spacecraft (for example, an infrared spectrometer for the Vega mission to comet $1 \mathrm{P} /$ Halley) and for the largest ground-based telescopes (such as the adaptive optics device Come-on). Combes has played an important role in developing planetary science in France, particularly by encouraging his younger colleagues to join international efforts in planetary space exploration. (M 35485)

Name suggested and citation prepared by $M$. Fulchignoni.

\section{(7390) Kundera}

1983 QE. Discovered 1983 Aug. 31 at the Klet Observatory at Klět.

Named in honor of Milan Kundera (1929- ), Czech novelist, playwright and poet. He has written various 
works combining the comedy of living with political criticism. His novel The Unbearable Lightness of Being is well known and received wide international exposure as a very successful movie. Since 1975 he has lived in France. (M 33386)

Name proposed by J. Tichá following a suggestion by M. Šidlichovský.

\section{(7391) Strouhal}

$1983 \mathrm{VS}_{1}$. Discovered 1983 Nov. 8 by A. Mrkos at Klet.

Named in memory of Vincenc Strouhal (1850-1922), professor of experimental physics. He founded and built up the Institute of Physics of the Czech part of Charles University (1907). (M 31297)

Name suggsted by J. Tichá and M. Šolc.

\section{(7392) Kowalski}

1984 EX. Discovered 1984 Mar. 6 by E. Bowell at Anderson Mesa.

Named in honor of Richard Kowalski (1963- ) of Quail Hollow Observatory, near Tampa, Florida. Kowalski is engaged in follow-up and discovery work on minor planets and comets. In 1998 he founded and has energetically maintained the Minor Planet Mailing List, a web-based information service and chat group for amateur and professional observers. Kowalski has also been the main organizer of the 1999 Amateur-Professional Minor Planet Workshop at the Lowell Observatory. (M 34343)

Citation written by the discoverer and P. G. Comba.

\section{(7393) Luginbuhl}

$1984 \mathrm{SL}_{3}$. Discovered 1984 Sept. 28 by B. A. Skiff at Anderson Mesa.

Christian B. Luginbuhl (1955- ), of the U.S. Naval Observatory's Flagstaff Station, is largely responsible for the enactment and continued enforcement of ordinances preserving the dark skies of northern Arizona. With the discoverer, he co-authored the Observing Handbook and Catalogue of Deep-Sky Objects. (M 36127)

\section{(7394) Xanthomalitia}

1985 QX $_{4}$. Discovered 1985 Aug. 18 by N. S. Chernykh at Nauchnyj.

Leonid Vasil'evich Xanthomaliti (Ksanfomaliti; b. 1932), radiometrist, photo-metrist, polarimetrist and altimetrist, discovered the Martian "anti-greenhouse" effect, hypothesized on the thunderbolt phenomena in Venus' atmosphere and predicted high volcanic activity on Venus. (M 38196)

The name was suggested by V. K. Abalakin.

\section{(7396) Brusin}

1986 EQ $_{2}$. Discovered 1986 Mar. 4 by W. Ferreri at La Silla.

Named in honor of Silvia Rosa Brusin, head of one of the principal Italian scientific programs. She is strongly involved in popular astronomy and is in close contact with scientists around the world. Her programs on Italian television constitute a serious reference for interested people. (M 34343)

\section{(7398) Walsh}

1986 VM. Discovered 1986 Nov. 3 by A. Mrkos at Klet.

Named in honor of Martin F. Walsh (1966- ) on the occasion of his marriage to Aurélie Machon near Paris on 1998 June 6. (M 32094)

Name suggested by G. V. Williams, who made the identifications for this object and has known the bridegroom for more than 20 years.

\section{(7403) Choustník}

$1988 \mathrm{AV}_{1}$. Discovered 1988 Jan. 14 by A. Mrkos at Klě́.

Choustník is a castle founded in the mid-thirteenth century. Under the brothers Beneš and Jan of Choustník two similar palaces with square towers were built. Choustník is a rare example of twin castles. It was abandoned in the seventeenth century. (M 42357) The name was suggested by M. Tichý.

\section{(7410) Kawazoe}

1990 QG. Discovered 1990 Aug. 20 by T. Seki at Geisei.

Named in honor of Akira Kawazoe (1934- ), a member of the Geisei Observatory staff with particular interests in meteorites and geology. (M 32095)

\section{(7412) Linnaeus}

1990 SL9. Discovered 1990 Sept. 22 by E. W. Elst at La Silla.

Named in memory of the great Swedish botanist Carl von Linné (1707-1778). At an early age, Linnaeus developed a great love for flowers and herbs. This led him to develop the first major systematic system of nomenclature for the flora, and this became the internationally accepted standard. He organized the large-scale collection of botanical specimens in far-away countries and had a lively correspondence with his comtemporaries. (M 30801)

\section{(7413) Galibina}

$1990 \mathrm{SH}_{28}$. Discovered 1990 Sept. 24 by L. V. Zhuravleva and G. R. Kastel' at Nauchnyj.

Named in honor of Irina Vladimirovna Galibina (1929- ), a celestial mechanician known for her research on the motions of long-period comets, minor planets and meteor streams. In recent years, in coauthorship with her husband, G. N. Katterfeld, Galibina published a series of papers devoted to the principal problems in astronomical geology. (M 34343) Name proposed by G. R. Kastel'.

\section{(7414) Bosch}

1990 TD $_{8}$. Discovered 1990 Oct. 13 by L. D. Schmadel and F. Börngen at Tautenburg.

Named in memory of Carl Bosch (1874-1940), outstanding German chemist, inventor of high-pressure ammonia synthesis, 1931 Nobel laureate in chemistry 
and enthusiastic amateur astronomer. During the 1920s he built a well-equipped private observatory on his estate at Heidelberg, where he carried out spectroscopic and photometric studies. He was an important patron of science, supporting especially the Heidelberg-Königstuhl Observatory, the Astronomische Gesellschaft and the Einstein Foundation. (M 34343)

Name proposed by the first discoverer, endorsed by G. Klare and H. Mandel.

\section{(7415) Susumuimoto}

$1990 \mathrm{VL}_{8}$. Discovered 1990 Nov. 14 by T. Seki at Geisei.

Susumu Imoto (1901-1981) studied the history of astronomy and old Japanese calendars. With I. Hasegawa \{see planet (3227)\}, he compiled a catalogue of meteor showers and lent support to the world calendar proposed by E. Achelis. (M 38197)

\section{(7416) Linnankoski}

$1990 \mathrm{WV}_{4}$. Discovered 1990 Nov. 16 by E. W. Elst at La Silla.

Named in memory of the Finnish writer Johannes Linnankoski, pseudonym of Vihtori Peltonen (18691913). He promoted Finnish independence from Russia. He became well known for his novel Laulu tulipunaisesta kukasta (1905), or "Song of the blood-red flower". In 1960 the discoverer set much of this novel to music. (M 31025)

\section{(7418) Akasegawa}

1991 EJ $_{1}$. Discovered 1991 Mar. 11 by T. Fujii and K. Watanabe at Kitami.

Genpei Akasegawa (1937- ) is a famous novelist in Japan and also an astronomy fan. His work contributes to the spread of amateur astronomy. (M 41935)

\section{(7420) Buffon}

$1991 \mathrm{RP}_{11}$. Discovered 1991 Sept. 4 by E. W. Elst at La Silla.

Named for the French naturalist Georges-Louis Leclerc de Buffon (1707-1788). In 1749 he started his project Histoire naturelle, an immense work of 36 volumes on nature, in which he treated in succession the history of the formation of the earth, the life of animals and plants and the world of minerals. In 1779 the work was completed with his famous Epoques de la nature. Buffon insisted on building his theories on facts, rather than on hypotheses, and he made experience the clue for scientific investigation. His elegant style raised writing on science to the ranks of great literature. (M 31025)

\section{(7421) Kusaka}

1992 HL. Discovered 1992 Apr. 30 by Y. Kushida and O. Muramatsu at Yatsugatake.

Hideaki Kusaka (1924-1991) was an amateur astronomer who wrote several books on mythology related to constellations and calendars. He worked for a publisher and for the Gotoh Planetarium and Astronomical
Museum in Tokyo before appearing frequently on science programs on radio and television. (M 45747)

\section{(7425) Lessing}

$1992 \mathrm{RO}_{5}$. Discovered 1992 Sept. 2 by E. W. Elst at La Silla.

Named for Gotthold Ephraim Lessing (1729-1781), German dramatist and writer on philosophy and aesthetics. He abandoned an early interest in theology for literature, philosophy and art. In 1766, his great treatise on aesthetics, Laokoon: oder über die Grenzen der Malerei und Poesie, was published. As a philosopher he is remembered for Nathan der Weise (1779), and especially for Die Erziehung des Menschengeschlechts (1780), in which he expressed his belief on the perfectability of the human race. Lessing's last years were lonely and poor, and upon his death he was buried at public expense. (M 31025)

\section{(7429) Hoshikawa}

1992 YB $_{1}$. Discovered 1992 Dec. 24 by T. Hioki and S. Hayakawa at Okutama.

Hoshikawa, or "Star River", flows between Kumagaya and Gyoda, in Saitama prefecture. There are many carp in the river, and on its banks events such as the Uchiwa Fan Festival and Daruma Ichi Market are held. (M 36127)

\section{(7430) Kogure}

$1993 \mathrm{BV}_{2}$. Discovered 1993 Jan. 23 by K. Endate and K. Watanabe at Kitami.

Named in honor of Tomokazu Kogure (1925- ), professor emeritus of Kyoto University. His specialties include early-type peculiar stars, emission nebulae, interstellar medium, and nuclei of active galaxies. He served as president of the Astronomical Society of Japan and is currently director of Bisei Observatory in Okayama Prefecture. He is a frequent contributor to research and education on astronomy in Asian countries, especially Indonesia and Sri Lanka. (M 34343)

Name proposed by the discoverers following a suggestion by K. Sakka and T. Sato.

\section{(7433) Pellegrini}

1993 KD. Discovered 1993 May 21 at the Farra d'Isonzo Observatory at Farra d'Isonzo.

Named in memory of Guglielmo Pellegrini (19371990), an amateur astronomer who built or modified many of the telescopes used by the Italian astrometric community. His ability, skill and kind temperament will long be remembered. His epigraph reads "In the stars you loved so much we'll find your light". (M 31025)

\section{(7434) Osaka}

$1994 \mathrm{AB}_{3}$. Discovered 1994 Jan. 14 by T. Kobayashi at Oizumi.

Osaka is the second largest city in Japan, administrative center of the prefecture, and an important industrial, cultural, business and scientific center. (M 46681) 


\section{(7435) Sagamihara}

$1994 \mathrm{CZ}_{1}$. Discovered 1994 Feb. 8 by K. Endate and K. Watanabe at Kitami.

Named for a city of 571000 located some $50 \mathrm{~km}$ west of Tokyo on the vast riverside of the river Sagamigawa. In 1892 the Sagamino Base Line for the nationwide triangulation was set up there. In recent years the city has grown into a large industrial center. In 1989 the campus of the Institute of Space and Astronautical Science, which develops Japanese scientific satellites, moved to Sagamihara, where the satellites Yoko and Haruka were built. (M 34343)

\section{(7436) Kuroiwa}

$1994 \mathrm{CB}_{2}$. Discovered 1994 Feb. 8 by K. Endate and K. Watanabe at Kitami.

Named in memory of Goro Kuroiwa (1912-1990), Japanese astronomer and observer of variable stars. A student in the department of astronomy at the University of Tokyo on the occasion of the total solar eclipse on 1936 June 19, he independently discovered the nova CP Lac, along with Kazuaki Gomi \{see planet (7035)\}. While serving with the Japanese army in 1942 he independently discovered the nova CP Pup. He represented Japan in the geodetic survey program using photoelectric observations of lunar occultations, carried out from 1950 to the 1960s by the U.S. Army Map Service Far East. (M 34343)

\section{(7437) Torricelli}

$1994 \mathrm{EF}_{3}$. Discovered 1994 Mar. 12 by V. Goretti and A. Boattini at Cima Ekar.

Named in memory of Evangelista Torricelli (16081647), mathematician and physicist. In 1641 he met and worked with Galileo ssee planet (697)\} in Florence. Torricelli continued Galileo's activities after the latter's death, making telescopes, microscopes and improving methods of lens-making. Torricelli is known for geometrical studies that presaged the development of calculus, for a theorem in fluid mechanics and for the invention of the barometer. (M 30802)

\section{(7438) Misakatouge}

$1994 \mathrm{JE}_{1}$. Discovered 1994 May 12 by A. Nakamura at Kuma.

Named for a pass, 720 meters above sea level, in the north of the town of Kuma \{see planet (6255)\}, where this minor planet was discovered. Because of its altitude and steepness, Misakatouge is often covered by thick snow in winter, and it suffers from heavy fog from spring to fall. Nevertheless, much traffic uses the pass, because it is a key route connceting the cities of Matsuyama and Kochi \{see planet (2396)\}, on the island of Shikoku \{see planet (4223)\}. (M 30101)

\section{(7440) Závist}

1995 EA. Discovered 1995 Mar. 1 by M. Tichý at Kleť.

Named for the site of the most important ancient Celtic town in Bohemia. Situated south of Prague on a hill above Vltava river ssee planets (2367) and (2123), respectively\}, it consists of two parts named Hradiště and Šance. It was founded in the sixth century B.C. and was destroyed five centuries later. The ramparts, stone walls, moats and an acropolis are the most impressive remnants showing the Celtic history of the discoverer's native country found up to this time. (M 34625)

\section{(7441) Láska}

1995 OZ. Discovered 1995 July 30 by J. Tichá and M. Tichý at Klèt.

Named in memory of Václav Láska (1862-1943), Czech astronomer, geophysicist, geodesist and mathematician, professor of Charles University in Prague and founder of geophysical research in Czechoslovakia. (M 30478)

\section{(7442) Inouehideo}

$1995 \mathrm{SC}_{5}$. Discovered 1995 Sept. 20 by K. Endate and K. Watanabe at Kitami.

Named in honor of Hideo Inoue (1917- ), Japanese astronomer. An astronomy enthusiast while still a child, he studied at the Tokyo College of Physics and at the Institute of Cosmical Physics in Kyoto. While participating in Kyoto University's expedition to the solar eclipse on 1941 Sept. 21 he obtained color photographs of the solar corona, the first in Japan. He later worked at the Peking Observatory, where he calculated the national ephemeris. After the war he taught at technical high schools in Japan. For the International Geophysical Year he led the Higasimatuyama Moonwatch Team. He is also an enthusiastic ham radio operator. (M 34343)

\section{(7445) Trajanus}

4116 P-L. Discovered 1960 Sept. 24 by C. J. van Houten and I. van Houten-Groeneveld at Palomar.

Named for the Roman emperor Marcus Ulpius Trajanus (53-117). Trajan was adopted by emperor Nerva and became his successor in 98. He expanded the Roman empire to Mesopotamia, Assyria and Armenia. In his time the Roman empire had its greatest expansion. The Trajan column in the Forum contains his ashes in a golden urn. (M 30802)

\section{(7446) Hadrianus}

2249 T-2. Discovered 1973 Sept. 29 by C. J. van Houten and I. van Houten-Groeneveld at Palomar.

Named for Publius Aelius Hadrianus (76-138), Roman emperor, who was adopted by Trajan \{see planet (7445)\} and who became his successor in 117. Hadrian stopped the expansion of the Roman empire, putting his energy instead into the construction of excellent roads, aquaducts and new cities. He also fortified the borders of the immense empire, notably with the wall between England and Scotland and the limes in Germany. He reformed the economy, administration and the law. An admirer of Greek culture, Hadrian built the Castello de Sant' Angelo in Rome. (M 30802) 


\section{(7447) Marcusaurelius}

1142 T-3. Discovered 1977 Oct. 17 by C. J. van Houten and I. van Houten-Groeneveld at Palomar.

Named for the Roman emperor Marcus Aurelius Antoninus (121-180), who became emperor in 161 upon the death of his adoptive father Antoninus Pius. He tried to reign with justice but could not prevent the decay of the empire. Marcus Aurelius was often far away from Rome, suppressing secessionist border lands. He died in Vienna during a fight against the Marcomanni. His equestrian statue in Rome is the only genuine bronze monument to an emperor. (M 30802)

\section{(7451) Verbitskaya}

1978 PU $_{2}$. Discovered 1978 Aug. 8 by N. S. Chernykh at Nauchnyj.

Professor of general linguistics Lyudmila Alekseevna Verbitskaya (1936- ) is an authority on Russian and experimental phonetics. As rector of St. Petersburg University she has created and supported favorable conditions for the development of higher education and science. (M 38197)

The name was suggested by K. V. Kholshevnikov.

\section{(7452) Izabelyuria}

1978 QU $_{2}$. Discovered 1978 Aug. 31 by N. S. Chernykh at Nauchnyj.

Renowned Russian singer Izabella Danilovna Yur'eva (1900-2000) was a unique performer of lyric songs and romances. (M 38197)

\section{(7453) Slovtsov}

1978 RV $_{1}$. Discovered 1978 Sept. 5 by N. S. Chernykh at Nauchnyj.

Petr Andreevich Slovtsov (1767-1843), historiographer of Siberia and founder of regional studies of Siberia, was a prominent historian, poet, philosopher and pedagogue, as well as a religious and public figure. (M 38197)

\section{(7456) Doressoundiram}

1982 OD. Discovered 1982 July 17 by E. Bowell at Anderson Mesa.

Named in honor of Alain Doressoundiram (1968- ) , French planetary scientist. Doressoundiram has worked on the collisional evolution of the population of minor planets, in particular the formation and evolution of binary systems during a family-forming collision. He has contributed to the spectroscopic characterization of a number of minor planet families and helped plan the Rosetta and DS4-Champollion space missions. (M 35485)

Name suggested and citation prepared by M. A. Barucci and M. Fulchignoni.

\section{(7461) Kachmokiam}

1984 TD. Discovered 1984 Oct. 3 at the Oak Ridge Observatory at Harvard.

Named in honor of Katherine Galindo, Christine Galindo, Molly Thompson, Kimberley Galindo and
Amy Galindo, nieces of Donna Thompson s see planet (3085)\}, administrator for the Minor Planet Center. (M 29673)

\section{(7462) Grenoble}

$1984 \mathrm{WM}_{1}$. Discovered 1984 Nov. 20 by E. Bowell at Anderson Mesa.

Named for the French city, located in the foothills of the western Alps. Originally the center of the indigenous population of the Allobroges, Grenoble took its name "Gratianopolis", from the Roman Emperor Flavius Gratianus (375-383). It became part of the French kingdom in the thirteenth century. Grenoble today is a very important industrial and research center. Some of its scientific facilities and institutions are connected with the prestigious Joseph Fourier University: a synchrotron accelerator, the astronomical observatory, the headquarters of the International Institute for Millimetric Radioastronomy, the glaciology laboratory and the new planetary sciences laboratory. (M 35486) Name suggested and citation prepared by $M$. Fulchignoni.

\section{(7463) Oukawamine}

1985 SB. Discovered 1985 Sept. 20 by T. Seki at Geisei.

Named for a high plateau at the boundary of Kochi and Ehime prefectures. (M 32348)

\section{(7464) Vipera}

1987 VB $_{1}$. Discovered 1987 Nov. 15 by A. Mrkos at Kleť.

Named for the viper family, particularly Vipera berus, the adder or northern viper, a nice rare snake that inhabits Kleť mountain. (M 43189)

The name was suggested by M. Tichý.

\section{(7465) Munkanber}

$1989 \mathrm{UA}_{3}$. Discovered 1989 Oct. 31 by B. G. W. Manning at Stakenbridge.

Named in honor of John Munger, Veikko Kanto and Richard Berry, the authors of The CCD Camera Cookbook. By providing detailed instructions and software, they have made it possible for the amateur astronomer to construct and operate an efficient, lowcost CCD camera. The final imaging and astrometry of this minor planet was carried out with such a camera made by the discoverer. (M 32348; M 32377)

\section{(7470) Jabberwock}

1991 JA. Discovered 1991 May 2 by T. Urata at Oohira.

The Jabberwock is a mythical creature that is the subject of the classic nonsense poem 'Jabberwocky' in Lewis Carroll's \{see planet (6984)\} delightful tale Through the Looking Glass and what Alice found there. (M 41935)

The citation was prepared by D. J. Asher. 


\section{(7472) Kumakiri}

1992 CU. Discovered 1992 Feb. 13 by M. Akiyama and T. Furuta at Mishima.

Named in honor of Kazuo Kumakiri (1923- ), an amateur astronomer in the Susono \{see planet (6419)\} area who has done much to develop a local interest in astronomy. (M 33788)

\section{(7475) Kaizuka}

$1992 \mathrm{UX}_{5}$. Discovered 1992 Oct. 28 by K. Endate and K. Watanabe at Kitami.

Named in memory of Sohei Kaizuka (1926-1998), one of the leading geomorphologists. His significant academic achievements covered various landforms, from global to local scale. Many scientists have been inspired by his ideas and advice. (M 35486)

\section{(7476) Ogilsbie}

1993 GE. Discovered 1993 Apr. 14 by T. B. Spahr at Tucson.

Brian K. Ogilsbie (1970-1997) was a close friend of the discoverer through grade school and high school. $\mathrm{He}$ is well remembered for long talks by the waterside as part of innumerable fishing trips. The name was also suggested by D. L. Blackburn. (M 45336)

\section{(7478) Hasse}

$1993 \mathrm{OA}_{4}$. Discovered 1993 July 20 by E. W. Elst at La Silla.

Named for Peter Hasse (1585-1640), the first wellknown organist to be appointed at the famous Marienkirche in Lübeck. On his death, he was succeeded by Franz Tunder \{see planet (7871)\}, who, according to the Lübeck custom, married Hasse's eldest daughter. Another of his daughters married the famous organist Nicolaus Bruhns \{see planet (5127)\}. (M 31025)

\section{(7480) Norwan}

1994 PC. Discovered 1994 Aug. 1 at the Palomar Observatory at Palomar.

Norwan, as the "dancing porcupine woman" of the California Wintuns, was a goddess of light who brought food to earth. A daughter of earth and sun, Norwan danced, light as warm air, above growing plants; she kept dancing every day until sunset. (M 29673)

\section{(7481) San Marcello}

$1994 \mathrm{PA}_{1}$. Discovered 1994 Aug. 11 by A. Boattini and M. Tombelli at Cima Ekar.

Named for San Marcello Pistoiese, the mountain village where the Pian dei Termini Observatory is located and an important all-year holiday Tuscan resort. Founded by the Romans in 224 B.C., its name comes from the Roman Consul Marcus Claudius Marcellus. A pedestrian suspension bridge on the river Lima is the longest in the world. (M 29673)

\section{(7483) Sekitakakazu}

$1994 \mathrm{VO}_{2}$. Discovered 1994 Nov. 1 by K. Endate and K. Watanabe at Kitami.
Named in memory of Takakazu Seki (1642-1708), Japanese mathematician and calendar scientist in Japan. His many achievements include the formulation of determinants ten years before Leibniz ssee planet (5149)\}. In 1674 he developed a theory of differential and integral calculus. (M 34626)

Name proposed by the discoverers following a suggestion by T. Sato and A. Fujii.

\section{(7484) Dogo Onsen}

$1994 \mathrm{WF}_{4}$. Discovered 1994 Nov. 30 by A. Nakamura at Kuma.

Named for a hot spring spa in Ehime, the prefecture in which this minor planet was discovered. Already known 3,000 years ago, Dogo Onsen is the oldest and one of the most famous hot spring spas in Japan. It is visited by some 1.3 million people each year. (M 30101)

\section{(7485) Changchun}

1994 XO. Discovered 1994 Dec. 4 by M. Koishikawa at Sendai.

Named after the city in China, Changchun is the international sister city of Sendai \{see planet (3133)\}, Japan, affiliated since 1980 . Changchun is the capital of the Kitsurin province and the center of political and economical activities of the province. (M 33788)

\section{(7488) Robertpaul}

$1995 \mathrm{~KB}_{1}$. Discovered 1995 May 27 by C. W. Hergenrother at Tucson.

Robert Paul Hergenrother (1976- ) is the brother of the discoverer. (M 45231)

\section{(7489) Oribe}

1995 MX. Discovered 1995 June 26 by C. W. Hergenrother at Tucson.

Takaaki Oribe (1972- ), researcher at Saji Observatory since its foundation in 1994, has contributed comet observations to the International Comet Quarterly. He serves as an executive member of a local astronomy club, "Tottori Society of Astronomy" and contributes to the popularization of astronomy. (M 45231)

\section{(7490) Babička}

$1995 \mathrm{OF}_{1}$. Discovered 1995 July 31 by P. Pravec at Ondřejov.

Named in memory of Marie Macháčová (1922-1998) and Marie Petrželová (1912-1998), the grandmothers of the discoverer's wife; and Emilie Dudková (1914-1977) and Aloisie Pravcová (1917- ), the grandmothers of the discoverer. This naming is also devoted to all grandmothers, who traditionally have a major role in bringing up children in the Czech nation. This role is also reflected in the novel "Babička" ("Granny"), written by Božena Němcová, based on her own childhood experience. (M 32790)

\section{(7491) Linzerag}

$1995 \mathrm{SD}_{2}$. Discovered 1995 Sept. 23 at the Osservatorio San Vittore at Bologna. 
Named on the occasion of 50th anniversary of the Linzer Astronomische Gemeinschaft, a very active association of amateur astronomers in Austria. The number of this minor planet, written backwards, corresponds to the year when the association was founded. (M 30101)

Name proposed by the discoverers following a suggestion from Herbert Raab, president of the association.

\section{(7492) Kačenka}

1995 UX. Discovered 1995 Oct. 21 by P. Pravec at Ondřejov.

Named in honor of Kateřina Macháčová (1975- ), who has been a constant source of support to the discoverer during many stages of his research on near-earth objects. This naming comes on the eve of her marriage to the discoverer, 1997 June 21 ssee also planet (4790)\}. (M 30101)

\section{(7493) Hirzo}

1995 US $_{2}$. Discovered 1995 Oct. 24 by J. Tichá at Klě́.

Named after Hirzo (?-1275), the knight of Bohemian king Přemysl \{see planet (7695)\} Otakar II and the efficient surveyor of royal towns and castles. Hirzo founded the royal town of Ceské Budějovice at the confluence of Vltava \{see planet (2123)\} and Malše rivers in 1265. Ceské Budějovice is the home town of the discoverer. (M 29673)

\section{(7494) Xiwanggongcheng}

$1995 \mathrm{UV}_{48}$. Discovered 1995 Oct. 28 at the Beijing Observatory at Xinglong.

Named for the tenth anniversary of Project Hope (Xiwang Gongcheng), a non-profit social welfare program operated by the China Youth Development Foundation. The project was initiated on 1989 Oct. 30 , with the aim of helping school dropouts in povertystricken areas return to school and finish primary education. Using contributions from people of all walks of life at home and abroad, more than 1.85 million children have been brought back to school and 6000 Hope Primary Schools have been built in the rural areas across the country. Project Hope has greatly promoted the development of elementary education in China's poor areas and has become China's most effective social welfare program in the 1990s. (M 33789)

\section{(7495) Feynman}

$1995 \mathrm{WS}_{4}$. Discovered 1995 Nov. 22 by M. Tichý and Z. Moravec at Klet.

Named in memory of Richard P. Feynman (19181988), outstanding theoretical physicist, 1965 Nobel prizewinner for physics, known for his works on liquid helium, quantum electrodynamics, elementary-particle physics and solid-state physics. Feynman was also an outstanding lecturer, and his three-volume introductory university course, The Feynman lectures on physics, has been an inspiration and a source of delight for generations of physicists and other scientists all over the world. His adventures, manner of thinking and curious character are recorded in Surely you're joking, Mr. Feynman and What do you care what other people think? (M 29673)

Obituaries published in Spaceflight, Vol. 30, No. 5 p. 218 (1988); Nature, Vol. 332, No. 6165, p. 588 (1988).

\section{(7496) Miroslavholub}

$1995 \mathrm{WN}_{6}$. Discovered 1995 Nov. 27 by M. Tichý at Klě̃.

Named in memory of Miroslav Holub (1923-1998), Czech immunologist, poet and essayist. His research resulted in the monograph Immunology of Nude Mice. His fine poetry combines the world of science and the world of everyday human experience, as shown, for example, in his book Supposed to Fly. (M 33387)

Name proposed by the discoverer following a suggestion by J. Tichá.

\section{(7497) Guangcaishiye}

$1995 \mathrm{YY}_{21}$. Discovered 1995 Dec. 17 at the Beijing Observatory at Xinglong.

Named for the Glory Project (Guangcai Shiye), an open poverty relief activity in China. The project actively assists the poor with training, initiating enterprises, developing resources and carrying out commerce. Its operation promotes traditional Chinese virtues and advances the prospects of the poor. (M 35486)

\section{(7498) Blaník}

1996 BF. Discovered 1996 Jan. 16 by Z. Moravec at Klě́.

Named for a hill in central Bohemia located about $50 \mathrm{~km}$ southeast of Prague. According to myth, there sleeps inside the hill the army of St. Václav, which will come and help the Czech nation in its darkest hours. (M 29673)

\section{(7500) Sassi}

1996 TN. Discovered 1996 Oct. 3 at the Farra d'Isonzo Observatory at Farra d'Isonzo.

Named in honor of Giorgio Sassi (1918- ) , Italian amateur astronomer, co-founder of the Osservatorio San Vittore \{see planet (2235)\}, in operation since 1969. He conceived and realized the optical and electronic elements involved in constructing an automated telescope and is still very active today. He wrote the "bible" for Italian amateurs who want to make optical instruments. (M 31025)

\section{(7501) Farra}

$1996 \mathrm{VD}_{3}$. Discovered 1996 Nov. 9 at the Farra d'Isonzo Observatory at Farra d'Isonzo.

Named for the small town in northeastern Italy that is the site of the observatory where this minor planet was discovered. A Roman village built in defense of the strategic bridge over the river Isonzo, it later became a Lombard stronghold. Located in the lowlands of Isonzo, Farra is well known for the excellent quality of its wines. (M 33789) 
(7506) Lub

4837 P-L. Discovered 1960 Sept. 24 by C. J. van Houten and I. van Houten-Groeneveld at Palomar.

Named in honor of Jan Lub (1946- ), Dutch astronomer in Leiden, on the occasion of his 51st birthday. After studying in Amsterdam he worked for the European Southern Observatory in Chile and Munich before moving to the Leiden Observatory. While in Leiden he was director of the Observatório Roque de los Muchachos for several years. Lub's fields of interest are photoelectric observations of RR Lyrae variables and other objects. (M 31026)

\section{(7507) Israel}

7063 P-L. Discovered 1960 Oct. 17 by C. J. van Houten and I. van Houten-Groeneveld at Palomar.

Named in honor of Frank P. Israel (1946- ), Dutch astronomer in Leiden, on the occasion of his 51st birthday. Before moving to the Leiden Observatory he worked at the California Institute of Technology and at the European Space Agency. His fields of interest are radio astronomical observations of dense interstellar clouds in galaxies, in particular the study of mass concentrations in the center of galaxies. (M 31026)

\section{(7508) Icke}

2327 T-3. Discovered 1977 Oct. 16 by C. J. van Houten and I. van Houten-Groeneveld at Palomar.

Named in honor of Vincent Icke (1946- ), Dutch astronomer in Leiden, on the occasion of his 51st birthday. After studies in Utrecht and Leiden, he worked at the Universities of Sussex and Cambridge, at the California Institute of Technology and at the University of Minnesota in Minneapolis. His fields of interest are theoretical investigations of celestial bodies and cosmology. He is also an ardent popularizer of astronomy. (M 31026)

\section{(7509) Gamzatov}

1977 EL. Discovered 1977 Mar. 9 by N. S. Chernykh at Nauchnyj.

Celebrated poet Rasul Gamzatovich Gamzatov (1923- ) is the national poet of Daghestan. (M 38197)

\section{(7512) Monicalazzarin}

$1983 \mathrm{CA}_{1}$. Discovered 1983 Feb. 15 by E. Bowell at Anderson Mesa.

Named in honor of Monica Lazzarin (1963- ), Italian planetary scientist at Padova Observatory. Lazzarin is an expert in the spectroscopic observation of comets and minor planets and has obtained interesting results on the relationship between these objects. She has studied aqueous alteration in C-class minor planets and has helped understand the compositions of the Centaurs. Lazzarin is involved in planning the Rosetta mission. (M 35486)

Name suggested and citation prepared by M. A. Barucci and M. Fulchignoni.
(7516) Kranjc

1987 MC. Discovered 1987 June 18 at the Osservatorio San Vittore at Bologna.

Named in memory of Aldo Kranjc (1919-1994), Italian astronomer at the observatories in Naples, Milan and Bologna. He succeeded F. Zagar \{see planet (6746)\} as director of Brera-Merate Observatory in 1971. His many activities and studies included general relativity and applications of electronic techniques to astronomy and spectroscopy. He was a pioneer in Italy on numerical electronic calculus. He wrote several programs and articles on orbit determination. (M 32348)

\section{(7519) Paulcook}

$1989 \mathrm{UN}_{3}$. Discovered 1989 Oct. 31 by B. G. W. Manning at Stakenbridge.

In the face of extreme physical problems resulting from an accident at age 12, Paul A. Cook (1981has shown remarkable determination to use his mental powers to study astronomy. He has learned how to use a computer by special means and has produced some extremely good graphics for the discoverer. (M 36127)

\section{(7525) Kiyohira}

1992 YE. Discovered 1992 Dec. 18 by A. Natori and T. Urata at Yakiimo.

Named in memory of Kiyohira Fujiwara (1056-1128), founder of the Fujiwara clan in the northern part of Japan. He built a castle in Esashi \{see planet (9368)\}, near Mizusawa \{see planet (7530)\}, and accumulated the means to reign over the wider area. He then moved to Hiraizumi, about $30 \mathrm{~km}$ south of Esashi, which rapidly became one of the most prosperous independent realms in Japan during the eleventh and twelfth centuries. Unburnt temples and remains tell us that the cultural level of the realm was comparable with that of Kyoto \{see planet (4352)\}. (M 34626)

Name proposed by the second discoverer following a suggestion by the citizens of Esashi City, where there is a geophysical station operated by the Mizusawa Observatory. Citation prepared by K. Yokoyama.

\section{(7528) Huskvarna}

1993 FS $_{39}$. Discovered 1993 Mar. 19 by the Uppsala-ESO Survey at La Silla.

Huskvarna (formerly Husqvarna) is a city located at the southernmost edge of lake Vättern in southern Sweden. The town is famous for the Husqvarna rifle factory founded in 1689 , now turned into a factory to produce sewing machines. (M 39650)

\section{(7529) Vagnozzi}

1994 BC. Discovered 1994 Jan. 16 at the Colleverde di Guidonia Observatory at Colleverde di Guidonia.

Named in honor of Antonio Vagnozzi (1950- ), who in 1993 became the first amateur astronomer in Italy to discover a minor planet with a CCD camera and, after Spacewatch \{see planet (4255)\}, the first person to have a CCD discovery numbered. In addition to 
his work on minor planets, he has more recently been engaged in a systematic search for supernovae and was a codiscoverer of SN 1996ae. (M 31611)

\section{(7530) Mizusawa}

$1994 \mathrm{GO}_{1}$. Discovered 1994 Apr. 15 by K. Endate and K. Watanabe at Kitami.

Named in commemoration of the hundredth anniversary of the International Latitude Observatory of Mizusawa, established by the Japanese government according to a resolution adopted by the International Association of Geodesy in 1899 as one of the six stations of the International Latitude Service, at a latitude of $+39^{\circ} 08^{\prime}$. In 1988 the Observatory was transferred to the Division of Earth Rotation of the National Astronomical Observatory. The observations have never been interrupted, even during the two World Wars. Mizusawa is located about $500 \mathrm{~km}$ north of Tokyo, and its citizens show a strong interest in the observatory's astronomical and geophysical research. (M 34626)

Name proposed by the discoverers following a suggestion by K. Hurukawa, who was an astronomer there during 1960-1969. Citation prepared by K. Yokoyama.

\section{(7531) Pecorelli}

1994 SC. Discovered 1994 Sept. 24 at the Santa Lucia Observatory at Stroncone.

A conductor on the trams and buses in Terni for 30 years, Antonio Pecorelli (1923-1986) was a poet whose direct contact with the moods of the people was later recorded in more than 300 sonnets in the local dialect. With a biting pen, he knew what to say, and he said what others did not dare to say. (M 45336)

\section{(7532) Pelhřimov}

$1995 \mathrm{UR}_{1}$. Discovered 1995 Oct. 22 by M. Tichý at Kleť.

Pelhrrimov is the south Bohemian town, founded in the thirteenth century, where the discoverer attended high school. (M 41567)

\section{(7536) Fahrenheit}

$1995 \mathrm{WB}_{7}$. Discovered 1995 Nov. 21 by Y. Shimizu and T. Urata at Nachi-Katsuura.

Named in memory of Daniel Gabriel Fahrenheit (1686-1736), German physicist who invented both the alcohol and mercury thermometers. He is best known for developing the temperature scale that bears his name. The number of this minor planet is related to 4169 , the number of the minor planet honoring the inventor of the Celsius temperature scale, in the same manner (to the nearest integer) as the relationship between the Celsius and Fahrenheit scales. (M 29673; M 29691)

Named by the Small Bodies Names Committee following a suggestion by P. Wild.

\section{(7537) Solvay}

$1996 \mathrm{HS}_{8}$. Discovered 1996 Apr. 17 by E. W. Elst at La Silla.

Named for the Belgian chemist and philantropist Ernest Solvay (1838-1922), prodigious industrialist, scientist and engaged citizen with audacious ideas on politics and society. Today he is considered a symbol of industrial Belgium. (M 31026)

\section{(7541) Nieuwenhuis}

4019 T-3. Discovered 1977 Oct. 16 by C. J. van Houten and I. van Houten-Groeneveld at Palomar.

Named in honor of Henk Nieuwenhuis (1938- ), curator of the Eise Eisinga \{see planet (5530)\} Planetarium in Franeker, The Netherlands. Since the 1960s he has been an enthusiastic organizer of exhibitions, meetings and lectures for amateur astronomers and the general public. He also has a keen interest in space research and in observing planets at the observatory he constructed. (M 31026)

Name proposed by the discoverers following a suggestion by T. Schoenmaker, who prepared the citation.

\section{(7543) Prylis}

1973 SY. Discovered 1973 Sept. 19 by C. J. van Houten and I. van Houten-Groeneveld at Palomar.

Named for a son of Hermes. Inspired by Athene \{see planet (881)\}, Prylis suggested that entry to Troy could be gained by means of a wooden horse. Epeius \{see planet (2148)\}, a carpenter, volunteered to build the horse. Afterwards, of course, Odysseus \{see planet (1143)\} claimed all the credit for his stratagem. (M 30478)

\section{(7544) Tipografiyanauka}

1976 UB $_{2}$. Discovered 1976 Oct. 26 by T. M. Smirnova at Nauchnyj.

The oldest printing-house (tipografiya in Russian) of the Russian Academy of Sciences bears the name "Nauka" (science). It was founded in 1727 in St. Petersburg. (M 39650)

\section{(7545) Smaklösa}

1978 OB. Discovered 1978 July 28 by C.-I. Lagerkvist at Mount Stromlo.

Named after the music group Smaklösa, which performs mainly on the island of Gotland off the Swedish coast during the summer. Celebrating 25 years together in 1998, they made at the beginning of their career the now-famous statement that only cowards rehearse before a performance. The lyrics of their songs are very intelligently written and are even more enjoyable to those more accustomed to the lifestyle and humor of Gotland. The live performances of the group are unforgettable, and the discoverer is very thankful for those he was able to attend during the summer of 1998. (M 33387) 


\section{(7548) Engström}

$1980 \mathrm{FW}_{2}$. Discovered 1980 Mar. 16 by C.-I. Lagerkvist at La Silla.

Named in memory of Albert Engström (1869-1940), Swedish artist and writer. Born in Lönneberga in the Swedish province of Småland, he went as a student to Uppsala in 1889, where he studied Greek and Latin before his artistic ambitions made him move to an art school in Gothenburg. Probably Sweden's best painter of caricatures, he is best known for his black and white drawings illustrating very short stories. He was also an outstanding writer, specializing in short stories. Appointed professor of drawing at the Swedish academy of art, in 1922 he became a member of the prestigious Swedish academy. (M 31611)

\section{(7549) Woodard}

$1980 \mathrm{TO}_{5}$. Discovered 1980 Oct. 9 by C. S. Shoemaker and E. M. Shoemaker at Palomar.

Named for Adrian Russell Woodard, youngest grandson of the discoverers. (M 32348)

\section{(7553) Buie}

1981 FG. Discovered 1981 Mar. 30 by E. Bowell at Anderson Mesa.

Named in honor of Marc W. Buie (1958- ), an astronomer at Lowell Observatory, who has made many important contributions to planetary astronomy. These include the identification of water ice on Pluto's satellite Charon, constraints on the albedo and frost distribution on Pluto and Charon and improvements in our knowledge of Charon's orbit. Buie is also a codiscoverer of several transneptunian objects and has developed a wide variety of astronomical software used at Lowell Observatory and elsewhere. (M 35486)

Citation provided by J. R. Spencer at the request of the discoverer.

\section{(7554) Johnspencer}

1981 GQ. Discovered 1981 Apr. 5 by E. Bowell at Anderson Mesa.

Named in honor of John R. Spencer (1957- ), an astronomer at Lowell Observatory, for his pioneering interdisciplinary work in planetary science. Spencer's research includes detailed and insightful probing into the nature and character of the Galilean satellites. In particular, he has led the field in using high-resolution, ground-based imaging of Io to provide an excellent time history of volcanism, important for bridging the gaps between spacecraft encounters. In his studies, Spencer applies a keen intuitive sense of the natural world and leaves us with a better appreciation and understanding of our solar system. (M 35486)

Citation provided by M. W. Buie at the request of the discoverer.

\section{(7555) Venvolkov}

$1981 \mathrm{SZ}_{6}$. Discovered 1981 Sept. 28 by L. V. Zhuravleva at Nauchnyj.
Veniamin Vasil'evich Volkov (1921- ), world-renowned ophthalmologist, made significant contributions to the treatment of cancer, trauma and burns to the eye. The American Biographical Institute proclaimed him 'Man of Year 1998' and made him a life member of the institute's International Research Council. (M 39650)

\section{(7558) Yurlov}

1982 TB$_{2}$. Discovered 1982 Oct. 14 by L. G. Karachkina at Nauchnyj.

Named in memory of Aleksandr Aleksandrovich Yurlov (1927-1963), Russian choir master and choral conductor. His innovative interpretations of sacred music defined his contribution to Russian art. He led what later became Yurlov's Chapel Choir from 1958 to 1963, performing compositions of Prokof'ev, Shostakovich \{see planet (2669)\} and Sviridov \{see planet (4075)\}. (M 32348)

Name suggested by G. Sviridov (1915-1998) and supported by the discoverer.

\section{(7560) Spudis}

1986 AJ. Discovered 1986 Jan. 10 by C. S. Shoemaker and E. M. Shoemaker at Palomar.

Named in honor of Paul D. Spudis, planetary geologist and expert on lunar geology, from the multi-ring basins to the genesis of highland breccias and origin and evolution of the lunar crust. He is a staff scientist with the Lunar and Planetary Institute and has served as deputy leader of the science team for the Clementine mission to the moon. Other important research by Spudis has been on the geology and impact mechanics of craters on all the terrestrial planets. (M 35486; M 35523)

\section{(7561) Patrickmichel}

$1986 \mathrm{TR}_{2}$. Discovered 1986 Oct. 7 by E. Bowell at Anderson Mesa.

Named in honor of Patrick Michel (1970- ), French dynamicist, who was the first to compute the locations and strengths of secular resonances in the inner solar system. He has also investigated the various effects that bear on the evolution of near-earth and Mars-crossing objects. Michel's work on the evolution of (433) Eros has shown that, although it is possible for this object to strike the earth in the distant future, the probability of such an event remains low. (M 35486)

Name suggested and citation prepared by A. Cellino and P. Farinella.

\section{(7562) Kagiroino-Oka}

$1986 \mathrm{WO}_{9}$. Discovered 1986 Nov. 30 by H. Kosai and K. Hurukawa at Kiso.

Named for a place in one of the poems in the collection Manyousyu \{see planet (7104)\}. The place is said to be the present-day Ouda, Nara prefecture. (M 34626) 


\section{(7571) Weisse Rose}

$1989 \mathrm{EH}_{6}$. Discovered 1989 Mar. 7 by F. Börngen at Tautenburg.

Named in memory of the members of Weisse Rose \{white rose\}, a circle of students, academics and artists around Hans and Sophie Scholl in Munich. They appealed for resistance against the Nazi regime in 1942-43, motivated by ethical and Christian arguments. Numerous members of the group were later condemned to death. (M 30478)

\section{(7572) Znokai}

1989 SF. Discovered 1989 Sept. 23 by K. Endate and K. Watanabe at Kitami.

Named for the $Z$ society (Z-no-kai in Japanese), a cultural and social organization of the staff of the Mizusawa \{see planet (7530)\} International Latitude Observatory. The name commemorates the Z-term in the latitude variation, discovered by Kimura \{see planet (6233)\}, the first director. (M 34626)

Name proposed by the discoverers following a suggestion of K. Hurukawa, who is a member of Z-no-kai. Citation prepared by K. Yokoyama.

\section{(7573) Basfifty}

1989 VX. Discovered 1989 Nov. 4 by B. G. W. Manning at Stakenbridge.

England's Birmingham Astronomical Society is currently celebrating its fiftieth anniversary. The Society was established in 1950, largely as a result of the University of Birmingham's extramural classes on astronomy. (M 41567)

\section{(7575) Kimuraseiji}

1989 YK. Discovered 1989 Dec. 22 by Y. Kushida and O. Muramatsu at Yatsugatake.

Named in honor of Seiji Kimura (1932- ), an amateur astronomer who first suggested sending a solar eclipse expedition to the U.S.S.R. in 1968. Since then he has organized several overseas expeditions to observe total solar eclipses. Secretary of the committee of the Japan Amateur Astronomers' Convention for over 14 years, Kimura established the Herschel Society of Japan in 1984 and has been editing bimonthly newsletters promoting knowledge of the Herschels and keeping contact with the William Herschel Society in the U.K. (M 33789)

Name proposed by the discoverers following a suggestion by S. Morikubo.

\section{(7578) Georgböhm}

$1990 \mathrm{SP}_{7}$. Discovered 1990 Sept. 22 by E. W. Elst at La Silla.

Named for the North German organist Georg Böhm (1661-1733), who studied under Buxtehude \{see planet (4344)\} in Lübeck. In 1698 Böhm was appointed organist at the St. Johannis church in Lüneburg \{see planet (10801)\}. There he wrote his imposing Prelude and Fugue in $\mathrm{C}$ major. This opens with a virtuoso pedal solo, highly characteristic of North German organ composers. (M 31026)

\section{(7580) Schwabhausen}

$1990 \mathrm{TM}_{7}$. Discovered 1990 Oct. 13 by F. Börngen and L. D. Schmadel at Tautenburg.

Named for the Jena University Observatory's outstation, located some $10 \mathrm{~km}$ to the west of the city. The station was established in 1962 on the watershed of the rivers Saale \{see planet (5409)\} and Ilm. It is located in a small preserved wood between the villages of Grossand Kleinschwabhausen, and the discoverer's principal residence is nearby. This minor planet was numbered as the result of astrometric CCD observations made at Schwabhausen in April 1997. (M 30101)

Name proposed by the first discoverer.

\section{(7581) Yudovich}

1990 VY 13 . Discovered 1990 Nov. 14 by L. G. Karachkina at Nauchnyj.

Named in honor of Viktor Iosifovich Yudovich (1934- ), a professor at Rostov University and notable specialist in the mathematical hydrodynamics of convective fluid and mathematical geophysics. Yudovich developed convective models for earthquakes and volcanic eruptions. (M 31026)

\section{(7583) Rosegger}

$1991 \mathrm{BA}_{3}$. Discovered 1991 Jan. 17 by F. Börngen at Tautenburg.

Named for the Styrian author Peter Rosegger (18431918), in his lifetime extremely popular in Austria. Particularly known are his novels Die Schriften des Waldschulmeisters and Als ich noch der Waldbauernbub war describing the people and manners in the villages of his homeland. (M 30101)

\section{(7584) Ossietzky}

1991 GK $_{10}$. Discovered 1991 Apr. 9 by F. Börngen at Tautenburg.

Named in memory of Carl von Ossietzky (1889-1938), German publicist and editor of the weekly paper Weltbühne from 1927 to 1933. A staunch republican, he warned against militarism and National Socialism. In 1931 he received an 18-month prison sentence for disclosing the rearmament of the Reich in violation of the treaty of Versailles. Imprisoned by the Nazis in 1933, Ossietzky received the 1935 Nobel Peace Prize but was not allowed to accept it. He was released in 1936 following worldwide protests but died shortly afterwards due to the ill-treatment he had received while in prison. (M 30478)

\section{(7586) Bismarck}

$1991 \mathrm{RH}_{7}$. Discovered 1991 Sept. 13 by L. D. Schmadel and F. Börngen at Tautenburg.

Named in memory of Prince Otto Eduard Leopold von Bismarck (1815-1898), Prussian prime minister and minister of foreign affairs and, from 1871, the 
so-called Great Chancellor of the German Reich. His name is closely connected with the unification of Germany and with his politics of a balance of power among the European states. Bismarck introduced a comprehensive collection of civil laws and promoted an extensive social welfare system which - in its essential parts - remains important even a century after his death. (M 32348)

Name proposed by the first discoverer

\section{(7587) Weckmann}

$1992 \mathrm{CF}_{3}$. Discovered 1992 Feb. 2 by E. W. Elst at La Silla.

Named for the North German organist Matthias Weckmann (1619-1674). Appointed organist at St. Jacobi's church in Hamburg in 1655, he had the mighty Arp Schnitger organ at his disposal until his death. A pupil of Heinrich Schütz \{see planet (4134)\}, he worked under the direction of Praetorius \{see planet (4889)\} and Scheidemann. In 1668 he founded the important Collegium musicum. Many of his organ and cembalo compositions (toccatas, canzones, suites and sonatas) survive. His Fantasia in D minor is a multisectional piece that is thoroughly contrapunctal in nature, and it reflects the great seriousness of Weckmann's style. (M 31026)

\section{(7590) Aterui}

$1992 \mathrm{UP}_{4}$. Discovered 1992 Oct. 26 by K. Endate and

K. Watanabe at Kitami.

Aterui, patriarch of the Ainu tribe in northern Japan in the late eighth century, was believed to have had a castle in the present Mizusawa see planet (7530)\} City. He resisted military invasion by the central government. He was eventually compelled to surrender to the commander of the Kyoto troops and was executed near Kyoto \{see planet (4352)\} in 801 . (M 38197)

\section{(7592) Takinemachi}

$1992 \mathrm{WR}_{3}$. Discovered 1992 Nov. 23 by S. Otomo at Kiyosato.

The town of Takine, in Fukushima prefecture $250 \mathrm{~km}$ north of Tokyo, is famous for its starry sky and stalactite cavern. The town established the Hoshinomura Observatory in 1991. (M 43189)

\section{(7594) Shotaro}

$1993 \mathrm{BH}_{2}$. Discovered 1993 Jan. 19 by T. Seki at Geisei.

Named in memory of Shotaro Miyamoto (1912-1992), professor of astrophysics at Kyoto University. His interests included relativistic cosmology, planetary nebulae, solar physics, lunar geology and Martian meteorology. He also contributed greatly to the popularization of astronomy through his many books and radio and television broadcasts. Director of the Kwasan and Hida Observatories, he also served as president of the International Lunar Society, vice president of the International Association of Planetology, president of the Astronomical Society of Japan and vice president of the Oriental Astronomical Association. (M 32790)

Name proposed by the discoverer following a suggestion by K. Sakka and T. Sato.

Obituary published in Yamamoto Circ., No. 2185, p. 2 (1992).

\section{(7595) Växjö}

$1993 \mathrm{FN}_{26}$. Discovered 1993 Mar. 21 by the UppsalaESO Survey at La Silla.

Växjö is the provincial capital of Kronoberg in southern Sweden, a town with a charter since 1342. It is known for its twelfth-century cathedral, fourteenthcentury castle and nowadays for the Museum of Emigrants. (M 39650)

\section{(7596) Yumi}

1993 GH. Discovered 1993 Apr. 10 by K. Endate and K. Watanabe at Kitami.

Named in honor of Shigeru Yumi (1916- ), the second director of the central bureau of the International Polar Motion Survey. During his 1962-1980 tenure he directed and saw the completion of the comprehensive work of rereducing the complete set of latitude observations. (M 34626)

Name proposed by the discoverers following a suggestion by K. Hurukawa. Citation prepared by K. Yokoyama.

\section{(7597) Shigemi}

1993 GM. Discovered 1993 Apr. 14 by S. Otomo at Kiyosato.

Shigemi Uchida (1952- ) is actively working to combat light pollution in Japan. He is an organizer of the Japan Section of the International Dark Sky Association and also a member of the Japanese dark-sky organization Hoshizora-wo-Mamoru-Kai. (M 41935)

\section{(7599) Munari}

1994 PB. Discovered 1994 Aug. 3 by A. Boattini and M. Tombelli at San Marcello Pistoiese.

Named in honor of Ulisse Munari (1960- ), staff astronomer at the Astronomical Observatories of Padua and Asiago \{see planets (363) and (7679), respectively\} since 1990. His researches are concerned with symbiotic stars, cataclysmic variables, novae and open clusters as well as minor planets. As a high-school student he founded the Minor Planet Section of the Italian National Amateur Organization, and he still maintains his links with amateurs, allowing them access to some of the Italian professional telescopes. The discoverers found their first asteroid with one of these instruments. (M 30478)

\section{(7600) Vacchi}

$1994 \mathrm{RB}_{1}$. Discovered 1994 Sept. 9 by V. S. Casulli at Colleverde di Guidonia. 
Named in honor of Ciro Vacchi (1916- ), amateur astronomer and co-founder of San Vittore ssee planet (2235)\} Observatory, near Bologna. In 1974 he began the San Vittore search for asteroids, and he has many new discoveries to his credit. Today he is still a leader in the Italian community of amateur astrometrists. (M 31026)

\section{(7603) Salopia}

$1995 \mathrm{OA}_{2}$. Discovered 1995 July 25 by S. P. Laurie at Church Stretton.

Named for the English county of Shropshire (or Salop), where Church Stretton is located. Situated in the once-tumultuous borderland of the Welsh Marches, the earliest major settlement was the Roman garnison town of Uriconium built near the Wrekin, the county's prominent hill. The current county town of Shrewsbury is situated on a meandering bend of the river Severn and was the birthplace of the naturalist Charles Darwin \{see planet (1991)\}. The other main town, Telford, includes the Coalbrookdale and Ironbridge areas that were the birthplace of the Industrial Revolution in the eighteenth century. The county was celebrated in A. E. Housman's A Shropshire Lad and is the original 'land of lost content'. (M 34626)

\section{(7607) Billmerline}

1995 SB $_{13}$. Discovered 1995 Sept. 18 by the Spacewatch at Kitt Peak.

Named in honor of William J. Merline (1954- ), planetary scientist at the Southwest Research Institute in Boulder, Colorado, and a dedicated instrumentalist and observer. While a graduate student at the University of Arizona's Lunar and Planetary Laboratory he codiscovered periodic variations of the radial velocity of the star Arcturus. He made thousands of hours of observations for a search for planets orbiting other stars and a study of the stability of the solar spectrum. $\mathrm{He}$ is now a member of the imaging team of the Galileo mission, studying cratering records from spacecraft imagery. He is also conducting a search for satellites of minor planets using coronagraphic imaging with groundbased telescopes. (M 33789)

\section{(7608) Telegramia}

$1995 \mathrm{UO}_{1}$. Discovered 1995 Oct. 22 by J. Tichá at Klět.

Named on the 75 th anniversary of the publication of the first IAU Circular, which was issued on 1922 Oct. 22 by the IAU Central Bureau for Astronomical Telegrams, then at the Copenhagen Observatory. The Bureau moved to the Smithsonian Astrophysical Observatory in 1965 and has now issued 6756 IAU Circulars, relating generally to transient astronomical objects and phenomena in urgent need of further observation. (M 30802)

Name proposed by the discoverer and endorsed by her colleagues M. Tichý and Z. Moravec.
(7620) Willaert

4077 P-L. Discovered 1960 Sept. 24 by C. J. van Houten and I. van Houten-Groeneveld at Palomar.

Named for the Flemish composer Adrian Willaert (1485-1562). From 1527 Willaert was a musician, conductor and organist at St: Mark's cathedral in Venice. He combined Dutch polyphony with Italian concertante music and started the Venetian school. His main works are motets and madrigals. (M 30802)

\section{(7621) Sweelinck}

4127 P-L. Discovered 1960 Sept. 24 by C. J. van Houten and I. van Houten-Groeneveld at Palomar.

Named for the Dutch composer and organist Jan Pieterszoon Sweelinck (1562-1621). At the age of 18, Sweelinck succeeded his father as organist of the Old Church of Amsterdam, a position he held to his death. He composed many choral songs, motets and madrigals. His fantasias and variations influenced North German organ music. Praetorius ssee planet (4889)\} was one of his pupils. (M 30802)

\section{(7622) Pergolesi}

6624 P-L. Discovered 1960 Sept. 24 by C. J. van Houten and I. van Houten-Groeneveld at Palomar.

Named for the Italian composer Giovanni Battista Pergolesi (1710-1736). He was a conductor in Naples and Rome and died in Pozzuoli in extreme poverty. $\mathrm{He}$ did not live to see the glory of his intermezzo La serva pedrona, which especially in France became the beginning of opera buffa. Pergolesi's Stabat mater for soprano, alto, string instruments and organ shows his ability to combine large choral and instrumental components. (M 30802)

\section{(7623) Stamitz}

9508 P-L. Discovered 1960 Oct. 17 by C. J. van Houten and I. van Houten-Groeneveld at Palomar.

Named for the German-Bohemian violinist and composer Johann Wenzel Anton Stamitz (1717-1757). He played in the orchestra during the coronation of Karl VII in Frankfurt in 1742. The Elector Palatine Carl Theodor invited Stamitz to Mannheim to conduct his orchestra. The composer of 74 symphonies, Stamitz started the Mannheim school of musicians and influenced Haydn, Mozart and Beethoven \{see planets (3941), (1034) and (1815), respectively\}. (M 30802)

\section{(7624) Gluck}

1251 T-1. Discovered 1971 Mar. 25 by C. J. van Houten and I. van Houten-Groeneveld at Palomar.

Named of the German composer Ritter Christoph Willibald von Gluck (1714-1787). After studying in Prague and Milan he traveled to London to meet Handel \{see planet (3826)\}. He also worked with the traveling opera companies of Mingotti and Locatelli. In 1752 Gluck became conductor in Sachsen-Hildburghausen and in Vienna. He composed 17 symphonies and 107 operas, including the three Italian reform operas Orfeo ed Euridice, Alceste and Paride ed Elena. (M 30802) 


\section{(7625) Louisspohr}

2150 T-2. Discovered 1973 Sept. 29 by C. J. van

Houten and I. van Houten-Groeneveld at Palomar.

Named for the German composer and violinist Louis Spohr (1784-1859). At the age of 15 he became a violinist in the orchestra of the duke of Brunswick. He made many journeys throughout Europe to give concerts and founded a school for violinists. His eleven operas included Faust and Jessonda, and he also composed nine symphonies, 15 violin concerti and much chamber music. (M 30802)

\section{(7627) Wakenokiyomaro}

$1977 \mathrm{DS}_{4}$. Discovered 1977 Feb. 18 by H. Kosai and K. Hurukawa at Kiso.

Named for the person, born in Okayama prefecture in the Nara Era, who moved the Japanese capital from Nara $\{$ see planet (7253)\} to Kyoto \{see planet (4352)\}. (M 34626)

\section{(7628) Evgenifedorov}

1977 QY. Discovered 1977 Aug. 19 by N. S. Chernykh at Nauchnyj.

Astrometrist Evgenij Pavlovich Fedorov (1909-1986) studied the rotation of the earth and was founder of the Kiev school for the study of polar motion. He served as director of the Main Astronomical Observatory of the Ukrainian Academy of Sciences for many years and was president of IAU Commission 19 during 1955-1961. (M 38197)

\section{(7629) Foros}

1977 QK 1 . Discovered 1977 Aug. 19 by N. S. Chernykh at Nauchnyj.

Named for the health resort on the south coast of the Crimea. (M 34626)

\section{(7631) Vokrouhlický}

1981 WH. Discovered 1981 Nov. 20 by E. Bowell at Anderson Mesa.

Named in honor of David Vokrouhlický (1966- ), a Czech physicist at Charles University, Prague, who has developed new physical models for the nongravitational forces acting on small minor planets and meteoroids. In particular, Vokrouhlický has studied the so-called Yarkovsky effect, which causes a slow orbital drift into main-belt resonances and is an important mechanism for transporting meteorites to Earth. (M 35486) Name proposed and citation written by P. Farinella.

\section{(7632) Stanislav}

1982 UT $_{5}$. Discovered 1982 Oct. 20 by L. G. Karachkina at Nauchnyj.

Named in memory of the Ukrainian writer, poet, literary scholar and public figure Stanislav Volodymyrovych Tel'nyuk (1935-1990). His daughters Lesya and Galnya are well known Ukrainian singers who have set his verses to music. (M 31026)

\section{(7633) Volodymyr}

1982 UD $_{7}$. Discovered 1982 Oct. 21 by L. G. Karachkina at Nauchnyj.

Named in honor of the vice president of the Ukrainian Astronomical Association and director of the Kiev University Observatory, Volodymyr Volodymyrovich Tel'nyuk-Adamchuk (1936- ). He is an expert in astrometry and is the author of observational and summary catalogues of precise stellar positions. (M 31026)

\section{(7634) Shizutani-Kou}

$1982 \mathrm{VO}_{3}$. Discovered 1982 Nov. 14 by H. Kosai and K. Hurukawa at Kiso.

Named for a school in Bizen-city, Okayama prefecture. Founded in 1668, it is the oldest Japanese school building in existence. (M 34626)

\section{(7636) Comba}

1984 CM. Discovered 1984 Feb. 5 by E. Bowell at Anderson Mesa.

Named in honor of Paul G. Comba (1926- ), who gave up a career in celestial mechanics and astronomy for one in mathematics and computer science. After teaching at the University of Hawaii during the 1950s, he worked for three decades at IBM in New York and Massachusetts, where he carried out software research and development in many areas, including database management, geometric modeling, elasticity and cryptography. Following his formal retirement to Prescott, Arizona, he undertook a program of astrometry of minor planets in 1995. He has already been credited with the discovery of 20 numbered objects. (M 34344)

Name proposed by the discoverer following a suggestion by B. G. Marsden, who prepared the citation.

\section{(7638) Gladman}

1984 UX. Discovered 1984 Oct. 26 by E. Bowell at Anderson Mesa.

Named in honor of Brett Gladman (1966- ), a Canadian astronomer and dynamicist who has made important contributions to modeling the dynamical evolution of near-earth objects and the transport of meteorites, including those from the moon and Mars. Gladman has also carried out observational surveys of transneptunian objects and in 1997 was codiscoverer of the two irregular satellites of Uranus. (M 35486) Name proposed and citation written by P. Farinella.

\section{(7639) Offutt}

$1985 \mathrm{DC}_{1}$. Discovered 1985 Feb. 21 at the Oak Ridge Observatory at Harvard.

Named in honor of Warren Offutt (1928- ), on the occasion of his 70th birthday, 1998 Feb. 13. After a career as an engineering executive, he turned in his retirement to the astronomical applications of CCDs, considering in particular the contributions that can be made by amateur astronomers. At his observatory in New Mexico he has made key observations of several 
of the objects discovered in the Kuiper Belt in recent years, as well as of other comets and minor planets as faint as 22nd magnitude. His follow-up of S/1997 U 2, one of the two recently discovered satellites of Uranus, played a crucial role in the establishment of its orbit. (M 31297)

\section{(7640) Marzari}

1985 PX. Discovered 1985 Aug. 14 by E. Bowell at Anderson Mesa.

Named in honor of Francesco Marzari (1961- ) , an Italian planetary scientist at the University of Padova who has carried out extensive and innovative work on the formation of planets, the dynamics of interplanetary dust, the collisional evolution of main-belt and Trojan minor planets and, in particular, minor planet families. (M 35487)

Name proposed and citation written by P. Farinella.

\section{(7644) Cslewis}

$1988 \mathrm{VR}_{5}$. Discovered 1988 Nov. 4 by A. Mrkos at Klě̌t.

Clive Staples Lewis (1898-1963) was a British scholar and novelist, author of the famous children's fantasy The Chronicles of Narnia. In his three science-fiction novels, Space Trilogy, he described a cosmic struggle betwen good and evil in the solar system. (M 42357) The name was suggested by M. Kočer.

\section{(7645) Pons}

$1989 \mathrm{AC}_{2}$. Discovered 1989 Jan. 4 by A. Mrkos at Klě́

Named in memory of Jean-Louis Pons (1761-1831), whose name appears on 26 different comets and who claimed to discover as many as 37. Initially hired as the doorkeeper of the Marseilles Observatory, he soon showed his proficiency for both constructing and using telescopes, and at the end of his career he was directing observatories in Tuscany. He discovered comet 2P/Encke in both 1805 and 1818, and although it is named for the person who recognized this and other apparitions of it as being one and the same body, Encke himself always referred to it as "Pons' comet". (M 31611)

Name suggested by J. Tichá, citation prepared by B. G. Marsden.

\section{(7647) Etrépigny}

$1989 \mathrm{SR}_{2}$. Discovered 1989 Sept. 26 by E. W. Elst at La Silla.

Named for a small village in the French Ardennes, close to the Belgian border. (M 30478)

\section{(7649) Bougainville}

$1990 \mathrm{SV}_{5}$. Discovered 1990 Sept. 22 by E. W. Elst at La Silla.

Named in memory of the French navigator LouisAntoine de Bougainville (1729-1811), best remembered for his circumnavigation on the Bondeuse (1766-1769) and his discovery of several archipelagos in Polynesia.
His adventures are recounted in his Voyage autour du monde (1771), wherein he expounds theories about the goodness and the moral virtues of man living in harmony with nature. (M 30802)

\section{(7650) Kaname}

1990 UG. Discovered 1990 Oct. 16 by T. Seki at Geisei

Named in memory of Kaname Nakamura (1904-1932), Japanese amateur astronomer and volunteer at the Kwasan Observatory. As a member of W. H. Pickering's \{see planet (784)\} League of Mars Observers, he was the first in Japan to make systematic observations of that planet. He was also a pioneer in astronomical optics and made many precision mirrors and lenses. (M 32790)

Name proposed by the discoverer following a suggestion by T. Sato and A. Fujii.

\section{(7651) Villeneuve}

1990 VD $_{6}$. Discovered 1990 Nov. 15 by E. W. Elst at La Silla.

Named in honor of Don Villeneuve, anthropologist and friend of the discoverer. (M 30478)

\section{(7655) Adamries}

$1991 \mathrm{YM}_{1}$. Discovered 1991 Dec. 28 by F. Börngen at Tautenburg.

Named for the famous German arithmetician Adam Ries (1492-1559), author of the first German arithmetic books, which were used over more than two hundred years and which explain the procedure of calculations in a clear manner. Ries made an effort to help the man in the street to appreciate arithmetic, which was considered at that time to be difficult. In 1539, Ries was appointed to the Churfürstlich Sächsischen Hofarithmeticus. (M 30478)

This is the discoverer's 100th numbered discovery.

\section{(7656) Joemontani}

1992 HX. Discovered 1992 Apr. 24 by the Spacewatch at Kitt Peak.

Named in honor of Joseph L. Montani (1952- ), instrumentalist, optics expert and observer with the Spacewatch project of the University of Arizona's Lunar and Planetary Laboratory. While making observations for Spacewatch he discovered comets P/1997 G1, C/1997 G2 and C/1998 M6 and more than 16 near-earth objects. Prior to joining the Spacewatch group, he made millimeter-wave observations of $\mathrm{CO}$ in the Magellanic Clouds, Orion and Monoceros, did high-resolution infrared spectroscopy of solar-system objects from the Kuiper Airborne Observatory and made a laboratory study of volatiles in asteroidal surface minerals. (M 33789)

\section{(7657) Jefflarsen}

$1992 \mathrm{HK}_{1}$. Discovered 1992 Apr. 25 by the Spacewatch at Kitt Peak.

Named in honor of astronomer Jeffrey A. Larsen (1967- ), whose software expertise has allowed the 
Spacewatch project to upgrade its computational capability in the automatic detection of small solar system bodies. While making observations for Spacewatch he discovered comets $\mathrm{P} / 1997 \mathrm{~V} 1$ and $\mathrm{C} / 1998 \mathrm{M} 3$ and more than seven near-earth objects. Prior to joining the Spacewatch group, he participated in the Automated Plate Scanner project at the University of Minnesota, where he studied a large asymmetry in the distribution of faint halo/thick disk stars in the Milky Way. (M 33789)

\section{(7661) Reincken}

1994 PK $_{38}$. Discovered 1994 Aug. 10 by E. W. Elst at La Silla.

Named for the North German organist Johann Adam Reincken (1623-1722), a central figure of Hamburg's musical life who lived to a legendary age of 99 years. A pupil of Scheidemann, he was appointed organist at the Katherinenkirche in Hamburg in 1663. In 1678 he was co-founder of Hamburg's famous opera. Reincken was one of the principal representatives of the art of playing the organ in North Germany, although his style was sometimes too vituoistic. J. S. Bach see planet (1814)\} went to Hamburg several times to hear the master play. In addition to his Hortus musicus, there survives his famous Prelude and Fugue in G minor, a piece that every organist likes to play, because of its extremely brilliant and fluent style. (M 31026)

\section{(7665) Putignano}

$1994 \mathrm{TK}_{3}$. Discovered 1994 Oct. 11 by V. S. Casulli at Colleverde di Guidonia.

This picturesque town in the Italian region of Puglia is famous for its carnival, grottoes and typical country houses known as "trulli". Putignano is also the birthplace of Silvano Casulli, director of the observatory where this discovery was made. (M 41028)

\section{(7666) Keyaki}

$1994 \mathrm{VC}_{1}$. Discovered 1994 Nov. 4 by K. Cross at Sendai.

Named for the Sendai "city tree". (M 31026)

The name, zelkova in English, was selected from many ideas submitted by Sendai citizens, among them K. and G. Miyashita.

\section{(7669) Malše}

1995 PB. Discovered 1995 Aug. 4 by M. Tichý and Z. Moravec at Klě́.

Named for a Czech river. The České Budějovice Observatory is situated at the confluence of the Malše and Vltava \{see planet (2123)\} rivers. (M 31297)

\section{(7670) Kabeláč}

1995 QJ. Discovered 1995 Aug. 20 by L. Šarounová at Ondřejov.

Named in memory of Miloslav Kabeláč (19081979), outstanding Czech composer and teacher of contemporary music. He displayed high moral qualities during difficult periods in the history of the discoverer's country. (M 31027; M 31045)

Name proposed by the discoverer's father, Jaroslav Šaroun, who was Kabeláč's student of composition.

\section{(7671) Albis}

$1995 \mathrm{UK}_{1}$. Discovered 1995 Oct. 22 by Z. Moravec at Kleť.

The Latin name for one of Europe's principal rivers, known in German as the Elbe and in Czech as the Labe. Rising in the Krkonoše mountains of the Czech Republic, the river continues into Germany through Dresden \{see planet (263) or (3053)\} to its mouth beyond Hamburg \{see planet (449) or (723)\}. Its most significant tributary is the Vltava (or Moldau) \{see planet (2123)\}, on which Prague \{see planet (2367)\} is located. (M 31297)

\section{(7672) Hawking}

$1995 \mathrm{UO}_{2}$. Discovered 1995 Oct. 24 at the Klet Observatory at Klě̌.

Named in honor of Stephen Hawking (1942- ), theoretical physicist, professor of mathematics at Cambridge University. He is renowned for his research on cosmology and quantum gravitation theory, as well as on the physics of black holes. Besides his scientific work, he is also the author of the well-known popularizations A Brief History of Time and Black Holes and Baby Universes and Other Essays. (M 31297)

\section{(7674) Kasuga}

$1995 \mathrm{VO}_{1}$. Discovered 1995 Nov. 15 by K. Endate and K. Watanabe at Kitami.

Named in honor of Ryo Kasuga (1950- ), Japanese Buddhist priest, opera singer, professional magician, television and radio personality. He is also an amateur astronomer, who operates a planetarium at his temple and is very active in the movement against light pollution. (M 34626)

Name proposed by the discoverers following a suggestion by T. Sato and A. Fujii.

\section{(7675) Gorizia}

$1995 \mathrm{WT}_{5}$. Discovered 1995 Nov. 23 at the Farra d'Isonzo Observatory at Farra d'Isonzo.

Named for the Italian town on the 1000th anniversary of the first mention of its actual name in an official document. Gorizia is the main city in the lowlands of the river Isonzo, on which Farra d'Isonzo \{see planet (7501)\} and its astronomical observatory rise. Under Hapsburg dominion for over four centuries, Gorizio is now a green city where buildings and streets continuously remind one of this Austro-Hungarian influence. (M 33789)

\section{(7678) Onoda}

$1996 \mathrm{CW}_{2}$. Discovered 1996 Feb. 15 by A. Nakamura at Kuma.

Named for the city in the southwest of Yamaguchi Prefecture where the discoverer was born. Long known 
for its coal mines, Onoda is now famous for its chemical industry and cement production. (M 30803)

\section{(7679) Asiago}

1996 CA9. Discovered 1996 Feb. 15 by U. Munari and M. Tombelli at Cima Ekar.

Named for the mountain town and region hosting the largest astronomical observatory on Italian territory. When dedicated in 1942, the 1.2-m telescope was the largest in Europe; a 1.8-m Cassegrain reflector was added in 1973. The observatory has been particularly active in the discovery and photometric and spectroscopic monitoring of all types of variables, including supernovae. A program to discover new minor planets has been conducted with Asiago Schmidts since 1993. (M 30478)

\section{(7680) Cari}

1996 HB. Discovered 1996 Apr. 16 at the Santa Lucia Observatory at Stroncone.

Named in memory of Amleto Cari (1904-1982). A versatile athlete of rare talent, from 1919 to 1933 he was captain of the Terni \{see planet (5654)\} football team that, under his guidance, reached the national league. (M 33789)

\section{(7681) Chenjingrun}

$1996 \mathrm{YK}_{2}$. Discovered 1996 Dec. 24 at the Beijing Observatory at Xinglong.

Named in memory of Jingrun Chen (1933-1996), member of the Chinese Academy of Sciences and superior research professor at the Mathematical Institute of the Chinese Academy of Sciences. He obtained brilliant results in the field of modern analytical number theory, notably "Chen's Theorem", which is concerned with the Goldbach conjecture. (M 35487)

\section{(7683) Wuwenjun}

1997 DE. Discovered 1997 Feb. 19 at the Beijing Observatory at Xinglong.

Wenjun $\mathrm{Wu}(1919-$ ), a member of the Chinese Academy of Sciences, is the originator in the research on mathematics mechanization in China. He made outstanding achievements in characteristic classes and imbedding classes and invented Wu's Method to prove geometry theorems by computers. (M 43189)

\section{(7684) Marioferrero}

1997 EY. Discovered 1997 Mar. 3 by P. G. Comba at Prescott.

Named in memory of Mario Ferrero (1904-1965) who encouraged and nurtured the discoverer's interest in astronomy when the latter was in his early teens. Ferrero was the co-discoverer of (1169) Alwine and (1218) Aster. He was an astronomer at Pino Torinese \{see planet (2694)\} in the 1930s. Because of his interest in teaching, Ferrero later joined the physics faculty at the Polytechnic Institute in Turin. He was also a music lover and accomplished organist. (M 30479)
(7686) Wolfernst

2024 P-L. Discovered 1960 Sept. 24 by C. J. van Houten and I. van Houten-Groeneveld at Palomar.

Named in honor of Wolfgang Ernst (1947- ), amateur astronomer who initiated the astrometric program at the Starkenburg \{see planet (6864)\} Observatory in Heppenheim. Since 1995, the major part of his work has consisted of making follow-up observations of objects discovered in the course of the 1990-1993 KSO-ARI minor planet surveys at Tautenburg. (M 33387)

Name proposed by L. D. Schmadel.

\section{(7687) Matthias}

2099 P-L. Discovered 1960 Sept. 24 by C. J. van Houten and I. van Houten-Groeneveld at Palomar.

Named in honor of Matthias Busch (1968- ), amateur astronomer at the Starkenburg s see planet (6864)\} Observatory in Heppenheim who has made a substantial contribution to the astrometry of minor planets. He is an ardent follow-up observer of near-earth objects and a keen developer of astronomical software. (M 33387)

Name proposed by L. D. Schmadel.

\section{(7688) Lothar}

2536 P-L. Discovered 1960 Sept. 24 by C. J. van Houten and I. van Houten-Groeneveld at Palomar.

Named in honor of Lothar Kurtze (1972- ), German amateur astronomer at the Starkenburg Observatory, Heppenheim, and a cofounder of the minor planet astrometry group in 1995. Kurtze played a major role in both the planning and the construction of the student observatory at the Werner Heisenberg senior high school in Weinheim. His lectures on astronomical topics inspired many young students. (M 34344) Name proposed by L. D. Schmadel.

\section{(7689) Reinerstoss}

4036 P-L. Discovered 1960 Sept. 24 by C. J. van Houten and I. van Houten-Groeneveld at Palomar.

Named in honor of Reiner Stoss (1975- ), German amateur astronomer at the Starkenburg Observatory, Heppenheim. Stoss is an ardent observer who detected most of the minor planets found there. His main interests are the establishment of an NEO search program and to make follow-up observations of known NEOs. (M 34344)

Name proposed by L. D. Schmadel.

\section{(7690) Sackler}

2291 T-1. Discovered 1971 Mar. 25 by C. J. van Houten and I. van Houten-Groeneveld at Palomar.

Named in honor of Raymond and Beverly Sackler, wise, perceptive and generous supporters of science and the arts. Their special interest in stimulating astronomical research through direct support, and the fostering of collaborations and exchange of knowledge among astronomers worldwide, has been a great boon 
to this exciting field, now in a truly "golden age". (M 31297)

\section{(7691) Brady}

3186 T-3. Discovered 1977 Oct. 16 by C. J. van Houten and I. van Houten-Groeneveld at Palomar.

Named in honor of Charles E. "Chuck" Brady, Jr. (1951- ), captain in the U.S. Navy, NASA astronaut, surgeon, experienced amateur radio operator and close friend to the name proposer. As a mission specialist, Chuck flew on the Life and Microgravity Spacelab mission aboard "Columbia" and has logged over 405 hours in space. In 1997, Chuck organized a radio expedition to Palmyra Island and the Kingman Reef in the Pacific. His ham call sign, N4BQW, could have been heard around the globe. (M 32790)

Name proposed and citation prepared by L. D. Schmadel, DK8UH, who contacted him on Palmyra.

\section{(7694) Krasetín}

1983 SF. Discovered 1983 Sept. 29 by A. Mrkos at Kleť

Krasetín is a small village east of the Klet ssee planet (2199)\} mountain. It is the nearest village to the Klet Observatory. (M 45232)

The name was suggested by M. Tichý.

\section{(7695) Přemysl}

1984 WA $_{1}$. Discovered 1984 Nov. 27 by A. Mrkos at Klě́t.

Named for a mythical hero Přemysl, called Ploughman. He married princess Libuše \{see planet (264)\}, and they became the mythical founders of the royal dynasty of the Přemyslids, ruling over Bohemia until 1306. Bohemian kings Přemysl Otakar I (?-1230) and Přemysl Otakar II (?-1278) are considered the most reputable members of this dynasty. (M 32095)

Name suggested by J. Tichá, M. Tichý and Z. Moravec.

\section{(7696) Liebe}

1988 JD. Discovered 1988 May 10 by W. Landgraf at La Silla.

Bodo Liebe, a professor at the University of Siegen, started a program in astronomy and established an observatory there. This enabled the discoverer to embark on his study of minor planets and comets. (M 42357)

\section{(7698) Schweitzer}

$1989 \mathrm{AS}_{6}$. Discovered 1989 Jan. 11 by F. Börngen at Tautenburg.

Named in memory of Albert Schweitzer (1875-1965), German theologian, doctor and philosopher, organist and musicologist. Early in his life he felt deep "reverence for life" and studied medicine as a professor of theology. In 1913 he founded a hospital in the jungle near Lambaréné, when he was working in Africa as a missionary-doctor. His philosophy culminated in a universal affirmative ethics of an active charity. His accomplishments involving organ music included an interpretation of Bach \{see planet (1814)\}. Schweitzer was awarded the 1952 Nobel Peace Prize for his efforts on behalf of the Brotherhood of Nations. (M 30803)

\section{(7699) Božek}

$1989 \mathrm{CB}_{4}$. Discovered 1989 Feb. 2 by A. Mrkos at $\mathrm{Kle}^{\smile}\{\mathrm{t}\}$.

Josef Božek (1782-1835) was a clockmaker at Prague Klementinum College and a creator of astronomical timekeepers. He also constructed the first steam engines in Bohemia. His son Romuald (1814-1898) reconstructed the Astronomical Clock of Prague Old Town. (M 47163)

\section{(7700) Rote Kapelle}

$1990 \mathrm{TE}_{8}$. Discovered 1990 Oct. 13 by F. Börngen and L. D. Schmadel at Tautenburg.

Named for the members of Rote Kapelle, a left-wing and communist resistance group who fought against the fascist regime, operating mainly in Berlin and Hamburg. Faced with the genocide of the European Jews, the group worked to accelerate both the breakdown of the fascist regime and the end of the war. Members of the group were, among others, Arvid Harnack, Harro Schulze-Boysen and Erika Gräfin Brockdorf. In 1942, the group was suppressed by the Geheime Staatspolizei, with the arrest of about 600 people, almost 60 of whom were executed. (M 31611)

Name proposed by the first discoverer.

\section{(7701) Zrzavý}

$1990 \mathrm{TX}_{8}$. Discovered 1990 Oct. 14 by A. Mrkos at Klě́.

Jan Zrzavý (1890-1977) was a Czech painter, graphic artist and illustrator, known for imaginary lyric landscapes and figures. (M 42357)

The name was suggested by J. Tichá.

\section{(7704) Dellen}

$1992 \mathrm{~EB}_{7}$. Discovered 1992 Mar. 1 by the Uppsala-ESO Survey at La Silla.

Dellen, two connected lakes in the Swedish province of Hälsingland, are appreciated among fly-fishermen for their unique population of salmon trout. This 15 -km-wide lake system was formed approximately 110 million years ago, as the result of a meteorite impact. (M 39650)

\section{(7705) Humeln}

$1993 \mathrm{FU}_{7}$. Discovered 1993 Mar. 17 by the Uppsala-ESO Survey at La Silla.

Humeln is a Swedish lake located close to the city of Oskarshamn, where the Baltic Sea meets Kalmarsund. The lake was formed by a meteorite impact during the Cambrian period. (M 39650)

\section{(7706) Mien}

$1993 \mathrm{FZ}_{36}$. Discovered 1993 Mar. 19 by the Uppsala-ESO Survey at La Silla.

Mien is a lake located in the province Småland in the southern part of Sweden. It is $9 \mathrm{~km}$ across and 
was formed by a meteorite impact about 120 million years ago. (M 39650)

\section{(7711) Ríp}

1994 XF. Discovered 1994 Dec. 2 by Z. Moravec at Klě̆.

Named for a hill in central Bohemia (459 m above sea level) located about $30 \mathrm{~km}$ north of Prague. When a mythological ancestor of Cech, the Father of the Czech nation, came to Bohemia, he is said to have climbed this hill, looked around and made the decision to stay there because of the wealth and fertility of the country. (M 31298)

\section{(7714) Briccialdi}

$1996 \mathrm{CC}_{1}$. Discovered 1996 Feb. 9 at the Santa Lucia Observatory at Stroncone.

Named in memory of Gulio Briccialdi (1818-1881). Flutist and composer, he became a famous concert musician at the age of 15 . He taught in Milan and Vienna and gave concerts in Europe and America. He invented a particular kind of flute and created the musical scales for it. (M 33387)

\section{(7715) Leonidarosino}

1996 CR $_{7}$. Discovered 1996 Feb. 14 by U. Munari and M. Tombelli at Cima Ekar.

Named in memory of Leonida Rosino (1915-1997), director of the Padua and Asiago Observatories from 1953 to 1985. His principal research was on globular clusters, variable stars of all kinds, and novae and supernovae. At Padua he was instrumental in establishing the first Italian department of astronomy in 1968. Rosino's undisputed great teaching ability, keen scientific guidance and everlasting enthusiasm benefited several generations of Italian astronomers. (M 30803)

Obituaries published in G. Astrom., Vol. 23, N. 3, p. 2 (1997); Mem. Soc. Astron. Ital., Vol. 69, N. 1, p. 11-14 (1998); Bull. Am. Astron. Soc., Vol. 31, No. 5, p. 1610 (1999)

\section{(7716) Ube}

$1996 \mathrm{DA}_{3}$. Discovered 1996 Feb. 22 by A. Nakamura at Kuma.

Named for the city in Yamaguchi prefecture where the discoverer attended high school. Famous for its chemical industry, Ube is also known as a 'sculpture city', a large sculpture exhibition being held there every two years, after which some of the pieces are purchased by the city and displayed along the downtown sidewalks in a unique 'open air museum'. (M 30803)

\section{(7718) Desnoux}

$1997 \mathrm{EP}_{30}$. Discovered 1997 Mar. 10 by C. Buil at Ramonville Saint Agne.

Named in honor of Valerie Desnoux, talented amateur astronomer. Together with J. P. Rozelot and J. Rosch, she assisted in the development of a scanning heliometer at the Pic du Midi Observatory. Her work on the evolution of the spectra of Be stars with the T60 amateur telescope has also been very much appreciated. (M 31027)

\section{(7720) Lepaute}

4559 P-L. Discovered 1960 Sept. 26 by C. J. van Houten and I. van Houten-Groeneveld at Palomar.

Named after Nicole-Reine Lepaute (1723-1788), extraordinarily talented French mathematician. The astronomers Lalande and Clairaut sought her help for the computations needed to predict the 1759 return of comet $1 \mathrm{P} /$ Halley. Lepaute's computations for the annular eclipse of 1764 were used throughout Europe. Unfortunately, years of calculation left her nearly blind. (M 31298)

\section{(7721) Andrillat}

6612 P-L. Discovered 1960 Sept. 24 by C. J. van Houten and I. van Houten-Groeneveld at Palomar.

Named in honor of Yvette Marie Josette Andrillat (1925- ), French spectroscopist who works mainly on infrared spectra of early-type stars. She has also contributed to the spectroscopy of galaxies, novae, planetary nebulae and comets. Near the end of her renowned career she became acting director of the Observatoire de Haute Provence. The planet is named also in honor of her husband, Henri Andrillat, who is a retired professor of astronomy and a prominent cosmologist. The couple now live in Toulouse. (M 31298; M 31457)

Name suggested and citation prepared by H. Haupt.

\section{(7722) Firneis}

2240 T-2. Discovered 1973 Sept. 29 by C. J. van Houten and I. van Houten-Groeneveld at Palomar.

Named in honor of Maria Gertrude Firneis (1947-

), a professor of astronomy at the University of Vienna. She has worked on delicate astrometric and statistical problems and is an authority on the history of astronomy. She is also engaged in dating ancient events and correlating them with celestial phenomena. (M 31298; M 31457)

Name suggested and citation prepared by H. Haupt.

\section{(7725) Sel'vinskij}

1972 RX $_{1}$. Discovered 1972 Sept. 11 by N. S. Chernykh at Nauchnyj.

Named in memory of Il'ya L'vovich Sel'vinskij (1899-1968), poet and publicist, born in the Crimea. As a journalist, he witnessed and participated in many events in the history of the U.S.S.R. and he depicted these events in his poetical works. (M 34626)

\section{(7727) Chepurova}

$1975 \mathrm{EA}_{3}$. Discovered 1975 Mar. 8 by N. S. Chernykh at Nauchnyj.

Valentina Mikhajlovna Chepurova, a celestial mechanician at the Sternberg Astronomical Institute in Moscow, is known for her research on the dynamics of the small bodies of the solar system by analytical and qualitative methods. As chair of celestial mechanics, 
she is also much involved with the education of students. (M 43381)

\section{(7728) Giblin}

$1977 \mathrm{AW}_{2}$. Discovered 1977 Jan. 12 by E. Bowell at Palomar.

Named in honor of Ian Giblin (1969- ), a British physicist who has performed a number of laboratory experiments to simulate hypervelocity impacts among minor planets. Giblin has developed new data analysis tools to study their outcome and to draw conclusions regarding the corresponding actual events. (M 35487) Name proposed and citation written by P. Farinella.

\section{(7729) Golovanov}

1977 QY $_{3}$. Discovered 1977 Aug. 24 by N. S. Chernykh at Nauchnyj.

Space engineer Yaroslav Kirillovich Golovanov (1932-

) writes scientific reviews on space problems. As the author of many hundreds of articles and more than 20 books, he is the laureate of many prizes and awards, including the "Golden Pen" medal, the highest award of the Union of Soviet Journalists. (M 42357)

\section{(7736) Nizhnij Novgorod}

1981 RC $_{5}$. Discovered 1981 Sept. 8 by L. V. Zhuravleva at Nauchnyj.

Nizhnij Novgorod is an old Russian city located at the confluence of the Volga and Oka rivers. Founded in 1221, the city is now a large industrial, scientific and cultural center. It is known for many architectural monuments and the famous Nizhnij Novgorod Fair. (M 42357)

\section{(7737) Sirrah}

1981 VU. Discovered 1981 Nov. 5 by E. Bowell at Anderson Mesa.

Named in honor of Alan William Harris (1952-

), British astronomer, now at the DLR Institute of Planetary Exploration, Berlin. Harris has made both ground-based and space-based (ISO) radiometric observations of minor planets, concentrating especially on near-earth objects, and he has developed improved fitting techniques to relate observed fluxes to diameters and albedos. The name chosen is "Harris" spelled backwards, to distinguish from another Harris of the exact same name \{see planet (2929)\}. (M 35487)

Name suggested and citation prepared by the other A. W. Harris.

\section{(7738) Heyman}

$1981 \mathrm{WS}_{1}$. Discovered 1981 Nov. 24 at the Oak Ridge Observatory at Harvard.

Named in honor of I. Michael Heyman (1930- ), secretary and linchpin of the Smithsonian Institution's diverse and incomparably rich programs. Educator, legal scholar, civil rights champion, he has unfailingly supported research at the frontiers of astronomy. (M 32348)

\section{(7739) Čech}

1982 CE. Discovered 1982 Feb. 14 by L. Brožek at Klě́.

Named in memory of Eduard Čech (1893-1960), Czech mathematician, professor at Charles University in Prague and Masaryk University in Brno. One of his papers, On bicompact spaces, introduced what today is called the Stone-Cech compactification of regular topological spaces. His research in topology is fundamental, but his work was also important in the development of functional analysis. (M 34344)

Name proposed by J. Tichá and Z. Moravec following a number of suggestions from Charles University.

\section{(7740) Petit}

$1983 \mathrm{RR}_{2}$. Discovered 1983 Sept. 6 by E. Bowell at Anderson Mesa.

Named in honor of the French astronomer Jean-Marc Petit (1961- ) for his work on the dynamics of planetary rings. Petit has also investigated the collisional evolution of the minor planet belt and the dynamical evolution of the (243) Ida-Dactyl system. (M 35487)

Name suggested and citation provided by A. Morbidelli.

\section{(7741) Fedoseev}

1983 RR $_{4}$. Discovered 1983 Sept. 1 by L. G. Karachkina at Nauchnyj.

Named in honor of Vladimir Ivanovich Fedoseev (1932- ), outstanding Russian conductor. He has been artistic director of Tchaikovsky's symphony orchestra in Moscow since 1974. He is also a principal conductor of the Vienna Symphony Orchestra and guest conductor in Tokyo and in many other cities. Fedoseev promotes the Russian classical music of Glinka, Mussorgsky, Rakhmaninov, Sviridov \{see, respectively, planets (2205), (1059), (4345) and (4075)\} and others. (M 32348)

Name suggested by G. Sviridov and supported by the discoverer.

\section{(7742) Altamira}

1985 US. Discovered 1985 Oct. 20 by A. Mrkos at Klě́.

Altamira is a cave in northern Spain, whose walls bear paintings and engravings - chiefly of bison, deer, horses and boar - dating from the Stone Age. It is one of the most important prehistoric painted caves. The paintings were discovered in 1879. (M 46008) The name was suggested by M. Tichý.

\section{(7747) Michałowski}

1987 SO. Discovered 1987 Sept. 19 by E. Bowell at Anderson Mesa.

Named in honor of Tadeusz Michałowski (1954- ), Polish astronomer at the Astronomical Observatory of Adam Mickiewicz University in Poznań. Michałowski developed a formalism for computing the pole orientation, shape and sidereal rotation period of a minor planet, incorporating both the magnitude and timing information contained in lightcurve observations, in a 
simultaneous least-squares solution. This method, or methods similar to it, are now widely used standard analysis tools, and they have greatly improved the quality of such determinations. (M 35487)

Name suggested by H. Rickman, citation prepared by A. W. Harris.

\section{(7749) Jackschmitt}

1988 JP. Discovered 1988 May 12 by C. S. Shoemaker and E. M. Shoemaker at Palomar.

Named in honor of Harrison Schmitt (1935- ), the last Apollo astronaut to walk on the moon and, as a planetary geologist, the only Apollo scientist. Schmitt later served as a member of the United States Senate from New Mexico. (M 32349)

\section{(7750) McEwen}

1988 QD $_{1}$. Discovered 1988 Aug. 18 by C. S. Shoemaker and E. M. Shoemaker at Palomar.

Named in honor of Alfred McEwen for his significant contributions to planetary geology in the fields of photogeology, photometry, spectroscopy, photoclinometry, instrument calibration and mission planning. His research has involved diverse topics concerning the earth, the moon, Mars, minor planets, Galilean satellites and outer planets. He has been (or is) a member of science teams on Cassini, Galileo, Clementine and Mars Global Surveyor. (M 33789)

Citation prepared by M. S. Robinson at the request of C. S. Shoemaker.

\section{(7752) Otauchunokai}

1988 US. Discovered 1988 Oct. 31 by T. Niijima and K. Kanai at Ojima.

Otauchunokai, founded in 1970, is an amateur astronomers' club in the Ota city area, Gunma prefecture. Club activities include observations, studies and public education in astronomy. The discoverers are members of this club. (M 41935)

\section{(7755) Haute-Provence}

$1989 \mathrm{YO}_{5}$. Discovered 1989 Dec. 28 by E. W. Elst at St. Michel.

Haute Provence is a very beautiful region in southern France where, in 1936, the astronomical observatory of Haute-Provence was established. In 1995, the first planet discovered orbiting a star (51 Peg), was found there. From 1986 to 1996 , the 60/90 Schmidt telescope was used to search for minor planets. (M 47163)

\section{(7756) Scientia}

$1990 \mathrm{FR}_{1}$. Discovered 1990 Mar. 27 by C. S. Shoemaker and E. M. Shoemaker at Palomar.

This Latin term for science or knowledge describes the purpose of the U.S. National Science Foundation on the occasion of its 50th anniversary in the year 2000 . The NSF has acted as a "patron for pure science", consistently championing excellence in activities that span the entire range of scientific endeavor. (M 38197)

\section{(7758) Poulanderson}

1990 KT. Discovered 1990 May 21 by E. F. Helin at Palomar.

Poul Anderson (1926- ) has trained three generations of scientists, engineers and others to appreciate humor, adventure, epic tragedy and the vast scale of the universe. Admired for his mentoring and personal warmth, he has won shelves of literary awards. (M 43381)

The name was suggested by D. Brin.

\section{(7763) Crabeels}

$1990 \mathrm{UT}_{5}$. Discovered 1990 Oct. 16 by E. W. Elst at La Silla.

Henri Crabeels (1904- ) is an internationally known organist and conductor in Antwerp. This minor planet is dedicated to him on the occasion of his 98th birthday. (M 46008)

\section{(7766) Jododaira}

$1991 \mathrm{BH}_{2}$. Discovered 1991 Jan. 23 by K. Endate and K. Watanabe at Kitami.

Named for the place where the first really big star parties were held in Japan, the "Chiro's Star Festivals", from 1975 to 1984 . Jododaira (1600 $\mathrm{m}$ above the sea) is near the top of Mt. Azuma, a famous volcano in Fukushima Prefecture in northeastern Japan. After the violent eruption of the volcano in 1893, Percival Lowell \{see planet (1886)\} climbed the mountain to investigate the result of the eruption. One hundred years later, an astronomical observatory was established there and is open to the public. (M 32790)

Name proposed by the discoverers following a suggestion by M. Koishikawa and T. Sato.

\section{(7767) Tomatic}

1991 RB $_{5}$. Discovered 1991 Sept. 13 by L. D. Schmadel and F. Börngen at Tautenburg.

Named in honor of A. U. Tomatic (1997- ), collaborator at the Minor Planet Center. An ardent computer of orbits and distributor of observational data of minor planets and comets, Tomatic published his first contribution to this field on MPEC 1997-Y01 (1997 Dec. 16). Tomatic is a godchild of the MPC astronomers B. G. Marsden and G. V. Williams. (M 34344)

Name proposed by the first discoverer in gratitude for Tomatic's indefatigable service.

\section{(7769) Okuni}

$1991 \mathrm{VF}_{4}$. Discovered 1991 Nov. 4 by S. Otomo at Kiyosato.

Tomimaru Okuni (1931- ), a retired teacher, is a Japanese amateur astronomer. He has been discovering new minor planets since 1995 at Nanyo in Yamagata prefecture. (M 41935)

\section{(7770) Siljan}

1992 EQ $_{8}$. Discovered 1992 Mar. 2 by the Uppsala-ESO Survey at La Silla. 
Lake Siljan, located in the beautiful Swedish province Dalarna, is the largest impact crater in the country, measuring $50 \mathrm{~km}$ across. It was formed some 360 million years ago. Unsuccessful attempts were made to drill for oil and gas there. (M 39650)

\section{(7771) Tvären}

1992 EZg. Discovered 1992 Mar. 2 by the Uppsala-ESO Survey at La Silla.

Tvären is a kilometer-sized bay close to Studsvik in Sweden. The maximum depth is 85 meters, and it constitutes an Ordovician impact crater. (M 39650)

\section{(7775) Taiko}

1992 XD. Discovered 1992 Dec. 4 by Y. Kushida and O. Muramatsu at Yatsugatake.

Named in honor of Taiko Takeuchi, a Japanese amateur astronomer who started observing the stars more than half a century ago. She then became a schoolteacher, was active in popularizing astronomy and computed the orbits of some minor planets. (M 30803)

Name proposed by the discoverers, following a suggestion by S. Kimura.

\section{(7776) Takeishi}

1993 BF. Discovered 1993 Jan. 20 by T. Urata at Oohira.

Named for Masanori Takeishi (1950- ）, a Japanese amateur astronomer who discovered a number of minor planets and was chief editor of the Japan Astronomical Circular from 1975 to 1993. (M 31027)

\section{(7777) Consadole}

$1993 \mathrm{CO}_{1}$. Discovered 1993 Feb. 15 by S. Ueda and H. Kaneda at Kushiro.

Consadolé, a team in the Japan Professional Football League J1, has its home in Sapporo city, Hokkaido. The team's name is an anagram combining the Japanese word Dosanco ("born in Hokkaido") and the Spanish olé ("bravo!"), a common international cheer at soccer games. (M 41935)

The name was suggested by K. Watanabe.

\section{(7778) Markrobinson}

$1993 \mathrm{HK}_{1}$. Discovered 1993 Apr. 17 by C. S. Shoemaker and E. M. Shoemaker at Palomar.

Named in honor of Mark Robinson, a planetary geologist who has worked on M-type bodies (Mercury, moon, Mars, and minor planets). He began his career in Alaska, where he prospected for mineral ores and earned his B.S. in geology at the University of Alaska. In Hawaii, he completed his doctorate in 1993 on lunar and Martian volcanism and then began his outstanding work on the Clementine mission to the moon as a member of the U.S. Geological Survey Astrogeology Branch. His efforts, which he continues from his new base at Northwestern University, are now directed to the NEAR spacecraft mission and to future exploration of Mercury. (M 33789)

Citation prepared with the assistance of A. McEwen.

\section{(7779) Susanring}

1993 KL. Discovered 1993 May 19 by J. B. Child at Palomar.

Named in honor of Susan Ivanka Ring, inspired and dedicated member of the Canberra Astronomical Society. Susan's love of astronomy has expressed itself through committed support of school observing programs and leadership in the Society, as well as through her devoted managing editorship of the magazine Southern Sky. (M 31027)

Citation enthusiastically endorsed by J. Mould and the Canberra Astronomical Society.

\section{(7780) Maren}

1993 NJ. Discovered 1993 July 15 by E. F. Helin and J. B. Child at Palomar.

Named in honor of Maren Elizabeth Child, contemporary paragon of compassion, generosity and patience. Her unselfish devotion to family, friends and community is, fortunately, more frequently observed than is this minor planet that now bears her name. Her support and understanding of the sometimes bizarre demands of her partner's minor planet observing schedules can only be interpreted as an equally serious commitment to astronomy. (M 35487)

\section{(7781) Townsend}

1993 QT. Discovered 1993 Aug. 19 by E. F. Helin at Palomar.

Named in honor of Charles Townsend, a retired laser physicist and community-college instructor of astronomy and mathematics, and a former president of the Ventura County Astronomical Society and the Western Amateur Astronomers. He has co-authored two books, Patrolling Night Skies (1984) and Observational Astronomy (1989), the latter being used to teach an advanced astronomy course at Moorpark College. One of his students, John E. Rogers \{see planet (5517)\}, is extremely grateful for Townsend's encouragement and leadership. This led to the existence of the Camarillo Observatory, which has contributed to the astrometry of near-earth objects and comets generally since 1992 . (M 31027)

\section{(7782) Mony}

1994 CY. Discovered 1994 Feb. 7 at the Santa Lucia Observatory at Stroncone.

Named in memory of Monica De Magistris (19771998), a student of physics at Perugia University and a great lover of astronomy who sometimes visited the Santa Lucia observatory. She organized an astronomy exposition as part of Italy's "Scientific and Technological Culture Week" in 1995, giving lectures on the subject to visitors. In her struggle with illness, she was an example of strength, intelligence and passion throughout her short life. (M 31611)

\section{(7787) Annalaura}

1994 WW. Discovered 1994 Nov. 23 by L. Tesi and A. Boattini at San Marcello Pistoiese. 
Named in honor of Annalaura Calvani Tesi, wife of the first discoverer. (M 30803)

\section{(7788) Tsukuba}

1994 XS. Discovered 1994 Dec. 5 by A. Nakamura at Kuma.

Named for the city located in the southwest of Ibaraki prefecture. Originally a region of pastoral farms at the foot of Mt. Tsukuba, it dramatically changed with the establishment in 1973 of the University of Tsukuba, from which the discoverer graduated. The city is now also home to 32 national laboratories and is known as the 'academic capital' of Japan. (M 30803)

\section{(7789) Kwiatkowski}

$1994 \mathrm{XE}_{6}$. Discovered 1994 Dec. 2 by E. Bowell at Palomar.

Named in honor of Tomasz Kwiatkowski, Polish astronomer at the Astronomical Observatory of Adam Mickiewicz University in Poznań. Kwiatkowski specializes in detailed photometric observations of minor planets and the computation of shape and pole orientations from lightcurves. (M 35487)

Name suggested by H. Rickman, citation provided by A. W. Harris.

\section{(7790) Miselli}

$1995 \mathrm{DK}_{2}$. Discovered 1995 Feb. 28 at the Santa Lucia Observatory at Stroncone.

Named in memory of Furio Miselli (1867-1949). Poet, singer, songwriter and singing master in Terni, he promoted "Cantamaggio", a folk style that is currently a popular tourist draw. He also founded a humor magazine, Sborbottu, which parodied city life at the end of the nineteenth century. (M 33387)

\section{(7791) Ebicykl}

1995 EB. Discovered 1995 Mar. 1 by M. Tichý at Kleť.

Ebicykl is a traditional holiday activity, since 1984, of a group of astronomers, who bike around the Czech and Slovak Republics to visit various observatories. Ebicykl is a symbolic word combining bicycling and Ptolemaic \{see planet (4001)\} epicycles. (M 41567)

\section{(7794) Sanvito}

$1996 \mathrm{AD}_{4}$. Discovered 1996 Jan. 15 by U. Munari and M. Tombelli at Cima Ekar.

Named in honor of Roberto di San Vito, amateur astronomer. Strongly committed to astronomy and astrometry, he is supporting a new observatory in Montelupo \{see planet (7198)\} that will bear his name, the "San Vito Observatory". (M 32790)

\section{(7796) Járacimrman}

1996 BG. Discovered 1996 Jan. 16 by Z. Moravec at Klě́t.

Named for Jára Cimrman, a fictitious Czech genius. An analogue to Leonardo da Vinci \{see planet (3000)\}, he was a playwright, composer, poet, painter, versatile scientist, inventor, polar explorer, sportsman, first man on the moon, etc. Although his name is not mentioned in any encyclopedia, his work is explored at the Jára Cimrman Theatre in Prague. This theater is headed by the famous cimrmanologists Z. Svěrák and L. Smoljak, who endorsed the name proposal. (M 31298)

\section{(7799) Martinšolc}

$1996 \mathrm{DW}_{1}$. Discovered 1996 Feb. 24 at the Klet Observatory at Klě̃.

Named in honor of Martin Šolc (1949- ), Czech astronomer and head of the Astronomical Institute of Charles University in Prague since 1987. His work deals with cosmic dust, dust in comets and isotopes. He participated in data evaluation from the Vega and Giotto missions to comet 1P/Halley in 1986-1987. At present he collaborates on the ISO project with the Institut für Kernphysik in Heidelberg. Much of his time is devoted to teaching. He is also working on a history of Czech astronomy, together with his wife Alena Šolcová (1950- ). (M 34344)

Name proposed by discoverers J. Tichá, M. Tichý and Z. Moravec.

\section{(7800) Zhongkeyuan}

$1996 \mathrm{EW}_{2}$. Discovered 1996 Mar. 11 at the Beijing Observatory at Xinglong.

Named for the Chinese Academy of Sciences (zhong guo ke xue yuan) on the occasion of its 50th anniversary. Founded on 1949 Nov. 1, it is China's most prestigious academic institution and comprehensive research and development center in science and technology. Over the past half century, the Chinese Academy of Sciences has made tremendous contributions to science and technology in China, to the country's economic construction and development and to human civilization and progress. (M 33789)

\section{(7801) Goretti}

$1996 \mathrm{GG}_{2}$. Discovered 1996 Apr. 12 by L. Tesi and A. Boattini at San Marcello Pistoiese.

Named in honor of Vittorio Goretti (1939- ), a high-school teacher of physics and mathematics in Bologna for almost three decades. As an amateur astronomer, he has focused primarily on the study of minor planets, and in 1976 he was one of the founders of the survey at San Vittore ssee planet (2235)\}. In 1995 he started a new program from his home in Pianoro that is mainly devoted to follow-up observations. (M 30803)

\section{(7804) Boesgaard}

3083 P-L. Discovered 1960 Sept. 24 by C. J. van Houten and I. van Houten-Groeneveld at Palomar.

Named in honor of Ann Merchant Boesgaard (1939- ), astronomer at the University of Hawaii, well-known for her investigations of the lithium and beryllium content of stellar atmospheres. (M 31298) 


\section{(7805) Moons}

7610 P-L. Discovered 1960 Oct. 17 by C. J. van Houten and I. van Houten-Groeneveld at Palomar.

Named in memory of Michèle Moons (1951-1998), well known for her work on celestial mechanics done at the department of mathematics of Facultés Universitaires N. D. de la Paix, Namur, Belgium. She was assistant editor of the journal Celestial Mechanics and Dynamical Astronomy for nearly ten years. In the early 1980s she developed an analytical theory of the libration of the moon that is widely used by several centers interested in analyzing the moon's motion. Her later work included studies on the effects of resonant motion in the minor planet belt. Her early death is a great loss to her family and to science. (M 32095)

Citation prepared by J. Henrard and J. Schubart, the name being suggested by the latter.

Obituary published in Celest. Mech. Dyn. Astron., Vol. 68, No. 3, p. 3-9 (1997/98).

\section{(7812) Billward}

1984 UT. Discovered 1984 Oct. 26 by E. Bowell at Anderson Mesa.

Named in honor of William R. Ward (1943- ), an accomplished theoretician who specializes in dynamics and celestial mechanics. Ward has made fundamental contributions to a wide variety of topics in modern planetary science, including both solar nebula and circumplanetary disk dynamics, the origin of the moon, planetesimal formation, planetary ring dynamics, and martian obliquity variations and their coupling to planetwide climatological change. Ward has spent most of his career at the Jet Propulsion Laboratory and Southwest Research Institute, Boulder. Both his talents and his good spirits are enjoyed by colleagues around the world. (M 35487)

Name proposed and citation written by S. A. Stern.

\section{(7813) Anderserikson}

$1985 \mathrm{UF}_{3}$. Discovered 1985 Oct. 16 by C.-I. Lagerkvist at Kvistaberg.

Anders Erikson (1965- ) studied minor-planet spin vectors in Uppsala and at the Institute of Planetary Exploration in Berlin. The discoverer has had a long and fruitful collaboration with him and is also grateful for his assistance during numerous trips to Berlin. (M 41383)

\section{(7815) Dolon}

1987 QN. Discovered 1987 Aug. 21 by E. W. Elst at La Silla.

Named for the sad Trojan hero who figures in Doloneia, the tenth book of the Iliad. Dolon penetrated the Greek's camp at night to learn of their intentions but was caught and killed without pity by Ulysses and Diomedes \{see, respectively, planets (5254) and (1437)\}. (M 30803)

\section{(7816) Hanoi}

1987 YA. Discovered 1987 Dec. 18 by M. Koishikawa at Sendai.

Named for the capital of Vietnam. The discoverer visited the city in 1997 with Yoshihide Kozai \{see planet (3040)\} to help Vietnamese astronomers install a 0.40-m Schmidt-Cassegrain telescope with a CCD camera and a $0.10-\mathrm{m}$ refractor. The equipment, installed at the National Pedagogical University, was obtained using funds from the Sumitomo Foundations, Japan, with the hope that astronomical research in Vietnam will thereby be promoted. (M 33790)

\section{(7818) Muirhead}

1990 QO. Discovered 1990 Aug. 19 by E. F. Helin at Palomar.

Named in honor of Brian K. Muirhead, flight system manager and deputy project manager of the Jet Propulsion Laboratory's Pathfinder mission. He was responsible for the design, development, test and launch of the Pathfinder spacecraft. He has been commended for his leading role in the successful Pathfinder project and became a highly recognized scientist in the media blitz reporting the status of this remarkable Mars landing. (M 31027)

\section{(7824) Lynch}

$1991 \mathrm{RM}_{2}$. Discovered 1991 Sept. 7 by E. F. Helin at Palomar.

Named in honor of William Lynch III of the Jet Propulsion Laboratory and an outstanding model of efficiency, friendliness and dedication to his work and responsibilities. He is the epitome of the NASA/JPL motto, "Faster, better and cheaper", in the sense that anyone who works in a highly-charged, positive fashion, streamlined for action, leads to a more successful and economical operation. Always with a big smile and a cheerful greeting, he is one of JPL's biggest assets. (M 31298)

\section{(7826) Kinugasa}

1991 VO. Discovered 1991 Nov. 2 by A. Takahashi and K. Watanabe at Kitami.

Named in honor of Sachio Kinugasa (1947- ), Japanese professional baseball player who was called the "Iron Man". From 1970 to 1987, he played 2215 games without interruption - the world record until it was broken by Cal Ripken, Jr. of the Baltimore Orioles. Throughout his 22-year professional career for the Hiroshima Toyo Carp team he had 2543 hits, including 504 home runs. Kinugasa is now a television and newspaper commentator, as well as a guest professor at the Hiroshima prefectural university. (M 34626)

Name proposed by the discoverers following a suggestion by T. Sato and A. Fujii.

\section{(7829) Jaroff}

$1992 \mathrm{WY}_{4}$. Discovered 1992 Nov. 21 by E. F. Helin at Palomar. 
Named in honor of Leon Jaroff (1927- ), science journalist with a long, distinguished association with Time magazine. Jaroff is internationally known for his well-researched, insightful articles and essays on scientific subjects combining factual reporting and intelligent commentary. He has won many awards and honors for his fine journalism. Through his writing, he has drawn attention to the issue of NEOs and the potentially catastrophic consequences for our civilization should a large comet or asteroid strike the earth. (M 32349; M 32561)

\section{(7830) Akihikotago}

1993 DC $_{1}$. Discovered 1993 Feb. 24 by Y. Kushida and $\mathrm{O}$. Muramatsu at Yatsugatake.

Named in honor of Akihiko Tago (1932- ) , credited with the discovery of comets C/1968 H1, C/1969 T1, C/1987 B1 (and an independent discovery of C/1970 U1) and the 1994 nova V2313 Oph. At the Satsuki Municipal Observatory in Yanahara, Okayama, Tago works as an instructor, popularizing astronomy, particularly among the young. (M 31298)

Name proposed by the discoverers, following a suggestion by H. Kosai, who prepared the citation.

\section{(7831) François-Xavier}

1993 FQ. Discovered 1993 Mar. 21 by E. F. Helin at Palomar.

Named in memory of François-Xavier Bagnoud (1961-1986), whose passion for flying made him, at the age of 23, the youngest professional IFR pilot in Europe of both fixed-wing airplanes and helicopters. That passion, combined with compassion for others in need, led him to join his father at Air Glaciers and to lead some 300 successful rescue missions in the Alps. On 1986 Jan. 14, François died in a tragic helicopter accident in Mali. The François-Xavier Bagnoud Foundation was born out of the desire of his family and close friends to continue the loving concern for others shown by François during his life. An observatory established in his name in Switzerland provides astronomers with many clear nights for observation. (M 34626)

Name proposed by M. Wilson, a classmate of François at the American School in Paris.

\section{(7833) Nilstamm}

$1993 \mathrm{FV}_{32}$. Discovered 1993 Mar. 19 by the UppsalaESO Survey at La Silla.

Nils Tamm (1876-1957) studied at Uppsala University in the late 19th century and later at the Royal Academy of Arts in Stockholm. At his private observatory he made observations of variable stars, and he also discovered several novae. His donation made the building of the Kvistaberg \{see planet (3331)\} Observatory possible. (M 39650)

\section{(7837) Mutsumi}

1993 TX. Discovered 1993 Oct. 11 by H. Abe and S. Miyasaka at Yatsuka.
Named in honor of Mutsumi Abe (1957- ), wife of the first discoverer. (M 30803)

\section{(7838) Feliceierman}

1993 WA. Discovered 1993 Nov. 16 at the Farra d'Isonzo Observatory at Farra d'Isonzo.

Felice Ierman (1922-1996), father of this minor planet's co-discoverer Giovanni Ierman, was a strong believer in science and technology who inspired his son's passion for astronomy. He also contributed morally and materially to the construction of the first Farra d'Isonzo \{see planet (7501)\} observatory. (M 36946)

\section{(7840) Hendrika}

$1994 \mathrm{TL}_{3}$. Discovered 1994 Oct. 5 by G. C. L. Aikman at Victoria.

Named in honor of Hendrika Cornelia Marshall Aikman (née Grootendorst), beloved wife of the discoverer. (M 31027)

\section{(7842) Ishitsuka}

1994 XQ. Discovered 1994 Dec. 1 by K. Endate and K. Watanabe at Kitami.

Named in honor of Mutsumi Ishitsuka (1930- ), who has worked in Peru since 1957, making coronagraphic observations of the sun at high altitude. In 1979 he built the Cosmos Observatory and in 1988 set up a new coronagraph there that was destroyed by a group of guerrillas. He is currently trying to reconstruct the observatory and to establish a Peruvian National Observatory for teaching astronomy. (M 35487)

Name proposed by the discoverers following a suggestion by T. Kuroda and Y. Yamada.

\section{(7846) Setvák}

1996 BJ. Discovered 1996 Jan. 16 by M. Tichý at Kleť.

Named in honor of Martin Setvák (1958- ), meteorologist and head of the Satellite Department of the Czech Hydrometeorological Institute in Prague, on the occasion of his 40th birthday, 1998 Feb. 14. His main professional interest is in convective storms, but his long-time hobby is astrophotography. This minor planet also honors his wife Stáňa Setváková (1967- ), a staff member of the Prague Planetarium. (M 31298) Name proposed by the discoverer and J. Tichá.

\section{(7847) Mattiaorsi}

$1996 \mathrm{CS}_{8}$. Discovered 1996 Feb. 14 by U. Munari and M. Tombelli at Cima Ekar.

Named for Mattia Orsi (1995- ）, nephew of Arcetri astronomer Giuseppe Forti. (M 31611)

\section{(7848) Bernasconi}

$1996 \mathrm{DF}_{1}$. Discovered 1996 Feb. 22 by M. Cavagna and A. Testa at Sormano.

Named in memory of the brothers Giovanni (19011965) and Angelo (1911-1990) Bernasconi, renowned Italian amateur astronomers. Giovanni was a codiscoverer of comets C/1941 K1 (although his discovery was not registered because of a delay in communications in 
wartime Europe), C/1942 C1 and C/1948 L1. Angelo developed a method for determining the real shape and orientation of cometary tails. Both brothers were active observers of comets, meteors and variable stars. In 1965 they established in Saronno a club of amateur astronomers, now named 'Gruppo Astrofili Giovanni e Angelo Bernasconi'. (M 30803)

Citation provided by L. Pansecchi at the request of the discoverers.

Obituary (A.B.) published in Universo, Vol. 12, No. 36, p. 51 (1992).

\section{(7849) Janjosefrič}

1996 HR. Discovered 1996 Apr. 18 by P. Pravec and L. Šarounová at Ondřejov.

Named in memory of Jan Frič (1863-1897) and Josef Frič (1861-1945), the two brothers who founded the Ondřejov Observatory. On 1898 Jan 21, one year after Jan's sudden death, Josef started to bring to fruition their shared idea of establishing an astronomical institution. He purchased the land, and he adopted Jan's name as his own second name. The observatory grew extensively during the twentieth century and became internationally renowned. It was at Ondřejov that Josef Jan Frič, together with František Nušl \{see planet (3424)\}, discovered an anomalous refraction effect and developed astrogeodetic instruments, such as the well-known Nušl-Frič circumzenithal, for the determination of geographical coordinates. (M 31027)

Name proposed by M. Kopecký, astronomer and archivist of the Ondřejov Observatory.

\section{(7850) Buenos Aires}

1996 LH. Discovered 1996 June 10 by L. Macri at Mount Hopkins.

Named for the capital city of Argentina. First founded in 1536 by Don Pedro de Mendoza, who named it Santa Maria de los Buenos Aires, the city was soon destroyed by the natives. It was founded anew in 1580 by Don Juan de Garay. (M 30803)

\section{(7851) Azumino}

$1996 \mathrm{YW}_{2}$. Discovered 1996 Dec. 29 by N. Sato at Chichibu.

Named for an area in Nagano prefecture, Azumino is the rice field area east of the Japanese Northern Alps. In various places, natural spring water surfaces to form clear mountain streams. Azumino is famous throughout Japan for its beautiful scenery year-round. (M 33387)

\section{(7852) Itsukushima}

7604 P-L. Discovered 1960 Oct. 17 by C. J. van Houten and I. van Houten-Groeneveld at Palomar.

Named for Itsukushima Island near Hiroshima City \{see planet (2247)\}. Known as "one of the Scenic Trio of Japan", the island is also called "Miyajima", which means "Shrine Island". The origin of the shrine is not known, but it goes back at least to the sixth century; in the twelfth century its building complex was much enlarged. The shrine and its giant torii gate stand in the sea at high tide. In 1996 the shrine was assigned "World Heritage" recognition by UNESCO. (M 32349)

Name proposed by Takeshi Sato.

\section{(7853) Confucius}

2086 T-2. Discovered 1973 Sept. 29 by C. J. van Houten and I. van Houten-Groeneveld at Palomar.

Named after Confucius (551-471 B.C.), the famous Chinese philosopher. Nothing written by Confucius has survived, but his pupils compiled a collection of his sayings and anecdotes in the Master Cung. Confucius was convinced that the self-discipline and virtue shown by society's leaders would influence everyone. During the Han dynasty, Confucius was venerated as a god, and in the Sung dynasty his rules of living filtered into politics and education. (M 32790; M 32819; M 33151)

\section{(7854) Laotse}

1076 T-3. Discovered 1977 Oct. 17 by C. J. van Houten and I. van Houten-Groeneveld at Palomar.

Named after Laotse (sixth century B.C.), the famous Chinese philosopher. He worked at the court of the emperor as a registrar, and it is said that he became a hermit and went to the West. Before he left, he was asked to record his doctrine. The result is the famous book of Tao, Tao-Te-King, which describes the origin of the universe and of Te, the strength possessed by all human beings. (M 32790)

\section{(7855) Tagore}

4092 T-3. Discovered 1977 Oct. 16 by C. J. van Houten and I. van Houten-Groeneveld at Palomar.

Named in memory of Rabindranath Tagore (18611941), Indian poet and writer. Opposed to the Indian caste system, he created a school (Viśva-Bharati) in Santiniketan, and it became a state university in 1951. Tagore tried to unit the positive elements of European and Eastern philosophy. He received the 1913 Nobel Prize in literature for his lyric work Gitanjali. (M 32790)

\section{(7856) Viktorbykov}

1975 VB $_{1}$. Discovered 1975 Nov. 1 by T. M. Smirnova at Nauchnyj.

Russian scientist Viktor Leonidovich Bykov (1934-

) is known for his work on the theory of satellite communication. He was a designer of the space communication systems "Ekran" and "Intersputnik", as well as of the direct government line between Russia and the U.S. (M 40702)

The name was suggested by the Institute of Applied Astronomy.

\section{(7857) Lagerros}

1978 QC $_{3}$. Discovered 1978 Aug. 22 by C.-I. Lagerkvist at Mount Stromlo. 
Named in honor of Johan S. V. Lagerros (1968to celebrate the completion of his Ph.D. thesis titled "Thermal Physics of Asteroids". In a series of papers, he extended and improved the Standard Thermal Model of minor planets. As a result, his model was used for the official calibration of ISO data. The discoverer has also benefited from his experience with computers on numerous occasions. (M 31611)

\section{(7858) Bolotov}

1978 SB $_{3}$. Discovered 1978 Sept. 26 by L. V. Zhuravleva at Nauchnyj.

Andrej Timofeevich Bolotov (1738-1833) was a Russian writer, scientist, agriculturist, selectionist, forester and builder of parks. (M 42357)

\section{(7859) Lhasa}

1979 US. Discovered 1979 Oct. 19 by A. Mrkos at Klet.

Lhasa, "God's ground", is the capital of Tibet, located on a fertile plain 3700 meters high, surrounded on all sides by hills. The main roads radiate from the great four-storey temple dating to the year 652 . (M 40702)

The name was suggested by J. Tichá and M. Tichý.

\section{(7860) Zahnle}

1980 PF. Discovered 1980 Aug. 6 by E. Bowell at Anderson Mesa.

Named in honor of Kevin J. Zahnle (1955- ）, senior research scientist at NASA Ames Research Center, for many fundamental contributions to understanding the physical nature and size-frequency distributions of minor planets and comets and the implications of their impacts with planets. Zahnle's research has elucidated the physics of atmospheric entry and thus identified the Tunguska ssee planet (5471)\} object as a stony object, provided critical predictions of the phenomena observed in the 1994 cometary impacts with Jupiter and quantified the expected environmental effects from earth impacts of NEOs over a wide energy range, leading to a determination of the threshold energy for global impact catastrophe. (M 35487)

Name suggested and citation provided by D. Morrison.

\section{(7863) Turnbull}

1981 VK. Discovered 1981 Nov. 2 by B. A. Skiff at Anderson Mesa.

Margaret C. ("Maggie") Turnbull (1975- ), a graduate student in astronomy, has among her goals the study of the nature of life and intelligence as part of the universe. (M 36127; M 41615)

\section{(7866) Sicoli}

1982 TK. Discovered 1982 Oct. 13 by E. Bowell at Anderson Mesa.

Named in honor of Piero Sicoli (1954- ), leader of a group of amateur astronomers who have, for some years, been observing minor planets and comets from
Sormano \{see planet (6882)\} Observatory, near Como. As well as making a number of discoveries, Sicoli has undertaken fine follow-up work of near-earth objects and has computed many orbits. (M 35488)

\section{(7867) Burian}

1984 SB $_{1}$. Discovered 1984 Sept. 20 by A. Mrkos at Klet..

The Czech artist Zdeněk Burian (1905-1981) was well known for his paintings and illustrations of prehistoric fauna and flora. (M 40702)

The name was suggested by M. Tichý and J. Borovička.

\section{(7868) Barker}

1984 UX $_{2}$. Discovered 1984 Oct. 26 by E. Bowell at Anderson Mesa.

Named in honor of Edwin S. Barker (1940- ), a research scientist at the McDonald Observatory of the University of Texas at Austin. Barker is well known for his work on physical observations of both major and minor planets. He served as McDonald Observatory superintendent for several years in the $1980 \mathrm{~s}$, simultaneously continuing his planetary studies and vastly improving seeing conditions at the observatory. He also conducted an extensive atmospheric-monitoring and data-reduction program that resulted in the recommendation of locating the Hobby-Eberly Telescope on Mt. Fowlkes. In the early 1990s he very successfully served as discipline scientist at NASA headquarters, and in 1997-1998 was chair of the Division for Planetary Sciences of the American Astronomical Society. (M 35488) Citation written by P. J. Shelus.

\section{(7871) Tunder}

$1990 \mathrm{SW}_{4}$. Discovered 1990 Sept. 22 by E. W. Elst at La Silla.

Named for the organist Franz Tunder (1614-1667), founder of the North German school of organ composition. In 1641 he became organist in Lübeck at the Marienkirche, with its beautiful organ that was destroyed in 1945. It was Tunder also who started the famous "Abendmusiken", which his successor, Dietrich Buxtehude \{see planet (4344)\}, continued and raised to further glory. (M 31027)

\section{(7873) Böll}

$1991 \mathrm{AE}_{3}$. Discovered 1991 Jan. 15 by F. Börngen at Tautenburg.

Named in honor of Heinrich Böll (1917-1985), outstanding German writer. In his work he described the reality of World War II and the postwar era, mostly through the fate of ordinary people. A democrat with great historical farsightedness, he defended the liberty of the mind whenwever it was endangered. In 1971-1974, he was president of the International PEN Club. His receipt of the Nobel Prize in literature in 1972 was the visible sign of his appreciation worldwide. (M 31612) 


\section{(7881) Schieferdecker}

$1992 \mathrm{RC}_{7}$. Discovered 1992 Sept. 2 by E. W. Elst at La Silla.

Named for the German organist Johann Christian Schieferdecker (1679-1732), who became Dietrich Buxtehude's \{see planet (4344)\} successor at the Marienkirche in Lübeck, by marrying the rather undesirable eldest daughter of his predecessor, apparently one of the side conditions for getting the job. Schieferdecker was a fine harpsichordist and had come to Lübeck in order to learn from Buxtehude the art of sacred composition. (M 31027)

\section{(7886) Redman}

1993 PE. Discovered 1993 Aug. 12 by D. D. Balam at Victoria.

Named in memory of Roderick Oliver Redman (19051975), professor of astronomy and longtime director of the University of Cambridge Observatories, and in honor of Russell Ormond Redman (1951- ) , a radio astronomer on the staff of the Dominion Astrophysical Observatory. The senior Redman established a lifelong association with the DAO when he obtained the observational material for his doctoral thesis there; he became renowned for his superlative observational techniques and designs for astronomical instrumentation. The junior Redman, whose association with the DAO began as a summer student assistant in 1970, has pioneered the study of minor planets at submillimeter wavelengths and is an authority in using the thermal emission spectra to study their surfaces. (M 32095)

Citation prepared by F. A. Feldman at the request of the discoverer.

\section{(7890) Yasuofukui}

$1994 \mathrm{TC}_{3}$. Discovered 1994 Oct. 2 by K. Endate and K. Watanabe at Kitami.

Named in honor of Yasuo Fukui (1951- ), professor at Nagoya University and a radio astronomer specializing in molecular clouds and the birth of stars. He established and directs the operation of the "Nanten" millimeter-wavelength radio telescope at the Las Campanas Observatory in Chile. He is a winner of the Vainu Bappu \{see planet (2596)\} Gold Medal and other prizes. (M 35488)

Name proposed by the discoverers following a suggestion by T. Sato and A. Fujii.

\section{(7891) Fuchie}

$1994 \mathrm{VJ}_{7}$. Discovered 1994 Nov. 11 by M. Hirasawa and S. Suzuki at Nyukasa.

Named in honor of the Tokyo Metropolitan Fuchie Senior High School, where the first discoverer teaches astronomy and geology. Fuchie means the bank of a large river. This place has been called Fuchie for nearly a thousand years. (M 32095)

\section{(7895) Kaseda}

$1995 \mathrm{DK}_{1}$. Discovered 1995 Feb. 22 by F. Uto at Kashihara.
Named for a city in the southwest of Kagoshima prefecture, where the discoverer was born. This town is fully blessed with natural beauty and is relatively free of light pollution. It once won the highest commendation for the most beautiful starry sky in Japan. (M 33387)

\section{(7896) Švejk}

1995 EC. Discovered 1995 Mar. 1 by Z. Moravec at Kleť.

Named for a literary character created by Jaroslav Hašek \{see planet (2734)\}, Czech writer and humorist (1883-1923). His "good soldier" Josef Švejk is devoted to the disintegrating Austrian-Hungarian monarchy regime, but by his simplicity (or perhaps his ingenuity) he helps to reveal its flaws. (M 34344)

\section{(7897) Bohuška}

1995 EL $_{1}$. Discovered 1995 Mar. 12 by L. Šarounová at Ondřejov.

Named in honor of the discoverer's mother, Bohumila Šarounová, in hearty thanks for her tolerance and support of the life and work of the discoverer. This minor planet was discovered on the discoverer's mother's birthday. (M 31027; M 31045)

\section{(7898) Ohkuma}

$1995 \mathrm{XR}_{1}$. Discovered 1995 Dec. 15 by T. Kobayashi at Oizumi.

Masami Ohkuma (1954- ) is an amateur astronomer who serves as chief editor of the Japanese astronomical monthly magazine Hoshi-Navi. He also plays an important role for the popularization of astronomy in Japan. (M 45336)

\section{(7900) Portule}

$1996 \mathrm{CV}_{8}$. Discovered 1996 Feb. 14 by U. Munari and M. Tombelli at Cima Ekar.

Named for the highest mountain peak in the Asiago \{see planet (7679)\} tableland, near the Asiago Astrophysical Observatory. The wild mountain range is a trekking favorite for local astronomers. (M 32349)

\section{(7902) Hanff}

$1996 \mathrm{HT}_{17}$. Discovered 1996 Apr. 18 by E. W. Elst at La Silla.

Named in memory of the German organist Johann Nicolaus Hanff (1665-1711). In 1696 he became organist and conductor to the Bishop of Lübeck. Hanff's style, with the melody moving slowly but with rich ornamentation above a slow-moving and not very clearly individualized accompaniment, was favored by Buxtehude \{see planet (4344)\}. (M 31027)

\section{(7903) Albinoni}

$1996 \mathrm{HV}_{24}$. Discovered 1996 Apr. 20 by E. W. Elst at La Silla.

Named for the Italian composer Tomaso Albinoni (1671-1750). Although he considered himself an amateur composer, his 50 or so operas and instrumental works achieved wide popularity. Particularly notable are his 
concerti for solo violin and for one or two oboes, as well as his famous "Adagio" for strings. (M 31027)

\section{(7904) Morrow}

$1997 \mathrm{JL}_{4}$. Discovered 1997 May 1 by the LINEAR at Socorro.

Named in honor of Walter W. Morrow, Jr. (1928-

), for his exceptional leadership as director of the Massachusetts Institute of Technology's Lincoln Laboratory for over 20 years, on the occasion of his retirement. (M 31028)

\section{(7905) Juzoitami}

1997 OX. Discovered 1997 July 24 by A. Nakamura at Kuma.

Named in memory of Juzo Itami (1933-1997), actor, translator, essayist, editor and well-known director since the great success of his first work Osoushiki (Funeral). His last work Shizukana Seikatsu (Quiet Life) is based on the novel written by Kenzaburo Oe, winner of the Nobel Prize in literature in 1994 and brother-in-law of Itami. (M 32095)

\section{(7906) Melanchton}

3081 P-L. Discovered 1960 Sept. 24 by C. J. van

Houten and I. van Houten-Groeneveld at Palomar.

Named after Philipp Melanchton (1497-1560), German reformer who worked closely with Martin Luther \{see planet (7100)\}. At the early age of twelve, he took lectures at the University of Heidelberg. His personal synthesis of humanism and the Christian faith left a strong mark on German Protestantism, expressed in the Confessio Augustana in 1530. (M 32790)

\section{(7907) Erasmus}

4047 P-L. Discovered 1960 Sept. 24 by C. J. van Houten and I. van Houten-Groeneveld at Palomar.

Erasmus of Rotterdam (1469-1536) was the son of a priest and became a priest himself. In 1517 he was released by the pope from his holy vows, becoming an advisor to the emperor Charles V. He published papers critical of the practices of the Church; eventually he became the father of European humanism. He translated the classics, books of the church fathers and the New Testament into Latin in a critical way. His collection of proverbs helped shed new light on ancient literature and influenced religion, art and sciences. (M 32791)

\section{(7908) Zwingli}

4192 T-1. Discovered 1971 Mar. 26 by C. J. van Houten and I. van Houten-Groeneveld at Palomar.

Named in memory of Ulrich Zwingli (1484-1531), Swiss reformer of the church. He was originally a Catholic priest, but under the influence of the books of Erasmus and Luther \{see, respectively, planets (7907) and $(7100)\}$ he felt the need for reform. In 1523 he broke with the bishop, married and became a fervent puritan. For him the holy communion was only a symbolic celebration, and in this respect he did not agree with Luther. Zwingli died in a fight against the catholic cantons as a clergyman of the reformed soldiers. (M 33387)

(7910) Aleksola

$1976 \mathrm{GD}_{2}$. Discovered 1976 Apr. 1 by N. S. Chernykh at Nauchnyj.

Aleksandr Anatolievich Solov'ev is a theoretical astrophysicist and solar physicist and a professor of Kalmyk University at Elista. He is also known as a poet. (M 38197)

\section{(7911) Carlpilcher}

1977 RZ $_{8}$. Discovered 1977 Sept. 8 by E. Bowell at Palomar.

Named in honor of Carl B. Pilcher, who directs NASA's Solar System Exploration Program. While at M.I.T. and the University of Hawaii, Pilcher studied Jupiter's atmosphere and satellites, especially Io's interaction with Jupiter's magnetosphere, using ground-based telescopes. He has been a member of the imaging team of the Galileo mission to Jupiter since 1977. Pilcher has also studied international relations, sponsored by the MacArthur Foundation, at Princeton's Woodrow Wilson School, and with the skills he acquired worked at the Office of Space Science at NASA headquarters. He undertook strategic planning and other responsibilities at NASA prior to joining the planetary program during a time of unprecedented resurgence of planetary spacecraft launches. (M 35488)

Citation written by C. R. Chapman.

(7912) Lapovok

$1978 \mathrm{PO}_{3}$. Discovered 1978 Aug. 8 by N. S. Chernykh at Nauchnyj.

Yakov Semenovich Lapovok (1932- ) is a radio engineer and inventor, scientific secretary of the A. S. Popov Museum at St. Petersburg Electrotechnical University. His name and voice are known to radio amateurs throughout the world. (M 38197)

\section{(7913) Parfenov}

1978 TU$_{8}$. Discovered 1978 Oct. 9 by L. V. Zhuravleva at Nauchnyj.

Anatolij Ivanovich Parfenov (1925-1993) was an outstanding Russian sportsman, a champion of the Melbourne Olympic games in 1956 in classical wrestling, an Honored Master of Sports and an Honored Coach of the U.S.S.R. The "Herculean games" devoted to his memory took place in Moscow in 1999. (M 42357)

\section{(7919) Prime}

$1981 \mathrm{EZ}_{27}$. Discovered 1981 Mar. 2 by S. J. Bus at Siding Spring.

Recognizing the importance that mathematics has played in science, this naming acknowledges that 7919 is the one-thousandth prime number. (M 34344)

Name proposed by the discoverer following a suggestion by D. Hamilton. 


\section{(7921) Huebner}

1982 RF. Discovered 1982 Sept. 15 by E. Bowell at Anderson Mesa.

Named in honor of Walter F. Huebner (1928- ), for his seminal contributions to small bodies studies in general, and to cometary studies in particular. Over several decades, Huebner has worked on opacities, equations of state and other physical constants relevant to both planetary science and astrophysics. He has served diligently on countless committees and at NASA headquarters, and he has written and edited scientific books and reviews. Huebner has spent the majority of his career at the Los Alamos National Laboratory, the Max-Planck-Institute in Germany, and the Southwest Research Institute in San Antonio. Colleagues around the world appreciate his technical talents, his warm personality and his mischievous sense of humor. (M 35488)

Citation written by S. A. Stern at the request of the discoverer.

\section{(7923) Chyba}

1983 WJ. Discovered 1983 Nov. 28 by E. Bowell at Anderson Mesa.

Named in honor of Christopher F. Chyba (1959- ), who holds the Carl Sagan \{see planet (2709)\} Chair for the Study of Life in the Universe at the SETI Institute of Mountain View, California. Chyba, who has also worked recently at the University of Arizona and on the U.S. White House science staff, has done pioneering work in understanding the role of impacts in forming the atmospheres of the earth and Mars and in transporting organic chemicals to the inner solar system. He studied the physics of atmospheric entry and applied the results to analysis of the Tunguska \{see planet (5471)\} object and to determination of the risk threshold for small minor planets colliding with the earth. Chyba currently chairs NASA's Solar System Exploration advisory committee. (M 35488)

Citation written by D. Morrison at the request of the discoverer.

\section{(7924) Simbirsk}

1986 PW $_{4}$. Discovered 1986 Aug. 6 by N. S. Chernykh and L. I. Chernykh at Nauchnyj.

Named for the city of Simbirsk (Ul'yanovsk since 1924), a large industrial and cultural center on the Volga river. Founded in 1648, it is connected with many great events and people in Russian history. (M 32349)

\section{(7925) Shelus}

$1986 \mathrm{RX}_{2}$. Discovered 1986 Sept. 6 by E. Bowell at Anderson Mesa.

Named in honor of Peter J. Shelus (1942- ), who has ably managed the Lunar and Satellite Laser Ranging Projects at McDonald Observatory since 1982. An astrometrist by training, Shelus has carried out long-term observations of the faint jovian satellites. Currently, he is providing software management and observing expertise for time-critical follow-up astrometry of newly discovered NEOs. His program leadership has been recognized by NASA in group achievement awards for satellite and lunar laser ranging and for development of ephemerides. His 20 years of service as treasurer of the Division of Dynamical Astronomy of the American Astronomical Society is also recognized. (M 35488)

Citation written by E. S. Barker.

\section{(7928) Bijaoui}

$1986 \mathrm{WM}_{5}$. Discovered 1986 Nov. 27 by the CERGA at Caussols.

Named after Albert Bijaoui, astronomer at the Observatoire de la Côte d'Azur and long-time supporter of the Schmidt telescope with which this object was discovered. Bijaoui's work has been essential in the introduction of modern image processing techniques in French astronomy. His latest work dealt with multiresolution analysis of astronomical data, and he designed the image processing routines involved in various programs performed on the Schmidt telescope. A corresponding member of the French Academy of Sciences, he teaches at the university. $\mathrm{He}$ is also active in the popularization of astronomy, through numerous conferences and through his involvement in local astronomy associations like ASSEM, which he served as president for many years. (M 35488)

\section{(7933) Magritte}

$1989 \mathrm{GP}_{4}$. Discovered 1989 Apr. 3 by E. W. Elst at La Silla.

Named for the Belgian painter René Magritte Lessines (1898-1967), well kown for his magical surrealistic style. In the 1930s he composed his Magritte dictionary, placing ordinary objects, such as apples, stones and pipes, in a surrealistic context, thereby aiming to surprise and alienate. The philosophy of his work may best be summarized as "creating the unknown with known things". (M 31298)

Citation written by K. Leterme at the request of the discoverer.

\section{(7934) Sinatra}

$1989 \mathrm{SG}_{1}$. Discovered 1989 Sept. 26 by E. W. Elst at La Silla.

Named in memory of Frank Sinatra (1915-1998), American singer. Beginning in 1935 when he won a radio talent show, Sinatra showed impeccable taste as an American song stylist for over 50 years. He won an "Oscar" in 1954 for his role in the movie "From Here to Eternity", and in 1985 he was awarded the Presidential Medal of Freedom. Throughout his career, he "did it his way". (M 32791)

\section{(7936) Mikemagee}

$1990 \mathrm{OW}_{2}$. Discovered 1990 July 30 by H. E. Holt at Palomar.

Michael Magee (1958- ) has had a distinguished career with the University of Arizona's Flandrau Science 
Center and Planetarium since 1980. Throughout two decades Magee has been largely responsible for the planetarium's production of astronomy shows and its outreach program. (M 42357)

\section{(7939) Asphaug}

$1991 \mathrm{AP}_{1}$. Discovered 1991 Jan. 14 by E. F. Helin at Palomar.

Named in honor of Erik Asphaug (1961- ), currently in the Earth Sciences Department at the University of California at Santa Cruz. Asphaug has pioneered the application of fracture mechanics and hydrodynamics to numerous problems in planetary science. Using a radar-derived model of (4769) Castalia, he has explored how effects of a hypervelocity impact depend on the projectile's energy, the equation of state of the target material and the target's internal configuration of fractures and voids. His calculations have important implications for our understanding of the collisional evolution of minor planets and for the mitigation of hazards due to comets and minor planets. (M 32791)

\section{(7940) Erichmeyer}

$1991 \mathrm{EO}_{1}$. Discovered 1991 Mar. 13 at the Oak Ridge Observatory at Harvard.

Named in honor of Erich Meyer (1951- ), Austrian amateur astronomer, on the occasion of his 20th anniversary as an astrometricist. Using a measuring engine he constructed himself, Meyer measured about 250 precise positions of minor planets and comets from photographic plates. Amoung the 2,600 positions he derived after switching to CCD equipment in 1993 are some for the 1997 opposition of this object, thereby rendering it appropriate for numbering. An electrical engineer by profession, Meyer is also a well-known astrophotographer and popularizer of astronomy. (M 32095)

\section{(7945) Kreisau}

$1991 \mathrm{RK}_{7}$. Discovered 1991 Sept. 13 by F. Börngen and L. D. Schmadel at Tautenburg.

Named in memory of an anti-Nazi resistance group formed in 1942 in Silesia at the Kreisau farm, the family estate of H. J. Graf von Moltke. The members of the group, called Kreisauer Kreis, were mainly conservative people from a variety of social backgrounds and political attitudes. They considered the possibility of eliminating the fascist regime and revising Germany's ethical and political character. Most of the members were executed following the assassination attempt on the fascist leader in July 1944. (M 31612)

Name proposed by the first discoverer.

\section{(7947) Toland}

$1992 \mathrm{BE}_{2}$. Discovered 1992 Jan. 30 by E. W. Elst at La Silla.

Named in memory of the controversial freethinker John Toland (1670-1722). In 1696 he published his celebrated Christianity not Mysterious, a classic exposition on deism. Later, in his Letters to Serena (1704), he severely attacked the deism of both Spinoza \{see planet (7142)\} and Newton \{see planet (8000)\} with the remark "That after admitting the Activity of Matter, there seems to be no need of presiding Intelligence", thus anticipating Holbach's \{see planet (6956)\} Système de la Nature. (M 31028)

\section{(7948) Whitaker}

1992 HY. Discovered 1992 Apr. 24 by the Spacewatch at Kitt Peak.

Ewen A. Whitaker (1922- ) was a founding member of the Lunar and Planetary Laboratory. He participated in the construction of lunar atlases and maps. For Apollo 12 he successfully identified the crater in which Surveyor III had landed. He located manmade impact craters using lunar surface imagery. (M 38197)

\section{(7950) Berezov}

1992 SS $_{26}$. Discovered 1992 Sept. 28 by L. V. Zhuravleva at Nauchnyj.

Named for a Siberian town, founded in 1593 situated on the Sos'va river in the Khanty-Mansi national district. In recent times a rich gas field was discovered that favored the growth of industry and the development of the town. Russian prince Aleksandr Danilovich Menshikov and his family were banished there in 1728. (M 34626)

\section{(7953) Kawaguchi}

1993 KP. Discovered 1993 May 20 by S. Otomo at Kiyosato.

Masaya Kawaguchi (1959- ) served as chief editor of the Japanese astronomical magazine Sky Watcher during 1987-2000. (M 42669)

\section{(7954) Kitao}

$1993 \mathrm{SQ}_{2}$. Discovered 1993 Sept. 19 by K. Endate and K. Watanabe at Kitami.

Named in honor of Koichi Kitao (1953- ～), Japanese amateur astronomer and director of the folklore section of the Oriental Astronomical Association. He is a winner of the I. Yamamoto Award (O.A.A.) and the S. Kaho Award (Japan Amateur Astronomical Conference) for his extensive studies of dialectal star names and star-related folklore. (M 35488)

Name proposed by the discoverers following a suggestion by S. Kuwabara, T. Sato and A. Fujii.

\section{(7955) Ogiwara}

1993 WE. Discovered 1993 Nov. 18 by T. Urata at Oohira.

Tetsuo Ogiwara (1950- ) is a Japanese amateur astronomer who since 1972 calculated circular and elliptical orbits of about 100 minor planets. (M 45747)

(7956) Yaji

1993 YH. Discovered 1993 Dec. 17 by T. Kobayashi at Oizumi.

Kentaro Yaji (1966- ) is the director of Kawabe Cosmic Park in Wakayama prefecture. He has con- 
tributed to teaching and popularizing astronomy, especially enhancing community-based solar observation in Japan. He is a member of the YOHKOH team and has also studied solar flares observed in x-rays and radio. (M 46681)

\section{(7957) Antonella}

1994 BT. Discovered 1994 Jan. 17 by A. Boattini and M. Tombelli at Cima Ekar.

Named in honor of Antonella Bartolini (1956- ), amateur astronomer and friend of the discoverers. (M 31612)

\section{(7958) Leakey}

$1994 \mathrm{LE}_{3}$. Discovered 1994 June 5 by C. S. Shoemaker and E. M. Shoemaker at Palomar.

Named for Mary Leakey (1913-1996), her husband Louis Leakey (1903-1972) and her son Richard Leakey (1944- ), all major figures in the paleoanthropology of Africa. Mary and Louis worked together for 30 years and proved that human evolution was centered in Africa, rather than in Asia. Many of their most important discoveries were made at Olduvai Gorge in Tanzania. With his team in Kenya, Richard Leakey discovered that the Koobi Fora site contained one of the richest and most varied assemblages of early human remains anywhere in the world. (M 31612)

\section{(7960) Condorcet}

$1994 \mathrm{PW}_{16}$. Discovered 1994 Aug. 10 by E. W. Elst at La Silla.

Named for the French philosopher of the Enlightenment, Marie-Jean-Antoine-Nicolas de Caritat, marquis de Condorcet (1743-1794), an advocate of educational reform and a believer in the indefinite perfectability of mankind. At an early age, Condorcet showed remarkable mathematical abilities, notably in probability theory, and as a friend of d'Alembert ssee planet (5956)\} he took an active part in the preparation of the Encyclopédie. But he is mainly remembered for his Esquisse d'un tableau historique des progrès de l'esprit humain (1795), with its fundamental idea of the continuous progress of humankind to an ultimate perfection. Suspected as a Girondin, he has to flee, but eventually he was captured and imprisoned at Bourg-La-Reine, where he was poisoned. (M 31028)

\section{(7961) Ercolepoli}

$1994 \mathrm{TD}_{2}$. Discovered 1994 Oct. 10 by V. S. Casulli at Colleverde di Guidonia.

Ercole Poli (1961-2000), fond of astronomy, was always committed to the discovery of new techniques and methodologies. (M 41028)

\section{(7963) Falcinelli}

1995 CA. Discovered 1995 Feb. 1 at the Santa Lucia Observatory at Stroncone.

Named in memory of Amleto Falcinelli (19211996), Italian bantam-weight boxing champion, who fought from 1936 to 1956 in Italian, European and international rings. Legendary are his five matches against the Spanish champion Romero for the European title, which he won several times. (M 33387)

\section{(7965) Katsuhiko}

1996 BD $_{1}$. Discovered 1996 Jan. 17 by K. Endate and K. Watanabe at Kitami.

Named in honor of Katsuhiko Sato (1945- ), professor at University of Tokyo and director of the Research Center of the Early Universe since 1995. He is an active leader in cosmology research and served as president of IAU Commission 47 during 1988-1991. He proposed an exponential expansion model of the early universe on the basis of the unified theory of interactions. This was named the Inflation Model by A. Guth, who proposed it independently. (M 35488)

Name proposed by the discoverers following a suggestion by Y. Yamada.

\section{(7967) Beny}

$1996 \mathrm{DV}_{2}$. Discovered 1996 Feb. 28 by Z. Moravec at Klě́.

Named in memory of Michal 'Beny' Böhm (19681998), schoolmate, roommate at Charles University and great friend of the discoverer. (M 34344)

\section{(7968) Elst-Pizarro}

1996 N2. Discovered 1996 July 14 by E. W. Elst and G. Pizarro at La Silla.

Originally classified as a comet because of the persistent appearance of a tail, this newly-numbered Themis-family minor planet is being given the same name it has had as a comet. (M 30803)

Normally, minor planets are not named after their discoverers. In this unusual case this decision was made by the Small Bodies Names Committee of Division III of the IAU.

\section{(7970) Lichtenberg}

6065 P-L. Discovered 1960 Sept. 24 by C. J. van Houten and I. van Houten-Groeneveld at Palomar.

Named in memory of Georg Christoph Lichtenberg (1742-1799). In his time he was one of Europe's best-known experimental physicists. He worked in Göttingen, Germany, and in Brighton, England. Even today, he is known for his aphorisms, such as: "it is almost impossible to carry the torch of the truth through a crowd without singeing someone's beard", "the healthy scholar is the man for whom thinking is not an illness" and "I always feel pain when a gifted person dies - the world has a greater need for these than the heavens". (M 33387)

Name proposed by K.-O. Groeneveld.

\section{(7971) Meckbach}

9002 P-L. Discovered 1960 Oct. 17 by C. J. van Houten and I. van Houten-Groeneveld at Palomar.

Named in memory of Wolfgang Meckbach (19191998), microwave spectroscopist who emigrated from Germany to Argentina in 1951, where he became the co-founder of the Centro Atómico Bariloche and founder of the Bariloche school of atomic collision 
physics. In spite of difficult times, he excelled as a teacher and researcher in atomic collision physics using ion penetration through matter. By sad coincidence, the name was proposed just as Meckbach suffered a fatal heart attack while skiing. (M 33387)

Name proposed and citation prepared by K.-O. Groeneveld.

\section{(7972) Mariotti}

1174 T-1. Discovered 1971 Mar. 25 by C. J. van Houten and I. van Houten-Groeneveld at Palomar.

Named in memory of Jean-Marie Mariotti (19551998), French astronomer, most recently in Garching at the European Southern Observatory. He led the pioneering project to establish optical interferometry with the new Very Large Telescope as a breakthrough new astronomical instrument for the next century. His interest was in the area of high angular resolution, and he was involved in interferometric projects both on the ground (e.g., FLUOR and VLTI) and in space (DARWIN). He hoped with these techniques to find low-mass companions, and ultimately planets, outside our solar system. He had an extraordinarily effective mix of technical expertise and scientific eagerness. (M 33387)

Name proposed and citation prepared by R. Le Poole.

Obituaries published in Messenger, No. 93, p. 47 (1998); J. Astron. Fr., No. 57-58, p. 3-5 (1998).

\section{(7973) Koppeschaar}

1344 T-2. Discovered 1973 Sept. 29 by C. J. van Houten and I. van Houten-Groeneveld at Palomar.

Carl Egon Koppeschaar is a science writer and reporter in the Netherlands. He is internationally known for popularizing astrophysics and space science, for debunking pseudoscience, and for taking action against light pollution. His Moon Handbook: a 21stCentury Travel Guide is a delight. (M 38197)

\section{(7974) Vermeesch}

2218 T-2. Discovered 1973 Sept. 29 by C. J. van Houten and I. van Houten-Groeneveld at Palomar.

Theo Vermeesch (1930- ), since 1968 the first director of the Volkssterrenwacht Simon Stevin in Hoeven, has played a key role in popularising astronomy and space research in the Netherlands, working with both professional institutions and the public. (M 39650)

The name was suggested by T. Gehrels and P. Smolders.

\section{(7979) Pozharskij}

$1978 \mathrm{SV}_{7}$. Discovered 1978 Sept. 26 by L. V. Zhuravleva at Nauchnyj.

Russian prince Dmitrij Mikhailovich Pozharskij (1578-1642) was a noted Russian statesman and soldier. He was leader of the second people's volunteer corps of Nizhnij Novgorod \{see planet (7736)\}, which defeated the regular Polish troops of Hetman Chodkiewicz near Moscow in 1612. (M 42357)

\section{(7980) Senkevich}

1978 TD $_{2}$. Discovered 1978 Oct. 3 by N. S. Chernykh at Nauchnyj.

Yurij Aleksandrovich Senkevich (1937- ) is a scientist at the Institute of Medical and Biological Problems of the Russian Academy of Sciences. He prepared space biological experiments, worked at the Antarctic station "Vostok", took part in three of Thor Heyerdahl's \{see planet (2473)\} expeditions and is a popular television journalist. (M 46009)

\section{(7983) Festin}

1980 FY. Discovered 1980 Mar. 16 by C.-I. Lagerkvist at La Silla.

Named in honor of Leif Festin (1967- ） to celebrate the completion of his Ph.D. thesis on the faint end of the luminosity function. He assisted with photometric observations of minor planets while he was working at the Nordic Optical Telescope \{see planet (2857)\} on La Palma. He is co-author of several publications on lightcurves of minor planets. (M 31612)

\section{(7991) Kaguyahime}

$1981 \mathrm{UT}_{7}$. Discovered 1981 Oct. 30 by H. Kosai and K. Hurukawa at Kiso.

Named for the main female character in the old Japanese romance Taketori-monogatari. (M 34627)

\section{(7992) Yozan}

1981 WC. Discovered 1981 Nov. 28 by T. Furuta at Tokai.

Uesugi Yozan (1751-1822), the ninth lord of Yamagata prefecture's Yonezawa Castle, was the greatest ruler of his clan. His rule led to economic recovery. He promoted austerity programs, wilderness cultivation, public education, the textile industry and silkworm breeding. (M 42669)

\section{(7994) Bethellen}

$1983 \mathrm{CQ}_{2}$. Discovered 1983 Feb. 15 by E. Bowell at Anderson Mesa.

Named in honor of Beth Ellen Clark (1964- ) on the occasion of the 1999 "Asteroids, Comets, Meteors meeting" at Cornell University. Clark served as the lead organizer of that meeting with dedication and an admirable combination of firm organization and style. Her $\mathrm{Ph} . \mathrm{D}$. thesis was on the mixing model analysis of spectra of minor planets to investigate space-weathering effects in relating these spectra to laboratory spectra of meteorites. She has been an associate member of the NEAR science team, and she has recently been appointed team leader for the near-infrared spectrometer to be flown aboard the MUSES-C spacecraft. (M 35489)

Citation provided by A. W. Harris.

\section{(7995) Khvorostovsky}

1983 PX. Discovered 1983 Aug. 4 by L. G. Karachkina at Nauchnyj.

Named in honor of the outstanding Russian baritone Dmitrij Aleksandrovich Khvorostovsky (1962- ), a 
people's artist of Russia. His extensive opera and chamber repertoire includes both Russian and world music. The last composition of G. Sviridov ssee planet (4075)\}, the poem 'Petersburg', is dedicated to him. (M 32349)

Name proposed by G. Sviridov and supported by the discoverer.

\section{(7996) Vedernikov}

$1983 \mathrm{RX}_{3}$. Discovered 1983 Sept. 1 by L. G. Karachkina at Nauchnyj.

Named in honor of brilliant Russian bass Aleksandr Filippovich Vedernikov (1927- ), a people's artist of Russia. He was the first to perform such works of G. Sviridov \{see planet (4075)\} as "Passionate oratorio", "Voice from the choir" and the solo part in "Pushkin's garland". (M 32349)

Name suggested by G. Sviridov and supported by the discoverer

\section{(7998) Gonczi}

1985 JK. Discovered 1985 May 15 by E. Bowell at Anderson Mesa.

Named in honor of Robert Gonczi (1945- ), a French dynamicist who has carried out important research on the dynamics of minor planets, in particular by developing new numerical techniques to explore the role of resonances and chaotic effects. Gonczi has also studied the dynamical evolution of comets, the delivery of meteorites and the interaction between resonances and Poynting-Robertson drag for orbiting particles. (M 35489)

Name suggested by C. Froeschlé and citation written by P. Farinella.

\section{(7999) Nesvorný}

1986 RA $_{3}$. Discovered 1986 Sept. 11 by E. Bowell at Anderson Mesa.

Named in honor of David Nesvorný (1969- ), a Czech dynamicist, currently at the Universidade de São Paulo, who has contributed to recent important discoveries on chaotic effects in the minor planet belt, their role in depleting resonant gaps, shaping the current belt population, and supplying Mars-crossing objects. In particular, Nesvorný has studied both analytically and numerically the effects of hitherto unstudied three-body resonances and slow, diffusionlike processes. (M 35489)

Citation written by P. Farinella at the request of the discoverer.

\section{(8000) Isaac Newton}

$1986 \mathrm{RL}_{5}$. Discovered 1986 Sept. 5 by H. Debehogne at La Silla.

Named for Isaac Newton (1643-1727), hailed by some as the greatest universal genius of all time. Newton formulated the laws of motion, with the specific application to gravitation, and is known for his 1687 publication Principia Mathematica. He also made seminal contributions to optics and the construction of the reflecting telescope. Newton was the last to observe, from his rooms at Trinity College, Cambridge, the great comet of 1860 - the first comet to have its motion explained on gravitational principles. He also served as master of the Royal Mint in London. (M 31298)

Named by the Small Bodies Names Committee.

\section{(8001) Ramsden}

$1986 \mathrm{TR}_{3}$. Discovered 1986 Oct. 4 by A. Mrkos at Klet.

Jesse Ramsden (1735-1800) was the British designer and producer of highly accurate sextants, theodolites and other instruments. Piazzi \{see planet (1000)\} discovered (1) Ceres using the Ramsden vertical circle of the Palermo Observatory. (M 43189)

The name was suggested by J. Tichá on seeing this instrument during the Asteroids 2001 conference.

\section{(8003) Kelvin}

1987 RJ. Discovered 1987 Sept. 1 by E. W. Elst at La Silla.

William Thomson (Lord Kelvin, 1824-1907), well known for the absolute temperature scale, contributed to modern physics through his major role in the development of the second law of thermodynamics. His theoretical work on submarine telegraphy led to the laying of the first transatlantic cable. (M 47163)

\section{(8005) Albinadubois}

1988 MJ. Discovered 1988 June 16 by E. F. Helin at Palomar.

Named in honor of Albina du Boisrouvray (1939- ), daughter of Count Guy du Boisrouvray and Luz Mila Patino. She was a journalist, publisher and film producer in Paris in the 1960s and 1970s. When her only son, François-Xavier Bagnoud \{see planet (7831)\}, died in a helicopter accident in 1986, she sold most of her possessions and began to support and participate in projects to rescue children in need. This extended to 17 countries, and the rights of such children are championed through a major center she funded at Harvard University. She continues "hands-on" philantropy through an endless schedule of visits to the projects and participation in advocacy forums. (M 34627)

Name proposed by the discoverer, following a suggestion by M. Wilson.

\section{(8006) Tacchini}

1988 QU. Discovered 1988 Aug. 22 at the Osservatorio San Vittore at Bologna.

Named in memory of Pietro Tacchini (1838-1905), Italian astronomer. He was a pioneer, with Secchi \{see planet (4705)\}, of astrophysics in Italy and cofounded the Società degli Spettroscopisti Italiani (1871), now the Italian Astronomical Society. Director of the Modena Observatory from 1859 to 1863, he moved to the Palermo Observatory in 1879. In 1902, he was called to Rome to become director of the Central Office of Meteorology and of the Astronomical Observatory 
of Collegio Romano. He also studied meteorology and seismology and founded the Società Sismologica Italiana (1895). (M 32349)

\section{(8009) Béguin}

$1989 \mathrm{BA}_{1}$. Discovered 1989 Jan. 25 by C. Pollas at Caussols.

Named in honor of the family of the discoverer's wife, Monick, on the occasion of her 50th birthday. She teaches in infant school. The discoverer's father-in-law, Pierre Béguin, a retired agricultural engineer, keeps his interests alive by traveling around the world, always curious for more knowledge. The word Béguin, or "flirtation" in English, gives rise to the vigorous dance of the French West Indies, the beguine. (M 35489)

\section{(8010) Böhnhardt}

1989 GB $_{1}$. Discovered 1989 Apr. 3 by E. W. Elst at La Silla.

Named in honor of Hermann Böhnhardt (1955- ), astronomer at the European Southern Observatory, known for his observational and theoretical studies of comets. He took a particular interest in (7968) Elst-Pizarro, a Themis-family \{see planet (24)\} minor planet that also appeared in the guise of comet 133P/1996 N2. In addition to the main, sunward tail temporariliy exhibited by this strange object, Böhnhardt detected a faint anti-sunward tail, which he had predicted by means of Finson-Probstein modeling. (M 31298)

With its numbering, the comet received the final designation 133P/Elst-Pizarro. See the citation of planet (7968) for more details.

\section{(8011) Saijokeiichi}

$1989 \mathrm{WG}_{7}$. Discovered 1989 Nov. 29 by K. Endate and K. Watanabe at Kitami.

Named in honor of Keiichi Saijo (1949- ), senior curator of the astronomy section of National Science Museum, Tokyo, known for observational research on eclipsing variables, long-period variables and for public education in astronomy. He has been chair of the Variable Star Observers League in Japan since its founding and secretary of the Association of Public Astronomical Observatories. He is also a distinguished fellow of Saji Observatory. (M 35489)

Name proposed by the discoverers following a suggestion by Y. Yamada.

\section{(8013) Gordonmoore}

1990 KA. Discovered 1990 May 18 by E. F. Helin at Palomar.

A life-long contributor to and supporter of education, research and technology, Gordon Moore (1929- ) is renowned for his revolutionary vision of the future of computers with "Moore's law". (M 45747)

\section{(8019) Karachkina}

$1990 \mathrm{TH}_{12}$. Discovered 1990 Oct. 14 by L. D. Schmadel and F. Börngen at Tautenburg.

Named in honor of Lyudmila Georgievna Karachkina
(1948- ), staff astronomer at the Institute of Theoretical Astronomy in St. Petersburg since 1978 and now at the Crimean Astrophysical Observatory. Her main fields of work are in astrometry and photometry of minor planets. Between 1978 and 1990 she discovered 99 minor planets. Since 1990 she has concentrated on photometry and colorimetry of solar system bodies. (M 35489)

Name proposed by the first discoverer in gratitude for her kind support and cooperation.

\section{(8020) Erzgebirge}

$1990 \mathrm{TV}_{13}$. Discovered 1990 Oct. 14 by F. Börngen and L. D. Schmadel at Tautenburg.

Named for the low mountain range along the border of Saxony and Bohemia, about $150 \mathrm{~km}$ in length and rich in forests. This region is relatively densely populated, owing to its past richness of silver and tin ore ("Erz", in German). Pitchblende ("Joachimsthaler Pechblende"), first found in the Erzgebirge, was used by the Curies \{see planet (7000)\} in 1898 to isolate the radioactive elements polonium and radium. The Sternwarte Drehbach, which is situated in Middle Erzgebirge, contributed an extensive series of observations to the minor planet in 1997, thereby enabling it to be numbered. (M 31299)

Name proposed by the first discoverer.

\section{(8021) Walter}

$1990 \mathrm{UO}_{2}$. Discovered 1990 Oct. 22 by C. S. Shoemaker and D. H. Levy at Palomar.

Walter Anderson (1944- ) is a long-time editor of Parade, a magazine that reaches more than 80 million readers weekly. For many years he has focused the magazine's positive and uplifting stories. $\mathrm{He}$ is also known for his commitment to many causes, including improving literacy in the United States. (M 36946)

\section{(8034) Akka}

1992 LR. Discovered 1992 June 3 by C. S. Shoemaker and E. M. Shoemaker at Palomar.

Akka was the Finnish earth mother and goddess of the harvest and female sexuality. She was the wife of the supreme sky God Ukko \{see planet (2020)\}. Akka symbolized love, agriculture and womanliness. (M 46101)

\section{(8036) Maehara}

$1992 \mathrm{UG}_{4}$. Discovered 1992 Oct. 26 by K. Endate and K. Watanabe at Kitami.

Named in honor of Hideo Maehara (1940- ), professor of the National Astronomical Observatory of Japan and director of the Okayama Astrophysical Observatory since 1993. He works at the observatories in Kiso and Okayama as a resident astronomer to provide advanced observational facilities to researchers. His research themes include wide-field surveys of latetype stars and ultraviolet-excess objects using the Kiso Schmidt telescope. (M 35489)

Name proposed by the discoverers following a suggestion by Y. Yamada. 


\section{(8040) Utsumikazuhiko}

$1993 \mathrm{SY}_{3}$. Discovered 1993 Sept. 16 by K. Endate and

K. Watanabe at Kitami.

Kazuhiko Utsumi (1937- ), made the first identification of many of the spectral lines and determined element abundances for carbon stars. At Hiroshima University he has taught astronomy and astrophysics to more than 30000 students. (M 36128)

The name was suggested by Y. Yamada.

\section{(8041) Masumoto}

$1993 \mathrm{VR}_{2}$. Discovered 1993 Nov. 15 by F. Uto at Kashihara.

Named in honor of Takeji Masumoto, who built the discoverer's observatory. Initially, he had to make a great effort to secure the land for the observatory. (M 33388)

\section{(8044) Tsuchiyama}

1994 YT. Discovered 1994 Dec. 28 by T. Kobayashi at Oizumi.

Yukiko Tsuchiyama (1963- ) is a Japanese amateur variable star observer who studies star names as a hobby. Her website service serves as an introduction to star names and as a beginner's guide of star watching. (M 45336)

\section{(8048) Andrle}

1995 DB $_{1}$. Discovered 1995 Feb. 22 by M. Tichý and Z. Moravec at Klě̌.

Named in memory of Pavel Andrle (1936-1991), Czech astronomer and celestial mechanician. Methods described in his textbook were used at Klet for the preliminary orbit determination of this minor planet. (M 31299)

Name proposed by the discoverers and endorsed by J. Tichá.

Obituaries published in Vesmír, Vol. 71, No. 2, p. 115 (1992); Bull. Astron. Inst. Czech., Vol. 42, No. 6, p. 408 (1991); Říše hvězd, Vol. 73, No. 1, p. 10 (1992).

\section{(8050) Beishida}

1996 ST. Discovered 1996 Sept. 18 at the Beijing Observatory at Xinglong.

Beishida, the Beijing Normal University, is one of the earliest well-known Chinese universities. Founded in 1902, it is an important center for scientific research and the training of excellent teachers and other professionals. (M 41383)

\section{(8051) Pistoria}

$1997 \mathrm{PP}_{4}$. Discovered 1997 Aug. 13 by L. Tesi and G. Cattani at San Marcello Pistoiese.

Named for the Italian city of Pistoria, situated about $30 \mathrm{~km}$ from Florence at the foot of the western slope of the Central Apennines between Tuscany and Aemilia. Pistoria is the ancient name of the settlement dating to its founding in the second century B.C. by the Romans. (M 32349)

\section{(8052) Novalis}

2093 P-L. Discovered 1960 Sept. 24 by C. J. van Houten and I. van Houten-Groeneveld at Palomar.

Friedrich Leopold Freiherr von Hardenberg, known under his pseudonym Novalis (1772-1801), is one of the greatest Romantic writers in German literature. The death of his fiancée and his pietistic thinking brought him to his romantic way of writing. In one of his novels he uses the image of a blue flower for the magical task poets have. Novalis had strong connections with the other Romantic writers of his time, such as Tieck ssee planet (8056)\} and Schlegel. (M 34344)

\section{(8053) Kleist}

4082 P-L. Discovered 1960 Sept. 25 by C. J. van Houten and I. van Houten-Groeneveld at Palomar.

Heinrich von Kleist (1777-1811) was a prolific writer who was not known during his lifetime. He traveled throughout Europe, living in Dresden \{see planet (3053)\} and Königsberg, where he studied the philosophy of Kant \{see planet (7083)\}. In 1811 he committed suicide together with his girlfriend. His plays, including Das Käthchen von Heilbronn, Prinz von Homburg and the popular Der zerbrochene Krug, are highly regarded nowadays, as are his novels and short stories. (M 34344)

\section{(8054) Brentano}

4581 P-L. Discovered 1960 Sept. 24 by C. J. van Houten and I. van Houten-Groeneveld at Palomar.

Named for the German Romantic poet Clemens Brentano (1778-1842), esteemed in his time by important German poets and writers. Together with his friend Achim von Arnim \{see planet (8055)\} he collected about 600 German folksongs in Des Knaben Wunderhorn. He also published famous fairy tales such as Gockel, Hinkel und Gackeleia. (M 34344)

\section{(8055) Arnim}

5004 P-L. Discovered 1960 Oct. 17 by C. J. van Houten and I. van Houten-Groeneveld at Palomar.

Achim (Ludwig Joachim) von Arnim (1781-1831) is one of the well-known German Romantics. Although he studied law and natural sciences, he dedicated his life to literature, especially German literature. With his friend Brentano \{see planet (8054)\} he published about 600 German folksongs in Des Knaben Wunderhorn. German poets from the "Heidelberger Romantik", such as the brothers Grimm, Tieck \{see planet (8056)\} and Runge, worked together with Arnim and Brentano. (M 34345)

\section{(8056) Tieck}

6038 P-L. Discovered 1960 Sept. 24 by C. J. van Houten and I. van Houten-Groeneveld at Palomar.

Ludwig Tieck (1773-1853) was one of the great Romantic poets and writers. He became friends with Brentano \{see planet (8054)\}, Fichte, Novalis \{see planet (8052)\}, the brothers Grimm and many other poets of his time. He wrote the ironic fairy tales Ritter 
Blaubart, Der gestiefelte Kater and other sensitive and imaginative stories. (M 34345)

\section{(8057) Hofmannsthal}

4034 T-1. Discovered 1971 Mar. 26 by C. J. van Houten and I. van Houten-Groeneveld at Palomar.

Hugo von Hofmannsthal (1874-1929) began writing poems at the age of 16 . His lyrical and dramatic work reflects Austrian impressionism and symbolism. Together with Richard Strauss \{see planet (5039)\} and Max Reinhardt, he founded the Salzburger Festspiele. His best-known play is Jedermann. (M 34345; M 34673)

A proposal for a minor planet with this name was made independently by F. Börngen.

\section{(8058) Zuckmayer}

3241 T-3. Discovered 1977 Oct. 16 by C. J. van Houten and I. van Houten-Groeneveld at Palomar.

Named for Jewish playwright Carl Zuckmayer (18961977). He wrote many comedies, his most famous play being Der Hauptmann von Köpenick. As a young soldier he took part in World War I. His plays were later banned in Germany, so he emigrated to Austria and in 1938 moved via Switzerland to the U.S. During 1940-1946 he earned his living on a farm. There he wrote the much-discussed drama Des Teufels General. Although he returned to Germany in 1947, he lived in Switzerland from 1958 onward. (M 34345)

\section{(8060) Anius}

1973 SD . Discovered 1973 Sept. 19 by C. J. van Houten and I. van Houten-Groeneveld at Palomar.

Named after Anius, son and priest to Apollo \{see planet (1862)\} on the isle of Delos. His three daughters could change anything into wine, grain or soil. So it was easy for Anius to supply the Greek army with these things. As a result, Agamemnon \{see planet (911)\} kidnapped the three daughters. But after they prayed to Dionysos \{see planet (3671)\}, the god transformed the girls into birds. (M 31612)

\section{(8061) Gaudium}

1975 UF. Discovered 1975 Oct. 27 by P. Wild at Zimmerwald.

Latin for joy, pleasure and delight, Gaudium is designed to compensate the gloom of (5708) Melancholia. (M 41383)

\section{(8062) Okhotsymskij}

1977 EZ. Discovered 1977 Mar. 13 by N. S. Chernykh at Nauchnyj.

Dmitrij Evgenievich Okhotsymskij (1921- ), a specialist in theoretical and applied mechanics, worked on the theory of control of space rockets and space vehicles at the Russian Academy of Sciences' Institute of Applied Mathematics, thereby making a valuable contribution to the Soviet space program. (M 42669)

\section{(8064) Lisitsa}

1978 RR. Discovered 1978 Sept. 1 by N. S. Chernykh at Nauchnyj.
Physicist Mikhail Pavlovich Lisitsa (1921- ) is a professor at Kiev University and department head at the Institute of Semiconductors of the Ukrainian Academy of Sciences, where he specializes in quantum electronics, nonlinear optics and molecular spectroscopy. (M 38197) The name was suggested by N. V. Steshenko.

\section{(8065) Nakhodkin}

$1979 \mathrm{FD}_{3}$. Discovered 1979 Mar. 31 by N. S. Chernykh at Nauchnyj.

Nikolaj Grigorievich Nakhodkin (1925- ～), a faculty head at Kiev University, works in the areas of physical electronics, radiophysics and radioastronomy. (M 38197)

The name was suggested by N. V. Steshenko.

\section{(8066) Poldimeri}

$1980 \mathrm{~PB}_{2}$. Discovered 1980 Aug. 6 by R. M. West at La Silla.

Leopold (1938- _ ) and Meri (1945- ） Bausbek are great devotees of astronomy and philosophy. This minor planet is named in recognition of a long and close friendship with the discoverer and his wife and with whom they have spent innumerable hours of enlightening discussions. (M 45336)

\section{(8067) Helfenstein}

1980 RU. Discovered 1980 Sept. 7 by E. Bowell at Anderson Mesa.

Named in honor of Paul Helfenstein (1954- ) of Cornell University, expert in solar-system photometry and developer of new techniques of extracting key photometric data about surfaces of minor planets from spacecraft observations. Helfenstein has been responsible for definitive analyses of Galileo's photometric observations of (951) Gaspra and (243) Ida and the NEAR data on (253) Mathilde and (433) Eros. (M 35489)

Name suggested by B. E. Clark and citation provided by J. Veverka.

\section{(8071) Simonelli}

1981 GO. Discovered 1981 Apr. 5 by E. Bowell at Anderson Mesa.

Named in honor of Damon P. Simonelli (1959-

), planetary scientist at Cornell University and an expert in the study of minor-planetlike bodies using spacecraft photometry. Simonelli was developer of the standard photometric model of Phobos, and a major contributor to the analysis of ground-based and Galileo observations of (951) Gaspra and (243) Ida. (M 35489)

Name suggested by B. E. Clark and citation provided by J. Veverka.

\section{(8072) Yojikondo}

$1981 \mathrm{GO}_{1}$. Discovered 1981 Apr. 1 at the Harvard College Observatory at Harvard.

Japanese-born U.S. astrophysicist Yoji Kondo (1933-

) headed the astrophysics laboratory during the Apollo mission, directed the IUE Observatory and serves 
as special advisor to the NASA administrator. Some time president of IAU Division $\mathrm{V}$ and Commissions 42 and 44 , he has also published seven science fiction novels. (M 39650)

\section{(8073) Johnharmon}

1982 BS. Discovered 1982 Jan. 24 by E. Bowell at Anderson Mesa.

John K. Harmon (1948- $\quad$ ), scientist at the Arecibo \{see planet (4337)\} Observatory, has for two decades made outstanding contributions to planetary radar astronomy of Mars, Mercury, the Galilean satellites and comets. (M 41935)

\section{(8074) Slade}

$1984 \mathrm{WC}_{2}$. Discovered 1984 Nov. 20 by E. Bowell at Palomar.

Martin A. Slade (1942- ) is a scientist at the Jet Propulsion Laboratory. His three decades of contributions to planetary science include analysis of the moon's orbit, radar ranging of Mercury for testing physical theories and the discovery of radar brightness anomalies at Mercury's poles. (M 41935)

\section{(8075) Roero}

1985 PE. Discovered 1985 Aug. 14 by E. Bowell at Anderson Mesa.

The region of Roero, in Piemonte \{see palnet (5162)\}, Italy, is greatly appreciated for its natural beauty, its agricultural products and for the delicious wines (both red and white) produced there. The citation was provided by V. Zappalà. (M 40702)

\section{(8077) Hoyle}

$1986 \mathrm{AW}_{2}$. Discovered 1986 Jan. 12 by E. Bowell at Anderson Mesa.

Fred Hoyle (1915-2001) is the leading proponent of steady-state cosmology. He predicted an excited state in the carbon atom and contributed extensively to the study of nucleosynthesis in stars. Hoyle served as president of the Royal Astronomical Society from 1971 to 1973 . (M 41028)

The name was suggested by S. Mitton.

Obituary published in Bull. Am. Astron. Soc., Vol. 33, No. 4, p. 1570 (2001).

\section{(8078) Carolejordan}

$1986 \mathrm{RS}_{2}$. Discovered 1986 Sept. 6 by E. Bowell at Anderson Mesa.

Carole Jordan, professor of physics at Somerville College, Oxford University, served as president of the Royal Astronomical Society (1994-1996) and as chairman of the National Organizing Committee for the Manchester IAU General Assembly (1997-2000). (M 41028)

The name was suggested by S. Mitton.

\section{(8079) Bernardlovell}

$1986 \mathrm{XF}_{1}$. Discovered 1986 Dec. 4 by E. Bowell at Anderson Mesa.

Bernard Lovell (1913- ) founded Jodrell Bank Observatory, which boasts the world's first large steerable radio telescope. Lovell served as president of the Royal Astronomical Society from 1969 to 1971. (M 41028)

The name was suggested by S. Mitton.

\section{(8080) Intel}

$1987 \mathrm{WU}_{2}$. Discovered 1987 Nov. 17 by the CERGA at Caussols.

The Intel 8080 microprocessor is the ancestor of a series of microprocessor chips going from the $8086,8088,80286,80386,80486$ to today's Pentium processors. Fundamental to the "PC revolution", the 8080 did much to advance astronomy at amateur and professional observatories worldwide. (M 38197)

\section{(8081) Leopardi}

1988 DD. Discovered 1988 Feb. 17 at the Osservatorio San Vittore at Bologna.

Named in memory of Giacomo Leopardi (1798-1837), Italian poet and prose writer famous for his collection of poems I Canti and the collection of prose Operette Morali. When he was only 15 years old he wrote an erudite history of astronomy, recently reprinted in Italy. (M 32349)

\section{(8082) Haynes}

1988 NR. Discovered 1988 July 12 by E. F. Helin at Palomar.

Norman R. Haynes (1936- ） spent a 41-year career in the leadership of planetary exploration. He worked at the Jet Propulsion Laboratory and served as Voyager Project Manager, Systems Division Manager, Director for Telecommunications and Mission Operations and Director for Mars Exploration. (M 41935)

\section{(8083) Mayeda}

1988 VB. Discovered 1988 Nov. 1 by T. Seki at Geisei.

Named in memory of Shizuo (Haruhisa) Mayeda (1914-1952), amateur astronomer and pioneer Mars observer who studied changes in the colors of albedo features on that planet. (M 32791)

Name proposed by the discoverer following a suggestion by T. Sato and A. Fujii

\section{(8084) Dallas}

1989 CL $_{1}$. Discovered 1989 Feb. 6 by M. Koishikawa at Sendai.

Named for the city in Texas, Dallas is the international sister city of Sendai \{see planet (3133)\}, Japan, affiliated since 1997. Dallas, popularly called "BIG D", is among the principal cities of the American southwest. (M 33790)

\section{(8086) Peterthomas}

$1989 \mathrm{RB}_{6}$. Discovered 1989 Sept. 1 by E. Bowell at Palomar.

Named in honor of Peter C. Thomas (1946- ), planetary scientist at Cornell University. Thomas has been a pioneer and leader in developing geodetic methods of determining the precise shapes and spin characteristics of irregularly shaped minor planets from 
spacecraft images and in geologic studies of minor planets and related small bodies. (M 35489)

Name suggested by B. E. Clark and A. W. Harris, citation provided by J. Veverka.

\section{(8087) Kazutaka}

$1989 \mathrm{WA}_{2}$. Discovered 1989 Nov. 29 by K. Endate and K. Watanabe at Kitami.

Named in honor of Kazutaka Kato (1949- ), director of the Hiroshima City Planetarium. He was president of the Hiroshima Astronomical Society from 1975 to 1980 and was admired for his enthusiasm in presenting the universe to the general public in easily understood terms. His support activities at the society ranged from telescope design to discussions of astrophysical discoveries. (M 35489)

Name proposed by the discoverers following a suggestion by Y. Yamada.

\section{(8088) Australia}

1990 SL 27 . Discovered 1990 Sept. 23 by G. R. Kastel' and L. V. Zhuravleva at Nauchnyj.

Named for the continent in the Southern Hemisphere. With this naming the first discoverer pays tribute to the feelings she experienced during her recent visit to this marvelous country. (M 32791)

\section{(8089) Yukar}

$1990 \mathrm{TW}_{7}$. Discovered 1990 Oct. 13 by L. D. Schmadel and F. Börngen at Tautenburg.

Yurij Vasil'evich Karachkin (1940- ) is a teacher of physics at the school of the Crimean Astrophysical Observatory at Nauchnyj. Many of his pupils entered a university education. 'Yukar' is the husband of Lyudmila Karachkina \{see planet (8019)\}, discoverer of more than 100 minor planets and dear friend of the first discoverer. (M 36946)

\section{(8096) Emilezola}

$1993 \mathrm{OW}_{3}$. Discovered 1993 July 20 by E. W. Elst at La Silla.

Named in memory of the French writer Emile Zola (1840-1902), founder of the naturalist movement in literature. His writings show a credulous faith in science and an uncritical acceptance of scientific determinism. Although he believed that human nature was completely determined by heredity, he thought that it could be perfected. The controversial views expressed in his famous "J'accuse", published in the newspaper L'Aurore on 1898 Jan. 13, forced his flight to England. Nevertheless, he received a public funeral in France, and his remains are preserved in the Panthéon, although he never became a member of the Académie. (M 31299)

\section{(8097) Yamanishi}

1993 RE. Discovered 1993 Sept. 12 by K. Endate and K. Watanabe at Kitami.

Named in honor of Masahiro Yamanishi (1960-

), senior researcher at Saji ssee planet (8738)\}

Observatory. He was director of the Matsuyama planetarium, Ehime Prefecture, from 1987 to 1993 and secretary of the Astronomical Society of Shikoku from 1985 to 1993 . He is an active observer of minor planets and supernovae with the 1.03-m telescope in Saji and an enthusiastic popularizer of astronomy. (M 35490)

Name proposed by the discoverers following a suggestion by Y. Yamada.

\section{(8098) Miyamotoatsushi}

$1993 \mathrm{SH}_{2}$. Discovered 1993 Sept. 19 by K. Endate and K. Watanabe at Kitami.

Named in honor of Atsushi Miyamoto (1961-

), senior researcher at Saji \{see planet (8738)\} Observatory and a board member of the Tottori Society of Astronomy. In June 1997 he initiated one of Saji Observatory's first research projects, using its $1.03-\mathrm{m}$ telescope to make follow-up observations of the faint transneptunian objects. This resulted in the first such observation in Japan, when $1997 \mathrm{CS}_{29}$ was detected on 1997 Dec. 25. (M 35490)

Name proposed by the discoverers following a suggestion by Y. Yamada.

\section{(8100) Nobeyama}

1993 XF. Discovered 1993 Dec. 4 by M. Hirasawa and S. Suzuki at Nyukasa.

Named for a village in central Japan, famous for its beautiful scenery and night sky. Nobeyama Radio Observatory is located there. (M 32095)

\section{(8101) Yasue}

1993 XK $_{1}$. Discovered 1993 Dec. 15 by T. Kobayashi at Oizumi.

Kunio Yasue (1951- ), director of the Science Laboratory at Okayama Seishin University, has studied mathematical physics and quantum field theory. One of his major contributions to astronomy is his work on spontaneous symmetry braking at an early stage of the universe's evolution. (M 46681)

\section{(8103) Fermi}

1994 BE. Discovered 1994 Jan. 19 at the Farra d'Isonzo Observatory at Farra d'Isonzo.

Named in memory of the Italian physicist Enrico Fermi (1901-1954), winner of the 1938 Nobel Prize in physics for his demonstration of the existence of new radioactive elements produced by neutron irradiation and for the related discovery of nuclear reactions primed by slow neutrons. A many-sided personality, Fermi has been a star in the heavens of this century's physics, as shown in his studies of nuclear and particle physics. He is the second Italian Nobel laureate in physics, joining Guglielmo Marconi \{see planet (1332)\} (1909). (M 33790)

\section{(8106) Carpino}

1994 YB. Discovered 1994 Dec. 23 by M. Cavagna and P. Sicoli at Sormano.

Named in honor of Mario Carpino (1957- ), Italian astronomer at Brera Astronomical Observatory in Milan. From his initial studies of satellite geodesy, 
he acquired a taste for extreme accuracy in orbit determination, applying these skills to the study of the dynamics of solar-system bodies in projects such as LONGSTOP and SPACEGUARD. When the Spaceguard Foundation was established in Rome in 1996 he became its secretary. (M 31299)

Citation prepared by A. Milani at the request of the discoverers.

\section{(8108) Wieland}

1995 BC $_{16}$. Discovered 1995 Jan. 30 by F. Börngen at Tautenburg.

Named for the author Christoph Martin Wieland (1733-1813), a representative of the Rococo period, as well as of the German Enlightenment. Founder of modern German storytelling prose, he translated the works of Shakespeare \{see planet (2985)\} and other writers and paved the way to the German classical period. The complete edition of his works contains 42 volumes. From 1773 to 1810 he was editor of the journal Der Teutsche Merkur. In 1772, he was appointed educator of the young Prince Carl August at the court in Weimar \{see planet (3539)\}, where he was a highly respected member of Goethe's s see planet (3047)\} sphere. (M 31612)

\section{(8111) Hoepli}

1995 GE. Discovered 1995 Apr. 2 by A. Testa and V. Giuliani at Sormano.

Named in memory of Ulrico Hoepli (1847-1935), the founder of Hoepli Publishing Company and Hoepli International Bookstore in Milan. One of the greatest publishers of his time, Ulrico Hoepli published several important astronomy works within the 8000 titles the company printed; he was the publisher of G. V. Schiaparelli \{see planet (4062)\}. Today the company is still managed by the Hoepli family. A city patron and benefactor, in 1930 he donated a planetarium to the city of Milan, among the first in the world. (M 32791)

Citation prepared by Hoepli family.

\section{(8112) Cesi}

1995 JJ. Discovered 1995 May 3 at the Santa Lucia Observatory at Stroncone.

Named in memory of Federico Cesi (1585-1630), a scientist and humanist of the Italian Renaissance who devoted his life and property to the Academy of the Lincei, which he founded at the age of eighteen and of which Galileo \{see planet (697)\} was a member. He published numerous works about nature, including Galileo's "History and evidence about sunspots" and tables of classification for the animal, vegetable and mineral kingdoms. (M 33388)

\section{(8113) Matsue}

1996 HD$_{1}$. Discovered 1996 Apr. 21 by R. H. McNaught and $\mathrm{H}$. Abe at Yatsuka.

Named for a city in the ancient Izumo district in western Japan. A beautiful city rich in culture, history and archeological remains, Matsue has been designated as an International Cultural Center. (M 31299)

\section{(8114) Lafcadio}

$1996 \mathrm{HZ}_{1}$. Discovered 1996 Apr. 24 by H. Abe at Yatsuka.

Named in memory of Lafcadio Hearn (1850-1904). Born of an Irish father and Greek mother on the Ionian isle of Lefkás, he worked 20 years as a newspaper reporter in the United States before moving to Japan in 1890, changing his name to Yakumo Koizumi and becoming a naturalized Japanese citizen. He was commissioned by the Japanese Ministry of Education to teach in a Shimane prefectural junior high school in Matsue \{see planet (8113)\}, and from insights and impressions gleaned during his stay there he wrote his first and perhaps most famous major work on Japan, "Glimpses of Unfamiliar Japan". (M 31299)

\section{(8115) Sakabe}

$1996 \mathrm{HB}_{2}$. Discovered 1996 Apr. 24 by R. H. McNaught and Y. Ikari at Moriyama.

Named in honor of Sanjirou Sakabe (1923- ), an amateur astronomer who studied under the late Issei Yamamoto \{see planet (2249)\}. Sakabe is the founder of the Dynic Astronomical Observatory, which contributes to the spread of astronomy in the surrounding area. (M 32349)

\section{(8116) Jeanperrin}

1996 HA $_{15}$. Discovered 1996 Apr. 17 by E. W. Elst at La Silla.

Named in memory of the French physicist Jean Perrin (1870-1942), who studied Brownian motion and thereby confirmed the atomic nature of matter. At the same time he formed his ideas about the atom and its electrons, envisaging an atom as a small solar system, thereby anticipating the model by Rutherford. In 1926 he was honored with the Nobel prize in physics. The Centre National de la Recherche Scientifique and the Palais de la Découverte in Paris were created through his efforts. French astronomers especially honor him for his creation of the Observatoire de Haute Provence in 1936. (M 31299)

\section{(8117) Yuanlongping}

1996 SD $_{1}$. Discovered 1996 Sept. 18 at the Beijing Observatory at Xinglong.

Named in honor of Longping Yuan (1930- ), member of the Chinese Academy of Engineering, head of the National Hybrid Rice Engineering and Technical Research Center of China. As the founder of the Chinese hybrid rice research effort, he contributes greatly to great production in China and worldwide. He has won many international prizes and is honored as the "Father of Hybrid Rice" by foreign colleagues. (M 35490)

\section{(8120) Kobe}

1997 VT. Discovered 1997 Nov. 2 by H. Abe at Yatsuka. 
Named for the primary port on the Seto Island Sea since the eighth century and one of Japan's most cosmopolitan cities, where the discoverer lived for five years during his student days. Kobe has made a remarkable recovery from the great earthquake in 1995. (M 33790)

Name proposed by the discoverer and citation proposed by I. Hasegawa.

\section{(8121) Altdorfer}

2572 P-L. Discovered 1960 Sept. 24 by C. J. van Houten and I. van Houten-Groeneveld at Palomar.

Albrecht Altdorfer (c.1480-1538) is one of the painters of the "Donauschool". He created the first landscape paintings without figures. He was also an architect in the city of Regensburg \{see planet (927)\} and a member of the municipality. In addition to his paintings, many of his copper engravings and etchings have been preserved. (M 34345)

\section{(8122) Holbein}

4038 P-L. Discovered 1960 Sept. 24 by C. J. van Houten and I. van Houten-Groeneveld at Palomar.

Named after Hans Holbein Sr. (c.1465-1524) and Hans Holbein Jr. (c.1497-1543), German painters. Holbein Sr. created mostly religious paintings in the transition style from Gothic to Renaissance. Holbein Jr. is more famous, working in Basel, Switzerland and England. He became court painter to king Henry VIII and made well-known portraits of the English aristocracy and other famous people of the time. (M 34345)

\section{(8123) Canaletto}

3138 T-1. Discovered 1971 Mar. 26 by C. J. van Houten and I. van Houten-Groeneveld at Palomar.

Canaletto, whose birth name was Giovanni Antonio Canal (1697-1768), developed the so-called Veduten style of painting, characterized by detailed and precise views of cities. Best known for his paintings of Venice, he also painted London and Dresden. (M 34345)

\section{(8124) Guardi}

4370 T-1. Discovered 1971 Mar. 26 by C. J. van Houten and I. van Houten-Groeneveld at Palomar.

Painter Francesco Guardi (1712-1793) was influenced by Pietro Longhi and Canaletto \{see planet (8123)\}. Guardi's style is more impressionistic, however, and he plays with the colors of light in the Venetian atmosphere more than Canelotto. His paintings are typical of the Rococo style. (M 34345)

\section{(8125) Tyndareus}

5493 T-2. Discovered 1973 Sept. 30 by C. J. van

Houten and I. van Houten-Groeneveld at Palomar.

Named for a king of Sparta, father of Clytemnestra and Helena \{see planets (179) and (101)\}. Often it is said, however, that Tyndareus was the foster-father of Helena, because Helena is generally considered to have been the daughter of Zeus and Leda \{see, respectively, planets (5731) and (38)\}. (M 31612)

\section{(8128) Nicomachus}

1967 JP. Discovered 1967 May 6 by C. U. Cesco and

A. R. Klemola at El Leoncito.

Named for Nicomachus of Gerasa, first-century arithmetician and numerologist who has been credited with the discovery that 496 and 8128 are the third and fourth perfect numbers, i.e., numbers that are the sums of their factors (including unity but excluding the numbers themselves). The perfection of 6 and 28 was known to even earlier Greek and Hindu mathematicians. In 1644, Mersenne \{see planet (8191)\} showed that the sequence of perfect numbers is given by the product of $2^{n}-1$ and $2^{n-1}$, where $2^{n}-1$ is prime - as then is $\mathrm{n}$, which takes the values $2,3,5$ and 7 for the first four cases. (M 31612)

Name proposed by the second discoverer, following a suggestion by B. G. Marsden, who wrote the citation.

\section{(8130) Seeberg}

1976 DJ $_{1}$. Discovered 1976 Feb. 27 by F. Börngen at Tautenburg.

Named for the Seeberg Observatory, situated upon a well-marked hill close to the town of Gotha see planet (1346)\}. In the time of the duke Ernst II von Sachsen-Gotha-Altenburg (1745-1804) and the astronomer F. X. von Zach \{see planet (999)\}, it was an important center for astronomy. The first meeting of European astronomers took place at the Seeberg Observatory in August 1789. This naming honors the 200th anniversary of that conference, as well as the 1998 International Spring Meeting of the Astronomische Gesellschaft in Gotha, held on the occasion of this anniversary. (M 31612)

Named endorsed by P. Brosche.

\section{(8131) Scanlon}

1976 SC. Discovered 1976 Sept. 27 by E. F. Helin at Palomar.

Named in honor of Leo J. Scanlon (1903- ), prominent amateur whose interest in astronomy was sparked by seeing comet $1 \mathrm{P} /$ Halley in 1910. A plumber by profession, he built his own astronomical equipment and instructed others in telescope making. With Chester B. Roe he co-founded the Amateur Astronomers Association of Pittsburgh on 1929. The following year he built the first aluminum observatory dome. He observed variable stars, and he helped organize the Moonwatch team at the Allegheny Observatory in 1957. In 1985 he was happy to be able to observe comet 1P/Halley again. (M 32095; M 33817)

Name proposed by the discoverer, following a suggestion by T. P. Kohman, who prepared the citation.

\section{(8134) Minin}

1978 SQ7. Discovered 1978 Sept. 26 by L. V. Zhuravleva at Nauchnyj.

Kuz'ma Minich Zakhar'ev Sukhorukij (Kuz'ma Minin, d. 1616) was one of the organizers of the second people's volunteer corps in Nizhnij Novgorod \{see 
planet (7736)\} during 1611-1612. He displayed great action and personal bravery in the battle with Polish troops near Moscow and is a favorite national hero in Russia. (M 42357)

\section{(8137) Kvíz}

1979 SJ. Discovered 1979 Sept. 19 at the Klet Observatory at Kleť.

Named in memory of Zdeněk Kvíz (1932-1993), Czech astronomer. His early works dealt with meteor showers, although his main interest was in light curves of close binaries and eclipsing binaries. Beginning in 1968 he lived in Australia, working also in Switzerland. The Czech Astronomical Society prize for young astronomers bears his name. (M 32349)

Name suggested by J. Tichá

\section{(8141) Nikolaev}

$1982 \mathrm{SO}_{4}$. Discovered 1982 Sept. 20 by N. S. Chernykh at Nauchnyj.

Nikolaev is a city and large industrial and cultural center in southern Ukraine. The Nikolaev Astronomical Observatory was established there in 1821. (M 43381)

\section{(8142) Zolotov}

1982 UR $_{6}$. Discovered 1982 Oct. 20 by L. G. Karachkina at Nauchnyj.

Named in honor of Andrej Andreevich Zolotov (1937-

), Russian screenwriter and art and music critic. $\mathrm{He}$ is the author of more than 30 documentary films about Russian musicians, composers and conductors. (M 32349)

Name suggested by G. Spiridov and supported by the discoverer.

\section{(8145) Valujki}

$1983 \mathrm{RY}_{4}$. Discovered 1983 Sept. 5 by L. V. Zhuravleva at Nauchnyj.

The small Russian town of Valujki, founded in 1593 as a southern fortress of the Moscow State, is the center of the Valujki district of the Belgorod region. Located at a picturesque place near the confluence of the Valuj and Oskol rivers, it is a town of railwaymen and of workers in the food industry. (M 42357)

\section{(8146) Jimbell}

1983 WG. Discovered 1983 Nov. 28 by E. Bowell at Anderson Mesa.

Named in honor of James F. Bell III (1965- ), planetary scientist at Cornell University. Bell is noted for his interpretation of reflectance spectra of solarsystem objects. He has made important contributions to the identification of minerals on the surface of Mars and has played a key role in NEAR's investigation of (253) Mathilde and (433) Eros. (M 35490)

\section{(8147) Colemanhawkins}

$1984 \mathrm{SU}_{3}$. Discovered 1984 Sept. 28 by B. A. Skiff at Anderson Mesa.

Coleman Hawkins (1904-1969) was the first to bring the tenor saxophone to prominence as a solo instrument, helping transform it into the symbol of Jazz itself. His famous 1939 rendition of "Body and Soul" includes notes "outside the galaxy of his time". The name was suggested by Jane Ira Bloom. (M 36128)

\section{(8149) Ruff}

$1985 \mathrm{JN}_{1}$. Discovered 1985 May 11 by C. S. Shoemaker and E. M. Shoemaker at Palomar.

Jan Ruff (1949- ） is the very capable, warm-spirited and enthusiastic chief of the Office of Public Affairs for Goddard Space Center, NASA. Steve Ruff (1949- ) is an imaginative, creative and knowledgeable middleschool teacher with a wonderful dry sense of humor. (M 39650)

\section{(8150) Kaluga}

1985 QL $_{4}$. Discovered 1985 Aug. 24 by N. S. Chernykh at Nauchnyj.

Kaluga, a town in the Russian Federation and the focus of the Kalugian region, is a prominent industrial and cultural center. Founded in 1371, the town is much recorded in the history of Russia. The Tsiolkovsky \{see planet (1590)\} Museum of Cosmonautics and one of the oldest theaters in Russia are located there. (M 41383)

\section{(8151) Andranada}

1986 PK $_{6}$. Discovered 1986 Aug. 12 by L. V. Zhuravleva at Nauchnyj.

Andrej Vladimirovich Shakhov (1954- ) works in the faculty of diseases of the ear, nose and throat at the Nizhnij Novgorod \{see planet (7736)\} State Medical Academy. His wife, Natalia Mikhailovna Shakhova (1957- ) works in the faculty of midwifery and gynecology. (M 42357)

\section{(8154) Stahl}

1988 CQ . Discovered 1988 Feb. 15 by E. W. Elst at La Silla.

Named in memory of the German physician and chemist Georg Ernst Stahl (1660-1734), who developed the phlogiston theory of combustion, which dominated chemical thought for almost a century. Contrary to the view of his friend Friedrich Hoffmann at the University of Halle, who considered living organisms as machines to be explained by the laws of mechanics, Stahl insisted that neither mechanical nor chemical laws alone were sufficient to account for the phenomenon of life. Most likely influenced by his pietism, he insisted that life required a force for which he reserved the Latin word anima, which in turn gave rise to the theory of animism (vitalism). (M 34345)

\section{(8155) Battaglini}

1988 QA. Discovered 1988 Aug. 17 at the Osservatorio San Vittore at Bologna.

Named in memory of Giuseppe Battaglini (18261894), Italian mathematician. University professor of superior geometry at Naples and Rome, he was founder of the Giornale di Matematiche ad uso degli studenti delle Università Italiane. He introduced Italy to the 
non-Euclidean geometry of Lobachevskij \{see planet (1858)\}, and his translations of some of Todhunter's texts were used for many years by Italian university students. (M 33790)

\section{(8156) Tsukada}

1988 TR. Discovered 1988 Oct. 13 by K. Endate and K. Watanabe at Kitami.

Named in honor of Shinsuke Tsukada (1954-

), director of the Yonago City Planetarium, Tottori Prefecture, and an executive member of the San-in Society of Astronomy, the Tottori Society of Astronomy. Provider of varied and informative planetarium programs for the general public on an on-going basis, he spends his free evenings searching for comets. (M 35490)

Name proposed by the discoverers following a suggestion by Y. Yamada.

\section{(8158) Herder}

$1989 \mathrm{UH}_{7}$. Discovered 1989 Oct. 23 by F. Börngen at Tautenburg.

Named for Johann Gottfried Herder (1744-1803), German philosopher, theologian, writer, translator and collector of folk songs. Through his study of history, language, culture, and literature, he became a great authority on the history of the European mind. Through Goethe, he was appointed head clergyman at the court of Weimar s see planet (3539) in 1776. With Goethe, Schiller and Wieland see, respectively, planets (3047), (3079), (8108)\}, Herder is one of the four "Greats" of the Weimar classical period. (M 31612)

\section{(8159) Fukuoka}

$1990 \mathrm{BE}_{1}$. Discovered 1990 Jan. 24 by K. Endate and K. Watanabe at Kitami.

Named in honor of Takashi Fukuoka (1948- ), director of the planetarium at Sanbe Shizenkan Open Field Museum, Shimane Prefecture, and president of the San-in Society of Astronomy. A hardworking and painstaking planner of astronomy events and workshops, he is particularly concerned with meeting the needs of those new to astronomy in his local area. His main research is luminosity functions of globular clusters. (M 35490)

Name proposed by the discoverers following a suggestion by Y. Yamada.

\section{(8161) Newman}

$1990 \mathrm{QP}_{3}$. Discovered 1990 Aug. 19 at the Oak Ridge Observatory at Harvard.

Named in honor of Constance B. Newman (1935-

), Smithsonian Institution undersecretary whose unwavering devotion to the principles of exemplary management and diversity has enabled the Smithsonian to flourish and the Astrophysical Observatory to thrive. (M 32349)

\section{(8163) Ishizaki}

$1990 \mathrm{UF}_{2}$. Discovered 1990 Oct. 27 by T. Seki at Geisei.
Named in honor of Masako Ishizaki (1902- ), longtime Japanese amateur astronomer and pioneer in the study of meteoric dust. In particular, she studied dust collected for her at the Showa Base in Antarctica, where terrestrial contamination is low. (M 32791)

Name proposed by the discoverer following a suggestion by S. Morikubo, I. Hasegawa and T. Sato.

\section{(8164) Andreasdoppler}

$1990 \mathrm{UO}_{3}$. Discovered 1990 Oct. 16 by E. W. Elst at La Silla.

Named in honor of Andreas Doppler (1963- ), German amateur astronomer and identifier of minor planets. (M 34345)

This name was independently proposed by F. Börngen and L. D. Schmadel.

\section{(8165) Gnädig}

1990 WQ $_{3}$. Discovered 1990 Nov. 21 by E. W. Elst at La Silla.

Named in honor of Arno Gnädig (1956- ), German amateur astronomer and identifier of minor planets. (M 34345)

This name was independently proposed by F. Börngen and L. D. Schmadel.

\section{(8166) Buczynski}

$1991 \mathrm{AH}_{1}$. Discovered 1991 Jan. 12 by B. G. W. Manning at Stakenbridge.

Denis Buczynski (1951- ), of the Conder Brow Observatory, near Lancaster, England, is a keen amateur astronomer with many crucial observations of suspected new objects to his credit, in particular the very difficult confirmation of the nova V838 Her in 1991 in a bright morning sky. (M 41935)

\section{(8167) Ishii}

$1991 \mathrm{CM}_{3}$. Discovered 1991 Feb. 14 by K. Endate and K. Watanabe at Kitami.

Named in honor of Takahiro Ishii (1959- ), Japanese amateur astronomer and active owner of the Kamogawa Observatory, Chiba Prefecture. He is a strong supporter of neighborhood amateurs, and his contribution to popularizing and disseminating celestial photography techniques makes him welcome in gatherings nationwide. (M 35490)

Name proposed by the discoverers following a suggestion by Y. Yamada.

\section{(8168) Rogerbourke}

$1991 \mathrm{FK}_{1}$. Discovered 1991 Mar. 18 by E. F. Helin at Palomar.

Roger D. Bourke (1938- ) devoted his career to the furtherance of planetary exploration missions. At the Jet Propulsion Laboratory, he worked on mission design for Mariner Mars (1971), Mariner Venus-Mercury (1973), Voyager (1977) Grand Tour of the Outer Planets missions and the Mars Exploration Program. (M 41935) 


\section{(8169) Mirabeau}

$1991 \mathrm{PO}_{2}$. Discovered 1991 Aug. 2 by E. W. Elst at La Silla.

Named in memory of French politician and orator Honoré-Gabriel Mirabeau (1749-1791), one of the greatest figures of the early French Revolution. In 1789 he was elected deputy at the States General to represent Marseille and Aix-en-Provence. From May to October 1789 he played a decisive part in the battle between the Third Estate (common people) and the privileged orders (clergy and nobility). This made him very popular in Paris, but intrigues with the court and his Machiavellian game in general led him to political defeat, since he was too much a monarchist for the revolution and too revolutionary for the monarchy. However, he was given a magnificent funeral at the new church of Sainte-Geneviève, which, in honor of him, was converted into the Panthéon, for the burial of great men. (M 34345)

\section{(8171) Stauffenberg}

$1991 \mathrm{RV}_{3}$. Discovered 1991 Sept. 5 by F. Börngen and L. D. Schmadel at Tautenburg.

Named in honor of the German count Claus Graf Schenk von Stauffenberg (1907-1944), the driving force behind a conspiracy of German military and politicians to overthrow the fascist regime. An unsuccessful attempt on the fascist leader's life was carried out personally by Stauffenberg on 1944 July 20. This had far-ranging consequences that can not always be fully appreciated, even though the immediate outcome was the arrest of approximately 1000 and the execution of more than 200, including Stauffenberg, the very same day. (M 31612)

Name proposed by the first discoverer

\section{(8175) Boerhaave}

$1991 \mathrm{VV}_{5}$. Discovered 1991 Nov. 2 by E. W. Elst at La Silla.

Named in memory of the Dutch physician and professor of medicine Hermannus Boerhaave (16681738). He was a brilliant teacher of botany, medicine and chemistry at the University of Leiden, where students came from all parts of Europe to hear him. Baron d'Holbach and de Lamettrie ssee planets (6956) and (7095), respectively\} studied with him. He is credited with founding the modern system of teaching medical students at the patient's bedside. He is the author of Institutiones Medicae and Aphorismi de Cognoscendis et Curandis Morbis, two textbooks widely used during and after his lifetime. (M 34346; M 34673)

\section{(8181) Rossini}

$1992 \mathrm{ST}_{26}$. Discovered 1992 Sept. 28 by L. V. Zhuravleva at Nauchnyj.

Named in memory of the famous Italian composer Gioacchino Antonio Rossini (1792-1868). (M 34627)

\section{(8182) Akita}

1992 TX. Discovered 1992 Oct. 1 by M. Yanai and K. Watanabe at Kitami.
Named in honor of Isao Akita (1948- ), president of the comet observers network in Japan, "Hoshi no Hiroba", since 1988. He is a well-known amateur astronomer and keen observer and photographer of comets and galaxies. He is especially at home assisting in the efforts of other comet enthusiasts, both within his group and throughout the country. (M 35490)

Name proposed by the discoverers following a suggestion by Y. Yamada.

\section{(8184) Luderic}

1992 WL. Discovered 1992 Nov. 16 by S. Ueda and H. Kaneda at Kushiro.

Luderic Maury (1984- ) has been an amateur astronomer, eclipse chaser and the joy and pride of his parents ever since his birth in Nice. The number of the minor planet is the sum of 3780 and 4404, the numbers of the minor planets honoring his parents, Alain and Carine Maury. (M 39651)

\section{(8187) Akiramisawa}

1992 XL. Discovered 1992 Dec. 15 by S. Otomo at Kiyosato.

Botanist Akira Misawa (1942-1994), a professor at Chiba University, conducted research on the effects of light pollution on plants. (M 41935)

\section{(8189) Naruke}

$1992 \mathrm{YG}_{3}$. Discovered 1992 Dec. 30 by T. Hioki and S. Hayakawa at Okutama.

Giiti Naruke (1949- ） is the first Japanese to achieve two consecutive wins at the world championship for radio-controlled airplanes, and he is making every endeavor to bring up a future champion. (M 41028)

\section{(8190) Bouguer}

$1993 \mathrm{ON}_{9}$. Discovered 1993 July 20 by E. W. Elst at La Silla.

Named in memory of the French scientist Pierre Bouguer (1698-1758), the founder of astronomical photometry. In 1720 he made some of the earliest measurements in astronomical photometry by comparing the apparent brightness of celestial objects to the light of a candle. In 1735 he followed de la Condamine to measure an arc of the meridian near the equator in Peru. During his stay he investigated the absorption of light in the atmosphere, which led to the formulation of "Bouguer's absorption law". (M 34346)

\section{(8191) Mersenne}

$1993 \mathrm{OX}_{9}$. Discovered 1993 July 20 by E. W. Elst at La Silla.

Named for Marin Mersenne (1588-1648), French mathematician and philosopher, best known for his discovery of prime numbers of the form $2^{n}-1$ and that $\mathrm{n}$ is then necessarily also prime. The number $8191=2^{13}-1$ is the fifth Mersenne prime. Mersenne correctly verified that the numbers are prime also for $\mathrm{n}=17,19$ and 31 - and that they are not prime for $\mathrm{n}=11,23$ and 29. The largest prime Mersenne correctly established was for $n=127$. (M 31612) 
Name proposed by the discoverer, following a suggestion by B. G. Marsden, who wrote the citation.

\section{(8192) Tonucci}

1993 RB. Discovered 1993 Sept. 10 at the Santa Lucia Observatory at Stroncone.

Named in memory of Giuseppe Tonucci (1938-1988), Italian road and track cycling champion. During his long career he won numerous competitions throughout Europe, distinguishing himself in the Rome Olympic Games in 1960 and in the World Championship in the Netherlands. (M 33388)

\section{(8193) Ciaurro}

1993 SF. Discovered 1993 Sept. 17 at the Santa Lucia Observatory at Stroncone.

Named in memory of Ilario Ciaurro (1889-1992), an art teacher and ceramist, but most famous as a painter. His favorite subject was Terni, his adopted town, and he loved using etchings, poems and stories to explore its innermost aspects. (M 33388)

\section{(8194) Satake}

1993 SB $_{1}$. Discovered 1993 Sept. 16 by K. Endate and K. Watanabe at Kitami.

Named in honor of Masaaki Satake (1956- ), a Japanese amateur astronomer and secretary of the Kansai Astronomical Society since 1972. Active in organizing local star parties for amateur astronomers and lay persons alike, he is a part-time journalist rigorous in describing and recording astronomy-related events in his native city of Kyoto. (M 35490)

Name proposed by the discoverers following a suggestion by Y. Yamada.

\section{(8197) Mizunohiroshi}

1993 VX. Discovered 1993 Nov. 15 by T. Kobayashi at Oizumi.

Hiroshi Mizuno (1951- ), Okayama Seishin University, is a theoretician on the origin of our solar system. He developed a theory about the formation of thick atmospheres of giant planets, such as Jupiter, with intensive studies on the sudden accretion of gas onto the solid core. This mechanism is called the Mizuno process. (M 46681)

\section{(8199) Takagitakeo}

1993 XR. Discovered 1993 Dec. 9 by T. Kobayashi at Oizumi.

Takeo Takagi (1909-1982) played an active part in astronomical education as one of the first planetarians in Japan. In 1939 he joined the staff of the Osaka ElectricScience Museum, famous for its 1937 installation of the first planetarium in Japan. After retiring from the museum, he opened a private planetarium. (M 46681)

\section{(8200) Souten}

1994 AY $_{1}$. Discovered 1994 Jan. 7 by M. Hirasawa and S. Suzuki at Nyukasa.

Named for the Waseda University Astronomy Association, nicknamed Souten. Established in 1959 by Hidetaka Tojo, Souten has produced an astronaut and many astrophotographers and observers. The discoverers of this minor planet were members of Souten. (M 34346)

\section{(8202) Gooley}

$1994 \mathrm{CX}_{2}$. Discovered 1994 Feb. 11 by K. Endate and K. Watanabe at Kitami.

Named in honor of Barry Gooley (1956- ), president of the astronomy shop Kokusai Kohki in Kyoto. An American amateur astronomer at home observing anywhere from California deserts to the summit of Mt.F̃uj, he introduced amateur-level astronomical CCD imaging to Japan and is active in promoting information exchange between Japanese and overseas amateurs. (M 35490)

Name proposed by the discoverers following a suggestion by Y. Yamada.

\section{(8203) Jogolehmann}

$1994 \mathrm{CP}_{10}$. Discovered 1994 Feb. 7 by E. W. Elst at La Silla.

Named in memory of the German geologist Johann Gottlob Lehmann (1719-1767), who made important contributions to stratigraphy, the study of order and sequence in bedded sedimentary rocks. Educated originally at the University of Wittenberg as a medical doctor, he soon discovered that his real field of interest was mines and mining. He successfully explained the origin of mineral deposits in mines and recognized that rocks do not fall in haphazard positions but form a historical sequence, thereby supplying a strong argument against the biblical diluvian theory. (M 34346)

\section{(8204) Takabatake}

$1994 \mathrm{GC}_{1}$. Discovered 1994 Apr. 8 by K. Endate and K. Watanabe at Kitami.

Named in honor of Tohru Takabatake (1957- ), a junior-high-school teacher and secretary of the Okayama Astronomical Society. A gifted speaker, he delights in explaining cosmic mysteries to his students, accompanying his talks with photographs of celestial objects. His main interests are comets and solar eclipse observation. (M 35490)

Name proposed by the discoverers following a suggestion by Y. Yamada.

\section{(8205) Van Dijck}

$1994 \mathrm{PE}_{10}$. Discovered 1994 Aug. 10 by E. W. Elst at La Silla.

Named in memory of the Flemish painter Anthony Van Dijck (Van Dyck or Vandyke; 1599-1641), after Rubens the most prolific painter of the seventeenth century. His work embraces portraits of the European aristocracy, depictions of religious subjects and paintings of enchanting mythological stories. In contrast to Rubens, the lights and shades of Van Dijck are more abrupt, the figures less harmoniously proportioned and their expressions exaggerated. In 1632 Van Dijck was appointed court painter of king Charles I of England 
and was knighted the same year. His style influenced the great English portrait painters of the eighteenth century. (M 34627)

\section{(8208) Volta}

$1995 \mathrm{DL}_{2}$. Discovered 1995 Feb. 28 by P. Sicoli and P. Ghezzi at Sormano.

Named in memory of Alessandro Volta (1745-1827), physicist at the University of Pavia. His discovery of the significance of separating silver-zinc disk pairs with disks of moist cardbord was the key to his invention of the battery, just 200 years ago. Volta also made important contributions to meteorology and the study of gases, notably with his discovery of methane. (M 34627; M 34673)

\section{(8212) Naoshigetani}

$1995 \mathrm{EF}_{1}$. Discovered 1995 Mar. 6 by S. Otomo at Kiyosato.

Naoshige Tani (b.1925) is a member of the Photovoltaic Popularization Association in Japan and producer of the organization's web site. (M 41936)

\section{(8216) Melosh}

1995 FX $_{14}$. Discovered 1995 Mar. 27 by the Spacewatch at Kitt Peak.

H. Jay Melosh (1947- ）, of the Lunar and Planetary Laboratory, has worked on the formation of impact craters on the terrestrial planets and the "giant impact" origin of the moon. His "Panspermia" idea involves the ejection by impact of spall products containing microorganisms and their transfer to other planets. (M 38197)

\section{(8217) Dominikhašek}

1995 HC. Discovered 1995 Apr. 21 by P. Pravec and L. Šarounová at Ondřejov.

Named in honor of Dominik Hašek (1965- ), goalkeeper, and the Czech Olympic hockey team, winners of the gold medal at the 1998 Winter Olympic Games in Nagano. Although the success was basically due to teamwork, Hašek's contribution was the most significant. This great win in "the hockey tournament of the century" was widely appreciated by the Czech people and recognized as one of the greatest achievements in the history of Czech sport. (M 31613)

\section{(8218) Hosty}

1996 JH. Discovered 1996 May 8 by R. H. McNaught at Siding Spring.

John Graham Hosty (1949-2001) was the visual discoverer of the nova HS Sge from Huddersfield, West Yorkshire, in 1977. This find, made with a simple $10 \times 50$ monocular, encouraged others to join the U.K. Nova Patrol to look for such objects. (M 43042)

The name was suggested by G. M. Hurst and B. G. Marsden.

\section{(8220) Nanyou}

$1996 \mathrm{JD}_{1}$. Discovered 1996 May 13 by T. Okuni at Nanyou.
Named for the city where the discoverer lives and his observatory is located. Nanyou City lies to the north of Tokyo, two and a half hours away on the Yamagata \{see planet (7039)\} line (the new express train). It is famous for Akayu-onsen (hot springs), the Kumano shrine and Kikuningyou (a doll made of chrysanthemums). (M 32791)

\section{(8221) La Condamine}

1996 NA $_{4}$. Discovered 1996 July 14 by E. W. Elst at La Silla.

Charles-Marie de La Condamine (1701-1774), a French naturalist and mathematician, went to Peru (1735-1743) to measure the length of a meridional arc of one degree. On his way home he made important ethnographic observations, published as Journal $d u$ voyage fait par ordre du roi a l'équateur. (M 47163)

\section{(8222) Gellner}

1996 OX. Discovered 1996 July 22 by M. Tichý and Z. Moravec at Kleť.

Named in memory of Czech poet František Gellner (1881-1914), a Bohemian anarchist. His poetry depicted, sometimes in shocking ways, night life in a big city. He died in the front lines during World War I. (M 34346)

\section{(8223) Bradshaw}

1996 PD. Discovered 1996 Aug. 6 by P. G. Comba at Prescott.

Named for the Bradshaw mountains, which lie to the south of Prescott, Arizona. This area of sparsely populated pine-covered mountains provides a dark southern sky for the Prescott Observatory. The mountains themselves were named for William D. Bradshaw, a Western adventurer and miner. (M 31613)

\section{(8224) Fultonwright}

1996 PE. Discovered 1996 Aug. 6 by P. G. Comba at Prescott.

Named in honor of Fulton Wright, Jr. (1937- ), a friend of the discoverer, professor at Yavapai College, active amateur astronomer and telescope maker, and accomplished double bassist. (M 31613)

\section{(8225) Emerson}

1996 QC. Discovered 1996 Aug. 16 by C. F. Durman and B. M. Ewen-Smith at Portimão.

Named in memory of David Emerson (1943-1996), lecturer in astrophysics at the Royal Observatory, Edinburgh. His research interests were in the interaction of matter and radiation and star formation. He was director of studies of the first discoverer. Emerson was also an ordained lay-preacher in the Scottish Episcopal Church. He died at a relatively young age on 1996 Sept. 26, just a few weeks after the discovery was made. (M 31613)

Obituary published in Astron. Geophys., Vol. 38, Issue 4, p. 38 (1997). 


\section{(8229) Kozelský}

$1996 \mathrm{YU}_{2}$. Discovered 1996 Dec. 28 by M. Wolf and

L. Sarounová at Ondřejov.

Named in honor of František Kozelský (1913- ), a Czech telescope maker well-known for his work in collaboration with V. Gajdušek \{see planet (3603)\}. Kozelský made a set of unique fine-mechanics tools that allowed Gajdušek to produce a number of telescope mirrors, resulting finally in the production of six excellent $0.6-\mathrm{m}$ mirrors, two of them now used at the Ondřejov and the Klet observatories in telescopes devoted to observations of minor planets. Kozelský also made a series of eight $0.2-\mathrm{m}$ refracting telescopes, twenty $0.3-\mathrm{m}$ reflecting telescopes, and several coelostats for small observatories in Czech Republic and Slovakia. (M 32791)

Name proposed by the discoverers, following a suggestion by G. Polášek.

\section{(8230) Perona}

1997 TW 16 . Discovered 1997 Oct. 8 at the Santa Lucia Observatory at Stroncone.

Named in memory of Renato Perona (1927-1984), a track cycling champion who for more than a decade was the undisputed ruler in national and international competitions. He won the gold medal in the London Olympic Games in 1948. (M 33388)

\section{(8231) Tetsujiyamada}

1997 TX $_{17}$. Discovered 1997 Oct. 6 by K. Endate and K. Watanabe at Kitami.

Named in honor of Tetsuji Yamada (1952- ), a well-known amateur astronomer in western Japan and the first secretary of the Fukuoka Astronomical Society (1977-1981). He has a large astronomical following, complementing his strong interest in astronomy education. His major interests include observing planets and comets. (M 35490)

Name proposed by the discoverers following a suggestion by Y. Yamada.

\section{(8234) Nobeoka}

1997 VK $_{8}$. Discovered 1997 Nov. 3 by T. Seki at Geisei.

Named for a town in Miyazaki \{see planet (6905)\} prefecture, at the mouth of the Gokase River. Although it is the site of one of the largest chemical factories in Japan, it remains rich in natural beauty. The sound of the bell at the top of the castle hill is described in a poem by Bokusui Wakayama \{see planet (8367)\}. (M 33388)

Name proposed by the discoverer following a suggestion by T. Sato and R. Ukishima.

\section{(8235) Fragonard}

2096 P-L. Discovered 1960 Sept. 24 by C. J. van Houten and I. van Houten-Groeneveld at Palomar.

Jean-Honoré Fragonard (1732-1806) was a student of Boucher. Both teacher and pupil painted the colorful world of the Rococo aristocracy. In his landscape paintings Fragonard shows the influence of the Venetian artists. (M 34346)

\section{(8236) Gainsborough}

4040 P-L. Discovered 1960 Sept. 24 by C. J. van Houten and I. van Houten-Groeneveld at Palomar.

Named for Thomas Gainsborough (1727-1788), British portrait and landscape painter. He was strongly influenced by the Rococo style and Dutch landscape painting, and his work is characterized by luminous colors. His portraits often feature fine landscapes, and he is notable for painting not only the aristocracy of England but also its farmers. (M 34346)

\section{(8237) Constable}

7581 P-L. Discovered 1960 Oct. 17 by C. J. van Houten and I. van Houten-Groeneveld at Palomar.

Named for the English painter John Constable (1776-1837), known for his landscapes painted directly from nature. A forerunner of the Impressionists of the late nineteenth century, he is notable for his use of color. For some time he made portraits, but later he went back to landscape painting. (M 34346)

\section{(8238) Courbet}

4232 T-1. Discovered 1971 Mar. 26 by C. J. van Houten and I. van Houten-Groeneveld at Palomar.

Gustave Courbet (1819-1877) was an autodidact who studied nature and the great paintings in the Louvre. Initially his paintings were not accepted in the salons of Paris; he then held his own exhibition, which was a great success. His harmonious colors influenced the French and German Impressionists. (M 34346)

\section{(8239) Signac}

1153 T-2. Discovered 1973 Sept. 29 by C. J. van Houten and I. van Houten-Groeneveld at Palomar.

Paul Signac (1863-1935) worked together with Seurat $\{$ see planet (6678)\} to develop the technique of pointillism. For his pointillistic paintings Signac mostly chose water, ships and ports as subjects. After Seurat and Signac not many painters worked in this time-consuming method. (M 34346)

\section{(8240) Matisse}

4172 T-2. Discovered 1973 Sept. 29 by C. J. van Houten and I. van Houten-Groeneveld at Palomar.

Henri Matisse (1869-1954) studied at the School of Fine Arts in Paris. After traveling through Europe and the Pacific islands, he initially developed an Impressionistic style of painting. Later he became the leader of a new school, Fauvism, characterized by bold use of color and distorted forms. (M 34346)

\section{(8241) Agrius}

$1973 \mathrm{SE}_{1}$. Discovered 1973 Sept. 19 by C. J. van Houten and I. van Houten-Groeneveld at Palomar.

Named after Agrius, a Greek from Aetolia and father of Thersites \{see planet (1868)\}. Thersites was the ugliest Greek in Troy. (M 32791)

\section{(8244) Mikolaichuk}

$1975 \mathrm{TO}_{2}$. Discovered 1975 Oct. 3 by L. I. Chernykh at Nauchnyj. 
Ivan Vasilievich Mikolaichuk (1941-1987) was a talented Ukrainian cinema artist, scenario writer and film director. As such he was a brilliant phenomenon in the Ukrainian cinema already in the 1960s. (M 42669)

\section{(8246) Kotov}

$1979 \mathrm{QT}_{8}$. Discovered 1979 Aug. 20 by N. S. Chernykh at Nauchnyj.

Solar physicist Valerij Aleksandrovich Kotov (1943-

) has worked at the Crimean Astrophysical Observatory for more than 30 years. In the early 1970s he pioneered the field of helioseismology, the study of the interior structure and energy sources of the sun and other stars. (M 38198)

\section{(8248) Gurzuf}

$1979 \mathrm{TV}_{2}$. Discovered 1979 Oct. 14 by N. S. Chernykh at Nauchnyj.

Gurzuf is a small town near Yalta at the south coast of the Crimea ssee, respectively, planets (1475) and (1140)\}, praised by A. S. Pushkin \{see planet (2208)\}, who visited it in 1820. (M 38198)

\section{(8249) Gershwin}

1980 GG. Discovered 1980 Apr. 13 by A. Mrkos at Klě́t.

American composer George Gershwin (1898-1937) was also an accomplished pianist. In his compositions the techniques and forms of art music are blended in varying degrees with the stylistic nuances and techniques of popular music and jazz. (M 36946) The name was suggested by J. Tichá and M. Tichý.

\section{(8250) Cornell}

1980 RP. Discovered 1980 Sept. 2 by E. Bowell at Anderson Mesa.

Named for Cornell University, on the occasion of its hosting the "Asteroids, Comets, Meteors" conference in July 1999. Cornell was founded in Ithaca, New York, in 1865 by Ezra Cornell. An acknowledged center for discovery, academic leadership and service, it is, in a very real sense, a world treasure. The university operates the Arecibo \{see planet (4337)\} Observatory, the premier site for radar astronomy in the world, and it continues to play a leading role in the exploration of minor planets and comets by spacecraft. (M 35491) Name proposed and citation written by J. Veverka.

\section{(8251) Isogai}

1980 VA. Discovered 1980 Nov. 8 by T. Furuta at Tokai.

Rensuke Isogai (1941- ), a high-school classmate of the discoverer, is an electrical engineer and amateur astronomer. He influenced the discoverer in astronomy, who began to observe stars with a telescope borrowed from him. (M 41383)

\section{(8257) Andycheng}

$1982 \mathrm{HO}_{1}$. Discovered 1982 Apr. 28 by E. Bowell at Anderson Mesa.
Named in honor of Andrew F. Cheng (1951- ), planetary scientist at the Applied Physics Laboratory of Johns Hopkins University. Cheng served as the project scientist on the NEAR mission to (433) Eros and has made significant contributions to a wide variety of solar-system topics, including the study of magnetospheres and investigations of minorplanet surfaces and geodesy using LIDAR techniques. (M 35491)

Name proposed by the discoverer and B. E. Clark, and citation written by J. Veverka.

\section{(8262) Carcich}

1985 RG. Discovered 1985 Sept. 14 by E. Bowell at Anderson Mesa.

Named in honor of Brian T. Carcich (1956- ), developer of innovative computer software at Cornell University. Carcich has been responsible for developing key software used to acquire remote sensing data on spacecraft missions to minor planets and comets, including NEAR, Galileo and CONTOUR. (M 35491)

Name suggested and citation provided by J. Veverka.

\section{(8266) Bertelli}

1986 TC. Discovered 1986 Oct. 1 at the Osservatorio San Vittore at Bologna.

Named in memory of Francesco Bertelli (1794-1844), Italian astronomer at the observatory of Bologna and successor to P. Caturegli (1786-1833) as professor of astronomy at the University of Bologna. Only the first volume of his book, Elementi di Meccanica Celeste, was published at Bologna (1841) before his untimely death. He collaborated in the calculation of the Effemeridi, the annual publication initiated in 1715 by E. Manfredi (1674-1739) and that ceased with Bertelli's death in 1844. (M 33790)

\section{(8268) Goerdeler}

1987 SQ 10 . Discovered 1987 Sept. 29 by F. Börngen at Tautenburg.

Named in memory of Carl Friedrich Goerdeler (18841945), mayor of the towns of Königsberg and Leipzig, respectively (1920-1937). Early on he opposed the fascist dictatorship. After the outbreak of World War II, he became the leading force behind a Resistance group of conservative-minded Germans, planning a coup d'état against the fascist leader through contacts with a military opposition. Goerdeler's main goal was to restore and institutionalize a state of law. In September 1944, he was condemned to death by the Volksgerichtshof. (M 31613)

\section{(8269) Calandrelli}

1988 QB. Discovered 1988 Aug. 17 at the Osservatorio San Vittore at Bologna.

Named in memory of Ignazio Calandrelli (1792-1866), professor of optics and astronomy in Bologna and Rome. He served as director of the Bologna Observatory during 1845-1848 and of Campidoglio at Rome from 
1848 to his death. He was an observer of the major planets, minor planets and comets, as well as an orbit computer. (M 34627)

\section{(8270) Winslow}

1989 JF. Discovered 1989 May 2 by E. F. Helin at Palomar.

Named in honor of John Seymour Winslow, a friend of the discoverer's husband, Ron, since grade school. John graduated from Caltech with a degree in physics and later returned for a master's degree in electrical engineering. He developed the equipment used to master the MCA video disc, and later became a partner in Optical Disc Corporation, a firm that provides mastering equipment for compact discs. This minor planet was presented on the occasion of the 45th reunion of John and Ron's Caltech Class of ' 53 . (M 32350)

\section{(8273) Apatheia}

$1989 \mathrm{WB}_{2}$. Discovered 1989 Nov. 29 by M. Akiyama and T. Furuta at Mishima.

Apatheia is a philosophical word that means "an immovable soul" in Greek philosophy. The name was proposed by the first discoverer following a suggestion by children who come to the Hakone Youth Center. (M 39651)

\section{(8274) Soejima}

$1990 \mathrm{TJ}_{1}$. Discovered 1990 Oct. 15 by K. Endate and K. Watanabe at Kitami.

Named in honor of Tsutomu Soejima (1950- ), a Japanese amateur astronomer and secretary of the Saga Astronomical Society since 1989. He is a board member of the astronomical society's observatory, the Tara Observatory and the Saga City Observatory. His main interests are comet hunting and photography. (M 35491)

Name proposed by the discoverers following a suggestion by Y. Yamada.

\section{(8275) Inca}

$1990 \mathrm{VR}_{8}$. Discovered 1990 Nov. 11 by E. W. Elst at La Silla.

At the time of the Spanish conquest (1531-1539) the Inca state was a highly civilized and sophisticated empire. With Cuzco \{see planet (8279)\} as the capital, it covered the southern part of modern Ecuador, all of Peru and Bolivia and the northern part of Chile. The main language spoken throughout the empire was Quechua. (M 47163)

\section{(8276) Shigei}

1991 FL. Discovered 1991 Mar. 17 by S. Otomo and O. Muramatsu at Kiyosato.

Named in honor of Mika Shigei (1968- ), lecturer and curator of the Gotoh Planetarium and Astronomical Museum in Tokyo, where she was in charge of an exhibition on meteorites. (M 34346)
(8279) Cuzco

$1991 \mathrm{PN}_{7}$. Discovered 1991 Aug. 6 by E. W. Elst at La Silla.

Cuzco was the capital of the Inca empire. In Nov. 1533 the city was occupied by Pizarro. Severely damaged by an earthquake in 1650, Cuzco suffered again from an earthquake in May 1950, causing almost complete destruction of all churches and buildings from the colonial era. (M 47163)

\section{(8282) Delp}

$1991 \mathrm{RR}_{40}$. Discovered 1991 Sept. 10 by F. Börngen at Tautenburg.

Named in memory of the German theologian Alfred Delp (1907-1945). Beginning in 1942, he was a member of the illegal "Kreisauer Kreis" \{see planet (7945)\}, a group of political conservatives who worked to eliminate the Nazi regime. With this group, Delp collaborated on a first draft of a Christian social order for his country. Following the 1944 attempt on the fascist leader's life, he was condemned to death and executed in February 1945. (M 32350)

\section{(8284) Cranach}

$1991 \mathrm{TT}_{13}$. Discovered 1991 Oct. 8 by F. Börngen at Tautenburg.

Named in honor of the German painter, draftsman and copper engraver Lucas Cranach the Elder (14721553). As a friend of Luther and Melanchton \{see planets (7100) and (7906)\}, he is reputed to be the primary master of the German Reformation period. His first work is ascertainable in Vienna; beginning in 1505 , he was an esteemed court painter for the elector of Saxony Friedrich der Weise in Wittenberg. One of his best-known works is the altarpiece in the main church of Weimar \{see planet (3539)\}, which was completed by his son Lucas Cranch the Younger. (M 32095)

\section{(8286) Kouji}

1992 EK $_{1}$. Discovered 1992 Mar. 8 by K. Endate and K. Watanabe at Kitami.

Named in honor of Kouji Yamamoto (1956- ), a Japanese architect and active amateur astronomer. He has also been secretary of the Astronomical Society of Oita since 1993. His main interests revolve around high-resolution color photographs of obscure NGC/IC, PK and MCG objects. (M 35491)

Name proposed by the discoverers following a suggestion by Y. Yamada.

\section{(8289) An-Eefje}

$1992 \mathrm{JQ}_{3}$. Discovered 1992 May 3 by H. Debehogne at La Silla.

Named in memory of the two young Belgian women An and Eefje, whose young and hopeful lives came dramatically to an end in 1996. May their memory stand for all women throughout the world who suffer from abuse. (M 32095) 


\section{(8291) Bingham}

$1992 \mathrm{RV}_{1}$. Discovered 1992 Sept. 2 by E. W. Elst at La Silla.

Hiram Bingham (1885-1956), a member of the history faculty at Yale University, went searching for the lost city of the Incas. After tremendous effort he found it - Machu Picchu - high in the Andes, not far from Cuzco $\{$ see planet (8279)\}, on 1911 July 24. (M 47163; M 47243)

\section{(8294) Takayuki}

$1992 \mathrm{UM}_{3}$. Discovered 1992 Oct. 26 by K. Endate and K. Watanabe at Kitami.

Named in honor of Takayuki Kawabata (1959- ), president of astronomy shop Planet Town, Kumamoto, Kyushu Island. An active amateur astronomer and an avid fan of CCD imaging and image processing techniques, he is well respected for both his varied image library and his ability to find astronomical details usually unseen by others. (M 35491)

Name proposed by the discoverers following a suggestion by Y. Yamada.

\section{(8295) Toshifukushima}

$1992 \mathrm{UN}_{4}$. Discovered 1992 Oct. 26 by K. Endate and K. Watanabe at Kitami.

Named in honor of Toshio Fukushima (1954- ), a Japanese astronomer working mainly on general relativity, positional astronomy and celestial mechanics. $\mathrm{He}$ is current president of the IAU Commission 31 and served as chair of the local organizing committee for the IAU General Assembly in Kyoto in 1997. He created the current version of Japanese Ephemeris, published by the Japanese Hydrographic Department, and contributed to the introduction of general relativity into the current IAU system of time systems, reference frames and astronomical constants. He has been the director of the public relations center of the National Astronomical Observatory of Japan since 1998. (M 35491)

\section{(8296) Miyama}

1993 AD. Discovered 1993 Jan. 13 by K. Endate and K. Watanabe at Kitami.

Named in honor of Shoken M. Miyama (1951- ), Japanese astrophysicist working mainly on star and planet formation. He was the principal investigator on the observation team that first detected the protoplanetary disk around a single star using the Nobeyama \{see planet (8100)\} radio telescope. He was the first director of the public relations center of the National Astronomical Observatory of Japan and since 1996 has been the executive vice-director. (M 35491)

\section{(8297) Gérardfaure}

1993 QJ $_{4}$. Discovered 1993 Aug. 18 by E. W. Elst at Caussols.

Gérard Faure is a French amateur astronomer and member of the "Millennium Club". He performs visual estimates of minor planets with magnitude discrepancies, pushing the limiting magnitude with his C8 telescope as far as visual magnitude 16.0 (Magnitude Alert Program). In 1996 he saw his 1000th minor planet visually. (M 46681)

\section{(8298) Loubna}

1993 SQ $_{10}$. Discovered 1993 Sept. 22 by H. Debehogne and E. W. Elst at La Silla.

Named in memory of the Moroccan-Belgian girl Loubna, whose young life came abruptly to an end. May she stand as a symbol for a hopeful life in a multicultural society. (M 32095)

\section{(8299) Téaleoni}

$1993 \mathrm{TP}_{24}$. Discovered 1993 Oct. 9 by E. W. Elst at La Silla.

Téa Leoni (Téa Pantleoni, b. 1966), who studied anthropology and psychology, became an actress, much admired in the futuristic movie Deep Impact (1998). (M 47163)

\section{(8301) Haseyuji}

$1995 \mathrm{BG}_{2}$. Discovered 1995 Jan. 30 by T. Kobayashi at Oizumi.

Yuji Hase (1964-2002), an instructor of material technology at Kumamoto \{see planet (9993)\} technical high school, played a leading role in amateur astronomical computing and was an active founding member of Kumamoto Civil Astronomical Observatory. (M 47163)

\section{(8306) Shoko}

$1995 \mathrm{DY}_{1}$. Discovered 1995 Feb. 24 by A. Nakamura at Kuma.

Named in honor of Shoko Sawada (1962- ), Japanese singer and songwriter. Since her debut in 1979, she has released 52 singles and 22 albums, ranging from touching ballads to rhythmical pop songs. Her recordings have fascinated many fans in Japan, including the discoverer of this minor planet. (M 32095)

\section{(8307) Peltan}

1995 EN. Discovered 1995 Mar. 5 by J. Tichá at Kleť.

Named for the discoverer's family, including her mother Marie (nee Kosová) Peltanová (1930- ), her father Bohuslav Peltan (1927-1983), her brother Jiří Peltan (1953- ), her sister-in-law Adéla (1951- ) and her nephews Petr (1983- ) and Libor (1989- ). (M 34346)

\section{(8308) Julie-Mélissa}

1996 HD $_{13}$. Discovered 1996 Apr. 17 by E. W. Elst at La Silla.

Named in memory of the two Belgian children Julie and Mélissa, who were murdered tragically in 1996, symbolizing all innocent children suffering from abuse. (M 32096) 


\section{(8310) Seelos}

$1996 \mathrm{PL}_{2}$. Discovered 1996 Aug. 9 by the JPL NEAT Program at Haleakala.

Named in honor of Frank P. Seelos IV who, as a student at Wolford College, participated in the 1998 CalTech Summer Undergraduate Research Fellow program. He assisted and carried out research with the Near-Earth Asteroid Tracking program at the Jet Propulsion Laboratory and developed the software package HAVANA, which rapidly accesses images of specified objects from the extensive observational archive available. Frank is an outstanding student with a double major in physics and mathematics. (M 33790)

\section{(8311) Zhangdaning}

$1996 \mathrm{TV}_{1}$. Discovered 1996 Oct. 3 at the Beijing Observatory at Xinglong.

Named for Daning Zhang (1944- ), physician and vice-president of Tianjin Traditional Chinese Medicine (TCM) Hospital, professor of Tianjin Medical University, guest professor of Taiwan Chinese Academic College, chairman of the International TCM Kidney Diseases Conference. As the founder of the kidney diseases practice of TCM, he has won many international awards. He has written more than 60 publications on kidney disease. (M 32350)

\section{(8313) Christiansen}

$1996 \mathrm{YU}_{1}$. Discovered 1996 Dec. 19 at the Beijing Observatory at Xinglong.

Named in honor of Wilbur N. Christiansen (1913- ), foreign member of the Chinese Academy of Sciences and unfailing friend of Chinese astronomers. A pioneer in radio astronomy, he invented and developed a series of radio telescopes that in their time provided the highest angular resolution. These were the "grating telescope", the "grating cross" and the "rotational synthesis telescope". His textbook on radio telescopes, with Högbom, was translated into Russian and Chinese. Immediately after the discovery of the 21-cm hydrogen line in space, he confirmed this and went on to make the first map that showed we live in a spiral galaxy. He served as a vice president of the IAU and as president of URSI, and he now is an honorary president of URSI. (M 33388)

\section{(8314) Tsuji}

1997 US $_{8}$. Discovered 1997 Oct. 25 by K. Endate and K. Watanabe at Kitami.

Named in honor of Takashi Tsuji (1937- ～), Japanese astronomer working mainly on stellar atmospheres and spectroscopy. His major interest extends from cool luminous stars such as red giants, supergiants and carbon stars to very low luminous objects, including brown dwarfs. He received the academy prize of the Japan Academy in 1984 for "Theoretical studies of the outer layers of cool stars". He served as the director of the Institute of Astronomy, Faculty of Science, University of Tokyo, during 1992-1996. He has been professor emeritus of the University of Tokyo since 1998. (M 35491)

\section{(8315) Bajin}

$1997 \mathrm{WA}_{22}$. Discovered 1997 Nov. 25 at the Beijing Observatory at Xinglong.

Named in honor of Jin Ba (1904- ), president of the Chinese Writer's Association. He is one of the most influential Chinese writers since the May 4 New Culture Movement, an eminent master of Chinese literature in the twentieth century and an outstanding translator, editor and publisher. His works are widely disseminated around the world. (M 35491)

\section{(8316) Wolkenstein}

3002 P-L. Discovered 1960 Sept. 24 by C. J. van Houten and I. van Houten-Groeneveld at Palomar.

Named for Oswald von Wolkenstein (?1377-1445), one of the last minstrels. We know much about his life and times from his own songs, which have been preserved. At the age of ten he became shield-bearer for a knight and traveled throughout the world as a groom, cook and singer, eventually returning to his home castle of Wolkenstein in the Grödner valley in Tirol. He was also ambassador to the emperor Sigismund and traveled to England and the Iberian peninsula in his name. Especially interesting are his financial documents, which have all been saved and show the difficult position of knights around 1400 . (M 31791)

\section{(8317) Eurysaces}

4523 P-L. Discovered 1960 Sept. 24 by C. J. van Houten and I. van Houten-Groeneveld at Palomar.

Named for the son of Ajax by Tecmessa \{see, respectively planets (1404) and (604)\}, known for his enormous shield. (M 32791)

\section{(8318) Averroës}

1306 T-2. Discovered 1973 Sept. 29 by C. J. van Houten and I. van Houten-Groeneveld at Palomar.

Named for Averroës (1126-1198), whose Arabian name was Ibn Roschd Abdul Walid and who studied law and medicine in Córdoba. He brought together the philosophy of Aristotle \{see planet (6123)\}, Islam and Christianity. Both Islam and the Christian church, especially Thomas Aquinas, condemned him. Most of his publications have been translated into Latin. (M 32792)

\section{(8319) Antiphanes}

3365 T-2. Discovered 1973 Sept. 25 by C. J. van Houten and I. van Houten-Groeneveld at Palomar.

Named after the Greek comic poet Antiphanes (408330 B.C.). Today 119 complete titles and about 300 fragments are known. He wrote parodies of Sophocles, Euripides \{see planets (2921) and (2930), respectively\} and many different characters and professions. (M 34346) 
(8322) Kononovich

1978 RL $_{1}$. Discovered 1978 Sept. 5 by N. S. Chernykh at Nauchnyj.

Aleksandr Konstantinovich Kononovich (1850-1910) was a professor at Novorossisk University and head of the Odessa Astronomical Observatory for many years. A pioneer in astrophysics, he is known for his photometric observations of the planets, photographic observations of the Sun and research on solar prominences. (M 41383)

\section{(8323) Krimigis}

1979 UH. Discovered 1979 Oct. 17 by E. Bowell at Anderson Mesa.

Named in honor of Stamatios M. (Tom) Krimigis (1938- ）, head of the Space Department of the Applied Physics Laboratory of Johns Hopkins University and a specialist in solar, interplanetary and magnetospheric physics. Krimigis has been principal investigator or coinvestigator on several space experiments, including the Low Energy Charged Particle experiments on Voyagers 1 and 2 and the Active Magnetospheric Particle Tracer Explorers. He spearheaded the establishment of NASA's Discovery program, and his department is managing NEAR, the first Discovery mission. (M 35491)

\section{(8326) Paulkling}

$1981 \mathrm{JS}_{2}$. Discovered 1981 May 6 by C. S. Shoemaker and E. M. Shoemaker at Palomar.

Paul Kling, the Oberbürgermeister of Nördlingen in the Ries \{see, respectively, planets (5725) and (4327)\} Crater of Germany, has successfully guided the prosperity and well-being of this ancient, walled Bavarian city as it has grown and developed and enters the twenty-first century. (M 39651)

\section{(8327) Weihenmayer}

$1981 \mathrm{JE}_{3}$. Discovered 1981 May 6 by C. S. Shoemaker and E. M. Shoemaker at Palomar.

Erik Weihenmayer (1968- ), sightless since age 13, holds the unique distinction of being the first blind mountain climber to conquer Mt. Everest. His sense of adventure, courage, fortitude and perseverance have also led him to the summits of Denali, Kilimanjaro and Aconcagua \{see planet (1821)\} (M 43762)

\section{(8331) Dawkins}

1982 KK $_{1}$. Discovered 1982 May 27 by C. S. Shoemaker and S. J. Bus at Palomar.

Richard Dawkins (1941- ), chaired professor at Oxford University, is the author of the seminal work The Selfish Gene (1976) and other best-selling books on science and evolution. His novel concept of the ethology of genes revolutionized the study of evolution and animal behavior. He is the husband of actress Lalla Ward \{see planet (8347)\}. (M 41383)

\section{(8332) Ivantsvetaev}

1982 TL $_{2}$. Discovered 1982 Oct. 14 by L. V. Zhuravleva and L. G. Karachkina at Nauchnyj.
Named in honor of Ivan Vladimirovich Tsvetaev (18471913), art critic, professor of philology at the universities in Warsaw, Kiev, Moscow and St. Petersburg. He was the founder and first director of the Moscow Museum of Fine Arts and the director of the Rumyantsev \{see planet (5495)\} Museum. (M 34627)

\section{(8336) Šafařík}

1984 SK $_{1}$. Discovered 1984 Sept. 27 by A. Mrkos at Klět.

Named in memory of Vojtěch Šafařík (1829-1902), known for his work in inorganic chemistry, Czech chemical nomenclature and textbooks, as well as for his observations of variable stars. He obtained about 20000 observations of variable stars. This minor planet also honors the memory of his wife and co-worker Paulína Šafaříková (1836-1920), who was interested in the history and popularization of astronomy. (M 34347)

Name suggested by J. Tichá and M. Tichý.

\section{(8339) Kosovichia}

$1985 \mathrm{RM}_{6}$. Discovered 1985 Sept. 15 by N. S. Chernykh at Nauchnyj.

Aleksandr Georgievich Kosovichev (1953- ), solar physicist and helioseismologist, has worked at the Crimean Astrophysical Observatory and at Stanford University. The naming also honors his wife, Tatiana Ivanova Kosovicheva, a doctor who worked in the Crimean Astrophysical Observatory's medical office. (M 41383; M 41427)

\section{(8340) Mumma}

$1985 \mathrm{TS}_{1}$. Discovered 1985 Oct. 15 by E. Bowell at Anderson Mesa.

A researcher at NASA's Goddard Space Flight Center, Michael J. Mumma (1941- ) has identified $\mathrm{H}_{2} \mathrm{O}, \mathrm{CH}_{3} \mathrm{OH}, \mathrm{CH}_{4}, \mathrm{C}_{2} \mathrm{H}_{2}$ and $\mathrm{C}_{2} \mathrm{H}_{6}$ in the infrared spectra of comets, and his work on comets as x-ray objects has helped provide a new probe for the solar wind. (M 36128)

\section{(8343) Tugendhat}

$1986 \mathrm{TG}_{3}$. Discovered 1986 Oct. 4 by A. Mrkos at Kleť.

Tugendhat House is one of the most magnificent pieces of modern architecture in the Czech Republic. It was built by Mies van der Rohe in Brno in 1930 as a family villa of great elegance, following the idea of freely floating space. (M 42357)

The name was suggested by J. Tichá.

\section{(8345) Ulmerspatz}

$1987 \mathrm{BO}_{1}$. Discovered 1987 Jan. 22 by E. W. Elst at La Silla.

The Ulmer Spatz (sparrow) is a copper statuette originally on top of the roof of the cathedral of Ulm. The legend goes that a sparrow, building its nest, showed the builders of Ulm how to move a large beam through a small entrance door. (M 47163) 


\section{(8347) Lallaward}

1987 HK. Discovered 1987 Apr. 21 by C. S. Shoemaker and E. M. Shoemaker at Palomar.

Lalla Ward (1951- ) is a British stage, film and TV actress and artist. She played Ophelia in the BBC TV production of Hamlet (1980) and is best known for her work as Romana, a companion of "Dr. Who" in the British series of the same name. She is the wife of writer Richard Dawkins \{see planet (8331)\}. (M 41383)

\section{(8353) Megryan}

$1989 \mathrm{GC}_{4}$. Discovered 1989 Apr. 3 by E. W. Elst at La Silla.

Margaret Mary Emily Anne Hyra (Meg Ryan, b. 1961) majored in journalism and later became an actress. She showed her talent in You've got Mail (1999). (M 47164)

\section{(8356) Wadhwa}

$1989 \mathrm{RO}_{2}$. Discovered 1989 Sept. 3 by C. S. Shoemaker and E. M. Shoemaker at Palomar.

Named in honor of Meenakshi Wadhwa, known as Mini to her friends. Mini's studies of the microdistribution of trace elements in all known martian meteorites have led to a better understanding of the origin of these rocks and have contributed to the igneous history of planet Mars. Her use of extinct and long-lived radioisotopes to decipher the chronology of meteorites is bringing new insights into the formation of a variety of objects from different asteroidal bodies. As Curator of Meteorites, Minerals and Gems at the Field Museum of Natural History, she is actively involved in public education about meteorites and their parent asteroids. (M 33790)

Citation prepared by M. S. Robinson at the request of C. S. Shoemaker.

\section{(8357) O'Connor}

$1989 \mathrm{SC}_{1}$. Discovered 1989 Sept. 25 at the Oak Ridge Observatory at Harvard.

Named in honor of J. Dennis O'Connor (1942-

), internationally acknowledged biological scientist, provost and staunch proponent of research excellence at the Smithsonian Institution, and resolute champion of the programs of the Astrophysical Observatory. (M 32350)

\section{(8358) Rickblakley}

1989 VN $_{5}$. Discovered 1989 Nov. 4 by C. S. Shoemaker and D. H. Levy at Palomar.

Since building his first telescope at age 8, Rick Blakley (1949- ) has become a mostly self-taught mechanical, structural and optical engineer. $\mathrm{He}$ has designed instrumentation for several large telescopes, including every detail of the beautiful new stereomicroscope now in use for the Shoemaker-Levy Double Cometograph. (M 36946)

\section{(8367) Bokusui}

$1990 \mathrm{UL}_{2}$. Discovered 1990 Oct. 23 by T. Seki at Geisei.
Named in memory of Bokusui (Shigeru) Wakayama (1885-1928), one of the most beloved of Japanese poets. Born in a village in Miyazaki \{see planet (6905)\} prefecture, he graduated from the nearby Nobeoka \{see planet (8234)\} Middle School and later from Waseda University. Fond of both travel and sake, he wrote many poems about the joys and sorrows of life and nature. After his death, his complete works were published in 13 volumes. (M 33388)

Name proposed by the discoverer following a suggestion by R. Ukishima and T. Sato.

\section{(8370) Vanlindt}

1991 RK $_{11}$. Discovered 1991 Sept. 4 by E. W. Elst at La Silla.

Marianne Van Lindt (1941- ) is a well-known Belgian artist of impressionistic aquarels and oil paintings. Her home in Antwerp is a place of social encounters among artists, scientists and musicians. (M 45336)

\section{(8371) Goven}

$1991 \mathrm{TJ}_{14}$. Discovered 1991 Oct. 2 by C. P. de Saint-Aignan at Palomar.

The village of Goven in Brittany is the home of the Bernardinis, who were an extraordinary host family for the discoverer during his year-long stay there. Jean-Paul Bernardini served as a navigator in the French Marine during the 1960s, frequently practising the dying art of celestial navigation. (M 36128)

\section{(8373) Stephengould}

1992 AB. Discovered 1992 Jan. 1 by C. S. Shoemaker and E. M. Shoemaker at Palomar.

Stephen Jay Gould (1941- ） is a biologist, geologist and historian of science at Harvard, but he may be best known for his long-running series of reflective articles in Natural History in which he has articulated his view of evolution. In 1972, working with Niles Eldredge, he developed his idea of "punctuated equilibrium". (M 36946)

\section{(8374) Horohata}

$1992 \mathrm{AK}_{1}$. Discovered 1992 Jan. 10 by S. Otomo at Kiyosato.

Horohata is an open area in Ishikawa town, Fukushima prefecture, $250 \mathrm{~km}$ north of Tokyo. A large star party is held there each autumn. (M 42669)

\section{(8375) Kenzokohno}

$1992 \mathrm{AP}_{1}$. Discovered 1992 Jan. 12 by T. Seki at Geisei.

Named in honor of Kenzo Kohno (1934- ), staff member of Akashi Planetarium since 1960 and its director from 1982 to 1995 . He served as president of the Japan Planetarium Society from 1983 to 1984. In 1981, he was awarded the Minister's Prize by the Japanese Ministry of Education. (M 33388)

Name proposed by the discoverer following a suggestion by T. Sato and A. Fujii. 


\section{(8377) Elmerreese}

1992 SD $_{1}$. Discovered 1992 Sept. 23 by K. Endate and

K. Watanabe at Kitami.

Elmer J. Reese (1919- ), American amateur astronomer, was an important contributing observer in the early years of the Association of Lunar and Planetary Observers, serving on its volunteer staff. His hypothesis of subsurface sources to explain the South Equatorial belt disturbances at the cloud deck on Jupiter is well known. (M 39651)

\section{(8378) Sweeney}

$1992 \mathrm{SN}_{1}$. Discovered 1992 Sept. 23 by E. F. Helin at Palomar.

During 1990-2000, Donal F. Sweeney (1933- ) was director of the Jet Propulsion Laboratory's Occupational Health Services. Always a compassionate and caring physician, JPL employees appreciated his medical advice and enjoyed his quick wit. (M 42669)

\section{(8379) Straczynski}

$1992 \mathrm{SW}_{10}$. Discovered 1992 Sept. 27 by the Spacewatch at Kitt Peak.

Named in honor of J. Michael Straczynski (1954- ), creator, executive producer, and writer of Babylon 5, an award-winning science-fiction novel for television that chronicles the story of the last of a series of space stations, the last best hope for peace in the galaxy. Straczynski has been involved in genre television for many years, editing and writing for a number of popular series. He has also published many short stories, an anthology and two fantasy/horror novels. Straczynski's primary criterion for a good science-fiction television series is that it must be good science fiction and good television. With Babylon 5 he succeeded superbly. (M 33790)

Name proposed by J. Scotti, W. Bottke and D. Durda. Citation by D. Durda.

\section{(8380) Tooting}

1992 SW $_{17}$. Discovered 1992 Sept. 29 by H. E. Holt at Palomar.

Named for a suburb of London. Tooting's postal code is SW17. (M 32350)

Name suggested by E. Bowell, who lived in Tooting for 13 years as a youngster.

\section{(8381) Hauptmann}

1992 SO $_{24}$. Discovered 1992 Sept. 21 by F. Börngen at Tautenburg.

Named for the dramatist and writer Gerhart Hauptmann (1862-1946), a leading personality in the field of German naturalism. His work frequently depicts social problems and the ups and downs of life, often viewed from his homeland of Silesia. Beginning in 1904, he lived on Hiddensee, a small island in the Baltic Sea, where he was also buried. Hauptmann was honored with the 1912 Nobel Prize in literature. (M 32096)
(8382) Mann

1992 SQ $_{26}$. Discovered 1992 Sept. 23 by F. Börngen at Tautenburg.

Named in memory of Heinrich (1871-1950) and Thomas Mann (1875-1955), born in the Hanseatic town of Lübeck, both prominent German writers and social critics. In 1930, Heinrich became director of the section "Art of Creative Writing" of the Prussian Academy of Sciences. Thomas received the 1929 Nobel Prize for literature. After emigrating in 1933, they later settled in the United States. (M 32096)

\section{(8386) Vanvinckenroye}

$1993 \mathrm{BB}_{6}$. Discovered 1993 Jan. 27 by E. W. Elst at Caussols.

The Vanvinckenroyes are a well-known family of five organists in Antwerp and Limburg. The most famous of them is the composer Jef Vanvinckenroye (1939- ), a very good friend of the discoverer. (M 45336)

\section{(8387) Fujimori}

1993 DO. Discovered 1993 Feb. 19 by T. Seki at Geisei.

Named in honor of Kenichi Fujimori (1934- ), an amateur astronomer who observes sunspots, faculae and prominences. A formal observer designated by the Sunspot Index Data Center, he served as director of the solar section of the Oriental Astronomical Association from 1971 to 1978 . (M 33388)

Name proposed by the discoverer following a suggestion by T. Sato and A. Fujii.

\section{(8391) Kring}

$1993 \mathrm{HH}_{3}$. Discovered 1993 Apr. 20 by the Spacewatch at Kitt Peak.

David A. Kring (1961- ) of the Lunar and Planetary Laboratory is a prolific geologist and meteoriticist who has studied the mineralogy of meteorites and the structure of terrestrial impact craters, particularly the Chicxulub crater, playing an important role in determining its origin and relationship to the K-T extinction event. (M 39651)

\section{(8393) Tetsumasakamoto}

1993 TJ J $_{1}$. Discovered 1993 Oct. 15 by K. Endate and K. Watanabe at Kitami.

Tetsuma Sakamoto (1908- ）, Japanese agricultural scientist and specialist in sericultural technology, has been an amateur astronomer since 1923. He has enthusiastically observed sunspots, meteors, zodiacal light, the gegenschein and artificial satellites. (M 39651)

\section{(8395) Rembaut}

1993 TQ $_{23}$. Discovered 1993 Oct. 9 by E. W. Elst at La Silla.

Named in memory of Peter Rembaut (1966-1997), industrial engineer at the electronic laboratory at the Royal Observatory at Uccle, who died tragically in 1997. Of great help to the discoverer for improving the software for the Zeiss comparator-measuring device, he was esteemed by everyone at the observatory for his kindness and ability. (M 34347) 


\section{(8397) Chiakitanaka}

1993 XO. Discovered 1993 Dec. 8 by S. Otomo at Kiyosato.

Chiaki Tanaka (1953- ) is an astromomical photographer and writer of books and articles in astronomical magazines. His name often appears in the list of judges for stellar photographic contests in magazines. (M 45336)

\section{(8398) Rubbia}

1993 XY. Discovered 1993 Dec. 12 at the Farra d'Isonzo Observatory at Farra d'Isonzo.

Named in honor of the Italian physicist Carlo Rubbia (1934- ), winner of the 1984 Nobel Prize in physics for his decisive contribution to the large project that led to the discovery of the field particles $\mathrm{W}$ and $\mathrm{Z}$, communicators of weak interaction. His discovery has supplied a fundamental check of the unified theory of electro-weak interactions. He is the fourth Italian Nobel laureate in physics. (M 33790)

\section{(8401) Assirelli}

1994 DA. Discovered 1994 Feb. 16 at the Farra d'Isonzo Observatory at Farra d'Isonzo.

Even outside Italy, Italian photographer Giuseppe Assirelli (1950-1998) was well known for his exhibitions and for his many books of photographs, depicting the beauty of his land, his town, his river and his people. (M 46681)

\section{(8405) Asbolus}

1995 GO. Discovered 1995 Apr. 5 by the Spacewatch at Kitt Peak.

The "black one", Asbolus was the centaur who supposedly made forecasts from the flight formations of birds. He caused the battle between the centaurs and Heracles and thus was indirectly responsible for the deaths of Pholus and Chiron see planets (5145) and (2060), respectively\}. (M 36128)

\section{(8406) Iwaokusano}

1995 HJ. Discovered 1995 Apr. 20 by K. Endate and K. Watanabe at Kitami.

Iwao Kusano (1908-1999) was an orthopedist who contributed greatly to practice and research. As an amateur astronomer, he played an important role in investigating the Yonouzu meteorite, building a monument at the impact site at his own expense. The 30-kilogram stone had fallen near his home on 1837 July 14. (M 39651)

\section{(8407) Houlahan}

1995 ON. Discovered 1995 July 25 by P. G. Comba at Prescott.

Named in honor of Padraig Houlahan (1958- ). Although Houlahan studied astronomy, he has worked mainly as a computer expert at various institutions, lately at Lowell Observatory. When the discoverer was first attempting to do astrometry by measuring photographic prints, Houlahan suggested putting the prints through a digital scanner and measuring them with a computer. The method, although slow, gave satisfactory results. Thereafter Houlahan and the discoverer, working jointly, measured more than 200 prints, including 20 with images of this minor planet. (M 32096)

\section{(8408) Strom}

$1995 \mathrm{SX}_{12}$. Discovered 1995 Sept. 18 by the Spacewatch at Kitt Peak.

At the Lunar and Planetary Laboratory, Robert G. Strom (1933- ) studied the cratering record on the terrestrial planets and their satellites. He participated in both manned and unmanned exploration of the solar system and has searched for evidence of ancient oceans and ice sheets on Mars. (M 38198)

\section{(8410) Hiroakiohno}

$1996 \mathrm{QZ}_{1}$. Discovered 1996 Aug. 24 by S. Ueda and H. Kaneda at Kushiro.

Hiroaki Ohno (1948- ), director of Hoshinomura Observatory in Fukushima prefecture, is also a member of Shirakawa Observatory in Japan and Chiro Observatory in Australia. He is well known for his astrophotography and greatly contributes to the popularization of astronomy by frequent television and radio appearances. (M 41936)

\section{(8411) Celso}

1996 TO. Discovered 1996 Oct. 3 at the Farra d'Isonzo Observatory at Farra d'Isonzo.

Celso Macor (1925-1998), a poet in the Italian region of Friuli, gave voice to the little things that form our everyday lives. (M 36128)

\section{(8413) Kawakami}

$1996 \mathrm{TV}_{10}$. Discovered 1996 Oct. 9 by S. Ueda and H. Kaneda at Kushiro.

Isamu Kawakami (1948- ） is a member of Shirakawa Observatory in Japan and Chiro Observatory in Australia. He is a pioneer in amateur telescope-making and played an important role in the development of the 0.84-m Chiro Telescope and other large portable telescopes. (M 41936)

\section{(8414) Atsuko}

1996 TW $_{10}$. Discovered 1996 Oct. 9 by S. Ueda and H. Kaneda at Kushiro.

Atsuko Tsuji (1953- ) is a science journalist from Asahi Shinbun. When she was in the U.S., she regularly reported on the activities of NASA and Japanese astronauts. She is a member of Shirakawa Observatory in Japan and Chiro Observatory in Australia. (M 41936)

\section{(8416) Okada}

1996 VB$_{8}$. Discovered 1996 Nov. 3 by S. Ueda and H. Kaneda at Kushiro.

Yoshiyuki Okada (1947- ), a member of Shirakawa Observatory in Japan and Chiro Observatory in Australia, is a talented amateur who played an important role in developing large portable telescopes, 
including the 0.84-m Chiro Telescope. These telescopes went on nationwide tours to show the beauty of the starry sky. (M 41936)

\section{(8417) Lancetaylor}

$1996 \mathrm{VG}_{8}$. Discovered 1996 Nov. 7 by K. Endate and K. Watanabe at Kitami.

Lance Taylor (1956- ) is a science educator who teaches at high school and college in Western Australia. He is a leading member of Chiro Observatory, established and jointly operated by Australian and Japanese amateur astronomers. (M 39651)

\section{(8418) Mogamigawa}

$1996 \mathrm{VS}_{30}$. Discovered 1996 Nov. 10 by T. Okuni at Nanyou.

Named for the longest river in the discoverer's home prefecture Yamagata \{see planet (7039)\}. One of the three wildest rivers in Japan, Mogamigawa has its source in Mt. Azuma, south of Yamagata. It flows north and pours into the Sea of Japan in Sakata City. Called "Mother River", it is very popular in this area. (M 32792)

\section{(8419) Terumikazumi}

1996 VK$_{38}$. Discovered 1996 Nov. 7 by S. Ueda and H. Kaneda at Kushiro.

Brothers Terumi (1947- ) and Kazumi Akiyama (1952- ) are members of Shirakawa Observatory in Japan and Chiro Observatory in Australia. They are enthusiastic calculators of orbits of comets and minor planets and are also active in popularizing astronomy. (M 41936)

\section{(8420) Angrogna}

1996 WQ. Discovered 1996 Nov. 17 by P. G. Comba at Prescott.

Named for a village nestled in the Cottian Alps, in the Piedmont region of Italy, where the discoverer's paternal ancestors were born and lived for at least six generations. (M 32096)

\section{(8421) Montanari}

1996 XA $_{9}$. Discovered 1996 Dec. 2 at the Osservatorio San Vittore at Bologna.

Named in memory of Geminiano Montanari (16331687), professor of mathematics at university of Bologna during 1664-1678. He invented and improved several astronomical instruments, discovered the variability of Algol and drew fine lunar maps. (M 34627)

\section{(8422) Mohorovičić}

$1996 \mathrm{XJ}_{26}$. Discovered 1996 Dec. 5 at the Farra d'Isonzo Observatory at Farra d'Isonzo.

Andrija Mohorovičić (1857-1936), Austro-Hungarian seismologist, researched seismic wave propagation and epicenter determination. After the 1909 earthquake in Croatia he determined the discontinuity that divides the crust of the earth and the mantle that today is called MOHO. (M 46681)
(8423) Macao

$1997 \mathrm{AO}_{22}$. Discovered 1997 Jan. 11 at the Beijing Observatory at Xinglong.

Named in honor of Macao, the beautiful peninsula near Zhuhai \{see planet (2903)\}. An international tourist attraction as well as a free trading point, Macao is famous for its combination of Chinese and Western cultures. (M 32792)

\section{(8425) Zirankexuejijin}

$1997 \mathrm{CJ}_{29}$. Discovered 1997 Feb. 14 at the Beijing Observatory at Xinglong.

The concatenation $\mathrm{Zi}$ Ran, Ke Xue, Ji Jin, or "Nature", "Science", "Fund", is derived from Guo Jia Zi Ran Ke Xue Ji Jin Wei Yuan Hui, "The National Science Foundation of China", which is celebrating its fifteenth anniversary. The Foundation provides support for the Xinglong program. (M 43381)

\section{(8428) Okiko}

1997 VJ $_{8}$. Discovered 1997 Nov. 3 by T. Seki at Geisei. Kochi native Okiko Seki (1941- ), wife of the discoverer, has many hobbies, including yoga, dance and handicraft. (M 43189)

\section{(8430) Florey}

1997 YB $_{5}$. Discovered 1997 Dec. 25 by F. B. Zoltowski at Woomera.

Named in memory of Howard Walter Florey (18981968), celebrated pathologist, born and educated in South Australia. He and the biochemist Ernst Chain isolated penicillin and formulated procedures for its extraction and production, thereby enabling its largescale production during the latter part of World War II. For his work, he shared the 1945 Nobel Prize in physiology and medicine with Chain and Fleming. (M 34627)

\section{(8432) Tamakasuga}

1997 YD $_{18}$. Discovered 1997 Dec. 27 by A. Nakamura at Kuma.

Named in honor of Ryoji Matsumoto (1972- ), Japanese sumo wrestler whose professional name is Tamakasuga. Born in Ehime prefecture, where this minor planet was discovered, he became a professional wrestler in 1994. In 1996 he was promoted to "Makunouchi", the top division in the official listing of rank. Famous for his powerful "tsuki-oshi", or pushingthrusting style, Tamakasuga has won the Outstanding Performance Award, the Technique Prize and the Fighting Spirit Prize (twice) in his 26 tournaments. (M 32096)

\section{(8433) Brachyrhynchus}

2561 P-L. Discovered 1960 Sept. 24 by C. J. van Houten and I. van Houten-Groeneveld at Palomar.

Named for Anser brachyrhynchus, or pink-footed goose. \{It belongs to the family of the Anatidae.\} (M 33790; M 34089)

This species as well as many of those described in the citations that follow, are species whose presence 
in Europe is endangered. This bird is on the Dutch Blue List of endangered birds. It does not breed in the Netherlands, but stays there during the winter. Therefore it is of international importance for it to find feeding places there. The Netherlands is a very important feeding ground for many migratory birds. In particular the birds find food in the Wadden Sea and along the Dutch coast.

\section{(8434) Columbianus}

6571 P-L. Discovered 1960 Sept. 24 by C. J. van Houten and I. van Houten-Groeneveld at Palomar.

Named for Cygnus columbianus, also called Cygnus bewickii, or Bewick's swan. \{It belongs to the family of the Anatidae. Bewick's Swan comes from Northern Russia and stays along the North Sea in winter. In 1994 only 3,000 pairs of Cygnus columbianus were counted.\} (M 33790; M 34089)

\section{(8435) Anser}

6643 P-L. Discovered 1960 Sept. 26 by C. J. van Houten and I. van Houten-Groeneveld at Palomar.

Named for Anser anser, or grey-lag goose. \{It belongs to the family of the Anatidae. The bird is on the Dutch Blue List of endangered birds, coming from the East and staying in the Netherlands in great numbers during the winter. It is of international importance to find feeding places for them.\} (M 33790; M 34089)

\section{(8436) Leucopsis}

2259 T-1. Discovered 1971 Mar. 25 by C. J. van Houten and I. van Houten-Groeneveld at Palomar.

Named for Branta leucopsis, or barnacle goose. \{It belongs to the family of the Anatidae. The bird is on the Dutch Blue List of endangered birds. It comes from the Arctic and stays during the winter in the Netherlands.\} (M 33791; M 34089)

\section{(8437) Bernicla}

3057 T-1. Discovered 1971 Mar. 26 by C. J. van Houten and I. van Houten-Groeneveld at Palomar.

Named for Branta bernicla, or Brant goose. \{It belongs to the family of Anatidae. In 1994 only 1,000 pairs were counted. It is also on the 'List of Vulnerable Birds in Europe' and on the Dutch Blue List of endangered birds.\} (M 33791; M 34089)

\section{(8438) Marila}

4825 T-1. Discovered 1971 May 13 by C. J. van Houten and I. van Houten-Groeneveld at Palomar.

Named for Aythya marila, or greater scaup. \{It belongs to the family of Anatidae. The bird does not breed in the Netherlands, but stays there during the winter.\} (M 33791; M 34089)

\section{(8439) Albellus}

2034 T-2. Discovered 1973 Sept. 29 by C. J. van Houten and I. van Houten-Groeneveld at Palomar.

Named for Mergus albellus, or smew. \{It belongs to the family of the Anatidae. The bird does not breed in the Netherlands, but stays there during the winter.\} (M 33791; M 34089)

\section{(8440) Wigeon}

1017 T-3. Discovered 1977 Oct. 17 by C. J. van Houten and I. van Houten-Groeneveld at Palomar.

Named after the bird Anas penelope; wigeon is its English name. It belongs to the family of the Anatidae. It is on the Dutch Blue List of endangered birds. Although this bird does not breed in the Netherlands, it stays there during the winter. (M 34347; M 34089)

\section{(8441) Lapponica}

4008 T-3. Discovered 1977 Oct. 16 by C. J. van Houten and I. van Houten-Groeneveld at Palomar.

Named for Limosa lapponica, or bar-tailed godwit. \{It belongs to the family of the Scolopacidae. In 1994 only 2,200 pairs were counted. The bird does not breed in the Netherlands, but stays there during the winter.\} (M 33791; M 34089)

\section{(8442) Ostralegus}

4237 T-3. Discovered 1977 Oct. 16 by C. J. van Houten and I. van Houten-Groeneveld at Palomar.

Named for Haematopus ostralegus, or oyster catcher. \{It belongs to the family of the Haematopodidae and is on the Dutch Blue List of endangered birds. (M 33791; M 34089)

\section{(8443) Svecica}

4343 T-3. Discovered 1977 Oct. 16 by C. J. van Houten and I. van Houten-Groeneveld at Palomar.

Named for Luscinia svecica, or bluethroat. \{It belongs to the family of the Turdidae.\} (M 33791; M 34089)

\section{(8444) Popovich}

1969 TR $_{1}$. Discovered 1969 Oct. 8 by L. I. Chernykh at Nauchnyj.

Pavel Romanovich Popovich (1930- ), a Soviet cosmonaut and specialist in space engineering, participated in the flights of Vostok 4, Soyuz 14 and Salyut 3. He was the first person admitted to the cosmonaut detachment in 1960 and one of the first six candidates selected for training for the first space flights. (M 43381)

\section{(8445) Novotroitskoe}

1973 QG $_{2}$. Discovered 1973 Aug. 31 by T. M. Smirnova at Nauchnyj.

This minor planet is being named on the occasion of the 50th anniversary of the signing of the friendship agreement between Novotroitskoe, the district center of the Chersonian region in Ukraine, and the town of Genichesk \{see planet (2093)\}, Ukraine, birthplace of the discoverer. (M 40702)

\section{(8446) Tazieff}

1973 SB $_{6}$. Discovered 1973 Sept. 28 by N. S. Chernykh at Nauchnyj.

Garun Tazieff (Taziev; 1914-1998), Polish-born Belgian geologist, volcanologist and writer, was the author 
of books and films about volcanoes and earthquakes. An outstanding connoisseur of volcanoes, he was one of the best popularizers of earth science. (M 41383)

\section{(8448) Belyakina}

$1976 \mathrm{UT}_{1}$. Discovered 1976 Oct. 26 by T. M. Smirnova at Nauchnyj.

Named in honor of Tamara Sergeevna Belyakina (1934- ), astrophysicist and stellar photometrist who worked at the Crimean Astrophysical Observatory from 1955 to 1990. She is known for her multicolor photometric observations of symbiotic stars. She first discovered nonradial pulsations of red giants in such systems and proposed the interpretation of this phenomenon. (M 32350)

\section{(8449) Maslovets}

$1977 \mathrm{EO}_{1}$. Discovered 1977 Mar. 13 by N. S. Chernykh at Nauchnyj.

Bogdan Pavlovich Maslovets (1940- ), an electrical engineer at Zaporozhye Transformer Works in Ukraine, began his career at this plant in 1962 as a foreman and later become one of the leaders of the enterprise. (M 41028)

\section{(8450) Egorov}

1977 QL $_{1}$. Discovered 1977 Aug. 19 by N. S. Chernykh at Nauchnyj.

Vsevolod Aleksandrovich Egorov (1930-2001) was one of the founders of the modern theory of the space flight dynamics. One of the leading researchers at the Keldysh Institute of Applied Mathematics and a professor at Moscow University, he was a pioneer in studying trajectories from the earth to the moon. (M 45232)

\section{(8451) Gaidai}

1977 RY $_{6}$. Discovered 1977 Sept. 11 by N. S. Chernykh at Nauchnyj.

Leonid Iovich Gaidai (1923-1993) was a prominent Soviet film producer and Peoples' Artist of the U.S.S.R. He directed several comedies that were popular in Russia and other countries. (M 38198)

\section{(8452) Clay}

1978 WB. Discovered 1978 Nov. 27 at the Harvard College Observatory at Harvard.

Named in honor of Landon and Lavinia Clay and their four sons, steadfast friends of science and the arts, Harvard University and the Smithsonian Institution. They are in particular enthusiastic and penetratingly knowledgeable supporters of astronomy, conservation biology and mathematics. (M 32350; M 32561)

\section{(8470) Dudinskaya}

1982 SA $_{4}$. Discovered 1982 Sept. 17 by N. S. Chernykh at Nauchnyj.

Ballerina Natalia Mikhailovna Dudinskaya (1912- ) was a soloist with the Kirov Theatre of Opera and Ballet at Leningrad from 1931 to 1962. A People's artist of the U.S.S.R., she was dedicated to the traditions of Russian classical ballet. (M 41028)

\section{(8471) Obrant}

1983 RX $_{4}$. Discovered 1983 Sept. 5 by L. V. Zhuravleva at Nauchnyj.

The ballet-master, producer and teacher-humanist Arkadij Efimovich Obrant (1906-1974) organized and headed a children's dancing ensemble during the siege of Leningrad in 1942-1945. The first Obrant contest of choreographic art took place in St. Petersburg in March 2002. (M 45747)

\section{(8472) Tarroni}

1983 TC. Discovered 1983 Oct. 12 at the Osservatorio San Vittore at Bologna.

Named in memory of the Italian amateur astronomer Gino Tarroni (1958-1986), a member of the Sezione Astrofili dell'Università Popolare Sestrese. A fine observer of the sun, he was in charge of the solar section of the Unione Astrofili Italiani, and he served as secretary of the Unione for the four years preceding his tragic death in a road accident. Tarroni also had interests in speleology and mountain climbing. (M 34627)

\section{(8474) Rettig}

1985 GA $_{1}$. Discovered 1985 Apr. 15 by E. Bowell at Anderson Mesa.

Terrence W. Rettig (1946- ) is a planetary astronomer and educator at the University of Notre Dame who has contributed to the understanding of comets and the evolution of planet-forming regions around young stars. He has also served as the National Science Foundation Special Progams Director for Physics. (M 38198)

\section{(8475) Vsevoivanov}

$1985 \mathrm{PC}_{2}$. Discovered 1985 Aug. 13 by N. S. Chernykh at Nauchnyj.

Vsevolod Vladimirovich Ivanov (1934- ) is a professor at St. Petersburg University and a theoretical astrophysicist known for his works on the theory of radiation transfer. His monograph on theoretical astrophysics has been used as a textbook by two generations of students at Russian universities. (M 39651)

\section{(8485) Satoru}

1989 FL. Discovered 1989 Mar. 29 by T. Seki at Geisei.

Satoru Honda (1913- ), some time kindergarten principal, is the widow of Minoru Honda, famed comet and nova hunter. When light pollution affected her husband's observatory at Kurashiki \{see planet (4578)\} she spent her retirement allowance to purchase a new mountain site. (M 38198)

The name was suggested by K. Kenmotsu and T. Sato.

\section{(8488) d'Argens}

1989 SR $_{1}$. Discovered 1989 Sept. 26 by E. W. Elst at La Silla. 
Jean-Baptiste de Boyer Marquis d'Argens (1703-1771) was a French writer and freethinker who spent 25 years at the court of Frederick II. There he wrote his 18-volume Correspondence philosophique, which helped spread the ideas of the Enlightenment. (M 47164)

\section{(8489) Boulder}

1989 TA $_{3}$. Discovered 1989 Oct. 7 by E. W. Elst at La Silla.

Named for the city of Boulder, Colorado, about 48 $\mathrm{km}$ northwest of Denver. Settled in 1859 by miners and named for the large stones in the area, the University of Colorado was founded there in 1876, making Boulder a center for scientific and environmental research. The water supply for the city is unique, coming from the Arapahoe glacier high in the Rocky Mountains. The discoverer and his wife spent a year there at the JILA institution during 1967-1968. (M 34347)

\section{(8491) Joelle-gilles}

1989 YL $_{5}$. Discovered 1989 Dec. 28 by E. W. Elst at St. Michel.

Joelle (1978- ～) and Gilles (1980- ） are the children of Martina Devos and Alain Meerbergen, close friends of the discoverer and his family. They spent a marvelous vacation together at Haute Provence, where this minor planet was discovered. (M 47164)

\section{(8492) Kikuoka}

1990 BZ. Discovered 1990 Jan. 21 by T. Seki at Geisei.

Hidekazu Kikuoka (1941- ) has been a planetarium educator at the Osaka Municipal Electric Science Museum and at the Science Museum of Osaka. He founded the Japan Astronomical Club in 1955 and served as its president during 1965-1985. (M 38198) The name was suggested by T. Sato and K. Kitao.

\section{(8494) Edpatvega}

$1990 \mathrm{OT}_{4}$. Discovered 1990 July 25 by H. E. Holt at Palomar.

Ed (1931- ) and Pat (1944- ) Vega have been a dynamic astronomical team for many years. Drawing on his experience as a pathologist, Ed Vega has completed a study, called "Comet Disaster", of the long-term effects to humanity of a large comet's impact on the earth. (M 42357)

\section{(8496) Jandlsmith}

$1990 \mathrm{QO}_{3}$. Discovered 1990 Aug. 16 at the Oak Ridge Observatory at Harvard.

Named in honor of Jim and Laurie Smith in recognition of their generosity and wisdom in the support of forefront tools to explore the heavens to the benefit of all of humanity. Most especially, their support was crucial for Harvard University's participation in the Magellan Project. (M 33388)

\section{(8498) Ufa}

$1990 \mathrm{RM}_{17}$. Discovered 1990 Sept. 15 by L. V. Zhuravleva at Nauchnyj.
The city of Ufa is a large industrial and cultural center in the south Urals. Founded in 1574, it is the capital of Bashkir \{see planet (2657)\}, a republic in the Russian Federation. (M 38198)

\section{(8500) Hori}

1990 TU. Discovered 1990 Oct. 10 by K. Endate and K. Watanabe at Kitami.

Named in honor of Gen-Ichiro Hori (1930- ), professor emeritus at Tokyo University who gave lectures on celestial mechanics at Tokyo University, Yale University and the University of Texas at Austin. He developed the famous perturbation theory based on Lie transformations that has been adopted by many scientists to solve a set of differential equations by perturbation methods. In fact, his publication on this in 1966 is the most frequently cited paper during the 50-year history of the Publication of the Astronomical Society of Japan. (M 32792)

Name proposed by the discoverers, following a suggestion by S. Murayama, K. Hurukawa and A. Fujii, and endorsed by Y. Kozai, K. Aksnes and B. G. Marsden.

\section{(8501) Wachholz}

$1990 \mathrm{TK}_{8}$. Discovered 1990 Oct. 13 by L. D. Schmadel and F. Börngen at Tautenburg.

Burkhard Wachholz (1940-2000), a dear friend of the first discoverer, was longstanding senior chief mechanic and department head at the Institute of Physics, University of Heidelberg. His wealth of ideas and excellent craftmanship, as well as his readiness to help, were indispensable for countless projects. (M 39651)

\section{(8502) Bauhaus}

1990 TR $_{12}$. Discovered 1990 Oct. 14 by F. Börngen and L. D. Schmadel at Tautenburg.

Named for the school of design founded in 1919 by the German architect W. Gropius (1883-1969) in Weimar \{see planet (3539)\}. The school's philosophy emphasized the unity of fine art and trade as the basis for artistic work. By incorporating engineering, the way was open for industrial design. The Bauhaus moved to Dessau in 1925 and was closed by the Nazis for its "decadence" in 1932. Many Bauhaus masters emigrated to the United States. In 1937, the New Bauhaus was founded by L. Moholy-Nagy (1895-1946) in Chicago. (M 32350)

Name proposed by the first discoverer.

\section{(8503) Masakatsu}

$1990 \mathrm{WX}_{3}$. Discovered 1990 Nov. 21 by K. Endate and K. Watanabe at Kitami.

Masakatsu Fujimoto (1948- $\quad$ ) played a leading role in constructing a laser interferometric gravitational wave detector, TAMA-300, which is the only interferometrictype detector in operation for gravitational waves emitted by a neutron-star binary or by supernovae in nearby galaxies. (M 39651) 


\section{(8521) Boulainvilliers}

$1992 \mathrm{GF}_{4}$. Discovered 1992 Apr. 4 by E. W. Elst at La Silla.

Named in memory of Henri de Boulainvilliers (1658-1722), French historian and political writer who influenced intellectual developments in the French Enlightenment. Claiming that historical studies can supply the tools for analyzing the present state of society, he worked out a theory of comparative historical study which approached the later writings of Montesquieu \{see planet (7064)\}. In 1683 he published his L'Idée d'un système général de la Nature, which anticipated Holbach's \{see planet (6956)\} Système de la Nature (1770). His Histoire de la religion et de la philosophie ancienne was published around 1700 . (M 34347; M 34673)

\section{(8523) Bouillabaisse}

1992 PX. Discovered 1992 Aug. 8 by E. W. Elst at Caussols.

Named for the famous French fish soup, the glory of Provençal cooking. It contains fish, shellfish, olive oil, onions, tomatoes, garlic, parsley, saffron, fennel, thyme, bay leaf and orange peel (according to the Marseille recipe). All ingredients must be boiled together quickly. (M 34347)

\section{(8524) Paoloruffini}

$1992 \mathrm{RJ}_{3}$. Discovered 1992 Sept. 2 by E. W. Elst at La Silla.

Named in memory of the famous Italian mathematician and physician Paolo Ruffini (1765-1822). In 1799 he published a book on the theory of equations, with the claim that the solution by radicals of a general equation of degree greater of four is impossible. Initially the mathematical community showed no interest in his work. However, in 1821 his work was acknowledged by Cauchy, who was influenced by his investigations and had generalized some of Ruffini's results. Due to political problems he had to leave his chair in mathematics at Modena and begin a career in medicine, tending to patients from the poorest to the richest. (M 34347)

\section{(8525) Nielsabel}

1992 RZ $_{5}$. Discovered 1992 Sept. 2 by E. W. Elst at La Silla.

Named in memory of the famous Norwegian mathematician Niels Henrik Abel (1802-1829). In 1824 he proved the impossibility of solving a general equation of the fifth degree by radicals. Through his friendship with the editor Crelle, who encouraged him in his work, he wrote his masterpiece Recherches sur les fonctions elliptiques (1827), from which he could prove that Jacobi's \{see planet (12040)\} work on elliptic integrals were consequences of his own work. It is interesting to note that neither Gauss \{see planet (1001)\} nor Cauchy showed interest in Abel's work. (M 34347)

\section{(8526) Takeuchiyukou}

$1992 \mathrm{SM}_{12}$. Discovered 1992 Sept. 23 by K. Endate and K. Watanabe at Kitami.

Yukou Takeuchi (1932- ), Japanese amateur astronomer, designed a quartet camera system with a rotating shutter to measure the velocity of meteors, a system that he later improved to be automatic. In 1990 he began video observation with an image intensifier. (M 39651)

\section{(8527) Katayama}

$1992 \mathrm{SV}_{12}$. Discovered 1992 Sept. 28 by K. Endate and K. Watanabe at Kitami.

Using unparalleled techniques in electron microscopy, Japanese biophysicist Eisaku Katayama (1949- ) revealed molecular shapes of various proteins in their functional states with a resolution that can only be superseded by x-ray study. He also contributed to new techniques in astronomical photography. (M 39651)

\section{(8529) Sinzi}

$1992 \mathrm{UH}_{2}$. Discovered 1992 Oct. 19 by K. Endate and K. Watanabe at Kitami.

Akira M. Sinzi (1922- ) directed the astronomical division of the Hydrographic Department of Japan and was president of IAU Commission 4 during 1979-1982. Although his death has not been confirmed, he disappeared while mountain-climbing alone in the Kanto area in 1995. (M 41028)

The name was suggested by A. Sengoku.

\section{(8530) Korbokkur}

1992 UK $_{5}$. Discovered 1992 Oct. 25 by M. Hirasawa and S. Suzuki at Nyukasa.

According to the legend of the Ainu people of northern Japan, the members of the Korbokkur tribe were only 3 to $6 \mathrm{~cm}$ tall and moved so swiftly they were difficult to see. Satoru Sato began publishing Korbokkur tales in 1959. They are very popular in Japan, and not only for children. (M 36946)

\section{(8531) Mineosaito}

$1992 \mathrm{WX}_{2}$. Discovered 1992 Nov. 16 by K. Endate and $\mathrm{K}$. Watanabe at Kitami.

Mineo Saito (1952-2000) was the founder and an active leader of the Ohkuma Astronomical Club in Kakuda City, Miyagi prefecture. He was devoted to the popularization of astronomical activities. (M 41383)

\section{(8533) Oohira}

1993 BM. Discovered 1993 Jan. 20 by T. Urata at Oohira.

The Oohira station of Nihondaira \{see planet (2880)\} Observatory, where this object was discovered, was very active in making observations of comets and minor planets from 1987 to 2000. (M 47164)

\section{(8534) Knutsson}

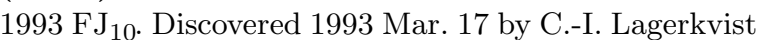
at La Silla. 
Named in memory of Gösta Knutsson (1908-1973), Swedish author and radio producer who introduced quiz programs to Sweden. His children's stories about the cat Pelle Svanslös \{see planet (8535)\} and his adventures in Uppsala have been very popular. The author of twelve books, the first in 1939, Knutsson lived not far from the locations where many of the adventures take place. (M 33791)

\section{(8535) Pellesvanslös}

$1993 \mathrm{FH}_{22}$. Discovered 1993 Mar. 21 by C.-I. Lagerkvist at La Silla.

Named for the fictional character Pelle Svanslös, a brave cat that appears in Gösta Knutsson's \{see planet (8534)\} children's stories. Some of the adventures of this cat, whose tail was bitten off by a rat when he was only a few days old, take place in the section of Uppsala where the astronomical observatory is located. (M 33791)

\section{(8536) Måns}

1993 FK $_{23}$. Discovered 1993 Mar. 21 by C.-I. Lagerkvist at La Silla.

Named for the fictional cat Måns, the eternal "bad guy" in the Knutsson \{see planet (8534)\} stories, always devising new ways of ridiculing Pelle Svanslös \{see planet (8535)\} over his nonexistent tail. (M 33791)

\section{(8537) Billochbull}

1993 FG $_{24}$. Discovered 1993 Mar. 21 by C.-I. Lagerkvist at La Silla.

Named for the fictional cats Bill and Bull, dim and fawning cronies of the bad cat Måns \{see planet (8536)\} of the Knutsson \{see planet (8534)\} stories. (M 33791)

\section{(8538) Gammelmaja}

1993 FR $_{26}$. Discovered 1993 Mar. 21 by C.-I. Lagerkvist at La Silla.

Named for Gammelmaja, an old and wise cat who seldom fails to notice when Pelle \{see planet (8535)\} is being treated unfairly and often takes his side in arguments. She lives in the belfry of the Uppsala cathedral. (M 33791)

\section{(8539) Laban}

$1993 \mathrm{FT}_{32}$. Discovered 1993 Mar. 19 by C.-I. Lagerkvist at La Silla.

Named for the Knutsson's \{see planet (8534)\} fictional cat Laban. He lived in the Observatory park in Uppsala and gave his name to one of the first modern computers at the Astronomical Observatory. (M 33791)

\section{(8541) Schalkenmehren}

$1993 \mathrm{TZ}_{32}$. Discovered 1993 Oct. 9 by E. W. Elst at La Silla.

Schalkenmehren is a small village not far from the city of Daun \{see planet (8665) $\}$ in the German Ardennes (Eifel). A small road leads to the Observatory of Hoher List \{see planet (14872)\}. (M 47164)

\section{(8543) Tsunemi}

$1993 \mathrm{XO}_{1}$. Discovered 1993 Dec. 15 by T. Kobayashi at Oizumi.

Hiroshi Tsunemi (1951- ), Osaka University, has worked in x-ray astronomy as a chief scientist of the $\mathrm{x}$-ray observing satellite ASCA. His scientific interest is focused on the structure and chemical composition of supernova remnants and related highenergy phenomena, as well as on the design of new x-ray detectors. (M 46681)

\section{(8544) Sigenori}

1993 YE. Discovered 1993 Dec. 17 by T. Kobayashi at Oizumi.

Sigenori Miyamoto (1931- ) is one of the pioneers of x-ray astronomy in Japan. In 1958, he invented a spark chamber that has been widely used for measuring the path of charged particles. Later, he started studies on x-ray objects and discovered the short time flux variation of x-ray sources. (M 46681)

\section{(8545) McGee}

$1994 \mathrm{AM}_{1}$. Discovered 1994 Jan. 2 by B. G. W. Manning at Stakenbridge.

Hazel McGee was meetings secretary of the British Astronomical Association \{see planet (4522)\} from 1988 to 1993 and has been editor of the association's Journal since 1994, carrying out this task most efficiently and introducing many improvements. She is an enthusiastic observer of variable stars and of stellar occultations by minor planets. (M 42357)

\section{(8546) Kenmotsu}

$1994 \mathrm{AH}_{3}$. Discovered 1994 Jan. 13 by K. Endate and K. Watanabe at Kitami.

Kunio Kenmotsu (1932- ) has been director of the Kurashiki Observatory since 1990. For many years he was an astronomer in the Hydrographic Department of the Maritime Safety Agency of Japan. He also served successively as director of its hydrographic stations in Shimosato, Kurashiki and Bisei from 1976 to 1989. (M 41383)

\section{(8548) Sumizihara}

$1994 \mathrm{ER}_{3}$. Discovered 1994 Mar. 14 by K. Endate and K. Watanabe at Kitami.

Sumizi Hara (1878-1968) provided the means for establishing the Kurashiki \{see planet (4578)\} Observatory in 1926 and for operating it thereafter. The observatory is open to the general public and was the first of its kind in Japan. Hara was awarded many prizes, including "Honorary Citizen of Kurashiki City". (M 41383)

\section{(8549) Alcide}

1994 FS. Discovered 1994 Mar. 30 at the Farra d'Isonzo Observatory at Farra d'Isonzo.

Named in memory of Alcide Bittesini (1913-1981), father of Luciano Bittesini, one of the Farra d'Isonzo amateur astronomers who discovered this minor planet. 
A natural sciences high-school teacher in Italy, Alcide Bittesini kindled his then-nine-year-old son's interest in astronomy by showing him a comet, using a handmade telescope constructed from a tin can, a pair of glasses and an eyepiece from his microscope. (M 33791)

\section{(8550) Hesiodos}

$1994 \mathrm{PV}_{24}$. Discovered 1994 Aug. 12 by E. W. Elst at La Silla.

Hesiodos (c. 700 B.C.), an early Greek poet, told the story of Pandora \{see planet (55)\}, who out of curiosity opened a jar, letting loose all evils on humanity. In the epic poem Works and Days Hesiod affirms his belief in justice and his feeling for the rhythm of life and nature. (M 39651)

\section{(8551) Daitarabochi}

$1994 \mathrm{VC}_{7}$. Discovered 1994 Nov. 11 by M. Hirasawa and S. Suzuki at Nyukasa.

According to myth, the giant Daitarabochi built Mt. Fuji \{see planet (1584)\} using nearby soil. The area from which he dug became Lake Biwa see planet (4289)\}, the largest lake in Japan. The myth also claims that the many lakes in Japan were the footsteps of Daitarabochi. (M 36946)

\section{(8552) Hyoichi}

1995 HE. Discovered 1995 Apr. 20 by A. Nakamura at Kuma.

Named in honor of Hyoichi Kohno (1958- ), Japanese adventurer, born in Ehime prefecture, where this minor planet was discovered. Since 1980, he has boated down the Yukon River; climbed Mt. McKinley (6194 m) and Cerro Aconcagua (6959 m), the highest mountains in North and South America; walked across Patagonia; walked from Los Angeles to New York; walked from Algeria to Togo across the Sahara desert; and so on. In 1997, he became the first Japanese to walk to the North Pole alone. (M 32096)

\section{(8553) Bradsmith}

1995 HG. Discovered 1995 Apr. 20 by K. Endate and K. Watanabe at Kitami.

Bradford A. Smith (1931- ) is an American astronomer who served as the principal investigator of the Imaging Experiment Team of the Voyager missions to the outer planets and has also contributed to many other NASA missions. He has also served as president of IAU Commission 16. (M 41383)

\section{(8554) Gabreta}

1995 KH. Discovered 1995 May 25 by M. Tichý at Klę̌.

Gabreta is an ancient, presumably Celtic name of the Šmava \{see planet (2403)\} mountains, or Böhmerwald, along the border of Bohemia and Bavaria. The name was first mentioned by Strabo \{see planet (4876)\} in his Geographica in the first century. (M 42358)

\section{(8555) Mirimao}

1995 LD. Discovered 1995 June 3 at the Santa Lucia Observatory at Stroncone.

Named in memory of Guido Mirimao (1909-1990), internationally known painter and draftsman. A graphic artist who contributed regularly to newspapers and magazines, from 1931 to 1940 he received a great number of prizes in national exhibitions. He also created art works and murals on sacred subjects in Italy and abroad. (M 33388)

\section{(8556) Jana}

1995 NB. Discovered 1995 July 7 by Z. Moravec at Klě́.

Named in honor of Jana Moravcová, wife of the discoverer, on the occasion of her thirtieth birthday, 1999 July 7. (M 34627)

\section{(8557) Šaroun}

1995 OK. Discovered 1995 July 23 by L. Šarounová at Ondřejov.

Named in honor of the discoverer's father, Jaroslav Šaroun (1943- ). A teacher at the Prague Academy of Musical Arts and a member of the Czech Philharmonic Orchestra, he is a pianist who is always in great demand as an accompanist for Czech and foreign singers. As a lover of astronomy, he influenced and supported his daughter in her desire to become an astronomer. This minor planet was discovered on the day after his birthday. (M 32350)

\section{(8558) Hack}

1995 PC. Discovered 1995 Aug. 1 by L. Tesi and A. Boattini at San Marcello Pistoiese.

Named in honor of Margherita Hack (1922- ), director of the Trieste Astronomical Observatory (1964-1987), director of the astronomy department of Trieste University (1985-1991 and 1996-1997) and a former president of IAU Commission 29. Although her studies have ranged from optics and solar physics to radioastronomy (galactic $21-\mathrm{cm}$ emission), her main fields of research remain stellar spectroscopy, stellar atmospheres and observable effects of stellar evolution. Her present interests are the ultraviolet and optical spectroscopy of close interacting binaries, atmospheric eclipsing binaries and symbiotic stars. (M 32350)

\section{(8560) Tsubaki}

$1995 \mathrm{SD}_{5}$. Discovered 1995 Sept. 20 by K. Endate and K. Watanabe at Kitami.

Takio Tsubaki (1935-1999) was a solar physicist concerned particularly with the observational study of the solar corona and prominences. He served as a dean at Shiga University, on the board of the Astronomical Society of Japan and on the Solar Physics Committee at the National Astronomical Observatory. (M 41384)

\section{(8564) Anomalocaris}

1995 UL $_{3}$. Discovered 1995 Oct. 17 by Y. Shimizu and T. Urata at Nachi-Katsuura. 
Anomalocaris, a large carnivorous arthropod, was one of the many uniquely shaped multicellular creatures that appeared during the Cambrian explosion. The fossil was first discovered in the Burgess Shale in the Canadian Rocky Mountains. (M 36128)

The name was suggested by I. Makino.

\section{(8568) Larrywilson}

$1996 \mathrm{RU}_{2}$. Discovered 1996 Sept. 10 by the JPL NEAT Program at Haleakala.

Named in honor of Lawrence (Larry) Wilson, whom discoverer E. F. Helin has known since his childhood. As the editor of the Pasadena Star News, he has been supportive of the discoverer's work at Caltech's Jet Propulsion Laboratory. (M 38198)

\section{(8572) Nijo}

$1996 \mathrm{UG}_{1}$. Discovered 1996 Oct. 19 by J. Tichá and M. Tichý at Klě́.

Named for Nijo Castle (Nijo-jo) in Kyoto \{see planet (4352)\}, built in 1603 as the official residence of the first Tokugawa shogun Ieyasu. The site is famous for its wooden architecture and the screen paintings of trees and birds of Ninomaru Palace, as well as for the beautiful Ninomaru garden, designed by the tea master and landscape architect Kobori Enshu. The discoverers visited and admired Ninomaru and several other famous gardens in Kyoto during the IAU General Assembly in 1997. (M 34627)

\section{(8573) Ivanka}

1996 VQ. Discovered 1996 Nov. 4 by Z. Moravec at Klět.

Named for Ivanka Moravcová (1943- ), the discoverer's mother. (M 34628)

\section{(8575) Seishitakeuchi}

1996 VL $_{8}$. Discovered 1996 Nov. 7 by K. Endate and K. Watanabe at Kitami.

Seishi Takeuchi (1961- ) is an amateur astronomer and a painter. He has served as a volunteer artist for the planetarium of Hiroshima Children's Museum for 20 years and has contributed to more than 70 planetarium shows. (M 41567)

\section{(8577) Choseikomori}

1996 VX $_{8}$. Discovered 1996 Nov. 7 by K. Endate and K. Watanabe at Kitami.

Chosei Komori (1935- ) is a planetary geologist who works as a leader of the Planetary Geological Society of Japan. He is now studying the surface geology of the terrestrial planets and the evolution of the solar system. He is also known as a popularizer of planetary science. (M 41384)

\section{(8580) Pinsky}

$1996 \mathrm{XZ}_{25}$. Discovered 1996 Dec. 14 by P. G. Comba at Prescott.

Named in honor of Robert Pinsky (1940- ), poet laureate of the United States since 1997. Besides several books of poetry, Pinsky has produced a much-acclaimed new English translation of Dante's \{see planet (2999)\} Inferno. Written in slant rhyme, Pinsky's version captures the rhythm and grandeur of the great Italian poet's masterpiece. (M 32096)

(8581) Johnen

$1996 \mathrm{YO}_{2}$. Discovered 1996 Dec. 28 by N. Sato at Chichibu.

Named for a mountain in Nagano prefecture, part of the Japanese Northern Alps. Popular with climbers, the $2857-\mathrm{m}$ peak is especially famous because an Englishman, Walter Weston (1861-1940), climbed it in 1894 and spread the word of its beauty all over the world. (M 33388)

\section{(8583) Froberger}

1997 AK$_{6}$. Discovered 1997 Jan. 8 by P. G. Comba at Prescott.

Named for Johann Jacob Froberger (1616-1667), organist and the foremost German keyboard composer of his day. A pupil of Frescobaldi, he combined features of many national styles. His toccate, full of imaginative chromatic harmonies, were copied out and imitated by J. S. Bach \{see planet (1814)\}. (M 32096)

\section{(8585) Purpurea}

2025 P-L. Discovered 1960 Sept. 24 by C. J. van Houten and I. van Houten-Groeneveld at Palomar.

Named for Ardea purpurea, or purple heron. \{It belongs to the family of the Ardeidae. The bird is on the Dutch Red List of birds endangered in the Netherlands and also on the 'List of Vulnerable Birds in Europe'.\} (M 33791; M 34089)

See also the remarks to planet (8600).

\section{(8586) Epops}

2563 P-L. Discovered 1960 Sept. 24 by C. J. van Houten and I. van Houten-Groeneveld at Palomar.

Named for Upupa epops, or hoopoe. \{It belongs to the family of the Upupidae.\} (M 33791; M 34089) See also the remarks to planet (8600).

\section{(8587) Ruficollis}

3078 P-L. Discovered 1960 Sept. 25 by C. J. van Houten and I. van Houten-Groeneveld at Palomar.

Named for Tachybaptus ruficollis, or little grebe. \{It belongs to the family of the Podicipidae and is on the Dutch Red List of endangered birds.\} (M 33791; M 34089)

See also the remarks to planet (8600).

\section{(8588) Avosetta}

4025 P-L. Discovered 1960 Sept. 24 by C. J. van Houten and I. van Houten-Groeneveld at Palomar.

Named for Recurvirostra avosetta, or avocet. \{It belongs to the family of the Recurvirostridae and is on the Dutch Red List of birds endangered in the Netherlands.\} (M 33791; M 34089)

See also the remarks to planet (8600). 


\section{(8589) Stellaris}

4068 P-L. Discovered 1960 Sept. 24 by C. J. van

Houten and I. van Houten-Groeneveld at Palomar.

Named for Botaurus stellaris, or bittern. \{It belongs to the family of the Ardeidae. It is on the Dutch Red List of birds endangered in the Netherlands as well as on the 'List of Vulnerable Birds in Europe'.\} (M 33791; M 34089)

See also the remarks to planet (8600).

\section{(8590) Pygargus}

6533 P-L. Discovered 1960 Sept. 24 by C. J. van Houten and I. van Houten-Groeneveld at Palomar.

Named for Circus pygargus, or Montagu's harrier. \{It belongs to the family of the Accipitridae and is on the Dutch Red List of birds endangered in the Netherlands.\} (M 33792; M 34089)

See also the remarks to planet (8600).

\section{(8591) Excubitor}

6543 P-L. Discovered 1960 Sept. 24 by C. J. van Houten and I. van Houten-Groeneveld at Palomar.

Named for Lanius excubitor, or great grey or northern shrike. \{It belongs to the family of the Laniidae and is on the Dutch Red List of birds endangered in the Netherlands.\} (M 33792; M 34089)

See also the remarks to planet (8600).

\section{(8592) Rubetra}

1188 T-1. Discovered 1971 Mar. 25 by C. J. van Houten and I. van Houten-Groeneveld at Palomar.

Named for Saxicola rubetra, or whinchat. \{It belongs to the family of the Turdidae and is on the Dutch Red List of endangered birds.\} (M 33792; M 34089) See also the remarks to planet (8600).

\section{(8593) Angustirostris}

2186 T-1. Discovered 1971 Mar. 25 by C. J. van Houten and I. van Houten-Groeneveld at Palomar.

Named for Marmaronetta angustirostris, also called anas angustirostris, marbled teal or marbled duck. \{ It belongs to the Anatidae family and is one of the birds on the 'List of Endangered Birds in Europe'. In 1994 only 200 pairs were counted.\} (M 33792; M 34089) See also the remarks to planet (8600).

\section{(8594) Albifrons}

2245 T-1. Discovered 1971 Mar. 25 by C. J. van Houten and I. van Houten-Groeneveld at Palomar.

Named for Sterna albifrons, or little tern. \{It belongs to the family of the Sternidae.\} (M 33792; M 34089) See also the remarks to planet (8600).

\section{(8595) Dougallii}

3233 T-1. Discovered 1971 Mar. 26 by C. J. van Houten and I. van Houten-Groeneveld at Palomar.

Named for Sterna dougallii, or roseate tern. \{It belongs to the family of the Sternidae. In 1994 only 1,600 pairs were counted.\} (M 33792; M 34089)

See also the remarks to planet (8600).

\section{(8596) Alchata}

1298 T-2. Discovered 1973 Sept. 29 by C. J. van Houten and I. van Houten-Groeneveld at Palomar.

Named for Pterocles alchata, or pin-tailed sandgrouse. \{It belongs to the Pteroclidae family and is one of the birds on the 'List of Endangered Birds in Europe'.\} (M 33792; M 34089)

See also the remarks to planet (8600).

\section{(8597) Sandvicensis}

2045 T-2. Discovered 1973 Sept. 29 by C. J. van Houten and I. van Houten-Groeneveld at Palomar.

Named for Sterna sandvicensis, or sandwich tern. \{It belongs to the Sternidae family and is on the Dutch Red List of endangered birds.\} (M 33792; M 34089) See also the remarks to planet (8600).

\section{(8598) Tetrix}

2202 T-2. Discovered 1973 Sept. 29 by C. J. van Houten and I. van Houten-Groeneveld at Palomar.

Named for Tetrao tetrix, also named lyrurus tetrix, or black grouse. \{It belongs to the family of the Tetraonidae. The bird is on the Dutch as well as on the European list of endangered birds.\} (M 33792; M 34089)

See also the remarks to planet (8600).

\section{(8599) Riparia}

2277 T-2. Discovered 1973 Sept. 29 by C. J. van Houten and I. van Houten-Groeneveld at Palomar.

Named for Riparia riparia, or sand martin. \{It belongs to the family of the Hirundinidae and is on the Dutch Red List of endangered birds.\} (M 33792; M 34089)

See also the remarks to planet (8600).

\section{(8600) Arundinaceus}

3060 T-2. Discovered 1973 Sept. 30 by C. J. van Houten and I. van Houten-Groeneveld at Palomar.

Named for Acrocephalus arundinaceus, or great reed warbler. \{It belongs to the family of the Sylviidae and is on the Dutch Red List of birds endangered in the Netherlands.\} (M 33792; M 34089)

The first letters of the names of minor planets (8585) to (8600) result in the well-known Latin motto "per aspera ad astra" \{Through difficulties to the Stars\}. This arrangement by L. D. Schmadel remained unnoticed after the publication of the new names in MPC itself.

\section{(8601) Ciconia}

3155 T-2. Discovered 1973 Sept. 30 by C. J. van Houten and I. van Houten-Groeneveld at Palomar.

Named for Ciconia ciconia, or white stork. \{It belongs to the family of the Ciconiidae and is on both the Dutch and the European list of endangered birds.\} (M 33792; M 34089) 


\section{(8602) Oedicnemus}

2480 T-3. Discovered 1977 Oct. 16 by C. J. van Houten and I. van Houten-Groeneveld at Palomar.

Named for Burhinus oedicnemus, or stone curlew. It belongs to the family of the Burhinidae and is endangered in the Netherlands and in Euope.\} (M 33792; M 34089)

\section{(8603) Senator}

3134 T-3. Discovered 1977 Oct. 16 by C. J. van Houten and I. van Houten-Groeneveld at Palomar.

Named for Lanius senator, or woodchat shrike. \{It belongs to the family of the Laniidae. The bird is on the Dutch Red List of birds endangered in the Netherlands and also on the 'List of Vulnerable Birds in Europe'.\} (M 33792; M 34089)

\section{(8609) Shuvalov}

$1977 \mathrm{QH}_{3}$. Discovered 1977 Aug. 22 by N. S. Chernykh at Nauchnyj.

Ivan Ivanovich Shuvalov (1727-1797), was a prominent Russian government figure who contributed to the development of Russian science and art and was a patron of scientists, writers and painters. He was a founder and first curator of Moscow University. (M 39651)

\section{(8610) Goldhaber}

1977 UD. Discovered 1977 Oct. 22 at the Harvard College Observatory at Harvard.

Brothers Maurice (1911- ) and Gerson (1924-

) Goldhaber contributed to 20th-century physics with discoveries that include charmed mesons and photodisintegration of the deuteron. They are still active members of the SuperKamiokande Collaboration and Supernova Cosmology Project. (M 39651)

Name suggested by C. Pennypacker.

\section{(8616) Fogelquist}

$1980 \mathrm{FY}_{4}$. Discovered 1980 Mar. 16 by C.-I. Lagerkvist at La Silla.

Named in honor of Rune Fogelquist (1924- ) for his inspiring activities in astronomy popularization within the Mariestad Astronomy Club, lovated near Lake Vänern in southern Sweden, and the building and running of the nearby Bifrost Observatory, the main instrument at which is a $0.60-\mathrm{m}$ reflector. The observatory has about 1000 visitors annually. The naming commemorates the twentieth anniversary of the Mariestad Astronomy Club, celebrated in August 1998. (M 32350)

Name proposed and citation prepared by H. Rickman.

\section{(8632) Egleston}

1981 FR. Discovered 1981 Mar. 28 at the Harvard College Observatory at Harvard.

Margaret Ericksen Egleston (1943- ） has since 1984 been a scientific programer at the Harvard-Smithsonian Center for Astrophysics, where she helps John Wolbach in his research on solar activity and climate. (M 39652)

\section{(8634) Neubauer}

1981 GG. Discovered 1981 Apr. 5 by E. Bowell at Anderson Mesa.

Fritz Neubauer (1940- ) is a pioneer in space science. His main fields are planetary magnetic fields and magnetospheres, interplanetary plasma and the interaction of the solar wind with comets. He has been principal and co-investigator on many NASA and ESA space missions. (M 40702)

The name was suggested by M. Pätzold.

\section{(8635) Yuriosipov}

$1985 \mathrm{PG}_{2}$. Discovered 1985 Aug. 13 by N. S. Chernykh at Nauchnyj.

Yurij Aleksandrovich Osipov (1965- ） is a physician at the Bakhchisaraj \{see also planet (3242)\} regional hospital in the Crimea. (M 41384)

\section{(8636) Malvina}

$1985 \mathrm{UH}_{2}$. Discovered 1985 Oct. 17 by the CERGA at Caussols.

On the day this minor planet was discovered by the observing team in which Alain Maury \{see planet (3780)\} participates, Malvina Maury (1985- ) was born in Poway, near San Diego, while her father was working at Palomar. (M 39651)

\section{(8640) Ritaschulz}

1986 VX $_{5}$. Discovered 1986 Nov. 6 by E. Bowell at Anderson Mesa.

Rita Schulz (1961- ) , a German planetary scientist at the European Space Agency, is an expert on the physical and chemical properties of comets. She studied the structure of the CN coma of comet $1 \mathrm{P} /$ Halley and is currently deputy project scientist on the Rosetta mission. (M 40702)

The name was suggested by M. A. Barucci.

\section{(8643) Quercus}

1988 SC. Discovered 1988 Sept. 16 by E. W. Elst at St. Michel.

Named for Quercus, a genus belonging to the family Fagaceae. The tree Quercus robur (English oak) reaches a height of $30-40 \mathrm{~m}$ and an age of more than a thousand years. (M 34347)

\section{(8644) Betulapendula}

1988 SD. Discovered 1988 Sept. 16 by E. W. Elst at St. Michel.

Named for Betula pendula (silver birch), a species in the genus Betula belonging to the family Betulaceae. It is a beautiful tree with an almost white bark. It grows fast and reaches a height of about $25 \mathrm{~m}$ and an age of 60-80 years. (M 34347)

\section{(8647) Populus}

1989 RG. Discovered 1989 Sept. 2 by E. W. Elst at St. Michel.

Named for Populus, a genus belonging to the family Salicaceae. Populus nigra (black poplar) is 
a fast-growing tree with a height of about $30 \mathrm{~m}$, whereas Populus tremula (trembling aspen) is easily recognizable by its shimmering appearance. (M 34347)

\section{(8648) Salix}

1989 RJ. Discovered 1989 Sept. 2 by E. W. Elst at St. Michel.

Named for Salix, a genus belonging to the family Salicaceae. Salix alba (white willow) is a small tree with long, thin leaves. This fast-growing tree is used for windbreaks and screens. Salix caprea (goat or pussy willow) is a fast-growing small tree with striking catkins in early spring. (M 34347)

\section{(8649) Juglans}

$1989 \mathrm{SS}_{2}$. Discovered 1989 Sept. 26 by E. W. Elst at La Silla.

Named for Juglans, a genus belonging to the family Juglandaceae. Juglans regia (English walnut) produces a particularly delicious fruit. (M 34347)

\section{(8651) Alineraynal}

$1989 \mathrm{YU}_{5}$. Discovered 1989 Dec. 29 by E. W. Elst at St. Michel.

Aline Raynal-Roques (1937- ), professor of botany at the Muséum National d'Histoire Naturelle de Paris, is known for her investigations on taxonomy of tropical plants, mostly parasitic and aquatic, and research in the Sahel desert. Her work was honored in 1995 by the Institut de France. (M 36946)

\section{(8652) Acacia}

$1990 \mathrm{EA}_{5}$. Discovered 1990 Mar. 2 by E. W. Elst at La Silla.

Named for Acacia, belonging to the family Mimosaceae. Acacia mearnsii (mimosa) is a shrub with feathery leaves composed of many small leaflets. The strongly scented tiny flowers are grouped in loose, rounded clusters. (M 34347)

\section{(8656) Cupressus}

1990 QY $_{8}$. Discovered 1990 Aug. 16 by E. W. Elst at La Silla.

Named for Cupressus, belonging to the family $\mathrm{Cu}-$ pressaceae. Cupressus macrocarpia (Monterrey cypress) produces a durable wood. Cupressus leylandii (Leyland cypress), hybridized from the macrocarpia, has scalelike green leaves that are arranged at various angles to the shoot. These trees are typical of the landscape in Tuscany. (M 34348)

\section{(8657) Cedrus}

1990 QE9. Discovered 1990 Aug. 16 by E. W. Elst at La Silla.

Named for Cedrus, belonging to the family Pinaceae. Cedrus libani (cedar of Lebanon) has a fruit that is an ovoid upright cone (M 34348)

\section{(8660) Sano}

$1990 \mathrm{TM}_{1}$. Discovered 1990 Oct. 15 by K. Endate and

K. Watanabe at Kitami.

Yasuo Sano (1959- ), a staff member of the Nayoro Municipal Kihara \{see planet (4795)\} Observatory, is the discoverer of supernova 1997ef and works as a popularizer of astronomy. (M 43189)

\section{(8661) Ratzinger}

1990 TA $_{13}$. Discovered 1990 Oct. 14 by L. D. Schmadel and F. Börngen at Tautenburg.

Joseph Cardinal Ratzinger (1927- ) ), German professor of theology, is one of the most authoritative voices in the Vatican. Under his supervision, the Vatican opened its archives in 1998 to enable researchers to investigate judicial errors against Galileo \{see planet (697) $\}$ and other medieval scientists. The name was proposed by the first discoverer. (M 40702)

\section{(8665) Daun-Eifel}

1991 GA $_{9}$. Discovered 1991 Apr. 8 by E. W. Elst at La Silla.

Daun is a city in the Eifel region of Germany, not far from the Belgian border. Well known for its volcanic lakes and healthy mineral water Dauner Sprudel, it has recently celebrated its 1000th anniversary. (M 47164)

\section{(8666) Reuter}

$1991 \mathrm{GG}_{10}$. Discovered 1991 Apr. 9 by F. Börngen at Tautenburg.

Named for the German poet and social critic Fritz Reuter (1810-1874), co-founder of the new Low German literature and one of its greatest humorists. He often expressed worldly wisdom by descriptions of celestial bodies, especially the sun. His work, most of which takes place in Mecklenburg \{see planet (6124)\}, criticizes unjust social conditions. As a student he was imprisoned for seven years because of his views in favor of democracy and the unity of Germany. Although written in a regional dialect, his work has been widely translated. (M 32792)

\section{(8667) Fontane}

$1991 \mathrm{GH}_{10}$. Discovered 1991 Apr. 9 by F. Börngen at Tautenburg.

Named for Theodor Fontane (1819-1898) on the occasion of the 100th anniversary of his death. He brought the German novel to worldwide importance. Descended from a Huguenot family, he worked as an apothecary, travel writer, editor, drama critic and finally as a full-time writer. Besides ballads and the multivolume Wanderungen durch die Mark Brandenburg, his novels are especially significant (e.g. Effi Briest, Der Stechlin). He chose his material mostly from Prussian history and the Berlin of his times. He combined love of tradition with open-mindedness for the new and skepticism with religious faith. (M 32792) 
(8672) Morse

$1991 \mathrm{PW}_{16}$. Discovered 1991 Aug. 6 by E. W. Elst at La Silla.

Samuel Finley Breese Morse (1791-1872) was an American painter and inventor who in 1838 developed the code of dots and dashes that now bears his name. After constructing the first telegraph between Baltimore and Washington, he became a philanthropist. (M 47164)

(8676) Lully

$1992 \mathrm{CT}_{2}$. Discovered 1992 Feb. 2 by E. W. Elst at La Silla.

Jean-Baptiste Lully (1632-1687), an Italian-French composer, created a very lively style of composition by introducing quicker dances such as the bourrée, gavotte and gigue into his ballets. A beautiful example of his music is La Marche des Combattans. (M 47164)

\section{(8677) Charlier}

1992 ES $_{5}$. Discovered 1992 Mar. 2 by the Uppsala-ESO Survey at La Silla.

Carl Vilhelm Ludvig Charlier (1862-1934), professor of astronomy at Uppsala during 1890-1897 and later at Lund \{see, respectively, planets (2191) and (809)\}, worked in several fields of astronomy, including celestial mechanics and photometry. He was one of the leading founders of stellar statistics, applying mathematical statistics to astronomical problems. (M 36946)

\section{(8678) Bäl}

1992 ER $_{6}$. Discovered 1992 Mar. 1 by the Uppsala-ESO Survey at La Silla.

Bäl is a small and typical country parish on the Swedish island of Gotland, often associated on Gotland with the well-known song "Farewell to Bäl". (M 36947)

\section{(8679) Tingstäde}

1992 EG8. Discovered 1992 Mar. 2 by the Uppsala-ESO Survey at La Silla.

Tingstäde is a parish on Gotland. In Tingstäde Träsk, the second largest lake on the island, the remains of a timber construction involving some 10000 logs, probably from the sixth century, is still visible on the lake floor. (M 36947)

\section{(8680) Rone}

1992 EJ $_{9}$. Discovered 1992 Mar. 2 by the Uppsala-ESO Survey at La Silla.

A small parish on Gotland, Rone is well known for the lyrics to the song Rune from Rone. Nearby Uggarde Rojr, a 3000-year-old burial mound from the bronze age with a diameter of 50 meters and a height of 7 meters, is one of the biggest in Sweden. (M 39652)

\section{(8681) Burs}

$1992 \mathrm{EN}_{9}$. Discovered 1992 Mar. 2 by the Uppsala-ESO Survey at La Silla.

Burs is a small parish on the Swedish island of Gotland. Gustav Edman (1881-1912), well known for his height (2.46 meters) and strength, was born in Burs. Burs also has the remains of the largest house $(67 \times 11$ meters $)$ in Sweden from the Roman Iron Age. (M 39652)

\section{(8682) Kräklingbo}

1992 ER. Discovered 1992 Mar. 2 by the Uppsala-ESO Survey at La Silla.

Kräklingbo is a small parish on the Swedish island of Gotland. Located here on a hill are the remains of a fortification nearly 2000 years old, the biggest in Scandinavia. From that hill many of the medieval churches on the island can be seen. (M 39652)

\section{(8683) Sjölander}

1992 EE $_{13}$. Discovered 1992 Mar. 2 by the Uppsala-ESO Survey at La Silla.

Nils Göran Sjölander (1951- ), formerly librarian at Uppsala Observatory, studies dwarf galaxies and has a keen interest in the history of astronomy. (M 45232)

\section{(8684) Reichwein}

$1992 \mathrm{FO}_{3}$. Discovered 1992 Mar. 30 by F. Börngen at Tautenburg.

Named for the German reform pedagogue Adolf Reichwein (1898-1944), who ran the Adult Education Courses in Jena during 1925-1929 and became professor of history and civics in Halle in 1930. An early opponent of facism, he was dismissed from Halle in 1933 and worked as teacher in an outlying village school. Reichwein took part in founding the illegal "Kreisauer Kreis" \{see planet (7945)\}, was among its closest advisors and designated to be the minister of education in a new liberated German State. He was arrested early in July 1944, condemned to death by the Volksgerichtshof three months later and executed the same day. (M 34628)

\section{(8685) Fauré}

$1992 \mathrm{GG}_{3}$. Discovered 1992 Apr. 4 by E. W. Elst at La Silla.

Gabriel Fauré (1845-1924) was a French composer who revolutionized French music by using daring harmonic progressions and modulations. A set of highly original nocturnes, barcaroles and impromptus was composed after the example of Chopin s see planet (3784)\}. His Ballade (1881) for piano is very popular. (M 47164)

\section{(8686) Akenside}

1992 OX $_{1}$. Discovered 1992 July 26 by E. W. Elst at La Silla.

Mark Akenside (1721-1770) was a British poet and physician who studied medicine at the University of Leiden. There he met the French philosopher d'Holbach \{see planet (6956)\}, who translated his well-known philosophical essay The Pleasures of Imagination (1744) into French (1759). (M 47164) 


\section{(8687) Caussols}

1992 PV. Discovered 1992 Aug. 8 by E. W. Elst at Caussols.

The observatory at Caussols, in the French AlpsMaritimes, is situated above the northern part of a 1100-m high, open and flat plain, the Plateau de Caussols, about $10 \mathrm{~km}$ from the Route Napoléon. Down the hill lies a tiny village Hamlet of Caussols, with only a few inhabitants. (M 47164)

\section{(8688) Delaunay}

$1992 \mathrm{PV}_{1}$. Discovered 1992 Aug. 8 by E. W. Elst at Caussols.

Charles-Eugène Delaunay (1816-1872) was a French mathematician and astronomer famous for his Théorie du mouvement de la lune, 1860-1867. Made a member of the Académie des Sciences in 1855, he succeeded Leverrier $\{$ see planet (1997) $\}$ as director of the Paris Observatory in 1870. (M 47164)

\section{(8690) Swindle}

$1992 \mathrm{SW}_{3}$. Discovered 1992 Sept. 24 by the Spacewatch at Kitt Peak.

Timothy D. Swindle (1955- ), of the Lunar and Planetary Laboratory, is a meteoriticist who has specialized in the study of noble gases in meteorites. Swindle has used meteorites, including the martian meteorites, to study the atmospheres of other planets and water products in the solar system. (M 39652)

\section{(8691) Etsuko}

$1992 \mathrm{UZ}_{1}$. Discovered 1992 Oct. 21 by Y. Kushida and

O. Muramatsu at Yatsugatake.

Named in honor of Etsuko Kobayashi (1926- ), the first female lecturer at the Gotoh Planetarium und Astronomical Museum in Tokyo, where she worked for 30 years until 1986. Famous for her lecturing style, which left many listeners spellbound, she has educated many young lecturers who are active in the field today. She also worked for the publisher of a science journal and is now a well-known author of astronomy books herself. (M 34348)

Name proposed by the discoverers following a suggestion by S. Kimura.

\section{(8693) Matsuki}

$1992 \mathrm{WH}_{1}$. Discovered 1992 Nov. 16 by K. Endate and K. Watanabe at Kitami.

Noboru Matsuki (1934- ) is an amateur astronomer who has accumulated a huge amount of observational data on sunspots since 1958. (M 43189)

\section{(8695) Bergvall}

$1993 \mathrm{FW}_{8}$. Discovered 1993 Mar. 17 by the Uppsala-ESO Survey at La Silla.

Nils Bergvall (1945- ), astronomer at Uppsala Observatory, studies galaxy evolution and is also interested in music. (M 45232)

\section{(8696) Kjeriksson}

$1993 \mathrm{FM}_{16}$. Discovered 1993 Mar. 17 by the UppsalaESO Survey at La Silla.

Kjell Eriksson (1948- ) is currently the director of Uppsala Observatory, where he studies stellar atmospheres. (M 45232)

\section{(8697) Olofsson}

$1993 \mathrm{FT}_{23}$. Discovered 1993 Mar. 21 by the UppsalaESO Survey at La Silla.

Kjell Olofsson (1955- ) is the director of undergraduate studies at the Uppsala Observatory and studies galaxies. (M 45232)

\section{(8698) Bertilpettersson}

$1993 \mathrm{FT}_{41}$. Discovered 1993 Mar. 19 by the UppsalaESO Survey at La Silla.

Bertil Pettersson (1945- ) studies star formation, especially T Tauri stars and Herbig-Haro objects. He is also the system manager at the Uppsala Observatory. (M 45232)

\section{(8700) Gevaert}

$1993 \mathrm{JL}_{1}$. Discovered 1993 May 14 by E. W. Elst at La Silla.

Lieven Gevaert (1868-1935) was a Belgian industrialist who established the "N.V. Gevaert Photo-Producten" at Mortsel, near Antwerp, beginning in 1890 with a small shop of homemade photographical paper. Gevaert glass plates have been used for many purposes in astronomy, especially for the astrometry of minor planets. (M 46681)

\section{(8703) Nakanotadao}

$1993 \mathrm{XP}_{1}$. Discovered 1993 Dec. 15 by T. Kobayashi at Oizumi.

Tadao Nakano (1926- ), Osaka City University, proposed in 1953 the so-called Nakano-Nishijima-GellMan rule of the statistics of elementary particles, which became one of the foundations of the quark model. His interests also extend to general relativity and to gauge theory. (M 46681)

\section{(8704) Sadakane}

1993 YJ. Discovered 1993 Dec. 17 by T. Kobayashi at Oizumi.

Kozo Sadakane (1947- ), Osaka Kyoiku University, is an expert on the analysis of stellar spectra, especially those of chemically peculiar and metal deficient old stars. Superficially normal A type stars with underabundances such as $21 \mathrm{Peg}$ and HR 7338 are often referred to as Sadakane stars. (M 46681)

\section{(8709) Kadlu}

$1994 \mathrm{JF}_{1}$. Discovered 1994 May 14 by C. S. Shoemaker and E. M. Shoemaker at Palomar.

The Eskimo thunder-goddess was originally a little girl who played so noisily that her parents told her and her sisters to go outside to play. They did, and they invented a game in which Kadlu jumped on hollow 
ice, causing a thunderous sound. Transported to the sky, the goddess lived in a whale-bone house far in the west. Some legends say that Kadlu made thunder by rubbing dry sealskins together, or by singing. (M 32350)

\section{(8710) Hawley}

1994 JK9. Discovered 1994 May 15 by C. P. de Saint-Aignan at Palomar.

Named in honor of the discoverer's friend and mentor, Walter N. Hawley, a physics and astronomy teacher at Saint Paul's School in Concord, New Hampshire. $\mathrm{He}$ is also director of the Saint Paul's Astronomy Center, an observatory of unequaled quality at the high-school level. Hawley has observed the night sky with his students since 1972, acquainting them with such wonders as the Aurora Borealis and Messier \{see planet (7359)\} Objects, as well as lesser wonders, such as Murphy's Law - and frostbite. (M 32792)

\section{(8712) Suzuko}

$1994 \mathrm{TH}_{2}$. Discovered 1994 Oct. 2 by K. Endate and K. Watanabe at Kitami.

Suzuko Hurukawa (1935- ), wife of astronomer Kiichirou Hurukawa, has inspired many Japanese amateurs, including the discoverers, with her kindness and hospitality. (M 42358)

\section{(8713) Azusa}

$1995 \mathrm{BT}_{2}$. Discovered 1995 Jan. 26 by K. Endate and K. Watanabe at Kitami.

Azusa Hurukawa (1968- ) is the daughter of astronomer Kiichirou Hurukawa. (M 42358)

\section{(8716) Ginestra}

$1995 \mathrm{SB}_{2}$. Discovered 1995 Sept. 23 by V. S. Casulli at Colleverde di Guidonia.

Named for a poem by Giacomo Leopardi \{see planet (8081)\} (1798-1837), the great poet and philosopher from the Italian Romantic period. Full of astronomical references, his poetry expresses the great sense of bewilderment of post-Copernican man, faced with an infinite variety of worlds of which he is no longer the center, but only infinitesimal and marginal. Nevertheless, the "Ginestra" becomes the symbol of man/flower in the middle of the cosmos/desert, a cosmos sustained by rigid mechanistic laws, indifferent to every desire and human sentiment, existing only to perpetuate the cycle of production and universal destruction. (M 32351)

Name suggested and citation prepared by M. Vicoli.

\section{(8719) Vesmír}

1995 VR. Discovered 1995 Nov. 11 at the Klet Observatory at Kleť.

The Czech monthly journal of science Vesmír was founded in 1871. Vesmír describes new findings from the whole spectrum of science including astronomy, biology, chemistry, cybernetics, genetics, geology, medicine and physics, as well as their interdisciplinary connections. (M 36947)
(8720) Takamizawa

$1995 \mathrm{WE}_{1}$. Discovered 1995 Nov. 16 by A. Nakamura at Kuma.

Named in honor of Kesao Takamizawa (1952- ), one of the most renowned amateur astronomers in Japan. During his 25-year visual search for comets, Takamizawa made two new discoveries and one independent discovery. In 1994, he moved from visual to photographic surveying. Since then, he has discovered two more comets, one supernova, two galactic novae, and many variable stars. (M 32792)

\section{(8721) AMOS}

$1996 \mathrm{AO}_{3}$. Discovered 1996 Jan. 14 by the JPL NEAT Program at Haleakala.

Named for the Air Force Maui Optical Station (AMOS), the research and development arm of the Maui Space Surveillance System at Haleakala on Maui, Hawaii. The AMOS project for observations of minor planets is the result of a collaboration between the Air Force Research Laboratory and Eleanor Helin's \{see planet (3267)\} observing programs at the Jet Propulsion Laboratory. This collaboration began in 1993 and continues today. AMOS performs follow-up observations for several programs, primarily the highly successful JPL NEAT program. (M 32351)

\section{(8722) Schirra}

1996 QU $_{1}$. Discovered 1996 Aug. 19 by R. G. Davis at Granville.

Walter M. Schirra, Jr. (1923- ), the only astronaut to command Mercury, Gemini and Apollo spacecraft, performed missions enabling the success of the manned lunar landings. His mastery of the celestial sphere and awareness of his orientation within it distinguish Schirra as a practical astronomer and master astronaut. (M 41384)

\section{(8723) Azumayama}

1996 SL $_{7}$. Discovered 1996 Sept. 23 by T. Okuni at Nanyou.

Azumayama is the volcanic mountain range that forms the border between Fukusima and Yamagata prefectures in the northern part of mainland Japan. It was designated a national park in 1950. (M 36947)

\section{(8725) Keiko}

$1996 \mathrm{TG}_{5}$. Discovered 1996 Oct. 5 by H. Abe at Yatsuka.

Named in honor of Keiko Morinaga (1969- ), a member of the Matsue Astronomy Club and observing partner of the discoverer. (M 32351; M 32377)

\section{(8728) Mimatsu}

$1996 \mathrm{VF}_{9}$. Discovered 1996 Nov. 7 by K. Endate and K. Watanabe at Kitami.

Masao Mimatsu (1888-1977) was a Japanese postmaster and an amateur volcanologist. He made extensive observations of the development of the new volcanic dome Syowashinzan in Hokkaido in the 1940s. This 
work is summarized in the internationally known "Mimatsu Diagrams". (M 42669)

\section{(8729) Descour}

$1996 \mathrm{VZ}_{12}$. Discovered 1996 Nov. 5 by the Spacewatch at Kitt Peak.

Anne S. Descour (1968- ) is an imaginative and energetic computer scientist at the University of Arizona's Lunar and Planetary Laboratory. Her software for interprocess communications and a graphical user interface has improved Spacewatch's \{see planet (4255)\} ability for detecting comets and minor planets. (M 40703)

\section{(8730) Iidesan}

$1996 \mathrm{VT}_{30}$. Discovered 1996 Nov. 10 by T. Okuni at Nanyou.

The Iidesan range forms the borders between Fukusima, Niigata and Yamagata prefectures in the northern part of mainland Japan and was designated as a national park in 1950. Mt. Iidesan itself has a height of 2105 meters. (M 36947)

\section{(8732) Champion}

$1996 \mathrm{XR}_{25}$. Discovered 1996 Dec. 8 by T. Seki at Geisei.

Born in Texas, Frank Champion (1884-1917) was an aviator who flew to Japan in a wooden airplane. He entertained 100000 Japanese with his acrobatic stunt flying over Kochi \{see planet (2396)\} City. But a wing accidentally broke, and he was killed. There is a memorial to him in Kochi. (M 38198)

\section{(8734) Warner}

1997 AA. Discovered 1997 Jan. 1 by P. G. Comba at Prescott.

Named in honor of Brian D. Warner (1952- ). For more than eight years he has published the Minor Planet Observer, a monthly newsletter with minor-planet finder charts and other news of interest to minor planet observers. In recent years he has taken up CCD imaging and contributed hundreds of astrometric observations. (M 34348)

\section{(8738) Saji}

1997 AQ $_{16}$. Discovered 1997 Jan. 5 at the Saji Observatory at Saji.

Saji observatory, with its 1.03-m telescope, is situated on a hill overlooking Saji village. Saji's 3200 residents constructed their observatory in 1994, and the village assembly adopted a rule of keeping the skies dark. (M 33792)

\section{(8740) Václav}

1998 AS $_{8}$. Discovered 1998 Jan. 12 by M. Tichý and Z. Moravec at Klě́.

Named for Czech prince Václav (c.908-c.929), Czech kings Václav I (1205-1253), Václav II (1271-1305) and his son Václav III (1289-1306), all from royal dynasty of Přemyslids \{see planet (7695)\}, and Czech king and
Roman emperor Václav IV of Luxembourg (1361-1419), the son of Charles IV. Prince Václav was killed by his brother, Boleslav I. Later he was worshipped as a saint and from the eleventh century he became patron of the Czech lands and the symbol of Czech statehood. King Václav III was also killed, and he was the last male descendant of the Přemyslids dynasty. Václav is still the most common Slavonic name in the Czech Republic. (M 34628)

Name endorsed by J. Tichá.

\section{(8742) Bonazzoli}

1998 CB $_{2}$. Discovered 1998 Feb. 14 by V. S. Casulli at Colleverde di Guidonia.

Roberto Bonazzoli (1940-1996) was a friend of the discoverer. Fond of astronomy, he offered technical support, notably concerning electronics, at the Colleverde Observatory. (M 41028)

\section{(8743) Kèneke}

$1998 \mathrm{EH}_{12}$. Discovered 1998 Mar. 1 by E. W. Elst at La Silla.

Kèneke is Flemish for "small child", and it is only from her photographs that the discoverer knows and remembers his elder sister, Virginia Margaretha Anna Elst (1930-1935), who died from meningitis before he was born. (M 36128)

\section{(8744) Cilla}

$1998 \mathrm{FE}_{59}$. Discovered 1998 Mar. 20 by the LINEAR at Socorro.

Named in memory of Priscilla Annette (1994-1998), niece of Lincoln Laboratory staff member Colleen Cilley. (M 33792)

\section{(8745) Delaney}

$1998 \mathrm{FO}_{65}$. Discovered 1998 Mar. 20 by the LINEAR at Socorro.

Named in honor of William P. Delaney, director's fellow at M.I.T. Lincoln Laboratory. This is a donation of the fruit of an optical search program to an expert in radar. (M 33792)

\section{(8747) Asahi}

1998 FS $_{73}$. Discovered 1998 Mar. 24 by T. Okuni at Nanyou.

Asahi is the mountain range forming the border between Niigata and Yamagata prefectures in the northern part of mainland Japan. Meaning "morning sun", the name is also that of several Japanese towns and villages, as well as of another mountain range. (M 36947)

\section{(8749) Beatles}

1998 GJ J10 $_{10}$. Discovered 1998 Apr. 3 by J. Broughton at Reedy Creek.

The great 1960s British popular rock group from Liverpool comprised John Lennon, Paul McCartney, George Harrison and Ringo Starr \{see also planets (4147) - (4150)\}. They are unequalled in the rock era as 
prolific song writers and innovative recording artists with George Martin. (M 43042)

\section{(8750) Nettarufina}

2197 P-L. Discovered 1960 Sept. 24 by C. J. van Houten and I. van Houten-Groeneveld at Palomar.

Named for Netta rufina, or red-crested pochard. IIt belongs to the family of the Anatidae and is on the Dutch Red List of birds endangered in the Netherlands.\} (M 33792; M 34089)

\section{(8751) Nigricollis}

2594 P-L. Discovered 1960 Sept. 24 by C. J. van Houten and I. van Houten-Groeneveld at Palomar.

Named for Podiceps nigricollis, or black-necked grebe. \{It belongs to the family of the Podicipidae and is on the Dutch Red List.\} (M 33792; M 34089)

\section{(8752) Flammeus}

2604 P-L. Discovered 1960 Sept. 24 by C. J. van Houten and I. van Houten-Groeneveld at Palomar.

Named for Asio flammeus, or short-eared owl. \{It belongs to the family of the Strigidae and is on the Dutch and European lists of endangered birds.\} (M 33792; M 34089)

\section{(8753) Nycticorax}

2636 P-L. Discovered 1960 Sept. 24 by C. J. van Houten and I. van Houten-Groeneveld at Palomar.

Named for Nycticorax nycticorax, or night heron. \{It belongs to the family of the Ardeidae and is endangered in the Netherlands.\} (M 33792; M 34089)

\section{(8754) Leucorodia}

4521 P-L. Discovered 1960 Sept. 24 by C. J. van Houten and I. van Houten-Groeneveld at Palomar.

Named for Platalea leucorodia, or spoonbill. \{It belongs to the family of the Plataleidae. The bird is mentioned on the Dutch and European lists of endangered species.\} (M 33792; M 34089)

\section{(8755) Querquedula}

4586 P-L. Discovered 1960 Sept. 24 by C. J. van Houten and I. van Houten-Groeneveld at Palomar.

Named for Anas querquedula, or garganey. IIt belongs to the family of the Anatidae. It is on the Dutch Red List of birds endangered in the Netherlands and also on the 'List of Vulnerable Birds in Europe'.\} (M 33792; m 34089)

\section{(8756) Mollissima}

6588 P-L. Discovered 1960 Sept. 24 by C. J. van Houten and I. van Houten-Groeneveld at Palomar.

Named for Somateria mollissima, or common eider. \{It belongs to the Anatidae family and is on the Dutch Red List of endangered birds.\} (M 33793; M 34089)

\section{(8757) Cyaneus}

6600 P-L. Discovered 1960 Sept. 24 by C. J. van Houten and I. van Houten-Groeneveld at Palomar.
Named for Circus cyaneus, or hen or northern harrier. \{It belongs to the family of the Accipitridae and is endangered in the Netherlands as well as in Europe.\} (M 33793; M 34089)

\section{(8758) Perdix}

6683 P-L. Discovered 1960 Sept. 24 by C. J. van Houten and I. van Houten-Groeneveld at Palomar.

Named for Perdix perdix, or partridge. \{It belongs to the family of the Phasianidae. It is on the Dutch Red List of birds endangered in the Netherlands and also on the 'List of Vulnerable Birds in Europe'.\} (M 33793; M 34089)

\section{(8759) Porzana}

7603 P-L. Discovered 1960 Oct. 17 by C. J. van Houten and I. van Houten-Groeneveld at Palomar.

Named for Porzana porzana, or spotted crake. \{This endangered bird belongs to the family of the Rallidae.\} (M 33793; M 34089)

\section{(8760) Crex}

1081 T-1. Discovered 1971 Mar. 25 by C. J. van Houten and I. van Houten-Groeneveld at Palomar.

Named for Crex crex, or corncrake. \{It belongs to the family of the Rallidae and is endangered in the Netherlands as well as in Europe. In 1994 only 3,800 pairs were counted.\} (M 33793; M 34089)

\section{(8761) Crane}

1163 T-1. Discovered 1971 Mar. 25 by C. J. van Houten and I. van Houten-Groeneveld at Palomar.

Named for the bird Grus grus; crane is its English name. It belongs to the family of the Gruidae and is an endangered species in Europe. (M 34348)

\section{(8762) Hiaticula}

3196 T-1. Discovered 1971 Mar. 26 by C. J. van Houten and I. van Houten-Groeneveld at Palomar.

Named for Charadrius hiaticula, or ringed plover. \{It belongs to the family of the Charadriidae and is on the Dutch Red List.\} (M 33793; M 34089)

\section{(8763) Pugnax}

3271 T-1. Discovered 1971 Mar. 26 by C. J. van Houten and I. van Houten-Groeneveld at Palomar.

Named for Philomachus pugnax, or ruff (male) and reeve (female). \{It belongs to the family of the Scolopacidae and is on the list of endangered birds in the Netherlands.\} (M 33793; M 34089)

\section{(8764) Gallinago}

1109 T-2. Discovered 1973 Sept. 29 by C. J. van Houten and I. van Houten-Groeneveld at Palomar.

Named for Gallinago gallinago, or snipe. \{It belongs to the family of the Scolopacidae and is on the Dutch Red List.\} (M 33793; M 34089)

\section{(8765) Limosa}

1274 T-2. Discovered 1973 Sept. 29 by C. J. van Houten and I. van Houten-Groeneveld at Palomar. 
Named for Limosa limosa, or black-tailed godwit. \{ It belongs to the family of the Scolopacidae. It is on the Dutch Red List of birds endangered in the Netherlands and also on the 'List of Vulnerable Birds in Europe.\} (M 33793; M 34089)

\section{(8766) Niger}

1304 T-2. Discovered 1973 Sept. 29 by C. J. van Houten and I. van Houten-Groeneveld at Palomar.

Named for Chlidonias niger, or black tern. \{It belongs to the family of the Sternidae and is on the Dutch Red List of endangered birds.\} (M 33793; M 34089)

\section{(8767) Commontern}

1335 T-2. Discovered 1973 Sept. 29 by C. J. van Houten and I. van Houten-Groeneveld at Palomar.

Named for the bird Sterna hirundo; common tern is its English name. It belongs to the family of the Sternidae. (M 34348)

\section{(8768) Barnowl}

2080 T-2. Discovered 1973 Sept. 29 by C. J. van Houten and I. van Houten-Groeneveld at Palomar.

Named for the bird Tyto alba; barn owl is its English name. It belongs to the family of Tytonidae. (M 34348)

\section{(8769) Arctictern}

2181 T-2. Discovered 1973 Sept. 29 by C. J. van Houten and I. van Houten-Groeneveld at Palomar.

Named for the bird Sterna paradisaea; arctic tern is its English name. It belongs to the family of the Sternidae. (M 34348)

\section{(8770) Totanus}

3076 T-2. Discovered 1973 Sept. 30 by C. J. van Houten and I. van Houten-Groeneveld at Palomar.

Named for Tringa totanus, or redshank. \{It belongs to the family of the Scolopacidae and is endangered in the Netherlands.\} (M 33793; M 34089)

\section{(8771) Biarmicus}

3187 T-2. Discovered 1973 Sept. 30 by C. J. van Houten and I. van Houten-Groeneveld at Palomar.

Named for Panurus biarmicus, or bearded tit. \{It belongs to the family of the Timaliidae and is on the Dutch Red List.\} (M 33793; M 34089)

\section{(8772) Minutus}

4254 T-2. Discovered 1973 Sept. 29 by C. J. van Houten and I. van Houten-Groeneveld at Palomar.

Named for Ixobrychus minutus, or little bittern. \{It belongs to the family of the Ardeidae. It is on the Dutch Red List of birds endangered in the Netherlands and also on the 'List of Vulnerable Birds in Europe'.\} (M 33793; M 34089)

\section{(8773) Torquilla}

5006 T-2. Discovered 1973 Sept. 25 by C. J. van Houten and I. van Houten-Groeneveld at Palomar.
Named for Jynx torquilla, or wryneck. \{It belongs to the family of the Picidae and is on the Dutch list of endangered birds.\} (M 33793; M 34089)

\section{(8774) Viridis}

5162 T-2. Discovered 1973 Sept. 25 by C. J. van Houten and I. van Houten-Groeneveld at Palomar.

Named for Picus viridis, or green woodpecker. IIt belongs to the family of the Picidae and is endangered in the Netherlands.\} (M 33793; M 34089)

\section{(8775) Cristata}

5490 T-2. Discovered 1973 Sept. 30 by C. J. van Houten and I. van Houten-Groeneveld at Palomar.

Named for Galerida cristata, or crested lark. \{It belongs to the Alaudidae family and is on the Dutch Red List.\} (M 33793; M 34089)

\section{(8776) Campestris}

2287 T-3. Discovered 1977 Oct. 16 by C. J. van Houten and I. van Houten-Groeneveld at Palomar.

Named for Anthus campestris, or tawny pipit. IIt belongs to the family of the Motacillidae. It is on the Dutch Red List of birds endangered in the Netherlands and also on the 'List of Vulnerable Birds in Europe'.\} (M 33793; M 34089)

\section{(8777) Torquata}

5016 T-3. Discovered 1977 Oct. 16 by C. J. van Houten and I. van Houten-Groeneveld at Palomar.

Named for Saxicola torquata, or stonechat. \{It belongs to the family of the Turdidae and is on the Dutch list of endangered birds.\} (M 33793; M 34089)

\section{(8781) Yurka}

$1976 \mathrm{GA}_{2}$. Discovered 1976 Apr. 1 by N. S. Chernykh at Nauchnyj.

Yuri Sergeevich Efimov (1935- ) is an astrophysicist who has worked at the Crimean Astrophysical Observatory since 1958. He is a prominent expert in stellar photometry and polarimetry and is well known for his research on peculiar stars and extragalactic objects. (M 41384)

\section{(8782) Bakhrakh}

1976 UG $_{2}$. Discovered 1976 Oct. 26 by T. M. Smirnova at Nauchnyj.

Lev Davidovich Bakhrakh (1921- ）, a corresponding member of the Russian Academy of Sciences, is the author of fundamental and applied investigations in radiophysics antenna techniques. He developed the theory of multi-mirror antennae widely used in radioastronomy and space communication. (M 41029)

\section{(8785) Boltwood}

1978 RR $_{1}$. Discovered 1978 Sept. 5 by N. S. Chernykh at Nauchnyj.

Paul Boltwood (1943- ) is a Canadian specialist in computer systems and outstanding amateur astronomer. He monitored the peculiar object OJ 287 for some two years. He also obtained deep-sky CCD images 
with limiting magnitude 24.5 using a home-built $0.4-\mathrm{m}$ reflector. (M 41384)

\section{(8786) Belskaya}

1978 RA $_{8}$. Discovered 1978 Sept. 2 by C.-I. Lagerkvist at La Silla.

Named in honor of Irina N. Belskaya, senior astronomer at the Kharkov Astronomical Observatory and a friend of the discoverer. Her research focuses on the spin and surface properties of main-belt minor planets, in particular, objects of the taxonomic type M. She has made important contributions in this field by combining photometric and polarimetric observations with optical laboratory measurements of the analogous asteroidal materials. (M 33389) Citation prepared by A. Erikson.

\section{(8787) Ignatenko}

1978 TL$_{4}$. Discovered 1978 Oct. 4 by T. M. Smirnova at Nauchnyj.

Vitalij Nikitich Ignatenko (1941- ), Russian journalist and film script-writer, is the general director of the largest Russian news agency, ITAR-TASS. From 1986 to 1990 he was editor-in-chief of the popular international magazine New Times. (M 41567)

The name was suggested by V. Fortov.

\section{(8788) Labeyrie}

$1978 \mathrm{VP}_{2}$. Discovered 1978 Nov. 1 by K. Tomita at Caussols.

Named in honor of Catherine and Antoine Labeyrie. Catherine was the hypersensitization expert at the 0.9-m Schmidt telescope with which this object was discovered; in recent years, she has devoted her energy to the preservation of the ecology of the Provence region. Antoine is an optician as well as an astronomer; he participated in the invention of holographic diffraction and is the inventor of speckle interferometry. The speckle technique, which has given birth to optical multi-telescope interferometry, has been used to obtain images of several minor planets. Antoine currently holds the chair of observational astrophysics at the Collège de France and is currently director of the Observatoire de Haute Provence. (M 34628) Citation prepared by A. Morely.

\section{(8793) Thomasmüller}

1979 QX. Discovered 1979 Aug. 22 by C.-I. Lagerkvist at La Silla.

Named in honor of Thomas G. Müller for his contribution to the study of minor planets in the thermal infrared. His observational work includes mid- to far-infrared photometry, spectroscopy and polarimetry with the Infrared Space Observatory. He has developed and applied various thermophysical models and techniques, in order to derive physical properties of minor planets. Because of the great accuracy he achieved, future telescope projects in the infrared will also benefit from these efforts, since minor planets are well suited as calibration targets. (M 33389)

Name proposed and citation prepared by J. S. V. Lagerros.

\section{(8804) Eliason}

$1981 \mathrm{JB}_{2}$. Discovered 1981 May 5 by C. S. Shoemaker and E. M. Shoemaker at Palomar.

Eric M. Eliason (1949- ), an expert in imageprocessing techniques and image analysis for the U.S. Geological Survey's Astrogeologic Team, has used this expertise for data restoration and publishing activities in support of the Voyager and Mars Observer projects and the Clementine Mission to the moon. (M 44185)

\section{(8806) Fetisov}

1981 UU $_{11}$. Discovered 1981 Oct. 22 by N. S. Chernykh at Nauchnyj.

Vyacheslav Aleksandrovich Fetisov (1958- ) is an outstanding Russian sportsman, ice-hockey player and champion of two Olympic Games. (M 41029)

\section{(8809) Roversimonaco}

$1981 \mathrm{WE}_{1}$. Discovered 1981 Nov. 24 by E. Bowell at Anderson Mesa.

Fabio Roversi Monaco (1938- ) has been rector of the University of Bologna since 1985. He encouraged and strongly supported the organization of the first (1991) and second (1999) Italian scientific expeditions to the site of the Tunguska \{see planet (5471)\} event. The citation was provided by M. Di Martino and G. Longo. (M 40703)

\section{(8811) Waltherschmadel}

1982 UX $_{5}$. Discovered 1982 Oct. 20 by L. G. Karachkina at Nauchnyj.

Named in memory of Heinrich Erwin Walther Schmadel (1902-1944), journalist and editor-in-chief of several German newspapers. He was killed in World War II in Russia near Stalingrad. His story is only an example of the common tragedy between Germans and Russians. There are thousands of people who never saw their fathers. Among these is Walther's son, astronomer Lutz D. Schmadel \{see planet (2234)\}. This planet is a sign of understanding, friendship and forgiveness for us all. (M 35491)

\section{(8812) Kravtsov}

1982 UY $_{6}$. Discovered 1982 Oct. 20 by L. G. Karachkina at Nauchnyj.

Named for Ukrainian pilot and writer Yurij Fedorovich Kravtsov (1924-1994). The author and the heroes in his books are examples of great human courage. (M 34348)

\section{(8813) Leviathan}

$1983 \mathrm{WF}_{1}$. Discovered 1983 Nov. 29 by E. Bowell at Anderson Mesa.

The Leviathan \{see also planet (7012)\} of Parsonstown is the nickname of the great reflecting telescope at Birr Castle, County Offaly, Ireland. Completed by the 
Third Earl of Rosse in 1845, the telescope was for 75 years the largest in the world. (M 41029)

The name was suggested independently by S. Mitton and T. Moseley.

\section{(8814) Rosseven}

1983 XG. Discovered 1983 Dec. 1 by E. Bowell at Anderson Mesa.

William Brendan Parsons, Seventh Earl of Rosse (1936- ), was inspired to restore the 1.8-m reflecting telescope (the "Leviathan \{see planet (8813)\} of Parsonstown") at Birr Castle, County Offaly, Ireland, to full working order. The task took three years and was completed in 1999. (M 41029)

The name was suggested by S. Mitton.

\section{(8816) Gamow}

1984 YN $_{1}$. Discovered 1984 Dec. 17 by L. G. Karachkina at Nauchnyj.

Named in memory of the scientist George (Georgij Antonovich) Gamow (1904-1968). His main scientific achievements include the creation of alpha and beta decay theory and the theory of the exploding Universe. Gamow was also the first to decipher the genetic code. He worked at institutions around the world, in Odessa, Leningrad, Göttingen, Copenhagen, Cambridge, as well as in the U.S. Through his popular lectures, articles and books he promoted public interest in science. In 1956 he received the Calling Prize awarded by UNESCO for the popularization of science. (M 34348)

Name suggested by S. P. Kapitza and supported by the discoverer.

\section{(8817) Roytraver}

$1985 \mathrm{JU}_{1}$. Discovered 1985 May 13 by C. S. Shoemaker and E. M. Shoemaker at Palomar.

Roy Traver (1947- ） is a photographer, philosopher, teacher, innovator and gourmet cook. Above all, he is a loyal friend to both young and old. (M 46009)

\section{(8822) Shuryanka}

1987 RQ2. Discovered 1987 Sept. 1 by L. G. Karachkina at Nauchnyj.

Named in honor of Aleksandra Semenova Morozova (1917- ), mother of the discoverer. Shuryanka is a pet name used by her parents. Before her retirement she worked as a barley selector. (M 34628)

\section{(8826) Corneville}

$1988 \mathrm{PZ}_{1}$. Discovered 1988 Aug. 13 by E. W. Elst at St. Michel.

Corneville is a small village in Normandy, the setting for the 1877 operetta by Robert Planquette Les cloches de Corneville. The castle has been abandoned. However, the bells will ring when the legal owner of the castle again takes possession of his property. (M 47164)

\section{(8827) Kollwitz}

$1988 \mathrm{PO}_{2}$. Discovered 1988 Aug. 13 by F. Börngen at Tautenburg.
Named for the distinguished German graphic artist and sculptor Käthe Kollwitz (1867-1945). She studied art in Berlin and Munich and was married to a physician. She became a professor and a member of the Prussian Academy of Arts in 1919 but was ousted in 1933. In her pictures, woodcuts, lithographs and sculptures, Kollwitz represented the destitution and misery of the poor, the unhappy fate of poor mothers and children, and the death of young men in war. She was deeply influenced by the tragedies of both world wars and the horrors of fascism, always hoping for a peaceful and humane society. (M 32792)

\section{(8831) Brändström}

$1989 \mathrm{CO}_{5}$. Discovered 1989 Feb. 2 by F. Börngen at Tautenburg.

Named in memory of the uncommon Swede Elsa Brändström (1888-1948). Born in St. Petersburg, she was a daughter of the diplomat general Edvard Brändström. During World War I, she stood up beyond all measure for indigent German prisoners in Russia. Under the sign of the Red Cross, she organized numerous relief missions to Siberian camps; from 1914 to 1920 , about 700000 prisoners benefited of her help, which gave her the honorary title "Angle of Siberia". After 1918, she founded several homes for war orphans and repatriates of war in Germany. After the fascists' seizure of power, she left Berlin together with her husband and emigrated in the U.S. There she stood up anew for needy refugees from Europe, persecuted for racial or political motives. (M 32792)

\section{(8832) Altenrath}

$1989 \mathrm{EC}_{3}$. Discovered 1989 Mar. 2 by E. W. Elst at La Silla.

Named in memory of Henricus Hubertus Altenrath (1832-1892), initiator and first director of the "Nijverheidsschool", a well-known Antwerp school for the teaching of technical professions. Under his direction, the school began teaching in Flemish, which was not common at that time. His name is still honored by the Association "Henric Altenrath". The discoverer has taught for many years at this school. (M 33389)

\section{(8833) Acer}

1989 RW. Discovered 1989 Sept. 3 by E. W. Elst at St. Michel.

Named for Aceraceae, the maple family, with two genera and more than 100 species. One well-known species is Acer saccharum (sugar maple), the sap of which is used for maple syrup and maple sugar. (M 34348)

\section{(8834) Anacardium}

$1989 \mathrm{SX}_{2}$. Discovered 1989 Sept. 26 by E. W. Elst at La Silla.

Named for Anacardiaceae, the cashew or mango family, with 80 genera and over 800 species of evergreen and deciduous trees, shrubs and climbing 
plants. Anacardium occidentale (western cashew) yields a delicious fruit. (M 34348)

\section{(8835) Annona}

$1989 \mathrm{SA}_{3}$. Discovered 1989 Sept. 26 by E. W. Elst at La Silla.

Named for Annonaceae, the custard apple family, with more than 2000 species. The trees are mainly tropical and include the species Annona squamose (sweetsop), which has a sweet, pulpy fruit. (M 34348)

\section{(8836) Aquifolium}

1989 SU $_{3}$. Discovered 1989 Sept. 26 by E. W. Elst at La Silla.

Named for Aquifoliaceae, the holly family, with 700 evergreens and deciduous species. Ilex aquifolium (English holly) belongs to this family, as does Ilex paraguariensis (Yerba maté), which makes a tasteful tea. (M 34348)

\section{(8837) London}

$1989 \mathrm{TF}_{4}$. Discovered 1989 Oct. 7 by E. W. Elst at La Silla.

London, on the River Thames, is the capital of England and the United Kingdom, founded by the Romans (Londinium) in the first century. It is a very pleasant city, known for its large green parks and spacious squares. The British Museum in London is known worldwide for its marvelous collections. (M 47164)

\section{(8839) Novichkova}

1989 UB $_{8}$. Discovered 1989 Oct. 24 by L. I. Chernykh at Nauchnyj.

Vera Stepanovna Novichkova (1937- ), doctor and hematologist, is the founder and head of the bloodtransfusion station at Bakhchisaraj \{see planet (3242)\} regional hospital in the Crimea. (M 41384)

\section{(8847) Huch}

$1990 \mathrm{TO}_{3}$. Discovered 1990 Oct. 12 by F. Börngen and L. D. Schmadel at Tautenburg.

Named in honor of the German novelist and poet Ricarda Huch (1864-1947). Born into a prosperous commercial family, she earned a doctorate in history in Zurich in 1891, afterwards working as a librarian and teacher. In 1897 she decided to become a writer. Her novels and stories depict historical figures and events. She was a critic of the fascist regime, and her last unfinished work was to portray the German resistance movement. In 1933, she retired from the Prussian Academy of Arts. (M 32792)

Name proposed by the first discoverer. Huch was already honored by planet (879) Ricarda.

\section{(8849) Brighton}

$1990 \mathrm{VZ}_{4}$. Discovered 1990 Nov. 15 by E. W. Elst at La Silla.

Brighton is a seaside resort about $80 \mathrm{~km}$ south of London. Originally a small fishing community, it grew to become an important seaside resort, due to the influence of king George IV, who patronized the city. The IAU chose Brighton for its General Assembly in 1970. (M 47164)

\section{(8850) Bignonia}

1990 VQ6. Discovered 1990 Nov. 15 by E. W. Elst at La Silla.

Named for Bignoniaceae, the catalpa family, with about 100 genera and 700 species with tubular flowers. Among them are Bignonia capreolata (trumpet flower) and Crescentia cujete (calabash). (M 34348)

\section{(8852) Buxus}

1991 GG $_{6}$. Discovered 1991 Apr. 8 by E. W. Elst at La Silla.

Named for Buxaceae, the box family, with four or five genera and some 60 species of evergreen trees and shrubs. Buxus sempervirens (English boxwood) has very small leaves and is used for hedges and borders. (M 34349)

\section{(8853) Gerdlehmann}

1991 GC $_{10}$. Discovered 1991 Apr. 9 by F. Börngen at Tautenburg.

Named in honor of Gerhard Lehmann (1960- ), an amateur astronomer who with Jens Kandler \{see planet (8861)\} measured some 70 precise positions of minor planets and comets from photographic plates obtained at Drebach \{see planet (6488)\}. Among the 1500 positions he has derived after switching to CCD equipment in 1994 are some for the 1998 opposition of this object. The Drebach positions have made more than 30 Tautenburg objects appropriate for numbering. A teacher of physics and astronomy, Lehmann is also a popularizer of astronomy and since 1997 the head of the minor planets section of the Vereinigung der Sternfreunde. (M 33389)

\section{(8855) Miwa}

1991 JL. Discovered 1991 May 3 by S. Otomo and O. Muramatsu at Kiyosato.

Named in honor of Miwa Saito, a junior high school science teacher. She has made an effort to popularize science and astronomy on her World Wide Web site. (M 33793)

\section{(8856) Celastrus}

$1991 \mathrm{LH}_{1}$. Discovered 1991 June 6 by E. W. Elst at La Silla.

Named for Celastraceae, the staff-tree family, with 100 genera and over 1000 species including many climbing plants. These include Celastrus candens (bittersweet) and Euonymus europaeus (European spindle tree), the latter having pink fruit and orange seeds. (M 34349)

\section{(8857) Cercidiphyllum}

$1991 \mathrm{PA}_{7}$. Discovered 1991 Aug. 6 by E. W. Elst at La Silla.

Named for Cercidiphyllaceae, a family with only one member, Cercidiphyllum japonicum (katsura), regarded 
as a plant of primitive origin. It was originally classified as belonging to the magnolias, but it seems more related to the planes. (M 34349)

\section{(8858) Cornus}

$1991 \mathrm{PT}_{7}$. Discovered 1991 Aug. 6 by E. W. Elst at La Silla.

Named for Cornaceae, the dogwood family, with about 12 genera and 100 species of evergreens, deciduous trees and shrubs. Species include Cornus sanguinea (red dogwood) and Cornus florida (flowering dogwood). (M 34349)

\section{(8860) Rohloff}

$1991 \mathrm{TE}_{5}$. Discovered 1991 Oct. 5 by L. D. Schmadel and F. Börngen at Tautenburg.

Ralf-Rainer Rohloff (1960- ) is a design engineer on the staff of the Max-Planck-Institut für Astronomie, Heidelberg. Head of the construction team, he played an important role in the development of adaptive optics devices for the MPIA and UKIRT telescopes. (M 41567)

The name was suggested by the first discoverer.

\section{(8861) Jenskandler}

$1991 \mathrm{TF}_{7}$. Discovered 1991 Oct. 3 by F. Börngen and L. D. Schmadel at Tautenburg.

Named in honor of Jens Kandler (1973- ), who has been an observer at Drebach \{see planet (6488)\} since the age of 14. Beginning in 1993, he has been observing minor planets and comets, at first photographically and then using a CCD. Among the Drebach observations are many from both the 1996 and 1998 oppositions of this object. A skilled industrial mechanic and tile setter, Kandler is an enthusiastic proponent of astronomy. (M 33389)

Name proposed by the first discoverer.

\section{(8865) Yakiimo}

1992 AF. Discovered 1992 Jan. 1 by A. Natori and T. Urata at Yakiimo.

The observing station in Shizuoka prefecture, where this object was discovered, was very active in making observations of comets and minor planets from 1975 to 1993 . (M 47164)

\section{(8866) Tanegashima}

1992 BR. Discovered 1992 Jan. 26 by M. Mukai and M. Takeishi at Kagoshima.

Named for the small, long and narrow island to the south of Kyushu Island in southeastern Japan. It contains the launch site for the National Space Development Agency. (M 33793)

\section{(8867) Tubbiolo}

$1992 \mathrm{BF}_{4}$. Discovered 1992 Jan. 29 by the Spacewatch at Kitt Peak.

Andrew F. Tubbiolo is a multitalented engineer and enthusiast of space flight working at the University of Arizona's Lunar and Planetary Laboratory. He built some of the electronics on the successful Mars Pathfinder Lander and a complex interface for Spacewatch \{see planet (4255)\} data acquisition. (M 40703)

\section{(8868) Hjorter}

$1992 \mathrm{EE}_{7}$. Discovered 1992 Mar. 1 by the Uppsala-ESO Survey at La Silla.

Olof Petrus Hjorter (1696-1750), Uppsala professor of astronomy in 1732-1737 and after 1746, independently discovered comet C/1743 X1 five days after Klinkenberg. With Celsius \{see planet (4169)\}, he discovered the magnetic nature of aurorae. He donated his library to the Uppsala Observatory, and it is still the rarest part of that collection. (M 36947)

\section{(8869) Olausgutho}

$1992 \mathrm{EE}_{11}$. Discovered 1992 Mar. 6 by the Uppsala-ESO Survey at La Silla.

Olaus Johannis Gutho, from the island of Gotland, was a student at Uppsala \{see planet (2191)\} University from 1477 to 1486 . His carefully written lecture notes (in seven volumes), the only ones preserved from that time, give good examples of the curricula in those days. (M 39652)

\section{(8870) von Zeipel}

1992 EQ $_{11}$. Discovered 1992 Mar. 6 by the Uppsala-ESO Survey at La Silla.

Hugo von Zeipel (1873-1959), professor of astronomy at Uppsala \{see planet (2191)\} University during 1911-1920, is still well known for his theoretical work in celestial mechanics and astrophysics. (M 39652)

\section{(8871) Svanberg}

1992 EA $_{22}$. Discovered 1992 Mar. 1 by the Uppsala-ESO Survey at La Silla.

Gustaf Svanberg (1802-1882), professor of astronomy at Uppsala \{see planet (2192)\} University from 1842 to 1878 , built the present building of Uppsala Astronomical Observatory and founded the meteorological observatory. His autobiography gives a good insight into the academic life in Uppsala during the nineteenth century. (M 39652)

\section{(8872) Ebenum}

$1992 \mathrm{GA}_{4}$. Discovered 1992 Apr. 4 by E. W. Elst at La Silla.

Named for Ebenaceae, the ebony family, with only two genera and 500 species. Male and female flowers are usually borne on separate plants. The Diospyros genus dominates, the fruit of the Diospyros virginiana (persimmon) being good to eat. Diospyros ebenum (Macassar ebony) is a valuable wood. (M 34349)

\section{(8874) Showashinzan}

1992 UY $_{3}$. Discovered 1992 Oct. 26 by K. Endate and K. Watanabe at Kitami.

Showashinzan is a new volcanic mountain in Hokkaido that grew during 1943-1945. Its current height is about 
270 meters above the original ground level and 408 meters above sea level. (M 42669)

\section{(8875) Fernie}

1992 UP $_{10}$. Discovered 1992 Oct. 22 by E. Bowell at Palomar.

J. Donald Fernie (1933- ), professor emeritus of astronomy at the University of Toronto and former director of the David Dunlap Observatory, is known for his work on variable stars, galactic structure, photoelectric photometry, and the history of astronomy of the nineteenth and twentieth centuries. (M 41936)

\section{(8877) Rentaro}

$1993 \mathrm{BK}_{2}$. Discovered 1993 Jan. 19 by T. Seki at Geisei.

Named in memory of Rentaro Taki (1879-1903), gifted Japanese composer. After he finished his schooling in Japan he went to Germany and trained at the Music Academy in Leipzig. Not long afterward, however, he developed tuberculosis and returned to Japan to die. His songs, which include "The Moon over the Ruins of a Castle", are among the best loved in Japan. (M 35492)

Name proposed by the discoverer following a suggestion by T. Funada and T. Sato.

\section{(8882) Sakaetamura}

$1994 \mathrm{AP}_{2}$. Discovered 1994 Jan. 10 by K. Endate and K. Watanabe at Kitami.

Sakae Tamura (1911- ) founded Gekkan Tenmon Guide ("Monthly Astronomy Guide") in 1965 and served as its chief editor until 1971. This magazine's circulation became the biggest of its kind in Japan. Earlier he was chief editor of Kodomo no Kagaku ("Children's Science"), a magazine that promoted science in general. (M 42669)

\section{(8883) Miyazakihayao}

$1994 \mathrm{BS}_{4}$. Discovered 1994 Jan. 16 by T. Kobayashi at Oizumi.

Animator and movie director Hayao Miyazaki (1941-

) received awards for Laputa, Castle in the Sky, My Neighbor Totoro, Spirited Away and many other animation films that closely relate to issues of the time, yet are also entertaining stories. (M 46009)

\section{(8885) Sette}

1994 EL $_{3}$. Discovered 1994 Mar. 13 by M. Tombelli and V. Goretti at Cima Ekar.

Named in honor of Giancarlo Sette (1927- ), Italian amateur astronomer. Since 1950 he has focused his attention mainly on astronomical photography with several groups of amateur astronomers in Bologna. From 1975 to 1981, at San Vittore Observatory, he was involved in the International Planetary Patrol Program of the Lowell Observatory. He still devotes his time to wide-field Schmidt astronomical photography. (M 32792)

\section{(8886) Elaeagnus}

1994 EG $_{6}$. Discovered 1994 Mar. 9 by E. W. Elst at Caussols.

Named for Elaeagnaceae, the oleaster family with three genera and about 50 species. In many cases the flowers develop into edible fruits. Elaeagnus augustifolia (Russian olive) has important commercial value for its fruits. (M 34349)

\section{(8887) Scheeres}

$1994 \mathrm{LK}_{1}$. Discovered 1994 June 9 by E. F. Helin at Palomar.

Named in honor of Daniel J. Scheeres (1963- ), currently in the Department of Aerospace Engineering Mechanics at Iowa State University. Scheeres has pioneered the investigation of the dynamics of orbits close to small, irregularly shaped minor planets. His research has included studies of the short-term evolution and the long-term stability of orbits around radar-derived models of (4179) Toutatis and (4769) Castalia. His work has far-reaching implications for the operation of spacecraft orbiting minor planets, for the cosmogony of satellites of minor planets and for understanding the distribution of non-escaping impact ejecta on small bodies. (M 32793)

\section{(8889) Mockturtle}

1994 OC. Discovered 1994 July 31 by Y. Shimizu and T. Urata at Nachi-Katsuura.

The Mock Turtle, which appears in Lewis Carroll's \{see planet (6984)\} Alice's adventures in Wonderland, has a turtle's shell and front flippers, but a cow's head and a cow's back legs and tail. Once he was a Real Turtle. The Mock Turtle has "large eyes full of tears". In a voice choked with sobs, he sings a song to Alice about soup. (M 42358)

\section{(8890) Montaigne}

1994 PS $_{37}$. Discovered 1994 Aug. 10 by E. W. Elst at La Silla.

Michel de Montaigne (1533-1592) was a French philosopher much preoccupied by the decline of intellectual optimism from the Renaissance through the Protestant Reformation. His Essays, intimate selfportraits advocating travel, reading and conversation, mark a new approach to literature. (M 47165)

\section{(8891) Irokawa}

$1994 \mathrm{RC}_{1}$. Discovered 1994 Sept. 1 by K. Endate and K. Watanabe at Kitami.

Hiroshi Irokawa (1930- ) was chief editor of Gekkan Tenmon Guide ("Monthly Astronomy Guide") from 1972 to 1974 . He has also edited many astronomical books. (M 42669)

\section{(8892) Kakogawa}

$1994 \mathrm{RC}_{11}$. Discovered 1994 Sept. 11 by M. Sugano and T. Nomura at Minami-Oda.

Named for the city, in the southwestern part of Hyogo prefecture, where the first discoverer was born 
and lives. This city has been nurtured with abundant water from the Kako river and blessed with a mild climate. It has a population of about 270000 , and its main enterprises are iron and steel production, sock manufacturing and rice growing. (M 35492)

\section{(8895) Nha}

1995 QN. Discovered 1995 Aug. 21 by K. Watanabe at Sapporo.

Named in honor of Nha Il-Seong (1932- ), professor emeritus at Yonsei University, Korea, on the occasion of the dedication of his Museum of Astronomy in Yecheon. Professor Nha's major works include photometry of close binary stars, the discovery of the apsidal motion in the CW Cep system and contributions to the history of Asian astronomy. He has served as president of the Korean Astronomical Society and director of Yonsei University Observatory. (M 34349)

Name proposed by the discoverer following a suggestion by K. Hurukawa. Citation by I. Hasegawa.

\section{(8897) Defelice}

1995 SX. Discovered 1995 Sept. 22 at the Santa Lucia Observatory at Stroncone.

Named in memory of Aurelio De Felice (1915-1996), Italian sculptor known for going "against the flow" in his creations, which appear in museums around the world. (M 34628)

\section{(8898) Linnaea}

$1995 \mathrm{SL}_{5}$. Discovered 1995 Sept. 29 by G. Emerson at Golden.

Linnaea Barton Keammerer (1980-1992) died in an accidental shooting. An avid student of nature, she was told while observing comet 1P/Halley in 1986 that she would almost certainly live to see it again. Linnaea enjoyed writing poetry: "One star silent in the sky, Twinkling, yet I don't know why." (M 41384)

\section{(8914) Nickjames}

$1995 \mathrm{YP}_{2}$. Discovered 1995 Dec. 25 by B. G. W. Manning at Stakenbridge.

Nick James (1962- ), is a leading CCD imager and photometrist who has produced large numbers of precision light curves of cataclysmic variables and images of unusual variables stars and comets. He is currently papers secretary of the British Astronomical Association and assistant editor of The Astronomer. (M 43762)

\section{(8922) Kumanodake}

1996 VQ30. Discovered 1996 Nov. 10 by T. Okuni at Nanyou.

Zao Kumanodake, located between Miyagi and Yamagata prefectures in the northern part of mainland Japan, was designated as a national park in 1963. Mt. Kumanodake has a height of 1841 meters. (M 40703)
(8924) Iruma

$1996 \mathrm{XA}_{32}$. Discovered 1996 Dec. 14 by N. Sato at Chichibu.

The Iruma area of Saitama prefecture, mentioned in such traditional literary works as Manyohshu \{see planet (7104)\}, has the first tea museum in Japan. (M 36128)

\section{(8925) Boattini}

$1996 \mathrm{XG}_{32}$. Discovered 1996 Dec. 4 by M. Tombelli and U. Munari at Cima Ekar.

Named in honor of Andrea Boattini (1969- ) ). After developing a growing interest in minor planets, he graduated in 1996 from the University of Bologna with a thesis on near-earth objects. He is involved in various projects related to NEO follow-up and search programs, with special interest in the NEO class known as Atens \{see planet (2062)\}. He currently works at the Istituto di Astrofisica Spaziale of the National Research Council in Rome. The discoverers have started their astrometric activity on minor planets together with him. (M 33793)

\section{(8933) Kurobe}

1997 AU $_{6}$. Discovered 1997 Jan. 6 by N. Sato at Chichibu.

The Kurobe ravine, in Toyama prefecture, is the largest and deepest in Japan, inaccessible for six months each year because of snowfall. An arch-type dam there is one of the largest of its kind in the world. (M 36128)

\section{(8935) Beccaria}

1997 AV $_{13}$. Discovered 1997 Jan. 11 by P. Sicoli and M. Cavagna at Sormano.

Cesare Beccaria (1738-1794) was an Italian Enlightenment thinker. In his most important work, Dei delitti e delle pene, Beccaria took sides against the death penalty, supporting the educational function of punishment. (M 40703)

\section{(8937) Gassan}

1997 AK $_{19}$. Discovered 1997 Jan. 13 by T. Okuni at Nanyou.

Gassan is a volcanic mountain in central Yamagata \{see planet (7039)\} prefecture, in the northern part of mainland Japan. It was designated as a national park in 1950. Mt. Gassan has a height of 1980 meters. (M 40703)

\section{(8940) Yakushimaru}

$1997 \mathrm{BA}_{2}$. Discovered 1997 Jan. 29 by T. Kobayashi at Oizumi.

Hiroko Yakushimaru (1964- ) is a Japanese actress and singer. Since her debut in 1978 on Yasei no Shomei, she has appeared in 23 movies and seven TV dramas and has released more than 20 records. The number 8940 can be read as "Ya-Ku-Shi-Maru" in Japanese. (M 41384)

The name was suggested by A. Nakamura. 


\section{(8944) Ortigara}

$1997 \mathrm{BF}_{9}$. Discovered 1997 Jan. 30 by U. Munari and

M. Tombelli at Cima Ekar.

Mount Ortigara, located near the Asiago Astrophysical Observatory, is one of the highest peaks in the Asiago Tableland and was the location of one of the most famous and bloodiest alpine battles of World War I. (M 32793)

\section{(8945) Cavaradossi}

1997 CM. Discovered 1997 Feb. 1 by P. G. Comba at Prescott.

Named for a character in Puccini's \{see planet (4579)\} opera Tosca. Cavaradossi, a revolutionary and fighter against despotism, is imprisoned and condemned to die. While awaiting execution, he sings the nostalgic aria "E lucevan le stelle", recalling the sweet times he had with his mistress Tosca and bemoaning his impending death. Meanwhile, Tosca tries to gain his release by bargaining with the lecherous chief of police Scarpia. They double-cross each other, and everyone dies a violent death. (M 32793)

\section{(8952) ODAS}

$1998 \mathrm{EG}_{2}$. Discovered 1998 Mar. 2 by the OCA-DLR Survey at Caussols.

From Oct. 1996 to Mar. 1999 the OCA-DLR Asteroid Survey operated the first and only quasiautomatic European near-earth-asteroid search program. In the course of this survey five NEAs, ten Mars-crossers and a comet were discovered. ODAS also produced more than 44000 astrometric positions of 2200 new minor planets. (M 41384)

\section{(8957) Koujounotsuki}

1998 FM $_{125}$. Discovered 1998 Mar. 22 by T. Seki at Geisei.

Named for a song composed in 1901 by Rentaro Taki (1879-1903). In English, the song's title is "The Moon over the Ruins of a Castle". The reference is specifically to Oka castle, symbol of Takeda City, in Oita Prefecture. (M 35492)

\section{(8958) Stargazer}

1998 FJ J $_{126}$. Discovered 1998 Mar. 23 by J. Broughton at Reedy Creek.

This name honors in general those who since time immemorial have gazed up at the night sky in wonderment. It honors in particular the noble pursuit of amateur astronomy. (M 44185)

\section{(8959) Oenanthe}

2550 P-L. Discovered 1960 Sept. 24 by C. J. van Houten and I. van Houten-Groeneveld at Palomar.

Named for Oenanthe oenanthe, or wheatear. \{It belongs to the family of the Turdidae. It is on the Dutch Red List of birds endangered in the Netherlands.\} (M 33793; M 34089)

\section{(8960) Luscinioides}

2575 P-L. Discovered 1960 Sept. 24 by C. J. van Houten and I. van Houten-Groeneveld at Palomar.

Named for Locustella luscinioides, or Savi's warbler. It belongs to the family of the Sylviidae and is endangered in the Netherlands.\} (M 33794; M 34089)

\section{(8961) Schoenobaenus}

2702 P-L. Discovered 1960 Sept. 24 by C. J. van Houten and I. van Houten-Groeneveld at Palomar.

Named for Acrocephalus schoenobaenus, or sedge warbler. \{It belongs to the family of Sylviidae and is on the Dutch Red List.\} (M 33794; M 34089)

\section{(8962) Noctua}

2771 P-L. Discovered 1960 Sept. 24 by C. J. van Houten and I. van Houten-Groeneveld at Palomar.

Named for Athene noctua, or little owl. \{It belongs to the family of the Strigidae. It is on the Dutch Red List of endangered birds.\} (M 33794; M 34089)

\section{(8963) Collurio}

4651 P-L. Discovered 1960 Sept. 24 by C. J. van Houten and I. van Houten-Groeneveld at Palomar.

Named for Lanius collurio, or red-backed shrike. \{This bird from the Dutch Red List of birds endangered in the Netherlands belongs to the family of the Laniidae.\} (M 33794; M 34089)

\section{(8964) Corax}

7643 P-L. Discovered 1960 Oct. 17 by C. J. van Houten and I. van Houten-Groeneveld at Palomar.

Named for Corvus corax, or raven. \{It belongs to the family of the Corvidae and is an endangered bird in the Netherlands.\} (M 33794; M 34089)

\section{(8965) Citrinella}

9511 P-L. Discovered 1960 Oct. 17 by C. J. van Houten and I. van Houten-Groeneveld at Palomar.

Named for Emberiza citrinella, or yellowhammer. \{It belongs to the family of the Emberizidae and is on the Dutch Red List.\} (M 33794; M 34089)

\section{(8966) Hortulana}

3287 T-1. Discovered 1971 Mar. 26 by C. J. van Houten and I. van Houten-Groeneveld at Palomar.

Named for Emberiza hortulana, or ortolan bunting. \{It belongs to the family of the Emberizidae. It is on the Dutch Red List of birds endangered in the Netherlands and also on the 'List of Vulnerable Birds in Europe'.\} (M 33794; M 34089)

\section{(8967) Calandra}

4878 T-1. Discovered 1971 May 13 by C. J. van Houten and I. van Houten-Groeneveld at Palomar.

Named for Miliaria calandra, or corn bunting. \{It belongs to the family of the Emebrizidae and is on the Dutch Red List.\} (M 33794; M 34089) 


\section{(8968) Europaeus}

1212 T-2. Discovered 1973 Sept. 29 by C. J. van Houten and I. van Houten-Groeneveld at Palomar.

Named for Caprimulgus europaeus, or nightjar. \{It belongs to the Caprimulgidae family and is an endangered bird in the Netherlands.\} (M 33794; M 34089)

\section{(8969) Alexandrinus}

1218 T-2. Discovered 1973 Sept. 29 by C. J. van Houten and I. van Houten-Groeneveld at Palomar.

Named for Charadrius alexandrinus, or Kentish plover. \{It belongs to the family of the Charadriidae and is on the Dutch Red List.\} (M 33794; M 34089)

\section{(8970) Islandica}

1355 T-2. Discovered 1973 Sept. 29 by C. J. van Houten and I. van Houten-Groeneveld at Palomar.

Named for Bucephala islandica, or Barrow's goldeneye. \{It belongs to the family of the Anatidae and is one of the birds on the 'List of Endangered Birds in Europe'. In 1994 only 200 pairs were counted.\} (M 33794; M 34089)

\section{(8971) Leucocephala}

2256 T-2. Discovered 1973 Sept. 29 by C. J. van Houten and I. van Houten-Groeneveld at Palomar.

Named for Oxyura leucocephala, or white-headed duck. \{It belongs to the Anatidae family and is endangered in Europe. Im 1994 only 210 pairs were counted.\} (M 33794; M 34089)

\section{(8972) Sylvatica}

2319 T-2. Discovered 1973 Sept. 29 by C. J. van Houten and I. van Houten-Groeneveld at Palomar.

Named for Turnix sylvatica, or Andalusian hemipode. \{It belongs to the Turnicidae family and it is one of the birds on the 'List of Endangered Birds in Europe'. In 1994, only five pairs were counted.\} (M 33794; M 34089)

\section{(8973) Pratincola}

3297 T-2. Discovered 1973 Sept. 30 by C. J. van Houten and I. van Houten-Groeneveld at Palomar.

Named for Glareola pratincola, or collared pratincole. \{It belongs to the Glareolidae family and is endangered in Europe.\} (M 33794; M 34089)

\section{(8974) Gregaria}

3357 T-2. Discovered 1973 Sept. 25 by C. J. van Houten and I. van Houten-Groeneveld at Palomar.

Named for Chettusia gregaria, or sociable plover. \{It belongs to the Chardadriidae family and is endangered in Europe. In 1994 only 1,000 pairs were counted.\} (M 33794; M 34089)

\section{(8975) Atthis}

4076 T-2. Discovered 1973 Sept. 29 by C. J. van Houten and I. van Houten-Groeneveld at Palomar.
Named for Alcedo atthis, or kingfisher. \{It belongs to the family of the Alcedinidae and it is on the Dutch Red List of birds endangered in the Netherlands. (M 33794; M 34089)

\section{(8976) Leucura}

4221 T-2. Discovered 1973 Sept. 29 by C. J. van Houten and I. van Houten-Groeneveld at Palomar.

Named for Oenanthe leucura, or black wheatear. \{It belongs to the Turdidae family and is endangered in Europe. In 1994 only 4,100 pairs were counted.\} (M 33794; M 34089)

\section{(8977) Paludicola}

4272 T-2. Discovered 1973 Sept. 29 by C. J. van Houten and I. van Houten-Groeneveld at Palomar.

Named for Acrocephalus paludicola, or aquatic warbler. \{It belongs to the Sylviidae family. It is one of the birds on the 'List of Endangered Birds in Europe'. In 1994 only 3,700 pairs were counted.\} (M 33794; M 34089)

\section{(8978) Barbatus}

3109 T-3. Discovered 1977 Oct. 16 by C. J. van Houten and I. van Houten-Groeneveld at Palomar.

Named for the bird Gypaetus barbatus, or lammergeier. IIt belongs to the Accipitridae family and it is an endangered bird in Europe. In 1994 only 200 pairs were counted.\} (M 34349)

\section{(8979) Clanga}

3476 T-3. Discovered 1977 Oct. 16 by C. J. van Houten and I. van Houten-Groeneveld at Palomar.

Named for the bird Aquila clanga, or greater spotted eagle. \{It belongs to the family of the Accipitridae and it is endangered in Europe. In 1994 only 860 pairs were counted.\} (M 34349)

\section{(8980) Heliaca}

4190 T-3. Discovered 1977 Oct. 16 by C. J. van Houten and I. van Houten-Groeneveld at Palomar.

Named for the bird Aquila heliaca, or imperial eagle. \{It belongs to the Accipitridae family. It is one of the birds on the 'List of Endangered Birds in Europe'. In 1994 only 320 pairs were counted.\} (M 34349)

\section{(8982) Oreshek}

1973 SQ3. Discovered 1973 Sept. 25 by L. V. Zhuravleva at Nauchnyj.

Oreshek is an ancient Russian fortress built in 1323 . From 1612 to 1702 it was in the possession of Sweden. Peter the Great then recaptured it for Russia. It is a unique architectural and historical monument. (M 41029)

\section{(8983) Rayakazakova}

1977 ED $_{1}$. Discovered 1977 Mar. 13 by N. S. Chernykh at Nauchnyj.

Raisa Konstantinovna Kazakova is a celestial mechanician at the Keldysh Institute of Applied Mathe- 
matics. She participated in work on the theory and calculation of the orbits of artificial satellites and the trajectories of spacecraft to the moon and planets. (M 43381)

\section{(8984) Derevyanko}

1977 QD 3 . Discovered 1977 Aug. 22 by N. S. Chernykh at Nauchnyj.

Cinema-artist Tatiana Timofeevna Derevyanko is director of the Dovzhenko Museum at the Dovzhenko Film Studio in Kiev. (M 41384)

\section{(8985) Tula}

1978 PV 3 . Discovered 1978 Aug. 9 by N. S. Chernykh and L. I. Chernykh at Nauchnyj.

Tula is a city in Russian Federation, the administrative focus of the region and prominent industrial and cultural center. Founded in 1146, the town is much known in history of Russia. (M 45232)

\section{(8986) Kineyayasuyo}

$1978 \mathrm{VN}_{2}$. Discovered 1978 Nov. 1 by K. Tomita at Caussols.

Named in honor of Yasuyo Kineya, the stage name of Nobuko Shimamura (1920- ), elder sister of the discoverer. Ever since her youth, she has devoted herself to Japanese traditional music, especially to Nagauta and Shamisen, and she is still active as a performer. The discoverer was inspired by her to become an astronomer. (M 34628)

\section{(8990) Compassion}

1980 DN. Discovered 1980 Feb. 19 at the Klet Observatory at Klě́t.

Named by the Committee for Small-Body Nomenclature to honor the compassion of people around the world for the friends and families of the victims of disasters, exemplified by the terrorist attacks on New York and Washington on 2001 Sept. 11, with the hope that they will overcome their sorrow. (M 43684)

\section{(8991) Solidarity}

$1980 \mathrm{PV}_{1}$. Discovered 1980 Aug. 6 at the European Southern Observatory at La Silla.

Named by the Committee for Small-Body Nomenclature to honor the solidarity of people around the world with both victims and survivors of terrorist attacks like those on New York and Washington on 2001 Sept. 11, in the goal of eliminating terrorism from the world. (M 43684)

\section{(8992) Magnanimity}

$1980 \mathrm{TE}_{7}$. Discovered 1980 Oct. 14 at the Purple Mountain Observatory at Nanking.

Named by the Committee for Small-Body Nomenclature to honor the magnanimity of people around the world in dealing with terrorist attacks like those on New York and Washington on 2001 Sept. 11, in the hope that terrorism will be countered with justice for all, not with revenge. (M 43684)

\section{(8993) Ingstad}

1980 UL. Discovered 1980 Oct. 30 by R. M. West at La Silla.

Helge Ingstad (1899-2001) was a pioneer explorer and archeologist. Foremost among his many achievements was his and his wife's discovery of remains from the Viking settlements on Newfoundland. This proved that the Vikings reached North America, probably as the first Europeans. (M 46009)

\section{(8994) Kashkashian}

1980 VG. Discovered 1980 Nov. 6 by B. A. Skiff at Anderson Mesa.

The classical violist Kim Kashkashian is known for her particular empathy with the works of composers of the late-twentieth century. (M 36128; M 36155)

\section{(9000) Hal}

1981 JO. Discovered 1981 May 3 by E. Bowell at Anderson Mesa.

Named in honor of the computer Hal 9000 that is the central character of both Clarke's \{see planet (4923)\} novel and Kubrick's \{see planet (10221)\} movie 2001: A Space Odyssey. Hal serves to this day, more than three decades later, as an icon for artificial intelligence and a beacon that has motivated an incalculable number of careers in computing, computer science, electrical engineering and space exploration. (M 34628)

\section{(9001) Slettebak}

$1981 \mathrm{QE}_{2}$. Discovered 1981 Aug. 30 by E. Bowell at Anderson Mesa.

Arne Slettebak (1925-1999) was for 16 years chair of the department of astronomy of Ohio State University. His principal research interests were stellar rotation and spectroscopy, particularly the study of Be stars. He led the effort to move the 1.8-m Perkins telescope from Ohio to the Lowell Observatory. (M 40703)

\section{(9005) Sidorova}

1982 UU $_{5}$. Discovered 1982 Oct. 20 by L. G. Karachkina at Nauchnyj.

Named in honor of Sophia Ivanovna Sidorova (1943-

), tireless worker on behalf of public education in Ukraine and leader of the Crimean Republic Committee for the education of workers. She is an educator of great ability, a brilliant organizer and a thoughtful wife and mother. (M 34349)

\section{(9006) Voytkevych}

1982 UA $_{7}$. Discovered 1982 Oct. 21 by L. G. Karachkina at Nauchnyj.

Named in honor of Vanda Georgievna Voytkevych (1949- ), a friend of the discoverer and specialist in analytical chemistry, particularly in its application to ecology and the metallurgy of welding. During 1971-1994 she was a researcher at the E. O. Paton Welding Institute. Now she lives in New Zealand with her family. (M 34628) 


\section{(9007) James Bond}

$1983 \mathrm{TE}_{1}$. Discovered 1983 Oct. 5 by A. Mrkos at Kleť.

Named for British Secret Service agent James Bond (007), the creation of novelist Ian Fleming, a former British naval intelligence officer. Between 1952 and 1964, Fleming churned out twelve novels and two collections of short stories. Eighteen movies were based on the Bond legend, including Dr. No, Goldeneye and Tomorrow Never Dies, all with the compelling ingredients of action, seduction, humor and high technology. Two of the best-known Bond players are Sean Connery and Pierce Brosnan. (M 34349)

Name suggested by J. Tichá, M. Tichý and Z. Moravec.

\section{(9008) Bohšternberk}

1984 BS. Discovered 1984 Jan. 27 by A. Mrkos at Kleť. Named in memory of Bohumil Šternberk (1897-1983), outstanding Czech astronomer and astrophysicist. He worked in a wide variety of fields, including photometry of variable stars, and he established the modern time service in Czechoslovakia. On the evening of 1930 Mar. 18, at the Stará D̃ala Observatory (O'Gyalla \{see planet (1259)\}, now Hurbanovo), he made the first deliberate astrometric observations of Pluto in Europe. Sternberk served as long-time director of the Astronomical Institute of the Czechoslovak Academy of Sciences (1954-1968) and as a vice-president of the IAU (1958-1964). (M 34628)

Name suggested by J. Tichá, M. Tichý and Z. Moravec, who made observations of this minor planet at Klet during its oppositions in 1997 and 1998.

Obituaries published in Říše hvězd, Vol. 64, p. 106107 (1983); Vesmír, Vol. 62, p. 156 (1983); Q.J.R. Astron. Soc., Vol. 25, No. 3, p. 379-380 (1984); Bull. Astron. Inst. Czech., Vol. 34, No. 4, p. 193-194 (1983).

\section{(9012) Benner}

1984 UW. Discovered 1984 Oct. 26 by E. Bowell at Anderson Mesa.

Lance A. M. Benner (1964- ) is a scientist at the Jet Propulsion Laboratory. His hard work and selfless dedication to dozens of radar experiments on minor planets at Goldstone and Arecibo have contributed dramatically to their success. He was the first to realize with certainty that $2000 \mathrm{DP}_{107}$ is a binary system. (M 41936)

\section{(9013) Sansaturio}

$1985 \mathrm{PA}_{1}$. Discovered 1985 Aug. 14 by E. Bowell at Anderson Mesa.

Maria Eugenia Sansaturio (1959- ), a mathematician at the University of Valladolid, has used new algorithms to find several hundred new identifications of minor planets during the past few years. This object was the first to be numbered as the result of her work. (M 39652)

The name was suggested by A. Milani.

\section{(9014) Svyatorichter}

1985 UG $_{5}$. Discovered 1985 Oct. 22 by L. V. Zhuravleva at Nauchnyj.

Svyatoslav Teofilovich Richter (1915-1997) was a brilliant Russian pianist and People's artist of the U.S.S.R. (M 41029)

\section{(9016) Henrymoore}

1986 AE. Discovered 1986 Jan. 10 by C. S. Shoemaker and E. M. Shoemaker at Palomar.

Named in memory of Henry J. Moore (1928-1998). A geologist with the U.S. Geological Survey since 1960, Moore took part in the fledling astrogeology program helping to train the Apollo astronauts in impact geology prior to the moon landings. He participated in the analysis of the lunar samples they brought back and worked with the photographs of the moon's surface taken from orbit. His experience in the selection of lunar landing sites transferred to the Mars Viking project. Moore's work on the Mars Pathfinder mission and with its Mars rover, Sojourner, were among his last contributions. (M 34349)

\section{(9017) Babadzhanyan}

$1986 \mathrm{TW}_{9}$. Discovered 1986 Oct. 2 by L. V. Zhuravleva at Nauchnyj.

Arno Arutyunovich Babadzhanyan (1921-1983) was an outstanding Soviet composer and brilliant pianist. He created romantic Heroic Ballade for piano accompanied by orchestra, a piano trio, violin and cello concerti and other chamber music. He also wrote many popular songs and music for plays and films. (M 42358)

\section{(9019) Eucommia}

$1987 \mathrm{QF}_{3}$. Discovered 1987 Aug. 28 by E. W. Elst at La Silla.

Named for Eucommiaceae, a famliy with only one member, the elmlike Eucommia ulmoides, a vigorous and decorative plant. It is the only tree from temperate regions that produces latex - in small quantities. (M 34349)

\section{(9020) Eucryphia}

1987 SG $_{2}$. Discovered 1987 Sept. 19 by E. W. Elst at Rozhen.

Named for Eucryphiaceae, a family with five species in a single genus. Eucryphia cordifolia (Chilean elm) may reach a height of $12 \mathrm{~m}$. Hybrids between the different species are cultivated for the garden. (M 34349)

\section{(9021) Fagus}

$1988 \mathrm{CT}_{5}$. Discovered 1988 Feb. 14 by E. W. Elst at La Silla.

Named for Fagaceae, the beech family, with eight genera and over 1000 species, including oaks and chestnuts. Well-known species are Fagus grandifolia (American beech) and Fagus sylvatica (European beech). (M 34349) 


\section{(9022) Drake}

1988 PC $_{1}$. Discovered 1988 Aug. 14 by C. S. Shoemaker and E. M. Shoemaker at Palomar.

Michael J. Drake (1946- ), popular director of the University of Arizona's Lunar and Planetary Laboratory and president of the Meteoritical Society, is a professor and researcher in cosmochemistry and geochemistry who studies the evolution of the earth, moon, igneous meteorites and other terrestrial planetary bodies. (M 41936)

\section{(9023) Mnesthus}

1988 RG $_{1}$. Discovered 1988 Sept. 10 by C. S. Shoemaker and E. M. Shoemaker at Palomar.

Mnesthus was a Trojan who went to what is present-day Italy to fight the Latins as an officer of Aeneas \{see planet (1172)\}. He distinguished himself at the funeral games for Anchises \{see planet (1173)\} by competing in both the sailing and the archery contests, winning second place in sailing. (M 41384)

\section{(9028) Konrádbeneš}

$1989 \mathrm{BE}_{1}$. Discovered 1989 Jan. 26 by A. Mrkos at Klě́t.

Konrád Beneš (1920-1999), a professor at the Technical University in Ostrava, was one of the pioneers of planetology in the Czech Republic and a past vice-president of the International Association of Planetology (1968-1977). (M 38198)

The name was suggested by J. Honěk, P. Martinec and M. Eliáš.

\section{(9032) Tanakami}

$1989 \mathrm{WK}_{4}$. Discovered 1989 Nov. 23 by T. Seki at Geisei.

Mt. Tanakami, extending over Shiga, Mie and Kyoto prefectures, is the site of the largest meteorite found in Japan. Tanakami is also the name of the village that is the birthplace of Issei Yamamoto, founder of the Oriental Astronomical Association. (M 38198)

The name was suggested by I. Hasegawa and A. S. Yamamoto.

\section{(9033) Kawane}

1990 AD. Discovered 1990 Jan. 4 by M. Akiyama and T. Furuta at Mishima.

Kawane is a small town about $230 \mathrm{~km}$ west of Tokyo, located on the west bank of the Ohi river and has some wonderful sights. Green tea, known as "Kawane-cha", is grown there. (M 41384)

\section{(9034) Oleyuria}

1990 QZ 17 . Discovered 1990 Aug. 26 by L. V. Zhuravleva at Nauchnyj.

Husband and wife piano duettists, Yurij Viktorovich Shcherbakov (1957- ) and Ol'ga Konstantinovna Shcherbakova (1962- ), won the Concours "Musical international tour" in Rome in 1992 and 1993. Their mastery has received the highest estimation of experts in many countries. (M 42358)

\section{(9038) Helensteel}

$1990 \mathrm{VE}_{1}$. Discovered 1990 Nov. 12 by D. I. Steel at Siding Spring.

Named in honor of Helen Margaret Steel (née Pope; 1959- ), wife of the discoverer and a native of Adelaide, South Australia. (M 34628)

\section{(9040) Flacourtia}

$1991 \mathrm{BH}_{1}$. Discovered 1991 Jan. 18 by E. W. Elst at St. Michel.

Named for Flacourtiaceae, the Indian plum family, with almost 90 genera and 900 species. Flacourtia indica (governor's plum) is one of the species, and the southeast Asian genus Hydnocarpus produces an oil that is used for treating some skin diseases. (M 34350)

\section{(9041) Takane}

1991 CX. Discovered 1991 Feb. 9 by S. Otomo and O. Muramatsu at Kiyosato.

Takane is name of the town in which the Otomo \{see planet (3911)\} observatory is located. This minor planet was the first discovery at the observatory. (M 45336)

\section{(9044) Kaoru}

1991 KA. Discovered 1991 May 18 by S. Otomo and O. Muramatsu at Kiyosato.

Named in honor of Kaoru Kimura (1964- ), lecturer and curator of the Gotoh Planetarium and Astronomical Museum in Tokyo, where she was in charge of an exhibition about the history of constellations. She traveled abroad several times to observe solar eclipses. (M 34350)

\section{(9052) Uhland}

$1991 \mathrm{UJ}_{4}$. Discovered 1991 Oct. 30 by F. Börngen at Tautenburg.

Named for the German poet Johann Ludwig Uhland (1787-1862), best known for lyric poetry and ballads in which historical and legendary themes dominate, and which were set to music by well-known composers. Uhland is the most famous representative of Swabian Romanticism. In his lifetime, his "Gedichte" (1815) were printed in 42 editions. He also engaged himself in political issues, and in 1848-49 was a member of the Frankfurt parliament. (M 32793)

\section{(9053) Hamamelis}

$1991 \mathrm{VW}_{5}$. Discovered 1991 Nov. 2 by E. W. Elst at La Silla.

Named for Hamamelidaceae, the witch hazel family, with about 25 genera and 100 species, typical in South America and Africa. Hamamelis virginiana (witch hazel) is not a true hazel, although the leaves are similar. (M 34350)

\section{(9054) Hippocastanum}

1991 YO. Discovered 1991 Dec. 30 by E. W. Elst at St. Michel.

Named for Hippocastanaceae, the horse-chestnut family, with only two genera and 15 species. Aesculus 
hippocastanum (common horse-chestnut) is known for its creamy yellow flowers, in large, conical, upright panicles. (M 34350)

\section{(9059) Dumas}

1992 PJ. Discovered 1992 Aug. 8 by E. W. Elst at Caussols.

Alexandre Dumas (1802-1870), the grandson of a French marquis and the son of a French general in Napoleon's army, is a very well known writer. Who has not heard of or read his novels Le Comte de Monte Cristo and Les trois Mousquetaires? (M 47165)

\section{(9060) Toyokawa}

1992 RM. Discovered 1992 Sept. 4 by S. Otomo at Kiyosato.

Hideji Toyokawa (1926-1995) is a curator of the Gotoh Planetarium and Astronomical Museum in Tokyo, where he worked for 29 years since 1957. He maintained planetarium equipment and exhibition facilities. (M 41936)

The name was suggested by O. Muramatsu.

\section{(9062) Ohnishi}

$1992 \mathrm{WO}_{5}$. Discovered 1992 Nov. 27 by T. Seki at Geisei.

Michikazu Ohnishi (1933- ) is a chemical plant engineer and lecturer in descriptive geometry. He made a particular study of a photographic method for panoramic sequences using a regular camera. (M 40703)

The name was suggested by H. Kikuoka and S. Harada. The citation was prepared by I. Hasegawa.

\section{(9063) Washi}

1992 YS. Discovered 1992 Dec. 17 by T. Seki at Geisei.

Shinsyo Washi (1951- ) is the director of the Sakai City Planetarium. He founded the Muroh Observatory in 1978 and is executive secretary of the Hoshi no Hiroba Comet Observer Association. (M 41567)

The name was suggested by H. Kikuoka.

\section{(9064) Johndavies}

$1993 \mathrm{BH}_{8}$. Discovered 1993 Jan. 21 by the Spacewatch at Kitt Peak.

John K. Davies (1955- ) of the Joint Astronomy Centre was instrumental in the successful discovery and follow-up of (3200) Phaethon and several comets with the IRAS satellite in 1983. He has also carried out studies of the infrared nature of distant minor planets and authored a number of popular books and articles. (M 38198)

\section{(9067) Katsuno}

1993 HR. Discovered 1993 Apr. 16 by K. Endate and

K. Watanabe at Kitami.

Gentaro Katsuno (1933- ) was chief editor of Gekkan Tenmon Guide ("Monthly Astronomy Guide") from 1975 to 1987 . He has also edited many astronomical books. (M 42669)

\section{(9069) Hovland}

1993 OV. Discovered 1993 July 16 by E. F. Helin at Palomar.

Larry E. Hovland (1947- ) is a talented senior engineer at the Jet Propulsion Laboratory responsible for the Raman Spectrometer Electronics and the Mars 2005 Op-Nav camera electronics. He generously provided his expertise to the discoverer in her early efforts to convert from photographic to electronic detection methods. (M 42669)

\section{(9070) Ensab}

$1993 \mathrm{OZ}_{2}$. Discovered 1993 July 23 by C. S. Shoemaker and D. H. Levy at Palomar.

Leo Enright (1943- ) and Denise Sabatini (1950-

) of Ontario are one of the foremost couples in Canadian amateur astronomy. Leo is an accomplished solar and auroral observer and has written the Beginner's Observing Guide. Denise's interests center on archeoastronomy and in providing access to astronomy for the disabled. (M 36947)

\section{(9074) Yosukeyoshida}

1994 FZ. Discovered 1994 Mar. 31 by K. Endate and K. Watanabe at Kitami.

Yosuke Yoshida (1945- ） was chief editor of Gekkan Tenmon Guide ("Monthly Astronomy Guide") from 1988 to 1993 . He has also edited many astronomical books. (M 42669)

\section{(9076) Shinsaku}

1994 JT. Discovered 1994 May 8 by A. Nakamura at Kuma.

Named in memory of Shinsaku Takasugi (1839-1867), Japanese revolutionary, who though a lower-ranking samurai, attracted many followers with his innovative ideas and extraordinary drive to modernize Japan. As a primary leader of anti-shogunate forces, he played the most important role in the success of the Meiji Restoration. (M 33389)

\section{(9077) Ildo}

1994 NC. Discovered 1994 July 3 at the Farra d'Isonzo Observatory at Farra d'Isonzo.

Named in memory of Ildo Lombardi (1934-1954), Italian gymnast and brother of Giuseppe Lombardi, a member of the team of amateur astronomers who discovered this minor planet. Ildo died by a fall from the parallel bars while training with the Italian team for the Melbourne Olympic games in 1956. (M 33794)

\section{(9080) Takayanagi}

1994 TP. Discovered 1994 Oct. 2 by K. Endate and K. Watanabe at Kitami.

Yuichi Takayanagi (1939- ) is a leading science commentator and producer of science programs of NHK Broadcasting Corporation in Japan. He very often appears in television programs on astronomy and space development. (M 42669) 


\section{(9081) Hideakianno}

1994 VY. Discovered 1994 Nov. 3 by A. Nakamura at Kuma.

Named in honor of Hideaki Anno (1960- ), Japanese animator and director, born in Ube City \{see planet (7716)\}, Yamaguchi Prefecture. Since 1981, he has contributed to the production of several highly successful works of animation. (M 33794)

\section{(9082) Leonardmartin}

1994 VR $_{6}$. Discovered 1994 Nov. 4 by C. S. Shoemaker and E. M. Shoemaker at Palomar.

Leonard J. Martin, planetary astronomer and cartographer at the Lowell Observatory, contributed to maps of the lunar surface prepared in support of the Apollo missions. He also developed a particular interest in seasonal changes in the ice caps, albedo features, clouds and global dust storms on Mars. (M 36128)

\section{(9083) Ramboehm}

$1994 \mathrm{WC}_{4}$. Discovered 1994 Nov. 28 by C. S. Shoemaker and D. H. Levy at Palomar.

Jeff Ramos (1962- ) and Art Boehm (1944- ) are friends of the discoverers. Their humanitarian efforts have helped take care of numerous families in Vail, Arizona. (M 36947)

\section{(9087) Neff}

$1995 \mathrm{SN}_{3}$. Discovered 1995 Sept. 29 at the Klet Observatory at Klět.

Named for Vladimír Neff and Ondřej Neff. Vladimír Neff (1909-1983) was an outstanding Czech writer, well-known for his five-part chronicle, spanning the midnineteenth to the mid-twentieth century, of the Prague entrepreneur family, the Borns and the Nedobyls. His last work was a great ironic novel The Vesture of Mr. de Balzac. Ondřej Neff (1945- ) is a Czech writer of science fiction, a journalist and son of Vladimír Neff. In 1996 he founded the first Czech independent Internet daily newspaper called Neviditelný pes, or "The invisible Dog". He continues this work today. (M 34350)

Name propsoed by discoverers J. Tichá, M. Tichý and Z. Moravec.

\section{(9088) Maki}

$1995 \mathrm{SX}_{3}$. Discovered 1995 Sept. 20 by K. Endate and K. Watanabe at Kitami.

Fusao Maki (1916-2001) was a songwriter who wrote many children's songs, school songs, home songs, citizen's songs and left hundreds of works. (M 43189)

\section{(9090) Chirotenmondai}

1995 UW $_{8}$. Discovered 1995 Oct. 28 by K. Endate and K. Watanabe at Kitami.

Named for Chiro Astronomical Observatory (Chiro tenmondai) in Western Australia. Founded in 1995 by the joint efforts of Australian and Japanese amateur astronomers, it is also operated by the two groups. It is considered a sister observatory to the Japanese amateurs' Shirakawa Observatory, the two sites being at approximately the same latitude in opposite hemispheres. (M 33389)

Name proposed by the discoverers following a suggestion by L. Taylor and T. Sato.

\section{(9097) Davidschlag}

$1996 \mathrm{AU}_{1}$. Discovered 1996 Jan. 14 at the Davidschlag Observatory at Linz.

Named for a small rural village, some $10 \mathrm{~km}$ to the north of Linz \{see planet (1469)\}, at the entrance to a region known as "Sterngartl", or "small garden of stars". This object is the first minor planet discovered at the amateur astronomical observatory that is located in this village. (M 34628)

\section{(9102) Foglar}

$1996 \mathrm{XS}_{18}$. Discovered 1996 Dec. 12 by M. Tichý and Z. Moravec at Klě́.

Named in memory of Jaroslav Foglar (1907-1999), Czech writer of adventure and educational literature for young boys and prominent in scouting organizations. His well-known books are Boys from the Beaver River, The Mystery of Conundrum and, especially, Rapid Arrows ("Rychlé šípy"). (M 35492)

\section{(9110) Choukai}

1997 AM $_{19}$. Discovered 1997 Jan. 13 by T. Okuni at Nanyou.

The Choukai volcanic mountain range forms a part of the border between Akita and Yamagata prefectures in the northern part of mainland Japan. It was designated as a national park in 1963. Mt. Choukai has a height of 2230 meters. (M 40703)

\section{(9111) Matarazzo}

$1997 \mathrm{BD}_{2}$. Discovered 1997 Jan. 28 by P. Sicoli and F. Manca at Sormano.

The Sicilian amateur astronomer Giuseppe "Corrado" Matarazzo (1946- ) is an experienced mathematician whose interests include orbital computations. In 1995 he co-authored Elementi di Calcolo delle Orbite. (M 36947)

\section{(9115) Battisti}

1997 DG. Discovered 1997 Feb. 27 by P. Sicoli and F. Manca at Sormano.

Named in memory of Lucio Battisti (1943-1998), innovative Italian composer and singer. He wrote many songs for himself and other singers, among them "Emozioni" and "I giardini di marzo". Beginning in 1973 , he lived in a small village in the neighborhood of the observatory where this minor planet was discovered. (M 33389)

\section{(9117) Aude}

$1997 \mathrm{FR}_{1}$. Discovered 1997 Mar. 27 by D. Morata and S. Morata at Martigues.

Named in honor of the French "Association des Utilisateurs de Detecteurs Electroniques" (Electronic Detectors User's Association). Founded by Christian Buil and Alain Maury ssee, respectively, planets 
(6820) and (3780) \} with the aim of assisting amateur astronomers in the use of electronic detectors, the organization is now heavily involved with the discovery and follow-up of solar-system objects and photometry of supernovae. (M 33794)

\section{(9119) Georgpeuerbach}

1998 DT. Discovered 1998 Feb. 18 at the Davidschlag Observatory at Linz.

Named in memory of Georg Aunpekh von Peuerbach (1423-1461), professor at the University of Vienna, astronomer at the court of emperor Friedrich III, mathematician, poet, early humanist and teacher of Regiomontanus \{see planet (9307)\}. He discovered the magnetic declination, introduced sines into trigonometry and invented the foldable sundial, the first trustworthy pocket timepiece. (M 34350)

Named on the occasion of the unveiling of a memorial tablet on St. Stephan's cathedral in Vienna, where Peuerbach is buried.

\section{(9121) Stefanovalentini}

1998 DJ $_{11}$. Discovered 1998 Feb. 24 by V. S. Casulli at Colleverde di Guidonia.

Stefano Valentini (1955- ) is an Italian amateur astronomer and able computer programmer well known for his software WinAstrometry, used at many Italian amateur observatories for the calculation of astrometric positions from CCD images. Since 1993 he has collaborated with the observatory where this discovery was made. (M 41029)

\section{(9122) Hunten}

$1998 \mathrm{FZ}_{8}$. Discovered 1998 Mar. 22 by the Spacewatch at Kitt Peak.

Donald M. Hunten (1925- ), of the Lunar and Planetary Laboratory, has studied the atmospheres of the planets and their satellites, participating in space missions from Pioneer to Cassini. He used mid-infrared spectroscopy to study the comet impacts on Jupiter and has studied Martian water vapor and lightning on Venus. (M 38198)

\section{(9127) Brucekoehn}

1998 HX $_{51}$. Discovered 1998 Apr. 30 by the LONEOS at Anderson Mesa.

Named in honor of Bruce W. Koehn (1948- ), who has developed much of the software used in the operation of LONEOS, the Lowell Observatory Near-Earth Object Search program. Among his many contributions, he devised moving-object detection and field-sequencing algorithms and has been central to the increasingly automated operation of LONEOS. Koehn has also written much of the code used in the minor-planet services at the Lowell Observatory's website. (M 34628)

Name suggested and citation written by E. Bowell.
(9130) Galois

1998 HQ 148 . Discovered 1998 Apr. 25 by E. W. Elst at La Silla.

Named in memory of the famous French mathematician Evariste Galois (1811-1832), well known for his contributions to group theory. At the age of only 16, he launched himself into a deeper understanding of the essential conditions that an equation must satisfy to be solvable by radicals (Galois theory). He died in Paris in a duel, under circumstances that have never been fully explained, although his republican activities and sympathies were well known. (M 33794)

\section{(9132) Walteranderson}

2821 P-L. Discovered 1960 Sept. 24 by C. J. van Houten and I. van Houten-Groeneveld at Palomar.

Named in honor of Walter Anderson, chief executive officer of Entreé International and long-time supporter of space exploration, most notably via the International Space University. (M 34350)

Name proposed and citation prepared by SBNC.

\section{(9133) d'Arrest}

3107 P-L. Discovered 1960 Sept. 25 by C. J. van Houten and I. van Houten-Groeneveld at Palomar.

Named in memory of Heinrich Louis d'Arrest (18221875), German astronomer. As an assistant astronomer at the Berlin Observatory, he, together with J. G. Galle \{see planet (2097)\}, discovered the planet Neptune in 1846. From 1852 d'Arrest served as an astronomer at the Leipzig Observatory and was appointed professor of astronomy. In 1857 he went to Denmark as director of the Copenhagen Observatory, where he discovered (79) Freia. He detected several comets, among them a famous short-period comet, and he was a prolific observer of minor planets and nebulae. (M 34350; M 34385)

Name proposed and citation prepared by L.D.Schmadel.

\section{(9134) Encke}

4822 P-L. Discovered 1960 Sept. 24 by C. J. van Houten and I. van Houten-Groeneveld at Palomar.

Named in memory of Johann Franz Encke (17911865), eminent German astronomer. Beginning in 1816, Encke was assistant professor and director of the Seeberg Observatory, near Gotha ssee, respectively planets (8130) and (1346)\}. He computed the orbit of a short-period comet discovered by Pons \{see planet (7645)\} and demonstrated that this object had been observed repeatedly. Later it was named comet 2P/Encke. In 1825 Encke was appointed director of the Berlin Observatory and member of the Berlin Academy of Sciences. Encke is most famous for editing the Berliner Astronomisches Jahrbuch from 1830 to 1866. This contained several very important papers on orbit determination and perturbation computations. (M 34350; M 34385)

Name proposed and citation prepared by L.D.Schmadel. 


\section{(9135) Lacaille}

7609 P-L. Discovered 1960 Oct. 17 by C. J. van Houten and I. van Houten-Groeneveld at Palomar.

Named in memory of Nicholas-Louis de Lacaille (1713-1762), French astronomer known as the "father of southern astronomy" for his naming of southern constellations and his countless astrometric observations of planets and stars. In 1750, the abbé Lacaille went to an expedition to the Cape for trigonometric determinations of the lunar and solar parallax, his observations being partly supported by simultaneous measurements by Lalande \{see planet (9136)\} in Berlin. Lacaille's observations of the southern heavens resulted in a famous catalogue of 9766 stars, a work that was eventually published in 1847 by Baily \{see planet (3115) \}. Lacaille is also known as a precise observer of comet 1P/Halley in 1759. (M 34350; M 34385)

Name proposed and citation prepared by L.D.Schmadel.

\section{(9136) Lalande}

4886 T-1. Discovered 1971 May 13 by C. J. van Houten and I. van Houten-Groeneveld at Palomar.

Named in memory of Joseph-Jérôme Lefrançais de Lalande (1732-1807), famous French astronomer who computed many useful tables for practical astronomical work and authored many papers and textbooks. After some years as an assistant to Delisle, Le Monnier and Lacaille see planet (9135)\}, Lalande went to Berlin in order to prepare measurements for determining the lunar parallax. He was a member of the Berlin and Paris academies of science and was editor of many volumes of the almanac Connaissance des temps during 1760-1776 and 1794-1807. His monumental Bibliographie astronomique (1802) has lasted for two centuries. (M 34350; M 34385)

Name proposed and citation prepared by L.D.Schmadel.

\section{(9137) Remo}

2114 T-2. Discovered 1973 Sept. 29 by C. J. van Houten and I. van Houten-Groeneveld at Palomar.

Named in honor of John L. Remo (1941- ), U.S. physicist who has contributed to laser resonator optics, quantum optics instrumentation, energy systems and materials interactions. He has also helped promote an international interest in policy toward the detction of earth-threatening minor planets and comets and their mitigation, notably with his organization of a conference on the subject at the United Nations \{see planet (6000)\} in New York in 1995 and publication of the proceedings. (M 34629)

\section{(9138) Murdoch}

2280 T-2. Discovered 1973 Sept. 29 by C. J. van

Houten and I. van Houten-Groeneveld at Palomar.

Named in memory of Jean Iris Murdoch (1919-1999), prolific novelist and philosopher, whose 26 moralistexistentialist fictional works in 41 years earned her a place among the leading twentieth-century writers in the English language. Already suffering from Alzheimer's disease when her last novel was published in 1995, Murdoch was lovingly cared for by her husband, the critic John Bayley, whose recent Elegy for Iris is a penetrating study of conflicting emotions. (M 34350)

Name proposed and citation prepared by SBNC.

\section{(9139) Barrylasker}

4180 T-2. Discovered 1973 Sept. 29 by C. J. van Houten and I. van Houten-Groeneveld at Palomar.

Named in memory of U.S. astronomer Barry M. Lasker (1939-1999), whose long-time association with the Space Telescope Science Institute includes the writing of the proposal to establish the Institute. Under his leadership the Guide Star Catalogue and the Digitized Sky Survey were created for Space Telescope operations. By leading the construction of these momentous enterprises, he provided tools of very broad astronomical use, including the astrometry of minor planets. (M 34351)

Name proposed and citation prepared by SBNC.

Obituaries published in Space Telesc. Sci. Inst., Newsl., Vol. 16, No. 2, p. 1-4 (1999); Phys. Today, Vol. 52, No. 6, p. 78-79 (1999); Bull. Am. Astron. Soc., Vol. 31, No. 5, p. 1603-1604 (1999).

\section{(9140) Deni}

4195 T-3. Discovered 1977 Oct. 16 by C. J. van Houten and I. van Houten-Groeneveld at Palomar.

Named after the Department of Education for Northern Ireland for its support of the Armagh Observatory, where Ernst Öpik \{see planet (2099)\} carried out seminal work on the collisional evolution and dynamics of small bodies. The DENI has promoted life-long learning and research across many disciplines, encompassing higher education, schools, museums, recreation and culture. It has sought for many years to advance knowledge and understanding of the natural world, and to provide the means by which as many people as possible may appreciate and continue to develop Northern Ireland's rich cultural heritage, its diversity and contributions to the scientific, intellectual and social life of the community. (M 34351)

Name proposed and citation prepared by SBNC.

\section{(9141) Kapur}

5174 T-3. Discovered 1977 Oct. 16 by C. J. van Houten and I. van Houten-Groeneveld at Palomar.

Named in honor of Shekhar Kapur (1945- ), Indian actor and Bombay film director whose recent acclaim has put "Bollywood" on the international map. The 800 feature films produced annually in Bombay represent nearly 20 percent of the world's total - and are twice as many as come from Hollywood. Kapur's 1998 movie Elizabeth received seven Oscar and 12 British Academy nominations. The showing of his 1994 movie The Bandit Queen, a true story about a low-caste woman who fought back after being gang-raped and was eventually elected to the Indian parliament, was initially banned in India. (M 34629) 
(9142) Rhesus

5191 T-3. Discovered 1977 Oct. 16 by C. J. van Houten and I. van Houten-Groeneveld at Palomar.

Named for the king of the Thracians and ally of the Trojans. He and his twelve companions were stealthily assassinated in their sleep by Odysseus and Diomedes \{see, respectively, planets (1143) and (1437)\}. (M 33389)

\section{(9145) Shustov}

1976 GG $_{3}$. Discovered 1976 Apr. 1 by N. S. Chernykh at Nauchnyj.

Boris Mikhailovich Shustov (1947- ) is deputy director at the Institute of Astronomy of the Russian Academy of Sciences, expert in astrophysics, known for his research in star formation, stellar and galactic evolution, and space astronomy. He was vice-president of the European Astronomical Society during 19932000. (M 46009)

\section{(9146) Tulikov}

1976 YG $_{1}$. Discovered 1976 Dec. 16 by L. I. Chernykh at Nauchnyj.

Composer Serafim Sergeevich Tulikov (1914- ), People's artist of the U.S.S.R., is the author of many lyrical and patriotic songs that are very popular with the Russian people. (M 42358)

\section{(9150) Zavolokin}

$1978 \mathrm{SE}_{1}$. Discovered 1978 Sept. 27 by L. I. Chernykh at Nauchnyj.

Gennadij Dmitrievich Zavolokin (1943-2001) was a famed player of the bayan (Russian accordion). A collector of folk songs, he was the founder and leader of a folk ensemble "Chastooshka" and the TV program Igraj, garmon' ("Play, accordion"), highly popular in Russia. (M 46009)

\section{(9155) Verkhodanov}

$1982 \mathrm{SM}_{7}$. Discovered 1982 Sept. 18 by N. S. Chernykh at Nauchnyj.

Vyacheslav Gennadievich Verkhodanov (1942- ） is a Ukrainian economics and management specialist. As chief of a fish industry company, he gives financial support to hospitals, schools and museums in the Crimea and helps to restore historical monuments. (M 45232)

\section{(9156) Malanin}

1982 TQ $_{2}$. Discovered 1982 Oct. 15 by L. G. Karachkina at Nauchnyj

Named in honor of Ivan Ivanovich Malanin (18971969), talented Russian accordionist, well known for his solo concerts throughout Siberia. He has also been an accompanist at performances of the Russian singers Lemeshev, Nezhdanova \{see, respectively, planets (4561) and (4361)\}, Obukhova and Pantofel'-Nechetskaya. (M 34629)

\section{(9158) Platè}

1984 MR. Discovered 1984 June 25 by T. M. Smirnova at Nauchnyj.
Nikolaj Alfredovich Platè (1934- ), chief scientific secretary of the Russian Academy of Sciences and director of the Institute of Petrochemical Synthesis in Moscow, is known for the synthesis of thermotropic liquid crystalline polymers, polymeric systems for drug targeting and membrane technology for gas separation. (M 42358)

\section{(9159) McDonnell}

1984 UD $_{3}$. Discovered 1984 Oct. 26 by E. Bowell at Anderson Mesa.

J. A. M. ("Tony") McDonnell (1938- ） is recognized for his research on cosmic dust. With colleagues, he was the first to demonstrate the intact capture of space particulates in aerogel. He has flown instruments on a number of missions and has analyzed impact craters on lunar samples and satellite surfaces exposed to space. (M 40703)

\section{(9164) Colbert}

1987 SQ. Discovered 1987 Sept. 19 by E. Bowell at Anderson Mesa.

Edwin H. Colbert $\{1905-2001\}$ is a distinguished U.S. vertebrate paleontologist who has made major contributions to our knowledge of dinosaur evolution and the earth's geological history, notably by proving the continental connection of Antarctica and southern Africa in Lower Triassic times. (M 41029)

The name was suggested by K. Kron.

\section{(9165) Raup}

1987 SJ $_{3}$. Discovered 1987 Sept. 27 by C. S. Shoemaker and E. M. Shoemaker at Palomar.

David M. Raup (1933- ), paleontologist and biological historian at the University of Chicago, is a master of quantitative approaches to the fossil record. With his colleague Jack Sepkowski, he has suggested new imaginative theories for the development and disappearance of life. (M 36947)

\section{(9168) Sarov}

$1987 \mathrm{ST}_{17}$. Discovered 1987 Sept. 18 by L. I. Chernykh at Nauchnyj.

Sarov is a small town in the Nizhnij Novgorod region of the Russian Federation where the All-Russian Research Institute of Experimental Physics is located. Sarov is known also as the dwelling-place of Serafim Sarovskij (1754-1833), a monk who was much respected in Russia for his integrity and kindness. (M 46009)

\section{(9172) Abhramu}

1989 OB. Discovered 1989 July 29 by C. S. Shoemaker and E. M. Shoemaker at Palomar.

Abhramu, the "cloud-knitter", was the original female elephant who was a supernatural winged being who could change her shape at will, like the clouds that resemble her children. According to Indian legend, Abhramu's tribe lost its wings and magic by mischance. (M 36947)

Addition by the discoverers: One day a large flock of elephants was flying slowly through the sky, changing 
into various shapes. Tiring, they spied a huge tree and began to alight on it. Alas, the combined weight of the elephant flock broke the tree's branches. An ascetic was sitting in yogic posture beneath the tree teaching his pupils. He was unharmed, but the falling branches and elephant bodies crushed all his students. Furious, the sage cursed the elephants and their wings dropped off leaving them earthbound ever since and trapped in the enormous cloud shapes they were wearing during the encounter.

\section{(9175) Graun}

$1990 \mathrm{OO}_{2}$. Discovered 1990 July 29 by H. E. Holt at Palomar.

Ken Graun (1955- ) has written two astronomical books. What's Out Tonight? is a major compilation of what the night sky will look like for the next 50 years. His introduction to the planets is intended for young children. (M 42358)

\section{(9176) Struchkova}

1990 VC $_{15}$. Discovered 1990 Nov. 15 by L. I. Chernykh at Nauchnyj.

Raisa Stepanovna Struchkova (1925- ), a brilliant Russian ballerina at the Moscow Bolshoi Theatre since 1944, has danced all the key roles. People's Artist of the USSR and professor at the State Institute of Theatrical Art, she has trained many talented young ballet dancers. (M 46009)

\section{(9179) Satchmo}

$1991 \mathrm{EM}_{1}$. Discovered 1991 Mar. 13 at the Oak Ridge Observatory at Harvard.

Louis 'Satchmo' Armstrong (1901-1971), born in poverty in New Orleans, received his first musical training at reform school at the age of 14. His innumerable contributions to jazz as a trumpeter and vocalist began around 1922. His nickname is short for "Satchel Mouth". (M 39652)

The name was suggested by M. Lohmiller.

\section{(9180) Samsagan}

1991 GQ. Discovered 1991 Apr. 8 by E. F. Helin at Palomar.

The son of Carl Sagan and Ann Druyan, Samuel Democritus Druyan Sagan (1991- ) is inspired by the beauty and power of words. He hopes to become a writer. Family and friends recognize his kind ways and concern for others. (M 45232)

\section{(9187) Walterkröll}

1991 RD $_{4}$. Discovered 1991 Sept. 12 by L. D. Schmadel and F. Börngen at Tautenburg.

Walter Kröll (1938- ) served for 15 years as chairman of the German Aerospace Center DLR. Under his leadership he brought new spirit into German space research, stimulated achievements of excellence and contributed significantly to progress in space science on a global level. (M 43189)

The name was suggested by the first discoverer.

\section{(9189) Hölderlin}

$1991 \mathrm{RH}_{41}$. Discovered 1991 Sept. 10 by F. Börngen at Tautenburg.

Named for the German poet Friedrich Hölderlin (1770-1843), who lived mainly in the Swabian town Tübingen \{see planet (1481)\}. In 1795, he studied in Jena \{see planet (526)\} and there wrote some of his patriotic hymns. He is one of the most original and well-known representatives of German idealism. His philosophy and vision shaped much of the poetry of the German language and were not fully appreciated until the twentieth century. (M 33795)

\section{(9190) Masako}

$1991 \mathrm{VR}_{1}$. Discovered 1991 Nov. 4 by Y. Kushida and O. Muramatsu at Yatsugatake.

Named in honor of Masako Muramatsu, wife of the second discoverer. (M 33795)

\section{(9193) Geoffreycopland}

1992 ED $_{1}$. Discovered 1992 Mar. 10 by D. I. Steel at Siding Spring.

Named for Geoffrey Malcolm Copland (1942- ), rector and vice-chancellor of the University of Westminster. Copland, an Oxford-educated physicist, has dedicated his career to the benefit of the students under his care, initially within the University of London, but more recently at the above institution. (M 34629)

Name proposed by the discoverer, who owes much to Copland's tutelage.

\section{(9196) Sukagawa}

$1992 \mathrm{WP}_{5}$. Discovered 1992 Nov. 27 by T. Seki at Geisei.

In the city of Sukagawa, Fukushima prefecture, there exists the best peony garden in the world. The city also hosts "Taimatsuakashi", one of the three large Japanese fire festivals. Sukagawa is the hometown of marathon runner Kokichi Tsuburaya and movie producer Eiji Tsuburaya. (M 42669)

The name was suggested by H. Sato.

\section{(9197) Endo}

$1992 \mathrm{WH}_{8}$. Discovered 1992 Nov. 24 by M. Hirasawa and S. Suzuki at Nyukasa.

Named in honor of Shu Endo (1953- ), one of Japan's leading astrophotographers. Endo's astrophotographs are famous for their beauty and detail. Many astrophotographers have been inspired by his ideas and advice. The films used to discover this minor planet were hypersensitized by him. (M 34351)

\section{(9198) Sasagamine}

1993 BJ $_{3}$. Discovered 1993 Jan. 25 by T. Seki at Geisei.

Some $1860 \mathrm{~m}$ above sea level, Sasagamine is a mountain in the central part of the Shikoku \{see planet (4223)\} range. (M 43190)

\section{(9203) Myrtus}

$1993 \mathrm{TM}_{16}$. Discovered 1993 Oct. 9 by E. W. Elst at La Silla. 
Named for Myrtaceae, the myrtle family of aromatic trees and shrubs, with more than 100 genera and nearly 4000 species. This family is typical of the Southern Hemisphere, where the Eucalyptus genus is prevalent. Myrtus communis (common myrtle) is a species native to the Mediterranean and is cultivated as far north as England. (M 34351)

\section{(9204) Mörike}

$1994 \mathrm{PZ}_{1}$. Discovered 1994 Aug. 4 by F. Börngen at Tautenburg.

Named for the Swabian poet Eduard Mörike (18041875), one of the great German lyric poets. The wonders of nature were revealed to him everywhere, even in the smallest thing. More than 50 of his poems were set to music by Hugo Wolf \{see planet (5177)\}, notably "At midnight". His most beautiful work in prose is the short novel "Mozarts Reise nach Prag", written in a fluid, breathtaking style similar to Mozart's \{see planet (1034)\} music. (M 33795)

\section{(9205) Eddywally}

$1994 \mathrm{PO}_{9}$. Discovered 1994 Aug. 10 by E. W. Elst at La Silla.

Named in honor of Eduard Van de Walle (1930- ), Flemish singer known as the "Voice of Europe". In a career that spans more than half a century, he recently scored a record sale of one million singles of his song "Chérie". He is also the first well-known Western musician to sing in Chinese. In Ertvelde (near Ghent) he operates the club "Paris-Vegas", which each weekend is visited by many fans. (M 33795)

\section{(9207) Petersmith}

$1994 \mathrm{SF}_{12}$. Discovered 1994 Sept. 29 by the Spacewatch at Kitt Peak.

Peter H. Smith (1947- ), planetary scientist at the Lunar and Planetary Laboratory, participated in the LPL Radial Velocity project and led the development of multispectral stereoscopic cameras flown to Mars. $\mathrm{He}$ is a coinvestigator on the descent imager aboard the Huygens probe. (M 39652)

\section{(9211) Neese}

1995 SB $_{27}$. Discovered 1995 Sept. 19 by the Spacewatch at Kitt Peak.

Trained in stellar astronomy, Carol Lynn Neese (1958- ) turned to solar system studies in 1992, joining the Planetary Science Institute in Tucson, making physical studies of minor planets and archiving data from groundbased and spacecraft communities into the Small Bodies Node of the NASA Planetary Data System. (M 38198)

\section{(9215) Taiyonoto}

1995 UB $_{45}$. Discovered 1995 Oct. 28 by K. Endate and

K. Watanabe at Kitami.

The famous monument Taiyonoto, "Tower of Sun", is in Suita City. It is the masterpiece of the famous Japanese artist Taro Okamoto (1911-1996) and in 1970 was a symbol of Osaka Expo. (M 45747)
The name was suggested by children who attended the Space Festival 2001 held in Osaka on the Japanese space day.

\section{(9216) Masuzawa}

1995 VS. Discovered 1995 Nov. 1 by S. Otomo at Kiyosato.

Hitoshi Masuzawa (1945- ) is a lecturer and curator of the Gotoh Planetarium and Astronomical Museum in Tokyo, where he worked for 32 years until 1998. He conducted historical research on Chinese constellations. (M 41936)

The name was suggested by O. Muramatsu.

\section{(9223) Leifandersson}

1995 YY $_{7}$. Discovered 1995 Dec. 18 by the Spacewatch at Kitt Peak.

Leif Erland Andersson (1943-1979) observed that most satellites of the outer planets rotate synchronously about their parent planets, helped determine Pluto's pole position and albedo map, and determined that Pluto and its satellite Charon would display mutual transits and eclipses. He also made a catalogue of lunar craters. (M 38198)

\section{(9224) Železný}

1996 AE. Discovered 1996 Jan. 10 by M. Tichý and Z. Moravec at Klě́.

Jan Železný (1966- ), Czech javelin-thrower, the world record holder (98.48 meters), won Olympic silver for the javelin in 1988 and Olympic gold in 1992, 1996 and 2000. (M 41936)

\section{(9232) Miretti}

1997 BG$_{8}$. Discovered 1997 Jan. 31 by V. Goretti at Pianoro.

Named in memory of Manlio Miretti (1928-1996), who, blessed with a powerful and warm baritone voice, devoted his whole life to the opera, even though he achieved a very high position in a bank. After studying with Gino Bechi's maestro, Raul Frazzi, and Valiano Natali, he performed the entire baritone repertoire. He loved Giuseppe Verdi's \{see planet (3975)\} music and characters best, especially "Rigoletto". He also successfully sang Toschi's classical songs, the Neapolitan ones and the "musica proibita". He sang in the theaters of Losanna and Bologna and at La Scala of Milan, and he also had a very busy concert career. (M 33795)

\section{(9235) Shimanamikaido}

$1997 \mathrm{CT}_{21}$. Discovered 1997 Feb. 9 by A. Nakamura at Kuma.

Named for a toll road, the Nishiseto Expressway, whose nickname is Shimanami Kaido. The third road connecting the islands of Honshu and Shikoku ssee planet (4223)\}, Shimanami Kaido is $60 \mathrm{~km}$ long and includes ten long-span bridges. Scheduled for use starting 1999 May 1, it is expected to encourage economic activity by increasing the interchange of goods and personnel in the Nishiseto area. (M 34629) 


\section{(9236) Obermair}

$1997 \mathrm{EV}_{32}$. Discovered 1997 Mar. 12 by E. Meyer at Linz.

Named in honor of the Austrian amateur astronomer Erwin Obermair (1946- ), who, together with the discoverer, is co-owner of the private observatory in Davidschlag, near Linz \{see, respectively, planets (9097) and (1469)\}. A technician by profession, Obermair is also a well-known astrophotographer and popularizer of astronomy. (M 34629)

\section{(9238) Yavapai}

$1997 \mathrm{HO}_{2}$. Discovered 1997 Apr. 28 by P. G. Comba at Prescott.

Named for the county in Arizona of which Prescott is the county seat. The county is named for the Yavapai tribe of American Indians that has lived in the region since the times preceding the European conquest. (M 33795)

\section{(9239) van Riebeeck}

$1997 \mathrm{JP}_{15}$. Discovered 1997 May 3 by E. W. Elst at La Silla.

Jan Anthoniszoon van Riebeeck (1619-1677), formerly an assistant surgeon, was sent by the Dutch authorities to southern Africa in 1652 to establish at Table Bay a fort and provisioning station for ships traveling to the East Indies. The station grew to become Cape Town. (M 47165)

\section{(9240) Nassau}

$1997 \mathrm{KR}_{3}$. Discovered 1997 May 31 by the Spacewatch at Kitt Peak.

Jason J. Nassau (1893-1965) was director of the Warner and Swasey Observatory and professor at Case Institute of Technology during 1924-1959. A pioneer in studies of galactic structure and early proponent of Schmidt telescopes, he led the effort to build the 61/91-cm Burrell Schmidt telescope, now located at Kitt Peak $\{$ see planet (2322)\}. (M 40703)

\section{(9242) Olea}

$1998 \mathrm{CS}_{3}$. Discovered 1998 Feb. 6 by E. W. Elst at La Silla.

Named for Oleaceae, the olive family, with about 25 genera and nearly 1000 species. Genera include ash, lilac, jasmine and forsythia. Olea europea (common olive) is profitable as a fruit and source of oil. (M 34351)

\section{(9244) Visnjan}

$1998 \mathrm{HV}_{7}$. Discovered 1998 Apr. 21 by K. Korlević and P. Radovan at Višnjan.

Višnjan is a small picturesque medieval town situated on the western rim of the Istrian peninsula highlands. Višnjan is known for the excellent quality of its olive oil and wines, and it is the site of the observatory where this minor planet was discovered. (M 42669)

\section{(9248) Sauer}

4593 P-L. Discovered 1960 Sept. 24 by C. J. van Houten and I. van Houten-Groeneveld at Palomar.
Named in honor of Carl G. Sauer, Jr., a principal flight mechanics engineer at NASA's Jet Propulsion Laboratory. Since 1952, when he began work at JPL, Carl has been a leader in the development of the analysis tools used for designing the ballistic and low-thrust spacecraft missions that explore the solar system. His work has included mission designs for advanced spacecraft propulsion systems, including solar electric ion propulsion, nuclear propulsion and solar sailing. His database of potential spacecraft trajectories to hundreds of comets and minor planets is an invaluable resource for mission design work at JPL. (M 34351)

Name proposed and citation prepared by SBNC.

\section{(9249) Yen}

4606 P-L. Discovered 1960 Sept. 24 by C. J. van Houten and I. van Houten-Groeneveld at Palomar.

Named in honor of Chen-wan L. Yen, a senior analyst within the Mission and Systems Architecture Section of NASA's Jet Propulsion Laboratory. Chen-wan has done seminal work in the development and application of optimization techniques to interplanetary trajectories. Using multiple-impulse and gravity-assist techniques, her optimized interplanetary trajectories have allowed significant payloads to be launched within current launch vehicle capabilities. Her work is evident in the interplanetary trajectories designed for the Galileo mission to Jupiter, the Magellan mission to Venus, the Cassini mission to Saturn, and the Stardust mission to return a dust sample from comet $81 \mathrm{P} /$ Wild 2 . (M 34351)

Name proposed and citation prepared by SBNC.

\section{(9250) Chamberlin}

4643 P-L. Discovered 1960 Sept. 24 by C. J. van Houten and I. van Houten-Groeneveld at Palomar.

Named in honor of Alan B. Chamberlin, a senior engineer within the Navigation and Flight Mechanics Section of NASA's Jet Propulsion Laboratory. Since joining the staff of JPL in 1996, Alan has shown his expertise in asrtonomical observing and celestial mechanics. His research work has centered on the search for gaseous emissions from suspected defunct comets and the uncertainties associated with the close approaches to the earth of the so-called potentially hazardous objects. For the New Millennium Deep Space One spacecraft that was launched on 1998 Oct. 25, Alan is responsible for the ephemeris development for both the mission targets and the two dozen well-observed minor planets that will be used by this spacecraft to navigate autonomously to its targets. (M 34351)

Name proposed and citation prepared by SBNC.

\section{(9251) Harch}

4896 P-L. Discovered 1960 Sept. 26 by C. J. van Houten and I. van Houten-Groeneveld at Palomar.

Named in honor of the Cornell University scientist Ann P. Harch, an expert in the design and execution of 
spacecraft camera sequencing and pointing commands. Ann played a major role in obtaining the first spacecraft images of (951) Gaspra and (243) Ida during the Galileo spacecraft flybys in Oct. 1991 and Aug. 1993. During the latter encounter, she was the first to note evidence for Ida's moon, Dactyl. In addition, Ann was instrumental in the successful imaging of (253) Mathilde and (433) Eros during the NEAR spacecraft flybys in June 1997 and Dec. 1998. (M 34351) Name proposed and citation prepared by SBNC.

\section{(9252) Goddard}

9058 P-L. Discovered 1960 Oct. 17 by C. J. van Houten and I. van Houten-Groeneveld at Palomar.

Named in memory of the American rocket pioneer Robert H. Goddard (1882-1945). Beginning in 1906, Goddard combined theory and practice in a long career of building and testing rockets. While he dedicated himself to the development of rockets, including the first test of a liquid fuel rocket in 1926, Goddard never lost sight of its ultimate purpose - the exploration of space. (M 34351)

Name proposed and citation prepared by SBNC.

\section{(9253) Oberth}

1171 T-1. Discovered 1971 Mar. 25 by C. J. van Houten and I. van Houten-Groeneveld at Palomar.

Named in memory of the German pioneer of space flight Hermann J. Oberth (1894-1989). In his 1923 work entitled Die Rakete zu den Planetenräumen, Oberth gave a thorough discussion of many phases of rocket travel, including the launching of payloads into earth orbit and the abnormal effects of pressure on the human body. (M 34351)

Name proposed and citation prepared by SBNC.

Obituary published in Spaceflight, Vol. 32, No. 4, p. 144 (1990).

\section{(9254) Shunkai}

2151 T-1. Discovered 1971 Mar. 25 by C. J. van Houten and I. van Houten-Groeneveld at Palomar.

Named in memory of Shibukawa Shunkai (16391715), who was an expert on the calendar. Born into a family of "go" teachers in Kyoto, he studied the calendar system and astronomy and found that the lunisolar calendar, which had been used without any modification for more than 800 years after it was imported from China, did not match observations. He revised the calendar using observations of the sun and moon, and his calendar system was adopted by the Tokugawa government in 1684 . He was then nominated as "The Astronomer", which was a new title for him. The title was inherited by his family. The Tokugawa government also established the observatory with Shunkai as the director. (M 34352)

Name proposed and citation prepared by SBNC.

\section{(9255) Inoutadataka}

3174 T-1. Discovered 1971 Mar. 26 by C. J. van Houten and I. van Houten-Groeneveld at Palomar.
Named in memory of Inou Tadataka (1745-1818), a very able geographer and surveyor. He began to study astronomy and surveying methods after he retired from his official job at the age of 50 . He began surveying in Hokkaido \{see planet (3720)\} at his own expense. Since the map he made was found to be excellent, the Tokugawa government asked him to continue the survey in Honshu. He completed his survey of the Japanese coastal area by measuring astronomical latitudes at 1200 places, and he derived the length of the meridional arc of one degree to be $110.8 \mathrm{~km}$. His map, smuggled to Europe on a Durch ship, won wide respect there. (M 34352)

Name proposed and citation prepared by SBNC.

\section{(9256) Tsukamoto}

1324 T-2. Discovered 1973 Sept. 29 by C. J. van Houten and I. van Houten-Groeneveld at Palomar.

Named in memory of Tsukamoto Akitake (18331885), a geographer who worked for both the Tokugawa and Meiji governments. He recommended that the Japanese government adopt the Gregorian calendar to replace the lunisolar calendar. The government accepted his advice, and Japan adopted the Gregorian calendar on 1873 Jan. 1. (M 34352)

Name proposed and citation prepared by SBNC.

\section{(9257) Kunisuke}

1552 T-2. Discovered 1973 Sept. 24 by C. J. van Houten and I. van Houten-Groeneveld at Palomar.

Named in memory of Kunisuke Kinoshita (1901-1931), an astronomer at the Tokyo Astronomical Observatory from 1924 to his death. At the observatory he worked with Oikawa \{see planet (2667)\} and discovered 1927 EB and 1927 FC. However, after he was sent to Malaysia in 1929 to observe the total eclipse, he became ill and stopped most of his work in 1930 . He also wrote excellent articles on modern astronomy in the Astronomical Herald, the monthly journal of the Astronomical Society of Japan, for which he served as editor after 1929. (M 34352)

Name proposed and citation prepared by SBNC.

\section{(9258) Johnpauljones}

2137 T-2. Discovered 1973 Sept. 29 by C. J. van Houten and I. van Houten-Groeneveld at Palomar.

Born in Scotland, John Paul Jones (1747-1792) was an American Revolutionary War hero. The "Father of the United States Navy", he was a courageous seaman, leader and tactician. Commander of several ships in action against the British, he notably defeated the H.M.S. Serapis aboard the Bonhomme Richard in 1779. (M 36947)

\section{(9259) Janvanparadijs}

2189 T-2. Discovered 1973 Sept. 29 by C. J. van Houten and I. van Houten-Groeneveld at Palomar.

Jan van Paradijs (1946-1999), professor at the universities of Amsterdam and Alabama, was a pioneer researcher on issues of high-energy astrophysics. His recognition of the first optical counterpart to a $\gamma$-ray 
burst led to improved understanding of the physics of these events, their source environment and typical distances. (M 36947)

Obituary published in Phys. Today, Vol. 53, No. 4, p. 87-88 (2000).

\section{(9262) Bordovitsyna}

1973 RF. Discovered 1973 Sept. 6 by T. M. Smirnova at Nauchnyj.

Tatiana Valentinovna Bordovitsyna (1940- ), head of the department of celestial mechanics and astrometry in the Institute for Applied Mathematics and Mechanics of Tomsk University, is an expert on the dynamics of natural and artificial satellites and orbit computation, as well as a gifted educator of young scientists. (M 42358)

\section{(9263) Khariton}

1976 SX $_{5}$. Discovered 1976 Sept. 24 by N. S. Chernykh at Nauchnyj.

Yulij Borisovich Khariton (1904- ) is a physicist and member of the Russian Academy of Sciences. He worked in nuclear physics, on combustion and explosion, and during 1939-1941, together with Ya. B. Zel'dovich \{see planet (11438)\}, calculated the chain reaction for the fission of uranium. (M 46009)

\section{(9265) Ekman}

1978 RC $_{9}$. Discovered 1978 Sept. 2 by C.-I. Lagerkvist at La Silla.

Agnita (1945- ) and Arne (1945- ) Ekman work for the National Encyclopedia of Sweden. Arne was for many years a staff member at the Uppsala ssee planet (2191)\} Astronomical Observatory. (M 39652)

\section{(9266) Holger}

$1978 \mathrm{RD}_{10}$. Discovered 1978 Sept. 2 by C.-I. Lagerkvist at La Silla.

Holger Pedersen (1946- ), astronomer at the European Southern Observatory, works on $\gamma$-ray bursts but has a deep interest in meteorites and minor planets. The discoverer very much appreciates his willingness to make early observations of comet P/1996 R2. (M 36128)

\section{(9267) Lokrume}

$1978 \mathrm{RL}_{10}$. Discovered 1978 Sept. 2 by C.-I. Lagerkvist at La Silla.

The church in the small parish of Lokrume, on the Swedish island of Gotland, was inaugurated in 1277 . The remains of one of the oldest medieval estates on the island are still visible in the village. Nearby is a meadow, typical of the island. (M 36128)

\section{(9273) Schloerb}

1979 QW $_{3}$. Discovered 1979 Aug. 22 by C.-I. Lagerkvist at La Silla.

University of Massachusetts astronomer Frederic Peter Schloerb (1952- ） is known for his comparative research on the interstellar medium and the origin of the solar system. (M 36947)

The name was suggested by J. S. V. Lagerros.

\section{(9274) Amylovell}

$1980 \mathrm{FF}_{3}$. Discovered 1980 Mar. 16 by C.-I. Lagerkvist at La Silla.

University of Massachusetts astronomer Amy Jean Lovell (1969- ) is known for her contribution to the study of comets and minor planets at millimeter wavelengths. (M 36947)

The name was suggested by J. S. V. Lagerros.

\section{(9275) Persson}

$1980 \mathrm{FS}_{3}$. Discovered 1980 Mar. 16 by C.-I. Lagerkvist at La Silla.

Jøran Persson (1530-1568) worked for Swedish king Erik XIV as counselor and prosecutor. Although he was at first seen as having a very large and bad influence on the king, later research has shown that he was a very efficient tool for the king's demands. He was tortured and beheaded after the king had been put into custody. (M 36948)

\section{(9277) Togashi}

$1980 \mathrm{TT}_{3}$. Discovered 1980 Oct. 9 by C. S. Shoemaker and E. M. Shoemaker at Palomar.

Tom Togashi (1937-2000) was a pioneering filmmaker whose stunning television documentaries included a Galactic Odyssey series and specials on solar eclipses, the aurora borealis, and the search for life in the universe. His goal for the 21st century was to inspire children with his passion for the wonders of outer space. (M 41384)

\section{(9291) Alanburdick}

1982 QO. Discovered 1982 Aug. 17 at the Oak Ridge Observatory at Harvard.

Alan Burdick (1965- ), a student of the natural world, is author of numerous popular magazine articles, including one about his efforts to get something in the universe named after him. This in turn helped to land him a writing job at the new Rose Center at the American Museum of Natural History in New York. (M 39652)

\section{(9295) Donaldyoung}

$1983 \mathrm{RT}_{1}$. Discovered 1983 Sept. 2 by E. Bowell at Anderson Mesa.

Donald L. Young (1935- ), recently retired from the Jet Propulsion Laboratory, was responsible for building and directing NASA/JPL's Table Mountain Facility. In addition to conducting astronomical research, the facility is a centerpiece of the JPL educational outreach program. (M 41029)

The name was suggested by C. Young.

\section{(9297) Marchuk}

1984 MP. Discovered 1984 June 25 by T. M. Smirnova at Nauchnyj. 
Gurij Ivanovich Marchuk (1925- ), director of the Institute of Numerical Mathematics of the Russian Academy of Sciences, is a specialist in numerical and applied mathematics, well known for his mathematical modeling of complex systems. From 1986 to 1991 he was president of the U.S.S.R. Academy of Sciences. (M 42358)

\section{(9298) Geake}

1985 JM. Discovered 1985 May 15 by E. Bowell at Anderson Mesa.

At the University of Manchester's Institute of Science and Technology, John E. Geake (1925-1998) was well known for his laboratory interpretation of the optical polarization of the lunar and asteroidal surfaces. He invented the first direct-reading linear refractometer, one of which he designed for the Cassini-Huygens Titan probe. (M 41029)

\section{(9299) Vinceteri}

$1985 \mathrm{JG}_{2}$. Discovered 1985 May 13 by C. S. Shoemaker and E. M. Shoemaker at Palomar.

Vince (1959- ) and Teri (1960- ) Grout are true friends to two-legged and four-legged animals. They are generous with their time and assistance to all those interested in the sport of dog sledding. (M 46009)

\section{(9300) Johannes}

1985 PS. Discovered 1985 Aug. 14 by E. Bowell at Anderson Mesa.

Johannes Andersen (1943- ), of the Niels Bohr Institute for Astronomy, works mainly on the chemical and dynamical evolution of the Milky Way's disk. As IAU General Secretary (1997-2000), he has offered sage guidance on the IAU's role with near-earth objects. The name is endorsed by B. G. Marsden and H. Rickman. (M 41029)

\section{(9305) Hazard}

$1986 \mathrm{TR}_{1}$. Discovered 1986 Oct. 7 by E. Bowell at Anderson Mesa.

British radio astronomer Cyril Hazard (1928- ) held positions in the U.K., U.S. and Australia. His work includes the first detection of radio waves from an extragalactic source, the use of lunar occultations for source position determination and the first detection of quasars having $z>3$. (M 41567)

\section{(9306) Pittosporum}

1987 CG. Discovered 1987 Feb. 2 by E. W. Elst at La Silla.

Named for Pittosporaceae, the Australian laurel family, with nine genera and more than 200 species, mainly in tropical Africa and Pacific islands. Among the species is Pittosporum eugenioides (lemonwood). (M 34352)

\section{(9307) Regiomontanus}

1987 QS. Discovered 1987 Aug. 21 by F. Börngen at Tautenburg.
Named for the German mathematician and astronomer Johannes Regiomontanus (1436-1476), originally called J. Müller, one of the most famous scholars of his time and trailblazer of the new world view. He improved mathematical methods and created modern trigonometry. He was sure that calculations of the orbits of celestial bodies could be improved essentially by new, more exact systematic observations. So in 1472 he founded the first German observatory in Nürnberg. His plan was interrupted by his early death. Calendars and ephemeris he calculated and published helped the sailors Columbus, da Gama and Vespucci. (M 33795)

\section{(9308) Randyrose}

1987 SD . Discovered 1987 Sept. 21 by E. Bowell at Anderson Mesa.

Randy Rose (1963- ) is an electrical engineer and currently leader of the Radio Astronomy and Radar Group at Goldstone. For more than a decade, he has been directly responsible for the success of numerous radar experiments on minor planets, including the discovery of the binary nature of $2000 \mathrm{DP}_{107}$. (M 41936)

\section{(9309) Platanus}

1987 SS $_{9}$. Discovered 1987 Sept. 20 by E. W. Elst at Rozhen.

Named ofr Platanaceae, the plane family, with one genus and seven species. They grow wild mainly in the United States and Mexico, but they are also typical of southern France. Platanus acerifolia (London plane) reaches a height of almost $30 \mathrm{~m}$ and is widely planted in cities because of its resistance to air pollution. The brown, bristly fruits, hanging two to four together on a single stalk, persist over the winter. (M 34352)

\section{(9313) Protea}

$1988 \mathrm{CH}_{3}$. Discovered 1988 Feb. 13 by E. W. Elst at La Silla.

Named for Proteaceae, the firebush family, with some 75 genera and over 1000 species. They are native to the Southern Hemisphere, where they grow wild. Some species, such as Protea mellifera (honeyflower), extend also to the warm regions of the Northern Hemisphere. The family is best known for its ornamental plants, such as Embothrium coccineum (Chilean firebush), which are cultivated for their edible nuts. (M 34352)

\section{(9315) Weigel}

$1988 \mathrm{PP}_{2}$. Discovered 1988 Aug. 13 by F. Börngen at Tautenburg.

Named for the German mathematician and astronomer Erhard Weigel (1625-1699) on the occasion of the 300th anniversary of his death. A lecturer at the University of Jena see planet (526)\} beginning in 1652, his larger-than-life personality and inventive mind contributed essentially to the prominence of this university in his time. He created, for example, giant globes with diameters of several meters, in which one could set foot and admire the artificial 
firmament in the daytime. In 1670, his seven-storeyed dwelling-house was completed, built according to his plans and supporting an observation platform. This unusual house was one of the "Seven Miracles of Jena". (M 33795)

\section{(9316) Rhamnus}

$1988 \mathrm{PX}_{2}$. Discovered 1988 Aug. 12 by E. W. Elst at St. Michel.

Named for Rhamnaceae, the buckthorn family of deciduous and evergreen trees, shrubs and climbing plants, with 60 genera and around 900 species. They grow wild in all parts of the world. Some of the species yield dyes. The berrylike fruits appear in dense clusters. Rhamnus purshina (bearwood) produces a dry bark (cascara sagrada) that is used as a laxative. (M 34352)

\section{(9322) Lindenau}

$1989 \mathrm{AC}_{7}$. Discovered 1989 Jan. 10 by F. Börngen at Tautenburg.

Named for the German scientist, statesman and promoter of the arts Bernhard August von Lindenau (1779-1854). From 1808 to 1819, he was the director of the Seeberg \{see planet (8130)\} Observatory. He communicated closely with contemporaries such as Goethe, A. von Humboldt, von Zach, Gauss and Bessel \{see, respectively, planets (3047), (4877), (999), (1001) and (1552)\}. At the beginning of the nineteenth century, he fostered the founding of several astronomical periodicals. Lindenau was a member of numerous renowned European academies. From 1830 to 1843, he served as a high public official in the Kingdom of Saxony. He donated his art collection, including a unique collection of early Italian panel paintings, to his hometown of Altenburg \{see planet (9336)\} to be displayed in the Lindenau Museum. (M 33795)

\section{(9323) Hirohisasato}

$1989 \mathrm{CV}_{1}$. Discovered 1989 Feb. 11 by T. Seki at Geisei.

Hirohisa Sato (1951- ) studies the orbits and brightness of comets for the Comet Section of the Oriental Astronomical Association. He also has interests in archeology and history. (M 42670)

The name was suggested by S. Harada.

\section{(9326) Ruta}

$1989 \mathrm{SP}_{2}$. Discovered 1989 Sept. 26 by E. W. Elst at La Silla.

Named for Rutaceae, the rue family, with over 150 genera and 1500 species, including citrus fruits. Ruta graviolensis (common rue) is a perennial herb with a particularly strong scent. The family thrives in tropical and warm, temperate regions. (M 34352)

\section{(9336) Altenburg}

$1991 \mathrm{AY}_{2}$. Discovered 1991 Jan. 15 by F. Börngen at Tautenburg.

Named for the town of Altenburg, noted for its outstanding buildings (e.g. the theater and Lindenau \{see planet (9322)\} Museum) and its eventful 1000-year history. It was first the palace of German kings and emperors (Ottonian, Hohenstaufen), later an imperial city and the capital of the duchy Sachsen-Altenburg. The Saxonian princes resided in this place for 600 years, until 1918. Altenburg is also renowned as the "town of playing cards", which have been produced here for 450 years. In 1813, "Skat", the chief card game of the Germans, was created here by impassioned players associated with the chancellor Hans Carl Leopold von der Gabelentz. (M 33795)

\section{(9339) Kimnovak}

$1991 \mathrm{GT}_{5}$. Discovered 1991 Apr. 8 by E. W. Elst at La Silla.

Kim Novak (1933- ) is a screen actress much admired for her work, together with William Holden \{see planet (9340)\}, in Picnic, a movie from the 1950s based on a Pulitzer prize-winning novel. (M 47165)

\section{(9340) Williamholden}

$1991 \mathrm{LW}_{1}$. Discovered 1991 June 6 by E. W. Elst at La Silla.

William Holden (1918-1981) was a screen actor admired for his work in Picnic (1955), with Kim Novak \{see planet (9339)\}, and in The Bridge over the River Kwai, with David Niven. He is also the initiator of a wildlife foundation in Kenya. (M 47165)

\section{(9341) Gracekelly}

$1991 \mathrm{PH}_{2}$. Discovered 1991 Aug. 2 by E. W. Elst at La Silla.

Grace Patricia Kelly (1929-1982) a renowned screen actress, was much admired in the movie To Catch a Thief (1955). Following the shooting she met Prince Rainier of Monaco and was married to him in 1956. (M 47165)

\section{(9342) Carygrant}

$1991 \mathrm{PJ}_{7}$. Discovered 1991 Aug. 6 by E. W. Elst at La Silla.

Cary Grant (Archibald Leach, 1904-1986), born in Bristol, England, was much appreciated in the movie To Catch a Thief (1955), together with Grace Kelly \{see planet (9341)\}. (M 47165)

\section{(9344) Klopstock}

$1991 \mathrm{RB}_{4}$. Discovered 1991 Sept. 12 by F. Börngen and L. D. Schmadel at Tautenburg.

Named for Friedrich Gottfried Klopstock (1724-1803), one of the most famous German poets between the late Baroque and the classical period. He studied theology in Jena \{see planet (526)\} and Leipzig. In his poems he proclaimed a new mentality - the Age of Sensibility. Klopstock's "Messias", a cycle of 20 religious poems, is the first great epic of the New High German literature. His inspired odes have love, friendship, fatherland and the experience of nature as their subjects. (M 33795; M 33817)

Name proposed and citation prepared by the first discoverer. 


\section{(9346) Fernandel}

$1991 \mathrm{RN}_{11}$. Discovered 1991 Sept. 4 by E. W. Elst at La Silla.

Fernand Joseph Désié Contandin, known as screen actor Fernandel (1903-1971), made the unforgettable movie La Vache et le Prisonnier in 1959, together with the cow Maguerite. He also created the character Don Camillo, based on the work of Giovanni Guareschi. (M 47165)

\section{(9349) Lucas}

1991 SX. Discovered 1991 Sept. 30 by R. H. McNaught at Siding Spring.

Named in memory of François Edouard Anatole Lucas (1842-1891), French number theorist, best known for his test for Mersenne \{see planet (8191)\} primes and the demonstration that $2^{127}-1$ is prime. His interests included magic squares and Fibonacci ssee planet (6765)\} numbers, and while studying the latter he devised the similar sequence $2,1,3,4,7, \ldots$, now known as Lucas numbers. The number of this minor planet is the twentieth member of this sequence. (M 33389)

Name proposed by the discoverer following a suggestion by B. G. Marsden.

\section{(9350) Waseda}

$1991 \mathrm{TH}_{2}$. Discovered 1991 Oct. 13 by M. Hirasawa and S. Suzuki at Nyukasa.

Named for one of the most prestigious private universities in Japan. It was established in 1882 by Shigenobu Okuma, who later became the eighth and the seventeenth prime minister of Japan. One of the primary objectives of the university was to promote the independence of study and spirit of progress known as Waseda Spirits. Both discoverers of this minor planet graduated from Waseda. (M 34352)

\section{(9357) Venezuela}

$1992 \mathrm{AT}_{3}$. Discovered 1992 Jan. 11 by O. A. Naranjo at Mérida.

The Republica Bolivariana de Venezuela ("Little Venice") was named in 1499 by Amerigo Vespucci because of the resemblance between the natives' houses, built on water, and the situation in Venice. (M 41936)

\section{(9358) Fårö}

$1992 \mathrm{DN}_{7}$. Discovered 1992 Feb. 29 by the Uppsala-ESO Survey at La Silla.

Fårö, an island in itself, is the northernmost parish on Gotland. It is famous for its seastacks and beautiful beaches. (M 42358)

\section{(9359) Fleringe}

1992 ED $_{11}$. Discovered 1992 Mar. 6 by the Uppsala-ESO Survey at La Silla.

Fleringe is a small parish on the Swedish island of Gotland. Here can be found several old limestone quarries, of which one has been turned into an industrial museum. (M 42358)

\section{(9364) Clusius}

$1992 \mathrm{HZ}_{3}$. Discovered 1992 Apr. 23 by E. W. Elst at La Silla.

Named for Carolus Clusius (Charles de l'Escluse; 1526-1609), a Flemish botanist well-known for his catalogue, published in Antwerp in 1576, of fine drawings of more than 200 plants he had studied in southern France, Portugal and Spain. His system of classification proposed the idea of natural families. The Clusiaceae, a family of plants and trees, was named after him. It is said that he introduced the tulip into Holland. (M 34352)

\section{(9365) Chinesewilson}

$1992 \mathrm{RU}_{3}$. Discovered 1992 Sept. 2 by E. W. Elst at La Silla.

Named for Ernest "Chinese" Wilson (1876-1930) a prolific hunter of plants, who introduced more than 1000 new plants from China into Europe. Because of him Europeans have the Azalea \{see planet (1056)\}, Hortensia and Magnolia wilsonii \{see also planet (1060)\}. He lost his leg while hunting the lily Lilium regale. (M 34352)

\section{(9368) Esashi}

$1993 \mathrm{BS}_{3}$. Discovered 1993 Jan. 26 by M. Mukai and M. Takeishi at Kagoshima.

Named for a small town in northern Hokkaido, on the sea of Okhotsk \{see planets (3720) and (4042), respectively\}, not far from the home of the second discoverer. Known as "The Town of the Solar Eclipse", it was visited by astronomers from all over the world during the total solar eclipses of 1896 Aug. 9 and 1936 June 19. After the former eclipse the American astronomer David P. Todd gave many books to the town, and these became the nucleus of the first public library to be established in Hokkaido. (M 34353)

\section{(9372) Vamlingbo}

$1993 \mathrm{FK}_{37}$. Discovered 1993 Mar. 19 by the UppsalaESO Survey at La Silla.

Vamlingbo is a parish on the island of Gotland. It has a medieval church and several remains from the Middle Ages. (M 42358)

\section{(9373) Hamra}

$1993 \mathrm{FY}_{43}$. Discovered 1993 Mar. 19 by the UppsalaESO Survey at La Silla.

Hamra is a small parish on southern Gotland. The general store, famous from the song snabbköpskassörskan, has now closed, as have most of the other general stores in the Gotland countryside. (M 42358)

\section{(9374) Sundre}

1993 F J $_{46}$. Discovered 1993 Mar. 19 by the Uppsala-ESO Survey at La Silla.

Sundre is the southernmost and smallest parish on the Swedish island of Gotland. (M 42358) 
(9376) Thionville

$1993 \mathrm{OU}_{7}$. Discovered 1993 July 20 by E. W. Elst at La Silla.

Named for the French city in northeastern France, near the Luxembourg border. It lies in the center of an iron-mining district. (M 34353)

\section{(9377) Metz}

$1993 \mathrm{PJ}_{7}$. Discovered 1993 Aug. 15 by E. W. Elst at Caussols.

Named for the French city in the Lorraine region of France, at the confluence of the Moselle and Seille rivers. It derives its name from the Gallic tribe Mediomatrici. In 843 it became the capital of Lorraine see planet (1114)\}. The Metz cathedral has remarkable stained glass windows from the thirteenth and fourteenth centuries. (M 34353)

\section{(9378) Nancy-Lorraine}

$1993 \mathrm{QF}_{3}$. Discovered 1993 Aug. 18 by E. W. Elst at Caussols.

Named for the French city Nancy, in the Lorraine \{see planet (1114)\} region of France, near the left bank of the river Meuse \{see planet (3016)\}. The city has a very handsome town hall. (M 34353)

\section{(9379) Dijon}

$1993 \mathrm{QH}_{3}$. Discovered 1993 Aug. 18 by E. W. Elst at Caussols.

Named for the capital of Côte d'Or, in east-central France. In the ninth century the city was known as Castrum Divionense. Dijon is a major communication center and offers many tourist attractions. It lies among beautiful, fertile vineyards. The city is famous for its strong mustard, vinegar and gingerbread. (M 34353)

\section{(9380) Mâcon}

1993 QZ $_{5}$. Discovered 1993 Aug. 17 by E. W. Elst at Caussols.

Named for the French city Mâcon in the Bourgogne, on the right side of the river Saône. Although a very old city (Matiscô), it has been ruined by several religious wars, and little of its original beauty is left. (M 34353)

\section{(9381) Lyon}

1993 RT $_{19}$. Discovered 1993 Sept. 15 by H. Debehogne and E. W. Elst at La Silla.

Named for the French city Lyon, capital of the Rhône department in east-central France, at the confluence of the Rhône and Saône rivers. Originally a Roman military colony (Lugdunum), it subsequently became the capital for the Gauls. As early as 1473 Lyon was the most active printing center in Europe. (M 34353)

\section{(9383) Montélimar}

$1993 \mathrm{TP}_{15}$. Discovered 1993 Oct. 9 by E. W. Elst at La Silla.

Named for the city in southeastern France, near the confluence of the Roubion and Rhône rivers. The city was called Acunum by the Romans and Monteil d'Adhémar in medieval times. It was a papal posession from 1340 to 1470 . The Chateau des Papes serves now as a prison. The city is famous for its candy. (M 34353)

\section{(9384) Aransio}

$1993 \mathrm{TP}_{26}$. Discovered 1993 Oct. 9 by E. W. Elst at La Silla.

Named for the city of Orange in southeastern France in the department Vaucluse. In early times the city was called Aransio and was a well-known Roman colony. In 406 and in 410 the city was pillaged, and during the seventeenth century it suffered from religious wars. In spite of this, some Roman architecture remains, such as the triumphal arch and the old theater. (M 34353)

\section{(9385) Avignon}

1993 TJ $_{30}$. Discovered 1993 Oct. 9 by E. W. Elst at La Silla.

Named for the city in southeastern France, at the east bank of the Rhône river. In 1309 it became the capital of the Roman Catholic papacy and harbored heretics and criminals. The city was well-known for its Saint-Bénézet bridge, which everyone knows from the song "Sur le pont d'Avignon". (M 34353)

\section{(9386) Hitomi}

$1993 \mathrm{XD}_{1}$. Discovered 1993 Dec. 5 by M. Hirasawa and S. Suzuki at Nyukasa.

Named in honor of Hitomi Doi (1955- ), wife of Takao Doi, the first Japanese space walker. Hitomi is the author of many articles and essays, mostly about astronomy. She is also an enthusiastic amateur astronomer. (M 34353)

\section{(9387) Tweedledee}

1994 CA. Discovered 1994 Feb. 2 by H. Shiozawa and T. Urata at Fujieda.

Tweedledee was one of the twins in Lewis Carroll's \{see planet (6984)\} Through the Looking Glass and what Alice found there. When Alice meets him, he is standing under a tree with his arm round the neck of his brother Tweedledum \{see planet (17681)\}. (M 41936)

The name was suggested by $\mathrm{T}$. Urata.

\section{(9389) Condillac}

$1994 \mathrm{ET}_{6}$. Discovered 1994 Mar. 9 by E. W. Elst at Caussols.

Named in memory of the philosopher and priest Etienne Bonnot de Condillac (1715-1780), the leading advocate in France of the ideas of John Locke \{see planet (7010)\}. In 1740 he became acquainted with the Encyclopaedists, establishing his position there with his first book Essai sur l'origine des connaissances humaines in 1746. In his Traité des sensations (1754), which inspired Holbach and Diderot ssee planets (6956) and (5351), respectively $\}$, he expressed his views on sensations: "Human knowledge is entirely and exclusively based on observations made by the sense perception". (M 34629) 


\section{(9392) Cavaillon}

$1994 \mathrm{PK}_{7}$. Discovered 1994 Aug. 10 by E. W. Elst at La Silla.

Cavaillon is a small city on the road from Avignon to Digne $\{$ see, respectively, planets (9385) and (10088) in southern France well-known for the cultivation of fruits and vegetables. The delicious Cavaillon, or perfumed melon, was named after it. (M 47165)

\section{(9393) Apta}

1994 PT $_{14}$. Discovered 1994 Aug. 10 by E. W. Elst at La Silla.

Apt, on the Calavon river, is a small city in southern France (Provence) and originally a Roman colony Colonia Julia Apta. It is now a well-known center for dried fruits, marmalade and lavender oil. (M 47165)

\section{(9394) Manosque}

1994 PV 16 . Discovered 1994 Aug. 10 by E. W. Elst at La Silla.

Manosque, a small city in southern France (Provence), not far from the Durance river, has become well known through the writings of Jean Giono \{see planet (6519)\}, who was born there. It still has many reminders of medieval times, including La porte Soubeyran, and is only $20 \mathrm{~km}$ away from the Observatory of Haute Provence $\{$ see planet $(7755)\}$. (M 47165)

\section{(9395) Saint Michel}

1994 PC $_{39}$. Discovered 1994 Aug. 10 by E. W. Elst at La Silla.

Saint Michel l'Observatoire is a small village only $2 \mathrm{~km}$ away from the Observatory of Haute Provence \{see planet (7755)\}. The village is surrounded by the Parc Naturel Régional du Luberon, creating a pleasant walk between lavender fields and green hills covered by aromatic herbs. (M 47165)

\section{(9397) Lombardi}

1994 RJ. Discovered 1994 Sept. 6 at the Santa Lucia Observatory at Stroncone.

Giuseppe Lombardi (1939- ) is an Italian amateur astronomer at the CCAF observatory in Farra d'Isonzo \{see planet (7501)\}. Now retired, he spends most of his sleepless nights at the observatory, where he shows the beauties of the sky to visitors and participates in almost all of the discoveries at this site. (M 36948)

\section{(9398) Bidelman}

$1994 \mathrm{SH}_{3}$. Discovered 1994 Sept. 28 by the Spacewatch at Kitt Peak.

William P. Bidelman (1918- ) was director of the Warner and Swasey Observatory during 1970-1975 and professor of astronomy at Case Western Reserve University (formerly Case Institute of Techology) during 1970-1986. He is a leader in stellar classification and the identification of chemically peculiar stars. (M 40703)

\section{(9399) Pesch}

$1994 \mathrm{ST}_{12}$. Discovered 1994 Sept. 29 by the Spacewatch at Kitt Peak.
Peter Pesch (1934- ), director of the Warner and Swasey Observatory during 1975-1994 and professor of astronomy at Case Western Reserve University during 1961-1997, is a leader in the search for unresolved blue objects (galaxies, QSOs and stars) through the use of low-dispersion prisms on the Burrell Schmidt Telescope. (M 40703)

\section{(9403) Sanduleak}

1994 UJ J11 $_{11}$. Discovered 1994 Oct. 31 by the Spacewatch at Kitt Peak.

Nicholas Sanduleak (1933-1990) was a staff scientist at the Warner and Swasey Observatory from 1967 to his death. Renowned as a classifier and cataloguer of stars, he was the co-discoverer of SS 433 (V1343 Aql) and the cataloguer of the precursor object of SN 1987A. (M 40703)

\section{(9407) Kimuranaoto}

$1994 \mathrm{WS}_{3}$. Discovered 1994 Nov. 28 by S. Otomo at Kiyosato.

For 20 years, Naoto Kimura (1956- ) has been a lecturer and curator at the Gotoh Planetarium and Astronomical Museum in Tokyo. He took many astrophotographs used for planetarium programs. (M 41936)

The name was suggested by O. Muramatsu.

\section{(9409) Kanpuzan}

$1995 \mathrm{BG}_{1}$. Discovered 1995 Jan. 25 by T. Seki at Geisei.

Kanpuzan is a 1763-m-high mountain to the west side of Mt. Sasagamine in the Shikoku \{see planets (9198) and (4223), respectively range, and it is the site of a long tunnel that supports vital transportation between Kochi prefecture and Ehime prefecture. (M 43190)

\section{(9413) Eichendorff}

1995 SQ54. Discovered 1995 Sept. 21 by F. Börngen at Tautenburg.

Named for the Silesian poet Joseph Freiherr von Eichendorff (1788-1857). He studied philosophy and law in Halle and Heidelberg. From 1816 to 1844, he was in the Prussian civil service. The most popular writer among the German romanticists, he sings of nature, walking, the woods and the night. The highlights of his work, some of which have been set to music, include "In einem kühlen Grunde", "O Täler weit, o Höhen", "Wer hat dich, du schöner Wald"). His most beautiful short story is "Aus dem Leben eines Taugenichts". (M 33795)

\section{(9420) Dewar}

$1995 \mathrm{XP}_{4}$. Discovered 1995 Dec. 14 by the Spacewatch at Kitt Peak.

James Dewar (1842-1923), Scottish-born chemist and physicist, studied chemical reactions at low (cryogenic) temperature and in 1872 invented the double-walled vacuum-insulated flask with cryopumping getter that is used today by astronomers to refrigerate electronic detectors. (M 41567) 


\section{(9421) Violilla}

$1995 \mathrm{YM}_{2}$. Discovered 1995 Dec. 24 by S. P. Laurie at Church Stretton.

Named in memory of the discoverer's mother, Violet Lilian Laurie (1921-1995), who died the same year that (9421) was discovered. (M 34629)

\section{(9423) Abt}

$1996 \mathrm{AT}_{7}$. Discovered 1996 Jan. 12 by the Spacewatch at Kitt Peak.

Helmut Abt (1925- ) is one of the founders of Kitt Peak \{see planet (2322)\} National Observatory and is known for his fundamental studies of stellar characteristics, multiple stars and publication practices. As editor-in-chief, Abt shepherded the Astrophysical Journal into the current electronic age. (M 41568)

\section{(9425) Marconcini}

$1996 \mathrm{CM}_{7}$. Discovered 1996 Feb. 14 by U. Munari and M. Tombelli at Cima Ekar.

Massimiliano Marconcini (1955- ) is an amateur astronomer of the Montelupo \{see planet (7198)\} group. A 1988 architecture graduate from the University of Florence, he designed the public observatory of Montelupo. (M 41029)

\section{(9426) Aliante}

$1996 \mathrm{CO}_{7}$. Discovered 1996 Feb. 14 by U. Munari and M. Tombelli at Cima Ekar.

Italian name for a glider, the silent plane. The Latin root of the name emphasizes the key role of the wings in the absence of an engine. (M 33796)

\section{(9427) Righini}

$1996 \mathrm{CV}_{7}$. Discovered 1996 Feb. 14 by M. Tombelli and U. Munari at Cima Ekar.

Named in memory of Guglielmo Righini (1908- ), Italian solar physicist. In 1934 he went to Utrecht to work with Minnaert. In 1953 he became full professor of astronomy at the University of Florence and director of the Arcetri Astrophysical Observatory, from which he retired in 1980. As a solar physicist he followed many total solar eclipses. With A. Deutsch he discovered the cold regions in the solar corona. He was one of the most active supporters of the Joint Organization for Solar Observations, and this resulted in a solar observatory built on the heights of Canary Islands. He has been president of the Italian Astronomical Society, a member of the scientific committee of the National Council of Researchers, president and vice-president of solar commissions in the IAU. (M 35492)

\section{(9428) Angelalouise}

$1996 \mathrm{DW}_{2}$. Discovered 1996 Feb. 26 by S. P. Laurie at Church Stretton.

Named in honor of the discoverer's wife, Angela Louise Laurie (née Freeman; 1962- ）. This naming is in recognition of the inspiration, encouragement and support she has given to her husband's astronomical endeavors. (M 34629)

\section{(9429) Poreč}

$1996 \mathrm{EW}_{1}$. Discovered 1996 Mar. 14 at the Višnjan Observatory at Višnjan.

Poreč is a town of cultural monuments, including the sixth-century Euphrasius Basilica. Its position on the coast of the Istrian peninsula guaranteed a history of hardship, but it is now a major tourist center. The charm of the old town and the beauty of the surrounding terrain each year attract and fascinate numerous visitors. (M 42670)

\section{(9438) Satie}

$1997 \mathrm{EE}_{16}$. Discovered 1997 Mar. 5 by the Spacewatch at Kitt Peak.

Erik Satie (1866-1925), French composer and pianist, is best known for his solo piano pieces, including the Gymnopedies, Gnossiennes, and Nocturnes. The tendency toward extreme simplicity in his music influenced his contemporaries Debussy \{see planet (4492)\}, Poulenc and Ravel \{see planet (4727)\}, and later in America, John Cage. (M 41568)

\section{(9445) Charpentier}

$1997 \mathrm{JA}_{8}$. Discovered 1997 May 8 by P. G. Comba at Prescott.

Named for the French musician Marc-Antoine Charpentier (1643-1704), composer of operas and church music, best known for his voluminous and inventive choral music that combines Italian influences and French refinement. (M 33796)

\section{(9446) Cicero}

$1997 \mathrm{JT}_{11}$. Discovered 1997 May 3 by E. W. Elst at La Silla.

Named in memory of Marcus Tullius Cicero (106-43 B.C.), Roman statesman, lawyer, scholar and writer. Perhaps the greatest orator of Roman times, he made his reputation in politics and in the law courts. He was trained by Molon of Rhodes. In his Brutus he gives a description of the equipment of an orator: a thorough knowledge of literature, a grounding of philosophy, legal expertise, a storehouse of history - as well as the capacity to tie up an opponent and reduce the jury to laughter. The more than 900 of his letters that have survived constitute a primary historical source of the ancient world. In his philosophical writings his aim was to provide Rome with a kind of philosophic encyclopedia. (M 34629)

\section{(9448) Donaldavies}

$1997 \mathrm{LJ}_{3}$. Discovered 1997 June 5 by the Spacewatch at Kitt Peak.

Donald W. Davies (1925-2000), a British expert in computer security, suggested in 1965 a robust multipath network between computers to divide data into small labeled packets and transmit them, on different paths if necessary, for reassembly at their destination. This is the basis for TCP-IP protocol in Internet communications. (M 41568) 


\section{(9449) Petrbondy}

1997 VU $_{2}$. Discovered 1997 Nov. 4 by L. Šarounová at Ondřejov.

Petr Kalaš, alias Bondy (1944-2000), was leader of the Prague Scout section Maják ("Lighthouse") and a lover of historical American cars. Bondy was appreciated by friends for his lack of reserve, his strong mind, kindness and sense of humor. He died exactly three years after the discovery of this minor planet. (M 42359)

\section{(9452) Rogerpeeters}

1998 DY $_{33}$. Discovered 1998 Feb. 27 by E. W. Elst at La Silla.

Named in honor of Roger Peeters (1948- ), head of the mechanical workshop at the Royal Observatory at Uccle \{see planet (1276)\} and responsible for maintaining all the telescopes. He was always available for keeping the Zeiss measuring instrument in good repair, and this was used in particular for measuring this minor planet. (M 34353)

\section{(9453) Mallorca}

$1998 \mathrm{FO}_{1}$. Discovered 1998 Mar. 19 by A. Lopez and R. Pacheco at Mallorca.

Named for the largest of the Balearic Islands, site of the discovery of this minor planet. (M 33796)

\section{(9460) McGlynn}

1998 HS $_{30}$. Discovered 1998 Apr. 29 by the JPL NEAT Program at Haleakala.

Named in honor of Thomas A. McGlynn (1956- ), currently the chief archive scientist for the High Energy Science Archive Research Center at the Goddard Space Flight Center. He has played an instrumental role in developing archives and analysis systems for many satellites. His research efforts include studies of diffuse $\gamma$-ray emission and emission from active galactic nuclei, as well as n-body calculations of the effects of interacting systems. He has developed the SkyView virtual observatory and the SkyMorph web site, which allows Internet users to access imagery and object information from the NEAT project database and to search for moving or variable objects therein. (M 35492)

\section{(9468) Brewer}

$1998 \mathrm{LT}_{2}$. Discovered 1998 June 1 by E. W. Elst at La Silla.

Named in honor of James Brewer, ESO astronomer working on stellar populations and carbon stars. Using intermediate band photometry, he has identified Cand M-type stars in M31 and demonstrated that the ratio of these stars tracks the metallicity gradient in the disk. He is currently working on the globular clusters of the Fornax dwarf spheroidal galaxy. During 1998 he was of great help to the discoverer in obtaining observations with the ESO Schmidt. (M 34353)

\section{(9470) Jussieu}

$1998 \mathrm{OS}_{10}$. Discovered 1998 July 26 by E. W. Elst at La Silla.
Named in memory of Bernard (1699-1777), Joseph (1704-1779), Antoine-Laurent (1748-1836) and AdrienLaurent-Henri (1797-1853) de Jussieu, a family of French botanists. Bernard found a method of plant classification based on the anatomical characters of the plant embryo, while Antoine-Laurent laid down the principles for a natural system of plant classification. Adrien-Laurent-Henri wrote a treatise on botany, and Joseph is well known from the voyage to Peru with de la Condamine to measure a meridional arc; Joseph remained in South America for 35 years, returning to Paris in 1771, when he introduced the common "garden heliotrope" into Europe. (M 34629)

\section{(9471) Ostend}

1998 OU $_{13}$. Discovered 1998 July 26 by E. W. Elst at La Silla.

Named for a town (Flemish Oostende, French Ostende) on the Belgian coast. A fishing village since the ninth century, it was fortified in 1583 as a Dutch stronghold in Belgium. However, in 1604, it fell to the Spanish troops after a three-year siege. With emperor Charles VI of Austria, who founded the "Ostend Company", Ostend entered into a period of prosperity. After Belgian independence in 1830 it became a fashionable seaside resort. Connected to England by sea and air services, Ostend is often called the "Gateway to Europe". (M 34629)

\section{(9472) Bruges}

1998 OD $_{14}$. Discovered 1998 July 26 by E. W. Elst at La Silla.

Named for Bruges (or Brugge), a beautiful small town in West Flanders that was already mentioned in the seventh century as "Municipium Brug ense", the name being derived from a Roman bridge over the Reie river. In the thirteenth century, together with Ghent \{see planet (9473)\} and Ypres, the town held a monopoly on English wool. During the fifteenth century the city began to decline when silt clogged the way to the port of Zeebrugge. However, the city remained a strong center for the Flemish school of painting, until the religious struggles of the sixteenth century completed its ruin. (M 34630)

\section{(9473) Ghent}

$1998 \mathrm{OO}_{14}$. Discovered 1998 July 26 by E. W. Elst at La Silla.

Named for the Flemish city Ghent (or Gand), capital of the province of East Flanders. One of the oldest cities (seventh century) in Belgium, united in wealthy guilds, it was virtually independent until 1584 . Its prosperity was and is still based on the cloth industry. The city will be always commemorated in the Pacification of Ghent (1576) and the Treaty of Ghent (1814). It is now the second largest Belgian port. It is also a horticultural center and every five years holds a great flower show known as "Les Floralies". (M 34630) 


\section{(9478) Caldeyro}

2148 P-L. Discovered 1960 Sept. 24 by C. J. van Houten and I. van Houten-Groeneveld at Palomar.

Named in memory of Roberto Caldeyro Barcia (1921-1996), Uruguayan physiologist who led a team of researchers, together with Hermógenes Alvarez, in a pioneering study of the physiological aspects of perinatology. Their investigations on uterine contractility were seminal for the development of procedures for the control of high-risk pregnancies and deliveries. Their unit system ("Montevideo Units"), introduced to measure the intensity of the uterine contractions, is used worldwide. During his term as president of the Program for the Development of Basic Science (1986-1996), Caldeyro Barcia played a fundamental role in restoring Uruguaian scientific research, which had been severely damaged during the previous period of military dictatorship. (M 34353)

Name proposed and citation prepared by SBNC.

\section{(9479) Madresplazamayo}

2175 P-L. Discovered 1960 Sept. 26 by C. J. van Houten and I. van Houten-Groeneveld at Palomar.

Named in honor of the group of women who became a symbol of human rights activism and courage by denouncing the crimes and atrocities commited by the military junta that ruled Argentina during 1976-1983. Dressed in black, they demonstrated for years every Thursday afternoon in the famous Plaza de Mayo in Buenos Aires, demanding to know the fates of their disappeared sons and daughters. During the course of their movement, many Mothers became themselves victims of the military regime. The Mothers of Plaza de Mayo stand out as a shining example to the world that courage and dignity can still blossom in the hearts of many people, even under the most oppressive regimes. (M 34630)

\section{(9480) Inti}

2553 P-L. Discovered 1960 Sept. 24 by C. J. van Houten and I. van Houten-Groeneveld at Palomar.

Named for the sun god in Inca religion, also called Apu-Punchau, believed to be the ancestor of the Incas. Inti was at the head of the state cult. He was usually represented in human form, his face portrayed as a gold disk from which rays and flames extended. Inti's sister was the moon, Mama-Kilya, who was portrayed as a silver disk with human features. (M 34353) Name proposed and citation prepared by SBNC.

\section{(9481) Menchú}

2559 P-L. Discovered 1960 Sept. 24 by C. J. van Houten and I. van Houten-Groeneveld at Palomar.

Named in honor of Rigoberta Menchú Tum (1959-

), a Mayan Indian from Guatemala who has campaigned for human rights, especially for indigenous people. Menchú, whose parents and brother were killed by government troops, became a symbol of peace and reconciliation in a country devastated by civil war. She was awarded the Nobel Peace prize in 1992. According to Nobel Committee Chairman Sejersted, Menchú belongs to "...the shining individual examples of people who manage to preserve their humanity in brutal and violent surroundings. Such people give us hope that there are ways out of a vicious circle." (M 34354)

Name proposed and citation prepared by SBNC.

\section{(9482) Rubéndarío}

4065 P-L. Discovered 1960 Sept. 24 by C. J. van Houten and I. van Houten-Groeneveld at Palomar.

Named in memory of Rubén Darío (1867-1916), pseudonym of Félix Rubén Garcia Sarmiento, Nicaraguan poet, journalist and diplomat who became a leader of the Spanish-American literary movement known as Modernism. Darío's poetry is notable for its remarkable musicality, grace and sonority, and he is indeed widely considered one of the greatest poets who ever wrote in Spanish. (M 34354)

Name proposed and citation prepared by SBNC.

\section{(9483) Chagas}

4121 P-L. Discovered 1960 Sept. 24 by C. J. van Houten and I. van Houten-Groeneveld at Palomar.

Named in memory of Carlos Chagas (1879-1934), Brazilian epidemiologist who first described the agent, vectors and clinical signs of a new disease, the American Trypanosomiasis. Also known as Chagas' disease, this is an infection produced by the flagellate protozoan Trypanosoma Cruzi that is transmitted to humans by blood-sucking insects. It is endemic in most rural areas of Central and South America. (M 34354)

Name proposed and citation prepared by SBNC.

\section{(9484) Wanambi}

4590 P-L. Discovered 1960 Sept. 24 by C. J. van Houten and I. van Houten-Groeneveld at Palomar.

Named for the Australian Aborigines' best known spirit, the Rainbow Snake, which is the rainbow and the revealer of truth. Wanambi is one of the rainbow's names. (M 34354)

Name proposed and citation prepared by SBNC.

\section{(9485) Uluru}

6108 P-L. Discovered 1960 Sept. 24 by C. J. van Houten and I. van Houten-Groeneveld at Palomar.

Named for the Australian Aboriginal sacred place, the center or navel of the island continent. It is also known as Ayers Rock. (M 34354)

Name proposed and citation prepared by SBNC.

\section{(9486) Utemorrah}

6130 P-L. Discovered 1960 Sept. 24 by C. J. van Houten and I. van Houten-Groeneveld at Palomar.

Named for the Australian Aboriginal poet Daisy Utemorrah (1922- ), teller of Dreamtime stories in the Kimberley: "Words are my gun and my spear". (M 34354)

Name proposed and citation prepared by SBNC. 


\section{(9487) Kupe}

7633 P-L. Discovered 1960 Oct. 17 by C. J. van Houten and I. van Houten-Groeneveld at Palomar.

Named for the legendary sailor and explorer whose discovery of the islands now known as New Zealand led to the coming there of the Maori people around the ninth century. (M 34354)

Name proposed and citation prepared by SBNC.

\section{(9488) Huia}

9523 P-L. Discovered 1960 Sept. 24 by C. J. van Houten and I. van Houten-Groeneveld at Palomar.

Named for the bird, extinct since 1907, with splendid green and black plumage and a long white-tipped tail (Heteralocha acutirostris). The tail feathers of the huia were highly prized by the Maori people as symbols of rank. Carved boxes, waka huia, were made to keep them in. (M 34354)

Name proposed and citation prepared by SBNC.

\section{(9489) Tanemahuta}

1146 T-1. Discovered 1971 Mar. 25 by C. J. van Houten and I. van Houten-Groeneveld at Palomar.

Named for the god of the forests of the Maori people in New Zealand and for the great kauri tree in the Waipoua forest that also bears this name. (M 34354) Name proposed and citation prepared by SBNC.

\section{(9490) Gosemeijer}

1181 T-1. Discovered 1971 Mar. 25 by C. J. van Houten and I. van Houten-Groeneveld at Palomar.

Dutch amateur astronomer Henny Gosemeijer (19241999) founded the Public Observatory Twente in 1984. He himself made many observations of satellites and meteors, in addition to his activities in popularizing astronomy. He was honored by NASA and awarded the Dutch "van der Bilt" and "Simon Stevin" prizes. (M 38199)

\section{(9491) Thooft}

1205 T-1. Discovered 1971 Mar. 25 by C. J. van Houten and I. van Houten-Groeneveld at Palomar.

Gerardus 't Hooft (1946- ) is professor of physics at University of Utrecht. Together with his colleague M. J. G. Veltman \{see planet (9492)\} he won the 1999 Nobel Prize in physics, awarded for placing the theory of particle physics on a firmer mathematical foundation and for elucidating the quantum structure of electroweak interactions. (M 39652)

\section{(9492) Veltman}

2066 T-1. Discovered 1971 Mar. 25 by C. J. van Houten and I. van Houten-Groeneveld at Palomar.

Martinus J. G. Veltman (1931- ) is professor of physics at the Universities of Utrecht and Michigan. Together with his colleague G. 't Hooft ssee planet (9491)\} he won the 1999 Nobel Prize in physics, awarded for placing particle physics theory on a firmer mathematical foundation and for elucidating the quantum structure of electroweak interactions. (M 39653)

\section{(9493) Enescu}

3100 T-1. Discovered 1971 Mar. 26 by C. J. van Houten and I. van Houten-Groeneveld at Palomar.

Romanian composer George Enescu (1881-1955), a student of Massenet and Fauré, achieved a synthesis between the music of the Romanian people and the great European musical traditions. His rhapsodies and symphonies are known and interpreted worldwide. (M 40703)

The name was suggested by M. Stavinschi.

\section{(9494) Donici}

3212 T-1. Discovered 1971 Mar. 26 by C. J. van Houten and I. van Houten-Groeneveld at Palomar.

Nicolae Donici (1875-1957), a founding member of the IAU and the first representative there of Romanian astronomy, was the most important messenger for Romanian astronomy around the world. Known for his research in solar physics, he observed six total solar eclipses. (M 40703)

The name was suggested by M. Stavinschi.

\section{(9495) Eminescu}

4177 T-1. Discovered 1971 Mar. 26 by C. J. van Houten and I. van Houten-Groeneveld at Palomar.

The Romantic poet Mihai Eminescu (1850-1889) tackled the essential problems of human existence life, death, love, faith, hope, struggle. He accomplished this by literary means that remain unique. As a genius of universal culture, he was often compared with Shakespeare and Goethe \{see planets (2985) and (3047), respectively\}. (M 40704)

The name was suggested by M. Stavinschi.

\section{(9496) Ockels}

4260 T-1. Discovered 1971 Mar. 26 by C. J. van Houten and I. van Houten-Groeneveld at Palomar.

Wubbo J. Ockels (1946- ) became the first Dutch astronaut in space during the Spacelab D-1 mission. After his flight aboard the Space Shuttle Challenger in 1985 he continued working for the European Space Agency and became professor of aerospace at the Technical University of Delft. (M 40704) The name was suggested by W. A. Froger.

\section{(9497) Dwingeloo}

1001 T-2. Discovered 1973 Sept. 29 by C. J. van Houten and I. van Houten-Groeneveld at Palomar.

The Dwingeloo 25-m radio telescope in The Netherlands supported investigations of the 21-cm emission from hydrogen in our Galaxy. Its principal contributions include the discoveries of the 3-kpc arm and the high-velocity-cloud phenomenon, as well as studies of the galactic center. (M 40704)

The name was suggested by W. A. Froger. 


\section{(9498) Westerbork}

1197 T-2. Discovered 1973 Sept. 29 by C. J. van

Houten and I. van Houten-Groeneveld at Palomar.

The Westerbork Synthesis Radio Telescope in The

Netherlands, dedicated in 1970, has excelled in studies of neutral hydrogen in nearby and distant galaxies, in continuum studies of radio galaxies, and in large-scale surveys. It is also an important part of the European VLBI network. (M 40704)

The name was suggested by B. Burton.

\section{(9499) Excalibur}

1269 T-2. Discovered 1973 Sept. 29 by C. J. van Houten and I. van Houten-Groeneveld at Palomar.

Excalibur was the name of the sword of King Arthur \{see planet (2597)\}. (M 41568)

\section{(9500) Camelot}

1281 T-2. Discovered 1973 Sept. 29 by C. J. van Houten and I. van Houten-Groeneveld at Palomar.

Camelot was the location of the castle of the King Arthur \{see planet (2597)\} legend. (M 41568)

\section{(9501) Ywain}

2071 T-2. Discovered 1973 Sept. 29 by C. J. van Houten and I. van Houten-Groeneveld at Palomar.

Ywain was a knight of the Round Table of King Arthur \{see planet (2597)\}. (M 41568)

\section{(9502) Gaimar}

2075 T-2. Discovered 1973 Sept. 29 by C. J. van Houten and I. van Houten-Groeneveld at Palomar.

Gaimar was a knight of the Round Table and lover of Morgane, sister of King Arthur \{see planet (2597)\}. (M 41568)

\section{(9503) Agrawain}

2180 T-2. Discovered 1973 Sept. 29 by C. J. van Houten and I. van Houten-Groeneveld at Palomar.

Agrawain, brother of Gawain \{see planet (2054)\}, was a knight of the Round Table. (M 41568)

\section{(9504) Lionel}

2224 T-2. Discovered 1973 Sept. 29 by C. J. van Houten and I. van Houten-Groeneveld at Palomar.

Lionel was one of the knights of the Round Table. (M 41568)

\section{(9505) Lohengrin}

4131 T-2. Discovered 1973 Sept. 29 by C. J. van Houten and I. van Houten-Groeneveld at Palomar.

Lohengrin, the knight of the Holy Grail, was the title character of an opera by Wagner \{see planet (3992)\}. (M 41568)

\section{(9506) Telramund}

5200 T-2. Discovered 1973 Sept. 25 by C. J. van Houten and I. van Houten-Groeneveld at Palomar.

Count Telramund, husband of Ortrud \{see planet (551)\}, is a character in Wagner's \{see planet (3992)\} opera Lohengrin \{see planet (9505)\}. He wished to reign over Brabant. (M 41568)

\section{(9507) Gottfried}

5447 T-2. Discovered 1973 Sept. 30 by C. J. van Houten and I. van Houten-Groeneveld at Palomar.

Gottfried of Brabant, brother of Elsa, was changed into a swan by Ortrud, wife of Telramund ssee planets (551) and (9506)\}. After Ortrud's death he again became a human being, as Lohengrin \{see planet (9505)\} had to leave Elsa. (M 41568)

\section{(9508) Titurel}

3395 T-3. Discovered 1977 Oct. 16 by C. J. van Houten and I. van Houten-Groeneveld at Palomar.

Titurel was father of Amfortas \{see planet (9509)\} and former king of Monsalvat in Wagner's opera Parsifal \{see,respectively, planets (3992) and (2095)\}. (M 41568)

\section{(9509) Amfortas}

3453 T-3. Discovered 1977 Oct. 16 by C. J. van Houten and I. van Houten-Groeneveld at Palomar.

Amfortas was the king of Monsalvat and of the knights of the Holy Grail in Wagner's opera Parsifal \{see, respectively, planets (3992) and (2095)\}. (M 41568)

\section{(9510) Gurnemanz}

5022 T-3. Discovered 1977 Oct. 16 by C. J. van Houten and I. van Houten-Groeneveld at Palomar.

Gurnemanz was an elderly knight of the Holy Grail in Wagner's opera Parsifal \{see, respectively, planets (3992) and (2095)\}. (M 41568)

\section{(9511) Klingsor}

5051 T-3. Discovered 1977 Oct. 16 by C. J. van Houten and I. van Houten-Groeneveld at Palomar.

The sorcerer Klingsor appeared in the opera Parsifal \{see planet (2095)\}. (M 41568)

\section{(9516) Inasan}

1976 YL $_{3}$. Discovered 1976 Dec. 16 by L. I. Chernykh at Nauchnyj.

The Institute of Astronomy of the Russian Academy of Sciences, abbreviated as INASAN from its Russian name, is a leading astronomical research institution, founded in 1936. Its main fields of research are stellar astrophysics, galaxies, planetary systems, geodynamics, space research, NEAs and space debris. (M 46009)

\section{(9518) Robbynaish}

1978 GA. Discovered 1978 Apr. 7 at the Harvard College Observatory at Harvard.

Hawaiian Robby Naish (1963- ) is known in the international windsurfing community as a competitor and an entrepreneur. Five-time world champion of the Professional Windsurfing Association, he is also a pioneer kitesurfer and won the 2000 King of the Air competition on Maui. (M 42359)

The name was suggested by R. Crane. 


\section{(9521) Martinhoffmann}

1980 FS $_{1}$. Discovered 1980 Mar. 16 by C.-I. Lagerkvist at La Silla.

Martin Hoffmann (1949- ） is a German astronomer who has made observations of variable stars and minor planets, including lightcurve studies and spectroscopic investigations. In recent years he has been much involved with the observations from ODAS, the O.C.A.-DLR Asteroid Survey. (M 36128)

The name was suggested by G. Hahn.

\section{(9531) Jean-Luc}

1981 QK. Discovered 1981 Aug. 30 by E. Bowell at Anderson Mesa.

Jean-Luc Margot (1969- ), a scientist at the Arecibo \{see planet (4337)\} Observatory, has used radar interferometry and self-built data-acquisition hardware to make the most detailed topographic maps available for the moon's polar regions. He also led the radar investigation of the binary near-earth-object $2000 \mathrm{DP}_{107}$. (M 41937)

\section{(9532) Abramenko}

$1981 \mathrm{RQ}_{2}$. Discovered 1981 Sept. 7 by L. G. Karachkina at Nauchnyj.

Named in honor of Aleksandr Nikolaevich Abramenko (1921- ), chief engineer at the Crimean Astrophysical Observatory. He created a special television system that has been used for observations of astronomical objects since 1963. This has produced unique data on novae, supernovae, cataclysmic variables, minor planets and comets. Abramenko is one of the authors of a monograph on television astronomy (1974, 1984). (M 34630)

\section{(9533) Aleksejleonov}

$1981 \mathrm{SA}_{7}$. Discovered 1981 Sept. 28 by L. V. Zhuravleva at Nauchnyj.

Aleksej Arkhipovich Leonov (1934- ), during a spaceflight in 1965 with P. I. Belyaev on Voskhod 2 , became the first human to "spacewalk" outside a spacecraft when he left the spacecraft for approximately 10 minutes. He was also the commander of the Soyuz spacecraft that linked with the Apollo spacecraft in 1975 \{see also planet (2228)\}. (M 43042)

\section{(9535) Plitchenko}

$1981 \mathrm{UO}_{11}$. Discovered 1981 Oct. 22 by N. S. Chernykh at Nauchnyj.

Aleksandr Ivanovich Plitchenko (1943-1997) was a Russian writer in Novosibirsk city, author of some 20 volumes of poetry and 5 books of prose works. He was the head of a Novosibirsk writers' association for some years. (M 46009)

\section{(9537) Nolan}

1982 BM. Discovered 1982 Jan. 18 by E. Bowell at Anderson Mesa.

Michael C. Nolan (1963- ), a scientist at the Arecibo \{see planet (4337)\} Observatory, has significantly advanced our theoretical understanding of the collisional evolution of minor planets and has conducted numerous radar observations, including the first delay-doppler imaging of the largest main-belt objects. (M 41937)

\section{(9539) Prishvin}

1982 UE $_{7}$. Discovered 1982 Oct. 21 by L. G. Karachkina at Nauchnyj.

Named in memory of the writer Mikhail Mikhajlovich Prishvin (1873-1954), famous for his deep philosophical descriptions of Russian nature. His affecting stories about animals are thrilling, especially for children. (M 34630)

\section{(9540) Mikhalkov}

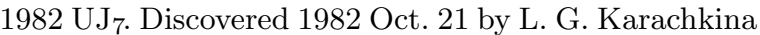
at Nauchnyj.

Named in honor of the Russian writer and poet Sergej Vladimirovich Mikhalkov (1913- ), whose wonderful verses and fables are the best companion for any child. (M 34630)

\section{(9541) Magri}

1983 CH. Discovered 1983 Feb. 11 by E. Bowell at Anderson Mesa.

Christopher Magri (1961- ) is a scientist at the University of Maine at Farmington. A former galactic radio astronomer, he has used analyses of radar echoes from main-belt minor planets to demonstrate that there is no radar evidence for a difference between the surface bulk densities of the S and C objects. (M 41937)

\section{(9542) Eryan}

$1983 \mathrm{TU}_{1}$. Discovered 1983 Oct. 12 by E. Bowell at Anderson Mesa.

Eileen V. Ryan (1960- ), of New Mexico Highlands University, has contributed to the field of fragmentation studies of minor planets by conducting laboratory impact experiments and developing numerical simulations. Recently, she has helped initiate an observational program to study minor planets of the Vesta s see planet (4)\} family. (M 41937)

\section{(9543) Nitra}

$1983 \mathrm{XN}_{1}$. Discovered 1983 Dec. 4 by M. Antal at Piszkéstetö.

Nitra, a historical town in western Slovakia, was a the seat of prince Pribina \{see planet (10293)\} and center of the Nitra principality early in the ninth century. Its history is connected with the first Christian church on the territory of Slovakia, as well as with the introduction of the old Slavonic alphabet "hlaholika". (M 43190)

\section{(9544) Scottbirney}

1984 EL. Discovered 1984 Mar. 1 by E. Bowell at Anderson Mesa.

D. Scott Birney (1926- ) was a professor of astronomy at Wellesley College, Massachusetts, from 1968 to 1991, serving as department chair. He 
authored two textbooks: Modern Astronomy (1969) and Observational Astronomy (1991). (M 42359)

The name was suggested by F. Vilas.

\section{(9545) Petrovedomosti}

1984 MQ. Discovered 1984 June 25 by T. M. Smirnova at Nauchnyj.

The oldest Russian daily newspaper Sankt-Peterburgskie Vedomosti ("St. Petersburg News") was founded in 1728. The great Russian scientist $M$. V. Lomonosov \{see planet (1379)\} was one of the first editors-in-chief of the newspaper. The tenth anniversary of the resumption of its publication is celebrated in 2001. (M 43042)

\section{(9548) Fortran}

1985 CN. Discovered 1985 Feb. 13 by the Spacewatch at Kitt Peak.

FORmula TRANslator, the first widely distributed symbolic programming language for digital computers, was developed at IBM in New York by John Backus and co-workers from 1953 to 1957. It made computers more accessible to scientists and engineers by freeing them of burdensome programming in assembly language. (M 41568)

\section{(9549) Akplatonov}

$1985 \mathrm{SM}_{2}$. Discovered 1985 Sept. 19 by N. S. Chernykh and L. I. Chernykh at Nauchnyj.

Aleksandr Konstantinovich Platonov (1931- ), a researcher in astrodynamics and robotics at the Keldysh Institute of Applied Mathematics since 1954, is a pioneer in the theory and computation of satellite orbits and the control of spacecraft trajectories to the moon and planets, as well as the motion of walking robots. (M 46009)

\section{(9550) Victorblanco}

1985 TY $_{1}$. Discovered 1985 Oct. 15 by E. Bowell at Anderson Mesa.

Victor M. Blanco (1918- ) was director of the Cerro Tololo Interamerican Observatory from 1967 to 1981. Under his leadership, Cerro Tololo developed into a major southern-hemisphere observatory, including the construction of the 4-meter telescope in 1975. (M 42359)

The name was suggested by F. Vilas.

\section{(9551) Kazi}

1985 UJ. Discovered 1985 Oct. 20 by A. Mrkos at Kleť.

Named for the oldest daughter of prince Krok \{see planet (3102)\} and wife of honorable hero Bivoj \{see planet (5797)\}, known from Bohemian myths. Kazi was experienced in magic, herbs, formulas and signs. (M 34354)

Name suggested by J. Tichá, M. Tichý and Z. Moravec.

\section{(9553) Colas}

$1985 \mathrm{UG}_{2}$. Discovered 1985 Oct. 17 by the CERGA at Caussols.

François Colas (1959- ) is an expert on modern solar-system astrometry at the Institut de Mécanique Celeste in Paris. He has contributed to numerous research papers in observational planetary astronomy. A strong supporter of the Pic du Midi Observatory, he has many fruitful relations with the amateur community. (M 36948)

\section{(9554) Dumont}

1985 XA. Discovered 1985 Dec. 13 by R. Chemin at Caussols.

Meudon mathematician and astronomer Simone Dumont (1924- ) has studied T Tauri stars, active galaxies, radiative transfer and the history of astronomy. Modest and tactful, she was editor of L'Astronomie for several years. (M 40704)

The citation was prepared by R. Chemin and C. Pollas.

\section{(9560) Anguita}

1987 EQ. Discovered 1987 Mar. 3 by E. Bowell at Anderson Mesa.

Claudio Anguita (1930-2000), an astrometrist at the Universidad de Chile, was critically helpful during the establishment of the Cerro Tololo Interamerican Observatory, forging links between AURA and the Universidad de Chile. He was an IAU Vice President during 1994-2000. (M 42359)

The name was suggested by F. Vilas.

\section{(9561) van Eyck}

1987 QT $_{1}$. Discovered 1987 Aug. 19 by E. W. Elst at La Silla.

Jan van Eyck (1395-1441) was a Flemish painter best known for The Adoration of the Lamb (1432), displayed in the cathedral of Ghent \{see planet (9473)\}. There is some mystery about a second name, Hubert, appearing on the Ghent Altarpiece. Hubert was also a Flemish painter and probably the brother of Jan. (M 47165)

\section{(9562) Memling}

1987 RG. Discovered 1987 Sept. 1 by E. W. Elst at La Silla.

Hans Memling (1430-1494) was a Flemish painter from the famous Bruges \{see planet (9472)\} School of painting. Known for his large triptych Adoration of the Magi, he made typical two-panel paintings, portraying the "donor" on one panel, gazing at the Madonna with Child on the other panel. (M 47165)

\section{(9563) Kitty}

1987 SJ $_{1}$. Discovered 1987 Sept. 21 by E. Bowell at Anderson Mesa.

Katherine ("Kitty") F. Putnam (1916- ) was, from 1975 through 1984, president of the Springfield, Massachusetts, Television Corporation. She was also 
the first woman elected to the board of the National Association of Broadcasters. (M 42359)

\section{(9564) Jeffwynn}

1987 SG $_{3}$. Discovered 1987 Sept. 26 by C. S. Shoemaker and E. M. Shoemaker at Palomar.

Jeffrey C. Wynn, a humorous, curious, inventive, adventurous geophysicist with the U.S. Geological Survey has studied the Wabar Craters of Saudi Arabia with Gene Shoemaker \{see planet (2074)\}, mapped the seafloor, analyzed mineral resources on land, studied aquifers and archaeological sites - and observed with the Shoemaker-Levy team. (M 36948)

\section{(9565) Tikhonov}

1987 SU 17 . Discovered 1987 Sept. 18 by L. I. Chernykh at Nauchnyj.

Russian mathematician Andrej Nikolaevich Tikhonov (1906-1993), a professor at Moscow State University, is known for his fundamental research in topology, functional analysis, theory of differential and integral equations, mathematical physics and computional mathematics. (M 46009)

\section{(9567) Surgut}

1987 US $_{4}$. Discovered 1987 Oct. 22 by L. V. Zhuravleva at Nauchnyj.

Founded in 1593, Surgut is one of the main administrative and supply centers for the vast oil and natural gas producing fields along the $\mathrm{Ob}$ River in the Khanty-Mansi autonomous district of the Tyumen province $\{$ see planet (2120)\} in Siberia. (M 43042)

\section{(9569) Quintenmatsijs}

1988 CL $_{2}$. Discovered 1988 Feb. 11 by E. W. Elst at La Silla.

Quinten Matsijs (1466-1530) was a Flemish painter well known for his monumental triptych altarpieces. He was also the painter of The Old Man and the Courtesan and The Money Changer and his Wife, in which he showed great subtlety in painting individual emotions. (M 47165)

\section{(9574) Taku}

1988 XB $_{5}$. Discovered 1988 Dec. 5 by T. Nakamura at Kiso.

Named in memory of Hiroshi Nakamura (18911974), Japanese medical biochemist and researcher of old maps. He was often called Taku, since the Chinese character representing his first name can also be pronounced as Taku. He is well-known in the community of historical cartography as twice the winner of the Imago Mundi prize, awarded by the authoritative international journal on old maps. Taku was a long-time member of the editorial board of this journal. He wrote several important books and papers on far-east Asian maps of the sixteenth and seventeenth centuries. He showed that, contrary to Western understanding, European sea charts and maps of far-east Asia then being made were largely influenced by the knowledge of contemporary Japanese and Chinese sailors. (M 34354)

\section{(9576) van der Weyden}

$1989 \mathrm{CX}_{2}$. Discovered 1989 Feb. 4 by E. W. Elst at La Silla.

Rogier van der Weyden (Rogier de la Pasture, 1399-1464) was a Flemish painter who dominated painting in France, Germany and Spain. A pupil of Robert Campin, he was also influenced by Jan van Eyck \{see planet (9561)\}. Following the spirit of his epoch, he painted his famous Descent from the Cross. (M 47165)

\section{(9577) Gropius}

$1989 \mathrm{CE}_{5}$. Discovered 1989 Feb. 2 by F. Börngen at Tautenburg.

Named for the German architect Walter Gropius (1883-1969), born in Berlin \{see planet (422)\} and one of the most fascinating representatives of twentiethcentury architecture. He turned away from all historical influence and favored expedient, glass and concrete constructions. In 1919, he founded the Bauhaus in Weimar \{see planets (8502) and (3139)\} and was its director until 1928. In 1933 he emigrated to England. From 1937 to 1952 he taught at Harvard University, where he founded an architecture school and the Architects Collaborative and built the Harvard Graduate Center. His public works can be found in Berlin, Dessau, Chicago, Athens, and New York (notably the Pan Am Building). (M 33976)

\section{(9580) Tarumi}

1989 TB$_{11}$. Discovered 1989 Oct. 4 by T. Nomura and K. Kawanishi at Minami-Oda.

Named for the ward in Kobe City where the first discoverer was born and lives. Tarumi is depicted in eighth-century Japanese poems, and it is also an obsolete word for waterfall. The world's longest suspension bridge, connecting Tarumi with the Awaji Island, was completed in 1998. (M 35492)

\section{(9584) Louchheim}

$1990 \mathrm{OL}_{4}$. Discovered 1990 July 25 by H. E. Holt at Palomar.

For many years Thomas Louchheim (1957- ), of Tucson, Arizona, has been a highly regarded counsellor for hundreds of Tucson-area families. Active in childhood education, Louchheim's optimistic philosophy has brightened the lives of many young people. (M 42359)

\section{(9609) Ponomarevalya}

$1992 \mathrm{QL}_{2}$. Discovered 1992 Aug. 26 by L. I. Chernykh at Nauchnyj.

Valentina Leonidovna Ponomareva (1934- ), of the Institute of History of Science and Technology, is a specialist on aircraft and spacecraft. One of five members of the Soviet female cosmonaut team, she 
was a back-up pilot for the spaceflight by Valentina Tereshkova in 1963. (M 46010)

\section{(9610) Vischer}

1992 RQ. Discovered 1992 Sept. 2 by F. Börngen and L. D. Schmadel at Tautenburg.

Named for Peter Vischer the Elder (c.1460-1529), the greatest German brasscaster master in the Middle Ages. Ledgers, tombs, artistic parcloses, baptismal fonts and statues made of bronze from his workshop in Nürnberg can be found throughout Germany. His father and sons also worked in this foundry. His masterpiece is the world-renowned Sebaldusgrab in St. Sebald church at Nürnberg, made during 1508-1519. (M 34354)

Name proposed by the first discoverer.

\section{(9612) Belgorod}

$1992 \mathrm{RT}_{7}$. Discovered 1992 Sept. 4 by L. V. Zhuravleva at Nauchnyj.

An industrial, scientific and cultural center in southern Russia, close to the Ukrainian border, Belgorod was mentioned in a chronicle in 1237. A fortress established in 1593 made Belgorod a key stronghold in protecting Russia's southern border against the Tatars in the seventeenth century. (M 41029)

\section{(9617) Grahamchapman}

$1993 \mathrm{FA}_{5}$. Discovered 1993 Mar. 17 by the Uppsala-ESO Survey at La Silla.

Graham Chapman (1941-1989) was a member of "Monty Python's Flying Circus", the internationally popular British television series of the 1970s known for its pioneering irreverent comedy. (M 39653)

\section{(9618) Johncleese}

1993 FQ8. Discovered 1993 Mar. 17 by the Uppsala-ESO Survey at La Silla.

John Cleese (1939- ) a member of Monty Python's Flying Circus, has also acted in movies such as A Fish Called Wanda and and the television comedy series Fawlty Towers. (M 39653)

\section{(9619) Terrygilliam}

1993 FS. Discovered 1993 Mar. 17 by the Uppsala-ESO Survey at La Silla.

Terry Gilliam (1940- ) was the American member of Monty Python's Flying Circus. (M 39653)

\section{(9620) Ericidle}

$1993 \mathrm{FU}_{13}$. Discovered 1993 Mar. 17 by the UppsalaESO Survey at La Silla.

Eric Idle (1943- ), another member of Monty Python's Flying Circus, is also well known for other projects, such as "All You Need Is Cash" and several books for children. (M 39653)

\section{(9621) Michaelpalin}

$1993 \mathrm{FT}_{26}$. Discovered 1993 Mar. 21 by the UppsalaESO Survey at La Silla.
Michael Palin (1943- ) is a member of Monty Python's Flying Circus. His sketch with the parrot will never be forgotten. He has also written several books for children and undertaken world travelogues for television. (M 39653)

\section{(9622) Terryjones}

$1993 \mathrm{FV}_{26}$. Discovered 1993 Mar. 21 by the UppsalaESO Survey at La Silla.

Terry Jones (1942- ), a member of Monty Python's Flying Circus, is also known for films such as Erik the Viking and The Crusades. (M 39653)

\section{(9623) Karlsson}

$1993 \mathrm{FU}_{28}$. Discovered 1993 Mar. 21 by the UppsalaESO Survey at La Silla.

Per Olow Karlsson (1934- ) is a skillful technician who worked at the Uppsala and Kvistaberg \{see, respectively, planets (2191) and (3331)\} Observatories for many years. (M 39653)

\section{(9631) Hubertreeves}

1993 SL $_{6}$. Discovered 1993 Sept. 17 by E. W. Elst at La Silla.

Hubert Reeves, a professional astronomer at the French CNRS, has become known worldwide for his popularization of astronomy through his many books and lectures on radio and television. (M 36128)

\section{(9633) Cotur}

1993 UP $_{8}$. Discovered 1993 Oct. 20 by E. W. Elst at La Silla.

Named in honor of Peter Cotur (1944- ), scientific journalist at the newspaper Het Laatste Nieuws in Brussels \{see planet (2689)\} and a good friend of the discoverer. Educated in biology at the University of Ghent \{see planet (9473)\}. he is especially interested in medicine, environmental problems, space technology and astronomy in general. Fascinated by history, he is currently occupied in discovering the earliest facts about technical and scientific inventions, as well as about peculiarities in the lives of the inventors. (M 34630)

\section{(9637) Perryrose}

$1994 \mathrm{PJ}_{2}$. Discovered 1994 Aug. 9 at the Palomar Observatory at Palomar.

Perry J. Rose (1966- ) is a former member of the Palomar Planet Crossing Asteroid Survey and currently lead solar observer on the 18-meter solar tower at Mt. Wilson Observatory. He discovered many minor planets, including near-earth objects. (M 39653)

\section{(9638) Fuchs}

$1994 \mathrm{PO}_{7}$. Discovered 1994 Aug. 10 by E. W. Elst at La Silla.

Named in memory of the German botanist and physician Leonhard Fuchs (1501-1566), whose botanical work Historia Stirpium commentarii insignes (1542) remains a landmark in the organized presentation of 
botanical observations. The book contains beautiful woodcuts and accurate descriptions (and a glossary) of more than 550 plants, most of them of medical use. His name is also commemorated in the Fuchsia genus of flowering plants. (M 34630)

\section{(9639) Scherer}

1994 PS $_{11}$. Discovered 1994 Aug. 10 by E. W. Elst at La Silla.

Named in honor of Marc Scherer (1944- ), a well-known scientist at The Belgian Institute for Space Aeronomy in Uccle. His main interest is the development of kinetic models for polar and solar winds, using the kinetic theory of gases. This naming also honors his sisters Elisabeth and Trixie Scherer, in sweet remembrance of a time at the Atheneum of Kapellen in Antwerp. (M 34630)

\section{(9640) Lippens}

$1994 \mathrm{PP}_{26}$. Discovered 1994 Aug. 12 by E. W. Elst at La Silla.

Named in honor of Carlos Lippens (1945- ), well known for his work on trace substances in the earth's atmosphere by means of infrared spectroscopy. Working at the Belgian Institute for Space Aeronomy, he was responsible for the GRILLE spectrometer on board Spacelab 1 (1983) and Atlas 1 (1992). Lippens was also closely involved with the MIRAS instrumentation on board MIR. As a computer specialist he has frequently helped solve data-communication problems in connection with the discoverer's work on minor planets. (M 34630)

\section{(9641) Demazière}

1994 PB $_{30}$. Discovered 1994 Aug. 12 by E. W. Elst at La Silla.

Named in honor of Martine De Mazière (1960- ), a scientist at the Belgian Institute for Space Aeronomy involved with the optical remote sensing of the lower atmosphere. Her main interest is in the atmospheric composition, including aerosols, and how it changes. She has also made a quantitative evaluation of the post-Pinatubo $\mathrm{NO}_{2}$ reduction and recovery, based on ten years of ultraviolet and optical spectroscopic measurements at the Jungfraujoch station. She shares with the discoverer a great love for music. (M 34630)

\section{(9645) Grünewald}

$1995 \mathrm{AO}_{4}$. Discovered 1995 Jan. 5 by F. Börngen at Tautenburg.

Named for the German painter and watercolor artist Matthias Grünewald (ca 1460-1528). His original name was Mathis Gothard Neithardt (or Niethart). His masterpiece is the Isenheimer altar in Colmar, one of the great works of Western art, featuring spiritual and realistic scenes juxtaposed and notable for the variety and beauty of the colors. Paul Hindemith \{see planet (5157)\} made Grünewald's life the subject of his opera and symphony Mathis der Maler. (M 34354)
(9651) Arii-SooHoo

1996 AJ. Discovered 1996 Jan. 7 by the JPL NEAT Program at Haleakala.

Computer mathematician Vicki Arii-SooHoo (1962-

) became team leader at AMOS in 1997 and is directly responsible for the successes of the AMOS program. With untiring support from her family, she has dedicated long hours and sleepless nights to ensure that the AMOS team is productive, efficient and motivated. (M 41568)

\section{(9657) Učka}

1996 DG $_{2}$. Discovered 1996 Feb. 24 by K. Korlević and D. Matković at Visnjan.

Učka is the highest mountain on the Istrian peninsula, which extends into the northern Adriatic sea. (M 46101)

\section{(9658) Imabari}

$1996 \mathrm{DD}_{3}$. Discovered 1996 Feb. 28 by A. Nakamura at Kuma.

Named for a city in eastern Ehime prefecture, famous for the shipbuilding and textile industries, especially the production of towels. Imabari is the terminal city on the Shikoku \{see planet (4223)\} Island side of the Nishiseto Expressway (Shimanami Kaido) \{see planet (9235)\} and expects to welcome many visitors after this road opens on 1999 May 1. (M 34630)

\section{(9662) Frankhubbard}

1996 GS. Discovered 1996 Apr. 12 by P. G. Comba at Prescott.

Named for the American harpsichord maker Frank Hubbard (1920-1976). After graduating from Harvard he traveled in Europe and gained a profound knowledge of early keyboard instruments, setting this down in his book Three Centuries of Harpsichord Making. In 1949, jointly with William Dowd, he set up a harpsichord workshop in Boston, which, through a process of fission, became the progenitor of several such workshops and led to the establishment of a tradition of harpsichord making in North America. (M 34355)

\section{(9663) Zwin}

1996 GC $_{18}$. Discovered 1996 Apr. 15 by E. W. Elst at La Silla.

The Zwin is a naturally protected reserve, the result of the silting up of the bay that stretched to Bruges in medieval times. Extending along the coast from Knokke in Belgium to Cadzand in the Netherlands, it gives shelter to many species of birds. (M 47165)

\section{(9664) Brueghel}

$1996 \mathrm{HT}_{14}$. Discovered 1996 Apr. 17 by E. W. Elst at La Silla.

Named in memory of Pieter Brueghel (Bruegel, Breughel; c.1525-1569), the greatest Flemish painter of the sixteenth century. He was apprenticed to Pieter Coecke, a leading Antwerp artist, whose daughter he married. Although Brueghel was little influenced by Coecke's italianate art, the apprenticeship provided an 
important contact with a humanistic milieu, sensitizing Brueghel for human life. Perhaps for this reason his landscapes show, not only trees, mountains and snow, but also humans suffering from one side and enjoying life from the other. Through his sons Jan and Pieter, Brueghel became the ancestor of a dynasty of painters that survived into the eighteenth century. (M 34631)

\section{(9665) Inastronoviny}

1996 LA. Discovered 1996 June 5 at the Klet Observatory at Kleť.

IAN, or Instantníastronomické noviny, is a Czech Internet Astronomical Newspaper founded by JiříDušek and Rudolf Novák in Brno in 1997. The webpages of the IAN report the latest reliable astronomical information to the Czech public. (M 36948)

\section{(9669) Symmetria}

$1997 \mathrm{NC}_{3}$. Discovered 1997 July 8 by P. G. Comba at Prescott.

Name suggested by the palindromic shape of the numeral 9669, and the fact that each pair of its digit is invariant under a rotation by 180 degrees. (M 33796)

\section{(9670) Magni}

1997 NJ J0 $_{10}$. Discovered 1997 July 10 by A. Boattini at Campo Imperatore.

Named in honor of Gianfranco Magni (1943- ), who joined the Istituto di Astrofisica Spaziale in Rome in 1975. He has worked on the physics of stellar interiors, in particular on the equation of state of gas at high pressure and temperature. Currently, his main field of interest is the origin of the solar system and of planetary systems in general, with special attention to the structure and evolution of circumstellar disks and the formation of giant planets. Involved also in the study of the origin and structure of comets, he is a team member of the cometary mission Rosetta. A lover of early music, he plays the recorder and belongs to two musical groups ,"L'Amoroso Cantar" (Medieval music) and "Il Martellato" (Renaissance music). (M 34355)

\section{(9671) Hemera}

1997 TU9. Discovered 1997 Oct. 5 by L. Šarounová at Ondřejov

The Greek goddess of bright day, daughter of goddess of night Nykta and god of darkness Erebus, Hemera, meaning 'day' in Greek, gives rise to the word "ephemeris". (M 41937)

\section{(9672) Rosenbergerezek}

1997 TA $_{10}$. Discovered 1997 Oct. 5 by P. Pravec at Ondřejov.

Named in honor of Kamila Rosenbergerová (1976- ) and Tomáš Rezek (1974- ). Tomáš, a friend of the discoverer, has worked as a research assistant at the Ondřejov Observatory for two years. His exceptional skill with various operating systems have often amazed his colleagues. This minor planet is being named on the occasion of the marriage of Kamila and Tomáš on 1999 June 19. (M 34631)

\section{(9673) Kunishimakoto}

$1997 \mathrm{UC}_{25}$. Discovered 1997 Oct. 25 by S. Otomo at Kiyosato.

For 21 years, Makoto Kunishi (1954- ) was a lecturer and curator at the Gotoh Planetarium and Astronomical Museum in Tokyo. His lectures were so powerful that many listeners were spellbound. (M 41937)

The name was suggested by O. Muramatsu.

\section{(9674) Slovenija}

1998 QU $_{15}$. Discovered 1998 Aug. 23 at the Crni Vrh Observatory at Crni Vrh.

Named for the European nation in which the Crni Vrh Observatory is situated. This is the first minor planet credited to Slovenian astronomers. (M 33796)

\section{(9676) Eijkman}

2023 P-L. Discovered 1960 Sept. 24 by C. J. van Houten and I. van Houten-Groeneveld at Palomar.

Christiaan Eijkman (1858-1930) won the Nobel Prize in physiology or medicine for his discovery of the antineuritic vitamin, now known as $\mathrm{B}_{1}$ or thiamine. Investigating the disease beriberi in Java, his observations of dietary deficiency led to the discovery of vitamins. He shared the 1929 Nobel Prize with Gowland Hopkins \{see planet (9677)\}. (M 41568)

\section{(9677) Gowlandhopkins}

2532 P-L. Discovered 1960 Sept. 24 by C. J. van Houten and I. van Houten-Groeneveld at Palomar.

Frederick Gowland Hopkins (1861-1947) received the Nobel Prize in physiology or medicine for his discovery of the growth-stimulating vitamins. He is also widely acknowledged as one of the founders of modern biochemistry. Gowland Hopkins shared the 1929 Nobel Prize with Christiaan Eijkman \{see planet (9676)\}. (M 41569)

\section{(9678) van der Meer}

2584 P-L. Discovered 1960 Sept. 24 by C. J. van Houten and I. van Houten-Groeneveld at Palomar.

Working together with his colleague C. Rubbia s see planet (8398)\}, Dutch physicist Simon van der Meer (1925- ) received the 1984 Nobel Prize in physics for their decisive contributions to the large project that led to the discovery of the field particles $\mathrm{W}$ and $\mathrm{Z}$, communicators of weak interaction. (M 41569) The name was suggested by W. A. Fröger.

\section{(9679) Crutzen}

2600 P-L. Discovered 1960 Sept. 24 by C. J. van Houten and I. van Houten-Groeneveld at Palomar.

Paul Crutzen (1933- ) was a co-recipient of the 1995 Nobel Prize in chemistry for work in atmospheric chemistry, particularly concerning the formation and decomposition of ozone. (M 41569) 
The name was suggested by W. A. Fröger.

The other Nobel Prize winners were Mario Molina and Sherwood F. Rowland \{see, respectively, planets (9680) and (9681)\}.

\section{(9680) Molina}

3557 P-L. Discovered 1960 Oct. 22 by C. J. van Houten and I. van Houten-Groeneveld at Palomar.

Mario J. Molina (1943- ) was a co-recipient of the 1995 Nobel Prize in chemistry, awarded for work in atmospheric chemistry. (M 41569)

The other Nobel Prize winners were Paul Crutzen and Sherwood F. Rowland \{see, respectively, planets (9679) and (9681)\}.

\section{(9681) Sherwoodrowland}

4069 P-L. Discovered 1960 Sept. 24 by C. J. van Houten and I. van Houten-Groeneveld at Palomar.

Frank Sherwood Rowland (1927- ) was a corecipient of the 1995 Nobel Prize in chemistry, awarded for work in atmospheric chemistry. (M 41569)

The other Nobel Prize winners were Paul Crutzen and Mario Molina ssee, respectively, planets (9679) and (9680)\}.

\section{(9682) Gravesande}

4073 P-L. Discovered 1960 Sept. 24 by C. J. van Houten and I. van Houten-Groeneveld at Palomar.

Willem J. 's Gravesande (1688-1742) was a professor of mathematics, astronomy and philosophy at Leiden University. During his life he wrote many textbooks on mathematics and philosophy, and he is also important as an exponent of Newton's philosophy in Europe. (M 42359)

The name was suggested by W. A. Fröger.

\section{(9683) Rambaldo}

4099 P-L. Discovered 1960 Sept. 24 by C. J. van Houten and I. van Houten-Groeneveld at Palomar.

Alfred E. Rambaldo (1879-1911), born on the island of Java, did extensive research on the upper layers of the atmosphere. He was also a great promoter of aviation, especially balloons/airships in the Netherlands and in the Dutch East Indies, where he died during a balloon accident. (M 42359)

The name was suggested by W. A. Fröger.

\section{(9684) Olieslagers}

4113 P-L. Discovered 1960 Sept. 24 by C. J. van Houten and I. van Houten-Groeneveld at Palomar.

Jan Olieslagers (1883-1942), Belgian aviation pioneer, caused the airport Deurne (Antwerp International Airport) to be built. In 1910 he made the first overland flight between two cities in the Netherlands. His popularity helped to promote aviation there and in Belgium. (M 43042)

The name was suggested by W. A. Fröger.

\section{(9685) Korteweg}

4247 P-L. Discovered 1960 Sept. 24 by C. J. van Houten and I. van Houten-Groeneveld at Palomar.

Diederik Johannes Korteweg (1848-1941), professor of mathematics at the University of Amsterdam, is known in particular for the Korteweg-de Vries equation on solitary waves and for editing the complete works of Christiaan Huygens \{see planet (2801)\}. (M 43042) The name was suggested by W. A. Fröger.

\section{(9686) Keesom}

4604 P-L. Discovered 1960 Sept. 24 by C. J. van Houten and I. van Houten-Groeneveld at Palomar.

Dutch physicist Willem Hendrik Keesom (1876-1956) specialized in cryogenics. In 1926 he became the first to solidify helium, and among his discoveries are He I and He II. In 1932 he achieved the temperature of $-272^{\circ} \mathrm{C}$, only one degree above absolute zero. (M 43042) The name was suggested by W. A. Fröger.

\section{(9687) Uhlenbeck}

4614 P-L. Discovered 1960 Sept. 24 by C. J. van Houten and I. van Houten-Groeneveld at Palomar.

Together with Samuel A. Goudsmit \{see planet (9688)\}, Dutch-American physicist George E. Uhlenbeck (1900-1988) proposed the concept of electron spin at the University of Leiden in 1925. Spin is a fundamental property of neutrons, protons and other elementary particles. (M 43042)

The name was suggested by W. A. Fröger.

\section{(9688) Goudsmit}

4665 P-L. Discovered 1960 Sept. 24 by C. J. van Houten and I. van Houten-Groeneveld at Palomar.

Together with G. E. Uhlenbeck \{see planet (9687)\}, Dutch-American physicist Samuel A. Goudsmit (19021978) formulated the concept of electron spin. This led to major changes in atomic theory and quantum mechanics. (M 43042)

The name was suggested by W. A. Fröger.

\section{(9689) Freudenthal}

4831 P-L. Discovered 1960 Sept. 24 by C. J. van Houten and I. van Houten-Groeneveld at Palomar.

Hans Freudenthal (1905-1990), a former president of the International Commission on Mathematical Instruction, was known for his effort to reform mathematical education and the didactics used to teach mathematics. He wrote not only about mathematics and astronomy but was also a writer of essays and poems. (M 43190)

\section{(9690) Houtgast}

6039 P-L. Discovered 1960 Sept. 24 by C. J. van Houten and I. van Houten-Groeneveld at Palomar.

Dutch solar physicist Jacob Houtgast (1908-1982) was associate professor at University of Utrecht, known for his much-quoted 1942 paper on noncoherent scattering of light in Fraunhofer lines. Famous as a scientific 
eclipse observer, he chaired the IAU's subcommittee for solar eclipses. (M 41569)

\section{(9691) Zwaan}

6053 P-L. Discovered 1960 Sept. 24 by C. J. van Houten and I. van Houten-Groeneveld at Palomar.

Cornelis Zwaan (1928-1999), professor of astrophysics at Utrecht University, was a recognized authority on solar and stellar magnetism. Just before his death he finished a book (with C. J. Schrijver) on stellar magnetic fields. (M 41569)

The name was suggested by C. de Jager.

\section{(9692) Kuperus}

6354 P-L. Discovered 1960 Sept. 24 by C. J. van Houten and I. van Houten-Groeneveld at Palomar.

Max Kuperus (1936- ), professor of astrophysics at Utrecht University, and a department chairman at the Royal Netherlands Academy of Arts and Sciences, specialized in theoretical magnetohydrodynamics and plasma physics. He wrote one of the first papers on the heating of the solar corona. (M 41569)

\section{(9693) Bleeker}

6547 P-L. Discovered 1960 Sept. 24 by C. J. van Houten and I. van Houten-Groeneveld at Palomar.

Johan Bleeker (1942- ), director of the Dutch Space Research Organization and professor of space physics at Utrecht University, wrote many papers on x-ray astrophysics. The codiscoverer of the diffuse x-ray background of the sky, he was also the first author of discovery papers on the primary electrons in cosmic rays. (M 41569)

\section{(9694) Lycomedes}

6581 P-L. Discovered 1960 Sept. 26 by C. J. van Houten and I. van Houten-Groeneveld at Palomar.

Lycomedes was king of Scyros during the Trojan war. At his court Thetis hid her son Achilles \{see, respectively, planets (17) and (588)\}, dressed in girl's clothes to save him from the Trojan war. He was found by Odysseus \{see planet (1143)\}. (M 34355)

\section{(9695) Johnheise}

6583 P-L. Discovered 1960 Sept. 24 by C. J. van Houten and I. van Houten-Groeneveld at Palomar.

John Heise (1942- ), professor of general physics at Utrecht University, specialized in high-energy space physics. In 1975 he discovered and detected sources of galactic x-ray bursts (1975). He was among the discoverers in 1998 of the origin of the cosmic $\gamma$-ray bursts. (M 41569)

The name was suggested by $\mathrm{C}$. de Jager.

\section{(9696) Jaffe}

6628 P-L. Discovered 1960 Sept. 24 by C. J. van Houten and I. van Houten-Groeneveld at Palomar.

Walter J. Jaffe (1947- ) is an American astronomer at Leiden Observatory with an interest in galaxies, their dynamics, internal and external (clusters) and gas processes therein. He also contributed to the software for the Hubble telescope. (M 41569)

\section{(9697) Louwman}

1295 T-1. Discovered 1971 Mar. 25 by C. J. van Houten and I. van Houten-Groeneveld at Palomar.

Peter J. K. Louwman (1935- ), a well-known popularizer of astronomy, was secretary for many years of the working group Moon and Planets of the Dutch Society for Astronomy and Meteorology. $\mathrm{He}$ is an expert on the history of telescope building. (M 41569)

\section{(9698) Idzerda}

2205 T-1. Discovered 1971 Mar. 25 by C. J. van Houten and I. van Houten-Groeneveld at Palomar.

Hanso Henricus Schotanus Steringa Idzerda (18851944) invented the vacuum triode for amplifying audio and radio signals. In November 1919 he started the first radio broadcasting station in the world from The Hague. (M 41569)

\section{(9699) Baumhauer}

3036 T-1. Discovered 1971 Mar. 26 by C. J. van Houten and I. van Houten-Groeneveld at Palomar.

Albert Gillis von Baumhauer (1891-1939) invented the tail rotor for helicopters and built the first Dutch helicopter, which took off on 1925 Dec. 17. He was strongly involved in pioneering gliding in the Netherlands and was killed in the Boeing Stratoliner plane crash in 1939. (M 41569)

\section{(9700) Paech}

3058 T-1. Discovered 1971 Mar. 26 by C. J. van Houten and I. van Houten-Groeneveld at Palomar.

Wolfgang Paech (1951- ) is an electronic engineer on the staff of the Institute of Geodesy at the University of Hannover, where he serves as technical manager of the astronomical station. An enthusiastic amateur astronomer, Paech is a keen observer of solar phenomena and eclipses. (M 41569)

The name was suggested by L. D. Schmadel.

\section{(9701) Mak}

1157 T-2. Discovered 1973 Sept. 29 by C. J. van Houten and I. van Houten-Groeneveld at Palomar.

Arie Mak (1914- _) is one of the best-known Dutch amateur astronomers, active in lunar occultations and solar observations. He developed scientific instrumentation for and joined in the eclipse expeditions of 1959 and 1966. He received the Van der Bilt Prize in 1951. (M 41570)

\section{(9702) Tomvandijk}

2108 T-2. Discovered 1973 Sept. 29 by C. J. van Houten and I. van Houten-Groeneveld at Palomar.

Thomas van Dijk (1915- ), versatile Dutch amateur astronomer, specialized in spectroscopic, nuclear and photographic techniques. He wrote 45 papers, including one in Nature on lunar luminescence and one 
on radioactivity of a meteorite in the 1953 Liège Colloquium proceedings. (M 41570)

\section{(9703) Sussenbach}

3146 T-2. Discovered 1973 Sept. 30 by C. J. van Houten and I. van Houten-Groeneveld at Palomar.

John Sussenbach (1938- ) is a Dutch amateur astronomer known for his excellent sky photographs. He founded the Dutch Working Group for Sky Photography and received the Van der Bilt Prize. (M 41570)

The name was suggested by C. de Jager.

\section{(9704) Georgebeekman}

5469 T-2. Discovered 1973 Sept. 30 by C. J. van Houten and I. van Houten-Groeneveld at Palomar.

George W. E. Beekman (1944- ) is one of the Netherlands' best science writers in the field of astronomy, known for his weekly contributions in the daily paper NRC-Handelsblad. He has been editor-inchief of the journal Zenit and is still a member of the editorial board of that monthly. (M 41570)

The name was suggested by C. de Jager.

\section{(9705) Drummen}

3137 T-3. Discovered 1977 Oct. 16 by C. J. van Houten and I. van Houten-Groeneveld at Palomar.

Since 1975, Mat Drummen (1945- ) has been director of "de Koepel", the Dutch center for dissemination of information on astronomy, space science and meteorology. He is author of the annual Sterrengids and coeditor of the Dutch popular journal Zenit. (M 41570)

The name was suggested by C. de Jager.

\section{(9706) Bouma}

3176 T-3. Discovered 1977 Oct. 16 by C. J. van Houten and I. van Houten-Groeneveld at Palomar.

Reinder J. Bouma (1949- ) is one of the best known Dutch amateur astronomers. He is very active in the observation of comets, variable stars and occultations by minor planets. (M 41570)

The name was suggested by C. de Jager.

\section{(9707) Petruskoning}

3226 T-3. Discovered 1977 Oct. 16 by C. J. van Houten and I. van Houten-Groeneveld at Palomar.

Petrus A. Koning (1934- ) has organized youth astronomy camps. Founder of the Bussloo Public Observatory, he was long a member of the observatory board. In 1995 he received the Van der Bilt Prize for his efforts to promote astronomy in the Dutch province of Gelderland. (M 42359)

The name was suggested by W. A. Fröger.

\section{(9708) Gouka}

4140 T-3. Discovered 1977 Oct. 16 by C. J. van Houten and I. van Houten-Groeneveld at Palomar.

On 1901 Sept. 1 Adriaan Jacobus Gouka (1879-1963) and Christiaan A. C. Nell \{see planet (9709)\} founded
NVWS, the Dutch Astronomical and Meteorological Society. (M 43190)

The name was suggested by $\mathrm{H}$. van Woerden.

\section{(9709) Chrisnell}

5192 T-3. Discovered 1977 Oct. 16 by C. J. van Houten and I. van Houten-Groeneveld at Palomar.

Christiaan A. C. Nell (1875-1960) was cofounder, together with Adriaan J. Gouka \{see planet (9708)\}, of the Dutch Astronomical and Meteorological Society. With 4000 members, the society continues to flourish on its 100th anniversary. (M 43190)

The name was suggested by $\mathrm{H}$. van Woerden.

\section{(9711) Želetava}

1972 PA. Discovered 1972 Aug. 7 by P. Wild and I. Bauersima at Zimmerwald.

Bearing a 13:12:5 Pythagorean relationship to (8964) [Corvus] Corax and (3735) Třeboň, (9711) Želetava is a small Moravian town near the center of the hypotenuse of a similar triangle with short leg centered on Třeboñ, Bohemia, and long leg running through Vranov (crow, Corvus), Moravia, and Raabs (raven, Corax), Austria. (M 40704)

\section{(9712) Nauplius}

$1973 \mathrm{SO}_{1}$. Discovered 1973 Sept. 19 by C. J. van Houten and I. van Houten-Groeneveld at Palomar.

Nauplius, a son of Poseidon \{see planet (4341)\} and Amymone, was king of Euboea and father of Palamedes \{see, respectively, planets (1119) and (2456)\}. After a false accusation by Odysseus \{see planet (1143)\} caused the death of Palamedes, Nauplius sailed to Troy to seek vengeance. But this was denied by Agamemnon \{see planet (911)\}, so Nauplius returned to Greece, together with his surviving son Oceax \{see planet (9713)\}. However, Nauplius earned his revenge. He misled the Greeks returning from Troy by placing lights on the cliffs of his land, so that many ships ran aground. (M 34355)

\section{(9713) Oceax}

$1973 \mathrm{SP}_{1}$. Discovered 1973 Sept. 19 by C. J. van Houten and I. van Houten-Groeneveld at Palomar.

Oceax was the son of Nauplius of Euboea and brother of Palamedes \{see planets (9712), (1119) and (2456), respectively\}. He traveled with his father from Troy to Greece. (M 34355)

\section{(9716) Severina}

1975 UE. Discovered 1975 Oct. 27 by P. Wild at Zimmerwald.

Severina Feitknecht-Gallati (1945-2000), who hailed from Glarus, the same home town as the discoverer, was a highly esteemed physician at Interlaken. She was also a persevering mountaineer, who died in a tragic accident in the Bernese Alps. (M 45337) 


\section{(9717) Lyudvasilia}

$1976 \mathrm{SR}_{5}$. Discovered 1976 Sept. 24 by N. S. Chernykh at Nauchnyj.

Lyudmila Vasil'evna Shaposhnikova (1926- ), orientalist and writer, investigates the creative works of Nicholas Roerich and has published books and papers on the culture of India and philosophical problems of the Roerich legacy. She is the founder and director of the Roerich International Center and Museum in Moscow. (M 43381)

\section{(9720) Ulfbirgitta}

$1980 \mathrm{FH}_{1}$. Discovered 1980 Mar. 16 by C.-I. Lagerkvist at La Silla.

Ulf and Birgitta Heyman are old friends of the discoverer and his wife. This naming is to celebrate Ulf's fiftieth birthday. (M 36948)

\section{(9721) Doty}

1980 GB. Discovered 1980 Apr. 14 by E. Bowell at Anderson Mesa.

Arthur G. Doty (1951-1999) was a lifelong amateur astronomer whose passion inspired a continuing interest in astronomy in his family and friends. (M 42670) The name was suggested by N. Carlson and N. Adams.

\section{(9732) Juchnovski}

$1984 \mathrm{SJ}_{7}$. Discovered 1984 Sept. 24 by V. G. Shkodrov and V. G. Ivanova at Rozhen.

Ivan Juchnovski (1937- ）, president of the Bulgarian Academy of Sciences since 1996, has carried out research on organic structural analysis that has gained wide recognition. A great admirer of astronomy, science, the sky and the music of Chopin \{see planet (3784)\} and Berlioz are his Universe. (M 39653)

\section{(9737) Dudarova}

$1986 \mathrm{SC}_{2}$. Discovered 1986 Sept. 29 by L. G. Karachkina at Nauchnyj.

Named in honor of Veronica Borisovna Dudarova (1916- ), the only woman conductor in Russia. She is a People's Artist of the U.S.S.R. (1977) and the state prize laureate of Russia (1980). She was artistic director and principal conductor of the Moscow State Symphony Orchestra from 1960 to 1989 and has been artistic director and principal conductor of the Veronica Dudarova Orchestra since 1991. Her innovative interpretations of such large musical forms as symphonies and oratorios with choruses has defined her contribution to Russian art. (M 34355)

Name suggested by G. V. Sviridov and S. P. Kapitza and supported by the discoverer.

\section{(9739) Powell}

$1987 \mathrm{SH}_{7}$. Discovered 1987 Sept. 26 by C. S. Shoemaker at Palomar.

James L. Powell (1936- ), director of the Los Angeles County Museum of Natural History and professor of geology for 20 years at Oberlin College, is the author of Night Comes to the Cretaceous, an account of the ideas, theories and personalities evolving around the theory of extraterrestrial impact and demise of the dinosaurs. (M 39653)

\section{(9741) Solokhin}

1987 UU U$_{4}$. Discovered 1987 Oct. 22 by L. V. Zhuravleva at Nauchnyj.

Valentin Fedorovich Solokhin (1933- ) is the director general of a company in Surgut of the Tyumen \{see planet (2120)\} province in Siberia. Under his leadership the unique single-pylon guy-rope bridge over the river $\mathrm{Ob}$ in Surgut was constructed in 2000. (M 43042)

\section{(9742) Worpswede}

$1987 \mathrm{WT}_{1}$. Discovered 1987 Nov. 26 by F. Börngen at Tautenburg.

Named for the German colony of artists near the city of Bremen \{see planet (6320)\}. Beginning in 1889, many painters settled in this lonely region, trying to live in harmony with nature. For their subjects they chose the heath and marshland, the farmhouses and the simple people. The poet R. M. Rilke ssee planet (9833)\} also lived here for some time. The fame of Worpswede as a paradise for painters, unique in nineteenth-century Europe, continues to fascinate art lovers all over the world. (M 34355)

\section{(9744) Nielsen}

1988 JW. Discovered 1988 May 9 by C. S. Shoemaker and E. M. Shoemaker at Palomar.

As the physician responsible for the mental and physical fitness of a close-knit team of researchers, construction workers and support staff at the Amundsen-Scott South Pole research station, Jerri Nielsen (1952- ) is noted for her friendship and concern for the "Polies" and her courage to face her own serious illness. (M 44110)

\section{(9745) Shinkenwada}

1988 VY. Discovered 1988 Nov. 2 by T. Seki at Geisei.

Tokyo-born Shinken Wada (1912-1952) worked as a radio announcer for NHK from 1934 to 1945. He had a talent for newscasting and was also the compère for entertainment programs. He reported for the Helsinki Olympic Games in 1952 but died in Paris on the way home. (M 45232)

\section{(9746) Kazukoichikawa}

1988 VS $_{1}$. Discovered 1988 Nov. 7 by Y. Kushida and M. Inoue at Yatsugatake.

Named in honor of Kazuko Ichikawa, who has loved dolls since her childhood. While working for a toy company as a designer of "Jenny", she was charmed by the lovely figures and started making teddy bears in 1987. She now attracts attention as one of the leading teddy-bear artists in Japan, and she teaches students the joy of making teddy bears themselves. Her works are introduced at Teddy Bear Museum as 
well as through her books, the best known of which is My Friend Teddy Bear. (M 34631)

Citation prepared by the second discoverer.

\section{(9748) van Ostaijen}

$1989 \mathrm{CS}_{2}$. Discovered 1989 Feb. 4 by E. W. Elst at La Silla.

Named in memory of Paul van Ostaijen (1896-1928), Flemish poet who influenced Belgian and Dutch poetry with his avant-garde writings. His second volume of poetry, Het Sienjaal (1918), inspired the Humanitarian Expressionist movement in Flanders. However, compromised as a political activist, he had to leave the country. He went to Berlin, where he was very disappointed by the artistic and political climate. Soon he developed his own poetic system, aiming at "pure poetry", without any personal and humanitarian confessions. His First book of Schmoll (1928) contains his best and most original poems. (M 34631)

\section{(9749) Van den Eijnde}

1989 GC $_{1}$. Discovered 1989 Apr. 3 by E. W. Elst at La Silla.

Peter Van den Eijnde (1966- ） has academic degrees in German philology and management and has always been active in astronomy. During the 1980s he helped the discoverer with the reduction of astrometric work. He is now park manager of the Antwerp Zoo. (M 47166)

\section{(9751) Kadota}

1990 QM. Discovered 1990 Aug. 20 by T. Seki at Geisei.

Ken-ichi Kadota (1961- ) is a computer engineer and renowned amateur astronomer in Ageo \{see planet (7137)\}, Saitama prefecture. He is well known for observing comets, often when they are low in the sky and difficult to detect. In November 2000 he discovered the new component $\mathrm{E}$ of comet 73P. (M 44185)

The name was suggested by K. Muraoka.

\section{(9757) Felixdejager}

1991 GA $_{6}$. Discovered 1991 Apr. 8 by E. W. Elst at La Silla.

Felix de Jager (1999- ） is the second grandson of the discoverer and son of Sigyn and Philip de Jager-Elst. The fourth generation of professional musicians, Felix shows great love and ability for musical performance. (M 47166)

\section{(9758) Dainty}

$1991 \mathrm{GZ}_{9}$. Discovered 1991 Apr. 13 by D. I. Steel at Siding Spring.

Named in honor of J. Christopher Dainty (1947- ), Pilkington Professor of Optics at Imperial College, London. Dainty has made numerous seminal contributions in the fields of stellar speckle interferometry, the characterisation of atmospheric turbulence, scattering and propagation of light, and adaptive optics. (M 34631)
Name proposed by the discoverer in recognition of the inspiration and guidance afforded him by Dainty whilst an undergraduate at the University of London.

\section{(9762) Hermannhesse}

$1991 \mathrm{RA}_{5}$. Discovered 1991 Sept. 13 by F. Börngen and L. D. Schmadel at Tautenburg.

Named in memory of Hermann Hesse (1877-1962), born in Swabia and since 1923 a citizen of Switzerland. As a lyric poet, writer, essayist, critic and illustrator, he was strongly impressed by Indian philosophy. Translated into many languages, his books were well received in the U.S.A. Hesse received numerous honors, among them the Nobel Prize for Literature in 1946 and the Peace Prize of the German Buchhandel in 1955. (M 34631)

Name proposed by the first discoverer.

\section{(9764) Morgenstern}

$1991 \mathrm{UE}_{5}$. Discovered 1991 Oct. 30 by F. Börngen at Tautenburg.

Named in memory of the German poet, writer and translator Christian Morgenstern (1871-1914). His most successful poems are the witty, grotesque and thoughtful Galgenlieder. His pensive contemplative poetry was influenced by Nietzsche \{see planet (7014)\}, later by Buddhism and the anthroposophy of his friend R. Steiner. (M 34631)

\section{(9766) Bradbury}

$1992 \mathrm{DZ}_{2}$. Discovered 1992 Feb. 24 by the Spacewatch at Kitt Peak.

Ray Douglas Bradbury (1920- ) is the critically acclaimed science fiction author whose works include The Martian Chronicles and The Illustrated Man. He has worked in television and as "Imagineer" of Disney's Spaceship Earth at the Epcot center in Florida. His work has inspired many young scientists and engineers. (M 41570)

\section{(9767) Midsomer Norton}

1992 EB $_{1}$. Discovered 1992 Mar. 10 by D. I. Steel at Siding Spring.

Named for the small but historic English town where the discoverer was born and bred. Formerly a coal-mining center, Midsomer Norton lies on the fringe of the Mendip Hills, eight miles from the city of Bath,where William Herschel \{see planet (2000)\} discovered Uranus in 1781, and on the Fosseway, the great Roman road stretching from central to southwestern England. The town was also a hiding place of king Charles II in the Civil War during the 1650s. (M 34631)

\section{(9768) Stephenmaran}

1992 GB $_{1}$. Discovered 1992 Apr. 5 by C. S. Shoemaker and E. M. Shoemaker at Palomar.

Stephen P. Maran (1938- ), long-time veteran of the space program, has made outstanding contributions to 
public understanding of astronomy as press officer for the American Astronomical Society. He has conducted professional research on many different telescopes and has lectured and written extensively on space discoveries. (M 39653)

\section{(9769) Nautilus}

$1993 \mathrm{DG}_{2}$. Discovered 1993 Feb. 24 by A. Natori and T. Urata at Yakiimo.

U.S. inventor Robert Fulton built a sailing ship/submarine called Nautilus in 1800. Jules Verne also used the name for the submarine in his 1869 novel Vingt mille lieues sous les mers. In 1955 the U.S.S. Nautilus became the world's first nuclear-powered submarine. (M 36129)

\section{(9770) Discovery}

1993 EE. Discovered 1993 Mar. 1 by T. Urata at Oohira.

Discovery was the name of the spaceship in Arthur Clarke's \{see planet (4923)\} novel and Stanley Kubrick's \{see planet (10221)\} movie 2001: A Space Odyssey. It is also the name of one of NASA's Space Shuttles. (M 36129)

\section{(9774) Annjudge}

1993 NO. Discovered 1993 July 12 by E. W. Elst at La Silla.

Ann Campana Judge (1951-2001) was the travel office manager for the National Geographic Society. While accompanying a group of students and teachers on an NGS-sponsored field trip to the Californian Channel Islands, she perished on the aircraft that was crashed by terrorists into the Pentagon. (M 44185)

\section{(9775) Joeferguson}

$1993 \mathrm{OH}_{12}$. Discovered 1993 July 19 by E. W. Elst at La Silla.

Joe Ferguson (1962-2001) was director of the geography education outreach program for the National Geographic Society. While accompanying a group of students and teachers on an NGS-sponsored field trip to the Californian Channel Islands, he perished on the aircraft that was crashed by terrorists into the Pentagon. (M 44185)

\section{(9777) Enterprise}

1994 OB. Discovered 1994 July 31 by Y. Shimizu and T. Urata at Nachi-Katsuura.

The U.S.S. Enterprise was the spaceship that appeared (originally in 1966) in the popular science fiction television and movie series Star Trek. It was also the name of the first Space Shuttle Orbiter. (M 36129)

\section{(9778) Isabelallende}

1994 PA $_{19}$. Discovered 1994 Aug. 12 by E. W. Elst at La Silla.

The Chilean writer Isabel Allende (1942- ) moved to Venezuela in 1973 and started writing in 1981.
Her best-known works include La casa de los espiritos (1982) and Eva Luna (1987), written in a style of magic realism. (M 47166)

\section{(9780) Bandersnatch}

1994 SB. Discovered 1994 Sept. 25 by Y. Shimizu and T. Urata at Nachi-Katsuura.

The 'frumious Bandersnatch' is a somewhat mysterious entity appearing in Lewis Carroll's \{see planet (6984)\} classic poem 'Jabberwocky' see planet (7470)\}. (M 41937)

The name was suggested by $\mathrm{T}$. Urata, and the citation was prepared by D. J. Asher.

\section{(9781) Jubjubbird}

1994 UB $_{1}$. Discovered 1994 Oct. 31 by Y. Shimizu and T. Urata at Nachi-Katsuura.

The 'Jubjub bird' is a mysterious but apparently dangerous creature appearing in Lewis Carroll's \{see planet (6984)\} classic poem 'Jabberwocky' see planet (7470)\}. (M 41937)

The name was suggested by $T$. Urata, and the citation was prepared by D. J. Asher.

\section{(9783) Tensho-kan}

1994 YD $_{1}$. Discovered 1994 Dec. 28 by T. Kobayashi at Oizumi.

Tensho-kan was the first planetarium in Japan, located at the science center in Osaka ssee planet (7434)\}. Over 10 million people visited the planetarium before it was closed in 1989. (M 46681)

\section{(9784) Yotsubashi}

1994 YJ $_{1}$. Discovered 1994 Dec. 31 by T. Kobayashi at Oizumi.

Yotsubashi, in the center of Osaka, is where the astronomers of the Edo period observed eclipses. The first science center in Japan was established in Yotsubashi in 1937. (M 46681)

\section{(9785) Senjikan}

$1994 \mathrm{YX}_{1}$. Discovered 1994 Dec. 31 by T. Kobayashi at Oizumi.

Senjikan was an astronomy group in Osaka in the Edo period. The group studied geodesy, positional astronomy and constructed the official calendar adopted by the Edo government. (M 46681)

\section{(9786) Gakutensoku}

1995 BB. Discovered 1995 Jan. 19 by T. Kobayashi at Oizumi.

Gakutensoku was the first Japanese robot, created in 1928 by Makoto Nishimura. Gakutensoku was featured in several world expositions until it was lost in Germany. A replica of Gakutensoku is displayed at the Osaka Science Museum. (M 46681)

\section{(9793) Torvalds}

1996 BW $_{4}$. Discovered 1996 Jan. 16 by the Spacewatch at Kitt Peak. 
Finnish computer scientist Linus Torvalds (1969- ) created the Linux \{see planet (9885)\} computer operating system used by Spacewatch ssee planet (4255)\} and several other asteroid surveys for their data collection and analysis. The development of Linux involved a large Internet collaboration and demonstrates the possibilities of the free exchange of information. (M 41570)

\section{(9795) Deprez}

1996 GJ $_{19}$. Discovered 1996 Apr. 15 by E. W. Elst at La Silla.

Brigitte Deprez (1939- ) is the wife of Uccle astronomer Jozef Denoyelle \{see planet (4120)\}, colleague of the discoverer. Brigitte always showed loving understanding when Jozef had to go abroad for astronomical observing duties. (M 47166)

\section{(9797) Raes}

$1996 \mathrm{HR}_{21}$. Discovered 1996 Apr. 18 by E. W. Elst at La Silla.

Named in honor of the Flemish writer Hugo Raes (1929- ), well known from his novels and other writings. One of his most sublime novels is De verwoesting van Hyperion ("The Destruction of Hyperion"), a 1978 science-fiction account of the rise and fall of a super civilization. (M 35492)

\section{(9809) Jimdarwin}

$1998 \mathrm{RZ}_{5}$. Discovered 1998 Sept. 13 by the LONEOS at Anderson Mesa.

James L. Darwin (1939- ), instrument maker at Lowell Observatory, machined most of the parts for the refurbishment of the LONEOS Schmidt telescope and construction of its CCD camera. (M 41029)

\section{(9811) Cavadore}

1998 ST. Discovered 1998 Sept. 16 by the OCA-DLR Survey at Caussols.

Cyril Cavadore (1969- ) is a professional CCD specialist at the European Southern Observatory and astronomical software programmer. He was one of the writers of the computer package used by many French amateur astronomers to discover minor planets. (M 40704)

\section{(9812) Danco}

1998 SJ $_{144}$. Discovered 1998 Sept. 18 by E. W. Elst at La Silla.

Emile Danco (1869-1898), who participated in the Antarctic expedition of Adrien de Gerlache, was responsible for the photography and observation of geomagnetism. He died during the trip, and his body was buried at sea near a newly discovered land, named Dancoland. (M 47166)

\section{(9815) Mariakirch}

2079 P-L. Discovered 1960 Sept. 24 by C. J. van Houten and I. van Houten-Groeneveld at Palomar.
Maria Margarethe Kirch, née Winkelmann (1670-1720), wife and mother of astronomers, was an astronomer in her own right, observing, computing and publishing calendars, working in Berlin and Danzig. Although the comet of April 1702 was first credited to her husband, she was later acknowledged as the discoverer. (M 41570)

\section{(9816) von Matt}

2643 P-L. Discovered 1960 Sept. 24 by C. J. van Houten and I. van Houten-Groeneveld at Palomar.

Elisabeth, Baroness von Matt (1762-1814), was the only female Austrian astronomer of her time with an international reputation. She worked mainly in positional astronomy. Her private observatory in Vienna was better equipped than the University Observatory. (M 43043)

The name was suggested by H. Haupt.

\section{(9817) Thersander}

6540 P-L. Discovered 1960 Sept. 24 by C. J. van Houten and I. van Houten-Groeneveld at Palomar.

Thersander, a son of the Theban Polyneices, was wounded by Telephus and later was one of the heroes in the Wooden Horse. (M 34355)

\section{(9818) Eurymachos}

6591 P-L. Discovered 1960 Sept. 24 by C. J. van Houten and I. van Houten-Groeneveld at Palomar.

Eurymachos was one of the heroes hidden in the Wooden Horse. (M 34355)

\section{(9819) Sangerhausen}

2172 T-1. Discovered 1971 Mar. 25 by C. J. van Houten and I. van Houten-Groeneveld at Palomar.

In the vicinity of the German city of Sangerhausen, a remarkable archaeological object was unearthed. This 4000-year-old bronze disc shows a quasi-real starry sky. Its similarity to Homer's \{see planet (5700)\} Iliad $18,484-486$ is striking. (M 47166)

The name was suggested by W. Schlosser and L. D. Schmadel.

\section{(9820) Hempel}

3064 T-1. Discovered 1971 Mar. 26 by C. J. van Houten and I. van Houten-Groeneveld at Palomar.

Rolf Hempel (1956- ) is a German amateur astronomer who determined many high-quality positions of minor planets using a quite unconventional measuring device. His orbit determination software is still in use at the Astronomisches Rechen-Institut. (M 47166) The name was suggested by L. D. Schmadel.

\section{(9821) Gitakresáková}

4033 T-1. Discovered 1971 Mar. 26 by C. J. van Houten and I. van Houten-Groeneveld at Palomar.

Margita Kresáková (1927- ) worked at the Astronomical Institute, Slovak Academy of Sciences, Bratislava. She was a very experienced meteor observer 
and comet hunter at Skalnaté Pleso Observatory. One comet carries her maiden name, Vozárová. (M 41570)

\section{(9822) Hajduková}

4114 T-1. Discovered 1971 Mar. 26 by C. J. van Houten and I. van Houten-Groeneveld at Palomar.

Mária Hajduková (1934- ), currently at the Astronomical Institute Comenius University, Bratislava (Modra Observatory), has been active in interplanetary matter research, mainly meteors - multicolor photometry and radiation (dependence of the color index on velocity). She educated a whole generation of astronomers in Slovakia. (M 41570)

\section{(9823) Annantalová}

4271 T-1. Discovered 1971 Mar. 26 by C. J. van Houten and I. van Houten-Groeneveld at Palomar.

Anna Antalová (1936- ) has worked at the Astronomical Institute, Slovak Academy of Sciences, Tatranská Lomnica, since 1958. She made various analyses of solar phenomena and significant contributions to the study of solar flares as well as solar cycle characteristics. (M 41570; M 41615)

The name was suggested by D. Chochol.

\section{(9824) Marylea}

3033 T-2. Discovered 1973 Sept. 30 by C. J. van Houten and I. van Houten-Groeneveld at Palomar.

Mary Lea Shane, née Heger (1897-1983), wife of Lick Observatory director C. Donald Shane \{see planet (1994)\}, was an astronomer in her own right. She identified the interstellar $\mathrm{Na}$ I absorption lines and discovered the first of the mysterious diffuse interstellar bands. She also established the Lick Observatory Archives. (M 41570)

\section{(9825) Oetken}

1214 T-3. Discovered 1977 Oct. 17 by C. J. van Houten and I. van Houten-Groeneveld at Palomar.

Lore Oetken (1929- ) has made significant contributions to the fields of magnetic stars, polarimetry and spectroscopy, a prominent part of the astronomical research at the Potsdam Observatory. (M 41570)

The citation was prepared by A. Schnell.

\section{(9826) Ehrenfreund}

2114 T-3. Discovered 1977 Oct. 16 by C. J. van Houten and I. van Houten-Groeneveld at Palomar.

As both a biochemist and an astronomer, Pascale Ehrenfreund (1960- ), currently at the Leiden Observatory, qualified as an expert on several space missions investigating dust and organic molecules in space. As an APART fellow of the Austrian Academy of Sciences, she encouraged international cooperation. (M 41570)

\section{(9828) Antimachos}

1973 SS. Discovered 1973 Sept. 19 by C. J. van Houten and I. van Houten-Groeneveld at Palomar.
Antimachos was one of the heroes hidden in the Wooden Horse. (M 34355)

\section{(9829) Murillo}

1973 SJ $_{1}$. Discovered 1973 Sept. 19 by C. J. van Houten and I. van Houten-Groeneveld at Palomar.

Bartolomé Estéban Murillo (1618-1682) created many religious paintings for churches. The painter from Seville is famous for his genre pictures of children that were poor but happy, and these are imitated even today. (M 34355)

\section{(9833) Rilke}

1982 DW $_{3}$. Discovered 1982 Feb. 21 by F. Börngen at Tautenburg.

Named for the Austrian poet Rainer Maria Rilke (1875-1926), husband of the sculptor Clara Westhoff. His monographs Auguste Rodin (1903) and Das Marienleben (1913), set to music by Hindemith \{see planet (5157)\}, were written in Paris. Duineser Elegien was his greatest late work. In his lyric creations he always strove for sonorous language. Some of his work is strongly influenced by religious longings. (M 34631)

\section{(9834) Kirsanov}

1982 TS $_{1}$. Discovered 1982 Oct. 14 by L. G. Karachkina at Nauchnyj.

Named in memory of the brilliant Russian poet Semen Isaakovich Kirsanov (1906-1972). The innovative form of his verses and poems is a reflection of his deep lyrical-philosophical world outlook, while his popular verses are enriched by his peerless humor. He was given an enthusiastic welcome at the Crimean Astrophysical Observatory. (M 34631)

Named by the discoverer, following a suggestion by R. E. Gershberg.

\section{(9836) Aarseth}

1985 TU. Discovered 1985 Oct. 15 by E. Bowell at Anderson Mesa.

Norwegian-born astronomer Sverre J. Aarseth (1934-

), of the Institute of Astronomy, Cambridge, developed a unique set of $n$-body codes and used them for studying gravitational systems, such as globular clusters and merging galaxies, where encounters and collisions are important. (M 43043)

The name was suggested by E. M. Standish.

\section{(9838) Falz-Fein}

$1987 \mathrm{RN}_{6}$. Discovered 1987 Sept. 4 by L. V. Zhuravleva at Nauchnyj.

Baron Eduard Aleksandrovich von Falz-Fein (1912-

) is an outstanding collector of works of art and historical documents, known for his charity. Born in Russia, his uncle Friedrich Falz-Fein was the founder in 1875 of the well-known reserve Askania-Nova in Ukraine. (M 41029) 


\section{(9839) Crabbegat}

$1988 \mathrm{CT}_{2}$. Discovered 1988 Feb. 11 by E. W. Elst at La Silla.

Crabbegat is an idyllic road at the border of the Wolvendael park, close to the Royal Observatory at Uccle $\{$ see planet (1276)\}. The name might refer to "crab", although Uccle is located near neither the sea nor even a stream. (M 47166)

\section{(9844) Otani}

$1989 \mathrm{WF}_{1}$. Discovered 1989 Nov. 23 by Y. Kushida and O. Muramatsu at Yatsugatake.

Named in honor of Toyokazu Otani (1928- ), first lecturer at the Gotoh Planetarium and Astronomical Museum in Tokyo, where he worked for 32 years until 1988. His deep knowledge of acoustics and classical music was instrumental in establishing the well-known BMG sound system, appreciated by planetarium audiences. Otani is also known as an eminent observer of the planets. (M 34355)

\section{(9848) Yugra}

$1990 \mathrm{QX}_{17}$. Discovered 1990 Aug. 26 by L. V. Zhuravleva at Nauchnyj.

Yugra is the historical name, used in Russia in medieval times, of the vast area to the east of the Northern Urals, extending to the river Taz. Inhabited then by the Hanty and Mansi tribes, it is now part of the territory of the Hanty-Mansi autonomous area within the Russian Federation. (M 41384)

\section{(9854) Karlheinz}

$1991 \mathrm{AC}_{3}$. Discovered 1991 Jan. 15 by F. Börngen at Tautenburg.

Named for Karlheinz Müller (1943- ), by profession an agricultural clerk. From his youth on, he committed himself to astrophotography and brightness estimates of variable stars. He has directed the Volkssternwarte Drebach since 1969 and oversaw the completion of a Zeiss planetarium and a new main building. He has helped popularize astronomy for people of all ages. Müller created the conditions for observing minor planets in Drebach. This minor planet was numbered with the help of positions observed in Drebach in 1996 and 1998. (M 35492)

\section{(9859) Van Lierde}

$1991 \mathrm{PE}_{5}$. Discovered 1991 Aug. 3 by E. W. Elst at La Silla.

Edmond Van Lierde (1888-1964), a brilliant student at the University of Brussels, later professor of mathematics, promoted modern mathematics and introduced this new discipline into Belgium. He was also a splendid pianist and an excellent tennis player. (M 45747)

\section{(9860) Archaeopteryx}

$1991 \mathrm{PW}_{9}$. Discovered 1991 Aug. 6 by E. W. Elst at La Silla.
Archaeopteryx is the early bird that had a dinosaur-like skeleton, a bird-like skull and teeth in the jaws. It lived during the Upper Jurassic. Feathers were preserved as impressions in rocks. (M 47166)

\section{(9861) Jahreiss}

1991 RB $_{3}$. Discovered 1991 Sept. 9 by L. D. Schmadel and F. Börngen at Tautenburg.

Hartmut Jahreiß (1942- ) is a staff astronomer at the Astronomisches Rechen-Institut. As a successor of W. Gliese \{see planet (1823)\}, he contributed much to our knowledge of the nearby stars. He also played a leading role in the construction of the HIPPARCOS Input Catalogue, as well as the FK5 and FK6. (M 42670)

\section{(9863) Reichardt}

$1991 \mathrm{RJ}_{7}$. Discovered 1991 Sept. 13 by F. Börngen and L. D. Schmadel at Tautenburg.

Named in memory of the German composer Johann Friedrich Reichardt (1752-1814), who for 20 years was conductor of the orchestra of the Royal Prussian court in Potsdam \{see planet (5816)\}. Dismissed because of his positive attitude towards the French revolution, he lived in Halle-Giebichenstein after 1794. For a time he was a collaborator of Goethe ssee planet (3047)\}. Numerous young poets and artists received encouragement from him. His extensive compositions include some 1000 songs in 30 collections using words from nearly all the German poets. He is considered the precursor of Schubert \{see planet (3917)\}. (M 34631) Name proposed by the first discoverer.

\section{(9866) Kanaimitsuo}

$1991 \mathrm{TV}_{4}$. Discovered 1991 Oct. 15 by S. Otomo at Kiyosato.

For 15 years, Mitsuo Kanai (1946- ) was a lecturer and curator at the Gotoh Planetarium and Astronomical Museum in Tokyo. An eminent observer of Algol, he also educated young lecturers, many of whom are now very active at various institutions. (M 41937)

The name was suggested by O. Muramatsu.

\section{(9872) Solf}

$1992 \mathrm{DJ}_{4}$. Discovered 1992 Feb. 27 by F. Börngen at Tautenburg.

Named in honor of Josef K. M. Solf (1934- ), professor of astronomy at Heidelberg and Jena, and since 1994 director of the Thüringer Landessternwarte Tautenburg. During 1969-1994 he served as staff member of the Max-Planck-Institut für Astronomie at Heidelberg and its Calar Alto Observatory. He is primarily interested in instrumentation for large optical telescopes. A pioneer in using high-resolution long-slit spectroscopic techniques, Solf made important contributions to the study of collimated mass outflows from both young and evolved stars, such as jets from pre-main sequence stars, Herbig-Haro objects, 
protoplanetary nebulae, nova shells and jets from symbiotic stars and central stars of planetary nebulae. (M 34555)

\section{(9878) Sostero}

1994 FQ. Discovered 1994 Mar. 17 at the Farra d'Isonzo Observatory at Farra d'Isonzo.

Giovanni Sostero (1964- ), an Italian amateur astronomer since age 10 and now at the Remanzacco Observatory, works on cataclysmic variables and field studies of comets. An aerospace engineer, he works at the Italian synchrotron radiation source and, during the summer, at the Višnjan School of Astronomy in Croatia. (M 46682)

\section{(9879) Mammuthus}

1994 PZ $_{29}$. Discovered 1994 Aug. 12 by E. W. Elst at La Silla.

Mammuthus or woolly mammoth was a kind of elephant, about 4 meters tall, with dense dark hair and an 8-cm-thick layer of fat, protecting the animal from the cold. Feeding itself with Tundra grasses, it was hunted by Paleolithic man. (M 47166)

\section{(9880) Stegosaurus}

1994 PQ31. Discovered 1994 Aug. 12 by E. W. Elst at La Silla.

Stegosaurus was a large dinosaur, 6 to 9 meters long, with a characteristic double row of large bony plates along the back. A herbivorous dinosaur, it lived in Jurassic and Cretaceous times. (M 47166)

\section{(9882) Stallman}

1994 SS $_{9}$. Discovered 1994 Sept. 28 by the Spacewatch at Kitt Peak.

Richard Stallman (1953- ) is the founder of the GNU \{see planet (9965)\} project and an advocate and developer of free software. He created the GNU system of tools, which made possible the GNU/Linux \{see planet (9885)\} operating system. This operating system is used by several minor-planet surveys for data collection and analysis. (M 41570)

\section{(9884) Příbram}

$1994 \mathrm{TN}_{3}$. Discovered 1994 Oct. 12 by M. Tichý and Z. Moravec at Klě̆.

The town of Prríbram, in central Bohemia, was the impact site, on 1959 Apr. $\tilde{7}$, of the first photographic detection of a meteorite fall. Analysis of the fireball trajectory by Z. Ceplecha \{see planet (2198)\} led to the discovery of four meteorites. (M 38199)

\section{(9885) Linux}

1994 TM $_{14}$. Discovered 1994 Oct. 12 by the Spacewatch at Kitt Peak.

The Linux operating system was created by Linus Torvalds \{see planet (9793)\} in 1991. The source code for Linux was placed on the Internet. A massive public collaboration resulted in a robust, feature-rich operating system that has been used by several minor-planet surveys for data collection and analysis. (M 41571)

\section{(9886) Aoyagi}

$1994 \mathrm{VM}_{7}$. Discovered 1994 Nov. 8 by S. Otomo at Kiyosato.

Fusao Aoyagi (1952- ) is the president of astronomical society in the town of Ishikawa, Fukushima prefecture. He is involved with the organization of the annual Ishikawa star party. (M 43190)

\section{(9897) Malerba}

$1996 \mathrm{CX}_{7}$. Discovered 1996 Feb. 14 by U. Munari and M. Tombelli at Cima Ekar.

Franco Malerba (1946- ), the first Italian astronaut, was a member of Space Mission STS-46 on board the Space Shuttle Atlantis during 1992 July 31-Aug. 8. $\mathrm{He}$ is working now on the development of new space activities. (M 41030)

\section{(9900) Llull}

1997 LL $_{6}$. Discovered 1997 June 13 by M. Blasco at Mallorca.

Named in memory of Ramon Llull (1232-1316), writer, philosopher, mystic, missionary and man of science, born in Mallorca. Among his more than 265 works and treatises, his Tractatus novus de astronomia, written in Paris around 1297, adheres to the ideas of Ptolomy \{see planet (4001)\}. (M 35492)

\section{(9902) Kirkpatrick}

1997 NY. Discovered 1997 July 3 by P. G. Comba at Prescott.

Named for Ralph Kirkpatrick (1911-1984), eminent American harpsichordist, clavichordist, musicologist and teacher. He traveled extensively in Europe, where he studied seventeenth-century and eighteenth-century performance practices in chamber music. He wrote a biography of Domenico Scarlatti \{see planet (6480)\} and prepared a facsimile edition of his more than 500 sonatas. He gave many concerts, specializing in the performance of works by Scarlatti and J. S. Bach \{see planet (1814)\}. (M 34356)

\section{(9903) Leonhardt}

1997 NA $_{1}$. Discovered 1997 July 4 by P. G. Comba at Prescott.

Named for Gustav Leonhardt (1928- ), eminent Dutch harpsichordist, conductor and pedagogue. As a harpsichordist, he has made many concert tours in Europe and North America and recorded a large number of baroque works. (M 34356)

\section{(9904) Mauratombelli}

1997 OC $_{1}$. Discovered 1997 July 29 by A. Boattini and L. Tesi at San Marcello Pistoiese.

Named in honor of Maura Tombelli (1952- ). Initially trained as an observer of variable stars, in 
1994 she started a five-year survey of minor planets at Asiago \{see planet (7679)\} Astrophysical Observatory with Ulisse Munari \{see planet (7599)\} and Giuseppe Forti in Arcetri \{see planets (6876) and (6645)\}. She also shared a lot of observing with the discoverers, especially the follow-up of NEOs, and she contributed to the discovery of 1994 QC, the first NEA found from Italy. She is currently involved in a project to build a new observatory near the town of Montelupo, where she lives. She is still the only female astrometrist in Italy. (M 34632)

\section{(9905) Tiziano}

4611 P-L. Discovered 1960 Sept. 24 by C. J. van Houten and I. van Houten-Groeneveld at Palomar.

Tiziano Vecellio (Titian; c.1477 or 1490-1576) was a typical Renaissance painter. He loved colors, the contrast of light and dark, and gave the people in his paintings a personal expression. Titian painted portraits of Charles V, Phillip II, Franz I and pope Paul III. (M 34356)

\section{(9906) Tintoretto}

6523 P-L. Discovered 1960 Sept. 26 by C. J. van Houten and I. van Houten-Groeneveld at Palomar.

Named after Venetian painter Jacopo Robusti (15181594), called Tintoretto. He was influenced by Titian \{see planet (9905)\}. His main work can be seen in the Scuola di S. Rocco and the palace of the Doge in Venice. (M 34356)

\section{(9907) Oileus}

6541 P-L. Discovered 1960 Sept. 24 by C. J. van Houten and I. van Houten-Groeneveld at Palomar.

Oileus was the father of Ajax the Little. Next to Achilles \{see planet (588)\}, Ajax was the fastest-running Greek hero. (M 34356)

\section{(9908) Aue}

2140 T-1. Discovered 1971 Mar. 25 by C. J. van Houten and I. van Houten-Groeneveld at Palomar.

Hartmann von Aue (c.1160-1210) was educated in a cloister and took part in the crusade of Barbarossa \{see also planet (1860)\}. He wrote epic works Erec, Iwein and Der arme Heinrich after the model of Chréstien de Troyes. He also created minstrel songs. (M 34356)

\section{(9909) Eschenbach}

4355 T-1. Discovered 1971 Mar. 26 by C. J. van Houten and I. van Houten-Groeneveld at Palomar.

Wolfram von Eschenbach (1168-1220) was, with von Aue \{see planet (9908)\} and Gottfried von Strassburg, one of the greatest poets of medieval times. Beginning as a song writer, he later wrote three great epics: Parzifal, with the fragmentarian Gralsepos of Chréstien de Troyes as a basis, and the two unfinished works Titurel and Willehalm. (M 34356)

\section{(9910) Vogelweide}

3181 T-2. Discovered 1973 Sept. 30 by C. J. van Houten and I. van Houten-Groeneveld at Palomar.

Walther von der Vogelweide (c.1170-1230) was probably born in Niederösterreich and died near Würzburg, Germany. A famous minstrel, his portrait appears in the Manesse-Handschrift from 1320. Quite a number of his songs with several verses have been preserved. (M 34356)

\section{(9911) Quantz}

4129 T-2. Discovered 1973 Sept. 29 by C. J. van Houten and I. van Houten-Groeneveld at Palomar.

Johan Joachim Quantz (1697-1773), the son of a smith, became city piper of Merseburg, Germany, and later came to the court in Dresden \{see planet (3053)\} as an oboe player. Thirty years later he took up the flute, studying throughout Europe and introducing new techniques for the flute. In 1741 he became the teacher and musical conductor for the Prussian king Friedrich II the Great. Quantz composed about 500 pieces for flute and published a book about playing the flute and on Baroque music in general. (M 34356)

\section{(9912) Donizetti}

2078 T-3. Discovered 1977 Oct. 16 by C. J. van Houten and I. van Houten-Groeneveld at Palomar.

The Italian composer Gaetano Donizetti (1797-1848) wrote symphonies, church and chamber music. After 1818 he composed 74 operas. He is still much esteemed today. (M 34356)

\section{(9913) Humperdinck}

4071 T-3. Discovered 1977 Oct. 16 by C. J. van Houten and I. van Houten-Groeneveld at Palomar.

Engelbert Humperdinck (1854-1921) was first assistant to Richard Wagner \{see planet (3992)\}. Later he traveled throughout Europe and Northern Africa and became a teacher in different conservatories and art academies. His greatest success was the opera Hänsel und Gretel, which remains a favorite today, with its folksong melodies. (M 34356)

\section{(9915) Potanin}

$1977 \mathrm{RD}_{2}$. Discovered 1977 Sept. 8 by N. S. Chernykh at Nauchnyj.

Grigorij Nikolaevich Potanin (1835-1920) was a Russian geographer, ethnographer and publicist, an explorer of Central Asia and Siberia who took part in several expeditions to Mongolia, North China and Tibet. He made a valuable contribution to the development of culture and education in Siberia. (M 42359)

\section{(9916) Kibirev}

1978 TR $_{2}$. Discovered 1978 Oct. 3 by N. S. Chernykh at Nauchnyj.

Sergej Feodosievich Kibirev (1950- ) is involved in new methods of the processing of information, 
organizing the production of microelectronics in Novosibirsk. A champion sprinter in his youth, he likes extreme forms of sports. He is also a poet. (M 42359)

\section{(9919) Undset}

$1979 \mathrm{QF}_{1}$. Discovered 1979 Aug. 22 by C.-I. Lagerkvist at La Silla.

The Norwegian author Sigrid Undset (1882-1949) received the Nobel prize for literature in 1928. She is best known for her trilogy Kristin Lavransdatter about a couple's love and life in Norway in the thirteenth century. (M 46682)

\section{(9922) Catcheller}

$1981 \mathrm{EO}_{21}$. Discovered 1981 Mar. 2 by S. J. Bus at Siding Spring.

Endowing the English language with a new term, the 1961 novel Catch-22 by U.S. writer Joseph Heller (1923-1999) epitomized both the problems of a sane person in an insane society and the absurdity of war. (M 38199)

The name was suggested by B. G. Marsden.

\section{(9927) Tyutchev}

1981 TW $_{1}$. Discovered 1981 Oct. 3 by L. G. Karachkina at Nauchnyj.

Named in memory of the Russian poet Fedor Ivanovich Tyutchev (1803-1873). One of the greatest representatives of Russian lyricism of the nineteenth century, he was a master of Russian poetry. Many of his verses were set to music and translated into other languages. (M 34632)

\section{(9929) McConnell}

$1982 \mathrm{DP}_{1}$. Discovered 1982 Feb. 24 at the Oak Ridge Observatory at Harvard.

John C. McConnell (1946- ) writes on the history of astronomy, and his photographic archive is much used by historians of science. Currently chairman of the East Antrim Astronomical Society, he was the 1999 recipient of the FitzGerald Medal of the Irish Astronomical Association for his popularization of astronomy. (M 42670)

\section{(9930) Billburrows}

1984 CP. Discovered 1984 Feb. 5 by E. Bowell at Anderson Mesa.

William E. Burrows (1937- ), of New York University, is a top authority on space, national security, spy satellites and spy planes. His books are extensively researched and detailed, yet enjoyably readable; they include, among others, Deep Black and Exploring Space. (M 43043)

The name was suggested by E. M. Standish.

\section{(9932) Kopylov}

1985 QP $_{5}$. Discovered 1985 Aug. 23 by N. S. Chernykh at Nauchnyj.

Ivan Mikheevich Kopylov (1928- ) was a stellar astrophysicist at the Crimean Astrophysical Obser- vatory from 1950 to 1966 and then director at the Special Astrophysical Observatory from 1966 to 1985. His main work concerns the physics and evolution of stars and astronomical instrumentation. (M 39653)

\section{(9933) Alekseev}

$1985 \mathrm{SM}_{3}$. Discovered 1985 Sept. 19 by N. S. Chernykh and L. I. Chernykh at Nauchnyj.

Anatolij Semenovich Alekseev (1928- ) , a professor in the department of mathematical geophysics at Novosibirsk University, is a pioneer in the mathematical theory of geophysical processes and phenomena. He has been engaged in the mathematical modeling of the geophysical consequences of asteroidal impacts on the earth. (M 42359)

\section{(9934) Caccioppoli}

1985 UC. Discovered 1985 Oct. 20 by E. Bowell at Anderson Mesa.

Francesco Caccioppoli (1855-1904) directed the Naval Institute in Procida, near Napoli, and was a passionate observer of the sky. Renato Caccioppoli (1904-1959) was an outstanding mathematician who carried out seminal work on linear and nonlinear differential equations. (M 42670)

The name was suggested by E. Perozzi

\section{(9937) Triceratops}

$1988 \mathrm{DJ}_{2}$. Discovered 1988 Feb. 17 by E. W. Elst at La Silla.

Triceratops was a heavy dinosaur with three horns, two above the eyes and one on the snout. It lived in Upper Cretaceous times. Many Triceratops skeletons have been found in Wyoming and Colorado. (M 47166)

\section{(9938) Kretlow}

1988 KA. Discovered 1988 May 18 by W. Landgraf at La Silla.

Mike Kretlow, a longtime friend of the discoverer, was a fellow student at the University of Siegen, where he wrote a masters' thesis about nongravitational forces on comets. (M 42359)

\section{(9941) Iguanodon}

$1989 \mathrm{CB}_{3}$. Discovered 1989 Feb. 4 by E. W. Elst at La Silla.

Iguanodon was a heavy bipedal, upright-standing dinosaur, balancing its long 10-meter body by a heavy tail. It lived in Lower Cretaceous times, and many skeletons have been found in Europe (M 47166)

\section{(9949) Brontosaurus}

$1990 \mathrm{SK}_{6}$. Discovered 1990 Sept. 22 by E. W. Elst at La Silla.

Brontosaurus was a gigantic dinosaur, as large as 20 meters and weighing about 30 tons. It lived in Upper Jurassic times and walked on all four legs. Many skeletons have been found in the United States. (M 47166) 


\section{(9951) Tyrannosaurus}

$1990 \mathrm{VK}_{5}$. Discovered 1990 Nov. 15 by E. W. Elst at La Silla.

Tyrannosaurus, a heavy bipedal dinosaur with a huge skull, long massive jaws and dagger-like teeth, was a most terrifying predator. Almost 14 meters long and 5 to 8 meters high, it lived during Upper Cretaceous times. (M 47166)

\section{(9954) Brachiosaurus}

$1991 \mathrm{GX}_{7}$. Discovered 1991 Apr. 8 by E. W. Elst at La Silla.

Brachiosaurus, the heaviest of all dinosaurs (about 70 tons) had a very long neck with a small head. Preferring swampy areas, where the water would have supported its weight, it lived during in Jurassic-Lower Cretaceous times. (M 47166)

\section{(9956) Castellaz}

1991 TX $_{4}$. Discovered 1991 Oct. 5 by L. D. Schmadel and F. Börngen at Tautenburg.

German physicist Peter Castellaz (1965- ) works in the Department of Science and Arts of the state of Baden-Württemberg. A specialist for fundamental aspects in research, he was instrumental in the support of work on minor planets at the Astronomisches Rechen-Institut. (M 42670)

The name was suggested by L. D. Schmadel.

\section{(9957) Raffaellosanti}

1991 TO$_{13}$. Discovered 1991 Oct. 6 by F. Börngen at Tautenburg.

The painter and architect Raphael (1483-1520), full name Raffaello Sanzio, is one of the most famous masters of the Italian Renaissance. His pictures, portraits, tapestry cartoons and frescoes are admired in illustrious galleries, palaces and churches, especially the Sixtine Madonna in Dresden. (M 47167)

\section{(9960) Sekine}

$1991 \mathrm{VE}_{4}$. Discovered 1991 Nov. 4 by S. Otomo at Kiyosato.

Masumi Sekine (1950- ) is the president of astromomical society at Ageo city. He has been involved with the organization of the annual Chichibu star party since 1983. (M 43190)

\section{(9962) Pfau}

$1991 \mathrm{YL}_{1}$. Discovered 1991 Dec. 28 by F. Börngen at Tautenburg.

Werner Pfau (1936- ), director of the Jena University Observatory from 1990 to 2000 and a former chairman of the Astronomische Gesellschaft, is a well-known German expert on the physics of the interstellar medium and a promoter of the education of teachers of astronomy. (M 41937)

The citation was provided by H. Zimmermann.

\section{(9963) Sandage}

1992 AN. Discovered 1992 Jan. 9 by E. F. Helin at Palomar.
Allan Sandage (1926- ), a distinguished American astronomer of Palomar and Mt. Wilson fame, is an international authority in stellar astronomy and observational cosmology. (M 43381)

The name was suggested by S. Kientz and endorsed by the discoverer, who first met Sandage at Palomar in the early 1970s.

\section{(9965) GNU}

$1992 \mathrm{EF}_{2}$. Discovered 1992 Mar. 5 by the Spacewatch at Kitt Peak.

GNU is the recursive acronym for "GNU is not Unix". The GNU project was created by Richard Stallman's \{see planet (9882)\} Free Software Foundation in 1984. It enabled computer programmers to trade and improve on each others' ideas freely. Linux ssee planet (9885)\} and academic computing owe much of their functionality to the firm foundations of GNU software. (M 41571)

\section{(9969) Braille}

1992 KD. Discovered 1992 May 27 by E. F. Helin and K. J. Lawrence at Palomar.

Named in memory of Louis Braille (1809-1852), who invented the Braille language so that those who could not see could obtain knowledge and explore through the 'written' word. Likewise, this minor planet provides knowledge about our universe and its origins to the people of the earth who, through Deep Space 1, are also able to explore and discover what previously they could not 'see'. (M 35492)

Name proposed by the discoverers following a suggestion by Kerry Babcock through The Planetary Society's "Name That Asteroid" contest.

\section{(9984) Gregbryant}

1996 HT. Discovered 1996 Apr. 18 by R. H. McNaught and J. B. Child at Macquarie.

Editor of the journal of the Astronomical Society of New South Wales, Gregory Bryant (1970- ) has contributed over 240 original articles. He also cofounded the South Pacific Star Party, and his enthusiastic promotion of this annual event has attracted participants from around the world. (M 39653)

\section{(9985) Akiko}

1996 JF. Discovered 1996 May 12 by R. H. McNaught and $\mathrm{H}$. Abe at Yatsuka.

Named in honor of Akiko Yamamoto (1963- ), a member of the Yatsuka Observatory and observing partner of the second discoverer. (M 34632)

\section{(9987) Peano}

$1997 \mathrm{OO}_{1}$. Discovered 1997 July 29 by P. G. Comba at Prescott.

Named for Giuseppe Peano (1858-1932), Italian mathematician, professor at the University of Turin and a founder of symbolic logic. Peano's Formulario Mathematico was intended to develop mathematics in its entirety from a set of basic postulates by use 
of a logic notation, and it had a profound influence on later studies in the foundations of mathematics. Peano was also the creator of the artificial language "Latino sine flexione". Later renamed "Interlingua", it had a simple grammar and a lexicon based on the Latin roots of words common to the major European languages. (M 34632)

\section{(9988) Erictemplebell}

$1997 \mathrm{RX}_{6}$. Discovered 1997 Sept. 9 by P. G. Comba at Prescott.

Named for Eric Temple Bell (1883-1960), ScottishAmerican mathematician and professor at the California Institute of Technology, where the discoverer attended his algebra class and was exposed to his acerbic wit. Bell wrote more than 250 scholarly papers, mainly in number theory, and several influential books of popularization, including Mathematics, Queen and Servant of Science. he also wrote several books of science fiction under the pseudonym John Taine. (M 34632)

\section{(9991) Anežka}

1997 TY $_{7}$. Discovered 1997 Oct. 5 by Z. Moravec at Kleť.

Named in honor of Anežka Moravcová (1924- ), the discoverer's grandmother, on the occasion of her 75th birthday. (M 34632)

\section{(9993) Kumamoto}

1997 VX $_{5}$. Discovered 1997 Nov. 6 by J. Kobayashi at Kumamoto.

Kumamoto is the name of both a prefecture and its capital city - home of the discoverer - on the Japanese island of Kyushu. With Mt. Aso, it is home to the biggest crater of an active volcano in the world. The observatory was built in 1982 by raising funds from the citizens of Kumamoto. (M 39653)

\section{(9994) Grotius}

4028 P-L. Discovered 1960 Sept. 24 by C. J. van Houten and I. van Houten-Groeneveld at Palomar.

The works Mare Liberum (1609; "Free Access to the Ocean for all nations") and De Jure Belli ac Pacis (1625; "On the Law of War and Peace") of the Dutch statesman Hugo Grotius (Huig de Groot, 1583-1645) laid the foundation for modern international law. (M 41571)

\section{(9995) Alouette}

4805 P-L. Discovered 1960 Sept. 24 by C. J. van Houten and I. van Houten-Groeneveld at Palomar.

The first Canadian satellite Alouette-1 was launched on 1962 Sept. 29. It was engaged in research and exploration of the upper atmosphere, especially the ionosphere. During its six-year lifespan it returned the first useful data on the ionosphere. The citation was prepared by W. Fröger. (M 41571)
(9996) ANS

9070 P-L. Discovered 1960 Oct. 17 by C. J. van Houten and I. van Houten-Groeneveld at Palomar.

The Astronomical Netherlands Satellite (ANS) was launched on 1974 Aug. 30 as the first Dutch satellite. Designed as an astronomical observatory, for 20 months it observed celestial objects at ultraviolet and X-ray wavelengths. ANS discovered the X-ray bursts and detected X-rays from Capella. (M 41571)

\section{(9997) COBE}

1217 T-1. Discovered 1971 Mar. 25 by C. J. van Houten and I. van Houten-Groeneveld at Palomar.

The American Cosmic Background Explorer COBE was launched 1989 Nov. 18 and helped to answer basic questions on the distribution of matter in the universe, on the first appearance of galaxies and on rotation of the universe. It also mapped interstellar and interplanetary dust clouds. (M 41571)

\section{(9998) ISO}

1293 T-1. Discovered 1971 Mar. 25 by C. J. van Houten and I. van Houten-Groeneveld at Palomar.

ISO, the Infrared Space Observatory, was launched on 1995 Nov. 17 to study the universe over a broad range of wavelengths. Among its many discoveries are water vapor on Saturn's moon Titan, infrared galaxies at immense distances, young stars in the Orion Association and the nature of the surface of major and minor planets. (M 41571)

\section{(9999) Wiles}

4196 T-2. Discovered 1973 Sept. 29 by C. J. van Houten and I. van Houten-Groeneveld at Palomar.

Named in honor of Andrew J. Wiles (1953- ), British mathematician and world-renowned for his 1993 proof of Fermat's \{see planet (12007)\} Last Theorem, one of the most difficult mathematical problems, which had remained unsolved for more than 350 years. A gap in the proof was closed by Wiles in 1994. His achievement came too late for him to receive the Field Medal, because Wiles was then over the age limit of 40. The International Mathematical Union therefore gave him its most prestigious award, the Silver Plaque. Wiles' fields of research are number theory and arithmetic geometry. He is a professor at Princeton University. (M 34356)

Name proposed and citation prepared by L.D.Schmadel.

\section{(10000) Myriostos}

1951 SY. Discovered 1951 Sept. 30 by A. G. Wilson at Palomar.

The Greek word for ten-thousandth, Myriostos honors all the astronomers, past and present, from all around the world, professional and amateur, observer and orbit computer, who participated, over an interval of 198 years, in the achievement of accumulating 10,000 minor planets with orbit determinations of the highest quality. (M 34632) 
This name was proposed by the majority of members of the Small Bodies Names Committee. Citation prepared by B. G. Marsden.

The naming of this planet was very controversial. The Minor Planet Center in a Editorial Notice (M.P.C. 33615) discussed the naming procedure during the nearly two centuries of minor planet discoveries: "... It has been traditional to have a special celebration with each thousandth numbering... Obviously, it would be appropriate to have some very special celebration to acknowledge (10000)... Most readers... will be aware of recent discussions in the press concerning a proposal that the number (10000) should be given to Pluto. The principal reasoning for this is the recognition during the past few years that Pluto was the first discovered and largest known member of the "Transneptunian Belt" of small objects beyond Neptune that possess some similarity, at least dynamically, to bodies in the Cisjovian Belt. Although as many as 95 members of the Transneptunian Belt are now listed, most of the orbital solutions are very weak... Although it is not unlikely that further Transneptunian Objects as large as Pluto will be discovered in the future, Pluto obviously holds a very special place in our appreciation of this new population, and by assigning to it the number (10000), we should guarantee that Pluto will be at the head of the Transneptunian list. It is also very important to affirm that there is absolutely no implied "demotion" or "reclassification" of Pluto from its position in the list of the "planets"..." All users of the M.P.C.s were invited to vote on this proposal or to make an alternative suggestion. An examination of the votes was published in M.P.C. 33817. Although the messages received were from 22 different countries, some 57 percent of the vote originated in the U.S. Respondents from outside the U.S. voted overwhelmingly - 82 percent - in favor of (10000) Pluto. Inside the U.S., the vote in favor of (10000) Pluto was 51 percent. A slight majority in the Small Bodies Names Committee was in favor, but this "...had a rather sudden change of heart following agitation by a group of planetary astronomers, mainly located in the U.S. Acting on this sudden decision, the IAU Secretariat announced on Feb. 3 that the Small Bodies Names Committee had "decided against assigning any Minor Planet number to Pluto"..."

\section{(10001) Palermo}

$1969 \mathrm{TM}_{1}$. Discovered 1969 Oct. 8 by L. I. Chernykh at Nauchnyj.

Palermo is the capital of Sicily. It was at the Palermo Observatory, on the evening of 1801 Jan. 1, that Giuseppe Piazzi \{see planet (1000)\} discovered (1) Ceres. The naming of this minor planet is being made in the first month of the twenty-first century, on the two-hundredth anniversary of that discovery. (M 41937)

\section{(10004) Igormakarov}

$1975 \mathrm{VV}_{2}$. Discovered 1975 Nov. 2 by T. M. Smirnova at Nauchnyj.

Igor' Mikhajlovich Makarov (1927- ) is known for his research on nonlinear and adaptive systems, artificial intelligence and the choice and acceptance of decisions. He was chief scientific secretary of the Russian Academy of Sciences during 1988-1996. (M 42360)

The name was suggested by the Institute of Applied Astronomy.

\section{(10005) Chernega}

$1976 \mathrm{SS}_{2}$. Discovered 1976 Sept. 24 by N. S. Chernykh at Nauchnyj.

Nikolaj Akimovich Chernega (1923- ） is a specialist in astrometry and the compilation of catalogues of highly precise stellar coordinates. He was head of the astrometric Department of the Astronomical Observatory of Kiev University during 1961-1988. (M 42360)

\section{(10010) Rudruna}

1978 PW $_{3}$. Discovered 1978 Aug. 9 by N. S. Chernykh and L. I. Chernykh at Nauchnyj.

RUDruNa, or Rossijskij Universitet Druzhby Narodov, is the Russian University of Friendship of Nations. It was founded in Moscow in 1960 to help developing countries in the training of educated specialists. (M 43381)

\section{(10011) Avidzba}

1978 QY . Discovered 1978 Aug. 31 by N. S. Chernykh at Nauchnyj.

Anatolij Mkanovich Avidzba (1951- ), orchardist and viticulturist, is a member of the International Academy of Vine-growing and Wine-making, a corresponding member of the Ukrainian Academy of Agrarian Sciences and director of the "Magarach" institute of Vine-growing and Wine-making in the Crimea. (M 42360)

\section{(10012) Tmutarakania}

$1978 \mathrm{RE}_{3}$. Discovered 1978 Sept. 3 by N. S. Chernykh and L. G. Karachkina at Nauchnyj.

Tmutarakania was a Russian principality in the Tamanian peninsula from the tenth to the twelfth centuries. (M 42360)

\section{(10022) Zubov}

$1979 \mathrm{SU}_{2}$. Discovered 1979 Sept. 22 by N. S. Chernykh at Nauchnyj.

Vladimir Ivanovich Zubov (1930-2000), Russian mathematician and mechanician, was founder of the Institute for Computational Mathematics and Control Processes at the Leningrad-St. Petersburg State University. (M 42360)

\section{(10023) Vladifedorov}

1979 WX $_{3}$. Discovered 1979 Nov. 17 by L. I. Chernykh at Nauchnyj. 
Vladimir Dmitrievich Fedorov (1933- ), an outstanding Russian surgeon, scientist and professor, is a member of the Russian Academy of Medical Sciences and director of the Institute of Surgery in Moscow. He is well known for research to perfect surgery of the digestive organs. (M 43381)

\section{(10024) Marthahazen}

1980 EB. Discovered 1980 Mar. 10 at the Harvard College Observatory at Harvard.

Known for her research on galaxies, planetary nebulae and variable stars, Martha Hazen (1931- ) tirelessly tended Harvard's unique archive of photographic plates for 33 years. She also edited the old Harvard Announcement Cards before the IAU Central Bureau for Astronomical Telegrams moved to Massachusetts. (M 43684)

\section{(10025) Rauer}

$1980 \mathrm{FO}_{1}$. Discovered 1980 Mar. 16 by C.-I. Lagerkvist at La Silla.

German planetary astronomer Heike Rauer (1961-

) is known for her observational work on cometary comae, in particular that of comet C/1995 O1 (HaleBopp). She is currently working at the Institute of Space Sensor Technology and Planetary Exploration in Berlin on a project to search for extrasolar planetary systems. (M 42360)

\section{(10027) Perozzi}

1981 FL. Discovered 1981 Mar. 30 by E. Bowell at Anderson Mesa.

Ettore Perozzi (1957- ）, of Telespazio, Rome, works on solar-system dynamics and on interplanetary mission analysis. He has been involved in the Cassini/Huygens mission and in proposals for missions to comets and minor planets. (M 42670)

The name was suggested by M. A. Barucci.

\section{(10029) Hiramperkins}

1981 QF. Discovered 1981 Aug. 30 by E. Bowell at Anderson Mesa.

Hiram Perkins (1833-1924) was a professor of mathematics and astronomy at the Ohio Wesleyan University from 1857 to 1907. In 1923 he used profits raised through hog farming during the Civil War to fund the construction of Perkins Observatory in Delaware, Ohio. (M 43043)

\section{(10030) Philkeenan}

1981 QG. Discovered 1981 Aug. 30 by E. Bowell at Anderson Mesa.

Philip Keenan (1908-2000) was a professor of astronomy with the Ohio State University at Perkins Observatory from 1946 until his death. He was an expert in the field of stellar spectra and one of the creators (with W. W. Morgan \{see planet (3180)\}) of the MK system of stellar classification. (M 43043)

The name was suggested by R. Martino.

Obituary published in Bull. Am. Astron. Soc., Vol. 33, No. 4, p. 1574 (2001).

\section{(10031) Vladarnolda}

1981 RB $_{2}$. Discovered 1981 Sept. 7 by L. G. Karachkina at Nauchnyj.

Vladimir Igorevich Arnold (1937- ) is an authority on the theories of dynamical systems, functions, differential equations and the mathematical methods of classical mechanics. (M 39654; M 40877)

The name was suggested by V. J. Yudovich.

\section{(10034) Birlan}

1981 YG. Discovered 1981 Dec. 30 by E. Bowell at Anderson Mesa.

Mirel Birlan (1963- ), of the Paris Observatory, Meudon, began his career in 1991 as an astronomer at the Bucharest Observatory. He has conducted observing campaigns on minor solar-system bodies and has been involved in groundbased science of Rosetta mission asteroid targets. (M 42670)

The name was suggested by M. A. Barucci.

\section{(10036) McGaha}

1982 OF. Discovered 1982 July 24 by E. Bowell at Anderson Mesa.

James E. McGaha (1946- ), Tucson astronomer, lecturer, U.S. Air Force pilot and skeptic, actively promotes science and the refutation of pseudoscience. $\mathrm{He}$ is a faculty member of the Center for Inquiry and a consultant for the Committee for the Scientific Investigation of Claims of the Paranormal. (M 43043)

\section{(10039) Keet Seel}

1984 LK. Discovered 1984 June 2 by B. A. Skiff at Anderson Mesa.

Keet Seel is a well-preserved prehistoric cliff-dwelling, occupied by ancestors of the modern Hopi people. The site is in what is now the Navajo National Monument in northern Arizona, and the name is apparently from a Navajo phrase meaning "houses that have been left behind". (M 36129)

The name was suggested by M. T. Gibson.

\section{(10041) Parkinson}

1985 HS $_{1}$. Discovered 1985 Apr. 24 by C. S. Shoemaker and E. M. Shoemaker at Palomar.

Bradford Parkinson led a team that developed the Global Positioning System with revolutionary tracking technology. The GPS has transformed navigation, recreation, law enforcement and all sciences requiring precise knowledge of location. (M 46682)

\section{(10042) Budstewart}

1985 PL. Discovered 1985 Aug. 14 by E. Bowell at Anderson Mesa.

L. R. ("Bud") Stewart (1903-1979) was a cofounder of the Columbus Astronomical Society in 1947 and its first president. (M 43043)

The name was suggested by R. Martino. 


\section{(10043) Janegann}

1985 PN. Discovered 1985 Aug. 14 by E. Bowell at Anderson Mesa.

Jane Gann (1910-1994) was cofounder and first female president of the Columbus Astronomical Society. She was a tireless promoter of amateur astronomy in central Ohio for more than four decades. (M 43043) The name was suggested by R. Martino.

\section{(10044) Squyres}

1985 RU. Discovered 1985 Sept. 15 by C. S. Shoemaker and E. M. Shoemaker at Palomar.

Steven W. Squyres (1956- ）, professor of astronomy at Cornell University, has used his knowledge of physics in the study of the solid planets and satellites in the solar system. He has participated in a number of space missions studying water ice on Mars, Ganymede, Callisto and Europa. (M 46682)

\section{(10049) Vorovich}

1986 TZ $_{11}$. Discovered 1986 Oct. 3 by L. G. Karachkina at Nauchnyj.

Academician of the Russian Academy of Sciences Iosif Izrailevich Vorovich (1920- ) is a prominent mathematician. He developed topological and variation methods of nonlinear analysis for the investigation of plates and shells. (M 39654; M 40877)

The name was suggested by V. J. Yudovich.

\section{(10050) Rayman}

$1987 \mathrm{MA}_{1}$. Discovered 1987 June 28 by E. F. Helin at Palomar.

Marc D. Rayman (1956- ) has been devoted to the exploration of space since childhood and is exceptionally effective at communicating this topic to the public. At the Jet Propulsion Laboratory he was instrumental in the success of Deep Space 1 as chief mission engineer. (M 41384)

\section{(10051) Albee}

1987 QG $_{6}$. Discovered 1987 Aug. 23 by E. F. Helin at Palomar.

Arden L. Albee (1928- ), Caltech professor of geology and planetary sciences, was dean of graduate studies for the last sixteen years. Albee has served in many capacities, including chief scientist of JPL, project scientist for the Mars Observer mission, and he has been a principal figure in many Mars-related science missions. (M 41571)

\section{(10054) Solomin}

1987 SQ 17 . Discovered 1987 Sept. 17 by L. I. Chernykh at Nauchnyj.

Yurij Mefodievich Solomin (1935- ), People's artist of the U.S.S.R, is a Russian actor who is especially popular for his parts in several Soviet films. He is the Artistic Director at the State Academic Maly Theatre at Moscow and professor at the Shchepkin Higher Drama School. (M 43381)
(10055) Silcher

1987 YC $_{1}$. Discovered 1987 Dec. 22 by F. Börngen at Tautenburg.

Named in memory of the German composer of popular songs Philipp Friedrich Silcher (1789-1860), musical director at the University of Tübingen ssee planet (1481)\} from 1817. He was a famous music educator, promoter of music for the laity and founder of several choirs. Silcher published numerous collections of folk-songs and composed, transcribed and arranged music for male and mixed choirs. Among his best-known compositions, still very popular today, are Ännchen von Tharau, Ich weiss nicht, was soll es bedeuten and Alle Jahre wieder. (M 34632)

\section{(10057) L'Obel}

1988 CO $_{1}$. Discovered 1988 Feb. 11 by E. W. Elst at La Silla.

Matthias de L'Obel (Lobelius, 1538-1616) was a Flemish physician and botanist. In his important work Stirpium adversaria nova (1570), he argued that botany, as well as medicine, must be based on thorough and exact observation. (M 40704)

\section{(10060) Amymilne}

1988 GL. Discovered 1988 Apr. 12 by C. S. Shoemaker and E. M. Shoemaker at Palomar.

Amy Rae Milne (1982- ), a vibrant, energetic, young Canadian woman who has dedicated herself to creating happiness for others, has led her life with spirit. A love of science and its relationship to understanding and preserving our environment has brought her national recognition. (M 46010)

\section{(10067) Bertuch}

$1989 \mathrm{AL}_{6}$. Discovered 1989 Jan. 11 by F. Börngen at Tautenburg.

Named for the German author, bookseller and successful liberal employer Friedrich Justin Bertuch (1747-1822), who lived in the city of Weimar. He translated the great Spanish romance Don Quixote \{see planet (3552)\} into German. In 1786, together with the illustrator G. M. Kraus, he founded the first German fashion magazine, Journal des Luxus und der Moden. In 1798 he published Allgemeine Geographische Ephemeriden, the first German astronomical journal, and the so-called "Black" star atlas by Goldbach. Bertuch was the owner of the Weimar Geographical Institute, in which von Zach \{see planet (999)\} was employed as a supervisor in the field of cartography. (M 35492)

Name endorsed by P. Brosche.

\section{(10068) Dodoens}

$1989 \mathrm{CT}_{2}$. Discovered 1989 Feb. 4 by E. W. Elst at La Silla.

Named in memory of the Flemish physician and botanist Rembertus Dodonaeus (1516-1585). The Stirpium historiae pemptades (1583) is considered one of 
the foremost botanical works of the late sixteenth century. His famous Cruydbook (1554), on herbs, was translated into French (1557), and it became a standard in England. (M 35493)

\section{(10069) Fontenelle}

$1989 \mathrm{CW}_{2}$. Discovered 1989 Feb. 4 by E. W. Elst at La Silla.

Named in memory of Bernard Le Bovier, sieur de Fontenelle (1657-1757), well-known for his famous work Entretiens sur la pluralité des mondes (1686). Many of the ideas of the Enlightenment appear in embryonic form in his works. In De l'origine des fables (1724), he compared pagan religion with established religion. (M 35493)

\section{(10079) Meunier}

$1989 \mathrm{XD}_{2}$. Discovered 1989 Dec. 2 by E. W. Elst at La Silla.

Named in memory of the Belgian sculptor and painter Constant Meunier (1831-1905), one of the principal social-realist artists of the late nineteenth century in Europe. His works show a humanitarian interest in laborers, particularly in the miners of the Borinage and the dockworkers of Antwerp. (M 35493)

\section{(10088) Digne}

1990 SG $_{8}$. Discovered 1990 Sept. 22 by E. W. Elst at La Silla.

Named for the town of Digne, in southern France, the capital of Alpes-de-Haute-Provence. Situated on the scenic "Route de Napoléon", it is well known for its cultivation of lavender and fruits for preserving. The city has a majestic Romanesque cathedral. (M 35493)

\section{(10089) Turgot}

1990 SS $_{9}$. Discovered 1990 Sept. 22 by E. W. Elst at La Silla.

Named in memory of Anne-Robert-Jacques Turgot (1727-1781), the famous French economist whose efforts for financial reform were blocked by the privileged classes. In his most famous work Réflections sur la formation et la distribution des richesses (1766), he introduced new economic methods for the peasant region he administered. During 1770-71 he successfully combated famine by maintaining free commerce in grain. (M 35493)

\section{(10090) Sikorsky}

$1990 \mathrm{TK}_{15}$. Discovered 1990 Oct. 13 by L. G. Karachkina and G. R. Kastel' at Nauchnyj.

Born in Russia, aircraft designer Igor' Ivanovich Sikorsky (1889-1972) built and flew the first multimotored airplanes. In 1919 he emigrated to the U.S. and created some 15 different types of aircraft. His helicopters were the first to fly across the Atlantic and Pacific oceans. (M 40704)

\section{(10092) Sasaki}

1990 VD $_{4}$. Discovered 1990 Nov. 15 by K. Endate and K. Watanabe at Kitami.

Katsuhiro Sasaki (b.1941), the director of the Department of Science and Engineering, National Science Museum, Tokyo, is known for research on Japanese clocks and for scientific education of the public. (M 45232)

\section{(10093) Diesel}

1990 WX $_{1}$. Discovered 1990 Nov. 18 by E. W. Elst at La Silla.

Named in memory of Rudolf Christian Karl Diesel (1858-1913), German thermal engineer, who devoted much of his time to developing an internal combustion engine that would approach the theoretical efficiency of the Carnot cycle. In 1892, this led to the invention of the so-called "Diesel engine". In 1913 he apparently fell from the deck of a mail steamer en route to London and drowned. (M 35493)

\section{(10095) Carlloewe}

$1991 \mathrm{RP}_{2}$. Discovered 1991 Sept. 9 by F. Börngen and L. D. Schmadel at Tautenburg.

Named in memory of the German composer Johann Carl Friedrich Loewe (1796-1869), born in Löbejün, near Halle. At the age of 23 he visited Goethe in Weimar \{see planet (3539)\}. From 1820 to 1866 he lived in Stettin and was organist, precentor, music teacher and director for music in the town. There he directed the Pomeranian music festivals. His compositional work includes about 400 ballads, for which he favored dramatic-epic and romantic words, particularly by Goethe, Uhland and Herder \{see, respectively, planets (3047), (9052) and (8158)\}. This form of song owes its real popularity to him. He performed his ballads himself at concerts. (M 34632; M 34673)

Name proposed by the first discoverer.

\section{(10099) Glazebrook}

1991 VB $_{9}$. Discovered 1991 Nov. 4 by the Spacewatch at Kitt Peak.

An astronomer at Johns Hopkins University, Karl Glazebrook (1965- ) is a specialist on the properties and evolution of faint high-redshift galaxies and large redshift surveys of nearby galaxies. His public domain astronomical software greatly aided the Spacewatch \{see planet (4255)\} survey during its 1997 upgrades. (M 41571)

\section{(10100) Bürgel}

$1991 \mathrm{XH}_{1}$. Discovered 1991 Dec. 10 by F. Börngen at Tautenburg.

As detailed in his autobiography, Vom Arbeiter zum Astronomen, Bruno H. Bürgel (1875-1948), first employed as a shoemaker, became an assistant at the Urania Sternwarte in Berlin, and later the best known German popular astronomical writer of his time. (M 36948) 


\section{(10101) Fourier}

$1992 \mathrm{BM}_{2}$. Discovered 1992 Jan. 30 by E. W. Elst at La Silla.

Named in memory of Jean-Baptiste-Joseph Fourier (1768-1830), French mathematician who exerted a strong influence on mathematical physics through his Théorie analytique de la chaleur (1822), wherein he showed that the conduction of heat in solid bodies may be analyzed in terms of infinite mathematical series, the so-called "Fourier series". In 1798 he accompanied Napoleon to Egypt, where he was engaged, until 1801, in extensive research on Egyptian antiquities. (M 35493)

\section{(10102) Digerhuvud}

1992 DA $_{6}$. Discovered 1992 Feb. 29 by the Uppsala-ESO Survey at La Silla.

Digerhuvud is the place on Gotland where seastacks are most common. (M 42360)

\section{(10103) Jungfrun}

$1992 \mathrm{DB}_{9}$. Discovered 1992 Feb. 29 by the Uppsala-ESO Survey at La Silla.

Jungfrun is the largest seastack on Gotland. (M 42360)

\section{(10104) Hoburgsgubben}

$1992 \mathrm{EY}_{9}$. Discovered 1992 Mar. 2 by the Uppsala-ESO Survey at La Silla.

Hoburgsgubben is a very characteristic seastack on southern Gotland, looking like an old man watching the sea. (M 42360)

\section{(10105) Holmhällar}

1992 EM $_{12}$. Discovered 1992 Mar. 6 by the Uppsala-ESO Survey at La Silla.

Holmhällar, on Gotland, contains an unusual area of seastacks. One of the expeditions from the Uppsala Observatory to the total solar eclipse on 1954 June 30 was based there. (M 42360)

\section{(10106) Lergrav}

$1992 \mathrm{EV}_{15}$. Discovered 1992 Mar. 1 by the Uppsala-ESO

Survey at La Silla.

Lergrav is one of the most exotic seastack sites on Gotland. (M 42360)

\section{(10108) Tomlinson}

1992 HM. Discovered 1992 Apr. 26 by C. S. Shoemaker and E. M. Shoemaker at Palomar.

Ray Tomlinson led the way in high-speed communication by developing a software program making it possible to send messages from one mainframe to another and to be sure they went to the right machine through the symbol for "at". Thus, he invented e-mail and revolutionized our lives. (M 46682)

\section{(10111) Fresnel}

$1992 \mathrm{OO}_{1}$. Discovered 1992 July 25 by E. W. Elst at Caussols.

Named in memory of Augustin-Jean Fresnel (17881827), French physicist who constructed the so-called
"Fresnel lens", following an original idea by Buffon (1748) \{see planet (7420)\} of dividing a lens surface into concentric rings. By studying the aberration of light, he removed a number of objections to the wave theory. (M 35493)

\section{(10114) Greifswald}

1992 RZ. Discovered 1992 Sept. 4 by L. D. Schmadel and F. Börngen at Tautenburg.

Greifswald, the old German Hanse city on the Baltic Sea, is a scientific, economic and cultural center. The Ernst-Moritz-Arndt University, founded around 1456, has an astronomical tradition that has now been revived through the associated Greifswald Observatory. (M 41937)

The name was suggested by the first discoverer.

\section{(10116) Robertfranz}

$1992 \mathrm{SJ}_{2}$. Discovered 1992 Sept. 21 by F. Börngen and L. D. Schmadel at Tautenburg.

Named in memory of Robert Franz (1815-1892), German composer of songs. An organist in his native city of Halle, he was also conductor of the Singakademie and the university director of music. Franz set more than 350 songs to music, using in particular the words by Heine \{see planet (7109)\} (Im Rhein, im heiligen Strome, Wie des Mondes Abbild). His arrangements and editions of compositions of Bach and Handel \{see planets (1814) and (3826), respectively\} were very important. He was appointed Knight of the Order of Maximilian for arts and sciences in 1878 by the king of Bavaria. (M 34632)

Name proposed by the first discoverer.

\section{(10117) Tanikawa}

1992 TW. Discovered 1992 Oct. 1 by M. Yanai and K. Watanabe at Kitami.

Kiyotaka Tanikawa (1944- ) is an associate professor at the National Astronomical Observatory of Japan who specializes in the study of the three-body problem. (M 45232)

\section{(10119) Remarque}

1992 YC $_{1}$. Discovered 1992 Dec. 18 by E. W. Elst at Caussols.

Named in memory of Eric Maria Remarque (18981970) German novelist, chiefly known for his Im Westen nichts Neues ("All Quiet on the Western Front", 1929). At 18 he was drafted into the German army and wounded several times. His novel records the daily horrors of war in laconic understatement, in shocking contrast to patriotic rhetoric. In 1933 his books were burnt by the Nazis. (M 35493)

\section{(10120) Ypres}

$1992 \mathrm{YH}_{2}$. Discovered 1992 Dec. 18 by E. W. Elst at Caussols.

With Bruges and Ghent ssee planets (9472) and (9473)\}, Ypres virtually controlled Flanders in the 
thirteenth century. During the Middle Ages, it became a major cloth-weaving city. Within the bulge of the British lines during World War I, Ypres was completely destroyed, subsequently to be rebuilt in its original style. (M 36129)

\section{(10136) Gauguin}

$1993 \mathrm{OM}_{3}$. Discovered 1993 July 20 by E. W. Elst at La Silla.

Named in memory of Paul Gauguin (1848-1903), leading French painter of the post-impressionist period, who abandoned imitative art for expressiveness through color. A meeting with van Gogh \{see planet (4457)\} at Paris (1886) and a journey to Martinique (1887) were decisive experiences in his life. In Tahiti he discovered the brilliant coloring and sensuous delights of a tropical landscape, enjoying in a primitive community the "natural" life. (M 35493)

\section{(10137) Thucydides}

$1993 \mathrm{PV}_{6}$. Discovered 1993 Aug. 15 by E. W. Elst at Caussols.

Named for Thucydides (ca. 460-400 BC), the greatest of the ancient Greek historians, who wrote strictly contemporary history of events through which he lived. His best known work, History of the Peloponnesian War, recounted the fifth-century-BC struggle between Athens and Sparta. He was filled with a passion for truth, keeping him free from vulgar partiality against the enemy: "I have written not for immediate applause, but for posterity". (M 35493)

\section{(10138) Ohtanihiroshi}

1993 SS $_{1}$. Discovered 1993 Sept. 16 by K. Endate and K. Watanabe at Kitami.

Hiroshi Ohtani (1939- ) is a professor in the department of astronomy at Kyoto University. His research themes include observational and theoretical studies of interstellar matter and observational study of active galaxies, especially of Seyfert and related galaxies. (M 45232)

\section{(10139) Ronsard}

$1993 \mathrm{ST}_{4}$. Discovered 1993 Sept. 19 by E. W. Elst at Caussols.

Named in memory of Pierre de Ronsard (1524-1585), the most important member of the group of poets known as "La Pléiade". Much inspired by Greek and Roman poetry, following Horatius' \{see planet (4294)\} example he composed the Odes (1550). He is most remembered for his Amours de Marie and the Sonnets pour Hélène. A reflection on the brevity of youth and beauty, his Mignonne, allons voir si la rose has been set to music half a dozen times since the sixteenth century. (M 35493)

\section{(10140) Villon}

1993 SX $_{4}$. Discovered 1993 Sept. 19 by E. W. Elst at Caussols.
Named in memory of François Villon (1431-1463), one of the greatest French lyric poets, known for his ballads, chansons and rondeaux. Le grand Testament is his master work. Herein he reviews his life, expressing his horror of sickness, old age, death and a poignant regret for his wasted youth. Known for his criminal excesses, he spent much time in prison, until he was condemned to be hanged (Ballade des pendus). However, in 1463 his sentence was commuted to banishment from Paris. (M 35493)

\section{(10141) Gotenba}

1993 VE. Discovered 1993 Nov. 5 by S. Otomo at Kiyosato.

Gotenba is a city at the foot of Mt. Fuji. Every year it is the site of a star party that promotes astronomical activities in cooperation with amateur astronomers to spread astronomy to the public. (M 46010)

\section{(10142) Sakka}

$1993 \mathrm{VG}_{1}$. Discovered 1993 Nov. 15 by A. Sugie at Taga.

Kazuyuki Sakka (1943- ）, the director of the Kyoto School of Computer Science, studied spectroscopic properties of galaxies and emission nebulae. He has also created software for astronomy education and popularization. (M 41937)

\section{(10143) Kamogawa}

$1994 \mathrm{AP}_{1}$. Discovered 1994 Jan. 8 by A. Sugie at Taga.

Kamogawa, a famous river in Japan, flows through the center of Kyoto city. Kamogawa has often appeared in Japanese literature and art. (M 41937)

\section{(10146) Mukaitadashi}

1994 CV $_{1}$. Discovered 1994 Feb. 8 by K. Endate and K. Watanabe at Kitami.

Tadashi Mukai (1945- ), a professor in the department of earth and planetary sciences at Kobe University, is known for studies of near-earth objects. (M 45232)

\section{(10149) Cavagna}

1994 PA. Discovered 1994 Aug. 3 by M. Tombelli and A. Boattini at San Marcello Pistoiese.

Named in honor of Marco Cavagna (1958- ), Italian amateur astronomer. He began observing comets, variable stars and occultations at an early age. In 1989 he was one of the promoters of the follow-up program, with special interest in NEOs, at Sormano \{see planet (6882)\} Observatory. Cavagna introduced the discoverers to the Italian astrometric community during its first meeting, held in Verona in 1991. (M 35494)

\section{(10151) Rubens}

$1994 \mathrm{PF}_{22}$. Discovered 1994 Aug. 12 by E. W. Elst at La Silla.

Named in memory of Peter Paul Rubens (1577-1640), the greatest exponent of sensuous Baroque painting. 
In 1600, after two years seniority as a master, he left Antwerp for Italy to study the ancient and modern masters of painting. In 1609 he settled permanently in Flanders and became a major religious painter (e.g. "Descent from the Cross", painted for the Antwerp cathedral). Because of his diplomatic capacities Rubens often served as an ambassador. The peace treaty of 1630 between England and Spain can be largely attributed to him personally. (M 35494)

\section{(10155) Numaguti}

$1994 \mathrm{VZ}_{2}$. Discovered 1994 Nov. 4 by K. Endate and K. Watanabe at Kitami.

Atusi Numaguti (1963-2001), an associate professor at Hokkaido University, was actively involved in research on the earth's hydrological cycle. The Atmospheric General Circulation Model he established is now used as a standard in Asia. He founded a summer school for young meteorologists. (M 45337)

\section{(10160) Totoro}

$1994 \mathrm{YQ}_{1}$. Discovered 1994 Dec. 31 by T. Kobayashi at Oizumi.

Hayao Miyazaki produced the animated movie $M y$ Neighbor Totoro in 1988, featuring the fairy Totoro. Through the movie, Totoro once again found his place in the hearts of Japanese children, in a time when the woods and darkness where Totoro lives are rapidly disappearing from the earth. (M 46010)

\section{(10162) Issunboushi}

1995 AL. Discovered 1995 Jan. 2 by T. Niijima and T. Urata at Ojima.

The extraordinarily small character Issunboushi Issun means about $3 \mathrm{~cm}$ in old Japanese - was the hero of many old Japanese tales. Born the size of a bean, he defeated ogres, succeeded in a stratagem that got him a beautiful bride, and shook a mallet that instantly transformed him into a normal young man. (M 36948)

\section{(10163) Onomichi}

$1995 \mathrm{BH}_{1}$. Discovered 1995 Jan. 26 by A. Nakamura at Kuma.

Named for a city in eastern Hiroshima ssee planet (2247)\} prefecture. Blessed with abundant natural beauty, Onomichi has been artistically captured by many Japanese novellists and artists. It has also been featured on film, thanks to the Onomichi Trilogy directed by Nobuhiko Obayashi. Onomichi is the terminal city on the Honshu side of the new Nishiseto Expressway \{see planet (9235)\}. (M 34632)

\section{(10168) Stony Ridge}

1995 CN. Discovered 1995 Feb. 4 by J. B. Child and J. E. Rogers at Stony Ridge.

Named in honor and memory of the gifted and talented amateur astronomers who founded Stony Ridge Observatory, near Mount Wilson, in 1957. They are Anthony L. Bland, Norman L. Boltz, Charles
Buzzetti, George A. Carroll, Roy R. Cook, Alvin E. Cram, Roy K. Ensign, W. H. Griffith, Harold J. Ireland, J. George Moyen, Norris A. Roberts, Easy Sloman, John Sousa, John Terlep and Dave Thomas. Starting in 1964, the observatory was used by the Aeronautical Chart and Information Center in St. Louis to map potential landing sites for the Apollo space program. (M 35494)

\section{(10170) Petrjakeš}

$1995 \mathrm{DA}_{1}$. Discovered 1995 Feb. 22 by M. Tichý and Z. Moravec at Klě̌t.

Named in honor of Petr Jakeš (1940- ), Czech geologist, geochemist and lecturer at Charles University. He was a member of the team that made a preliminary analysis of the lunar rocks returned by Apollo 14 and 15. He also studies meteorites and has searched for them in desert regions. (M 34632)

Name endorsed by J. Tichá.

\section{(10172) Humphreys}

1995 FW $_{19}$. Discovered 1995 Mar. 31 by the Spacewatch at Kitt Peak.

Minnesota astronomer Roberta M. Humphreys (1944-

) is a leader in studies of physical properties of massive stars in the Milky Way and in nearby galaxies. She headed the Automated Plate Scanner Project to digitize the Palomar Sky Survey and make a publicly available database of a billion stars and several million galaxies. (M 41571)

\section{(10173) Hanzelkazikmund}

1995 HA. Discovered 1995 Apr. 21 by P. Pravec and L. Šarounová at Ondřejov.

Czech globetrotters Jiří Hanzelka (1920- ) and Miroslav Zikmund (1919- ) visited 83 countries on five continents by car during 1947-1950 and truck during 1959-1964. A museum containing items collected and a rich archive of about 150000 photographs has recently opened in Zlin. (M 36129)

The name was suggested by J. Grygar.

\section{(10174) Emička}

1995 JD. Discovered 1995 May 2 by Z. Moravec at Klět.

Ema Moravcová (1999- ） is the discoverer's daughter. (M 42360)

\section{(10176) Gaiavettori}

$1996 \mathrm{CW}_{7}$. Discovered 1996 Feb. 14 by M. Tombelli and U. Munari at Cima Ekar.

Gaia Vettori (1999- ) is the daughter of Vincenzo Vettori, an amateur astronomer in the Montelupo Group. (M 40704)

\section{(10177) Ellison}

$1996 \mathrm{CK}_{9}$. Discovered 1996 Feb. 10 by the Spacewatch at Kitt Peak.

Harlan Ellison (1934- ) is science-fiction author whose works include I Have No Mouth and I Must 
Scream and Shatterday. He has served as consultant on several television series, particularly Babylon 5 . His original screenplay for the Star Trek episode The City on the Edge of Forever won one of his 11 Hugo Awards. (M 42670)

\section{(10181) Davidacomba}

$1996 \mathrm{FP}_{3}$. Discovered 1996 Mar. 26 by P. G. Comba at Prescott.

Named in honor of the discoverer's wife, Davida H. Comba (1928- ). A psychiatrist by profession and a nurturing mother and devoted wife, she constantly supported and encouraged the discoverer's passion for minor planet observations. (M 35494)

\section{(10182) Junkobiwaki}

$1996 \mathrm{FL}_{5}$. Discovered 1996 Mar. 20 by K. Endate and K. Watanabe at Kitami.

Junko Biwaki (1914- ) was a teacher of elementary and junior high-school in Yamaguchi prefecture for 43 years beginning in 1933 . She has been very active in improving education and the status of women. (M 43043)

\section{(10183) Ampère}

$1996 \mathrm{GV}_{20}$. Discovered 1996 Apr. 15 by E. W. Elst at La Silla.

Named in memory of André-Marie Ampère (17751836), French physicist who founded the science of electromagnetism. In 1820 he formulated a law that mathematically describes the phenomenon of deflection of a magnetic needle near a current-carrying wire. A full account of his theories has been given in his Mémoire sur la théorie mathématique des phénomènes électrodynamique (1827). (M 35494)

\section{(10184) Galvani}

$1996 \mathrm{HC}_{19}$. Discovered 1996 Apr. 18 by E. W. Elst at La Silla.

Named in memory of Luigi Galvani (1737-1798), Italian physician and physicist who conceived the electrical nature of nerve impulses. His discoveries led to the invention of the voltaic pile. His findings have been published in De viribus electricitatis in motu musculari commentarius (1791). (M 35494)

\section{(10185) Gaudi}

$1996 \mathrm{HD}_{21}$. Discovered 1996 Apr. 18 by E. W. Elst at La Silla.

The work of Spanish architect Antoni Gaudi (18521926) was strongly influenced by "Art Nouveau" ornamental elements, Neo-Gothic style and the Moors, this last with its mixture of cheap stone and colorful tiles. Gaudi's creations are mainly concentrated in Barcelona, site of the Sagrada Familia cathedral. (M 36948)

\section{(10186) Albéniz}

1996 HD $_{24}$. Discovered 1996 Apr. 20 by E. W. Elst at La Silla.
A child prodigy, the Spanish composer and pianist Isaac Albéniz (1860-1909) studied at the conservatories of Leipzig and Brussels. In Paris he was influenced by Vincent d'Indy and Paul Dukas. His fame rests chiefly on his piano music, notably the suite Iberia, which was colored by the spirit of Spanish folk music. (M 36948)

\section{(10188) Yasuoyoneda}

1996 JY. Discovered 1996 May 14 by R. H. McNaught and Y. Ikari at Moriyama.

Yasuo Yoneda (1942- ), the first director of "Tenkyukan", the Dynic Astronomical Observatory, is an amateur astronomer who observes sunspots. He contributes to the spread of astronomy and to the support of amateur astronomers. He also likes mountain climbing. (M 40704)

\section{(10189) Normanrockwell}

$1996 \mathrm{JK}_{16}$. Discovered 1996 May 15 by the Spacewatch at Kitt Peak.

Norman Rockwell (1894-1978) spent his career creating images showing American life as he saw it. His distinctive style conveyed emotions in a way rarely achieved in modern art. His work appeared in magazines such as Life, but he earned his reputation through the exposure of 322 covers on The Saturday Evening Post. (M 42670)

\section{(10193) Nishimoto}

$1996 \mathrm{PR}_{1}$. Discovered 1996 Aug. 8 by the JPL NEAT Program at Haleakala.

Physicist Daron L. Nishimoto (1966- ) has worked at AMOS \{see planet (8721)\} since 1988. The goodnatured support of his family has allowed him to spend long hours in support of AMOS programs. In particular, he is the driving force behind the highly successful Raven autonomous telescope program. (M 41571)

\section{(10195) Nebraska}

1996 RS $_{5}$. Discovered 1996 Sept. 13 by R. Linderholm at Lime Creek.

Named for the U.S. state of Nebraska, this is the first minor planet to be discovered from an observatory there. (M 34632)

\section{(10197) Senigalliesi}

1996 UO. Discovered 1996 Oct. 18 by V. Goretti at Pianoro.

Named in memory of the Italian amateur astronomer Paolo Senigalliesi (1936-1986). He was an ardent observer who devoted most of his time and energy to the observation of planets. In 1968, he was a founding member of the Italian Group of Observers of Planets, and he participated in the activities of the Jupiter Division Team with indefatigable professionalism. He played an important role in the dissemination of astronomical information and was one of the founders of the Amateur Astronomers Association of Marches. He also played an important role in the construction of the Pietralacroce Observatory at Ancona. (M 35494) 


\section{(10198) Pinelli}

$1996 \mathrm{XN}_{26}$. Discovered 1996 Dec. 6 by M. Tombelli and U. Munari at Cima Ekar.

Paolo Pinelli (1954- ) is an amateur astronomer of the Montelupo \{see planet (7198)\} group. He was the first to propose the construction of a public observatory in the city of Montelupo. (M 41030)

\section{(10199) Chariklo}

$1997 \mathrm{CU}_{26}$. Discovered 1997 Feb. 15 by the Spacewatch at Kitt Peak.

Chariklo, sometimes described as a sea nymph, sometimes as a female centaur, was the wife of Chiron \{see planet (2060)\}. Together they are are said to have had as many as five children, and she is also sometimes said to have been the mother of Tiresias, the famous seer. (M 36129)

\section{(10200) Quadri}

$1997 \mathrm{NZ}_{2}$. Discovered 1997 July 7 by V. Goretti at Pianoro.

Named in honor of Ulisse Quadri (1953- ) Italian teacher and amateur astronomer, author of articles and texts on science and mathematics for children. His interests in astronomy include astrometry and photometry of minor bodies, sundials and software development. He is one of the founders of the Bassano Bresciano \{see planet (6460)\} Observatory and planned and built the mechanical part of the automatic robotic telescope there. (M 35494)

\section{(10201) Korado}

$1997 \mathrm{NL}_{6}$. Discovered 1997 July 12 at the Farra d'Isonzo Observatory at Farra d'Isonzo.

Korado Korlević (1958- ) leads the team of amateur astronomers at the Višnjan Observatory in Croatia and has been enthusiastically involved with observations of minor planets, comets and meteors. This program was recently credited with the discovery of comet $\mathrm{P} / 1999 \mathrm{DN}_{3}$. He also teaches astronomical classes each summer. (M 36129)

\section{(10203) Flinders}

1997 PQ. Discovered 1997 Aug. 1 by F. B. Zoltowski at Woomera.

Named in memory of Matthew Flinders (17741814), British navigator and explorer who charted the Australian coastline. A self-educated navigator, he explored the Bass Strait between Australia and Tasmania and circumnavigated Australia, charting large sections of its coast. His use of the term Australia led to its acceptance as the name of the continent. (M 34632)

\section{(10204) Turing}

$1997 \mathrm{PK}_{1}$. Discovered 1997 Aug. 1 by P. G. Comba at Prescott.

Named in memory of Alan Mathison Turing (19121954), English mathematician and logician, a pioneer in the study of computability. In a fundamental paper published in 1936, he introduced the concept of an abstract computing machine and showed how such a machine can be programed to simulate the behavior of any other computing device. This concept, now referred to as a "universal Turing machine", was introduced years before the advent of programable computers, and it was used to demonstrate the existence of noncomputable numbers and undecidable mathematical propositions. (M 34633)

\section{(10205) Pokorný}

$1997 \mathrm{PX}_{1}$. Discovered 1997 Aug. 7 by M. Tichý and Z. Moravec at Klet.

Named in honor of Zdeněk Pokorný (1947- ), Czech astronomer who works at the Nicolas Copernicus Observatory and Planetarium, as well as at Masaryk University in Brno \{see planets (1841) and (2889), respectively\}. He started his career by studying the giant planets, but his main work consists of education and the popularization of astronomy. He created many programs for the Brno Planetarium and is the author of the first Czech astronomical multimedia CD-ROM "ASTRO 2001". In 1991 Pokorný founded and served as the first president of the Association of Observatories and Planetaria in Czechoslovakia. (M 34633)

Name endorsed and citation prepared by J. Tichá.

\section{(10207) Comeniana}

1997 QA. Discovered 1997 Aug. 16 by L. Kornoš and P. Kolény at Modra.

Bratislava's Comenius University (Universitas Comeniana in Latin), the leading institution of higher learning in the Slovak Republic, was founded in 1919, and the Institute of Astronomy, one of the university's first institutes, was established in 1943. The observatory in Modra also belongs to the university. (M 36129)

\section{(10209) Izanaki}

1997 QY $_{1}$. Discovered 1997 Aug. 24 by Y. Shimizu and T. Urata at Nachi-Katsuura.

According to the Japanese myth, Izanaki-no-mikoto is the god who descended to the island Onogoro with the goddess Izanami \{see planet (10227)\} and created the land there, including the island of Awaji \{see planet (3380)\}. (M 39654)

\section{(10210) Nathues}

$1997 \mathrm{QV}_{3}$. Discovered 1997 Aug. 30 by the OCA-DLR Survey at Caussols.

German geophysicist Andreas Nathues (1967- ) studied the physical properties of the Eunomia \{see planet (15) \} family of minor planets using innovative observing and data-analysis techniques at the German Aerospace Center (DLR), Berlin. (M 41385)

\section{(10211) La Spezia}

$1997 \mathrm{RG}_{3}$. Discovered 1997 Sept. 6 at the Monte Viseggi Observatory at Monte Viseggi. 
La Spezia is a town near the Monte Viseggi Observatory. It is famous for its "Poets' Gulf", in honor of the nineteenth-century English poets Byron \{see planet (3306) $\}$ and Shelley, who lived, loved and died in Italy, the country of their adoption. (M 36948)

\section{(10213) Koukolík}

$1997 \mathrm{RK}_{7}$. Discovered 1997 Sept. 10 by M. Tichý and Z. Moravec at Klě́.

Named in honor of František Koukolík (1941- ), Czech neuropathologist who works on the relationship between the brain and human behavior. He is also known as an excellent popularizer of science, being the author of many articles and several books of essays, such as An Ant and the Universe. (M 34633)

Name endorsed by J. Tichá.

\section{(10215) Lavilledemirmont}

1997 SQ. Discovered 1997 Sept. 20 by L. Šarounová at Ondřejov.

The work of French poet Jean de La Ville de Mirmont (1864-1914) evoked images of unreachable horizons and bitterness. His poetic opera L'Horizon Chimérique ("Fanciful Horizon") inspired the music of Gabriel Fauré. (M 42360)

The name was suggested by R. and A. Soubie.

\section{(10216) Popastro}

$1997 \mathrm{SN}_{3}$. Discovered 1997 Sept. 22 by S. P. Laurie at Church Stretton.

The U.K. Society for Popular Astronomy (SPA) celebrates its fiftieth anniversary in 2003. It was established as the Junior Astronomical Society to promote astronomy as a hobby, particularly among beginners. The SPA is one of three national societies for astronomy in the U.K. (M 45232)

\section{(10217) Richardcook}

$1997 \mathrm{SN}_{4}$. Discovered 1997 Sept. 27 by the JPL NEAT Program at Haleakala.

Richard Cook (1965- ) was the Mars Pathfinder Flight Operations Manager and was responsible for running the day-to-day operations of the Mars Pathfinder spacecraft during launch, the landing phase and surface operations on Mars. (M 45747)

\section{(10218) Bierstadt}

1997 SJ $_{23}$. Discovered 1997 Sept. 29 by the Spacewatch at Kitt Peak.

Albert Bierstadt (1830-1902), a landscape artist from the Hudson River School, was best known for his panoramic scenes of the American West, including the Rocky Mountains, Yosemite and the Grand Canyon. His work inspired those who followed him westward while forever preserving the power and beauty of the vanishing frontier. (M 42670)

\section{(10219) Penco}

1997 UJ J $_{5}$. Discovered 1997 Oct. 25 by L. Tesi and A. Boattini at San Marcello Pistoiese.

Named in honor of Italian physicist Umberto Penco. After teaching high school for several years, he became a researcher in the department of physics at the University of Pisa. He has worked in astrophysics, most recently on mathematical models of chemical evolution of galaxies, and he maintains an interest in science education at secondary-school level, training teachers in astronomy and physics. Penco has assisted the San Marcello \{see planet (7481)\} Observatory as a scientific consultant since it was first established, and he has given advice especially on the selection and improvement of the optical instrumentation. (M 35494)

\section{(10220) Pigott}

$1997 \mathrm{UG}_{7}$. Discovered 1997 Oct. 20 by R. A. Tucker at Tucson.

Named in memory of the English amateur astronomer Edward Pigott (1753-1825), discoverer of several comets and the variable stars $\eta$ Aql, R Sct and R CrB. A skilled user of the transit instrument, he determined the proper motions of several stars. Pigott was a friend and observing collaborator of John Goodricke \{see planet (3116)\}. (M 34633)

\section{(10221) Kubrick}

$1997 \mathrm{UM}_{9}$. Discovered 1997 Oct. 28 by P. Pravec at Ondřejov.

Named in memory of Stanley Kubrick (1928-1999), filmmaking genius, whose 1968 rendition of Arthus Clarke's \{see planet (4923)\} novel, 2001: A Space Odyssey, remains the definitive science-fiction movie. At least half of his 12 other feature films, from The Killing (1956) and Paths of Glory (1957), through Peter Sellers' performance in the brilliant Dr. Strangelove (1964), and on to A Clockwork Orange (1971), The Shining (1980) and Full Metal Jacket (1987), explored twentieth-century culture in a manner that was unprecedented in its artistry and its longevity. (M 34633)

\section{(10222) Klotz}

$1997 \mathrm{UV}_{10}$. Discovered 1997 Oct. 29 by C. Buil at Ramonville Saint Agne.

Alain Klotz, an amateur astronomer at the Centres d'Etudes Spatiales du Rayonnement in Toulouse, is a pioneer in amateur CCD spectroscopy at the T60 telescope at the Pic du Midi Observatory. He is currently president of AUDE \{see planet (9117)\}, the French electronic detectors users association. (M 40704)

\section{(10223) Zashikiwarashi}

1997 UD $_{11}$. Discovered 1997 Oct. 31 by T. Urata at Oohira.

Taking the form of a child with bobbed hair, Zashikiwarashi is a traditional spirit of the people 
of the Tohoku district. It haunts the Japanese-style rooms of old families. It is said that a family would be wealthy while the spirit lives and become poor when it leaves. (M 36948)

\section{(10227) Izanami}

$1997 \mathrm{VO}_{6}$. Discovered 1997 Nov. 4 by T. Kagawa and T. Urata at Gekko.

Izanami-no-mikoto is the mythical goddess who descended to the island Onogoro with the god Izanaki \{see planet (10209)\} and various other gods. After her death she was also called Yomotsu-ookami in the land of the dead. (M 39654)

\section{(10233) Le Creusot}

1997 XQ $_{2}$. Discovered 1997 Dec. 5 by J.-C. Merlin at Le Creusot.

Named for the home city and observatory site of the discoverer. It is in the Burgundy region of France, some $75 \mathrm{~km}$ southwest of Dijon \{see planet (9379)\}. (M 34633)

\section{(10234) Sixtygarden}

1997 YB $_{8}$. Discovered 1997 Dec. 27 by J. Tichá and M. Tichý at Kleť.

60 Garden Street is the street address of the HarvardSmithsonian Center for Astrophysics. Observers of minor planets and comets know it as the seat of the Minor Planet Center \{see planet (4999)\} and the Central Bureau for Astronomical Telegrams, which communicate fast-breaking news of astronomical discoveries to the international community. (M 36948)

\section{(10237) Adzic}

1998 SJ $_{119}$. Discovered 1998 Sept. 26 by the LINEAR at Socorro.

Vladislav Adzic (1984- ) is a finalist in the 2002 Intel International Science and Engineering Fair for his computer science project. He attends the Ward Melville High School, East Setauket, New York, U.S.A. (M 46101)

\section{(10239) Hermann}

1998 TY $_{30}$. Discovered 1998 Oct. 10 by the LONEOS at Anderson Mesa.

Shawn M. Hermann (1975- ), now at Raytheon Corporation, Tucson, was one of the first observers for LONEOS. During 1998-1999 he discovered two Apollos, an Amor and a comet. (M 41030)

\section{(10247) Amphiaraos}

6629 P-L. Discovered 1960 Sept. 24 by C. J. van Houten and I. van Houten-Groeneveld at Palomar.

The Greek seer Amphiaraos took part in the campaign of the Argonauts and the "Seven against Thebes". (M 38199)

\section{(10259) Osipovyurij}

1972 HL. Discovered 1972 Apr. 18 by T. M. Smirnova at Nauchnyj.

Yurij Sergeevich Osipov (1936- ) is an outstanding Russian mathematician and mechanician, known worldwide as an expert in the theory of control, as well as in the theory of differential equations and its applications. Since 1991 he has been president of the Russian Academy of Sciences. (M 42670)

\section{(10262) Samoilov}

1975 TQ $_{3}$. Discovered 1975 Oct. 3 by L. I. Chernykh at Nauchnyj.

Evgenij Valerianovich Samoilov (1912- ) is a wellknown Russian dramatic actor and People's Artist of the former U.S.S.R. He performs at the State Academic Maly Theatre in Moscow. (M 45232)

\section{(10263) Vadimsimona}

$1976 \mathrm{SE}_{5}$. Discovered 1976 Sept. 24 by N. S. Chernykh at Nauchnyj.

Russian physicist Vadim Aleksandrovich Simonenko is deputy director of the Russian Scientific Research Institute of Technical Physics at Snezhinsk. He is known for his work on the hazards of near-earth objects and the protection of the earth. (M 43381)

\section{(10264) Marov}

$1978 \mathrm{PH}_{3}$. Discovered 1978 Aug. 8 by N. S. Chernykh at Nauchnyj.

Mikhail Yakovlevich Marov (1933- ), professor and head of the planetary department at Keldysh Institute of Applied Mathematics, is one of the initiators and scientific leaders of research of Venus and Mars from space. He is also currently the president of IAU Division III. (M 46010)

\section{(10265) Gunnarsson}

$1978 \mathrm{RY}_{6}$. Discovered 1978 Sept. 2 by C.-I. Lagerkvist at La Silla.

Marcus Gunnarsson (1971- ） is a planetary scientist at Uppsala Astronomical Observatory who specializes in studying the activity of distant comets (M 46101; M 46173)

This planet was named first (10265) Undset (M 46010)

\section{(10269) Tusi}

$1979 \mathrm{SU}_{11}$. Discovered 1979 Sept. 24 by N. S. Chernykh at Nauchnyj.

Nasir ad-Din at-Tusi Abu Djafar Mukhammed ibn Mukhammed (1201-1274) was an outstanding Azerbaijanian astronomer, mathematician and philosopher. He founded the Maraga Observatory, then the largest in the world. (M 42360)

\section{(10283) Cromer}

$1981 \mathrm{JE}_{2}$. Discovered 1981 May 5 by C. S. Shoemaker at Palomar.

Dedicated teachers Michael (1941- ) and Sarah (1945- ） Cromer, of Flagstaff, Arizona, set a standard 
in education for hundreds of young students. Their active concern for the learning process and involvement in the welfare of successive generations, in and out of the classroom, is an example for all. (M 41030)

\section{(10286) Shnollia}

$1982 \mathrm{SM}_{6}$. Discovered 1982 Sept. 16 by L. I. Chernykh at Nauchnyj.

Simon Elievich Shnoll (1930- ） is a biophysicist and biochemist at Moscow University and at the Institute of Biophysics of the Russian Academy of Sciences. He is the author of books about the fates of outstanding Soviet biologists. (M 43381)

\section{(10287) Smale}

1982 UK $_{7}$. Discovered 1982 Oct. 21 by L. G. Karachkina at Nauchnyj.

American mathematician Stephen Smale (1930- ) is a member of National Academy of Sciences. He concentrates on the junction of algebraic topology and theory of differential equations and on problems of complexity of algorithms. (M 39654; M 40877) The name was suggested by V. J. Yudovich.

\section{(10288) Saville}

1983 WN. Discovered 1983 Nov. 28 by E. Bowell at Anderson Mesa.

Curt Saville (1946-2001) was an avid ocean and arctic explorer. He rowed across both the Atlantic and Pacific oceans. Saville also worked to encourage scientific exploration of the Earth and space. (M 43043)

The name was suggested by P. C. Thomas.

\section{(10289) Geoffperry}

1984 QS. Discovered 1984 Aug. 24 at the Oak Ridge Observatory at Harvard.

Geoffrey E. Perry (1927-2000), cheerfully eccentric physics teacher at Kettering Grammar School, England, taught his students to monitor radio signals from Soviet satellites. His group of students discovered the Plesetsk launch site and became the most reliable public source of space information during the Cold War. (M 39654)

\section{(10290) Kettering}

1985 SR. Discovered 1985 Sept. 17 at the Oak Ridge Observatory at Harvard.

The Kettering Group of amateur space sleuths, founded in the $1960 \mathrm{~s}$ by G. E. Perry ssee planet (10289)\}, monitored and analyzed radio transmissions from Soviet satellites, often scooping official news media. Perry's young students were eventually supplemented by a world-wide array of amateurs who continue the Group's work. (M 39654)

\section{(10293) Pribina}

$1986 \mathrm{TU}_{6}$. Discovered 1986 Oct. 5 by M. Antal at Piwnice.

Pribina (800?-861) was seated in Nitra ssee planet (9543)\}, where he built the first church in Slovakia and founded the Nitra principality, first state of ancient
Slovaks. In 833 he was forced to flee from Nitra but later acquired a large territory near Lake Balaton \{see planet (2242)\}, where he ruled as a duke, became Christian and built a dozen new churches. (M 43190)

\section{(10295) Hippolyta}

1988 GB. Discovered 1988 Apr. 12 by C. S. Shoemaker and E. M. Shoemaker at Palomar.

Hippolyta was one of the greatest queens of the Amazons \{see planet (1042)\}. She wore a beautiful golden girdle, a gift from her father Ares, the war-god, as a symbol of her Amazonian queenship. Heracles \{see planet (5143)\} was sent by the Greeks to acquire the girdle, a battle took place, and beautiful Hippolyta died. (M 41030)

\section{(10301) Kataoka}

1989 FH. Discovered 1989 Mar. 30 by K. Endate and K. Watanabe at Kitami.

Yoshiko Kataoka (1927- ) , an amateur astronomer in Takarazuka, Hyogo prefecture, is a director of the Oriental Astronomical Association. She was a pioneer in the study of meteoric dust. In 1993 she provided a fund to establish and keep the Vega Prize for distinguished women amateur astronomers. (M 42670)

\section{(10303) Fréret}

$1989 \mathrm{RD}_{2}$. Discovered 1989 Sept. 2 by E. W. Elst at St. Michel.

The famous French historian Nicolas Fréret (16881749), well known for his atheistic treatise Lettre de Thrasybule à Leucippe (1720), was imprisoned in the Bastille for alleging - correctly - that the Franks were evolved from German tribes. (M 36948)

\section{(10304) Iwaki}

1989 SY. Discovered 1989 Sept. 30 by K. Endate and K. Watanabe at Kitami.

Masae Iwaki (1933- ), an amateur astronomer in Oita, is the winner of the Vega Prize for distinguished women amateur astronomers. She has been very active in the popularization of astronomy through frequent star parties and lectures, as well as through writings in newspapers. (M 42670)

\section{(10305) Grignard}

$1989 \mathrm{YP}_{5}$. Discovered 1989 Dec. 29 by E. W. Elst at St. Michel.

Fernand (Ferre) Grignard (1939-1982), a member of an ancient family, became famous during the $1960 \mathrm{~s}$ in Western Europe for his folk songs and blues. Another well-known family member is Victor Grignard (1871-1935), who received the 1912 Nobel prize for chemistry. (M 39654)

\section{(10306) Pagnol}

1990 QY. Discovered 1990 Aug. 21 by E. W. Elst at St. Michel.

Marcel Pagnol (1895-1974) was a French writer who will be always remembered for his novels Jean de 
Florette and Manon des Sources. One of his comedies, Topaze, dealing with the corruptive power of money, brought him extraordinary success at the theater. (M 39654)

\section{(10310) Delacroix}

1990 QZ . Discovered 1990 Aug. 16 by E. W. Elst at La Silla.

Best known for his painting "Liberty leading the people", Eugène Delacroix (1798-1863) was inspired by contemporary events. His "Dante and Virgil in Hell" is one of the landmarks of French nineteenth-century romantic painting. Delacroix's choice of colors later influenced the impressionist painters. (M 36948)

\section{(10311) Fantin-Latour}

1990 QL9. Discovered 1990 Aug. 16 by E. W. Elst at La Silla.

Henri Fantin-Latour (1836-1904) was known for his still-life paintings with flowers and later for his lithographs. Famous also for his portrait groups, which he arranged in rows of heads, he immortalized many contemporary French celebrities. (M 36948)

\section{(10315) Brewster}

$1990 \mathrm{SC}_{4}$. Discovered 1990 Sept. 23 by E. F. Helin at Palomar.

Stephen C. Brewster (1945- ）, a former member of the Palomar Planet Crossing Asteroid Survey, has had a long fascination with astronomy. He is a member of the Outer Planets project at the Jet Propulsion Laboratory and a member of the board of trustees of Stony Ridge Observatory. He discovered comet 105P. (M 41030)

\section{(10316) Williamturner}

$1990 \mathrm{SF}_{9}$. Discovered 1990 Sept. 22 by E. W. Elst at La Silla.

The "Father of English Botany", William Turner (1508-1568), is best known for his book A New Herball. (M 36948)

\section{(10319) Toshiharu}

1990 TB$_{1}$. Discovered 1990 Oct. 11 by A. Takahashi and K. Watanabe at Kitami.

Toshiharu Hatanaka (1962- ) , a research associate in the department of information and knowledge engineering at Tottori University, is president of the Tottori Society of Astronomy. (M 45747)

\section{(10322) Mayuminarita}

$1990 \mathrm{VT}_{1}$. Discovered 1990 Nov. 11 by K. Endate and K. Watanabe at Kitami.

Mayumi Narita (1970- ) is a Japanese swimmer who is a paraplegic. At the Paralympic Games in Sydney in 2000, she won six gold medals and one silver medal. She also won two gold, two silver and one bronze in Atlanta in 1996. (M 43043)

\section{(10323) Frazer}

1990 VW $_{6}$. Discovered 1990 Nov. 14 by E. W. Elst at La Silla.

James George Frazer (1854-1941) is best remembered for The Golden Bough, a study in comparative religion (in 12 volumes). The work sets forth a mass of evidence for establishing the thesis that human beings must have begun with magic and progressed to religion and from that to science. (M 39654)

\section{(10324) Vladimirov}

1990 VB $_{14}$. Discovered 1990 Nov. 14 by L. G. Karachkina at Nauchnyj.

Vladimir Alekseevich Vladimirov (1951- ) is a prominent authority on stability theory in hydrodynamics and biophysical hydrodynamics. He is a professor of science in Hong Kong. (M 39654; M 40877)

The name was suggested by V. J. Yudovich.

\section{(10325) Bexa}

$1990 \mathrm{WB}_{2}$. Discovered 1990 Nov. 18 by E. W. Elst at La Silla.

The iceberg B10A, which measures some $80 \mathrm{~km}$ by $40 \mathrm{~km}$, broke off from the Thwaites glacier in Antarctica in 1992. Having taken hundreds of thousands of years to form, B10A now drifts in the South Atlantic driven by marine currents and wind. (M 36949)

\section{(10326) Kuragano}

$1990 \mathrm{WS}_{2}$. Discovered 1990 Nov. 21 by K. Endate and K. Watanabe at Kitami.

Sukehikro Kuragano (1933- ) is a member of Kawasaki Astronomical Association and has been an amateur observer of variable stars for about half a century. He independently discovered Comet C/1957 P1 (Mrkos) while he was climbing Mt. Fuji. (M 43043)

\section{(10327) Batens}

1990 WQ $_{6}$. Discovered 1990 Nov. 21 by E. W. Elst at La Silla.

Diderik Batens (1944- ) is a member of the philosophy department at the University of Ghent \{see planet (9473)\}. About 20 years ago he founded a new kind of logic ("adaptive logic") that has led to many publications. (M 39654)

\section{(10330) Durkheim}

$1991 \mathrm{GH}_{3}$. Discovered 1991 Apr. 8 by E. W. Elst at La Silla.

Émile Durkheim (1858-1917) was convinced that ethical and social structures were endangered by the advent of technology and mechanization. In 1895 he proposed an educational reform, Les Règles de la méthode sociologique, that could avoid the perils of social disconnectedness. (M 39654)

\section{(10331) Peterbluhm}

1991 GM $_{10}$. Discovered 1991 Apr. 9 by F. Börngen at Tautenburg.

Computer specialist Peter Bluhm (1942-1997) was known for his efforts in electronic communication 
among amateur astronomers in Germany since the early 1980s. In 1987 he founded the first Astronomical Bulletin Board System in Dahlenburg. (M 36129)

The name was suggested by A. Doppler.

\section{(10332) Défi}

$1991 \mathrm{JT}_{1}$. Discovered 1991 May 13 by C. S. Shoemaker and D. H. Levy at Palomar.

Défi Corporatif Canderel is a fundraising event for cancer research programs at universities in Montreal. Founded by Jonathan Wener, the event has been directed by Gerald Levy since its inception in 1990 . It features a costumed run through the streets of Montreal and has raised more than three million dollars. (M 36949)

\section{(10340) Jostjahn}

$1991 \mathrm{RT}_{40}$. Discovered 1991 Sept. 10 by F. Börngen at Tautenburg.

Jost Jahn (1959- ), a dental surgeon, has been editor of the German Astro-Fax-Circulars for amateurs and on the board of the Vereinigung der Sternfreunde since 1992. During 1995-1997, he was head of the minor planets section of this association. (M 39654)

\section{(10343) Church}

1991 VW $_{8}$. Discovered 1991 Nov. 4 by the Spacewatch at Kitt Peak.

Frederic Edward Church (1826-1900) was one of several American artists of the Hudson River School who strove to paint the wonders of nature in meticulous and dynamically detailed landscapes. He was perhaps the most famous American painter of his time. (M 42671)

\section{(10346) Triathlon}

1992 GA $_{1}$. Discovered 1992 Apr. 2 by C. S. Shoemaker and D. H. Levy at Palomar.

Since Pam Truty founded the Burn Lake Triathlon in Las Cruces, New Mexico, in 1984, the relay team of Wendee Wallach-Levy \{see planet (6485)\}, Laura Wright and Barbara Pardo has won medals every year, including 14 golds. Laura has also done more than 30 years volunteer work for the American Red Cross. (M 36949)

\section{(10348) Poelchau}

1992 HL $_{4}$. Discovered 1992 Apr. 29 by F. Börngen at Tautenburg.

As a chaplain at the penitentiaries of Tegel, Plötzensee and Brandenburg-Görden in Berlin during 1933-1945, protestant theologian Harald Poelchau (1903-1972) comforted more than a thousand people condemned to death by the nazi regime. (M 36949)

\section{(10351) Seiichisato}

$1992 \mathrm{SE}_{1}$. Discovered 1992 Sept. 23 by K. Endate and K. Watanabe at Kitami.

Seiichi Sato (1930- ) is a member of Kawasaki Astronomical Association. As a medical doctor he greatly contributed to the field of industrial diseases, and as an amateur astronomer he has been abroad 13 times to observe total solar eclipses. (M 43043)

\section{(10352) Kawamura}

$1992 \mathrm{UO}_{3}$. Discovered 1992 Oct. 26 by K. Endate and K. Watanabe at Kitami.

Mikio Kawamura (1931- _ ) is a member of Kawasaki Astronomical Association. He is a mechanical engineer by profession and has published five books on telescopemaking. He has frequently organized star parties for general public. (M 43043)

\section{(10354) Guillaumebudé}

$1993 \mathrm{BU}_{5}$. Discovered 1993 Jan. 27 by E. W. Elst at Caussols.

Guillaume Budé (1468-1540) was one of the first philologists in France to teach himself classical Greek, making him an expert on the language of Homer. Founder of the Collège de France (1530), he is well known for his Commentaires sur la langue grecque (1529). (M 39654)

\section{(10355) Kojiroharada}

1993 EQ. Discovered 1993 Mar. 15 by K. Endate and K. Watanabe at Kitami.

Kojiro Harada (1926- ), mechanical engineer, is a member of Kawasaki Astronomical Association. A long-time observer of double stars, he has also written many fairy tales on stars, dramatizing and performing in them himself. (M 43043)

\section{(10356) Rudolfsteiner}

1993 RQ $_{4}$. Discovered 1993 Sept. 15 by E. W. Elst at La Silla.

Rudolf Steiner (1861-1925) was the editor of the scientific works of Wolfgang Goethe \{see planet (3047)\}, and this inspired him to write his well-known work Die Philosophie der Freiheit (1894). In 1912 he founded the Anthroposophical Society upon the belief that there is a spiritual perception independent of the senses. (M 39654)

\section{(10358) Kirchhoff}

$1993 \mathrm{TH}_{32}$. Discovered 1993 Oct. 9 by E. W. Elst at La Silla.

Gustav Robert Kirchhoff (1824-1887) was a German physicist who, together with Robert Bunsen \{see planet (10361)\}, founded the discipline of spectrum analysis. They demonstrated that an element gives off a characteristic colored light when heated to incandescence. (M 39654)

\section{(10361) Bunsen}

1994 PR $_{20}$. Discovered 1994 Aug. 12 by E. W. Elst at La Silla.

Robert Wilhelm Bunsen (1811-1899) was a German chemist who discovered the alkali-group metals cesium and rubidium. He also found an antidote to arsenic poisoning (1834) and invented the carbon-zinc electric cell (1841). He is best remembered by every chemistry 
student for the development of the Bunsen burner. (M 39655)

\section{(10366) Shozosato}

$1994 \mathrm{WD}_{4}$. Discovered 1994 Nov. 24 by K. Endate and K. Watanabe at Kitami.

Shozo Sato (1943- ) is a maker and repairman of art clocks. He is an experienced lunar photographer and has coauthored a book on the moon. As president of Astro-Club, Fukuyama, Hiroshima prefecture, he has frequently organized star parties for general public. (M 43043)

\section{(10370) Hylonome}

$1995 \mathrm{DW}_{2}$. Discovered 1995 Feb. 27 by D. C. Jewitt and J. X. Luu at Mauna Kea.

Fairest of all the female centaurs, the beautiful and civilized Hylonome was in love with the handsome Cyllaros, who was accidentally killed by a javelin, thrown at a wedding. On witnessing this, Hylonome threw herself on the javelin and died. (M 41030)

\section{(10371) Gigli}

1995 DU $_{3}$. Discovered 1995 Feb. 27 by L. Tesi and A. Boattini at San Marcello Pistoiese.

Named in honor of Paolo Gigli, who, with the first discoverer, founded the Pian dei Termini Observatory. Early on, Gigli's main interests concerned the study of variable stars and the observation of the sun. Later he became a speaker on astronomy at Pian dei Termini Observatory, where public lectures are held three times a week. (M 35494)

\section{(10372) Moran}

1995 FO $_{10}$. Discovered 1995 Mar. 26 by the Spacewatch at Kitt Peak.

Landscape artist Thomas Moran (1837-1926) focused his work on the American frontier, from the shores of Lake Superior to the "Grand Canyon of the Yellowstone". His illustrations of the west appeared in Harper's Weekly and The Aldine, among others. He participated in John Wesley Powell's 1873 expedition to the Grand Canyon. (M 42670)

\section{(10375) Michiokuga}

$1996 \mathrm{HM}_{1}$. Discovered 1996 Apr. 21 by A. Nakamura at Kuma.

Named in memory of Michio Kuga (1927-1999), high school teacher and from 1971 to 1982 curator at the Yamaguchi Museum. A specialist on star scintillation, he also supervised a number of lectures and exhibitions concerning astronomy at the museum. His efforts made a significant contribution to the popularization of astronomy in Yamaguchi Prefecture. (M 35494)

\section{(10376) Chiarini}

1996 KW. Discovered 1996 May 16 at the Osservatorio San Vittore at Bologna.

Francesca (1981- ) and Gabriele (1986- ） Chiarini are grandchildren of Giorgio Sassi \{see planet (7500)\}, co-founder of Osservatorio San Vittore. Gabriele often transmits his grandfather's CCD images for reduction in Bologna, thereby saving time and a $100-\mathrm{km}$ round-trip journey. (M 38199)

\section{(10378) Ingmarbergman}

$1996 \mathrm{NE}_{5}$. Discovered 1996 July 14 by E. W. Elst at La Silla.

Ingmar Bergman (1918- ) has achieved worldwide fame with films such as Det sjunde inseglet (The Seventh Seal, 1956) and Smultronstöallet (Wild Strawberries, 1957). Although his films are morally complex, they can also be hopeful and lovely. (M 39655)

\section{(10379) Lake Placid}

1996 OH. Discovered 1996 July 18 by G. R. Viscome at Lake Placid.

A town in northern New York State in the U.S. that hosted the 1932 and 1980 Olympic Winter Games, Lake Placid is also the birthplace of the discoverer. Located in the Adirondack Mountains, Lake Placid is renowned for its natural beauty. (M 40704)

\section{(10380) Berwald}

$1996 \mathrm{PY}_{7}$. Discovered 1996 Aug. 8 by E. W. Elst at La Silla.

Franz Berwald (1796-1868) may be considered the founder of musical Romanticism in Sweden. Although his compositions are somewhat influenced by the German composers Spohr and von Weber ssee planet (4152)\}, they are highly original in construction and in the use of harmonic means. (M 39655)

\section{(10381) Malinsmith}

1996 RB. Discovered 1996 Sept. 3 by B. G. W. Manning at Stakenbridge.

Konrad Malin-Smith (1934- ), a retired science teacher, has given entertaining talks to local astronomical societies in southeastern England over the last 20 years. He and his daughter Beverley have entertained and befriended numerous eclipse chasers at recent solar eclipses - and also obtained superb photographic results. (M 44185)

\section{(10382) Hadamard}

$1996 \mathrm{RJ}_{3}$. Discovered 1996 Sept. 15 by P. G. Comba at Prescott.

Named in honor of the eminent French mathematician Jaques-Salomon Hadamard (1865-1963). Hadamard made major contributions to the theory of functions of a complex variable and the study of the partial differential equations of mathematical physics. In 1896 he gave a proof of the prime number theorem that defines the frequency of prime numbers among the integers. (M 35494)

\section{(10385) Amaterasu}

1996 TL $_{12}$. Discovered 1996 Oct. 15 by Y. Shimizu and T. Urata at Nachi-Katsuura.

Amaterasu-oomikami, the mythical Japanese goddess of the sun, was born from the left eye of the god Izanaki \{see planet (10209)\} and ruled the world of 
the heaven Takamagahara ssee planet (10831)\}. To protest the misconduct of her younger brother, the god Susanoo \{see planet (10604)\}, she hid in the cave called Ama-no-iwayado, and the world fell into complete darkness. (M 39655)

\section{(10386) Romulus}

1996 TS $_{15}$. Discovered 1996 Oct. 12 by V. S. Casulli at Colleverde di Guidonia.

Romulus, first king of Rome, reigned from 753 to 716 B.C. Legend has it that the twins Romulus and Remus were saved from the Tiber river by the wolf that raised them. In the first year of this reign Romulus founded the city. He was deified as Quirinus. (M 45337)

\section{(10387) Bepicolombo}

1996 UQ. Discovered 1996 Oct. 18 by P. Sicoli and F. Manca at Sormano.

Giuseppe (Bepi) Colombo (1920-1984), a mathematician at the University of Padova, made fundamental contributions to the theory of resonances, notably with regard to the Kirkwood \{see planet (1578)\} gaps and the rotation of Mercury. He also pioneered the use of planetary encounters for gravity assists in arranging space missions. (M 40704)

\section{(10389) Robmanning}

1997 LD. Discovered 1997 June 1 by the JPL NEAT

Program at Haleakala.

Rob Manning (1958- ） was the Flight System Chief Engineer for the successful Mars Pathfinder mission at JPL. He was responsible for all technical aspects of the Pathfinder spacecraft. He also led the team that designed, developed, tested and operated Pathfinder's very successful entry, descent and landing system. (M 45747)

\section{(10390) Lenka}

1997 QD 1 . Discovered 1997 Aug. 27 by P. Pravec and M. Wolf at Ondřejov.

Named in honor of Lenka Šarounová (1973- ), an assiduous observer at the Ondřejov Observatory. She has a broad range of interests, from astronomy and meteorology to music. She loves gaining new experiences through traveling and meeting people. Her photometric and astrometric observations of minor planets became an integral part of the discoverers' research project on NEOs. (M 35494)

\section{(10392) Brace}

$1997 \mathrm{RP}_{7}$. Discovered 1997 Sept. 11 by R. Linderholm at Lime Creek.

Named in memory of DeWitt Bristol Brace (18581905), who founded the department of physics and astronomy at the University of Nebraska in 1888. His was the first definitive study resulting in the broad dismissal of the "ether" theory. His work was recognized and applauded by Rutherford, among many others. In 1901 Brace was elected vice-president of the
American Association for the Advancement of Science. (M 35495)

\section{(10395) Jirkahorn}

1997 SZ . Discovered 1997 Sept. 23 by M. Wolf and P. Pravec at Ondřejov.

Named in memory of Jiř́ Horn (1941-1994), an astronomer at the Ondřejov Observatory. He worked in stellar astrophysics, observational astronomy and data reduction, making important contributions to all of them. He was a member of the team that in the late 1960s made the first calculations of the evolution of close binaries with mass loss. He played an important role in the commissioning phase of the 2-m telescope at Ondřejov. He created the user-friendly software SPEFO for the reduction of stellar spectra that is still in use by many astronomers. (M 35495)

Name proposed by the discoverers, following a suggestion by P. Koubský, who also prepared the citation.

\section{(10403) Marcelgrün}

1997 WU U$_{3}$. Discovered 1997 Nov. 22 by J. Tichá and M. Tichý at Kleť.

The Czech astronomer Marcel Grün (1946- ) is director of the Prague Planetarium. His main field of interest is education and popularization of astronautics, cosmonautics and space exploration. (M 38199)

\section{(10404) McCall}

$1997 \mathrm{WP}_{14}$. Discovered 1997 Nov. 22 by the Spacewatch at Kitt Peak.

Robert T. McCall (1919?- ) is a legendary space artist whose work has not only documented the development of NASA's efforts to place men on the moon but has provided a far-reaching vision of man's future in Space. His works include murals at the National Air and Space Museum and illustrations for 2001: A Space Odyssey. (M 42671)

\section{(10405) Yoshiaki}

$1997 \mathrm{WT}_{23}$. Discovered 1997 Nov. 19 by T. Okuni at Nanyou.

Yoshiaki Mogami (1546-1614) was a military commander during the Japanese feudal period. He was on the side of the Tokugawas, and in the decisive battle of 1600 he fought against Kanetugu Naoe ssee planet (10583)\}, the lord of Yonesawa (a part of the present Yamagata prefecture), who stood by the Toyotomis. (M 41385)

\section{(10412) Tsukuyomi}

$1997 \mathrm{YO}_{4}$. Discovered 1997 Dec. 21 by Y. Shimizu and T. Urata at Nachi-Katsuura.

According to myth, Tsukuyomi-no-mikoto, the Japanese god of night and the moon, was born from the right eye of the god Izanaki ssee planet (10209)\}. It is said that he made his older sister, the goddess Amaterasu \{see planet (10385)\}, very angry 
and caused the separate appearance of the sun in the day and the moon at night. (M 39655)

\section{(10413) Pansecchi}

1997 YG $_{20}$. Discovered 1997 Dec. 29 at the Osservatorio San Vittore at Bologna.

Luigi Pansecchi (1940- ) has made fine studies of cometary tails. As a member of the Gruppo Astrofili Giovanni e Angelo Bernasconi and of the Italian Astronomical Society, he collaborated with the Osservatorio San Vittore in Bologna and with the Osservatorio Astronomico of Brera in Milan. (M 41385)

\section{(10416) Kottler}

1998 VA $_{32}$. Discovered 1998 Nov. 14 by the LINEAR at Socorro.

MIT Lincoln Laboratory associate director Herbert Kottler (1939- ) headed the Aerospace Division (1984-1996), provided strong leadership of the Laboratory's space surveillance research (including initiating LINEAR) and led the Independent Readiness Review for the first Hubble Service Mission and the Cassini Mission for NASA. (M 46102)

\section{(10424) Gaillard}

$1999 \mathrm{BD}_{5}$. Discovered 1999 Jan. 20 by the OCA-DLR Survey at Caussols.

Boris Gaillard (1976- ) is an amateur astronomer and software engineer. He spent two successive and successful summers at the Caussols Schmidt, implementing a very efficient package inside PRISM for the automatic detection of minor planets, in recent years used by many members of the AUDE s see planet (9117)\} group. (M 40704)

\section{(10425) Landfermann}

$1999 \mathrm{BE}_{6}$. Discovered 1999 Jan. 20 by the OCA-DLR Survey at Caussols.

Dietrich Wilhelm Landfermann (1800-1882) emphasized classical languages as a base for humanism in science and society, notably at the LandfermannGymnasium in Duisburg, which he headed during 1835-1841. (M 41385)

The name was suggested by M. Hoffmann on the 200th anniversary of Landfermann's birth.

\section{(10427) Klinkenberg}

2017 P-L. Discovered 1960 Sept. 24 by C. J. van Houten and I. van Houten-Groeneveld at Palomar.

Dirk Klinkenberg (1709-1799), a Dutch astronomer and mathematician, discovered several comets, of which the great comet of 1744, more usually associated with the name of De Chéseaux, is the best known. He also calculated cometary orbits, notably for $1 \mathrm{P} /$ Halley in 1759. (M 43190)

The name was suggested by W. A. Fröger.

\section{(10428) Wanders}

2073 P-L. Discovered 1960 Sept. 24 by C. J. van Houten and I. van Houten-Groeneveld at Palomar.
Adrianus S. P. J. M. Wanders (1903-1984) was a Dutch astronomer who published important Dutch popular books on astronomy. In the 1930s he studied the sun, particularly sunspots, with M. G. J. Minnaert \{see planet (1670)\}. (M 43044)

The name was suggested by W. A. Fröger.

\section{(10429) van Woerden}

2546 P-L. Discovered 1960 Sept. 24 by C. J. van Houten and I. van Houten-Groeneveld at Palomar.

Hugo van Woerden (1926- ) was professor of astronomy in Groningen with a main interest in neutral hydrogen in galaxies. He has been very active in popularizing astronomy and received a Royal Medal "Ridder in de Orde van de Nederlandse Leeuw" in 1992. (M 43044)

The citation was prepared by U. Schwarz.

\section{(10430) Martschmidt}

4030 P-L. Discovered 1960 Sept. 24 by C. J. van Houten and I. van Houten-Groeneveld at Palomar.

Maarten Schmidt (1929- ) is a famous DutchAmerican astronomer. His identification of the wavelengths of the radiation emitted by quasars led to the theory that they may be among the most distant and the oldest objects ever observed. (M 43044)

The name was suggested by W. A. Fröger and H. Habing.

\section{(10431) Pottasch}

4042 P-L. Discovered 1960 Sept. 24 by C. J. van Houten and I. van Houten-Groeneveld at Palomar.

Stuart S. Pottasch (1932- ) is an American astrophysics professor in Groningen. He is an expert on planetary nebulae, on which subject he wrote a monograph. In addition, he is a specialist on cacti and parrots. (M 43044)

The citation was prepared by U. Schwarz.

\section{(10432) Ullischwarz}

4623 P-L. Discovered 1960 Sept. 24 by C. J. van Houten and I. van Houten-Groeneveld at Palomar.

Ulrich Schwarz (1932- ) is an astronomer in Groningen. He studied in Leiden and Berne. He worked mainly on radio astronomy and interstellar matter, as well as for improvements of the instruments of radio astronomy. (M 43044)

\section{(10433) Ponsen}

4716 P-L. Discovered 1960 Sept. 24 by C. J. van Houten and I. van Houten-Groeneveld at Palomar.

Jaap Ponsen (1931-1961) was a Leiden astronomer who worked on variable stars and made observations at the southern Leiden Station at Hartebeespoortdam \{see planet (1914)\}. He died on his return trip to Leiden. The citation was prepared by U. Schwarz. (M 43190) 


\section{(10434) Tinbergen}

4722 P-L. Discovered 1960 Sept. 24 by C. J. van Houten and I. van Houten-Groeneveld at Palomar.

Jaap Tinbergen (1934- ) is an expert on polarimetry who works mainly on the development of new instruments for radio astronomy. (M 43044)

The citation was prepared by U. Schwarz.

\section{(10435) Tjeerd}

6064 P-L. Discovered 1960 Sept. 24 by C. J. van Houten and I. van Houten-Groeneveld at Palomar.

Tjeerd S. van Albada (1936- ) is a professor of astronomy at Groningen. His main work is on the dynamics of extragalactic systems and the role of so-called dark matter. (M 43044)

The citation was prepared by U. Schwarz.

\section{(10436) Janwillempel}

6073 P-L. Discovered 1960 Sept. 24 by C. J. van Houten and I. van Houten-Groeneveld at Palomar.

Jan-Willem Pel (1943- ) is an astronomer at the University of Groningen. His main interest is photometry. He has also been project leader for a spectrograph on the Very Large Telescope. (M 43044) The citation was prepared by U. Schwarz.

\section{(10437) van der Kruit}

6085 P-L. Discovered 1960 Sept. 24 by C. J. van Houten and I. van Houten-Groeneveld at Palomar.

Piet van der Kruit (1944- ), a professor of astronomy at Groningen, works mainly on the structure of galaxies, using the radio synthesis telescope at Westerbork \{see planet (9498)\}. Among his early successes were the radio-continuum maps of M51. (M 43044)

The citation was prepared by U. Schwarz.

\section{(10438) Ludolph}

6615 P-L. Discovered 1960 Sept. 24 by C. J. van Houten and I. van Houten-Groeneveld at Palomar.

Ludolph van Ceulen (1540-1610) was a German-Dutch mathematician who is famous for his calculation of $\pi$ to 35 places. He did this using polygons of $2^{62}$ sides. His result, 3.14159265358979323846264338327950288, known as the Ludolphine number, is engraved on his tombstone in Leiden. (M 43190)

\section{(10439) van Schooten}

6676 P-L. Discovered 1960 Sept. 24 by C. J. van Houten and I. van Houten-Groeneveld at Palomar.

Frans van Schooten (c. 1615-1660), at the University of Leiden, wrote Exercitationes mathematicae (1657) and Geometria a Renato Des Cartes (1659-1661). A promotor of cartesian geometry, he printed the first Latin version of Descartes' \{see planet (3587)\} La Géométrie in 1649. (M 43190)

The name was suggested by W. A. Fröger.

\section{(10440) van Swinden}

7636 P-L. Discovered 1960 Oct. 17 by C. J. van Houten and I. van Houten-Groeneveld at Palomar.
Dutch physicist Jean H. van Swinden (1746-1823) was known for his contributions in the field of terrestrial magnetism in The Netherlands and for his study of the aurora borealis. He also contributed to the introduction of the metric system in Europe. (M 43190) The name was suggested by W. A. Fröger.

\section{(10441) van Rijckevorsel}

9076 P-L. Discovered 1960 Oct. 17 by C. J. van Houten and I. van Houten-Groeneveld at Palomar.

At his own expense, Elie van Rijckevorsel (18451928) made records at more than 300 places in The Netherlands of the declination, inclination and horizontal intensity of the earth's magnetic field. Carried out during 1889-1892, this was the first overall surveillance of the earth's magnetic field in The Netherlands. (M 43190)

\section{(10442) Biezenzo}

4062 T-1. Discovered 1971 Mar. 26 by C. J. van Houten and I. van Houten-Groeneveld at Palomar.

Dutch physicist Cornelis B. Biezenzo (1888-1975) was known for his work in the field of applied mechanics and especially for the calculations he made to improve methods to test materials that are exposed to great internal and external pressure. (M 43190)

The name was suggested by W. A. Fröger.

\section{(10443) van der Pol}

1045 T-2. Discovered 1973 Sept. 29 by C. J. van Houten and I. van Houten-Groeneveld at Palomar.

Dutch physicist and mathematician Balthasar van der Pol (1889-1959) is known for the second-order differential equation used to solve self-oscillatory problems within electrical waves. His best-known discovery is perhaps that of frequency modulation for radio. (M 43191)

The name was suggested by W. A. Fröger.

\section{(10444) de Hevesy}

3290 T-2. Discovered 1973 Sept. 30 by C. J. van Houten and I. van Houten-Groeneveld at Palomar.

Hungarian-Swedish physicist George de Hevesy (1885-1966) was awarded the Nobel Prize for chemistry in 1943 for his work on the use of isotopes as tracers in the study of chemical processes. Working with Dirk Coster \{see planet (10445)\} in Copenhagen in 1923, he discovered the element hafnium. (M 43044) The name was proposed by W. A. Fröger.

\section{(10445) Coster}

4090 T-2. Discovered 1973 Sept. 29 by C. J. van Houten and I. van Houten-Groeneveld at Palomar.

With de Hevesy, Dutch physicist Dirk Coster (18891950) received the Nobel Prize for chemistry in 1943 , largely for their discovery of the metallic element 72 hafnium, which closely resembles 40 zirconium in that it is resistant to high temperatures. (M 43044) The name was suggested by W. A. Fröger. 


\section{(10446) Siegbahn}

3006 T-3. Discovered 1977 Oct. 16 by C. J. van Houten and I. van Houten-Groeneveld at Palomar.

Swedish physicist Kai M. Siegbahn (1918- ) was awarded the Nobel Prize for physics in 1981 for his contribution to the development of high-resolution electron spectroscopy. (M 43044)

The name was suggested by W. A. Fröger.

\section{(10447) Bloembergen}

3357 T-3. Discovered 1977 Oct. 16 by C. J. van Houten and I. van Houten-Groeneveld at Palomar.

Nicolaas Bloembergen (1920- ), Dutch-American physicist, shared part of the 1981 Nobel Prize for physics with Arthur Schawlow \{see planet (10448)\} for contributions to the development of laser spectroscopy. (M 43044)

The name was suggested by W. A. Fröger.

\section{(10448) Schawlow}

4314 T-3. Discovered 1977 Oct. 16 by C. J. van Houten and I. van Houten-Groeneveld at Palomar.

Arthur L. Schawlow (1921-1999), American physicist, shared part of the 1981 Nobel Prize for physics with Nicolaas Bloembergen \{see planet (10447)\} for contributions to the development of laser spectroscopy. (M 43044)

The name was suggested by W. A. Fröger.

\section{(10456) Anechka}

$1978 \mathrm{PS}_{2}$. Discovered 1978 Aug. 8 by N. S. Chernykh at Nauchnyj.

Daughter of a friend of the discoverer in the town of Cherkassy, Anya (Anechka) Ivanchenko (1987-1999) was a young girl who liked to draw. (M 39655)

\section{(10457) Suminov}

$1978 \mathrm{QE}_{2}$. Discovered 1978 Aug. 31 by N. S. Chernykh at Nauchnyj.

Vyacheslav Mikhailovich Suminov (1932- ) is a professor and head of the faculty at the Moscow Aviation-Technological Institute, founder of the Russian scientific school on laser technology, a member of the Russian Academy of Technological Sciences and a State Prize laureate. (M 46010)

\section{(10478) Alsabti}

1981 WO. Discovered 1981 Nov. 24 by E. Bowell at Anderson Mesa.

Abdul Athem Alsabti (1945- ) introduced astronomy teaching into Iraq in 1970, was project leader in building the National Astronomical Observatory, founded the Iraq Astronomical Society and continues with astronomical projects both for the Arab-speaking world and in the U.K. (M 43762)

The citation was written by D. McNally.

\section{(10481) Esipov}

$1982 \mathrm{QK}_{3}$. Discovered 1982 Aug. 23 by N. S. Chernykh at Nauchnyj.
Valentin Feodorovich Esipov (1933- ) is head of the radioastronomy department at the Sternberg Astronomical Institute, Moscow University. A specialist in astronomical instrument-making and an outstanding observer, he is particularly known for his spectroscopic research on galaxies and unstable stars. (M 46010)

\section{(10482) Dangrieser}

$1983 \mathrm{RG}_{2}$. Discovered 1983 Sept. 14 by E. Bowell at Anderson Mesa.

Daniel Grieser (1926-1999) was an optical engineer with Battelle Memorial Institute in Columbus, Ohio. He was a serious promoter of amateur astronomy in central Ohio and served as a volunteer at Perkins Observatory for many years. (M 43044)

The name was suggested by R. Martino.

\section{(10483) Tomburns}

$1983 \mathrm{RP}_{2}$. Discovered 1983 Sept. 4 by E. Bowell at Anderson Mesa.

Under the leadership of Tom Burns (1952- ） since 1993, the Perkins Observatory began a new life as the premier public astronomy venue in central Ohio. With his weekly newspaper column and visits to area schools Burns has inspired and educated thousands of people. (M 43045)

The name was suggested by R. Martino.

\section{(10487) Danpeterson}

1985 GP $_{1}$. Discovered 1985 Apr. 14 by C. S. Shoemaker and E. M. Shoemaker at Palomar.

Dan Peterson (1949- ) is a juvenile probation director who works with troubled youth to keep them in school and help them find direction in their lives. He served previously as a smoke jumper in Alaska and is a piano player extraordinaire. (M 46010)

\section{(10498) Bobgent}

$1986 \mathrm{RG}_{3}$. Discovered 1986 Sept. 11 by E. Bowell at Anderson Mesa.

Robert Gent (1947- ) is an enthusiastic amateur astronomer and International Dark-Sky Association volunteer. Now retired, he was a U.S. Air Force space systems officer, analyzing data from $61-\mathrm{cm}$ infrared space telescopes in geosynchronous orbits. (M 40704) The name was suggested by D. R. Davis.

\section{(10501) Ardmacha}

1987 OT. Discovered 1987 July 19 by E. F. Helin at Palomar.

The city of Armagh is steeped in history. It is the ecclesiastical capital of Ireland and home of the venerable Armagh Observatory \{see planet (10502)\}. Tradition relates that St. Patrick chose what used to be called Ard Macha as the center of his mission in Ireland, building his main church on one of the seven hills of Armagh in 445. (M 41937) 


\section{(10502) Armaghobs}

$1987 \mathrm{QF}_{6}$. Discovered 1987 Aug. 22 by E. F. Helin at Palomar.

Armagh Observatory, founded in 1790 by Archbishop Richard Robinson, is a modern astronomical research institute with a rich heritage that includes T. R. Robinson's cup-anemometer, Dreyer's NGC Catalogue, Lindsay's Armagh-Dunsink-Harvard telescope and the work of the Estonian astronomer E. J. Öpik \{see planet (2099)\}. (M 41937)

\section{(10506) Rydberg}

1988 CW $_{4}$. Discovered 1998 Feb. 13 by E. W. Elst at La Silla.

Johannes Robert Rydberg (1854-1919) was a Swedish physicist educated at the University of Lund s see planet (809)\} who held the chair of physics from 1901 to 1919 . He is well-known for the Rydberg constant, which appears in a spectroscopic expression that relates the various lines in the spectra of chemical elements. (M 39655)

\section{(10509) Heinrichkayser}

$1989 \mathrm{GD}_{4}$. Discovered 1989 Apr. 3 by E. W. Elst at La Silla.

Heinrich Gustav Johannes Kayser (1853-1940) was a German physicist who demonstrated the presence of helium in the earth's atmosphere. Using the spectra of a large number of elements, he discovered closely grouped spectral lines, the spacing and intensity of which vary in a regular manner. (M 39655)

\section{(10515) Old Joe}

$1989 \mathrm{UB}_{3}$. Discovered 1989 Oct. 31 by B. G. W. Manning at Stakenbridge.

"Old Joe" is the students' name for the Joseph Chamberlain Clock Tower at the University of Birmingham, which received its charter in 1900 and is now celebrating its centenary. Birmingham, England's "second city", prospered from metal-working trades, from which enlightened industrialists founded the university. (M 38199)

\section{(10523) D'Haveloose}

$1990 \mathrm{SM}_{6}$. Discovered 1990 Sept. 22 by E. W. Elst at La Silla.

José D'Haveloose (1922-1996) was a surgeon in the West Flanders town of Tielt. He was magnificient in his efforts to relieve suffering, but his own neck injuries finally made him unable to operate any more. In his later days he developed a great love for astronomy. (M 36949)

\section{(10524) Maniewski}

$1990 \mathrm{SZ}_{7}$. Discovered 1990 Sept. 22 by E. W. Elst at La Silla.

Jan Maniewski (1933- ), a medical doctor in Antwerp, has been immortalized in Elsschot's \{see planet (6309)\} Tjip de Leeuwentemmer, which tells the story how he was kidnapped by his Polish grandmother in order to receive a catholic education. (M 40705)

\section{(10529) Giessenburg}

1990 WQ $_{4}$. Discovered 1990 Nov. 16 by E. W. Elst at La Silla.

The Dutch writer, freemason and editor Rudolf Charles d'Ablaing van Giessenburg (1826-1904) will always be remembered for the first complete edition (1864) of Le Testament de Jean Meslier \{see planet (7062)\}, Curé d'Etrépigny (1727). (M 36949)

\section{(10542) Ruckers}

$1992 \mathrm{CN}_{3}$. Discovered 1992 Feb. 2 by E. W. Elst at La Silla.

Hans Ruckers (1555-1623) was the most famous of all harpsichord makers and founder of a dynasty of Flemish instrument makers. His earliest (1581) known instrument is a virginal with two independent keyboards, now in New York City. These instruments were so prized that they were often rebuilt, enlarged and copied. (M 39655)

\section{(10543) Klee}

$1992 \mathrm{DL}_{4}$. Discovered 1992 Feb. 27 by F. Börngen at Tautenburg.

One of the most self-willed of the expressionists, Swiss painter and graphic artist Paul Klee (1879-1940) was a master at the Bauhäuser \{see also planet (8502)\} in Weimar and Dessau and professor at Düsseldorf until his dismissal by the nazi regime. (M 36949)

\section{(10546) Nakanomakoto}

1992 FS $_{1}$. Discovered 1992 Mar. 28 by K. Endate and K. Watanabe at Kitami.

Makoto Nakano (1956- ) is an associate professor in the Faculty of Education and Welfare Science at Oita University, known for his observational studies of pre-main-sequence objects. He has been an advisor to the Astronomical Society of Oita since 1993. (M 45233)

\section{(10549) Helsingborg}

$1992 \mathrm{RM}_{2}$. Discovered 1992 Sept. 2 by E. W. Elst at La Silla.

Helsingborg is a town in southern Sweden at the narrowest part of the Öresund. It is the most convenient place for motor traffic to cross to and from the European continent by ferry. In honor of Tycho Brahe \{see planet (1677)\}, who had his observatory in the vicinity, an appropriate monument has been erected there. (M 39655)

\section{(10550) Malmö}

$1992 \mathrm{RK}_{7}$. Discovered 1992 Sept. 2 by E. W. Elst at La Silla.

Malmö is Sweden's third largest town. Because of its busy port on the Öresund, it is an industrial and transportation center. Malmöhus, a sixteenth-century castle and fortress, has been transformed into a magnificent museum. (M 39655) 


\section{(10551) Göteborg}

$1992 \mathrm{YL}_{2}$. Discovered 1992 Dec. 18 by E. W. Elst at Caussols.

Founded in 1603, Göteborg, on the southwest coast, is Sweden's chief seaport and second largest city. Many of the early inhabitants were Dutch, and this is marked by its typical Dutch canal system. With the development of the Swedish East India Company in the early eighteenth century the city's prosperity increased. (M 39655)

\section{(10552) Stockholm}

$1993 \mathrm{BH}_{13}$. Discovered 1993 Jan. 22 by E. W. Elst at La Silla.

Stockholm, the largest city in Sweden, is also the capital. Built on numerous islands, it is sometimes known as "the Venice of the North". (M 39655)

\section{(10555) Tagaharue}

1993 HH. Discovered 1993 Apr. 16 by K. Endate and K. Watanabe at Kitami.

Harue Taga (1951- ) is astronomy curator of Chiba Municipal Planetarium. She plays an active part as a leader of the planetarium community. (M 45233)

\section{(10557) Rowland}

$1993 \mathrm{RL}_{5}$. Discovered 1993 Sept. 15 by E. W. Elst at La Silla.

Henry Rowland (1848-1901) was an American physicist who in 1885 developed a machine capable of engraving as many as 20000 lines per inch for the construction of diffraction gratings. His invention of the concave diffraction grating revolutionized spectrum analysis. (M 39655)

\section{(10558) Karlstad}

1993 RB $_{7}$. Discovered 1993 Sept. 15 by E. W. Elst at La Silla.

Karlstad, the capital of Värmland, lies in southwestcentral Sweden, on the northern shore of Lake Vänern. In 1865 the city was almost completely destroyed by fire. It was rebuilt along modern lines, with broad avenues and large parks. Karlstad's economy is based on forest products and heavy machinery. (M 39655)

\section{(10559) Yukihisa}

1993 SJ $_{1}$. Discovered 1993 Sept. 16 by K. Endate and K. Watanabe at Kitami.

Yukihisa Matsumoto (1962- ), a former researcher of the Nishi Mino Observatory, now works at the board of education of Fujihashi Village. This amateur astronomer formed a club in his school days and actively participated in astronomical activities. (M 45233)

\section{(10560) Michinari}

1993 TN. Discovered 1993 Oct. 8 by K. Endate and K. Watanabe at Kitami.

Michinari Yamamoto (1970- ) is a researcher at Ayabe City Observatory, known for his ability to organize excellent application software for observatory computer networks. (M 45233)

\section{(10561) Shimizumasahiro}

$1993 \mathrm{TE}_{2}$. Discovered 1993 Oct. 15 by K. Endate and K. Watanabe at Kitami.

Masahiro Shimizu (1956- ) is the president of the Shimizu Clinic, site of the largest astronomical observatory in a hospital in Japan. He has introduced astronomy to countless people and patients in his neighborhood. (M 45233)

\section{(10563) Izhdubar}

1993 WD. Discovered 1993 Nov. 19 by C. S. Shoemaker and E. M. Shoemaker at Palomar.

Izhdubar was an ancient Chaldean sun-god. He was responsible for slaying the dreaded dragon Tiamat, which personified primeval chaos and was hostile to gods and men. The exploits of Izhdubar are thought to represent the sun's annual passage through the twelve signs of the zodiac. (M 36949)

\section{(10566) Zabadak}

1994 AZ $_{2}$. Discovered 1994 Jan. 14 by Y. Kushida and O. Muramatsu at Yatsugatake.

Zabadak is a name of a Japanese music group that is led by Tomohiko Kira. Their music encourages respect for all creatures in the biosphere and gives thanks for our planet, creating a feeling of joy through their performance. (M 39656)

The name was suggested by M. Saito.

\section{(10569) Kinoshitamasao}

1994 GQ. Discovered 1994 Apr. 8 by K. Endate and K. Watanabe at Kitami.

Masao Kinoshita (1949- ) discovered that the number of radio-meteor echoes decreases as the radiant approaches the meridian. This is widely known as the Kinoshita Effect. (M 45233)

\section{(10570) Shibayasuo}

1994 GT. Discovered 1994 Apr. 8 by K. Endate and K. Watanabe at Kitami.

Yasuo Shiba (1961- ) is the data manager of the Japan Meteor Society. He specializes in fireballs, and all national fireball data witnessed in Japan are gathered in his office. (M 45747)

\section{(10573) Piani}

$1994 \mathrm{WU}_{1}$. Discovered 1994 Nov. 29 at the Santa Lucia Observatory at Stroncone.

Franco Piani (1955- ), Italian amateur astronomer, is the most experienced and agreeable proponent of astronomy at the CCAF observatory in Farra d'Isonzo \{see planet (7501)\}. He takes care of all mechanical aspects of the instruments and has participated in most of the new discoveries of this site. (M 36949) 


\section{(10579) Diluca}

1995 OE. Discovered 1995 July 20 at the Osservatorio San Vittore at Bologna.

Roberto Di Luca (1959- ), amateur observer of lunar and asteroidal occultations, is network manager at the Astronomical Observatory of the University of Bologna. As a member of the Associazione Astrofili Bolognesi, he often collaborates with the group at the Osservatorio San Vittore in Bologna. (M 36949)

\section{(10581) Jeníkhollan}

1995 OD $_{1}$. Discovered 1995 July 30 by P. Pravec at Ondřejov.

Jan (Jeník) Hollan (1955- ), an astronomer and environmentalist at the Brno Observatory, has deeply influenced many students and observers, including the discoverer. Sometimes in unorthodox ways, he makes a point of teaching his students to examine the most substantial points. (M 36129)

\section{(10582) Harumi}

1995 TG. Discovered 1995 Oct. 3 by Y. Ikari at Moriyama.

Harumi Ikari (1957- ） is the wife of the discoverer. (M 40705)

\section{(10583) Kanetugu}

$1995 \mathrm{WC}_{4}$. Discovered 1995 Nov. 21 by T. Okuni at Nanyou.

Kanetugu Naoe (1560-1619) was a military commander during the Japanese feudal period. He was on the side of the Toyotomis, and in the decisive battle of 1600 he fought against Yoshiaki Mogami ssee planet (10405)\}, the lord of Yamagata (a part of present Yamagata Prefecture), who stood by the Tokugawas. (M 41385)

\section{(10584) Ferrini}

1996 GJ $_{2}$. Discovered 1996 Apr. 14 by L. Tesi and A. Boattini at San Marcello Pistoiese.

Named in honor of the Italian physicist Federico Ferrini, professor of astronomical techniques at the University of Pisa. He has published more than 100 scientific papers in major astronomical journals. These cover many subjects in modern theoretical astrophysics, among them planetology, star formation, the interstellar medium, galactic evolution and its cosmological effects. He is responsible for the Italian light pollution commission and is coordinator of the Mediterranean Astronomical Network. (M 35495)

\section{(10585) Wabi-Sabi}

1996 GD $_{21}$. Discovered 1996 Apr. 13 by the Spacewatch at Kitt Peak.

Wabi-Sabi is the quintessential Japanese aesthetic. Valued are one-of-a-kind objects of natural materials in the private domain, showing a sense of the "rustic" and of simplicity, as well as functional sufficiency in the face of material poverty, obvious repair, or age. (M 42671)

The name was suggested by J. Montani.

\section{(10588) Adamcrandall}

1996 OE. Discovered 1996 July 18 by P. G. Comba at Prescott.

Named in honor of the discoverer's stepson, Adam Crandall Rees (1960

$$
\text { ). (M 35495) }
$$

\section{(10591) Caverni}

1996 PD $_{3}$. Discovered 1996 Aug. 13 by M. Tombelli and G. Forti at Montelupo.

Raffaello Caverni (1837-1900), a priest born in Montelupo, was also an amateur scientist. He wrote many books, the most important of them being Storia del Metodo Sperimentale in Italia, for which he received the award of the Royal Institute of Venice on 1890 May 25. (M 41385)

\section{(10598) Markrees}

1996 TT $_{11}$. Discovered 1996 Oct. 13 by P. G. Comba at Prescott.

Named in honor of the discoverer's stepson, Mark B. Rees (1963- ). (M 35495)

\section{(10601) Hiwatashi}

1996 UC. Discovered 1996 Oct. 16 by A. Nakamura at Kuma.

Named in honor of Kenji Hiwatashi (1922- ), electrical engineer at NHK (Japan Broadcasting Corporation) from 1947 to 1979 , on the occasion of his Kiju celebration (77th birthday). A pioneer in the field of human visual information processing research, Hiwatashi authored nine books and coauthored another 20, some of which have been the fundamental textbooks used by researchers in this field. More recently, he served as a professor at the Institute of Information Sciences and Electronics, University of Tsukuba (1979-1986), and as professor of electronics at Meisei University (1986-1996). (M 35495)

\section{(10604) Susanoo}

1996 VJ. Discovered 1996 Nov. 3 by T. Urata at Oohira.

Susanoo-no-mikoto is the Japanese god of heroes and the ancestor soul and a younger brother of the goddess Amaterasu \{see planet (10385)\}. Because of his rebellious spirit, he was banished from the heaven Takamagahara and descended to the country Izumo. He defeated the giant snake Yamata-no-orochi and created the basic land of this world. (M 39656)

\section{(10605) Guidoni}

$1996 \mathrm{VC}_{1}$. Discovered 1996 Nov. 3 by V. Giuliani and F. Manca at Sormano.

The astrophysicist and astronaut Umberto Guidoni (1954- ) made the first flight onboard of the Space Shuttle Columbia in 1996, performing electrodynamics 
experiments with the TSS satellite (ASI/NASA). Guidoni is the first Italian astronaut to achieve the title of Mission Specialist. (M 41937)

\section{(10606) Crocco}

1996 VD $_{1}$. Discovered 1996 Nov. 3 by V. Giuliani and F. Manca at Sormano.

Gaetano Arturo Crocco (1877-1968), Italian pioneer in aeronautics and space science, designed revolutionary airships and patented a cyclic pitch design for helicopter rotors. A professor of aeronautics in Rome, he founded the Italian Rocket Society. (M 45233)

\section{(10607) Amandahatton}

1996 VQ $_{6}$. Discovered 1996 Nov. 13 by P. G. Comba at Prescott.

Named in honor of the discoverer's stepdaughter, Amanda H. Hatton (1967- ). (M 35495)

\section{(10608) Mameta}

$1996 \mathrm{VB}_{9}$. Discovered 1996 Nov. 7 by K. Endate and K. Watanabe at Kitami.

Katsuhiko Mameta (1958- ) is one of Japan's top meteor observers. He is an active amateur astronomer who has been secretary of the Astronomical Society of Hyogo \{see planet (6879)\} since 2000. (M 45233)

\section{(10609) Hirai}

$1996 \mathrm{WC}_{3}$. Discovered 1996 Nov. 28 by A. Nakamura at Kuma.

Named in honor of Yuzo Hirai (1948- ), professor at the Institute of Information Sciences and Electronics, University of Tsukuba. His research interests include neural networks, modeling human visual information processing, associative memory and hardware implementation of neural networks. He has supervised more than 80 undergraduate and graduate students, including the discoverer of this minor planet. (M 35495)

\section{(10613) Kushinadahime}

$1997 \mathrm{RO}_{3}$. Discovered 1997 Sept. 4 by Y. Shimizu and T. Urata at Nachi-Katsuura.

Kushinadahime, the mythical empress of the god Susanoo-no-mikoto, was offered as a sacrifice to the giant snake Yamata-no-orochi but was saved by the god Susanoo \{see planet (10604)\}. (M 39656)

\section{(10616) Inouetakeshi}

1997 UW $_{8}$. Discovered 1997 Oct. 25 by K. Endate and K. Watanabe at Kitami.

Takeshi Inoue (1969- ) is astronomy curator of Akashi Municipal Planetarium, where he has been engaged in popularizing astronomy since 1997. (M 45233)

\section{(10617) Takumi}

1997 UK $_{24}$. Discovered 1997 Oct. 25 by M. Hirasawa and S. Suzuki at Nyukasa.

Amateur astronomer Takumi Takahata (1941- ) has created many computer programs that are used for astronomical calculations. The "measurescope" Takumi lent to the discoverers was used to determine the coordinates of this minor planet. (M 36949)

\section{(10619) Ninigi}

1997 WO $_{13}$. Discovered 1997 Nov. 27 by T. Kagawa and T. Urata at Gekko.

According to the Japanese myth, the god Ninigino-mikoto is a grandson of the goddess Amaterasu \{see planet (10385)\}. By the order of Amaterasu he descended from the heaven Takamagahara \{see planet (10831)\} to the peak Takachiho \{see planet (5403)\} to dominate the land. (M 39656)

\section{(10626) Zajíc}

1998 AP $_{8}$. Discovered 1998 Jan. 10 by L. Šarounová at Ondřejov.

Jan Zajíc (1910- ), founder and for a long time director of the observatory in Vlašim, has brought astronomy to many young people. In spite of many problems, this public observatory is currently one of the most active in the Czech Republic. The naming is on the occasion of Zajíc's 90th birthday. (M 38199)

\section{(10627) Ookuninushi}

1998 BW $_{2}$. Discovered 1998 Jan. 19 by Y. Shimizu and T. Urata at Nachi-Katsuura.

The mythical Japanese god Ookuninushi-no-mikoto \{see planet (10627)\} created the land, together with the god Sukunabikona-no-mikoto \{see planet (10725)\}. The name means "king of great land" and is a frequent reference in literature and folklore. A well-known story is that he helped a white rabbit skinned by a shark as the retribution for trickery. (M 39656)

\section{(10633) Akimasa}

$1998 \mathrm{DP}_{1}$. Discovered 1998 Feb. 20 by P. Pravec at Ondřejov.

Named in honor of Akimasa Nakamura (1961- _ ), a prolific Japanese observer of minor planets and comets. In the course of his observing program at the Kuma Kogen Astronomical Observatory he has obtained thousands of precise positions of minor bodies. His estimates of the magnitudes of minor planets are of particularly high quality and serve as the standard in the analysis of "astrometric" magnitude estimates. $\mathrm{He}$ is also Japanese coordinator for the International Comet Quarterly. This name marks the occasion of Nakamura's becoming a father in early 1999. (M 35495)

\section{(10634) Pepibican}

1998 GM $_{1}$. Discovered 1998 Apr. 8 by L. Šarounová at Ondřejov.

Josef ("Pepi") Bican (1913- ), proclaimed the century's best center-forward by the International Federation of Soccer Historians and Statisticians, represented Austria in 19 and Czechoslovakia in 14 international matches and scored more than 5000 goals 
in his career. After retirement he developed an interest in astronomy. (M 36129)

\section{(10637) Heimlich}

1998 QP $_{104}$. Discovered 1998 Aug. 26 by E. W. Elst at La Silla.

Henry J. Heimlich is an American surgeon who in the early 1970s devised the "Heimlich maneuver", a potentially life-saving procedure for propelling food or other foreign objects up and out of the throat. (M 40705)

\section{(10638) McGlothlin}

1998 SV $_{54}$. Discovered 1998 Sept. 16 by the LONEOS at Anderson Mesa.

Gerald R. McGlothlin (1952- ) was responsible for refurbishing much of the LONEOS dome, turning a bare photographic darkroom into a modern control room and computer room. In his spare time he is a skilled potter. (M 41030)

\section{(10639) Gleason}

1998 VV $_{41}$. Discovered 1998 Nov. 14 by the Spacewatch at Kitt Peak.

Arianna Gleason (1980- ） is a student observer with the Spacewatch Project. She has been instrumental in the data reduction for two Spacewatch papers on the outer solar system and is a prolific discoverer of Near-Earth Objects. (M 42671)

\section{(10642) Charmaine}

$1999 \mathrm{BF}_{8}$. Discovered 1999 Jan. 19 by A. Boattini and L. Tesi at San Marcello Pistoiese.

Named in honor of Charmaine Wilkerson (1962- ), wife of the first discoverer. An American-born writer and broadcaster, she has produced numerous reports on astronomical phenomena and missions. (M 35495)

\section{(10646) Machielalberts}

2077 P-L. Discovered 1960 Sept. 26 by C. J. van Houten and I. van Houten-Groeneveld at Palomar.

Machiel Alberts (1909- ) was the first astronomer in The Netherlands to succeed, with a home-built camera, to capture a meteor on film. He was actively engaged in meteor observations, as well as in building appliances and instruments for amateur astronomers to enable meteor photography and other types of meteor observation. (M 43191)

\section{(10647) Meesters}

3074 P-L. Discovered 1960 Sept. 25 by C. J. van Houten and I. van Houten-Groeneveld at Palomar.

P. G. Meesters (1887-1964) is the Nestor of amateur astronomy in the Netherlands. He built his own observatory and was an active observer of variable stars. His book Mijn Sterrenwacht, Speurtochten langs het Firmament/ ("My observatory, exploring the skies") is still known by amateurs. (M 47167)

\section{(10648) Plancius}

4089 P-L. Discovered 1960 Sept. 24 by C. J. van Houten and I. van Houten-Groeneveld at Palomar.

Petrus Plancius (Pieter Platevoet, 1552-1622) was a Dutch theologian, astronomer, navigator and appointed cartographer to the new Dutch East India Company. Plancius depicted the 12 new southern constellations on a globe he constructed in 1598. (M 46682)

\section{(10650) Houtman}

4110 P-L. Discovered 1960 Sept. 24 by C. J. van Houten and I. van Houten-Groeneveld at Palomar.

Cornelis de Houtman (1565-1599) sailed south with four ships in 1595 to find a route to the East Indies. In 1597 he returned and thus proved that, for the Dutch, trading with the Orient was possible. His brother Fredrick de Houtman (1571-1627) outlined twelve new southern constellations. (M 47167)

\section{(10651) van Linschoten}

4522 P-L. Discovered 1960 Sept. 24 by C. J. van Houten and I. van Houten-Groeneveld at Palomar.

Jan Huygen van Linschoten (1563-1611) lived in Asia from 1583 until 1588. After his return he wrote the first Dutch standard work about Asia, Itinerario (1596). It is a manual for sailors, as well as a trading guide and a treatise about countries and their people. (M 47167)

\section{(10652) Blaeu}

4599 P-L. Discovered 1960 Sept. 24 by C. J. van Houten and I. van Houten-Groeneveld at Palomar.

Willem Janszoon Blaeu (1571-1638) was the official cartographer of the Dutch East India Company from 1633 until his death. (M 47167)

\section{(10653) Witsen}

6030 P-L. Discovered 1960 Sept. 24 by C. J. van Houten and I. van Houten-Groeneveld at Palomar.

Nicolaas Witsen (1641-1717) was a Dutch lawyer, politician, scientist, graphic artist, collector, author and cartographer. He also was mayor of the city of Amsterdam and governor of the Dutch East India Company, beginning in 1693 . In this capacity he initiated research on people, flora and fauna in Asia. (M 47167)

\section{(10654) Bontekoe}

6673 P-L. Discovered 1960 Sept. 24 by C. J. van Houten and I. van Houten-Groeneveld at Palomar.

Willem Bontekoe (1587-1646) was a captain in the Dutch East India Company. However, he is not known because of his successful trips to the East, but because of the publication of his diary in 1646, with the memorable descriptions of his travels to the East Indies. (M 47167)

\section{(10655) Pietkeyser}

9535 P-L. Discovered 1960 Oct. 17 by C. J. van Houten and I. van Houten-Groeneveld at Palomar. 
Dutch navigator Pieter Dirkszoon Keyser (c. 15401596) sailed to the East Indies in 1595 . He is credited with having invented twelve new constellations in the southern sky, first depicted in 1598 on a globe by Petrus Plancius \{see planet (10648)\}. (M 47167)

\section{(10656) Albrecht}

2213 T-1. Discovered 1971 Mar. 25 by C. J. van Houten and I. van Houten-Groeneveld at Palomar.

German astronomer Carl Theodor Albrecht (18431915) was influential in setting up the International Latitude Service. He became the first head of the ILS when it was established in 1899 at the Prussian Geodetic Institute, Potsdam. (M 47167)

\section{(10657) Wanach}

2251 T-1. Discovered 1971 Mar. 25 by C. J. van Houten and I. van Houten-Groeneveld at Palomar.

Bernhard Karl Wanach (1867-1928) carried out pioneering work on polar motion with $\mathrm{C}$. T. Albrecht \{see planet (10656)\}, whom he succeeded as head of the International Latitude Service. (M 47167)

\section{(10664) Phemios}

5187 T-2. Discovered 1973 Sept. 25 by C. J. van Houten and I. van Houten-Groeneveld at Palomar.

Phemios was a singer with Telemachos, forced to play for Penelope's \{see planet (201)\} suitors, spared by Odysseus \{see planet (1143)\} for friendly deeds and because a singer is sacred. (M 38199)

\section{(10665) Ortigão}

3019 T-3. Discovered 1977 Oct. 16 by C. J. van Houten and I. van Houten-Groeneveld at Palomar.

Catarina Ortigão (1974- ) is a person of rare inner beauty, to whom Pedro Lacerda, a colleague of the discoverers, would like to pay tribute. She is a Portuguese-born scientist working in the field of medical physics. (M 46682)

\section{(10670) Seminozhenko}

$1977 \mathrm{PP}_{1}$. Discovered 1977 Aug. 14 by N. S. Chernykh at Nauchnyj.

Ukrainian physicist Vladimir Petrovich Seminozhenko (1950- ) is known for his research on the kinetics of excitation in superconductors and semiconductors and on high-temperature superconductivity. (M 43381)

\section{(10671) Mazurova}

1977 RR $_{6}$. Discovered 1977 Sept. 11 by N. S. Chernykh at Nauchnyj.

Ekaterina Yakovlevna Mazurova (1900-1995) was a Russian actress who worked in Moscow theaters and played many roles in films. In her youth and at the beginning of her artistic career she was connected with the town of Shuya, and she gave to the museum in Shuya her collection of more than 1000 pieces of Russian and foreign art. (M 43381)

\section{(10672) Kostyukova}

1978 QE. Discovered 1978 Aug. 31 by N. S. Chernykh at Nauchnyj.

Tatiana Andreevna Kostyukova (1957- ) is a botanist and cultivator of flowers in Kiev. Her collection of flowers won a diploma at the 2001 Moscow Autumn Flower Show. (M 46010)

\section{(10676) Jamesmcdanell}

$1979 \mathrm{MD}_{2}$. Discovered 1979 June 25 by E. F. Helin and S. J. Bus at Siding Spring.

James P. McDanell (1937- ) spent nearly three decades with the Jet Propulsion Laboratory before retiring in 1999. He was the Voyager Navigation Team Chief during the highly successful encounters with Saturn and its satellites. He subsequently became manager of the Navigation Systems Section. (M 41938)

\section{(10681) Khture}

$1979 \mathrm{TH}_{2}$. Discovered 1979 Oct. 14 by N. S. Chernykh at Nauchnyj.

The Kharkiv Technical University of Radioelectronics, founded in 1930, is a recognized school of specialists in radioelectronics, computer science, telecommunication, metrology and biotechnical and medical systems. Khture is also known for its time service and for radioastronomical research on meteors. (M 42360)

\section{(10683) Carter}

1980 LY. Discovered 1980 June 10 by C. S. Shoemaker and E. M. Shoemaker at Palomar.

Carter Worth Roberts (1946- ), president of the Eastbay Astronomical Society, is known for superlative dabbling in photography and puns and his ability to fix things. He collaborated on a safe solar-eclipseviewing booklet and helped restore "Rachel", the 0.5-m Brashear refractor for the Chabot Space and Science Center. (M 41030)

\section{(10711) Pskov}

$1982 \mathrm{TT}_{2}$. Discovered 1982 Oct. 15 by L. V. Zhuravleva at Nauchnyj.

Pskov is an old Russian city located on the banks of the Velikaya river where it enters the Pskov lake. Pskov was first mentioned in the Lavrent'evskaya chronicle in 903. Now the city is an administrative, industrial and cultural center. (M 46102)

\section{(10712) Malashchuk}

$1982 \mathrm{UE}_{6}$. Discovered 1982 Oct. 20 by L. G. Karachkina at Nauchnyj.

Valentina Mikhailovna Malashchuk (1947- ) is accountant general of the Crimean Astrophysical Observatory. (M 36949)

\section{(10713) Limorenko}

1982 UZ. Discovered 1982 Oct. 22 by L. G. Karachkina at Nauchnyj.

Leonid Pavlovich Limorenko (1951- ) is assistant director of the Crimean Astrophysical Observatory. (M 36949) 
(10715) Nagler

$1983 \mathrm{RL}_{4}$. Discovered 1983 Sept. 11 by B. A. Skiff at

Anderson Mesa.

Al Nagler (1935- ) is an optical designer best known for his innovative wide-field eyepieces and versatile, compact refractors. He also designed visual displays for the Gemini and Apollo Lunar Module simulators. (M 38199)

The citation was provided by S. and A. French.

\section{(10720) Danzl}

1986 GY. Discovered 1986 Apr. 5 by the Spacewatch at Kitt Peak.

Nichole Danzl is a biology student, artist and a past Spacewatch Observer. Danzl discovered several Near-Earth Objects and distant outer-solar system objects during her time as a NASA Space Grant undergraduate. (M 42670)

\section{(10721) Tuterov}

$1986 \mathrm{QO}_{4}$. Discovered 1986 Aug. 17 by L. G. Karachkina at Nauchnyj.

Vladimir Lukich Tuterov (1960- ), a splendid builder, is a friend of the discoverer's family. (M 36949)

\section{(10722) Monari}

1986 TB. Discovered 1986 Oct. 1 at the Osservatorio San Vittore at Bologna.

Elementary-school teacher Luisa Monari (1961- ) is the wife of Ermes Colombini \{see planet (7030)\}, one of the codiscoverers of this minor planet. (M 36949)

\section{(10725) Sukunabikona}

1986 WB. Discovered 1986 Nov. 22 by K. Suzuki and T. Urata at Toyota.

Sukunabikona is the Japanese god of a naughty character. Although he was extremely short, he dominated the land with the god Ookuninushi-nomikoto \{see planet (10627)\}. (M 39656)

\section{(10727) Akitsushima}

1987 DN. Discovered 1987 Feb. 25 by T. Niijima and T. Urata at Ojima.

Akitsushima ia an old name for Japan, used by the first emperor Jinmu, looking from the top of a mountain, to describe the form of the country. (M 36129)

\section{(10729) Tsvetkova}

$1987 \mathrm{RU}_{5}$. Discovered 1987 Sept. 4 by L. V. Zhuravleva at Nauchnyj.

Russian artist Valentina Petrovna Tsvetkova (1917-

) has lived and worked in the town of Yalta in the Crimea since 1937. Her works are in the collections of museums in Russia and abroad. Tsvetkova was recognized as one of the three best artists at women's art exhibitions in Paris in 1965 and 1968. (M 46102)

\section{(10733) Georgesand}

$1988 \mathrm{CP}_{1}$. Discovered 1988 Feb. 11 by E. W. Elst at La Silla.
Amandine-Aurore-Lucile Dudevant (1804-1876) was a French romantic writer who wrote under the pseudonym of George Sand. As a writer she was an idealist, creating characters in her novels of unbelievable innocence and charm. (M 39656)

\section{(10734) Wieck}

$1988 \mathrm{CT}_{4}$. Discovered 1988 Feb. 13 by E. W. Elst at La Silla.

Clara Josephine Wieck (1819-1896) was a German child prodigy and by 1835 had established a reputation as a pianist throughout Europe. In 1840 she married the famous composer Robert Schumann s see planet (4003)\}. She has left us a beautiful piano concerto, chamber music, songs and many pieces for solo piano. (M 39656)

\section{(10739) Lowman}

1988 JB$_{1}$. Discovered 1988 May 12 by C. S. Shoemaker and E. M. Shoemaker at Palomar.

Margaret D. Lowman (1953- ) has worked to understand the role tropical forests play in Earth's interconnected ecosystem. As a canopy biologist, field work has taken her to the treetops of Australia, Belize, Panama, Peru and Africa. She directs research and conservation at Florida's Marie Selby Botanical Gardens. (M 45747)

\section{(10740) Fallersleben}

$1988 \mathrm{RX}_{2}$. Discovered 1988 Sept. 8 by F. Börngen at Tautenburg.

For his "Unpolitische Lieder", liberal patriotic songs, the poet, writer, librarian and literary historian August Heinrich Hoffmann von Fallersleben (1798-1874) was ousted from his professorship of the German language in Breslau. He wrote the text of "Lied der Deutschen", the German national anthem. (M 36949; M 37373)

\section{(10745) Arnstadt}

$1989 \mathrm{AK}_{6}$. Discovered 1989 Jan. 11 by F. Börngen at Tautenburg.

Arnstadt is a town in Thuringia ssee planet (934)\} with a 1300-year history. The young J. S. Bach \{see planet (1814)\} was an organist here during 1703-1707. The town is home to the priceless doll's town "Mon plaisir", the life-work of princess Auguste Dorothea von Schwarzburg-Arnstadt. (M 38199)

\section{(10746) Mühlhausen}

$1989 \mathrm{CE}_{6}$. Discovered 1989 Feb. 10 by F. Börngen at Tautenburg.

In Carolinian times the Thuringian town of Mühlhausen was the haunt of emperors and kings. It became a Reichsstadt in 1180 and a member of the Hanse in 1418. J. S. Bach \{see planet (1814)\} was an organist here during $1707-1708$. The intact city is a jewel of town planning in medieval times. (M 38199) 


\section{(10747) Köthen}

$1989 \mathrm{CW}_{7}$. Discovered 1989 Feb. 1 by F. Börngen at Tautenburg.

Köthen is a Saxon-Anhaltian town. J. S. Bach \{see planet (1814)\} was the princely conductor there during 1717-1723, becoming the friend and travel attendant of the art-loving duke Leopold of Anhalt-Köthen. In Köthen Bach composed most of his chamber music, including all six Brandenburg concerti. (M 38199)

\section{(10749) Musäus}

$1989 \mathrm{GH}_{8}$. Discovered 1989 Apr. 6 by F. Börngen at Tautenburg.

Johann Carl August Musäus (1735-1787), a private tutor at the court of Weimar, was the satiric author of the five-volume Volksmärchen der Deutschen, which brought him the reputation as a precursor to the brothers Grimm \{see planet (6912)\}. (M 36949)

\section{(10753) van der Velde}

$1989 \mathrm{WU}_{4}$. Discovered 1989 Nov. 28 by F. Börngen at Tautenburg.

The Belgian architect and painter Henry Clemens van de Velde (1863-1957), who worked at the court of Weimar during 1900-1914, founded and directed the Arts and Crafts School, later changed into the Bauhaus \{see planet (8502)\}. To his regret, critics labeled "Der Neue Stil" of his art as "Jugendstil". (M 36950)

\section{(10760) Ozeki}

$1990 \mathrm{TJ}_{3}$. Discovered 1990 Oct. 15 by K. Endate and K. Watanabe at Kitami.

Takaaki Ozeki (1952- ), previously a teacher of science, is now astronomy curator of the Hoshinoko Yakata Observatory. $\mathrm{He}$ is an eager astronomical educator and has a number of astronomical publications to his credit. (M 45233)

\section{(10761) Lyubimets}

1990 TB$_{4}$. Discovered 1990 Oct. 12 by L. D. Schmadel and F. Börngen at Tautenburg.

Lyubimets, the Russian word for 'darling', seems to be an appropriate name for Grigorij (2000- ), grandson of the Crimean astronomer Lyudmila Karachkina. May he be the beloved sunshine for the whole family. (M 41938)

The name was suggested by the first discoverer.

\section{(10762) von Laue}

$1990 \mathrm{TC}_{4}$. Discovered 1990 Oct. 12 by F. Börngen and L. D. Schmadel at Tautenburg.

Max von Laue (1879-1960), student of Planck \{see planet (1069)\}, discovered the diffraction of x-rays in crystals, thereby permitting their structural analysis. For this he received the 1914 Nobel Prize in physics. He extended the theory of relativity, and he stood up for outlawed Jewish physicists like Einstein \{see planet (2001)\}. (M 43191)

\section{(10763) Hlawka}

$1990 \mathrm{TH}_{13}$. Discovered 1990 Oct. 12 by L. D. Schmadel and F. Börngen at Tautenburg.

Edmund Hlawka (1916- ) is the most famous living Austrian mathematician and a prominent university teacher in Vienna. He contributed important theorems to the geometry of numbers, to the theory of uniform distribution, and to numerical integration. (M 42360) The citation was prepared by H. Haupt.

\section{(10764) Rübezahl}

1990 TK$_{13}$. Discovered 1990 Oct. 12 by F. Börngen and L. D. Schmadel at Tautenburg.

The Silesian mountain goblin Rübezahl is master of the Riesengebirge. He teases the wanderer, gives presents to the poor and guards the treasures within the mountains. The first Rübezahl legends were collected in 1662 by J. Praetorius in his Daemonologia Rubinzalii Silesii. (M 36950)

\section{(10767) Toyomasu}

$1990 \mathrm{UF}_{1}$. Discovered 1990 Oct. 22 by K. Endate and K. Watanabe at Kitami.

Shinji Toyomasu (1967- ) is a research fellow of the Misato Observatory. Since 1995, his main functions have been to teach students and to perform radio meteor observations. (M 45233)

\section{(10768) Sarutahiko}

$1990 \mathrm{UZ}_{1}$. Discovered 1990 Oct. 21 by T. Urata at Oohira.

Sarutahiko is a Japanese god who was a giant with a long nose and sparkling red eyes. When the god Ninigi-no-mikoto \{see planet (10619)\} descended from heaven, Sarutahiko guided him. (M 39656)

\section{(10769) Minas Gerais}

$1990 \mathrm{UJ}_{5}$. Discovered 1990 Oct. 16 by E. W. Elst at La Silla.

The Brazilian state of Minas Gerais (general mines), located in the mineral-rich uplands of the Brazilian highlands, is the storehouse of the mineral riches of the country. The discovery of gold in 1692 and diamonds in 1729 led to a mad rush to the new mines. Minas is also widely known for its semiprecious gems. (M 39656)

\section{(10770) Belo Horizonte}

$1990 \mathrm{VU}_{5}$. Discovered 1990 Nov. 15 by E. W. Elst at La Silla.

Belo Horizonte is the beautiful capital (1897) of the Brazilian state of Minas Gerais \{see planet (10769)\}. It was the first of Brazil's planned cities, since the old capital at Ouro Prêto \{see planet (10771)\} could not accommodate the necessary expansions. Belo was modeled after Washington, D.C., and La Plata in Argentina \{see, respectively, planets (1029) and (469)\}. (M 39656) 


\section{(10771) Ouro Prêto}

$1990 \mathrm{VK}_{6}$. Discovered 1990 Nov. 15 by E. W. Elst at La Silla.

Ouro Prêto was the old capital of Minas Gerais \{see planet (10769)\}. Founded in 1698 as a mining settlement, it became the center of a great gold and silver rush. In 1933 the city was decreed a national monument, to preserve and restore its beautiful churches and houses. (M 39656)

\section{(10774) Eisenach}

$1991 \mathrm{AS}_{2}$. Discovered 1991 Jan. 15 by F. Börngen at Tautenburg.

Charmingly situated, Eisenach is a Thuringian \{see planet (934)\} town, founded in the the twelfth century. J. S. Bach \{see planet (1814)\} was born there in 1685 and lived there for his first ten years. (M 38199)

\section{(10775) Leipzig}

$1991 \mathrm{AV}_{2}$. Discovered 1991 Jan. 15 by F. Börngen at Tautenburg.

The Saxon city of Leipzig has a great number of splendid sights. J. S. Bach \{see planet (1814)\} worked as cantor in the Thomaskirche from 1723 to his death in 1750. (M 38199)

\section{(10778) Marcks}

1991 GN $_{10}$. Discovered 1991 Apr. 9 by F. Börngen at Tautenburg.

Sculptor and graphic artist Gerhard Marcks (18891981) was master of the potter's shop in Dornburg \{see planet (3802)\}, a teacher at the Bauhaus in Weimar \{see, respectively, planets (8502) and (3539)\} and until 1933 director of the Arts and Crafts School in Halle-Giebichenstein. Until 1945 his representations of animals, figurines, drawings and woodcuts were regarded as degenerate. (M 36950)

\section{(10780) Apollinaire}

$1991 \mathrm{~PB}_{2}$. Discovered 1991 Aug. 2 by E. W. Elst at La Silla.

French poet Wilhelm Apollinaris de Kostrowitzki (1880-1918), the son of a Polish emigrée, took poetry into unexplored channels. Inspired by an unhappy love-affair, he wrote his Chanson du mal-aimé. His poetic masterpiece Alcools (1913) utilizes unusual verbal associations and daring typographical arrangements. (M 40705)

\section{(10781) Ritter}

$1991 \mathrm{PV}_{31}$. Discovered 1991 Aug. 6 by F. Börngen at Tautenburg.

As the result of numerous physical experiments he conducted during the decade he lived in Jena, the German scientist Johann Wilhelm Ritter (1776-1810) discovered the electrochemical voltage ranking of the metals (1798) and the ultraviolet part of the radiation in the solar spectrum (1801). (M 39656)

\section{(10782) Hittmair}

$1991 \mathrm{RH}_{4}$. Discovered 1991 Sept. 12 by L. D. Schmadel and F. Börngen at Tautenburg.

Otto Hittmair (1924- ) is a well-known Austrian theoretical physicist. He was president of the Austrian Academy of Sciences in Vienna. His main contributions were on problems of quantum theory, superconductivity and general field theory. (M 42360)

The name was suggested by L. D. Schmadel, and the citation was prepared by H. Haupt.

\section{(10784) Noailles}

$1991 \mathrm{RQ}_{11}$. Discovered 1991 Sept. 4 by E. W. Elst at La Silla.

Anna de Noailles (1876-1933) was the daughter of a Romanian prince and granddaughter of a Turkish pasha. Her volumes of poems, such as Les Eblouissements (1907), are characterized by a sensual love of nature. (M 40705)

\section{(10785) Dejaiffe}

$1991 \mathrm{RD}_{12}$. Discovered 1991 Sept. 4 by E. W. Elst at La Silla.

René Dejaiffe (1940- ), of the Royal Belgian Observatory, has presided over national and international societies and organized more than 1400 conferences on astronomy and space science. Since 1997 he has been general secretary of the Société Royale Belge d'Astronomie, de Météorologie et de Physique du Globe. (M 36950)

\section{(10786) Robertmayer}

$1991 \mathrm{TC}_{3}$. Discovered 1991 Oct. 7 by F. Börngen and L. D. Schmadel at Tautenburg.

Julius Robert Mayer (1814-1878), a German doctor and naturalist, created the formula for the transformation of mechanical energy into heat. In 1842 he stated the law of energy conservation. This received little notice until his work was extended by Helmholtz \{see planet (11573)\}. (M 39656)

\section{(10787) Ottoburkard}

1991 TL$_{3}$. Discovered 1991 Oct. 4 by L. D. Schmadel and F. Börngen at Tautenburg.

Otto M. Burkard (1908- ), professor emeritus of meteorology and geophysics of the University of Graz, was one of the founders of the Space Research Institute of the Austrian Academy of Sciences. (M 42361)

The name was suggested by L. D. Schmadel, and the citation was prepared by H. Haupt.

\section{(10789) Mikeread}

$1991 \mathrm{VL}_{10}$. Discovered 1991 Nov. 5 by the Spacewatch at Kitt Peak.

Mike Read (1978- ) is a student working with Spacewatch as an observer and engineer. He has been responsible for the design, construction and wiring of some of the Spacewatch Camera electronics. He has performed some exceptionally difficult recovery 
observations. He has also served as the Spacewatch Webmaster. (M 42671)

\section{(10792) Ecuador}

1992 CQ $_{2}$. Discovered 1992 Feb. 2 by E. W. Elst at La Silla.

Ecuador, on the west coast of South America and on the equator, is a country containing an immense variety of terrain in the coastal plain, Andes mountain ranges and Amazonian rainforest. Cotapaxi is the world's highest active volcano. Ecuador administers the Galapagos Islands \{see planet (16809)\}, whose unique fauna entranced Charles Darwin ssee planet (1991)\}. (M 42671)

\section{(10793) Quito}

$1992 \mathrm{CU}_{2}$. Discovered 1992 Feb. 2 by E. W. Elst at La Silla.

Quito, astride the equator, is the capital of Ecuador and the oldest of all the South American capitals. The city was occupied in 1534 by a lieutenant of the conquistador Pizarro. (M 39656)

\section{(10797) Guatemala}

$1992 \mathrm{GO}_{4}$. Discovered 1992 Apr. 4 by E. W. Elst at La Silla.

Guatemala is a country on the western Pacific Coast of the Central American isthmus. Mountain ranges containing many active volcanoes in the south contrast with the dense rainforest and savannahs of the north. The beautiful quetzal bird inhabits the cloud forest of the Petén, once the center of the Mayan civilisation. (M 42671)

\section{(10799) Yucatán}

$1992 \mathrm{OY}_{2}$. Discovered 1992 July 26 by E. W. Elst at La Silla.

The Yucatán peninsula became a Mexican state in 1824. It is a popular tourist destination because of its old Mayan centers, such as "Uxmal". It is also the location of the presumed impact of a large minor planet or comet about 65 million years ago. (M 39656)

\section{(10801) Lüneburg}

1992 SK $_{26}$. Discovered 1992 Sept. 23 by F. Börngen at Tautenburg.

Lüneburg is one of the richest Hanse towns, more than 1000 years old. J. S. Bach \{see planet (1814)\} was a schoolboy there during 1700-1703. The six minor planets (10745), (10746), (10747), (10774), (10775) and (10801) are being named on the occasion of the 250th anniversary of Bach's death. (M 38199)

\section{(10802) Masamifuruya}

1992 UL $_{6}$. Discovered 1992 Oct. 28 by K. Endate and K. Watanabe at Kitami.

Masami Furuya (1973- ) is a research fellow at the Kawabe Observatory of Kawabe Cosmic Park. (M 45747)

\section{(10804) Amenouzume}

$1992 \mathrm{WN}_{3}$. Discovered 1992 Nov. 23 by T. Urata at Oohira.

Amenouzume is the mythical Japanese goddess who managed to free the goddess Amaterasu \{see planet (10385)\} by dancing in front of the rock door when she shut herself up in the cave Ama-no-iwayado. After that Amenouzume descended from heaven, following the god Ninigi-no-mikoto \{see planet (10619)\}. (M 39657)

\section{(10805) Iwano}

1992 WG $_{5}$. Discovered 1992 Nov. 18 by K. Endate and K. Watanabe at Kitami.

Hisaka Iwano (1957- ) is an engineer and amateur astronomer in Japan, active in organizing local star parties. (M 45747)

\section{(10806) Mexico}

$1993 \mathrm{FA}_{2}$. Discovered 1993 Mar. 23 by E. W. Elst at Caussols.

Mexico is a country in the southern part of North America. Much of it is high plateau cradled by three great mountain ranges, one of which contains active volcanoes. Several great civilizations, among them Olmec, Toltec, Mayan and Aztec, flourished there from about 100 A.D. to the time of the Spanish conquest. (M 42671)

\section{(10807) Uggarde}

$1993 \mathrm{FT}_{4}$. Discovered 1993 Mar. 17 by the Uppsala-ESO Survey at La Silla.

With a diameter of 50 meters, Uggarde Rohr is the largest of the 1400 cairns on Gotland that were constructed between 2000 and 400 B.C. (M 42361)

\section{(10808) Digerrojr}

$1993 \mathrm{FT}_{5}$. Discovered 1993 Mar. 17 by the Uppsala-ESO Survey at La Silla.

Digerrojr is a large cairn on Gotland. (M 42361)

\section{(10809) Majsterrojr}

$1993 \mathrm{FS}_{14}$. Discovered 1993 Mar. 17 by the Uppsala-ESO Survey at La Silla.

Majsterrojr, a large cairn on Gotland, is surrounded by several smaller graves from the Bronze Age. (M 42361)

\section{(10810) Lejsturojr}

$1993 \mathrm{FL}_{15}$. Discovered 1993 Mar. 17 by the Uppsala-ESO Survey at La Silla.

Lejsturojr is a large cairn on southern Gotland. (M 42361)

\section{(10819) Mahakala}

1993 HG. Discovered 1993 Apr. 19 by J. DeYoung at Washington.

Mahakala, or "Great Time", is one of the destructive aspects of Shiva in Vedic Hinduism, time being seen as the destroyer of all things. The naming also honors the long history of the U.S. Naval Observatory Time Service and its fundamental involvement in all scales 
of timekeeping from astronomical time to atomic time. (M 42671)

\section{(10820) Offenbach}

$1993 \mathrm{QN}_{4}$. Discovered 1993 Aug. 18 by E. W. Elst at Caussols.

Jacob (Jacques) Offenbach (1819-1880) was a GermanFrench composer who created the "opérette", or opéra bouffe, a type of comic opéra that became very popular, especially in Paris. Orphée aux Enfers ("Orpheus in the Underworld", 1859) and La Belle Hélène (1864) are among his most famous operettas. (M 40705)

\section{(10821) Kimuratakeshi}

1993 SZ. Discovered 1993 Sept. 16 by K. Endate and K. Watanabe at Kitami.

Takeshi Kimura (1943- ) is the senior executive officer at a consulting company in Tokyo and is also a well-known amateur astronomer. He is respected as a leader eager to spread astronomical knowledge among eastern Japan's amateur astronomers. (M 45233)

\section{(10822) Yasunori}

1993 SK $_{1}$. Discovered 1993 Sept. 16 by K. Endate and K. Watanabe at Kitami.

Yasunori Harada (1971- ) is a research engineer and amateur astronomer in Japan, well known for his beautiful stellar photographs. (M 45747)

\section{(10823) Sakaguchi}

$1993 \mathrm{SM}_{1}$. Discovered 1993 Sept. 16 by K. Endate and

K. Watanabe at Kitami.

Naoto Sakaguchi (1962- ） is an amateur astronomer well known around Tokyo for his efforts in arranging astronomical events for the public. (M 45233)

\section{(10825) Augusthermann}

$1993 \mathrm{SF}_{4}$. Discovered 1993 Sept. 18 by F. Börngen at Tautenburg.

The German theologian and pedagogue August Hermann Francke (1663-1727) founded the "Franckeschen Stiftungen" in Halle in 1695, which had about 2300 pupils at the time and continues to exist today. Francke's main intent was to educate the young and support the poor. (M 38199)

\section{(10827) Doikazunori}

1993 TC $_{3}$. Discovered 1993 Oct. 11 by K. Endate and K. Watanabe at Kitami.

Kazunori Doi (1952- ) is a Japanese architect and amateur astronomer. He is also one of the designers of a number of Japanese astronomical observatories, of which Saji \{see planet (8738)\} Observatory is a prominent example. (M 45233)

\section{(10828) Tomjones}

$1993 \mathrm{TE}_{5}$. Discovered 1993 Oct. 8 by the Spacewatch at Kitt Peak.

Thomas D. Jones (1955- ) is a planetary scientist who studies minor planets and comets. He flew four
Space Shuttle missions as a NASA astronaut between 1994 and 2001. Earth science and extra-vehicular activity were his specialties as an astronaut, with particular interest in EVA around and exploration of near-earth asteroids. (M 47167)

\section{(10831) Takamagahara}

$1993 \mathrm{VM}_{2}$. Discovered 1993 Nov. 15 by T. Urata at Oohira.

Takamagahara was the heaven that appears in Japanese ancient myth. The place was ruled by the goddess Amaterasu \{see planet (10385)\}. (M 39657)

\section{(10832) Hazamashigetomi}

1993 VN $_{2}$. Discovered 1993 Nov. 15 by T. Kobayashi at Oizumi.

Hazama Shigetomi (1756-1816) was an astronomer in the Japanese Edo period who studied positional astronomy. He devised a new calendar computation method, "Kansei-reki", with Takahashi Yoshitoki (1764-1804) \{see planet (12365)\}. He was also an able technician, inventing many new measuring instruments. (M 46682)

\section{(10834) Zembsch-Schreve}

1993 VU $_{5}$. Discovered 1993 Nov. 8 by the Spacewatch at Kitt Peak.

Guido Zembsch-Schreve (1916- ) parachuted as an allied agent into occupied France in 1943. He was betrayed in 1944 and eventually sent to Dora, where the V-2 rockets were manufactured. He escaped and wrote Pierre Lalande: Special Agent. (M 43382)

\section{(10835) Fröbel}

1993 VB$_{8}$. Discovered 1993 Nov. 12 by F. Börngen at Tautenburg.

The Thuringian pedagogue Friedrich Fröbel (17821852) was committed to the education of young children. In 1839 he founded the first nursery school, which he named Kindergarten. He created toys and tools for use by children in different age groups. (M 38199)

\section{(10838) Lebon}

$1994 \mathrm{EH}_{7}$. Discovered 1994 Mar. 9 by E. W. Elst at Caussols.

Gustave Le Bon (1841-1931) was a French social psychologist who became famous through his book La psychologie des foules (1895): "Crowd behavior is unanimous, emotional and intellectually weak". Freud's \{see planet (4342)\} Massa und Ich-analyse (1920) owes much to his ideas. (M 40705)

\section{(10839) Hufeland}

1994 GY $_{9}$. Discovered 1994 Apr. 3 by F. Börngen at Tautenburg.

The German physician Christoph Wilhelm Hufeland (1762-1836) was professor of medicine in Jena and Berlin \{see planets (526) and (422)\}. He attended Schiller and Goethe \{see planets (3079) and (3047)\}, 
tried to reconcile the methods of naturopathy with scientific findings and introduced smallpox vaccination. Die Kunst, das menschliche Leben zu verlängern is his chief work. (M 38200)

\section{(10847) Koch}

$1995 \mathrm{AV}_{4}$. Discovered 1995 Jan. 5 by F. Börngen at Tautenburg.

The German physician Robert Koch (1843-1910) is the chief founder of the methodology of modern bacteriology. In 1876, he showed that the anthrax bacillus causes an infectious disease. He discovered the tuberculosis and cholera bacilli and studied malaria and sleeping sickness. He won the Nobel prize for medicine in 1905. (M 38200)

\section{(10850) Denso}

$1995 \mathrm{BU}_{4}$. Discovered 1995 Jan. 26 by A. Nakamura at Kuma.

Denso Corporation, for which the discoverer worked for eight years as an electrical engineer, is the largest manufacturer of automobile parts in Japan. (M 41385)

\section{(10856) Bechstein}

1995 EG$_{8}$. Discovered 1995 Mar. 4 by F. Börngen at Tautenburg.

Carl Bechstein (1826-1900), born in the Thuringian town of Gotha \{see, respectively, planets (934) and (1346)\}, founded a piano factory in Berlin in 1853. His instruments were used by Liszt \{see planet (3910)\}, Bülow, Rubinstein and Wagner \{see planet (3992)\}. Branches of his factory in London, Paris and St. Petersburg testify to the esteem in which Bechstein's instruments are held. (M 38200)

\section{(10857) Blüthner}

1995 EZ $_{8}$. Discovered 1995 Mar. 5 by F. Börngen at Tautenburg.

Julius Blüthner (1824-1910) founded a piano factory in Leipzig \{see planet (10775) \} in 1853. His instruments found high recognition because of their sonority, tone color and several technical innovations. The name Blüthner inspired friends of music around the world. Despite the elements of mass production, every piano remained a work of art. (M 38200)

\section{(10861) Ciske}

$1995 \mathrm{MG}_{1}$. Discovered 1995 June 22 by the Spacewatch at Kitt Peak.

Ciske Staring was a courier in Amsterdam for the Resistance during World War II. This naming is to honor especially the women of the Resistance who executed dangerous tasks and kept up the human spirit in spite of gruesome conditions. (M 43382)

\section{(10864) Yamagatashi}

$1995 \mathrm{QS}_{3}$. Discovered 1995 Aug. 31 by T. Okuni at Nanyou.
The city of Yamagata, in the center of Yamagata prefecture, is famous for its castle town and casting industry. (M 43045)

\section{(10865) Thelmaruby}

$1995 \mathrm{SO}_{33}$. Discovered 1995 Sept. 21 by the Spacewatch at Kitt Peak.

Thelma Ruby is a British actress of international fame. One of her early accomplishments was to play Golda in the original theater version of Fiddler on the Roof. (M 42671)

\section{(10866) Peru}

$1996 \mathrm{NB}_{4}$. Discovered 1996 July 14 by E. W. Elst at La Silla.

Peru, on the west coast of South America, is dominated by the great Andes mountain ranges, and it extends east to include the headwaters of the Amazon river. The country has been the home of several Andean civilisations, notably the Incas. Lake Titicaca \{see planet (1801)\} on the southern border is the world's highest body of fresh water. (M 42671)

\section{(10867) Lima}

1996 NX $_{4}$. Discovered 1996 July 14 by E. W. Elst at La Silla.

Lima, a name corrupted from that of the Rimac river, on which it stands, is the capital of Peru. Established by Pizarro in 1535, the city is noted for the mathematical regularity of its original streets, which enclose square areas of nearly uniform size. (M 39657)

\section{(10870) Gwendolen}

$1996 \mathrm{SY}_{4}$. Discovered 1996 Sept. 25 by G. C. L. Aikman at Victoria.

Mary Gwendolen Ellery Read Aikman (1903-1994) was an inspiring educator and mother of the discoverer. (M 41938)

\section{(10872) Vaculík}

1996 TJ $_{9}$. Discovered 1996 Oct. 12 by J. Tichá and M. Tichý at Klě́.

Ludvík Vaculík (1926- ）, Czech writer and journalist, was one of the most famous writers in the former Czechoslovakia in the 1970s and 1980s. He described his experiences in the book A Cup of Coffee With My Interrogator. (M 38200)

\section{(10874) Locatelli}

1996 TN $_{19}$. Discovered 1996 Oct. 4 by the Spacewatch at Kitt Peak.

Pietro Antonio Locatelli (1695-1764), born in Bergamo, studied violin in Rome with Corelli and Valentini, becoming a virtuoso and composer. He performed in Italy, Bavaria, Berlin and settled in Amsterdam. His great L'arte del Violino (1733) comprises 12 violin concerti and 24 caprices. (M 42671) 
(10875) Veracini

$1996 \mathrm{TG}_{28}$. Discovered 1996 Oct. 7 by the Spacewatch at Kitt Peak.

Francesco Maria Veracini (1690-1768), born in Florence, studied violin with his uncle, Antonio Veracini, and with Casini and Feroci of Florence cathedral. His exuberant compositions and virtuosity caused the young Tartini to isolate himself to practice. The Sonate Accademiche (1711) show remarkable energy and brilliance. (M 42671)

\section{(10878) Moriyama}

1996 VV. Discovered 1996 Nov. 3 by Y. Ikari at Moriyama.

Moriyama is a city on east side of Lake Biwa ssee planet (4289)\}, the largest lake in Japan, in Shiga Prefecture. It was a beautiful rural town and as the population had increased it was upgraded to be a city in 1970. (M 43045)

\section{(10882) Shinonaga}

$1996 \mathrm{VG}_{5}$. Discovered 1996 Nov. 3 by K. Endate and K. Watanabe at Kitami.

Kouji Shinonaga (1952- ）, since 1991 the director of Kamagari Observatory, located in Hiroshima prefecture, is an experienced amateur telescope maker. (M 45747)

\section{(10884) Tsuboimasaki}

1996 VD $_{9}$. Discovered 1996 Nov. 7 by K. Endate and K. Watanabe at Kitami.

Masaki Tsuboi (1954- ) is president of the Hiroshima Astronomical Society and a leader of the amateur astronomy community in western Japan. (M 45747)

\section{(10885) Horimasato}

$1996 \mathrm{VE}_{9}$. Discovered 1996 Nov. 7 by K. Endate and K. Watanabe at Kitami.

Masato Hori (1957- ) is a specialist in civil engineering and a member of the Hiroshima Astronomical Society. He owns a substantial private observatory and often makes it available willingly to the local people in his area. (M 45747)

\section{(10888) Yamatano-orochi}

$1996 \mathrm{XT}_{30}$. Discovered 1996 Dec. 6 by Y. Shimizu and T. Urata at Nachi-Katsuura.

Yamatano-orochi is a giant snake appearing in Japanese ancient mythology. The snake had eight heads and eight tails and was long enough to cover eight valleys and eight peaks. It was defeated by the god Susanoo-no-mikoto see planet (10604)\}. (M 39657)

\section{(10891) Fink}

1997 QR $_{3}$. Discovered 1997 Aug. 30 by the OCA-DLR Survey at Caussols.

Uwe Fink (1939- ), at the Lunar and Planetary Laboratory, has made major contributions in the fields of planetary atmospheres, the surface composition of small bodies, reflection spectra, absorption coefficients of ices and cometary coma production rates. (M 43191)
The name was suggested by S. Mottola and U. Carsenty.

\section{(10894) Nakai}

$1997 \mathrm{SE}_{30}$. Discovered 1997 Sept. 30 by the Spacewatch at Kitt Peak.

R. Carlos Nakai (1946- ) is a musician and cultural anthropologist of Navajo-Ute descent. Classically trained on trumpet and cornet, he turned to wooden flute in 1972, mastered cedar flute-making and became a virtuoso player, composer and international recording artist. Nakai means "wanderer", as does planet in Greek. (M 42167)

\section{(10895) Aynrand}

1997 TC $_{18}$. Discovered 1997 Oct. 11 by G. R. Viscome at Lake Placid.

Ayn Rand (1905-1982), Russian-born philosopher and writer, emigrated to the United States at age 21. She was the author of several novels and books, of which The Fountainhead (1943) and Atlas Shrugged (1957) are best known. The discoverer also named his observatory as a tribute to her. (M 40705)

\section{(10907) Savalle}

$1997 \mathrm{XG}_{5}$. Discovered 1997 Dec. 6 by the OCA-DLR Survey at Caussols.

Renaud Savalle (1971- ), astronomical software programmer, wrote the CCD acquisition system used by the Asteroid Survey at Caussols that allowed this minor planet to be discovered. He now works at the Canada-France-Hawaii Telescope, where he is a systems programmer. (M 41030)

\section{(10908) Kallestroetzel}

$1997 \mathrm{XH}_{9}$. Discovered 1997 Dec. 7 by the OCA-DLR Survey at Caussols.

Karl-Heinz Stroetzel (1935- ）, at the DLR Institute of Space Sensor Technology and Planetary Exploration, was a major contributor to the development and construction of the CCD cameras for the search programs at Caussols, Kvistaberg \{see planet (3331)\} and Asiago $\{$ see planet (7679)\}. The naming is on the occasion of his retirement. (M 43191)

\section{(10914) Tucker}

1997 YQ $_{14}$. Discovered 1997 Dec. 31 by P. G. Comba at Prescott.

Roy Tucker (1951- ), an instrumentalist at Kitt Peak National Observatory, is owner and chief observer of southern Arizona's Goodricke-Pigott Observatory, where he has discovered two Atens, one Apollo \{see, respectively, planets (2062) and (1862)\} and a comet. (M 36950)

\section{(10918) Kodaly}

$1998 \mathrm{AS}_{1}$. Discovered 1998 Jan. 1 by the Spacewatch at Kitt Peak.

With his friend Béla Bartók \{see planet (4132)\}, Hungarian composer Zoltan Kodaly (1882-1967) collected melodies and rhythms from Hungarian folk 
songs into his own works. His highly expressionistic and demanding Sonata for Solo 'Cello (1915) was one of the first major works for unaccompanied 'cello since Bach's \{see planet (1814)\} Suites. (M 42671)

\section{(10921) Romanozen}

$1998 \mathrm{BC}_{2}$. Discovered 1998 Jan. 17 at the Madonna di Dossobuono Observatory at Madonna di Dossobuono.

Romano Zen (1946- ) is famous in Italy and abroad for his high-quality optical instruments. He works in a laboratory in Venice and has made some thousands of optical instruments for amateur and professional astronomers. (M 42361)

\section{(10924) Mariagriffin}

1998 BU $_{25}$. Discovered 1998 Jan. 29 by I. P. Griffin at Cocoa.

Maria Griffin (1962- ) is the wife of the discoverer. (M 36129)

\section{(10925) Ventoux}

1998 BK $_{30}$. Discovered 1998 Jan. 28 by P. Antonini at Bedoin.

Mont Ventoux is a mountain 1909 meters high in the French département of Vaucluse \{see planet (10927)\} (Provence). (M 41030)

\section{(10927) Vaucluse}

$1998 \mathrm{BB}_{42}$. Discovered 1998 Jan. 29 by R. Roy at Blauvac.

Vaucluse is a French département. This minor planet was discovered by a member of AUDE (Association des Utilisateurs de Detecteurs Electroniques) \{see planet (9117)\} based in the little Vaucluse village of Saint-Estève in the commune of Blauvac. (M 36950)

\section{(10928) Caprara}

1998 BW 43 . Discovered 1998 Jan. 25 by M. Tombelli and G. Forti at Cima Ekar.

Giovanni Caprara (1948- ) is science and space editor of Il Corriere della Sera, the most authoritative newspaper in Italy. Author of numerous books on astronomy and the exploration of the universe, he received the Glaxo-CEE award. (M 40705)

\section{(10929) Chenfangyun}

$1998 \mathrm{CF}_{1}$. Discovered 1998 Feb. 1 at the Beijing Observatory at Xinglong.

Fangyun Chen (1916- ) made initiative contributions to the research on radio electronics in China. A member of both the Chinese Academy of Sciences and the International Academy of Astronautics, he received several highest scientific achievement prizes in China. (M 43191)

\section{(10930) Jinyong}

$1998 \mathrm{CR}_{2}$. Discovered 1998 Feb. 6 at the Beijing Observatory at Xinglong.

Jinyong is a pen-name of Louis Cha (1924- ), author of 15 chivalrous romances in Chinese and the most widely read novelist in Chinese communities in the world. His novels have sold over 300 million copies in various languages. He has won many international honors and is an honorary professor at five universities. (M 42361)

\section{(10931) Ceccano}

1998 DA. Discovered 1998 Feb. 16 by G. Masi at Ceccano.

Ceccano, where the discovery observations of this minor planet were made, is a small city, some $90 \mathrm{~km}$ southeast of Rome. (M 36129)

\section{(10932) Rebentrost}

1998 DL $_{1}$. Discovered 1998 Feb. 18 by G. Lehmann at Drebach.

David Rebentrost (1614-1703) worked in Drebach \{see planet (6488)\} as a vicar, doctor and herbalist. The garden he designed for his vicarage received wide fame. As a reward for curing elector Johann Georg II, he was invited to pick some plants from the elector's garden. The rare species of crocus he selected continues to grow only in Drebach. (M 36129)

\section{(10934) Pauldelvaux}

1998 DN $_{34}$. Discovered 1998 Feb. 27 by E. W. Elst at La Silla.

Paul Delvaux (1897-1994) was a Belgian Surrealist painter who became famous for his somnambulistic nudes, walking in stations between the trains, between skeletons or sitting in front of ancient Greek temples. (M 40705)

\section{(10937) Ferris}

1998 QW $_{54}$. Discovered 1998 Aug. 27 by the LONEOS at Anderson Mesa.

William D. Ferris (1961- ), a video producerdirector at Northern Arizona University, has been an assiduous and successful observer for LONEOS since 1998. (M 41030)

\section{(10938) Lorenzalevy}

1998 SW $_{60}$. Discovered 1998 Sept. 17 by the LONEOS at Anderson Mesa.

Lorenza Levy (1976- ) has been an observer for LONEOS since mid-1999. (M 41030)

\section{(10943) Brunier}

$1999 \mathrm{FY}_{6}$. Discovered 1999 Mar. 20 by the OCA-DLR Survey at Caussols.

Serge Brunier (1958- ) worked as a reporter and editor -in-chief of Ciel et Espace magazine and wrote several articles on the world's observatories. Author of several popular astronomy books, he has a weekly astronomy program on French radio. (M 41030)

\section{(10974) Carolalbert}

2225 T-2. Discovered 1973 Sept. 29 by C. J. van Houten and I. van Houten-Groeneveld at Palomar.

Carol (Handahl) and Albert O. Grender, are aunt and uncle of and godparents to D. W. E. Green, who made the identifications involving this object. The 
Grenders, interested in astronomy since their college days, celebrate their 50th wedding anniversary in June 2002. (M 45233)

\section{(10989) Dolios}

1973 SL $_{1}$. Discovered 1973 Sept. 19 by C. J. van Houten and I. van Houten-Groeneveld at Palomar.

Dolios was the faithful servant of Laërtes at Ithaca \{see planet (1151)\}. (M 38200)

\section{(11002) Richardlis}

$1979 \mathrm{MD}_{1}$. Discovered 1979 June 24 by E. F. Helin and S. J. Bus at Siding Spring.

Richard J. Lis, M.D. (1951- ) has been an orthopedist and surgeon with the Orthopedic Institute of Pasadena \{see planet (2200)\} for over 15 years. A member of many professional medical associations, he also provides medical consultations to Caltech \{see planet (2906) \} students on a voluntary basis. (M 39657)

\section{(11006) Gilson}

$1980 \mathrm{TZ}_{3}$. Discovered 1980 Oct. 9 by C. S. Shoemaker and E. M. Shoemaker at Palomar.

Jewett Castello Gilson (1844-1926), Californian teacher, author and superintendent of schools, was determined to secure an astronomical observatory for the schools and people of Oakland. In 1883 he found a donor to fund what became the Chabot s see planet (12675)\} Observatory. (M 40705)

The name was suggested by the Eastbay Astronomical Society

\section{(11012) Henning}

$1982 \mathrm{JH}_{2}$. Discovered 1982 May 15 at the Palomar Observatory at Palomar.

John Henning (1947- ) assisted with the control software development during the conversion of the Palomar 1.2-m Oschin telescope. (M 45233)

The name was suggested by $R$. Thicksten.

\section{(11014) Svätopluk}

1982 QY $_{1}$. Discovered 1982 Aug. 23 by M. Antal at Piszkéstetö.

Svätopluk (d. 894) was a famous king of the ancient Slavs and prince of Great Moravia from 871 to 894 . Under his rule Moravia \{see planet (1901)\} achieved its greatest territorial reach and was independent of the Frankish Empire. Legend has it that after the king's death quarrels between his three sons were the reason for Moravia's decline. (M 43191)

\section{(11016) Borisov}

$1982 \mathrm{SG}_{12}$. Discovered 1982 Sept. 16 by L. I. Chernykh at Nauchnyj.

Vladimir Aleksandrovich Borisov (1809-1862), regional ethnographer in the town of Shuya and a member of Russian Geography Society, was the author of a book about Shuya and its environs. He had a vast collection of ancient handwritten rolls and books, old printed books and coins that are now at various museums. (M 43382)

\section{(11017) Billputnam}

1983 BD. Discovered 1983 Jan. 16 by E. Bowell at Anderson Mesa.

William L. Putnam (1924- ) is the Trustee of the Lowell Observatory. (M 44594)

\section{(11020) Orwell}

1984 OG. Discovered 1984 July 31 by A. Mrkos at Kleť.

British writer George Orwell (Eric Blair, 1903-1950) was renowned for his novels Animal Farm and 1984, the latter a brilliant examination of the dangers of totalitarian rule. (M 40705)

The name was suggested by J. Tichá and endorsed by B. G. Marsden, who made the identification involving this aptly designated object.

\section{(11021) Foderà}

$1986 \mathrm{AT}_{2}$. Discovered 1986 Jan. 12 by E. Bowell at Anderson Mesa.

Giorgia Foderà (1942- ） teaches history of astronomy at Palermo University. Curator of the Palermo Observatory museum, she published the inventory of its instruments, which include the vertical circle used by Piazzi $\{$ see planet (1000)\}. She was the principal organizer of the Palermo Observatory's celebration of Ceres' \{see planet (1)\} bicentennial. (M 43382)

\section{(11022) Serio}

$1986 \mathrm{EJ}_{1}$. Discovered 1986 Mar. 5 by E. Bowell at Anderson Mesa.

Salvatore Serio (1941- ) teaches astronomy at Palermo University, specializing in x-ray observations and modeling of solar and stellar coronae. As director of the Palermo Observatory and president of the Italian Astronomical Society, he served as a gracious and generous host for the celebrations of Ceres' \{see planet (1)\} bicentennial. (M 43382)

\section{(11027) Astaf'ev}

1986 RX $_{5}$. Discovered 1986 Sept. 7 by L. I. Chernykh at Nauchnyj.

Victor Petrovich Astaf'ev (1924-2001) was a prominent Russian writer. (M 45233)

\section{(11037) Distler}

1989 CD $_{6}$. Discovered 1989 Feb. 2 by F. Börngen at Tautenburg.

Hugo Distler (1908-1942), a composer, organist and director of renowned choirs, served in Lübeck, Stuttgart and Berlin. His works in a highly individual style brought him much respect in the new German church music. (M 38200)

\section{(11039) Raynal}

$1989 \mathrm{GH}_{2}$. Discovered 1989 Apr. 3 by E. W. Elst at La Silla.

Guillaume-Thomas Raynal (1713-1796) wrote a sixvolume history of the European colonies in India and America. His condemnation of the efforts of the colonists resulted in his condemnation by the Catholic 
church. In the French revolution he was elected to the States general, but he refused to serve, because he opposed violence. (M 36129)

\section{(11040) Wundt}

$1989 \mathrm{RG}_{1}$. Discovered 1989 Sept. 3 by E. W. Elst at St. Michel.

German physiologist Wilhelm Wundt (1832-1920) is acknowledged as the founder of experimental psychology. In one of the most important works in the history of psychology Grundzüge der physiologischen Psychologie (1873-1874), Wundt stressed the use of experimental methods in psychology. (M 40705)

\section{(11041) Fechner}

$1989 \mathrm{SH}_{2}$. Discovered 1989 Sept. 26 by E. W. Elst at La Silla.

Gustav Theodor Fechner (1801-1887) was a German physicist and philosopher who founded the science of psychophysics. In his Elemente der Psychophysik (1860) he established a relation between sensations and the stimuli producing them (i.e., the "Weber-Fechner Law"). (M 40705)

\section{(11042) Ernstweber}

1989 VD $_{1}$. Discovered 1989 Nov. 3 by E. W. Elst at La Silla.

Ernst Heinrich Weber (1795-1878) was a German physiologist who did fundamental research on the sense of touch. In his De Tactu (1834) he stated what became the Weber-Fechner Law: that there is a threshold of sensation that must be passed before an increase in the intensity of the stimulus can be detected. (M 40705)

\section{(11043) Pepping}

1989 YX $_{6}$. Discovered 1989 Dec. 25 by F. Börngen at Tautenburg.

Ernst Pepping (1901-1981) was an organist and professor of music in Berlin and one of the leading German composers of church music. He rejuvenated sacred and secular choir music. His instrumental and vocal works are very extensive, and his books Stilwende der Musik and Der polyphone Satz set the fashion for their time. (M 38200)

\section{(11050) Messiaën}

$1990 \mathrm{TE}_{7}$. Discovered 1990 Oct. 13 by F. Börngen and L. D. Schmadel at Tautenburg.

Olivier Messiaën (1908-1992) was organist at Ste. Trinité in Paris, as well as a composer and teacher of a whole generation of young composers. In his works for organ and orchestra numerous influences are merged, such as rhythms from oriental civilizations. (M 38200; M 38949)

\section{(11051) Racine}

$1990 \mathrm{VH}_{12}$. Discovered 1990 Nov. 15 by E. W. Elst at La Silla.

The dramatic poet Jean-Baptiste Racine (1639-1699) was the uncontested master of French classicism. The unforgettable characters of his plays suffer from feelings of incompleteness in a world of passionate self-interest. (M 36130)

The name was suggested by R. Josse.

\section{(11055) Honduras}

$1991 \mathrm{GT}_{2}$. Discovered 1991 Apr. 8 by E. W. Elst at La Silla.

Honduras, in the northern part of the Central American isthmus, is a country of rugged mountains and steep river gorges and dense forest, lined on the Caribbean coast by tropical jungle famed in past centuries for pirates. As in Guatemala \{see planet (10797)\} there are relics of the Mayan civilisation. (M 42672)

\section{(11056) Volland}

$1991 \mathrm{LE}_{2}$. Discovered 1991 June 6 by E. W. Elst at La Silla.

Sophie Volland (1720-1784) was the primary correspondent of Dénis Diderot \{see planet (5351)\}, who met her in 1755 near Vitry-le-François. Their friendship, based on common interests and natural sympathy, lasted for 30 years. (M 40507)

\section{(11061) Lagerlöf}

$1991 \mathrm{RS}_{40}$. Discovered 1991 Sept. 10 by F. Börngen at Tautenburg.

Swedish novelist Selma Lagerlöf (1858-1940) wrote beautiful stories, using popular tales of her Vaermlandian homeland. She dealt with social problems, questions of fault and responsibility from a religiousethical point of view. Awarded the Nobel prize for literature in 1909, she was the first female member of the Swedish Academy. (M 38200)

\section{(11063) Poynting}

$1991 \mathrm{VC}_{6}$. Discovered 1991 Nov. 2 by E. W. Elst at La Silla.

British physicist John Henry Poynting (1852-1914) introduced a theorem in 1884 in which he stated that the energy flow at a point can be expressed in terms of the electric and magnetic forces at that point. The so-called "Poynting vector" can be used to determine the radiated energy flow in the vicinity of an antenna. (M 40705)

\section{(11066) Sigurd}

1992 CC $_{1}$. Discovered 1992 Feb. 9 by C. S. Shoemaker and E. M. Shoemaker at Palomar.

Sigurd was the most famous of all Norse heroes and played the principal part in the Volsungasaga. He rides through a ring of fire to awaken Brynhild twice, once for himself and once for the king Gunnar, in a complicated tale of love and deception and treachery. (M 40706)

\section{(11067) Greenancy}

$1992 \mathrm{DC}_{3}$. Discovered 1992 Feb. 25 by the Spacewatch at Kitt Peak.

Boston-born Nancy Green (1952- ) studied violoncello at the Juilliard School, made her debut at 
Lincoln Center, studied in London with Jacqueline du Pré and taught 'cello at London's Guildhall School. A teacher at the University of Arizona since 1995, she performs and records internationally. (M 42672)

\section{(11072) Hiraoka}

1992 GP. Discovered 1992 Apr. 3 by K. Endate and

K. Watanabe at Kitami.

Hiroyuki Hiraoka (1957- ) is an elementary-school teacher and amateur astronomer, active in the Hiroshima Astronomical Society. (M 45747)

\section{(11073) Cavell}

1992 RA $_{4}$. Discovered 1992 Sept. 2 by E. W. Elst at La Silla.

Edith (Louisa) Cavell (1865-1915) was an English nurse who in 1907 was appointed to the Berkendael Institute in Brussels, where she greatly improved the standard of nursing. In 1915 she was sentenced to death and shot by the Germans, because she had helped Allied soldiers escape from Belgium. (M 40706)

\section{(11074) Kuniwake}

1992 SC $_{1}$. Discovered 1992 Sept. 23 by K. Endate and

K. Watanabe at Kitami.

Ryoku Kuniwake (1957- ), a longtime member of the Hiroshima Astronomical Society, uses many wonderful photographs taken at his private observatory for public education. (M 45748)

\section{(11075) Dönhoff}

$1992 \mathrm{SP}_{26}$. Discovered 1992 Sept. 23 by F. Börngen at Tautenburg.

Marion Gräfin Dönhoff (1909-2002) is a highly esteemed critical German journalist, engaged in problems from the past and present. Her analyses are characterized by objectivity and restraint. Among her honors is the peace prize of the German book trade. (M 38200)

The name was independently suggested by L. D. Schmadel.

\section{(11079) Mitsunori}

1993 AJ. Discovered 1993 Jan. 13 by K. Endate and K. Watanabe at Kitami.

Mitsunori Kaneko (1957- _ ) is an elementary-school teacher and was secretary of the Fukuoka Astronomical Society from 1981 to 1989 . (M 45748)

\section{(11083) Caracas}

$1993 \mathrm{RZ}_{6}$. Discovered 1993 Sept. 15 by E. W. Elst at La Silla.

Founded in 1567, Caracas is the capital of Venezuela and one of the principal cities of South America. (M 39657)

\section{(11084) Giò}

$1993 \mathrm{SG}_{3}$. Discovered 1993 Sept. 19 at the Farra d'Isonzo Observatory at Farra d'Isonzo.

Giuseppe Schilirò (1991-2000), an Italian student, was a good and big-hearted child. (M 46682)

The name was suggested by his schoolmates.

\section{(11085) Isala}

1993 SS $_{6}$. Discovered 1993 Sept. 17 by E. W. Elst at La Silla.

Since Belgian women were not allowed to study at the Catholic University of Leuven, Isala Van Diest moved to Switzerland and studied medicine at the University of Berne. In 1890, she became the first female doctor in Belgium authorized to exercise her profession. (M 40706)

\section{(11086) Nagatayuji}

$1993 \mathrm{TC}_{1}$. Discovered 1993 Oct. 11 by K. Endate and K. Watanabe at Kitami.

Yuji Nagata (1953- ), former director of the Fukuoka Astronomical Society, has interests in comets and solar eclipses. (M 45748)

\section{(11087) Yamasakimakoto}

$1993 \mathrm{TK}_{1}$. Discovered 1993 Oct. 15 by K. Endate and K. Watanabe at Kitami.

Makoto Yamasaki (1953- ）, director of the Fukuoka Astronomical Society from 1977 to 1982, has interests in comet hunting and photography. (M 45748)

\section{(11090) Popelin}

$1994 \mathrm{CT}_{12}$. Discovered 1994 Feb. 7 by E. W. Elst at La Silla.

In 1888, Marie Popelin (1846-1913) graduated from the Free University of Brussels as a lawyer. However, since female lawyers were not permitted to practise in Belgium, in 1892 she founded "La Ligue Belge du droit des Femmes" for defending the rights and protecting the interests of women. (M 40706)

\section{(11091) Thelonious}

1994 DP. Discovered 1994 Feb. 16 by the Spacewatch at Kitt Peak.

Thelonious Sphere Monk (1917-1982), American composer and jazz pianist, born in Rocky Mount, North Carolina, moved to New York City at age 3 and took up the piano at age 5. Monk was central to the development of the bebop style and a great procreator of musical advances. (M 42672)

\section{(11094) Cuba}

$1994 \mathrm{PG}_{17}$. Discovered 1994 Aug. 10 by E. W. Elst at La Silla.

Cuba is an island state in the Caribbean Sea, consisting of one large island and numerous smaller islands, islets and cays. Christopher Columbus reached its coasts during his first voyage to the Americas. At that time several Indian groups inhabited Cuba. (M 42672)

\section{(11095) Havana}

1994 PJ $_{22}$. Discovered 1994 Aug. 12 by E. W. Elst at La Silla.

The original urban nucleus of Havana, next to the port, is characterized by buildings in pure colonial style. More modern architecture is located near the Plaza de la Revolución. The city is an industrial, import and 
distribution center. Cuba's cigar production is well known throughout the world. (M 40706)

\section{(11098) Ginsberg}

$1995 \mathrm{GC}_{2}$. Discovered 1995 Apr. 2 by the Spacewatch at Kitt Peak.

Allen Ginsberg (1926-1997), American lyric poet and teacher, was born in Paterson, New Jersey, and studied at Columbia College, New York City. He became a central figure among the Beats (taking their name from the eight Beatitudes; Matthew 5:3-10) with the publication of his long poem Howl in October 1955. (M 42672)

\section{(11099) Sonodamasaki}

1995 HL. Discovered 1995 Apr. 20 by K. Endate and K. Watanabe at Kitami.

Masaki Sonoda (1954- ), an associate president of the Saga Astronomical Society since 1989, is active in organizing local star parties and is a volunteer member of the Saga City Observatory. (M 45748)

\section{(11100) Lai}

1995 KC. Discovered 1995 May 22 at the Osservatorio San Vittore at Bologna.

Luciano Lai (1948- ） has been an active observer and discoverer of minor planets at Madonna di Dossobuono \{see planet (7144)\} since 1983. He is interested in the design and construction of astronomical telescopes and optics, and he designed the focal reducer used by many Italian amateur astrometrists. (M 36950)

\section{(11101) Českáfilharmonie}

1995 SH. Discovered 1995 Sept. 17 by L. Šarounová at Ondřejov.

The Czech Philharmonic Orchestra is known for its spontaneous musicality and distinctive interpretive style. Its first concert was conducted by A. Dvořák \{see planet (2055)\} in 1896 and its current high level was developed by chief conductors V. Talich, K. Ančerl and V. Neumann. (M 41938)

\section{(11102) Bertorighini}

$1995 \mathrm{SZ}_{4}$. Discovered 1995 Sept. 26 by L. Tesi at San Marcello Pistoiese.

Alberto Righini (1942- ） is a professor of astronomy at the University of Florence and Arcetri \{see planet (6645)\} Observatory. His main field of interest is solar physics, and he has observed several eclipses around the world. He is also very active in the field of popularizing astronomy. (M 36950)

\section{(11103) Miekerouppe}

1995 SX $_{19}$. Discovered 1995 Sept. 18 by the Spacewatch at Kitt Peak.

Mieke Rouppe was concerned with issues of freedom and human rights, and she was willing to be a courier and participant in the Dutch Resistance in The Hague during World War II. (M 43382)

\section{(11104) Airion}

1995 TQ. Discovered 1995 Oct. 6 by the JPL NEAT Program at Haleakala.

Evelyn Airion Enyart (1952- ) teaches seminars in healing techniques. She was born in Louisiana, raised in Guatemala and educated at the University of New Mexico, receiving degrees in both Communications and Sign Language. She presents workshops around the world, writes books and produces videos on healing techniques. (M 43191)

\section{(11105) Puchnarová}

$1995 \mathrm{UR}_{2}$. Discovered 1995 Oct. 24 by J. Tichá at Klě́.

Dana Puchnarová (1938- ) is a Czech painter and graphic artist. Her abstract art comes from natural and cosmic structures. An important part of her work is teaching, and the discoverer, as a young girl, was one of her pupils. (M 42361)

\section{(11111) Repunit}

1995 WL. Discovered 1995 Nov. 16 by T. Kobayashi at Oizumi.

A repunit ("repeated unity") is a number consisting solely of the digit 1 . The name was introduced by Albert H. Beiler in his book Recreations in the Theory of Numbers (1964). (M 40706)

For this minor planet, the name was suggested by J. Meeus.

\section{(11112) Cagnoli}

$1995 \mathrm{WM}_{2}$. Discovered 1995 Nov. 18 at the Madonna di Dossobuono Observatory at Madonna di Dossobuono.

The Italian astronomer Antonio Cagnoli (17431816) worked to introduce the scientific ideas of the Enlightenment into Italian society, helping establish the "Italian Society", founded in 1781 to gather the best Italian scientists into a single organization. (M 38200)

\section{(11115) Kariya}

$1995 \mathrm{WC}_{7}$. Discovered 1995 Nov. 21 by A. Nakamura at Kuma.

Kariya City (population 126 000), where the discoverer lived for one and a half years, is located in the center of Aichi Prefecture. Although the city center is dominated by automobile industry facilities, its northern part is blessed with abundant nature. (M 39657)

\section{(11118) Modra}

1996 PK. Discovered 1996 Aug. 9 by A. Galád and D. Kalmančok at Modra.

Fortuitously coded 118, the observing site of the Institute of Astronomy at Comenius University where this minor planet was discovered is located in the small historical town of Modra, $30 \mathrm{~km}$ northeast of Bratislava. (M 36130)

\section{(11119) Taro}

$1996 \mathrm{PS}_{9}$. Discovered 1996 Aug. 9 by T. Okuni at Nanyou. 
Soutaro Ito (1925- ) has contributed much to the popularization of astronomy and established the Nanyo Astronomical Lovers Club in 1983. He was central to the establishment in 1986 of the society's observatory, the Nanyo Civil Astronomical Observatory. (M 45233)

\section{(11120) Pancaldi}

1996 QD $_{1}$. Discovered 1996 Aug. 17 at the Osservatorio San Vittore at Bologna.

Italian amateur astronomer Enelio Pancaldi (1947-

) was an observer of Jupiter, Saturn and Mars at the Osservatorio San Vittore from 1976 to 1980 during the patrol program organized by the Lowell Observatory for the study of planetary surfaces. A nuclear engineer by profession, he lives at Budrio, near Bologna. (M 41385)

\section{(11121) Malpighi}

1996 RD $_{1}$. Discovered 1996 Sept. 10 by V. Goretti at Pianoro.

Marcello Malpighi (1628-1694) holds a prominent position in the history of medicine and biology, working in Pisa, Bologna, Messina and Rome. A pioneer in the use of the microscope in anatomy, he made fundamental studies of the lungs. He later made contributions in hematology and embryology. (M 41030)

\section{(11122) Eliscolombini}

1996 RQ $_{2}$. Discovered 1996 Sept. 13 at the Osservatorio San Vittore at Bologna.

Elis Colombini (1957- ) is the editor of publications on the local history of his birthplace of Modena and the surrounding province. Elis is the brother of Ermes Colombini \{see planet (7030)\}, a codiscoverer of this minor planet. (M 41385)

\section{(11123) Aliciaclaire}

$1996 \mathrm{RT}_{24}$. Discovered 1996 Sept. 8 by the JPL NEAT Program at Haleakala.

Alicia Claire Contrite (1966- ） is an extraordinarily devoted mother, wife and daughter. She is a prosecuting attorney for the city of Santa Monica, California, primarily concerned with the plight of abused women. (M 41938)

The citation was prepared by M. Hibbs, Alicia's mother, at the request of E. Helin of the NEAT team.

\section{(11124) Mikulášek}

1996 TR $_{9}$. Discovered 1996 Oct. 14 by M. Tichý and Z. Moravec at Klě́.

The Czech astronomer Zdeněk Mikulášek (1947- _ ) is director of the Nicholas Copernicus Observatory and Planetarium in Brno \{see planet (2889)\}, working also at the Masaryk University there. His main research interests consist of the photometry and spectra of variable stars and the study of atmospheric extinction. (M 38200)

\section{(11126) Doleček}

1996 TC $_{15}$. Discovered 1996 Oct. 15 by P. Pravec at Ondřejov.

Josef ("Jožka") Doleček (1912- ） had a principal role in building the public observatory of Valašské Meziříčí and was its first director. His work gave a basis for the observatory's success in astronomy popularization in the Czech Republic. (M 36950) The name was suggested by L. Lenža.

\section{(11127) Hagi}

$1996 \mathrm{UH}_{1}$. Discovered 1996 Oct. 20 by K. Cross at Sendai.

The name "Hagi-Lespedeza" is derived from the flower in the symbol of Sendai city. (M 41938)

Among those suggesting the name was the nonagenarian Kiyoshi Yamada.

\section{(11128) Ostravia}

1996 VP. Discovered 1996 Nov. 3 by J. Tichá and M. Tichý at Kleť.

Ostrava (Ostravia in Latin) has been considered the center of the mining and steel industries in northern Moravia since the nineteenth century. In recent years Ostrava has turned into a commercial, educational and cultural site. The city has also been home to an observatory and planetarium since 1980. (M 41385)

\section{(11134) České Budějovice}

$1996 \mathrm{XO}_{2}$. Discovered 1996 Dec. 4 by M. Tichý and Z. Moravec at Kleť.

Ceské Budějovice $\{$ see also planet (2524)\} is the historic, cultural, educational, industrial and administrative center of south Bohemia. Originally known as Budiwoyz or Budoywiz, the German form of which is Budweis, the city is famous for its beer. There is an observatory in the city, and the Klet Observatory is situated on nearby Klet mountain. (M 36950)

\section{(11136) Shirleymarinus}

1996 XW $_{12}$. Discovered 1996 Dec. 8 by the Spacewatch at Kitt Peak.

Shirley Marinus (1921- ) served during a third of a century as secretary in the Lunar and Planetary Laboratory for the Polariscope program, the Imaging Photopolarimeters on Pioneers 10 and 11, the Space Science Series textbooks, and the Spacewatch survey of comets and minor planets. (M 43045)

\section{(11141) Jindrawalter}

1997 AX $_{14}$. Discovered 1997 Jan. 12 by J. Tichá and M. Tichý at Klě́.

Jindrrich Walter (1941- ) is the head of the Optical Facility of the Faculty of Mathematics and Physics of the Charles University in Prague. His deep knowledge and wide experience have been very helpful in building the new 1.06-m KLENOT telescope at the Klet Observatory. (M 45748) 


\section{(11142) Facchini}

1997 AP $_{17}$. Discovered 1997 Jan. 7 by V. S. Casulli at Colleverde di Guidonia.

Renato Facchini (1917- ) is a well-known Italian amateur astronomer who also builds and repairs telescopes. (M 41030)

\section{(11144) Radiocommunicata}

1997 CR $_{1}$. Discovered 1997 Feb. 2 by J. Tichá and M. Tichý at Klet.

The twentieth century can be called the age of communication. The staff of the Klet broadcasting tower, providing radio, television and radio-relay connections to south Bohemia since 1959, embodies the spirit of communication. (M 41030)

\section{(11147) Delmas}

$1997 \mathrm{XT}_{5}$. Discovered 1997 Dec. 6 by P. Antonini at Bedoin.

Robert Delmas (1955- ) is a French aeronautical engineer. Deeply interested in astronomy, he has devoted much time to AUDE \{see planet (9117)\}, the Association des Utilisateurs de Détecteurs Electroniques. (M 41030)

\section{(11148) Einhardress}

$1997 \mathrm{XO}_{8}$. Discovered 1997 Dec. 7 by the OCA-DLR Survey at Caussols.

Einhard Ress (1936- ) was an engineer and scientist at the German Aerospace Center (DLR). He used innovative technology to develop the focal-plane electronics of the ESA Mars Express mission and of an airborne digital camera. The naming is on the occasion of his retirement. (M 43191)

\section{(11150) Bragg}

1997 YG $_{1}$. Discovered 1997 Dec. 21 by F. B. Zoltowski at Woomera.

William Lawrence Bragg (1890-1971), born in Adelaide, shared the 1915 Nobel Prize in physics with his father, W. H. Bragg. W. L. Bragg's work in $\mathrm{x}$-ray diffraction led to techniques used to reveal the structure of molecules such as DNA and proteins. (M 41385)

\section{(11156) Al-Khwarismi}

$1997 \mathrm{YP}_{14}$. Discovered 1997 Dec. 31 by P. G. Comba at Prescott.

Muhammad ibn Musa al-Khwarismi (fl. c. 825) was an Arab mathematician and astronomer whose books, translated into Latin, were the main source through which Indian numerals and Arabic algebra came into Western Europe. (M 36950)

\section{(11158) Cirou}

1998 AJ $_{6}$. Discovered 1998 Jan. 8 by the OCA-DLR Survey at Caussols.

Alain Cirou (1958- ) is editor of Ciel et Espace \{see planet (7192)\} magazine. He began working for the Association Française d'Astronomie in 1981 and has brought its magazine to its current monthly readership of 70000 . He has also popularized astronomy on radio and television. (M 41031)

\section{(11166) Anatolefrance}

$1998 \mathrm{DF}_{34}$. Discovered 1998 Feb. 27 by E. W. Elst at La Silla.

Anatole France (Anatole Thibault, 1844-1924) was an ironic and skeptical French writer. In his L'Eglise et la République (1904) he severely attacked Napoleon for his "Concordat" with the Church. In 1896 he was elected to the French Academy, and in 1921 he won the Nobel Prize for literature. (M 40706)

\section{(11167) Kunžak}

$1998 \mathrm{FD}_{3}$. Discovered 1998 Mar. 23 by P. Pravec at Ondřejov.

Kunžak is a picturesque village in South Bohemia. In this village there is a small observatory, named "Na jitrech" (or "On Early Mornings"), mainly devoted to meteor astronomy. (M 36950)

The name was suggested by P. Spurný.

\section{(11169) Alkon}

$1998 \mathrm{FW}_{33}$. Discovered 1998 Mar. 20 by the LINEAR at Socorro.

Andy L. Alkon (1986- ) is a finalist in the 2002 Intel International Science and Engineering Fair for his physics project. He attends the Manhasset High School, Manhasset, New York, U.S.A. (M 46102)

\section{(11173) Jayanderson}

1998 FA $_{59}$. Discovered 1998 Mar. 20 by the LINEAR at Socorro.

Jay S. Anderson (1985- ) is a finalist in the 2002 Intel International Science and Engineering Fair for his physics project. He attends the Paint Valley High School, South Salem, Ohio, U.S.A. (M 46102)

\section{(11174) Carandrews}

1998 FR $_{67}$. Discovered 1998 Mar. 20 by the LINEAR at Socorro.

Carolyn Marie Andrews (1984- ) is a finalist in the 2002 Intel International Science and Engineering Fair for her engineering project. She attends the Lake Brantley High School, Longwood, Florida, U.S.A. (M 46102)

\section{(11176) Batth}

1998 FD $_{68}$. Discovered 1998 Mar. 20 by the LINEAR at Socorro.

Sukhjeet Singh Batth (1985- ) is a finalist in the 2002 Intel International Science and Engineering Fair for his biochemistry project. He attends the Fowler High School, Fowler, California, U.S.A. (M 46102)

\section{(11184) Postma}

1998 HJ $_{9}$. Discovered 1998 Apr. 18 by the Spacewatch at Kitt Peak.

Sep Postma (1921-1944) was concerned with human rights. He escaped occupied Holland via Spain and was trained in England as an agent for the Special 
Operations Executive. He parachuted into Holland to organize the Resistance. When caught, he faced the harshest of interrogations. (M 43382)

\section{(11187) Richoliver}

$1998 \mathrm{KO}_{4}$. Discovered 1998 May 22 by the LONEOS at Anderson Mesa.

Richard C. Oliver (1948- ）, an electronics specialist at the Lowell Observatory, spearheaded the extensive electrical overhaul of the LONEOS dome, including its Schmidt telescope, control room and computer room. (M 41031)

\section{(11189) Rabeaton}

1998 QQ $_{43}$. Discovered 1998 Aug. 17 by the LINEAR at Socorro.

Rachael Lynn Beaton (1985- ) is a finalist in the 2002 Intel International Science and Engineering Fair for her earth and space sciences project. She attends the Central Virginia Governor School, Lynchburg, Virginia, U.S.A. (M 46102)

\section{(11190) Jennibell}

$1998 \mathrm{RM}_{52}$. Discovered 1998 Sept. 14 by the LINEAR at Socorro.

Jennifer Marie Bell (1984- ) is a finalist in the 2002 Intel International Science and Engineering Fair for her medicine and health project. She attends the Freshman Learning Center Vero Beach High School, Vero Beach, Florida, U.S.A. (M 46102)

\section{(11193) Mérida}

1998 XN $_{96}$. Discovered 1998 Dec. 11 by O. A. Naranjo at Mérida.

This Venezuelan city, named in 1558 by Juan Rodriguez Suarez, is also known as "the city of the gentlemen" for its hospitality; "the city of the snowing mountains" for the surrounding Andes; and "the university city" for its famous Universidad de Los Andes. (M 41938)

\section{(11195) Woomera}

$1999 \mathrm{AY}_{22}$. Discovered 1999 Jan. 15 by F. B. Zoltowski at Woomera.

Woomera, Aboriginal for spear thrower, is a village in the Australian outback founded in 1947 as a rocket rangehead. Woomera and its range played a key role in Australia's space program, culminating in the orbital launch of WRESAT in 1967. It was home to the discoverer for twelve years. (M 41385)

\section{(11197) Beranek}

$1999 \mathrm{CY}_{25}$. Discovered 1999 Feb. 10 by the LINEAR at Socorro.

Benjamin Charles Beranek (1984- ) is a finalist in the 2002 Intel International Science and Engineering Fair for his gerontology project. He attends the Jefferson High School, Lafayette, Indiana, U.S.A. (M 46102)

\section{(11201) Talich}

1999 EL $_{5}$. Discovered 1999 Mar. 13 by L. Šarounová at Ondřejov.

Václav Talich (1883-1961) was a well-known Czech conductor, for many years the head of the National Theatre and from 1919 to 1941 head of the Czech Philharmonic Orchestra, which he brought to a high international standard. His creation of the tradition of interpreting the work of Czech composers was significant. (M 44594)

\section{(11202) Teddunham}

$1999 \mathrm{FA}_{10}$. Discovered 1999 Mar. 22 by the LONEOS at Anderson Mesa.

Edward W. Dunham (1952- ) , an astronomer at the Lowell \{see planet (1886)\} Observatory, is a co-discoverer of the rings of Uranus and a designer of instruments for both groundbased and space applications. His current research concerns the detection of extrasolar planets by means of photometry. (M 41031)

\section{(11203) Danielbetten}

$1999 \mathrm{FV}_{26}$. Discovered 1999 Mar. 19 by the LINEAR at Socorro.

Daniel Price Betten (1987- ) is a finalist in the 2002 Intel International Science and Engineering Fair for his earth and space sciences project. He attends the Richarsdon Home School Association, Palestine, Texas, U.S.A. (M 46102)

\section{(11206) Bibee}

$1999 \mathrm{FR}_{29}$. Discovered 1999 Mar. 19 by the LINEAR at Socorro.

Kristin Page Bibee (1984- ) is a finalist in the 2002 Intel International Science and Engineering Fair for her biochemistry project. She attends the Central Virginia Governor School, Lynchburg, Virginia, U.S.A. (M 46102)

\section{(11207) Black}

1999 FQ $_{58}$. Discovered 1999 Mar. 20 by the LINEAR at Socorro.

Maribeth Joanne Black (1984- ) is a finalist in the 2002 Intel International Science and Engineering Fair for her microbiology project. She attends the Hedgesville High School, Falling Waters, West Virginia, U.S.A. (M 46102)

\section{(11212) Tebbutt}

1999 HS. Discovered 1999 Apr. 18 by F. B. Zoltowski at Woomera.

John Tebbutt (1834-1916) was an Australian astronomer whose observations included many comets and the 1874 transit of Venus. His name is particularly associated with the great comets of 1861 and 1881 . He was the first president of the New South Wales branch of the British Astronomical Association. (M 41385)

\section{(11219) Benbohn}

$1999 \mathrm{JN}_{20}$. Discovered 1999 May 10 by the LINEAR at Socorro. 
Benjamin Josef Bohn (1985- ） is a finalist in the 2002 Intel International Science and Engineering Fair for his engineering project. He attends the Panola High School, Red Oak, Oklahoma, U.S.A. (M 46102)

\section{(11225) Borden}

$1999 \mathrm{JD}_{36}$. Discovered 1999 May 10 by the LINEAR at Socorro.

Timothy Calvin Borden (1985- ) is a finalist in the 2002 Intel International Science and Engineering Fair for his environmental science project. He attends the Canterbury School, Fort Myers, Florida, U.S.A. (M 46102)

\section{(11227) Ksenborisova}

$1999 \mathrm{JR}_{43}$. Discovered 1999 May 10 by the LINEAR at Socorro.

Ksenia V. Borisova (1983- ) is a finalist in the 2002 Intel International Science and Engineering Fair for her medicine and health project. She attends the Arkansas School for Mathematics and Sciences, Little Rock, Arkansas, U.S.A. (M 46102)

\section{(11228) Botnick}

$1999 \mathrm{JW}_{49}$. Discovered 1999 May 10 by the LINEAR at Socorro.

Aaron Michael Botnick (1984- ) is a finalist in the 2002 Intel International Science and Engineering Fair for his computer science project. He attends the Hahnville High School, Luling, Louisiana, U.S.A. (M 46103)

\section{(11229) Brookebowers}

$1999 \mathrm{JX}_{52}$. Discovered 1999 May 10 by the LINEAR at Socorro.

Brooke Nacole Bowers (1986- ) is a finalist in the 2002 Intel International Science and Engineering Fair for her zoology project. She attends the Tuscarawas Valley High School, Dover, Ohio, U.S.A. (M 46103)

\section{(11251) Icarion}

$1973 \mathrm{SN}_{1}$. Discovered 1973 Sept. 20 by C. J. van Houten and I. van Houten-Groeneveld at Palomar.

Icarion was the son of Ebalus of Sparta. By the nymph Periboea Icarion was the father of Penelope \{see planet (201)\}. (M 38200)

\section{(11252) Laërtes}

$1973 \mathrm{SA}_{2}$. Discovered 1973 Sept. 19 by C. J. van Houten and I. van Houten-Groeneveld at Palomar.

Laërtes, king of Ithaca \{see planet (1151)\}, was the son of Arcisius, who in turn was a son of Zeus \{see planet (5731)\}. Laërtes was the husband of Anticleia and father of Odysseus \{see, respectively, planets (651) and (1143)\}. (M 38200)

\section{(11253) Mesyats}

$1976 \mathrm{UP}_{2}$. Discovered 1976 Oct. 26 by T. M. Smirnova at Nauchnyj.

Russian physicist Gennadij Andreevich Mesyats (1936- ) is known for his work on the physics of electrical discharges in gas and vacuum, emission electronics, high-current accelerators of electrons and the power impulse technique. Since 1987 he has been a vice-president of the Russian Academy of Sciences. (M 42672)

\section{(11258) Aoyama}

1978 VP $_{1}$. Discovered 1978 Nov. 1 by K. Tomita at Caussols.

Aoyama Gakuin, a Christian educational institute founded in 1874, is the discoverer's Alma Mater. He was to know the joy of astronomy in his high-school days under the guidance of excellent teachers and became a professional astronomer. (M 43382)

The citation was prepared by M. Hara.

\section{(11264) Claudimaccone}

1979 UC $_{4}$. Discovered 1979 Oct. 16 by N. S. Chernykh at Nauchnyj.

Claudio Maccone (1948- ), an Italian scientific researcher and technical expert at the Alenia Spazio in Turin, has participated in the design of some scientific space missions and submitted a proposal for a space mission to exploit the radio magnification provided by the gravitational lens of the sun. (M 43382)

\section{(11269) Knyr}

1987 QG $_{10}$. Discovered 1987 Aug. 26 by L. G. Karachkina at Nauchnyj.

Engineer Igor' Ivanovich Knyr (1963- ) is a specialist on the introduction of new techniques in industry and a friend of the discoverer's family. (M 36950)

\section{(11277) Ballard}

$1988 \mathrm{TW}_{2}$. Discovered 1988 Oct. 8 by C. S. Shoemaker and E. M. Shoemaker at Palomar.

Robert D. Ballard (1942- ) is a marine scientist who has spent much of his professional career beneath the sea, partly as director of the Deep Submergence Laboratory. As leader of two expeditions, he discovered the Titanic. He is a director of the Jason Project for Education. (M 45748)

\section{(11278) Telesio}

$1989 \mathrm{SD}_{3}$. Discovered 1989 Sept. 26 by E. W. Elst at La Silla.

Bernardino Telesio (1509-1588) was an Italian philosopher and natural scientist who severely opposed the practice of reasoning without reference to concrete data. His studies of plants and animals led him to believe that heat is the source of life. Francis Bacon \{see planet (2940)\} called him "the first of the moderns". (M 39657)

\section{(11282) Hanakusa}

$1989 \mathrm{UY}_{2}$. Discovered 1989 Oct. 30 by K. Endate and K. Watanabe at Kitami.

Kiyotaka Hanakusa (1956- ), director of the Seiwa Kogen Observatory since 1995, is an astronomy scholar 
and popularizer of astronomy in Kumamoto Prefecture. (M 45748)

\section{(11284) Belenus}

1990 BA. Discovered 1990 Jan. 21 by A. Maury at Caussols.

Belenus, husband of Belisana \{see planet (178)\}, is the Gaulish god of light, with responsibilities also to sheep and cattle. (M 38200)

\section{(11289) Frescobaldi}

$1991 \mathrm{PA}_{2}$. Discovered 1991 Aug. 2 by E. W. Elst at La Silla.

Girolamo Frescobaldi (1583-1644) was an Italian organist and composer. He has left us with numerous vocal compositions (he owed his first reputation to his beautiful voice), including canzoni, motets and hymns. His work for the organ shows great ability in the art of the fugue. (M 39657)

\section{(11292) Bunjisuzuki}

$1991 \mathrm{RC}_{28}$. Discovered 1991 Sept. 8 by the Spacewatch at Kitt Peak.

Bunji Suzuki (1955- ) is a high-school teacher and an amateur astrophysicist specializing in comets. He researches them with spectroscopic and twodimensional polarization-imaging instruments. $\mathrm{He}$ is also a leader in astronomy education and popularization in Japan. (M 47167)

\section{(11298) Gide}

$1992 \mathrm{RE}_{6}$. Discovered 1992 Sept. 2 by E. W. Elst at La Silla.

André Gide (1869-1951), the French writer, humanist and moralist, is well-known for his novel Les FauxMonnayeurs (1926). Gide's lifelong emphasis was on the self-aware and sincere individual as the touchstone of both collective and individual morality. In 1947 he was awarded the Nobel prize for literature. (M 39657)

\section{(11299) Annafreud}

1992 SA $_{22}$. Discovered 1992 Sept. 22 by E. W. Elst at La Silla.

Anna Freud (1895-1982), the youngest daughter of Sigmund Freud \{see planet (4342)\}, escaped with her father in 1938 Austria and settled in London. In 1936 she published Das Ich und die Abwehrmechanismen. She is considered the founder of child psychoanalysis. (M 39657)

\section{(11302) Rubicon}

$1993 \mathrm{BM}_{5}$. Discovered 1993 Jan. 27 by E. W. Elst at Caussols.

The Rubicon (Latin "Rubico") was a small river that separated ancient Cisalpine Gaul from Italy. In 49 B.C. Caesar crossed this river without authorization. From this we have the expression " crossing the Rubicon", which means performing a step that definitely commits a person to a given course of action. (M 39657)

\section{(11309) Malus}

$1993 \mathrm{PC}_{7}$. Discovered 1993 Aug. 15 by E. W. Elst at Caussols.

Étienne-Louis Malus (1775-1812) was a French physicist who discovered the polarization of reflected light. In 1798 he accompanied Napoleon to Egypt as a member of the corps of engineers. In 1809 he published a paper on the discovery of the polarization of light. (M 39657)

\section{(11311) Peleus}

$1993 \mathrm{XN}_{2}$. Discovered 1993 Dec. 10 by C. S. Shoemaker and E. M. Shoemaker at Palomar.

Peleus, king of the Myrmidons in Thessaly \{see planet (1161)\}, helped Heracles \{see planet (5143)\} conquer Troy. He was married to the goddess Thetis \{see planet (17)\} - the only instance where a goddess married a mortal. He was also the father of Achilles \{see planet (588)\}. Too old to take part in the Trojan War, he gave his golden armor to his son. (M 41031)

\section{(11313) Kügelgen}

1994 GE $_{10}$. Discovered 1994 Apr. 3 by F. Börngen at Tautenburg.

Gerhard von Kügelgen (1772-1820) and his son Wilhelm (1802-1867) were prominent German painters. The former portrayed Goethe and Schiller \{see, respectively, planets (3047) and (3079)\}. The latter wrote the famous memoirs Jugenderinnerungen eines alten Mannes, a witty report on the civil and courtly life of the early nineteenth century. (M 41031)

\section{(11314) Charcot}

$1994 \mathrm{NR}_{1}$. Discovered 1994 July 8 by E. W. Elst at Caussols.

Jean-Martin Charcot (1825-1893) was one of France's greatest medical clinicians, working at Paris' famous clinic "La Salpêtrière" \{see planet (11315)\}). He was also a teacher of extraordinary competence, attracting students from all parts of the world. He is considered the founder of modern neurology. (M 39657)

\section{(11315) Salpêtrière}

$1994 \mathrm{NS}_{1}$. Discovered 1994 July 8 by E. W. Elst at Caussols.

Founded in Paris in 1862, "Salpêtrière Hospital" is a famous neurological clinic. Thanks to the clinician Jean-Martin Charcot \{see planet (11314)\}, the clinic became one of the greatest neurological centers of the time in Europe. In 1885 Sigmund Freud ssee planet (4342)\} visited Charcot and became interested in the psychological origins of neurosis. (M 39657)

\section{(11316) Fuchitatsuo}

$1994 \mathrm{TR}_{3}$. Discovered 1994 Oct. 5 by K. Endate and K. Watanabe at Kitami.

Tatsuo Fuchi (1952- ), a computer technology specialist and amateur astronomer, has been president of the Astronomical Society of Oita since 1989. (M 46010) 


\section{(11317) Hitoshi}

1994 TX $_{12}$. Discovered 1994 Oct. 10 by the Spacewatch at Kitt Peak.

Hitoshi Hasegawa (1957- ） is a computer programer and an amateur planetary scientist specializing on the atmospheres of the gas giants and on the small bodies in the solar system. In addition to his theoretical studies, he often uses the instruments at the National Astronomical Observatory of Japan. (M 47167)

\section{(11322) Aquamarine}

1995 QT. Discovered 1995 Aug. 23 by H. Abe at Yatsuka.

Aquamarine is the name of a Japanese duo group, Sachiko (1975- ) and Mimas (1971- ). They sing of stars and the universe. Their COSMOS is the main theme song of the "Star Week" event, produced by the National Astronomical Observatory of Japan. (M 42361)

\section{(11323) Nasu}

1995 QC $_{2}$. Discovered 1995 Aug. 21 by K. Endate and K. Watanabe at Kitami.

Eiichi Nasu (1955- ) was chief editor of the newsletter Astro Oita of the Astronomical Society of Oita for more than ten years, beginning in 1979. He is now the director of this society. (M 46010)

\section{(11324) Hayamizu}

1995 QQ 3 . Discovered 1995 Aug. 30 by K. Endate and K. Watanabe at Kitami.

Tsutomu Hayamizu (1962- ), since 1997 associate director of the Sendai Space Hall and Observatory, Kagoshima prefecture, is engaged in observations of occultations by the moon and by minor planets. (M 46010)

\section{(11325) Slavický}

1995 SG. Discovered 1995 Sept. 17 by L. Šarounová at Ondřejov.

Klement Slavický (1910-1999) was an outstanding Czech composer, whose personal musical expression was rooted in the folk-music culture of Moravia. He was also appreciated for his life-long high moral standards. In 1985 Slavický was awarded with the Golden Medal of the United Nations for his fourth Symphonietta. (M 36950)

\section{(11326) Ladislavschmied}

1995 SL. Discovered 1995 Sept. 17 by L. Šarounová at Ondřejov.

The Czech amateur astronomer Ladislav Schmied (1927- ) is well known for his systematic observations of the sun. He has made more than 10000 plots of the solar photosphere during the last 50 years. (M 36950) The name was suggested by P. Spurný.

\section{(11332) Jameswatt}

$1996 \mathrm{GO}_{20}$. Discovered 1996 Apr. 15 by E. W. Elst at La Silla.
In 1765, Scottish inventor James Watt (1736-1819) suggested using a separate condenser in the steam engine, lessening the consumption of steam and fuel in fire engines. With the invention of the double-acting machine, in which the piston pushed as well as pulled, "Watt's engine" was nearly complete. (M 39657)

\section{(11333) Forman}

1996 HU. Discovered 1996 Apr. 20 by P. Pravec and L. Šarounová at Ondřejov.

Early films of director Miloš Forman (1932- ), such as Černý Petr ("Black Peter") and Hoří, má panenko ("Firemen's Ball"), show de ep insight into the lives of ordinary Czech people. One Flew Over the Cuckoo's Nest, Hair and Ragtime deal with human freedom, while Amadeus describes Mozart's \{see planet (1034)\} fight with mediocrity. (M 36950)

\section{(11334) Rio de Janeiro}

1996 HM$_{18}$. Discovered 1996 Apr. 18 by E. W. Elst at La Silla.

Rio de Janeiro, founded in 1565 , is the city with the "Sugar Loaf" and a former capital of Brazil. (M 39658)

\section{(11335) Santiago}

$1996 \mathrm{HW}_{23}$. Discovered 1996 Apr. 20 by E. W. Elst at La Silla.

The capital of Chile see planet (4636)\}, Santiago was founded in 1541 by the Spanish conquistador Pedro de Valdivia \{see planet (2741)\}. (M 39658)

\section{(11337) Sandro}

$1996 \mathrm{PG}_{1}$. Discovered 1996 Aug. 10 by M. Tombelli and G. Forti at Montelupo.

Sandro Bartolini (1974- ) is the elder son of the first discoverer. (M 41571)

\section{(11338) Schiele}

1996 TL. . Discovered 1996 Oct. 13 by J. Tichá and M. Tichý at Kleť.

Egon Schiele (1890-1918), Austrian expressionist painter noted for the eroticism of his figurative works, lived and worked in Český Krumlov \{see planet (2747)\} from 1907 to 1917. (M 41031)

\section{(11339) Orlík}

$1996 \mathrm{VM}_{5}$. Discovered 1996 Nov. 13 by M. Tichý and Z. Moravec at Klět.

The Gothic castle of Orlík was built on a peninsula in the Vltava river in the thirteenth century and rebuilt in neo-Gothic style during the nineteenth century by the Schwarzenberg family. During the second half of the twentieth century it was surrounded by a dam. (M 42361)

\section{(11341) Babbage}

$1996 \mathrm{XE}_{2}$. Discovered 1996 Dec. 3 by P. G. Comba at Prescott.

Intending to automate complex arithmetical calculations, British mathematician Charles Babbage 
(1791-1871) developed plans for the analytical engine, a device controlled by punched cards, containing a "mill" to execute instructions and a memory unit to store partial results - the conceptual forerunner of modern computers. (M 36950)

\section{(11348) Allegra}

1997 BG $_{9}$. Discovered 1997 Jan. 30 by M. Tombelli and U. Munari at Cima Ekar.

Allegra Noccioli (1999- ） is the daughter of Fabrizio Noccioli, an amateur astronomer in the Montelupo Group. (M 40706)

\section{(11349) Witten}

$1997 \mathrm{JH}_{16}$. Discovered 1997 May 3 by E. W. Elst at La Silla.

Edward Witten (1951- ) is a physicist at the Institute for Advanced Study in Princeton and one of the premier theoretical physicists of our time. He has made fundamental contributions to particle physics and string theory. In 1990 he was awarded the Fields Medal, the highest prize in mathematics. (M 41031)

\section{(11350) Teresa}

$1997 \mathrm{QN}_{4}$. Discovered 1997 Aug. 29 by A. Lopez and R. Pacheco at Mallorca.

Teresa Chercoles (1951- ), wife of Rafael Pacheco, passes many nights at home while Pacheco and his colleagues are at the observatory enjoying the minor planets. (M 40706)

\section{(11352) Koldewey}

$1997 \mathrm{WP}_{22}$. Discovered 1997 Nov. 28 by the OCA-DLR Survey at Caussols.

Eberhard Koldewey (1937- ), at the DLR Institute of Space Sensor Technology and Planetary Exploration, contributed to the upgrade of the Bochum telescope at the European Southern Observatory, where he participated in many observing campaigns on minor planets. The naming is on the occasion of his retirement. (M 44110)

\section{(11353) Guillaume}

$1997 \mathrm{XX}_{5}$. Discovered 1997 Dec. 5 by the OCA-DLR Survey at Caussols.

Guillaume Scholl (1987- ) tested early versions of an automatic code for detecting minor planets developed by his father, astronomer Hans Scholl of the Observatoire de la Côte d'Azur. As a result, recent versions of the code are more user friendly. (M 40706)

\section{(11356) Chuckjones}

1997 YA. Discovered 1997 Dec. 18 by F. B. Zoltowski at Woomera.

Charles M. Jones (1912- ) is an animator and director known to many as the definitive Warner Brothers cartoon director. During his ongoing career, which spans over seven decades, he has created such memorable characters as Marvin the Martian, Pepé Le Pew and the Road Runner. (M 41385)

\section{(11359) Piteglio}

$1998 \mathrm{BP}_{24}$. Discovered 1998 Jan. 27 by L. Tesi and V. Cecchini at San Marcello Pistoiese.

The northern Tuscany village of Piteglio was founded in medieval times. Piteglio's government has contributed to the construction and maintenance of the Pian dei Termini Observatory, where this object was found. It is also where the second discoverer lives. (M 38200)

\section{(11360) Formigine}

1998 DL $_{14}$. Discovered 1998 Feb. 24 at the Osservatorio San Vittore at Bologna.

Formigine is a small Italian town located $10 \mathrm{~km}$ south of Modena. Interesting sights there include a medieval castle with boundary walls and a drawbridge. Formigine is the birthplace of the wife of Ermes Colombini \{see planet (7030)\}, a codiscoverer of this minor planet, and since 1986 it has also been their new residence. (M 41385)

\section{(11363) Vives}

1998 EB $_{12}$. Discovered 1998 Mar. 1 by E. W. Elst at La Silla.

Juan Luis Vives (1492-1540), a student of Erasmus, was a Spanish humanist. To avoid the Inquisition he went to Paris, later to Louvain and then to England. In his work De ratione studii puerilis (1523) he supported the education of women. (M 40706)

\section{(11364) Karlštejn}

$1998 \mathrm{FB}_{3}$. Discovered 1998 Mar. 23 by P. Pravec at Ondřejov.

The Gothic castle at Karlštejn was built in 1348 by Charles IV in the Kingdom of Bohemia, $27 \mathrm{~km}$ from the capital, Prague, to guard the crown jewels and state charters. The castle has survived well preserved to the present day, and it symbolizes Czech statehood within Europe. (M 41031)

The name was suggested by Z. Ceplecha.

\section{(11365) NASA}

1998 FK $_{126}$. Discovered 1998 Mar. 23 by J. Broughton at Reedy Creek.

NASA is an acronym for the National Aeronautics and Space Administration. This U.S. agency, formed in 1958 to explore space, led to the first manned moon landing in 1969, arguably mankind's greatest achievement. (M 42672)

\section{(11369) Brazelton}

1998 QE $_{33}$. Discovered 1998 Aug. 17 by the LINEAR at Socorro.

Mary Augusta Brazelton (1986- ） is a finalist in the 2002 Intel International Science and Engineering Fair for her mathematics project. She attends the Bishop McNamara High School, Fort Washington, Maryland, U.S.A. (M 46103) 


\section{(11370) Nabrown}

1998 QD $_{35}$. Discovered 1998 Aug. 17 by the LINEAR at Socorro.

Nachelle Diane Brown (1985- ) is a finalist in the 2002 Intel International Science and Engineering Fair for her engineering project. She attends the Red Mountain High School, Mesa, Arizona, U.S.A. (M 46103)

\section{(11371) Camley}

1998 QO $_{38}$. Discovered 1998 Aug. 17 by the LINEAR at Socorro.

Brian Andrew Camley (1985- ) is a finalist in the 2002 Intel International Science and Engineering Fair for his biochemistry project. He attends the William J. Palmer High School, Colorado Springs, Colorado, U.S.A. (M 46103)

\section{(11373) Carbonaro}

1998 QG $_{49}$. Discovered 1998 Aug. 17 by the LINEAR at Socorro.

Nicole Jean Carbonaro (1984- ) is a finalist in the 2002 Intel International Science and Engineering Fair for her physics project. She attends the Great Mills High School, Lexington Park, Maryland, U.S.A. (M 46103)

\section{(11374) Briantaylor}

1998 QU $_{60}$. Discovered 1998 Aug. 23 by the LONEOS at Anderson Mesa.

Brian W. Taylor (1964- ), a Lowell ssee planet (1886)\} Observatory instrumentation software specialist, designed the controller for LONEOS and other observatory CCD cameras. (M 41031)

\section{(11376) Taizomuta}

1998 SY $_{5}$. Discovered 1998 Sept. 20 by the Spacewatch at Kitt Peak.

Taizo Muta (1937- ) is a physicist. His main interest is in the application of quantum field theory to particle physics. He is a discoverer of the MS-bar scheme in quantum chromodynamics. An amateur astronomer, he is currently serving as president of Hiroshima University. (M 47167)

\section{(11377) Nye}

$1998 \mathrm{SH}_{59}$. Discovered 1998 Sept. 17 by the LONEOS at Anderson Mesa.

Ralph A. Nye (1945- ), Lowell \{see planet (1886)\} Observatory's instrument designer, used his considerable technical skills to transform into reality somewhat vague ideas about what LONEOS should look like and how it should function. (M 41031)

\section{(11378) Dauria}

1998 SV $_{60}$. Discovered 1998 Sept. 17 by the LONEOS at Anderson Mesa.

Florida amateur astronomer Tippy D'Auria (1935-

) is founder of the Winter Star Party. For many years he has worked to encourage both beginning and advanced sky-watchers in the hobby. (M 41938)

\section{(11379) Flaubert}

1998 SY $_{74}$. Discovered 1998 Sept. 21 by E. W. Elst at La Silla.

Gustave Flaubert (1821-1880) was a French writer who conceived a strong dislike of accepted ideas. He narrowly escaped conviction by the French government for the alleged immorality of his masterpiece, Madame Bovary (1857). (M 40706)

\section{(11384) Sartre}

1998 SW $_{143}$. Discovered 1998 Sept. 18 by E. W. Elst at La Silla.

Jean-Paul Sartre (1905-1980), French novelist and the exponent of Existentialism, used his pen his entire life for the defense of individual freedom and human dignity. His masterwork L'Etre et le Néant (1943) confronts "human consciousness" with "being". He won the 1964 Noble Prize for literature, but refused to accept it. (M 40706)

\section{(11385) Beauvoir}

$1998 \mathrm{SP}_{147}$. Discovered 1998 Sept. 20 by E. W. Elst at La Silla.

Simone de Beauvoir (1908-1986) was a French writer of great courage and integrity, who made a point of equal vocation for man and woman. In her treatise $L e$ Deuxième Sexe (1949) she pleaded passionately for the abolition of the myth of "eternal feminine". She was the lifelong companion of Jean-Paul Sartre \{see planet (11384)\}. (M 40706)

\section{(11401) Pierralba}

$1999 \mathrm{AF}_{25}$. Discovered 1999 Jan. 15 by the OCA-DLR Survey at Caussols.

Pierre Albanese (1992- ) showed a great interest in the sky, being able to recognize the major planets while he was only four years old. He made drawings inspired by the images obtained by his father, Caussols astronomer Dominique Albanese \{see planet (5576)\}. (M 41031)

\section{(11409) Horkheimer}

1999 FD $_{9}$. Discovered 1999 Mar. 19 by the LONEOS at Anderson Mesa.

Jack F. Horkheimer (1938- ）, the executive director of the Miami Space-Transit Planetarium, is best known as the creator and host of the television program Star Hustler (now known as Star Gazer). (M 41938)

\section{(11413) Catanach}

$1999 \mathrm{JG}_{21}$. Discovered 1999 May 10 by the LINEAR at Socorro.

Therese Anne Catanach (1985- ) is a finalist in the 2002 Intel International Science and Engineering Fair for her zoology project. She attends the Bishop Lynch High School, Allen, Texas, U.S.A. (M 46103)

\section{(11414) Allanchu}

$1999 \mathrm{JU}_{26}$. Discovered 1999 May 10 by the LINEAR at Socorro. 
Allan Chu (1984- ) is a finalist in the 2002 Intel International Science and Engineering Fair for his computer science project. He attends the Saratoga High School, Saratoga, California, U.S.A. (M 46103)

\section{(11417) Chughtai}

$1999 \mathrm{JW}_{117}$. Discovered 1999 May 13 by the LINEAR at Socorro.

Asma Latif Chughtai (1986- ) is a finalist in the 2002 Intel International Science and Engineering Fair for her environmental science project. She attends the Edward R. Murrow High School, Brooklyn, New York, U.S.A. (M 46103)

\section{(11419) Donjohnson}

$1999 \mathrm{KS}_{2}$. Discovered 1999 May 16 by the Spacewatch at Kitt Peak.

Donald Joe Johnson II (1959-2001) went from the field of aerospace to that of a testing engineer working towards the future. He was best known for his kindness, imagination and creativity in storytelling. In his stories he took friends and comrades to the stars in adventures with a brighter future for humanity. (M 45337)

\section{(11421) Cardano}

$1999 \mathrm{LW}_{2}$. Discovered 1999 June 10 by P. G. Comba at Prescott.

Gerolamo Cardano (1501-1576), prototypical Renaissance man, physician, mathematician, astrologer, inventor and gambler, was the first to publish the solution of the cubic and quartic equations and to give a systematic calculation of probabilities in connection with games of chance. (M 36951)

\section{(11422) Alilienthal}

1999 LD $_{7}$. Discovered 1999 June 10 by the Spacewatch at Kitt Peak.

Alfred Lilienthal (1889-1970) studied in England and was a businessman in Berlin during the 1930s. He spent the 1940s in Shanghai. (M 45748)

\section{(11423) Cronin}

$1999 \mathrm{LT}_{24}$. Discovered 1999 June 9 by the LINEAR at Socorro.

Kevin Michael Cronin (1984- ) is a finalist in the 2002 Intel International Science and Engineering Fair for his environmental science project. He attends the Sarasota High School, Sarasota, Florida, U.S.A. (M 46103)

\section{(11425) Wearydunlop}

1999 MF. Discovered 1999 June 18 by J. Broughton at Reedy Creek.

Edward 'Weary' Dunlop (1907-1993) was an Australian Army surgeon prisoner-of-war on the Burma railway and is legendary for repeatedly risking his own life to save sick allied soldiers. On one occasion he placed himself in front of guards with bayonets who were about to kill POWs too sick to work. (M 43382)

\section{(11428) Alcinoös}

4139 P-L. Discovered 1960 Sept. 24 by C. J. van Houten and I. van Houten-Groeneveld at Palomar.

Alcinoös, king of the Phaeacians, gave Odysseus \{see planet (1143)\} shelter and aid. (M 38201)

\section{(11429) Demodokus}

4655 P-L. Discovered 1960 Sept. 24 by C. J. van Houten and I. van Houten-Groeneveld at Palomar.

Demodokus who was a blind singer at the court of Alcinoös \{see planet (11428)\}. (M 38201)

\section{(11438) Zeldovich}

1973 QR $_{1}$. Discovered 1973 Aug. 29 by T. M. Smirnova at Nauchnyj.

Russian theoretical physicist Yakov Borisovich Zeldovich (1914-1987) was the author of classic works on nuclear physics, the physics of combustion and explosion, astrophysics and cosmology. (M 42672)

The name was suggested by the Institute of Applied Astronomy.

\section{(11450) Shearer}

1979 QJ $_{1}$. Discovered 1979 Aug. 22 by C.-I. Lagerkvist at La Silla.

Andrew Shearer (1953- ）, of the National University of Ireland, Galway, leads the group working in the field of high-time-resolution astrophysics and image processing. He was responsible for the measurements of the pulsed optical emission from PSR 0656-14 and Geminga. (M 41571)

\section{(11451) Aarongolden}

1979 QR $_{1}$. Discovered 1979 Aug. 22 by C.-I. Lagerkvist at La Silla.

Aaron Golden (1969- ), of the National University of Ireland, Galway, works in the field of high-time resolution astrophysics and image processing. He participated in the discovery of optical pulsations from two pulsars. (M 41571)

\section{(11484) Daudet}

$1988 \mathrm{DF}_{2}$. Discovered 1988 Feb. 17 by E. W. Elst at La Silla.

Alphonse Daudet (1840-1897), mainly remembered as a French writer of sentimental tales, believed that the world was misrepresented by novelists, who concentrated only on its uglier aspects. His Lettres de mon Moulin (1869) can therefore be considered a more joyful interpretation of the mystery of things and of individuals. (M 40706)

\section{(11485) Zinzendorf}

1988 RW $_{3}$. Discovered 1988 Sept. 8 by F. Börngen at Tautenburg.

Nikolaus Ludwig Graf von Zinzendorf (1700-1760) was counsellor at the court of his native town of Dresden (1721-1727). He settled Bohemian exiles at his Saxonian estate and founded the "Herrnhuter 
Brüdergemeine" there. He is known for his pedagogic work and hymns, and he stood for tolerance and missionary work. (M 40706)

\section{(11496) Grass}

$1989 \mathrm{AG}_{7}$. Discovered 1989 Jan. 10 by F. Börngen at Tautenburg.

Günter Grass (1927- ), German writer, sculptor and graphic artist, is a critic of both the immediate postwar years and the present. His passionate writing received only partial recognition in Germany but great acclaim elsewhere. He won the 1999 Nobel Prize for literature. (M 30201)

\section{(11498) Julgeerts}

1989 GS $_{4}$. Discovered 1989 Apr. 3 by E. W. Elst at La Silla.

Julien Armand Geerts (1909- ) is a well-known commercial artist in Belgium. He was for many years a good friend of the discoverer's parents. The naming is on the occasion of Geerts' ninetieth birthday. (M 36951)

\section{(11499) Duras}

1989 RL. Discovered 1989 Sept. 2 by E. W. Elst at St. Michel.

Marguerite Duras (Donnadieu, 1914-1996), French novelist, became internationally known for the screenplay of Hiroshima mon amour (1959). Her semiautobiographical novel L'Amant was nominated for the Prix Goncourt in 1984. (M 40707)

\section{(11504) Kazo}

1990 BT. Discovered 1990 Jan. 21 by T. Hioki and S. Hayakawa at Okutama.

Kazo is a city in Saitama prefecture, $50 \mathrm{~km}$ north of Tokyo. (M 42672)

\section{(11506) Toulouse-Lautrec}

$1990 \mathrm{ES}_{1}$. Discovered 1990 Mar. 2 by E. W. Elst at La Silla.

French painter Henri de Toulouse-Lautrec (18641901) helped set the course of avant-garde by using new kinds of subjects. A most significant work, painted with great psychological insight, is Elles (1896), a series of lithographs presenting a sensitive portrayal of brothel life. (M 40707)

\section{(11508) Stolte}

$1990 \mathrm{TF}_{13}$. Discovered 1990 Oct. 12 by L. D. Schmadel and F. Börngen at Tautenburg.

Dieter Stolte (1934- ） served for 20 years as director general of ZDF, the public German TV net and one of the largest European TV stations. A professor of media research, Stolte initiated international TV channels (ARTE, 3SAT) in a European cooperation. (M 43191) The name was suggested by the first discoverer.

\section{(11510) Borges}

$1990 \mathrm{VV}_{8}$. Discovered 1990 Nov. 11 by E. W. Elst at La Silla.
Jorge Luis Borges (1899-1986), Argentine poet and short-story writer, became famous through his poems Fervor de Buenos Aires (1923). In his El libro de los seres imaginarios (1967) the distinction between poetry and prose almost disappears. (M 40707)

\section{(11514) Tsunenaga}

$1991 \mathrm{CO}_{1}$. Discovered 1991 Feb. 13 by M. Koishikawa at Sendai.

In 1613 Hasekura Tsunenaga (1571-1622) led the first Japanese mission across the Pacific to the Americas (in Mexico), and he continued across the Atlantic to Europe, where he met with king Philip III of Spain and pope Paul V. His portrait was designated a national treasure for the first time in Sendai in June 2001. (M 43382)

\section{(11518) Jung}

$1991 \mathrm{~GB}_{3}$. Discovered 1991 Apr. 8 by E. W. Elst at La Silla.

Carl Gustav Jung (1875-1961) was a Swiss psychiatrist who developed the (much contested) concept of the collective unconscious (archetypes). From 1907 to 1912, he was a close collaborator of Sigmund Freud \{see planet (4342)\}, a relationship that later collapsed, because of Jung's irrational interests. (M 40707)

\section{(11519) Adler}

$1991 \mathrm{GZ}_{4}$. Discovered 1991 Apr. 8 by E. W. Elst at La Silla.

Alfred Adler (1870-1937) was an Austrian psychiatrist who introduced the term "inferiority feeling" (inferiority complex) into psychology: mental health is characterized by reason and social interest, mental disorder by inferiority, self concern and superiority over others". In 1934 the Austrian government closed his 30 clinics. (M 40707)

\section{(11520) Fromm}

$1991 \mathrm{GE}_{8}$. Discovered 1991 Apr. 8 by E. W. Elst at La Silla.

Erich Fromm (1900-1980) was a German psychoanalyst who believed that mankind could develop a psychologically balanced, sane society. $\mathrm{He}$ is widely known for Escape from Freedom (1941), but already in 1930 he had written Das Christus Dogma, which stresses the neglect of social factors in human psychology. (M 40707)

\section{(11521) Erikson}

$1991 \mathrm{GE}_{9}$. Discovered 1991 Apr. 10 by E. W. Elst at La Silla.

Erik H. Erikson (1902-1994) was a German-American psychoanalyst who made important contributions to the field of psychosocial development. Through his friendship with Anna Freud \{see planet (11299)\}, he became interested in child psychoanalysis. His views on personality development were published in Childhood and Society (1950). (M 40707) 


\section{(11524) Pleyel}

$1991 \mathrm{PY}_{2}$. Discovered 1991 Aug. 2 by E. W. Elst at La Silla.

Ignaz Jozef Pleyel (1757-1831) was an Austro-French composer who became famous as a piano builder. In 1795 he settled in Paris, where he founded a piano manufacturing company in 1807 . The famous Polish-French composer Chopin \{see planet (3784)\} preferred the Pleyel grand piano for performing his compositions. (M 41031)

\section{(11528) Mie}

1991 XH. Discovered 1991 Dec. 3 by Y. Kushida and O. Muramatsu at Yatsugatake.

Mie Nagata (1963- ) was a lecturer at the Gotoh Planetarium and Astronomical Museum in Tokyo from 1988 to 1994 . She is a part-time lecturer at other planetaria in Tokyo and has strong interest in preschool education in astronomy. (M 38201)

\section{(11530) d'Indy}

$1992 \mathrm{CP}_{2}$. Discovered 1992 Feb. 2 by E. W. Elst at La Silla.

Composer Vincent d'Indy (1851-1931) attempted to reform French symphonic and dramatic music. His beautiful Symphonie sur un chant montagnard français (1886), is composed along lines indicated by César Franck \{see planet (4546)\}. (M 40707)

\section{(11537) Guericke}

$1992 \mathrm{HY}_{6}$. Discovered 1992 Apr. 29 by F. Börngen at Tautenburg.

German physicist Otto von Guericke (1602-1686) studied in Jena and was mayor of Magdeburg. He invented the air pump and centrifuge, perceiving the substantial nature of air and determining its weight. His demonstration of the atmospheric pressure by means of the Magdeburg hemispheres is well known. (M 40707)

\section{(11547) Griesser}

1992 UP $_{8}$. Discovered 1992 Oct. 31 by F. Börngen at Tautenburg.

Swiss amateur astronomer Markus Griesser (1949-

) is cofounder of the Eschenberg Observatory in Winterthur. A passionate science writer and popularizer of astronomy, he is also a diligent observer of near-earth objects. This minor planet was numbered as a result of observations made by him in Sept. 1999. (M 36951)

\section{(11548) Jerrylewis}

1992 WD $_{8}$. Discovered 1992 Nov. 25 by C. S. Shoemaker and D. H. Levy at Palomar.

The devotion of U.S. actor-comedian Jerry Lewis (1926- ) to the Muscular Dystrophy Association has helped it raise upwards of 50 million dollars per year in its efforts to combat neuromuscular diseases. The M.D.A. funds medical research, treatment and quality-of-life programs like summer camps. (M 36951)

\section{(11569) Virgilsmith}

1993 KB $_{2}$. Discovered 1993 May 27 by C. S. Shoemaker and D. H. Levy at Palomar.

The design and contruction abilities of Virgil Smith (1941- ), of Corona, Arizona, have resulted in the successful completion of the Jarnac Observatory, located at the home of the second discoverer. (M 36951)

\section{(11571) Daens}

1993 OR $_{8}$. Discovered 1993 July 20 by E. W. Elst at La Silla.

Adolf Daens (1839-1907), a Flemish priest at Aalst, will always be remembered for his dedication to fighting industrial exploitation of the Flemish people. Confronting great resistance from the higher clergy for his actions, in 1899 he was finally ordered to resign his office by the bishop of Ghent. (M 40707)

\section{(11572) Schindler}

$1993 \mathrm{RM}_{7}$. Discovered 1993 Sept. 15 by E. W. Elst at La Silla.

Oskar Schindler (1905-1974) was an German industrialist during World War II. Through his heroic actions a group of Polish Jews avoided extermination by the Nazis in 1944. Director Steven Spielberg used this story for the movie Schindler's List (1993). (M 40707)

\section{(11573) Helmholtz}

$1993 \mathrm{SK}_{3}$. Discovered 1993 Sept. 20 by F. Börngen and L. D. Schmadel at Tautenburg.

Hermann Ludwig Ferdinand von Helmholtz (18211894), a German doctor, physiologist and physicist, was one of the most famous naturalists of the nineteenth century. In 1847 he extended Robert Mayer's \{see planet (10786)\} law of energy conservation to all known natural phenomena. (M 39658)

\section{(11574) d'Alviella}

$1994 \mathrm{BP}_{3}$. Discovered 1994 Jan. 16 by E. W. Elst at Caussols.

Count Goblet d'Alviella (1846-1925) was a Belgian historian. A Grandmaster of the Grand-Orient Belgian Masonic Lodge, he wrote a manual for the higher grades of freemasonry. He presided over the Belgian Academy and was a rector and professor at the Université Libre de Bruxelles. (M 40707; M 40735)

\section{(11580) Bautzen}

$1994 \mathrm{JG}_{4}$. Discovered 1994 May 3 by the Spacewatch at Kitt Peak.

The German city of Bautzen, founded in 1802, is located on the river Spree in the Lusatia region of the province of Saxony. (M 45337)

\section{(11581) Philipdejager}

$1994 \mathrm{PK}_{9}$. Discovered 1994 Aug. 10 by E. W. Elst at La Silla.

Philip de Jager (1969- ) is a Belgian percussionist. A brilliant student at the Antwerp Conservatory, he 
now performs with several Belgian orchestras. He has also performed for the musicals Les Misérables and The Phantom of the Opera. (M 41031)

\section{(11582) Bleuler}

1994 PC $_{14}$. Discovered 1994 Aug. 10 by E. W. Elst at La Silla.

Swiss psychiatrist Eugen Bleuler (1857-1939), author of Lehrbuch der Psychiatrie (1916), introduced the term "schizophrenia". He extended the work of Freud \{see planet (4342)\} with neurotic patients to psychotic patients, insisting that psychosis could have psychological, rather than physical causes. (M 40707)

\section{(11583) Breuer}

$1994 \mathrm{PZ}_{28}$. Discovered 1994 Aug. 12 by E. W. Elst at La Silla.

Jozef Breuer (1842-1925) was an Austrian physician who anticipated the process of psychoanalysis. In the famous case study of "Anna O.", Breuer concluded that neurotic symptoms result from unconscious processes. (M 40707)

\section{(11584) Ferenczi}

1994 PP $_{39}$. Discovered 1994 Aug. 10 by E. W. Elst at La Silla.

Sándor Ferenczi (1873-1933) was a Hungarian psychoanalyst who improved the therapeutic technique of free association. In The Development of Psychoanalysis (1924) he favored the creation of a loving, permissive atmosphere by the therapist. (M 40707)

\section{(11588) Gottfriedkeller}

$1994 \mathrm{UZ}_{12}$. Discovered 1994 Oct. 28 by F. Börngen at Tautenburg.

Gottfried Keller (1819-1890), Swiss author, is a representative of realistic poetry. Born in Zürich, he was the city's first public secretary (1861-1876). His novel Der grüne Heinrich and the collection of short stories Die Leute von Seldwyla became very popular. (M 40707)

\section{(11595) Monsummano}

1995 KN. Discovered 1995 May 23 by A. Boattini and L. Tesi at San Marcello Pistoiese.

Monsummano Terme is a town in northern Tuscany, about $40 \mathrm{~km}$ from Florence. The town is known for its hot springs and for shoe manufacturing. Poet Giuseppe Giusti and French singer Ives Montand were born here. The second discoverer also was born and grew up in Monsummano. (M 38201)

\section{(11598) Kubík}

1995 OJ. Discovered 1995 July 22 by L. Šarounová at Ondřejov.

The discoverer's brother, Jakub Šaroun (1974- ), is a talented amateur musician and photographer. This minor planet is being named on the occasion of his 25th birthday. (M 36951)

\section{(11600) Cipolla}

1995 SQ$_{2}$. Discovered 1995 Sept. 26 at the Santa Lucia Observatory at Stroncone.

Carlo Cipolla (1925- ) is a skillful chemist and amateur astronomer fond of popularizing astronomy and transmitting his passion and knowledge to the younger generations. (M 41938)

\section{(11605) Ranfagni}

1995 UP $_{6}$. Discovered 1995 Oct. 19 by L. Tesi and A. Boattini at San Marcello Pistoise.

Piero Ranfagni (1949- ) worked for many years as a technician at Arcetri Astrophysical Observatory. He is on the technical staff of the TIRGO Telescope and in the project office of LBT. He has also been very active in the history of astronomy and in popular astronomy. (M 40708)

\section{(11606) Almary}

$1995 \mathrm{UU}_{6}$. Discovered 1995 Oct. 19 by D. J. Tholen at Mauna Kea.

This minor planet is named for the parents of the discoverer, Alfred and Mary, on the occasion of their fiftieth wedding anniversary. (M 46103)

\section{(11612) Obu}

$1995 \mathrm{YZ}_{1}$. Discovered 1995 Dec. 21 by A. Nakamura at Kuma.

Obu City (population 76 000), where the discoverer lived for six and a half years, is located in the center of Aichi Prefecture. Known for its automobile industry, $\mathrm{Obu}$ is also famous for the 500-year-old "Doburoku Festival", held at Nagakusa-Tenjinsha Shrine. (M 39658)

\section{(11614) Istropolitana}

$1996 \mathrm{AD}_{2}$. Discovered 1996 Jan. 14 by A. Galád and A. Pravda at Modra.

Academia Istropolitana ("city on the Danube") was the first university in today's Slovak territory and an ancient predecessor of Comenius University. The academy was founded by the Hungarian king Matej Korvín (Mathias Corvin) \{see planet (1442)\} in Bratislava in 1465. (M 42361)

The name was suggested by F. Devínsky, Comenius University rector.

\section{(11621) Duccio}

$1996 \mathrm{PJ}_{5}$. Discovered 1996 Aug. 15 by M. Tombelli and G. Forti at Montelupo.

Duccio Bartolini (1976- ) is the younger son of the first discoverer. (M 41572)

\section{(11622) Samuele}

$1996 \mathrm{RD}_{4}$. Discovered 1996 Sept. 9 by A. Boattini and L. Tesi at San Marcello Pistoiese.

Samuele Marconi (1975- ) is a very active amateur astronomer at the San Marcello \{see planet (7481)\} Observatory who spends much of his time giving public lectures on astronomy. (M 41385) 
(11623) Kagekatu

$1996 \mathrm{TC}_{10}$. Discovered 1996 Oct. 8 by T. Okuni at Nanyou.

Kagekatu Uesugi (1555-1623) was a military commander during the Japanese feudal period. He was lord of Echigo Kasugayama castle from 1578, of Mutu Aizu castle from 1598 and of Dewa Yonezawa castle from 1601. (M 43382)

\section{(11625) Francelinda}

$1996 \mathrm{UL}_{1}$. Discovered 1996 Oct. 20 by L. Tesi and G. Cattani at San Marcello Pistoiese.

Francesca Tesi and Linda Tesi are granddaughters of the first discoverer. (M 38201)

\section{(11636) Pezinok}

$1996 \mathrm{YH}_{1}$. Discovered 1996 Dec. 27 by A. Galád and

A. Pravda at Modra.

Pezinok is a small town near Bratislava. The town is known for its wine producing traditions from the thirteenth century. From the fourteenth to nineteenth centuries gold was mined here. It is also the birthplace of the French astronomer Maurice Loevy (1833-1907) and Slovak astronomer Ján Štohl \{see planet (3715)\} (1932-1993). (M 45233)

\section{(11637) Yangjiachi}

$1996 \mathrm{YJ}_{2}$. Discovered 1996 Dec. 24 at the Beijing Observatory at Xinglong.

Jiachi Yang (1919- ), an expert in automatic control and space technology, devoted himself to the development of artificial earth satellites in China. He is a member of the Chinese Academy of Sciences and of the International Academy of Astronautics, and he received several highest scientific achievement prizes in China. (M 43191)

\section{(11652) Johnbrownlee}

$1997 \mathrm{CK}_{13}$. Discovered 1997 Feb. 7 by P. Sicoli and F. Manca at Sormano.

John W. Brownlee (1973- ) was the system administrator, principal programer and an observer on the Catalina Sky Survey team during 1998-2000. (M 44186)

The citation was prepared by T. B. Spahr.

\section{(11656) Lipno}

1997 EL $_{6}$. Discovered 1997 Mar. 6 by M. Tichý and Z. Moravec at Klět.

The Lipno dam was built on the Vltava ssee planet (2123)\} river in 1959 as the largest Czechoslovak dam. It is important for the water supply, as a source of power and also as a well-known South Bohemian holiday area. (M 41938)

\section{(11657) Antonhajduk}

$1997 \mathrm{EN}_{7}$. Discovered 1997 Mar. 5 by A. Galád and A. Pravda at Modra.

Anton Hajduk (1933- ) is a professor of astronomy at the Slovak Academy of Sciences. His research centers on the structure of meteor streams and radio studies of meteor head echoes and the secondary ozone layer. (M 42361)

\section{(11665) Dirichlet}

1997 GL $_{28}$. Discovered 1997 Apr. 14 by P. G. Comba at Prescott.

Peter Gustav Lejeune Dirichlet (1805-1859) was the successor of Gauss and the predecessor of Riemann \{see, respectively, planets (1001) and (4167)\} at Göttingen. He made important contributions in both pure and applied mathematics and gave the first rigorous proof of the convergence of Fourier \{see planet (10101)\} series. (M 36951)

Dirichlet is also honored by a lunar crater.

\section{(11666) Bracker}

1997 MD . Discovered 1997 June 29 by the Spacewatch at Kitt Peak.

Steve Bracker (1942- ） is a renaissance man - particle physicist, harpsichordist, astronomer, naturalist and software guru. The very first programmer with the Cerro Tololo Inter-American Observatory in Chile, he continued his involvement in astronomy with the Sloan Digital Sky Survey. (M 45337)

\section{(11667) Testa}

1997 UB $_{1}$. Discovered 1997 Oct. 19 by L. Tesi and A. Boattini at San Marcello Pistoiese.

Augusto Testa (1950- ), Italian amateur astronomer, observes minor planets at the Sormano \{see planet (6882)\} Astronomical Observatory. Over the past few years he has developed a lot of software dedicated to the observation of minor planets, and these are widely used by the Italian community of astrometric observers. (M 38201)

\section{(11668) Balios}

$1997 \mathrm{VV}_{1}$. Discovered 1997 Nov. 3 by P. Pravec at Ondřejov.

Balios was one of the fast, immortal horses of Achilles \{see planet (588)\}, born to the gale or harpy named Podarge and the stormy wind Zephyros. (M 43045)

\section{(11669) Pascalscholl}

$1997 \mathrm{XY}_{8}$. Discovered 1997 Dec. 7 by the OCA-DLR Survey at Caussols.

Pascal Scholl (1994- ) is the younger son of astronomer Hans Scholl \{see planet (2959)\}. (M 40708)

\section{(11672) Cuney}

1998 BC $_{15}$. Discovered 1998 Jan. 24 by the JPL NEAT Program at Haleakala.

Husband and wife team Bruce (1947- ) and Dana (1950- ) Cuney work at Palomar and were responsible for the remodeling of the old 1.2-m Schmidt dome interior. (M 45234)

The name was suggested by R. Thicksten.

\section{(11673) Baur}

1998 BJ $_{19}$. Discovered 1998 Jan. 26 at the Farra d'Isonzo Observatory at Farra d'Isonzo. 
German amateur astronomer Johann M. Baur (1930) founded the Chaonis \{see planet (4630)\} Observatory in northern Italy and there discovered many minor planets by means of photographic plates. The telescope he used to make his first discovery is still in use at the Farra see planet (7501)\} Observatory. (M 46682)

\section{(11675) Billboyle}

$1998 \mathrm{CP}_{2}$. Discovered 1998 Feb. 15 by P. Antonini at Bedoin.

William Boyle (1924- ) co-invented the CCD while at Bell Laboratories in 1969. This device has revolutionized both amateur and professional astronomy. This minor planet was automatically detected by a CCD during an amateur survey. (M 41031)

\section{(11678) Brevard}

1998 DT $_{10}$. Discovered 1998 Feb. 25 by I. P. Griffin at Cocoa.

Brevard County, Florida, is the location of the Astronaut Memorial Planetarium and Observatory, from where this object was discovered. Brevard County is also home to the Kennedy Space Center, the launch site of Galileo, NEAR and many other manned and unmanned missions of space exploration. (M 36951)

\section{(11679) Brucebaker}

$1998 \mathrm{DE}_{11}$. Discovered 1998 Feb. 25 by the JPL NEAT Program at Haleakala.

Bruce Baker (1949- ) fabricated and installed the mechanical portions of the slip rings and assisted in the fabrication of many small mechanical assemblies needed throughout the upgrade of the 1.2-m Schmidt at Palomar. (M 44594)

\section{(11682) Shiwaku}

1998 EX $_{6}$. Discovered 1998 Mar. 3 by H. Abe at Yatsuka.

Hideaki Shiwaku (1963- ) is one of promoters of the Matsue Astronomical Club, an amateur astronomers group in the Matsue area of Japan, and a good friend of the discoverer. (M 40708)

\section{(11685) Adamcurry}

$1998 \mathrm{FW}_{19}$. Discovered 1998 Mar. 20 by the LINEAR at Socorro.

Adam Michael Curry (1984- ) is a finalist in the 2002 Intel International Science and Engineering Fair for his earth and space sciences project. He attends the Palisade High School, Palisade, Colorado, U.S.A. (M 46103)

\section{(11688) Amandugan}

1998 FG $_{53}$. Discovered 1998 Mar. 20 by the LINEAR at Socorro.

Amanda Dyann Dugan (1986- ) is a finalist in the 2002 Intel International Science and Engineering Fair for her medicine and health project. She attends the Rockdale Magnet School for Science and Technology, Conyers, Georgia, U.S.A. (M 46103)

\section{(11690) Carodulaney}

$1998 \mathrm{FV}_{60}$. Discovered 1998 Mar. 20 by the LINEAR at Socorro.

Caroline Ann DuLaney (1985- ) is a finalist in the 2002 Intel International Science and Engineering Fair for her medicine and health project. She attends the Yorktown High School, Arlington, Virginia, U.S.A. (M 46103)

\section{(11691) Easterwood}

$1998 \mathrm{FO}_{66}$. Discovered 1998 Mar. 20 by the LINEAR at Socorro.

Jeffrey Michael Easterwood (1985- ） is a finalist in the 2002 Intel International Science and Engineering Fair for his chemistry project. He attends the Rockdale High School, Rockdale, Texas, U.S.A. (M 46103)

\section{(11693) Grantelliott}

$1998 \mathrm{FE}_{69}$. Discovered 1998 Mar. 20 by the LINEAR at Socorro.

Grant A. Elliott (1984- ) is a finalist in the 2002 Intel International Science and Engineering Fair for his computer science project. He attends the Suncoast Community High School, Wellington, Florida, U.S.A. (M 46103)

\section{(11694) Esterhuysen}

$1998 \mathrm{FO}_{70}$. Discovered 1998 Mar. 20 by the LINEAR at Socorro.

Stephanus Albertus Esterhuysen (1983- ) is a finalist in the 2002 Intel International Science and Engineering Fair for his engineering project. He attends the Technical High School Potchefstroom, Viljoenskroon, Free State, South Africa. (M 46104)

\section{(11695) Mattei}

1998 FA $_{74}$. Discovered 1998 Mar. 22 by the LONEOS at Anderson Mesa.

Janet Akyüz Mattei (1943- ）, a tireless promoter of the observation of variable stars by amateurs, has been the director of the American Association of Variable Star Observers since 1973. (M 41938)

\section{(11696) Capen}

$1998 \mathrm{FD}_{74}$. Discovered 1998 Mar. 22 by the LONEOS at Anderson Mesa.

Charles ("Chick") Franklin Capen (1926-1986) was best known for his observations of the planets, particularly Mars. He worked at the Lowell Observatory for many years as an observer and tour guide. (M 41938)

\section{(11697) Estrella}

1998 FX $_{98}$. Discovered 1998 Mar. 31 by the LINEAR at Socorro.

Allan Noriel Estrella (1984- ) is a finalist in the 2002 Intel International Science and Engineering Fair for his physics project. He attends the Manila Science High School, Manila, Philippines. (M 46104) 


\section{(11698) Fichtelman}

$1998 \mathrm{FZ}_{102}$. Discovered 1998 Mar. 31 by the LINEAR at Socorro.

Jon Roger Fichtelman (1986- ) is a finalist in the 2002 Intel International Science and Engineering Fair for his physics project. He attends the Freshman Learning Center Vero Beach High School, Vero Beach, Florida, U.S.A. (M 46104)

\section{(11702) Mifischer}

$1998 \mathrm{FE}_{117}$. Discovered 1998 Mar. 31 by the LINEAR at Socorro.

Michael Henry Fischer (1985- ) is a finalist in the 2002 Intel International Science and Engineering Fair for his physics project. He attends the Pacific Collegiate School, Santa Cruz, California, U.S.A. (M 46104)

\section{(11703) Glassman}

$1998 \mathrm{FL}_{121}$. Discovered 1998 Mar. 20 by the LINEAR at Socorro.

Elena Leah Glassman (1986- ) is a finalist in the 2002 Intel International Science and Engineering Fair for her engineering project. She attends the Central Bucks High School West, Pipersville, Pennsylvania, U.S.A. (M 46104)

\section{(11704) Gorin}

$1998 \mathrm{FZ}_{130}$. Discovered 1998 Mar. 22 by the LINEAR at Socorro.

Michael Adam Gorin (1985- ) is a finalist in the 2002 Intel International Science and Engineering Fair for his biochemistry project. He attends the Lynbrook High School, Hewlett, New York, U.S.A. (M 46104)

\section{(11707) Grigery}

$1998 \mathrm{HW}_{17}$. Discovered 1998 Apr. 18 by the LINEAR at Socorro.

Chelsea Nicole Grigery (1986- ) is a finalist in the 2002 Intel International Science and Engineering Fair for her chemistry project. She attends the Sikeston Junior High School, Sikeston, Missouri, U.S.A. (M 46104)

\section{(11709) Eudoxos}

$1998 \mathrm{HF}_{20}$. Discovered 1998 Apr. 27 by P. G. Comba at Prescott.

Eudoxos of Knidos (c.408-355 B.C.) was the prime mover behind two major developments in Greek mathematical thought: the theory of proportions that overcame the crisis caused by the discovery of irrational numbers, and the method of exhaustion for the calculation of areas and volumes. (M 11709)

\section{(11710) Nataliehale}

1998 HS $_{34}$. Discovered 1998 Apr. 20 by the LINEAR at Socorro.

Natalie Adele Hale (1986- ) is a finalist in the 2002 Intel International Science and Engineering Fair for her environmental science project. She attends the Juneau Douglas High School, Juneau, Alaska, U.S.A. (M 46104)

\section{(11711) Urquiza}

$1998 \mathrm{HV}_{50}$. Discovered 1998 Apr. 25 by the LONEOS at Anderson Mesa.

Luis Urquiza del Valle (1906-2000) was the much-loved grandfather of LONEOS observer L. Levy. (M 43045)

\section{(11712) Kemcook}

$1998 \mathrm{HB}_{51}$. Discovered 1998 Apr. 25 by the LONEOS at Anderson Mesa.

Kem H. Cook (1949- ), of Lawrence Livermore National Laboratory, is a founding member of the Massive Compact Halo Objects (MACHO) Project, which used a refurbished, 120-year-old telescope (The Great Melbourne Telescope) to survey the Magellanic Clouds for gravitational microlensing by baryonic, halo dark matter. (M 43045)

\section{(11713) Stubbs}

$1998 \mathrm{HG}_{51}$. Discovered 1998 Apr. 25 by the LONEOS at Anderson Mesa.

Christopher Stubbs (1958- ), of the University of Washington, has pursued a variety of projects in experimental physics and observational astrophysics, including searching for dark matter, measuring the rate of expansion of the universe with supernovae and testing the equivalence principle. (M 43045)

\section{(11714) Mikebrown}

1998 HQ 51 . Discovered 1998 Apr. 28 by the LONEOS at Anderson Mesa.

Michael E. Brown (1965- ) is assistant professor of astronomy at the California Institute of Technology. He is best known for his work on the Kuiper \{see planet (1776)\} belt, cometary comae and the atmospheres of planetary satellites. (M 46104)

\section{(11715) Harperclark}

$1998 \mathrm{HA}_{75}$. Discovered 1998 Apr. 21 by the LINEAR at Socorro.

Elizabeth Dee Pauline Harper-Clark (1984- ) is a finalist in the 2002 Intel International Science and Engineering Fair for her earth and space sciences project. She attends the Presdale School, Ware, Hertfordshire, U.K. (M 46104)

\section{(11716) Amahartman}

$1998 \mathrm{HY}_{79}$. Discovered 1998 Apr. 21 by the LINEAR at Socorro.

Amanda Nicole Hartman (1987- ) is a finalist in the 2002 Intel International Science and Engineering Fair for her microbiology project. She attends the China Spring High School, China Spring, Texas, U.S.A. (M 46104)

\section{(11718) Hayward}

1998 HD $_{95}$. Discovered 1998 Apr. 21 by the LINEAR at Socorro.

Nicholas Mark Edward Alexander Hayward (1984-

) is a finalist in the 2002 Intel International Science and Engineering Fair for his chemistry project. He 
attends the Dover Grammar School for Boys, Dover, Kent, U.K. (M 46104)

\section{(11719) Hicklen}

1998 HT $_{98}$. Discovered 1998 Apr. 21 by the LINEAR at Socorro.

Rachel Scarlett Hicklen (1984- ) is a finalist in the 2002 Intel International Science and Engineering Fair for her environmental science project. She attends the Blackman High School, Murfreesboro, Tennessee, U.S.A. (M 46104)

\section{(11720) Horodyskyj}

1998 HZ $_{99}$. Discovered 1998 Apr. 21 by the LINEAR at Socorro.

Ulyana N. Horodyskyj (1986- ) is a finalist in the 2002 Intel International Science and Engineering Fair for her earth and space sciences project. She attends the Padua Franciscan High School, North Royalton, Ohio, U.S.A. (M 46104)

\section{(11724) Ronaldhsu}

$1998 \mathrm{HH}_{146}$. Discovered 1998 Apr. 21 by the LINEAR at Socorro.

Ronald Hsu (1985- ) is a finalist in the 2002 Intel International Science and Engineering Fair for his mathematics project. He attends the West Shore Jr/Sr High School, Palm Bay, Florida, U.S.A. (M 46104)

\section{(11725) Victoriahsu}

$1998 \mathrm{HM}_{146}$. Discovered 1998 Apr. 21 by the LINEAR at Socorro.

Victoria Hsu (1987- ) is a finalist in the 2002 Intel International Science and Engineering Fair for her mathematics project. She attends the West Shore Jr/Sr High School, Palm Bay, Florida, U.S.A. (M 46104)

\section{(11726) Edgerton}

1998 JA. Discovered 1998 May 1 by R. Linderholm at Lime Creek.

Harold "Doc" Eugene Edgerton (1903-1990), born in Fremont, Nebraska, was professor of electrical engineering at the Massachusetts Institute of Technology during 1928-1966. His many inventions included the stroboscope and development of ultra high-speed photographic techniques. (M 43045)

\section{(11727) Sweet}

$1998 \mathrm{JM}_{1}$. Discovered 1998 May 1 by the JPL NEAT Program at Haleakala

During the 1.2-m Schmidt conversion Merle Sweet (1942- ), assistant superintendent at the Palomar Observatory, assisted in overseeing the details in the layout and construction of the slip-ring trolleys. He also worked in the rewiring of the dome. (M 45234) The name was suggested by $R$. Thicksten.

\section{(11728) Einer}

$1998 \mathrm{JC}_{2}$. Discovered 1998 May 1 by the JPL NEAT Program at Haleakala.
Palomar Observatory technician Steve Einer (1955- ） worked extremely hard removing old and installing new wiring during the upgrade of the 1.2-m Oschin telescope. He completely rewired the rotating portion of the dome. He consistently went above and beyond the call of duty. (M 43191)

The name was suggested by $\mathrm{R}$. Thicksten.

\section{(11730) Yanhua}

$1998 \mathrm{KO}_{31}$. Discovered 1998 May 22 by the LINEAR at Socorro.

Yan Hua (1984- ) is a finalist in the 2002 Intel International Science and Engineering Fair for his engineering project. He attends the Jinling High School, Nanjing, Jiangsu, China. (M 46105)

\section{(11739) Baton Rouge}

1998 SG $_{27}$. Discovered 1998 Sept. 25 by W. R. Cooney Jr and M. Collier at Baton Rouge.

Baton Rouge, the Louisiana state capital, is located on the banks of the Mississippi river and derives its name, French for "red stick", from an Indian marker at the site seen by a French expedition in 1699. The city is home to the Highland Road Park Observatory, where this minor planet was discovered. (M 38201)

\section{(11740) Georgesmith}

1998 UK $_{6}$. Discovered 1998 Oct. 22 by the OCA-DLR Survey at Caussols.

Georges Smith (1930- ) co-invented the CCD while at Bell Laboratories in 1969. This device has revolutionized both amateur and professional astronomy. This minor planet was automatically detected by a CCD during a professional survey. (M 41031)

\section{(11743) Jachowski}

$1999 \mathrm{JP}_{130}$. Discovered 1999 May 13 by the LINEAR at Socorro.

Matthew Douglas Apau Jachowski (1985- ) is a finalist in the 2002 Intel International Science and Engineering Fair for his earth and space sciences project. He attends the Maui High School, Pukalani, Hawaii, U.S.A. (M 46105)

\section{(11746) Thomjansen}

$1999 \mathrm{NG}_{4}$. Discovered 1999 July 13 by the LINEAR at Socorro.

Thomas Scott Jansen (1986- ) is a finalist in the 2002 Intel International Science and Engineering Fair for his microbiology project. He attends the Laramie Senior High School, Laramie, Wyoming, U.S.A. (M 46105)

\section{(11771) Maestlin}

4136 T-2. Discovered 1973 Sept. 29 by C. J. van Houten and I. van Houten-Groeneveld at Palomar.

Michael Maestlin (1550-1631), professor of astronomy at Tübingen $\{$ see planet (1481)\}, was an influential teacher of Johannes Kepler \{see planet (1134)\} and one 
of the earliest adherents to Copernicanism. Maestlin also made astrometric measurements of comets in 1577 and 1580. (M 45234)

The name was suggested by the object's identifier, D. W. E. Green.

\section{(11786) Bakhchivandji}

1977 QW. Discovered 1977 Aug. 19 by N. S. Chernykh at Nauchnyj.

Grigorij Yakovlevich Bakhchivandji (1909-1943) was a Soviet test pilot and pioneer in rocket flights who in 1942 piloted the first flight on the rocket-propelled experimental aircraft BI-1 of Bolkhovitinov and Isaev. He perished while piloting this aircraft's second flight. (M 46010)

\section{(11790) Goode}

1978 RU. Discovered 1978 Sept. 1 by N. S. Chernykh at Nauchnyj.

Philip R. Goode (1943- ), a professor at the New Jersey Institute of Technology and director of Big Bear Solar Observatory, is renowned for his work on helioseismology and solar activity. His wife Fran B. Goode (1944- ) is director of development at the same observatory. (M 43382)

\section{(11796) Nirenberg}

1980 DS $_{4}$. Discovered 1980 Feb. 21 by L. G. Karachkina at Nauchnyj.

American mathematician Louis Merses Nirenberg (1925- ) is an expert in the theory of differential equations, mathematical physics and functional analysis. (M 39658)

\section{(11823) Christen}

1981 VF. Discovered 1981 Nov. 2 by B. A. Skiff at Anderson Mesa.

Roland W. Christen (1944- ) is an optician and maker of affordable apochromatic refractors at the forefront of mechanical and optical design. (M 38201) The citation was provided by S. and A. French.

\section{(11830) Jessenius}

1984 JE. Discovered 1984 May 2 by A. Mrkos at Klet.

Ján Jesenský (Jessenius, 1566-1621) was a physician, head of Prague university beginning in 1618 and Tycho Brahe's \{see planet (1677)\} friend in Prague. He was executed at the beginning of the Thirty Years' War. (M 40708)

The name was suggested by J. Tichá and M. Tichý.

\section{(11833) Dixon}

1985 RW. Discovered 1985 Sept. 13 by the Spacewatch at Kitt Peak.

Roger Dixon (1947- ) is a staff physicist at the Fermi National Accelerator Laboratory in Batavia, Illinois, and Project Manager for the Cryogenic Dark Matter Search. He is in charge of and teaches in the Saturday morning physics program for high school students. (M 45337)

\section{(11836) Eileen}

1986 CB. Discovered 1986 Feb. 5 by C. S. Shoemaker and E. M. Shoemaker at Palomar.

Eileen Collins (1956- ), astronaut, became in Feb. 1995 the first woman to pilot a shuttle mission. In July 1999 she became NASA's first female shuttle commander. Her five-day mission launched the Chandra X-ray Telescope into orbit. (M 45337)

\section{(11842) Kap'bos}

$1987 \mathrm{BR}_{1}$. Discovered 1987 Jan. 22 by E. W. Elst at La Silla.

Kap'bos is a small village, about $20 \mathrm{~km}$ east of the city of Antwerp. In 1936 the discoverer was born there. It is currently the site of the Holbach s see planet (6956)\} Foundation. (M 43191)

\section{(11847) Winckelmann}

$1988 \mathrm{BY}_{2}$. Discovered 1988 Jan. 20 by F. Börngen at Tautenburg.

The German art historian Johann Joachim Winckelmann (1717-1768) was the founder of classic archaeology. His passionate interpretation of Greek art defined the ideal of the beauty of classicism. His extensive knowledge of ancient art and culture is stated in his main work Geschichte der Kunst des Altertums. (M 39658)

\section{(11849) Fauvel}

$1988 \mathrm{CF}_{7}$. Discovered 1988 Feb. 15 by E. W. Elst at La Silla.

Charles Fauvel (1904-1979) was a French aviator who in 1933 invented the flying wing. He solved the problem of the longitudinal stability of a double-curved wing by arranging for the center of gravity to be just ahead of one-quarter of the total length of the wing. (M 40708)

The name was suggested by R. Josse.

\section{(11853) Runge}

1988 RV $_{1}$. Discovered 1988 Sept. 7 by F. Börngen at Tautenburg.

The German painter and graphic artist Philipp Otto Runge (1777-1810) was a famous master of north German Romanticism. He favored pictures of figures in scenic surroundings and painted plants carefully and accurately. His most important works are in the art gallery of Hamburg. (M 39658)

\section{(11854) Ludwigrichter}

$1988 \mathrm{RM}_{3}$. Discovered 1988 Sept. 8 by F. Börngen at Tautenburg.

The German artist Adrian Ludwig Richter (18031884) taught for many years at the academy in his home town, Dresden \{see planet (3053)\}. He painted Italian and Saxonian-Bohemian landscapes in the late Romantic style and created woodcut illustrations for books. (M 39658) 


\section{(11855) Preller}

$1988 \mathrm{RS}_{3}$. Discovered 1988 Sept. 8 by F. Börngen at Tautenburg.

Friedrich Preller the Elder (1804-1878), German painter and etcher, was court painter in Weimar and, beginning in 1834, director of the "Freie Zeichenschule". His wall paintings were in late classical style with elements of Romanticism. His main works are the 16 monumental Odyssee frescos in the New Museum of Weimar $\{$ see planet (3539)\}. (M 39658)

\section{(11870) Sverige}

$1989 \mathrm{TC}_{3}$. Discovered 1989 Oct. 7 by E. W. Elst at La Silla.

Sverige (Sweden) is a nation in northern Europe, located on the Scandinavian peninsula together with Norway see planet (11871)\}. The country is dominated by forests of pine and birch. It has a very rich animal life. Sweden has always been celebrated for its high cultural and ethic standards. (M 43045)

\section{(11871) Norge}

$1989 \mathrm{TP}_{7}$. Discovered 1989 Oct. 7 by E. W. Elst at La Silla.

Norge (Norway) is a nation in northern Europe, well known for its beautiful coast. Two-thirds of the country is mountainous. Far from the European continent, the Norwegians have maintained a great homogeneity among their people and their way of life. (M 43045)

\section{(11874) Gringauz}

$1989 \mathrm{XD}_{1}$. Discovered 1989 Dec. 2 by E. W. Elst at La Silla.

Konstantin Gringauz (1918-1993) became involved in ionospheric studies early in his career. He participated in the launching of Sputnik 1 by constructing the beepbeep transmitter. During 1982-1986 he was responsible for designing and implementing plasma experiments aboard VEGA 1 and 2. (M 42672)

\section{(11876) Doncarpenter}

$1990 \mathrm{EM}_{1}$. Discovered 1990 Mar. 2 by E. W. Elst at La Silla.

For the past 42 years, Don Carpenter (1938- ) has been associated with the Stanford research group devoted to passive and active whistler-mode probing of the earth's ionosphere and magnetosphere. In 1966 he discovered the plasmapause in the electron-density distribution of the magnetosphere. (M 42672)

\section{(11881) Mirstation}

$1990 \mathrm{QO}_{6}$. Discovered 1990 Aug. 20 by E. W. Elst at La Silla.

The Russian space station Mir, launched in 1986, remained in service for more than 15 years as a laboratory for a wealth of scientific experiments performed on board by international crews. Mir was destroyed in March 2001 in order to avoid an uncontrolled return into the earth's atmosphere. (M 42672)

\section{(11886) Kraske}

1990 TT $_{10}$. Discovered 1990 Oct. 10 by L. D. Schmadel and F. Börngen at Tautenburg.

Konrad Kraske (1926- ) served as a member of the supervisory board of the public German TV net ZDF since its foundation in 1962 - the last decade as its chairman. Kraske was primarily engaged in the development of highly demanding TV channels. (M 43191)

The name was suggested by the first discoverer.

\section{(11887) Echemmon}

$1990 \mathrm{TV}_{12}$. Discovered 1990 Oct. 14 by F. Börngen and L. D. Schmadel at Tautenburg.

The hero Echemmon, son of the king of Troy Priamos \{see planet (884)\}, was killed together with his brother Chromios by Diomedes \{see planet (1437)\}, king of Argos. (M 42361)

The name was suggested by the first discoverer.

\section{(11895) Dehant}

1991 GU$_{3}$. Discovered 1991 Apr. 8 by E. W. Elst at La Silla.

Véronique Dehant (1959- ) is head of the section for time, earth rotation and space geodesy at the Royal Observatory, Uccle. She is currently involved with the NEIGE project, which plans a soft landing of a geodetic instrument on Mars. In 1999 she was awarded the Bomford prize for her work on the earth's nutation. (M 42672)

\section{(11896) Camelbeeck}

$1991 \mathrm{GP}_{6}$. Discovered 1991 Apr. 8 by E. W. Elst at La Silla.

Thierry Camelbeeck (1956- ) is a seismologist at the Royal Observatory, Uccle. He has carried out studies of seismicity in Belgium. (M 42672)

\section{(11897) Lemaire}

1991 GC $_{7}$. Discovered 1991 Apr. 8 by E. W. Elst at La Silla.

Joseph F. Lemaire (1939- ), head of the Fundamental Dynamics section at the Belgian Institute for Space Aeronomy, Uccle, is renowned for his research on radiation belts, the solar wind and planetary magnetic fields. With Konstantin Gringauz \{see planet (11874)\} he published the book The Earth's Plasmasphere in 1998. (M 42672)

\section{(11898) Dedeyn}

$1991 \mathrm{GM}_{9}$. Discovered 1991 Apr. 10 by E. W. Elst at La Silla.

Peter Paul De Deyn (1957- ) is head of the Laboratory of Neurochemistry and Behavior at the Born-Bunge Foundation of the University of Antwerp. During 1985-1986 he specialized in neuropsychiatry at the Ann Arbor Medical Center. He is currently involved with studies of human ethology and animal laboratory sciences. (M 42672) 


\section{(11899) Weill}

1991 GJ $_{10}$. Discovered 1991 Apr. 9 by F. Börngen at Tautenburg.

The German-American composer Kurt Weill (19001950) was born in Dessau. The Dreigroschenoper ("The Threepenny Opera", 1928), written with Brecht \{see planet (12298)\}, was a revolution in the musical theatre. In 1935, he emigrated to New York and became a highly successful composer on Broadway. (M 40708)

\section{(11900) Spinoy}

$1991 \mathrm{LV}_{2}$. Discovered 1991 June 6 by E. W. Elst at La Silla.

Constant Spinoy (1924-1997) was a famous Belgian artist and engraver who specialised in the design of postage stamps, of which he engraved more than 100 . These include Vielsalm, Towers of Ghent and Double astrograph at the Royal Observatory of Uccle. In 1977 he was honored with the Prize of Europe for his Jeugdfilatelie. (M 42673)

\section{(11905) Giacometti}

$1991 \mathrm{VL}_{6}$. Discovered 1991 Nov. 6 by E. W. Elst at La Silla.

The work of Swiss sculptor Alberto Giacometti (19011966), often compared to that of the Existentialists, contrasted with the avant-garde in that it attempted to equal reality so that a sculpture, like "Observing Head" (1927), would be perceived as if it were alive. Other masterpieces are "The Palace at 4 a.m." and $" 1+1=3 "$. (M 44186)

\section{(11911) Angel}

1992 LF. Discovered 1992 June 4 by C. S. Shoemaker and D. H. Levy at Palomar.

Founder and director of Steward Observatory's mirror lab at the University of Arizona, Tucson, Roger Angel (1941- ) has spearheaded the development of telescope mirrors as large as eight meters in diameter by a process called spin-casting. His work and ideas have resulted in an enormous increase in telescope light-gathering power. (M 41572)

\section{(11912) Piedade}

$1992 \mathrm{OP}_{5}$. Discovered 1992 July 30 by E. W. Elst at La Silla.

Serra de Piedade in the Brazilian state of Minas Gerais, east of the capital of Belo Horizonte, is the location of the Piedade Observatory. During the 1970s the discoverer spent many hours there observing variable stars. (M 40708)

\section{(11913) Svarna}

$1992 \mathrm{RD}_{3}$. Discovered 1992 Sept. 2 by E. W. Elst at La Silla.

Anneta Svarna (1951- ) is a mathematical logician who works on information theory for the European Union. The author of many publications on mathematical logic, in 1998 she published (with D. Sinachopoulos \{see planet (11914)\}) an important paper on Greek philosophy: Why Plato \{see planet (5451)\} was against observational astronomy. (M 42673)

\section{(11914) Sinachopoulos}

1992 RZ $_{3}$. Discovered 1992 Sept. 2 by E. W. Elst at La Silla.

Dimitrios Sinachopoulos (1951- ) is an astrophysicist at the National Observatory of Athens who conducts observational and theoretical work on galactic lenses. In 1991 he wrote (with A. Svarna \{see planet (11913)\}) The Teachings of Astronomy in Plato's Republic. He has often helped the discoverer with the treatment of CCD frames. (M 42673)

\section{(11916) Wiesloch}

1992 ST $_{17}$. Discovered 1992 Sept. 24 by L. D. Schmadel and F. Börngen at Tautenburg.

The city of Wiesloch celebrates the 1200th anniversary of its first documented mention in mid-2001. Situated some $16 \mathrm{~km}$ south of the famous Heidelberg-Königstuhl Observatory, it became the home town of the first discoverer more than 30 years ago. (M 43191)

\section{(11930) Osamu}

$1993 \mathrm{CJ}_{1}$. Discovered 1993 Feb. 15 by T. Hioki and S. Hayakawa at Okutama.

Oshima Osamu (1959- ) is a leading amateur astronomer and science teacher in Gunma prefecture and volunteer science instructor in great favor with children. His interests in astronomy are wide, currently CCD imaging of planetary nebulae. (M 43045)

\section{(11941) Archinal}

$1993 \mathrm{KT}_{1}$. Discovered 1993 May 23 by C. S. Shoemaker and D. H. Levy at Palomar.

An active amateur astronomer, Brent Archinal (1956- ) specializes in correcting catalog data for stellar groupings and nonstellar objects. He also has finished the most complete catalog yet assembled of open and globular clusters. Today he works for the U.S. Geological Survey in Flagstaff, Arizona. (M 41572)

\section{(11942) Guettard}

1993 NV. Discovered 1993 July 12 by E. W. Elst at La Silla.

Jean-Etienne Guettard (1715-1786) was a French geologist and mineralogist. From the evidence of fossils found in the volcanic hills of the Puy de Dôme, in south-central France, he concluded correctly that they conflicted with the time scheme of the Old Testament. (M 40708)

\section{(11943) Davidhartley}

$1993 \mathrm{OF}_{9}$. Discovered 1993 July 20 by E. W. Elst at La Silla.

David Hartley (1705-1757) was an English physician and philosopher who attempted to explain how thought processes occur. His major work, Observations on Man, His Frame, His Duty and His Expectations, is important 
in the history of psychology for suggesting that body and mind function in concert. (M 40708)

\section{(11944) Shaftesbury}

$1993 \mathrm{OK}_{9}$. Discovered 1993 July 20 by E. W. Elst at La Silla.

Anthony Ashley Cooper Shaftesbury (1671-1713) was an English politician and philosopher. Educated by philosopher John Locke \{see planet (7010)\}, he soon developed his own school of thought. His philosophy was also influenced by the "Cambridge Platonists", who stressed the existence of a natural moral sense. (M 40708)

\section{(11946) Bayle}

$1993 \mathrm{~PB}_{7}$. Discovered 1993 Aug. 15 by E. W. Elst at Caussols.

French philosopher Pierre Bayle (1647-1706) wrote the Dictionnaire historique et critique. Because it deliberately tried to destroy orthodox Christian beliefs, he aroused the ire of many of his colleagues. In 1682 he published some reflections on the comet of 1680 , deriding the superstition that comets presage catastrophes. (M 40708)

\section{(11955) Russrobb}

$1994 \mathrm{CA}_{1}$. Discovered 1994 Feb. 8 by D. D. Balam at Victoria.

Russell M. Robb (1952- ), astronomer at the University of Victoria, played the leading role in automating the university's $0.5-\mathrm{m}$ telescope and equipping it with a CCD camera. The telescope has been used extensively in the university's observational programs, including astrometric work on comets and minor planets. (M 38201)

\section{(11956) Tamarakate}

1994 CL $_{14}$. Discovered 1994 Feb. 8 by E. W. Elst at La Silla.

Tamara Kate Peiser (2001- ） is the second daughter of Gillian and Benny Peiser \{see planet (7107)\}. Her father, an anthropologist at Liverpool John Moores University, is known the world over for the Cambridge Conference network. (M 45337)

\section{(11963) Ignace}

$1994 \mathrm{PO}_{16}$. Discovered 1994 Aug. 10 by E. W. Elst at La Silla.

Ignace Van der Gucht (1959- ) is a graduate in electronics and chief of construction at the Royal Observatory at Uccle, where he places his abilities at the disposal of his colleagues, particularly when they have problems with configuring and upgrading their computers. (M 45337)

\section{(11966) Plateau}

$1994 \mathrm{PJ}_{20}$. Discovered 1994 Aug. 12 by E. W. Elst at La Silla.

Joseph Antoine Ferdinand Plateau (1801-1883) was a Belgian physicist who stated the so-called "Plateauproblem". The proof of the existence of a minimal surface (of least area) bounded by a simple closed curve in space was solved in 1930 by means of variational analysis. (M 40708)

\section{(11970) Palitzsch}

1994 TD. Discovered 1994 Oct. 4 by P. Sicoli and P. Ghezzi at Sormano.

Johann Georg Palitzsch (1723-1788) was a farmer by profession and an astronomer by vocation. He recovered comet $1 \mathrm{P} /$ Halley on its first predicted return in 1758 and observed further comets, as well as variable stars such as Mira and Algol. (M 45234)

The citation was prepared by P. Brosche.

\section{(11974) Yasuhidefujita}

1994 YF. Discovered 1994 Dec. 24 by T. Kobayashi at Oizumi.

Yasuhide Fujita (1961- ), a Japanese amateur astronomer, is a staff member at the Board of Education in Kuma Town \{see planet (8255)\}. He worked as a researcher at the Kuma Kogen Astronomical Observatory for eight years (1992-1999) and independently discovered the supernova 1994I. (M 46682)

\section{(11980) Ellis}

$1995 \mathrm{SP}_{8}$. Discovered 1995 Sept. 17 by the Spacewatch at Kitt Peak.

Kerry Ellis (1965- ) wrote a thesis at the University of Western Ontario in electrical engineering and specialized in meteor burst communication. (M 45337)

\section{(11981) Boncompagni}

1995 UY $_{1}$. Discovered 1995 Oct. 20 at the Osservatorio San Vittore at Bologna.

Prince Baldassarre Boncompagni (1821-1894) was editor of 20 volumes of Bullettino di Bibliografia e Storia delle Scienze Matematiche e Fisiche. This monumental work, published in Rome during 1868-1887, was fundamental in the history of the mathematical and physical sciences, with many articles on the history of astronomy. (M 41938)

\section{(11997) Fassel}

1995 YU $_{9}$. Discovered 1995 Dec. 18 by the Spacewatch at Kitt Peak.

Deborah Elizabeth Fassel (1950- ) and Charles Sebastian Fassel (1955- ) are amateur astronomers who live in St. Catharines, Ontario. (M 45337)

\section{(11998) Fermilab}

1996 AG $_{7}$. Discovered 1996 Jan. 12 by the Spacewatch at Kitt Peak.

The Fermi National Accelerator Laboratory was founded in Batavia, Illinois, in 1967. Among the discoveries made by Fermilab scientists are the bottom quark and the top quark. The Sloan Digital Sky Survey also has its headquarters there. (M 44186)

The name was suggested by P. and R. Jedicke. 


\section{(12001) Gasbarini}

1996 ED . Discovered 1996 Mar. 12 by the Spacewatch at Kitt Peak.

Ron Gasbarini (1960- ) is an amateur astronomer whose interest was inspired by the Apollo missions in the 1960s. He has served as president of the Royal Astronomical Society of Canada's Niagara Centre and won the service award of the society in 1995. (M 45337)

\section{(12002) Suess}

$1996 \mathrm{FR}_{1}$. Discovered 1996 Mar. 19 by P. Pravec and L. Šarounová at Ondřejov.

Austrian geologist Franz Eduard Suess (1867-1941), professor at the Technical College in Prague and the University of Vienna, worked on crystalline bedrock of the Bohemian Mass and made fundamental studies of the moldavites. He introduced the word "tektite". (M 38201)

The name was suggested by H. Raab.

\section{(12003) Hideosugai}

$1996 \mathrm{FM}_{5}$. Discovered 1996 Mar. 20 by T. Okuni at Nanyou.

Hideo Sugai (1930- ), a retired teacher, is a Japanese amateur astronomer. He has been observing variable stars since 1951, and his data have been reported to the Variable Star Observers League in Japan. (M 43192)

\section{(12007) Fermat}

1996 TD $_{7}$. Discovered 1996 Oct. 11 by P. G. Comba at Prescott.

Pierre Fermat (1601-1665), a lawyer in Toulouse, is considered the greatest amateur mathematician of all time. He was the co-inventor of analytic geometry and the founder of modern number theory. He bequeathed to mathematics a conjecture - the so-called Fermat's last theorem - that was proved only in the 1990s \{see also planet (9999)\}. (M 38201)

\section{(12014) Bobhawkes}

1996 VX $_{15}$. Discovered 1996 Nov. 5 by the Spacewatch at Kitt Peak.

Robert Lewis Hawkes (1951- ) became head of the physics department at Mount Allison University in Sackville, New Brunswick, in 2000. His graduate work at the University of Western Ontario in 1979 was on the dustball theory of meteoroids. (M 44594)

\section{(12016) Green}

1996 XC. Discovered 1996 Dec. 1 by P. G. Comba at Prescott.

George Green (1793-1841), a self-taught miller's son of Nottingham, was instrumental (along with Gauss see planet (1001)) in making the theories of electricity and magnetism a part of mathematical physics. His name is associated with the "Green's function" used in the solution of partial differential equations. (M 38201)

\section{(12022) Hilbert}

$1996 \mathrm{XH}_{26}$. Discovered 1996 Dec. 15 by P. G. Comba at Prescott.

David Hilbert (1862-1943), professor at Göttingen and one of the greatest mathematicians of all time, exerted a profound influence on the development of many branches of mathematics in the twentieth century: the foundations, geometry, algebra, analysis. His name is associated with the infinite-dimensional Hilbert space. (M 38201)

\section{(12032) Ivory}

$1997 \mathrm{BP}_{5}$. Discovered 1997 Jan. 31 by P. G. Comba at Prescott.

James Ivory (1765-1842), Scottish mathematician and professor at the Royal Military College, published more than ninety papers on various mathematico-physical problems, including the attraction of ellipsoids, orbits of comets, atmospheric refraction and the equilibrium of fluid bodies. (M 38201)

\section{(12033) Anselmo}

1997 BD . Discovered 1997 Jan. 31 by M. Tombelli and U. Munari at Cima Ekar.

Anselmo Antonini (1946- ) is an amateur astronomer in the Montelupo \{see planet (7198)\} Group. (M 41385)

\section{(12035) Ruggieri}

$1997 \mathrm{CP}_{13}$. Discovered 1997 Feb. 1 by V. Goretti at Pianoro.

Guido Ruggieri (1913-1976), talented Italian amateur astronomer, was well known for his work on visual observations of Mars and Jupiter. He also played an important role in the dissemination of astronomical information. (M 41572)

\section{(12040) Jacobi}

$1997 \mathrm{EK}_{8}$. Discovered 1997 Mar. 8 by P. G. Comba at Prescott.

Carl G. J. Jacobi (1804-1851), professor at Königsberg and Berlin, developed the theory of elliptic functions (also discovered independently by Gauss and Abel see, respectively, planets (1001) and (8525)). He is also known for a functional determinant now called the jacobian. He was one of the last mathematicians who published their researches in Latin. (M 38201)

\section{(12042) Laques}

1997 FC. Discovered 1997 Mar. 17 by C. Buil at Ramonville Saint Agne.

Pierre Laques (1934- ) started his career at the private observatory of the Chateau D'Abadia near Hendaye, moving to the Pic du Midi, where the 1-m telescope had just been built. $\mathrm{He}$ is one of the codiscoverers of the satellite Saturn XII (Helène). (M 41031)

\section{(12044) Fabbri}

1997 FU. Discovered 1997 Mar. 29 by M. Tombelli and G. Forti at Montelupo. 
Luciano Fabbri (1945- ) is an amateur astronomer in the Montelupo \{see planet (7198)\} Group. (M 41385)

\section{(12045) Klein}

$1997 \mathrm{FH}_{1}$. Discovered 1997 Mar. 30 by P. G. Comba at Prescott.

Felix Klein (1849-1925) was a professor of mathematics at Erlangen and later at Göttingen. Deeply impressed by the concept of a group of transformations as a unifying principle in geometry, he spent much of his life developing, applying and popularizing this notion. (M 38201)

\section{(12050) Humecronyn}

$1997 \mathrm{HE}_{14}$. Discovered 1997 Apr. 27 by the Spacewatch at Kitt Peak.

Through the efforts of Hume Blake Cronyn (18641933), Canada's National Research Council was established in 1920. After his death, his widow donated funds for the construction of the Hume Cronyn Memorial Observatory at the University of Western Ontario in London. (M 45337)

\section{(12051) Pícha}

1997 JO. Discovered 1997 May 2 by L. Šarounová at Ondřejov.

Jaroslav Pícha (1921-1998) was a Czech meteorologist and amateur astronomer. The observatory he built in Hradec Králové for the systematic monitoring of solar radiation and the ozone layer became one of the most respected in the world. (M 42361)

The name was suggested by M. Lehký.

\section{(12053) Turtlestar}

$1997 \mathrm{PK}_{2}$. Discovered 1997 Aug. 9 at the Starkenburg Observatory at Heppenheim.

The Turtle Star Observatory, located in Mülheim/ Ruhr, Germany, contributed follow-up observations for this object. This private observatory was built in 1995 by A. Boeker, K. Kleemann-Boeker, A. Martin and M. Tator and is named for a neighbor's turtle, which observed the construction with apparent great interest. (M 41032)

\section{(12056) Yoshigeru}

1997 YS $_{11}$. Discovered 1997 Dec. 30 by T. Kobayashi at Oizumi.

Yoshida Shigeru (1952-1997) was a Japanese physician who specialized in the circulatory system and the use of magnetic resonance imaging for the diagnosis of heart disease. His premature death cut short his plans for a minor-planet survey. (M 41938)

The name was suggested by J. Kobayashi and M. Namiki.

\section{(12057) Alfredsturm}

1998 DK $_{1}$. Discovered 1998 Feb. 18 at the Starkenburg Observatory at Heppenheim.

German amateur astronomer Alfred Sturm (1924- ） was one of the founders and has been president of the Starkenburg \{see planet (6864)\} Observatory since its beginnings in 1970. Sturm is heavily involved in astronomical public education. (M 42361)

\section{(12061) Alena}

$1998 \mathrm{FQ}_{2}$. Discovered 1998 Mar. 21 by T. Stafford at Edmond

Alena Ruth Robbins is the mother of the discoverer. (M 40708)

\section{(12064) Guiraudon}

$1998 \mathrm{FZ}_{15}$. Discovered 1998 Mar. 28 by the OCA-DLR Survey at Caussols.

In 1961 Jean-Claude Guiraudon founded the Fédération Nationale des Clubs Scientifiques, which later evolved into the Association Nationale Sciences Techniques Jeunesse. He now works at the international level with MILSET, the Mouvement International pour le Loisir Scientifique Et Technique, which he helped create. (M 41032)

\section{(12065) Jaworski}

$1998 \mathrm{FA}_{33}$. Discovered 1998 Mar. 20 by the LINEAR at Socorro.

Victor Jaworski (1984- ) is a finalist in the 2002 Intel International Science and Engineering Fair for his physics project. He attends the Saint Augustine High School, Saint Augustine, Florida, U.S.A. (M 46105)

\section{(12067) Jeter}

$1998 \mathrm{FH}_{42}$. Discovered 1998 Mar. 20 by the LINEAR at Socorro.

Crystal Lynn Jeter (1984- ) is a finalist in the 2002 Intel International Science and Engineering Fair for her zoology project. She attends the Ridgeview High School, Orange Park, Florida, U.S.A. (M 46105)

\section{(12068) Khandrika}

$1998 \mathrm{FZ}_{53}$. Discovered 1998 Mar. 20 by the LINEAR at Socorro.

Harish Gautam Khandrika (1987- _ ) is a finalist in the 2002 Intel International Science and Engineering Fair for his earth and space sciences project. He attends the La Jolla High School, La Jolla, California, U.S.A. (M 46105)

\section{(12070) Kilkis}

$1998 \mathrm{FK}_{63}$. Discovered 1998 Mar. 20 by the LINEAR at Socorro.

Siir Sirinyasam Kilkis (1984- ) is a finalist in the 2002 Intel International Science and Engineering Fair for her mathematics project. She attends the Greenwood Laboratory School, Springfield, Missouri, U.S.A. (M 46105)

\section{(12071) Davykim}

$1998 \mathrm{FV}_{63}$. Discovered 1998 Mar. 20 by the LINEAR at Socorro.

Davy Kim (1985- ) is a finalist in the 2002 Intel International Science and Engineering Fair for his mathematics project. He attends the Academy for the 
Advancement of Science and Technology, Englewood Cliffs, New Jersey, U.S.A. (M 46105)

\section{(12072) Anupamakotha}

1998 FA $_{65}$. Discovered 1998 Mar. 20 by the LINEAR at Socorro.

Anupama Kotha (1985- ） is a finalist in the 2002 Intel International Science and Engineering Fair for her medicine and health project. She attends the C. Leon King High School, Tampa, Florida, U.S.A. (M 46105)

\section{(12073) Larimer}

$1998 \mathrm{FD}_{66}$. Discovered 1998 Mar. 20 by the LINEAR at Socorro.

Curtis James Larimer (1986- ) is a finalist in the 2002 Intel International Science and Engineering Fair for his computer science project. He attends the William J. Palmer High School, Colorado Springs, Colorado, U.S.A. (M 46105)

\section{(12074) Carolinelau}

$1998 \mathrm{FZ}_{68}$. Discovered 1998 Mar. 20 by the LINEAR at Socorro.

Caroline Sue-Yuk Lau (1984- ) is a finalist in the 2002 Intel International Science and Engineering Fair for her microbiology project. She attends the Syosset High School, Syosset, New York, U.S.A. (M 46105)

\section{(12075) Legg}

1998 FX $_{69}$. Discovered 1998 Mar. 20 by the LINEAR at Socorro.

Tiffany Amelia Legg (1987- ) is a finalist in the 2002 Intel International Science and Engineering Fair for her earth and space sciences project. She attends the Duncan Senior High School, Duncan, Oklahoma, U.S.A. (M 46105)

\section{(12086) Joshualevine}

$1998 \mathrm{HC}_{22}$. Discovered 1998 Apr. 20 by the LINEAR at Socorro.

Joshua Levine (1985- ) is a finalist in the 2002 Intel International Science and Engineering Fair for his chemistry project. He attends the Ramaz, Great Neck, New York, U.S.A. (M 46105)

\section{(12087) Tiffanylin}

1998 HB $_{30}$. Discovered 1998 Apr. 20 by the LINEAR at Socorro.

Tiffany Fangtse Lin (1984- ） is a finalist in the 2002 Intel International Science and Engineering Fair for her biochemistry project. She attends the Montgomery Blair High School, North Potomac, Maryland, U.S.A. (M 46105)

\section{(12088) Macalintal}

$1998 \mathrm{HZ}_{31}$. Discovered 1998 Apr. 20 by the LINEAR at Socorro.

Jeric Valles Macalintal (1986- ) is a finalist in the 2002 Intel International Science and Engineering Fair for his physics project. He attends the Manila Science High School, Manila, Philippines. (M 46105)

\section{(12089) Maichin}

$1998 \mathrm{HO}_{35}$. Discovered 1998 Apr. 20 by the LINEAR at Socorro.

Diana Marie Maichin (1983- ) is a finalist in the 2002 Intel International Science and Engineering Fair for her physics project. She attends the Marlborough High School, Marlborough, Massachusetts, U.S.A. (M 46105)

\section{(12091) Jesmalmquist}

1998 HS $_{96}$. Discovered 1998 Apr. 21 by the LINEAR at Socorro.

Jessica Lea Malmquist (1987- ) is a finalist in the 2002 Intel International Science and Engineering Fair for her behavioral and social sciences project. She attends the Olympia Junior High School, Salt Lake City, Utah, U.S.A. (M 46106)

\section{(12093) Chrimatthews}

$1998 \mathrm{HF}_{99}$. Discovered 1998 Apr. 21 by the LINEAR at Socorro.

Christina Marie Matthews (1986- ) is a finalist in the 2002 Intel International Science and Engineering Fair for her medicine and health project. She attends the South River High School, Riva, Maryland, U.S.A. (M 46106)

\section{(12094) Mazumder}

1998 HX $_{99}$. Discovered 1998 Apr. 21 by the LINEAR at Socorro.

Mark Mohan Mazumder (1985- ) is a finalist in the 2002 Intel International Science and Engineering Fair for his medicine and health project. He attends the Little Rock Central High School, Little Rock, Arkansas, U.S.A. (M 46106)

\section{(12099) Meigooni}

$1998 \mathrm{HQ}_{124}$. Discovered 1998 Apr. 23 by the LINEAR at Socorro.

David Nima Meigooni (1986- ) is a finalist in the 2002 Intel International Science and Engineering Fair for his biochemistry project. He attends the Paul Laurence Dunbar High School, Lexington, Kentucky, U.S.A. (M 46106)

\section{(12101) Trujillo}

$1998 \mathrm{JX}_{2}$. Discovered 1998 May 1 by the LONEOS at Anderson Mesa.

Chadwick A. Trujillo (1973- ), of the California Institue of Technology, specializes in the study of Kuiper belt objects. He has conducted KBO searches and studied their orbital distribution and population statistics. (M 46106)

\section{(12104) Chesley}

$1998 \mathrm{KO}_{6}$. Discovered 1998 May 22 by the LONEOS at Anderson Mesa.

Steven R. Chesley (1965- ), of the Solar System Dynamics Group at the Jet Propulsion Laboratory, is an expert in determination of the orbits of minor planets and application to the study of earth-impact 
probability. He was also a member of the NEAR spacecraft navigation team. (M 46106)

\section{(12106) Menghuan}

$1998 \mathrm{KQ}_{31}$. Discovered 1998 May 22 by the LINEAR at Socorro.

Meng Huan (1985- ) is a finalist in the 2002 Intel International Science and Engineering Fair for his earth and space sciences project. He attends the Beijing No. 80 High School, Beijing, China. (M 46106)

\section{(12113) Hollows}

$1998 \mathrm{OH}_{12}$. Discovered 1998 July 29 by J. Broughton at Reedy Creek.

New Zealand-born Fred Hollows (1929-1993) was an ophthalmologist who saved the sight of thousands of aboriginal and poor people in third-world countries rather than make a comfortable living at home. His work outlives him, following his training of local doctors and establishing local interocular lens factories. (M 42673)

\section{(12117) Meagmessina}

$1999 \mathrm{JT}_{60}$. Discovered 1999 May 10 by the LINEAR at Socorro.

Meagan Elizabeth Messina (1985- ) is a finalist in the 2002 Intel International Science and Engineering Fair for her earth and space sciences project. She attends the Saint Joseph's Academy, Baton Rouge, Louisiana, U.S.A. (M 46106)

\section{(12118) Mirotsin}

$1999 \mathrm{NC}_{9}$. Discovered 1999 July 13 by the LINEAR at Socorro.

Yauhen Adolfovich Mirotsin (1985- ） is a finalist in the 2002 Intel International Science and Engineering Fair for his mathematics project. He attends the Gomel City Lyceum No. 1, Gomel, Belarus. (M 46106)

\section{(12119) Memamis}

$1999 \mathrm{NG}_{9}$. Discovered 1999 July 13 by the LINEAR at Socorro.

Megan Marie Miskowski (1984- ) is a finalist in the 2002 Intel International Science and Engineering Fair for her environmental science project. She attends the Ridgeview High School, Orange Park, Florida, U.S.A. (M 46106)

\section{(12125) Jamesjones}

$1999 \mathrm{RS}_{4}$. Discovered 1999 Sept. 3 by the Spacewatch at Kitt Peak.

James Jones (1939- ） studied at Sheffield University in Yorkshire and has been professor of physics at the University of Western Ontario since 1966. Jones pioneered the video observation of meteors and single-station radar radiant mapping. (M 45234)

\section{(12127) Mamiya}

1999 RD $_{37}$. Discovered 1999 Sept. 9 by K. Watanabe at Sapporo.
Rinzo Mamiya (1780-1844) was an explorer and surveyor of the northern area of Japan. In 1809, he reached the north Sakhalin and showed that Karafuto (Sakhalin) is an island separated by a narrow channel, now called the Mamiya strait. (M 41938)

\section{(12128) Palermiti}

$1999 \mathrm{RP}_{43}$. Discovered 1999 Sept. 13 by C. W. Juels at Fountain Hills.

Director of an observatory in Florida, Mike Palermiti (1949- ) provides expert consultation to the astronomical community about optics, telescope design and CCDs ssee planet (15000)\}. He contributed to the early development of low-light-level imaging and has made significant observations of novae, minor planets, comets and occultations. (M 41939)

\section{(12130) Mousa}

$1999 \mathrm{RD}_{146}$. Discovered 1999 Sept. 9 by the LINEAR at Socorro.

Ahmed Shaker Mousa (1984- ) is a finalist in the 2002 Intel International Science and Engineering Fair for his medicine and health project. He attends the Avon Grove High School, Lincoln University, Pennsylvania, U.S.A. (M 46106)

\section{(12164) Lowellgreen}

3067 T-2. Discovered 1973 Sept. 30 by C. J. van Houten and I. van Houten-Groeneveld at Palomar.

Lowell Clark Green (1925- ), a Lutheran pastor/theologian for more than half a century and Renaissance/Reformation scholar, now resident in Buffalo, New York, has given constant support and encouragement to the life and astronomical career of his son, D. W. E. Green, who found the identifications for this object. (M 42673)

\section{(12182) Storm}

1973 UQ $_{5}$. Discovered 1973 Oct. 27 by F. Börngen at Tautenburg.

The writer Theodor Storm (1817-1888) was a local judge in his northern German hometown Husum. He wrote impressive poems and more than 50 novels. As a representative of "poetic realism", he described the landscapes and the people of his north Frisian coastal district. (M 40708)

\section{(12185) Gasprinskij}

1976 SL $_{5}$. Discovered 1976 Sept. 24 by N. S. Chernykh at Nauchnyj.

Ismail Gasprinskij (1851-1914) was a Crimean-Tatar teacher, enlightener, writer, publisher and public figure who had a notable influence on the development of national education. (M 42673)

\section{(12187) Lenagoryunova}

1977 RL 7 . Discovered 1977 Sept. 11 by N. S. Chernykh at Nauchnyj. 
Elena (Lena) Viktorovna Goryunova (1961- ), hydrologist at Sebastopol Institute of Hydrography, is a friend of the discoverer's daughter. (M 43382)

\section{(12189) Dovgyj}

1978 RQ 1 . Discovered 1978 Sept. 5 by N. S. Chernykh at Nauchnyj.

Stanislav Alekseevich Dovgyj (1954- ), a corresponding member of the Ukrainian National Academy of Sciences, is a scientist in the field of mechanics, known for his research on the mathematical simulation of geophysical processes and on the problems of ecological safety. (M 42673)

\section{(12214) Miroshnikov}

$1981 \mathrm{RF}_{2}$. Discovered 1981 Sept. 7 by L. G. Karachkina at Nauchnyj.

Mikhail Mikhailovich Miroshnikov (1926- ) was director of the Vavilov State Optical Institute from 1966 to 1989 . He developed airborne detection instruments and imaging systems for industrial applications and medical diagnostics in the infrared and far-infrared regions that were used for space investigations. (M 43192)

\section{(12222) Perotto}

1982 WA. Discovered 1982 Nov. 19 at the Osservatorio San Vittore at Bologna.

Pier Giorgio Perotto (1930-2002) was an Italian electronics engineer. An employee at Olivetti, in 1964 he invented the world's first desktop programmable electronic calculator, known variously as "Programma 101" and "Perottina". (M 45337)

\section{(12223) Hoskin}

1983 TX. Discovered 1983 Oct. 8 at the Oak Ridge Observatory at Harvard.

Michael A. Hoskin (1930- ) founded the Journal for the History of Astronomy in 1970 and has since served as its editor. He established the archives at Churchill College, Cambridge, is a leading expert on William Herschel and has done pioneering archeoastronomical work around the western Mediterranean basin. (M 41939)

\section{(12224) Jimcornell}

$1984 \mathrm{UN}_{2}$. Discovered 1984 Oct. 19 at the Oak Ridge Observatory at Harvard.

Public Affairs Manager for the Smithsonian Astrophysical Observatory for 37 years, James Cornell (1938- ) provided media services, organized lecture series and produced award-winning books and documentaries. As president of the International Science Writers Association he created a forum for journalists in the developing world. (M 41939)

\section{(12225) Yanfernández}

1985 PQ. Discovered 1985 Aug. 14 by E. Bowell at Anderson Mesa.

Yanga R. Fernández (1971- ) completed his thesis on the albedo and size distribution of cometary nuclei at the University of Maryland in 1999. Since then, at the University of Hawaii, he has measured albedos of other small bodies, recovered comets and discovered new jovian satellites. (M 44110)

The name was suggested by M. F. A'Hearn.

\section{(12226) Caseylisse}

1985 TN. Discovered 1985 Oct. 15 by E. Bowell at Anderson Mesa.

Carey M. ("Casey") Lisse (1961- ) is an expert on cometary dust and has made significant contributions to understanding the size distribution of the dust using infrared observations. (M 44110) The name was suggested by M. F. A'Hearn.

\section{(12227) Penney}

$1985 \mathrm{TO}_{3}$. Discovered 1985 Oct. 11 by C. S. Shoemaker and E. M. Shoemaker at Palomar.

Big John Penney is representative of the team of workers who find a deep and abiding love for the challenges and rigors of wintering at South Pole Station. He has a unique capability for keeping machines operating under the worst and coldest of conditions by treating them like friends. (M 44594)

\section{(12235) Imranakperov}

1986 RB $_{12}$. Discovered 1986 Sept. 9 by L. G. Karachkina at Nauchnyj.

Akperov Imran Guru Ogly (1958- ), professor of economics and president of the inter-regional association of non-state education institutes in southern Russia, is also founder and rector of an institute in Rostovon-Don. (M 45234)

The name was suggested by S. S. Svetashev and R. Y. Gurnikovskaya.

\section{(12237) Coughlin}

1987 HE. Discovered 1987 Apr. 23 by C. S. Shoemaker and E. M. Shoemaker at Palomar.

Thomas B. Coughlin (1941- ) served as NEAR project manager throughout the development, launch and mission phases of this Discovery program. As program manager for Johns Hopkins Applied Physics Laboratory's Space Department, he accomplished several fast-track SDI programs. (M 41032)

\section{(12239) Carolinakou}

$1988 \mathrm{CN}_{4}$. Discovered 1988 Feb. 13 by E. W. Elst at La Silla.

Carolina Carreira Nakou (2001- ) is the daughter of Sandra Carreira and Thodoris Nakos. The latter works on galactic lenses at the Royal Observatory at Uccle. (M 45337)

\section{(12240) Droste-Hülshoff}

$1988 \mathrm{PG}_{2}$. Discovered 1988 Aug. 13 by F. Börngen at Tautenburg.

Annette Freiin von Droste-Hülshoff (1797-1848) was one of the most prominent German poets of her time. Her poems are frequently rooted in the landscape of her 
Westphalian home. Her prose writing in part anticipates civic realism in Germany. Her later work culminated in the poems Mondesaufgang and Durchwachte Nacht. (M 39658)

\section{(12241) Lefort}

$1988 \mathrm{PQ}_{2}$. Discovered 1988 Aug. 13 by F. Börngen at Tautenburg.

Gertrud Freiin von le Fort (1876-1971), German poet, deals with historical and religious topics in her poems, stories and novels. She asks for solidarity with the oppressed and persecuted and demands tolerance among nations, races and religions. (M 39658)

\section{(12242) Koon}

1988 QY. Discovered 1988 Aug. 18 by C. S. Shoemaker and E. M. Shoemaker at Palomar.

Koon, a notable fighter, was the eldest son of Antenor \{see planet (2207)\}. Grieved by the death of his brother Iphidamas at the hands of Agamemnon \{see, respectively, planets (4791 and (911)\}, he fought and wounded him but was in turn beheaded by Agamemnon. (M 41386)

\section{(12244) Werfel}

$1988 \mathrm{RY}_{2}$. Discovered 1988 Sept. 8 by F. Börngen at Tautenburg.

Austrian author Franz Werfel (1890-1945) was a playwright who achieved international success as a novelist and essayist (Die vierzig Tage des Musa Dagh; Das Lied von Bernadette; Between heaven and earth). After his rejection by the Prussian Academy of Poetry, he fled to the U.S. in 1940. (M 40708)

\section{(12252) Gwangju}

$1988 \mathrm{VT}_{1}$. Discovered 1988 Nov. 8 by M. Koishikawa at Ayashi.

On 2002 Apr. 20 Gwangju, Korea, became the seventh friendship city of Sendai \{see planet (3133)\}, Japan. Gwangju and Sendai are famous for their cultural, artistic and academic facilities, and each will host World Cup soccer games this year. (M 45748)

\section{(12259) Szukalski}

$1989 \mathrm{SZ}_{1}$. Discovered 1989 Sept. 26 by E. W. Elst at La Silla.

Polish-born sculptor Charles Albert Szukalski (19452000), working in Antwerp \{see planet (1294)\}, sometimes used very eccentric means for establishing his work. One of his foremost pieces of art concerns "La Cena", a monument of 13 statues that has been erected in the Nevada desert. (M 39658)

\section{(12275) Marcelgoffin}

$1990 \mathrm{VS}_{5}$. Discovered 1990 Nov. 15 by E. W. Elst at La Silla.

Marcel Goffin (1913-1999) was an accomplished amateur violin maker. He earned his living as a humble service technician by day but devoted most of his free time to his real vocation, violin making. In this art he was completely self-taught. He built a total of 50 instruments, the last one when he was 85 years old. (M 39658)

\section{(12284) Pohl}

1991 FP. Discovered 1991 Mar. 17 by E. F. Helin at Palomar.

Frederik Pohl (1919- ) is a U.S. science-fiction writer whose vivid imagination and stirring tales took readers to the moon, Venus, Mars, the Oort Cloud and black holes. (M 44110)

The name was suggested by D. Brin.

\section{(12298) Brecht}

$1991 \mathrm{PL}_{17}$. Discovered 1991 Aug. 6 by F. Börngen at Tautenburg.

Bertolt Brecht (1898-1956), German author, songwriter, producer and social critic, was born in Augsburg. His Leben des Galilei (1943) is a true masterpiece. In 1933 he left Germany and finally found refuge in the U.S. In 1949, he founded the Berliner Ensemble in East Berlin, together with H. Weigel. (M 40708)

\section{(12306) Pebronstein}

$1991 \mathrm{TM}_{14}$. Discovered 1991 Oct. 7 by C. P. de Saint-Aignan at Palomar.

Peter Bronstein (1947- ) is father in-law of the discoverer. An avid sailor, Bronstein is always happy to share his time and his boat with others. (M 45234)

\section{(12317) Madicampbell}

$1992 \mathrm{HH}_{1}$. Discovered 1992 Apr. 24 by the Spacewatch at Kitt Peak.

Margaret Diane Campbell (1976- ）, a Ph.D. student at the University of Western Ontario, became interested in astronomy as a young girl. (M 45748)

\section{(12318) Kästner}

$1992 \mathrm{HD}_{7}$. Discovered 1992 Apr. 30 by F. Börngen at Tautenburg.

German writer and journalist Erich Kästner (18991974) wrote witty, sociocritical and satiric poems, and amusing novels, comedies, plays and scripts. His captivating children's books became world famous. (M 40708)

\section{(12323) Häckel}

1992 RX. Discovered 1992 Sept. 4 by F. Börngen and L. D. Schmadel at Tautenburg.

The naturalist Ernst Häckel (1834-1919), a professor of zoology in Jena, was the greatest German representative of the theory of evolution. He extended this theory by inclusion of humans, as well as by formulation of the biogenetic law. In 1908 he founded Jena's Phyletic Museum. (M 40709)

\section{(12327) Terbrüggen}

1992 SX $_{1}$. Discovered 1992 Sept. 21 by L. D. Schmadel and F. Börngen at Tautenburg.

Dietrich Terbrüggen (1941- ) is a well-known German surgeon who served as a lecturer at the universities of Basle and Heidelberg. He coauthored 
a textbook and published many important papers on first-aid surgery. (M 45337)

\section{(12329) Liebermann}

$1992 \mathrm{SR}_{23}$. Discovered 1992 Sept. 23 by F. Börngen at Tautenburg.

The painter Max Liebermann (1847-1935) is one of the greatest masters of German impressionism. He painted outstanding portraits and landscapes, and he was a remarkable graphic artist. President of the Prussian Academy of Arts during 1920-1933, he was later ostracized. (M 40709)

\section{(12339) Carloo}

$1992 \mathrm{YW}_{1}$. Discovered 1992 Dec. 18 by E. W. Elst at Caussols.

Carloo, a small hamlet south of the Royal Observatory at Uccle \{see planet (1276)\}, was a former seigniory that was mentioned in the thirteenth-century Cariloe. The name means "open area in a bushy height". (M 47167)

\section{(12340) Stalle}

$1992 \mathrm{YJ}_{2}$. Discovered 1992 Dec. 18 by E. W. Elst at Caussols.

Stalle is a hamlet in the eastern part of the municipality of Uccle see planet (1276)\}. It was mentioned in the twelfth century as an important seigniory, part of the mighty abbey of Vorst. The name means "stable". (M 47167)

\section{(12341) Calevoet}

$1993 \mathrm{BN}_{4}$. Discovered 1993 Jan. 27 by E. W. Elst at Caussols.

Calevoet is a hamlet in the southwestern part of the municipality of Uccle $\{$ see planet (1276)\}. The name means "grassless ford". However, the name also means "bare foot", which gave birth to the legend that Charlemagne crossed the small river at Calevoet barefooted. (M 47168)

\section{(12342) Kudohmichiko}

1993 BL $_{12}$. Discovered 1993 Jan. 30 by Y. Kushida and $\mathrm{O}$. Muramatsu at Yatsugatake.

Michiko Kudoh (1942- ) has been associated with the Gotoh Planetarium and Astronomical Museum in Tokyo. She reaches out to other astronomers through her web site. (M 39658)

\section{(12343) Martinbeech}

$1993 \mathrm{DT}_{1}$. Discovered 1993 Feb. 26 by the Spacewatch at Kitt Peak.

Martin Beech (1959- ) is an assistant professor of astronomy at the University of Regina, Saskatchewan. He does research on meteor light curves, the dynamics of meteoroid streams, cometary aging and meteoroidstream formation. (M 44594)

\section{(12350) Feuchtwanger}

$1993 \mathrm{HA}_{6}$. Discovered 1993 Apr. 23 by F. Börngen at Tautenburg.
German author Lion Feuchtwanger (1884-1958), born in Munich, wrote stories, essays and historical novels of contemporary social criticism. In 1933 his books were burned, and he was expatriated from his homeland. He moved to the U.S. in 1940. (M 40709)

\section{(12364) Asadagouryu}

$1993 \mathrm{XQ}_{1}$. Discovered 1993 Dec. 15 by T. Kobayashi at Oizumi.

Asada Gouryu (1734-1799), an astronomer in the Japanese Edo period, studied positional astronomy. He also founded "Senjikan", a private school in astronomy, in Osaka, and educated many outstanding astronomers, including Takashi Yoshitoki and Hazama Shigetomi \{see planets (12365) and (10832), respectively\}. (M 46682)

\section{(12365) Yoshitoki}

1993 YD. Discovered 1993 Dec. 17 by T. Kobayashi at Oizumi.

Takahashi Yoshitoki (1764-1804) was chief of the Edo National Astronomical Observatory at Edo, Japan, from 1795 to 1804 . He mainly studied positional astronomy, devising a new calendar computation method, "Kansei reki", with Hazama Shigetomi \{see planet (10832)\}. (M 46682)

\section{(12368) Mutsaers}

$1994 \mathrm{CM}_{11}$. Discovered 1994 Feb. 7 by E. W. Elst at La Silla.

Utrecht-born Charlotte Mutsaers (1942- ) is a painter, woodcutter and writer. Her highly acclaimed novel Rachels Rokje ("Rachel's Skirt") was published in 1994. Her grandfather, a banker at Kapellen (Antwerp), was well known for his philanthropy. (M 42361)

The name was suggested by J. Geerts.

\section{(12372) Kagesuke}

1994 JF. Discovered 1994 May 6 by T. Kobayashi at Oizumi.

Shibukawa Kagesuke (1787-1856) was chief of the Edo National Astronomical Observatory in Edo, Japan, from 1809 to 1856 . His main field of interest was positional astronomy. He studied the calendar computation method "Tenpou-reki" to reform the calendar in use at the time. (M 46682)

\section{(12373) Lancearmstrong}

$1994 \mathrm{JE}_{9}$. Discovered 1994 May 15 by C. P. de Saint-Aignan at Palomar.

Lance Armstrong (1971- ) is an American cyclist and cancer survivor. After being diagnosed with advanced testicular cancer in 1996, he was able to return to cycling and is currently the three-time defending champion of the Tour de France. He serves as an inspiration to cancer survivors and athletes around the world. (M 43762)

\section{(12374) Rakhat}

1994 JG9. Discovered 1994 May 15 by C. P. de Saint-Aignan at Palomar. 
Rakhat is a planet with the first known extraterrestrial life in the novel The Sparrow, by Mary Doria Russell. First contact is established when a group of specialists organized by Jesuits is sent to the planet. (M 45234)

\section{(12382) Niagara Falls}

$1994 \mathrm{SO}_{5}$. Discovered 1994 Sept. 28 by the Spacewatch at Kitt Peak.

Niagara Falls is the thundering cataract on the Niagara River between Lake Erie and Lake Ontario and is famous as a honeymoon destination. Hydroelectric power has been generated there since 1916. (M 44594)

\section{(12386) Nikolova}

1994 UK $_{5}$. Discovered 1994 Oct. 28 by the Spacewatch at Kitt Peak.

Simona Rumenova Nikolova (1971- ), a graduate student at the University of Western Ontario, calculated comet data at the Royal Astronomical Observatory in Sofia and studied at the University of Regina, Saskatchewan. (M 45338)

\section{(12397) Peterbrown}

1995 FV $_{14}$. Discovered 1995 Mar. 27 by the Spacewatch at Kitt Peak.

Peter Gordon Brown (1970- ) studied at the University of Alberta and the University of Western Ontario and was appointed to the faculty of the latter. His specialties are meteoroid streams, meteor analysis and meteorite recovery. (M 44594)

\section{(12398) Pickhardt}

$1995 \mathrm{KJ}_{3}$. Discovered 1995 May 25 by the Spacewatch at Kitt Peak.

Wilhelm Pickhardt (1923- ) studied geology at the Rheinische-Friedrich-Wilhelms-Universität in Bonn. He conducted research at the Mining Research Institute for Bituminous Coal and held an adjunct professorship at the Technical University of Berlin. (M 45338)

\section{(12399) Bartolini}

1995 OD. Discovered 1995 July 19 by A. Boattini and L. Tesi at San Marcello Pistoiese.

Corrado Bartolini (1941- ), professor at the University of Bologna since 1970, has focused his interests on contact spectrophotometric binaries, RR Lyrae and magnetic stars and x-ray binaries. With colleagues, he was successful in 1997 in observing the first optical counterpart of a $\gamma$-ray burst. (M 41386)

\section{(12400) Katumaru}

$1995 \mathrm{OA}_{1}$. Discovered 1995 July 28 by T. Okuni at Nanyou.

Katumaru Okuni (1932- ) is the younger brother of the discoverer. (M 47168)

\section{(12401) Tucholsky}

1995 OG $_{10}$. Discovered 1995 July 21 by F. Börngen at Tautenburg.
German author Kurt Tucholsky (1890-1935) was a masterly critic of philistinism, nationalism, militarism and corruptibility. He wrote poems, chansons and stories. His best-known novels were Rheinsberg and Schloß Gripsholm. In 1933, he was expatriated from his homeland and later committed suicide. (M 40709)

\section{(12406) Zvíkov}

$1995 \mathrm{SZ}_{1}$. Discovered 1995 Sept. 25 by M. Tichý and Z. Moravec at Klě́t.

The Zvíkov castle was built by the Přemyslids \{see planet (7695)\} dynasty above the confluence of the Vltava and Otava \{see planets (2123) and (4405)\} rivers in the thirteenth century. The castle was partly rebuilt in the Renaissance style in the sixteenth century by the Švamberk family. In the nineteenth century the castle was repaired by the Schwarzenbergs. (M 43192)

\section{(12407) Riccardi}

$1995 \mathrm{SC}_{2}$. Discovered 1995 Sept. 23 at the Osservatorio San Vittore at Bologna.

The historian of mathematics Pietro Riccardi (18281898) wrote the monumental work Biblioteca Matematica italiana dall'origine della stampa ai primi anni del $X I X$ secolo, an annotated bibliography of all the books published by Italian scientists during the nineteenth century. (M 41939)

\section{(12408) Fujioka}

$1995 \mathrm{SP}_{2}$. Discovered 1995 Sept. 20 by A. Nakamura at Kuma.

Hiroshi Fujioka (1946- ), born in Kuma Town \{see planet (6255)\}, is an actor, martial artist, and a dedicated volunteer in Iraq, Ethiopia and Cambodia. Since his debut in 1970, he has starred in more than 20 movies and a number of TV dramas, including the most popular Japanese television program in the 1970s, Kamen Rider \{see planet (12796)\}. (M 39658)

\section{(12409) Bukovanská}

$1995 \mathrm{SL}_{3}$. Discovered 1995 Sept. 28 at the Klet Observatory at Klět.

Marcela Bukovanská (1935- ）, a research worker in meteoritics, was head of the department of mineralogy and petrology of the National Museum in Prague. (M 40709)

Name suggested by M. Šolc.

\section{(12414) Bure}

1995 SR $_{29}$. Discovered 1995 Sept. 26 by T. V. Kryachko at Zelenchukskaya.

Pavel Bure (1971- ) is an outstanding Russian sportsman, a world hockey champion and star of the National Hockey League. He is called the "Russian rocket". The name also honors all the Bure dynasty known in Russia. (M 41032)

\section{(12421) Zhenya}

$1995 \mathrm{UH}_{5}$. Discovered 1995 Oct. 16 by T. V. Kryachko at Zelenchukskaya. 
Eugenia Krysina (1952- ), a chemist who lives in Moscow, is a friend of the discoverer and displays a keen interest in astronomy, especially in minor planets. Zhenya is the diminutive form of Eugenia. (M 42673)

\section{(12423) Slotin}

1995 UQ16. Discovered 1995 Oct. 17 by the Spacewatch at Kitt Peak.

As a result of an accident on 1946 May 21 at the Los Alamos laboratory, Louis Alexander Slotin (1910-1946) received a lethal dose of radiation. He bravely insisted that doctors monitor his deteriorating health during his final nine days. (M 45338)

\section{(12426) Racquetball}

$1995 \mathrm{VL}_{2}$. Discovered 1995 Nov. 14 by the JPL NEAT Program at Haleakala.

Racquetball evolved from the Mayan Meso American ball game played throughout Central America from 2000 B.C. through 1500 A.D. Today the sport is played on a four-wall court by two to four players with a short racquet and a small rubber ball. John Africano, an AMOS team member, has a passion for playing the game. (M 40709)

\section{(12431) Webster}

1995 YY $_{10}$. Discovered 1995 Dec. 18 by the Spacewatch at Kitt Peak.

Alan Reginald Webster (1939- ), a professor in the department of electrical and computer engineering at the University of Western Ontario, has research interests that include meteor astronomy. (M 45338)

\section{(12433) Barbieri}

$1996 \mathrm{AF}_{4}$. Discovered 1996 Jan. 15 by M. Tombelli and U. Munari at Cima Ekar.

Giovanni Barbieri (1941- ) is an amateur astronomer in the Montelupo \{see planet (7198)\} Group. (M 41386)

\section{(12437) Westlane}

$1996 \mathrm{BN}_{6}$. Discovered 1996 Jan. 18 by the Spacewatch at Kitt Peak.

Westlane Secondary School is a high school located in Niagara Falls, Ontario, and was founded in 1960. (M 45338)

\section{(12439) Okasaki}

$1996 \mathrm{CA}_{3}$. Discovered 1996 Feb. 15 by T. Okuni at Nanyou.

During the past three decades amateur astronomer Kiyomi Okasaki (1950- ) has discovered two comets and three supernovae at his observatory in Kahoku, Yamagata prefecture. (M 43762)

\section{(12443) Paulsydney}

1996 EQ $_{2}$. Discovered 1996 Mar. 15 by the JPL NEAT Program at Haleakala.

With the gracious support of his family, Paul Sydney, a physicist on the AMOS team, has dedicated many long hours to demonstrating that U.S. Air Force assets could be applied successfully to following up minor planets. In return, the Air Force has benefited significantly from collaboration with the astronomical community. (M 40709)

\section{(12445) Sirataka}

$1996 \mathrm{HE}_{2}$. Discovered 1996 Apr. 24 by T. Okuni at Nanyou.

The town of Sirataka, where the discoverer was born, is located in the southern part of Yamagata s see planet (7039)\} prefecture. The town is famous for its textile industry and weir-fishing. (M 42673)

\section{(12447) Yatescup}

$1996 \mathrm{XA}_{12}$. Discovered 1996 Dec. 4 by the Spacewatch at Kitt Peak.

The Yates Cup is a trophy awarded in the autumn of every year to the winner of the Ontario Universities Athletics football championship. Founded by Henry Brydges Yates of McGill University and first presented in 1898, it is the oldest football trophy that has been contested continually. (M 45338)

\section{(12448) Mr. Tompkins}

1996 XW $_{18}$. Discovered 1996 Dec. 12 by M. Tichý and Z. Moravec at Klě́t.

Mr. Tompkins is the bank clerk well known from George Gamow's \{see planet (8816)\} popular books $M r$. Tompkins in Wonderland and Mr. Tompkins Explores the Atom. His fantastic dreams and adventures help explain Einstein's \{see planet (2001)\} theory of relativity, cosmology, atomic structure and quantum theory. (M 41032)

\section{(12464) Manhattan}

$1997 \mathrm{AH}_{8}$. Discovered 1997 Jan. 2 by Spacewatch at Kitt Peak.

The original island borough of New York City, obtained from the Manhattan Indians by the Dutch in 1626, became New York under the English in 1664. It is the commercial and cultural heart of the city. (M 47168)

\section{(12465) Perth Amboy}

1997 AD $_{10}$. Discovered 1997 Jan. 3 by Spacewatch at Kitt Peak.

Perth Amboy, a New Jersey city, was settled in 1683 and incorporated in 1718. It is an important industrial city and port of entry with a fine harbor near New York City. (M 47168)

\section{(12468) Zachotín}

1997 AE $_{18}$. Discovered 1997 Jan. 14 by L. Šarounová at Ondřejov.

Zachotín is a village in Vysočina that has hosted the Mobile Astronomical Expedition of Prague Štefánik Observatory each summer since 1981. This minor planet is named in appreciation of the hospitality of the residents of the village. (M 43045) 


\section{(12471) Larryscherr}

$1997 \mathrm{CZ}_{6}$. Discovered 1997 Feb. 6 by the JPL NEAT Program at Haleakala.

Lawrence Scherr (1949- ), an optical engineer and lens designer, designed the optics for the NEAT/Oschin instrument. He has designed, built, tested or analyzed stray light for prototype medical instruments, intraocular lenses, scaterometers, large surveillance telescopes, automated optical test systems and Mars camera lenses. (M 42673)

\section{(12472) Samadhi}

1997 CW $_{11}$. Discovered 1997 Feb. 3 by the Spacewatch at Kitt Peak.

Samadhi is the Sanskrit word for the mental state of unity of subject and object, characterized by the complete and ongoing absence of discrete thoughts. Practised meditators, artists and athletes know this empty state as one of spontaneous and easy attention to the matter at hand. (M 47168)

\section{(12473) Levi-Civita}

$1997 \mathrm{CM}_{19}$. Discovered 1997 Feb. 10 by P. G. Comba at Prescott.

Tullio Levi-Civita (1873-1941) developed and extended the tensor calculus, originally formulated by Ricci, which plays a central role in the theory of general relativity and in differential geometry. In 1938 Levi-Civita was removed from his professorship at the University of Rome because of his being Jewish. (M 38201)

\section{(12477) Haiku}

$1997 \mathrm{EY}_{20}$. Discovered 1997 Mar. 4 by the Spacewatch at Kitt Peak.

Haiku is a Japanese poetry form with 17 syllables in three lines. (M 47168)

\section{(12478) Suzukiseiji}

$1997 \mathrm{EX}_{25}$. Discovered 1997 Mar. 7 by T. Okuni at Nanyou.

Seiji Suzuki (1933- ), a retired teacher, is secretary of the Yamagata Astronomers Liaison Conference (since 1997) and the Yamagata Astronomers Club. (M 46682)

\section{(12479) Ohshimaosamu}

1997 EG $_{27}$. Discovered 1997 Mar. 5 by the Spacewatch at Kitt Peak.

Osamu Ohshima (1954- ) is a high school teacher and one of Japan's leading observers of variable stars. He was a staff member at Bisei \{see planet (17286)\} Astronomical Observatory and played an important role in the founding of the observatory, using his talent in mechanical and computer technology. (M 47168)

\section{(12482) Pajka}

$1997 \mathrm{FG}_{1}$. Discovered 1997 Mar. 23 by A. Galád and A. Pravda at Modra.

Paula Pravdová (1990- ) is the only daughter of the second discoverer. She inherited many of her father's interests (playing musical instruments, cycling, swimming, diving, singing, joking) and that is why she was very popular when visiting Modra Observatory. Pajka is her familiar name. (M 45234)

\section{(12485) Jenniferharris}

$1997 \mathrm{GO}_{1}$. Discovered 1997 Apr. 7 by the JPL NEAT Program at Haleakala.

Jennifer Harris Trosper (1968- ) led the Mars Pathfinder Surface Operations Test program and was Flight Director for Mars Pathfinder when it landed on 1997 July 4. (M 45748)

\section{(12493) Minkowski}

$1997 \mathrm{PM}_{1}$. Discovered 1997 Aug. 4 by P. G. Comba at Prescott.

Hermann Minkowski (1864-1909) was awarded a prestigious prize from the Paris Academy of Sciences while still a student. He was Einstein's \{see planet (2001)\} teacher at Zurich and later developed the concept of four-dimensional space-time - the mathematical foundation of the special theory of relativity. (M 38202)

\section{(12494) Doughamilton}

$1998 \mathrm{DH}_{11}$. Discovered 1998 Feb. 25 by the JPL NEAT Program at Haleakala.

Douglas P. Hamilton (1966- ) is a dynamicist specializing in small particles in the solar system. His major contributions involve motions and resonances when several different forces are involved, work for which he received the American Astronomical Society's Urey \{see planet (4716)\} prize in 1999. (M 41386)

The name was suggested by M. A'Hearn.

\section{(12496) Ekholm}

$1998 \mathrm{FF}_{9}$. Discovered 1998 Mar. 22 by the Spacewatch at Kitt Peak.

As a promising planetary scientist, Andreas G. Ekholm (1975-2001) contributed to the fields of impact cratering processes, geophysics of icy satellites, and photometry of KBOs and Centaurs. He was also active in humanitarian causes before his premature death in an automobile accident in his native Sweden. (M 47168)

\section{(12498) Dragesco}

1998 FY $_{14}$. Discovered 1998 Mar. 26 by the OCA-DLR Survey at Caussols.

Jean Dragesco (1920- ) is an accomplished biologist and amateur astronomer. For many years, using various telescopes, he worked in Africa, where he made exquisite high-resolution photographs of the solar system that have inspired many amateur astronomers around the world. (M 40709)

\section{(12500) Desngai}

$1998 \mathrm{FB}_{49}$. Discovered 1998 Mar. 20 by the LINEAR at Socorro.

Desmond Ngai (1985- ) is a finalist in the 2002 Intel International Science and Engineering Fair for his medicine and health project. He attends the Francis 
Libermann Catholic High School, Toronto, Ontario, Canada. (M 46106)

\section{(12501) Nord}

1998 FL $_{66}$. Discovered 1998 Mar. 20 by the LINEAR at Socorro.

Ashley Lynne Nord (1985- ) is a finalist in the 2002 Intel International Science and Engineering Fair for her earth and space sciences project. She attends the Stevens High School, Rapid City, South Dakota, U.S.A. (M 46106)

\section{(12504) Nuest}

$1998 \mathrm{FS}_{75}$. Discovered 1998 Mar. 24 by the LINEAR at Socorro.

Jennifer Elizabeth Nuest (1985- _ ) is a finalist in the 2002 Intel International Science and Engineering Fair for her environmental science project. She attends the Kouts High School, Kouts, Indiana, U.S.A. (M 46106)

\section{(12506) Pariser}

$1998 \mathrm{FR}_{108}$. Discovered 1998 Mar. 31 by the LINEAR at Socorro.

Andrew Robert Pariser (1985- ) is a finalist in the 2002 Intel International Science and Engineering Fair for his engineering project. He attends the Paul D. Schreiber Senior High School, Port Washington, New York, U.S.A. (M 46106)

\section{(12509) Pathak}

1998 FY $_{117}$. Discovered 1998 Mar. 31 by the LINEAR at Socorro.

Madhav Dilip Pathak (1987- ) is a finalist in the 2002 Intel International Science and Engineering Fair for his behavioral and social sciences project. He attends the Joy Higher Secondary School, Jabalpur, Madhya Pradesh, India. (M 46106)

\section{(12511) Patil}

1998 FQ $_{121}$. Discovered 1998 Mar. 20 by the LINEAR at Socorro.

Reshma Shivaputrappa Patil (1985- ) is a finalist in the 2002 Intel International Science and Engineering Fair for her gerontology project. She attends the White Station High School, Germantown, Tennessee, U.S.A. (M 46107)

\section{(12513) Niven}

$1998 \mathrm{HC}_{20}$. Discovered 1998 Apr. 27 by P. G. Comba at Prescott.

Ivan M. Niven (1915-1999) was a Canadian-U.S. mathematician who worked mainly in number theory. In 1943 he completed the proof of Waring's conjecture, a conjecture formulated in 1770 to the effect that every positive integer is the sum of a finite number of $n$-th powers of integers. (M 38202)

\section{(12514) Schommer}

$1998 \mathrm{HM}_{26}$. Discovered 1998 Apr. 20 by the Spacewatch at Kitt Peak.
Robert A. Schommer (1946-2001) was an astronomer at Cerro Tololo Inter-American Observatory. He was head of the United States Gemini Program Office at the time of his death. His science ranged from stellar populations of nearby galaxies, to the "Supernova Cosmology Project" and the "high-z Supernova Search Team". (M 47168)

Obituary published in Bull. Am. Astron. Soc., Vol. 34, No. 4, p. 1375 (2002).

\section{(12515) Suiseki}

$1998 \mathrm{HE}_{43}$. Discovered 1998 Apr. 30 by the Spacewatch at Kitt Peak.

Literally "Water-Stone" in Japanese, Suiseki is the Japanese art form of stone appreciation. Small, naturally shaped stones are collected and displayed for their beauty and power to suggest natural scenes or objects. (M 47168)

\section{(12517) Grayzeck}

1998 HD $_{52}$. Discovered 1998 Apr. 30 by the LONEOS at Anderson Mesa.

After years of research in galactic structure, Edwin J. Grayzeck (1945- ) became an expert on archiving technology and for more than a decade has been the archive manager for the Small Bodies Node of NASA's Planetary Data System at the University of Maryland. (M 46107)

The name was suggested by M. F. A'Hearn.

\section{(12519) Pullen}

$1998 \mathrm{HH}_{55}$. Discovered 1998 Apr. 21 by the LINEAR at Socorro.

Sarah Adele Pullen (1985- ) is a finalist in the 2002 Intel International Science and Engineering Fair for her microbiology project. She attends the Maclay School, Tallahassee, Florida, U.S.A. (M 46107)

\section{(12522) Rara}

1998 HL99. Discovered 1998 Apr. 21 by the LINEAR at Socorro.

Prem Vilas Fortran Moso Rara (1985- _ ) is a finalist in the 2002 Intel International Science and Engineering Fair for his microbiology project. He attends the Integrated Developmental School MSU-IIT, Iligan, Lanao Del Norte, Philippines. (M 46107)

\section{(12527) Anneraugh}

$1998 \mathrm{JE}_{3}$. Discovered 1998 May 1 by the LONEOS at Anderson Mesa.

With degrees in astronomy and computer science, Anne C. Raugh (1962- ) worked as a programer for the COBE mission and for more than a decade has been the lead applications programer for the Small Bodies Node of NASA's Planetary Data System at the University of Maryland. (M 46107)

\section{(12529) Reighard}

$1998 \mathrm{KG}_{41}$. Discovered 1998 May 22 by the LINEAR at Socorro.

Chelsea Lynne Reighard (1986- ) is a finalist in the 2002 Intel International Science and Engineering Fair 
for her biochemistry project. She attends the D.W. Daniel High School, Clemson, South Carolina, U.S.A. (M 46107)

\section{(12530) Richardson}

$1998 \mathrm{KO}_{46}$. Discovered 1998 May 22 by the LINEAR at Socorro.

Aaron Cole Richardson (1984- ) is a finalist in the 2002 Intel International Science and Engineering Fair for his botany project. He attends the Walton High School, DeFuniak Springs, Florida, U.S.A. (M 46107)

\section{(12533) Edmond}

1998 LA. Discovered 1998 June 2 by T. Stafford at Edmond.

Edmond, a city in central Oklahoma, was founded on 1889 Apr. 22 in the first of the Oklahoma land runs. It is home to the Zeno Observatory, where this minor planet was discovered. (M 40709)

\section{(12537) Kendriddle}

$1998 \mathrm{MT}_{34}$. Discovered 1998 June 24 by the LINEAR at Socorro.

Kendra LeeAnn Riddle (1983- ) is a finalist in the 2002 Intel International Science and Engineering Fair for her engineering project. She attends the Sikeston High School, Sikeston, Missouri, U.S.A. (M 46107)

\section{(12539) Chaikin}

$1998 \mathrm{OP}_{2}$. Discovered 1998 July 16 by the Spacewatch at Kitt Peak.

Andrew L. Chaikin (1956- ) is a renowned author and space historian whose interests include the Apollo program. His landmark book A Man on the Moon served as the basis for the HBO miniseries From the Earth to the Moon, which dramatized the first lunar exploration. (M 47168)

\section{(12542) Laver}

$1998 \mathrm{PN}_{1}$. Discovered 1998 Aug. 10 by J. Broughton at Reedy Creek.

Rodney Laver (1938- ) is a tennis player from the discoverer's home state of Queensland and widely regarded as one of the greats of the game. Dubbed the "Rockhampton Rocket", Laver is the only player to have won the grand slam twice, when in 1962 and 1969 he won all four major tournaments. (M 42673)

\section{(12548) Erinriley}

1998 QJ $_{25}$. Discovered 1998 Aug. 17 by the LINEAR at Socorro.

Erin Kathleen Riley (1983- ) is a finalist in the 2002 Intel International Science and Engineering Fair for her physics project. She attends the Palm Bay High School, Palm Bay, Florida, U.S.A. (M 46107)

\section{(12553) Aaronritter}

1998 QZ $_{46}$. Discovered 1998 Aug. 17 by the LINEAR at Socorro.
Aaron M. Ritter (1986- ) is a finalist in the 2002 Intel International Science and Engineering Fair for his earth and space sciences project. He attends the Bedford-North Lawrence High School, Williams, Indiana, U.S.A. (M 46107)

\section{(12556) Kyrobinson}

1998 QG $_{48}$. Discovered 1998 Aug. 17 by the LINEAR at Socorro.

Kylan Thomas Robinson (1985- $\quad$ ) is a finalist in the 2002 Intel International Science and Engineering Fair for his engineering project. He attends the Washington High School, Tacoma, Washington, U.S.A. (M 46107)

\section{(12557) Caracol}

1998 QQ54. Discovered 1998 Aug. 27 by the LONEOS at Anderson Mesa.

"El Caracol" at Chichén Itza in Yucatán \{see planet (10799)\}, Mexico, has been described as probably the most famous of all the astronomically related buildings in ancient Mesoamerica. (M 43192)

The name was suggested and citation provided by G. Bennett.

\section{(12566) Derichardson}

$1998 \mathrm{SH}_{54}$. Discovered 1998 Sept. 16 by the LONEOS at Anderson Mesa.

An expert on computational techniques, Derek C. Richardson (1968- ), of the University of Maryland, has made major contributions to the study of rubble piles, particularly their tidal distortion and their collisions. He is also applying his codes to the formation of planets. (M 46107)

The name was suggested by M. F. A'Hearn and P. Michel.

\section{(12572) Sadegh}

$1999 \mathrm{NN}_{8}$. Discovered 1999 July 13 by the LINEAR at Socorro.

Cameron Sadegh (1984- ) is a finalist in the 2002 Intel International Science and Engineering Fair for his chemistry project. He attends the Academy for the Advancement of Science and Technology, Franklin Lakes, New Jersey, U.S.A. (M 46107)

\section{(12574) LONEOS}

1999 RT. Discovered 1999 Sept. 4 by C. W. Juels at Fountain Hills.

LONEOS, the Lowell Observatory Near-EarthObject Search, looks for and has discovered many minor planets and comets that approach Earth. The LONEOS 0.59-m f/1.91 Schmidt telescope, which began full-time operations in March 1998, can survey the entire sky accessible from Anderson Mesa, Arizona, every month. (M 41939)

\section{(12575) Palmaria}

$1999 \mathrm{RH}_{1}$. Discovered 1999 Sept. 4 by P. Pietrapiana and L. Sannino at Monte Viseggi. 
Palmaria is the most important island in the gulf of La Spezia \{see planet (10211)\}, famous for its old quarry of a rare golden marble nicknamed "Portoro". (M 41032)

\section{(12576) Oresme}

$1999 \mathrm{RP}_{1}$. Discovered 1999 Sept. 5 by P. G. Comba at Prescott.

Nicole Oresme (c. 1323-1382), bishop of Lisieux, conceived the representation of time-varying quantities by two-dimensional graphs, using the latitude-longitude analogy. He drew a velocity-time graph for a body moving with constant acceleration, anticipating later discoveries in analytic geometry and kinematics. (M 38202)

\section{(12577) Samra}

$1999 \mathrm{RA}_{13}$. Discovered 1999 Sept. 7 by the LINEAR at Socorro.

Shamsher Singh Samra (1986- ) is a finalist in the 2002 Intel International Science and Engineering Fair for his earth and space sciences project. He attends the Clovis West High School, Fresno, California, U.S.A. (M 46107)

\section{(12578) Bensaur}

$1999 \mathrm{RF}_{17}$. Discovered 1999 Sept. 7 by the LINEAR at Socorro.

Benjamin Paul Saur (1983- ） is a finalist in the 2002 Intel International Science and Engineering Fair for his physics project. He attends the Marlborough High School, Marlborough, Massachusetts, U.S.A. (M 46107)

\section{(12579) Ceva}

$1999 \mathrm{RA}_{28}$. Discovered 1999 Sept. 5 at the Osservatorio San Vittore at Bologna.

The brothers Giovanni (1647-1734) and Tommaso (1648-1737) Ceva were Italian mathematicians interested in geometry and physics. Giovanni was in the service of the Duke of Mantua. Tommaso was professor of mathematics in the Jesuit college at Milan and was also known as a poet. (M 41939)

\section{(12580) Antonini}

$1999 \mathrm{RM}_{33}$. Discovered 1999 Sept. 8 by L. Bernasconi at St. Michel sur Meurthe.

Pierre Antonini is a retired mathematics professor who has discovered many minor planets and a supernova at his private observatory, using first a 16-cm telescope, now a $30-\mathrm{cm}$ telescope. (M 14032)

\section{(12583) Buckjean}

1999 RC $_{35}$. Discovered 1999 Sept. 11 by D. K. Chesney at High Point.

Named for the discoverer's father, a railroad conductor, and his mother, a registered nurse. Both worked long hours to bring up their children, Gary, Dennis, Karen and Linda in Clovis, New Mexico. A Christmas gift of binoculars from his parents ultimately led to this discovery. (M 39658)
(12585) Katschwarz

$1999 \mathrm{RN}_{64}$. Discovered 1999 Sept. 7 by the LINEAR at Socorro.

Kathleen Alice Schwarz (1984- ) is a finalist in the 2002 Intel International Science and Engineering Fair for her environmental science project. She attends the James S. Rickards High School, Tallahassee, Florida, U.S.A. (M 46107)

\section{(12593) Shashlov}

1999 RQ $_{136}$. Discovered 1999 Sept. 9 by the LINEAR at Socorro.

Anthon Michailovich Shashlov (1986- _) is a finalist in the 2002 Intel International Science and Engineering Fair for his computer science project. He attends the Gymnasium 1520 named after Kaptsov, Moscow, Russia. (M 46108)

\section{(12595) Amandashaw}

$1999 \mathrm{RD}_{149}$. Discovered 1999 Sept. 9 by the LINEAR at Socorro.

Amanda Bryce Shaw (1985- ) is a finalist in the 2002 Intel International Science and Engineering Fair for her mathematics project. She attends the Seton School, Manassas, Virginia, U.S.A. (M 46108)

\section{(12596) Shukla}

$1999 \mathrm{RT}_{154}$. Discovered 1999 Sept. 9 by the LINEAR at Socorro.

Kavita M. Shukla (1984- ） is a finalist in the 2002 Intel International Science and Engineering Fair for her biochemistry project. She attends the Centennial High School, Ellicott City, Maryland, U.S.A. (M 46108)

\section{(12598) Sierra}

$1999 \mathrm{RC}_{159}$. Discovered 1999 Sept. 9 by the LINEAR at Socorro.

Elizabeth Sierra (1985- ) is a finalist in the 2002 Intel International Science and Engineering Fair for her biochemistry project. She attends the Alhambra High School, Alhambra, California, U.S.A. (M 46108)

\section{(12599) Singhal}

$1999 \mathrm{RT}_{160}$. Discovered 1999 Sept. 9 by the LINEAR at Socorro.

Akshat Singhal (1985- ) is a finalist in the 2002 Intel International Science and Engineering Fair for his computer science project. He attends the St. Anselms Pink City Senior Secondary School, Jaipur, Rajasthan, India. (M 46108)

\section{(12601) Tiffanyswann}

$1999 \mathrm{RO}_{178}$. Discovered 1999 Sept. 9 by the LINEAR at Socorro.

Tiffany Nichole Swann (1985- ) is a finalist in the 2002 Intel International Science and Engineering Fair for her botany project. She attends the Houston County High School, Warner Robins, Georgia, U.S.A. (M 46108) 


\section{(12602) Tammytam}

$1999 \mathrm{RT}_{183}$. Discovered 1999 Sept. 9 by the LINEAR at Socorro.

Tammy Tam (1985- ) is a finalist in the 2002 Intel International Science and Engineering Fair for her biochemistry project. She attends the Alhambra High School, Alhambra, California, U.S.A. (M 46108)

\section{(12603) Tanchunghee}

$1999 \mathrm{RF}_{184}$. Discovered 1999 Sept. 9 by the LINEAR at Socorro.

Tan Chun Ghee (1984- ) is a finalist in the 2002 Intel International Science and Engineering Fair for his chemistry project. He attends the Raffles Junior College, Singapore, Singapore. (M 46108)

\section{(12604) Lisatate}

$1999 \mathrm{RC}_{194}$. Discovered 1999 Sept. 7 by the LINEAR at Socorro.

Lisa Michelle Tate (1986- ） is a finalist in the 2002 Intel International Science and Engineering Fair for her behavioral and social sciences project. She attends the Olympia Junior High School, Salt Lake City, Utah, U.S.A. (M 46108)

\section{(12649) Ascanios}

2035 T-3. Discovered 1977 Oct. 16 by C. J. van Houten and I. van Houten-Groeneveld at Palomar.

Ascanios was the son of Aeneas \{see planet (1172)\}. $\mathrm{He}$ is also named Julius and became under this name the ancestor of the Julius family. (M 40709)

\section{(12657) Bonch-Bruevich}

1971 QO$_{1}$. Discovered 1971 Aug. 30 by T. M. Smirnova at Nauchnyj.

Aleksej Mikhajlovich Bonch-Bruevich (1916- ), a corresponding member of the Russian Academy of Sciences, is renowned for his research in the field of laser radiation interaction with absorbing and transparent environments. He is founder of a new scientific branch on power optics. (M 43045)

\section{(12658) Peiraios}

1973 SL. Discovered 1973 Sept. 19 by C. J. van Houten and I. van Houten-Groeneveld at Palomar.

Peiraios, son of Klytios, was a friend of Telemachos. (M 40709)

\section{(12659) Schlegel}

1973 UR $_{5}$. Discovered 1973 Oct. 27 by F. Börngen at Tautenburg.

The brothers August Wilhelm (1767-1845) and Friedrich (1772-1829) Schlegel, both famous writers, philologists and teachers at the University of Jena, were leaders of the German early Romantic period and editors of its journal Athenaeum. (M 40709)

\section{(12661) Schelling}

$1976 \mathrm{DA}_{1}$. Discovered 1976 Feb. 27 by F. Börngen at Tautenburg.
Friedrich Wilhelm Joseph von Schelling (1775-1854) studied at the Stift in Tübingen \{see planet (1481)\} and was professor of philosophy in Jena \{see planet (526)\}. A natural philosopher, he communicated closely with the Romanticists and was one of the main proponents of German idealism. (M 40709)

\section{(12674) Rybalka}

$1980 \mathrm{RL}_{2}$. Discovered 1980 Sept. 7 by N. S. Chernykh at Nauchnyj.

Anatolij Nikolaevich Rybalka (1939- ) is an obstetrician and gynaecologist, professor at the Crimean Medical University, a member of several medical societies of Europe, an authoritative expert and teacher who educated many specialists in medicine. (M 42673)

\section{(12675) Chabot}

1980 TA $_{4}$. Discovered 1980 Oct. 9 by C. S. Shoemaker and E. M. Shoemaker at Palomar.

Anthony Chabot (1813-1888), one of the pioneering hydraulic engineers of the late ninteenth century and a developer of municipal water facilities, was the donor of the Oakland Chabot Observatory. He was a major contributor to public charities. (M 40709)

The name was suggested by the Eastbay Astronomical Society.

\section{(12694) Schleiermacher}

$1989 \mathrm{EJ}_{6}$. Discovered 1989 Mar. 7 by F. Börngen at Tautenburg.

Friedrich Daniel Ernst Schleiermacher (1768-1834), German philosopher and Protestant theologian, worked in Halle and Berlin. He contributed to theology, ethics, science, hermeneutics and aesthetics. His main philosophical work is the Dialektik (1839), but he is also known for his translations of Plato \{see planet (5451)\}. (M 40709)

\section{(12696) Camus}

$1989 \mathrm{SF}_{1}$. Discovered 1989 Sept. 26 by E. W. Elst at La Silla.

French novelist and essayist Albert Camus (19131960), well known for his novels L'Etranger and La Peste, won the 1957 Nobel prize for literature. He defended truth, moderation and justice, adhering to liberal humanism and rejecting the dogmatic aspects of both christianity and marxism. (M 39658)

\section{(12697) Verhaeren}

1989 SK $_{3}$. Discovered 1989 Sept. 26 by E. W. Elst at La Silla.

The Belgian poet Émile Verhaeren (1855-1916), although writing exclusively in French, took much inspiration from "Flanders Fields", glorifying the greatness of its painters and enjoying the pleasures of its common people. Other important themes in his work are human progress, brotherhood of man and his love for his wife. (M 39959) 


\section{(12704) Tupolev}

$1990 \mathrm{SL}_{28}$. Discovered 1990 Sept. 24 by L. V. Zhuravleva and G. R. Kastel' at Nauchnyj.

Andrej Nikolaevich Tupolev (1888-1972) is known worldwide as an airplane designer. More than 100 types of airplanes were created under his guidance, including the first passenger jet aircraft Tu-104. Among the many notable accomplishments of his airplanes was the flight from Moscow over the North Pole to the U.S.A. in 1937. (M 42361)

\section{(12714) Alkimos}

1991 GX $_{1}$. Discovered 1991 Apr. 15 by C. S. Shoemaker and E. M. Shoemaker at Palomar.

Alkimos was a son of Ares. Together with Automedon, he was in charge of Achilles' \{see, respectively, planets (2920) and (588)\} horses. After the death of Patroclus \{see planet (617)\}, they were the most honored of the companions of Achilles. (M 41386)

\section{(12722) Petrarca}

$1991 \mathrm{PT}_{1}$. Discovered 1991 Aug. 10 by E. W. Elst at La Silla.

Francesco Petrarca (1304-1374) was an Italian poet famous for his Sonnets (1327-1374), which were dedicated to his muse, Laura. He was born in Arezzo and died in the Euganean Hills. Petrarca may be regarded as one of the greatest scholars of his age. His critical spirit made him the founder of Renaissance humanism. (M 42362)

\section{(12729) Berger}

1991 RL$_{7}$. Discovered 1991 Sept. 13 by F. Börngen and L. D. Schmadel at Tautenburg.

The German medical doctor Hans Berger (1873-1941) was professor of neurology and psychiatry in Jena. He invented the electroencephalograph, placing electrical recording equipment on the surface of the skull. (M 40709)

\section{(12734) Haruna}

$1991 \mathrm{UF}_{3}$. Discovered 1991 Oct. 29 by A. Takahashi and K. Watanabe at Kitami.

Haruna Takahashi (1994- ) is the eldest daughter of the first discoverer. (M 41939)

\section{(12738) Satoshimiki}

1992 AL. Discovered 1992 Jan. 4 by T. Hioki and S. Hayakawa at Okutama.

Satoshi Hayakawa (1992- ) and Miki Hayakawa (1995- ) are children of the second discoverer and partners in his observations. (M 43045)

\section{(12753) Povenmire}

1993 HE. Discovered 1993 Apr. 18 by C. S. Shoemaker and E. M. Shoemaker at Palomar.

Katie Povenmire, a coronary critical care nurse, is a skilled observer of the skies with her husband Hal Povenmire. Meteor showers, lunar grazes and occultations for determining the diameters of minor planets come under her discerning eye. Katie understands well the joy and success of team work. (M 41032)

\section{(12762) Nadiavittor}

$1993 \mathrm{UE}_{1}$. Discovered 1993 Oct. 26 at the Farra d'Isonzo Observatory at Farra d'Isonzo.

Nadia Vittor (1949-1989), a woman of great kindness, was the aunt of Alberto Toso, one of the discoverers. (M 46682)

\section{(12782) Mauersberger}

1995 ED9. Discovered 1995 Mar. 5 by F. Börngen at Tautenburg.

Brothers Rudolf (1889-1971) and Erhard (1903-1982) Mauersberger were renowned German musicians and choirmasters. Rudolf was cantor of Dresden's \{see planet (3053)\} Crosschoir (Kruzianer) and composed sacred choir music. Erhard conducted the Bach \{see planet (1814)\} choir at Eisenach \{see planet (10774)\} and was cantor of Leipzig's Thomanerchor ssee planet (1023)\}. (M 40709)

\section{(12790) Cernan}

$1995 \mathrm{UT}_{2}$. Discovered 1995 Oct. 24 at the Klet Observatory at Klě́.

Eugene Andrew Cernan (1934- ), U.S. astronaut, was commander of the Apollo 17 mission, which concluded the Apollo Lunar program in 1972. (M 41572)

\section{(12796) Kamenrider}

1995 WF. Discovered 1995 Nov. 16 by A. Nakamura at Kuma.

Japanese TV character Kamen Rider, played by Hiroshi Fujioka \{see planet (12408)\}, is a cyborg and a lover of justice. Ninety-eight stories of Kamen Rider were broadcast from 1971 to 1973 . His fighting action and heroic stories fascinated all boys in Japan, including the discoverer. (M 39659)

\section{(12799) von Suttner}

$1995 \mathrm{WF}_{6}$. Discovered 1995 Nov. 26 at the Klet Observatory at Klě́.

Bertha Félicie Sophie, Freifrau von Suttner, née countess Kinsky (1843-1914), was an Austrian novelist and one of the first notable woman pacifists. She is credited with influencing Alfred Nobel \{see planet (6032) $\}$ in the establishment of the Nobel Prize for Peace, of which she was the recipient in 1905. (M 43762)

\section{(12800) Oobayashiarata}

1995 WQ7. Discovered 1995 Nov. 27 by T. Kobayashi at Oizumi.

Arata Oobayashi (1957-1999) was a Japanese amateur astronomer and computer engineer. He was also famous as a photographic artist, leaving excellent astronomical photographs. (M 41032)

The name was suggested by M. Namiki. 


\section{(12801) Somekawa}

1995 XD. Discovered 1995 Dec. 2 by T. Kobayashi at Oizumi.

Somekawa Shuichi (1962-1997) was a Japanese amateur astronomer and optical engineer. (M 41572) The name was suggested by M. Namiki.

\section{(12802) Hagino}

1995 XD $_{1}$. Discovered 1995 Dec. 15 by T. Kobayashi at Oizumi.

Japanese amateur astronomer Hagino Akira (19491999) died in a tragic accident while observing. He worked as an instructor of popular astronomy at a small astronomical facility in Yamanashi prefecture and inspired many children and visitors with interests in the wonderful night sky. (M 46010)

\section{(12833) Kamenný Újezd}

$1997 \mathrm{CV}_{1}$. Discovered 1997 Feb. 2 by J. Tichá and M. Tichý at Klét.

This pleasant village south of Ceske Budejovice \{see planet (11134)\}, first mentioned in 1263, was situated on an old road connecting South Bohemia with Austria. The road was replaced by the horse railroad to Linz \{see planet (1469)\} in the nineteenth century. (M 40710)

The name was endorsed by J. Vyžralová.

\section{(12835) Stropek}

$1997 \mathrm{CN}_{13}$. Discovered 1997 Feb. 7 at the Klet Observatory at Klét.

Václav Stropek (1938- ) has been a long-time technician at the Kleť Observatory. (M 41032)

\section{(12840) Paolaferrari}

1997 GR $_{5}$. Discovered 1997 Apr. 6 by L. Tesi and G. Cattani at San Marcello Pistoiese.

Paola Ferrari is head of the town library in San Marcello Pistoiese. Her contribution to the construction and the development of the Pian dei Termini Observatory has been remarkable over the years. (M 40710)

\section{(12848) Agostino}

1997 NK$_{10}$. Discovered 1997 July 10 by A. Boattini at Campo Imperatore.

Agostino Boattini (1932- ) is the father of the discoverer. (M 42673)

\section{(12852) Teply}

$1998 \mathrm{FW}_{30}$. Discovered 1998 Mar. 20 by the LINEAR at Socorro.

Grant Paul Teply (1987- ） is a finalist in the 2002 Intel International Science and Engineering Fair for his physics project. He attends the Nicolet High School, Glendale, Wisconsin, U.S.A. (M 46108)

\section{(12855) Tewksbury}

$1998 \mathrm{HS}_{32}$. Discovered 1998 Apr. 20 by the LINEAR at Socorro.
Carolyn Morgan Tewksbury (1985- ) is a finalist in the 2002 Intel International Science and Engineering Fair for her earth and space sciences project. She attends the Clinton High School, Deansboro, New York, U.S.A. (M 46108)

\section{(12859) Marlamoore}

$1998 \mathrm{KK}_{1}$. Discovered 1998 May 18 by the LONEOS at Anderson Mesa.

Marla H. Moore (1940- ）, a staff member at NASA's Goddard Space Flight Center, is known worldwide for her studies of the irradiation of ices and the implications of the irradiation processes for interstellar grains, comets, and icy satellites. (M 46108)

The name was suggested by M. F. A'Hearn.

\section{(12860) Turney}

$1998 \mathrm{KT}_{32}$. Discovered 1998 May 22 by the LINEAR at Socorro.

Shannon Quinn Turney (1986- ) is a finalist in the 2002 Intel International Science and Engineering Fair for her behavioral and social sciences project. She attends the Notre Dame Academy, Park Hills, Kentucky, U.S.A. (M 46108)

\section{(12861) Wacker}

$1998 \mathrm{KW}_{33}$. Discovered 1998 May 22 by the LINEAR at Socorro.

David Hubbell Wacker (1987- ) is a finalist in the 2002 Intel International Science and Engineering Fair for his computer science project. He attends the William J. Palmer High School, Colorado Springs, Colorado, U.S.A. (M 46108)

\section{(12863) Whitfield}

$1998 \mathrm{KE}_{48}$. Discovered 1998 May 22 by the LINEAR at Socorro.

Meghan Elizabeth Whitfield (1985- ) is a finalist in the 2002 Intel International Science and Engineering Fair for her engineering project. She attends the Glen Rose High School, Benton, Arkansas, U.S.A. (M 46108)

\section{(12866) Yanamadala}

$1998 \mathrm{KL}_{65}$. Discovered 1998 May 22 by the LINEAR at Socorro.

Vijay Yanamadala (1986- $\quad$ ) is a finalist in the 2002 Intel International Science and Engineering Fair for his environmental science project. He attends the Palos Verdes Peninsula High School, Palos Verdes Estates, California, U.S.A. (M 46108)

\section{(12868) Onken}

$1998 \mathrm{MZ}_{7}$. Discovered 1998 June 19 by the LONEOS at Anderson Mesa.

Christopher S. Onken (1979- ) was a summer student at the Lowell Observatory in 1998. As an observer, he made the first LONEOS near-earth-asteroid discovery and suggested many useful improvements to the observing protocol. (M 41032) 


\section{(12870) Rolandmeier}

$1998 \mathrm{MK}_{37}$. Discovered 1998 June 24 by the LONEOS at Anderson Mesa.

Roland Meier (1964- ), of Gretag Imaging, Zurich, is well known for his research on the chemistry of comets, ranging from studies of the chemistry observed in situ at $1 \mathrm{P} /$ Halley with Giotto to numerous optical and radio studies using ground-based telescopes. (M 46109; M 46469)

The name was suggested by M. F. A'Hearn.

\section{(12871) Samarasinha}

$1998 \mathrm{ML}_{37}$. Discovered 1998 June 24 by the LONEOS at Anderson Mesa.

Beginning with his demonstration of the excited rotational state of $1 \mathrm{P} /$ Halley, Nalin H. Samarasinha (1958- ), of the National Optical Astronomy Observatories, Tucson, has carried out many studies of the dynamical evolution of cometary nuclei and the related dynamical processes of dust in cometary comae. (M 46109)

\section{(12872) Susiestevens}

$1998 \mathrm{OZ}_{5}$. Discovered 1998 July 21 by the LINEAR at Socorro.

Susie Stevens (1950- ), a 2002 Intel Excellence in Teaching Award finalist, is a teacher at the Latta High School, Ada, Oklahoma, U.S.A. (M 46109)

\section{(12874) Poisson}

1998 QZ. Discovered 1998 Aug. 19 by P. G. Comba at Prescott.

Siméon-Denis Poisson (1781-1840) was a prolific French mathematician and inspiring teacher who left his mark on many branches of applied mathematics, including electricity and magnetism, celestial mechanics and elasticity. His name is also associated with the Poisson distribution in probability theory. (M 39659)

\section{(12878) Erneschiller}

$1998 \mathrm{QH}_{11}$. Discovered 1998 Aug. 17 by the LINEAR at Socorro.

Ernest Schiller (1949- ), a 2002 Intel Excellence in Teaching Award finalist, is a teacher at the Central Lee High School, Donnellson, Iowa, U.S.A. (M 46109)

\section{(12880) Juliegrady}

$1998 \mathrm{QM}_{25}$. Discovered 1998 Aug. 17 by the LINEAR at Socorro.

Julie Grady (1951- ), a 2002 Intel Excellence in Teaching Award finalist, is a teacher at the Blacksburg High School, Blacksburg, Virginia, U.S.A. (M 46109)

\section{(12881) Yepeiyu}

1998 QF $_{31}$. Discovered 1998 Aug. 17 by the LINEAR at Socorro.

Ye Peiyu (1950- ), a 2002 Intel Excellence in Teaching Award finalist, is a teacher at the No. 2 Secondary School Attached to East China Normal University, Shanghai, China. (M 46109; M 46469)

\section{(12897) Bougeret}

$1998 \mathrm{RY}_{5}$. Discovered 1998 Sept. 13 by the LONEOS at Anderson Mesa.

Jean-Louis Bougeret (1945- ) is Director of the Laboratoire d'Etudes Spatiales et d'Instrumentation en Astrophysique at Paris Observatory. He is an expert in the solar wind and interplanetary medium, and is active in space research. (M 46109)

The name was suggested by M. A. Barucci.

\section{(12898) Mignard}

$1998 \mathrm{RK}_{6}$. Discovered 1998 Sept. 14 by the LONEOS at Anderson Mesa.

François Mignard (1949- ) is Director of CERGA (Centre d'Etudes et de Recherches en Géodynamique et Astrométrie). Expert in space astrometry and solar system dynamics, Mignard is also involved in space missions such as HIPPARCOS and GAIA. (M 46109)

The name was suggested by E. Dotto and M. A. Barucci.

\section{(12909) Jaclifford}

1998 SK $_{58}$. Discovered 1998 Sept. 17 by the LONEOS at Anderson Mesa.

Jack Clifford (1933- ), of Scottsdale, Arizona, is a pioneering cable television entrepreneur, avid amateur astronomer and a major contributor to numerous science and educational institutions. He has been of great service on the Lowell Trustee's Advisory Board, particularly in fund raising. (M 46109)

\section{(12910) Deliso}

1998 SP $_{59}$. Discovered 1998 Sept. 17 by the LONEOS at Anderson Mesa.

Joseph John Deliso (1906-1994), contractor, manufacturer, public servant and philanthropist, served many years as Chairman of the Trustees of Springfield Technical Community College, Massachusetts, and was a major endower of that institution. (M 46109)

The name was suggested by W. L. Putnam.

\section{(12911) Goodhue}

1998 SQ59. Discovered 1998 Sept. 17 by the LONEOS at Anderson Mesa.

Samuel Harlowe Goodhue (1922- ), engineer and alpinist of Jackson, New Hampshire, was Chairman of the Trails Committee and then the Huts Committee for the Appalachian Mountain Club. He has been generous with his time and talents to both the Mount Washington (meteorological) and Lowell observatories. (M 46109; M 47243)

\section{(12926) Brianmason}

$1999 \mathrm{SO}_{9}$. Discovered 1999 Sept. 27 by J. L. Schiff and C. J. Schiff at Takapuna.

Renowned New Zealand-born meteoriticist Brian Mason (1917- ) worked at the American Museum of Natural History and the Smithsonian Institution. His research included the classification of Antarctic 
meteorites. The minerals brianite and stenhuggarite (Swedish for stone mason) are named for him. (M 41386)

\section{(12927) Pinocchio}

1999 SU9. Discovered 1999 Sept. 30 by M. Tombelli and L. Tesi at San Marcello Pistoiese.

Pinocchio was created by Italian writer Carlo Lorenzini, more properly known as Collodi. His book, written in 1883, tells the story of the wooden puppet that, through adventures and ups and downs in his life, finally became a real child. (M 40710)

\section{(12928) Nicolapozio}

$1999 \mathrm{SV}_{9}$. Discovered 1999 Sept. 30 by A. Boattini and G. Forti at San Marcello Pistoiese.

Nicola Pozio (1965- ) is an accountant for The Spaceguard Foundation. Without his dedication to the development and support of the Foundation it would not have been possible for the discoverers to initiate and maintain the activity on NEOs at the Spaceguard Central Node. (M 46010)

\section{(12931) Mario}

1999 TX $_{10}$. Discovered 1999 Oct. 7 by S. Sposetti at Gnosca.

Mario Sposetti (1916-1959) was the father of the discoverer. (M 40720)

\section{(12932) Conedera}

1999 TC $_{12}$. Discovered 1999 Oct. 10 by S. Sposetti at Gnosca.

Marina Conedera (1962- ) is the wife of the discoverer. (M 41386)

\section{(12934) Bisque}

$1999 \mathrm{TH}_{16}$. Discovered 1999 Oct. 11 by C. W. Juels at Fountain Hills.

Since 1984 Stephen (1960- ), Thomas (1963- ), Daniel (1965- ) and Matthew (1966- ) Bisque have been developing and distributing software and instrumentation for the astronomical community that completely automates telescope control and CCD \{see planet (15000)\} image acquisition. (M 41939)

\section{(12972) Eumaios}

$1973 \mathrm{SF}_{1}$. Discovered 1973 Sept. 19 by C. J. van Houten and I. van Houten-Groeneveld at Palomar.

Eumaios was the pig herder of Odysseus \{see planet (1143)\}. When Odysseus returned to Ithaca ssee planet (1151)\}, Eumaios helped him to conquer the suitors of Penelope ssee planet (201)\}. (M 40710)

\section{(12973) Melanthios}

1973 SY $_{1}$. Discovered 1973 Sept. 19 by C. J. van Houten and I. van Houten-Groeneveld at Palomar.

Melanthios was a goat herder of Odysseus ssee planet (1143)\}. He mocked Odysseus when the latter came to Eumaios \{see planet (12972)\} disguised as a beggar. Later Odysseus killed him. (M 40710)

\section{(12974) Halitherses}

$1973 \mathrm{SB}_{2}$. Discovered 1973 Sept. 19 by C. J. van Houten and I. van Houten-Groeneveld at Palomar.

Halitherses was an augur in Ithaca ssee planet (1151)\}. He went together with Telemachos to search for Odysseus \{see planet (1143)\}. He was also a friend of Odysseus himself. (M 40710)

\section{(12976) Kalinenkov}

1976 QK $_{1}$. Discovered 1976 Aug. 26 by N. S. Chernykh at Nauchnyj.

Nikifor Dmitrievich Kalinenkov (1924-1996) was professor of physics and astronomy at the Nikolaev State Pedagogical Institute in Ukraine. He was the first director of the Institute's astronomical observatory and contributed much to its instrumentation through "make-it-yourself" telescopes and other devices. (M 46011)

\section{(13001) Woodney}

1981 VL. Discovered 1981 Nov. 2 by B. A. Skiff at Anderson Mesa.

Laura M. Woodney (1970- ), now at the Lowell Observatory, recently completed her doctoral dissertation at the University of Maryland on the chemistry of comets. (M 41939)

\section{(13005) Stankonyukhov}

1982 SQ7. Discovered 1982 Sept. 18 by N. S. Chernykh at Nauchnyj.

Stanislav Nikolaevich Konyukhov (1937- ), a member of the Ukrainian National Academy of Sciences, is a specialist in mechanics, rocket and space engineering and the control of space systems. He is a general designer at the Yuzhnoe Design Office in Dnepropetrovsk. (M 46011)

\section{(13006) Schwaar}

$1983 \mathrm{AC}_{1}$. Discovered 1983 Jan. 12 by B. A. Skiff at Anderson Mesa.

Pierre-Yves Schwaar (1946-2000) was a well-regarded amateur optician and telescope maker. He was also an accomplished observer and photographer of the night sky, often making resourceful use of simple apparatus. (M 41939)

\section{(13009) Voloshchuk}

1985 PB $_{2}$. Discovered 1985 Aug. 13 by N. S. Chernykh at Nauchnyj.

Yurij Ivanovich Voloshchuk (1941- ) is a radioastronomer and professor at the Kharkov University of Radioelectronics. He has made valuable contributions to the development of science and education at this university and is especially known for his research on meteors and interrelated small bodies in the solar system. (M 46011)

\section{(13014) Hasslacher}

1987 WJ J $_{1}$. Discovered 1987 Nov. 17 by R. P. Binzel at Anderson Mesa. 
Marian Brasseau Hasslacher (1901-1997) and Charles Alfred (Carl) Hasslacher (1897-1973), maternal grandparents of the discoverer, encouraged and enabled his career as an astronomer. (M 40710)

\section{(13018) Geoffjames}

1988 GF. Discovered 1988 Apr. 10 by E. F. Helin at Palomar.

Deputy manager for earth sciences, Geoffrey K. James (1956- ) has provided outstanding support for minor-planet programs at the Jet Propulsion Laboratory. His experimental and theoretical research in electron scattering has led to the establishment of a unique high-resolution vacuum ultraviolet spectrometer facility. (M 46109)

\section{(13024) Conradferdinand}

1989 AJ $_{6}$. Discovered 1989 Jan. 11 by F. Börngen at Tautenburg.

The famous Swiss author Conrad Ferdinand Meyer (1825-1898) lived mostly in Zürich. He wrote poems, ballads, short stories and the epic Huttens letzte Tage. His subjects were the problems of power and morality, the christian religion and the Swiss landscape. (M 40710)

\section{(13025) Zürich}

1989 BA. Discovered 1989 Jan. 28 by P. Wild at Zimmerwald.

Capital of the canton and located at the northwestern end of the lake of the same name, Zürich is the largest city of Switzerland. The city was founded by the Romans in the first century B.C. on the right bank of the Limmat river, which issues from the lake. (M 43762)

\section{(13028) Klaustschira}

1989 GQ $_{6}$. Discovered 1989 Apr. 5 by M. Geffert at La Silla.

Klaus Tschira \{1940- $\}$, co-founder of a software giant, is a lover and supporter of astronomy. In 1995 he established the Klaus Tschira Foundation to further the development of science and technology and to encourage international scientific cooperation. (M 41032)

\section{(13049) Butov}

$1990 \mathrm{RF}_{17}$. Discovered 1990 Sept. 15 by L. V. Zhuravleva at Nauchnyj.

Anatolij Sergeevich Butov (1939- ), an expert in the field of computing in transport economics, is the rector of the St. Petersburg State University for Water Communications. (M 46011)

\section{(13055) Kreppein}

1990 TW 12 . Discovered 1990 Oct. 14 by L. D. Schmadel and F. Börngen at Tautenburg.

Wolfgang Kreppein (1948- ) is a German physician and dermatologist. $\mathrm{He}$ is a well-known expert on allergic diseases. (M 45338)

\section{(13057) Jorgensen}

$1990 \mathrm{VF}_{8}$. Discovered 1990 Nov. 13 by C. S. Shoemaker and D. H. Levy at Palomar.

Carl Jorgensen (1948- ) is a well-known amateur astronomer from Montreal. In the 1960s he chaired the Double Star Section of the Montreal Center of the Royal Astronomical Society of Canada, and was editor of the Center's newsletter, Skyward. Jorgensen has worked at McGill University for many years. (M 41572)

\section{(13062) Podarkes}

1991 HN. Discovered 1991 Apr. 19 by C. S. Shoemaker and E. M. Shoemaker at Palomar.

Podarkes, son of Ares and full brother of Protesilaos \{see planet (3540)\}, led the Achaians and took 40 black ships to the Trojan war. (M 41386)

\section{(13070) Seanconnery}

$1991 \mathrm{RO}_{2}$. Discovered 1991 Sept. 8 by E. W. Elst at St. Michel.

Sean Connery (1930- ) is a famous Scottish actor, well known from his James Bond \{see planet (9007)\} films. With this minor planet he is especially honored for the magnificent performance of his role in The Name of the Rose. (M 42362)

\section{(13084) Virchow}

1992 GC $_{8}$. Discovered 1992 Apr. 2 by F. Börngen at Tautenburg.

German pathologist Rudolf Virchow (1821-1902) was the founder of cellular pathology and a pioneer in modern anthropology and prehistoric research. He also promoted public health care. His textbook Handbuch der speziellen Pathologie und Therapie explored new paths. (M 41032)

\section{(13086) Sauerbruch}

$1992 \mathrm{HS}_{4}$. Discovered 1992 Apr. 30 by F. Börngen at Tautenburg.

German surgeon Ernst Ferdinand Sauerbruch (18751951) devised many improvements in surgical procedures, including the so-called pressure-difference procedure in thoracic surgery. He devised artificial limbs that move voluntarily after amputation by using the muscles of the stump. (M 41032)

\section{(13092) Schrödinger}

1992 SS $_{16}$. Discovered 1992 Sept. 24 by F. Börngen and L. D. Schmadel at Tautenburg.

The Austrian physicist Erwin Schrödinger (18871961), born in Vienna, founded wave mechanics in 1926. Later he worked in relativistic quantum mechanics, the theory of gravity and unified field theory. Together with Dirac, he received the 1933 Nobel prize in physics. (M 40710)

\section{(13093) Wolfgangpauli}

1992 SQ $_{24}$. Discovered 1992 Sept. 21 by F. Börngen at Tautenburg. 
Austrian physicist Wolfgang Pauli (1900-1958), born in Vienna, was co-founder of quantum theory. He discovered the Pauli principle, which explains the level structure of atoms. He received the 1945 Nobel prize in physics. (M 40710)

\section{(13111) Papacosmas}

1993 OW $_{1}$. Discovered 1993 July 23 by C. S. Shoemaker and D. H. Levy at Palomar.

Constantine Papacosmas (1939- ） an accomplished amateur astronomer in Montreal has guided thousands of people to learn the night sky. The telescopes he has constructed are among the finest in Canada, including a refractor that won an award at Stellafane ssee planet (3140)\} in 1979. (M 41572)

\section{(13121) Tisza}

$1994 \mathrm{CN}_{9}$. Discovered 1994 Feb. 7 by E. W. Elst at La Silla.

The Tisza is a major tributary of the Danube river, with its source in the Carpathian Mountains. The Tisza flows through a small portion of Ukraine and then into Hungary. The river has recently been heavily polluted by cyanide, endangering its fauna. (M 41032)

\section{(13122) Drava}

$1994 \mathrm{CV}_{9}$. Discovered 1994 Feb. 7 by E. W. Elst at La Silla.

The Drava is a major tributary of the Danube river. It flows from its source in the Italian Alps, through the Austrian federal states of Tirol and Kärnten. Huns and Slavs invaded the Alpine countries through its valley. (M 40710)

\section{(13123) Tyson}

1994 KA. Discovered 1994 May 16 by C. S. Shoemaker and D. H. Levy at Palomar.

Neil deGrasse Tyson (1958- ) is the youngest-ever director of New York's Hayden Planetarium. He spearheaded the complete redesign of the planetarium that reopened in 2000. He also teaches astronomy at Princeton University. (M 41572)

\section{(13145) Cavezzo}

1995 DZ $_{1}$. Discovered 1995 Feb. 27 by R. Calanca and R. Bonomi at Cavezzo.

The inhabitants of Cavezzo, a small town in northern Italy, supported the construction and development of the Public Astronomical Observatory 'G. Montanari'. The observatory is visited by about 2500 people every year and works to increase the public understanding and appreciation of astronomy. (M 42673)

\section{(13146) Yuriko}

$1995 \mathrm{DR}_{2}$. Discovered 1995 Feb. 20 by T. Okuni at Nanyou.

Yuriko Okuni (1934- $\quad$ ) is the wife of the discoverer. (M 42673)

\section{(13147) Foglia}

$1995 \mathrm{DZ}_{11}$. Discovered 1995 Feb. 24 by M. Tombelli at Cima Ekar.

In Milan, amateur astronomer Sergio Foglia (1972-

) has observed minor planets, comets, variable stars and occultations by the moon and minor planets. Since 1996 he has been the Minor Planet Section recorder of the Unione Astrofili Italiani. (M 41386)

\section{(13149) Heisenberg}

$1995 \mathrm{EF}_{8}$. Discovered 1995 Mar. 4 by F. Börngen at Tautenburg.

Werner Karl Heisenberg (1901-1976) was co-founder of quantum theory, formulated the uncertainty principle, worked in nuclear physics and cosmic radiation and tried to define a unified field theory. He also explained sociopolitical problems in popular publications. He received the Nobel prize for physics in 1932. (M 40710)

\section{(13150) Paolotesi}

1995 FS. Discovered 1995 Mar. 23 by L. Tesi and A. Boattini at San Marcello Pistoiese.

Paolo Tesi (1959- ) is the elder son of the first discoverer. (M 41939)

\section{(13151) Polino}

1995 OH. Discovered 1995 July 22 by G. Iatteri at Polino.

Polino, a typical village with about 250 inhabitants, is the smallest municipality in Italy. It rises $836 \mathrm{~m}$ above sea level in the province of Terni, Umbria, overhung by an antique polygonal tower in an area of woods and pastures. In 1248 pope Innocent IV granted it to the duchy of Spoleto. (M 40710)

\section{(13154) Petermrva}

1995 RC. Discovered 1995 Sept. 7 by A. Galád and A. Pravda at Modra.

Peter Mrva (1962- ) helped to build Modra \{see planet (11118)\} observatory and was one of the first astronomers there. During years of mostly manual labor he taught, helped to explain and inspired the second discoverer in some areas, including astronomy and computer graphics. (M 45338)

\section{(13181) Peneleos}

$1996 \mathrm{RS}_{28}$. Discovered 1996 Sept. 11 by the UppsalaDLR Trojan Survey at La Silla.

Peneleos, leader of Boeotia, killed by Eurypylus \{see planet (4501)\}, is said to have been one of those inside the wooden horse. (M 42362)

\section{(13192) Quine}

1997 BU $_{5}$. Discovered 1997 Jan. 31 by P. G. Comba at Prescott.

Willard Van Orman Quine (1908- ), American logician and philosopher, was initially trained in mathematics and became a professor of philosophy at Harvard University (1936-1978). He was a prolific scholar whose contributions range from mathematical logic to a constructivist analysis of philosophy. (M 39659) 


\section{(13200) Romagnani}

1997 EQ40. Discovered 1997 Mar. 13 by L. Tesi and G. Cattani at San Marcello Pistoiese.

Sauro Romagnani (1942- ), a teacher at the San Marcello junior high school, was selected to participate in a research teaching team for the Educational European Center. He contributed to the founding of the local public library and establishment of the Astronomical Observatory in the Pistoia area. (M 41939)

\section{(13207) Tamagawa}

$1997 \mathrm{GZ}_{25}$. Discovered 1997 Apr. 10 by A. Nakamura at Kuma.

Tamagawa (population 5800), located in the eastern part of Ehime prefecture, is home of Tamagawa Junior High School. The naming marks the participation of the school's students in "NEARlink", an educational project to simulate the launch and voyage of the NEAR spacecraft and analyze the actual data from it. (M 40710)

\section{(13208) Fraschetti}

$1997 \mathrm{GA}_{38}$. Discovered 1997 Apr. 5 by the JPL NEAT Program at Haleakala.

George Fraschetti (1941- ) is a technical advisor and contributor to the NEAT instruments. During his 33 years at the Jet Propulsion Laboratory, he has worked on many flagship projects, notably the Voyager and Galileo imaging systems and the Hubble Space Telescope Wide Field Planetary Cameras. (M 42673)

\section{(13212) Jayleno}

$1997 \mathrm{JL}_{13}$. Discovered 1997 May 3 by E. W. Elst at La Silla.

Jay Leno (1950- ) is an American television personality. He has the genius also to make his shows pleasant for the European public. (M 42362)

\section{(13221) Nao}

1997 OY. Discovered 1997 July 24 by A. Nakamura at Kuma.

Naomi Nakamura (1965- ), whose nickname is Nao, is the wife of the discoverer. (M 40710)

\section{(13223) Cenaceneri}

1997 PQ4. Discovered 1997 Aug. 13 by L. Tesi at San Marcello Pistoiese.

La Cena delle Ceneri ("The Dinner of the Ashes") is a work by the Italian philosopher Giordano Bruno (1548-1600) in which, for the first time in Western philosophical thought, there is discussion of the infinity of worlds in the universe. (M 40710)

\section{(13225) Manfredi}

1997 QU $_{1}$. Discovered 1997 Aug. 29 at the Osservatorio San Vittore at Bologna.

The brothers Eustachio (1674-1739), Gabriele (16811761) and Eraclito (1682-1759) Manfredi were professors at the University of Bologna, of astronomy, mathematics and medicine-cum-geometry. Eustachio was the author of the famous Istituzioni astronomiche, published as the second volume of his works. (M 41939)

\section{(13226) Soulié}

1997 SH. Discovered 1997 Sept. 20 by L. Šarounová at Ondřejov.

Guy Soulié (1920- ） made photometric observations of the zodiacal light, measured positions of comets, planets and their satellites and wrote astrometric reduction programs. A member of the Hipparcos Input Catalog team, he also discovered double stars and minor planets. (M 42362)

The name was suggested by J. Montanné.

\section{(13229) Echion}

$1997 \mathrm{VB}_{1}$. Discovered 1997 Nov. 2 by J. Tichá and M. Tichý at Klě́.

Echion was one of the Achaean warriors who entered Troy in the wooden horse. He died when he jumped from the horse. (M 40710)

\section{(13231) Blondelet}

1998 BL $_{14}$. Discovered 1998 Jan. 17 by the OCA-DLR Asteroid Survey at Caussols.

Jacques Blondelet (1934-1998) was a former president of the Société Lorraine d'Astronomie and vice president of the Observatoire Provençal d'Astrophotographie. A physician by profession, he has published many papers on cosmology in magazines such as the Echo d'Orion. (M 45338)

\section{(13234) Natashaowen}

$1998 \mathrm{FC}_{74}$. Discovered 1998 Mar. 22 by the LONEOS at Anderson Mesa.

Natalya Cherkassova Owen (1952- ) is Honorary Consul General of the Russian Federation in Hawaii. She has developed humanitarian missions to Eastern Russia, establishing a nonprofit foundation that is building a rehabilitation center near Vladivostok for children with cancer. (M 46682)

\section{(13239) Kana}

1998 KN. Discovered 1998 May 21 by A. Nakamura at Kuma.

Kana Nakamura (1999- ), whose initials are "KN", is the daughter of the discoverer. (M 40710)

\section{(13240) Thouvay}

$1998 \mathrm{KJ}_{1}$. Discovered 1998 May 18 by the LONEOS at Anderson Mesa.

Jacqueline Thouvay (1939- ) manages the Laboratoire d'Etudes Spatiales et d'Instrumentation en Astrophysique at Paris Observatory. (M 46109) The name was suggested by M. A. Barucci.

\section{(13241) Biyo}

$1998 \mathrm{KM}_{41}$. Discovered 1998 May 22 by the LINEAR at Socorro.

Josette Biyo (1958- ), a 2002 Intel Excellence in Teaching Award finalist, is a teacher at the 
Philippine Science High School, Western Visayas, Iloilo, Philippines. (M 46109)

\section{(13248) Fornasier}

$1998 \mathrm{MT}_{37}$. Discovered 1998 June 24 by the LONEOS at Anderson Mesa.

Sonia Fornasier (1972- ), of Padua Observatory, works on the physical properties of cisjovian and transneptunian objects. She is involved in the development of the Rosetta mission imaging system. (M 46109)

The name was suggested by M. A. Barucci and E. Dotto.

\section{(13249) Marcallen}

1998 MD $_{38}$. Discovered 1998 June 18 by the LONEOS at Anderson Mesa.

Marc Allen (1951- ） is a stellar and solar astronomer who has directed the Space Studies Board of the U.S. National Research Council (1991-1999) and is currently

Assistant Associate Administrator for Strategic and International Planning at NASA. (M 43045)

The name was suggested by L. A. McFadden, L. J. Lanzerotti and C. R. Canizares.

\section{(13250) Danieladucato}

1998 OJ. Discovered 1998 July 19 by A. Boattini and L. Tesi at San Marcello Pistoiese.

Daniela Ducato (1960- ), an active amateur astronomer, has organized many astronomical public events and observing gatherings in Sardegna (Sardinia). She also designed the public gardens of Guspini, her native town, following themes that resembled the constellations. (M 42674)

\section{(13251) Viot}

1998 OP. Discovered 1998 July 20 by the OCA-DLR Asteroid Survey at Caussols.

Hervé Viot (1961- ) built the CCD camera used for the ODAS survey. He was also involved in many other aspects of the telescope software and hardware. His work and competence were invaluable to the success of the project. He is now involved in other projects at the Observatoire de la Côte d'Azur. (M 45338)

\section{(13258) Bej}

1998 QT $_{12}$. Discovered 1998 Aug. 17 by the LINEAR at Socorro.

Gautam Ashim Bej (1989- ) is a finalist in the 2002 Discovery Channel Young Scientist Challenge (DCYSC), a middle school science competition, for his biochemistry, medicine, health, and microbiology project. He attends the Altamont School, Birmingham, Alabama. (M 46764)

\section{(13259) Bhat}

1998 QA $_{15}$. Discovered 1998 Aug. 17 by the LINEAR at Socorro.

Nivedita Bhat (1988- ) is a finalist in the 2002 Discovery Channel Young Scientist Challenge
(DCYSC), a middle school science competition, for her environmental sciences project. She attends the Arvida Middle School, Miami, Florida. (M 46764)

\section{(13260) Sabadell}

1998 QZ $_{15}$. Discovered 1998 Aug. 23 by F. Casarramona and A. Vidal at Montjoia.

The Agrupació Astronómica de Sabadell celebrated its 40th anniversary on $2000 \mathrm{Apr}$. 14. It is the most important amateur astronomical society in Spain. The discoverers belong to this society. (M 41032)

\section{(13265) Terbunkley}

1998 QP $_{23}$. Discovered 1998 Aug. 17 by the LINEAR at Socorro.

Terrance S. Bunkley (1987- ) is a finalist in the 2002 Discovery Channel Young Scientist Challenge (DCYSC), a middle school science competition, for his physical science project. He attends the Dunbar Middle School, Fort Worth, Texas. (M 46764)

\section{(13268) Trevorcorbin}

1998 QS $_{34}$. Discovered 1998 Aug. 17 by the LINEAR at Socorro.

Trevor Eugene Corbin (1988- ) is a finalist in the 2002 Discovery Channel Young Scientist Challenge (DCYSC), a middle school science competition, for his botany and zoology project. He attends the Harry F. Byrd Middle School, Richmond, Virginia. (M 46764)

\section{(13269) Dahlstrom}

1998 QV $_{34}$. Discovered 1998 Aug. 17 by the LINEAR at Socorro.

Kurt Martin Dahlstrom (1988- ) is a finalist in the 2002 Discovery Channel Young Scientist Challenge (DCYSC), a middle school science competition, for his environmental sciences project. He attends the Hillsboro High School, Hillsboro, North Dakota. (M 46764)

\section{(13272) Ericadavid}

1998 QH $_{37}$. Discovered 1998 Aug. 17 by the LINEAR at Socorro.

Erica Elizabeth David (1989- ) is a finalist in the 2002 Discovery Channel Young Scientist Challenge (DCYSC), a middle school science competition, for her physical science project. She attends the Pinedale Middle School, Pinedale, Wyoming. (M 46765)

\section{(13274) Roygross}

1998 QX $_{37}$. Discovered 1998 Aug. 17 by the LINEAR at Socorro.

Roy James Gross (1987- ) is a finalist in the 2002 Discovery Channel Young Scientist Challenge (DCYSC), a middle school science competition, for his botany and zoology project. He attends the Penndale Middle School, Lansdale, Pennsylvania. (M 46765)

\section{(13278) Grotecloss}

$1998 \mathrm{QK}_{42}$. Discovered 1998 Aug. 17 by the LINEAR at Socorro. 
Kristin Shannon Grotecloss (1988- ) is a finalist in the 2002 Discovery Channel Young Scientist Challenge (DCYSC), a middle school science competition, for her behavioral science project. She attends the Southside Fundamental Middle School, St. Petersburg, Florida. (M 46765)

\section{(13279) Gutman}

$1998 \mathrm{QN}_{43}$. Discovered 1998 Aug. 17 by the LINEAR at Socorro.

Jennifer Erin Gutman (1989- ) is a finalist in the 2002 Discovery Channel Young Scientist Challenge (DCYSC), a middle school science competition, for her physical science project. She attends the Mt. De Chantal Visitation Academy, Wheeling, West Virginia. (M 46765)

\section{(13280) Christihaas}

$1998 \mathrm{QM}_{44}$. Discovered 1998 Aug. 17 by the LINEAR at Socorro.

Christine Haas (1988- ) is a finalist in the 2002 Discovery Channel Young Scientist Challenge (DCYSC), a middle school science competition, for her botany and zoology project. She attends the Reyburn Intermediate School, Clovis, California. (M 46765)

\section{(13281) Aliciahall}

1998 QW $_{45}$. Discovered 1998 Aug. 17 by the LINEAR at Socorro.

Alicia Esther Hall (1988- ) is a finalist in the 2002 Discovery Channel Young Scientist Challenge (DCYSC), a middle school science competition, for her botany and zoology project. She attends the Valley High School, Hoople, North Dakota. (M 46765)

\section{(13283) Dahart}

1998 QF $_{51}$. Discovered 1998 Aug. 17 by the LINEAR at Socorro.

David Andrew Hart (1990- ) is a finalist in the 2002 Discovery Channel Young Scientist Challenge (DCYSC), a middle school science competition, for his environmental sciences project. He attends the Episcopal Day School, Lake Charles, Louisiana. (M 46765)

\section{(13285) Stephicks}

$1998 \mathrm{QK}_{52}$. Discovered 1998 Aug. 17 by the LINEAR at Socorro.

Stephanie Marie Hicks (1990- ) is a finalist in the 2002 Discovery Channel Young Scientist Challenge (DCYSC), a middle school science competition, for her botany and zoology project. She attends the Keystone Junior High School, San Antonio, Texas. (M 46765)

\section{(13286) Adamchauvin}

$1998 \mathrm{QK}_{53}$. Discovered 1998 Aug. 20 by the LONEOS at Anderson Mesa.

Christiane Adam Chauvin (1952- ), of Paris Observatory, is responsible for research relationships with the European Community. (M 46110)

The name was suggested by M. Fulchignoni.

\section{(13298) Namatjira}

$1998 \mathrm{RD}_{5}$. Discovered 1998 Sept. 15 by J. Broughton at Reedy Creek.

Landscape painter Albert Namatjira (1902-1959) was one of Australia's greatest artists. As an aboriginal he could not own land under the archaic laws of the time until public outrage forced the government to grant him full citizenship in 1957. A decade later this led to equal rights for all. (M 42674)

\section{(13302) Kezmoh}

$1998 \mathrm{RO}_{31}$. Discovered 1998 Sept. 14 by the LINEAR at Socorro.

Lorren J. Kezmoh (1990- ) is a finalist in the 2002 Discovery Channel Young Scientist Challenge (DCYSC), a middle school science competition, for her botany and zoology project. She attends the Brentwood Middle School, Pittsburgh, Pennsylvania. (M 46765)

\section{(13303) Asmitakumar}

1998 RX $_{32}$. Discovered 1998 Sept. 14 by the LINEAR at Socorro.

Asmita Kumar (1988- ) is a finalist in the 2002 Discovery Channel Young Scientist Challenge (DCYSC), a middle school science competition, for her physical science project. She attends the Goleta Valley Junior High School, Goleta, California. (M 46765)

\section{(13305) Danielang}

1998 RD $_{54}$. Discovered 1998 Sept. 14 by the LINEAR at Socorro.

Daniel Owen Lang (1988- ) is a finalist in the 2002 Discovery Channel Young Scientist Challenge (DCYSC), a middle school science competition, for his biochemistry, medicine, health, and microbiology project. He attends the Independence Home School, Yardley, Pennsylvania. (M 46765)

\section{(13315) Hilana}

1998 RX $_{71}$. Discovered 1998 Sept. 14 by the LINEAR at Socorro.

Hilana Megan Lewkowitz-Shpuntoff (1988- ) is a finalist in the 2002 Discovery Channel Young Scientist Challenge (DCYSC), a middle school science competition, for her biochemistry, medicine, health, and microbiology project. She attends the Great Neck South Middle School, Great Neck, New York. (M 46765)

\section{(13316) Llano}

$1998 \mathrm{RJ}_{75}$. Discovered 1998 Sept. 14 by the LINEAR at Socorro.

Rayden Llano (1988- ) is a finalist in the 2002 Discovery Channel Young Scientist Challenge (DCYSC), a middle school science competition, for his biochemistry, medicine, health, and microbiology project. He attends 
the Paul W. Bell Middle School, Miami, Florida. (M 46765)

\section{(13319) Michaelmi}

$1998 \mathrm{RD}_{79}$. Discovered 1998 Sept. 14 by the LINEAR at Socorro.

Michael Mi (1988- ～) is a finalist in the 2002 Discovery Channel Young Scientist Challenge (DCYSC), a middle school science competition, for his biochemistry, medicine, health, and microbiology project. He attends the Andrew W. Mellon Middle School, Pittsburgh, Pennsylvania. (M 46765)

\section{(13320) Jessicamiles}

1998 RL$_{79}$. Discovered 1998 Sept. 14 by the LINEAR at Socorro.

Jessica Lian Miles (1988- ) is a finalist in the 2002 Discovery Channel Young Scientist Challenge (DCYSC), a middle school science competition, for her biochemistry, medicine, health, and microbiology project. She attends the Keystone Junior High School, San Antonio, Texas. (M 46766)

\section{(13325) Valérienataf}

$1998 \mathrm{SV}_{14}$. Discovered 1998 Sept. 18 by the LONEOS at Anderson Mesa.

Valérie Nataf Lambert (1959- ) is a well-known French TV news journalist who covers major international events. (M 46110)

The name was suggested by M. A. Barucci and M. Fulchignoni.

\section{(13326) Ferri}

$1998 \mathrm{SH}_{23}$. Discovered 1998 Sept. 17 by the LONEOS at Anderson Mesa.

Francesca Ferri (1967- ) is a planetary scientist at the University of Padua. She is involved in space research, and played an important role on the Cassini/Huygens HASI instrument. (M 46110)

The name was suggested by M. Fulchignoni.

\section{(13327) Reitsema}

$1998 \mathrm{SC}_{24}$. Discovered 1998 Sept. 17 by the LONEOS at Anderson Mesa.

Harold J. Reitsema (1948- ), of Ball Aerospace, Boulder, has been a participant in many of the successful occultation expeditions to determine sizes and shapes of minor planets, and he has also used occultations to study planetary atmospheres. (M 46110)

The name was suggested by M. F. A'Hearn.

\section{(13332) Benkhoff}

1998 SM$_{58}$. Discovered 1998 Sept. 17 by the LONEOS at Anderson Mesa.

Johannes Benkhoff (1961- ) is a planetary scientist at the German Aerospace Center (DLR) in BerlinAdlerhof. His research is in the field of modeling cometary nuclei, in preparation for space missions like Rosetta and Contour. He was instrumental in organizing the ACM 2002 conference. (M 46110)

The name was suggested by G. Hahn.

\section{(13333) Carsenty}

1998 SU $_{59}$. Discovered 1998 Sept. 17 by the LONEOS at Anderson Mesa.

Uri Carsenty (1949- ) is an Israeli planetary scientist working at the German Aerospace Center (DLR) in Berlin-Adlerhof. He works on the development of cameras and electronics for planetary space mission. He has been the brains and heart behind the organisation of ACM 2002. (M 46110)

The name was suggested by G. Hahn.

\section{(13334) Tost}

1998 SX $_{60}$. Discovered 1998 Sept. 17 by the LONEOS at Anderson Mesa.

Wilfried Tost (1952- ) is a system manager at the German Aerospace Center (DLR) in Berlin-Adlerhof. $\mathrm{He}$ has a keen interest in astronomy, and is active at Wilhelm-Förster-Sternwarte in Berlin. He was instrumental in organizing the ACM 2002 conference. (M 46110)

The name was suggested by G. Hahn.

\section{(13335) Tobiaswolf}

1998 SK$_{61}$. Discovered 1998 Sept. 17 by the LONEOS at Anderson Mesa.

Tobias Wolf (1980- ) is an enthusiastic naked-eye observer of the moon, planets and other wonders of the sky. He shares the thirst for knowledge that drives professional scientists but will never be able to join their ranks due to Down Syndrome. (M 46110)

The name was suggested by U. Carsenty.

\section{(13346) Danielmiller}

1998 SP $_{133}$. Discovered 1998 Sept. 26 by the LINEAR at Socorro.

Daniel Louis Miller, Jr. (1988- ) is a finalist in the 2002 Discovery Channel Young Scientist Challenge (DCYSC), a middle school science competition, for his biochemistry, medicine, health, and microbiology project. He attends the Frick International Studies Academy, Pittsburgh, Pennsylvania. (M 46766)

\section{(13358) Revelle}

1998 TA $_{34}$. Discovered 1998 Oct. 14 by the LONEOS at Anderson Mesa.

Douglas O. ReVelle (1945- ), of the Los Alamos National Laboratory, is well known for his pioneering theoretical work in meteor physics and astronomy based on theoretical aerodynamics, in meteor acoustics and in the interpretation of infrasonic meteor observations. (M 46110)

The name was suggested by Z. Ceplecha.

\section{(13365) Tenzinyama}

1998 UL $_{20}$. Discovered 1998 Oct. 26 by T. Okuni at Nanyou. 
Tenzinyama is a mountain in the western part of Iwamuro village, Niigata prefecture. There is a castle at the summit of the 250-meter mountain. (M 46011)

\section{(13367) Jiří}

$1998 \mathrm{UT}_{24}$. Discovered 1998 Oct. 18 by the LONEOS at Anderson Mesa.

Jiří Borovička (1964- ), of the Astronomical Institute of the Academy of Sciences of the Czech Republic, is known for his work in meteor physics and astronomy, particularly in meteor spectroscopy. He discovered the low- and high-temperature components of meteor radiation. (M 46110)

The name was suggested by Z. Ceplecha.

\section{(13368) Wlodekofman}

$1998 \mathrm{UV}_{24}$. Discovered 1998 Oct. 18 by the LONEOS at Anderson Mesa.

Wlodek Kofman (1945- ) directs the Laboratoire de Planétologie at the Université Joseph Fourier, Grenoble. He is principal investigator on the Rosetta mission's CONSERT experiment, which will use the transmission of radio waves through the nucleus of comet $46 \mathrm{P} /$ Wirtanen to build up a three-dimensional image. (M 46110)

\section{(13370) Júliusbreza}

1998 VF. Discovered 1998 Nov. 7 by P. Kolény and L. Kornoš at Modra.

Július Breza (1917-1991) was one of the foremost otolaryngologists in Czechoslovakia. He was the head of the otolaryngology division at the Puerile Faculty hospital in Bratislava. His work centered on endoscopic procedures to treat disorders of the bronchi and lung in children. (M 46683)

\section{(13376) Dunphy}

1998 VO $_{32}$. Discovered 1998 Nov. 15 by I. P. Griffin at Cocoa.

Desmond Plunket Dunphy (1920-1998) was an Irish medical doctor. In a career lasting from 1945 to 1980 he patiently and diligently tended many tens of thousands of patients, both in Ireland and later in family practice in England. During the last decade of his life he provided much inspiration and encouragement to the discoverer. (M 39659)

\section{(13380) Yamamohammed}

1998 WQ$_{11}$. Discovered 1998 Nov. 21 by the LINEAR at Socorro.

Yahya Maqsood Mohammed (1988- $\quad$ ) is a finalist in the 2002 Discovery Channel Young Scientist Challenge (DCYSC), a middle school science competition, for his biochemistry, medicine, health, and microbiology project. He attends the C.W. Ruckel Middle School, Niceville, Florida. (M 46766)
(13389) Stacey

$1999 \mathrm{AG}_{24}$. Discovered 1999 Jan. 10 by J. V. McClusky at Fair Oaks Ranch.

Stacey Ward McClusky (1959- ） is the discoverer's wife. (M 42674)

\section{(13390) Bouška}

$1999 \mathrm{FQ}_{3}$. Discovered 1999 Mar. 18 by P. Pravec and M. Wolf at Ondřejov.

Jiří Bouška (1925- ), emeritus professor of astronomy at Charles University, Prague, studied interplanetary matter and for 30 years served as the editor of the magazine Říše hvězd (The Realm of Stars, \{see planet (4090)\}) and the Czech Astronomical Yearbook. He taught several generations of Czech astronomers, including one of the discoverers. (M 39659)

\section{(13395) Deconihout}

$1999 \mathrm{RH}_{35}$. Discovered 1999 Sept. 10 by L. Bernasconi at St. Michel sur Meurthe.

A French amateur astronomer who applies his skills to telescope construction, Serge Deconihout is the founder of Valmeca, a company at the Haute Provence Observatory that produces large telescopes for both amateurs and professionals. (M 41032)

\section{(13396) Midavaine}

1999 RU $_{38}$. Discovered 1999 Sept. 11 by L. Bernasconi at St. Michel sur Meurthe.

Thierry Midavaine is vice-president of the Association Française d'Astronomie. A dedicated observer, he is also a skilled optic-electronics engineer. For many years he has helped amateur astronomers improve their observations by using image-intensifier tubes. (M 41033)

\section{(13403) Sarahmousa}

$1999 \mathrm{RJ}_{167}$. Discovered 1999 Sept. 9 by the LINEAR at Socorro.

Sarah S. Mousa (1987- ) is a finalist in the 2002 Discovery Channel Young Scientist Challenge (DCYSC), a middle school science competition, for her biochemistry, medicine, health, and microbiology project. She attends the Engle Middle School, West Grove, Pennsylvania. (M 46766)

\section{(13404) Norris}

$1999 \mathrm{RT}_{177}$. Discovered 1999 Sept. 9 by the LINEAR at Socorro.

Noele Rosalie Norris (1988- ) is a finalist in the 2002 Discovery Channel Young Scientist Challenge (DCYSC), a middle school science competition, for her biochemistry, medicine, health, and microbiology project. She attends the George Washington Carver Middle School, Miami, Florida. (M 46766)

\section{(13405) Dorisbillings}

$1999 \mathrm{ST}_{1}$. Discovered 1999 Sept. 21 by G. W. Billings at Calgary. 
Doris Billings, née Dora Kawchuk (1925- ), is the mother of the discoverer. Some of his earliest memories are of her fascination with space. (M 42362)

\section{(13406) Sekora}

1999 TA$_{4}$. Discovered 1999 Oct. 2 by L. Šarounová at Ondřejov.

Ondřej Sekora (1899-1967), Czech journalist, cartoonist, illustrator and writer, is known mainly for his work for children and creation of the character of Ferda Mravenec ("Ferda the Ant"). Sekora's popular stories about the life of insects and animals are based on his exceptional knowledge of nature. (M 41939)

\section{(13411) OLRAP}

$1999 \mathrm{UO}_{7}$. Discovered 1999 Oct. 31 by P. Antonini at Bedoin.

OLRAP, the Orchestre Lyrique de Région Avignon Provence, was established in Avignon in 1982. The discoverer chose this name also to honor his wife, Marie-Françoise, who plays timpani in this orchestra. (M 41033)

\section{(13421) Holvorcem}

$1999 \mathrm{VO}_{12}$. Discovered 1999 Nov. 11 by C. W. Juels at Fountain Hills.

Brazilian mathematician Paulo Holvorcem (1967- ) has developed new numerical methods for simulating waves in rotating fluids and in free space. Since 1996 he has been observing near-earth objects and developing software that efficiently allocates telescope time during automated observations. (M 41939)

\section{(13423) Bobwoolley}

$1999 \mathrm{VR}_{22}$. Discovered 1999 Nov. 13 by C. W. Juels at Fountain Hills.

Robert Woolley (1953- ) taught astronomy and was planetarium director at Montgomery College (19761981) and president of the Von Braun Astronomical Society (1993-1994). Since 1994 he has been conducting week-long astronomical/geological educational experiences at a dark site near Flagstaff, Arizona. (M 41939)

\section{(13424) Margalida}

1999 VD $_{24}$. Discovered 1999 Nov. 8 by R. Pacheco and A. Lopez at Mallorca.

Margalida Rechac (1959- ) is the wife of discoverer Angel Lopez. (M 40710)

\section{(13425) Waynebrown}

$1999 \mathrm{VG}_{24}$. Discovered 1999 Nov. 15 by C. W. Juels at Fountain Hills.

Since 1993 Wayne Brown (1957- ) has developed and makes widely available CCD \{see planet (15000)\} imaging systems for the astronomical and biomedical communities. He has also designed and built CCD cameras used for imaging from space. (M 42362)

\section{(13433) Phelps}

$1999 \mathrm{VP}_{52}$. Discovered 1999 Nov. 3 by the LINEAR at Socorro.

Kels Gordon Phelps (1988- ) is a finalist in the 2002 Discovery Channel Young Scientist Challenge (DCYSC), a middle school science competition, for his biochemistry, medicine, health, and microbiology project. He attends the East Middle School, Butte, Montana. (M 46766)

\section{(13434) Adamquade}

$1999 \mathrm{VK}_{58}$. Discovered 1999 Nov. 4 by the LINEAR at Socorro.

Adam Robert Quade (1987- ) is a finalist in the 2002 Discovery Channel Young Scientist Challenge (DCYSC), a middle school science competition, for his biochemistry, medicine, health, and microbiology project. He attends the St. John the Baptist School, New Brighton, Minnesota. (M 46766)

\section{(13435) Rohret}

1999 VX $_{67}$. Discovered 1999 Nov. 4 by the LINEAR at Socorro.

Sasha Annalicia Rohret (1989- ) is a finalist in the 2002 Discovery Channel Young Scientist Challenge (DCYSC), a middle school science competition, for her botany and zoology project. She attends the Keystone Junior High School, San Antonio, Texas. (M 46766)

\section{(13436) Enid}

1999 WF. Discovered 1999 Nov. 17 by T. Stafford at Edmond.

Enid, a city in northern Oklahoma, was founded on 1893 Sept. 16 in the Cherokee Outlet land run. It lies on the Chisholm Trail, a major route of cattle drives from Texas to Kansas in the late 1800s. (M 40711)

\section{(13437) Wellton-Persson}

$1999 \mathrm{WF}_{8}$ Discovered 1999 Nov. 28 by the Uppsala-DLR Asteroid Survey at Kvistaberg.

Helen Wellton (1961- ) and Claes Wellton Persson (1943- ) are Swedish entrepreneurs whose interest in minor planets and comets has resulted in generous support and sponsorship for the Uppsala-DLR Asteroid Survey. (M 41033)

The name was suggested by G. Hahn.

\section{(13438) Marthanalexander}

$1999 \mathrm{XD}_{86}$. Discovered 1999 Dec. 7 by the LINEAR at Socorro.

Named in honor of Martha N. Alexander for mentoring a finalist in the 2001 Discovery Young Scientist Challenge (DYSC), a middle school science competition. Alexander is a teacher at the All Saints Episcopal School, Lubbock, Texas. (M 43684)

\section{(13463) Antiphos}

5159 T-2. Discovered 1973 Sept. 25 by C. J. van Houten and I. van Houten-Groeneveld at Palomar. 
Antiphos was a friend of Telemachos and Odysseus \{see planet (1143)\} and lived at Ithaca see planet (1151)\}. (M 40710)

\section{(13473) Hokema}

1953 GJ. Discovered 1953 Apr. 7 by K. Reinmuth at Heidelberg.

Peter Hokema (1955- ) is a German violinist and maker of musical instruments. He developed several instruments that can be played without knowledge of scales and notation. His instruments are used successfully in music therapy for handicapped people. (M 41033)

The name was suggested by A. Doppler.

\section{(13474) V'yus}

1973 QO $_{1}$. Discovered 1973 Aug. 29 by T. M. Smirnova at Nauchnyj.

Yurij Sergeevich Vasil'ev (1929- ), rector of St. Petersburg State Technical University, is a prominent expert in the field of hydropower engineering. He made a significant contribution to the mastering and use of water-power resources, as well as to the development of higher education in Russia. (M 45338)

\section{(13475) Orestes}

1973 SX. Discovered 1973 Sept. 19 by C. J. van Houten and I. van Houten-Groeneveld at Palomar.

Orestes, a son of Agamemnon \{see planet (911)\}, was a child at the time of the murder of his father. Electra \{see planet (130)\} brought him to his uncle, where he lived together with his cousin Pylades. To avenge his father, Orestes killed Aegisthus and Clytaemnestra \{see planet (179)\}. The Erinyen persecuted him until he was absolved by the special jury at the Areopagus. (M 40710)

\section{(13478) Fraunhofer}

1976 DB $_{1}$. Discovered 1976 Feb. 27 by F. Börngen at Tautenburg.

Joseph von Fraunhofer (1787-1826), a German autodidact, glassmaker, optician and scientist, had an uncommon talent. He improved the telescope, invented the diffraction grid, and measured the wavelengths of the absorption lines in the solar spectrum. In 1824 the Bavarian king elevated him to the nobility. (M 41033)

\section{(13480) Potapov}

1978 PX $_{3}$. Discovered 1978 Aug. 9 by N. S. Chernykh and L. I. Chernykh at Nauchnyj.

Mikhail Mikhailovich Potapov (1904- ） is a distinctive Russian painter who made a series of icon works in the twelfth-century Byzantine manner for several temples. He is especially known for his outstanding paintings and portraits in the ancient Egyptian style. (M 46011)

\section{(13488) Savanov}

1982 TK$_{1}$. Discovered 1982 Oct. 14 by L. G. Karachkina at Nauchnyj.

Igor' Spartakovich Savanov (1956- ) is the vicedirector of the Crimean Astrophysical Observatory. His principal research is in stellar spectroscopy, stellar atmospheres, abundance analysis of stars and investigations of chemically peculiar stars of different types. (M 41033)

\section{(13489) Dmitrienko}

1982 UO $_{6}$. Discovered 1982 Oct. 20 by L. G. Karachkina at Nauchnyj.

Elena Sergeevna Dmitrienko (1952- _ ) is a senior researcher at the Crimean Astrophysical Observatory and wife of astronomer Igor' Savanov ssee planet (13488)\}. She deals with the physical properties and behavior on different timescales of interactive binaries: symbiotic stars, magnetic stars and novae. (M 41033)

\section{(13492) Vitalijzakharov}

$1984 \mathrm{YE}_{4}$. Discovered 1984 Dec. 27 by L. G. Karachkina at Nauchnyj.

Vitalij Aleksandrovich Zakharov (1964- ) is an active surgeon-oncologist at the Simferopol cancer dispensary center. The discoverer credits him with saving the life of her husband. (M 43192)

\section{(13499) Steinberg}

1986 TQ5. Discovered 1986 Oct. 1 by the CERGA at Caussols.

Jean Louis Steinberg (1922- ) is a co-founder of the Nançay Radio Observatory and Astronomy and Astrophysics. He was among the first in France to launch space-astronomy missions using sounding rockets and satellites to study the physics of ionospheric plasma and the terrestrial magnetosphere. (M 40711)

\section{(13500) Viscardy}

1987 PM. Discovered 1987 Aug. 6 by the CERGA at Caussols.

Georges Viscardy (1917- ) is the founder of the Société Monégasque d'Astronomie and of the Observatoire de Saint Martin de Peille on the French Riviera. An inspiration for many amateur astronomers, he has dedicated his life to high-resolution imaging, producing a wonderful photographic atlas of the moon. (M 40711)

\section{(13530) Ninnemann}

$1991 \mathrm{RS}_{2}$. Discovered 1991 Sept. 9 by L. D. Schmadel and F. Börngen at Tautenburg.

Olaf Ninnemann (1947- ), German mathematician and leading expert in the field of information and documentation, is especially interested in number theory. He played a key role in the establishment of the Zentralblatt für Mathematik and has been its executive editor since 1978. (M 40711) 


\section{(13531) Weizsäcker}

$1991 \mathrm{RU}_{4}$. Discovered 1991 Sept. 13 by F. Börngen and L. D. Schmadel at Tautenburg.

Carl Friedrich Freiherr von Weizsäcker (1912- ), German physicist and philosopher, was involved in nuclear physics, quantum theory and astronomy. Together with H. Bethe, he explained the radiation energy of stars by processes of nuclear fusion. He also developed a theory for the formation of the solar system. (M 40711)

\section{(13540) Kazukitakahashi}

1991 UR $_{1}$. Discovered 1991 Oct. 29 by A. Takahashi and K. Watanabe at Kitami.

Kazuki Takahashi (1997- ) is the first discoverer's eldest son. (M 41939)

\section{(13559) Werth}

$1992 \mathrm{RD}_{1}$. Discovered 1992 Sept. 4 by L. D. Schmadel and F. Börngen at Tautenburg.

Hildegard Werth (1950- ) is an experienced TV journalist with the large German TV system ZDF. Besides her duties within the news service department she likes the sciences and the stars. (M 46011)

\section{(13579) Allodd}

$1993 \mathrm{NA}_{2}$. Discovered 1993 July 12 by E. W. Elst at La Silla.

The number of this minor planet consists of all odd digits, in increasing order. (M 40711)

The name was suggested by J. Meeus.

\section{(13610) Lilienthal}

1994 TS $_{16}$. Discovered 1994 Oct. 5 by F. Börngen at Tautenburg.

The German engineer Otto Lilienthal (1848-1896) explored the aerodynamics of the flight of birds. Beginning in 1891, he flew more than 2000 times with homemade gliders, with his last flight ending in a fatal crash. With his brother Gustav (1849-1933), he conducted experiments that provided important knowledge about flight. (M 41033)

\section{(13615) Manulis}

$1994 \mathrm{WP}_{13}$. Discovered 1994 Nov. 28 by C. S. Shoemaker and D. H. Levy at Palomar.

Ilan Manulis (1949- ） has enthusiastically promoted the study of near-earth objects from Israel and built awareness among the public by lectures and media programs. During the 1980s, he was chairman of the Israeli Astronomical Association. He now serves as IAA's head of small solar-system objects. (M 41572)

\section{(13624) Abeosamu}

$1995 \mathrm{UO}_{3}$. Discovered 1995 Oct. 17 by T. Okuni at Nanyou.

Japanese amateur astronomer Osamu Abe (1950- ） is by profession a researcher on snow and ice. He discovered comet C/1970 N1 from Shinjo, Yamagata prefecture. (M 44186)

\section{(13642) Ricci}

1996 HX. Discovered 1996 Apr. 19 by P. G. Comba at Prescott.

Gregorio Ricci-Curbastro (1853-1925) was a professor of mathematics at the University of Padua. Building on the work of Riemann \{see planet (4167)\} and Christoffel, he developed tensor analysis, a formalism for the study of those properties of physical systems or abstract spaces that remain invariant under changes of coordinates. (M 40711)

\section{(13653) Priscus}

$1997 \mathrm{CT}_{16}$. Discovered 1997 Feb. 9 by V. S. Casulli at Colleverde di Guidonia.

Tarquinius Priscus, fifth king of Rome, reigned from 616 to 579 B.C. He constructed the Circus Maximus and enlarged the Roman Forum. (M 46011)

\section{(13658) Sylvester}

1997 FB. Discovered 1997 Mar. 18 by P. G. Comba at Prescott.

James Joseph Sylvester (1814-1897) studied at Cambridge and was the founder, together with Cayley \{see planet (16755)\}, of the theory of algebraic invariants. He taught at University College, London; at Johns Hopkins University (1877-1883), where he helped establish a graduate program in mathematics; and finally at Oxford. (M 40711)

\section{(13667) Samthurman}

1997 GT $_{37}$. Discovered 1997 Apr. 5 by the JPL NEAT Program at Haleakala.

Sam Thurman (1961- ) led a team that helped develop the landing system for Mars Pathfinder that was key in proving that the landing approach would perform reliably on Mars. This used a Monte Carlo computer simulation that accurately modeled the spacecraft and its interaction with the Martian environment. (M 45748)

\section{(13672) Tarski}

1997 KH. Discovered 1997 May 30 by P. G. Comba at Prescott.

Alfred Tarski (1902-1983), Polish-born American mathematician and logician and professor at the University of California at Berkeley, made important contributions to algebra, measure theory, mathematical logic, set theory and metamathematics. (M 40711)

\section{(13673) Urysohn}

1997 LC. Discovered 1997 June 1 by P. G. Comba at Prescott.

Pavel Samuilovich Urysohn (1898-1924) was a Russian topologist. Much of his research centered on the study of dimensionality. Although his scientific activity lasted only about five years, it had a profound influence on later developments and laid the foundations of the Soviet school of topology. (M 40711) 


\section{(13674) Bourge}

$1997 \mathrm{MJ}_{2}$. Discovered 1997 June 30 by the OCA-DLR Survey at Caussols.

Pierre Bourge (1921- ) founded what was later to become the Association Française d'Astronomie in 1945, and its magazine Ciel et Espace ssee planet (7192)\} in 1972. An avid solar eclipse observer and telescope maker, he has been an inspiration to a generation of astronomers, amateur and professional. (M 41033)

\section{(13681) Monty Python}

1997 PY $_{1}$. Discovered 1997 Aug. 7 by M. Tichý and Z. Moravec at Kleť.

Monty Python's Flying Circus, a comedy show starring Graham Chapman, John Cleese, Eric Idle, Michael Palin and Terry Jones, aired on the BBC from 1969 Oct. 5 to 1974 Dec. 5. It also featured animations by Terry Gilliam. (M 41033)

\section{(13682) Pressberger}

$1997 \mathrm{PG}_{3}$. Discovered 1997 Aug. 10 by E. Meyer and H. Raab at Linz.

Rudolf Pressberger (1942-2001) invented an improved telescope fork mount, named the "Austria Mount". First released in 1986, it features a right-ascension axis built inside the fork, works without ball bearings and uses friction drives. Using this design, Pressberger also built a 1.0-m Ritchey-Chrétien telescope himself. (M 41033)

\section{(13688) Oklahoma}

$1997 \mathrm{RJ}_{7}$. Discovered 1997 Sept. 9 by T. Stafford at Edmond.

Oklahoma is a U.S. state, and this was the first minor planet to be discovered from an observatory there. (M 40711)

\section{(13689) Succi}

$1997 \mathrm{RO}_{7}$. Discovered 1997 Sept. 9 by V. Giuliani at Sormano.

Carlo Succi (1919-2000), a professor of physics at the University of Milan, was also director of the local section of the Istituto Nazionale di Fisica Nucleare. His interests ranged from a pioneering study of cosmic rays to the development of the Milan 50-MeV cyclotron. (M 44110)

\section{(13690) Lesleymartin}

1997 RG $_{9}$. Discovered 1997 Sept. 8 by T. Pauwels at Uccle.

Lesley and Martin Goldsmith took care of the discoverer after he had an accident in Savernake Forest, Wiltshire, England. (M 46110)

\section{(13691) Akie}

1997 SL $_{16}$. Discovered 1997 Sept. 30 by A. Asami at Hadano.

Akie Asami (1957- ) is the wife of the discoverer. (M 41033)

\section{(13699) Nickthomas}

$1998 \mathrm{MU}_{7}$. Discovered 1998 June 18 by the LONEOS at Anderson Mesa.

Throughout his career, Nicholas Thomas (1960- ), of Max-Planck-Institut für Aeronomie, KatlenburgLindau, has been associated with obtaining close-up images of solar system bodies, from his role on the Giotto multicolor camera, through the imager on Mars Pathfinder, to Rosetta's OSIRIS imager. (M 46110)

\section{(13701) Roquebrune}

1998 OR. Discovered 1998 July 20 by the OCA-DLR Survey at Caussols.

Roquebrune sur Argens is a typical Provençal village located at the foot of the well-known "Rocher des trois croix". This village shows a good cultural dynamism, particularly in astronomy since several observations are organized there each year, notably during the now-classic "Nuit des Etoiles" (night of the stars). (M 41033)

\section{(13704) Aletesi}

1998 PA $_{1}$. Discovered 1998 Aug. 13 by L. Tesi at San Marcello Pistoiese.

Alessandro Tesi (1964- ) is the younger son of the discoverer. (M 41939)

\section{(13705) Llapasset}

1998 QJ $_{2}$. Discovered 1998 Aug. 19 at the Bedoin Observatory at Bedoin.

Jean-Marie Llapasset is a highly active French amateur astronomer. His main interest is the CCD \{see planet (15000)\} observation of supernovae, and he is responsible for the coordination of measuring supernova magnitudes within the Association des Utilisateurs de Détecteurs Electroniques \{see planet (9117)\}. (M 41940)

\section{(13710) Shridhar}

1998 QU $_{13}$. Discovered 1998 Aug. 17 by the LINEAR at Socorro.

Nupur Shridhar (1989- ) is a finalist in the 2002 Discovery Channel Young Scientist Challenge (DCYSC), a middle school science competition, for her computer science project. She attends the Great Valley Middle School, Malvern, Pennsylvania. (M 46766)

\section{(13714) Stainbrook}

1998 QV $_{38}$. Discovered 1998 Aug. 17 by the LINEAR at Socorro.

Haileigh Kate Stainbrook (1989- ) is a finalist in the 2002 Discovery Channel Young Scientist Challenge (DCYSC), a middle school science competition, for her botany and zoology project. She attends the Fairmont Elementary, Sanger, California. (M 46766)

\section{(13715) Steed}

1998 QK $_{39}$. Discovered 1998 Aug. 17 by the LINEAR at Socorro. 
Jared Benjamin Steed (1988- ) is a finalist in the 2002 Discovery Channel Young Scientist Challenge (DCYSC), a middle school science competition, for his environmental sciences project. He attends the Buckeye Valley Middle School, Delaware, Ohio. (M 46766)

\section{(13716) Trevino}

1998 QJ $_{40}$. Discovered 1998 Aug. 17 by the LINEAR at Socorro.

Aron Michael Trevino (1990- ) is a finalist in the 2002 Discovery Channel Young Scientist Challenge (DCYSC), a middle school science competition, for his biochemistry, medicine, health, and microbiology project. He attends the Jackson Middle School, San Antonio, Texas. (M 46766)

\section{(13717) Vencill}

$1998 \mathrm{QM}_{42}$. Discovered 1998 Aug. 17 by the LINEAR at Socorro.

Kory Aaron Vencill (1988- ) is a finalist in the 2002 Discovery Channel Young Scientist Challenge (DCYSC), a middle school science competition, for his engineering project. He attends the Applegate Middle School, Applegate, Oregon. (M 46766)

\section{(13718) Welcker}

1998 QR $_{43}$. Discovered 1998 Aug. 17 by the LINEAR at Socorro.

Kelydra Elizabeth Welcker (1989- ) is a finalist in the 2002 Discovery Channel Young Scientist Challenge (DCYSC), a middle school science competition, for her environmental sciences project. She attends the Blennerhassett Junior High, Parkersburg, West Virginia. (M 46766)

\section{(13721) Kevinwelsh}

1998 QX $_{51}$. Discovered 1998 Aug. 17 by the LINEAR at Socorro.

Kevin William Welsh (1988- ) is a finalist in the 2002 Discovery Channel Young Scientist Challenge (DCYSC), a middle school science competition, for his botany and zoology project. He attends the St. Peter Chanel Interparochial School, Paulina, Louisiana. (M 46766)

\section{(13722) Campobagatin}

1998 QO $_{54}$. Discovered 1998 Aug. 27 by the LONEOS at Anderson Mesa.

Adriano Campo Bagatin (1962- ), of the University of Bern, has worked on the observation of transneptunian objects, the collisional evolution of minor planets and the physics of small-body fragmentation processes. (M 46110)

The name was suggested by P. Paolicchi.

\section{(13723) Kolokolova}

1998 QY $_{54}$. Discovered 1998 Aug. 27 by the LONEOS at Anderson Mesa.

Ludmilla Kolokolova (1951- ) is a scientist at the University of Florida, Gainesville. Her research centers on light scattering by particles and by the surfaces of solar-system bodies. (M 46110)

The name was suggested by H. Scholl.

\section{(13724) Schwehm}

1998 QF $_{55}$. Discovered 1998 Aug. 27 by the LONEOS at Anderson Mesa.

Gerhard Schwehm (1949- ） is head of the Planetary Missions Division of ESA-ESTEC, Noordwijk, and Project Scientist for the Rosetta Mission. He has worked mainly on the dynamical and physical properties of interplanetary dust particles. (M 46111)

The name was suggested by H. Scholl.

\section{(13729) Nicolewen}

$1998 \mathrm{RO}_{22}$. Discovered 1998 Sept. 14 by the LINEAR at Socorro.

Nicole J. Wen (1989- ) is a finalist in the 2002 Discovery Channel Young Scientist Challenge (DCYSC), a middle school science competition, for her botany and zoology project. She attends the Keystone Junior High School, San Antonio, Texas. (M 46767)

\section{(13730) Willis}

$1998 \mathrm{RE}_{47}$. Discovered 1998 Sept. 14 by the LINEAR at Socorro.

Emily Kathleen Willis (1988- ) is a finalist in the 2002 Discovery Channel Young Scientist Challenge (DCYSC), a middle school science competition, for her botany and zoology project. She attends the Rocky Mountain Middle School, Heber, Utah. (M 46767)

\section{(13732) Woodall}

1998 RC $_{56}$. Discovered 1998 Sept. 14 by the LINEAR at Socorro.

Ashley Renee Woodall (1987- ) is a finalist in the 2002 Discovery Channel Young Scientist Challenge (DCYSC), a middle school science competition, for her physical science project. She attends the Austin Academy for Excellence, Garland, Texas. (M 46767)

\section{(13733) Dylanyoung}

1998 RA $_{59}$. Discovered 1998 Sept. 14 by the LINEAR at Socorro.

Dylan Howard Young (1988- ) is a finalist in the 2002 Discovery Channel Young Scientist Challenge (DCYSC), a middle school science competition, for his biochemistry, medicine, health, and microbiology project. He attends the Hastings Middle School, Upper Arlington, Ohio. (M 46767)

\section{(13734) Buklad}

$1998 \mathrm{RC}_{66}$. Discovered 1998 Sept. 14 by the LINEAR at Socorro.

Naomi Buklad mentored a finalist in the 2002 Discovery Channel Youth Science Challenge (DCYSC), a middle school science competition. She teaches at the Altamont School, Birmingham, Alabama. (M 46767) 


\section{(13739) Nancyworden}

$1998 \mathrm{SW}_{1}$. Discovered 1998 Sept. 16 by the OCA-DLR Survey at Caussols.

Nancy Worden, now retired, had a distinguished career as a technical librarian. She served as chief librarian at the U.S. National Solar Observatory. She began the use of computer-based databases in several U.S. government and commercial space programs. The citation was provided by her husband, S. P. Worden. (M 40711)

\section{(13740) Lastrucci}

1998 SL $_{2}$. Discovered 1998 Sept. 18 by M. Tombelli and E. Masotti at Montelupo.

Liliana Lastrucci (1948- ) is wife of the second discoverer. (M 41386)

\section{(13743) Rivkin}

1998 SX $_{23}$. Discovered 1998 Sept. 17 by the LONEOS at Anderson Mesa.

Andrew S. Rivkin (1969- ), of the Massachusetts Institute of Technology, has wide-ranging interests, including $3-\mu \mathrm{m}$ observations of minor planets, Saturn's rings, stellar dust disks, science education, the moons of Mars and oblique impacts. He has also contributed to NEAR, Deep Space-1, ISO, MUSES-C and Rosetta. (M 46111)

\section{(13744) Rickline}

$1998 \mathrm{SY}_{25}$. Discovered 1998 Sept. 22 by the LONEOS at Anderson Mesa.

Rick Kline (1953- ) has been Data Manager of the Spacecraft Planetary Imaging Facility at Cornell University since 1987. Kline has provided imaging data for planetary and small body research, and has educated thousands of young space advocates in his educational outreach programs. (M 46111)

The name was suggested by B. E. Clark.

\section{(13750) Mattdawson}

$1998 \mathrm{ST}_{54}$. Discovered 1998 Sept. 16 by the LONEOS at Anderson Mesa.

Matthew Dawson (1959- ), of Roeser, Luxembourg, is an active amateur involved in the astrometry of fast-moving NEOs using a $45-\mathrm{cm}$ telescope. Dawson is also a musician who specializes in contemporary jazz and popular music. He recorded a hit song in Germany in 1991. (M 46111)

The name was suggested by R. A. Kowalski.

\section{(13751) Joelparker}

$1998 \mathrm{SS}_{55}$. Discovered 1998 Sept. 16 by the LONEOS at Anderson Mesa.

Joel W. Parker (1962- ）, of the Southwest Research Institute, Boulder, Colorado, specializes in the study of Kuiper Belt objects. He is editor of the periodical Distant EKOs. (M 46111)

\section{(13752) Grantstokes}

$1998 \mathrm{SF}_{58}$. Discovered 1998 Sept. 17 by the LONEOS at Anderson Mesa.
Grant H. Stokes (1959- ) is principal investigator of the Lincoln Near-Earth Asteroid Research (LINEAR), the most prolific asteroid and comet discovery program, which is currently responsible for about $70 \%$ of all small bodies found worldwide. (M 46111)

\section{(13753) Jennivirta}

1998 SY $_{59}$. Discovered 1998 Sept. 17 by the LONEOS at Anderson Mesa.

Jenni V. Virtanen (1975- ), of the University of Helsinki, specializes in orbit determination. She has recently developed an initial orbit determination method, termed statistical ranging, suitable for use on poorly observed or short-arc objects. (M 46111)

\section{(13760) Rodriguez}

$1998 \mathrm{SN}_{123}$. Discovered 1998 Sept. 26 by the LINEAR at Socorro.

Maria Rodriguez mentored a finalist in the 2002 Discovery Channel Youth Science Challenge (DCYSC), a middle school science competition. She teaches at the Arvida Middle School, Miami, Florida. (M 46767)

\section{(13761) Dorristaylor}

1998 SA $_{130}$. Discovered 1998 Sept. 26 by the LINEAR at Socorro.

Dorris Taylor mentored a finalist in the 2002 Discovery Channel Youth Science Challenge (DCYSC), a middle school science competition. She teaches at the Dunbar Middle School, Fort Worth, Texas. (M 46767)

\section{(13764) Mcalanis}

$1998 \mathrm{SW}_{135}$. Discovered 1998 Sept. 26 by the LINEAR at Socorro.

Edith McAlanis mentored a finalist in the 2002 Discovery Channel Youth Science Challenge (DCYSC), a middle school science competition. She teaches at the Barbara Bush Middle School, San Antonio, Texas. (M 46767)

\section{(13765) Nansmith}

1998 SM $_{138}$. Discovered 1998 Sept. 26 by the LINEAR at Socorro.

Nancy Smith mentored a finalist in the 2002 Discovery Channel Youth Science Challenge (DCYSC), a middle school science competition. She teaches at the Harry F. Byrd Middle School, Richmond, Virginia. (M 46767)

\section{(13766) Bonham}

$1998 \mathrm{SA}_{139}$. Discovered 1998 Sept. 26 by the LINEAR at Socorro.

Dan Bonham mentored a finalist in the 2002 Discovery Channel Youth Science Challenge (DCYSC), a middle school science competition. He teaches at the Hillsboro High School, Hillsboro, North Dakota. (M 46767)

\section{(13774) Spurný}

1998 TW $_{30}$. Discovered 1998 Oct. 10 by the LONEOS at Anderson Mesa. 
Pavel Spurný (1958- ), of the Astronomical Institute of the Academy of Sciences of the Czech Republic, leads the European Network for photographing bolides. $\mathrm{He}$ is well known for his work in meteor physics and astronomy and has published many precise trajectories and orbits of bolides. (M 46111)

The name was suggested by Z. Ceplecha.

\section{(13775) Thébault}

$1998 \mathrm{TL}_{32}$. Discovered 1998 Oct. 11 by the LONEOS at Anderson Mesa.

Philippe Thébault (1969- ), of Paris Observatory, is an expert on the dynamics of small solar system bodies. He has worked on the planetesimal accretion of planetary systems and collisions in the Kuiper Belt. (M 46111)

The name was suggested by M. A. Barucci and E. Dotto.

\section{(13777) Cielobuio}

$1998 \mathrm{UV}_{6}$. Discovered 1998 Oct. 20 by M. Cavagna and A. Testa at Sormano.

Cielobuio is the Italian association against light pollution. Cielobuio played a fundamental role in Lombardy to support the passage of a regional law, one of the most advanced in the world. Through its electronic mailing list, Cielobuio connects both amateur and professional astronomers. (M 41572)

\section{(13792) Kuščynskyj}

1998 VG. Discovered 1998 Nov. 7 by J. Tichá and M. Tichý at Klě́t.

Taras Kuščynskyj (1932-1983) was a Czech photographer, known for his beautiful black-and-white images of the female form, including fine-art nude studies. (M 46011)

\section{(13793) Laubernasconi}

1998 VB$_{4}$. Discovered 1998 Nov. 11 by the OCA-DLR Survey at Caussols.

Laurent Bernasconi (1966- ), amateur astronomer, has collaborated with the Pises Observatory for many years. He has built several CCD cameras and automated telescope control systems, used by many amateurs in France. A fine observer, he has also discovered several minor planets using automated means. (M 41033)

\section{(13798) Cecchini}

1998 VK $_{33}$. Discovered 1998 Nov. 15 by L. Tesi and A. Boattini at San Marcello Pistoiese.

Vasco Cecchini (1932- ) is a very active amateur astronomer, and in the last few years he has collaborated with the Pian dei Termini Observatory. (M 45338)

\section{(13815) Furuya}

$1998 \mathrm{YF}_{7}$. Discovered 1998 Dec. 22 by A. Asami at Hadano.

Kazuko Furuya (1954- ) has devoted herself to kindergarten education since 1975. At present she is making efforts to give great dreams and hope to children with a creative teaching method, in the position of vice principal at Hadano Municipal Honcho kindergarten in Kanagawa prefecture. (M 42362)

\section{(13816) Stülpner}

$1998 \mathrm{YH}_{27}$. Discovered 1998 Dec. 29 by J. Kandler at Drebach.

Karl Stülpner (1762-1841), a popular hero of Germany's Ore Mountains, lived in Scharfenstein, near Drebach. He and his group of hunters wandered through the Saxonian and Bohemian Ore mountains providing order and justice and helping those in need. (M 41033)

\section{(13818) Ullery}

$1999 \mathrm{RE}_{92}$. Discovered 1999 Sept. 7 by the LINEAR at Socorro.

Elaine Ullery mentored a finalist in the 2002 Discovery Channel Youth Science Challenge (DCYSC), a middle school science competition. She teaches at the Pinedale Middle School, Pinedale, Wyoming. (M 46767)

\section{(13820) Schwartz}

1999 VQ. Discovered 1999 Nov. 1 by C. W. Juels at Fountain Hills.

Michael Schwartz (1950- ) contributes to professional-amateur cooperative discovery and measurement of supernovae and efforts in improving automated astronomy at Tenagra Observatory in Patagonia, Arizona. (M 41940; M 45821)

\section{(13824) Kramlik}

$1999 \mathrm{VG}_{86}$. Discovered 1999 Nov. 5 by the LINEAR at Socorro.

Thomas Kramlik mentored a finalist in the 2002 Discovery Channel Youth Science Challenge (DCYSC), a middle school science competition. He teaches at the Penndale Middle School, Lansdale, Pennsylvania. (M 46767)

\section{(13825) Booth}

$1999 \mathrm{VJ}_{87}$. Discovered 1999 Nov. 4 by the LINEAR at Socorro.

Tempest Diane Booth mentored a finalist in the 2002 Discovery Channel Youth Science Challenge (DCYSC), a middle school science competition. She teaches at the Southside Fundamental Middle School, St. Petersburg, Florida. (M 46767)

\section{(13830) ARLT}

$1999 \mathrm{XM}_{7}$. Discovered 1999 Dec. 4 by C. W. Juels at Fountain Hills.

The ARLT (Automatic Radio-Linked Telescope), a $0.44-\mathrm{m} \mathrm{f} / 4.5$ Newtonian located $40 \mathrm{~km}$ from Silver City, New Mexico, was one of the first remotely controlled automated CCD imaging facilities. Some 20000 images obtained during 1991-1997 contributed to 22 publications or formal presentations. (M 42362) 


\section{(13840) Wayneanderson}

1999 XW $_{31}$. Discovered 1999 Dec. 6 by the LINEAR at Socorro.

Named in honor of Wayne E. Anderson for mentoring a finalist in the 2001 Discovery Young Scientist Challenge (DYSC), a middle school science competition. Anderson is a teacher at the House Junior High School, House, New Mexico. (M 43684)

\section{(13841) Blankenship}

$1999 \mathrm{XO}_{32}$. Discovered 1999 Dec. 6 by the LINEAR at Socorro.

Named in honor of Paula A. Blankenship for mentoring a finalist in the 2001 Discovery Young Scientist Challenge (DYSC), a middle school science competition. Blankenship is a teacher at the St. Michael Parish School, Wheeling, West Virginia. (M 43684)

\section{(13843) Cowenbrown}

1999 XQ $_{34}$. Discovered 1999 Dec. 6 by the LINEAR at Socorro.

Named in honor of C. Owen Brown for mentoring a finalist in the 2001 Discovery Young Scientist Challenge (DYSC), a middle school science competition. Brown is a teacher at the Alexandria Country Day School, Alexandria, Louisiana. (M 43684)

\section{(13845) Jillburnett}

$1999 \mathrm{XL}_{63}$. Discovered 1999 Dec. 7 by the LINEAR at Socorro.

Named in honor of Jill M. Burnett for mentoring a finalist in the 2001 Discovery Young Scientist Challenge (DYSC), a middle school science competition. Burnett is a teacher at the Canterbury School, Ft. Wayne, Indiana. (M 43684)

\section{(13848) Cioffi}

$1999 \mathrm{XD}_{75}$. Discovered 1999 Dec. 7 by the LINEAR at Socorro.

Named in honor of Jessica Cioffi for mentoring a finalist in the 2001 Discovery Young Scientist Challenge (DYSC), a middle school science competition. Cioffi is a teacher at the Oslo Middle School, Vero Beach, Florida. (M 43684)

\section{(13849) Dunn}

$1999 \mathrm{XN}_{86}$. Discovered 1999 Dec. 7 by the LINEAR at Socorro.

Named in honor of Deborah A. Dunn for mentoring a finalist in the 2001 Discovery Young Scientist Challenge (DYSC), a middle school science competition. Dunn is a teacher at the Mesa Union Junior High School, Somis, California. (M 43684)

\section{(13850) Erman}

$1999 \mathrm{XO}_{88}$. Discovered 1999 Dec. 7 by the LINEAR at Socorro.

Named in honor of Sister Dolores Erman for mentoring a finalist in the 2001 Discovery Young Scientist Challenge (DYSC), a middle school science competition. Erman is a teacher at the Holy Name School, Sheridan, Wyoming. (M 43685)

\section{(13852) Ford}

$1999 \mathrm{XM}_{96}$. Discovered 1999 Dec. 7 by the LINEAR at Socorro.

Named in honor of Ralph Ford for mentoring a finalist in the 2001 Discovery Young Scientist Challenge (DYSC), a middle school science competition. Ford is a teacher at the Manhattan Beach Middle School, Manhattan Beach, California. (M 43685)

\section{(13853) Jenniferfritz}

$1999 \mathrm{XR}_{96}$. Discovered 1999 Dec. 7 by the LINEAR at Socorro.

Named in honor of Jennifer K. Fritz for mentoring a finalist in the 2001 Discovery Young Scientist Challenge (DYSC), a middle school science competition. Fritz is a teacher at the Landisville Middle School, Landisville, Pennsylvania. (M 43685)

\section{(13859) Fredtreasure}

1999 XQ136. Discovered 1999 Dec. 13 by C. W. Juels at Fountain Hills.

Fred Treasure (1943- ) designed and built the wireless network and codeveloped the control system for the ARLT (Automatic Radio-Linked Telescope) \{see planet (13830)\}, one of the first completely automated remotely controlled CCD \{see planet (15000)\} imaging facilities. (M 42362)

\section{(13860) Neely}

$1999 \mathrm{XH}_{143}$. Discovered 1999 Dec. 15 by C. W. Juels at Fountain Hills.

A. W. Neely (1951- ) codesigned, constructed and operated one of the first completely automated remotely controlled CCD \{see planet (15000)\} imaging facilities, the ARLT (Automatic Radio-Linked Telescope) \{see planet (13830)\}, which collected 20000 CCD images during 1991-1997. (M 42362)

\section{(13868) Catalonia}

$1999 \mathrm{YZ}_{8}$. Discovered 1999 Dec. 29 by J. Guarro at Piera.

Catalonia is an autonomous region in northeastern Spain bordered by the Mediterranean Sea, France and the regions of Aragon and the Valencian community. The Piera Observatory is located some $50 \mathrm{~km}$ northwest of the capital, Barcelona. (M 40711)

\section{(13869) Fruge}

$2000 \mathrm{AR}_{194}$. Discovered 2000 Jan. 8 by the LINEAR at Socorro.

Named in honor of Norma A. Fruge for mentoring a finalist in the 2001 Discovery Young Scientist Challenge (DYSC), a middle school science competition. Fruge is a teacher at the F. K. White Middle School, Lake Charles, Louisiana. (M 43685) 


\section{(13904) Univinnitsa}

1975 TJ J $_{3}$. Discovered 1975 Oct. 3 by L. I. Chernykh at Nauchnyj.

Founded in 1912, the Vinnitsa Pedagogical University has played a great role in the training of teachers for primary and secondary schools in the Podoliya region of Ukraine. (M 46011)

\section{(13906) Shunda}

1977 QD 2 . Discovered 1977 Aug. 20 by N. S. Chernykh at Nauchnyj.

Mathematician Nikifor Nikolaevich Shunda (1932-

) has been a professor and since 1975 rector of Vinnitsa \{see planet (13904)\} Pedagogical University who has done much for the development of the university. (M 46011)

\section{(13915) Yalow}

$1982 \mathrm{KH}_{1}$. Discovered 1982 May 27 by C. S. Shoemaker and S. J. Bus at Palomar.

In 1977 Rosalyn Yalow (1921- ) became the first American woman (and second woman ever) to be awarded the Nobel Prize in physiology or medicine. Her work with radioisotopes revolutionized biological and medical research. She strongly encouraged women to pursue science. (M 45338)

\section{(13916) Bernolák}

1982 QA $_{2}$. Discovered 1982 Aug. 23 by M. Antal at Piszkéstetö.

Anton Bernolák (1762-1813) was a Catholic priest who codified the first form of the Slovak language, later called bernolákovčina (Bernolák's language, 1787). The language was based on dialects used in western Slovakia. Bernolák was an important linguist and founder of the Slovenské učené tovarišstvo (Slovak Learned Society). (M 43192)

\section{(13917) Correggia}

1984 EQ. Discovered 1984 Mar. 6 by E. Bowell at Anderson Mesa.

Matteo Correggia (1962-2001), from the Roero region of Piemonte, was one of the most exceptional Italian winemakers. Though young, his extraordinary talent, passion and modesty won him the highest accolades from international wine experts. (M 43192)

The name was suggested by the discoverer, A. W. Harris (JPL) and V. Zappalà.

\section{(13954) Born}

$1990 \mathrm{TF}_{8}$. Discovered 1990 Oct. 13 by F. Börngen and L. D. Schmadel at Tautenburg.

German physicist Max Born (1882-1970), a pioneer in modern theoretical physics, formulated a theory of the crystal lattice and created with his assistants the basis of quantum mechanics. He received the 1954 Nobel Prize for physics, together with W. Bothe. The name was proposed by the first discoverer. (M 41033)
(13977) Frisch

$1992 \mathrm{HJ}_{7}$. Discovered 1992 Apr. 29 by F. Börngen at Tautenburg.

Austrian zoologist Karl Ritter von Frisch (1886-1982) did fundamental investigations on fish and honey-bees. He studied the orientation of bees following colors, shapes, odors, the sun and polarized light. He received the 1973 Nobel prize for medicine. (M 41033)

\section{(13980) Neuhauser}

1992 NS. Discovered 1992 July 2 by E. F. Helin at Palomar.

For more that 30 years, Philipp D. Neuhauser (1930- ) was a key member of the Public Affairs Office at the Jet Propulsion Laboratory, and through his versatility in public outreach he became an effective advocate of the pivotal place of JPL in the space program. (M 42674) The citatin was prepared by R. House.

\section{(13991) Kenphillips}

$1993 \mathrm{FZ}_{6}$. Discovered 1993 Mar. 17 by the Uppsala-ESO Survey at La Silla.

Ken Phillips (1946- ), a solar physicist at the Rutherford Appleton Laboratory, works on the heating of the solar corona and x-ray spectroscopy and solar and stellar flares. (M 42674)

\section{(13992) Cesarebarbieri}

$1993 \mathrm{FL}_{8}$. Discovered 1993 Mar. 17 by the Uppsala-ESO Survey at La Silla.

Padua astronomer Cesare Barbieri (1942- ) is responsible for the construction and scientific calibration of the Wide Angle Camera for the OSIRIS system of the cometary mission ROSETTA. (M 42674)

\section{(13993) Clemenssimmer}

$1993 \mathrm{FN}_{9}$. Discovered 1993 Mar. 17 by the Uppsala-ESO Survey at La Silla.

Clemens Simmer (1954- ), a German meteorologist, works on radiative transport theory and remote sensing for meteorological applications. (M 42674)

\section{(13994) Tuominen}

1993 FA $_{15}$ Discovered 1993 Mar. 17 by the Uppsala-ESO Survey at La Silla.

Oulu astronomer Ilkka Tuominen works on the solar cycle, late-type star activity and astrophysical magnetohydrodynamics. (M 42674)

\section{(13995) Tõravere}

$1993 \mathrm{FV}_{16}$. Discovered 1993 Mar. 19 by the UppsalaESO Survey at La Silla.

Tõravere is a small village close to the Tartu Observatory. (M 42674)

\section{(14014) Münchhausen}

1994 AL $_{16}$. Discovered 1994 Jan. 14 by F. Börngen at Tautenburg.

Karl Friedrich Hieronymus Freiherr von Münchhausen (1720-1797), also known as the "lies baron", was a 
member of a German noble lineage, first mentioned in 1183. He was an excellent narrator of anecdotes and exaggerated adventure stories, which later were captured in novels, plays and films. (M 41034)

\section{(14025) Fallada}

$1994 \mathrm{RR}_{11}$. Discovered 1994 Sept. 2 by F. Börngen at Tautenburg.

German author Hans Fallada (Rudolph Ditzen, 18931947) wrote sociocritical novels. He described the milieu of the so-called "little people", their helplessness and valor. His most famous novels are Kleiner Mann-was nun, Wer einmal aus dem Blechnapf frißt and Der eiserne Gustav. (M 41034)

\section{(14040) Andrejka}

1995 QD $_{2}$. Discovered 1995 Aug. 23 by A. Galád and A. Pravda at Modra.

This minor planet was chronlogically the first to be discovered at Modra Observatory and is regarded there as a "precious stone". It is dedicated to Andrea Galádovà (1970- ), familiarly known as Andrejka, wife of the first discoverer. (M 44594)

\section{(14041) Dürrenmatt}

1995 SO $_{54}$. Discovered 1995 Sept. 21 by F. Börngen at Tautenburg.

The Swiss dramatist and narrative writer Friedrich Dürrenmatt (1921-1990) was honored with many literary awards. He wrote about the contradictions and self-delusions of his time satirically, with grotesque and horrible bents. Der Besuch der alten Dame and Die Physiker had worldwide success. (M 41034)

\section{(14042) Agafonov}

1995 UG $_{5}$. Discovered 1995 Oct. 16 by T. V. Kryachko at Zelenchukskaya.

Konstantin Vasil'evich Agafonov (1935-1997) was a well-known organizer of the electronic industry in Russia. He led the creation of the powerful domestic computer "Elbrus" and of the first domestic personal computer "Agat". During the 1990s he took an active part in the demilitarization of the Russian economy. (M 45234)

\section{(14056) Kainar}

$1996 \mathrm{AO}_{1}$. Discovered 1996 Jan. 13 at the Klet Observatory at Klě́.

Josef Kainar (1917-1971), was a Czech poet, dramatist, journalist and musician. His poetry collected in Poems and Blues creates a connection of words and music. It has been put to music by various musicians including jazz singers and rock groups, such as Eva Olmerová, Framus Five and ETC. (M 41940)

\section{(14057) Manfredstoll}

$1996 \mathrm{AV}_{1}$. Discovered 1996 Jan. 15 by E. Meyer and E. Obermair at Linz.

Viennese computer specialist Manfred Stoll (1938-

) is an expert in the practical application of computers in astronomy. Among other projects, he worked on software for digitizing photographic plates. He also developed a modern telescope drive system and control software, which is now also used at the observatory in Linz \{see also planet (9097)\}. (M 41034)

\section{(14068) Hauserová}

$1996 \mathrm{HP}_{1}$. Discovered 1996 Apr. 21 by J. Tichá and M. Tichý at Kleť.

Eva Hauserová (1954- ) is a Czech writer and journalist. Originally trained as a geneticist, she has become an important member of the Czech sciencefiction scene. At the same time, she is known for her original views on environmentalist issues, gender studies and feminism. (M 43045)

\section{(14072) Volterra}

1996 KN. Discovered 1996 May 21 by P. G. Comba at Prescott.

Vito Volterra (1860-1940), professor successively at Pisa, Turin and Rome, developed a general theory of functionals that yielded solutions to integral and integro-differential equations. He also studied mathematico-biological models of prey-predator systems, in terms of a pair of first-order differential equations. (M 40711)

\section{(14074) Riccati}

1996 NS. Discovered 1996 July 11 at the Osservatorio San Vittore at Bologna.

The family of Italian mathematicians of Jacopo Francesco Riccati (1676-1754) and his sons Vincenzo (1707-1775), Giordano (1709-1790) and Francesco (17181791) wrote principally on differential equations, geometry and the work of Newton \{see planet (8000)\}. Riccati's differential equation is famous. (M 41940)

\section{(14075) Kenwill}

1996 OJ. Discovered 1996 July 18 by G. R. Viscome at Lake Placid.

Kenneth A. Williams, of Lake Clear, New York, is an accomplished astrometrist, astrophotographer, and discoverer of numerous minor planets. (M 46683)

\section{(14080) Heppenheim}

1997 GB. Discovered 1997 Apr. 4 at the Starkenburg Observatory at Heppenheim.

The beautiful city of Heppenheim, with its medieval old town that was first mentioned in the year 755 , is situated in a traditional wine-growing region of southwestern Germany. On a hill above the city the ruins of the Starkenburg castle dominate the picturesque scenery. (M 41034)

\section{(14088) Ancus}

1997 JB $_{10}$. Discovered 1997 May 3 by V. S. Casulli at Colleverde di Guidonia.

Ancus Marcius, fourth king of Rome, reigned from 640 to 616 B.C. He transferred to Rome the neighboring populations, thereby beginning the long battle between Patricii and Plebeii. (M 46011) 


\section{(14097) Capdepera}

$1997 \mathrm{PU}_{4}$. Discovered 1997 Aug. 11 by A. Lopez and

R. Pacheco at Mallorca.

Capdepera, a village in eastern Mallorca where the first discoverer lived for many years, is celebrating its 700 th anniversary in 2000 . The village contains a well-preserved castle from the 14th century and a beautiful beach. (M 41386)

\section{(14098) Šimek}

1997 QS. Discovered 1997 Aug. 24 by A. Galád and A. Pravda at Modra.

Czech radio astronomer Miloš Šimek (1933- ) has worked at the Ondřejov \{see planet (7204)\} Observatory since 1956. He studied the structure of major meteor showers and meteor head echoes using long term observations by radar. (M 42674)

The name was suggested by J. Grygar.

\section{(14100) Weierstrass}

1997 RQ $_{5}$. Discovered 1997 Sept. 8 by P. G. Comba at Prescott.

Karl Weierstrass (1815-1897) was a very influential professor of mathematics at the University of Berlin. His work was characterized by great rigor. His major contributions are the concept of analytic continuation and the foundation of the theory of complex functions on the power series. (M 40711)

\section{(14111) Kimamos}

1998 QA $_{24}$. Discovered 1998 Aug. 17 by the LINEAR at Socorro.

Kim Amos mentored a finalist in the 2002 Discovery Channel Youth Science Challenge (DCYSC), a middle school science competition. She teaches at the Mt. De Chantal Visitation Academy, Wheeling, West Virginia. (M 46767)

\section{(14114) Randyray}

1998 QE $_{35}$. Discovered 1998 Aug. 17 by the LINEAR at Socorro.

Randy Ray mentored a finalist in the 2002 Discovery Channel Youth Science Challenge (DCYSC), a middle school science competition. He teaches at the Reyburn Intermediate School, Clovis, California. (M 46767)

\section{(14115) Melaas}

1998 QO $_{36}$. Discovered 1998 Aug. 17 by the LINEAR at Socorro.

Kathleen Melaas mentored a finalist in the 2002 Discovery Channel Youth Science Challenge (DCYSC), a middle school science competition. She teaches at the Valley High School, Hoople, North Dakota. (M 46768)

\section{(14116) Ogea}

1998 QC $_{40}$. Discovered 1998 Aug. 17 by the LINEAR at Socorro.

Amanda H. Ogea mentored a finalist in the 2002 Discovery Channel Youth Science Challenge (DCYSC), a middle school science competition. She teaches at the Episcopal Day School, Lake Charles, Louisiana. (M 46768)

\section{(14119) Johnprince}

$1998 \mathrm{QU}_{46}$. Discovered 1998 Aug. 17 by the LINEAR at Socorro.

John E. Prince mentored a finalist in the 2002 Discovery Channel Youth Science Challenge (DCYSC), a middle school science competition. He teaches at the Keystone Junior High School, San Antonio, Texas. (M 46768)

\section{(14124) Kamil}

1998 QN $_{60}$. Discovered 1998 Aug. 28 by L. Šarounová at Ondřejov.

Czech amateur astronomer Kamil Hornoch (1972- ) is an outstanding observer of comets and variable stars and a friend of the discoverer. The exactness of his astronomical work is appreciated by professional astronomers. (M 41940)

\section{(14129) Dibucci}

1998 QO $_{95}$. Discovered 1998 Aug. 19 by the LINEAR at Socorro.

Janet DiBucci mentored a finalist in the 2002 Discovery Channel Youth Science Challenge (DCYSC), a middle school science competition. She teaches at the Brentwood Middle School, Pittsburgh, Pennsylvania. (M 46768)

\section{(14134) Penkala}

$1998 \mathrm{RP}_{42}$. Discovered 1998 Sept. 14 by the LINEAR at Socorro.

Brad Penkala mentored a finalist in the 2002 Discovery Channel Youth Science Challenge (DCYSC), a middle school science competition. He teaches at the Goleta Valley Junior High School, Goleta, California. (M 46768)

\section{(14135) Cynthialang}

$1998 \mathrm{RZ}_{62}$. Discovered 1998 Sept. 14 by the LINEAR at Socorro.

Cynthia Lang mentored a finalist in the 2002 Discovery Channel Youth Science Challenge (DCYSC), a middle school science competition. She teaches at the Independence Home School, Yardley, Pennsylvania. (M 46768)

\section{(14141) Demeautis}

$1998 \mathrm{SR}_{1}$. Discovered 1998 Sept. 16 by the OCA-DLR Survey at Caussols.

Christophe Demeautis is an amateur astronomer who has been the leader and caretaker of observations of minor planets by the Association des Utilisateurs de Détecteurs Electroniques. Discoverer of several minor planets, he is also a skilled scuba diver. (M 41034)

\section{(14147) Wenlingshuguang}

1998 SG $_{43}$. Discovered 1998 Sept. 23 at the Beijing Observatory at Xinglong. 
Wenlingshuguang is the event of the first sunlight ("Shuguang" in Chinese) of the new millennium shining on Wenling, Zhejiang, the first geographical point on China's mainland. (M 41940)

\section{(14153) Dianecaplain}

1998 SA $_{80}$. Discovered 1998 Sept. 26 by the LINEAR at Socorro.

Diane S. Caplain mentored a finalist in the 2002 Discovery Channel Youth Science Challenge (DCYSC), a middle school science competition. She teaches at the Great Neck South Middle School, Great Neck, New York. (M 46768)

\section{(14154) Negrelli}

$1998 \mathrm{SZ}_{106}$. Discovered 1998 Sept. 26 by the LINEAR at Socorro.

David Negrelli mentored a finalist in the 2002 Discovery Channel Youth Science Challenge (DCYSC), a middle school science competition. He teaches at the Paul W. Bell Middle School, Miami, Florida. (M 46768)

\section{(14155) Cibronen}

1998 SK $_{122}$. Discovered 1998 Sept. 26 by the LINEAR at Socorro.

Cindy Bronen mentored a finalist in the 2002 Discovery Channel Youth Science Challenge (DCYSC), a middle school science competition. She teaches at the Andrew W. Mellon Middle School, Pittsburgh, Pennsylvania. (M 46768)

\section{(14157) Pamelasobey}

$1998 \mathrm{SA}_{133}$. Discovered 1998 Sept. 26 by the LINEAR at Socorro.

Pamela Sobey mentored a finalist in the 2002 Discovery Channel Youth Science Challenge (DCYSC), a middle school science competition. She teaches at the Keystone Junior High School, San Antonio, Texas. (M 46768)

\section{(14158) Alananderson}

1998 SZ $_{133}$. Discovered 1998 Sept. 26 by the LINEAR at Socorro.

Alan Anderson mentored a finalist in the 2002 Discovery Channel Youth Science Challenge (DCYSC), a middle school science competition. He teaches at the C.W. Ruckel Middle School, Niceville, Florida. (M 46768)

\section{(14172) Amanolivere}

$1998 \mathrm{VN}_{8}$. Discovered 1998 Nov. 10 by the LINEAR at Socorro.

Amanda Olivere mentored a finalist in the 2002 Discovery Channel Youth Science Challenge (DCYSC), a middle school science competition. She teaches at the Engle Middle School, West Grove, Pennsylvania. (M 46768)

\section{(14174) Deborahsmall}

1998 VO $_{13}$. Discovered 1998 Nov. 10 by the LINEAR at Socorro.

Deborah Small mentored a finalist in the 2002 Discovery Channel Youth Science Challenge (DCYSC), a middle school science competition. She teaches at the George Washington Carver Middle School, Miami, Florida. (M 46768)

\section{(14179) Skinner}

$1998 \mathrm{VM}_{32}$. Discovered 1998 Nov. 15 by I. P. Griffin at Cocoa.

Christopher J. Skinner (1963-1997), teacher of the discoverer, worked at Jodrell Bank, the Lawrence Berkeley Laboratory and the Space Telescope Science Institute. His many seminal papers were on subjects as diverse as the atmospheres of red giant stars and the dust disks of Vega-excess stars. (M 41034)

\section{(14181) Koromházi}

1998 WX $_{6}$. Discovered 1998 Nov. 20 by K. Sárneczky and L. Kiss at Piszkéstetö.

Beáta Koromházi is the mother of the first discoverer. (M 40712)

\section{(14182) Alley}

1998 WG $_{12}$. Discovered 1998 Nov. 21 by the LINEAR at Socorro.

Karen Alley mentored a finalist in the 2002 Discovery Channel Youth Science Challenge (DCYSC), a middle school science competition. She teaches at the East Middle School, Butte, Montana. (M 46768)

\section{(14185) Van Ness}

1998 WK $_{32}$. Discovered 1998 Nov. 21 by the LONEOS at Anderson Mesa.

Michael E. Van Ness (1974- ) has been an observer for LONEOS since 1998. He is interested in archaeoastronomy. (M 41034)

\section{(14186) Virgiliofos}

$1998 \mathrm{XP}_{2}$. Discovered 1998 Dec. 7 by A. Boattini and L. Tesi at San Marcello Pistoiese.

Virgilio Fossombroni (1946- ), a teacher of Italian Literature, developed a keen interest in science in general and taught the first rudiments of astronomy to the first discoverer when he was a little boy. (M 45338)

\section{(14189) Sèvre}

1998 XB $_{14}$. Discovered 1998 Dec. 15 by the OCA-DLR Survey at Caussols.

François Sèvre (1948- ) started his career as an infrared astronomy engineer at Meudon Observatory. He has participated in a large number of observing runs, most notably at the Pic du Midi Observatory, where his knowledge of the mountain and his human qualities have always been appreciated. (M 41034) 


\section{(14190) Soldán}

1998 XS $_{15}$. Discovered 1998 Dec. 15 by M. Tichý and Z. Moravec at Kleť.

Jan Soldán (1957- ) is a Czech astronomer, designer and developer of control software and programs for space and ground-based experiments, including CCD \{see planet (15000)\} cameras, robotic telescopes and real-time image processing. Since 1996 he has taken part in the INTEGRAL satellite project. (M 42362)

\section{(14206) Sehnal}

1999 CL $_{10}$. Discovered 1999 Feb. 15 by M. Tichý and Z. Moravec at Kleť.

Ladislav Sehnal (1931- ) is known for his work on the effects of solar radiation and atmospheric drag on the motions of artificial satellites and the theory of space accelerometric measurements. He served as director of the Astronomical Institute of the Czech Academy of Sciences during 1990-1996. (M 42362)

\section{(14214) Hirsch}

$1999 \mathrm{RP}_{86}$. Discovered 1999 Sept. 7 by the LINEAR at Socorro.

Theresa Hirsch mentored a finalist in the 2002 Discovery Channel Youth Science Challenge (DCYSC), a middle school science competition. She teaches at the St. John the Baptist School, New Brighton, Minnesota. (M 46768)

\section{(14217) Oaxaca}

1999 VV $_{19}$. Discovered 1999 Nov. 10 by J. M. Roe at Oaxaca.

The city and state of Oaxaca was the birthplace and home of Benito Juarez, the first native-born president of Mexico. The city is home to the observing station where this minor planet was discovered. (M 40712)

\section{(14223) Dolby}

1999 XW $_{1}$. Discovered 1999 Dec. 3 by C. W. Juels at Fountain Hills.

John Dolby (1961- ) was a telescope operator at the University of New Mexico's Capilla Peak Observatory during 1988-1989. Since 1995 he has provided consultation and technical assistance to the astronomical and biomedical communities about CCD \{see planet (15000)\} imaging systems. (M 42362)

\section{(14224) Gaede}

$1999 \mathrm{XU}_{33}$. Discovered 1999 Dec. 6 by the LINEAR at Socorro.

Named in honor of Allison Gaede for mentoring a finalist in the 2001 Discovery Young Scientist Challenge (DYSC), a middle school science competition. Gaede is a teacher at the Reyburn Intermediate School, Clovis, California. (M 43685)

\section{(14225) Alisahamilton}

$1999 \mathrm{XZ}_{49}$. Discovered 1999 Dec. 7 by the LINEAR at Socorro.
Named in honor of Alisa Hamilton for mentoring a finalist in the 2001 Discovery Young Scientist Challenge (DYSC), a middle school science competition. Hamilton is a teacher at the College Station Middle School, College Station, Texas. (M 43685)

\section{(14226) Hamura}

$1999 \mathrm{XR}_{50}$. Discovered 1999 Dec. 7 by the LINEAR at Socorro.

Named in honor of Jay Hamura for mentoring a finalist in the 2001 Discovery Young Scientist Challenge (DYSC), a middle school science competition. Hamura is a teacher at the St. Andrew's Priory, Honolulu, Hawaii. (M 43685)

\section{(14230) Mariahines}

$1999 \mathrm{XF}_{100}$. Discovered 1999 Dec. 7 by the LINEAR at Socorro.

Named in honor of Maria L. Hines for mentoring a finalist in the 2001 Discovery Young Scientist Challenge (DYSC), a middle school science competition. Hines is a teacher at the Orchard Day Home School, Ft. Wayne, Indiana. (M 43685)

\section{(14234) Davidhoover}

$1999 \mathrm{XZ}_{182}$. Discovered 1999 Dec. 12 by the LINEAR at Socorro.

Named in honor of David L. Hoover for mentoring a finalist in the 2001 Discovery Young Scientist Challenge (DYSC), a middle school science competition. Hoover is a teacher at the Middletown Middle School, Middletown, Maryland. (M 43685)

\section{(14238) d'Artagnan}

1999 YX $_{13}$. Discovered 1999 Dec. 31 by C. W. Juels at Fountain Hills.

D'Artagnan is the main character of Alexandre Dumas's novel The Three Musketeers. He is a swashbuckling swordsman who joins the three musketeers in many adventures and ultimately earns a commission as a King's Musketeer through his skill, loyalty and devotion. (M 42674)

The name was suggested by J. Greer.

\section{(14244) Labnow}

$2000 \mathrm{AT}_{29}$. Discovered 2000 Jan. 3 by the LINEAR at Socorro.

Named in honor of Troy Labnow for mentoring a finalist in the 2001 Discovery Young Scientist Challenge (DYSC), a middle school science competition. Labnow is a teacher at the Medea Creek Middle School, Agoura, California. (M 43685)

\section{(14250) Kathleenmartin}

$2000 \mathrm{AJ}_{63}$. Discovered 2000 Jan. 4 by the LINEAR at Socorro.

Named in honor of Kathleen B. Martin for mentoring a finalist in the 2001 Discovery Young Scientist Challenge (DYSC), a middle school science competition. Martin 
is a teacher at the Doolen Middle School, Tucson, Arizona. (M 43685)

\section{(14252) Audreymeyer}

$2000 \mathrm{AD}_{64}$. Discovered 2000 Jan. 4 by the LINEAR at Socorro.

Named in honor of Audrey W. Meyer for mentoring a finalist in the 2001 Discovery Young Scientist Challenge (DYSC), a middle school science competition. Meyer is a teacher at the Falmouth Academy, Falmouth, Massachusetts. (M 43685)

\section{(14258) Katrinaminck}

$2000 \mathrm{AM}_{116}$. Discovered 2000 Jan. 5 by the LINEAR at Socorro.

Named in honor of Katrina D. Minck for mentoring a finalist in the 2001 Discovery Young Scientist Challenge (DYSC), a middle school science competition. Minck is a teacher at the Manhattan Beach Middle School, Manhattan Beach, California. (M 43685)

\section{(14262) Kratzer}

$2000 \mathrm{AC}_{125}$. Discovered 2000 Jan. 5 by the LINEAR at Socorro.

Sherri Kratzer mentored a finalist in the 2002 Discovery Channel Youth Science Challenge (DCYSC), a middle school science competition. She teaches at the Great Valley Middle School, Malvern, Pennsylvania. (M 46768)

\section{(14275) Dianemurray}

$2000 \mathrm{BR}_{26}$. Discovered 2000 Jan. 30 by the LINEAR at Socorro.

Named in honor of Diane K. Murray for mentoring a finalist in the 2001 Discovery Young Scientist Challenge (DYSC), a middle school science competition. Murray is a teacher at the J. F. Kennedy Elementary School, Butte, Montana. (M 43685)

\section{(14277) Parsa}

$2000 \mathrm{CS}_{13}$. Discovered 2000 Feb. 2 by the LINEAR at Socorro.

Named in honor of Steve Parsa for mentoring a finalist in the 2001 Discovery Young Scientist Challenge (DYSC), a middle school science competition. Parsa is a teacher at the Palos Verdes Intermediate School, Palos Verdes, California. (M 43685)

\section{(14278) Perrenot}

$2000 \mathrm{CV}_{29}$. Discovered 2000 Feb. 2 by the LINEAR at Socorro.

Named in honor of Valerie T. Perrenot for mentoring a finalist in the 2001 Discovery Young Scientist Challenge (DYSC), a middle school science competition. Perrenot is a teacher at the Barbara Bush Middle School, San Antonio, Texas. (M 43685)

\section{(14309) Defoy}

A908 SA. Discovered 1908 Sept. 22 by J. Palisa at Vienna.
Until 1580 the ancestors of the Defoy family were landowners at Foy, near Bastogne, now in Belgium. This minor planet specifically honors Ilse Defoy (1892-1947), wife of Christoph Schubart and mother of Heidelberg astronomer Joachim Schubart, who found the identifications involving this minor planet. (M 41386)

\section{(14312) Polytech}

1976 UN $_{2}$. Discovered 1976 Oct. 26 by T. M. Smirnova at Nauchnyj.

Saint Petersburg State Technical University (former Polytechnical Institute), founded in 1899, is one of the largest universities laying the foundation of higher polytechnic education in Russia. (M 45338)

\section{(14313) Dodaira}

$1976 \mathrm{UZ}_{7}$. Discovered 1976 Oct. 22 by H. Kosai and K. Hurukawa at Kiso.

Dodaira station was dedicated in 1962 with a $0.91-\mathrm{m}$ reflector and $0.50-\mathrm{m}$ Schmidt telescope as a branch station of the Tokyo Astronomical Observatory in Saitama ssee planet (5618)\} prefecture, and its operation was terminated in Mar. 2000. It was located where the borders of Tokigawa, Ogawamachi and Higashichichibu meet. (M 41940)

\section{(14314) Tokigawa}

1977 DQ $_{3}$. Discovered 1977 Feb. 18 by H. Kosai and K. Hurukawa at Kiso.

With a population of 8000 , Tokigawa is a village east of the Chichibu mountain range in Saitama \{see planet (5618)\} prefecture, north of Tokyo, near where Dodaira station was located. This village was particularly supportive of the observatory. (M 41940)

The citation was prepared by Y. Kozai

\section{(14315) Ogawamachi}

1977 EL $_{5}$. Discovered 1977 Mar. 12 by H. Kosai and K. Hurukawa at Kiso.

Ogawamachi is a town of 32000 at the eastern edge of Chichibu mountain range in Saitama ssee planet (5618)\} prefecture and is famous for washi (Japanese paper) production. The Dodaira \{see planet (14313)\} station adjoined the town. (M 41940)

The citation was prepared by Y. Kozai.

\section{(14316) Higashichichibu}

$1977 \mathrm{ES}_{7}$. Discovered 1977 Mar. 12 by H. Kosai and K. Hurukawa at Kiso.

Higashichichibu, a village of 4000 at the eastern edge of the Chichibu mountain range in Saitama ssee planet (5618)\} prefecture, is famous for lumber production. The Dodaira \{see planet (14313)\} station was located nearby. (M 41940)

The citation was prepared by Y. Kozai. 


\section{(14361) Boscovich}

1988 DE. Discovered 1988 Feb. 17 at the Osservatorio San Vittore at Bologna.

Ruggiero Giuseppe Boscovich (1711-1787), Jesuit professor of mathematics and philosophy at Rome and Pavia, was for some years in Paris and later in Milan, where he founded the Brera Astronomical Observatory. He wrote on the determination of orbits of comets, mathematics and optics. (M 41940)

\section{(14365) Jeanpaul}

$1988 \mathrm{RZ}_{2}$. Discovered 1988 Sept. 8 by F. Börngen at Tautenburg.

Jean Paul (Friedrich Richter, 1763-1825) was a German writer and poet. His novels and stories are in an ebullient baroque style, but with philosophical humor, juxtaposing idealism and reality. He lived a short time in Weimar \{see planet (3539)\} and related his impressions there in his chief work, Titan. (M 41034)

\section{(14366) Wilhelmraabe}

1988 RX $_{3}$. Discovered 1988 Sept. 8 by F. Börngen at Tautenburg.

The Lower-Saxon novelist and poet Wilhelm Raabe (Jacob Corvinus, 1831-1910) is a great representative of German poetic realism. Descriptively and precisely, he depicts the repressed and deformed characters of society, with both idyllic and grotesque imagery. (M 41034)

\section{(14367) Hippokrates}

$1988 \mathrm{RY}_{3}$. Discovered 1988 Sept. 8 by F. Börngen at Tautenburg.

The Greek physician Hippokrates (460?-375 B.C.) is regarded as the founder of medicine as an empirical science. In antiquity and the Middle Ages, the Hippocratic oath bound the physicians to an unreserved preservation of human life, still today the basis of medical professional ethics. (M 41386)

\section{(14372) Paulgerhardt}

$1989 \mathrm{AD}_{6}$. Discovered 1989 Jan. 9 by F. Börngen at Tautenburg.

German poet and theologian Paul Gerhardt (16071676) wrote more than 130 hymns inspired by his deep piety and strong confidence in God. These include Nun ruhen alle Wälder, Befiehl du deine Wege and $O$ Haupt voll Blut und Wunden. They are the highlights of evangelic hymn-poetry after Luther ssee planet (7100)\}. (M 41034)

\section{(14395) Tommorgan}

$1990 \mathrm{TN}_{3}$. Discovered 1990 Oct. 15 by E. F. Helin at Palomar.

U.S. planetary scientist Thomas H. Morgan (1945-

) is also Near-Earth Objects and Minor Planets Program Scientist at NASA Headquarters. In the latter capacity he has been very supportive of the efforts to discover and track near-earth objects. (M 44110)

\section{(14400) Baudot}

$1990 \mathrm{WO}_{4}$. Discovered 1990 Nov. 16 by E. W. Elst at La Silla.

Jean-Maurice-Emile Baudot (1845-1903) invented a telegraphic code in 1874 that encoded each letter of the alphabet as a series of "on-or-off" signals. Because each signal has the same duration, this system is more efficient than Morse code, and it still used in telecommunications today. (M 41034)

The name was suggested by R. S. McMillan.

\section{(14412) Wolflojewski}

1991 RU $_{2}$. Discovered 1991 Sept. 9 by L. D. Schmadel and F. Börngen at Tautenburg.

Wolf von Lojewski (1937- ) is a prominent journalist, book author and long-standing correspondent of the German TV system ZDF in Europe and abroad. Head and anchorman of the popular newscast Heute Journal, von Lojewski set new standards as a moderator. (M 46011)

\section{(14413) Geiger}

$1991 \mathrm{RT}_{3}$. Discovered 1991 Sept. 5 by F. Börngen and L. D. Schmadel at Tautenburg.

German physicist Hans Geiger (1882-1945) studied radioactivity and scattering of $\alpha$-particles. Together with Erwin Wilhelm Müller, he invented the GM (Geiger) counter, which became an important measuring instrument in nuclear physics. Together with K. Scheel, he edited the 24-volume Handbuch der Physik (19261929). (M 41034)

\section{(14429) Coyne}

1991 XC. Discovered 1991 Dec. 3 by C. S. Shoemaker and D. H. Levy at Palomar.

George Coyne (1933- ）, S.J., has been an astronomer at the Vatican Observatory since 1969 and its director since 1978. He has helped with the completion of the large Vatican telescope on Mt. Graham, Arizona. His polarimetric studies have centered on cataclysmic variables, among other subjects. (M 41572)

\section{(14466) Hodge}

$1993 \mathrm{OY}_{2}$. Discovered 1993 July 25 by M. Hammergren at Ellensburg.

Paul W. Hodge (1934- ) is a professor of astronomy at the University of Washington and, since 1984, editor of the Astronomical Journal. He has made seminal contributions to the study of star-forming regions in galaxies, the extragalactic distance scale and terrestrial impact craters. The citation was prepared by T. Smith. (M 42362)

\section{(14486) Tuscia}

1994 TE. Discovered 1994 Oct. 4 by L. Tesi and G. Cattani at San Marcello Pistoiese.

Tuscia is the ancient name given to Tuscany, the central Italian region once inhabited by the Etruscans, and located between the Tyrrhenian Sea and the Arno and Tiber rivers. (M 41386) 
(14509) Lučenec

$1996 \mathrm{ER}_{2}$. Discovered 1996 Mar. 9 by A. Galád and

A. Pravda at Modra.

Lučenec is a small historical town, cultural and industrial center of Novohrad in the south of Slovakia, where the first discoverer spent his childhood. It dates from the thirteenth century. During its history it has twice been razed by fire (in 1622 and 1849). (M 45234)

\section{(14517) Monitoma}

$1996 \mathrm{LJ}_{1}$. Discovered 1996 June 13 by P. Pravec at Ondřejov.

Monika Pravcová (1976- ), sister of the discoverer, and Tomáš Kneslík (1977- ) fell in love in the year of the discovery of this minor planet and married in 2000 when it was numbered. (M 41034)

\section{(14526) Xenocrates}

$1997 \mathrm{JT}_{3}$. Discovered 1997 May 6 by P. G. Comba at Prescott.

Xenocrates of Chalcedon (396-314 B.C.), philosopher and mathematician, was a student of Plato and teacher of Epicurus \{see, respectively, planets (5451) and (5954)\}. As head of the Academy (339-314 B.C.) he upheld Plato's policy that geometry and music are prerequisites to the study of philosophy. He wrote on the history of geometry and on number theory. (M 41034)

\section{(14533) Roy}

1997 QY. Discovered 1997 Aug. 24 by P. Antonini at Bedoin.

René Roy (1938- ) is an amateur who has devoted much time to astronomical observations. He was especially interested in CCD technology applied to search and astrometry of minor planets and comets and has discovered two numbered minor planets. (M 41035)

\section{(14535) Kazuyukihanda}

1997 RF. Discovered 1997 Sept. 1 by H. Abe at Yatsuka.

Kazuyuki Handa (1926- ) is a member of the Sakurae Tenmon Doukoukai who popularizes astronomy in Shimane prefecture. He established "Chiisana Shizenkan" (The Small Nature Museum) at Sakurae, where he spreads his message of learning through nature. (M 42362)

\section{(14539) Clocke Roeland}

1997 RU9. Discovered 1997 Sept. 10 by T. Pauwels at Uccle.

Klokke Roeland (or 'Clocke Roeland', using the historic spelling) is the storm bell that is the symbol of the independent spirit of the city of Ghent \{see planet (9473)\}. The name in fact refers to three successive bells, cast in 1314, 1660 and 1948 respectively. (M 46683)

\section{(14542) Karitskaya}

1997 SW $_{9}$. Discovered 1997 Sept. 29 by R. A. Tucker at Tucson.
Eugenia Alexeevna Karitskaya (1947- ) is an astronomer at the Sternberg Astronomical Institute in Moscow and a specialist in the study of $\mathrm{x}$-ray variable stars. Among many accomplishments, she contributed to the compilation of the General Catalogue of Variable Stars. (M 42362)

\section{(14543) Sajigawasuiseki}

$1997 \mathrm{SF}_{11}$. Discovered 1997 Sept. 28 at the Saji Observatory at Saji.

Sajigawa-suiseki is a type of special rock found in the Saji River, which runs through Saji Village. Sajigawa-suiseki is popular and well known among Japanese and is favored for use in gardening, as well as in the making of specialty tray servers. (M 41940)

\section{(14551) Itagaki}

1997 UN $_{8}$. Discovered 1997 Oct. 22 by T. Okuni at Nanyou.

Koichi Itagaki (1947- ), a confectionery manufacturing industry president, is also an amateur astronomer in Yamagata. He is credited with the discovery of supernovae 2001bq and 2001gd. (M 44594)

\section{(14558) Wangganchang}

$1997 \mathrm{WG}_{1}$. Discovered 1997 Nov. 19 at the Beijing Observatory at Xinglong.

Ganchang Wang (1907-1998) was one of the founders of the researches on nuclear physics, cosmic-ray and particle physics in China. He became a member of the Chinese Academy of Sciences in 1955. (M 43192)

\section{(14567) Nicovincenti}

1998 MQ8. Discovered 1998 June 19 by the LINEAR at Socorro.

Nicole Vincenti mentored a finalist in the 2002 Discovery Channel Youth Science Challenge (DCYSC), a middle school science competition. She teaches at the Fairmont Elementary, Sanger, California. (M 46769)

\section{(14568) Zanotta}

1998 OK. Discovered 1998 July 19 by A. Boattini and M. Tombelli at San Marcello Pistoiese.

After early activity on variable stars, Milanese amateur astronomer Mauro Vittorio Zanotta (1963-

) developed a keen interest in hunting for comets. His efforts paid off when he codiscovered comet C/1991 Y1 (Zanotta-Brewington). (M 41386)

\section{(14570) Burkam}

1998 QS $_{37}$. Discovered 1998 Aug. 17 by the LINEAR at Socorro.

Ann Burkam mentored a finalist in the 2002 Discovery Channel Youth Science Challenge (DCYSC), a middle school science competition. She teaches at the Buckeye Valley Middle School, Delaware, Ohio. (M 46769)

\section{(14571) Caralexander}

1998 QC $_{45}$. Discovered 1998 Aug. 17 by the LINEAR at Socorro. 
Carolyn Alexander mentored a finalist in the 2002 Discovery Channel Youth Science Challenge (DCYSC), a middle school science competition. She teaches at the Applegate Middle School, Applegate, Oregon. (M 46769)

\section{(14575) Jamesblanc}

1998 QC $_{92}$. Discovered 1998 Aug. 28 by the LINEAR at Socorro.

James Blanc mentored a finalist in the 2002 Discovery Channel Youth Science Challenge (DCYSC), a middle school science competition. He teaches at the Blennerhassett Junior High, Parkersburg, West Virginia. (M 46769)

\section{(14576) Jefholley}

1998 QO $_{92}$. Discovered 1998 Aug. 28 by the LINEAR at Socorro.

Jeffrey Holley mentored a finalist in the 2002 Discovery Channel Youth Science Challenge (DCYSC), a middle school science competition. He teaches at the St. Peter Chanel Interparochial School, Paulina, Louisiana. (M 46769)

\section{(14582) Conlin}

1998 RK $_{49}$. Discovered 1998 Sept. 14 by the LINEAR at Socorro.

Kimberly Conlin mentored a finalist in the 2002 Discovery Channel Youth Science Challenge (DCYSC), a middle school science competition. She teaches at the Rocky Mountain Middle School, Heber, Utah. (M 46769)

\section{(14583) Lester}

$1998 \mathrm{RN}_{61}$. Discovered 1998 Sept. 14 by the LINEAR at Socorro.

Virginia Lester mentored a finalist in the 2002 Discovery Channel Youth Science Challenge (DCYSC), a middle school science competition. She teaches at the Austin Academy for Excellence, Garland, Texas. (M 46769)

\section{(14584) Lawson}

$1998 \mathrm{RH}_{63}$. Discovered 1998 Sept. 14 by the LINEAR at Socorro.

Melissa Lawson mentored a finalist in the 2002 Discovery Channel Youth Science Challenge (DCYSC), a middle school science competition. She teaches at the Hastings Middle School, Upper Arlington, Ohio. (M 46769)

\section{(14588) Pharrams}

$1998 \mathrm{RH}_{73}$. Discovered 1998 Sept. 14 by the LINEAR at Socorro.

Stacey Pharrams mentored a finalist in the 2002 Discovery Channel Youth Science Challenge (DCYSC), a middle school science competition. She teaches at the Carnegie Mellon University, Pittsburgh, Pennsylvania. (M 46769)

\section{(14594) Jindrašilhán}

1998 SS $_{26}$. Discovered 1998 Sept. 24 by P. Pravec at Ondřejov.

Jindřich Šilhán (1944-2000) was a major contributor to the development of visual observations in the Czech and Slovak Republics. He observed eclipsing binaries and organized a program to monitor them. His former students are some of the leaders of public observatories. (M 41035)

\section{(14613) Sanchez}

$1998 \mathrm{TP}_{2}$. Discovered 1998 Oct. 13 by the OCA-DLR Survey at Caussols.

Christian Sanchez is editor-in-chief of the French astronomy magazine Pulsar. A very nice and gentle person, he has worked with very little help to produce over 100 issues of a magazine that always contains much useful information for the amateur astronomer. (M 41035)

\section{(14617) Lasvergnas}

1998 UA $_{4}$. Discovered 1998 Oct. 21 by the OCA-DLR Survey at Caussols.

Olivier Las Vergnas (1954- ) is a former member of the Association Astronomique de Paris en Sorbonne, founder of the astronomy section of the Association Nationale Sciences Techniques Jeunesse and currently president of the Association Française d'Astronomie. (M 41035)

\section{(14621) Tati}

$1998 \mathrm{UF}_{18}$. Discovered 1998 Oct. 22 by J. Broughton at Reedy Creek.

French comic genius Jacques Tati (1908-1982), a film writer, director and actor, is famous for comedy farces such as Jour De Fête (1946), rich with sound effects but virtually free of dialogue. His brilliant characterization of the quirky Mr. Hulot places him alongside the greats Chaplin and Keaton. (M 42674)

\section{(14627) Emilkowalski}

1998 VA. Discovered 1998 Nov. 7 by R. A. Kowalski at Quail Hollow Observatory.

Emil Kowalski (1918-1994) of Syosset, New York, though not a scientist himself, encouraged and fostered the discoverer's childhood interest in observational astronomy and space technology. (M 43192)

\section{(14632) Flensburg}

1998 VY $_{33}$. Discovered 1998 Nov. 11 by N. Ehring at Bornheim.

Situated at the end of the beautiful firth, Flensburg is the most northern city in Germany. It is a bilingual town at the Danish border and hometown of the discoverer, who lived there for more than 20 years. (M 41386)

\section{(14643) Morata}

1998 WZ $_{30}$. Discovered 1998 Nov. 24 by R. Roy at Blauvac. 
Didier (1954- ) and Stephane (1977- ) Morata observe with a 0.30-m telescope from Martigues, in southern France. They have discovered novae in M31 and minor planets and are now undertaking spectroscopy of Be-type stars. Stephane is studying physics, and Didier is a chemist and editor of the magazine CCD et telescope. (M 41940)

\section{(14659) Gregoriana}

$1999 \mathrm{AF}_{24}$. Discovered 1999 Jan. 15 by M. Tombelli and G. Forti at Montelupo.

The Pontifical Gregorian University dates its origin to the founding of the Roman College in 1551. (M 45338)

The name was suggested by Vatican astronomer G. Consolmagno on the occasion of the 64th meeting of Meteoritical Society in Rome in Sept. 2001.

\section{(14669) Beletic}

1999 DC. Discovered 1999 Feb. 16 by the OCA-DLR Survey at Caussols.

James William Beletic (1956- ), a talented physician, led the European Southern Observatory's Optical Detector Team from 1994 Nov. 1 to 2000 Apr. 27. He contributed to the development of a new CCD controller for astronomy and is now deputy director of the Keck \{see planet (5811)\} Observatories. (M 41035)

\section{(14678) Pinney}

$1999 \mathrm{XN}_{33}$. Discovered 1999 Dec. 6 by the LINEAR at Socorro.

Named in honor of Stacie Pinney for mentoring a finalist in the 2001 Discovery Young Scientist Challenge (DYSC), a middle school science competition. Pinney is a teacher at the Annunciation Catholic Academy, Altamonte, Florida. (M 43686)

\section{(14679) Susanreed}

$1999 \mathrm{XN}_{42}$. Discovered 1999 Dec. 7 by the LINEAR at Socorro.

Named in honor of Susan K. Reed for mentoring a finalist in the 2001 Discovery Young Scientist Challenge (DYSC), a middle school science competition. Reed is a teacher at the Bernalillo Middle School, Bernalillo, New Mexico. (M 43686)

\section{(14683) Remy}

$1999 \mathrm{XG}_{156}$. Discovered 1999 Dec. 8 by the LINEAR at Socorro.

Named in honor of Jennifer M. Remy for mentoring a finalist in the 2001 Discovery Young Scientist Challenge (DYSC), a middle school science competition. Remy is a teacher at the Springville Middle School, Springville, Utah. (M 43686)

\section{(14684) Reyes}

1999 XQ $_{167}$. Discovered 1999 Dec. 10 by the LINEAR at Socorro.

Named in honor of Cynthia L. Reyes for mentoring a finalist in the 2001 Discovery Young Scientist Challenge
(DYSC), a middle school science competition. Reyes is a teacher at the Seven Springs Middle School, New Port Richey, Florida. (M 43686)

\section{(14693) Selwyn}

$2000 \mathrm{AH}_{144}$. Discovered 2000 Jan. 5 by the LINEAR at Socorro.

Named in honor of Marilyn Selwyn for mentoring a finalist in the 2001 Discovery Young Scientist Challenge (DYSC), a middle school science competition. Selwyn is a teacher at the Tanque Verde Elementary School, Tucson, Arizona. (M 43686)

\section{(14694) Skurat}

$2000 \mathrm{AR}_{145}$. Discovered 2000 Jan. 6 by the LINEAR at Socorro.

Named in honor of Sister Karen Skurat for mentoring a finalist in the 2001 Discovery Young Scientist Challenge (DYSC), a middle school science competition. Skurat is a teacher at the St. Rita School, Hamden, Connecticut. (M 43686)

\section{(14696) Lindawilliams}

$2000 \mathrm{AW}_{203}$. Discovered 2000 Jan. 10 by the LINEAR at Socorro.

Named in honor of Linda H. Williams for mentoring a finalist in the 2001 Discovery Young Scientist Challenge (DYSC), a middle school science competition. Williams is a teacher at the Beech Grove Middle School, Beech Grove, Indiana. (M 43686)

\section{(14708) Slaven}

$2000 \mathrm{CU}_{26}$. Discovered 2000 Feb. 2 by the LINEAR at Socorro.

Named in honor of Kathy Slaven for mentoring a finalist in the 2001 Discovery Young Scientist Challenge (DYSC), a middle school science competition. Slaven is a teacher at the Beech Grove Middle School, Beech Grove, Indiana. (M 43686)

\section{(14719) Sobey}

$2000 \mathrm{CB}_{85}$. Discovered 2000 Feb. 4 by the LINEAR at Socorro.

Named in honor of Glen Sobey for mentoring a finalist in the 2001 Discovery Young Scientist Challenge (DYSC), a middle school science competition. Sobey is a teacher at the Keystone Junior High School, San Antonio, Texas. (M 43686)

\section{(14734) Susanstoker}

$2000 \mathrm{DZ}_{78}$. Discovered 2000 Feb. 29 by the LINEAR at Socorro.

Named in honor of Susan L. Stoker for mentoring a finalist in the 2001 Discovery Young Scientist Challenge (DYSC), a middle school science competition. Stoker is a teacher at the Edgewood Middle School, Moriarty, New Mexico. (M 43686) 


\section{(14790) Beletskij}

1970 OF. Discovered 1970 July 30 by T. M. Smirnova at Nauchnyj.

Vladimir Vasil'evich Beletskij (1930- ), a corresponding member of the Russian Academy of Sciences and professor of Moscow University, is a prominent expert in celestial mechanics and spaceflight theory. He developed a nonlinear theory for the rotation and orientation of natural celestial bodies and artificial satellites. (M 44186)

\section{(14791) Atreus}

1973 SU. Discovered 1973 Sept. 19 by C. J. van Houten and I. van Houten-Groeneveld at Palomar.

Atreus was the son of Pelops, father of Agamemnon \{see planet (911)\} and Menelaos \{see planet (1647)\} and brother of Thyestes \{see planet (14792)\}. (M 42363)

\section{(14792) Thyestes}

1973 SG 1 . Discovered 1973 Sept. 24 by C. J. van Houten and I. van Houten-Groeneveld at Palomar.

Thyestes was the son of Pelops and brother of Atreus \{see planet (14791)\}. Atreus killed the children of Thyestes and gave them to Thyestes to eat. Because of this Thyestes cursed the family of Atreus. (M 42363)

\section{(14814) Gurij}

$1981 \mathrm{RL}_{2}$. Discovered 1981 Sept. 7 by L. G. Karachkina at Nauchnyj.

Gurij Timofeevich Petrovsky (1931- ), director of the Vavilov State Optical Institute and president of the Rozhdestvensky International Optical Society, is a leader in the study of the physics, chemistry and technology of optical materials. He is the author of pioneering works in fiber optics and cosmic technologies. (M 43192)

\section{(14815) Rutberg}

$1981 \mathrm{TH}_{3}$. Discovered 1981 Oct. 7 by T. M. Smirnova at Nauchnyj.

Filipp Grigor'evich Rutberg (1931- ), a prominent expert in electrophysics, is director of the Institute of Problems of Electrophysics in St. Petersburg. He is widely known for investigations of powerful discharges in dense gas media, non-equilibrium processes in plasma streams and for the design of new electrophysical equipment. (M 45338)

\section{(14826) Nicollier}

1985 SC $_{1}$. Discovered 1985 Sept. 16 by P. Wild at Zimmerwald.

Born in Vevey, Switzerland, Claude Nicollier (1944-

) studied astronomy in Lausanne and became the first European mission specialist of NASA. Astronomers owe him special thanks for his decisive part in the success of both servicing missions on the Hubble Space Telescope. (M 41386; M 41615)

\section{(14831) Gentileschi}

1987 BS $_{1}$. Discovered 1987 Jan. 22 by E. W. Elst at La Silla.

Artemisia Gentileschi (1593-1652), the only daughter of the Italian painter Orazio Gentileschi, became famous herself through paintings such as "Self-Portrait as the Allegory of Painting" and frieze "Inclinazione". Her paintings of powerful women struggling against male dominance were not appreciated by the male aristocracy. (M 41386)

\section{(14832) Alechinsky}

$1987 \mathrm{QC}_{3}$. Discovered 1987 Aug. 27 by E. W. Elst at La Silla.

Belgian painter Pierre Alechinsky (1927- ） founded the expressionist movement "CoBrA", a name linking the cities of Copenhagen, Brussels and Amsterdam. One of the leading artists in mid-century Europe, he is well known for his treatment of colors ("Walking Blue"), graphic humor and versatility in media and techniques. (M 41387)

\section{(14835) Holdridge}

$1987 \mathrm{WF}_{1}$. Discovered 1987 Nov. 26 by C. S. Shoemaker and E. M. Shoemaker at Palomar.

Mark E. Holdridge (1960- ) is an operations manager at the Applied Physics Laboratory of Johns Hopkins University. His skillful guidance of the small NEAR Shoemaker Mission Operations team since 1997 resulted in nearly all of the spacecraft's spectacular science return from (253) Mathilde and (433) Eros. (M 42674)

\section{(14836) Maxfrisch}

1988 CY. Discovered 1988 Feb. 14 by F. Börngen at Tautenburg.

Swiss writer and playwright Max Frisch (1911-1991) produced an extensive and multiformed body of work. His cardinal theme was the relationship of individuals to themselves and their environment. His dramas Biedermann und die Brandstifter, Andorra and Stiller show problems of the present. (M 41035)

\section{(14845) Hegel}

$1988 \mathrm{VS}_{6}$. Discovered 1988 Nov. 3 by F. Börngen at Tautenburg.

Georg Wilhelm Friedrich Hegel (1770-1831) is a very important philosopher of German idealism. The method and content of his thinking is the dialectic. He lectured at Jena \{see planet (526)\} during 1801-1807. $\mathrm{He}$ had great influence during the nineteenth and twentieth centuries, and many later philosophers refer to him. (M 41035)

\section{(14846) Lampedusa}

1989 BH. Discovered 1989 Jan. 29 at the Osservatorio San Vittore at Bologna.

Italian writer Giuseppe Tomasi di Lampedusa (18961957) is famous for Il Gattopardo, whose fictional protagonist, Prince Fabrizio Salina, modeled on the 
author's own grandfather, was an amateur astronomer who discovered and named minor planets "Salina" in honor of his family and "Svelto" in memory of his favorite dog. (M 41940)

\section{(14872) Hoher List}

1990 UR. Discovered 1990 Oct. 23 by E. W. Elst at Hoher List.

The Observatory of Hoher List, in the Ardennes near Daun (Eifel), was established in 1957 by the University of Bonn since light pollution had precluded astronomical observations at the Alte Sternwarte on Poppelsdorfer Allee. (M 45748)

\section{(14873) Shoyo}

$1990 \mathrm{UQ}_{2}$. Discovered 1990 Oct. 28 by K. Kawanishi and M. Sugano at Minami-Oda.

Shoyo Senior High School in Takasago has departments in home economics, commercial studies and general education. Shoyo means the evergreen pine tree and the glorious sun. To be spirited, progressive, autonomous and cooperative is the motto of this comprehensive school, of which the second discoverer is a graduate. (M 41387)

\section{(14902) Miyairi}

$1993 \mathrm{BE}_{2}$. Discovered 1993 Jan. 17 by Y. Kushida and O. Muramatsu at Yatsugatake.

Keinosuke Miyairi (1865-1946), of Kyushu Imperial University, a pioneer in epidemiology, discovered that the snail now called "Miyairi-gai" is an intermediate host for transmission of shistosoma japonicum infection. This enabled schistosomiasis to be controlled. (M 41387)

The name was suggested by S. Murayama and O. Muramatsu.

\section{(14919) Robertohaver}

1994 PG. Discovered 1994 Aug. 6 by A. Boattini and M. Tombelli at San Marcello Pistoiese.

Roberto Haver (1961- ) is an Italian amateur astronomer who has been actively involved in observing and studying comets and meteors for more than 20 years. He planned a search for comet 109P/Swift-Tuttle in 1992 with the Schmidt telescope at Cima Ekar and later found prerecovery images. (M 42674)

\section{(14939) Norikura}

1995 DG $_{1}$. Discovered 1995 Feb. 21 by A. Nakamura at Kuma.

Mt. Norikura (3026 m high), part of the northern Japan Alps, is an extinct volcano, located at the boundary of Nagano and Gifu prefectures. Its ninth stage, "Tatamidaira", Japan's highest site reachable by car, is visited by many astrophotographers. The Norikura Solar Observatory is located at one of its peaks. (M 41387)

\section{(14940) Freiligrath}

1995 EL $_{8}$. Discovered 1995 Mar. 4 by F. Börngen at Tautenburg.
The German poet Ferdinand Freiligrath (1810-1876) pleaded in his poetry for democratic and social reforms and for liberty. Because he yearned for a national uprising, he was shadowed at times. At the end of his life, in Bismarck's \{see planet (7586)\} time, he became a patriotic poet. (M 41035)

\section{(14947) Luigibussolino}

$1996 \mathrm{AB}_{4}$. Discovered 1996 Jan. 15 by M. Tombelli and U. Munari at Cima Ekar.

Italian aerospace engineer Luigi Bussolino (1947- ) has played a leading role in developing the integrated system IMPACT (International Monitoring Program for Asteroid and Comet Threat) and in designing STONES (Satellite To Observe Near Earth Object Spectra). (M 41035)

\section{(14953) Bevilacqua}

$1996 \mathrm{CB}_{3}$. Discovered 1996 Feb. 13 by M. Tombelli and G. Forti at Asiago.

Franco Bevilacqua (1937- ) is an Italian space engineer. His work since 1961 has been to promote space missions and to implement astrometric projects. In particular, he was involved with the Hipparcos mission and missions such as Giotto \{see planet (7367)\} to investigate minor planets and comets. (M 44594)

\section{(14960) Yule}

1996 KO. Discovered 1996 May 21 by P. G. Comba at Prescott.

George Udny Yule (1871-1951), statistician, lecturer at University College, London, and fellow of St. John's College, Cambridge, worked on regression and correlation, time series and epidemiology. His book A Statistical Study of Literary Style (1944) was a pioneering endeavor at a quantitative analysis of literary style. (M 41035)

\section{(14964) Robertobacci}

1996 VS. Discovered 1996 Nov. 2 by L. Tesi and G. Cattani at San Marcello Pistoiese.

Roberto Bacci (1965- ), an active amateur astronomer since his adolescence, has turned his primary interest to variable stars and meteors. (M 42674)

\section{(14965) Bonk}

1997 KC. Discovered 1997 May 24 by N. Ehring at Bornheim.

Werner Bonk (1923- ) is a German engineer and amateur astronomer who has measured several hundred positions of minor planets. He introduced the discoverer to astrometry and provided him with assistance and encouragement for many years. (M 41387)

\section{(14966) Jurijvega}

$1997 \mathrm{OU}_{2}$. Discovered 1997 July 30 by H. Mikuž at Črni Vrh.

Jurij Vega (1754-1802), Slovenian mathematician and military engineer, is known for his logarithmic and trigonometric tables, which were used worldwide 
until the start of computer era. This naming is on the occasion of the 100th anniversary of Jurij Vega Grammar School in Idrija, which was attended by the discoverer. (M 42674)

\section{(14967) Madrid}

$1997 \mathrm{PF}_{4}$. Discovered 1997 Aug. 6 by A. Lopez and R. Pacheco at Mallorca.

Madrid, capital city of Spain, is the birthplace and hometown of the second discoverer. (M 41387)

\section{(14968) Kubáček}

1997 QG. Discovered 1997 Aug. 23 by A. Galád and A. Pravda at Modra.

Dalibor Kubáček (1957- ) worked at the Slovak Academy of Sciences in Bratislava, where he studied the structure of cometary comae by means of image processing. He willingly taught students and friends (including the discoverers) and helped to explain to them this relatively unknown procedure. (M 45339)

\section{(14969) Willacather}

1997 QC $_{1}$. Discovered 1997 Aug. 28 by R. Linderholm at Lime Creek.

Born in Virginia, the novelist and Pulitzer Prizewinner Willa Cather (1873-1947) moved to Nebraska in 1883 . Her early life on the prairie and sympathy for the immigrant pioneer influenced her mature years and shows in her best-known novels, My Antonia and Death Comes for the Archbishop. (M 41387)

\section{(14972) Olihainaut}

$1997 \mathrm{QP}_{3}$. Discovered 1997 Aug. 30 by the OCA-DLR Survey at Caussols.

Belgian astronomer Olivier Hainaut (1966- ) is a specialist on distant comets and transneptunian objects. An active observer and recoverer of several comets, he now heads the New Technology Telescope of the European Southern Observatory in La Silla. (M 45338)

\section{(14973) Rossirosina}

1997 RZ. Discovered 1997 Sept. 1 by A. Boattini at San Marcello Pistoiese.

Rosina Rossi Boattini (1934- ) is the mother of the discoverer. (M 41572)

\section{(14974) Počátky}

1997 SK $_{1}$. Discovered 1997 Sept. 22 by M. Tichý at Kleť.

Počátky is the south Bohemian town where the discoverer was born. (M 41572)

\section{(14975) Serasin}

$1997 \mathrm{SA}_{3}$. Discovered 1997 Sept. 24 at the Farra d'Isonzo Observatory at Farra d'Isonzo.

Antonietta Serasin (1957- ) is an amateur astronomer who lives in Padua. (M 46683)

\section{(14976) Josefčapek}

1997 SD $_{4}$. Discovered 1997 Sept. 27 by P. Pravec at Ondřejov.

Josef Čapek (1887-1945) was a Czech artist with wide interests, including painting, graphic arts and writing, authoring stories for children and coauthoring dramas together with his brother Karel. Part of his art was influenced by the growing threat posed by the fascists to Czechoslovakia in the 1930s. (M 42674)

\section{(14977) Bressler}

$1997 \mathrm{SE}_{4}$. Discovered 1997 Sept. 26 by E. Meyer at Linz.

Austrian amateur astronomer Martin Bressler (1912-

) started his astrometric program on minor planets in 1982. Always eager to learn new techniques, he enthusiastically switched from photographic emulsions to a CCD in 1993. (M 41387)

\section{(14990) Zermelo}

1997 UY $_{10}$. Discovered 1997 Oct. 31 by P. G. Comba at Prescott.

Ernst F. F. Zermelo (1871-1953), German mathematician, was mainly interested in the calculus of variations. He is best remembered for his formulation of the axiom of choice: given any (possibly infinite) collection of non-empty sets, there exists a set having one element in common with each set in the collection. (M 41035)

\section{(14995) Archytas}

1997 VY $_{1}$. Discovered 1997 Nov. 5 by P. G. Comba at Prescott.

Archytas (ca. 428-365 B.C.) was a philosopher and mathematician of the Pythagorean s see planet (6143)\} school. He is believed to have established the quadrivium (arithmetic, geometry, music, astronomy), which together with the trivium (grammar, rhetoric, dialectics) was the foundation of classical education. (M 41572)

\section{(15000) CCD}

$1997 \mathrm{WZ}_{16}$. Discovered 1997 Nov. 23 by the Spacewatch at Kitt Peak.

A charge-coupled device, a two-dimensional array of light-sensitive microelectronic semiconductor capacitors, is used as an imaging detector. With its high sensitivity and stability, the CCD has almost completely replaced the photographic emulsion and photomultiplier as the detector of choice in quantitative scientific work. (M 41572)

\section{(15003) Midori}

$1997 \mathrm{XC}_{10}$. Discovered 1997 Dec. 5 by T. Kobayashi at Oizumi.

Midori Goto (1971- ) is an extremely talented violinist, and she has also contributed much to musical education for children. In July 2002, on the 20th anniversary of her international debut, she will give a series of recitals entitled Total Experience. (M 45339) 
(15008) Delahodde

$1998 \mathrm{QO}_{6}$. Discovered 1998 Aug. 24 by the OCA-DLR Survey at Caussols.

French astronomer Catherine Delahodde (1974- ), an active observer and recoverer of several comets, has been at the European Southern Observatory in La Silla for the past years. (M 45339)

\section{(15034) Décines}

1998 WH. Discovered 1998 Nov. 16 by M. Tombelli and L. Tesi at San Marcello Pistoiese.

Décines is a French town to the west of Lione and twinned with the municipality of Monsummano Terme, native city of second discoverer, and in which the amateur association Alepieri is very active in the popularization of astronomy. (M 45339)

\section{(15036) Giovannianselmi}

1998 WO $_{5}$. Discovered 1998 Nov. 18 at the Madonna di Dossobuono Observatory at Madonna di Dossobuono.

Giovanni Anselmi is the founder and director of an Italian magazine on astronomy. In his leading article each month he extols astronomy as having a poetic soul, which motivates people to admire the heavens. (M 42363)

\section{(15037) Chassagne}

$1998 \mathrm{WN}_{6}$. Discovered 1998 Nov. 22 at the Village-Neuf Observatory at Village-Neuf.

Robin Chassagne (1962- ), a computer engineer for the French Meteorologie Nationale in La Réunion is known for his supernova discoveries, of which there are now ten. (M 45339)

\section{(15041) Paperetti}

1998 XB $_{5}$. Discovered 1998 Dec. 8 by L. Tesi and A. Boattini at San Marcello Pistoiese.

Emiliano Paperetti (1951- ) is an amateur astronomer who lives in the Tuscan city of Pistoia. Among his primary interests there is the development of astronomical software that also served the team involved in research on minor planets at San Marcello Pistoiese. (M 43046)

\section{(15042) Anndavgui}

1998 XZ $_{8}$. Discovered 1998 Dec. 14 by J.-C. Merlin at Le Creusot.

The discoverer's spouse Annick (1953- ), and their two sons David (1985- ) and Guillaume (1989- ), are all musicians, playing the violin, trumpet and French horn, respectively. They provide strong support to the discoverer in his astronomical activity. Annick is also a teacher of French literature and a famous astrophotographer. (M 41035)

\section{(15052) Emileschweitzer}

1998 YD $_{2}$. Discovered 1998 Dec. 17 by the OCA-DLR Survey at Caussols.

Emile Schweitzer (1923- ） was for 25 years president of the Association Française des Etoiles Variables.
He collected and checked more than a million visual estimates of variable stars for the association's quarterly bulletin and worked with much dedication to develop this useful field of amateur astronomy. (M 45748)

\section{(15053) Bochníček}

$1998 \mathrm{YY}_{2}$. Discovered 1998 Dec. 17 by P. Pravec and U. Babiaková at Ondřejov.

Záviš Bochníček (1920- ）, a Czech astronomer living in Slovakia, worked on photographic observations of artifical satellites and computed their orbits. He discovered two novae and popularizes astronomy and cosmonautics. During 1956-1958 he was a director of the Astronomical Institute in Tatranská Lomnica. (M 41035)

\section{(15056) Barbaradixon}

$1998 \mathrm{YP}_{12}$. Discovered 1998 Dec. 28 by D. S. Dixon at Las Cruces.

Barbara Dixon is a talented software developer and engineer. It is only with her support that the work at the Jornada Observatory, Las Cruces, is possible. (M 41035)

\section{(15072) Landolt}

1999 BS $_{12}$. Discovered 1999 Jan. 25 by W. R. Cooney Jr and P. M. Motl at Baton Rouge.

Through four decades of meticulous observations, Arlo U. Landolt (1935- ) has established the widely used Landolt Photometric Standard Stars. Professor at Louisiana State University, he was secretary of the American Astronomical Society during 1980-1989 and since 1995, the year he received its Van Biesbroeck \{see planet (1781)\} Award. (M 41387)

\section{(15077) Edyalge}

1999 CA. Discovered 1999 Feb. 2 by S. Sposetti at Gnosca.

The Swiss amateur astronomer Edy Alge (1934- ) has built many homemade telescopes of various sizes and spent most of his time expressing enthusiasm for the science of astronomy. (M 41035)

\section{(15092) Beegees}

$1999 \mathrm{EH}_{5}$. Discovered 1999 Mar. 15 by J. Broughton at Reedy Creek.

U.K.-born recording artists Barry, Robin and Maurice Gibb, of BeeGees fame, and soloist brother Andy (19581988) were raised in Australia only $100 \mathrm{~km}$ from the discovery site of this minor planet. The phenomenal success of the BeeGees can be attributed to their renowned harmonies and songwriting ability. (M 42674)

\section{(15099) Janestrohm}

$2000 \mathrm{AE}_{92}$. Discovered 2000 Jan. 5 by the LINEAR at Socorro.

Named in honor of Jane Strohm for mentoring a finalist in the 2001 Discovery Young Scientist Challenge (DYSC), a middle school science competition. Strohm 
is a teacher at the Pistor Middle School, Tucson, Arizona. (M 43686)

\section{(15106) Swanson}

$2000 \mathrm{CA}_{45}$. Discovered 2000 Feb. 2 by the LINEAR at Socorro.

Named in honor of Marie Swanson for mentoring a finalist in the 2001 Discovery Young Scientist Challenge (DYSC), a middle school science competition. Swanson is a teacher at the Van Wyck Junior High School, Wappingers Falls, New York. (M 43686)

\section{(15107) Toepperwein}

$2000 \mathrm{CR}_{49}$. Discovered 2000 Feb. 2 by the LINEAR at Socorro.

Named in honor of Mary Anne J. Toepperwein for mentoring a finalist in the 2001 Discovery Young Scientist Challenge (DYSC), a middle school science competition. Toepperwein is a teacher at the William $\mathrm{P}$. Hobby Middle School, San Antonio, Texas. (M 43686)

\section{(15109) Wilber}

$2000 \mathrm{CW}_{61}$. Discovered 2000 Feb. 2 by the LINEAR at Socorro.

Named in honor of Harold T. Wilber for mentoring a finalist in the 2001 Discovery Young Scientist Challenge (DYSC), a middle school science competition. Wilber is a teacher at the Franklin Middle School, Springfield, Illinois. (M 43686)

\section{(15111) Winters}

$2000 \mathrm{CY}_{92}$. Discovered 2000 Feb. 6 by the LINEAR at Socorro.

Named in honor of Marlene K. Winters for mentoring a finalist in the 2001 Discovery Young Scientist Challenge (DYSC), a middle school science competition. Winters is a teacher at the International Montessori School, Venice, Florida. (M 43686)

\section{(15112) Arlenewolfe}

$2000 \mathrm{CY}_{94}$. Discovered 2000 Feb. 8 by the LINEAR at Socorro.

Named in honor of Arlene E. Wolfe for mentoring a finalist in the 2001 Discovery Young Scientist Challenge (DYSC), a middle school science competition. Wolfe is a teacher at the Venerini Academy, Worcester, Massachusetts. (M 43686)

\section{(15115) Yvonneroe}

$2000 \mathrm{DA}_{7}$. Discovered 2000 Feb. 29 by J. M. Roe at Oaxaca.

Yvonne Josephine (Rump) Roe (1935- ） is the wife of the discoverer. (M 41387)

\section{(15118) Elizabethsears}

2000 DP $_{82}$. Discovered 2000 Feb. 28 by the LINEAR at Socorro.

Named in honor of Elizabeth R. Sears for achievement as a finalist in the 2001 Discovery Young Scientist Challenge (DYSC), a middle school science competition.
Elizabeth is a student at the All Saints Episcopal School, Lubbock, Texas. (M 43687)

\section{(15120) Mariafélix}

2000 ES. Discovered 2000 Mar. 4 by J. J. Gómez at Marxuquera.

Maria Jesús Albors Félix (1965- ） is the wife of the discoverer. This naming is in acknowledgment of her support, patience and understanding in accommodating the discoverer's work in observing minor planets. (M 41387)

\section{(15126) Brittanyanderson}

2000 EA $_{44}$. Discovered 2000 Mar. 8 by the LINEAR at Socorro.

Named in honor of Brittany L. Anderson for achievement as a finalist in the 2001 Discovery Young Scientist Challenge (DYSC), a middle school science competition. Brittany is a student at the House Junior High School, House, New Mexico. (M 43687)

\section{(15128) Patrickjones}

$2000 \mathrm{EG}_{46}$. Discovered 2000 Mar. 9 by the LINEAR at Socorro.

Named in honor of Patrick K. Jones for achievement as a finalist in the 2001 Discovery Young Scientist Challenge (DYSC), a middle school science competition. Patrick is a student at the St. Michael Parish School, Wheeling, West Virginia. (M 43687)

\section{(15129) Sparks}

$2000 \mathrm{ET}_{47}$. Discovered 2000 Mar. 9 by the LINEAR at Socorro.

Named in honor of Branson B. Sparks for achievement as a finalist in the 2001 Discovery Young Scientist Challenge (DYSC), a middle school science competition. Branson is a student at the Alexandria Country Day School, Alexandria, Louisiana. (M 43687)

\section{(15132) Steigmeyer}

2000 EZ $_{69}$. Discovered 2000 Mar. 10 by the LINEAR at Socorro.

Named in honor of August J. Steigmeyer for achievement as a finalist in the 2001 Discovery Young Scientist Challenge (DYSC), a middle school science competition. August is a student at the Canterbury School, Ft. Wayne, Indiana. (M 43687)

\section{(15133) Sullivan}

$2000 \mathrm{~EB}_{91}$. Discovered 2000 Mar. 9 by the LINEAR at Socorro.

Named in honor of Cole J. Sullivan for achievement as a finalist in the 2001 Discovery Young Scientist Challenge (DYSC), a middle school science competition. Cole is a student at the Oslo Middle School, Vero Beach, Florida. (M 43687)

\section{(15139) Connormcarty}

$2000 \mathrm{EY}_{93}$. Discovered 2000 Mar. 9 by the LINEAR at Socorro. 
Named in honor of Connor W. McCarty for achievement as a finalist in the 2001 Discovery Young Scientist Challenge (DYSC), a middle school science competition. Connor is a student at the Mesa Union Junior High School, Somis, California. (M 43687)

\section{(15144) Araas}

$2000 \mathrm{EK}_{114}$. Discovered 2000 Mar. 9 by the LINEAR at Socorro.

Named in honor of Michael J. Araas for achievement as a finalist in the 2001 Discovery Young Scientist Challenge (DYSC), a middle school science competition. Michael is a student at the Holy Name School, Sheridan, Wyoming. (M 43687)

\section{(15145) Ritageorge}

$2000 \mathrm{EF}_{117}$. Discovered 2000 Mar. 10 by the LINEAR at Socorro.

Named in honor of Rita M. George for achievement as a finalist in the 2001 Discovery Young Scientist Challenge (DYSC), a middle school science competition. Rita is a student at the Manhattan Beach Middle School, Manhattan Beach, California. (M 43687)

\section{(15155) Ahn}

$2000 \mathrm{FB}_{37}$. Discovered 2000 Mar. 29 by the LINEAR at Socorro.

Named in honor of Ryan J. Ahn for achievement as a finalist in the 2001 Discovery Young Scientist Challenge (DYSC), a middle school science competition. Ryan is a student at the Landisville Middle School, Landisville, Pennsylvania. (M 43687)

\section{(15160) Wygoda}

$2000 \mathrm{FK}_{44}$. Discovered 2000 Mar. 29 by the LINEAR at Socorro.

Named in honor of Jennifer A. Wygoda for achievement as a finalist in the 2001 Discovery Young Scientist Challenge (DYSC), a middle school science competition. Jennifer is a student at the F. K. White Middle School, Lake Charles, Louisiana. (M 43687)

\section{(15228) Ronmiller}

1987 DG. Discovered 1987 Feb. 23 by C. S. Shoemaker and E. M. Shoemaker at Palomar.

Ron Miller (1955- ) is a forester for the Bureau of Indian Affairs. He maintains woodland areas and cultural resources for Native Americans. He runs sled dogs in Alaska, Colorado and Arizona and is a teacher and mentor for those entering the sport of dog sledding. (M 46011)

\section{(15230) Alona}

$1987 \mathrm{RF}_{1}$. Discovered 1987 Sept. 13 by H. Debehogne at La Silla.

Alona (1997- ) is a daughter of Valentina Arkadievna Andreichenko, who performed the reductions for astrometric measurements by the discoverer and served as translator for the Tomsk-Uccle Observational Program. (M 45234)

\section{(15262) Abderhalden}

$1990 \mathrm{TG}_{4}$. Discovered 1990 Oct. 12 by F. Börngen and L. D. Schmadel at Tautenburg.

Swiss physiologist Emil Abderhalden (1877-1950) lectured at the University of Halle during 19111945. He contributed more than 1000 articles to the physiologic chemistry of metabolism, created the basis of modern dietetics, discovered the defensive enzymes against exogenous proteins and promoted social welfare. (M 41387)

\section{(15264) Delbrück}

1990 TU $_{11}$. Discovered 1990 Oct. 11 by F. Börngen and L. D. Schmadel at Tautenburg.

German-born biophysicist Max Delbrück (1906-1981), who moved to the U.S. in 1937, was a cofounder of modern molecular biology and virus research. In 1969 he was a co-recipient of the Nobel Prize in medicine for the discovery of the genetic recombination of bacteriophages. (M 41387)

The name was suggested by the first discoverer.

\section{(15276) Diebel}

1991 GA $_{10}$. Discovered 1991 Apr. 14 by C. S. Shoemaker and D. H. Levy at Palomar.

John Diebel (1943- ) is a lifelong amateur astronomer and telescope enthusiast. Thanks largely to his vision in making complex optics and computer electronics available to many, Diebel has made a significant contribution towards encouraging the public to enjoy the night sky. (M 41940)

\section{(15282) Franzmarc}

$1991 \mathrm{RX}_{4}$. Discovered 1991 Sept. 13 by F. Börngen and L. D. Schmadel at Tautenburg.

Expressionist painter and graphic artist Franz Marc (1880-1916) created an individual style, especially with animal representations. He invented geometrized and rhythmically arranged image composition. He co-founded the group "Der blaue Reiter" in Munich in 1911. (M 41387)

The name was suggested by the first discoverer.

\section{(15294) Underwood}

1991 VD $_{5}$. Discovered 1991 Nov. 7 by C. S. Shoemaker and D. H. Levy at Palomar.

Building plans examiner Lynn Underwood (1949-

) of Vail, Arizona, has completed successful and innovative designs of two major extensions to the Jarnac Observatory, thus enabling it to redouble its observations and join in an expanded public observing program with Dean Koenig \{see planet (15321)\} and "Starizona". (M 41572)

\section{(15304) Wikberg}

1992 UX $_{4}$. Discovered 1992 Oct. 21 by C. S. Shoemaker and E. M. Shoemaker at Palomar.

Leonard Wikberg III (1959- ) is a well-known planetary animator and the creator of extraordinary space images. As a graphics artist, he has helped to 
produce programs for Canadian, English, German and Japanese television. His web site is a repository for information on cratering. (M 45339)

\section{(15318) Innsbruck}

$1993 \mathrm{KX}_{1}$. Discovered 1993 May 24 by C. S. Shoemaker at Palomar.

Innsbruck, capital of Tyrol \{see planet (6439)\} in the heart of the Alps on the great route from Italy, has a history deeply connected with the Habsburg dynasty. This city in western Austria lays claim to the 1936 Nobel prizewinner V. F. Hess and hosted two winter Olympic games. (M 42363)

The name was suggested by $P$. Teutsch and R. Weinberger.

\section{(15321) Donnadean}

$1993 \mathrm{PE}_{8}$. Discovered 1993 Aug. 13 by C. S. Shoemaker and D. H. Levy at Palomar.

With his wife Donna, Dean Koenig (1956- ) has devoted years to inspiring people to become interested in the night sky. Through observing sessions and other facilities of his store "Starizona", located in Tucson, Arizona, Koenig has a fine record of restoring and repairing telescopes. (M 41572)

\section{(15329) Sabena}

$1993 \mathrm{SN}_{7}$. Discovered 1993 Sept. 17 by E. W. Elst at La Silla.

Sabena was the National Belgian airline but had to stop its activities due to financial problems. This minor planet is dedicated to the flight crews and ground personnel, who did a marvelous job during all the years Sabena was flying. (M 45748)

\section{(15342) Assisi}

1994 GD $_{10}$. Discovered 1994 Apr. 3 by F. Börngen at Tautenburg.

Assisi is the birthplace of St. Franciscus (1181?1226; St. Francis, originally Giovanni Bernardone). He founded the first begging order. The Franciscans are bound to serve and preach worldwide, living in poverty and penance. They wandered barefoot, clothed in a brown cowled habit and white cord. (M 41387)

\section{(15346) Bonifatius}

$1994 \mathrm{RT}_{11}$. Discovered 1994 Sept. 2 by F. Börngen at Tautenburg.

Anglo-Saxon Benedictine monk Bonifatius (674?-754; Boniface, originally Wynfrieth) was sent as a missionary to the Teutons. He christianized Frisians, Thuringians and Hessians, established numerous bishoprics and became "Apostle of Germany". Slain by the heathen Frisians, he was interred in Fulda and later sanctified. (M 41387)

\section{(15350) Naganuma}

$1994 \mathrm{VB}_{2}$. Discovered 1994 Nov. 3 by Y. Kushida and O. Muramatsu at Yatsugatake.
Naganuma, Hokkaido, has for many years promoted the arts at the "Artists Atelier Village", with more than 20 workshops. The Naganuma Library has sponsored an exhibition of cloisonne works by $\mathrm{N}$. Iizawa to commemorate the 250th anniversary of the birth of Caroline Herschel. (M 41387)

The name was suggested by S. Kimura.

\section{(15370) Kanchi}

1996 NW. Discovered 1996 July 15 by A. Nakamura at Kuma.

Kanji Nagao, whose nickname is Kanchi, is the hero in Tokyo Love Story, originally a cartoon written by Fumi Saimon, and broadcast as a TV drama in 1991. (M 41388)

\section{(15374) Teta}

1997 BG. Discovered 1997 Jan. 16 by M. Tichý and Z. Moravec at Kleť

The second daughter of prince Krok ssee planet (3102)\}, known from old Bohemian myths, Teta served as a fortune-teller and heathen priestess. (M 41573)

\section{(15376) Marták}

$1997 \mathrm{CT}_{1}$. Discovered 1997 Feb. 1 by P. Kolény and L. Kornoš at Modra.

Ján Marták (1912-1945), a relative of the first discoverer, was a talented and dedicated teacher in the Slovak village Bzince pod Javorinou. He was known as a musician, public works organizer and stage director. (M 46683)

\section{(15378) Artin}

$1997 \mathrm{PJ}_{2}$. Discovered 1997 Aug. 7 by P. G. Comba at Prescott.

Emil Artin (1898-1962) was an Austrian-German mathematician who lived for some years in the United States and made important contributions to abstract algebra, including the theories of rings and of braids. (M 41573)

\section{(15381) Spadolini}

1997 RB $_{1}$. Discovered 1997 Sept. 1 by V. Goretti at Pianoro.

Mauro (1941- ) and Barbara (1944- ) Spadolini, long-standing friends of the discoverer, are dedicated secondary-school teachers who believe in crosscurricular work and in developing the human mind by arousing passion for knowledge and exploration. (M 41388)

\section{(15382) Vian}

1997 SN. Discovered 1997 Sept. 20 by L. Šarounová at Ondřejov.

Boris Vian (1920-1959), French writer (L'ecume des jours, L'arrache-coeur), singer (Le déserteur) and jazz musician, also has an interest in astrophysics, electronics and ecology. He links the rules of writing fiction with an intense and imaginative word play. (M 42363)

The name was suggested by J. Montanné. 


\section{(15384) Samková}

$1997 \mathrm{SC}_{4}$. Discovered 1997 Sept. 26 by P. Pravec at Ondřejov.

Filomena Samková (1931- ）, is a cook at the annual summer astronomy camp ("Expedice") held at the Úpice Observatory, Czech Republic. Camp participants have great memories of both the starry night sky and her kitchen. (M 41940)

The name was suggested by participants of the "Expedice Úpice 2000".

\section{(15385) Dallolmo}

$1997 \mathrm{SP}_{4}$. Discovered 1997 Sept. 25 at the Osservatorio San Vittore at Bologna.

With degrees in both law and physics, Umberto Dall'Olmo (1925-1980) was an amateur astronomer who principally observed Jupiter and studied flare stars with Rosino. He was also interested in the history of astronomy and worked as a technician at the University of Bologna's Institute of Astronomy. (M 42363)

\section{(15386) Nicolini}

$1997 \mathrm{ST}_{4}$. Discovered 1997 Sept. 25 at the Madonna di Dossobuono Observatory at Madonna di Dossobuono.

Martino Nicolini, a nuclear engineer, is very active in amateur astronomy. He measures positions of minor planets at the Cavezzo Observatory, near Modena, and has written software for processing CCD images. (M 42363)

\section{(15388) Coelum}

$1997 \mathrm{ST}_{17}$. Discovered 1997 Sept. 27 at the Osservatorio San Vittore at Bologna.

Coelum was one of the most renowned Italian astronomical magazines. Established in 1931 by Guido Horn d'Arturo \{see planet (3744)\}, it was edited by the department of astronomy of the University of Bologna and had more than 4000 subscribers. The magazine ceased publications in 1986. (M 42363)

The citation was prepared by F. Bonoli.

\section{(15389) Geflorsch}

$1997 \mathrm{TL}_{6}$. Discovered 1997 Oct. 2 by the OCA-DLR Survey at Caussols.

Gérard Florsch (1925-1976) was one of the founders of the Groupe de Lorraine of the Société Astronomique de France and the public observatory of Sarreguemines. He was also a pioneer in photoelectric photometry and the construction of telescopes. (M 45748)

\section{(15390) Znojil}

1997 TJ J10 $_{10}$ Discovered 1997 Oct. 6 by P. Pravec at Ondřejov.

Vladimír Znojil (1941- ) developed methods for investigating meteor showers by using large binoculars at several observing stations. He led such studies from the 1960s. More recently he has organized visual observations of comets in the Czech Republic and leads the Czech Society for Interplanetary Matter. (M 41388)

\section{(15392) Budějický}

1997 TO 19 . Discovered 1997 Oct. 11 by L. Šarounová at Ondřejov.

Czech radio astronomer Jaromír Budějický (19191991) was head of the Radio Department of the Ondřejov \{see planet (7204)\} Observatory in the 1950s. There he conducted a solar radio patrol service and contributed to the development of the Ondřejov meteor radar. (M 42675)

\section{(15395) Rükl}

1997 UV. Discovered 1997 Oct. 21 by P. Pravec at Ondřejov.

Czech astronomer Antonín Rükl (1932- ) was a master of mapping. His precise-retouch lunar maps eliminated the disadvantages of photographs, and he was the first to compile images of the moon from different viewing angles into composite maps. He wrote and illustrated a number of popular astronomy books. (M 41388)

\section{(15396) Howardmoore}

$1997 \mathrm{UG}_{2}$. Discovered 1997 Oct. 24 by P. G. Comba at Prescott.

Howard Moore (1943- ) of Chino Valley, Arizona, is an amateur astronomer and accomplished optician who made the $0.25-\mathrm{m}$ telescope with which this minor planet was discovered. (M 41388)

\section{(15397) Ksoari}

1997 UK $_{7}$. Discovered 1997 Oct. 27 at the Starkenburg Observatory at Heppenheim.

The KSO-ARI Minor Planet Surveys were conducted by F. Börngen \{see planet (3859)\} (Karl-SchwarzschildObservatorium, Tautenburg) and L. D. Schmadel \{see planet (2234)\} (Astronomisches Rechen-Institut, Heidelberg) with the Tautenburg Schmidt Telescope between 1990 and 1993. The surveys resulted in 501 discoveries of minor planets. (M 41388)

\section{(15399) Hudec}

1997 VE. Discovered 1997 Nov. 2 by J. Tichá and M. Tichý at Klě́.

René Hudec (1951- ), an Ondřejov astronomer who works in high-energy astrophysics, especially on $\gamma$-ray bursts, has designed spacebased and groundbased experiments. He established the European Observation Network for GRB optical counterparts. (M 42363)

\section{(15403) Merignac}

$1997 \mathrm{VH}_{6}$. Discovered 1997 Nov. 9 by L. Šarounová at Ondřejov.

The city of Merignac in southwestern France has expanded in recent years because of several aeronautics and space industries. However, the city also has a pleasant living environment, preserving trees and vegetation. (M 42363)

The name was suggested by J. Montanné. 


\section{(15415) Rika}

$1998 \mathrm{CA}_{1}$. Discovered 1998 Feb. 4 by A. Nakamura at Kuma.

Rika Akana, girlfriend of Kanchi \{see planet (15370)\}, is the heroine in Tokyo Love Story. Some stories of the TV drama were filmed on location in Kuma Town, where this minor planet was discovered. (M 41388)

\section{(15425) Welzl}

1998 SV $_{26}$. Discovered 1998 Sept. 24 by P. Pravec at Ondřejov.

Jan Welzl (1868-1948), Czech arctic explorer, trader, hunter, inventor, craftsman and adventurer, lived in Novosibirskie Ostrova for three decades. He became internationally known through the books written about his life, such as Thirty Years in Golden North. He authored the manuscript Trip around the World 1893-1898. (M 41388)

\section{(15460) Manca}

1998 YD $_{10}$. Discovered 1998 Dec. 25 by A. Boattini and L. Tesi at San Marcello Pistoiese.

Francesco Manca (1966- ), an amateur astronomer at the Sormano Astronomical Observatory, has made several observations of potentially hazardous asteroids, computing for each of them future and past close encounters with our planet. (M 41388)

\section{(15467) Aflorsch}

$1999 \mathrm{AN}_{24}$. Discovered 1999 Jan. 15 by the OCA-DLR Survey at Caussols.

Alphonse Florsch (1929- ) was, for many years, the director of the Observatoire de Strasbourg. A specialist in radial velocities in the Small Magellanic Cloud, he was also secretary of the Groupe d'Alsace of the Société Astronomique de France for 20 years. Now retired, he still continues to teach astronomy in schools. (M 45748)

\section{(15495) Bogie}

$1999 \mathrm{DF}_{2}$. Discovered 1999 Feb. 17 by J. Broughton at Reedy Creek.

American actor Humphrey Bogart (1899-1957) appeared on Broadway and was the star of many a Hollywood film. Often cast in the tough-guy role, Bogart won the Academy Award for best actor in 1951 and was voted male star of the twentieth century by the American Film Institute in 1999. (M 42675)

\section{(15497) Lucca}

$1999 \mathrm{DE}_{7}$. Discovered 1999 Feb. 23 by S. Donati at Monte Agliale.

The ancient city of Lucca, on the banks of the river Serchio, is the capital of Tuscany. It is in the center of a very fertile valley and is surrounded by hills. On one of these hills there can be found the Monte Agliale Observatory, from which this minor planet was discovered. (M 42675)

\section{(15522) Trueblood}

1999 XX $_{136}$. Discovered 1999 Dec. 14 by C. W. Juels at Fountain Hills.

Mark Trueblood (1948- ) managed the Hubble Space Telescope control center at Ford Aerospace Corporation and now manages the U.S. Gemini instrument program at the National Optical Astronomy Observatory. He built and operates Winer Observatory in Sonoita, Arizona, as a service to the astronomical community. (M 42675)

\section{(15530) Kuber}

$2000 \mathrm{AV}_{98}$. Discovered 2000 Jan. 5 by the LINEAR at Socorro.

Named in honor of Catharine M. Kuber for achievement as a finalist in the 2001 Discovery Young Scientist Challenge (DYSC), a middle school science competition. Catharine is a student at the Reyburn Intermediate School, Clovis, California. (M 43687)

\section{(15543) Elizateel}

2000 DD $_{96}$. Discovered 2000 Feb. 29 by the LINEAR at Socorro.

Named in honor of Elizabeth A. Teel for achievement as a finalist in the 2001 Discovery Young Scientist Challenge (DYSC), a middle school science competition. Elizabeth is a student at the College Station Middle School, College Station, Texas. (M 43687)

\section{(15550) Sydney}

$2000 \mathrm{FR}_{10}$. Discovered 2000 Mar. 31 by J. Broughton at Reedy Creek.

Australia's largest city, Sydney is also the birthplace of the discoverer of this minor planet. Established by the British in 1788, Sydney was the first European settlement in Australasia and is famous for its magnificent opera house, harbor, sandy beaches and as host city of the 2000 Olympics. (M 42675)

\section{(15553) Carachang}

$2000 \mathrm{FG}_{45}$. Discovered 2000 Mar. 29 by the LINEAR at Socorro.

Named in honor of Cara A. Chang for achievement as a finalist in the 2001 Discovery Young Scientist Challenge (DYSC), a middle school science competition. Cara is a student at the St. Andrew's Priory, Honolulu, Hawaii. (M 43687)

\section{(15559) Abigailhines}

$2000 \mathrm{GR}_{23}$. Discovered 2000 Apr. 5 by the LINEAR at Socorro.

Named in honor of Abigail M. Hines for achievement as a finalist in the 2001 Discovery Young Scientist Challenge (DYSC), a middle school science competition. Abigail is a student at the Orchard Day Home School, Ft. Wayne, Indiana. (M 43687)

\section{(15563) Remsberg}

$2000 \mathrm{GG}_{48}$. Discovered 2000 Apr. 5 by the LINEAR at Socorro. 
Named in honor of Jarrett R. Remsberg for achievement as a finalist in the 2001 Discovery Young Scientist Challenge (DYSC), a middle school science competition. Jarrett is a student at the Middletown Middle School, Middletown, Maryland. (M 43687)

\section{(15565) Benjaminsteele}

2000 GM $_{49}$. Discovered 2000 Apr. 5 by the LINEAR at Socorro.

Named in honor of Benjamin C. Steele for achievement as a finalist in the 2001 Discovery Young Scientist Challenge (DYSC), a middle school science competition. Benjamin is a student at the Medea Creek Middle School, Agoura, California. (M 43688)

\section{(15566) Elizabethbaker}

2000 GD $_{50}$. Discovered 2000 Apr. 5 by the LINEAR at Socorro.

Named in honor of Elizabeth A. Baker for achievement as a finalist in the 2001 Discovery Young Scientist Challenge (DYSC), a middle school science competition. Elizabeth is a student at the Doolen Middle School, Tucson, Arizona. (M 43688)

\section{(15567) Giacomelli}

$2000 \mathrm{GF}_{53}$. Discovered 2000 Apr. 5 by the LINEAR at Socorro.

Named in honor of Hillary N. Giacomelli for achievement as a finalist in the 2001 Discovery Young Scientist Challenge (DYSC), a middle school science competition. Hillary is a student at the Falmouth Academy, Falmouth, Massachusetts. (M 43688)

\section{(15569) Feinberg}

$2000 \mathrm{GC}_{60}$. Discovered 2000 Apr. 5 by the LINEAR at Socorro.

Named in honor of Rebecca M. Feinberg for achievement as a finalist in the 2001 Discovery Young Scientist Challenge (DYSC), a middle school science competition. Rebecca is a student at the Manhattan Beach Middle School, Manhattan Beach, California. (M 43688)

\section{(15574) Stephaniehass}

$2000 \mathrm{GF}_{66}$. Discovered 2000 Apr. 5 by the LINEAR at Socorro.

Named in honor of Stephanie A. Hass for achievement as a finalist in the 2001 Discovery Young Scientist Challenge (DYSC), a middle school science competition. Stephanie is a student at the Manhattan Beach Middle School, Manhattan Beach, California. (M 43688)

\section{(15576) Munday}

$2000 \mathrm{GK}_{68}$. Discovered 2000 Apr. 5 by the LINEAR at Socorro.

Named in honor of Emily S. Munday for achievement as a finalist in the 2001 Discovery Young Scientist Challenge (DYSC), a middle school science competition. Emily is a student at the J. F. Kennedy Elementary School, Butte, Montana. (M 43688)

\section{(15577) Gywilliams}

$2000 \mathrm{GN}_{68}$. Discovered 2000 Apr. 5 by the LINEAR at Socorro.

Named in honor of Genevieve Y. Williams for achievement as a finalist in the 2001 Discovery Young Scientist Challenge (DYSC), a middle school science competition. Genevieve is a student at the Palos Verdes Intermediate School, Palos Verdes, California. (M 43688)

\section{(15582) Russellburrows}

$2000 \mathrm{GZ}_{73}$. Discovered 2000 Apr. 5 by the LINEAR at Socorro.

Named in honor of Russell T. Burrows for achievement as a finalist in the 2001 Discovery Young Scientist Challenge (DYSC), a middle school science competition. Russell is a student at the Barbara Bush Middle School, San Antonio, Texas. (M 43688)

\section{(15583) Hanick}

$2000 \mathrm{GM}_{74}$. Discovered 2000 Apr. 5 by the LINEAR at Socorro.

Named in honor of Andrea L. Hanick for achievement as a finalist in the 2001 Discovery Young Scientist Challenge (DYSC), a middle school science competition. Andrea is a student at the Annunciation Catholic Academy, Altamonte, Florida. (M 43688)

\section{(15594) Castillo}

2000 GG $_{95}$. Discovered 2000 Apr. 6 by the LINEAR at Socorro.

Named in honor of Jesse L. Castillo for achievement as a finalist in the 2001 Discovery Young Scientist Challenge (DYSC), a middle school science competition. Jesse is a student at the Bernalillo Middle School, Bernalillo, New Mexico. (M 43688)

\section{(15599) Richardlarson}

$2000 \mathrm{GF}_{99}$. Discovered 2000 Apr. 7 by the LINEAR at Socorro.

Named in honor of Richard W. Larson for achievement as a finalist in the 2001 Discovery Young Scientist Challenge (DYSC), a middle school science competition. Richard is a student at the Springville Middle School, Springville, Utah. (M 43688)

\section{(15604) Fruits}

$2000 \mathrm{GT}_{108}$. Discovered 2000 Apr. 7 by the LINEAR at Socorro.

Named in honor of Benjamin R. Fruits for achievement as a finalist in the 2001 Discovery Young Scientist Challenge (DYSC), a middle school science competition. Benjamin is a student at the Seven Springs Middle School, New Port Richey, Florida. (M 43688)

\section{(15606) Winer}

2000 GU $_{122}$. Discovered 2000 Apr. 11 by C. W. Juels at Fountain Hills.

Irvin M. Winer (1935-1982) was a physicist, teacher and mentor who studied laser physics and experimental 
general relativity, as well as laboratory fusion initiation and containment. He held four U.S. patents. (M 42675) The citation was written by M. Trueblood.

\section{(15608) Owens}

$2000 \mathrm{GK}_{124}$. Discovered 2000 Apr. 7 by the LINEAR at Socorro.

Named in honor of Alexander C. Owens for achievement as a finalist in the 2001 Discovery Young Scientist Challenge (DYSC), a middle school science competition. Alexander is a student at the Tanque Verde Elementary School, Tucson, Arizona. (M 43688)

\section{(15609) Kosmaczewski}

2000 GP $_{124}$. Discovered 2000 Apr. 7 by the LINEAR at Socorro.

Named in honor of Sara G. Kosmaczewski for achievement as a finalist in the 2001 Discovery Young Scientist Challenge (DYSC), a middle school science competition. Sara is a student at the St. Rita School, Hamden, Connecticut. (M 43688)

\section{(15617) Fallowfield}

$2000 \mathrm{HK}_{10}$. Discovered 2000 Apr. 27 by the LINEAR at Socorro.

Named in honor of Heather L. Fallowfield for achievement as a finalist in the 2001 Discovery Young Scientist Challenge (DYSC), a middle school science competition. Heather is a student at the Beech Grove Middle School, Beech Grove, Indiana. (M 43688)

\section{(15618) Lorifritz}

$2000 \mathrm{HF}_{11}$. Discovered 2000 Apr. 27 by the LINEAR at Socorro.

Named in honor of Lori A. Fritz for achievement as a finalist in the 2001 Discovery Young Scientist Challenge (DYSC), a middle school science competition. Lori is a student at the Beech Grove Middle School, Beech Grove, Indiana. (M 43688)

\section{(15619) Albertwu}

$2000 \mathrm{HE}_{13}$. Discovered 2000 Apr. 28 by the LINEAR at Socorro.

Named in honor of Albert Y. Wu for achievement as a finalist in the 2001 Discovery Young Scientist Challenge (DYSC), a middle school science competition. Albert is a student at the Keystone Junior High School, San Antonio, Texas. (M 43689)

\section{(15620) Beltrami}

2000 HQ $_{14}$. Discovered 2000 Apr. 29 by P. G. Comba at Prescott.

Eugenio Beltrami (1835-1900) was an Italian mathematician who held professorships at Pisa, Pavia and Rome. He contributed to the differential geometry of curves and surfaces, particularly the pseudosphere of constant negative curvature as a model of Lobachevskian \{see planet (1858)\} geometry. (M 41573)
(15621) Erikhovland

$2000 \mathrm{HO}_{20}$. Discovered 2000 Apr. 29 by the JPL/MSSS NEAT at Haleakala.

Erik Hovland (1970- ) is a computer programmer at the Jet Propulsion Laboratory. He developed the NEAT operations software when it changed telescopes to the MSSS 1.2-m on Maui and has helped deploy the first phase of the Keck Interferometer. His little free time is spent with his son and wife. (M 42675)

\section{(15622) Westrich}

$2000 \mathrm{HY}_{20}$. Discovered 2000 Apr. 27 by the LINEAR at Socorro.

Named in honor of Bradford J. Westrich for achievement as a finalist in the 2001 Discovery Young Scientist Challenge (DYSC), a middle school science competition. Bradford is a student at the Edgewood Middle School, Moriarty, New Mexico. (M 43689)

\section{(15624) Lamberton}

$2000 \mathrm{HB}_{31}$. Discovered 2000 Apr. 28 by the LINEAR at Socorro.

Named in honor of Melissa L. Lamberton for achievement as a finalist in the 2001 Discovery Young Scientist Challenge (DYSC), a middle school science competition. Melissa is a student at the Pistor Middle School, Tucson, Arizona. (M 43689)

\section{(15627) Hong}

$2000 \mathrm{HW}_{52}$. Discovered 2000 Apr. 29 by the LINEAR at Socorro.

Named in honor of Danny Hong for achievement as a finalist in the 2001 Discovery Young Scientist Challenge (DYSC), a middle school science competition. Danny is a student at the Van Wyck Junior High School, Wappingers Falls, New York. (M 43689)

\section{(15628) Gonzales}

$2000 \mathrm{HA}_{53}$. Discovered 2000 Apr. 29 by the LINEAR at Socorro.

Named in honor of Eric A. Gonzales for achievement as a finalist in the 2001 Discovery Young Scientist Challenge (DYSC), a middle school science competition. Eric is a student at the William P. Hobby Middle School, San Antonio, Texas. (M 43689)

\section{(15629) Sriner}

$2000 \mathrm{HK}_{53}$. Discovered 2000 Apr. 29 by the LINEAR at Socorro.

Named in honor of Kimberly A. Sriner for achievement as a finalist in the 2001 Discovery Young Scientist Challenge (DYSC), a middle school science competition. Kimberly is a student at the Franklin Middle School, Springfield, Illinois. (M 43689)

\section{(15635) Andrewhager}

$2000 \mathrm{JV}_{27}$. Discovered 2000 May 7 by the LINEAR at Socorro.

Named in honor of Andrew T. Hager for achievement as a finalist in the 2001 Discovery Young Scientist 
Challenge (DYSC), a middle school science competition. Andrew is a student at the International Montessori School, Venice, Florida. (M 43689)

\section{(15651) Tlepolemos}

9612 P-L. Discovered 1960 Oct. 22 by C. J. van Houten and I. van Houten-Groeneveld at Palomar.

Tlepolemos was king of Rhodos, son of Heracles \{see planet (5143)\} and was one of the first kings to join the army against Troy. (M 42363)

\section{(15663) Periphas}

4168 T-2. Discovered 1973 Sept. 29 by C. J. van Houten and I. van Houten-Groeneveld at Palomar.

The Greek hero Periphas from Aetolia was killed by the god Ares. Ares tried to get the armor of Periphas, but Diomedes \{see planet (1437)\} wounded Ares, with the help of Pallas Athene \{see planet (881)\}. (M 43046)

\section{(15673) Chetaev}

$1978 \mathrm{PV}_{2}$. Discovered 1978 Aug. 8 by N. S. Chernykh at Nauchnyj.

Soviet mathematician and mechanician Nikolaj Gur'evich Chetaev (1902-1959), a professor at the universities in Kazan and Moscow, made valuable contributions to analytical mechanics and stability theory. (M 43382)

\section{(15710) Böcklin}

$1989 \mathrm{AV}_{6}$. Discovered 1989 Jan. 11 by F. Börngen at Tautenburg.

Swiss painter Arnold Böcklin (1827-1901) created landscapes and figures in a richly colored monumentalpathetic style. Frequently, his subjects are from classical mythology and are animated by a grand imagination. (M 41388)

\section{(15724) Zille}

$1990 \mathrm{TW}_{3}$. Discovered 1990 Oct. 12 by F. Börngen and L. D. Schmadel at Tautenburg.

Graphic artist and photographer Heinrich Zille (18581929) portrayed the milieu of ordinary Berliners in the streets, working-class quarters and fairgrounds. His popular pictures appeared in several magazines. His sociocritical illustrations united comedy and tragedy in a unique way. (M 41388)

The name was suggested by the first discoverer.

\section{(15728) Karlmay}

$1990 \mathrm{TG}_{11}$. Discovered 1990 Oct. 11 by F. Börngen and L. D. Schmadel at Tautenburg.

Karl May (1842-1912), Saxonian author of splendid fantasies, began with country stories out of his Erzgebirge home. His fascinating, exotic and colorful adventure novels were placed mostly in North America's Wild West and in the Far East. They became very popular and were translated into more than 25 languages. (M 41388)

Presumably, May is also honored by planet (348).

\section{(15729) Yumikoitahana}

1990 UB. Discovered 1990 Oct. 16 by A. Takahashi and $\mathrm{K}$. Watanabe at Kitami.

Since their high-school days, Yumiko Itahana (1965-

) worked together with the first discoverer and greatly influenced his astronomical career. (M 46683)

\section{(15762) Rühmann}

1992 SR $_{24}$. Discovered 1992 Sept. 21 by F. Börngen at Tautenburg.

Heinz Rühmann (1902-1994), German actor, inspired comic, brilliant character performer, stage director and orator, performed in renowned theaters beginning in 1920. He played starring roles brilliantly in more than 100 feature films and in television films from 1968 until he was a very advanced age. (M 41388)

\section{(15779) Scottroberts}

1993 OA $_{3}$. Discovered 1993 July 26 by C. S. Shoemaker and D. H. Levy at Palomar.

Scott Roberts (1959- ) for many years has encouraged amateur astronomers to pursue their love of the night sky, spending much time teaching people how to use and enjoy their telescopes. (M 41573)

\section{(15808) Zelter}

1994 GF $_{10}$. Discovered 1994 Apr. 3 by F. Börngen at Tautenburg.

Composer Carl Friedrich Zelter (1758-1834) set Goethe's \{see planet (3047)\} poems to music and wrote songs for male choirs. As director of the Berliner "Singakademie" beginning in 1800 , he performed in particular the music of Bach \{see planet (1814)\}. He founded in Berlin the first "Liedertafel", the prototype for choral societies in cities and towns around the world. (M 41388)

\section{(15811) Nüsslein-Volhard}

1994 ND $_{1}$. Discovered 1994 July 10 by F. Börngen at Tautenburg.

German biologist Christiane Nüsslein-Volhard (1942-

intensely studied the development stages of the fly Drosophila melanogaster and shared the 1995 Nobel prize for medicine for her epoch-making discoveries of the fundamental genetic steering mechanisms of embryogeny. (M 45748)

\section{(15817) Lucianotesi}

1994 QC. Discovered 1994 Aug. 28 by A. Boattini and M. Tombelli at San Marcello Pistoiese.

Luciano Tesi (1931- ） founded the Amateur Group of the Pistoiese Mountain in 1980. This later led to the construction of the Pian dei Termini Observatory. As director of the station, he has collaborated with the discoverers since 1994 in finding minor planets and following up near-earth objects. (M 41388)

\section{(15837) Mariovalori}

1995 DG $_{13}$. Discovered 1995 Feb. 25 by M. Tombelli at Cima Ekar. 
Mario Valori (1930-2000) was an amateur astronomer in the Montelupo \{see planet (7198)\} Group. (M 42363)

\section{(15841) Yamaguchi}

1995 OX. Discovered 1995 July 27 by A. Nakamura at Kuma.

Yamaguchi prefecture, where the discoverer was born, is located at the western-most end of Honshu island. Surrounded by the sea on three sides, it is known for its deep-sea fishery catch. Yamaguchi is also famous for its distinguished educators, who played an integral role in the Meiji Restoration. (M 41941)

\section{(15854) Numa}

$1996 \mathrm{CX}_{2}$. Discovered 1996 Feb. 15 by V. S. Casulli at Colleverde di Guidonia.

Numa Pompilius, second king of Rome, reigned from 715 to 672 B.C. He founded the sacred law and reformed the calendar so that the number of months in a year was increased from ten to twelve. (M 45749)

\section{(15860) Sirán̆}

1996 HO. Discovered 1996 Apr. 20 by A. Galád and D. Kalmančok at Modra.

Slovak geophysicist Gustáv Siráň (1934-2000) was a professor at Comenius University, Bratislava. From 1981 to 1989 he was head of the department of astronomy, geophysics and meteorology, and during this time the Astronomical and Geophysical Observatory in Modra \{see planet (11118)\} was built. (M 42363)

\section{(15868) Akiyoshidai}

1996 OL. Discovered 1996 July 16 by A. Nakamura at Kuma.

Akiyoshidai, located at the center of Yamaguchi \{see planet (15841)\} prefecture, is the biggest karst plateau in Japan, with an area of 130 square kilometers. Beneath the plateau, 380 caverns have been discovered, including Akiyoshido Cavern, the largest cavern in Japan. (M 41940)

\section{(15869) Tullius}

1996 PL. Discovered 1996 Aug. 8 by V. S. Casulli at Colleverde di Guidonia.

Tullius Hostilius, third king of Rome, reigned from 672 to 640 B.C. He was a warrior king, and during the war against the city of Alba Longa there was a famous fight between Oratii and Curiatii. (M 46011)

\section{(15870) Obůrka}

1996 QD. Discovered 1996 Aug. 16 by P. Pravec at Ondřejov.

Oto Obůrka (1909-1982), professor at Brno University of Technology, founded the Nicholas Copernicus Observatory there and led it for 20 years. He established a program, aimed at young amateurs, for monitoring short-period variable stars. He was an honorary president of the International Union of Amateur Astronomers. (M 41388)

\section{(15890) Prachatice}

1997 GY. Discovered 1997 Apr. 3 by M. Tichý and Z. Moravec at Klet.

Prachatice is a southern Bohemian town that began as a small settlement on the Golden Trail that had the rights to sell salt from Passau. The Prachatice of today, founded in the 14th century, is dominated by the Gothic Church of St. James. (M 46683)

\section{(15896) Birkhoff}

1997 LX $_{5}$. Discovered 1997 June 13 by P. G. Comba at Prescott.

George David Birkhoff (1884-1944) was one of the foremost American mathematicians of the early twentieth century. He made important contributions to ergodic theory, the topological theory of dynamical systems, ordinary differential equations and difference equations. (M 41573)

\section{(15897) Beňačková}

1997 PD $_{3}$. Discovered 1997 Aug. 10 by P. Pravec at Ondřejov.

Slovak soprano Gabriela Beňačková-Čápová (1947-

) belonged to the National Theatre in Prague and the Slovak National Theatre in Bratislava. She is a permanent guest of the Bavarian State Opera in Munich, Covent Garden in London and the Vienna State Opera and collaborates with the New York Metropolitan Theater. (M 41941)

\section{(15898) Kharasterteam}

1997 QP. Discovered 1997 Aug. 26 by P. Pravec and L. Šarounová at Ondřejov.

The asteroid group at the Astronomical Observatory of Kharkiv National University has made important contributions to studies of the physical properties of minor planets. The group's photometric and polarimetric techniques, as well as its numerical and laboratory modeling, are known worldwide. (M 42363)

\section{(15899) Silvain}

$1997 \mathrm{RR}_{1}$. Discovered 1997 Sept. 3 by P. Antonini at Bedoin.

Jacques Silvain (1926-1987) was an enthusiastic amateur astronomer who devoted much time to visual and photographic observations. He was an active member of the Société Astronomique de France and built several telescopes. (M 42675)

\section{(15905) Berthier}

1997 SV $_{15}$. Discovered 1997 Sept. 27 by the OCA-DLR Survey at Caussols.

Jérôme Berthier (1968- ) works on minor planets at the Institut de Mécanique Céleste in Paris. His main goal is to develop both accurate ephemerides and the reduction package PRIAM to predict stellar occultations by minor planets. (M 45749) 
(15907) Robot

$1997 \mathrm{TG}_{10}$. Discovered 1997 Oct. 6 by P. Pravec at Ondřejov.

The word "robot" was invented by Czech writer Josef Capek for an artificial man in the famous play R. U. R. ("Rossum's Universal Robots") written by his brother Karel Capek \{see planet (1931)\} in 1920. Later it became a general term used for automated devices of various kinds. (M 41941)

\section{(15913) Telemachus}

1997 TZ $_{27}$. Discovered 1997 Oct. 1 by the Uppsala-DLR Trojan Survey at La Silla.

Telemachus, son of Odysseus \{see planet (1143)\}, was born just before the Trojan war started. (M 42363)

\section{(15921) Kintaikyo}

1997 VP. Discovered 1997 Nov. 1 by A. Nakamura at Kuma.

Kintaikyo is one of the three most famous bridges in Japan, known collectively as Sanmeikyo. It spans the Nishikigawa River in Yamaguchi \{see planet (15841)\} prefecture. The original 193-m-long wooden five-arch bridge was constructed in 1673. After its destruction by a typhoon, it was reconstructed in 1953, using the same design. (M 41491)

\section{(15938) Bohnenblust}

1997 YA $_{8}$. Discovered 1997 Dec. 27 by P. G. Comba at Prescott.

H. Frederic Bohnenblust (1906-2000) was a SwissAmerican mathematician who held professorships at Princeton and later at Caltech, where he became dean of graduate studies. A great teacher and a strong advocate of mathematical education, he was the discoverer's thesis adviser. (M 41573)

\section{(15945) Raymondavid}

1998 AZ $_{5}$. Discovered 1998 Jan. 8 by the OCA-DLR Survey at Caussols.

Raymond David (1941- ), ski teacher by vocation and electronics specialist and amateur astronomer by avocation, has been invaluable in the construction and distribution of CCD cameras that have helped many amateurs to observe minor planets. (M 45339)

\section{(15947) Milligan}

$1998 \mathrm{AL}_{10}$. Discovered 1998 Jan. 2 by J. Broughton at Reedy Creek.

Spike Milligan (1918- ) is best known for his off-the-planet sense of humor in the groundbreaking BBC radio comedy series The Goon Show, which he wrote and starred in with Sellers, Secombe and Bentine in the 1950s. He later moved to film, television and writing novels, poetry and memoirs. (M 42675)

\section{(15949) Rhaeticus}

1998 BQ. Discovered 1998 Jan. 17 by E. Meyer and E. Obermair at Linz.

Rhaeticus (Georg Joachim Lauchen, 1514-1574) was a humanist, physician, mathematician and astronomer at the universities of Vienna, Leipzig and Wittenberg. He summarized and popularized the work of his teacher Copernicus, initiating the first printing of $D e$ Revolutionibus. (M 42363)

\section{(15950) Dallago}

$1998 \mathrm{BA}_{2}$. Discovered 1998 Jan. 17 at the Madonna di Dossobuono Observatory at Madonna di Dossobuono.

Vicenza amateur astronomer Giovanni Dal Lago (1964- ) writes a column for an Italian magazine on testing optical instruments and the use of CCD \{see planet (15000)\} cameras. (M 42363)

\section{(15955) Johannesgmunden}

1998 BS $_{13}$. Discovered 1998 Jan. 26 by E. Meyer at Linz.

Johannes von Gmunden (1380/1384-1442), a priest, humanist, mathematician and astronomer at the University of Vienna, brought the mathematical and astronomical knowledge of Arabia to Europe. Known for his precise ephemerides, he also published the first printed calendar in German. (M 42363)

\section{(15960) Hluboká}

1998 CH. Discovered 1998 Feb. 2 by M. Tichý and Z. Moravec at Klě́t.

Hluboká nad Vltavou is the most popular chateau in South Bohemia. The original thirteenth-century Gothic castle was rebuilt in Tudor style by the Schwarzenberg family during the nineteenth century. This typical English style gives the chateau almost an elfin appearance, which is accentuated by a vast park. (M 42364)

\section{(15964) Billgray}

1998 DU. Discovered 1998 Feb. 19 by J. M. Roe at Oaxaca.

Bill Gray (1965- ） has made several contributions to astrometry, in particular with his Guide series of starcharting software, his Charon astrometry program and his reduction of the GSC 1.1 star catalog to the ACT frame (GSC-ACT). (M 41389)

\section{(15965) Robertcox}

1998 DU $_{7}$. Discovered 1998 Feb. 23 by J. M. Roe at Oaxaca.

Robert E. Cox (1917-1989) contributed to amateur telescope making through his long-time editing of "Gleanings for Amateur Telescope Makers" in the magazine Sky and Telescope \{see planet (3243)\}, as well as by devoting much personal time to amateur groups. (M 41389)

\section{(15967) Clairearmstrong}

$1998 \mathrm{DN}_{20}$. Discovered 1998 Feb. 24 by M. Armstrong at Rolvenden.

Claire Armstrong, the wife of supernova discoverer Mark Armstrong, has provided unwavering support throughout the years of Mark's patrol. A large degree of Mark's success is due to Claire's support, which 
extends to practical help also: she co-discovered minor planet 1997 WQ28 with him. (M 41941)

\section{(15971) Hestroffer}

1998 FA $_{11}$. Discovered 1998 Mar. 25 by the OCA-DLR Survey at Caussols.

Daniel Hestroffer (1965- ) works at the Institut de Mécanique Céleste in Paris on the determination of an inertial frame from the Hipparcos observations of minor planets. He has also worked on the determination of the shapes of minor planets. (M 45339)

\section{(15986) Fienga}

$1998 \mathrm{XU}_{1}$. Discovered 1998 Dec. 7 by the OCA-DLR Survey at Caussols.

Agnes Fienga (1973- ) works at the Institut de Mécanique Céleste in Paris on the global adjustment of analytical theories of planetary motion to observations. She also worked on space navigation at CNES and JPL. (M 45339)

\section{(15992) Cynthia}

$1998 \mathrm{YL}_{4}$. Discovered 1998 Dec. 18 by G. Hug at Eskridge.

The name Cynthia can be translated to mean "of the moon". While (15992) is certainly not from the moon, this minor planet was imaged many times with the moon above the horizon in order to achieve an accurate orbit. The name also happens to be that of the discoverer's life partner. (M 41389)

\section{(16002) Bertin}

$1999 \mathrm{AM}_{24}$. Discovered 1999 Jan. 15 by the OCA-DLR Survey at Caussols.

Emmanuel Bertin (1973- ) is the author of the well-known sextractor package, which is used in several observing programs for the automatic detection of minor planets. A specialist in cosmology, he now works for the Terapix consortium at the Institut d'Astrophysique de Paris. (M 45339)

\section{(16046) Gregnorman}

1999 JK. Discovered 1999 May 5 by J. Broughton at Reedy Creek.

Greg Norman (1956- ), a professional golfer from Queensland, became the world's leading player several years running and was the winner of 86 tournaments, incuding two British opens. Nicknamed "The Shark", he is also a keen deep-sea fisherman. (M 42675)

\section{(16065) Borel}

$1999 \mathrm{RE}_{35}$. Discovered 1999 Sept. 11 by P. G. Comba at Prescott.

Émile Borel (1871-1956) was a prolific French mathematician who for a time was also minister of the navy. His main contributions were in set theory, function theory and measure theory. (M 41573)

\section{(16083) Jorvik}

$1999 \mathrm{TH}_{12}$. Discovered 1999 Oct. 12 by J. Tichá and M. Tichý at Klet.

Jorvik was the name of the ninth-century Viking settlement that preceded the modern York in northeastern England. The discoverers visited York, including archaeological remnants of Jorvik, during the IAU General Assembly in 2000. (M 41573)

\section{(16107) Chanmugam}

$1999 \mathrm{WQ}_{2}$. Discovered 1999 Nov. 27 by W. R. Cooney $\mathrm{Jr}$ at Baton Rouge.

Ganesar Chanmugam (1939-1996) was a superb teacher and cherished colleague of the physics and astronomy faculty at Louisiana State University. Born in Colombo, through more than 25 years of research he made broad contributions to our understanding of the magnetic and radiative properties of neutron stars and white dwarfs. (M 42675)

\section{(16110) Paganetti}

1999 WU $_{8}$. Discovered 1999 Nov. 28 by S. Sposetti at Gnosca.

Mariarosa Paganetti (1925- ) is the mother of the discoverer. (M 45339)

\section{(16112) Vitaris}

1999 XK $_{13}$. Discovered 1999 Dec. 5 by the LINEAR at Socorro.

Named in honor of Bethany A. Vitaris for achievement as a finalist in the 2001 Discovery Young Scientist Challenge (DYSC), a middle school science competition. Bethany is a student at the Venerini Academy, Worcester, Massachusetts. (M 43689)

\section{(16113) Ahmed}

$1999 \mathrm{XN}_{23}$. Discovered 1999 Dec. 6 by the LINEAR at Socorro.

Named in honor of Tahir Ahmed for achievement as a finalist in the 2002 Intel Science Talent Search, a science competition for high school seniors. Tahir is a student at the Midwood High School at Brooklyn College, Brooklyn, New York. (M 44929)

\section{(16114) Alyono}

$1999 \mathrm{XV}_{23}$. Discovered 1999 Dec. 6 by the LINEAR at Socorro.

Named in honor of Jennifer Christy Alyono for achievement as a finalist in the 2002 Intel Science Talent Search, a science competition for high school seniors. Jennifer is a student at the Montgomery Blair High School, Silver Spring, Maryland. (M 44929)

\section{(16116) Balakrishnan}

$1999 \mathrm{XQ}_{29}$. Discovered 1999 Dec. 6 by the LINEAR at Socorro.

Named in honor of Jennifer Sayaka Balakrishnan for achievement as a finalist in the 2002 Intel Science Talent Search, a science competition for high school 
seniors. Jennifer is a student at the Harvest Christian Academy, Barrigada, Guam. (M 44929)

\section{(16118) Therberens}

1999 XQ $_{56}$. Discovered 1999 Dec. 7 by the LINEAR at Socorro.

Named in honor of Theresa Joan Berens for achievement as a finalist in the 2002 Intel Science Talent Search, a science competition for high school seniors. Theresa is a student at the Humanities and Sciences Institute, Phoenix, Arizona. (M 44929)

\section{(16119) Bronner}

$1999 \mathrm{XS}_{60}$. Discovered 1999 Dec. 7 by the LINEAR at Socorro.

Named in honor of Mordechai Joseph Bronner for achievement as a finalist in the 2002 Intel Science Talent Search, a science competition for high school seniors. Mordechai is a student at the Rambam Mesivta, Lawrence, New York. (M 44929)

\section{(16120) Burnim}

$1999 \mathrm{XV}_{60}$. Discovered 1999 Dec. 7 by the LINEAR at Socorro.

Named in honor of Jacob Samuels Burnim for achievement as a finalist in the 2002 Intel Science Talent Search, a science competition for high school seniors. Jacob is a student at the Montgomery Blair High School, Silver Spring, Maryland. (M 44929)

\section{(16121) Burrell}

$1999 \mathrm{XD}_{66}$. Discovered 1999 Dec. 7 by the LINEAR at Socorro.

Named in honor of Marc Anthony Burrell for achievement as a finalist in the 2002 Intel Science Talent Search, a science competition for high school seniors. Marc is a student at the Nicolet High School, Glendale, Wisconsin. (M 44929)

\section{(16122) Wenyicai}

$1999 \mathrm{XW}_{67}$. Discovered 1999 Dec. 7 by the LINEAR at Socorro.

Named in honor of Wenyi Cai for achievement as a finalist in the 2002 Intel Science Talent Search, a science competition for high school seniors. Wenyi is a student at the Naperville Central High School, Naperville, Illinois. (M 44929)

\section{(16123) Jessiecheng}

1999 XQ83. Discovered 1999 Dec. 7 by the LINEAR at Socorro.

Named in honor of Jessie Cheng for achievement as a finalist in the 2002 Intel Science Talent Search, a science competition for high school seniors. Jessie is a student at the Byram Hills High School, Armonk, New York. (M 44929)

\section{(16124) Timdong}

$1999 \mathrm{XR}_{85}$. Discovered 1999 Dec. 7 by the LINEAR at Socorro.
Named in honor of Timothy Allen Dong for achievement as a finalist in the 2002 Intel Science Talent Search, a science competition for high school seniors. Timothy is a student at the Alhambra High School, Alhambra, California. (M 44929)

\section{(16127) Farzan-Kashani}

$1999 \mathrm{XK}_{92}$. Discovered 1999 Dec. 7 by the LINEAR at Socorro.

Named in honor of Raphael Farzan-Kashani for achievement as a finalist in the 2002 Intel Science Talent Search, a science competition for high school seniors. Raphael is a student at the John L. Miller - Great Neck North High School, Great Neck, New York. (M 44929)

\section{(16128) Kirfrieda}

$1999 \mathrm{XS}_{92}$. Discovered 1999 Dec. 7 by the LINEAR at Socorro.

Named in honor of Kirsten Linnea Frieda for achievement as a finalist in the 2002 Intel Science Talent Search, a science competition for high school seniors. Kirsten is a student at the Westlake High School, Austin, Texas. (M 44929)

\section{(16129) Kevingao}

1999 XG97. Discovered 1999 Dec. 7 by the LINEAR at Socorro.

Named in honor of Kevin Kuan Gao for achievement as a finalist in the 2002 Intel Science Talent Search, a science competition for high school seniors. Kevin is a student at the John B. Connally High School, Austin, Texas. (M 44929)

\section{(16130) Giovine}

$1999 \mathrm{XU}_{97}$. Discovered 1999 Dec. 7 by the LINEAR at Socorro.

Named in honor of Allegra Elizabeth Giovine for achievement as a finalist in the 2002 Intel Science Talent Search, a science competition for high school seniors. Allegra is a student at the Manhasset High School, Manhasset, New York. (M 44929)

\section{(16131) Kaganovich}

$1999 \mathrm{XV}_{97}$. Discovered 1999 Dec. 7 by the LINEAR at Socorro.

Named in honor of Mark Kaganovich for achievement as a finalist in the 2002 Intel Science Talent Search, a science competition for high school seniors. Mark is a student at the Bloomington High School North, Bloomington, Indiana. (M 44930)

\section{(16132) Angelakim}

$1999 \mathrm{XH}_{99}$. Discovered 1999 Dec. 7 by the LINEAR at Socorro.

Named in honor of Angela Soeun Kim for achievement as a finalist in the 2002 Intel Science Talent Search, a science competition for high school seniors. Angela is a student at the Great Neck South High School, Great Neck, New York. (M 44930) 
(16135) Ivarsson

$1999 \mathrm{XY}_{104}$. Discovered 1999 Dec. 9 by C. W. Juels at Fountain Hills.

Karl R. Ivarsson (1939- ） was a vertical transportation specialist in Los Angeles for 37 years. He helped design and construct roll-off structures at the Fountain Hills \{see planet (20898)\} Observatory in Arizona, where this minor planet was discovered. (M 43192)

\section{(16142) Leung}

$1999 \mathrm{XC}_{135}$. Discovered 1999 Dec. 6 by the LINEAR at Socorro.

Named in honor of Albert W. Leung for achievement as a finalist in the 2002 Intel Science Talent Search, a science competition for high school seniors. Albert is a student at the Stuyvesant High School, New York, New York. (M 44930)

\section{(16144) Korsten}

$1999 \mathrm{XK}_{144}$. Discovered 1999 Dec. 15 by C. W. Juels at Fountain Hills.

Erich E. Korsten (1945- ) is a hydrologist and amateur astronomer from Dresden who now lives in Fountain Hills, Arizona. He helped construct the Fountain Hills \{see planet (20898)\} Observatory, where this minor planet was discovered. (M 43192)

\section{(16147) Jeanli}

$1999 \mathrm{XL}_{175}$. Discovered 1999 Dec. 10 by the LINEAR at Socorro.

Named in honor of Jean Li for achievement as a finalist in the 2002 Intel Science Talent Search, a science competition for high school seniors. Jean is a student at the Montgomery Blair High School, Silver Spring, Maryland. (M 44930)

\section{(16154) Dabramo}

$2000 \mathrm{AW}_{2}$. Discovered 2000 Jan. 1 by A. Boattini and M. Tombelli at San Marcello Pistoiese.

At the University of Pisa, Germano D'Abramo (1973- ) studied the statistics of mutual collisions. Since November 1998 he has collaborated with the Spaceguard Foundation in maintaining the Spaceguard Central Node and working on modeling the near-earthobject population. (M 41573)

\section{(16155) Buddy}

$2000 \mathrm{AF}_{5}$. Discovered 2000 Jan. 3 by J. Broughton at Reedy Creek.

Charles Hardin Holley (Buddy Holly, 1936-1959), was a singer/songwriter from Lubbock, Texas, who was clearly the brightest star since Elvis when, at the age of 22 , he was tragically killed in a plane crash. His life has been celebrated on film and in the long running musical Buddy. His songs remain as timeless as ever. (M 42675)

\section{(16157) Toastmasters}

$2000 \mathrm{AS}_{50}$. Discovered 2000 Jan. 5 by C. W. Juels at Fountain Hills.
Toastmasters, a public speaking club, was started by Ralph C. Smedley in 1924 at a YMCA in Santa Ana, California. Today Toastmasters is an international organization that affords practice and training for men and women in the art of public speaking and in the presiding over meetings. (M 46111)

\section{(16158) Monty}

$2000 \mathrm{AV}_{50}$. Discovered 2000 Jan. 5 by C. W. Juels at Fountain Hills.

Monty Roberts (1935- ）, a true horse whisperer, has tirelessly taught that man-animal interactions, such as the traumatic breaking of horses, is bettered through nonviolent means. His writings extend these ideas and foster peaceable human-to-human interactions. (M 46111)

The citation was written by M. Schwartz.

\section{(16163) Suhanli}

$2000 \mathrm{AD}_{69}$. Discovered 2000 Jan. 5 by the LINEAR at Socorro.

Named in honor of Suhan Li for achievement as a finalist in the 2002 Intel Science Talent Search, a science competition for high school seniors. Suhan is a student at the Bronx High School of Science, Bronx, New York. (M 44930)

\section{(16164) Yangli}

$2000 \mathrm{AO}_{69}$. Discovered 2000 Jan. 5 by the LINEAR at Socorro.

Named in honor of Yang Li for achievement as a finalist in the 2002 Intel Science Talent Search, a science competition for high school seniors. Yang is a student at the Ward Melville High School, East Setauket, New York. (M 44930)

\section{(16165) Licht}

$2000 \mathrm{AW}_{83}$. Discovered 2000 Jan. 5 by the LINEAR at Socorro.

Named in honor of Jacob Licht for achievement as a finalist in the 2002 Intel Science Talent Search, a science competition for high school seniors. Jacob is a student at the William Hall High School, West Hartford, Connecticut. (M 44930)

\section{(16166) Jonlii}

$2000 \mathrm{AQ}_{84}$. Discovered 2000 Jan. 5 by the LINEAR at Socorro.

Named in honor of Jonathan Lii for achievement as a finalist in the 2002 Intel Science Talent Search, a science competition for high school seniors. Jonathan is a student at the Manhasset High School, Manhasset, New York. (M 44930)

\section{(16167) Oertli}

2000 AJ $_{89}$. Discovered 2000 Jan. 5 by the LINEAR at Socorro.

Named in honor of Nicole Anne Oertli for achievement as a finalist in the 2002 Intel Science Talent Search, a science competition for high school seniors. Nicole is a 
student at the Murphy High School, Mobile, Alabama. (M 44930)

\section{(16168) Palmen}

2000 AR $_{91}$. Discovered 2000 Jan. 5 by the LINEAR at Socorro.

Named in honor of Brandon Michael Palmen for achievement as a finalist in the 2002 Intel Science Talent Search, a science competition for high school seniors. Brandon is a student at the Mayo High School, Rochester, Minnesota. (M 44930)

\section{(16174) Parihar}

2000 AX $_{116}$. Discovered 2000 Jan. 5 by the LINEAR at Socorro.

Named in honor of Raminder Kaur Parihar for achievement as a finalist in the 2002 Intel Science Talent Search, a science competition for high school seniors. Raminder is a student at the Bronx High School of Science, Bronx, New York. (M 44930)

\section{(16175) Rypatterson}

$2000 \mathrm{AL}_{118}$. Discovered 2000 Jan. 5 by the LINEAR at Socorro.

Named in honor of Ryan Randall Patterson for achievement as a finalist in the 2002 Intel Science Talent Search, a science competition for high school seniors. Ryan is a student at the Central High School, Grand Junction, Colorado. (M 44930)

\section{(16177) Pelzer}

2000 AR $_{127}$. Discovered 2000 Jan. 5 by the LINEAR at Socorro.

Named in honor of Justin Raymond Pelzer for achievement as a finalist in the 2002 Intel Science Talent Search, a science competition for high school seniors. Justin is a student at the Evanston Township High School, Evanston, Illinois. (M 44930)

\section{(16180) Rapoport}

$2000 \mathrm{AZ}_{136}$. Discovered 2000 Jan. 4 by the LINEAR at Socorro.

Named in honor of Ezra Jacob Rapoport for achievement as a finalist in the 2002 Intel Science Talent Search, a science competition for high school seniors. Ezra is a student at the Horace Mann School, Bronx, New York. (M 44930)

\section{(16189) Riehl}

$2000 \mathrm{AT}_{187}$. Discovered 2000 Jan. 8 by the LINEAR at Socorro.

Named in honor of Emily Elizabeth Riehl for achievement as a finalist in the 2002 Intel Science Talent Search, a science competition for high school seniors. Emily is a student at the University High School, Normal, Illinois. (M 44930)

\section{(16191) Rubyroe}

$2000 \mathrm{AO}_{205}$. Discovered 2000 Jan. 10 by J. M. Roe at Oaxaca.
Ruby Bell (Neihart) Roe (1943-1996) was the mother of the discoverer's three children. (M 41389)

\section{(16199) Rozenblyum}

$2000 \mathrm{BX}_{26}$. Discovered 2000 Jan. 30 by the LINEAR at Socorro.

Named in honor of Nikita Rozenblyum for achievement as a finalist in the 2002 Intel Science Talent Search, a science competition for high school seniors. Nikita is a student at the Stuyvesant High School, New York, New York. (M 44930)

\section{(16202) Srivastava}

$2000 \mathrm{CE}_{28}$. Discovered 2000 Feb. 2 by the LINEAR at Socorro.

Named in honor of Siddharth Srivastava for achievement as a finalist in the 2002 Intel Science Talent Search, a science competition for high school seniors. Siddharth is a student at the Baton Rouge Senior High School, Baton Rouge, Louisiana. (M 44931)

\section{(16203) Jessicastahl}

$2000 \mathrm{CH}_{32}$. Discovered 2000 Feb. 2 by the LINEAR at Socorro.

Named in honor of Jessica Randi Stahl for achievement as a finalist in the 2002 Intel Science Talent Search, a science competition for high school seniors. Jessica is a student at the South Side High School, Rockville Centre, New York. (M 44931)

\section{(16209) Sterner}

$2000 \mathrm{CB}_{56}$. Discovered 2000 Feb. 4 by the LINEAR at Socorro.

Named in honor of Beckett William Sterner for achievement as a finalist in the 2002 Intel Science Talent Search, a science competition for high school seniors. Beckett is a student at the University of Chicago Laboratory School, Chicago, Illinois. (M 44931)

\section{(16211) Samirsur}

$2000 \mathrm{CL}_{83}$. Discovered 2000 Feb. 4 by the LINEAR at Socorro.

Named in honor of Samir Sur for achievement as a finalist in the 2002 Intel Science Talent Search, a science competition for high school seniors. Samir is a student at the Roxbury Latin School, West Roxbury, Massachusetts. (M 44931)

\section{(16212) Theberge}

$2000 \mathrm{CB}_{84}$. Discovered 2000 Feb. 4 by the LINEAR at Socorro.

Named in honor of Ashleigh Brooks Theberge for achievement as a finalist in the 2002 Intel Science Talent Search, a science competition for high school seniors. Ashleigh is a student at the Mount Ararat School, Topsham, Maine. (M 44931)

\section{(16214) Venkatachalam}

$2000 \mathrm{CM}_{87}$. Discovered 2000 Feb. 4 by the LINEAR at Socorro. 
Named in honor of Vivek Venkatachalam for achievement as a finalist in the 2002 Intel Science Talent Search, a science competition for high school seniors. Vivek is a student at the Governor Livingston High School, Berkeley Heights, New Jersey. (M 44931)

\section{(16215) Venkatraman}

$2000 \mathrm{CB}_{104}$. Discovered 2000 Feb. 11 by the LINEAR at Socorro.

Named in honor of Dheera Venkatraman for achievement as a finalist in the 2002 Intel Science Talent Search, a science competition for high school seniors. Dheera is a student at the Hunterdon Central Regional High School, Flemington, New Jersey. (M 44931)

\section{(16219) Venturelli}

$2000 \mathrm{DL}_{29}$. Discovered 2000 Feb. 29 by the LINEAR at Socorro.

Named in honor of Ophelia Shalini Venturelli for achievement as a finalist in the 2002 Intel Science Talent Search, a science competition for high school seniors. Ophelia is a student at the Walt Whitman High School, Bethesda, Maryland. (M 44931)

\section{(16220) Mikewagner}

$2000 \mathrm{DB}_{40}$. Discovered 2000 Feb. 29 by the LINEAR at Socorro.

Named in honor of Michael Jacob Wagner for achievement as a finalist in the 2002 Intel Science Talent Search, a science competition for high school seniors. Michael is a student at the John F. Kennedy High School, Bellmore, New York. (M 44931)

\section{(16221) Kevinyang}

2000 DX $_{48}$. Discovered 2000 Feb. 29 by the LINEAR at Socorro.

Named in honor of Kevin Yang for achievement as a finalist in the 2002 Intel Science Talent Search, a science competition for high school seniors. Kevin is a student at the Illinois Mathematics and Science Academy, Aurora, Illinois. (M 44931)

\section{(16222) Donnanderson}

$2000 \mathrm{DK}_{55}$. Discovered 2000 Feb. 29 by the LINEAR at Socorro.

Named in honor of Donna Anderson for mentoring a finalist in the 2002 Intel Science Talent Search, a science competition for high school seniors. Anderson is a teacher at the William Hall High School, West Hartford, Connecticut. (M 44931)

\section{(16225) Georgebaldo}

$2000 \mathrm{DF}_{71}$. Discovered 2000 Feb. 29 by the LINEAR at Socorro.

Named in honor of George J. Baldo for mentoring a finalist in the 2002 Intel Science Talent Search, a science competition for high school seniors. Baldo is a teacher at the Ward Melville High School, East Setauket, New York. (M 44931)

\section{(16226) Beaton}

$2000 \mathrm{DT}_{72}$. Discovered 2000 Feb. 29 by the LINEAR at Socorro.

Named in honor of John Beaton for mentoring a finalist in the 2002 Intel Science Talent Search, a science competition for high school seniors. Beaton is a teacher at the Harvest Christian Academy, Barrigada, Guam. (M 44931)

\section{(16230) Benson}

2000 EA $_{95}$. Discovered 2000 Mar. 9 by the LINEAR at Socorro.

Named in honor of Carol Benson for mentoring a finalist in the 2002 Intel Science Talent Search, a science competition for high school seniors. Benson is a teacher at the University High School, Normal, Illinois. (M 44931)

\section{(16234) Bosse}

$2000 \mathrm{FR}_{20}$. Discovered 2000 Mar. 29 by the LINEAR at Socorro.

Named in honor of Angelique Bosse for mentoring a finalist in the 2002 Intel Science Talent Search, a science competition for high school seniors. Bosse is a teacher at the Montgomery Blair High School, Silver Spring, Maryland. (M 44931)

\section{(16236) Stebrehmer}

2000 GG $_{51}$. Discovered 2000 Apr. 5 by the LINEAR at Socorro.

Named in honor of Stephen Brehmer for mentoring a finalist in the 2002 Intel Science Talent Search, a science competition for high school seniors. Brehmer is a teacher at the Mayo High School, Rochester, Minnesota. (M 44931)

\section{(16238) Chappe}

2000 GY $_{104}$. Discovered 2000 Apr. 7 by the LINEAR at Socorro.

Named in honor of Sean Chappe for mentoring a finalist in the 2002 Intel Science Talent Search, a science competition for high school seniors. Chappe is a teacher at the Hunterdon Central Regional High School, Flemington, New Jersey. (M 44932)

\section{(16239) Dower}

2000 GY $_{105}$. Discovered 2000 Apr. 7 by the LINEAR at Socorro.

Named in honor of Richard Dower for mentoring a finalist in the 2002 Intel Science Talent Search, a science competition for high school seniors. Dower is a teacher at the Roxbury Latin School, West Roxbury, Massachusetts. (M 44932)

\section{(16241) Dvorsky}

2000 GD 126 . Discovered 2000 Apr. 7 by the LINEAR at Socorro.

Named in honor of Mary Ann Dvorsky for mentoring a finalist in the 2002 Intel Science Talent Search, a science competition for high school seniors. Dvorsky is 
a teacher at the Montgomery Blair High School, Silver Spring, Maryland. (M 44932)

\section{(16246) Cantor}

$2000 \mathrm{HO}_{3}$. Discovered 2000 Apr. 27 by P. G. Comba at Prescott.

Georg Cantor (1845-1918) was a German mathematician and professor at Halle. In a series of papers beginning in 1870 he developed the theory of infinite sets and was the first to recognize and prove that there are different degrees of infinity. (M 41573)

\section{(16247) Esner}

2000 HY $_{11}$. Discovered 2000 Apr. 28 by the LINEAR at Socorro.

Named in honor of William Esner for mentoring a finalist in the 2002 Intel Science Talent Search, a science competition for high school seniors. Esner is a teacher at the Rambam Mesivta, Lawrence, New York. (M 44932)

\section{(16248) Fox}

$2000 \mathrm{HT}_{13}$. Discovered 2000 Apr. 28 by the LINEAR at Socorro.

Named in honor of Mitchell Fox for mentoring a finalist in the 2002 Intel Science Talent Search, a science competition for high school seniors. Fox is a teacher at the Bronx High School of Science, Bronx, New York. (M 44932)

\section{(16249) Cauchy}

$2000 \mathrm{HT}_{14}$. Discovered 2000 Apr. 29 by P. G. Comba at Prescott.

Augustin-Louis Cauchy (1789-1857) was a French mathematician who made fundamental contributions to the theory of functions of complex variables, the study of determinants and the mathematical theory of elasticity. He introduced a higher level of rigor in mathematical proofs. (M 41573)

\section{(16251) Barbifrank}

$2000 \mathrm{HX}_{48}$. Discovered 2000 Apr. 29 by the LINEAR at Socorro.

Named in honor of Barbi Frank for mentoring a finalist in the 2002 Intel Science Talent Search, a science competition for high school seniors. Frank is a teacher at the John F. Kennedy High School, Bellmore, New York. (M 44932)

\section{(16252) Franfrost}

2000 HQ 51. Discovered 2000 Apr. 29 by the LINEAR at Socorro.

Named in honor of Fran Frost for mentoring a finalist in the 2002 Intel Science Talent Search, a science competition for high school seniors. Frost is a teacher at the Baton Rouge Senior High School, Baton Rouge, Louisiana. (M 44932)

\section{(16253) Griffis}

$2000 \mathrm{HJ}_{52}$. Discovered 2000 Apr. 29 by the LINEAR at Socorro.
Named in honor of Wanda Griffis for mentoring a finalist in the 2002 Intel Science Talent Search, a science competition for high school seniors. Griffis is a teacher at the Murphy High School, Mobile, Alabama. (M 44932)

\section{(16254) Harper}

$2000 \mathrm{HZ}_{53}$. Discovered 2000 Apr. 29 by the LINEAR at Socorro.

Named in honor of Dan Harper for mentoring a finalist in the 2002 Intel Science Talent Search, a science competition for high school seniors. Harper is a teacher at the Westlake High School, Austin, Texas. (M 44932)

\section{(16258) Willhayes}

$2000 \mathrm{JP}_{13}$. Discovered 2000 May 6 by the LINEAR at Socorro.

Named in honor of William Hayes for mentoring a finalist in the 2002 Intel Science Talent Search, a science competition for high school seniors. Hayes is a teacher at the Bloomington High School North, Bloomington, Indiana. (M 44932)

\section{(16259) Housinger}

$2000 \mathrm{JR}_{13}$. Discovered 2000 May 6 by the LINEAR at Socorro.

Named in honor of Sharon Housinger for mentoring a finalist in the 2002 Intel Science Talent Search, a science competition for high school seniors. Housinger is a teacher at the University of Chicago Laboratory School, Chicago, Illinois. (M 44932)

\section{(16260) Sputnik}

$2000 \mathrm{JO}_{15}$. Discovered 2000 May 9 by J. Broughton at Reedy Creek.

Sputnik is the Russian name of a series of artificial satellites, the first of which ushered in the space age on 1957 Oct. 4. (M 42675)

\section{(16262) Rikurtz}

$2000 \mathrm{JR}_{32}$. Discovered 2000 May 7 by the LINEAR at Socorro.

Named in honor of Richard Kurtz for mentoring a finalist in the 2002 Intel Science Talent Search, a science competition for high school seniors. Kurtz is a teacher at the South Side High School, Rockville Centre, New York. (M 44932)

\section{(16264) Richlee}

$2000 \mathrm{JH}_{40}$. Discovered 2000 May 7 by the LINEAR at Socorro.

Named in honor of Richard Lee for mentoring a finalist in the 2002 Intel Science Talent Search, a science competition for high school seniors. Lee is a teacher at the Bronx High School of Science, Bronx, New York. (M 44932)

\section{(16265) Lemay}

$2000 \mathrm{JL}_{43}$. Discovered 2000 May 7 by the LINEAR at Socorro. 
Named in honor of Ron LeMay for mentoring a finalist in the 2002 Intel Science Talent Search, a science competition for high school seniors. LeMay is a teacher at the Nicolet High School, Glendale, Wisconsin. (M 44932)

\section{(16266) Johconnell}

$2000 \mathrm{JX}_{43}$. Discovered 2000 May 7 by the LINEAR at Socorro.

Named in honor of John McConnell for mentoring a finalist in the 2002 Intel Science Talent Search, a science competition for high school seniors. McConnell is a teacher at the Central High School, Grand Junction, Colorado. (M 44932)

\section{(16267) Mcdermott}

$2000 \mathrm{JY}_{43}$. Discovered 2000 May 7 by the LINEAR at Socorro

Named in honor of Frank McDermott for mentoring two finalists in the 2002 Intel Science Talent Search, a science competition for high school seniors. McDermott is a teacher at the Manhasset High School, Manhasset, New York. (M 44932)

\section{(16268) Mcneeley}

$2000 \mathrm{JD}_{44}$. Discovered 2000 May 7 by the LINEAR at Socorro.

Named in honor of Pam McNeeley for mentoring a finalist in the 2002 Intel Science Talent Search, a science competition for high school seniors. McNeeley is a teacher at the Naperville Central High School, Naperville, Illinois. (M 44933)

\section{(16269) Merkord}

$2000 \mathrm{JP}_{44}$. Discovered 2000 May 7 by the LINEAR at Socorro.

Named in honor of Pat Merkord for mentoring a finalist in the 2002 Intel Science Talent Search, a science competition for high school seniors. Merkord is a teacher at the John B. Connally High School, Austin, Texas. (M 44933)

\section{(16271) Duanenichols}

$2000 \mathrm{JC}_{55}$. Discovered 2000 May 6 by the LINEAR at Socorro.

Named in honor of Duane Nichols for mentoring a finalist in the 2002 Intel Science Talent Search, a science competition for high school seniors. Nichols is a teacher at the Alhambra High School, Alhambra, California. (M 44933)

\section{(16273) Oneill}

2000 JS$_{56}$. Discovered 2000 May 6 by the LINEAR at Socorro.

Named in honor of Barbara O'Neill for mentoring a finalist in the 2002 Intel Science Talent Search, a science competition for high school seniors. O'Neill is a teacher at the Mount Ararat School, Topsham, Maine. (M 44933)

\section{(16274) Pavlica}

$2000 \mathrm{JX}_{56}$. Discovered 2000 May 6 by the LINEAR at Socorro.

Named in honor of Robert Pavlica for mentoring a finalist in the 2002 Intel Science Talent Search, a science competition for high school seniors. Pavlica is a teacher at the Byram Hills High School, Armonk, New York. (M 44933)

\section{(16355) Buber}

1975 UA $_{1}$. Discovered 1975 Oct. 29 by F. Börngen at Tautenburg.

Martin Buber (1878-1965), Austrian-born Jewish philosopher and author, was a teacher of religious science, ethics and social philosophy. From 1938 he taught in Jerusalem, where he stood up for the peaceful coexistence of Arabs and Jews. His Hebrew-German version of the Bible shows a unique diction and exegesis. (M 41573)

\section{(16398) Hummel}

$1982 \mathrm{SN}_{3}$. Discovered 1982 Sept. 24 by F. Börngen at Tautenburg.

Johann Nepomuk Hummel (1778-1837), famous Austrian pianist and versatile composer, Mozart's pupil and Beethoven's friend \{see, respectively, planets (1034) and (1815)\}, made numerous concert tours. He was appointed conductor of the court orchestra in Weimar in 1819 and held this position until his death. His tomb is in the historical churchyard in Weimar \{see planet (3539)\}. (M 42364)

\section{(16418) Lortzing}

1987 SD 10 . Discovered 1987 Sept. 29 by F. Börngen at Tautenburg.

Albert Lortzing (1801-1851), who was born and died in Berlin, was a singer, an actor and later a conductor in Leipzig, Vienna and Berlin. His romantic-comic operas (Zar und Zimmermann, Der Wildschütz, Undine, Der Waffenschmied) became very popular and are full of humor. He mainly wrote the libretti himself. (M 42364)

\section{(16435) Fándly}

$1988 \mathrm{VE}_{7}$. Discovered 1988 Nov. 7 by M. Antal at Piwnice.

Juraj Fándly (1750-1811) was an Enlightenment writer, author of the first book in Bernolák's \{see planet (13916)\} language Dúverná zmlúva mezi mňíchom a diáblom ("The confidential pact between the monk and the devil", 1789). He was a zealous propagator of this language and a well-known educator. (M 43192)

\section{(16438) Knöfel}

$1989 \mathrm{AU}_{6}$. Discovered 1989 Jan. 11 by F. Börngen at Tautenburg.

German meteorologist André Knöfel (1963- ～） is the head of the Fireball Data Center of the International Meteor Organization and an observer of minor planets. He has located precovery observations of many objects in the Digital Sky Survey, among them this minor 
planet and the transneptunian object (20000) 2000

$\mathrm{WR}_{106}$, now (20000) Varuna. (M 42364)

\section{(16441) Kirchner}

$1989 \mathrm{EF}_{6}$. Discovered 1989 Mar. 7 by F. Börngen at Tautenburg.

Ernst Ludwig Kirchner (1880-1938), painter, graphic artist and sculptor, was a master of German expressionism and cofounder of the artist circle "Die Bruecke". After 1917, he worked and lived in Switzerland. In 1937, his art was confiscated and classified as "degenerate" in Germany, driving him to suicide. (M 41573)

\section{(16459) Barth}

$1989 \mathrm{WE}_{4}$. Discovered 1989 Nov. 28 by F. Börngen at Tautenburg.

The Swiss Protestant Reformed theologian Karl Barth (1886-1968), ousted from his post in Germany, was professor in Basel beginning in 1935. In Germany, he is known as the "Vater der Bekennenden Kirche". His main works are The Epistle to the Romans and Ecclesiastical Dogmatics. (M 41573)

\section{(16505) Sulzer}

$1990 \mathrm{~TB}_{13}$. Discovered 1990 Oct. 12 by F. Börngen and L. D. Schmadel at Tautenburg.

Robert Sulzer-Forrer (1873-1953), a socially minded Swiss industrialist at Winterthur, was an outstanding engineer with excellent skills for practical implementation. He was an enthusiastic observer of natural phenomena and a pioneer in fast motion film technology. (M 41573)

\section{(16514) Stevelia}

1990 VZ $_{6}$. Discovered 1990 Nov. 11 by C. S. Shoemaker and D. H. Levy at Palomar.

Steve (1949- ) and Amelia (1940- ) Goldberg have spent years teaching beginners to observe the night sky. Amelia's Universe Sampler, a booklet of simple projects for beginners with small telescopes, is an official project of the Astronomical League. The couple has also helped manage the annual Texas Star Party. (M 41573)

\section{(16522) Tell}

1991 AJ $_{3}$. Discovered 1991 Jan. 15 by F. Börngen at Tautenburg.

Wilhelm Tell, legendary hero of the well-known Swiss saga, distinguished himself in the fight for independence of the Inner Swiss against the Habsburg landvogt Gessler in the fourteenth century. Variously, this myth was treated in literature, e.g., by Schiller \{see planet (3079)\} in 1804. It still influences the Swiss national consciousness. (M 41573)

\section{(16524) Hausmann}

$1991 \mathrm{BB}_{3}$. Discovered 1991 Jan. 17 by F. Börngen at Tautenburg.

Manfred Hausmann (1898-1986), who was born in Kassel and died in Bremen, lived for many years in Worpswede \{see planet (9742)\} and wrote lyrical poetry, stories and novels. Widely traveled, he studied distant cultures and translated their works. After 1945 he turned to christianity and became a preacher. (M 42364)

\section{(16529) Dangoldin}

$1991 \mathrm{GO}_{1}$. Discovered 1991 Apr. 9 by E. F. Helin at Palomar.

Daniel S. Goldin (1940- ), NASA's administrator from 1992 to 2001, is credited with transforming the agency and its operations with an approach that became known as "faster, better, cheaper". He has been the agency's longest-serving administrator and is saluted for his vision and dynamic leadership. (M 44594)

\section{(16590) Brunowalter}

$1992 \mathrm{SM}_{2}$. Discovered 1992 Sept. 21 by F. Börngen and L. D. Schmadel at Tautenburg.

Berlin-born Bruno Walter (1876-1962; originally B. W. Schlesinger), great German-American conductor, was known particularly for interpretations of Mozart, Bruckner and Mahler \{see, respectively, planets (1034), (3955) and (4406)\}. He lived in exile after 1938, endeavoring to preserve a German mind and culture. After World War II he conducted in Europe again. (M 41574)

\section{(16599) Shorland}

$1993 \mathrm{BR}_{2}$. Discovered 1993 Jan. 20 by Y. Kushida and O. Muramatsu at Yatsugatake.

John Herschel Shorland, a direct descendant of John Herschel, has recently completed his own Herschel Archives in Norfolk, England. These archives include various documents and instruments associated with the Herschels, including the 7-foot telescope probably used by William Herschel \{see planet (2000)\} to discover Uranus. (M 42675)

\section{(16666) Liroma}

1993 XL $_{1}$. Discovered 1993 Dec. 7 by C. S. Shoemaker at Palomar.

The Meiers are a family of amateur astronomers living near Ottawa, Ontario. Linda (1950- ) is an active observer. Between 1978 and 1984, Rolf (1953-

) discovered four comets and has recently built an observatory. Son Matthew (1985- ) has joined the Royal Astronomical Society of Canada's Ottawa Center. (M 41941)

\section{(16672) Bedini}

$1994 \mathrm{BA}_{1}$. Discovered 1994 Jan. 17 by A. Boattini and M. Tombelli at Cima Ekar.

Daniele Bedini (1952- ) wrote a thesis on space architecture, the first of its kind in Europe. He is currently director af a university consortium in Florence and teaches space architecture at the Space International University in Strasbourg. (M 45339) 


\section{(16683) Alepieri}

1994 JY. Discovered 1994 May 3 by L. Tesi and G. Cattani at San Marcello Pistoiese.

Alessandro Pieri (1969-2000) was an amateur astronomer from childhood and was for many years a member of the Associazione Astrofili Valdinievole, an organization of amateur astronomers in northern Tuscany. He was an active meteor observer and an astrophotographer. (M 41941)

\section{(16693) Moseley}

$1994 \mathrm{YC}_{2}$. Discovered 1994 Dec. 26 by D. J. Asher at Siding Spring.

Terence J. C. A. Moseley (1946- ), editor of Stardust, 1992 Aidan P. Fitzgerald Medallist and founding member of the Irish Federation of Astronomical Societies, was the first amateur to use the recently restored six-foot Birr telescope in Sept. 2001. (M 46683)

The name was suggested by J. C. McConnell.

\section{(16700) Seiwa}

1995 DZ. Discovered 1995 Feb. 22 by T. Kobayashi at Oizumi.

Seiwa village, where the Seiwa-Kogen public observatory is located, is in the center of the island of Kyushu. The village is famous for its Bunraku puppet shows. (M 45339)

\section{(16705) Reinhardt}

$1995 \mathrm{EO}_{8}$. Discovered 1995 Mar. 4 by F. Börngen at Tautenburg.

Austrian stage director and theater manager Max Reinhardt (Max Goldmann, 1873-1943) worked mainly in Berlin and Vienna. He was a cofounder of the "Salzburger Festspiele". His productions of classic dramas caused an enormous stir. In 1933 he emigrated from Germany. (M 42364)

\section{(16706) Svojsík}

$1995 \mathrm{OE}_{1}$. Discovered 1995 July 30 by P. Pravec at Ondřejov.

Antonín Benjamin Svojsík (1876-1938) founded the Czech Boy Scout organization "Junák" in 1912, led it from 1914 until his death and was a member of the executive committee of the world Scout movement. After repeated bans between 1939 and 1989, "Junák" is now the most popular Czech children's organization. (M 41491)

\section{(16714) Arndt}

1995 SM $_{54}$. Discovered 1995 Sept. 21 by F. Börngen at Tautenburg.

German patriotic writer and poet Ernst Moritz Arndt (1769-1860), born on the island of Rügen, was a professor of history at the University of Greifswald \{see planet (10114)\} (which now bears his name), as well as in Bonn. A passionate agitator and singer of the German Wars for Liberation, he stood up for a revival in Germany. (M 42364)

\section{(16715) Trettenero}

1995 UN $_{5}$. Discovered 1995 Oct. 20 at the Osservatorio San Vittore at Bologna.

Italian astronomer Virgilio Trettenero (1822-1868) succeeded Santini \{see planet (4158)\} as professor of astronomy at Padua. At the observatory there he observed minor planets, comets and eclipses and calculated orbits and ephemerides. (M 45339)

\section{(16730) Nijisseiki}

$1996 \mathrm{HJ}_{1}$. Discovered 1996 Apr. 17 at the Saji Observatory at Saji.

The Niji-sseiki fruit is a type of locally cultivated pear representative of and having a strong affinity to Tottori \{see planet (4720)\} prefecture, a major pear producing area in which Saji \{see planet (8738)\} village is located. In English, Niji-sseiki translates as "twentieth Century". (M 41941)

\section{(16731) Mitsumata}

$1996 \mathrm{HK}_{1}$. Discovered 1996 Apr. 17 at the Saji Observatory at Saji.

Mitsumata is an ingredient used in traditional Japanese papermaking and represents a local Saji industry. Saji \{see planet (8738)\} village produces the major share of this country's handmade Japanese paper, the paper of choice for the writing of calligraphy. (M 41941)

\section{(16744) Antonioleone}

$1996 \mathrm{OJ}_{2}$. Discovered 1996 July 23 by L. Tesi at San Marcello Pistoiese.

Since the early 1970s, amateur astronomer Antonio Leone (1940- ), of Taranto, Italy, has developed principles of orbital motion in a manner easy for amateurs to understand. This has resulted in two books, Introduzione alla Meccanica Celeste and, with a co-author, Elementi di Calcolo delle Orbite. (M 42675)

\section{(16745) Zappa}

$1996 \mathrm{PF}_{5}$. Discovered 1996 Aug. 9 at the Osservatorio San Vittore at Bologna.

Italian astronomer Giovanni Zappa (1884-1923) was an assistant at the observatory of the Collegio Romano, adjunct astronomer at Catania, astronomer at Capodimonte and director of the observatory of Collurania and Collegio Romano. Interested in classical astronomy, he calculated orbits of minor planets and comets. (M 46011)

\section{(16750) Marisandoz}

1996 QL. Discovered 1996 Aug. 18 by R. Linderholm at Lime Creek.

Sandhills author Mari Sandoz (1896-1966) wrote 21 books and stories about life on the Great Plains. Her first book, Old Jules, was published in 1935 after it won the Atlantic Nonfiction Prize. She also wrote Crazy Horse, a biography of the Sioux Chief, and Cheyenne Autumn, about Native Americans leaving the reservation. (M 45339) 


\section{(16755) Cayley}

$1996 \mathrm{RE}_{1}$. Discovered 1996 Sept. 9 by P. G. Comba at Prescott.

Arthur Cayley (1821-1895) started out as a practicing lawyer but in 1863 became a professor of mathematics at Cambridge. He published papers on many topics in algebra and geometry and was the founder, together with Sylvester \{see planet (13658)\}, of the theory of algebraic invariants. (M 41574)

\section{(16759) Furuyama}

$1996 \mathrm{TJ}_{7}$. Discovered 1996 Oct. 10 by A. Nakamura at Kuma.

Shigeru Furuyama (1953- ) is a post-office clerk and renowned amateur astronomer in Japan. During his nine-year visual search for comets, Furuyama independently discovered C/1975 T2. In 1979 he changed from visual to photographic observing and later discovered C/1987 W2. (M 43192)

\section{(16761) Hertz}

$1996 \mathrm{TE}_{8}$. Discovered 1996 Oct. 3 by V. Goretti at Pianoro.

German physicist Heinrich Rudolf Hertz (1857-1894) substantially advanced knowledge of electricity. His experiments demonstrated the existence and examined the nature of electromagnetic waves, thereby opening the road to some of the most important achievements of modern technology. (M 42364)

\section{(16765) Agnesi}

1996 UA. Discovered 1996 Oct. 16 by P. G. Comba at Prescott.

Maria Gaetana Agnesi (1718-1799) was the first woman in the western world who can properly be called a mathematician. She wrote a treatise on algebra that was widely translated, and in 1750 she was appointed to a professorship at the University of Bologna. (M 41941)

\section{(16766) Righi}

1996 UP. Discovered 1996 Oct. 18 by V. Goretti at Pianoro.

Italian experimental physicist Augusto Righi (18501921) continued Heinrich Hertz's research on electromagnetism and served as an inspiration to his student Marconi \{see planet (1332)\}. (M 42364)

\section{(16781) Renčín}

1996 XU $_{18}$. Discovered 1996 Dec. 12 by M. Tichý and Z. Moravec at Klet.

Vladimír Renčín (1941- ) is a Czech graphic artist, illustrator and cartoonist. He published several books of cartoons, where various features of the Czech character are illustrated. (M 42364)

\section{(16783) Bychkov}

$1996 \mathrm{XY}_{25}$. Discovered 1996 Dec. 14 by R. A. Tucker at Tucson.

Victor Dmitrievich Bychkov (1952- ) is an astronomer at the Special Astrophysical Observatory,
Zelenchukskaya. He is a specialist in the study of magnetic stars and an expert photopolarimetrist. (M 42364)

\section{(16794) Cucullia}

1997 CQ $_{1}$. Discovered 1997 Feb. 2 by J. Tichá and M. Tichý at Klět.

The caterpillar of the North American Asteroid Moth Cucullia asteroides feeds on flowers of the family Asteraceae. The Latin word cucullus means a hood, and it refers to a hood-like arrangement of hairs on the thorax of the adult moth. (M 41941)

The citation was prepared by J. B. Tatum.

\section{(16797) Wilkerson}

$1997 \mathrm{CA}_{17}$. Discovered 1997 Feb. 7 by A. Boattini and L. Tesi at San Marcello Pistoiese.

Winston S. Wilkerson, uncle of the first discoverer's wife, is a member of the physics faculty at The Cooper Union for the Advancement of Science and Art in New York. His interests have concentrated on variable stars, and he has been a member of the American Association of Variable Star Observers for many years. (M 43046)

\section{(16801) Petřínpragensis}

$1997 \mathrm{SC}_{2}$. Discovered 1997 Sept. 23 by P. Pravec at Ondřejov.

Petřín is a memorable hill in the center of Prague. There is located the Stefánik Observatory, founded in 1928, the oldest active public observatory in the Czech Republic. Petřín is also a symbol of lovers and a place of beautiful gardens and a renowned rosarium. (M 42675)

\section{(16802) Rainer}

$1997 \mathrm{SP}_{3}$. Discovered 1997 Sept. 25 by E. Meyer at Linz.

Suffering from a serious heart disease since his birth, Rainer Gebetsroither (1976-1998) devoted his life to observations of nature as well as to the history and technology of railways. His parents Karin and Uwe are long-term members of the Linzer Astronomische Gemeinschaft. (M 45234)

\section{(16804) Bonini}

1997 SX $_{15}$. Discovered 1997 Sept. 27 by the OCA-DLR Survey at Caussols.

Daughter of Robert and Henriette Chemin \{see planet (3913)\}, observers at the Observatoire de la Côte d'Azur Schmidt telescope, Claire Bonini (1951- ) is a schoolteacher who been active in teaching astronomy in French primary schools. Her 1990 experiment in a Sevran kindergarten was extended nationally and to other age groups. (M 46683)

\section{(16807) Terasako}

1997 TW $_{25}$. Discovered 1997 Oct. 12 by A. Nakamura at Kuma.

Masanori Terasako (1951- _ ) is a renowned amateur astronomer in Japan. Terasako started his visual comet 
searching in 1971, and after sweeping for 1374 hours he discovered $\mathrm{C} / 1987 \mathrm{~B} 2$. He is also famous for his telescopic meteor observations. (M 43192)

\section{(16809) Galápagos}

1997 US. Discovered 1997 Oct. 21 at the Starkenburg Observatory at Heppenheim.

The Galápagos Islands are a world heritage site and provide a living history of evolution. Assisted by the Charles Darwin \{see planet (1991)\} Research Station located there, scientists have made many discoveries. The station also helps to preserve this National Park with its famous animals, such as the giant tortoises and the Darwin finches. (M 42364)

\section{(16810) Pavelaleksandrov}

$1997 \mathrm{UY}_{2}$. Discovered 1997 Oct. 25 by P. G. Comba at Prescott.

Pavel Sergeevich Aleksandrov (1896-1982) was a student of Urysohn \{see planet (13673)\}, with whom he later wrote a fundamental paper on compact topological spaces. After a stint as a theater producer, he became a professor at Moscow State University. (M 41941)

\section{(16817) Onderlička}

1997 UU $_{10}$. Discovered 1997 Oct. 30 by P. Pravec at Ondřejov.

Bedřich Onderlička (1923-1994) was a prominent Czech astrophysicist and enthusiastic pedagogue, head of the department of astrophysics of Masaryk University in Brno. He specialized in stellar kinematics and chemistry of late-type stars. (M 41941)

\section{(16847) Sanpoloamosciano}

1997 XK $_{10}$. Discovered 1997 Dec. 8 by M. Mannucci and N. Montigiani at San Polo a Mosciano.

The observatory at San Polo a Mosciano, a small town near Florence, is operated by the Associazione Astrofili Fiorentini. The first image of this minor planet shows it close to the M1 nebula. This was one of the few observations of minor planets taken at the observatory, which is usually involved in the study of variable stars. (M 42676)

\section{(16852) Nuredduna}

$1997 \mathrm{YP}_{2}$. Discovered 1997 Dec. 21 by A. Lopez and R. Pacheco at Mallorca.

Created by Majorcan poet Miquel Costa i Llobera in his poem The inheritance of the Greek genius, Nuredduna is a priestess, a great visionary who belonged to a primitive nation that built many megalithic monuments called Talaiots that even nowadays are present in the Balearic islands. (M 43046)

\section{(16856) Banach}

$1997 \mathrm{YE}_{8}$. Discovered 1997 Dec. 28 by P. G. Comba at Prescott.

Stafan Banach (1892-1945) was a Polish mathematician and professor at the University of Lvov. His major contributions were in functional analysis, particularly the theory of complete normed linear spaces, now generally known as Banach spaces. (M 41941)

\section{(16857) Goodall}

1997 YZ $_{8}$. Discovered 1997 Dec. 25 by the JPL NEAT Program at Haleakala.

Kirk Goodall (1964- ) was the Mars Pathfinder Web Engineer, and was instrumental in setting up the relationships with other countries and industry for mirror websites that allowed Mars Pathfinder to provide information to millions of people around the world. (M 45749)

\section{(16861) Lipovetsky}

$1997 \mathrm{YZ}_{11}$. Discovered 1997 Dec. 27 by R. A. Tucker at Tucson.

Valentin Alexandrovich Lipovetsky (1945-1996) was a senior researcher at the Special Astrophysical Observatory, Zelenchukskaya, and headed a group studying Blue Compact Galaxies. He was an expert on active galactic nuclei and participated in the production of the First Byurakan Survey. (M 42364)

\section{(16878) Tombickler}

1998 BL9. Discovered 1998 Jan. 24 by the JPL NEAT Program at Haleakala.

Thomas C. Bickler (1950- ) is responsible for the NEAT camera electronics. He has experience with imaging instruments and has worked with CCD camera electronics systems extensively. During his 21 years at the Jet Propulsion Laboratory he helped develop and deliver flight hardware for Galileo, Cassini and Space Telescope. (M 42676)

\section{(16887) Blouke}

$1998 \mathrm{BE}_{26}$. Discovered 1998 Jan. 28 by the OCA-DLR Survey at Caussols.

Morley Blouke (1941- ) is a well-known microelectronician, whose pioneering development of thinned CCDs gave rise to the WF/PC I focal plane. He now heads advanced development at Scientific Imaging Technologies, Inc., in Tigard, Oregon. (M 46683)

\section{(16888) Michaelbarber}

$1998 \mathrm{BM}_{26}$. Discovered 1998 Jan. 29 at the Farra d'Isonzo Observatory at Farra d'Isonzo.

Michael R. Barber (1947- ), a lawyer and amateur astronomer in the $\gamma$-ray bursts field at the Santa Barbara Astronomical Group, co-founded a small CCD \{see planet (15000)\} brand that in 1991 developed star tracking equipment, allowing the start of CCD revolution in the amateur astronomer's world. (M 46683)

\section{(16892) Vaissière}

$1998 \mathrm{DN}_{1}$. Discovered 1998 Feb. 17 by P. Antonini at Bedoin.

Franck Vaissière (1958- ) has been responsible for the technical activity to the T60 association at Pic du Midi. He also took part in $\mathrm{H} \alpha$ coronographic observations and cowrote a book on this extraor dinary astronomical site. He has long been treasurer 
of the Association des Utilisateurs de Détecteurs Electroniques \{see planet (9117)\}. (M 43192)

\section{(16900) Lozère}

$1998 \mathrm{DQ}_{13}$. Discovered 1998 Feb. 27 at the Pises Observatory at Draveil.

At 1699 meters, Mt. Lozère is the highest summit of the Cevennes mountains, which surround the Pises observatory. It is also the name of the 48th French département. (M 41941)

\section{(16901) Johnbrooks}

1998 DJ $_{14}$. Discovered 1998 Feb. 23 at the Farra d'Isonzo Observatory at Farra d'Isonzo.

John J. Brooks (1933- ), a mechanical engineer and amateur astronomer in the $\gamma$-ray bursts field at the Santa Barbara Astronomical Group, co-founded a small CCD \{see planet (15000)\} brand that in 1991 developed star tracking equipment, allowing the start of the CCD revolution in the amateur astronomer's world. (M 46683)

\section{(16906) Giovannisilva}

$1998 \mathrm{DY}_{23}$. Discovered 1998 Feb. 18 at the Osservatorio San Vittore at Bologna.

Italian astronomer Giovanni Silva (1882-1957) was an assistant at the International Latitude Station at Carloforte and later director of the Padua Observatory until 1952. He contributed to classical astronomy, celestial mechanics, geodesy, astrophysics and the calculus of probability. (M 45339)

\section{(16908) Groeselenberg}

1998 DD $_{33}$. Discovered 1998 Feb. 17 by E. W. Elst and T. Pauwels at Uccle.

Groeselenberg is the hill in Uccle where the Royal Observatory is located. The name refers to "a hill covered with spiny bushes". Well-known minor-planet discoverer Henri Debehogne \{see planet (2359)\} lives there on a street with the same name. (M 47168)

\section{(16912) Rhiannon}

1998 EP $_{8}$. Discovered 1998 Mar. 2 by the OCA-DLR Survey at Caussols.

Rhiannon was a version of the celtic horse-goddess Epona and of sovereignty. She was mistress of the Singing Birds. Sometimes she appeared as a beautiful woman in dazzling gold on a white horse. (M 42364)

\section{(16915) Bredthauer}

$1998 \mathrm{FR}_{10}$. Discovered 1998 Mar. 24 by the OCA-DLR Survey at Caussols.

Richard Bredthauer (1946- ) has been a CCD \{see planet (15000)\} designer for the last 23 years, providing high-performance CCDs to the astronomical community. Richard has also fabricated several flight CCDs for NASA missions. including the Hubble Space Telescope. (M 46683)

\section{(16929) Hurník}

$1998 \mathrm{FP}_{73}$. Discovered 1998 Mar. 31 by P. Pravec at Ondřejov.

Ilja Hurník (1922- ）, outstanding Czech composer, pianist, writer, musical pedagogue, speaker and popularizer, has a keen interest in science, particularly in astronomy. (M 41941)

The name was suggested by participants of the meeting organized on the occasion of naming the Johann Palisa Observatory and Planetarium in Ostrava-Poruba.

\section{(16930) Respighi}

$1998 \mathrm{FF}_{74}$. Discovered 1998 Mar. 29 at the Osservatorio San Vittore at Bologna.

Italian astronomer Lorenzo Respighi (1824-1889) was professor of optics and astronomy and director successively of the observatories of Bologna and of Campidoglio in Rome. He compiled stellar catalogues, observed the planets and discovered three comets. He introduced the use of the objective prism in stellar spectroscopy. (M 45339)

\section{(16951) Carolus Quartus}

1998 KJ. Discovered 1998 May 19 by P. Pravec at Ondřejov.

Karel IV (1316-1378), king of Bohemia and Holy Roman Emperor, supported cultural and scientific advancement. Charles University, which he founded in Prague, was the first university in central Europe. During his 30-year reign the Czech lands did not experience the hardship of wars. (M 42364)

The name was suggested by M. Juřík.

\section{(16953) Besicovitch}

$1998 \mathrm{KE}_{5}$. Discovered 1998 May 27 by P. G. Comba at Prescott.

Abram Samuilovitch Besicovitch (1891-1970) taught at various institutions in the Soviet Union and later at the University of Cambridge. He had an astounding geometric intuition and proved many counter-intuitive results, particularly with regard to sets of points of fractal dimension. (M 41942)

\section{(16969) Helamuda}

1998 UM $_{20}$. Discovered 1998 Oct. 29 at the Starkenburg Observatory at Heppenheim.

Helamuda is an acronym for Hessisches Landesmuseum Darmstadt, the museum of the federal state of Hessen. This unique institution features exquisite collections in both fine arts and natural sciences and conducts paleontological excavations at the nearby Messel site. (M 42364)

\section{(16984) Veillet}

$1999 \mathrm{AA}_{25}$. Discovered 1999 Jan. 15 by the OCA-DLR Survey at Caussols.

Christian Veillet (1954- ) was for several years head of the lunar-ranging station at the Observatoire de la Côte d'Azur. Now senior astronomer for the Canada-France-Hawaii Telescope, he is project scientist 
for the megaprime project. He recently discovered that the transneptunian object $1998 \mathrm{WW}_{31}$ is a binary. (M 46683)

\section{(17019) Aldo}

1999 DV $_{3}$. Discovered 1999 Feb. 23 by M. Tombelli and G. Forti at Montelupo.

Amateur astronomer Aldo Tombelli (1921-2001) was the father of the first discoverer. (M 43046)

\section{(17020) Hopemeraengus}

$1999 \mathrm{DH}_{4}$. Discovered 1999 Feb. 24 by I. P. Griffin at Cocoa.

Hope (1994- ), Merope (1995- ) and Aengus (1998- ) are the children of discoverer. (M 41942)

\section{(17023) Abbott}

1999 EG. Discovered 1999 Mar. 7 by J. Broughton at Reedy Creek.

Bud Abbott (1897-1974) was the gravely-voiced straight man of the Abbott and Costello s see planet (17024)\} comedy duo. Together they were masters of the straight man-funny man relationship. (M 42676)

\section{(17024) Costello}

1999 EJ $_{5}$. Discovered 1999 Mar. 15 by J. Broughton at Reedy Creek.

Louis Costello (1906-1959) was the funny man of the Abbott \{see planet (17023)\} and Costello comedy duo. Their relationship created a magical chemistry that would take them from the burlesque stage to radio to broadway to film and, finally, to television. (M 42676)

\section{(17025) Pilachowski}

1999 ES$_{5}$. Discovered 1999 Mar. 13 by R. A. Tucker at Tucson.

Caty Pilachowski (1949- ) is a specialist in the study of stellar evolution and compositions, nucleosynthesis and astroseismology. A long-time member of the scientific staff of the National Optical Astronomy Observatories, she was recently elected to serve as president of the American Astronomical Society. (M 43192)

\section{(17029) Cuillandre}

$1999 \mathrm{FM}_{6}$. Discovered 1999 Mar. 17 by the OCA-DLR Survey at Caussols.

Jean Charles Cuillandre (1968- ) is a French astronomer whose interest in CCDs s see planet (15000)\} has always been very strong. He worked on all the generations of CCD arrays used at the CFHT telescope, including the $12 \mathrm{~K}$ camera, with which he has produced exquisite color pictures of many celestial objects. (M 46683)

\section{(17038) Wake}

$1999 \mathrm{FO}_{21}$. Discovered 1999 Mar. 26 by J. Broughton at Reedy Creek.

Born in New Zealand, Australian journalist Nancy Wake (1912- ) joined the French Resistance during World War II, taking part in many risky sabotage raids and helping hundreds of people to escape capture. (M 43382)

\section{(17045) Markert}

$1999 \mathrm{FV}_{32}$. Discovered 1999 Mar. 22 by D. J. Tholen at Mauna Kea.

Thomas H. Markert (1948-1996) made some of the first x-ray observations of binary star systems, supernova remnants, suspected black holes and local group galaxies. He helped develop much of the instrumentation used on major x-ray observatories, including Einstein's FPCS and Chandra's HETG spectrometers. (M 41942)

\section{(17058) Rocknroll}

1999 GA $_{5}$. Discovered 1999 Apr. 13 by J. Broughton at Reedy Creek.

Rock and roll music, which had its roots in AfricanAmerican rhythm and blues, remains a prominent form of popular music worldwide since hitting the charts in the 1950s. (M 43046)

\section{(17059) Elvis}

1999 GX $_{5}$. Discovered 1999 Apr. 15 by J. Broughton at Reedy Creek.

Elvis Aaron Presley (1935-1977) was a flamboyant American singer. Known as the king of Rock and Roll \{see planet (17058)\}, he had a popularity that contributed toward making that genre a world-wide phenomenon. (M 43046)

\section{(17076) Betti}

1999 HO. Discovered 1999 Apr. 18 by P. G. Comba at Prescott.

Enrico Betti (1823-1892) taught at the University of Pisa and published on various topics in algebra and analysis. His research on the analysis situs (topology) of hyperspaces led to the definition of the "Betti numbers", which characterize the connectivity of a manifold. (M 41942)

\section{(17078) Sellers}

$1999 \mathrm{HD}_{3}$. Discovered 1999 Apr. 24 by J. Broughton at Reedy Creek.

Peter Sellers (1925-1980) was an English character actor whose extraordinary abilities of mimicry and comedic characterization first blossomed in BBC radio's The Goon Show. He later became a star of Hollywood films such as Dr. Strangelove and The Pink Panther. (M 42676)

\section{(17166) Secombe}

1999 MC. Discovered 1999 June 17 by J. Broughton at Reedy Creek.

Welshman Harry Secombe (1921-2001) was the chuckling roly-poly singer-actor-comedian "Neddy Seagoon" of The Goon Show fame. On receiving a knighthood he referred to himself as "Sir Cumference". Secombe was a unique combination of comedian with a magnificent tenor singing voice. (M 42676) 
(17184) Carlrogers

$1999 \mathrm{VL}_{22}$. Discovered 1999 Nov. 13 by C. W. Juels at Fountain Hills.

Carl R. Rogers (1902-1987) was a psychologist who developed a very popular method of psychotherapy called client-centered therapy. Two of his books are Client Centered Therapy (1951) and On Becoming a Person (1961). He was president of the American Psychological Association during 1946-1947. (M 43193)

\section{(17185) Mcdavid}

$1999 \mathrm{VU}_{23}$. Discovered 1999 Nov. 14 by C. W. Juels at Fountain Hills.

David McDavid (1950- ), an astronomer specializing in the photometry and polarimetry of Be stars, was a coinvestigator of the NASA International Ultraviolet Explorer (1989-1995). He is also an accomplished saxophone player. The citation was prepared by $\mathrm{M}$. Trueblood. (M 45340)

\section{(17190) Retopezzoli}

$1999 \mathrm{WY}_{8}$. Discovered 1999 Nov. 28 by S. Sposetti at Gnosca.

Reto Pezzoli (1959- ) is the best friend of the discoverer. They have spent lots of unforgettable summer and winter nights observing meteors. (M 41574)

\section{(17220) Johnpenna}

$2000 \mathrm{CX}_{26}$. Discovered 2000 Feb. 2 by the LINEAR at Socorro.

Named in honor of John Penna for mentoring a finalist in the 2002 Intel Science Talent Search, a science competition for high school seniors. Penna is a teacher at the Governor Livingston High School, Berkeley Heights, New Jersey. (M 44933)

\section{(17222) Perlmutter}

$2000 \mathrm{CU}_{44}$. Discovered 2000 Feb. 2 by the LINEAR at Socorro.

Named in honor of Frances Perlmutter for mentoring a finalist in the 2002 Intel Science Talent Search, a science competition for high school seniors. Perlmutter is a teacher at the Horace Mann School, Bronx, New York. (M 44933)

\section{(17224) Randoross}

$2000 \mathrm{CP}_{58}$. Discovered 2000 Feb. 5 by the LINEAR at Socorro.

Named in honor of Randolph Ross for mentoring a finalist in the 2002 Intel Science Talent Search, a science competition for high school seniors. Ross is a teacher at the Great Neck South High School, Great Neck, New York. (M 44933)

\section{(17225) Alanschorn}

$2000 \mathrm{CS}_{60}$. Discovered 2000 Feb. 2 by the LINEAR at Socorro.

Named in honor of Alan Schorn for mentoring a finalist in the 2002 Intel Science Talent Search, a science competition for high school seniors. Schorn is a teacher at the John L. Miller - Great Neck North High School, Great Neck, New York. (M 44933)

\section{(17233) Stanshapiro}

2000 DU $_{58}$. Discovered 2000 Feb. 29 by the LINEAR at Socorro.

Named in honor of Stan Shapiro for mentoring a finalist in the 2002 Intel Science Talent Search, a science competition for high school seniors. Shapiro is a teacher at the Midwood High School at Brooklyn College, Brooklyn, New York. (M 44933)

\section{(17240) Gletorrence}

2000 EK $_{95}$. Discovered 2000 Mar. 9 by the LINEAR at Socorro.

Named in honor of Glenda Torrence for mentoring a finalist in the 2002 Intel Science Talent Search, a science competition for high school seniors. Torrence is a teacher at the Montgomery Blair High School, Silver Spring, Maryland. (M 44933)

\section{(17247) Vanverst}

2000 GG $_{105}$. Discovered 2000 Apr. 7 by the LINEAR at Socorro.

Named in honor of Mary VanVerst for mentoring a finalist in the 2002 Intel Science Talent Search, a science competition for high school seniors. VanVerst is a teacher at the Illinois Mathematics and Science Academy, Aurora, Illinois. (M 44933)

\section{(17250) Genelucas}

2000 GW $_{122}$. Discovered 2000 Apr. 11 by C. W. Juels at Fountain Hills.

Gene A. Lucas (1946- ), an amateur astronomer and telescope maker since 1961, cofounded the Saguaro Astronomy Club in Phoenix in 1977 and was an astrovideography pioneer in live public-television broadcasts of comet 1P/Halley during 1985-1986. (M 43193)

\section{(17251) Vondracek}

2000 GA $_{127}$. Discovered 2000 Apr. 7 by the LINEAR at Socorro.

Named in honor of Mark Vondracek for mentoring a finalist in the 2002 Intel Science Talent Search, a science competition for high school seniors. Vondracek is a teacher at the Evanston Township High School, Evanston, Illinois. (M 44933)

\section{(17253) Vonsecker}

2000 GW $_{136}$. Discovered 2000 Apr. 12 by the LINEAR at Socorro.

Named in honor of Claire VonSecker for mentoring a finalist in the 2002 Intel Science Talent Search, a science competition for high school seniors. VonSecker is a teacher at the Walt Whitman High School, Bethesda, Maryland. (M 44933)

\section{(17258) Whalen}

$2000 \mathrm{HK}_{90}$. Discovered 2000 Apr. 29 by the LINEAR at Socorro. 
Named in honor of Patrice Whalen for mentoring a finalist in the 2002 Intel Science Talent Search, a science competition for high school seniors. Whalen is a teacher at the Humanities and Sciences Institute, Phoenix, Arizona. (M 44933)

\section{(17262) Winokur}

$2000 \mathrm{JS}_{62}$. Discovered 2000 May 9 by the LINEAR at Socorro.

Named in honor of Bruce Winokur for mentoring two finalists in the 2002 Intel Science Talent Search, a science competition for high school seniors. Winokur is a teacher at the Stuyvesant High School, New York, New York. (M 44933)

\section{(17269) Dicksmith}

$2000 \mathrm{LN}_{1}$. Discovered 2000 June 3 by J. Broughton at Reedy Creek.

A big-hearted Australian and avid adventurer, Dick Smith (1944- ) made the first helicopter flight around the world in 1983 and to the north pole in 1987. On a bet last year he accomplished a balloon flight from New Zealand to Australia against the prevailing wind. (M 42676)

\section{(17283) Ustinov}

$2000 \mathrm{MB}_{1}$. Discovered 2000 June 24 by J. Broughton at Reedy Creek.

The English actor-writer-producer Peter Ustinov (1921- ) is an excellent character actor, who has made made over 50 films. He is also a prolific playwright, a satirical comedian and a television documentary maker, while in recent years he has established a considerable reputation as a raconteur. (M 43046)

\section{(17285) Bezout}

2000 NU. Discovered 2000 July 3 by P. G. Comba at Prescott.

Étienne Bezout (1739-1783) was a French algebraist of great manipulative skills. He studied the problem of reducing multiple equations to a single one by elimination of variables, and proved that the degree of the resulting equation is the product of the degrees of the original equations. (M 41942)

\section{(17286) Bisei}

$2000 \mathrm{NB}_{6}$. Discovered 2000 July 8 by the Bisei Spaceguard Center at Tokyo-Okayama.

Bisei is the town in Okayama prefecture where the Bisei Spaceguard Center and the Bisei Astronomical Observatory are located. The town is famous for its local law protecting the night sky against light pollution. (M 45234)

\section{(17314) Aisakos}

1024 T-1. Discovered 1971 Mar. 25 by C. J. van Houten and I. van Houten-Groeneveld at Palomar.

Aisakos, a son of Priam \{see planet (884)\} from his first marriage, was a seer, as had also been his maternal grandfather, Merops. Aisakos said that Hecuba's \{see planet (108)\} future son would bring disaster to Troy. (M 42365)

\section{(17351) Pheidippos}

1973 SV. Discovered 1973 Sept. 19 by C. J. van Houten and I. van Houten-Groeneveld at Palomar.

Pheidippos was a hero from Nisyros, in the Kalydnian islands. Son of king Thessalos, brother of Antiphos and grandson of Heracles \{see planets (13463) and (5143), respectively\}, he fought against Telephos, king of Mysia. (M 42365)

\section{(17354) Matrosov}

1977 EU $_{1}$. Discovered 1977 Mar. 13 by N. S. Chernykh at Nauchnyj.

Vladimir Mefodievich Matrosov (1932- ) is known for his research in theoretical mechanics, the dynamics of nonlinear and complex systems and stability theory. He has worked in Kazan, Novosibirsk and Irkutsk. (M 43383)

\section{(17399) Andysanto}

1983 RL. Discovered 1983 Sept. 6 by C. S. Shoemaker and E. M. Shoemaker at Palomar.

Andrew G. Santo (1961- ) is a spacecraft engineer at the Applied Physics Laboratory of Johns Hopkins University. His diligent work as Spacecraft System Engineer throughout the development, launch and operations phases ensured the success of NEAR Shoemaker, NASA's initial "faster, better, cheaper" Discovery mission. (M 42676)

\section{(17408) McAdams}

1987 UZ $_{1}$. Discovered 1987 Oct. 19 by C. S. Shoemaker and E. M. Shoemaker at Palomar.

Jim V. McAdams (1961- ) optimizes spacecraft trajectories at the Applied Physics Laboratory of Johns Hopkins University. He designed trajectories for the NEAR Shoemaker mission from the formative phase of NASA's Discovery Program in 1989 to landing on (433) Eros in 2001. (M 42676)

\section{(17412) Kroll}

1988 KV. Discovered 1988 May 24 by W. Landgraf at La Silla.

Reinhold Kroll, of the Instituto de Astrofisica de Canarias, is known for his research on magnetic, chemically peculiar stars, particularly infrared observations of them. He was a fellow student of the discoverer at the University of Göttingen. (M 42365)

\section{(17447) Heindl}

1990 HE. Discovered 1990 Apr. 25 by E. F. Helin at Palomar.

Clifford J. Heindl (1926- ) has guided the Earth and Space Sciences Division of the Jet Propulsion Laboratory since 1978 as its deputy manager. His exceptional insight, outstanding administrative skills, expert knowledge, dedication to duty and personal integrity have earned him the highest respect at JPL. (M 41942) 


\section{(17459) Andreashofer}

1990 TJ$_{8}$. Discovered 1990 Oct. 13 by F. Börngen and

L. D. Schmadel at Tautenburg.

Innkeeper Andreas Hofer (1767-1810) headed the Tyrolese popular rising against French occupation and was executed by a firing squad on order of Napoleon. His patriotic and heroic engagement is the subject of numerous dramatic plays, stories and poems, notably by Rosegger, Eichendorff \{see planets (7583) and (9413), respectively\} and Koerner. (M 42365)

\section{(17472) Dinah}

1991 FY. Discovered 1991 Mar. 17 by T. Niijima and T. Urata at Ojima.

Dinah is Alice's cat in Lewis Carroll's s see planet (6984)\} Alice's adventures in Wonderland. The cat never appears in the story, but Alice thinks about her and talks about her to the creatures she meets in Wonderland, frightening some of them by telling how good Dinah is at catching mice and small birds. (M 45234)

\section{(17484) Ganghofer}

$1991 \mathrm{RY}_{4}$. Discovered 1991 Sept. 13 by F. Börngen and L. D. Schmadel at Tautenburg.

German author Ludwig Ganghofer (1855-1920), son of a forester, studied philosophy, was a dramatic advisor and editor, first in Vienna and later in Bavaria. He wrote numerous popular romantic dramas, short stories and novels, mainly with climbing or hunting themes. Some of these were made into movies. (M 42365)

\section{(17486) Hodler}

$1991 \mathrm{RB}_{41}$. Discovered 1991 Sept. 10 by F. Börngen at Tautenburg.

Ferdinand Hodler (1853-1918) founded modern Swiss painting with his use of allegorical themes, historical events, sights of the Alps, lakes and portraits. His monumental 1907-1908 mural Marching out of the Jenense students in the war of liberation in 1813 adorns the aula of Jena University. (M 42365)

\section{(17489) Trenker}

$1991 \mathrm{TS}_{6}$. Discovered 1991 Oct. 2 by F. Börngen and L. D. Schmadel at Tautenburg.

Luis Trenker (1892-1990), initially a herdsman, mountain guide and ski instructor in his South Tyrolese alpine homeland, later had great success as a scriptwriter, film director, screen actor and author. During 1928-1940 he lived in Berlin. His novels, which described and praised his native country, later became very popular. (M 42365)

\section{(17492) Hippasos}

$1991 \mathrm{XG}_{1}$. Discovered 1991 Dec. 10 by F. Börngen at Tautenburg.

Hippasos was one of Priam's \{see planet (884)\} many sons. He supported Aeneas \{see planet (1172)\} in the Trojan war. (M 42365)

\section{(17496) Augustinus}

$1992 \mathrm{DM}_{2}$. Discovered 1992 Feb. 29 by F. Börngen at Tautenburg.

Aurelius Augustinus (354-430), born in North Africa, converted to Christianity in Milan and was bishop of the antique town Hippo from 395. His principal works De Civitate Dei, De Trinitate Dei and Confessiones, strongly influenced Christian theology and ethics. (M 43383)

\section{(17508) Takumadan}

1992 JH. Discovered 1992 May 3 by T. Seki at Geisei.

Educated at the Massachusetts Institute of Technology, Takuma Dan (1858-1932) returned to Japan in 1881 and became a lecturer in astronomy at Tokyo Imperial University. He later directed the Japanese mining industry and became a financier. (M 43383)

\section{(17509) Ikumadan}

1992 JR. Discovered 1992 May 4 by T. Seki at Geisei.

Conductor Ikuma Dan (1924-2001), grandson of financier Takuma Dan \{see planet (17508)\}, was a leading member of the Art Academy of Japan. He composed symphonies, songs and operas, including the celebrated Yuzuru ("The Evening Crane"). (M 43383)

The name was suggested by K. Tomita, who was a classmate at Aoyama Gakuin High School.

\section{(17518) Redqueen}

1992 YD. Discovered 1992 Dec. 18 by A. Natori and T. Urata at Yakiimo.

The Red Queen is one of the chess pieces that make up the characters in Lewis Carroll's \{see planet 6984)\} Through the Looking Glass and what Alice found there. Alice has some very strange experiences and conversations with her. (M 44110)

\section{(17563) Tsuneyoshi}

$1994 \mathrm{CC}_{1}$. Discovered 1994 Feb. 5 by Y. Kushida and O. Muramatsu at Yatsugatake.

Tsuneyoshi Fujii (1949- ) is director of the Sunshine Planetarium in Tokyo. Earlier he was a lecturer and curator at the Gotoh Planetarium and Astronomical Museum in Tokyo, where he worked for eight years until 1971. (M 45234)

\section{(17579) Lewkopelew}

1994 TQ $_{16}$. Discovered 1994 Oct. 5 by F. Börngen at Tautenburg.

Lew Kopelew \{1912-1997\}, a Russian scientist and author of autobiographic texts, biographies, prose and essays, was persecuted as a critic of the Soviet regime and expatriated. Living in Germany since 1981, he received the Peace Prize of the Association of the German Book Trade. (M 47168)

\section{(17597) Stefanzweig}

1995 EK$_{8}$. Discovered 1995 Mar. 4 by F. Börngen at Tautenburg.

Austrian Stefan Zweig (1881-1941), biographer, essayist and writer, communicated with world figures 
and had great confidence in the good strengths of humanity. His books were translated into more than 20 languages. Having emigrated in 1934, he suffered from being abroad and eventually committed suicide. (M 42676)

\section{(17607) Táborsko}

1995 TC. Discovered 1995 Oct. 2 by M. Tichý and Z. Moravec at Klě̌.

Táborsko is a south Bohemian district historically known for the Hussite religious reformatory movement in the fifteenth century. Its center is Tábor, the second largest south Bohemian town, founded in 1420 with a beautiful historical center situated above the Lužnice river and the Jordán pond. (M 46011)

\section{(17611) Jožkakubík}

$1995 \mathrm{UP}_{2}$. Discovered 1995 Oct. 24 at the Klet Observatory at Klě́t.

Jožka Kubík III (1907-1978) was a gypsy musician and first violinist of a folk band. He inspired many musicians in Moravia and contributed to the development of traditional music in the Slovácko region there by merging Moravian folk music with gypsy themes. (M 42365)

\section{(17612) Whiteknight}

$1995 \mathrm{UW}_{6}$. Discovered 1995 Oct. 20 by N. Sato and T. Urata at Chichibu.

The White Knight is one of the chess pieces that make up the characters in Lewis Carroll's ssee planet (6984)\} Through the Looking Glass and what Alice found there. He often falls off his horse. He and the Red Knight fight to decide whose prisoner Alice shall be. (M 45235)

\section{(17625) Joseflada}

1996 AY $_{1}$. Discovered 1996 Jan. 14 by P. Pravec and L. Šarounová at Ondřejov.

Josef Lada (1887-1957) was a Czech painter and writer whose nostalgic pictures of life in a Czech village in the nineteenth century are loved by both children and adults. Lada illustrated many of his books, including Kocour Mikeš ("Mikeš, the Tomcat") and Jaroslav Hašek's The Good Soldier Švejk. (M 41942)

\section{(17627) Humptydumpty}

$1996 \mathrm{BM}_{3}$. Discovered 1996 Jan. 27 by T. Urata at Oohira.

Humpty Dumpty, whose head and body together are egg-shaped, is not only the subject of one of the most famous nursery rhymes in English but also a major character in Lewis Carroll's \{see planet (6984)\} Alice's adventures in Wonderland. He tells Alice a lot about the meaning of words, including the strange ones in the poem "Jabberwocky". (M 44594)

\section{(17637) Blaschke}

$1996 \mathrm{PA}_{1}$. Discovered 1996 Aug. 11 by P. G. Comba at Prescott.

Wilhelm Johann Eugen Blaschke (1885-1962) was instrumental in establishing the University of Hamburg as an important center of mathematical research. His own research centered on differential and integral geometry and kinematics, and he laid the foundations of topological differential geometry. (M 41942)

\section{(17638) Sualan}

1996 PB $_{1}$. Discovered 1996 Aug. 11 by G. R. Viscome at Lake Placid.

Sue and Alan French live in Scotia, New York. Both are avid amateur astronomers, telescope builders and writers who have for many years brought the wonders of astronomy to the public. (M 46683)

\section{(17651) Tajimi}

$1996 \mathrm{VM}_{1}$. Discovered 1996 Nov. 3 by T. Mizuno and T. Furuta at Tajimi.

Tajimi is the city in Gifu prefecture where the first discoverer lives and where this minor planet was discovered. The city is famous for the production of china. (M 42676)

\section{(17652) Nepoti}

1996 VQ $_{1}$. Discovered 1996 Nov. 3 by V. Goretti at Pianoro.

Giuliano Nepoti (1949- ), an enthusiastic amateur astronomer, is a dear friend of the discoverer. He is a very able mechanic who collaborated with the team of the Titus Lucretius Carus Observatory in Bologna on the construction of the telescope. (M 45235)

\section{(17653) Bochner}

$1996 \mathrm{VM}_{2}$. Discovered 1996 Nov. 10 by P. G. Comba at Prescott.

Salomon Bochner (1899-1982) was a Polish-American mathematician who spent most of his working life at Princeton, where he had many students who later became distinguished mathematicians. One of the many areas where he did original research is the theory of functions of many complex variables. (M 41942)

\section{(17670) Liddell}

$1996 \mathrm{XQ}_{19}$. Discovered 1996 Dec. 8 by T. Urata at Oohira.

Alice Pleasance Liddell (1852-1934) was the young girl, then aged 10, for whom Lewis Carroll \{see planet (6984)\} wrote Alice's adventures in Wonderland. (M 43762)

The name was suggested by J. Meeus.

\section{(17673) Houkidaisen}

$1996 \mathrm{XL}_{32}$. Discovered 1996 Dec. 15 at the Saji Observatory at Saji.

Houki Daisen is the highest peak in the Chugoku district of Tottori \{see planet (4720)\} prefecture. (M 41942)

\section{(17681) Tweedledum}

1997 AQ $_{6}$. Discovered 1997 Jan. 6 by T. Urata at Oohira.

Tweedledum was one of the twins in Lewis Carroll's \{see planet (6984)\} Through the Looking Glass and what Alice found there. When Alice meets him, he is 
standing under a tree with his arm round his brother's neck. Like his twin Tweedledee \{see planet (9387)\}, he gives his name to a minor planet of Hungaria s see planet (434)\} type. (M 41942)

The citation was prepared by D. J. Asher.

\section{(17683) Kanagawa}

1997 AR $_{16}$. Discovered 1997 Jan. 10 by A. Asami at Hadano.

Kanagawa is the prefecture in which Hadano is situated. In the east the active industries in Yokohama and Kawasaki have vitalized the Japanese economy. The west and north are blessed with beautiful natural scenery. In Yokohama is Kanagawa University, from which the discoverer graduated. (M 42365)

\section{(17693) Wangdaheng}

$1997 \mathrm{CP}_{28}$. Discovered 1997 Feb. 15 at the Beijing Observatory at Xinglong.

Daheng Wang (1915- ), research professor, director and honorary director of Changchun Institute of Optics and Fine Mechanics, is one of the founders of optical science and technology in China. He became a member of the Chinese Academy of Sciences in 1955. (M 45235)

\section{(17694) Jiránek}

$1997 \mathrm{ET}_{1}$. Discovered 1997 Mar. 4 by M. Tichý and Z. Moravec at Klět.

Vladimír Jiránek (1938- ） is a Czech graphic artist, illustrator and cartoonist. His newspaper and journal cartoons comment on the situation in the modern Czech Republic. Two rabbits named Bob and Bobek belong to the most popular characters of his animated cartoons. (M 42365)

\section{(17696) Bombelli}

$1997 \mathrm{EH}_{8}$. Discovered 1997 Mar. 8 by P. G. Comba at Prescott.

Rafael Bombelli (1526-1572) was a mathematician of Bologna. His widely read treatise on algebra introduced a consistent procedure for handling imaginary complex numbers, removing some of the mystery from the so-called irreducible case of the solution of the cubic equation. (M 41492)

\section{(17702) Kryštofharant}

1997 JD. Discovered 1997 May 1 by P. Pravec at Ondřejov.

Kryštof Harant z Polžic a Bezdružic (1564-1621), a man of wide interests, wrote poetry and a travelogue that he also illustrated and was renowned for his musical compositions. During 1600-1612 he was a valet and counsel of Rudolph II. He took part in the struggle against the Hapsburg king and was executed. (M 42365)

\section{(17703) Bombieri}

$1997 \mathrm{RS}_{5}$. Discovered 1997 Sept. 9 by P. G. Comba at Prescott.

Enrico M. Bombieri (1940- ) is an Italian mathematician who has also been a professor at the Institute for Advanced Study at Princeton. In 1974 he was awarded the Fields Medal - the highest honor for mathematical achievement - for his work in number theory. (M 41492)

\section{(17712) Fatherwilliam}

1997 WK $_{7}$. Discovered 1997 Nov. 19 by Y. Shimizu and T. Urata at Nachi-Katsuura.

In Lewis Carroll's \{see planet (6984)\} Alice's Adventures in Wonderland, Father William is a character in a poem that a Caterpillar tells Alice to repeat. $\mathrm{He}$ is rather old and in the end gets quite annoyed with a youth who, it emerges later in the poem, is his son, and who asks him one question after another. (M 42365)

\section{(17734) Boole}

1998 BW $_{3}$. Discovered 1998 Jan. 22 by P. G. Comba at Prescott.

George Boole (1815-1864) was a self-taught Englishman. His works The Mathematical Analysis of Logic (1847) and Investigation of the Laws of Thought (1854) stressed that logic should be associated with mathematics (rather than metaphysics), both disciplines being formal systems of symbols, axioms and rules of inference. (M 41942)

\section{(17737) Sigmundjähn}

$1998 \mathrm{BF}_{14}$. Discovered 1998 Jan. 27 by J. Kandler at Drebach.

Sigmund Jähn (1937- ) was the first German to travel into space. In August 1978 he spent nine days in the Soviet space station Salyut 6, together with the Russian commander Valery Bykovsky. Today Jähn works in the astronaut training center of DLR, the German Research Center for Aeronautics and Astronautics. (M 41942)

\section{(17744) Jodiefoster}

1998 BZ $_{31}$. Discovered 1998 Jan. 18 by the OCA-DLR Survey at Caussols.

Jodie Foster (1962- ) is an accomplished actress and film director. For most astronomers she will always be Eleanor "Ellie" Arroway in Robert Zemeckis' movie Contact, based on the novel by the same name written by the late Carl Sagan \{see planet (2709)\}. (M 46683)

\section{(17746) Haigha}

1998 BU $_{41}$. Discovered 1998 Jan. 30 by T. Kagawa and T. Urata at Gekko.

Haigha, pronounced to rhyme with "mayor", is an Anglo-Saxon messenger of the king in Lewis Carroll's \{see planet (6984)\} Through the Looking Glass and what Alice found there. He lives on the Hill. (M 42365) The name was suggested by $T$. Urata.

\section{(17759) Hatta}

1998 DA $_{24}$. Discovered 1998 Feb. 17 by Y. Shimizu and T. Urata at Nachi-Katsuura.

Hatta is one of the king's two messengers, one to fetch and one to carry, in Lewis Carroll's \{see planet (6984)\} Through the Looking Glass and what 
Alice found there. He is seen bounding away "like a grasshopper". (M 42365)

\section{(17764) Schatzman}

$1998 \mathrm{ES}_{1}$. Discovered 1998 Mar. 2 by the OCA-DLR Survey at Caussols.

Evry Schatzman (1920- ) assumed a leading role in the development of theoretical Astrophysics in France. His research interests cover a very wide range, from white dwarfs to the rotation of stars and the acceleration of cosmic rays. He has written many books on astrophysics and on science and society. (M 45340)

\section{(17768) Tigerlily}

$1998 \mathrm{EO}_{8}$. Discovered 1998 Mar. 3 by T. Urata at Oohira.

In Lewis Carroll's \{see planet (6984)\} Through the Looking Glass and what Alice found there, Alice comes upon a large flower-bed with a border of daisies and a willow-tree growing in the middle. The Tiger-lily tells Alice that all the flowers can talk as well as Alice and a great deal louder. (M 42365)

\section{(17776) Troska}

$1998 \mathrm{FF}_{3}$. Discovered 1998 Mar. 22 by P. Pravec at Ondřejov.

Jan Marzel, who used the pseudonym of J. M. Troska (1881-1961), was a great Czech writer of adventure science fiction in the 1930s. His greatest work, the trilogy Zápas s nebem ("Struggle with the Sky") describes a marvelous journey through the whole inner solar system, including visits to and being marooned on minor planets. (M 43046; M 43093)

\section{(17777) Ornicar}

$1998 \mathrm{FV}_{9}$. Discovered 1998 Mar. 24 by the OCA-DLR Survey at Caussols.

In elementary school French children often learn the sequence "mais ou et donc or ni car", which are the conjunctions that link phrases. The sequence could be interpreted as "but where could Ornicar be?" The naming of this minor planet, honoring French teachers around the world, provides one answer to that question. (M 45340)

\section{(17805) Švestka}

$1998 \mathrm{FV}_{72}$. Discovered 1998 Mar. 30 by M. Tichý and Z. Moravec at Klět.

Zdeněk Švestka (1925- ), a Czech-born astronomer and solar physicist, worked at the Space Research Organization in the Netherlands and at the Center for Astrophysics and Space Sciences at the University of California in San Diego. Since 1966 he has been editor of Solar Physics. (M 42366)

\section{(17806) Adolfborn}

1998 FO $_{73}$. Discovered 1998 Mar. 31 by P. Pravec at Ondřejov.

Czech painter and illustrator Adolf Born (1930- ) is known for his murkily-tinted pictures of bizarre fauna, Victorian gentlemen in top hats and topcoats and mysterious ladies with tall hairdos and plunging necklines. His slightly surrealistic work, with its strong undertone of humor, is loved by both children and adults. (M 41942)

\section{(17821) Bölsche}

$1998 \mathrm{FC}_{127}$. Discovered 1998 Mar. 31 by A. Knöfel and J. Kandler at Drebach.

Wilhelm Bölsche (1861-1939) was a naturalist, poet and writer. With his book Das Liebesleben in der Natur, he is considered the father of modern popularscience books in Germany. Bölsche, a protagonist of Darwinism, wrote popular biographies on Darwin \{see planet (1991)\} and Haeckel. (M 41943)

\section{(17823) Bartels}

1998 GA. Discovered 1998 Apr. 1 by J. M. Roe at Oaxaca.

Mel Bartels (1954- ) has contributed much to amateur astronomy, especially his public domain software for computer control of easily constructed altazimuth telescopes. (M 45235)

\section{(17826) Normanwisdom}

1998 GK $_{10}$. Discovered 1998 Apr. 3 by J. Broughton at Reedy Creek.

British comedy great Norman Wisdom (1915- ) is best known for his smash hit films of the 1950s as the downtrodden, accident-prone little man in the shrunken suit and skewhiff cap. A physical comedian, Wisdom did his trademark trip-up on the red carpet after being knighted by the Queen. (M 43046)

\section{(17855) Geffert}

1998 KK. Discovered 1998 May 19 at the Starkenburg Observatory at Heppenheim.

The German amateur astronomer Martin Geffert (1922- ) has been very dedicated to the Starkenburg \{see planet (6864)\} Observatory, being one of the founders and treasurer of the observatory since its beginnings in 1970 . He is also an excellent performer on the mandolin. (M 42366)

\section{(17869) Descamps}

$1998 \mathrm{MA}_{14}$. Discovered 1998 June 20 by the OCA-DLR Survey at Caussols.

Pascal Descamps (1961- ) works at the Institut de Mécanique Céleste in Paris on the modeling the Galilean satellites of Jupiter, with particular application to observations of their mutual phenomena. He has also studied the volcanoes on the satellite Io and has worked on the Uranian system using adaptive optics. (M 45340)

\section{(17879) Robutel}

1999 BA $_{14}$. Discovered 1999 Jan. 22 by the OCA-DLR Survey at Caussols.

Philippe Robutel (1964- ) works at the Institut de Mécanique Céleste in Paris on the stability of the three-body problem, especially on the existence 
of quasiperiodic motions for the application of KAM theory. (M 45340)

\section{(17891) Buraliforti}

1999 EA. Discovered 1999 Mar. 6 by P. G. Comba at Prescott.

Cesare Burali-Forti (1861-1931) taught at the Military Academy in Turin. He discovered a paradox in Cantor's \{see planet (16246)\} set theory: since the ordinal number of a set of ordinals is greater than the ordinal of each set element, "the ordinal of the set of all ordinals" is a self-contradictory concept. (M 41943)

\section{(17892) Morecambewise}

$1999 \mathrm{EO}_{5}$. Discovered 1999 Mar. 15 by J. Broughton at Reedy Creek.

Comedy duo Eric Morecambe (1926-1984) and Ernie Wise (1925-1999) teamed up in the 1940 s to create Britain's finest stage double act and later became TV favorites. Eric, 'the one with the glasses', was known for his witty retorts, giving slaps to the cheeks of Ernie for plays 'what he wrote'. (M 43046)

\section{(17893) Arlot}

1999 FO. Discovered 1999 Mar. 17 by the OCA-DLR Survey at Caussols.

Jean-Eudes Arlot (1948- ) is the current director of the Institut de Mécanique Céleste in Paris and chair of the IAU Commission 20 working group on satellites. He has worked on a theory of the motions of Jupiter's Galilean satellites and organised international campaigns to observe the mutual phenomena of these bodies. (M 45340)

\section{(17917) Cartan}

1999 GN $_{5}$. Discovered 1999 Apr. 15 by P. G. Comba at Prescott.

Élie Cartan (1869-1951), the son of a blacksmith, became a very influential French mathematician. His major contribution is the development of the theory of exterior differential forms, which he applied to the study of Lie groups, differential geometry and systems of differential equations. (M 42366)

\section{(17936) Nilus}

$1999 \mathrm{HE}_{3}$. Discovered 1999 Apr. 24 by J. Broughton at Reedy Creek.

Nilus is the Graeco-Roman personified god of the river Nile. The annual ebb and flow of the Nile sparked the advent of agriculture and farming around 6500 years ago. This inexorably led to the development of an ancient Egyptian civilization that was a keystone for those that followed. (M 44186)

\section{(17941) Horbatt}

$1999 \mathrm{JW}_{2}$. Discovered 1999 May 6 by R. A. Tucker at Tucson.

A skilled mechanical craftsman, Paul Allen Horbatt (1946- ) has contributed greatly to the development of the instrumentation at Goodricke-Pigott Observatory, near Tucson, where this minor planet was discovered.
His familiarity with detector enclosures and vacuum seals greatly speeded the fabrication of the instruments. (M 42366)

\section{(17942) Whiterabbit}

$1999 \mathrm{JG}_{6}$. Discovered 1999 May 11 by Y. Shimizu and T. Urata at Nachi-Katsuura.

The White Rabbit appears in Lewis Carroll's \{see planet (6984)\} Alice's Adventures in Wonderland. When Alice hears the Rabbit (who, of course, has pink eyes) talking to itself, she follows it down a huge rabbit-hole under a hedge, and her adventures begin. (M 42366)

The name was suggested by T. Urata, and the citation was prepared by R. E. Asher.

\section{(17945) Hawass}

$1999 \mathrm{JU}_{8}$. Discovered 1999 May 14 by J. Broughton at Reedy Creek.

Egyptian archeologist Zahi A. Hawass (1947- ) showed unfailing dedication in the battle of preserving Egypt's monuments and antiquities. He has also been involved in many important discoveries such as the pyramid builder's necropolis at Giza \{see planet (5249)\} and golden mummies of El Bahariya Oasis. (M 43046)

\section{(18024) Dobson}

$1999 \mathrm{KK}_{4}$. Discovered 1999 May 20 by J. M. Roe at Oaxaca.

John Dobson (1915- ） is one of the most important popularizers of astronomy of the twentieth century. His telescope design has spread around the world and enabled amateur astronomers to use larger apertures than before. He demonstrates a passion for sharing his knowledge of the universe with the public at large. (M 43762)

\section{(18055) Fernhildebrandt}

$1999 \mathrm{TJ}_{13}$. Discovered 1999 Oct. 11 by G. Hug and G. Bell at Eskridge.

Fern C. Hildebrandt (1927- ) instilled and cultivated an interest in astronomy in codiscoverer Gary Hug at a very early age. Resident now in Topeka, Kansas, she has been an example of dedication and triumph through difficult times and has inspired this codiscoverer to search the night sky. (M 42366)

\section{(18059) Cavalieri}

$1999 \mathrm{XL}_{137}$. Discovered 1999 Dec. 15 by P. G. Comba at Prescott.

Bonaventura Cavalieri (1598-1647) was a friar and a professor at the University of Bologna. He developed the method of indivisibles, which enabled him to find integrals of polynomials and centers of gravity of many curvilinear figures. His work ultimately influenced Leibniz' \{see planet (5149)\} discovery of the calculus. (M 42366)

\section{(18125) Brianwilson}

2000 OF. Discovered 2000 July 22 by J. Broughton at Reedy Creek. 
Californian songwriter and record producer Brian Wilson (1942- ) contributed to 1960 s pop culture, with songs like Fun Fun Fun, exemplifying the pastimes of modern teenage life, through the Beach Boys' pop group harmonies, giving out very good vibrations indeed. (M 43046)

\section{(18132) Spector}

$2000 \mathrm{ON}_{9}$. Discovered 2000 July 30 by J. Broughton at Reedy Creek.

New York-born record producer and songwriter Phil Spector (1940- ) who at 18 recorded his first hit song and by 1964 had produced 20 hits like the superb $B e$ My Baby, performed by the Ronettes. He broke new ground with his wall-of-sound techniques. (M 43046)

\section{(18156) Kamisaibara}

$2000 \mathrm{PU}_{4}$. Discovered 2000 Aug. 3 by the Bisei Spaceguard Center at Tokyo-Okayama.

Kamisaibara is the village in Okayama prefecture where the Kamisaibara Spaceguard Center is located. (M 45235)

\section{(18160) Nihon Uchu Forum}

2000 PY $_{12}$. Discovered 2000 Aug. 7 by the Bisei Spaceguard Center at Tokyo-Okayama.

Nihon Uchu Forum, or Japan Space Forum, is a Japanese foundation that aims to promote technology for developing space. JSF constructed the Bisei Spaceguard Center, where minor planets and space debris are observed optically, and it will construct the Kamisaibara Spaceguard Center for observing space debris by radar. (M 45235)

\section{(18182) Wiener}

$2000 \mathrm{QC}_{35}$. Discovered 2000 Aug. 27 by P. Pravec and P. Kušnirák at Ondřejov.

Norbert Wiener (1894-1964) contributed to many areas of mathematics, including cybernetics, stochastic processes and quantum theory. He was the author of the book Cybernetics, or control and communication in the animal and machine (1948). (M 43193)

\section{(18228) Hyperenor}

3163 T-1. Discovered 1971 Mar. 26 by C. J. van Houten and I. van Houten-Groeneveld at Palomar.

Hyperenor was one of the sons of Panthoos \{see planet (4754)\} and a great hero on the Trojan side. (M 42366)

\section{(18263) Anchialos}

5167 T-2. Discovered 1973 Sept. 25 by C. J. van Houten and I. van Houten-Groeneveld at Palomar.

The Greek heroes Anchialos and Menestheus \{see planet (4068)\} were together on their chariot when they were killed by Hector \{see planet (624)\}. (M 43046)

\section{(18268) Dardanos}

2140 T-3. Discovered 1977 Oct. 16 by C. J. van Houten and I. van Houten-Groeneveld at Palomar.
Dardanos was a son of Zeus \{see planet (5731)\} and a nymph, mythical ancestor of the Trojans. (M 42366)

\section{(18278) Drymas}

4035 T-3. Discovered 1977 Oct. 16 by C. J. van Houten and I. van Houten-Groeneveld at Palomar.

Drymas was a king of Phrygia and father of Priam's second wife Hekabe \{see planets (884) and (108), respectively\} (in Latin, Hecuba). (M 42366)

\section{(18281) Tros}

4317 T-3. Discovered 1977 Oct. 16 by C. J. van Houten and I. van Houten-Groeneveld at Palomar.

Tros was a grandson of Dardanos \{see planet (18268)\}. His country was named Troas after him, and its principal city was Troy. (M 42366)

\section{(18282) Ilos}

4369 T-3. Discovered 1977 Oct. 16 by C. J. van Houten and I. van Houten-Groeneveld at Palomar.

Ilos was the oldest son of Tros \{see planet (18281)\}, and he built the citadel Ilion, also named Ilios. Ilos was the father of Laomedon and the grandfather of Priam \{see planets (6997) and (884), respectively\}. (M 42366)

\section{(18286) Kneipp}

$1973 \mathrm{UN}_{5}$. Discovered 1973 Oct. 27 by F. Börngen at Tautenburg.

German priest Sebastian Kneipp (1821-1897), skilled in the art of healing, introduced manifold applications of cold and warm water and suggested that a healthy way of living conformed to nature. His papers were translated into many languages and were an essential influence on modern physical therapeutics and balneology. (M 42676)

\section{(18288) Nozdrachev}

$1975 \mathrm{VX}_{2}$. Discovered 1975 Nov. 2 by T. M. Smirnova at Nauchnyj.

Aleksandr Danilovich Nozdrachev (1931- ), a professor at St. Petersburg University is a prominent expert in physiology. He proved experimentally the existence of the metasympathetic nervous system and described general laws of the electrical processes in the nerves of animals. (M 46012; M 46173)

\section{(18292) Zoltowski}

1977 FB. Discovered 1977 Mar. 17 at the Harvard College Observatory at Harvard.

Frank B. Zoltowski (1957- ) discovered 60 numbered minor planets and made numerous critical observations of near-earth objects, notably a dramatic recovery of $1999_{10}$, while he was working in South Australia during 1997-1999. He continued to make astrometric contributions on his return to the U.S. (M 42676)

\section{(18301) Konyukhov}

1979 QZ9. Discovered 1979 Aug. 27 by N. S. Chernykh at Nauchnyj.

Fyodor Fyodorovich Konyukhov (1951- ) has performed 50 extensive travels, mainly alone. He 
conquered both poles and all the highest mountains of the world. The renowned Russian traveler has taken many of the world's most difficult land and sea routes and has sailed around the world three times. (M 43383)

\section{(18360) Sachs}

$1990 \mathrm{TF}_{9}$. Discovered 1990 Oct. 10 by F. Börngen and

L. D. Schmadel at Tautenburg.

Hans Sachs (1494-1576), master of the shoemaker guild in Nuremberg from 1520, is the most important German poet of the sixteenth century. He was immortalized in Wagner's opera Die Meistersinger von Nürnberg. More than 6000 of his works have been handed down to posterity. (M 42676)

\section{(18396) Nellysachs}

$1992 \mathrm{SN}_{2}$. Discovered 1992 Sept. 21 by F. Börngen and L. D. Schmadel at Tautenburg.

Lyric poet Nelly Sachs (1891-1970), coming from a Jewish family in Berlin, escaped abroad in 1940 and became a Swedish citizen. In her work she grappled with the fate of the Jewish people. She shared the Nobel prize for literature in 1966. (M 42676)

The name was suggested by the first discoverer.

\section{(18398) Bregenz}

1992 SQ$_{23}$. Discovered 1992 Sept. 23 by F. Börngen at Tautenburg.

Bregenz, capital of the Austrian province of Vorarlberg, is situated on the east shore of the Lake Constance and is known for the festivals on its famous seaside stage. The region was already settled in the Bronze Age. Later, the Romans established the mercantile town of Brigantium, and there was also an Alemannian colony. (M 42366)

\section{(18426) Maffei}

$1993 \mathrm{YN}_{2}$. Discovered 1993 Dec. 18 by E. Colzani and G. Ventre at Sormano.

The career of Paolo Maffei (1926- ）, former director of the Catania Observatory and an astronomer at Arcetri, Bologna, Asiago and Hamburg, has covered comets, variable stars, evolution of the universe, history of astronomy and popularization of astronomy through many inspired books. (M 46683)

\section{(18430) Balzac}

1994 AK$_{16}$. Discovered 1994 Jan. 14 by F. Börngen at Tautenburg.

Honoré de Balzac (1799-1850), the creator of the French realistic novel, was a keen observer of French human society in the post-Napoleonic time. His principal work La comédie humaine is a gigantic unfinished novel cycle, for which he had planned 137 volumes. (M 42676)

\section{(18458) Caesar}

$1995 \mathrm{EY}_{8}$. Discovered 1995 Mar. 5 by F. Börngen at Tautenburg.

Emperor Gaius Julius Caesar (100-44 B.C.) promulgated in 46 B.C. on the advice of the Alexandrine astronomer Sosigenes what is now called the Julian calendar. In 44 B.C., after the assassination of Julius, the fifth month "Quintilis" was renamed Julius (July). (M 45749)

\section{(18460) Pecková}

1995 PG. Discovered 1995 Aug. 5 by L. Šarounová at Ondřejov.

Dagmar Pecková (1961- ） is an outstanding Czech mezzo-soprano. In addition to her successful operatic career, which includes prominent roles in the works of Mozart and Rossini \{see planets (1034) and (8184), respectively\}, she is renowned for concert performances, especially of the songs by Mahler \{see planet (4406)\}. Her interpretation is characterized by exceptional emotional charge. (M 42366)

\section{(18462) Riccò}

$1995 \mathrm{QS}_{2}$. Discovered 1995 Aug. 26 at the Osservatorio San Vittore at Bologna.

Italian astronomer Annibale Riccò (1844-1919) was an assistant at the observatory of Modena and later astronomer and successively director of the observatories of Palermo and Catania. He was interested in solar spectroscopy, meteorology and seismology. (M 45340)

\section{(18498) Cesaro}

1996 MN. Discovered 1996 June 22 by P. G. Comba at Prescott.

Ernesto Cesaro (1859-1906) was a prolific mathematician and professor at the universities of Palermo and Naples. He made contributions to the intrinsic geometry of curves but is best remembered for his study of the summability of divergent series. (M 42366)

\section{(18510) Chasles}

1996 SN. Discovered 1996 Sept. 16 by P. G. Comba at Prescott.

Michel Chasles (1793-1880) was professor at the École Polytechnique and later at the Sorbonne. His main contributions were in projective geometry, which he developed with a synthetic approach. (M 42366)

\section{(18531) Strakonice}

$1996 \mathrm{XM}_{2}$. Discovered 1996 Dec. 4 by M. Tichý and Z. Moravec at Klet.

Strakonice is a southern Bohemian town known for a Gothic castle at the confluence of the Volyñka and Otava rivers. The town is situated in the heart of the Prácheñ Region - where the bagpipe has long been played. (M 46684)

\section{(18548) Christoffel}

1997 AN $_{12}$. Discovered 1997 Jan. 10 by P. G. Comba at Prescott.

Elwin Bruno Christoffel (1829-1900) was a professor at various German universities. His work on quadratic differential forms, inspired by Riemann, anticipated some of the results of tensor theory later developed 
by Ricci and Levi-Civita \{see planets (13642) and (12473)\}. (M 42366)

\section{(18550) Maoyisheng}

$1997 \mathrm{AN}_{14}$. Discovered 1997 Jan. 9 at the Beijing Observatory at Xinglong.

Yisheng Mao (1896-1989) was a world-renowned scientist and one of the founders of modern bridge engineering of China. In the 1930s, he designed and supervised the construction of the Qiantang River Bridge, which is the first bridge of its kind ever designed and built by the Chinese. (M 43193)

\section{(18555) Courant}

$1997 \mathrm{CN}_{4}$. Discovered 1997 Feb. 4 by P. G. Comba at Prescott.

Richard Courant (1888-1972) studied and later taught at Göttingen. In 1934 he became a professor at New York University, where he founded and led one of the most prestigious institutes of applied mathematics, later named in his honor. (M 42366)

\section{(18560) Coxeter}

$1997 \mathrm{EO}_{7}$. Discovered 1997 Mar. 7 by P. G. Comba at Prescott.

Harold Scott MacDonald Coxeter (1907- ) is an English-Canadian mathematician and former professor at the University of Toronto. He has been a prolific writer on intuitively simple geometric problems, such as the classification of polytopes and the tiling of the plane with convex polygons. (M 42367)

\section{(18567) Segenthau}

1997 SS $_{4}$. Discovered 1997 Sept. 27 at the Starkenburg Observatory at Heppenheim.

Segenthau, located in the Banat region south of the Maros river, is a small village founded in 1771 by German colonialists. It is also the childhood home of Reiner Michael Stoss \{see planet (7689)\}, discoverer of this minor planet. (M 47168)

\section{(18568) Thuillot}

$1997 \mathrm{TL}_{2}$. Discovered 1997 Oct. 3 by the OCA-DLR Survey at Caussols.

William Thuillot (1951- ) works at the Institut de Mécanique Céleste on the theory of the motions of Jupiter's Galilean satellites, including analysis of observations of eclipses by the planet and mutual phenomena. He has also been active observing stellar occultations by minor planets. (M 45340)

\section{(18572) Rocher}

$1997 W_{22}$. Discovered 1997 Nov. 28 by the OCA-DLR Survey at Caussols.

Patrick Rocher (1951- ) works at the Institut de Mécanique Céleste in Paris. His main task has been to to build an integration package to compute orbital parameters for minor planets and comets. He is also involved in the computation of ephemerides for the Bureau des Longitudes and is a specialist on historical calendars. (M 45340)

\section{(18574) Jeansimon}

$1997 \mathrm{WO}_{23}$. Discovered 1997 Nov. 28 by the OCA-DLR Survey at Caussols.

Jean-Louis Simon (1940- ) works at the Paris Institut de Mécanique Céleste on analytical planetary theory. He produced the first values of the secular variation of the orbital semimajor axes of the planets. (M 45749)

\section{(18579) Duongtuyenvu}

$1997 \mathrm{XY}_{6}$. Discovered 1997 Dec. 5 by the OCA-DLR Survey at Caussols.

Duong Tuyen Vu (1933- ) works at the Paris Institut de Mécanique Céleste on ephemerides of natural satellites. He wrote a complete package for the motions of Jupiter's Galilean satellites, which is one of the most difficult problems in celestial mechanics. (M 45340)

\section{(18581) Batllo}

$1997 \mathrm{XV}_{8}$. Discovered 1997 Dec. 7 by the OCA-DLR Survey at Caussols.

Valerie Batllo (1967- ) works on cometary orbits at the Institut de Mécanique Céleste in Paris. She studies in particular how the short-period comets could be produced by encounters with the giant planets. (M 45340)

\section{(18596) Superbus}

$1998 \mathrm{BA}_{4}$. Discovered 1998 Jan. 21 by V. S. Casulli at Colleverde di Guidonia.

Tarquinius Superbus, seventh and last king of Rome, reigned from 534 to 509 B.C. He placed under the dominion of Rome many cities of the Latium region. (M 46012)

\section{(18605) Jacqueslaskar}

1998 BL $_{26}$. Discovered 1998 Jan. 28 by the OCA-DLR Survey at Caussols.

Jacques Laskar (1955- ) is principally concerned with the chaotic behavior of the principal planets. A staff member of the Institut de Mécanique Céleste in Paris, he was the first to show the chaotic motion of the inner solar system and the stabilization of the obliquity of the ecliptic by the moon. (M 45340)

\section{(18610) Arthurdent}

$1998 \mathrm{CC}_{2}$. Discovered 1998 Feb. 7 at the Starkenburg Observatory at Heppenheim.

The earthling Arthur Dent is confronted with the adversities of life, the universe and everything in a highly amusing and entertaining way in Douglas Adam's famous five-volume trilogy The Hitch Hiker's Guide to the Galaxy. (M 42677)

\section{(18617) Puntel}

1998 DY $_{9}$. Discovered 1998 Feb. 24 by M. Boeuf at Les Tardieux.

Nathalie Puntel (1968- ) is a young, pretty and cheerful French woman who prefers deep-sky pictures to searches for minor planets. (M 42367) 


\section{(18623) Pises}

$1998 \mathrm{DR}_{13}$. Discovered 1998 Feb. 27 at the Pises Observatory at Draveil.

The Pises observatory, which was inaugurated in 1991, is located in the South of France. It is the Montpellier astronomical society observatory. (M 45235)

\section{(18647) Václavhübner}

$1998 \mathrm{FD}_{2}$. Discovered 1998 Mar. 21 by P. Pravec at Ondřejov.

Václav Hübner (1922-2000) was an enthusiastic amateur astronomer who contributed much to astronomical education and amateur astronomical activities in Pardubice and elsewhere in eastern Bohemia. (M 42677)

\section{(18676) Zdeňkaplavcová}

$1998 \mathrm{FE}_{73}$. Discovered 1998 Mar. 30 by P. Pravec at Ondřejov.

Czech radio astronomer Zdeňka Plavcová (1930- ) was codesigner of the meteor radar of the Ondřejov \{ see planet (7204)\} Observatory that has been in operation since 1958. After 1969 she was a software specialist in the astronomy department of the University of California at Los Angeles. (M 42677)

\section{(18734) Darboux}

$1998 \mathrm{MY}_{1}$. Discovered 1998 June 20 by P. G. Comba at Prescott.

Jean-Gaston Darboux (1842-1917) was a French mathematician and professor at the Sorbonne, whose main interest was the application of analysis to geometric problems in the theory of surfaces and their deformations and representations. (M 42367)

\section{(18747) Lexcen}

$1999 \mathrm{FN}_{21}$. Discovered 1999 Mar. 26 by J. Broughton at Reedy Creek.

Ben Lexcen (1936-1988) was the amiable Australian marine architect who designed Australia II, the yacht with the revolutionary winged keel that won the 1983 America's Cup, to the surprise of the yachting world. (M 43046)

\section{(18818) Yasuhiko}

$1999 \mathrm{MB}_{2}$. Discovered 1999 June 21 by T. Okuni at Nanyou.

Yasuhiko Takahashi (1934- $\quad$ ) is the younger brotherin-law of the discoverer. (M 47168)

\section{(18838) Shannon}

1999 OQ. Discovered 1999 July 18 by L. Šarounová and P. Kušnirák at Ondřejov.

American scientist Claude Elwood Shannon (19162001) became the father of information science and a cofounder of cybernetics through his numerous fundamental contributions, including the epoch-making paper A Mathematical Theory of Communication (1948). (M 44594)
(18839) Whiteley

1999 PG. Discovered 1999 Aug. 5 by J. Broughton at Reedy Creek.

Abstract artist Brett Whiteley (1939-1992) was Australia's leading painter of his generation and winner of all the major Australian art prizes many times over. As is evident in his self portraits, the Harpo-like Whiteley would not have looked out of place alongside the Marx Brothers. (M 43046)

\section{(18840) Yoshioba}

$1999 \mathrm{PT}_{4}$. Discovered 1999 Aug. 8 by T. Okuni at Nanyou.

Yoshio Oba (1934- ) is a retired professor of earth sciences at Yamagata University and an amateur astronomer who observes occultations. He is chairman of the Yamagata Astronomical Society. (M 45749)

\section{(18841) Hruška}

$1999 \mathrm{RL}_{3}$. Discovered 1999 Sept. 6 by J. Tichá and M. Tichý at Klě́.

As a consequence of difficult experiences in his life, Luboš Hruška (1927- ) turned his family orchard in Plzeň into a wonderful garden of meditation as a memorial to the victims of evil. (M 43047)

\section{(18872) Tammann}

$1999 \mathrm{VR}_{20}$. Discovered 1999 Nov. 8 by S. Sposetti at Gnosca.

Swiss cosmologist Gustav Tammann (1932- ), a professor of astronomy at the University of Basle, is a world-renowned specialist in the determination of the Hubble \{see planet (2069)\} constant. (M 43047)

\section{(18873) Larryrobinson}

$1999 \mathrm{VJ}_{22}$. Discovered 1999 Nov. 13 by M. Abraham and G. Fedon at Olathe.

Larry Robinson, an inspirational leader in the amateur minor-planet observing community, spent countless hours at the Sunflower \{see planet (19019)\} Observatory confirming, following and discovering many objects, as well as assisting numerous amateurs. He has trained over 50 people in science of minor planets and inspired many others. (M 41943)

\section{(18874) Raoulbehrend}

$1999 \mathrm{VZ}_{22}$. Discovered 1999 Nov. 8 by S. Sposetti at Gnosca.

Raoul Behrend (1964- ) is a Swiss astronomer living in the French-speaking part of Switzerland. He is a specialist in stellar modeling but astrometry and photometry of minor planets are among his interests, too. He also strongly supports the collaboration between professional and amateur astronomers. (M 47168)

\section{(18876) Sooner}

1999 XM. Discovered 1999 Dec. 2 by J. M. Roe at Oaxaca.

A sooner is a person settling on land in the early American west before the land was officially open to settlement. The name particularly honors the U.S. 
state of Oklahoma and the University of Oklahoma, alma mater of the discoverer. (M 45235)

\section{(18877) Stevendodds}

$1999 \mathrm{XP}_{7}$. Discovered 1999 Dec. 4 by C. W. Juels at Fountain Hills.

Steven L. Dodds (1961- ) has been furnishing telescope optics for the astronomical community since 1986. He constructed two parabolic off-axis segments (adaptive optic components) used in the Gemini North 8.1-meter telescope located on Mauna Kea. (M 43193)

\section{(18883) Domegge}

$1999 \mathrm{YT}_{8}$. Discovered 1999 Dec. 31 by M. Abraham and G. Fedon at Olathe.

A small town nestled in the Northeastern Italian Alps, surrounded by the rose-colored Dolomites, Domegge di Cadore's very dark and clear skies are an inspiration to any astronomer. (M 41943)

\section{(18903) Matsuura}

$2000 \mathrm{ND}_{29}$. Discovered 2000 July 10 by K. Watanabe at Sapporo.

The geographer and explorer Takeshirou Matsuura (1818-1888) traveled throughout the Ezo under the order of the Edo-shogunate. He showed understanding to and sympathy with the native Ainus. He renamed Ezo as Hokkaido \{see planet (3720)\} and introduced names for many places on the island. (M 42367)

\section{(18928) Pontremoli}

$2000 \mathrm{QH}_{9}$. Discovered 2000 Aug. 25 at the Monte Viseggi Observatory at Monte Viseggi.

Pontremoli is an Italian town important in medieval times because of its strategic position, in Lunigiana territory, on the pilgrims' Francigean way from Paris to Rome. Pontremoli is famous for the prehistoric Stele Statues museum and Premio Bancarella cultural event. (M 45235)

\section{(18932) Robinhood}

$2000 \mathrm{QH}_{35}$. Discovered 2000 Aug. 28 by J. Broughton at Reedy Creek.

Robin Hood was the legendary thirteenth-century English archer and outlaw of Sherwood Forest who, with his band of Merry Men, robbed rich unscrupulous officials to aid and protect the poor in what might be described as a medieval form of socialism. (M 43047)

\section{(18984) Olathe}

$2000 \mathrm{RA}_{8}$. Discovered 2000 Sept. 2 by L. Robinson at Olathe.

O-Lay'-tha is the old Shawnee word for "Beautiful". The township of Olathe, Kansas, was established in 1857 and later became a stop along the Santa Fe Trail. It is the site of the Sunflower \{see planet (19019)\} Observatory. (M 41943)

\section{(19019) Sunflower}

2000 SB. Discovered 2000 Sept. 17 by L. Robinson at Olathe.
The sunflower, the state flower of Kansas, always faces the sun. Its seeds provide food and oil for humans and wild and domestic animals. (M 41943)

\section{(19022) Penzel}

2000 SR $_{44}$. Discovered 2000 Sept. 26 by G. Lehmann at Drebach.

Edgar Penzel (1921- ) founded the school observatory in Rodewisch Saxony, and directed it from 1950 to 1986. In 1957, the astronomers on the observatory's staff were the first in Central Europe to watch the artificial Satellite Sputnik 1. The observatory was named for the first German astronaut, Sigmund Jähn, in 1979. (M 42367)

\section{(19096) Leonfridman}

1979 TY$_{1}$. Discovered 1979 Oct. 14 by N. S. Chernykh at Nauchnyj.

Architect Leonid Osherovich Fridman (1948- ) is director of the Crimean Institute of Design, Architect and Restoration. He has been instrumental in preserving and restoring many old historical buildings and monuments in the Crimea. (M 46012)

\section{(19119) Dimpna}

$1981 \mathrm{SG}_{3}$. Discovered 1981 Sept. 27 by L. G. Karachkina at Nauchnyj.

The Dictionary of Minor Planet Names (DiMPNa) is a catalogue edited by Lutz D. Schmadel \{see planet (2234)\} in 1991, 1993, 1996 and 1999. This reflection of the history of humanity is possible by intensive observational and numerical work of researchers on minor planets all over the world. (M 43383)

\section{(19120) Doronina}

$1983 \mathrm{PM}_{1}$. Discovered 1983 Aug. 6 by L. G. Karachkina at Nauchnyj.

Actress Tat'yana Vasil'evna Doronina (1933- ) created splendid roles for both stage and screen. She worked in the largest Leningrad and Moscow theaters and since 1992 has been leader of the Moscow Art Academic Gorky Theatre. She was awarded People's artist of Russia (1969) and of the U.S.S.R. (1975). (M 44594)

\section{(19126) Ottohahn}

1987 QW. Discovered 1987 Aug. 22 by F. Börngen at Tautenburg.

Otto Hahn (1879-1968), chemistry Nobel Laureate in 1944, participated in the discovery of numerous radioactive elements and isotopes, as well as of the nuclear fission of uranium by neutron bombardment in 1938. As president of the Max-Planck-Gesellschaft during 1948-1960 he warned of the dangers of atomic energy. (M 42367)

\section{(19127) Olegefremov}

$1987 \mathrm{QH}_{10}$. Discovered 1987 Aug. 26 by L. G. Karachkina at Nauchnyj.

Chief producer and actor of "Sovremennik" from 1956, Oleg Nikolaevich Efremov (1927-2000) created 
more than 80 acting roles. He also staged more than 30 plays and was responsible for many screen productions. A People's Artist of Russia and of the U.S.S.R., since 1970 he led the Moscow Art Academic Theatre. (M 45235)

\section{(19129) Loos}

1988 AL $_{1}$. Discovered 1988 Jan. 10 by A. Mrkos at Klět.

Austrian architect Adolf Loos (1870-1933) was one of the pioneers of the functionalist style in Europe. Influenced by the rationalist architecture of the Chicago School, he rejected the Art Nouveau style. Loos' radical style influenced architects in Germany, Austria and Bohemia. (M 46012)

\section{(19136) Strassmann}

1989 AZ $_{6}$. Discovered 1989 Jan. 10 by F. Börngen at Tautenburg.

Friedrich Wilhelm Strassmann (1902-1980), a collaborator at the Kaiser-Wilhelm-Institut in Berlin and professor at the University of Mainz since 1946, worked on artificial radio-nucleides and methods for geological age determinations. With Otto Hahn and Lise Meitner \{see planets (19126) and (6999), respectively\}, he received the Enrico Fermi prize in 1966. (M 42367)

\section{(19139) Apian}

1989 GJ J $_{8}$. Discovered 1989 Apr. 6 by F. Börngen at Tautenburg.

German mathematician and cartographer Peter Apian (1495-1552) made astronomical instruments. His major work, the Astronomicum Caesareum, is a sumptuous atlas of the skies, with revolving paper models for computations. He was the first European to illustrate that tails of comets always point away from the sun. (M 47168)

\section{(19140) Jansmit}

$1989 \mathrm{RJ}_{2}$. Discovered 1989 Sept. 2 by C. S. Shoemaker and E. M. Shoemaker at Palomar.

Jan Smit (1948- ～) has made important contributions to geology and paleontology by establishing the sequence of impact-generated events that occurred 65 million years ago, including ejecta fallout, tsunami propagation, geochemical disturbances and extinction of foraminifera and dinosaurs. (M 45749)

\section{(19178) Walterbothe}

$1991 \mathrm{RV}_{2}$. Discovered 1991 Sept. 9 by F. Börngen and L. D. Schmadel at Tautenburg.

A professor at Berlin, Giessen and Heidelberg, Walter Bothe (1891-1957) showed, together with W. Kohlhoerster, the particle structure of cosmic radiation. He investigated nuclear reactions and nuclear $\gamma$-rays and discovered artificial nuclear exitation. He shared the Nobel Prize for physics in 1954. (M 42677)

\section{(19183) Amati}

1991 TB $_{5}$. Discovered 1991 Oct. 5 by F. Börngen and L. D. Schmadel at Tautenburg.
The Amati family of violin makers worked in Cremona in the sixteenth and seventeenth centuries, establishing the renowned "Cremoneser School". The best known member was Niccolo Amati (1596-1684), the teacher of Guarneri and Stradivari \{see planets (19185) and (19189), respectively\}. The Amatis created a type of violin that is still effective today. (M 42677)

\section{(19185) Guarneri}

$1991 \mathrm{TL}_{13}$. Discovered 1991 Oct. 4 by F. Börngen at Tautenburg.

The Guarneri family of violin makers was active in Cremona for several generations. Giuseppe Antonio Guarneri (1698-1744) was its most successful member. (M 42677)

\section{(19189) Stradivari}

$1991 \mathrm{YE}_{1}$. Discovered 1991 Dec. 28 by F. Börngen at Tautenburg.

Antonio Stradivari (1644-1737) of Cremona is considered the master of all violin makers, and he was revered already during his lifetime. His instruments show a round stamp with a cross and the insignia $A S$. They became the standard to which following generations of violin makers aspired. (M 42677)

\section{(19234) Victoriahibbs}

$1993 \mathrm{VC}_{1}$. Discovered 1993 Nov. 9 by E. F. Helin at Palomar.

Victoria Pavin Hibbs (1954- ) has been known to the discoverer since her birth. She is now a learning specialist for children in science and mathematics and a water color installation artist. (M 45235)

\section{(19251) Totziens}

$1994 \mathrm{RY}_{1}$. Discovered 1994 Sept. 3 by P. Wild at Zimmerwald.

Totziens, the Dutch word for "goodbye", accompanies the discoverer's best wishes for the future of research on minor planets in general and the fate of this body in particular. Likely to be chronologically the last of his discoveries, it was found shortly after the IAU General Assembly in The Hague. (M 43047; W. A. Fröger)

\section{(19263) Lavater}

$1995 \mathrm{OH}_{10}$. Discovered 1995 July 21 by F. Börngen at Tautenburg.

Swiss writer, clergyman and religious philosopher Johann Kaspar Lavater (1741-1801), friendly with Herder and Goethe ssee planets (8158) and (3047), respectively , influenced the intellectual, religious and political life of his time. (M 42367)

\section{(19268) Morstadt}

1995 UZ. Discovered 1995 Oct. 21 by P. Pravec at Ondřejov.

Josef Morstadt (1797-1869) was a Czech astronomer, physicist and mathematician; he computed orbits of comets (notably of 3D/Biela) and was engaged in early meteor astronomy. His brother Vincenc (1802-1875) 
was a painter, known especially for his charming views, mainly of Prague. (M 43047)

\section{(19290) Schroeder}

$1996 \mathrm{JR}_{1}$. Discovered 1996 May 15 by the JPL NEAT

Program at Haleakala.

Jeff Schroeder (1954- ) has contributed to the mechanical design and fabrication of all the NEAT cameras, starting with the 1995 NEAT/GEODSS camera, continuing with the $2000 \mathrm{NEAT}$ /MSSS camera and concluding with the 2001 NEAT/Oschin camera. He has worked at the Jet Propulsion Laboratory for 22 years. (M 42677)

\section{(19291) Karelzeman}

1996 LF. Discovered 1996 June 6 by P. Pravec and L. Šarounová at Ondřejov.

Karel Zeman (1910-1989), Czech filmmaking genius and experimentator, combined different techniques of visual arts, as can be seen especially in his Invention for Destruction warning against the abuse of science. Other successful films of his are Journey to the Beginning of Time and the animated The Sorcerer's Apprentice. (M 42677)

\section{(19293) Dedekind}

1996 OF. Discovered 1996 July 18 by P. G. Comba at Prescott.

Richard Dedekind (1831-1916), a German mathematician and also an accomplished pianist and cellist, is best remembered for his rigorous definition of the real numbers in terms of the rational numbers, which hinges on the concept of the "Dedekind cut". (M 42367)

\section{(19310) Osawa}

$1996 \mathrm{VF}_{1}$. Discovered 1996 Nov. 4 by I. Sato and H. Fukushima at Mitaka.

Osawa, meaning "big dale", is the name of the area in the southwestern part of Mitaka City where the National Observatory is located. The name was selected by the observatory's Steering Committee among candidates nominated by observatory staff members. (M 45749)

\section{(19349) Denjoy}

$1997 \mathrm{CF}_{22}$. Discovered 1997 Feb. 13 by P. G. Comba at Prescott.

Arnaud Denjoy (1884-1974) was one of a group of French mathematicians (including Baire, Borel and Lebesgue) who in the early twentieth century initiated a new approach to the theory of functions of real variables, measure theory and integration. (M 42367)

\section{(19364) Semafor}

$1997 \mathrm{SM}_{1}$. Discovered 1997 Sept. 21 by L. Šarounová at Ondřejov.

Theatre Semafor was a special phenomenon of Prague cultural life in the 1960 s, with leading personalities Jiří Suchý (1931- ） and Jiří Šlitr (1924-1969). Many of their songs became popular and they can be still heard by campfires. (M 45340)

The name was suggested by L. Vašta.

\section{(19379) Labrecque}

1998 BR $_{7}$. Discovered 1998 Jan. 24 by the JPL NEAT Program at Haleakala.

Steve LaBrecque (1964- ) was responsible for the successful installation and operations of the NEAT/MSSS camera in 2000. At the Jet Propulsion Laboratory he has also worked on the Mars orbital camera. Earlier he developed and serviced shipboard oceanographic equipment at the Lamont Doherty Geological Observatory. (M 42677)

\section{(19384) Winton}

1998 CP $_{1}$. Discovered 1998 Feb. 6 by J. Tichá and M. Tichý at Klě̌.

Nicholas Winton (1909- ), a British stockbroker, managed to save more than 600 Czech Jewish children from occupied Czechoslovakia by bringing them to Great Britain in 1938-1939. This is a great example of resistance and courage in the atmosphere of a totalitarian regime. (M 43047)

\section{(19407) Standing Bear}

1998 FG $_{11}$. Discovered 1998 Mar. 25 by R. Linderholm at Lime Creek.

Arrested for refusing to be moved to Indian Territory, Standing Bear (1834-1908) petitioned the U.S. District Court in Omaha, Nebraska, in 1879 by writ of habeas corpus. The trial led to the decision that native Americans are "persons within the meaning of the law" and have the rights of citizenship. (M 44594)

\section{(19453) Murdochorne}

$1998 \mathrm{FM}_{126}$. Discovered 1998 Mar. 28 by J. Broughton at Reedy Creek.

Though also known for their work with others, the English comedy writer-performers Richard Murdoch (1907- ) and Kenneth Horne (1907-1969) teamed up for the zany 1940s-1950s radio series Much Binding in the Marsh, the goings on at a ramshackle RAF base bringing welcome comic relief in the austere post-war years. (M 43047)

\section{(19456) Pimdouglas}

$1998 \mathrm{HU}_{5}$. Discovered 1998 Apr. 21 by the OCA-DLR Survey at Caussols.

Pim (1995-2001), son of Nigel and Jantina Douglas, enjoyed a brief life and brought joy to his family. This minor planet was discovered on his third birthday. He is immortalized as a celestial commemoration of the many children, and their families, living with cerebral palsy. (M 43193)

The name was suggested by A. W. Harris (DLR). 


\section{(19458) Legault}

$1998 \mathrm{HE}_{8}$. Discovered 1998 Apr. 21 by M. Boeuf at Les Tardieux.

Thierry Legault (1962- ) is an amateur astronomer who produces amazing high-resolution astronomical pictures. He is a member of the French astronomical association AUDE $\{$ see planet (9117)\}. (M 42677)

\section{(19462) Ulissedini}

$1998 \mathrm{HE}_{20}$. Discovered 1998 Apr. 27 by P. G. Comba at Prescott.

Ulisse Dini (1845-1918) was a professor at the University of Pisa. His mathematical work centered at first on the study of mappings of surfaces. Later he worked on problems in complex analysis and integral equations. (M 42367)

\section{(19521) Chaos}

$1998 \mathrm{WH}_{24}$. Discovered 1998 Nov. 19 by M. W. Buie at Kitt Peak.

According to Hesiod \{see planet (8550)\}, Chaos gave birth to Nyx \{see planet (3908)\} (Night) and Erebus (Darkness). In the Pelasgian creation myth, Eurynome \{see planet (79)\}, the Goddess of All Things emerged from Chaos. In the Olympian version, Mother Earth emerged from Chaos. (M 45235)

\section{(19524) Acaciacoleman}

$1998 \mathrm{YB}_{7}$. Discovered 1998 Dec. 23 by E. Sheridan at Kanab.

Acacia Coleman is the granddaughter of the discoverer. (M 45749)

\section{(19528) Delloro}

$1999 \mathrm{~GB}_{1}$. Discovered 1999 Apr. 4 by G. D'Abramo and A. Boattini at San Marcello Pistoiese.

Aldo Dell'Oro (1971- ), recently awarded his doctorate by the University of Florence, works on the physics and the evolution of main-belt minor planets. He has developed new methods for the statistical analysis of collisions and for reconstructing conditions for the formation of Hirayama ssee planet (1999)\} families. (M 42367)

\section{(19535) Rowanatkinson}

$1999 \mathrm{HF}_{3}$. Discovered 1999 Apr. 24 by J. Broughton at Reedy Creek.

Rowan S. Atkinson (1955- ), one of Britain's finest comedy actors of the last two decades, was inspired by the work of Jacques Tati and John Cleese \{see, respectively, planets (14621) and (9618)\}. Whether the comedy is verbal, as in the television series Blackadder, or physical, as in Mr. Bean, Atkinson is always brilliant. (M 43047)

\section{(19539) Anaverdu}

$1999 \mathrm{JO}_{14}$. Discovered 1999 May 14 by J. Nomen at Ametlla de Mar.

Barcelona-born Ana Verdu, wife of the discoverer, is being honored on the occasion of her 38th birthday, 2001 March 8. (M 42367)
(19570) Jessedouglas

$1999 \mathrm{LH}_{6}$. Discovered 1999 June 13 by P. G. Comba at Prescott.

Jesse Douglas (1897-1965) was an American mathematician who first gave a general solution to the problem of Plateau: to prove the existence of a surface of least area bounded by a given contour. The problem had been worked on by many outstanding mathematician, including Riemann and Weierstrass \{see planets (4167) and (14100), respectively\}. (M 42367)

\section{(19578) Kirkdouglas}

1999 MO. Discovered 1999 June 20 by J. Broughton at Reedy Creek.

Kirk Douglas (1916- ), the straight-shooting American actor with a 45-caliber dimple in his chin, emerged from the depths of poverty to become a Hollywood great. After being silenced by a stroke in his $80 \mathrm{~s}$, he learned to speak all over again - another of his victories over adversity. (M 43047)

\section{(19617) Duhamel}

$1999 \mathrm{PH}_{1}$. Discovered 1999 Aug. 8 by P. G. Comba at Prescott.

Jean-Maria-Constant Duhamel (1797-1872) was a French applied mathematician who introduced a method to study the propagation of heat in solids with variable boundary temperatures. A generalization of this method is referred to as the Duhamel principle. (M 42367)

\section{(19618) Maša}

$1999 \mathrm{PN}_{3}$. Discovered 1999 Aug. 11 by J. Skvarč at Crni Vrh.

Maša Kandušer (1964- ) is an inspirational person and a woman for whom you want to save this world or discover a new one. (M 43047)

\section{(19619) Bethbell}

1999 QA. Discovered 1999 Aug. 16 by G. Bell at Eskridge.

Beth Bell (1973- ), the discoverer's daughter, shares an interest in astronomy and has been instrumental in reactivating her father's astronomical hobby. (M 42367)

\section{(19620) Auckland}

1999 QG. Discovered 1999 Aug. 18 at the Auckland Observatory at Auckland.

The largest city in New Zealand, Auckland is renowned for its beautiful harbors and its volcanic cones. (M 42367)

\section{(19629) Serra}

1999 RV $_{31}$. Discovered 1999 Sept. 8 by A. Klotz at Guitalens.

Catalan astrophysicist Guy Serra (1947-2000) was an active pioneer in the field of infrared and submillimeter space astronomy throughout Europe. The discoverer received his doctorate under Serra's direction. (M 44110) 


\section{(19630) Janebell}

$1999 \mathrm{RT}_{33}$. Discovered 1999 Sept. 2 by G. Bell at Eskridge.

Jane Bell (1945- ), wife of the discoverer, has encouraged his astronomical interests and been very understanding of his nights away from home. (M 42368)

\section{(19631) Greensleeves}

$1999 \mathrm{RY}_{38}$. Discovered 1999 Sept. 13 by J. Broughton at Reedy Creek.

Greensleeves is a timeless old English ballad by an unknown songwriter about his "Lady Greensleeves". The tune with the original lyrics first appeared in 1652 , but it was preceded by a melody that is thought to have originated in the late 1500s. (M 45340)

\section{(19694) Dunkelman}

1999 RX $_{230}$. Discovered 1999 Sept. 8 by the Catalina Sky Survey at Tucson.

Lawrence Dunkelman $\{1917-2002\}$, of the Naval Research Laboratory and NASA Goddard Space Flight Center, measured the solar near-ultraviolet spectral distribution from Mt. Lemmon in 1952 and helped advise the Mercury astronauts on observations of the upper atmosphere and space phenomena from orbit. (M 45235)

Obituary published in Bull. Am. Astron. Soc., Vol. 34, No. 4, p. 1359 (2002).

\section{(19704) Medlock}

$1999 \mathrm{TU}_{8}$. Discovered 1999 Oct. 7 by S. Brady at Hudson.

Kevin Medlock (1954- ) is a Californian awardwinning telescope and instrument maker known for large aperture, research-grade telescopes. He constructed the $0.75-\mathrm{m}$ reflector for the public program at Fremont Peak and helped restore the 0.5-m Brashear s see planet (5502)\} refractor at the Chabot Space and Science Center. (M 42368)

\section{(19718) Albertjarvis}

$1999 \mathrm{VF}_{2}$. Discovered 1999 Nov. 5 by D. S. Dixon at Las Cruces.

Albert G. Jarvis (1911-1996) invented fasteners for industry and the machines to produce them. In addition to being an inventor he was also a good friend and neighbor, always ready to help repair a neighbor's home or farm machinery, or help a teenager build a science project or rebuild his or her first automobile. (M 42368)

\section{(19719) Glasser}

1999 VB. . Discovered 1999 Nov. 9 by C. W. Juels at Fountain Hills.

William Glasser (1925- ) is a psychiatrist who developed the concepts of Choice Theory and Reality Therapy. Recent publications that emphasize promoting mental health include Choice Theory (1998), Every Student Can Succeed (2000) and Counseling with Choice Theory (2001). (M 45749)

\section{(19721) Wray}

1999 VW $_{11}$. Discovered 1999 Nov. 10 by C. W. Juels at Fountain Hills.

James D. Wray (1936- ) directed the Institute of Meteoritics (1966-1967) and was deputy P.I. for NASA Skylab Experiment S-019 (1969-1980). Author of The Color Atlas of Galaxies (1988), and founder of SciTech Astronomical Research (1989), he currently develops state-of-the-art automated observatories. (M 46684)

\section{(19730) Machiavelli}

$1999 \mathrm{XO}_{36}$. Discovered 1999 Dec. 7 by C. W. Juels at Fountain Hills.

Niccolò Machiavelli (1469-1527) was a Florentine statesman, Italian political theorist and writer who advocated a strong central government. His famous treatise, The Prince (1513), describes the achievement and maintenance of power by a determined ruler indifferent to moral considerations. (M 46111)

\section{(19763) Klimesh}

2000 MC. Discovered 2000 June 18 by the JPL/MSSS NEAT at Haleakala.

Matthew Klimesh (1968- ) developed the efficient data compressor for archiving the voluminous NEAT data. He has been with the Communications Systems and Research Section at Caltech's Jet Propulsion Laboratory since 1996. His research interests include data compression, rate-distortion theory and channel coding. (M 42677)

\section{(19776) Balears}

$2000 \mathrm{PA}_{5}$. Discovered 2000 Aug. 4 by J. Nomen at Ametlla de Mar.

The people of the western Mediterranean group of islands Mallorca, Menorca, Ibiza and Formentera, known as the Balears (or Balearic Islands), have a distinct culture and history. The name of the islands was given by Greek navigators after suffering the accurate sling shots (ballein) thrown at them by the islanders. (M 43193)

\section{(19783) Antoniromanya}

$2000 \mathrm{QF}_{71}$. Discovered 2000 Aug. 27 by J. Nomen at Ametlla de Mar.

Antoni Romanya (1900-1981) was the manager of the Observatorio del Ebro, in Roquetes-Tarragona, from 1939 to 1970. A tireless researcher in both geophysics and solar physics, he was a very dear and well-loved person in his country. (M 43193)

\section{(19848) Yeungchuchiu}

2000 TR. Discovered 2000 Oct. 2 by W. K. Y. Yeung at Arizona City.

At absolute magnitude 11.7, this largest minor planet found by the discoverer - just 1.2 west of Jupiter - is named in honor of his father, Chu Chiu Yeung (1925- ), for his unconditional support. (M 42368) 
(19857) Amandajane

$2000 \mathrm{UC}_{11}$. Discovered 2000 Oct. 19 by L. Robinson at Olathe.

Amanda Jennifer Jane Robinson is a student of psychology at the University of Kansas and an empathetic caregiver to those in need of emotional support. She is the daughter of the discoverer. (M 42368)

\section{(19913) Aigyptios}

1973 SU $_{1}$. Discovered 1973 Sept. 19 by C. J. van Houten and I. van Houten-Groeneveld at Palomar.

Aigyptios was the father of Antiphos \{see planet (13463)\}, who was a hero in Troy and companion of Odysseus \{see planet (1143)\}. (M 42368)

\section{(19914) Klagenfurt}

1973 UK $_{5}$. Discovered 1973 Oct. 27 by F. Börngen at Tautenburg.

Klagenfurt, the capital of the Austrian province of Kärnten, is situated on the eastern shore of the Wörther Lake in the greatest intra-mountainous basin of the Eastern Alps. This cultural center and tourist resort was first documented in 1195. (M 42677)

\section{(19955) Hollý}

$1984 \mathrm{WZ}_{1}$. Discovered 1984 Nov. 28 by M. Antal at Piszkéstetö.

Ján Hollý (1785-1849) was a famous Slovak classical poet, Catholic priest and member of the Slovak revival movement. He wrote epic ballads in Bernolák's \{see planet (13916)\} language and used rules of antique poetry. His most important works are the translation of Virgil's Aeneid and the first national epic Svätopluk \{see planet (11014)\}. (M 43193)

\section{(19970) Johannpeter}

1988 RJ $_{3}$. Discovered 1988 Sept. 8 by F. Börngen at Tautenburg.

Johann Peter Hebel (1760-1826), Heidelberg theologian and author of Alemannischen Gedichte (1803), collected his best-known stories in Schatzkästlein des rheinischen Hausfreundes ((1811). His linguistic skills, humor, simplicity and emotionality established his popularity. (M 42368)

\section{(19982) Barbaradoore}

1990 BJ. Discovered 1990 Jan. 22 by E. F. Helin at Palomar

Barbara Hendricks Doore (1933- ) is a cousin of the discoverer. Always an active sports enthusiast with boundless energy, she excelled at sailing and golf. As a popular leader/volunteer, she has devoted much of her later years to the Boys and Girls Club of Cathedral City, California. (M 46012)

\section{(19992) Schönbein}

1990 TS9. Discovered 1990 Oct. 10 by F. Börngen and L. D. Schmadel at Tautenburg.

German chemist Christian Friedrich Schönbein (17991868) was a professor in Basle from 1828. Best known for his discovery of ozone in 1839, he also invented nitrocellulose and collodion wool. He is considered a cofounder of geochemistry. (M 42368)

\section{(20000) Varuna}

$2000 \mathrm{WR}_{106}$. Discovered 2000 Nov. 28 by the Spacewatch at Kitt Peak.

Varuna is one of the oldest of the vedic deities, the maker and upholder of heaven and earth. As such he is king of gods and men and the universe, and he has unlimited knowledge. (M 42368)

The name was suggested by M. Sarabhai.

\section{(20004) Audrey-Lucienne}

1991 GS $_{6}$. Discovered 1991 Apr. 8 by E. W. Elst at La Silla.

Audrey Lucienne Van Landeghem (1984- ） was the last visitor during the event "Space for you" during 2001 Nov. 10-11 at the Royal Observatory at Uccle. She is planning to study astrophysics. (M 46012)

\section{(20006) Albertus Magnus}

$1991 \mathrm{GH}_{11}$. Discovered 1991 Apr. 11 by F. Börngen at Tautenburg.

German theologian, philosopher and naturalist Albertus Magnus (1200?-1280) was a thirteenth-century scholar with universal knowledge. He contributed extensively to botany and zoology. (M 42677)

\section{(20012) Ranke}

$1991 \mathrm{RV}_{4}$. Discovered 1991 Sept. 13 by F. Börngen and L. D. Schmadel at Tautenburg.

Leopold von Ranke (1795-1886) was a professor of history in Berlin from 1825 to 1871 . Treading new paths, he created the basis for the modern study of history by exact research and criticism of original sources. His complete works cover 54 volumes. (M 42677)

The name was suggested by the first discoverer.

\section{(20016) Rietschel}

1991 TU $_{13}$. Discovered 1991 Oct. 8 by F. Börngen at Tautenburg.

German sculptor Ernst Rietschel (1804-1861), a pupil of Rauch \{see planet (5266)\}, created in the classicistic style. His main works are the bronze sculptures of Lessing \{see planet (7425)\} in Braunschweig and Luther \{see planet (7100)\} in Worms. He also worked the popular Goethe and Schiller \{see, respectively, planets (3047) and (3079)\} monument in front of the Weimar national theater. (M 42677)

\section{(20074) Laskerschüler}

$1994 \mathrm{AF}_{16}$. Discovered 1994 Jan. 14 by F. Börngen at Tautenburg.

German authoress Else Lasker-Schüler (1869-1945) is a representative of expressionism who used in her poems pictures of oriental tales and Old Testament themes. The friendly rapprochement of Jew and Christian was a real concern to her. Beaten by brownshirts in a 
Berlin street in 1933, she subsequently lived in exile. (M 42677)

\section{(20081) Occhialini}

$1994 \mathrm{EE}_{3}$. Discovered 1994 Mar. 12 by V. Goretti and M. Tombelli at Cima Ekar.

Giuseppe Occhialini (1907- ) is a distinguished Italian physicist. He collaborated with P. M. S. Blackett at the Cavendish Laboratory of Cambridge on very important research work in cosmic radiation. (M 43047)

\section{(20106) Morton}

1995 QG. Discovered 1995 Aug. 20 by D. D. Balam at Victoria.

Donald C. Morton (1933- ), was director of the Anglo-Australian Observatory during 1976-1986 and of the Herzberg Institute of Astrophysics in Ottawa during 1986-2000. With a rocket he made the first ultraviolet spectral observations of stars. He played a leading role in the development of the Gemini Observatory. (M 42368)

\section{(20120) Ryugatake}

1995 WB $_{5}$. Discovered 1995 Nov. 24 by T. Kobayashi at Oizumi.

Ryugatake is a town in Kumamoto \{see planet (9993)\}, on the east coast of the beautiful AmakusaKamishima Island. It is also the name of the mountain where Myu-i public observatory is located. (M 45340)

\section{(20135) Juels}

1996 JC. Discovered 1996 May 7 by P. G. Comba at Prescott.

Charles W. Juels (1944- ) of Fountain Hills, Arizona, is a public health physician/psychiatrist and an amateur astronomer who discovered and demonstrated that hunting minor planets can be an addictive activity. In only a year and a half he has been credited with the discovery of 65 numbered objects. (M 42368)

\section{(20136) Eisenhart}

1996 NA. Discovered 1996 July 8 by P. G. Comba at Prescott.

Luther Pfahler Eisenhart (1876-1965) was a prolific American mathematician and professor at Princeton who made important contributions in Riemannian \{see planet (4167)\} and non-Riemannian geometry. (M 42368)

\section{(20140) Costitx}

1996 QT $_{1}$. Discovered 1996 Aug. 23 by M. Blasco at Mallorca.

The village of Costitx is the geographical zero point of the island of Majorca, a place of great archeological importance and home of the Astronomical Observatory of Majorca, where the minor planet was discovered. (M 42368)

\section{(20141) Markidger}

1996 RL$_{5}$. Discovered 1996 Sept. 13 by M. Blasco at Mallorca.

Mark Richard Kidger (1960- ) is a British-born astrophysicist of the Instituto de Astrofisica de Canarias, known for his contribution to Spanish astronomy with his dedication to the study of the nature of comets, meteors and minor planets, and for the support and friendship that connect him with the Observatorio de Mallorca. (M 45235)

\section{(20151) Utsunomiya}

$1996 \mathrm{TO}_{6}$. Discovered 1996 Oct. 5 by A. Nakamura at Kuma.

Syogo Utsunomiya (1956- ) is a farmer and renowned amateur astronomer in Japan. During his 27-year visual search for comets, Utsunomiya discovered $\mathrm{C} / 1997 \mathrm{~T} 1$ and $\mathrm{C} / 2000 \mathrm{~W} 1$, and in 1995 he rediscovered $122 \mathrm{P} /$ de Vico. He is the first Japanese person to receive the Edgar Wilson Award. (M 43193)

\section{(20155) Utewindolf}

1996 TS $_{11}$. Discovered 1996 Oct. 13 by P. G. Comba at Prescott.

Ute Windolf of Prescott, Arizona, is a very dear and generous friend who was particularly helpful and supportive during the long terminal illness of the discoverer's wife. (M 45749)

\section{(20156) Herbwindolf}

1996 TU $_{11}$. Discovered 1996 Oct. 13 by P. G. Comba at Prescott.

Herbert Windolf of Prescott, Arizona, is a very dear and generous friend who was particularly helpful and supportive during the long terminal illness of the discoverer's wife. Windolf is widely interested in scientific matters and a great enthusiast for space exploration. (M 45749)

\section{(20164) Janzajíc}

1996 VJ J $_{2}$. Discovered 1996 Nov. 9 by J. Tichá and M. Tichý at Klě́t.

Jan Zajíc (1950-1969) was a Czech student who burned himself to death on 1969 Feb. 25 in Wenceslas Square, Prague, as a protest against the occupation of Czechoslovakia the previous August. His hope for a democratic Czechoslovakia came true some 20 years after his death. (M 43383)

\section{(20174) Eisenstein}

1996 XD $_{20}$. Discovered 1996 Dec. 13 by P. G. Comba at Prescott.

Ferdinand Gotthold Max Eisenstein (1823-1852) was a brilliant German mathematician who published research on elliptic functions, cyclotomy, quadratic and biquadratic residues, as well as on cubic and biquadratic reciprocity laws. (M 42368) 


\section{(20197) Enriques}

1997 CK $_{22}$. Discovered 1997 Feb. 14 by P. G. Comba at Prescott.

Federigo Enriques (1871-1946), professor at the universities of Bologna and Rome, made major contributions to the theory of algebraic surfaces and wrote widely on the history and philosophy of science. He received numerous awards, including an honorary doctorate from the University of St. Andrews. (M 42678)

\section{(20200) Donbacky}

1997 DW. Discovered 1997 Feb. 28 by M. Tombelli and G. Forti at Montelupo.

Don Backy is the artistic name of the Italian singer and composer Aldo Caponi (1939- ). Among his many beautiful songs is L'Immensita. (M 45340)

\section{(20254) Úpice}

$1998 \mathrm{FE}_{2}$. Discovered 1998 Mar. 21 by P. Pravec at Ondřejov.

Úpice is a small town in northeastern Bohemia. A public observatory was built there with the help and support of almost all the Úpice residents and has operated since 1959. Its main activities are solar astronomy and astronomy education. Meteorological, ecological and seismic measurements are also made there. (M 42678)

\section{(20256) Adolfneckař}

$1998 \mathrm{FC}_{3}$. Discovered 1998 Mar. 23 by P. Pravec at Ondřejov.

Adolf Neckař (1909-1995) built a public observatory in Prostějov, Moravia, from 1950 at a provisional site on the roof of the local school building and from 1961 in a separate building. He was the observatory's director until 1971. His main focus was drawing and photographing the planets. (M 42678)

\section{(20314) Johnharrison}

$1998 \mathrm{FN}_{126}$. Discovered 1998 Mar. 28 by J. Broughton at Reedy Creek.

John Harrison (1693-1776) was an English clockmaker who worked for decades on the problem of finding longitude at sea, developing a portable timepiece of unprecedented accuracy. This was a great step forward in improving maritime safety and enabled the charting of the world's oceans. (M 44186)

\section{(20394) Fatou}

1998 MQ 17 . Discovered 1998 June 28 by P. G. Comba at Prescott.

Pierre Joseph Louis Fatou (1878-1929) was employed at the observatory of Paris all his working life, but his main interest was mathematics. He proved a fundamental theorem regarding Lebesgue integrals of sequences of functions. (M 42678)

\section{(20403) Attenborough}

1998 OW $_{11}$. Discovered 1998 July 22 by J. Broughton at Reedy Creek.
Englishman David Attenborough (1927- ) is by common consent the world's foremost naturalist and broadcaster of wildlife documentaries. His brother Richard (1923- ) is a fine character actor whose first attempt at producing and directing resulted in the 1982 Oscar-winning epic Gandhi. (M 44186)

\section{(20430) Stout}

$1999 \mathrm{AC}_{3}$. Discovered 1999 Jan. 10 by W. R. Cooney Jr and S. Lazar at Baton Rouge.

A music professor at Louisiana State University who was fascinated by the mysteries of space being revealed in his time and was always researching new ideas, Earl Douglas Stout (1895?-1985) was a great-grandfather of the second discoverer. (M 46012)

\section{(20433) Prestinenza}

1999 CL $_{12}$. Discovered 1999 Feb. 14 by G. Masi at Ceccano.

Luigi Prestinenza (1929- ) is a very active, appreciated and popular Italian amateur astronomer. A journalist by profession, he did impressive work to keep fresh the memory of important observers of the past like Cerulli, Schiaparelli \{see planet (4062)\} and Maggini. He is president of the "G. Ruggeri" astronomical group in Catania, Sicily. (M 42368)

\section{(20488) Pic-du-Midi}

1999 OL. Discovered 1999 July 17 at the Pises Observatory at Draveil.

The Pic-du-Midi Observatory was founded in the Pyrénées in the south of France in 1881. At an elevation of 2870 meters, the observatory pioneered observations of the solar corona and cosmic rays, as well as high-resolution techniques. The observatory is still in operation, with telescopes of aperture 2, 1 and 0.5 meter. (M 42368)

\section{(20495) Rimavská Sobota}

1999 PW $_{4}$. Discovered 1999 Aug. 15 by P. Pravec and P. Kušnirák at Ondřejov.

Rimavská Sobota, a small town with a rich history, lies in the Rimava river valley. A public observatory founded there in 1975 runs programs for observing the sun and occultations, and it coordinates visual meteor observations in Slovakia. The head office of the Slovak Association of Amateur Astronomers is also located there. (M 42678)

\section{(20512) Rothenberg}

1999 RW $_{32}$. Discovered 1999 Sept. 10 by A. Knöfel at Drebach.

Eckehard Rothenberg (1938- ) is technical director of the Archenhold Observatory in Berlin-Treptow and in the past leader of a youth study group there. Many of the group's former members (including the discoverer) are today active amateur and professional astronomers and owe him for a considerable share of their knowledge. (M 42368) 


\section{(20513) Lazio}

1999 RC $_{34}$. Discovered 1999 Sept. 10 by F. Mallia and G. Masi at Campo Catino.

Lazio is the Italian region containing Rome, the everlasting city. The Regione Lazio allowed the creation of Campo Catino Astronomical Observatory, where this minor planet was discovered. It was the first region in Italy that has approved a law against light pollution. (M 42369)

\section{(20517) Judycrystal}

1999 RB $_{35}$. Discovered 1999 Sept. 11 by L. Robinson at Olathe.

Judy Crystal (Andrews) Robinson (1949- ) is the wife of the discoverer. (M 42369)

\section{(20518) Rendtel}

1999 RC $_{36}$. Discovered 1999 Sept. 12 by A. Knöfel at Drebach.

Jürgen Rendtel (1954- ) is a solar physicist to the Astrophysical Institute in Potsdam and a keen amateur astronomer who has organized a study group for meteor observers in Germany (Arbeitskreis Meteore) in 1975. He has also been president of the International Meteor Organization since its foundation in 1988. (M 42369)

\section{(20522) Yogeshwar}

$1999 \mathrm{RK}_{40}$. Discovered 1999 Sept. 13 by A. Knöfel at Drebach.

Ranga Yogeshwar (1959- ), a physicist and scientific journalist, works as editor and presenter of excellent German public science television programs. His work is a most valuable contribution to the scientific education of the television audience. (M 42369)

\section{(20623) Davidyoung}

1999 TS $_{11}$. Discovered 1999 Oct. 10 by M. Abraham and G. Fedon at Olathe.

David Young (1955- ) has been for many years a great contributor to the astronomy community. He has always been there to help and has selflessly given countless hours to education, public programs and scientific research. He has often donated equipment and his technical expertise whenever and however needed. (M 42678)

\section{(20624) Dariozanetti}

1999 TB$_{12}$. Discovered 1999 Oct. 9 by S. Sposetti at Gnosca.

Dario Zanetti (1959- ) is a skilled artisan and friend of the discoverer. He helped greatly in the construction of the observatory where this minor planet was discovered. (M 46111)

\section{(20625) Noto}

$1999 \mathrm{TG}_{20}$. Discovered 1999 Oct. 9 by A. Tsuchikawa at Yanagida.

The Noto Peninsula is located in Japan's geographical center, facing the Sea of Japan. The U.S. astronomer Percival Lowell \{see planet (1886)\} visited the peninsula in 1889. His travelogue, Noto: An Unexplored Corner of Japan, was published in 1891. (M 42678)

\section{(20673) Janelle}

1999 VW. Discovered 1999 Nov. 3 by G. Bell at Eskridge.

Janelle Burgardt (1954- ), secretary and past president of the North East Kansas Amateur Astronomer's League, has for several years been one of the driving forces behind the success and growth of the organization. (M 42678)

\section{(20760) Chanmatchun}

2000 DR $_{8}$. Discovered 2000 Feb. 27 by W. K. Y. Yeung at Arizona City.

Mat Chun Chan (1934- ) is the discoverer's mother, and this minor planet is named for her unconditional love. (M 42369)

\section{(20789) Hughgrant}

2000 SU $_{44}$. Discovered 2000 Sept. 28 by C. W. Juels at Fountain Hills.

Hugh M. Grant (1933- ) is a retired educator and businessman from Vancouver and a member of the Royal Astronomical Society of Canada. He recently completed construction of a roll-off roof observatory at his winter home in Fountain Hills \{see planet 20898)\}, Arizona. (M 43193)

\section{(20804) Etter}

$2000 \mathrm{SW}_{209}$. Discovered 2000 Sept. 25 by the LINEAR at Socorro.

Dolores M. Etter is renowned for lifetime achievement in digital signal processing and contributions to science education. (M 43193)

\section{(20898) Fountainhills}

$2000 \mathrm{WE}_{147}$. Discovered 2000 Nov. 30 by C. W. Juels at Fountain Hills.

The town of Fountain Hills, Arizona, incorporated in 1989, is nestled in the foothills of the McDowell Mountains east of Scottsdale. It offers beautiful high Sonoran desert and mountain views, and it is home to one of the world's tallest water fountains, which can attain a height of 170 meters. (M 42678)

\section{(20947) Polyneikes}

2638 T-2. Discovered 1973 Sept. 29 by C. J. van Houten and I. van Houten-Groeneveld at Palomar.

Polyneikes was the father of Thersander ssee planet (9817)\}, son of Oedipus and friend of Diomedes' father Tydeus \{see planets (1437) and (20952), respectively\}. Polyneikes is a main character in The Seven against Thebes. He fought against his own brother. (M 42369)

\section{(20952) Tydeus}

5151 T-2. Discovered 1973 Sept. 25 by C. J. van Houten and I. van Houten-Groeneveld at Palomar.

Tydeus was an immortal hero, one of The Seven against Thebes. His son Diomedes \{see planet (1437)\} was a great hero at Troy. (M 42369) 


\section{(20961) Arkesilaos}

1973 SS $_{1}$. Discovered 1973 Sept. 19 by C. J. van

Houten and I. van Houten-Groeneveld at Palomar.

Arkesilaos, who was from Boeotia, was one of the first heroes to join the Greek army. (M 43047)

\section{(20963) Pisarenko}

1977 QN $_{1}$. Discovered 1977 Aug. 19 by N. S. Chernykh at Nauchnyj.

Georgij Stepanovich Pisarenko (1910-2000), a specialist in mechanics and in the theory of the strength of materials, was head of both the Ukrainian Space Research Committee and the faculty at Kiev Polytechnical Institute. (M 46012)

\section{(20964) Mons Naklethi}

1977 UA. Discovered 1977 Oct. 16 by A. Mrkos at Klet̆.

Mons Naklethi is the first known name of Klet \{see planet (2199)\} Mountain, which was mentioned in the Zlatá Koruna \{see planet (4408)\} monastery's thirteenth-century documents. This minor planet is the first one credited as a Klet discovery. (M 42678) The name was proposed by M. Tichý.

\section{(20969) Samo}

1979 SH. Discovered 1979 Sept. 17 by A. Mrkos at Klě́.

Samo (c. 600-c. 659) was a French merchant. Around the year 623 he organized the Slavic tribes into a kingdom and led this kingdom to defeat the Avars. Samo ruled over this Slavic kingdom, centered in Bohemia, until his death. This kingdom is the earliest state known to have been established in Bohemia. (M 44186)

\section{(20991) Jánkollár}

1984 WX $_{1}$. Discovered 1984 Nov. 28 by M. Antal at Piszkéstetö.

Ján Kollár (1793-1852), a great Slovak poet and a herald of Slavonic mutuality, was author of the extensive poetic work Slávy dcera ("Daughter of sláva", 1824-1832) and the folk verbal arts collection Národnie zpievanky ("National songs"). His work belongs equally to the literary heritage of both the Czech and Slovak republics. (M 43193)

\section{(21010) Kishon}

$1988 \mathrm{PL}_{2}$. Discovered 1988 Aug. 13 by F. Börngen at Tautenburg.

Israeli author, journalist and satirist Ephraim Kishon (1924- ) became known for his satiric stories and stage dramas. He also wrote radio plays and film scripts. For his literary and humorous work, which was translated into many languages, he was awarded many prizes. (M 42678)

\section{(21014) Daishi}

$1988 \mathrm{TS}_{1}$. Discovered 1988 Oct. 13 by T. Seki at Geisei.
Daishi is the grade school, established in Kochi city in 1880, that was attended by the discoverer from 1937 to 1943. (M 46012)

\section{(21016) Miyazawaseiroku}

1988 VA. Discovered 1988 Nov. 2 by T. Seki at Geisei. Brother of the author of Night On The Milky Way Train and The Twin Stars, Iwate-born Seiroku Miyazawa (1904-2001) devoted his long life to publishing the famous and fantastic stories, which appealed to Japanese of all ages. (M 46012)

\section{(21059) Penderecki}

1991 GR $_{10}$. Discovered 1991 Apr. 9 by F. Börngen at Tautenburg.

Krzysztof Penderecki (1933- ）, a Polish professor of composition at several conservatories, turned after his first experiments to plainer and more comprehensible compositions. He is a very essential representative of moderate modernity. His Dies irae and other sacred works attained worldwide success. (M 42678)

\section{(21074) Rügen}

$1991 \mathrm{RA}_{4}$. Discovered 1991 Sept. 12 by F. Börngen and L. D. Schmadel at Tautenburg.

Rügen is the largest German island in the Baltic. Off the Pomeranian coast, it is characterized by bights and sand bars. Since 1936 it was been connected to the continent by a dam $2.5 \mathrm{~km}$ long. The chalk cliffs Kap Arcona and Stubbenkammer are quite remarkable. (M 42678)

The name was suggested by the first discoverer.

\section{(21076) Kokoschka}

$1991 \mathrm{RG}_{4}$. Discovered 1991 Sept. 12 by F. Börngen and L. D. Schmadel at Tautenburg.

Austrian expressionist painter, graphic artist and writer Oskar Kokoschka (1886-1980) was known for his portraits, landscapes and views of famous towns, produced in a monumental manner and expressive colors. He emigrated in the 1930s and from 1953 lived in Switzerland. (M 42678)

\section{(21110) Karlvalentin}

1992 RC $_{1}$. Discovered 1992 Sept. 4 by F. Börngen and L. D. Schmadel at Tautenburg.

A Bavarian comedian, writer and film actor, Karl Valentin (Valentin Ludwig Fey, 1882-1948) had great success as a cabaret artist with his partner Liesl Karlstadt. He showed the universal powerlessness of the individual in comic sketches of abstract, absurd logic. (M 43047)

The name was suggested by the first discoverer.

\section{(21125) Orff}

$1992 \mathrm{YZ}_{4}$. Discovered 1992 Dec. 30 by F. Börngen at Tautenburg.

German composer Carl Orff (1895-1982), best known for his Carmina burana, developed music-pedagogic, rhythmic and tonal ideas with K. Maendler. Their "OrffInstrumentarium" obtained international acceptance 
and, in 1961, the Orff Institute was founded and directed by him in Salzburg. (M 43047)

\section{(21229) Sušil}

$1995 \mathrm{SM}_{1}$. Discovered 1995 Sept. 22 by L. Šarounová at Ondřjojov.

František Sušil (1804-1868), a great collector of Moravian folk songs, published almost 2400 songs in his compilation Moravské národní písně ("Moravian Folk Songs"). By walking the length and breadth of Moravia, he was able to record both lyrics and music directly from the local people. (M 42678)

The name was suggested by L. Vašta.

\section{(21234) Nakashima}

1995 WG. Discovered 1995 Nov. 16 by T. Kobayashi at Oizumi.

Takashi Nakashima (1956- ) is an amateur astronomer in Kumamoto prefecture. As a member of Kumamoto Civil Astronomical Observatory, he plays an active role in the popularization of astronomy amongst the public. (M 45341)

\section{(21254) Jonan}

$1996 \mathrm{BG}_{2}$. Discovered 1996 Jan. 24 by J. Kobayashi at Jonan.

Jonan is the town where the Kumamoto Civil Astronomical Observatory is located. The naming of the minor planet on the observatory's twentieth anniversary acknowledges the wonderful support of the townspeople. (M 45341)

\section{(21257) Jižní Čechy}

$1996 \mathrm{DS}_{2}$. Discovered 1996 Feb. 26 at the Klet Observatory at Klet.

Jižní Čechy (South Bohemia) is a region of the Czech Republic known for its pleasant landscape, historical towns and castles, picturesque rivers and ponds. There the Kleť \{see planet (2199)\} Observatory is situated. (M 42678)

The name was suggested by J. Tichá and M. Tichý.

\section{(21258) Huckins}

$1996 \mathrm{EH}_{1}$. Discovered 1996 Mar. 15 by the JPL NEAT Program at Haleakala.

Earle Knowlen Huckins, III (1943- ), Deputy Associate Administrator in the Office of Space Science at NASA Headquarters, has been responsible for the management, direction and oversight of NASA's space science flight program, mission studies, technology development and overall contract management of JPL. (M 43689)

\section{(21275) Tosiyasu}

$1996 \mathrm{SJ}_{7}$. Discovered 1996 Sept. 23 by T. Okuni at Nanyou.

Tosiyasu Funakosi (1953- ）, a farmer, is a Japanese amateur astronomer who has been observing occultations since 1981. (M 45235)
(21276) Feller

$1996 \mathrm{TF}_{5}$. Discovered 1996 Oct. 8 by P. G. Comba at Prescott.

William Feller (1906-1970) studied at Zagreb and Göttingen and taught at Kiel, Stockholm, Brown University and Cornell University. He was one of the founders of the modern probability theory based on concepts of measure theory. (M 42678)

\section{(21306) Marani}

$1996 \mathrm{XF}_{2}$. Discovered 1996 Dec. 1 by V. Goretti at Pianoro.

Giorgio "Doddo" Marani (1925-2000), was a longstanding friend of the discoverer. He was an accomplished mechanic who worked, together with the team of San Vittore \{see planet (2235)\} Observatory in Bologna, on the construction of a number of measuring instruments. (M 42679)

\section{(21311) Servius}

$1996 \mathrm{XC}_{9}$. Discovered 1996 Dec. 4 by V. S. Casulli at Colleverde di Guidonia.

Servius Tullius, sixth king of Rome, reigned from 578 to 535 B.C. He constructed the first wall around the city. (M 45749)

\section{(21331) Lodovicoferrari}

1997 BO. Discovered 1997 Jan. 17 by P. G. Comba at Prescott.

Lodovico Ferrari (1522-1565), assistant and protégé of Cardano \{see planet (11421)\} and lecturer in mathematics in Milan, discovered the solution of the quartic algebraic equation. (M 42679)

\section{(21346) Marieladislav}

1997 EL $_{11}$. Discovered 1997 Mar. 9 by P. Pravec at Ondřejov.

Marie Pravcová (1948- ) and Ladislav Pravec (1945- ), the parents of the discoverer, established a nice family environment in which the discoverer's interest in science flourished. This naming is on the occasion of the 35th anniversary of their marriage. (M 44595)

\section{(21451) Fisher}

$1998 \mathrm{HS}_{23}$. Discovered 1998 Apr. 28 by P. G. Comba at Prescott.

Ronald Aylmer Fisher (1890-1962), a graduate of the University of Cambridge, was the foremost statistician of his time. Initially interested in biological experiments, he made major contributions to significance testing, analysis of variance, parameter estimation and design of experiments. (M 42679)

\section{(21523) GONG}

$1998 \mathrm{MW}_{15}$. Discovered 1998 June 26 by R. A. Tucker at Tucson.

The Global Oscillation Network Group operates solar telescopes in California, Hawaii, Australia, India, the Canary Islands and Chile that provide doppler, magnetic and intensity images every minute. 
Helioseismic data acquired at the GONG stations have provided much information about the interior structure of the sun. (M 44186)

\section{(21526) Mirano}

$1998 \mathrm{MS}_{24}$. Discovered 1998 June 30 at the Farra d'Isonzo Observatory at Farra d'Isonzo.

Mirano Silvestri (1924- ) is an amateur astronomer and skilled professional photographer who took an active part in the construction of the Farra ssee planet (7501)\} Observatory. He also shared his knowledge of photography with many local astronomy club members. (M 46684)

\section{(21537) Fréchet}

1998 PQ. Discovered 1998 Aug. 15 by P. G. Comba at Prescott.

Maurice Fréchet (1878-1973), a student of Hadamard \{see planet (10382)\} and graduate of the École Normale Supérieur, was a pioneer in the study of the point set topology of abstract spaces and of functionals defined thereon. He introduced, among others, the concepts of compactness, completeness and separability. (M 42679)

\section{(21602) Ialmenus}

1998 YW $_{1}$. Discovered 1998 Dec. 17 by M. Tichý and Z. Moravec at Klet.

Ialmenus was one of the Achaean leaders and one of those who entered Troy in the Wooden Horse. He was the son of Ares and Astyoche. He is counted among the Argonauts and the suitors of Helen ssee planet (101)\}. (M 42679)

The citation was prepared by J. Tichá.

\section{(21650) Tilgner}

1999 OB $_{1}$. Discovered 1999 July 17 by S. Sposetti at Gnosca.

Bruno Tilgner (1933-2002) spent most of his career working for the European Space Agency. He later became a member of the strategy office. He greatly helped the discoverer in the identification of artificial satellites. (M 47168)

\section{(21651) Mission Valley}

$1999 \mathrm{OF}_{1}$. Discovered 1999 July 19 by G. Bell at Eskridge.

Mission Valley High School provides the land where Farpoint Observatory is sited. Situated at a dark site near Mission Creek, the high school has provided significant support to the research efforts of the North East Kansas Amateur Astronomer's League. (M 42679)

\section{(21655) Niklauswirth}

$1999 \mathrm{PC}_{1}$. Discovered 1999 Aug. 8 by L. Šarounová at Ondřejov.

Niklaus Wirth (1934- ), professor of computer science variously at Stanford University, the University of Zurich and the Swiss Federal Institute of Technology, Zurich, created the computer languages ALGOL, Pascal and Modula. His ideas are widely used in the architecture of contemporary computer systems. (M 43383)

\section{(21656) Knuth}

$1999 \mathrm{PX}_{1}$. Discovered 1999 Aug. 9 by P. Pravec and P. Kušnirák at Ondřejov.

Donald E. Knuth (1938- ), professor of computer science at Stanford University, is author of The Art of Computer Programming, the fine typesetting system $\mathrm{T}_{\mathrm{E}} \mathrm{X}$ and the METAFONT system. $\mathrm{T}_{\mathrm{E}} \mathrm{X}$ has been used to produce a lot of the world's scientific literature in physics and mathematics, including the Minor Planet Circulars. (M 42679)

\section{(21659) Fredholm}

$1999 \mathrm{PR}_{3}$. Discovered 1999 Aug. 13 by P. G. Comba at Prescott.

Ivar Fredholm (1866-1927) studied at the University of Uppsala and taught at the University of Stockholm. His main interest was in mathematical physics, and his fame rests on finding the general solution of the integral equation that now bears his name. (M 42679)

\section{(21660) Velenia}

1999 QZ $_{1}$. Discovered 1999 Aug. 20 by P. Pravec at Ondřejov.

Miroslav Velen (1972- ～) has developed programs for photometric and astrometric reduction of observations obtained by the minor planet observation program at the Ondřejov Observatory. This object is being named on the occasion of the marriage of Miroslav Velen and Jarmila Karásková in April 2001. (M 42679)

\section{(21661) Olgagermani}

1999 RA. Discovered 1999 Sept. 1 by G. Masi at Ceccano.

Italian poetess Olga Germani (1900-1983) worked with young students and performed for school festivities and charity. (M 45341)

\section{(21663) Banat}

1999 RM. Discovered 1999 Sept. 3 at the Starkenburg Observatory at Heppenheim.

The Banat, home of the "Donauschwaben", is a European region between the Maros river in the north, the Transylvanian Alps in the east, the Danube river in the south and Tisza river in the west. Since the Treaty of Trianon in 1920 the Banat has been divided between western Romania, northern Yugoslavia and eastern Hungary. (M 47169)

\section{(21664) Konradzuse}

$1999 \mathrm{RG}_{1}$. Discovered 1999 Sept. 4 by L. Šarounová at Ondřejov.

German engineer Konrad Zuse (1910-1995) developed and built the first binary digital computer. Working in complete isolation and secrecy, in 1941 he completed the Z3, the first operational program-controlled computer, before fleeing to Switzerland. Zuse computers were the first to be used by astronomers in Czechoslovakia. (M 43383) 


\section{(21665) Frege}

$1999 R_{1}$. Discovered 1999 Sept. 5 by P. G. Comba at Prescott.

Friedrich Ludwig Gottlob Frege (1848-1925), a professor at Jena, devoted his work to the goal of establishing the logical foundations of arithmetic. He introduced symbols for the concepts - now widely used in logic - of assertion, negation, implication and existential and universal quantifier. (M 42679)

\section{(21678) Lindner}

$1999 \mathrm{RK}_{27}$. Discovered 1999 Sept. 5 by G. Lehmann and J. Kandler at Drebach.

Klaus Lindner (1935- $\quad$ ) worked as a school teacher of astronomy in Germany for many years. He is known to amateur astronomers as the author of five astronomical books. One of them, Astronomie selbst erlebt, helped the first discoverer of this minor planet to make his first observations. (M 46111)

\section{(21680) Richardschwartz}

$1999 \mathrm{RS}_{31}$. Discovered 1999 Sept. 9 at the Farra d'Isonzo Observatory at Farra d'Isonzo.

Richard K. Schwartz (1933-1998) was an amateur astronomer in the $\gamma$-ray burster field at the Santa Barbara Astronomical Group. He co-founded a small CCD \{see planet (15000)\} brand that in 1991 developed star tracking equipment, sparking the CCD revolution in the world of amateur astronomy. (M 46684)

\section{(21682) Peštafrantišek}

$1999 \mathrm{RT}_{32}$. Discovered 1999 Sept. 9 by P. Pravec and P. Kušnirák at Ondřejov.

František Pešta (1905-1982), founder of the public observatory in the town of Sezimovo Ústí that now bears his name, was a keen popularizer of astronomy. He studied archival records of the Strkov (near Tábor, Bohemia) meteorite shower in 1753. (M 42679)

\section{(21684) Alinafiocca}

$1999 \mathrm{RR}_{33}$. Discovered 1999 Sept. 4 by M. White and M. Collins at Mission Viejo.

Alina Fiocca (1994- ) is a girl of Italian heritage born with Down's syndrome. A resident of Aliso Viejo, California, she is a bright and beautiful princess, a daily inspiration in her ability to love unconditionally and wholeheartedly. (M 42679)

\section{(21685) Francomallia}

$1999 \mathrm{RL}_{35}$. Discovered 1999 Sept. 11 by G. Masi at Ceccano.

Franco Mallia (1961- ), an amateur astronomer since 1974 , is involved with astronomy popularization at Campo Catino Astronomical Observatory, the most important public observatory in Italy. He also works with several observing programs and has discovered several minor planets. (M 42679)

\section{(21686) Koschny}

1999 RB $_{36}$. Discovered 1999 Sept. 11 by A. Knöfel at Drebach.
Aerospace engineer Detlef Koschny (1962- ) is a member of the Rosetta Project Scientists' Team of the European Space Research and Technology Center of the European Space Agency. He is also an active amateur astronomer and works on the subject of groundbased observations of meteors with intensified video cameras. (M 42679)

\section{(21785) Méchain}

$1999 \mathrm{SS}_{2}$. Discovered 1999 Sept. 21 by M. Tichý at Klet.

Pierre François André Méchain (1744-1804) discovered many comets and deep-sky objects. A colleague and friend of Messier \{see planet (7359)\}, he contributed much to Messier's catalogue of nebulae. Much of Méchain's career involved geodetic measurements along the Paris meridian, with the idea of defining the meter. (M 46012)

\section{(21795) Masi}

$1999 \mathrm{SN}_{9}$. Discovered 1999 Sept. 29 by F. Mallia at Campo Catino.

Gianluca Masi (1972- ), an amateur astronomer since 1980, is involved with several scientific projects, mainly on cataclysmic variable stars and minor planets. He has discovered a variable star and several minor planets. He collaborates with several institutions through several observing programs. (M 42679)

\section{(21799) Ciociaria}

1999 TP. Discovered 1999 Oct. 1 by F. Mallia and G. Masi at Campo Catino.

La Ciocia, from which the name is derived, is the ancient footwear of the early inhabitants of the Campo Catino area of southern Latium. The area is now nearly coincident with the Province of Frosinone, which permitted the Campo Catino Astronomical Observatory building. (M 42679)

\section{(21801) Ančerl}

$1999 \mathrm{TW}_{3}$. Discovered 1999 Oct. 2 by L. Šarounová at Ondřejov.

Karel Ančerl (1908-1973) was the head conductor of the Czech Philharmonic Orchestra during 1950-1968. He brought the orchestra to the highest standard by his demands and consistent work. He was an excellent interpreter of the music of the twentieth century and made some of Prague's best recordings. (M 45341)

\section{(21802) Svoren̆}

$1999 \mathrm{TE}_{6}$. Discovered 1999 Oct. 6 by L. Kornoš and J. Tóth at Modra.

Ján Svoreň (1949- ) is an astronomer at the Astronomical Institute of the Slovak Academy of Sciences, Tatranská Lomnica. He has worked on physical properties of comets and compiled a catalogue of the magnitudes of the long-period comets observed during 1861-1957. (M 44186) 


\section{(21804) Václavneumann}

1999 TC 8 . Discovered 1999 Oct. 4 by L. Šarounová at Ondřejov.

Václav Neumann (1920-1995) was the head conductor of the Czech Philharmonic Orchestra during 1968-1990. $\mathrm{He}$ became famous especially for his interpretation of the work of Martinů, Mahler \{see planet (4406)\}, Janáček \{see planet (2073)\} and Dvořák \{see planets (2047)\}. (M 45749)

\section{(21811) Burroughs}

$1999 \mathrm{TR}_{20}$. Discovered 1999 Oct. 5 by R. A. Tucker at Tucson.

The fantasy novels of Edgar Rice Burroughs (18751950) have fired the imaginations of generations of readers and inspired numerous motion pictures. His most enduring and popular fictional character is Tarzan of the Apes. (M 42679)

\section{(21873) Jindřichůvhradec}

1999 UU $_{3}$. Discovered 1999 Oct. 29 by J. Tichá and M. Tichý at Klě́t.

Jindřichův Hradec is the pleasant south Bohemian town founded in the thirteenth century, known for its Renaissance château and provost's Gothic church situated precisely on the fifteenth meridian east of Greenwich, as a line across its paving stones shows. (M 44595)

\section{(21903) Wallace}

$1999 \mathrm{VE}_{12}$. Discovered 1999 Nov. 10 by C. W. Juels at Fountain Hills.

Patrick T. Wallace (1946- ) is a specialist in telescope control software. From 1973 to 1980 he was on the staff of the Anglo-Australian Observatory. During 1982-2000 he directed the Starlink astronomical computing service in the U.K., and he is currently head of H.M. Nautical Almanac Office. (M 43762)

\section{(21985) Šejna}

$1999 \mathrm{XG}_{15}$. Discovered 1999 Dec. 2 by L. Šarounová at Ondřejov.

Karel Sejna (1896-1982) was the conductor of the Czech Philharmonic Orchestra during 1938-1972 and cocreator of the era of Talich and Ančerl. He was a significiant interpreter of Mahler, Wagner and Bruckner \{see, respectively, planets (4406), (3992) and (3955)\}, and his recordings of the compositions of Smetana, Dvořák \{see planets (2047) and (2055)\}, Fibich and Suk are superb. (M 45341)

\section{(21999) Disora}

$1999 \mathrm{XS}_{38}$. Discovered 1999 Dec. 7 by F. Mallia at Campo Catino.

Mario Di Sora is founder and manager of the Campo Catino Observatory. A lawyer by profession, as president of the Italian section of the International Dark Sky Association, he has promoted several regional laws on light pollution in Italy, notably by making Rome the first dark-sky capital in the world. (M 42680)

\section{(22177) Saotome}

$2000 \mathrm{XS}_{38}$. Discovered 2000 Dec. 6 by the Bisei Spaceguard Center at Tokyo-Okayama.

Masatoshi Saotome (1940- ) is one of the directors of the Japan Space Forum. He contributed greatly to the construction of Bisei Spaceguard Center. (M 45235)

\section{(22185) Štiavnica}

$2000 \mathrm{YV}_{28}$. Discovered 2000 Dec. 29 by P. Kušnirák and U. Babiaková at Ondřejov.

Banská Štiavnica, a town in the "Štiavnické vrchy" mountains, central Slovakia, known for its famous mining history, has been on the UNESCO World Heritage List since 1993. The Mining Academy, founded 1762, was the first of its kind in the world. The town is the birthplace of the second discoverer. (M 42680)

\section{(22199) Klonios}

4572 P-L. Discovered 1960 Sept. 24 by C. J. van Houten and I. van Houten-Groeneveld at Palomar.

Klonios was one of the first heroes to join the Greek army against Troy and came from Boeotia, as did Arkesilaos and Prothoenor \{see planets (20961) and (22203), respectively\}. (M 43047)

\section{(22203) Prothoenor}

6020 P-L. Discovered 1960 Sept. 24 by C. J. van Houten and I. van Houten-Groeneveld at Palomar.

Prothoenor was also a hero from Boeotia in the fight against Troy, as were Klonios and Arkesilaos \{see planets (22199) and (20961), respectively\}. (M 43047)

\section{(22222) Hodios}

3156 T-2. Discovered 1973 Sept. 30 by C. J. van Houten and I. van Houten-Groeneveld at Palomar.

The Greek herald Hodios went together with the other Greek herald Eurybates and Odysseus and Phoenix to Achilles \{see planets (3548), (1143), (4543) and (588), respectively\} to persuade Achilles to stop his quarrel with Agamemnon \{see planet (911)\} and fight the Trojans again. (M 43047)

\section{(22227) Polyxenos}

5030 T-2. Discovered 1973 Sept. 25 by C. J. van Houten and I. van Houten-Groeneveld at Palomar.

Polyxenos came from Elis and fought against the Trojans. (M 43048)

\section{(22250) Konstfrolov}

$1978 \mathrm{RD}_{2}$. Discovered 1978 Sept. 7 by T. M. Smirnova at Nauchnyj.

Konstantin Vasil'evich Frolov (1932- ), director of the Mechanical Engineering Research Institute in Moscow, is a prominent expert in ergonomics and biomechanics. He is one of the founders of the new scientific direction "man-machine-environment" widely used in aviation, space, shipbuilding and nuclear engineering. (M 45749) 
(22260) Ur

1979 UR. Discovered 1979 Oct. 19 by A. Mrkos at Kleť.

Ur was an important city of ancient southern Mesopotamia (Sumer), situated near the Euphrates River. The excavations at Ur discovered architectural monuments, including the ziggurat, and they greatly enlarged our knowledge of Mesopotamian history. (M 42680)

The name was suggested by J. Tichá.

\section{(22278) Protitch}

$1983 \mathrm{RT}_{3}$. Discovered 1983 Sept. 2 by H. Debehogne at La Silla.

Known for his work in celestial mechanics and fundamental astronomy, Milorad B. Protitch (19112001) was three times director of the Belgrade Observatory. He independently found comet C/1947 $\mathrm{Y} 1$ and discovered more than 30 minor planets. (M 44186)

The name was suggested by his daughter, V. ProtitchBenishek.

\section{(22291) Heitifer}

$1989 \mathrm{CH}_{5}$. Discovered 1989 Feb. 2 by F. Börngen at Tautenburg.

Heinrich (1998- ）, Tibère (1999- ) and Ferdinand (2000- ) are the three grandsons of the discoverer, who wishes all the best for them in the future. This is the 333rd numbered minor planet discovered with the Tautenburg $\{$ see planet (2424)\} 1.34-m Schmidt telescope. (M 42680)

\section{(22322) Bodensee}

1991 RQ $_{4}$. Discovered 1991 Sept. 13 by F. Börngen and L. D. Schmadel at Tautenburg.

Bodensee, Constance Lake, or Swabian Sea, is a border sea of the Alps, adjoining Germany, Switzerland and Austria. The river Rhine flows through it. It is an old cultivated and cultural landscape. (M 43048)

The name was suggested by the first discoverer.

\section{(22354) Sposetti}

1992 UR $_{8}$. Discovered 1992 Oct. 31 by F. Börngen at Tautenburg.

Stefano Sposetti is an amateur astronomer and teacher who lives in the Italian-speaking part of Switzerland in the Ticino Alps. Since his youth he has been a very active observer of minor planets, comets, artificial satellites and meteors. He is also a helpful friend to budding young amateur astrometrists. (M 42680)

\section{(22369) Klinger}

$1993 \mathrm{SE}_{3}$. Discovered 1993 Sept. 18 by F. Börngen and L. D. Schmadel at Tautenburg.

German sculptor, painter and etcher Max Klinger (1857-1920) worked in Leipzig, partly in Rome. His greatest achievements are some sets of etchings. His best-known sculptures are those of Brahms and
Beethoven \{see planets (1818) and (1815), respectively\} in Hamburg and Leipzig, respectively. (M 43048) The name was suggested by the first discoverer.

\section{(22370) Italocalvino}

$1993 \mathrm{TJ}_{2}$. Discovered 1993 Oct. 15 at the Bassano Observatory at Bassano Bresciano.

Italian writer Italo Calvino (1923-1985) produced fantastic tales such as Il visconte dimezzato (1952), Il barone rampante (1957) and Il cavaliere inesistente (1959). His Le cosmicomiche is a stream-of-consciousness narrative that treats the creation and evolution of the universe. (M 43048)

\section{(22401) Egisto}

$1995 \mathrm{DP}_{3}$. Discovered 1995 Feb. 24 by M. Tombelli at Cima Ekar.

Egisto Masotti (1944- ), amateur astronomer in the Montelupo group of amateur astronomers, is very active in the populatization of astromomy. (M 45341)

\section{(22402) Goshi}

1995 GN. Discovered 1995 Apr. 3 by A. Nakamura at Kuma.

Goshi Nakamura (2001- ), whose initials are those of the provisional designation of this minor planet, is the son of the discoverer. (M 42680)

\section{(22403) Manjitludher}

1995 LK. Discovered 1995 June 5 by D. J. Asher at Siding Spring.

Manjit Kaur Ludher specialises in linguistics and intercultural communication at Universiti Kebangsaan Malaysia. Her visit to Siding Spring in 1995 remains a high point in her life. Born in Kuala Lumpur, she also does voluntary social work related to community development. (M 45341)

\section{(22405) Gavioliremo}

1995 OB. Discovered 1995 July 19 at the Gavezzo Observatory at Gavezzo.

Remo Gavioli (1932- ） was one of the cofounders and a dedicated member of the Associazione Astronomica "Geminiano Montanari" of Cavezzo. Indefatigable in his work, he designed and constructed the 4.5-meter dome at the Cavezzo Observatory. He still helps the local amateur astronomers embrace the beauties of astronomy. (M 44186)

\section{(22442) Blaha}

$1996 \mathrm{TM}_{9}$. Discovered 1996 Oct. 14 by J. Tichá and M. Tichý at Klě́.

John Elmer Blaha (1942- ), is a U.S. astronaut who made five space missions from 1989 to 1997. Four of them were space-shuttle missions. For the fifth he spent four months aboard the MIR \{see planet (11881)\} space station. (M 43193) 


\section{(22465) Karelanděl}

1997 AK $_{18}$. Discovered 1997 Jan. 15 by M. Tichý and Z. Moravec at Klet.

Karel Anděl (1884-1948) was a teacher. In astronomy he was known as a moon cartographer, author of Mappa Selenographica (1926). He was one of the founders of the Czech Astronomical Society in 1917. (M 43048)

\section{(22474) Frobenius}

1997 ED 8 . Discovered 1997 Mar. 8 by P. G. Comba at Prescott.

Georg Ferdinand Frobenius (1849-1917), a professor at the University of Berlin, made major contributions to the theory of abstract groups. The abstract group unifies the concepts of permutation, transformation and composition. (M 42680)

\section{(22489) Yanaka}

1997 GR $_{24}$. Discovered 1997 Apr. 7 by A. Nakamura at Kuma.

Tetsuo Yanaka (1954- ) is a post office clerk and amateur astronomer in Japan. He started his visual search for comets in 1970, and after sweeping for 1068 hours, he independently discovered C/1988 P1. Five months later, he discovered two more comets, C/1988 Y1 and C/1989 A1, only three days apart. (M 46111)

\section{(22495) Fubini}

$1997 \mathrm{JU}_{3}$. Discovered 1997 May 6 by P. G. Comba at Prescott.

Guido Fubini (1879-1943) taught at the universities of Catania, Genoa and Turin. In 1938 he was invited to join the Institute for Advanced Study at Princeton. Fubini was a prolific and eclectic mathematician who made contributions in analysis, algebra, geometry and mathematical physics. (M 42680)

\section{(22497) Immanuelfuchs}

1997 KG. Discovered 1997 May 30 by P. G. Comba at Prescott.

Immanuel Lazarus Fuchs (1833-1902) received a doctorate from the University of Berlin and taught at various secondary schools and universities. His work was mostly in the study of solutions and singularities of homogeneous linear differential equations in the complex domain. (M 42680)

\section{(22503) Thalpius}

1997 TB $_{12}$. Discovered 1997 Oct. 7 by M. Tichý and Z. Moravec at Klě̌.

Thalpius, son of Eurytus, was leader of the Elean flotilla against Troy and one of those who entered Troy in the Wooden Horse. (M 42680)

The citation was prepared by J. Tichá.

\section{(22611) Galerkin}

1998 KB. Discovered 1998 May 17 by P. G. Comba at Prescott.

Boris Grigorievich Galerkin (1871-1945) studied engineering in his native Russia and abroad. His scientific work centered on various problems in the theory of elasticity and structural mechanics, in particular the curvature of thin plates and the torsion and flexure of prismatic rods. (M 43193)

\section{(22644) Matejbel}

1998 OZ $_{4}$. Discovered 1998 July 27 by P. Pravec and U. Babiaková at Ondřejov.

Matej Bel (1684-1749), Slovak historian and a great scholar of the eighteenth century, was a pioneer of collaborative research, member of numerous scholarly societies and author of the book Notitia Hungariae novae historico-geographica. The University of Banská Bystrica, Slovakia, bears his name. (M 43383)

\section{(22697) Mánek}

1998 RM. Discovered 1998 Sept. 7 by L. Šarounová at Ondřejov.

Czech amateur astronomer Jan Karel Mánek (1961-

) has been involved especially in occultation and variable-star observations and research. (M 43048)

The name was suggested by the discoverer and L. Vašta.

\section{(22791) Twarog}

1999 LL7 $_{7}$. Discovered 1999 June 14 by G. Bell at Eskridge.

Bruce Twarog (1952- ）, a professor at the University of Kansas, has studied globular clusters, open clusters, halo objects and stellar and cluster photometry. $\mathrm{He}$ has increased the understanding of the formation and evolution of the galactic disk, as well as of halo objects and their relationship to the galactic disk. (M 43048)

\section{(22824) von Neumann}

1999 RP $_{38}$. Discovered 1999 Sept. 12 by P. Pravec and P. Kušnirák at Ondřejov.

Hungarian-U.S. mathematician John Ludwig von Neumann (1903-1957) influenced many branches of mathematics, computer science, physics and economics. He established the basic concepts of programmable serial digital computing and in 1944 joined the team that produced ENIAC, the first U.S. electronic computer. (M 43193)

\section{(22900) Trudie}

$1999 \mathrm{TW}_{14}$. Discovered 1999 Oct. 11 by C. W. Juels at Fountain Hills.

Trudie R. Wilson (1913-2001) was the mother of the discoverer. (M 43194)

\section{(22901) Ivanbella}

1999 TY $_{15}$. Discovered 1999 Oct. 12 by P. Kušnirák and P. Pravec at Ondřejov.

Ivan Bella (1964- ) is the first Slovak cosmonaut. He performed astrobiological experiments and physical body tests during his eight-day stay onboard the MIR \{see planet (11881)\} Space Station in Feb. 1999. (M 43194)

The name was suggested by the Slovak Astronomical Society. 


\section{(22905) Liciniotoso}

$1999 \mathrm{TO}_{19}$. Discovered 1999 Oct. 14 at the Farra d'Isonzo Observatory at Farra d'Isonzo.

Licinio Toso (1920-1999) was a grandfather of Alberto Toso, one of the discoverers. (M 46684)

\section{(22978) Nyrola}

$1999 \mathrm{VO}_{24}$. Discovered 1999 Nov. 14 at the Nyrola Observatory at Jyväskylä.

Nyrola is a small rural village in central Finland and the site of the countryside observatory of the astronomical association Jyväskylän Sirius. This minor planet is the first to be found by Finnish amateur astronomers. (M 42680)

\section{(23032) Fossey}

1999 XB $_{8}$. Discovered 1999 Dec. 3 by J. Broughton at Reedy Creek.

American occupational therapist Dian Fossey (19321985) spent many years in Africa studying the behavior of the mountain gorilla, the largest and rarest of the great apes. Her campaign for their protection was largely responsible for bringing the species back from the brink of extinction. (M 44186)

\section{(23110) Ericberne}

2000 AE. Discovered 2000 Jan. 2 by C. W. Juels at Fountain Hills.

Eric L. Berne (1910-1970) was a physician and psychiatrist who developed Transactional Analysis, a system of group therapy that analyzes interactions between individuals. Two of his best known publications are Transactional Analysis in Psychotherapy (1961) and the best-seller Games People Play (1964). (M 43194)

\section{(23111) Fritzperls}

2000 AG. Discovered 2000 Jan. 2 by C. W. Juels at Fountain Hills.

Frederick "Fritz" Perls (1893-1970) was a German physician and psychiatrist who moved to the U.S. in 1946, where he developed a new method of psychotherapy he called Gestalt Therapy. Two of his books are Gestalt Therapy Verbatim and his autobiography In and Out of the Garbage Pail, both published in 1969. (M 43194)

\section{(23257) Denny}

$2000 \mathrm{YW}_{21}$. Discovered 2000 Dec. 29 by W. K. Y. Yeung at Arizona City.

The Pin Point Astrometry Engine and ACP telescope control of Robert B. Denny (1946- ) are significant contributions to the observation of minor planets. (M 43048)

\section{(23258) Tsuihark}

$2000 \mathrm{YY}_{21}$. Discovered 2000 Dec. 29 by W. K. Y. Yeung at Arizona City.

Hark Tsui (1951- ) is a brilliant Hong Kong move producer and director whose numerous productions include Chinese Ghost Story (1987) and Green Snake (1993). In 1991 Tsui won the Best Director award at the Hong Kong Film Awards with Once Upon a Time in China. (M 45235)

\section{(23318) Salvadorsanchez}

$2001 \mathrm{BT}_{13}$. Discovered 2001 Jan. 20 by J. Nomen at Ametlla de Mar.

Salvador Sanchez is the founder and managing director of the Observatorio Astronomico de Mallorca. His enthusiastic dedication to observational astronomy, especially to observing minor planets and comets, rekindled the interest and observations of these bodies in Spain after the death of astronomer J. Comas Solá \{see planet (1655)\}. (M 47169)

\section{(23355) Elephenor}

9602 P-L. Discovered 1960 Oct. 17 by C. J. van Houten and I. van Houten-Groeneveld at Palomar.

Elephenor was a king from Euboea. In the last year of the Trojan War he was killed by the Trojan Agenor \{see planet (1873)\}, as he tried to win the armor of Echepolos. (M 43048)

\section{(23382) Epistrophos}

4536 T-2. Discovered 1973 Sept. 30 by C. J. van Houten and I. van Houten-Groeneveld at Palomar.

Epistrophos was a hero from Phokis. Together with his brother Schedios \{see planet (23383)\} he fought against Troy. (M 43048)

\section{(23383) Schedios}

5146 T-2. Discovered 1973 Sept. 25 by C. J. van Houten and I. van Houten-Groeneveld at Palomar.

Schedios came together with his brother Epistrophos \{see planet (23382)\} from Phokis to fight against Troy. (M 43048)

\section{(23444) Kukučín}

$1986 \mathrm{TV}_{6}$. Discovered 1986 Oct. 5 by M. Antal at Piwnice.

Martin Kukučín (Matej Bencúr, 1860-1928) was a Slovak writer and the first important realistic novelist in Slovak literature. He spent part of his life in Chile and Argentina, as well as in Croatia (on the island of Brač), where he died. Kukučín was also a teacher and doctor. (M 43194)

\section{(23455) Fumi}

$1988 \mathrm{XY}_{4}$. Discovered 1988 Dec. 5 by T. Nakamura at Kiso.

Fumi Yoshida (1966- ) is a Japanese astronomer who studies the small bodies of the solar system. In collaboration with the discoverer she made clear the overall nature of spatial and size distributions for subkilometer-sized main-belt minor planets with the 8.2-m Subaru telescope. (M 46012)

\section{(23457) Beiderbecke}

$1989 \mathrm{GV}_{6}$. Discovered 1989 Apr. 5 by M. Geffert at La Silla.

U.S. jazz cornetist Leon Bismarck ("Bix") Beiderbecke (1903-1931), arguably the most original white trumpeter 
in jazz history, was also a noted composer, his piano piece In a Mist having been inspired by French Impressionist composers. (M 43762)

\section{(23473) Voss}

1990 TD $_{12}$. Discovered 1990 Oct. 11 by F. Börngen and L. D. Schmadel at Tautenburg.

Philologist and poet Johann Heinrich Voss (17511826) wrote idyllic scenes of civil life, partly in Low German dialect. His major achievements are translations or free renderings of Greek and Roman authors like Homer, Ovid, Virgil and Horace \{see planets (5700), (2800), (2798) and (4294), respectively\}, thereby opening up a new relation with the ancients for his contemporaries. (M 43048)

\section{(23514) Schneider}

1992 RU. Discovered 1992 Sept. 2 by F. Börngen and L. D. Schmadel at Tautenburg.

Reinhold Schneider (1903-1958) is a German writer and essayist. The topics of his stories, dramas and poems are the tragic conflicts between faith and unbelief, conscience and power, state and church, frequently related to historical events, such as Las Casas against Karl V. (M 43048)

\section{(23520) Ludwigbechstein}

1992 SM $_{26}$. Discovered 1992 Sept. 23 by F. Börngen at Tautenburg.

Writer Ludwig Bechstein (1801-1860) spent nearly all his life in the Thuringian town of Meiningen. Except for the Brothers Grimm \{see planet (6912)\}, he is the greatest German teller of fairy tales and myths, collecting and arranging them. (M 43048)

\section{(23583) Křivský}

1995 SJ $_{1}$. Discovered 1995 Sept. 22 by L. Šarounová at Ondřejov.

Ladislav Křivský (1925- ), Czech astronomer and meteorologist, worked particularly in solar physics and problems involving solar-terrestrial relations. Authors of many scientific papers and monographies, he has also dedicated much time to the popularization of astronomy. (M 45341)

\section{(23625) Gelfond}

1996 WX. Discovered 1996 Nov. 19 by P. G. Comba at Prescott.

Alexandr Osipovich Gelfond (1906-1968) studied and taught mathematics at the University of Moscow. His main contributions were in the theory of interpolation and approximation of functions of a complex variable, in number theory and the study of transcendental numbers and in the history of mathematics. (M 43194)

\section{(23644) Yamaneko}

1997 AW $_{17}$. Discovered 1997 Jan. 13 by A. Nakamura at Kuma.

The Yamaneko Group of Comet Observers, founded by K. Ichikawa and the discoverer in 1980, is the most prolific group of comet observers in Japan. The members have obtained some 12,300 astrometric and 6,300 photometric observations, contributing them to the MPC and International Comet Quarterly, respectively. (M 46111; M 46173)

\section{(23663) Kalou}

1997 EG $_{18}$. Discovered 1997 Mar. 10 by M. Meunier at Arbonne la Forêt.

Kalou is the nickname of the discoverer's wife, Caroline (née Schneider) Meunier (1964- ). Her help and patience contributed to the discovery of both this minor planet and comet C/1997 J2. (M 43194)

\section{(23699) Paulgordan}

1997 ND $_{3}$. Discovered 1997 July 8 by P. G. Comba at Prescott.

Paul Albert Gordan (1837-1912) was a German mathematician who taught at the University of Erlangen. He did research in the theory of invariants of algebraic forms, as well as on the substitution groups associated with the solution of algebraic equations. (M 43194)

\section{(23718) Horgos}

1998 GO $_{10}$. Discovered 1998 Apr. 2 by K. Sárneczky and L. Kiss at Piszkéstetö.

Horgos is a small town in northern Serbia, near the Hungarian border. The population is mainly Hungarian and numbers almost 8000 . The second discoverer grew up there. (M 43048)

\section{(23774) Herbelliott}

$1998 \mathrm{MZ}_{41}$. Discovered 1998 June 26 by J. Broughton at Reedy Creek.

Australian athlete Herb Elliott (1938- ） won gold by a wide margin in the $1500-\mathrm{m}$ at the 1960 Olympics with a record that stood for seven years. At 22 he retired having never been beaten over the mile equivalent distance. He has been voted by his peers as history's greatest middle distance runner. (M 45341)

\section{(23776) Gosset}

1998 QE. Discovered 1998 Aug. 17 by P. G. Comba at Prescott

William Sealy Gosset (1876-1937) studied mathematics and chemistry at Oxford. His most important contribution, published under the pseudonym "Student", was the derivation of a statistic, known as "t", that plays a central role in tests of hypotheses based on the analysis of small samples. (M 43194)

\section{(23777) Goursat}

1998 QT $_{5}$. Discovered 1998 Aug. 23 by P. G. Comba at Prescott.

Edouard Jean-Baptiste Goursat (1858-1936) made contributions to many areas of mathematical analysis. He was associated with several French universities and was regarded as an outstanding teacher. His 
monumental Cours d'analyse mathématique (19001910) was used by generations of students. (M 43194)

\section{(23880) Tongil}

1998 SG $_{5}$. Discovered 1998 Sept. 18 by T. H. Lee at Younchun

In Korean, Tongil means "reunification". This minor planet, the first one discovered by a Korean amateur astronomer, is named with the hope for an early reunification of the southern and northern parts of Korea, divided since 1945. (M 43383)

\section{(23884) Karenharvey}

1998 SY $_{12}$. Discovered 1998 Sept. 20 by R. A. Tucker at Tucson.

Karen Lorraine Harvey \{1942-2002\} has investigated extensively the relationship of solar magnetic fields to coronal heating, x-ray emission, large active regions, ephemeral active regions and the solar cycle. Her work has provided fundamental statistical data on the nature and evolution of the solar magnetic field. (M 44595)

Obituary published in Bull. Am. Astron. Soc., Vol. 34, No. 4, p. 1363 (2002).

\section{(23889) Hermanngrassmann}

1998 SC $_{28}$. Discovered 1998 Sept. 26 by P. G. Comba at Prescott.

Hermann Günther Grassmann (1809-1877) was a German scholar with wide interests, including Sanskrit, phonetics and theology. He was also a very inventive mathematician. His researches in noncommutative algebraic systems foreshadowed the development of the vector calculus and $n$-dimensional spaces. (M 43194)

\section{(23988) Maungakiekie}

1999 RB. Discovered 1999 Sept. 2 by I. P. Griffin at Auckland.

Maungakiekie, or "One Tree Hill", is the volcanic cone in the city where this minor planet was discovered. One Tree Hill is still commonly referred to by the Maori name. Maunga means "hill", and kiekie is a "strong climbing plant". (M 43048)

\section{(23989) Farpoint}

1999 RF. Discovered 1999 Sept. 3 by G. Hug and G. Bell at Eskridge.

Farpoint Observatory was constructed near the towns of Harveyville and Eskridge, Kansas. Finished in Sept. 1997, this facility was a project of the Northeast Kansas Amateur Astronomers League, Inc. NEKAAL members worked very hard over years to make Farpoint a first-class amateur-run observatory. (M 43194)

\section{(23990) Springsteen}

$1999 \mathrm{RM}_{1}$. Discovered 1999 Sept. 4 by I. P. Griffin at Auckland.

Bruce Springsteen (1949- ) is a singer and songwriter whose music has provided a social commentary upon late-twentieth-century America. On the night this minor planet was discovered, his music entertained the observers. (M 43048)

\section{(24046) Malovany}

$1999 \mathrm{TX}_{3}$. Discovered 1999 Oct. 2 by L. Šarounová at Ondřejov.

Joseph Malovany (1941- ), the Cantor of New York's Fifth Avenue Synagogue, and professor of Liturgical Music at Yeshiva University, holds many high artistic diplomas and awards. An outstanding tenor soloist, he performs in oratorios and symphonic pieces all over the world. (M 43383)

\section{(24048) Pedroduque}

1999 TL $_{11}$. Discovered 1999 Oct. 10 by J. Nomen at Ametlla de Mar.

In 1998 Spanish astronaut Pedro Duque (1963- ) flew as a mission specialist on the Space Shuttle Discovery STS-95 mission. (M 44595)

\section{(24101) Cassini}

1999 VA$_{9}$. Discovered 1999 Nov. 9 by C. W. Juels at Fountain Hills.

Giovanni Domenico (a.k.a. Jean Dominique) Cassini (1625-1712), an Italian-born French astronomer, was the first director of the Royal Observatory in Paris. He discovered four of the satellites of Saturn, the major gap in its rings, and was the first to record observations of the zodiacal light. (M 46684)

\section{(24102) Jacquescassini}

1999 VD $_{9}$. Discovered 1999 Nov. 9 by C. W. Juels at Fountain Hills.

Jacques Cassini (1677-1756), a.k.a. Cassini II, succeeded his father, G. D. Cassini (Cassini I) \{see planet (24101)\} as director of the Paris Observatory in 1712. He improved the geographic knowledge of France, studied the proper motion of stars and compiled the first tables of the orbital motions of Saturn's satellites. (M 46684)

\section{(24103) Dethury}

$1999 \mathrm{VS}_{9}$. Discovered 1999 Nov. 9 by C. W. Juels at Fountain Hills.

César-François Cassini (1714-1784), a.k.a. Cassini de Thury or Cassini III, succeeded his father, Jacques Cassini \{see planet (24102)\}, in 1740 as third director of the Paris Observatory. He was also a cartographer and was instrumental in producing the first modern map of France using the triangulation method. (M 46684)

\section{(24104) Vinissac}

$1999 \mathrm{VZ}_{9}$. Discovered 1999 Nov. 9 by C. W. Juels at Fountain Hills.

Jean-Dominique Cassini (1748-1845), a.k.a. Cassini IV, studied the behavior of chronometers at sea. He succeeded his father, Cassini de Thury ssee planet (24103)\}, as director of the Paris Observatory and with him published an account of the observatory's first 100 years. He also completed his father's map of France. (M 46684)

The name Cassin(IV) is spelled backwards in order to prevent a confusion with planet (24101). 


\section{(24162) Askaci}

1999 WD. Discovered 1999 Nov. 17 by L. Robinson at Olathe.

Askaci is an abbreviation for the Astronomical Society of Kansas City, an amateur astronomy club that supports amateur astronomical research and education in the Kansas City area. (M 44186)

\section{(24173) SLAS}

$1999 \mathrm{XS}_{1}$. Discovered 1999 Dec. 3 by J. M. Roe at Oaxaca.

SLAS, the St. Louis Astronomical Society, has promoted the wonder and science of astronomy since 1936 to the general populace of St. Louis, Missouri, and surrounding areas. (M 45235)

\section{(24260) Kriván̆}

1999 XW 127 . Discovered 1999 Dec. 13 by P. Kušnirák at Ondřejov.

At 2494 meters, Kriván̆ is the most beautiful Slovak peak and one of the national symbols of Slovakia. (M 43194)

\section{(24265) Banthonytwarog}

1999 XU $_{143}$. Discovered 1999 Dec. 13 by G. Hug and

G. Bell at Eskridge.

Barbara J. Anthony-Twarog is a professor of astronomy at Kansas University in Lawrence. While her astronomical credits and awards are numerous, she is best known locally for her outreach programs for amateur astronomers and the general public. (M 43194)

\section{(24305) Darrellparnell}

1999 YG $_{4}$. Discovered 1999 Dec. 26 by G. Hug and G. Bell at Eskridge.

Darrell Parnell taught astronomy at Washburn University of Topeka for nearly 40 years. During his tenure he inspired many astronomy students with his wit and talent for making hard concepts easy to understand. $\mathrm{He}$ is an exceptional educator and astronomer. (M 43194)

\section{(24308) Cowenco}

1999 YC $_{9}$. Discovered 1999 Dec. 29 by G. Hug and G. Bell at Eskridge.

Courtney, Wendy and Cody have the misfortune of being the offspring of an amateur astronomer. They have managed to adjust and mature despite the often neglected paternal oversight of a sleepy dad, the first discoverer of this object. (M 43194)

\section{(24450) Victorchang}

2000 QC $_{69}$. Discovered 2000 Aug. 29 by J. Broughton at Reedy Creek.

As a youth Victor Chang (1936-1991) emigrated from China to Sydney, where he later trained as a heart surgeon. There in the 1980s he set up the first transplant center in Australia. His skill and technical improvements achieved the world's highest rate of patient survival. (M 45341)

\section{(24643) MacCready}

1984 SS. Discovered 1984 Sept. 28 by C. S. Shoemaker and E. M. Shoemaker at Palomar.

Paul MacCready (1933- ) designed the first humanpowered aircraft, the Gossamer Condor, followed by the Gossamer Albatross, which was pedaled through the air to cross the English Channel in 1979. The Gossamer Penguin, the world's first solar airplane and the Solar Challenger were next. (M 46684)

\section{(24654) Fossett}

1987 KL. Discovered 1987 May 29 by C. S. Shoemaker and E. M. Shoemaker at Palomar.

On his sixth attempt, Steve Fossett (1944- ) became the first person to fly a balloon solo around the world. He took two weeks in his Spirit of Freedom to cover about $31268 \mathrm{~km}$ at southern latitudes. Fossett sails, flies airplanes, and has swum the English Channel, run the Iditarod dog sled race and car-raced successfully. (M 46684)

\section{(24662) Gryll}

1988 GS. Discovered 1988 Apr. 14 by A. Mrkos at Klet.

Matyáš Gryll of Gryllov (1551-1611), a professor at Prague University, took a particular interest in comets. In 1578 he published a survey of comets discovered until 1577, although he considered the comets to be miraculous signs from God. (M 46012)

The name was suggested by J. Tichá.

\section{(24666) Miesvanrohe}

1988 RZ $_{3}$. Discovered 1988 Sept. 8 by F. Börngen at Tautenburg.

Ludwig Mies van der Rohe (1886-1969), some time director of the Bauhaus in Dessau, emigrated in 1938 and worked for 20 years at the Illinois Institute of Technology in Chicago. $\mathrm{He}$ is one of the leading personalities forming the modern architectural style, thereby treading new revolutionary paths. (M 43194)

\section{(24671) Frankmartin}

$1989 \mathrm{AD}_{7}$. Discovered 1989 Jan. 10 by F. Börngen at Tautenburg.

Swiss composer Frank Martin (1890-1974) wrote operas and oratorios, as well as chamber, vocal and orchestral music. First influenced by the French late romanticism and impressionism, he turned later to the twelve-tone technique. His work received international exposure and appreciation. (M 43194)

\section{(24680) Alleven}

$1989 \mathrm{YE}_{4}$. Discovered 1989 Dec. 30 by R. H. McNaught at Siding Spring.

The number of this minor planet consists of the even digits in order. (M 43762)

The name was suggested by J. Meeus. 


\section{(24711) Chamisso}

$1991 \mathrm{PN}_{17}$. Discovered 1991 Aug. 6 by F. Börngen at Tautenburg.

German-French poet Adelbert von Chamisso (17811838), a member of the Prussian Academy of Sciences, paid particular attention to socio-critical connections. He was also a naturalist and a circumnavigator and is known as the author of a textbook on botany. (M 45749)

\section{(24712) Boltzmann}

$1991 \mathrm{RP}_{3}$. Discovered 1991 Sept. 12 by F. Börngen and L. D. Schmadel at Tautenburg.

Austrian physicist Ludwig Boltzmann (1844-1906) confirmed Maxwellian electrodynamics experimentally in 1872 and is one of the founders of the kinetic theory of gases. He explained thermodynamics in terms of statistical mechanics and black-body radiation. (M 43195)

The name was suggested by the first discoverer.

\section{(24748) Nernst}

1992 ST $_{13}$. Discovered 1992 Sept. 26 by F. Börngen and L. D. Schmadel at Tautenburg.

German Walther Hermann Nernst (1864-1941) is one of the founders of physical chemistry. He discovered the thermomagnetic and galvanomagnetic effects, developed a theory of electrical nerve stimulation and specified the third law of thermodynamics. He received the 1920 Nobel Prize for chemistry. (M 43195)

\section{(24750) Ohm}

1992 SR $_{17}$. Discovered 1992 Sept. 24 by F. Börngen and L. D. Schmadel at Tautenburg.

German physicist Georg Simon Ohm (1789-1854) discovered the fundamental law of electrical circuits in 1826 and also formulated the laws of current branchings. In 1843 he defined acoustic sound as a purely sinusoidal oscillation. (M 43195)

The name was suggested by the first discoverer.

\section{(24751) Kroemer}

$1992 \mathrm{SS}_{24}$. Discovered 1992 Sept. 21 by F. Börngen at Tautenburg.

German-born Herbert Kroemer (1928- ), who has lived in the United States since 1954, is one of the pioneers of semiconductor heterostructures, used in computers for the transmission of information. He shared the 2000 Nobel Prize for physics with Zh. Alferov and J. Kilby. (M 43195)

\section{(24837) Mšecké Žehrovice}

1995 UQ $_{1}$. Discovered 1995 Oct. 22 by M. Tichý at Klě́.

Mšecké Žehrovice is a central Bohemian village known for its remnants of an ancient Celtic sanctuary. A famous stone sculpture found there shows the head of a Celtic hero. This is the most important Celtic object found in Bohemia. (M 46012)

\section{(24838) Abilunon}

$1995 \mathrm{UJ}_{2}$. Discovered 1995 Oct. 23 by M. Tichý at Kleť.

Abilunon is the presumed name of an ancient Celtic town, founded in the first century B.C. on a strategic peninsula in the Vltava \{see planet (2123)\} river. The remains of the town are at the foot of Klet \{ see planet (2199)\} mountain. The name was mentioned on a map of the world by Ptolemy \{see planet (4001)\}. (M 43762)

\section{(24847) Polesný}

$1995 \mathrm{WE}_{6}$. Discovered 1995 Nov. 26 at the Klet Observatory at Klét.

Bohumil Polesný (1905-1976) served as the director of the České Budějovice \{see planet (11134)\} Observatory from 1955 to 1966. His main astronomical work involved the popularization of astronomy. He started the construction of the Klet Observatory in 1957. (M 43195)

\section{(24858) Diethelm}

$1996 \mathrm{BB}_{1}$. Discovered 1996 Jan. 21 by M. Wolf and P. Pravec at Ondř ejov.

Roger Diethelm (1948- ) is a Swiss observer of variable stars and editor of the variable-stars bulletin of the Schweizerische Astronomische Gesellschaft. He founded the R. Szafraniec Observatory in Metzerlen, where the first of the discoverers observed on several occasions. (M 45236)

\section{(24898) Alanholmes}

$1997 \mathrm{AR}_{17}$. Discovered 1997 Jan. 14 at the Farra d'Isonzo Observatory at Farra d'Isonzo.

Alan W. Holmes (1950- ) is an amateur astronomer in the $\gamma$-ray bursts field at the Santa Barbara Astronomical Group and optical engineer. He cofounded a small CCD \{see planet (15000)\} brand that in 1991 developed star tracking equipment, sparking the CCD revolution in the world of amateur astronomy. (M 46684)

\section{(24899) Dominiona}

1997 AU $_{17}$. Discovered 1997 Jan. 14 by G. C. L. Aikman at Victoria.

Canada is officially the "Dominion of Canada" under the Constitution Acts of 1867 and 1982. Such designation was inspired by Psalm 72 , verse 8 : "He shall have dominion also from sea to sea, and from the river unto the ends of the earth." (M 44110)

\section{(24907) Alfredhaar}

$1997 \mathrm{CO}_{4}$. Discovered 1997 Feb. 4 by P. G. Comba at Prescott.

Alfred Haar (1885-1933) was a Hungarian mathematician who worked on real and complex analysis and the calculus of variations. His fame rests mostly on the establishment of a measure on locally compact groups, now referred to as the Haar measure. (M 43195) 


\section{(24935) Godfreyhardy}

$1997 \mathrm{HP}_{2}$. Discovered 1997 Apr. 28 by P. G. Comba at Prescott.

Godfrey Harold Hardy (1877-1947) was the foremost English pure mathematician of his generation. He wrote hundreds of papers - many of them jointly with other outstanding mathematicians such as Littlewood and Ramanujan \{see planet 4130)\} - on Diophantine approximations, number theory, inequalities and summability of series. (M 43195)

\section{(24944) Harish-Chandra}

$1997 \mathrm{LZ}_{4}$. Discovered 1997 June 11 by P. G. Comba at Prescott.

Harish-Chandra (1923-1983) was born and educated in India but spent most of his academic career in the United States. He made profound contributions to the theory of infinite-dimensional representations of groups and their associated characters, as well as the differential equations they satisfy. (M 43195)

\section{(24947) Hausdorff}

$1997 \mathrm{NU}_{1}$. Discovered 1997 July 7 by P. G. Comba at Prescott.

Felix Hausdorff (1877-1942) taught at several German universities and did research in mathematical analysis and algebra. He wrote a fundamental treatise on set theory that expounded the connection between that theory and the then-nascent theories of metric spaces and general topology. (M 43195)

\section{(24948) Babote}

$1997 \mathrm{NU}_{6}$. Discovered 1997 July 9 at the Pises Observatory at Draveil.

The Babote tower, the former astronomical observatory at Montpellier, is now the meeting place of the members of the Montpellier astronomical society. (M 45236)

\section{(24950) Nikhilas}

1997 QF. Discovered 1997 Aug. 23 by Z. Moravec at Kleť.

Nikhilas Jonathan Marsden (1995- ) is the first grandson of Minor Planet Center director Brian G. Marsden \{see planet (1877)\}. This minor planet was discovered on his second birthday. (M 43195)

\section{(24962) Kenjitoba}

1997 UX $_{8}$. Discovered 1997 Oct. 27 by A. Nakamura at Kuma.

Kenji Toba (1950- ) is a staff member at the Ibaraki Prefectural Office and amateur astronomer in Japan. He started his visual search for comets in 1968, and after sweeping for 123 hours he found C/1971 E1. He has served as the director of the BiStar Observatory since its foundation. (M 46112)

\section{(24981) Shigekimurakami}

$1998 \mathrm{~KB}_{5}$. Discovered 1998 May 22 by A. Nakamura at Kuma.
Shigeki Murakami (1962- ), born in Shiga Prefecture, is a senior researcher at the Forestry and Forest Products Research Institute and amateur astronomer in Japan. Using a homemade 0.46-m Dobsonian telescope, he codiscovered C/2002 E2. (M 46112)

\section{(24998) Hermite}

1998 OQ $_{4}$. Discovered 1998 July 28 by P. G. Comba at Prescott.

Charles Hermite (1822-1901) was a very versatile French analyst and algebraist. He solved the quintic equations by means of elliptic functions, discovered a class of orthogonal polynomials that bear his name and proved the transcendence of $e$, the base of the natural logarithms. (M 43195)

\section{(24999) Hieronymus}

$1998 \mathrm{OY}_{4}$. Discovered 1998 July 24 by P. Pravec at Ondřejov.

Jerome van Aeken (Hieronymus Bosch, c. 1450-1516), was a Dutch painter of the late Middle Ages who showed the depths of the human mind. In works such as The Temptation of St. Anthony he used symbols to depict vulnerability to the temptation of evil and the obsessive attraction of lust, heresy and obscenity. (M 43195)

\section{(25000) Astrometria}

1998 OW $_{5}$. Discovered 1998 July 28 by P. G. Comba at Prescott.

Utilized in star cataloguing that brought the discovery of (1) Ceres, then for two centuries by means of micrometry and photography, astrometry with CCD cameras began flourishing vigorously in the 1990s, through all-sky surveys and in the hands of dedicated amateurs, now doubling minor-planet numberings in less than two years. (M 43195)

\section{(25029) Ludwighesse}

1998 QO $_{28}$. Discovered 1998 Aug. 26 by P. G. Comba at Prescott.

Ludwig Otto Hesse (1811-1874) was a German mathematician. Much of his work dealt with the study of cubic and higher-order curves, their inflections and intersections, as well as the algebraic transformations and invariants associated with them. (M 43195)

\section{(25058) Shanegould}

1998 QO $_{63}$. Discovered 1998 Aug. 25 by J. Broughton at Reedy Creek.

The Australian swimmer Shane Gould (1956- ) won three gold medals plus a silver and bronze at the 1972 Munich Olympics. She has the distinction of being the only swimmer, male or female, to have held world records at all five freestyle distances at the same time. (M 45341)

\section{(25082) Williamhodge}

1998 RP $_{1}$. Discovered 1998 Sept. 15 by P. G. Comba at Prescott. 
William Vallance Douglas Hodge (1903-1975) studied at Edinburgh and Cambridge and in 1936 was elected to the Lowndean chair of astronomy and geometry at Cambridge. His mathematical work was in algebraic geometry, specifically the theory of harmonic integrals and their applications to analysis. (M 43195)

\section{(25142) Hopf}

$1998 \mathrm{SA}_{28}$. Discovered 1998 Sept. 26 by P. G. Comba at Prescott.

Heinz Hopf (1894-1971), of German origin, was a professor of mathematics at the Swiss Institute of Technology in Zurich. His main contributions were in algebraic topology and global differential geometry. (M 43195)

\section{(25237) Hurwitz}

$1998 \mathrm{UG}_{7}$. Discovered 1998 Oct. 20 by P. G. Comba at Prescott.

Adolf Hurwitz (1859-1919), a student of Klein and teacher of Hilbert and Minkowski \{see, respectively, planets (12045), (12022) and (12493)\}, was associated for many years with the Swiss Institute of Technology. $\mathrm{He}$ did research on automorphic functions, Bessel functions, Fourier series and algebraic number theory. (M 43195)

\section{(25258) Nathaniel}

1998 VU. Discovered 1998 Nov. 7 by M. Tichý and J. Tichá at Klé̌.

Nathaniel Brian Marsden (1997- ) is the second grandson of Minor Planet Center director Brian G. Marsden \{see planet (1877)\}. This minor planet was discovered on his first birthday. (M 43196)

\section{(25273) Barrycarole}

1998 VN $_{32}$. Discovered 1998 Nov. 15 by I. P. Griffin at Cocoa.

Barry Paul Keith Griffin (1943- ) and Carole Anne Griffin (1944- ) are the parents of the discoverer. (M 43196)

\section{(25276) Dimai}

$1998 \mathrm{VJ}_{33}$. Discovered 1998 Nov. 15 by V. Goretti at Pianoro.

Alessandro Dimai (1962- ) is an amateur astronomer and friend of the discoverer. For over twenty years Dimai has been an active member of the team of the alpine Col Drusci Observatory at Cortina d'Ampezzo. With indefatigable enthusiasm he successfully devoted himself to the discovery of supernovae. (M 45341)

\section{(25384) Partizánske}

1999 UW $_{1}$. Discovered 1999 Oct. 18 by P. Kušnirák at Ondřejov

Partizánske, a town in western Slovakia at the confluence of Nitra ssee planet (9543)\} and Nitrica rivers, was known as the village of Symoni from 1260 and as the town of Batovany since 1938, when Ján Baťa built a shoe factory there. Since 1949 it has been called Partizánske. A public observatory was opened there in 1988. (M 43196)

\section{(25399) Vonnegut}

1999 VN $_{20}$. Discovered 1999 Nov. 11 by C. W. Juels at Fountain Hills.

Kurt Vonnegut (1922- ) is a revolutionary U.S. science-fiction writer who crossed over into mainstream literature and is often referred to as the "Mark Twain \{see planet (2362)\} of the second half of the twentieth century". He is most famous for his novel Slaughterhouse 5. (M 46112)

\section{(25472) Joanoro}

1999 XL $_{36}$. Discovered 1999 Dec. 6 by J. Nomen at Ametlla de Mar.

Joan Oro (1923- ), born in Lleida, Catalonia, has dedicated his whole professional life to the study of the origin of life. He has spread word of science in general, and of astronomy in particular, between Catalonia and his current home in Houston, Texas. (M 43383)

\section{(25593) Camillejordan}

1999 YA $_{5}$. Discovered 1999 Dec. 28 by P. G. Comba at Prescott.

Camille Jordan (1838-1921) was a French mathematician and the first to produce a purely analytical proof of the theorem that now bears his name: a simple non-self-intersecting closed curve in the plane divides the plane into two separate regions. (M 44595)

\section{(25594) Kessler}

1999 YA. Discovered 1999 Dec. 29 by G. Hug and G. Bell at Eskridge.

Marvin Kessler (1918- ) has been a member of the Northeast Kansas Amateur Astronomer's League for over twenty years. He has been quietly but enthusiastically showing the wonders of the night sky to anyone interested from preschool age children to senior adults. His zeal and patience in this endeavor have been exemplary. (M 45341)

\section{(25602) Ucaronia}

$2000 \mathrm{AA}_{3}$. Discovered 2000 Jan. 2 by A. Boattini and A. Caronia at San Marcello Pistoiese.

Umberto Caronia (1908-1993) was the father of the second discoverer. (M 45341)

\section{(25604) Karlin}

$2000 \mathrm{AM}_{6}$. Discovered 2000 Jan. 4 by P. G. Comba at Prescott.

Samuel Karlin (1924- ） spent most of his academic career at Stanford University. He has been a prolific reseacher in statistics and mathematical analysis and its applications, notably genetics. He is a member of the National Academy of Sciences and a recipient of the National Medal of Science. (M 45236)

\section{(25624) Kronecker}

$2000 \mathrm{AK}_{48}$. Discovered 2000 Jan. 6 by P. G. Comba at Prescott. 
Leopold Kronecker (1823-1891) was a German mathematician who published widely in a variety of fields. His researches in algebra and his program to "arithmetize" algebra and analysis had a considerable influence on early twentieth-century mathematics. (M 43762)

\section{(25625) Verdenet}

$2000 \mathrm{AN}_{48}$. Discovered 2000 Jan. 5 by J.-C. Merlin at Le Creusot.

Michel Verdenet (1944- ), a schoolteacher in Bourbon Lancy, France, has observed variable stars and comets for nearly 40 years and is currently president of the Association Française des Observateurs d'Etoiles Variables. He has inspired several generations of amateurs, including the discoverer of this minor planet. (M 43196)

\section{(25628) Kummer}

$2000 \mathrm{AZ}_{50}$. Discovered 2000 Jan. 7 by P. G. Comba at Prescott.

Ernst Eduard Kummer (1811-1893) was a professor at the Universities of Breslau and Berlin. He spent many years working on Fermat's \{see planet (12007)\} last theorem and obtained a partial proof of it. In the process he developed some important concepts in algebra. (M 44111)

\section{(25778) Csere}

$2000 \mathrm{CQ}_{34}$. Discovered 2000 Feb. 4 by P. Kušnirák at Ondřejov.

Elemír Csere (1917-1992) was a keen proponent of colaboration in amateur astronomy, founder of the public observatory in Hlohovec and its first director. He was a key person in amateur astronomy in Slovakia and an active member of the Slovak Astronomical Society and the Slovak Association of Amateur Astronomers. (M 45341)

\section{(25864) Banič}

2000 GR $_{82}$. Discovered 2000 Apr. 8 by P. Kušnirák at Ondřejov.

Štefan Banič (1870-1941) invented the parachute. In 1913 he constructed a prototype of a parachute and tested it in Washington, D.C., by jumping from a 41-floor building. In 1914 he jumped from an airplane. (M 45341)

\section{(25890) Louisburg}

$2000 \mathrm{VG}_{38}$. Discovered 2000 Nov. 3 by L. Robinson at Olathe.

Louisburg, Kansas, is the home of Powell Observatory, a public observatory owned and managed by the Astronomical Society of Kansas City. (M 44111)

\section{(25893) Sugihara}

$2000 \mathrm{WR}_{9}$. Discovered 2000 Nov. 19 by W. K. Y. Yeung at Arizona City.

Chiune Sugihara (1900-1986) was a Japanese consulgeneral stationed in Kaunas, Lithuania, during World War II. Putting his career and financial security at risk, in Aug. 1940 he defied his government's order and issued transit visas that allowed 6000 Jews to seek safety in Japan and the former Soviet Union. (M 43762)

\section{(25930) Spielberg}

2001 DJ $_{54}$. Discovered 2001 Feb. 21 by W. K. Y. Yeung at Arizona City.

Steven Spielberg (1946- ), regarded by many as one of the best movie directors in recent history, is a five-time winner of the Academy Best Director Award with Close Encounters of the Third Kind (1978), Raiders of the Lost Ark (1982), E.T., the Extra-Terrestrial (1983), Schindler's List (1994) and Saving Private Ryan (1999). (M 43763)

\section{(26119) Duden}

$1991 \mathrm{TN}_{7}$. Discovered 1991 Oct. 7 by F. Börngen at Tautenburg.

Philologist Konrad Duden (1829-1911), for a time a schoolmaster in Thuringia \{see planet (934)\}, was renowned for his trailblazing Orthographisches Wörterbuch der deutschen Sprache (1880). The "Duden", which has since gone through more than 20 revised editions, is the basis for uniform orthography in the German-speaking world. (M 44111)

\section{(26168) Kanaikiyotaka}

$1995 \mathrm{WT}_{8}$. Discovered 1995 Nov. 24 by T. Niijima at Ojima.

Kiyotaka Kanai (1951- ), a Japanese amateur astronomer, is a key member of the group Ota Uchuno Kai. A devoted observer of small bodies, he independently discovered C/1970 B1 and co-discovered (7752) Otauchunokai. Recently, he has become well known as a variable star observer. (M 46684)

\section{(26169) Ishikawakiyoshi}

1995 YY. Discovered 1995 Dec. 21 by T. Kobayashi at Oizumi.

Akiyoshi Ishikawa (1955- ), a Japanese amateur astronomer, is a key member of the group Ota Uchuno Kai. A devoted comet observer, he has had more than 1100 visual magnitude estimates published in the International Comet Quarterly since 1980. (M 46684) The name was suggested by A. Nakamura.

\section{(26195) Černohlávek}

1997 EN. Discovered 1997 Mar. 1 by P. Pravec at Ondřejov.

Ivo Cernohlávek (1960-1995) pioneered the Internet in the Czech Republic, cofounded the Czech academic network and helped to establish Brno as a center in information technology. A sportsman awarded the Fair Play prize for the rescue of a colleague on wild water, he died on a river in Norway. (M 43383)

\section{(26197) Bormio}

$1997 \mathrm{FN}_{1}$. Discovered 1997 Mar. 31 by F. Manca and P. Sicoli at Sormano. 
Bormio is a very ancient and pleasant village in the Rhaetian Alps, $200 \mathrm{~km}$ from Milan. It hosts a biennial meeting on planetary sciences, and the name was suggested by A. Manara on the occasion of the fourth meeting in the series. (M 45341)

\section{(26205) Kuratowski}

1997 LA $_{5}$. Discovered 1997 June 11 by P. G. Comba at Prescott.

Kazimierz Kuratowski (1896-1980) was a Polish mathematician who made important contributions to topology. Active in mathematical education and editorial work, he was also a foreign member of many academies, from the Royal Society of Edinburgh to the Accademia Nazionale dei Lincei. (M 45236)

\section{(26210) Lingas}

$1997 \mathrm{RC}_{3}$. Discovered 1997 Sept. 6 at the Pises Observatory at Draveil.

The Lingas plateau is located in the Cevennes National Park and is the site of the Pises \{see planet (18623)\} Observatory. (M 45236)

\section{(26214) Kalinga}

1997 US $_{10}$. Discovered 1997 Oct. 30 by P. Pravec at Ondřejov.

Bearing the old name of the Indian state of Orissa, UNESCO's Kalinga Prize has been awarded annually since 1952 to persons who contributed to the interpretation of the role of science in service to human society. The prize is sponsored by the Kalinga Foundation, established in 1951 by Indian philanthropist Biju Patnaik. (M 43383)

\section{(26276) Natrees}

$1998 \mathrm{SL}_{4}$. Discovered 1998 Sept. 20 by P. G. Comba at Prescott.

Nathaniel Paul Rees (1999- ) is a grandson of the discoverer. (M 45236)

\section{(26277) Ianrees}

$1998 \mathrm{SM}_{4}$. Discovered 1998 Sept. 20 by P. G. Comba at Prescott.

Ian Hudson Rees (2000- ) is a grandson of the discoverer. (M 45236)

\section{(26314) Škvorecký}

1998 UJ J $_{1}$. Discovered 1998 Oct. 16 by J. Tichá and M. Tichý at Klě́.

Josef Skvorecký (1924- ) is one of the preeminent Czech writers of the post-World War II generation known for mordant humor and sardonic irony. Together with his wife Zdena Salivarová, he operated The SixtyEight Publishers in Toronto, the main Czech exile publishing house. (M 43383)

\section{(26357) Laguerre}

1998 YK $_{10}$. Discovered 1998 Dec. 27 by P. G. Comba at Prescott.

French mathematician Edmond Nicolas Laguerre (1834-1886) published extensively in geometry and mathematical analysis. The class of polynomials that now bears his name has found application in many fields of mathematical physics, including the solution of Schrödinger's \{see planet (13092)\} equation. (M 43763)

\section{(26376) Roborosa}

$1999 \mathrm{~EB}_{3}$. Discovered 1999 Mar. 11 by P. Pravec at Ondřejov.

Róbert "Robo" Rosa (1964-1994) was a Slovak amateur astronomer and computer graphic designer who participated in the development of the graphic layout of the Slovak bimonthly journal Kozmos. He died in an accident at Fačkovské sedlo during the eleventh astronomy bike tour "Ebicykl". (M 45236)

\section{(26390) Rušin}

1999 UX $_{2}$. Discovered 1999 Oct. 19 by P. Kušnirák at Ondřejov.

Vojtech Rušin (1942- ), solar physicist of the Astronomical Institute, Slovak Academy of Sciences, is well known for his contribution to dynamics of prominences and corona. He was one of the first observers at the Lomnický Peak coronal station and greatly engaged in its further development. (M 45236)

\section{(26401) Sobotište}

1999 WX. Discovered 1999 Nov. 19 by P. Kušnirák at Ondřejov.

Sobotište is a village in southwestern Slovakia with a rich history. The first written reference is from 1251 . In 1845 a credit cooperative, the first in continental Europe, arose there. The local astronomical observatory, founded in 1972, participates in the observation of meteors and occultations. (M 43384)

\section{(26498) Dinotina}

$2000 \mathrm{CV}_{1}$. Discovered 2000 Feb. 4 by A. Boattini and L. Tesi at San Marcello Pistoiese.

Dino and Tina Grifoni, who have been living in Sydney, Australia, for many years, are uncle and aunt of the first discoverer. (M 45341)

\section{(26629) Zahller}

$2000 \mathrm{GZ}_{132}$. Discovered 2000 Apr. 12 by C. B. Luginbuhl at Flagstaff.

This minor planet honors the discoverer's mother, Cordelia Zahller Luginbuhl (1927-2001), and the Zahller family. This family was established in the U.S. in 1791 by her great-great grandfather Joseph Zahller (1758- ) when he emigrated from Canton Bern, Switzerland, to settle in Butler County, Pennsylvania. (M 47169)

\section{(26639) Murgaš}

$2000 \mathrm{JB}_{7}$. Discovered 2000 May 5 by P. Kušnirák at Ondřejov.

Jozef Murgaš (1864-1929), an inventor and pioneer in the field of radiotelegraphy, was the first anywhere in the world to broadcast the spoken word. In 1904 he was granted two patents from the U.S. Patent Office 
for his "Tonsystem". Altogether he registered twelve patents, all concerning radiotelegraphy. (M 45342)

\section{(26640) Bahýl}

$2000 \mathrm{JV}_{10}$. Discovered 2000 May 9 by P. Kušnirák at Ondřejov.

Ján Bahýl (1856-1916) invented and constructed many technical devices, such as a petrol motor-driven helicopter. In 1905 he improved its construction and himself flew for $1.5 \mathrm{~km}$ in Bratislava at a height of 4 meters. This attempt was recorded by the International Aeronautic Organization. (M 45342)

\section{(26661) Kempelen}

$2000 \mathrm{WY}_{67}$. Discovered 2000 Nov. 27 by P. Kušnirák at Ondřejov.

Wolfgang Kempelen (1734-1804), a polymath, mechanic and inventor, constructed a speech machine in 1778 based on imitating the human vocal organs. His most famous inventions are a chess machine, a writing machine for the blind and a pressurised conduit that took water from the Danube to Bratislava Castle. (M 45342)

\section{(26715) South Dakota}

2001 HJ. Discovered 2001 Apr. 16 by R. Dyvig at Quinn.

South Dakota, in which the Badlands Observatory is situated, became the fortieth U.S. state when the Dakota Territory was split in 1889. Possessing a rich western heritage, the state is also well known for agriculture, tourism, sunshine and dark skies. Pierre, its capital, is on the banks of the Missouri River. (M 45236)

\section{(26733) Nanavisitor}

$2001 \mathrm{HC}_{16}$. Discovered 2001 Apr. 22 by W. K. Y. Yeung at Arizona City.

Nana Visitor (1957- ) is a talented actress who started her career on the stage, but most of her work appeared on television. She is most famous for playing the role of Major Kira Nerys in the Star Trek series Deep Space Nine. (M 44111)

\section{(26734) Terryfarrell}

$2001 \mathrm{HG}_{16}$. Discovered 2001 Apr. 23 by W. K. Y. Yeung at Arizona City.

Terry Farrell (1963- ), an Elite teen model who turned to acting and appeared in a score of movies, is most famous for playing the role of Jadzia Dax in the popular TV series Deep Space Nine. (M 45236)

\section{(26757) Bastei}

$2001 \mathrm{KU}_{17}$. Discovered 2001 May 20 by the Volkssternwarte Drebach at Drebach.

The Bastei is a rock in the middle of the Elbsandsteingebirge, a mountaineous area of eastern Germany known as "Saxon Switzerland". The Bastei rises 193 meters above the winding Elbe river and provides a splendid panoramic view of the surrounding landsape. It has been a well-known natural monument for 200 years. (M 46112)

\section{(26821) Baehr}

$1988 \mathrm{FM}_{1}$. Discovered 1988 Mar. 17 by F. Börngen at Tautenburg.

George Baehr (1666-1738) was a famous architect of the Baroque period. His masterpiece, the Frauenkirche in Dresden \{see planet (3053)\} (1726-1734), is a centrally planned monumental Protestant church provided with a massive stone dome. This city landmark was destroyed in 1945 and is now being rebuilt. (M 45749)

\section{(26896) Josefhudec}

1995 OY. Discovered 1995 July 29 by P. Pravec at Ondřejov.

Josef Hudec (1895-1972) was a Czech amateur astronomer. He made visual observations and drawings of the solar photosphere and was a keen popularizer of astronomy. He built a public observatory in the town of Kroměrížz during the last three years of his life. (M 45342)

The name was suggested by J. Koukal.

\section{(26908) Lebesgue}

1996 GK. Discovered 1996 Apr. 11 by P. G. Comba at Prescott.

Henri-Léon Lebesgue (1875-1941), professor at the Collège de France, is considered one of the greatest mathematicians of his generation. His generalization of the Riemann \{see planet (4167)\} integral revolutionized the field of integration and has played a fundamental role in modern analysis. (M 43763)

\section{(26909) Lefschetz}

$1996 \mathrm{HY}_{1}$. Discovered 1996 Apr. 24 by P. G. Comba at Prescott.

Solomon Lefschetz (1884-1972), professor at Princeton University, made important contributions in algebraic geometry and algebraic topology. As a result of war work he became an expert on non-linear differential equations and control theory and made Princeton s see planet (508)\} a leading center in those disciplines. (M 44111)

\section{(26917) Pianoro}

$1996 \mathrm{RF}_{4}$. Discovered 1996 Sept. 15 by V. Goretti at Pianoro.

Pianoro, site of the observatory at which this minor planet was discovered, is a modern and pleasant little town at the foot of the Tuscan-Emilian Apennines near Bologna. (M 45342)

\section{(26921) Jensallit}

$1996 \mathrm{TF}_{15}$. Discovered 1996 Oct. 15 by G. Sallit at Southend Bradfield.

Jennifer Sallit is the wife of the discoverer. (M 45750)

\section{(26950) Legendre}

$1997 \mathrm{JH}_{10}$. Discovered 1997 May 11 by P. G. Comba at Prescott. 
Adrien-Marie Legendre (1752-1833) was a French mathematician who published important treatises on elliptic integrals, for which he provided a classification, and on number theory, where he first stated the law of quadratic reciprocity and gave a formula for the distribution of prime numbers. (M 43763)

\section{(26955) Lie}

$1997 \mathrm{MR}_{1}$. Discovered 1997 June 30 by P. G. Comba at Prescott.

Marius Sophus Lie (1842-1899) was a Norwegian mathematician who formulated the theory of finite continuous groups of transformations, now called Lie groups. This theory and its generalizations have had a major impact on the development of twentieth-century algebra, as well as in celestial mechanics. (M 43763)

\section{(26960) Liouville}

$1997 \mathrm{NE}_{3}$. Discovered 1997 July 8 by P. G. Comba at Prescott.

Joseph Liouville (1809-1882) was a French analyst and geometer and the first to prove the existence of transcendental numbers. Author of more than 400 papers, he was the founder and, for 39 years, the editor of the Journal de mathématiques pures et appliquées. (M 43763)

\section{(26963) Palorapavý}

$1997 \mathrm{PM}_{4}$. Discovered 1997 Aug. 13 by P. Pravec at Ondřejov.

Pavol "Palo" Rapavý (1955- ), director of the public observatory in Rimavská Sobota since 1981, is the main coordinator of visual meteor observations in Slovakia. As an indefatigable observer of the sun, meteors and stellar occultations, he is the life and soul of amateur astronomy in Slovakia. (M 44595)

\section{(26993) Littlewood}

1997 XC $_{1}$. Discovered 1997 Dec. 3 by P. G. Comba at Prescott.

John Edensor Littlewood (1885-1977) was an English mathematician mainly associated with Trinity College, Cambridge. Most of his work in analysis was done in collaboration with G. H. Hardy and extended over Diophantine approximations, number theory, the Riemann zeta function, inequalities and Fourier series. (M 44595)

\section{(27056) Ginoloria}

1998 SB $_{28}$. Discovered 1998 Sept. 26 by P. G. Comba at Prescott.

Gino Loria (1862-1954) was a professor of higher geometry at the University of Genoa. He wrote two treatises on plane and space curves, but his main interest was the history of mathematics from antiquity to his own time. He wrote biographies of Archimedes, Newton, \{see planets (3600) and (8000), respectively\} Cremona and Beltrami \{see planet (15620)\}. (M 44595)
(27079) Vsetín

1998 TO$_{6}$. Discovered 1998 Oct. 15 by P. Pravec at Ondřejov.

Vsetín is a town in the Valašsko (Wallachia) region of eastern Moravia. A public observatory founded there in 1950 concentrates on astronomical popularization and education, especially involving young people. (M 45342)

\section{(27088) Valmez}

$1998 \mathrm{UC}_{15}$. Discovered 1998 Oct. 22 by P. Pravec at Ondřejov.

Valmez is a colloquial abbreviation of the name of the Moravian town Valašské Meziřičí, a gateway to the Wallachia region and first mentioned as a settlement in 1297. A small private observatory founded there in 1929 was precursor to a major public observatory in 1955 that is well known for its architectural beauty. (M 45342)

\section{(27114) Lukasiewicz}

$1998 \mathrm{WG}_{2}$. Discovered 1998 Nov. 19 by P. G. Comba at Prescott.

Jan Lukasiewicz (1878-1956) was a Polish mathematician and logician and a professor at Warsaw and later at the Royal Irish Academy in Dublin. He is best known for inventing a parenthesis-free notation ("reverse Polish notation") for algebraic expressions that is widely used in computer language compilers. (M 44186)

\section{(27500) Mandelbrot}

$2000 \mathrm{GW}_{132}$. Discovered 2000 Apr. 12 by P. G. Comba at Prescott.

Benoit Mandelbrot (1924- ) is a French-American mathematician. He has studied geometric and physical structures, to which he gave the name fractals, that are self-similar at different scales. Fractal concepts have found application to many disciplines, from cardiology to the analysis of stock-market prices. (M 43763)

\section{(27502) Stephbecca}

2000 GR $_{137}$. Discovered 2000 Apr. 3 by L. H. Wasserman at Anderson Mesa.

Stephanie E. Wasserman (1977- ） and Rebecca N. Wasserman (1979- ) are the two daughters of the discoverer. (M 45236)

\section{(27514) Markov}

$2000 \mathrm{HM}_{3}$. Discovered 2000 Apr. 26 by P. G. Comba at Prescott.

Andrei Andreevich Markov (1856-1922), a professor at St. Petersburg University, introduced the study of "Markov processes" in probability theory. These are discrete-time systems where the state at a given instant depends only on the state at the immediately preceding instant, and not on other past history. (M 43763)

\section{(27525) Vartovka}

$2000 \mathrm{HZ}_{34}$. Discovered 2000 Apr. 29 by P. Pravec and P. Kušnirák at Ondřejov. 
Vartovka is a hill near the town of Banská Bystrica, Slovakia. A watchtower was built there in the sixteenth century to check possible aggression. In 1961 it was rebuilt as a public observatory. Its main activities are observations of interplanetary matter and the popularization of astronomy. (M 45342)

\section{(27710) Henseling}

1988 RY $_{1}$. Discovered 1988 Sept. 7 by F. Börngen at Tautenburg.

German teacher and author Robert Henseling (18831964) wrote numerous popular astronomical books and helped many to understand the wonders of the cosmos. He founded the Volkssternwarte in Stuttgart and, in 1921, the journal Die Sterne. One of his lasting cultural historical effects is his analysis of astrology. (M 44595)

\section{(27712) Coudray}

1988 VR $_{7}$. Discovered 1988 Nov. 3 by F. Börngen at Tautenburg.

Clemens Wenzeslaus Coudray (1775-1845), court architect in Fulda, was chief director of the building trade for the Weimar Grand Duchy. A friend of Goethe \{see planet (3047)\}, he was a prominent representative of the classicistic architectural style. He essentially designed the centers of the towns Weimar s see planet (3539) $\}$ and Bad Berka. (M 45342)

\section{(27748) Vivianhoette}

1991 AL. Discovered 1991 Jan. 9 by S. Izumikawa and O. Muramatsu at Yatsugatake.

Vivian Hoette, an educator at the Yerkes Observatory, holds astronomy workshops in the Midwestern U.S. She also contributes internationally by means of a live show between Yerkes and the Science Museum in Tokyo, where an afternoon audience in the latter can see the Yerkes night sky. (M 45342)

\section{(27758) Michelson}

$1991 \mathrm{RJ}_{4}$. Discovered 1991 Sept. 12 by F. Börngen and L. D. Schmadel at Tautenburg.

German-American physicist Albert Abraham Michelson (1852-1931), 1907 Nobel Physics Laureate, refuted the supposition of the ether and made an accurate determination of the speed of light. He also measured interferometrically the absolute diameters of several stars and resolved the structure of their spectral lines. (M 43763)

\section{(27764) von Flüe}

1991 RV $_{40}$. Discovered 1991 Sept. 10 by F. Börngen at Tautenburg.

Niklaus von Flüe (1417-1487), councillor, judge, mystic and father of ten children, saved Switzerland from decay several times by his political intervention. In 1467 he left his family and positions and became a hermit. (M 45342)

\section{(27791) Masaru}

1993 DD $_{1}$. Discovered 1993 Feb. 24 by Y. Kushida and O. Muramatsu at Yatsugatake.

Masaru Kubota (1959- ) is a broadcaster at a television station and a certified weather forecaster. He makes an effort to popularize science and astronomy through his weather reports. (M 46012)

\section{(27846) Honegger}

$1994 \mathrm{TT}_{16}$. Discovered 1994 Oct. 5 by F. Börngen at Tautenburg.

Swiss-French composer Arthur Honegger (1892-1955) was an uncommonly versatile and highly esteemed musician, He was renowned for his vocal stage play Roi David, his orchestral work Pacific 231 and his dramatic oratorio Jeanne d'Arc. (M 45342)

\section{(27864) Antongraff}

1995 EA $_{9}$. Discovered 1995 Mar. 5 by F. Börngen at Tautenburg.

Swiss Anton Graff (1736-1813), born in Winterthur, was a leading eighteenth-century portrait painter, teaching since 1766 at the Dresden Academy of Arts. He recorded many of the most famous of his contemporaries (Gellert, Lessing \{see planet (7425)\}, Herder \{see planet (8158)\}, Wieland \{see planet (8108)\} and Schiller \{see planet (3079)\}) and frequently also himself. (M 45342)

\section{(27915) Nancywright}

1996 UU $_{1}$. Discovered 1996 Oct. 30 by P. G. Comba at Prescott.

Nancy Wright of Prescott, Arizona, is a very dear and loyal friend of the discoverer and his late wife. Wright is interested in the history and culture of the American West, in particular the Native American lore of the constellations. (M 45342)

\section{(27922) Mascheroni}

$1996 \mathrm{XW}_{8}$. Discovered 1996 Dec. 8 by P. G. Comba at Prescott.

Lorenzo Mascheroni (1750-1800), professor at the University of Pavia and author of a treatise on statics, proved that all plane construction problems that can be solved with ruler and compass can also be solved with compass alone. (M 45342)

\section{(27947) Emilemathieu}

$1997 \mathrm{NH}_{3}$. Discovered 1997 July 9 by P. G. Comba at Prescott.

Emile Léonard Mathieu (1835-1890) was an applied mathematician who worked on potential theory, elasticity, capillarity and celestial mechanics. He introduced the "Mathieu functions", which are solutions of the two-dimensional wave equation for the motion of an elliptic membrane. (M 44595)

\section{(27952) Atapuerca}

$1997 \mathrm{PR}_{4}$. Discovered 1997 Aug. 11 by A. Lopez and R. Pacheco at Mallorca. 
Atapuerca is a small mountain chain in the Spanish province of Burgos. Important human fossil deposits have been discovered there, among the most ancient found in Europe. (M 47169)

\section{(27975) Mazurkiewicz}

1997 UJ $_{1}$. Discovered 1997 Oct. 23 by P. G. Comba at Prescott.

Stefan Mazurkiewicz (1888-1945) was a professor at the University of Warsaw and a founder of the contemporary Polish mathematics school. He worked mainly in probability theory and topology, where he solved some important problems that clarified the topological structure of the Euclidian plane. (M 45342)

\section{(27984) Herminefranz}

1997 VN. Discovered 1997 Nov. 1 at the Starkenburg Observatory at Heppenheim.

Hermine (1954- ) and Franz Stoss (1950- ) are the parents of Reiner Michael Stoss \{see planet (7689)\}, discoverer of this minor planet. They have strongly supported their son's activities in minor planet work at the Starkenburg Observatory, Heppenheim \{see, respectively, planets (6864) and (14080)\}. The family emigrated from the Banat \{see planet (21663)\} region to Germany in 1987. (M 47169)

\section{(27988) Menabrea}

$1997 \mathrm{VA}_{4}$. Discovered 1997 Nov. 7 by P. G. Comba at Prescott.

Luigi Federico Menabrea (1809-1896), Piedmontese mathematician and statesman, is best remembered for an article he wrote based on a lecture given in Turin by Charles Babbage \{see planet (11341)\}. Amplified by Ada Lovelace, this lecture was one of the earliest and clearest conceptualizations of a general-purpose computing engine. (M 45342)

\section{(28004) Terakawa}

1997 XA. Discovered 1997 Dec. 2 by M. Akiyama at Mishima.

Expert mirror polisher Syoji Terakawa (1951- ) has had an interest in telescope making and astronomy since he was 14 years old. (M 45343)

\section{(28019) Warchal}

1998 AW $_{8}$. Discovered 1998 Jan. 14 by L. Šarounová at Ondřejov.

Bohdan Warchal (1930-2000) was an outstanding violinist, conductor and teacher. A member of the Slovak Philharmonic Orchestra, he was from 1960 chief conductor and solo violinist of the Slovak Chamber Orchestra, which became widely renowned throughout Europe. (M 46012)

\section{(28196) Szeged}

1998 XY $_{12}$. Discovered 1998 Dec. 15 by K. Sárneczky and L. Kiss at Piszkéstetö.

Szeged, located in southern Hungary on the banks of Tisza river, was founded more than 750 years ago.
This minor planet was discovered as part of a project coordinated by the University of Szeged. (M 45236)

\section{(28220) York}

1998 YN $_{12}$. Discovered 1998 Dec. 28 by J. Tichá and M. Tichý at Klé̌.

York, the capital of northern England for more than 2000 years, is an impressive city with a surviving historical center. The most fascinating medieval building is the York Minster, a large cathedral with several fine stained-glass windows from medieval times. (M 46012)

\section{(28242) Mingantu}

$1999 \mathrm{AT}_{22}$. Discovered 1999 Jan. 6 at the Beijing Observatory at Xinglong.

Ming Antu (1692-1765?) was a Chinese astronomer and mathematician of the Qing Dynasty. During the decades of his service in the Imperial Observatory, he participated in compiling and editing three very important astronomical works. (M 45750)

\section{(28394) Mittag-Leffler}

1999 RY $_{36}$. Discovered 1999 Sept. 13 by P. G. Comba at Prescott.

Magnus Gustav Mittag-Leffler (1848-1927) was a professor in Helsinki and Stockholm. His main contributions were in complex analysis, where he proved an important theorem concerning the representation of one-valued functions. (M 44595)

\section{(28396) Eymann}

1999 RY $_{44}$. Discovered 1999 Sept. 13 by A. Klotz at Guitalens.

Raymond Eymann is a French amateur astronomer who built an astronomical observatory at Taissy. The discoverer, like many other people, learned experimental astronomy in his observatory. (M 45236)

\section{(28516) Möbius}

2000 DQ $_{3}$. Discovered 2000 Feb. 27 by P. G. Comba at Prescott.

August Ferdinand Möbius (1790-1868) was a professor of astronomy at Leipzig. He studied occultations of stars by the planets, but most of his work was in geometry, including the invention of the barycentric calculus. He is also remembered for his discovery of the Möbius strip, a one-sided surface. (M 44187)

\section{(28729) Moivre}

$2000 \mathrm{GF}_{123}$. Discovered 2000 Apr. 11 by P. G. Comba at Prescott.

Abraham de Moivre (1667-1754) was born in France but flourished in England. He wrote a major treatise on probability theory, where he gave an approximation to the binomial distribution and proved a trigonometric identity that played an important role in the early development of complex number theory. (M 44187) 


\section{(28766) Monge}

$2000 \mathrm{HP}_{14}$. Discovered 2000 Apr. 29 by P. G. Comba at Prescott.

While a student at the Ecole Royal du Génie, Gaspard Monge (1746-1818) solved a problem relating to the design of a fortress that became the germ of his later development of descriptive geometry, a technique for representing three-dimensional objects by their projections on several planes. (M 44595)

\section{(28878) Segner}

$2000 \mathrm{KL}_{41}$. Discovered 2000 May 26 by P. Kušnirák at Ondřjov.

In 1750 Slovak physicist and physician Ján Andrej Segner (1704-1777) constructed a simple-reaction waterwheel known as Segner's wheel, an invention significant for the development of early reaction water turbines. He was a member of many scientific societies and professor at universities of Jena, Göttingen and Halle. (M 45343)

\section{(28978) Ixion}

$2001 \mathrm{KX}_{76}$. Discovered 2001 May 22 by M. W. Buie at Cerro Tololo.

Ixion tried to win the love of Hera \{see planet (103)\}, but Zeus \{see planet (5731)\} thwarted this by creating the cloud Nephele \{see planet (431)\}, which resembled Hera and by whom Ixion fathered the Centaurs. For his crimes Ixion was bound to a wheel that turns forever in the underworld. (M 45236)

The name was suggested by E. K. Elliot.

\section{(29148) Palzer}

1988 JE. Discovered 1988 May 10 by W. Landgraf at La Silla.

Wolfgang Palzer, of the Astronomische Gesellschaft Urania in Wiesbaden, has observed occultations and undertaken observations and orbit computations of meteors. (M 45236)

\section{(29197) Gleim}

$1991 \mathrm{AQ}_{2}$. Discovered 1991 Jan. 15 by F. Börngen at Tautenburg.

Johann Wilhelm Ludwig Gleim (1719-1803) was secretary of the cathedral chapter at Halberstadt. He wrote odes in imitation of Horace ssee planet (4294)\} and Anacreon \{see planet (2339)\}, rhymed fables, romances and patriotic songs. His patronage of fledgling poets earned him the affectionate appellation of "Father Gleim". (M 45343)

\section{(29203) Schnitger}

1991 GS $_{10}$. Discovered 1991 Apr. 9 by F. Börngen at Tautenburg.

Arp Schnitger (1648-1719) was the most important organ builder in northern Europe during the Baroque period. The Schnitger style and sound served as a model for other organ builders, and his instruments in the Hanseatic cities between Hamburg and Groningen were the largest of the time. (M 45343)

\section{(29204) Ladegast}

1991 GB $_{11}$. Discovered 1991 Apr. 11 by F. Börngen at Tautenburg.

Friedrich Ladegast (1818-1905), a German organ builder of European repute, followed Romantic trends and worked in the town of Weissenfels from 1846. With four manuals and 81 stops, his 1855 organ in the Merseburg Cathedral was the largest in Germany, and it was used by Liszt $\{$ see planet (3910)\} in composing his prelude and fugue on B-A-C-H. (M 45750)

\section{(29208) Halorentz}

$1991 \mathrm{RT}_{2}$. Discovered 1991 Sept. 9 by F. Börngen and L. D. Schmadel at Tautenburg.

The Dutch physicist Hendrick Antoon Lorentz (1853-1928) formulated the classic electron theory and predicted the Zeeman \{see planet (29212)\} effect. He derived the Lorentz transformation, the Lorentz contraction, time dilation and the velocity dependence of the mass. He shared the 1902 Nobel Prize for physics with his student Zeeman. (M 46013)

\section{(29212) Zeeman}

$1991 \mathrm{RA}_{41}$. Discovered 1991 Sept. 10 by F. Börngen at Tautenburg.

Dutch physicist Pieter Zeeman (1865-1943) discovered the splitting of spectral lines in the magnetic field, allowing the analysis of the atomic fine structure. He also made a verification of special relativity. He shared the 1902 Nobel Prize for physics with his teacher Lorentz \{see planet (29208)\}. (M 45750)

\section{(29227) Wegener}

1992 DY $_{13}$. Discovered 1992 Feb. 29 by F. Börngen at Tautenburg.

German scientist Alfred Wegener (1880-1930) created the theory of continental drift, which explained even the climates of prehistoric times and was verified later by geotectonics. A participant in several polar expeditions, he perished on the Greenland ice sheet. (M 45750)

\section{(29246) Clausius}

1992 RV. Discovered 1992 Sept. 2 by F. Börngen and L. D. Schmadel at Tautenburg.

German physicist Rudolf Clausius (1822-1888) elaborated the kinetic theory of gases. $\mathrm{He}$ is one of the founders of the mechanical theory of heat. He formulated the second law of thermodynamics and introduced the term entropy. He is also one of the founders of statistical mechanics. (M 45750)

\section{(29329) Knobelsdorff}

$1994 \mathrm{TN}_{16}$. Discovered 1994 Oct. 5 by F. Börngen at Tautenburg.

Architect and painter Georg Wenzeslaus von Knobelsdorff (1699-1753), Frederick the Great's superintendent of the buildings in Prussia, is the main representative of the Frederician Rococo. Best known among his designs are the castle and Sanssouci palace in Potsdam, 
the opera house at Berlin and the Rheinsberg castle. (M 45343)

\section{(29346) Mariadina}

1995 DB $_{13}$. Discovered 1995 Feb. 25 by M. Tombelli at Cima Ekar.

Maria Dina Mannozzi (1927- ) has since 1950 been a midwife in Montelupo. (M 45343)

\section{(29348) Criswick}

1995 FD. Discovered 1995 Mar. 28 by D. D. Balam at Victoria.

John Criswick (1963- ) is a University of Victoria alumnus who, as a result of his passion for astronomy, has been an enthusiastic proponent for astronomy education in Canada. (M 45343)

\section{(29355) Siratakayama}

1995 QX $_{3}$. Discovered 1995 Aug. 28 by T. Okuni at Nanyou.

Siratakayama is a volcanic mountain, 993 meters high, in Yamagata prefecture. (M 46013)

\section{(29391) Knight}

1996 MB. Discovered 1996 June 17 at the George Observatory at Needville.

Kent Knight (1920-1994) was a founding member and past president of the Fort Bend Astronomy Club in Texas. He inspired the FBAC with his dedication to public outreach. He generously gave of his time, talent and treasure to the George Observatory and Challenger Center. (M 44595)

\section{(29435) Mordell}

1997 JB$_{8}$. Discovered 1997 May 8 by P. G. Comba at Prescott.

Louis Joel Mordell (1888-1972) was born in the U.S. but moved to England as a student and spent the rest of his life there, being associated with the University of Manchester and later with Cambridge. His research ranged widely in number theory and algebraic geometry. (M 45343)

\section{(29437) Marchais}

$1997 \mathrm{LG}_{1}$. Discovered 1997 June 7 by A. Klotz at Castres.

French amateur astronomer Denis Marchais (1976-

) spent a large part of his time writing the free astronomical software named AudeLA that drives telescopes and CCD cameras. (M 45343)

\section{(29447) Jerzyneyman}

$1997 \mathrm{PY}_{2}$. Discovered 1997 Aug. 12 by P. G. Comba at Prescott.

Jerzy Neyman (1894-1981) was born in Poland and moved to the University of California at Berkeley in 1937. He was one of the founders of the modern theory of statistics. His work on hypothesis testing, confidence intervals and survey sampling has revolutionized both statistical theory and practice. (M 44595)
(29448) Pappos

1997 QJ. Discovered 1997 Aug. 23 by P. G. Comba at Prescott.

Pappos of Alexandria (fl. 300-350) wrote the Synagoge, a collection and commentary that covers practically the whole field of Greek geometry. (M 45343)

\section{(29457) Marcopolo}

$1997 \mathrm{SO}_{4}$. Discovered 1997 Sept. 25 by V. Goretti at Pianoro.

Marco Polo (1254-1324) was a Venetian explorer. He traveled overland to China and became an expert in the language and culture of the Far East. After 20 years he returned by sea and wrote Il Milione, the momentous account of his travels and discoveries, while in prison in Genoa. (M 45343)

\section{(29458) Pearson}

1997 SJ $_{11}$. Discovered 1997 Sept. 30 by P. G. Comba at Prescott.

Karl Pearson (1857-1936) was a professor of mathematics and mechanics at University College, London, and later the Galton professor of eugenics. A man of great erudition, he is one of the founders of the modern theory of statistics. (M 45343)

\section{(29463) Benjaminpeirce}

1997 TB. Discovered 1997 Oct. 2 by P. G. Comba at Prescott.

Benjamin Peirce (1809-1880) was a professor of mathematics and astronomy at Harvard University and author of Linear Associative Algebra. He is regarded as the leading American mathematician of his day. (M 44187)

\section{(29464) Leonmiš}

$1997 \mathrm{TY}_{9}$. Discovered 1997 Oct. 5 by P. Pravec at Ondřejov.

Leon Miš (1972- ), an astronomer at the Úpice observatory, contributed much to the organization of astronomical summer youth camps and weekend gatherings of observers of the beauties of the sky. He also contributed to the reconstruction of the observatory's dome and telescopes. (M 45343)

\section{(29471) Spejbl}

$1997 \mathrm{UT}_{7}$. Discovered 1997 Oct. 27 by L. Šarounová at Ondřejov.

The Czech marionette Spejbl represents the father of mischievous Hurvínek \{see planet (29472)\}. They demonstrate the different opinions of two generations in performances of The Theatre of Spejbl and Hurvínek in Prague. Spejbl has amused children as well as adults in 31 countries around the world since his first appearance in 1920. (M 46013)

\section{(29472) Hurvínek}

1997 UV $_{7}$. Discovered 1997 Oct. 27 by L. Šarounová at Ondřejov.

Hurvínek, the Czech marionette representing Spejbl's \{see planet (29471)\} mischievous son, has performed 
at The Theatre of Spejbl and Hurvínek in Prague since the 1920s. Together with the other puppets of the show - Spejbl, Mánička, Lady Kateřina and dog Zeryk - Hurvínek has entertained children and adults in 31 countries. (M 46013)

\section{(29473) Krejčí}

$1997 \mathrm{UE}_{8}$. Discovered 1997 Oct. 21 by P. Pravec and L. Šarounová at Ondřejov.

František Krejčí(1901-1984), an honorary member of the Czechoslovak Astronomical Society, in 1963 founded the public observatory in Karlovy Vary and led it for 20 years, including its rebuilding after a disastrous fire in 1971. He operated an all-sky patrol camera for the European fireball network. (M 45343)

\section{(29476) Kvíčala}

1997 UX $_{14}$. Discovered 1997 Oct. 31 by P. Pravec at Ondřejov.

Jan Kvíčala (1913-1972), Czech jurist and amateur astronomer, was a keen observer of variable stars and meteors, as well as coauthor of a gnomonic atlas for meteor observations. He received the František Nušl \{see planet (3424)\} Award of the Czech Astronomical Society in 1940. (M 45343)

\section{(29477) Zdíkšíma}

1997 UE $_{15}$. Discovered 1997 Oct. 31 by J. Tichá and M. Tichý at Klét.

Zdislav Šíma (1947- ) is a Prague astronomer who works on the problems of the gravitational fields of the planets of the solar system. He is also interested in the history of astronomy and astronomical instruments, including sundials and the old astronomical clock in Prague. (M 45343)

\section{(29484) Honzaveselý}

$1997 \mathrm{VJ}_{6}$. Discovered 1997 Nov. 9 by L. Šarounová at Ondřejov.

Legendary Czech cyclist Jan 'Honza' Veselý (1923) started his sports career as a bakery apprentice. Twenty-seven times national cyclist champion, he won the international Peace Race in 1949 and four times was a member of the winning Czechoslovakian team. He was holder of the National Fair-Play Award in 1997. (M 45343)

\section{(29491) Pfaff}

1997 WB $_{1}$. Discovered 1997 Nov. 23 by P. G. Comba at Prescott.

Johann Friedrich Pfaff (1765-1825) was a German mathematician who proposed the first general method for integrating partial differenitial equations of the first order. (M 44595)

\section{(29565) Glenngould}

1998 FD. Discovered 1998 Mar. 17 by M. Boeuf at Les Tardieux.

Glenn Gould (1932-1982) was the preeminent Canadian pianist and composer of his time. (M 45344)
(29613) Charlespicard

1998 SB $_{2}$. Discovered 1998 Sept. 16 by P. G. Comba at Prescott.

Charles-Emile Picard (1856-1941) was a French mathematician and educator who worked primarily in mathematical analysis and algebraic geometry. His name is associated with a theorem that clarifies the behavior of an analytic function in the vicinity of an isolated essential singularity. (M 44595)

\section{(29624) Sugiyama}

1998 TA. Discovered 1998 Oct. 2 by M. Akiyama at Mishima.

Tomiei Sugiyama (1949- ) moved from Japan to the U.S. in 1969 in the hope of becoming a Major League baseball player. Now he is the supervisor of a high-school baseball team, devoting himself to the promotion of high school baseball in Japan. (M 45344)

\section{(29643) Plücker}

1998 VR$_{31}$. Discovered 1998 Nov. 15 by P. G. Comba at Prescott.

Julius Plücker (1801-1868), German mathematician and physicist, proposed that the fundamental element in geometry need not be the point but could be the straight line, and that a duality exists between points and lines. This elegant and fruitful idea was widely exploited by later geometers. (M 45344)

\section{(29646) Polya}

1998 WJ. Discovered 1998 Nov. 16 by P. G. Comba at Prescott.

George Polya (1887-1985), a Hungarian-American mathematician, was a prolific researcher in probability, complex analysis and number theory. A great teacher, he pioneered the study of heuristics in his books How to Solve It, Mathematics and Plausible Reasoning and Patterns of Plausible Inference. (M 45344)

\section{(29647) Poncelet}

1998 WY. Discovered 1998 Nov. 17 by P. G. Comba at Prescott.

Jean Victor Poncelet (1788-1867) was a French mathematician and engineer and one of the founders of projective geometry. He introduced the concepts of points and lines at infinity and imaginary points, leading to greater generality in the statement of geometric theorems. (M 44596)

\section{(29674) Raušal}

1998 XO $_{12}$. Discovered 1998 Dec. 15 by P. Pravec at Ondřejov.

Karel Raušal (1906-1983), Czech jurist and an honorary member of the Czechoslovak Astronomical Society, was an enthusiastic amateur astronomer known for his skill in astronomical photography and as excellent teacher. He was instrumental in building the university and public observatories in Brno in the 1950s. (M 45344) 


\section{(29700) Salmon}

1998 YU $_{5}$. Discovered 1998 Dec. 19 by P. G. Comba at Prescott.

George Salmon (1819-1904) was a fellow in mathematics at Trinity College, Dublin, and later a professor of divinity. Besides doing research on algebraic curves and surfaces, he wrote a series of outstanding textbooks on geometry and higher algebra that were translated into many European languages. (M 45344)

\section{(29736) Fichtelberg}

$1999 \mathrm{BE}_{7}$. Discovered 1999 Jan. 21 by J. Kandler at Drebach.

With its altitude of 1214 metres above sea level, the Fichtelberg is the highest mountain on the Saxon side of the Erzgebirge \{see planet (8020)\}. Oberwiesenthal, the highest situated German town, lies at the foot of the mountain. (M 46112)

\section{(29738) Ivobudil}

$1999 \mathrm{BT}_{8}$. Discovered 1999 Jan. 23 by J. Tichá and M. Tichý at Kleť.

Ivo Budil (1933- ）, Czech journalist and popularizer of science, including astronomy, is known as the efficient and eminent author of the journal Vesmír and the Czech Radio magazine Meteor. (M 46684)

\section{(29837) Savage}

$1999 \mathrm{FP}_{5}$. Discovered 1999 Mar. 21 by P. G. Comba at Prescott.

Leonard Jimmie Savage (1917-1971), American statistician, wrote important papers on the foundations of statistics, probability theory and philosophy. He was a proponent of the Bayesian approach and developed a comprehensive theory of subjective probability and utility. (M 45344)

\section{(29845) Wykrota}

$1999 \mathrm{FE}_{21}$. Discovered 1999 Mar. 22 by C. Jacques at Serra da Piedade.

A couple of Brazilian amateur astronomers, Zininha and Henrique Wykrota were pioneers in the study and popularization of astronomy at the state of Minas Gerais in the 1950s. They founded an active amateur club, the Center for Astronomical Studies and the Serra da Piedade Observatory. (M 45236)

\section{(29910) Segre}

$1999 \mathrm{JV}_{8}$. Discovered 1999 May 14 by P. G. Comba at Prescott.

Corrado Segre (1863-1924) was a professor of geometry at the University of Turin. He did research on geometric properties invariant under linear transformations, the role of imaginary elements in geometry, curves and ruled surfaces in hyperspace, as well as differential geometry. (M 45344)

\section{(30252) Textorisová}

$2000 \mathrm{HE}_{24}$. Discovered 2000 Apr. 30 by P. Kušnirák at Ondřejov.
Izabela Textorisová (1866-1949) was Slovakia's first female botanist. Her copious herbarium is still today a valuable source for botanists. She described more than a hundred new plants in the Turiec region. In 1893 she discovered a new species of thistle, later named Carduus textorisianus Marg. in her honor. (M 45344)

\section{(30305) Severi}

2000 JA. Discovered 2000 May 1 by P. G. Comba at Prescott.

Francesco Severi (1879-1961), a student of Corrado Segre $\{$ see planet (29910)\} and later a professor at the University of Rome, wrote more than 400 books and papers on mathematics, history, education and philosophy. He was one of the major exponents of the Italian school of algebraic geometry. (M 45344)

\section{(30306) Frigyesriesz}

2000 JD. Discovered 2000 May 2 by P. G. Comba at Prescott.

Frigyes Riesz (1880-1956), a Hungarian mathematician, did research in functional analysis and topology. The Riesz-Fisher theorem (proved also by Fisher in 1907) formed the mathematical basis for proving the equivalence of matrix machanics and wave mechanics, a fundamental result in early quantum mechanics. (M 45344)

\section{(30307) Marcelriesz}

2000 JE. Discovered 2000 May 2 by P. G. Comba at Prescott.

Marcel Riesz (1886-1969) was a Hungarian-born mathematician (and brother of Frigyes Riesz \{see planet (30306)\}) who spent most of his working life in Sweden. He did research in convexity theory, linear operators, potential theory and partial differential equations. (M 45344)

\section{(30417) Staudt}

2000 LF. Discovered 2000 June 1 by P. G. Comba at Prescott.

Karl Georg Christian von Staudt (1798-1867), a professor at the University of Erlangen, gave the first fully rigorous treatment of projective geometry, without making use of distances, perpendiculars and angles. (M 45236)

\section{(30418) Jakobsteiner}

2000 LG. Discovered 2000 June 1 by P. G. Comba at Prescott.

Jakob Steiner (1796-1863) was a self-made Swiss farmer's son who later became a professor at the University of Berlin. He developed new methods in projective geometry that enabled him to prove many beautiful and often intricate theorems. (M 45237)

\section{(30439) Moe}

2000 MB. Discovered 2000 June 21 by J. Broughton at Reedy Creek. 
Brooklyn-born Moe Howard (Harry Moses Horwitz, 1897-1975) was the mophaired leader of the slapstick comedy team "The Three Stooges", who entertained the world with their long-running series of Hollywood short and feature length films beginning in 1934 . (M 45344)

\section{(30440) Larry}

2000 MG. Discovered 2000 June 22 by J. Broughton at Reedy Creek.

Philadelphia-born Larry Fine (Louis Feinberg, 19021975) was a longtime member of "The Three Stooges". The one in the middle with a scared-porcupine hairstyle, Larry was often the recipient of the collateral damage of slaps, pokes and bumps while trying to keep the peace between the other two. (M 45344)

\section{(30441) Curly}

2000 MX. Discovered 2000 June 24 by J. Broughton at Reedy Creek.

Brooklyn-born Curly Howard (Jerome Horwitz, 19031952) of Three Stooges fame was one of the greats of comedy. Generally forgetful of his lines, he would ad-lib much of the time. (M 45344)

\section{(30443) Stieltjes}

2000 NR. Discovered 2000 July 3 by P. G. Comba at Prescott.

Thomas Jan Stieltjes (1856-1894) was a professor at the University of Groningen. He published widely in mathematical analysis and the theory of continued fractions. He defined the "Stieltjes integral", a generalization of the Riemann \{see planet (4167)\} integral with wide applications to physics. (M 45237)

\section{(30444) Shemp}

$2000 \mathrm{NY}_{1}$. Discovered 2000 July 5 by J. Broughton at Reedy Creek.

Brooklyn-born Shemp Howard (Samuel Horwitz, 1895-1955) of Three Stooges fame was an original member during their 1920s vaudeville years. In 1946 he appeared on screen to replace his ailing brother Curly \{see planet (30441)\}. Like Curly, Shemp was a naturally gifted comedian who brought his own style of comedy to the act. (M 45344)

\section{(30445) Stirling}

$2000 \mathrm{NJ}_{2}$. Discovered 2000 July 5 by P. G. Comba at Prescott.

James Stirling (1692-1770) was a Scottish mathematician best known for his derivation of an asymptotic formula for factorials. (M 45237)

\section{(30566) Stokes}

$2001 \mathrm{OO}_{81}$. Discovered 2001 July 29 by P. G. Comba at Prescott.

George Gabriel Stokes (1819-1903) was a British physicist and mathematician noted for his studies of the behavior of viscous fluids and for a fundamental theorem in vector analysis. (M 45237)
(30778) Döblin

1987 SX $_{10}$. Discovered 1987 Sept. 29 by F. Börngen at Tautenburg.

German narrative writer Alfred Döblin (1878-1957) originated from a Jewish merchant family. A doctor by profession, he lived in exile in France and the U.S. during 1933-1945. From his extensive literary work best known are his novels Berlin Alexanderplatz (1929) and Babylonische Wanderung (1934). (M 45344)

\section{(30788) Angekauffmann}

$1988 \mathrm{RE}_{3}$. Discovered 1988 Sept. 8 by F. Börngen at Tautenburg.

Swiss Angelica Kauffmann (1741-1807) painted pictures of mythological, allegoric and religious themes and became renowned for pleasing classicist portraits. She was a celebrated member of several European academies. (M 45237)

\section{(30798) Graubünden}

$1989 \mathrm{CR}_{5}$. Discovered 1989 Feb. 2 by F. Börngen at Tautenburg.

Graubünden, also known as Grisons (French), Grigioni (Italian) and Grishun (Romansh), is the largest canton of Switzerland. Its capital Chur was once Curia Raetorium in the Roman province of Raetia. It is an enchanting landscape with superb mountains and glaciers, high passes and picturesque villages. (M 45237)

\section{(30826) Coulomb}

1990 TS $_{1}$. Discovered 1990 Oct. 10 by F. Börngen and L. D. Schmadel at Tautenburg.

Charles-Augustin de Coulomb (1736-1806) was one of the most famous physicists of his time. Best known for the law, force and unit of charge that are named for him, he published his findings in the seven fundamental treatises Sur l'électricité et le magnétisme. (M 45345)

\section{(30828) Bethe}

1990 TK$_{4}$. Discovered 1990 Oct. 12 by F. Börngen and L. D. Schmadel at Tautenburg.

Hans Albrecht Bethe (1906- ) is a pioneering theoretician in quantum physics, atomic and nuclear processes and solid-state and reactor physics. He emigrated from Germany to the U.S. in 1933. He received the 1967 Nobel Prize in physics for his discoveries concerning the energy production of stars. (M 45345)

Prof. Bethe in a thank-you letter (dated 2002 Sept. 21) to the discoverers stated: "In der Beschreibung meiner Wissenschaft Könnten Sie hinzufügen - Discoverer of the carbon-nitrogen cycle which produces the energy of stars."

\section{(30830) Jahn}

1990 TQ 12 . Discovered 1990 Oct. 14 by F. Börngen and L. D. Schmadel at Tautenburg.

Friedrich Ludwig Jahn (1778-1852) was an educator, writer and the "father of gymnastics". He opened the first sports ground in Berlin in 1811 and founded 
the Turnverein (gym club) movement in Germany. He invented diverse apparatus that became standard equipment for sports activities. (M 45345)

\section{(30836) Schnittke}

$1991 \mathrm{AU}_{2}$. Discovered 1991 Jan. 15 by F. Börngen at Tautenburg.

Alfred Garriyevich Schnittke (1934-1998) was a teacher at the Moscow Conservatory during 1962-1972. He combined in his many-sided work elements of heterogeneous styles, which he aptly altered and placed against one another. This procedure, which he called "polystylism", led to a great musical impression. (M 45345)

\section{(30837) Steinheil}

$1991 \mathrm{AW}_{2}$. Discovered 1991 Jan. 15 by F. Börngen at Tautenburg.

Carl August von Steinheil (1801-1870) was a professor in Munich, where he established an optical workshop in 1854. The workshop gained recognition through the efforts of his son Hugo Adolph (1832-1893) and grandson Rudolf (1865-1930), and the first wideangle and aplanatic objective was constructed there. (M 45345)

\section{(30850) Vonsiemens}

$1991 \mathrm{TN}_{2}$. Discovered 1991 Oct. 7 by F. Börngen and L. D. Schmadel at Tautenburg.

German inventor Werner von Siemens (1816-1892) played an important role in the development of telegraphy. He invented the dynamo and built the world's first electric train and streetcar. He was the founder of electrotechnology and the electric power engineering. (M 45345)

\section{(30852) Debye}

1991 TR$_{6}$. Discovered 1991 Oct. 2 by F. Börngen and L. D. Schmadel at Tautenburg.

Dutch-American physical chemist Peter Debye (18841966), recipient of the 1936 Nobel prize in chemistry, carried out theoretical and experimental research in quantum physics, investigating molecular and crystalline structures, dipole moments, diffraction effects by $\mathrm{x}$-rays and the scattering of light in gases. (M 45345)

\section{(30883) de Broglie}

1992 SW 16 . Discovered 1992 Sept. 24 by F. Börngen and L. D. Schmadel at Tautenburg.

French physicist Louis-Victor de Broglie (1892-1987), late in deciding on his career, chose for his doctoral thesis in 1924 a revolutionary theory of electron waves, exposing the duality between wave and corpuscle and founding the wave-theory of matter. He received the 1929 Nobel Prize in physics. (M 45345)

\section{(30933) Grillparzer}

1993 UW $_{8}$. Discovered 1993 Oct. 17 by F. Börngen at Tautenburg.
The dramatic poet and playwright Franz Grillparzer (1791-1872) was a celebrated figure in Austrian literature, a lifelong loyal to the Hapsburg Dynasty and a friend of Beethoven \{see planet (1815)\}. Best known among his works are the historical tragedy King Ottocar, His Rise and Fall and the lyric tragedy The Waves of Sea and Love. (M 45345)

\section{(31043) Sturm}

1996 LT. Discovered 1996 June 11 by P. G. Comba at Prescott.

Charles-François Sturm (1803-1855) was a Swissborn French mathematician. He proved a theorem that specifies the number of real roots of an algebraic equation that lie between two values of the variable. $\mathrm{He}$ also studied differential equations whose solutions form complete orthogonal sequences. (M 45237)

\section{(31086) Gehringer}

1997 AT $_{17}$. Discovered 1997 Jan. 12 by R. A. Tucker at Tucson.

Nebraskan amateur astronomer and high-school science teacher Thomas P. Gehringer (1953-2002) was a source of inspiration to the teaching profession, for his dedication to students and colleagues while dealing with incredible health obstacles. He and his students analyzed Kitt Peak images and discovered 73 novae in M31. (M 44596)

\section{(31110) Clapas}

$1997 \mathrm{PN}_{4}$. Discovered 1997 Aug. 13 at the Pises Observatory at Draveil.

Clapas is the former name for stone houses in the Montpellier area. Nowadays, it's the nickname of the area. (M 45237)

\section{(31113) Stull}

1997 QC. Discovered 1997 Aug. 19 by D. R. DeGraff and J. S. Weaver at Alfred.

John Stull has selflessly spent much time and effort to build the observatory at Alfred University from a telescope lost in an attic to arguably one of the best undergraduate observatories in the U.S. He built or improved five telescopes, including a 0.8 -meter Newtonian that is the largest optical telescope in New York state. (M 45237)

\section{(31122) Brooktaylor}

1997 SD. Discovered 1997 Sept. 21 by P. G. Comba at Prescott.

Brook Taylor (1685-1731) was an English mathematician whose name is associated with a basic theorem in the differential calculus, whereby the value of a function at an arbitrary point is expressed as a power series involving the values of the function and its derivatives at another point. (M 45237)

\section{(31189) Tricomi}

1997 YZ $_{7}$. Discovered 1997 Dec. 27 by P. G. Comba at Prescott. 
Francesco Giacomo Tricomi (1897-1978) was a professor in Torino and a prolific researcher in classical mathematical analysis. In the 1920s he solved a partial differential equation with mixed (elliptic/hyperbolic) boundary conditions. In the 1940s Tricomi's equation became the basic tool for modeling transonic flow. (M 45237)

\section{(31192) Aigoual}

$1997 \mathrm{YH}_{16}$. Discovered 1997 Dec. 29 at the Pises Observatory at Draveil.

Mount Aigoual is the highest mountain of the Cevennes. (M 45237)

\section{(31240) Katrianne}

$1998 \mathrm{DB}_{2}$. Discovered 1998 Feb. 20 by G. Lehmann at Drebach.

Katrin Susanne Lehmann, wife of the discoverer, is a committed teacher of physics and astronomy, as well as the caring mother of two sons. Her love and support made possible the discovery of many minor planets at the Drebach Observatory. (M 46684)

\section{(31324) Jiřímrázek}

1998 HR $_{31}$. Discovered 1998 Apr. 27 by L. Šarounová at Ondřejov.

Jiří Mrázek (1923-1978) was a Czech geophysicist specializing in ionospheric studies but with much wider interests in science, philosophy and classical music. A master of the popularization of astronautics, astronomy, computer science and related subjects, he was a TV and radio star until his untimely death. (M 46013)

\section{(31665) Veblen}

$1999 \mathrm{JZ}_{2}$. Discovered 1999 May 10 by P. G. Comba at Prescott.

Oswald Veblen (1880-1960) was a professor at Princeton and later at the Institute for Advanced Study. Known for the clarity of his exposition, he made important contributions to topology, projective geometry and differential geometry, and he was a mentor to generations of mathematicians. (M 45237)

\section{(31823) Viète}

$1999 \mathrm{TN}_{3}$. Discovered 1999 Oct. 4 by P. G. Comba at Prescott.

François Viète (1540-1603) was a French lawyer and mathematician who introduced the modern algebraic notation, using letters to represent numbers. He also developed a systematic method for solving plane and spherical triangles. (M 45237)

\section{(31956) Wald}

2000 GA $_{133}$. Discovered 2000 Apr. 13 by P. G. Comba at Prescott.

Abraham Wald (1902-1950) was an American statistician whose most important work was the development of the theory of sequential testing of hypotheses. (M 45237)

\section{(31982) Johnwallis}

$2000 \mathrm{HS}_{20}$. Discovered 2000 Apr. 30 by P. G. Comba at Prescott.

John Wallis (1616-1703) was an professor of geometry at Oxford. His fame rests on a formula that represents $\pi$ as an infinite product and on the invention of the symbol $\infty$ for infinity. (M 45237)

\section{(32184) Yamaura}

$2000 \mathrm{NC}_{20}$. Discovered 2000 July 8 by the Bisei Spaceguard Center at Tokyo-Okayama.

Yuichi Yamaura (1955- ) is one of the leaders of the National Space Development Agency of Japan. He contributed greatly to the construction of Bisei Spaceguard Center. (M 45750)

\section{(32267) Hermannweyl}

$2000 \mathrm{PS}_{1}$. Discovered 2000 Aug. 1 by P. G. Comba at Prescott.

Hermann Weyl (1885-1955) was a German-American pure and applied mathematician. His work, from the study of the Riemann \{see planet (4167)\} surface to the application of group theory to quantum mechanics, shows his ability to find connections between previously unrelated subjects. (M 45237)

\section{(32564) Glass}

$2001 \mathrm{QM}_{68}$. Discovered 2001 Aug. 20 by C. Wolfe at Terre Haute.

Eugene Glass (1926- ) is an amateur astronomer and loyal supporter of the Rose-Hulman Oakley Observatory, where this minor planet was discovered. (M 45237)

The name was suggested by R. Ditteon.

\section{(32569) Deming}

2001 QW $_{71}$. Discovered 2001 Aug. 20 by C. Wolfe at Terre Haute.

Leo Deming (1918- ) is an amateur astronomer and one of the founders of the original observatory at Rose-Hulman, where this minor planet was discovered. (M 45237)

The name was suggested by R. Ditteon.

\section{(32809) Sommerfeld}

$1990 \mathrm{TJ}_{10}$. Discovered 1990 Oct. 10 by F. Börngen and L. D. Schmadel at Tautenburg.

Arnold Sommerfeld (1868-1951), a longtime professor in Munich, taught many renowned physicists. He extended the atomic model of Bohr, wave mechanics and the theory of electrons in metals. His textbook Atomic Structure and Spectral Lines (1919-1929) was a standard for decades. (M 45345)

\section{(32811) Apisaon}

$1990 \mathrm{TP}_{12}$. Discovered 1990 Oct. 14 by F. Börngen and L. D. Schmadel at Tautenburg.

The Trojan warrior Apisaon, son of the Phausios, fought against the approaching Aias. But he was deadly 
transfixed and deprived of his armor by Eurypolos. (M 45750)

\section{(32853) Döbereiner}

$1992 \mathrm{SF}_{2}$. Discovered 1992 Sept. 21 by F. Börngen and L. D. Schmadel at Tautenburg.

Johann Wolfgang Döbereiner (1780-1849), professor of chemistry at Jena and creator of the first chemical educational laboratory, was a lifelong friend of Goethe \{see planet (3047)\}. He discovered the catalytic properties of platinum and observed similarities among elements that anticipated the periodic system of elements. (M 45345)

\section{(32899) Knigge}

1994 PY $_{1}$. Discovered 1994 Aug. 4 by F. Börngen at Tautenburg.

Adolph Freiherr von Knigge (1752-1796) wrote novels, satires, dramas and autographic works, and he tranlated Italian and French authors into German. His best known work is Über den Umgang mit Menschen (1788; also known as Knigge), in which he offers a collection of maxims and precepts for a well-mannered life. (M 45345)

\section{(32944) Gussalli}

$1995 \mathrm{WC}_{3}$. Discovered 1995 Nov. 19 by P. Sicoli and F. Manca at Sormano.

Luigi Gussalli (1855-1950) was a mechanical engineer and designer of an experimental "double reaction" engine in 1920. He spent a considerable part of his life in studying and developing space-vehicle propulsion application devices to travel to the moon. (M 46112)

\section{(33058) Kovařík}

$1997 \mathrm{UP}_{20}$. Discovered 1997 Oct. 22 by P. Pravec and L. Šarounová at Ondřejov.

Oton Kovařík (1928- ), Czech actor, orator and painter, is now living in California with his wife Dáša, also an actress. The Kovaříks have propagated European culture and helped to maintain European cultural traditions among immigrants in California, by public recitals of poems and by art exhibitions. (M 46013)

\section{(33100) Udine}

1997 YK $_{9}$. Discovered 1997 Dec. 28 at the Farra d'Isonzo Observatory at Farra d'Isonzo.

Udine is the chief town in the Friuli district of Italy. Founded by Celtic tribes and later occupied by the Romans, it grew to great influence under the Patriarchate of Aquileia in the Middle Ages. Nowadays it is renowned for its castle and excellent wines. (M 46684)

The citation was prepared by G. Sostero.

\section{(33330) Barèges}

1998 SW. Discovered 1998 Sept. 16 by the OCA-DLR Survey at Caussols.

Barèges is a small mountain village situated at the foot of the Pic du Midi \{see planet (20488)\}, site of the well-known observatory. Historically known for its spa waters, it is also the base for the largest skiing area in the French Pyrenees. (M 46685)

\section{(33377) Večerníček}

$1999 \mathrm{CR}_{9}$. Discovered 1999 Feb. 12 by P. Pravec at Ondřejov.

Večerníček is an animated figure accompanied by music. It invites children to the Czech Television to see a bedtime story every evening. Ingeniously painted by R. Pilař, voiced by M. Citavý, and with the tune composed by L. Simon, it has become a real phenomenon loved by most Czech children since 1965 . (M 46013)

\section{(33528) Jinzeman}

1999 HL. Discovered 1999 Apr. 17 by P. Pravec at Ondřejov.

Jindřich Zeman (1894-1978), a Czech amateur astronomer living in the town of Hradec Králové, was an eager astrophotographer. His superb photographs of the night sky have been reproduced in many popular astronomy books. He received the František Nušl \{see planet (3424)\} Award of the Czech Astronomical Society in 1942. (M 45750)

\section{(34138) Frasso Sabino}

$2000 \mathrm{QE}_{9}$. Discovered 2000 Aug. 25 at the Frasso Sabino Observatory at Frasso Sabino.

Frasso Sabino is a pleasant medieval Italian town, which hosts the Frasso Sabino Observatory, at no charge, in a seventeenth-century flour mill that was modified for this purpose. Dedicated to Virginio Cesarini, the observatory was given in 1995 to the Roman Amateur Astronomers Association for didactic and scientific use. (M 45345)

\section{(34351) Decatur}

$2000 \mathrm{RZ}_{8}$. Discovered 2000 Sept. 3 by L. Ball at Decatur.

Decatur, Alabama, is on the south bank of the Tennessee river, approximately $25 \mathrm{~km}$ west of NASA's Marshall Space Flight Center. Emerald Lane Observatory is located in Decatur. (M 45345)

\section{(34366) Rosavestal}

$2000 \mathrm{RP}_{36}$. Discovered 2000 Sept. 4 by B. D. Warner at Colorado Springs.

Rosa Vallee Warner (née Vestal; 1922-2002), the discoverer's mother, encouraged her son's interest in astronomy from an early age. She also inspired others with her lifelong interest and study of philosophy, religion and political affairs. (M 45345)

\section{(34398) Terryschmidt}

$2000 \mathrm{RK}_{78}$. Discovered 2000 Sept. 9 by B. D. Warner at Colorado Springs.

Through self study, Terry Eugene Schmidt (19381993), a graduate of Aurora College in Illinois, became a recongized expert in the field of meteoritics. Among his other interests was determining minor-planet lightcurve 
parameters, which he passed on to the discoverer. (M 45345)

\section{(34419) Corning}

$2000 \mathrm{SA}_{7}$. Discovered 2000 Sept. 20 by A. J. Cecce at Elmira.

Corning is the home of a glassworks that makes professional telescope mirrors, including the disk for the 5-m Hale \{see planet (1024)\} Telescope at Palomar. The one-tenth-scale engineering model of the Hale telescope resides there, and it was used to discover this minor planet. (M 46112)

\section{(34611) Nacogdoches}

$2000 \mathrm{UF}_{11}$. Discovered 2000 Oct. 25 by W. D. Bruton and R. M. Williams at Nacogdoches.

Nacogdoches is the site of an Indian settlement, named for the Nacogdoche Indians. (M 47169)

\section{(34666) Bohyunsan}

$2000 \mathrm{XA}_{14}$. Discovered 2000 Dec. 4 by Y.-B. Jeon and B.-C. Lee at Bohyunsan.

Mt. Bohyunsan, located about $200 \mathrm{~km}$ to the south of Seoul, is the site of the largest astronomical observatory in Korea. The observatory is equipped with a $1.8-\mathrm{m}$ telescope and a solar-flare telescope, this minor planet having been discovered with the former. (M 45345)

\section{(34854) Paquifrutos}

$2001 \mathrm{TP}_{17}$. Discovered 2001 Oct. 13 by R. Ferrando at Pla D'arguines.

Paqui Frutos Frutos (1969- ) is the wife of the discoverer. (M 45346)

\section{(35197) Longmire}

1994 LH. Discovered 1994 June 7 at the Farra d'Isonzo Observatory at Farra d'Isonzo.

Matthew J. Longmire (1958- ) is an electrical engineer who co-founded a small CCD ssee planet (15000)\} brand that in 1991 developed star tracking equipment, sparking the CCD revolution in the world of amateur astronomy. (M 46685)

\section{(35229) Benckert}

$1995 \mathrm{FY}_{20}$. Discovered 1995 Mar. 24 by F. Börngen at Tautenburg.

Johann Peter Benckert (1709-1765) created stone, stucco and wooden sculptures for the court of the princebishop of Bamberg \{see planet (324)\}. After 1746, he worked primarily for the Prussian residences in Berlin and Potsdam \{see planets (422) and (5816), respectively ("Chinese Teahouse" in Sanssouci), evolving from the Baroque style into that of the Frederician Rococo. (M 45750)

\section{(35316) Monella}

1997 AW $_{13}$. Discovered 1997 Jan. 11 by P. Sicoli and M. Cavagna at Sormano.

Rinaldo Monella (1948- ) is a well-known Italian amateur astronomer who has specialized in photoelectric photometry, making in particular observations of novae and cataclysmic variables. He has written many articles for astronomical periodicals and is a member of several Italian and international associations. (M 46013)

\section{(36037) Linenschmidt}

1999 PQ3. Discovered 1999 Aug. 13 by W. D. Bruton and C. F. Stewart at Nacogdoches.

Robb Linenschmidt (1970-1993) was a friend and talented aerospace engineer who wanted to help open young minds to the wonders of space. (M 47169)

\section{(36182) Montigiani}

$1999 \mathrm{TY}_{12}$. Discovered 1999 Oct. 10 by M. M. M. Santangelo at Monte Agliale.

Montigiani Roberto (1944-2002) lived in Scandicci, near Florence. A friend of the discoverer, he died after a serious illness. He was an amateur astronomer skilled in the mechanics of telescopes and a member of the Associazione Astrofili Fiorentini. (M 47169)

\section{(36445) Smalley}

2000 QU. Discovered 2000 Aug. 23 by L. Robinson at Olathe.

Kyle Smalley (1961- ) is an amateur astronomer and team member of the Powell Observatory NearEarth-Object follow-up program. (M 46685)

\section{(37022) Robertovittori}

$2000 \mathrm{UT}_{1}$. Discovered 2000 Oct. 22 by F. Manca and G. Ventre at Sormano.

Italian astronaut Roberto Vittori (1964- ） made the first flight on board the Soyuz capsule in 2002, docking with the International Space Station and performing medical experiments. He is the third astronaut from the European Space Agency to visit the ISS. (M 46013)

\section{(37044) Papymarcel}

2000 UE $_{29}$. Discovered 2000 Oct. 27 by J.-C. Merlin at Le Creusot.

Marcel Alphonse Merlin (1922- ) is the father of the discoverer. Now celebrating his eightieth birthday, he was the principal artisan in the construction of the discoverer's private observatory. (M 46013)

\section{(37392) Yukiniall}

$2001 \mathrm{XP}_{16}$. Discovered 2001 Dec. 10 by T. Pauwels and $\mathrm{H}$. Boffin at Uccle.

Yuki and Niall are the children of codiscoverer Henri Boffin who, after postdoctoral studies in Japan and Wales, joined the Royal Observatory at Uccle in 1998. Yuki means snow in Japanese and Niall means chief or champion in Celtic. (M 46112)

\section{(37556) Svyaztie}

1982 QP $_{3}$. Discovered 1982 Aug. 28 by N. S. Chernykh and B. G. Marsden at Nauchnyj.

From Russian and English words meaning "connection", Svyaztie honors the enduring astronomical collaborations and friendships that transcend national boundaries and political philosophies. The name also acknowledges the exchange of neckwear by the codis- 
coverers on their first meeting at IAU Symposium No. 45 in 1970. (M 45750)

\section{(37582) Faraday}

$1990 \mathrm{TT}_{3}$. Discovered 1990 Oct. 12 by F. Börngen and L. D. Schmadel at Tautenburg.

The English naturalist Michael Faraday (1791-1867) discovered the liquefaction of chlorine and the benzene, electromagnetic induction, diamagnetism, the rotation of light's polarization plane by a magnetic field and the screening Faraday-cage. He also stated the basic laws of electrolysis. (M 45750)

\section{(37584) Schleiden}

1990 TC 9 . Discovered 1990 Oct. 10 by F. Börngen and L. D. Schmadel at Tautenburg.

The German botanist Matthias Jakob Schleiden (1804-1881), a professor at Jena \{see planet (526)\} during 1846-1863, utilized the microscope in research and teaching. He stated that cells are elementary units of organisms, and their nuclei are important for the cell division. He was co-founder (with Theodor Schwann) of the field of cytology. (M 45750)

\section{(37608) Löns}

1992 SY $_{16}$. Discovered 1992 Sept. 24 by F. Börngen and L. D. Schmadel at Tautenburg.

Herman Löns (1866-1914) was closely attached to North German people and landscape, especially Lüneburg Heath and Harz Mountains. He extolled them in his numerous novels, folk songs and animal descriptions ("Mümmelmann"). His work was misused in the Brown Era. (M 45750)

\section{(37859) Bobkoff}

$1998 \mathrm{FE}_{3}$. Discovered 1998 Mar. 23 by P. Pravec at Ondřejov.

Despite shooting through the urban skies of Denver, $\mathrm{CO}$, and around trees and houses from his apartment balcony, Robert Koff (1943- _ ) has produced numerous high-quality lightcurves for minor planets and eclipsing binary stars. His work is a testament to perseverance, dedication and the power of CCD imaging. (M 46112)

\section{(38083) Rhadamanthus}

$1999 \mathrm{HX}_{11}$. Discovered 1999 Apr. 17 by the Deep Ecliptic Survey at Kitt Peak.

Rhadamanthus was a son of Zeus and Europa \{see planets (5731) and (52), respectively\}. Because of his just and upright life, after death he was appointed a judge of the dead and the ruler of Elysium, a blissfully beautiful area of the Underworld where those favored by the gods spent their life after death. (M 46112) The name was suggested by E. K. Elliot.

\section{(38268) Zenkert}

1999 RV 32 . Discovered 1999 Sept. 9 by A. Knöfel at Drebach.

Arnold Zenkert (1923- ) was the director of the planetarium and of the Bruno H. Bürgel Memorial Plaza in Potsdam. Interested in historical sundials at churches and buildings, he serves on the sundial committee of the German Society for Chronometry. (M 46685)

\section{(38269) Gueymard}

$1999 \mathrm{RN}_{33}$. Discovered 1999 Sept. 10 by W. G. Dillon and K. Rivich at Needville.

Adolphe G. Gueymard (1913- ), distinguished Louisiana State University alumnus, is a successful businessman, generous benefactor of the George Observatory, and an admirable representative of the "Greatest Generation". (M 46685)

\section{(38541) Rustichelli}

$1999 \mathrm{VT}_{6}$. Discovered 1999 Nov. 7 at the Cavezzo Observatory at Cavezzo.

Vittorio Rustichelli (1927- ) is one of the most active and skilled telescope makers and amateur astronomers in Italy. With F. Caliumi ssee planet (4742)\}, he helped the Cavezzo Observatory staff in the design and realization of the mechanical mount of the main telescope. (M 46685)

\section{(38671) Verdaguer}

$2000 \mathrm{PZ}_{6}$. Discovered 2000 Aug. 7 by J. Nomen at Ametlla de Mar.

Jacint Verdaguer (1845-1902), born in Folgueroles, Catalonia, is considered one of the greatest poets in the Catalan language. He made possible the recovery of Catalan literature and culture after three centuries of literary decline. (M 47169)

\section{(39464) Pöppelmann}

1973 UO $_{5}$. Discovered 1973 Oct. 27 by F. Börngen at Tautenburg.

Matthäus Daniel Pöppelmann (1662-1736) was senior state architect to the court of the Saxonian king Augustus the Strong. His major work was the building complex of the Zwinger in Dresden \{see planet (3053)\}, one of the most successful realizations of the Baroque aesthetic. (M 47169)

\section{(39540) Borchert}

1991 GF $_{11}$. Discovered 1991 Apr. 11 by F. Börngen at Tautenburg.

Wolfgang Borchert (1921-1947) was one of the pioneers of German postwar literature. In poetry and prose, he described with great expression the effects of war. The life of a war repatriate is dramatically depicted in Outside of the door (1947). (M 47169)

\section{(39571) Pückler}

$1992 \mathrm{SN}_{24}$. Discovered 1992 Sept. 21 by F. Börngen at Tautenburg.

German Herman Graf von Pückler (1785-1871), given the rank of prince in 1822, created great landscape gardens in the English style in Muskau and Branitz. He was also a popular author of travel books. (M 47169) 


\section{(39699) Ernestocorte}

$1996 \mathrm{TF}_{8}$. Discovered 1996 Oct. 12 by V. Goretti at Pianoro.

Ernesto Corte, of La Jolla, California, an entrepreneur and founder of Gamma-Metrics, was a pioneer in the application of radiation physics to elemental analysis of materials. $\mathrm{He}$ is a fellow in the Institute of Electrical and Electronic Engineers and recognized for his leadership in, and contributions to, radiation technologies. (M 47169)

\section{(39791) Jameshesser}

$1997 \mathrm{PH}_{4}$. Discovered 1997 Aug. 13 by D. D. Balam at Victoria.

James E. Hesser, acting director of the Herzberg Institute of Astrophysics and 1997 recipient of the Michael Smith Award for Science Promotion, has contributed to the study of atomic and molecular spectroscopy, rapidly varying degenerate stars, stellar populations and chemical evolution in the Milky Way and nearby galaxies. (M 46112)

\section{(39890) Bobstephens}

1998 FA $_{3}$. Discovered 1998 Mar. 23 by P. Pravec at Ondřejov.

Robert Stephens (1955- ) is a Californian amateur astronomer who has determined some 30 sets of minor-planet lightcurve parameters since becoming active in the field in 1999. His high-quality work and generosity in sharing his time and knowledge within the amateur community have set a standard for others to follow. (M 46112)

\section{(40409) Taichikato}

$1999 \mathrm{RS}_{2}$. Discovered 1999 Sept. 6 by G. Masi at Ceccano.

Taichi Kato (1961- ) is an active researcher in astronomy at Kyoto University, mainly in the field of cataclysmic variables. He dedicates his efforts to the VSNET system, a network devoted to variable stars, which often succeeds in alerting observers about important phenomena. (M 46685)

\section{(40457) Williamkuhn}

1999 RG $_{43}$. Discovered 1999 Sept. 4 by M. Collins and M. White at Mission Viejo.

William Kuhn (1918- ) lives in Orange, California. He designed and directed the building of the $0.55-\mathrm{m}$ Kuhn telescope in Anza for the Orange County Astronomers. This telescope has been used for the discovery of numerous minor planets. Kuhn has dedicated his life to educating, assisting and inspiring astronomers of all ages. (M 47169)

\section{(40459) Rektorys}

$1999 \mathrm{RK}_{43}$. Discovered 1999 Sept. 14 by P. Pravec and P. Kušnirák at Ond ` $\{r\}$ ejov.

Karel Rektorys (1923- ), Czech mathematician and professor at the Czech Technical University in Prague, is the chief editor of the book Survey of Applicable
Mathematics, the English translation of which became an official handbook at M.I.T. in Boston. He is the author of several monographs on variational methods. (M 47169)

\section{(41206) Sciannameo}

1999 WG. Discovered 1999 Nov. 27 at the Osservatorio Polina at Terni.

Francesco Sciannameo (1941- ) is a professor of general surgery and head physician of the general surgery facility of the Terni hospital. As an amateur astronomer, he takes an active part in the life of the Polino \{see planet (13151)\} Observatory. (M 47169)

\section{(41279) Trentman}

1999 XD95. Discovered 1999 Dec. 8 by L. Robinson at Olathe.

Richard Trentman (1939- ) is an amateur astronomer and team member of the Powell Observatory Near-Earth-Object follow-up program. (M 46685)

\section{(41943) Fredrick}

$2000 \mathrm{XH}_{2}$. Discovered 2000 Dec. 3 by L. Robinson at Olathe.

Richard Fredrick (1953- $\quad$ ) is an amateur astronomer and team member of the Powell Observatory NearEarth-Object follow-up program. (M 46685)

\section{(42113) Jura}

$2001 \mathrm{AB}_{49}$. Discovered 2001 Jan. 15 at the Observatoire Astronomique Jurassien at Vicques.

Jura is the 23rd state of Switzerland, founded on 1974 June 23. The name of the French-speaking state derives from the Jura mountains, which extend from Geneva to Germany. In this rural region people enjoy life and like eating totche, tête de moine and drinking a damassine. (M 46112; M 46173)

\section{(42191) Thurmann}

2001 CJ $_{37}$. Discovered 2001 Feb. 14 at the Observatoire Astronomique Jurassien at Vicques.

The Swiss geologist and naturalist Jules Thurmann (1804-1855), resident in Porrentruy, first explained the formation of the Jura mountains. With other intellectuals he founded the Société jurassienne d'émulation for the promotion of science. (M 46112; M 46173)

\section{(42354) Kindleberger}

$2002 \mathrm{CK}_{43}$. Discovered 2002 Feb. 12 by C. W. Juels and P. R. Holvorcem at Fountain Hills.

Charles P. Kindleberger (1910- ) is an economist who wrote the 1978 classic, Manias, Panics, and Crashes: A History of Financial Crises. This book, with new editions in 1989 and 1996, documents four centuries of boom-and-bust financial cycles. He was president of the American Economic Association in 1985. (M 47169)

\section{(42747) Fuser}

1998 SU $_{10}$. Discovered 1998 Sept. 21 by V. Goretti at Pianoro. 
Ireneo Fuser (1902- ), professor of organ, piano and composition, holds the chair of organ at the Bologna Conservatoire. A great teacher, as well as a fine performer and composer, he is the author of the well-known book Italian Organ Classics. (M 47170)

\section{(42924) Betlem}

$1999 \mathrm{TJ}_{2}$. Discovered 1999 Oct. 2 at the Ondřejov Observatory at Ondřejov.

Hans Betlem (1954- ), Dutch amateur meteor astronomer and founder of the Dutch Meteor Society, is well known for his photographic observations of major meteor streams and has published many precise trajectories and orbits of meteors. He has organized several successful Leonid expeditions. (M 47170)

\section{(42981) Jenniskens}

$1999 \mathrm{TY}_{224}$. Discovered 1999 Oct. 2 at the Ondřejov Observatory at Ondřejov.

Peter Jenniskens (1962- ), meteor astronomer of NASA Ames, organized several successful airborne missions (Leonid multi-instrument aircraft campaigns) to observe the Leonid returns from 1998 to 2002. He has substantially improved our knowledge of the behavior of meteor streams. (M 47170)

\section{(43511) Cima Ekar}

$2001 \mathrm{CP}_{48}$. Discovered 2001 Feb. 11 by the Asiago-DLR Asteroid Survey at Cima Ekar.

Cima Ekar, near Asiago, hosts the largest astronomical facilities in Italy. (M 46685)

\section{(43669) Winterthur}

2002 GA $_{10}$. Discovered 2002 Apr. 15 by M. Griesser at Winterthur.

The charming town of Winterthur, founded in 1264 in northeastern Switzerland, is a regional center of business, culture and education, situated in a rural landscape and surrounded by wooded hills. It is the birthplace of the discoverer and home of Eschenberg Observatory. (M 46685)

\section{(43724) Pechstein}

1975 UY. Discovered 1975 Oct. 29 by F. Börngen at Tautenburg.

Max Pechstein (1881-1955) painted strongly colored pictures and was a leading member of the group of German expressionists known as "Die Brücke". (M 47170)

\section{(43790) Ferdinandbraun}

$1990 \mathrm{TY}_{3}$. Discovered 1990 Oct. 12 by F. Börngen and L. D. Schmadel at Tautenburg.

In 1897, German Ferdinand Braun (1850-1918) introduced a cathode-ray tube with a fluorescent screen ("Braun tube"), the forerunner of the television tube. In 1909, he shared with Marconi ssee planet (1332)\} the Nobel Prize in physics for the development of wireless telegraphy. (M 47170)

\section{(43806) Augustepiccard}

$1991 \mathrm{RG}_{7}$. Discovered 1991 Sept. 13 by F. Börngen and L. D. Schmadel at Tautenburg.

Swiss-Belgian physicist Auguste Piccard (1884-1962) studied the upper stratosphere and the depths of the sea. In 1932 he made a balloon ascent to a height of 16940 meters, and in 1953 he descended by bathyscaphe to a depth of 3150 meters. His son Jacques (1922- ) attained a submarine depth of $10910 \mathrm{~m}$. (M 47170)

\section{(44216) Olivercabasa}

1998 PH. Discovered 1998 Aug. 4 by E. Vigil and F. Casarramona at Teide.

Josep Maria Oliver i Cabasa (1944- ） is one of the most remarkable amateur astronomers in Spain. He co-founded the Agrupació Astronómica de Sabadell \{see planet (13260)\} in 1960 and has led it for more than 40 years. The main areas of work at Sabadell are popularizing astronomy and studying the history of amateur astronomy in Spain. (M 47170)

\section{(45737) Benita}

2000 HB. Discovered 2000 Apr. 22 by B. A. Segal at Boca Raton.

Benita Segal (1964- ) is the wife of the discoverer. Without her support the Boca Raton observatory would not exist. Like her husband, she is a physician. (M 47170)

\section{(46610) Bésixdouze}

1993 TQ . Discovered 1993 Oct. 15 by K. Endate and K. Watanabe at Kitami.

The decimal number 46610 translates to the hexadecimal B612, the designation of the fictitious minor planet in de St. Exupéry's \{see planet (2578)\} 1943 novel Le Petit Prince. B612 was allegedly spotted on a single night in 1909 and reported at a meeting in 1920. (M 47170)

The name was suggested independently by F. Hémery and J. Grygar.

\section{(50000) Quaoar}

$2002 \mathrm{LM}_{60}$. Discovered 2002 June 4 by C. A. Trujillo and M. E. Brown at Palomar.

Quaoar is the great force of creation in the diverse myths of the Tongva, the indigenous people of the Los Angeles basin. Quaoar has no form or gender and dances and sings Weywot, Sky Father, into existence. Together, they create Chehooit, Earth Mother, and the trio bring Tamit, Grandfather Sun, to life. (M 47170)

\section{Hermes}

1937 UB. Discovered 1937 October 28 by K. Reinmuth at Heidelberg.

Named after the messenger of the gods (named Mercury by the Romans), son of Zeus and Maia \{see planets (5731) and (66), respectively\}. His attributes are the most complex and varied of those of any of the major gods. He was a deity of wealth, god of trade 
and travelers, of commerce, manual skill, oratory and eloquence, of thieves, and of the wind - with whose speed he was able to move; he was also patron of athletes. Within a few hours of birth, he had stolen Apollo's \{see planet (1862)\} cattle. Hermes invented the lyre and gave it to Apollo who, in turn gave him the caduceus, a golden staff with wings at the top, intertwined with serpents - symbol of today's medical profession. His son Autolycus became the champion thief of the world. The name "Hermes" means hastener, and representations of him are symbolic of the messenger or of speed and majesty in flight. (Z 124; LDS)

Named by the Astronomisches Rechen-Institut (AN 264, 343 (1938)): "Da das von K. Reinmuth entdeckte Objekt wegen des ungewöhnlichen Charakters der Bahn dauernd in die Literatur eingehen wird, soll es mit Zustimmung des Entdeckers den Namen "Hermes" erhalten."

Hermes is the only planet which received a name but which got no number. The planet was very near the Earth, moving at an hourly rate of more than 20 minutes of arc in the discovery night. Hermes passed from opposition to conjunction within only two days. He reached closest approach on Oct. 30 with only 0.005 a.u. Unfortunately, the planet was lost immediately after discovery. 